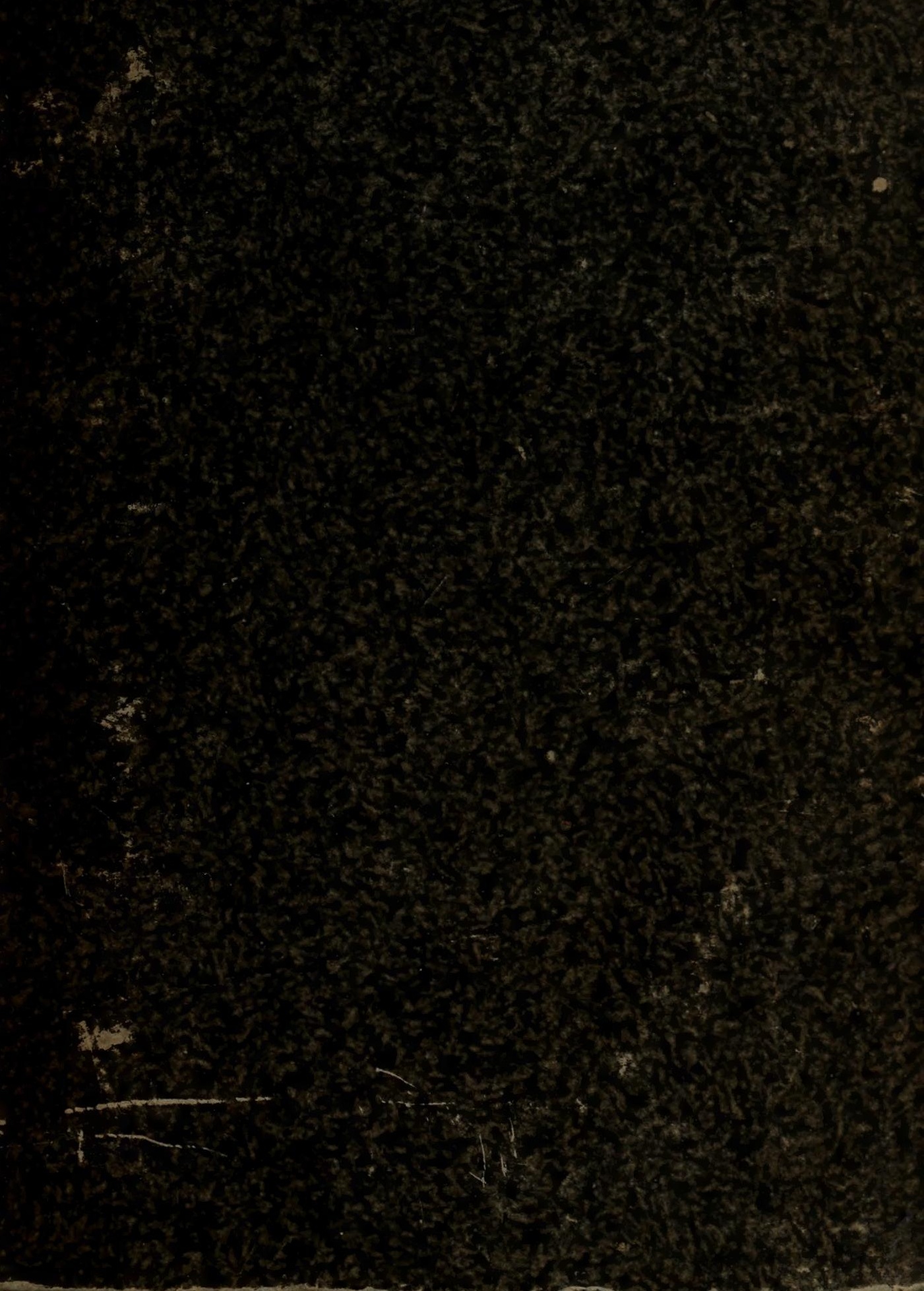


$2,45.6 / x_{11}$ call compel the. 5 Tafelu.

stocklectug!'

California Academy of Sciences

RECEIVED BY GIFT FROM

Dr. E. C. Van Dyke

Nay 19, 1949 
497kb /ranis, 



\section{GENERA ET SPECIES}

\section{S T A P H Y L I N O R U M}

AUCTORE

GUII. F. IRICESON. 


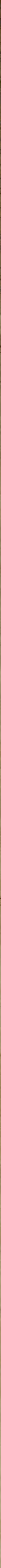




\title{
GENERA ET SPECIES
}

\section{S'T A P H Y L I N OR U M}

\section{INSECTORUM COLEOPTERORUM}

\author{
FAMILIAE
}

AUCTORE

\section{GUII. F. FRICHSON}

MEDICINAE ET PHILOSOPHIAE DOCTORE HISTOR. NAT. IN UNIVERS. LITTER. REG. FRIDERICA GUILELMA BEROLIN. PRiv. DOCENTE ACAD. SCIENC. REg. TAURIN. SOCIO ACAD. NAT. GURios. CAESAR. LEOPOLDINAE SOCIET. IMPERIAL. NAT. SCRUT. MOSQUENSIS ET SOC. ENTOMOL. LONDINENSIS SODALI SOCIET. NAT. SCRUTAT. BEROLINENSIS SOGIO HONORARIO

ACCEDUNT TABULAE AENEAE QUINQUE

BEROLINI

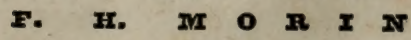
$\operatorname{MDCCXI}$ 


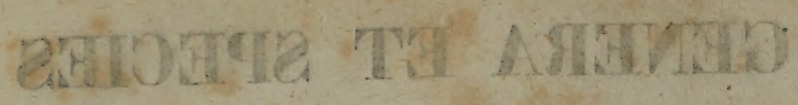

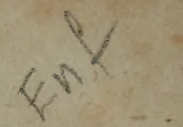

\section{MU भOVII I IAT}

\section{MUค०ЯभT}

\author{
BAIHIA
}

noetionse - 2 ants

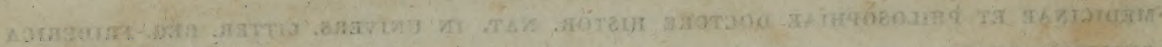

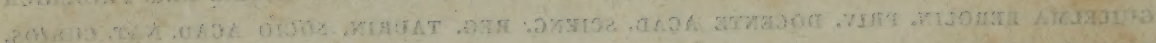

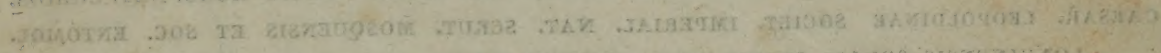

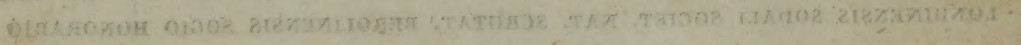

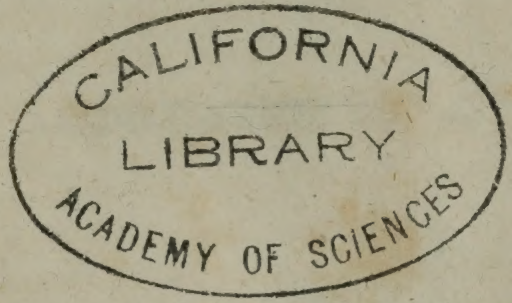


Amplam hanc innumerae Insectorum classis familiam, a Gravenhorstio olim ingeniose illustratam, iam, specierum copia prodigiosum in modum gliscente, omnibus forte Coleopterorum saltem reliquis familiis minus excultam, labore peculiari tractatam in medium me proferre, non est quod praefando excusem: de rationibus autem, quas hoc in opere conformando secutus sum, pauca praemoneam, cum non tam speciebus quam plurimis enumeratis quam rite examinatis, distinctis, dispositis historiae naturalis scientia promoveri videatur.

Nitidissimus huius Coleopterorum familiae cultor, cel. Gravenhorst nuper *) professus est, dispositiones nostras systematicas omnino arbitrarias neque ullo modo constitutas esse a natura, quae formas alteras exstinguere, alteras novas procreare continuaret, ita ut sectiones omnes confluerent et, simulatque characteribus circumscriberentur, artificiales evaderent: quam quidem opinionem non magis atque illa de speciebus hybridis olim adducta sententia, observationibus accuratioribus nullo modo confirmata et ab omnibus neglecta, arridere naturae scrutatores puto, et cui tanto minus accedere possum, quanto magis ex historiae naturalis penitiore studio persuasum me habeo, non generum solum, sed familiarum etiam tribuumque et reliquarum divisionum limites adeo esse firmos, ut non alio ac specierum modo a natura ipsa positi videantur. Quo autem dicto methodos systematicas omnes omnium anctorum nolo approbare, quorum recentiores plurimi, historiae naturalis studium vix periclitati, differentias sibi observatas quantum valeant perpendere inscii, temerarias venditant dispositiones. Interest, ut characteres naturales rite cognoscantur: naturalibus enim na-

p) Germar Zeitsch. f. d. Entomologie, II. p. 210. 
turales, artificialibus artificiales sectiones definiuntur: characteres antem quinam naturales et quinam artificiales sint, non subitaria observatione sed intimo studio perspiciuntur, praesertim cum saepe accidat, ut notas easdem, quibus in aliis divisionibus determinandis utimur certis et stabilibus, in aliis fallaces omnino et variabiles reperiamus, et ne proximae quidem in quibusdam generibus species earum inter se conveniant partium structura, quae in aliis constantes praebent differentias. Qui iisdem sectionibus naturalibus omnium partium structuram eandem esse volunt, non rigidas figuras geometricas nos tractrae obliviscuntur, sed corpora animalium, quae alma natura ad vitam procreavit et conformavit.

Sectiones huius familiae principales a Latreillio conditas conservare non potui, quippe quas non solum magis artificiales quam naturales, sed vacillantibus etiam notis circumscriptas reperi. Nora dispositione usus tribus et subtribus proposui, quarum plurimae generibus Gravenhorstianis respondent, et quas generum primariorum nominibus designavi. Staphylini genuini certe huius familiae principes sunt, et principium tenuissent, nisi ab Aleocharinis adscendendo, et ad Omalinos et Proteininos descendendo tribuum ordo naturalis minus interruptus esse videatur. Non omnes enim natura divisiones alteram alteri subiunxit, sed plurimas iuxta posnit, omnes autem vario intricavit affinitatum nexu: unde cum non possimus, quin in corporibus naturalibus enumerandis et describendis seriem simplicem evolvamus, ordo omnino naturalis nostris in libris constitui nequit.

Genera nova pauca addidi, multa a variis auctoribus proposita sippressi, reliqua recepi, omnia scrupulose examinavi, et speciebus mihi cognitis cunctis respectis descripsi, ne specie singula pro generis typo usus characteres adhibeam, qui reliquis non congruant. Sacpius antennarum formam, imprimis articulorum proportionem, nonnunquam palporum etiam et pedum structuram variam in variis eiusdem generis speciebus reperi, et potius inter speciei quam inter generis notas recensui. Oris structuram licet saepenumero non sine difficulfate perspiciendam quam plurimis in speciebus inquirendam nunquam neglexi, et partes eius interiores omnium fere generum delineavi, quo facilius differentiae, quae plerumque sat insignes et semper magni momenti sunt, recognoscantur. Observationibus his instituendis microscopii compositi mei Schiekiani lenticulis magnitudinem naturalem centies augentibus usus sum.

Describendis speciebus id praecipue agendum esse arbitror, ut notae differentiaeque speciales auctori perspectae sint, ut a lectore percipiantur: novi enim descriptiones, quae verbis uberrimae omnia 
continere videntur nisi notas distinctivas, quibus neglectis species descriptae non lectori solum sed auctori etiam ipsi dubiae remanent, et specierum cognitio saepe magis perturbatur quan illustratur. Verborum copiam descriptiones nequaquam distinctiores reddere, Linnaei, Fabriciique et Illigeri exemplo liquet, brevitate vero neminem praecellere video Sayum Americanum, qui descriptiones adeo edidit concisas, ut diagnoseos volumen vix superent, nihilominus adeo lucidas ut vix speciem quandam ab illo exhibitam unquam invenies dubiam. Sunt autem auctores quoque plurimi, simili describendi modo usi, illis tamen viris ingenio impares, qui descriptionibus abbreviatis species nonnisi dubias et obscuras provulgant. 'Tanto magis igitur evitandum mihi putavi, quod mancae quam quod verbosae evadaut descriptiones, quanto difficiliores et aegrius distinguendae plurimae Staphylinorum species apparent.

Quas enumeravi species omnes ipse examinavi, exceptis nonnullis mihi invisis, ubi de loco, quo inserendae sunt, minus haesi, et quas auctorum descriptionibus adhibitis addidi: reliquas ab auctoribus nimis mance descriptas et nimis dubias omnino omisi. Gravenhorstianos typos plurimos in Museo Regio asservatos, nonnullos ab auctore ipso transmissos lustravi : specierrnn Gyllenhalianarum plerarumque specimina ab auctore et a cel. Schönherro missa, a Schüppelio et Germaro communicata, vidi, unde gravissimorum horum auctorum synonymia vix unquam dubia remansit. Staphylinos quoque a reliquis auctoribus descriptos plerosque cognoscere mihi succesit. Species autem Anglicae numerosae a Stephensio editae mihi haud extricatae sunt: libro illius de Entomologia Brittanica petenti mihi a cel. D. von $\mathrm{He}$ den, Consule Francofurthensi, benigne communicato et usui longinquo commisso, ut species pro novis descriptas plurimas cognoscerem summum quidem studium adhibui, quo saepenumero iterato, semper autem pari modo frustrato, tandem non sine taedio, licet invitus ab hoc opere decessi, nihil persecutus, nisi quod genera, quibus Angli utuntur, recenserem, et specierum icones ab elegantissimo Westwoodio pictas allegarem. Videant perinde, qui cognoscendis typis Stephensianis prosperantur, ut speciebus, quascunque ab illo prius descriptas reperiunt, nomina priora scientiae e legibus restituant: vocabula nonnulla a me proposita peritura fore parum refert: observatis scientiam auxisse iuvat.

Studio meo summa Dom. Prof. Klugii benevolentia commissae erant opes Musei Regii Berolinensis, collectione Hellwig- Hoffmannseggiana olim locupletissima et celeberrima conditi, collectione Knochiana etc. aucti, plurimorum peregrinatorum collectis stipati, cui Dom. 
Schüppel generose totam suam collectionem, speciebus Europaeis certe ditissimam, scientiae in usum tradidit, et cui ipse omnia addidi, quaecunque olim iuvenili fervore collegi. D. Prof. Germar, D. Dr. A ubé, D. Chevrolat collectionum suarum Staphylinos cunctos mihi transmiserunt, D. Prof. Ge né Staphylinos in Sardinia sibi lectos cunctos communicavit; D. Prof. Germar magis e scientiae quam collectionis suae studio omnes huius familiae, quae singulae etiam ei erant, species liberaliter donavit, ut typi quam plurimi in Museo Berolinensi conserventur. D. D. Prof. Gené et Dr. A ubé omnia quae ultra dupla eiusdem speciei individua in eorum collectionibus invenerim, humaniter concederunt, Dom. Westermann omnes, quas duplas, multas etiam quas singulas habuit species, comiter dedit; multi praeterea multa contulerunt, unde successit, nt non solum uberrimam speciminum copiam examinandi et insignem specierum numerum describendi facultatem assecutus sim, sed quo etiam factum est, ut typi quam plurimi in Museo Regio Berolinensi collecti sint. Species omnes, quibus describendis speciminibus hoc in Museo conservatis usus sum, asterisco notavi.

Opere iam finito et integro edendo nihil restat, nisi quod gratias agam publicas, Vobis, D. D. Klug et Schüppel, quorum consilia mihi nunquam defuerunt, et Vobis omnibus, qui ex amicitia et scientiae studio laboribus meis subvenire benevole voluistis.

Berol. d. III. ante Cal. Aug. MDCCCXL. 


\section{S t a p h y 1 i n i.}

\section{Decharactere.nat urali.}

Magna haec familia, notis licet ab antennarum insertione, figura et articulorum numero, ab oris partibus, a tarsorum etiam articulorum numero derivatis omnino instabilibus, tamen, quod in omnibus familiis naturalibus fieri solet, a ceteris distinguitur constante charactere: abdomine segmentis sex vel septem distinctis, liberis, omnibus corneis, aut toto nudo, aut basi ab elytris obtecto, his abbreviatis, sutura commissis, alas complicatas omnino obtegentibus. Priores plerique anctores Staphylinorum familiam coleopteris abbreviatis, quorum etiam causa a Latreillio Brachelytrorum, a Gravenhorstio Micropterorum nomine signata est, distinxerunt, elytra abbreviata autem in plerisque aliis Coleopterorum familiis obveniunt, quae vero abdominis segmenta, si posteriora sola nuda, anteriora autem ab elytris obtecta sunt, illa sola cornea, haec membranea habent (ut Silphae, Histeri, Nitidulae etc.), cum in Staphylinis segmenta dorsalia anteriora, etiamsi nonnunquam elytrorum postrema pars is imposita est, pariter cornea atque in illis reperiamus, qui elytris pectus non superantibus, abdomine toto nudo instructi sunt. Alia nonnulla coleoptera, quorum elytra adeo abbreviata sunt, ut abdomen iis sit omnino nudum et segmentis dorsalibus omnibus corneis instructum, a Staphylinis aut alis sub elytra non recipiendis (Molorchus, Atractocerus), aut, si alis carent, elytris dehiscentibus (Meloe) divergunt: Staphylinis enim omnibus, apteris etiam, coleoptera sutura commissa sunt. Sola coleopterorum familia elytris abbreviatis, pectus haud excedentibus, alis sub eltyris complicandis, abdomine toto nudo et segmentis omnibus dorsalibus corneis cum Staphylinis congruens, Pselaphi, praeter plures alios characteres, abdomine segmentis distinctis tantum quinque compositis differt, in Staphylinis enim segmenta sex semper distincta, septimum etiam saepius conspicuum. Quaedam huius familiae genera (Anthophagus, Lesteua) Caraborum quorundam habitum prae se ferunt, praeter alias autem graviores notas abdominis etiam structura distinguuntur, cum Carabis segmenta tria anteriora connata, illis omnia sint libera. 
Staphylini a Latreillio Coleopterorum sectioni Pentamerorum adnumerantur, et a Gravenhorstio etiam praeter "elytra dimidiata" tarsis 5-articulatis a reliquis Coleopteris facillime distinguendi laudantur. At studii huius familiae cultor excellens, Com. Mannerheim (Brachelytr. p. 5.) Oxytelorum tarsos triarticulatos esse observavit. Hanc Latreille quidem observationem, quam difficillimam habet, non satis exaactam fuisse suspicatus est, (Nouv. Annal. du Mus. d. hist. nat. I. p. 79.) et Oxytelorum tarsos non infra 4 articulis compositos esse contendit, (Regn. anim. ed. II. IV. p. 4:38.), attamen ex meis observationibus non solum Oxyteli, sed quaedam etiam alia genera revera sunt trimera, alia tetramera, alia quodammodo heteromera, ut tarsorum articulorum numerus, in aliis plurimis familiis constantissimus, in hac eo minus gravıoris sit momenti, ac genera simillima et proxima saepius articulorum tarsalium numero differe videamus. Plurimi Staphylini revera tarsis ommibus 5-articulatis instructi sunt. Tarsis posterioribus 5-, anticis 4 -articulatis plura Ale ocharinorum genera distinguuntur: Myrmedonia, Antalia, Falagria, Bolitochara, Tachyusa, Homalota, Phytosus, Gyrophaena, Peliusa, Placusa, Euryusa, Dinarda, Lomechusa, SiIusa, Pronomaea, Myllaena, quae hoc modo Heteromera quasi inversa vocanda sunt. Eandem, quam in his Aleocharinis, articulorum dispositionem observamus in Malachiis quibusdam, antennarum, articulis nonnullis in maribus difformiter dilatatis, e quibus species nonnullae a Fabricio Pausso adiectae, et ad quos genera Laius Guèrin et M egadeut erus West-. wood referenda sunt. Apud hos autem maribus solis tarsi antici 4-articulati, feminae 5-articulati sunt, sicuti apud Mycetophagos tarsos anticos 3-articulatos in maribus, in feminis cum posticoribus 4 articulatos esse monuit Mïller (Illig. Mag. IV. p. 206.); in tota Staphylinorum familia vero tarsi in utroque sexu eodem articulorum numero gaudent. Tarsi revera heteromeri in hac familia nondum innotuerunt. - Tarsi 4-articulati obveniunt inter Aleocharinos in Hygronoma, Oligota, Diglossa, inter Tachyporinos in Hypocypto et Tangynatho, inter Steninos in Euaestheto. Tarsis 3-articulatis sunt Oxytelini genuini et inter Proteininos GIyptoma et Micropeplus instructi. Systemati Latreilliano hanc familiam omnino adversariam esse patet.

\section{De affinitatibus.}

Affinitates Staphylinorum cum aliis familiis naturalibus variae sunt atque insequentibus accuratius illustrandae. Caraborum quorundam (Dromiorum) habitum offerunt genera Anthophagus et Lesteua, ut non solum species quaedam a Linnaeo Staphylini caraboidis nomine signata sit, sed plures etiam auctores, Fabricius et Illiger ipse, Caraborum generi nonnullas huius generis species adscripserint. Quanvis omnino victu carnivoro cum Carabis Staphylini conveniunt, pluribus notis tamen ab is distjngunntur, et praeter oris fabrican, qua Carabi ab omnibus Coleopteris terrestribus satis distant, genera illa abdominis structura supra memorata, nec non fronte ocellis duobus instructa plurimisque levioribus notis habitualibus differunt.

Silphis Staphylini summa affinitate iunguuntur, ut facile pro Silphis 
elytris fortius abbreviatis haberi possint, non modo antennis saepius apicem versus leviter incrassatis, sed abdomine etiam in utraque familia segmentis sex composito, et evenit, ut a Fabricio, Illigero pluribusque aliis auctoribus plures Omalinorum species, quae corpore latiusculo et abdomine partim ab elytris obtecto magis earum habitum prae se ferant, pro meris Silphis descriptae sint. Silphis autem abdominis segmenta dorsalia anteriora membranacea sunt, et abdominis segmentum primum minus distinctum. Praeterea Silphis genuinis Staphylini genuini, Catopibus Tachyporini propiores mihi videntur.

Ps elaphi elytris pectus hand excedentibus et abdomine nudo, segmentis ommibus corneis composito Staphylinis sunt proximi, neque victu multum ab iis discedunt, ut Euplectos, qui corpore elongato, depressiusculo Staphylinorum habitum praebent, sub nomine Stenostheti in primo collectionis suae Catalogo cel. Com. Dejean inter Staphylinos enumeraverit. Sunt etiam, qui Pselaphos omnino Staphylinis adiungunt. (Laporte Etud. Ent. p. 137.) Abdomen illis autem segmentis tantummodo 5 compositum, et praeter multas alias notas habituales praecipue maxillarum mala exteriore faleiformi a Staphylinis differunt, licet iis affines et Aleocharinis imprimis propinqui videantur.

Scaphidia elytris abbreviatis et abdomine prominulo quoque Staphylinis similia atque abdomine acuminato, segmento primo maiore, reliqua recipiente et elytris longioribus $\mathbf{T}$ a chy porinis quibusdam habitu certe affinia sunt, et Hypocyptum longlcornem etiam Paykull et Gyllenhal inter Scaphidia posuerunt. Discedunt Scaphidia a Staphylinis abdomine distinctius 5-annulato, segmentis superioribus, quae ab elytris conduntur, haud oorneis, ooxis posticis distantibus, etc.

Nitidula multae elytris magis minusve abbreviatis et abdominis pluribus segmentis nudis Staphylinorum habitum saepius prae se ferunt, ut non solum Nitidulas quasdam inter Stenos (St. spissicornis, conicus, Ficus) collocaverit Fabricius, sed recentioribus etiam temporibus Com. Laporte Nitidularum quandam formam, statura magis elongata Ipum, elytris autem fortiter abbreviatis instructam, nomine Cillaei pro Omalinorum genere descripserit. (Etud. Ent. p. 133.) E Staphylinis praecipue Omalini corporis habitu et victu pluribus Nitidulis affines videntur, propiores autem iis sunt coxarum anticarum insertione, ocellis nullis et antennis distinctius apice incrassatis Proteinini, ut Micrapeplus a Latreillio ipso et principia Prote in us Nitidulis adiectae sint. Protein us certe ad Nitidularum, imprimis ad Cercorum affinitatem distincte se vergit, abdomine licet segmentis sex composito, et coxis pasterioribus approximatis ab iis discedit. Micropeplus autem, quamquam plerisque ab auctoribus Nitidulis adiungitur, tamen antemnis in scrobiculo in inferiore thoracis facie sito recipiendis, et coxis intermediis fortiter distantibus patius Histeris appropinquatur, et sculptura etiam corporis quandam Onthophilor um similitudinem ei praebet, abdomine segmentis sex composito autem, et coxis posticis appraximatis pluribusque aliis notis Staphylinis adiungitur, licet antennis capitulatis iis quodammodo alienus videtur. A Staphylinis Nitidulae differunt praeterea maxillarum mala singula, Histeri abdominis structura, de qua conf. quae Klug Jahrb. d. Insectenk. I. p. 84 et Col. March. I. p. 649 monui.

Xyloph a is Latr. nonnulla Staphylinorum genera victu non solum, sed corporis etiam habitu affinia sunt. Glyptomati Monotomae habitus est, et 
Piestini omnino Cucuios elytris abbreviatis simulant, ut Piesti et Lep tochiri speciem quandam Fabricius ipse inter Cucuios descripserit. Magis vero, praecipue thoracis etiam forma Is omalus Cucuiis minoribus similis videtur. Dom. Laporte inter Omalinos novum genus induxit (Etud. Ent. p. 135.) In o vocatum, quod licet elytris abbreviatis instructum sit, tamen revera ad Cucuios pertinet, et a $\mathrm{He}$ mipe $\mathrm{plo}$ Latr. haud diversum videtur. Abdomine segmentis $\mathbf{5}$ composito Cucuii a Staphylinis, et elytris pectus non excedentibus Piestini a Cucuis etiam brachypteris distinguuntur.

\section{De corporis structura exteriore.}

Corpus plurimis elongatum, lineare, plerisque subdepressum (Staphylinus), rarius complanatum, (Hygromoma, Holisus, Achenium, Isomalus,) nonnunquam cylindricum (Procirrus, Stenus, Osorius), aliis convexum, ant utrinque aut saltem apicem versus attenuatum (Tachyporini), aliis brevinsculum, interdum subquadratum seu oblongo-subquadratum (Omalini Proteininique plures), nonnunquam totum tomentosum (Staphylini quirlam), aut totum pube subtili brevi depressa sericante vestitum (Conurus), rarius totum glaberrimum (Oxyporus), plerumque tenuiter pubescens, capite thoraceque saepius pube rariore subtiliore vestitis, nonnunquam glaberrimis, et nonnisi versus latera parce pilosellis (Plilonthus). Abdomen quoque practer pubescentian subtiliorem plerumque parce pilosum, praecipue latera versus.

Caput thoraci aut insertum, basi saepius magis minusve in colli fornam coarctatum, rarius nullo modo constrictum (Tachyporini), aut exsertum, thoracis apici attenuato affixum, (Autalia, Falagria, Stilicus, Echiaster, Ophites), rarius deflexum (Tachyporini), vel inflexum (Aleochara), plerumque porrectum, fronte superiore rarius prona aut retusa, antrorsum spectante (Staphylinus versicolor). Caput inferius planum, superius saepius magis ininusve convexum, fronte integra, clypeo distincto nullo, spatio eius autem nonnunquam impresso et linea impressa circumdato (Oxytelus), nonnunquam cornuta (Piestus, Zirophorus, Bledius, Platystethus), aut margine dilatato ampliata (Phloeobium).

Oculi laterales, rotundati ovative, saepius minuti et minus prominuli, interdum magni, prominentes, (Stenus, Megalops), ocellis plerumque minutis et parum convexis, rarius maioribus et fere hemisphaericis (Oxytelini), semautem hexagonis compositi.

Ocelli frontales duo omnibus Omalinis, singulum Phloeobio clypeato, reliquis Staphylinis nulli. Errore quodam Euaesthetum ocellis instructum esse affert Kirby (Introduct. III. p. 506.)

Labrum sub frontis margine anteriore insertum, porrectum, plerumque transversum, rarius latitudine longius (Boletobius atricapillus etc.), aut adeo amplum, ut reliquas oris partes obtegat (Stilicus), saepius brevissimum (Pinophilus), aliis integrum, (Aleocharini, Tachyporini), aliis bilobum, lohss rotundatis (Staphylinus, Philonthus, Lathrobium) vel divergentibus (Oxyporus, Achenium), aliis apice denticulatum (Scytalinus, Lithocharis, Stilicus, Ophites, Sunius, Echiaster), his totum corneum (Aleocharini, Tachyporini pl. rique etc.), illis corneum, limbo aut laterali et anteriore (Staphylinus, P'lilonthus, etc.), aut laterali solo membranaceo (Xantholinus, Stilicus, ets.), 
pluribus simplex, ut reliquis coleopteris, multis etiam laciniis membraneis auctum, aut in angulo utroque anteriore affixis, acuminatis, paraglossis similes (Oxytelini, Piestini), aut limbi membranei saepius bilobi ad instar sub labii margine anteriore prominulis (Bledius, Omalini, Proteinini). Limbus ille membranaceus, quem apud plurimes Staphylininos observamus, substantia cornea versus margines evanescente exoritur, a labro ipso nullo modo distinctus, laciniae haec membraneae, quibus praecipue Oxytelini et Piestini insignes sunt, appendices peculiares videntur, e membrana, qua interior s. inferıor ląbri facies vestitur, nascentes. Limbus membranacens saepius supra fortiter pilosus setosusque, laciniae membraneae margine ciliatae. Labrum totum membranaceum videtur in Tanygnatho. Insolitam formam labrum inducit in Megalope: spims duabus acutis, sub frontis margine prominentibus, porrectis referri videtur.

Mandibulae corneae, acutae, plerumque falcatae, interdum rectae (Piestus), aliis muticae, aut breviores, haud prominentes (Aleocharini, Tachyporini, Omalini plerique etc.), aut elongatae (Ocypus fam. III, Belonuchus, Oxyporus etc.), aliis plerisque medio vel ante apicem dentatis, dentibus vel simplicibus, duplicibus triplicibusve, vel bi- aut tricuspidibus, saepius inaequalibus, mandibula sinistra plerumque fortius dentata, iam breviores et validiores (Staphylinus, Philonthus), iam elongatae, tenues (Paederini, Pinophilini, Stenini), aliis interne fortiter dentatae, (Leptochirus), aliis externe ante apicem denticulo prominulo instructae (Piestus), ore clauso plerumque complicatae et haud prominentes, nonnunquam prominentes, decussatae (Oxyporus, Belonuchus), aut porrectae, rectae (Leptochirus, Piestus). Margo interior lacinia membranea, interne subtiliter ciliata auctus, plerumque mandibulae unargini interiori connata, ita ut mandibulis breviusculis apex solus liber esse soleat, in tota autem Staphylininorum tribu libera, basi sola mandibulae radici affixa.

Maxilla e cardine brevi stipiteque corneis, hoc in Piestinis nonnullis infra palporum basin dilatato. Mala utraque distincta. Mala interior stipitis margini interiori connata, plerumque membranea membranaceave, mutica, interne apicem versus barbata, basin versus ciliata, apice nonnunquam unco corneo armata (Dinarda, Proteinini et omnes Omalini), saepius simplici, rarius duplici (Lomechusa, Proteinus), quam plurimum rhombea; mala exteriore brevior, rarius elongata, mala exteriori aequali, cornea, interne apicem versus denticulata (Aleocharini nonnulli et Trichophyus), rarissime mala exteriore longior (Silusa). - Mala exterior stipitis apici inserta, plerumque segmentis duobus composita, inferiore aut corneo aut coriaceo, iam breviore, iam longiore, apicali aut membraneo aut membranaceo, hoc aut toto aut apice plerumque introrsum vergente barbato, illo semper glabro, malam interiorem plerumque superans, interdum linearis, saepius apicem versus leviter dilatata, margine exteriore nonnunquam ampliato, in Hypocypto sinuato, interdum cum mala interiore elongata, tota cornea, semper mutica.

Palpi maxillares maxillae stipiti exterius ad apicem prope malam exteriorem inserti, 4-articulati, articulo primo quam plurimum minuto, brevi, Steninis solis elongato, secundo tertioque plerumque sat elongatis, hoc nonnunquam paulo breviore, interdum brevi (Megarthrus, Micropeplus), ubi autem articulus quartus subulatus est, maiore, magis minusve, praecipue apicem versus, incrassato, articulo quarto aut reliquis subaequali, apice leviter 
acuminato, rarius truncato (Scariphaeus), vel securiformi (Astrapaeus, Taenodema, Palaninus, Oedichirus), vel transversim introrsum producto (Pinophilus), saepius minuto, subuliformi, (Aleocharinı, Hypocyptus, Conurus, Tachyporus, Mycetoporus, Leptacinus, Holisus, Diochus, Paederini, Oxytelini genuini), vel minutissimo, non nisi oculo fortiter armato conspiciendo, quo palpi triarticulati videntur (Stilicus, Echiaster, Sunius et Stenini), nonnunquam pariter minimo, at obtuso (Dolicaon, Paederus).

Labium segmentis 4 , ut in reliquis insectis, compositum, nondum satis illustratis, in hac familia plerumque omnibus conspicuis et distinctis.

Segmentum primum est mentum, semper corneum, plerumque breve, transversum, apicem versus sensim angustatum, apice truncatum vel leviter lateque emarginatum, raro maius et reliquas labii partes omnino aut maxima e parte obtegens (Pronomaea, Micropeplus).

Segmentum secundum, innominatum, membranaceum coriaceumve, in reliquis coleopteris plerisque sub mento reconditum, in hac familia autem quam plurimum magis minusve exsertum, in nonnullis, ut videtur, retractile, basi menti apici latitudine subaequali, apicem versus sensim leniter angustatum, apice truncatum, in Oxyporo bidertatum. In hac familia haec pars a Fabricio pro ligula recensita est.

Segmentum tertium, in aliis etiam plurimis coleopteris distinctum et conspicuum, segmento secundo saepius paulo latius, vel apicem versus leviter dilatatum, coriaceum corneumve, palporum labialium stipites cylindricos, corneos, saepe sat distinctos continens. Eius apici ligula et paraglossae insertae sunt.

Segmentum quartum e ligula cum paraglossis constat. Ligula semper distincta, angusta, linearis, plerumque bifida, saepius elongata in Aleocharinis, minuta, brevis in Staphylininis, in utraque tribu reliquis labii partibus multo angustior, paraglossis distinctioribus, ligulam longe superantibus in Staphylininis, subaequalibus vel ea brevioribus vel plerumque omnino nullis in Aleocharinis, paraglossis et ligula membraneis, ilis nonnumquam membranaceis vel coriaceis in Staphylininis nonnullis. In reliqua hac familia ligula latior, segmento labii tertio haud angustior, apice rarius truncata, plerumque medio magis minusve emarginata, vel incisione profundiore biloba, his lobis nonnunquam divergentibus (Leptochirus), nonnunquam spatio latiore distantibus, (Lilhocharis, Stilicus, Echiaster, Sunius, Paederus,) paraglossis iam liberis, interdum ligulam excedentibus, nonnunquam ei aequalibus eique fere incumbentibus, iam ei connatis, ut sutura earum nonnisi ciliarum subtilium serie cognoscatur, iam ommino nullis (Boletobius, Mycetoporus, Platyprosopus, Oxyporus et Omalini omnes); ligula plerumque cum paraglossis membranea, rarius membranacea, nonnunquam cornea, paraglossis autem membraneis (Scopaeus, Megalops, Osorius, Holotrochus).

Palpi labiales labii segmento tertio inserti, plerisque ut reliquis coleopteris triarticulati, articulo tertio nomnunquam securiformi (Scytalinus, Staphylini et Ocypodes nomnulli, Astrapaeus, Euryporus), vel hemisphaerico (Sraphyl. canaliculatus), vel lunato (Oxyporus), saepius minuto, subulato (Iypoeyptus, Mycetoporus, Ieterothops, Leptaoinus, Holisus, Diochus, Paederini, Stenini), in plerisque filiformes, in Aleocharis etian, in Conuro, Tachyporo, Phoeocharide et in Oxytelmis genuinis, qui palpis maxillaribus subuliformibus instructi sunt. Quadri-artioulatos eos observavi in Aleochara, 
bıarticulatos in nonnullis Aleocharinorum generibus, neque in Trichophyo ultra duos articulos vidi. Palpis labialibus exarticulatis, setaceis nomnulla Aleocharinorum genera insignia sunt.

Antennae vel plerumque infra capitis marginem lateralem inter oculos et mandibulas, vel superne iam in frontis margine anteriore, intra mandibularum basin (Staphylinini), iam ad oculorum marginem interiorem (Aleocharini), iam in media fronte (Stenini) insertae, plerumque articulis 11, nonnunquam 10 (Oligota, Hypocyptus), vel 9 (Micropeplus) compositae, quam plurimum filiformes, vel apicem versus subincrassatae, nonnunquam articulis ultimis tribus praecedentibus paulo crassioribus, (Bledius, Acrognathus), interdum clavatae (Stenini, Megalops, Glyptoma), vel capitulatae (Micropeplus), paucis capillares, verticillato-pilosellae (Habrocerus, Trichophyus), plerisque rectae, aliis geniculatae, flagello antrorsum directo (Xantholinini genuini, Acylophorus, Cryptobium, Ophites), aut refractae, flagello retrorsum vergente (Oxytelini plurimi). Articulus primus magis minusve validior, et ubi antennae genuiculatae sunt, saepius sat elongatus, secundus tertiusque sequentibus quam plurmum paulo maiores, praecipue longiores, hic plerumque illo magis elongatus, prumo gracilior. Antennae interdum caput et thoracem longitudine excedunt, raro corporis fere longitudine (Prestus), saepius capite thoraceque breviores, nonnunquam capite vix longiores sunt.

Thorax sensu stricto seu prothorax forma magnopere varians, ple. risque marginatus, aliis immarginatus (Lathrobium), vel cylindricus (Stenus), nonnunquam fortiter elongatus (Ophites), apice interdum, ubi caput omnino exsertum est, attenıatus, (Autalia, Falagria, Ophites, Stilicus, Echiaster, Sunius), nonnunquam utrinque oblique truncatus (Xantholinus, Lithocharis), plerumque truncatus, in multis etiam emarginatus, angulis anterioribus prominulis, caput amplectentibus (Tachyporini), basi nonnunquam coleopteris arcte applicatus vel ea amplectens, (Tachyporini), interdum etiam ab iis remotus, (Leptochirus), aliis rotundatus, aliis truncatus; infra prosterno triangulari, coxarum anticarum insertionem haud excedente, e pi meris et epis ternis nullis, in plerisque spatio pone coxas anticas absque integumento cornen, nonnisi membrana clauso, stigmate prothoracico utrinque pone coxam anticam sito aut peritremate corneo distincto, nudo in Aleocharinis, Tachyporinis et Staphylinis Xantholininis et genuinis, vel processu membranaceo corneove triangulari obtecto in Staphylininis Oxyporinis, iam stigmate peritremate corneo nullo, sub integumento corneo pone coxas anticas introrsum producto occulto, in Paederinis, Oxytelinis, Phloeocharinis, Omalinis; in nonnullis integumento corneo integro, spatium pone coxas anticas etiam omnino claudente (Pinophilini, Stenini, Piestini, Proteinini).

Scutellum plerumque distinctum, triangulare aut rotundatum, rarius inconspicuum (Stenini, Oxytelini genuini plerique).

Elytra abbreviata, plerumque pectoris longitudine vel nonnunquam eodem paulo breviora (Aleochara), rarius pectore longiora, (Hypocyptus, Tachyporus, Conurus, Habrocerus, Tachinus, Omalini, Proteinini) et in his saepius abdominis summam basin, rarius maiorem eius partem (Lathrimaeum, Anthobium, Proteinus) obtegentia, apice truncata, saepius coniuncta emarginata, rarius angulo interiore producto (Anthobia quaedam), angulo exteriore iam rotundato (Omalini), iam saepius recto, iam in multis profundius inciso (Oxypoda, Tanygnathus), lateribus in omnibus inflexis, saepe marginatis, 
sut:ra plernmque ut in reliquis plurimis coleopteris integerrima, in Xantholinis genuinis imbricata.

Alae in plerisque Staphylinis obviae, exsertae abdominis apicem attingentes, longitudinaliter complicandae, plicaturis transversis duabus, altera infra, aliera ultra medium. pone plicaturam priorem stigmate oblongo coriaceo instruetae. Basi nervi longitudinales tres oriuntur, anterior in stigma, reliqui an marginem posteriorem, intermedius ad plicaturam seoundam, posterior ad plicaturam primam excurrunt. Nervi praeterea duo longitudinales pone plicaturam primam, anterior ex stigmate, posterior ante nervum e alae basi nascentem intermedium orientes longitudinaliter ad alae apicem vergunt, et anterior eorum ante, posterior pone alae apicem sensim tenuiores excurrunt.

Pectus mesothoracis breve, metathoracis amplius, mesosterno minuto, triangulari, plerumque simplice, interdum carina longitudinali subtili, (Conurus) rarius fortiore et magis prominente (Tachinus*) instructum, metasterno sat amplo, pectoris maxinam partem occupante, simplex, episternis et epimeris mesothoracis rhomboideis, methathoracis. ad metasterni latera sitis, maxima parte ab elytrorum margine inflexo obtectis, angustis, coniunctis pảrallelopipedis, sutura diagonali divisis, epısternis posterilis, epineris antrorsum angustatis, his nonnunquam metasternum excedentibus, posterius prominulis (Aleocharini).

Abdomen quam plurimum totum aut maxima e parte nudum, plerumq1:e lineare, saepius apicem versus angustatum, in nonnullis Tachyusis etiam hasin versus attennatum, in Omalinis latiusculum, saepius marginatum, rarius immarginatum (Conurus, Palaminus, Oedichirus, Procurrus, Steni permulti, Buaesthetus quidan, Osoriu, Holotrochus, Leptochirus, Lispinus, Glyptoma), marginatum plerumque dorso saltem depressiusculum, immarginatum plerumque cylindricum, vivis mobile, praecipue elevandum et deflectendum, nonnullis apice deorsum curvatum (Boletobius, Nycetoporus), aliis sursum revolutum (Aleocharini permulti, praecipue Myrmedonia, Autalia, Falagria, Lomechusa), pluribus etiam, quando cursum accelerant, elevatum; segmentis omnibus liberis, anterioribus plertunque subaequalibus, rarius inaequalibus, (Tachyusae quaedam, Hypocyptus), quinto nonnunquam reliquis paulo longiore. Segmenta sex semper valde distincta, dorso inter metathoracem et segmentum abdominis primum segmentum peculiare observandum, licet brevissimum, stigmate vero instructum, ita ut revera primum sit, a reliquis autem interstitio membraneo distinetum, metathoraci arctius adhaerens, inferne autem vestigio nullo detegendum, in descriptionibus mihr neglectum, ne in enumerandis segmentis segmenta dorsalia et ventralia numero incongrua lectorem irritent.

Abdominis segmentum septimum organa sèxualia exteriora continens it includens, quarlvivalve, valvula dorsali integra, ventrali in maribus integra, in feminis longitudinaliter oblique fissa, ceterum valvulae dorsali subaequali, nommunquam utrinque in processum styliformen elongata (Gymnnsa), val:ulis lateralibus saepe cylindricis, fortius pilosis setosisque, a reliquis magis remotis, stylos anales referentibus (Tachinus, Tachyporus, Staphylinini plerique et permulti Paederini Pinophilique etc.), nomnunquam basi compressis et valvuliformibus, apice styliformibus, vel uncinatis acuminatisgure (Achenium), aut valvulis intermediis longioribus (Lathrobium quadratum), ant isslem aequalibus (Staphylinus), aut iisdem brevioribus (Gymnusa) 
in reliquis totis valvuliformibus, valvulis intermediis arcte applicatis. In multis segmentum septimum totum reconditum (Aleocharini multi, Piestini, Omalini, Proteini), ut nisi nonnunquam in maribus, ubi segmentum sextum excisum sive emarginatum est, conspici nequeat, in plerisque autem exseren:dum, ut quanto magis abdomen potensum sit, tanto magis promineat, in aliis etiam totum exsertum et haud retractile, licet segmentis reliquis minus (Pliytosus, Lomechusa, et Oxytelini omnes).

Staphylinini plurimi, prehensi aut alio modo excitati prope anum utrinque papillam cutaneam exserunt, quibus forte odorem emittunt, quarum indoles autem nondum satis constat.

Pedes plerumque breviores, inter se longitudine subaequales, anteriores saepius paulo breviores et validiores, posteriores plerumque paulo longiores, raro reliquis debiliores (Xantholinus), antici et postici semper insertione approximati, intermedii saepe distantes, interstitio plerumque angusto, nomnunquam etiam latissimo, ut pedes intermedii pectoris lateribus insertae videantur (Oxyporus).

Cox a e anticae maiusculae, conicae, exsertae, retrorsum vergentes, thoracis spatium integumento corneo destitutum obtegentes in plerisque, minutae, parum prominulae in Steninis, parvae, globosae, haud exsertae in Piestinis, subcylindricae, oblique positae, ex acetabulis vix prominentes in Proteininis. Coxae intermediae oblique positae, conicae aut subcylindricae, ex acetabulis haud prominentes. Coxae posticae subconicae, minores, quodammodo mobiles in Staphylininis, Paederinis, Pinophilinis, Steninis, transversae, subcylindricae, pariter paululum secundum axem transversalem mobiles in Oxytelinis, Piestinis, Phloeocharinis, Omalinis et Proteininis, transversim parallelopipedae, fixae in Aleocharinis et Tachyporinis, in his nonnunquam amplioribus, scutiformibus (Boletobius, Mycetoporus).

Trochanteres anteriores simplices, postici aut simplices (Staphylilinini, Paederini, Stenini, Oxytelini, Piestini), aut fulcrantes (Aleocharini, Tachyporini, Phloeocharini, Omalini, Proteinini).

F emora plerumque simplicia et mutica, nonnunquam antica incrassata (Lathrobium), aut antica et postica inferne spinularum serie duplici instructa.

Tibiae nomnunquam spinulosae, et apice spinis apicalibus validioribus instructae, hae autem saepe minutissimae, anticae in aliis minus (Staphilinus, Philonthus etc.) in aliis magis spinulosae (Bledius), nonnunquam externe incrassatae et spinulis frequentibus muricatae (Xantholinus), interdum campressae et spinularum serie externe armatae (Oxytelus), aut denticulatae (Leptochirus, Piestus), pler!mque integrae, nonnunquam ante apicem excisae (Oxytelini nomulli); posteriores nonnunquam apice dilatatae, aut oblique truncatae (Lathrobium), aut emarginatae vel excisae (Pinophilini).

Tarsi articulorum numero inconstante supra iam accuratıus illustrati, antici aliis simplices, aliis articulis $\mathbf{4}$ primis magis minusve dilatatis, subtus plerumque tomento denso vestitis, nonnunquam lobis membraneis instructis (Pinophilus); posteriores simplices articulis primis ant aequalibus, brevibus, aut inaequalibus, primo magis minusve elongato, sequentibus sensim brevioribus, penultimo nonnunquam bilobo (Paederus, Steni permulti), aut minuto, subtus lobo membraneo aucto (Sunius, Pinophilini), ultimo s. unguiculari plerumque magis elongato, leviter clavato, unguiculis binis, aequalibus, simplicibus. 
Stigmata 10 in utroque corporis latere, primum (prothoracicum) pone coxas anticas in inferiore corporis pagina situm, magnum, in Aleocharinis, Tachyporinis et Staphylininis peritremate corneo instructo, secundo (mesothoracico) pone elytrorum insertionem inter mesothoracis dorsum et episternum situm, occultum, tertium (metathoracicum) in dorsi margine laterali sub elytris inter metathoracis scutum dorsale et eius epimera situm, permagnum, reliquis abdominalibus, primo in segmento dorsali basali, reliquis in segmentis abdominis sex sequentibus dorsalibus prope marginem lateralem sitis, parvis, omnibus oblongis, fimbria laciniata subtiliter ciliata clausis.

\section{De corporis structura interiore.}

Trachea e simplices, stipitibus maioribus in thorace, ubi stigmata sunt grandiora, fortioribus.

Systema nervorum cerebro bilobo, ganglio capitis, (cerebello) sub cerebro sito, ganglio prothoracico in anteriore thoracis parte sito, mesothoracico et metathoracico coalitis, ganglium singulum, reliquis multo mains, globosum, in mesothorace ante pedum intermediorum insertionem situm, formantibus; gangliis abdominalibus 7 , tribus primis in medio metathorace sitis, approximatis, primo maiore, tertio in summa abdominis (segmenti primi) basi, quinto in segmento secundo, reliquis duobus in segmento tertio sitis, approximatis, septimo (ganglio sexuali) oblongo, in mare inter testiculos, in femina inter ovaria sito. Nervorum intestinalium systematis imparis ganglion frontale sub anteriore frontis margine situm, systematis paris ganglia bina pone et fere infra cerrebrum oesophagi lateribus apposita, approximata.

Tubus intestinalis corpore vix sesqui longior. Oesophagus tenuis, sensim in ventriculum transiens. Ventriculus in mesothorace situs, parum amplus, subovalis, interne costis corneis longitudinalibùs dense vil. losis, per paria alternation fortioribus et fortius villosis, paribus earum fortioribus et subtilioribus quaternis. Duodenum amplissimum, a metathoracis basi ad abdominis apicem usque extensum, rectum, undique papillis intestinuliformibus dense quasi villosum. Intestinum ieiunum flexuosum, minus elongatum, colon simplex, absque coeco, rectum haud distinctum. Vasa biliaria bina, ansata, orificiis quatuor intestini duodeni apici inserta, libera (int. coloni haud affixa).

Organa sexualia mascula: Testiculi duo, integra, oblongi, vase deferente tenuissimo breviore ductui eiaculatorio inserti. Vasorum secernentium paria duo, in ductus eiaculatorii apice sita, interiora saepius longiora, cylindrica, intestinuliformia, exteriora sacciformia. Ductus eiaculatorius sat longus, flexuosus, apicem versus spinam longam tenuem corneam continens. Testiculorum structuram inquirens Leon Dufour vasis spermatici nullum vestigium, sed pulpam aequalem in is invenit. Ipse in Staphylino caesareo testiculum vasis cuiusdam spermatici ramosi finibus plurimis, intestimuliformibus, apicibus incrassatis glandulae conglohatae fere speciem pracbentihus, accuratius autem oculo fortiter armato examinatis, convolutis, apice sumumo puncto obscuro, forte acino instructo. Tracheae numerosae in testiculo pertextae sunt. Penis corneus, subcylindricus, seta comea laterali fultus. 
Organa sexualia feminea: Ovaria fusiformia, funiculis ova continentibus pancis (tres in Ocypod. olente observavit Leon Dufour, ipse in Staph. maxilloso quatuor). Calices elongati. Oviductus communis bipartitus. Portio anterior calices excipiens dilatata, subglobosa vel fere transversa, uteriformis, portio posterior longior, cylindrica; bursa copulatrix eiusdem apici inserta, pyriformis, apice vasculo filiformi instructa. Appendices aliae nullae.

Structura corporis interna Staphylini minus Carabis, qui vasis analibus, testiculo e vase singulo convoluto formato et vasis biliaris ternis discedunt, quam Silphis et Histeris propinqui sunt, cum illis testiculorum structura, cum his oviductu basi simplice dilatato conveniunt. Intestino (duodeno) papilloso maximo et amplo praecipue excellunt. Conf. de tubi intestinalis structura: Le on Dufour Annal. des Sciences naturelles III. p. 219. t. 10. f. 6. 7. (Staph. erythropterus) f. 8. (Staph: punctatissimus (?)) f. 9. (Paederus riparius). - Ramdohr Verdauungswerkzenge der Insecten p. 87. t. 3. f. 4. 5. 6. (Staph. politus) - de organis genitalibus masculis: Leon Dufour 1. c. VI. p. 161. t. 5. f. 5-8. (Staph. olens, maxillosus, erythropterus, punctatissimus, Paederus riparius), de organis genitalibus femineis: Le on Du four ibid. Vl. p. 435. t. 17. f. 7. (Staph. olens). Ipse Staphylno maxilloso et caesareo dissectis observationes anatomicas supplevi.

\section{De metamorphosi.}

Ov a Staphylinorum oblonga, sat magna, at pauca.

Larvae adultae corpus elongatum, apicem versus attenuatum.

Caput magnum, orbiculatum, basi constrictum, collo quasi seu isthıo brevissimo thoraci insertum, subtus planum, supra leviter convexum, fronte apice denticulata, clypeo haud distincto.

Ocelli 4, quadratim positi, approximati, in utroque capitis latere pone mandibularum basin siti.

Os clausum.

L abrum brevissimum, sub frontis margine occultum, aegre observandum.

Mandibulae magnae, porrectae, falcatae, acutae, simplices, interne ante apicem apertura instructae.

Maxill a e infra mandibulas insertae, a labio distantes, corneae, stipite elongato cylindrico, cardine brevi, mala singula, simplice.

Palpi maxillares stipiti crassiusculo, brevi, articulum basalem siminlanti insertae, 4-articulati, articulis primis duobus longioribus, subaequalibus, teretibus, tertio minore, tenuiore, apicem versus sensim attenuato, quarto minimo, subulato.

Mentum membraneum, transversum.

Labium subquadratum, basi corneum, apice membranaceum.

Ligula minuta, angusta, porrecta, cornea. subulato.

Palpi labiales triarticulati, articulo primo longiore, tertio minimo,

Antenna e 5-articulatae, articulo primo brevi, secundo elongato, tertio quartoque decrescentibus, quinto minimo, subulato.

Segmenta thoracica supra scutis corneis instructa, infra membra- 
nea, prothoracica maiore, infra antice sterno triangulari scutulisque dnobus adiacentibus instructo, meso - et metathoracico fortiter transversis.

Pedes breves, ad latera segmentorum thoracicorum inserti, coxis cylindricis, oblique introrsum directis, trochanteribus brevioribus, femoribus teretibus, inferne spinulosis, tibiis teretibus, undique spinulosis, tarsis minutis, articulo simplice et ungue leviter falcato, acuminato, singulo compositis.

Segmenta abdominalia 9, latitudine decrescentia, penultimis palilo longioribus, supra et infra areis binis coriaceis instructa, segmenta prima supra scuto corneo obtecto, ultimo toto coriaceo, cylindrico, apice caudis duabus articulatis instructo.

Caudae anales biarticulati, articulo primo longissimo, secundo te nuiore, apice seta longa rigida terminato.

Anus foriter prominens, tubulosus, descendens.

Stigmata 18, vel 9 paria, pari primo prothoracico, reliquis pari singulo in abdominis segmentis $1-8$ singulis siti.

Stigmata prothoracis maiora, infra in membrana interstitiali inter pro- et mesothoracem posita. Mesothorax et metathorax stigmatibus carent. Stigmata abdominalia in segmenti cuiusque facie superiore, in areae coriaceae dorsalis margine laterali, paulo ante medium postita, minuta, orificio elevato.

Segmenta thoracica ante quam penultima cuticula deponitur, membranea, abdominis segmentis aequalia, testibus Frisch (Ins. Germ. V. p. 49.) et Heer (Obs. ent. p. 20).

Staphylinorum larvae inter se satis convenire et nonnisi notis levioribus discedere videntur; ab aliorum Coleopterorum larvis facile distinguendae sunt. Caraborum larvae discedunt ocellis senis, ore aperto, mandibulis dentatis, maxillis prope labium insertis, mala biarticulata, palpiformi, tarsis bi-unguiculatis, abdominis segmento ultimo utrinque corniculato, caudis analibus nullis, stigmatibus abdominalibus lateralibus, inter segmenta dorsalia et ventralia sitis. Dytiscorum larvae corporis habitu, ore clauso, mandibulis simplicibus perforatis, maxillis distantibus, mala simplici instructis, palpisque gracilioribus eximie cum Staphylinorum larvis congruunt, differunt autem ocellis senis, maxillarum mala unciformi, ligula lata, transversa, tarsis bi-unguiculatis, ano haud exserto, caudis analibus elongatis, exarticulatis, tubulos respiratorios referentibus, stigmatibus, licet conspicuis, clausis.

Magis propinquae sunt Silpharum et Histerorum larvae. Illae (Silphae cuiusdam et Catopis fusci larvis comparatis) differunt capite minore, deflexo, ore aperto, labro exserto, mandibulis haud prominulis, maxillis mala interiore sat forti, interne denticulata aut spinulis armata, exteriore nonnunquam distinguenda, licet parva et obsoleta, labio lato, emarginato, ligula nulla, palpis minus elongatis, maxillaribus 3-, labialibus 2-articulatis, ocellis utrinque sex, 4 approximatis lateribus supra antennarum basin ut in Staphylinis, duobus ab his remotis in genis infra antennas versus mandibularum basin sitis, stigmatibus in inferiore corporis facie obviis - haec (secundum llist. merdarii larvam, cuius specimen a cel. Mïllero sibi missum Dom. Scliiippel mecum communicavit, a Paykullo Mon. Hist. t. I. f. I. perperam delineatam) multo magis affines, praecipue capite porrecto, labro occulto, palpis elongatis, gracilibus, mandibulis autem dentatis, maxillis mala 
destitutis, ligula nulla, ocellis omnino nullis, corporis segmento prino (prothoracico) solo corneo, pedibus omnibus brevissimis, ano tubuloso haud exserto.

Nympha membrana tenui obducta, uti reliquae coleopterorum nymphae, margine prothoracis anteriore setis erectis instructo insignis.

Primus Staphylinorum metamorphosin observavit noster Frisch, qui (Ins. Germ. V. p. 49. t. XXV.) speciei cuiusdam mediae magnitudinis, quam hutusque pro Staph. erythroptero caesareove habuerunt auctores, quae potius autem ad Tachinum quendam referenda videtur, historiam accuratius descripsit. Alterius cuiusdam speciei minutae, forte Oxyteli cuiusdam, (ibid. p. 50. t. XXVI.) cuius larvam in fimo sicciore auctor invenit, historia non indubia videtur, cum larva pedibus ventralibus instructa exhıbeatur, quam ob rem commutatione quadam Lepidopteri cuiusdam pusillam erucam pro Staphilini larva h. I. Suppositam esse suspicor. Cel. Gravenhorst deinde (Micr. p. LXI.), similitudine quadam exteriore deceptus, Carabi genuini larvam pro Staphylini cuinsdam maioris larvam perspicue descripsit. Recentioribus temporibus plures et magis exacte Staphylinorum larvae observatae sunt. Dom. B ouché Philonthi aenei (Hist. nat. I. 179. 1. t. VII. f. $29-35$.), Quedii fulgidi (variabilis) (ibid. 180. 2. t. VIII. f. 1-8.), Xantholini punctulati (ibid. 181. 3. t. VIII. f. 9-13.) et Platystheti morsitantis (ibid. 182. 4. t. VIII. f. $14-21$.) metamorphoses illustravit, Dom. Heer Ocypodis olentis historiam et larvae strueturam accuratius exhibuit (Obs. Ent. 16. 5. t. 3. A.), eiusdam speciei larvan et nympham Dom. Blanchard (Guerin Mag. Zool. VI. t. 165.) mance, Dom. R atzeburg (Forstinsect. I. p. 30. it. 1. f. 14.) eleganter delineaverunt, Dom. W a t erhous e denique (Transact. Soc. Ent. Lond. I. p. 32. t. 3. f. 2.) Quedii tristis larvam proposuit. Descriptiones auctorum modo laudatorum secundum singulum larvae cuiusdam (nescio num Staphylini an Ocypodis, anne potius Philonthi cuiusdam maioris, sine dubio autem Staphylinini cuiusdam genuini) specimen, plures per annos mihi conservatum, supplevi, et observationes quasdam maioris momenti, quae auctores reliquos fugerunt, de eius structura addidi. Plurimorum Staphylinorum metamorphoses illustrandas posteris relinquimus.

De victu.

Victu Staphilini plerique non solum putredine delectari, sed carnivori esse videntur, ut plurimi in fimo, in vegabilibus putridis et in boletis obvii, aliis etiam insectis, praecipue Dipterorum larvis, quibus materies illae putrescentes abundant, ibidem insidiari videantur. Multi etiam animalium cadavera copiosi aggrediuntur et cum Silphis carne putrescente vescuntur. Stercus praecipue habitant Tachini, Staphylini nonnulli, Philonthi, Oxyteli, vegetabia putrida Aleocharini plerique, Conuri, Tachypori, Quedii, Paederini plurimi, boletos Aleocharini permulti (Autalia, Bolitochara, Gyrophaena etc.), inter Tachyporinos Boletobii et Mycetopori, inter Staphylininos imprimis Oxypori. Caraborum more Staphylini maiores (Staphylini genuini, Ocypodes), interdiu in terra, sub musco, foliis deciduis et lapidibus latitant, noctu circumvagantes insecta venantur, alii interdiu in arena riparia humida summa agilitate cursitant (Steni, Tachyusae). Permulti etiam sub arborum cortice latent: inter Aleocharinos Phloeoporae nonnullae, Ho- 
malotae et secunda Oxypodarum sectio, inter Staphylininos Quedii nonnulli (Q. laevigatus, scitus), dein Piestini omnes et Phloeocharini, Glyptoma. Osorii sub cortice putrescente cuniculos sibi parant. Bledii quoque, alii in arena riparia vel littorali, alii in terra pingua cunıculos, nonnunquam sat profundos effodiunt. Simili ac nonnulli littorales Bledii vitae ratione Aleocharinorum species, Diglossa mersa, insignis, quae in arena littorali aestu inundata degens, alternis vicibus fluctu obtegitur. Floribus delectantur Nitidularum more Omalinorum plurimi et Proteinus.

In formicetis etiam quidam Staphilini quaerendi, praecipue Aleocharini: Lomechusa, Dinarda, Euryusa, Myrmedoniae, e reliquis etiam generibus species singulae, e. g. Falagria thoracica, Homalota anceps, Aleochara angulata, e reliquis Staphylinis pariter species singulae, e. c. Stenus aterrimus.

Permulti Staphylini in ripis occurrunt, praecipue Paederi et Steni, multi Aleocharini et complures Oxytelini. Nonnulli etiam nonnisi in maris littoribus obvii sunt, aut sub fucis putrescentibus (Philonthus xantholoma, fucicola), aut in humo fluctu salso humectata (Bledius furcatus, unicornis); hi pariter in lacuum salsorum ripis obveniunt, qui similem sale praegnantem glebam is praebent.

Larvis eadem vitae ratio ac imaginibus est. Plurimae pariter vagae sunt. Ocypodis olentis larva, larvarum Cicindelarum more, in cuniculo latet, quem, mandibulis terram arripiens et pedibus anterioribus proiiciens, dein ex profundo mandibulis terram tollendam auferens, dimidium vel totum pedem profundum, oblique descendentem parat. Plerumque larva in cuniculi orificio cubans, mandibulis apertis insectis praetereuntibus insidiatur, quae, simulatque ea prehendere valet, minora in cuniculi fundum secum detrahit, maiora, pedibus anterioribus praedam arripiens, posticis adnixa, in cuniculi orificio depascit.

O. olentis larvam erucam, quam ei praebuerat, devoravisse, alterius erucae, brevi tempore post ei oblatae tantummodo sanguinem bibisse tradit Dom. Heer, at patet ex oris omnino clausi, mandibulis solis perviis praediti structura, eam nonnisi sugendo ex praeda sua nutrimentum capere. Haec res accuratissimum Frischium non omnino fugit. Helices etiam larvam illam avide arripuisse, at ore muco illarum obducto relinquisse, helicem dissectam autem paulatim devoravisse Dom. Heer observavit. Nocte semel larvam extra cuniculum circumvagantem vidit. Ad cuticulam deponendam in cuniculi imam recedit partem, orificium terra clausum reliquens. In nymphae statum transiens speluncam ovatam, intus laevigatam et politam sibi parat. Quinque prope menses hoc statu peragit.

Larvae praecipue versus autumnum, per hiemem et primo vere obviae sunt. Imagines etiam plurimi in terra, in fimo, sub foliis putridis, musco, lapidibus et sub arborum cortice hibernant. Vere et autumno tempore mevitliano, aestate vesperi coelo sereno plurimı volitant.

\section{De distributione geographica.}

Cum omnino insectorum, quae non solum e remotis orbis nostri terrarum regionibus adportantur, sed in nostris etiam terris quotidie nova reperimtur, numero in immensum quantum continuo gliscente, tot tantisque terrarum plagis ne a fugitivo quidem nature strutatoris calce tactis, plerisque 
regionibus magis ex eo, quod forte in peregrinatorum manus incidit, cognitis, quam rite perlustratis, insectis ipsis denique, imprimis minutis, quae undique obveniunt, nondum satis examinatis et illustratis, ut, quae e diversis regionibus allata specie divergant conveniantve satis sit recensitum, iam omnino in eo esse nobis videri non possumus, ut nisi quod periculi speciem prae se ferat aliquid de distributione insectorum proferre valeamus, tum praecipue de Staphylinorum, qui ob studii diffultatem et corporis habitum ingratum et quam plurimum exiguum ab observatioribus et collectoribus insectorum plerisque maxime neglecti sunt, rationibus geographicis minus nondum instructos nos esse elucet. Etiamsi observatones meae hac de re paucae et imperfectae sunt, tamen en minus eas promere dubito, quanto magis studio huius familiae speciali intersunt.

Numerus Staphylinorum relativus certe non adeo exiguus est, yuam e faunis plerisque et e catalogis collectionum patere videtur. In collectione Dejeaniana, quam in omnibus coleopterorum familiis aequaliter fere locupletem esse constat, Staphylini vix ultra tricesimam partem occupant, et Carabis numero plus triplo inferiora sunt. In Stephensii contra enumeratione Insectorum Angliae Staphylini quartam paene Coleopterorum partem amplectuntur, et Carabis duplo prope sunt numerosiora, et idem fere in Fauna mea Marchica reperio, ubi Staphylini Carabos duplo numero superant. Hanc eandem proportionem etiam omnino valere mihi persuasum, nam specierum exoticarum copia eam ob causam exigua in collectionibus reperitur, quod peregrinatores Staphylinis plerisque parvulis et victu absconditis minus quam aliis Coleopteris colligendis operam navaverunt, et quamquam auctores quidem (Perty, Lacordaire) Staphylinos in tropicis terris multo minus copiosos esse quam apud nos affirmarunt, tamen hanc rem non solum ob causam modo laudatam revera sic sese habere acclamare nequeo, sed eo etiam de facto, quod insectorum quidem collector sedulus gnarusque, D o m. Moritz, ex America aequinoctiali tantum ex hac familia specierum numerum apportavit, ut non modo ne minutarum quidem specierum copia tropicis regionibus terrae nostrae praestare videantur, sed ex eadem etiam proportione, quam apud nos valere memoravi, duplum fere eorum quam Caraborum numerum collegerit. Cave autem, cum in quavis regione Staphylinorum copiam maiorem esse Caraborum numero constare videatur, ne ex eadem ratione omnino Staphylinos numero duplo superare Carabos concludas, cum Staphylinorum species singulae multo magis dissipatae sint, ut in regionibus aliquantum distantibus Caraborum fauna maxima ex parte alia, Staphylinorum eadem sit. Specierum Europaearum maiorum pars per totam hanc orbis terrarum partem obvia est, ut nostrarum plurimae pariter Lapponiam atque Siciliam habitent, et plurimae quae in tota Asia septentrionali (Sibiria) reperiantur species cum Europaeis congruant, multae etiam per totam Orientem (Asiam minorem, Syrian, Aegyptum) inveniantur, aliae pariter in America septentrionali indigenae sint, nonnullae remotioribus etiam locis reperiantur. Sequentia sunt quae hac de re hucusque observavi facta:

Totam fere Europam et Orientem habitant:

Homalota gregaria.

Aleochara tristis.

bisignata.

- nitida. 
Leptacinus batychrous.

Philonthus intermedius.
- cephalotes.
- ebeninus.
- bipustulatus.
- quisquiliarius.

Stenus bipunctatus.

Platysthetus cornutus.

Oxytelus piceus.

Per omnem Europam et in China meridionali occurrit:

Conurus pubescens.

Per omnem praeter maxime borealem Europam, in Mauritania et in Teneriffa invenitur:

Ocypus olens.

In omni Europa et in Africae fine meridionali obvenit:

Oxytelus sculpturatus.

Plures sunt species Americae septentrionali cum Europa communes, partim ab auctoribus secundum patriam alteram altero nomine impositae:

Homalota analis.

lividipennis (Oxypoda livida Dej.)

Aleochara fuscipes (Aleoch. lata Grav.)

Tachinus silphoides (Tachyporus marginalis Grav.)

Staph. fossor (Staph. fodiens Grav. forte).

Ocypus ater (Staph. nigripes Dej.)

Philonthus cyanipennis (Staph. coeruleipennis Mannerh.)

- a neneus.

- ventralis (Staph, anthrax Grav.)

- fulvipes.

Quedius fulgidus (Staph. Groenlandicus Zett.)

Stenus Juno. molochinus (Staph. laticollis Grav.)

e quibus Philonthus ventralis etiam in Americae meridionalis (Indiae occidentalis) insulis occurrit.

Nonnullae etiam Europaeae species pariter in Orientem atque in Americam septentrionalem patriam extendunt:

Philonthus debilis.

Oxytelus seulptus. nitidulus.

In locis magis distantibus et remotis observantur:

Philonthus varians in Europa, in Oriente, ad Promontorium Bonae Spei atque in Americae meridionalis insulis.

Aleochara morion.

Philonthus discoideus.

Lithocharis ochracea in Europa et in variis Americae meridionalis locis.

Species Americanae magis quam Europaeae certis limitibus circumscriItae videntur, ita ut Staphylini Columbiae plerique ab iis Brasiliae, Ame- 
ricae meridionalis ab iis Americae septentrionalis distinctae sint. Speciem nonnisi singulam novi, quae totam Americam habitare videtur: Oxytelus insignitus (O. Americanus Dej.), et paucae sunt ex iis, quae Americam septentrionalem incolunt, quae ultra eius fines, sicut Staph. villosus in Mexico quoque et in Cuba obvius est, vel ultra mare Antillarum, sicut Belonuchus formosus (Staph. rufipennis Fab.) Cayennam et Columbiam habitat, indigenae observantur.

Ut e reliquis insectis formae maiores secundum geographicas rationes distributae, minores et praecipue minimae per omnes plagas dissipatae esse videntur, sie apud Staphylinos etian genera pleraque e speciebus parvulis constituta per totum terrarum orbem occurrere videntur, speciebus tropicis et septentrionalibus simillimis. Steni in Europa numerosi, multi in America vel septentrionali vel meridionali, nonnulli in Madagascar occurrunt et in India orientali etiam posteriore eosdem sibi observatos esse literis certiores nos fecit Dr. Helfer. Falagriae, Homalotae, Aleocharae, Conuri, Bledii, Oxyteli eodem modo ubique obvenire videntur. Nonnullaè etiam genera, paucas tantum species continentia, pariter apúd nos et in America tropica reperiuntur, ut Tanygnathus, Heterothops. Alia autem sunt genera numerosiora nonnulla, quae regiones temperatas non excedere videntur, ut Tachypori ultra Europam et Americam septentrionalem haud observati sunt, et Tachinorum sectio altera praecipue tropicis plagis, altera Europae et Americae septentrionali minus calidae peculiaris videtur. Sunt etiam quae nonnisi tropos habitant, ut Piesti, Leptochiri. Et quamvis pleraque Staphylinorum geniera, licet iis, quae singulam vel paucas species continent, exceptis, Europae cum remotioribus etiam regionibus communia esse solent, tamen non omnino desunt, quae in variis Asiae, Africae, et Americae utrius. que regionibus obveniunt, quibus Europa omnino caret, ut Pinophilus, Osorius.

Fauna Europaea Omalinorum copia insignis videtur, et in ipsa Europa haec tribus in regionibus septentrionalibus et alpestribus frequentius occurrere videtur. Species boreales omnino facile in regionum temperatarum montibus reperiuntur, in quibus sat elevatis boreali climate foventur. Sic Tachinus elongatus non modo in Snecia et in Unalaschka, sed in Helvetiae etiam alpibus obvius. Alpibus aut montibus elevatioribus praeterea complures propriae videntur species, praecipue e genere Ocypode (O. macrocephalus, Italicus, alpestris, megacephalus, alpicola). Species alpinae saepenumero apterae: sic Paederus littoralis etiam, qui regiones elevatiores habitat, alis destitutus est. Species salinae minime arctis limitibus terminantur: Philonthus xantholoma in omni Europae littore reperitur. Bledius furcatus et unicornis Europae meridionalis et occidentalis littora nec non Germaniae interioris lacus salsos habitant. Bledius bicornis pariter ad eosdem Germaniae atque Iheriae lacus salsos observatur.

Asiae totae septentrionalis fauna in hac familia ab Europaea parum distincta videtur, ut et tota Asia occidentalis, praecipue Asia min or et Syria nec non Mesopotamia easdem plerasque species atque Europa proferunt. Indiae Staphylini parum imnotuerunt, nec peculiaris quidquam habere videntur. Genera Myrmedonia, Tachinus* *, Xantholinus, Staphylinus, Philonthus, Quedius, Paederus, Pinophilus, Osorius, Bledius, Leptochirus hucusque ex Indıa nobis allata sunt, et formas Europaeas plerasque inveniri, licet speciminibus raris, neque copiosis ut apud nos, a 
Helfero literis nobis relatum. Palaestrini forte genus Indiae orientali proprium.

Africani Staphylini non magis quam Indiae orientalis species innotuerunt. Madagascarienses plures legit Goudot, e quibus alii Europaeis simillimi et proximi (Tachinus pictus, Paederus Madagascariensis), alii magis Staphylinorum Americae meridionalis habitum prae se ferunt (Steni, Holotrochus, Lispinus, Isomalus). Staphylini $\mathrm{C}$ apens es pauci adhuc lecti, nonnulli ab Europaeis haud distincti (v. s.), alii speciebus Aegyptiis et Indicis approximati (Myrmedonia, Pinophilus). Africa a equinoctialis in Staphylinornm familia eximiam suam faunam nondam aperuit; quas cognovimus species paucae ad Aegyptum usque fines suos extendunt. A egy ptia fauna, ut in reliquis insectis, valde cum Europaea convenit, speciebus plnrimis omnino iisdem, immixtis autem multis formis partim Africae aequinoctiali, partim Indiae orientali propriis.

Americae septentrionalis Staphylini Europaeis omnino simillmi sunt et saepe omnino iidem. Genera nonnulla his ambobus orbis terrarum partibus propria videntur, ut Oxypori in America septentrionali, Anthophagi in Europa frequentiores occurrunt. America meridionalis magis peculiarem characterem prae se fert, putredine autem in calidis eius regionibus tantopere accelerata, observantibus Lacordaire et Perty, individua ibidem rariora. Specierum autem numerus, tot specierum minutarum copia a Beskio in Brasilia, a Moritzio in Columbia et in pluribus insulis lecta, nequaquam imminutus videtur, quamvis hac contentione Lacordaire et Perty consentiunt. Tropicae Americae cum Madagascariensi et Indiae orientalis insulis communes sunt Leptochiri et Osorii, peculiares videntur Piesti. Americae omni propria videntur quaedam genera, quae et in America septentrionali et meridionali occurrunt, e. g. Palaminns, Megalops, quaè autem succedentibus temporibus in Africa etiam et in India orientali forte reperientur. In Americae meridionalis (s. Indiae occidentalis) insulis et praecipue in Mexico Americae meridionalis et septentrionalis faunae conveniunt eo moro, ut plirimis speciebus peculiaribus aliae immixtae sint A. septentrionali (e. g. Staphylinus villosus), aliae Americae meridionali (e. g. Staph. versicolor) propriae.

Novae Hollandiae et reliquae Australiae Staphylinorum fauna adhuc parum cognita, ad quantum eam novimus, licet speciebus sat distinctis, formas ab indigenis differentes non profert.

$$
\text { De dispositione. }
$$

Totam Staphylinorum nostram familiam genus Linneanum Staphylinus amplectitur, in Fauna Suecica 21, in Systemate Naturse (Ed. X.) 26 species continens, e quibus $\mathrm{St}$. sanguineus ad Pselaphos, St. cantharellus ad Malthini genus pertinentes excludendae sunt. Sectionibus Linnaeus specierum numerum tam exiguum nullis distinxit, sequentes autem nonnulli auctores aut capite thoraci aequali eodemve angustiore (Paykul Mon. Staph.), aut thoracis in aliis paralleli, in aliis apicem, in aliis basin versus angustati, in aliis cylindrici forma (Müller), divisiones instituerunt. F a bricius primus genera altera duo addidit, Oxyporum et Paederum, illum palpis posterioribus securiformibus, hunc palpis anterioribus clavatis a Staphylino palpis ommibus filiformibus distinctum. Ceterum Staphy.- 
lino plurimas licet diversissimas species continenti, St. erythroptero pro typo proposito, labium. membranaceum, sub palpis elongatum, trifidum, lacinia intermedia latiore, apice rotundata, subemarginata, lateralibus paulo longioribus, distantibus, acutis, ligula paraglossisque computatis, oxyporo labium „elongatum, membranaceum, cylindricum, emarginatum cum mucrone" et $\mathrm{P}$ a edero ,porrectum, membranaceum, cylindricum, apice truncatum, obtusum, integrum," in utroque ligula et paraglossis omnino neglectis, tribuit, Oxyporo plurimos quos cognovit Tachyporinos, quamvis distincte palpos eorum filiformes esse monuit acutissimusque quisque auctor, pertinaciter adiiciens. In Systemate Eleutheratorum denique quartum genus, Stenus, a Latreillio conditum, a Paykullo receptum, palpis inaequalibus, anterioribus longissimis et antennis clava solida distinctum, addidit, generis autem illustrationem ex oris fabrica erroribus pluribus omnino perversam perperam a Paykullo, nisi Paykull ipse hanc misellam oris descriptionem a Fabricio acceperit, mutuavit, neque minus improspere Nitidulas quasdam elytris abbreviatis et Omalium quoddam generi huic quam maxime naturali adscripsit.

Maxime de hac familia meritus est cel. Gravenhorst, qui duabus Monographiis eandem (Microptera vocatam) illustravit et primus genera naturalia invenit et singulari habilitate distinxit. Notis imprimis habitualibus genera 14 cel. auctor in Micropt. Brunsv. hoc modo disposuit:

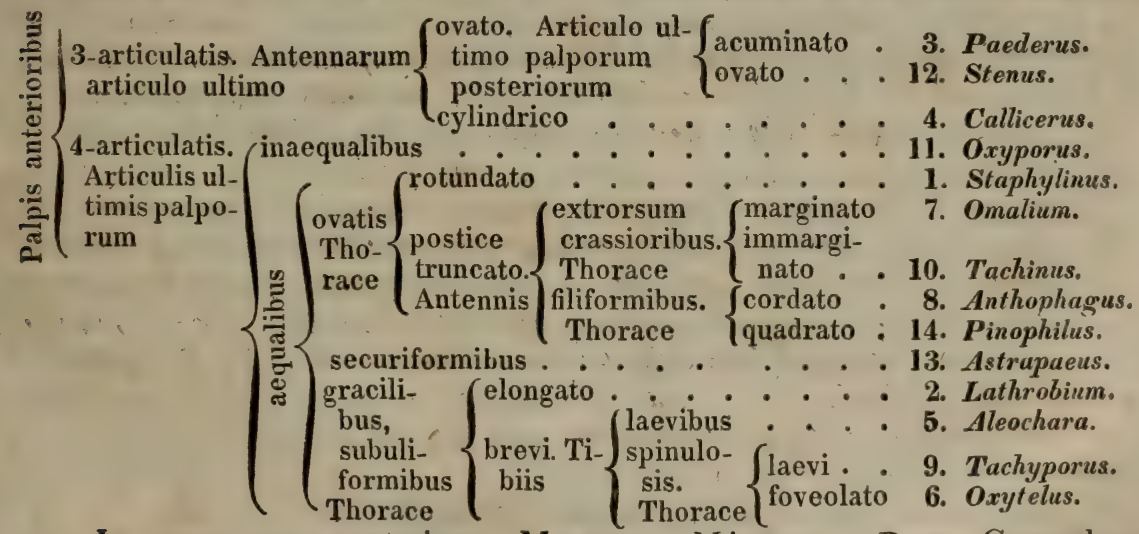

In opere suo posteriore, Monogr. Micropt. Dom. Gravenhorst, Callicerum Aleooharae, Astrapaeum Staphylino adiecit, et minus feltciter atque potius contra naturam Pinophilum Lathrobio subiunxit, nova autem tria genera addidit: Lomechusam ob thoracis formam ab Aleochara distinctam, Euaes thetum, structura thoracis cum Oxytelo, palporum et antennarum cum Steno convenientem, Piestum, corpore depresso, et pedibus brevibus, validis, tibiis serrato-ciliatis ab Anthophago discedentem. - „Lathrobiorum, Paederorum, Stenorum palporum structuram haud accuratissime vidisse Dom. Gravenhorst, - his insectis palpos maxillares articulis quatuor, ultimo tamen saepius ob exilitatem ope etiam microscopii vix conspicuo, compositos, - gen er a Staphylinorum ab illo auctore proposita naturalia, optima, sed characteribus novis, ex instrumentis cibariis praesertim depromendis fulcienda esse," praestantissime iam monuit Latreille (Gen. Crust. et Ins. I. p. 289). Palpos Calliceri et Paederorum quadriarticulatos sese vidisse Dom. Gravenhorst in M on, affert. 
Latreille in opusculo suo primario „Précis des Caractères génériques des Insectes" receptis generibus Fabricianis primus condidit genera Stenus, Proteinus et Lesteua, haec ultima dua autem a reliquis Staphylinorum generibus remotis, Proteinum Nitidulis, Lesteuam Carabis adiiciens. Magis iam provectum est systema, quod idem ille gravissimus auctor quinque annis post proposuit in $\mathrm{H}$ ist. nat. Crust. et Ins. vol. III, ubi Sta.* phylini familiam peculıarem (Staphyliniae), inter Necrophagos et Nitidularias positam constituunt, genera 6 continentem; Staphylinum (Staphylinus, Oxytelus, Aleochara, Omalium, Tachinus et Tachyporus), Leste a m (Anthophagus Grav.), Pa ederum (Lathrobium et Paederus Gr.), Stenum, Oxyporum, Astrapa eum, omnia imprimis secundum palporum figuram distincta. Deinde in eodem opere (Vol IX et $\mathbf{X}$ ) in speciebus enumeran. dis genera Gravenhorstiana Lathrobium; Aleochara, Oxytelus, Omalium, Tachyporus et Tachinus recepta sunt. Proteinus adhuc inter Nitidularias enumeratus. Nonnullis annis praeterlapsis in opere suo classico et summo studio elaborato, Genera Crustaceorum et Insectorum Latreille hanc familiam (Staphylinii) inter Palpatores (Scydmaenum) et Necrophagos collocatam, hoc modo in sectiones et genera dissolvit:

I. Palpi labiales articulo tertio sive torminali maiore, subtrigono fereque securiformi aut lunato.

Oxyporus, Astrapaeus.

II. Palpi labiales articulo tertio sive terminali haud maiore, nec trigono, nec lunato, saepius subcylindrico aut subconico, in nonnullis obsoleto.

1. Mandibulae ad latus internum processu aut saltem dente uno valido instructae.

Staphylinus, Lathrobium, Pa ed erus, S t enus, Oxytelus.

2. Mandibulae dentibus nullis internis aut unico tantum vixque obvio,

A. Antennae ante oculos insertae, a secundo baseos articulo ad angulum fere rectum haud divaricatae, articulis nullis aut perpancis $(3-4)$ transversis, plerisque obconicis aut subglobosis, terminali subovato, ad basin ro-. tundato, non truncato.

a. Mandibulae fissura interne parva aut subunidentatae.

Lestena, Omalium, Proteinus.

b. Mandibulae latere interño penitus edentulo.

$\mathrm{T}$ a chinus, T a ch y orus.

B. Antennae oculorum margini interno et antico insertae, a secundo baseos articulo ad angulum fere rectum divaracatae (subfractae et antrorsum arcuatim inflexae), articulis 5 - 10 transversis, perfoliatis, terminali ovatoconico, basi truncato.

Ale ochara.

Genera sunt pleraque Gravenhorstiana, at naturali modo disposita et characteribus certis circumscripta.

Nova disponendi methodo in hac familia, quam Brachypterorum (Brachilytres) nomine impositam secundam inter Adephaga et Serricornes collocavit Latreille in recentiore opere: „Familles naturelles du règne animal ( 1825$)$ " usus est, ubi sectiones quatuor distinxit:

1. Fissilabri, labro profunde bilobo: Oxyporus, Astrapaeus, St taphylinus, Xantholinus, antennis supra labrum, Pinophilus, Lathrobium, anteunis externe supra mandibularum basin insertis. 
2. Longipalpi, labro integro, palpis maxillaribus elongatis, articulo quarto vix conspicuo: Paederus, Stilicus, Euaesthetus.

3. Depressi, palpis maxillaribus brevioribus, articulo quarto distincto: Prognatha, Zirophorus, Osorius, Oxytelus, Piestus, Omalium, Lesteua, Proteinus, Aleo chara.

4. Microcephali, capite ad oculos usque thoraci immisso: Lomechusa, T a chinus, T a chy porus.

Dein in Cuvieri „Règne animal Ed. II" sectionem tertiam in duas dissolvit, alteram, Denticrura, tibiis spinulosis (Oxytelus, Osorins, Zirophorus, Prognatha, Coprophilus), alteram, Depressa, tibiis muticis (Omalium, Lesteua, Micropeplus, Proteinus, Al e o chara).

Maxime concisa inter has varias disponendi methodos videtur ea, quam Gienera Crust. et Ins, continent. Divisiones recentiores multo minus naturales esse patet, cum Fissilabres non solum species nonmullas labro integro contineant, sed-Lathrohia etiam iis adscripta summa affinitate cum Paederis, qui cum Stenis Longipalporum sectionem constituunt, iunctae sint, et nullo certo limite distinguantur; Longipalpi etiam plurimi labro medio magis minusve inciso instructi sint; Denticrura permulta tibiis omnino muticis praedita, sint; Depressi cum Omalinis plerisque Aleocharinorum par. tam alteram, cui caput est exsertum, Microcephali, cum Tachyporinis alteram contineant, quippe cui caput thoraci magis immissum est, v. c. genera nostra Aleocharam, Gyrophaenam, quas Lomechusae generi in hac sectione subiungere maluit auctor.

Innovatam huius familiae dispositionem et multo magis naturalem, fundamento licet Latreillianae methodi innixus, ingeniose elabaratam recentioribus temporibus proposuit Com. Mannerheim, sectiones Aleocharides secundum antennarum insertionem, $\mathrm{Om}$ alides et $\mathrm{Oxytelides} \mathrm{non} \mathrm{secun-}$ rlum tibias muticas spinulosasve, sed secundum tarsorum articulorum numerum, Tachinides ab Omalidibus autem tibiis spinulosis, Staphylinides labro emarginato, Stenides palporum maxillarium articulo ultimo occulto acute distribuens hoo modo:
吾 $\left\{\begin{array}{c}\text { emarginatum } \\ \text { integrum. } \\ \text { Tarsi }\end{array}\left\{\begin{array}{c}5 \text { articulati. } \\ \text { Palpi }\end{array}\right.\right.$

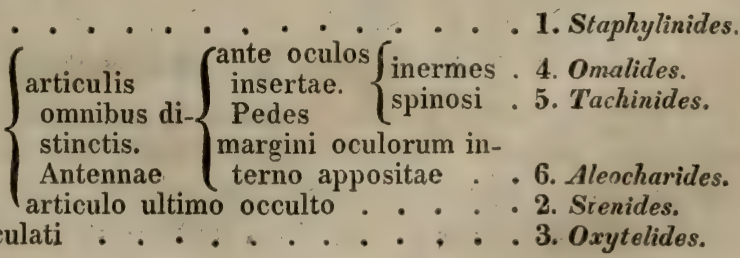

Staphylinides eodem modo atque a Latreillio Fissilabres circumscripti sunt, inter Stenides autem quaedam sunt genera, quibus palporum maxillarium articulus quartus non minus obsoletus est quam plurimis Lathrobiis, inter Omalides genera quaedam sunt tibiis spinulosis, et inter T a chinides tibiis muticis, et $\mathbf{O x y t e l i d e s}$ tarsis 3 -articulatis nimis stricte terminantur, cum genera nonnulla sint, quae aliis compluribus et constantibus characteribus cum iis conveniunt et ab Omalinis, quibus adscripta sunt, discedunt. Aleo charides vero charactere adhibito optime distinguuntur. Praeterea Com. Mannerheim genera multa nova proposuit aut ab aliis proposita recepit et publicavit. 
Sectiones tantum quatuor in Staphylinorum familia Dom. Stephens constituit: Tachyporidas, Aleocharinos et Tachyporinos continentem, Staphylinidas, Staphylininos cum Lathrobiis, Stenidas, Paederinos reliquos, Steninos, Oxyporum et Oxytelinos, O malidas, Euaesthetum, Syntomium, Coprophilum, Omalinos et Proteininos continentes. Genera permulta proposuit auctor, quae vero habitualibus solis plerumque notis distincta, characteribus systematicis autem destituta, potius in tyronum usum quam in scientiae incrementum provocata videntur, et singula loco suo mili recensenda sunt.

Ipse nova dispositione, iam in Coleopterorum Marchicorum de. scriptione tentata, usus, secundum stigmata prothoracica conspicua occultave, antennarum insertionem et coxarum anticarum posticorumque et trochanterum posticorum formam Tribus undecim, quae naturales mihi videntur, hoc modo distinxi:

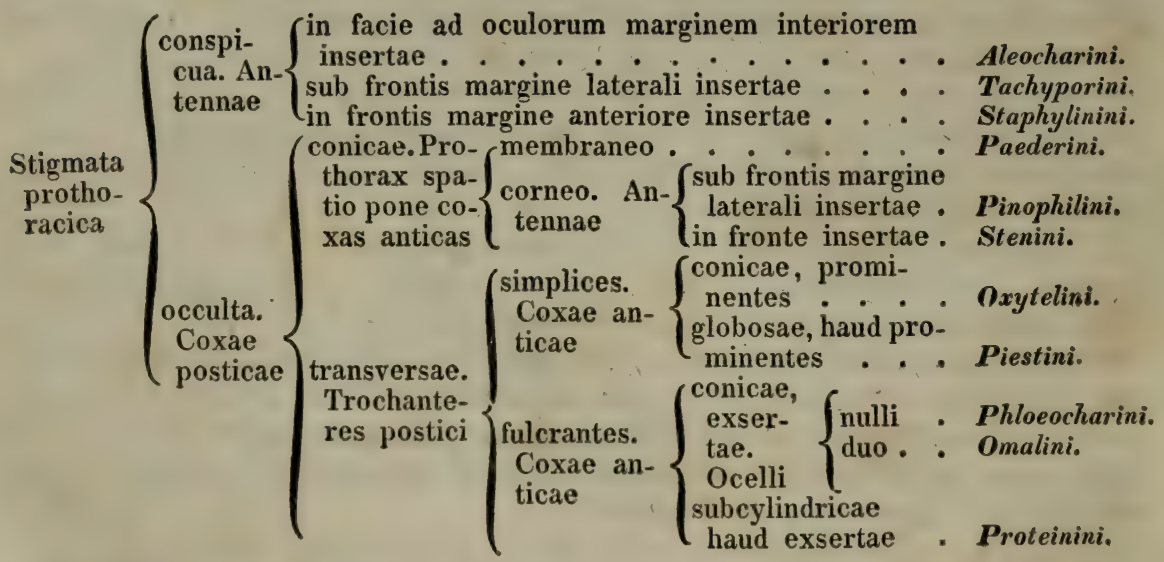

\section{Trib. I. Aleocharini.}

Palpi maxillares articulo primo brevi, quarto minuto, subulato. Labrum integrum, simplex. Ocelli nulli. Elytra pectoris longitudine. Coxae anticae conicae, exsertae, posticae transversae. Trochanteres postici fulcrantes. Abdomen marginatum, segmento septimo saepius occulto. 

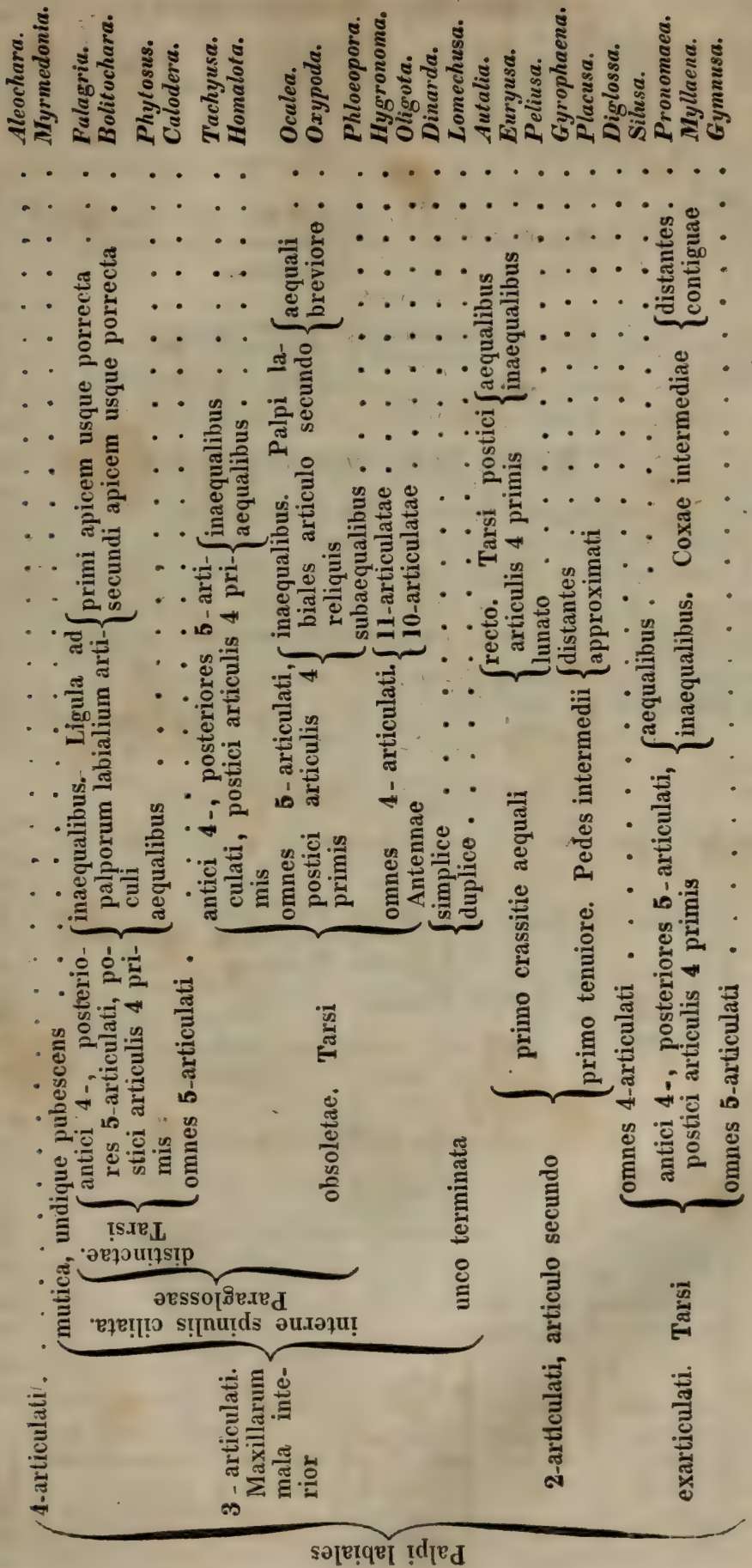


\section{Trib. Ir. Tachyporini.}

Labrum integrum, simplex. Mandibulae muticae, lacinia membranea interiore connata. Ocelli nulli. Coxae anticae conicae, exsertae. Trochanteres postici fulcrantes. Tibiae saepius spinulosae. Abdominis segmentum septimum vix conspicuum.

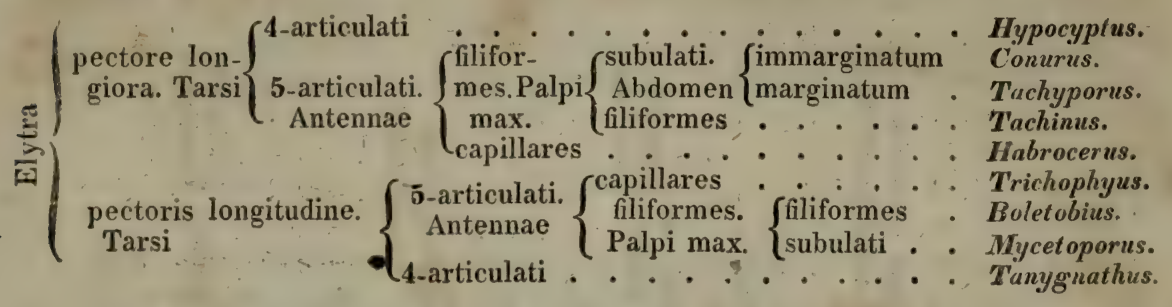

\section{Trib. III. Gtaphylimini.}

Labrum plerumque bilobum, limbo membranaceo coriaceove. Mandibulae lacinia membranea interiore-libera. Antennae $\mathbf{1 1}$-articulati. Ocelli nulli. Elytra pectoris longitudine. Coxae anticae conicae, exsertae, posticae conicae. Trochanteres postici simplices. Tibiae saepius spinulosae. Tarsi 5-artienlati. Abdomen marginatum, segmento septimo retractili.

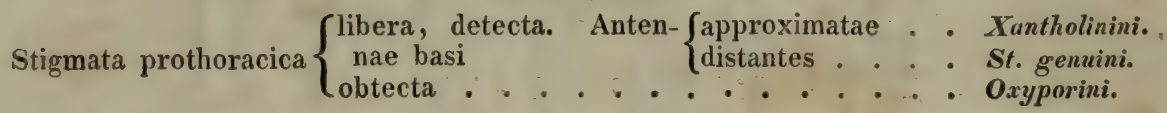

Subtrib. I. Xantholinini.

Antennae inter se non magis quam ah oculis distantes.

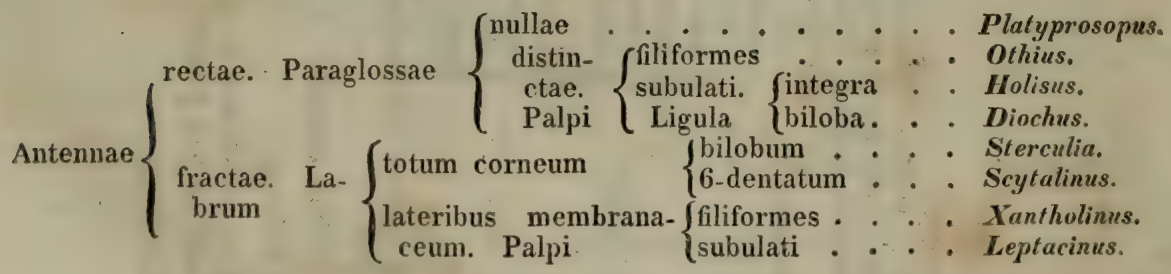

Subtrib. 2. St. genuini.

Antennae inter se magis quam ab oculis distantes.

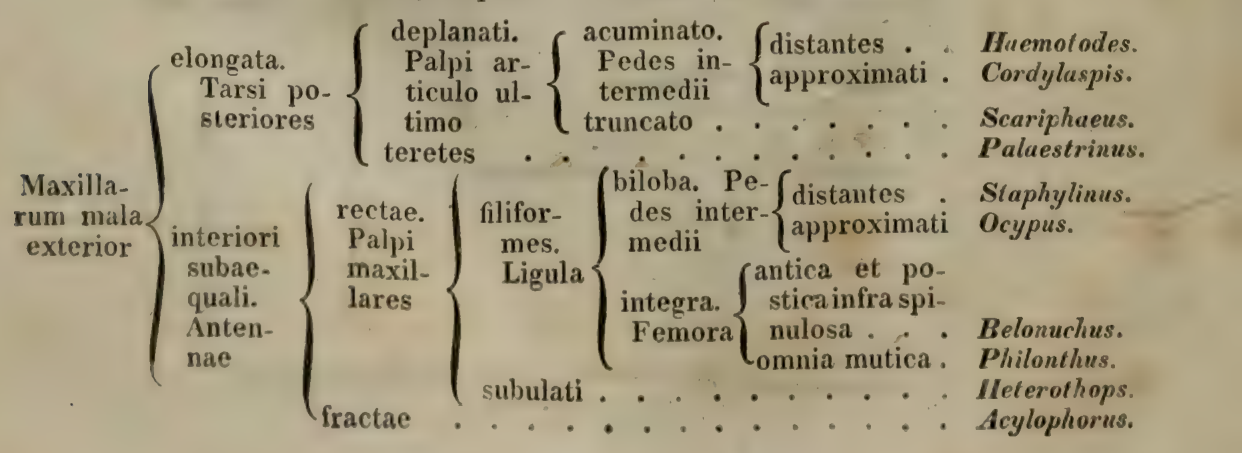


Subtrib. 3. Oxyporini.

Stigmata prothoracica utrumque processu triangulari corneo membranaceove obtecta.

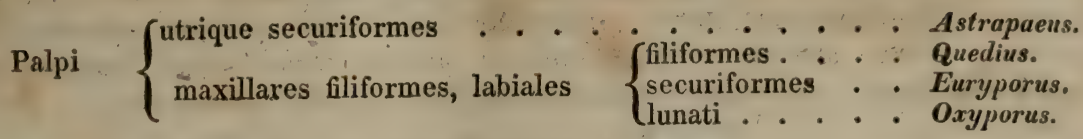

\section{Trib. IW. Paederini.}

Labrum lateribus saepius membranaceum. Mandibulae elongatae, falcatae, acutae, medio dentatae, Palpi maxillares magis. minusve elongati, articulo primo brevi, quarto minimo, saepe vix observando, labiales breves. Antennae sub frontis margine laterali insertae, 11 -articulatae, filiformes. Ocelli nulli, Elytra pectoris longitudine. Coxae anticae conicae, exsertae. Trochanteres postici fulcrantes. Tarsi 5 -articulati. Abdomen marginatum, segmento septimo retractili, saepius vix conspicuo.

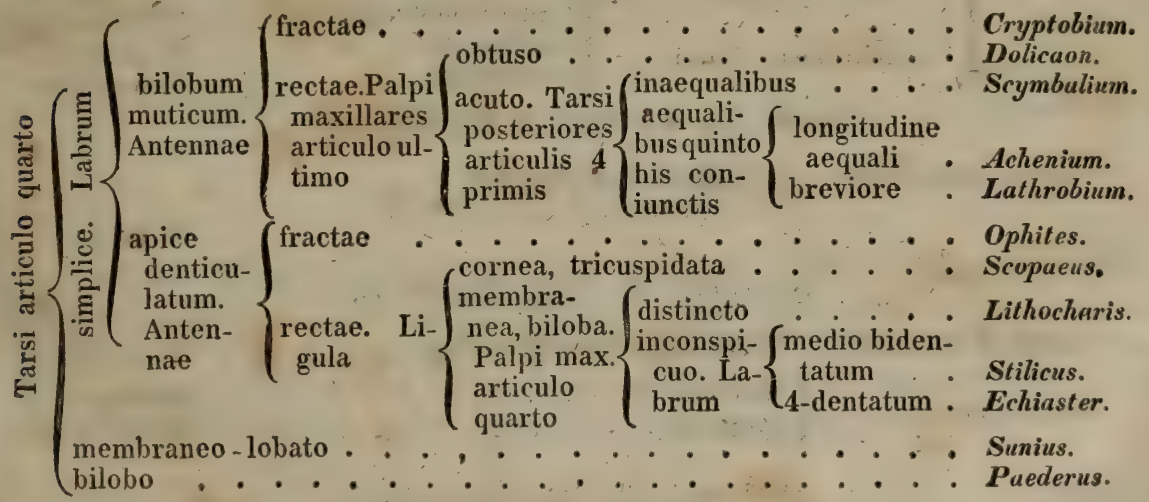

\section{Trib. $\nabla$. Pinophilini.}

Labrum corneum, simplex. Mandibulae elongatae, falcatae, acutae, medio dentatae. Palpi maxillares elongati, articulo primo brevi, quarto reliquis haud minore, labiales breves. Antennae 11-articulatae, filiformes. Ocelli nulli. Elytra pectoris longitudine. Coxae anticae conicae, exsertae. Trochanteres postici fulcrantes. Tarsi 5-articulati. Abdomen segmento septimo vix conspicuo.

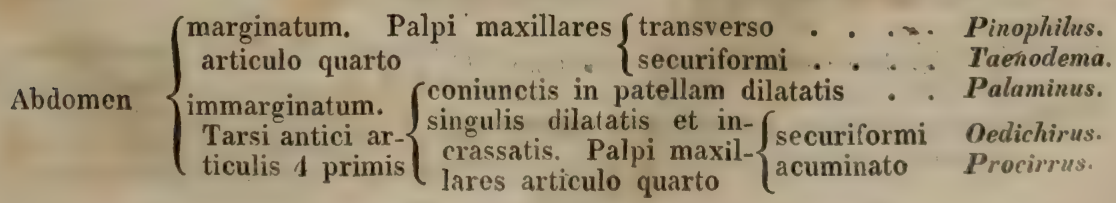




\section{Trib. VI. Stenini.}

Labrum semiorbiculare, totum corneum. Mandibulae elongatae, tenues, falcatae, acutae, medio dentatae. Palpi maxillares elongati, articulo primo elongato, tertio clavato, quarto minimo, vix observando, labiales minuti. Antennae 11-articulatae, tenues, clavatae. Ocelli nulli. Elytra pectoris longitudine. Coxae anticae minutae, conicae, parum prominulae. Trochanteres postici simplices. Abdomen segmento septimo saepius prominulo.

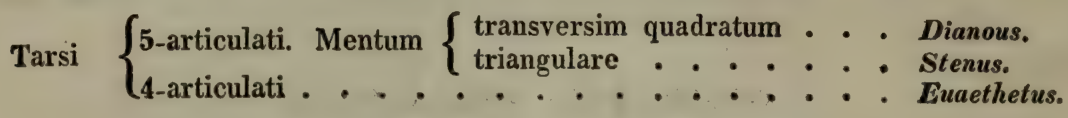

\section{Trib. VII. Oxytelini.}

Labrum corneum, plerumque apice utrinque lacinia membranea auctum. Paraglossae distinctae. Antennae sub frontis margine laterali insertae. Ocelli nulli. Thorax infra pone coxas anticas membraneus. Elytra pectoris longitudine. Abdomen segmento septimo distincto, haud retractili.

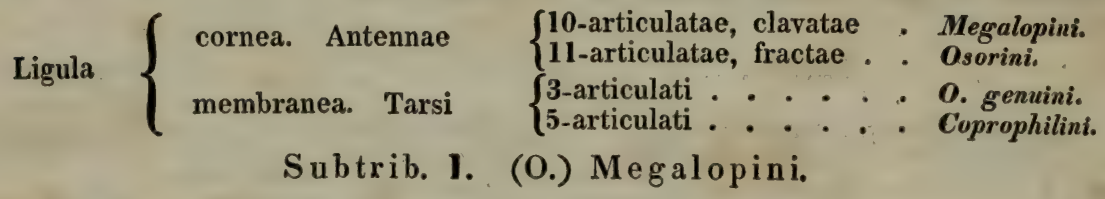

Tarsi 5-articulati. Abdomen marginatum.

Megalops.

Subtrib. 2. (O.) Osorini.

Tarsi 5-articulati. Abdomen immarginatum.

Tibiae anticas

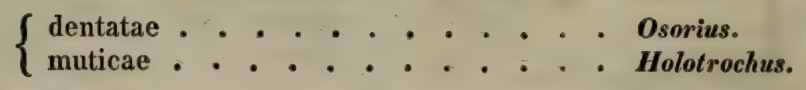

Subtrib. 3. O. genuini.

Palpi maxillares articulo quarto minuto, subulato. Abdomen marginatum.

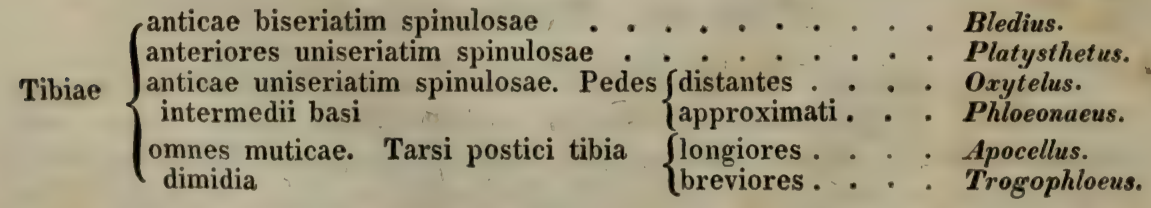

\section{Subtrib. 4. (O.) Coprophilini.}

Palpi maxillares filiformes. Abdomen marginatum.

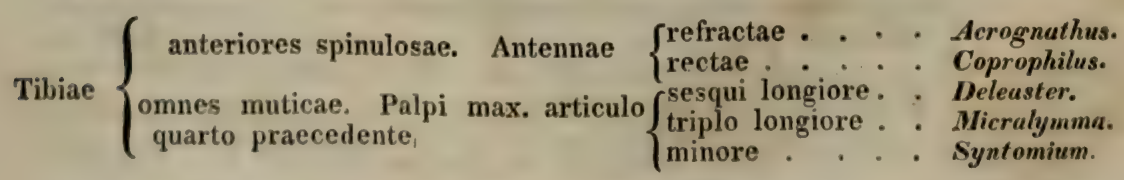




\section{Trib. VIII. Piestini.}

Labrum corneum, apice utrinque lacinia membranea auctum. Palpi filiformes. Antennae sub frontis margine laterali insertae, 11-articulatae, filiformes vel moniliformes. Ocelli nulli. Thorax infra totus corneus. Elytra pectoris longitudine. Tarsi 5-articulati. Abdomen segmento septimo omnino abscondito.

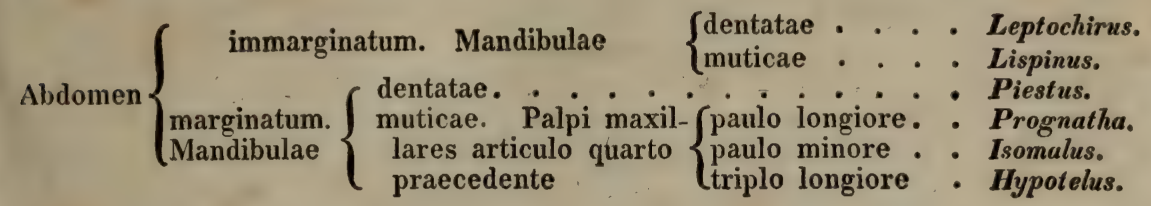

\section{Trib. IX. Phloeocharini.}

Labrum corneum, integrum. Paraglossae distinctae. Antennae sub frontis margine laterali insertae, 11-articulatae, filiformes. Ocelli nulli. Thorax infra pone coxas anticas membraneus. Elytra pectoris longitudine. Tarsi 5-articulati. Abdomen late marginatum, apicem versus sensim angustatum, segmento septimo haud exserto.

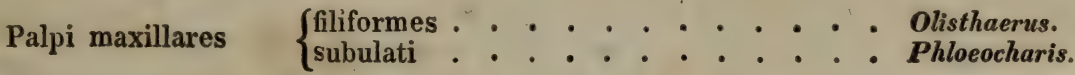

\section{Trib. X. Omalini,}

Labrum corneum integrum, apice saepius limbo membraneo bilobo prominulo auctum. Paraglossae nullae. Palpi filiformes. Antennae sub frontis margine laterali insertae, 11-articulatae. Ocelli duo. Thorax pone coxas anticas membraneus. Elytra pectore longiora. Tarsi 5-articulati. Abdomen tenuiter marginatum, segmento septimo haud exserendo.

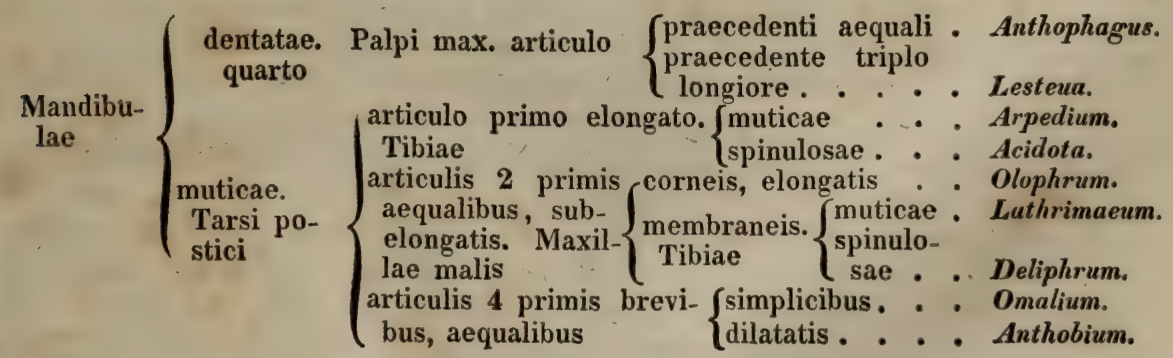

\section{Trib. XI. Proteinini.}

Labrum corneum, integrum. Paraglossae distinctae. Palpi filiformes, articulo secundo incrassato. Antennae sub frontis margine laterali insertae. Ocelli nulli aut singulus. Thorax infra totus corneus. Elytra pectore longiora. Abdomen segmento septimo haud exserendo. 
32

Staphylini.

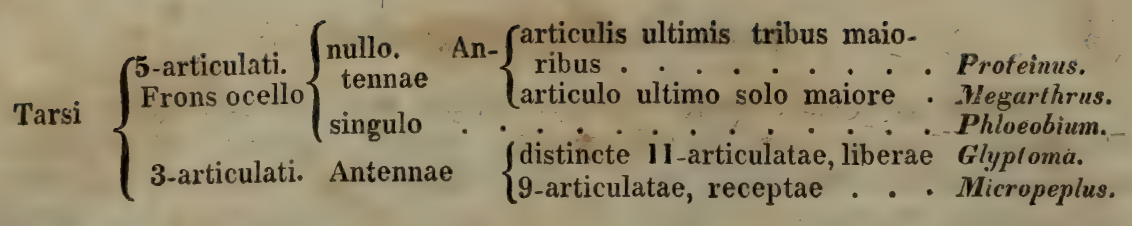




\section{Tribus prima.}

\section{A 1 e cha r i n}

Stigmata prothoracica conspicua.

Antennae in fronte ad oculorum marginem interiorem insertae.

Labrum integrum, corneum, laciniis membraneis nullis.

Mandibulae haud prominentes, subfalcatae, limbo membaneo margini interiori affixo intus fimbriatae, apice libero, acutiusculo,

muticae plerisque,

medio subdentatae PhI o eocharidi, ante apicem acute dentatae Gymnusae. corneis.

Maxillae cardine stipiteque corneis, malis iam membranaceis, iam

mala exteriore cornea, basi apiceque membranaceis, hoc barbatulo; interiore mutica, apice introrsum oblique subemarginata, sinu spinulis ciliato, membranacea, margine exteriore corneo: sic in plerisque;

mala exteriore subelongata, interiore apice pubescente in Myrmedonia, mala interiore unco corneo simplice in Diu arda, aut unco duplice terminata, in Lomechusa;

mala exteriore ut in praecedentibus, interiore elongata, cornea, apice uncinata in Silus a;

mala utraque elongata, interiore cornea, apice uncinata, ante apicem denticulata in Pronomaea, Diglossa, Silusa, Gymnusa.

Palpi maxillares 4-articulati, articulo primo minuto, secundo tertioque elongatis, quarto iterum minuto, subulato.

Mentum corneum.

L abium membraneum, magis minusve exserendum.

Ligula membranea, angusta, inter palporum articulos primos sita.

apice bifida plerisque;

apice bifida, laciniis iterum bifidis Autaliae;

integra Gyrophaenae, Peliusae, Placusae, Euryusae, Lomechusae, Silusae, Myllaenae. 
Aleocharini.

Paraglossae nullae plerisque;

obsoletae Tachyusae;

ligulae breviores Autaliae, Falagriae, Bolitocharae, Caloderae; Ale ocharae, Placusae, Dinardae;

ligulae aequales Myrmedoniae.

Palpi labiales 3-articulati plerisque;

4-articulati Aleocharae;

2-articulati Autaliae, Gyrophaenae, Peliusae, Placusae, Euryusae;

exarticulati, setacei Silusae, Pronomaeae, Diglossae, Myllaenae, Gymnusae.

Antennae ad oculorum marginem interiorem insertae, articulis tribus prumis paulo longioribus, secundo tertioque obconicis,

11-articulatae, filiformes vel apicem versus sensim leviterque incrassatae plerisque;

10-articulatae, clavatae Olig otae.

Oculi parvi, rotundati vel ovales, laterales.

C a p ut exsertum, interdum inflexum, saepe deflexum, plerumque porrectum, nonnunquam pedunculo tenui brevique thoraci affixum.

Thorax (Prothorax) margine posteriore coleopterorum basin attingens.

Prosternum triangulare, spatio pone coxas anteriores membraneo.

$\mathrm{Pectus}$ metathoracis epimeris magnis, retrorsum prommentibus.

Scutellum minutum, triangulare.

Elytra pectori longitudine aequalia.

Abdomen segmentis sex conspicuis, septimo plerumque omnino occulto, stylis analibus plerumque haud exsertis.

Pedes graciliores, coxis anticis exsertis, conicis, posticis transversis, fere parallelopipedis; trochanteribus posticis fulcrantibus; tibiis plerumque inermibus, spinulis apicalibus minutissimis, $\mathrm{t}$ ar $\mathrm{s}$ is

omnibus 5-articulatis Ocaleae, Caloderae, Phloeoporae, Oxypodae, Aleocharae, Gymnusae;

posterioribus 5-, anticis 4-articulatis Myrmedoniae, Autaliae, Falagriae, Bolitocharae, Tachyusae, Homalotae, Gyrophaenae, Peliusae, Placusae, Euryusae, Dinardae, Lomechusae, Silusae, Pronomaeae, Myllaenae;

omnibus 4-articulatis Hygronomae, Oligotae, Diglossae;

articulis primis tarsorum anticorum aequalibus, posteriorum longitudine sensim decrescentibus, articulo primo posticorum elongato in plerisque;

tarsis posterioribus articulis primis aequalibus aut subaequalibus in $\mathrm{Au}-$ talia, Hygronoma, Phloeopora, Homalota, Silusa;

articulo ultimo elongato, clavato plerisque;

relıquis aequali, depresso Hygronomae;

breviusculo, incrassato Diglossae;

unguiculis tenuibus, leviter falcatis, simplicibus plerisque;

brevibus, fortiter curvatis Digloss a e.

Sexus differentia saepius obscura; interdum antemnis longioribus validioribusque, interdum abdomims segmentis aut anterioribus aut posteriori- 
bus tuberculatis, aut segmento ventrali sexto apice triangulariter producto mas distinguitur.

Tarsi antici nunquam dilatati.

o b s e r v a tio n e s.

1. Corpus Aleocharinorum, minutum, agile, saepius lineare, habitu quodam peculiari, forma tamen varians, aliis (e. g. F a lag riis) Paederos, aliis (e. g. O xypodis, Mylla en is, Gymnusis) Tachyporos simulantibus. Antennis ad oculorum marginem interiorem insertis facilius distingui banc tribum primus docuit $\mathrm{Com}$. Mannerheim.

2. Nititur haec tribus numerosa, extricatu omnium difficillima, generibus $A$ l e ochara et Lomechusa, ingeniose a Gravenhorstio conditis. Com. Mannerh eim secundum corporis habitum et antennarum tarsorumque posticorum structiram non sine successu in genera plura eam dissoloit, e quibus, oris et tarsorum structura quantum valui accuratisse examinata, alia recepi, alia mutavi, alia castigavi, alia nova is addidi.

\title{
Myrmedonia Er.
}

\author{
Er. Col. Marck. I. p. 286.
}

Maxillae mala interiore mulica, apice undique subtiliter pubescent . Ligula brevis bifida; paraglossne ei aequales, subacuminalae. Palpi labiales 3-articulati, articulis longitudine subaeyualibus. Tarsi antici 4-, posteriores 5-articulati, postici articulo primo elongato.

Corpus oblongum vel elongatum, minus convexum, aliis apterum aliis alatum. Caput exsertum, porrectum, aut thoracis latitudine, aut eodem paulo angustius, rotundatum, basi constrictum, oculis mediocribus, modice prominulis. Labrum latiusculum, truncatum, mandibularum apicem haud obtegens. Mandibulae muticae. Maxillae (t. III. f. 21.) mala exteriore elongata, palpo maxillari subaequali, cornea, apice pubescente; interiore dimidio breviore, membranea, margine exteriore corneo, apice oblique truncata, densius pubescente. Palpi maxillares modice elongati, articulo secundo tertio breviore, hoc leviter incrassato, quarto minuto, subulato. Labium (t. III. f. 1.) mento transverso, leviter emarginato, ligula brevi, palpornm labialium articulo primo breviore, bıfida, paraglossis ligula longitudine subaequalibus, latis, subacuminatis, margine interiore haud ciliatis. Palpi labiales articulis tribus magnitudine decrescentibus compositi. Antennae crassiusculae vel crassae, articulis tribus primis magis elongatis, secundo tertio breviore, ultimo saepe subacuminato. Thorax coleopteris angustior, depressiusculus. Scutellum triangulare. Elytra apice oblique introrsum truncata, ad angulum exteriorem leviter sinuata. Abdomen coleopterorum latitudine, supra planum, subtus convexum, vivis revolutum. Pedes modice elongati, intermedii basi distantes, tarsis anticis 4-, posterioribus 5-articulatis, his elongatis, articulis 4 primis longitudine decrescentibus.

O b s e r a $t$ i o n e s.

1. Corpus aliis subtiliter punctatum, pube tenuissima sericea vestitum, aliis laevigatum, nitidum. Oris partibus respectis hoc genus facile distinguitur paraglossis ligulae aequalibus et maxillarum mala interiore pubescente, spinulis nullis ciliata. Praeterea ab aliis generibus tarsorum structura, ab aliis coxis intermediis maiore spatio distantibus distinguitur. Antennae validiores et abdomen revolutum notas leviores habituales praebent.

2. Com. Mannerheim plerasque species Bolitocharis adiungens e sola M. canaliculata constituit genus proprium: Drusilla, nomen a Leach pro- 
positum, prius autem a Swains on (Zool. Il: str. I. tab. 11) Papilionum generi impositum, quam ob rem Stephens (Illustr. V. p. 106) nomen Astilbus, a Dom. Dillwyn propositum, recepit. Idem autor deinde $\mathrm{M}$. fulgidae gen. $\mathrm{Zyr}$ as (Illustr. V. p. 430), et M. limbatae, humerali et funestae gen. Pella (ibid. p. 434), condidit, quae omnia, cum characteribus vagis aut nullis constituta invenio, Myrmedoniae subiungere non dubito.

3. Porus ochraceus Hope in opere Roylii infra citato depictus, petenti mihi cum oris partibus praeparatis a cel. Hope amicissime ad examinandum communicatus est. Oris structura, haud satis exacte cognita a Dom. Westwood, acutissimo ceterum pictore, (ligula praecipue haud acum!nata sed bifida) omnino eum huic generi adiungit, a quo hoc insectum nonnisi tibiis spinulosis et spinis apicalibus longioribus intructis discedit, quae notae mihi haud sufficere videntur, ut ex hac singula specie genus peculiare constituatur.

4. Species indigenae, quantum observavi, in formicetis degere solent, inde nomen.

\section{* A p t e r a e.}

* 1. M. canaliculata: Punctalissima, rufo-testacea, cápite abdominisque cingulo postico nigris, thorace oblongo, canaliculato impressoque. Long. 2 lin.

Er. Col. March. I. 290. 6.

Staphylin. canaliculatus Fab. Mant. Ins. I. 221. 29. Ent Syst. I. II. 528. 42. Sysı. El. II. 599. 22. - Payk. Mon. Staph. 31. 23. Faun Suec. III 385. 23. - Ross. Faun. Etr. Mant. 98. 219. (Faun. Etr. ed. Hellw. p. 443) - Oliv. Ent. III. 42. 21. 25. t. 3. f. 31. - Pauz. Faun. Germ. 27. 13. Ent. Germ. 356. 32. - Marsh. Ent. Britt. 507. 25.

Aleochara canaliculata Grav. Micr. 68. 1. Mon. 148. 1. - Latr. Hist. nat. Crust. et. Ins. IX. 378. 1. t. 80. f. 7. Gen. Crust. et Ins. I. 301. 2. - Gyll. Ins. Sıec. II 392. 14. - Zetterst. Faun. Lapp. I. 96. 1. Ins. Lapp. 75. 1. - Sahlb. Ins. Fenn. I. 356. 21. - Guér. Iconogr. Regn. Anim. Ins. t. 10. f. 5.

Drusilla canaliculata Mannerh. Brachelytr. 85. 1. - Boisd. et Lacord. Faun. Ent. Paris. I. 534. - Runde Brachel. Hal. 31. 1.

Paederus impressus Rossi Faun. Etr. I. 251. 627. (ed. Hellw. p. 314)

Habitat in Europa sub lapidibus.

Aptera. Corpus angustum, punctatissimum, densius pubescens, capite abdominisque segmentis quarto qumtoque nigris. Antennae validiusculae, fuscae, basi testaceae, articulo secundo tertio paulo breviore. Thorax oblongus, coleopteris angustior, subtiliter canaliculatus, dorso in femina postice, in mare secundum totam longitudinem impresso. Elytra thorace breviora. Abdomen reflexum, dorso parcius punctato pubescenteque, segmento ultimo maris emarginato. Pedes pallide testacei.

Mas thoracis disco late excavato, et abdominis segmento dorsali sexto apice emarginato distinctus.

O bs. Victitat, ni fallor, inter nidos Formicae flavae.

* 2. M. plicala: Punctatissima, obscure testacea, capite thoraceque subquadrato piceis, abdomine supra ante apicem piceo, segmento quarto supra medio elevato-plicato. - Long. 2 lin.

Er. Col. March. I. 289. 5.

IIabitat Berolini, Dom. Kirstein.

Aptera, punctatissina, densius pubescens, parum nitida, capite thorace- 
que nigro-piceis. Antennae capite thoraceque paulo longiores, validiusculae, articulo secundo tertio paulo breviore, apicem versus haud incrassatae, rufo. testaceae. Caput thoracis prope latitudine, suborbiculatum, fronte leviter convexa. Thorax coleopteris vix angustior, latitudine haud brevior, basi leviter rotundatus, apice truncatus, lateribus anterius subrotundatis, posterius subsinuatis, dorso depressiusculus, basi obsolete impressus. Scutellum punctatissimum, nigrum. Elytra thoracis longitudine, testacea. Abdomen obscure rufo-testaceum, apicem versus nigrum, supra segmento tertio medio tumidulo, quarto medio secundum totam longitudinem late abrupte elevato, segmentis tribus primis confertim punctatis, reliquis laeviusculis, nitidis. Pectus piceum. Pedes testacei.

Obs. 1. Praecedente haud longior, at paulo latior et antrorsum haud angustata. Elytra thorace haud breuiora, alarum autem rudimenta tantummodo exigua sub elytris conspiciuntur.

2. Abdominis dorsum in altero sexu forte simplex: mihi nonnisi unicum, in collectione Kirsteiniana olim contentum specimen visum.

\section{族 $\mathrm{A}$ a $\mathrm{t}$ a e.}

* 3. M. $\operatorname{limbata:~Subtilissime~punctulata,~fusco-testacea,~capite,~elytrorum~}$ disco abdomineque ante apicem fuscis, thorace subyuadrato, maris late profundeque, feminae obsolete canaliculato. - Long. $2 \frac{1}{4}$ lin.

Er. Col. March. I. 288. 3.

Staphyl. limbatus Payk. Mon. Staph. 51. 39. Faun. Suec. III. 399.41. - Marsh. Ent. Britt. 509. 30.

Al. limbata Gyll. Ins. Suec. II. 400. 22. - Zetterst. Faun. Lappon. I. 99. 10. Ins. Lappon. 76. 13. - Sahlb. Ins. Fenn. I. 365. 37.

Mas: Thorace medio longitudinaliler excavato, abdominis segmento ullimo dorsali emarginato.

Al. Iimbat a Grav. Micr. 69. 2. - Latr. Hist. nat. Crust. et. Ins. IX. 378. 3.

B olit och ara limbata Mannerh. Brachelytr. 81. 39.

Bolitochara limbata var. (foveicollis Dej.) Boisd. et Lacord. Faun. Ent. Paris. I. 551. 17.

Staph. divisus Marsh. Ent. Britt. 510. 33.

Fem.: Thorace obsolete canaliculato, abdominis segmento ullimo dorsali integro.

Al. la evis Grav. Micr. 95. 39. Mon. 169. 52. - Latr. Hist. nat. Crust. et Ins. IX. 389. 39.

A l. limb a t a Germ. Faun. Ins. Europ. 13. 7.

Bolitochara limbat a Boisd. et Lacord. Faun. Ent. Paris. I. 550. 17. - Runde Brachel. Hal. 31. 10.

Habitat in Europae campis, sub lapidibus, Formicae flavae, nisi memoria me fallit; hospes.

Corpus subtilissime punctulatum, pube temuissima grisea sericans, maris dilutius, feminae obscurius fusco-testaceum, capite, elytrorum, plerumque etiam thoracis disco, abdominisque fascia indeterminata ante apicem fuscis. Antennae sat validae, testaceae, articulo secundo tertio dimidio fere breviore. Caput thorace paulo angustius, fronte obsolete impressa, oris partibus testaceis. Thorax latitudine paulo brevior, coleopterorum prope latitudine, 
basin versus subangustatus, lateribus leviter rotundatus, maris longitudinaliter excavatus, feminae aequalis, obsolete canaliculatus. Elytra thorace paululum longiora. Abdomen supra punctulatum, segmento dorsali ultimo in mare profunde emarginato. Pedes testacei.

Sexus differentia supra notata.

Obs. Abdomine dorso punctulato a proxime sequentibus facile distinguenda.

* 1. M. humeralis: Subliliter punctata, fusca, elytrorum humeris, abdominis basi pedibusque rufo-testaccis, thorace subquadrato, depresso, inaequali. - Long. $2 \frac{1}{2}-3$ lin.

Er. Col. March. I. 287. 1.

Aleoch. hum eralis Grav. Micr. 90. 33. Mon. 169. 50. - Latr. Hist. nat. Crust. et Ins. IX. 387. 33. - Gyll. Ins. Suec. II. 399. 21. - Zetterst. Faun. Lapp. I. 99.

10. Ins. Lappon. 76. 12. - Sahlb. Ins. Fenn. I. 64.36.

Bolitochara humeralis Mannerh. Brachelytr. 81. 38. - Boisd. et Lacord. Faun.

Ent. Paris. I. 549. 16. - Runde Brachel. Hal. 30. 9.

Habitat in Europae silvis, Formicae fuliginosae socia.

Subtiliter punctulata, pube tenuissima grisea subsericans, fusca. Antennae validae, brumneae, - basi dilutiores, articulo secundo tertio dimidio breviore. Caput thorace multo angustius, fronte aliis aequali, aliis leviter impressa. Thorax coleopterorum fere latitudine, latitudine sua parum brevior, lateribus parum rotundatis, depressus, basi supra scutellum et utrinque ad marginem lateralem leviter impressus, aut totus fuscus, aut obscure rufo-testaceus, disco fusco. Elytra thorace vix longiora, aut fusca, humeris rufo-testaceis, aut rufo-testacea, disco fusco. Abdomen supra laevigatum, nigro-fuscum, basi rufo-testaceum, subtus rufo-testaceum, posterius minus infuscatum. Pectus iam fuscum, iam obscure rufo-testaceum. Pedes rufotestacei.

Obs. Specimina fronte impressa forte mares; in nonnullis etiam thorax per totam longitudinem obsolete canaliculatus, at aliae sexus differentiae me fugiunt. Specimen fronte fortius impressa, thorace late et sat profunde canaliculato valde insigne, e Suecia a Dom. Schönherr sibi communicatum, Dom. Schüppel Museo Regio dedit.

* 5. M. funesta: Subtiliter punclulata, nigra, nitida, antennis pedibusque brunneis, thorace subquadralo, basi leviler foveolato. - Long. $2 \frac{1}{2}$ lin.

Er. Col. March. I. 287. 2.

Aleoch. funesta Grav. Mon. 168.49. - Gyll. Ins. Suec. IV. 488. 22-23. - Suhlb. Ins. Fenn. I. 66. 38.

Bolit och ara funesta Mannerh. Brachelytr. 81. 39.

$V$ ar.: Fusca, elytrorum litura humerali abdominisque segmentorum anteriorum margine fusco-testaceis.

Habitat in Europae silvis, in Formicae fuliginosae societate semper mihi obvia.

Statura omnino praecedentis et parum minor, subtlius minus dense punctulata, nigra, subnitida, pube tenuissime grisea subsericans. Antennae capitis thoracisque longitudine, validae, rufo-testaceae brunneaeve, articulo secundo tertıo dimidio breviore. Caput thorace angustius, subtilissime parcius punctulatum, vel fere lacve. Thorax coleopterorum prope latitudine, latitu- 
dine sua peulo brevior, lateribus leviter rotundatus, basin versus paulo magis quam antrorsum angustatus, subdepressus, aequalis, basi foveola minuta obsoletiora supra scutellum impressus. Elytra thorace vix longiora, confertim subtiliter punctata. Abdomen supra laevigatum. Pedes picei vel brunnei.

Mas differt thorace obsolete canaliculato et abdominis segmento dorsali ultimo subemarginato.

Variat colore dilutiore, fusco, antennis pedibusque rufo-testaceis, elytrorum litura vel macula humerali, abdominis segmentorum anteriorum, nonnunquam etiam thoracis limbo brunneo-testaceis.

Obs. 1. A M. humerali praeter colorem capite fere laevi differt. Varietas descripta primo intuitu M. limbatam simulat, abdomine autem supra laevigato haud difficultur distinguitur.

2. Specimina Austriaca, nominibus Al. fuscicornis, laticollis, grandicollis et brevicornis a Dahlio accepta communicavit Dom. Sch ii pel. A. laticollis a specie genuina nullo modo, A. fuscicornis nonnisi elytris magis brunneis differunt. A. grandicolli is cum varietate dilutiore convenit, A. grandicollis Knochii autem, secundum collectionem Hoffmannseggianam speciei genuinae mas, idemque est A. brevicornis Dahl.

6. M. rigida: Confertim punctata, nigra, subnilida, tenuiler albido-pubescens, antennis libiis tarsisque rufo-brunneis, thorace transversim subquadrato, postice obsolete impresso. - Long. 2 lin.

Habitat in Sardinia, Mus. Reg. Taurin. A. Dom. Prof. Gené ad examinandum communicata.

Habitu praecedentium, at minor, $\mathbf{M}$. canaliculatae aequalis licet minus angustata, nigra, nitidula, pube brevi subtili albida cinerascens. Antennae capite thoraceque multo longiores, validae, brunneo-rufae. Palpi rufi. Mandibulae rufo-piceae. Labrum subtiliter carinatum, apice rufescens. Caput thorace parum angustius, fronte dense sat distincte punctata, convexa, antice subretusum, supra os leviter excavatum sublaevigatumque. Thorax coleopteris paulo angustior, latitudine paulo brevior, lateribus leviter rotundatus, basin versus subangustatus, basi rotundatus, apice late emarginatus, angulis anterioribus acutiusculis, posterioribus obtusis, subelevatus, dorso depressiusculus, densius subtiliter licet sat distincte punctatus, supra scutellum late obsolete impressus. Elytra thorace parum longiora, dense punctata. Abdomen supra segmentis quarto quintoque parce, reliquis crebre subtiliter punctatis. Pedes sat elongati, tibiis tarsisque rufo-brunneis.

Obs. M. funestae proxima, at minor, angustior, cinerascens, abdomine dorso punctato facile distinguenda.

* 7. M. lugens: Subtiliter punctulata, fusca, pedibus testaceis, thorace brevi, transverso, basi leviter foveolato. - Long. 2 lin.

Er. Col. March. I. 289. 4.

Al. lugens Grav. Micr. 95. 40. Mon. 169. 54. - Latr. Hist. nat. Crust. et Ins. IX. 389. 40.

Var.: Elytris basi testaceis.

Habitat in Germaniae silvis, intra Formicae fuliginosae societates.

Praecedentibus brevior, fusco-nigra, subtiliter dense punctulata, pube tenuissima grisea subsericans. Antennae capitis thoracisque longitudine, 
crassae, articulo secundo tertio vix dimidio breviore, ultimo, ut in praecedentibus subcompresso-acuminato, brunneae, basi dilutiores. Palpi rufo-testacei. Caput thorace angustius, sublaeve, fronte nonnunquam obsolete impressa. Thorax coleopterorum fere latitudine, latitudine sua duplo fere brevior, lateribus leviter rotundatis, subdepressus, basi supra scutellum obsolete impressus. Elytra thorace paulo longiora, fusca, basi extrorsum plerumque testacea. Abdomen supra laevigatum, nigrum, nitidum, segmentis anterioribus testaceo-marginatis. Pedes testacei.

* 8. M. fulgida: Nigra, nitida, thorace transverso, vage punctato, basi foveolalo, elytris parce profundeque punctatis antennisque rufo-testa-

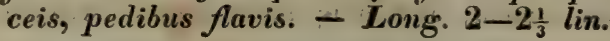

Aleoch. fulgida Grav. Mon. 163. 37.

Var.: Elytris angulo apicali exteriore late nigro. Zyras Haworthi Steph. Illustr. V. t. 26. f. 3.

Habitat in Austria, Hungaria, Dom. Schïppel.

Statura praecedentium, a quibus corpore glabro, nitido discedit. Antennae capitis thoracisque fere longitudine, extrorsum leviter incrassatae, rufo-testaceae, articulo secundo tertioque aequalibus. Caput thorace paulo angustius, lateribus parce grosseque punctatum, nitidissimum, nigrum, ore obscure testaceo. Thorax coleopteris paulo angustior, latitudine dimidio brevior, lateribus leviter rotundatus, basin versus subangustatus, subdepressus, vage punctis grossis piliferis impressus, basi supra scutellum foveola parva notatus, niger, pernitidus. Elytra thorace paulo longiora, parce profundeque punctata, rufo-testacea, nitida. Abdomen supra laevigatum, posterius punctis parcis maioribns sparsum, nitidum, obscure testaceum, segmentis singulis supra basi obscurioribus, ultimis duobus totis nigris.

Obs. Varietas indicata, cuius specimen Austriacum dedit Dom. Sch üppel, genuinis duplo maior, praecipue latior, abdomine dorso minus picescente, elytrorum angulo apicali exteriore late et distincte nigro, facile speciei peculiaris speciem prae se ferat, at notae satis distinctivae desiderantur. Specimen secundum, huic omnino congruens, Lutetiae lectum, in collectione Dom. Au bé vidi.

* 9. M. marginicollis: Nigro-picea, nitida, antennis pedibusque rufis, thorace transversim quadrato, basi obsolete foveolato, margine omni rufo, abdomine segmento dorsali penultimo utrinque longitudinaliter sulcato. - Long. $2 \frac{1}{2}$ lin.

Habitat ad Promont. Bon. Spei, Dom. Prof. Lichtenstein.

Statura fere M. funestae, nigro-picea, nitida, glabra. Antennae capitis thoracisque longitudine, mmus crassae, articulo secundo tertioque longitudine aequalibus, rufo-testaceae. Caput thorace paulo angustius, subglobosum, posterius parce subtiliter punctulatum, nigerrinum, pernitidum, ore testaceo. Thorax latitudine dimidio brevior, lateribus leviter rotundatis, basin versus subangustatus, disco leviter convexo, margine laterali depresso, vage subtilter punctatus, piceus, nitidus, margine omni dilutiore rufescente. Elytra thorace vix longiora, obsoletius punctata, tenniter pubescentia, picea, minus nitida. Abdomen nigro-piceun, apice testaceum, subtus densius punctatum, supra laevigatum, segmento penultimo utrinque stria longitudinali profunde impresso. Pedes rufo-testacei. 


\section{M. obscura: Nigra, nitida, thorace, elytris pedibusque obscure} brunneis. "

Staph. obscurus Fab. Syst. El. H. 595. 29.

Habitat in India orientali. Mus. Reg. Hafniense.

"Antennae nigrae, basi apiceque brunneae. Caput, atrum ore brunneo. Thorax et elytra subpunctata, fusco-brunnea, immaculata. Abdomen atrum, ano brunneo. Pedes brunnei." Fab.

Obs. Hanc speciem in Museo citato vidi, at mihi quidem haud accuratius examinata, tamen de eius loco et affinitatibus indubius sum. Affinis certe sequenti, nisi forte omnino eadem sit. Color, a Fabricio pro fusco-brunneo descriptus, potius rufo- testaceus est.

* 11. M. spinigera: Rufo-testacea, parce punctata, nitida, capile abdomineque nigris, hoc supra segmento primo apice laminato, utrinque bispinoso, secundo quintoque medio dentatis. - Long. 3 lin.

Habitat in Aegypto, Dom. Prof. Ehrenberg.

Caput thoracis prope latitudine, nigrum, opacum, subtiliter vage punctatum, ore flavo. Antennae capite duplo longiores, crassae, brunneae, basi rufo-testaceae, articulo secundo tertio duplo breviore. Thorax coleopteris paulo angustior, latitudine parum brevior, basin versus vix angustatus, depressus, undique tenuiter marginatus, parcius punctatus, rufo-testaceus, nitidus. Elytra thorace parum longiora, testacea, profunde punctata. Abdomen nigrum, nitidum, vage punctatum, segmento primo secundique lateribus obscure rufis, segmento primo supra margine apicali in laminam, segmenti secundi basin obtegentem, apice utrinque spinis duabus elongatis, interiore exteriori imposita eamque tegente, terminatam producto, segmento secundo supra medio dente compresso, segmento quinto tubercnlo acuto armatis. Pectus et pedes rufo-testacei.

* 12. M. armata: Brunnea, opaca, elytris fuscis, capite abdomineque nigris, hoc nitido, segmento primo apice sublaminato, utrinque unispinoso. - Long. $2 \frac{1}{2}$ lin.

IIabitat in Africa australi, Dom. Drège.

Statura praecedentis. Antennae capitis thoracisque longitudine, crassae, subcompressae, articulo secundo tertio plus duplo minore, fuscae, articulo tertio brunneo, primis duobus testaceis. Mandibulae et palpi rufo-testacei, labrum flavum. Caput thoracis prope latitudine, nigrum; parum nitidum, parcius subtiliter punctulatum, fronte leviter impressa. Thorax coleopteris paulo angustior, latitudine paulo brevior, basin versus subangustatus, lateribus pone medium subsinuatis, parum convexus, subtiliter minus dense punctatus, interstitiis subtilissime alutaceis, linea tenuissima canaliculatus, brunneo-testaceus, vix nitidus. Scutellum brunneo-testaceum. Elytra subtilissime alutacea, minus dense subtiliter punctata, fusco-nigra, basi brunnea, opaca. Abdomen supra laeve, subtus parcius punctatum, nigrum, subtus basi brunneum, segmento primo dorsali margine apicali paululum producto, intra marginem spina singula, elongata, subarcuata, acuta armato. Pectus brunneo-testaceum. Pedes testacei. 
* 13. M. speciosa: Rufa, opaca, capite, elytris abdominisque cingulo lato apicali atris, thorace oblongo, aeguali. - Long. ultra 3 lin.

Habitat in Aegypto, Dom. Prof. Ehrenberg.

Praecedentibus paulo maior. Antennae breves, crassae, rufo-brunneae, medio obscuriores, articulo secundo tertio duplo minore. Caput thoracis fere latitudine, rotundatum, atrum, ore testaceo, fronte convexiuscula, obsolete punctata. Thorax latitudine longior, coleopteris paulo angustior, subdepressus, subtilissime vage punctatus, postice obsolete canaliculatus, testaceo-rufus, opacus. Scutellum rufo-testaceum, Elytra thoracis longitudine, subtiliter punctata, atra, opaca, humeris piceis. Pectus, pedes et abdomen rufa, hoc segmentis duobus penultimis atris, dorso laevigato.

* 14. M. atricapilla: Rufo-testacea, parce subtilissime punctata, capile abdominisque apice nigris, elytris subtiliter granulalis, fuscescentibus.

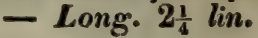

Habitat ad Promont. Bon. Spei, Dom. Krebs.

Statura praecedentium. Antennae capitis thoracisque longitudine, crassiusculae, testaceae, medio fuscescentes, articulo secundo tertio dimidio breviore. Caput thoracis latitudine, nigerrimum, nitidum, ore flavo, fronte impressa. Thorax latitudine parum brevior, coleopteris paulo angustior, basin versus leviter angustatus, lateribus rectis, depressus, rufo-testaceus, opacus, subtiliter vage punctatus. Elytra thorace vix longiora, subtiliter granulata, fuscescentia, humeris dilutioribus, opaca. Abdomen rufo-testaceum, segmentis duobus penultimis nigris. Pectus rufo-testaceum. Pedes pallidi.

*15. M. frontalis: Rufo-testacea, nitida, parce punctala, fronte nigra, thorace basi lateribusque impresso. - Long. 2 lin.

Habitat ad Prom. Bon. Spei, Dom. Krebs.

Statura M. limbatae. at paulo angustior, rufo-testacea, nitida, undique vage subtiliter punctata. Antennae capite thoraceque longiores, sat validae, articulo secundo tertio parum breviore. Frons convexiuscula, cum vertice, nigra. Thorax latitudine brevior, basi lateribusque leviter rotundatus, subdepressus, basi fovea transversa, prope marginem lateralem utrinque fovea maiore oblonga impressus. Elytra thorace sesqui longiora. Abdomen segmentis duobus penultimis medio fuscescentibus.

16. M. boops: Brunneo testacea, nitida, capite nigro, thorace latiore, fronte convexa, thorace brevissimo, elytris parce subtiliter punctalis. Long. $2 \frac{1}{4}$ lin.

Habitat prope Puerto Cabello Columbiae. Collect. Dom. Moritz.

Statura fere praecedentium, fusco-testacea, nitida, glabra. Antemnae capitis thoracisque fere longitudine, validiusculae, articulo tertio secundo sesqui longiore. Caput thorace paulo latius, transversum, convexum, fronte utrinque obsolete punctulata, nigrum, ore testaceo, oculis sat magnis convexis. Thorax coleopteris angustior, latitudine duplo brevior, apice trumcatus, hasi lateribusque rotundatus, supra leviter convexus, disco sparsim obsoletius punctatus. Elytra thorace sesqui longiora, subdepressa, parcius 
subtiliusque punctata, margine laterali apicem versus infuscato. Abdomen elongatum, subtus longitudinalıter convexum, supra longitudinaliter concavum, margine laterali sat elevato, acuto, laevigatum, subtus parce punctulatum parceque pilosellum. Pedes dilutius testacei.

* 17. M. collaris: Rufo-testacea, nitida, capite, elytris, pectore anoque nigris, thorace subquadrato, basi foveolato. - Long. 2 lin.

Er. Col. March. I. 290. 7.

Staph. collaris Payk. Faun. Suec. III. 401. 43. - Oliv. Ent. III. 42. 37. 54. t. II. $f .13$.

Aleoch. collaris Grav. Mon. 164. 43. - Gyll. Ins. Suec. II. 385. 8. - Zetterst. Ins. Lappon. 75. 6. - Sahlb. Ins. Fenn. I. 348. 6. - Steph. Illust. V. t. 26. f. 2. Bolit ochura collaris Mannerh. Brachelytr. 75. 1. - Boisd. et Lacord. Faun. Ent. Paris. I. 541. 1. - Runde Brachel. Hal. 29. 1.

Habitat in Europae silvis.

Antennae crassae, pilosae, fuscae, basi rufo-testaceae, articulis 4 ultimis flavescentibus, secundo tertioque subaequalibus. Caput thorace paulo angustius, nigrum, nitidum, nigro-pubescens, parce punctatum, fronte sublaevi. Thorax coleopteris nonnihil angustior, latitudine parum brevior, lateribus leviter rotundatus, parum convexus, parce pubescens, sparsim punctatus, basi medio foveolatus, rufo-testaceus, nitidus. Elytra thorace paulo longiora, parce pilosa, profunde parcius punctata, nigra, nitida. Abdomen supra fere impunctatum, rufo-testaceum, segmentıs quinto sextoque nigris. Pectus nigrum. Pedes flavi.

18. M. ochracea: Testacea, nitida, elytris profundius punctatis, antennis crassis, capite parum longioribus. - Long. 3 lin.

Porus ochraceus Hope Royle Himalaja. Zool. t. 9. f. 10.

Habitat in Nepalia, Mus. Dom. Hope.

Corpus totum testaceum, nitidum. Antennae capite parum longiores, crassae, articulo secundo tertio breviore, 4-10 brevibus, perfoliatis, ultimo ovato. Caput thoracis latitudine, basi parum constrictum, fronte plana, parce subtiliterque punctatum. Thorax coleopteris parum angustior, latitudine dimidio brevior, basin versus subangustatus, lateribus basique leviter, angulis posterioribus fortiter rotundatis, parum convexus, parce subtilissimeque punetatus. Elytra thorace paulo longiora, minus dense profunde punctata. Abdomen parallelum. Pedes breves, crassiusculi, tibiis omnibus extus spinulis brevissimis, apice calcaribus duobus fortioribus munitis.

Obs. Conf. quod supra in generis descriptione notavi.

* 19. M. coriacea: Nigra, nitidula, punctata, thorace angustiore, basi impresso, elytris disco late impressis: antennis, pedibus anogue piceis, femoribus posticis basi albis. - Long. $2 \frac{3}{4}$ lin.

Habitat in Brasilia: specimen alterum e collectione Virmondıana, alterum a def. Sellow prope San João del Rey lectum.

Piceo-nigra, nitidula, parce griseo-pubescens. Antennae capite thoraceque longiores, graciles, piceae, basi rufescentes, articulo secundo tertio vix 
breviore. Caput minutum, rotundatum, fronte convexiuscula, obsolete punctulata. Thorax coleopteris duplo angustior, latitudine parum brevior, lateribus antice leviter rotundatus, subdepressus, crebrius punctatus, postice impressus. Elytra thorace paulo longiora, oblique punctata, medio leviter impressa. Abdomen revolutum, dorso impunctato, laevi, subtus subtiliter vage punctatum. Pedes elongati, graciles, nigro-picei, geniculis fuscis, femoribus posticis basi albidis.

20. M. camura: Ferruginea, nilidula, capile globoso, nigro, thorace angustiore, transversim subquadralo, convexo, elytris scabralis, abdomine latiusculo. - Long. $1 \frac{1}{2}$ lin.

Habitat prope Puerto Cabello Columbiae. Collect. Dom. Moritz.

Habitu omnino praecedentıs, at plus duplo minor. Antennae capitis, thoracis elytrorumque prope longitudine, apicem versus sensim subincrassatae, articulo secundo tertio paulo breviore, totae testaceae. Caput thoracis latitudine, globosum, basi profunde constrictum, fronte convexa, laevissimum, nigrum, ore ferrugineo. Thorax coleopteris plus dimidio angustior, latitudine paulo brevior, angulis anterioribus rotundatis, posterioribus rectis, convexus, laevis, ferrugineus, nitidus. Scutellum ferrugineum. Coleoptera thorace basi dimidio, apice duplo latiora, leviter convexa, punctis crebris elevatis asperata, ferruginea, nitida. Abdomen latiusculum, medio coleopteris fere latius, ferrugineum, nitidum, supra planum vel leviter excavatum, recurvum, laeve, subtus convexum, apicem versus obsolete punctulatum, et pilis breviusculis rigidis nigris hispidulum. Pectus ferrugineo-testaceum. Pedes elongati, pallidius testacei.

* 21. M. labida: Testacea, abdomine ante apicem elytrisque fuscis, his basi margineque apicali flavo-testaceis, capile thoraceque transverso, basin versus subanguslato piceo-rufescentibus. - Long. $1 \frac{1}{3}$ lin.

Habitat in Guyana Venezuelensi, Dom. Moritz.

Statura fere Homalotae socislis, subdepressa, nitidula, pube brevissima subtilissimaque vestita. Antennae capitis thoracisque longitudine, articulis secundo tertioque aequalibus, ultimo oblongo, acuminato, testaceae, articulis basalibus pallidioribus. Caput thoracis latitudine, parce subtilissime punctulatum, piceo-rufo-testaceum, ore angustato, testaceo. Thorax coleopteris parum angustior, transversus, latitudine plus dimidio brevior, basin versus subangustatus, basi leviter rotundatus, apice truncatus, parum convexus, confertim subtilissime punctulatus, picescenti-testaceus. Scutellum rufo-piceum. Elytra confertim subtilissime punctulata, fusca, basi margineque apicali flavo-testaceis. Abdomen testaceum, segmentis tribus penultimis fuscis. Pectus picescenti-testaceum, Pedes testacei.

22. M. munda: Fusca, elytrorum humeris margineque apicali pedibusque favis, antennis basi apiceqae teslaceis, thorace basin versus subanguslato. - Long. 1 $\frac{1}{3}$ lin.

Ilabitat in Ainericae meridionalis ins. St. Thomae. Coll. Dom. Moritz. Habitu et statura omnino pracedentis, piceo-fusca, nitidula, omnium subtilis-ime pubescens. Antennae capite thoraceque paulo longiores, articulo 
secundo tertio breviore, ultimo oblongo, acuminato, fuscae, articulis duobus primis ultimisque tribus flavis. Caput thoracis prope latitudine, subtilissime punctulatum, fronte planiuscula, ore angustato cum palpis flavescente. Thorax coleoptoris paulo angustior, latitudine parum brevior, basin versus angustatus, lateribus pone medium subsinuatis, apice truncatus, leviter convexus, confertim subtilissime punctatus, rufescenti-piceus. Elytra confertim subtilissime punctata, fusco-picea, angulo humerali margineque apicali pallide flavescentibus. Abdomen supra laeve, fusco-piceum, segmentis secundo tertioque margine apicali testaceo. Pedes flavi.

23. M. ins cita: Nigra, antennarum basi, tibiis tarsisque testaceis, elytris fuscis, humeris margineque apicali albidis, thorace transverso, basin versus subangustato. - Long. $1 \frac{1}{3}$ lin.

Moritz.

Habitat in Columbia ad montes prope Puerto Cabello: Collect. Dom.

Statura et summa affinitas praecedentium. Nigra, nitidula, omnium subtilissime pubescens. Antennae capitis thoracisque longitudine, articulo secundo tertio vix breviore, ultimo oblongo, acuminato, nigrae, basi sordide testaceae. Caput thoracis fere latitudine, ore angustato, fuscescente. Thorax coleopteris parum angustior, latitudine duplo fere brevior, basin versus leviter angustatus, lateribus subrotundatis, parum convexus, laevis. Elytra thorace parum longiora, confertim subtilissime punctulata, fusca, nitida, macula transversa humeralı margineque apicali albidis. Abdomen supra laeve. Pedes nigri, tibiis tarsisque rufo-testaceis.

24. M. turbida: Picea, antennarum basi, pedibus, elytrorum macula humerali, abdominisque segmentorum anteriorum margine apicali testaceis, thorace transverso, basin versus subangustato. - Long. $1 \frac{1}{2}$ lin.

Habitat in valle Araguensi Columbiae. Coll. Dom. Moritz.

Statura praecedentium, at paululum maior, fusco-picea, nitidula, subtiliter pubescens. Antennae capitis thoracisque longitudine, articulo secundo tertioque snbaequalibus, ultimo oblongiusculo, pilosellae, piceae, articulis duobus primis testaceis. Caput thoracis latitudine, laeve vel parce subtilissime punctulato, ore angustato, piceo-testaceo. Thorax coleopteris paulo angustior, latitudine duplo fere brevior, lateribus subrotundatis, basin versus modice angustatus, leviter convexus, subtiliter punctulatus, margine laterali pilosello. Elytra thorace paulo longiora, confertim subtiliter punctulata, humeris sordide flavescentibus. Abdomen supra laeve, segmentis 2-4 margine posteriore testaceo. Pedes tenues, flavo-testacei.

25. M. parilis: Nigra, elytris fusco piceis, antennarum basi pedibusque luteis, thorace subquadrato, basin versus subangustato, dorso longitudinaliter obsolete impresso. - Long. 1 lin.

\section{Habitat ad Caracas Columbiae. Coll. Dom. Moritz.}

Statura praecedentium, at duplo minor, nigra, nitidula, elytris obscure fusco-piceis, tota confertissime subtilissimeque punctulata, pube subtilissima grisea sericans. Antennae capite thoraceque longiores, articulis 2 et 3 aequalibus, 4-10 elongato-subobconicis, ultimo elongato, acuminato, nigrae, 
articulo primo luteo. Caput thoracis fere latitudine, orbiculatum, fronte obsolete canaliculata, ore luteo. Thorax coleopteris angustior, latitudine vix brevior, basin versus sensim subangustatus, parum convexus, canalicula sat lata antrorsum evanescente minus profunde impressus. Elytra thorace paulo longiora, margine apicali obsolete pallescente. Abdomen subtus segmentis anterioribus margine apicali testaceo. Pedes lutei.

Obs. Species 5 ultimae inter se peraffines, Homalotarum quibusdam speciebus habitu simillima, facile autem distinguuntur tarsis posticis elongatis; a Tachyusis coxis intermediis distantibus differunt, et oris structura, quantum absque dissectione perspicere licet, huius generis esse mihi videtur.

* 26. M. tumidula: Brevis, ferruginea, densius cinereo-pubescens, capite abdomineque ante apicem fuscis, pedibus flavescentibus, thorace transverso, brevi, convexo. - Long. $1 \frac{1}{2}$ lin.

Habitat in Columbia, Dom. Moritz.

Brevis, crassiuscula, ferruginea, nitida, pube depressa grisea spissiore vestita. Antennae minus crassae, capite thoraceque paulo breviores, articulo tertio secundo vix breviore, at tenuiore, testaceae, ante apicem fuscescentes. Caput thorace angustius, at maiusculum, basi vix constrictum, omnium subtilissime punctulatum, fuscum, oris partibus testaceis. Thorax transversus, latitudine plus duplo brevior, basi coleopterorum prope latitudine, leviter bisinuatus, angulis posterioribus rectis, apicem versus modice angustatus, supra satis convexus, omnium subtilissime punctulatus. Elytra thorace sesqui longiora, apice truncata, minus depressa, evidentius punctulata, nonnunquam fuscescentia. Abdomen breviusculum, lateribus leviter rotundatum, supra parcius punctulatum, ante apicem fuscescens. Pedes flavescenti-testacei.

$\mathrm{O}$ bs. Non indubius hanc speciem ad hoc genus refero, habitus enim alienam quandam speciem prae se ferré videtur, et oris structura mihi haud perspecta. Differt autem ab Oxypodis et Aleocharis tarsis anticis 4-articulatis, ab Homalotis tarsis posticis articulo primo elongato: his notis et pedibus intermediis basi interstitio sat lato distantibus cum Myrmedoniis convenit, neque alii cuidam generi adscribi potest.

\section{Autalia Leach.}

Mannerh. Brachelytr. p. 87. - Er. Col. March. I. p. 291.

Maxillae mala interiore mutica, intus spinulis ciliata.

Ligula elongata bifida, laciniis bifidis, lacinia interiore perbrevi, exteriore lineari; paraglossae parvae, angustae, acuminatae.

Palpi labiales biarticulati.

Tarsi antici 4-, posteriores 5-articulati, postici articulis 4 primis aequalibus.

Corpus minutum, minus depressum, alatum. Caput exsertum, porrectum, basi profunde constrictum, collo quasi tenui thoraci affixum, suborbiculatum, thorace paulo latius, oculis mediocribus, parum prominulis. Labrum latiusculum, semi-orbiculare. Mandibulae parvae, muticae. Maxillae mala exteriore cornea, apice membranea pubescenteque, interiore exteriori longitudine aequal, extus cornea, intus membranea, apice introrsum oblique emarginata, sinu spinulis brevibus ciliato. Palpi maxillares modice elon- 
gati, articulo secundo tertioque subaequalibus, hoc apicem versus leviter incrassato, quarto minuto, subulato. Labium (t. III, f. 2.) mento sat magno, antrorsum leviter angustato, apice profunde inciso, lobis rotundatis; ligula angusta, elongata, apice bifida, laciniis iterum bifidis, laciniolis exterioribus longioribus extrorsum, interioribus brevioribus antrorsum vergentibus, paraglossis parvis, angustis, acuminatis, interne ciliatis. Palpi labiales biarticulati, articulo primo cylindrico, secundo hoc vix breviore, apice leviter incrassato. Antennae capitis thoracisque fere longitudine, crassiusculae, articulo primo cylindrico, secundo tertioque obconicis, magis elongatis, his inter se subaequalibus. Thorax coleopteris duplo fere angustior, subquadratus, augulis anterioribus rotundatis, apice attenuatus. Scutellum triangulare. Coleoptera sat ampla, abdomine paulo latiora, lateribus leviter rotundata, apice ad angulum exteriorem vix sinuata. Abdomen lineare, supra planum, subtus convexum, recurvum. Pedes mediores, intermedii basi leviter distantes, tarsi antici 4-, posteriores 5-articulati, parum elongati, articulıs 4 primis subaequalıbus.

$$
\text { O b s e r vation es. }
$$

1. Maxillae omnino ut in Homalotis (t. III. f. 22.), labium contra in hoc genere perquam singulare; paraglossae acuminatae affinitatem cum $\mathrm{Falagria}$ produnt, mentum autem profunde inscisum et ligula elongata, apice quadrifida huic peculiaria. Palpi labiales certe biarticulati.

2. Habitus thorace apice attenuato et capite remoto $\mathrm{Falagriis}$ affinis, discedit autem thorace impressionibus longitudinalibus plicato, et tarsis posticis haud elongatis, articulis 4 prioribus longitudine subaequalibus. Sunt autem quaedam $\mathrm{Ho}$ m a lo tae species (H. didyma et bisulcata,) quae thoracis et capitis a thorace remoti forma, tarsorum structura et omni habitu cum Autaliis conveniunt, ut non nisi oris examine instituto $a b$ is distinguantur.

3. Sexus differentia mihi haud observata.

\section{* 1. A. impressa: Rufo-testacea, capite abdominisque postico nigrícanti- bus, thorace sulculo antico foveisque quatuor posticis longitudinalibus impressis. - Long. 1 lin.}

Mannerh. Brachelytr. 87. 2. - Boisd. et. Lacord. Fuun. Ent. Paris, I. 558. - Er. Col. March. I. 292.1.

Staphyl. impressus Oliv. Ent. III. 42. 23. 28. t. 5. f. 11.

Aleoch. impressa Grav. Micr. 72. 7. Mon. 150. 4. - Latr. Hist. nat. Crust. et

Ins. IX. 380. 7. Gen. Crust. et Ins. 302. 3. - Gyll. Ins. Suec. II. 381. 4. Sahlb. Fenn. I. 346. 3.

\section{Habitat in Europae boletis.}

Obscure rufo-testacea, nitida, subtiliter pubescens. Caput nigricans, subtilissime punctatum. Thorax ante medium sulculo medio, postice sulculis duobus obliquis, abbreviatis, interioribus, et utrinque foveola exteriore rotundata impressus. Elytra fusco-testacea, subtilissime punctata, basi bifoveolata. Abdomen pone medium nigricans, summo apice dilute testaceo. Pedes testacei.

*2. A. rivularis: Nigra, nitida, antennis pedibusque piceis, thorace sulculo medio foveolisque quatuor basalibus impresso. - Long. $\frac{5}{6}$ lin.

Mannerh. Brachelytr. 87. 1. - Er. Col. March. I. 293. 2.

Aleoch. rivularis Grav. Micr. 73. 8. Mon. 150. 5. - Latr. Hist. nat. Crust. et

Ins. IX. 380. 8. - Gyll. Ins. Suec. IX. 362, 5. - Sahlb. Ins. Fenn, I. 347. 4. 


\section{Habitat in Europa.}

Praeredente paulo minor, nigra, nitida, parce subtiliter pubescens, antennis pedibusque rufo-piceis. Thorax sulco medio, antice abbreviato, ad basin autem continuato, foveisque quatuor basalibus impressus, his iisdem ut in praesedente, licet profundioribus. Elytra basi bifoveolata, vix punctulata. Abdomen apice piceum.

\section{Falagria Leach.}

\section{Mannerh. Brachelytr, p. 86. - Er. Col. March. 1. p. 293.}

Maxillae mala interiore mutica, intus spinulis ciliata.

Ligula elongala, linearis, apice bifida, paraglossae parvae, angustae, acuminatae.

Palpi labiales triarticulati, articulo secundo minore.

\section{Tarsi antici 4-, posteriores 5-articulati, postici articulo primo elongato.}

Corpus minutum, minus depressum, alatum. Caput exsertum; porrectum, basi profunde constrictum, collo quasi tenui thoraci affixum, suborbiculatum, thoracis fere latitudine, oculis mediocribus, haud prominulis. Labrum mediocre, semiorbiculatum. Mandibulae parvae, muticae. Maxillae mala exteriore cornea, apice membranea, pubescenteque, interiore exteriore breviore, membranea, margine exteriore corneo, apice introrsum oblique emarginata, sinu spinulis brevibus ciliato. Palpi maxillares modice elongati, articulo secundo tertioque subaequalibus, hoc apicem versus sensim incrassato, quarto parvo, subulato. Labium (t. III. f. 3.) mento transverso, apice leviter emarginato, ligula angusta, haud ultra primum palporum articulum porrecta, apice bifida, paraglossis parvis acuminatis, interne ciliatis. Palpi labiales tri-articulati, articulo primo subcylindrico, secundo hoc duplo fere breviore, parum discreto, tertio paulo tenuiore, apice leviter incrassato. Antennae capiti thoracique longitudine aequales vel paulo longiores, crassiusculae, apicem versus plerumque parum incrassatae, articulis tribus primis magis elongatis, secundo tertioque obconıcis, subaequalibus. Thorax basin versus angusiatus, apice obtuse angulatus. Scutellum triangulare. Coleoptera abdominis latitudine, apice truncata, ad angulum exteriorem vix sinuata. Abdomen lineare, supra planum, subtus convexum, saepe recurvum. Pedes modice elongati, intermedii basi leviter distantes, tarsi anticı 4-, posteriores 5-articulati, elongati, articulis 4 primis sensim decrescentibus.

\section{o b s e r va tiones.}

1. Maxillae omnino ut in Homalota (t. III. f. 22.). Paraglossae acuminatae ut in Autalia et Bolitochara. Cum Bolitochara summa similitudo in oris structura, at ligula minus elongata, palporum labialium articulum primum vix superans. Palpos labiales olim, licet non sine dubio quodam, biarticulatos descripsi, dein autem dissectione et examine reiteratis distincte triarticulatos vidi. Articulus secundus a primo minus distinctus.

2. Habitus huius generis gracilis, elegans, corpore plerumque subtilissime punctulato vel sublaevi, tenuiter subtilissimeque pubescente. Distinguitur facile a generibus affinibus thorace subcordato vel orbiculato, convexiusculo, et capite reinoto. Thorax saepe, nonnunquam etiam scutellum canaliculata.

3. Differentia sexus in plerisque speciebus mihi non observata: in nonnullis mares fronte impressa cognoscuntur. 
4. A Dom. Curtis loco infra apud F. thoracicam citato genus Falagria illustratum, at oris partes haud satis accurate observatae neque correcte delineatae. Ligula pictorem omnino fugit. Tarsos anticos elegantissimus auctor recte 4-articulatos vidit, posteriores autem observandos neglexit.

* 1. F. sulcata: Nigro-picea, thorace subcordato scutelloque profunde canaliculatis, coleopteris quadratis, subtilissime punctulatis. - Long. 1 lin.

Mannerh. Brachelytr. 86. 1. - Boisd. et Lacord. Faun. Ent. Paris. I. 556. 2. Runde Brachel. Hal. 31. 1.

Staph. sulcatus Payk. Mon. Staph. 32. 24. - Schrank Faun. Boic. I. 648. 888. Oliv. Ent. III. 42. 23. 27. t. 6. f. 52. - Marsh. Ent. Britt. 507. 25.

Al. sulcat a Grav. Micr. 73. 9. Mon. 150. 6 - Latr. Hist. mat. Crust. et Ins. IX. 380. 9. - Gyll. Ins. Suec. II. 378. 1. - Suhlb. Ins. Fenn. I. 345. 1.

Fulagria caesa Er. Col. March. I. 295. 2.

\section{Habitat in Europa.}

Nigro-picea seu fusco-prcea, nitida, pube subtili densiore grisea sericans. Antennae capitis thoracisque longitudine, crassiusculae, totae fuscae. Palpi fusci. Caput thoracis prope latitudine, fronte depressiuscula, omnium subtilissime punctulata, inter antennas obsolete bi-impressa. Thorax latitudine summa paene brevior, ante medium fortiter ampliatus, basin versus sensim angustatus, dorso subdepressus, subtilissime punctulatus, sulco profundo, apice summo abbreviato, basi dilatato canaliculatus. Scutellum bicarinatum. Coleoptera latitudine sua haud breviora, thorace longiora, subtilissime punctata. Abdomen confertim punctulatum, densius griseo-pubescens. Pedes fusco-testacei.

Obs. Nomen vulgatum restitui. Primo enim haec species a Paykul loco supra citato "antennis fuscescentibus " descripta est. Staph. sulc atum eiusdem auctoris in Fauna Suecica "antennis basi rufis " memoratum alteram speciem, Al. sulcatulam Grav., esse patet.

* 2. F. dissecta: Nigro-picea, thorace subcordalo scutelloque profunde canaliculatis, coleopteris transversis, subtiliter punctulatis. - Long. 1 lin.

Habitat in Pensylvania, Dom. Zimmermann.

Praecedenti simillima, nigro-picea, nitida, pube brevi subtili griseo-subsericans. Antennae capitis thoracisque longitudine, crassiusculae, nigro-piceae. Palpi picei. Caput thoracis latitudine, nigerrimum, subtilissime punctulatum, fronte convexiuscula. Thorax latitudme summa paulo brevior, ante medium fortiter rotundato-ampliatus, leviter convexus, subtiliter punctulatus, sulco profundo, apice abbreviato canaliculatus. Scutellum bicarinatum, inter carinas canaliculatum. Coleoptera latitudine sua paululum breviora, thorace paulo longiora, confertim subtiliter punctulata. Abdomen subtiliter punctulatum. Pedes picei, tarsis testaceis, vel rufo-testacei, tarsis dilutioribus.

Obs. A praecedente aegerrime distinguenda, at revera specie distincta videtur. Differt fronte convexiuscula, thorace lateribus magis rotundato, sulco basi haud $d$; latato, elytris brevioribus, distinctius punctulatis, pedibus obscuris, tarsis solis testaceis. 
* 3. F. sulcatula: Picea, thorace subcordato, scutelloque profunde canaliculatis, coleopteris transversis, laevibus. - Long. vix 1 lin.

Aleoch. sulcatula Grav. Mon. 151. 7.

Staph. sulcat us Payk. Faun. Suec. III. 385. 24.

Aleoch. sulcata var. b Gyll. Ins. Suec. II. 378. 1. - Sahlb. Ins. Fenn. I. 345. 1. Falagria sulcata Er. Col. March. I. 294. 1.

Fal. polita Curtis Britt. Ent. X. f. 462. n. 4.

Habitat in Europa.

Picea, vel interdum rufo-picea, abdomine pone medium migricante, nitida, parcissime subtilissimeque pubescens, haud sericans. Antennae capitis thoracisque prope longitudine, piceae, basi rufo-testaceae. Palpi picei. Caput thoracis latitudine, fronte depressiuscula, vix perspicue punctulata. Thorax latitudine summa haud brevior, antrorsum rotundato-ampliatus, basin versus sensim aequaliter angustatus, leviter convexus, vix perspicue punctulatus, sulco profundo longitudinali, apice summo abbreviato, basi subdilatato, exaratus. Scutellum bicarınatum, inter carinas canaliculatum. Coleoptera thorace haud longiora, latitudine sua distincte breviora, laevia. Abdomen dorso parce punctulatum. Pedes rufo-testacei.

Obs. Affinis certe F. sulcatae, at haud difficulter distinguenda statura strictiore, thorace longiore, coleopteris brevioribus, haud perspicue punctulatis, corpore haud sericante, magis rufo-piceo, antennis basi rufo-testaceis. De synonymis conf. quae apud illam ad calcem observavi.

* 4. F. discisa: Nigra, nitida, elytris antennisque fuscis, his apice pedibusque testaceis, thorace subcordato scutellogue profunde canaliculatis. - Long. 1 lin.

Habitat in Brasilia. Benevole dedit Dom. Melly.

Statnra praecedentium, nigra, nitida, omnium subtilissime pubescens. Antennae capite thoraceque longiores, basi rufo-brunneae, medio fuscae, apice sensim testaceae. Caput subtiliter vage punctatum, vertice longitudinaliter impresso. Thorax antice valde rotundato-ampliatus, basin versus fortiter angustatus, ante basin leviter constrictus, latitudine summa vix brevior, parum convexus, laevissimus; sulco profundo canaliculatus. Scutellum canaliculatum. Elytra fusco-testacea, nitida, subtilissime parce punctulata. Abdomen supra subtilissime obsolete punctulatum. Pedes testacei.

* 5. F. scissa: Rufo-picea, tenuiler pubescens, capite thoraceque fuscescentibus, hoc subcordalo, punctatissimo, postice utrinque foveolato scutelloque canaliculatis. - Long. $1 \frac{2}{3}$ lin.

Habitat prope Fuerto Cabello in Columbia, Dom. Moritz.

Praecedentibus paulo maior, rufo-picea, capite thoraceque fuscescentibus, subnitidis. Antennae capite thoraceque paulo longiores, crassiusculae, rufo-brunneae, ante medium fuscescentes. Caput subtiliter parcius punctatum, tenuissime pubescens, vertice obsolete impresso, fronte inter antennas leviter bi-impressa. Thorax latitudine summa paulo brevior, lateribus valde ampliatus, basin versus valde coarctatus, prope basin leviter constrictus, subdepressus, confertissime punctatus, subtilissime pubescens, canalicula profunda media foveolaque laterali utrinque pone medium impressus. Scutel- 
lum canaliculatum. Elytra fusco-testacea, subtilissime vage punctulata, dense subtilissime pubescentia. Abdomen parce punctatum, apicem versus piceum. Pedes testacei.

* 6. F. divisa: Picea, thorace subcordato, profunde canaliculato, rufopiceo, elytrorum humeris, abdominis el antennarum basi pedibusque testaceis. - Long. $1 \frac{1}{2}$ lin.

Habitat in Brasilia, Dom. Melly.

Praecedentibus paulo gracilior, F. sulcata paulo maior. Antennae longiores, piceae, basi testaceae (ultimi tres articuli desunt). Caput piceum, nitidum, laeve. Thorax latitudine summa longior, ante medium rotundatoampliatus, rufo-piceus, nitidus, laevis, profunde canaliculatus, inter canaliculam subtiliter punctatus. Scutellum obsolete bicarinatum, punctatum, rufo-piceum. Elytra thorace parum longiora, vage subtilissime punctata, nitıda, fusca, margine apicali humerisque sordide testaceis, pone scutellum impressione rotundata communi notata. Abdomen subtilissime densius punctatum pubescensque, obscure piceum, segmento primo secundoque testaceis, secundo obscuriore, subtus rufo-piceum, segmento primo flavo. Pedes testacei.

7. F. concinna: Nigra, nitida, thorace subcordato, profunde canaliculato, piceo, elytris fuscis, basi apiceque pallide testaceis, abdominis segmento primo, antennarum basi apiceque pedibusque teslaceis, his femoribus nigris. - Long. 1 lin.

Habitat in Brasilia. Amice dedit Dom. Prof. Germar.

Affinis praecedenti, at minor, statura ommino F. sulcatae. Antennae capitis thoracisque longitudinem prope superantes, validiusculae, piceae, articulis tribus primis ultimoque testaceis. Caput thorace paululum latius, laevissimum, nigrum, nitidum. Thorax latitudine summa vix longior, antice rotundato-ampliatus, basin versus angustatus, convexiusculus, laevissimus, profunde canaliculatus, rufescenti-piceus, nitidus. Scutellum subtilissime bicarinatum, testaceum. Elytra thorace haud longiora, omnium subtilissime punctulata, pube subtilissima tenuissimaque grisea vestita, fusca, nitida, basi margineque apicali pallide testaceis, pone scutellum foveola rotundata communi impressa. Abdomen subtiliter punctulatum griseoque-pubescens, nigrum, segmento primo dilute flavo-testaceo. Pectus nigrum. Pedes coxıs antrcis fuscis, posterioribus dilute flavo-testaceis, femoribus omnibus nigris, basi dilute testaceis, tibiis tarsisque dilute rufescenti-testaceis.

* 8. F. stricta: Picea, nitida, antennis pedibusque piceo-testaceis, basi pallidis, thorace elongato, profunde canaliculato. - Long. $1 \frac{1}{4}$ lin.

Habitat ad Caracas Columbiae, Dom. Moritz.

F. sulcatae magnitudine aequalis, at longior et gracilior, brunneo-picea, nitida, omnium subtilissime tenuissimeque cinereo-pubescens. Antennae capitis thoracisque longitudine, crassiusculae, piceo-testaceae, medio fuscesceutes, basi apiceque pallidiores. Palpi piceo-testacei. Caput laeve, fronte inter oculos obsolete transversim impressa. Thorax coleopteris duplo angustior, latitudine sua summa multo longior, ante medium rotundato-ampliatus, basin versus angustatus, modice convexus, laevissımus, profunde canaliculatus, postice subcompressus, ante basin utrinque sulculo transverso 
impressus. Scutellum obsolete bicarinatum. Coleoptera laevigata, infra scutellum impressa. Abdomen laeve, segments prmis duobus apice testaceis. Pedes piceo-testacei, basi pallidi, tarsis llavescentibus.

* 9. F. percisa: Fusco-picea, nilida, subtiliter pubescens, fronte thoraceque subcordato profunde canaliculatis, antennarum basi pedibusque testaceis. - Long. vix ultra 1 lin.

Habitat in Brasilia, Dom. Prof. Germar.

F. sulcata perfarum maior, at paulo magis depressa, fusco-picea, nitida, pube subtili densiore grisea vestita. Antennae capitis thoracisque longitudine, piceae, articulis duobus primis testaceis. Palpi testacei, articulo tertio piceo. Caput thorace paulo latius, subquadratum, angulis licet rotundatis, subdepressum, subtilissime obsolete punctulatum, per totam longitudinem canaliculatum, sulco in media fronte profundiore dilatatoque. Thorax coleopteris dimidio angustior, latitudine summa haud brevior, ante medium rotundato-ampliatus, basin vẹsus modice angustatus, munus convexus, obsoletissime punctulatus, sulco profundo canaliculatus. Scutellum confertissime punctulatum, obsolete bicarinatum. Elytra thorace parum longiora, fuscosubtestacea, confertim subtilissime punctulata. Abdomen confertim punctulatum. Pedes rufo-testacei.

* 10. F. thoracica: Rufo-picea, thorace subcordato, profunde canaliculalo pedibusque rufis, abdomine nigro. - Long. $1 \frac{1}{4}$ lin.

Curt. Britt. Ent. X. $t .462$.

Fal. lineolat a Boisd. et Lacord. Faun. Ent. Paris. I. 555. 1.

Hahitat in Germania, Helvetia, Dom. Schïppel et Waltl, in Gallia, Dom. Aubé, in Anglia, Curtis. Degit in formicetis observante Dom. Waltl.

Statura F. sulcatae at gracilior, subtilissime confertim punctata, pube tenuissima cinerea vestita. Antennae piceae, capitis thoracisque longitudine, basi apiceque summo rufo-testaceae. Palpi testacei. Caput piceum, fronte depressiuscula. Thorax latitudine summa haud longior, basin versus modice angustatus, sulco profundo canaliculatus, dilute rufus. Scutellum aequale, confertissime punctatum. Coleoptera thorace paulo longiora, quadrata, fusca. Abdomen vel totum nigrum, vel piceum, ante apicem nigrum. Pedes dilute rufo-testacei.

* 11. F. denigrata: Nigerrima, nitida, subtiliter griseo-pubescens, capite, thorace elytrisque dense subtiliter punctatis, thorace canaliculato. Long. 1 $\frac{2}{3}-2$ lin.

Habitat in Mexico, Dom. Schleiden.

Statura omnino F. sulcatae, at duplo maior et ultra, tota nigra, pube subtuli grisea sericeo-pubescens. Antemnae capitıs thoracisque longitudine, fortiusculae, nigrae. Palpi nigri. Caput creberrime minus subtiliter punctatum, obsolete canaliculatum. Thorax coleopteris plus dimidio angustior, ante medium rotundato-ampliatus, basin versus leviter angustatus, minus -onvexus, dense subtiliter, disco obsolete punctatus, profunde canaliculatus, c.analicula basi impressione parva transversali terminata. Scutellum aequale, 
confertim subtiliter punctatum. Elytra thorace sesqui fere longiora, dense subtiliter punctata. Abdomen parce subtiliter punctulatum. Pedes nigrir, tarsis piceis.

*12. F. discreta: Fusco-picea, nilidula, abdominis postico capileque nigris, thorace subcordato, subtiliter punctulato profunde canaliculato. Long. $1 \frac{1}{4}$ lin.

Habitat in valle Araguensi Columbiae, Dom. Moritz.

Praecedenti affinis, at dimidio minor. Antennae capitis thoracisque longitudine, crassae, fusco-piceae. Caput nigrum, nitidum, subtılissime obsolete punctulatum, fronte depressiuscula. Thorax antice rotundato-ampliatus, basin versus fortiter angustatus, latitudine summa paulo brevior, subdepressus, dense subtilissime punctulatus, profunde canaliculatus, fuscopiceus, nitidus, subtilissime cinereo-pubescens. Scutellum subtilissime punctulatum, linea tenui longitudinali elevata notatum, fusco-piceum, subtilissime pubescens. Elytra thorace paulo longiora, lucide fusco-picea, subtilissime punctulata, subtiliter cinereo-pubescentia. Abdomen parce subtilissime punctulatum, griseo-pubescens, segmentis anterioribus tribus dilute fusco-piceis, posterioributs tribus nigro-piceis, nitidis. Pectus dilute piceum. Pedes piceo-testacei, tarsis flavescentibus.

* 13. F. fissula: Fusco-picea, nitida, capite abdominisque poslico nigris, antennarum basi apiceque pedibusque testaceis, thorace cordato, subtiliter punctulato, profunde canaliculato. - Long. $\frac{3}{4}$ lin.

Habitat in Guyana Venezuelensi, Dom. Moritz.

Habitu omnino F. sulcatae, at dimidio minor, F. nigrae aequalis, piceofusca, nitidula, subtilissime griseo-pubescens. Antennae capitis thoracisque longitudine, validiusculae, piceae, articulis duobus primis tertioque testaceis. Palpi testacei, articulo tertio fusco. Caput thoracis latitudine, obsoletissime punctulatum, nigrum, nitidum. Thorax latitudine summa parum brevior, antice valde rotundato-ampliatus, basin versus fortiter angustatus, parum convexus, subtiliter punctulatus, sulco profundo exaratus. Scutellum acquale. Coleoptera thorace paulo latiora et longiora, vix perspicue punctulata, dilutius fusco-picea. Abdomen longius pubescens, segmentis penultimis duobus nigris. Pedes dilute flavo-testacei.

14. F. soluta: Picea, capile abdominisque apice nigris, thorace, abdominis basi pedibusque rufo-testaceis, thorace canaliculato. - Long. 1. lin.

Habitat in valle Araguensi Columbiae, Dom. Moritz.

Habitu omnino F. obscurae, at paululum minor. Antennae capitis thoracisque longitudine, nigrae, articulis duobus primis testaceis. Palpi testacei. Caput nigrum, nitidum, laeve. Thorax anterius lateribus modice dilatatus, leviter convexus, laevis, profunde canaliculatus, rufo-testaceus, nitidus. Scutellum aequale, rufo-testaceum. Elytra laevia, picea, nitida. Abdomen laeviusculum, segmentis anterioribus tribus rufo-testaceis, posterioribus tribus nigris. Pectus piceum. Pedes testacei. 
* 15. F. obscura: Rufo-testacea, thorace subcordato, obsolete canaliculato, capite abdomineque obscuris. - Long. 1 lin.

Mannerh. Brachelytr. 87. 2. - Boisd. et Lacord. Faun. Ent. Paris. I. 556. 3. Runde Brachelytr. Hal. 31. 2. - Er. Col. March. I. 295. 3.

Aleoch. obscura Grav. Micr. 74. 10. Mon. 151. 8. - Latr. Hist. nat. Crust. et Ins. IX. 381. 10. - Gyll. Ins. Suec. II. 379. 2. - Sahlb. Ins. Fenn. I. 346. 2.

Habitat in Europa.

Statura fere F. sulcatae, obscure rufo-testacea, nitida, densius et minus subtiliter pubescens. Antennae capitis thoracisque longitudine, apicem versus sensim leviter incrassatae, corpori concolores. Caput thoracis latitudine, orbiculatum, fronte convexa, nigrum, nitidum. Thorax coleopteris dimidio angustior, latitudine summa paululum brevior, basin versus angustatus, basi subacuminatus, lateribus rotundatis, convexus, omnium subtilissime punctulatus, dorso plerumque linea subtili longitudinali impressus. Scutellum basi subtiliter bicarinatum. Elytra thorace paulo longiora, subtilissime punctulata. Abdomen confertim subtiliter punctulatum, ante apicem nigricans. Pedes testacei.

Variat forte sexu vertice thoracisque disco longitudinaliter leviter impressis.

* 16. F. nigra: Picea, subtiliter punctulata, thorace subgloboso, obsolete canaliculato vel fovea tantum postica impresso. - Long. $\frac{3}{4}$ lin.

Mannerh. Brachelytr. 87. 3. - Runde Brachel. Hal. 31. 3. - Er. Col. Märch. I. 296.4.

Aleoch. nigra Grav. Micr. 75. 12. Mon. 152. 11. - Latr. Hist. nat. Crust. et

Ins. IX. 381. 12. - Gyll. Ins. Suec. II. 380. 3.

Aleoch. fracticornis Grav. Mon. 152. 9.

Aleoch. picea Grav. Micr. 75. 11. Mon. 152. 11. - Latr. Hist. nat. Crust. et Ins. IX. 381. 11.

Falagria pice a Mannerh. Brachelytr. 87. 4. - Runde Brachel. Hal. 32. 4.

Habitat in Europa.

Praecedente duplo minor, nigro-picea vel picea, subtilissime pubescens. Antennae capite thoraceque breviores, apicem versus sensim incrassatae, corpori concolores. Caput thoracis latitudine, suborbiculatum, fronte leviter convexa, vix perspicue punctulatum. Thorax coleopteris paulo angustior, latitudine brevior, undique rotundatus, basin versus magis angustatus, modice convexus, confertim subtilissime punctatus, obsolete canaliculatus, basi supra scutellum transversim impressus. Scutellum aequale, confertissime punctatum. Elytra thorace parum longiora, subtiliter punctata, apice dilutiora. Abdomen supra parcius punctulatum. Pedes picei.

Obs. Al. picea Grav. differt nonnisi thoracis canalicula omnino extincta, relicta foveola supra scutellum.

* 17. F. gratilla: Subtiliter punctulata, picea, thorace subgloboso, basi foveolato, vufo-picea, elytrorum limbo basali et apicali, antennarum basi pedibusque testaceis. - Long. $\frac{3}{4}$ lin.

Habitat in Mesopotamia, Dr. Helfer.

Statura omnino et summa affinitas praecedentis. Antennae capitis tho- 
racisque longitudine, apicem versus sensim incrassatae, brunneae, articulis duobus primis testaceis. Caput orbiculatum, thoracis latitudine, subtilissime punctulatum, nigrum, nitidum, oris partibus testaceis, palpis piceis. Thorax coleopteris plus dimidio angustior, suborbiculatus, modice convexus, crebre subtiliter punctulatus, basi foveola minuta impressus, piceo-rufescens, nitidus. Elytra thorace paulo longiora, confertim subtiliter punctata, tenuiter pubescentia, testacea, macula magna disci fusca, seu fusca, limbo omni, basali licet apicalique latiore, testaceo. Abdomen crebre punctulatum, griseopubescens. Pedes pallide testacei.

* 18. F. naevula: Rufo-testacea, thorace suborbiculalo, postice foveolato, elytris disco infuscatis, abdomine apice nigro. - Long. $\frac{5}{6}$ lin.

Habitat in Aegypto, Dom. Prof. Ehrenberg.

Statura F. nigrae. Subtilissime punctulata, omnium tenuissime pubescens, laete testacea. Antennae capite thoraceque breviores, apicem versus sensim modice incrassatae, corpori concolores. Caput thoracis latitudine, suborbiculatum, basi truncatum. Thorax coleopteris dimidio angustior, latitudine paulo brevior, undique rotundatus, basin versus magis angustatus, leviter convexus, posterius obsolete canaliculatus, basi leviter impressus. Scutellum aequale. Elytra thorace paulo longiora, flavo-testacea, macula magna discoidali fuscescente. Abdomen supra omnium subtilissime minus confertim punctulatum, segmentis ultimis nigris. Pedes flavo-testacei.

Variat forte sexu fronte thoracisque disco leviter impressis.

* 19. F. munda: Nitida, nigra, elytris subaeneis, thorace, pedibus, abdominis antennarumque basi rufis, thorace subquadrato fronteque longitudinaliter fortiter impressis. - Long. 1 lin.

Habitat in Brasılia, Dom. Prof. Germar.

Statura fere F. sulcatae. Antennae (mutilatae) piceae, articulo primo rufo-testaceo. Palpi testacei, articulo tertio fusco. Caput thoracis latitudine, orbiculatum, confertim subtilissime punctulatum, fronte medio sat fortiter longitudinaliter impressa, vertice obsoletius foveolato, nigrum, pernitidum, glabrum. Thorax coleopteris dimidio angustior, latitudine paulo brevior, lateribus leviter rotundatus, basin versus perparum angustatus, basi truncatus, angulis posterioribus obtusis, anterioribus late rotundatis, leviter convexus, subtilissime confertim punctatus, longitudinaliter sat late profundeque impressus, impressione antice sensim evanescente, rufus, pernitidus, glaber. Scutellum confertissime punctatum, aequale, nigrum, griseo-pube scens. Elytra thorace paulo longiora, subtiliter confertissime punctata, nigro-subaenea, nitida, subtiliter albido-pubescentia, infra scutellum impressa. Abdomen confertim punctulatum, longius pubescens, segmentis anterioribus tribus rufis, posterioribus nigris. Pectus nigrum. Pedes antici flavi, posteriores rufo-testacei.

* 20. F. venustula: Picea, punctulata, thorace suborbiculato, rufescente, elytris fuscis, humeris, abdominis basi pedibusque testaceis. - Long. $\frac{5}{6}$ lin.

Habitat in Pensylvania, Dom. Zimmermann. 
Statura fere F. nigrae, at paululum maior, pube subtilissıma vestita. Antennae capitis thoracisque longitudine, graciliores, pilosellae, testaceae, ante apicem fuscae. Palpi fusci. Caput thoracis latitudine, orbiculatum, fronte leviter convexa, confertissime minus subtiliter punctulatum, nigrum, vix nitidum. Thorax coleopteris paulo angustior, latitudine parum brevior, lateribus anterius rotundatus, basin versus leviter angustatus, modice convexus, confertissime subtiliter punctatus, fusco-rufescens, vix nitidus. Scutellum aequale, fuscum. Elytra thorace paulo Iongiora, confertissime subtiliter punctata, fusca, angulo humerali rufo-testaceo. Abdomen supra parcius punctulatum, segmentis duobus primis pallide flavo-testaceis, sequentibus nigris, nitıdis. Pectus nigrum. Pedes flavi.

*21. F. albicincta: Nigro-picea, subnitida, confertissime subtilissimeque punctata, antennarum articulo primo testaceo, elytris basi dilutioribus, margine apicali, tibiis tarsisque albidis. - Long. 1 lin.

Habitat ad Caracas Columbiae, Dom. Moritz.

Statura omnino praecedentis, nigro-picea, subnitida, confertissime subtilissimeque punctulata, pube subtilissima cinerea subsericans. Antennae capite thoraceque paulo longiores, nigrae, articulo primo crassiusculo, testaceo. Caput thoracis latitudine. Thorax coleopteris dimidio angustior, latitudine paulo brevior, basin versus leviter angustatus, parum convexus, dorso pone medium leviter late foveolatus. Coleoptera latitudne communi breviora, margine basali dılutiore, apicali albido. Pedes picei, tibiis tarsisque albidis.

* 22. F. deliciata: Nigra, subnitida, antennarum articulis duobus primis, tibiis tarsisque pallide teslaceis, elylris fuscis, basi dilutioribus, margine apicali albido. - Long. 1 lin.

Habitat in Brasilia, Dom. Prof. Germar.

Praecedenti simillima, nigra, subnitida, confertissime subtilissimeque punctulata, pube subtilissima cinerea subsericans. Antennae capite thoraceque paulo longiores, graciles, pilosellae, nigrae, articulis duobus primis dilute flavo-testaceis, tertio piceo. Caput thoracis latitudine, suborbiculatum, fronte leviter convexa. Thorax coleopteris paulo angustior, latitudine dimidio fere brevior, undique rotundatus, basin versus subangustatus, satis aequaliterque convexus. Scutelluh aequale. Coleoptera thorace paulo longiora, latitudine communi breviora, subtilissime punctulata, basi subtestacea, margine apicali albido. Abdomen supra confertim subtilissime punctulatum, nigram, segmento primo obscure piceo. Pedes nigri, tibiis tarsisque pallide testaceis.

Obs. A praecedente praecipue thorace breviore, magis rotundato, aequaliter convexo, antennarumque articulo secundo etiam téstaceo praecipue distincta.

*23. F. albo-guttata: Nigra, nitida, subtiliter punctulata, capite thoraceque rufo-piceis, elytris brunneis abdominisque basi albo-guttatis, femoribus posticis basi, geniculis tarsisque albidis. - Long. 1 lin.

Habitat in Columbia, Dom. Moritz, in Brasilia, Dom. Prof. Germar. F. venustula paulo gracilior. Antennae capite thoraceque multo lon- 
giores, articulis sex primis testaceis, reliquis nigris. Palpi picei. Caput thoracis latitudine, laeve, dilute rufo-piceum. Thorax coleopteris dimidio angustior, basin versus sensim subangustatus, latitudine haud brevior, dorso subdepressus, subtiliter punctatus, pube brevi erecta fusca vestitus, rufopiceus, narginibus dilutioribus. Scutellum nigrum. Elytra latitudine communi breviora, confertim subtıliter punctata, subtilissime cinereo-pubescentia, fusco-picea, nitida, macula transversali basali guttaque in angulo apicis albis. Abdomen nigrum, nitidum, segmentis duobus primis subtus totis albıs, supra nigris, sıngulo fascia lata, medio interrupta albida. Pectus nigrum. Pedes picei, postici trochanteribus femorumque basi, omnes geniculis tarsisque albidis, his longis, tenuibus.

\section{Bolitochara Mannerh.}

Mannerh. Brachelytr. p. 75. - Er. Col. March. I. p. 296.

Maxillae mala interiore mutica, intus spinulis ciliata.

Ligula elongata, linearis, apice bifida; paraglossae parvae, angustae, acuminatae.

Palpi labiales triarliculati, arliculo secundo breviore.

Tarsi antici 4-, posteriores 5-articulati, postici articulo primo elongato.

Corpus minus depressum, alatum. Caput exsertum, porrectum, rotundatum, basi profunde constrictum, a thorace remotum eodemque paulo angustius, oculis mediocribus, modice prominulis. Labrum sat magnum, latinsculum, apice leviter rotundatum. Mandibulae sub labro occultae, muticae. Maxillae mala exteriore cornea, basi apiceque membranea, portione membranea apicali dense pubescente, interiore exteriore parum breviore, membranea, margine exteriore corneo, apice introrsum oblique emarginata, sinu spinulis brevibus ciliato. Palpi maxillares modice elongati, articulo secundo tertioque longitudine subaequalibis, hoc parum incrassato, quarto minuto, subulato. Labium (t. III. f. 4.) mento latitudine paulo breviore, apicem versus angustato, apice leviter emarginato, ligula angusta, ad palporum labialium articuli secundi apicem usque porrecta, apice bifida, paraglossis parvis, acuminatis, interne ciliatis. Palpi labiales triarticulati, articulo primo secundoque cylindricis, hoc dimidio breviore, tertio tenuiore, apicem versus leviter incrassato, longitudine primo aequali. Antennae capitis thoracisque fere longitudine, crassiusculae, apicem versus incrassatae, articulis tribus primis subelongatis, secundo tertioque obconcis. Thorax coleopteris angustior, latitudine brevior, antrorsum angustatus, angulis anterioribus rotundatis. Scutellum triangulare. Elytra apice truncata, ad angulum exteriorem distincte sinuata. Abdomen coleopterorum latitudine, supra planum, subtus convexum, saepe recurvum., Pedes modice elongati, intermedii basi leviter distantes, tarsi anticı 4-, posteriores 5-articulati, elongati, articulis 4 primis sensim decrescentibus.

O b s e r v a tiones.

1. Maxillae omnino ut in Homalota (t. III. f. 22.). Paraglossae omnino ut in Falagria, ligula autem magis elongata.

2. Habitu quibusdam Oxypodarum Fam. II. speciebns (e. g. O. tereti) non dissimiles, discedunt autem capite basi constricto, remoto, et tarsis anticis 4-articulatis. Corpus rudius punctatum, parcius pubescens. 
3. Genus Bolitochara a Com. Mannerheim quidem conditum, at a me rerestrictum, plurimis a celeberrimo auctore enumeratis speciebus $\mathrm{Hom}$ alo ta e, aliis generibus aliis adscriptis.

4. Victus in fungis. signes.

5. Mares abdominis segmento sexto dorsali aut tuberculato aut granulato in-

1. B. lucida: Rufo-testacea, elytrorum disco posteriore abdominisque segmentis posterioribus basi fuscis, thorace suborbiculato, antrorsum angustato. - Long. 2 lin.

Aleoch. lucida Grav. Micr. 70. 4. Mon 167. 47. - Latr. Hist. nat. Crust. et Ins. IX. 379. 4.

Aleoch. lunulata var. Gyll. Ins. Suec. II. 386. 9.

Habitat in Germania, Suecia.

Rufo-testacea, nitida, pubescens. Antennae capitis thoracisque prope longitudine, concolores, basi apiceque paulo dilutiores. Caput thoracis basi paulo angustius, orbiculatum, fortius punctulatum. Thorax coleopterorum basi dimidio angustior, latitudine baseos paulo brevior, lateribus rotundatus, antrorsum angustatus, apice duplo quam basi angustior, modice convexus, fortius punctulatus, basi foveola transversali impressus. Elytra thorace sesqui longiora, sat fortiter punctata, disco posteriore exteriore et spatio communi scutellari infuscatis. Abdomen supra disperse minus subtiliter punctatum, segmentis quinto sextoque basi infuscatis. Pectus fuscum. Pedes dilutius testacei.

Mas elytris plicula longitudinali pone medium prope suturam, abdominisque segmento sexto superiore carina longitudinali elevatis.

Obs. Sequenti simillima, differe tamen videtur capite testaceo, thorace antrorsum angustato, nec non statura sesqui maiore.

* 2. B. lunulata: Rufo-testacea, capite, antennarum medio, elytris, exceptis humeris, abdomineque ante apicem fuscis, thorace suborbiculato. - Long. 1 $\frac{1}{2}-2$ lin.

Mannerh. Brachelytr. 75. 2. - Er. Col. March. I. 297. 1.

Staph. lunulatus Payk. Mon. Stapk. 58. 41. Faun. Suec. III. 415. 61. - Walk. Faun. Paris. I. 272. 18.

Aleoch. lunulata Gyll. Ins. Suec. II. 386. 9. - Zetterst. Faun. Lappon. I. 97. 5.

Ins. Lappon. 76. 7. - Sahlb. Ins. Fenn. I. 348. 7.

Aleoch. cincta Grav. Mon. 166. 46.

Aleoch. pulchra Grav. Mon. 164. 44.

Bolitochara pulchra Boisd. et Lacord. Faun. Ent. Paris. I. 541. 2.

Habitat in Europa.

Rufo-testacea, subnitida, flavescenti-pubescens. Antennae capitis thoracisque prope longitudine, fuscae, bası rufo-testaceae, articulo ultimo dilute testaceo. Palpi testacei. Caput thoracis prope latitudine, nigrum, nitidum, profundius punctatum. Thorax coleopteris dimidio angustior, latitudine parum brevior, lateribus rotundatus, antrorsum vix angustatus, leviter convexus, crebre punctatus, basi foveola transversa impressus. Elytra thorace sesqui longiora, crebre sat fortiter punctata, fusco-nigra, humeris margineque summo apicali rufo-testaceis, vel rufo-testacea, disco posteriore magis 
minusve fusco, Abdomen profunde vage punctatum, segmentis quinto toto et sexto basi nigris. Pedes pallidius testacei.

Mas elytris plicula longitudinali pone medium prope suturam abdominisque segmento dorsali sexto carina acuta longitudinali elevatis.

\section{B. obliqua: Fusca, elytrorum vitta obliqua pedibusque obscure ferru-} gineis. - Long. $1 \frac{1}{2}$ lin.

Er. Col. March. I. 298. 2.

Bol. cinct a Boisd. et Lacord. Faun. Ent. Paris. I. 542. 3.

Habitat in Germania.

Statura praecedentis, at paulo minor, fusca, parcius pubescens. Antennae capite thoraceque paulo breviores, crassiusculae, fuscae, apice concolores, basi obscure ferrugineae. Caput thorace parum angustius, nigrum, profundius punctulatum. Thorax coleopteris dimidio angustior, latitudine paulo brevior, lateribus rotundatus, basin versus subangustatus, leviter convexus, dense punctatus, basi foveola transversa profundiore impressus. Elytra thorace sesqui longiora, dense fortiter punctata, fusca, vitta obliqua, a humero ad angulum apicis internum percurrente, angusta, ad humerum dilatata, nonnunquam etiam margine laterali ferrugineis. Abdomen nigrum, segmentis anterioribus margine rufescentıbus, supra parce obsoleteque punctulatum. Pedes obscure ferruginei.

Mas abdominis segmento dorsali sexto granulato.

4. B. varia: Nigra, capite thoraceque rufo-testaceis, antennarum basi, pedibus coleopterisque testaceis, his maculis tribus nigris. - Long. $1 \frac{1}{2}$ lin.

Habitat in Sardinia, Dom. Prof. Gené.

Statura omnino praecedentium. Antennae capite thoraceque paulo breviores, apicem versus incrassatae, basi testaceae, medio rufo-testaceae, apice fuscae. Caput thoracis prope latitudine, parce subtilissime punctulatum, saturate rufo-testaceum, vel saepius rufo-piceum, nitidum. Thorax coleopteris plus dimidio angustior, latitudine dimidio brevior, lateribus ultra medium subrectis, ante medium rotundatis, et antrorsum angustatis, parum convexus, subtiliter obsoleteque punctulatus, supra scutellum late et parum profunde impressus, subtilissime pubescens, laete ruf 6 -testaceus, nitidus. Elytra thorace sesqui fere longiora, crebre fortiterque punctata, densius pubescentia, flavo-testacea, macula magna transversa exteriore ante apicem, aliaque parva scutellari communi nigris. Abdomen supra parce subtiliterque punctatum, parcius pubescens, nitidum, vel totum nigrum, vel segmentis anterioribus tribus testaceis, medio magis minusve nigris piceisve, plerumque nigris, singulis margine omni testaceo. Pectus nigrum. Pedes flavi vel testacei, femoribus posticis fuscis.

M as abdominis segmento dorsali sexto parcius granulato.

Variat colore obscuriore, capite piceo, thorace rufo, elytris piceotestaceis, antennarum basi pedibusque rufo-testaceis.

Obs. B. obliquae proxima, differt autem colore, capite, thorace abdomineque parcius obzoletiusque, elytris minus confertim punctatis.

Exempla numerosa misit cel. Prof. Gené. 


\section{Dealea $E r$.}

\section{Er. Col. March. I. p. 298.}

Maxillae mala interiore mutica, apice spinulis ciliata.

Ligula elongata, linearis, apice bifida; paraglossae nullae.

Palpi labiales 3-articulati, articulis longitudine subaequalibus, ultimo tenuiore.

Tarsi omnes 5-articulati, postici articulo primo elongato.

Corpus minus depressum, alatum. Caput exsertum, porrectum, rotundatum, basi contrictum, oculis mediocribus, parum prominulis. Labrum sat magnum, apice leviter rotundatum. Mandibulae sub labro reconditae, muticaè. Maxillae mala exteriore cornea basi apiceque membranea, portione membranea apicali dense pubescente, interiore exteriore parum breviore, membranea, margine exteriore corneo, apice introrsum oblique emarginata, sinu spinulis brevibus ciliato. Palpi maxillares modice elongati, articulo secundo tertioque longitudine subaequalibus, tertio leviter incrassato, quario minuto, subulato. Labium (t. III. f. 5.) mento transverso, apice leviter emarginato, ligula angusta, ad palporum labialium articuli secundi apicem usque porrecta, apice bifida, paraglossis omnino nullis. Palpi labiales triarticulati, articulo secundo paulo breviore, tertio secundo longitudine subaequali, at paulo tenuiore. Antennae minus crassae, articulis tribus primis longioribus, secundo tertioque subaequalibus. Thorax coleopteris paulo angustior, suborbiculatus. Scutellum triangulare. Elytra apice truncata, ad angulum exteriorem leviter sinuata. Abdomen coleopterorum latitudine, supra planum, subtus convexum. Pedes modice elongati, intermedii basi approximati, tarsis omnibus 5-articulatis, elongatis, articulis 4 primis sensim decrescentibus.

\section{O b s e r vationes.}

1. Maxillae omnino ut in Homalota (t. JII. f. 22.). Ligula bifida valde elongata omnino ut in Bolitochara, paraglossae autem omnino nullae.

2. Characteribus omnino genus hocce cum $0 x y p o d a$ convenit, ut vix nisi ligula elongata distinguatur; habitus autem magis differt, Caloderae et Tachy usa e similis, ab hac tarsis anticis 5-articulatis, ab illa, ut a plerisque aliis huius tribus generibus, palporum labialium articulo tertio secundo haud longiore distinctum.

3. Sexus differentiam peculiarem non observavi.

* 1. O. castanea: Fusco-castanea, subtiliter punctulata, thorace sub-orbiculato, basi foveolato, pedibus pallidis. - Long. 2 lin.

Er. Col. March. I. 299. 1.

Habitat in Germania. Sub musco humido in rivulorum ripis a def. Weber copiose lecta.

Statura fere Myrmedoniae collaris. Obscure brumnea, thorace elytrisque obscure castaneis, antennarum basi palpisque dute rufo-piceis, pedibus pallide testaceis; capite, thorace elytrisque parce subtiliterque vel fere obsolete punctatis, pube parca tenui fulva vestitis. Antennae eapitis thoracisque longitudine, apicem versus parum incrassatae. Caput thorace paulo angustius, basi fortiter constrictum, "inter antennas leviter transversim impressum. Thorax latitudine parum brevior, coleopteris paulo angustior, suborbicularis, leviter convexus, postice fovea parum profunda impressus, 
lateribus pilosellus. Coleoptera subquadrata, thorace paulo longiora. Abdomen fere nigrum, segmentorum marginibus, praecipue infra, rufo-brunneis, supra nitidum, subtiliter vage punctatum, pilis parcis depressis fulvis vestitum.

*2. O. badia: Rufo-picea, forlius punctulata, thorace orbiculato, postice foveolato. - Long. $1 \frac{1}{2}$ lin.

Er. Col. March. I. 300. 2.

Habitat Berolini, ipse, in Austria, Dom. Schïppel.

Praecedenti affinis, at minor, gracilior, rufo-brunnea, nitidula, pube parca flavescenti vestita. Antennae capitis thoracisque longitudine, apicem versus leviter incrassatae, rufo-testaceae, ante apicem obscuriores. Palpi rufo-testacei. Caput thorace paulo angustius, basi profunde constrictum, minus subtiliter at parum profunde vage punctatum. Thorax coleopteris paulo angustior, latitudine haud brevior, suborbiculatus, convexiusculus, densius fortiusque punctatus, basi foveola levi impressus. Coleoptera subquadrata, dense profundeque punctata. Abdomen brunneum, apice dilutius, supra vage punctatum, pilis parcis depressis flavescentibus aliisque erectis nigris vestitum.

* 3. O. spadicea: Rufo-picea, forlius punctala, thorace transverso, antice truncato, aequali. - Long. $1 \frac{2}{3}$ lin.

Er. Col. March. I. 300. 3.

Habitat Berolini.

Rufo-picea, pilis depressis flavescentibus parcius vestita. Antennae vix capitis thoracisque longitudine, apicem versus parum incrassatae, fusco-piceae. Caput thorace paulo angustius, basi perparum constrictum, subtilissime vage punctatum. Thorax latitudine dimidio brevior, coleopterorum fere latitudine, basi lateribusque leviter rotundatus, antice truncatus, angulis deflexis, supra parum convexus, confertim punctatus, fovea basali nulla. Coleoptera thorace haud longiora, confertim punctata, punctis obliquis. Abdomen supra vage subtiliter punctatum, nigro-piceum, apice brunneum.

4. O. procera: Picea, fortius punctata, thorace elytrisque castaneis, thorace transverso, antice truncato, basi impresso. - Long. $2_{\overline{2}}$ lin.

Habitat in Germania, Dom. Schiippel.

O. castanea dimidio maior et magis oblonga, statura elongata $\mathbf{O}$. badiae, at duplo maior. Antennae capitis thoracisque prope longitudine, apicem versus sensim subincrassatae, articulo tertio secundo paulo longiore, 4-10 sensim paulo crassioribus, subobconicis, ultimo praecedente sesqui longiore, ovato, apice acuminato, rufae, griseo-pubescentes. - Caput thorace paulo angustius, rotundatum, basi haud constrictum, convexum, parce subtiliter punctatum, parce pubescens, nigro-piceum, nitidum, ore rufo. Thorax coleopteris paululum angustior, latitudine dimidio brevior, lateribus modice, bası leviter rotundatus, apice truncatus, angulis omnibus obtusis, anterioribus deflexis, leviter transversim convexus, densius minus subtiliter punctatus, basi leviter transversim impressus, rufo-piceus seu rufo-castaneus, niti- 
dus, pube griseo-fulvescente densiore vestitus. Elytra thoracis longitudine, dense fortius punctata, castaneo-rufa, subnitida, pube longiore depressa fulvescente densius vestita. Abdomen elongatum, segmentis singulis basi crebre, apice parce punctatıs, nigro-piceum, nitidum, apice segmentorumque singulorum margine posteriore supra saturatius, subtus dilutius rufo-piceis, parcius fulvescenti-pubescens. Pectus nigro-piceum. Pedes sat elongati, rufi.

Obs. Praecedenti proxima, statura maiore, capite magis rotundato, thorace paulo breviore, basi impresso, angulis anterioribus magis rotundatis, abdominis segmentis basi crebrius punctatis praecipue distinguenda.

* 5. O. murina: Nigra, cinereo-pubescens, antennis pedibusque piceis, geniculis tarsisque flavis, thorace subquadrato, apice truncato, basifoveolato. - Long. $1 \frac{1}{2}$ lin. Gené.

Habitat in Austria et in Istria, Dom. Schïppel, in Sardinia, Dom. Prof.

Statura fere Homalotae graminicolae, praecedentibus paulo magis depressa, 0 . spadiceae capite basi minus constricto et thorace apice truncato affinis, nigra, subnitida, pube albido-cinerea densius vestita. Antennae capitis thoracisque longitudine, graciles, apicem versus perparum incrassatae, piceae. Palpi flavescentes, articulo tertio piceo. Caput thorace paulo an. gustius, basi leviter constrictum, obsoletius punctulatum. Thorax coleopteris paulo angustior, latitudıne paulo brevior, basi et lateribus leviter rotundatus, apice truncatus, angulis anterioribus deflexis rotundatis, leviter convexus, dense fortius punctatus, basi fovea parum profunda supra scutellum notatus. Elytra thorace paulo longiora, densius fortiusque punctata. Abdo-. men dorso crebrius punctatum. Pedes picei, geniculis tarsisque flavo-testaceis.

Mas antennis longioribus, articulo ultimo elongato, ovato, femina antennis brevioribus, (capite sesqui longioribus), rufis.

Obs. Habitus fere Aleoch arae genuinae, at secundum oris structuram nonnisi huic generi adscribenda, quorum reliqui characteres omnino conveniunt.

6. O. decumana: Nigra, cinereo-pubescens, antennis piceis, tibiis tarsisque testaceis, thorace transversim subquadrato, apice truncato, basi foveolato. - Long. 2 lin.

Habitat in Gallia? Mus. Dom. Chrevrolat.

Praecedenti affinis, at paulo maior, paulo magis depressa et subtilius punctata, nigra, subnitida, pube albida cinerascens. Antennae capitis thoracisque longitudine, graciles, piceae, basi apiceque rufo-brunneae. Palpi flavescentes, apice piceae. Mandibulae dilute rufae, basi nigrae. Caput thorace angustius, basi perparum constrictum, subtiliter punctulatum. Thorax coleopteris dımidio prope angustior, latitudine dimidio brevior, lateribus ultra medium subrectis, ante medium rotundatis, apicemque versus angustatis, angulis anterioribus rotundatis, subdeflexis, apice truncatus, basi rotundatus, parum convexus, parce subtiliterque punctatus, supra scutellum late et parum profunde impressus. Elytra thorace paulo longiora, parcius subtiliter punctata. Abdomen supra parce punctulatum. Pedes nigri, antici coxis apice femoribusque piceo-testaceis, tibiis tarsisque omnibus testaceis. 
Species mihi invisae, forte huius generis.

7. O.(?) prolixa: Rufo-picea, subnitida, pubesceris, antennis, elytris anoque dilutioribus, pedibus pallide testaceis.

Aleoch. prolixa Gyll. Ins. Suec. $W$. 484. 9-10.

Bolitochara prolixa Mannerh. Brachelytr. 75. 3.

Habitat in Scania, ad Abusa, rarissime.

Statura, magnitudo et affinitas Bol. lunulatae, sed color alius, antennae paulo longiores etc. Caput latitudine thoracis, rotundatum, nigrum, nitidum, pubescens, subtilissime punctulatum, ore rufo-piceo. Antennae longitudine capitis cum thorace, crassiusculae, basi apiceque rufo-ferrugineae, articulis mediis 3-6 obscurioribus infuscatis. Thorax latitudine antica vix longior, apice truncatus, basi rotundatus, supra convexus, nigro-fuscus, nitidns, tenuiter pubescens et pilosus, obsolete punctulatus, versus margines dilutior, ante medium baseos foveola parva obsoleta impressus. Scutellum parvum, triangulare, fuscum. Elytra thorace paulo latiora et longiora, apice truncata, supra modice convexa, fusco-testacea, iuxta scutellum obscuriora, undique confertim evidentius punctata, longius pubescentia. Abdomen pone elytra longitudine fere reliqui corporis, crassum, supra nigro-piceum, nitidum, vix punctulatum, ano testaceo. Corpus subtus dilutius rufo-testaceum, nitidum, obsolete punctulatum, segmentis ventralibus basi obscurioribus, nigro-piceis. Pedes elongati, tenues, pallide rufo-testacei. (Gyll.)

8. O.(?) rufilabris: Fusco-picea, subnitida, pubescens, ore, antennis, elytris, marginibus segmentorum abdominis anoque rufescentibus, pedidus pallidis, thorace canaliculato. - Long. $1 \frac{1}{2}$ lin.

Aleoch. rufilabris Sahlb. Ins. Fenn. I. 349. 8.

Habitat in Fennia australi, rarissime.

O.(?) prolixae similis, sed differt magnitudine minore, thorace evidentius canaliculato, antennis extrorsum minus incrassatis, elytrisque subtilius punctulatis. Caput thorace paulo angustius, rotundatum, fusco-nigrum, nitidum, subpubescens, subtilissime punctulatum, ore palpisque rufescentibus. Antennae longitudine thoracis, crassiusculae, ferrugineae, basi pallidiores. Thorax longitudine paulo latior, antice posticeque truncatus, lateribus vix dilatatus, angulis rotundatis, supra convexus, piceo-brunneus, subtiliter punctulatus, parce pubescens, canalicula sat evidenter impressa. Scutellum triangulare, piceo-ferrugineum, subtilissime punctulatum. Elytra thorace paulo longiora et latiora, apice truncata, iuxta angulum externum subsinuato-emarginata, supra subdepressa, subtiliter punctulata, subpubescentia, brunneo-rufescentia. Abdomen pone elytra longitudine corporis reliqui, nigro-piceum, obsolete subtilissime punctulatum, segmentorum marginibus et ano rufescentibus. Corpus subtus fusco-piceum, subnitidum, subtiliter punctulatum, pubescens, ano et marginibus segmentorum rufescentibus. Pedes elongati, toti pallide testacei. (S ahlb.) 


\section{Calodera Mannerh.}

Mannerh. Brachelytr. p. 85. - Er. Col. March. I. p. 301.

\section{Maxillae mala interiore mutica, intus spinulis ciliata. Ligula brevis, bifida; paraglossae breves. Palpi labiales 3-articulati, articulo secundo breviore, tertio tenuiore. Tarsi omnes 5-articulati, postici articulo primo elongato.}

Corpus elongatum, minus depressum, alatum. Caput exsertum, porrectum, thoracis fere latitudine, rotundatum, basi magis minusve constrictum, oculis mediocribus, parum prominulis. Labrum maiusculum, lateribus rotundatum, apice truncatum. Mandibulae muticae. Maxillae mala exteriore cornea, bası apiceque membranea, portione membranea apicali dense pubescente, interiore exteriore paulo breviore, membranea, margine exteriore corneo, apice introrsum oblique emarginata, sinu spinulis brevibus ciliato. Palpi maxillares modice elongati, articulo secundo tertioque longitudine subaequalibus, hoc modice incrassato, quarto minuto, subulato. Labium (t. III. f. 6.) mento perbrevi, antrorsum angustato, apice leviter emarginato, ligula breviuscula, non ultra articuli primi apicem producta, bifida, paraglossis ligula brevioribus, latis, rotundatis, margine haud ciliatis. Palpi labiales triarticulati, articulo secundo duplo fere breviore, tertio tenuiore, primo longitudine subaequali. Antennae crassiusculae vel crassae, articulis tribus primis magis elongatis, secundo tertioque obconicis, 4-10 plerumque transversis, ultimo oblongo-ovato. Thorax coleopteris angustior, subquadratus aut subovatus. Scutellum triangulare. Elytra apice truncata, ad angulum exteriorem profundius sinuata. Abdomen coleopterorum latitudine, lineare, supra planum, subtus convexum. Pedes modice elongati, intermedii basi subapproximati, tarsis omnibus 5-articulatis, his elongatis, articulis 4 primis longitudine decrescentibus.

\section{O b s e r vatio nes.}

1. Maxillae omnino ut in Homalota (t. III. f. 22.). Paraglossae Iatae, rotunda. tae ut in Aleochara, at ligula non adeo brevis.

2. Antennae in plerisque huius generis speciebus sat longae et fortes, ceterum habitu Tach y us is similes, a quibus praeter paraglossas praecipue tarsis anticis 5-articulatis differunt. Corpus plerisque confertissime subtilissimeque punctatum, pube brevissima subtilissimaque pruinae instar vestitum et sericans.

3. Tarsi postici in hoc genere satis elongati, articulis inaequalibus, primo fortiter elongato, nescio igitur quo errore Com. Mannerheim ei tarsos »articulis aequalibus" tribuit. Ceterum sine dubio illius $\mathrm{Caloder}$ a.cum nostra congruit. Addidi C. nigricollem, quippe quae licet habitu quodammodo discrepat, tarsis anticis 5-articulatis, et oris etiam structura omni modo convenit.

4. Victus plerisque speciebus in udis.

5. Sexus differentiam peculiarem haud observavi.

* 1. C. nigricollis: Rufo-picea, opaca, creberrime punctata, tenuiter pubescens, thorace subquadrato, fusco. - Long. $1 \frac{1}{2}-3$ lin.

Er. Col. March. I. 302. 1.

Staph. nigricollis Payk. Faun. Suec. III. 400. 42.

Aleoch. nigricollis Grav. Micr. 84. 24. Mon. 163. 36. - Latr. Hist. nat. Crust.

et Ins. IX. 385. 24. - Gyll. Ins. Suec. II. 384. 7.

Bolit och. nigricollis Boisd. et. Lacord. Faun. Ent. Paris. I. 545. 5. 
Habitat in Europae silvis.

Statura fere Myrmedoniae canaliculatae, at plerumque maior. Antennae rufae, validae, capite thoraceque longiores, articulo secundo tertio paulo breviore. Caput, thorax et elytra punctatissima, pube densiore flavescente vestita. Caput obscure rufum, postice parum constrictum. Thorax coleopteris paulo angustior, subquadratus, parum convexus, aequalis, nigricans. Elytra rufa. Abdomen parcius punctatum, supra subnitidum, piceum, apice rufo. Pedes dilute rufo-testacei.

Obs. Punctura fortiore, profunda et pube haud subtilissima primo intuitu in hoc genere aliena videtur.

* 2. C. forticornis: Rufo castanea, subtiliter punctulata, thorace suborbiculato, aequali, elytris forlius punctatis. - Long. 2 lin.

Bolitoch. forticornis Boisd. et Lacord. Faun. Ent. Paris. I. 543. 4.

Habitat in Germania, Austria, Dom. Schïppel, Lutetiae, Mus. Dr. Aubé. Rufo-castanea, nitida, pube minus subtili grisea parcius vestita. Antennae capite thoraceque breviores, crassae, articulo secundo tertioque subaequalibus, ultimo breviter ovato, obtuso. Caput subtilissime parce punctatum, basi profunde constrictum. Thorax suborbiculatus, basi, lateribus et angulis anterioribus rotundatis, angulis posterioribus obtusis, basi coleopterorum prope latitudine, antrorsum leviter angustatus, apice truncatus, lat1tudine baseos paulo brevior, leviter convexus, subtiliter parcius punctatus. Coleoptera thoracis longitudine, subquadrata, profundius punctata, punctis obliquis. Abdomen elongatum, supra laeve, segmentis basi summa transversim impressis ibique punctatis. Pedes rufo-testacei.

* 3. C. nigrita: Atra, subtilissime punctulata, subtilissime dense cinereopubescens, thorace subdepresso, obsolete canaliculato, ore tarsisque flavis. - Long. 2 lin.

Mannerh. Brachelytr. 86. 1. - Er. Col. March. I. 303. 2.

Habitat in Germania, locis uliginosis.

Atra, vix nitida, pube subtili, densa cinereo-sericea. Antennae capite thoraceque longiores, fuscae, articulis primis sub-testaceis, articulo secundo tertio sesqui longiore, ultimo ovato. Caput, thorax et elytra omnium subtilissime confertissimeque punctata. Caput basi fortiter constrictum, fronte obsolete impressa, ore flavescente. Thorax subquadratus, vel latitudine paulo longior, basin versus haud angustatus, lateribus ante medium leviter rotundatus, apice leviter angustatus, subdepressus, basi fovea transversa, dorso canalicula obsoletiore impressus. Coleoptera thorace paulo longiora et sesqui latiora. Abdomen supra confertim subtiliter punctulatum, planum et aequale. Pedes nigri, geniculis, tibiarum apice tarsisque flavescentibus.

4. C. humilis: Depressa, atra, subtilissime punctulata, subtiliter dense cinereo-pubescens, thorace subquadrato, obsolete canaliculato, abdomine supra confertissime punctato, ore, antennarum basi tarsisque favis. Long. $1 \frac{1}{2}$ lin.

Er. Col. March. I. 303. 3.

Habitat in Germania boreali, ipse, in Austria, Dom. Schïippel. 
Praecedente minor et magis depressa, atra, pube tenui subtili dense cinereo-sericea, tota subtilissime confertissimeque punctulata. Antennae capitis thoracisque longitudine, fuscae, bası dilutiores, articulo secundo tertio duplo maiore, ultimo ovato. Caput basi profunde constrictum, infra antennas flavum. Thorax subquadratus, latitudine hand longior, basin versus subangustatus, lateribus ante medium rotundatis, depressus, obsoletissime canaliculatus, basi foveola transversa impressus. Coleoptera thorace paulo latiora et vix longiora, depressa. Abdomen reliquo corpore non distinctius punctatum, dorso planum et aequale. Pedes ut in praecedente.

* 5. C. longitarsis: Atra, subtilissime punctulala, dense subtilissime cinereo-pubescens, thorace subdepresso, basi foveolato, abdomine supra confertissime punctato, palpis, antennarum basi tarsisque lestaceis. Long. 2 lin.

Er. Col. March. 1. 698. 3. a.

Habitat in Germania, Anglia, Gallia, Italia.

Habitu omnino proxime praecedentis, at paulo maior, C. nigritae aequalis, atra, tota subtilissime confertissimeque punctata, pube subtili cinereosericea dense vestita. Antennae capite thoraceque parum longiores, apicem versus sensim incrassatae, fuscae, basi dilutiores, articulo-primo testaceo, secundo tertioque aequalibus, ultimo maris elongato, antecedentibus duobus coniunctis aequali, feminae ovato, praecedenti sesqui longiore. Palpi fuscotestacei. Labrum piceum. Caput thorace paulo angustius, basi profundius constrictum. Thorax subquadratus vel latitudine sublongior, basin versus haud angustatus, lateribus ante medium leviter rotundatıs, apice angustatus, angulis anterioribus rotundatis, deflexis, parum convexus, basi foveola transversa impressus, certo situ obsolete canaliculatus. Coleoptera thorace sesqui latiora et paulo longiora. Abdomen aeque subtiliter ac reliquum corpus punctatum, apice attenuatum, dorso segmentis 4 primis summa basi transversim depressis. Pedes nigri, femoribus summo apice, tibiis tarsisque totis testaceis.

Variat minus matura colore corporis fusco.

Obs. 1. Praecentibus primo intuitu simillima, at antennarum articulis secundo tertioque aequalibus, sequentibus sensim crassioribus, haud transversis facile distinguenda. Hac structura T a chy us am simulat et cum T. umbratica facile confundi possit, at tarsi antici distincte 5-articulati.

2. A. cel. Dom. Spence ex Anglia missa nomine Aleocharae longitarsis Kirby. Duo huius speciei exempla Gallica in collectione Dom. Aubé vidi, alterum Bolitocharae cinereae. Dej., alterum B. perplexae Dej. nomine signatum. Specimina in Sardinia lecta ad examinandum communicavit Dom. Prof. Genè.

* 6. C. rubicunda: Rufa, subtilissime punctulata, subliliter cinereo-pube. scens, capite abdominisque segmentis duobus penultimis fuscis, thorace subovato, basi leviler foveolato, abdomine supra subtilissime punclalo. Long. 2 lin.

Tachyus и rubicunda Er. Col. March. 1. 309. 4., 689. 1.

Habitat in Germania: Berolini Dom. Schïppel et Weber, in Austria, Dom. Schiippel.

Statura, habitus et summa similitudo praecedentis. Corpus iam rufo- 
testaceum iam saturatius rufum vel rufo-piceum, parum nitidur, pube subtili sericante cinerea vestitum. Antennae eadem structura ut in praecedente, at paulo validiores, capite thoraceque longiores, apicem versus sensim modice incrassatae, rufae, basi testaceae, articulo secundo tertioque aequalibus, sequentibus sensim crassioribus, crassitie hand brevioribus, ultimo magno ovato. Palpi dilute testacei. Caput thorace paulo angustius, breviter ovatum, basi sat fortiter constrictum, subtulissime confertim punctatum. piceum, nitidum. Thorax coleopteris paululum angustior, latitudine summa vix longior, lateribus ante medium cum angtilis anterioribus rotundatus, basin versus subangustatus, satis convexus, confertim subtilissime punctatus, basi foveola supra scutellum impressus. Elytra thorace vix longiora, subdepressa, confertim subtiliter punctata. Abdomen aeque subtiliter ac reliquum corpus punctatum, segmentis 4 anterioribus summa bası transversim depressis, penultimis duobus nigricantibus.

Obs. Antennarum structura praecedenti associanda, a qua praeter colorem thorace convexiore, basin versus paululum angustato coleopterisque thorace vix longioribus et parum latioribus at distinctius punctatis specie distinguitur. Ipstim me olim habitus fefellit et antennarum structura aliena, ut Tach yusae hanc speciem adscripserim: iam alteris duobus speciminibus examinatis tarsos anticos distincte 5-articulatos cognovi.

7. C. rubens: Rufo-picea, subtilissime punctulata, subtiliter cinereopubescens, thorace quadrato, subdepresso, basi obsolete foveolato, abdomine supra subtilissime confertissimeque punctato. - Long. 2 lin.

Er. Col. March. I. 304. 5.

Habitat in Germania. Unicum specimen Berolini legi.

Statura omnino praecedentis, obscure rufa, opaca, aequaliter confertissime subtilissimeque punctata, pube densa, subtili, cinereo-sericea obducta. Antennae capite thoraceque panlo longiores, validae, rufae, articulis duobus primis rufo-testaceis, tertio secundo paulo breviore, sequentibus omnibus transversis, ultimo oblongo-ovato. Caput thorace paulo angustius, ovatum, basi parum constrictum, fusco-piceum, ore testaceo. Thorax subquadratus, lateribus ultra medium rectis, ante medium leviter rotundatis, apice angnstatus, angulis anterioribus rotundatis, deflexıs, latitudine haud longior, leviter convexus, dorso late at obsoletissime canaliculatus, basi parum profunde impressus. Coleoptera thorace paullulum latiora et longiora. Abdomen aeque subtiliter ac reliquum corpus punctatum, dorso plano et aequali, ante apicem nigricans. Pedes testacei.

Obs. Affinis C. nigritae, at paulo brevior, antennae crassiores, articulo tertio maiore, thorax latior. A sequentibus abdomine supra plano discedit.

8. C. uliginosa: Atra, subtilissime punctulata, parcius griseo-pubescens, thorace subovato, convexiusculo, basi foveolato, abdomine supra parce punctato, nitidulo, ore flavo, antennis tarsisque piceis. - Long. $1 \frac{3}{4}$ lin.

Er. Col. March. I. 305.6.

Aleoch. aethiops Gyll. Ins. Suec. II. 383. 6.

Habitat in Germania.

Atra, nitidula, pube griseo-sericea tenuiter vestita. Antennae piceae, 
capite thoraceque paulo longiores, artıculo tertio secundo aequali, sequentibus vix transversis, ultimo oblongo-ovato. Caput, thorax et elytra subtilissime confertim punctata. Caput thorace minus, rotundatum, basi fortiter constrictum, ore obscure flavo. Thorax latitudine paulo longior, coleopteris angustior, ante medium leviter rotundatus, basin versus subangustatus, angulis anterioribus rotundatis, deflexis, convexus, basi foveola minuta transversa impressus. Abdomen supra inaequale, parcius subtiliter punctatum, dorso segmentis 4 primis singulis convexis, basi fortiter transversim depressis. Pedes nigri, tarsis piceis.

* 9. C. riparia: Picea, subtilissime punctulata, griseo-pubescens, thorace suborbiculato, convexiusculo, basi foveola gemina impresso, abdomine supra parce punctulato, antennis pedibusque rufis. - Long. $1 \frac{1}{4}$ lin.

Er. Col. March. I. 305. 7.

Habitat in Germania.

Praecedenti affinis, at plus duplo minor, vel nigro-picea, vel thorace elytrisque dilutioribus, vel interdum tota rufo-testacea, nitidula, confertissime subtiliter punctata, tenuiter griseo-pubescens. Antennae vel rufo-piceae, vel testaceae, capitis thoracisque longitudine, validae, articulo tertio secundo dimidio breviore, sequentibus transversis, ultimo ovato. Caput thorace dimidio minus, rotundatum, basi profunde constrictum, ore rufo. Thorax latitudine summa haud longior, coleopteris dimidio angustior, lateribus ante medium et angulis anterioribus rotundatus, basin versus vix angustatus, convexiusculus, basi foveolis duabus rotundatis approximatis vel contiguis impressus. Elytra thorace parum longiora. Abdomen supra parce punctatum, segmentis 4 primis singulis leviter convexis, basi depressis. Pedes rufo-picei.

* 10. C. aethiops: Picea, subtiliter punctulata, griseo-pubescens, thorace suborbiculato, convexiusculo, basi foveola transversa impresso, abdomine supra confertissime punctato, antennis pedibusque piceis. - Long. 1 lin.

Er. Col. March. I. 306. 6.

Aleoch. a ethiops Grav. Micr. 77. 15. Mon. 153. 14. - Latr. Hist. nat. Crust. et Ins. IX. 382. 15.

Calodera testacea Mannerh. Brachelytr. 86. 3.

Aleach. testacea Sahlb. Ins. Fenn. I. 347. 5.

Habitat in Germania.

Praecedenti simillima, at minor, plerumque nigro-picea, rarius rufo-picea, vel testacea, nitidula, confertissime subtiliter punctata, pube densa griseo-sericea vestita. Antennae capitis thoracisque longitudine, validae, piceae, articulo secundo tertio duplo fere longiore, sequentibus transversis, ultimo ovato. Eaput thorace dimidio minus, suborbiculatum, basi profunde constrictum, ore flavescente. Thorax coleopteris dimidio angustior, lateribus ante medium et angulis anterioribus rotundatus, basin versus subangustatus, latitudine haud brevior, convexiusculus, basi foveola transversa impressus. Elytra thorace distincte longiora. Abdomen supra confertissime subtilter punctatum, opacun, pube aeque densa ac reliquum corpus vestitum, apice 
rufo-piceo, dorso segmentis 4 primis singulis leviter convexis, basi profunde transversim impressis. Pedes picei.

$\mathrm{Obs}$. A praecedente antennarum articulo tertio breviore et abdomine confertim punctato opacoque distinguenda.

* 11. C. umbrosa: Subdepressa, subtiliter punctata, cinereo-pubescens, nitidula, nigra, elylris fuscis, antennarum basi pedibusque flavis, thorace subquadrato, aequali. - Long. $1 \frac{1}{4}$ lin.

Er. Col. March. I. 304. 4.

Habitat in Germania: Berolini a Dom. Schïppel lecta.

Statura elongata, depressiuscula Homalotae, Hom. elongatulae non dissimilis, et minimis eius individuis aequalis, a plerisque huius generis punctura minus conferta discedens, C. aethiope perparum maior et paulo magis depressa, pube longiore minus subtili grisea vestita. Antennae capite thoraceque paululum breviores, crassiusculae, nigrae, articulis tribus primis testaceis, tertio secundo paulo breviore, sequentibus transversis, ultimo oblongo-ovato, apice obtuse rotundato. Palpi testacei. Caput thorace parum angustius, suborbiculatum, basi profunde constrictum, parce subtiliterque obsolete punctatum, nigrum, nitidum. Thorax coleopteris dimidio fere angustior, lateribus perparum rotundatus, neque basin neque apicem versus allgustatus, latitudine paululum brevior, subdepressus, aequalis, minus subtiliter punctatus, piceus, nitidus. Elytra thorace paulo longiora, crebre minus subtiliter punctata, piceo-testacea, nitida. Abdomen nigrum, nitidulum, parcius subtiliter punctulatum, segmentis tribus primis piceis, singulis dorso levissime convexis, basi distincte transversim impressis. Pedes testacei.

\section{Species mihi invisa:}

12. C. protensa: Linearis, nigra, griseo-pubescens, thorace elongalo, canaliculalo.

Manuerh. Brachelytr. 86. 2.

Habitat in Suecia.

C. uliginosa (Al. aethiope Gyll.) duplo minor, magis linearis, minus pubescens, nec non thorace longiore canaliculato diversa.

\section{Tachyusa $E r$.}

Er. Col. March. I. p. 307.

Maxillae mala interiore mutica, intus spinulis ciliata.

Ligula brevis, bifida; paraglossae vix ullae.

Palpi labiales 3-articulati, articulo secundo breviore.

Tarsi antici 4-, posteriores 5-articulati, articulo primo elongato.

Corpus elongatum, minus depressum, alatum. Caput exsertum, porrectum, thoracis latitudine, rotundatum, basi constrictum, oculis mediocribus, parum prominulis. Labrum transversum, apice truncatum, mandibulas haud obtegens. Mandibulae muticae. Maxillae mala exteriore cornea, bası apiceque membranea, portione membranea apicali pubescente, interiore exteriore paulo breviore, membranea, margine exteriore corneo, apice introrsum obli- 
que emarginata, sinu spinulis brevibus ciliato. Palpi maxillares modice elongati, articulo secundo tertioque longitudine aequalibus, hoc leviter incrassato, quarto minuto, subulato. Labium (t. III. f. 7.) breve, mento transverso, apice leviter emarginato, ligula brevı, palporum labialium articulum primum haud excedente, bifida, paraglossis obsoletis. Palpi labiales triarticulati, articulo secundo primo minore, tertio hoc tenuiore at paulo longiore. Antennae longiores, graciles, articulis tribus primis magis elongatis, inter se longitudine aequalibus, primo crassiore. Thorax coleopteris paulo angustior. Scutellum triangulare. Elytra apice introrsum oblique truncata, ad angulum exteriorem sinuata. Abdomen supra planiusculum, subtus convexum, vivis saepe elevatum. Pedes elongati, graciles, intermedii basi approximati, tarsis anticis 4-, posterioribus 5 -articulatis, his elongatis, articulis 4 primis longitudine decrescentibus.

\section{O b s e r vation es.}

1. Maxillae omnino ut in Homalota (t. III. f. 22.). Ligula fere ut in Calodera, at paraglossae valde obsoletae, nonnisi angulo prominulo indicatae.

2. Habitu gracili Tachyusae Caloderis et quibusdam Homalotis similes, ab illis antennis gracilioribus et tarsis anticis 4-articulatis, ab his pedibus magis elongatis et tarsis posticis longis, articulo primo elongato distinguuntnr. A Falagriis, quibuscum habitu et tarsorum structura conveniunt, paraglossis obsoletis, coxis intermediis magis approximatis et capite minus remoto differunt.

3. Abdomen in hoc genere saepius insigne segmentis inaequalibus, anterioribus longioribus: his plerumqne abdomen basi magis minusve coarctatum. Aliis abdominis segmenta magnitudine aequalia. Forte in posticum, ubi specierum numerus satis increvit, hac nota ad sectiones in hoc genere instituendas utendum erit, quibus, speciebus iam cognitis parum numerosis, nondum opus esse videtur. Nihilominus species abdominis segmentis inaequalibus et aequalibus haud commiscui.

4. Nomen Ischnopoda Stephens (Illustr. V. p. 430.) tribuit Aleocharis pedibus elongatis: species ab eo enumeratae partim ad hoc, partim ad praecedens genus pertinere videntur. Quodsi neque satis distinctum, neque nulla descriptione illustratum invenio istud genus, nomen citatum omnino negligendum esse non dubitavi.

5. Sexus differentias, si quas observavi, apud singulas species notavi.

6. Victus plerisque in ripis. Nonnullae ( $T$. constricta et coarctata) in arena humida riparia summa agilitate circumvaguntur, et territae abdomine elevato velocissime fugiunt.

* 1. T. constricta: Picea, subtiliter pubescens, antennis pedibusque rufis, thorace subovalo, abdomine basi fortiter angustato. - Long. $1 \frac{1}{3}$ lin.

Er. Col. Murch. I. 307. 1.

Habitat in Germania, Gallia.

Corpus eximie gracile, nigro-piceum, nitidulum, subtilissime punctatum, tenuissime griseo-pubescens. Antennae capitis thoracisque longitudine, testaceae, apicem versus leviter incrassatae, piceae. Caput rotundatum, basi profunde constrictum. Thorax longitudine vix angustior, lateribus ante medium cum angulis anterioribus rotundatus, basin versus leviter angustatus, convexiusrulus, medio subdepressus. Coleoptera thorace paulo longiora et latiora, lateribus subrotundata, leviter convexa, apice simul emarginata. Abdomen elongatum, hasi coleopteris duplo angustius, apicem versus sensim latius, apice coleopteris latitudine subaequale, segmentis inaequalibus, ante- 
rioribus transversis, supra parce subtilissime punctulatum. Pectus rufo-piceum. Pedes rufo-testacei.

* 2. T. coarctata: Nigra, subtiliter pubescens, antennis pedibusque piceis, thorace subovato, abdomine basi angustato. - Long. $1 \frac{1}{3}$ lin.

Er. Col. March. I. 308. 2.

Habitat in Germania, Gallia, Italia.

Praecedenti affinis at non adeo gracilis. Nigra, nitidula, subtilissime confertim punctata, pube tenui densius vestita. Antennae capite thoraceque vix breviores, apicem versus parum incrassatae, piceae. Caput rotundatum, basi profunde constrictum, fronte maris medio subimpressa. Thorax coleopteris paulo angustior, latitudine paululum brevior, lateribus ante medium leviter rotundatus, basin versus haud angustatus, angulis anterioribus deflexis rotundatis, leviter convexus, supra scutellum obsolete impressus. Elytra thorace longiora, parum convexa, lateribus subrotundata, apice simul emarginata. Abdomen basi coleopteris dimidio angustius, apicem versus sensim incrassatum, ibique coleopteris aequale, segmentis inaequalibus, anterioribus tribus longioribus, licet latitudine sua brevioribus, supra parce subtilissimeque punctatum. Pedes picei, tarsis flavescentibus.

Obs. Variat saepius corpore subcoerulescente: Al. coeruleam Sahlb. eandem putarem, ni notis pluribus, praecipue thoracis abdominisque structura, nimium discedere videatur.

* 3. T. balt eata: Nigra, nitidula, subtiliter pubescens, thorace subovato, basi foveolato, abdomine basi angustato, segmentis anterioribus duobus rufis, pedibus piceis. - Long. $1 \frac{1}{3}$ lin.

Habitat in Austria, Helvetia, Italia.

Species insignis, statura omnino praecedentis. Subtiliter punctata, pube subtili depressa grisea vestita, nigra, capite, thorace elytrisque supra fusconigris, nitidulis. Antennae capite thoraceque vix longiores, apicem versus leviter incrassatae, nigro-piceae, basi nonnunquam dilutiores. Palpi picei. Caput thoracis prope latitudine, orbiculatum, basi profunde constrictum. Thorax coleopteris dimidio angustior, latitudine haud brevior, lateribus ante medium cum angulis anterioribus rotuldatus, basin versus subangustatus, modice convexus, basi foveola minuta supra scutellum impressus. Coleoptera thorace paulo longiora, parum convexa, lateribus subrotundata, apice simul leviter emarginata. Abdomen basi angustatum, coleopteris dimidio angustius, apicem versus sensim leviter incrassatum, apice coleopteris latitudime subaequale, segmentis inaequalibus, anterioribus longioribus, licet latitudine sua brevioribus, supra parce subtilissime punctatum, segmentis duobus anterioribus rufis, posterioribus nigerrimis. Pedes picei, antici rufescentes, tarsi omnes rufo-testacei.

* 4. T. ferialis: Fusca, nilida, subtilissime pubescens, antennis basi pedibusque testaceis, thorace subovato, rufo-testaceo, abdomine basi angustalo, nigro, segmentis anterioribus duobus rufis. - Long. $1 \frac{1}{3}$ lin.

Habitat in Sardinia, Dom. Prof. Gené.

Animulculum elegans, statura ommino praecedentis. Corpus totum 
parcius subtilissime griseo-pubescens. Antennae capitis thoracisque longitudine, apicem versus sensin leviter incrassatae, piceae, basi testaceae. Palpi picei. Caput thoracis latitudine, orbiculatum, basi profunde constrictum, omnium subtilissime punctulatum, nigrum, nitidum. Thorax coleopteris vix dimidio angustior, latitudine vix longior, lateribus ante medium cum angulis anterioribus fortius rotundatis, basin versus angustatus, leviter convexus, dense subtiliter punctatus; supra scutellum foveola notatus, laete testaceorufus, nitidus. Coleoptera thorace vix longiora, lateribus subrotundata, apice simul leviter emargmata, minus confertim subtiliter punctata, nitida, fusca, humeris margineque apicali subtestaceis. Abdomen basi angustatum, coleopteris dimidio fere angustius, apıcem versus sensim leviter incrassatum, apice coleopteris latitudine aequale, dorso segmentis anterioribus tribus laevigatis, posterioribus parce obsoleteque punctulatis, segmentis inaequalibus ut in proxime praecedentibus, anterioribus duobus rufis, sequentibus nigerrimis. Pectus fuscum. Pedes testacei.

Mas vertice thoracisque disco longitudinaliter leviter impressis.

* 5. T. scitula: Nigra, subtiliter pubescens, antennarum basi, palpis tarsisque testaceis, thorace subovalo, abdomine subangustato. - Long. $1 \frac{1}{3}$ lin.

Er. Col. March. I. 308. 3.

Habitat Berolini, Dom. Schïppel et ipse.

Praecedentibus minus gracilis, nigra, subtilissime confertim punctata, pube tenui griseo-sericea vestita. Antennae capite thoraceque breviores, apicem versus vix incrassatae, piceae, basi testaceae. Palpi testacei. Caput thorace parum angustius, orbiculatum, basi profunde constrictum. Thorax coleopteris perparum angustior, latitudine vix brevior, ante medium leviter rotundatus, basin versus subangustatus, convexiusculus, supra scutellum foveola minuta impressus. Elytra thorace paululum longiora, subdepressa, apice truncata. Abdomen basi coleopteris paulo angustior, lineare, segmentis subaequalibus, dorso aequali modo ac reliquum corpus punctatum. Pedes picei, tibiis tarsisque omnibus testaceis, illis medio fuscescentibus.

* 6. T. exarata: Testacea, subtiliter pubescens, abdomine pone medium capiteque nigris, thorace subquadrato, late canaliculato, rufo. - Long. . 2 lin.

Drusilla exarata Mannerh. Brachelytr. 85. 2.

Habitat in Austria, Dom. Ullrich.

Statura ommino T. umbraticae, at sesqui maior, tota confertissime subtiliter punctata, pube brevissima sericante fulvescenti-grisea dense vestita. Antennae capite thoraceque parum longiores, apicem versus subincrassatae, testaceae. Caput thoracis latitudine, fronte leviter impressa, nigrum, oris partibus testaceis. Thorax coleopteris paulo angustior, latitudine haud brevior, lateribus ante medium leviter rotundatis, basi apiceque truncatus, parum convexus, dorso sat late longitudinaliter impressus, testaceo-rufus. Scutellum fuscum. Elytra thorace paulo longiora, fusco-testacea, basi dilutiora. Abdomen lineare, testaceum, segmentis aequalibus, duobus antepenultimis fusco-nigris. Pectus rufescenti-testaceum. Pedes dilute testacei. 
* 7. T. laesa: Nigro-fusca, opaca, antennarum basi pedibusque testaceis, abdomine lineari, nigro, nitido, thorace subquadrato, maris longitudinaliler excavato, feminae canaliculato. - Long. $1 \frac{1}{2}$ lin.

Habitat in Sardinia, Dom. Prof. Gené.

Statura omnino T. umbraticae, eaque vix maior, thoracis structura praecedenti affinis, nigro-fusca, vix nitida, subtilissime tenuiter griseo-pubescens. Antennae sat elongatae, capite thoraceque longiores, apicem versus perparum incrassatae, fuscae, articulo primo laete, sequentibus duobus obscure testaceis. Caput thoracis latitudine, suborbiculatum, densius subtilissime punctatum, ore subtestaceo, vertice maris longitudinaliter impresso. Thorax latitudine summa haud brevior, basin versus subangustatus, basi coleopteris dimidio angustior, truncatus, apice cum angulis anterioribus rotundatus, lateribus rectis, subdepressus, confertissime subtilissimeque punctatus, feminae fortiter canaliculatus, maris sat profunde lateque longitudinaliter excavatus. Elytra thoracis longitudine, subdepressa, dense subtiliterque punctata. Abdomen lineare, nigrum, nitidum, supra parce subtilissime punctatum, segmentis aequalibus. Pedes testacei.

Marem vertice impresso, thorace late longitudinaliter excavato, feminam thorace canalieulato, vertice integro differe in descriptione relatum.

* 8. T. atra: Atra, opaca, subtilissime cinereo-pubescens, thorace quadrato, leviler canaliculato, abdomine apicem versus sub-angustato, pedibus piceis, tarsis flavescentibus. - Long. $1 \frac{1}{2}$ lin.

Er. Col. March. I. 309. 5.

Aleoch. at ra Grav. Mon. 162. 35. - Gyll. Ins. Suec. I1. 395. 17. - Sahlb. Ins. Fenn. I. 358. 24.

Bolitochara atra Mannerh. Brachelytr. 79. 26. - Runde Brachel. Hal. 30. 8.

St a ph. leисори s Marsh. Ent. Britt. 506. 22.

Habitat in Europa.

Atra, opaca, vix perspicue punctata, pube tenuissima cinereo-sericea vestita. Antennae capite thoraceque longiores, tenues, apicem versus haud incrassatae, nigrae. Caput thorace vix angustius, orbiculatum, basi constrictum, fronte obsolete impressa. Thorax coleopteris paulo angustior, latitudine paululum brevior, neque basin neque apicem versus angustatus, lateribus ante medium rotundatus, angulis anterioribus obtusiusculis, subdeflexis, depressus, leviter canaliculatus. Coleoptera thorace paulo longiora, apice truncata. Abdomen minus elongatum, apicem versus subangustatum. Pedes graciles, picei, summa basi, geniculis tarsisque flavescentibus.

* 9. T. umbratica: Nigra, nitidula, subtilissime griseo-pubescens, thorace quadrato, obsolete canaliculato, abdomine lineari, antennis pedibusque rufo-piceis. - Long. $1 \frac{1}{2}$ lin.

Er. Col. March. I. 310. 6.

Habitat in Germania, Gallia.

Praecedentı aequalis, nigra, nitidula, capite, thorace elytrisque fusconitentibus, subtilissime punctata, pube tenui griseo-sericea obducta. Antennae capite thoraceque paulo longiores, apicem versus levissime incrassatae, 
rufo-piceae. Caput thoracis prope longitudine, suborbiculatum, basi constrictum, fronte obsolete impressa, ore piceo-testaceo. Thorax coleopteris dimidio angustior, latitudine haud brevior, neque basin neque apicem versus angustatus, lateribus ante medium et basi subrotundatus, apice truncatus, subdepressus, canalicula parum profunda, antrorsum obsolescente impressus. Coleoptera thorace paulo longiora. Abdomen parallelum, segmentis aequalibus. Pedes rufescenti-picei, tarsis flavescentibus.

10. T. fugax: Nigra, nitidula, subtilissime griseo-pubescens, thorace elytrisque fuscis, antennarum basi pedibusque teslaceis, thorace subquadrato, obsolete canaliculato, abdomine parallelo. - Long. $1 \frac{1}{2}$ lin.

Habitat in Sardmia, Mus. Reg. Taurin. Dom. Prof. Gené specimen singulum examandum communicavit.

Praecedenti aequalis, at minus gracilis, nigra, nitidula, subtilissime griseo-pubescens. Antennae capite thoraceque breviores, articulo tertio secundo parum minore, 4-10 transversis. ultimo maiusculo, praecedentibus ambobus longitudine aequali, ovato, subacuminato, fuscae, articulis duobus primis testaceis. Palpi testacei, maxillares articulo tertıo fusco. Caput thoracis fere latitudine, suborbiculatum, confertissime subtiliter punctatum, nigrum, nitidum. Thorax coleopteris dimidio prope angustior, latitudine haud brevior, basi truncatus, apice cum angulis anterioribus et lateribus ante medium rotundatus, his dein fere rectis, basin versus subangustatus, leviter convexus, obsoletius canaliculatus, basi leviter transversim impressus, confertissime subtiliter punctatus, fuscus, nitidulus. Elytra thorace paululum longiora, apice leviter sinuata, confertissime minus subtiliter punctata, fusca, nitidula. Abdomen coleopterorum latitudine, parallelum, segmentis aequalibus, supra confertim subtiliter punctatum. Pedes testacei.

$\mathrm{Obs}$ - A. praecedente antennarum structura facile distinguitur, a T. scitula, cui antemnarum structura magis convenit, abdominis segmentis omnino aequalibus differt.

Species mihi invisae, forte huius generis.

11. T.(?) flavitarsis: Nigra, subnitida, griseo-pubescens, antennis subfiliformibus, thorace longioribus, fusco-piceis, tarsis apiceque tibiarum testaceis, thorace longiore, postice foveola impresso. - Long. $1 \frac{1}{4}$ lin.

Aleoch. flavitarsis Sáhlb. Ins. Fenn. I. 349. 9.

Habitat in Fennia australi, rarissime.

Calodera nigrita paulo minor, structura antennarum ab illa imprimis distincta. Caput thoracis fere latitudine, orbiculatum, fronte subimpressa, nigrum, nitidum, subtilissime punctulatum, tenuiter pubescens, ore palpisque piceo-ferrugineis. Antennae thorace paulo longiores, subfiliformes, tenuiores, fusco-ferrugineae, articulis tribus baseos longis, primo subcylindrico, duobus insequentibus crassiore, $\mathbf{4}-\mathbf{1 0}$ brevioribus, et extrorsum valde parum incrassatis, ultimo ovato, obtuso. Thorax latitudine fere longior, antice rotundatus, lateribus ante medium dilatatus, posterius paulo angustior, basi truncatus?, angulis obtusis, supra niger, subnitidus, subtilissıme punctulatus, temuiter pubescens, canalicula longitudinali obsoletius, foveola auten ante scutellum evidentius impressa. Scutellum parvum, triangulare, nigrum, pu- 
bescens. Elytra thorace latiora et paulo longiora, apice truncata, supra convexa, nigra, subnitida, subtilissime punctulata, pube griseo-sericea adspersa. Abdomen pone elytra longitudine relıqui corporis, nigrum, nitidum, parce pubescens, subtilissime punctulatum. Corpus subtus nigrum, nitidum, punctulatum, pubescens. Pedes elongati, tenues, pubescentes, nigri, tarsis apiceque tibiarum ferrugineo-testaceis. (Sahlb.)

12. T.(?) coracina: Nigra, nitida, subpubescens, tibiis picco-fermugineis, tarsis pallidis, antennarum articulo ultimo elongato, thorace subquadrato, foveola postice impresso. - Long. $1 \frac{1}{2}$ lin.

Sahlb. Ins. Fenn. I. 35̄0. 10. - Zetterst. Ins. Lappon. 76. 8.

Habitat in Lapponia, rarissime.

Magnitudine et statura T. aterrimae valde similis, sed differre videtur forma thoracis magis quadrata, et articulo antennarum ultimo magis elongato. Caput thorace angustius, orbiculatum, fronte impressa, nigrum, nitidum, parce pubescens, ore et palpis concoloribus. Antennae thorace longiores, apicem versus parum incrassatae, nıgrae, subpubescentes, articulo primo longo, incrassato, secundo et tertio etiam elongatis, insequentibus brevibus, sensim crassioribus, ultimo duos antecedentes simul sumtos longitudine aequante. Thorax subquadratus, longitudine paulo latior, antice truncatus, angulis deflexis, Iateribus parum rotundatus, angulis posticis rotundatis, basi subtruncatus, supra convexiusculus, niger, nitidus, pube rariore conspersus, subtilissime punctulatus, foveola ante scutellum impressa. Scutellum triangulare, nigrum, subtilissime punctulatum. Elytra thorace multo latiora et paulo longiora, apice truncata, ad angulum externum vix sinuata, supra subdepressa, nigra, nitida, pube rara conspersa, crebre et evidenter punctulata. Abdomen pone elytra longitudine reliqui corporis, nigrum, nitidum, parce et subtilissime punctulatum, subpubescens. Corpus subtus nigrum, nitidum, paulo profundius et crebrius punctatum, parce pubescens. Pedes elongati, femoribus nigris, tibiis ferrugmeo-piceis, tarsis pallidis. (Sahlb.)

13. T (?) carbonaria: Atra, subnitida, griseo-pubescens, thorace subquadrato, postice foveolato, antennarum articulo ultimo oblongo-ovato, pedibus elongatis, tarsis ferrugineo-testaceis. - Long. $1 \frac{1}{4}$ lin.

Bolitochara carbonaria Mannerh. Brachelytr. 75. 4.

Aleoch. carbonaria Sahlb. Ins. Fenn. I. 351. 11.

Habitat in Fennia australi, rarissime.

A praecedente magnitudine minore, pubescentia densiore et articulo antennarum ultimo magis ovato, a T. atra antennis extrorsum crassioribus et a T. (?) flavitarsi thorace breviore differt. Caput thorace paulo angustius, suborbiculatum, nigrum, nitidum, vix punctulatum, palpis fusco-piceis. Antennae thorace longiores, nigrae, versus apicem parum incrassatae, art1culis ut in praecedente, ultimo tamen magis ovato. Thorax longitudine vix latior, subquadratus, lateribus angulisque parum rotundatis, antice et postice truncatus, supra subconvexus, niger, subnitidus, tenuiter griseo-pubescens, vix punctulatus, foveola ante scutellum obsoletius impressa. Scutellum breve, triangulare, nigrum. Elvtra, abdomen pone haec corpusque 
subtus ut in T. atra. Pedes elongati, nigri, genubus anguste, tibiis apice et tarsis totis pallide ferrugineis. (Sahlb.)

11. T.(?) coеrulea: Coerulescens, subnitida, sericeo-pubescens, antennis nigro-fuscis, subfiliformibus, thorace subguadrato, foveola ante scutellum impresso. - Long. $1 \frac{1}{4}$ lin.

Suhlb. Ins. Fenn. 1. 351. 12.

Ad Helsingforsiam semel tantum capta.

T. atrae magnitudine et statura similis. Caput thoracis fere latitudine, rotundatum, nigro-coerulescens, nitidum, palpis concoloribus. Antennae thoracis longitudine, subfiliformes, versus apicem admodum parum incrassatae, articulo ultimo oblongo-ovato, fusco-nigrae, subpubescentes. Thorax longitudine vix latior, antice truncatus, lateribus ante medium parum dilatatus, postice subtruncatus, angulis omnibus rotundatis, supra convexiusculus, foveola ante scutellum impressa, coerulescens, sericeo-pubescens, subnitidus. Scutellum minutum, triangulare, nigro-coerulescens. Elytra thorace latiora et paulo longiora, postice truncata, supra convexiuscula, coerulescentia, sericeo-pubescentia, subnitida. Abdomen pone elytra reliqui corporis longitudine corqusque subtus nigro-coerulescentia, tenuiter sericeo-pubescentia. Pedes elongati, nigro-coerulescentes, tarsis piceo-ferrugineis.

Obs. Conf. quod apud T. coarctatam ad calcem notavi.

\section{Phloeopora Er.}

Er. Col. March. I. p. 311.

Maxillae mala interiore mutica, apice spinulis ciliata.

Ligula brevis, apice bifida; paraglossae nullae. Palpi labiales 3-arliculati, articulo secundo breviore.

Tarsi omnes 5-articulati, postici articulo primo sequente paulo longiore.

Corpus elongatum, lineare, subdepressum, alatum. Caput exsertum, porrectum, thoracis latitudine, rotundatum, basi constrictum, oculis mediocribus, leviter prominulis. Labrum breve, truncatum, mandibulas non omnino obtegens. Mandibulae muticae. Maxillae mala exteriore cornea, basi apiceque membranea, portione membranea apicali pubescente; mala interiore exteriore paulo breviore, membranea, margine exteriore corneo, apice oblique introrsum emarginata, sinu spinulis brevibus ciliato. Palpi maxillares minus elongati, articulo tertio secundo paulo longiore, leviter incrassato, quarto parvo, subulato. Labium mento transverso, apice leviter emarginato, ligula brevi, palporum labialium articulum primum haud excedente, bifida, paraglossis nullis. Palpi labiales triarticulati, articulo secundo primo duplo fere minore, tertio tenuiore at primo parum breviore. Antennae breviusculae, articulis tribus primis leviter elongatis, seeundo tertioque obconicis, inter se subaequalibus, ultimo apice obtusiusculo. Thorax coleopteris parum angustior, subquadratus, subdepressus. Elytra apice introrsum oblique truncata, extrorsum ad angulum exteriorem leviter sinuata. Abolomen elongatum, lineare. Pedes breves, intermedii basi approximati, tarsis omnibus 5-articulatis, anterioribus articulis $\mathbf{4}$ primis brevibus, subaequalibus, postici articulo primo vix elongato. 


\section{O b s e r v a t i nes.}

1. Labium et maxillae omnino ut in Homalota ( $t$. III. f. 8. et 22.).

2. Habitus linearis, subdepressus Homalotarum plurimarum, a quibus nisi tarsis anticis 5-articulatis vix distinguatur. Cum Oxypodis quoque hoc genus plurimis characteribus convenit, at habitus alius, caput porrectum, subremotum, pedes breves, et tarsi postici minus elongati, tibia breviores, articulus primus sequentibus perparum longior, ultimo brevior.

3. Sexus differentia mihi haud observata.

4. Victus sub arborum cortice. Species indigenae sub cortice Pinus degunt.

* 1. Ph. reptans: Atra, ore, antennis, elytris, pedibus anogue mubris, thorace Iransversim quadrato, angulis anterioribus obtusis. - Long. $1 \frac{1}{3}$ lin.

Er. Col. March. I. 311. 1.

Ale och. reptans Grav. Mon. 154. 19. - Gyll. Ins. Suec. I1. 389. 12. - Sahlb.

Ins. Fenn. I. 354. 17. - Zetterst. Faun. Lappon. I. 98. 8, Ins. Lappon. 76, 11. Bolitoch. reptans Mannerh. Brachelytr. 76. 10. - Runde Brachel. Hal. 30, 5.

Habitat in Europa temperata et septentrionali sub cortice Pinus.

Fusco-atra, opaca, subtilissime dense punctata, pube tenuissima flavescenti-grisea obducta. Os rufo-testaceum. Antennae capite paulo longiores, articulu ultimo breviter ovato, apice subacuminato, testaceae, nonnunquam apicem versus fuscescentes. Thorax coleopteris vix angustior, latitudine paulo brevior, lateribus subrectis, apice truncatus, angulis anterioribus obtusis, basi interdum obsolete impressus. Elytra confertim evidentius punctata, rubra, basi plerumque fuscescentia. Abdomen supra crebrius punctulatum, segmentis piceo-marginatis, apice rubrum. Pedes rubri.

* 2. Ph. corticalis: Nigra, antennis pedibusque piceis, elytris fuscis, apice rufescentibus, thorace subquadrato, angulis anterioribus rotundatis. - Long. $1 \frac{1}{4}$ lin.

Er. Col. March. I. 312. 2.

Aleoch. corticalis Grav. Micr. 76. 13. Mon. 152. 12. - Latr. Hist. nat. Crust. et Ins. IX. 381. 13.

Aleoch. tenuis Grav. Micr. 84. 23. - Latr. Hist. nat. Crust. et Ins. IX. 384. 23. Aleoch. teres Grav. Micr. 79. 19. Mon. 155. 20. - Latr. Hist. nat. Crust. et. Ins. IX. 383. 19.

Habitat in Europa sub cortice Pinus.

Praecedenti simillima, differt autem statura gracliore, colore magis obscuro, et thoracis structura. Nigra, minus confertim subtiliter punctulata, parum nitida, pube tenui minus densa vestita. Antennae capite sesqui longiores, articulo ultimo breviter ovato, apice obtusiusculo, piceae, articulis tribus primis rufis vel rufo-piceis. Caput thoracis latitudine, suborbiculatum, subtiliter punctulatum, fronte medio subtiliter obsolete canaliculata, ore piceo. Thorax coleopteris paulo angustior, latitudine non brevior, basin versus subangustatus, lateribus ante medium cum angulis anterioribus rotundatus, basi plerumque foveola transversa, magis minusve obsoleta impressus. Elytra fusca, apice magis minusve rufescentia. Abdomen pilosellum, supra crebrius punctatum, apice interdum piceo. Pedes picei. 
* 3. Ph. latens: Nigra, nitida, antennarum basi pedibusque teslaceis, elytris rufis, basi fuscis, thorace subquadrato, angulis anterioribus rolundatis. - Long. $1 \frac{1}{4}$ lin.

Habitat in Pensylvania, Dom. Zimmermann; dedit Dom. Schüppel.

Statura et summa affinitas praecedentis. Nigra, nitida, griseo-pubescens. Antennae capite sesqui longiores, articulo ultimo breviter ovato, apice obtusiusculo, nigro-piceae, articulis duobus primis testaceis, apicali brunneo. Palpi testacei. Caput thorace paulo minus, licet vix angustius, suborbiculatum, parce punctulatum, tenuiter subtiliterque pubescens, fronte subtiliter leviterque medio canaliculata. Thorax latitudine haud brevior, coleopteris paulo angustior, basin versus subangustatus, lateribus ante nedium cum angulis anterioribus rotundatus, parcius subtiliter punctatus, tenuiter griseo-pubescens. Elytra thorace paulo longiora, dense evidentius punctata, nitida, rufa, basi ultra tertiam partem fusca, densius pubescentia. Abdomen parcius punctulatum, pube longiore et minus subtili parcius vestitum, ano concolore. Pedes testacei,

Obs. Differt a praecedente praecipue corpore nitido et punctura longe parciore.

* 4. Ph. subtusa: Nigra, ore, antennis, pedibus anoque testaceis, elytris fusco-testaceis, thorace fusco, subquadrato, obsolete canaliculato, basi foveola transversa impresso. - Long. 1 lin.

Habitat in Americae insula St. Johannis, Dom. Moritz.

Praecedenti affinis, at dimidio minor. Nigra, opaca, subtilissime confertim punctata, pube brevissima tenuissimaque vestita. Antennae rufo-testaceae, basi testaceae: Caput fronte obsolete canaliculata, ore testaceo. Thorax fuscus, coleopteris angustior, latitudine non brevior, angulis anticis rotundatis, depressus, obsoletius canaliculatus, basi foveola transversa impressus. Elytra fusco-testacea. Abdomen parcius punctatum, nigrum, nitdulum, ano testaceo. Pedes testacei.

* 5. Ph. colubrina: Brunnea, abdomine ante apicem capiteque nigricantibus, antennis, pedibus anoque testaceis, thorace obsolete canaliculato. - Long. $1 \frac{5}{6}$ lin. Moritz.

Habitat in Brasilia, Dom. Thorey, in valle Araguensi Columbiae, Dom.

Praecedentibus maior, habitu fere Lithocharidis. Corpus lineare, subdepressum, tenuiter pubescens. Antennae capite dimidio longıores, flavotestaceae. Caput thoracis latitudine, basi profunde constrictum, depressum, nigro-piceum, ore testaceo. Thorax fuscus, latitudine haud brevior, basin versus sensim angustatus, apice, praecipue angulis anticis rotundatus, depressus, late obsolete canaliculatus, basi medio transversim impressus, utrinque puncto impresso notatus. Coleoptera dilute brunnea, vel fusco-testacea. Abdomen coleopteris angustius, elongatum, supra parce subtiliter punctatum, brunneum, ante apicem nigrum, apice testaceum. Pedes flavotestacei. 
6. Ph. religata: Flavo-testacea, abdomine ante apicem nigro, capite nigricante, thorace basi foveola transversa impresso. - Long. vix ubtra 1 lin.

Habitat in Americae mer. ins. Puerto-Rico, Dom. Moritz.

Habitus omnino staturaque linearis depressa et summa affinitas praecedentis, at triplo minor, confertim subtiliter punctata, tenuter cinereo-pubescens, laete testacea, parum nitida. Antennae capite sesqui longiores, apicem versus sensim incrassatae. Caput thoracis latitudine, depressum, fronte obsolete canaliculata, piceum, ore testaceo. Thorax coleopterorum prope latitudine, latitudine paulo brevior, lateribus rectis, angulis posterioribus obtusis, anterioribus rotundatis, depressus, basi foveola angusta transversa impressus. Scutellum flavum. Elytra depressa, macula triangulari communi circa scutellum, aliaque valde obsoleta in medio margine laterali fuscescentibus. Abdomen supra parcius obsolete punctulatum, testaceum, apice fulvum, ante apicem, segmento penultimo dimidio et antepenultimo -toto, nigrum. Pedes pallide testacei.

\section{Hygronoma $E \boldsymbol{r}$.}

\section{Er. Col. March. I. p. 312. Hom a lo ta Curtis Britt. Ent. XI. $t .514$.}

Maxillae mala inleriore mulica, intus spinulis ciliata. Ligula brevis, bifida; paraglossae nullae. Palpi labiales 3-articulati, articulo secundo breviore. Tarsi omnes 4-articulati, articulis brevibus depressis.

Corpus elongatum, lineare, depressum, alatum. Caput exsertum, porrectum, thoracem latitudine paululum superans, subrhombicum, basi modice constrictum, oculis mediocribus, leviter prominulis. Labrum transversum, truncatum, mandibularum apicem haud obtegens. Mandibulae muticae. Maxillae mala exteriore cornea, bası apiceque membranea, portione membranea apicali pubescente, mala interiore exteriore paulo breviore, membranea, margine exteriore corneo, apice oblique introrsum emarginata, sinu spinulis brevibus ciliato. Palpi maxillares breviusculi, articulo secundo tertioque longitudine subaequalibus, hoc modice incrassato, quarto minuto, subulato. Labium mento transverso, apice leviter emarginato, ligula brevi, palporum articulum primum haud excedente, bifida, paraglossis nullis. Palpi labiales triartirulati, articulo secundo primo duplo fere minore, tertio hoc tenuiore, at paulo longiore. Antennae filiformes, articulis tribus primis leviter elongatis, inter se longitudine subaequalibus, secundo tertioque obconicis, ultimo subacuminato. Thorax coleopteris vix angustior, basin versus subangustatus. Scutellum triangulare. Elytra apice truncata. Abdomen lineare. Pedes breves, intermedii basi approximati, tarsis omnibus breviusculis, depressis, $\mathbf{4}$-articulatis, articulo primo reliquis paululum longiore, triangulari, ultimo s. unguiculari etian depresso, praecedentibus aequali.

$$
\text { o b s e r vation e s. }
$$

1. Labium et maxillae omnino ut in Homalota (t. III. f. 8. et 22.).

2. Habitus omnino Homalotarum quarundam linearium et maxime depressarum, pedibus brevibus autem et tarsis omnibus 4-articulatis, depressis, articulo ultimo non elongato hoc genus satis distinetum. 
3. Dom. Curtis in splendido suo opere supra citato hoc insectum pro typo generis Ho malotae depinxit, at Com. Mannerheim hoc genus ex Aleochara plana condidit, cui tarsi posteriores 5-articulati sunt, articulo ultimo elongato, reliquis coniunctis aequali, quem cel. Mannerheim generis sui "characterem affert. Dom. Curtis ipse dubius $H$. planam speciei. icone illustratae associat. Nomen quidem huic satis convenit, et magis quam generi sequenti, at typo primitivo servandum est. Ceterum generis huius (Hygronomae) characteres Dom. Curtis recte exhibuit.

4. Sexus differentia latet.

5. Victus in lacuum ripis et in paludosis, in arundinetis. Cursitat in arena humida inter arundines. Hybernat intra arundinum culmos.

1. H. dimidiata: Nigra, antennis basi pedibusgue rufis, elylris dimidiato-flavis. - Long. $1 \frac{1}{4}$ lin.

Er. Col. March. I. 313. 1.

Aleoch. dimidiata Grav. Mon. 149. 3.

Homalota dimidiata Curtis Britt. Ent. XI. $t .514$.

Habitat in Germania.

Nigra, opaca, pube tenuissima flavescenti-grisea vestita. Antennae rufae, apicem versus fuscescentes. Frons interdum obsolete impressa. Thorax capitis vix latitudine, latitudine paulo brevior, apicem versus subangustatus, basi leviter canaliculatus. Elytra flava, basi late nigra. Pedes rufi.

\section{Homalota Manner $h$.}

Mannerh. Brachelytr. p. 73. - Er. Col. March. I. p. 314.

Maxillae mala interiore mutica, intus spinulis ciliata.

Ligula brevis, bifida; paraglossae nullae.

Palpi labiales triarticulati, articulo secundo breviore.

Tarsi antici 4-, posteriores 5-articulati, postici articulis 4 primis aequalibus.

Corpus vel elongatum, vel oblongum, saepe depressum, plerumque alatum. Caput exsertum, porrectum, basi magis minusve constrictum, iam thoracis latitudine, jam eodem angustius, oculis mediocribus, parum prominulis. Labrum apice rotundatum, mandibulas obtegens. Mandibulae muticae. Maxilae (t. III. f. 22.) mala exteriore cornea, basi apiceque membranea, portione membranea apicali pubescente, mala interiore exteriore paulo breviore, membranea, margine exteriore corneo, apice oblique introrsum emarginata, sinu spinulis brevibus ciliato. Palpi maxillares leviter elongati, articulo secundo tertioque longitudine subaequalibis, hoc leviter incrassato, quarto minuto, subulato. Labium (t. III. f. 8.) mento transverso, apice leviter emarginato, ligula brevi, palporum labialium articulum primum haud excedente, bifida, paraglossis nullis. Palpi labiales triarticulati, articulo primo maiore, secundo hoc duplo fere minore, tertio tenuiore at praecedente longiore. Antennae articulis tribus primis reliquis magis elongatis, secundo tertioque inter se aequalibus. Thorax iam lateribus parallelis, iam antrorsum angustatus. Scutellum triangulare. Elytra apice truncata, Abdomen iam lineare, iam apicem versus angustatum. Pedes leviter elongati, tarsis anticis 4-, posterioribus 5-articulatis, illis articulis tribus, his art culis quatuor primis brevibus, inter se aequalibus. 
o b s ervationes.

1. Com. Mannerheim ex unica specie, Aleoch. plana Gyll., proposuit hoc genus, tarsorum posticorum structura bene observata. Reliquas plerasque sub Bol ito chara enumerat illust. auctor, quamquam tarsorum posticorum articulis 4 primis aequalibus cum $H$. plana omnino congruunt.

2. Homalotae, generis recte descripti, nomen temere mutare nolui, quamvis multis speciebus aegre quadrat. Occurrunt in hoc genere, sicut a me constitutum est, numerosissimo plerorumque aliorum huius tribus formae, ut saepenumero, nisi characteribus genericis acerrime observandis, de genere facile decipiaris. Simulat e. g. Hom. didyma Autaliam, H. trimaculata Bolitocharam, H. velata T achyus a m, H. callicera Cal oderam, H. lividipennis Oxypodam, H. cinnamomea Ale ocharam, H. notha Gyrophaenam, etc.

3. Sunt quaedam in hoc genere species, quae tarsorum posticorum articulo primo paululum elongato a ceteris discedere videntur, e. c. H. concolor, livida et a m bigua, characteres autem reliqui huius generis in iis observantur, ut nulli alii generi adscribi possint, nisi Oxypodae, cuius habitum magis minusve distincte prae se ferunt, quacum autem tarsorum posticorum structura minus conveniunt, quam tarsis anticis 4-articulatis ab ea distinguuntur.

4. Mas plerumque antennis validioribus instructus, in quibusdam etiam abdominis structura, in aliis speciebus alio modo distinguitur, quas differentias in singulis speciebus memoratas invenies.

Secundum corporis totius et thoracis formam sectiones quatuor in hoc genere distinguam.

* Lineares, thorace vel quadrato, vel subquarato.

- 1. H. graminicola: Nigra, nitida, elytris nigro-fuscis, pedibus piceis, thorace coleopteris angustiore, transversim subquadralo, postice late foveolato, abdomine supra parce obsoletegue punctato. - Long. $1 \frac{3}{4}$ lin.

Aleoch. graminicola Grav. Mon. 176. 75.

Aleoch. linearis Gyll. Ins. Suec. II. 292. 15. - Sahlb. Ins. Fenn. I. 357. 22.

Bolitochara linearis Mannerh. Brachelytr. 79. 24.

Aleoch. longiuscula Gyll. Ins. Suec. IV. 485. 12-13. - Sahlb. Ins. Fenn. I. 355.18.

Bolitochara long iuscula Mannerh. Brachelytr. 17. 13.

Aleoch. longicornis var. b. Gyll. Ins. Suec. II. 405. 27.

Aleoch. moesta Zetterst. Faun. Lapp. I. 101. 15. Ins. Lappon. 77. 20.

Bolitochara fracticornis Boisd. et Lacord. Faun. Ent. Paris, I. 544. 7. (forte)

Habitat in Europa temperata et boreali.

Nigra, nitida, parce temuissime pubescens. Antennae capitis thoracisque longitudine, graciles, apicem versus parum incrassatae, nigrae, articulo primo piceo, 4-10 subobconicis, ultimo elongato-ovato, praecedente duplo prope longiore, apice acuminato. Caput thorace angustius, basi constrictum, parce subtilissime punctatum, fronte medio interdum obsolete impressa. Thorax coleopteris paulo angustior, latitudine dimidio frre brevior, lateribus et basi leviter rotundatus, apice truncatus, basin versus haud angustatus, angulis posterioribus obtusis, subdepressus, parce subtilissime punctatus, basi fovea lata, antrorsum saepe ultra medium producta, interdum etiam parva, raro fere nulla, impressus. Elytra thorace paulo longiora, obscure fusca, dense evidenter punctata. Abdomen supra laevigatum, segmentis anterius punctis 
raris, posterius vix conspicuis sparsis. Pedes longiusculi, picei, tibiis tarsisque rufescentibus.

Mas differt fronte thoraceque magis impressis, et abdominis segmento superiore terminali punctis elevatis asperato.

Obs. 1. Thoracis structura ambigua inter hanc et sequentem sectionem.

2. Antennarum basis et pedes nonnunquam dilutiores: talia exempla cel. Gyllenhal nomine Al. lin ear is descripsisse puto: specimina Suecica non vidi, specimen tamen arcticum, ad Promont. boreale (Nordcap) lectum Dom. Schüppel dedit.

3. Al. linearis Gyll. magis ad marem, Al. longiuscula magis ad feminam spectare videtur. Vidi in collectione Dom. Prof. Germar specimen nom. Al. aterrimae e Fennia a cel. Prof. Sahlberg missum, quod cum feminis indigenis omnino congruit, et quocum descriptio Al. longiusculae apud Gyllenhal omnino convenit. Sub nomine Al. aterrimae a Sahlbergio plures species confusae esse videntur, qua de re v. quod ad H. socialem referam.

2. H. umbonata: Nigra, nilida, elylris pedibusque fusco-testaceis, thorace coleopteris angustiore, transversim subquadrato, postice leviter foveolato, abdomine supra parce subtiliter punctato, sublaevigato. Long. $1 \frac{3}{4}$ lin.

Habitat in Lusitania, Com. Hoffmannsegg, in Hispania meridionali, in Istria et in Austria Dom., Schïppel, in Sardinia, Dom. Prof. Gené, in Anglia, Dom. Rudd.

Statura et summa similitudo praecedentis. Nigra, nitida, tenuiter subtiliterque griseo-pubescens. Antennae capite thoraceque paulo longiores, minus graciles, apicem versus vix incrassatae, articulis 4-10 subcylindricis, crassitie haud brevioribus, ultimo oblongo-ovato, praecedente plus sesqui longiore, apice subacuminato, totae nigrae, unicolores. Palpi nigro-picei. Caput thorace paulo angustius, parce subtilius punctatum, fronte utrinque leviter impressa. Thorax coleopteris paulo angustior, latitudine dimidio fere br vior, lateribus et basi leviter rotundatus, apice truncatus, basin versus haud angustatus, angulis anterioribus subrotundatis, posterioribus obtusis, subdepressus, minus dense subtiliter punctatus, basi medio obsolete impressus. Elytra thorace sesqui prope longiora, depressa, confertim subtiliter punctata, testacea, margine exteriore fuscescente. Abdomen supra vage subtiliter punctatum, ceterum laevigatum. Pedes fusco-testacei, femoribus picescentibus.

Mas abdominis segmento dorsali secundo medio tuberculo minuto elevato, ultimo punctis elevatis subtiliter asperato.

* 3. H. rigidicornis: Fusca, subnitida, tenuiter griseo-pubescens, antennis validis, elytris, ano pedibusque testaceis, thorace coleopleris angustiore, basin versus leviter angustato, abdomine supra parce subtilius punctato. - Long. 2 lin.

Habitat Genevae, Dom. Schïppel.

Praccedentibus maior, antennis validis et statura Myrmedoniam facile simulans, at huius generis. Antennae capite thoraceque fere longiores, crassae, articulo secundo tertio paulo minore, his obconicis, sequentibus seu articulis 4-10 spissis, cylindricis, crassitie haud brevioribus, ultimo praecedente duplo longiore, cylindrico, apice rotundato vel obtuse acuminato, totae testaceo-rufae. Palpi rufo-testacei, articulo tertio fortius incras- 
sato. Labrum testaceum. Mandibulae rufo-piceae. Caput thorace angustius, suborbiculatum, basi constrictum, subtiliter punctatum, parum pube-scens, fusco-nigrum, minus nitidum, fronte medio depressiuscula. Thorax coleopteris paulo angustior, latitudine summa dimidio fere brevior, lateribus ante mediūm fortiter rotundatis, basin versus modice angustatus, basi subrotundatus, apice levissime emarginatus, angulis anterioribus obtusis, subdeflexis, posterioribus obtusiusculis, leviter prominulis, levissime convexus, obsolete latius canalıculatus, confertim subtiliter punctatus, densius subtiliter griseo-pubescens, fusco-niger, parum nitidus. Scutellum dense punctatum, fuscum. Elytra thorace paulo longiora, confertim subtiliter punctata, rufotestacea, parum nitida, fulvo-pubescentia. Abdomen nigrum, nitidulum, parcius pubescens, supra minus dense subtiliter punctulatum, segmento apicali piceo-testaceo, subtus confertim subtiliter punctatum, densius pubescens, segmentorum marginibus rufo-piceis. Pectus nigrum. Pedes flavo-testacei. Specimen unicum, abdominis segmento dorsali secundo medio tuberculo minuto prominulo instructum, forte masculum.

* 4. H. occulta: Linearis, nigra, opaca, elylris fuscis, pedibus fusco-testaceis, thorace transversim subquadrato, coleopteris angustiore, abdomine nitido, supra basi subtiliter parce punctato, apice laevi. - Long. $1 \frac{2}{3}$ lin.

Er. Col. March. I. 317. 4.

Habitat in Germania.

Statura H. elongatulae. Corpus nigrum, pube tenuissima grisea vestitum. Antennae capitis thoracisque longitudine, apicem versus non incrassatae, articulis 4-10 subobconicis, longitudine haud crassioribus, ultimo ovato, apice acuminato, totae nigrae. Caput et thorax subtilissime alutacea, opaca, parce subtilissime punctata. Caput thoracis latitudine, basi constrictum, fronte maris leviter impressa, feminae subconvexa, nitidula. Thorax coleopteris subangustior, latitudine sesqui prope brevior, lateribus leviter rotundatus, basin versus subangustatus, subdepressus, basi foveolatus, interdum obsolete canaliculatus. Elytra thorace sesqui longiora, subtilissime alutacea, dense subtilius punctata, fusca. Abdomen nitidum, supra segmentis quatuor primis parce punctatis, ultimis fere laevibus. Pedes fuscotestacei.

Mas abdominis segmento superiore sexto laevi, apice emarginato, margine laterali elevato.

* 5. H. pagana: Nigra, subnitida, thorace elytrisque fuscis, antennarum basi pedibusque testaceis, thorace subquadrato, coleopteris angustiore, abdomine supra parce obsoleteque punctato. - Long. $1 \frac{2}{3}$ lin.

Habitat Lutetiae, Dom. Dr. Aubé.

Statura omnino H. graminicolae. Antennae capite thoraceque paulo longiores, apicem versus vix incrassatae, fuscae, artıculis 2 vel 3 primis rufo-testaceis, sequentibus subcylindricis, crassitie paulo longioribus, ultimo ovato, acuminato. Palpi testacei. Caput thorace angustius, subovatum, fronte parum convexa, subtilius punctatum, linea media longitudinali laevi, tenuiter pubescens, nigrum, subnitidum, ore rufescente. Thorax coleopteris 
paululum angustior, latitudine sesqui prope brevior, lateribus subrotundatus, basin versus haud angustatus subdepressus, aequalis vel nonnunquam obsolete canaliculatus, griseo-pubescens, crebre subtilius punctatus, fuscus. Elytra thorace parum longiora, depressa, crebre subtilius punctata, tenuter griseo-pubescentia, testaceo-fusca. Abdomen nigrum, nitıdum, supra parce griseo-pubescens, parce obsoleteque punctatum, subtus obsoletius punctulatum, segmentorum marginibus anoque ferrugineis. Pectus nigro-fuscum. Pedes testacei.

Mas: Abdominis segmento dorsali sexto punctis elevatis asperato.

Obs. Sequenti proxima et sim:llima, distinguenda autem thorace breviore, basin versus minime angustato, antennis longioribus et abdominis segmento dorsali sexto maris asperato. Ad H. graminicolam etiam proxime accedit, differt autem antennis basi testaceis, corporis colore opaco, etc.

* 6. H. ve stita: Nigra, subnilida, elytris fuscis, antennarum basi pedibusque testaceis, thorace coleopteris angustiore, basin versus subangustalo, obsolete canaliculato, abdomine supra parce obsoleteque punciato. Long. $1 \frac{2}{3}$ lin.

Paederus vestitus Grav. Mon. 140. 6. - Oliv. Encycl. meth. Ins. VIII. 629. 11. Aleoch. quisquiliarum Gyll. Ins. Suec. II. 398. 20. - Sahlb. Ins. Fenn. I. 361.

30. - Zetterst, Faun. Lappon. I. 97. 4. Ins. Lappon. 75. 5.

Bolutoch. quisquiliarum Mannerh. Brachelytr. 80. 32.

Habitat in Germania, Suecia.

Statura praecedentium, nigra, nitidula, pube grisea sat conspicua vestita. Antennae marıs capitis thoracisque longttudine, feminae iisdem paulo breviores, apicem versus vix incrassatae, rufae vel rufo-piceae, articulis tribus primis rufo-testaceis, sequentibus obconicis, longitudine haud crassioribus, ultimo oblongo-ovato. Os cum palpis rufo-testaceum. Caput thorace paulo angustius, subovatum, basi leviter constrictum, subdepressum, fronte ulrinque crebrius subtiliter punctata. Thorax coleopteris paulo angustior, latitudine vix brevior, lateribus ante medium leviter rotundatus, pone medium subsinuatus, basin versus leviter angustatus, apice truncatus, subdepressus, densius subtiliter punctatus, obsolete subtiliterque canaliculatus, basi obsolete impressus, fusco-niger, lateribus saepe rufescentibus. Elytra thorace longiora, depressa, subtiliter dense punctata, fusca vel fusco-testacea. Abdomen nigrum, nitidum, apice rufo-piceum, supra parce obsoleteque punctatum, fere laevigatum. Pedes flavo-testacei.

Mas nonnisi antennis paulo longioribus et validioribus distinguendus.

* 7. H. callicera: Linearis, subdepressa, fusca, thorace subquadrato, coleopteris angustiore, basi foveolato, abdomine supra laevi, antennis articulis duobus ultimis elongatis. - Long. $1 \frac{1}{2}$ lin.

Er. Col. March. I. 319. 7.

Aleoch. callicera Grav. Mon. 153.17.

Callicera obseura Grav. Micr. 66. 1.

Callicerus Spencei Curtis Britt. Ent. X. t. 443.

Habitat in Germania, Anglia.

Statura fere proxime sequentium, ut paulo minor, fusca, opaca, pube 
subtili cinerea leviter incana. Antennae in utroque sexu capite thoraceque longiores, validiusculae, articulis tribus primis nigro-, reliquis rufo-fuscis, articulo secundo tertioque obconicis, sequentibus omnibus cylindricis, antepenultimis duobus vel tribus transversis, feminae penultimo crassitie paulo longiore, ultimo hoc duplo fere longiore, apice obtuse acuminato, maris articulo penultimo crassitie duplo fere longiore, ultimo hoc sesqui longiore. Os testaceum, palpi maxillares articulo tertio tumido, ovato, fuscescente. Caput thorace paulo angustius, basi modice constrictum, suborbiculatum, vix perspicue punctulatum, nigricans, opacum, fronte subimpressa, vertice leviter canaliculato. Thorax latitudine haud brevior, basin versus subangustatus, basi coleopteris dimidıo angustior, lateribus ante medium subangulatorotundatus, apice fortiter angustatus, subdepressus, basi subcanaliculatus impressusque, vix perspicue punctulatus, opacus, nigro-fuscus. Elytra thorace paulo longiora, confertim subtiliter punctata, fusca, opaca. Abdomen lineare, parcius subtilissime pubescens, nigro-piceum, nitidulum, supra laevigatum, subtus subtilissime punctulatum. Pedes testacei, coxis femoribusque fuscis.

Articuli ultimi duo coniuncti in mare tertiae, in femina quartae fere antennarum parti aequales.

Obs. 1. Antennarum structura in hac specie singularis, quare genus peculiare, Callic erus, primo a cel. Gravenhorst propositum, dein ab eodum auctore apte deletum, ab Anglis auctoribus restitutum est, quod autem, antennarum structura in hoc genere tam varia et inconstante, neque hoc charactere satis determinaturn, neque alia quadum nota confirmatum videtur.

2. Cave ne corporis habitu et antennarum structura insignem hanc speciem pro Calodera habeas, sunt ei enim tarsi antici 4-articulati, et postici articulis 4 primis aequalibus huius generis.

3. Entomologiae Brittannicae nitidus auctor loco supra citato nomine $\mathbf{C a l l i}$ ceri Spencei marem depinxit, Calliceri hybridi feminam descripsit.

4. Idem auctor tarsos 5-articulatos affert, et pedem anticum tarso 5-articulato delineavit, quod nonnisi errore fieri potuit. Equidem distinctissime tarsos anticos 4-articulatos observavi.

8. H. pavens: Linearis, subdepressa, nigra, subtiliter sericeo-pubescens, elytris fuscis, antennarum basi pedibusque testaceis, thorace subquadrato, coleopteris angustiore, obsolete canaliculato, abdomine supra parcius subtiliterque punctulato. - Long. $1 \frac{3}{4}$ lin.

Er. Col. March. I. p. 689.

Homalota quisquiliarum Er. Col. March. I. 317. 5.

\section{Habitat in Germania.}

Statura fere $\mathrm{H}$. elongatulae, et maioribus eins individuis aequalis, einsdem coloris, at densius punctata ideoque magis opaca. Antennae capite thoraceque fere longiores, apicem versus leviter incrassatae, piceae, basi testaceae, articulis $4-\mathbf{1 0}$ obconico-cylindricis, sensim brevioribus, primis eorum subelongatis, decimo crassitie paulo breviore, ultimo ovato, apice obtuse acuminato. Caput, thorax et elytra subtilissime confertim punctata, opaca, pube tenuissima griseo-sericea densius vestita. Caput thorace paulo angustius, rotundatum, basi constrictum, ore cum palpis rufo-testaceo. Thorax coleopteris paulo angustior, latitudine haud brevior, basin versus subangustatus, lateribus ante medium cum angulis anterioribus rotundatus, sub.. 
depressus, obsolete canaliculatus. Elytra thorace paulo longiora, fusca vel fusco-testacea. Abdomen nitidulum, supra parce pubescens, subtilissime minus confertim punctatum, segmento quinto laevigato glabroque. Pedes testacei.

Mas abdominis segmento dorsali quinto medio carinula apice acuminata munito et fronte leviter canaliculata distunctus.

* 9. H. languida: Linearis, subdepressa, nigra, elytris anoque fuscis, antennarum basi pedibusque flavis, thorace subquadrato, coleopteris angustiore, basi foveolato, abdomine subtiliter confertissime punctato, opaco. - Long. $1 \frac{3}{4}-2$ lin.

Er. Col. March. I. 318. 6.

Habitat in Germania; in ins. Corcyra, Dom. Schïppel.

Statura omnino praecedentis. Corpus nigrum, abdomine excepto parce pubescens. Antennae capite thoraceque fere longiores, piceae, basi testaceae, articulis 4-10 subobconicis, omnibus subelongatis, licet sensim paulo brevioribus, et primis eorum paulo gracilioribus, decimo vero longitudine haud crassiore, apicali elongato-ovato, apice modice acuminato. Caput thorace angustius, rotundatum, basi constrictum, nigrum, nitidulum, subtilissime punctatum. Thorax coleopteris paulo angustior, latitudine haud brevior, lateribus subrotundatus, basin versus haud angustatus, angulis anterioribus fortiter rotundatis, subdepressus, confertim subtiliter punctatus, basi foveola obsoletiore impressus, plerumque piceus, subnitidus. Elytra thorace paulo longiora, fusco-testacea, confertissime subtiliter punctata. Abdomen nigrum, apıce fuscescente, undique confertissime subtilissime punctatum, pube tenuissima densa obductum, segmentis duobus ultimis glabris, parce punctatis. Pedes testacei.

Mas abdominis segmento quinto dorsali tuberculo minuto acutiusculo munito distinctus.

Variat minus maturus corpore testaceo.

$\mathrm{Obs}$. Affinis certe praecedenti abdomine subtilissime punctato, differt autem punctis confertissimis, pube brevissima densa occultis, et thorace haud canaliculato, basin versus nullo modo angustato.

* 10.H. gracilicornis: Depressa, nigra, subnitida, confertim subtiliter punctata, densius griseo-pubescens, antennis tenuibus concoloribus, pedibus testaceis, elytris fuscis, thorace subquadrato, coleopteris angustiore, basi foveolato, abdomine supra confertim punctato. - Long. $1 \frac{1}{2} \cdot$ lin.

Habitat in Austria, Dom. Ullrich.

Oblonga, depressa, nigra, subnitida, sat dense minus subtiliter griseopubescens, pube minus sericante. Antennae capite thoraceque paulo longiores, tenues, apicem versus hand incrassatae, nigrae, articulis 2.-10 elongato-obconicis, inter se subaequalibus, ultimo elongato-ovato. Caput thorace paulo angustius, basi constrictum, subtiliter punctulatum, fronte medio leviter foveolata. Thorax coleopteris angustior, longitudine vix latior, basi lateribusque leviter rotundatus, basin versus haud angustatus, apice truncatus, confertim subtiliter punctatus, basi foveola minus profunda impressus. 
Scutellum nigrum. Elytra sat lata, depressa, fusca, subtilissime confertissimeque punctata, pube densiore et magis sericante quam reliquum corpus vestita. Abdomen latiusculum, lateribus subrotundatum, supra minus subtiliter dense punctatum. Pedes testacei, femoribus picescentibus.

Obs. Praecedentibus affinis, at paulo brevior, magis depressa, antennis tenuibus Tachyusae atrae, tarsis posticis autem huius generis.

* 11. H. debilicornis: Depressa, nigra, subnilida, omnium subtilissime punctala, densius pube brèvissima grisea vestita, antennis tenuibus elytrisque fuscis, thorace coleopteris angustiore, subquadrato, basi foveolato, abdomine supra parce subtilissime punctato. - Long. $1 \frac{1}{2}$ lin.

Habitat in Sardinia, Dom. Prof. Gené.

Statura omnino et summa affinitas praecedentis. Nigra, subnitida, pube brevissima densa griseo-subsericans. Antennae capite thoraceque paulo longiores, graciles, apicem versus haud incrassatae, articulis 2-10 elongatoobconicis, secundo tertioque reliquis longioribus, ultimo elongato-ovato, fuscae, articulo primo subtestaceo. Palpi testacei. Caput thorace paulo angustius, basi leviter constrictum, parce subtilissime punctatum, depressum, fronte leviter impressa. Thorax latitudine haud brevior, coleopteris dimidio fere angustior, basin versus subangustatus, lateribus ante medium et basi leviter rotundatus, apice truncatus, angulis omnibus obtusis, anterioribu= deflexis, subdepressus, confertim subtilissime punctatus, basi foveola obsoletius impressus. Elytra thorace paulo longiora, depressa, confertim subtilissime punctata, fusca, parum nitida. Abdomen parce subtilissime punctatum, segmentis quarto quintoque laevigatis, parce longius pubescens, nigrum, nitidum. Pedes testacei.

Mas abdominis segmento dorsali quinto medio tuberculo minuto compresso acutiusculo notatus.

* 12. H. gregaria: Linearis, subdepressa, fusco-nigra, subnilida, sericeopubescens, elytris fuscis, pedibus testaceis, thorace subquadrato, basi foveolato, abdomine supra segmentis 4 anterioribus crebre subtiliter punctatis. - Long. $1 \frac{1}{3}$ lin.

Habitat in Aegypto, frequens, Dom. Prof. Ehrenberg, in Sardinia, Dom. Prof. Gené, in Austria, Dom. Ullrich, Berolini, ipse.

Habitus et summa affinitas $H$. elongatulae, subnitida, nigra, capite thoraceque plerumque nigro-fuscis; vel fuscis, elytris dilutius fuscis, vel fuscotestaceis, abdomine toto nigro, nitidulo. Antennae capite thoraceque parum longiores, apicem versus parum incrassatae, articulis $4-10$ subcylindricis, crassitie subbrevioribus, ultimo oblongo-ovato, totae rufo-brumneae. Palpi testacei. Caput thoracis prope latitudine, orbiculatum, basi sat fortiter constrictum, subtilissime punctulatum. Thorax coleopteris antice parum angustior, basin versus subangustatus, latitudme vix brevior, subtilissime punctulatus, subdepressus, basi supra scutellum impressus. Elytra thorace paulo longiora depressa, confertim subtiliter punctata. Abdomen supra segmentis 4 anterioribus confertim subtiliter punctatis, quinto laevi, sexto iterum punctulato Pedes flavo-testacei.

$\mathrm{V}$ ariat thoracis dorso late longitudinaliter impresso. 
Obs. Ab H. elongatula praecipue thorace paulo longiore et abdominis segmento etiam quarto confertius punctulato distinguenda.

* 13. H. ravilla:' Linearis, nigra, opaca, subtilissime sericeo-pubescens, tibiis tarsisque testaceis, thorace subquadrato, coleopteris angustiore, basi canaliculato, abdomine supra sublaevigato. - Long. $1 \frac{1}{4}$ lin.

Habitat in Austria, Dom. Ullrich.

Statura omnino H. elongatulae, et minutis eius individuis aequalis, nigra, minus nitida, abdomine supra nitidulo. Antennae capite thoraceque paulo longiores, apicem versus sensim subincrassatae, articulis penultimis vix transversis, ultimo magno, ovato, praecentente triplo fere longiore, corpori concolores. Caput thoracis latitudine, rotundatum, basi constrictum, omnitim subtilissime punctulatum, fronte subimpressa. Thorax coleopteris paulo angustıor, latitudine vix brevior, lateribus rectis, basi apiceque truncatus, angulis omnibus rotundatis, parum convexus, omnium subtilissime punctulatus, basi ad medium usque late et parum profunde canaliculatus. Elytra thorace paulo longiora, confertim subtiliter punctata, concolora. Abdomen lineare, supra segmentis anterioribus duobus parce subtiliter obsoleteque punctulatis, parceque pubescentibus, reliquis laevigatis. Pedes nigri, tibiis tarsisque picescenti-testaceis,

Obs. Colore nigro et abdomine supra fere laevigato nec non antennarum structura ab affinibus satis distincta videtur.

* 14. H. labilis: Nigra, nitida, tenuiler griseo-pubescens, antennarum basi pedibusque rufo-piceis, thorace subquadrato, leviter convexo, abdomine supra creberrime subtilius punctato. - Long. $1 \frac{1}{2}$ lin.

Er. Col. March. I. 699. 7. a.

Ilabitat in Austria, Dom Ullrich, Berolini, Dom. Schïppel, Lutetiae Mus. Dom. Aubé, in Sardinia, Mus. Reg. Taurin.

Statura omnino, facies et summa similitudo Tachyusae umbraticae, at huius generis, nigra, nitida, pube minus densa parum sericante grisea vestita. Antennae capite thoraceque paulo longiores, tenuiusculae, apice leviter incrassatae, nigrae, articulis 3 vel 4 primis rufescenti-piceis, sequentibus elongato-obconicis, penultimis solis crassitie vix longioribus, ultimo oblongosubacuminato. Caput thorace paulo angustius, rotundatum, basi constrictum, subtiliter punctulatum. Thorax coleopteris angustior, latitudine vix brevior, lateribus anterims subrotundatus, basin versus subangustatus, leviter convexus, subtilissime punctulatus, basi foveola minuta angusta transversa impressus. Elytra thorace paulo longiora, sat crebre subtiliter punctata, concolora. Abdomen parallelum, supra confertim subtilius punctatum. Pedes rufo-picei, femoribus nigricantibus.

Mas fronte impressa et antennis paulo longioribus distinctus.

* 15. II. velat a: Nigra, sericeo-pubescens, thorace transversim subguadrato, abdomine toto sublilissime punctulato, antennis fuscis basi pedibusque pallide flavis. - Long. $1 \frac{1}{2}$ lin.

Er. Col. March. I. 319. 8.

IIabitat in Germania, Gallia. 
Statura et habitu fere Tachyusae. Antennae capite thoraceque breviores, apicem versus vix incrassatae, articulis penultimis longitudine paulo crassioribus, ultimo ovato, fuscae basi flavae, vel flavae apice subinfuscatae. Corpus atrum, parum nitidum, totum pube tenuissima densa cinereo-sericeum. Oris partes testaceae. Caput thorace paulo angustius, suborbiculatum, basi leviter constrictum. Thorax latitudine dimidio fere brevior, coleopteris paulo angustior, basin versus subangustatus, lateribus ante medium cum angulis anterioribus rotundatus, subdepressus, basi foveola punctiformi notatus. Elytra thorace sesqui longiora. Abdomen sub pube omnium subtilissime punctulatum. Pedes toti dilute flavi.

Obs. A praecende pube sericea conferta, thorace antennisque brevioribus et pedibus totis pallide flavo-testaceis distincta.

* 16. I. luteipes: Linearis, nigra, subnitida, antennis longioribus piceis, perlibus laete testaceis, thorace subquadrato, leviter convexo, abdomine supra subtilissime confertim punctato. - Long. $1 \frac{1}{3}$ lin.

Er. Col. March. I. 320. 9.

\section{Habitat Berolmi.}

Statura fere sequentis. Nigra, subnitida, pube tenerrima vix conspicua sericea. Antennae elongatae, capite thoraceque longiores, graciliores, apicem versus leviter incrassatae, nigro-piceae, basi apiceque plerumque fuscopiceae, articulis 4-10 subobconicis, crassitie haud brevioribus, terminali oblongo-ovato. Caput thorace paulo angustius, basi leviter constrictum, subtiliter densius punctatum, oris partibus testaceis. Thorax coleopteris vix angustior, latitudine haud brevior, basin versus haud angustatus, angulis anterioribus late rotundatis, supra leviter convexus, basi interdum obsolete foveolatus. Elytra thorace paulo longiora, subtilissime dense punctata. Abdomen supra anterius subtiliter confertissime, posterius subtilissime dense punctatum. Pedes laete testacei.

Obs. A sequente praecipue thorace antennisque longioribus et abdomine confertim punctato distincta.

* 17. H. elongatula: Linearis, subdepressa, nigra, subnitida, sericeo-pubescens, elytris fuscis, antennarum basi pedibusque testaceis, thorace transversim subquadrato, abdomine supra segmentis anterioribus 3 crebre punctulatis. - Long. $1 \frac{1}{4}-2$ lin.

Var. a: Thorace aequali.

Aleoch. terminalis Grav. Mon. 160. 29. - Gyll. Ins. Suec. II. 397. 19. - Sahlb. Ins. Fenn. I. 360. 27.

Bolit och, terminalis Mannerh. Brachelytr. 80. 30.

Var. b: Thorace basi foveolato.

Aleoch. elongat ula Grav. Micr. 79. 18. Mon. 153. 18. - Latr. Hist. nut. Crust. et Ins. IX. 383. 18. - Gyll. Ins. Suec. II. 398. 18. - Sahlb. Ins. Fenn. I. 359. 25. - Zetterst. Faun, Lappon. I. 97. 3. Ius. Lappon. 75. 3.

Ale och. teres Gyll. Ins. Suec. II. 390. 13. - Sahlb. Ins. Fenn. I. 355. 19, - Zetterst. Faun. Lappon. I. 98. 7. Ins. Lappon. 76. 10.

Bolitoch, teres Mannerh. Brachelytr. 76. 7.

Var. o: Thorace obsolete canaliculato. 
Bolitoch. complana Mannerh. Brachelytr. 79. 29.

Aleoch. complana Suhlb. Ins. Fenn. 1. 359. 26.

Bolit och. oblonga Boisd. et. Lacord. Faun. Ent. Paris. I. 548. 15.

Bolit och. ex ilis Mannerh. Brachelytr. 80. 31.

Aleoch. exilis Sahlb. Ins. Fenn. 1. 360. 28.

Bolitoch. elongat ula Boisd. et Lacord. Faun. Ent. Paris. I. 548. 14.

Bolitoch. planiuscula Mannerh. Brachelytr. 80. 33.

Bolit och. depressiuscula Mannerh. Brachelytr. 80. 34.

Aleoch. depressiuscula Sahlb. Ins. Fenn. I. 362. 32.

Habitat in Europa.

Linearis, subdepressa, nigra, subnitida, dense subtilissime punctata, pube tenuissima griseo-sericea vestita. Antennae capitis thoracisque longitudine, apicem versus vix incrassatae, articulis 4-10 subobconicis, crassitie haud brevioribus, ultimo oblongo-ovato, apice acuminato, nigro-piceae, basi ob-. scure testaceae, raro piceae. Caput thorace paulo minus, basi constrictum, subdepressum, subtilissime punctatum, oris partibus testaceis. Thorax coleopterorum fere latitudine, latitudine dimidio fere brevior, basin versus haud angustatus, subdepressus, confertissime punctatus, vel basi foveolatus, vel dorso obsolete canaliculatus, vel interdum omnino aequalis. Elytra thorace dimidio longiora, fusca, opaca. Abdomen supra nitidulum, segmentis 3 primis crebrius subtiliter, 4 et 5 vage, ultimo iterum dense punctatis, apice iam testaceo, iam piceo, iam concolore. Pedes testacei.

Species vulgaris, quodammodo instabilis, statura corporis lineari subdepressa, et abdominis punctura semper cognoscenda. Forte species complures sub hoc nomine coniungo, quarum autem differentiae, quanto magis eas petii, tanto magis me fugerunt. Varietatum agmen hoc modo coegi:

I. Antennae articulis 4-10 crassitie haud brevioribus.

A. Abdomen apice piceo. Long. $1 \frac{1}{3}-1 \frac{2}{3}$ lin. tissima.

a. Therace basi foveolato vel omnino aequali. - Apud non frequen-

b. Thorace canaliculato. - Sat frequens.

Huc Bolitochara complana et depressiuscula Mannerh. et Bolitochara oblong a Lacord. pertinent.

B. Abdominis apice testaceo segmentorumque singulorum marginibus rufis. Antennae plerumque totae rufae. Long. $1 \frac{2}{3}-1 \frac{3}{4}$ lin. - Haud infrequens.

a. Thorace basi foveolato. Hanc pro Aleochara elongatula sua Dom. Gyllenhal Dom. Schïppel communicavit.

b. Thorace canaliculato. - Huius specimen a Gyllenhal nomine A. terminalis acceptum Dom. Schiippel communicavit. Bolitochara exilis et planiuscula Mannerh. et Bolitochara elongatula Lacord. ad hanc revocandae.

C. Abdomine nigro, ano etiam concolore.

a. Abdominis segmentis dorsalibus tribus primis crebre profundiusque punctatis. Long. 2 lin. - Reliquis maior et robustior, ceterum haud distincta. Rarior.

b. Abdominis segmentis dorsalibus tribus primis crebrius punctulatis. 
Long. $1 \frac{x}{2}$ lin. - Haud infrequens, a typo nonnisi ano concolore divergens. Huic adscribenda Bolitochara oblonga Mannerh. Brachelytr. 79. 26. - Aleoch. el ongatula var. b Gyll. Ins. Suec. II. p. 396. Sahlb. Ins. Fenn. I. p. 359. Zetterst. Ins. Lappon. p. 75.

c. Abdominis segmentis dorsalibus tribus primis parce subtiliterque punctatis. Long. $1 \frac{\mathrm{r}}{3}$ lin. - Reliquis paulo minor et abdominis anteriore etiam dorso sublaevigato a reliquis discedens. Huius exempla 4 Dom. Schïppel communicavit, unum Berolini lectum, reliqua a Gyllenhal nomine Al. teretis e Suecia accepta.

II. Antennae articulis 4-10 crassitie paulo brevioribus, leviter transversis, totae nigrae. Anus etiam concolor. Reliquis minor, long. $1 \frac{x}{4}$ lin., ceterum vix distinguenda. Haud infrequens cum reliquis occurrit.

Variat praeterea pallidior, rufo-picea, capite abdominisque cingulo ante apicem nigricantibus. Huc pertinet forte Bolito chara longiuscula Boisd. et Lacord. Faun. Ent. Paris. I. 545. 8.

* 18. H. linearis: Linearis, nigra, antennis basi apiceque, pedibus anoque testaceis, fronte thoraceque subquadrato canaliculatis, elytris thoracis longitudine, rufo-brunneis, abdomine supra parce subtiliter punctulato. - Long. $1 \frac{1}{2}$ lin.

Er. Cot. March. I. 322. 12.

Ale och. lin e a ris Grav. Micr. 69. 2. Mon. 148. 2. - Latr. Hist, nat. Crust. et Ins. IX. 378. 2.

Habitat in Germania.

Statura fere praecedentium. Antennae capitis thoracisque longitudine, apicem versus leniter incrassatae, articulis penultimis transversis, ultimo leviter ovato, acuminato, rufo-testaceae, ante apicem fuscae. Corpus nigrum, subnitidum, tenuiter griseo-pubescens. Caput thorace paulo angustius, basi constrictum, subtilissime punctatum, minus nitidum, fronte subdepressa, parce subtiliterque punctata, parum profunde canaliculata, ore testaceo. Thorax coleopterorum fere latitudine, latitudine dimidio brevior, lateribus parum rotundatis, apice truncatus, angulis anterioribus obtusis, subdeflexis, depressus, omnium subtilissime punctulatus, in utroque sexu late canaliculatus. Elytra thorace vix longiora, depressa, confertim subtiliter punctata, rufobrunnea. Abdomen nigrum, nitidum, apice testaceum, segmentis anterioribus margine posteriore rufo-piceo, supra parce subtiliter punctatum, quarto quintoque in utroque sexu sublaevigatis. Pedes testacei.

Mas nonnisi thoracis frontisque canalicula latiore distinctus.

$\mathrm{Obs}$. Elytris thoraci longitudine subaequalibus ab affinibus discedit.

* 19. H. angustula: Linearis, subdepressa, nigra, anlennarum basi, elytris pedibusque testaceis, thorace quadrato, canaliculato, abdomine confertissime subtiliter punctulato. - Long. $1 \frac{1}{2}$ lin.

Er. Col. March. I. 322.13.

Aleoch. angustula Gyll. Ins. Suec. II. 393.16. - Sahlb. Ins. Fenn. I. 357. 23. -

Zetterst. Faun. Lappon. I. 97. 2. Ins. Lappon. 75. 2.

Bolit och. angust ula Mannerh. Brachelytr. 79. 25. - Boisd. et Lacord. Faun. Ent.

Paris. I. 547. 13. - Runde Brachel. Hal. 30. 7.

Aleach. linearis var. Grav. Mon. 149. 2. 
Habitat in Europa.

Angusta, linearis, subdepressa, nigra, subnitida, subtilissime dense punctata, tenuiter dense griseo-pubescens. Antennae capitis thoracisque longitudine, apicem versus subincrassatae, articulis penultimis longitudine paulo crassioribus, rufo-piceae, basi testaceae. Caput thoracis latitudine, -basi constrictum, feminae medio obsolete canaliculatum, maris late impressum: oris partibus testaceis. Thorax coleopterorum latitudine, latitudine vix brevior, lateribus ante medium leviter rotundatus, depressus, in mare late, in femina subtilius canaliculatus, opacus, niger, interdum piceus. Elytra thorace vix longiora, piceo-testacea, circa scutellum picea. Abdomen supra confertissime subtiliter punctatum, segmento sexto in mare supra granulato. $\mathrm{Pe}$ des testacei.

Mas fronte impressa, thorace late canaliculato et abdominis segmentis dorsalibus quinto sextoque granulatis distinctus.

* 20. H. a equata: Linearis, depressa, nigra, opaca, elylris fuscis, antennarum basi pedibusque rufis, thorace subquadrato, late canaliculato, abdomine nitidulo, parcius punctulato. - Long. $1 \frac{2}{3}$ lin.

Er. Col. March. I. 323.14.

Habitat in Germania.

Praecedenti affinis, at paulo magis elongata depressaque. Antennae capite sesqui longiores, articulis 6-10 transversis, ultimo subconico, piceae, articulis duobus primis rufis. Caput thoracis fere latitudine, nigrum, opacum, obsolete punctatum, fronte feminae plana, maris leviter impressa: oris partibus rufis. Thorax latitudine vix brevior, coleopteris paululum angustior, lateribus aequaliter leviter rotundatus, depressus, in utroque sexu late canaliculatus, subtilissime confertissimeque punctatus, niger, opacus. Coleoptera thorace vix longiora, depressa, subtiliter dense punctata, fusca, apice rufescentia. Abdomen nigrum, segmentis primis apice obscure rufopiceis, supra subtiliter minus dense punctatum, nitidulum. Pedes rufotestacei.

Mas fronte impressa et abdominis segmento dorsali quinto granulato distinctus.

Obs. Proxima praecedentl, a qua praecipue colore capitis, thoracis elytrorumque magis opaco, fronte maris minus impressa, feminae planata, et abdomine minus subtiliter et minus confertim punctato discedit.

* 21. H. nigella: Linearis, depressa, nigra, antennis.basi piceo-rufis, thorace subquadrato, leviter canaliculato, abdomine supra crebre fortins punctalo. - Long. $1 \frac{1}{4}$ lin.

Er. Col. March. I. 323. 15.

Habitat Berolini.

Statura praecedentium, at paulo minor. Corpus depressum, nigrum, unicolor, tenuissime parce griseo-pubescens. Antennae capite thoraceque breviores, apicem versus sensim incrassatae, articulis penultimis transversis, ultimo ovato, basi truncato, apice obtuso, articulis duobus primis obscure rulis. Palpi picei. Caput thoracis latitudine, basi constrictum, depressum, 
dense minus subtiliter punctatum, opacum, fronte feminae plana, maris leviter impressa. Thorax coleopteris vix angustior, latitudine parum brevior, basin versus subangustatus, lateribus ante medium leviter rotundatus, depressus, opaeus, confertim subtiliter punctatus, late et parum profunde canaliculatus. Elytra thorace paulo longiora, depressa, dense minus subtiliter punctata, opaca. Abdomen supra nitidulum, segmentis 4 anterioribus crebre fortiusque, ultimis tribus parcius subtilusquel punctatis. Pedes nigri, geniculis tarsisque piceis.

Mas abdominis segmento dorsali sexto subtiliter granulato distinctus.

* 22. H. arcana: Linearis, subdepressa, nigra, antennis concoloribus, pedibus testaceis, thorace subquadrato fronteque late longiludinaliter impressis, abdomine supra parce subtiliterque punctato, nitidulo. Long. $1 \frac{1}{3}$ lin.

Habitat in saltu Thuringensi, Dom. Kellner.

Statura omnino H. nigellae, nigra, parum nitida, subtiliter griseo-pubescens. Antennae capitis thoracisque prope longitudine, apicem versus vix incrassatae, articulo secundo tertioque aequalibus, 4-10 longitudine haud vel parum crassioribus, ultimo praecedentibus ambobus longitudine aequai, ovato, subacuminato, totae nigrae. Palpi nigri. Caput thorace parum angustius, subquadratum, obsolete punctulatum, fronte longitudinaliter impressa. Thorax coleopteris parum angustior, latitudine tertia fere parte brevior, lateribus subrectis, basi rotundatus, apice truncatus, angulis anterioribus obtusiusculis, deflexis, depressus, crebre subtilius punctatus, dorso secundum totam longitudinem late et papum profunde licet medio paulo profundius impressus, margine laterali pilosello. Elytra thorace sesqui prope longiora, confertim subtilius punctata, piceo-nigra. Abdomen supra nitidulum, parce subtiliter obsolefeque punctatum, segmento quinto sublaevi, sexto apice emarginato, septimo conspicuo ut in Oxytelinis. Pedes testacei.

\section{* 23. H. plana: Linearis, depressa, nigra, antennis piceis, pedibus anoque testaceis, fronte thoraceque transversim subquadrato canaliculatis, ely- tris thorace sesqui longioribus, brunneis, abdomine supra parce subtili- ter punctato. - Long. $1 \frac{1}{4}$ lin.}

Mannerh. Brachelytr. 73. 1. - Er. Col. March. I. 700. 15. a.

Ale och. pla na Giyll. Ins. Suec. II. 402. 24. - Sahlb. Ins. Fenn. I. 367. 40.

\section{Habitat in Germania, Suecia.}

H. lineari proxima eidemque simillima, at dimidio minor, fronte minus subtiliter punctata et elytris longioribus distincta, nigra, parum nitida, subtiliter tenuiterque pubescens. Antennae capite sesqui longiores, apicem versus leviter incrassatae, articulis 5-10 subtransversis, ultimo breviter ovato, obtuse acuminato, pilosellae, iam dilutıus, iam saturatius rufo-piceae. Palpi rufo-picei. Caput thorace parum angustius, suborbiculatum, basi parum constrictum, depressum, late parum profunde canaliculatum, crebre fortius punctatum, apice laeve, ore piceo. Thorax coleopteris paulo angustior, latitudine dimidio prope brevior, lateribus ante medium leviter rotundatus, basin versus subangustatus, depressus, omnium subtilissime confertim punctatus, late canaliculatus, canalicula basi profundiore, apice evanescente. 
Elytra thorace sesqui longiora, depressa, dense subtiliter punctata, iam fusco-, iam rufo-testacea. Abdomen nitidum, segmentis tribus anterioribus margine postico piceo, dorso parce subtiliterque punctatis, sequentibus laevigatis, apice testaceum. Pedes testacei, tibiis tarsisque dilutioribus.

$\mathrm{O}$ bs. Habitu, capite thoraceque canaliculatis et fronte fortius punctata $\mathrm{H}$. cuspidatae affinis, differt autem statura maiore, ano mutico, etc.

*24. H. debilis: Linearis, subdepressa, fusca, ore, antennis, elytris, pedibus anoque testaceis, thorace subquadrato, leviler canaliculato, abdomine supra subtiliter punctulato. - Long. $1 \frac{1}{2}$ lin.

Er. Col. March. I. 321. 11.

\section{Habitat Berolini.}

Praecedente gracilior, fusca, tenuiter griseo-pubescens. Antennae capipitis thoracisque longitudine, apicem versus parum crassiores, articulis 4-10 obconicis, crassitie haud brevioribus, ultimo ovato, subacuminato, totae testaceae. Caput thoracis latitudine, basi constrictum, subtiliter punctatum, nitidulum, medio obsolete canaliculatum, ore testaceo. Thorax coleopteris vix angustior, basin versus subangustatus, latitudine parum brevior, subnitidus, dense subtiliter punctatus, subdepressus, tenuiter canalienlatus. Elytra thorace paulo longiora, subtiliter dense punctata, fusco-testacea. Abdomen supra nitidulum, segmentis primis parcius subtiliter, quinto sparsim punctatis, sexto in utroque sexu laevi, septimo densius punctato, testaceo. Pedes pallide testacei.

M as nonnisi antennis paulo longioribus, apicem versus distinctius incrassatis, articulo ultimo oblongo-ovato distinguitur.

Obs. H. elongatulae affinis, at gracilior, antennis laete testaceis, thorace longiore, basin versus subangustato et abdomine confertius punctatis differt.

25. H. gracilenta: Elongata, linearis, nigra, nitida, antennis, ore, pedibus anoque testaceis, elytris fusco-testaceis, thorace subquadrato, aequali, abdomine supra laevigato. - Long. $1 \frac{1}{3}$ lin.

Habitat Lutetiae, Mus. Dr. Aubé.

Statura omnino H. elongatulae et minimis eius individuis aequalis, nigra, nitida, subtiliter pubescens. Antennae capitis thoracisque fere longitudine, apicem versus sensim incrassatae, articulis penultimis transversis, ultimo ovato, subacuminato, totae testaceo-flavae. Caput thoracis prope latitudine, basi profundius constrictum, subtilissime punctulatum, ore flavotestaceo. Thorax coleopterorum prope latitudine, latitudine paululum brevior, subdepressus, aequalis, sat crebre subtiliter punctulatus. Elytra thorace sesqui longiora, parce obsoleteque subtiliter punctulata, fúsco-testacea (basin versus magis fusca, apicem versus magis testacea). Abdomen supra laevigatum, apice testaceum. Pedes testaceo-flavi.

Obs. H. debili coloribns similis, statura autem paulo minore, minus depressa, thorace haud canaliculato, abdomine supra laevigato distincta. 
* 26. H. macella: Linearis, depressa, mfo-testacen, dense subtiliter griseo-pubescens, ore, antennis pedibusque testaceis, thorace quadrato fronteque obsolete canaliculatis, abdomine supra subtilissime punctulato. - Long. 1 lin.

Habitat Passaviae in Bavaria meridionali, Dom. Walti.

Habitus fere Lithocharidis, H. debili duplo minor, paulo angustior et multo magis depressa, rufo-testacea, opaca, pube brevi albida subsericans, omnium subtilissime et vix perspicue punctata. Antennae capitis thoracisque prope longitudine, apicem versus parum incrassatae, articulis penultimis subtransversis, ultimo oblongo-ovato, totae flavo-testaceae. Caput thoracis latitudine, basi fortiter constrictum, subquadratum, depressum, obsolete canaliculatum, ore testaceo. Thorax coleopteris perparum angustior, latititudine haud brevior, lateribus rectis, basi apiceque vix rotundatus, depressus, obsolete canaliculatus. Elytra thorace paulo longiora. Abdomen supra segmentis singulis margine apicali dilute testaceis, penultimis basi piceis, apice toto testaceo. Pectus piceum. Pedes flavo-testacei.

* 27. H. brevicornis: Elongata, linearis, subdepressa, nigra, nilida, elylris pedibusque fusco-testaceis, antennis capitis longitudine, abdominis segmentis 2 et 3 supra bicarinatis, - Long. $1 \frac{3}{4}$ lin.

Habitat in Brasilia.

Corpus admodum elongatum, lineare, subdepressum, nigrum, nitidum, subtiliter parce punctatum, tenuissime pubescens. Antennae capitis longitudine, apicem versus incrassatae, articulis 5-10 fortiter transversis, ultimo breviore, acuminato, piceae, basi rufescentes. Caput thoracis latitudine, transversim subquadratum, vertice transversim leviter impresso, fronte medio obsolete foveolata. Thorax subquadratus, latitudine paulo brevior, lateribus rectis, basi leviter rotundatus, apice leviter bisinuatas, subdepressus, aequalis. Elytra thorace paulo longiora, fusca, disco fusco-testacea, evidentius punctata. Abdomen supra laevigatum, segmento secundo et tertio utrinque acute carinato, sexto apice carinulis duabus elevatis, ultimo apice tricuspi. Pedes breves; fusco-testacei.

Obs. Habitu quibusdam Phloeoporis non dissimilis, at tarsi antici mihi quadriarticulati videntur.

* 28. H. illota: Depressa, nigra, tibiis, tarsis elytrisque luteis, his circa scutellum infuscatis, capile fortius punctato thoraceque basin versus subangustalo late canaliculatis, abdomine supra parce punctato. Long. $1 \frac{1}{3}$ lin.

Habitat in Brasilia.

Habitu fere $H$. elongatulae, at brevior et paulo magis depressa, nigra, parum nitida. Antennae capitis thoracisque longitudine, apicem versus sensim subincrassatae, articulis 5-10 leviter obconicis, longitudine vix crassioribus, ultimo ovato, pilosellae, nigrae, articulis tribus. primis piceis. Palpi maxillares picei, labiales pallidi. Caput thoracis latitudine, basi modice constrictum, planatum, dense fortius punctatum, obsolete canaliculatum, antice laeve. Thorax coleopteris angustior, latitudine paululum brevior, lateribus leviter rotundatis, basin versus subangustatus, depressus, longitudina- 
liter late at parum profunde impressus, confertissime subtiliter punctatus, uti caput pube densa, erecta, brevissima, nigra vestitus. Elytra thorace paulo longiora, depressa, subtiliter punctulata, tenuiter griseo-pubescentia, lutea, macula magna communi triangulari circa scutellum margineque laterali fuscis. Abdomen supra parce subtiliter punctatum parceque cinereo-pubescens, nitidum. Pedes nigri, tibiis tarsisque rufo-testaceis.

*29. H. intrusa: Linearis, subdepressa, nigra, opaca, elytris, antennarum basi pedibusque fusco-testaceis, thorace coleopteris angustiore, subquadrato, medio late impresso, abdomine nilidulo, antice crebre punclato, postice laevigato. - Long. $1 \frac{1}{4}$ lin.

Habitat in. Brasilia.

Habitu fere $H$. elongatulae, at minor, nigra, opaca, pube tenui vestita. Antennae capitis thoracisque longitudine, validiusculae, apicem versus sensim leviter incrassatae, articulis penultimis transversis, ultimo oblongo-ovato, nigrae, basi obscure testaceae. Caput thoracis fere latitudine, depressum, basi parum constrictum, subtiliter punctulatum, fronte plana. Thorax subquadratus, coleopteris plus dimidio angustior, latitudine vix brevior, lateribus ante medium rotundatis, depressus, subtiliter dense punctulatus, fovea lata longitudinali media per totam fere longitudinem excavatus. Elytra thorace paulo longiora, depressa, dense subtiliter punctata, fusco-testacea. Abdomen nitidum, supra segmentis anterioribus tribus crebre punctatis, posterioribus laevigatis, apice testaceum. Pedes testacei.

* 30. H. cuspidata: Linearis, depressa, fusca, capite thoraceque obsolete canaliculatis, abdomine apice testaceo, mucronato, - Long. $\frac{3}{4}$ lin.

Er. Col. March. I. p. 689.

Homalota plana Er. Col. March. I. 324. 16.

Habitat in Europa, sub arborum cortice.

Minuta, valde depressa, linearis, fusca. Antennae capite sesqui longiores, apicem versus incrassatae, articulis duobus primis tumidulis, penultimis transversis, ultimo subgloboso. Caput thoraci fere aequale, subquadratum, depressum, minus dense fortius punctatum, linea media laevi, plerumque subimpressa, ore testaceo. Thorax coleopteris non angustior, latitudine parum brevior, lateribus subrectis, depressus, subtiliter punctatus, leviter canaliculatus. Elytra thorace paulo longiora, subtiliter punctata, fusco-testacea. Abdomen basi fuscum, dein nigricans, apice testaceum, supra subtilius punctåtum, segmento ultimo apice acute mucronato. Pedes testacei.

Individuis nonnullis, forte masculis abdominis segmenta dorsalia intermedia utrmque tuberculo minuto instructa.

Varıat colore saepius in testaceum, rarius in nigrum vergente.

$\mathrm{Ob}$ s. Statura pusilla et abdomine apice mucronato facile cognoscenda.

* 31. H. immersa: Linearis, depressa, nigra, nitida, elytris fuscis, antennarum basi pedibusque testaceis, fronte thoraceque subquadrato late impressis, abdomine supra parce punctato. - Long. $\frac{3}{4}$ lin.

Er. Col. March. I. 324. 17.

Habitat in Germania. Unicum specimen Berolini legi. 
Praecedente latior, plana, nigra, nitida, tenuissime parce pubescens. Antennae capitis thoracisque longitudine, articulis $4-10$ aequalibus, transversim obconicis, ultimo maiore, ovato, pilosellae, piceae, basi pallide testaceae. Caput thoracis latitudine, transversim subquadratum, planum, fronte tota impressa, subtilissime parce punctata. Thorax antice coleopteris parum angustior, et latitudine vix brevior, basin versus subangustatus, subtiliter parce punctulatus, obsolete canaliculatus, a basi ultra medium late parum profunde impressus. Elytra thorace sesqui prope longiora, crebre distinctius punctata, fusco-testacea. Abdomen supra vage subtiliter punctatum, apice piceo-testaceum. Pedes dilute fusco-testacei.

* 32. H. vilis: Linearis, subdepressa, fusca, pedibus testaceis, thorace subquadrato, obsolete foveolato, abdomine nigro, supra conferlim subtiliter punctato, ano piceo, - Long. 1 lin.

Er. Col. March. I. 325.18.

Habitat in Germania. Singulum exemplum Berolini legi.

Habitu fere H. elongatulae, at multo minor, angusta, linearis, subdepressa, abdomine excepto fusca, opaca, subtilissime punctata, omnium tenuissime sericeo-pubescens. Antennae capitis thoracisque longitudine, apicem versus parum incrassatae, articulis $4-10$ longitudine vix crassioribus, ultimo ovato, rufo-piceae. Caput thoracis fere latitudine, basi leviter constrictum, aliquantulum distinctius punctatum, fronte medio obsolete canaliculata, oris partibus testaceis. Thorax coleopteris non angustior, latitudine paulo brevior, lateribus subrectis, angulis omnibus rotundatis, subdepressus, basi foveola minuta obsolete impressus. Elytra thorace longiora, dense subtiliter punctata, apice subdilutiora. Abdomen distinctius griseo-pubescens, undique confertim subtiliter punctatum, nitidum, nigrum, ano rufo-piceo. -Pedes testacei.

* 33. H. caesula: Linearis, fusca, antennis pedibusque tesiaceis, thorace subquadrato, fortiter canaliculato, abdomine nigro, parce subtilissime punctato, ano piceo. - Long. $\frac{3}{4}$ lin.

Habitat in Germania. Singulum specimen Dom. Schüppel dedit.

Praecedenti habitu affinis, at paulo minor et minus depressa, capite basi haud constricto et thorace profunde canaliculato satis distincta. Nigrofusca, subnitida, parce tenuissimeque griseo-pubescens, abdomine solo nigro. Antennae capitis thoracisque longitudine, apicem versus sensim modice incrassatae, articulis penultimis longitudine crassioribus, ultimo oblongo-ovato, pilosellae, totae obscure testaceae. Caput thoracis latitudine, basi haud constrictum, parce subtilissime punctulatum, ore testaceo. Thorax coleopterorum fere latitudine, latitudine vix brevior, lateribus subrectis, apice truncatus, angulis anterioribus obtusis, deflexis, posterioribus cum basi rotundatis, modice transversim convexus, subtilissime punctatus, canalicula lata sat profunda exaratus. Elytra thoracis longitudine, depressa, distinctius punctata, fusca. Abdomen nigrum, nitidum, apice piceum, supra segmentis tribus anterioribus parce subtiliterque punctatis, posterioribus laevigatis. Pedes testacei. 
* 34. H. circellaris: Aptera, rufo-testacea, subnitida, capite abdominisque cingulo piceis, thorace subquadrato, basi foveolato. - Long. 1 lin.

Er. Col. March. I. 315. 1.

Al. circellaris Grav. Mon. 155. 22. - Gyll. Ins. Suec. II. 388. 10. - Sahlb. Ins. Fenn. I. 353. 14. - Zett. Faun. Lapp. I. 98. 6. Ins. Lapp. 76. 9.

Bolitochara circellaris Mannerh. Brachelytr. 75. 5. - Runde Brachelytr. Hal: 30. 2.

\section{Habitat in Europa.}

Angusta, linearis, obscure rufo-testacea, subnitida, subtiliter griseo-pubescens. Antennae capitis thoracisque longitudine, apicem versus leviter incrassatae, basi dilutiores. Caput thorace angustius, oblongum, basi profunde constrictum, subtilissime punctatum, piceum, ore rufo-testaceo. Thorax coleopterorum latitudine, longitudne non latior, lateribus leviter, apice parum, basi fortiter rotundatus, supra leviter convexus, basi foveolatus. Elytra depressa, brevia, confertim punctata. Abdomen ante apicem nigro-piceum, apice ipso ferrugineo, supra segmentis anterioribus confertiu, posterioribus vage punctatis. Pedes testacei.

Mas differt elytris basi uni-tuberculatis, abdominis segmento penultimo supra ante apicem denticulo prominulo armato.

Obs. Bolitochara inguinalis Mannerh. Brachelytr. 76. 6. Aleoch. inguinalis Sahlb. Ins. Fenn. I. 353. 14., quam thorace longiore, foveola ante scutellum et duabus longitudinalibus impresso, antennis brevioribus, extrorsum multo magis incrassatis ut et colore fusco-ferrugineo, capite abdomineque obscurioribus distinctam esse Dom. Com. Mannerheim affert, a Dom. Prof. Sahlberg pro H. circella $\mathrm{r}$ is varietate habetur; specimen eius quoque nonnisi singulum observatum, et im. pressiones thoracis longitudinales facile fortuitae, quam ob rem differentiae eius specificae in praesens dubiae videntur.

* 35. H. procidua: Aplera, nigra, fortius punctata, thorace subquadrato, convexiusculo, pedibus piceis. - Long. 1 lin.

Er. Col. March. I. 315. 2.

Habitat in Germania. Specimen unicum Berolini legi.

Statura fere praecedentis, at paulo crassior, nigra, parum nitida, dense profundius punctata. Antennae capitis thoracisque longitudine, apicem versus subincrassatae, nigrae. Caput thoraci latitudine fere aequale, basi leviter constrictum, labro piceo, palpis nigris. Thorax latitudine paululum latior, coleopteris subangustior, convexus, lateribus subdeflexis praecipue ante medium rotundatis. Coleoptera thoracis longitudine. Abdomen crassiusculum, supra subtilius aequaliter punctatum. Pedes picei.

Obs. Species minuta, corpore crassiusculo et punctura forti profundaque insolita insignis.

* L i n e a r e s, thor a c e t r a n s $\mathrm{r}$ e $r$ s o.

* 36. H. brunnea: Depressa, testacea, nitida, capite abdominisque segmentis penultimis piceis, thorace transverso, postice late subimpresso, elytris parcius subtiliter punctatis, abdomine supra crebre fortius punctato, ante apicem laevigato. - Long. 2 lin.

Er. Col. March. I. 326. 19.

S'taph. brunneus Fub. Ent. Syst. Suppl. 180. 14. Syst. El. II. 600. 55. 
Aleoch. depressa Gyll. Ins. Suec. II. 401. 23. - Sahlb. Ins. Fenn. I. 366. 39. Bulitochara depressa Mannerh. Brachelytr. 81. 41 - Runde Brachel. Hal. 31. 11. St a ph. nigriceps Marsh. Ent. Britt. 515. 51.

Habitat in Europa temperata et septentrionali.

Corpus oblongum, depressum, testaceum, nitidum, pube brevi erecta grisea et pilis parcis erectis nigris vestitum. Antennae capite thoraceque breviores, tenuiores, articulo secundo tertio paulo breviore, articulis 6-10 transversis, ultimo praecedentibus ambobus longitudine aequali, oblongoovato, acuminato, testaceae, apice plerumque ultra medium fuscae nigraeve. Caput thorace multo angustius, basi haud constrictum, parce subtilius punctatum, fronte depressa, medio late subimpressa, piceum, nitidum, ore testaceo. Thorax coleopteris perparum angustior, latitudine dimidio brevior, basi leviter, lateribus fortius rotundatus, apice truncatus, angulis posterioribus rotundatis, subdepressus, dorso posterius late leviter impressus, parce subtilius punctatus, pilis raris erectis nigris sparsus. Elytra thorace paulo longiora, depressa, minus dense subtilius punctata, pilis raris erectis nigris sparsa, circa scutellum nonnunquam infuscata. Abdomen depressum, supra segmentis 4 primis crebre profundius punctatis, quarto sparsum punctato, quinto laevi, sexto iterum crebre punctato, apice leviter emarginato, pube brevi erecta parciore grisea et pilis raris erectis nigris vestitum, subtus aequaliter densius punctatum et pube longiore depressa fulvescenti-grisea vestitum, testaceum, segmentis quarto et quinto nigris, praecedentibus nonnunquam basi piceis. Pedes dilute testacei.

Mas nonnisi antennis paulo longioribus et validioribus distingutur.

* 37. H. depressa: Depressa, testacea, capite abdominisque segmentis penultimis piceis, thorace transverso, postice leviter longitudinaliter impresso, elytris abdomineque punclatis, hoc apicem versus sublaevi. Long. $1 \frac{2}{3}-2$ lin.

Aleoch. depressa Grav. Micr. 100. 49. Mon. 176. 74. - Latr. Hist. nat. Crust. et Ins. IX. 391. 49.

Bolitoch. depressa Boisd. et Lacord. Faun. Ent. Paris. I. 551. 18.

Habitat in Germania.

Statura omnino praecedentis, at paulo angustior, dilutius testacea, minus nitida, pube fulvescenti-grisea subdepressa et pilis raris erectis nigris vestita. Antennae capite thoraceque paulo longiores, tenuiores, apicem versus vix crassiores, articulo secundo tertio paulo breviore, sequentibus inter se subaequalibus, subobconicis, longitudine haud crassioribus, ultimo maiusculo, praecedentibus ambobus longitudine aequali, oblongo-ovato, apice acuminato, fuscae, articulis 3 vel 4 primis pallidius testaceis. Caput thorace multo angustius, basi vix constrictum, depressum, fronte antice subimpressa, utrinque parce obsoleteque punctata, piceum, vel piceo-testaceum, ore testaceo, saepius etiam totum testaceum. Thorax coleopteris tertia parie angustior, longitudine plus dimidio brevior, lateribus et basi leviter rotundatus, apice truncatus, angulis posterioribus obtusis, subdepressus, posterius aut leviter canaliculatus aut latius longitudinaliter leviter impressus, parce subtiliterque punctatus, pilis erectis nigris raris instructus. Elytra thorace sesqui longiora, depressa, minus dense subtilius punctata, pilis erectis nigris 
raris obsita, circa scutellum saepius infuscata. Abdomen depressum, supra segmentis anterioribus tribus parce subtilius punctatis, posterioribus sublaevibus, pube parca grisea et pilis raris erectis nigris vestitum, subtus crebrius subtilus punctatum, pube longiore depressa fulvescenti-grisea vestitum, testaceum, segmentis penultimis duobus nigro-piceis. Pectus piceo-testaceum. Pedes flavo-testacei.

Mas abdominis segmento dorsali quinto apice leviter tuberculato, sexto apice quadridentato insignis.

O b s. Praecedenti simillima atque mihi olim cum ea confusa et pro eius mare habita. Differt statura paulo graciliore, colore minus nitido, antennis longioribus, articulis penultimis haud transversis, thorace lateribus minus rotundato, abdomine supra parcius et subtilius punctato et differentia sexuali. Specimina Brunsvicensia a Gravenhorstio descripta ad hanc pertinent.

* 38. H. nigrifrons: Depressa, testacea, capite abdominisque segmentis penultimis nigris, thorace transversim subquadrato, leviter longitudinaliter impresso, elytris dense subtiliter punctatis, abdomine supra crebre. fortius punclato, ante apicem laeviore. - Long. $1 \frac{2}{3}-2$ lin.

Habitat in Gallia, Italia.

Statura omnino praecedentis, testacea, minus nitida, pube depressa griseo-fulvescente densius vestita. Antennae capitis thoracisque longitudine, tenuiores et apicem versus haud incrassatae, articulo tertio secundo vix longiore, 4-10 inter se fere aequalibus, subobconicis, crassitie sublongioribus, ultimo praecedente sesqui longiore, oblongo-ovato, acuminato, pilosellae, fuscae, articulis tribus primis testaceis. Caput thorace multo angustius, basi vix constrictum, depressum, parcius obsolete punctatum, fronte obsolete canaliculata, supra nigrum, ore testaceo, subtus testaceum. Thorax coleopteris paululum angustior, latitudine tertia parte brevior, lateribus et basi leviter rotundatus, apice truncatus, angulis posterioribus obtusis subrotundatis, subdepressus, longitudinaliter late subimpressus, crebrius subtiliter punctatus, rufo-testaceus, pube densiore et pilis raris erectis vestitus. Scutellum rufo-testaceum. Elytra thorace paulo longiora, depressa, dense subtiliter punctata, densius pubescentia, fusco-testacea. Abdomen depressum, supra pube depressa parciore et pilis erectis nigris rarss vestitum, segmentis trihus primis crebre punctatis, piceis, margine testaceis, quarto quintoque parce vageque punctatis, nigris, hoc apice testaceo, sexto iterum crebrius punctato, testaceo, subtus crebre punctatum, pube longiore et densiore vestitum, basi apiceque testaceum, medio piceum, ante apicem nigrum. Pectus piceo-testaceum. Pedes flavo-testacei.

Obs. 1. H. brunneae et depressae perquam affinis, cum illa abdominis punctura, cum hac antennarum structura convenit; differt ab utraque elytris dense punctatis, densius pubescentibus, at pilis erectis nullis instructis, et thorace longiore. Secundum thoracis structuram forte sectioni praecedenti adscribenda fuisset, ni summa affinitate cum speciebus duabus modo laudatis iungeretur.

2. Vidi hoc insectum in collectione Dom. Aubé nomine Bolitochara nigriceps Dej. signatum, quod autem, cum idem nomen specificum a Marshamio $\mathrm{H}$. brunneae tributum sit, mutandum censui. 
39. H. atricilla: Depressa, testacea, nitida, capile abdominisque segmento antepenultimo nigro-piceis, thorace brevi, transverso, aequali, elytris abdomineque supra parcius subtiliter punctatis. - Long. $1 \frac{1}{2}$ lin.

Habitat in Sardmia, Mus. Reg. Taurin.

Praecedentibus affinis, at minor, praecipue brevior, testacea, nitida, pube longiore subdepressa grisea vestita. Antennae capitis thoracisque longitudine, apicem versus sensim subincrassatae, articulo tertio secundo paulo longiore et tenuore, $4-10$ subobconicis, sensim paulo maioribus, longitudine haud crassioribus, ultimo praecedentibus ambobus longitudine subaequali, oblongo-ovato, subacuminato, pilosellae, fuscae, basi testaceae. Palpi testacei. Caput thorace angustius, suborbiculatum, minus depressum, parce subtiliter obsoleteque punctatum, nigrum, nitidum. Thorax coleopteris paulo angustior, latıtudine duplo prope brevior, basi et lateribus leviter rotundatus, antrorsum subangustatus, apice truncatus vel levissime emarginatus, angulis posterioribus modice obtusis, nullo modo rotundatis, subdepressus, aequalis, densius subtiliter punctatus, rufo-testaceus, margine laterali parce pilosello. Elytra thorace sesqui longiora, depressa, minus confertim subtiter punttata, luteo-testacea, ante apicem extrorsum fuscescentia. Abdomen subdepressum, supra parce subtilius punctatum, rufo-testaceum, segmento tertio piceo-testaceo, quarto nigro-piceo, quinto basi piceo, apice sextoque toto dilute testaceis. Pectus piceo-testaceum. Pedes dilute testacei.

Obs. Thorace brevi a praecedentibus facile distinguitur.

* 40. H. oblonga: Depressa, picea, capite nigro, elytris pedibusque testaceis, fronte fortius punctulala, thorace transversim subquadrato, dorso late subimpresso, abdomine antice parce subtiliterque punctalo, postice laevigato. - Long. $1 \frac{2}{3}$ lin.

Ale och, elongatulae var. Grav. Mon. p. 154.

Habitat in Germania.

Statura omnino H. depressae, at paulo minor, picea, subnitida, pube depressa grisea vestita. Antennae capitis thoracisque longitudine, apicem versus vix incrassatae, articulo tertio secundo paulo longiore, $4-10 \mathrm{sub}$ cylindricis, 4-7 crassitie haud brevioribus, 8-10 leviter transversis, ultimo maiusculo, praecedentibus ambobus longitudine aequali, oblongo-subovato, apice obtuse acuminato, totae piceae. Palpi piceo-testacei. Caput thorace angustius, bası parum constrictum, depressum, fronte crebrius sat fortiter punctata, nigrum, nitidum. Thorax coleopteris paulo angustior, latitudine tertia parte fere brevior, basi et lateribus leviter rotundatus, antrorsum subangustatus, apice truncatus, angulis posterioribus obtusis, subdepressus, parce subtiliterque punctatus, dorso pone medium late subimpres. sus, nigro-piceus, nitidus, versus latera magis brunneus. Elytra thorace tertia parte longiora, depressa, densius subtiliter punctata, fusco-testacea, circa scutellum infuscata, subnitida. Abdomen depressum, parce pubescens, supra segmentis tribus primis parce subtiliterque punctatis, posterioribus tribus laevigatis, subtus parce subtiliterque punctatum, nigro-piceum, ante apicem nigrum. Pectus piceum. Pedes testacei.

Obs. Thoracis structura propius ad sectionem praecedentem aggreditur, statura corporis autem omnina cum praecedentibus convenit, licet colore satis discedit. 
Frons fortius punctata huic speciei peculiaris videtur, cuius unicum specimen solum in collectione Hoffmannseggiana nomine supra citato signatum mihi hucusque obvium fuit.

* 41. H. hepatica: Nigra, antennis elytrisque brunneis, pedibus testaceis, thorace depresso, abdomine supra parce punctato, nitidulo, segmento sexto apice pliculis duabus conniventibus. - Long. $1 \frac{3}{4}$ lin.

Habitat in Germania. Exemplum unicum in Pomerania legi.

Statura praecedentis, H. sociali propior, antennis rufo-brunneis et abdominis structura praecipue distincta, piceo-nigra, minus nitida, crebrius punctata, pube minus tenui depressa flavescente vestita. Antennae capitis thoracisque longitudıne, validiores, apicem versus leviter sensim incrassatae, articulis 4-10 cylindricis, penultimis vix crassitie brevioribus ultimo praecedentibus ambobus longitudine aequali, elongato-conico, acuminato, rufae, basi rufo-piceae. Oris partes rufo-piceae. Caput thorace angustius, fronte subdepressa. Thorax latitudine dimidio brevior, coleopteris vix angustior, lateribus ante medium rotundatis, dein subrectis, parum convexus, dorso longitudinaliter depressus, sat crebre et parum subtiliter punctatus. Elytra thorace paulo longiora, depressa, sat crebre minus subtiliter punctata, rufo-brunnea. Abdomen nigrum, apice testaceum, segmentorum marginibus brunneis, supra nitidum, parce subtiliter punctatum, segmentis posterioribus tribus laevigatis. Pedes testacei.

Specimen singulum, segmento quinto apice pliculis duabus elevatis approximatis postice comniventibus instructo: forte mas.

* 42. H. a emula: Nigra, nitida, antennarum basi, elytris pedibusque testaceis, thorace subdepresso, basi leviler foveolato, obsolete canaliculato, abdomine supra laevigato, segmentis anterioribus subtiliter vage punctatis. - Long. $1 \frac{1}{2}$ lin.

Habitat in Pensylvania, Dom. Zimmermann.

Statura et summa similitudo sequentis et maximis eius individuis (var. a) aequalis, nigra, nitidissima, pube tenui raraque vestita. Antennae capitis thoracisque longitudine, apicem versus leviter incrassatae, articulis penultimis leviter transversis, ultimo oblongo-ovato, subacuminato, nigrae, basi testaceae. Palpi testacei. Caput thorace angustius, rotundatum, basi modice constrictum, parce obsoleteque punctatum. Thorax coleopteris paulo angustior, latitudine dimidio brevior, lateribus et basi leviter rotundatus, apice truncatus, angulis omnibus obtusis, subtiliter minus dense punctatus, parum convexus, obsolete canaliculatus foveolaque parum profunda bası impressus. Elytra thorace sesqui longiora, confertim evidentius punctata, testacea, nitida, lateribus fuscescentia. Abdomen ut in H. sociales var. a. Pedes testacei.

* 43. H. socialis: Nigra, tenuiter pubescens, elytris pedibusque testaceis, thorace subdepresso, basi obsolete foveolato, abdomine supra anterius parce sublilitergue punclato. - Long. $1 \frac{1}{3}-2$ lin.

Er. Col. March. I. 327. 21.

Staphyl. socialis Payk. Mon. Staph. 60. 43. Faun. Suec. III. 407. 51. - Oliv. Ent. JII. 42. 37. 53. $t$. 3. f. 25.

Aleoch. socialis Gyll. Ins. Suec. III. 406. 28. - Sahlb. Ins. Fenn. I. 370. 46. Zetterst. Faun. Lappon. I. 99. 11. Ins. Lapp, 76. 14. 
Bolitochara socialis Mannerh. Brachelytr. 77. 17, - Boisd. et Lacord. Faun. Ent. Paris. I. 546. 10.

Aleoch. Boleti Grav. Micr. 80. 21. Mon. 156. 23. - Latr. Hist. nat. Crust. ot Ius. IX. 384. 21.

Staphyl. sordidus Marsh. Ent, Britt. 514. 48.

Var, $a$.

Aleoch. sericans Grav. Mon. 159. 28. - Gyll. Ins. Suec. II. 404. 26. - Sahlb. Ins. Fenn. I. 367. 14. - Zetterst. Faun. Lappon. I. 100. 13. Ins. Lapp. 77. 18.

Bolit ochara sericans Mannerh. Brachelytr. 77. 14.

Homalota 's ericans Er. Col. March. 1. 326. 20.

Bolit ochara castanoptera Mannerh. Brachelytr. 77. 16.

Aleoch. castanoptera Sahlb. Ins. Fenn. I. 69.45.

Var. $b$.

Aleoch. longicornis Gyll. Ins. Suec. II. 405. 27. - Sahlb. Ins. Fenn. I. 386. 43.

Zetterst. Faun. Lappon. I. 100. 14. Ins. Lappon. 77. 19.

Bolit ochara Boleti Boisd. et Lacord. Faun. Ent. Paris. I. 545. 9.

Var.c.

Aleochara nigritula Grav. Micr. 85. 25. - Latr. Hist. nat. Crust. et Ins. IX. 385. 25. - Gyll. Ins. Suec. II. 408. 29. - Sahlb. Ins. Fenn. I. 372. 49.

Bolitochara nigritula Mannerh. Brachelytr. 77. 18.

Habitat in Europa.

Magnitudine valde variabilis, subdepressa, nigra, subnitida, tenuiter griseo-pubescens, vix sericans, thorace abdomineque lateribus parce nigro-pilosellis. Antennae caprtis thoracisque fere longitudine, validiusculae, articulo secundo tertio paululum breviore, 5-10 longitudine paulo crassioribus, ultimo praecedentibus ambobus longitudine aequali vel paulo longiore, oblongo, subacuminato. Caput thorace paulo angustius, basi modice constrictum, rotundatum, subtiliter punctatum. Thorax coleopteris parum angustior, latitudine dimidio brevior, basi leviter rotundatus, lateribus postice subrectis, ante medium rotundatis, apice truncatus, angulis anterioribus deflexis, minus obtusis, subdepressus, confertim subtiliter punctatus, basi plerumque late et parum profunde impressus. Elytra thorace sesqui longiora, apice truncata, depressa, confertim subtiliter punctata, lutea testaceave, circa scutellum et angulo apicali exteriore plerumque infuscata. Abdomen parallelum, subtus crebrius punctulatum, apice segmentorumque ventralium marginibus plerumque piceis vel rufo-picels. Pedes testacei,

$\mathrm{Ne}$ temere species notis vacillantibus diagnoscendas constituam timens, sub hoc nomine coniunxi species forte vere distinctas, quas saepe sedulo examinatas sufficientibus characteribus separare diu frustra conatus sum. Varietates praecipuas sequentes distinxi:

a. Maior, H. graminicola vix parum minor, nitidior, antennis crassioribus nigris piceisve, palpis piceis, thorace lateribus fortius rotundato, abdomine dorso toto laevigato, vel segmentis anterioribus subtilissime punctatis. Hanc a Gyllenhal nom. Al. sericantis, longicornis et socialis Dom. Schïppel missam communicavit.

b. Praecedente parum minor, at angustior et magis elongata, thorace lateribus minus rotundato, antennis paulo gracilioribus, rufo-testaceis, apice 
saepius fuscescentibus, palpis rufo-testaceis, abdomine segmentis tribus anterioribus parce subtiliterque punctatis.

c. Corporis habitu var. a., at duplo minor, antennis crassioribus, rufopiceis, palpis rufo-testaceis, abdomine segmentis tribus primis parce subtiliterque punctatis. Haec apud nos frequentissime obvia.

d. Magnitudine praecedentis, at magis linearis depressaque, sub. opaca, abdomine toto parce subtiliterque punctato.

D ifferentia sexus in omnibus his varietatibus eadem: mas abdominis segmento sexto superiore margine apicali crenato, utrinque denticulo magis prominulo terminato, inferiore apice magis triangulariter producto distinctus.

Obs. Synomimia huius speciei valde intricata, et dubito anne saepius sub eodem nomine plures species confusae sint. H. longicornem pro Al. seric ant e saepius miserunt Entomologi Sueci. Aleoch. aterrima Sahlb. Ins. Fenn. I. 368. 44. Bolito chara aterrim a Mannerh. Brachelytr. 78. 21. certe e compluribus speciebus conflata: Prof. Sahlberg ipse sub hoc nomine Hom. graminicolam et H. atramentariam D. Prof. Germaro communicavit. Apud utrumque autorem citatum var. a. ad H. graminicolam, var. b. ad H. atramentariam, var. c. ad H. socialem c forte pertinet. Bolit ochara cas ta n optera Mannerh. supra ad hanc speciem allegata, antennarum articulo ultimo magis elongato, ad sexum masculum spectare videtur.

* 44. H. sodalis: Nigra, nilida, antennis elytrisque castaneis, pedibus ferrugineis, thorace coleopteris angustiore, basi impresso, abdomine supra anterius parce punctato, apice laevi. - Long. $1 \frac{1}{2}$ lin.

Er. Col. March. 1. 328. 22.

Habitat in Germania.

H. sociali proxima et minoribus eius individuis (var. c.) aequalis, thorace angustiore nitido praecipue distincta. Corpus nigrum, nitidum, parce subtiliter pubescens. Antennae capitis thorarisque longitudine, crassiusculae, articulis penultimis leviter transversis, ultimo praecedentibus duobus longiore, sat magno, subovato, apice acuminato, rufo-brunneae, basi dilutiores. Palpi rufo-testacei. Caput thorace parum angustius, laeve. Thorax coleopteris dimidio angustior, latitudine dimidio brevior, basi leviter, lateribus praecipue ante medium fortius rotundatus, apice truncatus, angulis anterioribus rotundatis, leviter convexus, vage subtiliter punctatus, basi obsolete impressus, niger, nitidus. Elytra thorace sesqui longiora, dense subtiliter punctata, castanea, nitida. Abdomen supra segmentis tribus anterioribus fortius punctatis, subtus crebrius punctatum, segmentis ventralibus margine anoque piceis. Pedes rufo-testacei.

* 45. IH. ochracea: Testacea, capile abdominisque cingulo fuscis, thorace antrorsum subangustato, convexiusculo, abdomine supra parce punctato. - Long. $1 \frac{1}{2}$ lin.

Er. Col. March. I. 329. 24.

Habitat in Germania, Gallia, Anglia.

Statura omnino praecedentis, testacea, pube depressa flavescenti-grisea subtiliter vestita, capite abdominisque segmentis duobus penultimis fuscis. Antennae capitis thoracisque longitudine, apicem versus incrassatae, 
articulo secundo tertioque subaequalibus, quarto parvo globoso, 5-10 fortiter transversis, crassis, longitudine duplo crassioribus, ultimo praecedentibus ambobus vix aequali, conico, fuscae, basi testaceae. Caput thorace angustius, subtiliter punctatum. Thorax basi coleopteris paulo angustior, latitudine dimidio brevior, antrorsum subangustatus, basi rotundatus, utrinque subsinuatus, angulis posterioribus prope rectis, lateribus et angulis anterioribus rotundatis, apice truncatus, leviter, convexus, subtiliter dense punctatus. Elytra thorace sesqui longiora, apice ad angulum exteriorem subsinuata, subtiliter confertim punctata. Abdomen supra distincte, vage, segmentis posterioribus vix parcius quam anterioribus, punctatum.

* 46. H. Irimaculata: Nigra, antennarum basi apiceque, pedibus coleopterisque testaceis, his fusco-trimaculatis, thorace basi foveolato, lateribus piceo, abdomine basi rufo-piceo, supra fortius punclato. Long $1 \frac{3}{4}$ lin.

Habitat in Pensylvania, Dom. Zimmermann.

Praecedentibus maior, H. brunneae fere aequalis, ad minus depressa, statura omnino Bolitocharae lunulatae. Corpus nigrum, nitidulum, subtiliter flavescenti-pubescens. Antennae capitis thoracisque longitudine, crassiusculae, articulis 5-10 transversis, ultimo praecedentibus ambobus prope aequali, breviter ovato, apice acuminato, nigro-fuscae, basi apiceque testaceae. Caput thorace augustius, parcius punctatum, ore testaceo. Thorax coleopteris angustior, longitudine plus dimidio latior, basi fortius, lateribus leviter rotundatus, apice truncatus, convexiusculus, crebre profundius punctatus, basi transversim impressus, lateribus piceus. Coleoptera thorace sesqui longiora, fortius crebre punctata, dilute testacea, maculis tribus rotundatis fuscis, prima communi circa scutellum, reliquis duabus in angulo utroque exteriore. Abdomen segmentis 4 primis rufo-piceis, basi obscurioribus, reliquis nigro-piceis, supra crebrius fortiusque punctatum. Pedes testacei.

* 47. H. lunata: Nigra, antennarnm basi, pedibus, elytrorum fascia lunata basali, abdominis basi fasciaque ante apicem pallide testaceis, thorace coleopteris angustiore, transverso, subaeneo, - Long. $1 \frac{1}{2}$ lin.

Habitat in Brasilia, Dom. Thorey.

Antennae capite thoraceque longiores, testaceae, apice nigrae, articulis tribus primis elongatis, quarto quintoque crassitie duplo longioribus, teretibus, 6-10 subobconicis, sensim paulo crassioribus, ultimo elongato, acuminato. Caput thoracis latitudine, suborbiculatum, basi modice constrictum, nigrum, opacum, ore piceo, palpis testaceis, fronte depressa, sparsim obsolete punctata. Thorax coleopteris angustior, latitudine dimidio brevior, lateribus, basi et angulis posterioribus rotundatis, minus convexus, subtiliter punctatus, puncto maiore in medio baseos impressus, nigro-subaeneus, subnitidus, margine parce pilosellus. Elytra thorace paulo longiora, dense subtiliter punctata, nigra, fascia sublunata baseos, ab humero suturae medium petente, pallide rufescenti-flava. Abdomen apice subangustatum, segmentis 3 primis dilute rufo-testaceis, secundo tertoque supra macula oblonga media nigra notatis, reliquis nigris, sexto fascia apicali testacea. Pectus nigrum. Pedes pallide flavi. 
* 48. H. varia: Nigra, ore, antennis, pedibus, thorace, elytrorum macula humerali abdominegue testaceis, hoc maculis dorsalibus fasciaque anle apicem nigris. - Long. $1 \frac{1}{2}$ lin.

Habitat in Brasilia.

Statura omnino praecedentis. Antennae capite thoraceque paulo longiores, graciliores, apicem versus parum crassiores, articulis 4-10 subobconicis, crassitie haud longioribus, ultimo elongato, cylindrico, testaceae, apice subfuscescentes. Caput thoracis prope latitudine, laevissimum, inter oculos obsolete bifoveolatum, subaeneo-nigrum, pernitidum, ore testaceo. Thorax coleopteris paulo angustior, latitudine dimidio brevior, lateribus subrotundatus, basin versus subangustatus, parum convexus, aequalis, laevissimus, testaceus, nitidus, apice fuscescens. Elytra thorace sesqui fere longiora, confertim subtiliter punctata, nitıda, aeneo-nigra, basi magis picea, fascia basali, ad suturam obsoleta, testacea. Abdomen supra laeve, subtus parce punctulatum parceque pubescens, nitidum, dilute testaceum, segmento secundo tertioque macula dorsali media nigra, quarto nigro, basi testaceo, quinto toto nigro. Pectus nigrum. Pedes testacei.

* 49. H. picta: Testacea, elytrorum macula magna angulari, pectoris tateribus, abdominis punctis dorsalibus fasciaque subtus interrupta ante apicem nigris. - Long. $1 \frac{1}{3}$ lin.

Habitat in Brasilia, Dom. Prof. Reich.

Habitu omnino praecedentium, at paululum minor, capite, thorace elytrisque subtilissime confertim punctatis, parum nitidis. Antennae capitis thoracisque longitudine, graciliores, apicem versus leviter incrassatae, articulis 4-9 subobconicis, crassitie paulo longioribus, penultimo transverso, ultimo maiusculo, oblongo-conico, testaceae, articulo apicali fuscescente. Caput thoracis prope latitudine, testaceum. Thorax coleopteris parum angustior, latitudine dimidio brevior, lateribus anterius leviter rotundatis, posterius subsinuatis, bạsi leviter rotundatus, parum convexus, aequalis, testaceus. Scutellum testaceum. Elytra pube subtilissima fulva sericantia, nıgra, opaca, basi suturaque late testaceis. Abdomen parcius subtiliter punctatum, supra nitidum, segmentis 2-4 dorso in medio baseos puncto nigro, quinto supra toto, subtus lateribus nigro. Pectus piceo-testaceum, lateribus nigrum. Pedes flavi.

* 50. H. marcida: Obscure testacea, capite abdominisque cingulo postico piceis, pedibus pallidis, thorace transverso, subdepresso, basi obsolete impresso, abdomine supra parce subliliterque punctalo. - Long. $1 \frac{1}{2}$ lin.

Er. Col. March. I. 328. 23.

\section{Habitat in Germania.}

Statura H. socialis. Antennae capite thoraceque longiores, praecipue in mare, parum incrassatae, articulis 5-10 longitudine haud crassioribus, ultimo elongato-ovato, pilosellae, piceae, basi pallide testaceae. Corpus obscure testaceum. Caput thorace paulo angustius, rotundatum, basi leviter constrictum, piceum, nitidum, obsolete punctulatum. Thorax coleopteris dimidio prope angustior, latitudine dimidio brevior, basi, lateribus ante medium et 
angulis omnibus rotundatis, apice truncatus, supra subdepressus, dense subtiliterque punctulatus, basi medio obsolete impressus. Elytra dense subtiliterque punctata, sordide testacea, apicem versus fuscescentia. Abdomen supra laevigatum vel parce subtiliter obsoleteque punctatum, nitidum, ante apicem nigrum. Pedes pallide flavi.

M a s antennis longioribus differt.

$\mathrm{Obs}$. Antennis longioribus gracilioribusque et elytris longioribus ab H. sericante, abdomine supra laevigato praeterea a seqnentibus discedit.

* 51. H. spelaea: Nigra, parum nitida, antennarum basi elytris pedibusque testaceis, thorace basi foveolato, abdomine supra crebre punctato, basi brunneo. - Long. $1 \frac{1}{2}$ lin.

Habitat in specu Adelsbergensi Carinthiae, Dom. Schmidt.

Statura omnino $-H$. elongatulae et maioribus eius individuis aequalis, nigra, parum nitida, tenuissime parce pubescens. Antennae capitis thoracisque longitudine, apicem versus subincrassatae, articulo tertio secundo dimidio longiore, 5-10 longitudine vix crassioribus, ultimo praecedentibus ambobus longitudine subaequali, subovato, apice acuminato, piceae, basi testaceae. Palpi testacei. Caput thorace angustius, rotundatum, subtilissime punctulatum, fronte medio obsolete longitudinaliter impressa. Thorax coleopteris paulo angustior, latitudine dimidio brevior, basi et lateribus parum rotundatus, apice truncatus, angulis anterioribus obtusis, deffexis, perparum convexus, medio longitudinaliter depressus, basi foveola gemina impressus, confertim subtiliter punctatus, piceus, medio nigricans. Elytra thorace parum longiora, fusco - testacea, humeris dilutiora, confertim punctata. Abdomen anterius rufo-brunneum, posterius nigrum, supra confertim, apice minus crebre punctatum. Pedes testacei.

Obs. H. elongatulae proxima, at thorace breviore etc. satis distincta, ab $\mathrm{H}$. sociali statura magis lineari depressaque elytrisque brevioribus praecipue discedens.

\section{* 52. H. dichroa: Nigra, subnitida, antennis gracilioribus basi, elytris, pedibus anoque luteis, thorace subtiliter canaliculato, basi obsolete foveolato, abdomine supra confertim punctato. - Long. $1 \frac{1}{2}$ lin.}

Al. dichroa Grav. Micr. I. 186. 1. Mon. 158. 25.

Habitat in America septentrionali.

Statura omnino H. elongatulae. Corpus nigrum, subnitidum, pube tenuissima subsericeum, lateribus parce pilosellum. Antennae capite thoraceque fere longiores, graciliores, apicem versus subincrassatae, articulo tertio secundo paulo longiore, 5-10 subaequalibus, longitudine haud crassioribus, ultimo praecedentibus duobus aequali, apice subacuminato, nigrae, basi testaceae. Palpi testacei. Caput thorace paulo angustius, suborbiculatum, basi constrictum, laeve, fronte subdepressa. Thorax coleopteris non angustior, latitudine plus dimidio brevior, basi et lateribus leviter rotundatus, apice leviter emarginatus, angulis anterioribus acutiusculis, subdepressus, subtiliter canaliculatus, basi foveola obsolete impressus, subtilissime punctatus, nigropiceus, subopacus. Elytra thorace paulo longiora, subtliter punctata, opqca, Jutea. Abdomen supra nitidulum, confertim sat distincte punctatum, apice luteo. Pedes lutei. 
*53. H. propinqua: Linearis, subdepressa, nigra, elytris anoque fuscotestaceis, antennarum basi pedibusque testaceis, thorace transversim subquadrato, basi foveolato, abdomine supra densius punctulato. Long. $1 \frac{1}{2}$ lin.

Habitat in Americae insulis St. Thomae et St. Johannis, Dom. Moritz. H. elongutalae similis, thorace breviore autem diffinis, subdepressa, nigra, subtilissime punctata, tenuissime pubescens. Antennae capitis thoracisque longitudine, apicem versus leviter incrassatae, articulo tertio secundo paulo breviore, penultimis leviter transversis, ultimo praecedentibus ambobus longiore, apice acuminato, nigrae, basi testaceae. Caput thorace paulo angustius, rotundatum, confertim subtiliter punctatum, ore testaceo. Thorax coleopteris latitudine vix aequalis, hac dimidio brevior, basi et lateribus leviter rotundatus, apice truncatus, depressus, basi fovea oblonga impressus, nigro-piceus. Elytra thorace paulo longiora, fusco-testacea, circa scutellum infuscata. Abdomen nigrum, segmentorum anteriorum marginibus apiceque obscure testaceis, supra totum subtiliter crebrius punctatum. Pedes testacel.

Variat saepius corpore toto ferrugineo.

* 51. H. conformis: Linearis, subdepressa, nigra, elytris fuscis, antennarum basi apiceque pedibusque testaceis, thorace transversim subquadrato, basi foveolato, abdomine supra densius punctulato. - Long. $1 \frac{1}{2}$ lin.

Habitat prope Caracas Columbiae, Dom. Moritz.

Statura omnino et summa affinitas praecedentis. Antennae capitis thoracisque longitudine, apicem versus leviter incrassatae, piceae, articulo primo ultimoque laete testaceis, hoc longiore, acuminato. Palpi piceo-testacei. Caput thorace parum angustius, nigrum, subnitidum, omnium subtilissime punctatum, subtilissime pubescens. Thorax coleopteris paulo angustior, latitudine dimidio brevior, lateribus subrectis, subdepressus, omnium subtilissime pubescens, basi foveola transversa impressus, nigro-piceus, minus nitidus. Elytra thorace paulo longiora, confertim subtiliter punctulata, subtiliter griseo-pubescentia, opaca, fusca, angulo humerali rufescenti-testaceo. Abdomen supra totum subtiliter crebrius punctulatum, parcius tenuiter pubescens, nigrum, nitidum, basi saturate piceum, subtus piceum, segmentis singulis apice dilutioribus. Pectus nigrum. Pedes flavi.

*55. H. lurida: Nigra, subnilida, antennarum articulo primo elytrisque fusco-testaceis, pedibus pallidis, thorace transversim quadrato, aequali, abdomine supra crebrius punctulato, - Long. $1 \frac{1}{3}$ lin.

Habitat in Brasilia, Dom. Prof. Reich.

Habitu omnino praecedentium, at paululum minor, nigra, subnitida, subtilissime pubescens, abdomine apice pilosello. Antennae capite thoraceque paulo longiores, apicem versus subincrassatae, articulis peinultimis leviter transversis, ultimo praecedentıbus ambohus paulo longiore, apice acuminato, nigrae, articulo primo obscure testaceo. Caput thorace paulo angustius, suborbiculatum, subtilissime obsolete punctulatum. Thorax coleopteris parum angustior, latitudine dimidio brevior, lateribus subrectis, apice truncatus, parum convexus, aequalis, subtilissime obsolete punctulatus. Elytra 
thorace paulo longiora, depressa, confertissime subtiliter punctulata, fuscescenti-testacea, circa scutellum infuscata. Abdomen supra nitidulum, crebrius subtiliter punctulatum. Pedes pallide flavescenti-testacei.

* 56. H. semilutea: Fortiter punclata, testacea, elytris dilutioribus, peclore abdomineque nigris, hoc basi obscure testaceo, thorace leviter convexo, aequali. - Long. $1 \frac{2}{3}$ lin.

Habitat in Brasilia, Dom. Prof. Germar.

Statura linearis, subdepressa H. elongatulae et maioribus eius individuis aequalis. Antennae articulis duobus primis flavo-testaceis (reliqui desunt). Caput thorace paulo angustius, basi parum constrictum, fronte depressiuscula, sat crebre fortiterque punctatum, rufo-testaceum, nitidum, ore dilutiore. Thorax coleopteris parum angustior, latitudine dimidio brevior, basi modice, lateribus vix rotundatus, apice truncatus, leviter transversim convexus, aequalis, crebre fortiter grossiusque punctatus, testacens, nitidus. Scutellum nigrum. Elytra thorace sesqui longiora, subdepressa, crebre fortiter profundeque punctata, flava, nitida, parce pubescentia. Abdomen sat elongatum, lineare, crebrius minus subtiliter punctatum, pube minus subtili fulvescenti-grisea vestitum, nigrum, nitidum, supra segmentis duobus prumis piceo-testaceis, margine laterali testaceo, sexto margine posteriore piceo-testaceo, subtus segmentis omnibus margine posteriore, ultimo apice latiore, piceo-testaceo. Pectus nigrum. Pedes flavi.

* 57. H. laesicollis: Picea, opaca, capite abdominisque segmentis 3 et 4 nigris, thorace basi foveola magna longitudinali impresso, abdomine supra confertim, segmentis duobus ultimis parce punctato. - Long. $1 \frac{1}{3}$ lin.

Habitat in Brasilia.

Statura fere praecedentium. Obscure rufo-picea, opaca, pube tenui vestita. Antennae capitis thoracisque longitudine, crassiusculae, articulis penultimis transversis, ultimo praecedentibus tribus coniunctis longitudine aequali, oblongo, apice acuminato, nigrae, basi obscure testaceae. Caput thoracis latitudine, crebre subtiliter punctatum, piceo-nigrum, ore obscure testaceo, fronte subdepressa. Thorax coleopteris angustior, latitudine plus dimidio brevior, lateribus et basi perparum rotundatus, apice truncatus, subdepressus, subtilissime confertissimeque punctatus, fovea lata, a basi ultra medium adscendente excavatus. Elytra thorace dimidio longiora, subtilissime punctata. Abdomen supra segmentis $\mathbf{5}$ primis confertim, ultimis parce subtilius punctatis, tertio quartoque nigris, sexto rufo-testaceo. Pedes testacei.

* 58. H. incana: Elongata, subdepressa, nigra, opaca, dense cinereo-pubescens, antennis basi tarsisque rufis, thorace coleopteris angustiore, medio depresso, abdomine supra segmentis ultimis subtiliter granulatis. Long. $1 \frac{1}{2}-1 \frac{2}{3}$ lin.

Er. Col. March. I. 329. 25.

Habitat in Germania septentrionali.

H. sociali paulo magis elongata depressaque, nigra, opaca, pube tenui 
cinerea dense vestita. Antennae breviusculae, apicem versus leviter incrassatae, articulis penultimis vix transversis, ultımo ovato, subacuminato, 5 basalibus pallide rufis, reliquis nigris. Caput thoracis prope latitudine, subtiliter parce punctatum, fronte depressa, medio obsolete foveolata, palpis piceis. Thorax coleopteris dimidio angustior, latitudine dimidio brevior, lateribus leviter rotundatus, parum convexus, dorso longitudinaliter depressus. Elytra thorace sesqui longiora, dense subtiliter punctata. Abdomen supra parcius punctatum, subnitidum, segmentis 3 ultimis subtliter granulatis. Pedes nigri, trochanteribus, geniculis tarsisque rufescentibus.

Variat thoracis dorso longitudinaliter impresso.

49. H. excavata: Nigra, subnitida, elytris fuscis, pedibus testaceis, femoribus fuscescentibus, thorace fovea magna media excavato, abdomine supra parce subtiliterque punctato. - Long. I lin.

Aleoch. excavata Gyll. Ins. Suec. IV. 490. 30-31. - Sahlb. Ins. Fenn. I. 374. 52. Bolit ochara excavata Mannerh. Brachelytr. 78. 22. - Boisd. et Lucord. Faun. Ent. Paris. I. 547. 12.

Habitat in Suêcia, Dom. Schïppel, in Germania meridionali, Dom. Dr. Waltl.

Habitu fere $H$. elongatulae, at $H$. anali vix maior, nigra, subnitida, confertim subtilissime punctata, subtilissime griseo-pubescens. Antennae capite thoraceque paulo longiores, apicem versus sensim leviter incrassatae, arti culo secundo tertioque subaequalibus, 4-10 sensim paulo crassioribus, penultimis crassitie paulo brevioribus, ultimo praecedente sesqui longiore, ovato, subacuminato, totae nigrae. Caput thorace paulo angustius, suborbiculatum, fronte medio impressa. Thorax coleopteris paulo angustior, latitudine dimidio brevior, basin versus subangustatus, basi rotundatus, medio fovea magna sat profunde impressus, margine laterali parce pilosello. Elytra thorace sesqui longiora, iam obscurius iam dilutius fusca. Abdomen lineare, supra parce subtiliterque punctatum, segmentis quarto quintoque sublaevigatis, apice fuscum. Pedes testacei, femoribus fuscescentibus.

$\mathrm{O}$ bs. Variat fovea thoracis in duas divisa, altera maiore rotundata in medio disci, altera minuta in medio baseos, sec. Gyll.

60. H. deplanata: Depressa, thorace brevissimo, dorso longitudinaliter late subimpresso, fronte late leviter excavata, abdomine supra laevigato. - Long. 1 lin.

Aleoch. deplanata Grav. Micr. 100. 50. Mon. 177. 76. - Latr. Hist. nat. Crust. et Ins. IX. 391. 50.

Habitat in Germania, Mus. Univ. Wratislav.

H. anali vix longior, at minus angusta, fortiter depressa. Antennae capite vix sesqui longiores, articulo secundo crassiusculo tertioque hoc plus duplo minore obconicis, quarto transverso, sequentibus paulo angustiore, 5-10 inter se aequalibus, fortiter transversis, crassitie triplo brevioribus, fere perfoliatis, ultimo subgloboso, apice acuminato. Caput thorace paulo angustius, rotundatum, parce obsoleteque punctatum, fronte late leviter excavata, excavatione laevigata. Thorax coleopteris vix angustior, latitudine plus duplo brevior, basi et angulis posterioribus rotundatus, lateribus sub- 
rectis, depressus, dorso late obsolete impressus, parce obsoleteque punctulatus, tenuissime griseo-pubescens. Elytra thorace duplo prope longiora, parce subtiliterque punctulata, subtiliter pubescentia. Abdomen lineare, supra laevigatum.

Obs. Specimen unicum, examinandum mihi benevole a Dom. Prof. Gravenhorst communicatum, minus maturum mihi videtur. Sunt ei caput, thorax, pectus et abdomen rufo - testacea, nitidula, os antennae et elytra testacea, pedes pallido flavi, abdomen ante apicem nigrum. Antennarum brevium crassarumque structura, thorace brevissimo, elytris parce punctatis minuta haec species facile cognoscatur.

*61. H. viduata: Nigra, parum nitida, antennis pedibusque rufo-piceis, thorace transversim suborbiculato, convexiusculo, basi obsolete foveolato, abdomine supra confertissime punctulato. - Long. $1 \frac{1}{2}$ lin.

Er. Col. March. I. 330. 26.

Habitat Berolini.

Statura fere H. longicornis, at minus depressa, nigra, perparum nitida, pube subtilissima subsericea vestita. Antennae capite thoraceque paulo longiores, apicem versus leviter incrassatae, articulis 4-10 subcylindricis, penultimis crassitie haud longioribus, ultimo oblongo-ovato, apice acuminato, rufo-piceae, basi dilutiores. Caput thorace angustius, suborbiculatum, basi modice constrictum, subtilissime parce punctatum, palpis rufo-piceis. Thorax coleopteris vix angustior, latitudine dimidıo brevior, lateribus, basi angulisque ommibus rotundatis, leviter convexus, subnitidus, subtilissime dense punctatus, basi obsolete foveolatus. Elytra thorace paulo longiora, subtilissime dense punctata, opaca. Abdomen supra anterius confertissime, posterius confertim at minus subtiliter punctatum, apice piceum. Pedes rufo-picei.

* 62. H.atramentaria: Nigro-subaenea, subnitida, antennis basi palpisque nigris, thorace coleopteris angustiore, basi foveolato, abdomine nigerrimo, nitido, supra parcius punctalo. - Long. $1 \frac{1}{2}$ lin.

Aleoch. atramentaria Gyll. Ins. Suec. II. 408. 30. - Sahlb. Ins. Fenn. 1. 373.51. - Zetterst. Faun. Lappon. I. 100. 12. Ins. Lapp. 77. 15.

Bolitochara at ramentaria Mannerh. Brachelytr. 78. 20. - Boisd. et Lacord. Faun. Ent. Paris. I. 546. 11.

Aleochara a enescen s Zetterst. Ins. Lappon. 77. 16.

Habitat in Suecia, Germania septentrionali, Anglia, Sardinia.

Statura fere H. socialis. Corpus nigrum, nitidum, capite, thorace elytrisque subaeneis, modice nitidulis, tenuissime pubescens. Antennae vix capitis thoracisque longitudine, tenuiores, apicem versus parum incrassatae, articulis penultimis crassitie vix longioribus, ultimo praecedentibus ambobus prope breviore, apice acuminato, piceae, basi nigrae. Palpi nigri. Caput thorace paulo angustius, obsolete parce punctatum, fronte subdepressa, palpis nigris. Thorax coleopteris dimidio angustior, latitudme dimidio brevior, basi et lateribus leviter rotundatus, apice truncatus, parum convexus, basi foveolatus, crebre subtiliter punctatus. Elytra thorace sesqui longiora, subtilius punctata. Abdomen nigrum, nitidum, supra parce punctatum, lateribus pilosellum. Pedes picei.

Obs. 1. Insectum forte maritimum, mihi in littore maris Baltici sub fucis lectum. Dubito an revera Lutetiae lectum sit, commutatis et commixtis enim specie- 
bus similibus autores Faunae Ent. Parisiensis saepius specimina collectionis Dejednianae extranea descripsisse mihi videntur, et in collectione Dom. Aubé, qui Coleo. ptera Parisiensia diligentissime collegit, hanc speciem non inveni.

2. A l. a enescens Z ett, ,simillima atramentariae, sed differt thorace elytrisque subaenescentibus, glaberrimis, pedibus nigris, tarsis tantum testaceis, antennis pubescentibus, abdomine pilis rarioribus obsito, foveola antescutellari parva obsoleta in thoracis postico impressa" non satis distinctam puto. Color subaeneus H. atramentariae peculiaris videtur.

* 63. H. festinans: Linearis, subdepressa, nigra, nitida, elylris fuscis, antennarum basi pedibusque testaceis, thorace basi obsolete canaliculato, abdomine supra segmentis anterioribus crebrius, posterioribus parcius punctatis. - Long. $1 \frac{1}{2}$ lin.

Habitat in Pensylvania, Dom. Zimmermann.

Statura fere $H$. elongatulae, et minoribus eius individuis aequalis, nigra, nitida, tenuissime parce pubescens. Antennae capite thoraceque breviores, apicem versus vix incrassatae, articulis $4-10$ subaequalibus, haud transversis, ultimo praecedentibus ambobus vix aequali, apice acuminato, piceae, articulis primis testaceis. Caput thoracis latitudine, fronte subconvexa, parce subtiliter punctata. Thorax coleopteris vix angustior, longitudine dimidio latior, basi et lateribus rotundatus, apice truncatus, transversim convexus, parce subtiliter punctatus, canalicula parum profunda, brevi, vix medium superante impressus. Elytra thorace paulo longiora, picea, parce punctata. Abdomen nitidissimum, supra segmentis anterioribus densius, posterioribus vage punctatum. Pedes pallide testacel.

* 64. H. vestigialis: Linearis, subdepressa, nigra, subnilida, elylris fuscis, pedibus testaceis, thorace transverso, aequali, abdomine supra parce punclato. - Long. $1 \frac{1}{3}$ lin.

Habitat in Pensylvania, Dom. Zimmermann.

Praecedenti affinis, differt autem corpore minus nitido, antennis totis nigris, elytris densius, abdomine aequaliter parce punctatis. Corpus nigrum, subnitidum, pube tenui densius vestitum. Antennae capitis thoracisque longitudine, ap icem versus sensim incrassatae, articulis 5-10 transversis, longitudıne duplo crassioribus, ultimo oblongo, praecedentibus ambobus paulo longıore, apice acuminato, totae nigrae. Palpi picei. Caput thorace vix angustius, fronte subdepressa, parce subtiliter punctata. Thorax coleopteris latitudine aequalis, lateribus subrectis, apice truncatus, subdepressus, subtiliter parcius punctatus, basi haud impressus. Elytra thorace sesqui Iongiora, densius punctata, fusca. Abdomen supra aequaliter subtilissime parce punctatum, segmentorum anteriorum margine apiceque piceis. Pedes testacei.

* 65. H. gemina: Linearis, subdepressa, nigra, elytris fuscis, antennarum basi, pedibus anoque testaceis, thorace transverso, basi obsolete bifoveolato. - Long. 1 lin.

Er. Col. March. I. 330. 27.

Habitat in Germania.

Statura H. analis et maximis cius speciminibus vix maior, nigra, subnitida, subtilissime pubescens, dense subtiliterque punctata. Antennae capi- 
tis thoracisque longitudine, apicem versus submcrassatae, articulis 4-10 longitudine parum crassioribus, ultimo oblongo-ovato, apice acuminato, fuscae, basi testaceae. Caput rotundatum, thorace angustius, ore testaceo, fronte medio canalicula brevi obsolete impressa. Thorax coleopteris parum angustior, latitudine dimidio brevior, lateribus et basi rotundatus, antice leviter bisinuatus, angulis anterioribus rotundatis, posterioribus obtusis, parum convexus, basi punctis duobus maioribus approximatis, magis minusve distinctis impressus. Elytra thorace sesqui prope longiora, apıce medio coniuncta leviter emarginata, singula ad angulum exteriorem subsinuata, fuscia, thorace parum fortius punctata. Abdomen nigrum, apice testaceum, supra anterius confertim, posterius parcius punctatum. Pedes testacei.

$\mathrm{Obs}$. H. elongatulae perquam affinis est haecce species et dubito, an rite sit distincta, differre mihi autem videtur statura minore thoraceque paulo breviore.

* 66. H. autumnalis: Linearis, nigra, nitidula, antennarum basi pedibusque testaceis, elytris fuscis, thorace postice canaliculalo foveolatoque, abdomine supra creberrime punctato. - Long. $1 \frac{1}{2}$ lin.

Habitat in Germania meridionali, Dom. Dr. Waltl.

Statura lineari subdepressa fere $\boldsymbol{H}$. elongatulae et minoribus eius individus aequalis, nigra, nitidula, subtiliter pubescens. Antennae capite thoraceque breviores, apicem versus sensim leviter incrassatae, articulis 7-10 leviter transversis, ultimo maiusculo, breviter ovato, subacuminato, fuscae, basi testaceae. Palpi testacei. Caput thorace angustins, rotundatum, subtiliter punctulatum, fronte obsolete impressa. Thorax coleopteris dimidio angustior, latitudine plus dimidio brevior, basi fortius, lateribus leviter rotundatus, apice truncatus, angulis anterioribus rotundatis, posterioribus obtusis, parum convexus, subtiliter punctulatus, basi foveola maiore antrorsum in canaliculam elongata impressus. Elytra thorace sesqui longiora, confertim subtiliter punctata, nigro-fusca. Abdomen parallelum, supra minus subtiliter sat crebre punctatum, segmentis ultimis duobus parcius punctatis, punctis autem exasperatis. Pedes testacei.

* 67. H. oblita: Linearis, subdepressa, nigra, parum nitida, pedibus testaceis, elytris fuscis, thorace canaliculato, abdomine supra anterius subtiliter punctulato. - Long. $1 \frac{1}{4}$ lin. Waltl.

Habitat Lutetiae, Dom. Dr. Aubé, in Germania meridionali, Dom. Dr.

Habitu H. socialis, at minor, H. clanculae aequalis, nigra, opaca, temiter pubescens. Antennae capite thoraceque panlo breviores, extrorsum leviter incrassatae, articulis $5-10$ transversis, ultimo praecedentibus duobus aequali, apice acuminato, fusco-nigrae. Palpi picei. Caput thorace vix angustius, subtilissime obsoleteque punctatum, fronte depressa. Thorax coleopteris latitudine subaequalis, longitudine dimidio latior, basi fortius, lateribus leviter rotundatus, apice truncatus, angulis omnibus obtusis, supra subdepressus, subtiliter punctatus, canalicula plerumque antrorsum abbreviata impressus. Elytra thorace paulo longiora, crebre punctata, fusca. Abdomen nigruir, nitidum, supra punctulatum, apice laevigatum. Pedes testacei. 
Obs. H. clanculae proxima, antennarum autem structura abdomineque parallelo facile distinguenda.

* 68. H. cla n cula: Brevis, nigra, subnilida, elytris fuscis, antennarum basi pedibusque testaceis, thorace transverso, leviter convexo, basi obsolete canaliculato, abdomine supra aequaliter punctato, margine laterali subrotundato. - Long. 1 lin.

Er. Col. March. I. 331. 28.

\section{Habitat Berolini.}

Brevis, crassiuscula, nigra, subnitida, confertissime subtiliter punctata, tenuissime griseo-pubescens. Antennae capitis thoracisque fere longitudine, apicem versus subincrassatae, articulis $4 .-10$ subturbinatis, crassitie vix brevioribus, ultimo ovali, fuscae, basi testaceae. Palpi testacei. Caput thorace parum angustius, basi leviter tantum constrictum, fronte convexiuscula. Thorax coleopteris vix angustius, latitudine duplo brevior, lateribus subrectis, angulis anterioribus fortiter rotundatis, leviter convexus, basi obsolete canaliculatus. Elytra thorace sesqui longiora, apice coniunctim emarginata, ad marginem distincte sinuata, confertim evidentius punctata, fusca. Abdomen supra aequaliter densius punctatum, pube longiore vestitum, margine laterali lato, elevato, rotundato. Pedes testacei.

* 69. H. lut eola: Brevis, favo-testacea, abdomine postice nigricante, thorace transverso, basi obsolete foveolato, abdomine supra confertissime punctalo. - Long. 1 line.

Habitat in America septentrionali, Dom. Zimmermann.

Parva, brevis, statura et habitu fere praecedentis, flavo-testacea, tenuiter pubescens. Antennae capite thoraceque breviores, extrorsum parum incrassatae, articulis penultimis subtransversis, ultimo oblongo, apice acuminato. Caput thorace angustius, basi vix constrictum, crebre profundius punctatum, interdum nigricans, nitidum. Thorax coleopteris latitudine aequalis, longitudine duplo latior, basi et lateribus leviter, angulis anterioribus fortiter rotundatis, posterioribus obtusis, subdepressus, confertim subtiliter punctatus, lasi foveola obsoleta transversa notatus. Elytra thorace paulo longiora, confertim evidentius punctata. Abdomen segmentis anterioribus duobus exceptis. nigro-piceum, supra nitidum, crebre minus subtiliter punctatum. Pectus lateribus piceum. Pedes et elytra magis flavescunt.

Mas antennis paulo longioribus, articulo ultimo magis ovato, obtusiore distinctius.

* 70. II. analis: Linearis, subdepressa, nigra, thorace elytrisque piceis, antennis, pedibus anoque testaceis, thorace suborbiculalo, leviler convexo, basi foveola transversa impresso. - Long. $\frac{3}{4}-1$ lin.

Er. Col. March. I. 332. 30.

Alecth. analis Grav. Micr. 76. 14. Mon. 153. 13. - Latr. Hist, nat. Crust. et Ins. IX. 382. 14.

Bolitochara analis Runde Brachel. Hal. 30.'4.

Bolitochara evanescens Mannerh. Brachelytr. 81. 37.

Aleochara evanescens Sahlb. Ins. Fenn. I. 364. 35.

Bolitochara teres Runde Brachel. 30. 3. 


\section{Var.: Thorace elytrisque rufo-piceis.}

- Bolitochara bifoveolata Mannerh. Brachelytr. 79. 23.

Aleochara bifoveolata Suhlb. Ins. Fenn. 1. 374. 53.

Habitat in Europa frequens: in America septentrionali legit Dom. Zimmerm.

Angustula, subdepressa, linearis, subtilissime griseo-pubescens. Antennae capite thoraceque breviores, apicem versus vix incrassatae, articulis 4-10 subturbinatis, longitudine parum crassioribus, ultimo maiusculo, ovato, apice subacuminato, testaceae. Caput thoracis fere latitudine, rotundatun:, basi profunde constrictum, ut pedunculo quasi brevi thoraci insertum videatur, confertissime subtiliter punctatum, nigrum vel piceum, ore testaceo. Thorax coleopteris hand angustior, latitudine dimidio brevior, lateribus, basi et angulis omnibus rotundatus, supra leviter convexus, confertissime subtiliter punctatus, basi foveola transversa profunde impresșus, piceus. Elytra thorace parum longiora, subtiliter dense punctata, picea. Abdomen subtiliter dense punctatum, nirgum, apice testaceum. Pedes testacei.

Variat thorace elytrisque piceo-testaceis.

* 71. H. exilis: Linearis, depressa, nigra, tenuiter sericeo-pubescens, elytris fuscis, antennarum basi, pedibus anogue testaceis, thorace transversim subquadralo, abdomine supra conferlim punclulato. - Long. $\frac{3}{1}$ lin.

Er. Col. March. I. 333. 32.

Al. analis var. (exilis Ku.) Grav. Mon. 153. 13.

Habitat in Germania.

H. anali plerumque minor, angustior, depressa, nigro-picea, parum nitida, subtilissime punctata, pube tenui grisea vestita. Antennae capite vix longiores, apicem versus fortiter incrassatae, articulis $4-10$ valde transversis, fere perfoliatis, ultimo maiusculo, breviter ovato, obtusiusculo, fuscae, basi testaceae, Caput thoracis latitudine, subquadratum, obsolete canaliculatum, antice leviter impressum, ore testaceo. Thorax coleopteris parum angustior, latitudine dimidio brevior, lateribus subrectis, perparum convexus, medio longitudinaliter depressus. Elytra thorace paulo longiora, munus subtiliter punctata, fusca. Abdomen nigrum, apice testaceum, minus subtiliter confertim punctatum. Pedes testacei.

Variat saepe corpore testaceo.

* 72. H. palleola: Linearis, subdepressa, teslacea, elytris fusco-testaceis, capile abdominisque segmentis penultimis piceis, thorace transversim suborbiculato, leviter convexo, abdomine supra parce punctato.-Long. $\frac{3}{4}$ lin.

Er. Col. March. I. 333. 31.

Habitat in Germania.

Statura H. analis et minoribus eius individuis magnitudine aequalıs, testacea, parce subtiliter pubescens. Antennae capitis thoracisque longitutudine, apicem versůs sensim incrassatae, articulis 4-10 transversis, ultimo breviter ovato, subacuminato, pilosellae, fuscae, bası testaceae. Caput thorace parum angnstius, rotundatum, basi leviter constrictum, laeve, nitidum, 
piceum, ore testaceo. Thorax coleopteris dimidio angustior, latitudine dimidio brevior, lateribus, basi angulisque omnibus rotundatis, apice truncatus, leviter convexus, subtilissime vage punctatus. Elytra thorace plus sesqui longiora, subtiliter densius punctata, fusco-testacea. Abdomen testaceum, nitidum, supra antrorsum vage punctatum, apicem versus laeve, segmentis duobus antepenultimis nigris. Pectus piceum. Pedes flavi.

* 73. H. inconspicua: Linearis, nigra, opaca, fortius punclulata, tenuiter sericen-pubcscens, tarsis flavescentibus, thorace transverso, obsolete canaliculato. - Long. $\frac{3}{4}$ lin.

Habitat in Germania, Dom. Dr. Waltl, Lutetiae, Dom. Dr. Aubé.

Statura H. exilis, nigra, opaca, confertim fortius punctata, pube tenuissima vestita. Antennae capitis thoracisque longitudine, apicem versus subincrassatae, articulo ultimo ovato, corpori concolores. Caput thorace paulo angustius, basi leviter constrictum. Thorax coleopteris parum angustior, latitudine plus dimidio brevior, lateribus et angulis omnibus rotundatis, leviter convexus, obsoletissime canaliculatus. Elytra thorace duplo fere longiora. Abdomen supra nitidulum, anterius fortius, apicem versus obsoletims punctulatum. Pedes concolores, geniculis piceis, tarsis flavescentibus.

* 74. H. inquinula: Linearis, subdepressa, nigra, tenuiler sericeo-puibescens, elytris fuscis, pedibus obscure testaceis, thorace transversim subquadrato. - Long. $\frac{1}{2}$ lin.

Er. Col. March. I. 334. 33.

Al. inquinula Grav. Micr. 78. 16. Mon. 153. 15. - Latr. Hist. nat C'rust. et. Ins. IX. 382. 16.

Habitat in Germania.

Forma praecedentium, at minutissima, angusta, subdepressa, nigra, parum nitida, pube tenui grisea vestita. Antennae capitis thoracisque longitudine, apicem versus subincrassatae, articulis $4-10$ leviter transversis, ultimo breviter ovato, subacummato, nigricantes. Caput thoracis prope latitudine, subtilissime punctatum, fronte planiuscula, medio subimpressa. Thorax coleopteris parum angustior, latitudine dimidio brevior, lateribus rectis, basi rotundatus, subdepressus, confertissime subtilissimeque punctatus. Elytra thorace sesqui longiora, dense subtiliter punctata, fusca. Abdomen parcius punctatum, apice piceum. Pedes fusco-testacei.

* 75. II. didyma: Testacea, capite exserto, fronte antice transversim impressa, thorace transverso, antice rotundato, basi transversim impresso foveolatoque. - Long. 1 lin.

Habitat in Columbia, Dom. Moritz.

llabitus omnino Autaliae impressae, at duplo fere minor. Corpus testaceum, nitidulum, subtilissme punctulatum, dense subtilius pubescens. Antemnae capitis thoracıque longitudine, crassiusculae, apicem versus distincte crassiores, articulis $6-10$ fortiter transversis, nltimo ovato, subacuminato. Caput thoracis fere latitudine, rotundatum, pedunculo angusto thoraci insertum, fronte convexiuscula, supra antennarum insertionem transversim leviter impressa. Thorax coleopteris tertia parte angustior, longitudine duplo fere 
latior, basi truncatus, apice cum angulis anterioribus rotundatus, supra leviter cönvexus, basi foveolis quatuor distantibus impressus, exterioribus obsoletioribus, interioribus sulculo transverso connexis. Abdomen segmentis dorsalibus depressis, subglabris, vix punctatis. Anus et pedes pallidiores. Caput interdum piceum.

Obs. Adeo haec species habitu Autaliam simulat, ut nonnisi ex oris structura examinata locum eius naturalem cognoverim.

* 76. H. bisulcata: Obscure rufo-testacea, capite exserto, abdominis segmento quinto antennisque nigris, his basi testaceis, thorace transverso, dorso bisulcato. - Long. 1 lin.

Habitat in Columbia, Dom. Moritz.

Statura praecedentis. Corpus obscure rufo-testaceum, totum confertim subtilissime punctulatum, pube tenuissima densius obductum, opaculum. Antennae capitis thoracisque longitudine, apicem versus parum incrassatae, articulis 6-10 longitudine paulo crassioribus, ultımo articulis tribus praecedentibus coniunctis vix breviore, subcylindrico, apice subacuminato, fuscae, basi testaceae. Caput pedunculo brevi thoracı insertum, rotundatum, piceum, nitidulum, supra antennas transversim subimpressum. Thorax coleopteris angustior, longitudine duplo latior, basi apiceque truncatus, lateribus rotundatus, angulis anticis obtusis, subrotundatis, supra leviter convexus, sulcis duobus dorsalibus latis, postice confluentibus, antice abbreviatis, et ante apicem lineola minuta longitudinali impressus. Abdomen supra subti. liter punctulatum, segmento quinto nigro-piceo, ano pallidiore. Pectus piceum. Pedes testacei.

* 77. H. ustulata: Testacea, capile abdominisque segmento quarlo quintoque nigris, elytris fuscis, humeris pallidioribus, antennis nigricantibus, basi apiceque testuceis, thorace transverso, basi obsolete foveolato. - Long. 1 lin.

Habitat in Columbia, Dom. Moritz.

Statura fere praecedentium. Corpus totum subtilissime pubescens. Anten nae capitis thoracisque longitudine, apicem versus leviter incrassatae, articulis penultimis transversis, ultimo maiore, ovato, subacummato, nigricantes, basi summoque apice testaceis. Caput thorace parum angustius, suborbiculare, subtiliter punctatum, nitidum, nigrum, ore piceo, palpis pallidis. Thorax coleopteris parum angustior, latitudine dimidio brevior, lateribus et basi leviter rotundatus, apice truncatus, supra parum convexus, basi foveola parva obsoleta impressus, confertissime -subtiliter punctulatus, obscure rufo-testaceus, parum nitidus. Elytra thorace parum longiora, subtilius confertissime punctata, opaca, dilute fusca, macula humerali testacea. Abdomen dorso parcius distinctiusque punctulatum, rufo-testaceum, segmentis quarto quin toque nigris. Pectus nigrum. Pedes flavi.

* 78. H. melanura: Rufo-testacea, capite, ano antennisque nigris, his basi testaceis, elytris flavis, thorace transverso, basi profunde foveolato. Long. 1 lin.

Habitat in Americae insulis St. Johannis et Puerto Rico, Dom. Moritz. 
Statura ominmo praecedentis, dense subtiliter punctata, tenuiter flavescenti-pubescens. Antennae capitis thoracisque longitudine, apicem versus incrassatae, articulis 5-10 longitudine paulo crassioribus, ultimo maiore, ovato, apice vix acuminato, bası testaceae. Caput thorace parum. angustius, subnitidum, nigrum, ore. rufescente. Thorax coleopteris parum angustior, latitudine duplo brevior, lateribus et basi parum rotundatus, subdepressus, basi foveola profunda impressus, rufo-testaceus. Elytra thorace sesqui longiora, obscure flava. Abdomen parcius subtiliter punctatum, segmentis quatuor anterioribus rafo-testaceis, reliquis nigris. Pectus testaceum, lateribus piceum. Pedes flavi.

* 79. H. flavipennis: Nigra, nitida, antennarum basi, elytris pedibusque flavis, thorace transverso, basi obsolete foveolato, abdomine supra parcius punctulato. - Long. 1 lin.

Habitat in Americae ins. St. Johannis, Dom. Moritz.

Statura fere praecedentıum, nigra, tenuissime pubescens, subtilissime confertissimeque punctata, parum nitida. Anternae capitis thoracisque longitudine, crassiusculae, articulis $5 \mathbf{- 1 0}$ fortius transversis, ultimo maiore, ovato, subacuminato, nigrae, basi testaceae, articulo primo flavo. Caput thoracis fere latitudine, fronte latiuscula, plana. Thorax coleopteris dimidio yrope angustior, latitudine fere duplo brevior, lateribus ante medium rotundatis, basin versus subangustatis, angulis posterioribus minus obtusis, supra parum convexus, basi foveola transversa obsolete impressus. Elytra thorace paulo longiora, flava. Abdomen nitudulum, minus confertim punctatum, praecipue apicem versus. Pedes flavi.

* 80. I. obsoleta: Nigra, nitida, elytris fuscis, humeris, antennarum basi pedibusque testaceis, thorace transverso, convexiusculo, basi obsolete foveolato, abdomine supra parcius punctulato. - Long. 1 lin.

Habitat in Columbia, Dom. Moritž.

Statura exacte praecedentis. Antennae capitis thoracisque longitndine, rrassiusculae, articulis secundo tertioque obconicis, hoc minore, 4-10 sat fortiter transversis, ultimo maiore, ovato, subacuminato, nigrae, articulis tribus primis testaceis, primo dilutiore. Corpus nigrum, parum nitidulum, subtilissime punctulatum, pube subtilissima vestitum. Caput thoracis latitudine, basi parum constrictum, fronte leviter convexa. Thorax coleopteris parum angustior, latitudine duplo brevior, basi lateribusque parum rotundatiss, apice truncatus. Elytra thorace paulo longiora, nigro-fusca, humeris transversim testaceis. Abdomen supra parcius punctulatum. Pedes testacei, femoribus basi piceis.

* 81. II. curticollis: Nigra, nitida, elytris fuscis, humeris apiceque, antennarum basi pedibusque obscure testaceis, thorace transverso, convexiusculo, basi profunde foveolalo, abdomine supra crebrius punclulato. - Long. 1 lin.

Habitat in valle Araguensı Columbiae, Dom. Moritz.

Statura et summa affinitas praecedentis. Nigra, nitidula, minus subtiliter griseo-pubescens. Antennae capitis thoracisque vix longitudine, ab ar- 
ticulo quarto inde crassae, articulis 5-10 longitudine triplo fere crassioribus, ultimo maiore, ovali, apice obtuso, pilosellae, nigrae, basi testaceae. Caput thoracis latitudine, basi parum constrictum. Thorax coleopteris parum angustior, latitudine duplo prope brevior, lateribus parum rotundatus, supra convexiusculus, crebre subtiliter punctatus, basi foveola profunda transversa impressus. Elytra thorace paulo longiora, crebre profundius punctata, fusca, humeris rufescentibus, margine apicali flavescente. Abdomen supra crebrius punetulatum. "Pedes obscure testacei.

Obs. A praecedente thorace profunde foveolato, elytris fortius punctatis, margineque eorum apicali pallido facile distinguenda.

* 82. H. decipula: Ferruginea, nitida, antennis medio nigricantibus, apice ferrugineis, thorace transverso, basin versus subanguslato, basi foveolato, elytris fortius punctulatis, abdomine supra laevi. - Long. 1 lin.

Habitat in Americae merid. ins. Puerto Rico, Dom. Moritz.

Habitus omnino Oxypodae cuiusdam sectionis II (prolixae), at huius generis, linearis, piceo-rufa, nitidula, tenuiter fulvescenti-pubescens. Antentnae capite thoraceque paulo longiores, apicem versus sensim incrassatae, articulis penultimis transversis, ultmo maiore, ovato, dense longius pubescentes, basi rufo-piceae, medio fuscae, articulis ultimis duobus dilute testaceis. Caput thorace paulo angustius, basi leviter constrictum, confertim subtiliter punctatum, ore subattenuato. Thorax coleopteris vix angustior, latitudine dunidio brevior, basin versus subangustatus, lateribus anterius leviter rotundatis, posterius subsinuatis, supra leviter convexus, subtilissime punctulatus, basi foveola media transversa sat distincta iupressus. Elytra thorace paulo longiora, sat crebre minus sultiliter punctulata. Abdomen lineare, dorso laeve, subtus parce obsoleteque punctulatum. Pedes testacei.

* 83. H. nigripennis: Rufo-teslacea, nilida, elytris nigris, peclore anlennisque nigricantibus, his basi apiceque testaceis. - Long. 1 lin.

Habitat in Americae insula St. Johannis, Dom. Moritz.

Statura fere H. analis. Laete rufo-testacea, nitida, subtilissime pubescens. Antennae fere capitis thoracisque longitudine, apicem versus leviter mcrassatae, articulis penultimis transversis, ultimo maiusculo, ovato, nigrae, basi rufo-testaceae, articulo ultimo dilute testaceo. Corpus rufo-testaceum. Caput thorace paulo angustius, basi leviter constrictum, subtiliter parce punctatum. Thorax coleopteris vix angustior, latitudine duplo brevior, lateribus et basi leviter rotundatus, apice late leviter emarginatus, subdepressus, subtiliter parcius punctatus. Elytra thorace haud longiora, mgerrima, distinctius confertim punctata. Abdomen supra subtiliter vage punctaium. Pectus piceum.

* 84. II. alternata: Nigra, elytris basi, abdomine et antennis basi apice-a que pedibusque flavis. - Long. 1 lin.

Habitat in Americae ins. St. Thomae, Dom. Moritz.

Statura praecedentis. Antennae capitis thoracisque fere longitudine, apicem versus leniter incrassatae, articulis penultimis transversis, ultimo ovato, subacuminato, nigrae, basi testaceae, arciculo ultimo laete testaceo. 
Thorax coleopteris vix angustior, latıtudine dimidio brevior, lateribus et basi leviter rotundatus, parum convexus, laevis, niger. Elytra thorace parum longiora, subtilissime punctata, parte dimidia anteriore pallide flava, posteriore nigra. Abdomen laeve, laete testaceum vel flavum, segmmntis quarto quintoque nigris. Pectus nigrum. Pedes flavi.

* 85. I seminigra: Linearis, dilute rufo-testacea, pectore abdomineque nigris, hoc basi teslaceo, antennis nigris, basi flavis, thorace transverso, leviter convexo. - Long. $1 \frac{1}{3}$ lin.

Habitat in Columbia, Dom. Moritz.

Habitu omnino praecedentis, at sesqui maior, subtilissime punctulata pubescensque. Antennae capite sesqui longiores, apicem versus leviter incrassatae, articulis 4-10 transversis, ultimo ovato, nigrae, articulis 4 primis pallide flavis. Caput thorace minus et angustius, testaceum. Thorax coleopteris parum angustior, latitudine dimidio brevior, basi leviter rotundatus, lateribus subrectis, leviter transversim convexus, aequalis, testaceus. Scutellum testaceum. Elytra thorace paulo longiora, flavo-testacea. Abdomen sat elongatum, supra laevigatum, subtus segmentis anterioribus subtiliter punctulatis, segmento primo testaceo, secundo piceo, reliquis nigerrimis, nitidis, ano picescente. Pectus posterius nigrum. Pedes flavi.

* 86. H. stigma: Linearis, flavo-testacea, abdomine segmento quarto macula magna dorsali atra, thorace transverso, leviter convexo, aequali. - Long. $1 \frac{1}{4}$ lin.

Habitat in Brasilia, Dom. Prof. Germar.

Statura omnino H. seminigrae, tota pallide testacea, elytris pectoreque magis flavescentibus, nitidula, tenuiter subtiliterque griseo-pubescens. Antemnae capite sesqui longiores, apicem versus sensim incrassatae, articulis duobus primis maiusculis, subaequalibus, secundo tertioque, hoc dimidio minore, obconicis, 4-10 longitudine subaequalibus, sensim crassioribus et fortius transversis, penultimis longitudine duplo crassioribus, ultimo breviter ovato. Caput thorace paulo angustius, suborbiculatum, basi vix constrictum, fronte depressa, confertim minus subtiliter punctatum. Oculi nigri. Thorax coleopteris parum angustior, latitudine plus dimidio brevior, basi et lateribus modice rotundatus, apice truncatus, angulis omnibus obtusis, leviter transversim convexus, aequalis, crebre fortius punctatus. Elytra thorace sesqui longiora, subdepressa, sat crebre fortius punctata. Abdomen lineare, minus confertim subtilius punctatum, supra segmento quarto macula magna media aterrima, subtus immaculatum. Pedes pallidi.

* 87. Ir silacea: Testacea, antennis apice abdomineque ante apicem nigris, thorace transverso, aequali, abdomine dorso subtiliter punctulato. - Long. $\frac{4}{5}$ lin.

Habitat in America septentionali, Dom. Zimmermann.

Statura omnino et summa affinitas proxime praecedentium, at paulo minor, flavo-testacea, parum nitida, subtilissime griseo-pubescens. Antennae capite parum longiores, apicem versus sat distincte sensim incrassatae, articulis penultimis transversis, ultimo subgloboso, testaceae, articulis ultimis 4 
nigris. Caput thorace paulo angustius, basi leviter constrictum, subtilissime punctulatum, fronte planiuscula. Thorax coleopterorum prope latitudine, latitudine duplo brevior, basi lateribusque leviter rotundatus, confertim subtiliter punctatus, dilutius flavo-testaceus. Elytra thorace plus sesqui longiora, confertim subtliter punctata, subfuscentia. Abdomen supra subtiliter punctulatum, segmentis antepenultimis duobus totis, penultimo basi nigris. Pedes pallide flavo-testacei.

* 88. H. cinctella: Testacea, pectore abdominisque segmentis tribus penultimis nigris, elytris nigricantibus, basi teslaceis, antennis apice nigris. - Long. $\frac{3}{4}$ lin.

Habitat in Columbia, Dom. Moritz.

Statura omnino praecedentis, subtiliter punctulata, subtilissime pube scens. Antennae capite paulo longiores, apicem versus sensm incrassatae, articulis penultimis transversis, ultimo maiusculo, subgloboso, testaceae, apice fuscae. Caput thorace paulo angustius, testaceum. Thorax coleopteris parum angustior, latitudine duplo brevior, basi et lateribus aequaliter rotundatus, leviter transversim convexus, aequalis, dilute testaceus. Elytra thorace sesqui prope longiora, piceo-nigra, basi dilutiora, humeris testaceis. Abdomen supra subtiliter punctulatum, segmentis duobus primis testaceis, terito, quarto quintoque nigris, hoc margine apicali sextoque toto iterum testaceis. Pectus posterius nigrum. Pedes pallide testacei.

* 89. H. atratula: Linearis, atra, parum nitida, antennarum basi, tibiis tarsisque rufo-testaceis, thorace transverso, convexiusculo. - Long. 1 lin.

Habitat in Columbia, Dom. Moritz.

Statura H. analis. Corpus lineare, atrum, parum nitidum, vix pubescens. Antennae capite parum longiores, apicem versus subincrassatae, articulis penultimis transversis, ultimo ovato, subacuminato, pilosellae, nigrae, articulis 4 primis pallide rufo-testaceis. Caput profunde crebreque punctatum, rotundatum, thorace paulo angustius, feminae fronte convexiuscula, marıs late profundeque excavata. Thorax coleopteris paulo angustior, latitudme duplo fere brevior, lateribus et basi parum, angulis anterioribus fortiter rotundatis, creberrme punctatus, feminae convexiusculus, aequalis, maris profunde lateque canaliculatus. Elytra thorace plus sesqui longiora, crebre punctata. Abdomen supra parcius punctatum, pilis raris depressis vestitum, segmento ultimo maris supra plano, subtiliter granulato. Pedes nigrı, tibiis tarsisque rufis, tibiis posterioribus medio saepe infuscatis.

Mas fronte excavata, thorace late canaliculato, abdominis segmento ultimo supra granulato distinctus.

* 90. H. fervidula: Nigro-picea, capite thoraceque transverso rufis, pedibus antennisque teslaceis, his apice nigris. - Long. $\frac{3}{4}$ lin.

Habitat in Columbia, Dom. Moritz.

Statura H. analis. Corpus lineare, tenuissime pubescens. Antennae capite paulo longiores, apicem versus sensim incrassatae, articulis penulti- 
mis transversis, ultimo maiusculo, subgloboso, testaceae, apice nigrae. Caput thoracis latitudine, pedunculo brevi thoracı insertum, profunde punctatum, rufum. Thorax coleopteris parum angustior, latitudine dimidio brevior, lateribus et basi parum rotundatis, angulis anterioribus fortiter rotundatis, supra parum convexus, aequalis, subtiliter creberrime punctulatus, laete rufus. Elytra thorace sesqui longiora, crebre punctata, picea. Abdomen supra parcius punctulatum, nigro-piceum, nitidulum. Pectus nigrum. Pedes testacei.

*91. Ir. cauta: Nigra, nitidula, pedibus fuscis, thorace transverso, leviler convexo, basi obsolete canaliculato abdomineque supra basi conferlim, postice parce punctato margine pilosellis. - Long. I lin.

Er. Col. March. I. 334. 34.

Homalota pulicaria Er. Col. March. I. 340. 45.

Habitat in Germania.

Forma fere $H$. socialis, at multo minor, nigra, nitidula, pube tenurssima parce vestita, thoracis abdominisque lateribus pilosellis. Antennae capitis thoracisque longitudine, apicem versus vix incrassatae, articulis $4-6$ subglobosis, 7-10 subturbinatis, longitudine haud crassioribus, ultimo elongato-ovato, apice subacuminato, totae nigrae. Caput thorace angustius, rotundatum, crebre minus subtiliter punctatum, basi leviter constrictum. Thorax coleopteris paulo angustior, latitudine dimidio brevior, lateribus et basi leviter rotundatus, apice truncatus, angulis anterioribus fortiter rotundatis, deflexis, leviter transversim convexus, subtilissime punctatus, basi obsolete canaliculatus. Elytra thorace paulo longiora, confertissime punctata, minus nitida, fusco-nigra. Abdomen nitidulum, supra segmentis quatuor primis confertim, reliquis parce punctatis. Pedes fusci vel fusco-testacei, tarsis dilutioribus.

Obs. Hom. pulicaria secundum singulum specimen descripta, accuratius examinata ab hac specie distingui non debet.

* 92. II. celata: Nigra, subopaca, pedibus fusco-testaceis, thorace transverso, parum convexo, basi obsolete canaliculato, abdomine supra tolo confertim punctato. - Long. vix 1 lin.

Er. Col. March. I. 335.35.

Habitat in Germania.

Praecedenti simillima, nigra, subopaca. Antennae vix capitis thoracisque longitudine, apicem verșus subincrassatae, articulis 4-10 longitudine vix crassioribus, ultimo oblongo-ovato, nigrae. Caput thorace paulo angustius, rotundatum, basi leviter constrictum, confertissime punctatum, fronte supra canalicula abbreviata leviter impressa. Thorax coleopteris paulo angustior, latitudine dimidio brevior, lateribus et basi leviter rotundatus, apice truncatus, angulis anteriorilus fortiter rotundatis, parum convexus, confertissime punctatus, basi obsoletius canaliculatus. Elytra thorace sesqui fere longiora, confertissime punctata, fusco-nigra. Abdomen supra aequaliter confertim punctatum, lateribus vix pilosellum. Pedes fusci, tarsis flavescentibus, interdum toti fusco-testacei. 
Obs, Praecedenti proxima et aegre distinguenda, differe autem videtur thorace lateribus haud pilosello, abdomine supra toto confertim punctato et colore magis opaco.

* 93. H. recondita: Nigra, nilidula, tarsis piceis, thorace transverso, leviter convexo abdomineque supra aequaliter densius punctato margine pilosellis. - Lòng. 1 lin.

Habitat in Pensylvania, Dom Zimmermann.

Praecedentibus proxima, nigra, parce et omnium subtilissime pubescens, thoracis abdominisque margine laterali plosello. Antennae capitis thoracisque longitudine, apicem versus vix incrassatae, articulis penultimis vix transversis, ultimo oblongo, apice subacuminato, totae nigrae. Caput thorace angustius, basi parum constrictum, parce punctatum. Thorax coleopteris vix angustior, latitudine duplo brevior, lateribus et basi leviter rotundatus, leviter transversim convexus, subtiliter punctulatus, basi interdum obsolete canalıculatus. Elytra thorace paulo longiora, dense subtilius punctata, apice medio coniunctim emarginata. Abdomen supra totum dense minus subtiliter punctatum. Pedes nigri, tarsis vel etiam tibiis anticis piceotestaceis.

Obs. Statura H. I ute olae proxima, differt autem thoracis abdominisque margine laterali pilosello. Utraque habitu quibusdam sectionis quartae speciebus (e. g. H. fungi) appropinquata, sunt autem is neque thorax neque abdomen apicem versus angustata.

* 94. II. subida: Nigra, nilidula, elytris fuscis, tibiis tarsisque testaceis, thorace transverso, aequali, leviter convexo, abdomine supra parcius aequaliter punctato. - Long. vix 1 lin.

Habitat in Brasilia, Dom. Prof. Germar.

Statura praecedentium, nigra, nitidula, thorace abdomineque margine haud pilosellis. Antennae capite thoraceque paulo longiores, apicem versus leviter incrassatae, articulis penultimis subtransversis, ultimo ovato, totae nigrae. Caput thorace parum angustıus, rotundatum, basi modice constrictum, subtilissime parce punctatum. Thorax coleopteris paulo angustior, latitudine dımidio brevior, lateribus et basi leviter rotundatus, apice truncatus, angulis anterioribus rotundatis, leviter convexus, subtilissime punctatus. Elytra thorace paulo longiora, nigro-fusca, densius evidenter punctata. Abdomen supra totum aequaliter parce subtiliter punctatum, apice pllosellum. Pedes testacei, femoribus fuscescentibus.

* 95. II. sordidula: Nigra, opaca, elytris anoque fuscis, pedibus pallidis, fronte impressa, thorace transversim subquadrato, subtiliter canaliculato, abdomine supra toto confertim punctato. - Long. $\frac{2}{3}$ lin.

Er. Col. March. I. 335. 36.

Habitat Berolini, Dom. Schïppel.

Forma praecedentium, at minor, nigra, opaca. Antennae capite thoraceque longiores, apicem versus parum incrassatae, articulis $4-10$ longitudine haud crassioribus, ultimo elongato, apice subacuminato, nigrae. Caput thorace parum angustius, rotundatum, basi leviter constrictum, fronte late camaliculata. Thorax coleopteris paulo angustıor, latitudine dimidio brevior, 
lateribus subrectis, basi rotundatus, apice truncatus, angulis anterioribus obtusiusculis, parum convexus, subtiliter canaliculatus. Elytra thorace paulo Iongiora, nigro-fusca. Abdomen dense punctatum, apice piceum. Pedes flavescentes, femoribus fuscescentibus.

Obs. Antemnis longioribus, fronte canaliculata, colore opaco et statura minima a praecedentibus praecipue discedens.

* 96. H. luteicornis: Linearis, subdepressa, distinctius punclulata, nigra, elytris fuscis, ore, antennis pedibusque testaceis, abdomine supra crebre, apice parcius punclato. - Long. 1 lin.

Er. Col. March. I. 332. 29.

Habitat in Germania: Berolini singulum specimen cepi.

Corpus minutum, lineare. H. anali magnitudine aequalis, nigra, parum nitida, tenuiter griseo-pubescens. Antennae capite sesqui longiores, apicem versus sensim leviter incrassatae, articulo secundo crassiusculo, tertio hoc duplo minore, $4-10$ brevibus, sensim paulo crassioribus et simul fortius transversis, penultimis longitudine duplo crassioribus, ultimo maiusculo, breviter ovato, totae luteo-testaceae. Caput thoracis prope latitudme, subdeflexum, confertim minus subtiliter punctatum, ore testaceo. Thorax coleopterorum latitudine, lateribus et basi parum rotundatus, apice truncatus, angulis subrectis, anterioribus deflexis, leviter transversim convexus, aequalis, confertim minus subtiliter punctatus. Elytra thorace paulo longiora, confertim minus subtiliter punctata, obscure fusca, apice ferruginea, ad angulum exteriorem subsinuata. Abdomen confertim minus subtiliter punctulatum, longius pubescens, segmento quinto parce punctato, apice piceum, segmentis ventralibus margine postico picescente. Pedes testacei.

Obs. Capite deflexo, basi nullo modo constricto ad Oxypodas accedit, at tarsi omnino huius generis.

* 97. H. flavipes: Nigra, nitida, subtilius punctulala, antennis basi apiceque pedibusque testaceis, elytris rufo-piceis, thorace aequali, angulis posterioribus acutiusculis, abdomine supra sublaevigalo. - Long. prope 2 lin.

Aleochar a flavipes Grav. Mon. 161. 32. - Gyll. Ins. Suec. II. 421. 43. - Sahlb. Ins. Fenn. I. 386. 73.

Bolitochara flavipes Mannerh. Brachelytr. 82. 42.

Habitat Lutetiae, Dom. Dr. Aubé.

Maximis H. socialis individuis longitudine aequalis, at latior crassiorque, nigra, nitida, pube grisea sericante vestita. Antennae capitis thoracisque fere longitudine, validiusculae, articulo secundo tertioque subaequalıbus, $\mathbf{1 - 1 0}$ inter se itidem aequalibus, longitudine haud crassioribus, ultimo elongato, praecedentibus tribus conimnetis prope aequali, acuminato, rufae, medio fuscae. Caput thorase paulo angustius, globosum, fronte satis convexa, parce subtilissime punctata, oris partibus rufis. Thorax latitudine duplo brevior, basi coleopterorum prope latitudine, antrorsum subangustatus, angulis anterioribus fortiter rotundatis, basi rotundatus, utrinque sinuatus, angulis posterioribus acutinsculis, parum convexus, aequalis, subtilius crebriusque punctulatıs. Scutellum punctulatum, nigrum. Elytra thorace sesqui longiora, con- 
fertım subtilius punctulata, rufo-brunnea, circa scutellum et versus latera nigricantia, apice ad angulum exteriorem leviter sinuata. Abdomen supra parce subtiliter punctatum, fere laevigatum, segmentis anterioribus penultimoque margine apicali, ultimoque toto, subtus segmentorum omnium marginibus anoque rufo-piceis. Pedes rufo-testacei.

* 98. H. subsinuata: Nigra, nitidula, subtiliter punctata, pedibus piceotestaceis, thorace leviter convexo, basi forliter rotundato, utrinque subsinuato, angulis posterioribus prominulis, abdomine supra parce subti. liter punctato, nitido._- Long. $1 \frac{1}{2}$ lin.

Habitat in Germania meridionali, Dr. Waltl.

Praecedente duplo minor, angustior, minus crassa, sequentibus aequalis, nigra, nitida, subtiliter tenuiterque griseo-pubescens. Antennae capitis thoracisque longitudine, apicem versus sensim incrassatae, articulo secundo tertioque aequalibus, $\mathbf{4}-\mathbf{1 0}$ subobconcis, sensim paulo crassioribus, penultimis duobus transversis, ultimo maiusculo, praecedentibus ambobus sublongiore, oblongo-ovato, totae nigrae. Palpi picei. Caput minutum, thorace multo minus, rotundatum, basi haud constrictum, fronte leviter convexa, subtiliter minus dense punctatum. Thorax coleopteris dimidio brevior, basi coleopterorum latitudine, antrorsum subangustatus, apice truncatus, lateribus leviter rotundatus, basi medio late et sat fortiter rotundatus, utrinque subsinuatus, angulis posterioribus prominulis, subrectis, at minutis, anterioribus rotundatis, leviter transversim convexus, densius subtiliter punctatus, basi supra scutellum foveola minuta leviter impressus. Elytra thorace paulo lengiora, apice ad angulum exteriorem subsinuata, confertim subtiliter punctata, minus nitida. Abdomen lineare, nigrum, nitidum, segmentis tribus primis parcius, sequentibus duobus parce, ultimo iterum crebrius subtiliter punctatis, hoc piceo. Pedes piceo-testacei.

* 99. H. anceps: Fusco-nigra, opaca, punctatissima, pedibus luteis, thorace plano, canaliculato, angulis posticis subrectis, abdomine supra subtiliter punchulato, nitidulo, ano piceo. - Long. $1 \frac{1}{2}$ lin.

Er. Col. March. I. 336. 37.

Habitat Berolini, rarissime, Lutetiae, Dom. Aubé.

Statura fere $H$. socialis et minoribus eius individuis magnitudine aequalis, fusco-nigra, opaca, tenuissime pubescens. Antennae capitis thoracisque vix longitudine, graciliores, apicem versus parum incrassatae, articulis 4-10 longitudine haud crassioribus, ultimo praecedentibus ambobus longitudine aequali, oblongo-ovato, apice subacuminato, fuscae, basi obscure Inteae. Caput thorace angustius, basi vix constrictum, confertim punctatum. Thorax coleopteris paulo angustior, latitudine plus dimidio brevior, antrorsum subangustatus, lateribus leviter rotundatus, basi utrinque subsinuatus, angulis posterioribus subrectis, supra depressus, confertissime punctatus, leviter canaliculatus. Elytra thorace sesqui longiora, confertissime punctata, subrugulosa, apice ad angulum exteriorem sinuata. Abdomen parallelum, nigrum, nitidulum, apice piceum, supra subtiliter confertissime punctatum. Pedes lutei. 
Obs. 1. Tarsi postici articulis 4 primis longitudine aequalibus.

2. A. Dom. Aubé in societate Formic ae rufae lecta.

* 100. H. concolor: Nigra, parum nitida, pube cinerascenti sericea, tarsis piceis, thorace subdepresso, supra scutellum foveolato, basi utrinque sinuato, angulis posticis acutiusculis. - Long. $\mathrm{J} \frac{1}{3}$ lin.

Habitat in Germania meridionali, Dom. Dr. Waltl.

Statura omnino praecedentis, nigra, minus nitida, pube subtilissima densa cinereo-sericea, omnium subtilissime confertissimeque punctata. Antennae capite thoraceque breviores, tenuiores, apicem versus haud incrassatae, articulo secundo tertio paulo minore, 4 - 10 subaequalibus, ultimo praecedentibus ambobus longitudine aequali, apice acuminato, totae nigrae. Palpı nigri. Caput thorace paulo angustius, rotundatum, basi leviter constrictum. Thorax latitudine dimidio prope brevior, basi coleopteris vix angustior, antrorsum parum angustatus, basi leviter rotundatus, ad angulum utrinque sinuatus, lateribus leviter rotundatus, apice subemargmatus, angulis anterioribus leviter rotundatis, posterioribus acutiusculis, subdepresus, basi foveolatus. Elytra thorace paulo longiora, apice ad angulum exteriorem subsinuata. Abdomen apicem versus subangustatum. Pedes nigri, tarsis testaceis.

Obs. Tarsi postici articulis 4 primis longitudine sensim decrescentibus, nihilominus huius generis videtur, summa affinitate cum praecedentibus coniuncta.

\section{**** $\mathrm{R}$ o $\mathrm{t}$ u $\mathrm{n}$ d a $\mathrm{t}$ a $\mathrm{e}$.}

* 101. H. notha: Brevis, nigra, nitida, griseo-pubescens, anlennarum basi pedibusque rufis, thorace brevi, convexo, abdomine lateribus rotundato. - Long. 1 lin.

Habitat in Carinthia, Dom. Schmidt.

Statura brevi crassulaque omnino sequentis, at duplo mmor, pariter Gyrophaenam simulans. Antennae capite thoraceque vix longiores, extrorsum sensim leviter incrassatae, articulis penultimis transversis, ultimo breviter ovato, acummato, fuscae. Corpus nigrum, nitidum, griseo-pubescens, lateribus pilosellum. Caput subdeflexum, basi parum constrictum, fronte utrinque vage punctata, palpis rufis. Thorax coleopteris parum angustior, latitudene duplo brevior, lateribus leviter rotundatus, antice truncatus, basi rotundatus, supra undique sat convexus, vage subtilissime punctatus. Elytra thorace vix longiora, dense punctata, densius longiusque pubescentia. Abdomen breve, rotundatum, supra obsolete punctatum, pubescens, planum, margine elevato, subtus convexum. Pedes rufi, femoribus posterioribus medio piceis.

Variat corpore brunneo, capite abdominisque apice nigris.

* 102. H. hirta: Brevis, ferruginea, griseo-hirla, antennis fuscis, basi apiceque testaceis, thorace brevi, convexo, abdomine supra subglabro, parce punctato, - Long. $1 \frac{1}{2}$ lin.

Habitat in Brasilia.

Ferruginea, nitida, pilis densis erectis griseis hirta. Antennae graciles, capitis thoracisque longitudine, articulis 5-10 subobconicis, longitudine haud crassioribus, ultimo ovato, acuminato, basi aprceque testaceae, medio fuscae. Caput deflexum, thorace angustius, basi vix constrictum. Thorax coleopteris an- 
gustior, latitudine plus duplo brevior, valde convexus, subtiliter vage punctatus. Elytra thorace paulo longiora, apice ad angulum exteriorem leviter sinuata, fortius minus dense punctata. Abdomen subtus convexum, supra pilis depressis raris vestitum, minus crebre punctatum, ante apicem piceum, apice testaceum. Pedes testacel,

$\mathrm{Obs}$. Species singularis in hoc genere, a reliquis habitu discedens, Gyrophaenam.simulans, at neque corpus grabrum neque pedes intermedii basi spatio maiore distantes; capite deflexo et corpore puberulo Aleocharam etiam facile mentiens, ab utroque genere autem tarsorum structura remota.

103. H. imporfuna: Brevis, testacea, nitida, glabra, capite thoraceque nigris, hoc parvo, brevi, leviter convexo, abdomine lateribus rotundalo. - Long. $1 \frac{1}{3}$ lin.

Ilabitat in valle Araguensi Columbiae, Dom. Moritz.

Hahitu fere Gyrophaenae, ad huius generis videtur. Antennae capitis thoracisque prope longitudine, apicem versus sensim incrassatae, testaceae, articulis duobus primis flavis. Caput thoracis latitudine, suborbiculatum, fere transversum, basi profunde constrictum, fronte leviter convexa, laevissimum, utrinque subtiliter nigro-pilosellum, nigrum, nitıdum, oris partibus flavis. Thorax coleopteris duplo angustior, latitudine dimidio brevior, basi lateribusque eorem arcu rotundatus, apice truncatus, leviter convexus, basi distinctius marginatus, laevissimus, niger, nitidus, vix pubescens. Scutellum testaceum. Elytra thorace paulo longiora, minus depressa, parce obsoletissime punctulata, testacea, nitida. Abdomen rufo-testaceum, supra concavum, margine laterali sat elevato, acuto, modice rotundato. Pectus rufotestaceum. Pedes flavi, intermedii basi spatio lato distantes, posteriores tarsis sat elongatıs, postici tibiis elongatis, leviter curvatis.

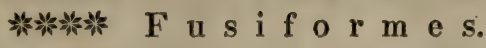

* 104. H. cinnamomea: Rufo-brunnea, subtilissime punctulata, thorace transverso, leviter convexo abdomineque nigro, supra polito apicem versus angustatis. - Long. 2 lin.

Er. Col. March. I. 336. 38.

Al. cinnamomea Grav. Micr. 88. 30. Mon. 160. 30. - Latr. Hist. nat. Crust et Ins. IX. 386. 30. - Gyll. Ins. Suec. II. 412.34. - Sahlb. Ins Fenn. I. 382. 65. Bolitochara cinnamomea Mannerh. Brachelytr. 82. 43. - Boisd. et Lacord. Faun. Ent, Paris. I. 552. 19.

Habitat in Europa.

Statura fere Aleocharae. Rufo-brunnea, opaca, subtilissime punctata, tenuiter pubescens, lateribus pilosella. Antennae vix capitis thoracisque longitudine, apicen versus incrassatae, articulo secundo tertio dimidio breviore, $\mathbf{5}$ - 10 transversis, sensim paulo crassioribus, ultimo praacedentibus tribus coniunctis parum breviore, acuminato, pilosellae, fuscae, articulis tribus primis et ultimo apice testaceis. Palpi testacel. Caput thorace angustius, basi vix constrictum, fronte parum convexa. Thorax basi coleopteris paululum angustior, latitudine duplo brevior, antrorsum leviter angustatus, lateribus praecipue ante medium et basi rotundatus, apice truncatus vel subemarginatus, angulis anterioribus deflexis, subrotundatis, posterioribus obtusis, leviter con- 
vexus, aequalis. Elytra thorace paulo longiora, apice truncata, ad angulum exteriorem subsinuata, sutura basi elevata, carinata. Abdomen nigrum, nitidum, apice segmentorumque margine rufo-piceis, infra convexum, parcius punctatum, supra planum, laevigatum, recurvum. Pedes testacei.

Mas abdominis segmento dorsali sexto tuberculo minuto munito distinctus.

105. H. semirufa: Nigra, thorace, elytris, antennis pedibusque rufis, thorace transverso, leviter convexo abdomineque supra parce punctato apicem versus subangust atis. - Long. $1 \frac{1}{3}$ lin.

Habitat in Gallia? Mus. Dom. Chevrolat.

Habitu omnino praecedentis, at triplo minor. Antennae capite thoraceque breviores, apicem versus incrassatae, articulo secundo tertıque subaequalibus, 5-10 transversis, sensim paulo crassioribus, ultimo praecedentibus ambobus paulo longiore, acuminato, pilosellae, rufae, medio fuscescentes. Caput thorace paulo angustius, deflexum, bası vix constrictum, fronte leviter convexa, parce punctulatum, griseo-pubescens, nitidulum, piceum, ore rufescente. Thorax latitudine duplo prope brevior, basi coleopteris vix angustior, apicem versus vix angustatus, lateribus ante medium et basi fortius rotundatus, basi utrinque subsinuatus, apice truncatus, angulis obtusis, subrotundatis, anterioribus deflexis, leviter convexus, supra scutellum leviter impressus, subtilter punctulatus, rufus, nitidus, griseo-pubescens. Elytra thorace paulo longiora, apice truncata, ad angulum exteriorem leviter sinuata, minus dense distinctius punctata, rufa, nitıda, griseo-pubescentia. Abdomen apicem versus subangustatum, supra parcius punctulatum, nigerrimum, nitidum, longius griseo-pubescens. Pectus parce punctatum, nigropiceum. Pedes rufi, coxis omnibus concoloribus.

Mas abdominis segmento quinto dorsali carinula acuta elevata instructo distinctus.

Obs. Habitus fere Silusae, at palpi labiales distincte triarticulati.

106. H. discors: Nigra, nitida, confertim punctata, antennarum basi pedibusque testaceis, elytris brevibus abdomineque rufis, illis angulo exteriore, hoc ante apicem nigris, thorace brevissimo, basi foveolato. Long. 2 lin.

Habitat ad Caracas Columbiae, Dom. Moritz.

Habitu fere Aleocharae, at huius generis, H. cinnamomeae aequalis, licet paulo latior, nigra, nitidula, tenuiter pubescens. Antennae capite thoraceque paulo breviores, apicem versus sensim leviter incrassatae, articulis 5 - 10 transversis, ultimo sat magno, compresso, nigrae, articulis 3 primis testaceis, ultimo summo apice ferrugineo. Palpi testacei. Caput basi haud constrictum, thoraci immersum, breviusculum, subtiliter punctulatum. Thorax coleopterorum prope latitudine, antice paulo angustior, latitudine plus duplo brevior, lateribus rotundatus, supra modice convexus, crebre subtiliter punctatus, basi supra scutellpm foveola transversa sat profunda impressus. Elytra thorace sesqui longiora, sat crebre punctata, prope basin medio leviter elevata, apice ad angulum exteriorem leviter sinuata, testaceo-rufa, angulo exteriore apicali nigro. Abdomen apicem versus leviter attenuatum, supra 
sublaevigatum, rufum, segmentis duobus antepenultimis nigris. Pedes rufotestacei.

* 107. H. longicornis: Oblonga, subdepressa, nigra, nitida, creberrime punctulata, elytris, pedibus anoque testaceis, thorace suborbiculato, abdo. mine supra confertissime punctato. - Long. $1 \frac{1}{2}$ lin.

Er. Col. March. I. 337. 40.

Al. longicornis Grav. Micr. 87. 29. - Latr. Hist. nat. Crust. et Ins. IX. 386. 89. Bolit ochara longicornis Mannerh. Brachelytr. 83. 50.

Aleoch. validicornis var. $b$ Sahlb. Ins. Fenn. I. 369. 44.

Var. Fusco-testacea, immatura.

Bolitochara validicornis Mannerh. Brachelytr. 83. 51.

Aleoch. validicornis Sahlb, Ins. Fenn. I. 369. 44.

Habitat in Europa.

Praecedente magis depressa et paulo minor, nigra, nitida, pube depressa parce vestita, lateribus pilosella. Antennae capite thoraceque longiores, crassiusculae, articulo secundo tertio paulo minore, 5-10 crassitie paulo longioribus, cylindricis, ultimo praecedentibus ambobus paulo breviore, elongato-ovato, piceae, basi interdum rufescentes. Palpi fusco-testacei. Caput parvum, rotundatum, subtiliter parce punctatum, fronte parum convexa vel subdepressa. Thorax coleopterorum prope latitudine, antrorsum subangustatus, longitudine parum brevior, lateribus et basi rotundatus, apice truncatus, angulis omnibus obtusis, anterioribus deflexis, posterioribus subrotundatis, parum convexus, dense subtiliter punctatus, interdum obsolete canaliculatus. Elytra thorace parum longiora, apice truncata, depressa, confertissine punctata, fusco - testacea. Abdomen nitidulum, nigrum, apice et segmentorum siugulorum marginibus piceo-testaceis, undique dense punctatum. Pedes testacei.

Obs. 1. Tibiae setis longis instructae et spinulis apicalibus longioribus munitae - affinitatem quandum cum Aleocharis genuinis indicare videntur. Thoracis forma ambigua inter hanc et secundam sectionem est haec species, H. sociali facie simillima, abdomen autem distincte apicem versus attenuatum.

2. Typus Gravenhorstianus perditus, inde in Mon. emissa. Descriptio cítata huic speciei satis congruit. Ab auctoribus Suecis saepius cum $H$. sociali confusa esse videtur, nam specimen pro Al. sericante Gyll. a Dom. Schönherr mis. sum Dom. S chüppel communicavit.

* 108. H. lividipennis: Nigra, opaca, dense subtiliter punctata, sericeopubescens, antennis longis, crassis, piceis, pedibus elytrisque testaceis, his circa scutellum infuscalis. - Long. $1 \frac{2}{3}$ lin.

Oxypoda lividipennis Mannerh. Brachelytr. 70. 2.

Aleoch. lividipennis Sahlb. Ins. Fenn. I. 388. 77.

Ho malota livida Er. Col. March. 1. 337. 39.

Habitat in Europa, America septentrionali.

Statura fere Oxypodae opacae et parum minor. Caput nigrum, opacum, confertissime subtiliter punctatum, pube tenui griseo-sericea obductum. Antennae capite thoraceque longiores, crassae, articulo tertio secundo paulo longiore, 4-10 longitudine paulo crassioribus, cylindricis, ultimo praece- 
dentibus ambobus longiore, elongato - cylindrico, acuminato, totae nigro - vel fusco-piceae. Caput thorace multo angustius, rotundatum, deflexum, fronte convexa, palpis fuscis. Thorax basi coleopterorum latitudine, antrorsum angustatus, latitudine postica dimidio brevior, basi et lateribus rotundatus, apice subemarginatus, angulis omnibus obtusis, anterioribus deflexis, leviter convexus, basi leviter transversim impressus, obsolete canaliculatus. Elytra thorace vix longiora, apice ad angulum exteriorem leviter sinuata, dilute testacea, macula communi triangulari fuscescente circa scutellum. Abdomen apicem versus sensim attenuatum, margine pilosellum, apice et segmentorum singulorum marginibus obscure testaceis. Pedes testacei.

Variat elytris testaceis, unicoloribus, nonnunquam etiam thoracis lateribus obscure testaceis.

* 109. H. terminata: Nigra, subnitida, antennarum articulo ultimo ferrugineo, pedibus piceis, thorace transverso, abdomine basi parcius, apice crebrius punclato, - Long. $1 \frac{1}{2}$ lin.

Habitat in Puerto Rico, Dom. Moritz.

Corpus nigrum, nitidulum, pube parca subtili depressa vestitum. Antennae capite thoraceque paulo longiores, apicem versus leviter incrassatae, articulis 5-10 transversis, sensim paulo crassioribus, nigrae, articulo ultimo ferrugineo. Caput thorace multo angustius, rotundatum, parce punctatum, ore subangustato, rufo-piceo. Thorax latitudine duplo fere brevior, basi coleopterorum latitudine, antrorsum paulo angustior, lateribus et basi rotundatus, apice truncatus, angulis omnibus obtusis, posterioribus subrotundatis, anterioribus deflexis, parum convexus, dense subtiliter punctatus. Elytra thorace paulo longiora, apice ad angulum exteriorem subsinuata, confertissime subtiliter punctata. Abdomen apicem versus leviter angustatum, supra laevigatum, segmentis singulis postice vage punctatis, sexto solo dense punctato. Pedes picei, geniculis tarsisque dilutioribus.

Mas distinctus elytris angulo apicali interiore tuberculo elevato, abdominis segmento tertio, sextoque carinatis.

Variat interdum colore corporis dilutiore, ferrugineo.

110. I. rubicula: Rufa, nitida, antennarum medio pectoreque piceis, elytris abdominisque segmentis duobus penultimis nigris, thorace transverso, basi subfoveolato. - Long. vix 1 lin.

Habitat in valle Araguensi Columbiae, Dom. Moritz.

Habitu fere praecedentis, at triplo prope minor. Antennae validae, capite thoraceque longiores, apicem versus sensim incrassatae, testaceae, articulis intermediis fuscis. Caput thorace angustius, basi parum constrictum, rufum, nitidum. Thoraxilatitudine duplo brevior, basi coleopteris paululum angustior, apicem versus leviter angustatus, lateribus leviter rotundatus, modice convexus, vix nisi obsoletissime punctulatus, basi obsolete foveolatus, rufus, nitidus, pube tenui erecta grisescente parce vestitus. Scutellum piceum. Elytra thorace duplo fere longiora, fortius crebriusque punctata, longius pubescentia, nigra, nitida, callo humerali, sutura margineque apicali piceis. Abdomen apicem versus subangustatum, parce pubescens, rufum, nitidum, segmentis duobus penultimis nigris. Pectus piceum. Pedes flavo-testacei. 
*111. H. testudinea: Breviuscula, nigra, nitida, creberrime munctulata, elytris pedibusque testaceis, thorace convexo, abdomine crebrius subtiliter punctalo. - Long. I lin.

Habitat in Germania: specimen singulum Dom. Schüppel prope Berolinum legit.

H. longicorni parum minor, statura fere $\mathrm{H}$. lividipennis, at brevior, fortius convexa, apicem versus magis attenuata, habitu fere Tachypori, nigra, nitida, pube brevissima tenuissimaque grisea parcius vestita. Antennae capitis thoracisque longitudine, tenuiores, apicem versus haud incrassatae, articulo secundo tertio vix breviore, 4-10 subaequalibus, crassitie haud brevioribus, ultimo praecedentibus ambobus longitudine aequali, subcylindrico, apice acuminato, nigrae, articulis tribus primis obscure piceis. Caput malusculum, thorace autem multo minus et angustius, rotundatum, fronte leviter convexa, subtilissime punctata. Thorax latitudine postica tertia parte brevior, basi coleopteris fere latior, antrorsum angustatus, apice dimidio angustior, basi leviter, lateribus fortius rotundatus, angulis omnibus deflexis, anterioribus subrotundatis, posterioribus obtusis, fortiter transversim convexus, confertissime subtiliter punctatus, aequalis. Elytra thorace paulo longiora, apice ad angulum exteriorem subsinuata, confertm subtilius punctata, piceo-testacea, circa scutellum fuscescentia. Abdomen apicem versus sensim at fortiter attenuatum, acuminatum, confertim subtiliter punctatum, lateribus pilosellum, apice piceum. Pedes testacei.

*112. H. fungi: Nigra, nitidula, creberrime punctulata, antennis pedibusque rufis, thorace transverso, convexiusculo, aequali. - Long. $1 \frac{1}{4}$ lin.

Er. Col. Mareh. I. 338. 41.

Al. fungi Grav. Mon. 157. 24. - Gyll. Ins. Suec. I1. 410. 32. - Sahlb. Ins. Fenn. 1. 378. 58. - Zetterst. Faun. Lappon. I. 102. 17. Ins. Lapp. 78. 25.

Bolit och ara fungi Mannerh. Brachelytr. 83. 52. - Runde Brachelytr. Hal. 32.12.

Habitat in Europa.

Breviuscula, utrinque subangustata, nigra, nitidula, parce subtilissime pubescens, confertim punctata. Antennae capitis thoracisque longitudine, graciles, apicem versus parum incrassatae, articilo primo crassiusculo, penultimis longitudine crassioribus, ultimo praecedentibus ambobus aequali, oblongo-ovato, acuminato, pilosellae, rufae, apice interdum fuscescentes. Caput thorace multo angustius, rotundatum, deflexum, fronte leviter convexa, ore piceo, palpis testaceis. Thorax basi coleopterorum latitudine, antrorsum leviter angustatus, latitudine postica dimidio brevior, lateribus et basi leviter rotundatis, angulis omnibus obtusis, subrotundatis, anterioribus deflexis, supra transversim convexus, aequalis. Elytra thorace paulo longiora, densius et minus subtiliter punctata, minus nitida. Abdomen supra confertim, postice parcius punctatum, margine pilosellum.. Pedes rufo-testacel.

Variat thorace elytrisque rufo-piceis, vel corpore toto rufo.

* 113. H. vernacula: Nigra, nitidula, confertissime punctulata, thoracis lateribus elytrisque ferrugineis, antennarum basi pedibusque testaceis, thorace transverso, convexiusculo, subtiliter canaliculato. - Long. $1 \frac{1}{4}$ lin. 
Er. Col. March. I. 339. 42.

Bolitochara fungi Boisd. et Lacord. Faun. Ent. Paris. I. 553. 22.

Habitat in Europa.

Statura omnino praecedentis, nigra, nitidula, confertim punctata, subtilissime parce pubescens. Antennae capite thoraceque paulo longiores, apicem versus leviter incrassatae, articulo primo crassiusculo, penultimis longitudine vix crassioribus, ultimo praecedentibus ambobus prope aequali, oblongo-ovato, subacuminato, fuscae, basi testaceae. Caput thorace angustius, rotundatum, parcius subtiliter punctatum, nigrum, nitidum, ore concolore, palpis flavo-testaceis. Thorax basi coleopterorum prope latitudine, antrorsum subangustatus, latitudine dimidio brevior, lateribus et basi rotundatus, apice truncatus, angulis posterioribus obtusis, anterioribus rotundatis, leviter transversim convexus, subtiliter canaliculatus, basi foveola impressus, confertim et minus subtiliter punctatus, nigro-piceus, lateribus rufescentibus. Elytra thorace paulo longiora, dense mmus subtiliter punctata, rufo-ferrugmea, circa scutellum et lateribus leviter infuscata. Abdomen nigrum, apice piceum, segmentis singulis piceo-marginatis, supra dense punctatum, margine pilosellum. Pedes testacei.

Mas abdominis segmento dorsali sexto apice 4-dentato distinctus.

Obs. 1. Statura praecedenti simillima, differt autem colore, punctura minus subtili, thorace canaliculato, basi impresso, angulis posterioribus haud rotundatis.

2. Bolitochara patruelis Boisd. et Lacord. Faun. Ent. Paris. I. 553. 23. „,huic paulo maior (Long. I lin. lat. $\frac{\mathrm{r}}{3} \mathrm{lin}$.) ceterum forma et colore simillima, elytris fuliginosis, macula magna obscure ferruginea, pedibus rufescenti-brunneis," mihi obscura et dubia, num ab ea vere distincta sit. - Oxypoda obfuscata Boisd. et Lacord. Faun. Ent. Paris. I. 539. 4. quoque ad H. vernaculam pertinere videtur.

* 114. H. ox bata: Nigra, nitidula, creberrime punctulata, elytris rufo-brunneis, pedibus testaceis, thorace transverso, convexiusculo, aequali. long. 1 lin.

Er. Col. Murch. I. 339. 43.

Bolitochara a garicola Mannerh. Brachelytr. 84. 53. (forte)

Aleoch. agaricola Sahlb. Ins. Fenn. I. 379. 59. (forte)

Habitat in Germania.

H. fungi simillima, nigra, nitidula, confertim punctata, subtilissime parce pubescens. Antennae capite thoraceque paulo longiores, apicem versus vix incrassatae, artıculo primo crassiusculo, penultimis longitudine haud crassioribus, ultimo penultimis ambobus paulo longiore, acuminato, totae nigro-fuscae. Caput thorace paulo angustius, orbiculatum, deflexum, parce subtiliterque punctulatum, ore piceo, palpis testaceis. Thorax amplus, latitudine tertia parte brevior, basi coleopterorum latitudine, antrorsum parum angustatus, lateribus et basi leviter rotundatus, angulis ommibus obtusis, subrotundatis, transversim convexus, aequalis, confertim subtiliter punctatus. Elytra thorace paulo longiora, confertim mmus subtiliter punctata, rufo-brunnea. Abdomen supra conferim, apice parcius punctatum, margine pilosellum, ano piceo. Pedes testacei.

$\mathrm{Obs}$. Ab H. fungi antennis obscuris et thorace paulo longiore distinguitur. 
* 115. H. clientula: Nigra, nitidula, subtiliter punctulata, elytris fortiter punctatis pedibusque ferrugineis, thorace transverso, convexiue sculo, abdomine supra parce punctato. - Long. 1 lin.

Habitat in ins. Corcyra, Dom. Parreyss.

Praecedentibus angustior, nigra, nitida, puhe tenui depressa parcius vestita. Antennae capitis thoracisque longitudine, apicem versus subincrassatae, articulo primo crassiusculo, penultimis longitudine haud crassioribus, ultimo praecedente sesqui longiore, ovato, fuscae. Palpi testacei. Caput thorace multo minus et angustius, deflexum, rotundatum, subtilissime vage punctatum. Thorax latitudine dimidio fere brevior, basi coleopteris vix angustior, antrorsum distinctius angustatus, lateribus et bası leviter rotundatus, apice truncatus, angulis omnibus obtusis, subrotundatis, leviter convexus, subtiliter punctatus, aequalis. Elytra thorace paulo longiora, apice ad angulum exteriorem distinctius sinuata, confertim fortius punctata, saturate testacea. Abdomen apicem versus distincte attenuatum, supra parcius subtiliusque punctatum, ano piceo. Pedes testacei.

Varietatem antennis, thorace elytrisque rufo-testaceis in Aegypto collegit Dom. Prof. Ehrenberg.

$\mathrm{Obs}$. Affinis praecedentibus, statura autem angustiore, thorace lateribus minus rotundato, elytris fortiter punctatis et apice sinuatis differt.

* 116. H. orphana: Nigra, nitidula, confertim punctulata, antennarum basi pedibusque obscure testaceis, thorace transverso, convexiusculo, aequali. - Long. $\frac{3}{4}$ lin.

Er. Col. March. I. 310. 44.

Habitat in Germania.

H. aterrima paulo minor, ceterum habitu praecedentrum, nigra, distincte punctulata, subtiliter parce pubescens, nitidula. Antennae capitis thoracisque longitudine, apicem versus leviter incrassatae, articnlo primo crassiusculo, articulis 6-10 longitudine paulo crassioribus, ultimo praecedentibus ambobus aequali, oblongo-ovato, subacuminato, pilosellae, nigricantes, articulo primo, interdum etiam secundo obscure testaceo. Caput thorace angustius, orbiculatum, parce subtiliter punctatum, ore piceo, palpis testaceis. Thorax basi coleopterorum latitudine, antrorsum subangustatus, latitudine dimidio brevior, basi rotundatus, utrinque subsinuatus, angulis posterioribus obtusis, lateribus angulisque anterioribus rotundatis, apice truncatus, leviter transversim convexus, aequalis, confertim subtiliter punctatus. Elytra thorace sesqui longiora, apice ad angulum exteriorem leviter sinuata, dense minus subti. liter punctata, fusco-nigra. Abdomen nitidulum, crebrius distinctiusque punctulatum, margine pilosellum. Pedes fusco-testacei.

* 117. H. aterrima: Nigra, subopaca, tenuiter sericeo-pubescens, pedibus flavescentibus, thorace transverso, convexiusculo, aequali. - Long. 1 lin.

Er. Col March. I. 341, 46. Aleoch. a terrima Grav. Micr. 83. 22. Mon. 162. 33.

Bolit ochara fuscula Mannerh. Brachelytr. 84. 64. Aleochara fuscula Sahlb. Ins. Fenn. I. 37960 - Zetterst. Ins. Lappon. 78. 24 
Var. a: Elylris brunneis.

Aleoch. pygmaea Grav. Micr. 36. 27. Mon. 163. 39. - Latr. Hist. nat. Crust. et Ins. IX. 385. 27.

Aleoch. umbrat a Grav. Micr. 90. 32. Mon. 163. 42. - Latr. Hist. nut. Crust. et Ins, IX. 387. 32.

Bolitochara minutissima Boisd. et Lacord. Faun. Ent. Paris I. 553. 21. (forte)

Var. b: Thoracis lateribus elytrisque brunneis.

Aleoch. obfuscata Grav. Micr. 87. 28. Mon. 163. 40. - Latr. Hist. nat. Crust. et Ins. IX. 386. 28. - Gyll. Ins. Suec. II. 418. 40. - Sahlb. Ins. Fenn. I. 385. 71. Oxypoda obf uscata Mannerh. Brachelytr. 72. 12.

Habitat in Europa.

Statura fere $H$. fungi, at paulo minor, angustior, subopaca, subtilissime dense punctata, pube subtili griseo-sericea dense vestita. Anfennae capite thoraceque paulo longiores, apicem versus parum incrassatae, articulo primo haud incrassato, penultimis longitudine vix crassioribus, articulo ultimo oblongo-ovato, subacuminato, nigrae, articulis primis saepe flavescentibus. Palpi fuscescentes. Caput thorace angustius, rotundatum, ore paulum attenuato, deflexum, fronte convexa, nigrum. Thorax coleopteris basi haud angustior, antrorsum leviter angustatus, latitudine postica plus dimidio brevior, basi et lateribns rotundatus, apice truncatus, angulis omnibus obtusis, anterioribus leviter deflexis, subrotundatis, leviter transversim convexus, aequalis, niger vel fuscus, lateribus saepe dilutioribus. Elytra thorace sesqui longiora, apıce ad angulum exteriorem subsinuata, nigra, apicem versus saepe brunnea, vel brunnea, basi magis minusve nigricantia. Abdomen apicem versus attenuatum, supra confertissime subtiliter punctatum, minus opacum, nigrum, apice piceum, parce pilosellum. Pedes obscure flavi, coxis anticis dilutioribus.

Individuis praecocibus thorax et eiytra vel corpus totum rufo-testacea.

* 118. H. ambigua: Nigra, opaca, sericeo-pubescens, thorace elytrisque fusco-testaceis, antennarum basi pedibusque flavis, thorace convexiusculo. - Long. 1 lin.

Habitat in America septentionali, Dom. Zimmermann.

Affinis praecedenti, at angustior, sublinearis, fusco-nigra, opaca, subtilissime confertim punctata, pube tenuissima griseo-sericea dense vestita. Antennae capitis thoracisque longitudine, apicem versus sensim leviter incrassatae, articulo secundo tertio sesqui maiore, penultimis leviter transversis, ultimo maiusculo, oblongo-ovato, apice subacuminato, fuscae, basi flavae. Caput thorare parum angustius, rotundatum, nigrum. Thorax latitudine parum brevior, lateribus et basi rotundatus, apice truncatus, angulis posterioribus obtusis, anterioribus subrotundatis, leviter convexus, aequalis, nigro-piceus. Elytra thoracis latitudine, fusco-testacea. Abdomen supra totum subtiliter confertissime punctatum, nigrum. Pedes flavi, tarsis posticis articulo primo sequentibus paulo longiore.

$$
\text { Species mihi invisae, forte huius generis. }
$$

119. H. (?) crassicornis: Brevior, nigra, pedibus testaceis, elytris brunneis, thorace amplo, suborbiculato, antennis longis, crassis, totis, nigris. - Long. 1 $\frac{1}{3}$ lin.

Aleoch, crassicornis Gyll. Ins. Suec. IV. 486. 20-21. - Sahlb. Ins. Fenn. I.362. 31. 
Bolitochara crassicornis Mannerh. Brachelytr. 77. 12.

Habitat in Suecia, in succo arborum, fungis et quisquiliis, passim.

Statura brevior, latior et crassior quam H. elongatulae, H. sociali (longicorni) propinqua, sed thorax multo maior, longior, suborbiculatus. Caput thorace paulo minus, rotundatum, convexum, nigrum, nitidum, punctulatum, ore palpisque nigro-piceis. Antennae capite cum thorace multo longiores, crassae, nigrae, articulo primo longo, clavato, basi piceo, 2, 3 longiusculis, obconicis, $\mathbf{4 - 1 0}$ cyathiformibus, sensim crassioribus, ultimo adhuc maiore, oblongo-ovato, acuminato. Thorax amplus, suborbiculatus, vel longitudine perparum latior, supra subdepressus, minus saturate niger, subtiliter punctulatus, tenuiter pubescens, in medio baseos foveola subrotunda et ante illam impressiones obsoletae in medio dorsi. Scutellum parvủm, triangulare, concolor. Elytra thoracis medio non latiora, nec illo longiora, apice subsinuata, supra subdepressa, confertim subtilissime punctulata, aut saturatius aut dilutius brunnea, subopaca. Abdomen pone elytra illis duplo longius, nigrnm, nitidum, apice obtusum. Corpus subtus nigro-piceum, nitidum, punctulatum, pubescens, segmentorum ventralium marginibus anoque testaceis. Pedes mediocres, toti testacei. (Gyll.)

120. H. (?) annularis: Linearis, subnitida, rufo-testacea, capite abdominisque cingulo piceis, thorace aequali, antennis validioribus, brevibus, antrorsum parum incrassatis. - Long. vix 1 lin.

Bolit ochara an ularis-Mannerh. Brachelytr. 76. 8.

Aleochara annularis Sahlb. Ins. Fenn. I. 353. 15.

Habitat in Fennia australi, rarius.

H. circellari similis, sed differt corpore magis lineari, thorace breviore et antennis validioribus brevioribusque. Caput thorace paulo angustius, rotundatum, convexum, ferrugineo-piceum, nitidum, vix punctulatum. Os et palpi testacea. Antennae thorace breviores, basi pallide testaceae, extrorsum crassiores, fusco-ferrugineae. Thorax longitudine latior, antice truncatus, lateribus parum rotundatus, postice subtruncatus, supra modice convexus, rufo-testaceus, vix punctulatus, pube sericante obductus. Scutellum minutum, triangulare, rufo-testaceum. Elytra thorace vix latiora, sed eodem paulo longiora, supra rufo-testacea, depressa, subtilissime punctulata. Abdomen pone elytra longitudine reliqui corporis, fusco-piceum, segmentis ultimis testaceis. Corpus subtus ferrugineo-testaceum, segmentis abdominis anterioribus piceis, marginibus tamen ferrugineis. Pedes elongati, pallide testacei. (Sahlb.)

121. H. (?) haemorrhoa: Nigra, subnitida, longius pubescens, antennarum basi, pedibus, apice elytrorum anoque mifis, articulo antennarum ultimo magno, subgloboso. - Long. $\frac{2}{3}$ lin.

Bolut ochara haemorrhoa Mannerh. Brachelytr. 76. 11.

Aleochara ha emorrhoa Sahlb. Ins. Fenn. I. 355. 20.

Habitat in Fennia australi.

Phloeopora reptanti statura simillima, sed duplo minor est, longius pubescens, et aliter colorata, antennisque gaudet brevioribus. Caput thorace 
angustius, convexiusculum, nigrum, subnitidum, vix subtilissime punctulatum, pubescens; os et palpi testacea. Antennae thorace breviores, validiusculae, versus apicem incrassatae, fusco-ferrugineae, basi pallidiores, articulo ultimo magno, subgloboso. Thorax longitudine paulo latior, antice truncatus, angulis deflexis, lateribus parum dilatatus, postice subtruncatus, angulis obtusis, supra convexus, niger, subnitidus, subtilissime punctulatus, pube longiore grisescente parcius adspersus. Scutellum brevissimum, nigrum. Elytra thorace paulo latiora et longiora, apice subtruncata, supra nigra, versus apicem rufescentia, subnitida, longius pubescentia, crebre et evidentius punctulata. Abdomen pone elytra longitudine corporis reliqui, nigrum, subnitidum, pubescens, pnnctulatum, ano rufescente. Corpus subtus nigrum, subnitidum, pubesces, segmentorum margmibus anoque rufis. Pedes elongat, pallidi. (Sahlb.)

Obs. Dubito anne potius ad $\mathrm{Phloe}$ oporae genus revocanda sit, Phl. corticali longe minor esse videtur.

122. H. (?) angustata: Linearis, elongata, nigro-picea, ore, antennarum basi, elytris, ano pedibusque testaceis, thorace longiore, postice angustiore, basi foveola impresso. - Long. $\frac{3}{4}$ lin.

Aleoch. angustata Sahlb. Ins. Fenn. I. 363. 33.

Bolitochara compressa Mannerh. Brachelytr. 80. 35.

Habitat in Fennia australi, rarissime.

H. elongatulae minoribus individuis (Al. depressiusculae) magnitudine et statura similis, sed differt imprimis thoracis forma et antennis paulo crassioribus. Caput basi truncatum, antice rotundatum, nigrum, subtiliter punctulatum, ore et palpis testaceis. Antennae thoracis longitudine, basi testaceae, versus apicem nigro-fuscae et incrassatae, articulo primo incrassato, clavato, ultimo ovato, obtuso. Thorax longitudine parum latior, antice truncatus, angulis anterioribus obtusis, basi subtruncatus, supra depressus, nigro-piceus, subopacus, subtiliter punctulatus, subpubescens, basi foveola obsoleta impressus. Scutellum minutissimum, nigrum. Elytra thorace latiora et longiora, subquadrata, apice truncata, supra depressa, testacea, subtiliter punctulata, subpubescentia. Abdomen pone elytra reliquo corpore brevius, corpusque subtus nigro-picea, subpubescentia, ano testaceo. Pedes mediocres, toti testacei. (Sahlb.)

123. H. (?) tenella: Fusco-picea, linearis, antennis longis, extrorsum vix crassioribus, thorace subquadrato, canaliculato, tibiis tarsisque pallidioribus. - Long. $\frac{2}{3}$ lin.

Bolitochara ten ella Mannerh. Brachelytr. 81. 36.

Aleoch. te nella Suhlb. Ins. Fenn. I. 364. 34.

Habitat in Fennia australi, rarius.

Praecedente (angustata) plus quam duplo minor, minus depressa, thorace latiore subquadrato et colore diversa. (Mannerh.)

124. H. (?) luridipennis: Linearis, nigro-picea, opaca, pubescens, antennarum basi, elytris, pedibus anoque livido-testaceis, thorace subquadrato, postice foveolato.

Bolitochara luridipennis Mannerh. Brachelytr. 77. 15.

Habitat Petropoli. 
H. sociali triplo maior, magis pubescens, opaca, thorace longiore, antennis medio haud incrassatis diversa. (Mannerh.)

Obs. Forte $\mathbf{H}$. elongatulae var.

\section{米将}

125. H. (?) macilenta: Creberrime punctulata, subnitida, fusco-nigra, elytris quadratis pedibusque fusco-testaceis, thorace obsolete canaliculato. Aleoch. macilenta Sahlb. Ins. Fenn. I. 371. 47. - Zetterst. Ins. Lapp. 77. 21. Aleoch. pygmaea Zetterst. Faun. Lappon. I. 101. 16.

Habitat in Lapponia, sub cortice Betulae mense Augusto capta.

Pusilla, H. sociali minor, H. fungi subaequalis. Caput thorace paulo angustius, subtilissime punctulatum, nitidum, nigrum, ore fusco-testaceo. Antennae thorace parum longiores, pubescentes, graciles, extrorsum paulo crassiores, totae nigrae. Thorax latitudine paulo latior, supra depressus, niger, parum nitidus, vix pubescens, creberrime punctulatus, in medio baseos foveola parva obsoleta. Elytra subquadrata, tenuiter pubescentia, subtilissime punctulata, testacea. Corpus fusco-nigrum, pubescens. Pedes pallide testacei. (Zetterst.)

Obs. H. oblitae affinis videtur.

126. H. (?) fusca: Brunneo-fusca, nitida, crebre punctulata, sericeo-pubescens, capile abdomineque nigris, thorace obsolete canaliculato, antennis longis, filiformibus, testaceis. - Long. $1 \frac{1}{6}$ lin.

Aleoch. fusca Sahlb. Ins. Fenn. I. 371. 48. - Zetterst. Ins. Lappon. 78. 22.

Habitat in Lapponia, rarissime, unicum specimen invenit F. Sahlberg. H. sociali (longicorni) statura satis similis, sed differt colore, antennis tenuioribus et thorace magis depresso. Caput thorace angustius, rotundatum, nigrum, nitidum, subtilissime punctulatum, subpubescens, ore palpisque fusco-brunneis. Antennae thorace longiores, fuscescentes, filiformes, articulo ultimo oblongo-ovato, subacuminato. Thorax transversus, antice truncatus, angulis compressis, lateribus et postice rotundatus, supra subdepressus, obsoletius canaliculatus, brunneo-fuscus, ad latera parum pellucidus, crebre punctulatus, sericeo-pubescens. Scutellum minutum, triangulare, punctulatum, pubescens. Elytra thorace vix vel parum latiora et longiora, apice truncata, supra subdepressa, crebre punctulata, pubescentia, brunneo-fusca. Abdomen pone elytra longitudine reliqui corporis, ovatum, nigrum, nitidum, tenuiter pubescens, vix punctulatum, segmento sexto piceo-ferrugineo. Corpus subtus brunneo-fuscum, nitidum, punctulatum, pubescens, segmentis ventralibus piceo-nigris, sexto piceo-ferrugineo. Pedes toti pallide testacei. (Sahlb.)

Obs. Staphyl. fuscus Marsh. Ent. Britt. 514. 49. quoque ad hoc genus pertinet, mihi autem non extricatus.

127. (H.) scapularis: Piceo-ferruginea, nitida, capile, abdominis medio elytrisque nigro-fuscis, humeris, basi antennarum, ano et pedibus pallide rufescentibus, antennis brevibus, apice incrassatis. - Long. vix 1 lin. Aleoch. scapularis Sahlb. Ins. Fenn. I. 372. 50. 
Bolitochara axillaris Mannerh. Brachelytr. 78. 19.

Habitat in Fennia australi, rarissime.

H. sociali var. c. (nigritulae) similis, sed differt thorace paulo longiore et convexiore. Caput thorace angustius, rotundatum, basi truncatum, nigrofúscum, nitidum, subtilissime punctulatum, foveola frontis impressa. Antennae thorace paulo breviores, ferrugineo-piceae, basi pallide rufescentes, articulo primo elongato, incrassato, secundo et tertio itidem longioribus, sequentibus brevibus, versus apicem sensim incrassatis, ultimo oblongo-ovato, apice obtusiusculo. Thorax subtransversus, antice truncatus, angulis depressis, lateribus et postice rotundatus, supra subconvexus, piceo-ferrugineus, nitidus, crebre punctulatus, pubescens. Scutellum minutum, triangulare, nigro-fuscum, punctulatum. Elytra thorace latiora et paulo Iongiora, apice truncata, supra depressa, nigro-fusca, humeris rufescentibus, crebre punctulata, pubescentia. Abdomen pone elytra vix longitudine reliqui corporis, piceo-ferrugineum, nitidum, segmentis $4-6$ nigro-fuscis, ano pallide rufescente, vix punctulatum. Corpus subtus piceo-ferrugineum, nitidum, subtilissime punctulatum, pubescens, segmentis $4-6$ ventralibus nigro-fuscis, ano pallide rufescente. Pedes toti pallıde rufescentes. (Sahlb.)

128. H. (?) borealis: Nigra, nitida, subtiliter punctulata, pubescens, tarsis piceo-ferrugineis, thorace postice subangulato-rotundato. - Long. $1 \frac{1}{4}$ lin.

Aleoch. borealis Sahlb. Ins. Fenn. I. 361. 29. - Zetterst. Ins. Lappon. 74. 4.

Habitat in Lapponia, rarissime.

Magnitudine et statura Tachyusae atrae, sed ab hac et ceteris thoracis forma imprimis distincta. Caput thorace angustius, suborbiculatum, nigrum, nitidum, subtilissime punctulatum, subpubescens, fronte obsolete foveolata. Antennae thorace longiores, versus apicem incrassatae, articulo nltimo oblongo-ovato. Thorax longitudine latior, antice truncatus, lateribus longe ultra medium subrectus, vel parum tantum rotundatus, iuxta basin vero subangulatim angustatus, basi truncatus, supra depressus, niger, subtilissime punctulatus, pubescens. Scutellum triangulare, nigrum. Elytra thorace latiora et longiora, apice truncata, supra subdepressa, nigra, parum aenescentia, subtiliter punctulata. Abdomen pone elytra longitudine reliqui corporis, nigrum, nitidissımum, punctulatum, parce pubescens. Corpus subtus nigrum, nitidum, pube depressa longiore parce obsitum. Pedes nigropicei, tarsis piceo-ferrugineis. (Sahlb.)

Obs. H. ancipiti et concolori affinis videtur.

\section{*将将}

129. H. (?) marginalis: Nigra, nitida, punclulata, pubescens, ore, antennis, thoracis lateribus, elytris, pedibus anoque rufo-testaceis, elytrorum angulo apicis fusco. - Long. $1 \frac{1}{2}$ lin.

Aleoch. marginalis Grav. Mon. 161. 31. - Gyll. Ins. Suec. II. 420. 42.

Habitat in Gallia, Suecia.

Oxypoda alternante paulo latior et crassior, sed non longior. Caput thorace parum angustius, subtransversum, nigrum, nitidum, crebre 
punctulatum, versus. os angustatum, ore palpisque rufo-testaceis; oculi magni, oblongi, brunnei. Antennae vix longitudine thoracis, crassiusculae, in medio fusco-ferrugineae, basi apiceque dilutius rufo-testaceae. Thorax brevis, transversus, antice truncatus, angulis deflexis, valde compressis, unde ibl angustior apparet, lateribus parum rotundatus, basi truncatus, angulis obtusis, supra convexus, niger, nitidus, subtilissime crebre punctulatus, tenuiter pubescens, angulıs posticis late rufo-testaceis, qui color iuxta marginem et basin anguste extenditur. Scutellum breve, triangulare, fuscum, punctulatum. Elytra thoracis basi vix latiora, sed illo dimidio longiora, subquadrata, supra depressa, rufo-testacea, nitida, confertissime et evidentius rugoso-punctata, tenuiter pubescentia, angulo exteriore apicis oblique infuscato. Abdomen pone elytra longitudine reliqui corporis, crassum, obtusum, nigrum, nitidum, creberrime punctulatum, ano rufo-testaceo. Corpus subtus nigrum, nitidum, crebre punctulatum, segmentorum ventralium marginibus anoque late rufo-testaceis. Pedes mediocres, toti rufo-testacei. (Gyll.)

Obs. H. cinnamomeae affinis videtur.

130. H. (?) Mannerheimii: Brevis, lata, nigra, subnitida, subtilissime punctulata, pubescens, pedibus fusco-testaceis, antennis thorace canaliculato multo longioribus. - Long $\frac{2}{3}$ lin.

Aleoch. Mannerheimii Sahlb. Ins. Fenn. I. 36̋0. 61.

Habitat in Fennia, sub lapidibus, rarissime.

Media inter $\mathrm{H}$. aterrimam et sequentem, ab illa thorace canaliculato et minus convexo, ab hac antennis multo longioribus, ab utraque corpore paulo latiore distincta. Caput thorace angustius, rotundatum, basi truncatum, nigrum, nitidum, subtilissime punctulatum. Antennae thorace multo longiores, extrorsum parum incrassatae, nigrae, articulo ultimo oblongo-conico, acuminato. Thorax latitudine plus quam dimidio latior, antice paulo angustior, truncatus, angulis compressis, lateribus et postice rotundatus, supra subconvexus, niger, subritidus, subtilissime punctulatus, tenuiter sericeo-pubescens, obsolete canaliculatus. Scutellum triangulare, nigrum, subtilissime punctulatum. Elytra thorace vix latiora vel longiora, apice truncata, supra depressa, nigra, subtilissime punctulata, densius pubescentia, subopaca. Abdomen pone elytra reliquo corpore brevins, corpusque subtus nigra, nitida, pubescentia. Pedes fusco-testacei. (Sahlb.)

131. H.(?) parva: Nigra, nitida, vix pubescens, antennis brevibus, tenuioribus, extrorsum vix incrassatis, thorace canaliculato, elytris piceis, pedibus pallidis. - Long. vix $\frac{2}{3}$ lin.

Ale och. parva Sahlb. Ins. Fenn. I. 380. 62.

Bolitochara parvula Mannerh. Brachelytr. 84. 55.

Habitat in Fennia australi.

Antennis brevioribus, extrorsum vix incrassatis et thorace canaliculato ab H. aterrima (fuscula) differt. Caput ut in praecedente, sed palpi piceo-testacei. Antennae longitudine thoracis, totae nigrae, extrorsum vix vel parum omnino incrassatae, articulo ultimo ovato. Thorax transversus, longitudine dimidio latior, antice angustior, truncatus, angulis compressis, 
lateribus et postice rotundatus, supra convexus, niger, nitidus, subtilissime punctulatus, canaliculatus. Scutellum triangulare, nigrum, subtilissime punctulatum. Elytra thorace vix latiora, sed eodem paulo longiora, apice truncata, supra depressa, nigro - picea, nitida, crebre punctulata, vix pubescentia. Abdomen pone elytra vix reliqui corporis longitudine, corpusque subtus nigra, nitida, subtilissime punctulata, ano picea. Pedes testacei. (Sahlb.)

132. H. (?) pallidula: Supra luteo-ferruginea, subnitida, oculis nigris, abdominisque cingulo fusco, subtus pallidior, thorace brevi, valde convexo, basi foveolato. - Long. vix $\frac{1}{2}$ lin.

Bolitochara pallidula Mannerh. Brachelytr. 84. 56.

Aleoch. pallidula Sahlb. Ins. Fenn. I. 381. 63.

Habitat in Fennia australi.

Praecedente adhuc duplo minor, colore et thorace multo convexiore ab eadem distincta, H. (?) annulari quoad colorem affinis, sed differt thorace breviore et latiore. Corpus totum, praeter oculos nigros et segmenta abdominis 3 et $\mathbf{4}$ infuscata, supra luteo-ferrugineum, subtus pallidius, subnitidum, tenuiter pubescens. Caput thorace angustius, rotundatum, basi truncatum. (Antennae in typo desunt.) Thorax transversus, longitudine fere duplo latior, antice angustior, truncatus, angulis compressis, lateribus parum rotundatus, basi subtruncatus, supra valde convexus, foveola supra scutellum obsoleta impressus. Scutellum triangulare. Elytra thorace vix longiora vel latiora, apice truncata, supra depressa. Abdomen pone elytra longitudine reliqui corporis. (Sahlb.)

133. H. (?) t enera: Nigra, nitida, creberrime punctulata, palpis, segmentorum ventralium marginibus, ano pedibusque piceo-testaceis, elytris nigro-piceis, apice subemarginatis, antennis subfiliformibus. - Long. vix I lin.

Aleoch. ten era Sahlb. Ins. Fenn. I. 386. 74.

Habitat in Fennia australi, rarissime.

Magnitudine et statura Myllaenae dubiae, a qua tamen multis notis differt, $a b$ H. flavipede, cui etiam similis est, thorace longiore et angulis eius posterioribus haud acutis satis diversa. Caput thorace multo minus, subtransversum, nigrum, nitidum, subtilissime punctulatum, subpubescens, palpis piceo-testaceis. Antennae thorace paulo longiores, subfiliformes, fusco-nigrae, pubcscentes, articulis tribus baseos elongatis, primo incrassato, 2 et 3 obconicis, ilio tamen hoc paulo breviore, insequentibus brevibus, subaequalibus, ultimo oblongo-conico, acuminato. Thorax transversus, longitudine dimidio latior, antice angustior, truncatus, angulis deflexis, lateribus rotundatus, basi subtruncatus, angulis posterioribus obtusis, supra convexus, niger, nitidus, creberrime et subtilissime punctulatus, tenuiter pubescens. Scutellum triangulare, nigrum, subtilissime punctulatum. Elytra thoracis basi vix latiora, sed eodem paulo longiora, apice intra angulum exteriorem sinuato - subemarginata, supra depressa, nigro-picea, nitida, creberrime punctulato - rugosa, tenuiter pubescentia. Abdomen pone elytra reliquo corpore paulo brevius, nigrum, nitidum, vix punctulatum. Corpus subtus nigrum, 
nitidum, subtilissime punctulatum, pubescens, segmentorum ventralium marginibus anoque piceo-testaceis. Pedes mediocres, piceo-testacei. (Sahlb.)

134. H. (?) impressifrons: Nigra, nitida, pedibus piceo-testaceis, capile thorace vix angusliore, vertice obsolete foveolato, thorace brevi, rotundalo, antennis thorace longioribus, hirsutis, extrorsum paulo crassioribus, - Long. $\frac{3}{4}$ lin.

Var. Antennarum basi et elytris fusco-testaceis, pedibus pallidioribus. Bolitochara impressifrons Mannerh. Brachelytr. 81.57.

Aleoch. impressifrons Sahlb. Ins. Fenn. I. 387. 75.

Habitat in Fennia australi, rarius.

Statura ad Staphylini genus aliquatenus accedit. Caput thorace vix angustius, rotundatum, basi truncatum, nigrum, nitidum, vix subtilissime pronctulatum, vertice foveola plus minusve conspicua impresso. Os et palpi piceo-testacea. Antennae thorace paulo longiores, fusco-nigrae, dense pilosae, articulis baseos tribus piceo-testaceis, elongatis, primo insequentibus crassiore, secundo subcylindrico, tertio obconico, 4-10 brevibus, extrorsum sensim crassioribus, ultimo magno, ovato, subacuto. Thorax longitudine latior, antice truncatus, lateribus et postice rotundatus, supra subdepressus, niger, vix subtilissime punctulatus, subpubescens, ante scutellum obsolete foveolatus. Scutellum minutum, triangulare, nigrum. Elytra thorace latiora et nonnihil longiora, subquadrata, apice truncata, supra depressa, nigra, subtilissıme punctulata, tenuiter pubescentia. Abdomen pone elytra reliquo corpore brevius, corpusque subtus nigra, nitida, pubescentia. Pedes mediocres, toti piceo-testacei.

V a r. colore pallidiore tantum differt. Antennae fuscescentes, basi pallidiores. Thorax nigro-fuscus. Elytra fusco-testacea, et pedes toti pallidi.

Obs. Sub diversa sectione, thorace capite vix latiore, suborbiculato et abdomine sublineari distincta, hanc speciem proponit Com. Mannerheim. - (Sahlb.)

\section{Oxypoda Mannerh.}

\section{Mannerh. Brachelytr. p. 69. - Er. Col. March. I. p. 342.}

Maxillae mala interiore mutica, intus spinulis ciliata.

Ligula apice bifida; paraglossae nullae.

Palpi labiales 3-articulati, articulo 'secundo breviore.

Tarsi omnes 5-articulati, postici articulo primo elongato.

Corpus vel oblongum. vel elongatum, minus depressum, alatum. Caput exsertum, saepe deflexum, basi haud constrictum, oculis mediocribus, vix prominulis. Labrum apice leviter rotundatum, mandibulas obtegens. Mandibulae muticae. Maxillae mala exteriore cornea, basi apiceque membranea, portione membranea apicalı pubescente, mala interiore exteriore paulo breviore, membranea, apice oblique introrsum emarginata, sinu spinulis brevibus ciliato. Palpi maxillares modice elongati, articulo secundo tertioque longitudine subaequalibus, hoc leviter incrassato, quarto minuto, subulato. Labium mento transverso, apice leviter emarginato, ligula minus brevi, palporum labialium articulum primum excedente, apice bifida, paraglossis nullis. Palpi labiales tri-articulati, articulo primo maiore, secundo hoc duplo minore, tertio te- 
nuiore, at primo parum breviore. Antennae articulo secundo tertıoque reliquis magis elongatis, inter se aequalibus. Thorax iam antrorsum angustatus, convexus, iam lateribus parallelis. Scutellum triangulare. Elytra apice introrsum oblique truncata, extrorsum ad angulum exteriorem sinuata. Abdomen iam apicem versus angustatum, iam lmeare. Pedes leviter elongati, intermedii basi approximati, tarsis omnibus 5 -articulatis, postici articulo primo elongato.

$$
\text { O b s e r vationes. }
$$

1. Oris structura omnino ut in Homalota (v. t. III. f. 8. et f. 22.) Distinguitur ab hoc genere tarsis posticis articulo primo elongato et imprimis tarsis anticis 5-articulatis.

2. Genus Sphenoma Mannerh. Brachelytr. p. 68. ab Oxypoda nullo modo distinctum. Auctor illustrissimus errore quodam tarsorum articulos aequales observavit.

3. Mas saepius antennis validioribus, et apice magis incrassatis, nonnunquam etiam abdominis segmento inferiore sexto apice medio producto distinguitur.

Duas in hoc genere sectiones condidi:

Sectio prima habitu Tachyporino, i. e. thorace amplo, convexo, elytrorum basin et caput amplectente, abdomine apicem apicem versus attenuato, apice saepius pilosello, corpore plerumque dense subtiliterque punctato, pube brevissima subtilissimaque sericante obducto. - Victus in fungis et sub foliis deciduis, musco, et in quisquliiis.

Sectio altera corpore lineari, elongato, thorace subquadrato, capite magis exserto, abdomine lineari, punctura et pubescentia minus confertis subtilibusque. - Victus sub arborum cortice.

$$
\text { * F u s i o r m e s. }
$$

* 1. O. ruficornis: Nigra, nitida, antennis, pedibus, elytris anoque testaceis, thorace parum convexo, postice foveolato obsoleteque canaliculato. - Long. $2 \frac{1}{2}$ lin.

Mannerh. Braehelytr. 69. 1.

Aleoch. ruficornis Gyll. Ins. Suec. II. 422.44.

Oxypoda lut eip ennis var. Er. Col. March. I. 343. 1.

Habitat in Germania septentrionali, Suecia, Dom. Schïppel et Weber, in Gallia. Mus. Dom. Aubé.

Procera in hoc genere, sequente plus duplo maior, nigra, nitida, pube subtili griseo-sericea vestita. Antennae capite thoraceque paulo longiores, graciles, articulo secundo tertio vix breviore, ultimo oblongo, acuminato, totae rufo-testaceae. Palpi rufo-testacei. Caput deflexum, subtiliter punctatum. Thorax basi coleopteris haud angustior, latitudine dimidio brevior, basi et lateribus leviter rotundatus, antrorsum subangustatus, apice truncatus, angulis omnibus obtusiusculis, anterioribus deflexis, dorso leviter convexus, densius subtiliter punctatus, postice obsolete canaliculatus, supra scutellum profundius impressus, margine laterali plamusculo, rufo-piceo. Elytra thorace longiora, confertim subtiliter punctata, testacea. Abdomen apicem versus at:enuatum, confertissime subtilissimeque punctatum, ano segmentorumque singulorum marginibus rufo-testaceis. Pedes dilute testacei, tarsis posticis articulis intermeciiis elongatis, articulo primo sequentibus ambobus aequali. 
Mas abdominis segmento ventrali sexto apice triangulariter producto distinctus.

Obs. 1. Revera distincta videtur a sequente, statura multo maiore, thorace minus convexo, antrorsum minus angustato, margine laterali planiusculo, antennis elytrisque unicoloribus, et tarsorum posticorum articulis intermediis elongatis.

2. Aleocharam ruficornem Grav. in genere proxime sequente quaeras.

* 2. O. luteipennis: Nigra, sericeo-pubescens, antennarum basi, pedibus elytrisque testaceis, his circa scutellum lateribusgue infuscatis, thorace leviter convexo, postice foveolato obsoleteque canaliculato. - Long. $1 \frac{3}{4}$ lin.

Er. Col. March. I. 343. 1.

Aleoch. ruficornis var. 6 Gyll. Ins. Suec. II. 422.

Aleoch. ruficornis Sahlb. Ins. Fenn. I. 388. 76.

\section{Habitat in Germania, Suecia.}

O. opaca paulo maior et minus convexa, nigra, parum nitida, pube tenui cinereo-sericea dense vestita. Antennae capitis thoracisque longitudine, apicem versus subincrassatae, articulo secundo tertioque longitudine aequalibus, ultimo apice abrupte compresso, articulo primo testaceo, proximis rufo-piceis, reliquis nigris. Palpi testacei. Caput deflexum, confertım subtiliter punctatum. Thorax basi coleopteris paululum angustior, latitudine dimidio brevior, antrorsum angustatus, basi leviter, lateribus fortius rotundatus, apice truncatus, angulis omnibus obtusis, anterioribus deflexis, supra leviter aequaliterque convexus, confertim subtiliter punctatus, obsolete canaliculatus, basi foveolatus, limbo laterali rufo-piceo. Elytra thorace longiora, confertim subtiliter punctata, testacea, circa scutellum lateribusque infuscata. Abdomen apicem versus attenuatum, confertissime subtilissimeque punctatum, apice segmentorumque marginibus rufo-testacess. Pedes testacei, tarsis posticis articulo primo sequentibus tribus coniunctis longitudine aequali.

Mas abdominis segmento ventrali sexto apice utrinque sinuato, medio triangulariter producto distinguendus.

* 3. O. prospera: Subdepressa, rufu-testacea, opaca, capite, pectore abdomineque piceis, hoc apice segmentorumque marginibus rufo-lestaceis, thorace parum convexo, basi obsolete foveolato. - Long. $1 \frac{3}{4}$ lin.

Habitat in Germania boreali, Dom. Schüppel.

Statura ab affinibus paululum discedens, Homalotae similis, H. brunnea paulo brevior et minus depressa, at huius generis. Corpus rufo-testaceum, pube depressa grisea subsericea densius vestitum. Antennae capite thoraceque paulo breviores, minus tenues, articulo secundo tertioque subaequalibus, apicem versus leniter subincrassatae, articulo ultimo ovato, apice subacuminato, totae rufo-testaceae. Palpi testacei. Caput crassiusculum, deflexum, confertim subtilissime punctatum, piceum. Thorax coleopteris perparum angustior, latitudine dimidio brevior, antrorsum vix angustatus, basi leviter, lateribus fortius rotundatus, apice subemarginatus, angulis omnibus obtusis, subrotundatis, leviter transversim convexus, confertim subtilissime punctatus, basi obsolete impressus, rufo-testaceus, disco picescente, margine dilutiore. Abdomen apicem versus parum angustatum, confertissime subtilissimeque pubescens, nigrum, ano segmentorumque marginibus latis rufo-testaceis. Pectus medio piceum. Pedes testacei. 
Mas abdominis segmento ventrali sexto apice obtuse triangulariter producto.

4. O. opaca: Brevior, nigra, fusco-pubescens, antennarum basi pedibusque rufis, elytris brunneis, thorace convexo, aequali. - Long. $1 \frac{2}{3}$ lin.

Mannerh. Brachelytr. 70. 4. - Boisd. et Lacord. Faun. Ent. Paris. I. 538. 1. Er. Col. March. I. 344. 2.

Aleoch. о paca Grav. Micr. 89. 31. Mon. 163. 41. - Latr. Hist. nat. Crust. et Ins. IX. 386. 31. - Gyll. Ins. Suec. II. 423. 45. - Suhlb. Ins. Fenn. I. 390. 79. Zett. Faun. Lapp. I. 103. 20. Ins. Sapp. 79. 29.

Ale och. pulla Grav. Micr. 96. 43. Mon. 172. 65. - Latr. Hist. nat. Crust. et Ins. IX. 389. 43.

Habitat in Europa.

Habitu fere Tachypori, nigra, parum nitida, pube subtili, densa, fuscosericea obtecta. Antennae capite thoraceque longiores, validiusculae, articulo secundo tertio paulo breviore, ultimo oblongo - ovato, praecedentibus ambobus longiore, nigrae, basi rufo-piceae. Caput confertissime subtilius punctatum. Thorax coleopterorum latitudine, longitudine dimidio latior, antrorsum angustatus, angulis anterıoribus subrectis, deflexis, subtiliter confertissime punctatus, limbo laterali rufo-piceo. Elytra thorace paulo longiora, confertissime punctata, undulatim subrugosa, brunnea, interdum piceo-testacea, basi nigricantia. Abdomen breviusculum, apicem versus attenuatum, segmentorum marginibus supra rufo-piceis, subtus testaceis. Pedes testacei.

Mas abdominis segmento ventrali sexto apice triangulariter producto distinctus.

5. O. umbrata: Elongata, nigra, subnitida, sericeo-pubescens, antennarum basi pedibusque rufo-testaceis, elytris obscure brunneis, thorace convexo, anlice subcompresso, lateribus piceo. - Long. $1 \frac{2}{3}$ lin.

Mannerh. Brachelytr. 70 5. - Er. Col. March. I. 344. 3.

Ale och. umbirata Gyll. Ins. Suec. II. 424. 46. - Sahlb. Ins. Fenn. I. 390. 80.

Habitat in Germania, Suecia.

Praecedente parum brevior, at multo angustior, nigra, subnitida, pube tenuissima griseo - sericea vestita, omnium subtilissime confertissimeque punctata. Antennae capitis thoracisque longitudine, articulo secundo tertio sub. aequali, apicem versus subincrassatae, articulis penultimis tribus transversis, ultimo subovato, apice acuminato, piceae, articulis duobus primis rufo-testaceis. Palpi testacei. Caput thorace angustius, deflexum, rotundatum, fronte convexiuscula. Thorax latitudine paulo brevior, basi coleopterorum latitudine, antrorsum leviter angustatus, basi et lateribus modicè rotundatus, apice truncatus, angulis omnibus obtusis, anterioribus deflexis, fortiter transversim convexus, lateribus praecipue antice deflexis, limbo laterali piceo, interdum rufescente. Elytra thorace paulo longiora, fusco-picea, opaca. Abdomen elongatum, apice attenuatum, segmentis ventralibus ferrugineo-marginatis. Pedes rufo-testacei.

-6. O. longiuscula: Elongata, nigra, subnitida, tenuiter sericeo-pubescens, antennarum basi pedibusque rufo-testaceis, thorace leviter convexo, basi foveolato. - Long. $1 \frac{1}{2}$ lin.

Er. Col. March. I. 315. 4. 
Aleoch. longiuscula Grav. Micr. 80. 20. Mon. 155. 21. - Latr. Hist. nat. Crust. et Ins. IX. 383. 20.

Oxypoda proc erula Mannerh. Brachelytr. 71. 9.

Aleoch. procerula Suhlb. Ins. Fenn. I. 392. 82.

Habitat in Germana; in Anglia, Dom. Rudd.

Praecedente minus convexa, nigra, parum nitida, confertissime subtiliter punctata, pube tenuissima griseo-sericea vestita. Antennae capite thoraceque longiores, apicem versus incrassatae, articulo tertio secundo paulo breviore, 4-10 omnibus crassiusculis, subcylindricis, crassitie haud brevioribus, ultimo maris magno, praecedentibus ambobus longiore, oblongo, apice subacuminato, feminae maiusculo, ovato, nigrae, articulis duobus primis piceotestaceis. Palpi piceo - testacel. Caput thorace angustius, deflexum, rotundatum. Thorax latitudine paulo brevior, basi coleopterorum prope latitudine, antrorsum angustatus, apice duplo fere angustior, basi leviter rotundatus, utrinque subsinuatus, lateribus modice rotundatus, apice truncatus, angulis anterioribus rotundatis, deflexis, posterioribus subrectis, modice transversim convexus, basi foveola transversa impressus. Elytra thorace paulo longiora, picea, interdum cum thorace rufo-picea. Abdomen apice subangustatum, ano late segmentorumque ventralium marginibus rufo-piceis. Pedes rufo-testacei.

7. O. alternans: Elongata, testacea, capite, pectore, elytrorum angulo exteriore abdominisque cingulo postico nigricantibus. - Long. $1 \frac{1}{2}$ lin.

Mannerh. Brachelytr. 71. 8. - Boisd. et Lacord. Faun. Ent. Paris. I. 539. 3. Er. Col March. I. 345. 5.

Aleoch. alternans Grav. Micr. 85. 26. Mon. 163. 38. - Latr. Hist. nat. Crust. et Ins. IX. 385. 26. - Gyll: Ins. Suec. II. 419. 41. - Sahlb. Ins. Fenn. I. 385. 71. Zetterst. Faun. Lappon. I. 103. 20. Ins. Lappon. 78. 28.

Habitat in Germaniae, Suecrae boletis.

Statura angusta praecedentium, dilute testacea, confertim subtilissime punctata, pube tenuissima griseo-sericea vestita. Antennae capitis thoracisque longitudine, apicem versus leviter incrassatae, articulo secundo tertioque aequalibus, 5-10 transversis, ultimo praecedentibus tribus coniunctis vix breviore, subovato, apice acuminato, rufae vel rufo-piceae vel nigricantes, basi testaceae. Caput oblongum, deflexum, subtiliter punctulatum, nigricans aut piceum, ore testaceo. Thorax coleopteris paulo angustior, latitudine baseos dimidio brevior, antrorsum angustatus, apice dimidio angustior, basi et lateribus modice rotundatus, apice truncatus, angulis omnibus obtusis, anterioribus deflexis, transversim leviter convexus, confertim subtiliter punctatus, basi foveola parva impressus. Elytra thorace sesqui longiora, confertim subtilius punctata, fusco-testacea, circa scutellum et in angulo apicis exteriore fuscescentia vel nigricantia. Abdomen apicem versus sensim attenuatım, confertissime subtiliter punctatum, segmento quarto quintoque basi nigricantibus. Pectus nigricans.

Variat thoracis disco anteriore infuscato.

* 8. O. togata: Elongata, nigra, capite piceo, thorace elytrisque rufis, antennarum basi pedibusque testaceis. - Long. $1 \frac{2}{3}$ lin.

Er. Col. March. 1. 346. 8.

Habitat Berolini. 
Statura omnino O. umbratae. Corpus pube sericea subtilsssima et minus quam in affinibus obvia. Antennae capitis thoracisque Jongitudine, apicem versus leniter incrassatae, articulo secundo tertio paulo maiore, articulis penultimis vix transversis, ultimo oblongo-ovato, praecedentibus ambobus paulo longiore, apice acuminato, piceae, basi testaceae. Palpi testacei. Caput deflexum, piceum, nitidum, dense punctatum. Thorax latitudine paulo brevior, bası coleopterorum latitudine, antrorsum angustatus, basi leviter, lateribus fortius rotundatus, apice truncatus, angulis anterioribus obtusis, subrotundatis, deflexis, posterioribus rotundatis, transversim convexus, subtilissime confertim punctatus, rufus. Elytra thorace paululum longiora, confertissime subtilius punctata, rufa. Abrlonen elongatum, fere parallelum, apice angustatum, confertissime subtilius punctatum, nigrum, nitidum, segmentis piceo-marginatis. Pectus nigrum. Pedes rufo-testacei.

* 9. O sagulata: Elongata, nigra, capile piceo, thorace basi foveolato elytrisque rufis, antennis pedibusque teslaceis. - Long. $1 \frac{1}{2}$ lin.

Habitat in Pensylvania, Dom. Zimmermann.

Praecedenti proxima. Corpus pube brevissima, vix observanda, fulvescente vestitum. Antennae capitis thoracisque longitudine, apicem versus leniter incrassatae, articulo secundo tertio paulo maiore, sequentibus sensim panlo crassioribus, 7-10 leviter transversis, ultimo maiusculo, ovato, apice obtuso, testaceae. Caput deflexum, subtilissime punctulatum, nigro-piceum, ore rufo-piceo. Thorax latitudine dimidio brevior, basi coleopteris latitudine aequalis, antrorsum angustatus, basi perparum, lateribus modice rotundatus, apice truncatus, angulis omnibus obtusis, subrotundatis, anterioribus deflexis, transversim leviter convexus, subtilissime punctulatus, basi plerumque obsolete foveolatus, rufus. Elytra thorace paulo longiora, confertissime distinctius punctata, thoraci concolora. Abdomen elongatum, subparallelum, apice attenuatum, supra creberrime minus subtiliter punctatum, subnitidum, nigrum, segmientorum marginibus apiceque obscure rufis. Pedes rufo-testacei.

Obs. Praecedente paulo minor, antennarum articulo ultimo apice obtuso, thorace breviore, basi foveolato sat distincta.

*10. O. abdominalis: Elongata, pallide rufa, griseo-sericea, thorace convexo, coleopteris latiore, abdomine nigro, segmentorum marginibus apiceque rufis. - Long. $1 \frac{1}{2}$ lin.

Er. Col. March. 1. 316.7.

Sphenoma abdominale Mannerh. Brachelytr. 69. 1.

Aleoch. abdominalis Sahlb. Ins. Fenn. I. 93.83.

Habitat in Germania, Fennia.

Dilute rufa, subnitida, pube griseo-sericea distinctiore vestita. Antennae capitis thoracisque longitudine, apicem versus leniter incrassatae, articulo secundo tertio subaequali, articulis $\mathbf{7 - 1 0}$ lenter transversis, ultimo praecedentubus ambobus aequali, subovato, apice obtusiusculo, rufo-testaceae, bası dilutiores. Palpi testacei. Caput subtilissime punctulatum, deflexum, subrotundatum, rufo-piceum. Thorax basi latitudine coleoptera excedens, 
longitudine sesqui latior, antrorsum angustatus, basi perparum, lateribus leniter rotundatus, apice truncatus, angulis omnibus obtusis, anterioribus deflexis, transversim convexus, subtilissime punctulatus. Elytra thorace vix longiora, confertissime subtiliter punctata. Abdomen apicem versus sensim attenuatum, confertissime subtiliter punctatum, nigrum, segmentorum marginibus apiceque rufis. Pectus rufum. Pedes testacei.

* 11. O. testacea: Elongala, rufo-testacea, subtiliter sericeo-pubescens. thorace brevi, levit $r$ convexo, abdomine distinctius punctato, segmentis intermediis basi fuscescentibus. - Long. $1 \frac{1}{2}$ lin.

Er. Col. March. I. 347. 8.

Habitat in Germania septentrionali.

Praecedentibus aequalis, at paulo magis linearis, dilute rufo-testacea. pube tenui griseo-sericea vestita. Antennae capite thoraceque breviores, crassusculae, articulo secundo tertio paulo maiore, $4-10$ brevibus, fortiter transversis, penultimis longitudine plus duplo crassioribus, ultimo maiusculo, subgloboso, apice obtuso. Caput subtilissime punctatum. Thorax latitudine coleopteris aequalis eademque vix dimidio brevior, antrorsum angustatus, basi subtruncatus, lateribus leviter rotundatus, apice truncatus, angulis anterioribus obtusis, deflexis, posterioribus subrectis, transversim convexus, subtilissime punctatus. Elytra thorace vix longiora, confertissime subtilius punctata. Abdomen elongatum, parallelum, apice subangustatum, confertissime subtilius punctatum, obscure rufo-testaceum, segmentis intermediis basi nigricantibus, apice pallidiore.

* 12. O. helvola: Elongata, linearis, testacea, sericeo-pubescens, thorace leviter convexo, elytris thorace subbrevioribus, abdomine segmento quinto basi nigricante. - Long. 1 lin.

Er. Col. March. I. 317. 9.

Habitat in Germania.

Statura angusta praecedentium, at multo minor, laete rufo-testacea, -subtilissime confertim ponctata, pube tenui flavescenti-sericea densius vestita. Antennae capite thoraceque breviores, crassiusculae, articulo secundo tertio paulo longiore, $\mathbf{4}-10$ transversis, ultimo subgloboso, obtusiusculo. Thorax coleopterorum latitudine, longitudine sesqui latior, antrorsum angustatus, lateribus et basi leviter rotundatus, apice truncatus, angulis omnibus obtusis, anterioribus deflexis, transversim convexus. Elytra thorace panlo breviora, minus subtiliter punctata. Abdomen elongatum, lineare, apice angustatum, segmento quinto basi nigricante.

* 13. O. ferruginea: Elongata, linearis, ferruginea, tenuiter pubescens, Shorace leviler convexo, elyiris thorace subbrevioribus, depressis, abdomine nigro, apice testaceo. - Long. 1 lin.

Habitat in Germania.

Praecedenti affinis, at panlo angustior et magis depressa, pube subtili depressa griseo-pubescens. Antennae capite thoraceque paulo breviores, apicem versus leviter sensim incrassatae, articulo secundo tertio duplo maiore, 
4-10 longitudine subaequalibus, sensim paulo crassioribus, transversis, ultimo praecedentibus ambobus fere aequali, oblongo-ovato, apice acuminato, pubescentes, ferrugineae, basi testaceae. Palpi testacei. Caput thorace paulo angustius, oblongum, deflexum, confertim subtiliter punctulatum, obscure ferrugineum. Thorax coleopteris paulo latior, basi leviter, lateribus fortius rotundatus, apice truncatus, angulis omnibus obtusis, anterioribus sub. rotundatis, deflexis, transversim leviter convexus, confertim subtiliter punctatus, basi foveola minuta obsolete impressus, ferrugineus, subnitidus. Elytra thorace paulo breviora, fortiter depressa, crebre minus subtiliter punctata, ferruginea. Abdomen elongatum, lineare, apice attenuatum, confertım subtliter punctatum, nigrum, subnitidum, segmentis singulis piceo-marginatis, quinto apice late sextoque toto rufo-testaceis. Pectus piceum. Pedes testacei, coxis omnibus concoloribus.

Obs. A praecedente statura tenuiore, antennis paulo longioribus, minus incrassatis, elytris depressis et colore obscuriore distincta videtur.

* 14. O. promiscua: Elongata, sublinearis, picea, capite abdomineque nigris, ano, antennarum basi pedibusque testaceis, thorace leviter convexo, aequali, elytris thorace paulo longioribus. - Long. 1 lin.

Habitat in Germania; Berolini a Dom. Schïppel lecta.

Statura et summa affinitas proxime praecedentium, elytris autem longioribus satis distincta. Parva, linearis, nitida, pube minus subtili depressa grisea densius vestita. Antennae capite thoraceque paulo breviores, apicem versus sensim incrassatae, articulo tertio secundo dimidio minore, $4-10$ longitudine aequalibus, brevibus, sensim crassioribus et fortius transversis, ultimo praecedentibus ambobus longitudine aequali, crassiore, acuminato, fuscae, basi testaceae. Caput thorace paulo angustius, oblongum, deflexum, subtilissime punctatum, nigrum, nitidum, ore testaceo. Thorax basi coleopterorum prope latitudine, apicem versus leviter angustatus, latitudine dimidio brevior, basi et lateribus leviter rotundatus, apice truncatus, angulis anterioribus rotundatis, fortiter deflexis, posterioribus obtusis, transversim convexus, aequalis, densius subtilissime punctatus, fusco-piceus, nitidus. Elytra thorace paulo longiora, minus subtiliter confertim punctata, dilutius fusco-picea. Abdomen elongatum, apicem versus leviter angustatum, confertim subtiliter punctatum, nigrum, nitidum, segmentis singulis piceo-marginatis, quinto apice late sextoque toto lacte rufo-testaceis. Pectus picenm. Pedes testacei.

* 15. O. praecox: Testacea, immaculata, thorace transversim convexo, aequali, elytris thorace paulo longioribus, abdomine apicem versus sensim fortius attenuato, nigro-pilosello. - Long. 1 lin.

Habitat in Austria, Dom. Schïppel.

Habitu omnino $\mathrm{O}$. abdominalis, at multo minor, $\mathrm{O}$. helvolae aequalis, tota dilute testacea, subnitida, pube subtili tenuique fulvescente subsericans. Antennae capite thoraceque paulo breviores, apicem versus sensim fortius incrassatae, articulo tertio secundo duplo breviore et paulo tenuiore, 4 - 10 breviusculis, longitudine aequalibus, at sensim paulo crassioribus et fortius transversis, ultimo praecedente sesqui longiore, crassiusculo, subcom- 
presso, apice truncato. Caput thorace plus duplo angustius, oblongum, deflexum, confertim subtiliter punctatum, oculis nigris. Thorax basi coleopterorum latitudine, antrorsum leviter angustatus, apice dimidio quam basi angustior, latitudine baseos dimidio brevior, basi et lateribus modice rotundatus, apice truncatus, angulis anterioribus obtusis, subrotundatis, deflexis, posterioribus subrectis, transversim convexus, aequalis, confertim subtilius punctatus. Elytra thorace paulo longiora, confertim minus subtiliter punctata. Abdomen longiusculum, apicem versus sensim sat distincte attenuatum, confertim subtiliter punctatum, lateribus praecjpue versus apicem breviter nigropilosellum. Pedes flavo - testacei.

Obs. O. helvolae magnitudine et colore similis, distincta autem corpore non lineari sed fusiformi, elytris longioribus et abdomine pilosello.

* 16. O. exoleta: Elongata, testacea, sericeo-pubescens, thorace leviter convexo, elytris thorace longioribus, abdomine ante apicem nigricante.

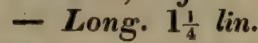

Habitat in Germania.

Statura elongata O. helvolae, at paulo maior et minus linearis, sordide testacea, parum nitida, pube brevissima densa griseo-fulvescente sericans. Antennae capite thoraceque paulo breviores, apicem versus leviter sensim incrassatae, articulo tertio secundo dimidio minore, 4-10 breviusculis, longitudine inter se aequalibus, at sensim paulo crassioribus et magis transversis, ultimo praecedentibus ambobus longitudine subaequali, apice rotundato, obtuso, fusco-testaceae, articulo primo flavo-testaceo. Caput thorace paulo angustius, oblongum, deflexum, confertim subtiliter punctatum, fuscotestaceum, ore flavescente. Thorax basi coleopterorum latitudine, antrorsum angustatus, apice basi tertia parte angustiore, latitudine baseos plus dimidio brevior, basi leviter, lateribus vix rotundatus, apice truncatus, angulis omnibus obtusis, anterioribus deflexis, transversim convexus, aequalis, confertim subtiliter punctatus, rufescenti-testaceus. Elytra thorace paulo longiora, confertim subtilius punctata, fuscescenti-testacea. Abdomen elongatum, apicem versus sensim leniter attenuatum, confertim subtiliter punctatum, rufotestaceum, segmento quarto toto, quinto basi nigricantibus, quinto apice late sextoque toto laete rufo-testaceis. Pectus rufo-testaceum. Pedes flavotestacei.

* 17. O. cuniculina: Brevior, nigra, sericeo-pubescens, thorace breviusculo, leviter convexo elylrisque piceis, abdomine apicem versus attenuato, segmentis piceo-marginatis. - Long. $1 \frac{1}{4}$ lis.

Er. Col. March. I. 318. 10.

Habitat in Germania: Berolini, Dom. Schïppel, in Bavaria, Dom. Waltl, ill Austria, Dom. Ullrich.

O. umbratae affinis, at multo brevior, nigra, subtilissime confertissimeque punctata, pube tenui griseo-sericea obducta. Antemnae capite thoraceque paulo breviores, apicem versus sensim modice incrassatae, articulo secundo subcylindrico, tertio obconico, secundo paulo breviore, $3-10$ arcte contiguis, 6-10 transversis, ultimo maiusculo, ovato, obtuso, piceae, basi dilutiores. Thorax latitudine duplo brevior, basi coleopterorum latitudine antrorsum angustatus, basi et lateribus rotundatus, apice truncatus, angulis omnibus ob- 
tusis, anterioribus deflexis, transversim convexus, supra scutellum obsolete impressus, piceus, disco nigricans. Elytra thorace paulo longiora, rufo-picea. Abdomen apicem versus attenuatum, nigrum, segmentis margine rufopiceis. Pedes testacei.

* 18. O. exigua: Nigra, nitidula, thorace leviter convexo elytrisque piceis, antennarum basi pedibusque testaceis, abdomine distinctius punctulato. - Long. 1 lin.

Er. Col, Murch. I. 348. 11.

\section{Habitat Berolini.}

Habitu omnino praecedentis, at minuta, minus convexa, nitidula, nigra, thorace elytrisque pube tenuissima sericeo-micantibus. Antennae fere capitis thoracisque longitudine, articulo secundo tertio paulo longiore, apicem versus subincrassatae, articulis $7-10$ transversis, ultimo maiusculo, breviter ovato, obtuso, nigrae, basi flavescentes. Palpi piceo-testacei. Caput deflexum, rotundatum, subtilissime punctatum. Thorax latitudine plus dimidio brevior, coleopterorum latitudine, antrorsum parum angustatus, basi et lateribus leviter rotundatus, apice truncatus, angulis posterioribus subrectis, anterioribus rotundatis, leviter transversim convexus, subtiliter punctulatus, nigro-piceus. Elytra thoracis longitudine, picea, subtiliter dense punctata. Abdomen elongatum, apice angustatum, distinctius rage punctatum, pilis longis depressis parce vestitum, apice pilosellum. Pedes rufo-testacei.

* 19. O. cunctans: Brevis, nigra, opaca, sericeo-pubescens, antennarum basi pedibusque rufo-testaceis, thorace brevi, leviter convexo, postice leviter lisinuato, abdomine supra confertissime subtiliter punctato. Long. $1 \frac{1}{3}$ lin

Er. Col. March. I. 349. 12.

\section{Habitat Berolini.}

Praecedentibus brevior, latior et supra minus convexa, nigra, opaca, pube tenui grisescenti-sericea obducta. Antennae capitis thoracisque longitudine, apıcem versus leviter incrassatae, articulo secundo tertio paulo crassiore, $4-10$ cylindricis, crassiusculis, crassitıe autem vix brevioribus, ultimo oblongo, praecedentibus ambobus paulo longiore, apice obtuse acuminato, piceae, basi testaceae. Palpi testacei. Caput subtilissime confertim punctatum, fronte convexa. Thorax coleopterorum latitudine, antrorsum parum angustatus, longitudine duplo latior, lateribus rotundatus, basi utrinque leviter sinuatus, apice truncatus, angulis omnibus obtusis, subrotundatis, parum convexus, subtilissime dense punctatus, supra scutellum leviter impressus. Elytra thorace sesqni longiora, subtilissime. dense punctata. Abdomen apicem versus leviter angustatum, confertim subtiliter punctatum, subtus apice et marginibus segmentoruin ventralium singulorum late rufo-piceis. Pedes testacei.

20. O. lentula: Brevior, nigra, opaca, sericeo-pubescens, antennis pedibusque piceis, thorace transverso, parum convexo, basi foveola transversa inipresso. - Long. $1 \frac{1}{4}$ lin.

Er. Col. March. I. 349. 13.

Habitat Berolini. 
Praecedente paulo minor, pube tenui griseo-sericea vestita, confertissim ? subtilissimeque punctata, opaca, vel tota nigra, vel thorace elytrisque piceis. Antennae capitis thoracisque longitudine, articulo secundo tertioque subae: qualibus, sequentibus leviter transversis, sensim paulo crassioribus, ultimo praecedentibus ambobus' subaequali, subovato, apice obtusiusculo, apicem versus parum inerassatae, nigro-piceae, vel piceae, basi dilutiores. Caput deflexum, fronte convexa, oris partibus inferioribus testaceis, palpis picescentibus. Thorax coleopterorum latitudine, antrorsum parum angustatus, latitudine duplo fere brevior, basi leviter, lateribus fortiter rotundatus, apice truncatus, angulis anterioribus rotundatis, posterioribus obtusis, subrotundatis, transversim convexus, basi foveola transversa impressus. Elytra thorace parum longiora. Abdomen breviusculum, apicem versus parum angustatum, apice piceum. Pedes picei.

$\mathrm{Obs}$. A praecedente praecipue elytris brevioribus abdomineque subtilius punctatis distincta.

* 21. O. curtula: Brevis, nigra, subnitida, distinctius punctata, subtilissine parce pubescens, antennis pedibusque ferrugineis, thorace brevi, transverso, basi leviter bisinuato. - Long. 1 lin.

Er. Col. March. I. 350. 14.

\section{Habitat Berolini.}

Aleocharae morioni sumilis, at huius generis videtur. Brevis, nigra. nitidula, dense ac minus subtiliter punctata, pube subtilissima vix observanda obducta. Antennae capitis thoracisque longitudine, articulo secundo tertio paulo maiore, praecipue crassiore, apicem versus sensim incrassatae, articulis penultimis transversis, ultimo maiusculo, subgloboso, rufo-piceae, hasi testaceae. Caput breviusculum, subtilius punctatunt. Thorax basi coleoptera latitudine aliquantulum superans, longitudine duplo latior, antrorsum angustatus, lateribus rotundatus, basi utrinque leviter sinuatus, apice truncatus, angulis anterioribus obtusis, subrotundatis, posterioribus rectis, retrorsum leviter prominulis, supra parum convexus, confertissime punctatus, basi medio obsolete impressus, margine laterali haud deflexo. Elytra thorace fere duplo longiora et paulo fortius punctata, apice medio coniunctim emarginata. Abdomen apicem versus leviter angustatum, confertissime punctatum. Pedes testacei, femoribus nigricantibus.

Obs. Specimen unicum coleopteris utrinque prope scutellum tuberculo mi. nuto prominulo notatis insigne: num proprio speciei an sexui?

Species mihi invisae, forte huius generis et sectionis.

22. O. melanaria: Nigra, nitida, subpubescens, subtilissime puncluluta, elytris piceo-testaceis, segmentorum ventralinm marginibus, ano pedibusque rufo-testaceis, antennis filiformibus, thorace foveola postica obsolete impresso. - Long. I $\frac{1}{4}$ lin.

Mannerh. Brachelytr.70. 3.

Aleoch. melanaria Sahlb. Ins. Fenn. I. 389. 78.

Habitat in Fennia.

Magnitudo Homalotae lividipennis, sed convexior, nitidior, levius punctata, antennae longiores et thorax antice minus angustatus. Caput thorace 
multo minus, rotundatum, convexum, nigrum, nitidum, parce pubescens, subtilius adhuc quam in Hom. lividipenni et vix visibiliter punctulatum, ore et palpis piceo-rufescentibus. Antennae thorace multo longiores, filiformes, nigrae. articulo primo elongato, obconico, secundo breviore et ceteris fere angustiore, tertio iterum elongato, obconico, quarto insequentibus paulo hreviore, 5-10 longitudine et latitudine inter se aequalibus, ultimo elongato, acuminato. Thorax antice paulo angustior, trụncatus, lateribus et postice rotundatus, supra convexus, niger, nitidus, subtilissime et parcius punctulatus, tenuiter pubescens, foveola ante scutellum obsoletissime impressus. Scutellum breve, triangulare, nigrum, punctulatum. Elytra thorace vix latiora, sed paulo longiora, apice intra angulum exteriorem emarginata, supra depressa, piceo-testacea, subtilissime et crebre punctulata, subpubescentia. Abdomen pone elytra reliquo corpore longius, nigrum, subnitidum, subtilissime punctulatum, subpubescens. Corpus subtus fusco-nigrum, subnitidum, subtilissime punctulatum, densius pubescens, marginibus segmentorum ventralium anoque rufo-testaceis. Pedes elongati, tenues, rufo-testacei, articulo tarsorum primo insequente paulo longiore. (Sahlb.)

23. O. pellucida: Nigro-fusca, pubescens, antennarum basi, thorace, ano, marginibus segmentorum pedibusque piceo-ferrugineis, thoracis depressiusculi lateribus testacbis, angulo elytrorum exteriore infuscato. - Long. $1 \frac{1}{4}$ lin.

Mannerh. Brachelytr. 70. 6. - Runde Brachelytr. Hal. 29. 1.

Aleoch. pellucida Salb. Ins. Fenn. I. 391. 81.

Habitat in fungis Fenniae.

O. opacae affinis, sed brevior, latior, caput magis prominulum, pedes postici minus elongati, abdomen parum attenuatum, colorque alius. Caput thorace multo minus, rotundatum, convexiusculum, fusco-nigrum, nitidum, subtilissime punctulatum, palpis testaceis. Antennae longitudine thoracis, piceo-ferrugineae, extrorsum fuscescentes, articulo primo elongato, incrassato, secundo et tertio itidem elongatis, obconicis et inter se aequalibus, 4-10 brevibus, extrorsum sensim crassioribus, ultimo magno, conico-ovato, subacuto. Thorax transversus, longitudine fere duplo latior, antice angustior, truncatus, angulis compressis, lateribus et postice rotundatus, angulis tamen parum prominulis, supra subdepressus, obsolete canaliculatus, piceoferrugineus, subtilissime punctulatus, pubescens, lateribus pellucido-testacels. Scutellum minutum, triangulare, fuscescens. Elytra thorace paulo latiora et longiora, apice subtruncata, intra angulum exteriorem vix sinuata, supra depressa, piceo - ferruginea vel ferrugineo-testacea, angulis apicis externis, interdum etiam sutura infuscatis, subtilissime punctulata, pubescentia. Abdomen pone elytra reliquo corpore brevius corpusque subtus nigro-fusca, pubescentia, marginibus segmentorum, imprimis subtus, anoque ferrugineis. Pectus distinctius punctatum. Pedes mediocres, piceo-ferruginei, interdum testacei; articulus tarsorum primus insequente paulo longior. (Sahlb.)

24. O. lateralis: Nigra, punctulata, pubescens, antennis thorace longioribus basi, thorace lateribus, humeris, marginibus segmentorum veniralium pedibusque rufo-testaceis. - Long. $1 \frac{1}{3}$ lin.

Mannerh. Brachelytr. 70. 7.

Ale och. lat eralis Sahlb. Ins. Fenn. I. 391. 82. 
Habntat in fungis Fenniae.

Praecedenti simillima, differt autem statura angustiore, antennis thorace longioribus, pubescentia densiore, elytris obscurioribus, ad angulum exteriorem evidentius sinuatis et ano nunquam rufo. $O$. opacae etiam affinis, sed caput maius, prominulum, pedes postici minus elongati, abdomen parum tantum attenuatum. Caput ut in praecedente. Antennae thorace paulo longiores, extrorsum incrassatae, nigrae, articulis tribus baseos elongatis, rufo-testaceis, ultimo magno, conico-ovato, subacuto. Thorax nigro-fuscus, lateribus rufotestaceis, foveola ante scutellum obsolete impressus, structura ut in praecedente. Scutellum triangulare, nigrum, punctulatum, pubescens. Elytra thorace paulo longiora et latiora, apice intra angulum exteriorem nonnihil sinuata, supra depressa, fusca, subtilissime punctulata, pubescentia, humeris indeterminate rufo-testaceis. Abdomen pone elytra reliquo corpore brevius corpusque subtus nigra, subtilissime punctulata, pubescentia, marginibus segmentorum ventralium rufo-testaceis. Pedes mediocres, rufo-testacei, articulo tarsorum primo inseqnente paulo longiore. (Sahlb.)

25. O. sericata: Fusca, opaca, subtiliter punclulata, sericeo-pubescens, antennarum basi, pedibus anoque pallidioribus.

Mannerh. Brachelytr. 71. 10.

Habitat Petropoli.

o. umbratae quodammodo similis, magnitudine duplo minore, capite vix occulto, antennis longioribus, punctura subtiliore, pubescentia densiore ut et colore diversa. (Mannerh.)

26. O. cingulata: Livido-testacea, subtilissime punctata, griseo-pubescens, capite abdominisque cingulo nigris, thorace basi foveolato.

Mannerh. Brachelytr. 71. 11.

Habitat Petropoli.

Praecedenti iterum statura et 'magnitudine fere aequalis, antennae, vero breviores, articulo nltimo magis globoso, thorax antice angustior, postice foveolatus, et color diversus. (Mannerh.)

\section{* L i n e a r e s.}

*27. O. corticina: Piceo-rufa, abdomine ante apicem capiteque piceis, ano, antennis pedilusque ferrugineis, thorace transverso, subdepresso, angulis posterioribus rectis. - Long. $1 \frac{1}{3}$ lin.

Er. Col. March. I. 351.15.

Habitat in Germania sub cortice Pinus.

Piceo - rufa, parum nitida, pube tenussima fuscescenti densius obtecta. Antennae capite thoraceque vix breviores, apicem versus subincrassatae, articulis 4-10 transversis, ultimo ovato, subacuminato, ferrugineae. Caput piceum, subtilissime punctatum, fronte convexa, ore ferrugineo. Thorax coleoptera latitudine fere excedens, longitudine plus sesqui latior, antrorsum vix angustatus, basi medio rotundatus, utrinque subsinuatus, lateribus modice rotundatus, apice late emarginatus, angulis anterioribus acutiusculis, leviter deflexis, posterioribus subrectis, leviter transversim convexus, confertissime 
subtilius punctatus. Elytra rufa, fortius punctata. Abdomen parallelum, rufopiceum, ante apicem nigricans, apice ferrugineuin. Pectus fortius punctatum, piceum. Pedes ferruginei.

28. O. a micta: Nigra, opaca, antennis, elytris, ano pedibusque laete rufis, thorace apicem versus subangustato. - Long. 1 lin.

Habitat in Sardinia, Prof. Gené, Mus. Reg. Taurin.

Praecedenti affinis, at gracilior, nigra, opaca, tota sat fortiter confertissime punctata, pube subtili depressa grisea vestita. Antennae capitis thoracisque longitudine, validiusculae, articulo secundo tertio vix breviore, apicem versus leviter incrassatae, articulis penultimis vix transversis, ultimo oblongo, praecedentibus ambobus paulo longiore, apice obtusiusculo, totae rufo-ferrugineae. Palpi rufo-ferruginei. Caput thorace multo minus, deflexum. Thorax latitudine vix dimidio brevior, coleopterorum latitudine, basi medio parum rotundatus, utrinque subsinuatus, lateribus ultra medium rectis et parallelis, dein apicem versus rotundato-angustatis, apice truncatus, angulis anterioribus obtusis, deflexis, posterioribus rectis, parum convexus, margine laterali anguste rufo. Elytra thorace longiora, laete rufa. Abdomen apicem versus sensim subangustatum, apice segmentorumque singulorum nargine tenui apicali rufo-testaceis. Pedes graciles, rufo-testacei.

*29. O. analis: Rufo-picea, abdomine ante apicem nigricante, apice, antennis pedibusque ferrugineis, thorace transverso, subdepresso, angulis posterioribus obtusis. - Long. $1 \frac{1}{3}$ lin.

Aleoch. analis Gyll. II. 388.11. - Sahlb. Ins. Fenn. I. 354. 16.

Habitat in Suecia, Dom. Schïppel.

Corpus lineare, rufo-piceum vel piceo-rufum, opacum, pube subtili depressa flaveseenti-grisea parcius vestitum. Antennae capitis thoracisque vix longitudine, articulo secundo tertio subaequali, apicem versus sensim incrassatae, articulıs 5-10 transversis, ultimo breviore, apice acuminato, totae ${ }^{\circ}$ rufo-ferrugineae. Caput thorace parum angustius, sublaeve, fuscopiceum, ore attenuato, testaceo. Thorax latitudine dimidio brevior, coleopterorum latitudine, lateribus ante medium modice rotundatus, basin versus subangustatus, basi leviter rotundatus, apice truncafus, angulis anterioribus deflexis, subrectis, posterioribus obtusis, parum convexus, confertim subtiliter punctulatus, basi leviter impressus. Elytra thorace sesqui longiora, confertim minus subtiliter punctata. Abdomen lineare, crebre minus subtiliter punctulatum, ante apicem nigro-piceum, apice ipso ferrugineo. Pedes ferruginei.

$\mathrm{Obs}$. Intermedia quasi inter $\mathrm{O}$. corticinam et prolixam, ab illa statura magis elongata, thorace minus lato, angulis posterioribus obtusis, ab hac statura magis depressa et punctura multo subtiliore distincta.

*30. O. gracilis: Elongala, rufo-teslacea, abdomine ante apicen, capite elytrisque picescentibus, thorace basin versus angustato, canaliculato, margine subreflexo. - Long. $1 \frac{1}{2}$ lin.

Er. Col. March. I. 351. 16.

Habitat Berolini, Dom. Weber. 
Statura admodum gracili, antennis pedibusque elongatis insignis, rufotestacea, parum nitida, pube subtili, brevi, flavescente leviter vestita. Antennae capite thoraceque multo longiores, apicem versus perparum incrassatae, articulo secundo tertio paulo breviore, 4-10 subcylindricis, sensim paulo brevioribus crassioribusque, decimo ipso crassitie paulo longiore, ultimo oblongo, praecedentibus anibobus paulo longiore, apice acuminatopallidoque. Caput dilute piceum, confertim subtiliter punctatum, fronte supra antennarum basin obsolete impressa, ore testaceo. Thorax coleopteris prope angustior; latitudine fere dimidio brevior, lateribus rotundatus, praesertim ante medium, basin versus angustatus, basi leviter rotundatus, apice late emarginatus, angulis posterioribus obtusis, anterioribus acutis, prominulis, supra subdepressus, confertim subtiliter punctatus, obsolete canaliculatus, margine laterali acuto, subreflexo. Elytra thorace sesqui longiora, sub-picescentia, fortius punctata. Abdomen elongatum, parallelum, confertim subtiliter punctatum, ante apicem supra picescens. Pedes elongati, tenues.

Obs. Habitu fere Tachyusae, at huius generis videtur, et in hac sectione collocanda.

*31. O. prolixa: Elongata, rufo-ferruginea, nitida, fortius punctata, abdomine ante apicem capiteque piceis, ano, antennis pedebusque ferrugineis, thorace transversim quadrato, convexiusculo, basi foveolato. Long. $1 \frac{1}{2}$ lin.

Er. Col. March. I. 352.17.

Aleoch. prolixa Grav. Micr. 71. 5. Mon. 165. 45. - Latr. Hist. nat. Crust. et Ins. IXX. 379. 5.

Habitat in Germania, Gallia, Suecia.

o. corticinae coloribus similis, at nitidior, magis elongata, fortius punctata, pube brevi, parum depressa, flavescente tenuiter vestita. Antennae capite thoraceque breviores, apicem versus modice incrassatae, articulo secundo tertioque subaequalibus, $7-10$ transversis, ultimo praecedentibus ambobus longttudine aequali, ovato, apice subacuminato, ferrugineae. Caput thorace parum angustius, deflexum, vage punctatum, piceum, ore attenuato, ferrugineo. Thorax coleopteris paulo angustior, latitudine dimidio brevior, lateribus modice rotundatus, basin versus subangnstatus, basi leviter rotundatus, apice leviter emarginatus, angulis posterioribus obtusis, anterioribus deflexis, subrectis, modice convexus, confertim minus subtiliter punctatus, supra scutellum transversin impressus. Elytra thorace sesqui longiora, dense fortiter punctata, rufa, circa scutellum et lateribus infuscata. Abdomen parallelum, crebre punctatum, rufum, ante apicem nigricans, apice ferrugineum. Pedes ferruginei.

Obs. Specimen e Suecia meridionali, a Dom. Schönherr nom. Al. obfu. scata e communicatum dedit Dom. Schiippel.

* 32. O. ruficollis: Elongata, nigro-picea, nitida, thorace transverso, basin versus subangustato, rufo, ano, pedibus antennisque ferrugineis, his medio infuscatis. - Long. $1 \frac{1}{4}$ lin.

Habitat Brunsvigae, Knoch, in Hercynia, stth cortice Abietis, Dom. Saxesen, Lutetiae, Mus. Dom. Aubé, in Anglia, Dom. Rudd. 
Praecedenti affinis, at dimidio minor. Nigro-picea, nitida, parce pubescens. Antennae capite thoraceque breviores, apicem versus incrassatae, articulo secundo tertio paulo maiore, 7-10 sensim magis transversis crassioribusque, ultimo subgloboso, ferrugineae, ante apicem fuscae. Caput thoracis fere latitudine, parce subtiliter punctatum, ore attenuato, testaceo. Thorax coleopteris haud angustior, latitudine dimidio brevior, lateribus ante medium leviter rotundatis, basin versus subangustatus, basi leviter rotundatus, apice vix emarginatus, angulis anterioribus rectis, deflexis, posterioribus subrotundatis, supra leviter convexus, aequalis, parce subtilissime punctatus, rufus. Elytra thoracis longitudine, nigra, nitida, minus dense fortiter punctata, medio subimpressa. Abdomen elongatum, parallelum. vel apicem versus subincrassatum, laeve, ano ferrugineo. Pedes ferruginei.

* 33. O. fumida: Nigra, subnitida, antennarum basi, ore pedibusque testaceis, ano rufo, thorace basin versus subangustato, basi foveolato. Long. $1 \frac{1}{3}$ lin.

Habitat Lutetiae, Dom. Aubé, in Thuringia, Dom. Kellner.

Statura omnino praecedentis, 0 . corticinae aequalis, nigra, minus nitida, pube grisea canescens. Antennae capitis thoracisque prope longitudine, apicem versus leniter incrassatae, articulo secundo tertio paulo maiore, 5-10 sensim paulo crassioribus, penultimis transversis, ultimo breviter ovato, subacuminato, fuscae, articulis tribus primis laete testaceis. Caput thorace paulo angustius, subtiliter punctulatum, ore angustato, testaceo. Thorax latitudine dimidio brevior, coleopteris paulo angustior, basin versus subangustatus, lateribus ante medium modice rotundatus, basi leviter rotundatus, apice late emarginatus, angulis anterioribus acutis, deflexis, posterioribus subrectis, leviter convexus, confertim subtilius punctatus, basi supra scutellum obsolete impressus. Elytra thorace sesqui longiora, sat crebre fortiterque punctata. Abdomen parallelum, supra crebrius subtiliter punctatum, ano rufo-ferrugineo. Pedes laete testacei.

Mas abdominis segmento dorsali penultimo tuberculo minuto oblongo, satis prominulo, insignis.

$\mathrm{Obs}$. O. anali proxime affinis, colore autem thoraceque coleopteris angustiore distincta.

* 34. O. maura: Nigra, nilida, ore testaceo, antennis pedibusque piceis, thorace quadrato, convexo, coleopteris angustiore, elycris fortius punctulatis. - Long. $1 \frac{1}{3}$ lin.

Er. Col. March. I. 352.18.

Habitat in Germania, Berolini, Dom. Schiippel et ipse.

Statura fere 0 . prolixae, at minus elongata, nigra, nitida, tenuiter griseo-pubescens. Antennae capitis thoracisque longitudine, articulo secundo tertio duplo maiore, apicem versus incrassatae, articulis 4-10 sensim crassioribus, penultimis transversis, ultimo mainsculo, ovato, subacuminato, pubescentes, piceae, basi rufescentes. Caput dense subtilius punctatum, ore attenuato, testaceo. Thorax coleopteris paulo angustior, latitudine haud brevior, basi leviter rotundatns, lateribus subrectis, apice truncatus, angulis omuibus subrectis, anterioribus deflexis, supra convexus, aequalis, confertim 
ininus subtiliter punctatus. Elytra thorace paulo longiora, leviter convexa, dense fortius punctata. Abdomen parallelum, subtilius parciusque punctatum. segmentis tribus primis basi fortiter transversim depressis. Pedes picei, geniculis tarsisque rufescentibus.

Species mihi invisae, forte huius generis et sectionis.

35. O. suturalis: Nigra, nitida, tenuiter pubescens, ore, antennis, elytrorum sutura anoque rufis, antennarum articulo ultimo oblongo-ovato, elytris intra apicem exteriorem profunde sinuatis. - Long. 1 lin.

Bolitochara suturalis Mannerh. Brachelytr. 82. 47.

Aleochara suturalis Suhlb. Ins. Fenn. 1. 376. 55.

Habitat in Fennia australi, rarissime.

Caput thorace angustius, rotundatum, basi truncatum, nigrum, nitidum. tenuiter pubescens, ore palpisque rufis. Antennae longitudine thoracis, versus apicem vix incrassatae, articulo ultimo oblongo-ovato, rufo, in medio nonnihil obscuriores. Thorax transversus, longitudine duplo fere latior, antice truncatus, angulis compressis, lateribus rotundatus, postice subtruncatus, angulis nonnihil prominulis, supra valde convexus, niger, nitidus, pubescens. Scutellum breve, triangulare, nigrum. Elytra thorace vix latiora, sed eodem longiora, apice intra angulum exteriorem profundius sinnato-emarginata, supra subdepressa, nigra, nitida, subtilissime punctulata, pubescentia, sutura margineque apicis rufis. Abdomen pone elytra vix reliqui corporis longitudine corpusque subtus nigra, nitida, marginibus segmentorum ventralium anoque rufis. Pedes mediocres, toti rufi. (Sahlb.)

36. O. pulchella: Nigro-picea, opaca, crebre punctulata, subpubescens, antennis extrorsum crassioribus, ore, elytris, ano pedibusque rufis, articulo antennarum ultimo subgloboso, elytris apice emarginatis. Long. 1 lin.

Bolitochara pulchella Mannerh. Brachelytr. 83. 48.

Ale ochara pulchella Sahlb. Ins. Fenn. I. 377. 56.

Habitat in Fennia australi, rarissime, semel capta.

A praecedente differt colore, thorace paulo longiore et angustiore, antennis versus apicem incrassatis et articulo harum ultimo subgloboso. Caput omnino ut in praecedente. Antennae thorace fere longiores, versus apicem incrassatae, articulis tribus baseos, ut in ceteris, elongatis, $4-8$ sensim paulo crassioribus, ultimo maximo, subgloboso, rufae, versus apicem lutescentes. Thorax subtransversus, longitudine dimidio latıor, antice truncatus, angulis compressis, lateribus rotundatus, postice subtruncatus, angulis nonnihil prominulis, supra convexus, nigro-piceus, opacus, subtilissime punctulatus, pubescens, foveola ante scutellum obsolete impressa. Scutellum subtriangulare, nigro-piceum, subtilissime punctulatum. Elytra thoracis latitudine, illoque vix longiora, apice intra angulum exteriorem sinuato-emarginata, supra depressa, obscura rufa, crebre punctulata. Abdomen longitudine fere reliqui corporis, nigro-piceum, punctulatum, pubescens, segmentis ventralibus primis fere tots, marginibus insequentium et ano rufescentibns. Pedes mediocres, pallide rufi. (Sahlb.) 
37. O. elegantula: Lineari-elongata, rufa, nilida, capile, thoracis disco abdominisque cingulo nigro-piceis, thorace elytris apice emarginatis angustiore, basi foveolalo, antennarum articulo ultimo ovalo. - Long $1 \frac{1}{6}$ lin.

Bolitochara elegantula Mannerh. Brachelylr. 377. 57.

Aleochara elegantula Sahlb. Ins. Fenn. I. 377. 57. - Zetterst. Ins. Lapp. 78. 23.

Habitat in Fennia, Suecia, Lapponia sub cortice Pinus.

A praecedente colore, thorace elytris angustiore et minus convexo, nec non forma articuli antennarum ultimi distincta. Caput ut in proxime praecedentibus. Antennae longitudine thoracis, versus apicem sensim crassiores, rufescentes, extrorsum fuscescentes, articulo ultimo ovato. Thorax subtransversus, longitudine vix dimidio latior, antice truncatus, angulis compressis, lateribus rotundatus, postice subtruncatus, angulis parum prominulis, supra convexus, nigro-piceus, limbo omni anguste rufescente, subnitidus, pubescens. Scutellum breve, triangulare, piceo-rufescens. Elytra thorace latiora et longiora, apice intra angulum externum sinuato-emarginata, supra depressa, rufescentia, disco posteriore fusco-picea, crebre punctulata, pubescentia. Abdomen pone elytra reliquo corpore fere longius corpusque subtus rufescentia, nitida, pubescentia, cingulo abdominis piceo-nigro, ano pallide rufo. Pedes toti rufi. (Sahlb.)

\section{Aleochara Grav.}

Mannerh. Brachelytr. p. 66. - Er. Col. March. I. p. 353.

Maxillae mala interiore mutica, intus spinulis ciliata.

Ligula brevis, bifida; paraglossae brevissimae.

Palpi labiales 4-articulati, articulis sensim minoribus, ultimo parvo, subulato. Tarsi omnes 5-articulati, postici articulo primo elongato.

$\|$

Corpus oblongum, crassiusculum, alatum. Caput exsertum, deflexum, basi haud constrictum, thorace plerumque angustius, oculis mediocribus, oblongis, parum prominulis. Labrum transversum, apice truncatum. Mandibulae breviusculae, muticae. Maxillae mala exteriore cornea, basi apiceque membranea, portione membranea apicali pubescente, mala interiore exteriore paulo breviore, membranea, margine exteriore corneo, apice introrsum oblique truncata, sinu spmulis brevibus ciliato. Palpi maxillares leviter elongati, articulo secundo tertioque longitudine subaequalibus, hoc parum incrassato, quarto minore, subulato. Labium (t. III. f. 9.) mento brevi, apice late emarginato, ligula brevi, palporum labialıum articuli primi apicem vix attingens, latiuscula, bıfida, paraglossis brevissimis, latis, subacuminatis, interne haud ciliatis. Palpi labiales $\mathbf{4}$-articulati, articulo primo maiore, sequentibus decrescentibus, quarto minimo, at distincto. Antennae plerumque breviores, articulis tribus primis magis elongatis, secundo tertioque obconicis, primo crassiusculo. Thorax transversus, basi coleopterorum latitudine, antrorsum angustatus, apice truncatus, basi et lateribus rotundatus. Elytra brevia, truncata. Abdomen plerumque parallelum, rarius apicem versus angustatum, supra planum, subtus convexum, in vivis reclinatum. Pedes breviores, intermedii basi leviter distantes, tarsis omnibus 5 -articulatis, posticis articulo primo elongato. 
O b s ervation es.

1. Maxillae omnino ut in Homalota (t. III. f. 22). Ligula brevissima biloba, paraglossis latis brevissimis vix longiore, et palpis labialibus 1 -articulatis hoc genus insigne. Unicum hucusque coleopterorum genus, in quo mihi ultra tres palporum labialium articuli veri observati sunt, palporum stipites enim saepius articuli basalis specimen prae se ferunt, ut in Cicindelis plurimisque Carabis.

2. Facies huius generis quodammodo peculiaris pube haud sericante, corpore crassiusculo, elytris, antennis pedibusque brevioribus, abdomine saepius revoluto. A Myrmedonia distinguitur praeter palporum structuram tarsis anticis 5-articulatis.

3. Victus in fimo, cadaveribus, saepius etiam in quisquiliis.

4. Mas distinguitur abdominis segmento inferiore sexto apice utrinque sinuato, medio leviter triangulariter producto.

* 1. A. fuscipes: Nigra, nilida, antennis brevibus, fusiformibus basi pedibusque rufis, elyiris thorace brevioribus, rufis, lateribus fuscis, abdomine supra parcius punclato, - Long. $2 \frac{1}{2}-3$ lin.

Grav. Micr. 92. 36. Mon. 170. 56. - Latr. Hist nat. Crust. et Ins. IX. 388. 36. - Gyll. Ins. Suec. II. 428. 50. - Germ. Faun. Ins. Europ. XIII. 8. - Boisd. et Lacord. Faun. Ent. Paris. I 528. 1. - Mannerh. Brachelytr. 66. 1. - Runde Brachelytr. Hal. 28. 1. - Er. Col. March. I. 354. 1.

Staph. fuscipes Fab. Syst. Ent. 266 12. Spec. Ins. I 336. 15 Mant. Ins. 1. 221.

22. Ent. Syst I. II. 527. 38. Syst. El. II. 598. 47. - Payk. I aun. Suec. III. 397. 39. - Schrank Faun. Boic. I. 645. 845. - Walk. Faun. Ent. Paris. I. 271. 13. Cederh. Faun. Ingr. 119. 364. - Marsh. Ent. Britt. 525. 77.

Staph. brachypterus Fourc. Ent. Par. I. 167. 12.

Staph. à étuis très-courts Geoffr. Hist. Ins. I. 365. 12.

Var. Elytris concoloribus, antennarum basi pedibusque piceis.

Alesch. lata Grav. Mier. 186. 2. Mon. 170, 57.

Habitat in Europa et in America septentrionali.

Magnitudine variabilis, speciminibus minutis A. tristis individuis maioribus aequalibus, plerumque duplo vel triplo maior, lata, nigra, nitida, capite thoraceque nonnunquam subaeneis, parcius flavescenti-villosa. Antennae capite sesqui longiores, crassae, articulo secundo tertio dimidio breviore, quarto sequentibus angustiore, vix transverso, 5-10 fortiter transversis, crassitie duplo brevioribus, inter se aequalibus, ultimo praecedentibus duobus coniunctis longitudine aequali, subconico, nigrae fuscaeve, basi rufae vel rufotestaceae, apice etiam nonnunquam rufescentes, Palpi rufi. Caput thorace multo angustius, deflexum, parce punctatum. Thorax latitudine dimido brevior, basi coleopterorum prope latitudine, basi et lateribus rotundatus, antrorsum angustatus, angulis omnibus obtusis, anterioribus deflexis, modice convexus, sat crebre distincteque punctatus. Elytra thorace paulo breviora, angulo exteriore rotundato, creberrime sat fortiter punctata, punctis oblique impressis, rufa, lateribus fusca. Abdomen parallelum, utrinque sat fortiter, supra minus confertim punctatum, segmentis dorsalibus ultimis duobus, ventralibus omnibus saepius margine apicali rufo-piceo, rarins concolore. Pedes rufi, femoribus posticis plerumque magis minusve piceis.

Variat elytris totis nigris, antemis basi pedibusque piceis, his ge niculis tarsisque rufis.

Obs. 1. Specimina Americana cum Europaeis omnino congruunt. Varietas elytris concoloribus rarior, individua Pensylvanica supersunt e Mus. Knochiano et Hoffmannseggiano, exemplum Austriacum addidit Dom. Schippel. 
2. Staph. fuscipes Fabricii certe huic speciei adscribitur, ipse enim insectum in auctoris Museo vidi. Reliqua synonyma indubia puto. Marshamianum locum non sine haesitatione allegavi, temere enim auctor synonyma contraria (Linnei, Fabricii et Panzeri) composuit et descriptione Linneana illustravit. Staph. fuscipes Panz. apud Tachinos citandus, Staph. fus cipes Linnei species dubia quidem est, at certe distincta a nostra, ,thorace, capite et maxillis insignibus," forte ad Oxytelum vel potius Platysthetum quendam spectans.

* 2. A. chrysorrhoa: Nigra, nitida, antennis brevibus fusiformibus basi, ano pedibusque anterioribus testaceis, elytris thorace subbrevioribus, abdomine supra parcius punctato. - Long. 3 lin.

Habitat in Brasilia, Dom. Virmond.

Statura praecedentis, nigra, nitida, parcius griseo-pilosa. Antennae capite paulo longıres, articulo secundo tertio dimidio breviore, sequentibus crassis, 5-8 fortiter transversis, crassitie plus duplo brevioribus, praecedentibus duobus his paulo angustioribus, licet transversis, at longitudine vix duplo crassioribus, ultimo iterum paulo angustiore, oblongo-ovato, medio leviter constricto, fuscae, articulis tribus primis testaceis, ultimo apice subferrugineo. Palpi picei, articulo terminali pallide testaceo. Caput thorace multo minus, deflexum, fronte planiuscula, crebre fortiterque punctata, linea media longitudinali laevi. Thorax latitudine dimidıo brevior, basi coleopteris paululum angustior, basi leviter, laterıbus fortius dilatatis, apicem versus modice angustatus, apice truncatus, angulis omnibus obtusis, anterioribus deflexis, leviter convexus, sat crebre fortiterque punctatus. Elytra thorace perparum breviora, angulo apicali exteriore rotundato, dense fortiter punctata. Abdomen apicem versus subangustatum, utrinque parcius punctatum, segmento penultimo apice ultimoque totis fulvis, segmentis ventralibus piceo-marginatis. Pedes testacei.

* 3. A. dilatata: Nigra, nitida, anlennis brevibus, fusiformibus basi, ano pedibusque rufo-testaceis, elytris thorace brevioribus, abdomine supra parcius punclato. - Long. 2 lin.

\section{Habitat in Madagascar, Dom. Goudot.}

Magnitudine A. bipunctatae, at brevior, nigra, nitida, snbtiliter puberula. Antennae capite parum longiores, crassae, articulo secundo tertio dimidio breviore, quarto leviter transverso, 5-10 brevissimis, longitudine triplo crassioribus, ultimo praecedentibus duobus coniunctis sublongiore, ovatoconico, fuscae, articulis 3 primis testaceis. Palpi testacei. Caput parvum, deflexum, fronte depressa, parce punctata. Thorax latitudine plus dimidio brevior, basi coleopterorum prope latitudine, basi et lateribus leviter rotundatus, apice truncatus, angulis anterioribus rotundatis, deflexis, posterioribus obtusissimis, transversim leviter convexus, crebrius punctatus. Elytra thorace dimidio prope breviora, angulo apicali exteriore rotundato, densius profunde punctata. Abdomen breviusculum, apicem versus subangustatum, supra parcius profundiusque punctatum, segmento penultimo margine apicali ultunoque toto testaceis, subtus crebrius punctatum, densius griseo-pilosum, segmentis singulis margine apicali tenui ferrugineo. Pedes testacei. 
* 4. A. Cayennensis: Rufo-testacea, capite abdominisque segmentis qua. tuor intermediis nigris, antennis nigris, basi testaceis, elytris thorace brevioribus, abdomine supra parcius punctato. - Long. 2 lin.

Laporte Etud. Ent. p. 136.

Habitat in Cayenna, Dom. Buquet.

Statura A. rufipennis, rufo-testacea, subnitida, fulvescenti-puberula. Antennae capite sesqui longiores, articulo secundo tertio paulo breviore, quarto turbinato, crassitie haud breviore, 5-10 trausversis, longitudine sesqui fere crassioribus, ultimo praecedentibus crassitie aequali, oblongoovato, praecedentibus tribus coniunctis vix breviore, fusco-nigrae, articulis 4 primis testaceis. Palpi picei. Caput deflexum, nigrum, parce obsoletius punctatum. Thorax latitudine dimidio brevior, basi coleopterorum prope latitudine, apicem versus angustatus, basi et lateribus leviter rotundatus, apice truncatus, angulis omnibus obtusissimis, subrotundatis, anterioribus deflexis, transversim leviter convexus, dorso subdepressus, subtilius dense punctatus, rufo-testaceus, medio lineis duabus approximatis, utrinque abbreviatis, obscuris. Elytra thorace paulo breviora, confertım punctata, angulo apicali exteriore rotundato, subfusco. Abdomen parallelum, supra parcius profundiusque punctatum, basi obscure rufo-testaceum, segmentis $2-5$ nigris, subtus margine apicali ferrugineo, ultimis duobus dilute testaceis. Pedes dilute testacei.

* 5. A. lateralis: Nigra, anlennis medio subincrassalis basi pedibusque rufo-testaceis, ano elytrisque rufis, his thorace brevioribus, macula laterali nigra, abdomine supra crebrius punctato. - Long. $2 \frac{2}{3}$ lin.

Habitat in Columbia, Dom. Moritz.

A. fuscipede angustior, nigra, nitida, griseo-puberula. Antennae capite sesqui longiores, ab articulo quarto inde incrassatae, medio paulo crassiores, apicem versus parum attenuatae, articulo quarto cyathiformi, crassitie paulo breviore, 5-10 transversis, crassitie duplo brevioribus, ultimo ovatosubconico, praecedentibus duobus coniunctis longitudine aequali, fuscae, articulis tribus primis testaceo-rufis. Labrum rufum. Palpi testaceo-rufi. Caput deflexum, disperse sat profunde punctatum. Thorax latitudine plus dimidio brevior, basi coleopterorum prope longitudine, apicem versus subangustatus, basi leviter, lateribus fortius rotundatus, angulis omnibus obtusis, leviter transversim convexus, confertim punctatus. Elytra thorace paulo breviora, angulo apicali exteriore rotundato, confertissime punctata, rubra, macula marginali, humerum haud attingente, nigra. Abdomen apice parum angustatum, supra fortius crebriusque punctatum, longius pilosum, segmento penultimo apice ultimoque toto saturate rubris, subtus dense punctatum, segmentis singulis margine apicali rufo-piceo. Pedes testaceo-rufi.

6. A. breviuscula: Piceo-nigra, nilida, antennarum basi pedibusque testaceis, thoracis lateribus elyirisque rufo-piceis, his thorace brevioribus, lateribus nigris, abdomine supra parce punctato, antennis crassis, subfusiformibus. - Long. $1 \frac{1}{2}$ lin.

Habitat in Columbia, Dom. Moritz.

Habitu fere praecedentium, at minor, A. pullae similis et eadem pa- 
rum longior, at crassula et antennis crassis dissimilis, piceo-nigra, ni tida, tenuiter griseo-puberula. Antennae capite sesqui longiores, crassae, medio subincrassatae, articulis 4-10 transversis, fuscae, basi rufo-testaceae. Caput parce obsoletius punctatum, ore testaceo. Thorax coleopteris vix angustior, latitudine dimidio brevior, modice transversim convexus, crebrius punctatus, lateribus rufo-piceus. Elytra thorace paulo breviora, crebrius punctata, rufo-picea, lateribus nigra. Abdomen breviusculum, apicem versus parum angustatum, supra parce punctatum, ano segmentisque singulis margine apicali rufo-piceis. Pedes flavescenti-testacei.

* 7. A. rufipennis: Nigra, nitida, elytris thorace subbrevioribus rufis, lateribus nigris, pedibus piceis, abdomine supra parce punctato. Long. 2 lin.

Aleoch. la evigat a Boisd. et Lacord. Faun. Ent. Paris. I. 530. 6.

Habitat in Austria, Gallia, Italia.

Habitu ommmo A. tristis, nigra, nitida, densius subtiliter griseo-puberula. Antennae capite duplo longiores, crassiusculae, apicem versus incrassatae, articulo secundo tertio paulo breviore, 5- 10 transversis, ultimo his crassitie aequali, ovato, praecedentibus duobus coniunctis fere longiore, basi obscure piceae. Palpi maxillares picei, articulo terminali pallide testaceo. Caput deflexum, parce obsoletius punctatum. Thorax latitudine dimidio brevior, coleopterorum prope latitudine, antrorsum vix angustatus, basi leviter, lateribus fortius rotundatus, apice truneatus, angulis ommibus obtusissimis, subrotundatis, anterioribus deflexis, transversim leviter convexus, crebre subtilius punctatus. Elytra thorace paululum breviora, angulo apicali exteriore rotundato, dense punctata, laete rufa, latere nigro. Abdomen apicem versus subangustatum, supra sub-glabrum, parcius profundiusque punctatum, subtus crebrius punctatum, longius pilosum, segmentis singulis margine apicali obscure piceo. Pedes picei, geniculis tarsisque rufis.

* 8. A. tristis: Nigra, nilida, elylris thorace brevioribus, macula apicali rufo-testacea, pedibus piceis, thorace aequaliter punctato, abdomine parallelo, supra confertissime punctato. - Long. $1 \frac{1}{2}-2 \frac{1}{4}$ lin.

Grav. Mon. 170. 59. - Gyll. Ins. Suec. II. 430. 59. - Sahlb. Ins. Fenn. I. 395. 86. - Boisd. et Lacord. Faun. Ent. Paris, I. 529. 2. - Mannerh. Brachelytr. 66. 2. - Runde Brachelytr. IIal. 2〕. '2. - Er. Col. March. I. 355. 2.

Staph. geometricus Schrank Faun. Boica I. 642. 869.

$V$ ar. Elytris rufo-testaceis.

Aleoch. crassiuscula Sahlb. Ins. Fenn. I. 396. 89.

Habitat in Europa et in Oriente.

Statura fere A. fuscipedis, at plerumque duplo minor, magnitudine magnopere varians, nigra, subaeneo-nitidula, breviter dense cinereo-puberula. Antennae capite paulo longiores, articulo secundo tertio subaequali, apicem versus sensim leviter incrassatae, articulis penultimis transversis, ultimo praecedentibus duobus coniunctss longitudine subaequali, subconico, nigrae, articulo primo interdum piceo. Palpi picei. Caput deflexum, parcius punctatum. Thorax latitudine plus dimidio brevior, coleopteris latitu- 
dine aequalis, apicem versus vix angustatus, basi leviter, lateribus fortins punctatus, apire truncatus, angulis omnibus obtusisssimis, subrotundatis, anterioribus deflexis, transversim modice convexus, confertim punctatus, disco interdum punctis quatuor, quadratim positis, vel sex evidentioribus. Elytra thorace paulo breviora, angulo apicali exteriore rotundato, confertissime punctata, subrugulosa, prope suturam macula magna apicali rufo-testacea notata. Abdomen parallelum, crassiusculum, supra infraque confertissime punctatum. Pedes picei, tarsis rufescentibus.

V ariat interdum elytris rufo-testaceis, saepius basi et circa scutellum, maculaque laterali fuscescentibus.

Obs. Occurunt nonnunquam individua minuta, long. $1 \frac{\mathrm{r}}{2}-1 \frac{2}{3}$ lin, elytris totis rufo-testaceis, thorace parcius obsoletiusque punctato, ab hac vix specie distinguenda. Huc forte referenda Al. crassicornis Boisd. et Lacord.

9. A. bipunctata: Nigra, nilida, elytris thorace dimidio brevioribus, apice sanguineis, pedibus testaceis, thorace convexo, creberrime punctato, abdomine apicem versus attenualo, supra crebre punctato. Long. $2 \frac{1}{4}$ lin.

Grav. Micr. 93. 37. Mon. 171. 61. - Latr. Hist. nat. Crust et Ins. IX. 338. 37. Gen. Crust. et Ins. I. 301. 1. - Gyll. Ins. Suec. II. 430. 52. - Zetterst. Faun. Lappon. I. 104. 23. Ins. Lapp. 79. 33. - Sahlb. Ins. Fenn. I. 95. 87. - Boisd. et Lacord. Faun. Ent. Paris. I. 529. 3. - Er. Col. March. I. 355. 3.

Staph. bipunctatus Olv. Ent. II. 42. 31. 43. t. 5. f. 44. (forte)

Al. intricata Mannerh. Brachelytr. 66. 4* - Runde Brachelytr. Hal 28.4. - Sahlb.

Ins. Fenn.I. 396. 88.

Habitat in Europa.

Praecedenitibus brevior et magis convexa, nigra, nitidula, pube brevi subtili depressa fusca vestita. Antennae capite paulo longiores, tenuiores, articulo secundo tertio longitudine aequali, apicem versus lenter incrassatae, articulis penultimis subtransversis, ultimo praecedentibus ambobus vix longiore, oblongo-ovato, nigrae, basi obscure piceae. Palpi maxillares nigri, articulo terminali testaceo. Caput deflexum, dense punctatum. Thorax latitudine dimidio brevior, basi coleopterorum latitudine, antrorsum angustatus, basi lateribusque rotundatus, apice truncatus, angulis anterioribus subrectis, deflexis, posterioribus obtusis, sat convexus, subtiliter confertim punctatus. Elytra thorace dimidio breviora, angulo apicali exteriore rotundato, confertissme vel ruguloso-punctata, opaca, apice sanguinea. Abdomen apicem versus sensim attenuatum, supra dense, subtus fortius punctatum, segmentis ventralibus singulis margine posteriore rufo-pıceo. Pedes rufo-testacei.

* 10. A. brevipennis: Nigra, nitida, antennarum basi pedibusque testaceis, elytris thoracis longitudine, creberrime punctalis, immaculatis, abdomine apicem versus altenualo, supra parcius punclalo. - Long. 2 lin.

Grav. Mon. 169. 53. - Er Col. March. I. 356. 4.

Al. carnivora Gyll. Ins. Suec. II. 431. 53. - Sahlb. Ins. Fenn. I. 397. 90. Zetterst. Faun. Lapp. I. 104. 24. Ins. Lapp. 79. 34. - Boisd. et Lacord. Faun. Ent. Paris. I 350. 4. - Mannerh. Brachelytr. 66. 5.

Habitat in Europa.

Statura A. bipunctatae, nigra, subaeneo-nitida, lanugine depressa fla- 
vescenti-grisea, densius vestita. Antennae capite duplo longiores, articulo secundo tertio paulo breviore, apicem versus sensim leniter incrassatae, articulis penultimis longitudine haud crassioribus, ultimo praecedentibus ambobus longitudine aequali, oblongo-ovato, apice compresso, nigrae, articulo primı rufo. Palpi rufi. Caput deflexum, fronte parce punctata. Thorax latitudine plus dimidio brevior, basi coleopterorum latitudine, apicem versus fortiter angustatus, basi leviter, lateribus fortius rotundatus, apice truncatus, angulis omnibus obtusis, anterioribus deflexis, sat fortiter convexus, parcius subtiliter punctatus. Elytra thoracis longitudine, angulo apıcali exteriore rotundato, profunde confertissime punctata, subrugulosa, nigro-subaenea, opaca, apice concolore. Abdomen apicem versus sensim leviterque angustatum, supra parcius, subtus crebrius fortiter punctatum, segmentis ventralıbus apice piceo-marginatis. Pedes testacei, femoribus interdum fuscescentibus.

* 11. A. verberans: Nigra, nilida, antennarum basi pedibusque rufis, femoribus posticis nigris, elytris thoracis longiludine crebre, fortilergue punclatis, apice rufescentibus, abdomine parallelo, supra parce punctato. - Long. 2 lin.

Habitat in Brasilia, Columbia.

Statura et summa similitudo A. lanuginosae. Corpas nigrum, nitidum, pube tenuiore depressa fulvescente parce vestitum. Antennae capite sesqu Iongiores, articulo secundo tertioque aequahbus, apicem versus sensim incrassatae, articulis 7-10 transversis, ultimo subovato, apice fortiter compresso, praecedentibus ambobus longitudine aequali, nigrae, articulo primo secundoque rufis. Palpi picei. Caput deflexum, fronte.parce obsoleteque, vertice crebre distinctius punctatum. Thorax latitudine dimidio brevior, coleopterorum prope latitudine, antrorsum vix angustatus, basi et lateribus leviter rotundatus, apice truncatus, angulis anterioribus obtusis, deflexis, posterioribus obtusissimis, subrotundatis, transversim leviter convexus, basi distincte, apicem versus sensim obsoletius punctatus, basi obsolete biimpressus, ut in A. lanuginosa. Elytra thoracis longitudine, angulo apicali exteriore rotundato, creberrime profundius punctata, interstitis subrugosis, sub-aeneo-nigra, apice magis minusve rufescentia. Abdomen parallelum, supra parce punctatum, subtus segmentis singulis margine apicali ferrugineo. Pedes rufi, femoribus posticis nigris, apce rufis.

Obs. Specimina huius speciei duo, prope Caracas Columbiae lecta communicavit D. Moritz, alterum Brasiliensibus magnitudine aequale, alterum duplo maius.

* 12. A. vulnerata: Nigra, nilida, antennarum basi, pedibus elytrisque rufis, his thorace brevioribus, sutura latereque late nigris, abdomine apicem versus attenuato, supra profunde punctato. - Long. $2 \frac{1}{4}$ lin.

Habitat in Madagascar, Dom. Goudot.

Statura fere praecedentis, nigra, nitida, subtiliter griseo-lanuginosa. Antennae capite sesqui longiores, articulo secundo tertioque aequalibus, apıcen versus leniter incrassatae, articulis penultmis longitudine paulo crassioribus, ultimo his crassitie et penultimis duobus coniunctis longitudine aequali, oblongo-ovato, nigrae, basi rufae. Thorax latitudine dimidio bre- 
vior, antrorsum angustatus, basi et lateribus leviter rotundaius, apice tran catus, angulis anterioribus obtusis, deflexis, posterioribus subrotundatis, transversim convexus, confertim punctatus. Elytra thorace paulo breviora, angulo apicali exteriore subrotundato, confertissime punctata, rufa, sutura basi dilatata limboque lato laterali, antice abbreviato, nigris. Abdomen apicem versus sensim attenuatum, supra parce pilosum, profundius minus dense punctatum, longitudinaliter subrugosum, subtus segmentis singulis ferrugineomarginatis. Pedes rufi.

* 13. A. puberula: Nigra, fusco-pubescens, antennarum basi, thoracis limbo, elytrorum disco pedibusque rufis, elytris thoracis longitudine, abdomine dense punctato. - Long. 2 lin.

Klug Coleopt. Madagasc. 51. 44.

Habitat in Madagascar, Dom: Goudot.

Statura intermedia fere inter A. tristem et brevipennem: Nigra, sub. nitida, pube depressa fusca densius vestita. Antennae capitis thoracisque longitudine, articulo secundo tertio paulo longiore, apicem versus incrassatae, articulis penultimis transversis, ultimo praecedentibus ambobus longitudine aequali, conico, acuminato, nigrae, basi rufo-testaceae, apice ferrugineo. Caput subglobosum, deflexum, confertim subtiliter punctatum. Thorax Iatitudine dimidio brevior, basi coleopterorum latitudine, lateribus et basi leviter rotundatus, antrorsum fortius angustatus, apice truncatus, angulis anterioribus rectis, fortiter deflexis, posterioribus obtusis, leviter transversim convexus, confertim subtilius punctatus, limbo omni obscure rufo. Elytra thoracis longitudine, angulo apicali exteriore rotundato, fortius confertissime punctata, rufa, basi, sutura maculaque magna laterali fuscis. Abdomen apicem versus sensim attenuatum, fortius confertim punctatum, nigrum, segmentorum marginibus rufo-piceis. Pedes testacei.

* 14. A. taeniata: Nigra, subopaca, antennarum basi, elytrorum vilta lata arcuata pedibusque testaceis, elytris thorace dimidio brevioribus, abdomine supra densius punclato. - Long. 2 lin.

Habitat in Americae ins. St. Johannis, Dom. Moritz.

Statura fere A. tristis, at paulo magis depressa. Nigra, vix nitida, densius griseo-pubescens. Antennae capite sesqui longiores, articulo secundo tertio brevioré, apicem versus inerassatae, articulis penultimis transversis, ultimo praecedentibus ambobus vix longiore, ovato, nigrae, basi testaceae. Palpi maxillares picei, articulo terminali testaceo. Caput deflexum, subtiliter punctatum. Thorax latitudine dimidıo brevior, coleopterorum latitudine. basi lateribusque leviter rotundatus, antrorsum subangustatus, apice truncatus, angulis omnibus obtusis, anterioribus deflexis, leviter transversim convexus, subtiliter densius punctatus. Elytra thorace dimidio breviora, angulo apicali exteriore rotundato, creberrime minus fortiter punctata, testacea, sutura infuscata, macula magna laterali nigra. Abdomen apice attenuatum, supra densius punctatum, nigrum, segmentis anterioribus apice obscure testaceis, subtus segmentorum singulorum margine lato posteriore anoque ferrugineis. Pedes testacei, coxis piceis. 
* 15. A. fumata: Nigra, subnitida, antennis basi pedibusque testaceis, thoracis lateribus elytrisque piceis, his thoracis longitudine, creberrime punctatis, abdomine apicem versus sensim subangustalo, supra parcius profunde punctato. - Long. $1 \frac{1}{2}$ lin.

Er. Col. March, I. 357. 6.

Al. fumat a ar. 2 Grav. Micr. 96. 42. Mon. 172. 64. - Latr. Hist. nat. Crust. et Ins. IX. 389. 42.

Al. curta Sahlb. Ins. Fenn. 1. 400. 97.

\section{Habitat in Europa.}

Statura A. brevipennis, at triplo minor, pube depressa grisea densius vestita. Antemnae capitis thoracisque fere longitudine, artıculo secundo tertio paulo breviore, apicem versus incrassatae, articulis 6-10 leviter transversis, ultimo praecedentibus ambobus aequali, ovato, subacuminato, rufae, basi testaceae. Palpi rufi. Caput deflexum, fronte subtilter parceque punctata. Thorax basi coleopterorum latitudine, hac duplo prope brevior, basi leviter, lateribus fortius rotundatus, antrorsum angustatus, apice truncatus, angulis omnibus obtusis, anterioribus deflexis, sat convexus, confertim subtiliter punctatus, lateribus obscure piceis. Elytra thorace vix breviora, angulo apicali exteriore rotundato, confertim profundius punctata, nigro-vel fusco-picea, minus nitida. Abdomen apicem versus sensim subangustatum, supra parce profundeque punctatum, subtus segmentis singulis late piceomarginatis. Pedes testacei.

Obs. 1. Proxima A. brevip enni, differt autem statura multo minore, thorace lateribus et elytris piceis, his paulo brevioribus, minus dense punctatis.

2. Ab A. moerente, quacum olim mihi confusa, discedit statura breviore et elytrorum angulo apicali exteriore rotundato.

* 16. A. bisignata: Nigra, nitida, pedibus piceis, thorace parce subtiliterque aequaliter punctato, elytris thoracis longitudine, crebre punctatis, macula apicali rufa, abdomine' parallelo, supra parcius profunde punctato. - Long. I $\frac{1}{2}$ lin.

Er. Col. March. I. 357. 7.

Habitat in Europa et in Oriente.

Statura omnino A. nitidae, nigra, nitida, parcius griseo-lanuginosa. Antennae capite paulo longiores, crassiusculae, articulo secundo tertioque aequalıbus, 5 - 10 transversis, longitudine plus duplo crassioribus, inter se aequalibus, ultimo praecedentibus ambobus vix longitudme aequali, subovato, acummato, totae nigrae. Palpi maxillares nigri, articulo terminali testaceo. Caput deflexum, laeve. Thorax latitudine duplo prope brevior, coleopterorum latitudine, basi leviter, lateribus nodice rotundatus, antrorsum subangustatus, apice truncatus, angulis omnibus obtusis, anterioribus subdeflexis, leviter transversim convexus, subtiliter parceque punctatus. Elytra thoracis Iongitudine, angulo apicali exteriore rotundato, profunde fortiterque crebre punctata, nigro-picea, macula magna apicali rufa prope suturam signata. Abdomen parallelum, supra minus crebre fortius punctatum, nitidum. Pedes picei, gemculss tarsisque rufescentibus, 
* 17. A. bimaculata: Nigra, nitida, antennarum basi pedibusque rufopiceis, elytris thorace subbrevioribus, macula magna testacea, thorace lateribus crebre, dorso biserialim, abdomine supra confertim punctato. - Long 2 lin.

Grav. Micr. 187. 3. Mon. 170. 58. - Say Act. Acad. nut. Scienc. Philadelyh. III. $p .157$.

Habitat in Pensylvania.

Statura A. tristis. Nigro-subaenea, nitida, pube parca depressa fulvescente vestita. Antennae capite parum longiores, articulo secundo tertio vix breviore, apicem versus paulum incrassatae, articulis $6-10$ transversis, ultimo praecedentibus ambobus vix breviore, subconico, basi obscure rufae. Palpi rufi. Caput deflexum, fronte utrinque parce sparsim punctata, vertice laevissimo. Thorax coleopterorum latitudine, hac dimidıo brevior, basi leviter, lateribus modice rotundatus, antrorsum subangustatus, apice truncatus, angulis anterioribus obtusis, subrotundatis, deflexis, posterioribus rotundatis, transversim convexus, lateribus crebre obsoletius punctatus, lineis duabus longitudinalibus impressis, irregulariter fortias punctatis, spatio intermedio laevi. Elytra thorace paululum breviora, angulo apicali exteriore rotundato, dense fortiter punctata, macula magna apicali rufo-testacea. Abdomen parallelum, crassiusculum, supra crebre punctatum, subtus segmentis singulis margine apicali obscure piceo. Pedes picei, tarsis rufis, interdun rufi, femoribus posticis solis piceis.

Variat statura duplo maiore.

18. A. duplicuta: Nigra, nitida, antennarum basi pedibusque rufo-piceis, elytris thorace brevioribus, macula apicali testacea, thorace lateribus parce subtiliterque, dorso biseriatim, abdomine supra confertim punctato - Long. $1 \frac{2}{3}$ lin.

Habitat prope Caracas Columbiae, Dom. Moritz.

Praecedentibus affinis, A. bimaculata duplo fere minor, A. nitidae aequalis, nigro-subaenea, nitida, elytris abdomineque subtilissime puberulis. Antemnae capite sesqui longiores, apicem versus sensim incrassatae, nigrae, basi rufescenti-piceae. Caput deflexum, disperse obsoletius punctatum. Thorax lateribus disperse subtiliusque punctatus, medio laevis, lineis dnabus longitudinalibus impressis, inaequaliter punctatis. Elytra thorace paulo breviora, dense punctata, macula magna apicali triangulari rufo-testacea. $\mathbf{A b -}$ domen parallelum, creberrime punctatum. Pedes rufi, femoribus piceis.

* 19. A. not ula: Nigra, nitida, antennarum basi, pedibus elytrorumque macula apicali rufo-lestaceis, his thorace brevioribus, thorace biserialim, elytris abdomineque parcius punctatis. - Lang. $1 \frac{1}{4}$ lin.

Habitat in Americae merid. ins. St. Thomae, Dom. Moritz.

A. 'nitidae affinis, at paulo minor, mgro-subaenea, nitida, elytris abdomineque subtiliter puberulis. Antennae capite paulo longiores, articulo secundo tertioque aequalibus, apicem versus sensim leniter incrassatae, articulis 5-10 transversis, ultimo maiusculo, praecedentibus ambobus longiore, subconico, piceae, basi testaceae. Palpi testacei. Caput deflexum, utrinque punctis raris impressum. Thorax latitudine plus dinidio brevior, coleopte- 
ris hasi latitudıne subaequalis, antrorsum leviter angustatus, basi et lateribus leviter rotundatus, apice truncatus, angulis omnibus obtusissimis, anterioribus deflexis, transversin convexus, dorso obsolete bilineatim impressus, in lineis obsolete irregulariter punctatus, punctis quatuor (binis) maioribus, quadratim positis, in medio dorsı notatus, lateribus parce vageque subtilissime punctulatus, punctoque uno alterove maiore impressus. Elytra thorace paulo breviora, angulo apicali exteriore rotundato, sat fortiter profundeque minus dense punctata, macula magna apicali rufo-testacea. Abdomen parallelum, parcius punctatum, subtus apice et singulorum segmentorum margine apicali lato ferrugineis. Pedes testaceo-rufi.

* 20. A. nitida: Nigra, nitida, thorace medio biseriatim punctato, elytris thoracis longitudine, profunde punctatis, macula apicali rufa, abdomine supra parcius punctato. - Long. $1 \frac{1}{4}-1 \frac{3}{4}$ lin.

Grav. Micr. 97. 44. Mon. 172. 63. - Latr. Hist. nat. Crust. et Ins. IX. 390. 44. - Gyll. Ins. Suec. II. 435. 57. - Sahlb. Ins. Fenn. I. 401. 98. - Boisd. et Lacord. Faun. Ent. Paris. I. 531. 8. - Mannerh. Brachelytr. 68. 14. - Er. Col. March. I. 358. 8.

Var. Elytris immaculatis.

Al. bilineata Gyll. Ins. Suec. II. 436. 58. - Sahlb. Ins. Fenn. I. 401. 98. Boisd. et Lacord. Faun. Ent. Paris. I. 532. 9. - Mannerh. Brachelytr. 68. 15.

Habitat in Europa et in Oriente.

Nigra, nitida, parce griseo-puberula. Antennae capite sesqui longiores, articulo secundo tertioque subaequalibus, apicem versus subincrassatae, articulis 5-10 transversis, ultimo praecedentibus ambobus magnitudine aequali, subovato, nigrae. Palpi maxillares nigro-picei, articulo terminali pallide testaceo. Caput deflexum, fronte utrinque parce punctata. Thorax coleopterorum latitudine, hac duplo brevior, bası leviter, lateribus modice rotundatus, antrorsum subangustatus, apice truncatus, angulis omnibus obtusissimis, subrotundatis, transversim convexus, antrorsum subcompressus, medio biseriatim, lateribus vage punctatus. Elytra thoracis longitudine, angulo apicali exteriore subsinuato, profunde fortiterque minus dense punctata, interstitiis laevibus, apice macula magna rufa notata. Abdomen parallelum, parcius punctatum. Pedes picei, geniculis tarsisque dilutioribus.

Elytra interdum fere tota testacea, saepius etiam tota nigra.

Obs. In Gravenhorstii Mon. allegatus apud hane speciem Staph. bipunctatus Oliv. et Staph. bipustulatus Lin. Ille, nisi ad Al. bipunctatam Grav., potius ad Al. tristem pertinere mihi videtur, Staph. bipustulatus Lin. (Faun. Suec. 232. 847. Syst. Nat. I. II. 685.16) autem ob ,,magnitudinem minoris pediculi, antennas clavatas et elytra brevia" forte apud hanc speciem respiciendus esset, nisi punctum ferrugineum in elytri singuli $\mathrm{m}$ edio notatum esset, quare hoc citatum nimis dubium existimo.

*21. A. lanuginosa: Nigra, nitida, pube erecta vestila, antennis totis nigris, elytris thoracis longitudine, crebre fortiler punctalis, apice rufescentibus, abdomine parallelo, supra parcius punctato. - Long. 2 lin.

Grav. Micr. 94. 48. Mon. 171. 62. - Latr. Hist. nat. Crust. ot Ins. IX. 388. 8. - Gyll. Ins. Suec. II. 432. 54. - Sahlb. Ins. Fenn. I. 398. 93. - Germ. Faun. Ins. Europ. XIII. 9. - Boisd. et Lacord. Faun. Ent. Paris. I. 530. 5. - Mannerh. Brachelytr. 67. 8. - Runde Brachelytr. Hal. 28. 6. - Er. Col. March, I. 35̄6. 5. Habitat in Europa.

Nigra, capite, thorace elytrisque subaeneis, nitida, pube erecta grisea 
vestita. Antennae capite duplo longiores, articulo secundo tertio subaequali, apicem versus leviter incrassatae, articulis penultimis longitudine vix crassioribus, ultimo praecedentibus duobus coniunctis longitudine prope aequali, ovato-subconico, nigrae. Palpi picei. Caput deflexum, fronte parcius punctata. Thorax latitudine plus dimidio brevior, vix coleopterorum latitudine, basi et lateribus rotundatus, antrorsum leviter angustatus, apice truncatus, angulis anterioribus obtusis, deflexis, posterioribus rotundatis, leviter transversim convexus, crebre punctatus, basi foveis duabus approximatis longitudinalibus obsoletis vel obsoletissimis, at densius fortiusque punctatis. Elytra thoracis longitudine, vel eodem sublongiora, apıce ad angulum exteriorem subsinuata, fortiter profunde denseque punctata, interstitiis planis, margine apicali rufescente. Abdomen parallelum, supra segmentis singulis basi densius, apice parcius punctatis, subtus fortius punctatum, segmentis singulis margine posteriore piceo. Pedes nigri, tibiis piceis, tarsis rufescentibus.

Variat 1, antennis elytrisque rufo-piceis, pedibus rufis.

2, antennis rufo-piceis, elytris, ano pedibusque rufo-testaceis.

O bs. Pube praecipue thoracis erecta ab affnibus distinguenda.

* 22. A. moerens: Nigra, nitida, antennarum basi, pedibus anoque rufotestaceis, elytris thoracis longitudine, dense punctatis, castaneis, abdomine apicem versus subangustato, parcius profundiusque punctato. Long. 2 lin.

Gyll. Ins. Suec.IV.493.53-54. - Sahlb. Ins. Fenn. I. 398.91. -Mannerh. Brachel. 66. 6. Ale och. fumata var. 1 Grav. Micr. 96. 42.

Habitat in Europa.

Nigra, nitida, tenuiter griseo-paberula. Antennae capite thoraceque paulo breviores, articulo secundo tertioque aequalibus, apicem versus sensim incrassatae, articulis 5-10 sensim fortius transversis, ultimo praecedentibus ambobus longitudine aequali, acuminato, piceae, basi rufo-testaceae. Palpi rufo-testacei. Caput deflexum, parce obsoleteque punctatum, ore piceo. Thorax latitudine plus dimidio brevior, basi coleopterorum latitudine, antrorsum angustatus, basi et lateribus modice rotundatus, apice truncatus, angulis posterioribus obtusis, anterioribus subrotundatis, deflexis, modice transversim convexus, crebrius punctatus, lateribus interdum piceus. Elytra thoracis longitudine, apice ad angulum exteriorem leviter sinuata, dense punctata, punctis obliquis, rufo-picea castaneave. Abdomen apicem versus sensim subangustatum, subtus densius, supra parcius longius pilosum, snbtus crebre, supra segmentis anterioribus crebrius, posterioribus parcius punetatis, ano rufo-testaceo, segmentis ventralibus piceo-marginatis. Perles rufo-testacei.

Mas abdominis segmento ventrali sexto apice medio triangulariter producto distinctus.

O bs. 1. Statura intermedia quasi inter A. fumatam et moestam, ab illa elytris apice subsinuatis, ab hac thorace abdomineque apicem versus subangustatis, hoc crebrius punctato distinguenda. Ab Al. lanuginosa pube depressiuscula et elytris dense minusque fortiter punctatis discedit.

2. Specimina Suecica, a Gyllenhalio communicata dedit Dom. Schüppel. 
* 23. 4. mo esta: Elongata, subdepressa, nigra, nitida, parce subtiliter punclala, antennarum basi pedibusque piceis, elytris thoracis longitudine, fortius crebre punclatis, abdomine supra sublaevigato. - Long. $1 \frac{1}{2}-$ $2 \frac{1}{4}$ lin.

Grav. Micr. 96. 41. Mon. 170. 55. - Latr. Hist. nat. Crust. et Ins. I. 389. 41. Er. Col. March. I. 358. 9.

Al fumata Gyll. Ins. Suec II. 434. 56. - Sahlb. Ins. Fenn. I. 400. 96. - Zetterst. Faun. Lappon. I. 105. 25. Ins. Lapp. 79. 36. - Mannerh. Brachelytr. 67. 10. Runde Brache ytr. Hal. 29. 8.

Al. haemorrhoidalis Mannerh. Brachelytr. 67. 7. - Sahlb. Ins. Fenn. I. 398. 92.

\section{Habitat in Europa.}

Praecedentrbus paulo magis elongata depı esaque, nigra, nitida, parcius griseo-puberula. Antennae capite thoraceque paulo breviores, articulo secundo tertioque subaequalibus, apicem versus sensim subincrassatae, articulis 5-10 leviter transversis, ultimo praecedentibus ambobus longitudine aequali, ovato-subconico, nigrae aut piceae, basi piceae aut rufo-piceae, articulo primo dilutiore, rufo. Palpi rufi. Caput parce punctatum. Thorax coleopteris paulo angustior, latitudine dimidio brevior, basi et lateribus leviter rotundatus, antrorsum subangustatus, apice truncatus, angulis omnibus obtusis, anterioribus leviter deflexis, parum convexus, parcius punctatus. Elytra thoracis longitudine, apice ad angulum exteriorem subsinuata, crebre profundius punctata, aut nigro-, aut rufo-picea. Abdomen longiusculum, parallelum, supra vix punctatum. Pedes picei aut rufo-picei.

M as abdominis segmento ventrali sexto apice medio triangulariter producto distinctus.

Obs. Proxime affinis A. lanuginosae, at statura minore, graciliore, et abdomine supra nonnisi raris punctis impresso distinguenda.

*21. A. ruficornis: Ferruginea, capite, thoracis disco abdominisque seg.menlorum intermediorum basi piceis, antennis elongatis, elytris thorace longioribus. - Long. $2 \frac{2}{3}$ lin.

Grav. Micr. 91. 34. Mon. 169. 51. - Latr. Hist. nat. Crust et Ins. IX. 387. 34.

Habitat in Germania media.

Statura magna A. fuscipedis, at gracilior, et antennis multo longioribus discedens. Rufo-testacea vel rufo-ferruginea, pube flavescente parcius vestita. Antennae capite thoraceque paulo longiores, graciles, articulo secundo tertio paululum breviore, apicem versus sensim subincrassatae, articulis 6- 10 longitudine perparum crassioribus, ultimo praecedentibus ambobus longitudine aequali, sensim acuminato, ferrugineae, articulo ultimo testaceo. Caput deflexum, parcius punctatum, nigrum, ore rufo. Thorax latitudine dimidio prope brevior, coleopterorum fere latitudine, antrorsum vix angustatus, lateribus et bası leviter rotundatus, apice truncatus, angulis omnibus obtusis, anterioribus deflexis, minus convexus, crebre punctatus, disco picescente. Elytra thorace sublongiora, apice ad angulum exteriorem subsinuata, creberrime punctata. Abdomen parallelum, supra parcius punctatum, segmentis intermediis basi picescentibus. Pedes dilute testacei.

Mas abdominis segmento dorsali secundo apice dente erecto, apice truncato, tertio medio tuberculo minuto acutiusculo, sexto ante apicem me- 
dio transversim elevato, sexto ventrali apıce bisinuato, medio leviter triangulariter producto insignis.

-25. A. erythroptera: Nigra, antennarum basi, elytris, ano pedibusque rufis, antennis elongatis, elytris thorace longioribus. - Long. 2 lin.

Grav. Mon. 158. 26.

Al. moesta var. $b$ Er. Col. March. I. 359. 10.

Habitat in Germania.

Habitu omnino praecedentis, colore, antennis apicem versus magis incrassatis etc. distincta, nigra, minus nitida, parcius flavescenti-puberula. Antennae capite thoraceque longiores, articulo secundo tertio paulo breviore, apicem versus sensim incrassatae, articulis $4-10$ subobconicis, penultimis etiam crassitie vix brevioribus, ultimo ovato, fuscae vel rufo-piceae, articulis tribus primis rufis. Palpi rufi. Caput deflexum parce obsoleteque punctatum, fronte convexa, inter antennas leviter impressa. Thorax latitudine dimidio brevior, basi coleopterorum latitudine, antrorsum angustatus, basi et lateribus modice rotundatus, apice truncatus, angulis posterioribus obtusis, anterioribus rotundatis, deflexis, transversim convexus, minus crebre punctulatus, lateribus interdum obscure piceus. Scutellum confertissime punctatum, nigrum. Elytra thorace paulo longiora, apice ad angulum exteriorem subsinuata, dense fortius punctata, laete rufa, parum nitida. Abdomen apicem versus sensim subangustatum, subtus parcius, supra parce punetatum, nigrum, nitidum, ano et subtus segmentorum singulorum margine posteriore lato rufis. Pedes toti cum coxis rufo - testacei.

M a s abdomine supra segmento secundo et sexto ante apicem medio tuberculo minuto munitis, subtus segmentis secundo tertioque basi transversim fortiter impressis, in impressione fortius villosis, sexto apice medio triangulariter producto distinctus. Antennae articulo ultimo maris praecedente duplo, feminae sesqui longiore.

Obs. 1. Oxyporus erythropterus Panz., a Gravenhorstio ad hanc speciem allegatus, in Tachyporo genere quaerendus.

2. Cum hanc speciem satis distinctam A. moestae subiungerem, feminam solam cognovi.

*26. A. amplicollis: Nigra, nitida, parce sublilissime pubescens, antennis, pedibus anoque piceis, elytris thoracis longiludine, apice ad angulum exteriorem profundius sinuala, abdomine supra parcius punctato. Long 2 lin.

Habitat in Madagascar, Dom. Goudot.

Nigra, nitida, pube subtili depressa grisea parce vestita. Antennae capitis thoracisque fere longitudine, apicem versus leniter incrassatae, articulo tertio secundo paulo longiore, 4-10 sensim brevioribus et crassioribus, penultimis duobus crassitie paulo brevioribus, ultimo his ambolbus longitudine aequali, oblongo, apice subacuminato, compresso, piceae, basi dilutiores. Caput parce subtiliterque punctatum, ore rufo-piceo. Thorax latitudine dimidio brevior, bası coleopterorum latitudine, antrorsum angustatus, lateribus et basi rotundatus, apice emarginatus, angulis omnibus obtusis, 
anterioribus leviter deflexis, medio laevissimus, versus latera subtilissime punctulatus. Elytra thoracis Iongitudine, crebre punctata, bası secundum suturam elevata, apice ad angulum exteriorem profundius sinuata. Abdomen apicem versus subattenuatum, supra parcius subtiliusque punctatum, segmento quinto medio subtilissime longitudinaliter biseriatim tuberculato, subtus minus subtiliter pubescens, ano piceo. Pedes picei.

Obs. Specimen unicum, mutilatum, habitu fere Gymnusae brevicollis, at huius generis videtur.

* 27. A. peltata: Nigra, nilida, antennarum basi, pedibus elytrisque rufopiceis, his thorace sublongioribus, angulo posteriore exteriore nigricante, abdomine supra laevigato. - Long. 2 lin.

Habitat in Mexico.

Nigra, nitida, pube depressiuscula, minus densa grisea vestita. Antennae capite duplo longiores, articulo secundo tertio paulo breviore, apicem versus incrassatae, articulis $6-10$ transversis, crassitie duplo brevioribus, ultimo praecedentibus ambobus longitudine aequali, subovato, apice valde acuminato, nigrae, articulis duobus primis testaceis, ultimo apice flavescente. Palpi maxillares testacei, articulo tertio piceo. Mandibulae rufae. Caput deflexum, vage punctatum. Thorax latitudine plus dimidio brevior, coleopteris paululum angustior, basi, angulis posterioribus lateribusque rotundais, antrorsum subangustatıs, apice subemarginatus, angulis anterioribus obtusis, leviter deflexis, parum convexus, sat crebre fortiter profundeque punctatus, margine basali elevato. Elytra thorace paululum longiora, apice ad angulum exteriorem subsinuata, minus dense fortiter punctata, brunneo-rufa, angulo posteriore exteriore late fuliginoso. Abdomen apice subangustatum, dorso laevigatum glabratumque, subtus parcius punctatum, longius pubescens, segmentis singulis utrinque margine posteriore rufo-piceo. Pedes rufo-picei。

* 25. A. vaga: Fusca, antennarum basi apiceque, thoracis limbo, elytrorum vitta obsoleta, abdominis segmentorum marginibus pedibusque rufis, abdomine supra densius punctalo. - Long. $1 \frac{2}{3}$ lin.

Ilabitat ad Promont. bon. Spei, Dom. Bergius.

A. pulla paulo maior et nulto latior, fusca, creberrime punctata, pube tenui grisea densius vestita. Antennae capite sesqui longiores, articulo seemndo tertio paululum breviore, apicem versus sensim subincrassatae, articulis 5 - 10 transversis, longitudine dimidio crassioribus, ultimo oblongo, praecedentibus ambobus longiore, acuminato, basi rufae, articulo ultimo acuminato, ferrugineo. Caput subporrectum, parcius punctulatum, nigrum, ore rufo. Thorax latitudine dimidio brevior, basi coleopterorum latitudine, antrorsum angustatus, basi et lateribus modice rotundatus, apice truncatus, angulis omnibus obtusis, anterioribus deflexis, transversim convexus, creberrime subtiliter punctatus, fuscus, limbo omni rufo. Elytra thoracis longitudine, apice ad angulum exteriorem leviter sinuata, creberrime punctata, vitta ab hnmero incipiente, arcuatim deflexa, obsoletiore, rufa. Abdomen breviusculum, apice subangustatum, supra profundius densiusque punctatum, nitidum, nigrum, segmentis margine rufis. Pedes rufi. 
* 29. A. deserta: Nigra, antennarum basi apicequs pedibisque testaceis, thorace, elytris anoque dilute rufo-piceis, abdomine supra crebre punclalo. - Long. $1 \frac{1}{2}$ lin.

Habitat in Arabia deserta, Dom. Prof. Ehrenberg.

Sequente vix longior, at paulo latior. Antennae capitis thoracisque longitudine, parum incrassatae, articulo secundo tertioque aequalibus, 5-10 transversis, longitudine sesqui fere crassioribus, ultimo praecedentibus ambobus paulo longiore, oblongo-ovato, apice acuminato, nigrae, articulis primis et ultimo testaceis. Capnt subdeflexum, nigrum, subtiliter punctatum, ore testaceo. Thorax latitudine dimidio brevior, basi coleopterorum latitudine, apicem versus angustatus, basi et lateribus leviter rotundatus, angulis omnibus obtusis, anterioribus deflexis, transversim convexus, subtiliter confertim punctatus, rufo-piceus, limbo dilutiore. Elytra thoracis longitudine, apice ad angulum exteriorem subsinuata, confertım subtiliter punctata, dilute rufo-picea. Abdomen apicem versus subangustatum, supra fortius crebre punctatum, segmentis singulis piceo-marginatis, ano dilute rufo-piceo. Corpus totum pube tenui depressa fulvescente vestitum. Pedes testacei.

* 30. A. pulla: Nigra, subnitida, confertissime purclata, dense grisescentipubescens, elytris thorace longioribus, brunneis, antennis nigris, basi apiceque pedibusque testaceis. - Long. $1 \frac{1}{2}$ lin.

Gyll. Ins. Suec. IV. 494. 56-57. - Mannerh. Brachelytr. 68. 13. - Boisd, et Lacord. Faun. Ent. Paris. I. 533. 10. - Er. Col. March. I. 359. 10.

Habitat in Germania, Suecia.

Nigra, parum nitida, confertissime punctata, pube brevi flavescentigrisea nitida densius vestita. Antennae capite thoraceque parum breviores, crassiusculae, articulo secundo tertio paulo longiore, 4-10 fortiter transversis, longitudine duplo crassioribus, ultimo ovato, subacuminato, nigrae, articulıs primis ultimoque rufo-testaceis. Palpi rufo-testacei. Caput deflexum, confertim fortiter profundeque punctatum, linea media longitudinali tenui laevi. Thorax brevis, latitudine duplo fere brevior, basi coleopteris vix angustior, apicem versus modice angustatus, basi et lateribus leviter rotundatus, apice truncatus, angulis omnibus obtusis, anterioribus deflexis, leviter transversim convexus, minus subtiliter dense aequaliterque punctatus. Elytra thorace paulo longiora, apice ad angulum exteriorem leviter sunuata, eodem modo punctata, aut nigro-fusca, aut rufo brunnea, thorace sesqui longiora. Abdomen apice subangustatum, utrinque dense et minus subtiliter punctatum, segmentis singulis margine apicali piceo. Pedes rufotestacei.

31. A. spissicornis: Nigra, nitida, antennis crassis basi, pedibus, elytris anoque rufis, abdomine supra parce punctato. - Long. vix ultra 1 lin.

Habitat Lutetiae, coll. Dom. Aubé.

Minuta, antennarum structura praecipue insignis, nigra, nitida, pube depressa grisea vestita. Antennae capite thoraceque paululum breviores, crassae, apicem versus sensim crassiores, articulo secundo tertio sesqui longiore, hoc obconico, 5-10 fortiter transversis, longitudine triplo crassio- 
ribus, perfoliatis, ultimo magno, subacuminato, rufo-piceae, basi testaceorufae. Caput deflexum, parce obsoleteque punctulatum, ore rufo-testaceo. Thorax latitudine duplo fere brevior, basi coleopterorum prope latitudine, apicem versus subangustatus, basi et lateribus leviter rotundatus, apice truncatus, angulis posterioribus obtusis, anterioribus rotundatis, deflexis, modice transversim convexus, subtiliter punctulatus, niger, nitidus, lateribus piceus. Elytra thoracis longitudine, apice ad angulum exteriorem subsinuata, fortius oblique punctata, lateritia, nitida. Abdomen parallelum, supra parce fortins punctatum, ano rufo, subtus segmentis singulis margine apicali rufo-piceo. Pedes testaceo-rufi.

* 32. A. laevigata: Nigra, nitida, parce subtiliterque punctata, elytris thoracis longitudine, crebre punctatis pedibusque rufis, abdomine parallelo, supra parcius profundiusque punctalo. - Long. $1 \frac{2}{3}$ lin.

Gyll. Ins. Suec. I1. 433. 55. - Sahlb. Ins. Fenn. I. 399. 95. - Mannerh. Brachel. 68. 11.

Habitat in Suecia, Dom. Schïppel.

Statura omnino A. nitidae, nigra, nitida, parce subtiliterque pubescens. Antennae capite paulo longiores, articulo secundo tertioque aequalibus, apicem versus sensim leviter incrassatae, articulis $\mathbf{5}-10$ transversis, ultimo maiusculo, praecedentibus ambobus paulo longiore, subacuminato, nigrae, basi piceae. Palpi picei. Caput deflexum, utrinque subtilissime obsoleteque punctulatum. Thorax latitudine duplo brevior, coleopterorum latitudine, basi leviter, lateribus modice rotundatus, antrorsum vix angustatus, apice truncatus, angulis ommbus obtusıs, anterioribus deflexis, transversin convexus, subtilissime obsoleteque parce punctatus. Elytra thoracis longitudine, apice ad angulum exteriorem leviter sinuata, dense fortius punctata, punctis obliquis, densius pubescentia, rufa, subnitida. Abdomen parallelum, minus confertim profundius punctatum, subtus segmentorum margine posteriore piceo. Pedes rufi.

*33. A. restricta: Nigra, nitidula, griseo-pubescens, antennis, tibiis tarsisque rufis, elytris thorace sesqui longioribus, forlius punctatis, abdomine apicem versus altenuato, supra conferlim punclato.-Long. $1 \frac{1}{3}$ lin.

Habitat in Brasilia, Dom. Prof. Germar.

Habitus et summa affinitas A. morionis, at paulo maior, nigra, nitidula, pube longiore depressa fuscescenti-grisea densius vestita. Antennae capite sesqui fere longiores, articulo secundo tertio duplo prope minore, apicem versus sensim incrassatae, articulis 4-10 transversis, sensim paulo crassioribns, ultimo praecedentibus ambobus prope longiore, apice abrupte acuminato, dilute rufae, basi testaceae. Palpi pallide testacei. Caput deflexum, subtilissime punctulatum. Thorax basi coleopterorum prope latitudine, antrorsum leviter angustatus, latitudine baseos duplo fere angustor, basi medio rotundatus, utrinque subsinuatus, lateribus rotundatus, apice truncatus, angulis anterioribus deflexis, rotundatis, posterioribus subrectis, sat fortiter convexus, crebrius subtiliter punctatus. Elytra thorace sesqui longiora, apice ad angulum exteriorem smuata, confertim fortius punctata, nigro-picea, humeris et margine summo apicali picescentibus. Abdomen apicem versus sensim attenuatum, subtilius crebre punctatum, segmentis singulis margine po- 
steriore rufescentibus, apice summo rufo. Pedes picei, tibiis tarsisque dilute rufis.

*34. A. morion: Nigra, subnitida, antennarum basi pedilusque rufis, ely. tris thorace longioribus, fortius punctalis, abdomine apicem versus attenuato, supra crebre punctato, apice rufo-piceo. - Long. $\frac{3}{4}-1 \frac{1}{4}$ lin.

Grav. Micr. 97. 45. Mon. 175. 69. - Latr. Hist. nat. Crust. et Ins. IX. 390. 45. Sahlb. Ins. Fenn. I. 402 100. - Mannerh. Brachel. 68. 16. - Er. Col March. I. 361. 13. Aleoch. exigua Mannerk. Brachelytr. 68. 17. - Sahlb. Ins. Fenn. I. 402. 101.

Habitat in Europa et in America meridionali.

Habitu omnino A. bipunctatae, at multo minor, nigra, subnitida, pube rara subtilique vestita. Antennae eapitis thoracisque longitudine, articulo secundo tertioque aequalibus, apicem versus incrassatae, articulis 4-10 transversis, ultimo maiusculo, ovato, nigrae, basi rufae. Palpi rufo-picei. Caput deflexum, parce subtilius punctatum. Thorax latitudine duplo brevior, basi coleopterorum latitudine, modice rotundatus, utrinque subsinuatus, late. ribus leviter rotundatus, antrorsum angustatus, apice truncatus, angulis omnibus obtusis, anterioribus deflexis, transversim convexus, confertim subtilius punctatus. Elytra thorace paulo longiora, apice ad angulum exteriorem sinuata, fortiter dense punctata, reliquo corpore densius pubescentia. Abdomen apicem versus attenuatum, supra sat crebre licet segmentis posterioribus minus dense et subtilius punctatum, apice rufo-piceum. Pedes rufi.

Obs. 1. Al. exigua antennis longioribus praecipue ab Al. morione disce. dens nisi sexu nullo modo ab hac differre videtur. Magnitudine haec species, uti plures huius generis valdopere variat, quod e longitudinis mensura indicata patet.

2. Specimina Americana cum Europaeis exactissime conveniunt; exemplum in Brasilia a Dom. Beske lectum dedit Dom. Thorey, alterum e Columbia a Dom. Moritz allatum. Forte eliam Americam septentrionalem habitat.

*35. A. an gulata: Rufo--brunnea, antennarum basi apiceque anoque ferrugineis, thorace depresso, obsolete canaliculato, angulis" posticis acttis. - Long. I $\frac{1}{2}$ lin.

Er. Col. March. I. 360.11.

Habitat B rolini; Lutetiae etiam in societate Formicae rufae lecta a Dom. Aubé.

Statura fere A. pullae, at supra magis plana, pube tenuissima depressa grisea parce vestita, rufo-brunnea. Antennae capite sesqui longiores, articulo secundo tertioque subaequalibus, apicem versus sensim leniterque incrassatae, articulis arcte contiguis, penultimis leviter transversis, ultimo praecedentibus tribus longitudine vix inferiore, oblongo, apice subacuminato, rufo-brunneae, articulis primis ultimoque ferrugineis. Caput parvum, subdeflexum, obsoletissime punctulatum, opacum, nigrum, ore rufo. Thorax coleopterorum latitudine, eaque duplo brevior, antrorsum angustatus, lateribus parum, basi praecipue medio fortius rotundatus, basi utrinque sinuatus, apice truncatus, angulis anterioribus obtusis, deflexis, posterioribus acutis, supra subdepressus, obsolete canaliculatus, basi distincte transversim impressus, subtiliter obsoleteque punctatus, opacus. Elytra thorace vix longiora, apice prope angulum exteriorem sinuata, dense punctata, opaca. Abdomen apice 
angustatum, infra longius pubescens, supra parcius punctatum, nitidulum, ante apicem obscurum, apice late rufo-testaceum. Pedes rufo-testacei.

\section{* 36. A. praet exta: Nigra, nitida, antennis, elytrorum limbo omni, abdo minis apice segmentorumque marginibus pedibusque rufis, thorace brevi, angulis posticis acutiusculis. - Long. $1 \frac{1}{2}$ lin.}

Er. Col. March. I. 361. 12.

Habitat in Germania, Gallia.

Linearis, nigra, nitida, pube depressa flavescente parcius vestita. Antennae capite thoraceque breviores, articulo secundo tertio paulo maiore, 4 - 10 transversis, arcte contiguis, ultimo ovato, apice compresso, totae rufae. Caput porrectum, maiusculum, obsolete punctatum, ore rufo. Thocoleopterorum latitudine, eaque duplo brevior, antrorsum vix angustatus, basi modice, lateribus leviter rotundatus, basi utrinque leviter sinuatus, angulis posterioribus acutiusculis, apice truncatus, angulis anterioribus obtusis deflexis, transversim parum convexus, parcius subtiliter punctatus. Elytra thorace sesqui longiora, apice ad angulum exteriorem profundius sinuata, subtiliter punctata, limbo suturali, apicali et lateribus rufis. Abdomen parallelum, parcius punctatum, segmentis 5 primis rufo-marginatis, ultimis duobus totis rufo-testaceis. Pedes rufi.

* 37. A. obscurella: Atra, opaca, pube brevi crassiuscula grisea densius vestila, antennis pedibusque rufo-piceis, elytris thorace sesqui longioribus. - Long. $1 \frac{2}{3}$ lin.

Grav. Mon. 159. 27. - Gyll. Ins. Suec. II. 403. 25.

Oxypoda serice a Boisd. et Lacord. Faun. Ent. Paris. I. 538. 2.

Habitat in Germania septentrionali, Suecia, Gallia.

Elongata, subdepressa, atra, opaca, pube brevi, parum depressa, grisea, micante densius vestita. Antennae capite parum longiores, rufo-piceae, articulo secuudo tertio longitudine aequali, licet paulo crassiore, apicem versus sensim subincrassatae, articulis 5-10 transversis, ultimo ovato-subconico. Palpi rufo-picei. Caput thorace parum angustius, porrectum, rotundatum, fortius punctatum, linea media subelevata laevi. Thorax coleopterorum latitudine, eaque plus dimidio brevior, antrorsum vix angustatus, lateribus et basi leviter rotundatus, apice truncatus, angulis anterioribus obtusis, deflexis, posterioribus subrotundatis, transversim parum convexus, parce subtiliterque punctatus. Elytra thorace sesqui longiora, apice truncata, crebre punctata, picescentia. Abdomen parallelum, crebrius punctatum, subtilius pubescens, supra nitidulum. Pedes picei, geniculis tarsisque rufescentibus.

\section{Species mihi invisae.}

35. A. ha morrhoidalis: Nigro-coerulea, nilida, antennis fusiformilus, capite, thorace elytrisque crebre punctatis, abdomine nigro, apice ferrugineo, pedibus atris.

Guérin Voy. d. l. Coquille, Ins. t. 1. f. 24. - Boisd. Faun. Ent Ocean. 57. 1.

Habitat in Nova Hollandia. (Port Jackson.)

Obs. A chrysorrboae affinis videtur. 
39. A. villosa: Sublinearls, nigra, opaca, creberrime punclata, pube brevi fusca undigue tecla, antennis thorace longioribus basi pedibusque piceis. - Long. $1 \frac{3}{4}$ lin.

Mannerh. Brachelytr. 67. 9. - Sahlb. Ins. Fenn. I. 399. 94. - Zetterst. Ins. Lap pon. 79. 35. - Runde Brachelytr. Hal. 29. 7.

Habitat in Fennia, Lapponia.

Ab $\Lambda$. lanuginosa differre videtur corpore angustıore, magis lineari, antemis thorace longioribus, basi piceis, thorace elytris fere angustiore, margine elytrorum nunquam rufo, et pubescentia breviore, fuscescente. 1) cetero eidem adeo simmlis est, ut ulteriori non opus sit descriptione. (Sahlb.)

Obs. Mihi omnino dubia.

40. A. crassicornis: Nigra, nitida, antennis crassis, fuscis, pedibus elytrisque rufo-testaceis, his margine laterali infuscalo. - Long. $1 \frac{1}{4}-1 \frac{1}{3} \mathrm{lin}$.

Boisd. et Lacord. Faun. Ent. Paris. I. 531. 7.

Habitat Lutetiae.

A. rufipenni quodammodo affinis, at multo minor. Antennae breves; crassae, fuscae. Caput rotundatum, nigro-subaeneum, nitidum; subtilissime punctatum et pubescens, palpis maxillaribus fuscis, labialıbus testaceis. Thorax ut in praecedentibus, subtilissime punctatus et pubescens, nigro-subaeneus, nitıdus, margine laterali subferrugineo. Sıutellum triangulare, laeve, piceum. Elytra dilute testacea, margine laterali magis minusve anguste fuliginoso, apice truncata, depressa, thorace et capite fortius punctata, tenuiter pubescentia. Abdomen totum nigro-subaeneum, nitidissimum, elongatum, punctatum et pubescens ut in praecedentibus (A. rufipenni, lanuginosa etc ${ }_{i}$ ) Pedes rufo-testacei. (Boisd. et Lacord.)

Obs. In A. Iristis var, minor, capitis thoracisque punctura obsoleta?

\section{Pliytosus Rudd. \\ Curt. Britt. Ent. XV.pl. 718 .}

Mavillue mala interiore mutica, intus spinulis ciliata.

Ligula subintegra; paraglossae angustae, acuminatae.

Pripi labiales 3 -arliculati, articulo secundo et tertio longitudine aequalibus. Tarsi antici 4-, posteriores 5-arliculati, postici articulis 4 primis uequalibus. Tibiae anteriores spinulosae.

Corpus elongatum, lineare, subdepressum. Caput exseritum, porrectum; basi hand constrictum, thoracis latitudine. Labrom apice truncatum, mandibularum apices haud obtegens. Mandibulae muticae. Maxillae mala exteriore cornea, basi apiceque membranea, portione nembranea apicali pube scente, mala interiore exteriore vix breviore, membranacea, margine exteriore corneo, apice oblique introrsum fortius emarginata, sinu spinulis brevibus clíato. Palpi maxillares elongati, articulo tertio secundo paulo longiore, apicem versus sensim lenter incrassato, quarto minuto, subulato. Labium mento transverso, antrorsum angustato, apice late emarginato, ligula brevi, apice vix emarginata, paraglossis sat elongatis, angustis, acumiuatis, interne eiliatis. Palpi labiales triarticulati, articnlo primo secundoque minus perspicue distinctis, loc paulo breviore, tertio secundo longitudne subaequali, 
basi tenniore, apice incrassatulo. Antennae breviores, articulis duobus primis elongatis. Thorax coleopteris paulo angustior, basin versus subangustatus. Scutellum triangulare. Elytra truncata. Abdomen elongatum, lineare, segmento septimo distincte conspicuo. Pedes breves, intermedii basi approximati, tibiis anterıoribus externe seriatim sat fortiter spinulosis, posticis muticis, tarsis brevibus, anticis 4-, posticis 5-articulatis, articulis primis brevibus, aequalibus, ultimo elongato, illis coniunctis fere aequali.

\section{O b s e r v a t i o n e s.}

1. Maxillae fere ut in Homalota (t. III. f. 22.), at mala interior apice fortius sinuata, et palpi maxillares articulo tertio magis elongato, haud tumidulo. Palpi labiales ut in Falagria (t. III. f. 3.), at articulo secundo tertio haud breviore, paraglossae ut in Autalia (ibid. f. 2.), mentum ut in Bolitochara (ibid. f. 4); ligula mihi forte haud satis accurate observata, at brevis et latiuscula mihi visa est, ut in Aleochara, at apice haud biloba, immo vix emarginata.

2. Habitu fere Pron omaeae, at corpus dense sericeo-pubescens. Proxime affiuis videtur Aleocharae, (v. c. Al. obscurellae,) at palporum labialium et tarsorum structura discedit. Tarsorum structura cum Homalota congruit, differt autem paraglossis distinctis. Tibiis anterioribus fortiter spinulosis hoc genus in hac tribu valde distinctum, tibiis anticis fossoriis et abdominis segmento septimo conspicuo pulchre $\mathrm{Oxy}$ telinor um tribum in animum revocans, nuperrime ab auctore ipso benevole mihi communicatum hoc loco inserui, cum non modo ligulae structura intermedium inter Aleocharam et sequentia genera, sed summa etiam affinitatis specie Aleocharae obscurellae iunctum videatur.

3. Sexus differentia infra indicata.

* 1. Ph. spinifer: Niger, dense cinereo-pubescens, antennis pedibusque rufis. - Long. $1 \frac{1}{3}$ lin.

Curtis Britt. Ent. $\boldsymbol{X} \boldsymbol{V}, \boldsymbol{t}, 718$.

Habitat in Anglia, Dom. Rudd.

Cinerascenti-niger, vix nitidus, pube minus subtili, depressa, cinerea, sericea dense vestitus. Antennae capite sesqui longiores, apicem versus parum incrassatae, articulis duobus primis maioribus, longitudine fere aequalibus, primo crassiusculo, secundo elongato-obconico, tertio obconico, secundo duplo breviore, sequentibus breviusculis, sensim paulo crassioribus, penultimis 4 transversis, ultimo praecedentibus ambobus longitudine aequali, ovato, apice obtuse acuminato, dilute rufae, articulo ultımo fusco. Caput thoracis prope latitudine, rotundatum, confertim subtiliter punctatum, fronte leviter convexa, ore subacuminato, rufescente. Thorax coleopteris tertia parte fere angustior, latitudine haud brevior, basin versus subangustatus, lateribus anterius rotundatis, posterius subsinuatis, basi rotundatus, apice Iruncatus, angulis anterioribus obtusis, posterioribus subrectis, levifer convexus, confertim subtiliter punctatus, obsolete canaliculatus, basi leviter foveolatus. Elytra subdepressa, confertim subtiliter punctata. Abdomen confertim subtiliter punctatum, segmento qunto margine apicali subtestaceo. Pedes pallide rufi, femoribus nigricantibus.

Mas Alatus, elytris thoracis longitudine.

Femina Aptera, elytris thorace dimidio brevioribus.

Variat minus maturus testaceus, abdomine ante apicem capiteque nigricantibus. 


\section{Oligota Mannerh.}

\section{Mannerh. Brachelytr. p. 72 - Er. Col. March, I. p. 362.}

Maxillae mala interiore mutica, intus spinulis ciliata.

Ligula brevis bifida; paraglossae nullae.

Palpi labiales 3-arliculati, articulis duobus primis crassiusculis, subuequalibus, tertio tenui, acuminato.

Antennae 10-articulatae, apice fortiter incrassalae.

\section{Tursi omnes 4-arliculali, postici arliculo primo elongato.}

Corpus minimum, vel elongatum et sublineare, vel subovatum, alatumi Caput thorace angustius, deflexum, basi haud constrictum, oculis mediocribus, parum prominulis. Labrum transversum, breve, apice truncatum, mandibularum ajices haud obtegens. Mandibulae muticae. Maxillae malis breviusculis, membraneis, exteriore apice pubescente, interiore huic subaequali, apice introrsum oblique subemarginata, sinu spinulis brevibus ciliato. Palpi maxillares modice elongati, articulo secundo tertioque longitudine subaequalibus, hoc sat tumidulo, quarto minuto, subulato. Labrum (t. III. f. I0.) mento transverso, apice leviter emarginato, ligula minuta, bifida, paraglossis nullis. Palpi labiales triarticulati, articulo primo secundoque grossiusculis, inter se aequalibus, tertio minuto, subulato. Antennae breviusculae. 10-articulatae, articulis duobus primis crassiusculis, reliquis longioribus, sequentibus minutis, ultimis 3 vel 4 clavam oblongam formantibus. Thorax perbrevis, bası coleopteris latitudine subaequalis, leviter bisinuatus, modice convexus. Coleoptera apice coniunctim late emarginata. Abdomen vel lineare, vel apicem versus sensim angustatum. Pedes breviusculi, intermedii basi distantes, tarsi omnes -articulati, postici articulo primo subelongato.

\section{O b s e r v a t i o $n$ e s.}

1. Maxillae omnino ut in Homalota (t. III. f. 22), palpi maxillares autem articulo ultimo longiore aciculari differunt. Labii structura pari modo cum Homalotis satis convenit, palpi labiales vero itidem aliter constructi. Ceterum hoc genus admodum insigne antennis clavatis 10-articulatis et tarsis omnibus 4 -articulatis.

2 Habitu hoc genus, speciebus minimae magnitudinis compositum, duas continet formas. Alteram constituunt $O$. pusillima, at o maria et subtilis, corpore elongato, lineari, abdomine apicem versus haud angustato, alteram $O$. granaria, flavicornis et a picat a, corpore crassiusculo breviusculoque, utrinque attenuato, forma Tachyporina, ceterum autem omnibus characteribus cum illis congruentia, ut speciebus tam paucis vix sectione distinguantur. Antennarum tarsorumque stru. ctura Oligotae insigniter cum Hypocypto, Tachyporinorum genere conveniunt, cuius habitum $O$. granaria, flavicornis et apicata concinne simulant.

3. Sexus differentia latet.

4. Victus aliis sub arborum cortice, aliis in pratis

5. Genus Microcera Mannerh. (Brachelytr p. 7\%.) Oligotae affine videiur et dubito an revera sit distinctum. Convenit palporum maxillarium structura et antennarum articulis ultimis crassioribus, differt praecipue corpore anterius attenuato, postice latiore, ano truncato.

* 1. O. pusillima: Linearis, nigra, nitida, antennis, pedibus anoque rufis, antennarum articulis ultimis tribus abrupte crassioribus. - Long. $\frac{1}{2}$ lin.

Munnerh. B achelytr. 72. 1. - Er. Col. Murch. I. 363. 1.

Aleoch. pusillima Grav Mon. 175. 71. - Gyll. Ins. Suec. IV. 491. 38-39. -

Salle. Ins. Fenn. I. 384. 70. 
Habitat in Europa.

Corpus angustum, nigrum, nitidum, parce subtiliter pubescens. Antennae capite sesqui longiores, articulis duobus primis mainsculis crassiusculisque, 3-7 minutis, 7 to praecedentibus subaequali, ultimis tribus multo maioribus, 8to et 9to aequalibus, fortiter transversis, ultimo his ambobus parum minore, subgloboso, ferrugineae, clava fuscescente. Caput thorace paulo angustius, deflexum, subtilissime punctulatum, ore ferrugineo. Thorax coleopteris haud angustior, latitudine duplo brevior, basin versus haud angustatus, basi medio leviter rotundatus, utrinque subsinuatus, lateribus leviter rotundatus, apice truncatus, angulis omnibus obtusis, subrotundatis, anterioribus fortius deflexis, convexus, subtilissime punctulatus. Elytra thorace sesqui longiora, apice coniuncta late emarginata confertım fortius punctata. Abdomen parallelum, confertim subtiliter punctatum, apice rufescens. Pedes rufi.

Obs. 1. Al. pusillimam Gyll olim O. subtili allegavi, specimina autem Suecica, quae Dom. Schïppel a Dom. Schönherr sub hoc nomine accepit, ad hanc speciem pertinent, neque descriptio Gyllenhaliana huic contraria.

2. Statura magis lineari praecipue a proxime sequentibus distincta.

* 2. O. atomaria: Linearis, nigra, pedibus antennisque fusco-piceis, his articulis ultimis tribus abmupte crassioribus. - Long. $\frac{1}{2}$ lin.

Er. Col. March. I. 363. 2.

Habitat in Germania; specimen singulum Berolini legi.

Praecedenti affinis, at paulo latior, nigra, nitidula, parce subtiliter pubescens. Antennae capite sesqui longiores, articulis duobus primis maiusculis crassiusculisque, $3-7$ minutis, 6 et 7 praecedentibus vix crassioribus, 8-10 clavam validam oblongam formantibus, 8 et 9 crassitie brevioribus, 10 his ambobus paulo minore, breviter ovato, apice obtusinsculo, piceae, basi testaceae. Palpi fusco-picei. Caput thorace duplo prope angustius, deflexum, subtiliter punctatum, ore piceo. Thorax coleopterorum prope latitudine, antrorsum modice angustatus, latitudine baseos duplo, apicis dimi dio brevior, basi medio late rotundatus, utrinque subsinuatus, lateribus rotundatus, apice truncatus, angulis omnibus obtusis, anterioribus leviter deflexis, leviter transversim convexus, confertim subtiliter punctatus. Elytra thorace duplo longiora, confertim minus subtiliter punctata. Abdomen apicem versus subangustatum, confertim subtlius punctatum, apice piceum. Pedes piceo - testacei.

* 3. O. subtilis: Linearis, picea, elytris anoque rufo-piceis, pedibus antennisque rufis, his articulis ultimis quatuor sensim crassioribus. - Long. $\frac{1}{2}-\frac{1}{3} \operatorname{lin}$.

Er. Col. Mareh, I. 364. 3.

Habitat in Germania.

Statura praecedentium, at saepius paulo maior, nigro-picea, pube subcili depressa densius vestita, elytris, ano, interdum etian thorace rufo-piceis. Antennae rapite sesqui longiores, articulis duobus primis maiusculis, $3-6$ minutis, licet sexto praecedentibus paulo crassiore, septimo intermedio inter pratecedentes et sequentes, ullis distincte maiore, his distinete minore, ultimis 
tribus reliquis crassioribus, penultimis duobus transversis, ultimo his ambobus magnitudine aequali, subconico, rufae, basi pallide testaceae. Caput thorace plus dimidio angustius, deflexum, subtilissime punctulatum, ore testaceo. Thorax elytris paulo angustior, antrorsum subangustatus, latitudine baseos duplo, apicis plus dimidio brevior, basi medio leviter rotundatus, utrinque subsinuatus, lateribus leviter rotundatus, apice truncatus, angulis anterioribus fortiter deflexis, subrotundatis, posterioribus rectis, transversim conve xus, subtilissime punctatus. Elytra thorace duplo fere longiora, confertim subtilius punctata. Abdomen lineare, confertim subtiliter punctatum, ano late picea. Pedes rufo-testacei.

Obs. O. pusill imae valde affinis et aegre distinguenda, praecipue corpore paulo latiore, thorace antrorsum leviter angustato, minus convexo, angulis posterio. ribus rectis, elytris longioribus et antennarum structura differe videtur.

4. O. granaria: Ovata, nigra, pedibus antennisque ferrugineis, his articulis ultimis quatuor sensim crassioribus. - Long. $\frac{1}{2}$ lin.

Er. Col. March. I. 364. 4.

Habitat in Germania; Berolini specimina duo legi.

Statura ommino sequentis, at sesqui maior, nigra, nitidula, subtiliter parce pubescens, confertim subtiliter punctulata. Antennae breves, crassinsculae, articulo secundo primo multo maiore, obconico, $\mathbf{4 - 6}$ minutis sen. sim paulo crassioribus, 7-9 magnis et crassis, itidem sensim paulo crassioribus, transversis, ultimo maiore, praecedentibus anibobus longitudine aequali, at paulo crassiore, subovato, apice obtuse acuminato, obscure ferrugineae. Caput thorace multo angustius, deflexum, ore piceo-testaceo. Thorax basi coleopterorum prope longitudine, antrorsum fortiter angustatus, latitudine baseos duplo, apicis vix dimidio brevior, apice truncatus, lateribus et angulis anterioribus rotundatis, basi medio leviter rotundatus, an-gulis posterioribus subrectis, leviter convexus. Coleoptera thorace duplo prope longiora, planiuscula, lateribus subrotundata, thorace distinctius punctati. Abdomen apicem versus attennatum, apice piceum. Pedes ferruginei.

Obs. Sequenti affinis, at structura et colore antennarum satis distincta.

* 5. O. flavicornis: Ovala, nigra, pedibus ferrugineis, antennis flaris, articulis ultimis tribus abrupte crassioribus. - Long. vix $\frac{1}{2}$ lin.

Er. Col. March. I. 364. 5.

Uypocyphtus flavicornis Boisd. et Lacord. Faun. Ent. Paris, I, 521. 4.

Habitat in Germania, Gallia.

O. pusillima longitudine fere aequalis, at plus sesqui latior, utrinque attenuata, statura fere Hypocypti, nigra, nitida, parce subtiliter pubescens, Antenuae capite sesqui longiores, articulis duobus primis maiusculis, sub aequalibus, $3-7$ minutis, aequalibus, $8-10$ abrupte multo crassioribus. magnis; 8 et 9 aequalibus, transversis, deoimo magno, globoso, totae lacte flavae. Palpi pallide flavi. Caput thorace multo angustius, deflexum, con fertim subtiliter punotatum, ore flavo. Thorax basi coleopterorum prope latitudine, antrorsum angustatus, latitudine baseos duplo prope, apicis dimidio angustior, apice truncatus, lateribus parum rotundatis, angulis anterio ribus subrectis, deflexis, basi medio leviter rotundatus, utrinque subsmuatus, 
angulis po-terioribus obtusis, subrotundatis, leviter convexus, confertim subtiliter punctatus. Coleoptera thorace sesqui longiora, lateribus subrotundata, medio thorace latiora, confertim minus subtiliter punctata. Abdomen breve, apicem versus attenuatum. Pedes ferruginei, posteriores fuscescentes.

Obs. Hypocypthus flavicornis Faunae Parisiensis teste Dom. Aubé certe ad hoc insertum revocandus.

* 6. O. a picala: Ovata, nigra, thorace elytrisque coslaneis, ano late pedibusque fulvis. - Long. $\frac{1}{2}$ lin.

Er. Col. March. I. 365.6.

Habitat in Germania: Berolini singulum specimen legi.

Statura praccedentis. Antennae nutilatae, articulis basalibus fulvis, secundo primo paulo longiore. Caput thorace angustius, deflexum, nigrum, nitidum, subtilissime punctatum, , ore testaceo. Thorax basi coleopterorum prope latitudine, antrorsum angustatus, latitudine baseos duplo, apicis dimidio brevior, apice utrinque subsinuatus, lateribus et angulis anterioribus subrotundatis, basi medio leviter rotundatus, utrinque subsinuatus, angulis posterioribus subrectis, subtilissime punctatus, castaneus. Coleoptera thorace duplo longiora, lateribus subrotundata, medio thorace latiora, confertim punctata, stibtiliter pubescentia, castanea. Abdomen apicem versus attenuatumi, nigrum, segmentis duobus ultimis laete fulvis. Pedes fulvi.

\section{Gyrophaena Mannerh.}

Manuerh. Brachelytr. p. 74. - Er. Col. March. I. p. 365.

Maxillae mala interiore mutica, intus spinulis ciliata.

Ligula lrevis, integra, rotundata; paraglossae mullae.

'ralpi labiales 2-arliculati, articulo primo cylindrico, secundo tenui, acuminato. Tarsi antici 4-, posteriores 5-articulati, postici articulo primo elongato.

Corpus parvum, latiusculım, subtus convexum, alatum. Caput exsertum, deflexum, basi haud constrictum, thorace paulo angustius, oculis plerumque sat magnis, modice prominulis. Lalırum latiusculum, lateribus rotundecum, apice truncatum, mandibulas obtegens. Mandibulae muticae. Maxillae malis corneis, exteriore basi apiceque membranea, membrana apicali malam interiorem superante, hac interne membranea, apice oblique introrsum subemarginata, sinu spinulis confertis ciliato. Palpi maxillares parum elongat, articulo secundo tertioque subaequalıbus, hoc leviter incrassato, quarto parvo, subalato. Labium mento perbrevi, apice leviter emarginato, ligula brevi, rotundata, integra, paraglossis nullis. Palpi labiales biarticulati, articulo primo cylindrico, secundo hoc parum breviore, tenui, subacuminato. Antemnae ab articulo quarto inde incrassatae, articulis tribus primis leviter elongatis, longitudine subaequalibus, tertio graciliore. Thorax coleopteris angustior, transversus, hasi rotundatus, tenuter marginatus. Scutellum transversim triangulare. Elytra truncata. Abdomen lateribus magis minusve rotundatum, supra planum, margine latiore, medio elevato, subtus convexum, in vivis reclinatum. Pedes breviusculi, tenues, intermedii hasi modice distantes, tarsis anticis 4-, posterioribus $\mathbf{y}$ articulatis, posticis articulo prímo parum elongato. 


\section{0 b s e $x$ a $t$ i o n e s.}

1. Maxillae omnino ut in Homalota (t. III. f. 22.). Labium ab codem omnium prâecedentium generum ligula integra et palpis labialibus biarticulatis discedit.

2. Habitus huius generis peculiaris corpore minuto, breviusculo, glabro, thorace coleopteris angustiore, transverso, subtiliter marginato, capite deflexo, fronte planiuscula, oculis prominulis, abdomine rotundato, lateribus late marginato, supra plano, subtus convexo, in vivis reclinato, antennis crassiusculis, pedibus intermediis basi distantibus.

3. Genus Encephalus Kirby antennis brevioribus, apicem versus sensim incrassatis et thorace antorsum angustato haud satis distinctum et, reliquis omnibus notis habitualibus et pedum et oris structura pariter congruentibus, huic generi subiungendum mihi videtur.

4. Differentia sexualis abdomine tuberculis notato saepius indicata.

5. Victus in fungis.

\section{G. complicans: Brevis, nigra, nitida, thorace basi subtiliter margi-} nato, laevissimo, elytris medio brunneis, antennis pedibusque ferrugi neis. - Long. 1 lin.

Er. Col. March. I. 366. 1.

Encephalus complicans Westwood Guérin Mug. Zool. III. cl. 1X. t. 69. - Steph. Illustr. $V . t$. 26. $f .4$.

Habitat in Germania, Anglia.

Lata, crassiuscula, nigra, nitida. Antennae capitis longitudine, apicem versus sensim incrassatae, articulo tertio secundo plus duplo minore et tenuiore, $4-7$ minutis, tenuioribus, at sensim paulo brevioribus et crassioribıs, 8 - 10 inter se aequalibus, transversis, ultimo crassitie vix longiore, apice acuminato, ferrugineae. Caput laeve, ore ferrugineo. Thorax basi fere coleopterorum latitudine, antrorsum angustatus, latitudine baseos plus duplo brevior, basi leviter rotundatus, apice profundius sinuatus, lateribus parum rotundatis, cum angulis anterioribus productis acutis sat fortiter deflexis, angulis posterioribus obtusis, transversim convexus, laevis, basi medio supra scutellum leviter marginatus, margine summo piceo. Scutellum magnum, triangulare, laeve. Elytra brevissima, thorace vix longiora, laevia, medio simul depressa, brunnea, margine exteriore tumidulo, nigro. Abdomen piceum, laeve, subtus convexum, supra planum, margine laterali elevato, lato, rotundato, dentato. Pedes testacei, femoribus posticis nigricantibus.

Obs. Incedit hoc insectum abdomine reclinato, reliquum corpus obtegente, globuli instar, Agathidii cuiusdam speciem simulans. (Conf. Kirby et Spence Introduet. II. p 232.)

* 2. G. nitidula: Brevis, nigra, nitida, antennarum basi, elytrorum disco pedibusque testaceis, thorace brevissimo, parce punclato, basi late marginato. - Long. 1 $\frac{1}{4}$ lin.

Mannerh. Brachelytr. 74. 1.

Aleoch. nitidula Gyll. Ins. Suec. II. 413. 35.

Habitat in Suecia, Dom. Schüppel.

Sequenti affinis, at duplo maior, nigra, nitida. Antennae capitis thoracisque prope longitudine, articulo tertio secundo vix breviore, at multo tenuiore, quarto minuto, 5 - 10 inter se aequalibus, crassitie vix brevioribus, ultimo praecedente sesqui longiore, acuminato, densius pubescentes et 
pilosellae, fusco-nigrae, articulis tribus primis pallide testaceis, Caput plaviusculum, fronte utrinque longitudinaliter subimpressa et parce punctata, medio laevi, ore ferrugineo. Thorax latitudine plus duplo brevior, coleopteris angustior, basi et lateribus fortius rotundatus, apice truncatus, angulis anterioribus deflexis, posterioribus obtusis, subrotundatis, basi praesertim uedio late marginatus, supra convexus, ad margines punctis paucis sparsis, medio punctss obsoletioribus crebris biseriatis impressus, parce griseo-pubescens. Elytra thorace sesqui longiora, subdepressa, humeris elevatis, crebre rugoso-punctata, tenuiter pubescentia, saturate rufo testacea, regione scutelli triangulariter fusca, angulo apicis exteriore late nigro. Abdomen ovatım, crassum, nigro-piceum, nitidum, segmentorum marginibus anoque subtus lacte, supra obsoletius rufo-testaceis. Pedes rufo-testacei.

* 3. G. nana: Picea, antennis, pedibus, thoracis limbo, elytris abdominisque basi pallide testaceis, thorace marginato, parce punclato, elytris disco creberrime rugoso-punctatis. - Long. 1 lin.

Mannerh. Brachelytr. 74. 2. - Runde Brachel. Hal. 20. 1. - Er, Col. March. I. 367. 2. Staphyl. nanus Payk. Faun. Suec. III. 408. 52.

Aleoch. na na Grav. Micr. 98. 47. Mon. 176. 72. - Latr. Hist. nat. Crust. et Ins. IX. 390. 46. - Gyll. Ins. Suec. II. 414. 36. - Sahlb. Ins. Fenn. I. 382. 66. - Zetterst. Fuun. Lappon. I. 102. 19. Ins. Lapp. 78. 27.

G'yrophaena nitidula Boisd. et Lacord. Faun. Ent. Paris. I. 536. 2.

situphyl. fasciatus Marsh. Ent. Britt. 514, 47.

Habitat in Europae fungis.

Antennae capite thoraceque multo breviores, articulo tertio secundo Juulto ninore, tenui, quarto breviter obconico, 5-10 aequalibus, transversis, ulimo praecedentibus ambobus longitudine subaequali, acuminato, pubesrentes, totae flavo-testaceae. Caput nigrum, nitidum, fronte plana, utrinque leviter impressa et parce punctata, ore testaceo. Thorax coleopteris plus sesqui angustior, latitudine duplo prope brevior, basi et lateribus leviter rotundatus, apice truncatus, angulis anterioribus subrectis, deflexis, posterioriluns obtusis, utrisque subrotundatis, basi tenuiter marginatus, parum convexus. punctis paucis, dorso biseriatis, terminalibus distinctis, reliquis obsoletis impressus, niger, niticlus, margine omni testaceo. Elytra thorace sesqui longiora, dense intricato-punctata, testacea, angulo apicis exteriore nigro. Abdomen basi testaceum, apice nigrum, ano iterum testaceo. Pectus nigrum. Pedes flavi.

Abdominis segmentum dorsale penultimum in utroque sexu pliculis sex elevatis ornatum, ultimum maris tridentatum, fepnin a e simplex.

Variat 1, colore aut pallidiore, corpore testaceo, capite abdommisque cingulo nigris, aut saturatiore, corpore nigro, thoracis limbo et abdominis basi obsoune ferrugineis, elytris nigris, macula magna humerali testacea.

2, punotura elytrorum subtiliore, absolescente. Specimina nomulla, ceterum omnino cum genuinis congruentia, Austriaca misit Dom. Ull rich.

* 4. G. affinis: Teslacea, capile abdominisque cingulo piceis, thorace marginato, serialim punclato, elytris parce punctatis, - Long. 1 lin.

Mannerh. Brachelytr. 74. 3. - Er. Col. March. I. 368, 3.

Ileach. affinis Suhlb. Ins. Fenn. I. 383. 67. 
Gyrophaen. amabilis Botsd. et Lacord. Faun. Ent. Paris. I. 535. 1.

Gyrophaen, nana Boisd. et Lacord. Faun. Ent. Paris. I. 537. 3.

Habitat in Europae fungis.

Praecedenti simillima. Antennae capitis thoracisque longitudine, articulo secundo elongato, parum incrassato, tertio hoc triplo minore, minuto, quarto obconico, 5- 10 aequalibus, subcylindricis, longitudine haud crassioribus, ultimo praecedente sesqui longiore, apice acuminato, pubescentes, parce p1losellae, testaceae, basi dilutiores. Caput depressum, fronte utrinque subimpressa et parce punctata, piceum, ore testaceo. Thorax coleopteris plus dimidio angustior, latitudine dinnidio brevior, lateribus ante medium et basi leviter rotundatus, apice truncatus, angulis anterioribus subrectis, leviter deflexis, posterioribus obtusis, utrisque subrotundatis, subdepressus, basi tenuissime marginatus, testaceus, punctis paucis, dorso biseriatis impressus: Elytra thorace paulo longiora, depressa, omnium subtilissime alutacea, parce punctata, aut flava, angulo apicis exteriore fusco nigrove, aut fusco-testacea, humeris luteis. Abdomen rufo-testaceum, segmentis duobus penultimis pieeis. Pedes flavi.

Abdominis segmentum dorsale penultimum feminae aequale, maris tuberculo minuto ante marginis posterioris medium munito, ultimum fe mina simplex, maris bispinum, spinis subhamatis.

Variat abdomine toto rufo-testaceo, supra ante apicem macula minuta nigricante notato.

* 5. G. gentilis: Testacea, capite nigro, elytris apice, abdominis macula dorsali pectoreque piceis, thorace marginato, biseriatim punctato, elytris dense subtiliter punctatis. - Long. $1 \frac{1}{4}$ lin.

Habitat in Carinthia, Dom. Schmidt.

Antennae debiles, capite sesqui longiores, artıculo tertio secundo vix breviore, at multo tenuiore, quarto paulo crassiore, obconico, 5-10 subaequalibus, leviter transversis, ultimo praecedente duplo fere longiore, apice acuminato, pilosellae, fusen-testaceae, basi flavae. Caput thorace paululum angustius, fronte plana, utrinque subimpressa et crebrius fortiusque punctata, nigrum, nitidum, ore testaceo. Thorax coleopteris multo angustior, latitudine dimidio fere brevior, basi modice, lateribus ante medium leviter rotundatus, apice truncatus, angulis anterioribus subrectis, leviter deflexis, posterioribus obtusissimis, utrisque subrotundatis, basi tenuiter marginatus, parum convexus, dorso bilineatim leviter impressus, lineis punctis obsoletioribus at sat crebris notatis, praeterea punctis raris dispersis impressus, testaceus, disco piceo. Scutellum testaceum. Elytra thorace sesqui longiora, depressa, sat crebre subtiliter punctata, tenuiter pubescentia, testacea, apice praecipue extrorsum picea. Abdomen lateribus minus rotundatum, testaceum, dorso segmento antepenultimo nigro-piceo. Pectus piceum. Pedes flavi. aequale.

Sexus differentia latet. Abdomims segmentum dorsale penultimum

Obs. G. nan a duplo fere maior, latior, elytris subtilius et minus iniricatim punctatis, abdominisque segmento penultimo laevissimo, pliculis elevatis nullis, satis distincta. A G. affini statura elytrorumque punctura differi. 
* 6. G. vinula: Testacea, nitida, capite, elytrorum angulis exterioribus abdominisgue macula nigris, thorace marginato, subtiliter punclato, elytris parce punclatis. - Long. $1 \frac{1}{4}$ lin.

Habitat in Pensylvania, Dom. Zimmermann.

(i. nana paulo maior et magis oblonga depressaque, rufo-testacea, nitida. Antemne capite thoraceque paulo breviores, minus validae, articulo secundo tertioque elongatis, hoc tenuiore et breviore, quarto sub-obconico, $\mathbf{5}-10$ crassitie aequalibus, subcylindricis, sensim paulo brevioribus; ultimo praecedentibus ambobus longitudine prope aequali, subcylindrico, apice acuminato, pubescente, pilosellae, dilute testaceae, basi flavae. Caput nigerrmum, fronte utrinque subseriatim punctata, ore testaceo. Oculi magni. Thorax coleopteris paulo angustior, latitudine duplo brevior, basi modice, lateribus parum rotundatus, apice truncatus, angulis anterioribus subrectis, leviter deflexis, posterioribus obtusis, utrisque subrotundatis, basi tenuiter marginatus, subdepressus, parce subtiliter punctatus, punctis medio irregulariter biseriatis. Elytra thorace sesqui longiora, depressa, subtiliter parce griseo-pubescentia, parce subtiliterque punctata, angulo apicis exteriore nigerrimo. Abdomen supra ante apicem macula magna nigra.

* 7. G. dissimilis: Picea, capite nigro, thorace, elytris, abdominis basi, antennis pedibusque testaceis, thorace marginato, parce punctato, elytris aut parce punctatis aut subtiliter granulatis. - Long. 1 lin.

llabitat in Carolina, Dom. Zimmermann.

G. nanae aequalis. Antennae capitis thoracisque longitudine, articulo secundo crassiusculo, tertio hoc paulo breviore et multo tenuiore, quarto tertio duplo breviore et crassiore, 5-10 subaequalibus, longitúdine paulo crassioribus, ultimo praecedentibus ambobus aequali, oblongo-ovato, apice obtuse acuminato, pilosellae, testaceae, basi flavescentes. Caput nigerrinum, nitidum, fronte punctis nommulis iuxta utrumque oculum impressa, ore testaceo. Oculi magni. Thorax coleopteris paulo angustior, latitudine dujlo brevior, bası leviter, lateribus perparum marginatus, apice truncatus, angulis anterioribus subrectis, minus deflexis, posterioribus obtusissimis, víx ullis, parum convexus vel subdepressus, dorso punctis parcis biseriatis, terminalibus in utraque serie binis maioribus, reliquis sat subtilibus, ceterum laevissimms, testaceus, nitidus. Elytra thorace sesyui longiora, subdepressa, aut vage subtilius punctata, aut in altero sexu densius subtiliterque granulata, parce tenuiterque grisea-pubescentia, testacea, apice praecipue extrorsum fusca. Abdomen nigrum, basi supra late, infra anguste testaceum. Pectus nigrum. Pedes testacei.

Sexus differentia praeter elytrorum puncturam mihi non observata. Sprecimina elytris granulatis mascula esse mili videntur.

Obs. Caput maiusculum, fronte minus depressa, oculis magnis convexis omnino ut in G. vinula.

* 8. G dispar: Testacea, pectore nigro, capile, elytrorum apice abdominisque cingulo piceis, thorace marginato, parce punclato, elytris aut granulatis aut laevigatis. - Long. 1 lin.

Ilabitat in Brasilia. 
Statura omnino G. nanae. Antennae capitis thoracisque prope longitudine, articulo secundo crassiusculo, tertio hoc duplo minore, quarto tertio breviore at paulo crassiore, 5-10 subaequalibus, longitudine haud crassioribus, ultımo praecedente duplo longiore, apice acuminato, totae testaceae. Caput nigro-piceum, nitidum, fronte depressa, punctis raris dispersis impressa, ore testaceo. Thorax coleopteris angustior, latitudine duplo latior, basi modice, lateribus ante medium leviter rotundatus, apice truncatus, angulis anterioribus subrectis, leviter deflexis, posterioribus obtusis, utrisque subrotundatis, basi tenuiter marginatus, dorso biseriatım punctatus, punctis serierum parcis, subtilibus, obsoletis, terminali posteriore solo sat conspicuo, ceterum laevissimus, nitidus, testaceus, medio piceus. Elytra thorace plus sesqui longiora, depressa, alterius sexus dense granulata, alterius laevigata, testacea, apice praecipue exterius picea. Abdomen testaceum, pone medium macula supra minore, infra maiore picea. Pectus nigrum. Pedes testacei.

M as praeter elytra granulata antennis longioribus distinctus.

* 9. G. congrua: Testacea, capite abdominisgue cingulo piceis, thorace fusco-testaceo, dorso biseriatim punctato, elytris subtilissime punctulatis. - Long. $\frac{3}{4}-1$ lin.

Er. Col. March. I. 368. 4.

Habitat in Germania.

G. nana plerumque paulo minor et brevior. Antennae capite thoraeqque paulo longiores, articulo secundo crassiusculo tertioque hoc plus duplo breviore obconicis, quarto fere transverso, sequentibus crassiusculis, 5- 10 subaequalibus, crassitie paulo brevioribus, ultimo praecedente duplo longiore, subovato, apice subacuminato, pilosellae, fuscae, basi testaceae. Caput thorace vix angustius, fronte planiuscula, utrinque subtilissime et parce punctata, piceum, parum nitidum, ore testaceo. Thorax coleopteris dimidio angustior, latitudine plus dimidio brevior, basi modice, lateribus leviter rotundatus, apice truncatus, angulis anterioribus rectis posterioribusque obtusis subrotundatis, leviter convexus, basi tenuiter marginatus, omnium subtilissime alutaceus, dorso punctis parcis, biseriatis, obsoletis, terminali posteriore solo maiore, lateribus puncto uno alterove subtili impressus, fusco-testaceus, nitidus. Elytra thorace sesqui longiora, subdepressa, subtilissime alutacea, subtilissimeque punctulata, luteo-testacea, angulo exteriore apicis nigro. Abdomen rufo-testaceum, segmentis duobus penultimis nigricantibus. Pedes testacei.

\section{Sexus differentia latet.}

- 10. G. lucidula: Nigra, nitida, antennarum basi, pedibus elytrisque pullide testaceis, his angulo apicali exteriore nigro, thorace dorso biserialim punctato, elytris laevissimis. - Long. $\frac{2}{3}$ lin.

Er. Col. March. I. 369. 5.

\section{Habitat Berolini.}

Statura praecedentium, at minor, nigra, nitida. Antennae capitis thoracisque longitudine, articulo secundo sat magno, tertio hoc plus dupio ninore, praecipue breviore, quartoque tertio breviore et crassiore obconicis, sequentibus crassiusculis, 5-10 aequalibus, leviter transversis, ultimo prae 
cedente duplo longiore, acuminato, pilosellae, fuscae, basi testaceae. Caput thorace paulo angustius, fronte depressiuscula, utrinque leviter longitudinaliter subimpressa, at impunctata, laevissimum, nitidum, ore tẹstaceo. Thorax coleopteris dimidio prope angustior, latitudine duplo brevior, lateribus et basi leviter rotundatus, apice subemarginatus, angulis anterioribus. subrectis, leviter deflexis posterioribusque obtusis subrotundatis, leviter convexus, basi distincte margmatus, dorso punctis paucis biseriatis obsoletissimis, excepto pari sungulo pone medium sat forti impressus, ceterum laevissimus. Elytra thorace plus sesqui longiora, laevigata, testacea, angulo apicis exteriore late nigro. Abdomen totum nigrum. Pedes flavi.

Sexus differentia latet.

* 11. G. flaveola: Teslacea, antennis fuscis, basi pallidis, thorace marginaio, convexo, elytris parce punctatis. - Long. $\frac{3}{4}$ lin.

Habitat in Brasilia.

Statura (i. affinis et minimis eius individuis aequalis, testacea, nitida, laevis. Antennae capitis thoracisque prope longitudine, articulo secundo crassiusculo, tertio hoc multo minore et angustiore, quarto breviusculo, 5 - 10 aequalibus, longitudine vix crassioribus, ultimo apice acuminato, pilosae, nigro-fuscae, articulis $\mathbf{3}$ primis flavis. Caput thorace paulo angustius. fronte prope utrumque oculum punctis paucis impressa. Thorax coleopteris paulo angustior, latitudine duplo fere brevior, basi et lateribus leviter rotundatus, apice truncatus, angulis anterioribus subrectis, leviter deflexis, posterioribus obtusissimis, subrotundatis, leviter convexus, basi tenuiter marginatus, laevissimus, dorso punctis parcis biseriatis notatus, terminalibus distmctioribus, reliquis subtilibus, vix conspicuis. Elytra thorace sesqui prope longiora, punctis subtilibus raris sparsa, interstitiis laevissimis, parce pubescentia, magis lutea. Abdomen laeve, tenuissime pubescens. Pedes lutei,

Mas abdominis segmento dorsali quinto pliculis duabus longitudinalibus notato, sexto apice bispinoso, femina iisdem simplicibus distinguuntur,

*12. G. splendidula: Nigra, nitida, antennarum basi pedibusque testaceis, thorace marginalo, disco 4-punctato, elylris aut laevibus aut parce granulatis, callo humeralo testaceo. - Long. $\frac{3}{4}-1 \frac{1}{4}$ lina.

Habitat in Americae merid. insula St. Thomae, Dom. Moritz, in Brasilia, Dom. Prof. Germar.

Ilabitu (i. politae, magnitudine instabilis, individuis maximis G. nanam prope superantibus, mgra, nitida. Antennae capite tharaceque paulo longiore-. articulo secundo haud incrassato, tertio hoc parum tenuiore et paulo longiore, quarto obconico, praecedente paulo breviore et crassiore, 5-10 subaequalibus, Iongitudine hand crassioribus, ultimo paulo longiore, apice acuminato, fuscae, articulis 4 primis flavo-testaceis. Caput thorace multo anguctius, fronte plana, aequali, utrinque sparsim paree punctata, ceterum laeviasimum, ore magis minusve rufo-pioeo. Thorax basi coleopteris parum angustior, antrorsum subangustatus, latitudine duplo fere latior, basi et lateribus fortius rotundatus, apice truncatus, anguls anterioribus deflexis, suls rectis, posterioribus ohtucis, transversim sat fortiter convexus, tenuitev mar- 
ginatus, disco punctis 4 sat profundis, quadratim dispositis impressus, inter medium et marginem puncto uno alterove obsoletiore notatus, ceterum laevissimus. Elytra thorace paulo longiora, laevigata, in altero sexu laevissima, in altero tuberculis vel punctis elevatis raris, in series duas oblique introrsum vergentes digestis ohsita, glaberrima, nitida, nigra, callo humerali testaceo. Abdomen tenuiter pubescens, subtus nigrum; basi apiceque piceum, supra obscure testaceum, segmentis intermediis basi piceis. Pedes flavotestacei.

Mas elytris tuberculatis et abdominis segmento dorsali ultimo merlio producto, apice truncato, utrinque'spinis duabus porrectis, lobum intermedium prope superantibus armato insignis.

* 13. G. corrus cula: Nigra, nilida, antennis pedibusque teslaceis, elylris abdominisque basi piceis, thorace obsolete subtilissime biseriatim punctato, elytris parce obsoleteque punctatis. - Long. $\frac{1}{2}-\frac{2}{3}$ lin.

Habitat in Carolina meridionali, Dom. Zimmermann.

Habitu omnino G. affinis, at minor, nigra, nitida. Intennae capite thoraceque paulo longiores, validiusculae, articulo secundo sat magno, primo subaequali, tertio hoc dimidio breviore et multo tenuiore, quarto iterum dimidio breviore, at crassiore, obconicis, 5-10 aequalibus, longitudine crassioribus, ultimo praecedente plus dimidio longiore, apice acuminato, laete testaceae, basi flavae. Caput thorace paulum angustius, laevigatum, glaberrimum, fronte aequali, utrinque parce punctata, ore testaceo. Thorax coleopteris paulo angustior, latitudine plus duplo brevior, basi et lateribus leviter rotundatus, apice subemargınatus, angulis anterioribus subrectis, leviter deflexis, posterioribus obtusis, leviter transversim convexus, basi tenuiter marginatus, dorso subtilissime obsoleteque parce biseriatim punctatus, ceterum laevissimus. Elytra thorace sesqui longiora, subdepressa, parce obsoleteque subtiliter punctata, interstitiis laevissimis, pilis raris brevissimis subtilissimis obsita, picea, nitida, lateribus nigricantia, callo humerali dilutiore. Abdomen crassiusculum, laeve, nigrum, basi piceum. Pedes testacei.

Mas abdominis segmento dorsali secundo tubereulo minuto acutiusculo in medio margine posteriore, quinto tuberculis duobus leviter distantibus ante apicem, sexto tuberculis duobus obsoletioribus approximatis in medio munitis distinctus.

* 14. G. socia: Nigra, nilida, antennis pedibusque teslaceis, elylris abdominisque basi piceis, thorace utrinque vage subtiliter punctato, elylris crebrius punctatis, - Long. $\frac{1}{2}$ lin.

Habitat in Carolina meridionali, Dom. Zimmermann.

Praecedenti affinis et minoribus eius speciminibus aequalis, nigra, nitida. Antennae capite thoraceque fere longiores, articulo secundo crassiusculo, primo paulo breviore, tertio hoc duplo minore, praecipue tenuiore, quartoque hoc breviore et vix crassiore obconicis, 5 - $\mathbf{l}$ (1) gequalibus, crassis, longitudine duplo fere crassioribus, ultimo crassitie ligfal longiore, obtuse acuminato, testaceae, basi flavae. Caput thorace vix angustius, fronte aequali, parce disperse punctata, ore testacen. Thorax coleopteris parum angustior, latitudine plus duplo brevior, basi modice, lateribus leviter ro- 
tundatus, apice truncatus, angulis anterioribus rectis, parum deflexis, poste rioribus obtusis, parum convexus, basi minus subtiliter marginatus, lateribus parce vageque subtiliter punctatus, medio longitudinaliter laevis pilis longioribus albidis parce adsperus. Elytra thorace plus sesqui longiora, subdepressa, crebrius subtiliusque punctata, parcius longius albido-pubescentia, picea, humeris dilutıoribus, subtestaceis. Abdomen supra subglabrum, subtus parcius longiusque albido-pubescens, nigrum, basi apiceque piceum. Pedes flavo - testacei.

Obs. Cum praecedente occurrere, nihilominus specie distincta videtur, thoracis elytrorumque punctura pubescentiaque differentibus, neque pro altero eius sexu haberi potest, cum uterque illius sexus, mas abdomine tuberculato, femina abdomine simplice, obvius sit. Omnia, quaecunque vidi, huius speciei individua abdominis segmento apicali apice bifido instructa sunt, omnia forte mascula.

- 15. G. manca: Nigra, nitida, antennis pedibusque favo-testaceis, thorace crebrius, elytris crebre punctatis. - Long. $\frac{2}{3}$ lin.

Habitat in Germania: Berolini, ipse.

Statura omnino praecedentis et parum maior, nigra, nitida, elytris concoloribus. Antennae capitis thoracisque longitudine, articulo secundo crassiusculo, obconico, tertio hoc dimidio breviore et praecipue tenuiore, quarto hoc breviore et paulo crassiore, 5- 10 crassis, inter se aequalibus, longitudine dimidio crassioribus, ultimo praecedente duplo prope crassiore, acuminato, flavo-testaceae. Caput thorace angustius, fronte aequali, utrinque punctis paucis obsoletıoribus impressa, ore testaceo. Thorax coleopteris paulo angustior, latitudine duplo brevior, lateribus et basi leviter rotundatus, apice truncatus, angulis anterioribus subrectis, deflexis, posterioribus obtusis, leviter transversim convexus, basi subtiliter marginatus, crebrius, lateribus disperse, dorso subseriatim subtilius punctatus, interstitiis laevissimis, glaber. Elytra thorace sesqui longiora, sat crebre minus subtiliter punctata, interstitiis laevissimis, tenuiter albido-pubescentia. Abdomen subtitilissime punctulatum, tenuissime subtilissimeque albido-pubescens, ano lntescente. Pedes flavo-testacei.

Sexus differentia latet.

Obs. Olim cum G. polit a mihi confusa, a qua thoracis elytrorumque sculptura, nec non corpore latiusculo differt. Propius accedit ad praecedentem, a qua thorace elytrisque crebrius punctatis, thorace basi subtilius marginato, et elytris concoloribus distinguenda videtur.

* 16. G. polita: Oblonga, picea, antennis pedibusque pallidis, thorace disco obsolete biseriatim punctato, elylris parce obsoletius punctatis, interstitiis subtilissime alutaceis. - Jong. $\frac{2}{3}$ lin.

Mannerh. Brachelytr. 74. 4. - Er. Col. March. I. 369. 6.

Al. polita Grav. Micr. 99. 48. Mon. 176. 73. - Latr. Hist. nat. Crust. et Ins. IX. 391. 47. - Gyll. Ins. Suec. II. 415. 37. - Suhlb. Ins. Fenn. I. 483. 68.

Habitat in Enropa.

Nigro-pice nitidula. Antennae capite sesqui longiores, articulo secundo crassiuscuto, obconico, tertio hoc parum breviore, at tenuiore, quarto minuto, transverso, 5-10 crassiusculis, transversis, ultimo praecedente vix duplo longiore, crassiusculo, subgloboso, apice acuminato, testaceae. 
Caput minutum, fronte aequali, utrinque parce obsoleteque punctata, ore testaceo. Thorax coleopteris dimidio angustior, latitudine dimidio brevior, antrorsum subangustatus, basi leviter rotundatus, lateribus subrectis, apice truncatus, angulis anterioribus rectis, fortiter deflexis, posterioribus obtusis, parum convexus, basi subtiliter marginatus, seriebus duabus dorsalibus punctorum subtilium obsoletorumque. Elytra thorace sesqui longiora, subtilissime alutacea, vage obsolete punctata, picea. Abdomen latiusculum, apice testaceum. Pedes testacei.

* 17. G. strictula: Oblonga, nigra, nitidula, abdomine piceo, ante apicem nigro, antennis pedibusque testaceis, thorace laevi, elytris subtilissime alutaceis, obsoletissime punctulatis. - Long. $\frac{2}{3}$ lin.

Habitat in Hungaria, Dom. Frivaldsky, in Gallia, Mus. Dom. Aubé.

Statura omnino praecedentis, nigra, nitidula. Antennae capite thoraceque breviores, apicem versus sensim subincrassatae, articulo secundo crassiusculo, obconico, tertio hoc dimidio breviore et multo tenuiore, quarto minuto, transverso, 5-10 crassiusculis, transversis, sensim paulo crassioribus, ultimo maiusculo, breviter ovato, apice subacuminato, lacte flavo-testaceae. Caput thorace paulo angustius, fronte aequali, planinscula, sparsim obsolete punctata. Thorax coleopteris plus dimidio angustior, latitudine dimidio brevior, basi et lateribus leviter rotundatus, apice truncatus, angulis anterıoribus subrectis, leviter deflexis, posterioribus obtusissimis, leviter convexus, basi minus subtiliter marginatus, laevis vel obsolete biseriatim impressus, pone medium punctorum maiorum pari singulo notatus. Elytra thorace plus sesqui longiora, omnium subtilissime alutacea, parce subtiliter et valde obsolete punctata, nigro-picea. Abdomen nigrum, apice, interdum etiam basi piceum. Pedes flavi.

Abdominis segmentum dorsale penultimum in altero sexu pliculis brevissinis longitudinalibus instructum, in altero laeve.

Obs. Differt a praecedente statura paulo maiore, antennis apicem versus sensim crassioribus, elytris subtiliter punctatis, thorace apicem versus nullo modo angustato, basi minus subtiliter marginato.

* 18. G. Boleti: Elongata, nigro-fusca, nitida, sublilissime punctulata, ore, antennis pedibusque favis, elytris fusco-testaceis, thorace marginalo, subtilissime crebre punctato. - Long. $\frac{1}{2}$ lin.

Staphyl. Boleti Linn. Faun. Suec. n 859. Syst. Nat. I. I1. 636. 26. - De Geer Ins. IV. 28. 13. t. 1. f. 15-17. - Miill. Prodr. 97. 1093. - Goeze Ent. Beitr. I. 722. 26. - De Vill. Ent. I. 419. 26.

Aleoch. Boleti Gyll. Ins. Suec. II. 416. 38. - Sahlb. Ins. Fenn. I. 384. 69.

Bolitochara Boleti Mannerh. Brachelytr. 82. 46.

Habitat in Suecia, Germania.

Minima, picea, subtiliter pubescens. Antennae capitis thoracisque fere longitudine, crassiusculae, extrorsum sensim crassiores, articulo secundo crassiusculo tertioque hoc duplo minore obconicis, quarto minuto, transverso, 5-10 transversis, crassis, sensim paulo crassioribus, ultimo subgloboso, flavae. Caput laeve, nigrum, nitidum, ore testaceo. Thorax coleopteris vix angustior, latitudine plus dimidio brevior, basi et lateribus leviter 
rotundatus, apice truncatus, angulis anterioribus rectis, leviter deflexis, posterioribus obtusis, leviter transversim convexus, lateribus et basi rotundatus, basi anguste marginatus, subtiliter crebre punctulatus, tenuiter albidopubescens. Elytra thorace sesqui longiora, crebre subtiliter punctata, tenuiter albido-pubescentia. Abdomen nigro-piceum, subtilissme punctulatum, tenuiter subtiliterque albido-pubescens, ano obscure testaceo. Corpus subtus pallidius. Pedes flavi.

Variat corpore fusco-testaceo, capite abdominisque medio nigro-fuscis, elytris pallide testaceis.

* 19. B. minima: Rufo-testacen, nilida, thorace medio obsolete punctalo, elylris parce punctatis. - Long. $\frac{1}{2}$ lin.

Er. Col. March. 1. 370. 7.

Habitat Berolini, Dom. Kirstein.

Praecedenti affinis. Corpus dilute ferrugineum vel rufo-testaceum, nitidum. Antennae capitis thoracisque longitudine, articulo secundo crassiusculo tertioque hoc multo minore, praecipue angustiore obconicis, quarto minuto, breviusculo, tertio autem paulo crassiore, sequentibus crassis, $\mathbf{5}-10$ aequalibus, transversis, ultimo praecedente duplo fere longiore, subacuminato. Caput thorace vix angustius, laeve, vertice piceo. Thorax coleopteris angustior, latitudine duplo brevior, lateribus et basi leviter rotundatus, apice truncatus, angulis anterioribus rectis, posterioribus obtusis, subdepressus, basi tenuiter marginatus, nitidus, laevis, medio longitudinaliter vage subtiliterque punctatus. Elytra thorace sesqui longiora, subdepressa, parce punctata, subtilissime pubescentı, angulo apıcis exteriore piceo. Abdomen ante apicem interdum piceum.

\section{Peliusa Er.}

Maxillae mala interiore mutica, intus spinulis ciliala.

Ligula brevis, integra; paraglossae nullae.

Palpi labiales 2-articulati, articulis subaequalibus, secundo sublunalo.

Tarsi antici 4-, posteriores 5-arliculali, poslici articulo primo elongulo.

Corpus oblongum, subtus leviter convexum, alatum. Caput exsertum, deflexum, basi haud constrictum, oculis mediocribus, modice prominulis, ore producto, clypei spatio membranaceo. Labrum maiusculum, lateribus leviter rotundatum, apice truncatum, mandibulas obtegens. Mandibulae muticae. Maxillae malis corneis, exteriore basi apiceque inembranea, portione membranea apicali malam interiorem superante, hac interne membranea, apice oblique introrsum subemarginata, sinu spinulis confertis cilato. Palpi maxillares morlice elongati, articulo secundo tertioque longitudine subaequalibus, hoc parum incrassato, quarto parvo, subulato. Labium (t. III. f. 12.) mento apice profunde emarginato, angulis anterioribus spiniformibus, porrectis, ligula brevi, rotundata, integra, paraglossis nullis. Palpi labiales biarticulati, articulis subaequalibus, primo cylindrico, secundo sublunato. Antennae breves crassiusculaeque, subclavatae, articulo primo crassinsculo, secundo tertoque clavatis, elongatis, sequentibus sensim paulo crassioribus, ultimo apice albrupte acuminato. Thorax coleopterorum prope latitudine, transversus, 
basi rotundatus, leviter convexus. Scutellum minutum, triangulare. Elytra truncata, ad angulum exteriorem subsinuata. Abdomen parallelum, supra planum, subtus convexum, reclinandum. Pedes breviores, intermedii basi approximati, tarsis anticis 4-, posterioribus 5-articulatis, posticis articulo primo leviter elongato.

\section{O b s e r vation e s.}

1. Maxillae omnino ut in Homalota (t. III. f. 22.), ligula omnino ut in Gy rophaena, a qua ceterum mento longiore, antrorsum angustato, profunde emarginato, angulis anterioribus spiniformibus et palporum-labialium articulo secundo differt.

2. Habitus intermedius quasi inter Myrmedoniam et Aleocharam, ab illa coxis intermediis approximatis, ab hac tarsis anticis 4-articulatis discedens. Caput deflexum, fronte planiuscula, et antennae breves subclavatae affinitatem cum Gyrophaena produnt, a qua autem praeter notas supra allatas coxis intermediis basi approximatis facile distinguitur. Corpus parce pilosellum, ut in Aleochara, neque pube sericea obductum.

3. Sexus differentia antennarum structura et abdominis segmentis dorsalibus duobus in mare tuberculatis in specie unica huius generis constituitur.

4. De victu nihil compertum.

\section{* 1. P. labiata: Nigro-picea, ore albido, antennis pedibusque rufis. - Long 2 lin.}

T. 1. $f .1$.

\section{Habitat in Madagascar, Dom. Goudot.}

Nigro-picea, subnitida, subtiliter pubescens. Antennae capite parum longiores, maris articulis tribus primis sequentibus coniunctis prope longioribus, primo secundo tertioque coniunctis vix breviore, crassiusculo, his fortiter clavatis, tertio paululum longiore, $\mathbf{4}-\mathbf{1 0}$ sensim paulo brevioribus et crassioribus, penultimis brevissimis, perfoliatis, ultimo praecedentibus ambobus paulo longiore, apice abrupte acuminato, feminae articulis 3 primis sequentibus coniunctis paulo brevioribus, primo secundo sesqui longiore, crassiusculo, tertio hoc paulo longiore, at multo tenuiore, elongato-obconico, sequentibus apicem versus sensim leviter incrassatis, 4-10 sensim paululum crassioribus, non autem brevioribus, ultimo praecedentibus ambobus paulo longiore, apice abrupte magis quam in mare acuminato, rufo-testaceae vel rufae. Caput fronte plana, vage punctata, clypeo-labioque testaceis, palpis rufis. Thorax coleopteris vix angustior, latitudine plus dimidio brevior, basi modice, lateribus fortius rotundatus, apice truncatus, angulis anterioribus subrectis, leviter deflexis, posterioribus obtusis, omnibus subrotundatis, leviter convexus, crebrius minus subtiliter punctatus. Elytra thorace paulo longiora, apice ad angulum exteriorem subsinuata, crebrius fortiusque punctata. Abdomen supra subconvacum, parcius et minus subtililiter punctatum, parce pubescens, concolor, subtus convexum, minus dense punctatum, longius pubescens, segmentis 4 primis margine apicali piceo, quinto sextoque totis rufo-testaceis. Caput et thorax subtus rufotestacea. Pedes rufo-testacei.

Mas abdominis segmento dorsali secundo medio, quinto ante apicen tuberculo minuto munitis, femina segmentis iisdem muticis. 


\section{Placusa Er.}

\section{Er. Col. March. I. p. 370.}

Maxillae mala interiore mutica, intus spinulis ciliata.

Ligula brevis, integra; paraglossae breves.

Palpi labiales breves, 2-articulati, articulo primo crasso, secundo tenui.

Tarsi antici 4-, posteriores 5-articulati, postici articulo primo subelongato.

Corpus oblongum, depressum, alatum. Caput thorace minus, exsertum, porrectum, basi haud constrictum, os versus triangulariter attenuatum, oculis mediocribus, modice prominulis. Labrum transversum, truncatum, mandibularum apicem haud obtegens. Mandibulae muticae. Maxillae mala exteriore interiorem paululum superante, cornea, basi apiceque membranea, portione membranea apicalı subtiliter pubescente, mala interiore membranea, margine exterıore corneo, apice oblique introrsum subemarginata, sinu spinulis confertis ciliato. Palpi maxillares minus elongati, articulo secundo tertioque longitudme subaequalibus, hoc modice incrassato, quarto minuto, subulato. Labium (t. III. f. 13.) mento transverso, apice leviter emarginato, ligula latiuscula, integra, paraglossis distinctis, at minutis, ligula multo brevioribus, intra marginem interiorem subtilissime ciliatis. Palpi labiales biarticulati, articulo primo crasso, secundo hoc parum breviore, at multo tenuiore. Antennae apicem versus sensim leviter incrassatae, articulis secundo tertioque obconicis, hoc praecedente paulo minore, articulo ultimo rotundato. Thorax transversus, plerumque basi utrinque sinuatus. Scutellım triangulare. Elytra apice truncata. Abdomen parallelum, vel apicem versus leviter angustatum. Pedes breves, intermedii basi approximati, tarsi antici 4-, posteriores 5-articulati, postici articulo primo leviter elongato.

\section{o b s e r va tiones.}

1. Maxillae omnino ut in Homalota (t. III. f. 22.). Labium distinctum ligula lata suborbiculari et paraglossis distinctis. Paraglossae olim me fugerant.

2. A. Gyrophaena coxis intermediis approximatis et reliquis generibus, quibuscum ligula integra et palpis labialibus biarticulatis convenit, corpore valde depresso discedit. Habitu intermedia quasi inter Homalotam et Oxypodam, hac autem magis depressa, et tarsis anticis 4-articulatis, ab illa tarsorum posticorum articulo primo leviter elongato distincta.

3. Victus, quantum constat, in fungis.

4. Mas abdominis segmento dorsali sexto utrinque spina armato, apice tuberculato aut denticulato, femina segmento eodem simplice distinguuntur.

* 1. P. complanata: Depressa, nigra, opaca, antennarum basi pedibusque testaceis, elytris fuscis, thorace coleopterorum latitudine, depresso, basi bisinuato, angulis posterioribus obtusis. - Long. $1 \frac{1}{4}$ lin.

Habitat in Germania, Dom. Schïppel.

Corpus latiusculum, complanatum, nigrum, opacum, pube brevissima fusca densius vestitum. Antennae capite thoraceque paulo breviores, tenuiores, apicem versus vix incrassatae, articulis tribus primis longioribus, se-. cundo tertioque aequalibus, primo paulo brevioribus, $4-10$ aequalibus, crassitie paulo brevioribus, ultimo breviter ovato, apice acutiusculo, fuscae, basi testaceae. Palpi testacei. Caput thorace duplo prope angustius, subtriangulare, confertissime subtiliter punctatum, fionte depressa, ore rufo- 
piceo. Thorax coleopterorum latitudine, latitudine duplo brevior, lateribus rotundatus, antrorsum subangustatus, apice subemarginatus, angulis anterioribus obtusis, leviter deflexis, basi medio late sat fortiter rotundatus, utrinque sinuatus, angulis posterioribus acutiusculis, retrorsum prominulis, fortiter depressus, confertissime subtiliter punctatus. Elytra thorace sesqui longiora, apice ad angulum exteriorem leviter sinuata, depressa, omnium confertissime subtiliter punctata, testaceo-fusca, ad suturam et angulum apicis exteriorem nigricantia. Abdomen depressum, apicem versus sensim subangustatum, supra segmentis tribus primis confertim subtiliter, quarto quintoque parce subtilissime punctatis, parce tenuiterque pubescens, nitidulum, apice summo testaceo, subtus subtilius parciusque aequaliter punctatum, nigrum, nitidum, segmentis singulis piceo-marginatis. Pedes testacei, femoribus fuscescentibus.

Mas abdominis segmento dorsali sexto apice tuberculo prominulo terminato, utrinque spina longiore tenui, introrsum vergente, armato cognoscitur.

* 2. P. pumilio: Depressa, nigra, opaca, antennurum basi pedibusque testaceis, elytris fuscis, thorace coleopterorum latitudine, subdepresso, basi bisinuato, angulis posterioribus subrectis. - Long. 1 lin.

Aleoch. pumilio Grav. Mirr. 98. 46. Mon. 175. 70. - Latr. Hist. nut. Crust. et Ins, IX. 390. 46. - Gyll. Ins. Suec. II. 411. 33 - Sahlb. Ins. Fenn. I. 382. 61. - Zetterst. Faun. Lapp. I. 102. 18. Ins. Lapp. 78. 26.

Bolit ochara pumilio Mannerh. Brachelytr. 82. 44. - Boisd. et Lacord. Faun. Ent. Paris. I. 652. 20.

\section{Habitat in Germania, Suecia, Gallia.}

Praecedente paulo minor, nigra, opaca, pube brevissima grisea densius vestita. Antennae capitis thoracisque prope longitudine, apicem versus subincrassatae, articulo secundo crassiusculo, tertio hoc paulo minore, obconico, 4-10 transversis, crassitie duplo brevioribus, ultimo maiusculo, subgloboso, - apice obtusiusculo, pilosellae, fusco-ngrae, basi fusco-testaceae. Palpi fusco-testacel. Caput thorace dimidio angustius, triangulare, basi rotrindatum, confertissime subtiliter punctatum, opacum. Thorax coleopterorum latitudine, latitudine duplo brevior, antrorsum vix angustatus, lateribus rotun. datus, apice subemarginatus, angulis anterioribus obtusis, subrotundatis, leviter deflexis, basi medio late rotundatus, utrinque sinuatus, angulis posterioribus rectis, minutis, prominulis, subdepressus seu perparum convexus, confertissime subtiliter punctatus. Elytra thorace sesqui longiora, apice truncata, depressa, confertissime subtiliter punctata, testaceo-fusca seu fusco-testacea. Abdomen depressum, apicem versus sensim subangustatum, supra segmentis tribus primis confertim, quarto quintoque parcius subtiliter, subtus aequaliter parcius subtiliter punctatum, densius pubescens, subnitidum, nigrum, ano testaceo. Pedes testacei.

Mas abdominis segmento dorsali sexto tuberculo prominulo terminato, utrinque spina longiore tenui armato distinctus.

Obs. Affinis praecedenti, satis distincta autem antennarum articulis 4-10 fortius transversis, thorace minus depresso, antrorsum vix angustato, basi medio minus fortiter rotundato, utrinque minus fortiter sinuato, angulis posterioribus minoribus, minus acutis, elytris apice externe non sinuatis, statura minore, non adeo plana. 
* 3. P. humilis: Depressa, nigra, opaca, antennarum basi pedibusque teslaceis, thorace coleopterorum prope longitudine, subdepresso, basi rotundato, angulis posterioribus obtusis. - Long. 1 lin.

Placusa pumilio Er. Col. Murch. I. 371. 1.

Habitat in Germania.

Statura depressa P. complanatae, at paulo minor et angustior, mgra, opaca, pube brevissima fusca densius vestita. Antennae capite thoraceque paulo breviores, tenuiores, articulo secundo crassiusculo tertioque obconico longitudine aequalibus, 4-10 subaequalibus, crassitie paulo brevioribus, ultimo ovato, apice obtusiusculo, fusco-nigrae, basi testaceae. Caput thorace duplo fere angustius, triangulare, confertissime subtiliter punctatum, fronte plana, ore rufo-testaceo. Thorax basi coleopteris haud angustior, latitudine duplo brevior, antrorsum subangustatus, apice truncatus, angulis anterioribus rotundatis, leviter deflexis, basi rotundatus, ad angulos posteriores vix sinuatus, his obtusis, fortiter depressus, confertissme subtilissimeque punctatus. Elytra thorace sesqui longiora, apice truncata, confertissime subtilissimeque punctata, fusco-nigra. Abdomen depressum, apicem versus sensim subangustatum, confertim subtiliter punctatum, supra parcius pubescens, nitidulum, subtus opacum, nigrum, segmentis anterioribus late piceomarginatis, ano testaceo. Pedes testacei, femoribus saepe fuscescentibus.

Mas abdominis segmento dorsali sexto tuberenlo prominulo terminato, utrinque spina longiore tenui, introrsum vergente, armato distinctus.

Variat thorace elytrisque fuscis, abdomine rufo-piceo, ante apicem nigro.

Obs. P. complanatae magis quam praecedenti affinis corpore omnino complanato et antennis tenuioribus, ab utraque autem thoracis forma satis distincta. Hae tres species a sequentibus abdominis in masculis structura discedunt, inter se autem conveniunt.

* 4. P. infima: Nigra, antennarum basi pedibusque testaceis, elylris fuscis, thorace coleopterorum prope longiludine, transversim convexo, basi leviter bisinuato, angulis posterioribus rectis. - Long. $1-1 \frac{1}{4}$ lin.

Habitat in variis Germaniae regionibus; in montibus Uralensibus, Dom. Prof. Eversmann.

Praecedente paulo minus depressa, nigra, subnitida, pube subtili brevique grisea tenuius vestita. Antennae capitis thoracisque prope longitudine, graciliores, apicem versus vix incrassatae, articulo secundo tertioque subaequalibus, quarto sequentibus minore, 5-10 transversis, subaequalibus, ultimo breviter ovato, apice obtusiusculo, parce pilosellae, fuscae, basi testaceae. Palpi testacei. Caput thorace duplo fere angustius, densius subtiliter punctatum, fronte munus depressa. Thorax basi coleopteris vix angustior, latitudine baseos duplo prope brevior, antrorsum leviter angustatus, lateribus rotundatus, apice truncatus, angulıs anterioribus obtusis, subrotundatis, leviter deflexis, basi medio late rotundatus, prope angulos posteriores leviter sinuatus, his rectis, at parum prominulis, leviter transversim convexus, confertim subtiliter punctatus. Elytra thorace sesqu longiora, apice truncata, depressa, confertim subtiliter punctata, fusca, seu fusco-testacea. Abdomen apice sensim attenuatum, confertissime subtilissimeque punctatum, 
supra brevissime, subtus longius pubescens, nitidulum, nigrum, apıce summo testaceum. Pedes testacei.

Mas abdominis segmento dorsali sexto supra granulis nonnullis instructo, margine apicali subtiliter denticulato, utrinque spina laterali breviore armato distinguendus.

Variat ant elytris nigricantibus, aut dilutior, thorace fusco, elytris fusco-testaceis, abdomine fusco, ante apicem nigro.

Obs. Habitus huius speciei, minus quam praecedentes depressae, intermedius quasi inter Homalotam et Oxypodam.

5. P. despecta: Nigra, pedibus testaceis, elytris fuscis, thorace coleopterorum latitudine, Iransversim convexo, angulis posterioribus obtusis. - Long. $\frac{3}{4}$ lin.

Habitat in Carolina meridionali, Dom. Zimmermann.

Habitu fere Homalotae aterrimae, at paulo magis depressa, nigra, parum nitida, pube subtili grisea vestita. Antennae capite thoraceque paulo breviores, apicem versus sensim subincrassatae, articulo secundo crassiusculo, tertio hoc paulo breviore et duplo fere tenuiore, obconico, 4-10 sensim paulo crassioribus, crassitie paulo brevioribus, ultimo maiusculo, praecedentibus ambobus maiore, ovato, apice obtuso, pilosellae, nigrae, basi piceae. Caput thorace multo angustius, confertim subtilissime punctatum, fronte minus depressa, ore piceo. Thorax basi coleopterorum latitudme, latitudine dimidio brevior, antrorsuin leviter angustatus, lateribus rotundatus, apice truncatus, angulis anterioribus obtusis, subrotundatis, deflexis, basi late mo dice rotundatus, ad angulos posteriores subsinuatus, his obtusis, haud prominulis, leviter transversim convexus, confertim subtilissime punctatus. Elytra thorace paulo longiora, apice ad angulum exteriorem subsinuata, depressa, confertissime subtiliter punctata, fusca seu fusco-testacea, circa scutellum infuscata. Abdomen apicem versus sensim angustatum, minus confertim subtiliter punctatum, piceum, medio nigrum. Pedes testacei.

Mas abdominis segmento dorsali sexto supra granulis nonnullis notato, margine apicali acute denticulato, utrinque spina laterali breviore armato distinctus.

Variat thorace rufo-piceo, elytris testaceis, abdomine rufo-piceo, ante apicem nigro.

Obs. Cum praecedente thorace transversim convexo convenit, differt autem statura minore brevioreque, thorace minus brevi, angulis posterioribus obtusis, abdomine minus elongato. Abdominis segmentum sextum maris omnino ut in illa.

* 6. P. adscita: Linearis, subdepressa, nigra, antennarum basi pedibusque testaceis, elytris fuscis, thorace coleopteris angusiore, subdepresso. Long. 1 lin.

Habitat in Sardinia, Dom. Prof. Gené.

Statura elongata $P$. humilis, at paulo minor et magis depressa, nigra, subnitida, tenuiter subtilissime griseo-pubescens. Antennae capite thoraceque paulo breviores, apicem versus fortius incrassatae, articulo secundo crassiusculo tertioque paulo tenuiore longitudine aequalibus, obconicis, quarto minuto, prope transverso, 5-10 aequalibus, crassiusculis, transversis, cras- 
sitie duplo brevioribus, ultimo breviter ovato vel subgloboso, apice obtusiusculo, pilosellae, pubescentes, fuscae, basi fusco-testaceae. Palpi testacei. Caput thorace paulo angustius, basi leviter constrictum, confertissime subtiliter punctatum, fronte parum convexa, antice transversim depressa.' Thorax coleopteris dimidio prope angustior, latitudine dimidio brevior, antrorsum non angustatus, basi et lateribus rotundatus, apice truncatus, angulis omnibus obtusis, subrotundatis, anterioribus leviter deflexis, parum convexus seu subdepressus, confertim subtiliter punctatus. Elytra thorace sesqui longiora, apice truncata, depressa, crebre minus subtiliter punctata, fusca. Abdomen lineare, depressum, confertim subtiliter punctatum, nitidulım. Pedes testacei.

Mas abdominis segmento dorsali sexto apice spina media acuta, basi bidenticulata, utrinque spina tenui laterali, intermediae longitudine aequali, introrsum curvata, armato insignis.

Obs. Corporis habitus et thoracis forma omnino Homalotae, at certe huius generis, etiam secundum oris structuram.

Species mihi invisa, forte huius generis.

7. P. (?) atrata: Brevis, lata, depressa, nigra, subnitida, antennis longiludine thoracis pedibusque fuscescentibus, tibiis tarsisque dilutioribus, thorace brevissimo, ante scutellum obsolete foveolato. - Long. $\frac{2}{3}$ lin.

Bolitochara atrata Mannerh. Brachelytr. 82. 45.

Var. b: Ore elytrisque fusco-testaceis, pedibus totis pallidioribus, thorace haud foveolato.

Aleochara atrata Sahlb. Ins. Fenn. I. 375. 54. - Zetterst. Ins. Lappon. 77. 17.

Habitat in Fennia australi, rarius. Var. b in Lapponia legit F. Sahlberg.

P. pumilıoni statura satis similis, sed differt thorace depresso, postice vix sinuato. Caput thorace multo angustius, rotundatum, nigrum, nitidum, subtilıssime punctulatum, ore palpisque fusco-piceis. Antennae thoracis longitudine, fuscescentes, apice parum incrassatae, articulo ultimo ovato, obtuso. Thorax transversus, longitudine duplo latior, antice truncatus, angulis depressis, lateribus et postice rotundatus, supra depressus, ater, opacus, densius pubescens, subtilissime punctulatus, foveola ante scutellum obsolete impressa. Scutellum triangulare, nigrum, subtilissime punctulatum. Elytra thorace parum latiora et dimidio longiora, apice truncata, supra depressa, subtiliter punctulata, pubescentia, nigra, subopaca. Abdomen pone elytra reliquo corpore brevius, latum, depressum, nigrum, subnitidum, vix punctulatum, pubescens. Corpus subtus nigrum, nitidum, subtiliter punctulatum, pubescens. Pedes mediocres, femoribus fuscis, tibiis tarsisque pallidioribus.

V ar. b colore tantum pallidiore et thorace paulo densius pubescente atque haud foveolato differt. Vix diversa species. - Specimen var. b et colore et statura simillimum, sed duplo maius, e Lapponia acceptum possideo, quod huc pertinere credo. (Sahlberg.)

Ohs. De genere vix mihi dubium est. Statura plana et thoracis angulis posterioribus haud prominentibus affinis forte $\mathrm{P}$. humili, differre autem videtur statura zninore, colore nitidiore, magis nigro et thorace basi foveolato. Var. b forte a P. humili non distincta, praesertim specimen allatum maius 


\section{Euryusa $E r$.}

Er. Col. March. I. p. 371

Maxillae mala interiore mutica, intus spinulis ciliala.

Ligula elongala, integra; paraglossae nullae.

Palpi labiales 2-articulati, articulo primo paulo longiore.

Tarsi antici 4-, posteriores 5-articulati, postici articulo primo elongato.

Corpus oblongum, latiusculum, supra depressum, subtus leviter convexum, alatum. Caput maiusculum, deflexum, basi rotundatum, apice leviter angustatum, oculis parvis, rotundatis, leviter prominulis. Labrum transversum, apice subrotundatum, mandibularum apicem haud obtegens. Mandibulae muticae. Maxillae (t. III. f. 23.) mala exteriore cornea, basi apiceque membranea, portione membranea apicali pubescente, malam interiorem parum superante, hac cornea, margine exteriore incrassato, interiore membraneo, apice introrsum oblique subemarginato, sinu spinulis confertis ciliato. Palpi maxillares modice elongati, articulo secundo tertio panlo breviore, hoc incrassato, quarto parvo, subulato. Labium (t. III. f. 14.) mento transverso, apice truncato, ligula angusta, lineari, palporum labialium articulo prino fere aequali, integra, paraglossis nullis. Palpi labıales biarticulati, articulis crassitie subaequalibus, prımo paulo longiore. Antennae breviusculae crassiusculaeque, apicem versus leviter incrassatae, articulis tribus primis leviter elongatis, secundo tertioque leviter obconicis, articulis $6-10$ transversis, ultimo maiore, subacuminato. Thorax coleoptera latitudine excedens, antrorsum parum angustatus, basi bisinuatus, apice truncatus. Scutellum transversim triangulare. Elytra apice truncata, ad angulum exteriorem emarginata. Abdomen apıcem versus sensim leviter angustatum, supra planum, subtus convexıusculum. Pedes breviusculi, intermedii basi approximati, tarsi antici 4-, posteriores 5-articulati, postici articulo primo modice elongato.

\section{O b s e r vatio n e s.}

1. Habitus corporis omnino Din ardae, ut nisi antennis paulo longioribus, apicem versus sensim incrassatis vix distinguatur, at tanto magis oris partibus ab illa discedit. Sunt enim huic generi maxillae mala interiore ut in Homalota (t. III. f. 22.) illi apice unco terminata, huic mentum apice truncatum, illi profundius emarginatum, ligula huic integra, illi bifida, paraglossae huic nullae, illi distinctae, palpi labiales huic 2-, illi 3-artioulati, palporum maxillarium articulus ultimus huic tenuis. simus, subulatus, illi conieus, acuminatus. Alii cuidam generi Euryusa neque habitu, neque characteribus accedit. Ligula elongata et lineari reliquis generibus, quibus palpi labiales 2-articulati sunt, discrepat.

2. Palpos labiales olim triarticulatos descripsi, nuper autem, oris examine reiterato, duos tantummodo articulos observo, quorum primum maiorem solidum nec duobus compositum, ut olim putavi, cognosco.

3. Sexus differentiam non observavi.

4. Victus in formicetis.

* 1. E. sinuata: Testacea, subtiliter punctulala, thorace lalo, brevi, basi leviler bisinuato. - Long. $1 \frac{1}{4}$ lin.

Tab. 1. $f$. 2.

Er. Col. March. I. 372. 1.

Habitat in Germania: Berolini, Weber, in Austria Dom. Ullrich; in Gallia, Dom. Aubé. 
Corpus confertim subtiliter punctulatum, pube tenuissima depressa flavescentı vestitum, fusco-testaceum, abdomine ante apicem nigro. Antennae thorace sesqui longiores, apıcem versus sensim leviter incrassatae, articulo tertio secundo paulo longiore, quarto tertio paulo crassiore at dimidio breviore, 5 - 10 longitudine aequalibus, transversis, sensim paulo crassioribus, subcylindricis, ultimo maiusculo, praecedentibus tribus coniunctis longitudine prope aequali et paulo crassiore, subovato, apice subacuminato, rufae, articulo ultimo ferrugineo. Caput fronte leviter convexa. Thorax coleopteris paulo latior, latitudine duplo brevior, antrorsum leviter angustatus, lateribus et angulis anterioribus rotundatus, apice leviter emarginatus, basi leviter bismuatus, angulis posterioribus retrorsum leviter prominulis, rotundatis, supra parum convexus, margine laterali late planato. Elytra thorace paulo longiora, subdepressa. Abdomen longius pubescens et praecipue versus apicem parcius profundiusque punctatum.

\section{Dinarda Leach.}

Mannerh. Brachelytr. p. 65. - Er. Col. March. I. p. 373.

Lomechusa Curtis Britt. Ent. IX. t. 410.

Maxillue mala interiore unco simplice terminata.

Iigula angusta, bifida; paraglossae latae, breves, rotundatae.

Palpi maxillares 3-articulati, articulo secundo paulo breviore.

Tarsi antici 4-, posteriores 5-articulati, postici articulo primo vix elongalo.

Corpus latiusculum, alatum. Caput parvum, rotundatum, insertum, ocnlis parvis rotundatis, vix prominulis. Labrum breve, apice truncatum, lateribus rotundatum, mandibulas haud obtegens. Mandibulae muticae. Maxillae (t. III. f. 24.) mala exteriore interiorem haud superante, cornea, apice membranea, dense pubescente, mala interiore cornea, margine interiore membraneo, longins dense introrsum barbato, margine exteriore incrassato, apice unco simplice introrsum spectante malam terminante. Palpi maxillares breviores, articulo secundo tertio paulo breviore, hoc parum incrassato, quarto tenui, subulato. Labium (t. III. f. 15.) mento brevi, apice emarginato, ligula angusta, palporum labialium articulum primum paulum excedente, bifida, paraglossis ligula duplo brevioribus, triangularıter acuminatis. Palpı labiales triarticulati, articulo primo crassiusculo, maiore, sscundo tertio paulo breviore. Antennae breves, crassae, medium versus incrassatae, articulo secundo tertio duplo fere breviore, hoc leviter elongato, obconico, articulis 5-10 subtransversis, arcte coactis, ultimo longiore, subacuminato. Thorax coleopterorum latitudine, brevis, antrorsum angustatus, apıce profunde emarginatus, basi bisinuatus, margine laterali dilatato, plano, angulis posterioribus elongatis, acuminatis. Scutellum triangulare. Elytra apice truncata, ad angulum exteriorem profunde emarginata, hoc elongato, acuminato. Abdomen apicem versus sensin angustatum, supra planiusculum, subtus leviter convexum, segmento septimo conspicuo, licet minuto. Pedes breves, intermedii approximati, tarsi antici 4-, posteriores 5-articulati, postici articulis 4 primis sensim subdecrescentibus.

O b s e r v a t i o n e s.

1. Genus satis distinctum, cuius affinitates partim cum Lomechusa, partim 
cum Aleochara esse videntur, illis thoracis elytrorumque forma et maxillarum mala interiore apice uncinata, his corporis habitu et labii structura propius accedit.

2. Differt ab Aleochara imprimis ligula graciliore, palpis Iabialibus triarticulatis, maxillarum mala interiore apice uncinata, palpis maxillaribus articulo conico-acuminato terminatis, thorace lateribus dilatato, tarsis anticis 4-articulatis.

3. Differt a Lomechus a praecipue antennis brevibus, fusiformibus, ligula bifida, paraglossis distinctis, maxillarum mala interiore unco simplice terminata, thorace apice emarginato, abdomine non revoluto, segmento sexto dorsali integro, pedibus brevibus, intermediis basi approximatis.

4. Differentias ab Euryusa in huius generis illustratione notavi.

5. Dom. Curtis Dinardam dentatum pro generis Lomechus a typo depinxit. Oris partes dissectae ab eadem desumtae, at uncus corneus, quo maxillarum mala interior terminatur, et paraglossae auctorem fugerunt, ceterum illae sat exacte depictae.

6. Sexus differentia abdominis segmento inferiore penultimo in maribus emarginato constare videtur.

7. Victus in formicetis.

* 1. D. dentata: Nigra, thoracis lateribus elytrisque brunneis, capite thorace elytrisque crebre punctatis. - Long. $1 \frac{1}{2}-2$ lin.

Mannerh. Brachelytr. 65. 1. - Boisd. et Lacord. Faun. Ent. Paris. I. 524. 1. - Runde Brachelytr. Hal. 27. 1. - Er. Col. March. I. 374. 1.

Lomechusa dentata Grav. Mon. 181. 4. - Gyll. Ins. Suec. II. 441 4. - Zetterst.

Ins. Lappon. 74. 3. - Curtis Britt. Ent. IX. t. 410.

St aph. strumosus Payk. Fn. Suec. III. 402. 45.

Habitat in Europa.

Nigro-picea, sericeo-micans. Antennae capite sesqui longiores, crassiusculae, subfusiformes, articulo quarto praecedente dimidio breviore, at paulo crassiore, $\overline{\mathbf{5}} \mathbf{- 1 0}$ transversis, sensim paulo crassioribus, ultimo praecerlentibus ambobus longiore, at minus crasso, apicem versus sensim attenuato, nigrae, basi apiceque ferrugineae. Caput dense punctatum, fronte subimpressa, antice retusa, ore rufescente. Thorax coleopteris paulo latior, Jatitudine baseos plus duplo brevior, antrorsum angustatus, lateribus fortiter ampliato-rotundatus, apice profunde emarginatus, basi profunde bisinuatus, angulis posterioribus retrorsum valde prominulis, anterioribus obtusis acuminatis, supra lateribus late explanatis, medio parum convexus, obsolete canaliculatus, confertim punctatus, breviter pubescens, niger, lateribus late obscure ferrugineis, seu saturate rufo-ferrugineus, disco nigro. Elytra thoracis longitudine, confertim punctata, breviter pubescentia, ferruginea, angulo apicis exteriore retrorsum valde prominulo, acuminato. Abdomen segmentis tribus anterioribus parcius, posterioribus tribus parce punctatis, supra parcius, subtus densius longiusque fulvescenti-pubescens, segmentorum marginibus anoque ferrugineis. Pedes ferruginei.

Obs. Insectum rarum, plerumque in Formicae rufae nidis obvium. Dom. Aubé eam etiam in Formicae cuniculariae societatibus observavit, et exem. pla prope Lutetiam in silva Boloniensi ex utroque formiceto cum formicis benevole mihi communicavit. Specimina cum F. rufa degentia omnino congruunt cum iis, quae e Germania, Hungaria et Suecia hic exstant, individua e nidis F. cunicularia e recepta illis quidem sunt duplo minora, ceterum vero nullo modo distincta. Cave igitur, ne in variis formicetis varias hospitum species gigni credas. Forte eiusdem speciei magnitudinis varietas e vario insecti loco natali derivanda, cum apud formicam maiorem individua maiora, apud minorem minora nascantur. 


\section{Comechusa Grav.}

Grav. Mon. p. 178. - Mannerh. Brachelytr. p. 65. - Er. Col. March. I. p. 375.

Maxillae mala interiore unco duplice terminalae.

Ligula brevis, integra; paraglossae nullae.

Palpi labiales 3-arliculati, articulo primo paulo maiore.

Tarsi antici 4-, posteriores 5-articulati, postici articulo primo elongato.

Corpus latiusculum, crassiusculum, alatum. Caput minutum, sub-porrectum, fronte planiuscula, oculis parvis, rotundatis, modice prominulis. Labrum transversum, apice truncatum, mandibulas haud obtegens. Mandibulae muticae. Maxillae (t. III. f. 25.) mala exteriore cornea, apice membranea pubescenteque, malam interiorem paulo superante, hac cornea, margine interiore membraneo, pubescente, exteriore incrassato, apice unco bispino, introrsum spectante, malam terminante. Palpi maxillares breviores, articulo secundo apicem versus leviter incrassato, tertio hoc paulo crassiore, haud mcrassato, quarto parvo, subulato. Labium (t. III. f. 16.) mento transverso, apice emarginato, ligula lata, rotundata, integra, paraglossis nullis. Palpi labiales 3-articulati, articulo primo crassiusculo, maiore, secundo hor: duplo minore, tertio secundo tenuiore et parum longiore. Ántennae elongatae, fortes, apicem versus subattenuatae, articulo primo incrassato, ultimo leviter elongato, acuminato. Thorax coleopterorum latitudine, apice truncatus, basi bisinuatus, margine laterali dilatato, incrassato, angulis anterioribus rotundatis, posterioribus acuminatis, disco plano. Scutellum triangulare. Elytra apice truncata. Abdomen parallelum, subtus convexum, supra planum, revolutum, segmentis tribus primis margine barbato, sexto apice late profundeque emarginato, lobis acuminatis, septimo superiore in praecedentis sinu sat conspicuo, inferiore occulto. Pedes elongati, crassi, intermedii basi late distantes, tibiae apice subattenuatae, tarsi temues, haud elongati, antici 4-, posteriores 5-articulati, postici articulo primo modice elongato.

O b s e r v a t i o n e s.

1. Habitus huius generis valde singularis, corpore in hac tribu maiusculo, crasso, abdomine fortiter revoluto, capite minuto, antennis validioribus, filiformibus, elongatis, acuminatis, pedibus elongatis, sat robustis, thorace margine dilatato, basi profunde bisinuato, abdominis segmento dorsali sexto emarginato. Maxillarum structura eadem fere ut in Dinarda, at mala interior unco duplice sive fisso terminata. Labii forma magis cum Gyrophaena convenit, at ligula latior et palpi labiales triarticulati. Habitu Myrmedoniae nunnullae quodammodo Lomechusae speciem prae se ferre videntur antennis fortioribus rigidis, abdomine revoluto et pedibus intermediis basi late distantibus.

2. Gravenhorst genus Lomochusam praecipue secundum thoracis elytrorumque formam condidit, quare etiam $\mathrm{L}$. dentatam, reliquis omnibus notis adeo distinctam, huic generi subiunxit. Mannerheim, Lomechusam et Dinardam palporum maxillarium articulo ultimo conico-acuto a reliquis Aleocharinis distinxit, in Lomechusa autem palpi maxillares articulo terminali eodem modo quam in reliquis huius tribus generibus constructo mihi videntur.

3. Atemeles Dillwyn seu Goniodes Kirby, (Stephens Illustr. V. p. 107.) certe idem hoc genus, cui L. strumosa adscribitur, thoracis angulis posterioribus obtusis a Lomechusa thoracis angulis posterioribus acuminatospinosis distinctum. Lome chusa e typum Dom. Stephens L. emarginatam affert, dubito autem, an eadem sit ac nostra, cum ei antennae medio magis incrassatae et fortius fusiformes quam Lomechusae et Dinardae tribuantur (p. 109.); neque suspicandum est, hanc meram esse Dinardam dentatam, cum abdominis segmentum penultimum emarginatum, processibus duobus styliformibus instructum et pedes elongati descripta sint. 
4. Hospitatur hoc genus in formicetis. Villis in abdominis basi forte quaedam analogia est cum illis, quos Müller (Germ. Mag. III. p. 79. et 95.) in Clavigero foveolato observavit. Notatu dignum videtur, quod reliqua huius tribus insecta, quaecunque in formicetis degunt, his villis destituta sunt.

* 1. L. strumosa: Ferruginea, thorace subtiliter granulato, canaliculato, antrorsum angustato. - Long. 3 lin.

Grav. Mon. 179. 1. - Gyll. Ins. Suec. II. 437. 1. - Sahlb. Ins. Fenn. I. 403. 1. - Zetterst. Ins. Lappon. 64. 1. - Munnerh. Brachelytr. 65. 1. - Runde Brachelytr. Hal. 27. 1.

Staph. strumosus Fab. Ent. Syst. I. II. 525. 28. Syst. El. II. 597. 36.

Aleoch. st rumosa Grav. Micr. 91. 35. - Latr. Hist. nut. Crust. et Ins, IX. 387. 35.

Habitat in Germania, Suecia.

Obscure rufo-ferruginea, elytris pedibusque paulo dilutioribus. Antennae articulo primo breviusculo, crasso, tertio secundo duplo prope longiore, clavato seu apice subito incrassato, $4-10$ cyathiformibus, sensim paululum longioribus, ultimo praecedente duplo prope longiore, acuminato, pube brevissima subtilissimaque depressa albida obducta. Caput laeve, pilis parcis depressis griseis adspersum, antice subretusum, fronte late impressa. Thorax basi coleopteris parum angustior, antrorsum angustatus, lateribus et angulis anterioribus rotundatus, apice truncatus, basi profunde bisinuatus, angulis posterioribus retrorsum vix prominulis, subrectis, apice summo rotundatis, lobo intermedio fortiter producto, rotundato, supra medio subdepressus, subtiliter canaliculatus, margine laterali late elevato, crassiusculo, parce subtiliter granulatus, pilis subtilissimis depressis griseis adspersus. Elytra thorace paululum longiora, apice truncata, subtiliter punctata, pube subtilissima depressa grisea adspersa. Abdomen medio fuscum, segmentis basalibus margine laterali et apicali fulvo-villosis, segmento dorsali sexto minus profunde emarginato, lobis lateralibus triangularibus. Pedes fulvo - tomentosi, basi glabri.

Differt sexu abdominis segmenti dorsalis quinti angulo apicali aut simplice aut lateraliter elevato prominuloque.

Obs. Prof. Sahlberg hanc speciem in societate cum Formica, (Myrmica) rubra lectam esse memorat.

* 2. L. paradoxa: Ferruginea, thorace laevi, utrinque leviter impresso, lateribus rotundalo-ampliato. - Long. $2-2 \frac{1}{2}$ lin.

Grav. Mon. 180. 3. - Gyll. Ins. Suec. II. 438. 2. - Germ. Faun. Ins. Europ. V. 2. - Mannerh. Brachelytr. 65. 2-Guér. Jconogr. Regn. Amin. Ins. t. 10 f. 6. - Boisd. et Lacord. Faun. Ent. Paris. I. 5'26. 1. t. 2. f. 2. - Runde Brachel. Hal. 27. 2. - Er. Col. March. I. 376. 1.

Staph. emarginatus var. Payk. Mon. Staph. p. 57. not. Faun. Subc. III. p. 402. not. - Oliv. Ent. III. 42. t. 2. f. 12. b.

Habitat in Europa.

Sequenti valde affinis, at plerumque paulo maior, saturate ferruginea vel brunneo-testacea. Antennae articulo primo crasso, tertio elongato, secundo duplo prope longiore, apicem versus sensim leviter incrassato, 4 - 10 crassitie aequalibus, sensim paulo longioribus, prioribus transversis, ultimis crassitie haud longiorıbus, ultimo praecedentibus anıbobus longiore, sensim attenuato et acuminato, pube subtilissima longiore albida vestita, 
certo situ quasi velatae. Caput inter antennas leviter impressum, glabrum, nigricans, ore ferrugineo. Thorax latitudine dimidio prope brevior, coleopteris vix angustior, antrorsum haud angustatus, lateribus ampliatus, pone medium subsinuatus, ante medium cum angulis anterioribus rotundatus, apice truncatus, basi profundius bisinuatus, angulis posterioribus oblique productis, acutis, lobo intermedio subtruncato, laevis, glaber, obsolete canaliculatus, utrinque leviter impressus, margine laterali elevato, incrassato, Elytra thorace paulo longiora, apice sinuata, confertissime subtilissimeque punctata, subtilissime fulvo-pubescentia. Abdomen parce subtilissime punctulatum, segmentis basalibus margine laterali fulvo-villoso, segmentis quarto quintoque nigris, segmento dorsali sexto profunde emarginato, lobis acuminatis, spiniformibus, apice villosis. Pedes glabri.

Sexus differentia latet.

Obs. 1. In Myrmicae rubrae nidis D. Aubé hanc speciem cepit, ,in societate cum Formica parva nigra" eam repertam esse refert Gyllenhal (Ins. Suec. IV. p. 495.); ipse eam in gramine prope Formica e rufae nidos legi. Conf. quae apud Dinardam dentatam observavi.

2. Specima illa, quae ipse prope oppidum Freyenwalde legi cum exemplis Suecis a Dom. Schüppel communicatis congruunt statura maiore et colore saturatiore. Exempla collectionis Hoffmannseggianae, a Dahlio in Germania transrhenana lecta his sunt minora et pallidiora, statura et colore L. emarginatae aequalia. Specimina Lutetiae collecta, a Dom. Aubé mihi communicata, his intermedia sunt.

3. Staphylinus emarginatus Oliv. a Gravenhorstio ad hanc, a Gyllenhalio ad sequentem speciem allegatur, mihi ambae ab Oliviero sub nomine illo confusae videntur; fig. a. L. e marginat am, fig. b. L. paradoxam, praecipue secundum thoracis formam bene exhibet.

* 3. L. emarginata: Ferruginea, thorace subtilissime punctulato, antrorsum angustato. - Long. 2 lin.

Grav. Mon. 179. 2. - Gyll. Ins. Suec. II. 440. 3. - Sahlb. Ins. Fenn. I. 404. 2. - Munnerh. Brachel. 65. 3. - Boisd. et Lacord. Faun. Ent. Paris. I. 526. 2. - Runde Brachelytr. Hal. 27. 3. - Er. Col. March. I. 376. 2.

Staphyl. emarginatus Payk. Mon. Staph. 56. 40. Fann. Suec. 11I. 401. 44. Fab Ent. Syst. I. II. 528. 46. Syst. El. II. 600. 57. - Oliv. Ent. III. 42. 31. 44.

t. 2. $f$. 12. $a$.

Habitat in Europa.

Ferruginea, vel rufo-testacea, abdomine ante apicem pectoreque piceis nigrisve, saepius quoque capite, nomnunquam etiam thoracis disco vel thorace fere toto nigricantibus. Antennae articulo primo crasso, secundo tertioque obconicis, hoc paululum longiore, 4-10 cvlindricis, sensim paulo longioribus, prioribus crassitie vix brevioribus, ultimis eadem paulo longioribus, apicali elongato, praecedentibus tribus coniunctis longitudine aequali, sensim attenuato et acuminato, dense subtilissime longius albido-pubescentes ut in praecedente. Caput subtilissime punctulatum, inter antennas obsolete impressum. Thorax latitudine baseos dimidio brevior, basi coleopterorum prope latitudine, antrorsum aequaliter angustatus, ante medium cum angulis anterioribus rotundatus, apice truncatus, basi profunde bisinuatus, angulıs posterioribus oblique productis, valde acuminatıs, lobo intermedio leviter rotundato, supra subtilissime punctulatus, obsolete canaliculatus, utrinque leviter impressus, margine laterali elevato, haud incrassato. Elytra thorace 
paulo longiora, apice exterius leviter sinuata, confertissime subtiliter punctata, pube subtilissima depressa fulva densius vestita. Abdomen parce subtilius punctatum, segmentis duobus primis margine laterali fulvo-villoso, dorsali penultimo profunde emarginato, lobis acuminatis, spiniformibus, apice villosis. Pedes glabri.

Sexus differentia latet.

Obs. 1. Praecedenti simillima et aegre distinguenda, differt autem thorace antrorsum sensim angustato, angulis posterioribus paulo acutioribus, dorso punctulato et antennis paulo longioribus, articulo ultimo magis, articulo tertio autem non elongato.

2. Habitat secundum Gyllenhal semper in Formica e rufae nidis, Dom. Aubé autem specimen in Formicae cunicularia societate legit. Forte, ut afines, in variis formicetis obvija.

3. In Museo Regio exemplum inveni patria America septentrionali signatum, certe ad hanc speciem pertinet, an etiam patria eius indubia?

\section{Species mihi invisa.}

4. L. inflata: Parum punctala, fusco-.mefescens, antennis subfiliformibus, thoracis lateribus incrassatis, elytris pedibusque saturate rufotestaceis, thoracis elytrorumque angulis posticis prominulis.

\section{Zetterst. Faun. Lappon. I. 95. 1. Ins. Lapp. 74. 2.}

Habitat in Lapponia rarissime, sub cortice Betulae albae emortuae et trunco perforato unicum specimen cum Formica rufa ad Wittargi Lapponiae Tornensis, initio mensis Junii inveni.

L. strumosae similis et affinis, sed differt antennis dilutioribus, thoraracis lateribus magis incrassatis, disco obscuriori, et quod duplo minor et ultra, L. paradoxae aequalis. Caput parvum, nigrum, laeve, fronte foveata. Os rufescens. Antennae elongatae, rufo-ferrugineae, articulo primo crassissimo, 2 brevissimo, 3 longiore, obconicis, $4-10$ nodiformibus, remotis, subaequalibus. ultimo elongato, angustiore, conico, acuto. Thorax fere ut in L. strumosa formatus, scilicet brevis, transversus, postice in medio productus, utrinque sinuatus, angulis subrectis, minime prominulis, supra discum depressus, inaequalıs, vix canaliculatus, margine antico et postico parum, lateribus valde elevatis, et his etiam incrassatis, fusco-piceus, nitidus, lateribus ferrugineo-testaceis, opacis, totus parce et obsoletissime punctulatus, subpilosus. Elytra, abdomen et pedes omnino ut in L. strumosa, etiam quoad pubescentiam. (Zett.)

Obs. Pedibus tomentosis propius ad L. strumosam, quam ad Li parado$\mathrm{xam}$ accedere videtur.

\section{Silusa $E r$.}

\section{Er. Col. March. I. p. 377.}

Maxillae malis inaequalibus, interiore elongata, cornea, apice uncinata, intus subserrata.

Ligula elongata, angusta, integra.

Palpi labiales exarticulati, setacei.

Tarsi antici 4-, postici 5-articulati, omnes articulis primis aequalibus.

Corpus elongatum, lineare, supra depressum, subtus sat convexum, ala- 
tum. Caput exsertum, deflexum, basi haud constrictum, subglobósum, ore attenuato, leviter elongato, oculis mediocribus, minus prominulis. Labrum minutum, semiorbiculare. Mandibulae muticae. Maxillae (t. lII. f. 26.) mala interiore valde elongata, cornea, cultriformi, apice acuto introrsum adunco, margine interiore ante apicem spinulis minutis brevissimis serrulata, dein tenuiter cilıato, mala exteriore haud elongata, interiore duplo breviore, medio cornea, basi apiceque membranea, portione membranea apicali pubescente. Palpi maxillares malam interiorem parum excedentes, articulo secundo tertioque subaequalibus, illo elongato-subobconico, hoc tumidulo, quarto minuto, subuliformi. Labrum (t. III. f. 17.) mento sat magno, apice sat fortiter emarginato, ligula tenui, filiformi, integra, paraglossis nullis. Palpi labiales setacei, valde elongati, prominuli, subarticulati, articulo primo secundoque subaequalibus, tertio minimo. Antennae crassiusculae, articulo secundo tertioque obconicis, subaequalibus, 5-10 subtransversis, ultimo oblongo-ovato. Thorax transversus, basi coleopterorum prope latitudine, apicem versus parum angustatus. Scutellum triangulare. Elytra apice truncata, ad angulum exteriorem profunde excisa. Abdomen parallelum. Pedes breviusculi, intermedii basi approximati, tarsi antici 4-, posteriores 5-artıculati, articulis 4 primis aequalibus.

\section{O b s e r vatione s.}

1. Genus oris fabrica satis distinctum, mandibularum mala altera solita structura, altera elongata, ambiguum quasi inter praecedentia et sequentia.

2. Habitu Aleoch ara e generis quibusdam speciebus accedit, a quibus tarsorum structura differt. Tarsis anticis 4-articulatis, posterioribus articulis 4 primis inter se aequalibus cum Homalotis convenit, a quibus praeter caput basi haud constrictum et os attenuatum nisi ore accuratius inspecto aegre distinguatur.

3. Abdominis segmentum inferius sextum $m$ aris apice bisinuatum, medio leviter productum, feminae rotundatum.

4. De victu nihil mihi compertum.

*1. S. rubiginosa: Confertim punctata, nigra, antennis, pedibus elytrisque rufis, his circa scutellum anguloque exteriore apicis fuscis, thorace busi foveolato. - Long. $1 \frac{3}{6}$ lin.

Er. Col. March. I. 378. 1.

Habitat Berolini, Dom. Schïppel et Dom. Weber, in Austria, Dom. Schiippel, Lutetiae, Mus. Dom. Aubé.

Corpus totum griseo-puberulum. Antennae vix capitis thoracisque longitudine, rufae. Caput laeve, subnitidum, nigrum, ore rufescente. Thorax coleopteris paulo angustior, latitudine duplo fere brevior, lateribus leviter rotundatus, antrorsum vix angustatus, angulıs anterioribus rotundatis, posterioribus rectis, parum convexus, subtilissime punctatus, basi foveola transversa impressus, niger, margine laterali obscure rufescente. Elytra thorace paulo longiora, confertim fortiter punctata, sutura elevata, opaca, rufa, inacula communi scutellari anguloque posteriore exteriore fuscis, seu fusca, vitta lata oblique ab humero ad angulum interiorem descendente rufa. Abdomen densius fortiter punctatum, minus subtiliter pubescens, nigrum, segmentis quatuor primis margine piceis. Pedes rufi.

Mas abdominis segmento dorsali quinto acute carinato distinctus. 
Obs. 1. Al. foveolatae Dej. nomine hoc insectum in collectione D. Aubé signatum vidi.

2 Labrum maiusculum, mandibulas omnino obtegens.

* 2. S. rubra: Punctatissima, rufa, abdomine supra parce punctalo, anle apicem capiteque piceis, thorace basi fovea lata impresso. - Long. $1 \frac{3}{4}$ lin.

Habitat in Germania meridionali, Dom. Schiippel.

Statura omnino praecedentis, rubra seu rubro-testacea, punctatissima, subtiliter pubescens. Antennae capitis thoracisque longitudine, apicem ver sus subincrassatae. Caput confertim sat fortiter punctatum, infra antennas laeve, nigro-picerm, oris partibus rufo-testaceis. Thorax coleopteris parum angustior, latitudine dimidio brevior, lateribus leviter rotundatus, angulis omnibus subrectis, anterioribus deflexis, leviter convexus, confertim sat profunde punctatus, basi fovea transversa, antrorsum explanata, media et utrinque puncto impressus. Elytra thorace paulo longiora, fortiter punctata, subrugosa. Abdomen elongatum, obscure rufum, ante apicem nigricans, supra parce punctatum, segmentis posterioribus sublaevibus. Pectus piceum. Pedes flavo-testacei.

Mas abdominis segmento dorsali quinto bicarinato insignis. Femina mihi invisa. coloribus.

Variat colore minus saturo, rufo-testaceo, capite pectoreque con-

Obs. Labrum minus quam in praecedente, et mandibulae sub eodem prominentes. Nihilominus cum praecedente, quantum examinatione exteriore videre licet, oris reliqui et praecipue maxillarum structura haud differt.

\section{Pronomaea $\boldsymbol{E} \boldsymbol{r}$.}

\section{Er. Col. March. I. p. 378.}

Maxillae malis aequalibus, elongatis, interiore cornea, apice uncinala, intus serrala.

Ligula bifida, minuta, sub mento occulla; paraglossae nullae.

Palpi labiales exarticulati, setacei.

Tarsi antici 4-, posteriores 5 articulati, postici articulo primo elongato.

Corpus elongatım, lineare, supra subdepressum, infra modice convexum, alatum. Caput exsertum, cernuum, basi haud constrictum, ore attentato, valde elongato, oculis mediocribus, parum prominulis. Labrum dependens, fere oblongum, apice rotundatum, mandibulas obtegens. Mandibulae muticae, membranula fimbriatae, apice libero, acuto, introrsum adunco. Maxillae (t. III. f. 27.) mala utraque elongata, lineari, tenui, interiore cornea, apice acuto, introrsum adunco, margine interıore apicem versus spinulis minutis deorsum versis serrulato, inferius ciliato, mala exteriore membranacea, margine tennissimo interiore apiceque membranea, apice pubescente, malae interiori aequali. Palpi maxillares elongati, articulis secundo tertioque aequalıbus, parum uncrassatıs, quarto minimo, subulato. Labium (t. III. f. 18.) mento sat magno, apice profunde exciso, ligula brevissima, biloba, sub mento occulta, paraglossis nullis. Palpi labiales valde elongati, setacei, exarticulati. Antenmae apicem versus sensim subincrassatae, articulo secundo 
tertioque subaequalibus, ultimo ovato. Thorax coleopterorum latitudine, apicem versus haud angustatus. Scutellum triangulare. Coleoptera apice coniunctim leviter emarginata, ad angulum apicalem exteriorem profundius excisa. Abdomen lineare. Pedes breviusculi, intermedii brevi spatio distantes, tarsi antici 4-, posteriores 5-articulati, postici articulo primo subelongato.

O b s e r vation es.

1. Mentum magnum, ligulam omnino occultans, quae nonnisi mento destructo conspicitur.

2. Habitus corporis linearis Oxypodae Sect. II, a qua autem non modo tarsis anticis 4-articulatis distinguitur, sed capite etiam tumido, ore producto, attenuato, fere rostrato, palpis maxillaribus elongatis et labialibus quam plurimum exsertis, setaceis discedit.

3. Sexus differentiam non cognovi.

4. Victus in silvis in musco et sub foliis deciduis.

* 1. P. rostrata: Nigra, nitida, thorace basi foveolato, elytris pedibusque piceis. - Long. $1 \frac{1}{2}$ lin.

T. 1. $f .3$.

Er. Col. March. I. 379. 1.

Habitat in Germania, Gallia. In Sardinia etiam a Dom. Prof. Gené lecta.

Linearis, nigra, nitida, subtiliter punctata, tenuiter pubescens. Antennae capite thoraceque breviores, crassiusculae, obscure piceae, basi dilutiores, apice summo ferrugineo. Caput sat magnum, subtilissime punctulatum, fronte leviter convexa, clypeo apice membranaceo, luteo, labro piceo. Thorax coleopteris paulo angustior, latitudine dimidio brevior, lateribus subrectis, basin versus subangustatus, angulis anterioribus rotundatis, deflexis, posterioribus obtusis, supra leviter convexus, subtiliter punctulatus, basi foveola impressus. Elytra thorace paulo longiora, crebre fortius punctata, longius pubescentia, picea. Abdomen supra parce punctatum, fere laevigatum, parce pubescens, ano piceo. Pedes rufo-picei.

\section{Diglossa Haliday.}

\section{Ent omol. Mag. IV. $p, 252$.}

Maxillae malis aequalibus, elongatis, exteriore cornea, apice uncinata, intus serrata.

Ligula sub mento occulta.

Palpi labiales exarticulati, setacei.

Tarsi omnes 4-articulati.

Corpus elongatum, apterum. Caput exsertum, porrectum, thorace haud angustius, basi haud constrictum, ore attenuato, producto, oculis minutis. Labrum transversum, apice leviter sinuatum. Mandibulae productae, prominulae, angustae, acutae, apice leviter introrsum incurvae, medio obsolete dentatae. Maxillae malis elongatis, longitudine aequalibus, exteriore setacea, interiore lineari, apice introrsum curvata, cornea, margine interiore subtiliter denticulato. Palpi maxillares elongat, articulo primo minuto, secundo tertioque longis, longitudine subaequalibus, hoc vix clavato, quarto obsoleto. Mentum transversum, antrorsum angustatum, apice trun- 
catum. Ligula sub mento occulta. Palpi labiales exarticulati, setacei, porrecti. Antennae graciliores, articulo primo cylindrico, secundo paulo longiore, clavato, tertio breviore, obconico, sequentibus brevibus, subglobosis, extremis sensim paulo crassioribus, fere transversis, ultimo iterum longiore, subgloboso-ovato. Thorax coleopteris angustior, basin versus leviter angustatus. Elytra truncata, ad angulum exteriorem vix sinuata. Abdomen elongatum, lineare. Pedes breviores, tibis anticis angulo apicali exteriore profunde emarginato, sinu dentibus prominulis acutis terminato, tarsis omnibus 4-articulatis, anterioribus brevissimis, posticis brevibus, articulo primo paulo longiore, quarto (unguiculari) primo breviore crassioreque, unguicnlis brevibus, fortiter curvatis, validis.

1. D. mersa: Nigra, subtiliter pubescens punctataque, palpis pedibusque ferrugineis. - Long. 1 lin.

Haliday Ent. Mag. IV. p. 252.

Habitat in arenis maritimis Hiberniae, aestu alterno opertus et retectus.

Nigra, leviter pubescens, capite, thorace elytrisque subtiliter punctulatis. Antennae capite thoraceque paulo longiores, apicem versus perparum incrassatae, obscure ferrugineae. Palpi saturate ferruginei. Mandibulae dilutius ferrugineae. Thorax capite elytrisque angustior, latitudine longior, lateribus ante medium rotundatus, basin versus angustatus, basi apiceque truncatus. Elytra thorace haud longiora. Pedes saturate ferruginei, tibiis pubescentibus medio femoribusque obscurioribus, tarsis dilutis.

$\mathrm{Obs}$. Insectum mihi invisum, ab auctore citato 1 . c. accuratius descriptum et icone ligno inciso illustratum, corporis habitu et oris structura summam cum Pro. nomae a rostrata nostra similitudinem prae se fert. Tarsi 4-articulati, articulo ultimo brevi incrassato, unguiculis brevibus, fortibus, fortiter curvatis instructo et tibiae anticae apice emarginatae huic generi peculiares. Victus Blediorum quorundam. Analogia cum Oxytelis tibiarum anticarum structura probatur. Nomen generis ex errore, quo auctor palpos labiales pro ligulae lacinias habuit, ortum, non sine dubio immutatum recepi.

\section{Myllaena Er. \\ Er. Col. March. I. p. 382. \\ Centroglossa Mutthews Ent. Mag. V.p. 191.}

Maxillae malis aequalibus, elongatis, interiore cornea, apice uncinata, intus serrala.

Ligula brevis, integra.

Palpi labiales exarliculati, setacei.

Tarsi antici 4-, posteriores 5-arliculati, antici arliculo primo brevissimo, postici subelongato.

Corpus oblongum, antice obtusum, anum versus sensim attenuatum, acuminatum, convexum, alatum. Caput basi haud constricta a thorace receptum, deflexum, subglobosum, ore attenuato, modice elongato, fronte convexa, oculis lateralibus, mediocribus, parum prominulis. Labrum coriaceum, semi-orbiculare, mandibulas obtegens. Mandibulae muticae. Maxillae (t. III. f. 29.) mala utraque valde elongata, interiore cornea, linearicultriformi, apice acuto introrsum adunco, margine interiore apicem versus 
spinulis brevissimis subtiliter serrulato, exteriore membranea, lineari. interiori aequali, apice pilosulo. Palpi maxillares malas parum superantes, articulo secundo satis elongato, tertio hoc paulo breviore, tumidulo, quarto minuto, subulato. Labium (t. III. f. 20.) mento transverso, apice leviter emarginato, utrinque spina porrecta, lineari, valde elongata terminata, ligula brevissima, rotundata, integra, paraglossis nullis. Palpi maxillares valde elongati, prominuli, setacei, exarticulati. Antennae tenuiusculae, articulo secundo tertio sesqui longiore, ultimo oblongo-ovato, apice acuminato. Thorax basi coleopterorum latitudine, eaque amplectens, lateribus rotundatus, apicem versus fortiter angustatus, convexus. Scutellum thoracis margine obtectum. Coleoptera apice coniunctim emarginata, utrinque ad angulum exteriorem excisa. Abdomen apicem versus sensim attenuatum, acuminatum, stylis analibus exsertis. Pedes breviusculi, intermedii bası approximati, tibuis glabris, tarsis anticis 4-, posterioribus 5 articulatis, anticis articulo primo brevissimo, posticis elongato.

\section{O b s e r va tionies.}

1. Corpus totum subtilissime punctatum, pube densa subtilissima brevissimaque sericeum. Thorace amplo et abdomine apicem versus attenuato habitus omnino Tachypororum, Oxypodis sectionis prioris quoque non dissimiles minutae hae species, quibuscum insuper elytris apice ad angulum exteriorem excisis congruunt, distinctae tamen ore attenuato, subrostrato. Palpi labiales setacei plerumque prominent.

2. Ingeniose Com. Mannerheim Myllaenam sequenti generi adscribit, attamen accuratius examinata oris et tarsorum structura, tibiisque haud spinulosis satis distincta.

3. Abdominis segmentum inferius sextum in altero sexu apice truncatum, in altero acute rotundatum.

4. Victus in silvis in musco et sub foliis deciduis.

* 1. M. dubia: Nigra, opaca, cinereo-sericea, thoracis angulis posticis prominulis. - Long. $1 \frac{1}{4}$ lin.

Er. Col. March. I. 383. 1.

Aleoch. dubia Grav. Mon. 173. 67. - Gyll. Ins. Suec. 1T. 426. 48. - Suhlb. Ins.

Fenn. I. 395. 85. - Zetterst. Ins. Lappon. 79. 32.

Gymn us a dubia Mannerh. Brachelytr. 66. 2.

Centrogloss a conuroides Natchews Ent. Mag. V. p. 195. f. 1.

Habitat in Europa.

Antemae fuscae, arliculo primo flavo. Palpi flavi, articulo tertio fusco. Thorax antrorsum angustatus, lateribus angulisque anterioribus rotundatis, angulis posterioribus retrorsum prominulis, basi profundius bisinuatus. Abdomen apice segmentorumque ventralium marginibus rufo-piceis. Pedes flavi, femoribus fuscis.

* 2. M. intermedia: Nigra, opaca, cinereo-sericea, thoracis angulis poslicis subrectis. - Long. $\frac{3}{4}$ lin.

Er. Col. Murch. I. 383. 2.

Habitat in Germania.

Praecedenti affims, at plus duplo minor. Antennae fuscae, articulo prime flavo. Os flavum. Thiorax antrorsum angustatus, lateribus minus 
rotundatus, basi leviter bisinuatus, angulis posterioribus parum prominulis, subrectis. Abdomen apice testaceum. Pedes testacei, postici fuscescentes.

Variat immatura colore rufo-testaceo, abdominis basi pectoreque nigris.

3. M. minuta: Nigra, opaca, cinereo-sericea, thoracis angulis posticis oblusis. - Long. $\frac{1}{2}$ lin.

Er. Col. March. I. 384. 3.

Aleoch. minuta Grav. Mon. 174. 68. - Gyll. Ins. Suec. 11. 427. 29.

Habitat in Germania, Suecia.

Praecedenti simillima, at paulo angustior et duplo minor. Antennae articulo primo concolore. Os fusco-testaceum, palpis maxillarıbus fuscis. Thorax antrorsum vix angustatus, lateribus parum rotundatus, basi levissime bisinuatus, angulis posterioribus obtusis. Pedes fusco-testacei.

\section{Gymmusa Karsten.}

Grav. Mon. p. 173. - Mannerh. Brachelytr. p. 66. - Er. Col. March. I p. 380.

Maxillae malis aequalibus, elongatis, interiore cornea, apice uncinala, inius inaequaliter serrala.

Ligula bifida, laciniis porrectis, elongatis, setacęis, palpis aequalibus; pan aglossae nullae.

Palpi labiales setacei, exarticulati.

Tarsi omnes 5-articulati, postici articulo primo elongato.

Corpus oblongum, utrinque attenuatum, convexum, alatum. Caput basi haud constricta a thorace receptum, deflexum, subglobosum, ore attenuato, elongato, fronte convexa, oculis facialibus, mediocribus, parum prominulis, ovatis. Labrum maiusculum, suborbiculare, dependens, mandibularum apicem tegens. Mandibulae elongatae, lineares, apice acute bidentatae, dente altero apicali, altero ante apıcem sito, margine interno infra dentes membranula interne acute denticulata fimbriato. Maxillae (t. III. f. 28.) mala utraque cornea, valde elongata, interiore cultriformi, apice acuto, adunco, margine interiore ante apicem inaequaliter acute serrato, exteriore lineari, ad basin sinuato-excisa, apice setulis duabus barbulaque introrsum vergente terminata. Palpi maxillares itidem valde elongati, tenues, articulo secundo longissimo, tertio hoc paulo breviore, apicem versus parum incrassato, quarto minimo, subulato. Labium (t. III. f. 19.) mento sat magno, apice profunde emarginato, ligula elongata, bifida, laciniis coriaceis, linearibus vel subsetaceis, palpis subaequalibus, paraglossis nullis. Palpi labiales elongati, setacei, apice obsolete articulati, ita ut, si articulatos respicias, articulus primus sit longissimus, secundus minimus, tertius hoc paululum longior. Antennae tenues, articulis $2-10$ subobconico-teretibus, 11 mo ovato. Thorax basi coleopterorum latitudine, eaque amplectens, basi utrinque subsinuatus, antrorsum angustatus, lateribus rotundatus, supra convexus. Scutellum thoracis margine obtectum. Coleoptera apice coniunctim emarginata, utrinque ad angulum exteriorem excisa. Abdomen apicem versus sensim attenuatum, stylis analibus distuctis. Mesosternum subtiliter carinatum. Pedes breviu- 
sculi, intermedii basi approximati, tibiis spinulosis, tarsis omnibus 5-articulatis, postici articulo primo valde elongato.

\section{o b s e r vatio n e s.}

1. Genus insigni modo distinctum, neque cum aliquo confundendum. Mandibulae acute dentatae, oculi in capitis facie anteriore siti, tibiae spinulosae et styli anales exserti characteres sunt singulares in hac tribu, in cuius finem collocavi hoc genus, pariter ad Tachyporinos atque ad Staphylininos vergens.

2. Abdomen segmento sexto inferiore maris apice leviter emarginato, septimo fortiter inciso, feminae segmento sexto apice utrinque leviter sinuato, medio acute rotundato, septimum occultante. Qua sexus differentia a reliquis Aleocharinis hoc genus quodammodo discedit, magis autem Staphylininis quam Tachyporinis appropinquatur.

3. Victus sub musco et ad arborum radices.

* 1. G. brevicollis: Nigra, antennarum articulo primo tarsisque testaceis. - Long. $2 \frac{1}{2}$ lin.

Mannerh. Brachelytr. 66. 1. - Boisd. et Lacord. Faun. Ent. Paris. I. 534. 1. Er. Col. March. I. 381. 1.

Staphyl. brevicollis Payk. Faun. Suec. III 398. 40.

Aleoch. brevicollis Gyll. Ins. Suec. II. 425. 47. - Sahlb. Ins. Fenn. I. 394. 84.

- Zetterst. Faun. Lappon. I. 103. 22. Ins. Lappon. 79. 31.

Aleoch. carnivora Grav. Mon. 171. 60.

Aleoch. excusa Grav. Mon. 172. 66.

Habitat in Germania, Suecia.

Nigerrima, subnitida, subtilissime tenussimeque cinereo-pubescens. Antennae articulo primo rufo. Caput laeve. Thorax basi coleopterorum latitudine, latitudine paulo brevior, basi subsinuatus, angulis posticis obtusiusculis, convexus, subtiliter punctatus. Elytra thoracis longitudine, confertim subtiliter punctata, opaca. Abdomen minus subtiliter punctatum. Pedes nigri, tarsis rufo-testaceis.

2. G. laticollis: Atra, tenuiter sericeo-pubescens, palpis tarsisque luteofuscis. - Long. $1 \frac{3}{4}$ lin.

Habitat in Germania, Gallia.

Habitu omnino praecedentis, at plus duplo minor, tota confertissime subtilissimeque punctulata, atra, pube tenuissima cinereo-sericea dense vestita. Antennae filiformes, basi obscure fuscescentes. Labrum transversim orbiculatum palpique flavescenti-fusca. Thorax coleopters sublatior, brevis, longitudine duplo latior, basi bisinuatus, angulis posterioribus subrectis, retrorsum prominulis, supra leviter convexus. Elytra thorace longiora. Pedes nigri, geniculis tarsisque fusco-luteis.

Obs. Statura triplo fere minore, pube densa, sericante, labro transverso, thorace breviore et latiore a praecedente facile distinguitur. 


\section{Tribus secunda.}

\section{Tach y $\mathbf{p}$ or i n}

Stigmata prothoracica conspicua.

Antennae sub frontis margine laterali insertae.

Labrum integrum, corneum, fimbria et lacinïs membraneis nullis.

Mandibulae haud prominentes, muticae, trigonae aut subfalcatae, limbo membraneo, interne ciliato, margini interiori affixo intus fimbriatae, apice libero acuto in plerisque;

valde elongatae, tenues, falcatae, acutae in $\mathrm{T}$ an $\mathrm{ygn}$ atho.

Maxilla e cardine stipiteque corneis, malis coriaceis membranaceisve, exteriore apice, interiore margine interiore barbatis in plerisque;

malis, elongatis, linearibus, interiore apice unicata in Trichophyo.

Palpi maxillares 4-articulati, articulo primo minuto, secundo tertioque elongatis, quarto

minuto, subulato in Hy p o cy t o, C o nuro, T a ch yporo, My c e top oro; elongato, apice valde acuminato in $\mathrm{Habrocero.}$

praecedenti aequali, apice leviter acuminato in $\mathrm{T}$ achino, Trichophyo, Boletobio, Tanygnatho.

Mentum corneum, tranversum, antrorsum angustatum, apice truncatum aut leviter emarginatum.

Labinm membranaceum magis minusve exserendum.

Ligula membranea,

lata biloba, paraglossis ei connatis, linea ciliata indicatis in Conuro, T ach y oro, Habrocero, T a chino;

angustiore, paraglossis nullis in Boletobio et Mycetoporo;

rotundata, medio producta, paraglossis nullis in Нy о сурto;

bifida, paraglossis eadem brevioribus in Trichophyo.

Palpi labiales triarticulati plerisque;

filiformes Conuro, Tachyporo, Habrocero, Tachino, Bol e tobio: articulo ultimo subulato aut fere subulato Hypocypto, Mycetoporo, Tan y gnatho;

biarticulati (?) Trich oph y o. 
Antennae infra oenlos sub capitis margine laterali insertae, 11 -articulatae, filiformes plerisque;

tenues, articulis singulis verticillato-pilosis, primis duobus crassiusculis in Habrocero et Trichophyo;

10-articulatae, clavatae in $\mathrm{Hypocypto.}$

O culi parvi rotundati aut ovales, haud prominentes.

C a put thoraci insersum, basi haud constrictum, deflexum vel inflexum.

Thorax amplus, convexus, postice coleopterorum basin, antice caput amplectens.

Prosternum triangulare, spatio pone coxas anteriores membraneo.

Pectus metathoracis epimeris magnis, retrorsum prominentibus.

Scutellum triangulare.

Elytra pectore distincte longiora in Hypocyto, Conuro, Tachyporo, Habrocero, Tachino;

aut pectus longitudine vix superantia in Trich ophyo, Boletobio, Mycetoporo, Tanygnatho.

Abdomen apicem versus attenuatum, segmentis sex primis distinctis, septimo saepius occulto, stylis analibus plerumque haud distinctis;

marginatum in plerisque;

immarginatum in Conuro.

Pedes coxis anticis exsertis, conicis, posticis parallelopipedis, trochanteribus posticis fulcrantibus, tibiis aut omnibus aut posterioribus plerumque, nonnunquam etiam femorum apice spinulosis, tarsis

5 -articulatis in plerisque,

4-articulatis in Hypocypto et Tanygnatho, anticis saepe dilatatis;

unguiculis tenuibus, falcatis, simplicibus.

Sexus differentia saepius abdominis segmentorum posteriorum figura et tarsis anticis maris fortius dilatatis cognoscitur, in generibus et speciebus variis vario modo se habens, et in isdem describendis accuratius illustranda.

$$
\text { O b s e r vation es. }
$$

1. Corpus minutum, agile, habitu quodam peculiari, convexum, ante et postice attenuatum, licet antice obtusiusculum, abdomine in vivis modice elongato.

2. Huius tribus minus numerosae plerasque sibi cognitas species Fabricius immerito Oxyporo subiunxit, Gravenhorst genera Tachyporum et Tachi$11 \mathrm{um}$ ex is constituit, illud primo (Micr. p, 124.) species palpornm maxillarium articulo quarto subulato, dein (Mon. p. I), methodo magis naturali, species elytris longioribus continens, hoc primo (Micr. p. 134) species palpis maxillaribus filiformibus, dein (Mon. p. 22.) species elytris pectore haud longioribus amplectens. Genera hodierna pleraque iam ab auctore celebri familiarum nomine in utroque genere suo distincta sunt.

\section{Hypocyptus Schupp.}

Er. Col. March. I. p. 387.

IIypocyphtus Mannerh. Brachelytr. p. 58. - Boisd. et Lacord. Fuun. Ent. Paris. I. $p .519$.

Cypha Stephens Illustr. V.p. 187.

Antennae 10-artirulatue, articulis ultimis tribus crassioribus.

Palpi maxillares. articulo quarlo subulato. 
Ligula rotundata, integra. Elytra pectore longiora.

\section{Tarsi 4-articulati.}

Corpus parvum, globatum, alatum. Caput latum, inflexum, oculis rotundatis, parum prominulis. Labrum transversum, integrum. Mandibulae minutae, muticae. Maxillae (t. IV. f. I. b.) malis membraneis, interiore apıce oblique truncata, ihıque barbata, exteriore extus profunde sinuata, apice introrsum barbata, interiorem paulum superante. Palpi maxillares articulo primo minimo, secundo elongato, subclavato, tertio ovato, tumidulo, quarto minimo, subulato. Labium (t. IV. f. 1. a.) mento transverso, apice truncato, ligula membranea, semiorbiculari, medio processu minuto umbonata, paraglossis nullis. Palpi labiales articulis duobus primis crassiusculis, secundo breviore, tertio sat elongato, tenui, subuliformi. Antennae 10-articulatae, articulis primis duobus crassiusculis, ultimis tribus leviter Incrassatis, clavam oblongam formantibus. Thorax transversus, basi coleopteris latitudine subaequalis, antrorsum angustatus, rotundatus, basi utrinque sinuatus, leviter convexus. Scutellum obtectum. Elytra convexiuscula, apice singula rotundata. Abdomen minus elongatum, apicem versus attenuatum. Pedes breves, debiles, intermedii basi satis distantes, interstitio aequali, coxae posticae haud amplae, parallelopipedae, tibiae omnes laeves vel subtilissine setulosae; tarsi omnes 4-articulati, articulo primo leviter elongato, tarsorum anticorum incrassato, sequentibus duobus minimis, ultimo primo paulo breviore.

o b s e r v a t i o n e s.

1. Corpus laeve, parce pubescens, capite thoraceque fortiter inflectendis globatile, globatum Agathidiorum more seminulum mentiens.

2. Affinitates huius generis cum Aleocharinis admodum obviae videntur, ligulaeque forma affirmantur. Antennarum insertio autem huius Tribus. Cum genere Oligota arctissime coniungitur, non solum corporis figura, sed etiam articulorum antennarum tarsorumque numero comminuto.

3. Victus in sylvis, vel sub lignornm cortice recentiore, nondum exsiccato latitantes vel in gramine herbisque vagantes reperias. Reliqua vivendi ratio latet. Praeter indigenas paucas nulla mihi innotuit species.

4. Genus hocce sub Scaphidio apud Payku? et Gyllenhal, sub Tachyporo apud Gravenhorst militans, primus cognovit et proposuit Dom. Schüppel. Vulgo scribunt Hypocyphtus contra regulas etymologicas, scribendum esset aut $\mathrm{Hy}$ pocyphthus aut Hypocyptus. Hoc ultimum nomen ab inventore erudito pro suo agnoscitur.

* 1. H longicornis: Niger, nilidus, parce pubescens, antennis apicem versus sensim incrassatis pedibusque teslaceis, thoracis angulis posterioribus subrectis. - Long. $\frac{2}{3}-\frac{3}{4}$ lin.

Mannerh. Brachelytr. 58 1. - Boisd. et Lacord. Faun. Ent. Paris. I. 521. 3. Er. Col. March. I. 388. 1.

Scaphidium longicorne Payk. Faun. Suec. III. 340. 3. - Gyll. Ins. Suec. I.

191. 6 IV. p. 294. - Salelb. Ins. Fenn. I. 63. 4.

Scaphidium aequinatum Marsh. Ent. Britt. 234. 3.

Tachyporus granulum Grav. Mon. 3. 1.

Hypocyphtus granulum Boisd. et Lacord. Faun. Ent. Paris. I. 520. 1.

Hypocyptus globulus Boisd. et Lacord. Faun. Ent. Paris. I. 521. 2.

Habitat in Europa, sub arborum cortice. 
Niger, nitidus, pube subtili depressa cinerea parce adspersus. Antennae testaceae, articulis duobus primis sat magnis, primo subgloboso, secundo cylindrico, $3-5$ tenuibus, inter se aequalibus, crassitie vix longioribus, 6 et 7 paulo crassioribus et sensim paulo longioribus, subobconicis, sequentibus tribus clavam valde elongatam, parum incrassatam, fusiformem formantibus, penultimis duobus aequalibus, obconicis, ultimo his coniunctis longitudine aequali, at non crassiore, apicem versus sensim attenuato. Palpi testacei. Caput fronte planiuscula, laevi. Thorax basi coleopterorum prope latitudine, antrorsum angustatus, latitudine baseos plus duplo brevior, lateribus cum angulis anterioribus fortiter rotundatus, apice truncatus, basi leviter bisinuatus, angulis posterioribus subrectis, fortiter convexus, margine laterali dilatato, pallido, pellucido. Elytra thorace sesqui longiora, apice rotundata, convexa, parcius subtilissime punctata, nigro-picea. Abdomen parce subtilissime punctatum, apice plerumque piceum. Pedes testacei.

Mas abdominis segmento sexto inferiore apice profunde triangulariter exciso, femina eodem integro rotundato. Tarsi antici in utroque sexu simplices.

Obs. H. granulum Boisd. et Lacord. thorace elytrisque piceis, H. globulus eorundem auctorum nonnisi statura paulo minore a genuinis discedunt.

* 2. H. discoideus: Niger, pubescens, antennis arliculis ultimis tribus abrupte maioribus pedibusque testaceis, elytris disco rufis, thorace angulis posterioribus rotundatis. - Long. $\frac{1}{2}$ lin.

Er. Col. March. I. 388. 2.

Habitat Berolini, Dom. Schïppel et ipse.

Praecedente dimidio vel duplo minor, nigro-piceus, pube longiore, depressa, fulvescenti-grisea densius vestitus. Antennae flavo-testaceae, pilosae, articulis $3-7$ tenuioribus, 8 et 9 his duplo crassioribus, subobconicis, ultimo his coniunctis longitudine aequali, elongato, apice acuminato, his ultimis tribus clavam valde elongatam at parum incrassatam formantibus. Caput parcius subtiliter punctatum, nigrum, nitidum, ore testaceo. Thorax basi coleopterorum latitudine, antrorsum angustatus, latitudine baseos plus duplo brevior, basi subbisinuatus, angulis posterioribus rotundatis, transversim convexus, parcius subtilissime punctatus, piceus, margine basali tenui et laterali subdilatato testaceo-pallidis. Elytra thorace sesqui longiora, apice oblique truncata, leviter convexa, crebre subtiliter punctata, testaceo-rufa, basi et lateribus fusca. Abdomen parce subtiliter punctatum, piceum, supra segmentis anterioribus quatuor margine posteriore rufescente, ultimis duobus totis rufo-testaceis, subtus rufo-testaceum, basi piceum. Pedes testacei.

Mas abdominis segmento sexto inferiore apice emarginato, tarsis anticis articulo primo dilatato.

Femina abdominis segmento sexto inferiore apice rotundato, tarsis anticis simplicibus.

3. H. laeviusculus: Niger, antennis articulis ultimis tribus abrupte maioribus pedibusque nigricantibus, thorace angulis posterioribus subrectis. - Long. $\frac{1}{2}$ lin.

Mannerh. Brachelytr. 58. 2. - Er. Col. March, I. 389. 3. 
Scaphid. longicorne var. b Gyll. Ins. Suec. II. 191. 6. - Sahlb. Ins. Fenn. I. 63. 4.

Habitat in Europae pratis.

H. longicorni duplo minor, niger, nitidus, parce subtiliterque cinereopubescens. Antennae articulis duobus primis crassiusculis, $3-7$ minutis, subaequalibus, 8 et 9 maioribus, inter se aequalibus, ultimo his coniunctis longitudine aequali et paulo crassiore, apice acuminato, cum is clavam elon gatam minus incrassatam formante, albido-pilosellae, nigro- vel fusco-piceae, basi nonnunquam dilutiores. Palpi nigro-picei. Caput parce subtilissime punctatum. Thorax basi coleopterorum latitudine, antrorsum angustatus, latitudine baseos plus triplo fere brevior, basi subbisinuatus, angulis posterioribus subrectis, acumine summo rotundatis, transversim convexus, parce subtilissime punctatus, margine laterali anguste obsoleteque obscure testaceo-pellucente. Coleoptera thorace sesqui longiora, apice oblique truncata, convexa, crebrius subtiliter punctata. Abdomen crebrius punctulatum, longius pubescens, segmentis singulis piceo-marginatis. Pedes vel nigrovel fusco-picei, tarsis subtestaceis.

Mas abdominis segmento sexto inferiore apice emarginato, tarsis, anticis articulo primo dilatato.

F emin a abdominis segmento sexto inferiore apice rotundato, tarsis anticis simplicibus.

Variat immaturus colore corporis ferrugineo.

* 4. G. seminulum: Niger, nitidus, antennis ultimis tribus abruple maioribus pedibusque testaceis, thorace angulis posterioribus subrectis. Long. $\frac{1}{3}$ lin.

Er. Col.: March. I. 389. 4.

Habitat in Germania: Berolini a me lectus.

Praecedente plerumque paulo minor, niger, nitidus, tenuiter subtiliterque cinereo-pubescens. Antennae articulis duobus primis crassiusculis, $\mathbf{3} \mathbf{- 5}$ minutis, subaequalibus, 6 et 7 vix crassioribus, 8 et 9 distincte maioribus, ultimo his coniunctis longitudine subaequali et paulo crassiore, apice acuminato, longius pilosellae, totae rufo-testaceae. Palpi rufi. Caput parce subtilissime punctatum. Thorax basi coleopterorum latitudine, antrorsum angustatus, latitudine baseos triplo fere brevior, basi leviter bisinuatus, angulis posterioribus subrectis, convexus, laevis, margine laterali tenui pallidopellucido. Elytra thorace tertia parte longiora, apice oblique truncata, crebrius subtiliter punctata. Abdomen parcius punctulatum, subtus apice piceorufescens. Pedes rufo-testacei, femoribus posticis nigro-piceis.

Mas latet.

Femina abdominis segmento sexto inferiore apice rotundato, tarsis anticis simplicibus.

* 5. H. pulicarius: Niger, nitidus, thorace elytrisque piceis, antennis articulis ultimis tribus abrupte maioribus pedibusque testaceis, thorace angulis posterioribus subrotundatis. - Long. $\frac{1}{2}$ lin.

Habitat in Germania: Berolini a Dom. Schüppel lectus. 
Praecedenti affinis, at paulo maior, niger, nitidus, pube longiore de. pressa grisea parce vestitus. Antennae longiores, articulis duobus primis maiusculis, $3-5$ minutis, aequalibus, 6 et 7 his paulo longioribus, at vix crassioribus, 8 et 9 distincte maioribus, subobconicis, inter se aequalibus, ultimo elongato, his coniunctis paulo longiore et paulo crassiore, fusiformi, apice fortiter acuminato, parce plosellae, totae laete rufo-testaceae. Caput laeve, ore cun palpis rufo-testaceo. Thorax basi coleopterorum latitudine, apicem versus angustatus, latitudine baseos plas duplo brevior, basi vix sinuatus, angulis posterioribus subrotundatis, convexus, laevis, piceus, margine anteriore et posteriore dilutiore, rufescente, laterali latiore, testaceopellucido. Elytra thorace tertia parte longiora, oblique truncata, convexa, parce subtilissime punctata, picea. Abdomen parce subtilius punctatum, ajice rufo-piceum. - Pedes dilute testacei.

\section{Mas latet.}

Femina abdominis segmento sexto inferiore apice rotundato, tarsis anticis simplicibus.

Obs. Praecedenti proxime affinis, differe autem videtur statura maiore, antennis longioribus et pedibus dilutioribus, thoracis angulis posterioribus potius rotundatis, elytris parce punctatis.

\section{Conurus Steph.}

Steph. Illustr, V. p. 188.

Tachyporus * Er. Col. March. I. p. 390.

Antennae 11-articulatae, filiformes.

Palpi maxillares articulo quarto subulalo.

Ligula biloba, lobis emarginatis.

Elytra pectore longiora.

Abdomen immarginatum.

Tarsi 5-articulati.

Corjus oblongum, antice obtuse rotundatum, postice sensim attenuatum, convexum, alatum. Caput thoraci insertum, deflexun, convexum, ore obtusitusculo, oculis mediocribus rotundatis, parum prominentibus. Labrum perbreve, integrum. Mandibulae breves, trigonae, intus membrana angusta fimbriatae. Maxillae malis membranaceis, apice barbatis. exteriore interiorem vix superante. Palpi maxillares articulo primo minuto, secundo tertioque longitudine subaequalibus, hoc leviter incrassato, quarto parvo subulato. Labium (t. IV. f. 2.) mento transverso, ligula membranea, incisione profundiore biloba, lobis latis, fortiter emarginatis, apice introrsum spinulis nomullis validiorıbus munitis, paraglossis ligulae aequalibus eique omnino connatis, nonnisi ciliarum serie indicatis. Palpi labiales articulo primo crassiusculo, secundo hoc duplo breviore, tertio primo longitudine aequali, tenuiore, acuminato. Antennae filiformes, apicem versus saepius subincrassatae. Thorax convexus, basi elytris arete applicatus, antrorsum magis minusve angustatus, apice truncatus, angulis anterioribus tamen leviter prominentibus, acutiusculis. Elytra pectore paulo longiora, lateribus marginata, angulo apicali exteriore recto. Abdomen immarginatum, apicem versus sensim fortiter attenuatum, vivis sat-elongatum. Mesosternum carinatum. Pedes elongati, coxis posterioribus parallalelopipedis, ad femorum basin 
scutiformi-elevatis, antici femoribus tibiisque muticis, posteriores femoribus apice tibisque totis magis minusve spinulosis, spinis tibiarum terminalibus omnibus subtilibus, tarsis omnibus articulis 4 primis decrescentibus, posterioribus valde elongatis, undique glabris, articulo ultimo leviter elongato.

O b s e r v a t i n e s.

1. Corpus totum pube subtili depressa sericante vestitum, abdomine lateribus et apice magis minusve pilosellum.

2. Genus summa affinitate cum Tach y poro coniunctum, at notis pluribus, praeter habitum peculiarem distinctum videtur. Differt imprimis ligulae laciniis emarginatis, mesosterno carinato, abdomine immarginato, femoribus posterioribus apice spinulosis, tibiis autem minus spinulosis, tarsis subtus hand pubescentibus, articulo quarto non adeo minuto et corpore toto pube sericante obducto.

3. Differentia sexualis fere ut in Tachyporo :

Mas abdominis segmento sexto superiore integro, vel apice subacuminato, inferiore apice exciso, septimo, conspicuo.

F emin a abdominis segmento sexto superiore apice quadrifido, inferiore apice subacuminato, setis rigidis dense ciliato.

4. Victus sub arborum cortice, in truncis putridis et sub foliis deciduis.

* 1. C. littoreus: Fuscus, sericeo-pubescens, antennis basi apiceque, thoracis angulis posterioribus, elytrorum macula basali pedibusque rufotestaceis. - Long. 2 lin.

St aphyl. littoreus Linn. Faun. Suec. n. 852. Syst. Nat. I. II. 685. 18. - Goeze Eint. Beitr. I. 720. 18. - De Vill. Ent. I. 416.18.

Tachyporus littoreus Er, Col. March. 1. 390, 1.

Oxyporus cellaris Fab. Ent. Syst. I. II. 532. 5. Syst. El. II. 605. 5.

Staphyl. cellaris Payk. Faun. Suec. HII. 421. 67.

Tach ypor. cella ris Grav. Micr. 131. 10. Mon. 5. 7. - Latr. Hist. nat. Crust. et Ins. X. 8. 10. - Gyll. Ins. Suec. II. 244. 9. - Suhlb. Ins. Fenn. 1. 292. 9. Zetterst. Ins. Lappon. 55. 8. - Mannerh. Brachelytr. 60. 11. - Boisd. et Lacord. Faun. Ent. Paris. I. 518. 9.

Staph. pubescens Payk. Mon. Carab. App. 138. 53-54.

St aph. tomentos us Rossi Faun. Etr. Mant. 95. 219. (ed. Hellw. 443. 218.)

Oxyporus 2-maculatus Fab. Ent. Syst. I. II. 533. 8. Syst. El. II. 606. 8.

Staph. maculat us Fourc. Ent. Par. I. 169. 20.

le Staph. noir à taches jaunes Geoffr. Hist. Ins. 1. 369. 20.

Habitat in Europa.

Leviter convexus, fuscus, opacus, dense subtiliterque sericeo-pubescens. Antennae capite thoraceque paulo longiores, apicem versus vix incrassatae, articulis 5-10 subobconicis, sensim paulo brevioribus et crassioribus, ultimo ovato, abrupte acuminato, testaceae, medio fuscae. Caput fronte leviter convexa, parce subtilissime punctatum, nigrum, ore flavo-testaceo. Thorax coleopteris perparum latior, latitudine paululum brevior, antrom sum angustatus, apice plus dimidio quam basi angustiore, lateribus praecipue pone medium rotundatis, basi utrinque subsinuatus, angulis posterioribus postice prominulis, acutis, modice convexus, dense subtilissime punctatus, an-. gulis posterioribus macula magna rufo-testacea notatis. Elytra thorace sesqui prope longiora, apice oblique truncata, parum convexa, confertissime subtilissimeque punctata, macula magna statim pone basin, aequali spatio a sutura et a margine exteriore distante, rhomboidea rufo-testacea. Abdo- 
men parcius subtilissime punctulatum, longius pubescens, minus pilosellum, segmentis singulis margine apicali rufescentibus. Mesosternum modice carinatum. Pedes testacei, coxis anterioribus concoloribus, tibiis parce spinulosis, tarsis posticis valde elongatis.

Mas abdominis segmento sexto subtus apice sat fortiter triangulariter exciso, tarsis anticis articulis tribus primis leviter dilatatis.

Femina abdominis segmento sexto inferiore apice medio triangulariter producto, setis rigidis dense ciliato, superiore quadrifido, laciniis intermediis profunde divisis, tarsis anticis simplicibus.

Variat elytrorum macula effusa, discum totum occupante, margine tenui, angulo scutellari latius, apice exteriore late fuscis. Thoracis latera ante maculam testaceam saepe fusco-rufa.

Obs. 1. Oxyporum bimaculatum Fabr. nonnisi secundum eius descriptionem huic speciei allegavi, specimen enim descriptum in collectione citata desideratur.

2. Exemplum nomine Tachypori trinotati a Dahlio missum, in Carinthia lectum, communicavit Do m. S chüppel.

* 2. C. grossus: Fusco-niger, sericeo-pubescens, elytris thorace paulo longioribus, pedibus rubris, antennis longis, articulis duobus primis rubris. - Long. 3 lin.

Habitat in Madagascar, Dom. Goudot.

Reliquis multo maior, sat convexus, fusco-niger, subnitidus, pube fusconigra vestitus. Antennae elongatae, coleopterorum apicem fere attingentes, apicem versus haud incrassatae, articulis a tertio inde omnibus elongatis, ultimo apice sensim acuminato, nigro-fuscae, articulis duobus primis rubris. Palpi rubri. Caput parcius subtiliter punctatum, fronte leviter convexa, nigrum, infra oculos rufo-piceum. Thorax coleopteris paulo latior, latitudine baseos paulo brevior, antrorsum fortiter angustatus, apice basi triplo fere breviore, lateribus aequaliter rotundatus, margine basali recto, angulis posterioribus fortiter prominentibus, subrotundatis, fortiter convexus, sat dense subtiliter punctatus. Elytra thorace paululum longiora, apice oblique truncata, transversim convexa, confertissime subtiliter punctata. Abdomen minus confertim subtiliter punctatum, parcius pubescens, fortiter nigro-pilosellum, summo apice nonnunquam rufescente. Pectus fortiter carinatum. Pedes rubri, coxis anticis concoloribus, femoribus posterioribus apice fortins, tibiis interne parcius breviterque spinulosis, tarsis posticis sat elongatis.

I as abdominis segmento quinto subtus apice leviter emarginato, sexto inferiore profunde inciso, superiore sat acute acuminato, tarsis anticis articulis tribus prinis fortiter dulatatis, antennis longioribus, articulis ultimis magis elongatis.

Femina abdominis segmento sexto inferiore apice rotundato, setis fulvis dense ciliato, superiore quadrifido, laciniis intermediis sat profunde divisis, tarsis anticis articulis tribus primis leviter dilatatis, antennis articulis ultimis minus fortiter elongatis.

Variat corpore subtus toto rufo-brunneo vel castaneo. 
3. C. australis: Niger, fusco-pubescens, antennis basi apiceque testaceis, pedibus rubris, elytris thorace tertia parte longioribus, apice oblique truncalis. - Long. 2 lin.

Habitat in Terra Van-Diemenii, Dom. Schayer.

Habitu omnino C. pubescentis, at paulo maior, praecipue latior, $\mathbf{C}$. littoreo aequalis, hoc autem multo convexior, niger, subnitidus, pube brevi, depressa, fusca, subsericante vestitus. Antennae capitis thoracisque prope longitudine, articulis 3 et 4 elongatis, teretibus, 5 - 10 subobconicis, sensim paulo brevioribus et crassioribus, ultimo ovato, apice acuminato, articulis duobus primis pallide testaceis, tertio testaceo, apice fusco, $5-10$ fuscis, ultimo testaceo. Caput convexiusculum, laevigatum, parcius pubescens, nigrum, nitidum, ore rufo-testaceo. Thorax coleopteris paulo latior, latitudine paulo brevior, antrorsum angustatus, apice duplo quam basi angustior, lateribus rotundatus, margine basali recto, angulis posterioribus leviter retrorsum prominentibus, subrectis, convexus, confertim subtilissime punctatus, margine basali piceo. Elytra thorace tertia parte longiora, apice oblique truncata, convexa, confertissime subtiliter punctata. Abdomen confertim subtiliter punctulatum, segmentis singulis piceo-marginatis, lateribus et apice fortius pilosellum. Mesosternum acute carınatum. Pedes rubri seu ferruginei vel testacei, coxis anticis concoloribus, tarsis posticis sat elongatis.

Mas abdominis segmento sexto inferiore apice triangulariter exciso, superiore apice rotundato, tarsis anticis articulis tribus primis modice dilatatis.

Femina abdominis segmento sexto inferiore apice obtuse acuminato, setis rigıdis ferrngineis dense ciliato, superiore quadrifido, laciniis intermediis ad segmenti medium usque divisis.

Obs. C. pubescenti proximus, differt autem statura paulo robustiore, antennis brevioribus et debilioribus magis fuscis, thoracis angulis posterioribus magis prominentibus, elytris apice oblique truncatis, abdomine fortius pilosello.

* 4. C. pubescens: Fusco-niger, griseo-pubescens, elytris thorace longioribus, antennis pedibusque rufo-testaceis. - Long. 2 lin.

Tachyporus pubescens Grav. Micr. 130. 9. Mon. 5. 8. - Latr. Hist. nat. Crust. et Ins. X. 8. 9. - Gyll. Ins. Suec. II. 243. 8. - Sahlb. Ins. Fenn. I. 292. 8. - Mannerh. Brachelytr. 60. 10. - Botsd. et Lacord. Faun. Ent. Paris. I. 518. 10. - Er. Col. March. I. 390. 2.

Staph. pubescens var. $\beta$ Payk. Mon Carab. App. 138. $53-54$.

Staph. cellaris var. $\beta$ Payk. Faun. Suec. III. 421. 67.

Staph. tomentosus var. $\beta$ Rossi Faun. Ltr. Mant. 97. 218. (Ed. Hellw. I. 443. 218.)

Var. a: Fuscus, elytris brunneis.

Tach yporus sericeus Boisd. et Lacord. Faun. Ent. Paris. I. 519. 11.

Var. b: Totus pallide testaceus, immaturus.

Oxурогиs testaceus Fab. Ent. Syst. I. II. 535. 18. Syst. El. II. 607. 18. Panz. Ent. Germ. 361. 14.

Habitat in Europae silvis, in truncis putridis. In China meridionali etiam lectus a Prof. Meyen.

Pube brevi depressa griseo-sericea dense vestitus. Antennae capitis 
thoracisque longitudine, apicem versus sensim subincrassatae, articulis $\mathbf{3}-\mathbf{5}$ elongatis, teretibus, 6-10 subobconicis, sensim paulo crassioribus breviori busque, ultimo apice abrupte acuminato, testaceae, medio fuscae. Os cum palpıs testaceum. Caput modice convexum, laevigatum, parcius subtiliter pubescens, nigrum, nitidum. Thorax coleopteris latior, latitudine parum brevior, antrorsum fortiter angustatus, apice duplo prope angustior quam basi, lateribus aequaliter rotundatus, basi utrinque subsinuatus, angulis posterioribus postice vix prominulis, subrectis, fortiter convexus, omnium subtilissime confertim punctatus, piceo-niger, pube derasa nitidus, margine sumımo basali rufescente. Elytra thorace tertia fere parte longiora, convexa, confertissime subtiliter punctata, apice truncata. Abdomen fuscum, apice pilosello segmentorumque singulorum margine apicali late castaneis. Pectus nigrum, nitidum, mesosterno acute carinato. Pedes testacei, coxis anticis concoloribus, posteriores femoribus apice tibïsque parce spinulosis, tarsis posticis sat elongatis.

Mas abdominis segmento quinto subtus apice leviter emarginato, sexto inferiore leviter triangulariter exciso, superiore apice rotundato, tarsis anticis articulis tribus primis modice dilatatis, antennis paulo longioribus.

Femina abdominis segmento sexto inferiore apice leviter triangulariter producto, setis rigıdis ferrugineis dense ciliato, superiore quadrifido, lacinis intermedis ad medium segmenti usque divisis, tarsis anticis articulis tribus primis leviter dilatatis.

Variat colore corporis aut nigro, elytris aut concoloribus aut castaneis, aut fusco, elytris dilutius rufo-brunneis, aut toto ferrugineo, aut minus maturus testaceo.

Obs. Specimina nigra elytris concoloribus nomine Tachypori alpestris ex alpibus Carinthiae, et T. tristis e Styria, specimen immaturum, corpore testaceo nomine T. rufescentis ex Austria a Dahlio sibi missa, dedit Dom. Sch üppel. Oxy porus testaceus Fab. secundum ipsum specimen ab auctore descriptum hoc loco allegatus.

* 5. C. crassus: Fusco-niger, tenuiter griseo-pubescens, antennis testaceis, thoracis margine, elytrorum basi, ano pedibusque rufescentibus, elytris thorace parum longioribus. - Long. $2 \frac{1}{2}$ lin.

Tachyporus crassus Grav. Micr. 190. 1. Mon. 6. 9.

Habitat in America septentrionali.

Praecedente triplo maior, multo latior, fortiter convexus, fusco-niger, nitidus. Antennae capitis thoracisque prope longitudine, apicem versus parum incrassatae, testaceae, articulis 3 et $\downarrow$ elongatis, teretibus, $5-10$ subobconicis, sensim paulo brevioribus et crassioribus, basi fuscescentibus, ultimo oblongo-ovato, toto flavo. Caput parum convexum, omnium subtilissime punctatum, parcius pubescens, nigrum, ore cum palpis rufo-testaceo. Thorax coleopterorum basi parum latior, latitudine paulo brevior, antrorsum angustatus, apice plus duplo quam basi angustior, lateribus fortius aequaliter rotundatis, basi utrinque subsinuatus, angulis posterioribus retrorsum parum prominulis, rotundatis, valde convexus, omnium subtilissime punctulatus, pube depressa griseo-fusca tenuter vestitus, margine laterali basalıque sanguineo. Elytra thorace paululum longiora, apice oblique truncata, 
convexa, confertim minus subtiliter punctata, nigro-fusca, tenuiter pubescentia, margine basalı sanguineo, densius pubescente. Abdomen breviusculum, subtilissime punctulatum, pube depressa griseo-fulva sericante densius vestitım, lateribus et apice fortins pilosellum, segmentorum singulorum margine apicali rufo-piceo, ano rufo-testaceo. Mesosternum fortiter carinatum. Pedes rufo-testacei, coxis anticis concoloribus, postici femoribus apice fortiter, tibiis interne parce breviterque spinulosıs, tarsis posticis modice elongatis.

Mas mihi invisus.

Femina abdomims segmento sexto inferiore apice acuminato, setis rigidis fulvis dense ciliato, superiore quadrifido, laciniis intermediis ultra segmenti medium divisis, tarsis anticıs articulis tribus primis leviter dilatatis.

\section{C. tumidus: Fuscus, griseo-pubescens, thoracis margine summo ely- trorumque basi rufescentibus, pedibus rufo-testaceis, antennis nigris, articulis 1 primis ultimoque testaceis. - Long. 2 lin.}

Habitat prope Puerto Cabello Columbiae, Dom. Moritz.

Statura omnino praecedentis, at paulo minor, T. littoreo paulo latior et multo convexior, fuscus, nitidus, subtiliter punctulatus, pube minus subtili depressa fulvo-grisea densius vestitus. Antennae capitis thoracisque prope longitudine, apicem versus sensim leviter incrassatae, articulis 4 primis testaceis, tertio quartoque elongatıs, teretıbus, $5-10$ obconicis, sensim paulo brevioribus et crassioribus, nigris, ultimo ovato, apice acuminato, flavo, basi fuscescente. Palpı dilute testacei. Caput leviter convexum, parce subtilissime punctulatum, ore et subtus totum rufo-testaceum. Thorax coleopteris paulo latior, antrorsum angustatus, apice quam basi plus duplo angustior, latitudine baseos paulo brevior, lateribus aequaliter rotundatus, basi truncatus, angulis posterioribus retrorsum haud prominulis, obtusis, subrotundatis, fortiter convexus, parce subtilissime punctatus, margine laterali et basali rufescente. Elytra thorace paulo longiora, convexa, apice vix oblique truncata, parcius subtilissıme punctata, tascia basali, parum distincta, externe abbreviata rufescente. Abdomen crebrius subtiliter punctatum, densius pubescens, segmentis singulis piceo-marginatis, apice testaceum et pilosellum. Mesosternum subtiliter at sat acute carinatum. Pedes rufo-testacei, posteriores femoribus apice tibiisque fortius spinulosis, tarsis posticis fortiter elongatis.

Mas abdominis segmento sexto inferiore apice fortiter triangulariter exciso, tarsis anticis articuiis tribus primis valde dilatatis.

F e min a latet.

* 7. C. bipustulatus: Niger, subtiliter griseo-pubescens, antennis basi upiceque pedibusque testaceis, elytris thorace paulo longioribus, macula basali rhombea rufa. - Long. 2 lin.

Ta chyporus bipustulatus Grav. Micr. 132. 11. - Latr. Hist. nat. Crust. et Ins. X. 9. 11. - Gyll. Ins. Suec. 11. 245. 10.

Tachyporus bimaculatus Grav. Mon. 5. 6.

Habitat in Hungaria, Dahl, in Styria et in Suecia, Dom. Schïppel.

Statura omnino C. pubescentis, at paulo maior, convexus, niger, ni- 
tidulus, pube depressa subtili fulvescenti-grisea tenuiter vestitus. Antennae capite thoraceque parum breviores, apicem versus leviter sensim incrassatae, testaceae, articulis 3 et 4 elongatis, teretibus, 5-10 subobconicis, sensim paulo brevioribus et crassioribus, fuscis, ultimo oblongo-ovato, flavo. Caput modice convexum, parce omnium subtilissime punctatum, ore rufotestaceo. Thorax coleopteris paulo latior, antrorsum angustatus, apice duplo quam basi angustior, latitudine baseos paulo brevior, lateribus sat rotundatus, margine basali medio late recto, angulis posterioribus retrorsum modice prominulis, subrectis, convexus, minus confertim subtilissime punctatus. Elytra thorace paulo longiora, apice parum oblique truncata, convexa, confertim subtiliter punctata, macula rhombea subtransversa testaceo-rufa ad basin, basin ipsam haud attingente, a margine exteriore paulo magis quam a sutura remota, sat distincta et terminata. Abdomen sat dense subtiliter punctatum, segmentis ultimis rufo-marginatis, apice pilosellum. Mesosternum subtiliter carinatum. Pedes ruf, tibiis intermediis parce, posticis vix spinulosis, tarsis posticis tibia parum longioribus.

Mas abdominis segmento sexto inferiore apice fortiter triangulariter exciso, superiore apice rotundato, tarsis anticis articulis tribus primis modice dilatatis.

Femina abdominis segmento sexto inferiore apice rotundato, setis rigidis fulvis dense ciliato, superiore quadrifido, laciniis intermediis profunde divisis, tarsis anticis articulis tribus primis leviter dilatatis.

Obs. Nomine Tachypori interrupti a Dahlio et Zieglero missus.

* 8. C. binotatus: Fuscus, fulvescenti-pubescens, antennis pedibusque rufo-testaceis, elytris thorace sesqui longioribus, macula magna basali rufa. - Long. $1 \frac{2}{3}$ lin.

Tachyporus binotat us Grav. Micr. 132. 12. Mon. 5. 5. - Latr. Hist. nat. Crust. ot Ins. X. 9. 12. - Er. Col. March. I. 391. 3.

\section{Habitat in Germania.}

C. pubescente paulo minor, fuscus, nitidulus, pube subtiliore depressa fulvescente vestitus. Antennae capite thoraceque paulo breviores, apicem versus leviter incrassatae, articulis 5-10 sensim paulo brevioribus et crassioribus, obconicis, ultimo ovato, apice abrupte acuminato, pilosellae, rufotestaceae, articulo ultimo flavo. Caput leviter convexum, parce subtilissime punctatum, nigrum, nitidum, ore testaceo. Thorax coleopteris parum latior, antrorsum angustatus, apıce vix duplo quam basi angustior, latitudine baseos dimidio prope brevior, lateribus sat rotundatus, basi utrinque subsinuatus, angulis posterioribus retrorsum sat prominulis, rotundatis, modice convexus, densius subtiliter punctatus, margine basali rufescente. Elytra thorace sesqui longiora, apice truncata, leviter convexa, confertim subtiliter punctata, macula magna rotundata rufo-testacea, a basi ad elytri medium usque descendente, margini exteriori et suturae aequaliter approximata, minus distincte terminata, margine apicali summo rufescente. Abdomen densius subtiliter punctatum, segmentis singulis margine rufis, apice testaceum et parcius pilosellum. Mesosternum subtiliter carinatum. Pedes rufo-testacei, tibiis intermediis longius, posticis vix spinulosis, tarsis posticis tibia paulo longioribus. 
Mas abdominis segmento sexto inferiore apice sat fortiter triangulariter exciso, superiore apice obtuse acuminato, tarsis anticis articulis tribut; primis leviter dilatatis.

Femina abdominis segmento sexto inferiore apice rotundato, pilis brevissimis tenuiter ciliato, superiore quadrifido, laciniis intermediis sat profunde divisis, tarsis anticis levissime dilatatis.

* 9. C. basalis: Fuscus, nilidus, griseo-pubescens, elylris macula basuli transversali summoque margine-apicali rufescentibus, antennis elongatis pedibusque testaceis. - Long. $1 \frac{1}{2}$ lin.

Habitat in Carolına meridionali, Dom. Zimmermann.

C. binotato paulo minor, convexus, fuscus, subnitidus, pube depressa fulvescenti-grisea sericante densius vestitus. Antemnae sat elongatae, graciles, apice leviter incrassatae, articulis $3-5$ elongatis, teretibus, $6-10$ elongato-obconicis, sensin paulo crassioribus at vix brevioribus, ultimo oblongo-ovato, apice abrupte acuminato, obscure testaceae, basi flavescentes, articulo ultimo dilute flavo. Caput convexum, vix punctulatum, nigrum, nitidum, ore late testaceo. Thorax coleopteris latior, antrorsum angustatus, apice duplo fere quam basi angustior, latitudine baseos paulo brevior, lateribus aequaliter rotundatus, margine basali medio late recto, angulis posterioribus modice retrorsum prominentibus, acutiusculis, fortiter convexus, confertissime subtiliter princtatus, nigro-fuscus, margine basali et apicali rufescente. Elytra thorace longiora, apice truncata, convexa, confertissime subtiliter punctata, fusca, macula magna in ipsa basi, a margine exteriore magis quam a sutura distante, rufa, margine summo apicali rufescente. Abdomen subtilissime punctulatum, segmentis singulis apice piceis, posterioribus subtestaceis, densius pubescens, lateribus et apice fortiter nigro-pilosum. Mesosternum acute carinatum. Pedes testacei, coxis anticis concoloribus, femoribus posteriorbus apice parce, tibiis vix spinulosis, tarsis posticis sat elongatis, anticis articulis tribus primis in utroque sexu leviter dilatatis.

Mas abdominis segmento sexto inferiore apice triangulariter exciso, antemis capite thoraceque longioribus.

Femina abdominis segmento sexto superiore quadrifido, laciniis intermediis profunde divisis.

V ariat corpore dilutiore, fusco-rufescente.

10. C. interruplus: Fuscus, griseo-pubescens, coleopteris fascia basali, medio interrupta pedibusque rufis, antennis teslaceis, medio fuscis. Long. $1 \frac{1}{2}$ lin.

Hacitat in valle Araguensi Columbiae, Dom. Moritz.

Praecedenti affinis, at paulo angustior, convexus, fuscus, nitidulus, subtiliter punctulatus, pube depressa griseo-fulvescente subsericante tenuiter vestıtus. Antennae capitis thoracisque longitudine, apice sensim incrassatae, articulis 4 primis testaceis, tertio quartoque teretibus, modice elongatis, 5 - 10 subobconicis, sensim crassioribus at vix brevioribus, ultimo crassiusculo, ovato, apice acuminato, 5-9 fuscis, ultimis duobus laete testaceoflavis. Caput modice convexum, vix punctulatum, ore cum palpis testaceo. 
Thorax coleopteris parum latior, antrorsum modice angustatus, apice dimidio fere quam basi angustior, latitudine baseos parum brevior, lateribus leviter rotundatus, basi truncatus, utrinque subsinuatus, angulis posterioribus retrorsum vix prominulis, rectis, valde convexus, parcius omnium subtilissime punctulatus, margine basali et laterali obsolete rufescentibus. Elytra thorace parum longiora, apice oblique truncata, leviter convexa, densius subtiliter punctata, fascia basali ad suturam abbreviata rufo-testacea, margine summo apicali rufescente. Abdomen subtilissime punctulatum, apice testaceum, densius pubescens, lateribus et apice fortiter nigro-pilosum. Me. sosternum leviter carinatum. Pedes testacel, coxis anticis concoloribus, posteriores femoribus apice tibiisque parce spinulosis, tarsis posticis modice elongatis.

Mas segmento abdominis sexto inferiore apice leviter triangulariter exciso, tarsis anticis articulis tribus primis fortius dilatatis.

Femin a latet.

Obs. Affinis praecedenti, statura autem paulo angustiore, antennis articulis 5 - 9 distincte fuscis, coleopterorum fascia ad marginem exteriorem continuata etc. satis distinctus.

* 11. C. cinctulus: Niger, subnitidus, tenuiter pubescens, antennis basi apiceque pedibusque teslaceis, coleopteris fascia basali integra rufa, sulura abdomineque densius pubescentibus. - Long. $1 \frac{1}{2}$ lin.

Habitat in Carolina meridionali, Dom. Zimmermann.

Statura et summa affinitas C. basalis. Antennae capitis thoracisque longitudine, apicem versus sensim leviter incrassatae, articulis $\mathbf{2}-\mathbf{4}$ subelongatis, teretibus, $5-10$ subobconicis, sensim paulo brevioribus et crassioribus, penultimis transversis, ultimo breviter ovato, apice subacuminato, artıculis tribus primis flavis, sequentibus fuscis, ultimo testaceo. Caput modice convexum, parce subtiliter punctulatum, parce griseo-pubescens, nigrum, nitidum, ore testaceo. Thorax coleopteris paulo latior, antrorsum leviter angustatus, apice dimidio fere quam basi angustior, latitudine baseos distincte brevior, laterıbus rotundatus, margine basali medio late recto, angulis posterioribus retrorsum leviter prominentibus, acutıusculis, fortiter convexus, dense subtiliter punctatus, fusco-niger, subnitidus, margine basali et laterali tenui rufescente, pube depressa flavescenti-grisea tenuiter vestitus. Scutellum fuscum. Elytra thorace paulo longiora, apice oblique truncata, leviter convexa, confertissime subtiliter punctata, nigro-fusca, subnitida, fascia integra in ipsa basi rufa, tenuiter fusco-pubescentia, fascia basali et sutura pube densa depressa griseo-fulvescente sericante obductis. Abdomen confertissime subtiliter punctatum, nigrum, segmentis singulis margine apicali piceo, quinto testaceo, pube depressa griseo-fulvescente dense vestitum, apice nigro-pilosellum. Pectus nigrum. Pedes rufo-testacei, coxis anticis concoloribus, posteriores femoribus apice tibiisque parcius spinulosis, tarsis posticis minus elongatis, tibiae longitudine aequalibus.

Mas abdominis segmento sexto inferiore apice triangulariter exciso, tarsis anticis articulis tribus primis leviter dilatatis.

F' euina latet. 
Obs. Differt a praecedentibus coleopterorum fascia integra, antennarum colore, abdomine lateribus haud piloso etc.

* 12. C. varius: Niger, sericeo-pubescens, thorace pedibusque testaceis, elytris nigro testaceoque variegalis. - Long. $1 \frac{1}{5}$ lin.

Habitat prope Caracas Columbiae, Dom. Moritz.

C. fusculo paulo angustior, totus pube minus subtıli, depressa, griseofulvescente minus dense vestitus. Antennae capite thoraceque parum breviores, apicem versus leviter incrassatae, articulis $2-4$ elongatis, subteretibus, 5 - 10 brevioribus, subobconicis, sensim paulo crassioribus, rultmo maiusculo, subovato, apice acuminato, rufo-testaceae, basi flavescentes. Caput parum convexum, vix punctulatum, nigro-piceum, nitidum, ore testaceo. Thorax basi coleopteris paulo latior, antrorsum angustatus, apice quam basi duplo angustior, latitudine baseos distincte brevior, lateribus parum rotundatus, basi utrinque subsinuatus, angulis posterioribus retrorsum haud prominulis, obtusiusculis, modice convexus, parce subtilissime punctulatus, testaceus, nitidus. Scutellum nigrum. Elytra thorace tertia parte longiora, apice truncata, convexa, subtiliter sat crebre punctata, nigra, maculis oblongis confluentibus testaceis variegata. Abdomen piceum, lateribus et apice fortiter nigro-pilosum. Pectus nigrum. Pedes testacei.

Mas latet.

F emina abdominis segmento sexto inferiore apice leviter producto, setis rigidis densius ciliato, superiore apice quadrifido, tarsis anticis leviter dilatatis.

13. C. venustulus: Tenuiter pubescens, piceus, capite, thorace pectoreque rufis, elylris nigris, his macula magna basali pedibusque flavis. long. $1 \frac{1}{4}$ lin.

Habitat prope Puerlo Cabello Columbiae, Dom. Moritz.

Statura omnino C. fusculi. Corpus totum pube depressa fulvescentigrisea parce vestıtum. Antennae capite thoraceque paulo breviores, apicem versus sensim leviter incrassatae, articulis $2-4$ elongatis, teretibus, $5-10$ sensim paulo brevioribus et crassioribus, $5-7$ subobconicis, $8-10$ transversis, ultimo breviter ovato, apice obtuse acuminato, testaceae, articulis $7-10$ fuscis. Palpi testacei. Caput parum convexum, parce disperse subtiliter punctatum, nitidum, testaceo-rufum. Thorax coleopteris perparum latior, antrorsum angustatus, apice dimidio fere quam basi angustior, Jatitudine baseos parum brevior, lateribus leviter rotundatus, basi truncatus, angulis posterioribus retrorsum paululum prominulis, acutiusculis, morlice convexus, parcius subtiliter punctatus, testaceo-rufus, nitidus. Scutellum testaceum. Elytra thorace longiora, apice vix oblique truncata, modice convexa, dense minus subtiliter punctata, nigerrima, nitida, macula magna densius pubescente in ipsa basi flavo-testacea. Abdomen piceum, densius pubescens, lateribus et apice fortiter nigro-pilosum. Pecus rufum. Pedes flavo-testacei, coxis anticis concoloribus, postici femoribus apice tibisque parce longius spinulosis, tarsis posticis satis elongatis.

Mas latet. 
F e min a abdominis segmento sexto inferiore apice producto et setis rigidıs parcioribus ciliato, superiore quadrifido, laciniis intermediis profunde divisis, tarsis anticis articulis tribus primis parum dilatatis.

* 14. C. obsoletus: Fuscus, flavesceuti-pubescens, thorace elytrisque rujo. teslaceis, his thorace sesqui longioribus, antennarum basi pedilusgue testaceis. - Long. $1 \frac{1}{4}$ lin.

Habitat prope Caracas Columbiae, Dom. Moritz.

Statura omnino T. fusculi. Corpus totum pube tenui depressa griscoflavescente subsericante minus dense vestitum. Antennae capite thoraceque paulo breviores, apicem versus vix incrassatae, articulis $2-4$ morlice elongatis, teretibus, $\mathbf{5}-\mathbf{1 0}$ brevioribus, subobconcis, sensim paulo brevioribus at vix crassioribus, ultimo praecedentibus ambobus paulo longiore, apice acuminato, fuscae, articulis 5 primis pallide testaceis. Palpi flavi. Caput parum convexum, laeve, testaceo-rufum vel rufo brunneum, nitidum, ore rufescente. Thorax basi coleopterorum laticudine, antrorsum angustatus, apice duplo prope quam basi angustior, latitudine baseos brevior, lateribus parum rotundatus, apice truncatus, angulis posterioribus retrorsum haud prominulis, subrectis, modice transversim convexus, vix punctulatus, rufotestaceus, nitidus. Scutellum fuscum. Flytra thorace sesqui longiora, leviter convexa, subtilissime punctulata, rufo-testacea, lateribus medio infuscatis. Abdomen fuscum, lateribus et apice fortiter nigro-pilosum. Pectus fuscum. Pedes flavo-testacei, postici fumoribus apice et tibiis parce spinulosis, tarsis posticis sat elongatis.

Sexus differentia in specime descripto haud perspicua.

* 15. C. fumatus: Fuscus, nitidus, fulvescenli-pubescens, antennarum basi pedibusque lestuceis, thorace limbo rufescente, angulis posterioribus haud prominulis, rotundatis, elytris thorace longioribus. - Long. $1 \frac{1}{2}$ lin.

Habitat in Terra Van-Diemenii, Dom. Schayer.

Statura intermedius quasi inter C. pubescentem et fusculum, utrique affinis, ab utroque autem pube minus subtili et thoracis angulis posterioribus haud prominulis rotundatis satis distinctus. Nigro-fuscus, nitidus, pube depressa minus subtili fulvescente sericante leviter vestitus. Antennae lon giores, articulis 4-10 subobconicis, sensim paulo brevioribus at vix crassioribus, fuscae, articulis 1 primis testaceis; (ultimus specimini unico deest). Caput fortiter convexum, laevissimum, ore testaceo. Thorax colcopteris vix latior, antrorsum sat angustatus, apice duplo quam basi angustior, latitudine baseos dimidio brevior, lateribus fortiter rotundatus; basi trincatus, utrinque subsinuatus, angulis posteriorihus retrorsum haud prominulis, $10-$ tundatis, modice transversim convexus, parce subtiliter punciatus, limbo ommi piceo-rufo, disco indeterminate fusco-picco. Elytra thorace tertia parte longiora, apice oblique truncata, leviter convexa, densius subtiliter punctata, fusca, margine summo apicali rufescente. Abdomen parce subtiliterque punctatum, parcus pubescens, lateribus et apice longius nigro-pilosum, apice et segmentorum singulorum margine posteriore rufo-piceo. Mesosternum subtiliter carinatım. Pedes rufo-testacei, tibiis posterioribus vix spinulosis, tarsis posticis minus elongatio, tibia haud longioribus. 
Mas abdominis segmento sexto inferiore apice sat fortter triangulariter exciso, superiore apice rotundato, tarsis anticis articulis tribus primis leviter dilatatis.

* 16. C. fusculus: Fusco-niger, griseo-pubescens, antennis basi testaceis, apice flavis, pedibus rufis, elytris thorace longioribus. - Long. $1 \frac{1}{4}$ lin.

Tachyporus fusculus Er. Col March. 1. 591. 4.

T'achy porus pedicularius Buisd. et Lacord. Faun. Ent.Paris. I. 519. 12.

Habitat in Germania.

Habitus et summa similitudo C. pubescentis, at triplo minor, convexus, fusco-niger, pube subtili depressa grisea sericante vestitus. Antennae capitis thoracisque fere longitudine, articulis 3 et 4 elongatis, teretibus, 5-10 subobconicis, sensim brevioribus et paulo erassioribus, primis eorum sat elongatis, ultimo praecedente parum maiore, fuscae, articulis tribus primis testaceis, ulimis duobus flavis. Caput leviter convexum, laevigatum, nigrum, nitidum, ore testaceo. Thorax coleopteris paulo latior, antrorsum angustatus, apice duplo quam basi angustior, latitudine baseos paulo brevior, lateribus modice rotundatus, basi utrinque subsinuatus, angulis posterioribus retrorsum paululum prominulis, acutis, convexus, confertim subtilissime punctatus, margine basali summo rufescente. Elytra thorace paululum longiora, apice truncata, leviter convexa, confertissine subtiliter punctata, margine apicali rufescente. Abdomen confertim subtiliter punctatum, segmentis singulis margine postico rufescente, apice pilosellım. Mesosternum acute carinatum. Pedes rufo-ferruginei, coxis anticis concoloribus, tibiis interınediis parce, posticis vix spinulosis, tarsis posticis modice elongatis, tibia parum longioribus.

Mas abdominis segmento sexto inferiore apice sat fortiter triangulariter exciso, superiore subacuminato, tarsis anticis articulis tribus primis modice dilatatis.

Femina abdominis segmento sexto inferiore apice rotundato, setis rigidis fulvis dense ciliato, superiore apice quadrifido, laciniis intermediis brevi spatio divisis, tarsis anticis articulis tribus primis leviter dilatatis.

Variat minus maturus corpore ferrugineo vel rufo-testaceo.

Obs. C. pediculario similis, statura autem sesqui maiore, antennis medio fuscis, thoracis angulis posterioribus acutis et elytris longioribus facile distinguendus.

* 17. C. lividus: Rufo-testaceus, fulvescenti-pubescens, pectore piceo, elytris thorace paulo longioribus. - Long. 1 lin.

Ilabitat Lutetiae, Dom. Dr. Aubé, in Sardinia, Dom. Prof. Gené.

Statura et summa affinitas C. pedicularii, rufo-testacens, pube depressa minus subtili fulvescente densius vestıtus. Antennae longiores, apice sensim subincrassatae, articulis teretıbus, penultimis tribus quatuorve subobconicis, ultimo praccedente sesqui maiore, apice abrupte acuminato, flavo-testaceae. Caput leviter convexum, laevissimum. Thorax coleopteris paululum latior, antrorsum angustatus, tertia parte quam basi angustior, latitudine baseos paulo brevior, lateribus rotundatus, margine basali medio recto, angulis posterioribus leviter retrorsum prominentibus, acutiusculis, convexus, omnium subtilissime punctatus. Elytra thorace paulo longiora, apice oblique truncata, 
convexa, confertim subtilins punctata. Abdomen subtilissime punctatum, segments duobus prinis summa basi nigricantibus, apice nigro-pilosellum. Pectus piceum. Mesosternum acute carinatum. Pedes testacei, tibis posterioribus haud spinulosis, tarsis posticis tibia paulo brevioribus.

$\mathrm{M}$ as abdominis segmento sexto inferiore apice fortiter triangulariter exciso, superiore apice obtuse rotundato, tarsis anticis leviter dilatatis, antennis capite thoraceque longịoribus.

Femina abdominis segmento sexto inferiore apice leviter triangulariter producto et dense fulvo-ciliato, superiore apice quadrifido, tarsis anti. cis simplicibus, antennis capitis thoracisque longitudine.

Obs. A C. pediculario differt antennis elytrisque longioribus, thoracis angulis posterioribus acutioribus et mesosterni carina fortiore, acuta etc., a C. fusculo statura minore elytris brevioribus, ab utraque pube minus subtili. Ceterum speciminibus eorum immaturis similis, at color testaceus huic speciei normalis.

*18. C. pedicularius: Nigro-piceus, nitidus, subtiliter griseo-pubescens, antennis pedibusque testaceis, elytris thorace subbrevioribus. — Long. 1 lin.

Tachyporus pedicularius Grav. Micr. 133. 14. Mon. 4. 2. - Latr. Hist. nat. Crust. et Ins. X. 10. 14. - Gyll. Ins. Suec. II. 216. 11. - Sahlb. Ins. Fenn. I. 293. 11. - Mannerh. Brachelytr. 60. 13. - Runde Brachel. Hal. 25. 7. - Er. Col. March. I. 392. 5.

Var.: Totus testaceus, immaturus.

Tachypor. truncatellus Grav. Mon. 5. 3.

Habitat in Europa.

Minutus, convexus, nigro-piceus, nitidulus, pube subtili depressa grisea sericante densius vestitus. Antennae capitis thoracisque prope longitudine, apicem versus subincrassatae, articulis $5 \mathbf{- 1 0}$ sensim paulo brevioribus et rrassioribus, subobconicis, ultimo praecedente sesqu maiore, apice abrupte acuminato, totae testaceae. Caput convexum, laeve, nigrum, ore testaceo. Thorax coleopteris latior, antrorsum angustatus, apice duplo fere quam basi angustior, lateribus sat rotundatus, margine basali medio recto, angulis posterioribus retrorsum fortiter prominulis, rotundatis, valde convexus, densius omnium subtilissime punctatıs, margine basali summo rufescente. Elytra thoracis longitudine vel paulo breviora, apice oblique truncata, convexa, confertim subtiliter punctata, margine apicali rufescente. Abdomen dense subtilissime punctulatum, segmentis singulis margine postico rufescente, apice parcius nigro-pilosum. Mesosternum leviter carinatum. Pedes rufo-testacei, tibiis posterioribus muticis, tarsis posticis tibia paulo brevioribus.

Mas abdominis segmento sexto inferiore apice fortter triangulariter exciso, superiore apice obtuse rotundato.

Femina abdominis segmento sexto mferiore apice leviter triangulariter producto et subtilius fulvo-ciliato, superiore apice quadrifido, tarsis anticis haud dilatatis.

Variat minus maturus corpore ferrugineo vel testaceo.

* 19. C. bipunctatus: Niger, nilidus, tenuiler sericeo-pubescens, elytrorum marula basali arcuala pedibusque rubris, antennis testaceis, medio fuscis. - Long. 1 lin. 
Tachyporus bipunctatus Grav. Micr. 133. 13. Mon. 5. 4. - Latr. Hist. nat. C'rust. et Ins. X. 9. 13. - Gyll. Ins. Suec. III. 702. $10-11$. - Sahlb. Ins. Fenn. I. 293. 10. - Mannerh. Brachelytr. 60. 12. - Er. Col. March. I. 392. 6.

Habitat in Germania, sub cortıce Salicis.

C. pediculario statura et magnitudine aequalis, niger, nitidus, pube subdepressa grisea tenuiter vestitus. Antemnae capite thoraceque breviores, apicem versus sensim leviterque mcrassatae, articulis 3 et, 4 leviter elongatis, subobconicis, $\mathbf{5}-\mathbf{1 0}$ transversis, sensim paulo crassioribus, ultimo praccedente paulo longiore, apice subacuminato, testaceae, medio fuscae. Caput parce subtiliter punctatum, nigrum, nitidum, ore testaceo. Thorax coleopteris paulo latior, antrorsum angustatus, apice duplo fere quam basi angustior, latitudine baseos paulo brevior, lateribus rotundatus, basi utrinque subsinuatus, angulis posterioribus retrorsum sat prominulis, rotundatis, convexus, parce subtilissime punctatus. Elytra thorace sesqui fere longiora, apice oblique truncata, convexa, densius subtiliusque punctata, margine laterali setoso, macula magna testaceo-rufa, ante basin transversali, dein secundum suturam elongata, ideoque arcuatim ab humero ad angulum suturalem apicalem pertingente. Abdomen parce subtilissime punctatum, segmentis singulis margine postico rufo-piceo, apice rufum, dorso parce, lateribus et apice crebre nigro-pilosum. Mesosternum subtiliter carinatum. Pedes rufi, tarsis testaceis, tibiis posterioribus vix spinulosis, tarsis posticis tibia haud Jongioribus.

Mas abdominis segmento sexto inferiore apice triangulariter exciso, superiore apice obtuso, tarsis antıcis leviter dilatatis.

Femina abdominis segmento sexto inferiore apıce rotundato ciliatoque, superiore quadrifido, laciniis intermediis profundius divisis, tarsis anticis vix dilatatis.

Variat elytrorum macula obliqua basali et litura longitudinali subsuturali disiunctis.

\section{Tachyporus Grav.}

\section{Tachyporus $^{* *}$ Er. Col. March. I. p. 392.}

Antennae 11-articulatae, filiformes.

Palpi maxillares articulo quarto subulato.

Ligula biloba, lobis rotundatis.

Elytra pectore longiora.

Abdomen marginatum.

Tarsi 5-arliculati.

Corpus oblongum, antice obtusiusculum, postice sensim attenuatum, convexum, alatum. Caput thoraci insertum, fronte convexiuscula, antice angustata, oculis medıcribus, rotundatis, convexis. Labrum transversum, integrum. Mandibulae breves, trigonae, intus membrana angusta interne ciliata finbriatae. Maxillae (t. III. f. 3. b.) malis corneis, apice barbatis, exteriore interiorem parum superante, hac interne membranea. Palpi maxillares articulo primo minuto, secundo tertioque modice elongatis, longituduè subacqualibus, hoc incrassato, quarto parvo, subulato. Labium (t. IV. f. 3. a.) mento transverso, ligula lata, membranea, biloha, lobis integris, rotundatis, divergentibus, paraglossis ligulae connatis, nomnisi ciliarum serie cognoscen- 
dis. Palpi labiales articulis duobus primis crassiusculis, subaequalibus, tertio hand breviore at tenuiore, acuminato. Antennae filicormes, apicem versus plerumque subincrassatae. Thorax amplus, transversim convexus, transversus, basi coleopteris arcte applicatus, antrorsum angustatus, apice truncatus, licet angulis anterioribus sat promentibus, acutis. Scutellum triangulare. F! vetra pectore longiora, tenuiter marginata, angulo apicali exteriore truncato. Abdomen distincte marginatum, apicem versus sensim at sat fortiter angustatum, vivis modice elongatum. Mesosternum simplex. Pedes modice elongati, coxis postıeis parallelopipedis, ad femorum basin scutiformielevatis, femoribus omnibus laevibus, tibiis anticis muticis, posterioribus sat fortiter spinulosis, tarsis pasterioribus elongatis, omnibus articulis 3 primis decrescentibus, subtus pubescentibus, quarto minimo, quinto leviter elongato.

O b s e r v a t i o n e s.

1. Caput et thorax laevissima, glaberrima, elytra subtiliter punctata, iam glabra, iam tenuiter pubescentia, margine laterali pilosello. Abdomen saepius subtilissime pubescens, lateribus et apice pilosellum.

2. Mas abdominis segmento sexto superiore integro, inferiore apice exciso, septimo conspicuo.

F e m in a abdominis segmento sexto superiore apice quadrifido, laciniis aequalibus, acutis, inferiore integro, apice pilis rigidis dense ciliato.

3. Victus in quisquiliis, sub foliis deciduis, musco etc.

* 1. T. obtusus: Testaceo-rufus, nitidus, pectore, elytrorum basi abdominisque apice nigris. - Long. $1 \frac{2}{3}$ lin.

Mannerh. Brachelytr. 59. 6. - Er. Col. March. I. 392. 7.

Staph. obtusus Linn. Syst. Nat. I. II. 684. 9. - Fab. Syst. Ent. 266. 10. Spec.

Ins. I. 336. 11. Mant. Ins. I. 221. 17. - Schrank Enum. Ins. Aust. 237. 451. -

Goeze Ent. Beitr. I. 718. 9. - De Vill. Ent. I. 414.9. - Rossi Faun. Etr. I. 251. 621. (Ed. Hellw, 311. 621.) - Marsh. Ent. Britt. 520. 61.

Oxypor. analis Fab. Mant. Ins. I. 222. 3. Ent. Syst. I. II. 533. 10. Syst. El. II. 606. 10. - Panz. Faun. Germ. 22. 16. Ent. Germ. 360. 6.

Tachypor. a nalis Grav. Mirr. 129. 8. Mon. 6. 10. - Latr. Hist. nat. Crust. et Ins. X. 8. 8 - Gyll. Ins. Suec. II. 239.4 - Zetterst. Faun. Lappon. I. 58. 4.

Ins. Lapp. 55. 5. - Sahll. Ins. Fenn. I. 290. 4. - Boisd. et Lacord. Faun. Ent.

Paris. I. 516. 4. - Runde Brachelytr. Hal. 24. 3.

Staph. vernalis Müll. Prod. 98. 1103. - Gaeze Ent. Beitr. I. 727. 27.

Stuph. dispar var. y Payk. Mon. Staph. 78. 54. Faun. Suec. III. 423. 69.

Staph. chrysomelinus var, 2 Walk. Faun. Paris, I. 273. 19.

Staphyl. melanurus Marsh. Ent. Britt. 525. 80.

Habitat in Europa.

Antennae capite thoraceque paulo longiores, apicem versus parum incrassatae, testaceae, articulis 4 primis flavis. Caput laevissimum, rufo-testaceum, oculis nigris. Thorax coleopteris paulo latior, latitudine dimidio brevior, angulis posterioribus obtusis, externe rotundatis, basi utrinque subsinuatus, transversim convexus, laevissimus, totus rufo-testaceus. Scutellum nigrum. Elytra thorace sesqui longiora, subtiliter punctata, rufo-testacea, lrasi lata nigra. Abdomen rufo-testaceum, segmentis ultimis duobus nigris, ommibus basi punctatis. Pectus nigrum. Pedes testacei.

Mas tarsis anticis leviter, fe $\mathrm{mina}$ vix dilatatis. 
* 2. T. abdominalis: Rufo-lestaceus, nitidus, pectore abdomineque fuscescentibus, elytris thorace parum longioribus. - Long. $1 \frac{1}{3}$ lin.

Er. Col. Murch. I. 393. 8.

Tachypor. abdominalis var. a Gyll. Ins. Suec. II. 238. 3. - Zetterst. Fuun.

Lappon. I. 58. 3. Ins. Lappon. 55. 4. - Sahlb. Ins. Fenn. I. 290. 3. - Mannerh.

Brachelytr. 59. 4.

Habitat in Europa.

Habitu omnino praecedentis, at paulo minor, rufo-testaceus, nitidus, pectore abdomineque toto fuscescentibus, hoc segmentis singulis margine late testaceis. Antemae capitis thoracisque longitudine, apice sensim subincrassatae fuscescentesque. Caput laevissimum. Thorax latitudine plus dimidio brevior, hasi utrinque subsinuatus, angulis posterioribus retrorsum parum prominulis, rotundatis, transversim convexus, laevissimus. Elytra thorace parum longiora, parcits subtilissime punetata, tennissime pubescentia, immaculata. Abdomen parcius subtiliter punctulatum.

Mas tarsis antıcis leviter dilatatis, femin a simplicılus.

Obs. Synonymia huius speciei minus perspicua, et dubito an loci a Gyllenhalio citati omnes huc referri possint. Tachyp. abdominalis Grav. certe ad T. brunneum pertinet. Oxy o rus ab d o minalis F ab. (Spec. Ins. Suppl. 501.6. Mant Ins. I. 222. 7. Ent. Syst. I. II. 535. 17. Syst. El. II. 507. 17.) mihi omnino dubius, in Museo etiam a Fabricio citato invisus, minime ad speciem nostram revocandus videtur, huic enim minime est ab domen atrum, nitidum. - T. abdominalis var. b apud Gyllenhal aegre ad hanc speciem alleganda, specimina ab auctore ipso sub hoc nomine missa, quae Dom. Sch üppel mihi communicavit, potius specimina omnino immatura alius cuiusdam speciei vel aliarum quarundam specierum esse puto.

* 3. T. rufus: Rufo-testaceus, nitidus, pectore abdamineque nigris, elylris thorace sesqui longioribus, basi prope scutellum nigricantibus. - Long. $1 \frac{2}{3}$ lin.

Tachypor. abdominalis Boisd. et Lacord. Faun. Ent. Paris, I. 515. 5.

Habitat Lutetiae, Dom. Aubé.

Statura omnino T. chrysomelini. Antennae capite thoraceque paulo Iongiores, tenuiores, apicem versus leviter sensim incrassatae, articulo ultimo apice abrupte acuminato, flavae, articulis penultimis tribus fuscis, ultimo testaceo. Caput laevissimum, dilute rufo-testaceum, nitidum. Thorax coleopteris paulo latior, latitudine baseos dimidio brevior, basi utrinque subsinuatus, angulis posterioribus retrorsum leviter prominulis, externe rotundatis, transversim convexus, laevissimus, dilute rufo-testaceus. Scutellum piceum. Elytra thorace sesqui longiora, subtiliter crebre punctata, basi prope scutellum nigricantia. Abdomen crebrius punctatum, nigrum, nitıdum, segmentis 4 primis margine apicali olsscure testaceis, quinto fere toto testaceo, sexto nigro. Pectus mesothoracis rufo-testaceum, metathoracis nigrum. Pedes dilute testacei, coxis omnibus concoloribus; posticis basi nigris.

Mas tarsis antıcis fortius, femina leviter dilatatis.

$\mathrm{Obs}$. Differt a praecedente praecipue statura sesqui maiore, abdomine magis nigro, elytris longioribus et basi nigricantibus. A T. chrysomelino facile distingui, tur capite rufo-testaceo. 
4. T. saginatus: Niger, nitidus, thorace, elylris pedibusque rufis, antennis brevioribus, latiusculis, compressis, ferrugineis. - Long. 2 lin.

Grav. Mon. 6. 11. - Mannerh. Brachelytr. 59. 1. - Er. Col. March. I. 393. 9.

Habitat in Germania.

T. chrysomelino duplo maior, praecipue latior. Antennae capite thoraceque breviores, crassiusculae, apicem versus sensim incrassatae, ab articulo quarto inde sensim magis compressae, ferrugineae. Caput convexum, laevissinum, nigro-piceum, nitidum, subtus oreque rufis. Thorax coleopterorum latitudine, latitudine baseos dimidio brevior, basi truncatus, angulis posterioribus postice haud prominulis, rotundatis, transversim convexus, laevissimus, testaceo-rufus, nitidus. Scutellum piceum. Elytra thorace paulo longiora, subtiliter crebrius punctulata, testaceo-rufa, basi prope scutellum fuscescentia. Abdomen subtiliter punctulatum, nigrum, nitidum, segmentis singulis margine summo postico obscure testaceo. Pectus nigrum. Perles rufo-testacei, coxis anterioribus concoloribus.

Mas tarsis anterioribus levissime dilatatis, femin a simplicibus.

5. T. erythropterus: Niger, nitidus, elytris pedibusque rufis, antennis brevioribus, crassis, ferrugineis. - Long. $1 \frac{3}{4}$ lin.

Oxyporus erythropterus Panz. Faun. Germ. 27, 21.

Habitat in Germania meridionali, Dom. Dr. Waltl.

Hahitu ommino T. saginati, at minor, T. hypnorum perparum maior. Antennae capite thoraceque breviores, crassiusculae, apicem versus incrassatae, ab articulo quarto inde sensim fortius compressae, ferrugineae. Caput laevissimum, nigrum, nitidum, ore testaceo. Thorax coleoptera latitudine parum excedens, latitudine baseos paulo brevior, antrorsum minus fortiter angustatus, lateribus minus rotundatis, basi utrinque leviter sinuatus, angulis posterioribus retrorsum modice prominentibus, late rotundatis, fortiter convexus, laevissimus, niger, nitidus, margine summo basali lateralique rufescente. Scutellum nigrum. Elytra thorace parum longiora, subtiliter punctata, saturate rufa, nitida, basi et circa scutellum tenui spatio nigricantia. Abdomen nigrum, nitidum, parcius subtilıter punctatum, segmentis sungulis margine summo postico rufescente. Pectus nigrum. Pedes rufi, coxis anticis piceis, breviusculi fortiusculique, tarsis brevioribus, subcompressis.

Mas tarsis anticis vix dilatatis. Femina latet.

$\mathrm{Obs}$. T. s a ginato antennarum structura affinis, differt autem thorace scutelloque nigris, thorace angulis posterioribus prominentibus, elytris distinctius punctulatis. A. T. hypnorum antennarum structura satis distinctus.

* 6. T. hypnorum: Niger, thoracis margine testaceo, pedibus elytrisque rufis, his macula marginali nigra. - Long. $1 \frac{2}{3}$ lin.

Er. Col. March. I. 394. 11.

Staph. hypnorum Fab. Syst. Ent. 266. 13. Spec. Ins. I. 336. 16. Mant. Ins. I. 221. 23. - Goeze Ent. Beitr. I. 724. 7. - Marsh. Ent. Britt. 525. 79.

Oxурогиs hypnorum Fab. Ent. Syst. I. II. 535. 22. Syst. El. II. 607. 22. Panz. Ent. Germ. 361. 17. 
Staphyl. nit idulus Fab. Spec. Ins. I. 337. 17. Mant. Ins. I. 221. 24. - Oliv. Ent. III. 42. 34. 48. t. 3. f. 28. - Marsh. Ent. Britt. 520.64.

Oxyporus minut us Fab. Ent. Syst. I. II. 535. 20. Syst. El. II. 607. 20.

Oxyporus marginatus Panz. Ent. Germ. 359. 4. Faun. Germ. 27. 17.

T'achyporus marginatus Grav. Mirr. 127. 5. Mon. 7. 13. - Latr. Hist. nut. Crust. et Ins. X. 6.5 - Gyll. Ins. Suec. II. 237. 2. - Zetterst. Faun. Lappon. I. 57. 2. Ins. Lappon. 55. 3. - Sahlb. Ins. Fenn. I. 290. 2. - Mannerh. Brachelytr. 59. 3. - Guér. Iconogr. t. 10. f. 9. - Boisd. et Lacord. Faun Ent. Paris. I. 514. 1. - Ru de Brachelytr. Hal. 24. 2.

Staph. Blattinus Schrank Enum. Ins. Aust. 236. 447. Faun. Boic. I. 446. 878.

Staph. conicus De Vill. Ent. I. 425. 72.

Staph. martialis Schrank Enum. Ins. Aust. 237. 450.

Staph. dispar var. $\beta$ Payk Mon. Staph. 78. 54. Faun. Suec. III. 421. 69.

Staph. chrysomelinus var. I Walk. Faun. Paris. I. 272. 19.

Habitat in Europa.

Statura omnino T. chrysomelni. Antennae capitis thoracisque longitudine vel paulo longiores, graciliores, apicem versus parum crassiores, testaceae, apice subinfuscatae. Caput laevissimum, nigrum, ore testaceo. Thorax coleopteris paulo latior, latitudine baseos dimidio brevior, basi truncatus, angulis posterioribus postice haud prommentibus, obtusis, externe rotundatis. fortiter convexus, niger, nitidus, margine basali angusto lateralique basin versus sensim latiore testaceis. Scutellum nigrum. Elytra thorace paulo longiora, subtiliter punctata, rufa, macula parva triangulari circa scutellum maculaque oblonga laterali nigris, tenuissime pubescentia. Abdomen crebrius subtiliter punctatum, nigrum, segmentis singulis margine apicali ferrugineo. Pectus nigrum. Pedes testacei, coxis piceis.

Mas tarsis anticis leviter, femina vix dilatatis.

* 7. T. anticus: Viger, nitidus, thorace elytris pedibusque rufo-testaceis, thorace disco nigro. - Long. $1 \frac{1}{2}$ lin.

Habitat in Aegypto, Dom. Prof. Ehrenberg.

T. hypnorum panlo minor et gracilior. Antennae capitis thoracisque prope longitudine, apicem versus haud incrassatae, testaceae, apice fuscescentes. Caput convexum, laevissimum, nigrum, nitidum, palpis testaceis. Thorax coleopterorum latitudine, latitudine baseos dimidio brevior, basi truncatus, angulis posterioribus haud prominulis, rotundatis, leviter transversim convexus, laevissimus, nitidus, testaceus, disco anteriore late nigro, seu niger, margine laterali et basali lato, anteriore angusto testaceo. Scutellum piceum. Elytra thorace sesqui prope longiora, subtiliter punctata, rufotestacea, immaculata, nitida. Abdomen subtiliter punctatum, nigrum, segmentis singulis margine postico, quinti latiore, ferrugineo. Pectus nigrum. Pedes testacei, coxis anticis concoloribus.

Obs. T. hypnorum simillimus, distinctus autem statura minore, minus convexa, thorace coleopteris haud latiore, elytris constanter immaculatis, coxis anticis testaceis etc. A. T. brunneo differt statura duplo maiore, antennis apicem versus haud incrassatis etc.

* 8. T. chry somelinus: Niger, nitidus, antennarum basi, pedibus, thorace elytrisque testaceo-rufis, his thorace paulo longioribus, crebre subtiliter punclatis, circa scutellum et margine laterali nigris. - Long. $1 \frac{2}{3}$ lin. 
Giav. Mier, 128. 7. Mon. 7. 12. - Latr. Hist. nat. Crust. et Ins. X. 7. 7. t. 79: f. 9. Gen. Crust. et Ins. I. 300. 1. - Gyll. Ins. Suec. II. 236. 1. - Suhlb. Ins. Fenn. I. 269. I. - Zetterst. Faun. Lappon. I. 57. 1. Ins, Lappon. 54 1. Manne h Brachelylr. 59. 2. - Boisd. et Lacurd. Faun Ent. Paris. I. 515. 2. Runde Brachelytr. Hal. 24. 1. - Er. Col. March. I. 393. 10.

Staph. chrysomelinus Linn. Faun. Suec. n 855. Syst Nat. I. II. 685. 21. Fab. Syst. Ent. 267. 17. Spec. Ins. 337. 21 Mant. Ins. I 221. 28. - Schrank Enum. Ins. Aus/r. 2:36 418 Faun. Boic. I. 616. 789. - Ström. Act. Nidros. III. 415. 28. - Müll Prod. 98. 1105. - Goeze Ent. Beitr. 1. 720. 21. - De Vill. Ent. 1. 417. 21. - Walk. Faun. Paris. 1. 272. 19. - Fouer. Ent. Paris. 169.18. - Rossi Fuun. Etr I. 250. 616. (Ed. Hellw. 309. 616. var. 1. a.)-Oliv. Ent. III. 42. 33. 47. t. 3. $f$. 22. - Marsh. Ent. Britt. 519. 42.

Oxyporus chrysomelinus Fab. Ent. Syst. I II. 534. 15. Syst. El. II. 606. 14. - Panz. Faun. Germ. 9. 14. Ent. Germ. 360. 12 - Cederh. Fiun. Ingr. 120. 371. Oxyporus melanocephalus Fab. Ent. Syst. I. II. 534. 16. Syst. El. II. 607. I6. Staph merdarius Marsh. Ent. Britt. 521. 68.

Oxyporus mérdarius Panz. Ent. Germ. 360. 8. Faun Germ 27. 18.

Staph. chrysomelinusvar. a Payk. Mon. Staph. 57. 74.

Staph. dispar var. a Payk. Faun. Suec. III. 423. 69.

Le Staph. couleur de paille Geoffr. Hist. Ins. I. 368. 18.

Habitat in Europa.

Statura et magnitudo T. obtusi. Antennae capitis thoracisque longitudine, gracilıs, apice vix incrassatae, articulis 5-10 sensim paulo brevioribus at parum crassioribus, subobconicis, ultimo his paulo crassiore, ovato, apice abrupte acuminato, articulis tribus primis dilute testacess, reliquis rufo. fuscescentibus. Caput mediocre, leviter convexum, laevissimum, nitidum, nigrum, ore testaceo. Thorax coleopteris paulo latior, latitudine baseos tertia fere parte brevior, basi truncatus, angulis posterioribus retrorsum haud prominulis, obtusis, externe fortius rotundatis, transversim convexus, lacvissimus, rufo-testaceus, nitidus. Scutellum nigrum. Elytra thorace tertia fere parte longiora, leviter convexa, erebrius subtiliter punctata, glabra, nitida, rufo-testacea, spatio parvo communi triangulari circa scutellum, et margine laterali, postice abbreviato, nigris. Abdomen crebrius subtiliter punctatum, glabrum, lateribus et apice pilosellum, nigrum, segmentis singulis margine posteriore late rufo-testaceo, ultimo piceo-testaceo. Pectus nigrum. Pedes testacei, coxis anticis concoloribus.

Mas tarsis anticis modice, femina perparum dilatatis.

* 9. T. solutus: Niger, nilidus, ore, antennis, pedibus, thorace elyirisque rufo-testaceis, his thorace paulo longioribus, circa scutellum infuscatis. - Long. $1 \frac{2}{3}$ lin.

Tachyporus saginatus Boisd. et Lacord. Faun. Ent. Paris. I. 515. 13.

Habitat in Europa.

Statura et summa affinitas $\mathrm{T}$. chrysomelini, et maximis eius individuis magnitudine aequalis. Antennae capite thoraceque panlo longiores, apicen versus distincius incrassatae, articulis ultimis sex evidenter crassioribus, crassitie antem haud brevioribus, leviter obconicis, excepto ultimo oblongo-ovato. apice acuminato. Caput mediocre, leviter convexum, laevissimum, nitidum, nigrum, ore magis minusve testaceo. Thorax coleopteris paulo latior, lati- 
tudine baseos tertia fere parte brevior, basi truncatus, angulis josterioribus obtusis, externe subrotundatis, sat fortiter transversim convexus, laevissimus, nitidus, rufo-testaceus. Scutellum nigrum. Elytra thorace teria fere parte longiora, leviter convexa, sat crebre subtiliter punctata, glabra, rufo-tesiacea, nitida, basi spatio communi triangulari nigricante. Abdomen sat crelre subtiliter punctatum, glabrum, lateribus et apice nigro-pilosellum, nigrum, nitidum, segmentis 4 primis margine tenui posteriore testaceo. Pectus nigrum. Pedes testacei, coxis antieis concoloribus.

Mas tarsis anticis modice, femina leviter dilatatis.

Obs. 1. Differt a T. chrysomelino antennis extrorsum crassioribus, totis testaceis, elytris margine laterali concolore, ano nigro, a T. saginato statura minore, minus lata, et antennarum structura.

2. Ta chypori chrysomelini var. b Gyll. Sahlb. Zett. vix ad hanc speciem referenda, quae speciei genuinae magnitudine inferior fertur. Oxyporus merdarius Panz. pariter potius T. chry somelinum quam hanc speciem exhibere videtur, hac enim minor est, et antennae apicem versus fuscescunt.

* 10. T. tersus: Niger, nilidus, antennarum basi, pedibus thorace elylrisque rufo-testaceis, his thorace sesqui longioribus, parce oúsoleteque punclatis, margine laterali et cirea scutellum nigris. - Long. $1 \frac{1}{2}$ lin.

\section{Habitat in Germania, Kirstein.}

T. chrysomelino similis, at minor, angustior et mints convexus, statura omnino T. pusilli. Antennae capitis thoracisque longitudine, apicem versus perparum incrassatae, articulis $5-10$ sensim paululum brevioribus et crassioribus, subobconicis, ultimo praecedente paulo crassiore, ovato, apice abrupte acuminato, fuscae, articulis 4 primis testaceis. Caput mediocre, leviter convexum, laevissimum, politum, nigrum, ore concolore, oris partibus inferioribus testaceis. Thorax coleopterorun latitudine, laiitu. dine baseos dinidio fere brevior, basi utrinque subsimuatus, angulis posterioribus rotundatis, transversim convexus, laevissimus, nitidus, rufo-testacens. Flytra thorace sesqui longiora, leviter convexa, parce subsiliter obsoleteque punctata, glabra, nitida, rufo-testacea, spatio parvo communi trangulari circa scutellum, et margine laterali tenuore, summo apice abbreviato, nigris. Ab. domen parcius subtiliter punctatum, glabrum, lateribus et apice parse nigropilosellum, nigrum, nitidum, segmentis singulis margine apicali obscure testaceis. Pectris nigrum. Pedes testacei,- coxis anticis concoloribus.

Mas tarsis anticis leviter dilatatis, fe mina simplucibus.

Obs. Affinis certe T. chrysomelino, at distinctus statura minore, angustiore, minus convexa, thorace breviore, coleopteris haud breviore, his parce obsoleteque punctatis, fere laevigatis, et ore testaceo.

* 11. T. arduus: Niger, nitidus, ore, antennarum basi, pedibus, thorace elytrisque rufo-lestaceis, his thorace paulo longioribus, parcins punclatis, circa scutellum et margine laterali nigris. - Long. $1 \frac{1}{2}$ lin.

Habitat in Pensylvania, Dom. Zimmermann.

T. chrysomelino minor et angustior, statura omnino T. scituli. Antennae capite thoraceque paulo longiores, apicem versus sensim leviter incrassatae, articulis 5 - $\mathbf{1 0}$ sensim paulo brevioribus et crassioribus, ultimo praecedente paulo crassiore, subovato, apice abrupte acuminato, rufo fuscae, 
articulis 4 primis testaceis. Caput mediocre, convexum, laevissimum, nitidum, nigrum, ore testaceo. Thorax coleopteris vix latior, latitudine baseos tertia fere parte brevior, basi truncatus, angulis posterioribus retrorsum haud prominulis, rotundatis, transversim convexus, laevissimus, nitidus, rufo-testaceus. Scutellum nigrum. Elytra thorace tertia fere parte longiora, leviter convexa, parcius et minus subtiliter punctata, subtiliter tenuiterque pubescentia, rufo-testacea, nitida, spatio parvo communi triangulari circa scutellum, et vitta marginali abbreviata, nonnunquam obsoleta, nigricantibus. Abdomen crebrius minus subtiliter punctatum, subtilissime tenuissimeque pubescens, lateribus et apice longius nigro-pilosellum, nigrum, nitidum, segmentis singulis margine posteriore, anterioribus 4 angustiore, quinto latiore rufo-testaceis, ultimo apice saepius piceo. Pectus nigrum. Pedes testacei, coxis anticis concoloribus.

Mas tarsis anticis leviter dilatatis, femin a simplicibus.

Variat elytris spatio inter maculam scutellarem et marginalem magis minusve infuscato.

O bs. Ab Europaeis omnino distinctus, differt a sequentibus ore testaceo, a praecedentibus statura minore, elytris pubescentibus, minus subtiliter punctatis.

* 12. T. humerosus: Niger, nitidus, antennarum basi, pedibus, thorace elytrisque rufo-testaceis, his thoruce longioribus, crebrius subtiliter punctatis, pubescentibus, lateribus et macula scutellari nigris. - Long. $1 \frac{1}{3}-1 \frac{1}{2}$ lin.

Tachyporus ruficollis var. (humerosus Knoch) Grav. Mon. p. 8.

Tachyporus lateralis Grav. Micr. 127. 4. Mon. 7. 14. - Latr. Hist. nat. Crust. et Ins. X. 6. 4. (forte)

Tachyporus ruficollis Runde Brachelytr. Hal. 25. 4.

Habitat in Germania.

T. chrysomelino dimidio vel duplo minor, brevior et convexior. Antennae capitis thoracisque longitudine, tenuiores, apicem versus vix incrassatae, articulis $4-10$ sensim paulo brevioribus at vix crassioribus, subobconicis, ultimo praecedente duplo prope longiore, subovato, apice abrupte acuminato, fuscae, basi testaceae. Palpi testacei. Caput magnum, convexum, laevissimum, nitidum, nigrum, ore concolore. Thorax coleopteris vix latior, latitudine baseos tertia fere parte brevior, antrorsum leviter angustatus, basi truncatus, angulis posterioribus rotundatis, sat fortiter transversim convexus, laevissimus, rufo-testaceus, nitidus. Scutellum nigrum. Elytra thorace tertia parte longiora, sat convexa, crebrius subtiliter punctata, densius subtiliter pubescentia, nitida, rufa, spatio minuto communi triangulari circa scutellum, margineque basali et laterali, hoc apice abbreviato, nigris, spatio interiacente saepius magis minusve infuscato, limbo apicali magis rufo-testaceo. Abdomen crebrius subtiliusque punctatum, subtilissime tenuiter pubescens, lateribus et apice nigro-pilosellum, nigrum, nitidum, segmentis 4 primis margine posteriore testaceo. Pectus nigrum. Pedes testacei, coxis anterioribus concoloribus.

Mas tarsis anticis leviter dilatatis, femina simplicibus.

$\mathrm{Obs}$. T. chrysomelino similis, distinguitur autem corpore minore, convexiore, elytris pubescentibus et ore concolore, T. ruficolli magis affinis, differt autem an- 
tennis longioribus, praeter basin fuscis, thorace breviore, antrorsum evidenter angustato, elytris longioribus, et tarsis anticis maris leviter dilatatis.

*13. T. ruficollis: Niger, nitidus, thorace pedibusque rufis, elylris thoracis longitudine, piceis, apice rufescentibus. - Long. $1 \frac{1}{2}$ lin.

Grav. Micr. 128. 6. Mon. 7. 16. - Latr. Hist. nat. Crust. et Ins. X. 7. 6. S tuph. chrysomelinus var. 1. $\alpha$. $\beta$ Rossi Faun. IStr. Ed. Hellw. I. 309. 616.

Habitat in Germania.

Antemnae capitis thoracisque prope longitudine, tenues, apicem versus vix incrassatae, articulis $5-10$ sensim paululum brevioribus et crassioribus, subobconicis, ultimo praecedente perparum maiore, subobconico, apice abrupte acuminato, totae testaceae. Palpi testacei. Caput magnum, convexum, laevissimum, nigrum, nitidum, ore concolore. Thorax coleopteris paulo latior, latitudine baseos paulo brevior, antrorsum parum angustatus, basi truncatus, angulis posterioribus retrorsum haud prominentibus, rotundatis, fortiter convexus, laevissimus, testaceo-rufus, nitidus. Scutellum piceum, Elytra thorace vix longiora, convexa, subtiliter punctata, subtilissime tenuiter pubescentia, iam nigro-, iam fusco-picea, nitida, margine apicali rufescente. Abdomen crebre subtiliter punctatum, subtilter tenuiterque pubescens, lateribus et apice parce nigro-pilosellum, nigrum, nitidum, segmentis singulis margine summo postico testaceo. Pectus nigrum. Pedes rufo-testacei, coxis anterioribus concoloribus.

Mas tarsis anticis fortiter dilatatis, femina simplicibus.

Variat elytris rufo-piceis vel omnino rufis.

Obs. Omnino distinctus statura brevi, convexa, capite magno, antennis brevibus tenuibusque, totis testaceis, thorace longiore et antrorsum perparum angustato. Var. ad calcem memorata T. humeroso fimilis, notis autem modo laudatis distinguenda. T. ruficollis Gyll. ad T. transversalem referendus.

* 14. T. pusillus: Niger, nitidus, thoracis margine elylrisque fuscis, his thorace sesqui longioribus, macula marginali nigra. - Long. $1 \frac{1}{4}$ lin.

Grav. Mon. 9. 18. - Gyll. Ins. Suec. II. 241. 6. - Zetterst. Faun. Lappon. I. 59. 6. Ins. Lappon. 55. 7. - Sahlb. Ins. Fenn. I. 291. 6. - Mannerh. Brachel. 60. 8. - Boisd. et Lacord. Faun. Ent. Paris. I. 516. 6. - Runde Brachelytr. Hal. 25. 5. - Er. Col. Mareh. I. 394. 12.

Habitat in Europa.

Antennae caputis thoracisque longitudine, apicem versus parum crassiores, fuscae, basi testaceae. Palpi pices, articulis duobus primis flavotestaceis. Caput mediocre, leviter convexum, laevissimum, nigrum, nitidum, ore concolore. Thorax coleopterorum latitudine, latitudine baseos dimidio brevior, basi truncatus, angulis posterioribus haud prominentibus, obtusis, externe rotundatis, modice convexus, laevissimus, niger, nitidus, margine basali angustiore lateralique lato fusco-testaceo. Scutellum nigrum. Elytra thorace sesqui longiora, crebre subtiliter punctata, fusca, margine laterali nigro. Pectus et abdomen nigra, nitida, confertim subtiliter punctata. Pedes testacei, coxis anticis piceis.

Mas tarsis anticis leviter dilatatis, femina simplicibus.

$\mathrm{Obs}$. Tachyporo hypnorum colore, licet obscuriore, affinis, differt autem statura minore, minus convexa, thoraceque coleopteris haud latiore. 
* 15. T. scitulus: Niger, nitidus, thoracis margine laterali elytrorumque apicali rufo-piceis, antennarum basi pedibusque rufis, elytris thorace paulo longioribus. - Long. $1 \frac{1}{4}$ lin.

Er. Col. March. I. 395.13.

Tachyporus pusillus var. Grav Mon. 9. 18.

Tachypor. pusillus var. b Gyll. Ins. Suec. II. 241. 6. - Zetterst. Faun. Lappon. I. 59. 6. Ins. Lappon. 55. 7. - Sahlb. Ins. Fenn. I. 291. 6. - Mannerh. Brachelytr. 60.8.

\section{Habitat in Europa.}

Statura T. pusilli, at paulo convexior, nitidus. Antennae capitis thoranisque fere longitudine, apicem versus parum incrassatae, fuscae, basi testaceae. Caput mediocre, convexum, laevissimum,- nigrum, ore concolore, oris partibus piceo-testaceis. Thorax coleopteris parum latior, latitudine baseos dimidio brevior, basi truncatus, angulis posterioribus haud prominulis, obtusis, externe rotundatis, modice transversim convexus, margine laterali latiore summoque basali piceo-rufescentibus. Elytra thorace paulo longiora, subtilissime punctulata, tenuiter subtiliterque pubescentia, margine apicali piceo-rufescente. Abdomen crebre subtiliter punctatum, segmentis $2-5$ saepius tenuiter rufo-marginatis. Pedes rufo-testacei, coxis anticis picescentibus.

Mas tarsis anticis leviter dilatatis, femin a simplicibus.

Variat thoracis margme laterali et basali elytrorumque apicali laete rufo-testaceis.

Obs. T. pusillo similis, differt corpore paulo convexiore, elytrorum colore, et punctura parciore et subtiliore.

* 16. T. nanus: Niger, nitidus, ore, antennarum basi, elytrorum apice pedibusque rufis, thoracis margine piceo, elytris thorace longioribus, distinclius punctatis. - Long. $1 \frac{1}{4}$ lin.

Habitat in Pensylvania, Dom. Zimmermann.

Statura et summa affinitas praecedentis. Niger, nitidus. Antennae capitis thoracisque prope longitudine, graciles, apice paulo crassiores, piceorufae, basi testaceae. Caput mediocre, convexum, laevissimum, ore testaceo. Thorax coleopteris paululum latior, latitudine baseos dimidio brevior, basi truncatus, angulis posterioribus hand prominentibus, rotundatis, modice convexus, laevissimus, margine basali lateralique tenuiore piceo-rufescente. Elytra thorace tertia'parte longiora, crebre minus subtiliter punctata, parce pubescentia, apice (tertia elytri parte) laete rufa. Abdomen parce subtiliter punctatum, segmentis singulis margine postico rufescente. Pedes rufotestacei, coxis anticis femoribusque picescentibus.

Mas tarsis anticis leviter dilatatis. F e min a latet.

Obs. A. T. scitulo distinctus antennis brevioribus, dilutioribus, ore testaceo, elytris distinctius punctatis, apice latius rufis, etc.

* 17. T. transversalis: Niger, nitidus, thorace elytrisque rufis, antice dimidiato-nigris, pedibus testaceis. - Long. $1 \frac{1}{4}$ lin.

Gruv, Mon, 8. 17. - Er. Col. March, I. 395. 14. 
T. ruficollis Gyll. Ins. Suec. II. 210. 5. - Zelterst. Faun. Lappon. I. 58. 5. Ins. Lappon. 55. 6. - Suhlb. Ins. Fenn. I. 291. 5. - Mannerh. Brachelytr. 59. 7. T. dispar var. of Payl. Mon Staph. 78. 54. Faun. Suec. III. 424. 69.

Habitat in Germania.

Statura T. pusilli. Antennae capitis thoracisque longitudine, apicem versus parum crassiores, ferrugineae, medio fuscescentes. Palpi testacei, articulo tertio fusco. Caput minusculuu, leviter convexum, laevissimum, nigrum, nitidum, ore testaceo. Thorax coleopteris paulo latior, latitudine baseos dimidio brevior, basi truncatus, modice convexus, angulis posterioribus haud prominentibus, rotundatis, satis convexus, laevissimus, testaceorufus, antice plerumque dimidiato-nigricans, nitidus. Scutellum nigrum. Elytra thorace paulo longiora, crebre subtiliter punctata, parce subtiliterque pubescentia, nitida, antice nigra, pone medium testaceo-rufa. Abdomen crebre subtiliter punctatum, nigrum, segmentis singulis margine postico late rufo. Pectus nigrum. Pedes rufo-testacei, coxis anticis concoloribus.

Mas tarsis anticis vix dilatatis, femina simplicibus.

* 18. T. brunneus: Rufo-testaceus, capite, thoracis disco pectoreque piceis, elytris thorace sesqui longioribus. - Long. $1 \frac{1}{4}$ lin.

Er. Col. March. I. 395. 15.

Oxyporus brunneus Fab. Ent. Syst. 1. II. 535. 19. Syst. El. 11. 607. 19. Panz. Ent. G.rm. 361. 15.

Staphyl. nit idulus Oliv. Ent. III. 42.34 .48 t. $3 . f .28$.

Tachyporus nitidulus Grav. Micr. 126. 2. Mon. 11. 20. - Latr. Hist. nat. Crust. el Ins. X. 6. 2. - Gyll. Ins. Suec. II. 242. 7. - Sahlb. Ins. Fenn. I. 292. 7. Mannerh. Brachelytr. 60. 9. - Botsd. et Lacord. Faun. Ent. Paris. I. 517. 7. Runde Brachelytr. Hal. 25. 6.

Var.: Tolus testaceus.

Tarhyporus abdominalis Grav. Micr. 127. 3. Mon. 7. 15. - Latr. Hist. nat. Crust. et Ins. X. 6. 3.

Taclyporus scutellaris Boisd. et Lacord. Faun. Ent. Paris. I. 517. 8.

Habitat in Europa; in Aegypto, Dom. Prof. Ehrenberg; in America septentrionali, Dom. Zimmermann.

Praecedentibus minor, angustior et minus convexus. Antennae capitis thoracisque longitudine, apice vix crassiores, totae testaceae. Caput minusculum, leviter convexum, laevissimum, piceum, nitidum, ore testaceo. Thorax coleopterorum latitudine, latitudine baseos dimidio brevior, basi truncatus, angulis posterioribus haud prominulis, obtusis, externe rotundatis, leviter convexus, laevissimus, testaceus, nitidus, disco piceo. Scutellum piceotestaceum. Elytra thorace sesqui longiora, crebre subtilius punctata, tenuter subtiliterque pubescentra, testacea, nitida. Abdomen crebre minus subtiliter punctatum, fusco-testaceum, segmentis singulıs apice dilutioribus. Pectus piceum. Pedes flavo-testacei.

Mas tarsis anticis leviter dilatatis, fe min a simplicibus. Variat capite, thoracis disco pectoreque testaceis concoloribus. 
S.pecies mihi invis a e.

19. T. nigricornis: Nigro-piceus, nitidus, antennarum articulo ultimo, thoracis lateribus pedibusque poslicis mfo-teslaceis, elytris rufis, regione scutelli nigris.

Gyll. Ins. Suec. IV. 469. 1 - 2.

Habitat in Vestrogothia.

T. chrysomelino et affinibus magnitudine, statura et partium formatione simillimus, colore antennarum et pedum anteriorum a reliquis praecipue distinctus. Caput nigrum, nitidissimum, glabrum, laeve, ore palpisque etiam nigris, pubescentibus. Antennae paulo breviores et validiores quam in affinłbus, extrorsum crassiores, nigrae, articulo ultimo solo testaceo. Thorax amplus, nigro-brunneus, lateribus rufescens. Scutellum nigrum. Elytra rufotestacea, circa scutellum "nigricantia, et inxta humerum litura fusca notata. Abdomen nigro-piceum, segmentorum marginibus dilutioribus. Corpus subtus uigro-pıceum. Pedes quatuor anteriores nigro-picei, postici et tarsi anteriores testacei. (Gyll.)

20. T. obscurellus: Convexus, nitidus, laevis, glaber, niger, antennarum basi, thorace pedibusque anterioribus rufo-testaceis, elytris fuscis. Long. $1 \frac{1}{4}$ lin.

Zetterst. Ins. Lappon. 54. 2.

Habitat in Lapponia Umensi rarins.

Similis T. chrysomelino, marginato, etc., colore ab illis tantum differt. Caput nigrum. Antennae fuscae, articulo primo testaceo. Thorax rufus. Elytra obscura s. fusco-rufa, margine summo apicali pallido. Abromen nigrum. Pedes obscure rufo-testacei, femoribus posticis nigricantibus s. fuscés, tibiis eiusdem paris testaceis, tarsis pallidis. (Zetterst.)

Obs. Colore corpors cum T. ruficolli Gr. convenire videtur, at antennarum et pedum posticorum colore differt.

21. T. nigriceps: Latus, subconvexus, pallidus, capite nigro, ano infuscalo. Mannerh. Brachelytr. 59. 5.

Habitat in Fennia: ad Wilnäs semel captus.

T. abdominali duplo minor, capite nigro, postice transversim profunlins impresso, et thorace elytris parum latiore diversus. (Mannerh.)

Obs. Species perquam dubia, forte castiganda.

\section{Habrocerus $\boldsymbol{E} \boldsymbol{r}$.}

\section{Er. Col. March. I. p. 400.}

Antennae 11-articulatae, capillares.

Palpi maxillares articulo quarto acuminato.

Ligula biloba, lobis truncatis.

Elylva pectore longiora.

Tarsi 5-cirliculati.

Corpus oblongum, leviter convexum, alatum. Caput thoraci insertum, rotundatum, convexum, deflexum, oculis mediocribus, rotundatis, modice pro- 
minulis. Labrun subquadratum, apice leviter sinuatum. Mandiliulae minutae. Maxillae (t. IV. f. 4. b.) mala interiore rhomboidea, externe coriacea, interne membranea, apice breviter barbata, mala exteriore interne coriacea, externe et apice dilatato-rotundato barbnta, membranea. Palpi maxillares elongati, articulo primo minuto, secundo tertioque longitudine subaequalibus, hoc apicem versus sensim incrassato, quarto huic fere aequali, elongatoconico, acuminato. Labium (t. IV. f. 4. a.) mento transver o, ligula lata, truncata, medio incisa, membranea, paraglossis ligulae connatis, eique aequalibus, non nisi linea ciliata indicats. Palpi labiales ligulam vix superantes, articulo primo sat magno, cylindrico, secundo tertioque minutis, subaequalibus, hoc apice truncato. Antennae (t. IV. f. 4. c.) 11-ariculatae, articulis duobus primis crassiusculis, reliquis tenuibus, verticillato-pilosellis. Thorax transversus, basi coleopterormm latitudine, antrorsum leviter angustatus, transversim convexus, basi truncatus, ajice pro receptione capiris emarginatus, lateribus leviter rotundatis, angulis posterioribus obtusis, subrotundatis. Scutellum minutum, triangulare. Elytra thorace paulo longiora, angulo apicali exteriore oblique truncato. Abdomen marginatum, apicem versus sensim angustatum, apice depressum, segmentis sexto septimoque occulti:Mesosternum antice carinatum. Pedes breviusculi, coxis intermediis approximatis, postucis triangularibus, trochanteribus posticis maiusculis, tibiis omnibus subtilissime spinulosis, tarsis. 5 -articulatis, tenuibus, posterioribus articulo primo elongato, sequentibus tribus sensim longitudine decrescentibus, anticis ii utroque sexu simplicibus.

\section{O b s e r vationes.}

1. Habitus corporis omnino Tachypori, at minus convexus. Caput et thorax laevissima glaberrimaque, hic margine parce pilosello, elytra punctulata, glabra, margine parce pilosello, abdomen subtiliter tenuiterque pubescens, lateribus et apice longius pilosellum.

2. Quodammodo intermedium videtur hoc genus inter Tachyporum et Tachin um, palporum maxillarium articulus tertius apice acutus ut in Tachyporo, at elongatus, et basi tertio crassitie aequalis, ut in Tachino; ab utroque praeterea notis pluribus discedit, praecipue antennarum abdominisque structura nec non coxis posticis triangularibus. Antennarum figura insolita cum Trich o phyo convenit.

3. Mas abdominis segmento quinto inferiore apice leviter emarginato, sexto paululum eminulo, femin a segmento quinto apice truncato, sexto omnino occulto distinguuntur.

\section{* 1. H. capillaricornis: Nigro-piceus, nitidus, antennis pedibusque te- staceis. - Long. $1 \frac{1}{4}$ lin.}

Er. Col. March. I. 401. 1.

Tachyporus capillaricornis Grav. Mon. 10. 19.

Habitat in Germania, in silvis, sub foliis deciduis, in Gallia, Mus. Dom. Dr. Aubé, in Sardinia, Dom. Prof. Gené.

Piceus vel nigro-piceus, nitidus, ore, antennis pedibusque testaceis, capite, thorace scutelloque glaberrimis, thorace apice punctis quatuor transversim positis, sat distinctis notato. Elytra obsolete parceque punctata, glabra. Abdomen confertim subtiliter punctatum, subtiliter pubescens, pilosellum. 
Tachinus Grav.

Tachinus Fam. I. Grav. Micr. I. p. 135.

Antennae 11-articulatae, filiformes.

Palpi maxillares filiformes.

Ligula biloba.

Elytra pectore longiora.

Tarsi 5-articulati.

Corpus oblongum, magis minusve convexum, plerumque alatum. Capnt thoraci insertum, fronte convexiuscula, antice angustata, oculis medicoribus, rotundatis, leviter prominulis. Labrum transversum, apice leviter sinuatum. Mandibulae trigonae, obtusiusculae, intus membrana tenui, subtiliter ciliata fimbriatae. Maxillae (t. IV. f. 5. b.) malis basi subcorneis, apice membraneis, interiore apice oblique truncato, exteriore rotundato barbatis, hac interiori aut aequali aut eam leviter superante. Palpi maxillares modice elongati, filiformes, articulo primo minuto, brevi, secundo tertio paulo longiore, quarto tertio vel paulo longiore, vel subaequali, apice acuminato. Labium (t. IV. f. 5. a.) mento transverso, ligula lata, medio incisa, lobis oblique introrsum truncatis, nembranea, paraglossis ligulae omnino connatis eamque haud excedentibus, interne subtiliter ciliatis. Palpi labiales filiformes, articulo primo secundo paulo longiore, tertio praecedentibus haud tenuiore, primo longitudine aequali, apice subacuminato. Antemae filiformes, apice saepius leniter sensimque subincrassatae, articulo ultimo ovato. Thorax transversus, basi coleopterorum latitudme, vel iis paulo latior, antrorsum angustatus, apice pro receptione capitis emarginatus, lateribus rotundatus, basi vel truncata vel utrinque leviter simuata, coleopteris arcte applicata, angulis posterioribus saepe postice prominentibus, anterioribus acutiusculis. Scutellum rotundatum. Elytra sat magna. Abdomen marginatum, apicem versus sensim attenuatum. Pedes breviusculi, coxis posticis parallelopipedis, ad femorum basin scutiformi-elevatis, tibiis omnibus spinulosis, tarsis 5-articulis, minus elongatis, articulis \& primis longitudine sensim decescentibus.

\section{Fam. I.}

\section{Mesosternum carinatum.}

Tarsi antici in utroque sexu simplices.

Statura Tachypori, corpus saepius convexius, posterius attenuatum, antice obtuse rotundatum. Palpi maxillares articulo ultimo magis acuminato, nomunquam conico, penultimo saepius haud longiore. Femora valida, compressa.

Mas abdominis segmento sexto superiore apice quadrifido, laciniis spiniformibus, intermediis longioribus, inferiore fisso, quinto inferiore plerisque integro.

Femina segmento sexto superıore et inferiore apice quadrifidis, laciniis spiniformibus, aequalibus.

O b s e r vatio nes.

1. Corpus minutum, convexum, posterius valde attenuatum, capite, thorace elytrisque glaberrimis, abdomine saepius tenuissime subtilissimeque pubescente, la- 
teribus et apice parce pilosello. Scutellum magnum, Elytra convexa, lateribus subtiliter marginata, secundum marginem saepius longitudinaliter impressa, angulo apicali exteriore obtuso,

2. Habitus omnino Tachy pori, notas autem distinctivas praebent abdominis segmentum sextum aliter constructum, mesosternum carinatum, tarsi antici in utroque sexu simplices, posteriores haud elongati, tibia breviores.

3. A F a m. altera haecce notis supra laudatis discedit, reliqui characteres satis exacte congruunt, oris etiam structura, qua nonnisi palpis maxillaribus paululum magis acuminatis differt. Generi igitur peculiari condendo characteres aegre sufficiant.

* 1. T. silphoides: Niger, nitidus, thoracis limbo, elylrorum vilta submarginali, sutura apiceque pedibusque flavis. - Long. $1 \frac{1}{3} \mathrm{lin}$.

Gyll. Ins. Suec. II. 267. 14. - Sahlb. Ins. Fenn. I. 303. 13. - Munnerh. Brachelytr. 62. 13. - Baisd. et Lacord. Faun. Ent. Paris. I. 513. 11. - Runde Brachelytr. Hal. 26. 6. - Er. Col. March. I. 396. 1.

Staphyl. silphoides Linn. Syst. Nat. I. II. 684. 11. - Goeze Ent. Beitr. I. 719.

10. - De Vill. Ent. I. 414. 11. - Marsh. Ent. Britt. 521. 66.

Oxyporus suturalis Panz. Faun. Germ. 18. 20. Ent. Germ. 360. 7.

T'achinus suturalis Grav. Micr. 144. 15. - Latr. Hist nat. Crust. et Ins. IX. 397. 15.

Tachyporus suturalis Grav. Mon. 13. 22.

Tachinus marginalis Grav. Micr. 192. 4.

Tachyporus marginalis Grav. Mon. 13. 23.

Tachyporus limbatus Grav. Mon. 12. 21. (forte)

St aph. dispar var. ל Payk. Mon. Staph. 79. 54.

Staph. dispar var. E Payk. Faun. Suec, III. 424. 69.

\section{Habitat in Europa et in America septentrionali.}

Statura ommino Tachypori ruficollis, niger, nitidus. Antennae capite thoraceque paulo longiores, apice haud crassiores, articulis $4-10$ subobconicis, crassitie longioribus, ultimo oblongo, apice acuminato, ferrugineae, basi flavo-testaceae. Palpi testacei. Caput magnum, convexum, laevissimum. Thorax coleopterorum latitudine, latitudine dimidio fere brevior, an trorsum parum angustatus, lateribus leviter ratundatus, basi utrinque leviter sinuatus, angulis posterioribus retrorsum leviter prominentibus, subrectis, externe rotundatis, convexus, laevissimus, limbo laterali lato margineque tenui basali et apicali fiavo-testacess. Elytra thorace paulo longiora, modice convexa, angulo apicali exteriore oblique truncato, dense subtilissime punctulata, margine suturali et apicali vittaque submarginali, ian ante flavedinem abrupta, iam cum illa confluente, flavo-testaceis. Abdomen dense subtiliter punctulatum, densius subtilissime pubescens, lateribus et apıce nigro-pilosellum, subtus apice testaceum. Mesosternum subtiliter carinatum. Pedes testacei.

Obs. 1. Elytra signaturis flavis iam angustioribus iam latioribus, ita ut nonnunquam evadant flavo - testacea, macula oblonga submarginali alteraque discoidali nigris, utraque cum nigridine baseos cohaerente.

2. T. marginalis Americanus cum T. silphoide Europaeo exacte convenit. T ach yp. li mbatus Grav., quem solis palpis acuminatis differre affert Grav., neque Tachyporum, neque speciem peculiarem esse mihi persuasum, quamvis a Dejeanio ipso idem Latreillianae collectionis specimen sub genere illo enumeratur.

3. Mas abdominis segmento inferiore quinto apice emarginato a reliquis huius sectionis speciebus discedit. 
* 2. T. pictus: Niger, nitidus, pedibus, ano, thoracis limbo elylvisque flavis, his macula rotundata media nigra. - Long. $1 \frac{1}{3}$ lin

Habitat in Madagascar, Dom. Goudot.

Statura et summa affinitas praecedentis. Antennae capite thoraceque paulo longiores, apice vix crassiores, articulis 3 - 10 subobconicis, crassitie longioribus, ultimo elongato, cylindrico, apice obtuse acuminato, nigrae, articulis duobus primis flavis. Palpi flavi, apice picei. Caput sat magnum, convexum, laevissimum, nigrum, nitidum. Thorax coleopterorum latitudine, latitudine dimidio fere brevior, antrorsum parum angustatus, lateribus modice rotundatus, basi utrinque subsinuatus, angulis posterioribus retrorsum parum prominentibus, rotundatis, modice transversim convexus, laevissimus, nitidissimus, niger, margine anteriore et posteriore tenui limboque laterali lato flavis. Scutellum laeve, nigrum. Elytra thorace paulo longiora, modice convexa, angulo apicali exteriore oblique truncato, parcius subtilissime punctulata, nitida, flava, macula magna ovali media nigra, margine laterali medio infuscato. Abdomen crebre subtiliter punctatum, densius subtilissime pubescens, lateribus et apice parce nigro-pilosellum, nigrum, apice lato testaceo. Pectus nigrum, mesosterno subtiliter carinato. Pedes flavi.

Obs. Differt constanter a praecedente praecipue elytrorum macula media antrorsum haud elongata, basi nigredine nulla tincta, margine laterali medio solummodo infuscato, ano superne et inferne testaceo, elytris parcius punctulatis, thoracis angulis posterioribus paulo magis rotundatis. Sexus differentia omnino ut in illo.

* 3. T. piceus: Leviter convexus, piceus, nilidus, capile, thorace elytrisgue laevissimis, antennarum basi pedibusque testaceis, thoracis margine elytrorumque limbo apicali rufescentibus, his thorace paulo longioribus. - Long. 1 lin.

Habitat in ins. Puerto Rico, Dom. Moritz.

Sequenti affinis, leviter convexus, piceus, nitidus. Antennae capitis thoracisque fere longitudine, apice crassiores, articulis 2 et $\mathbf{3}$ elongatis, longitudine subaequalibus, 5 - 10 praecedentibus distincte crassioribus, aequalibus, transversis, ultimo subgloboso, nigro-piceae, articulis 4 primis dilute testaceis. Caput parum convexum, laevissimum, ors partibus testaceis. Thorax basi coleopterorum basi hand latior, latitudine baseos duplo brevior, basi utrinque late leviterque sinuatus, angulis posterioribus retrorsum parum prominulis, acutiusculis, externe rotundatis, modice convexus, laevissimus, piceus, margine basali lateralique dilutiore. Elytra thorace vix sesqui longiora, apicem versus sensim angustata, angulo apicali exteriore oblique truncato, secundum marginem lateralem profundius impressa, laevissima, margine laterali apicaliyue dilutiore. Abdomen subtiliter punctulatum, tenuiter subtilissime pubescens, apice dilutius. Mesosternum subtiliter carinatum. Pedes rufo-testacei.

* 4. T. cinctellus: Convexiusculus, nigro-piceus, nilidus, capite, thorace elylrisque laevissimis, antennarum busi apiceque pedibusque testaceis, thoracis elylrorumque margine laterali apicaligue piceis, his thorace plus sesqui longioribus. - Long. 1 lin.

Habitat in Brasilia, Dom. Thorey.

Corpus parvum, convexiusculum, piceo-nigrum, nitidum. Antennae 
capitis thoracisque longit:dine, aricem versus sensim suljincrassatae, articulis 2 et 3 leviter elongatis, sequentibus sensim paulo brevioribus et paululum crassioribus, subobconicis, ultimo breviter ovato, apice abrupte acuminato, fusco-nigrae, articulis 4 primis ultimoque testaceis. Caput laevissimun. ore rufo-piceo. Thorax basi coleopterorum basi haud latior, latitudine baseos duplo brevior, antrorsum fortius angustatus, lateribus rotundatis, basi bisinuatus, angulis posterioribus retrorsum leviter prominentibus, latis, rotundatis, convexus, laevissimus, margine laterali basalique indeterminate piceo rufescentibus. Elyira thorace plus sesqui longiora, apicem versus sensim angustata, angulo apicali exteriore oblique truncato, secundnm marginem lateralem leviter impressa, laevissima, apice (ad tertiam elytri partem usque) margineque tenui laterali indeterminate piceo-rufis. Abdomen densius subtilissime pubescens, subtus apice piceum. Mesosterum subtiliter carinatum. Pedes rufo-testacei.

* 5. T. pulchellus: Leviter convexus, nigro-piceus, nitidus, capile thu race elyirisque laevissimis, pedibus, thoracis limbo, elytris postice margineque lalerali piceo-rufis, antennis basi lestaceis. - Long. 1 lin.

Var.: Thorace elytrisque testaceis, illis disco his basi piceis.

Habitat in Puerto Rico et in Columbia, Dom. Moritz.

Praecedentibus sımillimus, modice convexus, nigro-piceus, nitidus. Antennae capitis thoracisque prope longitudine, apice paulo crassiores, ariiculis 2 et 3 elongatis, aequalibus, sequentibus sensim paulo brevioribus et crassioribus, ultimo ovato, apice subacuminato, nigro-piceae, basi testaceae. Palpi rufo-testacei. Caput leviter convexum, laevissimum, ore dilutiore. Thorax basi coleopterorum basi haud latior, latitudine baseos duplo brevior, antrorsum fortiter angustatus, lateribus rotundatus, basi leviter bisinuatus, angulis posterıoribus retrorsum parum prominentibus, rotundatis, modice convexus, limbo basali lateralique iam tenuiore iam latiore piceo-rufo. Elytra thorace sesqui longiora, apicem versus sensim angustata, angulo apicali exteriore oblique truncato, secundum marginem lateralem vix impressa, laevissima, apice lato (ar dimidiam fere elytri partem usque) margineque laterali testaceo-rufis. Abdomen confertim subtiliter punctulatum, dense subtiliter pubescens, apice piceum. Mesosternum subtiliter at acute carinatum. Pedes testacei.

Variat thorace elytrisque testaceis, illo disco, his basi piceis, vel interdum totus testaceus, capite, thoracis disco elytrorumque basi paulo saturatioribus.

* 6. T. nitidulus: Leviter convexus, nigro-piceus, nilidus, capite, thorace ely/risque laevissimis, capite, thorace, pedibus antennisque testaceis, elytris abdomineque apice rufescentibus. - Long. $\frac{3}{4}$ lin.

Habitat in Puerto - Rico, Dom. Noritz.

Habitu omnino praecedentium, at paulo minor. Corpus leviter convexum. Antennae capitis thoracisque prope longitudine, apice paulo crassio res, articulis 2 et 3 elongatis, aequalibus, sequentibus sensim paulo brevioribus et crassioribus, penultimis crassitie sua brevioribus, ultimo breviter acuminato, testaceae, apice fuscae. Caput parum convexum, rufo-testa- 
ceum, lanvissimum. Thorax basi coleopterorum basi haud latior, latitudine baseos duplo brevior, antrorsum fortiter angustatus, lateribus rotundatus, basi vix sinuatus, angulis posterioribus vix prominentibus rntundatis, leviter convexus, laevissimus, rufo-testaceus, nitidus. Scutellum nigro-piceum. Elytra thorace plus sesqui longiora, apicem versus sensim leviter angustata, angulo apicali exteriore obtuso, secundum marginem lateralem leviter impressa, laevissima, nitida, obscure fusco-picea, basi fere nigra, margine laterali apicalique indetermmate testaceo-rufescentibus. Abdomen subtiliter punctulatım, parce subtilissime pubescens, nigro-piceum, apice late testaceorufum. Pectus nigrum, mesostern’s subtiliter carınato. Pedes rufo-testacei.

* 7. T. convexus: Convexus, picen-niger, nilidus, capite thoraceque laevissimis, elytris parce subtilissime punclatis, antennarum basi pedibusgue rufis. - Long. 2 lin.

Habitat tn Brasilia, Dom. Melly.

Corpus convexum, nigro-piceum, nitidum. Antennae capite thoraceque paulo breviores, apice parum crassiores, articulis $\mathbf{2}$ et $\mathbf{3}$ leviter elongatis, sequentibus sensim paululum brevioribus et crassioribus, subobconicis, ultimo ovato, fuscae, articulis tribus primis rufo-testaceis. Caput laevissimum fronte convexiuscula, ore rufo, palpis testaceis. Thorax basi coleopterorum basi latitudine aequalis, latitudine baseos duplo brevior, basi utrinque sinuatus, antrorsum valde angustatus, lateribus fortiter rotundatus, angulis posterioribus postice leviter prominentibus, acutiusculis, acumine rotundato, valde convexus, laevissimus, margine basali lateralique summo piceo - rufescente. Elytra thorace sesqui prope longiora, apicem versus sensim leviter angustata, valde convexa, angulo apicali exteriore obtusiusculo, secundum narginem lateralem haud impressa, convexa, minus dense subtilissime punctata. Abdomen subtiliter punctulatum, parce subtilissime pubescens, piceum, apice segmentorumque singulorum margine postico rufescente. Mesosternum fortiter acuminatum, valde prominens. Pedes rufi.

* 8. T. elatus: Convexus, piceo-niger, nilidus, capile thoraceque laevissimis, hoc lateribus castaneo, elytris parce sublilissime punclatis, ore, antennarum basi pedibusque rufo-teslaceis. - Long. 2 lin.

Habitat Novae Valenciae in Columbia, Dom, Moritz.

Statura et summa similitudo praecedentis, fortius convexus, piceo-niger, nitidus. Antennae capite thoraceque paulo breviores, tenuiores, apice vix incrassatae, articulo tertio secundo paulo longiore, sequentibus sensim paulo brevioribus et paululım crassioribus, subobconicis, ultimo subovato, apice abrupte acuminato, nigrae, articulis tribus primis testaceis. Caput laevissimum, fronte parum convexa, ore testaceo. Thorax basi coleopterorum basi haud, latitudine baseos duplo fere brevior, antrorsum valde angustatus, lateribus fortiter rotundatus, basi utrinque levissime sinuatus, angulis posterioribus retrorsum leviter prominentibus, acutis, sat convexus, laevissimus, nitidus, dorso piceo-niger, margine laterali indeterminate oastaneo. Elytra thorace tertia fere parte longiora, apicem versus sensim leviter angustata, angulo apicali exteriore rotundato, secundum marginem lateralem laud impressa, valde convexa, parcius subtiliter punctata. Abdomen crebre 
subtilius punctulatum, parce subtilissime pubescens, segmentis singulis rufomarginatis. Nesosternum acute carinatum. Pedes rufi.

Obs. T convexo simillimus, at non adeo convexus et antennis in utroque sexu longioribus tenuioribusque, mesosternoque minus prominenter carinato distinctus.

* 9. T. hepalicus: Convexus, piceo-castaneus, nitidus, capite thoraceque laevissimis, elytris vage sublilissime punclatis, antennis basi rufis, apice ferrugineis. - Long. $1 \frac{1}{2}$ lin.

Habitat in Columbia, Dom. Moritz.

T. convexo dimidio minor et paulo minus convexus, piceo-castaneus, nitidus. Antennae capitis thoracisque fere longitudine, apice leviter crassiores, articulo tertio secundo panlulum longiore et tenuiore, $4-10$ sensim paulo brevioribus et crassioribus, subobconicis, ultimo oblongo, praecedentibus ambobus prope-longiore, subcylindrico, apice abrupte acuminato, fuscae, articulis tribus primis rufo-testaceis, ultimo ferrugineo. Palpi rufotestacei. Caput vix convexum, laevissimum, nigrum, ore rufo-piceo. Thorax basi coleopterorum basi vix latior, latitudine duplo brevior, antrorsum fortiter angustatus, lateribus modice rotundatus, basi leviter bisinuatus, angulis posterioribus retrorsum prominentibus, acutiusculis, acumine extrorsum rotundato, modice convexus, laevissimus. Elytra thorace vix tertia parte longiora, apicem versus sensim leviter angustata, angulo apicali exteriore obtuso, subrotundato, modice convexa, minus dense subtilissime punctata. Abdomen subtiliter punctulatum, omnium subtilissime parce pubescens. Mesosternum fortiter acuteque carinatum, modice prominens. Pedes rufotestacei,

* 10. T. brunneus: Convexus, piceus, nitidus, capile thoraceque laevissimis, elytris vage subtilissime punclatis, antennarum basi perlibusque rufis. - Long. $1 \frac{1}{3}$ lin.

Habitat in Columbia, Dom. Moritz.

Praecedenti affunis, at dimidio minor et paulo magis convexus. Antemmae capite thoraceque breviores, tenuiores, apice leviter crassiores, articulo tertio secundo tenuiore at vix breviore, sequentibus sensim paulo brevioribus et crassioribus, ultimo subovato, apice abrupte acuminato, fuscae, articulis tribus primis rufo-testaceis. Palpi rufo-testacei. Caput leviter convexum, laevissimum, nigro-piceum, ore rufo-piceo. Thorax basi coleopterorum basi paulo, latior, latitudine vix duplo brevior, antrorsum fortiter angustatus, lateribus fortius rotundatis, basi utrinque leviter sinuatus, posterioribus retrorsum leviter prominentibus, acutis, externe rotundatis, sat convexus, laevissimus, nitidus, saturate piceo-castaneus, dorso indeterminate piceo-nigro. Scutellum nigro-piceum, nitidum. Elytra thorace tertia fere parte longiora, apicem versus sensim leviter angustata, angulo apicali exteriore obtuso, secundum marginem lateralem vix impressa, convexa, minus confertim subtilissime punctata, saturate fusco-picea, nitida, margine laterali apicalique summo castaneo. Abdomen subtiliter punctulatum, vix perspicue pubescens, piceum, nitidum, subtus apice late rufo-picenm. Mesostermun subtiliter carinatum. Pedes testaceo-rufi. 
Obs. Differt a praecedente statura minore, magis convexa, thorace paulo longiore, convexiore, antemis tenuioribus, apice haud ferrugineis, mesosterno subtiliter carinato, haud prominente.

* 11. T. terminalis: Convexus, nigro-piceus, nitidus, capite thoracegue laevissimis, elytris crebre subliliter punctatis, pedibus antennisque rufis, his upice ferrugineis. - Long. $1 \frac{1}{3}$ lin.

Hahitat in ins. Puerto Rico, Dom. Moritz.

Statura ommino praecedentis. Antennae capitis thoracisque prope longitudine, apice leviter crassiores, articulo tertio secundo paulo longiore et tenuiore, sequentibus sensim paulo brevioribus at vix crassioribus, ultimo praecedentibus ambobus longitudine subaequali, oblongo-ovato, apice abrupte acuminato, piceo-rufae, articulis tribus primis rufo-testaceis, nltimo flavo-testaceo. Palpi rufo-testacei. Caput leviter convexum, laevissimum, piceo-nigrnm, nitidum, ore piceo-subrufo. Thorax basi coleopterorum basi paulo latior, latitudine duplo fere brevior, antrorsum fortiter angustatus, lateribus modice rotundatus, basi utrinque simuatus, angulis posterioribus retrorsum leviter prominentibus, acutiusculis, externe rotundatis, convexus, laevissimus, nigro-piceus, marginibus dilutioribus: Scutellum nigro-piceum. Elytra thorace teria fere parte longiora, apicem versus sensim leviter angustata, angulo apicali exteriore obtuso, secundum marginem lateralem obsolete impressa, convexa, densius subtiliter punctata, nigro-picea, nitida, marginibus dilutioribus, parce subtilissime brevissimeque pubescens. Abdomen parcius subtiliter punctulatum, piceum, subtus apicem versus rufescens. Mesosternum subtiliter carinatum. Pedes testaceo-rufi.

Obs. Praecedentibus admodum affinis, elytris autem crebrius minusque subtiliter punctatis distinctus.

* 12. T. apicalis: Convexiusculus, nigro-piceus, nilidus, capite thoraceque laevissimis, elytris sublilissime punclatis, pedibus antennarumque basi testaceis, his articulo apicali favo. - Long. 1 lin.

Habitat in ins. Puerto Rico, Dom. Moritz.

Statura omnino T. picei et vix paululum maior, praecedente plus dimidio minor, modice convexus, piceo-niger, nitidus. Antennae capite thoraceque paulo breviores, apicem versus sensim levter incrassatae, articulo tertio secundo tenuiore et paulo longiore, sequentibus sensim brevioribus et paulo crassioribus, penultimis transversis, ultimo breviter ovato, apice acuminato, nigrae, ariculis 4 primis testaceis, ultimo flavo. Caput mainsculum, fronte parum convexa, ore dilute testaceo. Thorax basi coleopteris vix latior, latitudine triplo prope brevior, antrorsum fortius angustatus, lateribus leviter rotundatis, basi truncatus, angulis postericribus hand prominulis, acumine summo rotundatis, laevissimus, margine summo laterali brumeo. Elytra thorace duplo prope longiora, apicem versus sensim angustata, angulıs posterioribus obtusiusculis, secundum marginem lateralem haud impressa, omnium subtilissine functulata. Abromen parce omnium subtilissime punctulatum, vix pubescens, apice rufescens. Mesosternum subtiliter carinatum. Pedes dilute tistacei.

Obs. Differt a praecedente statura nulto minore, elytris omnium subtilissime, vix perspicue punctulatis elc. a T. piceo capite maiore, antemarum articulo ultimo flavo, elytris subtilissime punrtulatis. 
* 13. T. humilıs: Parum converus, nigro-piceus, nitidus, capite thoraceque laevissimis, ely/iis subtilissime punctulatis, ore testaceo, antennarum basi pedibusque rufis, - Long. $1 \frac{1}{3}$ lin.

Habitat in Brasilia, Dom. Prof. Germar.

Corpus leviter convexum, nigro-piceum, nitidum. Antennae capitis thoracisque longitudine, crassiusculae, apice sensim crassiores, articnlo tertio secundo evidenter longıre, sequentibus sensim paulo brevioribus at vix crassioribus, ultimo oblongo, praecedentibus ambobus longitudine aequali, apıce sat fortiter acuminato, fuscae, articulis tribus primis rufis. Caput parum convexum, laevissimum, ore testaceo. Thorax basi coleo teris parum latior, latitudine plus duplo brevior, antrorsum fortiter angi:stat:s, lateribus modice rotundatus, basi utrinque vix sinuatus, angulis posterioribus retrorsum haud prominulis, acumine summo rotundatis, leviter transversim convexus, laevissimus, nigro-picens, marginibus dilutioribus. Elytra thorace duplo prope longiora, apicem versus sensim leviter angustata, angulo apicali exteriore obtusiusculo, secundum marginem lateralem canaliculata, subtilissime punctulata. Abdomen subtilissime punctulatum, vage tenuissime subtilissimeque pubescens. Pedes testaceo-rufi.

Obs. Distinctus a praecedentibus statura minus convexa thoraceque breviore, basi vix sinuato, angulis posterioribus postice haud prominentibus.

14. T. brevicollis: Subdepressus, nigro-piceus, nitidus, capite thoraceque laevissimis, elytris omnium subtilissime punctulatis, abdomine evidentius punctalo, antennarum basi pedibusque testaceis. - Long. $1 \frac{1}{3}$ lin.

Habitat Novae Valenciae in Columbia, Dom. Moritz.

Statura et summa affinitas praecedentis, perparum convexus; nigro-piceus, nitidus. Antennae capitis thoracisque prope longitudine, apicem versus leviter incrassatae, articulo tertio secundo paululum longiore, $4-10$ sensim paulo brevioribus at vix crassioribus, ultimo ovato, apice abrupte acuminato, nigrae, articulis tribus primis testaceis. Oris partes testaceae. Caput laevissimum, fronte parum convexa. Thorax basi coleopteris parum latior, latitudine baseos triplo fere brevior, antrorsum fortiter angustatus, lateribus leviter rotundatus, basi utrinque subsinuatus, angulis posterioribus retrorsum prominentibus, externe rotundatis, leviter transversim convexus, laevissimus, nigro-piceus, marginibus rufescentibus. Elytra thorace plus sesqui longıora, apicem versus sensim leviter attenuata, angulo apicali exteriore obtusiusculo, secundum marginem lateralem canaliculata, subtilissime parcius punctulata. Abdomen crebre distincteque licet sat subtiliter punctulatum, tenuissime subtilissimeque pubescens, apice piceo-testaceum. Mesosternum subtiliter carinatum. Pedes rufo-testacei. differt.

Obs. T. humili proximus, abdomine autem crebre evidenter punctato satis

* 15. T. depressus: Subdepressus, niger, nilidus, capite, thorace elytrisque confertim subliliter punctatis, his piceo-castaneis, antennarum basi pedibusque testaceis. - Long. $1 \frac{3}{4}$ lin.

Habitat in Columbia, Dom. Moritz.

Corpus parum convexum, nigrum, nitidum. Antennae capite thoraceque paulo longiores, apice vix crassiores, articulo secundo tertioque aequalibus, 
sequentibus sensim paulo brevioribus, at vix crassioribus, ultimo oblongo. ovato, apice abrupte acuminato, fusco-nigrae, articulo primo toto, secundo tertioque basi testaceis. Palpi testacei. Caput parum convexum, subtilissime punctulatum. Thorax basi coleopterorum basi vix latior, latitudine plus duplo brevior, antrorsum fortiter angustatus, lateribus leviter rotundatus, basi utrinque leviter sinuatus, angulis posterıoribus retrorsum modice prominentibus, acutiusculis, externe rotundatis, parum convexus vel subdepressus, confertim subtiliter punctulatus, margine postico piceo-pellucente. Ely. tra thorace sesqui longiora, apicem versus sensim subangustata, angulo apicali exteriore oblique truncato, subdepressa, secundum marginem lateralem longitudinaliter leviter impressa, confertim subtiliter punctulata, piceo-castanea, nitida, lateribus nigra. Abdomen crebre subtiliter punctatum, tenuissime subtilissimeque pubescens, segmentis ultimis duobus apice piceo-castaneis. Mesosternum subtiliter carinatum. Pedes rufo-testacei.

* 16. T. melanarius: Parum convexus, niger, nilidus, antennarum basi pedibusque rufo-piceis, capile thoraceque subtilissime punclulalis, elytris conferlim subtiliter punctatis. - Long. 1 lin.

Habitat in Bengala, Dom. Hope.

T. gibbulo minor et multo minus convexus, fere subdepressus, niger, nitidus. Antennae capitis thoracisque prope longitudine, apice vix crassiores, articulo secundo tertioque aequalibus, obconicis, sequentibus inter se subaequalibus, leviter compressis, ultimo paulo maiore, subovato, compresso, apice abrupte acuminato, nigricantes, basi piceae. Caput parum convexum, subtilissime punctulatum, oris partibus piceis. Thorax basi coleopterorum basi latitudine aequalis, apice duplo angustior, latitudine baseos duplo brevior, lateribus sat fortiter rotundatus, basi leviter bisinuatus, angulis posterioribus retrorsum leviter prominentibus, acutis, leviter transversim convexus, subtilissime punctulatus, margine baseos summo rufescente. Scutellnm subtiliter punctulatum. Elytra thorace plus sesqui longiora, apicem versus sensim subangustata, angulo apicali exteriore oblique truncato, parum convexa, ngra, nitida, confertim subtiliter punctata, secundìm marginem lateràlem canaliculata, margine apicali summo piceo-rufescente. Abdomen crebre subtiliter punctulatum, segmentis anterioribus apice piceo-marginatis, subtus apice rufo-piceum. Pedes rufo-picei.

* 17. T. gibbulus: Convexus, piceo-niger, nitidus, capile thoraceque laevissimis, elytris conferlim subtiliter punctatis, ore antennis pedibusque rufis. - Long. $1 \frac{1}{3}$ lin.

Ilabitat in America septentrionali, Dom. Zimmermann. Nonine 'T achypori gibbuli etiam a Com. Dejean communicatus.

Corpus convexum, nigrum, nitidum. Antennae capitis thoracisque prope longitudine, apice sensim crassiores, articulo tertio secundo tenuiore et prope breviore, 3-5 obconicis, sensim brevioribus et crassiorihus, 6-10 sensim magis transversis, ultimo breviter ovato, apice acmminato, totae rufae. Caput leviter convesum, laevissimum, ore cum palpis rufo-testaceo. Thorax basi coleopterorum basi parum latior, latitudine duplo brevior, antrorsum fortiler angustatus, lateribus fortiter rotundatus, basi ntrinque leviter sinuatus, 
angulis posterioribus retrorsum modice prominentibus, acutiusculis, externe rotindatis, fortirs convexus, laevissmus, margine postico lateralique piceopellucente. Elytra thorace sesqui longiora, apicem versus sensim subangustata, angulo apicali exteriore subrecto, secundum marginem lateralem longitudinaliter modice impressa, crebrius subtiliter puncrata, margine laterali et apicali indeterminate rufo-piceis. Abdomen subtilissime punctulatum, vix pubescens, segmentis singulis margine apicali piceo. Pedes testaceo-rufi.

* 18. Trutilus: Leviter convexus, rufus, nilidus, capile thoraceque laevissimis, elylris parcius subtiliter punctatis. - Long. $1 \frac{1}{3}$ lin.

Hahitat in Americae ins. Puerto Rico et St. Thomae, in Columbia, Dom. Moritz.

Statura ommino T. gibbuli, totus testaceo-rufus, nitidus. Antennae capitis thoracisque prope longitudine, apicem versus leniter crassiores, articulo tertio secundo tenniore et paulo breviore, 4-10 sensim paulo brevioribus et crassioribus, subobconicis, ultimo crassiore, subovato, apice abrupte acuminato, testaceo, medio fuscescentes. Caput laevissimum. Thorax basi coleopteris paulo latior, latitudine duplo brevior, antrorsum fortiter angustatus, lateribus modice rotundatus, utrinque leviter sinuatus, angulis posterioribus retrorsum leviter prominentibus, rotundatis, satis convexus, laevissimus. Elytra thorace sesqui longiora, apicem versus sensim leviter angustata, angulo apicali exteriore obtusiusculo, secundum marginem lateralem medio impressa, parcius subtiliter obsoleteque punctata. Abdomen subtiliter punctulatum, tenuissime subtilissimeque pubescens. Mesosternum subtiliter carinatum. Pedes rufo-testacei.

\section{Fam. II.}

Mesosternum simplex.

Tursi antici maris dilatati.

Corpus plerumque maius, magis oblongum et minus convexum. Palpi maxillares articulo ultimo subcylindrico, apice acuminato, saepius penultimo duplo longiore. Mesosternum simplex. Tarsi posteriores articulis duobus primis subaequalibus.

Mas tarsis anticis articulis 3 primis dilatatis, abdominis segmento superiore sexto apice 4 -dentato, inferiore incisione profunda bifido, lobis acuminatis, saepius compressis, septimo conspicuo, quinto inferiore apice magis minusve emarginato.

F emin a tarsis anticis simplicibus, abdominis segmento sexto superiore vel trifido vel quadrifido, laciniis lateralibus profundius divisis, inferiore apice 6 -fido, laciniis intermediis duabus obtusioribus, apice setulis rigidis fulvis ciliatis, reliquis acuminatis, lateralibus brevioribus, nisı segmento fortiter exserto observandis, intermediis 4 longitudine subaequalibus.

o b s e r v a t i o n e s.

1. Caput, thorax et elytra magis minusve subtiliter, saepius subtilissime punctata, interstitiis nonnunquam omnium subtilissime alutaceis, glaberrima, abdomen omnium subtilissime tenuissimeque pubescens, pube omnium brevissima, apice vix unquam pilosellum. Scutellum mediocre. Elytra lateribus subtiliter marginata, angulo apicali exteriore subrotundato. 
2. Dom. Prof. Gravenhorst primo secundum palporum structuram Tachinum a Tachyporo distiuxit, dein corporis habitum magis respiciens, B ol et ob ium et Mycetoporum sub hoc nomine coniunxit, quod auctores recentiores generi nostri restituerunt. Habitu generali, coxarum posticarum et ligulae figura magis ad Tachyporum accedit, palporum autem et tarsorum structura facile distinguitur.

3. Victus plerisque in fimo. Europae et Americae septentrionalis regionibus temperatis et frigidis huius sectiones species propriae videntur, intra tropos etiam in Europa australi vix obviae.

* 19. T. rufipes: Convexus, piceo-niger, nitidus, antennarum basi pedibusque rufis, elylris thorace sesqui longioribus, puncto humerali margineque apicali picescentibus. - Long. 3 lin.

Er. Col. March I. 397. 2.

Staphyl rufipes Degeer Ins. IV. 24. 11. t. 1. f. 14. - Fab. Syst. Ent. 267. 17. Spec. Ins. I. 337. 22. Mant. Ins. 222. 31. - Payk. Mon. Staph. 75. 53. Faun.

Suec. III. 418. 65. - Walk. Faun. Paris. I. 273. 20.

St aph. rufipes Schrank Fauna Boica I. 644. 874. (forte)

Oxурогиs rufipes Fab. Ent. Syst. 1. II. 235. 21. Syst. El. II. 607. 21. - Cederh. Faun. Ingr. 121. 372. - Panz. Ent. Germ. 361. 16.

Ox yporus rufipes Pauz. Faun. Germ. 27. 20. (male)

Tachinus pullus Grav. Micr. 140. 6. - Latr. Hist. nat. Crust. et Ins. IX. 395. 6. - Gyll. Ins. Suec. I1. 262. 10. IV. 472. 10. - Zetterst. Faun. Lappon. I. 62. 4. Ins. Lappon. 57. 4. - Suhlb. Ins. Fenn. I. 299. 8. - Mannerh. Brachelytr. 61. 8.

Tachyporus pullus Grav. Mon. 16. 30.

Tachinus signatus Grav. Micr. 139. 5. - Latr. Hist. nat. Crust. et Ins. IX. 395. 5. - Boisd. et Lacord. Faun. Ent. Paris. I. 508. 3.

Tachyporus signatus Grav. Mon. 17. 32.

Var. a: Thoracis limbo laterali elytrisque castaneo-testaceis, his dorso subinfuscatis. (Minus malurus.)

Tachinus laticollis Gyll. Ins. Suec. IV. 471. 5-6. - Sahlb. Ins. Fenn. 297. 4. - Mannerh. Brachelytr. 61. 5. (forte.)

Var. b: Rufo-testaceus, capite thoracisque disco fusco-piceis. (Immaturus.)

Tuchinus pallens Gyll. Ins. Suec. II. 259. 7. - Sahlb. Ins. Fenn. I. 298. 6.

Habitat in Europa.

Piceo-niger, nitidus. Antennae capite thoraceque paulo longiores, graciles, apice vix crassiores, articulo tertio secundo paululum longiore, $5-10$ elongato-obconicss, subaequalibus, ultimo oblongo-ovato, subacuminato, apice compresso, nigri-picei, articulo primo rufo-testaceo, sequentibus tribus rufo-piceis. Palpi rufo-picei. Caput convexum, omnium subtilissime punctulatum, ore concolore. Thorax coleopteris latior, latitudine baseos quarta parte brevior, antrorsum modice angustatus, apice profundius emarginatus, lateribus'fortiter rotundatus, basi truncatus, angulis anterioribus modice prominentibus posterioribusque obtusis, subrotundatis, convexus, omnium subtilissime punctulatus, niger, nitidus, margine summo laterali saepe piceo. Scutellum parce punctatum, nigrum. Elytra thorace vix sesqui longiora, confertissime subtilissimeque alutaceo-strigosa, subtihter vage punctulata, nigropicea, puncto humerali margineque summo apicali dilutioribus. Abdomen distinctius licet subtiliter crebrius punctatum, pube brevissima subtilissimaque 
adspersum, nigrum, segmentis singulis margine summo apicali rufo-piceó. Pedes rufi.

Mas abdominis segmento superiore sexto quadridentato, dentibus acutis, fere spiniformibus, intermediis magis prominentibus, segmentis inferioribus 3 -5 subimpressis, quinto apice leviter triangulariter emarginato, margine intra sinum spongioso, sexto bifido, laciniis vix elongatis, compressis, leviter curvatis, acuminatis.

Femin a abdominis segmento superiore sexto trifido, laciniis intermediis longioribus, spiniformibus, intermedio lato apice lanceolato-acuminato.

Obs. T. pallens Gyllenh. secundum exemplum a Dom. Schüppel communicatum, ab autore ipso missum, ad T. humeral em quidem pertineat, licet speciminibus genuinis minor, descriptio Gyllenhali autem potius huic speciei adaptanda mihi videtur, praecipue ob caput et thoracem multo subtilius punctata.

* 20. T. flavipes: Piceo-niger, pedibus elylrisque brunneo-ferrugineis, his thorace sesqui longioribus, dorso plerumque infuscatis, antennis basi nigricantibus. - Long. 3 lin.

Er. Col. March. I. 398. 3.

Oxyporus flavipes Fab. Syst. Ent. 268. 3. Spec. Ins. I. 339. 5. Mant. Ins. I. 222. 6. Ent. Syst. I. II. 534. 14. Syst. El. II. 606. 13. - Panz. Ent. Germ. 360. 11. St aphyl rufipes Marsh. Ent. Britt. 518. 60.

Tachinus rufipes Grav. Micr. 137. 4. - Latr. Hist. nat. Crust et Ins. IX. 294. 4. Gen. Crust. et Ins. I. 299. 1. - Gyll. Ins. Suec. II. 260. 9. - Zetterst. Faun. Lappon. I. 62. 3. Ins. Lappon. 57. 3. - Sahlb. Ius. Fent. I. 298. 7. Mannerh. Brachelytr. 61. 7. - Boisd. et Lacord. Paun. Ent. Paris. I. 507. 2. Runde Brachelytr. Hal. 26. 3.

Tachyporus rufipes Grav. Mon. 17. 15.

Var. Thoracis limbo laterali latiore castaneo-testaceo.

Tachinus castaneus Grav. Micr. 140. 7. - Latr. Hist. nat. Crust. et Ins. IX. 395. 7.

Tachyporus fimetarius var. Grav. Mon. p. 15.

Tachypurus rufipes? Grav. Mon. p. 18.

Tachinus dubius Gyll. Ins. Suec. II. 258. 6. - Sahlb. Ins. Fenn. I. 298. 5. Mannerh Brachelytr. 61. 6. - Runde Brachelytr. Hal. 25. 2.

Habitat in Europa.

Statura fere T. rufipedis, at minus convexus. Antennae capitis thoracisque longitudine, apice paulo crassiores, articulo tertio secundo paulo longiore, 5-10 subobconicis, sensim paululum brevioribus, penultimis crassitie subbreviorıbus, ultimo breviter ovato, apice compresso, piceae, basi nigricantes. Palpi nigro-picei. Caput confertim subtiliter punctulatum, nigrum, ore concolore. Thorax coleopteris vix latior, latitudine baseos tertia parte brevior, antrorsum leviter angustatus, apice late et parum profunde emarglnatus, basi truncatus, angulis anterioribus leviter prommentibus posterioribusque rotundatis, parum convexus, confertim subtiliter punctatus, nitidus, niger, limbo tenui basali lateralique testaceo. Scutellum piceum, subtiliter punctulatum. Elytra thorace plus sesqui longiora, confertim subtiliter punctata, castaneo-testacea, dorso magis minusve infuscato, praecipue in femina. Abdomen minus confertim subtiliter punctatum, pube brevissima subtilissimaque adspersum, nigrum, nitidum, segmentis singulis margine summo apicali 
piceo-tastaceo. Pectus nigrum. Pedes rufo-testacei, femoribus basi nonnunquam picescentibus.

Mas abdominis segmento superiore sexto quadridentato, dentibus acutiusculis, intermediis multo magis prominentibus; segmento inferiore quinto apice leviter emarginato, margine intra sinum spongioso, sexto profunde inciso, laciniis triangularibus, acuminatis.

F e m in a abdominis segmento superiore sexto trifido, laciniis longitudine aequalibus, lateralibus spiniformibus, intermedia latiore, sensim angustata, acute acuminata.

Variat thoracis limbo laterali latius testaceo, elytris dorso haud aut parum infuscatis. Feminae semper obscuriores.

Obs. 1. Differt a T. rufipede antennis basi nigricantibus, statura minus conrexa, capite, thorace elytrisque distinctius punctatis.

2. Tachinus intricatus Sahlb. Ins. Femn. I. 300. 9. absque dubio ad hanc speciem pertinet: elytrorum sculptura "punctis in lineolas confuse intricatas aliquatenus ordinatis" certe fortuita.

* 21. T. frigidus: Niger, nitidus, antennarum basi, palpis, pedibus thoracisque limbo laterali rufo-ferrugineis, elytris thorace sesqui longioribus, piceis, punclo humerali margineque apicali ferrugineis. - Long. $2 \frac{1}{2}$ lin.

Habitat in ins. Unalaschka, Dom. v. Chamisso.

Niger, nitidus. Antennae capitis thoracisque longitudine, apicem versus sensim leviter incrassatae, articulo tertio secundo paulo longiore, 5-10 subobconicis, sensim paulo brevioribus et crassioribus, ultimo ovali, acuminato. apice compresso, fuscae, basi rufae, articulo primo dilutiore. Palpi toti rufo-testacei. Caput subtiliter punctulatum. Thorax coleopterorum latitudine, latitudine baseos dimidio brevior, antrorsum leviter angustatus, apice profundius emarginatus, lateribus rotundatus, basi truncatus, angulis anterioribus leviter prominentibus posterioribusque subrotundatis, modice convexus, confertim subtiliter punctatus, margine postico tenui lateralique latiore testaceo. Scutellum subtilissime punctulatum, nigrum. Elytra thorace sesqui longiora, dense subtilius punctata, vel nigro-vel rufo-picea, puncto humerali margineque apicali ferrugineis. Abdomen distinctius punctatum, pube parca subtilissima brevissimaque adspersum, ano subtus rufo-piceo. Pedes testacei.

Mas abdominis segmento superiore sexto quadridentato, dentibus acutiusculis, intermediis fortiter prominentibus; segmentis inferioribus $3 \mathbf{- 5}$ subimpressıs, quinto apice leviter emarginato, margine intra sinum spongioso, sexto bifido, laciniis minus elongatis, compressis, modice curvatis, acuminatis.

Femina latet.

Obs. Affinis T. pallipedi, rufipedi et flavipedi, ab hoc antennis basi rufis, ab illis statura minus convexa et capite thoraceque crebre evidentius punctatis distinctus.

* 22. T. humeralis: Niger, nitidus, antennarum basi, pedibus thoracisque limbo rufo-ferrugineis, elytris thorace plus sesqui longioribus, rufoferrugineis, dorso magis minusve fuscescentibus. - Long. $3 \frac{1}{3}$ lin.

Grav. Mier. 130. 3. var. 2. 3. - Latr. Hist, nat. Crust. et Ins. IX. 394. 3. 
- Zetterst. Faun. Lappon. I. 62. 2. Ins, Lappon. 56. 2. - Sahlb. Ins. Fenn. I. 296. 3. - Mannerh. Bra,helytr. 61. 4. - Boisd. et Lacord. Faun. Ent. Paris. I. 507. 1. - Runde Brachelytr. Hal. 25. J.

Tachyporus humeralis Grav. Mon. 19. 36.

Tachinus humeralis var. b Gyll. Ins. Suec. II. 257. 5.

Staphyl. cinctus Marsh. Ent. Britt. 519. 61.

Habitat in Europa.

T. rufipede maior, latior et minus convexus. Antennae capite thoraceque paulo longiores, apice parum crassiores, articulo tertio secundo paulo longiore, 5-10 aequalibus, obconicis, ultimo fusiformi, nigro-fuscae, bası rufae. Palpi rufi. Caput crebre subtiliter punctatum, nigrum, nitidum. Thorax coleopteris vix latior, latitudine baseos dimidio brevior, antrorsum modice angustatus, apice minus profunde emarginatus, lateribus rotundatus, basi utrinque subsinuatus, angulis anterioribus leviter prominentibus posterioribusque subrotundatis, leviter convexus, crebre subtiliter punctatus, nitidus, disco nigro, limbo antico posticoque angustioribus lateralique latiore rufoferrugineis. Elytra thorace duplo prope longiora, confertim subtiliter punctata, nitidula, ferruginea, dorso magis minusve infuscata. $\Lambda$ bdomen crebre distinctius punctatum, pube subtilissima brevissimaque parcius adspersum, nigrum, nitidum, segmentis singulis margine postico piceo. Pectus nigrum, nitidum. Pedes dilute rufi.

Mas abdominis segmento superiore sexto quadridentato, dentibus omnibus obtusis, subrotundatis, intermediis magis prominentibus; segmento inferiore quinto medio late impresso, apice emarginato, margine intra sinum retuso et spongioso, sexto bifido, laciniis modice elongatis, compressis, acuminatis, parum curvatis.

F emina abdominis segmento superiore sexto trifido, laciniis lateralibus paulo longioribus, spiniformibus, intermedia lata, apice triangulariter acuminata.

* 23 T. picipes: Piceo-niger, nitidus, ore antennarumque basi rufis, pedibus piceis, elylris thorace sesqui longioribus. - Long. $3 \frac{1}{2}$ lin.

Habitat in America septentrionali, Dom. Zimmermann.

Habitu omnino T. rufipedis, at duplo maior, T. finbriati minoribus individuis aequalis, piceo-niger, nitidus, capite, thorace, scutello elytrisque omnium confertissime subtilissimeque alutaceo-strigosis. Antennae capite thoraceque paulo breviores, crassiusculae, articulo tertio secundo duplo prope longiore, 5 - 10 crassioribus, crassitie aequalibus, sensim paulo brevioribus, penultimis fere transversis, ultimo ovato, apice compresso, nigrae, articulis 4 primis rufis, ultimo ferrugineo. Caput subtilissime punctulatum, ore rufo. Thorax coleopterorum latitudine, latitudine baseos tertia parte brevior, antrorsum modice angustatus, apice minus profunde emarginatus, lateribus modice rotundatus, basi utrinque leviter sinuatus, angulis anterioribus leviter prominentibus, subrotundatis, posterioribus subrectis, modice convexus, minus confertim subtilissime punctulatus, margines versus nonnunquam picescens. Scutellum piceum, laeve. Elytra thorace plus sesqui longiora, vage subtiliter punctata. Abdomen crebre subtiliter punctatum. Pedes picei, antici rufescentes, posteriores nigricantes. 
Mas abdominis segmento superiore sexto quadridentato, dentibus lateralibus obtusiusculis, intermediis parum magis prominentbus, acutis; segmento inferiore quinto late at parum profunde triangulariter impresso, apice emarginato et utrinque obtuse bidentato, sexto bifido, laciniis modice elongatis, gracilioribus, compressis, leviter curvatis, acuminatis.

Femina abdominis segmento superiore sexto quadrifido, laciniis longitudine aequalibus, acuminatis, intermediis vix ad segmenti medium usque divisis.

Variat immaturus corpore testaceo, capite obscuriore.

* 24. T. memnonius: Nigro-piceus, opacus, ore, antennarum basi pedibusque rufis, thoracis limbo elytrorumque puncto humerali rufo-piceis, his thorace plus sesqui longioribus. - Long. 3 lin.

Tachinus memnonius Grav. Micr. 192. 3. (Mas)

Tachyporus memnonius Grav. Mom. 17. 31.

Tachinus batychrous Grav. Micr. 191. 1. (Fem.)

Tachyporus batychrous Grav. Mon. 20. 37.

Habitat in America septentrionali.

Statura omnino T. flavipedis, nigro- aut fusco-piceus, opacus, capite, thorace, scutello elytrisque omnium confertissime subtilissimeque alutaceostrigosis. Antennae captis thoracisque prope longitudine, extrorsum paululum crassiores, articulo tertio secundo paulo longiore, 5-10 longitudine subaequalibus, at sensim paululum crassioribus, obconicis, ultimo subovato, apice acuminato, fuscae, articulis 4 primis rufis. Caput impunctatum, nigrum, ore late rufo. Thorax coleopteris vix latior, latitudine baseos dimidio brevior, antrorsum modice angustatus, apice leviter emarginatus, lateribus rotundatus, basi truncatus, angulis anterioribus leviter prominentibus, rotundatis, posterioribus obtusis, subrotundatis, parum convexus, parce obsoleteque subtilissime punctatus, margine omni piceo-rufescente. Elytra thorace duplo prope Iongiora, subtilissime vage punctata, opaca, macula maiore minoreve humerali, saepe obsoleta, margineque summo apicali rufo-piceis. Abdomen distinctius crebre punctatum, parce subtilissime brevissimeque pubescens, seginentis singulis margine postico piceo-rufescente. Pedes testaceo-rufi.

Mas abdominis segmento superiore sexto acute quadridentato, dentibus intermediis longioribus et magis prominentibus; segmento inferiore quinto late triangulariter impresso, impressione spongiosa, apice late profundius emarginato, intra sinum utrinque setis rigidis densis vel contiguis, deorsum curvatis, ciliato, sexto bifido, laciniis elongatis, validis, compressis, curvatis, acuminatis.

Femin a abdominis segmento superiore sexto trifido, laciniis lateralibus paulo longioribus, linearibus, intermedia latiore, canaliculata, apice blfida, laciniis valde acuminatis.

* 25. T. fimbrialus: Niger, nitidus, pedibus piceis, ore antennarumque basi rufis, elytris substrialo-punctalis, castaneis, apice nigro-marginatis. - Long. 4 lin.

Grav. Micr. 191: 2. - Mannerh. Brachelytr. 60. 1.

Tachyporus fimbriatus Grav. Mon, 17. 34. 
Habitat in America septentrionali.

Habitu omnino T. humeralis, at duplo maior, niger, nitidus. Antennae capitis thoracisque prope longitudine, articulo tertio secundo plus sesqui longiore, 5-10 aequalibus, subobconicis, crassitie hand brevioribus, ultimo subovato, apice compresso, nigricantes, articulis 4 primis rufis, ultimo apice ferrugineo. Caput subtiliter punctulatum, interstitiis confertissime subtiliter alutaceis, ore rufo, mandibulis piceis. Thorax coleoptera latitudine vix superans, latitudine baseos tertia parte brevior, antrorsum leviter angustatus, basi leviter emarginatus, lateribus modice rotundatus, basi utrinque leviter sinuatus, angulis anterioribus parum antrorsum prominentibus posterioribusque obtusis, modice convexus, confertissime subtilissimeque alutaceus, vage subtilissime obsoleteque punctulatus. Elytra thorace sesqui longiora, subtilissime confertissimeque alutacea, distincte subseriatim punctata, dilute castanea, nitida, margine apicali nigricante. Abdomen crebre distinctius punctatum. Pedes rufo-picei, femoribus obscurioribus.

Mas abdominis segmento superiore sexto quadridentato, dentibus oninibus acutis, intermedis magis prominentibus segmento inferiore quinto apice profundius emarginato, sexto bifido, laciniis longioribus, validis, compressis, parum curvatis, acuminatis.

F emina abdominis segmento superiore sexto trifido, laciniis lateralibus spiniformibus, intermedia his breviore, apice acute emarginata, bicuspi.

Variat minus maturus thoracis margine laterali rufescente, elytris apice concoloribus, vel totus dilute castaneus, fronte nigricante.

* 26. T. sublerraneus: Niger, nilidus, antennarum basi ely/rorumque macula humerali oblonga rufo-testaceis, pedibus piceis. - Long. 3 lin.

Grav. Micr. 135. 1. - Latr. Hist. nat. Crust. et Ins. IX. 393. 1. - Gyll. Ins. Suec. II. 252. 2. - Sahlb. Ins. Fenn. I. 295. 1. - Mannerh. Brachelytr. 60. 2. - Boisd. et Lacord. Faun. Ent. Puris, I. 510. 6.

Staph. subterraneus Linn. Faun. Suec. n. 849. Syst. Nat. I II. 684. 12. - Mïll. Prodr. 98. 1111. - Goeze Ent. Beitr. I. 719. 12. - De Vill. Ent. I. 414. 12. Payk. Mon. Staph. 73. 52. Faun. Suec. I1I. 420. 66. - Marsh. Ent. Britt 518. 59. Oxyporus subterraneus Fab. Ent. Syst. I. II. 532. 4. Syst, El. II, 605. 4. Tachyporus subterraneus Grav. Mon. 21.40.

Var. Thoracis lateribus elytrisque rufo-testaceis, his sutura margineque upicali nigris.

Oxyporus marginat "s Fab. Ent. Syst. I. II. 532. 6. Syst. EI. II. 605. 6.

Tachinus marginatus Gyll. Ins. Suec. II. 255. 4.

Tachyporus bicolor Grav. Mon. 17. 33.

Tuchinus biplagiatus Boisd. et Lacord. Faun. Ent. Paris. I 511. 7.

Staphyl. lat us Marsh. Ent. Britt. 524. 76.

Habitat in Europa.

Corpus parum convexum, nigrum, nitidum. Antennae capitis thoracisque longitudine, articulo secundo tertioque subaequalibus, 5-10 subobconicis, inter se aequalibus, ultimo oblongo-ovato, cinereo-pubescentes, nigricantes, articulis 4 primis rufo-testaceis, glabris. Palpi rufo-picei. Caput crebre subtiliter punctulatum, ore concolore. Thorax basi coleopterorum latitudine, latitudine baseos dimidıo brevior, antrorsum leviter angustatus, 
apice profundius emarginatus, angulis anterioribus subrotundatis, lateribus rotundatus, basi recte truncatus, angulis posterioribus obtusiusculis, leviter convexus, subtilissime alutaceus, crebre subtiltter punctulatus, margine laterali saepe rufescente. Elytra thorace duplo longiora, subtilissime alutacea, subtiliter punctulata, macula magna oblonga, prope marginem exteriorem ab humero ultra medium descendente, satis determinata, rufo-testacea. Abdomen crebre profundius punctulatum, segmentis singulis margine apicali rufo-piceis. Pedes iam rufo-, iam fusco-picei.

Mas abdominis segmento superiore sexto apice quadridentato, dentibus ommibus obtusis, intermediis magis prominentibus; segmento inferiore quinto apice emarginato, utrinque spina valida, apice bifida, lacinia interiore muricata, armato, intra sinum late impresso, sexto bifido, laciniis validis, compressis, deorsum curvatis, acuminatis.

Femina abdominis segmento superiore sexto apice quadrifido, laciniis lateralibus validis, linearibus, intermediis his multo brevioribus et tenuioribus, spiniformibus.

Variat elytrorum macula dilatata: nomnunquam elytra tota rufo-testacea, sutura margineque laterali exceptis.

* 27. T. bipustulatus: Nigro-piceus, antennis, pedibus, thoracis limbo maculaque transversali baseos elytrorum rufis. - Long. 3 lin.

Grav. Micr. 135. 2. - Latr. Hist. nat. Crust. et Ins. IX. 394. 2. - Gyll. Ins. Suec. II. 254. 3. - Mannerh. Brachelytr. 61. 3.

Oxyporus bipustalatus Fab. Ent. Syst. I. II. 533. 9. Syst. El. II. 606. 9. -

Panz Faun. Germ. 16. 21. Ent. Germ. 369. 5. - Cederh. Faun. Ingr. 120. 370.

Tachyporus bipustulatus Grav. Mon. 21. 39.

Staph. subterraneus var. Payk. Faun. Suec. III. 420. 66. not,

Habitat in Europa.

Corpus modice convexum, nigro-piceum, nitidum. Antennae capite thoraceque breviores, extrorsum crassiores, articulo tertio secundo paulo longiore, articulis $5-10$ sensim paululum brevioribus, ultino ovato, compresso, totae rufae. Palpi rufi. Caput subtilissime punctulatum, fronte utrinque leviter impressa, nigrum, ore concolore. Thorax basi coleoptera latitudine vix superans, latitudine baseos paulo brevior, apice emarginatus, lateribus rotundatus, basi utrinque subsinuatus, angulis anterioribus antrorsum leviter prominentibus posterioribustue rotundatis, modice convexus, omnium subtilissime confertissimeque alutaceus, crebre subtilissime punctulatus, nigro-piceus, limbo omni indeterminate rufescente. Elytra thorace plus sesqu longiora, confertissime subtilissimeque alutacea, crehre subtiliter punctata, nigro-picea, macula magna basali transversa indeterminata rufa. Abdomen distinctius crebreque punctatum, pube subtili brevissima cinerea adspersum, segmentis ommibus margine postico rufo-piceis. Pedes rufi.

Mas abdominis segmento superiore sexto quadridentato, dentibus acutiusculis, intermediis multo magis prominentibus: segmento mferiore quinto apice late profundius emarginato, sexto bifido, laciniis breviusculis, validis, compressis, leviter curvatis, acutiusculis.

Femina abdominis segmento superiore sexto qradrifido, laciniis late- 
ralibus validioribus, linearibus, intermediis his parum brevioribus, tenuibus, spiniformibus, acutis, inter se ad segmenti medium usque divisis.

Obs. Oxyporum bipustulatum Fab. potius ad Conurum bipustulatum quam ad hanc speciem pertinere autumat Gyllenhal. (Ins. Suec. II. p. 225.) Equidem autem insectum modo descriptum sub hoc nomine in collectione Fabri. ciana vidi, quare hoc synonymum indubie attuli.

*28. T. pallipes: Niger, nilidus, antennarum basi, pedibus thoracisque limbo laterali rufo ferrugineis, elylris thorace paulo longioribus, nigropiceis, puncto humerali margineque apicali rufescentibus. - Long. 3 lin.

Boisd. et Lacord. Faun. Ent. Paris. I. 508. 4.

Tachyporus pallipes Grav. Mon. 20.38.

Tachinus humeralis var. 1 Grav. Micr. 130. 3.

Tachinus humeralis var. a Gyll. Ins. Suec. II. 256. 5.

Habitat Lutetiae et in Hercyniae, Austriae Uralensibusque montibus.

Statura omnino T. rufipedis, niger, nitidus. Antennae capite thoraceque paulo longiores, apice paulo crassiores, articulo tertio secundo panlo longiore, 5-10 subobconicis, sensim paulo brevioribus et crassioribus, ultimo subovato, articulo primo rufo-testaceo, reliquis piceis. Palpi picei, basi testacei. Caput omnium subtilissime punctulatum, ore concolore. Thorax coleopteris vix latior, latitudine baseos tertia parte brevior, antrorsum leviter angustatus, apice late emarginatus, lateribus rotundatus, basi truncatus, angulis anterioribus leviter prominentibus posterioribusque rotundatis, convexus, omnium subtilissime punctatus, margine anteriore posterioreque tenui obscurius, laterali latiore distinctoque testaceis. Scutellnm parvum, laeve, nigro-piceum. Elytra thorace sesqui longiora, subtiliter punctulata, nigro-picea, nitıda, puncto humerali margineque apicali dilutioribus, rufopiceis. Abdomen distinctius licet subtiliter punctatum, pube brevissma subtilissimaque adspersum. Pedes rufo-testacei.

Mas abdominis segmento superiore sexto acute quadridentato, dentibus intermediis multo magis prominentibus; segmentis inferioribus $\mathbf{3} \mathbf{- 5}$ medio leviter impressis, quinto apice late at minus profunde emarginato, sexto bifido, lacinis minus elongatis, parum curvatis, apice compressis, acuminatis.

Femina abdominis segmento superiore sexto quadrifido, laciniis acuminatis, spiniformibus, intermediis acutissimis, ad segmenti medium usque divisis.

Variat elytrorum macula basali transversali indeterminata testacea, pedibus pallidioribus, et minus maturus elytris ferrugineis, durso posterius infuscato. drifido.

Obs. 1. Ab affinibus facile distinguitur femina segmento abdominis subqua-

2. A Gyllenhalio cum T. humeralis mare confusus, quod ex eius descriptione patet: exemplum etiam femineum $T$. pallipedis pro $T$. humeralis mare a Schönherro missum in collectione Dom. Prof. Germar exstat.

* 29. T. axillaris: Piceo-niger, nitidus, antennarum basi, pedibus thoracisque limbo rufo-teslaceis, elylris thorace sesqui longioribus, macula humerali summoque margine apicali rufis. - Long. $2 \frac{2}{3}$ lin.

Habitat in America septentrionali, Dom. Zimmermann. 
Statura ommino T. flavipedis, at paulo minor, piceo-niger, nitidus. Antennae capite thoraceque fere longiores, apice paulo crassiores, articulo tertio secundo sesqui longiore, 5-10 erassioribus, subobconicis, inter se subaequalibus, ultimo oblongo-ovato, compresso, nigrae, articulis duobus primis rufis. Palpi nigro-picei. Caput omnium subtilissime punctulatum, ore concolore. Thorax coleopterorum latitudine, latitudine baseos dimidio brevior, antrorsum leviter angustatus, apıce leviter emarginatus, lateribus rotundatus, basi truncatus, angulis anterioribus parum prominentibus posterioribusque rotundatis, leviter convexus, omnium subtilissime alutaceus, crebre subtiliscime punctatus, margine basali apicalique tenui lateralique latiore castaneo-testaceo. Scutellum piceum. Elytra thorace sesqui longiora, ounium subtilissime alutacea, crebre subtiliter punctata, nigro-vel brunneojicea, macula humerali indeterminata, saejius per totam basin extensa, margineque summo apicali rufis. Abdomen crebre subtilius punctatum, segmentis singulis margine postico rufo. Pedes rufi.

Mas abdominis segmento superiore sexto quadridentato, dentıbus lateralibus acutiusculis, intermediis valde prominentibus, acutis, prope spiniformibus; segmento inferiore quarto leviter triangulariter impresso, quinto apice late profundius emarginato, secundum totan longitudinem late et parum. profunde impresso, sexto bifido, laciniis longioribus validioribusque, leviter curvatis, acuminatis.

F emin a abdommis segmento superiore sexto quadrifido, laciniis omnibus aequalibus, spiniformibus.

* 30. T. basalis: Niger, nitidus, antennarum basi pedibusque rufis, elytris thorace paulo longioribus, basi rufis. - Long. $2 \frac{1}{2}$ lin.

Ilabitat in montibus Uralensibus, Dom. Prof. Eversmann.

Statura fere T. marginelli et maioribus eius individuis aequalis, niger, nitidus. Antennae capitis thoracisque longltudine, extrorsum crassiores, articulis 2 et 3 aequalibus, 5-10 leviter obconicis, sensim panlo brevioribus et crassioribus, ultimo crassiusculo, ovato, piceae, articulis 4 primis rufotestaceis. Palpi rufo-picei. Caput laeve, parce omnium subtilissime punctulatum, ore concolore. Thorax coleopteris paulo latior, latitudine dimidio brevior, apice leviter emarginatus, lateribus rotundatus, basi truncatus, angulis anterioribus leviter prominentibus, obtusiusculis, posterioribus rotundatis, leviter convexus, parcius obsolete subtiliterque punctatus. Scutellum piceum. Elytra thorace longiora, fortius crebre punctata, nitida, fusco-picea, basi indeterminate castaneo-rufa, Abdomon parce subtiliter punctatum, nigrum, nitidum, segmentis singulis margine apicali rufo-piceo. Pedes diJute rufi.

Mas abdominis segmento superiore sexto quadridentato, dentibus ommibus acutiusculis, intermediis multo magis productis, approximatıs; segmento inferiore quinto late leviter emarginato, sexto profunde inciso, laciniis acuminatis, externe unidentatis.

Femin a latet. 
* 31. T. marginellus: Nigro-piceus, nitidus, antennarum basi, pedibus, thoracisque limbo castane-lestaceis, elytris thorace sesqui longioribus, nigro-piceis, villa intramarginali margineque apicali dilutioribus. Long. $1 \frac{1}{2}-2$ lin.

Grav. Micr. 143. 14. - Latr. Hist. nut. Crust. et Ins. IX. 397. 14. - Gyll. Ins. Suec. 1I. 265. 12. - Zetterst. Faun. Lappon. I. 63. 6. Ins. Lappon. 57. 6. Sahlb. Ins. Fenn. I. 301. 11. - Mannerh. Bruchelytr. 62. 11 . - Boisd. et Lacord. Faun Ent. Paris. 5. 512. 9. - Runde Brachelytr. Hal. 26. 5. - Er. Col. March. I. 399. 5.

Staphyl. marginellus Fab. Spec. Ins. I. 337. 20. Mant. Ins. I. 221. 27.

Oxyporus marginellus Fab. Ent. Syst. I. II. 536. 23. Syst. El. II. 607. 23. -

Panz. Faun. Germ. 9. 13. Ent. Germ. 361. 18.

Tachyporus marginellus Grav. Mon. 13. 27.

Tach in us laticollis Grav. Micr. 141. 10. - Latr. Hist. nat. C, ust. et Ins. IX.

396. 10. - Boisd. et Lacord. Faun. Ent. Paris. I. 509. 5.,

Tachyporns laticollis Grav. Mon 1529.

Staphylin. laevigatus Marsh. Ent. Britt. 519. 62.

Tachinus intermedius Mannerh. Brachelytr. 62. 9.

Staphyl. rufipes var. $\beta$ Payk. Mon. Staph. 76. 53.

Strphyl. rufipes var. 2 Payk. Faun. Suec. III. 419. 65.

Staphyl. rufipes var. 1 Walk. Faun. Paris. I. 273. 20.

Stuphyl. marginat us Fourcr. Ent. Par. I. 169. 18.

Le Staph. à étuis bordés de jaune Geoffr. Hist. Ins. I. 168. 19.

Var. Testaceus, capite thoracisque disco fuscis (immaturus).

Tuchinus immaturus Grav. Micr. 142. 12. - Latr. Hist. nat. Crust. et Ins. IX. 396. 12.

Tachyporus immaturus Grav. 13. 25.

Habitat in Europa.

Habitu omnino rnfipedis, at triplo fere minor. Antennae capite thoraceque paulo longiores, apice parum crassiores, articulo tertio secundo perparum longiore, 5 - 10 subobconicis, sensim paulo brevioribus, ultimo oblongo, subovato, nigro-piceae, basi rufae, articulo primo rufo-testaceo. Palpi picei. Caput subtilissime punctulatum, nigrum, nitidum, ore concolore. Thorax coleopteris paulo latior, latitudine baseos tertia parte brevior, antrorsum modice angustatus, apice profundius emarginatus, lateribus fortius rotundatus, basi truncatus, angulis anterioribus modice prominentibus posterioribusque obtusis, convexus, dense subtiliter punctatus, niger, nitidus, limbo laterali latiore posticoque tenui testaceis. Scutellum nigrum, subtilissime punctulatum. Elytra thorace sesqui longiora, dense minus subtiliter punctata, obscure brunneo-picea, vitta intramarginali, interdum obsoleta, margineque apicali testaceis. Abdomen minus dense subtiliter punctatum, pube subtilissima grisea adspersum, piceo-nigrum, nitidum, segnentis singulis mar.gine postico rufo-piceo. Pedes rufo-testacei.

Mas abdominis segmento superiore sexto quadridentato, dentibus omnibus valde acutis, intermediis paulo magis prominentibus; segmento inferiore quinto apice profunde sinuato, margine intra sinum late spongioso, sexto profundo inciso, laciniis triangularibus, apice fortiter acuminatis seu mucronatis.

Femina abdominis segmento superiore sexto quadrifido, laciniis omnibus spiniformibus, acuminatis, intermediis paulo brevioribus tenuioribusque. 
Obs. Oxyp. marginellus Panz, a Gravenhorstio ad T. humeralem relatus, ob magnitudinem minorem potius ad hanc speciem pertinere videtur, et quidem ad individua obscuriora, elytrorum vitta intramarginali obsoleta. T. laticoll is nonnisi statura paulo maiore, thorace lateribus magis rotundato eiusque limbo laterali minus determinato a $\mathbf{T}$. marginello genuino differt.

* 32. T. fimetarius: Niger, nitidus, pedibus, thoracis limbo elytrisque castaneo-testaceis, his dorso plerumque infuscatis, antennis nigris. Long. 2 lin.

Grav Micr. 141. 9. - Latr. Hist. nat. Crust. et Ins. IX. 396. 9. - Gyll. Ins. Suec. 1I. 263. 11. - Zetterst. Faun. Lappon. I. 63. 5. Ins. Lappon. 57. 5. Sahlb. Ins. Fenn. I. 300. 10. - Mannerh. Brachelytr. 62. 10. - Boisd. et Lacord. Faun. Ent. Paris. I. 511. 8. - Runde Brachelytr. Hal. 26. 4. - Er. Col. Murch. I. 398. 4.

Tachyporus fimetarius Grav. Mon. 14. 28.

Tach in us sordidus Grav. Micr. 141. 8. - Latr. Hist. nat. Crust. et Ins. IX. 395. 8. Staphyl. fuscipes Panz. Ent. Germ. 356. 28. Faun. Germ. 27. 12.

Spec. intermed. inter T. laticollem et fimeturium: Grav. Mon. p. 15.

\section{Habitat in Europa.}

Habitu omnino T. flavipedis, at duplo minor. Antennae capitis thoracisque longitudine, apice vix crassiores, articulo tertio secundo paulo longiore, 5-10 elongato-obconicis, subaequalibus, ultimo elongato, fusiformi, acuminato, totae nigrae. Palpi nigro-picei. Caput laeve, nigrum, nitidum, ore concolore. Thorax coleopterorum latitudine, latitudine baseos quarta fere parte brevior, antrorsum modice angustatus, apice leviter emarginatus, lateribus rotundatus, basi truncatus, angulis anterioribus parum prominentibus posterioribusque rotundatıs, leviter transversim convexus, laevis, niger, nitidus, limbo antico posticoque tenuibus lateralique latiore castaneo-testaceis. Scutellum piceum, laeve. Elytra thorace plus sesqui longiora, parce subtiliter punctulata, castaneo-testacea, nitidula, dorso magis minusve infuscata. Abdomen nigrum, nitidum, parcius subtiliter punctulatum, pube parca brevissima subtilissimaque adspersum. Pectus nigrum, nitidum. Pedes testacei.

Mas abdominis segmento superiore sexto quadridentato, dentibus longitudine subaequalibus, acutis, lateralibus fere spiniformibus; segmento inferiore quinto apice medio profunde sinuato, sinu utrinque denticulo acuto terminato, sexto profunde inciso, laciniis triangularibus, fortiter acuminatis.

Femina abdominis segmento superiore sexto apice quadrifido, laciniis subaequalibus, fortiter acuminatis.

Obs. T. flavipedi habitu et colore similis, differt autem statura duplo minore, capite thoraceque impunctatis, abdominisque in utroque sexu structura. - T. castaneus Grav. secundum specimina typica ad T. flavipedem pertinet.

* 33. T. collaris: Dense punctatus, nigro-piceus, antennis, pedibus thoraceque rufis, hoc disco plerumgue infuscato. - Long. $1 \frac{1}{2}-1 \frac{2}{3}$ lin.

Grav. Micr. 133. 13. - Latr. Hist. nat. Crust et Ins. IX. 397. 13. - Gyll. Ins. Suec. II. 266. 13. - Sahlb. Ins. Fenn. I. 302. 12. - Mannerh. Brachelytr. 62. 12. - Boisd. et Lacord. Faun. Ent. Paris, I. 512. 10. - Er. Col. March, I. 400.6. Tachyporus collaris Grav. Mon. 13. 24.

Var. Pallidus, immaturus.

Tach inus corticinus Grav. Micr. 131. 11. - Latr. Hist. nat. Crust. et Ins. IX. 396. 11. 
Tachyporus corticinus Grav. Mon. 13. 16.

Tachin us flavellus Zetterst. Faun. Lappon. I. 61. 7. Ins. Lappon. I. 57.7. (forte)

Habitat in Europa.

Statura fere T. marginelli. Antennae capite thoraceque paulo longiores, apice paulo crassiores, articulo tertio secundo paulo longiore, 5-10 obconicis, longitudine subaequalibus, at sensim paulo crassioribus, ultimo oblongo, apice acuminato et subcompresso, rufae, apicem versus obscuriores. Palpi picei. Caput crebre subtiliter punctatum, nigrum, nitidum, ore concolore. Thorax coleopteris paulo latior, latitudine baseos dimidio brevior, antrorsum modice angustatus, apice profundius emarginatus, lateribus rotundatus, basi utrinque subsinuatus, angulis anterioribus modice prominentibus, rotundatis, posterioribus subrectis, externe rotundatis, convexus, dense subtilius punctatus, piceo-rufus, disco saepius infuscato. Scutellum piceum. Elytra thorace sesqui longiora, dense minus subtiliter punctata, iam fuscoiam rufo-picea, nitida. Abdomen parcius subtiliter punctatum, pube subtilissima brevissimaque adspersum, nigrum, nitidum, segmentis singulis margine postico piceo. Pectus nigrum, Pedes rufo-testacei.

Mas abdominis segmento superior sexto quadridentato, dentibus breviusculis, intermedis multo magis prominentibus; segmento inferiore quinto apice fortiter triangulariter exciso, sexto inciso, laciniis triangularibus, apice acuminatis, fere mucronatis.

F e mina abdominis segmento superiore sexto apice quadrifido, laciniis subaequalibus, acuminatis.

*34. T. elong atus: Elongalus, nigro-piceus, nitidus, antennis pedibusque rufis, elytris subtiliter substriato-punctatis, margine apicali rufescente. - Long. $3 \frac{1}{2}$ lin.

Gyll. Ins. Suec. II. 251. 1. - Zetterst. Faun. Lappon. I. 61. 1. Ins. Lappon. 56. 1.

Habitat in Suecia, Dom. Schïppel, in Helvetia, Dom. Guyot, in Unalaschka, Dom. Chamisso.

Statura elongata, linearis, fere subcylindrica a congeneribus discedens, piceo-niger, subnitidus. Antemnae capitis thoracisque longitudine, crassiusculae, articulo tertio secundo sesqui longiore, 5-10 sensim paulo brevioribus at vix crassioribus, ultimo subovato, apice abrupte compresso, totae rufae. Palpı rufi. Caput omnium subtilissime parce punctulatum. Thorax coleopteris vix latior, latitudine baseos quarta parte brevior, antrorsum parum angustatus, apice profundius emarginatus, lateribus leviter rotundatus, basi truncatus, angulis anterioribus modice prominentibus, acutiusculis, acumine rotundato, posterioribus rotundatis, trausversim convexus, omnium subtilissime parce punctulatus. Elytra thorace vix sesqui longiora, subseriatim subtilius punctata, nigro-picea, margine apicali rufescente. Abdomen parallelum, subtiliter punctatum, versus latera tenuiter griseo-pubescens, segmentis piceo-marginatis. Pedes rufi.

Mas abdominis segmento superiore sexto quadridentato, dentibus minutis, intermediis paulo magis prominentibus; segmento inferiore quinto apice late profundeque emarginato, sexto bifido, laciniis validis, elongatis, compressis, fortius deorsum curvatis, apice acuminatis. 
F emin a abdominis segmento superiore sexto apice quadrifido, laciniis suhaequalibus, acuminatis.

Variat thorace elytrisque rufo-piceis.

* 35. T. discoideus: Nigro-piceus, nitidus, antennis pedibusque rufis, elytris forlius punclatis, rufis, margine omni piceo. - Long. $1 \frac{2}{3}$ lin.

Habitat in Austria.

Antennae capitis thoracisque fere longitudine, validiusculae, apicem versus leviter incrassatae, articulo 2 et 3 subaequalibus, 5-10 longitudme subaequalibus at sensim paulo crassioribus, ultimo oblongo-ovato, apice acuminato, totae rufo-testaceae. Caput parvum, parcius subtiliter punctatum, nigro-piceum, nitidum, ore rufo-testaceo. Thorax basi coleopterorum latitudine, latitudiue baseos quarta fere parte brevior, antrorsum leviter angustatus, apice profundius emarginatus, lateribus leviter rotundatus, basi truncatus, angulis anterioribus modice prominentibus, leviter deflexis posterioribusque obtusis subrotundatis, parum convexus, parce vageque subtiliter punctatus, iam nigro- iam rufopicens, nitidus. Scutellum laeve, piceum. Elytra thorace sesqui prope longiora, crebrius fortiusque punctata, punctis hinc inde subseriatis, nitida, disco laete rufo, limbo omni piceo. Abdomen minus subtiliter punctulatum, nigropiceum, segmentis singulis margine apicali rufo-piceo. Pectus nigrum, nitidum. Pedes rufo-testacei.

Mas abdominis segmento superiore sexto quadridentato, dentibus minutis, mtermediis fortius prommentibus; segmento inferiore quinto apice leviter triangulariter emarginato, sexto profunde inciso, lobis triangularibus, apice acuminatis.

Femina abdominis segmento superiore sexto apice quadrifido, laciniis subaequalibus, acuminatis.

\section{Species mihi invis a:}

36. T. rufipennis: Niger, nitidus, glaber, antennis basi rufo-piceis, elytris profunde punctalis, rufis, apice nigro-marginalis, iarsis ferrugineis.

Gyll. Ins. Suec. II. 259. 8.

Habitat in Sueciae stercoratis rarius.

Statura omnino T. humeralis, sed adhuc panlo maior, et vere distinctus. Caput rotundatum, nigrum, nitidissimum, subtiliter punctulatum, linea tenui angulata inter antennas impressum; os et palpi nigro-picei. Antennae thorace paulo longiores, nigro-fuscae, basi rufo-piceae. Thorax latus, transversus, fere ut in T. humerali, antice tamen profundius emarginatus, supra valde convexus, subtilissime punctulatus, totus niger, nitidissimus. Scutellun triangulare, rufo-piceum, subtiliter punctulatum. Elytra thorace multo angustiora, sed fere duplo longiora, apice truncata, angulis ut in prioribus, supra convexa, crebre et sat profunde vage punctata, saturate rufa, nitida, margine postico late nigro, nigredine iuxta marginem lateralem altius adscedente, sutura etiam anguste nigra. Abdomen pone elytra illarum longitudine, convexum, totum nigrum, nitidum, crebre punctatum; anus secundum sexum ut in $\mathrm{T}$. rufipede armatus. Corpus totum subtus nigrum, nitidum, 
profunde punctatum. Pedes elongati, nigri, nitidi, spinulis tibiarum tarsisque ferrugineis. (Gyll.)

\section{Trichopliyus Er.}

Er. Col. March. I. p. 402.

Trichophya Mannerh. Brachelytr. p. 73.

Antennae 11-articulatae, capillares.

Palpi maxillares filiformes.

Ligula apice emarginata, paraglossis distinclioribus, ligula duplo brevioribus. Elytra pectori longitudine aequalia.

Tarsi 5-articulati.

Corpus oblongum, subdepressum, alatum. Caput deflexum, thorace minus et angustius, subtriangulare, oculis parvis, rotundatis, prominulis. Labrum transversum, apice rotundatum. Mandibulae muticae, margine interno limbo menibraneo fimbriato. Maxillae (t. IV. f. 8. b.) mala utraque leviter elongata, lineari, membranacea, longitudme altera alteri subaequali, exteriore apice barbata, interiore apice leviter uncinata, dein spinulis tribus minutis armata, margine interiore medio barbato. Palpi maxillares sat elongati, articulo secundo elongato, tertio quartoque singulis hoc paulo brevioribus, inter se subaequalibus, quarto apice acuminato. Labium (t. IV. f. 8. a.) mento transverso, ligula angustata, prominula, apice emarginata, paraglossis - ligulae connatis, et eadem brevioribus. Palpi labiales biarticulati, articulo secundo parvo, acuminato. Antennae longitudine dimidii corporis, articulo primo secundoque crassiusculis, primo clavato, secundo subgloboso, sequentibus valde tenuibus, sensim angustioribus, pilis longis verticillatis undique adspersis.*) Thorax coleopterorum prope latitudine, antrorsum haud angustatus, parum convexus. Scutellum triangulare. Elytra pectus haud excedentia. Abdomen apicem versus subangustatum. Pedes breves, intermedii basi adproximati, coxae posticae triangulares, tibiae pubescentes, tarsi omnes 5-articulati, antici articulis 4 primis leviter dilatatis, posteriores articulo primo leviter elongato.

O b s e r v a t i n e s.

1. Genus admodum distinctum, statura autem minus convexa, thorace minus amplo, capite magis exserto, huic tribui quodammodo alienum videtur. Aleocharis adscribi nequit, antennae enim infra oculos sub capitis margine laterali insertae, palporum maxillarum articulus ultimus haud subulatus, et tarsi antici dilatati. Quibus notis cum Tachyporinis congruit: oris autem structura in Trichophyo singularis, Aleocharorum genera postrema in animum revocans. Palpi labiales perbreves bi-articulati mihi videntur.

2. Antennarum structura singulari cum Habrocero satit quidem convenit, reliquis autem characteribus omnibus discedit.

3. Sexus differentia latet.

4. Victus sub arborum emortuarum cortice, sec. Gyll. Specimen nostrum in foro lignario yolitans captum est.

5. Nomen generis, huic tribui adscripti, aliquantum mutavi, quoniam omnia Tachyporinorum nomina masculina sunt.

*) Antennae in nostro specimine mutilatae, quare earum descriptionem secundum Gyllenhalium supplevi. 
1. T. pilicornis: Niger, punctatus, pubescens, elytris fuscis, pedibus fusco-testaceis. - Long. $1 \frac{1}{2}$ lin.

Er. Col. March. I. 403. 1.

Trichophya pilicornis Mannerh. Brachelytr. 73. 1.

Aleochara pilicornis Gyll. Ins. Suec. II. 417. 39.

Habitat in Germania, Suecia.

Caput crebrius punctatum, nigrum, nitidum, ore fusco, oris partibus antennarumque articulis primis rufo-testaceis. Thorax latitudine plus sesqui brevior, lateribus rotundatns, basin versus non minus quam antrorsum angustior, basi leviter rotundatus, angulis posterioribus obtusis, apice leviter emarginatus, supra parum convexus, lateribus basique planiusculis, confertim punctatus, tenuiter griseo-pubescens, fusco-niger, nitidus. Elytra thorace sesqui longiora, apice oblique introrsum truncata, dense punctata, tenuius pubescentia, fusca, opaca. Abdomen pectusque dense punctata, tenuiter pubescentia, nigra, ano fusco. Pedes testacei.

\section{Boletobius $\boldsymbol{L}$ each.}

Manuerh. Brachelytr. p. 64.

Megacronus Steph. Illustr. V. p. 165 et Boletobius ibid. p. 171.

Bry och a ris Boisd. et Lacord. Faun. Ent. Paris. I. p. 502 et Bo le tobius ibid. p. 497.

Antennae 11-articulatae, filiformes.

Palpi maxillares filiformes.

Jigula apice emarginata.

Elytra pectori subaequalia.

Tarsi 5-arliculati.

Corpus elongatum, utrinque attenuatum et deorsum curvatum, alatum. Caput thoraci immissum, deflexum, aliis breviusculum, alis oblongum vel elongatum, oculis mediocribus, ovalibus, vix prominulis. Labrum aliis transversum, aliis (capite elongato) quadratum, apice truncatum. Mandibulae minores, apice falcatae, acutae, interne basi membrana fimbriatae. Maxillae (t. IV. f. 6. b.) malis coriaceis, interiore interne, exteriore apice ciliatis. Palpi maxillares leviter elongati, articulo primo minuto obconico, secundo tertioque vel subaequalibus, vel secundo paulo longiore, apicem versus leviter incrassatis, quarto praecedenti aequali vel eodem paulo longiore, plurimis cylindrico, apice obtuse acuminato. Labium (t. IV. f. 6. a.) mento transierso, parte membranacea ante palporum basin elongata, ligula rotundata, medio incisa, membranea, paraglossis ligulae multo brevioribus, eique connatis et nomnisi linea ciliata distinguendis. Palpi labiales articulis duobus prinis subaequalibus, tertio paulo longiore, apice obtuse acuminato. Antennae utrinque infra oculos insertae, filiformes, apicem versus plerumque leniter incrassatae. Thorax bası fere coleopterorum latitudine, apicem versus angustatus, latitudine parum brevior, lateribus rotundatus, basi truncatus, apice pro receptione capitis emarginatus, lateribus, praecipue anterius, deflexis. Scutellum triangulare. Elytra apice truncata. Abdomen apicem versus sensim attenuatum, deorsum curvatum. Mesosternum haud carinatum. Pedes graciliores, coxis intermediis valde approximatis, posticis amplis, parallelopipedis, scutatis, femoribus saepius apice obsolete setosis, 
tibiis omnibus spinulosis, "spinis terminalibus validioribus, tarsis 5 -articulatis, elongatis, gracilioribus, posterioribus articulo primo elongato, sequentibus sensim decrescentibus, ultimo iterum longiore.

$$
\text { O b s e r v a t i o n e s. }
$$

1. Corpore graciliore, incurvo, elytris coxas posticas vix superantibus, his parallelopidedis, amplis, ut in Mordellis scutatis, pedibus etiam ut in hac familia constructis a praecedentibus discedens, summa affihitate cum genere sequento iungitur.

2. Caput laevissimum; thorax laevissimus, ad margines punctis paucis, interdum etiam dorso punctorum pari impressus; scutellum laeve; elytra plerisque punctorum seriebus tribus ordinariis notata, intima striae leviter exaratae suturali, extima striae tenui marginali impositis, intermedia discoidali; abdomine punctato.

3. M e ga cronus Steph. nonnisi capite minus elongato et antennis minus gracilibus, Bryocharis Boisd. et Lacord. nonnisi tarsis anticis in mare dilatatis distinguuntur. Distinctio illa omnino arbitraria, haec temeraria; tarsi enim dilatati simplicesve vix unquam in tota Staphylinorum familia characterem genericum praebent, speciebus inter se maxime affinibus saepius hac nota discrepantibus.

4. Sexu's differentia varia, apud singulas species notanda.

5. Victus in silvis, in boletis et sub muscis et foliis deciduis.

* 1. B. analis: Niger, nitidus, pedibus cum coxis anticis, antennis articulis 4 primis ultimoque testaceis, ano elytrisque rufis. - Long. $2 \frac{1}{2}-3$ lin.

Mannerh. Brachelytr. 64. 3. - Runde Brachelytr. Hal. 26. 1. - Er. Col. March. I. 403. 1.

Staphyl. analis Payk. Mon. Staph. 47. 34. Fuun. Suec. III. 394. 34. - Walk. Faun. Paris. I. 272, 17. - Oliv. Ent. II. 42. 28. 38. t. 3. f. 24. - Marsh. Ent. Britt. 522. 70.

Tachinus analis Grav. Mon. 148. 20. - Latr. Hist. nat. Crust. et Ins. IX. 399. 20. - Sahlb. Ins. Fenn. I. 303. 14. - Zetterst. Ins. Lappon. 58. 8.

Tachinus analis var. 2 Grav. Mon. 31. 16.

Tachinus a nalis var. b Gyll. Ins. Suec. IV. 472. 13.

Staph. anali's Schrank Faun. Boica. 1. 649. 890. (forte)

Var. Thorace elytris anoque testaceo-rufis.

Staph. analis var. $\beta$ Payk. Mon. Staph. 47. 34. Faun. Suec. III. 395. 34.

Tachinus merdarius Gyll. Ins. Suec. II. 270. 16. - Sahlb. Ins. Fenn. I. 304. 15.

Habitat in Europa.

. Niger, nitidus. Antennae capite thoraceque paulo longiores, apicem versus sensim leniterque subincrassatae, articulo tertio secundo sesqui longiore, 5- 10 sensim paulo brevioribus et crassioribus, fuscae, farticulis 4 primis ultimoque testaceis, hoc maris oblongo, cylindrico, apice obtuse rotundato, praecedente plus duplo maiore, feminae ovato, praecedente sesqui maiore. Caput parvum, laevissimum, ore late testaceo. Thorax coleopterorum prope latitudine, latitudine baseos parum brevior, lateribus rotundatus, antice paulo magis quam postice angustatus, basi leviter rotundatus, angulis posterioribus obtusissimis, fere rotundatis, satis convexus, laevissimus. Scutellum laevissmmum. Elytra thorace tertia parte longiora, rufa, nitida, seriebus tribus ordinariis punctorum remotorum. Abdomen parce punctatum, parceque longius pubescens, segmento ultimo penultimoque rufis, hoc basi nigro. Pedes testacei, antici coxis concoloribus. 
M as tarsis anticis leviter dilatatis, abdominis segmento inferiore sexto apice medio leviter triangulariter producto, antennarum artıculo ultimo praecedentibus tribus coniunctis subaequali.

Femina tarsis anticis simplicibus, abdominis segmento inferiore sexto apice rotundato, antennarum articulo ultimo praecedentibus ambobus vix aequali.

Obs. Tach. merdarius Gyll. nonnisi thorace rufo differt, quare vix pro specie peculiari rite habendus: differentiae a Gyllenhalio notatae ad sequentem speciem spectant. Specimina Suecica dedit Dom. S ch üppel.

* 2. B. cingulatus: Niger, nitidus, antennis articulis 3 primis ultimisque duobus pedibusque testaceis, his coxis anticis nigris, ano elytrisque rufis. - Long. $3-3 \frac{1}{2}$ lin.

Mannerh. Brachelytr. 64. 2. - Er. Cul. March. I. 404. 2.

Tachinus analis var. 1 et 3 Grav. Mon. 31. 16.

Tachinus analis Gyll. Ins. Suec. II. 269.15.

Bryocharis analis Boisd. et Lacord. Faun. Ent. Paris. I. 502. 1.

Oxyporus bicolor Rossi Fun. Nitr. I. 253. 625. (Ed. Hellw. I. 314. 626.) forte.

Habitat in Europa.

Statura et summa affinitas praecedentis, at plerumque paulo maior et vere distinctus. Corpus nigrum, nitidum. Antennae capite thoraceque paulo longiores, apicem versus vix incrassatae, articulo tertio secundo duplo prope longiore, 5-10 sensim paulo brevioribus at perparum crassioribus, articulis duobus primis testaceis, tertio rufo-testaceo, vel, ferrugineo, 4-9 nigris, feminae penultımo ferrugineo, ultimo hoc paulo maiore, ovato, subacuminato, testaceo, maris ultimis duobus sulphureis, ultimo elongato, praecedentibus duobus longiore. Caput minutum, laevissimum, nigrum, ore late testaceo. Thorax basi coleopterorum latitudine, ibique longitudine paulo latior, apice basi duplo fere angustior, lateribus et basi leviter rotundatus, angulis posterioribus obtusis, leniter convexus, laevissimus. Elytra thorace tertia parte longiora, rufa, nitida, punctorum seriebus tribus ut in praecedente omnino. Abdomen parce punctatum, parceque longius pubescens, ano piloso, segmento sexto toto quintoque apice lato rufis, septimo, quando conspicitur, nigro-piceo. Pedes rufo-testacei, coxis ommibus nigris.

M as tarsis anticis fortius dilatatis, abdominis segmento inferiore sexto canaliculato, apice leviter producto, antennis articulo ultimo praecedentibus ambobus paulo longiore.

Femin a tarsis anticis simplicibus, abdominis segménto inferiore sexto apice rotundato, antennıs articulo ultimo praecedentibus ambobus breviore.

Variat $\mathbf{~}$, ántennis articulis $\mathbf{3}$ et $\mathbf{1 0}$ piceis, ultimo solo flavo. Specimen Austriacum dedit Dom. S chïppel.

2, antennis articulis ultimis tribus flavis. Specimen in Germania septentrionali lectum communicavit Dom. S chïp pel.

$\mathrm{Obs}$. 1. Distinguendus a praecedente praeter antennarum colorem articulo earum ultimo apice acuminato neque obtuso, thorace minus cohvexo, postice multo latiore, angulis posterioribus minus obtusis, coxis anticis nigris, tarsis anticis maris fortius dilatatis.

2. Oxyp. bicolor liossi ob magnitudinem ultra 3 lin. potius ad hanc quam ad praecedentem speciem pertinere videtur. 
3. B. inclinans: Rufo-teslaceus, nilidus, cupite, pectore abdomineque nigris, hòc segmenlis singulis piceo-marginatis, elylris crebre punclatis. - Long. $3 \frac{1}{2}$ lin.

Er. Col. Murch. I. 405.3.

Tachinus inclinans Grav. Mon. 33. 20.

Habitat in Germania.

Antennae capite thoraceque longiores, apice haud incrassatae, articulo tertio secundo plus sesqui longiore, sequentibus sensim paulo brevioribus, ultimo praecedente paulo longiore, acuminato, testaceae, medio fuscescentes. Caput laevissinum, nigrum, nitidum, ore late testaceo. Thorax posterius coleopteris paululum latior, latitudine summa paulo brevior, apice duplo quam basi angustior, lateribus leviter rotundatis, basi subsinuatus, angulis posterioribus obtusis, leviter convexus, dorso ante medium punctorum pari impressus, rufo-testaceus, nitidus. Scutellum laeve, rufo-testaceum. Elytra thorace sesqui longiora crebre punctata, parcius ferrugineo-pubescentia, rufo-testacea, nitida. Abdomen parce punctatum, parceque pubescens, nigrum, nitidum, segmentis margine apicali piceis, ultimo penultimoque dimidio piceis. Pectus nigrum, nitidum. Pedes testacei, coxis anterioribus concoloribus.

Mas tarsis anticis articulis duobus primis fortiter dilatatis, tibiis intermediis spinis apicalibus fortioribus, tarsis intermediis articulo primo compresso-dilatato, abdominis segmento inferiore quinto apice leviter inciso.

Femin a tarsis anterioribus simplicibus, abdominis segmento inferiore quinto integro.

* 4. B. formosus: Rufo-testaceus, nitidus, capite abdomineque nigris, hoc ano rufo, antennis fuscis, basi testaceis, elytris vage punctatis. Long. '2 $\frac{1}{2}$ lin.

Mannerh. Brachelytr. 64. 1.

Tachinus formosus Grav. Mon. 32. 19.

Megacronus farmosus Steph. Illustr. Bt. E. I. t. 26. f. 5.

Tachinus merdarius Grav. Micr. 149. 21. - Latr. Hist. nut. Crust. et Ins. IX. 399. 21.

Habitat in Germania.

Corpus gracilius, rufo-testaceum, nitidum. Antennae capite thoraceque multo longiores, apice hand crassiores, articulo tertio secundo plus sesqui longiore, sequentibus sensim paulo brevioribus, ultmo praecedente paulo longiore, acuminato, fuscae, articulıs duobus primis ultimoque testaceis. Caput laevissimum, nigrum, nitidum, ore testaceo. Thorax posterius coleopteris paulo latior, latitudine baseos paulo brevior, apice duplo prope angustior, lateribus leviter rotundatus, basi subtrisinuatus, angulis posterioribus subrectis, convexus, dorso ante medium punctorum pari impressus. Scutellum laeve. Elytra thorace haud longiora, parcius fortusque vage punctata, puncto quoque pilo brevi reclinato instructo. Abdomen parce sat fortiter punctatum, parce longius pubescens, nigrum, nitidum, segmento quinto dimidio sextoque toto testaceo-rufis. Pectus cum pedibus testaceum.

Obs. T a chin, merdarius Grav, secundum specimen typicum coll. Hoffmanns- 
eggianae a Staph. merdario Fab. et Oliv omnino distinctus, cum T. formoso postea descripto omnino convenit.

5. B. obscurus: Nigro-piceus, nitidus, antennis testaceis, pedibus anoque rufo-piceis, elytris vage punctatis. - Long. 2 lin.

Habitat in ins. Puerto-Rico, Dom. Moritz.

Statura angusta B. formosi, nigro-piceus, nitidus. Antennae capite thoraceque multo breviores, apicem versus sensim modice incrassatae, articulo tertio secundo plus sesqui longiore, sequentibus sensim paulo brevioribus et parum crassioribus, penultimis crassitie brevioribus, ultimo breviter subovato, compresso, totae testaceae. Palpi flavi, maxillares articulo ultimo conico, penultimo haud longiore. Caput breve, laevissimum, ore testaceo. Thorax basi coleopterorum prope latitudine, latitudine baseos vix brevior, antrorsum angustatus, apice plus dimidio quam basi angustior, basi et lateribus leviter rotundatus, angulis posterioribus subrectis, convexus, dorso ante medium punctorum pari impressus. Scutellum laeve. Elytra thorace sesqui longiora, crebre fortius vage punctata, stria suturali impressa, tenuiter pubescentia. Abdomen parcius punctatum, longius pubescens, apice segmentorumque singulorum marginibus rufo-piceis. Pedes rufo-testacei.

6. B. seriatus: Nigro-piceus, nitidus, antennarum basi pedibusque testaceis, elytris crebre seriatim punctatis. - Long. 2 lin.

Habitat Novae Valenciae in Columbia, Dom. Moritz.

Statura omnino B. striati, at minor, nigro-piceus, nitidus. Antennae capite thoraceque paulo breviores, apicem versus sensim sat fortiter incrassatae, articulo tertio secundo plus sesqui longiore, sequentibus sensim paulo brevioribus et crassioribus, penultimis transversis, ultimo subovato, apice acuminato, nigrae, articnlis duobus primis testaceis. Caput breviusculum, laevissimum, ore flavo-testaceo. Thorax basi coleopterorum prope latitudine, latitudine baseos. paulo brevior, antrorsum angustatus, apice dimidio quam basi angustıor, basi et lateribus leviter rotundatus, angulis posterioribus subrectis, convexus, marginibus summis brunneis. Elytra thorace sesqui longiora, dorso punctorum sat fortium seriebus pluribus (sex) striaque suturali impressa, parce pubescentia. Abdomen parcius punctatum, longius pubescens, segmentis singulis castaneo-marginatis. Pedes testacel.

* 7. B. cernuนs: Niger, nitidus, antennarum basi pedibusque testaceis, elytris rufis, punctorum seriebus obsoletioribus, interstitiis obsoletissime punctulatis. - Long. $2-2 \frac{1}{2}$ lin.

Mannerh. Brachelytr. 61. 4. - Boisd. et Lacord. Faun. Ent. Paris. I. 500. 5. Er. Col. March. I. 406. 4.

Tachinus cernuus Grav. Mon. 31. 18. - Gyll. Ins. Suec. I1. 271. 17. - Sahlb. Ins. Fenn. I. 304. 16. - Zettẹrst. Faun. Lappon. I. 64. 8. Ins. Lappon. 58. 2.

Var. Thorace elytrisque rufis.

Staph. merdarius Oliv. Ent. III. 42. 29. 39. t. 5. f. 45.

Bolitobius merdarius Boisd. et Lacord. Faun. Ent. Paris. I. 501. 6.

Habitat in Europa.

Statura omnino B. striati. Antennae capitis thoracisque prope longi- 
tudine, tenuiores, apice parum incrassatae, articulo tertio secundo plus sesqui longiore, sequentibus sensim paulo brevioribus et crassioribus, ultimo ovato, praecedente sesqui longiore, apice subcompresso, acuminato, pilosellae, fuscae, articulis tribus primis testaceis, ultimo interdum obscure testaceo. Palpi maxillares articulo quarto praecente paulo breviore, conico. Caput breviusculum, nigrum, nitidum, ore testaceo. Thorax basi coleopterorum latitudine, latitudine baseos paulo brevior, apice plus dimidio quam basi angustior, lateribus praecipue antice deflexis, leviter rotundatis, basi subtruncatus, angulis posterioribus obtusis, laevissimus, margine punctis singulis, dorso ante apicem punctorum pari impressus, nitidus, iam nigerrimus, iam piceo-rufescens, iam testaceo-rufus. Scutellum piceum, nitidum, laevissimum. Elytra thorace tertia parte longiora, rufa vel testaceo-rufa, nitida, punctorum sat remotorum subtilium seriebus tribus, prima ad suturam, secunda in medio dorso, tertia ad marginem lateralem, interstitiis punctis distantibus seriatis subtilibus obsoletisque impressis. Abdomen vage fortus punctulatum, longius griseo-pubescens, nigrum, nitıdum, segmentis 4 primis margine postico, quinto apice, sexto toto rufis. Pectus nigrum, nitidum. Pedes rufo-testacei, coxis anterioribus iam concoloribus, iam nigro-piceis, tarsis anticis in utruque sexu simplicibus.

* 8. B. rufus: Rufo-testaceus, nilidus, abdominis segmentis anterioribus basi fuscescentibus, antennis fuscis, basi testaceis, elytris punctorum seriebus obsoletioribus, interstiliis subtiliter subserialim punctatis. Long. $2 \frac{1}{2}$ lin.

Er. Col. March. I. 407. 5.

Var. Capile pectoreque nigro-piceis.

Habitat in Germania.

Statura et summa affinitas praecedentis. Antennae capitis thoracisque prope longitudine, apicem versus fortins incrassatae, articulo tertio secundo sesqui longiore, 4-7 sensim brevioribus et crassioribus, 7-10 subaequalibus, longitudine paulo crassioribus, ultimo praecedente sesqui longiore, breviter subovato, apice compresso, obtuse rotundato, fuscae, articulis quatuor primis rufo-testaceis. Palpi maxillares articulo tertio modice incrassato, quarto hoc dimidio prope breviore et duplo tenuiore, valde acuminato. Caput minutum, triangulare, saturate rufo-testaceum, nitidum, ore dilutiore, vertice nonnunquam fuscescente. Thorax basi coleopterorum prope latitudine, apice duplo angustior, latitudine baseos tertia parte prope brevior, basi et lateribus leviter rotundatus, angulis posterioribus subrotundatis, laevissimus vel interdum subtiliter obsoletissimeque vage punctulatus, apice prope marginem anteriorem punctorum pari impressus, saturate rufo-testaceus, nitidus. Scutellum concolor, laevissimum, nitidum. Elytra thorace sesqui longiora, punctorum maiorum seriebus tribus, interstitiis parcius subtiliter obsoleteque subseriatim punctatis, rufo-testacea, nitida. Abdomen supra vage profundius punctatum, subtus crebre fortiter profundeque punctatum, parce fulvopubescens, piceo-testaceum seu castaneum, nitidum, segmentis singulis mar-gine apicali rufescente. Pectus saturate rufo-testaceum. Pedes testacei.

$\mathrm{V}$ ariat nonnunquam capite pectoreque nigro - piceis. 
Obs. Differt a praecedente praeter colorem antennis apicem versus magis incrassatis, thorace lateribus minus rotundato, punctorum pari apici propiore, elytris in interstitiis distinctius punctulatis. Palporum maxillarium articulo quarto breviore conicoque anceps quasi inter Boletobium et Mycetoporum.

9. B. bicolor: Niger, nitidus, capite, thorace, scutello, pedibus elytrisque rufis, his angulo exteriore apicis nigro. - Long. $2 \frac{1}{2}-3 \frac{1}{2}$ lin.

Tachinus bicolor Grav. Mon. 28. 9.

Habitat in Hercynia, Borussia.

B. anali robustior et saepe duplo maior. Antennae vix capitis thoracisque longitudine, apice paulo crassiores, articulo tertio secundo plus sesqui longiore, 5 - 10 modice compressis, subtriangularibus, latitudine apicis vix brevioribus, inter se aequalibus, ultimo oblongo, praecedente plus duplo longiore, compresso, apice rotundato, fusco-nigrae, articulis 4 primis testaceis, ultimo apice summo ferrugineo. Caput oblongum, testaceo-rufum, ore testaceo. Thorax basi coleopterorum prope latitudine, latitudine summa non brevior, apice paulo angustior, basi et lateribus leviter rotundatus, angulis posterioribus obtusis subrotundatis, leniter convexus, laevissimus, testaceo-rufus, nitidus. Scutellum laevissimum, testaceo-rufum, nitidum. Elytra thorace paulo longiora, punctorum seriebus tribus ordinariis, punctis sat distinctis, serie dorsali quaque striae leviter exaratae imposita, testaceo-rufa, nitida, angulo apicali exteriore a medio margine laterali usque ad suturae apicem nigerrimo. Abdomen crebrius punctatum, parcius nigro-pubescens, nigrum, nitidum. Pectus nigrum, nitidum, mesosterno rufo-testaceo. Pedes testacei, coxis anterioribus concoloribus, femoribus apice fortius spinulosis, tarsis anticis in utroque sexu simplicibus.

Mas abdominis segmento inferiore quinto ante apicem carinula parra longitudinali dentiformi instructo.

Femina abdominis segmento inferiore quinto mutico.

* 10. B. axillaris: Piceus, nitidus, antennarum basi apiceque pedibusque anticis testaceis, capile elytrisque nigris, his vilta longitudinali margineque apicali testaceis. - Long. 3 lin.

Yachin us axillaris Grav. Mon. 29. 11.

Habitat in America septentrionali.

Statura omnino praecedentis. Antennae capitis thoracisque longitudine, apice parum crassiores, articulo tertio secundo sesqui longiore, 5 - 10 crassioribus, modice compressis, subtriangularibus, $\mathbf{6}-\mathbf{1 0}$ latitudine apicis paulo brevioribus, aequalibus,-ultimo praecedente duplo longiore et paulo angustiore, oblongo, compresso, nigrae, articulis duobus primis ultimoque testaceis. Caput oblongum, nigrum, nitidum, labro palpisque testaceis. Thorax basi coleopterorum prope latitudine, apice dimidio angustior, latitudine baseos paulo brevior, basi et lateribus leviter rotundatus, angulis posterioribus obtusis, laevissimus, nigro-piceus, nitidus. Scutellum nigrum, nitıdum. Elytra thorace sesqui fere longiora, serie dorsali punctis fere sex satis distantibus composita, nigra, nitida, margine apicali vittaque longitudinali, ab angulo humerali apicis medium petente, marginem apicalem haud attingente, 
testaceis. Abdomen supra parcius, subtus crebrius fortiusque punctatum, piceum, nitidum, segmentis singulis margine apicali dilutiore. Pedes antici cum coxis testacei, posteriores picei, femoribus piceo - testaceis.

M as abdominis segmento inferiore quinto ante apicem carinula longitudinali dentiformi instructo.

F e min a latet.

* 11. B. niger: Niger, nitidus, antennarum articulo primo testaceo, abdominis segmento quinto apice rufo, elytris punctorum seriebus obsoletioribus. - Long. $4 \frac{1}{2}-6$ lin.

Tachinus niger Grav. Micr. 193. 5. Mon. 30. 12.

Var. Abdominis segmento quinto apice concolore.

Habitat in America septentrionalı.

Magnus, niger, nitidus. Antennae capite thoraceque paulo breviores, articulis 3 primis teretibus, 2 et 3 subobconicis, hoc praecedente sesqui longiore, sequentibus latioribus, modice compressis, triangularibus, 5 - 10 latitudine apicis paulo brevioribus, aequalibus, ultimo paulo angustiore, oblongo - ovato, nigrae, articulo primo testaceo, secundo piceo, ultimo apice ferrugineo. Caput oblongum, clypeo pallido, labro palpisque piceis. Thorax basi coleopterorum prope latitudine, latitudine baseos haud brevior, apice dimidio angustior, basi et lateribus leviter rotundatus, angulis posterioribus obtusis, laevissimus. Scutellum laevissimum. Elytra thorace parum longiora, punctorum seriebus tribus ordinariis, punctis earum obsoletis, inter se sat remotis. Abdomen segmentis anterioribus parcius, posterioribus crebrius punctatum. Pedes nigro-picei, tarsis anticis in utroque sexu simplicibus.

Mas abdomine apice concolore, segmento inferıore sexto tricarinato, carina intermedia apice, lateralibus basi abbreviatis, apice inter carinas laterales emarginato.

F e min a abdominis segmento quinto apice late sanguineo, sexto simplice.

Obs. Utriusque sexus nonnisi unicum specimen vidi, nescio igitur an differentia coloris in abdominis apice semper cum differentia sexus conveniat.

* 12. B. striatus: Nigro-piceus, nitidus, pedibus segmentorumgue abdominis marginibus rufis, elylris rufis, angulo apicali exteriore nigro. Long. $2-2 \frac{2}{3}$ lin.

Mannerh. Brachelytr. 64. 6. - Boisd. et Lacord. Paun. Ent. Paris. I. 500. 4. Runde Brachelytr. Hal. 26. 3.

Staphyl. striatus Oliv. Ent. III. 42. 28. 37. t. 5. f. 47.

Tachinus striatus Grav. Micr. 146. 17. Mon. 27. 6. - Latr. Hist. nat. Crust. et Ins. IX. 398. 17. - Gyll. Ins. Suec. II. 272. 18. - Sahlb. Ins. Fenn. I. 304. 17. Staphyl. angularis Payk. Faun. Suec. 1II. 395. 35.

Staphyl. ana lis var. $\gamma$ Payk. Mon. Staph. 48. 34.

Habitat in Europa.

Antennae capite thoraceque breviores, fortius incrassatae, articulo secundo tertioque aequalibus, $\mathbf{5}-\mathbf{1 0}$ crassis, transversis, ultimo praecedente sesqui longiore, compresso, ovato, fuscae, articulis 4 primis rufo-testaceis, ultimo testaceo. Caput oblongum, nigro-piceum, nitidum, ore rufo-testaceo. 
Thorax basi coleopterorum prope latitudine, apice dimidio angustior, latitudine baseos paulo brevior, basi et lateribus leviter rotundatus, angulis posterioribus omnino rotundatis, laevissimus, nigro-piceus, nitıdus, margine summo piceo-rufo. Scutellum laevissimum, rufo-piceum, nitidum. Elytra thorace paulo longiora, punctorum -seriebus tribus ordinariis, punctis sat remotis, rufa, nitida, macula magna transversa apicali, exterius plerumque latiore nigro-picea, margine apicali ipso summo rufo. Abdomen fortius punctatum, longius pubescens, nigro-piceum, nitidum, segmentis 4 primis margine postico, quinto apice, sexto toto rufis. Pectus nigro-piceum, nitidum. Pedes testacei, coxıs anticis concoloribus, tarsis anticis in utroque sexu simplicibus.

Mas abdominis segmento inferiore sexto apice sub-bisinuato.

Femina abdominis segmento inferiore sexto apice rotundato.

\section{* 13. B. dimidiatus: Niger, nilidus, elytrorum basi pedibusque rufis. - Long. $2 \frac{1}{2}$ lin.}

Habitat in America septentrionali.

Statura omnino praecedentis, niger, nitidus. Antennae capite thoraceque multo breviores, apicem versus fortiter incrassatae, articulo tertio secundo paulo longiore, 5-10 crassis, sensim paulo crassioribus, transversis, ultimo angustiore, breviter subovato, apice subacuminato, nigrae, articulis tribus primis rufo-testaceis, ultimo ferrugineo. Caput oblongum, laevissimum, ore testaceo. Thorax basi coleopterorum latitudine, apice duplo prope angustior, latitudine baseos parum brevior, bası, lateribus angulisque posterioribus rotundatis, laevissimus. Elytra thoracis longitudine, serie dorsali punctis sat distinctis sex composita, nitida, nigra, basi prope ad medium usque rufa. Abdomen crebrius fortiusque punctatum, griseo-pubescens, segmentis singulis margine apicali rufo-piceo. Pedes rufi, coxis anticis picescentibus.

Mas abdominis segmento inferiore sexto apice sub-bisinuato.

Femin a abdominis segmento inferiore sexto apice rotundato.

* 14. B. atricapillus: Rufus, nitidus, capite, peclore, ano elytrisque nigris, his lunula basali margineque apicali albidis. - Long. $2 \frac{1}{2}-3$ lin.

Mannerh. Brachelytr. 64. 7. - Boisd. et Lacord. Faun. Ent. Paris. I. 497. 1. Runde Brachelytr. Hal. 27. 5. - Er. Col. March. I. 408. 6.

Staph. at ricapillus Fab. Syst. Ent. 267. 15. Spec. Ins. I. 337. 19. Mant. Ins. I. 221. 26. Ent. Syst. 1. II. 527. 40. Syst. El. II. 599. 49. - Goeze Ent. Beitr. I. 724. 9. - Payk. Mon. Staph. 49. 35̃. Faun. Suec. III. 414. 60. - Oliv. Ent. III. 42. 29. 40. t. 4. f. 39. - Panz. Ent. Germ. 456. 30. - Schrank Fauna Boica I. 645. 877. - Mursh. Ent. Britt. 522. 71.

Tachinus atricapillus Grav. Micr. 148. 19. Mon. 30. 14. - Latr. Hist. nat. Crust. et Ins. IX. 399. 19. - Gyll. Ins. Suec. II. 273. 19. - Suhlb. Ins. Fenn。 I. 305. 18. - Guér. Iconogr. Ins. t. 10. f. 8.

Oxyporus lunulatus Fab. Syst. Ent. 268. 2. Spec. Ins. I. 338. 2. Mant. Ins. I. 222. 2. Ent. Syst. I. II. 532. 3. Syst. El. II. 605. 3. (forte) - Panz. Ent. Germ. 359. 3. Faun. Germ 22. 15.

Tachinus lunulat us Zetterst. Faun. Lappon. I. 65. 9. Ins. Lappon. 58. 10.

Habitat in Europae boletis. 
Antennae capitis thoracisque prope longitudine, apice crassiores, articulo tertio secundo paulo longiore, 5-10 sensim paululum brevioribus et crassioribus, subobconicis, ultimo oblongo-ovato, praecedentibus ambobus longitudine aequali. fuscae, articulis 4 primis ultimoque testaceis. Caput valde elongatum, angustatum, nigrum, nitidum, ore flavo. Thorax basi coleopterorum prope latitudine, latitudine baseos parum brevior, apice plus dimidio quam basi angustior, basi et lateribus leviter rotundatus, angulis posterioribus obtusis, laevissimus, apice punctorum pari notatus, testaceorufus, nitidus. Scutellum nigrum, nitidum. Elytra thorace paulo longiora, punctorum remotorum seriebus tribus ordinariis, nigra, nitidissima, macula lunata humerali margineque apicali aibidis. Abdomen parce punctatum, rufum, nitidum, segmentis ultimis duobus nigris, penultimo apice albido. Pectus nigrum. Pedes flavi, coxis anticis concoloribus, tarsis anticis in utroque sexu simplicibus.

Mas abdominis segmento inferiore sexto apice truncato.

Femina abdominis segmento inferiore sexto apice rotundato.

Obs. 1. Ox. lunulatus Fabricii ob ,abdomen apice nigrum, annulo albo" ad hanc speciem referendns videtur: in hac enim annulus albus in segmenti penultimi margine apicali situs conspicuus, in sequente specie tenuissimus neque nisi oculo armato observandus. Staph. atrica pilli nomine signata in Museo Fabriciano Boletochara lunulata exstat.

2. Dom. Prof. Z etterstedt speciem hanc pro vero Staph. lunulato Lin. habet, praecipue quod frequentius obvius sit, descriptio Linneana autem aegre ab hoc insecto desumta

* 15. B. speciosus: Rufus, nitidus, capile, peclore, ano elytrisque nigris, his basi margineque apicali inaequaliter teslaceis, stria dorsali multipunctata. - Long. 4 lin.

Habitat in Hungariae montibus, Dom. Schüppel.

Habitu omnino praecedentis, at plus duplo maior. Antennae capitis thoracisque longitudine, "apice parum crassiores, subcompressae, articulo tertio secundo sesqui prope longiore, 5-10 subobconicss, sensim paululum brevioribus at vix crassioribus, ultimo praecedente parum longiore, ovato, compresso, nigrae, articulis 4 primis ultimoque testaceis. Caput fortiter elongatum, angustum, nigerrimum, nitidum, ore testaceo. Thorax coleopterorum basi paululum angustior, apice duplo prope quam basi angustior, latitudine baseos vix brevior, basi et lateribus leviter rotundatus, angulis posterioribus obtusis, laevissimus, testaceo-rufus, nitidus. Scutellum testaceum. Elytra thorace tertia fere parte longiora, punctorum seriebus tribus ordinariis, punetis seriei intermediae numerosis (circiter 10), nitidissima, nigra, fascia basali, postice profunde sinuata, margineque inaequali apicali testaceis. Abdomen segmentis 4 primis parce punctatis, nigro-pilosellis, rufis, nitidis, reliquis crebre punctatis, nigerrimis, nitidis, quinto margine apicali tenuissimo albo. Pectus nigerrimum. Pedes pallidi, coxis anticis concolo ribus, posterioribus nigris, posticis margine postico albido.

Mas abdominis segmento inferiore sexto apice leviter emarginato.

F e min a latet. 
* 16. B. lunulatus: Rufus, nitidus, capite, pectore, ano, elytrisque nigris, his basi tota margineque apicali testaceis, serie dorsali parumpunctata. - Long. $2 \frac{1}{2}$ lin.

Mannerh. Brachelytr. 64. 6. - Runde Brachelytr. Hal. 27. 4. - Er. Col. March. I. 408. 7 .

Staphyl. lunulatus Linn. Faun. Suec. n. 845. Syst. Nat. I. II. 684. 7. - Müll. Faun. Frid. 23. 225. Prodr. 98. 1104. - Goeze Ent. Beitr. I. 718. 7. - De Vill. Ent. I. 413. 7. - Payk. Mon. Staph. 58. 41. Faun. Suec. III. 415. 61. - Marsh. Ent. Britt. 523. 72.

Oxyporus lunulatus Cederh. Faun. Ingr. 120. 369.

Tachinus lunulatus Grav. Micr. 147. 18. Mon. 30. 13. - Latr. Hist. nat. Crust. et Ins. IX. 398. 18. - Gyll. Ins. Suec. II. 274. 20. - Sahlb. Ins. Fenn. I. 305. 19. Tachinus atricapillus Zetterst. Faun. Lappon. I. 65. 10. Ins. Lappon. 58. 11.

\section{Habitat in Europa.}

Statura et summa affinitas praecedentis. Antennae capitis thoracisque longitudine, apice leviter crassiores, artıculo tertio secundo sesqui longiore, 6 - 10 sensim paululum brevioribus et crassioribus, subobconicis, ultimo ovato, praecedente sesqui longiore, compresso, apice abrupte acuminato, fuscae, articulis 4 primis ultimoque testaceis. Caput modice elongatum, nigrum, nitidum, ore flavo. Thorax basi coleopterorum prope latitudine, apice dimidio quam basi angustior, latitudine baseos vix brevior, basi et lateribus leviter rotundatus, angulis posterioribus obtusis, laevissimus, testaceo-rufus, nitidus. Scutellum testaceum, nitidum. Elytra thorace paulo longiora, punctorum seriebus tribus ordinariis, punctis seriei intermediae paucis, distantibus, nigra, nitidissıma, fascia basali integra, elytri quadrantem fere occupante, margineque apicali testaceis. Abdomen parce punctatum, rufum, nitidum, segmentis ultimis duobus nigris, penultimo margine apicali tenuissimo albo. Pectus nigrum. Pedes flavi, coxis anterioribus concoloribus, tarsis anticis in utroque sexu simplicibus.

M as abdominis segmento inferiore sexto apice truncato.

F emin a abdominis segmento inferiore sexto apice subacuminato.

* 17. B. cinctus: Rufus, nitidus, capite, pectore, ano elytrisque nigris, his basi, sutura margineque apicali teslaceis. - Long. ' $2 \frac{2}{3}$ lin.

Tachinus cinctus Grav. Micr. 193. 6. Mon. 30. I5.

Tachinus atricaudatus Say Journ. of the Acad. of natur. scienc. of Philadelph. III. $p .158$.

Habitat in America septentrionali.

Statura et summa affinitas praecedentium. Antennae capitis thoracisque longitudine, apice leniter crassiores, subcompressae, articulo tertio secundo sesqui longiore, 5-10 subobconicis, sensim paulo crassioribus et paululum brevioribus, ultimo praecedente sesqui longiore, ovato, apice acuminato, fuscae, articulis 4 primis ultimoque testaceis. Caput elongatum, angustum, nigrum, nitidum, ore testaceo. Thorax basi coleopterorum latitudine, antice plus dimidio quam basi angustior, latitudine baseos paulo brevior, basi et lateribus leviter rotundatus, angulis posterioribus obtusis, laevissimus, testaceo-rufus, nitidus. Scutellum rufo-testaceum, nitidum. Elytra thorace paulo longiora, punctorum seriebus ordinariis tribus, punctis seriei interme- 
diae pancis, distantibus, nitidissima, nigra, basi tota, sutura basi leviter dilatata, margineque apicali testaceis. Abdomen parce punctatum, nitidum, segmentis quatuor primis rufis, ultimis duobus nigris, penultimo apice testaceo. Pectus nigrum. Pedes flavi, coxis anterioribus concoloribus, posticis nigris, margine postico testaceo.

* 18. B. trimaculatus: Niger, nitidus, thorace elytrisque testaceis, illo disco, his angulo exteriore late nigris, antennis pedibusque teslaceis, elytrorum serie dorsali multipunctata. - Long. $2 \frac{1}{2}$ lin.

Mannerh. Brachelytr. 65. 9. - Boisd. et Lacord. Faun. Ent. Paris. I. 498. 2. Oxyporus trimaculatus Fab. Ent. Syst. I. II. 533. 7. Syst, El. II. 605. 7.

Staphyl. trimaculutus Payk. Faun. Suec. III. 422. 68.

Tachinus trimaculatus Gyll. Ins. Suec. II. 275. 21. - Sahlb. Ins. Fenn. I. 306. 20. - Zetterst. Ins. Lappon. 58. 12.

Staphyl. littoreus Payk. Mon. Staph. 80. 55.

Habitat in Suecia, Fennia, Dom. Schïppel.

Sequentibus affinis, at maior, B. cernuo aequalis, medio tamen latior, et apicem utrumque versus magis angustatus. Antennae capitis thoracisque prope longitudine, apice parum crassiores, articulo tertio secundo paulo longiore, 5-10 leviter obconicis, subaequalibus, ultimo elongato-subovato, apice acuminato, testaceae, medio magis minusve fuscescentes. Caput breviusculum, laevissimum, nigrum, nitidum, ore testaceo. Thorax basi coleopteris distincte angustior, apicem versus leviter angustatus, apice dimidio quam basi angustior, latitudine baseos parum brevior, basi et lateribus parum rotundatus, angulis posterioribus obtusis subrotundatis, laevissimus, nitidus, rufo-testaceus, disčo longitudinali basin versus angustato nigro. Scutellum laevissimum, nigrum. Elytra thorace sesqui longiora, luteo-testacea, nitida, angulo posteriore exteriore a suturae apice inde usque ad lateris medium margineque toto inflexo nigerrimo, stria dorsali ordinaria circiter 12-punctata. Abdomen breviusculum, sparsim fortius punctatum, pube longiore depressa grisea parcius vestitum, nigrum, nitidum, segmentis singulis margine apicali piceo-testacea. Pectus nigerrimum. Pedes testacei, coxis anterioribus concoloribus, posticis nigris, margine posteriore albido, tarsis anticis in utroque sexu simplicibus.

Obs. Differt a B. trin otato et pygmaeo elytrorum stria dorsali multipunctata, a B. exolet o statura multo maiore et duplo latiore ut et colore.

* 19. B. trinotatus: Testaceus, nitidus, capite, elytrorum macula scutellari aliaque postica nigris, antennis fuscis, basi testaceis, elytris serie dorsali mullipunctata. - Long. 2 lin.

Er. Col. March. I. 309. 8.

Staph. bimaculatus Schrank Faun. Boic. I. 644. 872. (forte).

Habitat in Germania.

Antennae capitis thoracisque longitudine, apice leviter crassiores, articulis 2 et 3 longitudine aequalibus, 4-10 subobconicis, sensim paululum brevioribus et crassioribus, ultima ovato, apice acuminato, pilosae, fuscae, articulis 4 primis dilute testaceis. Caput oblongum, nigrum, nitidum, labro, palpis reliquisque oris partibus dilute testaceis. Thorax basi coleopteris 
angustior, apice basi vix dimidio angustior, latitudine baseos parum brevior, basi et lateribus medio leviter rotundatus, angulis posterioribus obtusis, laevissimus, rufo-testaceus, nitidus. Scutellum testaceum. Elytra thorace plus sesqui longiora, flavo-testacea, nitida, macula communi circa scutellum aliaque sat magna intra angulum apicalem exteriorem rotundatis nigris, saepius magis minusve obsoletis, serie dorsali ordinaria punctis circiter 8-9 composita. Abdomen rufo-testaceum, segmentis singulis rarius basi piceis, nitidum, supra punctis raris impressum, subtus crebrius fortiter punctatum. Pectus nigrum, nitidum. Pedes flavo-testacei, coxis anterioribus concoloribus, posticis nigris, margine postico testaceo, tarsis anticis in utroque sexu simplicibus.

M a s abdominis segmento inferiore sexto longitudinaliter obsolete impresso.

F emin a abdominis segmento inferiore sexto simplice.

* 20. B. exoletus: Testaceus, nitidus, capite nigro, elytris macula apicali obsoleta fusca, antennis ante apicem fuscescentibus, elytris serie dorsali mullipunctata. - Long. $1 \frac{1}{2}$ lin.

Er. Col. March. I. 409. 9.

Habitat in Germania, ipse, in Gallia, Dom. Dr. Aubé, in Sardinia, Dom. Prof. Gené.

Statura sequentis et maioribus eius individuis aequalis, at paulo angustior. Antennae capite thoraceque paulo longiores, apice leviter crassiores, articulo tertio secundo paulo longiore, 5-10 leviter obconicis, aequalibus, ultimo ovato, apice acuminato, testaceae, ante apicem paulo obscuriores. Caput breviusculum, nigrum, nitidum, oris partibus testacess. Thorax basi coleopterorum latitudine, apice dimidio fere angustior, latitudine baseos vix brevior, basi parum, lateribus leviter rotundatus, angulis posterioribus obtusis, testaceus, nitidus. Scutellum testaceum. Elytra thorace plus sesqui longiora, thoracis basi haud latiora, testacea, nitida, apice macula transversa fusca obsoletiore, in angulo exteriore sita, notata, margine apicali summo plerumque testaceo, serie dorsali ordinaria punctis sat confertis, numero circiter 12-14 oomposita. Abdomen utrinque parce punctatum, testaceum, nitidum, segmentis singulis basi obscurioribus. Pectus piceum. Pedes flavi, coxis anterioribus concoloribus, posticis piceis, margine postico dilutiore, tarsis anticis in utroque sexu simplicibus.

Mas abdominis segmento inferiore sexto apice summo subemarginato.

Femina abdomınis segmento inferiore sexto apice rotundato.

Variat thoracis disco piceo, elytrorum macula nigerrima, maiore, ultra elytri tertiam partem dilatata.

O bs. Praecedenti et sequenti admodum affinis, ab illo autem statura minore, angustiore, capite breviore etc., ab hoc elytrorum serie dorsali multipunctata satis distinctus.

*21. B. pygmaeus: Piceo-testaceus, nitidus, capite elytrorumque macula angulari nigris, antennis fuscis, basi testaceis, elytrorum serie dorsali parumpunclata. - Long. $1 \frac{1}{3}-2$ lin.

Mannerh. Brachelytr. 65. 10. - Botsd. et Lacord. Faun. Ent. Paris. I. 499. 3. Er. Col. March. I. 410. 10. 
охурогиs pygmaeus Fab. Spec. Ins. I. 339. 4. Mant. Ins. I. 222. 5. Ent. Syst. I. 1I. 534. 13. Syst. El. 1I. 606. 12. - Panz. Ent. Germ. 360. 10. Faun. Germ. 27.19. Tachinus pygmaeus Gyll. Ins. Suec. II. 277. 22. - Zetterst. Faun. Lappon. I. 66 11. Ins. Lappon. 58. 13. - Sahlb. Ins. Fenn. I. 306. 21.

Oxyporus thoracicus Fab. Spec. Ins. I. 338. 3. Mant. Ins. I. 222. 4. Ent. Syst. I. II. 534. 12. Syst. El. II. 606. 12. Panz. Ent. Germ. 360. 9.

Tachinus melanocephalus Grav. Micr. 144. 16. Mon. 27. 7. - Latr. Hist. nat. Crust. et Ins. IX. 398. 16.

Staphyl. melanocephalus Marsh. Ent. Britt. 523. 73. (forte)

Staphyl. trimaculatus var. $\beta$, y Payk. Faun. Suec. III. 422. 68.

Boletobius merdarius Runde Brachelytr. Hal. 26. 2.

St aph. pallidus Rossi Faun. Etr. Mant. 99. 221. (Ed. Hellw. 1. 444. 221.) forte.

Habitat in Europa.

Magnitudo variat, speciminá maxima B. trinotato aequalia, pleraque autem duplo minora et ultra. Antennae capite thoraceque breviores, apice crassiores, articulis 2 et 3 aequalibus, $5-10$ subobconicis, sensim paulo crassioribus, ultimo compresso, breviter ovato, apice obtuso, fuscae, articulis 5 primis testaceis. Caput breviusculum, nigrum, nitidum, ore testacen. Thorax basi coleopteris paulo angustior, apice duplo prope quam basi angustior, latitudine baseos paulo brevior, basi et lateribus leviter rotundatus, angulis posterioribus obtusis, laevissimus, testaceus, nitidus, disco magis minusve picescente. Scutellum piceo-testaceum. Elytra pallide testacea, nitida, macula magna rotundata intra angulum apicalem, rarius obsoleta, picea, nonnunquam etiam circa scutellum picescentia, serie dorsali ordinaria pun. ctis sat distantibus, circiter $5-6$ composita. Abdomen supra parcius, subtus crebrius sat fortiter punctatum, piceum, nitidum, apice segmentorumque singulorum margine postico rufo-testaceis, nonnunquam omnino rufotestaceum. Pectus nigro-piceum. Pedes pallide testacei, coxis anterioribus plerumque concoloribus, rarius picescentibus, posticis nigro-piceis, margine postico testaceo, tarsis anticis in utroque sexu simplicibus.

Mas abdomiuis segmento sexto inferiore medio obsolete tuberculato, pone tuberculum leviter longitudinaliter impresso.

F emina abdominis segmento inferiore sexto simplice.

Variat rarius thorace abdomineque omnino nigro-piceis, frequentius omnino testaceus, capite solo nigro.

$$
\mathrm{S} \text { pecies } \mathrm{mih} \text { i invis a. }
$$

22. B. pulchellus: Rufo-testaceus, nitidus, capite, antennarum medio, pectore, elytromum fascia postica anoque nigris.

Mannerh. Brachelytr. 64. 8.

Habitat in Fennia, prope Aboam.

B. atricapillo similis, paulo tamen angustior et aliter coloratus. B. lunulato etiam affinis, sed quadruplo minor, nitidior et respectu magnitudinis angustior, antennarum articulo ultimo longiore toto pallido. (Mannerh.)

\section{Mycetoporus Mannerh.}

Mannerh. Bruchelytr. p. 62.

Ischnosoma Steph. Illustr. V. p. 168.

Antennae 11-articulatae, filiformes. 
Palpi maxillares articulo ultimo subulato.

Ligula inlegra, apice rotundata.

Elytra pectori longitudine aequalia.

Tarsi 5-articulati.

Corpus elongatum, aut lineare aut utrinque attenuatum, utrinque deorsum curvatum, alatum. Caput thoraci immissum, deflexum, oculis rotundatis, parum prominulis. Labrum subquadratum, apice leviter emarginatum. Mandibulae parvae, apice incurvae, acutae, interne basi membrana ciliatae. Maxillae (t. IV. f. 7. b.) malis coriaceis, interiore interne, exteriore apice barbatis. Palpi maxillares leviter elongati, articulo primo minuto, secundo tertioque inter se longitudine subaequalibus, subobconicis, tertio reliquis crassiore, quarto minuto, tenui, subulato. Labium (t. IV. f. 7. a.) mento transverso, parte membranacea ante palporum basin sat elongata, ligula rotundata, membranea, paraglossis ligulae connatis, nonnisi linea ciliata distinguendis, eamque hand superantibus. Palpi labiales breviusculi, crassiusculi, articulo primo cylindrico, secundo breviore, subgloboso, tertio minuto, subulato. Aritennae ante mandibularum basin insertae, filıformes, apicem versus magis minusve incrassatae. Thorax coleopterorum fere latitudine, antrorsum angustatus, latitudine parum brevior, lateribus rotrndatus, basi truncatus, antice pro receptione capitis leviter emarginatus, transversim convexus. Scutellum triangulare. Elytra apice truncata, angulo apıcali exteriore oblique truncato. Abdomen aut lineare aut apicem versus sensim attenuatum, deorsum curvatum. Pedes breviusculi, coxis intermediis valde approximatis, posticis amplis, parallelopipedis, scutatis, tibiis omnibus spinulosis, tarsis 5-articulatis, posterioribus elongatis, gracilibus, articulo primo elongato, anticis crassiusculis, articulo primo reliquis paulo longiore, in utroque sexu simplicibus.

\section{O b s e r vatio ne s.}

1. Genus praecedenti proximum, at ligula integra et palporum maxillarium articulo ultimo subulato sat distinctum.

2. Caput laevissimum, thorax laevissimus, margine punctis singulis, dorso saepius punctis nonnullis inter medium et latera sitis, apice semper punctis quatuor transversim positis, margine anteriori magis minusve approximatis impressus, scutellum laevissimum, elytra punctorum seriebus tribus ordinariis, una suturali, secunda dorsali, tertia marginali; abdomen parcius fortiusque punctatum.

3. Mas plerumque antennis apice paulo crassioribus et abdominis segmento inferiore sexto minus rotundato, septimoque igitur conspicuo distinguendus.

4. Victus in silvis, sub muscis et foliis deciduis.

* 1. M. splendens: Oblongus, niger, anlennis brevioribus, subclavutis, thorace disco laevissimo, pedibus elytrisque rubris, his punctorum serie dorsali simplice. - Long. 2 lin.

Er. Col. March. I. 411. 1.

Staphyl. splendens Marsh. Ent. Britt. 524. 75.

Habitat in Germania.

Habitu fere Boletobii cernui, at paulo minor, niger, nitidus. Antennae capite thoraceque paulo breviores, apicem versus fortius incrassatae, apice subcompressae, articulo tertio secundo paulo longiore, $4-6$ obconicis, sensim crassioribus et paulo brevioribus, $7-10$ transversis, ultimo breviter 
ovato, pilosae, fuscae, articulis duobus primis testaceis. Palpi testacei. Caput breve, subrotundatum. Thorax basi coleopterorum prope latitudine, apice dimidio angustior, latitudine baseos parum brevior, lateribus modice, basi leviter rotundatus, angulis posterioribus rotundatis, modice convexus, ad apicem punctis quatuor transversim positis impressus. Elytra thorace paulo longiora, punctorum seriebus tribus ordinariis, interstitiis laevissimis, saturate rufa, nitida, margine laterali nigro. Abdomen apicem versus leviter attenuatum, pilis brevibus depressis parce pubescens, segmentis singulis fortius punctatis, apice laevioribus, margine postico rufo-piceo. Pedes anteriores rufi, postici rufo-picei, femoribus nigricantibus.

* 2. M. punctus: Oblongus, niger, pedibus antennisque teslaceis, his ante apicem fuscescentibus, thorace rufo, disco utrinque punctis duobus, elytris rufis, lateribus nigris, intra seriem dorsalem punctis nonnullis impressis. - Long. 2 lin.

Munnerh. Brachelytr. 63. 5. - Er. Col. March. 1. 412. 2.

Tachyporus punctus Gyll. Ins. Suec. I1. 248. 13. - Zetterst. Ins. Lapp. 56. 11. Tachinus punctus Grav. Mon. 27. 5. (forte)

\section{Habitat in Germania.}

Statura omnino praecedentis, punctura vero M. lepidi. Antennae capite thoraceqne parum breviores, apicem versus leviter incrassatae, articulo tertio secundo paulo longiore, $5 \mathbf{- 1 0}$ subcylindricis, sensim paululum brevioribus et crassioribus, penultimis crassitie parum brevioribus, ultimo ovato, apice subacuminato, testaceae, ante apicem flavo-testaceum fuscescentes. Caput breviusculum, nigro-piceum, ore testaceo. Thorax basi coleopterorum fere latitudine, apice duplo angustior, latitudine baseos paulo brevior, basi et lateribus leviter rotundatus, angulis posterioribus subrotundatis, leviter convexus, dorso utrinque punctis duobus, a margine laterali et a medio aequaliter remotis, apice punctis quatuor, transversim positis, notatus, rufus, nitidus. Scutellum piceum, nitidum. Elytra thorace sesqui prope longiora, punctorum seriebus tribus ordinariis, punctis sat distantibus, et praetera interstitio interiore punctis nonnullis, saepius seriem dorsalem accessoriam constituentibus impressa, rufa, nitida, margine laterali nigro. Abdomen apicem versus sensim attenuatum, supra parce fortiter punctatum, parce griseo-pubescens, nigrum, segmentis singulis margine postico late rufo-piceo. Pectus nigrum. Pedes rufo-testacei.

Variat minus maturus testaceus, capite solo nigro-piceo.

* 3. M. longulus: Elongatus, niger, nitidus, antennis filiformibus, thorace disco utrinque puncto uno alterove impresso, pedibus elytrisque rubris,

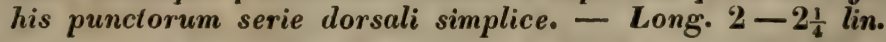

Mannerh. Brachelytr. 63. 4. - Boisd. et Lacord. Faun. Ent. Paris. I. 503. 1. Er. Col. March. I. 413. 3.

Habitat in Germania.

M. splendenti affinis, at magis elongatus, niger, nitidus. Antennae capitis thoracisque longitudine, apice parum incrassatae, articulo tertio secundo sesqui longiore, 5 - 10 sensim paulo brevioribus at parum crassioribus, omnibus, penultimis etiam, crassitie longioribus, ultimo oblongo-ovato, apice acuminato, fuscae, articulis duobus primis testaceis. Caput breve, apicem 
versus angustatum, ore testaceo. Thorax basi coleopterorum latitudine, apice duplo prope angustior, latitudine baseos paulo brevior, basi, lateribus et angulis posterioribus rotundatis, leviter convexus, medio utrinque punctis duobus tribusve, apice punctis quatuor, transversin positis, impressus. Elytra thorace sesqui prope longiora, punctorum seriebus tribus ordinariis, ${ }^{\circ}$ punctis sat distantibus, interstitiis laevissimis, rufa, ritida, margine laterali summoque basali nigro. Abdomen elongatum, apicem versus sensim attenuatum, densius griseo-pubescens, segmentis singulis crebre fortiter punctatis, margine postico rufo-piceo. Pedes anteriores ruf, postici rufo-picei, femoribus nigricantibus.

* 4. M. lepidus: Elongatus, linearis, piceus, pedibus testuceis, thorace disco utringue punclis duobus, elytris prope seriem dorsalem punctis duobus impressis. - Long. $1 \frac{1}{2}-2$ lin.

Mannerh. Brachelytr. 63. 1. - Er. Col. March. I. 413. 4.

Tachinus lepidus Grav. Mon. 26. 4.

Tachyporus lepidus Gyll. Ins. Suec. II. 247. 12. - Zelterst. Faun. Lappon. I.

59. 7. Ins. Luppon. 55. 9. - Sahlb. Ins. Fenn. I. 294.12.

Staphyl. punctato-striatus var. $\alpha-\gamma$ Payk. Faun. Suec. III. 417. 64.

Staphyl. merdarius Schrank Faun. Boic. I. 647. 884.

Staph. merdarius Fab. Syst. Ent. 266. 14. Spec. Ins. I. 337. 18. Mant. Ins. I.

221. 25. Syst. El. II. 598. 46. - Goeze Ent. Beitr. I, 724. 8. (forte)

Oxуроrus merdarius Fab. Ent. Syst. I. II. 533. 11. (forte)

Var. a: Nigro-piceus, elytris rufis.

Mycetoporus lepidus Boisd, et Lacord. Faun. Ent. Paris. I. 504. 2.

Var. b: Vigro-piceus, elytris rufis, macula postica nigricante.

Mycetoporus bimaculat us Boisd, et Lacord. Faun. Ent. Paris. I. 505. 3.

Var. c: Minor, nigro-piceus, antennarum basi pedibusque picescentibus. Tachinus trist is Grav. Mon. 29. 10.

\section{Habitat in Europa.}

Elongatus, angustus, linearis, plerumque iam obscure piceus, iam castaneus, vel interdum testaceus, nitidus. Antennae capitis thōracisque longitudine, apicem versus parum incrassatae, articulo tertio secundo sesqui prope longiore, 5-10 sensim paululum crassioribus at vix brevioribus, penultimis longitudine paulo crassioribus, ultimo breviter ovato, subacuminato, piceae, basi testacei. Caput breve, rotundatum, nigro-piceum, ore testaceo. Thorax basi coleopteris paulo latior, apice duplo fere angustior, latitudine baseos vix brevior, basi et lateribus modice rotundatus, angulis posteriori-bus obtusis, subrotundatis; modice transversim convexus, dorso utrinque punctis duobus tribusve, apice punctis quatuor, exterioribus in ipso margine, impressus. Elytra thorace paulo longiora, punctorum seriebus tribus ordinariis, punctis modice distantibus, et prope seriem intermediam interne punctis duobus impressa, plerumqne corpori concolora, rarius rufa, interdum macula nigra ante apicem notata Abdomen elongatum, parallelum, fortius punctatum, parce griseo-pubescens. Pedes testacei vel rufo-testacei.

$\mathrm{O}$ b s. 1. Magnitudine et colore instabilis, statura lineari, elongata facilius cognoscítur. 
2. Staph. merdarius Fab. secundum specimen in collectione auctoris con. servatum, ad hanc speciem pertinet, cum autem ab eo Museum Banksianum citatum sit, non sine dubio descriptionem mancam allegavi.

3. Staph. brunneus Marsh. Ent. Britt. 524 71, secundum specimen autoris ipsius a Dom. Stephens in hoc genere enumeratus, forte ad hanc speciem pertinet. Marsham descriptionem a Paykulo mutuavit, qui hôc nomine Omalium significavit, locus Marshamianus igiter neque apud hoc neque apud illud insectum citandus.

* 5. M. Americanus: Oblongus, niger, nilidus, antennarum basi, thorace, elytris pedibusque rufo-testaceis, thorace dorso utrinque punctis duobus impresso, elylris punclorum serie dorsali simplice. - Long. $1 \frac{1}{2}$ lin.

Habitat in America septentrionali, Dom. Zimmermann.

Habitu omnino M. proni, at sesqui fere maior. Antennae apicem versus incrassatae, articulo tertio secundo vix aequali, obconico, sequentibus sensim crassioribus, nigrae, basi rufo-testacei (articuli ultimi desunt). Caput parvum, breve, nigro-piceum, nitidum, ore rufo. Thorax basi coleopterorum fere latitudine, apice duplo angustior, latitudine baseos distincte brevior, basi et lateribus leviter rotundatus, angulis posterioribus obtusis, modice transversim convexus, dorso utrinque punctis duobus, a margine laterali et a medio aequaliter distantibus, et paulo ante apicem punctis 4, exterioribus margini magis approximatis, impressus, rufo-testaceus, nitidus. Scutellum demersum, piceum. Elytra thorace paulo longiora, serie dorsali sat regulari, punctis crebrioribus, interstitiis punctis impressis nullis, rufo-testacea, nitida, circa scutellum picea, margine laterali nigro. Abdomen apicem vérsus sensim attenuatum, crebrius fortiter punctatum, fulvo-pubescens, nigro-piceum, segmentis singulis margine postico rufopiceo. Pectus nigro-piceum. Pedes rufo-testacei, coxis anticis concoloribus.

Obs. M. prono affinis at paulo maior et thoracis punctis discoidalibus lateralibus distinctus.

* 6. M. pronus: Elongalus, rufo-teslaceus, nitidus, pectore abdomineque nigricantibus, thorace disco laevissimo, elytris punclorum serie dorsali

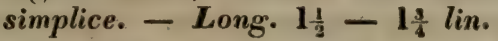

Er. Col. March. I. 414. 5.

Habitat in Germania.

M. lepido minor minusque linearis. Antennae capite sesqui longiores, apicem versus fortiter incrassatae, articulo tertio secundo tenuiore nec longiore, obconico, sequentibus sensim crassioribus, 6-10 fortiter transversis, ultimo subgloboso, apice obtuso, rufo-testaceae, apice fuscescentes, vel fuscae, basi testaceae. Caput breviusculum, rufo-testaceum, vertice interdum piceo. Thorax basi coleopterorum prope latitudine, apice duplo fere angustıor, latitudine baseos paulo brevior, lateribus et basi leviter rotundatus, angulis posterioribus obtusiusculis, modice convexus, ante apicem punctis quatuor, transversim positis, sat distinctis, impressus, disco laevissimus, rufotestaceus, nitidus. Elytra thorace parum longiora, punctorum seriebus tribus ordinariis, interstitiis laevissimis, rufo-testacea, nitida. Abdomen apicem versus leviter attenuatum, parce fortiter punctatum, parce griseo-pubescens, nigro-piceum, nitidum, apice segmentorumque singulorum margine postico rufis. Pectus nigro-piceum. Pedes testacei. 
Mas abdominis segmento inferiore sexto apice truncato, antennisque crassioribus cognoscitur.

Variat 1, Elytris circa scutellum et margine laterali nigricantibus. Genuinis plerumque paulo maior, colore saturatiore, et antennis minus fortiter incrassatis, praecipue in feminis.

2, Capite, ore excepto, piceo. Elytra saepius ut in var. 1, nonnunquam pone medium macula discoidali fuscescente notata. Genuinis paulo minor.

O bs. Distinguitur corporis statura fere fusiformi, antennis crassis vel crassiusculis, elytrorum serie punctorum dorsali simplice et thoracis disco punctis lateralibus nullis, [punctis ad apicem impressis autem spatio quodam a margine anteriore remotis.

* 7. M. nanus: Oblongus, niger, nitidus, antennarum basi pedibusque piceis, thorace disco laevissimo, elytris serie punctorum dorsali sesquialtera. - Long. $1 \frac{1}{2}$ lin.

Er. Col. March. I. 415. 6.

Tachinus nanus Grav. Mon. 28. 8.

Habitat in Germania, Polonia.

Habitu praecedentis omnino, at paulo minor, niger, nitidus. Antennae capite thoraceque breviores, apicem versus leviter incrassatae, articulo tertio secundo vix longiore, sequentibus sensim paululum crassioribus, penultimis vix transversis, ultimo breviter ovato, apice obtusiusculo, compresso, nigrae, basi piceae. Caput oblongum, ore cum palpis piceo. Thorax basi coleopterorum latitudine, apice duplo angustior, latitudine baseos haud brevior, basi et lateribus leviter rotundatus, angulis posterioribus obtusis, modice convexus, apice punctis quatuor transversim positis impressus, disco laevissimo. Elytra thorace paulo longiora, punctorum seriebus tribus ordinariis, serie intermedia punctis crebrioribus composita, interne punctorum serie accessoria dımidia approximata quasi duplicata, margine apicali piceo. Abdomen apicem versus sensim angustatum, parce subtiliter punctatum, parce griseo-pubescens, segmentis singulis margine postico piceis. Pedes picei.

Variat. Thorace elytrisque piceis, rufo-piceis, vel testaceis: his caput piceum, ore testaceo, antennae testaceae, basi dilutiores, pedes testacei.

Obs. 1. Specimen thorace elytrisque rufo-testaceis pro Tachini nani typo benevole communicavit Dom. Prof. Gravenhorst, hoc synonymum igitur indubium, quamvis descriptio anceps videtur: thorax enim punctis 2 dorsalibus impressus potius ad M. lepidum spectare videtur. Color etiam typi mihi communicati aegre cum descriptione convenit.

2. A praecedente differt statura paulo minore, antennis parum incrassatis, thoracis punctis ad apicem impressis margini anteriori approximatis, elytrorum seriebus crebre punctatis, intermedia quasi duplicata.

* 8. M. lucidus: Oblongus, piceus, nitidus, thorace disco medio laevissimo, elytris dorso vage punclatis. - Long. 2 lin.

Er. Col. March. I. 415. 7.

Habitat in Germania.

M. lepido longitudine fere aequalis, at in elytris duplo latior, utrinque attenuatus, fusiformis. Antennae capite duplo longiores, apicem versus le- 
viter incrassatae, articulo tertio secundo paulo longiore, sequentibus sensim paululum brevioribus et crassioribus, penultimis etiam autem vix transversis, ultimo breviter ovato, apice compresso, rufo-piceae, hasi testaceae. Caput breviusculum, nigro-piceum, nitidum, ore testaceo. Thorax basi coleopterorum fere latitudine, apice duplo angustior, latitudine baseos paulo brevior, lateribus modice, basi leviter rotundatus, angulis posterioribus obtusis, leviter convexus, longe ante apicem punctis quatuor, transversim positis, impressus, disco laevissimus, rufo-piceus, nitilus, disco nonnunquam nigricante. Scutellum piceum. Elytra thorace sesqui longiora, striis tribus ordinariis subtiliter regulariterque punctatis, interstitio interiore vage punctato, picea, lucida. Abdomen apicem versus sensim attenuatum, nigropiceum, nitidum, segmentis singulis margine postico rufo-piceo. Pectus nigro-piceum. Pedes rufo-testacei.

Variat minus maturus colore corporis rufo-testaceo.

$\mathrm{Obs}$. Elytris dorso fere 4 -seriatim punctatis et thoracis punctis 4 transversalibus medio inter medium et apicem sitis valde distinctus.

* 9. M. splendidus: Elongatus, testaceus, vertice, elytrorum, basi, pectore abdomineque piceis, elytris serie punctorum dorsali simplice. - Long. $1 \frac{1}{2}-2$ lin.

Mannerh. Brachelytr. 63. 2. - Boisd. et Lacord. Faun. Ent, Paris. I. 505. 4. Er. Col. March. I. 416. 8.

Ta chinus splendidus Grav. Mon. 24.3.

Tachyporus splendidus Gyll. Ins. Suec. II. 249. 13. - Zetterst. Faun. Lappon.

I. 60. 8. Ins. Lappon. I. 55. 10. - Sahlb. Ins. Fenn. I. 295. 13.

\section{Habitat in Europa.}

Antennae elongatae, capitis thoracisque longitudine, apice leviter incrassatae, articulo tertio secundo sesqui longiore, 4-10 subobconicis, longitudine subaequalibus et sensim perparum crassioribus, ultimo ovato, testaceae, at ticulo secundo sequentibusque nonnullis fuscis. Caput elongatum, rufo-testaceum, basi plerumque piceum. Thorax basi coleopterorum fere latitudine, apice dimidio angustior, latitudine baseos paulo brevior, lateribus modice, basi vix rotundatus, angulis posterioribus obtusis, vix rotundatis, leviter convexus, apice punctis quatuor transversim positis notatus, disco laevissimus, testaceus, nitidus. Scutellum piceum. Elytra thorace sesqui prope longiora, punctorum seriebus tribus ordinariis, serie intermedia punetis sat distantibus, testacea, basi plerumque picea. Abdomen apicem versus leviter attenuatum, parce punctatum, undique pilosellum, fuscum, apice segmentorumque singulorum margine lato testaceis. Pectus piceum. Pedes elongati testacei.

Mas abdominis segmento inferiore sexto profunde inciso, quinto margine dense piloso.

Femin a abdominis segmento inferiore sexto integro, apice leviter rotundato, quinto simplice.

Variat 1, capite nigro-piceo, ore solo testaceo, elytris basi ultra medium piceis.

2, Corpore rufo-testaceo. Hic plerumque genuinis sesqui maior, ceterum autem nullo modo distinctus videtur. 
Obs. M. pallidulus Mannerh. Brachelytr. 63. 3, „,M. splendido minor, angustior, elytrorum striis vix conspicuis et articulo antennarum ultimo breviore" vix satis ab hoc differe videtur, forte nonnisi sexu distinctus.

\section{Tanygnathus $E r$.}

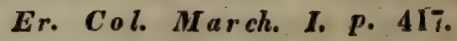

Antennae 11-articulatae.

Palpi maxillares elongati, filiformes.

Elytra pectori longiludine aequalia.

\section{Tarsi 4-articulati.}

Corpus oblongum, utrinque attenuatum, alatum. Corpus thoraci immissum, deflexum, oblongum, oculis mediocribus, ovalibus, parum prominulis. Labrum amplum, apice leviter emarginatum, membranaceum. Mandibulae longae, tenues, falcatae, decussatae. Palpi maxillares valde elongati, tenues, articulo primo minuto, reliquis tribus inter se longitudine aequalibus, ultimo acuminato. Palpi labiales articulo primo secundo paulo breviore, hoc cylindrico, tertio hoc paulo breviore, tenui, acuminato. Antennae capite thoraceque longiores, subrefractae, filiformes, apicem versus haud incrassatae, articulis cylindricis, primo leviter elongato, 2-10 subaequalibus, ultimo iterum paulo longiore, apice acuminato. Thorax transversus, basi coleoptera amplectens, apicem versus angustatus. Scutellum sat magnum, triangulare. Coleoptera apice coniunctim leviter late emarginata, ad angulum exteriorem profundius excisa. Abdomen apicem versus angustatum, pilosellum. Pedes breviusculi, validiusculi, intermedii basi approximati, coxis posticis parvis, angustis, interne scuti instar productis, femorum insertionem obtegentibus, tibiis parce spinulosis, tarsis 4 -articulatis, omnibus simplicibus, articulo primo modice elongato, quarto haud breviore, sequentibus duobus sensim minoribus, quarto tenui.

\section{O b s e r v a $t$ i o n e s.}

1. Oris structuram accuratius examinare nondum mihi contigit, genus autem satis distinctum, mandibulis elongatis, falciformibus, decussatis a reliquis huius tribus discedens, habitu intermedium inter Tachyporum et Heterothopem, elytris pectore non longıoribus, apice ad angulum exteriorem profunde sinuatis $\mathrm{O} x \mathrm{y}$ podam quodammodo referens.

2. Caput et thorax laevissima, glaberrima, polita, hoc punctorum pari uno alterove notato; scutellum, elytra et abdomen punctata et pubescentia.

3. Sexus differentia latet.

4. De victu nihil constat.

* 1. T. terminalis: Niger, nilidus, thorace piceo, palpis, pedibus elytrorumque margine postico rufis, antennis elongatis, nigris, articulo primo testaceo. - Long. $1 \frac{3}{4}$ lin.

Tab. 1. f. 4.

Er. Col. March, 1. 418. 1.

Habitat Berolini, rarissimus.

Antennae capite thoraceque longiores, nigrae, apice fuscescentes, articulo primo testaceo. Oris partes testaceae. Caput laevissimum, nigrum, nitidum. Thorax basi coleopterorum latitudine, antrorsum angustatus, basi et laterıbus leviter rotundatus, angulis posterioribus obtusis, latitudine baseos 
paulo brevior. transversim convexus, dorso medıo utrinque puncto singulo impressus, ceterum laevissimus, nitidus, disco nigro-piceo, margine laterali basalique late rufo-piceis. Scutellum confertim subtiliter punctatum, tenuter pubescens, nigrum. Elytra thorace paulo longiora, confertim subtiliter punctata, pube tenui depressa grisea densius vestita, nigra, parum nitida, margine apicali tenui rufo. Abdomen minus subtiliter minusque dense punctatum, minus subtiliter griseo-pubescens, pilis raris rigidis nigris sparstm, nigrum, subnitidum, segmentis singulis rufo-marginatis. Pectus nigrum. Pedes rufo-testacei, coxis anticis concoloribus.

* 2. T. collaris: Niger, nilidus, thorare, scutello palpis pedibusque rufotestaceis, antennis testaceis, medio fuscis. - Long. $1 \frac{2}{3}$ lin.

Habitat in Guyana Venezuelensi, Dom. Moritz.

Statura omnino praecedentis, at paulo minor. Antennae capisis thoracisque longitudine, articulo primo testaceo, sequentibus fuscis, ultimis 3 vel 4 ferrugineis. Oris partes pallide testaceae. Caput nigrum, nitidum. Thorax basi coleopterorum latitudine, apicem versus leviter angustatus, basi et lateribus leviter rottindatus, angulis posterioribus obtusis, latitudine parum brevior, transversim convexus, dorso medio et apice utrinque puncto singulo impressns, ceterum laevissimus, rufo-testaceus, nitidus. Scutellum confertim subtiliter punctatum, rufo-testaceum. Elytra thoracis longitudine, confertim subtiliter punctata, pube subtili depressa cinerea vestita, nigra, parum nitida, margine apicali rufescente. Abdomen creberrime subtilius punctatum, fortius densiusque griseo-pubescens, nigro-piceum, subnitidum, segmentorum marginibus rufo-piceis. Pectus piceum. Pedes testacei, coxis anterioribus ${ }^{-}$concoloribus.

Variat thorace piceo, marginibus piceo-rufis.

3. T. laticollis: Rufo-piceus, nitidus, capite, thoracis disco elytrisque nigro-piceis, thorace coleopteris latiore. - Long. 2 lin.

Habitat in Amer. mer. ins. St. Vincentii, Mus. Dom. Hope.

Antennae capite thoraceque longiores, testaceae, apice flavae. Oris partes pallide testaceae. Caput laevissimum, fusco-piceum, nitidum. Thorax basi coleopteris multo latior, apicem versus fortiter angustatus, basi modice, lateribus fortiter rotundatus, angulis posterioribus rotundatis, latitudine baseos plus dimidio brevior, leviter transversim convexus, dorso ante medium et prope basin utrinque puncto singulo minuto subtilique impressus, punctis posterioribus multo magis distantibus, ceterum laevissimus, piceus, nitidus, margine omni rufescente. Scutellum parce subtilissime punctatum, piceum. Elytra thorace paulo breviora, parcius subtiliter obsoleteque punctata, tenuiter subtiliterque pubescentia, margine laterali nigro-pilosello, picea, nitida, margine summo apicali rufescente. Abdomen crebrius subtiliter punctatum, longius griseo-pubescens, piceo-rufum, nitidulum. Pectus piceorufum. Pedes testacei, femoribus anticis basi lineola longitudinali nigra. 


\section{Tribus tertia.}

\section{St a p ln y 1 i n i n i.}

\section{Sligmala prothoracica conspicua.}

Antennae in frontis margine anteriore insertae.

Labrum plerisque bilobum, saepius limbo exteriore membranaceo coriaceove, piloso.

Mandibula e magis minusve prominentes, falcatae, acutae, medio saepius dentatae, basi lacinia membranea libera, interne ciliata instructae.

Maxillae cardine stipiteque corneis, malis membranaceis coriaceisve, interiore interne, exteriore apice fortius barbatis.

Palpi maxillares 4-articulati, articulo primo minuto, secundo tertioque magis minusve elongatis, quarto his subaequali vel securiformi vel subulato.

Mentum breve, corneum.

Labium membranaceum, exsertum.

Ligula membranea membranaceave, minuta, iam biloba, iam integra, paraglossis magnis multo breviore plerisque;

sat magna, biloba, paraglossis nullis Platyprosopo, Oxyporo.

Palpi labiales omnibus triarticulati.

Anten nae in capitis margine anteriore intra mandibularum basin insertae, 11 -articulatae, articulis 3 primis reliquis paulo magis elongatis, filiformes, vel apicem versus sensim paulo crassiores.

Oculi laterales, parum prominentes.

Caput exsertum, saepius porrectum, basi magis minusve constrictum.

Thorax basi lateribusque marginatus, apice truncatus, margine posteriore rotundato coleopterorum basi applicatus.

Prosternum triangulare, spatio pone coxas membraneo.

Scutellum triangulare.

Elytra pectoris longitudine.

Abdomen margmatum, segmentis sex distinctis, septino saepius conspicuo, stylis analibus plerumque exsertis. 
Pedes plerumque breviusculi, coxis anticis exsertis, conicis, posticis subconicis, trochanteribus posticis simplicibus, tibiis vel omnibus vel posterioribus saepius spinulosis, spinis apicalibus validioribus, tarsis 5 -articulatis, anticis saepe dilatatis.

Sexus differentia plerumque abdominis segmento inferiore sexto maris apice emarginato vel inciso, feminae rotundato integroque obvia; tarsi antici etiam maris saepe magis quam feminae dilatati.

$$
\text { O b s e r vat i o. }
$$

Remotis Lathrobiis, quae stigmatibus prothoracicis occultis et antennarum insertione differunt, haec tribus cum sectione Brachelytrorum fissilabrium Latreillei et Mannerheimii convenit, at characterem a labro derivato relinquendum putavi, in nonnullis generibus et speciebus (e. g. Quedio molochino) omnino obsoletum. Cum genere Staphylino Gravenhorstii autem exactissime congruit tota haec tribus, antennarum insertione et stigmatibus prothoracicis conspicuis a reliquis satis determinata.

\section{Subtribus prima. \\ X a n tho I o n i n i.}

Sligmata prothoracica detecta.

Anlenuae basi inter se non magis quam ab oculis distantes.

Lahrum transversum, bilobum, lateribus coriaceum membranaceumve plerisque;

totum corneum, bilobum Sterculiae;

totum corneum, sexdentatum Scytalino;

integrum, apice membrana elongata porrecta biloba auctum Platyp rosopo.

Mandibulae plerumque haud prominentes.

Maxillae mala exteriore coriacea, oblonga, apice haud dilatata Platyprosopo, Othio, Sterculiae;

apice extrorsum leviter dilatata et praeter barbam introrsum vergentem setosa Holiso, Dio cho, Xantholino, Leptacino;

segmento inferiore corneo apice extrorsum fortiter dilatatato Scytalino.

Palpi maxillares filiformes Platyprosopo, Othio, Sterculiae, Scytalino, Xantholino;

articulo ultimo subulato $\mathrm{H}$ oliso, Diocho, Leptacino.

Ligula minuta, integra, rotundata Othio, Holiso, Sterculiae, Scytalino, Xantholino;

minuta, rotundata, medio incisa Diocho, Leptacino;

magna, biloba Platyprosopo.

$P$ araglossae ligula multo longiores, ciliatae plerisque;

nullae Platyprosopo.

Palpi labiales filiformes Platyprosopo, Othio, Xantholino; articulo ultimo securiformi Sterculiae, Scytalino; artıculo ultimo subulato $\mathrm{Holis}$, Diocho, Leptacino.

Antennae rectae Platyprosopo, Othio, Holiso, Diocho;

fractae Sterculiae, Scytalino, Xantholino, Leptacino. 
Caput collo quasi tenui brevique thoraci affixum plerisque;

basi modice constrictum, thoraci insertum Othio;

basi haud aut leviter constrictum, thoraci insertum Platyprosopo.

Th or ax oblongus, apice truncatus plerisque;

oblongus vel elongatus, apice attenuatus Sterculiae; trapezoideus Holis o.

Elytra sutura integerrima Platyrosopo, Othio, Holiso, Diocho; sutura imbricata Sterculiae, Scytalino, Xantholino, Leptacino.

Abdomen elongatum, plerisque lineare.

Pedes breviusculi plerisque;

elongati Sterculiae;

intermedii basi approximati Platyprosopo, Othio, Holiso, Diocho, Leptacino * et *******;

basi distantes St e rculiae,Scytalino, Xan tholino, Leptacino ** et****, tibiis omnibus spinulosis Othio, Holiso, Diocho;

anticis externe incrassatis et muricato-spimulosis, Scytalino, Xantho-

lino, Leptacino;

anticis inermibus Platyprosopo;

omnibus inermibus vel subtilissime spinulosis Sterculiae;

tarsis breviusculis,

anticis simplicibus Holiso, Sterculiae, Scytalino, Xantholino, Leptacino* et **;

anticis dilatatis Platyprosopo, Othio, Diocho, Leptacino *** et ****.

O b s e r v a t i o n e s.

1. Antennarum structura et elytrorum sutura in duas sectiones haec subtribus dividi potest, altera antennis rectis et elytrorum sutura in tegerrima Platyprosopum, Othium, Holisum et Diochum, altera antenn is fractis et elytrorum sutura imbricata Sterculiam, scytalinum, Xantholinum et Leptacinum continente. Exceptis paucis Leptacini speciebus genera illa coxis intermediis approximatis, haec coxis intermediis distantibus conveniunt. Platyprosopus iabri ligulaeque structura magis forte discrepat.

2. Corpus plerumque magis quam in Staphylininis genuinis elongatum, a quibus haec subtribus praecipue antennarum insertione distinguitur.

* Antennae rectae. Elytrorum sutura integerrima.

\section{Platyprosopus Mannerh.}

Mannerh. Brachelytr. p. 36.

Antennae rectae.

Ligula biloba; paraglossae nullae.

Palpi omnes filiformes.

Corpus elongatum, alatum. Caput sat magnum, thoracis fere latitudine, porrectum, basi haud constrictum, oculis parvis, haud prominulis. Labrum (t. IV. f. 25. c.) transversum, membrana biloba, antrorsum producta auctum, lobis acuminatis. Mandibulae sat validae, medio bidentatae. Maxillae ( $t$. IV. f. 25. b.) mala interiore membranacea, interne barbata, exteriore elongata, portione basali cornea, apicali membranacea, apice barbata. Palpi maxillares articulo primo breviore, reliquis longitudine subaequalibus. Labium (t. IV. f. 25 . a.) mento transverso, ligula sat elongata, membranacea, biloba, 
lobis margine interiore ciliatis, paraglossis nullis. Palpi labiales articulo primo secundoque leviter obcomcis, hoc paulo maiore, tertio iterum paulo maiore, apice truncato. Antennae hasi ab oculis magis quam inter se distantes, rectae, apicem versus sensim attenuatae, articulo primo leviter elongato, secundo obconico, sequentibus sensim leniter decrescentibus, ultimo apice oblique truncato subemarginatoque. Thorax coleopteris latitudine aequalis vel amplior, basi lateribusque rotundatus. Scutellum sat magnum, triangulare. Elytra apice oblique introrsum truncata, sutura integerrima. Abdomen elongatum, apice attenuatum. Pedes breviusculi, validiusculi, tibiis posterioribus spinulosis, anticis dense pubescentibus, tarsis anticis dilatatis, posterioribus artioulo primo elongato,.. sequentibus tribus triangularibus, sensim paululum minoribus.

\section{O b s e r v a t i n e s.}

1. Capite basi haud constricto et thorace ampliore ad Tachyporinos habitu, oris structura quodammodo ad $\mathrm{Oxytelinos}$ et $\mathrm{Omalinos}$ accedit, stigmatibus autem prothoracis detectis conspicuisque et antennarum insertione ab is distinguitur. Corporis habitu $\mathbf{X}$ antholininos cum T achyporinis coniungit.

2. In hac subtribu hoc genus valde insigne labro haud sinuato, processu mem braneo valde elongato bilobo aucto, et ligula biloba, paraglossis omnino nullis, qua nomnisi cum $\mathrm{O} \times \mathrm{y}$ poro, generi altero hanc tribum terminante, congruit

3. Mas abdominis segmento inferiore sexto apice emarginato, femina rotundato distinguuntur.

* 1. P. beduinus: Niger, fusco-pubescens, capite thoraceque glabris, pedibus rufis. - Long. $6 \frac{1}{2}-9$ lin.

Nordm. Symb. 133. 1.

Habitat in Nubia, Dom. Prof. Ehrenberg.

Corpus elongatum, subdepressum, nigrum, nitidum, capite thoraceque nitidis. Antennae capite thoraceque paulo breviores, articulo secundo tertio dimidio breviore, rufo-piceae, apice dilutiores, articulo secundo nigricante. Oris partes rufae. Caput magnum, coleopterorum latitudine, subovatum, supra parum convexum, versus latera dense subtiliter, medio parcius subtilissime punctatum, utrinque punctis paucis maioribus sparsum et puncto singulo grossiusculo notatum, glabrum, lateribus et infra confertissime punctatum, fusco-pubescens. Thorax capite et coleopteris latior, latitudine tertia parte brevior, basin versus subangustatus, lateribus leviter rotundatis, basin versus subsinuatis, basi leviter rotundatus, apice truncatus, angulis posterioribus obtusis, anterioribus rectis, leviter deflexis, leviter trans-versim convexus, confertim subtilissime punctatus, medio utrinque inter medium et latera puncto singulo grossiusculo notatus, glaberrimus. Elyira thorace tertia parte breviora, subdepressa et scutellum confertissime subtiliter punctata, pube depressa fusco-grisea densius vestita. Abdomen coleopteris paulo angustius, apicem versus sensim attenuatum, confertissime subtiliter punctatum, punctis raris maioribus sparsum, pube depressa griseofusca dense obductum, parce pilosum, segmento quinto margine apicali, sexto supra apice, infra toto, septimoque obscure rufis. Pedes rufi, coxis anticis concoloribus. 
* 2. P. elongatus: Niger, griseo-pubescens, thorace glabro coleopterorum latitudine, his antennis pedibusque rufis. - Long. 6 lin.

Mannerh: Brachelytr. 36. 1. - Nordm. Symb. 154. 2.

Habitat Grusia, Dom. Marschall a Bieberstein, in Chersoneso Taurica, Dom Schüppel.

Elongatus, subdepressus, niger. Antennae capite thoraceque paulo breviores, articulo tertio secundo sesqui longiore, dilute rufi. Oris partes rufae. Caput thoracis latitudine, oblongum, lateribus subrectis, supra leviter convexum, creberrime subtilius punctatum, linea tenui media longitudinali laeviore, pube depressa grisea densius vestitum. Thorax coleopteris vix latior, latitudine sesqui prope longior, lateribus vix rotundatis, pone medium subsinuatis, basi modice rotundatus, apice truncatus, angulis posterioribus subrotundatis, anterioribus rectis, parum convexus, parce subtilissime punctatus, punctorum maiorum seriebus quatuor longitudinalibus notatus, seriebus intermediis 5-6-, lateralibus 3-punctatis, glaberrimus, limbo laterali confertissime subtiliter punctato, griseo-pubescente. Elytra thorace paulo longiora et scutellum testaceo-rufa, dense subtiliter punctata, pube depressa fulvescentigrisea obducta. Abdomen elongatum, dense subtiliter punctatum, segmentis singulis margine apicali, ultimo apice latiore rufo-piceis. Pectus rufo-piceum. Pedes cum coxis anterioribus ruf.

\section{Othius Leach.}

Steph. Illustr., V. p. 253. - Er. Col. March. I. p. 420.

Cafius Boisd. et Lacord. Faun. Ent. Paris. I p. 411.

Antennae rectae.

Ligula integra; paraglossae lineares.

Palpi omnes filiformes.

Corpus mediocre, elongatum, lineare, alatum. Caput subovale, basi modice constrictum, collo brevi angusto thoraci insectum, oeulis parvis, rotundatis, hand prominulis. Labrum angustum, transversum, medio incisum. Mandibulae breves, medio obtuse dentatae. Maxillae (t. IV. f. 2. b.) mala interiore ampliore membranacea, interne barbata, exteriore tenuiore, basi cornea, subcylindrica, apice coriacea, barbata. Palpi maxillares articulo primo minuto, secundo tertioque longitudine subaequalibus, quarto minore, subacuminato. Labium (t. IV. f. 21. a.) mento transverso, ligula rotundata, integra, membranea, paraglossis divergentibus, membranaceis, interne ciliatis, ligulam superantibus. Palpi labiales articulis sensim paulo longioribus, ultimo apice subacuminato. Antennae basi ab oculis totidem atque inter se distantes, breviusculae, filiformes, rectae, articulo primo modice elongato, secundo tertioque obconicis, ultimo ovato-subacuminato. Thorax oblongus, basi rotundatus, apice truncatus. Scutellum triangulare. Elytra apice truncata, sutura integerrima. Abdomen lineare. Pedes breves, coxis intermediis contiguis, tibiis spinulosis, tarsis posterioribus articulo primo leviter elongato, anticis articulis 4 primis dilatatis, subtus spongioso-tomentosis.

O b s e r v a t i n e s.

1. A Xantholinis, quibuscum a plerisque auctoribus coniungitur, hoc genus distinctum antemnis rectis, elytrorum sutura integerrima, coxis intermediis approximatis et tarsis anticis dilatatis. 
2. Dom. Lacordaire recte quidem hoc genus a Xantholino distinxit, nomine autem $\mathrm{C}$ a fii, ab Anglis auctoribus aliis huius tribus speciebus tributo, errore quodam inductus, usus est. Com. Dejean in recentissimo collectionis suae Catalogo idem hoc genus nomine Sauriodes distinxit, nomen autem Anglis prius usitatum praevalere debet.

3. Mas abdominis segmento sexto subtus apice leviter emarginato, femina rotundato distinguuntur.

4. Victus in silvis sub musco, foliis deciduis lapidibusque et sub cortice truncorum emortuorum.

* 1. O. fulvip ennis: Niger, nitidus, antennis, pedibus, ano elytrisque rufis, his punctulatis. - Long. $4 \frac{1}{2}-5 \frac{1}{2}$ lin.

Er. Col. March. 1. 420. 1.

Paederus fulvipennis Fab. Ent. Syst. 1. II. 537. 4. Syst. El. II. 609. 4. Panz. Ent. Germ. 362. 5. Faun. Germ. 27. 3.

Staph. fulgidus Payk. Mon. Staph. 22. 14. Faun. Suec. III. 377. 14.

Staph. fulminans Grav. Micr. 47. 70. Mon. 105. 107. - Latr. Hist. nat. Crust. et Ins. IX 332. 89. - Gyll. Ins. Suec. II. 357. 72. - Sahlb. Ins. Fenn. I. 334. 71. Gyrohypn. fulminans Mannerh. Brachelytr. 33. 9. - Runde Brachelytr. Hal. 11. 7. - Nordm. Symb 119. 14.

Cafius fulminans Boisd. et Lacord. Faun. Ent. Paris. I. 411. Staph. fulvapterus Fourer. Ent. Par. I. 167. 11. (forte)

Le Staph. à étuis marans pointillés Geoffr. Hist. Ins. I. 365. 11. (forte)

Staph. istulat us Grav. Micr. 46. 69. - Latr. Hist. nat. Crust. et Ins. IX. 332. 88.

Habitat in Europa.

Elongatus, linearis, niger, nitidus. Antennae capite paulo longiores, articulo tertio secundo sesqui longiore, $4-10$ sensim paulo brevioribus et crassioribus, pilosellae, rufae. Palpi rufi. Caput thoracis latitudine, oblongum, antrorsum subangustatum, angulis posterioribus fortiter rotundatis, supra parum convexum, utrinque supra oculos parce vageque punctatum, sulculis duobus anticis inter antemas leviter convergentibus, lateralibusque obliquis ante oculos brevioribus obsoletioribusque notatum, inter oculos medio obsolete transversim impressum. Thorax coleopteris perparum angustior, latitudine sesqui longior, basin versus haud angustatus, lateribus pone mediun subsinuatus, apice truncatus, angulis anterioribus deflexis, subrotundatis, dorso junctis utrinque tribus, duobus versus apicem, tertio pone medium impressus, versus margines plerumque rufescens. Scutellum laeve. Elytra vix thoracis longitudine, parcius punctata, parce suhtiliterque cinereo-pubescentia, rufa, nitida. Abdomen minus crebre subtiliter punctulatum, tenuiter griseo-pubcscens, segmentis singulis margine apicali, et subtus segmento ultimo toto rufis. Pedes cum coxis rufi.

V a riat thorace etiam rufo, interdum medio picescente, capite, pectore, abdominisque segmentorum singulorum basi rufo-piceis.

Ubs. Staph. ustulatus Grav. specimen est coleopteris disco nigricantibus (conf. Grav. Mon. p. 106.).

* 2. O. melanocephalus: Piceus, capile nigro, thorace antennis pedibusque testaceis, elytris punctalis, thorace paulo brevioribus. - Long. $2 \frac{1}{2} \mathrm{lin}$.

Er. Col March. 1. 421. 2

Staph. melanocephalus Grav. Mon. 107. 111. - Gyll. Ins. Suec. II. 360. 71. Sahlb. Ins. Fenn. I, 336. 73. 
Gyrohypn. melanocephalus Mannerh. Brachelytr. 34. 15. - Nordm. Symb 120. 21.

\section{Habitat in Europa.}

Antennae capite paulo longiores, articulo tertio secundo sesqui longıre, 4-10 sensim paulo brevioribus et crassioribus, testaceae. Os rufo-testaceum. Caput thorace paulo angustius, oblongo-ovatum, supra leviter convexum, utrinque supra oculos parce vage punctulatum, sulculis duobus anticis inter antennas profundioribus, subparallelis, lateralibus obliquis ante oculos omnino fere obsoletis, fronte punctis 4 quadratim positis impressa, nigrum, nitidum. Thorax coleopteris perparum angustior, latitudine sesqui longior, basin versus houd angustatus, lateribus pone medium vix sinuatis, apice truncatus, angulis anterioribus deflexıs, leviter rotundatis, dorso utrinque punctis duobus, altero ante, altero pone medium, testaceus, nitidus. Scutellum nigrum, laeve. Elytra thorace paulo breviora, fusco-picea, nitida, parcius profundius punctata. Abdomen subtilissime punctulatum, subtiliter parceque pubescens, piceum, nitidum, subtus segmentorum marginibus apiceque testaceis. Pectus piceum. Pedes cum coxis testacei.

3. O. punctipennis: Niger, nitidus, pedibus testaceis, elytris punclatis, thorace paulo longioribus. - Long. $2 \frac{1}{2}$ lin.

Staph. punctipennis Boisd. et Lacord. Faun. Ent. Paris. I. 409. 44.

Habitat in Austria, Helvetia, Italia, Gallia, Anglia.

Statura et summa similitudo praecedentis, niger, nitidus. Antennae capite sesqui longiores, apicem versus haud incrassatae, articulo secundo tertioque aequalibus, $\mathbf{4}-\mathbf{I 0}$ sensim paulo brevioribus at vix crassioribus, penultimis leviter transversis, obscure ferrngineae, articulis tribus primis nigris. Os piceum. Caput vix thoracis latitudine, subovatum, supra parum convexum, supra oculos utrinque parce punctatum, fronte punctis quatuor quadratim jositis notata, sulculis duobus anticis inter antennas parallelis, minus profundis licet sat distinctis, lateralibus ante oculos omnino nullis. Thorax ut in praecedente omnino, at nigerrimus, et puncta in dorso utrinque impressa paulo magis distantia. Scutellum laeve. Elytra thorace paulo longiora, profundius punctata, parce griseo-pubescentia, nigro-picea, margine apicalı piceo-testaceo. Abdomen subtilissime parce punctulatum, tenuiter griseopubescens. Pedes testacei, coxis posterioribus nigris.

Obs. 1. Praecedenti admodum affinis, praeter colorem autem antennarum articulis 2 et 3 aequalibus, capite minus oblongo, et elytris longioribus sat distinctus.

2. Nomine Othii laeviusculi Kirby (Steph. Illustr. V. 255. 8.) ex Anglia a Dom. Rudd benevole communicatus.

1. O. pilicornis: Niger, nitidus, antennis pedibusque piceis, elytris laevibus, stria suturali impressa. - Long. 3 lin.

Er. Col. March. I. 421. 3.

Staph. pilicornis Payk. Mon. Car. App. 335. 14-15. Fann. Suec. III. 379. 16. - Schrank Faun. Boic. I. 642. 868. - Gyll. Ins. Suec. II. 359. 73. - Sahlb. Ins. Fenn. I. 335. 72.

Xantholinus pilicornis Zetterst. Faun. Lappon. I. 81. 3. Ins. Lappon. 66. 5. Gyrohypn. pilicornis Mannerh. Brachelytr. 34. 10. - Nordm. Symb. 119. 16. 
Var. b: Rufus, capile, elytris abdominisque segmentis duobus penultimis nigro-piceis.

Staph. pilicornis var. b Payk. Faun. Suec. III. 379. 16. - Gyll. Ins. Suec. II. 359. 73. - Sahlb. Ins. Fenn. I. 335.72.

Gyrohypn. pilicornis var. b Mannerh. Brachel. 34. 10.

Staph. alternans Grav. Micr. 45. 72. Mon. 107. 109. - Latr. Hist. nat. Crust. et Ins. IX: 333. 91.

Gyrohypn. alternans Mannerh. Brachelytr. 31. 12. - Runde Brachelytr. Hal.

12. 8. - Nordm. Symb. 119. 16.

Gyrohypn. nigriceps Mannerh. Brachelytr. 34. 11. - Nordm. Symb. 120. 17.

Var. c: Fusco-rufescens, subtus dilutior, capile picescente.

Sta ph. pilicornis var. Payk. Faun. Suec. III. 380. 16. - Gyll. Ins. Suec. II. 359. 73. - Sahlb. Ins. Fenn. I. 335. 72.

Xanth. pilicornis var. b Zetterst. Ins. Lappon. 66. 5.

Staph. affinis Payk. Mon. Staph. 24. 16.

Habitat in Suecia, Germania, sub cortice Pinuum.

Linearis, subdepressus. Antennae capite sesqui longiores, apicem versus leviter incrassatae, articulo tertio secundo vix longiore, 4-10 sensum crassioribus, 6-10 crassis, transversis, ultimo conico, rufo-piceae vel rufae, pilosellae. Palpi rufi. Mandibulae prominentes, rufo-piceae. Caput thorace latius, subquadratum, angulis posterioribus fortiter rotundatis, convexum, laeve, punctis subtlibus 4 inter oculos nonnullisque aliis in fronte impressum, sulcis duobus anticis inter antennas minus profundis, parallelis, apice obsoletis, lateralibus ante oculos omnino nullis, nigro-piceum, nitidum. Thorax coleopteris paulo angustior, latitudine sesqui longior, lateribus subrectis, angulis anterioribus leviter rotundatis, leviter convexus, puncto unico utrinque in medio dorsi, unicoque maiore angulos anteriores versus notatus. Elytra thoracis longitudine, laevia vel parce subtiliterque obsoletissime punctulata, stria suturali impressa. Abdomen laeve. Pedes rufotestacei.

V ariat colore corporis vel nigro-piceo, vel rufo-testaceo, capite elytrisque nigro-piceis et abdominis segmento quarto quintoque fuscis, vel interdum corpore toto testaceo, capite solo magis minusve picescente. Var. secunda apud nos frequentior occurrit.

Obs. Gyrohypnus nigriceps Mannerheim statura paulo maiore et capite latiore specie haud satis distinctus.

Species mihi invisa.

5. O. macrocephalus: Piceus, nilidus, palpis, antennis, capite postico segmentorumque marginibus rufescentibus, elytrorum dimidia parte anteriore pedibusque rufo-testaceis, thorace utringue 3-punctato. Long. 2 lin.

Gyrohypnus macrocephalus Nordm. Symb. 124. 26.

Habitat in America boreali occidentali, ad littora ins. Sitchae a cel. Eschscholtz lectus.

Antennae capite longiores, extrorsum sat distuncte crassiores, rufae, longius pilosae. Palpi rufescentes. Caput thorace latius, quadratum, antice vix angustatum, supra convexum, nigrum, basi, prảesertim lateribus, piceo- 
rufescens, nitidum, angulis verticis et regione ophthalmica punctis nonnullis impressum, in antico frontis inter antennas foveola, certo situ conspicua, infra rufescens, glabrum (?), tenue pubescens (?). Clypeus valde angustus, pallide flavescens, labro rufo-ferrugineo. Collum nigro-piceum, nitidum, laeve. Thorax antice subrotundatus, paulo latior quam basi, angulis modice deflexis, lateribus subobliquis, basi attenuatus, postice fere truncatus, supra convexus, nigro-piceus, nitidus, laevis, antice ad latus prope marginem utrinque punctum unum maiusculum, pauloque ab eo in disco puncta duo remota, quorum ultimum obsoletum. Scutellum parvum, apice subacuminatum, nigro-piceum, impunctatum. Elytra thorace paulo latiora, sed vix longiora, supra minus convexa, nitida, antice laete flavo-testacea, dimidia parte posteriore nigra, superficie laevi vel vix conspicue punctulata. Abdomen elytris triplo longius, nigrum, nitidum, vix pubescens, segmentorum marginbus, praesertim infra et ano rufo-ferrugineis. Pedes pallide flavescentes. O. pilicorni similis, differt thorace et elytris paulo angustioribus, colore ete. (Nordm.)

\section{Holisus $E r$.}

\section{Antennae rectae.}

Ligula rotundata, integra, brevissima; paraglossae amplae. Palpi omnes articulo ultimo subulatos

Corpus elongatum, lineare, valde depressum, alatum. Caput sat maguum, quadratum, angulis rotundatis, basi profunde constrictum, collo quasi brevi tenui thoraci affixum, exsertum, porrectum, oculis parvis, rotundatis, haud prominulis. Labrum transversum, bilobum. Mandibulae apice aduncae, medio obtuse dentatae. Maxillae (t. IV. f. 23. b.) mala interiore membranacea, introrsum barbata, exteriore segmento primo triangulari, corneo, altero membraneo, barbato. Palpi maxillares leviter elongati, articulo primo minuto, brevi, secundo twrtioque longitudine subaequalibus, hoc apicem versus sensim leviter incrassato, quarto tenui, subulato. Labium (t. IV. f. 23. a.) mento brevi, transverso, ligula brevissima, ultra palporum insertionem haud prominente, paraglossis sat prominulis, acuminatis, membranaceis, pubescentibus. Palji labiales articulo primo cylindrico, modice elongaro, secundo hoc paulo breviore, ulimo praecedenti longitudine aequali, at tenui acutoque. Antennae aeque ab oculis atque inter se distantes, filifornes, rectae, articulo primo reliquis maiore, obconico, incurvo, apicem versus sensim subincrassaiae, articulo ultimo ovato. Thorax quadrangulus, angulis rotundatis, basin versus angustatus, basi truncatus, apice utrinque oblique truncatus. Scutellum triangulare. Elytra apice truncata, sutura integerrima. Abdomen lineare, subtilius marginatum. Pedes breves, coxıs intermediis contiguis, tibiis ommibus subtiliter spinulosis, tarsis brevibus, articulis 4 primis subaequalibı-, crassinsculis, quinto brevi, tenui, unguiculis tenuibus, elongatis, tarsis araicis simplicibus.

O b s e r v a t i o n e s.

1. Corpore valde depresso, plano Achenio assimilis, at huius tribus, oris structnra $\mathrm{X}$ a ntholino propinquus, at sutura elytrorum integerrima, ligula breviscima, paraglossae ampliores, et palporum utrorumque articulus ultimus subulatus a Leptacino ligula integra distinctus: Othio anteunis rectis propior, at para- 
glossis amplis, ligula brevissima, maxillarum mala exteriore apice dilatata, palporum articulo ultimo subulato et tarsis anticis simplicibus diversus.

2. Sexus differentia latet.

3. Species omnes ex America meridionali allatae. De victu earum nihil compertum.

* 1. H. humilis: Niger, nitidus, anlennis pedibusque piceis, capite thoraceque vage punctatis, linea media longitudinali laevi. - Long. $1 \frac{3}{4}$ lin. Habitat in Brasilia.

Piceo-niger, nitidus. Antennae capite paulo longiores, articulo secundo tertioque subaequalibus, 5 - 10 sensim paulo crassioribus, ultimo ovato, apice abrupte acuminato, nigro-picei, basi dilutiores. Pal, i rufo-testacei. Caput thorace multo maius, coleopterorum latitudine, oblongo-subquadratum, angulis posterioribus obtusis, subrotundatis, punctis profundioribus aequaliter sparsum. Thorax coleopteris paulo angustior, latitudine antica vix brevior, basin versus angustatus, lateribus leniter rotundatus, ante basin subsinuatus, basi leviter rotundatus, apice utrinque oblique truncatus, angulis anterioribus rotundatis, posterioribus abtusis, planus, supra punctis parcis sparsisque subtilioribus impressus, linea media longitudinali laevi. Elytra thorace tertia parte longiora, dense subtilius punctata, tenuiter griseo-pubescentia. Abdomen parcius minus subtiliter punctatum, tenuiter griseo-pubesoens, segmento ultimo apice piceo. Pedes picei.

* 2. H. an alis: Niger, nitidus, ano rufo, femoribus piceis, capite thoraceque utrinque parce punctatis. - Long. $3 \frac{1}{2}$ lin.

T. I. $f .5$.

Habitat prope Caracas Columbiae, Dom. Moritz.

Habitu ommino praecedentis, at multo maior, niger, nitidus. Antennae capite plus sesqui longiores, articulo tertio secundo paulo longiore, $4-10$ sensim paulo brevioribus et crassioribus, ultimo ovato, apice abrupte acuminato, pilosellae, nigrae. Palpi rufo-picei. Caput thoracis latitudine, subquadratum, angulis posterioribus subrotundatis, supra punctis rarioribus vagis profundis impressum, secundum marginern lateralem punctorum serie sat regulari notatum. Thorax latitudine anteriore paulo brevior, basin versus angustatus, basi truneatus, apice utrinque oblique truncatus, lateribus leviter rotundatus, angulis omnibus obtusis, planus, dorso utrinque punctis rarioribus vagis profundis impressus. Elytra thorace sesqui longiora, plana, dense subtiliter punctata, tenuiter griseo-pubescentia. Abdomen sat crebre minus subtiliter punctatum, tenuiter pubescens, lateribus parce pilosellum, segmento ultimo apice dimidiato-testaceo. Pedes picei, tibiis nigricantibus.

3. H. debilis: Piceus, nitidus, antennarum basi, pedibus, elytris anoque teslaceis, thorace utrinque capileque nigro crebrius punctalis. Long. 2 lin.

Habitat in Americae meridionalis ins. St. Johannis, Dom. Moritz.

Statura omnino H. humilis, at paululum maior. Antennae capite paulo longiores, rufo-piceae, articulis duobus primis testaceis. Os rufo-piceum, palpis testaceis. Caput thorace paulo latius, subquadratum, angulis posterioribus leviter rotundatis, planum, crebrius sat profunde vage punctatum, fronte 
antice sulcis duobus subtilibus obsoletioribus obliquis notata, nigrum. Thorax latitudine antica haud brevior, basin versus angustatus, lateribus leviter rotundatus, basi truncatus, apice utrinque oblique truncatus, angulis anterioribus rotundatis, planus, dorso utrinque vage punctatus, linea lata longitudinali media laevi, piceus, nitidus. Elytra dense subtiliter punctata, tenuiter griseo-pubescentia, luteo-testacea, nitida. Abdomen minus dense punctatum, tenuiter pubescens, nigro-piceum, nitidulum, segmento ultimo toto, penultimo apice, reliquis margine postico testaceis. Pectus et pedes flavotestacea.

4. H. Guildingii: Niger, nilidus, antennis pedibusque rufo-piceis, elytris pallidis, basi fuscis, thorace capiteque ulrinque parce punclalis, hoc antice bistriato. - Long. $2 \frac{1}{2}$ lin.

Habitat in Americae meridionalis ins. St. Vincentii, Mus. Dom. Hope.

Habitu H. humilis, at duplo maior, niger, nitidus. Antennae capite paulo longiores, articulo secundo tertioque subaequalibus, 4-10 sensim paulo brevioribus et crassioribus, ultimo apice abrupte acuminato, rufo-piceae, basi dilutiores. Palpi rufo-testacei. Caput thorace paulo latius, subquadratum, angulis posterioribus leviter rotundatis, utrinque parcius punctatum, punctis oblongis et sat profundis, antice inter antennas sulcis duobus parallelis, sat profundis, in fronte desinentibus, impressum. Thorax coleopteris angustior, latitudine paulo longior, basin versus subangustatus, lateribus rectis, apice utrinque oblique truncatus, angulis anterioribus rotundatis, depressus, utrinque parce subtilus, dorso sub-biseriatim punctatus. Elytra thorace paulo longiora, crebrius subtiliter punctata, tenuiter pubescentia, pallide flavo-testacea, basi fusca. Abdomen parce obsoleteque punctulatum, segmentis singulis margine tenui apicali piceo. Pedes rufo-picei.

\section{Diochus $\boldsymbol{E} r$.}

Antennae rectae.

Iigula emarginata; paraglossae lineares.

Palpi omnes articulo ultimo subulato.

Corpus pusillum, leviter elongatum, lineare, minus depressum, alatum. Caput oblongum, antrorsum leviter angustatum, basi truncatum, collo quasi brevissimo tenui thoraci affixum, exsertum, liberum, oculis parvis, rotundatis, ante capitis medium sitis. Labrum angustum, tranversum, medio sinuatum. Mandibulae breves, haud prominentes. Maxillae mala interiore membranacea, interne barbata, exteriore cornea, apice membranacea barbataque. Palpi maxillares articulo primo parvo, sequentibus duobus longitudine subaequalibus, tertıo crassiore, quarto minuto, subulato. Labium mento transverso, ligula brevi, rotundata, medio emarginata, membranea, paraglossis ligulam superantibus, membranaceis. Palpi labiales articulo secundo primo paulo longiore, ultimo minuto, subulato. Antemnae inter se aeque atque oculis approximatae, breves, crassiusculae, rectae, articulo primo reliquis paulo maiore, secundo tertioque subaequalibus, obconicis, sequentibus brevibus, transversis, ultimo subacuminato. Thorax oblongo-subquadratus, basi angulisque posterioribus rotundatus. Scutellum triangulare. Elytra apice truncata, sutura integerrima. Abdomen lineare. Pedes breves, coxis inter- 
mediis approximatis, tibiis subtiliter spinulosis, tarsis anticis leviter dilatatis, posterioribus articulo primo elongato.

\section{O b s e r vation es.}

1. Habitus huius insecti fere minimi Philonthi, at antennae basi minus distantes et caput a thorace magis remotum. Oris structura omnino cum Leptacino (conf. t IV. f. 22.) convenit, discedit autem ab eo antennis rectis et sutura elytrorum integerrima. A genere praecedente paraglossis linearibus, palporum articulo ultimo multo breviore et tenuiore et tarsis anticis dilatatis, ab Othio palporum articulo ultimo subulato, ab utroque ligula biloba et corporis habitu distinguitur.

2. Sexus differentia latet.

3. De victu nihil constat.

* 1. D. nanus: Nigro-piceus, nitidus, antennis pedibusque testaceis, capile thoruceque oblongis, politis, hoc 4-seriatim parce punctalo, elytris parce obsoleleque punclatis. - Long. $1 \frac{1}{3}$ lin.

T. 1. $f .6$.

Habitat in variis Americae meridionalis regionibus, e Columbia a Dom. Moritz allatus.

Minutus, nigro-piceus, capite, thorace elytrisque nitidissimis. Antennae capite parum longiores, crassiusculae, articulo tertio secundo paulo minore, 4- 10 transversis, subaequalibus, ultimo subovato, apice abrupte acuminato, testaceae, basi dilutiores. Os testaceum. Caput oblongum, thorace paulo angustius, basi truncatum, angulis posterioribus subrotundatis, antrorsum leviter angustatum, postice laevissimum, anterius parce subseriatim punctatum, sulculis duobus apicalibus brevibus obsoletisque, lateralibus ante oculos omnino nullis. Thorax coleopteris parum angustior, latitudine paulo longior, basin versus haud angustatus, lateribus subrectis, apice utrinque oblique truncatus, angulis anterioribus obtusis, leviter transversim convexus, seriebus quatuor punctorum subtilium, duobus dorsalibus, approximatıs, 4-punctatis, reliquis utraque laterali, 4-punctata, ceterum laevissimus, dilutius piceus. Elytra thorace haud longiora, parce obsoleteque seriatim punctata. Abdomen breviusculum, omnium subtilissime punctulatum, segmentis singulis margine apicali piceo. Pedes cum coxis testacei.

Variat thorace rufo-testaceo, capite elytrisque fusco-piceis, his apice indeterminate rufo-testaceis, abdominis singulis segmentis margine apicali lato rufo-piceis.

* Antennae fractae. Elytrorum sutura imbricata.

\section{Sterculia Laporte.}

Laporte Etud. Ent.p. 118.

Agrodes Nordm. Symb. 161. 29.

Araeocnemis Nordm. Symb. 163. 30.

Antennae fractae.

Ligula integra.

Labrum tolum corneum, bilobum.

Corpus maiusculum, elongatum, alatum. Caput sat magnum, exsertum, pedunculo angusto thoraci affixum, porrectum, oculis minutis, lateralibus, 
inter medium et apicem sitis. Labrum angustum, transversum, medio sinuatum, totum corneum. Mandibulae longiores brevioresve, basi denticulatae, et ante denticulum membrana ciliata instructae. Maxillae (t. IV. f. 19. b.) malis brevibus, coriaceis, introrsum barbatis. Palpi maxillares minus elongati, crassiusculi, articulo primo minuto, angusto, secundo leviter elongato, obconico, quarto subovato. Labium (t. IV. f. 19. a.) mento transverso, ligula minuta, rotundata, integra, coriacea, paraglossis sat amplis, ligulam longe superantibus, membranaceis, intus ciliatis. Palpi labiales articulis duobus primis subaequalibus, tertio crassiore, subovato. Antennae intra mandibularum basin insertae, inter se aeque atque oculis approximatae, fractae, articulo primo elongato, secundo brevi, obconico, tertio iterum elongato, primo autem duplo fere breviore, reliquis inter se arcte coactis, $4-10$ transversis, ultimo obtuse acuminato, interdum apicem versus leniter incrassatae. Thorax oblongus, coleopteris angustior, apice angustatus. Scutellum triangulare. Elytra truncata, sutura imbricata. Abdomen mediocriter elongatum. Pedes elongati, graciles, coxis intermediis late distantıbus, tibiis pubescentibus, inter pubem subtilissime spinulosis, anticis haud incrassatis, tarsis omnibus simplicibus, posterioribus articulis duobus primis subelongatis.

\section{- O b s e r a t i o n e s.}

1. Genus valde insigne, habitu thorace antrorsum attenuato et pedibus elongatis a Xanthol in o discedens, a quo ceterum praecipue labro lateribus haud membranaceo, ligula breviore, palporum structura et tibiis haud distincte spinulosis, anticis haud incrassatis differt.

2. Prof. Nordmann genera duo Agrodem palpis labialibus truncatis, et Aira e o c n emum palpis filiformibus distinxit. Palporum structura autem omnes fere species magis minusve inter se discedunt, quam ob rem hoc genus omnino naturale dissolvi nequit. In Catalogo Dejeaniano nomine Ploch ionoceri signatum est.

3. Sexus differentia latet.

4. Victus latet. Species hucusque cognitae in America meridionali obviae

* 1. St. coelestina: Coerulea, nitida, thorace elylris breviore, capile lalo, subquadrato, mandibulis capilis longitudine. - Long. 11 lin.

Habitat in Brasilia, Dom. Virmond.

St. fulgenti duplo maior, laete viridi-coerulea, nitida, tenuiter nigropubescens. Antemnae apicem versus vix incrassatae, articulo tertio elongato, secundo plus duplo Iongiore, 4-10 leviter transversis, inter se aequalibus, ultimo acuminato, nigrae, articulis tribus primis cyaneis. Palpi maxillares articulo ultimo penultimo paulo breviore, labiales articulo tertio fortiter securiformi. Mandibulae capitis longitudine. Caput thorace latius, basi leviter, angulis posterioribus fortius rotundatum, lateribus subrectis, neque retrorsum, neque antrorsum angustatum, latitudine vix angustius, posterius levissime convexum, confertissine punctatum, longitudinaliter subrugulosum. Thorax coleopterorum basi dimidio angustior, latitudine baseos plus sesqui longior, antrorsum angustatus, lateribus ante medium leviter rotundatis, modice transversim convexus, utrinque subtilissime disperse punctatus, spatio medio longitudinali laevissimo, postice utrinque oblique impressus, margine angulari postexiore late leviter elevato. Scutellum punctulis nonnullis impressum. Elytra thorace paulo longiora, apicem versus sensim paulo laiora, subtiliter parce punctata. Abdomen breviusculum, apicem versus sen- 
sim angustatum, depressiusculum, late marginatum, subtiliter parce punctulatum, lateribus et subtus breviter nigro-pilosellum. Alae nigro-violaceae.

* 2. St. fulgens: Cyanea, nitida, thorace elytris breviore, capite oblongo, mandibulis capite brevioribus. - Long. 7 lin.

D'Orbigny It. Amer. mer. Ins. t. 5. f. 6.

Staph. fulgens Fab. Ent. Syst. I. II. 522. 13. Syst. El. II. 592. 15. - Grav. Mon. 91. 87.

Araeocnemis fulgens Nordm. Symb. 164. 1. t. 2. f. 8 .

Staph. violaceus Oliv. Ent. III. 42. 8. 3. t. 1. f. 8.

Habitat Jalapae in Mexico, Dom. Deppe, Cayennae et Surinami sec. Fab. et Oliv.

Corpus violaceo-cyaneum, nitidım, tenuiter nigro-puberulum, subtus laetius cyaneum, abdomine certo sito viridi-nitente. Antennae apicem versus vix incrassatae, articula tertio secundo duplo prope longiore, 4-10 sensim paululum crassioribus, ultimo apice abrupte acuminato, nigrae, articulis tribus primis cyaneis. Palpi maxillares articulo quarto tertio aequali, labiales articulo tertio securiformi. Mandibulae capite breviores. Caput thorace paulo latius, latitudine paulo longius, basi cum angulis posterioribus rotundatum, lateribus subrectum, neque antrorsum neque basin versus angustatum, subdepressum, creberrime fortius rugoso-punctatum, opacum. Thorax coleopterorum basi dimidio angustior, latitudine sesqui fere longior, antrorsum subangustatus, lateribus leviter, angulis anterioribus deflexis fortiter rotundatis, modice transversim convexus, subtilissime disperse punctatus, spatio longitudinali medio et plaga utrinque laterali laevissimis, postice utrinque oblique impressus, margine angulari posteriore elevato. Scutellum punctulis nonnullıs impressum. Elytra thorace longiora, subtiliter parce punctata. Abdomen apicem versus parum angustatum, depressiusculum, margine laterali sat elevato, subtiliter parce punctatum. Alae nigro-violaceae.

3. St. ele gans: Cyanea, nilida, thorace angusto, elytrorum longitudine, capileque elongatis, hoc basi allenualo, mandibulis capite triplo brevioribus. - Long. 8 lin.

Agrodes elegans Nordm. Symb. 162. 1. t. 2. f. 9.

Habitat in Para interiore Brasiliae, Sieber.

Magnitudo praecedentis. Corpus nigro-pilosellum, coerulescenti-cyaneum, subtus viridi-coeruleum. Antennae apicem versus haud incrassatae, articulo tertio secundo sesqui longiore, 4-10 sensim paulo brevioribus, ultimo apice acuminato, nigrae, articulis tribus primis cyaneis. Palpi maxillares articulo quarto tertio longiore, labiales articulo tertio cylindrico, apice acuminato. Mandibulae capite multo-breviores. Caput thorace paulo latius, elongato - subovatum, latitudine duplo longius, basi attenuatum, supra perparum transversim convexum, creberrime punctatum, utrinque longitudinaliter subrugosum, apice ante oculos laevinsculum. Thorax angustus, elongatus, coleopterorum bası duplo fere angustior, latitudine triplo fere longior, antrorsum sensim attenuatus, modice transversim convexus, subtilissime disperse punctatus, linea media longitudinali laevi, , one medium utrinque oblique leniter impressus. Elỵtra thoracis longitudine, subtilissime pun- 
ctulata. Abdomen crassiusculum, densius subtiliter punctatum. Alae nigro violaceae.

4. St. Leprieuri: Coerulea, nitida, pubescens, thorace elytrorum longitudine, capite oblongo-ovato, mandibulis capite triplo brevioribus. Long. 6 lin.

Laporțe Etud. ent. I. 118. 1. (perperam descripta.)

Habitat in Cayenna, Dom. Buquet.

Praecedentibus minor, laete coerulea, nitida, elytris cyaneis, subtiliter nigro-puberula, elytrorum basi margineque apicali abdominisque segmentorum marginibus longius cinereo-pubescentıbus. Antennae apicem versus leviter incrassatae, articulo tertio secundo duplo prope longiore, $4-10$ sensim paululum crassioribus, transversis, ultimo crassiusculo, subovato, apice acuminato, nigrae, articulis tribus primis coeruleis. Palpi maxillares articulo tertio quarto breviore, labiales articulo tertio subsecuriformi, s. apicem versus subincrassato, apice truncato. Mandibulae capite multo breviores. Caput thorace haud latius, latitudine duplo prope longius, basin versus magis quam antrorsum angustatum, oblongo-obovatum, subdepressum, confertissime punctatum, opacum. Thorax basi coleopteris duplo prope angustior, latitudine baseos plus duplo longior, lateribus pone medium rectis, parallelis, a medio usque ad apicem sensim attenuatus, leviter transversim convexus, utrinque subtilissime densius punctatus, spatio longttudinali medio angusto laevi, pone medium utrinque oblique impressus. Elytra thoraci longitudine aequalia abdomenque apicem versus subangustatum densius subtiliter punctata.

* 5. St. formicaria: Nigro-subaenea, opaca, griseo-pubescens, capile oblongo-ovali. - Long. $6-7$ lin.

Laporte Etud. ent. I. 119. 2. t. 3. f. 3.

Araeocnemis flagellic ornis Nordm. Symb. 165. 2.

$V$ ar. Densius pubescens.

Araeocnemis pubescens Nordm. Symb. 167. 3.

Habitat in Brasilia, Dom. Sellow, Surinami, Dom. Cordua, Cayennae sec. Laporte, in Columbia, Dom. Moritz.

Corpus nigro-subaeneum, opacum, in illaesis speciminibus pube griseolutescente obductum. Antennae apicem versus sensim incrassatae, articulo tertio secundo vix sesqui longiore, $4-10$ transversis, sensim paululum crassioribus, ultimo apice obtusius acuminato, nigrae, articulo secundo basi rufo. Mandibulae capite triplo breviores, validae. . Caput thorace haud latius, latitudine plus sesqui longius, basi cum angulis posterioribus fortiter, lateribus leviter rotundatum, subtilius confertissime punctatum. Thorax basi coleopteris duplo fere angustior, latitudine baseos duplo fere longior, lateribus paulo ante medium subangulato-rotundatis, pone medium subsinuatis, antice angus:âtus, leviter convexus, omnium confertissime punctatus, linea media longitudinali laevi elevata, pone medium tenui. Elytra thoracis longitudine, subtilissime dense punctata. Abdomen subparallelum, crassiusculum, subtiliter crebre punctatum, nitidulum. Alae fuscae. 


\section{Scytalinus $E r$.}

Antennae fractae.

Iabium totum, corneum, sexdentatum.

Palpi maxillares filiformes, labiales articulo ultimo securiformi.

Ligula integra.

Corpus valde elongatum, lineare, subcylindricum, alatum. Caput subquadratum, angulis rotundatis, supra leviter convexum, basi profunde constrictum, collo quasi brevi cylindrico thoraci affixum, exsertum, porrectum, oculis parvis, rotundatis, vix prominulis. Labrum angustum, transversum, totum corneum, 6-dentatum, margine fortiter setosum. Mandibulae sat fortes, subfalcatae, medio fortiter dentatae. Maxillae (t. IV. f. 20. b.) mala interiore brevi, coriacea, introrsum barbata, exteriore cornea, depressa, triangulari, angulo exteriore producto, setoso, interiore lobo coriaceo barbato instructo. Palpi maxillares filiformes, articulo primo minuto, reliquis tribus subaequalibus. Labium (t. IV. f. 20. a.) mento transverso, ligula brevissima, integra, membranea, paraglossis eam longe superantibus, coriaceis. Palpi labiales articulo primo parvo, secundo leviter obconico, tertio modice securiformi. Antennae basi inter se magis quam oculis approximatae, geniculatae, articulo primo modice elongato, leviter incurvo, subclavato, secundo tertioque leviter obconicis, hoc praecedente sesqui longiore, articulis reliquis brevibus, pubescentibus, ultimo breviter ovato, subacuminato. Thorax coleopteris paulo angustior, latitudine longior, basin versus leviter angustatus, basi rotundatus, apice truncatus, angulis posterioribus rotundatis, anticis subrectis, subdeflexis. Scutellum triangulare. Elytra apice truncata, sutura imbricata. Abdomen lineare. Pedes breves, postici anterioribus paulo debiliores, coxis intermediis distantibus, tibiis spinulosis, anticis leviter incrassatis, extus spinulis densioribus muricatis, tarsis omnibus simplicibus, articulis $1-4$ subobconicis, sensim decrescentibus.

o bs e r v a t i o n e s.

1. Habitu omnino Xantholini, et huic generi nimis fere affinis, distinguendus autem videtur: 1, labro lateribus haud membranaceo, medio haud profundius inciso, apice 4-, lateribus utrinque 1-dentato; 2 , maxillarum malae segmento inferiore corneo apice extrorsum fortiter producto; 3 , palpis labialibus articulo ultimo securiformi.

2. Sexus differentia latet.

* 1. Sc. serpentinus: Niger, nitidus, abdomine apice summo rufo, capite subquadrato, fronte inaequaliter punctata. - Long. 8 lin.

T. 1. $f .7$.

Var. Elytris rufis.

Habitat in Brasilia, Dom. Prof. Germar.

Corpus elongatum, subcylindricum, nigrum, nitidum, elytris aut concoloribus aut rufis, abdomine segmenti quinti margine sextique apice rufis. Antennae capite paulo longiores, articulo tertio modice elongato, secundo sesqui longiore, 4-10 sensim paulo crassioribus, et paulo magis transversis, piceae, articulis tribus primis nigris. Caput thorace latius et brevius, subquadratum, parum depressum, lateribus laevissimum, fronte sparsim punctata, plaga media inaequali laeviore, ante utrinque longitudinaliter subim- 
pressa. Thorax coleopteris angustior, latitudine plus sesqui longior, basin versus modice angustatus, lateribus subrectis, apice utrinque oblique truncatus, angulis anterioribus rectis, transversim modice convexus, laevissimus, apice haud procul ab angulo anteriore utrinque puncto profundo, basi medio lineola brevissima subtili impressus. Scutellum apice 4-punctatum. Elytra thorace paulo longiora, dorso fortius subseriatim punctata, ad latera laevissima, lateribus infexis profundus punctatis. Abdomen supra nitidum, subtus opacum, utrinque punctis raris subtilibus sparsum, parce griseo-pubescens, apıce rufo longins fulvo-pilosum. Tarsi picei.

\section{Kantholinus Dahl.}

Encycl. Meth. X. p. 475. - Zetterst. Faun. Lappon. I. p. 80. Ins. Lappon. p. 66. - Boisd. et Lacord. Faun. Ent. Paris. I. p. 411. - Er. Col. March. I. p. 422.

Gyrohypnus Kirby Mannerh., Brachelytr. p. 33. - Steph. Illustr. V. p. 258. Nordm. Symb. $p$. 113.

Eulissus Mannerl., Brachelytr. $p .35$.

Antennae fractae.

Labium bilobum, lateribus membranaceum.

Palpi omnes filiformes.

Ligula integra.

Corpus elongatum, lineare, plerumque subdepressum, alatum. Caput plerisque oblongum, basi profunde constrictum, collo quasi brevi cylindrico thoraci affixum, exsertum, porrectum, oculis parvis, rotundatis, apicem versus positis, vix prominulis. Labrum angustum, transversum, medio profunde sinuatum, apice setosum, corneum, limbo laterali membranaceo. Mandibulae braviores, medio dentatae, basi lacinia triangulari membranea, interne ciliata. Maxillae (t. IV. f. 21. b.) mala interiore breviore, coriacea, interne barbata, exteriore cornea, obconica, apice barbata. Palpi maxillares filiformes, arti culo primo parvo, sequentibus tribus subaequalibus vel ultimo praecedentibus parum breviore, apice subacuminato. Labium (t. IV. f. 21. a.) mento transverso, ligula brevi, rotundata, integra, membranea, paraglossis ligulam superantibus, membranaceis. Palpi labiales filiformes, articulis sensim longioribus, ultimo apice subacuminato. Antennae basi inter se non magis quam ab oculis distantes, breviusculae, geniculatae, articulo primo modice elongato, secundo tertioque leviter obconicis, hoc plerumque longiore, reliquis brevibus, pubescentibus, ultimo ovato, apice subacuminato. Thorax plerumque oblongus, basin versus subangustatus, basi rotundatus, apice truncatus, angulis anterioribus saepius lateraliter prominentibus. Scutellum triangulare. Elytra apice truncata, sutura imbricata. Abdomen lineare. Pedes breves, postici anterioribus debiliores, coxis intermediis late distantibus, tibiis spinulosis, anticis subincrassatis, extus spinuloso-muricatis, tarsis omnibus simplicibus, articulo pruno secundoque subaequalibus, intermediis paulo longioribus.

O b s e r vation es.

1. Caput antice sulculis quatuor abbreviatis impressum, duobus interioribus, inter antennarum basin adscendentibus, frontem versus plerumque convergentibus, saepius distinctioribus, alteris duobus exterionbus obliquis ante oculos sitis, plerumque obsoletioribus. Thorax saepe punctorum seriebus quatuor notatus, seriebus dorsalibus rectis, lateralibus lituis s. sinuatis, antice circumflexis. Elytra dorso sae- 
pius subseriatim punctata, secundum marginem lateralem laevia, margine laterali inflexo iterum punctato.

2. Nomen $\mathbf{X}$ a ntholinus praetuli, prius a Com. Dejean vulgatum, et ab au. ctoribus Encyclopediae methodicae et a Latreillio (Regn. An. IV. p. 435.) receptum; praeterea nomen Gyrohypnus perperam compositum. Eulissus Mannerheim mihi nullo modo ab hoc genere distinguendus videtur: idem iam monuit Dom. Brullé. (Hist. nat. Ins. VI. p. 72.)

3. Mas saepius abdominis segmento inferiore sexto apice truncato, septimo pall. lulum conspicuo, femina segmento inferiore sexto apice rotundato, septimo occulto, distinguuntur.

4 Victus in silvis et campis sub lapidibus, foliis deciduis muscisve et in fimo. Corpus in quiete spirae instar convolutum.

5. Larvae habitu et moribus omnino imaginum, quibuscum occurrunt. Xantholini punctulati larvam Dom. Bouche observavit et hoc modo descripsit: Corpus lineare, posterius attenuatum, pilosellum, albido-flavescens. Caput oblongum, subquadrangulum, angulis rotundatis, dilute fuscum. Antennae subulatae, 4-articulatae (articulis sensim decrescentibus). Labrum semiorbiculatum, medio emarginatum. Mandibulae validae, falcatae. Maxillae oblongae, (mala singula), palpig validioribus, subulatis, 4-articulatis. Prothorax antrorsum angustatus, testaceus. Pedes subulati. Abdomen incisuris profundis, segmentis singulis rotundatis, convexis, segmento anali caudis duabus triarticulatis, subulatis, articulis earum cylindricis, secundo primo dimidio breviore, tertio setiformi. Anus tubulatus. Habitat vere in fimo equino; victitat rapina. (Naturgesch. d. Ins. I. 18I. 3. t. ViII. f. $9-13$. )

1) Thorax punctorum seriebus dorsalibus lateralibusque null is.

1. X. canaliculatus: Depressus, nigerrimus, nitidus, ano rufo-testaceo, elytris laevigatis, capite oblongo, canaliculato, utrinque sulcato, angulis posterioribus rectis. - Long. 6 lin.

Habitat Bogatae in Columbia, a Dom. Buquet nom. Xanth. canaliculati Dej. communicatus; in Mexico, collect. Dom. Chevrolat.

Statura fere Belonuchi haemorrhoidalis, totus nigerrimus, politus, nitidus, abdominis segmento quinto apice sextoyue toto rufo-testaceis. Antennae capite paulo longiores, articulo tertio elongato, secundo duplo longiore, 4-11 rufo-piceis, cinerascentibus. Palpi picei. Caput thorace paulo longius et sesqui latius, basi truncatum, lateribus angulisque posterioribus rectis, his prominulis, antrorsum vix angustatum, planum, supra laevissimum, sulculis duabus obliquis inter antennas in media fronte fere conniventibus, dein usque ad basin canaliculatum, utrinque prope oculos sulco profundo, postice abbreviato, longitudinali, impressum, vertice punctorum serie transversali notatum, lateribus crebre punctatum, subtus medio et prope latera longitudinaliter canaliculatum. Thorax latitudine longior, antice coleopteris latitudine aequalis, apice utrinque oblique truncatus, basin versus sensim modiceque angustatus, lateribus haud sinuatus, angulis anterioribus obtusis, modice prominentibus, depressus, laevissimus. Scutellum laeve. Elytra thorace paulo longiora, laevissima, lateribus pilosella. Abdomen parce punctulatum parceque pilosellum, coleopteris angustius, apice attenuatum, subtus longius pilosum. Pedes nigri, spinulis tibiarum tarsisque piceis.

2. X. flavipennis: Niger, nitidus, elytris rufo-testaceis, laevgatis, capite oblongo, canaliculato, utrinque subsulcato, angulis poslerioribus oblusis. - Long. $5 \frac{1}{2}$ lin. 
Habitat in Mexico, collect. Dom. Chevrolat.

Praecedenti affinis, licet paulo angustior et minus depressus, nigerrimus, pernitidus. Antennae capite vix longiores, articulo tertio minus elongato, secundo vix sesqui longiore, piceae, articulo primo nigro. Caput thorace paulo latius, oblongum, antrorsum subangustatum, basi utrin"que oblique truncatum, angulis posterioribus obtusis, depressum, laeve, fronte canalicula tenui media, in summa basi abbreviata, antice cum sulculis duobus obliquis ordinariis ad antennarum basin, in fronte coniunctis, confluente, sulcoque secundum capitis marginem lateralem, breviore, latiusculo, obsoletiore exarata, lateribus supra oculos dense subtiliter punctatum, subtus medio et secundum latera canaliculatum. Thorax coleopteris paulo angustior, latitudine sesqui fere longior, basin versus leviter angustatus, apice utrinque oblique truncatus, lateribus haud sinuatus, subdepressus, laevissimus, versus angulos anteriores utrinque puncto singulo obsoletiore impressus. Scutellum laeve. Elytra thoracis longitudine, laevigata, testaceo-rufa, nitida. Abdomen laeve, nigerrimum, ano concolore, subtus nitidum, griseopilosellum. Pedes nigro-picei, geniculis tarsisque rufescentibus.

3. X. divisus: Niger, nilidus, elytris laevigatis, pectore, ano pedibusque rufo-iestaceis, capite oblongo, canäliculato, ulrinque sulcalo, angulis posterioribus obtusis. - Long. 6 lin.

Habitat Vera-Cruce in Mexico, collect. Dom. Chevrolat.

Statura praecedentium. Antennae capite vix longiores, articulo tertio modice elongato, secundo duplo prope longiore, piceae. Palpi rufo-picei. Caput thorace latius, oblongum, antrorsum vix angustatum, basi utrinque oblique truncatum, lateribus rectum, angulis posterioribus obtusis, subprominentibus, depressum, nigerrinum, nitidum, fronte canalicula media, postice subabbreviata, antice cum sulculis duobus ordinariis ad antennarum basin, in fronte comexis, confluente, sulcoque secundum marginem lateralem, postice abbreviato, exarata, ceterum supra laevissimum, lateribus creberrime punetatum, subtus medıo longitudinaliter impressum et subtiliter canaliculatum, secundum marginem lateralem sulcatum. Thorax apice coleopterorum latitudine, basin versus sensim angustatus, latitudine apicis sesqui fere longior, apice utrinque oblique truncatus, angulis anterioribus subrectis, modice prominentibus, lateribus rectis, nullo modo sinuatis, subdepressus, laevissimus, puncto utrinque singulo prope angulum anteriorem impressus, nigerrimus, nitidus. Scutellum testaceo-rufum, laeve. Elytra thoracis Iongitudine, in medio disci punctis tribus, longitudinaliter dispositis, impressa, ceterum laevigata, rufo - testacea, nitida. Abdomen parce punctulatum parreque pilosellum, subtıs longius griseo-pilosum, nitidum, nigrum, segmento quinto apice sextoque toto testaceo-rufis. Pectus rufo-testaceum. Pedes cum coxis ommibus testaceo-rufi, tibiis anticis piceis.

* 4. X. laticeps: Depressus, niger, nitidus, peulibus piceis, elytris subseriatim punclalis, capite lato, suborbiculato, subtiliter punctulato. - Long. 5 lin.

Hahitat in Java, Dom. Com. Hoffmannsegg.

Depressus, niger, nitidus. Antennae capite paulo longiores, articulo tertio modice elongato, secundo duplo prope longiore, piceae, articulis tri- 
bus primis nigricantibus. Palpi picei. Caput magnum, suborbiculatum, depressum, fronte medio transversim subtiliter punctulata, apice sulculis duobus intermediis sat profundis, inter oculos foveolis $\mathbf{5}$ minutis, rotundatis, trans versim positis, supra oculos punctis grossis utrinque tribus oblique positis, vertice pluribus irregulariter transversim sitis impressum, lateribus dense punctatum, subtus canaliculatum, parce subtiliterque sparsim punctatum. Thorax coleopteris angustior, latitudine sesqui longior, basin versus angustatus, lateribus sfibsinuatus, apice utrinque oblique truncatus, angulıs anterioribus obtusiusculis, modice prominulis, depressus, laevissimus, in angulo utroque anteriore punctis tribus subtilioribus impressus. Scutellum leviter impressum, quadripunctatum. Elytra thoracis longitudine, dorso subseriatim punctata, lateribus inflexis subtiliter vage punctatis. Abdomen parce punctulatum, parcius nigro-pilosum, apice piceum, subtus totum piceo-rufescens. Pedes picei, tarsis rufescentibus.

* 5. X. lynceus: Nigerrimus, nitidus, abdomine subcoerulescente, elytris punclatis, obscure coeruleis, capile orbiculato, limbo punctato. - Long. $6-7$ lin.

Habitat Bogotae in Columbia interiore, a Dom. Buquet sub hoc nomine communicatus.

Subdepressus, nigerrimus. Antennae capite sesqui longiores, articulo tertio elongato, secundo plus duplo longiore, nigrae, cinereo-pruinosae, articulis tribus primis glaberrimis. Palpi apice picei. Caput maris thorace duplo, feminae vix sesqui latius, orbiculatum, depressum, utrinque subtilius punctulatum, et, ut in vertice, punctis nonnullis grossis impressum, fronte media late laevissima, nitidissima. Thorax latitudine sesqui longior, coleopteris dimidio prope angustior, basin versus vix angustatus, lateribus subsinuatus, apice utrinque oblique truncatus, angulis anterioribus obtusis, subrotundatis, supra parum convexus, in angulo utroque anteriore punctis tribus impressus, ceterum laevissimus, ntidissimus. Scutellum punctis nonnullis impressum. Elytra thoracis longitudine, dorso parcius subseriatim, lateribus crebrius subtiliusque vage punctata, obscure coerulea, nitida. Abdomen apice angustatum, parce subtiliterque punctulatum, nigro-subcoerulescens, nitidum, nigro-pilosum. Pedes graciliores, nigri, tarsis concoloribus.

* 6. X. chalybeus: Coeruleus, nitidus, pedibus rufis, tibiis tarsisque nigris, capite triangulari, laevissimo. - Long. 8-9 lin.

Brullé Hist. nat. Ins. VI. 72. 1.

Eulissus chalybaeus Mannerh. Brachelytr. 35. 1. - Nordm. Symb. 129. 1. Staphyl. saphyrinus Perty Delect. An. art.p. 31. t. 7. f. 5.

Habitat in Brasilia.

Magnus, robustus, laete coeruleus, pernitidus, abdomine subvirescente. Antennae vix capitss longitudine, articulo tertio elongato, secundio duplo longiore, nigro - piceae, articulo ultimo apice ferrugineo. Palpi picei. Caput hası thoracis apice vix latius, basi truncatum, angulis posterioribus rotundatis, lateribus subrectis, antrorsum angustatum, triangulare, supra modice convexum, laevissimum, fronte sulculis inter antennas obsoletis, inter oculos punctis duobus, maioribus distantibus impressa. Thorax apice coleopteris 
vix angustior, ibıque longitudini latitudine subaequalis, basin versiss angustatus, lateribus suhrectis, apice truncatus, angulis anterioribus acutiusculis, leviter deflexis, leviter convexus, laevissimus, puncto singulo utrinque hand procul ab angulo anteriore impressus. Scutellum punctulatum. Elytra apice et lateribus vage subtiltter punctulata, dorso biseriatim obsolete punctata, serie altera suturali, altera in medio dorsi. Abdomen breviusculum, apicem versus attenuatum, parce subtiliter punctulatum, longius nigro-pilosum. Pedes tibiis tarsisque nigrss, femoribus omnibus coxisque anticis totis, intermediis infra rufis. Alae fuscae.

* 7. X. Mannerheimii: Laete viridi-aeneus, pedibus flavis, elytris, pectoris lateribus abdominisque margine laterali luleis, capite triangulari. - Long. 7 lin.

Eulissus Mannerhe imii Laporte Etud. Ent. I. 118. 2. t. 3. f. 5.

Habitat Cayennae.

Statura omnino praecedentis, at dimidio minor. Antennae vix capitis longitudine, articulo tertio leviter elongato, secundo sesqui longiore, 4-10 sensim paulo minoribus, piceo-testaceae, apice dilutiores, articulo ultimo flavo. Palpi et labrum rufo-picea. Caput thoracis longitudine eoque haud latius, basi truncatum, angulis posterioribus obtusis, antrorsum sensim angustatum, supra sat convexum, laete viridi-aeneum, nitidum, laevissimum, sulculis inter antennas distinctis, puncto maiusculo utrinque ad oculi marginem interiorem, alioque ad marginem eius superiorem impressum, margme verticali punctato. Thorax coleopteris parum angustior, longitndine paulo longior, basin versus leviter angustatus, lateribus rectis, nullo modo sinuatis, apice utrinque oblique truncats, angulis anterioribus subrectis, leviter deflexis, supra leviter convexus, laevissimus, puncto singulo prope angulum utrumque anteriorem notatus, laete lucideque viridi-aeneus, margine anguları antico flavo. Scutellum parce punctatum, flavum, aeneo-nitidulum. Elytra thoracis longitudine, lutea, dorso biseriatim punctata, serie altera suturali, altera in medio dorsi, lateribus inflexis subtilius punctatis. Abdomen densius griseo-pilosum, subtiliter punctulatum, apice attenuatum, lucide laeteque viridi-aeneum, margine laterali luteo. Pectus viridi-aeneum, flavo-limbatum. Pedes dilute flavi, coxis anterioribus disco viridi-aeneo.

* 8. X. limbatus: Niger, nilidus, elytris margine laterali luteo, capite sublriangulari, confertim punctulato. - Long. 7 lin.

Staphyl. limbatus Klug Col. Madag. 50. 42. t. 1. f. 13.

Habitat in Madagascar, Dom. Goudot.

Statura robustior $\mathbf{X}$. chalybei, at minor, niger, nitidus, elytrorum margine laterali inflexo solo luteo. Antennae capite vix longiores, articulo tertio secundo sesqui longiore, nigrae, articulis 4-10 cinerascentibus, ultimo ferrugineo. Palpi rufo-picei. Caput thorace parum latius, eique longitudine aequale, basi truncatum, angulis posterioribus rotundatis, denticulo minutissimo prominulo notatis, antrorsum angustatum, lateribus vix rotundatum, supra infraque confertim punctulatum. Thorax apice coleopteris haud angustior, latitudine antica parum longior, basin versus angustatus, lateribus medio subsinuatis, apice utrinque oblique truncatus, angulis anterioribus acutiusculis, leviter deflexis, 
leviter convexus, laevissimus, puncto utrinque singulo haud procul ab angulo anteriore impressus. Scutellum punctulatum. Elytra thoracis latitudine, dorso subtiliter rugulosa, subtilissime punctulata, biseriatim fortius punctata, serie altera suturali, altera dorsali, lateribus vage subtiliter punctatis, luteis. Abdomen sparsim punctatum, parce pilosum. Pedes nigri, tarsis piceis.

- 9. X. cyanoplerus: Nigerrimus, nitidus, elytris subtiliter triseriatim punctatis, chalybeis, capite oblongo, laevi. - Long. $5 \frac{1}{2}$ lin.

Habitat in Terra Van-Diemenii, Dom. Schayer.

Habitu fere praecedentis at paulo minor, totus nigerrimus, nitidissimus, elytris cyaneis. Antennae capite parum longiores, articulo tertio secundo duplo longiore, ultimo apice ferrugineo. Palpi apice picei. Caput thoracis latitudine, latitudine paulo longius, basi et lateribus leviter, angulis posterioribus fortiter rotundatis, antrorsum paululum angustatum, supra convexum, subtilissime punctulatum, punctis utrinque tribus in capitis margine postico, duobus ad oculum utrumque impressum, sulculis duobus anticis intermediis parallelis. Thorax coleopteris parum angustior, latitudine paulo longior, basin versus subangustatus, apice truncatus, angulis anterioribus lateribusque subrectis, leviter convexus, puncto utrinque singulo intra angulum anteriorem sat profundo impressus. Scutellum obsolete 4-punctatum. Elytra thorace paulo longiora, triseriatim punctata, serie prima suturali, secunda dorsali, tertia marginali, omnibus sat regularibus, margine apicali et lateribus inflexis vage punctatis. Abdomen parce punctatum, parce nigro-pilosum. Pedes nigri, tarsis piceis. Alae fusco-hyalinae.

* 10. X chloropterus: Niger, capite triangulari laevi thoraceque opacis, elytris viridibus, abdomine nigro-subaeneo, nilidulis. - Long. 9 lin.

Habitat in Terra Van-Diemenii, Dom. Schayer.

$\mathrm{X}$. chalybeo longitudine aequalis, at gracilior, corporis habitu potius $\mathbf{X}$. glabrati Antennae capite vix longiores, articulo tertio elongato, secundo duplo longiore, $\mathbf{4}-10$ crassitie aequalibus; at sensim paulo brevioribus, nigrae, ultimo apice subferrugineo. Palpi nigri, apıce rufo-picei. Caput thoracis longitudine et basi eius apici latitudine aequale, antrorsum angustatum, oblongo-subtriangulare, basi et lateribus perparum, angulis posterioribus fortiter rotundatum, supra leviter convexum, puncto maiusculo singulo ad interiorem, alteroque itidem singulo ad superiorem oculi marginem impresso, ceterum praeter sulculos anticos ordinarios laeve, nigrum, subopacum. Thorax apice coleopterorum latitudine, basin versus modice angustatus, latitudine antıca paulo longior, lateribus rectis, apice utrinque oblique truncatus, angulis anterioribus subrotundatis, modice prominentibus, leviter convexus, longe intra apicem puncto singulo impressus, ceterum laevissimus, niger, subopacus. Scutellum medio punctatum, nigrum, parum nitidum. Elytra thorace vix longiora, triseriatım punctata, serie prima suturali, secunda dorsali, tertia marginali, margine inflexo summoque apice vage punctatis, viridia, nitudula. Abdomen elongatum, parallelum, parce subtiliter punctatum, parce tenuiterque nigro-pilosellum, nigro - subaeneum, nitudulum. Corpus subtus nigro-subaeneum, nitidum. Pedes nigri. Alae fuscae. 
11. X. chalcopterus: Niger, nilidus, elytris triseriatim punctatis, cyaneoaeneis, pedibus rufo-fulvis, capite oblongo, laevi. - Long. 5 lin.

Habitat in Nova Hollandia, ad Cygnorum flumen, Mus. Dom. Hope.

Habitu omnino X. fulgidi, at duplo maior, niger, pernitidus. Antennae capite panlo longiores, articulo tertio secundo plus sesqui longiore, nigrae, articulo secundo tertioque basi rufo-piceis, ultimo apice ferrugineo. Palpi picei. Caput thorace paulo latius, latitudine longius, basi cum angulis posterioribus rotundatus, lateribus subrectis, antrorsum haud angustatum, subdepressum, omnium subtilissime obsoletissimeque punctulatum, puncto maiusculo singulo ad interiorem, duobus approximatis ad superiorem utriusque oculi marginem, pluribusque irregulariter transversim positis verticis impressum, sulculis duobus anticis intermediis prope parallelis. Thorax latitudine paulo longior, basin versus angustatus, lateribus pone medium subsinuatis, basi coleopteris angustior, parum convexus, puncto singulo ad angulum utrumque anteriorem impressus. Scutellum parumpunctatum. Elytra thorace paululum longiora, subtilius triseriatim punctata, serie prima-suturali, secunda in medio dorsi, tertia marginali, omnibus sat regularibus, cyaneoaenea, nitida. Abdomen parce vageque punctulatum, tenuiter pilosum. Pedes omnes cum coxis anterioribus rufo-fulvi. Alae fuscae.

* 12. X. speciosus: Cyaneus, nilidus, elytris anoque rufis, capile subquadruto, punctulalo, angulis posterioribus subdentatis. - Long. 9 lin.

Habitat in Brasilia, Dom. Virmond.

Magnus. - Corpus subtus cum pedibus nigrum, supra cyaneum, nitidum, elytris rufis, abdominis segmento quinto rufo-testaceo, basi cyaneo, sexto toto testaceo. Antennae capite vix longiores, articulo tertio secundo sesqui longiore, nigrae, articulo ultimo apice testaceo. Palpi picei. Mandibulae elongatae. Caput magnum, subquadratum, thorace plus sesqui latius, basi utrinque oblique truncatum, lateribus rectum, angulis posterioribus obtusis, inferne denticulo armatis, antrorsum subangustatum, depressum, totum crebrius punctatum punctisque maioribus utrinque nonnullis impressum. Thorax coleopteris angustior, latitudine plus sesqui longior, basin versus vix angustatus, lateribus rectis, apice utrinque oblique truncatus, angulis anterioribus obtusis, leviter convexus, ommium subtilissime punctulatus, dorso medio punctis quatuor, quadratim positis, obsoletis impressus. Elytra thorace paulo longiora, subtllissime punctulata, dorso punctorum maiorum distantium serie instructa, rufo-testacea, nitida, coeruleo-subnitentia. Abdomen parallelum, sublaeve, punctis subtlibus raris impressum, parce nigro-pilosum. Pedes leviter elongati, graciliores, nigri, tarsis piceis.

* 13. X. insignis: Vigro-subaeneus, nilidus, elytris anoque rufo-testaceis, capite subtriangulari, angulis posterioribus rolundatis. - Long. 8 lin. Habitat in Brasilia, Doñ. Prof. Germar.

Affinis praecedenti, obscure nigro-aeneus, pernitidus, abdominis segmento qunto apice sextoque toto elytrisque rufo-testaceis. Antennae capitis longitudine, articulo tertio secundo paulo longiore, nigro-piceae, articulis 4-11 dense griseo-tomentosis. Palpi picei. Caput magnum, basi thorace sesqui latius et utrinque oblique truncatum, angulis posterioribus 
rotundatis, lateribus subrectis, antrorsum fortius angustatum, depressum, vage subtiliter punctatum, fronte utrinque punctis grossis subvariolosa. Thorax latitudine sesqui longior, basin versus angustatus, lateribus rectis, apice utrinque oblique truncatus, angulis anterioribus subrectis, modice prominentibus, leviter convexus, laevissimus, punctis tribus in angulo utroque ante $\lrcorner$ riore impressus. Scutellum punctis nonnullis fortibus notatum. Elytra thorace paulo longiora, dorso parce subseriatim punctata, rufo-testacea, metallico-nitida. Abdomen apice attenuatum, parce nigro-pilosum, laevigatum, punctis raris subtilibus prope segmentorum margines sparsum, apice rufotestaceum. Corpus subtus nigro-subaeneum. Pedes nigri, tarsis piceis.

\section{* 14. X. festivus: Cyaneus, nilidus, elylris rufo-testaceis, capile oblongo, punctulato. - Long. 8 lin.}

Habitat in Brasilia, Dom. Prof. Germar.

Corpus cyaneum, splendidum, elytris solis rufo-testaceis. Antennae capite paulo longiores, articulo tertio secundo paulo longiore, nigrae, articulo secundo piceo, articulis 4-11 dense griseo-tomentosis. Palpi picei. Caput thoracis longitudine eoque parum latius, basi rotundatum, lateribus subrectis, angulis posterioribus obtusis, denticulo minutissimo obtusiusculo notatis, antrorsum subangustatum, supra subdepressum, sparsim subtilius punctatum, fronte utrinque punctis nonnullis maioribus notata, sulculis intermediis in fronte antica conniventibus, fortiter impressis. Thorax latitudine dupls prope longior, basin versus vix angustatus, lateribus rectis, apice truncatus, angulis anterioribus obtusiusculis, transversim convexus, laevissimus, intra-angulum utrumque anteriorem punctis nonnullis notatus. Scutellum punctis paucis impressum. Elytra thorace sesqui latiora et paulo longiora, subtiliter punctata, punctorum maiorum seriebus tribus, prima suturali, secunda dorsali media, tertia marginali, punctis earum autem parum profundis et sat distantibus. Abdomen elongatum, parallelum, laevigatum, vel punctis subtilissimis raris impressum, glabrnm, solo apice nigro-piloso. Pedes graeiliores, tarsis piceis.

\section{* 15. X. lucidus: Niger, nitidissimus, elytris anoque rufo-testaceis, thorace dorso bipunctato, capite oblongo, vage punctulato. - Long. $5 \frac{1}{2}$ lin.}

\section{Habitat in Brasilia, Dom. Prof. Germar.}

Corpus nigrum, nitidissimum, abdominis segmento penultimo apice, ultimo toto elytrisque testaceo-rufis. Antennae capite paulo longiores, articulo tertio secundo parum longiore, rufo-piceae, articulo primo nigro. Palpi rufi. Caput thoracis fere longitudine, eoque parum latius, antrorsum subangustatum, basi utrinque oblique truncatum, angulis posterioribus obtusis, subrotundatis, depressiusculum, vage parcius punctatum, fronte utrinque punctis nonnullis grossiusculis notata, sulcis ordinariis in antica fronte inter antennas sat longis profundeque impressis. Thorax coleopteris paulo angustior, latitudine paulo longior, basin versus subangustatus, lateribus pone medium subsinuatis, apice utrinque oblique truncatus, angulis anterioribus obtusis, leviter convexus, omnium subtilissime punctulatus, punctis duobus in medio dorsi et tribus intra angulum utrumque anteriorem impressus. Scutellum bipunctatum. Elytra thorace longiora, subtidter punctulata, pun- 
ctorum maiorum serie in medio dorsi, rufo-testacea, nitida, sub-pellucida. Abdomen parallelum, segmentis singulis utrinque parcius subtiliter punctatis, parce pilosum, apice rufo-testaceum. Pedes graciles, nigri, tarsis rufopiceis.

\section{X. phoenicopterus: Niger, nitidus, tarsis piceis, elytris rubris, pur- pureo-nitentibus, triseriatim punctatis, capile oblongo, laevi. - Long. 5 lin.}

Habitat in Nova Hollandia, Mus. Dom. Hope.

Statura omnino X. analis, nigerrimus, pernitidus. Antennae capite parum longiores, articulo tertio elongato, secundo duplo longiore, nigrae. Palpi picei. Caput thoracis latitudine, latitudine paulo longius, antrorsum subangustatum, lateribus rectis, angulis posterioribus rotundatis, punctis utrinque singulo maiusculo ad interiorem, bins approximatis, oblique positis, ad superiorem oculi marginem, paucisque irrigulariter transversim positis verticis impressum, ceterum praeter sulculos anticos ordinarios laevissimum. Thorax coleopteris paulo angustior, longitudine paulo longior, basin versus modice angustatus, lateribus medio vix sinuatis, apice utrinque oblique truncatus, angulis anterioribus obtusis, modice prominentibus, parum convexus, intra angulum anteriorem utrinque puncto magno profundo et in margine anteriore punctis utrunque nonnullis impressus. Scutellum punctulatum. Elytra thorace paululum longiora, punctorum seriebus tribus sat regularibus notata, prima suturali, secunda in medio dorsi, tertia marginali, rubra, nitore purpureo resplendentia. Abdomen parallelum, parcius subtiliter punctulatum, nigrum, pernitıdum, immaculatum. Pedes breves, nigri, tarsis piceis. Alae fusco-hyalinae.

* 17. X. analis: Niger, nitidus, elytris anoque rufis, thorace dorso quadripunctato, capite oblongo, utrinque parce punclato. - Long. $4 \frac{1}{2}-5 \frac{1}{2}$ lin. Gyrohypnus analis Nordm. Symb. 123. 25.

Habitat in Brasilia.

Corpus nigrum, pernitidum, abdominis segmento penultimo apice, ultimoque toto elytrisque rufis. Antennae capite parum longiores, articulo tertio secundo paulo longiore, 4-10 transversis, sensim paululum crassioribus, rufo-piceae, articulo primo nigro, ultimo ferrugineo. Palpi rufi. Caput thoracis longitudine eoque paulo latius, basi et angulis posterioribus rotundatum, lateribus subrectum, antrorsum vix angustatum, supra leviter convexum, fronte utrinque punctis grossiusculis profundisque parcis sparsa, ceterum praeter sulculos anticos ordinarios sat profundos laevissimum. Thorax coleopteris angustior, latitudine sesqui fere longior, basin versus leviter angustatus, lateribus subrectis, apice utrinque oblique truncatus, angulis anterioribus subrectis, modice prominentibus, leviter convexus, dorso medio punctis subtilioribus quatuor, quadratim positis, pone medium puncto uno alterove, lateribus utrinque ante medium punctis profundioribus quatıor impressus. Scutellum parce punctatum. Elytra thoracis longitudine, dorso et lateribus parce subtiliterque subseriatim punctata, seriebus tribus punctorum maiorum, prima suturali, secunda dorsali, tertia marginali. Abdomen punctis raris subtilioribus impressum, parce nigro-pilosellum, apice laete 
rufo, densius nigro-rufoque piloso. Pedes graciliores, tarsis piceis. Alae fusco - hyalinae.

* 18. X. illucens: Niger, nitidus, elytris testaceis, scutello punctulato, capite oblongo, utrinque parum-punctato, subtilissime strigoso. - Long. 5 lin.

\section{Habitat in Columbia, Dom. Moritz.}

Corpus nigrum, pernitidum, aeneo-relucens, elytris testaceis. Antennae capite paulo longiores, articulo tertio secundo vix longiore, 4-10 sensim paulo brevioribus, penultimis transversis, rufo-piceae, articulo basalı nigro, apicali ferrugineo. Palpi rufi. Caput thoracis longitudine eoque vix latius, basi et lateribus parum, angulis posterioribus fortiter rotundatis, antrorsum parum angustatum, supra modice convexum, subtilissime minus dense longitudinaliter strigosum, fronte utrinque punctis nonnullis (circiter 5) grossiusculis impressa. Thorax coleopteris angustior, latitudine paulo longior, basin versus leviter angustatus, lateribus subrectis, apice truncatus, angulis anterioribus subrotundatis, supra modice convexus, laevissimus, lateribus subtilissime strigosis, utrinque ante medium punctis tribus impressus, angulis anterioribus summis rufis. Scutellum punctulatum, longe parceque fulvopilosum. Elytra thoracis longitudine, crebrius punctata, punctis dorso subseriatis. Abdomen parcius subtliter punctatum, segmentis ventralibus tenuiter testaceo-marginatis, subtiliter tenuiterque griseo-pilosellum. Pedes nigropicei, geniculis tarsisque rufo-piceis, trochanteribus omnibus testaceis, coxis anticis testaceis, disco anteriore et posteriore nigro. Alae fuscae.

* 19. X. castigatus: Niger, nitidus, antennarum basi, pedibus, elytris, thorace subtus, pectore anoque rufis, capite suborbiculato, utrinque fortiter punctulato. - Long. $4 \frac{1}{2}$ lin.

Habitat in Columbia, Dom. Moritz.

Subdepressus. Antennae capite paulo longiores, articulo tertio secundo tertia parte longiore, 4-10 sensim paulo brevioribus et crassioribus, penultimis fortiter transversis, rufo-piceae, articulo primo rufo, ultimo ferrugineo. Palpı rufi. Mandibulae piceae. Caput thorace latius, suborbiculatum, depressum, fronte utrinque punctis grossiusculis oblongis vage fortiterque impressa, nigrum, nitidum. Thorax coleopteris angustior, latitudine apicis paulo longior, basin versus angustatus, lateribus rectis, apice truncatus, angulis anterioribus subrectis, modice prominentibus, subdepressus, supra utrinque punctis $\mathbf{5}$ sat profundis impressis, nigro-piceus, nitidus, marginibus rufescentibus, subtus rufus. Scutellım rufum, parce punctulatum. Elytra thoracis longitudine, dorso parce subseriatim, lateribus crebrius vage subtiliterque punctata, testaceo-rufa, nitida. Abdomen parallelum, parce subtiliterque punctulatum, supra parce tenuiterque pilosellum, subtus longius griseo-pilosum, nigrum, segmento quinto apice, sexto toto rufis. Pectus cum pedibus rufum. Alae fusco-hyalinae.

20. X. vagus: Niger, nitidus, pedibus posterioribus rufo-brunneis, elytris punctatis, nigro-subaeneis, capite oblongo, lateribus parce punclato. - Long. 4 $\frac{2}{3}$ lin.

Habitat prope Caracas Columbiae, Dom. Moritz. 
Habitu fere $\mathbf{X}$. linearis, at triplo fere maior, niger, pernitidus. Antennae capite paulo longiores, articulo tertio secundo parum longiore, 4-10 sensim paululum crassioribus, nigrae. Palpi rufo-picei. Caput thoracis latitudine, oblongo-ovatum, fronte leviter convexa, utrinque parce punctata, sulculis anticis intermediis obsoletioribus, parallelis. Thorax coleopteris paulo angustior, latitudine plus sesqui longior, basin versus haud angustatus, lateribus pone medium subsinuatis, angulis anterioribus rotundatis, posterioribus obtusis, leviter convexus, utrinque lateribus antice punctis paucıs maioribus, postice punctis nonnullis sparsis subtilioribus impressus. Scutellum punctis quatuor impressum. Elytra thorace paulo longiora, dorso et lateribus crebre punctata, nigro - subaenea, nitida. Abdomen parallelum, parce subtiliter punctatum, tenuiter pilosum, nigro-subaeneum, nitidum, apice summo piceotestaceo, densius piloso. Pedes antici nigro-picei, posteriores rufo-brunnei. Alae fuscae.

* 21. X. gagat in us: Nigerrimus, nitidus, elytris angulo humerali testaceo, capile oblongo-subquadrato, crebre fortiterque punctato. - Long. prope 5 lin.

Habitat in Madagascar, Dom. Goudot.

Habitu corporis $\mathbf{X}$. fulgidi, at duplo prope maior, nigerrimus, nitidus. Antennae capite paulo longiores, crassiusculae, apicem versus sensim leniter incrassatae, articulo tertio secundo paulo longiore, 4-10 transversis, sensim crassioribus, piceae, articulo primo nigro. Caput thoracis latitudine eodemque paulo latius, basi truncatum, angulis posterioribus leviter rotundatis, lateribus subrectss, antrorsum vix angustatus, supra modice convexus, punctis magnis, profundis, oblongis, crebrius variolosum, sulcis anticss intermediis sat profundis, posterius leviter conniventibus, interstitio sulcis duobus approximatis obsoletioribus canaliculato, minus nitidum. Thorax coleopteris paulo angustior, latitudine apicis plus sesqui longior, basin versus sensim leniter angustatus, lateribus subrectis, apice truncatus, angulis anterioribus subrectis, modice prominentibus, sat convexus, nitidissimus, subtilissine parce punctatus, antice utrinque punctis maiusculis tribus, pone medium ad marginem lateralem singulo notatus. Scutellum impressum. Elytra thorace paulo longiora, dorso punctorum seriebus tribus, prima suturali, secunda discoidali, tertia marginali, notatis, interstitiis parce, lateribus inflexis crebrius subtiliter punctatis, angulo summo humerali testaceo. Abdomen parce subtilius punctatum, tenuiter griseo-pubescens. Tarsi picei.

22. X. anachoreta: Niger, nitidus, antennis pedibusque nigro-piceis, elytris triseriatim punctatis, apice lutescentibus, capite subtriangulari, lateribus crebre punctato. - Long. 6 lin.

Habitat in Bengala, Mus. Dom. Hope.

Statura omnino X. glabrati, nigerrimus, nitidus. Antemnae capite paulo longicres, articulo tertio secundo sesqui longiore, nigro-piceae. Palpi picei. Caput thorace vix latius, latitudine baseos vix longior, subtriangulare, angulis posterioribus fortiter rotundatis, supra leviter convexum, laevissinum, prope oculos punctis nonnullis grossis rugiformibus profundis impressum, lateribus crebre subtilius punctatum, medio laevissimum, sulcis anticis inter- 
mediis sat profundis, ad mediam frontem usque adscendentibus, parum conniventibus. Thorax apice coleopterorum latitudine, basin versus sensim leviter angustatus, latitudine apicis paulo longior, lateribus pone medium subsinuatis, ante medium leviter rotundatis, angulis anterioribus obtusis, parum convexus, laevissimus, puncto utrinque singtilo intra angultum anteriorem impressus. Scutellum parce punctatum. Elytra thorace haud longiora, triseriatim punctata, serie prima suturali secundaque in medio dorsi distinctroribus, tertia marginali valde obsoleta, nigra, apice indeterminate lutescentia. Abdomen crebrius punctulatum, segmentis dorsalibus medio longitudinaliter laevibus, tenuiter griseo-pubescens. Pedes nigro-picei, geniculis tarsisque rufescentibus, tibiis fortius spinulosis.

23. X. dispilus: Niger, nitidus, antennis pedibusque rufo-piceis, elylris margine inflexo maculaque discoidali tesiaceis, capite triangulari, fronte punctata, lateribus sulcala. - Long. $3 \frac{2}{3}$ lin.

Habitat in Bengala, Mus. Dom. Hope.

Subdepressus, niger, nitidus. Antennae capite parum longiores, articulo secundo tertioque longitudine aequalibus, apicem versus subattenuatae, rufopiceae. Palpi piceo-rufi. Caput thorace latius, latitudine haud longius, triangulare, basi truncatum, angulis posterioribus rotundatis, subdepressum, spatio transverso frontali dense subtilius punctato, lateribus prope oculos sulculo profundo, apice sulcis quatuor longitudinalibus impressum, intermediis eorum ordinariis ad mediam frontem usque adscendentibus, parum conniventibus, vertice punctis nomnullis maioribus profundis, irregulariter transversim pesitis, notato. Thorax apice coleopteris haud angustior, basin versus sensim angustatus, latitudine apicis parum longior, lateribus rectis, apice utrinque oblique truncatıs, angulis anterioribus obtusiusculis, subdepressus, laevissimus, puncto utrinque singulo prope angulum anteriorem impressus. Scutellum subtilitèr punctulatum. Elytra thorace haud longiora, triseriatim punctata, serie prima suturali secundaque in medio dorsi sat distinctis, tertia marginali obsoletiore, nigro - picea, macula magna discoidali testacea. Abdomen apicem versus sensim attenuatum, subtiliter punctulatum, dorso linea lata media longitudinali laevi, parce griseo-pilosellum, segmentis smgulis marginibus piceis. Pedes piceo-rufi vel piceo-testacei.

*14. X. volvulus: Subcylindricus, niger, nitidus, antennis pedibusque pi-
ceis, ano rufo, elytris laevibus, capite oblongo, punclato. - Long. 4 lin. Habitat in Brasilia, Dom. Virmond.

Statura tenuis fere $\mathbf{X}$. linearis, at magis cylindricus, niger, pernitidus, abdominis segmento quinto apice, sexto toto rufo-testaceis. Antennae capite paulo longiores, articulo tertio secundo paulo breviore, 4-10 sensim paulo crassioribus, rufo-piceae, articulo primo nigro. Palpi rufi. Os piceum. Caput thorace aliquantum latius, at paulo brevius, basi truncatum, lateribus subrectis, angulis posteriorihus rotundatis, antrorsum haud angustatum, supra leviter convexum, crebrius profunde punctatum, utrinque punctis nonnullıs maioribus impressum. Thorax coleopteris angustior, latitudine duplo longior, lateribus posterius subsinuatus, apice truncatus, angulis anterioribus subrectis, subcylindricus, ante medium útrinque punctis duobus 
oblique positis impressus, ceterum laevissimus. Scutellum laeve. Elytra thorace paulo longiora, obsolete subtilissime punctata. Abdomen parce punctulatum parceque griseo-pilosellum, apice rufo-testaceum. Pedez picei.

$$
\text { Species mihi invi sae: }
$$

25. X. rutilus: Aureo-viridis, nitidus, pectore, pedibus elytrisque brunneoflavis, his aureo-micantibus. - Long. 5 lin.

Staph. rutilus Perty Delect. an. art. p. 30. t. 7. f. 2.

Habitat in prov. Minarum Brasiliae.

Statura omnino $\mathbf{X}$. chalybei videtur, at minor. Caput viridi-aureum, nitidissimum, laevigatum, striola et punctum utrinque inter oculos, punctis duobus utrinque pone oculos, et punctorum serie irregulari ad marginem posticum impressis. Mandibulae nigrae. Palpi brunnei. Thorax viridi-aureus, nitidissimus, punctis duobus utrinque ad angulos anteriores, et singulo ad angulos posteriores valde rotundatos impressus. Scutellum magnum, dilute brunneum, vage punctulatum. Elytra flavo-brunnea, aureo-micantia, punctulata, ad apicem ciliata. Abdomen viride, nitidum, apice flavicante. Antennae capite thoraceque breviores, ad basin brunneae, apice grisescentipilosae, articulo ultimo flavicante. Pedes brunneo-flavi.

26. X. at er: Niger, nitidus, elytris biseriatim puñctatis. - Long. 10 lin. Eulissus at er Laporte Etud. Ent. I. 117. 1. t. 3. f. 4.

Habitat in Senegalia.

Statura omnino $\mathrm{X}$. lateralis, at maior, totus ater, immaculatus, nitidus. Caput thorace latius, magnum, antice sulculis duobus impressum. Thorax coleopteris parum angustior, latitudine antica vix longior, basin versus angustatus, laevissimus, puncto utrinque singulo prope angulum anteriorem impressus. Elytra thoracis longitudine, seriebus duabus punctorum instructa. Abdomen punctulatum.

27. X. vagepunctus: Nitidus, nigricans, laevis, coleopterorum disco vage punctato. - Long. 5 lin.

Staph. vagepunctus. Grav. Mon. 88. 83. - Latr. Hist. nat. Crust. et Ins. IX. 301. 14.

\section{Habitat?}

Caput orbiculatum, thoracis magnitudine, nitidum, laeve, punctis tantum paucis in baseos angulis impressum, antennis capitis longitudine. Thorax convexus, quadratus, angulis obtusis, coleopteris brevior et angustior, nitidus, laevis, puncto uno laterali distincto impressus. Coleoptera quadrata, nitida, depilia, excepto margine apicali setis rigidis fimbriato, laevia, margine laterali confertim punctato, disco vage punctato, nigricantia, margine summo laterali rufescente. Abdomen nigrum, ano fuscescente. Pedes fuscescentes.

Variat coleopteris fuscescentibus, margine laterali pallidiore, pedibus segmentorumque marginibus fuscis. (Grav.)

Obs. Elytra secundum descriptionem Latréillianam dorso seriatim punctata. Forte recte ad hoc genus allatus. 
2) Thorax punctorum seriebus dorsalibus nullis, lateralibus distinctis.

* 28. X. fulgidus: Niger, nilidus, elytris rufis, capite profunde punctalo, thorace laleribus unisulcato. - Long. 4 lin.

Er. Col. March. I. 423. 1.

Staph. fulgidus Fab. Mant. Ins. I. 220. 14.

Paederus fulgidus Fab. Syst. El. II. 609. 6. Ent. Syst. I. II. 537. 6.

Stuph. pyropterus Grav. Mon. 102. 103. - Latr. Hist. nat. Ins. Crust. et Ins.

IX. 334. 95. - Gyll. Ins. Suec. II. 356 71. - Suhlb. Ins. Fenn. I. 334. 70.

Xanthol. pyropterus Boisd. et Lacord. Faun. Ent. Paris. I. 413. 2.

Gyrohypn. pyropterus Mannerh. Brachelytr. 33. 8. - Nordm. Symb. 119. 15.

Habitat in Europa, minus frequens.

Nigerrimus, pernitidus, elytris rufis. Antennae capite paulo longiores, articulo tertio elongato, secunda duplo prope longıre, 4-10 sensim paulo brevioribus et crassioribus, piceae, articulo primo nigro. Palpi rufo-picei. Caput thoracis longitudine eoque paulo latius, basi truncatus, angulis poste. rioribus fortiter rotundatis, lateribus rectis, antrorsum haud angustatum, punctis magnis, profundis, oblongis, lateribus in series continuas sulciformes digestis, in media fronte rarioribus, impressum, fronte utrinque sulco long1tudinali abbreviato notata. Tnorax coleopteris paulo angustior, latitudine plus sesqui longior, basin versus angustatus, lateribus pone medium subsinuatus, angulis anterioribus obtusiusculis, modice prominentibus, parum convexus, dorso laevissimus, lateribus sulco profundo, leviter flexuoso, puncta 8-9 continente, et praeterea punctis binis approximatis utrinque ad marginem anteriorem impressus. Scutellum punctis nonnullis notatum. Elytra thoracis longitudine, biseriatim punctata, serie altera suturali, altera discoidali, irregularibus, spatio inter series punctss raris sparsis impressum, spatio ante marginem lateralem laevi, margine laterali inflexo subtilius punctato. Abdomen lineare, subtiliter parce punctatum, parce nigro-pilosum. Pedes picei, tarsis rufescentibus.

3) Thorax punctorum seriebus dorsalibus rectis lateralibusque lituis impressus.

*29. X. glabratus: Niger, nilidus, antennis pedibusque piceis, elytris rufis, capite lateribus disperse punctato thoraceque parce subtilissime punclulatis, hoc seriebus dorsalibus 5-7 punctatis. - Long. $5 \frac{1}{2}-6 \frac{1}{2}$ lin.

Er. Col. March. I. 424. 2.

Staph. glabratus Grav. Micr. 178. 38 Mon. 101. 100.

Gyrohypn. Glabratus Nordm. Symb. 113.1.

St a ph. fulgidus Grav. Micr. 48. 71. Mon. 106. 108. - Oliv. Ent. III. 42. 18. 19.

t. 4. f. 34. a. d. - Latr. Hist. nat. Crust. et Ins. IX. 832. 90. Gen. Crust. eb Ins. I. 288.4.

Staph. nitidus. Panz. Faun. Germ. 27. 8.

Staph. cruent at us Marsh. Ent. Britt. 516. 56.

Xanthol. fulgidus Boisd, et Lacord. Faun. Ent. Paris. I. 412. 1. - Brulle Hist. nat. Ins. VI. 73. 2.

Gyrohypn. relucens Nordm. Symb. 115. 5.

Var, a: Pedibus rufis.

Gyrohypn, merdarius Nordm. Symb, 116. 6. 


\section{Var. b: Elytris pallidius testaceis, antennis pedibusque mufis.}

Oliv. Ent. III. 42. t. 4. f. 34. b.

Staph. relucens_Grav. Mon. 101.102.

Xanthol. cadaverinus Botsd. et Lacord. Faun. Ent. Paris. I. 414. 4.

Gyrohypn. ochropterus Nordm. Symb. 118. 13.

Habitat in Europa temperata et meridionali, hic frequentior.

Nigerrimus, nitidus, elytris rufis. Antennae capite paulo longiores, articulo secundo tertioque aequalibus, quarto globoso, 5-10 subaequalibus, rufo-piceae. Palpi rufi. Caput thoracis longitudine eodemque basi parum latius, basi truncatum, angulis posterioribus rotundatis, lateribus subrectis, antrorsum leniter angustatum, supra leniter convexum, subtilissime parce punctulatum, utrinque punctis magnis sparsis impressum. Thorax coleopteris paulo angustior, latitudıne sesqui prope longior, basin versus sensim angustatus, lateribus pone medium subsinuatus, angulis anterioribus obtusis, leviter convexus, subtilissime parce punctatus, seriebus dorsalibus 5-7-punctatis, serıe laterali litua 6-7-punctata. Scutellum laeve.'- Elytra thoracis longitudine, parcius irregulariter punctata. Abdomen parce subtiliter punctatum, subtiliter tenuiterque griseo-pubescens, parce nigro-pilosum. Pedes picei, tarsis rufescentibus.

Mas abdominis segmento ventrali sexto truncato, septimo apice inciso, femina segmento sexto apice rotundato, septimo integro, distinguuntur.

Obs. Capite thoraceque subtilissime interpunctatis bene distinctus. Var. a tantummodo pedibus potius rufis quam piceis, var. b pedibus rufo-testaceis et elytris pallide testaceis, statura saepius paulo minore magis a genuinis discedit, at haec forte minus matura minime speciem peculiarem constituere videtur.

30. X. erythropterus: Subdepressus, niger, nilidus, elytris, ano pedibusque rufis, capite subquadrato, utrinque parce punctato, thorace seriebus dorsalibus parumpunclatis, - Long. 6 lin.

Habitat in Nova Hollandia, Mus. Hope.

X. glabratum longitudine haud superans, at paulo latior et magis depressus, niger, nitidus. Antennae capite parum longiores, articulo tertio elongato, secundo duplo prope longiore, $4-10$ cylindricis, leviter transversis, aequalibus, piceae, articulo primo rufo-piceo, ultimo apice ferrugineo. Palpi et labrum piceo-rufa. Caput thorace latius, subquadratum, basi truncatum, angulis posterioribus rotundatis, lateribus rectis, antrorsum vix angustatus, suprá subdepressum, utrinque punctis nonnullis sparsis impressum, sulculo laterali ante oculos brevissimo, obsoleto, interne foveola latiore parum profunda terminato. Thorax coleopteris paulo angustior, basin versus vix angustatus, latitudine paulo longior, angulis anterioribus subrectis, modice prominentibus, subdepressus, seriebus dorsalibus punctis $4-5,3$ vel 4 ante medium, et singulo a reliquis distante pone medium compositis, serie laterali 5- vel 6-punctata, punctis omnibus subtilioribus. Scutellun punctulatum. Elytra thorace paulo longiora, vage subiliter punctata, margine laterali laevi, rufa, nitida. Abdomen parce subtiliter punctatum parceque pilosum, segmento quinto apice sextoque toto rufo-testaceis. Pedes piceo-rufi. 
* 31. X. lubricus: Niger, nitidus, elytris abdominisque segmentis duvbus ultimis rufis, capite oblongo, utrinque parce punctato, thorace seriebus dorsalibus parum-punctatis. - Long. 4 lin.

Habitat prope San Joâo del Rey Brasıliae, Dom. Sellow.

Statura omnino $\mathbf{X}$. fulgidi, niger, pernitidus, elytris abdominisque segmentis duobus apicalibus rufis. Antennae capite paulo longiores, crassiusculae, articulo tertio modice elongato, secundo duplo prope longiore, 4 - 10 sensim paulo crassioribus, $5-10$ transversis, rufo-piceae, articulo primo tertioque nigris, secundo rufo, ultimo apice ferrugineo. Palpi rufi. Caput thoracis longitudine eoque paulo latius, basi truncatum, angulis posterioribus rotundatis, lateribus subrectis, antrorsum leviter angustatum, supra parum convexum, utrinque parce sparsim punctatum. Thorax coleopteris angustior, latitudine sesqui longior, basin versus angustatus, lateribus pone medium subsinuatus, angulis anterioribus obtusiusculis, subrotundatıs, leviter convexus, seriebus dorsalibus parum-punctatis, serie laterali exuosa circiter 11-punctata. Scutellum punctis nonnullis obsoletis impressum. Elytra thoracis longitudine, dorso parcius subseriatim, lateribus subtilius crebriusque vage punctata, rufa, nitida. Abdomen parce punctulatum, parce griseo pilosum, apice late rufum. Pedes nigri, tarsis piceis.

Obs. Speciem unicum, thoracis medio acu laesum, quare punctorum in serie dorsali numerus dubius est.

* 32. X. calidus: Niger, nitidus, elylris rufis, abdomine summo apice rufopiceo, capite utrinque fortiter punclato, thorace seriebus dorsalibus 6-7-punctatis. - Long. 5 lin.

Habitat in Columbia, Dom. Moritz.

Statura X. glabrati et minoribus eius individuis aequalis, niger, pernitidus, elytris rufis. Antennae capite paulo longiores, articulo tertio modice elongato, secundo sesqui longiore, 4-10 sensim paulo brevioribus et cras. sioribus, 5-10 sensim paulo magis transversis, rufo-piceae, articulis tribus primis nigris, ultimo apice ferrugineo. Palpi rufi. Caput thoracis prope longitudine eoque parum latius, basi et lateribus subrectis, angulis antem posteriorioribus late fortiterque rotundatis, antrorsum leviter angustatum, supra leviter convexum, utrinque parcius fortiusque vage punctatum. Thorax coleopteris angustior, latitudine tertia parte longior, basin versus subangustatus, lateribus pone medium subsinuatus, angulis anterioribus obtusis, parum convexus, seriebus dorsalibus 6- vel 7-punctatis, postice duplicatis, serie laterali flexuosa circiter 11-punctata. Scutellum punctis paucis obsoletis impressum. Elytra thoracis longitudine, dorso subseriatum, lateribus crebre punctata, rufa, nitida. Abdomen parce subtiliterque punctulatum, tenuiter griseo-pilosum, segmento penultimo margine summo apicalı, sexto apice rufo-piceis. Petes picei, tarsis dilutioribus. Alae fusco-hyalinae.

* 33. X. castanopterus: Niger, nilidus, antennis pedibusque rufo-piceis, elytris rufis, capite oblongo, crebre fortiterque punctato, thorace seriebus dorsalibus 10-punctatis. - Long. 4 lin.

Habitat in Brasilia, Dom. Prof. Germar.

Statura omnino X. fulgidi, niger, pernidus, elytris saturate rufis. Au- 
tennae capite paulo longiores, crassiusculae, articulo tertio secundo parum longiore, 4-10 transversis, subaequalibus, rufo-piceae, articulo primo rufopiceo, secundo rufo, ultimo apice ferrugineo. Palpi ruf. Mandibulae et labrum rufo-picea. Caput thorace parum brevius eique latitudine aequale, basi cum angulis posterioribus rotundatum, lateribus subrectis, antrorsum leviter angustatum, supra leviter convexum, fortiter profundeque sat crebre punctatum, spatio medio longitudinali laeviore, sulcis anticis intermediis sat profundis, ad mediam frontem usque adscendentibus, vix conniventibus, lateralibus valde obsoletis. Thorax coleopteris paulo angustior, latitudine plus sesqui longior, basin versus vix angustatus, lateribus pone medium subsinuatis, angulis anterioribus rotundatis, supra leviter convexus, seriebus dorsalibus minus regularibus, punctis circiter 10 compositis, serie laterali flexuosa fere 12-punctata, praetera punctis binis pone medium prope seriem dorsalem et pluribus intra utrumque angulum anteriorem impressus, punctis omnihus profundioribus. Scutellum impressum, impunctatum. Elytra thoracis longitudine, dorso parcius subtiliusque subseriatim, lateribus crebrius subtiliter punctata, saturate rufa, nitida, parce griseo-pubescentia. Abromen parce subtilius punctatum, supra parce, subtus densius grisenpubescens, segmento quinto sextoque margine postico rufo-piceo. Pedes nigro-picei, tibiis tarsisque rufis.

* 34. X. pectoralis: Niger, nitidus, elytris, ano, pectore pedibusque rufis, capite utrinque parce punctato, thorace seriebus dorsalibus 6-punctatis. - Long. $4 \frac{1}{2}-5$ lin.

Habitat in Columbia, Dom. Moritz.

Statura praecedentium, niger, nitidus, elytris, abdominis segmento quinto margine apicali sextoque toto, pedibus pectoreque rufis, hoc medio nigricante. Antennae capite parum longiores, articulo tertio secundo sesqui longiore, $4-10$ sensim paulo brevioribus crassioribusque et magis transversis, rufo-piceae, articulo ultimo apice ferrugineo. Palpi rufi. Caput thoracis longitudine eoque parum latius, basi et apice parum, angulis posterioribus late fortiterque rotundatis, antrorsum modice angustatum, supra leviter convexum, utrinque parce punctatum. Thorax coleopteris paululum angustior, latitudine sesqui longior, basin versus subangustatus, lateribus pone medium subsinuatis, angulis anterioribus rotundatis, leviter convexus, seriebus dorsalibus 6-punctatis, serie laterali irregulari, flexuosa, circiter 12-punctata. Scutellum punctis nonnullis obsoletis impressum. Elytra thoracis longitudine, dorso parcius subseriatim, lateribus crebrius subtiliusque vage punctata, laete rufa, nitida, parce tenuiterque griseo-pubescentia. Abdomen parce subtiliterque punctatum, tenuter griseo-pilosum, apice rufum. Pectus rufum, medio nigrum. Pedes cum coxis ommibus laete rufi.

Obs. Hanc speciem nomine $X$ spreti in Catalogo collectionis suae signatum esse 'ill. Com. Dejean litteris certiores nos fecit.

* 35. X. rufipeñnis: Niger, nitidus, elytris pedibusque rufis, capite subovalo, utvingue parce punctalo, thorace seriebus dorsalibus 10-11-punctatis. - Long. $3 \frac{1}{2}$ lin.

Habitat in Sicilia, Dom. Dr. Schultz, in Syria, Dom. Dr. Aubé. 
X. glabrato triplo minor, niger, nitidus, elytris pedibusque rufis. Antennae capite parum longiores, articulo secundo tertioque obconicis, aequalibus, 4-10 subcylindricıs, crassitie vix brevioribus, itidem inter se subaequalibus, rufo-piceae. Palpi rufi, articulo ultimo pallido. Labrum rufum. Caput thorace paulo brevius et parum latius, basi et lateribus leviter, angulis posterioribus fortiter rotundatis, antrorsum modice angustatum, supra leviter convexum, utrinque minus subtilus at sat profunde disperse punctatum, fronte media laevi, sulculis anticis intermediis parallelis, sulculis oblıquis ante oculos obsoletioribus; interne puncto maiusculo terminatis. Thorax coleopteris paulo angustior, latitudine sesqui longior, basin versus leviter angustatus, lateribus pone medium vix sinuatis, angulis anterioribus rotundatis, leviter convexus, seriebus dorsalibus minus regularibus, $10-11$-punctatis, serie litua laterali 11-12-punctata, spatio inter seriem dorsalem et lateralem punctis nonnullis dispersis notato. Scutellum obsoletius tripunctatum. Elytra thorace parum longiora, dorso minus subtiliter subseriatim punctata, secundum marginem lateralem laevia, margine laterali inflexo subtilius punctato, laete rufa, nitida, fulvo-pubescentia. Abdomen parce subtiliterque punctatum, subtus segmentis duobus ultimis piceis, tenuiter parceque griseo-pubescens, subtiliter parceque nigro-pilosum. Pedes cum coxis anticis laete rufi.

* 36. X. elegans: Rufo-testaceus, nitidus, capite abdomineque nigris, hoc segmentorum marginibus testaceis, capite oblongo, ulrinque subtiliter parce punctato, thorace seriebus dorsalibus subtiliter 8-punctatis. -

Staph. elegans Oliv. Ent. II. 42. 19. 20. t. 5. f. 50. - Latr. Hist. nat. Crust. et Ins. IX. 333 L. 87.

Xanthol. meridionalis Boisd, et Lacord. Faun. Ent. Paris. 1. 413. 3.

Gyrohypnus meridionalis Nordm. Symb. 117. 12.

Habitat in Gallia meridionali, Hispania.

Statura omnmo $\mathbf{X}$. linearis, at sesqui maior. Antennae capite paulo longıres, articulo secundo tertioque subaequalibus. 4-10 sensim paulo brevioribus et crassioribus, penultimis leviter transversis, rufo-piceae, articulis tribus primis rufis, ultimo apice ferrugineo. Palpi rufi. Os piceum. Caput thoracis fere longitudine eoque parum latius, basi et lateribus parum, angulis posterioribus fortiter rotundatis. antrorsum leviter angustatum, supra leviter convexum, nigrum, pernitidum, utrinque subtiliter parce punctatum, spatio medio longitudinali laevi, sulculis intermediis inter antennas brevibus, parallelis, parum profundis, sulculis obliquis ante oculos longiorsbus, sat distinctıs. Thorax coleopteris paulo angustior, latitudme sesqui longior, basin versus angustatus, lateribus subrectis, apice utrinque oblique truncatus, angulis anterioribus lateraliter sat prominentibus, subrotundatis, leviter convexus, rufo-testaceus, pernitidus, seriebus dorsalibus 8-punctatıs, serie litua laterali circiter 9-punctata, punctis omnibus sat subtilibus. Scutellum piceum, obsolete bipunctatum. Elytra thorace prope breviora, testacea, nitida, dorso subseriatim punctata, secundum marginem lateralem laevia, margine laterali inflexo subtilius punctato. Abdomen subtiliter parceque punctatum, nitidulum, supra nigro-piceum, segmentis ultimis margine testaceis, subtus rufotestaceum, segmentis smgulis basi picescentibus. Pectus piceo-testaceum. Pedes breviusculi, graciliores, testacei. 
* 37. X. collaris: Niger, nitidus, ano pedibusque mifis, capile oblongo, utrinque parce punctato thoraceque sanguineo subtilissime parcius punclulatis, hoc seriebus dorsalibus $6-7$-punctalis. - Long. $3 \frac{1}{2}-4$ lin.

Er. Col. March. I. 424. 3.

Habitat prope Berolinum, Dom. Schüppel, in Germania meridionali, Dom. Godet, in Sardinia, Dom. Prof. Gené.

Statura omnino $\mathrm{X}$. lenti, at paulo maior. Antennae capite parum longiores, crassiusculae, articulo tertio secundo paulo longiore, $4-10$ transversis, sensim paulo brevioribus et crassioribus, rufo-piceae, articulo ultimo apice ferrugineo. Palpi rufi. Caput thoracis fere longitudine eoque paulo latius, basi truncatum, lateribus rectis, angulis posterioribus subrotundatis, antrorșum vix angustatum, subdepressum, nigrum, nitidum, subtilissime disperse punctulatum, utrinque punctis grossiusculis oblongis sparsum. Thorax coleopteris paulo angustior, latitudine plus sesqui longior, basin versus subangustatus, lateribus subrectis, apice utrinque oblique truncatus, angulis anterioribus rectis, modice prominentibus, parum convexus, rufo-sanguineus, nitidus, subtilissime parce punctulatus, seriebus dorsalibus 6-7-punctatis, serie litua laterali 6-punctata, punctis sat subtilibus. Scutellum nigrum. Elytra thoracis longitudine, dorso parcius subseriatim punctata, secundum marginem lateralem laevia, lateribus inflexis subtilius punctatis, nigro-picea, margine apicali pallido. Abdomen parce subtilissime punctatum, nigrum, nitidum, segmento quinto supra apice, subtus fere toto, sextoque toto rufis. Pectus nigrum. Pedes cum coxis anterioribus rufo-testacei.

*38. X. decorus: Rufus, nitidus, capite, elytris ano pectoreque nigris, capite oblongo, parce subtilius punctuto, thorace seriebus dorsalibus 7-8-punctatis. - Long. $3 \frac{1}{3}$ lin.

Habitat in Austria, Dom. Schiippel, in Hungaria montana, Dom. Waltl. $\mathrm{X}$. glabro statura similis, at gracilior. Antennae capite sesqui longiores, articulo tertio secundo sesqui longiore, 4-10 sensim paulo crassioribus et magis transversis, totae rufae. Palpi rufo-brunnei. Caput thorace paulo latius, oblongo-ovatum, supra leviter convexum, parce sparsim subtilius punctatum, sulcis anticis intermediis brevibus et parum profundis, sulculis obliquis ante oculos distinctis, nigrum, pernitidum, mandibulis rufo-piceis. Thorax coleopteris vix angustior, latıtudine plus sesqui longior, lateribus parallelis rectisque, angulis omnibus rotundatis, convexus, seriebus dorsalibus $7-8$-, lateralıbus lituis fere 12 -punctatis, punctis omnibus subtilibus, laete rufus, pernitidus. Scutellun subimpressum, nigrum. Elytra thoracis longitudine, parcius subseriatim punctata, parceque griseo-pubescentia, nigerrima, pernitida. Abdomen parce punctatum, parceque griseo-pilosellum, nitidum, segmentis anterioribus 4 rufis, reliquis nigris. Pectus nigrum. Pedes rufo-testacei.

Obs. Corporis colore Paederum simulat.

* 39. X. emmesus: Testaceus, nitidus, capile oblongo, utrinque parce punclato, nigro, thorace rufo-teslaceo, seriebus dorsalibus 4-punctatis. Long. $2 \frac{2}{3}$ lin.

Staph. emmesus Grav. Mier. 176. 35. Mon. 98. 97.

llabitat in America septentrionali. 
Statura et summa affinitas $\mathbf{X}$. glabri. Antennae capite paulo longiores, articulo secundo tertioque breviusculis, aequalibus, $4-\mathbf{l 0}$ transver:is, rufopiceae, articulis 3 primis rufis, ultimo apice ferrugineo. Os rufo-piceum. Caput thoracis fere longitudine eoque parum latius, basi truncatum, angulis posterioribus fortiter rotundatis, lateribus rectis, antrorsum haud angustatum, supra leviter convexum, utrinque parcius fortiter punctatum, medio longitudinaliter laeve, nigrum, nitidum. Thorax coleopteris perparmm angustior, latitudine atertia parte longior, basin versus subangustatus, lateribus subrectis, angulis anterioribus obtusis subrotundatis, modice convexus, rufo-testaceus, nitidus, seriebus dorsalibus 4-punctatis, serie laterali litua 5 -- 6-punctata. Scutellum testaceum; laeve. Elytra thoracis longitudine, luteo- testacea, nitida, triseriatim punctata, serie prima suturali irregulari, secunda in medio dorsi, tertia marginali, his sat regularibus, lateribus inflexis laevibus. Abdomen parce punctulatum, subtus testaceum, supra segmentis anterioribus 5 basi fuscescentibus. Pectus et pedes testacei.

* 40. X. glaber: Niger, nitidus, elytris pedibusque brunneo-testaceis, capite suborbiculato, utrinque parce subtiliter punctato, thorace seriebus dorsalibus 5-9-punclutis. - Long. $3 \frac{1}{2}$ lin.

Er. Col. March. I. 425. 4.

Gyrohypn. glaber Nordm. Symb. 114. 4.

Staph. glaber var. 2 Grav. Mon. 100. 99.

Xantholin. lentus var. b Zetterst. Faun. Lappon. I. 81. 2.

Staph. diaphanus Marsh. Ent. Britt. 514. 46. (forte)

Habitat in Germania.

Niger, nitıdus. Antennae capite parum longiores, articulo secundo tertioque brevioribus, subaequalibus, $4-10$ brevibus, transversis, sensim paulo crassioribus, ultimo ovato, apice compresso, rufo-piceae, articulo primo medio nigricante. Palpi rufo-picei. Caput thorace vix latius et paulo brevius, subovatum, antrorsum leviter angustatum, supra leviter convexum, utrinque punctis parcis sparsis rotundis subtilioribus impressum, interstitiis laevissimis, sulculis anticis intermediis sat profundis, parum conniventibus, lateralibus ad oculum utrumque obsoletioribus, licet distinctis. Thorax coleopteris parum angustior, latitudine sesqui prope longior, basin versus subangustatus, lateribus pone medium vix sinuatis, apice truncatus, angulis anterioribus subrotundatis, leviter convexus, laevissimus, seriebus dorsalibus 8-9-punctatis, serie laterali litua 7-8-punctata. Scutellum laeve. Elytra thorace parum longiora, dorso seriebus tribus parce punctatis, prima suturali, secunda discoidali, tertia -marginali, interstitiis serierum praeterea punctis raris subtilibus impressis, lateribus parcius subseriatim punctatis, brunneo-testacea, nitida. Abdomen parce subtiliter obsoleteque punctulatum, griseo-pilosellum, segmentis singulis margine tenui, segmento ultimo toto piceo-testaceo. Pedes brunneo-testacei, femoribus piceis, tarsis dilutioribus.

* 11. X. lentus: Subdepressus, niger, nitidus, elytris pedibusque bmuncotestaceis, capile subquadrato, utrinque crebrius fortiter punctato thoraceque subtilissime parce punctulatis, hoc seriebus dorsalibus 7-8-pun-

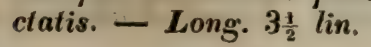


Zetterst. Faun. Lappon. I. 80. 2. Ins. Lappon. 66. 3. - Er. Col. March. I. 426. 5. Staph. lentus Grav. Mon. 101. 101. - Gyll. Ins. Suec. II. 354. 69. - Sahlb. Ins. Fenn. I. 333. 68.

Gyrohypn. lent us Mannerh. Brachelytr. 33. 6. - Nordm. Symb. 118. 10.

Staph. glaber var. 1 Grav. Mon. 100. 99.

Staph, tricolor var. b Payk. Faun. Suec. III. 378. 15.

Habitat in Germania, Suecia.

Statura et magnitudo omnino $\mathbf{X}$. punctulati, subdepressus, niger, nitidus. Antennae capite paulo longiores, articulo secundo tertioque longitudine subaequalibus, 4 - I0 sensim paululum crassioribus, penultimis leviter transversis, rufae. Falpi rufi. Mandibulae piceae. Caput thoracis prope latitudine eodemque basi latius, basi leviter, angulis posterioribus fortius rotundatis, lateribus subrectis, antrorsum subangustatum, supra parum convexum, utrinque punctis sat magnis oblongis crebrius sparsum, undique subtilissime parce punctulatum, sulculis duobus anticis intermedius brevioribus, sat latis, at parum profundis, lateralibus ad oculi utriusque marginem inferiorem obsoletis. Thorax coleopteris paulo angustior, latitudine sesqui longior, basin versus leniter angustatus, lateribus pone medium subsinuatis, apice truncatus, angulis anterioribus subsinuatis, subdepressus, parce subtilissime punctulatus, seriebus dorsalibus $7-8$-punctatis, serie laterali litua $\mathbf{4}-5$-punctata. Seutellum laeve. Elytra thorace parum longiora, crebrins vage punctata, secundum marginem lateralem laevia, brunneo-testacea, nitida. Abdomen subtilissime parce punctatum, tenuiter griseo-pubescens, subtus segmento penultimo margine summo, ultimo apice picescentibus. Pedes cum coxis omnibus rufo-testacei.

* 42. X. consentaneus: Subdepressus, niger, nitidus, elytris pedibusque brunneo-testaceis, capite oblongo, utrinque parce punclato thoraceque sublilissime disperse punctulatis, hoc seriebus dorsalibus 6-7-punctatis. - long. $3-3 \frac{1}{2}$ lin.

Gyrohypn. consentaneus Nordin. Symb. 122. 24.

Gyrohypn. flavipennis Nordm. Symb. 121. 23.

Habitat in America septentrionali.

Statura subdepressa et summa affinitas praecedentis, at magis elongatus, niger, nitidus. Antennae capite vix longiores, articulo secundo tertioque aequalibus, $\mathbf{4}-\mathbf{1 0}$ transversis, subaequalibus, rufae. Palpı testacei. Caput oblongum, thoracis fere longitudine, eoque parum latius, basi truncatum, angulis posterioribus rotundatis, lateribus subrectis, antrorsum vix angustatum, supra parum convexum, utrinque parcius subseriatim punctatum, undique subtilissime parce punctulatum, sulculis dnobus anticis intermediis sat profundis, leviter conniventibus, lateralibus obliquis ad oculorum marginem inferiorem obsoletioribus, licet distinctis. Thorax coleopteris paulo angustior, latitudine plus sesqui longior, basin versus subangustatus, lateribus pone medium subsinuatus, apice truncatus, angulis anterioribus subrectis, parum convexus, parce subtilissime punctatus, seriebus dorsalibus 6-7-punctatis, punctis posterioribus magıs distantibus, seriebus lateralibus lituis 6-punctatis. Scutellum laeve. Elytra thoracis longitudine, dorso parcius subseriatim, lateribus subtilius crebriusque vage punctata, testacea, nitida. Abdomen lineare, parce 
subtiliterque punctulatum, tenuiter griseo-pilosellum, subtus piceum, segmentis singulis apice testaceis, seu piceo-testaceum, segmentis singulis basi lateribusque nigricantibus. Pedes toti testacei.

Obs. Specimina sub nomine Gyrohypni flavipennis a Dom. Nordmann descripta nonnisi statura paulo minore et colore elytrorum pedumque dilutiore differunt.

* 43. X. brunneipennis: Niger, nitidus, elytris pedibusque brunneo-tesiaceis, capite utringne disperse, medio biserialim punctato, thorace seriebus dorsalibus 7 - 9-punctatis. - Long. $3 \frac{2}{3}$ lin.

Habitat in Columbia, Dom. Moritz.

Statura, magnitudo et summa affinitas X. lenti. Niger, pernitidus. Antennae capite paulo longiores, articulo secundo tertioque aequalibus, 4-10 transversis, sensim paulo crassioribus, rufo-piceae, articulo primo tertioque obscurioribus, ultimo apice ferrugineo. Palpi rufi. Labrum rufo-piceum. Caput thoracis fere longitudine eoque parum latius, basi cum angulis posterioribus rotundatum, antrorsum subangustatum, supra leviter convexum, utrinque crebrius sat profunde punctatum, medio longitudinaliter laeve, spatio laevi biseriatim punctato, sulculis anticis intermediis sat fortibus, ad mediam frontem usque adscendentibus, lateralibus obliquis ad oculorum marginem inferiorem fere omnino obsoletis. Thorax coleopteris panlo angustior, latitu. dme sesqui longior, basin versus subangustatus, lateribus pone medium subsinuatis, angulis anterioribus rotundatis, posterioribus obtusis, parum convexus, suriebus dorsalibus minus regularıbus, $7-9$-punctatis, serie laterali litua 8-9-punctata, punctis minus subtillbus. Scutellum obsolete punctatum. Elytra thoracis longitudine, dorso minus dense subseriatim profundius punctata, secundum marginem lateralem laevia, margine inflexo iterum punctato, rufo-brunnea, nitida. Abdomen lineare, parce subtiliterque punctulatum, segmentis smgulis margine summo brunneo. Pedes nigri, tibiis rufopiceis, tarsis dilutius rufis.

* 44. X. humeralis: Nigro-aeneus, nitidus, elytris angulo humerali pallido, capite subquadrato, utrinque fortiter punciato, thorace seriebus dorsalibus irregularibus 6-punctatis. - Long. $3 \frac{1}{2}$ lin.

Habitat in Americae meridionalis ins. St. Johanus, Dom. Moritz.

Statura omnino $\mathbf{X}$. punctulati, at paulo maior, nigro-aeneus, pernitidus. Antennae capite sesqui longiores, crassiusculae, articulo tertio secundo paulo longiore, 4-10 sensim paululum crassioribus, 5-10 transversis, rufopiceae, articulo ultimo apice ferrugineo. Palpi rufi. Caput thorace latius, eiusque prope longitndine, orbiculato - subquadratum, basi truncatum, angulis posterioribus rotundatis, lateribus subrectis, antrorsum haud angustatum, supra parum convexum, utrinque vage parceque profunde punctatum, spatio medio longitudinali laevi, sulculis anticis intermediis sat profundis, subflexuosis, ad mediam frontem usque adscendentibus, parum conniventibus, lateralibus obliquis ad oculi utriusque marginem inferiorem valde obsoletis. Thorax coleopteris parum angustior, latitudine tertia parte longior, basin versus leniter angustatus, lateribus utrinque subsinuatus, apice utrinque oblique truncatus, angulis anterioribus subrotundatis, leviter convexus, seriebus dorsalibus irregularibus, postice punctis nomullis lateraliter adiectis auctis, cir- 
citer sexpunctatis, serie laterali valde flexuosa circiter 9-punctata, punctis fortioribus. Scutellum laeve. Elytra thoracis longitudine, dorso crebrius profundiusque subseriatim punctata, secundum marginem lateralen laevia, margine laterali inflexo subtiliter punctato, angulo humerali luteo. Abdomen parce subtiliter punctatum, tenuiter longius griseo-pilosum, segmento quinto sextoque margine apicali summo testaceo. Pedes picei, coxis femoribusque nigro-aeneis, geniculis tarsisque rufo-piceis. Alae parum infuscatae.

45. X. rufescens: Piceus, nitidus, abdomine capiteque nigro-aeneis, hoc utrinque parce profundeque punctato, thorace seriebus dorsalibus 6-7punclatis, elytris dorso vage punctatis. - Long. $2 \frac{2}{3}$ lin.

Habitat in montibus prope Puerto Cabello Columbiae, Dom. Moritz.

Statura fere X. glabri, brunneo-piceus, nitidns, nitore aeneo perfusus, capite nigro-subaeneo, nitidissimo. Antennae capite sesqui longiores crassiusculae, articulo secundo tertioque subaequalibus, 4-10 transversis, sensim paulo crassioribus, rufo-piceae. Palpi dilute rufo-picei. Caput thorace parum latius et paulo brevius, basi cum angulis posterioribus rotundatum, lateribus subrectis, antrorsum haud angustatum, subdepressum, utrinque punctis parcis profundisque notatum, sulculis anticis intermediis sat profundis, leviter flexuosis, vix conniventibus, ad mediam frontem usque adscendentibus, lateralibus, obliquis ad oculorum marginem inferiorem brevioribus, obsoletis. Thorax coleopteris paulo angustior, latitudine sesqui longior, basin versus leviter angustatus, lateribus pone medium vix sinuatis, angulis anterioribus obtusis, subrotundatis, leviter convexus, seriebus dorsalibus minus regularibus, sat fortiter 6- vel 7-punctatis, serie laterali litua 7- vel 8-punctata. Elytra thoracis longitudine, dorso et lateribus crebrius et profundius vage punctata. Abdomen obscure aeneum, nitidum, apice summo piceo-testaceo, tenuiter griseo-pilosum, Pedes dilute rufo-picei.

* 46. X. punctulatus: Niger, nitidus, elytris nigro-virescentibus, capile dense punctato-ruguloso, fronte medio laeviore, thorace seriebus dorsalibus 6 - 11-punclatis. - Long. 3-31 lin.

Boisd, et Lacord. Faun. Ent. Paris. I. 415. 6. - Er. Col. March. I. 426.6.

Staph. punctulatus Payk. Mon. Staph. 30. 22. Faun. Suec. III. 380. 17. - Fab. Ent. Syst. I. II. 528. 45. Syst. El. II. 600. 56. - Panz Ent. Germ. 357. 35. Gyll. Ins. Suec. II. 353. 68. - Sahlb. Ins. Fenn. I. 333. 67.

Gyrohypn. punctulatus Mannerh. Brachelytr. 33. 4. - Runde Brachelytr. Hal. 11. 4. - Nordm. Symb. 117. 7.

Staph. elong at us Fourc. Ent. Par. I, 171. 27. - Latr, Hist. nat. Crust. et Ins. IX. 330. 84. - Grav. Mon. 98. 98.

Staph. elongatus var. 5 Grav. Micr. 45. 66.

St aph. fracticornis Müll. Prodr. 99. 118. - Gocze Ent. Beitr. I. 728. 31.

Var. a: Elytris antennis pedibusque rufo-piceis.

Staph. punctulatus var. b Payk. Faun. Suec. HI. 380. 71.

Staph. elongatus var. 1-4 Grav. Micr. 45. 66.

Staph. elongativar. intermed. Grav. Mon. 99.

Staph. ochraceus Gyll. Ins. Suec. II. 352. 67. - Sahlb. Ins. Fenn. 1. 332.64.

Gy rohypn. ochraceus Mannerh. Brachelytr. 33. 2. - Runde Brachelytr. Mal. 11. 2. - Nordm. Symb, 113. 2. 
Xantholin. ochraceus Zetterst. Ins. Lappon. 66. 2.

Var. b: Testaceo-piceus, elytris, antennis, pedibus anoque testaceis.

Habitat in omni Europa sat frequens.

X. lineari aequalis, individuis licet maioribus paulo latioribus, niger, nitidus. Antennae capite paulo longiores, articulo secundo tertioque subaequalibus, quarto quintoque sequentibus paulo angustioribus, $6-10$ transversis, aequalibus, rufo-piceae, articulo primo saepius nigricante. Caput vix thoracis latitudine eodemque paulo brevius, basi medio subsinuatum, utrinque oblique rotundatum, angulis posterioribus denticulo minutissimo notatis, lateribus subrectis, antrorsum leviter angustatum, minus nitidum, fortiter crebreque punctatum, punctis saepe confluentibus subrugulosum, fronte media laeviore, sulculis anticis internediis sat fortibus, leviter conniventibus, lateralibus obliquis ad oculi utriusque marginem inferiorem valde obsoletis, parce pubescens, ore plerumque piceo. Thorax coleopteris perparum angustior, latitudine sesqui longior, basin versus vix angustatus, lateribus pone medium subsinuatıs, angulis anterioribus rotundatis, leviter convexus, seriebus dorsalibus plerumque 8- vel 9-, laterali flexuosa 8-12-punctatis. Elytra thorace parum longiora, minus crebre, introrsum vage, extrorsum seriatim punctata, secundum marginem lateralem laevia, lateribus inflexis dense subtiliter punctatis, iam nigro-subaenea, iam fusco-testacea. Abdomen parce subtiliter obsoleteque punctulatum, densius griseo-pubescens, parce nigro-pilosellum. Pedes vel nigro - vel rufo-picei.

Variat statura maiore latioreque et minore angustioreque. Specimina maiora colore plerumque nigra, antennis pedibusque obscuris, elytris nigroaeneis, thoracis in serie dorsali punctis saepius paucioribus, specimina minora statura simul angustiore, thoracis in serie dorsali punctis interdum ultra 8, antennnis pedibusque dilute rufo-piceis, elytris rarius nigro-aeneis, plerumque testaceo-piceis vel piceo-testaceis, nonnunquam corpore piceo-testaceo, capite nigro-piceo, antennis, pedibus, elytris anoque dilutioribus differre videntur, at speciminibus numerosis sedule examinatis haec differentiae minus stabiles mili repertae, ut speciebus distinguendis sufficere videantur.

* 47. X. Hesperius: Subdepressus, niger, nitidus, elytris nigro-subaeneis, margine apicali testaceo, capite parce subtiliter punctato, thorace seriebus dorsalibus 10 - 12-punctatis. - Long. $3 \frac{1}{2}$ lin.

Habitat Ulyssipone in Lusitania, Dom. Com. Hoffmannsegg et Dom. Schiippel, in Andalusia, Dom. Waltl.

Statura $X$. punctulati et maximis eius speciminibus magnitudine aequalis, at paulo magis depressus, niger, subnitidus. Antennae capite paulo longiores, articulo secundo tertioque aequalibus, $4-10$ sensiu paulo crassioribus, transversis, rufae, articulo primo medio piceo. Palpi rufi. Mandibulae piceae. Caput basi thorace paululum latius, eoque vix brevius, basi medio subsinuatum, utrinque cum angulis posterioribus rotundatum, lateribus subrectis, antrorsum leviter angustatum, supra parum convexum, parce subtilius punctatum, plaga media longitudinali laevi, sulculis anticis intermediis profunlioribus, modice conniventibus, lateralibus obliquis ad oculi utriusque marginem inferiorem sat distinctis, minus brevibus, interne puncto maiusculo terminatis. Thorax coleopteris paulo angustior, latitudine plus sesqui lon- 
gior, basin versus leviter angustatus, lateribus angulisque anterıribus subrectıs, parum convexus, seriebus dorsalibus 10- vel 12-, lateralibus flexuosis fere 12-punctatis, punctis omnibus subtilioribus. Elytra thorace paulo longiora, dorso interne vage, externe subseriatim punctata, secundum marginem lateralem laevia, lateribus inflexis crebre subtiliter punctatis, nigro-subaenea, nitida, margine apicali luteo-testaceo. Abdomen parce subtiliter obsoleteque punctulatum, tenuiter griseo pubescens, segmentis singulis margine tenui apicali testaceo. Pedes picei, tibiis tarsisque rufis.

O bs. Capitis thoracisque punctura X. lineari affinis, a quo autem thoracis serie laterali flexuosa haud dispersa, elytris longioribus, apice testaceis, externe evidenter seriatim punctatis distinguitur.

-48. X. obscurus: Nigro-piceus, nitidus, elytris pedibusque pireo-teslaceis, capite utrinque crebre punctato, thorace seriebus dorsalibus 9-12punctatis. - Long. 3 lin.

Habitat in Pensylvania, Dom. Zimmermann.

Statura omnino $\mathbf{X}$. punctulati et minimis eius individuis aequalis, niger, nitidus. Antennae capite sesqui longiores, articulo secundo tertioque aequalibus, 5- 10 sensim paululum brevioribus at parum crassioribus, sensim paulo magis transversis, rufo-piceae, articulo primo nigricante. Palpi rufi. Caput oblongum, thoracis fere longitudine latitudineque, basi cum angulis posterioribus rotundatum, lateribus subrectis, antrorsum subangustatum, supra parum convexum, utrinque minus fortiter sat crebre punctatum, spatio medio longitudinali laevissimo, sulculis anticis intermediis sat profundis, leviter convergentibus, lateralibus oblıquis ad oculi utriusque marginem inferiorem fere omnino obsoletis. Thorax coleopteris paulo angustior, latitudine sesqui longior, basin versus vix angustatus, lateribus subrectis, angulis anterioribus obtusiusculis, parum convexus, seriebus dorsalibus irregulariter 9 - 12-punctatis, serie laterali litua circiter 14-punctata, punctis omnibus minus subtilibus. Scutellum laeve. Elytra thorace perparum longiora, dorso sat crebre fortiterque subseriatim punctata, secundum marginem lateralem laevia, margine ipso punctorum serie sat regulari notato, lateribus inflexis crehre subtilius punctatis, piceo-testacea, nitida. Abdomen parcius subtiliter punctulatum, tenuiter cinereo-pubescens, ano segmentorumque singulorum margine summo obscure testaceis. Pedes rufo-testacei.

-49. X. at tenuatus: Niger, nitidus, pedibus testaceis, elytris piceis, apice pallidioribus, capile utrinque crebre punctato, thorace seriebus dorsalibus 7-9-punctatis. - Long. $2 \frac{3}{3}$ lin.

Habitat in Americae insulis St. Thomae et Puerto-Rico, Dom. Moritz, St. Vincentii, Mus. Dom. Hope, in Brasilia, Dom. Melly.

Statura omnino Leptacini hatychroi, et maioribus eius individuis magnitudine aequalis, picens, pernitidus, capite nigro. Antennae capite paulo longiores, articulo secùndo tertioque brevioribus, aequalibus, $\mathbf{1}-\mathbf{1 0}$ brevibus, transversis, inter se acqualibus, totae rufo-piceae. Palpi rufo-testacei. Os piceum. Caput thoracis prope longitudine eoque parum latius, basi leviter rotundatum, angulis posterioribus denticulo prominulo minuto notatis, lateribus subrectis, antrorsum vix angustatum, supra leviter convexum, utrinque 
grosse punctatum, spatio medio longitudinali laevissimo, sulcis anticis intermediis profundis, ad mediam frontem usque adscendentibus, leviter convergentibus, sulculis lateralibus obliquis ad oculi utriusque marginem inferiorem breviusculis obsoletisque. Thorax coleopteris parum angustior, latitudine tertia parte longior, lateribus pone medium vix sinuatis, angulis anterioribus obtusis, basin versus vix angustatus, parum convexus, seriebus dorsalibus et serie laterali litua $7-\mathbf{9}$-punctatis, punctis minus subtilibus. Scutellum laeve. Elytra thorace paulo longiora, dorso interius vage, exterius subseriatim punctata, secundum marginem lateralem laevia, margine ipso punctorum serie sat regulari notato, margine inflexo confertim subtiliter punctato, picea, apice pallida, pellucida. Abdomen parce subtiliter obsoleteque punctulatum, tenuiter griseo-pubescens, nigro-piceum, segmentis singulis margine piceo-testaceis. Pedes rufo-testacei.

Obs. Ad Leptacinum batychroum habitu, colore et punctura prope accedit, at huius generis est.

4) Thorax punctorum seriebus dorsalibus rectis, integris, lateralibus confusis.

* 50. X. procerus: Niger, nitidus, elytris, pedibus, ano, ventre pectoreque rufis, capite ovato, utrinque subtiliter punctato, thorace seriebus dorsalibus 15-punctatis. - Long. 6 lin.

Habitat in Germania boreali, Dom. Schmidt, in Hispania, Mus. Dr. Waltl, in Sardinia, Mus. Reg. Taurin.

Forma X. linearis, at magnus, $\mathbf{X}$. glabrato longior et gracilior. Antennae capite paulo longiores, crassiusculae, articulo tertio secundo sesqui longiore, 4-10 sensim paululum crassioribus, leviter transversis, fusco-piceae, articulo basali rufo-piceo, apicali ferrugineo. Caput thorace paulo latius eique longitudine subaequale, ovatum, antrorsum leviter angustatum, supra leviter convexum, utrinque minus dense subtiliter punctatum, medio longitudinaliter laeve, sulculis anticis intermediis brevibus subparallelis, lateralibus obliquis ad oculi utriusque marginem inferiorem subtilioribus, longioribus, interne puncto maiusculo terminatis, nitidum, nigrum, ore rufescente. Thorax latitudine duplo prope longior, basin versus subangustatus, lateribus pone medium subsinuatis, angulis anterioribus obtusis, subrotundatis, supra leviter convexus, niger, nitidus, seriebus dorsalibus irregularibus, subtiliter circiter 15-punctatis, lateribus vage subtiliterque multipunctatis, subtus rufus. Scutellum laeve piceum. Elytra thoracis longitudine, crebrius vage punctata, rufa. Abdomen subtilissime punctulatum, tenuiter griseo-pubescens, apicem versus subincrassatum, supra nigrum, segmentorum marginibus castaneis, ano late rufo, subtus rufum, segmentis anterioribus basi nigris. $\mathrm{Pe}$ ctus et pedes ruf.

* 51. X. tricolor: Rufo-testaceus, nitidus, capite, thoracis dorso postico abdomineque supra nigro-piceis, capite utrinque subtiliter punclato, thorace seriebus dorsalibus 12-punctalis. - Long. 4 lin.

Zetterst. Faun. Lappon. I. 66. 4. Ins. Lappon. 66. 4. - Er. Col. March. 1. 427. 7. Staph. tricolor Fab. Mant. Ins. I. 221. 30. - Payk. Mon. Staph. 33. 15. Faun. Suec. III. 378. 15. - Latr. Hist. nat. Crust. et Ins. IX. 330. 86. - Gyll. Ins. Suec. II. 355. 70. - Sahlb. Ins. Fenn. I. 334. 69. 
Paederus tricolor Fab. Ent. Syst. I. II. 537. 7. Syst. El. II. 609. 7. - Panz. Ent. Germ. 363. 8.

Gyrohypn. tricolor Mannerh. Brachelytr. 33. 7. - Runde Brachelytr. Hal. 11.6. - Nordm. Symb. 118. 11.

Staph. elegans Grav. Micr. 46. 68. Mon. 103.104.

St aph. affinis Marsh. Ent. Britt. 517. 57.

Habitat in Europa.

Statura fere $X$. linearis at paulo maior et minus gracilis. Antennae capite paulo longiores, articulo secundo tertioque subaequalibus, $4-10$ sensim paulo crassioribus et magis transversis, totae rufae vel rufo-piceae. Palpi rufi. Caput magnum, thoracis longitudine eodemque paulo latius, oblongo-ovatum, antrorsum leviter angustatum, nigro-piceum, nitidum, supra leviter convexum, utrinque subtiliter sparsim punctatum, spatio medio longitudinali laevissinı, sulculis apicalibus intermediis sat profundis, parallelis, brevioribus, lateralibus obliquis ad oculi utriusque marginem inferiorem longioribus, at subtilibus, interne puncto maiusculo terminatis. Tnorax latitudine media duplo prope longior, basin versus leviter angustatus, lateribus vix sinuatus, apice truncatus, angulis anterioribus subrotundatis, leviter convexus, rufotestaceus, 'basin versus plerumque magis minusve piceus, nitidus, seriebus dorsalibus subtiliter 12-punctatis et ultra, lateribus subtiliter disperse punctatus. Scutellum piceum, laeve. Elytra thorace distincte breviora, minus subtiliter crebrius punctata, rufo-testacea, nitida. Abdomen subtiliter parcius punctatum, tenuiter griseo-pubescens, nitidum, supra nigrum, segmento quinto' apice sextoque toto testaceis, subtus cum pectore pedibusque rufo. testaceum.

Variat thorace rufo-testaceo, unicolore.

* 52. X. linearis: Nigro-subaeneus nitidus, capite utrinque subtiliter punctato, thorace seriebus dorsalibus 12-punctatis, - Long. $3 \frac{1}{2}$ lin.

Er. Col. March. I. 428. 8.

Staph. linearis Oliv. Ent. III. 42. 19. 21. t. 4. f. 38. - Fab. Ent. Syst. Suppl. 180. 41 - 42. Syst. El. II. 599. 51. - Marsh. Ent. Britt. 516. 51.

Staph. longiceps Grav. Micr. 177. 36. - Latr. Hist. nat. Crust. et Ins. IX. 334. 94. - Gyll. Ins. Suec. II. 350. 66. - Sahlb. Ins. Fenn. I. 331. 63.

Xantholin. longiceps Zetterst. Faun. Lappon. I. 80 1. Ins. Lappon. 66. 1.

Gyrohypn. longiceps Mannerh. Brachelytr. 33. 1. - Runde Brachelytr. IIal. 11. 1. - Nordm. Symb. 114. 3.

Staph. punctulatus Schrank Fann. Baica 1. 649. 889. - Grav. Micr. 177. 37. Mon. 98. 96.

$V$ ar. Corpore piceo-teslaceo, elytris pedibusque dilutioribus.

Stapl. ochraceus Grav. Micr. 43. 65. Mon. 97. 95. - Latr. Hist. nat. Crust. et Ins. IX. 329. 83.

Xantholin. ochraceus Boisd. et Lacord. Faun. Ent. Paris. I. 416. 8.

Habitat in Europa.

Elongatus, tenuis, niger, nitidus, capite, thorace elytrisque nigro-subacneis, his saepe fusco piceis; variat etian saepe corpore toto piceo, elytris pedibusque testaceis, vel fusco-testaceo, elytris pedibusque dilutiorbus. Antennae capite sesqui longiores, crassiusculae, articulo secundo tertioque subaequalibus, 4 - 10 sensim paulo crassioribus et magis transversis, rufo- 
piceae, apıce ferrugineo. Palpi rufi. Labrum rufum. Caput thoracis longitudine eodemque vix latius, oblongo ovatum, antrorsum leviter angustatum, supra leviter convexum, utrinque subtiliter disperse punctulatum, spatio medio longitudinali laevi, sulculis anticss intermediis brevibus, sat profundis, parallelis, laterahbus obliquis ad oculi utriusque marginem inferiorem subtilioribus et paulo longioribus. Thorax coleopteris paulo angustior, latitudine antica plus sesqui longior, basin versus leniter angustatus, lateribus pone medium subsinuatis, apice truncatus, angulis anterioribus rotundatis, leviter convexus, seriebus dorsahbus subregularibus, 12-punctatis et ultra, lateribus disperse punctatis, punctis omnibus sat subtilibus. Scutellum laeve. Elytra thorace paululum breviora, subtiliter subseriatim punctata, secundum marginem lateralem laevia, tenuiter griseo-pubescentia. Abdomen parce punctulatum, tenuiter griseo-pubescens. Pedes picei vel testacei.

\section{Heptacinus $E r$.}

\section{Er. Col. March. I. p. 429.}

Antennae geniculatae.

Labrum margine laterali membranaceo.

Palpi articulo ultimo subulato.

Ligula apice emarginata.

Corpus valde elongatum, lineare, subdepressum, alatum. Caput oblongum, basi profunde constrictum, collo quasi brevi cylindrico thoraci affixum, exsertum, porrectum, oculis parvis, rotundatis, apicem versus positis, vix prominulis. Labrum angustum, transversum, medio profunde sinuatum, limbo laterali membranaceo, apice setosum. Mandibulae breviores, medio dentatae. Maxillae (t. IV. f. 22. b) mala interiore membranacea, interne barbata, exteriore cornea, apice membranacea barbataque. Palpi maxillares articulo primo parvo, sequentibus duobus subaequalibus, quarto minuto, subulato. Labium (t. IV. f. 22. a.) mento transverso, ligula brevi, rotundata, medio emarginata, membranea, paraglossis ligulam superantibus, membranaceis. Palpi labiales articulo secundo primo paululum longiore, ultimo minuto, subulato. Antennae basi inter se non minus quam oculis approximatae, breves, geniculatae, articulo primo leviter elongato, secundo tertioque aequalibus, obconicis, reliquis brevibus, pubescentibus, ultimo subovato. Thorax oblongus, basin versus subangustatus, basi rotundatus, apice truncatus, angulis anterioribus subrectis, subdeflexis. Scutellum triangulare. Elytra apice truncata, sutura imbricata. Abdomen lineare. Pedes breves, coxis intermediis vel modice distantibus, vel approximatis, tibiis spinulosis, anticis externe subincrassatis, extus spinuloso-muricatis, tarsis aut omnibus simplicibus aut anticis dilatatis.

\section{o b s e r vationes.}

1. Habitu omnino generis praecedentis, et sectio secundo nonnisi palporum et ligulae structura $a b$ eodem distincta. Notatu dignum videtur, pedum intermediorum insertionem et tarsorum anticorum structuram, in illo genere constantissimas, in hoc tam propinquo variare.

2. Sexus differentia latet.

3. Victus et mores cum genere praecedente conveniunt. 
* Coxae intermediae approximatae. Tarsi antici simplices.

* 1. L. brevicornis: Niger, nitidus, pedibus ru s, capite punctulato. Long. $3 \frac{1}{2}$ lin., lat. $\frac{1}{2}$ lin.

Habitat in Austria, Dr. Waltl.

Corpus valde elongatum, tenue, subcylindricum, nigrum, pernitidum. Antennae capite breviores, articulo secundo tertioque brevibus, aequalibus, 4-10 brevissimis, sensim paulo crassioribus, subcompressis, fortiter transversis, penultimis latitudine triplo brevioribus, ultimo praecedente duplo fere longiore, apıce abrupte acuminato, pilosellae, rufo-piceae. Caput thorace paulo longius latiusque, basi truncatum, angulıs posterioribus leviter rotundatis, lateribus rectis, antrorsum subangustatum, supra leviter convexum, densius subtiliter punctatum, spatio medio angusto laeviore, sulculis duobus anticis inter antennas brevibus obsoletioribus, spatio interiacente elevato, prominulo, canaliculato, sulculis obliquis ante oculos nullis, subtus parcius punctulatum, canaliculatum, utrinque secundum marginem lateralem sulcatum. Thorax coleopteris parum angustior, latitudine sesqui longior, basin versus subangustatus, lateribus medio subsinuatis, angulis anterioribus late rotun. datis, leviter convexus, subtilissime parce punctulatus, dorso utrinque punctis nonnullis maioribus, lateribus sulculo leviter flexuoso tenui obsolete imsculptus. Elytra thorace paulo longiora, subtilissime obsoleteque vage punctulata. Abdomen laevigatum, parce nigro-pilosellum. Pedes rufi, tarsis testaceis.

\section{* 2. L. filarius: Niger, nitidus, elytris pedibusque piceis, capile laevi. - Long. 3 lin.}

Habitat in Columbia, Dom. Moritz.

Affinis praecedenti, at minus cylindricus, niger, nitidus. Antennae capitis longitudine, articulo secundo tertıo paulo maiore, obconicis, quarto paulo breviore et crassiore, subcylindrico, 5-10 fortiter transversis, subcompressis, ultimo praecedente sesqui longiore, ovato, dense pilosellae, rufo-piceae, ultimo apice ferrugineo. Palpi rufo-picei. Caput thoracis longitudme eodemque distincte latius, basi truncatum, angulis posterioribus leviter rotundatis, lateribus rectis, antrorsum subangustatum, latitudine parum longius, ideoque subquadratum, subdepressum, sulculis anticis inter antennas profundioribus, at brevissinis, distantibus, parallelis, spatio interiacente plano, sulculis lateralibus obliquis ante oculos sat distinctis, ad mediam frontem adscendentibus, in ipso ocnli utriusque margine lineola brevi, supra oculum utrumque lineola Inngitudinali, et supra hanc lineolam puncto oblongo impressum, ceterum laevissimum. Thorax antice coleopteris vix angustior, latitudine plus sesqui longior, basin versus leniter angustatus, lateribus medio subsinuatis, utrinque oblique truncatus, angulis anterioribus obtusis, subdepressus, paulo ante medium dorsi punctis 1 transversim positis, et paulo infra haec exterius utrinque puncto singulo, summo apice utrinque punctis duobus impressis notatus. Elytra thoracis longitudine, laevia, testaceopicea. Abdomen laevigatum, parce tenuiterque griseo-pilosellum. Pedes picei, tarsis testaceis. 
* Coxae intermediae distantes. Tarsi antici simplices.

* 3. L. parum punctatus: Niger, nilidus. elytris piceo-testaceis, angulo apicali pallido, capite utrinque fortiter punctalo, thorace seriebus dorsalibus 5 - 6-punctatis. - Long. $2 \frac{2}{3}$ lin.

Staph. parumpunctatus Gyll. Ins. Suec.IV.481.67-68. - Sahlb. Ins. Fenn. I. 333.66.

Xantholin. parumpunctatus Boisd. et Lacord. Faun. Ent. Paris. I. 414. 5.

Gyrohypn. parumpunctatus Mannerh. Brachelytr. 33. 5. - Runde Brachelytr. Hal. 11. 5. - Nordm. Symb. 117. 9.

Habitat in Germania, Suecia, Dom. Schtippel.

Statura omnino sequentis, at paulo maior, niger, nitidus. Antennae capite parum longiores, articulo secundo tertio vix maiore, his obconicis, 4-10 cylindricis, transversis, inter se subaequalibus, ultimo apice abrupte acuminato, rufo-piceae. Palpi rufi. Caput thoracis longitudine eodemque basi parum latius, antrorsum angustatum, basi medio leviter emarginatum, angulis posterioribus rotundatis, parum convexum, utrinque punctis magnis oblongis minus crebre umpressum, spatio lato medio longitudinali interstitiisque laevissimis, sulcis anticis intermediis et lateralibus ante oculos longitudine aequalibus et aequaliter fortibus profundisque. Thorax coleopteris paulo angustior, latitudine longior, basin versus subangustatus, lateribus pone medium subsinuatis, apice utrinque oblique truncatus, angulıs anterioribus obtusis, subrotundatis, parum convexus, seriebus dorsalibus fortiter 5-6-punctatis, serie laterali litua 5-punctata. Elytra thoracis longitudine, parce subtilıus seriatim punctata, nigro-picea, apicem versus saepe sensim piceo-testacea, angulo apicis exteriore pallido. Abdomen parce subtiliter punctatum, tenuiter griseo-pubescens pilosellumque, subtus segmentis ultimis apice piceo-testaceis. Pedes testacei.

* 4. L. batychrus: Niger, nitidus, elytris piceo-testaceis, angulo xpicali pallido, capite utrinque crebre punctato, thorace seriebus dorsalibus 12 - 16-punctatis. - Long. $2-2 \frac{1}{2}$ lin.

Er. Col. March. I. 429. 1.

Slaph. batychrus Gyll. Ins. Suec. IV. 480. 67-68. - Sahlb. Ins. Fenn. I. 332. 65. Gyrohypn. batychrus Mannerh. Brachelytr. 33. 3. - Runde Brachelytr. Hal. 11. 3. - Nordm. Symb. 117. 8.

Staph. linearis Grav. Micr. 43. 64. Mon. 97. 94. - Latr. Hist. nat. Crust. et Ins. IX. 329. 82.

Gyrohypn. linearis Nordm. Symb.'120. 20.

Xantholin. episcopalis Boisd. et Lacord. Paun. Ent. Paris. I. 416. 7.

Xantholin. minutus Boisd. et Lacord. Faun. Ent. Paris. I. 417. 9.

Habitat in Europa et in Asia minore.

Habitu fere Xantholini punctulati, at minimis eius individuis duplo, triplo vel quadruplo minor, magnitudine varians, subdepressus, niger, nitidus. Antennae capite paulo longiores, articulo secundo tertioque subaequalibus, obconicis, 4-10 cylindricis, vix transversis, inter se aequalibus, ultimo subovato, apice leniter acuminato. Caput thoracis longitudine, eodemque basi paulo latius, basi leviter, angulis posterioribus fortius rotundatis, lateribus subrectis, antrorsum leniter angustatum, minus depressum, utrinque 
crebrius fortiter punctatum, interstitiis spatioque medio longitudinali laevissimis, sulcis anticis intermediis leviter convergentibus, profundis, lateralibus obliquis ante oculos sat distinctis, licet minus fortibus, utrisque ad mediam frontem prope adscendentibus. Thorax coleopteris parum angustior, latitudine plus sesqui longior, basin versus leniter angustatus, lateribus pone medium subsinuatis, angulis anterioribus obtusis, subrotundatis, parum convexus, seriebus dorsalibus sat regularibus, 12-punctatis et ultra, serie laterali litua multipunctata. Scutellum laeve. Elytra thoracis longitudine, dorso minus crebre, introrsum vage, extrorsum seriatim, lateribus inflexis subtiliter subseriatim punctata, piceo-testrea, basi obscuriora, saepe nigricantia, apice sensim dilutiora, saepius lutescentia, angulo apicali exteriore saepius late pallido. Abdomen subtiliter parce punctatum, parce tenuiter griseo-pubescens, segmentis duobus ultimis apice piceo-testaceis. Pedes piceo-testacei, tarsis dilutioribus.

- 5. L. tenellus: Piceus, nitidus, elytris piceo-testaceis, capite oblongo, utrinque subtiliter punctato, thorace seriebus dorsalibus 10-punclatis. - Long. 2 lin.

Habitat in Madagascar, Dom. Goudot.

Habitu omnino Xantholini linearis, at multo minor, subdepressus, testaceo-piceus, nitidus, capite nigro. Antennae articulo secundo obconico, tertio hoc breviore, subcylindrico, 4-10 brevibus transversisque, sensim paulo crassioribus, ultimo maiusculo, ovato, totae dilute rufo-piceae. Palpi testacei. Caput thoracis fere longitudine eoque parum latius, basi truncatum, angulis posterioribus rotundatis, lateribus subrectis, antrorsum vix angustatum, subdepressum, utrinque parcius subtiliter punctatum, spatio medio longitudinali laevissimo, sulculis duobus apicalibus intermediis sat profundis, modice convergentibus, sulculis ante oculos distinctis, licet brevibus subtilibusque. Thorax coleopteris angustior, latitudine duplo prope longior, basin versus leniter angustatus, lateribus pone medium subsinuatis, angulis anterioribus obtusis, parum convexus, seriebus dorsalibus serieque laterali litua subtiliter circiter 10-punctatis. Scutellum laeve. Elytra vix thoracis longitudine, parce subtiliterque seriatim punctata. Abdomen parce subtilissime obsoleteque punctulatum, tenuiter griseo-puberulum. Pedes testacei.

6. L. debilis: Nigro-piceus, nitidus, antennis, elytris pedibusque fuscotestaceis, capite utrinque parce punctato, thorace seriebus dorsalibus 8-punctatis. - Long. $1 \frac{2}{3}$ lin.

Habitat in valle Araguensi Columbiae, Dom. Moritz.

Statura et summa affinitas praecedentis. Antennae capite sesqui longiores, articulo tertio secundo duplo fere minore, apicem versus leviter incrassatae, articulis $4-\mathbf{1 0}$ sensim paulo crassioribus et magis transversis, ultimo ovato, fusco-testaceae, articulo primo testaceo, ultimo ferrugineo. Os fusco-testaceum. Caput thorace paulo latius, latitudine parum longius, basi truncatum, angulis posterioribus rotundatis, lateribus rectis, antrorsum subangustatum, subdepressum, utrinque punctis parcis minus subtilibus impressum, spatio medio longitudinali lato laevi, sulcis anticis intermediis sat profundis, parallelis, ad mediam frontem fere adscendentibus, lateralibus obli- 
quis ante oculos brevibus et valde obsoletis, nigrum, nitidum. Thorax coleopteris paulo angustior, latitudine longior, basin versus subangustatus, lateribus pone medium subsinuatis, angulis anterioribus obtusis, subrotundatis, parum convexus, niger, nitidus, seriebus dorsalibus sat regularibus, 8-punctatis, serie laterali litua circiter 6-punctata. Scutellum laeve, piceum. Elytra thoracis longitudine, introrsum vage, extrorsum biseriatim punctata, piceotestacea, nitida. Abdomen laeve, tenuiter griseo-pilosellum, piceum, segmentorum marginibus dilutioribus. Pectus piceum. Pedes testacei.

* 7. L. subtilis: Piceus, nitidus, antennis pedibusque testaceis, capile thoraceque lateribus elytrisque subtilissime punclulatis. - Long. 2 lin.

Habitat in Columbia, Dom. Moritz.

Statura tenui praecedentis, piceus, nitidus, capite, thorace elytrisque fusco-subaeneis. Antennae capite sesqui longiores, apicem versus sensim fortius incrassatae, articulo secundo tertioque obconicis, hoc paulo breviore, 4- 10 fortiter transversis, sensim crassioribus, arcte cohaerentibus, ultimo praecedente plus duplo longiore, apice obtuse acuminato, rufo-testaceae. Palpi testacei. Caput thorace parum latius, oblongum, basi cum angulis posterioribus rotundatum, lateribus subrectis, antrorsum vix angustatum, supra leviter convexum, utrinque parce subtilissime punctatum, sulculis anticis intermediis sat distantibus, parallelis, lateralibus obliquis ante oculos obsoletis, utrisque brevibus. Thorax coleopteris paulo angustior, latitudine plus duplo fere longior, basin versus leviter angustatus, lateribus anterius leviter rotundatis, posterius subsinuatis, angulis anterioribus omnino nullis, transversim convexus, utrinque vage subtilissime punctatus. Elytra thoracis longitudine, obsolete subtilissime vage punctata, parce subtiliterque pubescentia. Abdomen parce subtilissime punctatum, segmentis singulis tenuiter testaceo-marginatis. Pedes testacei.

8. L. clavicornis: Niger, nilidus, antennis, pedibus capiteque rufo-piceis, hoc thoraceque lateribus subtiliter punctalis, elytris vage subtiliter punctatis, margine apicali testaceo. - Long. $2 \frac{1}{2}$ lin.

Habitat in valle Araguensi Columbiae, Dom Moritz.

Habitu praecedentium, at paulo maior. Antennae capite paulo longiores, articulo secundo tertioque obconicis, apicem versus fortiter incrassatae, articulis 4-10 sensim crassioribus et fortius transversis, ultimo conico, piceo-rufae. Palpi testacei. Caput thorace parum latius, oblongum, basi truncatum, angulis posterioribus late rotundatis, antrorsum subangustatum, parum convexum, utrinque crebrius subtiliter punctatum, sulcis anticis intermediis brevissimis, sulculis lateralibus ante oculos omnino obsoletis, piceorufum, nitidum. Thorax coleopteris paulo angustior, latitudine duplo fere longior, basin versus leviter angustatus, lateribus pone medium subsinuatus, angulis anterioribus subrectis, leviter convexus, nigro-piceus, nitidus, utrinque vage subtiliter punctatus, spatio angusto longitudinali medio laevi. Scutellum laeve, piceum. Elytra thoracis longitudine, vage subtilius punctata, nigra, nitida, margine apicali testaceo. Abdomen subtiliter punctulatum, nigrum, nitidulum, subtiliter tenuiterque pubescens, segmentis anterioribus margine apicali summo piceo-testaceo. Pedes testacei. 


\section{* Coxae intermediae distantes. Tarsi antici dilatati.}

9. L. nothus: Subdepressus, niger, antennis pedibusque rufo-ferrugineis, capite confertissime punctalo-subrugoso, thorace elylrisque dense punctatis, illo linea media longitudinali laevi. - Long. $2 \frac{1}{2}-3$ lin.

Habitat in Croatia meridionali, Dom. Schïppel, in Mesopotamia, Dom.Helfer.

Corpus elongatum, lineare, subdepressum, nigrum, nitidum, totum breviter tenuiterque griseo-pubescens. Antennae capite sesqui longiores, articulo primo sat elongato, secundo tertioque modice elongatis, aequalibus, 4-10 transversis, ultimo penultimo sesqui longiore, cylindrico, apice rotundato, totae rufo-ferrugineae. Palpi testacei. Os piceum. Caput thorace vix latius, oblongum, basi utrinque oblique truncatum, angulis posterioribus rotundatis, lateribus subrectis, antrorsum vix angustatum, supra parum convexum, confertissime punctatum, longitudinaliter subrugulosum, opacum, linea tenui obsoletaque longitudinali sublaevi, sulculis antıcis intermediis brevissimis lateralibusque obliquis ante oculos perbrevibus obsoletis. Thorax coleopteris parum angustior, latitudine duplo longior, basin versus subangustatus, a)ice cum angulis anterioribus fortiter rotundatus, lateribus medio sinuatus, subdepressus, crebre punctatus, linea media longitudinali laevi. Scutellum leviter impressum. Elytra vix thoracis longitudine, dense punctata. Abdomen densius subtiliter punctulatum, apice piceum. Pedes breviusculi, rufopicei, tarsis fulvis, anticis dilatatis.

***** Coxae intermediae approximatae. Tarsi antici dilatati.

* 10. L. tenuicornis: Piceo-testaceus, opacus, abdomine fusco, segmentorum marginibus testaceis, capite thoraceque obscure ieneis, ulrinque subtiliter punctatis. - Long. 4 lin.

Gyrohypn. tenuicornis Nordm. Symb. 125. 27.

Habitat in Promontorio bonae spei, Dom. Bergius.

Maximis Xantholini punctulati individuis paulo maior. Antennae capitis longitudine, apicem versus hand incrassatae, articulo primo sat elongato, tertio leviter elongato, secundo sesqui longiore, 4-10 sensim paululum hrevioribus, ultimo ovato, apice subacuminato, rufae, apice summo ferrugineo. Palpi rufi. Mandibulae piceae. Caput thorace vix latius eodemque paulo brevius, basi et lateribus leviter, angulis posterioribus fortins rotundatum, antrorsum parum angustatum, supra leviter convexum, obscure aeneum, parum nitidum, fronte utrinque subtilius parce punctata, sulculis duobus anticis intermediis brevioribus, parallelis, sat distinetis, lateralibns obliquis ante oculos obsoletioribus, inter oculos punctis quatuor maioribus transversim positis minus profundis impressum. Thorax coleopteris paulo angustior, latitudine sesqui longior, basin versus subangustatus, lateribus rectis, apice truncatus, angulis anterioribus rectis, leviter transversim convexus, ohseure aeneus, limbo tenuiore iudeterminate fusco-piceo, parum nitidus, utrincue parcius disperse subtiliter punctatus, spatio medio longitudinali laevi. Scutellum fusco-testaceum, laeve. Elytra thorace paulo breviora, fusco-testacea, aeneo-sub-micantia, aequaliter crebrius punctata. Abdomen subtilissime punctulatum, nigro-piceum, opacum, segmentis margine fuscotestaceis. Pectus rufo-piceum. Pedes rufo-testacei. 


\section{Subtribus secunda.}

\section{G e n u i n i.}

\section{Stigmatá prothoracica detecta.}

Antennae basi distantes.

Labrum transversum, bilobum, limbo exteriore coriaceo membranaceove.

Mandibulae magis minusve prominentes.

Maxillae malis coriaceis, exteriore basi cornea, hac apice, illa intus barbatis;

utraque breviuscula plerisque,

exteriore elongata, Haematodi, Cordylaspidi, Scariphaeo, Pala estrino.

Palpi maxillares filiformes plerisque;

articulo ultimo truncato, subsecuriformi $\mathrm{Scariphaeo,} \mathrm{Palaestrino;}$ articulo ultimo subulato $\mathrm{Heterothopi.}$

Ligula minuta, rotundata:

medio incisa vel biloba Haematodi, Cordylaspidi, Scariphaeo, Staphylino, Ocypodi;

integra, Belonucho, Philontho, Heter othopi, A cylophoro.

$P$ araglossae ligulam longe superantes.

Palpi labiales filiformes plerisque;

articulo tertio magis minusve securiformi Staphylini fam. XI, Ocy.. podis fam II et III;

articulo tertio hemisphaerico Staphylini fam. XII;

articulo tertio subulato $\mathrm{Heterothopi.}$

Antennae rectae, filiformes vel apicem versus leniter incrassatae, articulis tribus primis leviter elongatis, ultimo saepius apice truncato vel emarginato et inferne acuminato plerisque;

compressae, apicem versus attenuatae Cordylaspidi;

in clavam fusiformem coactae $\mathrm{Haematodi}$;

serratae, articulo ultimo tricuspidato Staphylini fam. X;

fractae, articulo primo fortius elongato Acylophoro.

Caput basi constrictum, collo quasi crassiusculo thoraci insertum.

Thorax basi rotundatus, apice truncatus.

Elytra truncata, sutura integerrima.

Abdomen aut parallelum aut apicem versus leniter angustatum.

Pedes plerumque breviusculi, tibiis saepissime aut omnibus aut posterioribus spinulosis, tarsis aut omnibus simplicibus aut anticis minus magisve dilatatis, posterioribus articulis 4 primis longitudine decrescentibus, teretibus plerisque;

totis depressis Ha ematodi, Cordylaspidi, Scariphaeo. 


\title{
Haematodes Laporte.
}

\author{
Láporte Etud. Ent. p. 113. \\ Platycnemus Nordm. Symb. p. 135.
}

Antennae rectae, breves, compressae, clavatae.

Palpi articulo ultimo acuminato.

Maxillae mala exteriore elongata.

Ligula apice emarginata.

Pedes inlermedii basi distantes.

Tarsi posteriores depressi.

Corpus maioris magnitudinis, oblongum, convexum, alatum. Caput thorace vix angustius, suborbiculatom, supra convexum, basi modice constrictum, thoraci immissum, oculis parvis, obliquis, haud prominulis. Labrum corneum, bilobum, margine membranaceo setoso. Mandibulae subfalcatae, validiores, medio dentatae. Maxillae (t. IV. f. 16. b.) mala interiore oblonga, coriacea, interne barbata, exteriore elongata, cornea, apice ciliatobarbata. Palpi maxillares breves, malam exteriorem haud excedentes, articulo primo minuto, secundo tertioque subaequalibus, obconicis, apice setosis, quarto parum longiore, subacuminato. Labium (t. IV. f. 16. a.) mento transverso, ligula sat prominula, rotundata, apice leviter sinuata, membranea, paraglossis divergentibus, ligulam superantibus, membraneis, introrsum dense ciliatis. Palpi labiales articulo primo minuto, secundo crassiusculo, obco. nico, tertio huic longitudine subaequali, leviter ovato. Antennae perbreves, articulo primo breviusculo, obconico, piloso, reliquis glabris, arcte coactis, compressis, clavam oblongam fusiformem formantibus, ultimo apice emarginato. Thorax coleopterorum latitudine, transversus, transversin convexus, basi fortiter rotundatus, lateribus deflexis, rectis, apice truncatus, utrinque subsinuatus, angulis posterioribus obtusis, anterioribus deflexis, acuriusculis. Scutellum sat magnum, rotundato-triangulare. Elytra apice extrorsum leviter rotundata, introrsum oblique truncata. Abdomen breviusculum, apice attenuatum. Pedes breves, crassi, coxis intermediis modice distantibus, tihiis femoribus recipiendis profunde canaliculata, tibiis compressis, externe spinulis numerosis muricatis, tarsis perbrevibus, depressis, articulo pıimo sequentibus vix longiore, anticis articulis 4 primis leviter dilatatis, subtus utrinque fasciculato-setosis.

O b s e r vatio.

Habitu quodammodo ad Staphylinum hirtum accedit, at thorax latior et convexior, ceterum antennarum structura et tibiis externe muricatis hoc genus sat insigne.

* 1. H. bicolor: Convexus, niger, nigro-pilosus, capite, thorace, elytris anoque rufis. - Long. 3 lin.

Laporte Etud. Ent. I. p. 113. t. 3. f. 6.

Platycnemus lateritius Nordm. Symb. 135. 1. t. 2. f. 4.

llabitat in Brasilia meridionali, Sellow.

Antennae captte breviores, piceae, nitidae, articulis compressis, angulis fusco-pubescentibus. Mandibulae nigrae. Caput thorace angustius, orbiculatum, convexum, rufum, nitidum, nigro-pllosum, punctatum, margine postico frontisque medio laevibus. Thorax rufus, nitidus, margine laterali nigro, 
dorso laevissimus, ad latera vage punctulatus et nigro-pilosus. Scutellum punctatissimum, nigrum. Elytra thorace vix longiora, leviter convexa, parcius punctata, rufa, nitida, rufo-pubescentia. Abdomen punctulatum, segments quatuor anterioribus nigris, nigro-pubescentibus, ultimis duobus rufis, rufopubescentibus. Pectus nigrum. Pedes breves, validi, nigri. Alae fuscae.

Mas abdominis segmento inferiore sexto apice leviter emarginato, quinto medio macula magna triangulari rufo-villosa instructo distinctus.

\title{
Cordylaspis Nordm.
}

\author{
Nordm. Symb. p. 17. \\ Smilax Laport. Etud. Ent.p. 116.
}

Antennae rectae, compressae, acuminatae.

Palpi articulo ultimo minuto, acuminalo.

Maxillae mala exteriore elongata.

Ligula apice emarginala.

Pedes intermedii basi approximati.

Tarsi posteriores depressi.

Corpus maioris magnitudinis, oblongum, dılatatum, utrinque attenuatum, alatum. Caput thorace minus et angustius, transversim suborbiculatum, basi profunde constrictum, collo quasi brevi angustoque thoraci immissum, oculis haud prominulis. Labrum transversum, bilobum, corneum, membranaceolimbatum. Mandibulae angustae, acutae, parum arcuatae, muticae. Maxillae (t. IV. f. 17. b.) mala interiore coriacea, intus barbata, exteriore elongata, cornea, apice coriacea barbataque. Palpi maxillares mala exteriore paulo longiores, articulo primo minuto, secundo tertioque aequalibus, leviter elongatis, quarto his duplo breviore, acuminato. Labium (t. IV. f. 17. a.) mento transverso, ligula brevi, biloba, membranea, paraglossis elcngatıs, linearibus, coriaceis, intus ciliatis, ligulam longe superantibus. Palpi labiales articulo primo brevi, obconico, secundo elongato, crassiusculo, cylindrico, intus spinulosa, tertio hoc duplo breviore tenuioreque. Antennae breves, compressae, apicem versus leviter attenuatae, utrinque pubescentes, articulo primo tertioque reliquis maioribus, ultimo apice emarginato. Thorax transversus, coleopterorum latitudine, antrorsum leviter angustatus, basi lateribusque leviter rotundatus, apıce late emarginatus, angulis pasterioribus obtrisis, anterioribus acutiusculis, leviter transversim convexus. Scutellum triangulare. Elytra thoracis longitudine, apice introrsum oblique truncata, angulo exteriore extrorsum oblique truncato. Abdomen breviusculum, apicem versus sensim angustatum. Pedes breves, coxis intermediis contiguis, femoribus tibiisque compressis, illis tibias recipientibus, his extus spinulosis, tarsis depressis, articulis arcte coactis, primo subelongato, anticis articulis $\mathbf{4}$ primis leviter dilatatis coniunctis ovatis, subtus utrinque squamoso-pubescentibus.

\section{O b s e r vation e s.}

1. Hoc cum praecedente et sequente genere a genuino Staphylino differt maxillarum mala exteriore elongata et tarsis posteriobus latiusculis, depressis, (conf. t IV. f. 23. c), inter se autem corporis habitu, antennarum, palporum et tibiarum structura distinguuntur. Cordylaspis praeterea mandibulis muticis discedit.

2. Femora compressa, tibias rectractas partim occultantia, Drepanum (Ca$r$ borum genus) in animum revocaut. 
3. Nomen generis a Com. Laporte de Castelnau propositum praetermittendum mihi visum est, quo iam dudum pro notissimo plantarum generi usitati sunt Botanici.

4. Sexus differentiam haud cognovi, at feminas solas mihi observatas esse credo.

5. De victu nihil constat.

1. C. pilosus: Piceus, capite thorace cyanescentibus nitidulis elytrisque subtiliter tuberculatis utrinque pilosis, - Long. 6 lin.

Staph. pilosus Fab. Mant. Ins. I. 220. 10. Ent. Syst. I. I. 523. 18. Syst. El. II. 594. 20. - Oliv. Ent. III. 42. 24. 30. t. 1. f. 3.

Smilax Americanus Laporte Etud. Ent, I. p. 117.

Cordylaspis tuberculatus Nordm. Symb. 17. 1. t. I. f. 6.

Habitat in America meridionali: Columbia, Cayenna, Surinamo, Brasilia.

Corpus piceum, opacum, ano rufescente, capite thoraceque supra subcyaneis, nitidis. Antennae capite vix longiores, dilute piceae. Caput fortius parce punctatum, pilosum, fronte modice convexa. Thorax latitudine dimidio brevior, coleopterorum basi paulo latior, leviter transversim convexus, dorso obsolete canaliculatus, parce disperseque punctatus, glaber, versus latera densius subtilius punctatus, fusco-pubescens, margine laterali longius densiusque nigro-piloso. Scutellum subtiliter punctulatum. Elytra subtiliter confertim punctata, fusco-pubescentia, tuberculis minutis sparsis parce obsita, tuberculo quoque seta reclinata nigra instructo, lateribus nigro-pilosa. Abdomen depressum, confertim subtiliter punctulatum, fuscopubescens, segmento quinto apice sextoque toto piceo-rufis. Pedes dilute rufo-picei, tibiis tarsisque nigricantibus. Alae fusen-hyalinae.

Obs. Errore quodam vel potius calami lapsu Dom. Nordmann pro patria huius insecti Sumatram affert.

\section{Scariphaeus $\boldsymbol{E} r$.}

Antennae rectae, moniliformes, subcompressae.

Palpi articulo ultimo truncato.

Maxillae mala exteriore elongata.

Ligula apice emarginata.

Pedes inlermedii basi distantes.

Tarsi posteriores depressi.

Corpus maioris magnitudinis, oblongum, alatum. Caput thorace paulo angustius, transversim suborbiculatum, basi profunde constrictum, collo quasi angusto brevique thoraci immissum, oculis haud prominulis. Labrum breve, transversum, bilobum, corneum, membranaceo-limbatum. Mandibulae parum falcatae, extus canaliculatae, intus medio subdentatae. Maxillae (t. IV. f. I8. b.) mala interiore coriacea, intus barbata, exteriore elongata, cornea, apice coriacea barbataque. Palpi maxillares breves, mala exteriore paulo longiores, articulo primo parvo angustiore, reliquis tribus crassiusculis, subaequalibus, quarto oblique truncato. Labium (t. IV. f. I8. a.) mento transverso, ligula brevi, leviter emarginata, membranea, paraglossis membranaceis, intus dense ciliatis, ligulam superantibus. Palpi labiales filiformes, articulis sensim paulo longioribus, ultimo apice summo truncato. Antennae breviusculae, articulo primo leviter elongato, obconico, secundo tertioque subaequalibus, obconi- 
eis, reliquis transversis, fere perfoliatis, ultimo apice fortiter emarginato. Thorax transversus, coleopterorum latitudine, basi lateribusque rotundatus, apıce truncatus, angulis posterioribus nullis, anteriorıbus subrectis, deflexis, modice convexus, lateribus basique explanato-marginatus. Scutellum triangulare. Elytra thoracis fere latitudine, truncata, angulo exteriore oblique truncato. Abdomen apicem versus leniter angustatum. Pedes breves, crassi, coxis intermediis approximatis, femoribus subtus pro tibiis recipiendis profunde canaliculatis, tibiis omnibus externe spinulosis, tarsis brevibus, depressis, articulis arcte coactis, primo subelongato, (tars. postic. t. IV. f. 18. c.) anticis articulis $\mathbf{4}$ primis leviter dilatatis, coniunctis ovatis, subtus dense spongioso - tomentosis.

O b s e r va t i o n e s.

1. Habitu a genuino Staphylino parum discedit, quibus antennarum quoque structura magis appropinquatur, licet tarsorum. maxillarumque structura arcte Cordylaspidi et Ha ematodi iungitur, ab hoc autem femoribus basi approximatis, ab illo mandibulis medio dentatis praeter antennarum structuram distinguitur.

2. Temere Dom. Runde hoc insectum $Q u$ edio dilatato sub genere VeIIeio associat, cum ne antennae quidem serratae sint, aliis omnibus characteribus praetermissis, et equidem hanc ob rem ex descriptione citata aegre illud cognovissem, nisi typus a celeberrimo Prof. Germar amice mihi communicatus sit.

3. Sexus differentia ut in genuinis Staphylinis se habet.

* 1. S. luridipennis: Niger, nitidus, capite fortius punctato thoraceque cyaneis, elytris anoque rufis. - Long. 7 lin.

Velleius luridipennis Runde Brachelytr. Hal. p. 1. not.

- Habitat in Brasilia, Dom. Virmond.

Staph. caesareo brevior, latitudine autem ei fere aequalis, niger, nititidus. Antennae capite vix longiores, artıculis secundo tertioque aequalibus, obconicis, quarto quintoque modice transversis, 6-10 his paulo latioribus et brevioribus, fortiter transversis, fere perfoliatis, modice compressis, ultimo paulo angustiore, oblique emarginato, articulis $\mathbf{1}-\mathbf{5}$ nigrrs, reliquis obscure ferrugineis. Caput supra leviter convexum, parce fortius punctatum, cyaneum, nitidum, parce tenuiter pubescens. Thorax latitudine paulo brevior, suborbiculatus, apice truncatus, modice convexus, laevissimus, glaber, cyaneus, subnitidus. Scutellum confertissime subtiliter punctatum, nigrum, tenuiter fulvo-pubescens. Elytra thorace vix longiora, confertiin subtiliter punctata, testaceo-rufa, nitida, pube depressa fulva dense vestita. Abdomen coleopteris paulo angustior, nigrum, nitidum, segmentis duobus ultimis rufis, supra glabrum et utrinque parce disperse punctatum, subtus crebrius punctatum, puncto quoque pilo brevi appresso instructo, segmentis anterioribus 4 nigro-, ultimis duobus rufo-pubescentibus. Pedes nigri.

Mas abdominis segmento sexto apice triangulariter inciso distinguitar.

\section{Palaestrinus $E$ r.}

Antennae rectae.

Palpi ariculo ultimo apice truncato.

Maxillae mala exteriore elongata.

Pedes intermedii basi distantes.

Tarsi posteriores teretes. 
Corpus elongatum, alatum. Caput thorace paulo latius, oblongum, supra convexum, basi profunde constrictum, oculis parvis, haud prominulis. Labrum transversum, bilobum, corneum, margine pilosum, absque limbo coriaceo vel membranaceo. Mandibulae validae, medio dentibus duobus fortibus arinatae. Maxillae mala exteriore elongata, cornea, apice coriacea barbataque. Palpi maxillares breviusculi, articula primo minuto, secundo tertioque obconicis, hoc paulo crassiore, ultimo praecedente breviore, at vix crassiore, fere semigloboso, apice truncato. Palpi labiales articulo ultimo praecedente longiore, cylindrico, apıce truncato. Antennae filiformes, articnlo ultimo apice emarginato et inferne acuminato. Thorax oblongus, convexus. Scutellum triangulare. Elytra apice truncata, angulo apicis exteriore rotundato. Abdomen longiusculum, subcylindricum, lateribus tenuiter marginatum. Pedes tenuiores, tibiis posterioribus spinulosis, anticis incrassatis, externe laevibus, interne tomentosis, tarsis posterioribus modice elongatis, articulis 4 primis longitudine decrescentibus, tarsis anticis minutis, articulis 4 primis leviter dilatatis, subtus longius pubescentibus.

$$
\text { O b s e r va tio } n \text { e s. }
$$

1. Maxillarum mala exteriore elongata cum praecedentibus tribus generibus convenit, discedit autem tarsorum structura. Pedum anticorum palporumque maxillarium structura insigne videtur hoc genus, exemplo singulo viso haud accuratius mihi examinatum

2. Mas abdominis segmento inferiore sexto apice emarginato cognoscendus. Femina latet.

1. P. Sykesii: Niger, capite thoraceque obscure aeneis, aureo-tomentosis, ely/ris punctato-rugosis, rufo-aureo-pubescentibus, abdomine fasciis duabus aureo-tomentosis, pedibus rufo-piceis. - Long. 7 lin.

Habitat in India orientali, Mus. Dom. Hope.

Antennae capite sesqui longiores, nigrae, articulo tertio modice elongato, secundo sesqui longiore, $\mathbf{4}-\mathbf{1 0}$ subaequalibus, leviter obconicis, crassitie paulo longioribus, ultimo apice oblique emarginato et inferne acuminato. Mandibulae nigrae. Caput thorace paulo latius, subovatum, supra valde convexum, creberrime punctatum vel punctato-subrugosum, nigro-aeneum, nitıdulum, tomento aureo obtectum. Thorax coleopteris plus dimidio angustior, latitudine paulo longior, basin versus leviter angustatus, valde convexus, subtiliter punctato-rugosus, linea tenui media longitudinali laevi, obscure aeneus, nitidus, dense aureo-tomentosus. Elytra thorace paulo longiora, punctato-rugosa, obscure violacea, nitidula, pube longiore depressa rubro-aurea densius vestita. Abdomen nigrum, supra basi fasciisque duabus in segmenti quarti quintique basi sitis dense aureo-tomentosis, subtus minus dense aureo-villosum. Pectus nigrum, aureo-pubescens. Pedes piceo - castanei.

Species mihi invisa, forte huius generis.

2. P. (?) aureus: Capite, thorace elytrisque villoso-aureis, abdomine nigro, fasciis cinereis.

Staph. aureus Fab. Mant. Ins. I. 219. 1. Ent. Syst. I. II. 519. 1. Syst. El. I. 589. 1. - Oliv. Ent. III. 42. 7. 1. t. 1. f. 2.

Habitat in Siam. 
Statura Staph. hirti. Antennae-pilosae, nigrae, articulo ultimo ovato, testaceo. Caput magnum, villosum, ferrugineo-aureum. Clypeus porrectus, rotundatus, cilatatus, integer. Thorax et elytra pilis brevibus dense villosa, ferrugineo-aurea. Pectus villoso-aureum. Abdomen atrum, fasciis duabus latis villoso-cinereis, nigro-punctatis. Pedes anteriores rufi, femoribus supra nigris.

\section{Staphylinns $L$.}

\section{Er. Col. March. I. p. 430.}

\section{Antennae rectae.}

Palpi maxillares filiformes.

Ligula apice emarginata.

Pedes intermedii basi distantes.

Tarsi posteriores teretes.

Corpus maioris magnitudinis, elongatum, alatum. Caput suborbiculatum, vel subquadratum, thoraci plerumque magnitudine subaequale, exsertum, collo quasi angusto thoraci immissum. Labrum corneum, transversum, bilobum, membranaceo- coriaceove-limbatum. Mandibulae plerumque sat fortes. Maxillạe mala interiore trapezoidea, introrsum barbata, exteriore basi obconica cornea, apice coriacea barbataque, palpis longe breviore. Palpi maxillares filiformes, articulo primo parvo, secundo subelongato, ultimo apice subacuminato. Labium (t. IV. f. 14.) mento transverso, ligula brevi, medio sinuata, membranea, paraglossis coriaceis, interne ciliatis, ligulam longe superantibus. Palpi labiales articulo ultimo plerumque longiore, aut subacuminato aut apice truncato. Antennae ante mandibularum basin insertae, capite thoraceque plerumque paulo breviores, articulo primo leviter elongato. Thorax basi rotundatus, apice truncatus, angulis anterioribus plerumque rectis, subdeflexis. Scutellum rotundato-triangulare. Elytra apice aut rotundata aut introrsum oblique truncata. Abdomen plerumque parallelum. Pedes coxis intermediis magis minusve distantibus, tarsis posterioribus filiformibus, articulo primo subelongato, anticis plerumque articulis 4 primis dilatatis, patellam ovalem formantibus, subtus spongioso-tomentosis.

\section{O b s e r vation e s.}

1. Distinguitur hoc genus, speciebus locuplex, formas varias continens, a praecedentibus praecipue tarsis posterioribus haud complanatis, maxillarum mala exteriore elongata, a proxime sequenti imprimis pedibus intermedis magis minusve distantibus. Coxae intermediae nonnunquam quidem valde approximatae, acetabula autem semper interstitio disiuncta.

2. Mas abdominis segmento inferiore sexto apice emarginato vel inciso, nonnunquam quoque capite grandiore distinctus.

3. Victus in cadaveribus, in fimo, in sylvis sub musco. In fimo potius insectorum fimetariorum rapina degere quam fimo ipso delectari videntur. Staph. hir tum in stercore Onthophagum nurhicornem devorantem ipse observavi.

Distinxi in hoc genere Familias duodecim, quorum plures iam ab auctoribus variis pro generibus peculiaribus descriptae sunt, quae vero recipere dubitavi, cum characteres milhi leviores et minus constantes videantur. Nihilominus has familias plerasque naturales existimo, et notas earum distinctivas accuratius eruere conatus sum. 


\section{Fam.. I.}

Emus Le ach. Curtis Britt. Ent. XII. t. 534. Sleph. Illustr. Britt. Ent. V. p. 203

Antennae apicem versus subincrassatae, articulis $6-10$ transuersis, articulo ultimo integro.

Palpi omnes filiformes, maxillares articulo quarto tertio breviore.

Pedes breves, tibiis omnibus spinulosis, tarsis anticis dilatatis.

Corpus subtus longius pubescens, supra dense villosum. Antennae breviores, articulo primo modice elongato, secundo tertioque obconicis, quarto quintoque subglobosis, 6 - 10 paulo latioribus, transversis, inter se aequalibus, ultimo breviter ovato, apice subcompresso et utrinque impresso, articulis $\mathbf{5}$ primis leviter puberulis, reliquis pube subtilissima cinerea dense obductis. Caput sat magnum, leviter deflexum, oculis minoribus parum convexis. Labrum limbo latiore membranaceo instructum. Mandibulae validae, apice leviter falcatae, acutae, medio fortiter dentatae. Palpi maxillares articulo secundo tertio paulo longiore, quarto tertio paulo breviore, acuminato, labiales articulis duobus primis aequalibus, ultimo paulo longiore, apice subacuminato. Thorax basin versus angustatus. Elytra angulo apicali ex teriore oblique truncato. Abdomen coleopterorum latitudine, parallelum. Pedes breviusculi, validi, intermedii basi satis distantes, tibiis omnibus dense pubescentibus, crebre spinulosis, spinis apicalibus mediocribus, tarsis posterioribus breviusculis latiusculisque, articulo primo leviter elongato, sequentibus tribus sensim paulo minoribus, apice fere bifidis, tarsis anticis articulis 4 primis dilatatis, patellam ovatam subtus tomentoso-spongiosam formantibus.

Mas capite saepius maiore, abdominis segmento inferiore sexto apice leviter emarginato et pedum -structura distinctus.

Obs. Affinis Fam. sequenti, distincta autem praeter corporis vestimentum tarsis brevibus, et antennarum articulis $6-10$ aequalibus.

* 1. St. hirtus: Niger, hirsulus, capite, thorace abdominisque apice flavovillosis, elytris fascia postica cinerea. - Long. 7 - 11 lin.

Linn. Faun. Suec. n. 839. Syst. Nat. I. II. 589. 2. - Fab. Syst. Ent. 264. 1. Spec. Ins. I. 334. 1. Mant. Ins. I. 219. 2. Ent. Syst. I. II. 519. 2. Syst. El. II. 589. 2. - Sulz. Hist. Ins. p. 69. t. 7. f. 16. - Müll. Prodr. 97. 1091. - Goese Ent. Beitr. I. 417. 1. - Fourcr. Ent. Paris. I. 165. 7. - De Vill. Ent. I. 409. 1.-Payk. Mon. Staph. 1. 1. Fuun. Suec. 1IJ. 368. 1.-Schrank Faun. Boicu. I. 639. 860. - Harrer Beschr. d. Ins. I. 249. 410. - Rossi Faun. Etr, Mant. 95. 214. Ed. Hellw. I. 441. 214. - Walken. Faun. Paris. I. 268. 1. - Oliv. Ent. III. 12. 7. 2. t. 1. f. 6. - Panz. Faun. Germ. 4. 19. Ent. Germ. 351. 1. - Mart. Engl. Jint. t. 42. f. 40. - Grav. Micr. 159. 1. Mon. 125. 148. - Latr. Ilist. nat. Crust. et Ins. IX. 292. 1. t. 79. f. 4. Gen. Crust. et Ins. I. 286. 1. - Mursh. Ent. Britt. 496. 1. - Don. Britt. Ins. XVI. t. 552. - Gyll. Ins. Suec. II. 281. 2. - Nordm. Symb. 38. 18. - Er. Col. Ma,ch. I. 431. 1.

Emus hirtus Mannerh. Brachelytr. 20. 1. - Curt. Britt. Ent. N11. t. 534. Boisd. et Lacord. Faun. Ent. Paris. I. 360. 2. - Runde Brachelytr. Hal. 2. 1.

Staph. Bombylius De Geer Ins. IV. 20. 5.

Le Staph. Bourdon Geoffr. Hist. Ins. I. 363. 7.

Staph. quintus Schaeff. Icon. I. t. 36. f. 6. Ablandl. I. t. 2. f. 12.

Bombylius corpore longissimo, cornibus quasi Scarabaeus armatus Petiver Op. I. t. 138. f. 20.

Ilabitat in Europa. 
Niger, parum nitidus, supra subtiliter punctatissimus. Antennae capite vix longiores, minus crassae, articulo tertio secundo paulo longiore, 6-10 praecedentibus crassioribus, transversis, ultimo apice utrinque impresso. $\mathrm{Ca}$ put thorace vix latins, supra modice convexum, pilis densis flavo-aureis villosum, subtus glabrum. Thorax coleopteris paulo angustior, latitudine paulo brevior, basin versus leviter angustatus, basi angulisque posterioribus rotumdatis, lateribus subrectis, apice truncatus, angulis anterioribus acutiusculis, parum convexus, pube erecta densa flavo-aurea uti caput vestitus, limbo posteriore libero, atro-pubescente. Scutellum nigro-tomentosum. Elytra thorace panlo longiora, basi nigro-pubescentia, apice latius cinereotomentosa, maculis punctisque nigris interdum immixtis vix variegata. Abdomen supra segmentis tribus primis nigro-pubescentibus; reliquis tribus tomento spisso flavo-aureo obductis, subtus violaceum, nitidum, segmento quarto macula utrinque laterali, quinto fascia integra aureo -villosis. Pedes validiusculi, nigri, nigro - pubescentes.

Mas trochanteribus posticis unco apice truncato bicuspique armatis, tibiis posticis leviter" sinuatis insignis.

\section{Fam. II.}

Creophilus Kirby Mannerh. Brachel. p. 20. - Steph. Illustr. Britt. Ent, V.p. 202.

Antennae subclavatae, articulis 7-10 transversis, sensim crassioribus. Palpi omnes filiformes, maxillares arliculo quarto tertio breviore. Pedes tibiis posterioribus spinulosis, tarsis anticis dilatatis.

Caput et thorax glabra, scutellum, elytra et abdomen pubescentia vel tomentosa. Antennae capite vix vel parum longiores, articulo primo longiusculo, secundo tertioque obconicis, quarto, quinto sextoque lenticularibus, saepius transversis, septimo, octavo, nono et decimo his distinctius cras sioribus, transversis, saepius sensim paulo crassioribus, ultimo praecedente paulo angustiore, breviusculo, obtuse acuminato, apice subcompresso et plerumque impresso, articulis $\mathbf{1 - 6}$ breviter pilosellis, $7-\mathbf{1 1}$ pube brevissima grisea dense obductis. Caput porrectum, oculis minutis, oblongis, parum prominulis. Labrum breve, limbo angustiore coriaceo fortiter barbato cinctum. Mandibulae validae, leviter falcatae, apice acutae, medio fortiter dentatae. Palpi maxillares articulo secundo tertioque subaequalibus, quarto minore, acuminato, labiales articulo secundo primo dimidio breviore, tertio longıre, primo aequali, apice subacumincto. Elytra angulo apicali exteriore rotundato. Abdomen coleopterorum latitudine, fere parallelum. Pedes breviu. sculi, minus validi. Tibiae anticae interne, posteriores undique spinulosae, spinis apicalibus validioribus. Tarsi antici articulis 4 primis sensim minus dilatatis, posteriores graciliores, articulo primo leviter elongato, sequentibus tribus leviter decrescentibus.

Mas capite subquadrato, vel thoracis latitudine, vel saepius thorace latiore, mandibulis longioribus validioribusque, thorace basin versus magis angustato, angulis anterioribus acutioribus, abdominis segmento inferiore sexto apice triangulariter inciso.

Femin a capite subtriangulari, thorace angustiore. 
* 2. St. maxillosus: Niger, nitidus, thoracis angulis posterioribus rotundatis, elytris fascia cinerea, abilomine subtus segmentis 4 vel 5 cinereo-tomentosis, pectore nigro-pubescente. - Long. 6-10 lin.

Linn. Fuun. Suec. n. 891. Syst. Nat. I. II. 683. 3. - Ström Act. Nidros. III. 403. 25. - Fab. Syst. Ent. 265. 3. Spec. Ins. I. 334. 3. Mant. Ins. I. 220. 5. Ent. Syst. I. II. 521. 9. Syst. El. II. 592. 11. - Müll. Faun. Frid. 23. 222. - Goeze Ent. Beitr. I. 715. 3. - De Vill. Ent. I. 410. 3 - Payk. Mon. Staph. 5. 2. Faun. Suec. III. 369. 2. - Rossi Fanu. Etr. I. 246. 607. Ed. Hellw. I. 304. 607. Schrank Faun. Boic. I. 639. 861. - Cederh. Faun. Ingr. 117. 357. - Walken. Faun. Paris. I. 269. 4. - Martyn Eugl. Ent. t. 29. f. 4. 5. - Panz. Ent. Germ. 353. 8. Faun. Germ. 27. 2. - Oliv. Ent. III. 42. 9. 5. t. 1. f. 5 - Grav. Micr. 2. 1. Mon. 126. 150. - Latr. Hist nat. Crust. et Ins. IX. 293. 2. - Donor. Britt. Ins. III, t. 96. f. 3. - Marsh. Ent. Britt 498. 5. - Gyll. Ins. Suec. II. 279. 1. - Zetterst. Faun. Lappon. I. 69. 7. Ins. Lapp. 60. 8. - Sahlb. Ins. Fenn. I. 308. 1. - Er. Col. March.I. 432. 2.

Emus maxillosus Boisd. et Lacord. Faun. Ent. Paris. I. 358. 1.

Creophilus maxillosus Mannerh. Brachelytr. 20. 1. - Runde Brachelytr. Hal. I.

1. - Nordm. Symb. 21.1.

Staph. nebulosus Fourc. Ent. Paris. 165. 5.

Staph. aпопутиs Sulz. Kennz. d. Ins. 17. 22. t. 7. f. 49.

St a ph. balteat us De Geer Ins. IV. 18. 4. t. 1. f. 7. 8. - Müll. Prod. 98. 1114.

- Harrer Beschr. d. Ins. I. 251. 414.

Staph. fasciatus Fuesly Verz. Schweiz. Ins. 21. 410. - Goeze Ent. Beitr. I. 724. 4. Le Staph. nebuleux Geoffr. Hist. Ins. I. 362. 5.

Staph. tertius Schaeff. Icon. I. 20. 1.

Habitat in Europa.

Corpus totum nigrum, capite thoraceque nitidis. Antennae subclavatae, articulis 2 et 3 aequalibus, obconicis, $4-6$ sensim paulo brevioribus, $7-10$ sensim crassioribus, transversis, ultimo apice compresso et utrinque impresso. Caput maris thorace maius, feminae eodem minus, subtilissime punctulatum, fronte media laevi, basi utrinque crebre punctatum et nigro-pilosellum. Thorax coleopteris paulo angustior, latitudine dımidio brevior, lateribus et basi rotundatus, apice truncatus, angulis anterioribus acutiusculis, posterioribus rotundatis, leviter convexus, laevissimus, glaberrimus, limbo angusto punctulato, margine anteriore utrinque nigro-griseoque-puberulo. Scutellum dense punctatum, griseo-pubescens, apice macula nigro-tomentosa. Elvtra punctata, dorso serie longitudinali punctorum maiusculorum natata, nigro-pubescentia, fascia lata inaequali nigro-punctata cinereo-tomentosa. Abdomen supra pube nigra cinereaque variegatum, subtus segmentis quatuor primis tomento spisso cinereo obtectis, secundo quartoque puncto utrinque laterali nigro, quinto sextoque pube nigra interdum maculatim cinerascente vestita. Pectus nigro-pubescens. Pedes nigri.

3. St. arcticus: Niger, nitidus, thoracis angulis posterioribus subrotundalis, elyiris fascia cinerea, abdomine sublus segmento secundo tertioque cinereo-tomenlosis, pectore nigra-pubescente. - Long. 9 lin.

Habitat in Kamtschatka, Dom. Chamisso.

Niger, capite thoraceque nitidis. Antennae subclavatae, articulis 2 et 3 aequalibus, obconicis, 4-6 sensim paulo brevioribus, $7-\mathbf{1 0}$ sensim crassioribus, transversis, ultuno apice compresso, utrinque impresso. Caput parcius subtiliter punctatum, fronte media laeviore, pone oculos utrinque 
punctis nonnullis maioribus impressum, basi utrinque cinereo-villosulum. Thorax coleopteris paulo angustior, latitudine anteriore dimidio brevior, basi et lateribus modice rotundatis, his pone medium subsinuatis, apice truncatus, angulis-posterıorıbus obtusissimis, subrotundatis, leviter convexus, laevissimus, limbo angusto punctulato, basi utrinque 'crebre punctato et einereo-villoso. Scutellum nigro-tomentosum. Elytra thorace sesqui longiora, dense subtiliter punctata, nigra, nigro-pubescentia, fascia lata cinereo-pubescente. Abdomen supra nigro-pubescens, segmento secundo tertioque utrinque cinereo-tomentosis, sexto pilis cinereis pubi nigrae immixtis canescente, subtus nigro-pubescens, segmento secundo tertioque cinereo-tomentosis. Pedes nigri.

Obs. Intermedius videtur inter St. maxillos um et villosum, ab hoc pectore nigro-pubescente, capite subtilius punctato, antennis sensim crassioribus, thoracis angulis posterioribus minus rotundatis, ab illo thorace apice utrinque cinereo-villosulo, angulis posterioribus minus rotundatis, abdominis segmentis ventralibus duobus tantum cinereo-tomentosis distinguendus. Specimen singulum femineum a def. Chamissone allatum.

* 4. St. villosus: Niger, nitidus, thorace antice utrinque cinereo-villoso, angulis posterioribus obtusis, elytris fascia cinerea, subtus pectore abdominisque segmentis 4 primis cinereo-tomentosis. - Long. 9 lin.

Grav. Micr. 160. 2. Mon. 126. 149.

Creophilus villosus Nordm. Symb. 21. 2.

Habitat in America septentrionali, sat frequens, in Mexico, Dom. Deppe, in Cuba, Dom. Otto.

Statura et summa affinitas C. maxillosi, at vere distinctus. Antennae subclavatae, articulo secundo tertioque aequalibus, obconicis, $4-6$ sensim paulo crassioribus, $7 \mathbf{- 1 0}$ abrupte crassioribus, fortiter transversis, ultimo apice emarginato. Caput maris thoracis latitudine vel eodem paulo latius, feminae angustius, crebrius subtiliusque punctatum, fronte medıo paulo laeviore, basi utrinque cinereo-villosulum. Thorax coleopteris paulo angustior, basin versus angustatus, latitudine antica tertia parte brevior, basi et lateribus rotundatis, his pone mediun subsinuatis, apice truncatus, angulis posterioribus obtusis, subrotundatis, anterioribus maris acutiusculis, feminae obtusiusculis, leviter convexus, laevissimus, limbo angusto punctulato, apice utrinque cinereo-villoso. Scutellum dense punctatum, nigropubescens, apice macula nigro-tomentosa. Elytra thorace sesqui longiora, punctata, nigro-pubescentia, fascia inaequali cinereo-tomentosa. Abdomen segmentis tribus primis cinereo-tomentosis, nigro-varipgatis, reliquis nigropubescentibus, pilis paucis cinereis immixtis vix variegata, subtus segmento secundo, tertio quartoque tomento spisso cinereo obductis, quarto apice, quinto sextoque nigro-pubescentibus, immaculatis. Pectus dense cinereopubescens. Pedes nigri.

Obs. Creophilus fasciatus Laporte Etud. Ent. p. 111, „Maxilloso similis, at paulo lat or, capite magis transverso, thorace antice magis dilatato, elytrorum fascia griseo-tomentosa angusta, abdominis fascia ventrali angustiore, nonnisi segmenta duo occupante" long. 7 lin. ex America septentrionali forte ad huius speciei marem referendus. 
* 5. St. cinerarius: Niger, nitidus, elytris fascia cinerea, subtus peclore abdominisque segmentis 4 primis cinereo-tomentosis, his utrinque nigro-punctatis. - Long. 9 lin.

Habitat in Aegypto, Dom. Prof. Ehrenberg.

C. maxilloso simillimus, at pectore cinereo-pubescente distinctus. Antennae subclavatae, articulo secundo tertioque obconicis aequalibns, $4-6$ sensim paulo brevioribus, $\mathbf{7}-\mathbf{1 0}$ abrupte paulo crassioribus, transversis, ultimo apice compresso et utrinque impresso. Caput glabrum, omnium subtilissime obsoleteque punctulatum, supra oculos punctis nonnullis maiusculis notatum, basi utrinque crebre punctatum et tenuiter cinereo-pubescens. Thorax coleopteris paulo angustior, basin versus angustatus, latitudine antica tertia parte brevior, lateribus subrectis, pone medium subsinuatis, basi cum angulis posterioribus rotundatus, apice truncatns, angulis anterioribus maris acutis, feminae subrectis, laevissimus, glaber, limbo tenui, apice utrinque latiore, punctulato et cinereo-pubescente. Scutellum dense punctatum, cinereo-pubescens, macula minore apicali nigro-tomentosa. Elytra thorace tertia parte longiora, subtiliter punctata, nigro-pubescentia, fascia inaequali cinereo - tomentosa, nigro - punctata. Abdomen supra pubescens, segmento primo ultimisque duobus nigris, cinereo-variegatis, secundo, tertio quartoque nigro-variegatis, subtus segmento primo apice sequentibusque tribus totis tomento spisso cinereo vestitis, his singulis puncto laterali nigro, ultimis duobus nigris, cinereo-variegatis. Pectus dense cinereo-pubescens. Pedes nigri.

Obs. St. villoso proximus, at: capite minus evidenter punctato, thoracis angulis posterioribus magis rotundatis et abdomine supra magis variegato, subtus segmento quarto aeque ac praecedentia tomentoso distinctus.

6. St. incanus: Niger, nilidus, thoracis angulis posterioribus obiusis, elytris fascia conerea, abdomine subtus segmentis 4 primis aequaliter albido-pubescentibus. - Long. 6- 10 lin.

Klug Col. Madag. 49. 40.

Habitat in Madagascar, Dom. Goudot.

Praecedentibus valde affinis, niger, nitidus. Antennae subclavatae, articulis 2 et 3 aequalibus, obconicis, $4-7$ sensim paululum brevioribus, 7-10 sensim paulo crassioribus, fortiter transversis, ultimo subgloboso, apice compresso. Caput maris thorace latius, subquadratum, feminae thorace angustius, omnium subtilissime punctulatum, glabrum. Thorax coleopteris paulo angustior, basin versus angustatus, latitudine antica tertia parte brevior, basi modice rotundatus, apice truncatus et utrinque subsinuatus, Iateribus vix rotundatis, pone medium subsinuatis, angulis anteriorıbus acutiusculis, posterioribus obtusis, leviter convexus, laevis, intra angulos posteriores foveola minuta impressus, glaber, margine impunctato, anteriore etiam non pubescente. Scutellum dense punctatum, nigro-pubescens. Elytra punctata, tenuiter nigro-pubescentia, paululum infra medium fascia angusta undulata cinereo-pubescente. Abdomen supra nigro-pubescens, segmentis secundo, tertio quartoque cinereo-variegatis, subtus segmento primo apice cinereo - ciliato, secundo tertio quartoque tomento denso caesio-albido obductis, quinto sextoque parcius nigro-pubescentibus, immixtis pilis nomullis albidis. Pectus parce cinereo-pubescens. Pedes nigri. 
Obs. St. maxilloso proximus, a quo praeclpue thorace paulo longiore, limbo impunctato, apice haud pubescente, basi fortius rotundato, angulis posterioribus autem non rotundatis, elytrorum fascia angusta, et abdominis tomento ventrali subvirescente discedit. A cel. Klug femina descripta, marem Dom. Goudot nuper attulit.

7. St. variegatus: Niger, nilidus, abdomine elytrisque pubescentibus,

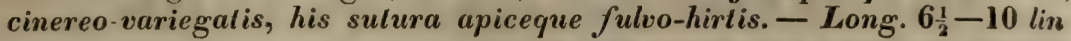

Creophilus variegal us Mannerh. Brachelytr. 20. 2. - Nordm. Symb. 21. 3.

Habitat in Brasilia.

Statura omnino C. maxillosi, niger, nitidus. Antennae clavatae, articulo tertio secundo paulo longiore, $4-6$ sensim paulo brevioribus, $7-10$ sensim at fortiter crassioribus, ultimo apice subcompresso, nigrae, articulis intermediis $(4-7)$ testaceis. Caput maris thorace maius, omnium subtilissime punctulatum, feminae eodem minus, crebrius subtiliter punctatum, glabrum, basi utrinque cinereo - pubescens. Thorax coleopteris angustior, latitudine antica in mare paulo, in femina vix brevior, basin versus in mare fortius, in femina parum angustatus, basi rotundatus, lateribus subrectis, prope basin sinuatis, angulis posterioribus prominulis licet obtusis, anterioribus acutiusculis, supra parum convexus, laevissimus, apice utrinque subtiliter punctatus, intra angulum posteriorem utrinque foveolatus, glaber, apice utrinque cinereo-pubescens, hasi tenuiter fulvo-ciliatus. Scutellum cinereopubescens, macula magna atro-holosericea. Elytra thorace sesqui longiora, vage punctata, nigro-pubescentia, cinereo-variegata, sutura apiceque fulvohirtis, margine laterali testaceo. Abdomen nigro-pubescens, cinereo-variegatum, subtus dense cinereo-pubescens. Pectus et pedes parce cinereopubescentia.

Obs. Insectum in Brasilia non infrequens pro Anglico descripsit Dom. Stephens nomine Creophili ciliaris. (Illustr. V. p. 202):

* 8. St. erythrocephalus: Niger, thorace nitido, angulis posterioribus rotundalis, elytris nigro-cyaneis, capite rufo, macula frontali oreque nigris. - Long. $8-9$ lin.

Fab. Syst. Ent, 265. 6. Spec. Ins. I. 335. 6. Mant. Ins. I. 220. 9. Ent. Syst. I. II. 523. 17. Syst. El. I. 593. 19. - Oliv. Ent. III. 42. 12. 9. t. 2. f. 9. - Goeze Ent. Beitr. I. 724. 6. - Latr. Hist. nat. Crust. et Ins. 1X. 293. 3. - Boisduv. Faun. Ent. Ocean. 55. 2.

Creophilus erythrocephalus Nordm. Symb. 23. 4.

Habitat in Nova Hollandia.

Statura omnino C. maxillosi et minoribus eius individuis magnitudine aequalis. Antennae leviter clavatae, articulo tertio secundo paulo longiore, 4 -6 leviter transversis, subaequalibus, 7-10 abrupte paulo crassioribus, transversis, ultimo apice subcompresso, nigrae. Os nigrum. Caput maris thoracis magnitudine, feminae eodem paulo minus, laevissimum, glaberrimum, fulvo-rufum, macula parva nigra in media fronte. Thorax coleopteris paulo angustior, latitudine antica dimidio brevior, lateribus et basi aequaliter rotundatus, illis pone medium subsinuatis, angulis posterioribus rotundatis, anterioribus subrectis, leviter convexus, laevissimus - glaberrimusque, apice utrinque parce punctulato tenuiterque nigro-pubescente, niger, nitidus. Scu- 
tellum dense punctatum, nigro-pubescens, macula apicali nigro-holosericea. Elytra confertim subtilius punctata, nigro-cyanea, parum mitida, nigro-pubescentia, callo humerali oblongo nigro, nitido, laevissimo, glabro. Abdomen, pectus et pedes nigra, opaca, nigro-pubescentia. Alae fusco-violaceae.

* 9. St. lanio: Niger, thorace nitido, angulis posterioribus obtusis, capite rufo, macula frontali oreque nigris. - Long. 8-10 lin.

Staph. oculatus var. Grav, Mon. p. 127.

- Hahitat in Terra Van - Diemenii.

Statura et summa affinitas praecedentis, at thoracis angulis posterioribus haud rotundatis et elytris non cyaneis constanter diversus. Niger. Antennae leviter clavatae, articulo secundo tertioque aequalibus, 4-6 sensim paulo brevioribus, leviter transversis, 7-10 leviter abrupte crassioribus, transversis, ultimo apice compresso et utrinque subimpresso, nigrae. Os nigrum. Caput maris thorace paulo latius, feminae eodem minus, parce subtilissimeque punctulatum, glabrum, rufum, nitidum, macula plerumque leviter transversa nigra in media fronte notatum. Thorax coleopteris paulo angustior, basin versus leviter angustatus, latitudine antica dimidio brevior, basi et lateribus leviter rotundatus, his pone medium subsinuatis, apice truncatus, angulis anterioribus rectis, posterioribus obtusis, nullo modo rotundatis, leviter convexus, apice utrinque subtiliter punctulatus et nigro-pubescens, ceterum laevissimus glaberrimusque, nitidus. Scutellum dense punctatum, nigro-pubescens. Elytra thorace sesqui longiora, confertim subtiliter punctata, nigro-pubescentia, opaca, callo humerali oblongo laevigato, glabro, nitido. Abdomen, pectus et pedes opaca, nigro-pubescentia.

*10. St. oculatus: Niger, nitidus, capite pone oculos utrinque rufo. Long. 9 lin.

Fab. Syst. Ins, 265. 4. Spec. Ins. I. 335. 4. Mant. Ins. I. 220. 6. Ent. Syst. I. II. 521. 10. Syst. El. II. 592. 12. - Goeze Ent. Beitr. I. 724. 5. - Oliv. Ent. III. 42. 11. 8. t. 2. f. 19. - Grav. Mon. 126. 151. - Boisduv. Faun. Ent. Oceun. 54. 1. Creophilus oculatus Nordm. Symb. 23. 5.

Habitat in Nova Seelandia, Hübner.

Statura omnino et summa affinitas praecedentium. Corpus nigrum. Caput maris thorace paulo maius, vertice utrinque parcius punctato, ceterum laevissimum, nitıdum, supra lateribus pone oculos rufis, subtus rufum, ore nigro. Thorax coleopteris parum angustior, latitudine antica dimidio brevior, basin versus leviter angustatns, lateribus et basi rotundatis, illss pone medium subsinuatis, angulis posterioribus obtusis, anterioribus subrotundatıs, modice convexus, laevissimus, nitidus. Scutellum subtilius punctulato-rugulosum. Elytra thorace sesqui longiora, subtiliter punctato-rugulosa, subtiliter pubescentia, subopaca, callo humerali laevigato, glabro, nitido. Abdomen, pectus et pedes dense nigro-pubescentia, opaca.

Obs. Praecedenti affinis, praeter capitis colorem autem thorace convexiore, anguilis anterioribus summo apice rotundatis, et elytris rugulosis distinctus. Antennae in specimine singulo, quod exstat in Museo, (masculo,) mutilatae. 


\title{
Fam. III.
}

\author{
Brachydirus Nordm. Symb. p. 31.
}

Antennae breves, tenues, subclavatae, articulo ultimo integro, acuminato. Palpi omnes filiformes, maxillares articulo ultimo praecedente paulo longiore. Pedes graciles, tibiis setulosis, tarsis anticis fortiter dilatatis.

Corpus totum tenuiter pubescens. Antennae capite vix vel parum longiores, articulo primo modice, secundo tertioque leviter elongatis, quarto quintoque obconicis, sequentibus transversis, sensim crassioribus, ultimo apice acuminato. Caput fortiter depressum, suborbiculatum, oculis maiusculis, modice prominulis. Labrum breve, transversum, limbo latiore membraneo cinctum. Mandibulae breviores, apice falcatae, tenues, acutae, basi dilatatae, muticae. Maxillarum malae latiusculae, membranaceae. Palpi tenues, maxillares articulo tertio secundo breviore, quarto iterum longiore, secundo aequali, apice acuminato, labiales articulo secundo primo paululum longiore, interne parcius setuloso, tertio paulo longiore, apice subacuminato. Thorax transversim subquadratus. Elytra apice cum angulo exteriore rotundata. Abdomen apicem versus sensim attenuatum. Pedes graciliores, at minus elongati, tibiis setis longioribus instructis, spinis apicalibus longioribus, gracilibus, tarsis anticis fortiter dilatatis, articulis 4 primis patellum ovalem, tibia duplo vel triplo latiorem, subtus dense tomentoso-spongiosam formantibus, posterioribus gracilibus, articulis $\$$ primis longitudine decrescentibus, primo leviter elongato.

Mas nonnisi abdominis segmento inferiore sexto apice inciso distinctus.

Obs. Capite depresso, antennis brevibus subclavatis et tarsis anticis fortiter dilatatis facile distinguitur haec familia. Antennae omnibus testaceae vel flavae. Omnes Americam meridionalem habitant.

\section{* 11. St. xanthoc'erus: Niger, nitidus, antennis, ore anoque testaceis. -} Long. 4 lin.

\section{Brachydirus xanthocerus Nordm. Symb. 131. 1. t. 2. f. 3.}

\section{Habitat in Brasilia.}

Niger, nitidus. Antennae articulo secundo tertioque longitudine subaequalibus, quarto hoc paulo breviore, elongato-obconicis, 5-10 subobconicis, sensim leviter crassioribus, decimo leviter transverso, ultimo ovato, apice acuminato, totae flavo-testaceae. Os flavo-testaceum, mandibulis obscurioribus. Caput depressum, thoracis latitudine, creberrime fortius punctatum, tenuiter griseo-pubescens. Thorax coleopteris angustior, latitudine haud brevior, basi angulisque posterioribus rotundatis, lateribus subsinuatis, antice leviter emarginatus, angulis anterioribus acutiusculis, supra parum convexus, fortiter vage punctatus, linea media longitudinali laevi, parce griseo-pilosus. Scutellum punctulatum, griseo-pubescens. Elytra crebre minus profunde punctata, basi apiceque griseo-, medio nigro-pubescentia. Ahdomen apicem versus sensim attenuatum, parce subtiliterque punctulatum, nigro-, segmento secundo tertioque griseo-pubescens, segmento quinto apice sextoque toto rufo-testaceis, stylis analibus nigris. Pedes postici nigri, anteriores picei, femoribus anterioribus apice tibiisque anticis basi testaceis, 
pedes intermedii maris intus densius pubescentes, femoribus basi dilatatis. Alae fuscae.

Variat pedibus anterioribus totis femoribusque posticis testaceis.

* 12. St. velitaris: Niger, nitidus, cinereo-pubescens, capite, thorace, ano pedibusque anterioribus testaceis. - Long. 4 lin.

Habitat in Brasilia, Dom. Virmond.

Statura omnino praecedentis. Antennae articulo tertio secundo paulo longiore, quarto tertio dimidio breviore, his elongato-obconicis, quinto quarto paulo breviore, obconico, 6-10 transversis, sensim paulo crassioribus, ultimo breviter ovato, apice acummato, totae flavae. Caput thoracis latitudine, depressum, creberrime fortiterque punctatum, basi summa laeve, testaceum, minus nitidum, parce pilosum. Thorax coleopteris paulo angustior, latıtudine paululum brevior, basi angnlisque posterioribus rotundatis, lateribus ante medium rotundatis, pone medium subsinuatis, antice late leviterque emarginatus, angulis anterioribus acutiusculis, leviter convexus, fortiter profundeque vage punctatus, linea media longitudinali laevi. rufo-testaceus, nitidus, margine nigro-pilosus. Scutellum testaceo-piceum, punctulatum, griseopubescens. Elytra thorace tertia parte longiora, crebre punctata, nigra, nitida, pube longiore depressa grisea vestita. Abdomen parce punctulatum, pilis longis depressis griseis vestitum, segmento secundo tertioque griseopubescentibus, nigrum, segmento quinto apice sextoque toto testaceis, stylis analibus brunneis. Pectus nigrum, mesosterno testaceo. Pedes anteriores cum coxis toti flavo-testacei, postici nigri, geniculis tarsisque piceis. Alae fuscae.

* 13. St. testaceus: Testaceus, abdomine nigro, ano teslaceo. - Long. 5 lin. Fab. Syst. El. IJ. 595. 27.

Habitat in Columbia, Dom. Moritz.

Antemnae capite fere breviores, articulo secundo tertioque modice elongatis, subaequalibus, quarto quintoque subobconicis, hoc parum breviore, 6- 10 brevibus, sensim crassioribus, transversis, ultimo crassitie haud longiore, apice fortiter acuminato, testaceae, apice fuscescentes. Caput thoracis latitudine, depressum, anterius confertissime, posterius crebre fortiterque punctatum, testaceum, parce pilosum. Thorax coleopteris angustior, latitudine paulo brevior, basi angulisque posterioribus rotundatis, lateribus angulisque anterioribus subrectis, antice truncatus, leviter convexus, fortius vage punctatus, linea media longitudinali laevi, testaceus, nitidus, parce fusco- testaceoque pilosus. Scutellum testaceum, apice punctatum flavoque fulescens. Elytra thorace paulo longiora, crebrius punctata, testacea, pube longiore depressa testacea densius vestita. Abdomen parce subtiliterque punctulatum, parce subtiliterque nigro-pubescens, segmentis secundo, tertio quartoque apice cinereo-pubescentibus, nigrum, segmento quinto apice sextoque toto testaceis, stylis analibus nigris, basi testaceis. Pectus testaceum. Pedes toti testacei. Alae fuscae.

* 14. St.facialis: Testaceus, nilidus, capite antice abdomineque nigris, ano testaceo. - Long. $3 \frac{1}{2}$ lin.

Habitat in Cayenna, Dom. Buquet. 
Antennae vix capitis longitudine, articulo secundo tertioque leviter elongatis, longitudine aequalibus, hoc autem tenuiore, quarto quintoque subobconicis, hoc paulo breviore, 6-10 sensim crassioribus, transversis, ultimo conico, acuminato, crassitie paulo longiore, testaceae. Caput thorace paulo latius, depressum, supra parte anteriore maiore confertissime punctata, opaca, nigra, posteriore minore, parce punctata, nitida, testacea, subtus totum testaceum. Thorax coleopteris angustior, latitudine paulo brevior, hasi rotundatus, apice truncatus, lateribus levier sinuatus, angulis posterioribus obtusis, anterioribus acutiusculis, subdepressus, fortiter profundeque vage punctatus, linea media longitudinali laevi, rufo-testaceus, nitidus, parce nigroz pilosus. Scutellum rufo-testaceum, apice subtiliter punctulatum. Elytra thorace tertia parte longiora, fortius punctata, testacea, testaceo-pubescentia, parce nigro-pilosa. Abdomen parce subtiliterque punctulatum, nigro-pubescens, segmento secundo, tertio quartoque, pube grisea immixta, nigrum, segmento quinto supra margine summo apicali sextoque toto testaceis. Pe ctus testaceum. Pedes toti testacei.

\section{Fam. IV.}

Antennce tenues, filiformes, ab arliculo sexto inde subserratae, articulo ultimo integro, acuminato.

Palpi omnes elongati, filiformes, apice subacuminatae, maxillares articulo ultimo praecedente paulo longiore.

Pedes graciles, tibiis omnibus setulosis, tarsis anticis simplicibus.

Corpus parce pubescens. Antennae longiores, graciles, basi satis distantes, articulis 5 primis elongatis, teretibus, articulo primo reliquis parum crassiore, tertio secundo sesqui longiore, quarto secundo aequali vel parum longiore, quinto hoc paulo breviore, 6-10 apice inferius magis prominulis ideoque leviter serratis, ultimo oblongo, apice acuminato, totae tenuiter pilosellae. Caput porrectum, suborbiculatum, oculis modice prominulis. Labrum latum, at breve, limbo latiusculo membraneo cinctum. Mandibulae longiores, falcatae, tenues, acutre, medio unidentatae. Maxillae malis parvis. Labium ligula brevı, medio sinuata. Palpi tenues, modice elongati, maxillares articulo quarto tertio sesqui longiore, labiales articulo primo breviore, secundo tertioque aequalibus. Thorax coleopteris angustior. Elytra angulo apicali exteriore oblique truncato. Abdomen apicem versus sensim leniter angustatum. Pedes modice elongati, graciles, intermedii basi sat late distantes, tibiis ommbus setulosis, spinis apicalibus subtilioribus, tarsis posterioribus articulo primo leviter elongato, sequentibus tribus leviter decrescentibus, quinto iterum elongato, anticis in utroque sexu simplicibus vel maris articulis tribus primis singulis leviter dilatatis.

Mas abdominis segmento inferiore sexto apice levius triangulariter inciso distinguendus.

Obs. Habitu quibusdam $\mathrm{Philonth}$ is non dissimiles sunt haec species, inter se concinne congruentes, at illi magis quam huic generi alienae videntur, licet corporis forma, palpis tenuibus elongatis et tarsis anticis simplicibus $\mathrm{Ph}$. $\mathrm{rufipenni}$, Baltimorensi etc, evidenter appropinquantur. Characteribus secundariis omnino inconstantibus, habitualibus saepe ambiguis, tanto magis characteres primarii observandi sunt. Ligula mihi emarginata videtur, qua a Philonthis discedunt haec insecta. Constituunt igitur in hoc genere familiam peculiarem, tarsis anticis simplicibus 
eximiam, antennis subserratis sequenti propinquam, habitu graciliore, thorace parcius fortiusque punctato, ano vel toto abdomine testaceo, elytris cyaneis, fasciis e pube cinerea ornatis insignem. Species omnes bucusque cognitae Americam meridionalem habitant.

* 15. St. comptus: Niger, ano teslaceo, elytris cyaneis, fasciis duabus cinereo-pubescentibus. - Long. 5 lin.

Habitat in Brasilia, Dom. Beske.

Niger, nitidus. Antennae capite sesqui longiores, articulo ultimo oblongo-ovato, apice sensim acuminato, totae nigrae. Caput thorace multo latius, suborbiculatum, supra parum convexum, parce disperseque grosse punctatum, parce nigro-pilosum. Thorax coleopteris longe angustior, basin versus sensim leviterque angustatus, latitudine apicis pallo longior, lateribus anterus rotundatus, posterius leviter sinuatus, basi cum angulis posterioribus rotundatus, apice truncatus, transversim convexus, parce disperseque fortiter punctatus, linea longitudinali media laevi, parce nigropilosus. Scutellum laeve, opacum, apice cinereo-pubescens. Elytra thorace paulo longiora, dense punctata, cyanea, nitida, fasciis duabus cinereo-pubescentibus, altera pone basin, altera interne leviter arcuata ante apicem. Abdomen parcius punctulatum, nigrum, nitidum. parce nigro-pubescens, segmentis duobus apicalibus testaceis, testaceo-pubescentibus. Pectus lateribus cinereo-pubescens. Pedes graciles, setulosi, nigri.

Mas abdominis segmento inferiore quinto linea media transversali brevi dense longeque testaceo-pilosa instructo, tarsis anticis simplicibus.

* 16. St. ornatus: Niger, nitidus, ano rufo-testaceo, elylris cyaneis, fasciis duabus, abdomine fascia singula cinereo-tomentosis. - Long. $5 \frac{1}{2}$ lin.

Habitat in Cayenna, Dom. Buquet.

Statura omnimo praecedentis, niger, nitidus. Antennae tenues, capite duplo fere longiores, nigrae, articulis ultimis doohus ferruginen, ultimo obIongo, apice obtusius acuminato. Caput thorace latius, orbiculatum, subdepressum, utrinque fortiter punctatum, spatio medio longitudinali laevi, inter oculos transversim irregulariter punctato. Thorax coleopteris dimidio angustior, basin versus subangustatus, lateribus pone medium subsinuatis, basi cum angulis posterioribus rotundatus, apice truncatus, angulis anterioribus rectis, latitudine apicis haud longior, modice transversim convexus, utrinque fortius crebriusque punctatus; spatio medio longitudinali laevi, lateribus subtiliter cinereo-pubescens. Scutellum opacum, dense punctulatum, apice cinereo-tomentosum. Elytra confertim subtilins punctata, cyanea, nitida, fasciis duabus dense cinereo-tomentosis, altera basali, altera apicali, angulis posterioribus exterioribus nigro-pilosellis. Abdomen subtiliter punctulatum, supra parce nigro-pubescens, segmento secundo fascia apicali cinereo-tomentosa, subtus segmentis secundo tertioque cinereo-pubescentıbus, segmentis duobus apicalibus totis rufo-testaceis. Pectus dense cinereo pubescens. Pedes graciles, setulosi, nigrı, coxis femoribusque subtus cinereopubescentibus. 
17. St. fetialis: Niger, nilidus, coxis femoribusque anterioribus anoque rufo-teslaceis, elytris cyaneis, fasciis duabus cinereo-pubescenlibus. - Long. $-4 \frac{1}{3}$ lin.

Habitat in Mexico, collect. Dom. Chevrolat.

Habitu omnino praecedentium, at paulo minor, niger, nitidus. Antennae capite thoraceque panlo breviores, nigrae, articulo ultimo ferruginen, apice abrupte acuminato. Mandibulae et palpi elongati, picei. Caput thorace paulo latius, suborbiculatum, fortiter punctatum, spatio angusto medio laeviore, parce griseo-pubescens et nigro-pilosellum. Thorax coleopteris dimidio angustior, latitudine apicis hand brevior, basin versus subangustatus, lateribus anterius leviter rotundatus, posterius subsinuatus, basi cum angulis posterioribus rotundatus, apice truncatus, angulis anterioribus obtusiusculis, transversim convexus, sat crebre punctatus, linea media longitudi. nali laevi, parcius cinereo- nigroque puberulus. Scutellum nigrum, crebre punctulatim, cinereo-pubescens. Elytra thorace paulo longiora, densıus minus fortiter punctata, cyanea, nitida, tenuiter nigro-pubescentia, fasciis duabus e pube cinerea, altera basali, altera ante apicem. Abdomen parce obsolete punctatum, parce nigro-pubescens, nitidum, segmentis ultimis duobus testaceis. Pedes nigri, anteriores coxis, trochanteribus femoribusque testaceo-rufis.

Mas tarsis anticis simplicibus.

* 18. St. scenicus: Niger, abdomine rufo-testaceo, elytris cyaneis, fasciis duabus cinereo-pubescentibus. - Long. $5 \frac{1}{2}$ lin.

Habitat in Cayenna, Dom. Buquet.

Statura praecedentium. Antennae capite duplo fere longiores, nigrac. articulo apicali obscure ferrugineo, apice obtuse acuminato. Caput thorace paulo latius, suborbiculatum, subdepressum, nigrum, nitidum, utrinque parce profundius punctatum, fronte medio laevi, antice parcius grosse punctata. Thorax coleopteris dimidio fere angustior, basin versus leviter angustatus, lateribus anterius leviter rotundatus, posterius subsinuatus, basi cum angulis posterioribus rotundatus, apice truncatus, angulis anterioribus subrectis, latitudine apicis paulo brevior, modice transversim convexus, niger, nitidus, utrinqe obsoletius parce subseriatım punctatus, ad marginem lateralem cinereo-pubescens. Scutellum nigrum, nitidum, apice punctulatum denseque cinereo-pubescens. Elytra crebrius punctata, laete cyanea, subnitida, fascii: duabus cinerea-pubescentibus, altera basali, altera paulo infra medium. $\Lambda \mathrm{b}$ domen rufo-testaceum, nitidum, subtilius punctulatum, parcius testaceo-pubescens. Pectus nigrum, cinereo-pubescens. Pedes nigri, graciles, setulosi.

* 19. St. venustus: Niger, vitidus, abdomine pedibusque mufo-testaceis, elytris cyaneis, fasciis duabus cinereo-pubescentibus. - Long. 4 lin.

Habitat in Cayenna, Dom. Buquet.

Antennae capite duplo longiores, testaceae, articulis $7-9$ fuscis, ultimo apice obtuse acuminatu. Palpi pallide flavo-testacei. Caput thorace vix latius, suborbiculatum, subdepressum, nigrum, nitidum, utrinque fortiter punctatum, fronte medio laevi, antice parce grosse punctata. Thorax coleopteris vix dimidio angustior, basin versus haud angustatus, lateribus an- 
tice leviter rotundatus, postice subsinuatus, basi cum angulis posterioribus rotundatus, apice truncatus, angulis anterioribus obtusiusculis, latitndine panlulum brevior, modice transversm convexus, niger, nitidus, utrinque parce subseriatim punctatus. Scutellum nigrum, dense junctulatum, dense cinereopubescens. Elytra crebrius punctata, coerulea, fasciis duabus cinereo-pubescentibus, altera basali, altera paulo infra medium. Abdomen testaceorufum, summa basi nigrum, laeve, parce ferrugineo-pubescens. Pectus nigrum. Perles graciles, setulosi, testacei, coxis omnibus nigris.

Mas abdominis segmento stiperiore sexto apice trisinuato, sinu intermedio maiore, medio denticulo instructo, septimo elongato, fisso, portione utraque apice truncata, intus spinula, lateribus processu deflexo, interne spimuloso terminato, segmento inferiore sexto longitudinaliter bi-impresso, apice utrinque sinuato, medio profunde inciso, tarsis anticis articulis tribus primis leviter dilatatis, singulis oblongis.

Femina abdomine integro, tarsis anticis simplicibus.

\section{Fam. $\boldsymbol{V}$.}

L eistotrophus Perty Delect. An. art. p. 30.

Schizochilus Gray An. Kingd. XIV. p. 310.

Antennae tenues, articulis basalibus valde elongalis, apice leviter incrassalae, ab articulo sexto inde subserratae, articulo ultimo apice emarginato.

Iulpi omnes filiformes, maxillares articulo ultimo praecedente longe breviore. Pedes elongati, tibiis infra medium pubescentibus, tarsis anticis in utroque sexu leviter dilatatis.

Corpus tomento brevi densius obductum. Caput magnum, nutans, fronte verticali, planiuscula, oculis mediocribus, convexis. Antennae ab-oculis distantes, tenues, articulis 3 primis teretibus, primo sequentibus duobus coniunctis paulo longiore, secundo tertio dimidio prope breviore, quarto quintoque leviter elongato-obconicis, hoc paulo breviore, $6-10$ sensim faulo brevioribus et crassioribus, subcompressis, interne subserratic, ultimo ovato, acummato. Lal)rum magnum, latum, distinctius membraneo-limbatum. Mandibulae falcatae, tenues, acutae, medio dente bicnspi armatae. Palpi maxillares articulo terio secundo minore, quarto minuto, tenui, acuminato, labiales articulo secundo maiore, interne pilis rigidis ciliato, tertio minnto, tenui, acuminato. Thorax parvus, coleopteris multo angustior. Abdomen coleopteris angustius, apicem versus sensim angustatum. Pectus tumens. Coxae intermediae interstitio lato distantes. Pedes elongati, graciliores, femoribus antıcis basi leviter incrassatis, tibiis oninibus inermibus, a medio ad apricem usque densius pubescentibus vel breviter barbatis, spinis apicalibus subtilioribus, tarsis gracilibus, posterioribus articulis 1 primis decrescentibus, primo leviter elongato, antici articulıs 4 primis in utroque sexu singulis leviter dilatatis, inter se aequalibus, triangularibus, subtus apice membraneolobatis.

Mas capite maiore, mandibulis valde elongatis, coxis intermediis dentatis, tibiis intermediis leviter flexuosis, abdominis segmento inferiore sexto apice leviter emarginato distinctus.

Obs. Insectum unicum continet haec familia, plurimis notis admodum sin- 
gulare, ut genus proprium et eximium constituere habeatur Accuratius inspectum et examinatum minus ab hoc genere discedere videtur, et praecipue summa affinitate cum $\mathrm{Fam}$. proxime sequente coniungitur, neque magis ab ea distat, quam haec a ceteris huius generis familiis discedit. Corporis indumento etiam cum illa omnino convenit. Antennae tenuiores, apicem versus subserratae in familia etiam proxime praecedente observantur.

* 20. St. versicolor: Niger, tomento fusco nebulosus, elytris inaequalibus, extrorsum subcoslatis, pedibus tesiaceo-annulatis. - Long. 7 - 9 lin.

Grav. Mon. 119. 138. - Encycl. Meth. X. 477. 1. - Nordm. Symb. 27. 1.

Leistotrophus Gravenhorsti Perty Delect. An. art. p. 30. t. 7. f. 1. - Laport. Etud. Ent. p. 112.

Schizochilus Brasiliensis Gray An. Kingd. XIV.p. 304. t. 32. f. 3.

Staph. infuscatus Nordm, Symb. 29. 2.

Habitat in America meridionali: in Parà Brasiliae, in silvis humidis in fructibus putrescentibus legit Sieber, prope Rio Janeiro, Dom. v. Olfers, in Surinamo, Dom. Cordua, in Columbia, Dom. Moritz, in Mexico, Dom. Deppe.

Antennae capite sesqui fere longiores, articulis $\mathbf{5}$ primis tenuibus elongatis, sequentibus leviter incrassatis, introrsum subserratis, testaceae, ante apicem fuscescentes. Palpi nigro-picei. Corpus nigro-ohscurum. Caput subdepressum, nutans, maris permagnum, mandibulis longis, falcatis, supra parce punctulatum, subtiliter carinatum, tomentosum, subnebulosum, subtus atrum, glahrum, nitidum. Thorax parvus, capite multo angustior, latitudine antica hrevior, basin versus valde angustatus, basi angulisque posterioribus aequaliter rotundatis, angulis anterioribus acutis, lateribus subcompressis, leviter convexus, olivaceo - fuscoque nebuloso-tomentosus. Scutellum magnum, nebuloso-tomentosum. Elytra ampla, nigro-subaenea, margine humerali testaceo, inaequalia, versus latera subcarinata, tomento olivaceo, nigro fuscóque variegata. Abdomen angustatum, supra tomento fusco, olivaceo nigroque variegato, apice tomento olivaceo-subaureo aequali vestitum, subtus nigrum, tomento argenteo micante versicolor. Pectus amplum, utrinque tuberosum. Pedes elongati, nigri, antici femoribus apice, tibiis tarsisque testaceis, posteriores femoribus ammulo basali apiceque, tibiis basi tarsisque testaceis. Alae fulvo-hyalinae.

Obs. Staphyl. in fuscatus Nordm. Mexicanus, specimen femineum, nonnisi statura minore et alis fuscis apice late dilutius flavescenti-hyalinis discrepat, aegre specie discernendus.

\section{Fam. VI.}

Antennae filiformes, articulo ullimo integro, acuminato.

Palpi omnes filiformes, maxillares arliculo ultimo praecedente minore.

Pedes tibiis posterioribus tenuiter spinulosis, tarsis anticis dilalatis.

Corpus tomento brevi dense obductum. Antennae mediocres, tenuiores, apicem versus haud incrassatae, articulo primo modice elongato, sequentibus duobus coniunctis vix longitudine aequali, secundo tertio breviore, sequentibus sensim paulo brevioribus, penultimis leviter transversis, ultimo apice oblique emarginato, abrupte acuminato. Caput leviter deflexum, thoracis latitudine vel paululum latius, subquadratum, fronte planiuscula, oculis me- 
diocribus, modice convexis, Labrum sat magnum, late membraneo-limbatum. Mandibulae longiores, falcatae, acutae, medio dente bicuspi armatae. Palpi maxillares articulo tertio secundo longitudine aequali, quarto hoc multo minore, tenuiore, acuminato. Palpi labiales articulis duobus primis subaequalibus, tertio secundo paulo tenuiore, at vix breviore, acuminato. Abdomen coleopteris parum vel vix angustius, apicem versus subangustatum. Pedes mediocres, graciliores, femoribus basi subincrassatis, tibiis posterioribus parcius tenuiterque spinulosis, intermediis leviter arcuatis, spinis apicalibus longioribus, tarsis posterioribus articulis 4 primis sensim decrescentibus, primo subelongato, anticis articulis 4 primis modice dilatatis, tibia panlo latioribus, singulis transversis, latitudine decrescentibus, subtus dense tomentosis.

Mas nonnisi abdominis segmento inferiore sexto apice emarginato distinctus.

Obs. Ingeniose hanc Fam. cum Emo coniunxit Com. Mannerheim, et iis magis quam $\mathrm{Fa} \mathrm{m}$. VIII. propinqua videtur, licet pedibus gracilioribus, tibiis anticis haud spinulosis et antennarum structura satis distinguitur. Propius accedit ad proxime praecedentem $\mathrm{F}$ am., St. murinus tamen minus quam $\mathrm{St}$. nebulos us, et maxime St. cingulatus, antennarum articulis inferioribus magis elongatis et tibiis posterioribus minus spinulosis.

*21. St. cingulatus: Niger, tomento fusco-nebuloso veslitus, pectore anoque aurichalceo-lomenlosis, palpis pedibusque teslaceis, femoribus subtus nigris. - Long. 7-8 lin.

Grav. Micr. 166. 14. Mon. 121. 140. - Nordm. Symb. 31. 5.

Emus speciosus Mannerh. Brachelylr. 21. 3. - Nordm. Symb. 31. 4.

Habitat in America septentrionali.

Statura et summa affinitis St. nebulosi. Niger, capite, thorace elytrisque tomento depresso cinereo- fuscoque nebuloso obductis. Antennae capite plus sesqui longiores, articulo tertio secundo duplo prope longiore, sequentibus duobus leviter elongatis, teretibus, sexto subobconico, crassitie longiore, 7-10, obconicis, crassitie haud brevioribus, testaceae, extrorsum fuscescentes. Palpi testacei. Caput thorace vix latius, suborbiculatum. Thorax coleopteris angustior, latitudine antica fere longior, basin versus sensim angustatus, lateribus subsinuatus, basi angulisque posterioribus rotundatis, apice truncatus, angulis anterioribus antrorsum prominulis, acutis, parum convexus. Scutellum macula gemina nigro-tomentosa notatum. Elytra thorace parum longiora, margine laterali inflexo testaceo. Abdomen supra segmentis quatuor primis tomento fusco, nigro-nebuloso, quarto aurichalceo-versicolore, quinto sextoque tomento denso depresso aequali aurichalceo nitido vestitis, subtus segmento singulo basi aurichalceo-pubescente. Pectus dense aurichalceotomentosum, nitidum. Pedes testacei, femoribus subtus, coxis trochanteribusque nigris.

$\mathrm{Obs}$. Errore quodam apud Nordmannum $\mathrm{St}$. spin os us nominatus.

* 22. St. nebulosus: Niger, tomento fusco-nebuloso vestilus, palpis pedibusque testaceis, his basi nigris. - Long. 6-8 lin.

Fab. Ent. Syst. I. II. 520. 3. Syst. El. II. 590. 3. - Payk. Faun. Suec. III. 375. 11. - Panz. Ent. Germ. 352. 2. - Grav. Mlicr. 13. 14. Mon. 121. 139. - Latr. Hist. nat. Crust. et Ins. IX. 295. 5. - Gyll. Ins. Suec. II. 282. 3. - Zetterst. Ins. Lappon. 59. 1. - Nordm. Symb. 30. 3. - Er. Col. March. I. 432. 3. 
Emus nebulosus Mannerh. Brachelytr. 20. 2. - Boisd. et Lacord. Faun. Ent. Paris. I. 361. 3. - Runde Brachelytr. Hal.2. 2.

Staph. tess ellat us Fourcr. Ent. Par. I. 165. 6.

St aph. hybridus Marsh. Ent. Britt. 500. 9.

Staph. murinus Harrer Beschr. d. Ins. I. 252. 415. - Panz. Faun. Germ. 66. 16. Staph. villosus var. maior Degeer Ins. IV. 12. 1. t. 16. f. 1-6.

Le Staph. velouté Geoffr. Hist. Ins. I. 362. 6.

Staph. secundus Schaeff. Icon. I. t. 4. f. 11.

Habitat in Europa.

Antennae capite plus sesqui longiores, articulo tertio secundo sesqui longiore, sequentibus tribus crassitie longioribus, testaceae, extrorsum fuscae. Palpi testacei. Mandibulae rufo-piceae. Caput thorace paulo latius, suborbiculatum. Thorax coleopteris angustior, basin versus angustatus, latitudine antica haud brevior, lateribus subsinuatus, basi angulisque posterioribus rotundatis, angulis anterioribus acutiusculis, parum convexus. Elytra thorace parum longiora. Caput, thorax et elytra tomento denso depresso cinereo, fusco-subnebuloso obducta. Scutellum macula magna nigro-tomentosa tectum. Abdomen supra tomento fusco, fulvo-nitente, maculatim nigro-variegato, apicem versus rariore, vestitum, subtus nigrum, segmento singulo fascia basali argenteo-pubescente versicolore. Pectus fusco-cinereo-pubescens. Pedes coxis, trochanteribus et femoribus nigris, his apice, tibiis tarsisque testaceis.

* 23. St. marginalis: Nigro-subaeneus, tomento depresso fusco-nebuloso, vestitus, palpis nigris, pedihus testaceis, basi nigris. - Long. 6 lin.

Emus marginalis Gené Act. Reg. Scienc. Acad. Taurin. XXXIX. 171. 10. $t$. 1. $f .4$.

Habitat in Sardinia, Prof. Gené, in Lusitania, Com. Hoffmannsegg.

Statura et summa affinitas omnino St. murini, at vere distinctus. Antennae articulo tertio secundo sesqui longiore, sequentibus crassitie hand longloribus, testaceae, apice fuscescentes. Palpl nigri. Caput, thorax et elytra viridi-aenea, vix nitida, confertissime punctata, tomento depresso fulvo, fusco cinereoque maculatim variegatis, elytris margine laterali inflexo summoque apicali testaceis. Caput thoracis latitudine, subdepressum. Thorax coleopteris paulo angustior, latitudine antica paulo brevior, basin versus angustatus, apice leviter emarginatus, lateribus subrectis, angulis posterioribus obtusissimis, fere rotundatis, anterioribus acutis, parum convexus. Scutellum macula magna nigro-tomentosa. Elytra thorace paululum longiora. Abdomen supra segmentis anterioribus fuseo-tomentosis, nigro-maculosis, ultimis duobus, ut subtus omnibus, basi cinereo-pubescentibus. Pectus dense aureopubescens. Pedes nigri, femoribus apice, tibiis tarsisque testaceis.

$\mathrm{Obs}$. Intermedius quasi inter St. nebulosum et murinum, huic statura et corporis forma, illi antennarum pedumque colore simillimus, ab utroque elytrorum margine laterali inflexo testaceo distinctus. Pectus confertius quam in $\mathrm{St}$ murino punctatum.

*24. St. murinus: Niger, tomento depresso fusco-nebuloso vestitus, palpis pedibusque nigris. - Long. 6 lin.

Linn. Faun. Suec. n. 840. Syst. Nat. I. II. 683. 2. - Fab. Syst. Ent. 265. 2. Spec. Ins. I. 334. 2. Mant. Ins. I. 219. 3. Ent. Syst, I. II. 520. 4. Syst. El. II. 590. 
4. - Goeze Ent. Beilr. I. 714. 2. - De Vill. Ent. I. 409. 2. - Payle. MIon. Staph. 14. 8. Paun. Suec. III.376. 12.-Panz. Ent. Germ. 352. 3. - Ceder. Fuun. Ingr. 116354 - Walken. Faun. Paris. I. 269. 2. - Oliv. Ent. III. 42. 15. 14. t. 6. f. 51. - Marsh. Ent. Britt. 499. 8. - Grav. Micr. 14. 15. MIon. 122. 142. - Latr. Hist. nat. Crust. et Ins. IX. 294. 4. - Gyll. Ins. Suec. II. 283. 4. Zetterst. Faun. Lappon. I. 67. 1. Ins. Lappon. 59. 2. - Suhlb. Ins. Fenn. I. 308. 2. - Nordm. Symb. 31. 10. - Er. Col. March. I. 433. 4.

Emus murinus Mannerh. Brachelytr. 21. 7. - Botsd. et Lacord. Faun. Ent. Paris. I. 363. 6. - Runde Brachelytr. Hal. 2. 4.

Staph. villosus var. minor Degeer Ins. IV. 12. 1.

Staph. murinus Scop. Ent. Carn. 100. 302. - Schrank Enum. Ins. Aust. 229. 433. Müll. Faun. Frid. 223. 21. Prod. 98. 1115. - Preyssl. Böhm. Ins. I. 18. 12. Rossi Faun. Etr. I. 247. 608. Ed. Hellw. I. 305. 608. (forte)

Habitat in Europa.

Niger, capite, thorace elytrisque tomento fusco, fulvo cinereoque maculatim variegato subnebulosis. Antennae capite sesqu longiores, articulo tertio secundo sesqui longiore, sequentibus duobus crassitie paulo longioribus, testaceae, apicem versus fuscescentes. Palpi nigri. Caput thoracis latitudine, transversum, subdepressum. Thorax coleopteris paulo angustior. basin versus sub-angustatus latitudine antica paulo brevior, apice vix emarginatus, lateribus rectis, angulis posterioribus obtusissinis, fere rotundatis, angulis anterioribus acutis, parum convexus. Scutellum macula gemina nigro-pubescente. Elytra thorace vix longiora. Abdomen supra segmentis anterioribus fusco-tomentosis, nigro-maculosis, ultimis duobus ut subtus omnibus basi fascia cinerea-pubescente. Pectus tenuiter cinereo-pubescens. Pedes nigri.

25. St. leucomus: Nigro-aeneus, tomento brevi olivaceo-obluctus, albosubnebulosus, pectore elylrisque albido-tomentosis, his basi olivaceo-nebulosis. - Long. 6 lin.

Habitat in Nepal, Mus. Dom. Hope.

Corpus nigro-aeneum, tomento denso brevi obtectum. Antennae capite plus sesqui longiores, articnlis primis elongatis, tertio secundo sesqui longiore, 4-6 teretibus, modice elongatis, 7-10 obconicis, crassitie haud brevioribus, ultimo apice sat fortiter emargmato, nigrae, articulo primo rufopiceo. Palpi picei. Caput thorace paulo latius, subtiliter punctatissimum, olivaceo- subtiliter tomentosum, albo-subnebulosum. Thorax coleopteris duplo fere angustior, latitudine antica paulo longior, basin versus angustatus, lateribus subrectis, basi leviter rotundatus, apice truncatus, angulis omnibus subrotundatis, fortiter transversim convexus, subtiliter punctatissimus, dense olivaceo-pubescens, albo-subvariegatus, carinula media tenui laevi medio late interrupta. Scutellum olivaceo-pubescens, macula atro-tomentosa. Elytra thorace tertia parte longiora, albo-tomentosa, subnebulosa, circa scutellum late fusco-olivaceo-pubescentia. Abdomen coleopteris angustius, olivaceo pubescens, supra tomento atro bifariam submaculato, segmento ultimo albo-villoso, subtus segmentis 4 primis sextoque albido-tomentosis, quinto fuscojubescente. Pectus totum dense albido-tomentosum. Pedes modice elongati, nigri, albido-pubescentes, tibiis posterioribus parce spinulosis, infra medium densius pubescentibus, anticis apicem versus sensim subincrassatis, inermibus, castaneis. 
Obs. A praecedentibus notis nonnullis discrepat, praecipue fronte thoraceque convexis, hoc prope subcylindrico, angulis anterioribus obtusis, tibiis anticis dilatatis, et tibiis posterioribus apice densius pubsscentibus, antennarum articulis 6 primis elongatis, teretibus, nec non abdomine angustiore ambiguus quasi inter hanc et praecedentem familiam videtur, at tibiis posterioribus licet parce spinulosis, tarsorum anticorum et oris structura propius ad genuinas huius familiae species accedit.

Species mihi invisae, forte huius familiae.

26. St. Sibiricus: Niger, capile thoraceque fulvo-, abdomine albido-tomentosis, elytris fuscis, fascia obliqua albida. - Long. 6 lin.

Gebl. Ledebour. It. App. III. 71. 16.

Habitat prope Barnaul in Sihiria.

Opacus, tomento brevi tectus, adspersus pilis longis nigris. Caput orbiculare, nigrum, subtilissime alutaceum. Antennae capite longiores, griseotomentosae. Thorax longitudine capiteque paulo angustior, antice truncatus, lateribus rectus, postice angustior et rotundatus, supra tenuissime alutacens, antice convexus, ultra medium carinulatus. Seutellum nigro-tomentosum. Elytra thorace latiora, nec longiora, apice truncata, supra fusco-tomentosa, subtilissime alutacea, punctis sparsis maioribus impressis, fascia lata, a parte marginis posteriore ad apicem sutura descendente, albido-tomentosa, hinc inde fusco-punctata. Pygidium tomento albido, fulvo nigroque variegatum. Pectus subtus fulvo-, abdomen albido-tomentosum. Pedes nigro- fulvoque tomentosi. (Gebl.)

Obs. Praecedenti forte affinis.

27. St. inauratus: Pubescens, niger, angustior, capile, thorace elytrisgue e fusco et aureo nebulosis, thorace postice haud carinato.

Emus inauratus Mannerh. Brachelytr. 21. 7.

Habitat in Dauria.

St. murino angustior, magis linearis, thorace postice haud carinato et jube aurea micante in capite, thorace et elytris conspersus. (Mannerh.)

\section{Fam. VII.}

Antennae filiformes, articulo ultimo integro, apice acuminato. Palpi omnes filiformes, maxillares articulo quarto tertio aequali.

Pedes breviusculi, tibiis posterioribus parce tenuiterque spinulosis, tarsis anticis fortius dilatatis.

Corpus tenuiter subtiliterque pubescens, capite thoraceque subglabris. Antennae breviores, apicem versus haud incrassatae, articulo primo sequentibus ambobus paulo breviore, vix clavato, secundo tertioque teretibus, hoc longiore, sequentibus sensim paulo brevioribus, magis minusve obconicis, ultimo ovato, apice acuminato. Caput porrectum, plerumque subquadratum, repressum, fronte plana, oculis mediocribus, parum prominulis. Labrum ninutum, transversum, minus late coriaceo-limbatum, limbo barbato. Mandibulae breviores, apice falcatae, acutae, medio dente valido munitae. Palpi maxillares articulo secundo paulo longiore, tertio quartoque aequalibus, hoc acuminato, labiales articulis tribus sensim longioribus, tertio cylindrico, apice subacuminato. Thorax coleopteris angustior. Elytra angulo apicali exteriore rotundato. Abdomen apicem versus parum angustatum. Pedes bre- 
viusculi, validiusculi, femoribus anticis basin versus modice dilatatis, tibiis omnibus dense pubescentibus, posterioribus parce spinulosis, spinis apicalilibus subtilioribus, tarsis posterioribus articulis tribus intermediis subaequalibus, primo leviter elongato, anticis in utroque sexu articulis quatuor primis fortiter dilatatis, - patellam ovatam vel suborbiculatam, subtus dense spongioso-tomentosam formantibus.

Mas abdominis segmento inferiore sexto apice emarginato distinctus.

Obs. Habitus fere Philonthi, capite thoraceque prope glabris, reliquo corpore subtiliter pubescente, thoraceque medio nonnunquam biseriatim punctato, eidem similis, at characteris omnino huius generis, et capite depresso subquadrato ad $\mathrm{Fam}$. praecedentem accedit. A F am. sequente praeripue antennarum articulo; ultimo apice acuminato differt.

* 28. St. sapphirinus: Niger, nitidus, abdomine segmentis ultimis duobus rufis, elytris cyaneis, antennis testaceis. - Long. 6 lin.

Habitat in Parà interiore, Sieber, in Columbia, Dom. Moritz.

Niger, nitidus. Antennae capite sesqui longiores, articulo tertio secundo duplo prope longiore, 4 - 10 sensim paulo brevioribus, penultimo etiam haud transverso; ultimo oblongo-ovato, apice valde acuminato, totae testaceae. Palpi testacei. Labrum piceum. Caput thoracis latitudine, subquadratum, depressum, subtilius crebriusque punctatum, linea media longitudinali laeviore, parce nigro-pubescens. Thorax coleopteris paulo angustior, latitudine haud brevior, basi angulisque posterioribus rotundatus, lateribus subrectis, apice truncatus, angulis anterioribus rectis, leviter convexus, utrinque crebrius subtiliusque punctatus, linea media longitudinali laevi, parce nigro-pubescens. Scutellum dense punctatum, nigro-pubescens. Elytra thorace parum longiora, densius punctata, nigro-pubescentia, cyanea, nitida. Abdomen densius punctulatum, nigro-pubescens, segmentis ultimis duobus totis testaceo-rufis, rufo-pubescentibus. Pedes nigri, dense nigropubescentes, tarsis anticis ohscure ferrugineis. Alae fuscae.

Mas abdominis segmento inferiore quinto lineola brevi transversa dense longeque fulvo-pilosa notato, sexto apice profunde inciso.

* 29. St. calidus: Niger, nitidus, abdomine segmentis ultimis duobus rufis, elytris virescenti-coeruleis, labro antennisque testaceis. - Long. 6 lin. Habitat in Columbia, Dom. Moritz.

Statura praecedentis, at paulo gracilior, niger, nitidus. Antennae capite plus sesqui longiores, articulo tertio secundo sesqui longıre, $4-10$ sensim paulo brevioribus, penultimis vix transversis, ultimo ovato, apice acuminato, totae dilute testaceae. Maxillae rufae. Palpı testacei. Mandibulae piceae. Labrum testaceum. Caput thoracis prope longitudine, subquadratum, depressum, crebre fortius punctatum, fronte medio longitudinaliter laevi, antice autem sat crebre punctata, parce tenuiterque nigro-pilosellum. Thorax coleopteris dimidio prope angustior, latitudine haud brevior, lateribus rectis, parallelis, basi cum angulis posterioribus rotundatus, apice truncatus, angulis posterioribus rectis, modice transversim convexus, utrinque minus crebre profundius punctatus, linea lata media longitudinali laevi, parce nigropilosellus (puncto quoque pilifero). Scutellum crebre punctatum, nigro-pu- 
bescens. Elytra thorace paulo longiora, parcius punctata, tenuiter nigropubescentia, virescenti-coerulea, pernitida. Abdomen crebrius at parum profunde punctatum, parce nigro-pubescens, segmentis ultumis duobus totis rufis, parce rufo-pubescentibus. Pedes nigri, tarsis anticis ferrugineis. Alae fuscae.

Obs. Differt a praecedente statura graciliore, capite thoraceque minoribus, fortius et minus dense punctatis, labro testaceo, elytris laete virescenti-coeruleis ut in St. cyanelytrio.

* 30. St. hilaris: Niger, nitidus, abdomine segmentis ultimis duobus rufis, elytris cyaneis, antennis testaceis, ante apicem fuscis. - Long. $5 \frac{1}{2}$ lin.

Habitat in Cayenna, Dom. Buyuet.

Statura et summa affinitas St. sapphirini, niger, nitidus. Antennae capite plus sesqui longiores, articulo tertio secundo sesqui longiore, 4-10 sensim paulo brevioribus, penultimis etiam haud transversis, ultimo ovato, apice fortiter acuminato, rufo-testaceae, artıculis 5-9 fuscis, ultimis duobus ferrugineis. Palpi rufo-testacei. Labrum rufum. Caput thoracis latitudine, transversim subquadratum, depressum, parcius subtiliusque punctatum, fronte media laevi. Thorax coleopteris paululum angustior, latitudine haud brevior, basi angulisque posterioribus rotundatis, lateribus angulisque anterioribus rectis, apice truncatus, parum convexus, utrinque parce subtiliterque punctatus, linea media longitudinali laevi, ut caput parce subtiliterque nigropilosus (puncto quoque pilifero). Scutellum punctulatum, parcius nigropubescens. Elytra thorace tertia parte longiora, subtiliter densius punctata, longius moro-pubescentia, cyanea, nitida. Abdomen crebre punctulatum, longius nigro-pubescens, segmentis ultimis duobus totis rufis, rufo-pubescentibus. Pedes validiusculi, nigri, nigro-pubescentes, tarsis anticis concoloribus.

* 31. St. tepidus: Niger, nitidus, abdomine segmentis ullimis duobus testaceis, elytris cyaneis, antennis fuscis, basi testaceis. - Long. $5 \frac{1}{2}$ lin.

Habiiat in Cayenna, Dom. Buquet.

Statura et summa affinitas praecedentis. Niger, nitidus. Antennae capite vix sesqui longiores, articulo tertio secundo vix longiore, 4-10 sensim paulo brevioribus et crassioribus, 7-10 transversis, ultimo breviter ovato, apice acuminato, dilute fuscae, articulis 4 primis testaceis. Palpi et labrum testacea. Caput thoracis latitudins, transversim subquadratum, depressum, supra versus latera et inter oculos punctis parcis profunde impressus, parce pilosus. Thorax coleopteris dimidio prope angustior, latitudine paululum brevior, lateribus modice rotundatus, pone medium subsinuatus, basi cum angulis posterioribus rotundatus, apice truncatus, angulis anterioribus rectis, leviter transversim convexus, sat profunde parce punctatus, punctis exterioribus sparsis, dorso in series duas longitudinales digestis, spatio intermedio latiore laevi, versus latera parce nigro-pilosellus. Scutellum crebre punctatum, tenuiter pubescens. Elytra thorace paulo longiora, densius punctata, cyanea, nitida, longius nigro-pubescentia. Abdomen crebre punctatum, nigro-pubescens, segmentis ultimis duobus totis laete testaceis, testaceo-pubescentilus. Pedes nigri, tarsis anticis concoloribus. 
*32. St. iopterus: Niger, nitidus, ano flavo, elytris violaceis, antennis testaceis. - Long. 6 lin.

Habitat in Brasilia.

Statura et summa similitudo St. sapphırinı. Niger, nitidus. Antennae graciliores, articulo tertio secundo plus sesqui longiore, 4-6 sensim brevioribus, $7-10$ subaequalibus, leviter obconicis, crassitie haud brevioribus, ultimo breviter ovato, apice fortiter acuminato, totae dilute testaceae. Labrum et palpi testacea. Caput thoracis latitudine, subquadratum, depressum, disperse punctatum, punctis in media fronte rarioribus, parce mgro-pilosellum. Thorax coleopteris paulo angustior, latitudine haud brevior, basi rotundatus, lateribus subrectis, apice truncatus, angulis posterioribus obtusis, fere rotundatis, anterioribus rectis, modice convexus, utrinque crehrius punctatus, nigro-puberulus, linea media longitudinali laevi. Scutellum dense punctatum, nigro-pubescens. Elytra thorace longiora, profundius punctata, violacea, nitida, longius nigro-pubescentia. Abdomen densius punctulatum, parce nigro-pubescens, segmenti penultimi dimidio apicali segmentoque ultimo toto cum stylis analibus testaceo-flavis et testaceo-pubescentibus. Pedes nigri, tarsis anticis ferruginess. Alae fusco-hyalinae.

33. St. cyanelytrius: Niger, nitidus, ano testaceo, elytris coeruleis, antennis basi testaceis. - Long. $6 \frac{1}{2}$ lin.

Perty Delect. an. art, p. 30. t. 7. f. 3.

Habitat in Brasilia, Dom. Virmond.

Niger, nitidus. Antennae capite sesqui longiores, graciliores, articulo tertio secundo sesqu longiore, $\mathbf{4} \mathbf{- 1 0}$ subobconicis, sensim paulo brevioribus, penultimis crassitie haud brevioribus, ultimo subovato, apice subito acuminato, fusco-nigrae, articulis tribus primis testaceis. Palpi testacei. Caput thoracis latitudine, subquadratum, supra subdepressum, disperse pun-。 ctatum, punctis in fronte rarioribus, media fronte laevi, parce nigro-pilosellum. Thorax coleopteris dimidio fere angustior, latitudine haud brevior, basin versus subangustatus, basi rotundatus, lateribus pone medium subsinuatus, apice truncatus, angulis posterioribus obtusis, anterioribus acutiusculis, leviter transversim convexus, utrinque disperse punctatus, linea media longitudinali laevi, parce nigro-pilosellus (puncto quoque pilifero). Scutellum crebre punctatum, tenuiter nigro-pubescens. Elytra thorace sesqui longiora, minus profunde punctata, nigro-pubescentia, virescenti-coerulea vel laete cyanea, nitida. Abdomen nitidum, metallico-versicolor, parce punctulatum parceque nigro-pubescens, ano usque ad segmenti quinti dimidium testaceo. Pedes mgri, nigro-pubescentes, tarsis anticis concoloribus. Alae fuscae.

* 34. St. chrysopygus: Niger, nitidus, ano favo, elytris coeruleis, antennis teslaceis. - Long. 6 lin.

Nordm. Symb. 45. 26.

Habitat in Brasilia, Dom. v. Olfers.

Statura et summa similitudo sequentis. Niger, nitidus. Antennae capite plus sesqui longiores, graciliores, articulo tertio secundo sesqui lon- 
giore, 4-6 teretibus, crassitie longioribus, licet sensim brevioribus, 7-10 inter se subaequalibus, leviter obconicis, crassitie vix brevioribus, ultino ovato, apice abrupte acuminato, totae rufo-testaceae. Palpi rufo-testacei. Labrum ferrugineum. Caput thoracis latitudine, subquadratum, depressum, media fronte laevi. Thorax coleopteris dimidio angustior, latitudine vix brevior, basi rotundatus, lateribus anterius rotundatis, posterius sinuatis, apice truncatus, angulis posterioribus obtusis, anterioribus subrectis, levite transversim convexus, utrinque disperse parce punctatus, linea media longitudinali laevi. Scutellum dense punctatum, nigro-pubescens. Elytra thorace sesqui prope longiora, densius minus profunde punctata, tenuiter ni-gro-pubescentia, coerulea, nitida. Abdomen parce punctatum, parce nigropuhescens, nitidum, metallico - versicolor, segmenti penultimi dimidio apicali, ultimoque toto cum stylis analibus testaceo-flavis, testaceo-pubescentibus. Pedes nigri, nigro-pubescentes, tarsis anticis ferrugineis. Alae fuscae.

* 35. St.pyraster: Niger, nitidus, capite thoraceque subviolaceis, elytris violaceis, antennarum arliculis duobus primis anoque testaceis. Long. 5 lin.

Staph. haemorrhoidalis Germ. Spec. Ins. 54. 56.

Habitat in Brasilia, Dom. Prof. Germar.

Statura fere St. sapphirini, at paulo minor, niger, nitidus. Antennae capite sesqui longiores, articulo tertio secundo paulo longiore, 4-10 sensim paulo brevioribus et crassioribus, $7-10$ transversis, ultimo breviter ovato, apice abrupte acuminato, pilosellae, nigrae, articulis duobus primis rufo-testaceis. Palpi rufo-testacei. Labrum nigro-piceum. Caput thoracis latitudine, subquadratum, depressum, supra utrinque parce, supra oculos crebre punctatum, medio late longitudinaliter laeve, nigro-violaceum, utrinque parce pilosellum, subtus nigrum. Thorax coleopteris paulo angustior, latitudine vix longior, lateribus rectis, basi cum angulis posterioribus rotundatus, apice truncatus, utrinque subsinuatus, angulis anterioribus acutiusculis, sat convexus, crebre fortiterque punctatus, linea media longitudinali laevi, nigro-violaceus. Scutellum crebre punctatum, nigrum, nigro-pubescens. Elytra thorace longiora, crebrius punctata, longius nigro-pubescentia, laete violacea, nitida. Abdomen crebre punctatum, parcius nigro.-pubescens, segmentis ultimis duobus testaceis, testaceo-pubescentibus, penultimo basi nigro. Pedes nigri, tarsis anticis concoloribus. Alae fusco-hyalinae.

* 36. St. chrysurus: Niger, nilidus, abdominis segmentis ultimis duobus rufis, elytris cyaneis. - Long. 3 lin.

Philonithus chrysurus Nordm. Symb. 108. 98.

Habitat in Parà interiore Brasiliae, Sieber.

Statura omnino praecedentis at quadruplo fere minor, niger, nitidus. Antennae capite paulo longiores, crassiusculae, articulo tertio secundo sesqui prope longiore, $4-10$ sensim paulo crassioribus, 6-10 transversis, ultimo subovato, apice subito acuminato, totae nigrae. Caput thoracis latitudine, transversim subquadratum, subdepressum, punctis raris dispersis profunde impressum. Thorax coleopteris paulo angustior, latitudine haud brevior, basin versus subangustatus, lateribus ante medium leviter rotundatis, 
pone medium leviter sinuatis, apice truncatus, basi cum angulis posterioribus rotundatus, apice utrinque oblique truncatus, angulis anterioribus acutiusculis, subdepressus, dorso seriebus duabus minus regularibus $9-10$ punctatis, utrinque punctis parcis dispersis notatus. Scutellum punctulatum. Elytra thorace paulo longiora, parcius punctata, longius nigro-pubescentia. Abdomen fortius crebriusque punctulatum, nigro-pubescens, segmentis ultimis duobus totis rufis, rufo-pubescentibus. Pedes breves, nigri, femoribus anticis compressis, tarsis piceis. Alae fusco-hyalinae.

* 37. St. fau st us: Niger, nilidus, abdominis segmentis ultimis duobus favo. testaceis, elytris cyaneis, antennarum basi, coxis femoribusque anticis testaceis. - Long. 4 lin.

Habitat in Cayenna, Dom. Buquet.

Subdepressus, niger, nitidus. Antennae capite plus sesqui longiores, articulo secundo tertioque modice elongatis, hoc longiore, 4-10 sensim paulo brevioribus et crassioribus, $7-\mathbf{1 0}$ transversis, ultimo ovato, apice abrupte fortiter acuminato, fuscae, articulis duobus primis testaceis, tertio quartoque rufo-piceis. Palpi rufi. Labrum ferrugineum. Caput thorace paululum latius, transversim suborbiculatum, depressum, parce fortiter vage punctatum, fronte medio laeviore. Thorax coleopteris angustior, latitudine paulo brevior, basin versus subangustatus, lateribus anterius rotundatis, pone medium subsinuatis, basi cum angulis posterioribus rotundatus, apice truncatus, angulis anterioribus obtusiusculis, subdepressus, dorso utrinque serie minus regulari 8-9-punctata, lateribus parce disperseque punctatus, punctis omnibus sat profundis, parce nigro-pilosellus. Scutellum dense punctatum, nigro-pubescens. Elytra thorace longiora, levius punctata, nigro-pubescentia, cyanea, nitida. Abdomen parce punctatum parceque nigro-pubescens, segmentis ultimis duobus totis testaceo-flavis, flavo-pubescentibus. Pedes nigri, coxis femoribusque anticis testaceis, tarsis anticis ferrugineis.

\section{Fam. VIII.}

Antennae filiformes, articulo ultimo apice emarginato.

Palpi omnes filiformes, maxillares articulo quarto tertio aequali.

Pedes breves, tibiis posterioribus spinulosis, tarsis anticis dilatatis.

Corpus subtiliter pubescens tomentosumve, scutello plerumque dense tomentoso. Antennae saepius breviores, apicem versus haud incrassatae, articulo primo modice elongato, secundo tertioque obconicis, $\mathbf{6 - 1 0}$ saepius transversis, ultımo apice truncato vel emarginato et inferne acuminato, articulis 4 primis breviter pilosellis, sequentibus pube subtilissima brevissimaque densius vestitis. Caput porrectum, oculis minoribus obliquis, ovatis, minus prominulis, apici magis quam basi capitis approximatis. Labrum breve, limbo angustiore coriaceo, densius barbato cinctum. Mandibulae validae, at minus elongatae, falcatae, medio fortiter dentatae. Palpi breviusculi, maxillares articulo secundo paulo longiore, tertio quartoque longitudine subaequalibus, hoc apice acuminato, labiales articulis tribus sensim paulo longioribus, secundo interne setuloso, tertio apice subacuminato. Elytra angulo apicali exteriore rotundato. Abdomen iam parallelum iam apicem versus sensim magis minusve angustatum. Pedes breviusculi, tibiis posterioribus spinulosis, spinis 
apicalibus fortioribus, tarsis posterioribus brevioribus, articulo primo leviter elongato, sequentibus tribus sensim paululum brevioribus, tarsis anticis ar. ticulis 4 primis dilatatis, patellam ovatam, subtus dense tomentoso-spongiosam formantibus.

Mas plerumque nonnisi abdominis segmento inferiore sexto apice emarginato distinctis.

Obs. Species plurimas continet haec Fam., quae genuina in hoc genere videtur. Abdomen saepius maculis tomentosis ornatum.

* 38. St. Chrysis: Rufus, capite flavo, thorace postice elytrisque aureotomentosis, abdomine nigro-aeneo, segmentis singulis late rufo-marginalis. - Long. 10 lin.

Grav. Mon: 124. 147. - Nordm. Symb. 31. 7.

Staph. a uricomus Brull. D'Orbigny It. Am. mer. Ins. t. 5. f. 6.

Habitat in Bahia, Gomez.

Antennae capite sesqui longiores, apice subattenuatae, articulo tertio secundo paulo longiore, $\mathbf{4}-\mathbf{7}$ cyathiformibus, sensim paulo brevioribus, $8-10$ transversim subobconicis, ultimo transverso, apice emarginato, interne abrupte acuminato, piceae, apice et articulo primo obscure rufis. Palpi rufo-brunnei. Mandibulae nigro-piceae. Labrum rufo-brunneum. Caput thorace paulo angustius, orbiculatum, convexum, subtilissime punctulatum, dilute flavum, aeneo-micans, subtliter denseque flavo-aureo-pubescens, macula rhombea inter antennas subimpressa obscure aenea opaca, infra antennas et subtus rufo-brunneum. Thorax basi coleopteris paulo angustior, latitudine parum brevior, antrorsum subangustatus, basi, angulis posterioribus lateribusque eodem arcu rotundatis, antrorsum subangustatus, apice truncatus, angulis anterioribus acutiusculis, basi et lateribus marginatus, dorso modice convexus, nigro-subaeneus, opacus, antıce nigro-, postice fulvo-aureo - dense tomentosus. Scutellum atro-tomentosum. Elytra thorace haud longiora, confertim punctato-subrugulosa, nigro-brumea, pube depressa rufo-aurea dense vestita. Abdomen apicem versus sensim angustatum, parce punctulatum, tenuiter nigro-pilosum, nitidum, nigro-subaeneum, segmentis singulis late sinuatim rufo-marginatis, sexto toto rufo. Pectus rufo-brunneum. - Pedes rufi. insignis.

Mas abdominis segmento inferiore quinto arcu longe ciliato impresso

* 39. St. re galis: Rufo-testaceus, capite, thorace elytrisque aureo-tomentosis, thorace, elyirorum fascia abbreviata, abdominis maculis fasciaque violaceis. - Long. 7 lin.

Habitat in Brasilia, Dom. Prof. Germar.

Statura omnino praecedentis, at dimidio minor. Antennae capite paulo longiores, articulo tertio secundo paulo longiore, quarto quintoque obconicis, sequentibus leviter transversis, ultimo apice truncato, inferne abrupte acuminato, totae nigrae. Palpi rufi. Mandibulae rufae, apice nigrae. Caput thoracis latitudine, supra minus colfvexum, crebre subtiliter punctatum, totum rufo-testaceum, supra pube depressa aurea nitida densiore, et pilis subtilibus longioribus nigris parcis vestitum. Thorax coleopteris dimidio 
angustior, basin versus subangustatus, latitudine antice haud longior, basi et lateribus leviter rotundatus, apice truncatus, angulis posterioribus sub. rotundatis, anterioribus rectis, modice convexus, confertissime punctatus, linea tenui elevata laevi, purpureo-violaceus, nitidulus, pube depressa aurea nitida dense obductus. Scutellum nigrum, nigro-tomentosum. Elytra thorace longiora, confertissime subtilius punctata, rufo-testacea, pube longiore depressa aurea nitida dense vestita, fascia media, ad suturam abbreviata violacea, nigro-pubescente. Abdomen apicem versus sensim angustatum, parce subtiliter punctatum, tenuiter aureo-pubescens, segmentis 4 primis rufo-testaceis, singulo supra et infra maculis ternis nigris, transversim positis, intermedia maiore transversa, lateralibus marginalibus minutis rotundatis, segmento quinto nigro-subviolaceo, summa basi rufo-testaceo, summo margine apicali flavo. Pectus rufo-testaceum, dense aureo-tomentosum. Pedes rufo-testacei.

$\mathrm{O} \mathrm{b} \mathrm{s}$. Sequentibus duobus coloribus assimilis, thorace autem aureo-tomentoso primo intuitu distinctus.

* 40. St. biplagiatus: Rufo-testaceus, thorace cupreo, nitido, elytris aureo-pubescentibus, macula media transversa cyanea, abdomine nigro, segmentis. singulis rufo-marginatis. - Long. 10 lin.

Perty Delect. An. art. p. 31. t. 7. f. 4.

Habitat Cassapavae in Brasilia, Sellow.

Antennae capite paulo longiores, crassiusculae, articulo primo elongato, tertio secundo sesqui longiore, 5- 10 fortius transversis, interne subserratis, ultimo transverso, apice leviter emarginato et inferne acuminato, nigrae, ariculo primo piceo. Palpi rufo-picei. Mandibulae rufae, apice nigrae. Caput thorace latius, transversim suborbiculatum, snpra leviter convexum, dilutius testaceum, metallico-subnitidum, punctatum, tenuiter fulvo-pubescens. Thorax coleopteris angustior, latitudine paulo brevior, basi fortiter, lateribus vix rotundatus, apice truncatus, angulis anterioribus rectis, posterioribus rotundatis, lateribus et basi marginatus, dorso modice convexus, crebre punstatus, linea media longitudinali laevi, cupreus, nitidus, violaceo-micans, parce tenuiter nigro-puberulus. Scutellum nigrum, atro-tomentosum. Elytra thorace paulo longiora, subtiliter punctulata, longius fulvo-pubescentia, testacea, macula magna media transversa seu fascia ad suturam abbreviata nigro-subviolacea. Abdomen apicem versus sub-angustatum, nigro-subcyaneum, nitidum, parcius punctatum, parce pubescens, segmentis singulis late sinuatim rufo-marginatis, ultimo toto rufo. Pectus rufum, aureo-tomentosum, antice nigricans. Pedes rufo-testacei. Alae fuscae.

$\mathrm{O} \mathrm{bs}$. Antennae ab oculis remotae, vix magis inter se quam ab his distantes.

* 41. St. cyanicollis: Rufo-testaceus, fronte puncto violaceo, thorace cysnen, nilido, elytris aureo-pubescentibus, macula transversa cyanea, abdomine nigro, segmentis singulis rufo-marginatis. - Long. 7 lin.

Laporte Etud. Ent. I. I15. 5.

St aph. interruptus Brull. D'Orbigny It. Am. mer. Ins. t. 5. f. 7.

Habitat in Brasilia, Sellow.

Praecedente dimidio minor. Antenuae capite paulo longiores, articulo 
tertio secundo paulo breviore, 5-10 transversis, ultimo transverso, apice leviter emarginato et inferne acuminato, fuscae, articulis primis rufo-piceis. Oris partes rufo-testaceae, mandibulae apice nigrae. Caput thorace vix latius, supra minus convexum, crebre fortius punctatum, testaceum, nitidum, fronte paulo ante oculos macula minuta media violacea notata, tenuiter aureo-pubescens, parce nigro-pilosum. Thorax coleopteris parum angustior, basin versus haud angustatus, latitudine paulo longior, basi rotundatus, lateribus subrectis, apice truncatus, angulis anterioribus deflexis rectis, posterioribus obtusis, subrotundatis, modice convexus, crebre profundius punctatus, linea media longitudinali laevi, cyaneus, nitidus, violaceo-micans, parce tenuiterque nigro-pubescens, lateribus longius nigro-pilosellus. Scutellum nigrum, nigro-tomentosum. Elytra thoracis longitudine, confertim subtilius licet sat profunde punctata, testacea, dense aureo-pubescentia, parce nigropilosa, macula transversa, vel fere obliqua, biloba, seu fascia interne abbreviata nigro-violacea. Abdomen apicem versus subangustatum, crebrius punctatum, parcius fulvo-pubescens et nigro-pilosellum, nigrum, nitidum, segmentis 4 anterioribus margine apicali lato sinuatoque, quinto margine tenui apical, sexto toto rufis. Pectus rufo-testaceum, tenuiter fulvo-pubescens. Pedes rufo - testacei.

Mas abdominis segmento inferiore quinto arcu longıus densiusque villoso notato insignis.

Obs. Praecedenti similis, antennarum autem ab oculis minus distantium structura, thorace longiore, fronte minus convexa, macula violacea notata, etc. sat distinctus.

* 42. St. chrysocephalus: Niger, tomento fusco-nebuloso vestilus, ventre argenteo-villoso, capite femorumque annulo testaceis. - Long. 5-7 lin.

Fourcr. Ent. Paris. I. 165. 8. - Latr. Hist. nat. Crust. et Ins. IX. 296. 7. Grav. Mon. 124. 146. - Nordm. Symb. 31. 12.

Emus chrysocephalus Mannerh. Brachelytr. 21. 4. - Boisd. et Lacord. Faun. Ent. Paris. I. 362. 5.

Staph. pubescens Rossi Faun. Etr. Mant. 97. 217. Ed. Hellw. I. 442. 217. Walken. Faun. Paris. I. 269. 3. - Oliv. Ent. III. 42. 16. 15. $t$. 2. $f$. 15.

Le St uph. à tête jaune Geoffr. Hist. Ins. I. 363. 8.

Habitat in Gallia, Italia, Dalmatia.

Statura et summa affinitas speciei sequentis, plerumque tamen paulo maior. Antennae capite paulo longiores, articulo tertio secundo paulo longiore, 6-10 sensim paulo brevioribus et fortins transversis, ultimo apice oblique emarginato et inferne acute acuminato, testaceae, articulis ultimis 5 fuscis. Palpi testacei. Mandibulae nigrae, basi testaceae. Caput maris thorace latius, feminae eiusdem latitudinis, suborbiculatum, testaceum, pube densa flavescenti-grisea, albido-versicolore vestitum, punctis duobus minutis inter oculos nigris. Thorax coleoptet is dimidio fere angustior, latitudine antica parum longior, lateribus ante medium subangulato-rotundatis, pone medium sinuatis, basi leviter rotundatus, apice truncatus, angulis posterioribus obtusissimis, anterioribus suhrectis, parum convexus, niger, ferrugineo-subvariegatus, tomento subfasciculato fusco nebulosus. Scutellum maculis duabus oblongis nigro-tomentosis. Elytra thorace paulo longiora, nigra, tomento fusco reticulatim nebulosa, margine humerali testaceo. $\mathrm{Ab}$ - 
domen nigrum, supra segmentis singulis apice medio ferrugineis, tomento dense fusco-variegato, subtus tomento spisso cinereo-albido vestitum. Pectus nigrum, cinereo-pubescens. Pedes nigri, annulo testaceo ante femorum apicem ornati.

Mas capite latiore et tibiis intermediis leviter curvatis distinctus.

Obs. Sequenti similis et affinis, capite autem testaceo insignis. Europae meridionali proprius.

* 43. St. pubescens: Niger, tomento denso fusca-nebuloso vestilus, ventre argenteo-villoso, capite flavescenti-villoso, femoribus annulo testaceo. - Long. $5-7$ lin.

De Geer Ins. IV. 17. 2. Fab. Ent. Syst. I. 11. 520. 5. Syst. El. II. 590. 6. Payk. Mon. Staph. 16. 9. Faun. Suec. III. 376. 13. - Panz. Ent. Germ. 352. 4. - Cederh. Faun. Ingr. 117. 355. - Grav. Micr. 12. 13. Mon. 123. 144. Latr. Hist. nat. Crust. et Ins. IX. 295. 6. - Marsh. Ent. Britt. 500. 10. Gyll. Ins. Suec. II. 284. 5. - Zetterst. Faun. Lappon. 1. 67. 2. Ins, Lappon. 59. 3. - Sahlb. Ins. Fenn. I. 309. 3. - Nordm. Symb. 31. 9. - Er. Col. March. I. 434.5.

Emus pubescens Mannerh. Brachelytr. 21. 5. - Boisd. et Lacord. Faun. Ent. Paris. I. 361. 4. - Runde Brachelytr. Hal. 2. 3.

\section{Habitat in Europa.}

Antennae capite paulo longiores, articulo tertio secundo panlo longiore, 6-10 transversis, subaequalibus, ultimo transverso, apice emarginato et inferne acuminato, nigrae, articulis basalibus testaceis, supra nigris. Palpi nigri. Mandibulae nigrae, basi testaceae. Labrum testaceum. Corpus nigrum. Caput maris thorace latius, feminae eiusdem latitudine, orbiculatum, nigrum, villis densis flavo-griseis obductum, macula minuta in media fronte punctisque nonnullis sparsis laevissimis. Thorax coleopteris angustior, latitudine antica vix longior, lateribus ante medium leviter rotundatis, pone medinm subsinuatis, basi rotundatus, apice truncatus, angulis posterioribus ohtusis, subrotundatis, anterioribus subrectis, supra tomento subfasciculato fuseo-nebulosus, margine basali summo ferrugineo. Scutellum maculis duabus oblongıs nigro-tomentosis. Elytra thorace paulo longiora, simili modo uti thorax fusco-tomentosa, margine humerali testaceo. Abdomen supra totum tomento fusco-variegato obductum, subtus cum pectore tomento spisso cinereo-albo, argenteo-micante vestitum. Pedes nigri, albido-pubescentes, femoribus ante apicem annulo testaceo.

M a s capite latiore et tibiis intermediis curvatis distinctus.

$\mathrm{Obs}$. Corporis tomento similis omnino St. nebuloso et murino, licet antennarum, palporum, labri et tarsorum structura satis distinctus, neque iis affinis.

* 44. St. chloropterus: Capite thoraceque cupreis, elytris viridibus, abdomine ferrugineo, basi obscuro, pedibus testaceis, femoribus fusco-annulatis. - Kong. $4 \frac{1}{2}$ lin.

Panz. Faun. Germ. 36. 20. - Grav. Micr. 166. 15. Mon. 121. 141. - Fab. Syst. El. 11. 590. 5. - Latr. Hist. nat. Crust. et Ins. IX. 306. 22. - Nordm. Symb. 33. 14. Emus chloropterus Boisd. et Lacord. Faun. Ent. Paris. I. 364. 7.

Habitat in Austria.

Antennae capite duplo longiores, articulo tertio secundo paulo lon- 
giore, quarto quintoque oblongis, cylindricis, 6-10 subobconicis, sensim paululum brevioribus, licet omnibus crassitie longioribus, ultimo praecedente paulo breviore, apice truncato et inferne acuminato, testaceae. Os testaceum. Caput subquadratum, thoracis latitudine, subdepressum, confertim subtilius punctatum, cupreo-aeneum, nitidulum, parcius griseo-pubescens. Thorax coleopteris paulo angustior, latitudine haud brevior, lateribus parallelis, subrectis, basi fortius rotundatus, apice truncatus, angulis posterioribus obtusissimis, subrotundatis, anterioribus subrectis, perparum convexus, confertim punctatus, basi linea longitudinali subelevata laevi abbreviata, cupreo-aeneus, nitidulus, griseo-pubescens. Scutellum nigro-tomentosum. Elytra thorace vix longiora, obsolete punctata, viridia, opaca, margine laterali apicalique tenui testaceo, pube grisea nebulosa vestita. Abdomen ferrugineum, opacum, griseo-pubescens, segmentis anterioribus basi nigricantibus, maculis binis nigro-holosericeis. Pectus nigrum, griseo-pubescens. Pedes testacei, coxis nigris, femoribus omnibus facie antica macula media fusca notatis.

45. St. ochropygus: Niger, capite, thorace elytrisque coeruleis, his fascia undulala cinereo-pubescente, scutello atro-tomentoso, abdomine apice testaceo, supra fusco-tessellato. - Long. 7 lin.

Nordm. Symb. 46. 28.

Emus nebulosus Percheron Genera Ins. III. Nr. 1. (Coleopt.) tab. 5.

Habitat in Parà interiore Brasiliae, Sieber; in Cayenna, Dom. Buquet.

Statura omnino St. chalcocephali. Antennae capite vix longiores, articulo secundo tertioque obconicis subaequalibus, sequentibus transversis, 6 - 10 brevioribus, inter se aequalibus, ultimo leviter transverso, apice truncato et inferne acute acuminato, nigro-piceae, apice summo ferrugineo. Palpi picei. Caput thorace paulo angustius, subtriangulare, subdepressum, supra sat crebre punctatum, fusco-pubescens, coeruleum, parum nitidum, subtus nigrum, nitidum. Thorax basi coleopteris latitudine aequalis, latitudine haud brevior, antrorsum leviter angustatus, lateribus subrectis, basi cum angulis posterioribus rotundatus, apice truncatus, utrinque subsinuatus, angulis anterioribus acutiusculis, parum convexus, dense punctatus, postice lineola media longitudinali laevi, fusco-pubescens, coeruleus, parum nitidus. Scutellum dense atro-tomentosum. Elytra thorace vix longiora, subtiliter alutacea, parcins punctulata, cyanea, opaca, fascia media valde undulata dense cinereo-pubescente, basi etiam undulatim cinereo-pubescente, interstitiis subtilissime nigro-tomentosis. Abdomen nigrum, segmentis ultimis duobus testaceis, reliquis supra tomento brevissimo fusco variegatis, subtessellatis, subtus parce pubescentibus. Pectus nigruin, lateribus subtiliter cinereo-pubescens. Pedes nigri vel picei.

Mas femoribus anteriorıbus basi leviter sensim dilatatis, tibiis intermediis subarcuatis.

Variat femoribus omnibus rufo-piceis:

*46. St. antiquus: Niger, capite thorace elytrisque obscure aeneis, pube fusco-grisea subvariegalis, scutello nigro-pubescente, abdomine supra fusco-subtessellato, ano rufo-testaceo. - Long. 5- $7 \mathrm{lin}$.

Nordm. Symb. 35. 16.

Habitat in Columbia, Brasilia. 
Habitu omnino St. chalcocephali, plerumque autem paulo minor. Antennae capite paulo longiores, articulo secundo tertio paulo breviore, 6- 10 transversim subobconicis, inter se aequalibus, ultimo praecedente paulo longiore, apice emarginato et inferne acuminato, nigrae, articulo primo subtus rufo-piceo. Palpi picei. Caput thorace minus et angustius, subtriangulare, subdepressum, supra dense fortius punctatum, carinula minuta frontali laevi, obscure aeneum, subopacum, densius fusco-pubescens. Thorax coleopteris paulo angustior, latitudine vix longior, antrorsum subangustatus, lateribus perparum rotundatis, pone medium nullo modo sinuatis, basi rotundatus, apice truncatus, angulis anterioribus rectis, posterioribus obtusss, subdepressus, confertissime fortius punctatus, carinula postica polita, obscure aeneus, opacus, densius fusco-puhescens, lateribus parce longius pilosus. Scutellum atro-tomentosum. Elytra thorace vix longiora, subtiliter alutacea, obscure aenea, opara, pube densa subtili fusca cinereaque nebulosa. Abdomen nigrum, segmento quinto apice sextoque toto rufotestaceis, supra tomento tenui fusco-griseo nigroque variegatum. Pectus nigrum. Pedes nigri, femoribus anticis supra linea longitudinali lutea. Alae fuscae. Antennae femina e capite vix longiores.

* 47. St. latro: Niger, capile thoraceque punctatissimis, opacis, nigropubescentibus, scutello airo-tomentoso, elyiris obscure aeneis, abdomine supra bifariam nigro-maculato, ano rufo-testaceo. - Long. $7 \frac{1}{2} \mathrm{lin}$.

Habitat in Brasilia, Dom. Prof. Germar.

Affinis praecedenti. Antennae capite sesqu longiores, articulo tertio secundo sesqui longiore, $4-10$ subaequalibus, leviter obconicis, crassitie paululum longioribus, ultimo apice leviter emarginato et inferne acuminato, totae nigrae. Palpi picei. Caput thoracis latitudine, subquadratum, basi emarginatum, angulis posterioribus retrorsum leviter prominentibus, supra depressiusculum, confertissime punctatum, pube breviuscula erecta nigra parcius vestitum, nigrum, opacum, infra sublaeve glabrumque, nitidum. Thorax coleopteris vix angustior, latitudine haud brevior, lateribus rectis, parallelis, basi cum angulis posterioribus rotundatus, apice truicatus, angulis anterioribus rectis, supra parum convexus; confertissime punctatus, pube brevi erecta nigra vestitus, niger, opacus. Scutellım nigrum, atro-tomentosum. Elytra thorace paulo longıra, confertissime subtiliter punctata, aenea, subopaca, e pube brevi densiore nigra griseaque obsolete variegata. Abdomen apicem versus sensim angustatum, parcius obsoletius punctatum, nigrum, supra opacum, tenuiter nigro-pubescens, segmentis 5 primis singulo maculis duabus triangularibus approximatis atro-tomentosis, tomento subtiliore fulvo-grisea cinctis ornatis, apice aureo-pubescente, margine apicali pallido, infra nitidum, metallico-versicolor, tenuiter nigro-pubescens, segmento sexto toto rufo-testaceo, subtiliter aureo-pubescente. Pectus nigrum, subnitidum, subtiliter nigro - pubescens. Pedes nigri.

* 48. St. exulans: Niger, capite, thorace elylrisque obscure aeneis, scutello atro-tomentoso, elytris abdominisque dorso griseo-subtessellatis. - Long. 5 lin.

Habitat in America septentrionali, Dom. Prof. Germar. 
Statura omnino St. antiqui et minoribus eius individuis aequalis, niger, parum nitidus. Antennae capite paulo longiores, articulo tertio secundo sesqui longiore, $6-10$ transversis, at sensim paulo brevioribus, ultimo apice emarginato et inferne acuminato, piceae, articulis tribus primis nigris. Caput thorace minus et angustius, subtriangulare, subdepressum, supra crebre fortius punctatum, linea media longitudinali antice abbreviata laevi, griseopubescens, nigro-aeneum, nitidum, ore nigro, subtus parce punctatum, nigrum, nitidum, subtiliter nigro-pubescens. Thorax basi coleopteris parum angustior, latitudine haud brevior, apicem versus leviter angustatus, lateribus leviter, basi cum angulis posterioribus fortiter rotundatus, apice truncatus, angulis anterioribus subrectis, parum convexus, creberrime fortius punctatus, linea media longitudinali medio subinterrupta laevi, griseo-puberulus, nigro-aeneus nitidus. Scutellum atro-tomentosum. Elytra thorace paulo longiora, subtilissime rugoso-punctulata, nigro-aenea, opaca, e pube subtili depressa obsoletius griseo nigroque tessellata. Abdomen e pube subtili depressa supra nigro-griseoque variegatum, subtus segmentis singulis basi cinereo-pubescentibus. Pedes nigri, geniculis tarsisque piceis.

* 49. St. scriptus: Niger, dense fulvo-pubescens, antennis pedibusque tesluceis, elytris ferrugineis abdomineque tomento fusco-variegulis. Long. 7 lin.

Nordm. Symb. 32. 13.

Habitat ad Promont. Bonae Spei, Dom. Prof. Lichtenstein.

Antennae capite paulo longiores, articulo secundo tertioque obeonicis, subaequalibus, quarto quintoque subglobosis, $6-10$ transversis, aequalibus, ultimo iterum subgloboso, apice profunde transversim impresso. Palpi et labrum testacea. Mandibulae nigrae. Caput thoracis prope latitudine, antrorsum parum angustatum, supra subdepressum, subtiliter punctulatum, dense aureo-pubescens, nigro-subaeneum, margine antico orbitalique ferrugineo, subtus nigrum, nitidum, glabrum. Thorax coleopteris pailo angustior, la.. titudine paululum longior, lateribus parallelis subrectis, basi cum angulis posterioribus rotundatus, apice truncatus, angulis anterioribus subrectis, leviter convexus, confertirsime subtiliter punctatus, linea media longitudinali elevata laevissima medio interrupta, pube densa aurea obtectus, nigro - subaeneus, margine omni tenuiter ferrugineo. Scutellum nigro-tomentosum. Elytra thorace vix longiora, ferruginea, subtiliter punctata, fulvo-pubescentia, maculis liturisque fuscis variegata. Abdomen supra nigro-subaeneum, segmentis singulis margine apicali ferrugineis, absolete punctulatum, punctis maioribus parcis sparsum, fulvo-pubescens, pube fusca maculosum, subtus nigrum, segmentis singulis basi dense argenteo-pubescentibus. Pectus $\mathrm{ml}$ grum, fulvo-pubescens. Pedes rufo-testacei, coxis maculaque magna oblonga femorum basali nigris.

* 60. St. maculosus: Nigro-aeneus, capite thoraceque ferrugineo-variegatis, elytris ferrugineis, fulvescenti-pubescens, elytris abdomineque fusco-maculosis. - Long. 8- 10 lin.

Grav. Micr. 165. 13. Mon. 123. 145. - Nardm. Symb. 31. 6. Staph. viduatus Fab. Syst. El. II. 591. 7. Staph. erythropennis Mannerh. Brachelytr, 22. 6. - Nordm. Symb. 62. 47. 


\section{Habitat in America septentrionali.}

Antennae capite paulo longiores, articulo tertio secundo paulo longiore, quarto subgloboso, 6-10 transversis, aequalibus, ultimo apice profundius emarginato, inferne acuminato, testaceae, articulo tertio fusco, vel fuscae bası testaceae. Caput subquadratum, thoracis latitudine, supra subdepressum, confertissime punctatum, fulvescenti-pubescens, aeneum, parum nitidum, magis minusve ferrugineo-variegatum, interdum ferrugineo-bivitta- . fum. Thorax coleopteris parum angustior, latitudine antica vix brevior, basin versus subangustatus, lateribus subrectis, basi cum angulis posterioribus rotundatus, apice truncatus, angulis anterioribus acuts, leviter convexus, confertim punctatus, lmea media longitudinali, antrorsum mox obsoleta, elevata laevi, fulvescenti-pubescens, obscure aeneus, vix nitidus, basi apiceque ferrugineo-variegatus, interdum ferrugineo-bivittatus. . Scutellum aeneum, maculis duabus longitudinalibus nigro-holosericeis. Elytra thorace vix longiora, subtiliter punctata, fulvescenti-pubescentia, fusco-maculosa. Abdomen subtiliter punctulatum, supra nigro-subaeneum, segmentis singulis apice obscure ferrugineis, pube subtiliori densa fusco-nebulosa vestitum, biseriatim nigro-maculatum, subtus vigrum, flavescenti-pubescens, segmentis singulis basi densius flavescenti- griseo - pubescentibus. Pectus nigrum, flavescentipubescens. Pedes rufo-testacei, femoribus supra coxisque anterioribus nigris.

* 51. St. fuscomaculatus: Niger, capite thoraceque aeneo-ferrugineoque variegatis, elytris ferrugineis, pedibus teslaceis, femoribus nigro-maculatis. - Long. $6 \frac{2}{3}$ lin.

Emus fuscomaculatus Laporte Etud. Ent. I. p. 113.

Habitat in Mexico, Dom. C. Ehrenberg.

Praecedenti affinis, at multo minor et minus robustus. Antennae capite paulo longiores, articulo tertio secundo sesqui longiore, sequentibus sensim paulo brevioribus, penultimis tribus vel quatuor transversis, ultimo subovato, apice emarginato et inferne acuminato, nigrae, articulo.primo testaceo, apicali ferrugineo. Palpi picei. Mandibulae nigrae. Caput thoracis latitudine, antrorsum modice angustatum, supra parum convexum, confertissime punctatum, fulvescenti-pubescens, ferrugineum vel testaceum, fronte magis minusve aeneo-variegata, lateribus nigro-aeneis, subtus nigrum, nitidum, glabrum. Thorax elytris parum angustior, latitudine haud brevior, lateribus parallelis, rectis, basi cum angulis posterioribus rotundatus, apice truncatus, angulis anterioribus rectis, supra parum convexus, confertissime punctatus, linea longitudinali media laevi medio obsoleta, tenuius fulvescentipubescens, vel aeneus, vittis duabus irregularibus ferrugineis, vel testaceus, vittis tribus longitudinalibus inaequalibus nigro-aeneis, lateralibus brevioribus, arcuatis. Scutellum nigro-subaeneum, nigro-tomentosum, basi utrinque cinereo-pubescens. Elytra thorace paulo longiora, subtiliter punctata, ferruginea vel testacea, fulvescenti-pubescentia, fusco-substrigosa. Abdomen nigrum, griseo-pubescens, subtus segmentis singulis macula laterali basali testacea, segmentis rectractis occulta. Pectus nigrum, flavescenti-pubescens. Pedes testacei, coxis nigris, femoribus anterioribus disco anteriore et posteriore nigro, posticis bas lineola dorsali nigra. Alae fusco-hyalinae. 
* 52. St. fossor: Niger, capile thoraceque brunneo-rufis, tibiis, tarsis elytrisgue rufo-testaceis, his apice dilutioribus, flavo-pubescentibus, scutello atro-tomentoso, abdomine variegato. - - Long. 8 lin.

Scop. Ann. hist. nat. V. 109. 105. - Goeze Ent. Beitr. I. 725. 17. - Fah. Ent. Syst. I. II. 523. 16. Syst. El. II. 593. 18. - Panz. Ent. Germ. 353. 12. Faun. Germ. 27. 6. - Grav. Micr. 10. 9. Mon. 117. 136. - Latr. Hist. nat. Crust. et Ins. IX. 299. 12. - Nordm. Symb. 60. 43.

Emus fossor Boisd. et Lacord. Faun. Ent. Paris. I. 367. 11.

Staph. erythropterus var. 2 Scop. Ent. Carn. 101. 306.

Staph. fodiens Grav. Mon. 116. 134. - Nordm. Symb. 62. 45.

Habitat in Europa temperata.

Antennae capitis thoracisque prope longitudine, articulo tertio secunclo paulo longiore, sequentibus sensim paulo brevioribus, penultimo vix transverso, ultimo apice inferne acuminato, nigrae, apicem versus picescentes, articulo ultimo ferrugineo. Palpi picei, apice rufi. Caput thoracis latitudine, suborbiculatum, supra parum convexum, confertissime subtiliter punctatum, brunneo-rufum, opacum, brevissime fulvo-pubescens, subtus nigrum, nitidum. Thorax coleopteris angustior, latitudine antica paulo longior, basin versus subangustatus, lateribus ante medium leviter rotundatis, pone medium subsinuatis, basi leviter, angulis posterioribus fortius rotundatis, apice truncatus, angulis anterioribus subrectis, deflexis, parum convexus, subtiliter obsoleteque carmatus, confertim subtiliter punctatus, opacus, brunneo-rufus, pube brevissima fulvo-sericans. Scutellum atro-tomentosum. Elytra thorace vix longiora, confertissime subtiliter punctata, opaca, dilutius brunneo-rufa, fulvo-pubescentia, apice oblique dilutiora et densius flavo-aureo-pubescentia. Abdomen nigrum, supra subtilissime brevissimeque nigro-tomentosum, segmentis singulis basi macula minuta triangulari aureo-tomentosa terminata, subtus segmentis $2-\mathbf{4}$ fascia basali cinereo-pubescente, nitida. Pectus nigrum. Pedes nigri, tibiis tarsisque rufo-testaceis.

Obs. Staph. fodiens Grav. e Carolina a St. fossore Europaeo nullo modo distinctus videtur. Gravenhorst ipse dubius hanc speciem separavit, neque ulla ex eius descriptione differentia patet. Constat varias huius familiae species Europae et Americae septentrionali communes esse. Fortasse etiam specimen collectionis Boscianae, a Gravenhorstio descriptum, patria falsa notatum fuit.

* 53. St. erythropterus: Niger, opacus, antennarum basi apiceque, elytris pedibusque rufis, scutello maculisque posterioribus abdominis orichalceo-tomentosis. - Jong. $6-7 \mathrm{lin}$.

Linn. Faun. Suec. n. 842. Syst. Nat. I. II. 683. 4. - Ström. Act. Nidros. III. 404. 26. $t$. 6. f. 8. - De Geer. Ins IV. 21. 6. - Mïll. Faun. Frid. 23. 223. Prodr. 97. 1092. - Goeze Ent. Beitr. I. 716. 4. - De Vill. Ent. I. 411. 4. - Oliv. Ent. III. 42. 12. 10. t. 2. f. 14. - Cederh. Fuun. Ingr. 117. 358. - Er. Col. March. I. 434. 6.

Staph. erythrapterus var. Fab. Ent. Syst. I. II. 522. 14.

Staph. castanopterus Grav. Micr. 10. 10. Mon. 116. 132. - Latr. Hist. nat. Crust. ot Ins. IX. 298. 10. - Gyll. Ins. Suec. II. 295. 14. - Zetterst. Faun. Lappon. I. 68. 4. Ins. Lappon. 60. 5. - Suhlb. Ins. Fenn. I. 312. 12. - Mannerh. Brachelytr. 22. 3. - Nordm. Symb. 55. 36. - Runde Brachelytr. Hal. 2. 2.

Habitat in Europa. 
Niger, opacus. Antennae capite thoraceque paululum breviores, articulo secundo tertio paulo breviore, 4-10 sensim paulo brevioribus, 4-7 subcylindricis, 8-10 obconicis, hoc vix transverso, ultimo apice inferne acuminato, fuscae, basi apiceque rufae.-Palpi ruf. Caput thorace latius, orbiculatum, supra subdepressum, subtliter confertim punetatum, fronte posterius subtilissime carinata, anterius inter oculos pedunculoque orichalceopubescentibus. Thorax coleopteris angustior, latitudine paulo longior, basin versus subangustatus, lateribus modice subsinuatis, basi cum angulis posterioribus rotundatus, apice truncatus, angulis anterioribus subrectis, leviter deflexis, leviter transversim convexus, confertim subtiliter punctatus, uti caput brevissime subtiliter nigro-pubescens. Scutellum orichalceo-tomentosum. Elytra thoracis longitudine, subtiliter punctata, rufa, rufo-pubescentia. Abdomen confertim subtilissime punctatum, subtiliter nigro-pubescens, supra segmento primo, quarto, quinto sextoque utrinque macula; subtus segmentis ultimis tribus fascia basali interrupta aurichalceo-tomentosa ornatis. Pectus parapleuris orichalceo-tomentosis. Pedes rufi, coxis nigris.

$\mathrm{Obs}$. Hunc verum $\mathrm{Staph}$. erythropterum Linnei esse edescriptione sua satis patet.

* 54. St. caesareus: Niger, opacus, elytris pedibusque rufis, untennis testaceis, apice fuscis, scutello atro-tomentoso, thorucis margine poste. riore maculisque abdominis orichalceo-tomentosis. - Long. 8 -9 lin.

Cederh. Faun. Ingr. 335. 1055. t. 3. f. c. - Fr. Col. March. I. 435.7.

Staph. erythropterus Fab. Syst. Ent. 265. 5. Spec. Ins. I. 335. 5. Mant. Ins. I. 220. 8. Ent. Syst. I. II. 522. 14. Syst. El. II. 593. 16. - Schrank linum. Ins Aust. 230. 435. Faun. Boica. I. 640. 862. - Harrer Beschr, d. Ins. I. 150. 114. - Foucr. Ent. Par. I. 166. 9. - Walken. Faun. Paris. I. 270. 7. - Donov. Britt. Ins. IX. t. 308. - Rossi Faun. Etrusc. I. 247. 609. Ed. Hellw. I. 306. 609. - Payk. Mon. Staph. 7. 3. Fuun. Suec. III. 369. 3. - Panz. Faun. Gierm. 27. 1. Ent. Gierm. 353. 10. t. 12. f. 10. - Marsh. Ent. Britt. 499. 6. - Grav. Micr. 10. 11. Mon. 116. 133. - Latr. Hist. nat. Crust. et Ins. IX. 297. 9. Gen. Crust. et Ins. I. 297. 2. - Gyll. Ins. Suec. II. 293. 13. - Zetterst Faun. Lappon. I. 68. 3. Ins. Lappon. 59. 4. - Sahlb. Ins. Fenn. I. 311. 11. - Mannerh. Brachelytr. 22. 2. Nordm. Symb. 55. 37. - Runde Brachelytr. Hal. 2. 1.

Emus erythropterus Boisd. et Lacord. Faun. Ent. Paris. I. 365. 8.

Staph. erythropterus var. 1. Scop. Ent. Carn. 101. 306.

Le St aph. à étuis couleur de rouille Geoffr. Hist. Ins. I. 364. 9.

Staph. primus Schaeff. Icon. I. t. 2. f. 2. Elem. Ent. t. 11\%.

Habitat in Europa.

Niger, opacus. Antennae capite thoraceque breviores, articulo tertio leviter elongato, secundo paulo longiore, sequentibus subobconicis, sensim paulo brevioribus, penultimis duobus vel tribus transversis, ultimo apice leviter emarginato et inferne acuminato, testaceae, apice fuscae. Palpi testacei. Caput thoracis latitudine, suborbiculatum, supra subdepressum, subtilius confertissime punctatum, breviter subtiliterque nigro-pubescens, fronte posterius subtilissime carinata, antice, pone oculos pedunculaque orichalceopubescens. Thorax coleopteris paulo angustior, latitudine perparum longior, lateribus vix rotundatis, pone medium subsinuatis, basi cum angulis posterioribus rotundatus, apice utrinque subsinnatus, angulis anterioribus subrotundatis, leviter transversim convexus, subtiliter confertissime punçta- 
tus, longitudinaliter subtilissime carinatus, brevissime subtiliter nigro-pubescens, margine posteriore orichalceo-tomentoso. Scutellum atro-tomentosum, margine laterali basi orichalceo-pubescente. Elytra thorace paulo longiora, confertissime subtiliter punctata, rufa, rufo-pubescentia. Abdomen subtilissime confertissimeque punctatum, subtiliter nigro-pubescens, supra segmento primo margine apicali, sequentibus quatuor macula laterali obliqua, subtus omnibus, primo excepto, macula utrinque transversali hasali orichalceo-tomentosa. Pectus apice orichalceo-pubescens, lateribus utrinque maculis duabus orichalceo-tomentosis. Pedes rufi, coxis nigris.

Variat antennis totis testaceis.

Obs. Staph. aeneocephalus Panz. Faun. Germ. 27. 5, elytris fuscis, havid differe videtur.

55. St. vulpinus: Niger, supra ferrugineo-pubescens, capite supra obscure rufo, antennarum basi, pedibus, elytris anoque rufis, scutello atro-tomentoso, abdomine flavo- tomentoso-submaculato. - Long. $8 \frac{1}{2}$ lin.

Nordm. Symb. 53. 34.

St aph. immaculat us Mannerh. Brachelytr. 22. 7.- Nordm. Symb. 62. 48. (forte)

Habitat Philadelphiae, Kinn.

Statura omnino St. maculosi et parum minor. Antennae capite paulo longiores, articulo tertio secundo paulo breviore, sequentibus sensim paulo brevioribus, penultimo autem non transverso, ultimo apice truncato et inferne acute acuminato, fuscae, basi rufae. Palpi rufi. Mandibulae nigrae. Caput thoracis latitudine, oblongum, antrorsum subangustatum, supra perparum convexum, fortius confertim punctatum, supra os impressum, obscure rufum, macula minuta mediae frontis nigricante, ferrugineo-pubescens, subtus nigrum, nitidum, glabrum. Thorax coleopteris parum angustior, latitudine paulo brevior, lateribus subrectis, parallelis, basi cum angulis posterioribus fortiter rotundatus, apice truncatus, angulis anterioribus rectis, leviter transversim convexus, confertim punctatus, subtiliter carinatus, niger, opacus, dense ferrugineo-pubescens. Scutellum nigro-tomentosum. Elytra thorace parum longiora, subtiliter dense punctata, rufa, ferrugineo-pubescentia. Abdomen nigrum, supra subtilissime nigro-tomentosum, segmentis 4 primis macula utrinque obliqua, minus distincta, pubescente orichalcea, margine laterali apicalique ferrugineo-pubescentibus, subtus flavo-pubescentibus, apice ferrugineo-marginatis, segmento sexto toto rufo. Pectus orichalceo-pubescens. Pedes rufi, coxis nigris, anticis apice rufescentibus.

Obs. Descriptio Mannerheimiana supra citata nimis manca: „Linearis, rufopiceus, opacus, abdomine obscuriore, subtiliter punctulatus, antennis, eapite, pedibus, elytris anoque rufo - cinnabarinis, pectore segmentorumque abdominalium marginibus flavo-aureis. - Statura St. lutarii, sed maior, magis linearis et aliter coloratus.".

*56. St. castaneus: Niger, supra ferrugineo-pubescens, capite obscure rufo, antennarum basi, elytris, pedibus anoque rufis, scutello atro-1omentoso. - Long. 8 lin.

Nordm. Symb. 54. 35.

Habitat in Mexioo, Dom. Deppe. 
Statura et summa affinitas praecedentis, niger, opacus. Antennae capite parum longiores, articulo tertio secundo sesqui prope longiore, quarto subgloboso, $5-10$ sensim paulo brevioribus, $7-10$ transversis, ultimo apice truncato et inferne acuminato, nigrae, basi rufae. Palpi rufi. Caput thoracis prope latitudine, antrorsum subangustatum, supra subdepressum, subtiliter confertissime punctatum, obscure rufum, ferrugineo-pubescens, subtus nigrum, nitidum. Thorax coleopteris paululum angustior, latitudine parum brevior, lateribus subrectis, basi cum angulis posterioribus fortiter rotundatus, apice truncatus, angulis anterioribus rectis, transversim convexus, confertissime subtililer punctatus, postice carinula subtili polita, ferrugineo-pubescens. Scutellum atro-tomentosum. Elytra thorace vix longiora, confertissime subtiliter punctata, rufa, rufo-pubescentia. Abdomen supra nigrum, subtiliter fusco-pubescens, e pube nigra bifariam maculatum, margine laterali elevato segmentique quinti margine apicali obscure rufo, subtus parcius pubescens, segmentis singulis rufo-marginatis, segmento sexto toto obscure rufo. Pectus fulvo-pubescens. Pedes rufi, coxis nigris, anticis rufescentibus.

* 57. St. phoеnicurus: Niger, nigro-pubescens, scutello atro-tomentoso, elytris anoque rufis, rufo-pubescentibus. - Long. 7 lin.

Nordm. Symb. 57, 40.

\section{Habitat in Mexico, Dom. Deppe.}

Statura omnino St. stercorarii et maioribus eius individuis aequalis. Niger, opacus. Antennae capite sesqui longiores, articulo secundo tertio dimidio prope breviore, 4-10 subobconicis, sensim paulo brevioribus, penultimis vix transversis, ultimo apice truncato et inferne acuminato, nigrae, articulo ultimo obscure ferrugineo. Palpi picei. Caput thoracis latitudine, antrorsum subangustatum, supra perparum convexum, confertim minus subtiliter punctatum, carinula longitudinali tenuissima antice abbreviata, nigro-pubescens. Thorax coleopterorum prope latitudine, latitudine vix brevior, lateribus parum, basi cum angulis posterioribus fortiter rotundatis, apice truncatus, angulis anterioribus rectis, leviter transversim convexus, minus subtiliter confertissime punctatus, subtiliter carinatus, nigro-pubescens. Scutellum atrotomentosum. Elytra thorace vix longiora, confertissime subtiliter punctata, rufa, rufo-pubescentia. Abdomen subtiliter punctulatum, nigro-pubescens, supra e pube densiore bifariam nigro-maculatum, segmento sexto toto rufo. Pedes nigri.

* 58. St. stercoraxius: Niger, capite thoraceque nigro-pubescentibus, antennarum basi elytris pedibusque rufis, scutello alro-tomentoso, abdomine cinereo - sericeo-maculato. - Long. 6-8 lin.

oliv. Ent. III. 42. 18. I8 t 3. f. 23. - Latr. Hist. nat. Crust. et Ins. IX. 299. 11. - Marsh. Ent. Britt. 499. 7. - Grav. Micr. 11. 12. Mon. 115 . 130. - Gyll. Ins. Suec. II. 296. 15. - Sahlb. Ins. Fenn. I. 312. 13. - Mannerh. Brachelytr. 22. 4. - Nordm. Symb. 55. 38. - Runde Brachelytr. Hal. 2. 3. - Er. Col. March. I. 436. 8.

Emus stercorarius Boisd. et Lacord. Faun. Ent. Paris. I. 366. 10.

Ilabitat in Europa.

St. erythroptero plerumque paulo minor, praecipue angustior et magis 
parallelus, niger, opacus. Antennae capite paulo longiores, articulo tertio secundo longiore, $6-10$ transversis, subaequalibus, ultimo apice truncato et inferne acuminato, rufae, extrorsum piceae. Palpi rufi. Caput thoracis latitudine, antrorsum leviter angustatum, supra subdepressum, sat crebre punctatum, dense nigro-pubescens. Thorax coleopterorum fere latitudine, latitudine paulo brevior, lateribus subrectis, parallelis, basi cum angulis posterioribus rotundatus, apice truncatus, angulis anterioribus rectis, supra parum convexus, confertim punctatus, carinula postica polita iam infra medium abbreviata, dense nigro-pubescens. Scutellum-atro-tomentosum. Elytra thoracis longitudine, subtuliter punctulata, rufa, rufo-pubescentia. Abdomen supra subtilissime brevissimeque nigro-tomentosum, segmentis quatuor primis macula obliqua laterali, ultimis duobus fascia lata basali cinereo- sericeo-tomentosis, subtus segmentis omnibus fascia basali cinereo-sericeopubescente. Pedes breves, rufi, coxis nigris, anticis subtus rufis.

* 59. St. lutarius: Niger, capite thoraceque supra aeneis, fulvo-pubescentibus, antennis, elytris, tibiis tarsisque rufis, scutello atro-tomentoso, abdomine cinereo - sericeo-maculato, - Long. 8 lin.

Grav. Mon. 115. 131. - Mannerh. Brachelytr. 23. 8. - Nordm. Symb. 58. 41. Staph. flavopunctat us Latr. Hist nat. Crust. et. Ins. IX. 297. 8.

Habitat in Austria.

Niger, capite thoraceque supra aeneis. Antennae capite vix longiores, articulo tertio secundo aequali, sequentibus transversis, sensim magis obconicis, ultimo transverso, apice emarginato et inferne acuminato, rufo-testaceae, apice fuscescentes. Palpi testacei. Caput thorace paulo mimus et angustius, subtriangulare, supra subdepressum, dense punctatum, fulvo-pubescens, subtus nigrum, parce nigro-pubescens. Thorax coleopterorum prope latitudine, latitudine paulo brevior, antrorsum subangustatus, lateribus subrectis, basi cum angulis posterioribus rotundatus, apice truncatus, angulis anterioribus rectis, supra parum convexus, dense punctatus, fulvo-pubescens. Scutellum macula magna rotundata apicali atro-holosericea. Elytra thorace paulo longiora, subtiliter crebre punctata, rufa, fulvo-pubescentia. Abdomen breviter subtiliterque nigro-tomentosum, supra segmentis tribus primis basi maculıs tribus, quarto quintoque fascia, subtus segmentis omnibus, ultimo excepto, fascia basali cinereo-tomentosis, argenteo-nitidulis. Pectus nigrum, cinereo-pubescens. Pedes nigri, femoribus apice, tibiis tarsisque omnibus rufis.

V ariat femoribus magis minusve nigris.

* 60. St. chalcocephalus: Niger, cupite thoraceque supra aeneis, fulvescenti-pubescentibus, elytris, tibiis larsisque mifis, scutello atro-tomentoso, abdomine cinereo-sericeo-maculato. - Long. 7 lin.

Fab. Syst. El. I1. 593. 17. - Er. Col. March. I. 436. 9.

Staph. aeneocephalus Fab. Ent. Syst. I. II. 522. 17. - Panz. Ent Germ. 353. 11. Staph. ochropterus Germ. Spec. Ins. 34. 5i. Faun. Ins. Europ. VIII. 14. Nordm. Symb. 59. 42.

Emus Carinthiacus Boisd, et Lacord. Faun. Ent, Paris. I. 365. 9.

Habitat in Germania, Borussia, Gallia. 
Niger, capite thoraceque supra aeneis. Antennae capite sesqui longiores, articulo tertio secundo sesqui prope longiore, sequentibus sensim paulo brevioribus, 7-10 transversis, ultimo apice truncato et inferne acuminato, nigrae, apice interdum picescentes. Palpi rufi. Caput thorace minus et angustius, subtriangulare, supra subdepressum, confertim sat fortiter punctatum, fulvo-pubescens. Thorax basi coleopterorum latitudine, latitudine vix brevior, antrorsum subangustatus, lateribus perparum, basi et angulis posterioribus fortiter rotundatis, apice truncatus, angulis posterioribus subrectis, perparum convexus. confertim sat fortiter punctatus, basi carinula abbreviata polita, fulvo-pubescens. Scutellum atro-tomentosum. Elytra thorace vix longiora, subtiliter punctulata, rufa, fulvo-pubescentia. Abdomen supra subtilissime brevissimeque nigro-tomentosum, segmentis anterioribus quatuor basi maculis tribus, ultimis duobus fascia cinereo-sericeo-tomentosis, illis inter maculas brunneo-tomentosis, subtus segmento singulo fascia basali cinereo - sericeo - tomentosa. Pedes nigri, tibiis tarsisque rufis.

Obs. Staph. latebricolae specim. Boruss. Grav. Mon. p. 115. ad hanc speciem pertinet.

-61. St. latebricola: Niger, capite thoraceque supra aeneis, fulvescenlipubescentibus, elytris pedibusque rufis, scutello atro-tomenioso, abdomine cinereo - sericeo-maculato. - Long. $5 \frac{1}{2}$ lin.

Grav. Mon. 113. 129. - Nordm. Symb. 56. 39. - Er. Col. March. 1. 437. 10. a Dahlio.

Habitat in Germania, Brunsvigae in acervis formicarum rufarum lectus

Niger, capite thoraceque supra aeneis. Antennae capite sesqui Iongiores, articulo tertio secundo paulo longiore, 6-10 transversim subobconicis, aequalibus, ultimo crassitie haud breviore, apice truncato et inferne acuminato, piceae, basi nigrae. Palpi piceae. Caput thorace vix angustius, subquadratum, fulvescenti-pubescens. Thorax coleopterorum prope latitudine, latitudine vix brevior, lateribus subrectis, antrorsum subangustatus, apice truncatus, angulis anterioribus rectis, basi cum angulis posterioribus rotundatus, leviter convexus, dense profunde punctatus, carinula postica laevi, fulvescenti-pubescens. Scutellum atro-tomentosum. Elytra thorace vix longiora, subtiliter punctulata, rufa, fulvo-pubescentia. Abdomen supra subtilissime brevissimeque nigro-tomentosum, segmentis quatuor primis basi maculis tribus, ultimis duobus, ut subtus omnibus fascia cinereo- sericentomentosis. Pedes rufi, coxis trochanteribusque nigris, femoribus anticis basi piceis.

$\mathrm{Obs}$. Praecedenti valde affinis, differt autem statura minore et angustiore, thorace minus lato, capite minus triangulari, minus confertim punctato, femoribus posterioribus totis rufis.

*2. St. fulvipes: Niger, opacus, capile, thorace elytrisque obscure cyaneis, abdomine segmentis ultimis duobus basi cinereo-tomenlosis, antennis basi apiceque pedibusque rufis. - Long. 6 - 7 lin.

Scop. Ent. Carn. 99. 301. - Goeze Ent. Beitr. I. 725. 12. - Er. Col. March. I. 438. 11.

Staph. bicinctus Rossi Faun. Etr. I. Mant. 96. 216. Ed. Hellw. 442. 216. - Block

Ins. Vull. Plauens, 115. 3. f. 3. 
St uph. erythropus Payk. Fuun. Suec. III. 372. 7. - Gyll. Ins. Suec. II. 290. 11. - Sahlb. Ins. Fenn. I. 310. 8. - Germ. Faun. Ins. Europ. VI. 14. - Mannerh. Brachelytr. 24. 22. - Nordm. Symb. 73. 71. - Runde Brachelytr. IIal. 4. 15. Staph. tricolor Grav. Micr. 7. 6. Mon. 110. 113. - Latr. Hist. nat. Crust. et Ins. IX. 305. 20.

St aph. azureus Gebl. Ledebour. It. Append. III. 70. 4.

Habitat in Europa et Sibiria, ubique rarus.

Statura fere St. chalcocephali, at paulo angustior. Antennae capite thoraceque parum breviores, articulo tertio secundo parum longiore, sequentibus sensim paulo brevioribus, penultimis etiam crassitie haud brevioribus, ultimo apice subemarginato et inferne acuminato, nigrae, articulis duobus basalibus duobusque apicalibus rufis. Palpi rufi. Caput thorace minus, subtriangulare, supra subdepressum, crebre sat profunde punctatum, nigro-subcyaneum vel subvirescens, parum nitidum, nigro-puhescens. Thorax coleopterorum latitudine, latitudine paululum brevior, lateribus vix rotundatus, antrorsum subangustatus, apice truncatus, angulis anterioribus subrectis, basi cum angulis posterioribus rotundatus, parum convexus, creberrime punctatus, nigro-cyaneus, breviter nigro-pubescens. Scutellum nigrum, nigrotomentosum. Elytra thorace haud longiora, punctato-subrugulosa, nigropubescentia, cyanea vel virescentia, nigro-pubescentia. Abdomen nigrum, nigro-pubescens, supra segmentis ultimis duobus fascia e tomento subtili albido-cinereo, argenteo-micante. Pectus nigrum. Pedes ruf, coxis nigris.

Obs. Abdomine contracto fasciae haud conspicuae.

* 63. St. Buquetii: Niger, capite, thorace elytrisque nigro-cyaneis, opacis, subliliter atro-tomentosis, alis fuscis. - Long. 10 - 12 lin.

Laporte Etud. Ent. I. 114. 2.

Staph. atrox Nordm. Symb. 38. 19.

Habitat in Brasilia.

Magnus, robustus, niger, subtus subnitidus, supra opacus, capite, thorace elytrisque obscure cyaneis, tomento subtili brevissimo nigro-sericante vestitus. Antennae capite paulo longiores, tenuiores, subcompressae, articulo tertio secundo sesqui longiore, 4-10 sensim paulo brevioribus, 8-10 leviter transversis, ultimo apice profunde emarginato et inferne acuminato, nigrae, articulis 4 primis nigro-pilosellis, reliquis dense subtilissime cinereopubescentibus. Caput thoracis latitudine, antrorsum subangustatum, supra subdepressum, subtiliter confertissime punctatum. Thorax coleopteris paulo angustior, latitudıne paulo brevior, lateribus rectis, parallelis, basi cum angulis posterioribus rotundatus, apice truncatus, angulis anterioribus rectis, parum convexus, subtiliter confertissime punctatus, postice carinula tenuissima parum distıncta. Scutellum spissius atro-tomentosum. Elytra thorace longiora, omnium confertissime subtilissime alutacea. Abdomen supra densius nigro-pubescens, tomento atro bifariam maculatum. Pedes nigri. Alae fuscae, violaceo - nitidae.

Obs. Prof. Nordmann errore quodam Mexico huius insecti patriam affert. 
* 64. St. ferox: Niger, capite, thorace elytrisque cyaneis, subtiliter nigrotomentosis, alis fulvis. - Long. 10 lin.

Nordm. Symb. 39. 20.

Habitat Jalappae in Mexico, Dom. Deppe.

Statura et summa similitudo praecedentis. Niger, subtus subnitidus, supra capite, thorace elytrisque saturate cyaneis, opacis, subtiliter tenuiterque nigro-holosericeis. Antennae capite paulo longiores, árticulo tertio secundo sesqui longiore, 4-10 sensim brevioribus, $8-10$ fortiter transversis, ultimo transverso, apice profunde emarginato et inferne acuminato, nigrae. Caput thoracis fere latitudine, subquadratum, supra subdepressum, confertissime subtiliter punctatum. Thorax coleopteris paulo angustior, latitudine vix brevior, lateribus antice rectis, postice cum angulis posterioribus et basi rotundatis, apice truncatus, utrinque subsinuatus, angulis anterioribus acutiusculis, leviter transversim convexus, subtiliter confertissime punctatus, postice carinula tenui laevi. Scutellum atro-holosericeum. Elytra thorace paululum longiora, confertissime subtilissime punctato-rugulosa. Abdomen supra densius nigro-pubescens, tomento atro bifariam maculato. Pedes nigri. Alae fulvo-luteae, nitidae.

* 65. St. fulvomaculatus: Niger. capite, thorace elytrisque cyaneis, opacis, subtiliter atro-tomentosis, elytris macula magna laterali auranliaca, alis fulvis. - Kong. $12-14$ lin.

Nordm. Symb. 39. 21.

Habitat Jalappae in Mexico, Dom. Deppe.

Statura omnino et similitudo St. Buquetii, niger, capite, thorace elytrisque supra saturate cyaneis, parum nitidis, supra subtiliter nigro-tomentosus. Antennae capite haud longiores, subcompressae, articulo tertio secundo paulo longiore, sequentibus omnibus transversis, sensim brevioribus, ultimo apice emarginato et inferne acuminato, nigrae. Palpi nigro-picei. Mandibulae nigrae. Caput thoracis latitudine, transversim subquadratum, antrorsum subangustatum, supra parum convexum, confertim subtilissine punctatum. Thorax coleopteris paulo angustior, latitudine haud brevior, basin versus subangustatus, lateribus pone medium subsinuatis, basi fortiter rotundatus, apice truncatus, angulis anterioribus deflexis, subrotundatis, posterioribus obtusis, modice transversim convexus, confertissime subtiliter punctatus. Scutellum nigrum, nigro-tomentosum. Elytra thoracis longitudine, confertissime subtiliter punctato-subrugulosa, macula magna laterali ovata aurantiaca notata. Abdomen apicem versus sensim angustatum, creberrime subtiliter punctulatum, tenuiter nigro-pubescens, dorso e tomento densiore bifariam nigro-maculato. Pedes nigri. Alae fulvae, fusco-marginatae.

Mas abdominis segmento inferiore quinto scopo medio longitudinali atro-piloso instructo.

* 66. St. nobilis: Niger, capite thoraceque cyaneis, nitidis, elytris fulvis, margine laterali nigro. - Long. 9 lin.

Nordm. Symb. 41. 22.

St a ph. chrysopterus Brullé D'Orbigny It. Am. mer. Ins. t. V. f.8. (forte)

Ilabitat Cassapavae in Brasilia, Sellow. 
Corpus nigrum, subnitidim. Antennae capitis longitudine, articulo tertio secundo longiore, 4-10 fortiter transversis, 5-10 aequalibus, ultimo apice profunde emarginato et inferne acuminato, nigrae, articulis 4 primis nigro-pilosellis, reliquis tomento subtilissino fusco-cinereo dense obductis. Caput thorace paulo angustius, apicem versus sensim angustatum, subtriangulare, cyaneum, nitidum, supra perparum convexum, densius subtiliusque punctatum, tenuiter nigro-pubescens pilosusque, subtus nigrum. Thorax colenpterorum latitudine vel basi eadem paululum superans, latitudine baseos brevior, antrorsum angustatus, lateribus parum, basi fortiter rotundatus, apice truncatus, angulis anterioribus leviter deflexis, subrectis, posterioribus obtusis, subrotundatis, supra leviter transversim convexus, cyaneus, nitidus, subtiliter punctatus, tenuiter nigro-pubescens pilosusque. Scutellum nigrum, dense nigro pubescens. Elytra thorace paulo longiora, fulvo-aurea, pube depressa fulva nitida dense vestita, margine basali aeneo, margine laterali inflexo nigro, lateribua longe nigro-pilosella, apice nigro-ciliata. Abdomen punctulatum, nigro-pubescens, subtus metallico-versicolor. Pedes validiusculi, nigri, nigro-pubescentes. Alae fuscae, nitidae.

* 67. St. erythrocnemus: Niger, opacus, capite, thorace elytrisque nigrosubaeneis, fulvo-pubescentibus, his margine laterali fusco-tesluceo, scutello atro-tomentoso, tibiis tarsisque rufis. - Long. 9 lin.

Nordm. Symb. 42.24.

\section{Habitat ad Promont. Bonae Spei, Krebs.}

Statura et prope magnitudo St. maculosi, niger, opacus. Antennae capite vix longiores, articulo tertio secundo paulo longiore, 4-10 sensim brevioribus, $6-10$ transversis, ultimo apice profunde emarginato et inferne acuminato, nigrae. Palpi picei. Caput basi prope thoracis latitudine, antrorsum angustatum, supra parum convexum, confertissime punctatum. Thorax coleopterorum prope latitudıne, latitudine vix brevior, lateribus subrectis, parallelis, basi cum angulis posterioribus fortiter rotundatus, apice truncatus, angulis anterioribus rectis, supra parum transversim convexus, confertissime punctatus, linea media longitudinalı laevi. Elytra thorace vix longiora, subtiliter punctata. Caput, thorax et elytra supra pube crassiuscula densa fulvo-aurea vestita, nigro-subaenea, elytra margine laterali fusco-testaceo. Scutellum atro-tomentosum. Abdomen supra subtiliter nigro-tomentosum, e tomento atro bifariam maculatum, subtus segmentis singulis fascia basali cinereo-pubescente micante. Pedes nigri, tibiis tarsisque testaceo-rufis. Alae fulvo-hyalinae.

* 68. St. dimidiatus: Niger, opacus, capite thoraceque supra aenei., dense ferrugineo-pubescentibus, scutello atro-tomentoso, antennis, tibiis tarsisque rufis. - Long. 9 lin.

Laporte Etud. Ent. 115. 4.

Staph. velutinus Nordm. Symb. 44. 25.

Habitat ad Promont. Bonae Spei, Krebs.

Statura omnino praecedentis, at minus robustus, ater, opacus. Antennae capite parum longiores, articulo tertio secundo paulo longiore, 4-10 sensim brevioribus, $6-10$ transversis, ultimo apice emarginato et inferne 
acuminato, totae testaceo-rufae. Palpi rufi. Caput basi thoracis latitudine, apicem versus leviter angustatum, supra leviter convexum, confertissime punctatum, aeneo-cupreum, dense ferrugineo-pubescens, subtus nigrum, nitidum. Thorax coleopteris paulo angustior, latitudine haud brevior, lateribus subrectis, parallelis, basi cum angulis posterioribus rotundatus, apice truncatus, angulis anterioribus rectis, supra leviter transversim convexus, confertissime punctatus, linea media longitudinali laevi, aeneo-cupreus, dense ferrugineo-pubescens, lateribus nigro-pilosellus. Scutellum atro-tomentosum. Elytra thorace paulo longiora, confertissime subtilissimeque punctatorugulosa, nigro-pubescentia. Abdomen dense nigro-pubescens, dorso e tomento atro bifariam maculatum. Pedes nigri, tibiis tarsisque testaceo-rufis.

*69. St. Dauricus: Niger, capite thoraceque subaeneis, fulvo-pubesrentibus, scutello atro-tomentoso, elytris, tibiis tarsisque testaceis. - Long. $8-9$ lin.

Mannerh. Brachelyir. 22. 5. - Nordm. Symb. 62. 46.

Habitat in Sibiria, sub cortice arborum corruptarum et sub fimo sicco, Pallas. Dedit Dom. Schüppel.

Statura fere St. maculosi et minoribus eius individuis aequalis, at paulo brevior, niger, parum nitidus, capite thoraceque supra aeneis. Antennae capite vix longiores, articulo tertio secundo haud longiore, sequentibus sensim paulo brevioribus, $6-10$ transversis, ultimo his angustiore, apice emarginato et inferne acuminato, nigrae. Caput maris thoracis latitudine, feminae eodem angustius et minus, antrorsum angustatum, subtriangulare, supra subdepressum, confertissime punctatum, nigro-subaeneum, pube brevi fulva dense vestitum, subtus nigrum, nitıdum. Thorax coleopteris parum angustior, latitudine vix brevior, basin versus subangustatus, lateribus perparum, angulis posterioribus et basi fortiter rotundatus, apice truncatus, angulis anterioribus rectis, supra leviter transversim convexus, confertissime subtilius punctatus, posterius carinula abbreviata polita notatus, nigro-subaeneus, minus nitidus, pube brevi fulva pubescens. Scutellum atro-tomentosum. Elytra thorace paulo longiora, confertim subtiliter punctata, fulvo-pubescentia, rufa, obsolete fusco-maculosa. Abdomen nigro-pubescens, segmentis duobus primis fulvo-ciliatis. Pectus flavescenti-pubescens. Pedes nigri, tibiis tarsisque rufis.

* 70. St. fossator: Niger, opacus, nigro-pubescens, elytris macula apicis aureo-tomentosa. - Long. 7 lin.

Grav. Micr. 164. 12. Mon. 117. 135. - Nordm. Symb. 52. 33.

Habitat in America septentrionali, Knoch.

Statura et magnitudo omnino St. chalcocephali, niger, opacus, pube brevi depressa nigra vestitus. Antennae articulo tertio secundo panlo longiore, 6 - 10 transversis, aequalıbus, ultimo apice emarginato et inferne acuminato, nigrae. Palpi picei. Caput thorace paulo angustius, subtriangulare, supra subdepressum, fortius confertim punctatum. Thorax basi coleopteris parum angustior, latitudine vix brevior, antrorsum subangustatus, lateribus perparum, basi cum angulis posterioribus fortius rotundatus, apice truncatus, 
angulis anterioribus rectis, subdepressus, confertım fortius punctatus, postice carinula brevi polita. Scutellum atro-tomentosum. Elytra thorace vix longiora, parcius subtiliter punctata, opaca, macula magna apicali, suturam haud attingente, aureo-tomentosa. Abdomen supra parce subtiliterque punctulatum,' subtus parce pubescens. Pedes nigri.

Obs. Elytra in nostro specimine obscure fusca, in specime altero melius conservato autem, a Dom. Hope benevole communicato, corpori concolora.

* 71. St. a urifluus: Niger, capile thoraceque supra cyaneis, elytris brunneis, apice aureo-tomentosis. - Long. 7 lin.

Habitat in Brasilia, Dom. Prof. Germar.

Statura ommino praecedentis. Antennae capite sesqui longiores, tenuiores, articulo secundo tertioque modice elongatis, hoc longiore, sequentibus sensim paulo brevioribus, penultimis tribus transversis, ultimo apice truncato et inferne acuminato, nigrae. Caput thoracis latitudine, antrorsum vix angustatum, angulis posterioribus tumidulis, supra subdepressum, crebre punctatum, cyaneum, subnitıdum, subtiliter tenuiterque nigro-pubescens, ore nigro, subtus nigrum, nitidum. Thorax coleopteris angustior, latitudine hand brevior, lateribus subrectis, parallelis, basi cum angulis posterioribus rotundatus, apice truncatus, angulis anterioribus obtusiusculis, supra parum convexus, dense minus subtiliter punctatus, posterius linea tenui abbreviata subelevata laevi, cyaneus, subnitidus, densius nigro-pubescens, lateribus parce nigro-pilosellus. Scutellum atro-tomentosum. Elytra thorace paulo longiora, obsoletius punctata, brunnea, humeris et lateribus inflexis dilutioribus, dorso nigricantia, subtiliter nigro-pubescentia, apice aureo-tomentosa. Abdomen coleopteris angustius, apicem versus sensim attenuatum, obsolete punctulatum, nigrum, nitidum, supra parce nigro-pubescens, e tomento subtilissimo atro bifariam maculato, subtus metallico-versicolor, segmentis singulis basi subtilter tenuiterque griseo-pubescentibus. Pectus nigrum, tenuiter subtiliterque nigro-pubescens. Pedes tenuiores, nigri.

* 72. St. gentilis: Niger, capite thoraceque violaceis, scutello atro-tomentoso, elytris aureo-tomentosis, basi maculisque nonnullis disci nigricantibus. - Long. $6-7$ lin.

Habitat in Brasilia, Dom. Virmond.

Praecedenti affinis. Antennae capite paulo longiores, articulo tertio secundo sesqu longiore, sequentibus sensim brevioribus, 6-10 transversis, ultimo apice emarginato, nigrae. Palpi picei. Caput basi thoracis latitudine, antrorsum leviter angustatum, supra perparum convexum, crebre sat fortiter punctatum, parcius nigro-pubescens, violaceum, nitidulum, ore nigro, subtus nigrum, nitidum. Thorax coleopteris paulo angustior, latitudine brevior, lateribus rectis, parallelis, basi cum angulis posterioribus fortiter rotundatus, apice truncatus, angulis anterioribus rectis, supra parum convexus, crebre punctatus, nigro-pubescens, violaceus, nitidulus. Scutellum atro-tomentosum. Elytra thorace longiora, subtiliter confertissime punctatorugulosa, brunnea, dense fulvo - aureo - tomentosa, nitida, tenuiter nigro-pubescentia, basi maculaque marginali punctoque dorsali medio nigris, dense nigro-pubescentibus. Abdomen nigrum, nigro-pubescens pilosellumque, 
supra e tomento brevissimo obsolete bifariam atro-maculato, subtus nitidulnm. Pectus nigrum, pube brevi griseo-sericans. Pedes nigri.

* 73. St. caliginosus: Niger, opacus, nigro-lomentosus, ano sanguineo, antennarum articulo primo subtus testaceo. - Long. $5 \frac{1}{2}$ lin.

Habitat in Mexico.

Affinis St. tomentoso, at paulo minor, totus niger, opacus, tomento brevi nigro obductus. Antennae capite parum longiores, articulo secundo tertioque aequalibus, $4-\mathbf{1 0}$ subobconicis, inter se aequalibus, longitudine vix crassioribus, ultimo apice emarginato et inferne acuminato, nigrae, articulo primo subtus testaceo. Palpi rufo-picei. Caput thorace paulo angustius, subtriangulare, supra leviter convexum, confertissime punctatim, fronte subtilissime carinata, subtus laeve, glabrum, nitidum. Thorax coleopteris vix angustior, latitudine haud brevior, antrorsum vix angustatus, lateribus rectis, basi cum angulis posterioribus rotundatus, apice truncatus, angulis anterioribus rectis, leviter convexus, confertissime subtiliter punctatus, subtilissime carinatus. Scutellum dense aterrimo-tomentosum. Elytra thoracis longitudine, confertissime subtiliter ruguloso-punctata. Abdomen supra omnium subtilissime rugulosum, e tomento aterrimo bifariam maculato, subtus confertim subtiliter punctatum, supra segmento penultimo dimidio ul. timoque toto, subtus segmentis duobus ultimis obscure sanguineis. Pedes nigri, tarsis concoloribus. Alae fulvo-hyalinae.

* 74. St. sepulchralis: Niger, opacus, nigro-pubescens, antennis concoloribus, tarsis medio piceis. - Long. $5 \frac{1}{2}$ lin.

Habitat in Mexico, Dom. Prof. Germar.

Statura omnino praecedentis, niger, opacus, dense subtilius nigro-pubescens. Antennae capite paulo longiores, articulo tértio secundo paulo longiore, sequentibus sensim paulo brevioribus, penultimis tribus leviter transversis, ultimo iterum paulo longiore, apice truncato et inferne acuminato. Palpi rufo-picei. Caput thorace paulo angustius, antrorsum angustatum, subtriangulare, supra subdepressum, confertissime fortius punctatum, pube brevi nigra densius vestitum, parce pilosellum, subtus parce subtiliter punctatum, glabrum, nitidum. Thorax coleopteris vix angustior, latitudine laud longior, antrorsum nullo modo angustatus, lateribus subrectis, parallelis, basi cum angulis posterioribus rotundatus, apice truncatus, angulis anterioribus rectis, parum convexus, confertim minus subtiliter punctatus, posterius carinula subtili valde abbreviata laevi nitida instructus, pube brevi depressa nigra densius obductus. Scutellum atro-tomentosum. Elytra thorace prope breviora, densius subtiliter punctata, dense nigro-pubescentia. Abdomen supra parce obsoleteque punctulatum, pube brevi subtilique nigra dense aequaliter obductum, subtus nitıdum, confertim punctatum, parce te nuiterque pubescens. Pectus densius nigro-pubescens, opacum. Pedes nigri, tarsis medio rufescenti-piceis.

Obs. St. tomentos o simillimus et proxime affinis, statura autem paulo minore, corpore minus tomentoso quam pubescente, abdomine maculis atro-tomentosis destituto, capite thorareque fortius punctatis, antennarum articulis secundo et tertio minus elongatis, tarsis medio rufescentibus distinguendus. 
* 75. St. fuscicornis: Niger, opacus, nigro-tomentosus, antennis, pulpis anoque brunneis. - Long. 6 lin.

Germ. Ins. Spec. 33. 35.

Staph. lugubris Nordm. Symb. 49. 31.

Habitat in Brasilia meridionali, Sellow.

Statura praecedentis, plerumque autem paulo maior, niger, opacus, pube depressa subtiliore nigro- fusca densius obductus. Antennae capite paulo longiores, articulo tertio secundo sesqui prope longiore, sequentibus sensim paulo brevioribus, penultimis vix transversis, ultimo praecedente paulo longiore, apıce leviter emarginato et inferne acuminato, totae ferrugineae. Palpi castanei. Caput thoracis prope latitudine, antrorsum posterius leviter, antice subito fortiter angustatum, supra subdepressum, dense punctatum, subnitidum, subtus parce punctulatum, glabrum, nitidum. Thorax coleopterorum latitudine, latitudine vix brevior, antrorsum vix angustatus, lateribus rectis, basi rotundatus, angulis posterioribus obtusis, apice truncatus, angulis anterioribus rectis, leviter convexus, confertissime subtilius punctatus, carinula tenui postica laevi. Elytra thoracis longitudine, confertissime subtiliter punctato-rugulosa. Abdomen supra parcius obsoletiusque punctulatum, aequaliter nigro-pubescens, subtus nitidulum, parcius punctatum parceque pubescens, segmento quinto margine summo apicali sextoque toto brunneis. Pedes nigri, tibiis tarsisque interdum brunneis, tibiis anticis fulvo-pubescentibus. Alae fusco-hyalinae.

Obs. Antennis totis ferrugineis ab affinibus distinctus.

* 76. St. tomentosus: Niğer, opacus, nigro-tomentosus, tarsis concoloribus, antennis apice ferrugineis. - Long. 6 lin.

Grav. Micr. 161. 4. Mon. 111. 118. - Nordm. Symb. 50. 32.

Habitat in America septentrionali, Knoch.

Statura omnino St. stercorarii, totus niger, opacus, tomento brevi fu. sco- nigro vestitus. Antennae capite sesqui longiores, articulo secundo tertioque leviter elongatis, hoc paulo longiore, sequentibus sensim paulo brevioribus, penultimis tribus leviter transversis, ultimo iterum paulo longiore, apice subemarginato et inferne acuminato, nigrae, articulis penultimis sub. tus ultimoque toto obscure ferrugineis. Palpi nigri, articulo ultimo rufo-piceo. Caput thorace paulo angustius, antrorsum angustatum, subtriangulare, supra subdepressum, confertissime minus subtiliter punctatum. Thorax basi coleopterorum prope latitudine, latitudine haud brevior, antrorsum subangustatus, lateribus subrectis, pone medium subsinuatis, basi et angulis posterioribus rotundatis, apice truncatus, angulis anterioribus rectis, supra modice convexus, confertissime subtiliter punctatus. Elytra thoracis longitudine, subtiliter confertissime subruguloso-punctata. Abdomen supra confertissime subtilissimeque punctatum, parce punctulatum, segmentis anterioribus basi punctis duobus atro-tomentosis notatis, subtus parcius punctulatum, parce pubescens, subnitidum. Pedes nigri, tarsis çoncoloribus.

* 77. St. afer: Niger, opacus, nigro-tomentosus, palpis tarsisque piceis. - Long. $6 \frac{1}{2}$ lin.

Habitat ad Promont. Bonae Spei, Dom. Westermaun. 
Statura omnino St. chalcocephali, niger, opacus, dense nigro-tomentosus. Antennae capite sesqui longiores, articulo tertio secundo sesqui prope longiore, sequentibus sensim paulo brevioribus, penultimis tribns leviter transversis, ultimo apice truncato et inferne acuminato, totae nigrae. Palpi rufo-picei. Caput thorace angustius et minus, subtriangulare, supra depressiusculum, confertissime minus subtiliter punctatum. Thorax basi coleopterorum latitudine, latitudine paulo brevior, antrorsum leviter angustatus, lateribus rectis, bası cum angulis posterioribus rotundatus, apice truncatus, angulis anterioribus rectis, parum convexus, confertissime punctatus. Elytra thorace paululum longiora, subtiliter confertissime punctata. Abdomen confertissime punctatum, supra aequaliter tomentosum, subtus parum nitidum, parcius pábescens. Pedes nigri, tarsis piceis.

Obs. Differt a praecedente antennis nigris et ano concolore, a St. tomen -, toso abdomine supra aequaliter tomentoso, immaculato, a St sepulchrali statura latiore, thorace breviore, antrorsum angustato.

* 78. St. cinnamopterus: Niger, capite thoraceque aeneis, elytris, tibiis, uno abdominisque segmentorum marginibus rufis, scutello atro-tomentoso. - Long. 6 lin.

Grav. Micr. 164. 11. Mon. 113. 127. - Mannerh. Brachelytr. 23. 9. - Nordm. Symb. 59. 40.

Var. Capite thoraceque badio-rufis.

Staph.zonatus Grav. Micr. 162. T. Mon. 113. 128. - Nordm. Symb. 61. 44.

Staph. badius Mannerh. Brachelytr. 23. 10. - Nordm. Symb. 59. 39.

Habitat in America septentrionali.

Antennae capite sesqui fere longiores, articulo secundo tertioque leviter elongatis, hoc paulo longiore, sequentibus sensim paulo brevioribus, penultinis vix transversis, ultimo apice truncato et inferne acuminato. Palpi rufi. Caput thoracis latitudine, latitudine paulo longius, antrorsum vix angustatum, subdepressum, suprā fortius confertim punctatum, tenuiter ferrugineo-pubescens, vel obscure aeneum, subnitidum, vel obscure rufum, subtus nigrum, nitidum, paree subtiliterque punctatum. Thorax coleopteris paulo angustior, latitudine vix longior, lateribus subrectis, basi cum angulis posterioribus rotundatus, apice truncatus, angulis anterioribus rectis, leviter transversim convexus, fortius confertim punctatus, linea media longitudinali laevi, ferrugineo-pubescens, vel obscure aeneus, basi magis minusve rufescens, vel totus obscure rufus. Scutellum nigrum, atro-tomentosum. Elytra thorace vix longiora, subtilius confertim punctato-subrugulosa, rufo-castanea, ferrugineo-pubescentia. Abdomen parce punctulatum, longius pubescens, nigrum, opacum, segmentis singulis rufo-marginatis, sexto toto rufo. $\mathrm{Pe}$ ctus nigrum. Pedes coxis nigris, femoribus piceis, tibiis tarsisque rufotestaceis.

*79. St. Hottentottus: Niger, capite thoraceque aeneis, subnilidis, elytris brunneis abdomineque pubescenti-subcariegatis, sculello atro-lomen1080. - Long $5 \frac{1}{2}$ lin.

Nordm. Symb. 37. 17.

Habitat ad Promont. Bonae Spei. 
Statura omnino St. cinnamapteri. Antennae capite sesqui longiores, articulo secundo tertioque leviter elongatis, hac paulo longiore, sequentibus sensim paulo brevioribus, penultimis vix transversis, ultimo subovato, apice emarginato et inferne acuminato, abseure piceae, basi nigrae. Palpi picei. Caput thoracis fere latitudine, subquadratum, apice subito angustatum, supra subdepressum, aeneum, nitidulum, crebre punctatum, linea media longitudinali laevi, densius griseo-pubescens, ore nigro, subtus nigrum, nitidum. Thorax coleopteris paulo angustior, latitudine vix brevior, basin versus subangustatus, lateribus perparum, basi et angulis posterioribus fortiter rotundatis, apice truncatus, angulis anterioribus rectis, supra leviter convexus, sat crebre punctatus, linea media longitudinali subelevata postice distincta, antrorsum obsoletiore, griseo-pubescens, aeneus, nitidulus. Scutellum nigrum, macula magna nigra-velutina. Elytra thoracis longitudine, subtiliter punctulata, rufo-brunnea, pube subtili cinerea maculatim densiore vestita. Abdomen subtiliter punctulatum, segmentis singulis supra punctis quatuor maioribus transversim positis impressis, nigrum, nitidulum, pubescens, supra anterius fusoo subnebulosum, segmentis 5 primis in medio baseos macula minuta triangulari flavescenti-pubescente notatis. Pectus nigrum. Pedes nigri, tarsis, interdum etiam tibiis, picess.

* S0, St. cupricallis: Niger, griseo-pubeseens, capite thoraceque aeneis, subnitidis, elytris fusco-subaeneis, opacis, densius fusco-griseo-pubescentibus, scutello fusco-tomentosa. - Long. 6 lin.

Nordm. Symb. 34. 15.

Habitat in Brasilia, in prov. Minarum, Dom. Beske.

Statura omnino St. lutarii, at paulo minor. Antennae capite parum longiores, artionlo secunda tertioque aequalibus, obconicis, quarto subgloboso, 5 - 10 transversis, sensim paulo brevioribus, ultimo subovato, apice emarginato et inferne acuminato, obscure piceae, basi nigrae. Palpi picei. Caput thorace paula angustius, subtriangulare, subdepressum; supra aeneum, nitidulum, sat crebre punctatum, griseo-pubescens, ore nigro, subtus nigrum, nitidum. Thorax coleopteris vix angustior, latitudine paulo brevior, lateribus subrectis, parallelis, basi et angulis posterioribus rotundatis, apice truncatus, utrinque subsinuatus, angulis anterioribus acutiusculis, leviter transversim convexus, aequaliter sat crebre punctatus, postice liveola longitudinali media subelevata laevissima, griseo-pubescens, aeneus, nitidus. Scutellum nigrum, fusco-tomentasum. Elytra thoracis fere longitudine, subtiliter confertissime punctato-alutacea, sparsim subtilius punctulata, fusco-subaenea, opaca, densius fusco-griseo-pubescentia. Abdomen subtiliter punctulatum, nigrum, supra densius fusco-pubescens, segmentis quatuor anterioribus macula minuta triangulari in medio baseos flavescenti-pubescente, subtus nitidulum, metallico-versicolor, parcius pubescens, segmentis singulis basi tenuiter griseo-pubescentibus. Pectus nigrum, cinereo-pubescens. Pedes nigri. tarsis piceis.

81. St. praelangus: Niger, capite, therace elytrisque obscure viridi-subaeneis, illis glabris, crebre punctatis, line media laevi, his abdomineque fusco-pubescentibus, seutello atro-tomentoso. - Long. 7 lin.

Munnerh. Brachelytr. 24. 21. - Nordm. Symb. 73. 69. 
Habitat in America septentrionali, collect. Dom. Chevrolat.

Statura omnino praecedentis. Antennae capite vix longiores, articulo secundo tertioque leviter elongatis, hoc longiore, sequentibus sensim paulo brevioribus, quarto oblongo, penultimis vix transversis, ultimo subovato, apice inferne acuminato, nigrae. Palpi nigro-picei. Caput thorace angustius, subtriangulare, dense sat fortiter punctatum, linea media longitudinali laevi, supra obscure viridi-aeneum, nitidulum, tenuiter nigro-pilosellum, ore nigro, subtus nigrum, nitidum, glabrum. Thorax coleopteris. angustior, latitudine paulo longior, lateribus subrectis, parallelis, basi rotundatus, angulis posterioribus obtusis, apice truncatus, angulis anterioribus rectis; modice transversim convexus, supra dense sat fortiter punctatus, linea media longitudinali sat lata subelevatá laevi, obscure viridi-aeneus, nitidus. Scutellum macula rotundata atro-tomentosa notatum. Elytra thoracis longitudine, obscure aenea, opaca, subtiliter confertissime punctato-rugulosa, tenuiter nigropubescentia. Abdomen crassiusculum, supra nigrum, subnitidum, subtiliter punctatum, tenuiter fusco- griseo-pubescens, supra bifariam e pube densiore atro-punctatum, subtus rufo-piceum, metallico versicolor, tenuiter pubescens. Pectus nigrum, griseo-pubescens. Pedes nigri.

82. St. cyanomelas: Niger, nitidus, capite, thorace elytrisque supra cyaneis, nitidis, tenuiter nigro-pubescens, scutello densius atro-tomentoso. - Long. 7 lin.

Habitat in Mexico, collect. Dom. Chevrolat.

Statura omnino St. lutarii, niger, nitidus, capite, thorace elytrisque supra cyaneis, nitidis, abdomine metallico-versicolore, totus tenuiter subtiliterque nigro-pubescens, Antennae capite paulo longiores, articulo tertio modice elongato, secundo sesqui longiore, sequentibus sensim paulo longioribus, quarto oblongo, penultimis $3-4$ leviter transversis, ultımo apice leviter emarginato et inferne obtuse acuminato, nigrae. Caput thorace paulo angustius, antrorsum subangustatum, sat dense fortius punctatum, ore nigro; subtus nigrum, nitidum, glabrum. Thorax coleopteris parum angustior, latitudine vix brevior, antrorsum vix angustatus, lateribus rectis, basi cum angulis posterioribus fortiter rotundatus, apice truncatus, angulis anterioribus rectis, supra parum convexus, sat dense aequaliter punctatus. Scutellum pube densa depressa nigra obtectum. Elytra thoracis longitudine, subtiliter punctulata, interstitiis subtilissime alutaceis. Abdomen parcius subtiliter punctatum. Pedes nigri.

* 83. St. violaceus: Niger, subnitidus, capite thoraceque subcyaneis, elytris violaceis, abdomine supra anterius griseo-pubescente. - Long. $5-6$ lin.

Grav. Micr. 162. 6. Mon. 110. 115. - Nordm. Symb. 48. 30.

Habitat in America septentrionali, Knoch.

Antennae capite sesqui longiores, graciliores, articulo secundo tertioque leviter elongatis, hoc longiore, $4-10$ subobconicis, sensim brevioribus, onnibus crassitie hand brevioribus, ultimo apice leviter enarginato et infrrne acuminato, nigrae. Palpi picei. Corpus nigrum, capite thoraceque subcyaneis, nitidulum. Caput thoracis latitudine, subquadratum, tenuiter sub- 
tiliterque nigro-pubescens, subdepressum, supra dense fortius punctatum, linea longitudinali tenuissima laevi, antice obliterata, ore nigro, subtus parce punctatum, nigrum, nitidum, glabrum. Thorax coleopteris paulo angustior; latitudine paulo brevior, lateribus levissime, basi cum angulis posterioribus fortiter rotundatus, apice truncatus, angulis anterioribus rectis, subprominulis, supra modice transversim convexus, dense fortius punctatus, linea tenui longitudinali laevi, subtiliter tenuiterque nigro-pubescens, lateribus longius nigro-pilosellus. Scutellum nigrum, opacum, confertissime punctatum, apice atro-tomentosum. Elytra thorace paulo longiora, subtilissime punctato-rugulosa, violacea, opaca, densius subtiliter nigro-pubescentia, immixta pube rara brevi grisea. Abdomen parcius punctulatum, nigro-pubescens, segmentis tribus primis supra pube densiore grisea micante vestitis, reliquis parcius nigro-pubescentibus. Pedes graciliores, nigri.

* 84. St. chrysaster: Niger, capite, thorace elytrisque supra coeruleis, nilidulis, abdomine apice testaceo, segmentis ultimis duobus supra aureotomentosis. - Long. 5 lin.

Habitat in Brasilia, Dom. Prof. Germar.

Statura omnino St. latebricolae, niger, nitidus, capite, thorace elytrisque supra coeruleis aut virescenti-coeruless, nitidulis. Antennae capite sesqui longiores, articulo tertio sećundo paulo longiore, 6-10 transversis, subaequalibus, ultimo ovato, apice truncato et inferne acuminato, nigrae. Caput thoracis latitudine, subquadratum, supra subdepressum, sat profunde minus confertim punctatum, parce subtiliterque nigro-pubescens, ore nigro, subtus nigrum, nitidum, laeve glabrumque. Thorax coleopteris paululum angustior, latitudine vix brevior, lateribus parallelis, rectis, basi rotundatus, apice truncatus, angulis anterioribus rectis, posterioribus obtusis, subrotundatis, parum convexus, sat fortiter dense punctatus, carinula postica laevi, parce subtiliterque nigro-pubescens. Scutellum nigrum, confertissime punctulatum, nigro-pubescens. Elytra thorace paulo longiora, subtilissime alutacea, subtiliter punctulata, tenuiter subtiliterque nigro-pubescentia. Abdomen nigrum, nitidum, parce pubescens, segmento quinto margine apicali, sexto toto testaceis, his duobus supra totis dense aureo-tomentosis. Pedes nigri.

Species mihi invisae, forte huius familiae.

85. St. femoratus: Nigro-subaeneus, pube obscura nebulosus, ano femoribusque anterioribus testaceo-ochraceis, his macula nigra notatis. - Long. 6 क क $6 \frac{1}{2}$ lin.

Fab. Syst. El. II. 594. 24. - Grav. Mon. 122. 143. - Nordm. Symb. 31. 11.

Habitat in Carolina.

Corpus subaeneum ut St. murino. Antennae capite paulo longiores, fuscae, articulis duobus primis rufis. Palpi articulis nigris, apice rufis. Caput thorace minus, subtriquetrum, linea media longitudinali laevi obsoleta. Thorax capitis colore atque punctura, linea media laevi longitudinali, angulis anticis obtusioribus quam in St. murino, paulo acutioribus quam in St. pubescente. Coleoptera subgriseo-nebulosa, subquadrata. Abdomen pilosellum, nigrum, dorso subrufo-varium, ventre subsericans, sub-aeneo-ni- 
tens, segmento ultimo ochraceo. Pectus subsericans. Pedes nigricantes, femoribus ochraceis, lateribus, imprimis femorum posticorum nigris. (sec. Grav.)

Obs. Simillimus videtur St. antiquo, at praecipue antennis basi rufis pedumque colore distinctus.

86. St. chrysocomus: Niger, opacus, pubescens, subtiliter punctulatus, thorace violaceo-micante, antennis, capite, elytris pedibusque fulvo-aureis. - Long. 6 - 7 lin.

Mannerh. Brachelytr. 21. 1. - Nordm. Symb. 41. 23.

Staph. chrysopterus Gebl. Nouv. Mem. d. l. Soc. Imp. des Nat. de Mosc. I1. 41.1. (Gebl.).

Habitat in Dauria (Mannerh.), prope Nertschinsk Sibiriae occidentalis

St. xanthoptero vix angustior, sed multo brevior. Caput thorace multo latius, subquadrangulare, creberrime punctulatum, fulvum, pilis aureo-micantibus dense adspersum. Antennae thorace breviores, fulvae. Thorax antice parum latior, latitudine longior, antice truncatus, lateribus fere rectis, niger, subtiliter punctulatus, violaceo-micans, parce pubescens. Scutellum rotundatum, holosericeo-atrum. Elytra thorace latiora, subquadrata, angulo exteriore rotundata, subtilissime punctulata, fulva, dense aureo-sericea. Abdomen nigrum, tenue pubescens, segmentorum ventralium marginibus aureomicantibus. Pedes fulvi, aureo-sericei. (Mannerh.)

Obs. Staph. chrysopterus Gebler thorace nigro-aeneo, linea longitudinali in medio baseos, abdominis segmento secundo basi aureo-pubescente, coxis nigris, a specie Mannerheimiana haud diversus videtur.

87. St. Herculeanus: Cyaneus, tomentosus, subtus subvirescens, thorace angulis anticis fortiter productis. - Long. 15 lin.

Laporte Etud Ent. I. 114. 2. t. 3. f. 1.

Habitat in Brasilia.

Cyaneo-subviolaceus, tomentosus. Antennae nigrae. Thorax basi rotundatus, lateribus subrectis, angulis anterioribus productis, rotundatis, margine antico medio rotundato, utrmque profunde sinuato, supra sulco longitudinali medio posteriore distinote impressus. Elytra subtilissime grannlata. Corpus subtus et pedes subvirescentia. (Lap.)

Obs. Forte prope St. Buquetii inserendus. Speciebus Fam. X. corpore tomentoso alienus videtur.

88. St. lugubris: Thorace tolo punctato, ater, atro-pubescens. - Long. 15 lin.

Encycl. Meth. X. 477. 2.

Habitat in Cayenua.

Maximus, totus niger, opacus, pube brevi concolore obductus, infra subnitidus. Caput angulis posterioribus prominulis. (Enc.)

89. St. haemorrhoidalis: Nigro-violaceus, abdomine apice rufo,

Oliv. Ent. III. 42. 11. 7. t. 2. f. 20.

Habitat in Cayenna. 
Magnitudo Staph. erythrocephali. Antennae nigrae, capite paulo longiores. Caput, thorax et elytra nigro-violacea, nitida, nigro-pubescentia. Abdomen nigrum, apice rufum. Pedes nigri. Alae nigricantes. (Ol.)

90. St. Goryi: Nigro-subaneus, pubescens, scutello atro-tomentoso, elyIris viridi-pubescentibus, macula gemina basali punctisque duobus marginalibus atro-tomentosis. - Long. 11 lin.

Laporte Etud. Ent. I. 113. 1. t. 3. f. 2.

Habitat in India orientali. (Decan.)

Nigro-subaeneus, confertissime punctatus, pubescens. Thorax brevis, linea media longitudinali subelevata. Scutellum nigrum, tomentosum. Elytra laete viridia, pube concolore vestita, macula interrupta baseos punctisque duobus marginis exterioris atro-tomentosis. Alae violaceae. Corpus subtus et pedes nigra, tarsis rufescentibus. (Lap.)

\section{Fam. IX.}

\section{Antennae filiformes, arliculo ultimo apice emarginato.}

Palpi omnes filiformes, maxillares articulo quario tertio longiore.

Pedes graciliores, tibiis posterioribus spinulosis, tarsis anticis dilatatis.

Corpus parcius pubescens, capite thoraceque parce pilosellis. Antennae sat elongatae, apicem versus haud incrassatae, articulo primo sequentibus ambobus multo breviore, crassiusculo, his elongato-obconicis, $4-10$ leviter obconicis, crassitie longioribus, ultimo oblongo-ovato, apice oblique emarginato et inferne acuminato, tenuiter pilosellae. Caput rotundatum, supra leviter convexum, oculis mediocribus, leviter convexis. Labrum breve, limbo membranaceo minus dilatato. Mandibulae apice falcatae, acutae, basin versus sensim latiores, muticae. Palpi modice elongati, maxillares articulo secundo elongato, tertio hoc duplo prope breviore, quarto iterum elongato, secundo aequali, apice subacuminato, labiales, articulo primo breviore, secundo tertioque aequalibus, illo interne parce setuloso, hoc apice iam subacuminato (St. luridipes, anceps, terminalis,) iam truncato (St. segmentarius, fasciatus). Thorax basin versus subangustatus. Elytra apice oblique truncata. Abdomen apicem versus leviter angustatum. Pedes graciles, modice elongati, tibiis posterioribus parce spinulosis, spinis apicalibus mediocribus, tarsis posterioribus articulo primo modice elongato, sequentibus tribus subaequalibus, anticis articulis 4 primis maris fortiter, feminae levius dilatatis, subtus dense Iongius tomentosis.

\section{* 91. St. luridipes: Niger, capite, thorace elytrisque aeneis, subopacis, pedibus fusco-luteis. - Long. 4 lin.}

Habitat in Columbia, Dom. Moritz.

Antennae capitis thoracisque fere longitudine, articulo tertio secundo sesqui longiore, 4 - 10 subobconicis, sensim paulo brevioribus, penultimis etiam crassitie haud brevioribus, ultimo subovato, apice oblique truncato et inferne acuminato, nigrae. Palpi picei, apice rufescentes. Corpus nigrum, nitidum. Caput thoracis fere latitudine, orbiculatum, supra convexiusculum, profunde punctatum, fronte medio late laevi, antice inter antennas late le- 
viterque impressa, obscure aeneum, parum nitıdum, parce nigro-pilosellum, infra nigrum, nitidum, laeve. Thorax coleopteris dimidio angustior, latitudine paululum longior, basin versus modice angustatus, lateribus ante medium leviter rotnndatis, dein sinuatis, basi rotundatus, apice truncatus, angulis posterioribus obtusis, subrotundatis, anterioribus acutiusculis, parum convexus, obscure aeneus, opacus, utrinque subtilius punctatus, puncto quoque pilum nigrum erectum emittente, linea media longitudinali laevi, nitidiore. Scutellum obscure aeneum. dense punctatum, flavescenti-pubescens. Elytra thorace vix longiora, dense punctata, obscure aenea, subnitida, basi apiceque flavescenti-pubescentia. Abdomen nigrum, nitidum, concolor, punctulatum, parcius nigro-pubescens. Pedes obscure lutei, coxis fuscis. Alae infuscatae.

* 92. St. anceps: Niger, capite, thorace elytrisque aeneis, opacis, abdominis segmento penultimo rufo, pedibus luteis. - Long. 4 lin.

Habitat in Columbia, Dom. Moritz.

Statura et summa affinitas praecedentis. Antennae capite thoraceque paulo longiores, articulo tertio secundo sesqui longiore, $4-10$ sensim paulo brevioribus, penultimis etiam crassitie longioribus, $6-10$ leviter obconicis, ultimo oblongo-ovato, apice truncato et inferne acuminato, nigrae, articulo ultimo ferrugineo, primo subtus rufo-piceo. Palpi picei, articulo ultimo testaceo. Mandibulae rufo-picei. Corpus mgrum, nitidulum. Caput thoracis latitudine, orbiculatum, supra convexiusculum, fortiter punctatum, fronte medio laevi, antice inter antennas leviter impressa, obscure aeneum, subnitidum, parce nigro-pilosellum, infra nigrum, nitidum. Thorax coleopteris paulo angustior, latitudine vix longior, basin versus subangustatus, lateribus anterius subrotundatis, posterius leviter sinuatis, basi rotundatus, apice truncatus, angulis posterioribus obtusis, subrotundatis, anterioribus acutiusculis, supra parum convexus, obscure aeneus, opacus, utrinque minus fortiter punctatus, puncto quoque pilum subtilem nigrum emittente, linea media longitudmali laevi. Scutellum subtiliter punctulatum, dense flavescenti-pubescens. Elytra thorace paulo longiora, dense punctata, obscure aenea, subnitida, fusco-, basi apiceque flavescenti-pubescentia. Abdomen punctulatum, parce longius nigro-pubescens, nigrum, nitidum, segmento quinto rufo-testaceo, basi- nigro, subtus etiam segmentis 4 primis margine apicali testaceis. Pedes lutei, coxis fuscis.

*93. St. terminalis: Niger, capite thoraceque nigro-subaeneis, opacis, ano rufo-testaceo, pedibus piceis. - Long. 4 lin.

Habitat in Brasilia, Dom. Virmond.

Statura et summa affinitas praecedentium. Corpus nigrum. Antennae capite thoraceque paulo longiores, articulo tertio secundo paulo longiore, 4-10 subobconicis, sensim paulo brevioribus, penultimis etiam crassitie paulo longioribus, ultimo ovato, apice oblique truncato et inferne acuminato, totae nigrae. Palpi, mandibulae et labrum picea. Caput thoracis latitudine orbiculatum, supra parum convexum, nigro-subaeneum, nitidum, fortiter punctatum, fronte ucedio laevi, antice late leviter impressa, parce nigro-pilosellum, basi utrinque griseo-pubescens, subtus nigrum, nitidum. Thorax 
coleopteris dimidio angustior, latitudine paulo longior, basin versus subangustatus, lateribus anterius leviter rotundatis, dein subsinuats, basi rotundatus, apice truncatus, angulis posterioribus obtusis, anterioribus acutiusculis, parum convexus, nigro-subaeneus, opacus, utrinque minus fortiter punctatus, puncto quoque pilo erecto nigro instructo, linea media longitudinali laevi, subnitida. Scutellum dense punctulatum, flavescenti-pubescens. Elytra thorace parum longiora, dense punctata, parum nitida, dense nigro-, bası anguste flavescenti-pubescentia. Abdomen segmentis singulis basi confertim subtiliter punctatis, nigro-pubescens, segmenti quinti parte dimidia apiçali segmentoque sexto toto rufo-testaceis, subtus segmentis reliquis margine apicali rufo-piceo. Pedes testaceo-picei.

* 94. St. fasciatus: Capite, thorace scutelloque nigro-aeneis, parum nilidis, elytris pectoreque dilute rufis, abdomine rufo-nigroque fasciato, pedibus testaceis. - Long. 4 lin.

Philonthus fasciatus Nordm. Symb. 112.102.

Habitat in Mexico, Dom. Deppe.

Praecedenti proximus. Antennae capite thoraceque longiores, articulo tertio secundo sesqui longiore, 4-10 sensim paulo breviorihus, penultimis etiam crassitie longioribus, $6-10$ leviter obconicis, ultimo subovato, apice oblique emarginato et inferne acuminato, apice subferrugineae, articulo primo subtus rufo-piceo. Palpi piceae, apice testaceae. Mandibulae rufo-piceae. Caput thorace paululum latius, orbiculatum, supra leviter convexum, obscure aeneum, nitidulum, fortiter punctatum, puncto quoque pilum longum depressum griseum emittente, fronte medio late laevi, antice late levissime impressa, parce nigro-pilosellum, subtus nigrum, nitidum. Thorax coleopteris dimidio prope angustior, latitudine vix longior, basin versus subangustatus, lateribus anterius leviter rotundatis, pone medium subsinuatis, basi rotundatus, apice truncatus, angulis posterioribus obtusis, subrotundatis, anterioribus obtusiusculis, subdepressus, obscure aeneus, subopacus, punctatus, puncto quoque pilo erecto nigro instructo, linea media longitudinali laevi, subnitida. Scutellum nigro-aeneum, dense punctulatum, flavo-pubescens. Elytra thorace paulo longiora, dense punctata, dilute rufa, flavopubescentia. Abdomen parcius punctulatum, pubescens, supra segmentis duobus, subtus tribus primis rufis, reliquis nigris, margine apicali rufo, ultimo nigro, basi rufo. Pectus rufum. Pedes testacei, coxis rufis.

* 95. St. segmentarius: Capile thoraceque aeneis, opacis, scutello, elytris pectoreque rufis, abdomine rufo-nigroque fasciato, pedibus testaceis. - Long. 4 lin.

Habitat in Columbia, Dom. Moritz.

Statura et summa affinitas praecedentium. Antennae capitis thoracisque longitudine, articulo tertio secundo sesqui longiore, sequentibus subobconicis, sensim paulo brevioribus, penultimis etiam crassitie longioribus, ultimo ovato, apice leviter emarginato et inferne acuminato, nigro-piceae. Palpi picei, apice rufi. Mandibulae rufae. Caput thoracis latitudine, orbiculatum, supra convexiusculum, fortiter punctatum, fronte medio laevi, antice inter antennas late leviter impressa, nigro-aeneum, sub-opaeum, parce nigro- 
pilosellum, subtus nigrum, nitidum. Thorax coleopteris dimidio fere angustior, latitudine paululum longior, basin versus angustatus, lateribus anterius leviter rotundatis, posterius subsinuatis, basi cum angulıs posterioribus rotundatus, apice truncatus, angulis anterioribus subrectis, parum convexus, nigro-aeneus, opacus, utrinqne minus fortiter punctatus, puncto quoque pilo nigro instructo, linea media longitudinali laevi, subnitida. Scutellum rufum, subtliter punctulatum, flavo-pubescens. Elytra thorace parum longiora, densius punctata, dilute rufa, opaca, fulvo-pubescentia. Abdomen subtiliter punctulatum, segmento primo rufo, sequentibus tribus rufis, macula transversa basali, sensim maiore, nigra, quinto nigro, apice rufo, sexto toto nigro. Pectus rufum, mesosterno piceo. Pedes cum coxis dilute testacei. Alae infuscatae.

\section{Fam. X. \\ Triacrus Nordm. Symb. p. 19.}

Antennae ab articulo quinto inde subserratae, articulo ultimo tricuspi. Palpi omnes filiformes, maxillares articulis ultimis duobus subaequalibus. Pedes tibiis posterioribus spinulosis, tarsis anticis dilatatis.

Corpus tenuiter, caput et thorax supra tenuissime subtilissimeque pubescentia. Antennae breviores, basi satis distantes, articulo primo modice elongato, secundo obconico, tertio hoc sesqui longiore, elongato-obconico, quarto cyathiformi, apice longitudine prope crassiore, sequentibus crassioribus, brevioribus, perfoliatis, deorsum fortius prominentibus ideoque subserratis, ultimo tripartito, portione superiore maiore porrecta, inferioribus minoribus, inter se aequalibus, leviter deflexis, omnibus acuminatis. Caput porrectum, sat magnum, orbiculatum, supra parum convexum, oculis minoribus, vix prominulis. Labrum minutum, transversum, membranaceo-lumbatum. Mandibulae validae, apice incurvae, acutae, medio bidentatae. Palpi minus elongati, maxillares articulo secundo tertioque aequalibus, quarto his longitudine aequali, at paulo tenuiore, apice subacuminato, labiales articulis sensim paulo longioribus. Thorax coleopteris angustior. Elytra angulo apicali exteriore oblique truncato. Abdomen apicem versus sensim attenuatum. Pedes breviores, validi, tibiis posterioribus subtiliter spinulosis, spinis apicalibus validioribus, tarsis posterioribus articulis 4 primis sensim paulo brevioribus, primo leviter elongato, anticis articulis 4 primis dilatatis, patellam ovalem, tibia parum latiorem, subtus tomentoso-spongiosam formantibus. exciso.

Mas abdominis segmento inferiore sexto apice leviter triangulariter

* 96. St. superbus: Niger, capite thoraceque cyaneis, elytris violaceis, ano rufo, antennis subserratis. - Long. 13 lin.

Triacrus dilatus Nordm. Symb. 19. 1. $t$. 1. f. 7 .

Habitat in Brasilia, Dom. v. Langsdorf.

Magnus. Corpus nigrum, nitidulum. Antennae capite sesqui longiores, nigrae, articulis tribus primis obconicis, quarto subgloboso, 4-10 transversis, perfoliatis, introrsum magis quam extrorsum dilatatis ideoque subserratis, ultimo excavatione profunda tripartito, lobıs duabus basalibus 
minoribus, aequalibus, deorsum spectantibus. Mandibulae nigrae. Caput thorace paulo latius, suborbiculatum, supra subdepressum, cyaneum, subnitidum, vage punctulatum, parce subtilissime pubescens, subtus nigrum, nitidum. Thorax coleopteris paulo angustior, latitudine brevior, lateribus medio leviter rotundatis, posterius subsinuatis, basi modice emarginatus, angulis posterioribus obtusiusculis, apice truncatus, utrinque subsinuatus, angulis anterioribus acutiusculis, supra modice transversim convexus, cyaneus, subnitidus, subtiliter vage punctulatus, parce subtilissime nigro-pubescens. Scn• tellum nigrum, punctatissimum, subtiliter nigro-pubescens. Elytra thorace longiora, densius subtiliter punctato-subrugulosa, violacea, subtiliter nigropubescentia. Abdomen punctulatum, tenuiter nigro-pubescens, segmento nltimo cum stylis analibus rufo, rufo-pubescente. Pedes nigri, nigro-pubescentes.

Variat capite thorace maiore, mandibulis capite longitudine aequalibus, et capite thorace aequali, mandibulis capite brevioribus.

O bs. Prof. Nordmann hanc speciem in collectione Langsdorfiana nomine Staph. dilati Le ach signatam fuisse tradit: revera autem loco illo a Latreillio huic insecto eximio tantummodo nota fuit affixa, qua $S t a p h$. dilatatus $F$. ad animum revocetur, quocum antennis serratis comparetur, et cui Dom. Leach genus Velleius condidisset. Nomen igitur illud, tali errore huic speciei impertitum, delendum putavi.

\section{Fam. XI. a, ,}

Trigonophorus Nordm. Symb. p. 8. t. 1.f. 1.

Antennae apicem versus subincrassatae, articulo ultimo apice, emarginalo. Palpi maxillares filiformes, articulo quarto terlio subaequali, apice acuminato, labiales arliculo tertio subsecuriformi. Pedes validi, tibiis posterioribus spinulosis, tarsis anticis dilatatis.

Corpus subtiliter pubescens, capite thoraceque glaberrimis. Antennae breviores, articulo primo parum elongato, secundo tertioque subobconicis, penultimis 5 transversis, ultimo apice emarginato et inferne acuminato, articulis 4 primis breviter pilosellis, reliquis pube brevissima subtilissimaque cinerea dense obductis. Caput porrectum, sat magnum, thoracis prope latitudine, oculis parvis, oblongis, vix prominulis. Labrum mediocre, transversum, angustius coriaceo-limbatum, limbo barbato. Mandibulae breviores, validae, apice falcatae, acutae, medio fortiter dentatae. Palpi maxillares articulo secundo paulo longiore, quarto tertio fere aequali, apice acuminato, labiales articulis thibus sensim longioribus, ultimo apicem versus magis minusve incrassato, apice truncato, leviter securiformi. Thorax coleopteris paulo angustior. Elytra angulo apicali exteriore rotundato. Pedes breviusculi, validi, tibiis intermediis leviter curvatis, posterioribus spinulosis, spinis apicalibus validioribus, tarsis posterioribus articulo primo modice elongato, sequentibus tribus sensim paulo minoribus, anticis articulis quatuor primis dilatatis, patellam ovalem, subtus dense tomentoso-spongiosam formantibus.

Mas abdominis segmento inferiore sexto apice leviter inciso distinctus.

Obs. Habitus specierum partim Fam. VIII. partim Fam. II., a quibus palporum labialium articulo ultimo apice truncato, subsecuriformi distinguuntur. Caput et thorax laevissima, reliquum corpus parce et subtilissime pubescens. 
- 97. St. columbinus: Cyaneus, nitidus, antennis pedibusque nigris, thorace laevissimo, margine laterali punctatissimo. - Long. 13 lin.

Habitat in Brasilia, Dom. Virmond.

Corpus magnum, cyaneum, nitidum. Antennae capite vix, longiores, articulo tertio secundo paulo longiore, quarto quintoque subglobosis, 6-10 transversis, sensim paulo brevioribus, ultimo penultimo plus sesqui longiore, apice truncato et inferne acuminato, nigrae, basi cyanescentes. Palpi labiales articulo ultimo cylindrico, apice truncato Oris partes nigrae. Caput thoracis latitudine, ovatum, supra leviter convexum, oculis parvis, ante medium sitis, laevissimum, lateribus prope basin crebre punctatum. Thorax coleopteris paulo angustior, latitudine fere brevior, lateribus leviter rotun. datus, posterius subsinuatus, basi cum angulis posterioribus rotundatus, apice truncatus, angulis anterioribus antrorsum prominentibus, acutis, modice convexus, laevissinus, limbo, basi apiceque medio interrupto, punctatissimo. Scu• tellum dense subtiliter punctatum, nigro-pubescens. Elytra thorace longiora, violacea, subopaca, confertissime subtiliter subruguloso-punctata, pube brevi nigra vestita. Abdomen confertissime subtiliter punctatum, nigro-pubescens. Pedes nigri. Alae fusco-violaceae.

* 98. St. myrtillin? : Cyaneus, nitidus, antennis pedibusque nigris, capile thoraceque parc niciliterque punctatis. - Long. 10 lin.

Trigonophorus myrtiv.nus Nordm. Symb. 8. 1. t. 1. f. 1.

Habitat in Brasilia, Dom, v. Olfers.

Habitu omnino praecedentis, at duplo minor, cyaneus, nitidus. Antennae capite vix longiores, articulo tertio secundo longiore, quarto subgloboso, 5-10 transversis, sensim paulo brevioribus, ultimo subovato, apice emarginato et inferne acuminato, nigrae. Mandibulae et palpi nigri, palpi labiales articulo tertio leviter securiformi. Caput thoracis latitudine, subovatum, supra parum convexum, parce subtiliterque punctatum. Thorax coleopteris angustior, latitudine vix longior, basin versus subangustatus, lateribus subrectis, basi cum angulis posterioribus rotundatus, apice truncatus, angulis anterioribus antrorsum productis, acutis, modice transversim convexus, undique disperse subtiliterque parce punctatus. Scutellum subtiliter punctatum, nigro-pubescens. Elytra thorace paululum longiora, subtiliter punctata subtiliterque nigro-pubescentia. Abdomen subtilius punctatum, parce subtliterque nigro-pubescens. Pedes nigro-subcyanei, nigro-pubescentes.

* 99. St. badiipennis: Laete viridis, nitidus, pedibus cyaneis, elytris luteis. - Long. 8 lin.

Creophilus badiipennis Nordm. Symb. 25. 6.

Habitat in Brasilia, Dom. v. Olfers.

Statura fere St. maxillosi. Antennae capite haud longiores, articulo secundo tertio paululum maiore, his obconicis, quarto quintoque subglobosis, 6-10 paulo latioribus et sensim paulo brevioribus, transversis, ultimo subovato, apice inferne leviter emarginato, nigrae. Mandibulae nigrae. Palpi et labrum rufo-pice palpi labiales articulo tertio leviter securiformi. Cor- 
pus lucide viride, nitidum, abdomine apice sub-coerulescente. Caput thorace paulo angustius, subovatum, supra parum convexum, punctis paucis subtilibus adspersum, nitidissimum, subtus nigrum. Thorax coleopteris paulo angustior, latitudine haud brevior, lateribus rectis, parallelis, basi cum angulis posterioribus rotundatus, apice truncatus, utrinque subsinuatus, angulss anterioribus acutiusculis, leviter transversim convexus, nitidissimus, apicem versus punctis raris subtilibus impressus. Scutellum punctatum, viridi-cyaneum, tenuiter luteo-pubescens. Elytra thorace parum longiora, subtiliter punctata, lutea, tenuiter luteo-pubescentia. Abdomen crebrius subtiliter punctulatum, subtiliter nigro-pubescens. Pectus cyaneo-nitidum. Pedes cyanei, nitidi, tibüs nigris, tarsis piceis.

* 100. St. Chloris: Laete viridi-metallicus, nitidus, elylris cyaneis, pedibus nigris. - Long. 6 lin.

Creophilus Chloris Nordm. Symb. 26. 8.

Habitat in Brasilia, Dom. v. Olfers.

Habitu omnino St. maxillosi, laete lucideque metallice viridis, nitidus. Antennae capitis longitudine, articulo secundo tertioque obconicis, aequalibus, quarto subgloboso, quinto leviter transverso, $6-10$ fortius transversis, sensim paulo brevioribus et latioribus, ultimo ovato, apice leviter acuminato, nigrae. Os nigrum. Palpi labiales articulo ultimo cylindrico, apice truncato. Caput thorace paulo angustius, ovatum, leviter convexum, supra oculos utrinque punctis parcis impressum. Thorax coleopteris paulo angustior, latitudine vix brevior, lateribus subrectis, parallelis, basi cum angulis posterioribus rotundatus, apice truncatus, utrinque subsinuatus, angulis anterioribus rectis, modice transversim convexus, laevissimus. Scutellum cyaneum, subtiliter punctulatum, subtiliter pubescens. Elytra thorace paulo longiora, laete cyanea, subnitida, parce minus subtiliter punctata, subtiliter nigro-pubescentia. Abdomen punctulatum, tenuiter nigro-pubescens. Pedes nigri.

* 101. St. Erithacus: Viridi-coerulescens, nitidus, elytris cyaneis, ano rufo, pedibus nigris. - Long. 6 lin.

Creophilus Erithacus Nordm. Symb. 25. 7.

Habitat in Brasilia, Dom. v. Olfers.

Habitu omnino praecedentium. Laete viridi-coerulescens, nitidus: Antennae capite vix longiores, nigrae, articulo secundo tertioque aequalibus, quarto transversim obconico, quinto transverso, 6-10 abrupte paulo crassioribus, transversis, inter se aequalibus, ultimo ovato, ajice compresso, acuminato. Palpi rufo-picei, labiales articulo ultimo cylindrico, apice truncato. Caput thorace paulo angustius, apicem versus subangustatum, pone oculos utrinque punctis paucis sparsis impressum. Thorax coleopteris parum angustior, latitudine vix brevior, lateribus rectis, parallelis, basi cum angulis posterioribus rotundatus, apice truncatus, utrinque subsinuatus, angulis anterioribus acutiusculis, leviter transversim convexus, laevissimus, glaberrimus. Scutellum cyaneum, subtiliter punctulatum, subtiliter tenuiterque nigro-pubescens. Elytra thorace paulo longiora, parce subtiliterque puuctata, cyanea, opaca, parce subtiliterque nigro-pubescentia. Abdomen pun- 
ctulatum, parce subtiliterque nigro-pubescens, segmento ultimo rufo. Pedes nigri, femoribus subviolaceis.

Obs. Prope ad Fam. II. accedit habitu, palporum maxillarium articulo ultimo breviore, acuminato, labialium articulo tertio apice haud latiore, discedit autem antennarum structura, capite maris neque thorace latiore neque subquadrato, et elytris abdomineque parce et vix perspicue pubescentibus.

* 102. St. purpurascens: Niger, capite thoraceque purpureo-cupreis, nitidis, elytris cyaneis, opacis. - Long. $7 \frac{1}{2}$ lin.

Nordm. Symb. 47. 21.

Habitat in Brasilia, Dom. v. Langsdorf.

Corpus elongatum, nigrum, subnitidum. Antennae capite sesqui longiores, articulo tertio secundo paulo longiore, 4 - I1) sensim paulo brevioribus, penultimis transversis, ultimo subgloboso, apice inferius acuminato, nigrae. Palpi pices, labiales articulo tertio crassiur,culo, cylindrico, apice truncato. Mandibulae nigrae. Caput et thorax supra purpureo-cuprea, splendida. Caput thoracis latitudine, subquadratum, supra depressum, versus margines punctis parcis impressum, subtus nigrum, nitidum. Thorax coleopteris angustior, basin versus subangustatus, latitudine longior, lateribus pone medium subsinuatis, basi rotundatus, angulis posterioribus obtusis, apice truncatus, angulis anterioribus subrectis, leviter transversim convexus, intra angulos anteriores punctis nonnullis, dorso ante medium punctis quatuor transversim positis impressus. Scutellum nigrum, punctis paucis impressum. Elytra thorace paululum longiora, subtilissime rugulosa, subtiliter punctata, opaca, saturate cyanea, parce tenuiterque nigro-pubescentia. Abdomen parce punctulatum, parce nigro-pubescens. Pedes minus validi, nigri. Alae fulvohyalinae.

\section{Fam. XII.}

Tympanophorus Nordm. Symb. p 9. t. 1. $f .2$.

Antennae apicem versus sensim subincrassatae, articulo ullimo apice emarginato.

Palpi maxillares articulo ultimo penultimo breviore, acuminato, labiales arliculo ultimo hemisphaerico, apice truncato.

Pedes breviusculi, tibiis omnibus dense spinulosis, tarsis anticis simplicibus.

Corpus punctatum, tenuter pubescens. Antennae capite plus sesqui longiores, articulo primo leviter elongato, secundo tertioque aequalibus, obconicis, sequentibus subcydindricis, sensim paulo brevioribus et crassioribus, ultimo transverso, apice truncato et inferne acuminato, articulis 4 primis tenniter pilosellis, reliquis pube brevissima grisea dense obductis. Caput porrectum, orbiculatum, thorace minus. Labrum breve, transversum, membranaceo-limbatum. Mandibulae breviores et debiliores, medio dentatae. Palpi maxillares articulo secundo tertioque subaequalibus, quarto multo minore, tenuiore, fortiter acuminato, fere subulato, labiales articulis duobus primis minutis, tertio valde incrassato, hemisphaerico, apice truncato, tympaunformi. Thorax coleopteris angustior, angulis anterioribus deflexis. Elytra anguln apicali exteriore oblique truncato. Abdomen crassiusculum. Pedes breviusculi, tibnis omnibus densius breviter spinulosis, spinis apicalibus va- 
IIdioribus, tarsis posterioribus articulo primo modice elongato, sequentibus tribus sensim paulo brevioribus, ultimo minus elongato, praecedentibus ambobus haud longiore, anticis feminae simplicibus.

Mas latet.

* 103. St. canaliculatus: Niger, opacus, capite, thorace elytrisque dense punctatis. - Long. 6 lin.

Tympanophorus canaliculatus Nordm. Symb. 10. 1.

Habitat in Brasilia, Dom. v. Olfers.

Niger, Jarum nitidus, capite nigro-subaeneo. Antennae capite plus sesqui longiores, piceae, articulis 6-10 transversis. Caput thorace angustius et multo minus, suborbiculatum, subdepressum, fortius crebre punctatum, grisen-subpubescens. Thorax coleopterss paulo angustior, latitudine vix brevior, lateribus et basi leviter rotundatus, apice truncatus, angulis posterioribus rotundatis, anterioribus obtusiusculis, parum convexus, sat crebre fortius punctatus, linea longitudinali media laevi, postice canaliculata. Scutellum subtuliter punctulatum, griseo-pubescens. Elytra thorace paulo longiora, dense punctata, cinereo-pubescentia. Abdomen crassiusculum, nitidum, subtiliter punctulatum, griseo-pubescens, subtus segmentis singulis apice tenuiter piceo-marginatis. Pedes nigri. Alae fuscae, costa nigra.

\section{Ocypus Kirby.}

\section{Er. Col. March. I. p. 439.}

Antennae reclae.

Palpi maxillares filiformes.

Ligula apice emarginata.

Pedes intermedii basi approximati.

Tarsi posteriores leretes.

Corpus maioris magnitudinis, elongatum, lineare, aliis alatum, aliis apterum. Caput sat magnum, thoracis circiter magnitudine, suborbiculatum vel subquadratum, porrectum, exsertum, collo quasi brevi thoraci immissum, oculis parvis, haud prominulis. Labrum transversum, bilobum, corneum, lateribus latius, antice angustins membranaceo-limbatum. Mandibulae plerumque sat validae, aliis medio dentatae, aliis graciliores, falcatae, edentatae, basi lacinia elongata, lineari, inferne ciliata instructae. Maxilla malis brevibus, coriaceis, interiore interne, exteriore apıce barbata, hac basi cornea. Palpi maxillares articulo primo minuto, secundo tertioque subaequalibus, quarto praecedenti aut aequali aut eodem parum breviore, apice aut subacuminuto, aut plerumque truncatulo. Labium mento transverso, ligula membranea, biloba, paraglossis membranaceis, interne ciliatis, ligulam paulo superantibus. Palpi labiales articulis duobus primis brevioribus, tertio aut cylindrico, apice truncato, aut leviter fortiusve securiformi. Antennae filiformes, articulo primo subelongato, articulis a quarto vel a quinto inde magnitudine decrescentibus, ideoque apicem versus subangustatae. Thorax coleopteris parum angustior, basi rotundatus, apice truncatus, angulis posterioribus obtusis, magis minusve rotundatis, anterioribus plerumque rectis, subdeflexis. Scutellum triangulare. Elytra apice extrorsum leviter rotun- 
daia, introrsum oblique truncata. Abdomen lineare. Pedes breviusculi, coxis intermediis contiguis, tibiis posterioribus spinulosis, tarsis posterioribus filiformibus, articulo primo leviter elongato, anticis articulis 4 primis dilatatis, subtus dense spongioso-tomentosis.

\section{o b s e r v a t-i o n e s.}

1. Genus praecedenti admodum affine, praeter notas plures leviores praecipue ab illo distinctum coxis intermediis contiguis, acetabulis earum medio confluentibus.

2. Mas abdominis segmento inferiore sexto apice emarginato distinguendus.

3. Victus in silvis et arvis sub musco et sub lapidibus. Species omnes Europaeae, plures Alpestres, singula simul in America septentrionali obvia.

4. Larra O. olentis observata est a Dom. Heer. (Obs. ent.) et a Dom. Blanchard (Guer. Mag. Zool.). Corpus eius elongatum, apicem versus sensim attenuatum. Caput sat magnum, rotundato-subquadratum. Antennae capite breviores, 4 articulatae, articulo primo minuto, secundo tertio paulo longiore, apice interne processu aucto, quarto minuto, subulato. Clypeus apice denticulatus. Mandibulae sat magnae, falcatae. Maxillae cylindricae, processu minuto, acuminato, palpo 4-articulato, articulo primo brevissimo, crasso, secundo tertioque aequalibus, teretibus, quarto minuto, conico. Labium obconicum, apice medio acuminatum, palpis bi-articulatis, articulo primo terete, longiore, secundo conico. Prothorax capite paulo angustior, quadrangulus, latitudine dimidio brevior, lateribus leviter rotundatus. Meso- et metathorax transversi, prothoraci paulo latiores. Pedes breviusculi, tibiis brevioribus, spinulosis, tarsis unguiculo simplice. Abdomen segmentis sensim angustioribus, dorso areis binis corneis. Anus tubulosus, descendens. Caudae anales setaceae, 3-articulatae. - Victitat in silvis, in terra, in cubiculis mandibularum ope effossis, mandibulas exserens, Cicindelorum larvarum more insecta, quae ei appropinquantur, arripiens, lacerans, devorans, noctu interdum circumvagans. (Conf. Heer l. c. p. 18.) Nympha thoracis margine antico pilis longis 12 coronato.

Secundum antennarnm, mandibularum palporumque structuram sectiones quatuor in hoc genere constituendae sunt, quae quodammodo familias naturales referunt, quarum autem notae pro characteribus genericis rite valere non videntur. Prima earum palpis labialibus filiformibus, ultima mandibulis muticis, secunda antenuarum articulo ulimo integro, acuminato, tertia palforum maxillarium articulo ultimo in maribus subsecuriformi insignis.

\section{Fam. I.}

Goërius Leach Stepl. Illust. Britt, Ent, V.p. 208. Trichoderma Steph. ibid. p. 435.

Antennae arliculo ultimo apice emarginato. Palpi labiales articulo ultimo cylindrico.

Mandibulae medio dentalae.

Corpus elongatum, saepius apterum. Caput sat magnum, suborbieulat:m, hasi profunde constrictum, oculis parvis, haud prominulis. Antennae hasi minus late distantes, apicem versus subattenuatae, articulo ultimo apice oblique truncato. Mandibulae breviores, validae, falcatae, acutae, medio dentatae. Palpi maxillares articulo quarto paulo minore, subacuminato, lahiales articulis duobus primis brevioribus, ultimo cylindrico. Elytra saepiu; thorace breviora. Pedes tibiis intermediis densius, posticis parcius spinulosis, tarsis anticis fortius dilatatis.

Obs. Genus Trichoderma ex O. picipenni a Dom. Steph, conditum. Cha. racterem elytra tessellata praebent. 
* 1.P. olens: Alalus, niger, opacus, supra subtilissime atro-tomenlosus, antennis apice ferrugineis, elytris thoracis longiludine. - Long. $11-13$ lin.

Er. Col. March. I. 439. 1.

Staph. olens Müll. Faun. Fridr. 23. 228. Prodr. 97. 1090. - Fab. Mant. Ins. I. 219. 4. Ent. Syst. I. II. 520. 6. Syst. El II. 591. 8. - Goeze Ent. Beitr. I. 726. 19. - De Vill. Ent. I. 421. 66. - Payk. Mon. Staph. 9. 4. Paun. Suec. III. 371. 5. - Oliv. Ent. III. 42. 9. 4. t. 1. f. 1. - Cederh. Faun. Ingr. 117. 358. - Walken. Faun. Paris. I. 270. 6. - Panz. Ent. Germ. 352. 5. Faun. Germ. 27. 1. Grav. Micr. 4. 2. Mon, 111. 117. - Latr. Hist. nat. Crust. et Ins. IX. 302. 16. - Marsh. Ent. Britt. 497. 2. - Shaw General Zool. VI. 108. t. 39. - Gyll. Ins. Suec. II. 285. 6. - Mannerh. Brachelytr. 23. 15. - Nordm. Symb. 63. 50. - Runde Brachelytr Hal. 3. 8.

Emus olens Baisd. ef Lacord. Fann. Ent. Paris. I. 367. 12.

Staph. unicalor Herbst Archiv. I49. 4.

Staph. maxillosus Schrank Enum. Ins. Austr. 230. 434. - Fourcr. Ent. Par. I. 164.1 .

Staph. maior Degeer. Ins, IV. 17. 3. - De Vill. Ent. I. 420. 38.

Le grand Staphyl. noir lisse Geaffr. Hist. Ins. I. 360. 1. t. 7. f. 1.

Habitat in Europa omni temperata meridionalique et in Sibiria, in Mauritania, Dom. Wagner, in Teneriffa, Dom. Richter.

Magnus, totus niger, opacus, tomento brevissimo nigro supra vestitus. Antennae capite sesqui longiores, articulo tertio secundo vix longiore, 4-10 sensim paulo brevioribus, prioribus subcylindricis, sequentibus sensin paulo magis obconicis, ultimo apice oblique truncato et inferne acute acuminato, nigrae, apice ferrugineae. Palpi articulo ultimo piceo. Caput thoracis latitudine vel eodem paulo latius, orbiculatum, supra confertissime subtiliter punctatum, apacum, subtus parce punctatum, nitidum. Thoras coleopterorum prope latitudine, latitudine paulo brevior, lateribus leviter, basi fortius rotundatus, apice truncatus, angulis anterioribus subrectis, deflexis, posterioribus obtusis, leviter transversim convexus, confertissime subtiliter punctatus. Elytra thoracis longitudine vel eodem paulo longiora scutellumque confertissime subtiliter punctata. Abdomen supra subtilissine punctulatum, subtus parcius subtiliter punctatum, tenuiter pubescens. Alae flavescenti-hyalinae.

* 2. O. cyaneus: Alatus, niger, subopacus, capite, thorace elytrisque supra obscure coeruleis, elylris thoracis longiludine. - Long. 7-10 lin.

Er. Col. March. I. 440, 2.

Staph. cyaneus Payk. Mon. Staph. 13. 7. Faiun. Suec. III. 370. 4. - Fab. Ent. Syst. I. II. 521. 11. Syst. El. II. 592. 13. - Oliv. Ent. III. 42. 14. 13. t. 1. f. 4. - Walken. Faun. Paris. I. 270. 5. - Rossi Funn. Etr. Mant. 96. 215. Ed. Ilellw. 1. 442. 215. - Panz. Faun. Germ. 27. 3. - Grav. Micr. 6. 5. Mon. 110. 114. - Latr. Hist. nut. Crust. et Ins. IX. 304. 19. - Marsh. Ent. Britt. 501. 11. - Gyll. Ins. Suec. 1I. 286. 7. - Sahlb. Ins. Fenn. I. 309. 4. - Kirby et Spence Introd. I. t. 1. f. 2. - Mannerh. Brachelytr. 24. 16. - Nordm. Symb. 69. 60. - Runde Brachelytr. Hal. 3.9.

Emus cyaneús Boisd. et Lacord. Faun. Ent. Paris. I. 363. 13.

Staph. azurescens Mannerh. Brachelytr. 23. 15. - Nordm. Symb. 69. 59.

Staph. ophthalmicus Scop. Ent. Carn. 99. 300. - Goeze Ent. Beitr. I. 725 11. Staph. coerulescen s Fourcr, Ent. Par. I. 164. 2 - De V'ill. Ent. Par, I. 42139. 
Staph. atro-coerulescens Gueze Ent. Beitr. I. 729. 38.

Le Staph. ble u Geoffr. Ins. I. 361, 2.

\section{Habitat in Europa.}

O. simili plerumque panlo maior, niger, parum nitidıs, capite, thorace elytrisque supra nigro-coeruleis, undique pube brevi subtilique nigro-cyaneo sericans. Antennae capite duplo prope longiores, articulo tertio secundo paulo longiore, sequentibus sensim paulo brevioribus, penultimis subobconicis, ultimo apice oblique truncato et inferne acuminato, nigrae, apice summo obscure ferrugineo. Palpı apice picei. Caput thoracis latitudine vel eodem paulo latius, orbiculato-subquadratum, creberrime subtilius punctatum, carinula frontali subtilissima, parum distincta, saepe omnino obsoleta, subtus farce punctatum, nigrum, nitidum. Thorax coleopteris paululum angustior, latitudine haud brevior, basi rotundatus, lateribus leviter rotundatis vel subrectis, apice truncatus, angulis posterioribus obtusis, subrotundatis, anterioribus deflexis, iam rectis vel subrectis, iam obtusiusculis, leviter transversim convexus, confertissime subtilius punctatus, carinula postica tenuissima, parum distıncta, saepe omnino obsoleta. Scutellum nigro-tomentosum. Elytra thoracis longitudine, subtilius confertissime punctata. Abdomen subtiliter punctato-subrugulosum. Alae flavescenti-hyalinae.

Obs. 1. Variat magnitudine, exemplis maximis praecedenti duplo minoribus, minimis $O$. simili aequalibus; colore interdum subvirescente; capitis thoracisque punctura, iam fortiore, iam subtiliore et magis conferta, carinula media longitudinali magis minusve obsoleta vel omnino nulla; thoracis lateribus iam leviter rotundatis, iam fere rectis, angulis anterioribus iam obtusiusculis iam rectis; quae autem differentiae nullo modo stabiles videntur, et species ab auctoribus et mercatoribus nonnullis propositae (St. cyanescens Ziegl. subcyaneus et violaceus Dahl, azurescens Dej) rite distingui nequeunt. St azurescens secundum Com. Mannerheim carinula frontis thoracisque omnino deficiente a genuino $\mathrm{O}$. cyaneo differt, quae autem in indigenis saepius quam in speciminibus ex Europa meridionali obsolescit.

2. Pinguedine corruptus totus niger evadit. Huc referendus videtur $\mathrm{Staph}$. mordax Block Ins. Vall. Plauens. 115. 2. f. 2. - Staph. rugifrons Runde Brachelytr. Hal. 4. 14. certe huc pertinet, quod ex specimine ab aurtore descripto ipso a Dom. Zschorn mihi benevole communicato rompertum habeo. (Conf. Col. March p. 440.)

* 3. O. Italicus: Apterus, niger, subliliter ferrugineo-pubescens capile thoraceque confertissime subtililer punctatis, hoc basi rotundato, elytris thorace brevioribus, brunneis. - Long. 9-11 lin.

Habitat in montibus Appeninis, Dom. Schiippel.

Statura et summa affinitis. O. macrocephali, niger, supra fere opacus, subtus subnitidus. Antennae capite paulo longiores, tenuiores, articulo tertio secundo sesqui longiore, sequentibus sensim brevioribus, ultimo apice oblique emarginato et inferne acuminato, nigro-piceae, apice ferrugineae. Palpi picei, apice rufescentes. Caput magnum, plerumque thorace latius, suborbiculatum, supra subdepressum, omnium confertissıme subtiliter punctatum, linea tenuissima longitudinali laevi, anterius obsoleta, dense subtiliter ferrugineo-pubescens, sulitus parce punctatus, glaber, nitidus. Thorax coleopterorum latitudine, latitudine vix longior, basin versus subangustatıs, lateribus ante medium subangulatis, basi rotundatus, apice truncatus, angulis anterioribus leviter deflexis, subrectis, posterioribus ohtusis, parum convexus, 
confertissime subtiliter punctatus, linea tenuissima media longitudinali, anterius obsoleta, laevi, dense subtiliter ferrugineo-pubescens. Scutellum confertim subtiliter punctatum, subtiliter nigro-pubescens. Elytra thorace dimidio breviora, depressa, confertissime subtiliter punctata, rufo-brunnea, dense ferruginea-pubescentia. Abdomen densius subtilissime punctatum, opacum, subtiliter ferrugineo-pubescens, subtus subnitidum, tenuiter nigra pubescens. Pedes nigri.

O bs. Simillimam O. mácrocephal o hanc speciem, distinctam autem capitis thnracisque punctura confertissima, hoc basin versus subangustato, basi fortius rotundato, Dom. Schüppel nomine Staph. It alici Gené signatam a Dom Frivaldsky accepit.

4. O. macrocephalus: Apterus, niger, ferrugineo-pobescenss,capite thoraceque densins subtiliter punctafis, hoc basi subtruneato, elylris thorace brevioribus, rufo-brunneis. - Long. 10-11 lin.

Staph. macrocephalus Grav. Micr. 160. 3. Mon. 111. 116. - Latr. Hist. nat. Crust, et Ins. IX. 305. 21. - Nordm. Symb. 64. 52. hynia.

Habitat in Hercyniae Austriaeque montibus, in Carpathibus et in Vol-

Statura fere $\mathbf{O}$. similis, at multo maior, niger, capite thoraceque subaeneis, subnitidis, undique pube brevi fusco-ferruginea vestitus. Antennae capite plus sesqui langiores, articulo tertio secunda sesqui prope longiore, 4-10 sensim paulo brevioribus, subcylindricis, penultimis leviter obconicis, ultimo apice oblique truncata et inferne acuminato, nigrae, apice rufo-testaceae. Palpi picei, apice rufescentes. Caput magnum, thorace latius, suborbiculatum, supra subdepressum, densius subtiliter punctatum, subtus laeve, glabrum, nitidum. Thorax coleopterorum latitudine, subquadratus, latitudine vix longiar, basi subtruncatus, lateribus parallelis, ante medium subangulatis, apice truncatus, angulis posterioribus obtusis, subrotundatis, anterioribus leviter deflexis, abtusiusculis, leviter convexus, densius subtiliter punctatus, basin versus obsolete canaliculatus. Scutellum piceum. Elytra thorace dimidio hreviora, depressa, crebrius subtiliter obsoleteque punctulata, rufobrunnea, apaca. Abdomen subtiliter punctulatum, piceum, segmentis singulis margine postico rufo-piceo. Perles picei.

* 5. O. megacephalus: Apterus, nigro-aeneus, capite thoraceque dense furtins punctatis, hoc basi fortiler rotunduto, tylris thorace longe brevioribus, rufo-testaceis.

Staph. megacephalus Nordm. Symb. 63. 51.

Habitat in Carinthiae mantibus, Dahl.

Statura omnino praecedentis, at minor. Antennae capite sesqui longiores, articulo tertio secundo sesqui longiore, sequentibus sensim paulo brevioribus, subcylindricis, penultimis leviter transversis, ultimo apice oblique truncato et inferne acuminato, nigrae, apice testaceae. Palpi rufo-picei. Caput thorace latius, subquadrato-orbiculatum, basi emarginatum, supra parum convexum, obscure aeneum, nitidulum, dense fortius punctatum, linea media longitudinali subelevata laevi, subtiliter griseo --pubescens, lateribus parce pilosellum, subtus parce punctatum parceque pubescens, nigrum, nitidum. Thorax coleopterorum latitudine, latitudine paulo longior, basin versus 
subangustatus, basi cum angulis posterioribus fortiter rotundatus, lateribus subrectis, apice utrinque oblique truncatus, angulis anterioribus subrectis, leviter convexus, creberrime minus subtiliter punctatus, linea angusta media longitudinali subelevata laevi, obscure aeneus, nitidulus, tenuiter grisen-pubescens, lateribus parce pilosellus. Scutellum nigrum, nigro-pubescens. Elytra thorace dimidio breviora, depressa, subtiliter punctata, lateritia, testaceo-pubescentia. Abdomen piceo-nigrum, subtilissime punctulatum, supra tomento brevissimo fusco immixtis pilis fulvis vestitum, subtus tenuiter griseo-pubescens, segmentis singulis margine apicali dilutiore. Pedes nigropicei, tarsis rufescentibus.

* 6. Alpe firis: Apterus, niger, opacus, elytris thorace dimidio brevioribus. - Long. 7-9 lin.

Habitat in alpibus Carinthiacis, Dahl, Tyrolensibus, Stentz.

O similem colore et magnitudine aequans, ceterum autem abunde distinctus, O. macrocephalo proximus. Totus niger, opacus, subtiliter nigrojubescens. Antennae capite sesqui longiores, articulo tertio secundo sesqui longıre, sequentibus sensim minoribus, praecipue brevioribus, cylindricis, penultimis leviter obconicis, ultimo apice oblique emarginato et inferne acuminato, apice testaceae. Palpi rufo-picei. Caput magnum, thorace multo Jatius, orbiculatum, supra perparum convexum, dense subtiliter punctatum, linea longitudinali tenuissima laevi anterius obsoleta, subtiliter nigro-fuscove pubescens subtus laevis, giaber, nitidus. Thorax coleopterorum latitudine, latitudine vix longior, basin versus subangustatus, lateribus subrectis, basi leviter rotundatus, apice truncatus, angulis posterioribus obtusis, subrotundatis, anterioribus rectis, leviter transversim convexus, subtiliter dense punciatus, basi obsolete canaliculatus, subtiliter nigro-fuscove pubescens. Scutellum nigro-tomentosum. Elytra thorace dimidio breviora, depressa, confertissime punctata. Abdomen subtliter punctulatum, segmentis singulis margine apicali piceo. Pedes apice picei.

Obs. 1. Ab O simili capite magno et elytris thorace multo brevioribus facile distinguendus, habitu omnino $O$. macrocephali eique nimis forte affinis, at statura minore et thorace basin versus subanigustato, basi distincte rotundato, angulis anterioribus rectis constanter differre videtur. Elytra quoque plerumque concolora, rarius cum pedibus picea.

2. Specimina Tyrolensia Carinthiacis magnitudine paulo inferiora, capite- minus lato, magis subquadrato quam suborbiculato, ceterum autem omnino congruentia, et cum non nisi gradu, non autem proportione differant, haud rite distinguenda. Occurrunt etiam inter Carinthiaca specimina debiliora, his simillima, et inter Tyrolensia exempla validiora, ab illis nullo modo differentia.

3. Varietatem multo minorem, O. morioni aequalem, capite thorace haud latiore, subquadrato, nomine Staph. tenuipenuis Dahl ex Austria missam dedit Dom. Schuppel, practer staturam debilem nullo modo a $O$. alpestri discedentem, ab $O$. simili elytris brevioribus et punctura minus conferta distinctam.

7. O. similis: Apterus, niger, opacus, elytris thorace paulo brevioribus. - Long. 8-9 lin.

Er. Col. March. I. 410. 3.

Staph. similis Fab Ent. Syst. I. II. 521. 7. Syst. El. II. 591. 9. - Panz. Ent.

Germ. 352. 6. - Girav. Micr. 5. 3. Mon, 111. 119. - Latr. Mist. nat. Crust. et 
Ins. IX. 302. 17. - Gyll. Ins. Suec. II. 287. 8. - Mannerh. Brachelytr. 24. 17. - Nordm. Symb. 68. 56. - Runde Brachelytr. Hal. 3. 10.

En us similis Boisd. et Lacord. Faun. Ent. Paris. I. 368. 14.

St aph.- lugens Nordm. Symb. 67. 54.

Staph. niten s Schrank Enum. Ins. Austr. 231. 436. Faun. Boica I. 610. 863.

Staph. niger Degeer Ins, IV, 22. 7.

Staph. globulifer Fourcr. Ent. Par. 1. 164. 3.

Habitat in Europa et in Sibiria.

Elongatus, niger, opacus, subtiliter breviterque nigro - pubescens. Antennae capite sesqui longiores, articulo tertio secundo parum longiore, sequentibus sensim minoribus, prioribus cylindricis, penultimis leviter obconicis, ultimo apice truncato et inferne acuminato, nigrae, apice ferrugineae. Caput thoracis latitudine, subquadratum, angulis omnibus rotundatis, supra subdepressum, confertissime subtiliter punctatum, linea tenui longitudinali laevi, anterius obsoleta, supra parcius punctatum, nitidum, glabrum. Thorax coleopterorum latitudine, latitudine paulo brevior, lateribus rectis, basi rotundatus, apice utrinque oblique truncatus, angulis anterioribus subrectis, posterioribus obtusissimis, subrotundatis, leviter transversim convexus, confertissime subtiliter punctatus, linea tenui longitudinali laevi subelevata. Elytra thorace paulo breviora, depressa scutellumque confertissime subtiliter punctata: Abdomen subtilissime punctulatum. Pedes nigri.

Obs. 1. Specimina cum hac specie omnino convenientia nom. St. subterranei, brachypteri et hortensis a Dahlio ex Austria missa dedit Dom. Schüppel.

2. St a ph. lugens Nor dm. nullo modo ab $\mathrm{O}$. simili distinctus.

* 8. O. masculus: Alatus, niger, opacus, palpis antennisque rufo-piceis, his basi nigris, elytris thoracis longitudine. - Long. 7 lin.

Staph. masculus Nordm. Symb. 67. 55.

Habitat in Lusitania, Com. Hoffmannsegg.

Primo intuitu $\mathrm{O}$. simili affinis videtur, at minor, et satis distinctus, niger, opacus, supra tomento tenui fusco-nigro vestitus. Antennae capite sesqui longiores, articulo tertio secundo paulo longiore, sequentibus sensim paulo minoribus, subobconicis, ultimo subovato, apice oblique truncato et inferne acuminato, basi nigrae, apice rufo-piceae. Palpi rufo-picei. Caput thoracis latitudine, subquadratum, supra subdepressum, subtiliter confertim punctatum. Thorax coleopterorum prope latitudine, latitudine vix longır, lateribus subrectis, basi fortiter cum angulis posterioribus rotundatus, apice truncatus, angulis anterioribus rectis, subdepressus, subtiliter confertissime punctatus. Scutellum atro-holosericeum. Elytra thoracis prope longitudine, subtiliter punctato-subrugulosa. Abdomen parcius subtiliter punctulatum. Pedes nigri, tibiis piceis, tarsis rufescentibus.

* 9. O. picipes: Alatus, niger, opacus, antennis, palpis pedibusque piceis, thorace elytris subcrassiore, his thorace subbrevioribus. - Long. 7 lin.

Staph. picipes Nordm. Symb. 68. 58.

Habitat in Austria et in Istria, Dahl, in ins. Jonicis, Parreyss.

Praecedenti affinis, niger, opacus, tomento subtili nigro-fusco obductus. 
Antennae capite vix sesqui longiores, articulo tertio secundo sesqui longiore, sequentibus sensim paulo brevioribus, cylindrıcis, penultimis leviter obconicis, ultimo subovato, apice emarginato et inferne acuminato, rufopiceae, apice ferrugineae. Palpi rufi. Caput thoracis prope latitudine, subquadratum, angulis omnibus fortiter rotundatis, supra parum convexum, confertim subtiliter punctatum. Thorax coleopteris prope latior, latitudine haud brevior, lateribus subrectis, parallelis, basi fortiter rotundatus, apice truncatus, angulis anterioribus subrectis, deflexis, posterioribus obtusissimis, leviter transversim convexus, confertissime subtiliter punctatus, postice linea longitudinali elevata, subtilissima, vix observanda. Scutellum nigro-pubescens. Elytra thoracis prope longitudine, confertissime subtiliter ruguloso-punctata. Abdomen apicem versus sensim attenuatum, subtilissime punctulatum, supra puncto fulvo-pubescente in medio baseos singuli segmenti. Pedes coxis posterioribus nigris, anticis femoribusque omnibus rufo-piceis, tibiis tarsisque rufis.

Obs. 1. Thorace crassiusculo et abdomine apicem versus sensim attenuato habitu quodammodo a praecedentibus discedit.

2. A Dahlio nom. Staph. picipedis et fuscipedis missus.

* 10. O. brunnipes: Apterus, niger, opacus, capile thoraceque nitidis, antennis basi apiceque pedibusque rufis, elytris thorace dimidio brevioribus. - Long. 6 lin.

Er. Col. March. I. 411. 4.

Staph. brunnipes Fab. Spec. Ins. I. 336. 8. Mant. Ins. I. 220. 12. Ent. Syst I. II. 521. 23. Syst. El. II. 595. 26. - De Vill. Ent. I. 419. 27. - Oliv. Ent. III 42. 15. 11. t. 1. $f$. 7. - Latr. Hist. nat. Crust. et Ins. IX. 326. 75 - Marsh. Ent. Britt. 502. 13. - Grav. Mon. 112. 124. - Gyll. Ins. Suec. II. 289. 10. Sahlb. Ins. Fenn. I. 310 7. - Mannerh. Brachelytr. 24. 23. - Nordm. Symb. 73. 72. - Runde Brachelytr. Hal. 4. 16.

Emus brunnipes Boisd, et Lacord. Faun. Ent. Paris. I. 371. 20.

Habitat in Germania, Gallia, Anglia, Suecia.

Statura omnino O. fuscati, niger, opacus, subtiliter breviterque nigropubescens, capite thoraceque nitidis. Antennae capite duplo Jangiores, articulo tertio secundo paulo longiore, $4-8$ subaequalibus, cylindricis, sequentibus sensim paulo minoribus, penultimis duobus leviter obconicis, ultimo apice truncato et inferne acuminato, basi rufae, medio nigrae, apice testaceae. Palpi rufi. Mandibulae rufo-piceae. Caput thoracis latitudine, suborbiculatum, supra leviter convexum, posterius creberrime, anterius parce punctatum, linea media longitudinali laevi, tenuiter subtiliterque nigro-pubescens, subtus parce punctatum, glabrum. Thorax coleopterorum latitudine, latitudine haud brevior, antrorsum subangustatns, lateribus rectis, basi fortius rotundatus, apice truncatus, angulis anterioribus subrectis, posterioribus obusis, subrotundatis, modice convexus, sat crebre minus subtiliter punctatus, linea tenui media longitudinali laevi, parce subtiliterque pubescens. Elytra thorace dimidio breviora scutellumque subtiliter confertissime punctata, subtiliter nigro-pubescentia, opaca. Abdomen dense subtiliter punctulatum. Pedes rufi, coxis piceis. Alae brevissimae. 
* 11. O. alpicola: Apterus, niger, opacus, capite thoraceque vitidis, subaeneis, antennis basi pedibusque rufis, illis apice flavis, elytris thorace paulo brevioribus. - Long. $6 \frac{1}{2}$ lin.

Habitat in Carinthiae Carnioliaeque alpibus.

O. brunnipedi proxime affinis, at paulo maior, niger, opacus, capite thoraceque nigro-subaeneis, nitidis. Antennae capite duplo longiores, articulo tertio secundo paulo longiore, $4-8$ subaequalibus, cylindricis, sequentibus sensim paulo minoribus, penultimis duobus leviter obconicis, ultimo apice oblique truncato et inferne acuminato, nigrae, basi rufae, apice flavae. Palpi rufi. Mandibulae piceae. Caput thoracis latitudine, suborbiculatum, supra parum convexum, minus subtiliter sparsim punctatum, anterius sublaeve, interstitiis subtiliter punctatis, subtiliter tenuiterque nigropubescens, subtus parce punctatum, tenuiter pubescens. Thorax coleopteris prope latior, latitudme vix longior, lateribus subrectis, parallelis, basi cum angulis posterioribus rotundatus, apice truncatus, angulıs anterioribus obtusiusculis, modice convexus, inaequaliter sat crebre subtilius punctatus, linea media longitudinali laevi obsoletiore, tenuiter pubescens. Elytra thorace parum breviora, depressa scutellumque subtiliter confertissime punctata, subtiliter nigro-pubescentia, opaca. Abdomen subtilissime minus confertim punctatum, supra opacum, subtus subnitidum. Pedes rufi, coxis rufo-piceis. Alae brevissimae.

Obs. A praecedente differt antennis apice dilutioribus, capite subtiliter interpunctato, thorace minus crebre punctato, antrorsum nullo modo angustato, longius pubescente.

* 12. O. fuscatus: Alatus, niger, opacus, capile thoraceque nigro-aeneis, nitidis, ely/ris thoracis longitudine. - Long. 6 lin.

Er. Col. March I. 441. 5.

Staph. fuscatus Grav. Micr. 164. 10. Mon. 112. 123.

Staph. cras sicollis Grav. Micr. 7. 7. - Latr. Hist. nat. Crust. et Ins. IX. 302. 15. staph. subpunctatus Gyll. Ins. Suec. IV. 474. 9. - Sahlb. Ins. Fenn. I. 310. 6.

- Nannerh. Brachelytr. 24. 19. - Nordm. Symb. 72. 67. - Runde Brachelytr.

Hal. 3. 12.

St a ph. morio Gyll. Ins. Suec. II. 288. 9. - Zetterst. Faun. Lappon. I. 69. 6. Ins. Lappon. 60. 7.

Staph. punctulatus Marsh. Ent. Britt. 501. 7.

Stuph. politus Degeer Ins. IV. 22. 7.

Habitat in Europa.

Niger, opacus, subtiliter nigro-pubescens, capite thoraceque glabris, supra nigro-aeneis, pernitidis. Antennae capite sesqui longiores, articulo tertio secundo sesqui lougiore, sequentibus sensim brevioribus, primis eorum subglobosis, penultimis transversim obconicis, ultimo apice truncato et inferne acuminato, nigrae, apice summo obscure ferrugineae. Palpi rufi. Caput thorace paulo angustius, suborbiculatum, supra parum convexum, undique creberrime, disco parce subtilius punctatum. Thorax coleopterorum latitudine, latitudine haud brevior, antrorsum subangustatus, lateribus rectis, basi rotundatus, apice truncatus, angulis anterioribus obtusiusculis, posterioribus obtusis, subrotundatis, transversim convexus, parcius subtilinsque puncratus. Scutellum creherrime punctulatum, densius pubescens. Elytra tho- 
racis longitudine, omnium confertissime subtiliter punctata, dense subtiliterque nigro-pubescentia, opaca. Abdomen parcius subtiliter punetatum, subtilissime nigro-tomentosum. Pedes nigrı, tarsis piceis. Alae fusco-hyalinae.

* 13. O. picipennis: Alatus, niger, capite thoraceque aeneis, nitidis, densius subliliter punctatis, tenuiter pubescentibus, elytris tarsisque piceis, abdomine cinereo-lineato. - Long. 7 - 8 lin.

Er. Col March. 1. 442. 6.

Staph. picipennis Fab. Ent. Syst. I. II. 521. 8. Syst. El. II. 591. 10. - Panz. Ent. Germ. 353. 7. - Runde Brachelytr. Hal. 2. 4.

Staph. aeneocephalus Payk. Mon. Staph. 11. 6. Faun. Suec. III. 374. 10. Grav. Mier. 8. 8. Mon. 113. 126. - Gyll. Ins. Suec. I1. 291. 12. - Zetterst. Faun. Lappon. I. 68. 5. Ins. Lappon. 60. 6. - Suhlb Ins. Fenn. 310. 9. - Mannerk. Brachelytr. 23. 11. - Nordm. Symb. 70. 61.

Emus a neocephalus Boisd. et Lacord. Faun. Eut. Paris. I. 373. 22.

Staph. penetrans Müll. Prodr. 97. 1102. - Goeze Ent. Beitr. I. 727. 26. - Harrer Beschr. d. Ins. I. 251.412.

Staph. quartus Schueff. Icon. I. $t$. 35 . f. 9.

Var. Elytris nigro-piceis.

Staph. tristis Fab. Ent. Syst. I. II. 524. 21. Syst. El. 1I. 594. 23.

Staph. sericeus Marsh. Ent. Britt. 508. 29.

Staph. leucophthalmus Mursh. Ent. Britt. 511. 39.

Staph. chalcocephalus Mannerh. Brachelytr. 23. 12.

Emus chulcocephalus Boisd, et Lacord. Faun. Ent. Paris. I. 374. 23.

Habitat in Europa.

Antennae capite sesqui longiores, articulo tertio secundo paulo longiore, sequentibus sensim brevioribus, prioribus subcylindricis, reliquis snbobconicis, ultimo apice oblique truncato et inferne acuninato, rufo-piceae, basi nigricantes. Palpi rufo-picei. Caput thoracis fere latitudine, orbiculato-subovatum, supra parum convexum, dense subtiliterque punctatum, subtiliter griseo-pubescens, aeneum, nitidum, subtus nigrum, nitidum, parce nigro-pubescens. Thorax coleopterorum latitudine, latitudine vix Inngior, antrorsum hand angustatus, lateribus subrectis, basi cum angulis posterioribus rotundatus, apice truncatus, angulis anterioribus deflexis, subrectis, transversm convexus, dense subtiliterque punctatus, linea media longitudinali tenui obsoletius carinata, subtiliter griseo-pubescens, aenens, nitidus. Scutellum nigrum, macula rotundata nigro-tomentosa. Elytra thoracis longitudine, subtiliter omnium confertsssme punctata, densius plagiatim subtilter cinereo-pubescentia, plerumque piceo-castanea, rarius fusco-nigricantia. Abdomen subtiliter punctulatum, punctis raris maioribus sparsis impressum, nigrum, opacum, supra pube densiore grisea 5-lineatum, linea intermedia distinctiore, angusta. Pectus nigrum. Pedes nigri, tibiis interdum piceis, tarsis rufo-piceis.

* 14. O. cupreus: Alatus, niger, capite thoraceque aeneis, nitidulis, conferlıssime subtilius punclatis, hoc carinato, elytris fuscis, tarsis piceis, abdomine cinereo-lineato. - Long. 5 - 7 lin.

Er. Col. March. I. 443. 7. 
Staph. cupreus Rossi Faun. Etr. I. 248. 612. t. 7. f. 13. Ed. Hellu. I. 307. 612.

t. 7. f. 13. - Fourcr. Ent. Paris. I. 173. 33.

Staph. ae neocephalus Degeer Ins. IV. 22. 8. - De Vill. Ent. I. 423. 58.9-

Latr. Hist. nat. Crust. et Ins. IX. 300. 13.

St uph. a en eicollis Gyll. Ins. Suec. IV. 475. 12-13. - Sahlb. Ins. Fenn. I. 311.

10. - Mannerh. Brachelytr. 23. 13. - Nordm. Symb. 70. 63. - Runde Brachelytr. Hal. 3. 5.

Emus a en eicollis Boisd. et Lacord. Faun. Ent. Paris. I. 24.74.

Staph. sericeicollis Menetr. Cat. 143. 570. - Nordm. Symb. 70. 64.

Staph. strigatus Nordm. Symb. 70. 65.

St uph. puberulus Runde Brachelytr. Hul. 3. 7.

Habitat in Europa.

Praecedenti simullimus, at vere distinctus, apud nos eodem dimidio rel duplo minor, specimina Italica nonmuquam illum aequantur. Antennae eapit: sesqui longiores, articulo tertio secundo paulo longiore, sequentibus sensin paulo brevioribus, prioribus subcylindricis, reliqnis leviter obconicis, ultimo apice truncato et inferne acuminato, rufae, medio, interdum etiam basi nigropiceae. Palpi rufi. Caput thorace angustius, suborbiculatum, supra parum convexum, coufertim subtilius punctatum, posterius linea tenui longitudinali subelevata, densius griseo-pubescens, aeneum, nitidulum, subtus nigrum, nitidum. Thorax coleopteris paulo angustior, latitudine paulo longior, apicen versus sensim subangustatus, lateribus subrectis, basi cum angulis posterioribus rotundatus, apice truncatus, angulis anterioribus obtusiusculis, transversim convexus, confertim subtilius punctatus, linea media longitudinali laevi elevata, densius griseo-pubescens, aeneus, nitidulus. Scutellum nigrum, griseo-pubescens, macula magna nigro-tomentosa. Elytra thoracis longitudine, omnium confertissime subtiliter punctata, aequaliter cinereo-pubescentia, fusco-picea. Abdomen dense subtiliter punctulatum, punctis maioribus raris sparsis impressum, opacum, supra pube densiore grisea 5-lineatum, lineis lateribus obsoletioribus, intermedia latiore distinctioreque. Pectus nigrum. Pedes nigri, tibiis tarsisque piceis.

* 15. O. fulvipennis: Alatus, niger, capile thoraceque nigro-aeneis, nilidis, antennis, elytris pedibusque rufis, abdomine griseo-sablineato. long. 5 - 6 lin.

Staph. chalcocephalus Nordm. Symb. 70.62. - Runde Brachelytr. Hal. 3. 6. Staph. picipennis Nordm. Symb. 71. 66.

Emus picipennis Botsd. et Lacord. Faun. Ent. Paris. I. 374. 25.

Habitat in Austria.

Statura omnino praecedentis. Antennae capite plus sesqui longiores, articulo tertio secundo paulo longiore, sequentibus sensim paulo brevioribus, subobconicis, ultimo apice truncato et inferne acuminato, rufo-testaceae, medio interdum piceae. Palpi rufi. Caput thorace paulo angustius, suborbiculatum, supra parum convexum, subtiliter densius punctatum, subtiliter griseo-pubescens, nigro-aeneum, nitidum, subtus laeve, glabrum, nigrum, nitidum. Thorax coleopterorum prope latitudine, latitudine paululum longior, antrorsum vix angustatus, lateribus levissime, basi fortiter rotundatus, apice truncatus, angulis anterioribus rectis, posterioribus obtusissimis, modice transversim convexus, dense subtilius punctatus, linea media longitu- 
dinali tenui haud elevata, subtiliter tenuiterque griseo-pubescens, obscure aeneus, nitidus. Scutellum griseo-pubescens, apice nigro-tomentosum. Elytra thoracis longitudine, confertissime subtiliter punctata, rufo-testacea, aequaliter fulvo-pubescentia. Abdomen subtiliter punctulatum, punctis raris sparsis maioribus impressum, nigrum, opacum, supra griseo-pubescens, sublineatum. Pectus nigrum. Pedes rufi, coxis nigris, anticis piceis.

O bs. Lapsu forte typographico a Nordm. l. c. apud Staph. picipennem A u stralasia pro huius insecti patria indicata est.

\section{Fam. II.}

Physetops Mannerh. Brachelytr. p. 32. - Nordm. Symb. p. 14. t. 1. f. 4.

Antennae articulo ultimo integro.

Palpi labiales articulo ultimo securiformi.

Mandibulae medio dentatae.

Corpus elongatum, subcylindricum, alatum. Caput thorace paulo latius, oblongum, leviter convexum, basi minus profunde constrictum, oculis parvis leviter prominulis. Antennae basi distantes, articulo ultimo oblongo, acuminato. Labrum perbreve. Mandibulae prominentes, validae, leviter falcatae, acutae, medio fortiter dentatae. Palpi maxillares articulo quarto praecedente paulo minore, subacuminato, labiales articulis duobus primis breviusculis, ultimo leviter securiformi. Thorax oblongus, basin versus angustatus. Pedes tibiis intermediis crebre, posterioribus creberrime spinulosis, tarsis anticis leviter dilatatis.

Obs. Statura cylindrica praecipue a congeneribus discedit, vix autem rite genere distinguendus, labro paulo breviore, mandibulis prominentibus, antennarum articulo ultimo integro, acuminato et tarsis anticis leviter dilatatis diversus, palporum structura cum $\mathrm{F} \mathrm{am}$, sequente conveniens.

* 16. O. Tataricus: Alatus, subcylindricus, niger, nilidus, capite thoraceque crebre punctatis, elytris thorace longioribus. - Long. 10 lin.

Staph. Tataricus Pall. It. App. n. 74. - Goeze Ent. Beitr. I. 723. 3. - Sturm Catal. 61. IX. t. I. f. 9. - Guér. Iconogr. Regn. An. Ins. t. 9. f. 5.

Physetops Tartaricus Mannerh. Brachelytr. 33. 1. - Nordm. Symb 14. 1.

Habitat in desertis Russiae meridionalis.

Elongatus, subcylindricus, niger, nitidus. Antennae capite parum longiores, articulo tertio secundo sesqui longiore, quarto quinto paululum breviore, 5-10 sensim paulo brevioribus, penultimis duobus leviter transversis, ultimo praecedente duplo prope longiore, acuminato, nigrae, apice obscure ferrugineae. Caput oblongo-subquadratum, licet angnlis rotundatis, crassum, fronte modice convexa, crebre punctata, lateribus subrugosa. Thorax capitis fere longitudine, latitudine antica paulo longır, basin versus angustatus, coleopteris angustior, lateribus pone medium sinuatis, basi rotundatus, apice truncatus, angulis omnibus obtusis rotundatisque, anterioribus fortiter deflexis, subcylindricus, supra subtilius crebriusque punctatus, lateribus punctato - rugulosus. Scutellum creberrime punctatum. Elytra thorace longiora, subtilissime parce griseo-pubescentia, subtilius minus crebre punctata, interstitiis subtiliter rugulosis. Abdomen subtiliter griseo-pubescens, 
apice nigro-pilosellum, subtiliter punctulatum punctisque maioribus sparsis impressum. Pedes nigri, tibis tarsisque piceis.

O b s. „In deserto Tatarico circa lacum salsum Inderiensem primum observa. tus, at frequentissimus in montoso tractu orae meridionalis Chersonesi tauricae, ubi circa vias, praesertim fimo allectus recenti, perfrequens cursitat, sero praesertim autumno. Cornicula odorifera ex caudae apice exserit alba, papillaria, fragrantissima, odore modo corniculorum larvae Machaonis, modo rosaceo, Cerambycis fere moschati." Pall. mspt.

\section{Fam. III.}

Tasgius Steph. Illustr. Britt. Ent. V.p. 213. - Curtis Britt. Ent. X. t. 438.

Antennae articulo ullimo apice truncato.

Palpi labiales articulo tertio securiformi.

Mandibulae medio dentatae.

Corpus elongatum, alatum. Caput basi profunde constrictum, collo quasi angusto thoraci insertum, suborbiculatum et subdepressum. Antennae apicem versus subattenuatae, articulo ultimo apice oblique truncato et inferne acuminato. Labrum latiusculum. Mandibulae longiores, validiores, falcatae, acutae, medio fortiter dentatae. Palpi breviores, maxillares articulo ultimo maris tertio fere aequali, apice truncato, subsecuriformi, feminae tertio minore, subacuminato, labiales in utroque sexu articulis duobus primis breviusculis, tertio leviter securiformi. Thorax basin versus subangustatus. Pedes tibiis intermediis crebre, posticis parce spinulosis, tarsis anticis fortiter dilatatis.

* 17. O. pedator: Alatus, niger, capile thoraceque nilidis, antennis pedibusque rufis, elylris thorace longioribns. - Long. 9-10 lin.

Staph. pedat or Grav. Micr. 163. 9 Mon. 113. 125. - Nordm. Symb. 65. 53.

Astrapaeus rufipes Latr. Gen. Crust. ot Ins. I. 285. 2.

Emus rufipes Boisd. et Lacord. Faun. Ent. Paris. I. 371. 19.

Tasgius rufipes Curt. Britt. Ent. X. $t .438$.

Habitat in Gallia, Italia, Dalmatia.

Habitu omnino $\mathbf{O}$. atri, et duplo maior at minus depressus, O. cyaneo aequalıs, at angustior, niger, subnitidus, capite thoraceque nitidioribus. Antennae capitis thoracisque longitudine, articulo tertio secundo paulo longiore, sequentibus sensim minoribus, cylindricis, ultimo oblongo-ovato, apice truncato et inferne acuminato, obscure rufae, medio obscuriores. Palpi rufi. Mandibulae piceae. Caput thorace fere angustius, orbiculatum, supra parum convexum, minus subtiliter creberrime punctatum, parce pilosum. Thorax coleopterorum prope latitudine, latitudine paulo longior, basin versus subangustatus, lateribus rectis, basi rotundatus, apice truncatus, angulis anterioribus deflexis, subrectis, posteriorilus obtusissimis, transversim convexus, crebre minus subtiliter punctatus, linea tenu longitudinali laevi, subelevata, pube subtili rara depressa vix conspicua vestitus, lateribus parce pilosus. Scutellum confertissime punctulatum, tenuiter pubescens. Elytra thorace paulo longiora, confertissime subtilius punctata, tenuiter nigro-pubescentia, cyanescenti-nigra, minus nitida. Abdomen subtiliter confertissime punctatun, 
sparsim fortius punctatum, densius nigro-pubescens, parcius nigro-pilosellum. Pectus piceum. Pedes rufi, coxis omnibus concoloribus.

Obs. Palpi labiales articulo ultimo in utroque sexu subsecuriformi, maxillares articulo ultimo $\mathrm{m}$ aris apice truncato, subsecuriformı, fe min a e subacuminato.

* 18. O. ater: Alatus, niger, nitidus, antennis apice ferrugineis, capile thoracegue parcius punctatis, elytris thorace sublongioribus. - Long. 8 lin.

Er. Col. March. I. 444. 8.

St aph. ater Grav. Micr. 161. 5. Mon. 112. 120.

St a ph. fuscatus Gyll. Ins Suec. IV. 474. 9-10. - Nordm. Symb. 69. 58.

Staph. obscurius Marsh. Ent. Britt. 514. 50.

Emus nigripes Boisd. et Lacord. Faun. Ent. Paris. I. 370. 18.

Tasgius confinis Curt. Britt. Ent. X. fol. 138. n. 2.

Staph. Uralensis Mannerh. Brachelytr. 24. 20. - Nordm Symb. 72. 68. (forte)

Habitat in Europa infrequens; in montibus Uralensibus, Dom. Prof. Eversmann; in America septentrionali, Knoch.

Elongatus, subdepressus, niger, capite thoraceque nitidis. Antennae capite plus sesqui longiores, articulo tertio secundo sesqui longıre, sequentibus sensim brevioribus minoribusque, subcylindricis, penultimis leviter obconicis, ultimo apice oblique truncato et inferne acuminato, nigrae, apice obscure ferrugineae. Palpi picei. Caput thoracis fere latitudine, suborbiculatum, supra parum convexum, parcius fortiusque punctatum, linea media longitudinali laevi, parce subtiliterque nigro-pubescens. Thorax coleopteris paulo angustıor, latıtudine paululum longior, basin versus subangustatus, lateribus rectis, basi cum angulis posterioribus rotundatus, apice truncatus, angulis anterioribus rectis, parum convexus, parcius punctatus, linea media longitudinali posterius subelevata laevi. Elytra thorace paulo longiora, depressa scutellumque confertim subtiliter punctata, minus nitida, densius subtiliter nigro-pubescentia. Abdomen confertim punctulatum, minus nitidum. Pedes nigri, tarsis piceis.

Obs. 1. Palpi labiales sat fortiter securiformes in utroque sexu, maxillares maris subsecuriformes, feminae cylindricae, apice truncatae.

2. Synonymiam huius speciei confusam extricavi: specimina Europaea ab 0 . atro Americano, cuius exemplum a Gravenhorstio descriptum in Museo regio conservatur, nullo modo distincta, quare non potui quin $\mathrm{Staph}$. nigripedem Dej. (Staph. fuscatum Gyll.) huic subiungerem. Staph. Uralensem Mannerh. non sine dubio allegavi, qui "convexus" et "thorace postice foveols duabus longitudinalibus parum profundis punctatis impresso" describitur. Foveolas hasce autem thoracis linea longitudinali posterius fortius elevata exortas esse suspicor: thorax etiam hoc loco crebrius punctatus est, et apud $O$. morionem quoque hoc modo nonnunquam thorax postice bi-impressus videtur.

\section{Fam. IV.}

Oсури Steph. Illustr. Britt. Ent. V. p. 211.

Anodus Nordm. Symb. p. 11. t. 1. f. 1.

Antennae arliculo ultimo apice truncato.

Palpi labiales arliculo tertio securiformi.

Mandibulae elongatae, falcatae, edentatae.

Corpus subdepressum, onmibus alatum. Caput depressiusculum, thorace 
saepe latius, oculis parvis, hat:d prominulis. Antennae basi magis distantes, graciles, apicem versus leviter attenuatae, arciculis singulis crassitie tenuioribus, pilosellae, ab articulo quarto inde pube brevissima cinerea dense obducta. Labrum perbreve. Mandibulae elongatae, leviter falcatae, tenues, apice acuminatae, simplicissimae. Palpi breves, maxillares articulo quarto tertio subaequali, apice acuminato, labiales articulis duobus primis breviusculis. Thorax basin versus subangustatus. Abdomen parallelum, depressum. Perles tibiis intermediis crebrius, posticis parcius spinulosis, tarsis anticis in utroque sexu fortiter dilatatis.

* 19. O. morio: Alatus, niger, opacus, antennis apice ferrugineis, thorace angustiore, subliliter carinato, elytris thoracis longiludine. - Long. 5-7 lin.

Er. Col. Murch I. 444. 9

Staph. morio Grav Micr. 6. 4. Mon. 112. 121. - Latr. Hist. nat. Crust. et Ins. IX. 303. 18. - Gyll. Ins. Suec. IV. 373. 8-9. - Sahlb. Ins. Fenn. I. 309. 5. Mannerh. Brachelytr. 24. 18. - Runde Brachelytr. Hal. 3. 11.

Emus mörio Boisd. et Lacord. Faun. Ent. Paris. I. 369. 15.

Anodus morio Nordm. Symb. 13. 3.

Staph. edentulus, Block Ins. Vall. Plauens. 115. 1. $f$. 1.

Staph. similis Payk. Mon. Staph. 10. 5. Faun. Suec. III. 371. 6.

Simus angustatus Boisd. et Lacord. Faun. Ent. Paris. I. 369. 16.

Emus fuscat us Buisd. et Lacord. Faun. Ent. Paris. I. 372 21.

Staph. obscurūs Runde Brachelytr. Hal. 4. 13.

Habitat in Europa.

Elongatus, subdepressus, niger, opacus, capite thoraceque subnitidis, subtiliter nigro pubescens. Antennae capite duplo fere longiores, articulo tertio secundo sesqui longiore, sequentibus sensim paulo brevioribus, penultimis leviter transversıs, ultimo praecedente paulo longiore. apice truncato et inferne acuminato, nigrae, apice ferrugineae. Palpi nigri, labiales articulo ultimo fortius securiformi. Mandibulae piceae. Caput thorace plerumque paulo latius, orbiculatum, supra subdepressum, minus subtiliter crebre punctatum, linea media longitudinali obsoleta, tenuiter subtiliterque pubescens. Thorax coleopteris angustior, latitudine vix longior, basin versus leviter angustatus, lateribus rectis, basi leviter rotundatus, apice truncatus, angulis anterioribus subrectis, posterioribus obtusis, subdepressus, confertim minus subtiliter punctatus, linea media longitudinali subelevata magis minusve distincta, tenuiter pubescens. Elytra thoracis longitudine vel eodem parum longiora scutellumque confertissime subtiliter punctata, densius pubescentia. Abdomen dẹse subtiliter punctatum, densius pubescens. Pedes nigri, tarsis plerumque piceis, interdum picei, tarsis dilutioribus.

Obs. Variat statura maiore minoreve, capite thorace magis minusve latiore; feminae saepius capite thoracem latitudine haud superante instructae sunt.

* 20. O. cerdo: Alalus, niger, opacus, confertissime punctatus, antennarum articulis tribus primis ultimoque, palpis tarsisque rufis, ely/ris thoracis longiludine. - Long. 7-8 lin.

Habitat in Italia: in montibus Appeninis, Dom. Schïppel, in Sardinia, Dom. Gené. 
Statura et summa affinitas $\mathrm{O}$. compressi. Niger, vix nitidus, pube brevi subtili nigra dense vestitus. Antennae capite duplo fere longiores, articulo tertio secundo sesqui prope longiore, 4-7 subaequalibus, cylindricis, 8-10 sensim paulo minoribus, leviter obconicis, ultimo paulo crassiore, oblique truncato et apice inferne acuminato, nigrae, articulis tribus primis rufis, ultimo ferrugineo. Palpi rufi, labiales articulo tertio fortiter securiformi. Mandibulae nigro-piceae. Labrum nigrum. Caput subquadratum, thoracis prope latitudine, supra subdepressum, confertissime minus subtiliter punctatum. Thorax coleopteris vix angustior, latitudine sublongior, basin versus subangustatus, lateribus rectis, basi modice rotundatus, apice truncatus, angulis anterioribus subrectis, posterioribus obtusis, supra parum convexus, confertissime subtilius punctatus, pone medium linea longitudinali laevi subtilissima, vix observanda. Elytra thoracis longitudine et scutellum confertissime subtilius punctata. Abdomen densius subtiliter punctulatum. Pedes nigri, tibiis piceis, tarsis rufis.

Obs. $\mathrm{Ab} \mathrm{O}$. morione capite thoraceque confertissime punctatis, antennarum hasi rufa, ab 0 . compresso capite thoraceque minus subtiliter punctatis, pedibus nigris, antennarum articulo ultimo solo testaceo facile distinguendus.

* 21. O. compressus: Alatus, niger, opacus, pedibus, palpis antennisque rufis, his medio fuscis, elytris thoracis longiludine. - Long. 7 lin.

Staph. compressus Marsh. Ent. Britt. 503. 15.

Emus rufipalpis Boisd. et Lacord. Faun. Ent. Paris. I. 370. 17.

Habitat in Anglia, Hollandia, Gallia, Hungaria.

O. morioni affinis et maioribus eius speciminibus aequalis, niger, opacus, subtiliter nigro-pubescens. Antennae capite plus sesqui longiores, articulo tertio secundo plus sesqui longiore, sequentibus sensim paulo minoribus, penultimis leviter transversis, ultimo apice oblique truncato et inferme acuminato, rufae, medio fuscae. Palpi rufi, labiales articulo ultimo fortiter securiformi. Mandibulae piceae. Labrum rufo-piceum. Caput thoracis latitudine, suborbiculatum, basi truncatum, supra subdepressum, confertissime subtiliter punctatum, subtilissime nigro-pubescens, subtus laeve, nitidum. Thorax coleopteris paululum angustior, latitudine vix longior, basin versus subangustatus, lateribus rectis, basi rotundatus, apıce truncatus, angulis anterioribus rectis, posterioribus obtusis, parum convexus, confertissime subtiliter punctatus, dense subtiliter nigro-pubescens, opacus. Elytra thoracis longitudine scutellumque subtiliter confertissimeque subruguloso-punctata, dense subtiliter nigro-pubescentia. Abdomen subtiliter punctulatum, subtiliter nigro-tomentosum. Pedes laete rufi, coxis nigris, anticis intus rufescentibus.

* 22. O. falcifer: Alalus, niger, capile, thorace elylrisque supra coeruleis, antennis basi apiceque pedibusque rufis. - Long. $4 \frac{1}{2}-7 \mathrm{lin}$.

Anodus falcifer Nordm. Symb. 12. 2.

Anodus messor Nordm. Symb. 11. 1.

Habitat in Italia, Dahl.

Statura omnino O. morionis, at magnitudine magis quam ille instabilis. Antennae caprte plus sesqui longiores, articulo tertio secundo sesqui longiore, sequentibus sensim paulo brevioribus, penultimis leviter obconicis, ultimo ovato, apice inferne acuminato, fuscae, basi apiceque rufae. Palpi 
rufi, labiales articulo ultimo leviter securiformi. Mandibulae nigrae. Caput thorace plerumque latius, subquadrato-orbiculatum, supra subdepressum, parrius punctatum, linea medıa longitudinali laevi, parce subtilissime nigro-pubescens, coeruleum, nitidum, subtus nigrum. Thorax coleopteris angustior, basin versus leviter angustatus, latitudine apicis parum longior, lateribus rectis, basi leviter rotundatus, apice utrinque oblique truncatus, angulis anterioribus rectis, posterioribus obtusis, subrotundatis, supra parum convexus, crebre punctatus, linea media longitudinali laevi subcarinata, subtiliter tenui terque nigro-pubescens, coeruleus, nitidus. Scutellum confertim punctulatum, nigrum, subtiliter pubescens. Elytra thorace paulo longiora, depressa, confertim subtiliter punctata, densius subtiliter nigro-pubescentia, coerulea, minus nitida. Abdomen dense subtilius punctatum, densius subtiliter nigro-puhescens, nigrum, subnitidum. Pectus migrum. Pedes laete rufi, coxis posterioribus nigro-piceis.

Obs. 1. Individua maiora capite latiore et magis subquadrato, minora capite minore et magis orbiculato, minima capite thorace haud latiore instructa sunt.

2. Anodus falcifer et messor Nordm. nonnisi sexu differunt: ille mas hic femina.

3. Staph. morsitans Rossi Faun. Etr. I. 249. 614. Ed. Hellw. I. 308. 614, huic proximus videtur, at palpi nigri et caput, thorax et elytra nigro-aenea descripta: an autem revera distinctus?

\section{Belonuchus Nordm.}

Nurdm. Symb. p. 129. t. 2. f. 2.

Antennae rectae.

Palpi filiformes.

Ligula rolundata, integra.

Femora antica et postica sublus biseriatim spinulosa.

Corpus subdepressum, elongatum, saepe lineare, alatum. Caput exsertum, porrectum, basi profunde constrictum, oculis vix prominulis. Labrum transversum, medio incisum, limbo nembranaceo, setoso. Mandibulae prominulae, tenues, decussatae, falcatae, apice valde acutae, muticae. Maxillae malis coriaceis, interiore intus ciliata, exteriore minuta, apice barbata. Palpi maxillares modice elongati, filiformes, articulo primo munto, secundo ceteris paulo magis incrassato, quarto saepius tertio paulo longiore, apice leviter acuminato. Labium mento transverso, ligula minuta, rotundata, membra.. nea, paraglossis ligulam paulo superantibus, membranaceis. Palpi labiales filiforines, artıculis omnibus subelongatis. Antennae filiformes, articulo primo modice elongato, uftimo apice oblique emarginato et inferne acuminato. Thorax coleopteris angustior, basin versus saepius angustatus, basi rotundatus, apice truncatus. Scutellum triangulare. Elytra truncata. Abdomen lineare. Pedes coxis intermediis distantibus, femoribus omnibus subtus leviter canaliculatis, anticis saepius leviter dilatatis posticisque subtus spinulis minutis biseriatis munitis, intermediis muticis, tibiis spinulosis, tarsis setulosis, posterioribus articulo primo leviter elongato, anticis in utroque sexu simplicibus.

$$
\text { O b s e r v a t i n e s. }
$$

1. Genus Philontho proximum, non sine dubio mihi receptum et ab illo distinctum. Oris structura omnino eadem, et femora antica et postica subtus biseriatim spinulosa solam fere notam distinctivam praebent. Congruunt praeterea species in hoc genere enumeratae statura corporis magis minusve depressa, capite maiusculo, por- 
recto, fronte antice sulco versus capitis medium evanescente impressa, mandibulis porrectis, muticis, apice falcatis, acutis, tibiis omnibus fortius spinulosis et tarsis anticis in utroque sexu simplicibus. Species quaedam thorace magis elongato (e. g. B. haemorrhoidalis) habitu Xantholinum simulant.

2. Corpus ut in Philontho punctulatum, pubescens, saepius parce piloselIum, capite thoraceque laevissimis, illo punctis 4 transversis inter oculos et pluribus supra oculos, hoc punctis praeter marginalia nonnullis dorsalibus et lateralibus impresso. Puncta dorsalia rarius singula, saepius utrinque 5 in series dorsales digesta sunt. Series dorsales infra et ultra hunc panctorum numerum nondum in hoc genere observatae.

3. Mas abdominis segmento inferiore sexto apice emarginato vel inciso distinctus, saepius etiam capite et mandibulis insignis.

4. Species omnes hucusque cognitae Americam meridionalem habitant.

\section{1) Thorax punctorum seriebus dorsalibus nullis.}

* 1. B. haemorrhoidalis: Elongatus, depressus, niger, nitidulus, abdomine apice rufo. - Long. 4 -5 lin.

Nordm. Symb. 130. 1.

Staph. ha emorrhoidalís Fab. Syst. El. II. 596. 33.

Habitat in America meridionali, in Brasilia, Dom. Beske, Sieber, in Columbia, Dom. Moritz.

Statura elongata fere Xantholini, depressus, niger, nitidus. Antennae capite plus sesqui longiores, apicem versus vix incrassatae, articulo tertio secundo paulo longiore, 4-10 subobconicis, sensim paulo crassioribus, penultimis leviter transversis, nigrae. Palpi picei. Mandibulae modice elongati. Caput thorace latius, depressum, subquadratum, angulis posterioribus subdentatis, utrinque supra oculos punctis paucis profundis, inter ocnlos anterius utrinque punctis duobus transversim positis impressum, fronte antice leviter canaliculata, canalicula ante apicem dilatata. Thorax coleopteris angustior, latitudine antica paulo longior, basin versus angustatus, lateribus pone medıum sinuatis, angulis posterioribus rotundatis, apice utrinque oblique truncatus, angulis anterioribus subrectis, depressus, praeter puncta marginalia antice utrinque puncto unico dorsali, alteroque laterali impressus. Scutellum punctulatum. Elytra thorace paulo longiora, subtilius punctata, parce griseo-pubescentia, pilis raris longioribus erectis, e punctis impressis maioribus nascentibus. Abdomen subtilius punctatum, nigro-puhescens, segmento quinto apice sextoque toto rufis. Pedes breviusculi, nigri. Alae fuscae.

2. B. dichrous: Elongatus; depressus, nitidus, niger, thorace, peclore, elytris, ano pedibusque rufo-testaceis. - Long. 5 lin.

Habitat in monte Orizaba in Mexico, collect. Dom. Chevrolat.

Statura et suinma affinitas praecedentis. Antennae capite sesqui longiores, articulo tertio secundo paulo longiore, sequentibus duobus subcylindricis, crassitie paulo longioribus, 6-10 leviter obconicis, subaequalibus, nigrae, articulo ultimo ferrugineo. Palpi rufo-picei. Mandibulae modice elongatae, nigrae. Caput thorace latius, depressum, subquadratum, angulis posterioribus subdentatis, posterius utrinque punctis paucis profundis et inter oculos binis transversim positis impressum, fronte antice fortius ca- 
naliculata, nigrum, nitidum. Thorax coleopteris angustior, latitudine antica vix longior, basin versus angustatus, lateribus pone medium subsinuatis, angnlis posterioribus rotundatis, apice utrinque oblique truncatus, angulis anterioribus rectis, depressus, punctis nonnullis marginalibus ternisque utrinque discoidalibus, hinis dorsalibus altero medio, altero ante apicem, tertioque lateri impressus, testaceo-rufus, nitidus. Scutellum subtiliter confertissime punctatum, rufum. Elytra dense subtiliter punctata punctisque paucis maioribus impressa, rufo-testacea, nitida, fulvo-pubescentia. Abdomen crebre subtiliter punctulatum, parcius nigro-pubescens, segmenti quinti margine apicali sextoque toto rufo-testaceis, Pectus totum rufo-testaceum. Pedes cum coxis rufo-testacei.

Obs. Differt a praecedente praeter colorem elytris subtilius, abdomine crebrius punctatis.

2) Thorax seriebus dorsalibus 5-punctatis.

* 3. B. Satyrus: Niger, nilidus, elylris rufis, ano late rufo-testaceo. Long. 4 - 5 lin.

Habitat in Columbia, Dom. Moritz.

Statura omnino Philonthi aenei, niger, nitidus, capite thoraceque supra serice - -versicoloribus, elytris lateritiis, abdominis segmento quinto rufotestaceo, basi nigro, sexto testaceo. Antennae capite sesqui longiores, apicem versus leviter incrassatae, articulo tertio elongato, secundo sesqui longiore, 4-10 sensim paulo brevioribus et crassioribus, nigrae, articulo secundo basi rufo. Falpi picel. Mandibulae longae, falcatae, decussatae, acutae, piceae. Caput maris thorace latius, feminae eius latitudine, suborbiculatum, utrinque supra oculos punctis pluribus, inter oculos utrinque duobus transversim positis fortibus profundisque, antice sulco lato longitudinali in frontis medio evanescente impressum, in mare intra antennarum insertionem utrinque corniculo prominulo munitum. Thorax coleopteris angustior, latitudine haud longior, basin versus subangustatus, lateribus pone medium subsinuatis, angulis posterioribus cum basi rotundatis, apice truncatus, angulis anterioribus subrectis, deflexis, parum convexus, seriebus dorsalibus punctis 5, antico et postico remotioribus, compositis, lateribus punctis praeter marginalia utrinque 6 impressus, punctis omnibus profundioribus. Scutellum subtiliter punctulatum, fulvo-pubescens. Elytra thorace parum longiora, subtiliter punctata, pube depressa fulva et pilis raris erectis fuscis vestita. Abdomen parce subtilissime punctulatom, tenuiter nigro-pubescens. Pedes nigri, tarsis piceis. Alae fusco-hyalinae.

\section{* 4. B. xanthopterus: Niger, nilidus, antennarum basi, pedibus, elytris pectorisque lateribus rufis, ano testaceo. - Long. 5 lin.}

Philonthus $x$ anthopterus Nordm. Symb. 99. 83.

Habitat in Parà Brasiliae interiore, Sieber.

Statura omnino praecedentis. Antennae capite sesqui longiores, apicem versus leviter incrassatae, articulo tertio secundo paulo longiore, 4- 10 sensim paulo brevioribus et crassioribus, leviter obconicis, penultimis 4 leviter transversis, nigrae, articulis tribus primis testaceo-rufis, ul- 
timo ferrugineo. Palpi testaceo-rufi. Mandibulae longiusculae, acutae, piceae. Labrum rufum. Caput nigrum, nitidum, thorace latius, transversim subquadratum, pone oculos utrinque punctis nonnullis vagis, inter oculos utrinque duobus transversim positis profundis, apice sulco lato, ante medium obsolescente, impressum, intra antennarum insertionem utrinque subdentatum. Thorax coleopteris angustior, latitudine paulo brevior, basin versus vix angustatus, lateribus pone medium subsinuatis, basi cum angulis posterioribus rotundatus, apice utrinque oblique truncatus, angulis anterioribus subrectis, leviter convexus, seriebus dorsalibus punctis $\mathbf{5}$, antico et postico paulo remotioribus, compositis, lateribus punctis praeter marginalia utrinque 6 impressus, punctis omnibus profundioribus, niger, nitidus. Scutellum piceum, creberrime punctulatum, fulvo-pubescens. Elytra thorace paulo longiora, crebre subtilius punctata, testaceo-rufa, fulvo-pubescentia. Abdomen punctulatum, longius nigro-pubescens, nigrum, nitidum, segmento quinto apice, sextoque toto testaceis. Pectus rufum, medio piceurn. Pedes ruf, coxis anterioribus migris.

* 5. B. mordens: Niger, nitidus, ano late testaceo, thorace lateribus subrotundato, elytris subtiliter punctatis. - Long. 5 lin.

Habitat in Brasilia, Dom. Prof. Germar.

Statura omnino praecedentium. Corpus nigrum, nitidulum, capite thoraceque nitidis. Antennae capite sesqui longiores, articulo tertio secundo sesqui longiore, $\mathbf{4} \mathbf{- 1 0}$ subobconicis, sensim paulo brevioribus, fere transversis, ultimo oblongo, apice emarginato et inferne acuminato, fuscae, basi nigro-piceae, articulo ultimo ferrugineo. Palpi picei. Mandibulae longiusculae, acutae, piceae. Labrum rufo-piceum. Caput thorace paulo latius, subquadratum, depressiusculum, supra oculos utrinque punctis parcis, inter oculos utrinque duobus oblique positis profunde impressum, fronte antice late canaliculata. Thorax coleopteris angustior, latitudine paulo brevior, basin versus vix angustatus, lateribus leviter rotundatis, pone medium vix sinuatis, basi cum angulis posterioribus rotundatus, apice utrinque oblique truncatus, angulis anterioribus obtusiusculis, leviter convexus, seriebus dorsalibus punctis 5 , postico paulo remotiore, compositis, lateribus punctis praeter marginalia utrinque 6 impressus. Scutellum crebre punctatum. Elytra thorace longiora, confertm subtilius punctata, pube depressa grisea pilisque raris longioribus erectis, e punctis maioribus nascentibus, vestita. Abdomen parce punctulatum, nigro-pilosellum, segmentis ultimis duobus totis testaceis. Pedes nigro-picei, tarsis piceis.

* 6. B. latro: Niger, nitidus, ano late rufo-testaceo, thorace lateribus recto, elytris fortius punctatis. - Long. 4 lin.

Habitat - - E collectione Herbstiania.

Statura et summa affinitas praecedentis, at paulo minor, niger, nitidus, abdominis segmentis duobus apicalibus totis rufo-testaceis. Antennae capite plus sesqui longiores, articulo tertio secundo paulo longiore, 4-7 sensim paulo brevioribus et crassioribus, $7-\mathbf{1 0}$ aequalibus, 5-10 transversis, ultimo ovato, apice subemarginato et inferne acuminato, fuscae, basi jíceae, apice obscure ferrugineae. Palpi picei. Mandibulae longiusculae, 
acutae, piceae. Labrum rufo-piceum. Caput thoracis latitudine, subquadratum, depressiusculum, utrinque supra oculos punctis pluribus, inter oculos utrinque duobus transversim positis sat magnis profundisque impressım, antice canalıculatum, sulco latiusculo, ultra frontis medium adscendente. Thorax coleopteris angustior, latitudine haud brevior, lateribus rectis, basi rotundatus, apice truncatus, angulis anterioribus subrectis, posterioribus obtusis, supra leviter convexus, seriebus dorsalibus punctis $\overline{\mathbf{5}}$, apicali paulo minore et remotiore, compositis, laterbus punctis praeter marginalia utrinque 5 impressus, punctis omnibus fortibus et sat prafundis. Scutellum crebre punctatum. Elytra thorace paulo longiora, minus dense profundeque punctata, pube depressa nigra pilisque rarıs erectis vestita. Abdomen punctulatum, nigro-, segmentis ultimis duobus fulvo-pilosellum. Pedes picei. Alae fusco-hyalinae.

O bs. A praecedente differt statura paulo minore, capite utrinque fortius punctato, thorace longiore, lateribus recto, elytris brevioribus, minus subtiliter punctatis.

7. B. avidus: Niger, nilidus, ano rufo-testaceo, antennis arliculo ultimo ferrugineo, thorace lateribus recto, elylvis forlius punctatis. - Long. $3 \frac{1}{2}$ lin.

Habitat Novae Vảlenciae in Columbia, Dom. Moritz.

Praecedenti proximus, at dimidio minor, niger, nitidus, ano testaceo. Antennae capite thoraceque paulo breviores, apicem versus parum incrassatae, articulo secundo tertioque aequalibus, $4-10$ crassiusculis, subcylindrivis, crassitie vix longioribus, inter se aequalibus, ultimo ovato, apice truncato et inferne acuminato, nigrae, articulo ultimo obscure ferrugineo. Palpi elongati, nigro-picei. Caput thoracis latitudine, subquadratum, inter oculos punctis quatuor transversim positis, supra oculos utrinque punctis nonnullis dispersis impressum, fronte antice profunde sulcata. Thorax coleopteris dimidio angustior, latitudine paululum longior, basin versus subangustatus, lateribus subrectis, basi cum angulis posterioribus rotundatus, apice truncatus, angulis anterioribus subrectis, leviter convexus, seriebus dorsalibus punctis 5, apicali paulo rematiore, compositis, lateribus punctis praeter marginalia utrinque 6 impressus, punctis omnibus sat profundis. Scutellum crebre punctulatum. Elytra thorace paulo longiora, densius sat profunde punctata, longius griseo-pubescentia. Abdomen minus confertim punctatum, longius nigro-pubescens, segmenta penultimo margine lato apicali ultimoque toto laete rufo-testaceis. Pedes nigri, tarsis apice piceis.

8. B. agilis: Depressus, niger, nilidus, ano late rufo, thorace basin versus angustato, elytris sublilius punctatis. - Long. 5 lin.

Habitat in Cuba, collect. Dom. Chevrolat.

Statura depressa et summa similitudo B. haemorrhoidalis, niger, nitidus, parce nigro-pilosellus, capite thoraceque sericeo-micantibus, abdomine segmentis ultimis duobus totis rufis. Antennae capite sesqui longiares, articulo secundo tertioque elongatis, aequalibus, quarto subgloboso, $\mathbf{\mathbf { J }}-\mathbf{1 0}$ transversim subobconicis, aequalibus, ultimo subovato, apice emarginato et inferne acuminato, totae nigrae, articulo ultimo concolore. Palpi picei. Caput thorace paulo latius, depressum, quadratum, punctis $\mathbf{4}$ transversim positis 
inter oculos et nonnullis in fronte superiore sparsis, sat profundis, impressum, fronte antice subtiliter canaliculata et inter antennas obsolete impressa. Thorax coleopteris dimidio angustior, latitudine paulo longior, basin versus angustatus, lateribu's anterius leviter rotundatus, basi subtruncatus, apice utrinque oblique truncatus, angulis anterioribus obtusiusculis, posterioribus obtusis, depressus, seriebus dorsalibus punctis 5, apicali paulo remotiore, compositis, lateribus punctis praeter marginalia utrinque 5 impressus, punctis omnibus subtilioribus. Scutellum crebre punctatum. Elytı thorace jaulo longiora, minus dense subtilius punctata, subtiliter nigro-pubescentia. Abdomen sublaeve, parce obsoleteque punctatum. Pedes toti nigri.

* 9. B. gagates: Subdepressus, niger, nilidus, antennis palpis pedibusque concoloribus, capile suborbiculato. - Long. $3-4$ lin.

Habitat in Puerto Rico, Dom. Moritz, in Cuba, Mus. Dom. Chevrolat.

Statura omnino B. formosi, totus aterrimus, pernitidus. Antennae capite thoraceque paulo breviores, apicem versus leviter incrassatae, articulo tertio secundo sesqui prope longiore, 4-10 crassiusculis, sensim breviorihus et crassioribus, penultimis transversis, ultimo subovato, apice oblique emarginato et inferne acuminato, totae nigrae. Mandibulae palpique elongati nigri. Caput thorace panlo latius, suborbiculatum, supra oculos utrinque punctis nonnullis, inter oculos 4 transversim positis sat profundis impressum, fronte antice sulcata. Thorax coleopteris angustior, latitudine paulo longior, basin versus subangustatus, lateribus anterius subrotundatis, pone medium subsinuatis, basi cum angulis posterioribus rotundatus, apice truncatus, angulis anterioribus obtuse rotundatis, parum convexus, seriebus dorsalibus punctis $\mathbf{5}$, apicali paulo remotiore, compositis, lateribus punctis praeter marginalia utrinque 5 impressus, punctis omnibus subtilioribus. Scutellum crebre punctatum. Elytra thorace paulo longiora, subtilius minus confertim punctata, tenuiter nigro-pubescentia. Abdomen parce puncțatum parceque nigro-pubescens et pilosellum. Pedes nigri. Alae fusco-hyalinae.

* 10. B. minax: Subdepressus, niger, nitidus, anlennarum basi apiceque pedibusque testaceis, capile suborbiculato. - Long. 3-4 lin.

Habitat in Americae insulis St. Thomae et St. Johannis, Dom. Moritz. Elongatus, subdepressus, niger, nitidus, capite thoraceque nitidissimis. Antennae capite thoraceque breviores, articulo secundo tertioque aequalıbus, articulis $4-10$ sensim paulo brevioribus at vix crassioribus, penultimis crassitie paulo brevioribus, ultimo ovato, apice oblique truncato et inferne acuminato, nigrae, articulis basalibus tribus rufo-testaceis, apicalibus duobus ferrugineis. Palpi rufo-testacei. Mandibulae elongatae, falcatae, acutae, rufo-piceae. Caput thoracis latitudine, vel maris saepe thorace latius, suborbiculatum, supra oculos utrinque punctis sat profundis pluribus vagis, inter oculos 4 transversim positis impressum, fronte antice longitudinaliter sulcata. Thorax coleopteris angustior, latitudine haud longior, basin versus subangustatus, lateribus subrectis, basi cum angulis posterioribus rotundatus, apice truncatus, angulis anterioribus subrectis, parum convexus, seriebus dorsalibus punctis $\mathbf{5}$ compositis, lateribus punctis praeter marginalia utrinque 6 impressus, punctis omnibus profundioribus. Scutellum crebre 
punctatum. Elytra thorace paulo longiora, subtilius minus confertim punctata, tenuiter nigro-pubescentia. Abdomen nigro-piceum, segmentis ommibus apice piceo-marginatis, subtiliter punctulatum, parcius nigro-pubescens. Pedes rufo-testacei. Alae fuscescenti-hyalinae.

\section{* 11. B. planiceps: Elongatus, depressus, niger, antennarum basi pedibus-} que testaceis, capite subquadrato. - Long. $2 \frac{2}{3}$ lin.

Habitat in Columbia, Dom. Moritz.

Praecedenti affinis, at minor et magis depressus, niger, capite thoraceque nitidis. Antennae capite sesqui longiores, crassiusculae, articulo secundo tertioque aequalibus, $4-10$ crassiusculis, 5-10 crassitie aequalibus, sensim paulo brevioribus et magis transversis, ultimo ovato, apice subemarginato et inferne acuminato, nigrae, apice concolores, artioulis tribus primis rufo-testaceis. Palpi rufo-testacei. Mandibulae arcuatae, acutae, rufo-piceae. Caput thorace latius, subquadratum, depressum, utrinque inter oculos punctis duobus oblique positis, supra oculos punctis pluribus grossiusculis, minus profundis, vage impressum, fronte apice longitudinaliter sulcata. Thorax coleopteris dimidio fere angustior, latitndine paulo longior, basin versus leviter angustatus, lateribus subrectis, basi cum angulis posterioribus rotundatus, apice utrinque oblique truncatus, angulis anterioribus subrectis, depressus, seriebus dorsalibus punctis $\mathbf{5}$, apicali vix remotiore, compositis, lateribus punctis praeter marginalia utrinque $\mathbf{5}$ impressus, punctis minus subtilibus. Elytra thorace paulo longiora et scutellum dense subtilius punctata, tenuiter griseo-pubescentia. Abdomen parcius subtiliter punctulatum, parcius griseo-pubescens, segmento quarto quintoque pube rigidiore depressa obsitis, subtus segmentorum marginibus piceis. Pedes rufo-testacei, coxis anterioribns tibiisque ommbus piceis. Alae hyalinae.

\section{B. mundus: Elongatus, subdepressus, niger, elytris rufo-testaceis,} pectore rufo, mandibulis palpis pedibusque rufo-piceis. - Long. 3 lin.

Habitat in Americae meridionalis ins. St. Vincentii, Mus. Dom. Hope.

Statura omnino praecedentium. Antennae capite sesqui longiores, apicem versus modice incrassatae, articulo tertio secundo sesqui longiore, 4-10 sensim crassioribus at vix brevioribus, ultino subovato, apice oblique truncato et inferne acuminato, nigro-piceae, articulo ultimo obscure ferrugineo. Mandibulae palpique elongati, rufo-picei. Caput thorace latius, subquadratum, punctis 4 transversim positis inter oculos et utrinque supra oculos pluribus vagis sat fortibus impressum, fronte anterius fortius sulcata, nigrum, pernitidum. Thorax coleopteris dimidio angustior, latitudine paulo longior, hasin versus subangustatus, lateribus subrectis, basi cum angulis posterioribus leviter rotundatus, apice truncatus, angulis anterioribus leviter deflexis, rotundatis, parum convexus, seriebus dorsalibus punctis 5 aequaliter distantibus compositis, lateribus punctis praeter marginalia utrinque 6 impressus, punctis omnibus sat fortibus profundisque, niger, pernitidus. Scutellum punctatissimum, nigrum. Elytra thorace vix longiora, depressa, minus dense subtilius punctata, subtiliter testaceo-pubescentia, rufo-testacea, nitida. Abdomen parcius punctatum, tenuiter griseo-pubescens, nigrum, nitidum. Pectus rufum. Pedes dilute picei, coxis concoloribus. 
* 13. B. formosus: Rufus, capite, thorace, abdominis apice antennisque nigris, his basi apiceque pedibusque testaceis. - Long. 3 lin.

Staph. formosus Grav. Mon. 72. 61.

Staph. rufipennis Fab. Syst. El. II. 597. 39.

- Habitat in Columbia, Dom. Moritz, Cayennae, Dom. Banon, in Caro.lina sec. Gravenhorst.

Antennae capite duplo fere longiores, articulo secundo tertioque aequalibus, 4-10 sensim paulo brevioribus, 5-10 crassitie aequalibus, penultimo leviter transverso, ultimo subovato, apice oblique truncato et inferne acuminato, nigrae, articulo primo laete, secundo tertioque obscure testaceis, ultimo ferrugineo. Palpi testacei. Mandibulae longiusculae, falcatae, acutae, rufo-piceae. Caput thoracis latitudine, vel eodem paulo latius, rotundato-subquadratum, punctis 4 transversim positis inter oculos et pluribus vagis utrinque supra oculos, omnibus sat fortibus, impressum, fronte antice late sulcata, nigrum, nitidum. Thorax coleopteris angustior, latitudine parum longior, basin versus vix angustatus, lateribus rectis, basi cum angulis posterioribus fortius rotundatus, apice truncatus, angulis anterioribus subrectis, leviter convexus, seriebus dorsalibus punctis 5 compositis, lateribus punctis praeter marginalia utrinque 6 impressus, punctis omnibus sat fortibus profundisque, niger, nitidus. Scutellnm creherrime punctatum, piceum. Elytris thoracis longitudine, subtilius punctata, rufa, nitida, pube depressa flavescente pilisque raris erectis fuscis vestita. Abdomen parcius punctulatum, longius tenuiter griseo-pubescens, rufum, nitidum, segmentis ultimis duobus nigris, nigro-pubescentibus. Pectus rufum. Pedes rufo-testacei. Alae fuscae.

$\mathrm{Obs}$. In describendo hoc insecto Fabricius abdominis segmenta 4 anteriora rufa neglexit, quare nonnisi specimine, quod auctor ipse descripsit, inspecto et examinato, hoc synonymum cognovi. Gravenhorstii descriptio exacte convenit, nisi quod antennarum basin testaceam haud memorat, nihilominus eius citatum pro certo habeo, et nomen eius praetuli, quod ille prius quam Fabricius alii speciei (Philonth. rufipenni) tribuerit. In Catalogo Dejeaniano recentiore haec species nomine $\mathrm{C}$ a fii a i $\mathrm{c}$ alis signata est.

\section{Philonthus Leach.}

Curt. Britt. Ent. XIII. t. 610. - Nordm. Symb. p. 73. - Er. Col. March, 1. p. 145. Philonthus Steph. Illustr. V. p. 226. - Cafius ibid. p. 245. - Curt. Britt. Ent.

VII. p. 322. - Munnerh. Brachelytr. p. 31. - Bisnius Steph. l. c. p. 247. Gabrius Steph. ibid. p. 249. - Remus Holme Transact. Ent. Soc, Lond. $\boldsymbol{I I}$. I. $p .64$.

Antennae rectae.

Palpi filiformes.

Ligula rolundata, integra.

Pedes femoribus omnibus muticis.

Corpus plerisque mediae magnitudinis, elongatum, lineare, plerisque alatum. Caput aliis suborbiculatum, aliis ovatum, exsertum, collo quasi crassiusculo thoraci immissum. Labrum transversum, medio incisum, margine membranaceo setosoque. Mandibulae falcatae, medio leviter dentatae. Maxillae (t. IV. f. 12. b.) malis parvulis, coriaceis, interiore intus, exteriore 
apice barbata. Palpi maxillares modice elongati, articulo primo minuto, secundo reliquis paulo magis elongato, ultimo apice magis minusve acuminato. Labium (t. IV. 12. a.) mento brevi, transverso, ligula semiorbiculari, rotundata, membranea, paraglossis coriaceis, interne ciliatis, ligulam superantibns. Palpı labiales filiformes, articulis tribus sensim paulo longioribus. Antemnae filiformes, articulo primo leviter elongato, ultimo apice truncatulo vel magis minusve emarginato et inferne acuminato. Thorax coleopteris plerumque paulo angustior, basi rotundatus, apice truncatus, angulis posterioribus obtusis vel rotundatis, anticis deflexis, magis minusve rotundatis. Scutellum triangulare. Elytra truncata. Abdomen lineare. Pedes breviusculi, coxis intermediis aliis approximatis, aliis magis minusve distantibus, tibiis aut omnibus aut posterioribus spinulosis, tarsis setulosis, posterioribus ariiculo primo ultimoque leviter elongatis, anticis aut in utroque sexu aut in masculis solis dilatatis, aut in utroqtie sexu simplicibus.

\section{O b s e r v a t i o n e s.}

1. Corpus punctulatum, pubescens, capite thoraceque politis, glaberrimis, plerumque punctis parcis notatis, illo punctis 2 vel plerumque 4 inter oculos et pluribus supra utrumque oculum, hoc seriebus dorsalibus e punctis plerumque $\mathbf{3}, \mathbf{4}, \mathbf{5}$, 6 aut pluribus et nonnullis in utroque latere inter seriem dorsalem et marginem, plerisque in anteriore parte sitis, notato. Nonnullis (divis. 8.) caput et thorax crebrius punctata et puncto quoque pilifero subtiliter pubescentia, spatio medio longitud nali laevissimo. A Staphylino genuino et ab $\mathrm{Ocypode}$ distinguitur hoc genus imprimis ligula integra, reliqui enim characteres non satis stabiles.

2. Characteribus mancis plura ab auctoribus condita sunt genera, quae huic subiunxi :

Cafius, species quasdam marium littoribus proprias continens, corpore elongato, depressiusculo, ab auctoribus recentioribus plerisque receptum et antennarum articulo ultimo ovato, apice haud emarginato a reliquis distinctum. In $\mathbf{P h}$. $\mathbf{x a n}$ tholomate, huius generis typo, antennarum articulus terminalis revera vix distincte apice emarginatus, attamen non omnino ovatus sed apice abrupte subacuminatus; in $\mathrm{Ph}$. fucicola apice truncatulus et inferne subacuminatus, ut in multis aliis; in $\mathrm{Ph}$. fontic ol a, qui $\mathrm{Ph}$. $\mathrm{x}$ antholo $\mathrm{mat}$ is habitum insigniter prae se fert et corporis structura et pubescentia cum eo congruit, apice profundius emarginatus. $\mathrm{Ph}$. xantholomate pro $\mathrm{Cafii}$ typo prosito, huic adiungendi essent $\mathrm{Ph}$. variega. tus, fucicola, cicatricosus, australis et fonticola, auctores autem parum congruunt in Cafii generis limitibus determinandis. Com. Mannerheim. Ph. nanum et aterrimum, Com. Dejean in Catalogo collectionis suae recentiore species plerasque, quibus genus B elonuchus Nordm. componitur et nonnullos alios $\mathrm{Philonthos}$ ( $\mathrm{Ph}$. cribricollem) cum $\mathrm{Ph}$. xantholomate coniungunt. Dom. L a cordaire denique, potius characterem quam typum propositum respiciens, tantum aberravit, ut $\mathrm{O}$ thium fulvipen ne in pro mero Cafio cognosceret (V.s. p. 295.).

Bisnius, pro cuius typo $\mathrm{Ph}$. cephalotes proponitur, et cui $\mathrm{Ph}$ sordidus, fimetarius, fuscus, placidus et blandus summa affinitate adiunguntur, a Dom. Stephens palporum articulo ultimo acuminato a Philontho genuino distinguitur. Potius praeter corporis staturam elongatam species laudatae tarsis anticis in utroque sexu simplicibus, quamvis hoc charactere Dom. Stephens cum Philon tho Bisnium componit, inter se conveniunt, differentia autem in palporum acumine adeo exigua et nulla, ut qui eam observare possit nesciam.

Gabrius contra tarsis anticis simplicibus a $\mathrm{Phil}$ ontho distinguitur ab auctore modo laudato: licet species sub hoc genere enumeratae pleraeque ( $\mathrm{Ph}$. $\mathrm{na}$ nus, aterrimus, quibus forte $\mathrm{Ph}$. nitidulus et vernalis adnumerandi sunt) hac nota inter se conveniunt, tamen nullo modo ab aliis permultis huius generis speciebus eadem nota distinguuntur. Ph. cinerascens etiam Gabrio adscriptus, tarsis anticis in utroque sexu dilatatis gaudet.

Remus, genus a Dom. Holme propositum thoracis crebre punctati, quo cum $\mathrm{L}$ athrobiis conveniret, et palporum fliformium causa, quibus ab is distin- 
guatur. Palpi omnino huius generis, sculptura e characteribus genericis reiicienda Species ab auctore descripta $P h$. cinerascenti simillima et summa afinitate cum eodem iuncta.

Philonthus denique ipse a Dom. Stephens antennarum apice abrupte acuminato, tarsis anticis mediocriter dilatatis, articulo ultimo eorum elongato, ocu. lis mediocribus, palporum articulo ultimo truncato distinguitur.

3. Phil onthi ab auctoribns plerisque $\mathrm{Staphylinis}$ genuinis adscripti sunt. Com. Dejean hos sub Emi nomine cum Ocypode coniunxit, illis nomen Linneanum retinens. Prof Nordmann Philonthi genus recepit, $Q$ uedios vero nondum distinxit, nonnullos autem Philonthos minores corpore elongato, quippe quos Com. Mannerheim Cafio substituit, Gyrohypno (Xantholino) adiecit.

4. Species nonnullae in huius generis calce descriptae, $\mathrm{Ph}$. prolixus, procerulus, elongatulus, sobrinus, humilis, cognatus, ludicrus et pal$\mathrm{mula}$, palporum maxillarium articulo ultimo fortius acuminato, acumine elongato, acutissimo, a reliquis magis recedere videntur, ceterum capite thoraceque crebre punctatis, hoc seriebus dorsalibus nullis et tarsis anticis leviter dilatatis ad $\mathbf{P}$ h. cinerascentem propius accedunt, nec genus peculiare iis condendum putavi, quod charactere etiam laudato, solo, quo a Philonthis distinguuntur, species enumeratae nonnullae aliquantulum inter se discedunt.

5. Mas abdominis segmento inferiore sexto apice emarginato vel plerumque inciso, saepius quoque tarsis anticis fortius dilatatis distinguitur. Nonnullae etiam species capite in masculis validiore insignes, mares earum autem capitis forma quodammodo váriant secundum individui staturam, maioribus caput maius, latius, et antrorsum magis - dilatatum, minoribus caput minus et magis orbiculare vel ovatum esse solet, ita ut minima specimina eius proportione a femineis vix distinguantur. Caveas igitur, ne speciei eiusdem individua ob capitis disparem figuram pro speciebus distinctis habeas.

6. Victus in cadaveribus, in stercore, sub foliis deciduis, musco et lapidibus. Per omnem terrarum orbem occurrit hoc genus.

7. Philonthi aenei larvam observavit Dom. Bouché et hoc modo descripsit: "Linearis, apicem versus angustata, depressa, grisea, parce ferrugineosetulosa. Caput lenticulare, piceum, subtilissime rugulosum, nitidum, glabrum. Antennae subuliformes, 5-articulatae, articulo primo et secundo brevibus, cylindricis, tertio secundo triplo longiore, obconico, tenui, quarto eadem figura, at dimidio breviore, quinto minuto, conico, quarto interne ad apicem processu parvo elliptico aucto. Clypeus brevis, rotundatus, apice 6-denticulatus. Labrum breve, membraneum, inflexum. Mandibulae longae, tenues, falcatae, muticae, parce setosae. Maxillae oblongo-lineares, processu brevi elliptico, palpo lato, 5 -articulato, articulo basali brevi. Labium parvum, rotundatum, palpis subulatis, 2 -articulatis. Prothorax quadrangulus, latitudine paulo longior, lateribus leviter marginatus, capite paulo angustior. Meso- et metathorax transversi, prothorace latiora, quadrangula. Pedes Jongi, tenues, femoribus basi seta longa, tenui, subtus spinulis ferrugineis biseriatis instructis, tibiis brevibus, spinulosis, spinulis ferrugineis, tarsis minutis, ferrugineis, unguiculo simplice et spinis binis terminatis. Abdomen segmentis aequalibus, supra et infra maculis binis quadratis ohscuris, segmento anali angustato, caudis duabus elongatis subulatis, triarticulatis, ferrugineo-setulosis, segmento anali sextuplo longioribus. Inus tubulosus, verticaliter descendens, parce rufo-setosus, segmento anali quadruplo longiore. Stigmata testacea, elevata. Long 10 lin. - Victitat autumno et hyeme in fimo et sub vegetabilibus putridis. Dipterorum larvis aliisque insectis strenue insidiatur. Carne etiam crudo pascitur. (Bouché Hist. nat. Ins. I. 179. 1. t. 7. f. $29-41$.)

8. Irusta conatus genus hoc speciebus copiosum, corporis habitu et pluribus rharacteribus quodammodo instabile, in sectiones familiasve naturales distribuere, di. visiones a Gyllenhalio primo propositas secundum thoracis puncturam recipere non dubitavi, quamquam non solum species maxime affines diyelluntur, sed punctorum etiam in thoracis seriebus dorsalibus numerus in quibusdam individuis aut comminutus aut aurtus ohservatur. Cum autem talia individua rarius occurrant, ut punctorum illorum numerum omnino inconstantem et variabilem censeamus, non 
est, quod divisiones ex iis derivatas relinquam: speciebus facilus eruendis sine dubio prosunt.

1) Thorax punctorum seriebus dorsalibus nullis.

* 1. Ph. splendens: Niger, nitidus, elylris virescenti-aeneis, thorace lnteribus subsinuato, disco laevissimo. - Long. $4 \frac{1}{2}-6$ lin.

Norrm. Symb. 73. 1. - Er. Col. March. I. 447. 3.

Staph. splendens Fab. Ent. Syst. I. II 523. 19. Syst. El. II. 594. 21. - Payk. Faun suec. III. 373. 9. - Panz Ent. Germ. 353. 13. - Cederh. Faun. Ingr. IIt女. 359. - Grav. Micr. 16. 16. Mon. 87. 82. - Latr. Mist. nat. Crust. et Ins. IX. 306. 23. - Gyll. Ins. Suec. II. 297. 16. - Sahlb. Ins. Fenn. I. 313. 14. - Zetterst. Faun. Lappon. I. 69. 8. Ins. Lappon. 60. 9. - Mannerh Brachelytr. 25. 21. - Boisd. et Lacord. Fumn. Ent. Paris I. 387. 3. - Runde Brachelytr. Hul. 5. It. Stuph иeneus Müll. Prodr. 98. 1110. - Harrer Beschr.d. Ins I. 251. 413.

St uph. sextus Schäff. Icon. I. t. 30. f. 12.

St aph niger Müll. Faun. Frid. 23. 229. Prodr. 98. 1109. - Goeze Ent. Beitr. I. 726. 20. (forte)

Hahitat in Europa.

Ph. aeneo affinis, plerumque autem maior, niger, nitidus, elytris aeneis. Antennae capite sesqui longiores, articulo tertio modice elongato, secundo paulo longiore, sequentıbus sensim paululum brevioribus, intermednis crassioribus, ultimo ovato, apice oblique emarginato, totae nigrae. Palpi nigri, apice picei. Caput feminae thoraci latitudine aequale, maribus maioribus eodem latius, supra parum convexum, pone oculos utrinque parce fortiterque punctatum, inter oculos punctis 4 transversim positis foveolaque minuta obsoletaque media notatum. Thorax coleopteris paulo angustior, latitudine fere brevior, basin versus subangustatus, basi rotundatus, lateribus anterius rotundatis, pone medium subsinuatis, apice truncatus, angulis anterioribus subrectis, posterioribus obtusis, modice convexus, disco impunctatus, lateribus utrinque punctis duobus tribusve impressus. Scutellum nigrum, confertim punctatum. Elytra thorace longiora, densius punctata, nigro-pubescentia. Abdomen parcius punctulatum, parcius nigro pubescens, ano longius piloso. Pedes nigrı, tarsis apice piceis, tibiis omnibus densius spinulosis; coxis intermediis distantibus.

Tarsi antici maris vix dilatati, feminae simplices.

Obs. Habitus omnino $\mathrm{Ph}$. aenei, plerumque autem maior et thoracis disco impunctato distinctus.

* 2. Ph. intermedius: Niger, nilidus, capite thoraci latiludine aequali, thoraceque lateribus subrotundalo viridi-aeneis, nilidissimis, elylris aeneis, parcius profundiusque punctatis. - Long. 4-5 lin.

Er. Col. March. I. 447. 2.

St aph. int ermedius Boisd. et Lacord. Faun. Ent. Paris. I. 338. 4.

Philonth. laminatus Nordm. Symb. 74. 3.

Habitat in Germania, Gallia, Italia, Graecia, Mesopotamia.

Intermedius quasi inter $\mathrm{Ph}$. laminatum et splendentem, niger, nitidus, antennis pedibusque concoloribus, capite thoraceque viridi-aeneis, nitidissimis, elytris aeneis, abdomine dorso subaeneo-nitidulo. Antennae capite duplo fere longiores, articulo tertio modice elongato, secundo paulo lon- 
giore, sequentibus sensim paulo brevioribus, penultimis leviter transversis, ultimo apice profunde emarginato. Palpi apice picei. Caput thoracis latitudine, vel maribus maioribus eodem latius, ommum subtilissime sparsim punctulatum, supra oculos utrinque inaequaliter punctatum, inter oculos punctis 4 transversim positis maiusculis impressum. Thorax coleopteris paulo angustior, latitudine vix brevior, antrorsum haud angustatus, basi fortius, lateribus leviter rotundatis, his ante basin subsinuatis, apice truncatus, angulis posterioribus obtusis, anterioribus deflexis, acutiusculis, paruň convexus, ad latera utrinque punctis tribus impressus. Scutellum aeneum, dense punctatum. Elytra thorace paulo longiora, parcius punctata. Abdomen parce punctulatum, longius nigro-pubescens. Pedes tibiis ommibus densius spinulosis, tarsis anticis in utroque sexu modice, licet in mare fortius dilatatis, coxis intermediis leviter distantibus.

Abdominıs segmentum inferius quartum in mare apice prolongatum, uinti maximam partem obtegens, in femin a simplex.

Obs. Ph. laminato affinis, distinctus autem capite maiore, thorace apicem versus haud angustato, elytris fortius et minus confertim punctatis et colore magis aeneo.

3. Ph. laminatus: Niger, nitidus, capite thorace angustiore, thoraceque lateribus rolunlato viridi-aeneis, nitidissimis, elytris viridibus, confertim subtiliter punctatis. - Long. $4 \frac{1}{2}$ lin.

Er. Col. March. I. 446. 1.

Staph. laminatus Creutz. Ent. Vers. 128. 9. t. 3.f. 31. - Panz, Faun. Germ. 67. 20. - Grav. Micr. 16. 17. Mon. 86. 81. - Latr. Hist. nat. Crust. et Ins. IX. 307. 24. - Gyll. Ins. Suec. II. 298. 17. - Sahlb. Ins. Fenn. I. 313. 15. - Zetterst. Faun. Lappon. I. 70. 9. Ins. Lappon. 60. 10. - Mannerh. Brachelytr. 25. 25. - Boisd. et Lacord. Faun. Ent. Paris. I. 389. 5. - Runde Brachelytr. Hal. 5. 19. Philonth. viridanus Nordm. Symb. 74. 3.

Staph. ae neus Marsh. Ent. Britt. 511. 37.

Habitat in Europa.

Niger, nitidus, antennis palpis pedibusque concoloribus, capite thoraceque viridi-aeneis, nitidissimis, elytris viridibus, minus nitidis. Antennae capite plus duplo longiores, articulo tertio secundo paulo longiore, sequentibus sensim paulo brevioribus, penultimis autem haud transversis, ultimo ovato, apice emarginato. Caput in utroque sexu thorace angustius, suborbiculatum, omnium subtilissime punctulatum, utrinque supra oculos fortiter punctatum, inter oculos punctis 4 transversim positis impressum. Thorax coleopteris parum angustior, latitudine paululum brevior, basi lateribusque aequaliter rotundatns, antrorsum leviter angustatus, apice subemarginatus. angulis anterioribus deflexis, subrotundatis, posterioribus obtusis, supra leviter convexus, latera versus utrinque punctis tribus impressus. Scutellum dense punctatum. Elytra thorace paulo longiora, confertim subtiliter punctata, nigro-pubescentia. Abdomen subtiliter minus confertim punctulatum, parce nigro-pubescens. Pedes tibiis omnibus dense spinulosis, tarsis anticis In utroque sexu leviter dilatatis, coxis intermediis leviter distantibus.

Abdominis segmentum inferius quartum maris apice prolongatum, quintum fere omnino obtegens, femin ae simplex. 
Variat elytris cyanescentibus.

Obs. Staph. splendens var. Grav. Mon. p. 87. ad hanc varietatem .pertinet

* 4. Ph. cribratus: Niger, nilidus, pedibus piceis, elytris crebre profundeque punctatis, thorace laevissimo, capite orbiculato. - Long. 4-5 lin. Habitat in Istria, Gallia meridionali, Sardinia, Lusitania.

Statura omnino Ph. atrati, at paulo maior, niger, subnitidus, capite thoraceque nitidissimis. Antennae capite cum thorace paulo breviores, articulo tertio secundo paulo longiore, 4-10 sensim paulo brevioribus, penultimis haud transversis, ultimo apice oblique truncato et inferne acuminato, nigropiceae, apice ferrugineae. Palpi et mandibulae picei. Caput thoracis latitudine, orbiculatum, lateribus supra utrumque oculum parce punctatum, inter oculos punctis 4 transversim positis impressus. Thorax coleopteris angustior, latitudine paulo longior, neque basin neque apicem versus angustatus, lateribus anterius leviter rotundatis, posteribus subsinuatis, basi rotundatus, apice truncatus, angulis anterioribus subrotundatis, posterioribus obtusis, convexus, intra angulum anteriorem punctis nonnullis impressus. Scutellum crebre punctatum. Elytra thorace paulo longiora, sat crebre profundeque punctata, parce pubescentia. Abdomen minus dense subtilius punctatum, parce pubescens. Pedes fusco-picei, tibiis posterioribus parcius spinulosis, tarsis anticis in utroque sexu fortiter dilatatis, coxis intermediis approximatis.

\section{2) Thorax dorso utrinque 1-punctatus.}

* 5. Ph. ruficollis: Niger, nitidus, thorace anoque rufis, - Long. 4 lin. Staph. ruficollis Grav. Mon. 71. 58.

Habitat in Terra Van-Diemenii, Dom. Schayer.

Niger, nitidus. Antennae capite plus sesqui longiores, articulo tertio secundo vix longiore, $4-10$ subcylindricis, sensim paulo brevioribus et crassioribus, penultimis crassitie haud brevioribus, ultimo ovato, apice abrupte acuminato, nigro - piceae, articulis ultimis duobus ferrugineis. Palpi nigri, apice summo testaceo. Labrum transversum, integrum. Caput thorace paulo angustius, suborbiculatım, basi haud constrictum, supra oculos punctis utrinque tribus, inter oculos puncto utrinque singulo in ipso oculi margine interiore impressum, ceterum laevissimum. Thorax basi coleopterorum latitudine, artrorsum modice angustatus, latitudine brevior, lateribus leviter, basi cum angulis posterioribus fortius rotundatus, apice truncatus, angulis anterioribus deflexis, subrotundatis, transversim convexus, punctis nonnullis marginalibus et in disco ante medium punctorum pari singulo notatus, ceterum laevissimus, saturate rufus seu sanguineus, nitidissimus. Scutellum obscure sanguineum, crebrius punctatum, nigro-pubescens. Elytra thorace paulo longiora, minus confertim fortius punctata, parcius nigro-pubescentia, -nigerrima, nitida. Abdomen minus subtiliter crebrius punctatum, nigro-pubescens, segmento quinto margine apicali sextoque toto rufis. Pedes nigri, coxis anterioribus cum trochanteribus sanguineis, coxis intermediis approximatis, tibiis omnibus parce spinulosis, tarsis piceis, anticis in utroque sexu dilatatis.

Obs. - Habitus omnino Quedii, at stigmata antica haud obtecta. 
* 6. Ph. hylridus: Subdepressus, niger, capite subquadrato thoraceque nitidissimis, antennarum basi elytrorumque margine apicali obscure testaceis, pedibus piceis. - Long $2 \frac{1}{2}$ lin.

Habitat in Terra Van-Diemenii, Dom. Schayer.

Corpus depressiusculum, nigrum, subnitidum, capite thoraceque nitidissimis. Antennae capite sesqui prope longiores, articulo tertio secundo paulo tenuiore et vix longiore, sequentibus sensim paulo brevioribus, vix autem crassioribus, penultimis leviter transversis, ultimo oblongo-ovato, apice abrupte acuminato, nigrae, articulis duobus primis testaceis. Palpi picei, maxillares articulo quarto tenuiore, acuminato. Labrum breve, medio leviter sinuatum. Caput sat magnum, thoracis latitudine, subquadratum, basi distincte constrictum, subdepressum, supra oculos punctis utrinque tribus maioribus, inter oculos puncto utrinque singulo in ipso oculi margine interiore impressum, ceterum laevissimum, infra parce punctatum. Thorax coleopteris paulo angustior, basin versus angustatus; latitudine antica paulo brevior, lateribus modice, basi cum angulis posterioribus fortius rotundatus, apice truncatus, angulis anterioribus deflexis, acutiusculis, leviter transversım convexus, praeter puncta marginalia punctorum pari discoidali singulo ante medium impressus. Scutellum crebre punctatum, cinereo-pubescens. Elytra thorace sesqui longiora, depressa, crebrius subtiliter punctata, cinereopubescentia, margine apicali indeterminate testaceo. Abdomen apicem versus sensim angustatum, crebre minus subtiliter punctatum, cinereo-pubescens, lateribus parce nigro-pilosellum. Peres breviusculi, picei, apice dilutiores, coxis intermediis approximatis, tibiis posterioribus parcius spinulosis.

Mas tarsis anticis modice dilatatis, intermediis articulo primo incrassato. F e min a latet.

3) Thorax seriebus dorsalibus 3-punctatis.

* 7. Ph. cinctulus: Niger, nitidus, antennis pedibusque piceis, elytris aeneis, capite orbiculato. - Long. 5 lin.

Staph. cinctulus Grav. Micr. 167. 16. Mon. 89. 84.

Habitat in Bengala, Dom. Daldorf.

Statura et magnitudo $\mathrm{Ph}$. intermedii, niger, nitidus, capite thoraceque nitidissimis, elytris aeneis. Antennae capite thoraceque paulo breviores, articulo tertio secundo paulo longiore, sequentibus sensim paulo brevioribus, vix autem crassioribus, ultimo ovato, apice abrupte acuminato, ferrugineae, articulis tribus primis piceo-rufis. Caput thorace vix angustius, suborbiculatum, utrinque supra oculos inaequaliter punctatum, inter oculos punctis utrinque duobus transversim positis impressum. Thorax coleopteris paulo angustior, latitudine haud brevior, lateribus parallelis, anterius leviter rotundatis, pone medium subsinuatis, basi cum angulis posterioribus rotundatus, apice truncatus, angulis anterioribus deflexis, rotundatis, transversim convexus, seriebus dorsalibus punctis ternis, duobus prope apicem, tertio longe pone medium compositis, praeterea lateribus punctis pluribus $(5-7)$ impressus. Scutellum nigrum, crebre punctulatum, griseo-pubescens. Elytra thorace paulo longiora, parcius et minus subtiliter punctata, parce griseo-pubescentia. Abdomen metallico-versicolor, subtiliter punctulatum, griseo-pu- 
berulum. Pedes rufo-picei, tibiis omnibus crebre spinulosis, coxis intermediis leviter distantibus.

Mas latet. Femina tarsis anticis leviter dilatatis.

Obs. Abdominis cingula albida, quae a Gravenhorstio laudantur, membranis intersegmentariis, quae in hoc specimine extensae erant, exorta sunt.

* 8. Ph. la evicollis: Niger, nilidus, capite, thorace elylrisque nigro-aeneis, abdominis segmentorum marginibus pedibusque piceis, elylris parce obsoleteque punclatis. - Long. $3 \frac{1}{2}-4$ lin.

Staph. la e vicollis Boisd, et Lacord. Faun. Ent. Paris. I. 397. 21.

Habitat in Carinthia, Dom. Schuippel.

Statura omnino Ph. atrati, niger, capite thoraceque supra nigro-aeneis, pernitidis, elytris aeneis, nitidulis. Antennae capitis thoracisque prope longitudine, articulo tertio secundo paulo longiore, $\$-10$ subobconicis, sensim paululum brevioribus et crassioribus, penultimis crassitie haud brevioribus, ultimo subovato, apice oblique emarginato, nigrae. Palpi picei. Caput thorace paulo angustius, subovatum, parce omnium subtilissime punctulatum, supra oculos utrinque punctis nonnullis distantibus, inter oculos punctis utrinque duobus transversim positis impressum. Thorax coleopteris paulo angustior, latitudine vix longior, lateribus leviter rotundatus, apicem versus paululum magis quam basin versus angustatus, basi rotundatus, apice leviter late emarginatus, angulis anterioribus subrotundatis, posterioribus obtusis, leviter convexus, seriebus dorsalıbus tripunctatis, puncto postremo in disci medio, antico ad marginem anteriorem sito, praeterea ad latera praeter marginalia puncto singulo notatus, punctis omnibus subtilibus. Scutellum punctulatum, nigrum, parce griseo-pubescens. Elytra thorace paulo longiora, confertissime subtiliter alutacea, parce vageque obsolete punctata, lateribus et margine apicali cinereo-pubescentibus. Abdomen crebre minus subtiliter punctatum, pube depressa fusco-grisea densius vestitum, segmentis singulis margine apicali piceis. Pedes picei, tibiis omnibus spinulosis, coxis intermediis modice distantibus.

Tarsi antici maris modice, femina e leviter dilatati.

4) Thorax seriebus dorsalibus 4-punctatis.

* 9.Ph. cyanipennis: Niger, nitidus, elylris cyaneis, thorace lateribus rotundato, capite suborbiculato. - Long. 5 - $5 \frac{1}{2}$ lin.

Staph. cyanipennis Fab. Ent. Syst. I. II. 525. 29. Syst. El. II. 597. 37. - Walken. Faun. Paris. I. 271. 12. - Grav. Micr, 168. 17. Mon. 86. 78. - Boisd. et Lacord. Faun. Ent. Paris. I. 387. 2. - Ruinde Brachelytr. Hal. 7. 35.

Staph. amo enus Oliv. Ent. III. 42. 26. 32. i. 4 f. 36. - Latr. Hist. nat. Crust. et Ins. IX. 308. 27.

Staph. coeruleipennis Mannerh. Brachelytr. 27. 43.

Philonth. coeruleipennis Nordm. Symb. 80. 25.

Habitat in Galla, in Austria, in Chersoneso Taurica et in Pensylvania.

Statura omnino $\mathrm{Ph}$. splendentis, niger, nitidus. Antennae capite cum thorace - paulo breviores, articulo tertio elongato, secundo sesqui longiore, quarto duplo breviore, terete, 5-10 subobconicis, sensim paulo breviori- 
bus at parum crassioribus, ultimo ovato, apice oblique emarginato et inferne acuminato, nigrae, articulo apicali subferrugineo. Mandibulae et palpi elongati, picei. Caput maris thoracis fere latitudine, transversim quadratoorbiculatum, feminae thorace angustius, ovali-suborbiculatum, fronte depressa, utrinque supra oculos parce vageque punctatum, inter oculos utrinque submimpressum et punctis duobus transversim positis notatum. Thorax coleopteris paulo angustior, latitudine brevior, basi, angulis posterioribus et lateribus rotundatis, his deflexis, antrorsum subangustatus, apice truncatus, angulis anterioribus obtusis, modice transversim convexus, antice subcompressus, seriebus dorsalibus punctis 4 aequaliter distantibus compositis, utrinque praeter margines punctis circiter 5 impressus, omnibus subtilioribus. Scutellum nigrum, crebre punctulatum, tenuiter pubescens. Elytra thorace tertia parte longiora, laete cyanea vel vrrescenti-cyanea, nitidula, rebre subtiliter punctulata, nigro-pubescentia. Abdomen apicem versus sensin attenuatum, parce subtiliter punctulatum, parce nigro-pubescens, dorso coelulescenti-nitidulum. Pedes gracilıres, nigri, coxis intermediis modice distantibus, tibiis omnibus spinulosis, tarsis piceis, anticis in utroque sexu simplicibus.

Obs. Specimina Americana cum Europaeis exacte congruunt, nisi quod, observante D. Prof. Gravenhorst, puncta inter oculos intermedia in illis distincta, in his obsoleta esse solent. Occurrunt inter Europaea individua, quibus hoc punctum in altero latere distinctius, in altero obsoletum est.

* 10. Ph. furvus: Niger, capile thoraceque nitidissimis, elytris margine inflexo luteo, thorace lateribus subsinuato, capile orbiculalo. - Long. 5 lin.

Nordm. Symb. 88. 50.

Habitat in Mexico, Dom. Deppe.

Statura et summa affinitas $\mathrm{Ph}$. aenei, niger, nitidulus, capite thoraceqne nitidissimis, elytrorum margine laterali inflexo solo luteo. Antennae capitis thoracisque fere longitudine, articulo tertio secundo sesqui longiore, sequentibus sensim paulo brevioribus, subobconicis, penultimis crassite haud brevioribus, ultimo ovato, apice oblique emarginato et inferne acuminato. Caput maiusculum, thorace vix angustius, orbiculatum, utrinque supra oculos punctis pluribus fortioribus, inter oculos utrinque punctis duobus oblique positis. Thorax coleopteris paulo angustior, latitudine haud brevior, lateribus leviter rotundatis, postice subsinuatis, basi rotundatus, apice trun-catus, angulis anterioribus subrotundatis, posterioribus obtusis, supra leviter convexus, seriebus dorsalibus punctis 4, antico paulo remotiore, submarginali, compositis, lateribus punctis utrinque praeter marginalia $\mathbf{5}$ impressus, punctis ommibus modice profundis. Scutellum confertissime punctatum, tenuiter nigro-pubescens. Elytra densius subtiliter punctata, nigro-pubescentia. Abdomen parcius punctulatum, parce nigro-pubescens. Pedes nigri, coxis intermediis modice distantibus, tibiis onnibus spinulosıs.

Tarsi antici maris leviter dilatati, femina e simplices.

* 11. Ph. nigerrimus: Niger, capite thoraceque nilidissimis, tylris creberrime subtiliter punctatis, thorace lateribus subsinualo. capite orbiculato. - Long. 5 lin.

Habitat in Mexico, Dom. C. Ehrenberg. 
Statura omnino $\mathrm{Ph}$. aenei, totus nigerrimus, capite thoraceque nitidissimis. Antennae capite cum thorace breviores, articulo tertio secundo paulo longiore, 4-10 sensim paulo brevioribus, prioribus eorum subcylindricis, penultimis subobconicis, his crassitie haud brevioribus, ultimo subovato, apice subemarginato et inferne acuminato, totae nigrae. Caput thorace vix angustius, orbıculatum, utrinque supra oculos punctis nonnullis et inter ocuIns punctis 4 transversim positis impressum. Thorax coleopteris parum angustior, latitudine vix brevior, antrorsum haud angustatus, lateribus rotundatis, postice subsimnatis, basi rotundatus, apice truncatus, angulis anterioribus deflexis, subrotundatis, pnsterioribus obtusis, supra leviter transversim convexus, seriebus dorsalibus punctis $\mathbf{4}$ aequaliter distantibus compositis, lateribus utrinque punctis circiter 4 praeter marginalia impressus, omnibus subtilioribus. Elytra thoraee paulo longiora et scutellum parum nitida, subtiliter confertissime punctata, nigro-pubescentia. Abdomen nitidulum, densius subtiliter punctulatum, nigro-pubescens. Pedes concolores, coxis intermediis parum distantibus, tibiis omnibus spinulosis.

Tarsi anticis maris modice dilatati. Femina latet.

* 12. Ph. testaceipennis: Nigerrimus, nitidus, elytris rufo-testaceis, thorace lateribus subsinuato, abdomine supra parce punctato. - Long. 5 lin.

Habitat in Mexico.

Habitu omnino $\mathrm{Ph}$. nitidi, nigerrimus, nitidus, elytris solis rufo-testaceis. Antennae capite sesqui longiores, medio subincrassatae, articulo tertıo secundo paulo longiore, $\mathbf{4}-\mathbf{1 0}$ subobconicis, sensim paulo brevioribus, pennltimis haud transversis, ultimo oblongo-ovato, apice emarginato. Mandibulae parum prominentes. Caput thoracis prope latitudine, suborbiculatum. inter oculos punctis 4 transversim positis, supra oculos utrinque punctis nonnullis sparsis impressum. Thorax coleopteris paulo angustior. latitudine haud brevior, lateribus leviter rotundatis, postice subsinuatis, basi rotundatus, apice leviter emarginatus, angulis anterioribus deflexis, subrotundatis, posterioribus obtusıs, supra leviter convexus, seriebus dorsalibus punctis 4 aequaliter distantibus compositis, lateribus punctis utrinque 3 praeter marginalia impressus, omnibus minus subtilibus. Scutellum crebre subtiliter punctatum, nigro-pubescens. Elytra thorace paulo longiora, subtilius minus dense punctata, rufo - testacea, nitida, tenuiter fulvo-pubescentia. Abdomen parce leviter punctatum, parce nigro-pubescens, apice densius longiusque nigro-pilosum. Pedes nigri, coxis intermediis modice distantibus, tibiis omnibus spinulosis.

Tarsi ${ }_{\text {antici }}$ feminae simplices. Mas latet.

* 13. Ph. nitidus: Niger, nitidus, elytris mifis, thorace lateribus subsinuato, abdomine supra crebre punctato. - Long. 5-6 lin.

Nordm. Symb. 90. 52. - Er. Col. March. I. 448. 4.

St aph. nitidus Fab. Mant. Ins. I. 220. 13. Ent. Syst. T. II. 524. 24. Syst. El. II. 596. 30. - Payk. Mon. Staph. 40. 30. Paun. Suec. III. 390. 30. - Panz. Ent. Germ. 354. I6. - Cederh. Faun. Ingr. 118. 361. - Sihrank Faun. Bvicu I. 640. 864. - Gyll. Ins. Suec. II. 315. 31. - Zetterst. Faun. Lappon. I. 74. 17. Ins. 
Lappon. 63. 23. - Sahlb. Ins. Fenn. I. 320. 29. - Germ. Faun. Ins. Europ. XIII. 12. - Mannerh. Brachelytr. 27. 42.

Staph. coenosus Grav. Mon. 51. 15. - Boisd. et Lacord. Faun. Ent Paris. I. 386. 1.

Habitat in Europa.

Statura omnino Ph. aenei et maximis eius individuis magnitudine aequalis, niger, nitidus, elytris testaceo-rufis. Antennae capite cum thorace breviores, articulo tertio elongato, secundo paulo longiore, $4-10$ sensim paulo brevioribus, subobconicis, penultimis leviter transversis, ultimo apice emarginato et inferne acuminato. Caput orbiculatum, feminae thoracis latitudine, maris eodem paulo latius, supra oculos utrinque dense punctatum, fronte utrinque punctis pancis fortioribus et inter oculos punctis 4 transversim positis impressa. Thorax coleopteris parum angustior, latitudine paulo brevior, lateribus antice rotundatis, postice subsinuatis, basi modice rotundatus, apice truncatus, angulis anterioribus deflexis, obtusiusculis, posteroribus obtusis, transversim convexus, seritbus dorsalibus punctis t aequaliter distantibus compositis, lateribus utrinque puncris circiter 9 praeter marginalia notatus, omnibus fortioribus. Scutellum disco confertim punctatum. Elytra thorace paulo longiora, confertim subtiliterque punctata, rufescentipubescentia. Abdomen densius punctatum, fusco-pubescens. Pedes nigri, coxis intermediis modice distantibus, tibiis omnibus spinulosis, tarsis anticis in utroque sexu simplicibus.

Variat thoracis seriebus dorsalibus vel utrisque 5-punctatis, vel altera 4 -, altera 5-punctata.

* 14. Ph. asphaltinus: Niger, nitidus, tibiis tarsisque rufo-piceis, elylris subtiliter punclatis, thorace lateribus subsinuato, capite magno subquadrato. - Long. 5 lin.

Habitat in Germania meridionali, Dom. Godet.

Statura Ph. aenei, at paulo gracilior. Corpus totum cum elytris nigerrimum, nitidum, capite thoraceque nitidissimis. Antennae capite duplo longiores, articulo tertio secundo sesqui longiore, 4-10 subobconicis, sensim paulo brevioribus at vix crassioribus, ultimo apice oblique leviter emarginato et inferne fortiter acuminato, nigro-piceae, articulo ultimo ferrugineo. Mandibulae et palpi picei. Caput magnum, thoracem latitudine superans, subquadratum, utrinque supra oculos vage subtiliterque punctatum, fronte inter oculos superius punctis $\mathbf{6}$, arcuatim dispositis, anterius punctis 4 transversim positis, omnibus subtilioribus, impressa. Thorax coleopteris paulo angustior, latitudine vix brevior, lateribus leviter subrotundatis, postice subsinuatis, basi leviter rotundatus, apice truncatus, angulis anterioribus deflexis, subrotundatis, posterioribus obtusis, leviter transversim convexus, seriebus dorsalibus punctis $\mathbf{4}$ distantibus compositis, lateribus punctis circiter 7 praeter marginalia impressus, omnibus sat subtilibus. Scutellum subtiliter punctatum. Elytra thorace multo longiora, minus dense subtiliter punctata, subtiliter parceque nigro-pubescentia. Abdomen parce subtiliter punctatum, tenuiter nigro-pubescens. Pedes graciles, nigri, coxis intermediis perparum distantibus, thbiis omnibus parce subtiliterque spinulosis tarsisque piceo-rufis.

- Tarsi antici maris simplices. Femina latet. 
* 15. Ph. carbonarius: Niger, nilidus, elytris nigro-aeneis, capile subquadrato, thorace lateribus subsinuato, utrinque impresso, abdomine parcius punclalo, parce nigro-pubescenle. - Long. $4-5 \frac{1}{2}$ lin.

Er. Col. March. I. 448. 5.

Staph. nigritus Runde Brachelytr Hal. 7, 33.

$\boldsymbol{V}$ ar. Pedibus piceis, abdominis segmentis ventralibus rufo-marginatis.

Staph. carbonarius Gyll. Ins. Suec. II. 319. 35. - Mannerh. Brachelytr. 28. 15.

Habitat in Europa.

Statura et summa similitudo Ph. aenei. Niger, nitidus. Antennae capite thoraceque breviores, articulis tribus primis modice elongatis, tertio secundo paulo longiore, 4 - 10 sensim paulo brevioribus et crassioribus, subobconicis, penultimis leviter transversis, ultimo apice emarginato et inferne acuminato, nigrae, articulo apicali ferrugineo, interdum totae ferrugineae. Palpi nigri. Caput maris thoracis latitudine vel eodem paulo maius, subquadratum, feminae thorace angustius, orbiculato-subquadratum, supra oculos utrinque vage fortiter punctatum, fronte anterius inter oculos utrinque punctis duobus transversim positis impressa. Thorax coleopteris paulo angustior, latitudine vix brevior, antrorsum subangustatus, lateribus antrorsum leviter rotundato-ampliatus, pone medium subsinuatus, basi rotundatus, apice truncatus, angulis omnibus rotundatis, leviter convexus, versus latera utrinque oblique leviter impressus, seriebus dorsalibus punctis 4 aequaliter distantibus compositis, lateribus punctis praeter marginalia utrinque 4 impressus, punctis omnibus minus profundis. Scutellum dense punctatum, nigrum. Elytra thorace paulo longiora, crebre punctata, nigro-aenea, nigropubescentia. Abdomen dorso parcius punctulatum, parce nigro-pubescens, subaeneo-, interdum etiam metallico-versicolor. Pedes graciliores, coxis intermediis modice distantibus, tibiis omnibus spinulosis, tarsis anticis in utroque sexu simplicibus.

Abdominis segmentum inferius quintum in mare apice leviter emarginatum.

Obs. 1. Cum $\mathrm{Ph}$. aeneo plerumque confusus, distinctus autem statura saepius paulo minore, elytris obscurioribus abdomineque parcius distinctiusque punctulato nigro-pubescentibus, tarsisque anticis in utroque sexu simplicibus. Caput maris speciminibus maioribus maius, minoribus minus, ut in $\mathrm{Ph}$. aeneo.

2. Nomen a Gyllenhalio usitatum retinui, quamvis $S t a p h$. carbonarius Grav. ad aliam speciem, $\mathrm{Ph}$. varium, pertinet. Specimen a Gyllenhalio ipso e Suecia sibi missum dedit Dom. Schüp pel.

* 16. Ph. a eneus: Niger, capite thoraceque nigro-aeneis, elytris viridiaeneis, capile subquadrato, thorace lateribus subsinuato, utrinque leviter impresso, abdomine subtilius punctulato, cinereo-pubescente. - Long. 4 - 6 lin.

Nordm. Symb. 81. 26. - Er. Col. March. I. 449. 6.

Staph. a en eus Rossi Faun. Etrusc. I. 249. 613. Ed. Hellw. 1. 307. 613. - Grav. Micr. 17. 18. Mor. 86. 80. - Latr. Hist. nat. Crust. et Ins. IX. 307. 25. - Gyll. Ins. Suec. II. 314. 30. - Sahlb. Ins. Fenn. I. 319. 28. - Zetterst. Faun. Lappon. I. 73. 16. Ins. Lappon. 62. 22. - Mannerh. Brachelytr. 27. 48. - Botsd. et Lacord. Faun. Ent. Paris. I. 389. 6. - Runde Brachelytr. Hal. 6. 27.

St aph. laticeps Zetterst. Faun. Lappon. I. 73. 15. Ins. Lappon. 62. 21. 
St a ph. metallicus Boisd. et Lacord. Faun. Enf. Paris. I. 390. 7. Staph. similis Marsh. Ent. Britt. 497. 3.

Var. Pedibus rufo-piceis.

Staph. a trat us Boisd. et Lacord. Faun. Ent. Paris. I. 392. 11.

Habitat in Europa Asiaque confini et in America septentrionali frequens.

Niger, capite thoraceque nigro-aeneis, ntidis, elytris viridi-aeneis. Antennae capite thoraceque paulo longiores, articulis tribus primis modice elongatis, tertio secundo paulo longiore, $4-10$ subobconicis, sensim paulo brevioribus et crassioribus, penultimis transversis, ultimo subovato, apice emarginato et inferne acuminato, nigrae, articulo apicali ferrugineo, interdum fusco. Caput maribus nuaioribus magnum, thorace latius, transversim subquadratum, minoribus minus, interdum vix thoracis latitudine, pone oculos minus angulatum, feminae thorace paulo angustius, orbiculato-subquadratum, supra ocuJos vage fortiter punctatum, inter oculos punctis 4 transversim positis impressum. Thorax coleopteris paulo angustior, latitudine paulo brevior, antrorsum subangustatus, lateribus ante medium leviter rotundato-ampliatis, pone medium subsinuatis, basi rotundatus, apice truncatus, angulis anterioribus subrotundatis, posterioribus obtusis, parum convexus, versus latera utrinque oblique leviter impressus, seriebus dorsalibus punctis 4 aequaliter distantibus compositis, lateribus punctis praeter marginalia utrinque 2, rarius 3 vel 4 impressus, punctis ommibus modice profundis. Scutellum nigrum, dense subtiliterque punctatum, griseo-pubescens. Elytra thorace paulo longiora, dense punctata, griseo-pubescentia. Abdomen densius subtiliter punctatum, griseo-pubescens. Pedes nigr, tibiis omnibus spinulosis tarsisque saepe piceis, coxis intermediis modice distantibus.

Abdominis segmentum inferıus quintum $\mathrm{m}$ aris apice leviter emarginatum. Tarsi antici maris fortiter dilatati, feminae simplices.

Obs. 1. Staph. a eneus auctorum plerorumque ad specimina maiora mascula capite grandi spertat, Staph. laticeps Zett. ad eadem, Staph. a e neus Zetterst. contra et Staph. metallicus Boisd. et Lacord. ad individua minora mascula capite thorace haud latiore pertinent. Pro Staph. atrato auctores modo citati huius speciei specimen femineum, pedibus rufo-piceis, descripsisse videntur.

2. Specimen a Gravenhorstio Mon. p. 52. pro Staph. coenosi varietate? descriptum, e collectione citata conservatum, huius speriei individuum est immaturum, elytris pedibusque fuscis.

* 17. Ph. scutatus: Niger, capite orbiculato, thorace elytrisque obscure aeneo-virescentibus, nitidis, pedibus piceis, elytris dense subliliter punctalis. - Long. 6 lin.

Habitat in Germania meridionali, Hungaria, Sardinia, Persia.

Statura omnino $\mathrm{Ph}$. atrati, at paulo maior, niger, capite, thoraceque nigrovirescentibus, nitidissimis, elytris concoloribus, nitidis. Antennae capite thoraceque parum breviores, graciliores, articulo tertio secundo perparum longiore, sequentibus sensim paulo brevioribus, subcylindricis, reliquis subobconicis, penultimis crassitie haud brevioribus, ultimo oblongo-ovato, apice inferne abrupte acuminato, nigrae. Palpi picei. Caput orbiculatum, thorace paulo angustius, leviter convexum, parce subtilissime punctatum, supra oculos utrinque punctis nomullis maioribus, inter oculos punctis 4 transversim jositis inpressum. Thorax coleopteris paulo angustior, latitudine paulo 
brevior, antrorsum subangustatus, basi et lateribus leviter rotu datis, his postice subsinuatis, apice truncatus, angulis anterioribus deflexıs, subrotundatis, posterioribus obtusis, supra modice convexus, amnium subtilissime parcius punctulatus, seriebus dorsalibus punctis 4 , antico et postica paulo remotioribus, compositis, lateribus punctis praeter marginalia utrinque $4 \mathrm{im}$ pressus, punctis impressis subtilioribus. Scutellum nigrum, creberrime punctulatum, nigro-pubescens. Elytra thorace tertia parte longiora, dense subtiliter punctata, longius griseo-pubescentia. Abdomen punctulatum, longius griseo-pubescens. Pedes picei, coxis intermediis approximatis, tibiis omnibus spinulosis, tarsis anticis in utroque sexu leviter dilatatis.

Abdominis segmentum inferius quartum in mare apice prolongatum, lamina eius segmentum quintum obtegente.

Obs. 1. Abdominis maris structura omnino cum Ph. la minato et in termedi o congruens, at thorax seriebus dorsalibus 4-punctatis instructus.

2. Specimen in Persia septentrionali prope Lankoran ad littora maris Caspici occidentalia lectum Dom. Ménétries pro Staph. rotundicolli suo communicavit, at descriptio eius (Catal. rais. 145. 581.) nimis manca, et nomine eodem a Com. Dejean in Catalogo collectionis suae apud Ph. carbonarium citato, sub nomine illo plures commutatas fuisse species suspicandum esse videtur.

* 18. Ph. atrat us: Niger, nilidus, elytris aeneo-viridibus, parcius punclatis, capite orbiculato, thorace paulo minore. - Long. $3-4$ lin.

Nordm. Symb. 82. 30. - Er. Cal. March. I. 450. 7.

Staph. atratus Grav. Micr. 21. 23. Man. 84. 74. - Lair. Hist. nat. Crust et Ins. IX. 310. 29. - Gyll. Ins. Suec. II. 319. 34. - Sahlb. Ins. Fenn. I. 321. 32.

- Zetterst. Ins, Lappon. 83. 25, - Mannerh. Brachelytr. 28. 29.

Staph. metallicus Grav. Micr. 168. 78. - Latr. Hist, nat. Crust. et Ins. IX. 323. 61.

Var. Elytris viridi-coeruleis.

St aph. coerulescens Raisd, ot Lacord. Faun. Ent. Paris. I. 393. 13.

Habitat in Eurapa.

Ph. polita paula minor et angustior, niger, capite thoraceque nitidissiınis, interdum subaeneıs, elytris metallico-viridibus, antennis, palpis, pedibusque nigris. Antennae oapite thoraceque paulo breviores, articulo tertio secundo paulo longiore, 4-10 subobcanicis, sensim paulo brevioribus at vtx orassioribus, penultimis crassitie haud breviaribus, ultimo avato, apice trunoato et inferne acuminato. Caput in utroque sexu thorace minus et angustius, orbioulatum, supra leviter convexum, pone oculos utrinque parce fortiter punctatum. Tharax basi fere coleopteris latitudine aequalis, antrorsum subangustatus, latitudine paula brevior, basi madice, lateribus leviter rotundatis, postice subsinuatis, apice truncatus, angulis anterioribus rotundatis, posterioribus obtusis, leviter convexus, seriebus dorsalibus punctis aequaliter distantibus, licet antico paulo magis extrorsum sito, compositis, lateribus punctis praeter marginalia utrinque 5 impressus, punotis omnibus fortioribus. Scutellum nigrum, confertissime punctatum, parce griseo-pubesoens. Elytra tharaois longitudine, minus subtiliter parcius punctata, parce griseo-pubescentia. Abdamen supra parcius punctulatum, parce griseapubesoens. Pedes coxis intermediis approximatis, tıbiis omnibus spinulasis, tarsis anticis in utroque sexu, licet in mare fortius dilatatis.

Variat elytris magis minusve coerulescentibus. 
Obs. 1. Ab affinibus praecipue elytrorum punctura minus conferta, fortiore distinctus.

2. Staph. metallicus Grav., cuius specimen singulum typicum benevole mihi communicavit celeberrimus auctor, nonnisi thoracis serie altera 5-punctata a $\mathrm{Ph}$. atrato genuino differt.

* 19. Ph. atramentarius: Nigerrimus, nitidus, femoribus piceis, capite ovato, thorace oblongo, antrorsum subangustalo, abdomine confertim subtiliter punctato. - Long. 4 lin.

Habitat in Columbia, Dom. Moritz.

Ph. polito gracilior, nigerrimus, nitidus, capite thoraceque pernitidis. Antennae capite thoraceque prope longiores, minus graciles, articulo tertio secundo sesqui prope longiore, 4-10 subcylindricis, sensim paulo brevioribus, at non crassioribus, omnibus crassitie multo longioribus, ultimo oblongo-ovato, apice emarginato et inferne acuminato, nigrae. Palpi picei. Caput thorace paulo angustius, subovatum, leviter convexum, utrinque supra oculos punctis parcis, inter oculos utrinque punctis duobus transversim positis impressum. Thorax coleopteris duplo prope angustior, latitudine sesqui longior, apicem versus subangustatus, lateribus rectis, ad apicem subrotundatis, basi cum angulis posterioribus rotundatus, apice truncatus, angulis anterioribus leviter deflexis, subrotundatis, leviter convexus, seriebus dorsalibus punctis 4 remotis et aequaliter distantibus compositis, lateribus punctis praeter marginalia utrinque 4 impressus. Scutellum subtiliter punctatum, tenuiter nigro-pubescens. Elytra thorace paulo longiora, crebrius subtiliter punctata, densius subtiliter nigro-pubescentia. Abdomen supra dense subtiliter punctatum, densius subtiliter nigro-pubescens, subtus lucidum, parcius subtiliter punctatum, parce nigro-pubescens. Pedes graciliores, coxis intermediis approximatis, coxis anterioribus testaceo-piceis, femoribus piceis, tibiis ommibus spinulosis. Alae fusco-hyalinae.

Tarsi antici maris leviter dilatati. Femina latet.

* 20. Ph. coelites: Niger, nitidus, capite ovato thoraceque violaceis, elytris parcius punctalis, cyaneis, abdomine parce punctato - Long. 4 lin.

Habitat in Brasilia, Dom. Prof. Germar.

Statura omnino $\mathrm{Ph}$. flagrantis, Ph. decoro minor et gracilior, niger, nitidus, capite thoraceque supra violaceis, pernitidis, elytris laete nitideque cyaneis. Antennae capite thoraceque vix breviores, articulo tertio secundo paululum longiore, 4 - 10 sensim paulo brevioribus et crassioribus, penultimo crassitie haud longiore, ultimo ovato, apice emarginato et inferne acuminato, nigrae. Palpi nigri. Caput thorace angustius, oblongo-ovatum, utrinque supra oculos punctis nonnullis, inter oculos puncto singulo ad utriusque oculi marginem interiorem notatum, apice sulco abbreviato impressum. Thorax coleopteris duplo prope angustior, latitudine sesqui longior, antrorsum vix angustatus, lateribus rectis, antrorsum subrotundatis, basi cum angulis posterioribus rotundatus, apice truncatus, angulis anterioribus leviter deflexis, subrotundatis, leviter convexus, seriebus dorsalibus punctis 4 sat remotis, aequaliter distantibus, compositis, lateribus punctis praeter marginalia utrinque 4 impressus, punctis omnibus subtilioribus. Scutellum nigrum, nitidum, parce punctatum. Elytra thorace paulo longiora, parcius subtilius- 
que punctata. Abdomen apicem versus sensim angustatum, parce subtilius punctatum, parce nigro-pubescens, lateribus et apice nigro - pilosellum. $\mathrm{Pe}$ des graciles, nigri, coxis intermediis modice distantıbus, tibiis omnibus spinulosis, tarsis piceis.

Tarsi antici feminae simplices. ${ }^{\circ}$ Mas latet.

* 21. Ph. flagrans: Niger, nitidus, capite thoraceque mgro-violaceis, elytris viridi-cupreis, splendidis. - Long. $4 \frac{1}{2}$ lin.

Habitat in Mexico; in Columbia etiam a Dom. Moritz lectus.

Statüra omnino et summa affinitas praecedentis, nigerrimus, nitidus, capite thoraceque supra nigro-violaceis, nitidis, elytris viridi-aeneis, dorso cupreis, splendidis. Antennae capite thoraceque parum breviores, apicem versus subincrassatae, articulo secundo tertio vix breviore, 4-10 subcylindricis, sensim paulo brevioribus et crassioribus, penultimis crassitie haud longioribus, ultimo ovato, apice leviter emarginato et subacuminato, nigrae. Palpi nigri. Caput thoracis apice vix angustius, subovatum, utrinque supra oculos punctis paucis, inter oculos ntrinque puncto singulo notatum, fronte anterius utrinque secundum oculi marginem lateralem leviter longitudinaliter impressa, apice medio profunde sulcata. Thorax coleopteris multo angustior, antrorsum subangustatum, latitudine paulo longior, lateribus subrectis, basi rotundatus, àpice truncatus, angnlis anterioribus leviter deflexis, subrotundatis, posterioribus obtusis, parum convexis, seriebus dorsalibus punctis 4 distantibus composits, lateribus punctis praeter marginalia utrinque 5 impressus, punctis omnibus subtilioribus. Scutellum nigrum, subtiliter parce punctulatum, tenuiter pubescens. Elytra thorace vix longiora, minus confertim subtiliter punctata, tenuiter cinereo-pubescentia. Abdomen apicem versus sensim attenuatum, punctis raris obsoletis impressum, latera versus parce pubescens. Pedes elongati, graciles, coxis intermediis leviter distantibus, tibiis omnibus spinulosis, tarsis anticis in utroque sexu simplicibus.

\section{* 22. Ph. ambiguus: Niger, capite, thorace elytrisque obscure virescenti- bus, abdomine versicolore, elytris creberrime punctatis, capite minore, suborbiculato. - Lang. 4 lin.}

\section{Habitat in Columbia, Dom. Moritz.}

Statura fere $\mathrm{Ph}$. politi. Antennae capite cum thorace paulo breviores, crassiusculae, articulo tertio secundo sesqui prope longiore, 4-10 sensim paulo brevioribus et crassioribus, prioribus subcylindricis, penultimis subobconicis, leviter transversis, ultimo ovato, apice oblique emarginato et inferne acuminato, nigrae. Palpi picei. Caput thorace minus et angustius, suborbiculatum, supra leviter convexum, utrinque pone oculos profunde punctatum, antice inter oculos utrinque punctis duobus transversim positis fortibus notatum, nigro-virescens, nitidum. Thorax coleopteris panlo angustior, latitudine haud brevior, antrorsum haud angustatus, lateribus subrectis, hasi cum angulis posterioribus rotundatus, apice truncatus, angulis anterioribus fortiter rotundatis, leviter convexus, nigro-virescens, politus, seriebus dorsalibus punctis 4, antico paulo remotiore, compositis, lateribus punctis praeter marginalia 4 impressus, punctis tribus posterioribus serierum dorsalium sat fortibus, reliquis modice profundis. Scutellum nigrum, crebre 
punctatum, nigro-pubescens. Elytra thorace pawlo longiora, nigro-subaenea, subnitida, dense fortius punctata, pube crassiore depressa nigra vestita. Abdomen temere punctatum, pube depressa rara rigida nigra obsitum, nigrum, nitore viridi-aureo splendide versicolor. Pedes nigri, coxis intermediis leviter distantibus, tibiis -omnibus spinulosis, tarsis picescentibus, anticis in utroque sexu simplicibus.

23. Ph. fibularius: Niger, capite subovato, thorace elytrisque viridiaeneis, his creberrime punctatis, abdomine versicolore, tibiis piceo-testaceis. - Long. $3 \frac{2}{3}$ lin.

Habitat in Mexico, coll. Dom. Chevrolat.

Habitu omnino $\mathrm{Ph}$. politi, at paulo minor, praecedente gracilior, niger, nitidus, capite thoraceque nigro-aeneis, pernitidis, elytris virescenti aeneis, nitidulis. Antennae capite thoraceque paululum breviores, articulo tertio secundo paulo longiore, $4-10$ sensim paulo brevioribus et crassioribus, penultimo crassitie haud longiore, ultimo apice oblique truncato et inferne acuminato, nigrae. Palpi picei. Caput thorace paulo angustius, suborbiculatum, pone oculos utrinque crebre fortius punctatum, inter oculos punctis 4 transversim positis impressum. Thorax coleopteris angustior, latitudine vix longior, lateribus rectis, parallelis, basi cum angulis posterioribus rotundatus, apice truncatus, angulis anterioribus deflexis, subrotundatis, convexus, seriebus dorsalibus punctis $\mathbf{4}$, anterioribus tribus magis distantibus, compositis, lateribus punctis praeter marginalia utrinque 4 impressus, punctis omnibus snbtilioribus. Scutellum obscure viridi-aeneum, confertissime punctatum, densius griseo - pubescens. Elytra thorace paulo longiora, minus fortiter dense punctata, densius griseo-pubescentia. Abdomen apicem versus sensim attenuatum, minus dense profunde punctatum, pube depressa longiore et fortiore nigra vestitum, splendidius metallioo-versicolor. Pedes graciliores, picei, coxis intermediis modice distantibus, tibiis omnibus spinulosis, testaceis.

Tarsi antici maris leviter dilatati. Femina latet.

$\mathrm{Obs}$. In specimine singulo descripto in serie thoracis dorsali altera basin versus punctum quintum exstat, a quarto remotum et subtilius, forte fortuitum.

*24. Ph. decorus: Niger, capite ovato thoraceque nigro-virescentibus, elytris subtiliter punctalis, nigro-aeneis, opacis, abdomine segmentis ventralibus ferrugineo-marginatis. - Long. 5 lin.

Nordm. Symb. 82. 31. - Er. Col. March. 1. 451. 8.

Staph. decorus Grav. Micr. 19. 20. Mon. 85. 77. - Gyll. Ins. Suec. 11. 316. 32. - Suhlb. Ins. Fenn. I. 320. 30. - Mannerh. Brachelytr. 27. 44. - Boisd. et Lacord. Faun. Ent. Paris. I. 391. 9. - Runde Brachelytr. Hal. 7. 28.

Habitat in Europa.

$\mathrm{Ph}$. polito habitu affinis, at paulo maır. Antennae elongatae, graciles, articulo tertio secundo vix sesqui longiore, 4-10 sensim paulo brevioribus, licet omnibus crassitie longioribus, ultimo ovato, apice truncato et inferne abrupte acuminato, nigrae. Palpi rufo-picei, basi nigricantes. Corpus nigrum. Caput et thorax nigro-virescentia, subnitida. Caput thorace angustius et ninus, subovatum, supra leviter convexum, basi utrinque orebre 
punctatum, utrinque supra oculos punctis paucis maioribus, antice inter oculos punctis 4 transversim positis impressum. Thorax coleopteris angustior, latitudine paulo longior, antrorsum subangustatus, basi modice, lateribus leviter rotundatis, his ante basin subsinuatis, apice truncatus, angulis anterioribus deflexis, rotundatis, posterioribus obtusis, leviter convexus, seriebus dorsalibus punctis $\mathbf{4}$, antico remotiore, compositis, lateribus punctis praeter marginalia utrinque 5 impressus, punctis omnibus subtilibus. Scutellum nigrum, subtiliter punctulatum, fusco-pubescens. Elytra thorace parum longiora, obscure aenea, opaca, dense subtiliterque punctata, densius subtiliterque fusco-pubescentia. Abdomen supra densius subtiliter punctulatum, tenuiter fusco-pubescens, subtus segmentis singulis apice tenuiter ferrugineomarginatis. Pedes nigri, coxis intermediis approximatis, tibiis omnibus spinulosis tarsisque rufo-piceis, tarsis antıcis in utroque sexu simplicibus.

Varietatem colore capitis thoracisque cupreo, splendido, elytrorum eyanescenti-viridi, opaco insignen Dom. Prof. Gené in Sardinia legit.

\section{* 25. Ph. lucens: Niger, capile ovalo, thorace angustiore thoraceque nili- dis, elytris conferlim subtilius punctatis, opacis. - Long. $4 \frac{1}{2}$ lin.}

Nordm. Symb. 81. 28. - Er. Col. March. I. 452. 9.

Staph. lucens Mannerh. Brachelytr. 28. 48.

Habitat in Germania.

Ph. polito magnitudine aequalis; paulo tamen latior, niger, parum nitidus, capite thoraceque politis, interdum virescenti-subaeneis. Antennae capite thoraceque paulo breviores, articulo tertio secundo vix longiore, 4-10 sensim paulo brevioribus et crassioribus, prioribus subcylindricis, penultimis transversim subobconicis, ultimo ovato, apice inferius abrupte acuminato, nigrae, concolores, Palpi nigri. Caput thorace angustius et multo minus, supra oculos punctis nonnullis subtilioribus, inter oculos duobus transversim positis utrinque impressum. Thorax latitudine paulo brevior, basi coleopteris latitudine aequalis, antrorsum leviter angustatus, basi et lateribus rotundatus, apice truncatus, angulis anterioribus rotundatis, posterioribus obtusis, subrotundatis, modice convexus, seriebus dorsalibus punctis 4 aequaliter distantibus, antico paulo magis extrorsum sito, compositis, lateribus punctis praeter marginalia utrinque 2 versus medium et 5 intra angulum interiorem impressus, punctis omnibus subtilioribus. Elytra thorace-paulo longiora et scutellum confertissime subtiliter punctata, perparum nitida, subtiliter tenuiterque nigro-pubescentia. Abdomen subtilius minus dense punctatum, parce breviterque nigro-pubescens, metallico-versicolor. Pedes nigro-picei, coxis intermediis leviter distantibus, tibiis omnibus spinulosis, tarsis anticis in utroque sexu simplicibus.

Obs. 1. A Ph. polito statura paulo breviore, colore obscuriore et antennarum articulo primo concolore facile distinguendus.

2. Descriptio Mannerheimiana nimis manca, nonnisi ex auctoritate Prof. Nordmanni citata, qui collectionem celeberrimi huius auctoris lustravit.

*26. Ph. politus: Niger, supra subvirescens, capite ovali, thorace angustiore thoraceque nitidis, antennarum arliculo primo subtus testaceo. - Long. 5 lin.

Nordm. Symb, 81. 27. - Er. Col March. 1. 452. 10. 
Staph. polities Fab. Syst. Ent. 266. 7. Spec. Ins. I. 335. 7. Mant. Ins. I. 220. 11. Ent. Syst. I. II. 524. 20. Syst. El. II. 594. 22. - Panz. Ent. Germ. 351. 11. Oliv. Ent. III. 42. 25. 31. t. 2. f. 10. - Gruv. Micr. 17. 19. Mon. 85. 76. - Lalr. Hist. nat. C'rust. et Ins. IX. 308. 26. Gen. Crust. et Ins. I. 287. 3. - Gyll. Ins. Suec. II. 317. 33. - Zetterst. Faun. Lappon. I. 74. 18. Ins. Lappon. 63. 21. Sahlb. Ins. Fenn. 1. 320. 31. - Mannerh. Brachelytr. 28. 46. - Boisd. et Lacord. Faun. Ent. Paris. I. 392. 10. - Runde Brachelytr. Hal. 7. 29.

\section{Habitat in Europa.}

Niger, capite thoraceque supra obscure viridi-subaeneis, politis, elytris obscure viridi-aeneis, subnitidis, palpis pedibusque nigris. Antennae capite thoracisque longitudine, graciles, articulo tertio secundo paululum longiore, 4 - I0 sensim paulo brevioribus at vix crassioribus, omnibus crasstie longioribus, ultimo ovato, apice oblique emarginato, nigrae, articulo primo testaceo, supra nigro. Caput thorace minus et angustius, subovatum, supra oculos utrinque parce punctatum, inter oculos punctis utrinque duobus transversim positis notatum. Thorax latitudine haud brevior, basi coleopterorum fere latitudine, antrorsum modice angustatus, basi fortius, lateribus leviter rotundatus, apice subemarginatus, angulis anterioribus leviter deflexis, subrotundatis, posterioribus obtusis, modice convexus, seriebus dorsalibus punctis 4 aequaliter distantibus compositis, lateribus punctis praeter marginalia utrinque 5 impressus, punctis omnibus subtilioribus. Scutellum nigrum, confertim punctulatum, subtiliter fusco-pubescens. Elytra thorace vix longiora, dense subtiliterque punctata, subtiliter fusco-pubescentia. Abdomen subnitidum, subtilius punctatum, tenuiter nigro-pubescens. Pedes graciliores, coxis intermediis approximatis, tibiis omnibus parcius spinulosis.

Tarsi antici $\mathrm{m}$ aris modice dilatati, feminae simplices.

Obs. 1. Staph. politus Lin., secundum collectionem Linneanam ad Ph. a eneum pertinet, at descriptio Linneana hane speciem non magis quam multas alias significat, immo plures ab eo confusas esse patet. Paykul itidem plures species confusas pro St. polito descripsit. Loci citati igitur sequentes a Ph. polito nostro excludendi :

St aph. politus Linn. Faun. Suec. n. 843. Syst. Nat. I. II. 683. 5. -- Ström. Act. Nidros.

III. n. 27. - Müll. Faun. Frid. 23. 224. Prodr. 98. 11118 . - Goeze Ent. Beilr. I.

717. 5. - De Vill Ent. I. 412. 5. - Scop. Ent. Curn. 100. 304. - Schrank Enum. Ins. Austr. 231. 437. Faun. Boica. I. 641. 865. - Walk. Faun. Paris. I, 271. 11. - Cederh. Faun. Ingr. 118. 360. - Payk. Mon. Staph. 42. 31. Faun. Suec. III. 391. 31. - Marsh. Ent. Britt. 504.18.

Staph. a eneus Degeer Ins. IV. 23. 9. - Fourcr. Ent. Par. I. 168. 17.

Le Staph. à et uis bronzés Geoffr. Hist. Ins. I. 367. 17

Citatum Fabricianum, specimine in auctoris collectione ipso examinato, indubium.

2. Staph. fuscipennem Mannerh Brachelytr. 28. 47. nonnisi elytris fuscocastaneis et pedibus piceis a $\mathrm{Ph}$. polit o diversum, revera distinctum esse, mihi non satis persuasum est, cum varietates aliarum specierum ( $\mathrm{Ph}$. varii, albipedis et. ebenini) analogae nobis sint.

* 27. Ph. marginatus: Viger, nitidus, thoracis laleribus pedibusque fa. vis, capite ovato. - Long. 4 lin.

Curt. Britt. Ent. XIII. t. 610. - Nordm. Symb. 84. 38 - Er. Col. March. I. 453. 11. Staph. marginatus Fab. Syst. Ent. 266. 8. Spec. Ins. I. 336. 9. Mant. Ins. I. 221. 15. Ent. Syst. I. II. 526. 30. Syst. El. II. 597. 38. - Strüm. Act. Nidr. IV. n. 13. - Müll. Faun. Fridr. 23. 230. Prod. 97. 1100. - Goeze Ent. Beitr. I. 726. 21. - Payk. Mon. Staph. 44. 32. Faun. Suec. III. 392. 32. - Olv. Ent. III. 42. 26. 33. $t$. 3. f. 29. - Marsh. Ent. Britt. 512. 40. - Grav. Micr. 24. 32. 
Mon. 71. 56. - Latr. Hist. nat. Crust. et Ins. IX. 313. 37. - Gyll. Ins. Suec. II. 322. 38. - Zelterst. Faun. Lappon. I. 75. 22. Ins. Lappon. 64. 31. - Sallb. Ins. Fenn. I. 322. 36. - Mannerl. Brachelytr. 28. 54. - Boisd. et Lacord. Faun. Ent. Paris. I. 397. 22. - Runde Brachelytr. IIal. 7. 34.

Habitat in Europa.

St. polito paulo minor et gracilior. Antennae capite thoraceque parum breviores, graciliores, articulo tertio secundo paulo longiore, sequentibus sensim paulo brevioribus at haud crassioribus, omnibus crassitie longioribus, ultimo apice emarginato, nigrae, articulo primo flavo, supra nigro. Palpi utrique nigri, articulis duobus primis flavis. Caput ovatum, thorace angustius et minus, supra oculos utrinque parce punctatum, inter oculos utrinque punctis duobus oblique positis impressum, nigrum, nitidum. Thorax latitudine haud brevior, basi coleopteris paulo angustior, antrorsum leviter angustatus, basi modice, lateribus leviter rotundatus, apice truncatus, angulis anterioribus rotundatis, posterioribus obtusis, leviter convexus, seriebus dorsalibus punctis 4 aequaliter distantibus compositis, lateribus punctis praeter marginalia utrinque 4 impressus, punctis omnibus subtilioribus, niger, nitidus, margine laterali late flavo. Scutellum nigrum, confertim punctulatum, griseo-pubescens. Elytra thorace paulo longiora, densius subtiliter punctata, griseo-pubescentia, virescenti-nigra, subnitida. Abdomen parce subtiliterque punctulatun, nigrum, supra metallico-versicolor, subtus segmentis singulis apice ferrugineo-marginatis. Pectus nigrum. Pedes flavi, coxis anterioribus concoloribus, intermediis approximatis, tibiis anticis breviter, posterioribus longius spinulosis, tarsis nigricantibus.

Tarsi antici maris fortius, feminae leviter dilatati.

* 28. Ph. umbratilis: Niger, nitidus, capile orbiculato, elytris nigro-aeneis, subtiliter punctatis, pedibus obscure testaceis. - Long. 3 lin.

Er. Col. Murch. I. 454. 12.

Staph. umbratilis Grav. Micr. 170. 21. Mon. 69. 46.

Staph. subfuscus Gyll. Ins. Suec. II. 326. 42. - Sahlb. Ins. Fenn. I. 323. 39. -

Mannerh. Brachelytr. 29. 57. - Boisd. et Lacord. Faun. Ent. Paris. I. 395. 18. -

Runde Brachelytr. Hal. 8. 36.

Philonth. subfuscus Nordm. Symb. 84. 41.

Philonth, umbratilis Nordm. Symb. 84. 47.

Habitat in Europa et in America septentrional.

Habitu fere $\mathrm{Pl}$. atrati, $\mathrm{Pl}$. vario aequalis, niger, nitidus, elytris nigro-subaeneis. Antennae capite thoraceque vix longiores, articulo tertio secundo paulo longiore, 4-10 subobconicis, sensim paululum crassioribus at haud brevioribus, crassitie longioribus, ultimo oblongo, inferne abrupte acuminato, piceo-nigrae. Palpi picei. Caput maris thoracis latitudine, feminae eodem paulo angustius, orbiculatum, supra oculos utrinque parce fortiter punctatum, inter oculos punctis utrinque duobus impressum. Thorax coleopteris paulo angustior, latitudme vix brevior, antrorsum haud angustatus, lateribus subrectis, basi cum angulis posterioribus rotundatus, apice truncatus, angulis anterioribus deflexis, subrotundatis, parum convexus, seriebus dorsalibus punctis 4 profundioribus, anterioribus duobus paulo magis approximatis, compositis, lateribus punctis praeter marginalia utrinque 4 impressus, sericeoversicolor. Scutellum confertissime subtiliter punctulatum, griseo-pubescens. 
Elytra thorace vix longiora, dense subtiliter punctata, minus subtiliter griseo-pubescentia. Abdomen supra subtilius punctatum, densius griseopubescens, subtus segmentis ultimis apice ferrugineo-marginatis. Pedes fusco-testacei, coxis intermediis leviter distantibus, tibiis omnibus spinulosis.

Tarsi antici $\mathrm{maris}$ fortiter dilatati, feminae simplices.

Obs. Specimen Americanum a Gravenhorstio e collectione Knochiana descriptum, nunc in Museo regio asservatum, ab Europaeis non differt nisi antennis basi piceis, palpis pedibusque dilutioribus, elytris margine sumno suturali et apicali abdominisque segmentis omnibus margine apicali piceo, specie nullo modo ab his distinguendum.

*29. Ph. piceatus: Niger, nitidus, elytris nigro-subaeneis, pedibus fuscotestaceis, abdomine infra segmentis rufo-marginalis, capite orbiculato. - Long. $3 \frac{1}{2}$ lin.

Nordm. Symb. 85. 45.

Habitat in Mexico, Dom. Deppe.

Affinis praecedenti, at duplo maior, niger, nitidus, capite thoraceque politis, elytris nigro-subaeneis. Antennae nigrae. Palpi fusco testacei. Caput thorace vix angustius, maiusculum, orbiculatum, utrinque supra oculos punctis paucis, inter oculos punctis utrinque duobus transversin posiris notatum. Thorax coleopteris latitudine fere aequalis, longitudine nomilil latior, antrorsum subangustatus, lateribus subrectis, basi rotundatus, apice truncatus, angulis anterioribus deflexis, subrotundatis, posterioribus obtusis, transversim convexus, seriebus dorsalibus punctis $\mathbf{4}$ aequaliter distantibus compositis, lateribus punctis praeter marginalia utrinque $\mathbf{4}$ impressus, punctis omnibus fortioribus. Scutellum nigrum, dense punctulatum, griseo-pubescens. Elytra thorace paulo longiora, crebre punctata, densius longiusque cinereo-pubescentia. Abdomen laevigatum, vel punctis rarissimis, praecipue segmentorum margines versus, impressum, nigrum, pernitidum, metallico-versicolor, segmentis ventralibus rufo-marginatis. Pedes fusco-testacei, coxis intermediis approximatis, tibiis anticis breviter, posterioribus longius spinulosis.

Tarsi antici maris fortiter dilatati; femina latet.

Obs. 1. Differt a praecedente statura duplo maiore, elytris densius punctatis, abdomine prope laevigato.

2. Antennae in nostro specimine unico mutilatae: articuli 5 primi nigri, tertius secundo paulo longior.

* 30. Ph. cautus: Niger, nitidus, antennarum basi, elytrorum margine summo, ano pedibusque testaceis, capite orbiculato. - Long. 3 lin.

Habitat in Carolina meridionali, Dom. Zimmermann, a Dom. Prof. Germar benevole communicatus.

Statura Ph. umbratilis, habitu $\mathrm{Ph}$. discoideo propior, niger, capite thoraceque pernitidis. Antennae capite paulo longiores, apicem versus hand crassiores, articulo tertio secundo paulo longiore, sequentibus cylindricis, 4-10 sensim paulo brevioribus, penultimis transversis, ultimo apice leviter emarginato et inferne subacuminato, fuscae, articulo primo testaceo, secundo piceo-testaceo. Palpi picei. Mandibulae rufo-piceae. Caput sat magnum, thoracis latitudine, suborbiculatum, perparum convexum, supra oculos utrin- 
que punctis paucis, inter oculos punctis 4 transversim positis, intermediis magis distantibus, omnibus subtilibus, impressum. Thorax basi coleopteris vix angustior, latitudine baseos vix longior, antrorsum modice angustatus, lateribus subrectis, basi cum angulis posterioribus rotundatus, apice truncatus, angulis anterioribus deflexis, rotundatis, satis convexus, seriebus dorsalibus punctis 4 sat distantibus, apicali subtili et a reliquis magis remoto, compositis, lateribus punctis praeter marginalia utrinque. 5 impressus, punctis ommibus subtilioribus. Scutellum crebrius subtiliusque punctulatum, griseo-pubescens. Elytra crebrius et minus subtiliter punctata, densius griseopubescentia, margine laterali inflexo summoque apicali determinato testaceis. Abdomen parcius subtiliusque punctulatum, longius griseo-pubescens, segmento ultimo toto testaceo, ventralibus margine apicali late testaceis. Pedes hreviusculi, testacei, coxis concoloribus, intermediis approximatis, tibiis omnibus spinulosis.

Tarsi antici maris fortius dilatati, femin a latet.

* 31. Ph. varius: Niger, nitidus, elytris viridi-aeneis, capile thorace angustiore, subovato. - Long. $3-3 \frac{1}{2}$ lin.

Nordm. Symb. 84. 37. - Er. Col. March. I. 455. 14.

Staph. varius Gyll. Ins. Suec. II. 321. 37. - Zetterst. Faun. Lappon. I. 74. 19. Ins. Lappon. 63. 28. - Sahlb. Ins. Fenn. I. 321. 35. - Mannerh Brachelylr. 28. 53. - Boisd. et Lacord. Fuun. Ent. Paris I. 395. 17. - Runde Brachel. Hal. 7. 32. Staph, varians Grav. Micr. 20. 21. - Latr. Hist. nat. Crust. et Ins. IX. 309. 28.

V ar. a, Pedibus piceo-testaceis.

Staph. carbonarius Grav. Micr. 23. 31. Mon. 67. 42. - Latr. Hist. nat: Crust. et Ins. IX. 313, 36.

Var. b, Elytris apice rutilis.

Var. c, Elytris pedibusque rufis.

Habitat in Europa.

Habitu fere $\mathrm{Ph}$. politi, at multo minor, niger, nitıdus, capite thoraceque politis, elytris viridi-aeneis, nitidis. Antennae capitis thoracisque longitudine, articulo tertio secundo paululum longiore, sequentibus subcylindricis, dein sensim subobconicis, omnibus crassitie longioribus, ultimo oblongoovato, apice truncato et inferne acuminato, nigrae. Palpi nigri. Caput thorace multo minus et angustius, subovatum, supra oculos utrinque punctis parcis, inter oculos utrinque punctis duobus impressum. Thorax basi fere coleopterorum latitudine, latitudine haud brevior, antrorsum leviter angustatus, lateribus subrectis, basi cum angulis posterioribus rotundatus, apice subemarginatus, angulis anterioribus deflexis, rotundatis, transversim convexus, seriebus dorsalibus punctis 4 aequaliter distantibus compositis, lateribus punctis praeter marginalia utrinque $\mathbf{5}$ impressus, punctis subtilioribus. Scutellum nigrum, confertim punctulatum. Elytra thoracis longitudine, minus dense subtilius punctata, griseo-pubescentia. Abdomen subtiliter parceque punctatum, griseo-pubescens. Pedes plerumque nigri, interdum fusci vel fusco-testacei, coxis intermediis leviter distantibus, tibiis omnibus spinulosis.

Tarsi antici maris fortiter, femina leviter dilatati.

Variat elytris minus magisve rufescentibus, vel nonnunquam totis rufis. 
Obs. 1. Staph. lucidus Grav. Micr. 21. 24, a Gravenhorstio Mon. 82. Staph. fimetario subiunctus, at vix rite: speciminum enim duorum a cel. auctore descriptorum alterum fuit $\mathrm{Ph}$. varius, alterum $\mathrm{Ph}$. quisquiliarius.

2. St a ph. nitens Grav. Micr. 26. 36. Mon. 78. 71. (Latr. Hist. nat. Crust. et Ins. IX. 315. 41.) forte ad hanc speciem, forte etiam ad Ph. albipedem pertinet, mihi omnino dubius.

* 32. Ph. gilvipes: Niger, nitidus, elytris viridi-aeneis, anlennis pedibusque testaceis, capite minuto, oblongo-ovato. - Long. 3 lin.

Er. Col. March. I. 456. 15.

Habitat in Germania, Dom. Schïppel.

$\mathrm{Ph}$. vario statura affinis, niger, capite thoraceque nitidissimis, elytris virescenti-aeneis, subnitidis. Antennae capite thoraceque parum breviores, artıculo tertio secundo paulo longiore, $\mathbf{t - 1 0}$ subobiconcis, sensim paulo brevioribus et crassioribus, penultunis crassitie vix brevioribus, ultimo oblongo - ovato, apice truncato et inferne acuminato, fusco-testaceae, articulis duobus primis testaceis. Palpi testacei. Caput parvulum, thorace multo angustius, oblongo-ovatum, supra oculos utrinque punctis 4 vel $\overrightarrow{5}$, inter oculos utrinque punctis 2 transversim positis impressum. Thorax basi coleopteris latitudine aequalis, longitudine paululum latıor, antrorsum angustatus, lateribus leviter, basi cum angulis posterioribus fortius rotundatus, apice truncatus, angulis anterioribus deflexis, subrotundatis, convexus, seriebus dorsalibus punctis 4 remotis, aequaliter distantibus, compositis, lateribus punctis praeter marginalia utrinque $\mathbf{5}$ impressus, punctis subtilibus;, angulis anterioribus summo margine rufis. Scutellum nigrum, crebre punctulatum. Elytra thorace paulo longiora, subtiliter dense punctata, densius griseo-pubescentia. Abdomen crebrius punctulatum, griseo-pubescens, segmentis ventralibus rufo-marginatis. Pedes testacei, coxis anticis nigricantibus, intermediis approximatis, tibiis omnibus spinulosis.

Tarsi antici maris modice dilatati, femina e simplices.

Obs. A Ph. vario antennis pedibusque testaceis, elytris magis virescentibus abdomineque densius subtiliusque punctatis, capite angustiore, a $\mathrm{Ph}$. albiped $\theta$ statura duplo maiore et elytris viridibus distinctus.

* 33. Ph. bimaculatus: Niger, nitidus, capite subovato, elytris aeneis, macula apicali rufa. - Long. 3 lin.

Nordm. Symb. 92. 59. - Er. Col. March. I. 454. 13.

Staph. bimaculatus Grav. Micr. 38. 55. Mon. 63. 32. - Latr. Hist. nat. Crust. et Ins. IX. 321. 60. - Boisd. et Lacord. Faun. Ent. Paris. I. 400. 26. - Runde Brachelytr. Hal. 9. 44.

Staph. nitidicollis Boisd, et Lacord. Faun. Ent. Paris. I. 108. 28.

St aph. dubius Grav. Mon. 74. 63. (forte)

Habitat in Borussia, Germania, Gallia, Italia.

Statura et magnitudo fer: $\mathrm{Ph}$. varii, niger, nitidus, capite thoraceque politis, elytris viridi-aeneis, nitidis, macula apicali lateritia minore maioreve, nonnunquam per totum elytri discum effusa. Antennae capite thoraceque paulo breviores, articulo tertio secundo paulo longiore, 4-10 subobconicis, sensim paulo brevioribus, penultimis crassitie haud brevioribus, ultimo ovato, apice inferne abrupte acuminato, nigrae. Palpi nigri. Caput thorace 
mínus et angustius, subovatum, supra oculos utrinque parce fortius punctatum, inter oculos punctis 4 trausversim positis impressum. Thorax coleopteris vix angustior, latitudine fere brevior, antrorsum subangustatus, basi modice, lateribus leviter rotundatus, apice truncatus, angulis anterioribus deflexis, subrotundatis, posterioribus obtusissimis, modice convexus, seriebus dorsalibus punctis \& aequaliter distantibus compositis, lateribus punctis prae. ter marginalia utrinque $\mathbf{5}$ impressus, punctis fortioribus. Scutellum nigrum, confertim punctulatum. Elytra thoracis longitudine, crebrius fortiusque punctata, griseo-pubescentia. Abdomen parcius subtiliter punctatum, griseopubescens. Pedes nigri, tibiis tarsisque saepe rufo-piceis, coxis intermediis approximatis, tibiis anticis breviter, posterioribus longius spinulosis.

Tarsi antici maris fortiter, femina e leviter dilatati.

Variat thoracis seriebus dorsalibus 5 -punctatis, minus vero regularibus.

Obs. Staph. nitidicollis Boisd. et Lacord, nonnisi macula per maximam elytrorum partem effusa a genuino differt. Staph. dubius Grav. ad eadem individua pertinere videtur.

* 34. Ph. albipes: Niger, nitidus, abdominis segmentorum ventralium marginibus pedibusque tes/aceis, elylris nigro-piceis, crebre punctatis, capite ovato. - Long. $2 \frac{1}{2}$ lin.

Er. Col. March. I. 457. 16.

St aph. albipes Grav. Micr. 28. 40. Mon. 76. 68. - Latr. Hist. nat. Crust. et Ins. IX. 316. 45. - Gyll. Ins. Suec. II. 327. 43. - Zetterst. Faun. Lappon. I. 75. 23. Ins. Lapp. 64. 33. - Sahlb. Ins. Fenn. I. 323. 14. - Mannerh. Brachelytr. 29. 58.

- Buisd. et Lacord. Faun. Ent. Paris. I. 405.37.

Habitat in Germania, Suecia, Gallia.

Habitu Ph. varii, at plus duplo minor, niger, capite thoraceque nitidis. Antennae capite thoraceque breviores, articulo tertio secundo vix longiore, 4- 10 subobconicis, sensim paululum brevioribus et crassioribus, penultimis crassitie haud brevioribus, ultimo oblongo-ovato, apice emarginato et inferne subacuminato, nigrae, articulis duobus primis piceis. Palpi nigri. Caput thorace angustius minusque, ovatum, supra oculos utrinque punctis nonnullis, inter oculos utrinque punctis duobus transversim positis notatum. Thorax basi coleopterorum latitudine, latitudinis fere longitudine, antrorsum perparum angustatus, Jateribus subrectis, hasi cum angulis posterioribus rotundatus, apice truncatus, angulis anterioribus deflexis, subrectis, modice convexus, seriebus dorsalibus punctis 4 sat distantibus compositis, lateribus punctis praeter marginalia utrinque $\mathbf{5}$ impressus, punctis omnibus subtilioribus, sericeo-versicolor. Scutellum nigrum, confertim punctulatum. Elytra nigro-picea, nitidula, subtilius dense punctata. Abdomen parcius subtiliter punctatum, cum elytris pube densiore, longiore et minus subtili, depressa, grisea vestitum, segmentis inferioribus apice ferrugineo-marginatis. Pedes testacei, coxis intermediis leviter distantibus, tibiis ommibus spinulosis.

Tarsi antici maris leviter dilatati, femina e simplices.

V ariat 1, Antennis basi piceo-testaceis. Specimina Suecica dedit Dom. Schiippel.

2, Antennis basi pedibusque flavo-testaceis, elytris obscure rufis. Specimen singulum Dom. Schïppel Berolini legit.

3, Thoracis serie dorsali altera 4-, altera 5-punctata. 
* 35. Ph. lepidus: Niger, nitidus, antennarum basi, elytris pedibusque rufis, capite ovato. - Long. 3 lin.

Er. Col. March. I. 457. 17.

st a ph. lepidus Grav. Micr. 31. 45. Mon. 74. 64. - Latr. Hist. nat. Crust. et Ins. IX. 318. 50. - Gyll. Ins. Suec. II. 328. 44. - Sahlb. Ins. Fenn. I. 323. 41. Boisd. et Lacord. Faun. Ent. Paris. I. 401. 29.

Staph. flavopterus Grav. Mon. 74. 65.

Philonth. flavopterus Nordm. Symb. 89. 51.

St aph. fulvipes Runde Brachelytr. Hal. 10. 52.

Habitat in Germania, Suecia, Gallia.

Apterus, niger, capite thoraceque pernitidis. Antennae capitis thoracisque prope longitudine, articulo tertio secundo paulo longiore, 4-10 subobconicis, sensim paululum brevioribus at non crassioribus, omnibus crassitie longioribus, ultimo oblongo, apice leviter emarginato et inferne acuminato, nigrae vel uigro-piceae, articulo prino, interdum etiam secundo, rufotestaceo. Palpi nigro-picei. Caput thorace minus angustiusque, ovatum, supra oculos utrinque punctis nonnullis, inter oculos utrinque punctis duobus transversim positis impressum. Thorax coleopteris latitudine aequalis, latitudine vix brevior, antrorsum subangustatus, lateribus parum, basi cum angulis posterioribus fortius rotundatus, apice truncatus, angulis posterioribus deflexis, subrotundatis, convexus, seriebus dorsalibus punctis 4 remotis compositis, lateribus punctis praeter marginalia utrinque 4 impressus, punctis omnibus subtilioribus. Scutellum nigrum, confertim subtiliter punctatum. Elytra thorace fere breviora, confertim subtiliter punctata, lateritia, griseopubescentia. Abdomen subtiliter punctatum, densius subtiliter griseo-pubescens, parce nigro-pilosum, segmentis inferioribus apice tenuiter ferrugineomarginatis. Fedes cum coxis anterioribus rufo-testacei, coxis intermediis approximatis, tibiis anticis breviter, posterıoribus longius spinulosis.

Tarsi antici maris fortius dilatati, feminae simplices.

*36. Ph. nitidulus: Niger, nitidus, pedibus testaceis, elytris brevibus, profunde punctalis, piceis, capite ovato. - Long. 2 lin.

Nordm. Symb. 85. 43. - Er. Col. March. 1. 458. 18 .

St uph. nitidulus Grav. Micr. 27. 37. Mon. 69. 51. - Latr. Hist. nat. Crust. et

Ins. IX. 315. 42. - Gyll. Ins. Suec. II. 330. 46. - Sahlb. Ins. Fenn. I. 323. 42.

- Mannerh. Brachelytr. 29. 60. - Runde Brachelytr. Hal. 8. 37.

Staph. denigrator Grav. Mon. 92. 88.

Philonth. denigrator Nordm. Symb. 85. 44.

Habitat in Germania, Suecia.

Apterus, niger, capite thoraceque pernitidis. Antennae capite thoraceque breviores, crassiusculae, articulo tertio secundo haud longiore, 5-10 subaequalibus, crassitie paulo brevioribus, ultimo ovato, apice truncato et abrupte subacuminato, dilutius saturatiusve rufo-piceae. Palpi picei, articulo ultimo apice fortius acuminato. Caput thorace angustius, ovatum, supra oculos utrinque punctis paucis, inter oculos punctis 4 transversim positis, aequaliter distantibus, impressum. Thorax coleopteris latitudine aequalis, latitudine prope longior, antrorsum leviter angustatus, lateribus levissime, basi cum angulis posterioribus fortius rotundatus, apice truncatus, angulis anterioribus deflexis, rotundatis, fortius transversim convexus, seriebus dor- 
salibus punctis 4 sat distantibus compositis, lateribus punctis praeter marginalia utrinque 5 impressus, punctis omnibus subtilibus. Scutellum obsolete punctulatum. Elytra thorace breviora, minus dense fortiter punctata, parce griseo-pubescentia, piceo-suhaenea, nitida. Ahdomen parcius subtiliušctê punctulatum, parce griseo-pubescens, segmento ultimo subtus apice rufo-piceo. Pedes cum coxis anterioribus testacei, coxis intermediis tenui spatio distantibus, tibiis omnibus spinulosis, tarsis anticis in utroque sexu simplicibus.

\section{*37. Ph. hepaticus: Niger, thorace abdominisque segmentorum margini- bus fusco-piceis, elytris fuscis, apice pallidis, antennarum basi pedi- busque flavo-tesiaceis, capite ovalo. - Long. vix 2 lin.}

Habitat in America septentrionali, e coll. Knochiana; a Dom. Zimmermann quoque missus.

Statura fere $\mathrm{Ph}$. albipedis, at paulo minor. Antennae capite cum thorace paulo breviores, articulo tertio secundo paulo longiore, sequentibus subobconicis, sensin paululum brevioribus, non autem crassioribus, penultimis crassitie haud brevioribus, ultimo oblongo-ovato, apice truncato et inferne acuminato, fuscae, articulis 2 primis testaceis. Palpi picei. Caput thorace angustius, subovatum, supra oculos utrinque punctis nonnullis, inter oculos punctis \& transversim positis, intermediis remotioribus, impressum, nigro-piceum, nitidum. Thorax basi coleopteris paulo angustior, latitudine haud brevior, antrorsum leviter angustatus, lateribus subrectis, basi cum angulis posterioribus rotundatus, apice truncatus, angulis anterioribus deflexis, subrotundatis, transversim convexus, seriebus dorsalibus punctis 4 aequaliter distantibus et sat remotis compositis, lateribus punctis praeter marginalia utrinque 4 impressus, punctis minus subtilibus, rufo-piceus, nitidus. Elytra thorace paulo longiora et scutellum fusca vel fusco-testacea, illa dorso infuscata, margine apicali pallıdo, subtilius crebre punctata, griseopubescentia. Abdomen subtiliter punctulatum, griseo-pubescens, nigro-fuscum, segmentorum marginibus rufo-piceis vel fusco-testaceis, infra apice testaceum. Pedes flavo-testacei, coxis intermediis leviter distantibus, tibiis anticis subtiliter, posterioribus fortius spinulosis.

Tarsi antici maris fortiter, femina é levter dilatati.

* 38. Ph. vilis: Nigro-piceus, nitidus, antennarum basi, pedibus abdominisque segmentorum ventralium marginibus testaceis, thorace piceo, capite subovalo. - Long. 2 lin.

Habitat in Americae meridionalis ins. St. Thomae, Dom. Moritz.

Praecedenti affinis, coloribus $\mathrm{Ph}$. ventrali similis, at multo minor, praesertim angustior, statura $\mathrm{Ph}$. aterrimi, nigro-piceus, nitidus, capite thoraceque nitidissimis. Antennae capite thoraceque breviores, crassiusculae, articulo tertio secundo paulo longiore, $4-10$ sensin páalo brevioribus, non autem crassioribus, penultimis crassitie vix brevioribus, ultimo subovato, apice truncato et inferne abrupte acuminato, nigrae, articulis duobus basalibus testaceis. Os cum palpis obscure testaceum. Caput thorace parlo angustius, breviter subovatum, utrinque supra oculos punctis paucis subtilioribus, inter oculos punctis 4 transversim positis, intermediis remotioribus, impres- 
sum. Thorax coleopteris paulo angustior, latitudine haud longior, antrorsum leviter angustatus, lateribus subrectis, basi cum angulis pòsterioribus rotundatus; apice truncatus, angulis anterioribus subrotundatis, leviter convexus, seriebus dorsalibus punctis 4 aequaliter distantibus et sat remotis compositis, lateribus punctis praeter marginalia utriñque 5 impressus, punctis omnihus minus fortibus, piceus. Scutellum nigrum, crebre punctatum, griseo-pubescens. Elytra thorace paulo longiora, nigro-picea, nitida, parcius minus profunde punctata, longius griseo-pubescentia. Abdomen parce subtilissime punctulatum, griseo-pubescens, segmentorum ventralium marginibus rufo-testaceis. Pedes cum coxis anterioribus flavo-testacei, coxis intermediis approximatis, tibiis omnibus parcius spinulosis, tarsis anticis in utroque sexu fortiter dilatatis.

* 39. Ph. orphanus: Niger, nitidus, antennarum basi abdominisque segmentorum ventralium marginibus testaceis, pedibus flavis, thorace oblongo, capite subovato. - Long. 2 lin.

Habitat ad Caracas Columbiae, Dom. Moritz.

Statura omnino $\mathrm{Ph}$. aterrimi et maximis eius individuis parum maior, niger, nitidus. Antennae capite thoraceque breviores, articulo tertio secundo parum longiore, $4-10$ sensim brevioribus at vix crassioribus, penultimis subtransversis, ultimo oblongo-ovato, apice oblique truncato et inferne subacuminato, nigrae, articulis duobus primis piceo-testaceis. Mandibulae rufopiceae. Palpi nigro-picei. Caput thoracis antico latitudine prope aequale, subovatum, modice convexum, supra oculos utrinque punctis paucis, inter nculos punctis 4 transversim positis, intermediis paulo remotioribus, impressum. Thorax latitudine paulo longior, coleopteris dimidio prope angustior, apicem versus subangustatus, lateribus subrectis, basi rotundatus, apice truncatus, angulis omnibus fortius rotundatis, leviter convexus, seriebus dorsalibus punctis 4 sat remotis et aequaliter distantibus compositis, lateribus punctis praeter marginalia utrinque 4 impressus, punctis omnibus subtilioribus. Scutellum subtilissime punctulatum, tenuiter pubescens. Elytra thorace paulo longiora, minus confertim subtilius punctata, tenuiter griseo-pubescentia. Abdomen parcius subtliter punctatum, tenuiter griseo-pubescens, subtus segmentis singulis margine postico rufo-testaceis. Pedes flavo-testacei, coxis antericribus concoloribus, intermediis tenui spatio distantibus, tibiis anticis subtilissime, posterioribus distincte spinulosis.

Tarsi antici $\mathrm{m}$ aris fortius, fe minae leviter dilatati.

Variat minus maturus nigro-piceus, elytris fusco-testaceis.

* 40. Ph. xantholoma: Niger, elytris opacis, margine inflexo luleo, abdomine cinereo-linealo, pedibus fusco-testaceis, thorace basin versus angustato. - Long. $3 \frac{1}{2}$ lin.

Staph. xantholoma Grav. Mon. 41. 3. - Gyll. Ins. Suec. II. 323. 39. - Germ. Faun. Ins. Europ. XIII. 13. - Zetterst. Ins. Lappon, 64. 32.

C'afius xantholona Curtis Britt. Ent. VII. fol. 322. - Mannerh. Brachelytr. 31. 1. Gyrohypn.xantholoma.Nordm. Symb. 126. 28.

Habitat in Germaniae septentrionalis, Sueciac, Angliae, Lusitaniae Italiaeque littoribus. 
Statura fere Ph. cephalotis. Antemae capite cứm thorace breviores, articulo tertio secundo parum longiore, $4-10$ sensim paulo brevioribus, crassitie autem aequalibus, ultimo subovato, apice abrupte acuminato, nigropiceae. Palpi picei, apice rufescentes. Mandibulae rufo-piceae. Caput maiusculum, thorace plerumpue latius, subquadratum, utrinque supra oculos punctis magnis at parum profundis parcis impressum, fronte inter orulos utrinque punctis duobus transversim positis notata, medio leviter foveolata. nigrum, nitidum. Thorax coleopteris duplo fere angustior, latitudine parum longior, basin versus subangustatus, lateribus leviter rotundatıs, pone medium subsinuatis, basi rotundatus, apice truncatus, angulis anterioribus levi. ter deflexis, rotundatis, posterioribus obtusis, parum convexus, punctis se rierum dorsalium posterioribus tribus grossis, antico remotiore, minuto, lateribus intra angulum anteriorem punctis nonnullis impressus, nigro-piceus, nitidus. Elytra thorace sesqui fere longiara et scutellum subtilissime confertissinieque punctata, nigra, opaca, densius griseo-pubescentia, illa margine laterali inflexo luten. Abdomen subtilissime confertissimeque punctatum, opacum, nigrum, cinereo-pubescens, dorso lineis duabus macularibus e pube cinerea ornatum. Pectus nigrum, opacum. Pedes fusco-testacei, coxis intermediis tenui spatio distantibus, anticis femoribusque obscurioribus, piceis, tibiis omnibus spinulosis, tarsis anticis in utroque sexu leviter dilatatis.

Abdominis segmentum inferius quintum in mare medio longitudiualiter impressum et leviter emarginatum.

* 11. Ph. variegatus: Niger, thoracis limbo sanguineo, elytris opacis, margine inflexo luteo, abdomine ferrugineo, supra nigro-cinereoque variegalo, pedibus tesiaceis, thorace basin versus angustato. - Long. $3 \frac{1}{2}$ lin.

Habitat in Sicilia, Dom. Grohmann.

Statura et summa affinitas praecedentis. Antennae capite thoraceque breviores, articulo secundo tertioque subaequalibus, 4-10 subaequalibus, crassitie vix longioribus, ultimo ovato, apice abrupte acuminato, nigrae. Palpi picei, apice dilute rufescentes. Caput thoracis latitudine, subquadratum, supra oculos utrinque obsolete punctatum, inter oculos punctis utrinque duobus transversim positis notatum et medio longitudinaliter obsolete impressum, nigrum, nitidum. Thorax latitudine paulo longior, basin versus leviter angustatus, basi coleopteris duplo prope angustior, lateribus ante medium leviter rotundatis, pone medium leviter sinuatis, basi rotundatus, apice truncatus, angulis anterioribus leviter deflexis, rotundatis, posterioribus obtusis, leviter convexus, serierum dorsalium punctis tribus posterioribus maioribus, postico et antico subtiliore remotioribus, lateribus intra angulum anteriorem punctis paucis impressus, rufo-sanguineus, disco lato et macula minuta in utroque ansulo anteriore summo nigris, nitidus. Scutellum confertissime subtiliter punctatum, griseo-pubescens, rufum, opacum. Elytra thorace tertia parte longiora, confertissime subtiliter punctata, dense subtiliterque cinereo-pubescentia, nigra, opaca, margine laterali inflexo summoque apicali luteis. Abdomen confertim subtiliter punctatum, subtus aequaliter subtiliter pubescens, supra maculis biseriatis e pube densiore cinerea et triseriatis nigris alternantibus variegatum seu tessellatum. Pectus nigrum, densius cinereo-pubescens. Pedes testacei, coxis intermediis tenui spatio distantibus, femoribus posterioribus fuscis, tibiis omnibus spmulosis. 
* 42. Ph. fucicola: Brunneus, pectore capiteque nigricantibus, pedibus ferrugineis, abdomine biseriatim subfoveolato, thorace basin versus angustato. - Long. 5 lin.

Nordm. Symb. 84. 42.

Cafius fucicola Curtis Britt. Ent. VII. 322.

Habitat in Anglia, Dom. Leach.

Statura omnino Ph. xantholomatis, at maior et alius. Antennae capite cum thorace breviores. articulo tertio secundo paululum breviore, 4 - 10 sensim paululum hrevioribus, penultimis longitudine haud crassioribus, ultimo ovato, apice subtruncato et inferne subacuminato, nigricantes, basi brunneae, articulo apicali ferrugineo. Caput oblongo-subquadratum, thorace paulo latius, basi lateribus grosse punctatum, fronte inter oculos medio leviter impressa, supra nigro-piceum, subnitidum, ore brunneo, infra ferrugineum. Thorax coleopteris multo angustior, latitudine paululum longior, basin versus angustatus, lateribus anterins rotundatis, pone medium leviter sinuatis, basi parum, angulis posterioribus fortius rotundatis, apico truncatus, angulis anterioribus leviter deflexis, rotundatis, leviter convexus, serierum dorsalium punctis tribus posterioribus grossis, quarto antico remoto, subtiliore, lateribus secundum anguli anterioris marginem punctis 4 maioribus impressus, ommium subtilissime alutaceus, supra brunneus, nitidus, infra ferrugineus. Elytra thorace paulo longiora et scntellum creberrime subtilius punctata, tenuiter pubescentia, fusca, opaca. Ablomen crebre punctulatum, segmentis singulis dorso obsolete bi-impressis, supra brunneum, subnitidum, infra ferrugineum. Pectus nigricans. Pedes rufo-ferruginei, coxis intermediis leviter distantibus, tibiis omnibus spinulosis, tarsis anticis (feminae) leviter dilatatis.

Variat interdum thoracis serie dorsali altera 5 -punctata.

* 43. Ph. cicatrisosus: Elongatus, piceus, antennis, pedibus abdomineque ferrugineis, thorace basin versus angustato, capile magno, quadrato. - Long. 5 lin.

Habitat in Sicilia.

Statura elongata et depressa omnino praecedentis. Antennae capite thoraceque breviores, articulo tertio secundo sesqui prope longiore, 4-10 sensim brevioribus, primis eorum cylindricis, reliquis subobconicis, penultimo crascitie vix breviore, ultımo ovato, apice truncatulo et inferne subacuminato, ferrugineae, basi piceae. Palpi ferruginei. Caput thorace latius, magnum, depressum, oblongo-subquadratum, piceum, nitidum, margine laterali et verticali punctato, fronte utrinque longitudinaliter punctis grossis inaequalibus parum profundis et obsolescentıbus variolosa, medio canalicula brevissima obsolete impressa. Thorax coleopteris angustior, latitudine apicis parum longior, basin versus fortius angustatus, lateribus ante medium leviter rotundatis, pone medium subsinuatis, basi parum, angulis posterioribus fortius rotundatis, apice truncatus, angulis anterioribus rotundatis, depressus, serierum dorsalium punctıs posterioribus approximatis, grossis at parum profundis et obsoletioribus, irregularibus, uno alterove saepe exstincto, antico remoto, pariter grossiusculo, lateribus utrinque ad angulum anteriorem et pone inedium ad marginem lateralem punctis nonnullis irregularibus, parum profundis notatus, piceus, nitidus. Scutellum crebrius punctatum, sub- 
tiliter pubescens. Elytra thorace paulo longiora, picea aut ferruginea, confertim fortius punctata, subtiliter pubescentia. Pectus fusco-piceum. Abdomen ferrugineum, subtiliter punctulatum, subtiliter griseo-pubescens, dorso obsolete variegatum. Pedes graciliores, ferruginei, coxis femoribusque piceis, coxis intermediis approximatis, tibiis omnibus spinulosis, tarsis anticis in utroque sexu modice dilatatis.

* 44. Ph. albilabris: Niger, nitidus, pedibus favis, antennis apice ferrugineis, thorace oblongo, capite magno, orbiculato. - Long. 3 lin.

Nordm. Symb. 86. 46.

Habitat in Japonia, Dom. v, Langsdorf.

Statura fere $\mathrm{Ph}$. fimetarii, niger, nitidus, capite thoraceque nitidissimis, elytris vix aenescentibus. Antennae capite cum thorace parum breviores; sat elongatae, articulo tertio secundo plus sesqui longiore, 1-10 elongatoobconicis, sensim paululum crassioribus, at vix brevioribus, ultimo oblongo, apice oblique truncato et inferne acuminato, nigrae, basi piceae, apice ferrugineae. Mandibulae longae et palpi picei. Caput thorace fere latius, orbiculatum, leviter convexum, utrinque supra oculos punctis nonnullis, inter oculos punctis utrinque duobus transversim positis, omnibus sat fortibus profundisque impressum. Thorax coleopteris angustior, Iatitudine paulo longior, lateribus rectis, parallelis, basi cum angulis posterioribus rotundatus, apice truncatus, angulis anterioribus leviter deflexis, subrotundatis, modice convexus, seriebus dorsalibus punctis 4 aequaliter distantibus compositis, lateribus punctis praeter marginalia utrinque 4 impressus, punctis omnibus profundioribus. Scutellum confertim punctatum, griseo-pubescens. Livira thorace tertia parte longiora, minus confertim subtilius punctata, densius griseo-pubescentia. Pedes pallide flavi, coxis omnibus nigris, intermediis leviter distantibus, tibiis anticis breviter, posterioribus longius spinulosis.

Tarsi antici $\mathrm{m}$ aris modice dilatati. Femin a latet.

* 45. Ph. cephalotes: Elongatus, niger, elytris aeneis, fortius punctatis, pedibus fusco-piceis, capite latiore, suborbiculato. - Long. $3-4$ lin. Nordm. Symb. 82. 35. - Er. Col. March. I. 439. 19.

Staph. cephalotes Grav. Mier. 22. 27. Mon. 71. 55. - Latr. Hist. nat, Crust. et Ins. IX. 311. 32. - Gyll. Ins. Suec. II. 320. 36. - Sahlb. Ins. Fenn. I. 321. 34. - Zetierst. Ins. Luppon. 63. 27. - Mannerh. Brachelytr. 28. 52. - Boisd. et Lacoid. Faun. Ent. Paris. I. 90. 8.

Ilabitat in Europa; in Syria et Aegypto etiam a Prof. Ehrenberg lectus.

Elongatus, linearis, niger, capite thoraceque pernitidis, elytris aencis, nitidulis. Antennae capite thoraceque paulo breviores, articulo tertio secundo paulo longiore, 4 - 10 subobconicis, sensim paulo brevioribus, penultimo crassitie fere breviore, ultimo ovato, apice subemarginato et inferne acuminato, nigro-piceae. Palpi picei. Caput feminae minoribusque indivividuis masculis thoracis fere latstudine, maribus maioribus thorace magis mimusve latius, suborbiculatum, supra oculos utrinque punctis paucis, inter oculos punctis quatnor transversim positis notatum. Thorax coleopteris paulo angustior, latitudine vix longior, basin versus subangustatus, lateribus anterius leviter rotundatis, posterius subsinuatis, basi rotundatus, apice trunt 
catus, angulis anterioribus leviter deflexis, rotundatis, posterioribus obtusis, basin versus subangustatus, parum convexus, seriebus dorsalibus punctis 4 aequaliter distantibus compositis, lateribus punctis praeter marginalia utrinque 5 impressus, punctis omnibus modice profundis. Scutellum confertim subtiliter punctulatum, griseo-pubescens. Elytra thorace paulo longiora, densius profundiusque punctata, griseo-pubescentia. Abdomen subtiliter punctatum, densius longiusque griseo pubescens, segmentis ventralıbus ferrugineo-marginatis. Pedes picel, coxis intermediis approximatis, tibiis omnibus spinulosis, tarsis anticis in utroque sexu simplicibus.

Variat thoracis seriebus dorsalibus 5-punctatis.

Obs. Caput apud masculos secundum corporis magnitudinem magnitudine variat, ut in $\mathrm{Ph}$. aeneo, carbonario, etc., ita ut quanto validius sit specimen, tanto grossiore capite, quo debilius, eo minore capite instructum sit; masculi igitur mi . nores, qui frequentius occurrunt, capitis forma et proportione parum a femina discedunt.

* 46. Ph. fimetarius: Elongatus, niger, nilidus, elytris viridi-aeneis, sul,tilius punctatis, pedibus flavis, capite suborbiculalo. - Long. 3 lin.

Er. Col. March. I. 460. 21.

Staph. fimetarius Grav. Micr. 175. 32. Mon. 80. 72. - Latr. Hist. nat. Crust. et Ins. IX. 325. 72. - Gyll. Ins. Suec. II. 324. 40. - Zetterst. Faun. Lappon. I. 75. 21. Ins. Lappon. 63. 30. - Suhlb. Ins. Fenn. I. 322. 37. - Mannerh. Brach. elytr. 29. 55. - Boisd. et Lacord. Faun. Eut. Paris. I. 40t. 38.

Staph. rigidicornis Grav. Micr. 23. 29. Mon. 69. 49. - Latr. Hist. nat. Crust. et Ins. IX. 312. 34.

Philonth. rigidicornis Nordm. Symb. 82. 33.

Habitat in Europa.

Habitu praecedentis, niger, capite thoraceque pernitidis, elytris lucide viridi-aeneis, nitidis. Antennae capite thoraceque paulo breviores, articulo tertio secundo paulo longiore, 4-10 sensim perparum brevioribus et crassioribus, crassiusculis, crassitie haud brevioribus, ultimo ovato, apice oblique emarginato et inferne acuminato, nigrae. Palpi picei. Caput in utroque sexu thoracis latitudine, suborbiculatum, supra oculos utrinque punctis paucis fortibus, inter oculos utrinque punctis duobus transversim positis et medio impressione lata at parum profunda notatum. Thorax coleopteris angustior, latitudine paulo longior, lateribus parallelis, subrectis, vel pone medium levissime sinuatis, basi rotundatus, angulis posterioribus obtusis, apice truncatus, angulis anterioribus leviter deflexis, rotundatis, parum convexus, seriebus dorsalibus punctis 4 , posterioribus tribus remotioribus, compositis, lateribus punctis praeter marginalia utrinque 5 impressus, punctis ommibus sat magnis profundisque. Scutellun punctulatum, griseo-pubescens. Elytra thorace tertia parte longiora, densius subtiliusque punctata, longius griseo-pubescentia, segmentis singulis supra infraque ferrugineo-marginatis. Pedes laete flavi, coxis anticis picescentibus, intermediis tenui spatio distantibus, tibris omnibus spinulosis, tarsis anticis in utroque sexu simplicibus.

* 47. Ph. sordidus: Elongalus, niger, nitidus, elylvis aeneis, parcius profunde punctatis, pedibus piceis, capile suborbiculato. - Long. 3 lin.

Nordm. Symb. 84. 40. - Er. Col. March. I. 459. 20.

Staph. sordidus Grav. Micr. 176. 33. - Gyll. Ins. Suec. I. 326. 41. - Zetterst. 
Faun. Lappon. 1. 75. 20. Ins. Lappon. 63. 21. - Sahlb. Ins. Fenn. I. 322. 38. Mannerh. Brachelytr. 29. 55. - Boisd. et Lacord. Faun. Ent. Paris. I. 396. 19. Philonth. pachycephalus Nordm. Symb. 82. 35.

Habitat in Europa.

$\mathrm{Pl}$. cephaloti affinis, at paulo minor, niger, capite thoraceque pernitidis, elytris aeneis, nitidis. Antennae capite thoraceque paulo breviores, articulo tertio secundo paulo longiore, 4-10 sensim paulo hrevioribus et crassioribus, subobconicis, penultimis crassitie vix brevioribus, ultimo ovato, apice oblique truncato et inferne acuminato, nigrae. Caput thoracis fere latitudine, suborbiculatum, leviter convexum, supra oculos utrinque punctis paucis sparsis, inter oculos punctis $\mathbf{4}$ transversim positis impressum. Thorax coleopteris paulo angustior, basin versus subangustatus, latitudine vix longior, lateribus subrectis vel pone medium levissime sinuatis, basi cum angulis posterioribus rotundatus, apice truncatus, angulis anterioribus deflexis, leviter rotundatis, parum convexus, seriebus dorsalibus punctis 4 sat remotis, aequaliter distantibus, compositis, lateribus punctis praeter marginalia utrinque 5 impressus, punctis omnibus profundioribus. Scutellum confertim punctulatum, tenuiter griseo-pubescens. Elytra thorace parum longiora, parcius fortiter profundeque punctata, parce griseo-pubescentia. Abdomen subtiliter punctatum, griseo-pubescens, segmentis ventralibus ferrugineomarginatis. Pedes plerumque piceo-testacei, interdum picei vel nigro-picei, coxis intermedis leviter distantibus, tibiis omnibus spinulosis, tarsis anticis in utroque sexu simplicibus.

$\mathrm{Obs}$. Caput in hac specie plerumque thoracis latitudine, in utroque sexu aequale; invidua mascula solito paulo maiora et capite paulo grossiore instructa a Prof. Nordmann nomine $\mathrm{Ph}$. pachycephali pro peculiari specie descripta sunt. Differunt a P. cephalote elytrorum punctura rariore profundioreque et capite magis orbiculato.

* 45. Ph. fuscus: Elongatus, niger, nitidus, thorace, elytris pedibusque rufis, abdominis segmentis rufo-marginatis. - Long. 3 lin.

Nordm. Symb. 90. 54. - Er. Col. March. I. 461. 22.

St aph. fuscus Grav. Micr. 29. 41. Mon. 59. 26. - Latr. Hist. nat. C'rust. et Ins.

IX. 317. 46. - Gyll. Ins. Suec. II. 329. 45. - Mannerh. Brachelytr. 29. 59.

St aph. subuliformis Grav. Micr. 29. 42. Mon. 61. 30. - Latr. Hist. nat. ('rust. et Ins. IX. 317. 47.

St aph. terminatus Grav. Micr. 30. 43. - Latr. Hist. nat. Crust. et Ins. IX. 317. 48. staph. fragilis Grav. Micr. 30. 44. - Latr. Hist. nat. Crust. et Ins. IX. 317. 49.

Habitat in Germania, Suecia.

Statura praecedentium. Antennae tenues, capite parum longiores, articulo tertio secundo paulo longiore, 4-10 sensim paulo brevioribus et crassioribus, 5 - 10 transversim obconicis, ultimo subovato, apice oblique emarginato et inferne acuminato, rufae, medio magis minusve piceae, apice ferrugineae. Labrum et palpi rufa, mandibulae rufo-piceae. Caput feminae minoribusque individuis masculis thoracis vix latitudine, maribus maioribus thorace paulo latius, orbiculatum, leviter convexum, supra oculos utrinque punctis paucis, inter oculos punctis 4 transversim positis impressum, nigrum, nitidum. Thorax coleopteris paululum angustior, latitudine vix longior, lateribus subrectis, parallelis, basi rotundatus, angulis posterioribus obtusis, apice truncatus, angulis anterioribus leviter deflexis, rotundatis, parum convexus, seriebus dorsalibus punctis $\mathbf{4}$, posterioribus tribus remotio- 
ribus, compositis, lateribus punctis praeter marginalia utrinque circiter $5 \mathbf{~ i m - ~}$ pressus, punctis omnibus subtilioribus, rufus, nitidus, dorso antice plerumque nigricans. Scutellum nigricans, dense subtiliter punctulatum, griseo-pubescens. Elytra thorace parum longiora, dense subtiliter punctata, subtiliter griseo-pubescentia, rufo-picea. Abdomen subtiliter punctulatum, subtiliter griseo-pubescens, nigrum, segmentis singulis rufo-marginatis. Pectus nigrum. Pedes cum coxis anterioribus ruf, coxis intermediis leviter distantibus, tibiis amnibus spinulosis, tarsis anticis in utroque sexu simplicibus.

V ariat thorace toto rufo.

Obs. Caput magnitudine variat ut in Ph. cephalote, at in hac specie caput feminae thorace angustius, masculorum validiorum thorace parum latius-et magis orbiculatum.

* 49. Ph. placidus: Elongatus, niger, nitidus, pedibus elytrisque rufis, his circa scutellum nigricantibus. - Long. 3 lin.

Var. Elytris rufis, plaga communi lata, apice abbreviata, nigra.

Habitat in Chersoneso Taurica, Dom. Schüppel et Parreyss, in Hungaria, Dom. Frivaldsky.

Statura omnino sequentis, niger, nitidus, capite thoraceque nitidissimis, elytris rufis. Antennae capite cum thorace breviores, articulo tertio secundo paulo longiore, 4-10 paulo brevioribus at haud crassioribus, penultimis haud transversis, vltimo ovato, apice oblique emarginato et inferne acuminato, ferrugineae, basi nigro-fuscae. Palpi dilute rufi. Caput orbiculatum, maiusculum, plerumque thoracis latitudine vel masculis matoribus paulo latius, supra oculos punctis parcis dispersis, inter oculos punctis 4 transversim positis subtiloribus impressum. Thorax coleopteris parum angustior, latitudine haud brevior, lateribus parallelis, snbrectis, basi cum angulis posterioribus rotundatus, apice truncatus, angulis anterioribus leviter deflexis, rotundatis, leviter convexus, seriebus dorsalibus punctis 4 aequaliter distantibus compositis, lateribus punctis praeter marginalia saepius $\mathbf{5}$ impressus, punctis omnibus sat subtilibus. Scutellum nigrum, crebre punctatum, tenuiter griseo-pubescens. Elytra thorace parum longiora, crebrius subtiliusque punctata, parce tenuiterque griseo-pubescentia, rufa, nitida, circa scutellum tenui spatio nigricantia. Abdomen parce subtiliterque punctatum, griseo-pubescens, segmentis ventralibus obscure rufo-marginatis. Pedes rufi, coxis omnibus nigris, intermediis leviter distantibus, femoribus posterioribus saepe nigricantibus, tibis omnibus spinulosis, tarsis anticis in utroque sexu simplıcibus.

$\mathrm{Obs}$. Varietatis supra memoratae specimen singulum masculum, genuinis paulo maior, capite validiore, thorace paulo longiore, ceterum nullo modo distinctum, a Dom. Dr. Frivaldsky e Hungaria communicatum est.

50. Ph. blandus: Nilidus, rufus, capite, pectore, elytris abdominisquie apice nigris, capite orbiculalo. - Long. 3 lin.

Staph. blandus Grav. Mon. 72. 60.

Habitat in America septentrionali, Knoch.

Statura omnium praecedentium. Antennae capite thoraceque multo breviores, articulo tertio secundo paulo longiore, sequentibus sensim paulo 
crassloribus at vix brevioribus, penultimis subtransversis, ultimo subovato, apice oblique emarginato et inferne acuminato, nigrae, basi obscure testaceae, apice pallidae. Palpi obscure testacei. Caput maiusculum, thoracis latitudine, orbiculatum, supra oculos punctis parcis dispersis, inter oculos 4 transversim positis subtilioribus impressum, nigrum, nitidum. Thorax coleopteris angustior, latitudine paulo longior, lateribus parallelis, subrectis, vel ante basin levissime sinuatis, basi cum angulis posterioribus rotundatus, apice truncatus, angulis anterioribus leviter deflexis, rotundatis, modice convexus, punctis serierum et nonnullis utrinque inter series et marginem lateralem sitis subtilioribus, testaceo-rufus, nitidus. Scutellum punctatum, nigrum. Elytra thorace parum longiora, nigra, nitida, parcius punctata, tenuiter griseo-pubescentia. Abdomen parce subtıliterque punctulatım, nitidulum, rufum, segmentis ultimis tribus nigricantibus. Pectus nigrum. Pedes cum coxis rufo-testacei, coxis intermedis tenui spatio distantibus, tibiis omnibus spinulosis, tarsis anticis maris simplicibus.

Obs. In specimine unico, quod in Museo regio exstat, thorax serie punctorum dorsali altera 4-, altera 5-punctata, punctis lateralibus in altera latere 6 , in altero 8 impressus est; cum praecedentibus summa affinitate iuncta haec species videtur.

\section{Species mihi in visae.}

51. Ph. suturalis: Niger, nitidus, antennis et pedibus fusco-piceis, elytris rufis, crebre punclatis, sutura nigra. - Long. $4 \frac{1}{3}$ lin.

Nordm. Symb. 91.57.

Habitat in Sibiria et Russia orientali.

$\mathrm{Ph}$. polito paulo brevior, capite thoraceque maioribus, antennis multo brevioribus.' Antennae capite paulo longiores, extrorsum nonnihil crassiores, fusco-pubescentes. Palpi mandibulaeque nigro-picei. Caput magnum, thorace tamen vix latius, subquadrangulum, angulis rotundatis, nigrum, nitidissimum, laeve, inter oculos puncta 4 , et in angulis verticis puncta plura pilifera, maiuscula, profunde impressa. Thorax magnus, antice truncatus, angulis compressis, lateribus versus basin subobliquis et paululum sinuatis, postice obtuse rotundatus, supra sat convexus, tenuissime marginatus, niger, nitidissimus, in angulis anticis puncta quatuor maiora, quorum tria oblique versus latus, quartum ad marginem anticum impressum, series dorsales profunde punctatae. Scutellum nigrum, subnitidum, creberrime et subtilissime punotatum. Elytra thorace latiora et longiora, supra depressa, rufo-testacea, creberrime et subtiliter punctulata, flavescenti-pubescentia, margine suturali laevi, nitido, nigra. Alae dilute fuscescentes. Abdomen elytris fere duplo longius, nigrum, nitidum, crebre et rude punctulatum, pubescens et nigro-pilosum, segmento ultimo in mare sat profunde emarginato. Pedes toti nigro-picei, tarsis anticis in mare paulo dilatatis. (Nordm.)

$\mathrm{O}$ bs. An a Ph. bimaculato satis distinctus?

52. Ph. microcephalus: Nitidus, niger, pedibus rufis, capite suborbiculato, thorace seriebus dorsalibus 4-punctis. - Long. 3 lin.

Staph. microcephalus Grav. Mon. 70. 52.

Habitat Lutetiae. 
Caput latitudine paulo longius, thorace minus, nigrum, antennis capitis longitudine et palpis fuscis. Thorax coleopteris paulo minor, $2,3,4$ punctus. Coleoptera quadrata, fuscescenti-nigricantia, subsericantia. Abdomen nigrum, griseo-sericans, segmentis marginibus ventralibus summis rufis. Pedes rufi, capitibus femorum obscuris. (Grav.)

\section{5) Thorax seriebus dorsalibus 5-punctatis.}

* 53. Ph. flavipennis: Niger, nitidus, elylris lucide testaceis, summa basi violaceis. - Long. 5 lin.

Habitat Bogotae in Columbia interiore, a Dom. Buquet cum Staph. flavipennis Dej. nowine communicatus.

Nigerrimus, nitidus, capite thoraceque nitidissimis, elytris solis testaceis, metallico - nitentibus, basi angusta violacea. Antennae capite sesqui longiores, articulo tertio secundo paulo longiore, 4-10. sensim paulo brevioribus et crassioribus, $6-10$ transversis, ultimo apice emarginato et inferne acuminato, nigrae. Palpi nigri. Mandibulae longiusculae, falcatae, acutae, Caput maris thorace paulo latius, feminae eiusdem lattudine, subquadratum, utrinque supra oculos punctis parcis, inter oculos posterius punctis utrmque tribus oblique positis, anterius duobus transversim positis, sat profundis, notatum, fronte antice subimpressa. Thorax coleopteris multo angustior, latitudine vix brevior, neque basin neque apicem versus angustatus, lateribus leviter rotundatis, basi rotundatus, apice truncatus, angulis anterioribus leviter deflexis, subrotundatis, posterioribus obtusis, supra parum convexus, seriebus dorsalibus 5-punctatis, lateribus punctis praeter marginalia utrinque 5 vel 6 impressus, punctis omnibus minus profundis. Scutellum crebre punctatum, nigrum, subtiliter griseo-pubescens. Elytra thorace plus sesqui longiora, subtiliter parceque punctata, flavescenti-pubescentia. Abdomen supra segmentis singulis lateribus subtilius punctulatis, tenuiter nigro-pubescentibus, medio laevigatis, infra punctulatum. Pedes graciles, coxis intermediis distantibus, tibiis omnibus subtilius spinulosis, tarsis anticis in utroque sexu simplicibus.

54. Ph. candens: Niger, nilidus, elytris crebrius punclalis, cupreis, ful gidis. - Long. 4-5 lin.

Habitat Bogotae in Columbia interiore, nom. Staph. candentis Dej. a Dom. Buquet et Dejean communicatus.

Nigerrimus, nitidus, capite thoraceque nitidissimis, elytris fulgidis, cupreis, lateribus sensim virescenti-cupreis. Antennae capitis thoracisque fere longitudine, articulo tertio secundo paulo longiore, 4-10 elongato-subobconicis, sensim paulo brevioribus, ultimo ovato, apice oblique emarginato et inferne acuminato. Mandibulae longiusculae, falcatae, acutae. Caput thorace latius, maris interdum multo latius, ovatum, fronte supra oculos punctis paucis et inter oculos punctis $\mathbf{4}$, omnibus transversim positis, impressum, inter antennas in mare foveolatum. Thorax coleopteris duplo fere angustior, latitudine vix longior, basin versus subangnstatus, lateribus anterius leviter rotundatis, posterius subsinuatis, basi leviter rotundatis, apice truncatus, angulis anterioribus deflexis, rotundatis, posterioribus obtusis, leviter convexus, seriebus dorsalibus punctis 5, apicali remotiore, compositis, 
lateribus punctis utrinque 5 vel 6 impressus, punctis omnibus subtilioribus. Scutellum subtilius crebre punctatum. Elytra thorace paulo longiora, crebrius punctata, pube parca brevi depressa grisea vix conspicua vestita. Abdomen apicem versus sensim angustatum, subtiliter parce punctulatum, parce nigro - pubescens. Pedes elongati, graciles, coxis intermediis distantibus, tibiis omnibus subtiliter spinulosis, tarsis anticis in utroque sexu simplicibus.

*55. Ph. gratiosus: Niger, nitidus, elytris parce punclatis, cupreo-purpureis, fulgidis. - Long. $3 \frac{1}{2}$ lin. .

Habitat Bogotae in Columbia interiore, Dom. Com. Dejean.

Praecedenti affinis, at duplo minor, nigerrimus, nitidus, capite thoraceque nitidissimis, elytris splendide purpureo-cupreis. Antennae capite thoraceque paulo breviores, articulo tertio secundo sesqui prope longiore, quarto subovato, 5-10 subobconicis, crassiusculis, crassitie haud brevioribus, subaequalibus, ultimo ovato, apice abrupte subacuminato. Caput thoracis latitudine, ovatum, posterius utrinque parce fortiter punctatum, inter oculos punctis 4 transversim positis notatum, antice inter antennas sulco longitudinali abbreviato impressum. Thorax coleopteris duplo angustior, latitudine paulo longior, lateribus ponè medium subsinuatis, basi leviter rotundatus, apice truncatus, angulis anterioribus leviter deflexis, subrotundatis, posterioribus obtusis, convexus, seriebus dorsalibus punctis 5, apicali paulo remotiore, compositis, lateribus punctis praeter marginalia utrinque 5 vel 6 impressus, punctis subtilioribus. Scutellum crebre punctulatum, tenuiter pubescens. Elytra thorace sesqui longiora, parce punctata, tenuiter pilosella. Abdomen apicem versus sensim angustatum, punctis raris subtilibus impressum, parce nigro-pilosum. Pedes elongati, graciles, coxis intermediis distantibus, tibiis omnibus subtilius spinulosis, tarsis anticis in utroque sexu simplicibus.

* 56. Ph, ebeninus: Niger, nilidus, elytris viridi-aeneis, abdomine parcius punclalo, capite suborbiculato. - Long. $2 \frac{1}{2}-4$ lin.

Philonth. varians Er. Col. March. I. 461. 23.

Var. maior:

Staph. ebeninus Grav. Micr. 170. 22. Mon. 67. 21. - Latr. Hist. nat. Crust. et Ins. IX. 323. 66. - Gyll. Ins. Suec. II. 326. 52. - Sahlb. Ins. Fenn. I. 325. 48. - Mannerh. Brachelytr. 30. 66. - Boisd. et Lacord. Faun. Eut. Paris. I. 394. 15. Philouth. ebeninus Nordm. Symb. 93. 63.

Staph. brevicornis Grav. Micr. 22. 28. Mon. 69. 50. - Latr. Hist. nat. Crust. et Ins. IX. 312. 33.

Philonth. brevicornis Nordm. Symb. 94. 69.

Var. minor:

Staph. varians Grav. Mon, 82. 73. - Gyll. Ins. Suec. II. 342. 58. - Zetterst. Faun. Lappon. I. 77, 27. Ins. Lappon. 65. 37. - Suhlb. Ins. Fenn. I. 329. 55. Mannerh. Brachelylr. 30. 73. - Boisd. et Lacord, Faun. Ent. Paris. I. 394. 16. - Runde Brachelytr. Hal. 9. 47.

Philonth. varians Nordm. Symb. 93. 65.

Staph. concinnus Grav. Micr. 21. 25. 
Var. Pedibus fusco-testaceis:

Staph. ochropus Grav. Micr. 39. 57. Mon. 67. 39. - Latr. Hist. nat. Crust. et Ins. IX. 322. 62. - Gyll. Ins. Suec. 11. 336. 51. - Mannerh. Brachelylr. 29. 65. - Runde Brachelytr. Hal. 8. 40.

Philonth. ochropus Nordm. Symb. 93. 62.

Habitat in Europa, Sibiria, Asia minore, Syria, Aegypto, frequens.

Variat magnitudine, individuis maioribus $\mathrm{Ph}$. atrato, minoribus $\mathrm{Ph}$. vario aequalibus, niger, capite thoraceque pernitidis, elytris viridi-aeneis, nitidis. Antennae capitis thoracisque longitudine, articulo tertio secundo paulo longiore, 4-10 subobconicis, sènsim perparum brevioribus crassioribusque, penultimo haud transverso, ultimo subovato, apice emarginato et inferne subacuminato, nigrae. Caput suborbiculatum, individuis maioribus thoracis latitudine, minoribus eodem minus et angustius, supra oculos utrinque punctis parcis vagisque, inter oculos punctis utrinque duobus transversim positis impressum. Thorax prope coleopterorum latitudine, latitudine vix brevior, antrorsum subangustatus, lateribus subrectis, basi cum angulis posterioribus rotundatns, apice truncatus, angulis anterioribus deflexis, subrotundatis, modice convexus, seriebus dorsalibus punctis 5, apicali remotiore compositis, lateribus utrinque punctis praeter marginalia 4 impressus, punctis omnibus modice profundis. Scutellum dense subtiliter punctulatum, subtiliter pubescens. Elytra thoracis longitudine, subtilius densiusque punctata, tenuiter griseo-pubescentia. Abdomen subtilius et minus dense punctulatum, parce pubescens. Pedes nigri, saepe picei vel interdum subtestacei, coxis intermediis interstitio angusto distinctis, tibïs omnibus spinulosis. Alae infuscatae.

Tarsi antici maris fortiter, femina e leviter dilatati.

Variat 1, Pedibus fusco-testaceis.

2, Elytris rufis.

3, Thoracis seriebus dorsalidus altera 5-, altera 4-punctata.

$\mathrm{Obs}$. 1. Individuis minoribus, ubique copiose obviis sexus habitu simillimi, maioribus, minus frequentibus, mares capite maiore, thoracis latitudine, instructi sunt, simili modo ut in Ph. aeneo, carbonario, cephalote, etc.; aliae differentiae speciminibus plurimis examinatis comparatisque autem desiderantur, quamobrem plures ab auctoribus distinctas species huic subiunxi. Staph ebeninus et brevicornis Gr. ad individua maxima spectant, Staph. ochropus ad varietatem pedibus fuscotestaceis pertinet. Magis discedere videtur var. sub n. 2 indicata, cuius exemplum singulum, minimis huius speciei individuis magnitudine aequale, Dom. Sch üppel Berolini legit, quod autem praeter elytrorum colorem nullo modo ab eadem differt, et cum varietates analogas iam apud $\mathrm{Ph}$. varium et albipedem observaverim, eo magis hanc pro specie peculiari habere dubito.

2. Staph. variantem auctorum veterum ab hoc satis distinctum esse patet, quare hoc nomen illi restitui.

*57. Ph. corvinus: Niger, nilidus, elylris concoloribus, abdomine supra parcius punctalo, capite orbiculato. - Long. $3 \frac{2}{3}$ lin.

Er. Col. March. 1. 462. 24.

Habitat in Germania.

Statura omnino praecedentis, maioribusque eius, non autem maximis individuis magnitudine aequalis, his vero paulo gracilior, nigerrimus, nitidus, elytris concoloribus, capite thoraceque pernitidis. Antennae capitis thoracisque longitudine, articulo tertio secundo paulo longiore, 4-10 oblongosubobconicis, sensim paulo brevioribus at vix crassioribus, omnibus crassitie 
longioribus, ultimo oblongo ovato, apice subemarginato et inferne acuminato. Caput thoracis latitudine, suborbiculatum, modice convexum, supra oculos utrinque fortiter parce vageque punctatum, fronte inter oculos utrinque punetis maioribus, superius tribus oblique positis, anterius duobus transversim positis impressa. Thorax coleopteris latitudine prope aequalis, latitudine vix brevior, antrorsum subangustatus, lateribus subrectis, basi rotundatus, angulis posterioribus obtusis, apice truncatus, angulis anterioribus leviter deflexis, subrotundatis, modice convexus, seriebus dorsalibus punctis 5, apicali paulo remotiore, compositis, lateribus punctis praeter marginalia utrinque 4 vel 5 impressus, punctis omnibus modice profundis. Scutellum subtiliter punctulatum, tenuiter pubescens. Elytra thoracis longitudine, subtiliter minus dense punctata, tenuiter nigro-pubescentia. Abdomen parcius subtiliusque punctatum, parcius nigro-pubescens. Pedes nigri, coxís intermediis interstitio angusto distantibus, tibiis omnibus spinulosis, tarsis, nonnunquam etiam tibiis piceis.

Tarsi antici maris fortiter, feminae leviter dilatati.

Obs. A praecedente constanter elytrorum colore nigerrimo, a sequente abdominis punctura distinctus.

"58.Ph. fumigatus: Niger, nilidus, elylris nigro-subaeneis, pedibus fuscis, tibiis tarsisque ferrugineis, abdomine supra crebrius subtiliter punctulato, capite orbiculato. - Long. $3 \frac{1}{2}$ lin.

Er. Col. March. I. 463. 25.

Staph. atrati var. intermed. Grav. Mon. p. 85.

Habitat in Germania, Gallia.

Statura omnino praecedentium, minoribus $\mathrm{Ph}$. ebenini individuis paulo maior, niger, capite thoraceque pernitidis, elytris nigro-aeneis, nitidulis. Antennae capite thoraceque paulo breviores, articulo tertio secundo paulo longiore, sequentibus subobconicis, sensim paululum brevioribus et crassioribus, penultimis crassitie haud brevioribus, ultimo apice truncato et inferne subacuminato, nigrae. Palpi picei. Caput maiusculum, thorace tamen paulo angustius, suborbiculatum, supra oculos utrinque punctis parcis vagisque, inter oculos punctis utrinque duobus transversim positis impressum. Thorax coleopteris haud angustior, latitudine haud brevior, antrorsum subangu status, lateribus subrectis, basi rotundatus, angulis posterioribus obtusis, apice truncatus, angulis anterioribus leviter deflexis, subrotundatis, leviter convexus, seriebus dorsalibus punctis $\mathbf{5}$, apicali paulo remotiore, compositis, lateribus punctis praeter marginalia subtiliora utrinque 5 impressus, punctis omnibus minus profundis. Scutellum dense punctulatum, tenuiter griseopubescens. Elytra thoracis longitudine, densius fortiusque punctata, tenuiter griseo-pubescentia. Abdomen apicem versus sensim angustatum, praecipue supra confertim subtiterque punctulatum, pube subtili densiore depressa vestitum, versicolor, subtus segmentis singulis tenuiter ferrugineo-marginatis. Pedes nigro-picei, coxis intermediis leviter distantibus, tibiis anticis muticis, posterioribus spinulosis tarsisque ferrugineis, tarsis anticis in utroque sexu, licet in mare fortius, dilatatis.

Obs. Differt ab affinibus praecipue thorace latiore, abdomine confertim subtiliter punctulato, tibiis anticis haud spinulosis. 
* 59. Ph. umbrinus: Nigro-piceus, nilidus, pedibus fusco-testaceis, abdomine supra parce punclalo, segmenlis ventralibus rufo-marginalis. - Long. 3 lin.

\section{Mas. Capite orbiculato.}

- Staph. umbrinus Grav. Micr. 169. 20. Mon. 69. 47.

Fem. Capite subovalo.

Staph. moestus Grav. Mon. 47. 9.

Philonth. moestus Nordm. Symb, 97. 73.

Habitat in America septentrionali.

Statura omnino Ph. ebenini et magnis eius individuis magnitudine aequalis. Antennae capite thoraceque multo breviores, articulo tertio secundo paulo longiore, 4-10 subobconicis, sensim paulo brevioribus et crassioribus, penultimis leviter transversis, ultimo ovato, apice emarginato et inferne acuminato, fusco-piceae, articulo ultımo subferrugineo. . Mandibulae et palpi picei. Caput maris thoracis apice vix angustius, orbiculatum, feminae thorace multo angustius, ovatum, utrinque supra oculos parce punctatum, fronte inter oculos punctis maioribus utrinque posterius tribus oblique, anterius duobus transversim positis impressa, nigrum, nitidissimum. Thorax basi coleopteris haud angustior, longitudine paulo latior, antrorsum angustatus, antice subcompressus, lateribus subrectis, basi cum angulis posterioribus rotundatus, apice truncatus, angulis anterioribus deflexis, rotundatis, modice convexus, seriebus dorsalibus punctis 5, apicali paulo remotiore, compositis, lateribus punctis praeter marginalia utrinque $\overline{5}$ imprressus, punctis omnibus profundioribus, nigro-piceus vel piceus, nitidissimus. Elytra thoracis longitudine et scutellum nigro-picea, vel picea, nitida, crebre punctata, griseo-pubescentia. Abdomen parce punctulatum, griseo pubescens, nigrum, nitidulum, segmentorum ventralium marginibus rufo-piceis. Pedes cum coxis anterioribus obscure testacei, coxis intermediis leviter distantibus, tibiis omnibus spinulosis.

Tarsi antici maris fortiter, femin a e leviter dilatati.

Variat thoracis serie dorsali altera 4-, altera 5-punctata.

* 60. Ph. figulus: Niger, nitidus, abdomine supra parcius punctalo, versicolore, segmentis ventralibus anoque rufis, femoribus testaceis, capile subovato. - Long. 4 lin.

Habitat in Brasilia, Dom. Westermann.

Statura praecedentium, niger, nitidus, capite thoraceque pernitidis. Antennae capitis thoracisque fere longitudine, crassiusculae. articulo tertio secundo paulo longiore, 4 - 10 sensim paulo brevioribus, obconicis, ultimo apice truncato et inferne acuminato, nigrae, apice obscure ferrugineae. Palpi picei. Caput thorace paulo angustius, breviter subovatum, supra leviter convexum, utrinque supra oculos punctis paucis, inter oculos binis, oculo approximatis, oblique positis, impressum. Thorax basi coleopteris panlo angustior, latitudine baseos panlo longior, antrorsum modice angustatus, lateribus rectis, basi eum angulis posterioribus rotundatus, apice truncatus, angulis anterioribus leviter deflexis, subrectis, transversim convexus, seriebus dorsalibus punctis 5 aequaliter distantibus compositis, lateribus punctis 
praeter marginalia utrinque 3 , longitudinaliter dispositis impressus, punctis onmibus fortioribus, piliferis. Scutellum confertim subtilius punctulatuni, densius nigro-pubescens. Elytra thorace paulo longiora, densius subtiliusque punctata, minus subtiliter nigro-pubescentia. Abdomen supra parcius, infra crebrius minus subtiliter punctulatum, parcius minus subtiliter nigropubescens, supra laete metallico-versicolor, segmento quinto apice sextoque toto rufo-ferrugineis, praeterea segmentis ventralibus quatuor primis determinate rufo-marginatis. Pedes coxis anterioribus piceo-testaceis, femoribus omnibus testaceis, anticis dilutioribus, tibiis tarsisque omnibus nigris, tibiis omnibus spinulosis.

Tarsi antici maris fortius dilatati; femin a latet.

* 61. Ph. suspectus: Niger, nilidus, elytris subvirescentibus, pedibus anterioribus obscure tesluceis, capile suborbiculato. - Long. $3 \frac{2}{3}$ lin.

Habitat prope Caracas Columbiae, Dom. Moritz.

Statura omnino $\mathrm{Ph}$. ebenini et maximis eius individuis magnitudine aequalis, niger, nitidus. Antennae capite sesqui longiores, articulo tertio secundo paulo longiore, 4-10 crassiusculis, crassitie subaequalibus, sensim paulo brevioribus, ultimo apice emarginato et inferne subacuminato, nigro-piceae. Palpi picei. Caput thoracis prope latitudine, suborbiculatum, leviter convexum, fronte supra punctis parcis, vagis, inter oculos punctis quatuor transversim positis, intermediis maioribus, dilatatis, multo magis distantibus, notata, antice inter antennas longitudinaliter leviter impressa. Thorax coleopteris paululum angustior, latitudine sublongior, lateribus parallelis, subrectis, basi cum angulis posterioribus rotundatus, apice truncatus, angulis anterioribus deflexis, subrotundatis, modice convexus, seriebus dorsalibus punctis 5, apicali paulo remotiore, compositis, lateribus punctis praeter marnalia subtiliora utrinque 5, duobus eorum margini approximatis, impressus, punctis sat profundis. Scutellum punctulatum, tenuiter pubescens. Elytra thoracis longitudine, minus crebre punctata, tenuiter pubescentia, nigro-subvirescentia, nitida. Abdomen parcius punctatum, tenuiter nigro-pubescens, subtus segmentis singulis margine posteriore rufo-piceo. Pedes anteriores obscure testacei, postici nigri, coxis intermediis modice distantibus, tibiis omnibus spinulosis, tarsis anticis in utroque sexu simplicibus.

* 62. Ph. corruscus: Niger, nilidus, elytris rufis, capite suborbiculato. Long. $3 \frac{1}{2}$ lin.

Nordm. Symb. 98. 81. - Er. Col. March. I. 463. 26.

Staph. corruscus Grav. Micr. 33. 47. Mon. 5I. 14. - Latr. Hist, nat. Crust, et Ins. IX. 319. 52.

Staph. nitidus Marsh. Ent. Britt. 511. 38.

Staph. planus Boisd. et Lacord. Faun. Ent. Paris. 1. 401. 27.

Habitat in Europa temperata.

Statura omnino $\mathrm{Ph}$. ebenini et mediis eius individuis magnitudine aequalis, niger, nitidus, capite thoraceque pernitids, elytris saturate lateritiis. Antennae capitis thoracisque longitudine, articulo secundo tertioque aequalibus, 4-10 subobconicis, sensim paululum brevioribus crassioribusque, penultimis crassitie hand brevioribus, ultimo apice leviter emarginato et inferne 
subacuminato, nigrae. Palpi nigri. Capnt thorace minus et angustius, orbiculatum, supra oculos utrinque punctis paucis, inter oculos utrinque duobus, transversim positis, fortibus impressum. Thorax basi coleopterorum fere latitudine, latitudine vix brevior, antrorsum subangustatus, lateribus subrectis, basi rotundatus, apice truncatus, angulis anterioribus deflexis, subrotundatis, posterioribus obtusis, leviter convexus, seriebus dorsalibus punctis 5, apicali paulo remotiore, compositis, lateribus punctis praeter marginalia subtiliora utrinque 5 impressus, punctis modice profundis. Scutellum confertim punctulatum, longius griseo-pubescens. Elytra thoracis longitudine, minus subtiliter et minus dense punctata, tenuiter griseo-pubescentia. Abdomen parcius subtiliusque punctulatum, parce tenuiterque griseo-pubescens. Pedes nigri, coxis intermediis interstitio angusto distantibus, tibiis omnibus spinulosis, piceis, tarsis rufescentibus.

Tarsi antici-maris modice, feminae vix dilatati.

* 63. Ph. Caucasicus: Niger, nitidus, elytris rufis, basi inaequaliler nigris, antennis pedibusque fusco-piceis, capite suborbiculato. - Long. 3 lin.

Nordm. Symb. 99. 22.

Habitat in Asia occidentali.

Statura omnino $\mathrm{Ph}$. ebenini et minoribus eius individuis aequalis, niger, nitidus, capite thoraceque pernitidis, elytris rufis, dorso macula magna basali ad humerum dilatata et cum sutura descendente nigra. Antennae capite thoraceque multo breviores, articulo secundo tertioque aequalibus, 4-10 crassiusculis, sensim paulo brevioribus, penultimis leviter transversis, ultimo ovato, apice emarginato et inferne acuminato, nigro-piceae, articulis tribus primis nigris. Palpi nigro-picei. Caput thorace paulo angustius, suborbiculatum, leviter convexum, utrinque punctis supra oculos parcis dispersis, inter oculos binis transversim positis impressum. Thorax coleopteris parum angustior, latitudine baseos vix longior, apicem versus vix angustatus, lateribus leviter rotundatis, ante basin subsinuatis, basi rotundatus, apice truncatus, angulis anterioribus leviter deflexis, subrotundatis, posterioribus obtusis, modice convexus, seriebus dorsalibus punctis 5, apicali remotiore, compositis, lateribus punctis praeter marginalia subtiliora utrinque 4 impressus, punctis minus subtilibus. Scutellum subtilius punctulatum, griseo-pubescens. Elytra thorace paulo longiora, minus confertin et minus subtiliter punctata, griseo-pubescentia. Abdomen crebrius subtiliter punctulatum, densius longiusque griseo-pubescens. Pedes picei, coxis intermediis modice distantibus, tibiis omnibus spinulosis.

Tarsi antici femina e leviter dilatati. Mas latet.

Obs. Similis $\mathrm{Ph}$. bimaculato, at antennis brevioribus, thorace antrorsum vix angustato, elytris basi fusco-nigris neque aeneis, margine laterali inflexo rufo distinguendus.

64. Ph. turbatus: Niger, nitidus, elylris, palpis, tibiis tarsisque rufis, capite suborbiculato. - Long. 3 lin.

Habitat in Sardinia, Mus. Reg. Taurin.

Statura omnino $\mathrm{Ph}$. ebenini, niger, nitidus, capite thoraceque pernitidis. 
Antennae breviusculae, capite sesqui longiores, crassiusculae, fuscae, articulis tribus primis nigris. Palpi rufi. Mandibulae rufo-piceae. Caput thoracis prope latitudine, suborbiculatum, supra oculos utrinque punctis pluribus sat fortibus notatum. Thorax basi coleopterorum prope latitudine, antrorsum subangustatus, lateribus leviter rotundatis, latitudine brevior, modice convexus, punctss ordinariis sat fortibus. Scutellum subtiliter punctulatum, parcius griseo-pubescens. Elytra thorace paulo longiora, minus confertim minusque subtiliter punctata, lateritia, nitida, fulvo-pubescentia. Abdomen crebre minus subtiliter punctatum, nigro-pubescens, segmentorum marginibus concoloribus, sexto subtus apice piceo. Pedes nigro-picei, tibiis tarsisque rufis, tarsis anticis feminae simplicibus.

Obs. Affinis $\mathrm{Ph}$. corrusco, at minor, praecipue brevior et distinctus antennis brevioribus, palpis, tibiis tarsisque rufis. Specimen singulum ad examinandum communicavit Dom. Prof. Gené.

* 65. Ph. sanguinolentus: Niger, nitidus, elytris sutura maculaque humerali sanguineis, coxis anticis testaceis, capile suborbiculato. Long. 4 lin.

Nordm. Symb. 97. 76. - Er. Col. March. I. 464. 27.

Staph. sanguinolentus Grav. Micr. 36. 53. Mon. 64. 34. - Latr. Hist. nat. Crust. et Ins. IX. 320: 58. - Gyll. Ins. Suec. II. 338. 54. - Sahlb. Ins. Fenn. 1. 326. 50. - Mannerh. Brachelytr. 30 68. - Boisd. et Lacord. Faun. Ent. Paris. I. 399. 24. - Runde Brachelytr. Hal. 8. 42.

Var. Elytrorum maculis confluentibus.

Staph. cont a minatus Grav. Micr. 174. 31. - Latr. Hist. nat. Crust, et Ins. IX. 325. 71. - Runde Brachelytr. Hal. 9. 45.

Habitat in Europa.

Statura omnino et magnitudine $\mathrm{Ph}$. ebenini individuis maioribus aequalis, niger, capite thoraceque pernitidis, elytris nigris, sutura maculaque humerali sanguineis, plerumque discretis, saepe dilatatis et confluentibus, interdum strictioribus et macula humerali obsoleta. Antennae capite thoraceque breviores, articulo tertio secundo paulo longiore, sequentibus oblongo-subobconicis, inter se subaequalibus, ultimo apice truncato et inferne subacuminato, nigrae. Palpi nigri. Caput maiusculum, thorace paululum angustius, orbiculatum, supra oculos utrinque punctis parcis, inter oculos punctis 4 transversim positis notatum. Thorax prope coleopterorum latitudine, latitudine haud brevior, lateribus parallelis, subrectis, basi cum angulis posterioribus rotundatus, apice truncatus, angulis anterioribus leviter deflexis, subrotundatis, modice convexus, seriebus dorsalibus punctis $\mathbf{5}$, apicali remotiore, compositis, lateribus punctis praeter marginalia subtiliora utrinque $\mathbf{5}$ impressus, punctis profundioribus. Scutellum confertim punctulatum, griseo-. pubescens. Elytra thorace vix longiora, confertim subtilius punctata, tenuiter griseo-pubescentia. Abdomen confertim subtilissime punctulatum, pube subtili densiore subtomentosa fusco-grisea vestitum. Pedes nigri, tibiis tarsisque obscure rufo-piceis, coxis anticis rufo-testaceis, coxis intermediis modice distantibus, tibiis anticis parce subtiliterque, posterioribus longius fortiusque spinulosis, tarsis anticis in utroque sexu, licet in mare fortius, dilatatis. 
66. Ph. stragulatus: Niger, nitidus, elytris mufo-testaceis, plaga lata communi longitudinali nigra, coxis anticis piceo-lestaceis, capite subovato. - long. 3 lin.

Hebitat Massiliae, collect. Dom. Aubé.

Habitu omnino $\mathrm{Ph}$. fumarii, at paulo minor, niger, nitidus, capite thoraceque pernitidis. Antennae capitis thoracisque longitudine, nigrae. Palpi nigri. Caput thorace paulo angustius, subovatum, utrinque supra oculos parcius punctatum. Thorax basi coleopteris parum angustior, antrorsum leviter angustatus, latitudine baseos vix brevior, transversim convexus, punctis ordinariis minus profundis. Scutellum subtiliter punctulatum. Elytra thorace vix longiora, confertim subtiliter punctata, tenuiter griseo-pubescentia, rufo-testacea, nitida, plaga longitudinali communi sat lata, apicem versus sensim leniter angustata, nigra. Abdomen dense subtiliter punctatum, fusco-pubescens. Pedes picei, antici coxis piceo-testaceis, femoribus testaceo - picess.

Tarsı antıci maris leviter dilatati; femin a latet.

* 67. Ph. bipustulatus: Niger, nitidus, elytris macula postica sanguinea, coxis anticis nigris, immaculatis, capite ovato. - Long. $3 \frac{1}{2}$ lin.

Nordm. Symb. 98. 78. - Er. Col. March. I. 464. 28.

Staph. bipust ulatus Panz. Fuun. Germ. 27. 10. - Latr. Hist. nat. Crust. et Ins.

IX. 321. 59. t. 79. f. 5. - Grav. Mon. 63. 33. - Gyll. Ins. Suec. II. 339. 55.

- Suhlb. Ins. Fenn. I. 327. 52. - Mannerh. Brachelytr. 30. 70. - Buisd. et Lacord. Faun. Ent. Paris. I. 399. 25. - Runde Brachelytr. Hal. 8. 43.

St aph. bipustulatus var. 3 Grav. Micr. 37. 54.

Habitat in Europa, in Asia minore, Syria.

Statura omnino Ph. ebenini et minoribus eius individuis paulo maior, niger, capite thoraceque pernitidis. Antennae capite thoraceque paulo breviores, articulo tertio secundo paulo longiore, 4-10 obconicis, sensim paulo brevioribus, at vix crassioribus, omnibus crassitie sublongioribus, ultimo ovato, apice emarginato et inferne acuminato, piceae. Caput thorace angustius minusque, ovatum, supra oculos utrinque punctis parcis, inter oculos utrinque punctis duobus transversim positis impressum. Thorax basi prope coleopteris angustior, latitudine paululum longior, antrorsum vix angustatus, lateribus subrectis, basi cum angulis posterioribus rotundatus, apice truncatus, angulis anterioribus subrotundatis, modice convexus, seriebus dorsalibus punctis $\mathbf{5}$, apicali remotiore, compositis, lateribus punctis praeter marginalia utrinque $\mathbf{5}$ impressus, punctis minus subtilibus. Scutellum confertim punctulatum, nigro-pubescens. Elytra thorace parum longiora, confertim subtilius punctata, nigro-pubescentia, macula rufa, infra medium sita, notata. Abdomen subtilius parciusque punctatum, nigro-pubescens. $\mathbf{P e}-$ des nigri, coxis anticis plerumque immaculatis, rarius interne testaceis, intermediis interstitio angusto distantibus, tibiis omnibus spinulosis. Alae albo-Lyalinae.

Tarsi antici maris fortiter, fe mina e leviter dilatati.

Variat elytris immaculatis.

Obs. 1. Ph, varianti affinis, at capite minus ovato, thorace antrorsum minus an- 
gustato, elytrorum abdominisque punctura paulo fortiore, elytrorum macula ante apicem neque in medio sita et coxis anticis concoloribus distinguendus.

2. Staph. bipustulatus L. ,magnitudine minoris pediculi et antennis clavatis" potius ad Aleocharam quandam pertinet. (Conf. quae supra apud Al. nitidam p. 168. monui.) Staph. bipustulatus Fab. Syst. 266. 11. Spec. Ins. I. 336. 12. Mant. Ins. I. 221. 18, nonnisi diagnosi et citato Linneano descriptus. Staph. bipustulatu s Fab Ent. Syst. I. II. 526. 34, Syst. El. II. 598. 44, "elytrorum puncto p o stico ferrugineo" distinctius ad Aleocharam quandum, A. bipustulatum, tristem nitidamve spectare, huic autem generi alienus videtur. In collectione Fabriciana de hac specie nihil mihi memoratum.

* 68. Ph. aeruginosus: Niger, nitidus, coxis anticis intus testaceis, alis fuscis, abdomine fortius punctulato, segmentis ventralibus rufo-marginatis, capite ovato. - Long. 4 lin.

Nordm. Symb. 95. 71.

Habitat in America meridionali: in Brasilia, Dom. Sellow, in Columbia, Dom. Moritz.

Statura et summa affinitas $\mathrm{Ph}$. variantis, at maximis eius individuis fere maior et robustior, totus nigerrimus, capite thoraceque nitidissimis, elytris et abdomine nitidulis, coxarum anticarum parte interiore, interdum etiam femoribus anterioribus testaceis. Antennae capitis thoracisque longitudine, graciles, articulo tertio secundo paulo longiore, sequentibus elongato-subobconicis, subaequalibus, ultimo ablongo, apice oblique emarginato et inferne acuminato, fusco-nigrae. Palpi nigro-picei. Caput thorace minus et angustius, ovatum, utrinque supra oculos punctis paucis, inter oculos binis oblique positis impressum. Thorax basi coleopteris angustior, latitudine baseos haud longior, antrorsum leviter angustatus, basi et lateribus leviter rotundatus, apice truncatus, angulis anterioribus leviter deflexis posterioribusque subrotundatis, modice convexus, seriebus dorsalibus punctis 5 , postremo paululum remotiore, compositis, laterıbus punctis praeter marginalia subtilia utrinque 5 impressis, punctis modice profundis. Elytra thorace paulo longiora et scutellum crebre subtiliter punctata, densius griseo-pubescentia. Abdomen iridescens, parcius et fortius punctulatum, pilis appressis nigris parcius vestitum, segmentis ventralibus rufo-marginatis. Pedes graciliores, coxis intermediis approximatis, tibiis omnibus spinulosis. Alae fuliginosae.

Tarsi antici maris modice, femina e leviter dilatati.

* 69. Ph. feralis: Nigerrimus, nitidus, alis fuscis, abdomine subtilissime punctulato, capile parvulo, ovato. - Lorig. $3 \frac{1}{2}$ lin.

Habitat in Columbia, Dom. Moritz.

Statura et summa affinitas praecedentis, at dimidio minor. Corpus totum nigerrimum, capite thoraceque nitidissimis, elytris et abdomine nitidulis. Antennae capite thoraceque paulo longiores, articulo tertio secundo paulo longiore, 4-10 sensim brevioribus at haud crassioribus, omnibus crassitie longioribus, subabconicis, ultima oblango-avato, apice truncato et inferne acuminato. Caput thorace multo minus et angustius, ovatum, convexum, utrinque supra oculos punctis paucis dispersis et inter oculos binis oblique positis notatum. Thorax latitudine baseos tertia parte longior, basi coleopteris dimidio angustior, apicem versus leviter angustatus, lateribus subrectis, 
basi cum angulis posterioribus rotundatus, apice truncatus, angulis anterioribus deflexis, subrotundatis, transversim convexus, seriebus dorsalibus pun-. ctis $\mathbf{5}$ aequaliter distantibus compositis, lateribus. punctis praeter margmalia utrinque 4 impressus, punctis omnibus subtilioribus. Scutellum subtiliter punctulatum, tenuiter nigro-pubescens. Elytra thoracis longitudine, crebrius subtiliusque punctulata, densius nigro-pubescentia. Abdomen concolor, subtilissime parce punctulatum, pube parca longiore depressa nigra tenuiter vestitum, segmentorum ventralium marginibus summis obscure rufescentibus. Pedes nigro-picei, coxis anticis intus piceis, intermediis leviter distantibus, tibiis omnibus spinulosis. Alae fuscae, basi dimidiatim albohyalinae.

Tarsi antici maris fortius dilatati, feminae simplices. Segmentum abdominis inferius sextum feminae apice emarginatum.

Obs. Proximus praecedenti, distinctus autem statura minore, thorace longiore, abdominis punctura subtilissima.

* 70. Ph. varians: Niger, nitidus, elylris macula media sanguinea, coxis anticis testaceis, capite ovato. - Long. $3-3 \frac{1}{2}$ lin.

Staph. varians Payk. Mon. 45. 33. Faun Suec. III. 393. 33.

Staph. op acus Grav. Mon. 64. 35. - Gyll. Ins. Suec. II. 310. 56 - Zetterst.

Faun. Lappon. I. 77. 25. Ins. Lappon. 64. 35. - Suhlb. Ins. Fenn. I 328. 53. -

Mannerh. Brachelytr, 30. 71. - Boisd. et Lacord. Faun. Ent. Paris. I. 404. 34.

Philonth. opacus Nordm. Symb. 98. 79. - Er. Col March. 1. 465. 29.

Staph. bipustulatus var. 1, 2, 4-7 Grav. Micr. 37. 51.

Staph. bimaculatus Marsh. Ent. Britt. 525. 78.

Var. a, Elytris immaculatis. - Long $3-3 \frac{1}{2}$ lin.

Staph. varians Fab. Ent. Syst. I. II. 524. 22. Syst. El. II. 594. 25, - Oliv. Ent. III 42. 27. 35. $t$. 3. f. 46 . - Panz. Ent. Germ. 354. 15.

Staph. opacus Grav. Micr. 26. 35. - Latr. Hist. nat. Crust. et Ins. IX. 315. 40.

St a ph. aterrimus Marsh. Ent. Britt. 513. 44.

Var. b, Elytris immaculatis, antennis articulo primo subtus flavo. Long. $3 \frac{\mathrm{I}}{2}$ lin.

Philonth. scybalarius Nordm. Symb. 94. 70.

Philonth. fuscicornis Nordm. Symb. 96. 72.

Var. c, Niger, immaculatus. - Long. $2-2 \frac{1}{2}$ lin.

Staph. simplex Marsh. Ent. Britt. 505. 20. (forte)

$V a r . d$, Niger, elytris fuscis, apice ferrugineis, pedibus fuscis. - Long. $2-2 \frac{1}{2}$ lin.

Staph. a gilis Grav. Mon. 77. 70. - Gyll. Ins. Suec. 11. 341. 57. - Sahlb. Ins.

Fenn. I. 328. 54. - Zetterst. Faun. Lappon. I. 77. 26. Ins. Lappon. 64. 36. Manne $r$. Brachelytr. 30. 72.

Philonth. agilis Nordm. Symb. 98. 80.

St aph. parvicorn is Grav. Micr. 23. 30. Mon. 69. 48. - Latr. Hist. nat. Crust. et Ins. IX. 313. 35.

Staph. discoideus Boisd, et Lacord. Faun. Ent. Paris. I. 403. 33. (forte)

Habitat in Europa; ad Promont. Bonae Spei, Dom. Bergius, in Americae mer. ins. St. Johannis, Dom. Moritz, St. Vincentii, Mus. Dom. Hope, Cuba, collect. Dom. Chevrolat. 
Habitu et statura omnino Ph. varii, niger, capite thoraceque pernitidis. Antenirae capite thoraceque paulo breviores, articulo secundo tertioque aequalibus, 4-10 subobeonicis, sensim paululum brevioribus at non crassioribus, omnibus crassitie longioribus, ultimo oblongo, apice emarginato et inferne acuminato, nigrae, articulo primo plerumque toto nigro, interdum (var. h.) subtus testaceo. Caput parvum, thorace multo minus angustiusque, ovatun, utrinque supra oculos punctis nonnullis, inter oculos punctis 4 transversim positis, intermediis magis distantibus, impressum. Thorax basi coleopterorum prope latitudine, latitudine vix brevior, antrorsum fortius angustatus, lateribus subrectis, basi cum angulis posterioribus fortius rotundatus, apice truncatus, angulis anterioribus deflexis, rotundatis, leviter convexus, seriebus dorsalibus punctis $\mathbf{5}$, anteriore et posteriore paulo magis remotis, compositis, lateribus punctis praeter marginalia utrinque 5 impressus, punctis ommibus subtilioribus. Scutellum confertin punctulatum, nigro-pubescens. Elytra thorace parum longiora, densius subtiliter punctata, nigropubescentia, minus nitida, macula vel litura media obscure rufa, saepe obsoleta. Abdomen subtiliter punctatum, nigro-pubescens, subtus segmentis singulis interdum rufo-prceo-marginatis. Pedes nigri, coxis anticis raro totis nigris, plerumque vel interne vel totis testaceis, femoribus anticis etiam interdum basi testaceis, coxis intermediis approximatis, tibiis omnibus spinulosis. Alae albo-hyalinae.

Tarsi antici $\mathrm{maris}$ fortiter, feminae leviter dilatati.

Obs. In Museo Hafniensi (coll. Sehestedt), a Fabricio citato, nom. St. variantis plures huius generis species (ebeninum, sanguinolentum, arium, ventralem etc. confusas vidi. Patet autem Staph. variantem Paykuli, Fabricii ipsius et Olivieri, cum e reliqua descriptione, tum praecipue ex alis albis memoratis, ad hanc speciem pertinere, nomen igitur restitui, huic speciei magnopere variabili egregie adaptatum. Varietates indicatae, primo intuitu saepius nimium differentes, accuratius examinatae et plurimis speciminibus comparatis, certo limite nullo distinctae videntur. Phil fuscicornis Nordm. Capensis ab indigenis non magis discedit, quam specimina plura e variis Americae meridionalis insulis allata.

* 71. Ph. flavolimbatus: Niger, nitidus, elytrorum limbo laterali et apicali, ant ennarum basi pedibusque flavis, capite ovato. - Long. 2 lin.

Habitat in Columbia, Dom. Moritz.

Habitu omnino $\mathrm{Ph}$. variantis, at minimis eius individuis minor, niger, nitidus. Antennae capite thoraceque multo brevıres, articulo secundo tertioque aequalibus, sequentibus sensim paulo brevioribus at vix crassioribus, omnibus crassitie longioribus, ultimo ovato, apice subemarginato et inferne subacuminato, fuscae, articulis duobus primis testaceis. Caput thorace angustius, utrinque supra oculos punctis paucis, inter oculos punctis 4 transversim positis, intermediis remotioribus, impressum. Palpi nigro-picei. Thorax latitudine haud longior, basi coleopteris paulo angustior, antrorsum angustatus, lateribus subrectis, basi rotundatus, apice truncatus, angulis anterioribus leviter deflexis, subrotundatis, posterioribus obtuśs, transversim convexus, seriebus dorsalibus punctss 5, antico et postico paulo remotioribus, compositis, lateribus punctis praeter marginalia utrinque $\mathbf{5}$ impressus, punctis omnibus subtilioribus. Scutellum obsolete punctulatum. Elytra thoracis longitudine, sat crebre punctata, longius griseo-pubescentia, nigro-subvirescentia, margine laterali inflexo limboque apicali, interne dilatato, sutu- 
ram autem haud attingente, flavis. Abdomen crebre subtiliter punctatum, longius griseo-pubescens, subtus segmentis singulis margine postico testaceo. Pedes testacei, coxis anterioribus concoloribus, intermediis approximatis, tibiis omnibus spinulosis.

Tarsi antici maris fortius, feminae leviter dilatati. Abdominis segmentum inferius šextum femin ae apice emarginatum.

* 72. Ph. infirmus: Niger, nitıdus, antennis, elytris pedibusque fuscescentitestaceis, capite minuto, ovato. - Long. $2 \frac{1}{2}$ lin.

Habitat in Arabia felice, Dom. Prof. Ehrenberg.

Statura omnino variantis et minimis eius individuis aequalıs, nigro-piceus, capite thoraceque nitidissimis, antennis, elytris et pedibus cum coxis anterioribus dilute fuscescenti- rufo-testaceis. Antennae capite cum thorace multo breviores, articulo secundo tertioque aequalibus, $4-10$ crassiusculis, subobconicis, sensim paulo brevioribus, penultimis crassitie prope brevioribus, ultimo ovato, apice leviter emarginato et inferne acuminato. Mandibulae et palpi picei. Caput thorace multo angustius, ovatum, utrinque supra oculos punctis paucis, inter oculos punctis 4 transversim positis, intermediis remotioribus, notatum. Thorax basi coleopteris paulo angustior, latitudine parum brevior, antrorsum angustatus, lateribus subrectis, basi cum angulis posterioribus rotundatus, apice truncatus, angulis anterioribus deflexis, subrotundatis, convexus, seriebus dorsalibus punctis 5, antico posticoque paululum remotioribus, compositis, lateribus punctis praeter marginalia utrinque 5 impressus, punctis omnibus minus subtilibus. Scutellum nigricans, punctulatum, griseo-pubescens. Elytra thorace paulo longiora, crebre subtilius punctata, densius griseo-pubescentia. Abdomen apicem versus attenuatum, crebre subtiliter punctulatum, pube brevi depressa fuscescenti-grisea dense vestitum, segmentorum marginibus supra anguste, subtus late rufo-piceis. Pedes coxis intermediis leviter distantibus, tibiis omnibus spinulosis.

Tarsi antici feminae simplices. $M$ as latet.

* 73. Ph. debilis: Niger, nitidus, elylris pedibusque fuscis, capite suborbiculato. - Long. $2-2 \frac{1}{2}$ lin.

Er. Col. March. I. 467. 31.

Staph. debilis Grav. Micr. 35. 52. - Latr. Hist. nat. Crust, et Ins. IX. 329. 57. Staph. lucidus Grav. Micr. 21. 21. - Latr. Hist. nat. Crust. et Ins. IX. 311. 30. Staph. fimetarii var. Grav. Mon. p. 82.

Staph. agilis Boisd. et Lacord. Faun. Ent. Paris. I. 407. 42.

Habitat in Germania, Gallia ; in Aegypto, Dom. Prof. Ehrenberg, in Carolina, Dom. Zimmermann.

$\mathrm{Ph}$. variantis var. $\mathrm{d}$ similis, at alius, habitu potius $\mathrm{Ph}$. ebenini, cui magnitudine sempèr inferior est, niger, capite thoraceque pernitidis. Antennae capite thoraceque paulo breviores, articulo tertıo secundo paulo longiore, 4 - 10 crassiusculis, penultimis crassitie paulo brevioribus, ultimo ovato, apice truncato et inferne acuminato, nigro-fuscae, basi saepius piceae. Mandibulae rufo-piceae. Palpi picei. Caput thorace paulo minus et angustius, suborbiculatum, supra oculos utrinque punctss paucis, inter oculos punctis 
4 transversim positis, intermediis late distantibus, impressum. Thorax coleopteris paulo angustior, latitudine haud brevior, antrorsum subangustatus, lateribus subrectis, basi rotundatus, apice truncatus, angulis anterioribus leviter deflexis, rotundatis, posterioribus obtusis, leviter convexus, seriebus dorsalibus punctis $\mathbf{5}$, aequaliter distantibus, compositis, lateribus punctis praeter marginalia utrinque 4 impressus, punctis omnibus subtilioribus. Scutellum subtiliter punctatum. Elytra thorace paulo longiora, densius subtiliusque punctata, fusca, minus subtiliter griseo-pubescentia. Abdomen subtiliter punctulatum, pube longiore depressa grisea densius vestitum, subtus segmentorum marginibus rufo-piceis. Pedes dilute fusci, coxis intermediis leviter distantibus, tibiis anticis breviter, posterioribus fortius spinulosis. Alae albo-hyalinae.

Tarsi antici maris fortius, fe mina modice dilatati.

Variat thoracis serierum dorsalium altera 4-punctata.

O bs. A Ph. variantis var. d praecipue distinguitur capite minus ovato, abdomine confertius subtiliter punctato, densius griseo-pubescente.

* 74. Ph. ventralis: Nigro-piceus, nitidus, antennarum basi, pedibus abdominisque segmentorum ventralium marginibus testaceis, capite orbicu-

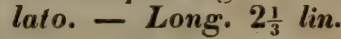

Nordm. Symb. 93. 60. - Er. Col. March. I. 468. 32.

Staph. ventralis Grav. Micr. 174. 29. Mon. 60. 28. - Gyll. Ins. Suec. II. 334.

49. - Sahlb. Ins. Fenn. I. 325. 45. - Mannerh. Brachelytr. 29. 63. - Boisd. et

Lacord. Faun. Ent. Paris. I. 437. 41.

St aph. immundus Grav. Mon. 66. 36.

Staph. anthrax Grav. Micr. 176. 34. Mon. 67. 38.

Philonth. anthrax Nordm. Symb. 97. 74.

Habitat in Europa; in America septentrionali, Knoch., in Amer. mer. ins. St. Vincentii, Mus. Dom. Hope.

Statura omnino $\mathrm{Ph}$. debilis, nigro-piceus, thorace plerumque dilutiore, fusco-piceo, elytris nigricantibus, capite thoraceque pernitidis. Antennae capite thoraceque breviores, articulo tertio secundo paulo longiore, 4-10 crassiusculis, sensim paululum brevioribus, non autem crassioribus, penultimis crassitie paulo brevioribus, ultimo ovato, apice leviter emarginato et inferne acuminato, fusco-nigrae, articulo primo testaceo. Palpi fusco-testacei. Caput thorace parum minus et angustius, orbiculatum, supra oculos utrinque punctis parcis, inter oculos punctis 4 transversim positis, intermedis remotioribus, impressum. Thorax coleopteris paulo angustior, latitudine vix longior, lateribus parallelis, subrectis, basi rotundatus, apice truncatus, angulis anterioribus leviter deflexis, rotundatis, posterioribus obtusis, leviter convexus, seriebus dorsalibus punctis 5, antico et postico remotioribus, compositis, lateribus punctis praeter marginalia utrinque $\mathbf{5}$ impressus, punctis omnibus sat magnis profundisque. Scutellum subtiliter punctulatum. Elytra thorace vix longiora, minus dense minusque subtiliter punctata, griseo-pubescentia. Abdomen parce subtiliterque punctulatum, longius griseo-pubescens, subtus segmentorum marginibus late rufo-testaceis. Pedes rufotestacei, coxis anterioribus concoloribus, intermediis leviter distantibus, tibiis omnibus spinulosis, tarsis anticis in utroque sexu simplicibus. Alae albohyalinae. 
* 75. Ph. discoideuls: Niger, nitidus, antennis, pedibus elytrorumque limbo testaceis, capite orbiculato. - Long. $2-2 \frac{1}{2}$ lin.

Nordm. Symb. 97. 75. - Er. Col. March. I. 469. 33.

Staph. discoideus Grav. Micr. 38. 56. Mon. 58. 24. - Latr. Hist. nat. Crust. et

Ins. IX. 322. 61. - Gyll. Ins. Suec. II. 331. 47. - Sahlb. Ins. Fenn. I. 324. 43.

- Mannerh. Brachelytr. 29. 61. - Germ. Faun. Ins. Europ. XIII. 4. - Runde Brachelytr. Hal. 8. 38.

St aph. conformis Boisd. et Lacord. Faun. Ent. Paris. I. 398. 23.

Staph. testaceus Grav. Mon. 60. 27. (forte)

Habitat in Europa; in Cuba, collect. Dom. Chevrolat.

Statura fere praecedentis, niger, capite thoraceque pernitidis. Antennae capite thoraceque multo breviores, tenuiores, articulo secundo tertioque aequalibus, $4-10$ sensim paululum brevioribus, non autem crassioribus, penultimis crassitie haud brevioribus, ultimo ovato, apice leviter emarginato et inferne subacuminato, totae rufo-testaceae. Os fusco-'testaceum. Caput thoracis fere latitudine et magnitudine, suborbiculatum, vel in maribus interdum subquadratum, supra oculos utrinque punctis parcis profundis, intei oculos punctis 4 transversim positis, intermediis magis distantibus, impressum. Thorax coleopterorum fere latitudine, latitudine vix brevior, lateribus parallelis, subrectis, basi rotundatus, apice truneatus, angulis anterioribus leviter deflexis posterioribusque subrotundatis, leviter convexus, seriebus dorsalibus punctis 5, antico porticoque remotioribus, compositis, lateribus punctis praeter marginalia utrinque $\mathbf{5}$ impressus, punctis ordinariis maioribus profundioribusque. Scutellum crebre punctulatum, griseo-pubescens. Elytra thoracis longitudine, densius fortiusque punctata, minus subtiliter griseo-pubescentia, nigro-fusca, marginibus, imprımis margine laterali et suturali testaceis. Abdomen subtiliter parcius punctulatum, densius griseo-pubescens, segmentorum marginibus supra piceis, subtus testaceis. Pedes fusco-testacei, coxis intermediis leviter distantibus, tibiis omnibus spinulosis.

Tarsi antici maris fortiter, feminae leviter dilatati.

Variat thoracis serie dorsali altera 4-punctata.

* 76. Ph. palliatus: Niger, nilidus, antennarum lasi, elylris pedibusyue rufo-teslaceis, coxis nigris, capite orbiculato. - Long. 2 lin.

Staph. palliatus Grav. Mon. 53. 16.

Habitat in America septentrionali.

Niger, capite thoraceque nitidissimis, elytris testaceo-rufis. Antemnae articulis duobus basalibus testaceis, reliquis fuscescentibus, tertio secundo paulo longiore. Mandibulae et palpi rufo-picei. Caput thorace parum angustius, orbioulatum, utrinque supra oculos parcc punctatum, inter oculos punctis 4 transversim positis, intermediis remotioribus. Thorax coleopteris vix angustior, latitudine paulo longior, antrorsum hand angustatus, lateribus leviter, basi fortius rotundatus, apice truncatus, angulis anterioribus deflexis posterioribusque subrotundatis, convexus, seriebus dorsalibus punctis $\mathbf{5}$ sat distantibus compositis, lateribus punctis praeter marginalia utrinque $\mathbf{5}$ impressus, punctis omnibus profundioribus. Scutellum nigrum, parce punctulatum, tenuiter griseo-pubescens. Elytra thoracis longitudine, parcius punctata, parce griseo-pubescentia. Abdomen crassiusculum, parcius punctatum, 
griseo-puberulum, segmentis ventralibus piceo-marginatis. Perles testacei, coxis omnibus nigris.

Tarsi antici feminae modice dilatati. M as latet

* 77. Ph. rubidus: Niger, antennarum basi, pedibus elytrisque rufis, his basi summa nigricantibus, capile suborbiculato. - Long. 3 lin.

Staph. dimidiat ns Boisd. et Lacord. Faun. Ent. Paris. I. 402. 31.

Phitonth. dimidiatus Er. Col. March. I. 467. 30.

Habitat in Germania, Gallia.

Statura omnino $\mathrm{Ph}$. ebenini, at minimis eius individuis vix magnitudine aequalis, niger, capite thoraceque pernitidis. Antennae capitis thoracisque prope longitudine, articulo tertio secundo paulo longiore, 4-10 oblongosubobconicis, sensin paulo brevioribus, non autem crassioribus, omnibus crassitie longioribus, ultimo oblongo, apice obsolete emarginato et subacuminato, fuscae, articulo primo toto, secundo basi rufis. Palpi rufi: Caput thorace paulo minus et angustius, suborbiculatum, utrinque supra oculos punctis pluribus, antice inter oculos punctis binis oblique positis impressum. Thorax coleopteris paulo angustior, latitudine vix longior, antrorsum vix angustatus, lateribus et basi leviter rotundatus, apice truncatus, angulis anterioribus leviter deflexis posterioribusque subrotundatis, param convexus, seriebus dorsalibus punctis 5, primo paulo remotiore, compositis, lateribus punctis praeter marginalia utrinque 5 vel 6 impressus, punctis omnibus minus subtilibus. Scutellum nigrum, dense subtiliter punctulatum, griseo-pubescens. Elytra thorace paulo longiora, densius subtiliter punctata, griseopubescentia, laete rufa, basi summa nigricante. Abdomen densius subtiliter punctatum, pube brevi grisea densius vestitum. Pedes rufo-testacei, coxis concoloribus, intermediis approximatis, tibiis omnibus spinulosis, fuscescentibus.

Tarsi antici maris fortiter dilatati, femina simplices.

Obs. Ob speciem huius generis a Sahlbergio prius descriptam nomen mutavi.

* 78. Ph. quisquiliarius: Elongatus, niger, nitidus, elytris virescentibus, antennarum basi pedibusque flavis, capite suborbiculato.-Long. $3 \frac{1}{2}$ lin.

Nordm. Symb. 93. 61. - Er. Col. March. I. 469. 31.

Staph. qui squiliarius Gyll. Ins. Suec. II. 335. 50. - Sahlb. Ins. Fenn. I. 325.

46. - Mannerh. Brachelytr. 29: 64. - Boisd. et Lacord. Faun. Ent. Paris. I. 406.

39. - Runde Brachelytr. Hal. 8. 39.

Habitat in Europa; in Syria et Aegypto etiam a Prof. Ehrenberg lectus.

$\mathrm{Ph}$. ebenino angustior et minimis eius individuis aequalis, elongatus, niger, capite thoraceque pernitidis. Antennae capitis thoracisque longitudine, articulo tertio secundo paulo longiore, 4-10 subobconicis, sensim paulo brevioribus et crassioribus, omnibus crassitie longioribus, ultimo ovato, apice emarginato et inferne subacuminato, nigrae, articulo primo testaceo, inter dum dorso nigricante. Palpi piceo-testacei, apice nigricantes. Caput thorace paulo minus angustiusque, suborbiculatum, supra oculos utrinque parce profundeque punctatum, inter oculos punctis 4 transversim positis, intermediis fortius distantibus, notatum. Thorax coleopteris paulo angustior, 
latitudine haud brevior, antrorsum subangustatus, lateribus subrectis, basi cum angulis posterioribus rotundatus, apice truncatus, angulis anterioribus deflexis, subrotundatis, parum convexus, seriebus dorsalibus punctis 5, primo paululum remotiore, compositis lateribus punctis praeter marginalia utrinque 5 impressus, punctis omnibus profundioribus. Scutellum dense punctulatum, griseo-pubescens. Elytra thorace paulo longiora, confertim subtilius punctata, longius griseo - pubescentia, nigro-virescentia, nitidula. Abdomen densius subtiliter punctulatum, tenuiter griseo-pubescens. Pedes flavi, coxis anticis nigro - piceis, femoribus posticis fuscescentibus, coxis intermediis approximatis, tibis omnibus spinulosis. Alae albo-hyalinae.

Tarsi antici maris fortiter dilatati, feminae simplices.

* 79. Ph. alcyoneus: Elongatus, niger, nitidus, capite thoraceque nigrosubaeneis, capite suborbiculato. - Long. 3 lin.

Habitat in Sardinia, Dom. Prof. Gené.

Statura elongata omnino $\mathrm{Ph}$. quisquiliarii, niger, nitidus, capite thoraceque supra nigro-subaeneis, pernitidis. Antennae capitis thoracisque prope longitudine, articulo tertio secundo paulo longiore, 4-10 subobconicis, sensim paulo brevioribus et crassioribus, penultimis crassitie haud brevioribus, ultimo ovato, apice leviter emarginato et inferne subacuminato, nigrae. Palpi nigri. Caput feminae thoracis latitudine, suborbiculatum, maris thorace paulo latius, orbiculato-subquadratum, supra oculos utrinque parce fortiter profundeque punctatum, inter oculos punctis utrinque duobus ablique positis notatum. Thorax coleopteris paulo angustior, latitudine paulo longior, basin versus subangustatus, lateribus anterius subrotundatis, basi rotundatis, apice truncatus, angulis anterioribus leviter deflexis, subrotundatis, posterioribus obtusis, leviter convexus, seriebus dorsalibus punctis 5 , aequaliter distantibus, compositis, lateribus punctis utrinque 5 impressus, punotis omnibus sat magnis profundisque. Scutellum punctulatum, longius albido-pubescens. Elytra thorace vix longiora, minus dense punctata, viridi-coerulea, nitida, tenuiter albido pubescentia. Abdomen parcius punctatum, pube pallide grisea certo situ incanum. Pedes nigri, coxis intermediis approximatis, tibiis omnibus spinulasis, tarsis anticis in utroque sexu leviter dilatatis. Alae hyalinae.

* 80. Ph. rufimanus: Elongatus, niger, nitidus, elytris cyaneis, coxis femoribusque anterioribus rufo-testaceis, capite suborbiculato. - Long. 3 lin.

Habitat in Carinthia, Dom. Schmidt.

Statura elongata $\mathrm{Ph}$. quisquiliarii, niger, nitidus, capite thoraceque pernitidis. Antennae capitis thoracisque prope longitudine, articulo tertio secundo paulo longiore, 4-10 subobconicis, sensim paulo brevioribus et crassioribus, omnibus crassitie longioribus, ultimo ovato, apice emarginato et inferne subacuminato, totae nigrae. Palpi nigri. Caput thoracis latitudine, suborbiculatum, leviter convexum, posterius punctis parcis, inter oculos utrinque punctis duobus, ablique positis, fortioribus impressum. Thorax coleopteris dimidio angustior, latitudine paulo longior, lateribus parallelis, subrectis, basi rotundatus, apice truncatus, angulis anterioribus leviter deflexis posterioribusque subrotundatis, leviter convexus, seriebus dorsalibus 
punctis 5, apicali paululum remotiore, lateribus punctis praeter marginalia utrinque 5 impressus, punctis omnibus fortioribus. Scutellum nigrum, punctulatum, tenuiter albido-pubescens. Elytra thorace paulo longiora, ninus dense subtilus punctata, laete virescenti-cyanea, tenuiter albido-pubescentia. Abdomen parcius subtiliter punctatum, cinereo-pubescens. Pedes nigri, coxis femoribusque anterioribus laete rufo-testaceis, coxis intermediis approximatis, tibiis omnibus spinulosis.

Tarsi antici maris fortiter, femin a e leviter dilatati.

* 81. Ph. la etus: Niger, nilidus, thorace abdominisque basi rufis, antennis apice pedibusque albidis, femoribus tibiisque apice nigris. - Long. $3 \frac{1}{2}$ lin.

Habitat in Columbia, Dom. Moritz, in Brasilia, Dom. Prof. Germar.

Statura gracilis fere et colores Paederi. Antennae capite thoraceque parum breviores, crassiusculae, articulo tertio secundo sesqui prope longiore, 4-10 cylindricis, sensim paulo brevioribus et crassioribus, ultimo subovato, apice minus abrupte acuminato, nigrae, basi piceae, apice late albido-luteae. Palpi nigro-picei. Mandibulae tenues, falcatae, rufo-piceae. Caput thorace latius, orbiculatum, leviter convexum, nigrum, nitıdum, supra oculos utrinque punctis parcis, inter oculos punctis 4 transversim positis, intermediis late distantibus, impressum, fronte apice sulcata. Thorax coleopteris duplo angustior, latitudine plus sesqui longior, basin versus subangustatus, lateribus ante medium leviter rotundatis, pone medium subsinuatis, basi rotundatus, apice utrinque oblique truncatus, angulis anterioribus rotundatis, posterioribus obtusis, convexus, seriebus dorsalibus punctis 5, apicali paululum remotiore minoreque, compositis, lateribus punctis praeter marginalia utrinque 5 impressus, omnibus fortibus profundisque, laete rufus, nitidus. Scutellum dense punctulatum, nigrum. Elytra thorace vix longiora, fortiter punctata, tenuiter nigro-pubescentia, nigra, nitida. Abdomen segmentis singulis basi fortius punctulatis, apice laevibus, nitidis, primis tribus obscure rufis, reliquis nigris, nigro-pilosellum. Pectus nigrum. Pedes elongati, graciles, ooxis anterioribus testaceis, intermediis distantibus, femoribus albidis, apice nigris, tibiis anticis muticis, nigris, basi pices, posterioribus spinulosis, albidis, apice nigris, tarsis testaceis, anticis in utroque sexu simplicibus.

82. Ph. angularius: Rufus, capile thoraceque nigro-aeneis, nitidissimis, abdominis postico nigro, coleopterorum angulis posterioribus femoribusque piceis. - Long. 3 lin.

Habitat in Mexico, collect. Dom. Chevrolat.

Statura fere praecedentis. Antennae capitis thoracisque prope longitudine, articulo tertio secundo paulo longiore, 4-10 subcylindricis, crassiusculis, penultimo crassitie hand longiore, ultimo apice oblique truncato, nigrae, apice ferrugineae. Palpi elongatı, picei. Mandibulae elongatae, grales, rufo-piceae. Caput thorace latius, suborbiculatum, posterius utrinque parce punctatum, inter oculos punctis 4 transversim positis, intermediis magis distantibus impressum, fronte anterius sulcata, nigro-aeneum, nitidissimum. Thorax coleopteris dimidio angustior, latitudine paulo longior, basin versus leviter angustatus, lateribus posterius. subsinuatis, basi rotundatus, 
apice truncatus, angulis anterioribus minus deflexis, posterioribus subrotundatis, modice convexus, seriebus dorsalibus punctis 5 aequaliter distantibus compositis, lateribus punctis praeter marginalia utrinque circiter 7 impressus, punctis ommibus sat fortibus profundisque, nigro-aeneus, nitidissimus. Scu-. tellum nigro - aeneum, punctatissimum. Elytra thorace paulo longiora, minus dense sat fortiter punctata, tenuiter griseo-pubescentia, rufa, nitida, angulo posteriore exteriore nigricante. Abdomen parce punctatum, longius pubescens, nitidum, segmentis $\mathbf{3}$ anterioribus rufis, posterioribus nigris, penultimo margine postico late testaceo. Pectus rufum. Pedes coxis anterioribus nigris, posticis rufis, femoribus piceis, tibiis albidis, apice tarsisque rufotestaceis, coxis intermediis distantibus, tibiis anticis subtiliter, posterioribus longius parce spinulosis.

Tarsi antici feminae simplices. Mas latet.

Obs. Habitus fere Belonuchi formosi, et femora antica subtus subtilis. sime spinulosi, at femora postica omnino mutica.

* 83. Ph. vernalis: Elongatus, niger, nilidus, antennarum basi pedibusque testaceis, capite ovato. - Long. $2 \frac{2}{3}$ lin.

Nordm. Symb. 93. 59. - Er. Col. March. I. 470. 35.

Staph. vernalis Grav. Mon. 75. 67. - Gyll. Ins. Suec. II. 332. 48. - Sahlb. Ins. Fenn. I. 324. 44. - Mannerh. Brachelytr. 29. 62, - Boisd. et Lacord. Faun. Ent. Paris. I. 404. 36.

Habitat in Europa, stib lapidibus et folis deciduis.

Corpus elongatum, nigrum, nitidum, capite thoraceque pernitidis. An.tennae capite thoraceque breviores, articulo tertio secundo paulo longiore, sequentibus subobconicis, sensim paulo brevioribus crassioribusque, penultimis crassitie vix brevioribus, ultimo apice subemarginato et inferne subacuminato, nigrae, articulo primo testaceo. Oris partes testaceae. Caput thorace minus et angustius, oblongo-ovatum, supra oculos utrinque punctis parcis, inter oculos utrinque punctis binis approximatis oblique positis impressum. Thorax coleopterorum fere latitudine, latitudine paulo longior, antrorsum subangustatus, lateribus parum, basi modice rotundatus, apice truncatns, angulis anterioribus leviter deflexis posterioribusque subrotundatis, modice convexus, seriebus dorsalibus punctis $\mathbf{5}$ sat distantibus compositis, lateribus punctis praeter marginalia utrinque $\mathbf{5}$ impressus, punctis omnibus subtilioribus. Scutellum punctulatum, griseo pubescens. Elytra thorace paulo breviora, dense fortius punctata, minus subtiliter griseo-pubescentia, nigro-picea. Abdomen subtiliter punctulatum, griseo pubescens. Pedes testacei, coxis anterioribus concoloribus, intermediis approximatis, tibiis omnibus spinulosis, tarsis anticis in utroque sexu simplicibus.

Obs. Vivus olet.

* 84. Ph. splendidulus: Elongatus, piceus, nitidus, antennis, ore pedibus. que testaceis, thorace oblongo, capite ovato. - Long. 2-2 $\frac{1}{2}$ lin.

Er. Col. March. I. 470, 36.

St a ph. splendidulus Grav. Micr. 41. 60. Mon. 93. 89. - Latr. Mist. nat. Crust. et Ins. IX. 327. 78. - Gyll. Ins. Suec. II. 348. 64. - Sahlb. Ins. Fenn. I. 330.61. Cafius splendidulus Mannerh. Brachelyir. 32. 3. 
Gyrohypn. splendidulus Nordm. Symb. 126. 30.

St aph. nanus Grav. Mon. 96. 93. - Gyll. Ins. Suec. II. 347. 63. - Suhlb. Ins.

Fenñ. I. 330. 60. - Zetterst. Faun. Lappon. I. 79. 30. Ins. Lappon. 65. 40.

Cafius nanus Mannerh. Brachelytr. 32. 2. - Runde Brachelytr. Hal. 10. 1.

Gyrohypn. nanus Nordm. Symb. 126. 29.

Staph. parvulus Grav. Micr. 42. 63. Mon. 95. 91. - Latr. Hist. nat. Crust. et Ins. IX. 328. 81.

Habitat in Europae truneis putridis.

Parvus, elongatus, linearis, iam nigro-, iam testaceo-piceus, nitidus. Antemnae capite sesqui longiores, crassiusculae, articulo tertio secundo vix longiore, 4-10 sensim paulo brevioribus at vix crassioribus, 6-10 transversis, ultimo subovato, apice subacuminato ef prope acumen leviter impresso, totae testaceae. Palpi testacei, articulo ultimo fortiter acuminato. Caput thoracis vix longitudine, ovatum, supra oculos utrinque parce punctatum, inter oculos punctis utrinque duobus transversim positis notatum, fronte inter antennas obsolete longitudinaliter impressa, ore testaceo. Thorax coleopteris paulo angustior, latitudine sesqui prope longior, basin versus subangustatus, lateribus subrectis, basi cum angulis posterioribus rotundatus, apice truncatus, angulis anterioribus leviter deflexis, rotundatis, leviter convexus, seriebus dorsalibus punctis $\mathbf{5}$ sat distantibus compositis, lateribus punctis praeter marginalia utrinque $\mathbf{5}$ impressus, punctis omnibus subtilibus. Scutellum subtiliter punctulatum. Elytra thoracis longitudine, minus dense fortius punctata, tenuiter griseo-pubescentia, corpore dilutiora. Abdomen subtilter punctulatum, tenuiter pubescens, segmentis margine dilutioribus. Pedes testacei, coxis anterioribus concoloribus, intermediis approximatis, tibiis omnibus spinulosis, tarsis anticis in utroque sexu simplicibus.

Obs. Xantholinum simulat, corpore etiam spirae instar involuto quiescens. stäph. splendidulus, nanus et parvulus Grav., speciminibus ab auctore descriptis ipsis inter se comparatis, specie distingui nequeunt, neque $\mathrm{St}$. splendidulum et nanum Gyll., exemplis ab auctore ipso missis et a Dom. Schüppel mihi traditis, examinatis, nisi colore immaturo saturove differunt. - A Ph. aterrimo facilius distinguitur corpore magıs elongato linearique, thoracis seriebus dorsalibus 5-punctatis, antennis totis testaceis etc.

\section{Species mihi invisae.}

85. Ph. immundus: Niger, nitidus, antennarum basi, pedibus segmenlotorumque ventralium marginibus rufo-testaceis, capile subovato.

Nordm. Symb. 93. 64.

Staph. immundus Gyll. Ins. Suec. I1. 337. 53. - Sahlb. Ins. Fenn. I. 326. 49.

Habitat in Suecia.

Statura et fere magnitudo $\mathrm{Ph}$. ebenini (maioris), $\mathrm{Ph}$. ventrali colore simillimus, sed plus duplo maior, caput magis ovatum, etc. Caput subovatum, vel latitudine paulo longius, thorace vix angustius, nigrum, nitidissimum, laeve, punctis paucis in angulis verticis et inter oculos, ut in prioribus; os et palpi picei. Antennae longitudine thoracis, fliformes, nigro-fuscae, articulo primo toto ferrugineo. Thorax antice truncatus, angulis deflexis, compressis, lateribus et postice rotundatus, supra convexus, niger, nitidissimus, laevis, punctis eodem ordine ac numero ut in prioribus. Elytra thorace panlo latiora, sed vix longiora, apice truncata, supra subdepressa, nigra, vix vel parum 
virescentia, crebre rugoso-punctata, pubescentia, margine laterali piceo. Alae amplae, albo-hyalinae. Abdomen pone elytra longitudine reliqui corporis, nigrum, violaceo-micans, punctulatum, pubescens. Corpus subtus nigro-piceum, punctulatum, segmentorum ventralium marginibus anoque late rufo-ferrugineis; anus maris late emarginatus. Pedes elongati, validi, rufoferruginei, tarsis anticis dilatatis. Masculos tantum vidi. (Gyll.)

$\mathrm{Obs}$. Affinis videtur $\mathrm{Ph}$. umbrino. A Com. Dejean $\mathrm{Ph}$. fumario subiungitur, huic autem thoracis series dorsales 6-punctatae et alaê fortiter infuscatae.

86. Ph. dimidiatus: Niger, nitidus, elytris postice rufo-testaceis, pedibus totis nigro-piceis, capite thorace paulo angustiore, orbiculato, antennis extrorsum crassioribus, thorace brevioribus.

Nordm. Symb. 97. 77.

Staph. dimidiatus Sahlb. Ins. Fenn. I. 326. 51. - Mannerh, Brachelytr, 30. 69.

Habitat in Fennia meridionali.

Magnitudo et statura $\mathrm{Ph}$. sanguinolenti, colore coxarum et antennis brevioribus ab illo imprimis distinctus. Caput latitudine fere thoracis, orbiculatum, nigrum, nitidum, laeve, punctis in angulo verticis et quatuor inter oculos ut in praecedentibus impressis. Antennae thorace breviores, extrorsum paulo crassiores, articulis tribus baseos nigris, nitidis, longioribus, ceteris fusco-pubescentibus, brevibus, longitudine latioribus, ultimo longiore. Thorax antice truncatus, lateribus vix dilatatus, postice rotundatus, supra convexus, niger, nitidus, inter angulum anticum puncta duo, dein iterum duo, et in seriebus dorsalibus $\mathbf{5}$ sat profunde impressa, aequali spatio a se invicem remota. Scutellum triangulare, acuminatum, depressum, nigrum, . crebre punctatum. Elytra thorace nonnihil latiora, vix illo longiora, apice oblique truncata, supra depressa, sat crebre et profunde punctata, tenue pubescentia, nitida, nigra, macula magna postica, dimidium elytri occupante, suturam non attingente, sed iuxta marginem exteriorem parum adscendente, rufo-testacea. Abdomen pone elytra longitudine fere reliqui corporis, nigrum, subopacum, pubescens, subtiliter punctulatum. Corpus subtus nigrum, subopacum, subtiliter punctulatum. Pedes elongati, nigro-picei, tarsis paulo dilutioribus. (Sahlb.)

87. Ph. celer: Niger, nitidus, antennis fuscis, pedibus rufo-testaceis, segmentorum marginibus ventre rufis, thorace seriebus dorsalibus 5-punctis, capite subovato. - Long. 3 lin.

Nordm. Symb. 94. 68.

Staph. celer Grav. Mon. 66. 37.

Habitat Lutetiae.

Caput subovatum, thorace paulo angustius, nigrum, palpis antennisque fuscis, his capite duplo longioribus. Thorax coleopteris paululum minor, nigricans, 5, 3, 1 punctus, punctis distinctis. Coleoptera subdepilia, piceonigra. Pedes tarsis tenuibus. (Grav.)

$\mathrm{Obs}$. Ph. ventrali affinis videtur, species mihi perquam dubia. 
88. Ph. irregularis: Niger, nitidus, elytris fusco virescentibus, pedibus fusco-piceis, capite thorace maiore, subquadrato, thoracis seriebus dorsalibus irregularibus.

Nordm. Symb. 93. 66.

Staph. irregularis Mannerh. Brachelytr. 30.74.

Habitat Petropoli. '

Ph. ebenino colore similis, capite autem maiore, subquadrato et elytris minus crebre punctatis. In thorace etiam prope seriem dorsalem extus punctum maiusculum utrinque impressum, unde series minus regulares. (Mannerh.)

Obs. An a $\mathrm{Ph}$. ebenino revera distinctus, anne forte varietas fortuita?

6) Thorax seriebus dorsalibus 6-punctatis.

* 89. Ph. nigrita: Nigerrimus, thorace griseo-subsericante, elytris subtililiter confertissime punctatis, capite ovato. - Long. 3 lin.

Nordm. Symb. 101. 86. - Er. Col. March. I. 471. 37.

Staph. nigrita Grav. Mon. 68. 44.

Habitat in Germania, Suecia.

Habitu'omnino $\mathrm{Ph}$. variantis et maximis eius individuis aequalis, nigerrimus, capite thoraceque pernitidis, hoc certo situ griseo-subsericante. Antennae capite thoraceque longiores, graciliores, articulo tertio secundo paulo longiore, sequentibus omnibus elongato-obconicis, 4-10 sensim paulo brevioribus, ultimo praecedente paulo longiore, apice truncato et abrupte subacuminato, nigrae, articulo ultimo brunneo. Palpi nigri. Caput thorace multo minus et angustius, ovatum, supra oculos utrinque parce punctatum, inter oculos utrinque punctis duobus approximatis oblique positis impressum. Thorax basi coleopterorum prope latitudine, latitudine baseos vix longior, antrorsum leviter angustatus, lateribus vix, basi leviter rotundatus, apice truncatus, angulis anterioribus leviter deflexis posterioribusque sub.rotundatis, modice convexus, seriebus dorsalibus punctis 6 , apicali paulo remotiore compositis, lateribus punctis utrinque 5 impressus, punctis omnibus subtilioribus. Scutellum subtiliter punctulatum, subtiliter pubescens. - Elytra thorace paulo longiora, confertim subtiliter punctata, tenuiter subtiliterque nigro-pubescentia. Abdomen subtiliter minus confertim punctatum, tenuiter nigro-pubescens. Pedes mgri, coxis intermediis approximatis, tibiis omnibus spinulosis, geniculis piceis, tarsis rufo-piceis.

Tarsi antici maris modice, femina leviter dilatati.

$\mathrm{V}$ ariat thoracis seriebus dorsalibus 4-punctatis.

Obs. E Suecia nomnunquam pro $\mathrm{Ph}$. virgine missus.

* 90. Ph. thoracicus: Niger, thorace rufo, antennarum basi, pedibus elytrisque testaceis, capile ovali. - Long. $3 \frac{1}{2}$ lin.

Staph. thoracicus Grav. Micr. 170. 23. Mon. 71. 57.

Habitat ir America septentrionali.

Statura et magnitudo omnino $\mathrm{Ph}$. nigritae. Antennae capitis thoracisque longitudine, articulo tertio secundo paulo longiore, sequentibus subob- 
conicis, sensim crassioribus, 4-10 sensim paulo brevioribus, penultimis crassitie vix longioribus, ultimo apice truncato et inferne subacuminato, fuscae, articulis 3 primis ultimoque testaceis. Palpi testacei. Mandibulae rufo-piceae. Caput thorace multo angustius, oblongo-ovatum, utrinque supra oculos punctis paucis, inter oculos punctis 4 transversim positis impressum, nigrum, nitidum. Thorax basi coleopterorum prope đatitudine, latitudine baseos vix brevior, antrorsum angustatus, lateribus subrectis, basi cum angulis posterioribus rotundatus, apice truncatus, angulis anterioribus leviter deflexis, rotundatis, modice convexus, seriebus dorsalibus punctis 6 , apicali paulo remotiore, compositis, lateribus punctis praeter marginalia utrinque 5 impressus, punctis omnibus subtilibus, rufus, nitidus. Elytra thorace vix longiora et scutellum crebre subtiliter punctata, fuscescenti-testacea, griseo-pubescentia. Abdomen subtilius punctulatum, griseo-pubescens, nigrum, nitidulum, segmentorum marginibus rufo-piceis. Pectus nigrum. Pedes cum coxis anterıoribus flavo-testacei, coxis intermediis approximatis, tibiis ommibus spinulosis.

Tarsi antici feminae simplices. Mas latet.

* 91. Ph. fumarius: Niger, nitidus, pedibus fulvis, elytris virescentibus, dense subtiliter punctatis, capite ovato. - Long. $3 \frac{\mathrm{I}}{2}$ lin.

Nordm. Symb. 100. 84. - Er. Col. March. I. 472. 38.

St aph. fumarius Grav. Mon. 67. 43.

Habitat in Germania.

Habitu $\mathrm{Ph}$. variantis, at duplo fere maior, niger, capite thoraceque nitidissimis, hoc certo situ griseo-subsericante. Antennae capite thoraceque longiores, articulo tertio secundo paulo longiore, 4-10 subobconicis, sensim paulo brevioribus crassioribusque, omnibus crassitie longioribus, ultimo oblongo, apice subtruncato et inferne subacuminato, nigrae, articulis $\mathbf{3}$ primis obscure piceis, ultimo brunneo. Palpi piceo-testacei. Caput thorace minus et angustius, ovatum, supra oculos utrinque punctis parcis, inter oculos punctis 4 transversim positis, intermediis magis distantibus, impressum. Thorax basi coleopterorum prope latitudine, latitudine baseos vix brevior, antrorsum leviter angustatus, lateribus parum, basi modice rotundatus, apice truncatus, angulis anterioribus leviter deflexis posterioribusque subrotundatis, modice convexus, seriebus dorsalibus punctis 6 , plerumque aequaliter distantibus, compositis, lateribus punctis praeter marginalia utrinque 5 impressus, punctis omnibus subtilioribus. Scutellum nigrum, subtiliter punctulatum, tenuiter pubescens. Elytra thorace paulo longiora, confertim subtiliter punctata, griseo - pubescentia, nigro - virescentia, nitidula. Abdomen densius subtiliter punctulatum, densius griseo-pubescens, subtus segmentorum marginibus obscure ferrugineis. Pedes fulvi, coxis omnibus nigris, intermediis approximatis, tibiis omnibus spinulosis. Alae fuscae.

Tarsi antici maris modice, feminae levissime dilatati.

92. Ph. lomat us: Niger, nitidus, antennarum articulo primo, palpis, pe. dibusque testaceis, elytris confertim subtiliter punctalis, viridi-aeneis, margine laterali temeique apicali obscure testaceis, capite ovalo. Long. 3! lin.

Habitat in America septentrionali, Mus. Dom. Chevrolat. 
Statura omnino praecedentium, niger, nitidus. Antennae capite thoraceque paulo longiores, graciles, articulo tertio secundo paulo longiore, 4- 10 elongato-subobconicis, sensim paulo brevioribus at vix crassioribus, ultimo oblongo, apice oblique truncato et inferne acnminato, nigrae, articulo primo testaceo, ultimo brunneo. Caput thorace multo angustius, ovatum, utrinque supra oculos punctis paucis, inter oculos punctis itrinque duobus transversim positis impressum. Thorax basi coleopterorum prope latitudine, latitudine baseos vix longior, antrorsum angustatus, lateribus leviter, basi fortius rotundatus, apice truncatus vel subemarginatus, angulis anterioribus leviter deflexis, subrotundatis, posterioribus obtusis, modice convexus, seriebus dorsalibus punctis 6 , apicali remotiore, compositis, lateribus punctis praeter marginalia utrinque 5 impressus, punctis omnibus subtilibus. Scutellum subtiliter punctulatum, griseo-pubescens. Elytra thorace vix longiora, subtiliter confertim punctata, densius griseo-pubescentia, obscure viridi-aenea, nitidula, margine laterali tenuique apicali saturate testaceo. Abdomen subtiliter punctulatum, longius griseo-pubescens, segmentorum marginibus rufo-piceis. Pedes testacei, coxis omnibus piceis, intermediis approximatis, tibiis omnibus parce spinulosis.

Tarsi antici maris fortiter dilatati, femin a latet.

* 93. Ph. virgo: Niger, nilidus, pedum geniculis tarsisque piceis, elytris subtiliter punctulatis, capite ovato. - Long. $2 \frac{3}{4}$ lin.

Nordm. Symb. 101. 85.

Staph. virgo Grav. Micr. 169. 19. Mon. 69. 45. - Latr. Hist. nat. Crust. et Ins. IX. 323. 65. - Gyll. Ins. Suec. I1. 315. 61. - Sahlb. Ins. Fenn. I. 330. 58. Zetterst. Faun. Lappon. 1. 78. 28. Ins. Lappon. 65. 38. - Mannerh. Brachelytr. 31. 77. - Boisd. et Lacord. Faun. Ent. Paris, I. 404. 35.

Habitat in Lusitania, Com. Hoffmannsegg, in Sardinia, Dom. Prof. Géne, in Suecia, Dom. Prof. Zetterstedt.

Statura Ph. micantis, at plerumque paulo maior, $\mathrm{Ph}$. nigrita multo minor, niger, capite thoraceque nitidis, haud sericeo-micantibus. Antennae capitis thoracisque prope longitudine, articulo tertio secundo paulo longiore, 4 - 10 subobconicis, sensim leviter crassioribus, non autem brevioribus, omnibus crassitie longioribus, ultimo oblongo, apice inferne abrupte subacuminato, nigrae. Palpi nigri. Caput thorace angustius, breviter subovatum, utrinque supra oculos punctis pluribus, inter oculos punctis utrinque dnobus transversim positis impressum. Thorax coleopteris dimidio angustior, latitudine vix longior, antrorsum perparum angustatus, lateribus parum, basi modice rotundatus, apice truncatus, angulis anterioribus leviter deflexis, posterioribus shbrotundatis, modice transversim convexus, seriebus dorsalibus panctis 6, apicali plerumque paulo remotiore, compositis, lateribus punctis praeter marginalia utrinque 5 impressus, punctis minus subtilibus. Elytra thorace paulo longiora et scutellum subtiliter punctulata, minus subtiliter griseo-pubescentia, subnitida.... Abdomen densius- subtiliter punctulatum, longius densiusque griseo-pubescens, lateribus nigro-pilosellum, nitidulum, segmento ventrali ultimo apice subtestaceo. Pedes nigro-picei, coxis intermediis approximatis, tibiis omnibus spinulosis, geniculis tarsisque dilutioribus. Alae hyalinae.

Tarsi antici maris fortiter, femin a e leviter dilatati. 
* 94. Ph. turbidus: Niger, nitidus, antennarum basi apiceque, palpis pedibusque fulvis, elytris dense subtiliter punctatis, capile oblongo-ovato. - Long. 4 lin.

\section{Habitat in Madagascar, Dom. Goudot.}

Statura omnino Ph. fumarii, at paulo malor, niger, nitidus, capite thoraceque pernitidis, hoc certo situ griseo-subsericante. Antemnae capitis thoracisque longitudine, articulo tertio secundo paulo longiore, $4-10$ sensim paulo brevioribus et crassioribus, primis eorum cylindricis, sequentibus subobconicis, penultimis crassitie paulo longioribus, ultimo oblongo-ovato, apice subemarginato et inferne acuminato, fuscae, articulis tribus primis ultimoque saturate testaceis. Palpi testacei. Caput thorace angustius, oblongo-ovatum, leviter convexum, supra oculos utrinque punctis pluribus dispersis, inter oculos utrinque duobus transversim positis impressum. Thorax coleopteris angustior, latitudine baseos tertia fere parte longior, antrorsum leviter angustatus, lateribus levissime, basi modice rotundatus, apice truncatus, angulis anterioribus leviter deflexis posterioribusque subrotundatis, modice convexus, seriebus dorsalibus punctis 6 compositis, lateribus punetis praeter marginalia utrinque $\mathbf{5}$ impressus, punctis omnibus subtilioribus. Scutellum crebre punctatum, tenuiter nigro-pubescens. Elytra thorace tertia parte longiora, dense subtiliter punctata, subtiliter nigro-pubescentia. Abdomen crebrius subtiliter punctatum, tenuiter nigro-pubescens, nitidulum, metallico-subversicolor. Pedes fulvi, coxis anterioribus concoloribus, intermediis approximatis, tibiis omnibus spinulosis.

Maris tarsi antici fortiter dilatati, abdominis segmentum inferius quintum apice emarginatum. F emina latet.

V ariat immaturus piceo-testaceus, capite elytrisque nigricantibus.

\section{* 95. Ph. micans: Niger, opacus, capite thoraceque nitidis, sericantibus,} pedibus testaceis, capite ovato. - Long. $2 \frac{1}{2}$ lin.

Nordm. Symb. 102. 88. - Er. Col. March. I. 473. 40.

Staph. micans Grav. Micr. 25. 34. Mon. 76. 69. - Latr. Hist. nat. Crust. et Ins.

IX. 314. 39. - Gyll. Ins. Suec. II. 344. 60. - Sahlb. Ins. Fenn. I. 329. 67. -

Zetterst. Faun, Lappon. I. 78. 29. Ins. Lappon. 65. 39. - Mannerh. Brachelytr. 31.

76. - Boisd. et Lacord. Faun. Ent. Paris. I. 406. 40.

Staph. pullus Runde Brachelytr. Hal. 9. 48.

staph. luridus Runde Brachelytr. Hal. 9. 50.

Staph. varians var. y Payk. Mon. Staph. p. 46. Faun. Suec. III. p. 394.

Habitat in Europa.

Habitu $\mathrm{Ph}$. variantis et minoribus eius individuis aequalis, niger, opacus, capite thoraceque solis nitidis, hoc distinctius sericeo-micante. Antennae capitis thoracisque longitudine, articulo secundo tertio paulo longiore, 4-10 elongato obconicis, sensim paulo crassioribus at vix brevioribus, ultimo oblongo, apice emarginato et inferne subacuminato, nigrae. Palpi picei. Mandibulae piceae. Caput thorace minus et angustius, subovatum, leviter convexum, supra oculos utrinque punctis pluribus, inter oculos utrinque duobus, transversim positis impressum. Thorax basi coleopteris paulo angustior, latitudine baseos vix longior, antrorsum subangustatus, lateribins levissime, basi nodice rotundatus, apice truncatus, angulis anterioribus leviter deflexis 
posterioribusque rotundatis, leviter convexus, seriebus dorsalibus punctï $\mathbf{6}$, apicali saepius paulo remotiore, compositis, lateribus praeter marginalia punctis utrinque 4 impressus, punctis omnibus subtilioribus. Elytra thorace longiora et scutellum subtilissime confertissimeque punctata, pube subtili densa cinerascentia. Abdomen confertim subtilissime punctatum, subtiliter dense cinereo-pubescens, subtus segmentoum marginibus late rufo-ferrugineis. Pedes testacei, coxis nigris, intermediis approximatis, tibiis amnibus spinulosis. Alae hyalinae.

Tarsi antici maris fortiter, femina e vix dilatati.

Obs. Staph. pullus et luridus Runde, mihi ad examinandum a Dom. Zschorn benevole communicati, certe ad hanc speciem pertinent, Staph. velox Runde 1. c. p. 9. n. 49. quoque eidem subiungendus videtur; Staph. pusillus eiusdem etiam auctoris 1. c. p. 10. f. 54. partim ad Phil. micantem partim ad Phil. debilem revocandus est.

*96. Ph. fulvipes: Niger, antennarum basi, elylris pedibusque laete testaceo-rufis, capite ovato. - Long. $2 \frac{1}{2}$ lin.

Nordm. Symb. 102. 89. - Er. Col. March. I. 473. 41.

Staph. fulvipes Fab. Ent Syst. I. II. 526. 31. Syst. El. II. 597. 40. - Panz. Ent. Germ. 355. 21. Faun. Germ. 29. 9. (male) - Grav. Micr. 24. 33. Mon. 75.

66. - Latr. Hist. nat. Crust. et Ins. IX. 314. 38. - Gyll. Ins. Suec. II. 343. 59. - Sahlb. Ins. Fenn. I. 329. 56. - Mannerh. Brachelytr. 30. 75. - Boisd. et Lacord. Fuun. Ent. Paris. I. 402. 30.

St aph. mendax Runde Brachelytr. Hal. 10. 51.

Staph. flavopterus var. A Fourcr. Ent. Par. 1. 166. 10. (forte)

Le Staph. noir à étuis fauves et corselet strié Geoffr. Hist. Ins. I. p. 365.

Habitat in Europa frequens; in America septentrionali, Mus. Dom. Chevrolat.

Statura $\mathrm{Ph}$. micantis, niger, capite thoraceque nitidis, haud sericantibus. Antennae capitis thoracisque longitudine, articulo tertio secundo paululum longiore, 4-10 subcylindricis, sensim paulo brevioribus et crassioribus, penultimis crassitie parum longioribus, ultimo oblongo, apice truncato et inferne acuminato, nigrae, articulis tribus primis testaceis. Palpi testacei. Caput thorace minus et angustius, ovatum, supra oculos utrinque punctis parcis, inter oculos utrinque duobus transversim positis impressum. Thorax basi coleopteris paulo angustior, latitudine baseos parun longior, antrorsum subangustatus, lateribus levissime, basi fortius rotundatus, apice truncatus, angulis anterioribus leviter deflexis posterioribusque subrotundatis, leviter convexus, seriebus dorsalibus punctis 6, primo parum remotiore, compositis, lateribus punctis praeter marginalia utrinque 5 impressus, punctis omnibus subtilioribus. Scutellum confertim punctulatum, nigrum, griseopubescens. Elytra thorace paululum longiora, subtiliter confertim punctata, lacte testaceo-rufa, subtiliter testaceo-pubescentia. Abdomen confertim subtiliter punctatum, tenuiter griseo-pubescens. Pedes testacei, coxis anterioribus concoloribus, intermediis approximatis, tibiis omnibus subtiliu spinulosis.

Tarsi antici maris fortius, feminae vix dilatati.

V ariat antennarum articulıs 3 primis piceis. 
* 97. Ph. brunneus: Piceus, nitidus, antennarum basi, pedibus abdominisque segmentorum marginibus testaceis, thorace rufescenti-piceo. Long. $2 \frac{1}{2}$ lin.

St aph. brunneus Grav. Micr. 172. 26. Mon. 57. 22.

Staph. sericans Grav. Micr. 171. 25. Mon. 59. 25.

Habitat in America septentrionali.

Statura omnino $\mathrm{Ph}$. debilis. Antennae capite thoraceque paulo breviores, articulo tertio secundo paululum longiore, 4-10 sensim paulo brevioribus at vix crassioribus, penultimis crassitie subbrevioribus, nltimo apice truncato et inferne subacuminato, fuscae, basi testaceae, apice ferrugineae. Os obscure testaceum. Caput maris thoracis fere latitudine, orbiculatum, feminae thorace angustius, ovatum, utrinque supra oculos punctis paucis, inter oculos punctis $\mathbf{4}$, intermediis magis distantibus, notatum, nigrum, nitidum. Thorax coleopteris paulo angustior, latitudine baseos vix longior, antrorsum subangustatus, lateribus subrectis, basi cum angulis posterioribus rotundatus, apice truncatus, angulis anterioribus deflexis, subrotundatis, modice transversim convexus, seriebus dorsalibus punctis 6 , apicali paulo remotiore compositis, lateribus punctis praeter marginalia utrinque 5 impressus, punctis omnibus minus subtilibus, plerumque rufo-, rarius nigro-piceus, nitidus. Elytra thorace vix longiora et scutellum crebre subtilius punctata, minus subtiliter griseo-pubescentia, fusco-picea. Abdomen subtiliter punctulatum, densius griseo-pubescens, piceum, segmentis omnibus rufo-marginatis. Pectus piceum. Pedes cum coxis anteriaribus testacei, coxis intermediis approximatis, tibiis omnibus spinulosis.

Tarsi antici maris fortiter, feminae leviter dilatati.

Obs. Staph. brunneus et sericans Grav. nullo puncto differunt. Thoracem sericeo - micantem, quem Grav. apud St. sericantem suum laudat, equidem in eodem specimine observare nequeo. Conf. Grav. Mon. 59. 25.

* 98. Ph. fimbriolat us: Piceus, nitidus, antennarum basi, pedibus elytrorumque margine tenui apicali testaceis, sutura abdominisque segmentorum marginibus ferrugineis, capile orbiculato. - Long. $2 \frac{1}{4}$ lin.

Habitat in Madagascar, Dom. Goudot.

Praecedenti affinis, at minor, $\mathrm{Ph}$. aterrimo parum minor, licet minus gracilis. Antennae capite thoraceque breviores, articulo secundo tertioque aequalibus, $4-10$ sensim paulo brevioribus, at vix crassioribus, primis eorum subcylindricis, sequentibus subobconicis, penultimis crassitie vix brevioribus, ultimo subovato, apice subemarginato et inferne subacuminato, fuscae, articulis 3 primis testaceis, ultimo ferrugineo. Caput thoracis latitudine, suborbiculatum, utrinque supra oculos punctis pluribus sparsis, inter oculos utrinque duobus transversim positis notatum, fronte anterius medio subimpressa, nigro-piceum, pernitidum, ore rufo-piceo, palpis testaceis. Thorax coleopteris dimidio prope angustior, latitudine tertia parte longior, lateribus parallelis, rectis, basi rotundatus, apice truncatus, angulis anterioribus leviter deflexis posterioribusque subrotundatis, leviter convexus, seriebus dorsalibus punctis 6 , antico remotiore et subtuliore, reliquis sat fortibus, compositis, lateribus punctis praeter marginalia utrinque 5 suhtilioribus impressus, piceus, pernitidus. Scutellum nigro-piceum, parce subtiliterque punctatum, 
parce pubescens. Elytra thoracis longitudine, minus confertim profundius punctata, parce griseo-pubescentia, fusco-picea, nitida, humeris suturaque rufescentibus, margine angusto apicali testaseo. Abdomen parce subtiliter punctulatum, parcius longiusque griseo-pubescens, minus nitidum, nigrum, segmentis omnibus apice ferrugineo-marginatis. Pedes testacei, tibiis omnibus spinulosis.

Tarsi antici maris simplices, femin a latet.

* 99. Ph. cribricollis: Nilidus, niger, antennarum basi apiceque oreque testaceis, thorace, elytrorum abdominisque basi rufis, pedibus albidis. Long. $3 \frac{1}{3}$ lin.

Habitat in Columbia, Dom. Moritz, in Mexico, coll. Dom. Chevrolat.

Statura et affinitas $\mathrm{Ph}$. laeti. Antennae capite thoraceque parum breviores, validiores, articulo tertio secundo paulo longiore, 4-10 subcylindricis, sensim paulo brevioribus et crassioribus, penultimis crassitie perparum longioribus, ultimo apice inferne abrupte acuminato, brumneae, articulis tribus basalibus duobusque apicalibus testaceis. Mandibulae falcatae, acutae, cum toto ore rufo-testaceae. Caput thorace latius, orbiculatum, nigro-piceum, nitidissimum, utrinque parce grosseque punctatum, inter oculos punctis ntrinque duobus transversim positis impressum, fronte antice longitudinaliter fortiter sulcata. Thorax coleopteris duplo angustior, latitudine sesqui longior, lateribus ante medium leviter rotundatis, pone medium subsinuatis, basi rotundatus, apice truncatus, angulis anterioribus fortiter rotundatis, posterioribus obtusis, convexus, seriebus dorsalibus punctis 6 , apicali parum remotiore, compositis, lateribus punctis praeter marginalia utrinque 6 impressus, punctis omnibus grossis et profundis, rufus, nitidissimus, metallico-lucidus. Scutellum crebre punctatum, rufum. Elytra thoracis longitudine, confertim fortiter punctata, tenniter griseo-pubescentia, nigra, basi rufa. Abdomen nitidum, segmentis singulis basi subtilius punctulatis, tribus primis rufis, parce pubescentibus, reliquis nigris, densius nigro-pubescentibus, quinto margine apicali testaceo. Pectus nigrum. Pedes elongati, graciles, albidi, femoribus tibiisque apice fuscescentibus, coxis anterioribus testaceis, posticis rufis, coxis intermediis modice distantibus, tibiis omnibus subtiliter spinulosis, tarsis anticis in utroque sexu simplicibus.

Obs. Nomine Cafii cribricollis hanc speciem sibi impositam esse monuit D. Com. Dejean.

100. Ph. angusticollis: Niger, nitidus, antennis apice ferrugineis, thorace abdominisque segmentis 3 primis rufis, pedibus albidis, geniculis fuscis. - Long. $3 \frac{1}{3}$ lin.

Habitat in Mexico, collect. Dom. Chevrolat.

Statura et summa affinitas praecedentis. Antennae capite thoraceque parum breviores, validiusculae, articulo tertio secundo paulo longiore, 4-10 subcylindricis, sensim paulo brevioribus, at parum crassioribus, penultimo crassitie parum longiore, ultimo apice inferne abrupte acuminato, nigrae, articulo secundo basi testaceo, ultimis duobus ferrugineis. Mandibulae et palpi piceo-testacei. Caput thorace latius, orbiculatum, posterius punctis parcis profundis, inter oculos utrinque duobus transversim positis impressum, fronte an- 
tice canaliculata, nigro-subaeneum, nitidissimum. Thorax coleopteris duplo prope angustior, latitudine longior, basin versus subangustatus, lateribus anterius leviter rotundatis, posterius subsinuatis, basi leviter rotundatus, angulis posterioribus obtusis, apice cum angulis anterioribus rotundatus, modice convexus, seriebus dorsalibus punctis 6, apicali paulo remotiore, compositis, lateribus punctis praeter marginalia utrinque 6 vel 7 impressus, punctis omnibus sat fortibus profundisque, rufus, nitidus. Scutellum confertim punctatum, obscure -rufum. Elytra thorace paulo longiora, minus crebre sat fortiter punctata, tenuiter nigro-pubescentia, nigra, nitida, summa basi obscure rufa. Abdomen segmentis anterioribus tribus sublaevibus, laete rufis, nitidis, posterioribus parcius punctulatis, nigro-pubescentibus, nigris, penultimo apice testaceo. Pectus nigrum. Pedes elongati, graciles, albidi, femoribus apice fuscis, coxis intermediis sat distantibus, tibiis omnibus subtiliter spinulosis, tarsis anticis in utroque sexu simplicibus.

* 101. Ph. tenuis: Nitidus, niger, thorace, pedibus elytrisque rufis, his basi nigris, capite ovato. - Long. $2 \frac{1}{3}$ lin.

Nordm. Symb. 103. 91. - Er. Col. March. I. 474. 42.

Staph. te nuis Fab. Ent. Syst. I. II 528. 43. Syst. El. II. 599. 53. - Panz. Ent. Germ. 357. 33. - Grav. Micr. 39. 58. Mon. 72. 59. - Latr. Hist. nat. Crust. et Ins. IX. 322. 63. - Boisd. et Lacord. Faun. Ent. Paris. I. 403. 32. - Runde Brachelytr. Hal. 10. 53.

Paederus dimidiatus Panz. Faun. Germ. 27. 24. Ent. Germ. 362. 3.

Habitat in Germania.

Antennae capite thoraceque paulo breviores, articulo secundo tertioque subaequalibus, sequentibus sensum brevioribus et crassioribus, penultimis lon-* gitudine crassioribus, ultimo subovato, apice emarginato et inferne acuminato, nigrae, articulis duobus primis obscure rufis. Caput thorace paulo minus et angustius, ovatum, supra oculos utrinque punctis subtilibus pluribus, inter oculos utrinque duobus transversim positis impressum, nigrum, nitidum. Thorax coleopteris paulo angustior, latitudine longior, lateribus parallelis, subrectis, basi cum angulis posterioribus rotundatus, basi truncatus, angulis anterioribus subrotundatis, convexus, seriebus dorsalibus punctis 6, apicali paululum remotiore, compositis, lateribus punctis praeter marginalia utrinque 5 impressus, punctis omnibus subtilibus, rufus, nitidus. Scutellum confertim punctulatum, nigrum. Elytra thoracis longitudine, subdepressa, densius subtilissime punctata, subtiliter griseo-pubescentia, dimidiatim basi nigra, apice rufa. Abdomen dense subtiliter punctatum, nigrum, subnitidum, subtiliter densius griseo-pubescens, dorso pilis dispersis erectis nigris instructum. Pectus nigrum. Pedes graciles rufi, coxis anterioribus concoloribus, intermediis approximatis, tibiis omnibus parce subtiliterque spinulosis.

Tarsi antici maris fortiter, feminae levissime dilatati.

*102. Ph. pullus: Niger, nilidus, elytris nigro-subvirescentibus, thorace ollongo, convexo, capile subovato. - Long. $2 \frac{1}{3}$ lin.

Nordm. Symb. 104. 92. - Er. Col. March. I. 475.43.

Habitat in Germania, Gallia. 
Statura omnino praecedentis, miger, nitidus, capite thoraceque pernitidis. Antennae vix capitis thoracisque longitudine, articulo secundo tertioque subaequalibus, 4-10 subcylindricis, sensim panlo brevioribus crassioribusque, penultimis crassitie paulo brevioribus, ultimo apice subemarginato et inferne acuminato, nigrae. Palpi nigri. Caput thorace paulo minus et angustius, ovatum, pone oculos lateribus utrinque confertim subtiliter punctatum, supra utrinque supra oculos punctis paucis, inter oculos utrinque duobus approximatis transversim positis subtilioribus impressum. Thorax coleopteris dimidio propé angustior, latitudine paulo longior, lateribus parallelis, subrectis, basi cum angulis posterioribus rotundatus, apice truncatus, angulis anterioribus leviter deflexis, rotundatis, convexus, seriebus dorsalibus punctis $\mathbf{6}^{6}$, apicali paulo remotiore, compositis, lateribus punctis praeter marginalia utrinque 5 impressus, punctis omnibus subtilibus. Scntellum confertissime subtiliter punctatum, subtiliter griseo-pubescens. Elytra thoracis longitudine, subtilius minus dense punctata, nigro-subvirescentia, subtus griseo-pubescentia. Abdomen subtiliter punctatum, pube grisea micante densius vestitum, dorso pilis erectis nigris sparsum. Pedes graciles, nigri ant nigro-picei, coxis intermediis approximatis, tibiis omnibus parce spinulosis.

Tarsi antici maris fortiter, femin a e leviter dilatati.

* 103. Ph. lustralis: Nigro-subaeneus, nitidus, elytris fusco-aeneis, pedibus flavis, thorace oblongo, apice attenuato, capite subovalo. Long. $2 \frac{1}{2}$ lin.

\section{Habitat in ins. Puerto Rico, Dom. Moritz.}

Statura fere praecedentis, nigro-subaeneus, capite thoraceque nitidssimis, elvtris fuscis, nitore aeneo perfusis, seu aeneis, basi fuscescentibus. Antennae capite thoraceque parum breviores, articulo tertio secundo longiore, 4-10 subcylindricis, sensîn paulo brevioribus et crassioribuis, penultimis crassitie vix longioribus, ultimo apice oblique truncato et inferne acuminato, nigrae, articulo primo piceo. Mandibulae et palpi piceo-testacei. Caput thoracis latitudine, subobovatum, supra oculos utrinque sparsim punctatum, anterius inter oculos punctis 4 subtilibus, intermediis fortius distantibus, impressum. Thorax coleopteris duplo fere angustior, latitudine sesqui longior, lateribus rectis, parallelis, basi cum angulis posterioribus rotundatus, angulis anterioribus deflexis, fortiter rotundatis, convexus, seriebus dorsalibus punctis 6, apicali remotiore, compositis, lateribus punctis praeter marginalia utrinque 5 impressus, punctis omnibus minus subtilibus. Scutellum subtiliter punctulatum. Elytra thoracis longitudine, dense profundius punctatata, minus subtiliter griseo-pubescentia. Abdomen crebrius subtiliusque punctatum, parcius griseo-pubescens. Pedes flavo-testacei, coxis anterioribus concoloribus, intermediis approximatis, tibiis omnibus spinulosis, tarsis anticis in utroque sexu simplicibus.

Abdominis segmentum inferius sextum maris apice profunde bisinuatum, femina integrum.

* 104. Ph. trepidus : Elongatus, niger, nitidus, elytris obscure virescenlibus, antennarum basi pedibusque testaceis, thorace oblongo, capite ovato. - Long. 3 lin.

Habitat in Americae ins. St. Johannis et Puerto Rico, Dom. Moritz. 
Statura et affinitas Ph. quisquiliarii. Niger, capite thoraceque nitidissimis, elytris obscure viridi-aeneis, subnitidis. Antennae capitis thoracisque longitudine, articulo tertio secundo longiore, $4-10$ subobconicis, sensim paulo brevioribus et crassioribus, penultimis crassitie haud brevioribus, ultimo oblongo, apice oblique subemarginato et inferne acuminato, nigrae, articulo primo testaceo, interdum medio piceo, ultimo plerumque ferrugineo. Palpi piceo-testacei. Mandibulae piceae. Caput thorace parum angustius, ovatum, utrinque supra oculos, lateribus verticeque crebrius punctatum, inter oculos punctis utrinque duobus transversim positis impressum. Thorax coleopteris dimidio angustior, latitudine plus sesqui longior, lateribus parallelis, subrectis, basi rotundatus, apice truncatus, angulis anterioribus leviter deflexis posterioribusque subrotundatis, leviter convexus, seriebus dorsalibus punctis 6, apicali remotiore, compositis, lateribus punctis praeter margma.. lia utrinque 5 vel 6 impressus, punctis omnibus subtilioribus. Scutellum nigrum, subtiliter punctulatum, subtiliter nigro-pubescens. Elytra thorace paulo longiora, subtiliter dense punctata, densius subtiliter nigro-pubescentia. Abdomen subtiliter punctulatum, subtiliter fusco-pubescens. Pedes testacei, coxis anterioribus, femoribus posticis, interdum etiam tibiis piceis, coxis intermediis approximatis, tibiis omnibus spinulosis. Alae fuscae.

Tarsi antici maris modice, feminae leviter dilatati.

* 105. Ph. alumnus: Niger, nitidus, antennis basi testaceis, pedibus fusco-testaceis, elytris confertim subtiliter punctatis, opacis, capite subovato. - Long. $2 \frac{1}{2}$ lin.

Habitat in ins. Puerto Rico, Dom. Moritz.

$\mathrm{Ph}$. micanti affinis, at paulo gracilior, niger, nitidus, capite thoraceque haud sériceo-micantibus. Antennae capitis thoracisque longitudine, articulo tertio secundo paulo longiore, $\mathbf{4} \mathbf{- 1 0}$ subobconicis, sensim parum brevioribus et crassioribus, omnibu's crassitie longioribus, ultimo oblongo, apice oblique truncato et inferne acuminato, nigrae, articulis duobus basalıbus testaceis, supra infuscatis. Palpi piceo-testacei. Caput thorace paulo angustius, bre viter subovatum, utrinque supra oculos parcius punctatum, inter oculos punetis utrinque duobus transversim positis impressum. Thorax coleopteris dimidio angustior, latitudine paulo longior, lateribus parallelis, subrectis, basi cum angulis posterioribus rotundatus, apice truncatus, angulis anterioribus leviter deflexis, rotundatis, modice convexus, seriebus dorsalibus punctis $\mathbf{6}$ compositis, lateribus punctis praeter marginalia utrinque 5 impressus, punctis omnibus subtilioribus. Elytra thorace paulo longiora et scutellum subtiliter dense punctata, densius subtiliter griseo-pubescentia, subopaca. Abdomen subtuliter crebrus punctulatum, nitidulum, dessius griseo-pubescens, segmentis ventralibus piceo-marginatis. Pedes fusco-testacei, geniculis tarsisque dilutioribus, coxis omnibus nigris, coxis intermediis approximatis, ti. biis omnibus spinulosis.

Tarsi antici maris fortiter, feminae modice dilatati.

Obs. Staph. Havaniensis Laporte, Etud. Ent. 116. 7, e Cuba, forte ad hanc, forte etiam ad praecedentem speciem pertinet, descriptione manca ambiguus. 
* 106. Ph. luxurians: Elongatus, niger, nitidus, capite thoraceque subaeneis, elylris cyaneis, antennis articulo apicali luteo, capile suborbiculato. - Long. 3 lin.

Habitat in Sardinia, Dom. Prof. Gené.

Statura omnino $\mathrm{Ph}$. ebenini et minoribus eius individuis aequalis, niger, nitidus, capite thoraceque supra nigro-aeneis, politis. Antennae capitis thoracisque prope longitudine, articulo tertio secundo paulo longiore, 4-10 subcylindricis, sensim brevioribus et paulo crassioribus, penultimis crassitie brevioribus, ultimo ovato, apice leviter emarginato et inferne acuminato, nigrae, articulo ultimo laete luteo. Palpi nigri. Caput thorace paulo angustius, suborbiculatum, supra oculos utrinque punctis pluribus dispersis, inter oculos utrinque duobus transversim positis impressum. Thorax latitudine panlo longior, coleopteris dimidio angustior, antrorsum subangustatus, basi et lateribus leviter rotundatus, apice truncatus, angulis anterioribus deflexis posterioribusque subrotundatis, modice convexus, seriebus dorsalibus punctis 5 aequaliter distantibus compositis, lateribus punctis praeter marginalia utrinque 5 impressus, punctis omnibus minus subtilibus. Scutellum punctulatum, nigrum, nigro -pubescens. Elytra thoracis longitudine, minus confertim punctata, cyanea, nitida, parce subtiliterque nigro-pubescentia. Abdomen nitidum, supra crebrius, subtus pàrce punctatum, parce nigro-pubescens. Pedes nigri, coxis intermediis approximatis, tibiis omnibus spinulosis, tarsis piceis.

Tarsi antici feminae leviter dilatati. Mas latet.

* 107. Ph. exiguus: Niger, nitidus, pedibus teslaceis, elytris viridi-aeneis, parcius punctatis, capite ovato. - Long. 2 lin.

Nordm. Symb. 105. 93. - Er. Col. March. I. 475. 44.

\section{Habitat in Germania.}

Habitu fere $\mathrm{Ph}$. micantis, at dimidio minor, niger, capite thoraceque pernitidis, hoc nullo modo sericeo-micante. Antennae capite thoraceque breviores, articulo tertio secundo paulo longiore, 4- 10 sensim paulo brevioribus et crassıoribus, penultimis crassitie parum brevioribus, ultimo ovato, apice leviter emarginato et inferne acuminato, nigrae, articulıs tribus primis fusco-piceis. Palpi testacei. Mandibulae rufo-piceae. Caput thorace paulo minus et angustius, oblongo-ovatum, supra oculos utrinque punctis nonnullis, inter oculos utrinque duobus approximatis oblique positis impressum. Thorax coleopteris angustior, latitudine paulo longior, antrorsum subangustatus, lateribus subrectis, basi cum angulis posterioribus rotundatus, apice truncatus, angulis anterioribus modice deflexis, subrotundatis, modice convexus, seriebus dorsalibus punctis 6 compositis, lateribus punctis praeter marginalia utrinque 6 , interioribus eorum 4 in seriem alteram longitudinalem dispositis, impressus, punctis omnibus subtilioribus. Scutellum subtiliter punctulatum. Elytra thoracis longitudine, minus confertim subtilius punctata, minus subtiliter griseo-pubescentia, viridi-aenea, nitidula. Abdomen subtilıter punctulatum, griseo-pubescens, subtus apice testaceum. Pedes testacei, coxis anticis piceis, intermediis leviter distantibus, tibiis omnibus spinulosis.

Tarsi antici feminae simplices. Mas latet. 
* 10s. Ph. astutus: Elongatus, niger, nitidus, antennis basi piceis, ore pedibusque teslaceis, thorace oblongo, capite ovato. - Long. 3 lin.

Habitat in Austria, Dom. Ullrich.

$\mathrm{Ph}$. aterrimo affinis, at plus duplo maior, et magis elongatus, niger, nitidus. Antennae capite thoraceque parum breviores, articulo tertio secundo sesqui prope longiore, $4-10$ subobconicis, sensim paulo brevioribus et crassioribus, penultimis crassitie parum longioribus, ultimo ovato, apice subemarginato et inferne acuminato, fuscae, basi piceae. Os rufo-testaceum, jalpis testaceis, naxillaribus articulo ultimo fortiter acuminato. Caput thoracis fere latitudine, subovatum, pone oculos utrinque punctis pluribus, inter oculos utrinque duobus approximatis oblique positis impressum, fronte medio obsolete canaliculata. Thorax coleopteris dimidio angustior, latitudine sesqui longior, basin versus subangustatus, lateribus subrectis, basi cum angulis posterioribus rotundatus, apice truncatus, angulis anterioribus leviter deflexis, rotundatis, leviter convexus, seriebus dorsalibus punctis 6 compositis, lateribus punctis praeter marginalia utrinque 5 impressus, punctis omnibus minus subtilibus. Scutellum crebre punctulatum. Elytra thorace paulo longiora, crebre punctata, minus subtiliter griseo-pubescentia, nigro-picea. Abdomen subtiliter punctulatum, longius griseo-pubescens, segmentorum marginibus piceis, apice summo testaceum. Pedes cum coxis anterioribus rufo-testacei, femoribus posticis infuscatis, coxis intermediis approximatis, tibiis omnibus spinulosis. Alae hyalinae.

Tarsi antici feminae simplices. Mas latet.

Obs. Differt a $\mathrm{Ph}$. aterrimo statura maiore et magis elongata, thoracis angulis anterioribus magis rotundatis, elytris longioribus et crebrius minusque fortiter punetatis.

* 109. Ph. aterrimus: Elongatus, niger, antennis basi piceis, pedibus testaceis, capite ovato. - Long. 2 lin.

Er. Col. March. I. 476. 45.

St aph. at errimus Grav. Micr. 41. 62. - Latr. Hist. nat. Crust. et Ins. IX. 328.

80. - Gyll. Ins. Suec. II. 349. 65. - Sahlb. Ins. Fenn. I. 331. 62. - Zetterst.

Faun. Lappon. I. 79. 31. Ins. Lappon. 65. 41. - Boisd. et Lacord. Faun. Ent.

Paris. I. 408. 43.

Cafius at errimus Mannerh. Brachelytr. 32. 5. - Runde Brachelytr. Hal. 11. 2.

Gyrohypnus aterrimus Nordm. Symb. 126. 31.

Staph. nigritulus Grav. Micr. 41. 61. Mon. 94. 90. - Latr. Hist. nat. Crust. et Ins. IX. 328. 79.

Cafius nigritulus Mannerh. Brachelytr. 32. 6.

Gyrohypnus nigritulus Nordm. Symb. 126. 32.

Cafius pumilus Mannerh. Brachelyb. 32. 4.

Philouth. trossulus Nordm. Symb. 102. 90.

Habitat in Europa frequens; ex America septentrionali etiam a Dom. Zimmermann missus.

Minutus, niger, nitidus. Antennae capite thoraceque paulo breviores, articulo secundo tertioque subaequalibus, $\mathbf{4}-\mathbf{1 0}$ sensim paulo brevioribus et crassioribus, penultimis crassitie haud longioribus, ultimo ovato, apice truncato et inferne subacuminato, nigrae, basi piceae. Palpi piceo-testacei. Caput maris thoracis latitudine vel interdum eodem latius, marium debilio- 
rum et feminae thorace paulo angustius, depressiusculum, utrinque supra oculos punctis pluribus sparsis, inter oculos utrinque duobus oblique positis impressum, fronte maris medio obsolete canaliculata. Thorax coleopteris dimidio angustior, latitudine sesqui longior, basin versus subangustatus, lateribus subrectis, basi cum angulis posterioribus rotundatus, apice truncatus, angulis anterioribus leviter deflexis, subrotundatis, leviter convexus, seriebus dorsalibus punctis 6 , apicali paulo remotiore, compositis, lateribus punctis praeter marginalia utrinque 5 impressus, punctis omnibus minus subtilibus. . Scutellum punctulatum. Elytra thorace paulo longiora, minus dense sat fortiter punctata, tenuiter minus subtiliter griseo-pubescentia. Abdomen subtilius punctulatum, dense griseo-pubescens, subtus segmentis singulis piceo-marginatis. Pedes testacei, coxis intermediis approximatis, tibiis omnibus spinulosis, tarsis anticis in utroque sexu simplicibus.

Variat thoracis serie dorsali altera $\tilde{5}$-punctata.

Obs. 1. Magnitudine et capitis forma instabilis: caput maribus maioribus maius, thorace paulo latius, antrorsum subdilatatum, minoribus thoracis latitudine, oblongosubquadratum, minimis thorace paulo angustius, oblongo - ovatum ut in femina.

2. Ph. trossulus Nord. a femina non distinctus, Caf. pumilus Mannerh. ad individua feminea minus matura spectare videtur.

Species mihi invisae.

110. Ph. puella: Niger, subnitidus, ore tarsisque fusco-ferrugineis, elytris nigris, subopacis, subtiliter punctulatis, thoracis lateribus multipunclatis, capite subovato.

Nordm. Symb: 101. 87. - Er. Col March. 1. 472. 39.

\section{Habitat Berolini.}

$\mathrm{Ph}$. virgini simillimus et valde affinis. Caput, palpi, oculi, antennae et elytra ut in $\mathrm{Ph}$. virgine omnino. Thorax nonnihil brevior et latior, supra paulo minus convexus, angulis anticis minus quam in illo deflexis, sericeo-micans, lateribus obliquis; postice obtuse rotundatus, intra angulum anticum et versus medium laterum puncta $12-14$ sine ordine sparsa et series dorsales punctis $6-7$ impressis, omnibus sat conspicuis et profundis. Pedes nigro-picei, tarsis dilutioribus, ceterum ut in Ph. virgine. Species haec nisi quod ad puncturam thoracis attinet vix a $\mathrm{Ph}$. virgine differt. - Individuum unicum, femina, tempore vernali, anno 1830, in quisquiliis lectum. (Nordm.)

111. Ph. (?) stenoides: Nitidus, oculis magnis prosilientibus. - Long, fere 6 lin.

Habitat in Java.

Caput forma tota capitis Stenorum, orbiculatum, et oculis magnis globosis fere transversum, thorace latius, punctum, viridi-subcupreo-aeneum, subtus nigrum, clypeo, labro et primo antennarum articulo (reliqui articuli desunt) testaceis, mandibulis falcatis, longis, acutis; nigris, maxillis nigris, apice rufo-testaceis, palpis longis, gracilibus, filiformibus, articulis duobus ultimis aequali longitudine et crassitie, haud clavatis, articulis omnibus nigris, summo apice rufo-testaceo. Thorax convexus, quadratus, basi rotun- 
datus et paulo angustior quam apice, coleopteris angustior et brevior, nitidus, viridi-aeneus, in angulis apicis multipunctus, seriebus dorsalibus 6-punctis, et praeterea punctis quibusdam vagis maioribus impressus. Scutellum pallide viridi-sericans. Coleoptera quadrata, elytris planiusculis, punctis, viridicupreo-aenescentibus, macula magna disci pallida viridi-sericante. Abdomen nigrum, pectore sub-flavo-sericante, segmentorum marginibus testaceis. Pedes graciliores quam reliquis Staphylinis, capitibus femorum nigris, femoribus anterioribus testaceis, margine superiore nigro, posticis testaceis, geniculis nigris, tibiis anterioribus testaceis, margine superiore nigko, posticis testaceis, apice nigro, tarsis obscuris, anticis fossoriis. (Grav.)

Obs.' An huius generis?

\section{7) Thorax seriebus dorsalibus multipunctatis.}

* 112. Ph. helvolus: Testaceus, nitidus, thorace utrinque parce punctato,

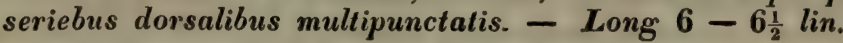

Habitat in Madagascar, Dom. Goudot.

Corpus totum testaceum, nitidum, capite thoraceque rufo testaceis, abdominis leviter versicoloris segmentis basi fusco-testaceis. Antennae capite sesqui longiores, articulo tertio secundo sesqui longiore, 4 et 5 subcylindricis, longitudine decrescentibus, sexto praecedenti aequali, subobconico, 7- 10 obconicis, crassitie brevioribus, ultimo subovato,-apice compresso, testaceae, ante apicem fuscescentes. Caput maris magnum, thorace latius, transversim subquadratum, antrorsum dilatatum, antice inter oculos transversim impressum, crebrius punctatum, mandibulis valde elongatis, falcatis, acutis, piceis, - feminae thoracis latitudine, subquadratum, utrinque vage punctatum, supra antennarum insertionem utrinque oblique transversim impressum, impressione punctata, mandibulis mediocribus, piceis. Thorax coleopteris angustior, latitudine vix brevior, lateribus leviter, basi cum angulis posterioribus fortius rotundatus, apıce truncatus, angulis anterioribus subrectis, modice convexus, seriebus dorsalibus irregulariter 11-12-punctatis, lateribus punctis praeter marginalia fere totidem, in lineam flexuosam dispositis, impressus. Scutellum crebre punctatum. Elytra thorace sesqui longiora, minus fortiter crebrius punctata, fulvo-pubescentia. Abdomen parcius subtiliter punctulatum, parce pubescens. Pedes dilutiores, coxis intermediis sat distantibus, tibiis omnibus subtiliter spinulosis.

Tarsi antici maris dilatati, femina e simplices, femora intermedia maris basi cum trochanteribus dilatati, trochanteres postici apice dentati, femora postica pone medium dente acuto fortiter hamato armata.

113. Ph. mirabilis: Rufus, nilidus, capite pedibusque nigris, antennis abdomineque apice albidis, ante apicem nigris, elytris splendidis, viridibus, fascia media cuprea. - Long. 5 lin.

Habitat Bogatae in Columbia interiore, Staph. mirabilis Dej. nomine a Dom. Buquet. communicatus.

Species pulcherrima, statura Ph. Baltimorensi affinis. Antennae capite sesqui longiores, articulis duobus primis testaceis, apice piceis, sequentibus tribus nigris, reliquis sex lutescenti-albidis. Palpi testacei. Caput thoracis 
latitudine, suborbiculatum, utrinque parcius inaequaliter punctatum, fronte medio longitudinaliter late laevi, inter oculos punctis nonnullis vagis notata, nigrum, pernitidum. Thorax coleopteris duplo angustior, latitudine paulo longior, basin versus subangustatus, lateribus subrectis, basi rotundatus, apice truncatus, angulis anterioribus leviter deflexis, subrotundatis, posterioribus obtusis, modice convexus, seriebus dorsalibus irregularibus, $10-11$-punctatis, lateribus punctis praeter marginalia utrinque fere 16, partim subseriatis, impressus, punctis omnibus subtilioribus, rufus, nitidus. Scutellum rufum, parce subtiliter punctulatum. Elytra ampla, thorace sesqui longiora, parcius subtiliter punctata, parce nigro-griseoque-pubescentia, laete splendideque viridia, fascia media lata cupreo-aurea fulgente. Abdomen coleopteris angustius, apicem versus angustatum, infra parcius punctulatum, supra segmentis tribus primis laevissimis, quarto et quinto basi dense punctulatis, rufum, segmento quinto basi nigro, apice dimidiato-, sexto toto albido-flavo. Pectus rufum. Pedes nigri, coxis anticis testaceis, posterioribus rufis, intermediis modice distantibus, tibiis anticis inermibus, posterioribus spinulosis. Alae fusco-hyalinae.

Tarsi antici maris modice dilatati; femin a latet.

*114. Ph. bicolor: Rufus, capite thoracegue cyaneis, abdomine cingulo nigro ante apicem. - Long. 6 lin.

Staph. bicolor Laporte Etud. Ent. 115. 6.

Habitat in Cayenna, Dom. Banon.

Statura omnino sequentis. Antennae breviusculae, capite paulo longiores, apicem versus sensim leviter incrassatae, articulo tertio secundo longiore, quarto subgloboso, 5- 10 transversis, sensim crassioribus, ultimo breviter subacuminato, apice abrupte acuminato, articulis 4 primis rufis, reliquis nigris. Palpi rufi. Mandibulae piceae. Labrum rufum. Caput thorace paulo angustius, suborbiculatum, supra depressiusculum, punetis raris dispersis impressum, laete cyaneum, parum nitidum, subtus nigrum, nitidum. Thorax coleopteris dimidio angustior, latitudine parum longior, lateribus anterius leviter rotundatis, pone medium subsinuatıs, basi rotundatus, apice truncatus, angulis anterioribus deflexis, subrectis, posterioribus subrotundatis, parum convexus, seriebus dorsalibus circiter 9-punctatis, lateribus punctis praeter marginalia utrinque fere 15 dispersis notatus, punctis omnibus fortioribus, laete cyaneus, subnitidus. Scutellum parcius punctatum, nigrum. Elytra thoracis longitudine, profundius dense punctata, rufo-testacea, tenuiter fulvo-pubescentia. Abdomen parcius punctatum, tenuiter fulvopubescens, rufum, segmento quarto apice, quinto basi nigris, hoc apice sextoque toto testaceis. Pectus rufum, antice nigricans. Pedes ruf, coxis anterioribus obscurioribus, intermediis sat distantibus, tibiis omnibus spinulosis, tarsis anticis in utroque sexu leviter dilatatis.

* 115. Ph. analis: Niger, nitidus, capite, thorace elytrisque cyaneis, abdomine segmentis ultimis duobus rufis. - Long. 7 lin.

Habitat in Cayenna, Dom. Buquet; in Columbia, Dom. Moritz.

Niger, nitidus, capite, thorace elytrisque supra virescenti-coeruleis, ano rufo. Antennae capite sesqui fere longiores, apicem versus sensim leviter 
incrassati, articulo tertio paulo longiore, quarto subgloboso, 6-10 transversis, sensim brevioribus at vix crassioribus, ultimo breviore, apice abrupte acuminato, nigrae. Palpi rufo-picei. Mandibulae breves, piceae. Caput thorace paulo angustius, suborbiculatum, depressiusculum, fronte posterius laevi, anterius punctis raris impressa, pone oculos utrinque crebrius punctatum. Thorax coleopteris dimidio angustior, latitudine paulo longior, basin versus subangustatus, lateribus anterius leviter rotundatis, pone medium subsinuatis, basi rotundatus, apice truncatus, angulis anterioribus deflexis, subrectis, posterioribus subrotundatis, transversim con-vexus, seriebus dorsalibus minus regularibus, circiter 9-punctatis, lateriribus punctis praeter marginalia utrinque fere 18 irregulariter dispersís impressus, punctis omnibus subtilioribus. Scutellum nigrum, crebre punctatum, parce pubescens. Elytra thoracis longitudine, crebre profundius punctata, tenuiter subtiliterque nigro-pubescentia. Abdomen parce subtiliterque punctulatum, parce nigro-pubescens, segmentis ultimis duobus rufis, rufo-pubescentibus. Pedes breviusculi, nigri, coxis intermediis distantibus, tiljiis omnibus spinulosis, tarsis anticis in utroque sexu leviter dilatatis. Alae fuscae.

Obs. Antennis brevioribus, apicem versus crassioribus et abdomine latiore cum praecedente Staphylini familiae secundae habitu non dissimilis, at ligula integra et huius generis mihi videtur.

* 116. Ph. xanthopygus: Niger, nitidus, abdomine segmentis duobus ultimis rufo-testaceis, capile subquadrato. - Long. 6 lin.

Staph. xanthopygus Nordm. Symb. 45. 27.

Habitat in Brasilia, Dom. Virmond, in Columbia, Dom. Moritz, in Mexico, Dom. Deppe.

Subdepressus, niger, capite thoraceque nitidis, elytris abdomineque subnitidis, abdominis segmentis ultimis duobus solis testaceo-rufis. Antennae capite cum thorace breviores, crassiusculae, apicem versus haud incrassatae, articulo tertio secundo sesqui longiore, 4 et 5 subglobosis, $6-10$ transversis, ultimo breviter subovato, apice abrupte acuminato, nigrae. Palpi breviores, nigri. Caput orbiculato subquadratum, thoracis latitudine, lateribus et vertice crebrius punctatum, fronte punctis parcis sparsis notata, medio longitudinaliter laevissima, antice inter antennas linea arcuata punctis notata impressa. Thorax coleopteris parum angustior, latitudine haud brevior, basin versus modice angustatus, lateribus praecipue ante medium leviter rotundatıs, pone medium subsinuatus, basi cum angulis posterioribus rotundatus, apice truncatus, angulis anterioribus leviter deflexis, subrectis, leviter convexus, seriebus dorsalibus minus irregularibus, punctis fere 10 compositis, lateribus praeter margines utrinque punctis fere 16, anterius crebrioribus, impressus, punctis omnibus subtilioribus, angulis anterioribus limbo crebre subtiliterque punctato. Scutellum creberrime punctulatum, nigro-pubescens. Elytra thorace paulo longiora, dense subtiliter punctata, densius subtiliter nigro-pubescentia. Abdomen subtiliter punctulatum, parcius nigro-, apice in segmentis rufis testaceo-pubescens. Pedes breves, validiusculi, coxis intermediis leviter distantibus, tibiis omnibus spinulosis, tarsis breviusculis, anticis in utroque sexu fortius dilatatis. Nlae fuscae. 
* 117. Ph. opulentus: Nigro-subaeneus, capite thoraceque purpureo-violaceis, nitidis, elytris testaceis, circa scutellum nigricantibus, capite subquadrato. - Llong. 7 lin.

Habitat in Brasilia, Dom. Prof. Germar.

Antennae capite sesqui longiores, articulo tertio secundo paulo longiore, 4-10 sensim panlo brevioribus at vix crassioribus, $7-10$ crassitie paulo breviorıbus, ultimo breviter subovato, apice emarginato et inferne subacuminato, nigrae. Palpi nigri. Caput thoracis latitudine, subquadratum, supra parum convexum, utrinque, praecipue supra oculos, crebrius profundiusque punctatum, fronte medio longitudinaliter laevi, antice punctis paucis notata, nitidum, violaceum vel purpureum, subtus cum ore nigrum. Thorax coleopteris paulo angustior, latitudine haud brevior, basin versus subangustatus, basi et lateribus anterius modice rotundatis, his pone medium leviter sinuatis, apice truncatus, angnlis anterioribus leviter deflexıs, subrectis, posterioribus obtusis, modice transversim convexus, seriebus dorsalibus minus regularibus fere 10 -punctatis, lateribus praeter margines punctis utrinque fere 21, plerisque subseriatis, impressus, punctis omnibus subtilioribus, violaceus vel purpureus, nitidus. Scntellum parce subtiliter punctulatum, nigrosubaeneum, opacum, tenuiter pubescens. Elytra thorace paulo longiora, parcius subtiliter punctata, parcius longius testaceo-pubescentia, testacea, farum nitida, spatio angustiore semicirculari basali communi circa scutellum nigro-subaeneo. Abdomen parce subtiliter punctatum et parce nigro-pubescens, apice summo fulvo-pilosum, nigro-subaeneum, subnitidum, segmento sexto limbo apicali testaceo. Pectus nigrum. Pedes nigri, coxis intermediis approximatis, tibiis omnibus spinulosis.

Tarsi antici feminae fortius dilatati. Mas latet.

V ariat abdominis segmento sexto apice concolore.

* 118. Ph. herilis: Nigro-subaeneus, capite thoraceque cyaneis, elytris fusco-virescentibus, abdominis segmentis duobus ultimis rufo-testaceis, thorace utrinque parce punctato, capite subquadrato, - Long. $5 \frac{1}{2}$ lin.

Habitat in Brasilia, Dom. Virmond.

Statura omnino praecedentis, at duplo minor. Antennae capite thoraceque breviores, articulo tertio secundo paulo longiore, quarto quintoque subcylindricis, crassitie paulo longioribus, $6-10$ paulo crassioribus, transversis, ultimo subovato, apice emarginato et inferne acuminato, piceae. Palpi picei. Caput thoracis fere latitudine, subquadratum, supra depressiusculum, utrinque supra oculos et in margine verticali crebrius punctatum, fronte punctis nomnullis dispersis versus latera et apicem notata, violaceo-cyanenm, nitidum, subtus nigrum. Thorax coleopteris paulo angustior, latitudine apicis vix longior, basin versus leviter angustatus, lateribus ante medium rotundatis, posterius subsinuatis, basi rotundatus, apice truncatus, angulis anterioribus leviter deflexis, rectis, posterioribus subrotundatis, transversim convexus, violaceus, nitidus, seriebus dorsalibus sat regularibus, $7-8$-punctatis, lateribus praeter margines utrinque punctis fere 15 irregulariter seriatis impressus, punctis omnibus subtilioribus, violaceo-cyaneus, nitidus. Elytra thorace paulo longiora et scutellum fusco-virescentia, subopaca, sericeo-micantia, parce subtiliter punctata, tenuiter fusco-pubescentix. Abdomen parce pun- 
ctatum, nigro-aeneum, nitidulum, fusco-pubescens, segmento quinto basi excepta sextoque toto rufo-testaceis, testaceo-pubescentibus. Pectus nigrum. Pedes fusco-picei, coxis intermediis approximatis, tibiis omnibus spinulosis, tarsis anticis in utroque sexu modice dilatatis.

* 119. Ph. punctifer: Nigerrimus, nitidus, thorace utrinque crebrius punclato, capite orbiculaio. - Long. 4 lin.

Nordm. Symb. 107. 96.

\section{Habitat in Mexico, Dom. Deppe.}

Ph. puncto affinis, at paulo maior, praecipue latior, totus nigerrimus, capite thoraceque nitidis. Antennae capite thoraceque paulo breviores, apicem versus haud incrassatae, articulo tertio secundo paulo longiore, $4-10$ sensim paulo brevioribus, penultimis crassitie haud longioribus, ultimo ovato, apice truncato et inferne acuminato. Caput thorace paulo angustius, orbiculatum, supra lateribus crebrius subtiliusque punctatum, fronte media late laevi, inter oculos transversim punctata. Thorax basi coleopteris parum angustior, latitudine paulo brevior, antrorsum subangustatus, lateribus leviter, basi fortıus rotundatus, apice truncatus, angulis anterioribus leviter deHexis posterioribusque subrotundatis, transversim convexus, seriebus dorsalibus fere 16-punctatis, lateribus praeter margines punctis utrinque numerosis (ultra 40) dispersis impressus, punctis omnibus subtilioribus. Elytra thorace paulo longiora, subopaca, creberrime subtiliter punctata, subtiliter nigro pubescentia. Abdomen nitidulum, subtiliter crebrius punctatum, nigro-pubescens. Pedes coxis intermediis approximatis, tibiis omuibus spinulosis, tarsis antcis diuatatis.

* 120. Ph. punctus: Niger, nitidus, thorace lateribus crebre punclalo, capite orbiculato, crebre punctato, medio laevi. - Long. 4 lin.

Er. Col. March. I. 477. 47.

Staph. punct us Grav. Micr. 20. 22. Mon. 85. 75. - Boisd. et Lacord. Faun. Ent.

Paris. I. 393. 14. - Runde Brachelytr. Hal. 10. 55.

Staph. punctal us Latr. Hist. nat. Crust. et Ins. IX. 309. 29.

Staph. multipunctatus Mannerh. Brachelytr. 31. 79.

Philonth. wullipunctatus Nordm. Symb. 106. 95.

Staph. politus Panz. Faun. Germ. 27. 7.

Habitat in Germania; in Sardinia etiam a Dom. Prof. Gené lectus.

Statura omnino Ph. atrati, niger, subnitidus, capite thoraceque pernitidis. Antennae capite thoraceque parum breviores, articulo tertio secundo paulo longiore, 4 - 10 subobconicis, sensim paulo brevioribus et crassioribus, prioribus elongatis, penultimis crassitie vix longioribus, ultimo subovato, apice emarginato et inferne acuminato, nigrae. Caput thorace parum angustius, orbiculatum, supra fortiter crebre punctatum, fronte medio laevi. Thorax coleopteris paulo angustior, latitudine haud brevior, antrorsum subangustatus, lateribus subrectis, basi rotundatus, apice truncatus, angulis anterioribus leviter deflexis, posterioribusque subrotundatis, leviter convexus, seriebus dorsalibus circiter 12-punctatis, lateribus punctis praeter marginalia utrinque numerosis (fere 30), aequaliter dispersis, minus subtilibus impressus. Scutellum confertim punctatum, nigro-pubescens. Elytra thorace paulo longiora, densius subtiliusque punctata, vix virescentia, tenuiter nigro-pubescentia. 
Abdomen parcius punctulatum, tenuiter nigro-pubescens. Pedes nigri, coxis intermediis approximatis, tibiis omnibus spinulosis. Alae fuscae.

Tarsi antici maris fortiter, feminae leviter dilatati.

* 121. Ph. parumpunctatus: -Niger, nitidus, elytris nigro-aeneis, thorace lateribus paree punctato, capile orbiculato. - Long. 4 lin.

Staph. punctus Gyll. Ins. Suec. II. 346. 62. - Sahlb. Ins. Fenn. 1. 330. 59. Mannerh. Brachelylr. 31. 78.

Philonth. punctus Nordm. Symb. 106. 94. Eversmann.

Habitat. in Suecia, sec. Gyll, in montibus Uralensibus, Dom. Prof.

Statura omnino $\mathrm{Ph}$. variantis et maximis eius individuis aequalis, niger, nitidus, capite thoraceque pernitidis, elytris obscure aeneis, nitidulis. Antennae capite sesqui longiores, articulo tertio secundo vix longiore, 4-10 subobconicis, sensim paulo brevioribus et haud crassioribus, penultimo crassitie vix breviore, ultimo subovato, apice leviter emarginato et inferne acuminato, piceae. Palpi picei. Caput thoracis latitudine, orbiculatum, leviter convexum, supra oculos utrinque punctis pluribus, inter oculos punctis 4 transversim positis, inter se aequaliter distantibus, profundioribus, impressum. Thorax coleopteris paulo angustior, latitudine haud longior, antrorsum subangustatus, basi et lateribus leviter rotundatus, apice truncatus, angulis anterioribus leviter deflexis posterioribusque rotundatis, modice convexus, seriebus dorsalibus punctis circiter $\mathbf{8}$ compositis, lateribus praeter margines utrinque punctis parcis (vix ultra 12) dispersis impressus, punctis omnibus minus subtılibus, Scutellum subtiliter punctulatum, parce nigro-pubescens. Elytra thorace paulo longiora, crebre profundius punctata, parcius longiusque griseo-pubescentia. Abdomen parce subtiliter punctulatum, tenuiter griseo - pubescens. Pedes breviusculi, picei, coxis intermediis approximatis, tibiis omnibus spinulosis. Alae fuscae.

Tarsi antici maris modice dilatati, feminae simplices.

Obs. A praecedente satis distinctus statura paulo minore, capitis thoracisque punctura, elytris aeneis.

* 122. Ph. orphanus: Nigro-piceus, nitidus, pedibus testaceis, capite subquadrato, thorace seriebus dorsalibus 7-, lateribus crebrius subtiliter punctatis. - Long. $2 \frac{1}{2}$ lin.

Hahitat in Madagascar, Dom. Goudot.

Habitu fere Ph. debilis, nigro - piceus, nitidus. Antennae tenuiores, articulo tertio secundo paulo longiore, sequentibus teretibus, vix sensim brevioribns, fuscae, articulo primo rufo-piceo (articulı ultimi tres desunt). Palpi rufo-picei. Mandibulae piceae. Caput maiusculum, thorace paulo latius, subquadratum, parum convexum, utrinque parce subtiliter punctatum, spatio medio longitudinali lato laevi. Thorax coleopteris paulo angustior, latitudine paulo longior, basin versus subangustatus, lateribus ante medium leviter rotundatus, pone medium subsinuatus, basi rotundatus, apice truncatus, angulis anterioribus deflexis, rotundatis, posterioribus obtusis, subcylindricus, seriebus dorsalibus minus regularibus, fere 7 -punctatis, lateribus punctis praeter marginalia pluribus (fere 16) utrinque impressus, punctis omni- 
bus subtilibus. Scutellum punctis parcis subtilibus notatum. Elytra thorace sesqui fere longiora, parcius subtiliusque punctata, parce pubescentia. Abnomen crebre subtilius punctulatum, longius et minus subtiliter nigro-pubescens, subtus segmentis singulis apice piceo-marginatis. Pedes rufo-testacei, coxis piceis, intermediis approximatis, tibiis omnibus subtiliter spinulosis.

Tarsi antici feminae simplices. Mas latet.

* 123. Ph. dimidiatipennis: Elongatus, niger, antennarum articulis 3 primıs, pedibus elytrisque rufis, his basi nigris, thorace seriebus dorsalibus 7-8-punctatis, lateribus parumpunctato. - Long. $2 \frac{1}{2}$ lin.

Habitat in Sicilia, collect. Dom. Aubé, in Mesopotamia, Dr. Helfer.

Elongatus, linearis, subdepressus, niger, nitidus. Antennae capitis thoracisque prope longitudine, articulo secundo tertioque subaequalibns, 4-10 sensim brevioribus et crassioribus, penultimis transversis, ultimo subovato, apice leviter emarginato et inferne subacuminato, nigrae, articulis 3 primis rufo-testaceis. Palpi rufo-testacei. Mandibulae rufo-piceae. Caput thoracis latitudine, subovatum, utrinque crebrius punctatum, spatio medio longitudinali laevi. Thorax coleopteris angustior, latitudine paulo longior, lateribus parallelis, rectis, basi cum angulis posterioribus rotundatus, apice truncatus, angulis anterioribus deflexis, subrotundatis, parum convexus, seriebus dorsalibus $7-8$-punctaris, lateribus praeter margines punctis utrinque 4 vel 5 impressus. Scutellum punctulatum, tenuiter pubescens. Elytra thorace paulo longiora, crebrius sat distincte punctata, tenniter griseo-pubescentia, testaceo-rufa, nitida, parte tertia basali nigra. Abdomen crebre subtiliter punctatum, minus nitidum, densius griseo-pubescens, pube certo situ sericante, subtus segmentis singulis apice piceo-marginatis. Pedes rufo-testacei, coxis omnibus concoloribus, posticis antice nigricantibus, intermediis approximatis, tibiis omnibus parce spinulosis.

Tarsi antici feminae leviter dilatati. Mas latet.

Obs. A Ph. prolixo statura duplo maiore, minus depressa, capitis spatio medio longitudinali laevi latiore, thorace aliter punctato, abdomine subtiliter punctato, coxis anticis rufo-testaceis, etc. valde distinctus.

124. Ph. labilis: Niger, elytris pectoreque rufis, opacis, antennarum basi, palpis pedibusque flavis, thorace seriebus dorsalibus mullipunclalis, capile orbiculalo. - Long. $2 \frac{2}{3}$ lin.

Habitat in Guyana Venezuelensi, Dom. Moritz.

Ph. fulvipedi similis, at paulo gracilior, niger, capite thoraceque nitidis. Antennse capitis thoracisque longitudine, articulo tertio secundo paulo longiore, 4-10 oblongo-obconicis, sensim paulo brevioribus et crassioribus, vilumo oblongo, apice oblique truncato et inferne acuminato, fuscae, articulo primo toto, secundo tertioque hasi testaceis. Palpi flavo-testacei. Caput thoracis prope latitudine, suborbiculatum, utrinque supra oculos parce punctatum. Thorax latitudine paululum longior, coleopteris dimidio angustior, antrorsum subangustatus, lateribus levissime, basi fortius rotundatus, apice truncatus, angulis anterioribus leviter deflexis, rotundatis, posterioribus obtusis, leviter convexus, seriebus dorsalibus 8-9-punctatis, lateribus praeter margmem punctis utrinque 5 impressus, punctis omnibus subtilibus. Scu- 
tellum obsolete puncta'nm, opacum, tenuiter griseo-pubescens. Elytra thorace paulo longiora, dense subtilissime punctata, laete rufa, opaca, dense subtiliter griseo-pubescentia. Abdomen dense subtiliter punctatum, densius griseo-pubescens, opacum, nigrum, subtus apice testacenm. Pectus obscure rufum. Pedes flavo-testacei, coxis anterioribus concoloribus, intermediis approximatis, tibiis omnibus spinulosis.

Tarsi antici feminae leviter dilatati. Mas latet.

* 125. Ph. pacificus: Elongatus, niger, abdomine subtus, elytrorum margine inflexo et summo apicali pedibusque ferrugineis, capile oblongosubquadrato, thorace seriebus dorsalibus 11 -punctatis, lateribus parce punctatis. - Long. 5 lin.

Hahitat in Terra Van-Diemenii, Dom. Schayer.

Statura elongata subdepressa omnino $\mathrm{Ph}$. fucicolae. Antennae capite sesqui longiores, apicem versus haud incrassatae, articulo tertio secundo tenuiore et sesqui longiore, $\mathbf{4 - 1 0}$ sensim brevioribus, penultimo crassitie vix longiore, ultimo ovato, apice truncatulo et inferne acuminato, fuscae, articulis tribus primis nigris. Palpi picei, articulo ultimo rufo. Mandibulae piceae. Caput thorace paulo latius, oblongo-subquadratum, parum convexum, utrinque crebrus vage fortiter profundeque punctatum, spatio medio longitudinali inaequali laevi, nigrum, nitidum. Thorax coleopteris plus dimidio angustior, latitudine sesqui longior, basin versus leviter angustatus, basi et lateribus ante medium leviter rotundatıs, his pone medium subsinuatis, apice truncatus, angulis anterioribus rotundatis, posterioribus obtusis, leviter convexus, seriebus dorsalibus sat regularibus, lineae leviter impressae impositis, circiter 11 -punctatis, lateribus punctis praeter marginalia utrinque fere $\mathbf{1 0}$, partim subseriatis, impressus, niger, nitidus, margine summo apicali et laterali inflexo sanguineo. Scutellum crebre punctatum, nigrum, opacum, subtiliter nigro-pubescens. Elytra thorace sesqui Iongiora, confertissime subtilius punctata, subrugulosa, nigra, opaca, limbo laterali inflexo et margine summo apicali ferrugineis, subtiliter nigro-pubescentia, apice cinereo-ciliata. Abdomen crebrius subtiliter punctatum, subnitidum, supra nigrum, segmentis 4 primis macula obsoleta, quinto apice, . sexto toto subferrugineis, subtus totum ferrugineum, tenuiter subtiliterque supra nigro-, subtus ferrugineopubescens. Pectus nigrum. Pedes ferruginei, coxis intermediis leviter distantibus, tibiis omnibus subtiliter spinulosis.

Tarsi anteci feminae leviter dilatati. Mas latet.

* 126. Ph. fonticola: Ferrugineus, cinereo-sericeus, opacus, capite subquadrata thoraceque basin versus angustatis nitidis, supra nigropiceis, nilidis, elytris nigris, margine laterali, macula basali apicalibusque pallidis. - Long. 3 lin.

Habitat in montibus Sinai, in regione montis S. Catharinae media ad fontes lectus a Dom. Prof. Ehrenberg.

Affinis Pl. xantholomati, statura antem breviore, crassiuscula. Antennae capite parum longiores, apice haud crassiores, articulo tertio secundo tenuiore at vix longiore, sequentibus omnibus transversis, sensim paulo brevioribus, ultimo ovato, apice profundius emarginato et inferne acuminato, 
totae rufo-ferrugineae. Palpi rufi. Caput thorace fere latius, subquadratum, parum convexum, dense fortiter punctatum, spatio medio longitudinali, basin versus angustato, laevissimo, polito, nigro-piceum, nitidum. Thorax coleopteris paulo angustior, latitudine parum longior, basin versus angustatus, lateribus ante medium cum angulis anterioribus fortius, basi cum angulis posterioribus leviter rotundatis, leviter convexus, seriebus dorsalibus multipunctatis, duplicatis, interstitio subelevato, lateribus utrinque confertim punctatus, punctis omnibus piliferis, nigro--piceus, nitidus. Scutellum brunneum, creberrime punctulatum, griseo-pubescens. Elytra thorace sesqui longiora, confertissime subtiliter punctata, subtiliter cinereo-pubescentia, opaca, brunnea, margine laterali inflexo, puncto ad basin scutelli, macula in angulo apicis exteriore, punctoque in angulo apicis interiore pallide flavis, puncto ad apicem scutelli ferrugineo. Abdomen confertissime subtiliter punctatum, pube densiore brevi tenui cinereo-sericea vestitum, supra e pube densiore bifariam submaculatum, supra obscure, subtus dilute ferrugineum. Pectus ferrugineum. Pedes ferruginei, femoribus extus nigricantibus, coxis intermediis leviter distantibus, tibiis omnibus spinulosis.

Tarsi antici feminae fortius dilatati. Mas latet.

*127. Ph. bistriatus: Elongatus, nigro-piceus, opacus, abdomine subtus pedibusque ferrugineis, elytrorum margine inflexo ochraceo, thorace lateribus crebre punctato, dorso lineis duabus multipunclatis impresso. - Long. $3 \frac{1}{2}$ lin.

Habitat in Americae septentrionalis Insula Longa (Long-Island), Dom. Zimmermann.

Habitu prope $\mathrm{Ph}$. xantholomatis, at angustior et paulo minor magisque depressus. Antennae capite plus sesqui longiores, apicem versus haud incrassatae, articulo tertio secundo subaequali, 4-10 sensim paulo brevioribus, ultimo subovato, apice truncatulo et inferne subacuminato, piceae, articulo primo nigricante. Mandibulae et palpi rufo-picei. Caput thorace vix latius, oblongo-subquadratum, antrorsum subangustatum, basi truncatum, angulis posterioribus leviter rotundatis, supra subdepressum, crebrius fortiusque profunde punctatum, plaga media longitudinali antrorsum dilatata laevi, nigrum, opacum, subtilissime nigro-pubescens, parce fusco-pilosum. Thorax coleopteris dimidio prope angustior, latitudine tertia parte longior, basin versus leviter angustatus, basi rotundatus, lateribus rectis, pone medium subsinuatus, apice utrinque oblique truncatus, angulis anterioribus subrectis, posterioribus obtusis, subrotundatis, subdepressus, dorso striis duabus longitudinalibus parallelis impressis, apice evanescentibus, series dorsales e punctis numerosis continentibus, spatio interiecto laevissimo, nitidulo, lateribus sat crebre subaeyualiter minus fortiter punctatis, opacis, tenuiter subtiliterque griseo-pubescentibus. Scutellum dense subtiliter punctatum. Elytra thorace sesqui longiora, dense subtiliter punctata, pube brevi depressa grisea sericante densius vestita, brunneo-picea, margine laterali inflexo ochraceo. Abdomen confertim -subtiliter punctatim, pube depressa grisea sericante densius vestitum, supra nigro-piceum, segmento sexto et subtus totum rufo-piceum vel ferrugineum. Pedes cum coxis anterioribus ferruginei, tibiis omnibus spinulosis.

Tarsi antici $\mathrm{f} e \mathrm{~min}$ a e leviter dilatati. Mas latet. 
128. Ph. bilineatiss: Elongatus, niger, antennarum basi, pedibus, abdominisque segmentorum ven/ralium marginibus piceis, elytris dense subtiliter punclatis, thorace lateribus crebre punctalo, dorso lineis duabus longitudinalibus impresso. - Long. 3 lin.

Habitat in Americae meridionalis ins. St. Johannis, Dom. Moritz.

Statura omnino et summa affinitas praecedentis. Elongatus, subdepressus, niger, capite thoraceque nitidis. Antennae capite thoraceque paulo breviores, articulo tertio secundo paulo longiore, 4-10 sensin paulo brevioribus at non crassioribus, crassitie paulo longioribus, ultimo ovato, apice truncato et inferne acuminato, nigrae, articulo primo piceo. Palpi picei. Caput thorace prope latius, subovatum, leviter convexum, fronte utrinque crebrius profunde.punctata, spatio medio longitudinali angustiore et inaequali laevi. Thorax coleopteris plus dimidio angustior, basin versus leviter angustatus, latitudine apicis sesqui longior, lateribus anterius leviter rotundatis, pone medium subsinuatis, basi rotundatus, apice utrinque oblique truncatus, angulis anterioribus rotundatis, posterioribus obtusis, leviter convexus, utrinque crebre punctatus, spatio medio longitudinali angustiore laevi, utrinque linea longitudinali impressa, punctorum fere $\mathbf{1 6}$ impressorum seriem continente, terminato. Scutellum crebre subtiliter punctulatum, pubescens. Elytra thorace tertia parte longiora, dense subtiliter punctata, densius subtiliter griseo-pubescentia. Abdomen crebrius subtiliter punctatum, densius griseo - pubescens, subtus segmentis singulis apice rufo-piceis. Pedes picei, coxis intermediis approximatis, tibiis omnibus parcius spinulosis.

Tarsi antici femina e leviter dilatati. Mas latet.

Obs. Praecedenti proximus, at capite minus crebre punctato, thoracis angulis anterioribus rotundatis, elytrorum margine inflexo concolore, abdomine supra nitido etc. distinctus.

8) Thorax crebre punctatus, linea media longitudinali laevi.

* 129. Ph. Baltimorensis: Rufo-castaneus, capite thoraceque nigris, nilidis, hoc lateribus subtiliter vage punctato. - Long. $5 \frac{1}{2}$ lin.

Nordm. Symb. 109. 99.

Staph. Baltimorensis Grav. Micr. 163. 8. Mon. 112. 122.

Habitat in America septentrionali.

Antennae capite sesqui longiores, articulo tertio secundo paulo Iongiore, 4-10 sensim paulo brevioribus et crassioribus, 5-10 transversis, ultimo apice truncato et inferne subacuminato, nigro-picei, articulis ultimis 4 ,vel 5 rufo-ferrugineis. Palpi rufo-picei. Caput maris thorace latius, feminae thoracis latitudine, orbiculatum, parce subtilius punctatum, spatio medio longitudinali laevi, nigrum, nitidum. Thorax coleopteris dimidio angustior, latitudine paulo longior, basin versus subangustatus, lateribus anterius leviter rotundatis, posterius subsinuatis, basi rotundatus, apice truncatus, angulis anterioribus leviter deflexis, obtusiusculis, posterioribus subrotundatis, convexus, utrinque parcius aequaliter subtiliterque punctatus, niger, nitidus. Scutellum crebre subtuliter punctatum, nigricans. Elytra thoracis longitudine, castaneo - rufa, nitidula, subtilius punctata, tenuiter griseo-pubescentia. Abdomen apicem versus sensim attenuatum, crebrius punctulatum, tenuiter griseo-pubescens, rufo-castaneum, segmento sexto utrinque nigro-limbato. 
Pectus nigro-piceum. Pedes rufo-, rarius nigro-picei, coxis intermediis sat distantibus, tibiis intermediis crebrius, anticis posticisque parce spinulosis.

Tarsi anticı maris leviter dilatati, feminae simplices. Mas praeterea capite maiore, antrorsum dilatato, et mandibulis elongatis distinctus.

*130. Ph. haematurus: Niger, nilidus, abdomine pone medium obscure
sanguineo, thorace utrinque crebrius punclalo. Long. 5 lin.

Habitat in America septentrionali.

Affinis praecedenti, at corpus nigrum, nitidum. Antennae capite sesqui longiores, articulo tertio secundo paulo longiore, 4-10 leviter obconicis, subaequalibus, crassitie paulo longioribus, ultimo subovato, apice oblique subemarginato et inferne acuminato, basi nigrae, dein fuscae, articulo apicali ferrugineo. Palpi picei. Caput thoracis latitudine, suborbiculatum, crebrius fortiusque punctatum, fronte spatio medio longitudinali laevi. Thorax coleopteris dimidio angustior, latitudine paulo longior, basin versus subangustatus, lateribus subrectis, basi cum angulis posterioribus rotundatus, apice truncatus, angulis anterioribus deflexis, sat convexus, utrinque crebrius punctatus, spatio medio longitudinali angusto laevi. Scutellum creberrime subtiliter punctatum. Elytra thorace vix longiora, subtilius punctata, nigropubescentia. Abdomen apicem versus attenuatum, crebrius fortiusque punctulatum, nigro-pubescens, abdominis segmento quarto apice obscure sanguineo, quinto toto sanguineo, ultimo sanguineo, apice nigro. Pedes nigri, coxis intermediis sat distantibus, tibiis anticis posticisque parce, intermedïs crebrius spinulosis.

Tarsi antici maris leviter dilatati, feminae simplices.

$\mathrm{Obs}$. In specimine nostro masculo caput maris perparum maius quam feminae, et mandibulae parum magis elongatae.

* 131. Ph. rufipennis: Niger, nitidus, elytris, tibiis tarsisque rufis, antennis apice ferrugineis, thorace utrinque crebrius punclato. - Long. 5 lin.

Nordm. Symb. 110. 100. - Er. Col. March. I. 477. 46.

Staph. rufipennis Grav. Micr. 40. 59. Mon. 101. 105. - Latr. Hist. nat. Crust. et Ins. IX. 327. 77.

Habitat in Germania, rarus; in Gallia a Dom. Aubé, in Sardinia a Dom. Prof. Gené lectus.

Statura Ph. Baltimorensis. Niger, nitidus, capite thoraceque pernitidis, elytris rufis. Antennae capite sesqui longiores, articulo tertio secundo paulo longiore, 4-10 subobconicis, sensim paulo brevioribus et erassioribus, penultimis crassitie prope brevioribus, ultimo ovato, apice oblique subemarginato et inferne subacuminato, nigro-piceae, articulo ultimo ferrugineo. Palpi rufi. Mandibulae rufo-piceae. Caput maris magnum, thorace paulo latius, orbiculato-subquadratum, feminae thoracis latitudine, suborbiculatum, fronte parcins fortiusque punctata, spatio medio longitudinali laevi. Thorax coleopteris dimidio angustior, latitudine paulo longior, basin versus subangustatus, lateribus subrectis, basi leviter rotundatus, apice truncatus, angulis anterioribus leviter, posterioribus fortius rotundatis, sat convexus, crebrius subtiliusque aequaliter punctatus, spatio medio longitudinali angustiore laevissimo. Scutellum dense subtiliter punctulatum, tenuiter pubescens. Elytra 
thorace paulo longiora, parcius punctata, tenuiter griseo-pubescentia. $\mathrm{Ab}$ domen apicem versus sensim attenuatum, parcius punctulatum, parce nigropubescens, lucidum. Pedes picei, tibiis tarsisque dilutioribus, coxis intermemediis sat distantibus, tibiis anticis posticisque parce, intermediis crebrius spinulosis.

Tarsi antici maris leviter dilatati, feminae simplices. Mas praeterea capite maiore, antice angulato et mandibulis modice elongatis distmetus.

* 132. Ph. egregius: Rufus, capile nigro-aeneo, elytris viridibus, abdomine apice albido-flavo, pedibus antennisque nigris, his apice lutescentibus. - Long. 5 lin.

Habitat Bogotae in Columbia interiore, a Dom. Buquet nomine Staph. ruficollis Dej. communicatus.

Statura fere $\mathrm{Ph}$. decori. Antennae longiores, capite thoraceque hand breviores, apicem versus haud incrassatae, articulo tertio secundo paulo longiore, 4-10 cylindricis, sensim paulo brevioribus, omnibus crassitie longioribus, ultimo oblongo - ovato, apice inferne acuminato, nigrae, apice griseo-lutescentes. Palpi nigri, apice summo testaceo. Caput thoracis fere latitudine, orbiculatum, utrinque vage crebrius profundus punctatum, fronte medio longitudinaliter laevi, anterius punctis parcis dispersis notata, nigroaeneum, nitidulum, collo rufo. Thorax coleopteris dimidio angustior, latitudine paulo longior, basin versus leviter angustatus, lateribus anterius leviter et basi rotundatus, apice truncatus, angulis anterioribus leviter deflexis, subrectis, posterioribus obtusis, leviter convexus, crehre subtilius punctatus, spatio medio longitudinali angustiore laevissimo, rufus, nitidus. Scutellum dense subtiliter punctatum, tenuiter pubescens, nigrum. Elytra thorace sesqui longiora, cyanescenti-viridia, nitida, densius subtiliter punctata, tenuiter nigro-pubescentia. Abdomen apicem versus subangustatum, subtiliter punctulatum, tenuiter nigro-pubescens, rufum, segmento quinto nigro, apice cum sexto flavo. Pedes cum coxis anterioribus nigri, coxis intermediis approximatis, tibiis omnibus parcius spinulosis.

Tarsi antici feminae simplices. Mas latet.

* 133. Ph. fervidus: Niger, nitidus, antennarum basi, capite, thorace abdominisque apice rufis, elytris viridibus. - Long. 5 lin.

\section{Habitat in Columbia, Dom. Moritz.}

Statura omnino praecedentis, at antennae breviores et crassiores. Antennae capite sesqui longiores, crassiusculae, articulo tertio secundo paulo longiore, 4-10 sensim brevioribus et crassioribus, 6-10 transversis, ultimo apice inferne acuminato, nigrae, articulis tribus primis rufis. Caput thorace paulo angustius, suborbiculatum, supra parum convexum, fronte me-dio late laevi, lateribus et antice inter oculos fortiter irregulariter punctata, totum rufum, nitidum. Thorax coleopteris angustior, basin versus subanangustatus, latitudine vix longior, lateribus ante medium leviter rotundatis, pone medium subsinuatis, basi cum angulis posterioribus rotundatus, apice truncatus, angulis anterioribus leviter deflexis, subrectis, transversim conve- 
xus, utrinque fortius crebriusque aequaliter punctatus, spatio medio longi-. tudinalı angustiore laevissimo, rufus, nitidus. Scutellum nigrum, crebre punctatum, parce nigro-pubescens. Elytra thorace paulo longiora, cyanescenti - viridia, nitida, fortiter punctata, nigro-pubescentia. Abdomen nigrum, iridescens, segmento quinto apice rufescente, sexto rufo, nigro-pubescens, parce punctulatum, supra segmentis anterioribus tribus laevibus, utrinque lineola tenui obliqua impressis. Pectus nigrum. Pedes cum coxis nigri, coxis intermediis leviter distantibus, tibiis omnibus spinulosis, tarsis anticis in utroque sexu simplicibus.

\section{*134. Ph. viduus: Niger, subnitidus, elytris eyaneis, abdominis segmento ultimo subtus flavo. - Long. 6 lin.}

Habitat in Columbia, Dom. Moritz.

Corpus nigrum, subnitidum. Antennae capite thoraceque paulo breviores, apicem versus haud incrassatae, articulo tertio secundo sesqui longiore, 4-10 sensim paulo brevıoribus, subobconicis, ommibus crassitie longioribus, ultimo ovato, apice oblique truncato et inferne acuminato, totae nigrae. Palpi nigri. Mandibulae subelongatae, arcuatae, tenues, acutae. Caput thorace vix latius, suborbiculatum, utrinque crebre fortius punctatum, spatio medio longitudinali angustiore laevi, inter antennarum basin utrinque obsolete longitudinaliter impressum. Thorax coleopteris duplo fere angustior, latitudine sesqui longior, basin versus subangustatus, lateribus ante medium perparum rotundatis, pone medium leviter sinuatis, basi rotundatus, apice truncatus, angulis anterioribus leviter deflexis, rectis, posterioribus subrotundatis, transversim convexus, fortius crebre punctatus, spatio medio longitudinali angustiore laevi. Scutellum dense punctulatum, nigrum, nigropubescens. Elytra thorace paulo longiora, subtiliter punctata, cyanea, subnitida, nigro-pubescentia. Abdomen parcius punctulatum, supra subaeneum, subtus segmento anali flavo. Pedes nigri, coxis intermediis leviter distantibus, tarsis omnibus spinulosis. Alae fuscae.

Tarsi antici maris leviter dilatati, feminae simplices.

* 135. Ph. binotatus: Niger, nilidus, elytris angulo apicis exteriore late rufo, capite orbiculato. - Long. $3 \frac{2}{3}$ lin.

Staph. binotatus Grav. Mon. 73. 62.

Habitat in Borussia, Kugelann.

Statura onınino $\mathrm{Ph}$. puncti eoque vix minor, niger, nitidus, elytrorum angulo apicali exteriore solo late a suturae apice inde ultra marginis lateralis medium usque rufo. Antennae capitis thoracisque longitudine, articulo tertio secundo longiore, 4-10 elongato-obconicis, sensim paulo brevioribus et crassioribus, ultimo oblongo, apice subtruncato et inferne acuminato, nigrae. Palpi nigri. Caput thorace parum angustius, orbiculatum, crebrius punctatum, puncts in fronte rarioribus, sparsis. Thorax coleopteris paulo angustior, latitudine haud brevior, lateribus parallelis, subrectis, basi cum angulis posterioribus rotundatus, apice truncatus, angulis anterioribus leviter deflexis, subrotundatis, modice convexus, crebre profundius punctatus, spatio medio longiturlinali angusto laevissimo. Elytra thorace paulo longiora et scutellum crebrius subtiliusque punctata, griseo-pubescentia. Abdomen 
crebrius punctulatum, griseo-pubescens. Pedes concolores, coxis intermedis approximatis, tibiis omnibus spinulosis.

Tarsi antici maris fortiter dilatati, femin a latet.

* 136. Ph. ephippium: Niger, nitidus, pedibus elylrisque rufis, his macula communi scutellari nigra, capite orbiculato. - Long. $3 \frac{3}{4}$ lin.

Nordm. Symb. 110. 101 .

Habitat in Grusia, Dom. Marschall v. Bieberstein.

Affinis praecedenti, niger, capite thoraceque nitidis, elytris laete rufis, macula magna communi subquadrata circa scutellum nigra, pedibus dilute rufis. Antennae capitis thoracisque fere longitudine, articulo tertio secundo sesqui prope longiore, 4-10 oblongo-obconicis, sensim paulo brevioribus at vix crassioribus, ultimo oblongo, apice truncatulo et inferne acuminato, fusconigrae, basi piceae. Palpi dilute picei. Caput thorace angustius, orbiculatum, supra leviter convexum, crebrius punctatum, fronte medio longitudina-liter laevi, nonnisi inter oculos parce punctata. Thorax basi coleopteris angustior, latitudine paulo longior, antrorsum leviter angustatus, lateribus subrectis, hasi rotundatus, apice truncatus, angulis anterioribus leviter deflexis posterioribusque subrotundatis, modice transversim convexus, supra crebre fortius punctatus, punctis ut in capite omnibus piliferis, spatio medio longitudinali angusto laevissimo. Scutellum densius punctulatum, nigrum, griseo-pubescens. Elytra subtilius crebriusque punctata, thorace tertia parte longiora, griseo-pubescentia. Abdomen parcius subtiliter punctulatum, griseo-pubescens. Pedes dilute rufi, coxis omnibus nigris, intermediis approximatis, tibiis omnibus spinulosis.

Tarsi anticis maris fortius, feminae leviter dilatati.

137. Ph. leucotus: Niger, capite thoraceque nigro-subaeneis, nitidulis, pedibus elytrisgue rubro-testaceis, his fascia sulfusca, abdominis segmentis inferioribus 3 primis rufis, antennis articulis ultimis 5 albidis. - Long. 5 lin.

Habitat in Nepal, Mus. Dom. Hope.

Antennae capitis thoracisque fere longitudine, articulo tertıo secundo' sesqui longiore, $4-10$ sensim paulo brevioribus at vix crassioribus, prioribus elongatss, teretibus, penultimis oblongo-subobconicis, ultimo oblongoovato, apice inferne acuminato, nigrae, articulis $7-11$ albis. Mandibulae et palpi modice elongati, rufo-picei. Caput thorace paulo angustius, orbiculatum, parum convexum, creberrime punctatum, fronte medio laevi, nigro-subaeneum, nitidulum. Thorax coleopteris parum angustior, latitudine vix brevior, antrorsum subangustatus, lateribus subrectis, basi rotundatus, apice subemarginatus, angulis anterioribus leviter deflexis posterioribusque subrotundatis, leviter convexus, confertissime punctatus, linea media longitudinali angusta subelevata laevi, nigro-subaeneus, nitidulus, tenuiter subtiliterque griseo-pubescens. Scutellum punctatissimum, tenuiter pubescens, nigrun. Elytra thoracis longitudine, confertissime punctata, fulvo-puhescentia, rubro-testacea, pone medium fascia arcuata obsoleta fusca. Abdomen subtilius dense punctatum, tenuiter griseo-pubescens, supra nigrum, subnitidum, segmento quinto margine apicali tenui albo, subtus nigruı, vitidum, 
segmentis tribus primis rufis. Pectus nigrum, subnitidum. Pedes longiores, rubro-testacei, coxis omnibus nigris, coxis intermediis approximatis, tibiis anticis muticis, posterioribus parcius spinulosis. Alae fusco-hyalinae.

Tarsi antici maris leviter dilatati. Femina latet.

* 138. Ph. elatus: Niger, nitidus, elytris viridi-melallicis, ano rufo, thorace elongato, valde convexo, confertim subtiliter punctalo. - Long. $5 \frac{1}{2}$ lin.

\section{Habitat in Madagascar, Dom. Goudot.}

Habitus omnino sequentis, at duplo fere maior. Caput deest. Thorax coleopteris paulo angustior, basin versus sensim angustatus, latitudine longior, basi cum angulis posterioribus leviter rotundatus, lateribus anterius leviter rotundatis, posterius subsinuatis, apice truncatus, angulis anterioribus rotundatis, elevatus, valde convexus, crebre subtiliter punctatus, tenuiter subtilius nigro-pubescens, linea angusta media longitudinali laevi, niger; pernitidus. Scutellum subtiliter dense punctatum, nigrum, densius griseo-pubescens. Elytra thorace vix longiora, minus confertim fortius punctata, stria suturali impressa, pube parca longiore nigra vestita, splendide viridimetallica. Abdomen crebre fortius punctatum, pube parca longiore fortiore depressa nigra vestitum, nigrum, supra cupreo-versicolor, segmento sexto toto, quinto apice rufis. Pectus nigrum. Pedes nigri, griseo-pubescentes, tarsis piceis, tibiis posterioribus spinulosis.

Tarsi antici feminae modice dilatati. Mas latet.

* 139. Ph. compressicollis: Elongatus, niger, nilidus, elytris chalybeis, thorace elongato, convexo, utrinque subtiliter panclato, capile orbiculato. - Long. $4 \frac{1}{2}$ lin.

Staph. dompressicollis Klug Col. Madag. 50. 41. t. 1. f. 12.

Habitat in Madagascar, Dom. Goudot.

Statura elongata et facies fere Paederi, niger, nitidus, elytris chalybeis, nitidis. Antennae capite thoraceque paulo breviores, apicem versus hatt crassiores, articulo tertio secundo sesqui prope longiore, 4-10 sensim paulo brevioribus et paulo magis obconicis, omnibus crassitie multo longioribus, ultimo oblongo-ovato, apice extrorsum acuminato, rufo-ferrugineae, articulo basali piceo. Palpi rufi. Caput thorace paulo latius, orbiculatum, supra parum convexum, subtiliter punctulatum, punctis in media fronte rarioribus. Thorax coleopteris duplo angustior, latitudine duplo longior, basin versus subangustatus, lateribus antice cum angulis anterioribus leviter rotumdatis, pone medium subsinuatis, basi cum angulis posterioribus leviter rotundatus, fortius convexus, subtiliter crebrius punctatus, spatio medio longitudinali angusto laevi. Scutellum nigrum, creberrime subtiliter punctulatum. Elytra thoracis longitudine, convexiuscula, subtilius minus dense punctulata, tenuiter cinereo-pubescentia. Abdomen parce cinereo-pubescens, supra segmentis singulis basi subtiliter punctatis, apice sublaevibus, subtus segmentis basi anterioribus fortiter, posterioribus sensim subtilius punctatis. Pedes nigri, tarsis piceis, coxis intermediis approximatis, tibiis omnibus parce spinulosis.

Tarsi antici maris fortius dilatati. Fémina latet. 
* 140. Ph. cineras cens: Niger, antennarum basi pedibusque testaceis, capite thoraceque utrinque crebre punclatis, elytris abdomineque subtilissime confertissimeque punctalis, subtiliter cinereo-pubescenlibus. - Long. 2 lin.

Nordm. Symb. 108. 97. - Er. Col. March. I. 478. 48.

Staph. cinerascens Grav. Micr. 49. 74. Mon. 117. 137. - Latr. Hist. nat. Crust. et Ins. IX. 334. 94. - Gyll. Ins. Suec. II. 361. 75. - Sahlb. Ins. Fenn. I. 336. 74. - Mannerh. Brachelytr. 31. 80.

\section{Habitat in Europa.}

Elongatus, linearis, subdepressus, niger, capite thoraceque nitidulis, elytris abdomineque opacis. Antennae capite paulo longiores, articulis duobus primis crassiusculis, tertio secundo longitudine aequali, 4-10 sensim paulo brevioribus et crassioribus, subobconicis, penultimo crassitie haud longiore, ultimo oblongo, apice oblique truncato et inferne acuminato, fuscae, articulo primo apiceque plerumque testaceis. Palpi maxillares articulo tertio brevi, quarto duplo longiore, fortiter acuminato. Os testaceum. Caput thoracis latitudine, oblongo - subquadratum, supra leviter convexum, confertissime subtiliter punctatum, linea angustiore media longitudinali laevi, basi apiceque evanescente. Thorax coleopteris angustior, latitudine tertia parte longior, lateribus parallelis, ante medium cum angnlis anterioribus rotundatis, apice truncatus, basi rotundatis, angulis posterioribus obtusis, leviter convexus, crebrius punctałus, spatio medio angusto per totam longitudinem laevi. Elytra thorace tertia parte longiora, scutellum et abdomen confertissime subtiliter punctata, pube brevissima subtili cinerea dense vestita, abdominis segmentis omnibus a jice ferrugineo-marginatis. Pedes obscure testacei, coxis omnibus nigris, intermediis approximatis, tibiis omnibus parce spinulosis, tarsis anticis in utroque sexu. leviter dilatatis.

* 141. Ph. sericeus: Elongatus, niger, opacus, subtiliter cinereo-pubescens, antennis pedibusque piceis, capite thoraceque utrinque crebre, elytris abdomineque subtilissime creberrimeque punctatis. - Long. $2 \frac{1}{3}$ lin.

Remus sericeus Holme Transact. Ent. Soc. Lond. II. p. 58.

Habitat Lutetiae, Dom. Aubé, in Anglia, Dom. Rudd.

Elongatus, linearis, subdepressus, corpore toto cinerascenti-nigro, opaco. Antennae capite thoraceque paulo breviores, articulo tertio secundo paulo longiore, 4-10 sensim paulo brevioribus et crassioribus, subobconicis, penultimo crassitie vix longiore, ultimo oblongo, apice truncato et inferne acuminato, ferrugineae, articulis tribus primis nigro-piceis. Palpi maxillares articulo quarto tertio sesqui longiore, modice acuminato. Os piceum. Caput thoracis latitudine, oblongo-subquadratum, subdepressum, utrinque subtilius licet profunde sat crebre punctatum, linea media longitudinali angusta integra laevi, anterius tenuiter obsoleteque canaliculata, subtiliter tenuiterque cinereo-pubescens. Thorax coleopteris plus dimidio angustior, latitudine tertia parte longior, lateribus parallelis, rectis, basi rotundatus, apice trun-catus, angulis anterioribus fortiter rotundatis, posterioribus obtusis, subdepressus, dense subtiliter punctatus, linea media longitudinali laevi, postice subelevata, subtiliter cinereo-pubescens. Elytra thorace paulo longiora, scutellumque confertim subtilissime punctata, pube subtili densa cinerea ob- 
ducta. Abdomen confertím subtilissime punctatum, dense subtiliter cinereopubescens. Pedes picei, geniculis tarsisque piceo-testaceis, coxis intermediis approximatis, tibiis omnibus parcius spinulosis, tarsis anticis in utroque sexu leviter dilatatis.

Obs. Affinis praecedenti, statura autem magis elongata, capite thoraceque opacis, pubescentibus, hoc dense punctato etc. valde distinctus. Palporum maxillarium articulus tertius minus brevis, quartus minus elongatus et minus acutus.

142. Ph.pruinosus: Elongatus, niger, antennis rufo-teslaceis, basi piceis, pedibus pice-testaceis, capite thoraceque utrinque creberrime punctatis, elytris abdomineque subtiliter confertissimeque punclatis, subtiliter dense cinereo-pubescentibus. - Long. $2 \frac{1}{3}$ lin.

Habitat in Sardinia, Mus. Reg. Taurin., a Dom. Prof. Gené ad examinandum communicatus.

Statura omnino $\mathrm{Ph}$. cinerei, capite autem maiore discedens, niger, vix nitidus, corpore pube subtili depressa cinerea subsericante dense vestito, capite thoraceque parce cinereo-pubescentibus. Antennae capite thoraceque paulo breviores, rufo-testaceae, articulis tribus primis nigro-piceis. Caput thorace paulo latius, subquadratum, depressum, dense profundius punctatum, linea media longitudinali laevi, medio subtiliter canaliculata, antice inter antennas, leviter excavatum, ore rufo, mandibulis validioribus prominentibus. Thorax latitudine paulo longior, basin versus subangustatus, basi coleopteris vix dimidio angustior, minus subtiliter confertim punctatus, linea media leviter elevata laevi. Scutellum confertissime subtiliter punctatum. Elytra thorace vix longiora, depressa, confertissime subtiliter punctata. Abdomen confertim subtiliter punctulatum. Pedes piceo-testacei.

Tarsi antici maris leviter dilatati. F emin a latet.

Obs. Affinis $\mathrm{Ph}$. cinerascenti, at paulo maior, et capite thoraceque creberrime punctatis distinctus, $\mathrm{Ph}$. sericeo propior, at capite thoraceque parce cinereo-pubescentibus elytrisque brevioribus etc. discedens.

* 143. Ph. prolixus: Elongatus, niger, antennarum basi pedibusque testaceis, capile thoraceque utrinque crebre punctatis, elytris distincte punctatis, rufo-testaceis, basi nigricantibus. - Long. '2 lin.

\section{Habitat in Austria, Dom. Ullrich.}

Elongatus, linearis, subdepressus, niger, nitidus. Antennae capite plus sesqui longiores, articulo secundo tertioque subaequalibus, $4-10$ sensim paululum crassioribus at vix brevioribus, penultimis crassitie subbrevioribus, ultimo ovato, apice truncato et inferne subacuminato, fuscae, articulis duobus basalibus rufo-testaceis, tertio rufo-piceo. Palpi maxillares articulo quarto tertio haud longiore, conico, acuminato, acuto. Os rufo-testaceum. C'aput thorace fere latius, oblongum, subdepressum, crebre et sat profunde punctatum, relicto spatio medio longitudinali angusto, apice dilatato, laevi. Thorax coleopteris plus dimidio angustior, longitudine plus sesqui longior, basin versus subangustatus, lateribus subrectis, basi leviter rotundatus, apice truncatus, angulis anterioribus leviter deflexis posterioribusque subrotundatis, parum convexus, utrinque crebre aequaliter profundius punctatus, spatio medio longitudinali angusto laevissimo. Scuteilum subtiliter punctulatum, nigrum. Elytra thorace sesqui longiora, distincte at minus dense punctata, 
tenuiter minus subtiliter griseo-pubescentia, saturate rufo-testacea, basi usque ad tertiam elytri partem et lateribus nigricantia. Abdomen parcius subtiliter punctulatum, segmentis anterioribus basi transversim depressis et fortius punctatis, densius griseo-pubescens. Pedes rufo-testacei, coxis anterioribus picescentibus, intermediis approximatis, tibiis omnibus parce spinulosis, tarsis anticis in utroque sexu leviter dilatatis.

$\mathrm{Obs}$. Affinis $\mathrm{Ph}$. procerulo, differt autem statura magis elongata, capite oblongo, elytris ultra medium rufis.

* 144. Ph. procerulus: Elongatus, niger, antennarum basi pedibusque fusco-testaceis, thorace utrinque capiteque punotatis, elytris nigro-piceis, apice subrufescentibus. - Long. $1 \frac{1}{2}-2$ lin.

Er. Col. March. I. 479. 49.

St aph. procerulus Grav. Mon. 95. 92. - Boisd. ot Lacord. Faun. Ent. Paris. I. 409. 45.

Gyrohypn. procerulus Mannerh. Brachelytr. 34. 16. - Nordm. Symb. 120. 22.1

Staph. planatus Grav. Mon. 108. 112. (forte)

Habitat in Germania.

Statura fere $\mathrm{Ph}$. cinerascentis, at paulo angustior, niger, capite thoraceque nitidis. Antennae capitis thoracisque fere longitudine, validinsculae, articulo secundo tertioque subaequalibus, $\mathbf{1}$ - $\mathbf{1 0}$ sensim paulo crassioribus at vix brevioribus, penultimis crassitie paulo brevioribus, nitimo ovato, apıce inferno acuminato, nigricantes, articulis tribus primis fusco-testaceis. Palpi maxillares articulo quarto tertio duplo longiore, conico, fortiter acuminato, acutissimo. Os testaceum. Caput thoracis latitudine, oblongo-subquadratum, parum convexum, fortiter crebrius punctatum, spatio medio medio longitudinali angustiore laevi, antice leviter impresso. Thorax coleopteris dimidio angustior, latitudine sesqui longior, basin versus subangustatus, lateribus rectıs, basi cum angulis posterioribus rotundatus, apiee truncatus, angulis anterioribus subrectis, parum convexus, fortiter crebrius punctatus, spatio medio longitudinali angusto laevissimo, basi subelevato. Elytra thorace tertia parte longiora, subtiliter licet distincte densius punctata, minus subtiliter griseo-pubescentia, nigro-picea, margine apicali piceo-testaceo. Abdomen crebrius subtiliter punctulatum, densius griseo pubescens, segmentis singulis apice piceo-marginatis. Pedes obscure testacei, coxis anterioribus fuscis, intermediis approximatis, tibiis omnibus parcius spinulosis, tarsis anticis in utroque sexu leviter dilatatis. Alae albo-hyalinae.

Obs. Staph. planatum Grav. non reperi in collectione Hellwig-Hoffmannseggiana, unde secundum descriptionem cïtatam non sine ullo dubio huc eum retuli.

* 145. Ph. elongatulus: Elongatus, niger, antennis pedibusque testaceis, capile thoraceque utrinque vage punctalis, elylris piceo-lestaceis, distincle punctalis. - Long. $1 \frac{2}{3}$ lin.

Er. Col. March. I. 479. 50.

Habitat in Germania.

Praecedenti affinis, niger, capite thoraceque nitidis. Antennae capitis thoracisque prope longitudine, articulo tertio secundo tenuiore et vix lon- 
gitudine ei aequali, tertio quartoque subcylindricis, crassitie panlo longioribus, 5-10 crassioribus, transversim subobconicis, ultimo ovato, apice truncatulo et inferne obtuse acuminato, laete testaceae. Caput thorace paulo latius, depressiusculum, subquadratum, lateribus fortiter minus dense punctatum, spatio medio longitudinali late laevi, antice subimpresso. Thorax coleopteris dimidio angustior, latitudine tertia parte longiar, basin versus subangustatus, lateribus subrectis, basi cum angulis posterioribus rotundatus, apice truncatus, angulis anterioribus fortiter rotundatis, parum convexus, fortiter minus confertim subseriatim punctatus, spatio medio longitudinali angustiore laevissimo. Scutellum parce subtilissime punctulatum. Elytra thorace paulo longiora, minus confertim subtiliter licet distincte punctata, minus subtiliter griseo-pubescentia, fusco-picea, apice sensim dilutiora, testacea. Abdomen crebrius subtiliter punctulatum, densius griseo-pubescens, segmentis singulis apice supra tenuiter, infra laete ferrugineo-marginatis. Pedes laete testacei, coxis anterioribus concoloribus, intermediis approximatis, tibiis omnibus subtiliter spinulosis. Alae albo-hyalinae.

Tarsi antici maris fortius, feminae leviter dilatatae.

* 146. Ph. sobrinus: Elongalus, niger, antennarum basi apiceque pedibusque testaceis, capite thoraceque utrinque multi-punctatis, elytris distincte punctalis, margine apicali testaceo. - Long. 2 lin.

Habitat in Pensylvania, Dom. Zimmermann.

Elongatus, minus, depressus, niger, nitidus. Antennae capitis thoracisque fere longitudine, articulo tertio secundo paulo longiore et temuiore, 4-10 sensim crassioribus at vix brevioribus, penultimo crassitie hatid longiore, ultimo oblongo, apice subtruncato et inferne acuminato, fuscae, apice ferrugineae, articulis basalibus tribus flavo-testaceis. Palpi maxillares articulo quarto tertioque sesqui longiore, conico, apice fortiter acuminato acutoque. Os testaceum. Caput thoracis latitudine suborbiculatum, leviter convexum, parce punctatum, spatio medio longitudinali minus lato laevi, antice inter antennas foveola impressa. Thorax coleopteris dimidio angustior, latitudine tertia parte longior, basin versus subangustatus, lateribus ante medium leviter rotundatus, pone medium subsinuatus, basi cum angulis posterioribus rotundatus, apice truncatus, angulis anterioribus subrotundatis, leviter convexus, utrinque punctatus, punctis minus crebris, hinc inde subseriatis, spatio medio longitudinali angusto laevissimo. Scutellum parce subtiliterque punctulatum, nigrum. Elytra thorace paulo longiora, distincte parcius punctata, minus subtiliter griseo -.pubescentia, nigro-picea, margine apicali indeterminate flavo-testaceo. Adbdomen griseo-pubescens, segmentis singulis basi crebrius, apice parcius obsoletiusque punctulatis, margine apicali piceis. Pedes cum coxis anterioribus testaceis, coxis intermediis approximatis, tibiis omnibus parce subtiliterque spinulosis.

Tarsi antici maris fortius, feminae leviter dilatati.

* 147. Ph. humilis: Elongatus, niger, antennarum basi pedibusque testaceis, eapite thoraceque utrinque crebre punctatis, elytris dislincte punctatis, margine apicali testaceo. - Long. $1 \frac{2}{3}$ lin.

Habitat in ins. Puerto Rico, Dom. Moritz. 
Statura omnino praecedentis, at dimidio minor, niger, nitidus. Antennae capite thoraceque paulo breviores, articulo secundo tertioque subaequalibus, $4-10$ sensim paulo crassioribus, at vix brevioribus, penultimis crassitie paulo brevioribus, ultimo oblongo, apice truncatulo et inferne subacuminato, nigro-fuscae, articulis tribus basalibus testaceis. Palpi maxillares articulo quarto tertio sesqui longiore, conico, acuminato, acuto. Os testaceum. Caput thoracis latitudine, orbiculatum, crebre profunde punctatum, spatio medio longitudinali angusto laevi, antice foveola minuta obsoleta notatum. Thorax coleopteris dimidio angustior, latitudine sesqui prope longior, basin versus subangustatus, lateribus subrectis, basi cum angulis posterioribus rotundatus, apice utrinque oblique truncatus, angulis anterioribus obtusiusculis, parum convexus, utrinque sat crebre profunde aequaliter punctatus, spatio medio longitudinali angusto laevissimo. Scutellum parce subtiliterque punctulatum, nigrum. Elytra thorace paulo longiora, parcius subtiliterque at distincte punctata, tenuiter griseo-pubescentia, nigra, margine apicali determinate testaceo. Abdomen densius subtiliter punctulatum, densius griseopubescens, segmentorum marginibus rufo-piceis. Pedes cum coxis anterioribus testacei, coxis intermediis approximatis, tibiis omnibus parce spinulosis, tarsis anticis in utroque sexu fortius dilatatis. Alae albo-hyalinae.

* 148. Ph. agnatus: Elongatus, subdepressus, nig $r$, antennarum basi pedibusque testaceis, capite thoraceque ulrinque crebrius punclatis; punctis thoracis subserialis, elylris distincte punctatis, margine apicali testaceo. - Long. 2 lin.

Habitat in valle Araguensi Columbiae, Dom. Moritz.

Ph. humili paulo maior, niger, nitidus. Antennae capitis thoracisque prope longitudine, crassiusculae, articulo tertio secundo paulo longiore et tenuiore, 4-10 sensim crassioribus at vix brevioribus, penultimis crassitie paulo brevioribus, ultimo ovato, apice subemarginato et inferne acuminato, nigro-fuscae, basi testaceae. Palpi maxillares articulo ultimo tertio duplo longiore, conico, apice fortiter acuminato, acutissimo. Os testaceum. Caput thoracis latitudine, subovatum, crebre punctatum, spatio medio longitudinalı angustiore laevi, antice obsolete impresso. Thorax coleopteris dimidio prope angustior, latitudine tertia parte longior, basin versus subangustatus, lateribus ante medium leviter rotundatis, pone medium subsinuatis, basi rotundatus, apice utrinque oblique truncatus, angulis anterioribus leviter deflexis posterioribusque subrotundatis, leviter convexus, crebrius subseriatim punctatus, spatio medio longitudinali angusto laevi. Scutellum parce subtiliterque punctulatum. Elytra thorace paulo longiora, minus dense subtilius punctata, tenuiter griseo-pubescentia, nigra, margine apicali determinate testaceo. $\mathbf{A b}$ domen parce subtilissime punctatum, longius griseo-pubescens, segmentorum marginibus rufo-piceis. Pedes flavi, coxis anterioribus concoloribus, intermediis approximatis, tibiis omnibus parce subtiliterque spinulosis.

Tarsi antici maris modice dilatati. Femin a latet.

$\mathrm{Obs}$. $\mathrm{Ph}$. humili proximus, differt autem statura maiore, thorace lateribus minus crebre et subseriatim punctato, abdomine vix perspicue punctulato. 
149. Ph. ludicrus: Elongatus, niger, nilidus, pedibus anlennisque testuceis, his medio fuscis, capile thoraceque ulrinque crebre punclatis, hoc rufo, disco fusco, elytris distincle punctatis, margine apicali testaceo. - Long. $1 \frac{2}{3}$ lin.

\section{Habitat in Guyana Venezuelensi, Dom. Moritz.}

Statura et summa afinitas praecedentium. Antennae capite thoraceque breviores, crassiusculae, articulo tertio secundo paulo breviore et tenuiore, 4 - 10 sensin crassioribus at paulo brevioribus, subobconicis, penultimis crassitie brevioribus, ultimo ovato, apice emarginato et inferne acuminato, nigrae, articulis tribus primis flavo-testaceis. Palpi maxillares articulo quarto tertio duplo longiore, conico, apice fortiter acuminato, acutissimo. Os testaceum. Caput thoracis latitudine, leviter convexum, subquadratum, crebre profundeque punctatum, spatio medio longitudinali angustiore laevissimo, nigrum, nitidum. Thorax latitudine sesqui prope longior, coleopteris dimidio angustior, basin versus subangustatus, lateribus subrectis, basi cum angulis posterioribus leviter rotundatus, apice utrinque oblique truncatus, angulis anterioribus subrotundatis, sat crebre profundeque punctatus, spatio medio longitudinali angusto laevissimo, nitidus, piceus, limbo omni indeterminate rufo. Scutellum parce subtiiter punctulatum, nigro-piceum, nitidum. Elytra thorace tertia parte longiora, minus dense subtilius punctata, tenuiter griseopubescentia, nigra, nitida, margine apicali determinate testaceo. Abdomen subtiliter punctulatum, griseo-pubescens, nitidulum, nigrum, segmentis smgulis piceo-marginatis, subtus cum pectore rufo-picenm. Pedes flavi, coxis anterioribus concoloribus, intermediis leviter distantibus, tiliis omnibus parce subtiliterque spinulosis, tarsis anticis in utroque sexu modice dilatatis. Alae albo-hyalinae.

Variat antennis testaceis, articulis $\mathbf{3}-\mathbf{6}$ fuscescentibus.

$\mathrm{Obs}$. Ph. humili affinis, at magis elongatus et coxae intermediae distantes.

* 150. Ph. palmula: Elongalus, niger, antennis pedibusque testaceis, elytris abdomineque rufis, hoc anle apicem nigro, capile thoraceque ulrinque crebre punclatis. - Long. $2 \frac{1}{2}$ lin.

S iaph. palmula Grav. Micr. 49. 73. Mon. 107. 110

S aph. cinctus Latr. Hist. nat. Crust. et Ins. IX. 333. 92.

Habitat in Germania, Knoch.

Elongatus, subdepressus. Antennae capite sesqui longiores, articulo tertio secundo breviore et tenuiore, $4-10$ sensim crassioribus, vix autem brevioribus, $6-10$ sensim magis transversis, ultimo apice truncatulo et inferne acuminato, totae testaceae. Palpi maxillares articulo quarto tertio sesqui longiore, conico, fortiter acuminato et acuto. Os testaceum. Caput thorace paululum latius, subquadratum, depressiusculum, profunde minus crebre punctatum, spatio medio longitudinali laevi, antice dilatato et leviter impresso, parce griseo-pubescens, nigrum, nitidum. Thorax coleopteris dimidio angustior, latitudine paulo longior, lateribus parallelis, rectis, basi rotundatus, apice utrinque oblique truncatus, angulis anterioribus subrotundatis, posterioribus obtusis, parum convexus, utrinque fortius crebriusque vage punctans, linea media lata longutudinali laevi, nigro-piceus, nitidus. sicutellum parce subtilissime punctatum, rufo-piceum. Elyira thorace paulo 
longiora, crebrius subtiliusque punctata, tenuiter pubescentia, rufa, margine apicali testaceo. Abdomen basi coleopterorum latitudine, apicem versus leniter sensim incrassatum, tenuiter griseo-pubescens, supra laeve, subtus parce punctatum, rufum, mitidum, segmentis penultimis duobus nigris, apice ultimoque toto ferrugineis. Pectus nigro-piceum. Pedes testacei, coxis intermediis modice distantibus, tibiis spinulosis.

Tarsi antici maris leviter dilatati. Femin a latet.

Obs. Corporis antrorsum angustati habitu inter affines insignis.

\section{Teterothops Kirby.}

Steph. Illustr. V. p. 256. - Er. Col. March. I. p. 480

Trichopygus Nordm. Symb. p. 137. t. 2. f. 5.

\section{Antennae rectae.}

Ligula rotundata, integra.

Palpi arliculo ullimo subulato.

Corpus minutum, oblongum, utrinque attenuatum, fere fusiforme, alatum. Caput thorace angustius minusque, ovatum, basi leviter constrictum, deflexum, oculis mediocribus, parum prominulis. Labrum transversum, apice setosum, medio incisum. Mandibulae breves, medio obtuse dentatae. Maxullae (t. IV. f. 13. b.) malis membranaceis, interiore intus, exteriore apice barbatis. Palpi maxillares modice elongati, articulo primo minuto, secundo elongato, tertio hoc longitudine aequali, crassiusculo, subovato, quarto minuto, subulato. Labium (t. IV. f. I3. a.) mento transverso, ligula membranea, rotundata, paraglossis membranaceis, intus ciliatis, divergentibus, ligulam superantibus. Palpi labiales articulo primo minore, secundo sesqui longiore, crasso, cylindrico, tertio parvo, subulato. Antennae rectae, filiformes, apicem versus haud incrassatae, articulo ultimo apice truncatulo et inferne subacuminato. Thorax transversim convexus, basi fere coleopterorum latitudine, antrorsum leviter angustatns, basi fortiter rotundatus, apice truncatus. Scutellum triangulare. Elytra truncata. Abdlomen apicem versus sensim attenuatum, vivis sat elongatum, stylis analibus longioribus exsertis. Pedes breviusculi, coxis intermediis contiguis, tibiis anticis muticis, posterioribus spinulosis, tarsis anticis articulis quatuor primis dilatatis, subtus spongioso-tomentosis, posterioribus setulôsis, articulo primo ultimoque leviter elongatis.

$$
\text { O b s e r vatio n e s. }
$$

1. Corpus punctulatum, pubescens, capite thoraceque laevissimis, glabris, illo puncto singulo ad utriusque oculi marginem interiorem, nonnullis supra oculos et duobus verticalibus ante stricturum transversim positis, hoc punctis praeter pauca marginalia binis dorsalibus, paulo ante medium, et binis ad apicem in omnibus no-tatis. Habitu proxime ad Quedios minutos accedunt, a quibus autem stigmate prothoracico detecto et palporum structura differunt.

2. Mas abdominis segmento inferiore sexto apice leviter emarginato, tarsisque anticis fortius dilatatis ah altero sexu distinguitur.

3. Victus in quisquiliis, sub musco et sub foliis deciduis. 
* 1. H. praevius: Niger, pedibus rufo-piceis, capite breviler ovato, ely/ris thorace paulo longioribus, fusco-piceis, apice rufescentibus. - Long. 2 lin.

Er. Col. March. 1. 480. 1.

Trichopygus dissimilis Nordm. Symb. 137. 2.

Emus subuliformis Boisd. et Lacord. Faun. Ent. Paris. I. 385. 42.

Habitat in Germania.

Niger, capite thoraceque politis. Antennae capite sesqui longiores, articulo tertio secundo paulo minore, 4-10 subobconicis, sensim paulo brevioribus, penultimis crassitie haud longioribus, ultimo oblongo-ovato, apice emarginato et inferne acuminato, fusco-nigrae, basi obscure rufo-piceae. Palpi picei. Caput thorace angustius, breviter ovatum, punctis verticalibus duobus, utrinque supra ocnlos tribus, longitudinalıter dispositis, profundioribus, inter oculos utrinque puncto singulo ad ipsius oculi marginem interiorem impressum. Thorax basi coleopterorum prope latitudine, latitudine baseos fere brevior, antrorsum angustatus, apice dimidio quam basi angustior, lateribus rectis, basi cum angulis posterioribus rotundatus, apice truncatus, angulis anterioribus deflexis, subrotundatis, convexus, dorso ante medium punctorum pari et in ipso margine anteriore punctis duobus subtilioribus et paulo magis distantibus notatus, nigro-piceus, nitidus. Scutellum subtiliter punctulatum. Elytra thorace paulo longiora, densius punctulata, longius pubescentia, fusco-picea, apice rufescentia. Abdomen punctulatum, pube depressa fusco-grisea sericans, nigro-piceum, segmentorum marginibus apiceque rufo-ferrugineis. Pedes cum coxis rufo-picei.

$\mathrm{O}$ bs. Differt a $\mathrm{H}$. dissimili statura paulo maiore, capite minus angusto, elytris longioribus, antennis brevioribus et crassioribus.

* 2. H. binotatus: Niger, nilidus, anlennarum basi pedibusque testaceis, capile suborbiculato, elylris thorace paulo longioribus, nigro-piceis, margine summo apicali subtestaceo. - Long. $2 \frac{1}{3}$ lin. .

Habitat in Anglia, Dom. Rudd.

Praecedentis maximis individuis aequalis, niger, capite thoraceque politis. Antennae eapite thoraceque paulo breviores, articulo tertio secundo paulo longiore, 4-10 subcylindricis, sensim paulo brevioribus, penultimis etiam crassitie longioribus, ultimo oblongo, apice leviter emarglnato et inferne subacuminato, piceae, articulis trihus primis testaceis. Palpi nigro-picei. Caput thorace paulo angustius, suborbiculatum vel breviter ovatum, depressiusculum, punctis utrinque tribus longitudinalitèr dispositis supra oculos, singulo inter utrumque oculum, fortioribus, duobus transversim positis verticalibus 'subtilioribus impressum: Thorax basi coleopterorum prope latitudine, latitudine baseos paulo brevior, antrorsum modice angustatus, apice vix tertia parte quam hasi angustior, lateribus leviter, basi fortius rotundatus, apice truncatus, angulis anterioribus leviter deflexis posterioribusque subrotundatis, leviter convexus, dorso ante medium et apice punctis binis notatus, apicalibus subtilioribus et magis distantibus, nigro-piceus, nitidus. Scutellum crebre subtiliter punctulatum, tenuiter nigro-pubescens. Elytra thorace paulo longiora, densius punctulata, nigro-pubescentia, nigro-picea, margine summo apicali piceo-testaceo. Scutellum dense cubtilius punctulatum, densius griseo-pubescens, segmenti 
sexti margine apicali testaceo, segmentorum ventralium reliquorum ferrugineo. Pedes testacei, coxis piceis.

Obs. Differt a praecedente thorace minus convexo, antrorsum minus angustato, antennis basi testaceis. Teste Dom. Rudd sub nomine eodem Steph. Illustr. V. p. 257 descriptus.

* 3. H. dissimilis: Niger, antennarum basi pedibusque testaceis, elytris thoracis longiludine, piceis, apice rufescentibus, capite oblongo-ovato. - Long. $1 \frac{3}{4}$ lin.

Er. Col. March. I. 480. 2.

T'achyporus dis similis Grav. Micr. 125. 1.-Latr. Hist. nat. C'rust, et Ins. X. 5. 1. T'achinus dissimilis Grav. Mon, 23. 1.

St aph. subuliformis Gyll. Ins. Suec. II. 312. 29. - Sahlb. Ins. Fenn. I. 319. 27.

- Mannerh. Brachelytr. 27, 40.

Habitat in Germania, Suecia.

Niger, capite thoraceque politis. Antennae capite cum thorace paululum breviores, articulo tertio secundo paulo minore, $4-10$ subcylindricis, sensin vix brevioribus, ommibus crassitie longioribus, ultimo oblongo, apice truncatulo et inferne subacuminato, fusco-nigrae, articulis duobus primis testaceis. Palpi testacei. Caput thorace duplo angustius, elongatum, punctis verticalibus duobus, supra oculos utrinque tribus longitudinaliter dispositis, et ad oculi utriusque marginem interiorem puncto singulo subtilioribus impressum. Thorax coleapterorum fere latitudine, latitudine baseos haud brevior, antrorsum angustatus, antice tertia parte quam basi angustior, lateribus subrectis, basi cum angulis posterioribus rotundatus, apice truncatus, angulis anterioribus deflexis, subrotundatis, convexus, dorso ante medium et apice bipunctatus, punctis apicalibus haud subtilioribus at magis distantibus, nigro-piceus, nitidus. Scutellum punctulatum. Elytra thorace haud longiora, densius punctulata, longius pubescentia. Abdomen sat crebre punctulatum, apice segmentorumque singulorum margine apicali piceis infra rufis. Pedes testacei, coxis anticis concoloribus.

Variat aetate minus maturus thorace elytrisque rufo-piceis.:

* 4. H. 4-punctulus: Niger, antennis concoloribus, pedibus piceo-testaceis, elytris thoracis longitudine, capite ovato. - Long. $1 \frac{3}{4}$ lin.

Er. Col. March. I. 481.3.

Tachinus 4-punctulus Grav. Mon. 24. 2.

Staph. subuliformis Zetterst. Faun. Lappon. I. 72. 14. Ins. Lapp. 62. 20.

Trichopygus pumilio Nordm. Symb. I38. 4.

Habitat in Germania.

Statura et summa affinitas praecedentis, niger, nitidulus, capite thoraceque politis. Antennae capitis thoracisque prope longitudine, articulo tertio secundaque subaequalibus, $\mathbf{1 - 1 0}$ subcyludricis, sensim paulo brevioribus, penultimis crassitie vix longioribus, ultimo oblongo, apice truncatula et inferne subacuminato, piceo-nigrae, basi coneolores. Palpi nigro-picei. Caput thorace duplo prope angustius, ovatum, supra oculos utrinque punctis tribus longitudinaliter dispositis, singulo ad oculi utriusque marginem interiorem et duobus transversim positis verticalibus impressun. Thorax 
basi coleopteris paulo angustior, latitudine baseos paulo longior, antrorsum leniter angustatus, apice vix quarta parte quam basi angustior, lateribus subrectis, basi cum angulis posterioribus rotundatus, apice truncatus, angulis anterioribus deflexis, subrotundatis, modice transversim convexus, dorso ante medium et apice bipunctatus, punctis apicalibus magis distantibus. Scutellum subtiliter punctulatum. Elytra thorace vix longiora, subtiliter parcius punctulata, parcius pubescentia, concolora. Abdomen subtiliter punctulatum, parcius pubescens, subtus apice piceum. Pedes piceo-testacei, coxis anticis concoloribus.

Obs. Differt a praecedente antennis elytrisque concoloribus, capite minus oblongo, elytris abdomineque subtilius punctulatis. Specimen in collectione Hoffmannseggiana pro typico asservatum (a Dahlio Brunsvigae lectum), ad speciem praecedentem perti,et: cui autem descriptio Gravenhorstiana contraria est. Quae igitur denominatio errore quodam exorta videtur, quod in speciebus adeo difficulter distinguendis facile accidere potuit, eamque retinere eo magis dubitavi, cum cel. Gravenhorst collectionem laudatam non citaverit.

* 5. H. exilis: Niger, ore, antennis pedibusque flavis, elytris thorace longioribus, capite breviter ovato. - Long. $1 \frac{1}{3}$ lin.

Habitat in Columbia, Dom. Moritz.

Habitu omnino praecedentium, at duplo minor, niger, capite thoraceque politis. Antennae capitis thoracisque prope longitudme, articulo secundo crassiusculo, tertio duplo prope longiore, 4-10 subobconicis, sensim paulo hrevioribus, omnibus crassitie longioribus, ultimo paulo crassiore, ovato apice subtruncato et inferne subacuminato, luteae, basi flavae. Os flavum. Caput breviter ovatum, prope oculi utriusque marginem superiorem et in Inargine oculi utriusque interiore, puncto singulo, vertice punctis 4 transversim positis subtilioribus impressum. Oculi sat magni, modice prominuli. Thorax basi coleopterorum latitudine, latitudine baseos vix brevior, antrorsum angustatus, apice tertia parte quam basi angustior, lateribus subrectis, basi rotunciatus, apice truncatus, angulis anterioribus deflexis posterioribusque subtotundatis, modice convexus, dorso ante medium et apice bipunctatus, punctis apicalibus magis distantibus. Scutellum punctulatum. Elytra thorace perparum longiora, densius subtiliter punctulata, parce pubescentia, margine summo apicali rufescente. Abdomen densius punstulatum, apice marginibusque tenuibus segmentorum singulorum rufescentibus. Pedes flavi, coxis anterior.bus concoloribus,

$$
\text { Species milhi invis a. }
$$

6. Ir. nitens: Convexior, niger, nilidissimus, antennis basi, segmentorum ventralium marginibus, ano pedibusque rufo-piceis, elylris ulira medium ab apice rufo-testaceis, nilidis. - Long. $1 \frac{1}{3}$ lin.

Trichopygus nitens Nardm. Symb. 138. 3.

Habitat in Chersoneso Taurica.

Praecedentibus similis et affinis, sed multo minor. Anteunae fuscopiceae, articulis basalibus dilutioribus. Elytra convexa, laete rufo-testacea, versus scutellum paulo infuscata, nitidissima, subtilissime punctulata, fulvescenti-pubescentia. Pedes picei-ferruginei. (Nordm.) 


\title{
Reylophorus Nordm.
}

\author{
Nordm. Symb. p. 127. t. I. f. 19.
}

\section{Antennae fractae, articuls primo elongato.}

\section{Ligila rolundata, integra.}

Corpus minoris magnitudinis, fere fusciforme, alatum. Caput thorace multo minus, oblongo-ovatum, basi vix constrictum, inflexum, oculis haud prominulis. Labrum transversum, apice ciliatum, medio tenuiter incisum. Mandibulae parvae, acutae, basi fortiter bidentatae. Maxillae (t. IV. f. 9. b.) malis brevilus, coriaceis, apice barbatis. Palpi maxillares mediocres, articulo primo minuto, secundo elongato-obconico, tertio obconico. Labium (t. IV. f. 9. a.) mento transverso, corneo, ligula brevi, rotundata, coriacea, paraglossis minutis, ligulam haud superantibus. Palpi labiales articulo primo minuto, secundo obconico tertioque ovato vel subgloboso crassiusculis. Antenuae tenuiusculae, fractae, articulo primo elongato, capite paulo breviore, apice subincrassatae, articulo ultimo globoso. Thorax basi coleopterorum latitudine, antrorsum angustatus, convexus, lateribus deflexis basique rotundatus, apice truncatus. Scutellum triangulare, sat magnum. Elytra thoracis longitudine, truncata. Abdomen apicem versus sensim attenuatum, stylis analibus mediocribus, hirsutis. Pedes breviusculi, coxis intermediis oontiguis, tibiis anticis muticis, posterioribus spinulosis, tarsis anticis breviusculis, crassiusculis, cylindricis, articulis parum distinetis, quatuor primis brevissimis, quinto his coniunctis fere longiore, unguiculis validis, tarsis posterioribus tenuiusculis, articulo primo elongato, quinto unguionlis minutis, debilibus.

\section{O b s e r v a t i o n es.}

1. Corpus punctulatum, pubescens, capite thoraceque laevissimis, glaberrimis, nonnisi punctis paucis notatis. Habitus huius generis, capite inflexo, antennis fractis et tarsorum anticarum structura in hac subtribu valde distincti, propius ad Tachyporinos accedit, neque etiam Gymnusae dissimilis videtur, corporis penitiore structura autem et antennarum insertione huic tribui et subtribui adscribendum.

2. Palporum maxillarium structura species 5 mihi examinatae non omnino inter se congruunt.

3. Sexus differentia latet.

4. Victus speciei indigenae in silvis sub musco.

* 1. A. glabricollis: Niger, niiidus, tarsis fulvis, elytris fortiter puncta. tis. - Long. 3 lin.

Er. Col. March. I. 482. 1.

Staph. glabricollis Buisd. et Lacord. Faun. Ent. Paris. I. 896. 20.

Staph. rufilabris Zetterst. Ins. Lappon. 65. 42.

Acylophorus Ahrensii Nordm. Symb. 127. 1.

Habitat in Europa.

Niger, nitidus, capite thoraceque politis. Antennae capitis thoracisque longitudine, articulo secundo tertio maiore, 4-10 sensim brevioribus $e_{i}$ crassioribus, subobconicis, penultimis crassitie vix longioribus, ultimo subgloboso, apice compresso, obtuso, nigrae, articulo primo summa basi flavescente. Palpi nigro-picei, maxillares articulo ultimo ovato. Caput oblongum, lateribus supra oculos subtilissime punctulatum et subtiliter pubescens, 
supra utrinque inter oculos puncto singulo fortiore, verticem versus punctis binis, oblique positis subtilioribus impressum. Thorax basi coleopterorum prope latitudine, latitudine baseos haud brevior, antrorsum angustatus, lateribus et basi modice rotundatus, apice truncatus, angulis anterioribus deflexis, posterioribus obtusis, modice convexus, dorso medio punctorum pari, et lateribus ante medium utrinque puncto singulo notatus. Scutellum parce punctatum parceque pubescens. Elytra thoracis longitudine, minus dense fortius punctata, pube parca depressa minus subtili nigra vestita. Abdomen parcius punctulatum, minus subtiliter longius pubescens, supra margine apicali segmenti quinti testaceo, subtus segmentorum 5 anteriorum piceo. Pedes nigri, tarsis fulvis. Alae fusco-hyalinae.

* 2. A. longicornis: Niger, nitidus, ano pedibusque rufis, elytris fortius punctalis. - Long. $3 \frac{2}{3}$ lin.

Habitat in Cayenna, Dom. Buquet.

Praecedente sesqui fere maior, niger, nitidus. Antennae elongatae, capite thoraceque prope longiores, graciliores, articulo secundo tertioque subaequalibus, quarto sequente paulo minore, $5-8$ sensim paulo brevioribus, omnibus teretibus, sequentibus duobus sensim brevioribus et crassioribus, subobconicis, ultimo subgloboso, praecedenti arctius applicato, nigrae, articulo primo basi rufo-piceo. Palpi rufi, maxillares articulo quarto cylindrico, apice acuminato. Caput ovatum, inter oculos puncto singulo utrinque ovatum. Thorax basi coleopterorum latitudine, latitudine baseos parum brevior, antrorsum modice angustatus, lateribus, basi et angulis posterioribus rotundatus, apice truncatus, angulis anterioribus deflexis, subrectis, modice convexus, punotorum pari altero in dorso paulo ante medium, altero ante apicem, et lateribus prope marginem ante medium puncto minuto singulo utrinque notatus. Scutellum punctatum, fusco-pubescens. Elytra thoracis longitudine, minus confertim fortius punctata, densius longiusque fusco-pubescentia. Abdomen minus confertim fortius punctulatum, fortiter nigropubescens, subtus coloribus laetis metallicis resplendens, segmento quinto sextoque apice testaceis. Pedes rufi, coxis nigris, anticis interne rufescentıbus.

* 3. A. femoralis: Niger, nitidus, pedibus piceis, femoribus tarsisque rufis, elytris parce fortius punctatis. - Long. $2 \frac{3}{4}$ lin.

Nordm. Symb. 128. 2.

Habitat in Brasilia prope Rio Janemo, Dom. v. Olfers.

A. glabricolli aequalis, niger, nitidus. Antennae capite thoraceque multo breviores, articulo secundo tertio duplo maiore, $3-10$ sensim paulo breviuribus, 5 - 10 sensim paulo crassioribus, penultimis duobus transversis, ultimo subgloboso, piceae, articulo primo basi rufo. Mandibulae rufae. Palpi rufi, maxillares articulo ultimo incrassato, ovato, apice acuminato. Caput oblongo-ovatum, puncto singulo utrinque inter oculos impressum. Thorax bası coleopterorum latitudine, latitudine baseos paulo brevior, antrorsum leviter angustatus, basi, lateribus et angulis posterioribus rotundatus, apice leviter emarginatus, angulis anterioribus leviter deflexis, subrotundatis, modice convexus, dorso paulo ante medium et paulo ante apicem punctis binis, et lateribus prope inarginem lateralem anterius puncto utrinque singulo 
impressus. Scutellum laeve. Elytra thorace paulo longiora, minus confertim fortius punctata, pilo brevi crasso rigido declinato e quovis puncto enascente hispida. Abdomen parce subtilius punctatum, parcius nigro-pubescens, segmentis inferioribus primis apice piceo-marginatis. Pedes femoribus tarsisque rufis, tibiis piceis.

* 4. A. picipes: Niger, nitidus, pedibus piceis, elytris subtilius punctatis, griseo-pubescentibus. - Long. 3 lin.

Habitat in Columbia, Dom. Moritz.

Statura omnino praecedentium, niger, subnitidus, capite thoraceque nitidissimis. Antennae capite thoraceque paulo breviores, apice leviter incrassatae, articulo secundo tertio paulo longiore at parum crassiore, quarto sequente breviore et tenuiore, 5-10 subobconicis, sensim brevioribus, $5-7$ leniter, 8-10 fortius sensim crassioribus, penultimis duobus crassitie brevioribus, ultimo subgloboso, nigrae, articulo primo rufo, apice piceo. Palpi rufi, maxillares articulo ultimo conico, acuminato. Caput ovatum, lateribus supra oculos confertissime subtiliter punctulatum, dense griseo-pubescens, supra inter oculos puncto singulo, verticem versus binis oblique positis utrinque impressum. Thorax basi coleopterorum latitudine, latitudine baseos paulo brevior, antrorsum angustatus, lateribus, basi et angulis posterioribus rotundatus, apice truncatus, angulis anterioribus deflexis, subrotundatis, modice convexus, laevissimus, dorso ante medium altero et ante apicem altero punctorum pari et lateribus prope marginem lateralem longe ante medium puncto utrinque singulo impressus. Scutellum punctulatum, griseo-pubescens. Elytra thoracis longitudine, crebrius minus fortiter punctata, longius densiusque griseo-pubescentia. Abdomen punctulatum, nigrogriseoque pubescens, metallico-versicolor, segmento penultimo margine apicali rufo-piceo. Pedes picei, anteriores rufescentes.

5. A. pronus: Niger, nitidus, pedibus rufis, femoribus posterioribus piceis, elytris parcius subtiliusque punctatis, nigro-pubescentibus. - Long. $2 \frac{1}{2}$ lin.

Habitat in America septentrionali, Mus. Dom. Chevrolat.

A. glabricolli dimidio minor, niger, nitidulus, capife thoraceque nitidissimis. Antennae articulo secundo tertio sesqui longiore, quarto quinto paulo minore, hoc cum sequentibus duobus terete, sensim paulo brevioribus, (articuli reliqui desunt), piceae, articulis singulis basi rufis. Palpi rufo-picei, maxillares articulo tertio avato, apice acuminato. Caput oblongum, lateribus supra oculos subtilissime confertissimeque punctatum, inter oculos puncto singulo, verticem versus punctis binis oblique positis subtilioribus impressum. Thorax basi coleopterorum prope latitudine, latitudine baseos perparum brevior, antrorsum angustatus, lateribus basi et angulis posterioribus rotundatus, apioe truncatus, apice leviter emarginatus, angulis anterioribus deflexis subrotundatis, convexus, anterius subcompressus, punctorum pari, altero in medio dorsi, altero paulo ante apicem punctoque singulo utrinque prope marginem lateralem inter medium et apicem impressus. Scutellum sublaeve, sive parce subtiliter obsoleteque punctulatum. Elytra thorace vix longiora, parcius subtiliusque p'nctata, longius nigro-pubescentia. Abdomen parce subtilius punctulatum, longius nigro-pubescens. Pedes rufi, coxis omni!sus femoribusque posticis nigro-piceis. 


\section{Subtribus tertia.

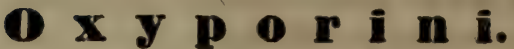

Sligmalioa prothoracica obtecta.

Antennae basi distantes.

Labrum transversum, bilobum, lobis rotundatis, lateribus membranaceum plerisque;

integrum aut subintegrum $Q$ ued. molochino, frontali, fuliginoso; totum corneum, medio incisum Eury poro;

totum corneum, bilobum, lobis divergentibus. Oxyp oro.

Mandibulae haud prominentes, basi mediove dentatae plerisque;

muticae Astrapaeo;

fortiter prominentes, porrectae, decussatae, muticae Oxy poro.

Maxilla mala exteriore apice, interiore interne barbatis; utraque coriacea, plerisque;

exteriore coriacea, interiore membranea Oxyporo.

Palpi maxillares filiformes plerisque;

articulo quarto securiformi Astrapaeo.

Me ntum corneum, transversum, apice truncatum, interstitio inter mentum et ligulam membranaceo, simplice plerisque;

brevissimum, apice late sinuatum, interstitio inter mentum et ligulam coriaceo, apice acute bidentato $O x y$ poro.

Ligula brevis vel brevissima;

integra Quedio, Europoro;

leviter incisa Astrapaeo;

elongata, profunde biloba, lobis acuminatis $0 \times$ yporo.

Paraglossae liberae, ligulam longe superantes plerisque;

nullae Oxyporo.

Palpi labiales filiformes $Q$ uedio;

articulo tertio securiformi Astrapaeo, Europoro;

articulo tertio lunato $\mathrm{Oxy}$ poro.

Antennae rectae, filiformes vel apicem versus leviter incrassatae, articulis tribus primis reliquis magis elongatis, glabris, ultimo apice saepius abrupte acuminato aut oblique truncato plerisque;

apicem versus dilatatae, compressae, articulis penultimis pluribus fortiter transversis $\mathrm{Oxy}$ poro.

Caput basi parum constrictum, collo quasi crasso thoraci insertum.

Thorax basi rotundatus, apice truncatus, margine laterali distincto Quedio, Astrapaeo, Euryporo; inflexo, subtilissimo, indistincto Oxyporo.

Elytra truncata, sutura integerrima.

Abdomen plerumque apicem versus sensim attenuatum.

Pedes breviusculi, coxis intermediis approximatis Quedio, Astrapae o, Europoro;

late distantibus Oxy poro; 
tibiis spinulosis Quedio, Astrapaeo, Euryporo;

muticis Oxyporo;

tarsis posterioribus articulis 4 primis decrescentibus, anticis

dilatatis $Q u$ edio, Astrapaeo;

simplicibus Euryporo, Oxyporo.

\title{
Quedius Leach.
}

\author{
Er. Col. March. I. p. 483.
}

Quedius Steph. Illestr. V. p. 215. Curt. Britt. Ent. XIV. t. 638. - Microsuurus Dej. Cat. p. 69. - Steph. Illustr. V. p. 435. - Velleius Mannerh. Brachelytr. p. 19. - Steph. Illustr. V. p. 201. - Boisd. et Lacord. Faun. Ent. Paris. I. p. 356. - Raphirus Steph. Illustr. V. p. 241.

Palpi utrique filiformes.

Ligula rolundala, inlegra, paraglossis breviore.

Pedes intermedii approximali.

Corpus plerumque mediocre, oblongum vel elongatum, alatum. Caput thorace minus, suborbiculatum vel subovatum, basi leviter constrictum, thoraci immissum, oculis minoribus maioribusve, minus magisve prominulis. Labrum transversum, bilobum vel medio incisum, nonnullis (e. g. Q. molochino) integrum, limbo laterali membranaceo. Mandibulae minores, haud prominentes, acutiusculae, intus bidenticulatae. Maxillae malis minutis, coriaceis, interiore intus, exteriore extus barbatis. Palpi maxillares parum elongati, filiformes, articulo primo minuto, secundo tertio paulo longiore, quarto tertio vel aequali vel plerumque breviore, vel interdum paulo longiore. Labium mento transverso, corneo, ligula perbrevi, rotundata, integra, membranea, paraglossis minutis, ligulam tamen superantibus, divergentibus, coriaceis, intus ciliatis. Antennae ante mandibularum basin insertae, filiformes, articulo ultimo subacuminato. Thorax coleopteris plerumque latitudine aequalis, suborbiculatus, apice truncatus. Scutellum triangulare. Elytra truncata. Abdomen plerumque apicem versus sensim angustatum. Pedes breviusculi, coxis intermediis contiguis, tibiis posterioribus spinulosis, tarsis anticis articulis quatuor primis dilatatis, patellam ovalem formantibus, subtus spongioso - tomentosis, posterioribus setosis, articulo primo leviter elongato,

\section{O b s e r y a t i o n e s.}

1. Proximum hoc genus, praecipue oris, antennarum pedumque structura, nec non corporis punctura et pubescentia videtur $\mathrm{Phil}$ ontho, ut praeter stigmata prothoracica obtecta vix ulla exstet nota distinctiva. Habitus capite basi minus constricto, thorace lateribus magis rotundato, abdomine saepius apicem versus sensim attenuato a Philontho aliquatenus distinctus et ad Tachyporinorum formam quodam. modo vergit.

2. Genera plura ab Anglis auctoribus condita sunt, quae nonnisi levioribus et non satis constantibus notis temere distincta Quedio subiungo:

Velleius, a plerisque recentioribus auctoribus pro genere receptus, speciem singulam, statura et antennis serratis insignem continens. Antennarum figura sola in hac tribu generibas condendis non sufficit:

Microsaurus. Toto huic generi, Velleio excepto, Com. Dejean hoc nomen imposuit, quo Dom. Stephens lateralem a reliquis Quediis distinxit, quamvis nullo charactere ab iis discedere videtur.

Taphirus oculis magnis a Quedio genuino distinguitur, qua nota nonnullao quidem species satis insignes esse videntur, quam autem non satis constantem 
reperio, ut sectionis etiam notam praebeat. Sectionis secundae species plurimae huc pertinent, e. g. Q. attenuatus, boops.

3. Mas abdominis segmento inferiore sexto apice emarginato a femina distinctus. Femina in nonnullis tarsis anticis minus dilatatis vel simplicibus a mare differt. Caput in utroque sexu plerumque aequale, in paucis speciebus (e. g. Q. fulgido) maribus maioribus maius, sicut in nonnullis Philonthis.

4. Victus in fimo, in quisquilis, sub musco, foliis deciduis, lapidibus.

5. Q. fulgidi larva a Dom. B ou ché hoc modo descripta: "Linearis, posterius attenuata, supra leviter convexa, pallide flava, parce setosa. "Caput oblongoquadrangulare, angulis rotundatis, dilute piceum, nitidum, laeve, parce pilosum. Antennae conicae, 6-articulatae, articulo primo secundoque crassis, brevibus, cylindricis, penultimo intus apice processu parvo elliptico aucto. Mandibulae elongatae, tenues, falcatae. Clypeus apice sexdentatus. Labrum breve, inflexum. Maxillae subcylindricae, apice intus processu parvo elliptico, extus palpo subulato, 5-articulato. Labium breve, subcordatum, medio acumine parvo subulato instructum, palpis minutis, subulatis, 2-articulatis. Thorax parce pilosus. Prothorax latitudine langior, testaceus, nitidus, laevis. Meso - et metathorax latitudine breviores. Pedes dilute picei, ferrugineo-spinulosi. Abdomen sordide albo-flavescens, multi-setosum, setis brevibus, clavatis, clava muricata. Stigmata minuta, flava. Segmentum anale angustatum, apice caudis duabus 3-articulatis, subulatis, segmento duplo longioribus, articulo primo reliquis ambobus longitudine aequali. Anus tubulosus, perpendicularis, pedis officio inserviens, caudis longior, parce setosus. Long. 3-4 lin. Victitat per hiemem in vegetabilibus putrescentibus. Insidiatur imprimis Dipterorum larvis. Carne etiam crudo vescitur." (Hist. nat. Ins. I. 180. 2. t. VIII. f. 1 - 8.)

Q. fulginosi (tristis) larva a Dom. Wat erhouse observata et sequenti modo descripta: ,Caput et prothorax coriacea, saturate nigro-picea. Meso.. et metathorax subcoriacei, flavescenti-albi. Abdomen molle, supra pallide fuscum. Long. 6 $\frac{\mathrm{T}}{2}-7$ lin. Caput subquadratum, depressum. Antennae 4-articulatae, articulo basali brevi, secundo tertioque magis elongatis, ultimo gracili, acuto. Mandibulae longae, acutae, simplices. Labrum transversum, tuberculis numerosis instructum. Labium minutum. Palpi labiales 3-articulati. Maxillae elongatae, graciles, lobo singulo interne instructae. Palpi maxillares 4-articulati, articulo basali brevi, secundo tertioque mediocribus, subaequalibus, terminali acuto. Prothorax quadratus, capite angustior. Meso- et metathorax transversi, prothoraci latitudine subaequales. Abdomen segmentis omnibus longitudine subaequalibus, excepto ultimo, elongato, caudis duabus instructo. - Nympha artubus contiguis, abdomine recto, capite prothoraceque antrorsum inflexis, illo truncum tangente. - Larva iisdem locis atque imago obvia. Versus Martii finem in nymphae statum transit. Imago excluditur ultra medium Maii." (Transact. Ent. Soc. Lond. I p. 32. t. III. f. 2.)

Praeter numerum articulorum antennarum at palporum, forte ab altero auctore haud satis accurate observato haec larvae satis convenire videntur.

$$
\text { * Thorax processu pone coxas anticas corneo. }
$$

1. Thorax seriebus dorsalibus 3-punctatis.

* 1. Q. dilatatus: Niger, parum nitidus, thoracis margine dilatalo, antennis serratis. - Long. 8 - 10 lin.

Er. Col. March. I. 484, 1.

Staph. dilat atus Fab. Mant. Ins, I. 220. 7. Ent. Syst. I. II. 522. 12. Syst. El. II. 592 14. - Payk. Faun. Suec. HI. 359. 29. - Panz. Ent. Germ. 353. 9. Latr. Hist. nat. Crust. et Ins. IX. 326. 74. - Grav. Mon. 89. 85. - Gyll. Ins. Suec. II. 299. 18. - Germ. Faun. Ins. Europ. VI. 13.

Velleius dilat at us Mannerh. Brachelytr. 19. 1. - Steph. Illustr. Britt. Ent. V.t. 26. f. 6. - Boisd. et Lacord. Faun. Ent. Paris. I. 357. - Nordm. Symb. 16. 1. Runde Brachelytr. Hal. 1. 1.

Staph. se: raticornis Schrank Faun. Boic. 1. 641.866.

Staph.concolor Marsh. Ent. Britt. 498. 4.

Habitat in Europa.

Magnus in hoc genere, niger, parum nitidus, thorace abdomineque se- 
riceo-micantibus, elytris opacis. Antennae capite paulo longiores, medio crassiores, articulo tertio secundo plus duplo longiore, $\$-10$ introrsum productis, serratis, ultimo oblongo-ovato, integro, rufo-piceae, basi nigrae, apice ferrugineae. Caput thorace multo angustius, sat magnum, subovatum, supra oculos et in fronte ad oculi marginem interiorem puncto singulo utrinque impressum. Thorax latitudine tertia parte brevior, coleopteris paulo latior, lateribus et basi aequaliter rotundatus, apice truncatus, ntrinque subsinuatus, medio convexus, margine laterali et basali late explanato, seriebus dorsalibus punctis tribus, apicali panlo remotiore, compositis, lateribus praeter plura marginalia singulo puncto inter medium et marginem utrinque impressus, punctis omnibus subtilibus. Scutellum punctulatum. Elytra thorace paulo longiora, subtiliter confertim punctata, breviter nigro-pubescentia. Abdomen apicem versus sensim angustatum, parcius punctulatum nigroque pubescens. Pedes concolores.

Tarsi antici maris fortiter, feminae modice dilatati.

Obs. In Vespae Crabronis nido aliquando lectus a Gyllenhal.

* 2. Q. lateralis: Niger, nilidus, antennarum basi, palpis tarsisque rufopiceis, elylris confertim punclatis, margine laterali teslaceo. - Long. 5 lin.

Curt. Britt. Ent. X1V. t. 638. - Er. Col. March. I. 485. 2.

Staph. lateralis Grav. Micr. 35. 50. Mon. 42. 4. - Latr. Hist. nat. Crust. et Ins. IX. 319. 55. - Gyll. Ins. Suec. IV. 477. $20-21$.

Philonth. lateralis Nordm. Symb. 76. 7.

Emus lateralis Boisd. et Lacord. Faun. Ent. Paris. I. 375. 26.

Habitat in Europa.

Statura omnino Q. fulgidi, at maior et praesertim latior, niger, capite, tnorace scutelloque pernitidis. Antennae capite paulo longiores, tenuiores, articulo tertio secundo sesqui longiore, $4-10$ sensim paulo brevioribus, subcylindricis, ultimo oblongo, apice sensim acuminato, piceae, articulo basali rufo. Palpi rufo-picei. Caput thorace angustius, suborbiculatum, utrinque supra oculos punctis duobus, in fronte utrinque ad oculi marginem puncto singulo impressum. Oculi mediocres, parum prominuli. Thorax coleopteris paulo latior, latitudine vix brevior, lateribus et basi aequaliter rotundatis, supra leviter convexus, apice truncatus et utrinque subsinuatus, margine laterali pone medium explanato, seriebus dorsalibus punctis tribus aequaliter distantibus compositis, lateribus utrinque punctis praeter marginalia duobus impressus, punctis minus fortibus. Scutellum laevissimum. Elytra thorace parum longiora, dense subtiliter punctata, pube tenui nigra obtecta, subnitida, margine laterali inflexo testaceo. Abdomen breviusculum, apicem versus sensim angustatum, confertim subtilius punctulatum, tenniter nigro-pubescens, cupreo-versicolor. Pedes picei, tarsis anticis in utroque sexu fortiter dilatatis.

* 3. Q. fulgidus: Niger, nilidus, antennis pedibusque piceis, thorace lateribus subdilatato. - Long. 3 - 5 lin.

Er. Col. March. I. 486. 3.

Staph. variabilis Gyll. Ins. Suec. II. 303. 21. - Zetterst. Fann. Lappon. I. 70.

10. Ins. Lappon. 61. 11. - Sahlb. Ins. Fenn. I. 314. 18. - Mannerh. Brachel. 25.29. Philonth. variabilis Nordm. Symb 78. 15.

St aph. nitidus Grav. Micr. 31. 46. Mon. 42. 5. - Latr. Hist. nat. Crust. el Ins. IX. 318. 51. 
Emus $n$ itidus Boisd. et Lacord. Faun. Ent. Paris. I. 377. 29.

Elytris rufis.

Staph. fulgidus Fab. Mant. Ins. I. 220. 14. Ent. Syst. I. II. 525. 25. Syst. El. 11. 596. 3i. - Panz, Ent. Germ. 354. 17.

Staph. fuscipennis Block Ins. Vall. Plauens. 116. 4. $f$. 4.

Staph. rufitarsis Marsh. Ent. Britt. 512. 42.

Staph. distinctus Runde Brachelytr. Hal. 6. 22.

Staph. iracundus Say Transact. Am. Philosoph. Soc. Philadelph. Nov. Ser. IV. 449. 3. Emus floralis Boisd. et Lacord. Faun. Ent. Paris. 1. 380. 33.

Philonth. assimilis Nordm. Symb. 78. 76.

Elytris concoloribus.

Staph. mesomelinus Marsh. Ent. Britt. 510. 32.

Staph. Grönlandicus Zetlerst. Ins. Lappon. 61. 13.

Emus occultus Boisd. et Lacord. Faun. Ent. Paris. I. 379. 31.

Habitat in Europa et in America septentrionali.

Niger, nitidus, capite, thorace scutelloque pernitidis, elytris aut nigris, interdum nigro-piceis, sutura rufescente, aut rufis. Antennae capite sesqui longiores, articulo tertio secundo duplo prope longiore, 4 et 5 subcylindricis, 6-10 subobconicis, crassitie vix brevioribus, ultimo ovato, subcompresso, apice inferius abrupte acuminato, piceae, articulis basalibus nigricantibus. Palpi nigro-picei. Caput thorace angustius, subovale, in mare interdum capitis latitudine, suborbiculatum, omnium subtilissime punctulatum, supra utrinque supra oculos punctis tribus, in fronte utrinque ad oculi marginem interiorem puncto singulo impressum, lateribus supra oculos subtilus punctulatum. Oculi mediocres, parum prominuli. Thorax elytris latitudine aequalis, latitudine paulo brevior, basi lateribusque aequaliter rotundatis, antrorsum leviter angustatus, leviter convexus, margine laterali subexplanato, seriebus dorsalibus punctis tribus approximatis compositis, lateribus punctis praeter marginalia utrinque pluribus impressus, praeterea omnium subtilissime vage obsoleteque punctulatus. Scutellum laevissimum. Elytra thorace paulo longiora, subtilius minus confertim punctata, tenuiter griseo-pubescentia. Abdomen apice angustatum, crebre subtilius punctulatum, pube subtili depressa grisea rariore vestitum, segmentis singulis piceo-marginatis. Pedes nigro-picei vel fusco-picei, tarsis rufo-piceis, anticis in utroque sexu fortius dilatatis. Alae fusco-hyalinae.

V a riat I, Niger, elytris rufis.

2, Niger, elytris concoloribus, pedibus saepius piceis.

3 , Niger, pedibus piceis, abdomine rufo-brumneo, basi nigricante.

4, Dilute fusco-piceus, vel piceo-testaceus, capite elytrisque obscurioribus: immaturus.

5, Piceus, capite pectoreque nigricantibus, pedibus abdominisque segmentorum marginibus rufo-piceis, elytris rufis, ano testaceo.

Obs. 1. Coloribus instabilis, antemis basi nigricantibus et thoracis margine laterali subexplanato ab affinibus facile distinguendus. Mas variat capite maiore minoreve, eodem modo ac Phil, acneus alique.

2. Nomen Fabricianum, quo duo huius insecti exempla in auctoris collectione signata vidi, restitui. Typus Fabricianus elytris rufis a nonnullis auctori- 
bus pro specie peculiari habetur, at vix rite, nullae enim praeter elytrorum colorem, in pluribus huius familiae speciebus eodem modo variantem, differentiae obviae sunt. Ex America septentrionali nobis quidem nonnisi individua elytris rufis allatae, at non est, quod illis in terris nonnisi eiusmodi specimina occurrere afferam. Staph. Grönlandicus Westerm. e Grönlandia, ab il. Prof. Zetterstedt inter Insecta Lapponica 1. c. descriptus, a Dom. Westermann amice comunicatus, nullo modo ab huius speciei individuis elytris concoloribus differt.

* 4. Q. cruentus: Niger, nitidus, antennarum basi, palpis, pedibus anoque mufis, elytris parcius punctatis, rufis nigrisve. - Long. 3-4 lin.

Staph. cruentus Oliv. Ent. III. 24. 27. 34. t. 5. f. 49.

Staph. fulgidus Marsh. Ent. Britt. 503. 16.

IIabitat in Germania, Gallia, Italia, Volhynia.

Statura fere praecedentis, niger, nitidus, capite, thorace scutelloque: pernitidis. Antennae capite sesqui longiores, articulo tertio secundo sesqui longiore, 4 et 5 cylindricis, crassitie haud brevioribus, $6-10$ paulo crassioribus, transversis, subaequalibus, ultımo ovato, apice abrupte acuminato, nigro-pıceae, articulis tribus primis testaceo-rufis. Palpi rufo-testacei. Caput thorace angustius, vel maris saepius eiusdem latitudine, orbiculatum, depressiusculum, supra vertice utrinque punctis duobus, supra oculos et inter oculos utrinque puncto singulo impressum, lateribus basi subtiliter punctulatis. Thorax coleopteris vix latior, latitudine summa paulo brevior, basi et lateribus cum angulis posterioribus aequaliter rotundatus, apicem versus leviter angustatus, apice truncatus, angulis anterioribus deflexis, rectis, convexus, seriebus dorsalibus punctis tribus, apicali paulo remotiore, compösitis, lateribus punctis practer marginalia utrinque 4 impressus, punctis minus fortibus. Scutellum laevissimum. Elytra thorace tertia parte longiora, minus fortiter parcius punctata, parcius griseo-pubescentia. Abdomen parallelum, parce subtiliter punctatum, parce longius griseo-pubescens, segmentis 4 primis margine apicali, quinto apice, sexto toto rufis. Pedes rufotestacei, coxis omnibus nigro-jiceis, tarsis anticis in utroque sexu fortius dilatatis.

V ariat 1, Elytris rufo-testaceis.

2, Elytris nigro-piceis, sutura picescente.

3, Elytris nigerrimis, abdominis segmentis tribus primis concoloribus, ultimis margine apicali testaceo, coxis nigris.

Obs. I. Distinctus ab affinibus abdomine parallelo, antennis brevioribus, articulis earum 6 - 10 transversis, a praecedente praeter thoracis structuram antennarum basi pedibusque rufo-testaceis, a sequente coxis etiam anticis nigro-piceis nigrisve.

$\therefore$ V ar. 3 colore corporis nigerrimo et abdominis segmentorum ultimorum solo margine teńui apicali testaceo magis diversa, aliae autem differentiae desiderantur, quare pro specie peculiari rite haberi nequit. Specimina cum genuinis in Sardinia lerta communicavit Dom. Prof. Gené.

* 5. Q. xanthopus: Nigro-piceus, antennis, pedibus abdominisque segmentorum marginibus testaceis, elytris forlius punclatis. - Long. $3 \frac{1}{2}$ liit.

Er. Col. March. I. 487. 4.

staph. variabilis var. c Gyll. Ins. Suec. II. 303. - Sahlb. Ins. Fenn I. 314.

Habitat in Germaniae silvis frondosis. 
Statura omnino Q. fulgidi, at paulo minor, niger vel nigro-piceus, nitidus, capite, thorace scutelloque pernitidis. Antennae capite plus sesqui longiores, articulo tertio secundo sesqui longiore, 4-10 sensim paulo crassioribus at vix brevioribus, subobconicis, penultimis crassitie vix longioribus, ultimo ovato, apice abrupte acuminato, testaceae, apice interdum fuscescentes. Os rufo-piceum, palpis testaceis. Caput in utroque sexu thorace angustius, subovale, laevissimum, supra utrinque supra oculos punctis tribus, in fronte utrinque ad oculi marginem interiorem puncto singulo impressum. Oculi mediocres, parum prominuli. Thorax coleopterorum latitndine, latitudine summa vix brevior, basi et lateribus rotundatus, angulis posterioribus obtusis, subrotundatis, apice truncatus et utrinque subsinuatus, angulis anterioribus deflexis, acutiusculis, antrorsum subangustatus, leviter convexus, seriebus dorsalibus punctis tribus aequaliter distantibus compositis, lateribus punctis praeter marginalia utrinque duobus impressus, punctis minus fortibus. Scutellum laevissimum. Elytra thorace tertia parte longiora, crebrius fortiusque punctata, pube tenui haud depressa parcius vestita, nigropicea, nitida, sutura saepe rufescente. Abdomen apice angustatum, parce subtiliter punctulatum, longius parciusque griseo-pubescens, nigro-pilosellum, segmentorum marginibus rufo-testaceis. Pedes cum coxis testacei, tarsis anticis in utroque sexu fortius dilatatis.

Obs. Propinquus Q. fulgido, at antennis pedibusque testaceis, elytris longioribus, fortius punctatis, abdomine parcius punctato discedens, neque unquam cum eo obvenit; propior praecedenti, at antennarum structura, elytris crebrius fortiusque punctatis, abdomine apicem versus evidenter angustato et coxis fomnibus testaceis diversus, proximus sequenti, at colore, elytris crebrius punctatis et antennarum articulo secundo tertio subaequali distinctus.

* 6. Q. scitus: Rufo-testaceus, nitidus, capite nigro, thoracis disco, peclore elylrorumque angulis posticis segmentisque singulis abdominis basi piceis, elytris parcius punctatis. - Long. 3 lin.

Er. Col. March. I. 487. 5.

Staph. scitus Grav. Mon. 50. 13. - Gyll. Ins. Suec. II. 306. 22. - Suhlb. Ins. Fenn. 1. 316. 19. - Mlannerh Brachelyir. 26. 30. - Runde Brachelytr. Hal. 6. 23. Philonthus scitus Nordm. Symb. 79. 18.

V'ar. a: Elytris rufo-testaceis, immaculatis.

Staph. analis Fab. Mant. Ins. I. 221. 19. Ent. Syst. 1. II. 526. 35. Syst. El. II. 598. 45. - Panz. Ent. Germ. 355. 25.

Var. b: Rufo-teslaceus, capite solo piceo.

Staph. atricillus Grav. Mon. 55. 19.

Staph. pygmaeus Grav. Mon. 57. 23.

Habitat in Europa, sub cortice Pinus.

Q. fulgido minor et angustior. Antennae capite plus sesqui longiores, articulo secundo tertio vix breviore, 4-10 sensim paulo brevioribus et crassioribus, $\mathbf{6}-\mathbf{1 0}$ subobconicis, penultimis crassitie vix brevioribus, ultimo ovato, apice abrupte acuminato, totae testaceae. Caput in utroque sexu thorace angustius, subovatum, supra vertice utrinque punctis duobus subtilioribus, supra oculos in fronte ad oculi marginem puncto utrinque singulo notatum, nigrum vel nigro-piceum, nitidum, ore infra antennas cum palpis testaceo, mandibulis piceis. Oculi mediocres, parum prominuli. Thorax 
coleopteris saepius paulo latior, latitudine summa paulo brevior, basi fortius, lateribus modice rotundatus, antrorsum subangustatus, apice truncatus et utrinque subsinuatus, angulis anterioribus acutiusculis, deflexis, posterioribus subrotundatis, leviter convexus, seriebus dorsalibus punctis 3 , apicali remotiore, compositis, lateribus punctis praeter marginalia utrinque duobus impressus, punctis subtilioribus, nitidus, rufo-piceus, disco nigricante, nonnunquam etiam fero omnino niger, interdum totus rufo-testaceus. Scutellum laevissimum, piceum. Elytra thorace tertia parte longiora, pareius minus subtiliter punctata, subtiliter parcius pubescentia, rufo-testacea, nitida, angulo apicis exteriore saepe picescente. Abdomen elongatum, coleopteris angustius, apicem versus sensim attenuatum, parcius punctulatum, longius parciusque griseo-pubescens, undique pilis raris nigris longis erectis obsi. tum, rufo-testaceum, segmentis singulis plerumque basi fuscescentibus. Pectus plerumque piceum, rarius testaceum. Pedes cum coxis testacei, tarsis anticis in utroque sexu fortius dilatatis.

Obs. 1. Statura corporis minore, posterius attenuata, colore, licet quodammodo variabili, omnino dilutiore facile a praecedentibus distinguitur.

2. Staph. analis Fab. secundum specimen in auctoris museo ipsum ad hanc speciem allatus: nomen autem recipere dubitavi, cum ab insecto (Boletobio anali) a Paykulo sub endem nomine accuratius descripto et a Fabricio citato, omnino distinctum sit et distinctum esse e descriptione Fabriciana non satis pateat.

3. Staph. pygmaeum Grav. ab auctore benevole examinandum mihi communicatum, praeter magnitudinem duplo minorem vix distinctum esse me persuasum putavi.

7. Q. la evigatus: Niger, nilidus, antennarum basi, segmentorum abdominis marginibus, pedibus elytrisque rufis, his glabris, sublaevibus. Long. 4 lin.

Er. Col. March. I. 488. 6.

Staph. la evigatus Gyll. Ins. Suec. I1. 306. 23. - Zetterst. Faun. Lappon. I. 71.

11. Ins. Lappon. 61. 14. - Sallb. Ins. Fenn. 1. 316. 20. - Mannerh. Brachelylr, 26. 31.

Emus la evigutus Boisd. et Lacord. Faun. Ent. Paris. I. 380. 32.

Philonth. laevigatus Nordm. Symb. 79. 19.

Staph. glaber Mïll. Prodr. 98. 1106. (forte)

Staph. flavopterus Fourcr. Ent. Par. I. 166. 10. (forte)

L.e Staph. noir à étuis fauves et lisses Geoffr. Hist. Ins. I. 364. 10. (forle)

Habitat in Suecia, Germania, sub cortice Abietis, in Lapponia sylvatioa (sec. Zetterst.) frequentissimus.

Statura Q. fulgidi individuis minoribus aequalis, at magis depressus, nigro-piceus, nitidulus. Antennae capite paulo longiores, articulo tertio secundo sesqui prope longiore, $4-7$ sensim crassioribus, 6-10 transversis, $7-10$ aequalibus, ultimo ovato, apice obtuse acuminato, nigrae, articulis tribus primis rufis. Labrum et palpi rufi. Caput thorace vix angustius, suborbiculatum, depressiusculum, utrinque vertice puncto singulo, supra oculos punctis duobus, fronte utrinque ad oculi marginem interiorem puncto singulo impressum. Thorax coleopteris haud angustior, latitudine paulo brevior, basi et lateribus modice rotundatus, antrorsum non angustatus, apice truncatus, angulis anterioribus deflexis, subrectis, posterioribus subrotundatis, parum convexus, seriebus dorsalibus punctis tribus, apicali 
remotiore, reliquis duobus approximatis, compositis, lateribus praeter marginem punctis nullis, ad marginem paulo ante medium puncto singulo maiusculo impressus. Scutellum laevissimum. Elytra thorace tertia parte longiora, rufa, glabra, subnitida, biseriatim obsolete punctata, serie altera suturali, altera dorsali. Abdoinen parallelum, subtiliter parcius punctulatum, tenuiter pubescens, segmentis singulis rufo-marginatis. Pedes breves, cum coxis rufi.

Tarsi antici in mare paulo magis quam in femina dilatati.

Obs. Q. cruento magnitndine, corpore depressiusculo, antennarum structura et abdomine parallelo similis, elytris autem laevigatis et coxis rufis facile distinguendus.

* 8. Q. impressus: Niger, vilidus, elytris biseriatim forlius punctatis, margine omni testaceo, fronte inter oculos bipunctata. - Long. $3 \frac{1}{2}$ lin.

Er. Col: March. I. 489. 7.

Staph impressus Panz. Fann. Germ. 36. 21. - Grav. Micr. 35. 51. Mon. 39. 1. - Latr. Mist. nat. Crust. et Ins. IX. 3̈20. 56. - Gyll. Ins. Suec. II. 307. 24. Sahlb. Ins. Fenn. I. 317. 21. - Nannerh. Brachelytr. 26. 32.

Emus impressus Boisd. et Lacord. Faun. Ent. Paris. I. 381. 35.

Philonth. impressus Nordm. Symb. 79. 20.

St aph. cinctus Payk. Mon. Car. App. 137. 34-35. Fain. Suec. III. 395. 36.

Staph. marginellus Marsh. Ent. Britt. 505. 21.

Staph. nitidus var. 6 Grav. Micr. 32. 46.

Habitat in Europa.

Niger, nitidus, capite, thorace scutelloque pernitidis. Antennae capite sesqui longiores, minus graciles, articulo tertio secundo sesqui longiore, 4 - 10 cylindricis, sensim brevioribus at vix crassioribus, penultimis crassitie vix brevioribus, ultimo orato, apice inferne abrupte acuminato, nigrae, apicem versus fuscescentes. Palpi picei. Caput thorace paulo angustius, subovale, puncto singulo maiusculo supra oculos, alioque in oculi margine interno, duobus subtilioribus in vertice vtrinque impressum. Oculi mediores, parum prominuli. Thorax coleopteris vix angustior, latitudme paulo hrevior, basi fortius, lateribus leviter rotundatus, antrorsum subangustatus, ajice truncatus et utrinque subsinuatus, angulis anterioribus acutiusculis, posterioribus rotundatis, leviter convexus, seriebus dorsalibus punctis tribus, antico paulo remotiore, compositis, lateribus punctis praeter marginalia utrinque fere $\mathbf{5}$ impressus, punctis minus subtilibus. Scutellum laevissimum. Elytra thorace paulo longiora, subtilissime punctulata, punctorum maiorum seriebus tribus, prima prope suturam, reliquis duabus in medio dorso, glabra, lateribus et margine apicali parcius pubescentibus, nigro-picea, nitida, limbo suturali, apicali lateralique testaceo. Abdomen parce subtlius punctulatum, parcius longiusque griseo-pubescens, cupreo-versicolor, nitidulum, segmentis singulis nonnumquam tenuiter testaceo-marginatis. Pedes picei, genicu-

lis tarsisque lutescentibus, tarsis anticis in utroque sexu fortius dilatatis.

Obs. Staphylinus flavescens Fab. Syst. Ent. 266. 9. Spec。 Ins. I. 336. 10. Munt. Ins. I. '221. 16. Ent. Syst. I. II. 526. 32. Syst. El. II. 597. 41. - Miill. Prod. S8. 1113. - Goeze Ent. Beitr. I. 719. 13. - Panz. Ent. Germ. 355. 23. Cederh. Faun. Ingr. 118. 362

forte ad hocce insectum revocandus; a Cravenhorstio quidem ad Philonthun di- 
scoldeum relatus est, magnitudo autem, quam in Syst. Entomologiae Philontho marginali aequalem affert Fabricius, magis huic speciei convenire videtur.

* 9. Q. pediculus: Niger, nitidus, elylris biseriatim punctatis, piceo-mar. ginatis, fronle inter oculos 4-punclata. - Long. 3 lin.

Philonth. pediculus Nordm. Symb. 79. 24.

Habitat in Unalaschka, Def. Chamisso.

Praecedenti affinis, niger, nitidus. Antennae capite duplo prope longiores, articulo tertio secundo paulo longiore, $4-\mathbf{1 0}$ sensim paulo brevioribus et crassioribus, $4-6$ cylindricis, $7-10$ subobconicis, penultimis crassitie hand brevioribus, ultimo ovato, apice acuminato, nigrae, articulo secundo summa basi testaceo. Caput thorace dimidio angustius, orbiculatum, parum convexum, supra oculos punctis utrinque 3 vel 4 , inter oculos punctis 4 transversim positis, aequaliter distantibus. Oculi mediocres, parum prominuli. Thorax coleopterorum latitudine. latitudine summa vix brevior, basi et lateribus codem arcu rotundatus, apice truncatus et utrinque subsinuatus, angulis anterioribus acntiusculis, leviter convexus; seriebus dorsalibus punctis tribus approximatis compositis, lateribus punctis praeter marginalia utrinque duobus impressus. Scutellum laevissimum. Elytra thorace paulo longiora, subtiliter obsoleteque punctulata,- seriebus tribus punctorum maiorum impressis, prima suturali, reliquis duabus dorsalibus, lateribus et margine apicali pubescentibus, ceterum subglabra', margine laterali et apicali piceis. Abdomen apicem versus sensim angustatum, subtilius punctatum, longius pubescens, metallico-versicolor, segmentorum marginibus piceis. Pedes nigro-picei, tarsis piceis, anticis in utroque sexu șat fortiter dilatatis.

Obs. Affinis sequenti, at gracilior, elytris longioribus, piceo-marginatis et abdomine parcius punctato distinctus.

* 10. Q. capucinus: Niger, nitidus, palpis pedibusque piceis, elylris irregulariler triseriatim fortius punclatis, fronte inter oculos punctis 4 transversalibus impressa. - Long. 3 lin.

Staph. capucinus Grav. Mon. 40. 2.

Philonth. сарисinus Nordm. Symb. 79. 23.

Staph. inversus Say Transact. Am. Philosoph. Soc. Philadelph. Nov. Ser. IV.419.5.

Habitat in America septentrionali.

Statura omnino Q. impressi, at paulo minor, niger, nitidus, capite, thorace scutelloque pernitidis. Antennae capite sesqui longiores, articulo secundo tertio vix breviore, $4-\mathbf{1 0}$ sensim paulo brevioribus et crassioribus, penultimis crassitie paulo brevioribus, ultimo ovato, apice inferius abrupte acuminato, piceae, articulis tribus primis nigris. Falpi picei. Caput thorace paulo angustius, rotundatum, utrinque supra octilos punctis paucis, inter oculos punctis 4, transversim positis, aequaliter distantibus impressum. Thorax basi coleopteris vix angustior, latitudine summa vix brevior, antrorsum angustatus, basi fortius, lateribus leviter rotundatus, apice truncatus, angu-. lis anterioribus subrectis, posterioribus subrotundatis, transversim convexus, seriebus dorsalibus punetis tribus modice approximatis compositis, lateribus punctis praeter marginalia utrinque nomnullis impressus, punctis subtilioribus. Elytra thoracis longitudine, nitida, parcius subtiliter obsoleteque punctulata, seriebus irregularibus tribus punctorum maiorum, 
una suturali, reliquis duabus dorsalibus, lateribus et margine apicali parce pubescentia, ceterum glabra. Abdomen apicem versus sensim angustatum, crebrius punctulatum, nigro - pubescens, aeneo-nitidulum. Pedes picei, tarsis rufescentibus, anticis in utraque sexu dilatatis.

11. Q. chlorophanus: Viridi-metallicus, nitidus, abdomine metallico-versicolore, ano ferrugineo. - Long. 4 lin.

Habitat in Bengala, Mus. Dom. Hope.

Statura omnino Q. fulgidi, viridi-metallicus, nitidus. Antennae capite sesqui fere longiores, apice haud crassiores, articulo terto secundo longiore, 4- 10 subaequalibus, ultimo ovato, apice acuminato, nigrae. Mandibulae et palpi apice picei. Caput thorace dimidio angustius, subovatum, depressiusculum, supra oculos punctis utrinque tribus, inter oculos utrinque puncto singulo impressum. Oculi mediocres, parum prominuli. Thorax coleopterorum latitudine, latitudine summa tertia parte brevior, lateribus rotundatis, apicem versus leviter angustatus, basi leviter rotundatus, apice truncatus, angulis anterioribus subrectis, deflexis, posterioribus obtusis, leviter convexus, margine laterali subexplanato, seriebus dorsalibus punctis tribus, anterioribus duobus magis approximatis, compositis, lateribus punctis praeter marginalia utrinque 4 impressus. Scutellum laevissimum. Elytra thoracis longitudine, minus dense aequaliter punctata, parce griseo-pubescentia. Abdomen apicem versus sensim angustatum, parcius punctatum, tenuiter pubescens, fortiter metallico-versicolor, segmento quinto apice sextoque toto ferrugineis. Pedes tarsis piceis, anticis in utroque sexu fortiter dilatatis.

\section{2) Thorax seriebus dorsalibus 2-punctatis.}

* 12. Q. viridulus: Niger, nitidus, capite thoraceque obscure virescentibus, elytris laete viridibus, subtiliter punctatis, scutello punctulato. - Long. 4 lin.

Habitat Bogotae in Columbia interiore, Dom. Buquet.

Statura omnino Q. impressi, niger, nitidus, capite thoraceque politis, nigro - virescentibus, elytris laete cyanescenti-viridibus, nitidis. Antennae. capite sesqui longiores, articulo tertio secundo paulo longiore, 4-10 sensim paulo brevioribus et crassioribus, penultimis subobconicis, crassitie vix longioribus, ultimo ovato, apice abrupte acuminato, nigrae. Palpi nigri, maxillares articulo quarto minore. Caput thorace paulo angustius, suborbiculatum, fronte planiuscula, punctis utrinque tribus oblique positis ad verticem, duobus approximatis supra oculos, singulo ad oculi marginem interiorem impressum. Oculi parvi, rotundati, parum prominuli. Thorax coleopteris paulo angustior, basi et lateribus leviter rotundatis, his pone medium subsimuatis, antrorsum subangustatus, apice truncatus et utrinque subsinuatus, angulis anterioribus deflexis, subrotundatis, posterioribus obtusis, parum convexus, seriebus dorsalibus punctis duobus prope apicem sitis compositis, lateribus punctis praeter marginalia nullis, marginali maiusculo singulo utrinque ante medium impressus. Scutellum subtiliter punctulatum. Elytra thorace sesqui longiora, subtiliter minus dense punctata, tenuiter nigro-pubescentia. Abdomen breviusculum, coleopteris angustius, apicem versus sensim 
attenuatum, nigro-subaeneum, nitidum, parce subtiliterque punctulatum, parce nigro-pubescens. Pedes nigri.

Tarsi antici femin a modice dilatati. Mas latet.

3) Thorax seriebus dorsalibus nullis.

* 13. Q. labiatus: Niger, nilidus, capite anlice rufo, elytris punctis nonnullis profundis impressis, - Long. 3 lin.

Habitat in Columbia, Dom. Moritz.

Statura ommino Q. impressi, at paulo minor, niger, capite, thorace scutelloque pernitidis. Antennae capite sesqui longiores, articulo tertio secundo paulo longiore, 4 - 10 sensim paulo brevioribus et crassioribus, penultimis crassitie paulo brevioribus, ultimo subovato, apice abrupte acuminato, rufae, medio fuscescentes. Palpi rufi. Caput thorace paulo angustius, oculis magnis, prominulis, infra oculos rufum, puncto singulo in margine oculi utrinque notatum. Thorax basi vix coleopteris paulo angustior, latitudine summa haud brevior, antrorsum subangustatus, basi cum angulis posterioribus fortius, lateribus leviter rotundatus, apice truncatus, angulis anterioribus subrectis, modice convexus, puncto singulo maiusculo utrinque ad marginem anteriorem notatus, ceterum praeter puncta nonnulla marginalia subtiliora laevissimus. Scutellum laevissimum. Elytra thoracis longitudine, laevigata, nitida, stria suturali profundius impressa, punctorum rariorum seriebus duabus, altera in stria suturali, altera dorsali, et praeterea punctis duobus vel tribus maioribus in medio disci, apice pilis parcis nigris ciliata. Abdomen longius parciusque nigro-pubescens, parce punctulatum, cupreo - chalybeove nitidulum, segmento quarto subtus medio late laevi. Pedes antici testacei, intermedii piceo-testacei, postici picei, tarsis testaceis. Alae fusco-hyalinae.

Tarsi antici maris fortiter, femina e leviter dilatati.

Variat. 1, Thorace, elytris abdomineque concoloribus.

2, Thorace elytrisque concoloribus, abdomine segmentis ultimis duobus rufis. mis rufis.

3, Thorace concolore, elytris, abdominisque segmentis duobus ulti-

4, Elytris concoloribus, thorace abdominisque segmentis duobus ulti mis rufis.

5, Thorace, elytris abdominisque segmentis ultimis duobus rufis.

14. Q. Srenatus: Testaceus, nitidus, thoracis pectorisque lateribus abdomineque nigris, elytris dorso triseriatim profunde punctatis. - Long. 3 lin.

Habitat prope La-Guayram in Columbia, Dom. Moritz.

Praecedenti affinis. Antennae capite sesqui longiores, articulo tertio secundo paulo longiore, 4 - 10 sensim brevioribus et parum crassioribus, 4 et 5 cylindricis, reliquis subohconicis, penultimis crassitie paulo brevioribus, ultimo ovato, apice abrupte acuminato, totae testaceae. Caput thorace paulo angustius, oculis permagnis, prominulis, inter oculos puncto utrinque singulo, ad oculi marginem interiorem sito, supra oculos punctis duobus notatum, totum cum ore testaceum, nitidum. Thorax basi coleo- 
pterorum latitudine, latitudine summa paulo brevior, antrorsum modice angustatus, lateribus, bası et angulis posterioribus rotundatis, apice truncatus, angulis anterioribus deflexis, subrotundatis, modice convexus, punctis 4 transversim positis ad marginem anteriorem impressus, ceterum praeter puncta plura marginalia subtiliora laevissimus, rufo-testaceus, nitidus, limbo laterali nigro. Scutellum laeve, nigro - piceum. Elytra thoracis longitudine, luteo - testacea, circa scutellum picea, nitida, disco glabra, dorso punctorum sat profundorum seriebus tribus, prima prope suturam, in stria suturali impressa sita, regulari, reliquis duabus discoidalibus, irregularibus, lateribus punctis pluribus profundis subseriatis impressis. Abdomen parce punctatum, nigro-pubescens, nigrum, segmento quinto margine apicali, sexto toto testaceis. Pectus obscure testaceum, lateribus nigrum. Pedes testacei.

Maris tarsi antici fortiter dilatatı, abdominis segmenta quartum et quintum inferiora medio longitudinaliter leviter impressa, impressione dense fulvo - villosa. F e min a latet.

15. Q. buphthalmu Niger, nilidus, capile, thorace elytrisque aeneis, his variolosis, femoriobus basi albis, anlennis clavalis, oculis maximis. Long. $3 \frac{1}{2}$ lin.

Ilabitat in Mexico, Mus. Dom. Chevrolat.

Insectum singulare, oculis magnis prominentibus et antennis tenuibus clavatis insigne, ab hoc genere autem rite haud distinguendum. Antennae capite prope breviores, tenues, articulis $\mathbf{5}$ primis elongatis, secundo primo plus duplo breviore, tertio secundo paulo longiore, $\mathbf{3}-\mathbf{5}$ sensim paulo brevioribus, $6-10$ brevibus, sensim paulo crassioribus, sexto subgloboso, 7 - 10 transversis, ultimo conico, acuminato, articulis 6 primis piceotestaceis, sequentibus fuscis, ultimo luteo. Palpi piceo-testacei. Caput magnum, thorace parum angustius, oculis permagnis, fortiter prominentibus, fronte planiuscula, subtiliter vage punctata, utrinque longitudinaliter subimpressa, supra obscure viridi-aeneum, pernitidum, subtus nigrum. Thorax coleopterorum latitudine, latitudine dimidio fere brevior, antrorsum haud angustatus, basi et lateribus eodem arcu rotundatus, apice truncatus, angulis anterioribus deflexis, subrotundatis, fortiter convexus, ad marginem apicalem punctis 4 transversim positis notatus, dorso inter apicem et medium utrinque leviter oblique impressus, margine laterali explanato, inaequali, obscure viridi-aeneus, pernitidus. Scutellum punctato-variolosum, viridi-aeneum. Elytra thorace paulo longiora, inaequalia, fortiter inaequaliter punciata, ảenea, nitida. Abdomen breviusculum, nigrum, nitidum, parce nigro-pubescens. Pectus nigrum, nitidum. Pedes graciliores, picei, femoribus basi uitra medium albidis.

Tarsi antici feminae modice dilatati. Mas latet.

16. Q. curtus: Brevis, niger, nitidus, elytris rufis, parce subliliterque punclatis. - Long. 4 lin.

Habitat in Sardinia, Mus. Reg. Taurin.

Q. fulgidi maximis individuis latitudine aequalis, at multo brevior, statura curtata ab alis huus generis speciehus discedens. Niger, nitidus, capite thorace scutelloque politis. Antennae capite parum longio- 
res, tennes, articulo tertio secundo paulo longiore, ultimo apice oblique truncato, rufo-picea.. Palpi rufi. Labrum rufo-piceum. Caput thorace angustius, oblongum, basi vix constrictum, parce subtilissime punctulatum, fronte utrinque supra oculos et ad oculi marginem interiorem puncto maiusculo singulo impressa. Thorax coleopteroim latitudine, antrorsum subangustatus, latitudine tertia fere parte brevior, basi fortiter, lateribus leviter rotundatus, apice truncatus, utringue subsinuatus, angulis anterioribus deflexis, antrorsum leviter prominentibus, rotundatis, transversim convexus, laevissimus, ad angulos posteriores utrinque subimpressus. Elytra thoracis longitudine, apice rotundata, parcius subtiliter punctata, rufa, nitida, parce subtiliterque griseo-pubescentia. Abdomen breve, triangulare, minus parce subtiliterque punctatum, nigrum, nitidum, segmentis singulis margine apicali obscure piceo, parce subtiliterque griseo-pubescens. Pedes rufo-picei, femoribus nigris.

Tarsi antici maris modice, feminae leviter dilatati.

* 17. Q. brevis: Brevis, piceus, nitidus, antennis elytrisque rufis, his parcius punctatis. - Long. 2 lin.

Habitat in Germania septentrionali.

Q. fulgidi minimis individuis latitudine aequalis at multo brevior. Piceus, nitidus, capite, thorace scutelloque politis. Antennae capite paulo longiores, articulo tertio secundo vix longiore, $4-7$ sensim paulo brevioribus et crassioribus, $7-\mathbf{1 0}$ aequalibus, crassitie brevioribus, ultimo oblongo, apice oblique truncato, totae rufae. Os rufum. Caput thorace paulo angustius, basi profundius constrictum, supra punctis duobus fortibus baseos et puncto utrinque ad oculi marginem interiorem impressum. Thorax coleopteris paulo latior, latitudine quarta fere parte brevior, antrorsum subangustatus, basi et lateribus leviter rotundatus, apice truncatus, angulis anterioribus subrectis, posterioribus obtusis, convexus, ante marginem anteriorem puncto utrinque singulo notatus, ceterum laevissinus, margine lateralı, praecipue posterius, explanato, piceo-rufescens. Scutellum laevissimum. Elytra thorace paululum longiora, parcius et minus subtiliter punctata, tenuiter longius pubescentia, rufa, nitida, apice leviter rotundata. Abdomen breviusculum, apicem versus leniter angustatum, crebrius punctatum, pubescens, lateribus pilosellum, segmentis singulis apice rufo-marginatis, ano testaceo. Pedes rufi.

Tarsi antici feminae modice dilatati. Mas latet.

Obs. Affinis praecedenti, at multo minor et minus contractus.

* Thorax processu pone coxas anticas membranaceo.

Series dorsales tripunctatae.

* 18. Q. molochinus: Niger, nitidus, antennis pedibusque rufo-piceis, elytris thorace brevioribus, caslaneis, scutello punctulato. - Long. 5 lin.

Er. Col. March. I. 489. 8,

Staph. molochinus Grat. Mon. 46. 6. - Gyil. Ins. Saec. II. 302. 20, - Sahlb. Ins. Fenn. 1. 314. 17. - Mannerh. Brachelytr. 25. 28. - Runde Brachelytr. Hal.5. 21. Em us molochinus Boisd. et Lacord. Faun. Ent. Paris. 1. 37\%. 28.

Philonth. molochinus Nordm. Symb. 76. 6. 
Staph. laticollis Grav. Micr. 173. 28. Mon. 47. 8. Staph. picipennis Payk. Faun. Suec. III. 373. 8.

Staph. Lapponicus Zetterst. Ins. Lappon. 61. 12.

Staph. laevicollis Runde Brachelytr. Hal. 6, 24.

Habitat in omni Europa et in America septentrionali.

Niger, capite thoraceque pernitidis. Antennae capite duplo longiores, apicem versus haud incrassatae, tenuiores, articulo tertio secundo sesqui longiore, 4-10 sensim paulo brevioribus, crassitie longioribus, ultimo subcompresso, apice oblique truncato et inferne acuminato, rufae, articulis 2-4 fuscescentibus. Palpi rufi. Labrum rotundatum, integrum. Caput thorace angustius, subovale, utrinque supra oculos punctis 3 vel 4 , et in fronte utrinque ad oculi marginem interiorem puncto singulo notatum. Oculi mediocres, parum prominuli. Thorax coleopteris paulo latior, latitudine summa haud brevior, antrorsum subangustatus, basi modice, lateribus leviter rotundatus, apice subemarginatus, angulis anterioribus fortiter deflexis, subrectis, posterioribus subrotundatis, fortiter convexus, seriebus dorsalibus punctis tribus approximatis compositis, lateribus punctis praeter marginalia utrinque duobus, oblique positis, versus angulos anteriores sitis impressus. Scutellum punctulatum. Elytra thorace breviora, subtiliter dense punctata, cinereo-pubescentia, oparsa, aut castanea aut nigra. Abdomen elongatum, apicem versus vix attenuatum, densius subtiliter punctulatum, tenuiter griseopubescens, cupreo-versicolor, nitidulum, subtus segmentis singulis castaneomarginatis. Pedes picei.

Tarsi antici maris fortiter, feminae modice dilatati.

* 19. Q. frontalis: Niger, nitidus, antennis, palpis, tibiis tarsisque mufopiceis, elytris thorace longioribus, scutello punctulato, fronte inter oculos punctis sex transversalibus impressa. - Long. 5 lin.

Philonth. frontalis Nordm. Symb. 76. 5.

Habitat in Gallia, Italia, Dalmatia, Graecia.

Praecedenti affinis, at robustior, statura omnino sequentis, niger, capite thoraceque nitidis. Antennae capite paulo longiores, tenuiores, apicem versus haud incrassatae, articulo tertio secundo sesqui longiore, 4-10 sensim brevioribus, 4-6 cylindricis, 7-10 subobconicis, penultimis etiam crassitie longioribus, ultimo subovato, apice oblique truncato et inferne acuminato, totae rufae. Palpi rufi. Labrum rotundatum, integrum. Caput thorace angustius, subovale, utrinque supra oculos punctis nonnullis, fronte inter oculos punctis sex, in seriem transversalem medio late interruptam dispositis. Oeuli maiusculi, parum prominuli. Thorax basi coleopterorum latitudine, latitudine summa haud brevior, antrorsum leviter angustatus, basi fortius, lateribus leviter rotundatus, apice subemarginatus, angulis anterioribus deflexis, subrectis, posterioribus subrotundatis, convexus, seriebus dorsalibus punctis tribus aequaliter distantibus compositis, lateribus punctis praeter marginalia utrinque 5 impressus. Scutellum subtiliter punctulatum. Elytra thorace paululum longiora, subtiliter confertissime punctata, tenuiter nigropubescentia, opaca. Abdomen apicem versus parum angustatum, subtiliter crebre punctulatum, densius subtiliter nigro-pubescens, plerumque laete 
viridi-versicolor. Pedes nigri, tibiis tarsisque rufo-piceis, tarsis anticis in utroque sexu fortiter dilatatis.

Obs. Intermedius inter Q. molochinum et fuliginosum, illi scutello punctulato, huic fronte inter oculos sexpunctata affinis, abdomine laetis coloribus resplendente insignis, olim a Dahlio nomine $\mathrm{S}$ taph. chloroventris impositus.

* 20. Q. fuliginos us: Niger, nilidus, antennis, palpis tarsisque rufis, fronte inter oculos punctis sex transversalibus impressa. - Long. 5 lin.

Er. Col. March. I. 490.9.

St uph. fuliginosus Grav. Micr. 34. 49. Mon. 48. 10. - Latr. Hist. nat. Crust. et Ins. IX. 319. 56.

Staph. tristis Grav. Micr. 34. 48 Mon. 48. 11. - Latr. Hist. nat. Crust. et Ins. IX. 319. 55. - Gyll. Ins. Suec. II. 301. 19. - Sahlb. Ins. Fenn. I. 314. 16. Mannerh. Brachelytr. 25. 26. - Runde Brachelytr. Hal. 5. 20.

Emus tristis Boisd. et Lacord. Faun. Ent. Paris. I. 376. 27.

Philonth.tristis Nordm. Symb. 75. 4.

Staph. dilatat us Marsh. Ent. Britt. 504. 19.

Habitat in Europa.

Niger, capite, thorace scutelloque pernitidis. Antennae capite sesqui longiores, tenuiores, apicem versus haud incrassatae, articulo tertio secundo sesqui prope longiore, 4-10 sensim paulo brevioribus, 4-6 cylindricis, 7- 10 subobconicis, penultimis etiam crassitie paulo longioribus, ultimo oblongo-ovato, apice oblique truncato et inferne acuminato, rufae, articulis 4 primis dorso picescentibus. Palpi rufo-testacei. Labrum medio subsinuatum. Caput thorace paulo angustius, subovale, utrinque supra oculos punctis 2 vel 3 , fronte inter oculos punctis 6 , in seriem transversalem medio late interruptam dispositis impressum. Oculi maiusculi, modice prominuli. Thorax basi coleopterorum latitudine, latitudine summa vix brevior, antrorsum subangustatus, basi et lateribus leviter rotundatus, apice truncatus et utrinque subsinuatus, angulis anterioribus subrectis, deflexis, posterioribus obtusis, convexus, seriebus dorsalibus punctis tribus, sat approximatis, aequaliter distantibus compositis, lateribus punctis praeter marginalia utrinque 3 vel 4 impressus. Scutellum laevissimum. Elytra thorace haud breviora, confertissime subtiliter punctata, perbe tenui, depressa, nigra densius obtecta, opaca. Abdomen apicem versus parum angustatum, subtiliter densius punctulatum, tenuiter nigro-pubescens, obsolete cupreo-versicolor. $\mathrm{Pe}$ des picei, tarsis rufo-piceis, anticis in utroque sexu fortiter dilatatis.

* 21 Q. picipes: Niger, nitidus, antennis, pedibus elytrisque rufis, his crebre punctatis. - Long. 4 lin.

Er. Col. March. I. 491. 10.

Staph. picipes Mannerh. Brachelytr. 26. 34.

Philonth. picipes Nordm. Symb. 77. 11.

Philonth. varicalor Nordm. Symb. 76. 9.

Habitat in Germania rarius, prope Berolinum, Weber, in Austria, Dom. Schiippel, in Coroyra frequens, Parreyss.

Habitu fere Q. maurorufi, at multo maior, Q. fulgido statura aequalis, niger, capite thoraceque pernitidis. Antennae capite sesqui longiores, tenuiores, apicem versus vix incrassatae, articulo tertio secundo sesqui lon- 
giore, 4-10 sensim parum brevioribus et vix crassioribus, 4-6 cylindricis, 7-10 subobconicis, omnibus crassitie longioribus, ultimo oblongo, apice inferius sensim acuminato, totae rufae. Palpi rufi. Caput thorace parum angustius, orbiculatum, punctis utrinque supra oculos duobus, ad oculi marginem interiorem singulo impressum. Thorax coleopterorum latitudme, latitudine summa vix brevior, antrorsum subangustatus, lateribus leviter, basi cum angulis posterioribus fortiter rotundatus, apice truncatus, angulis anterioribus deflexis, subrectis, convexus, seriebus dorsalibus punctis tribus aequaliter modice distantibus compositis, lateribus punctis praeter marginalia utrmque duobus vel tribus impressus. Scutellum laevissimum. Elytra thoracis longitudine, crebre subtilins punctata, rufa, nitida, subtiliter tenuiterque griseo-pubescentia. Abdomen apicem versus sensim sat fortiter attenuatum, mimus dense punctatum, pube nigra longiore depressa minus subtili parcius vestitum, cupreo-versicolor. Pedes cum coxis rufo-testacei, tarsis anticis in utroque sexu leviter dilatatis.

Obs. Ph. variicol or Nordm. e Gallia meridionali quo differat a Q. plcipede e descriptione satis accurata non patet.

22. Q. plancus: Niger, capite thoraceque nigro-aeneis, nilidis, elylris crebre sublilius punclalis, abdominis segmentorum marginibus, antennarum basi pedibusque testaceis, tibiis fuscis. - Loug. paulum ultra 3 lin. Habitat in Sardinia, Mus. Reg. Taurin.

Statura et summa affinitas Q. fimbriati, at paulo minor. Antennae ca. pite duplo longiores, articulo tertio secundo sesqui longiore, ultimo apice leviter oblique emarginato, acuminato, nigrae, articulis tribus primis testaceis, secundo tertioque apice fuscis. Oris partes testaceae. Caput thoracis apice parum angustius, basi profundius constrictum, supra oculos utrinque crebre subtiliter punctatum, punctisque quatuor maioribus notatum, fronte subdepressa, inter oculos punctis quatuor, transversim positis, aequaliter distantibus impressa, nigro-subaeneum, nitidum. Thorax basi coleopteris paulo angustior, antrorsum subangustatus, latitudini baseos longitudine aequalis, bası fortiter, lateribus leviter rotundatus, apice subemarginatus, angulis anterioribus acutiusculis, fortiter deflexis, transversim modice convexus, nigro-subaeneus, nitidus, lateribus piceus. Scutellum laevissimum, nigrum, nitidum. Elytra thorace tertia parte longiora, dense subtilius punctata, pube longiore depressa fulvescenti-grisea tenuiter vestita, fusco-testacea, subnitida. Abdomen crebre subtilius punctatum, pube longiore depressa fulvescenti-grisea vestitum, nigro-pilosellum, nigrum, nitidum, iridescens, segmentis singulis margine testaceo, anterioribus angustiore et saturatiore, ultimis duobus lato et dilutiore. Pectus nigrum. Pedes dilute testacei, coxis anterioribus concoloribus, tibiis, omnibus fuscis, apice obscure testaceis, tarsis etiam posterioribus articulis omnibus depressis, ultimo s. unguiculari reliquis vix angustiore.

Mas latet. F emina tarsis anticis fortiter dilatatis.

*23. Q. ochropterus: Niger, nitidus, capile thoraceque nigro-subaeneis, antennis, elytris, abdominis segmentorum marginibus pedilusyue.rufis, coxis omnibus femoribusque posticis peceis. - Long. 4 lin.

Habitat in Austria, Dom. Schiippel. 
Habitu omnino sequentis, at sesquí maior, niger, capite thoraceque supra nigro-subaeneis, pernitidis. Antennae capite plus sesqui longiores, tenuiores, apicem versus haud incrassatae, articulo tertio secundo paulo longiore, 4-10 sensim brevioribus, cylindricis, penultimis etiam crassitie longioribus, subobconicis, ultimo oblongo-ovato, apice sensim acuminato, rufo-testaceae, apice summo flavescente. Palpi rufo-testacei. Caput thorace paulo angustius, orbiculatum, supra utrinque punctis duobus profundioribus, oblique positis supra oculos, et singulo ad oculi utriusque marginem interiorem impressum. Oculi magni, modice prominentes. Thorax basi coleopterorum latitudine, latitudine summa vix brevior, antrorsum subangustatus, basi et lateribus leviter rotundatus, apice truncatus, angulis anterioribus subrectis, leviter deflexis, posterioribus obtusis, subrotundatis, leviter convexus, seriebus dorsalibus punctis tribus aequaliter modice distantibus compositis, lateribus punctis praeter marginalia anterius ntrinque duobus, sat distantibus, oblique positis impressus. Scutellum laevissimum. Elytra thorace paululum longiora, crebre subtilius punctata, transversim subrugulosa, dilute rufo-brunnea, pube breviore depressa grisea tenuiter vestita. Abdomen apicem versus sensim et sat fortiter attenuatum, parcius subtiliter punctatum, pube subtiliore depressa fusco-grisea vestitum, metallico-versicolor, segmentis omnibus apice rufo-marginatis. Pedes graciliores, rufo-testacei, coxis omnibus nigro-piceis, femoribus posterioribus picescentibus.

Tarsi antici maris modice dilatati. Femina latet.

Obs. A Q. picipede thorace minus convexo, elytris paulo longioribus, coxis nigro - piceis, et abdominis segmentis apice rufo-marginatis facile distinguitur.

* 24. Q. fimbriatus: Niger, nitidus, antennis, pedibus elylrisque testaceis, his grebrius punctalis, macula magna communi quadrata nigricante. Long. $3 \frac{2}{3}$ lin.

Habitat in Austria.

Habitu ommino praecedentis, at minor, niger, capite thoraceque pernitidis. Antennae capite plus sesqui longiores, tenuiores, apicem versus vix incrassatae, articulo tertio secundo paulo longiore, 4-10 sensim paulo brevioribus et paululum crassioribus, cylindricis, penultimis subobconicis, crassitie vix longioribus, ultimo ovato, apice acuminato, totae rufotestaceae. Palpi testacei. Caput thorace parum angustius, suborbiculatum, perparum convexum, utrinque supra oculos punctis duobus oblique positis, ad marginem oculi utriusque interiorem puncto singulo impressum. Oculi maiusculi, modice prominuli. Thorax basi coleopteris haud angustior, latitudine paulo brevior, basi lateribusque modice rotundatus, antrorsum parum angustatus, apice truncatus et utrinque subsinuatus, angulis anterioribus leviter deflexis, acutiusculis, posterioribus subrotundatis, modice convexus, scriebus dorsalibus punctis tribus sat approximatis, antico subtiliore, compositis, lateribus punctis praeter marginalia utrinque singulo ante medium prope marginem lateralem profundiore impressus. Scutellum laevissimum. Elytra thorace paulo longiora, crebrius profunde punctata, fortius griseo-pubescentia, dorso nigricantia, lateribus et margine apicali fusco-testaceis. Abdomen apicem versus sensim fortius attenuatum, crebrius subtiliter punctulatum, pube minus subtili longiore depressa lutescenti-grisea densius vestitum, 
nitidulum, viridi-versicolor, segmentis omnibus testaceo-marginatis. Pedes cum coxis omnibus testacei; tarsis anticis in utroque sexu fortius dilatatis.

Obs. Proximus praecedenti, at distinctus pedibus totis cum coxis testaceis, abdomine elytrisque pube minus subtili, longiore, densiore, lutescente vestitis, his minus confertim at profundius punctatis, interstitiis punctorum laevibus, dorso praeter apicem nigris.:

* 25. Q. peltatus: Brunneus, abdomine versicolore, antennis fusco-piceis, basi nigricantibus, capite orbiculato, nigro, thorace latiore, elytris densius subtiliter punctatis. - Long. 3 lin.

Qued. praecox Er. Col. March. I. 492. 12.

Habitat in Germania, Hungaria.

Q. maurorufo antrorsum magis dilatatus, obscure brunneus, capite, thorace scutelloque nitidis. Antennae capite plus sesqui longiores, tenuiores, apicem versus sensim leniter incrassatae, articulo tertio secundo paulo longiore, 4-10 sensim brevioribus et crassioribus, subobconicis, penultimis etiam crassitie longioribus, ultimo oblongo, apice inferne sensim acuminato, pilosellae, piceae, articulis singulis, imprimis basalibus, medio nigricantibus. Caput depressiusculum, thorace multo angustius minusque, utrinque supra oculos punctis duobus, oblique positis, superiore minore, ad oculi utriusque marginem interiorem puncto singulo notatum, lateribus pone oculos sublaeve, nigrum, ore infra antennas piceo-testaceo. Oculi mediocres, prominentes. Thorax basi coleopterorum latitudine, basi fortius, lateribus cum angulis posterioribus leviter rotundatus, antrorsum leviter angustatus, apice subemarginatus, angulis anterioribus deflexis, leviter prominentibus, subrotundatis, leviter convexus, seriebus dorsalibus punctis tribus sat approximatis compositis, lateribus punctis praeter marginalia utrinque anterius duobus, altero prope seriem dorsalem, altero prope marginem lateralem, impressus, punctis minus subtilibus. Scutellum laevissimum. Coleoptera latiuscula, thorace parum longiora, subtilius dense punctata, opaca, pube depressa grisea tenuiter vestita, brunnea, dorso nigricantia, margine tenui apicali obscure testaceo. Abdomen coleopteris angustius, apicem versus sensim fortius angustatum, parcius punctulatum, tenuissime pubescens, segmentis singulis basi viridi-, apice cupreo-versicoloribus. Pedes rufo-picei, femoribus posticis medio vridi-micantibus. Alae fusco-hyalinae.

Tarsi antici maris fortiter, feminae modice dilatati.

Obs. Olim, cum Q. praecocis specimen singulum a Gravenhorstio descriptum immaturum novissem, ab hoc mihi non distinctus visus est; speciminibus autem maturis a Prof. Gené comuunicatis, has duas species inter se simillimas distinxi. Q. peltatus thorace paulo latiore, capite orbiculato, planiusculo, antennis basi nigricantibus, elytris minus dense et minus profunde, abdomine paulo parcius et minus subtiliter punctatis praecipue discedit. A sequentibus thorace coleopterisque latioribus et elytris paulo longioribus differunt.

* 26. Q. praecox: Brunneus, abdomine versicolore, antennis basi pedibusque piceo-testaceis, capite ovato, nigro, elytris conferlim sublilius punctatis. - Long. 3 lin.

Staph. praecox Grav. Micr. 172. 27. Mon. 57. 21. - Latr. Hist, nat. Crust, ot Ins. IX. 324. 68.

Habitat in Lusitania, Com. Hoffmannsegg, in Sardinia, Prof. Gené. 
Praecedenti proximus. Obscure brunneus, capite thorace scutelloque nitidis. Antennae capite duplo longiores, tenuiores, apicem versus vix incrassatae, articulo tertio secundo sesqui longiore, 4-10 sensim paulo brevioribus, subcylindricis, penultimis etiam crassitie longioribus, leviter obconicis, ultimo oblongo, apice sensim acuminato, piceae, articulis tribus primis testaceis. Palpi testacei. Caput parvulum, thorace duplo angustius, ovatum, supra leviter convexum, punctis utrinque duobus oblique positis supra ocnlos, et singulo ad oculi utriusque marginem interiorem impressum, lateribus supra oculos utrinque confertim subtilissime punctulatum, nigrum, nitidum, ore piceo-testaceo. Oculi mediocres, modice prominuli. Thorax basi coleopterorum prope latitudine, latitudine summa vix longior, basi fortiter, lateribus cum angulis posterioribus leviter rotundatus, antrorsum leviter angustatus, apice subemarginatus, angulis anterioribus fortiter deflexis, acutiusculis, modice convexus, seriebus dorsalibus punctis tribus, posterioribus sat approximatis, antico paulo remotiore, compositis, lateribus punctis praeter marginalia anterius utrinque tribus, duobus prope seriem dorsalem, tertio prope marginem impressus, limbo undique brunneo, disco late nigropiceo. Scutellum laevissimum, piceum. Elytra thorace paulo longiora, dense subtilius punctata, pube longiore depressa grisea vestita, brumnea, dorso nigricantia, margine apicali obscure testaceo. Abdomen apicem versus sensim fortius angustatum, parcius subtiliter punctatum, pube depressa grisea tenuiter vestitum, piceum, metallico-versicolor, segmentis singulis margine apicali piceo-testaceo. Pectus nigrum. Pedes cum coxis omnibus piceo-testacei.

Tarsi antici maris fortiter, femina e leviter dilatati.

27. Q. umbrinus: Brunneus, capile nigro, abdomine versicolore, antennis
totis fusco-piceis, elytris brevioribus, fortiter punctatis, - Long. 3 lin. Er. Col. March. I. 491. 11.

St aph. maurorufus Gyll. Ins. Suec. II. 309. 25. - Suhlb. Ins Fenn. I. 317. 22.

- Zetterst. Ins. Lappon. 61. 15. - Munnerh. Brachelytr. 26. 36.

Philonth. maurorufus Nordm. Symb. 77. 10.

Habitat in Suecia, Germania.

Obscure brunneus, nitidus, capite, thoracè scutelloque pernitidis. Antennae capite duplo prope longiores, apicem versus vix crassiores, articulo tertio secundo duplo longiore, $4-10$ subobconicis, sensim brevioribus et crassioribus, penultimis crassitie haud brevioribus, ultimo ovato, apice obltque truncato et inferne acuminato, pilosellae, piceae, articulis primis medio nigricantibus. Caput thorace paulo angustius, suborbiculatum, utrinque supra oculos punctis duobus, oblique positis, prope oculi utriusque marginem interiorem puncto singulo impressum, nigrum, ore infra antennas piceo. Oculi maiusculi, modice prominentes. Thorax coleopteris prope latior, latitudine summa haud brevior, basi modice, lateribus vix rotundatus, antrorsum subangustatus, apice subemarginatus, angulis anterioribus deflexis, acutiusculis, posterioribus obtusis, modice convexus, seriebus dorsalibus punctis tribus, antico remotiore, posterioribus approximatis, compositis, lateribus punctis praeter marginalia anterius utrinque duobus, altero prope seriem dorsalem, altero prope marginem lateralem impressus, niger, margine omni sensim piceo-brunneo. Scutellum laevissimum, piceum. Elytra thorace paulo bre-- 
viora, confertim fortiter punctata, parum nitida, tenuiter griseo-pubescentia, nigro-brunnea, margine summo apicali obscure testaceo. Abdomen apicem versus sensim angustatum, parcius et minus subtiliter punctulatum, pube parca depressa minus subtili grisea vestitum, lucidum, segmentis singulis virescentiapice cupreo-versicoloribus, infra apice testaceo-marginatis. Pedes rufobrunnei.

Tarsi antici maris fortiter, feminae modice dilatati.

* 28. Q. maurorufus: Testaceo-brunneus, capile nigro, abdomine versicolore, antennarum basi pedibusque tesiaceis, elytris dense sublilius punctulatis. - Long. 3 lin.

Er. Col. March. I. 492. 13.

Staph. maurorufus Grav. Mon. 56. 20.

St aph. at tenuatus Grav. Mon. 61. 31.

Staph. praecox Gyll. Ins. Suec. I1. 310. 26. - S.九lb. Ins. Fenn. I. 318. 21. Zetterst. Ins. Lappon. 61. 16. - Mannerh. Brachelytr. 27. 37.

Emus praecox Boisd. et Lacord. Faun. Ent. Paris. I. 382. 37.

Philonth. praecox Nordm. Symb. 78. 12.

Var. Thorace elytrisque testaceis. - Long. $3 \frac{1}{2}$ lin.

Staph. attenuatus var. 3 Grav. Mon. 62.

Habitat in Germania, Suecia.

Plerumque testaceo-, rarius fusco - vel nigro-brunneus, nitidus, capíte thorace scutelloque pernitidis. Antennae capite sesqui longiores, apicem versus haud incrassatae, articulo tertio secundo paulo longiore, 4-11) sen. sim paulo brevioribus, subcylindricis, penultimis crassitie haud brevioribus, subobconicis, articulo ultimo oblongo, apice abrupte acuminato, dilute rufopiceae, articulo primo testaceo. Palpi testacei. Caput thorace paulo angustius, subovatum, supra oculos utrinque punctis duobus oblique positis, ad oculi utriusque marginem interiorem puncto singulo impressum, lateribus pone oculos crebre subtilissime punctulatum, nigrum, infra antennas dilute rufo-piceum. Oculi sat magni, prominuli. Thorax coleopteris paululum angustior, latitudine haud brevior, basi lateribusque modice rotundatus, antrorsum subangustatus, apice truncatus, angulis anterioribus subrectis, posterioribus subrotundatis, modice convexus, seriebus dorsalibus punctis tribus sat approximatis compositis, lateribus punctis praeter marginalia anterius utrinque duobus, altero prope seriem dorsalem, altero prope marginem lateralem impressus, testaceo-brunneus, disco plerumque obscuriore. Scutellum laevissimum. Elytra thoracis longitudine, dense subtilius punctata, densius griseo-pubescentia, fusco - testacea, dorso plerumque nigricantia, subopaca. Abdomen apicem versus angustatum, subtiliter punctulatum, lucide irideo-versicolor, segmentis omnibus in individuis dilutioribus apice testaceo-marginatis. Pedes testacei, tarsis anticis maris fortius, feminae leviter dilatatis.

Obs. Var. citata, a Dahlio olim nomine Staph. limbati signata, colore thoracis elytrorumque testaceo, praecipue statura duplo maiore insignis, vix autem aliis notis rite distincta. 
29. Q. infuscat us: Nigro-piceus, caplte nigro, antennarnm bast, abdomine segmentorum marginibus pedibusque piceo-lestaceis, sculello parce punctato, elytris fusco-testaceis, dorso nigricantibus, parce subtiliuo punctatis. - Long. $2 \frac{1}{2}$ lin.

Habitat Lutetiae, coll. Dom. Aubé.

Habitu omnino praecedentis, at plerumque dimidio minor. Antennae capite sesqui longiores, minus graciles, apicem versus leviter incrassatae, articulo tertio secundo paulo longiore, 4- 10 subobconicis, sensim paulo brevioribus et crassioribus, penultimis etiam crassitie hand brevioribus, ul-timo ovato, apice abrupte acuminato, piceae, basi piceo-testaceae. Palpi testacei. Caput thorace paulo angustius, suborbiculatum, supra leviter convexum, utrinque punctis duobus oblique positis supra oculos, et singulo ad oculi utriusque marginem interiorem impressum, nigrum, nitidum, ore infra antennas piceo-testaceo. Oculi mediocres, modice prominentes. Thorax coleopteris paulo angustior, latitudine haud brevior, antrorsum subangustatus, basi fortius, lateribus modice roiundatus, apice truncatus, angulis anterioribus deflexis, subrotundatis, posterioribus obtusis, modice convexus, seriebus dorsalıbus punctis tribus sat approximatis compositis, lateribus punctis praeter marginalia antrorsum utrinque duobus, altero prope seriem dorsalem, altero prope marginem lateralem impressus, piceo-brunneus, nitidus. Scutellum nigrum, nitidum, parce obsoletius punctatum. Elytra thorace longiora, parcius subtıliusque punctata, parcius longius griseo-pubescentia, fusco-testacea, nitida, dorso nigricantia. Abdomen apicem versus sensim angustatum, parcius minus subtiliter punctatum, pube longiore depressa minus subtili grisea vestitum, nigro-pilosellum, nigrum, nitidum, segmentis omnibus margine apicali latiore piceo-testaceo. Pectus nigrum. Pedes testacei, coxis anterioribus concoloribus, postici coxis femorumque basi picescentibus.

Tarsi antici maris fortiter dilatati. Femina latet.

Obs. Praecedenti proximus, at statura minore, scutello parce punctato, elytris longioribus abdomineque parcius punctatis distinctus.

* 30. Q. rufipes: Niger, antennis pedibusque rufis, scutello elytrisque sublilissime confertissimeque punctatis, nigro-pubescenlibus. - Long. $3 \frac{1}{2}-4$ lin. Staph. rufipes Grav. Micr. 171. 24. Mon. 67. 40. - Latr. Hist. nat. Crust. es Ins. IX. 324. 67.

Staph, ruficornis Grav. Mon. 50. 12. - Latr. Hist, nat. Crust. et Ins. IX. 326. 76. Emus at ten u a tus Boisd. et Lacord. Faun. Ent. Paris. I. 383. 38.

\section{Habitat in Europa australiori.}

Q. attenuato maior et latior, niger, capite thoraceque politis, nitidiss!mis. Antennae capite sesqui longiores, graciliores, apicem versus leniter incrassatae, articulo tertio secundo paulo longiore, $4-10$ sensim paulo brevioribus et crassioribus, penultimis crassitie haud brevioribus, ultimo subovato, apice oblique truncato et inferne acuminato, totae rufo-testaceae. Palpi rufi. Caput minutum, thorace duplo angustius, ovatum, utrinque supra oculos punctis duobus, oblique positis, ad oculi utriusque marginem interiorem puncto singulo impressum, lateribus pone oculos subtiliscime punctulatum. Oculi ovales, sat magni, modice prominuli. Thorax basi co- 
leopterorum latitudine, latitudine baseos haud brevior, antrorsum angustatus, lateribus parum, basi cum angulis posterioribus tortius rotundatus, apice truncatus, angulis anterioribus deflexis, subrotundatis, transversim convexus, seriebus dorsalibus punctis tribus aequaliter distantibus compositis, lateribus punctis praeter marginalia anterius utrinque duobus oblique positis impressus, punctis subtilioribus. Elytra thoracis longitudine et scutellum subtilissime confertissimeque punctulata, nitidula, pube densa depressa nigra fuscave obtecta. Abdomen apicem versus sensim angustatum, subtiliter punctulatum, subnitidum, cupreo - versicolor, pube densa depressa nigra fuscave vestitum. Pedes cum coxis anterioribus rufi.

Tarsi antici $\mathrm{m}$ aris modice dilatati, feminae simplices.

* 31. Q. monticola: Niger, nitidulus, antennis pedibusque rufo-testaceis, scutello punctulato, elytris subtiliter punctatis. - Long. $3 \frac{1}{2}$ lin.

.Habitat in montibus Tyrolensibus, Dom. Stentz.

Statura omnino Q. mauroruf, et maximis eius individuis aequalis, niger, subnitidus, capite thoraceque nitidissimis. Antennae capite sesqui longiores, graciliores, apicem versus vix incrassatae, articulo tertio secundo longiore, 4-10 sensim brevioribus at vix crassioribus, penultimis crassitie paulo longioribus, ultimo ovato, apice oblique truncato et inferne acuminato, totae rufo-testaceae. Palpi rufo-testacei. Caput thorace paulo angustius, suborbiculatum, parum convexum, utrinque punctis duobus oblique positis supra oculos, et puncto singulo ad oculi utriusque marginem interiorem impressum, lateribus pone oculos subtilissime punctulatum. Oculi sat magni et prominulı. Thorax coleopterorum latitudine, latitudine baseos haud brevior, antrorsum subangustatus, lateribus, basi et angulis posterioribus leviter rotundatis, apice truncatus, angulis anterioribus deflexis, subrectis, sat convexus, seriebus dorsalibus punctis tribus aequaliter distantibus compositis, lateribus punctis praeter marginalia anterius utrinque binis oblique positis notatus. Scutellum punctulatum, fusco-pubescens. Elytra thoracis longitudine, densius subtiliter punctata, nitidula, pube depressa fusca densius vestita. Abdomen apicem versus sensim attenuatum, subtiliter punctulatum, fusco-pubescens, nitidulum, subcupreo-versicolor, subtus segmentorum marginibus tenuiter rufo-piceis. Pedes cum coxis anterioribus rufo-testacei, femoribus postieis medio viridi-micantibus.

Tarsi antici maris fortiter, feminae leviter dilatati.

Obs. A praecedente, cui proximus est, praecipue differt habitu, capite maiore, scutello elytrisque minus subtiliter denseque punctatis.

* 32. Q. semiobscurus: Niger, pedibus cum coxis anticis antennisque testaceis, elytris thorace longioribus, fusco-subaeneis, subtilissime punctulatis, scutello punctulato. - Long. $2 \frac{3}{4}-3 \frac{1}{4}$ lin.

Staph. semiobscurus Marsh. Ent. Britt. 512. 41.

Habitat in Anglia, Dom. Spence, in Sardinia, Dom. Prof. Gené.

Habitu omnino praecedentis, at dimidio minor, Q. attenuato proximus, at plerumque paulo maior et robustior. Niger, capite thoraceque nitidissimis. Antennae capite sesqui longiores, graciliores, apicem versus haud incrassa- 
tae, articulo secundo tertioque subaequalibus, 4-10 sensim paulo brevioribus, omnibus crassitie longioribus, ultimo oblongo-ovato, apice inferne sensim acuminato. Antennae totae dilute testaceae. Palpi testacei, articulo apicali piceo. Caput thorace paulo angustius, suborbiculatum, parum convexum, utringue supra oculos punctis duobus oblique positis, ad oculi ntrius. que marginem interiorem puncto singulo impressum. Oculi magni, prominentes. Thorax basi coleopteris paululum angustior, latitudine baseos vix longior, antrorsum leviter angustatus, lateribus leviter, basi cum angulis posterioribus fortius rotundatus, apice truncatus, angulis anterioribus deflexis, subrotundatis, convexus, seriebus dorsalibus punctis tribus modice distantibus compositis, lateribus punctis praeter marginalia anterius utrinque duobus, oblique positis, sat distantibus impressus. Scutellum dense subtiliterque punctulatum, subtiliter pubescens. Elytra thorace paulo longiora, confertim subtilissime punctulata, pube subtiliore longioreque depressa grisea densius vestita, virescenti - vel fusco-subaenea, subnitida, margine apicali testaceo. Abdomen apicem versus sensim angustatum, confertim subtilius punctatum, densius fusco-pubescens, subsericans, minus nitidum, supra parum, subtus fortius metallico-versicolor, segmentis ventralibus apice ferrugineo-marginatis. Pedes dilute flavo-testacei, coxis anticis concoloribus, intermediis piceis, posticis nigris, femoribus posticis picescentibus. Alae albo-hyalinae.

Tarsi antici maris modice dilatati, feminae simplices.

obs. I. Differt a $Q$. attenuato statura maiore, latiore, elytris longioribus, coxis intermediis piceis.

2. Descriptio Marshamiana manca ex auctoritate Spencei ad hanc speciem allata.

\section{* 33. Q. collaris: Niger, antennis, pedibus cum coxis anterioribus, thora- ceque rufo-testaceis, hoc medio piceo, elytris thoracis longiludine scu- telloque subtiliter punctulatis. - Long. 4 lin.}

Habitat in Volhynia, Dom. Schïppèl.

Habitu omnino Q. attenuati, at plus duplo maior. Antennae capite sesqui longiores, tenues, apicem versus haud incrassatae, articulo tertio secundo paululum longiore et tenuiore, 1-10 sensim paululum brevioribus, teretibus, ultimo oblongo, apice oblique truncato et inferne acuminato, totae rufo-testaceae. Palpi rufo-testacei, articulo ultimo concolore. Caput thorace paulo angustius, orbiculatum, parum convexum, utrinque punctis duobus oblique positis supra oculos, et puncto singulo ad oculi utriusque marginem interiorem notatum, lateribus pone oculos subtilissime punctulatum, nigrum, pernitidum. Oculi permagni, prominentes. Thorax basi coleopteris vix angustior, latitudine baseos hand longior, antrorsum leviter angustatus, basi modice, lateribus leviter rotundatus, apice truncatus, angulis anterioribus deflexis, subrotundatis, posterioribus obtusis, modice convexus, seriebus dorsalibus punctis tribus modice distantibus compositis, lateribus punctis praeter marginalia anterius utrinque duobus, altero prope seriem dorsalem, altero prope marginem lateralem impressus, nitidus, rufo-testaceus, disco indeterminate nigricante. Scutellum punctulatum, nigrum, nitidum. Elytra thoracis longitudine, confertim subtiliter punctulata, pube densiore depressa nigra vestita, nigra, subnitida, margine summo apicali ferru- 
gineo. Abdomen elongatum, apicem versus sensim attenuatum, confertim subtiliter punctulatum, pube subtiliore depressa fusca subsericans, minus nitıdum, nigrum, segmentis singulis apice tenuiter rufo-marginatis. Pectus nigrum. Pedes dilute rufo - testacei, coxis anterioribus concoloribus, posticis piceo-testaceis. Alae hyalinae.

Tarsi antici feminae leviter dilatati. Mas latet.

Obs. Q. attenuato proximus, praeter staturam maiorem autem et colorem thorace minus convexo, angulis posterioribus minus rotundatis diversus.

* 34. Q. attenuatus: Niger, pedibus cum coxis anterioribus antennisque testaceis, elytris thoracis longitudine, subaeneis, subtilissime punctatis, scutello punctulato. - Long. $2 \frac{3}{4}$ lin.

Er. Col. March. I. 493. 14.

Staph. attenuatus Gyll. Ins. Suec. II. 311. 27. - Zetterst. Faun. Lappon. I. 71. 12. Ins. Lappon. 62. 17. - Sahlb. Ins. Fenn. I. 318. 25. - Mannerh. Brachelytr. 27. 38. - Runde Brachelytr. Hal. 6. 15.

Staph. maurorufus Runde Brachelytr. Hal. 6. 26.

Philonth. attenuatus Nordm. Symb. 78. 13.

E $m$ us scintillans Boisd. ot Lacord. Faun. Ent. Parls. I. 384. 40.

Habitat in Germania, Anglia, Suecia.

Niger, nitidus, capite thoraceque pernitidis, elytris nigro-subaeneis, nitidis. Antennae breviusculae, capite paulo longiores, tenuiores, apicem versus haud incrassatae, articulo secundo tertioque subaequalibus, sequentibus sensim paulo brevioribus, ultimo ovato, oblique truncato et inferne acuminato, totae testaceae. Palpi testacei, articulo apicali piceo. Caput thorace parum angustius, rotundatum, utrinque supra oculos punctis duobus oblique positis, ad oculi utriusque marginem interiorem puncto singulo impressum. Oculi permagni, prominentes. Thorax basi fere coleopterorum latitudine, latitudine baseos vix brevior, antrorsum modice angustatus, lateribus leviter, basi cum angulis posterioribus fortiter rotundatus, apice truncatus, angulis anterioribus deflexis, subrotundatis, sat convexus, seriebus dorsalibus punctis tribus modice distantibus compositis, lateribus punctis praeter marginalia utrinque duobus, oblique positis, distantibus impressus. Scutellum subtiliter punctulatum. Elytra confertim subtiliter punctulata, densius subtıliter griseo - pubescentia. Abdomen elongatum, apicem versus sensim angustatum, dense subtiliter punctulatum, pube brevi depressa tenuissima vectitum, parum nitidum, infra magis quam supra metallico-versicolor. Pedes cum coxis anterioribus laete testacei.

Tarsi antici $\mathrm{maris}$ fortiter, feminae modice dilatati.

V ariat elytris fusco-testaceis, magis minusve aeneo-micantibus.

Obs. 1. Staph. maurorufus Runde secundum collectionem Germarianam, ab auctore citatam, ab hac specie non distinctus.

2. St aph. 4-punctatum Zetterst. Faun. Lappon. I. 76. 24. Ins. Lappon. 64. 34, cuius specimen singulum in Lapponia a cel. auctore captum est, tantummodo huius speciei varietatem thoracis seriebus dorsalibus 4-punctatis habeo, neque auctori ipsi praeter magnitudinem minorem aliud discrimen observatum. Apud Philonthos punctorum in seriebus dorsalibus numerus saepius variabilis, neque in Quediis pluribus omnino constans repertus est. 
* 35. Q. hyperboreus: Niger, pedibus anterioribus cum coxis anlennisque piceo-les/aceis, elytris thorace brevioribus, nigro-subaeneis, subtiliter punctulalis. - Long. 3 lin.

Staph. Fellmanni Zetterst. Ins. Lappon. 62. 18. (forle)

Habitat in Unalaschka, Dom. v. Chamisso.

Statura et summa affinitas praecedentis, niger, capite thoraceque pernitidis. Antennae capite sesqui longiores, tenues, apicem versus haud crassiores, articulo tertio secundo hand longiore et panlo tenuiore, $4-10$ sensim brevioribus, penultimis longitudine haud crassioribus, ultimo paulo crassiore, subovato, apice oblique truncato et inferne acuminato, totae piceo-testaceae. Palpi testacei, articulo nltimo piceo. Caput thorace dimidio angustius, orbiculatum, parum convexum, utrinque supra oculos punctis duobus oblique positis, ad oculi utriusque marginem interiorem puncto singulo impressum, lateribus pone oculos subtilissime punctulatum. Oculi permagni, prominentes. Thorax basi coleopterorum prope latitudine, latitudine summa haud longior, antrorsum leviter angustatus, lateribus leviter, basi cum angulis posterioribus fortius rotundatus, apice truncatus, angulis anterioribus deflexis, subrectis, sat convexus, seriebus dorsalibus punctis tribus modice distantibus compositis, lateribus punctis praeter marginalia anterius utrinque duobus, oblique positis, sat distantibus impressus. Scutellum punctulatum. Elytra thorace paulo breviora, crebrius subtiliter punctata, pube subtiliore longiuscula depressa nigra densius vestita, nigro - subaenea, nitida. Abdomen elongatum, apicem versus sensim attenuatum, confertim subtilius punctatum, pube subtili depressa fusca densius vestitum, subsericans, segmentis inferioribus apice piceo-marginatis. Pedes cum coxis antici dilute testacei, intermedii piceo - testacei, postici picei.

Tarsi antici maris fortiter, feminae leviter dilatati.

Obs 1. Elytris brevioribus, minus subtiliter punctulatis et pedibus obscurioribus praecipue a praecedente distinctus.

2. St a ph. F ellmanni, e Lapponia, num recte ad hanc speciem allatus sit, e descriptione manca non satis patet. Descriptio citata haec est: „Affinis et similis St. attenuato, sed forte paulo maior, antennis aperte paulo longioribus et pedibus tantum anterioribus testaceis distinctus. Elytra iam fusca iam nigra. Pedes postici fusci vel obscure testacei."

* 36. Q. virgulatus: Niger, nitidus, antennis pedibusque testaceis, scutello punclulato, elytris dense subtiliter punctatis, abdomine tristriato-cinereo-pubescente. - Long. $2 \frac{1}{2}$ lin.

Habitat in Sardinia, Dom. Prof. Gené.

Habitu et summa affinitas Q. attenuati, at minor, Q. boope parum maior. Niger, nitidus, capite thoraceque politis. Antennae capite sesqui longiores, articulo tertio secundo paululum longiore et tenuiore, 4-10 sensim paulo brevioribus, penultimis crassitie brevioribus, ultimo apice inferius acuminato, totae laete flavo-testaceae. Palpi testacei. Caput thorace angustius, suborbiculatum, utrinque supra oculos punctis duobus oblique positis, inter oculos ad oculi utriusque marginem interiorem puncto singulo maiusculo impressum. Oculi permagni, prominuli. Thorax basi coleopteris paulo angustior, antrorsum leviter angustatus, latitudine postica vix longior, basi cum angulis posterioribus fortiter, lateribus parum rotundatus, apice trun- 
catus, angulis anterioribus subrectis, deflexis, transversim sat convexus, seriebus dorsalibus punctis tribus modice distantibus compositis, lateribus punctis praeter marginalia anterius utrinque dnobus, altero prope seriem dorsalem, altero prope marginem lateralem. Scutellum punctulatum, pubescens. Elytra thorace paulo longiora, crebre subtiliter punctata, nigro-subaenea, pube subtilissima depressa vestita, immixtis pilis sparsis crassioribus, itidem depressis, fulvis, nitidis, apice fulvo-ciliata. Abdomen apicem versus sensim attenuatum, crebre subtilissime punctatum, nigrum, nitidum, subiridescens, supra pube subtilissima depressa nigra vestitum, lineis tribus cinereo-pubescentibus, in singuli segmenti apice ciliis fulvis interruptis, subtus magis iridescens, segmentis singulis margine posteriore rufo-piceo, tenuiter cinereo-pubescens, immixtis pilis rarioribus sparsis fulvis. Pedes laete flavo-testacei,' anteriores coxis concoloribus, posteriores femoribus tibiisque fuscescentibus.

Tarsi antici maris fortiter, femin a leviter dilatati.

Obs. Elytrorum et abdominis pubescentia satis distinctus, ceterum Q. attenuato et boopi proximus.

* 37. Q. boops: Niger, nitidus, antennis, pedibusque testaceis, elytris thoracis longitudine, subtilius punctatis, scutello punctulato. - Long. $2-2 \frac{1}{4}$ lin.

Er. Col. March. I. 494. 15.

St aph. boops Grav. Micr. 21. 26. Mon. 71. 54. - Latr. Hist. nat. Crust. et Ins.

IX. 311. 31. - Gyll. Ins. Suec. II. 312. 28. - Zetterst. Fuun. Lappon. I. 72. 13.

Ins. Lappon. 62. 19. - Sahlb. Ins. Fenn. I. 318. 26. - Mannerh. Brachelytr. 27. 39.

Emus bo ops Boisd. et Lacord. Faun. Ent. Paris. I. 385. 41.

Philonth. boops Nordm. Symb. 78. 14.

Habitat in Germania, Suecia.

Q. attenuato proximus, at duplo minor, niger, nitidus, capite thoraceque pernitidis, elytris nigro-piceis, nitidulis. Antennae capite sesqui longiores, articulo tertio secundo paulo minore, $4-10$ sensim brevioribus, penultimis crassitie parum longioribus, subobconicis, ultimo ovato, apice acuminato, totae testaceae. Palpi testacei. Caput maiusculum, thorace vix angustius, rotundatum, utrinque supra oculos punctis duobus, ad marginem oculi utriusque interiorem puncto singulo impressum, lateribus pone oculos subtilissime punctulatum. Ocul permagni, prominulı. Thorax coleopteris perparum angustior, latitudine vix longior, antrorsum subangustatus, basi cum angulis posterioribus fortiter, lateribus leviter rotundatus, apice truncatus, angulis anterioribus deflexis, subrectis, leviter convexus, seriebus dorsalibus punctis tribus, antico paulo remotiore, compositis, lateribus punctis praeter marginalia auterius utrinque duobus, altero prope seriem dorsalem, altero prope marginem lateralem impressus. Scutellum subtilissime parce punctulatum. Elytra thoracis longitudine, confertim subtilius punctata, tenuiter griseo-pubescentia. Abdomen elongatum, parce subtiliter punctulatum parceque tenuter griseo-pubescens, apice nigro-pilosellum, subtus segmentis singulis piceo-marginatis. Pedes cum coxis laete testacei.

Tarsi antici maris fortiter, feminae modice dilatati. 
* 38. Q. oblitteratus: Niger, nitidus, anlennis, thoracis lateribus, abdominis segmentorum marginibus pedibusque lestaceis, elytris dense punclalis, pallidis, pluga subsulurali nigra. - Long. 3 lin.

Habitat in Sardinia, Dom. Prof. Gené.

Statura omnino Q. attenuati, niger, nitidus, capite thorace scutelloque politis. Antennae capite thoraceque paulo breviores, articulo tertıo secundo tenuiore et sesqui longiore, 4-10 sensim panlo brevioribus at vix crassioribus, penultimis crassitie vix longioribus, ultimo apice distincte obliqre emarginato et inferne acuminato, saturate rufo-testaceae, basi dilutiores. Palpi testacei. Caput thorace angustius, orbieulatum, utrinque supra oculos punctis duobus, ad oculi utriusque marginem interiorem puncto singulo impressum, lateribus supra oculos confertissime subtiliter punctulatum. Oculi magni. Thorax coleopteris paulo angustior, antrorsum subangustatus, latitudine postica fere longior, basi cum angulis posterioribus fortiter, lateribus leviter rotundatus, apice truncatus, angulis anterioribus subrectis, deflexis, transversim sat convexus, seriebus dorsalibus punctis tribus, anteriore remotiore, compositis, lateribus punctis praeter marginalia anterius utrinque duobus, altero prope seriem dorsalem, altero prope marginem lateralem, nigro-piceus, lateribus testaceis. Scutellum laevissimum. Elytra thorace paululum longiora, subdepressa, dense minus fortiter punctata, pube longiore subdepressa grisea vestita, pallide lutea, plaga longitudinali prope suturam, parum distincta, nigra. Abdomen modice elongatum, apicem versus sensim angustatum, sat crebre subtilius punctatum, pube longiore depressa fulvescenti-grisea densius vestitum, nigrum, nitidulum, subiridescens, segmentis singulis testaceo-marginatis. Pedes laete testacei, coxis anterioribus totis, posticis apice concoloribus.

Tarsi antici maris fortiter, femina e leviter dilatati.

Obs. Intermedius inter plures species diffines: habitu omnino et capitis forma cum $Q$. attenuato et $\mathrm{s}$ cintillan te congruit, ab illo autem scutello laevissimo, ab hoc fronte inter oculos bipunctata differt; ab utroque antennarum structura diecedit, qua Q. maurorufo appropinquatur.

* 39. Q. scintillans: Nigro-aeneus, nitidus, antennarum basi pedibusque tesiaceis, elytris parcius forliter punctalis, fronle inter oculos punctis 4 transversalibus impressa. - Long. $2 \frac{1}{2}$ lin.

Er. Col. March. J. 494.16.

Staph. scintillans Grav. Mon. 70. 53.

Habitat in Germania.

Statura omnino praecedentium, at minus elongatus, obscure aeneus, capite, thorace scutelloque nitidissimis. Antennae capite paulo longiores, apicem versus leviter incrassatae, articulo tertio secundo tenuiore at parum breviore, 4-10 sensim paulo brevioribus et crassioribus, ultimo oblongoovato, apice inferne acuminato, rufo-piceae, articulo primo testaceo. Palpi picei. Caput thorace angustius, rotundatum, utrinque supra oculos punctis duobus, inter oculos serie transversali e punctis quatuor, aequaliter distantibus, lateralibus in oculi ipso margine sitıs obsoletioribus, intermediis sat profundis notatum, lateribus pone oculos subtilissime punctulatis. Oculi magni, prominuli. Thorax basi coleopteris latitudine aequalis, latitudine 
summa haud brevior, antrorsum leviter angustatus, basi et lateribus subae. qualiter rotundatus, apice truncatus, angulis anterioribus deflexis, subrectis, posterioribus subrotundatis, leviter convexus, seriebus dorsalibus punctis tribus modice approximatis compositis, lateribus punctis praeter marginalia anterius utrinque 4 impressus. Scutellum laevissimum. Elytra thorace paulo longiora, minus dense fortiter punctata, albido-pubescentia. Abdomen apicem versus sensim attenuatum, subtiliter parcius punctulatum, pube longiore depressa fusco - grisea densius vestitum, nigro - pilosellum, subtus lucide metallico-versicolor, segmentis singulis piceo-marginatis. Pedes cum coxis anticis testacei, tarsis anticis in utroque sexu fortiter dilatatis.

* 40. Q. lucidulus: Viridi-aeneus, nitidus, antennarum basi, pedibus, elytris abdomineque testaceis, elytris dense subtilius punclalis, fronte inter oculos punctis 4 transversalibus impressis. - Long. $2 \frac{1}{2}$ lin.

Er. Col. March. 1. 495. 17.

Habitat in Germania.

Statura et summa affinitas praecedentis. Antennae capite paulo longiores, crassiusculae, articulo secundo tertioque subaequalibus, 4-10 sensin paulo crassioribus at vix brevioribus, subobconicis, ultimo ovato, apice inferius acuminato, rufo-piceae, basi testaceae. Os testaceum. Caput thorace angustius, rotundatum, lucide viridi-aeneum, politum, utrinque supra oculos punctis duobus, inter oculos serie transversali e punctis quatuor aequaliter distantibus impressum. Oculi magni, prominuli. Thorax basi coleopterorum latitudine, latitudine summa vix brevior, antrorsum angustatus, basi fortius, lateribus leviter rotundatus, apice truncatus, angulis anterioribus deflexis, subrectis, posterioribus subrotundatis, modice convexus, seriebus dorsalibus punctis tribus modice approximatis compositis, lateribus punctis praeter marginalia anterius utrinque 4 impressus, lucide viridi-aeneus, politus. Scutellum laevissimum. Elytra thorace paulo longiora, fuscotestacea, supra aeneo-nitidula, confertim subtilius punctata, pube lutescentigrisea minus subtili vestita. Abdomen apicem versus sensim attenuatum, confertim subtiliter punctatum, pube depressa, minus tenui, lutescenti-grisea dense vestitum, nigro-pilosellum, obscure testaceum, virescenti-nitidulum, linea longitudinali dorsali angusta viridi. Pectus nigricans. Pedes testacei, coxis femoribusque anticis flavis, tarsis anticis in utroque sexu fortiter dilatatis.

\section{Species mihi invisa e.}

41. Q. peregrinus: Vitidus, nigricans, antennis, palpis, elytris, pedibus, thoracis laleribus et segmentorum marginibus rufescentibus. - Long. 3 lin. Staph. peregrinus Grav. Mon. 53. 17.

Habitat in Carolina.

Habitu et thoracis forma Q. fulgido (nitido) affinis, capite autem ovato et colore satis differt. Caput ovatum, thoracis longitudine, sed eo angustius, nitidum, punctis perpaucis maioribus impressum, nigrum, antennis (quarum articulus ultimus deest) capite paulo longioribus palpisque rufis. Thorax punctis quibusdam impressus, niger, lateribus rufescentibus. Coleoptera 
quadrata, subpilosa, piceo-rufescentia. Abdomen segmentorum marginibus rufis, supra nigricans, infra fuscum. Pedes testaceo-rufi, tarsis anticis dilatatis. (Grav.)

12. Q. tenellus: Nigro-fuscus, abdomine pedibusque pallidioribus, elylris testaceis, thorace seriebus dorsalibus 4-punctis. - Long. $3 \frac{1}{2}$ lin.

Staph. tenellus Grav. Mon. 54. 18.

Staph. nitidi var. 13. Grav. Micr. p. 32.

Habitat in Germania.

Statura graciliore, colore et thoracis punctura satis a Q. fưgido (nitido) distinctus est. Caput suborbiculatum, latitudine paulo longius, thorace monus, nigrum, nitidissimum, in angulis baseos punctum, puncts 3 distinctioribus, antennis fuscescentibus. Thorax orbiculatus, Iatitudine fere eadem ac in Q. fulgido, nigro-fuscus, marginibus pallidioribus, puncto marginali uno, serie laterali 3-puncta, seriebus dorsalibus 4-punetis, punctis autem subconfluentibus. Praeterea punctum marginale in angulo baseos, ante humeros coleopterorum impressum est, distinctius quam in reliquis huius familiae Staphylinis. Scutellum nigro-fuscum. Coleoptera quadrata, dilute testacea, nitida, subtiliter puncta, pilis tenuissimis vestita. Abdomen coleopteris triplo longius, pilosellum fuscum, subtiliter punctum. Pedes fusci, tarsis anterioribus pallidioribus, anticis brevibus. (Grav.).

$\mathrm{Obs}$. Forte huius generis.

43. Q. rufo-cinctus: Niger, nitidus, elylris glabris, rufo-marginatis, haud striato-punctatis, abdomine subcoerulescente, segmentorum marginibus rufo-ferrugineis.

Staph. rufocinctus Mannerh. Brachelytr. 26. 33.

Philonth. rufocinctus Nordm. Symb. 79. 21.

Habitat in Fennia meridionali.

Statura et magnitudo Q. impressi, a quo differt elytris haud striatopunctatis: an igitur species diversa? (Mannerh.)

44. Q. maurus: Niger, nitidus, ore, antennis ex/rorsum pedibusque piceoferrugineis, elytris profunde punctalis, antennis thorace brevioribus, mediocribus. - Long. $22_{4}^{3}$ lin.

Staph. maurus Sahlb. Ins. Fenn. I. 317. 23. - Mannerh. Brachelytr. 26. 35.1

Philonth. maurus Nordm. Symb. 79. 22.

Habitat in Fennia meridionali.

Magnitudine et statura Q. umbrino (waurorufo S.) simillımus, colore, antennis brevioribus et oculis minoribus ab illo distinctus. Caput thorace paulo angustius, orbiculatum, nigrum, nitidum, laeve, puncto pone singulum oculum magno et quibusdam minoribus in angulis verticis. Palpi et reliquae oris partes piceo-ferrugineae. Oculi mediocres, nigri. Antennae thorace breviores, extrorsum paulo crassiores, articulis tribus baseos nigris, nitidis, longioribus, ceteris piceo ferrugineis, brevibus, ultimo longiore. Tho rax antice subemarginatus, angulis deflexis, lateribus et postice exacte orbiculato-rotundatus, supra convexus, niger, nitidus, laevis, punctura ut in 
Q. umbrino. Scutellum triangulare, nigrum, nitidum, laevissimum. Elytra thoracis medio nonnihil angustiora, apice oblique truncata, supra depressa, nigra, nitida, profunde sed parcius punctata, tenue pubescentia. Abdomen pone elytra longitudine fere reliqui corporis, subnitidum, nigrum, punctulatum, pubescens. Corpus subtus nigrum, subnitidum, punctulatum, pubescens. Pedes piceo-ferruginei. (Sahlb.)

45. Q. vicinus: Niger, nilidus, pedibus abdomineque testaceis, hoc cupreoversicolore, elytris pallide favis, forliter punclatis.

Emus vicinus Boisd. et Lacord. Faun. Ent. Paris. I. 383. 39.

Habitat Lutetiae.

Q. attenuato paulo brevior et latior. Caput nigrum, nitidum, in utroque sexu aequale, thorace angustius, oblongum, laevissimum, vertice punctis duobus, fronte ad oculi utriusque marginem interiorem singulo, et ntrinque supra oculos tribus vel quatuor impressum. Thorax capiti concolor, amplus, suborbicularis, laevissimus, seriebus dorsalibus 3-punctatis, praeterea punctis duobus approximatis nonnunquam oonfluentibus prope marginem lateralem, nonnullis sparsis versus margines disci impressus, basi leviter punctata. Scutellum triangulare, nigrum, nitidum, laevissimum. Elytra pallide flava, elongata, apice oblique truncata, fortiter punctata, pubescentia. Abdomen modice elongatum, apice attenuatum, subtiliter rugulosum et pubescens, testaceum, laete aeneo cupreoque versicolor. Pedes abscurius testacei, tibiis intermediis perparum spinulosis. (Sec. Boisd. et Lacord.)

Obs, A Q. lucidulo fronte inter oculos utrinque 1.punctata discedit.

\section{Astrapaeus Grav.}

Grav. Mon. p. 199. - Latr. Gen. Crust. et Ins. I. p. 284. - Guér. Iconogr. Regn. An. Ins. $t$. 9. $f .2$.

Palpi utrique articulo ultimo securiformi.

Ligula rotundala, medio incisa, paraglossis breviore.

Pedes intermedii approximati.

Corpus mediocre, lineare, alatum. Caput thorace minus, ovatum, basi vix constrictum, declinatum, oculis haud prominulıs. Labrum breve, transversum, bilobum, lobis rotundatis, limbo laterali membranaceo, apice setis rigidis obsitum. Mandibulae capite fere breviores, fortes, muticae, apice aduncae, acutae. Maxillae (t. IV. f. 11. b.) malis coriaceis, exteriore apice, interiore intus barbatis. Palpi maxillares mediocres, articulo primo minore, tenui, cylindrico, secundo tertioque crassiuseulis, subobconicis, tertio paulo breviore, quarto maris fortiter, feminae leviter securiformi. Labium (t. IV. f. II. a.) mento transverso, corneo, ligula brevi, rotundata, medio leviter incisa, membranea, paraglossis longioribus, ooriaceis, intus oiliatis. Antennae filiformes, artioulo ultimo apice oblique subemarginato. Thorax coleopteris fere latior, antrorsum leviter angustatus, latitudine brevior, transversim convexus, lateribus deflexis basique rotundatus, basi utrinque subsinuatus, antice truncatus. Scutellum triangulare. Elytra thorace paulo longiora, truncata. Abdomen longiusculum, lineare, apice attenuatum. Pedes breviusculi, antici breves, femoribus compressis, subtus sinuatis, tibiis brevibus, 
intus breviter parceque spinulosis, tarsis articulis 4 primis in utroque sexu dilatatis, subtus spongioso-tomentosis, pedes posteriores tibiis spinulosis, tarsis articulo primo ultimoque leviter elongatis. Coxae intermediae contiguae.

$$
\text { o b s e r va tiones. }
$$

1. Habitus omnino $Q u e d i i$, palporum structura, et ligula medio incisa imprimis distinctus.

2. Mas palporum maxillarium articulo ultimo fortius securiformi, tarsis anticis fortius dilatatis, abdominisque segmento sexto subtus apice leviter emarginato distinctus.

\section{* 1. A. Ulmi: Niger, nilidus, elytris abdominisque segmento quinto apice} rufis. - Long. 5- 6 lin.

Grav. Micr. 199. 1. - Panz. Faun. Germ. 88. 4. - Latr. Hist. nat. Crust. et Ins. IX. p. 288. t. 79. f. 3. Gen. Ins. I. 284. 1. - Mannerh. Brachelytr. 19. 1. Nordm. Symb. 16. 1.

Staph. Ulmi Rossi Faun. Etr. 1. 248. (Ed. Hellw. 307.) 611. t. 5. f. 6. - Oliv.

Ent. III. 42. 17. 17. t. 4. f. 37. - Grav. Mon. 47. 7.

Staph. Ulmineus Fab. Syst. El. II. 595. 28.

Astrapaeus ulmineus Buisd. et Lacord. Faun. Ent. Paris. I. 356.

Habitat in Gallia, Italia, Dalmatia, Hungaria (,sub cortice Ulmi primo vere" Rossi).

Niger, capite thoraceque nitidissimis. Antennae capitis thoracisque longitudine, articulo tertio secundo paulo longiore, 4-10 sensim paulo brevioribus at non crassioribus, leviter obconicis, basi rufae, apice ferrugineae. Palpi rufi. Caput parce subtilissime obsolete punctulatum, supra oculos utrinque punctis duobus maioribus, ad oculi utriusque marginem interiorem puncto singulo impressum. Thorax parce omnium subtilissime punctulatus. Scutellum laeve. Elytra saturate rufa, nitida, subtiliter punctulata, stria suturali impressa, et in medio dorsi punctorum maiorum distantium serie longitudinali notata. Abdomen minus nitidum, crebre punctulatum, breviter nigro-pubescens, segmento quinto apice late rufo. Pedes nigri, tibiis tarsisque rufo-piceis.

\section{Euryporns $E r$.}

Er. Col. March. I. p. 496.

Pelecyphorus Nordm. Symb. p. 13. $t$. 1. $f$. 5.

Palpi maxillares filiformes, labiales articulo tertio securiformi.

Ligula rotundata, integra, paraglossis breviore.

Pedes intermedii approximati.

Corpus mediocre, oblongum, alatum. Caput thorace multo minus, oblongo-ovatum, basi vix constrictum, deflexum, oculis vix prominulis. Labrum latum, transversum, medio profunde incisum, totum corneum, apice setulosum. Mandibulae fortiter arcuatae, acutae, basi unidentatae. Maxillae (t. IV. t. 10. b.) malis coriaceis, minutis, exteriore apice, interiore intus barbatis. Palpi maxillares mediocres, articulo primo minuto, brevi, tertio secundo paulo breviore, quarto secundo aequali, cylindrico. Labium (t. IV. f. 10. a.) mento transverso, corneo, ligula brevissima rotundata, integra, 
membranea, paraglossis minutis, membranaceis, intus ciliatis, ligulam superantibus. Palpi labiales articulo primo secundoque subaequalibus, brevibus, subobconicis, tertio securiformi. Antennae filiformes, articulo ultimo apice oblique truncato. Thorax coleopteris paululum latior vel iisdem subaequalis, antrorsum angustatus, latitudine brevior, lateribûs et basi rotundatus, apice truncatus, transversim convexus. Scutellum rotundato-trianguiare. Elytra thoracis longitudine, truncata. Abdomen latiusculum, apice attenuatum. Pedes mediocres, graciliores, tibiis omnibus spinulosis, tarsis gracilibus, articulo primo ultimoque leviter elongatis, tarsis anticis etiam in utroque sexu simplicibus. Coxae intermediae contiguae.

\section{O b s e r va tio nes.}

1. Habitus fere $Q u e d i i$, at caput minus, praeterea palporum et tarsorum anticorum structura distinctus. Paykull et Gyllenhal hoc genus minus apte ob palporum formam cum $0 x y$ poro coniungunt: proxime accedit ad Astrapaeum, a quo praecipue palpis maxillaribus teretibus, mandibulis basi dentatis tarsisque anticis simplicibus discedit.

2. Mas palporum labialium articulo ultimo fortius securiformi abdominisque segmento sexto subtus apice leviter emarginato ab altero sexu differt.

3. Victus in silvis sub musco.

1. E. picipes: Niger, nitidus, thorace laevissimo, antice biseriatim tripunctato. - Long. $4-4 \frac{1}{2}$ lin.

Er. Col. Murch. I. 496. 1.

Oxyporus picipes Payk. Faun. Suec. III. 426. 2. - Gyll. Ins. Suec. II. 443, 2. Pelecyphorus picipes Nordm. Symb. 14. 1.

Habitat in Suecia, Germania.

Niger, nitidus, capite thoraceque nitidissimis. Antennae capitis thoracisque prope longitudine, filiformes, apicem versus haud incrassatae, articulo tertio secundo sesqui longiore, 4-10 sensim brevioribus at haud crassioribus, 4 et 5 subcylindricis, sequentibus leviter obconicis, penultimo crassitie vix longiore, ultimo apice abrupte acuminato, nigrae, articulis duobus basalibus rufis. Os rufum. Caput laevissimum, supra oculos punctis utrinque duobus impressum. Thorax basi coleopteris paulo latior, latitudine baseos paulo brevior, antrorsum angustatus, basi cum angulis posterioribus et lateribus rotundatus, apice truncatus, angulis anterioribus leviter deflexis, subrectis, convexus, laevissimus, antice seriebus dorsalibus e punctis tribus sat approximatis, lateribus praeter marginalia punctis utrinque duobus, altero prope seriem dorsalem, altero prope marginem lateralem notatus. Scutellum laeve. Elytra thorace paulo breviora, crebre punctata, nigro-pubescentia. Abdomen punctulatum, breviter rigideque parce nigro-pubescens, metallico-versicolor. Pedes nigri, tibiis piceis, tarsis rufescentibus.

2. E. puncticollis: Niger, nitidus, thorace crebre punclato, linea media laevi. - Long. $4 \frac{1}{2}$ lin.

Habitat in America septentrionali.

Praecedente corpore medio paulo latior, niger, nitidus. Antennae capite thoraceque breviores, apicem versus sensim leviter incrassatae, articulo tertio secundo paulo longiore, 4 - 10 sensim crassioribus at vix brevioribus, 6-10 cylindricis, penultimis crassitie paulo brevioribus, ultimo subgloboso, 
apice leviter impresso et inferne acuminato, nigrae, apice summo ferrugineo. Os piceum. Caput minutum, crebre punctatum, fronte medio laevi. Thorax coleopteris paulo angustior, latitudine summa paulo brevior, apice truncatus, basi, lateribus et angulis omnibus, anterioribus leviter deflexis, rotundatis, leviter convexus, crebre punctatus, linea media longitudinali laevi subelevata. Scutellum punctulatum. Elytra thoracis longitudine, sat crebre punctata. Abdomen apicem versus sensim leniter angustatum, supra punctulatum, segmentis tribus primis basi utrinque striola abbreviata impressis, ultimis duobus subtilius punctulatis, parce tenuiterque griseo-pubescens, subtus segmentis singulis basi fortius densiusque punctatis, longius cinereopubescens. Pedes nigro-picei, tarsis rufescentibus.

Abdominis segmentum inferius quintum in $\mathrm{mare}$ ante apicem impressum, ante foveolam elevato-biplicatum. F e min a latet.

\section{Oxyporus Fab.}

Fab. Syst. Ent. p. 267. - Grav. Micr. p. 151. - Latr. Gen. Crust. et Ins. I. p. 283.

Palpi maxillares filiformes, labiales articulo tertio lunato.

Ligula biloba, paraglossis nullis.

Pedes intermedii distantes.

Corpus oblongum, infra modice convexum, alatum. Caput magnum, exsertum, basi parum constrictum, oculis parvis', rotundatis, parum prominulis. Labrum transversum, acute emarginatum. Mandibulae elongatae, porrectae, falcatae, decussatae, acutae, muticae. Maxillae (t. V. f. 6. b.) mala exteriore coriacea, apice rotundato, membraneo, margine barbato, interiore membranea, margine exteriore corneo, interiore pilis brevissimis dense ciliato. Palpi maxillares leviter elongati, articulo primo minuto, secundo elongato, tertio hoc paulo breviore, obconico, quarto hoc paulo breviore, apice subacuminato. Labium (t. V. f. 6. a.) mento córneo, transverso, utrinque antrorsum producto, portione intermedia inter mentum et ligulam coriacea, apice bicuspi, ligula biloba, lobis acuminatis. Palpi labiales articulo primo breviore, secundo sat elongato, tertio dilatato, apice emarginato, transversim triangulari vel semilunari. Antennae breviores, rectae, apicem versus sensim compressae dilatataeque, articulis penultimis $\mathbf{5}$ utrinque dilatatis, transversis, ultimo breviter ovato. Thorax coleopteris paulo angustior, basi rotundatus, apice truncatus, lateribus subtilissime marginatus, basin versus angustatus. Scutellum triangulare. Elytra apice truncata, angulo exteriore leviter rotundato. Abdomen corpore dimidio brevius, supra planum, lateribus late marginatum, subtus leviter fornicatum. Pectus amplum. Pedes leviter elongati, graciles, intermedii pectoris lateribus inserti, late distantes, tibiis omnibus muticis, tarsis breviusculis, articulo primo longiore, secundo leviter elongato, tertio quartoque decrescentibus, quinto his coniunctis sublongiore.

\section{o b s e.r v a tio nes.}

1. Caput et thorax laevia, hoc nonnunquam transversaliter impresso. Elytra stria suturali impressa. Abdominis segmenta 5 prima dorsalia prope marginem utrinque linea obliqua subarcuata insculpta.

2. Mas capite grandiore instructus esse solet: praeterea a femina differt abdominis segmento sexto apice leviter emarginato, septimo parvo conspicuo.

3. Victus in Agaricis et Boletis. 
* 1. O. rufus: Niger, thorace, abdomine pedibusque rufis, illo apice, his basi nigris, elylris macula magna humerali testacea. - Long. $2 \frac{1}{2}-4 \mathrm{lin}$.

Fab. Syst. Ent. 267. 1. Mant. Ins. 222. 1. Ent. Syst. 1. II. 531. 1. Syst. El. II. 604. 1. - Rossi Faun. Etr. 1. 252. 624. Ed. Hellw. I. 313. 624. - Payk. Faun. Suec. III. 425. 1. - Cederh. Faun. Ingr. 120. 367. - Walken. Faun. Paris. I. 274. 1. - Panz. Faun. Germ. 16. 19. Ent. Germ. 359. 1. - Oliv. Ent. III. 43. 4. 1. t. 1. f. 1. Encycl. meth. VIII. 607. 2. - Grav. Micr. 151. 1. Mon. 235. 2. - Latr. Hist. nat. Crust. et Ins. IX: p. 358. 1. t. 80. f. 3. Gen. Crust. et Ins. I. 284. - Gyll. Ins. Suec. II. 442. 1. - Sahlb. Ins. Fenn I. 405. 1. Guér. Iconogr. Regn. An. Ins. t. 9. f. 1. - Mannerh. Brachel. 19. 1. - Boisd. et Lacord. Faun. Ent. Paris. I. 354. 1. - Runde Brachelytr. Hal. 1. 1. Nordm. Symb. 7. 1. - Er. Col. March. I. 498. 1.

Staph. rufus Linn. Faun. Suec. n. 814. Syst. nat. I. II. 684. 6. - Degeer Ins. IV. 24. 10. t. 1. f. 11 -13. - Schrank En. Ins. Austr. 232. 438. - Scop. Ent. Carn. 101. 307. - Müll. Prod. 99. 1116. - Goeze Ent. Beitr. I. 717. 6. - De Vill. Ent. I. 412. 6. - Fourcr. Ent. Paris. I. 170. 22. - Payk. Mon. Staph. 18. 10. - Marsh. Ent. Britt. 502. 14.

Staph. nigrofulvus Fourcr. Ent. Par. I. 173. 32.

Staph. octavus Schaeff. Icon t. 85. f. 3.

Le Staph. jaune à tête, étuis ét anus noirs Geoffr. Hist. Ins. 1. 370. 22.

Habitat in Europae boletis.

Antennae et palpi rufo-testacei. Labrum testaceum. Caput maris thorace paulo latius, feminae eiusdem latitudine, parce subtilissime punctulatum, nigrum, nitidum, apice utrinque leviter impressum. Thorax coleopteris paulo angustior, latitudine dimidio brevior, leviter convexus, aequalis, laevissimus, rufus, nitidus. Scutellum nigrum. Elytra thorace paulo longiora, nigra, nitida, macula magna quadrata humerali testacea, disco punctorum seriebus duabus longitudinalibus minus regularibus, punctisque nonnullis sparsis impressa. Abdomen rufum, segmentis ultimis duobus totis, antepenultimo apice nigris. Pectus nigrum. Pedes rufo-testacei, femoribus basi, trochanteribus coxisque nigris.

Variat rarius pedibus totis cum coxis testaceis.

* 2. O. maxillosus: Testaceus, capite, thorace pecloreque piceis, elytris angulo apicali exteriore nigro. - Long. 3 - 4 lin.

Fab. Ent. Syst. I. IJ. 531. 2. Syst. El. II. 605. 2. - Cederh. Faun Ingr. 120. 2. t. 3. f. 6. - Wall. Faun. Paris I. 274. 2. - Panz. Faun. Germ. 16. 20. Ent. Germ. 359. 2. - Grav. Micr. 152. 2. Mon. 235. 5. - Latr. Hist. nat. Crust. et Ins. IX. 358. 2. - Oliv. Encycl. meth. VIII. 607. 3. - Suhlb. Ins. Fenni. 1. 405. 2. - Curt. Britt. Ent. IX. t. 418. - Mannerh. Brachelytr. 19. 2. - Nordm. Symb. 7. 2. - Er. Col. March. I. 498. 2.

Var. a: Abdomine nigro, pedibus basi interdum picescentibus.

Oxyp. angularis Gebler Ledebour. It. App. 111. 69. 1.

Var. b: Abdomine femoribusque nigris.

Oxyp. Schönherri Mannerh. Brachelytr. 19. 3. - Sahlb. Ins. Fenn. I. 106. 3. Nordm. Symb. 7. 3.

Habitat in Germaniae agaricis, passim.

Antennae et palpi rufo-testacei, labrum testaceum. Caput maris thorace maius, feminae ei aequale, parce subtilissime punctulatum, nitidum, apice utrinque obsolete impressum, nigro- vel brunneo- vel rufo-piceum, vel piceo-testaceum, ore dilutiore. Thorax coleopteris dimidio fere angustior, 
latitudine tertia parte brevior, modice convexus, laevissimus, dorso ante medium utrinque transversim impressus, capitis colore, disco saepe dilutiore. Scutellum testaceum. Elytra thorace sesqui longiora, pallide testacea, angulo apicis exteriore late nigro, stria suturali seriebusqrie duabus dorsalibus impressis sat regulariter punctatis, punctisque nonnullis prope striam dorsalem interiorem impressis. Abdomen rufescenti-testaceum, supra ante apicem nonnunquam picescens, subtus segmentis penultimis duobus utrinque piceis, raro abdomen totum nigro-piceum. Pectus piceum. Pedes cum coxis flavo - testacei.

Obs. O. angularis, a Dom. Gebler in Sibiria detectus, etiam in Germania licet raro obvius, indubia $O$. maxillosi varietas. $O$. S ch ö $n$ herr $i$ etiam in Fennia in agaricis lectus, huius speciei varietas videtur, ab $\mathrm{O}$. angulari nonnisi femoribus nigris, et a $O$. maxilloso genuino, quantum e descriptione accuratissima Sahlbergiana patet, nonnisi abdominis pedumque colore distinctus, quam ob rem pro mera huius speciei varietate eum habere non dubito.

\section{O. Mannerheimii: Niger, tarsis testaceis, antennis obscure testa-} ceis, articulo primo nigro. - Long. $3 \frac{2}{3}$ lin.

Gyll. Ins. Suec. IV. 495. 1 - 2. - Mannerh. Brachelytr. 19. 4. - Sahlb. Ins. Fenn. I. 407. 4. - Germ. Faun. Ins. Europ; XVI. 5. - Nordm. Symb. 19. 4.

Habitat in Lapponiae boletis, Dom. Sturm et Schïppel.

Statura omnino praecedentium, nigerrimus, nitidus. Antennae rufotestaceae, articulo primo piceo. Labrum pallide testaceum. Palpi picei. Caput thorace parum latius, parce subtilissime punctulatum, apice utrinque impressum. Thorax basi coleopteris vix dımidio angustior, latitudine dimidio fere brevior, convexus, basi subtiliter canaliculatus, ceterum aequalis, laevissimus. Elytra thorace sesqui longiora, humeris prominulis, lateribus omnino rectis, dorso depressa, in medio disco minus regulariter biseriatim, introrsum vage obsoletius punctata. Tarsi dilute testacei.

Variat thorace, elytris corporeque subtus piceis.

4. O. maior: Niger, tarsis testaceis, elytris flavis, margine, sutura vittaque tenui nigris. - Jong. $4 \frac{1}{2}$ lin.

Grav. Mon. 234. 1. - Oliv. Encycl. meth. VIII. 607. 1.

Habitat in America septentrionali, e mus. Knoch.

Práecedentibus duplo maior, niger, nitidus. Antennae fusco-testaceae, articulo primo nigro. Palpi picei. Caput maximum, parce obsoleteque punctulatum, apice obsolete 3-impressum. Thorax basi coleopteris dimidio angustior et longitudine haud latior, lateribus parum rotundatus, antrorsum sensim incrassatus, dorso ante apicem et in medio leviter transversim impressus. Elytra thorace paulo longiora, humeris prominulis, pallide testacea, swtura antrorsum, margine laterali apice dilatatis, margineque tenui apicali nigris, dorso striis duabus obliquis punctatis approximatis, punctisque nonnullis sparsis utrinque impressa, striarum interstitio nigro elytri aream flavam discindente. Abdomen et pectus nigra, immaculata. Pedes nigri, tarsis dilute testaceis. 
5. O. femoralis: Niger, nitidus, elytris pallide favis, sutura margineque laterali nigris, tibiis tarsisque testaceis. - Long. $3 \frac{2}{3}$ lin.

Grav. Micr. 196. 3. Mon. 235. 7. - Latr. Hist. nat. Crust. et Ins. IX. 359. 5. - Oliv. Encycl, meth. VIII. 608. 6.

Habitat in America septentrionali.

Statura omnino O. maxillosi et minoribus eius individuis aequalis, niger, nitidus. Antennae fusco-piceae, articulo primo nigro, sequentibus rufescentibus. Palpi maxillares picei, labiales testacei. Caput maris thorace latius et maius, feminae eiusdem fere latitudine, basi subtiliter punctatum, ante apicem obsolete longitudınaliter impressum. Thorax basi coleopteris dimidio angustior, antrorsum leviter rotundato-incrassatus, latitudine paulo brevior, leviter convexus, ante apicem utrinque obsolete transversim impressus. Elytra humeris antrorsum prominulis, pallide flava, sutura basi, limboque laterali apice dilatato nigris, disco punctis minus regulariter biseriatis nonnullisque sparsis subtilius impressa, angulo apicali exteriore late subtiliter aciculato-ruguloso. Abdomen et pectus nigra. Pedes nigri, tibiis tarsisque testaceis, illis basi apiceque summis nigris.

Variat I, Pedibus flavis, coxis, trochanteribus, femorum tibiarumque summa basi summoque apice nigris.

2, Pedibus totis flavis, coxis solis piceis.

* 6. O. vittatus: Niger, nitidus, elytris pedibusque testaceis, illis sutura margineque laterali nigris, his immaculatis. - Long. 3 lin.

Grav. Micr. 195. 2. Mon 235. 6. - Latr. Hist. nat. Crust. et Ins. IX. 359. 4. - Oliv. Encycl. meth. VIII. 608. 5.

Var.: Peclore ventreque testaceis.

Oxyp. cinctus Gruv. Micr. 196. 4. Mon. 235. 8. - Latr. Hist. nat. Crust. et Ins. IX. 359. 6. - Oliv. Encycl. meth. VIII. 608. 7.

Habitat in Pensylvania, Knoch.

Niger, nitidus. Antennae parvae, fusco-piceae, basi testaceae. Palpi testacei. Labrum testaceum. Mandibulae mediocres. Caput thorace paulo maius, convexum, basi subtiliter obsoleteque punctatum, apice leviter bi-impressum. Thorax coleopteris parum angustior, latitudine dimidio brevior, lateribus fortius rotundatus, modice convexus, lateribus medio obsolete impressus. Elytra thorace sesqui longiora, humeris antrorsum prominulis, testacea, sutura basi leviter dilatata, limbo laterali apice dilatato margineque tenui apicali nigris, disco punctis biseriatis aliisque sparsis impressa. Abdomen segmentis singulis margine summo testaceo. Pedes cum coxis toti testacei.

Variat 1, Thorace dorso medio rufo-piceo, pectore toto nigro, abdomine segmentis tribus primis ficeis, limbo laterali et apicali late testaceis, quarto quintoque totis nigris, sexto testaceo.

2, Thorace supra rufo, basi apiceque nigro, metasterno testaceo, pectore reliquo nigro, abdomıne testaceo, supra segmentis tribus primis summa basi medio piceis, quarto quintoque nigro-piceis, margine summo apicali nigro, infra segmentis ultimis tribus fuscescentibus.

3, Thorace nigro piceove, pectore toto flavo-testaceo, abdomine infra flavo-testaceo, unicolore, supra piceo, limbo laterali integro testaceo. 
Obs. Exempla genuina et var. 1 mascula, var. 2 et 3 feminea. Oxyp. cinctus Grar. ad var. 3 pertinet. - A praecedente statura minore, pedibus cum coxis testaceis et elytrorum angulo apicali exteriore laevissimo facile aistinguendus.

* 7. O. lateralis: Rufo-testaceus, nitidus, capitis thoracisque lateribus elytrorumque angulo apicali exteriore nigris. - Long. $3 \frac{2}{3}$ lin.

Grav. Micr. 195. 1. Mon. 235. 3. - Latr. Hist. nat. Crust. et Ins. IX. 358. 3. - Oliv. Encycl. meth. VIII. 607. 4.

Habitat in Pensylvania, Knoch.

Rufo-testaceus, minus nitidus. Antennae longiusculae, minus compressae dilatataeque, articulis $5-8$ obconicis, sensim paulo crassioribus, penulultimis vix transversis, concolores. Palpi testacei. Mandibulae maris ante apicem obtuse dentatae. Caput maris thorace paulo maius, feminae ei aequale, apice utrinque leviter longitudinaliter impressum, ante medium foveola minuta oblonga magis minusve distincta notatum, laeve, utrinque vitta laterali nigro-picea maculaque frontali media fusca. Thorax basi coleopteris duplo fere angustior, lateribus modice rotundatus, latitudine dımidio brevior, leviter convexus, lateribus pone medium oblique impressus, utrinque vitta laterali nigro-picea. Elytra duplo prope longiora, testacea, angulo apicali exteriore late nigro, disco seriebus duobus impressis punctorum irregularter dispositorum punctisque nonnullis sparsis notata. Abdomen aut immaculatum aut dorso segmento quoque utrinque macula fusca signato. Pedes toti flavo-testacei.

\section{Species mihi invisa.}

\section{O. Stygicus: Niger, tarsis rufis. - Long. 3 lin.}

Say Trunsact. Amer. Philosoph. Soc. Philadelph. Nov. Ser IV. pag. 459.

Habitat in Indiana Americae septentrionalis.

Niger, politus. Antennae articulis $2-5$ rufis. Labrum rufum. Palpi testacei. Thorax margine laterali inflexo depresso. Elytra nigra, immaculata, stria subsuturali aliaque abbreviata media, et prope hanc stria obsoleta punctisque nonnullis maioribus impressa, margine laterali impunctato. Pedes nigro - picei, tarsis pallide rufis.

Obs. Thorax paulo longior, quam in $\mathrm{O}$. cincto Gr., et elytrorum puncta numerosiora. (Say).

\section{O b s e r $\nabla$ a t i o.}

Speciem succino inclusam Gravenhorst Mon. p. 235 hoc modo descripsit nomine O. Blumenbachii: „Caput quadratum, angulis obtusis, thorace maius. Antennis capitis longitudine, pilosellis, articulo primo longiore, 7 sequentibus dimidia illius longitudine, ultimis haud rite dignoscendis, sed, uti videtur, materie heterogena obductis, qua speciem clavae praebent (antennae alterius pars dimidia deficit). - Oculi haud dignoscendi sunt. - Clypeus exarte ut in Oxyporis hodiernis for matus, transversus, margine anteriore paululum emarginato. - Instrumenta cibaria maximam partem destructa sunt, ita ut forma eorum haud exacte dignosci possit. Thorax transversus, exacte ut in nostris Oxyporis formatus, margine anteriore recto, posteriore rotundato, capitis latitudine, sed dimidia eius longitudine. Scutellum haud dignoscendum. Coleoptera paululum e situ naturali remota, thoracis magnitudine, elytris quadratis. Abdomen coleopteris triplo longius, e segmentis 8 constat. Pedes numero, forma, longitudine et proportione partium omnino respondent pedibus Oxyporum nostrorum; numerus autem articulorum in tarsis haud perspicue videri potest. Color pallide flavus est. Color naturalis verisimile omnino evanuit." 


\section{Tribus quinta.}

\section{p a e d e r i i.}

Stigmatica prothoracica occulta; spatio pone coxas anticas membraneo. Coxae posticae conicae.

Labrum corneum, limbo laterali saepe membranaceo, bilobum, muticum, lobis elongatis, divergentibus Achenio;

lobis brevibus, rotundatis Cryptobio, Scimbalio, Lathrobio; brevissimum, medio leviter emarginatum, Dolica oni, Pa ed ero; apice bidentatum, inter dentes incisum Scopaeo, Lithocharidi, Stilic o, Ophiti, Sunio;

apice 4-dentatum Echiasteri.

Mandibulae longae, tenues, falcatae, acutae, medio dentatae.

Maxillae malis brevioribus, interiore interne, exteriore apice barbatis, huius barba introrsum vergente.

Palpi maxillares magis minusve elongati, articulo primo minuto, brevi, secundo tertioque elongatis, hoc apicem versus magis minusve acuminato, quarto minimo;

acuminato, subulato, distincto Cryptobio, Scimbalio, Áchenio, Lathrobio, Scopaeo, Litho charidi, Ophiti;

obtuso, distincto, Dolic a o ni, P a e d ero;

acuto, at minutissimo, aegerrime conspiciendo Stilico, Echiasteri, Sunio.

- Mentum corneum, transversum, breve.

Ligula membranea, biloba,

lobis approximatis, Cryptobio, Dolicaoni, Scimbalio, Achenio, Lathrobio, Ophiti;

lobis distantibus Lith o ch aridi, Stilico, E chi as teri, Sunio, Paedero; cornea, apice tridentata Scopaeo.

$P$ aragl ossa e lineares, membraneae, interne ciliatae.

Palpi labiales triarticulati, articulo tertio tenuiore, acuminato.

Antenna e infra oculos sub capitis margine laterali insertae, 11-articulatae, rectae plerisque; 
geniculatae, articulo primo elongato Cryptobio, Ophiti.

C ap ut exsertum, collo quasi tenui thoraci affixum vel

distinctius pedunculatum Scopaeo, Ophiti, Stilico, Echiasteri, Sunio.

Th or ax immarginatus, basi truncatus,

apice attenuatus Scopaeo, Ophiti, Stilico, Echiasteri, Sunio;

spatio pone coxas anticas absque integumento corneo.

Scutellum distinctum, triangulare.

Elytra pectoris longitudine.

Abdomen elongatum, marginatum, segmento septimo saepius minuto, bivalvi:

valvulis styliformibus Cryptobio, Dolicaoni, Scimbalio, Ophiti, Paedero;

valvulis unciformibus Achenio.

Pedes coxis anticis conicis, exsertis, intermediis approximatis, posticis conicis, tibiis muticis, tarsis 5-articulatis, articulo quarto simplice, plerisque; bilobo Paedero;

lobo membraneo instructo Sunio.

tarsis posterioribus articulis 4 primis longitudine sensim decrescentibus plerisque;

longitudine aequalibus Achenio, Lathrobio;

tarsis anticis articulis 4 primis fortiter dilatatis Scimbalio, Achenio, Lathrobio;

leviter dilatatis, Dolica oni, Pa edero, Lith ocharidi;

simplicibus Cryptobio, Scopaeo, Ophiti, Stilico, Echiasteri, Sunio.

\section{o b s e r vatio.}

Continetur haec tribus genere Fabriciano $\mathrm{Pa}$ edero, quod Gravenhorst secundum palporum maxillarium haud satis exactam observationem in genera Lathrobium et Paederum dissolvit. Latreille secundum labri figuram. Lathrobium Staphylinorum genuinorum sectioni associavit, Paederum Stenis apposuit. Primo intuitu Lathro oi a habitu quodammodo divergunt a Paederis, imprimis pedibus robustioribus, tibiis apice oblique truncatis, palpis maxillaribus minus elongatis, genera autem Scopaeus et Lithoch aris omnino intermedia, ut subtribu etiam distingui nequeant.

\section{Crýptobium Mannerh.}

Mannerh. Brachelytr. p. 38. - Steph. Britt. Ent. V. p. 271. - Boisd. et Lacord. Faun. Ent. Paris. 1. p. 427. - Er. Col. March. I. p. 500.

Lathrobium Fam. III. Grav. Mon. p. 129.

\section{Labrum bilobum.}

Palpi maxillares articulo ultimo acuto. Antennae fractae,

Tarsi articulo quarto simplice, posteriores arliculis 4 primis decrescentibus.

Corpus eiongatum, lineare, alatum. Caput plerumque oblongum, basi constrictum, collo quasi brevi thoraci immissum, exsertum, porrectum, lateribus pone oculos rotundatis, tumidulis, ante oculos abrupte paulo angustius, oculis minutis, rotundatis, parum prominulis. Labrum breve, transversum, bilobum, lobis divergentibus, margine setosum. Mandibulae longae, 
falcatae, acutae, medio fortiter acuteque bi- vel tridentatae. Maxillae (t. IV. f. 28. b.) malis coriaceis, interiore interne, exteriore apice barbatis. Palpi maxillares modice elongati, articulo primo parvo, secundo tertioque aequalibus, hoc apicem versus sensim leviter incrassato, quarto minimo, subulato. Labium (t. IV. f. 28. a.) mento transverso, ligula membranea, biloba, lobis rotundatis, paraglossis acuminatis, membranaceis, ciliatis, ligulam paulo superantibus. Palpi labiales articulis duobus primis cylindricis, secundo primo paulo longiore, tertio minuto, tenui, acuminato. Antennae filiformes, tenues, fractae, articulo primo elongato, interdum apice subclavato. Thorax plerumque coleopteris angustior, subcylindricus, basi apiceque truncatus. Scutellum triangulare. Elytra truncata. Abdomen lineare, stylis analibus ex sertis, pilosis. Pedes modice elongati, graciles, antici haud incrassati, tibiis omnibus pubescentibus pilosisque, spinis apicalibus longioribus, tarsis omnibus simplicibus, articulo primo elongato, reliquis sensim decrescentibus, ultimo praecedentibus ambobus subaequali.

$$
\text { O b s e r vatio n e s. }
$$

1. Genus valde distinctum tarsis anticis simplicibus et antennis geniculatis. Caput et thorax pube subtili erecta e punctis oriunda vestita. Thorax nonnunquam subseriatim punctatus.

2. Species Americanae a Com. Dejean in recentiore collectionis suae Catalogo sub genere proprio Stilico enumerantur, at neque hoc nomen is vacat, neque omnino ab Europaeo Cryptobio fracticorni genere distingui possunt.

3. Mares alii abdominis segmento inferiore tertio apice in processum longum elongato, alii segmento inferiore sexto apice inciso, alii ambabus notis a femina distinguuntur.

4. Victus speciei indigenae in silvis palustribus, sub musco et sub foliis putrescentibus.

* 1. C. badium: Rufo-castaneum, nilidum, pedibus testaceis, capite coleopterorum latitudine, oblongo, crebrius punclato, piceo, thorace utrinque subseriatim punclalo. - Long. 5 lin.

La throb. badium Grav. Micr. 53. 3. Mon. 135. 16. - Latr. Hist. nat. Crust. et Ins. IX. 338. 3.

Habitat in America septentrionali, Knoch.

Castaneo-rufum, nitidum, capite piceo, pedibus testaceis. Antennae capite thoraceque longe breviores, articulo tertio secundo sesqui prope longiore, sequentibus sensim brevioribus, ultimo apice abrupte acuminato, dilute rufo-piceae. Caput thorace sesqui fere latius, oblongum, subdepressum, crebrius punctatum, antice inter antennas laevius et utrinque subimpressum. Oculi infra capitis medium siti. Thorax coleopteris dimidio angustior, latitudine plus sesqui longior, subcylindricus, crebrius vage, passim subseriatim punctatus, plaga media longitudinali laevi. Scutellum laeve. Elytra thorace paulo longiora, crebre profundeque punctata, subtiliter fusco-pubescentia. Abrlomen subtilius punctulatum, longius fusco-pubescens. Pedes testacei, tibiis basi piceis.

Abdominis segmentum inferius tertium maris subtus medio processu elongato, segmentum quartum longe superante, margine nigro-piloso instructum, reliqua integra.

Obs. A Gravenhorstio errore quodam inter species Brunsvicenses descriptum. 
2. C. Carolinum: Nigrum, nilidum, thorace, elytris anoque rufo-piceis, pedibus testaceis, capile coleopterorum latitudine, crebre punctalo, thorace utrinque subserialim punclalo. - Long. $4 \frac{1}{2}$ lin.

Habitat in Carolina meridionali, Dom. Zimmermann.

Statura et summa similitudo praecedentis et sequentis. Antennae capite thoraceque parum breviores, tenues, articulo tertio secundo plus sesqui longiore, sequentibus sensin brevioribus, ultimo apice abrupte subacuminato, rufae, articulo secundo sequentibusque pluribus piceis. Palpi rufi. Labrum obscurius rufo-piceum. Caput thorace sesqui latius, sat magnum, oblongum, nigrum, nitidum, parce griseo-pubescens, fortius crebre punctatum, infra oculos laeve vel punctis paucis sparsis minus profundis impressum, antice inter antennas utrinque fortius impressum. Oculi infra capitis medium siti. Thorax coleopteris dimidio angustior, latitudine plus sesqui longior, subcylindricus, rufo-piceus, nitidus, utrinque crebrius subseriatim punctatus, plaga media longitudinali angusta laevi. Scutellum obsolete bipunctatum, piceum, Elytra thorace vix longiora, sat fortiter crebre punctata, tenuiter fusco-pubescentia, rufo-picea, nitida. Ahdomen parcius punctulatum griseoque pubescens, nigrum, nitidum, segmentis ultimis duobus rufis. Pectus nigrum, mesosterno piceo. Pedes testacei, femoribus pallidioribus.

Abdominis segmentum inferius tertium maris subtus apice in processum, segmento quarto saepius breviorem, latiorem, subsemiorbiculatum, margine nigro-pilosum productum, reliqua integra.

Variat minus maturus corpore rufo-testaceo, elytris abdominisque segmentis ultimis duobus dilutioribus, pedibus pallidis.

Obs. Distinctum a C. bicolore praecipue punctura fortiore, capite maiore, elytris brevioribus, ut et segmento quarto maris processu minus elongato instructo.

3. C. bicolor: Nigrum, nilidum, thorace, elytris anoque mufis, pedibus leslaceis, capite coleopteris angustiore, oblongo, crebre punctalo, thorace utrinque crebre punctato. - Long. $4 \frac{1}{2}$ lin.

Luthrobium bicolor Grav Micr. 179. 1. Mon. 135. 17. - Say Transact. Amer. Philosoph. Soc. Nov. Ser. IV. 454. 1. - Nordm. Symb. 145. 15. - Kirby Faunit Boreali-Amer. 87. 4.

Habitat in America septentrionali, e mus. Knoch.

Antennae tenuiusculae, capitis thoracisque prope longitudine, articulo tertio secundo duplo prope longiore, sequentibus leviter elongatis, sensim brevioribus, ultimo apice truncato et abrupte subacuminato, rufae, medio fuscescentes. Palpi rufi. Labrum rufum. Mandibulae rufo-piceae. Caput thorace vix sesqui latius, coleopteris angustior, oblongo-subovatum, nigrum, parum nitidum, crebre punctatum, antice laeve, inter antennas utrinque impressum. Oculi infra capitis medium siti. Thorax coleopteris plus dimidio angustior, latitudine duplo prope longior, subcylindricus, utrinque crebrins vage punctatus, plaga media longitudinali angusta laevi, rufus, modice nitidus. Scutellum rufum, obsolete bipunctatum. Elytra thorace paulo longiora, fortius dense punctata, modice nitida, rufa. Abdomen distinctius punctulatum, griseo-pubescens, nigrum, segmentis ultimis duobus rufis. Pectus nigrum, mesosterno rufo. Pedes testacei, femoribus pallidioribus. 
Abdominis segmentum inferius tertinm maris apice processu elongato, segnientum quartum superante, margine longe piloso, apice rotundato, piceo instructo, reliqua integra.

* 4. C. melanocephalum: Testaceum, pedibus pallidis, capite coleopterorum latitudine, oblongo, fortius crebre punctato, nigro, thorace uirin-

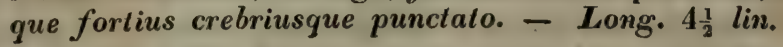

Habitat in America septentrionali, Dom. Zimmermann.

Statura et summa affinitas praecedentium, corpore pallidius testaceo, modice nitido, capite solo piceo vel nigro, elytris dorso infuscatis. Antennae capitis thoracisque prope longitudine, tenues, articulo tertio secundo vix sesqui longıre, $4-8$ modice elongatis, aequalibus, $8-10$ sensim brevioribus, ultimo subovato, apice abrupte subacuminato, basi pallide testaceae, medio fuscae, apice rufo-testaceae. Os rufo-testaceum. Caput thorace sesyui latius, oblongum, fortius sat crebre punctatum, antice infra oculos laeve, punctorum serie transversali in fronte antica notatum, inter antennas utrinque subimpressum, tenuiter nigro-pubescens. Oculi infra capitis medium siti. Thorax coleopteris dimidio angustior, latitudine sesqui fere longior, subcylindricus, rufo-testaceus, nitidus, subtıliter nigro-pubescens, utrinque fortius crebriusque subinaequaliter punctatus, linea longitudinali media laevi postice subelevata. Scutellum laeve. Elytra thorace paulo longiora, depressa, dense punctata, tenuiter cinereo-pubescentia, pallidius testacea, dorso communi infuscato. Abdomen punctulatum, parce supra tenuiter, subtus longius cinereo-pubescens, pallidius testaceum. Pectus pallide testaceum. Pedes pallide flavi.

Abdominis segmentum inferius tertium $\mathrm{m}$ aris apice processu longiore, segmentum quartum longe superante, lato, apice rotundato, margine longe nigro - piloso instructo, reliqua integra.

Obs. Praecedenti proximum, colore autem, capite maiore, elytris amplioribus, et processu segmenti quarti abdominis in mare latiore etc, distinctum videtur.

* 5. C. prolixum: Nigrum, subnitidum, pedibus testaceis, coxis nigropiceis, capite thorace latiore, oblongo, creberrime punctato, thorace anguslo, crebre punctato, coleopteris thorace sesqu longioribus. - Long. $4 \frac{1}{2}$ lin.

Habitat in Columbia, Dom. Moritz.

Praecedentibus paululum gracilius, nigrum, subnitidum. Antennae capitis thoracisque fere longitudine, tenues, articulo tertio secundo duplo longiore, 4 - 8 modice elongatis, aequalibus, 8 - 10 sensim brevioribus, ultimo apice truncato et abrupte subacuminato, rufo-piceae, apice rufotestaceae. Os rufo-piceum. Caput thorace sesqui fere latius, coleopteris plerumque paulo angustius, oblongum, subdepressum, creberrime sat fortiter punctatum, antice infra oculos laeviusculum, opacum, inter antennas utrinque mmpressum. Oculi infra capitis medium siti. Thorax coleopteris duplo fere angustior, latitudine plus sesqui longior, subcylindricus, sat crebre fortiterque subinaequaliter punctatus, linea media longitudinali subelevata laevi. Scutellum obsolete bipunctatum, opacum. Elytra thorace sesqui lonciora, confertim punctata, subtiliter nigro-pubescentia. Abdomen parcius 
subtiliusque punctulatum, griseo-pubescens, nigro-piceum, nitidum, subtus basi rufescenti-piceum, apice summo piceum. Pedes testacei, coxis piceis, femoribus flavo-testaceis.

Abdominis segmentum inferius tertium maris apice processu longiore, segmentum quartum stiperante, lineari, apice rotundato, margine longe nigro-piloso instructum, reliqua integra.

6. C. longipenne: Nigrum, subnilidum, pedibus testaceis, coxis piceis, capile thorace latiore, conferlissime subtilius punctato, thorace angusto, creberrime punclalo, elytris thorace plus sesqui longioribus. - Long.5 lin.

Habitat in Mexico, coll. Dom. Chevrolat.

Habitus et summa affinitas praecedentis, at sesqui fere maius. Nigrum, subnitidum. Antennae capite thoraceque breviores, tenues, articulo tertio secundo duplo fere longiore, 4-6 modice elongatis, aequalibus, reliquis sensim brevioribus, articulo ultimo apice truncato et abrupte subacuminato, rufo-testaceae. Palpi rufo-testacei. Mandibulae piceae. Labrum rufotestaceum. Caput thorace sesqui vel interdum fere duplo latius, oblongum, depressum, densius subtiliter nigro-pubescens, confertissime subtiliter punctatum, opacum, apice laeviusculum, utrinque modice impressum. Oculi paulo infra capitis medium siti. Thorax coleopteris duplo angustior, latitudine sesqui longior, subcylindricus, lateribus ante medium levissime rotundatus, creberrime punctatus, linea media longitudinali subelevata antice abbreviata laevi, subtiliter nigro-pubescens, lateribus nigro-pilosellus, nitidus. Scutellum laeve, opacum. Elytra thorace plus sesqui longiora, depressa, confertissime punctata, subrugulosa, subnitida, subtiliter densius nigro - pubescentia. Abdomen crebre subtiliter punctulatum, subnitidum, densius fusco-pubescens, apice piceum. Pedes testacei, coxis piceis.

M as latet.

Obs. Proximum praecedenti, pube autem densiore, capite densius subtiliusque punctato, opaco, thorace crebrius punctato, elytris longioribus distinctum.

7. C. fasciatum: Rufo-piceum, subnilidum, pedibus testaceis, elyfronum fascia abdomineque ante apicem nigro-piceis, capile thorace latiore, oblongo, subtiliter crebrius punctalo, opaco, nigro, thorace utrinque crebrius punctalo. - Long. 4 lin.

Habitat in Columbia, Dom Moritz.

Antennae capite thoraceque breviores, tenues, articulo tertio secundo sesqui longiore, $4-7$ modice elongatis, subaequalibus, sensim brevioribus, ultimo apice truncato et abrupte subacuminato, rufae, articulis $3-7$ basi fuscescentibus, reliquis rufo-testaceis. Palpi rufo-testacei. Labrum rufum. Mandibulae rufo-piceae. Caput thorace vix sesqui latius, oblongum, subdepressum, nigrum, opacum, subtiliter nigro-pubescens, subtiliter crebrius punctatum, antice infra oculos laeve, inter antennas utrinque obsolete im pressum. Oculi infra capitis medium siti. Thorax coleopteris dimidio fere angustior, latitudine plus sesqui longior, subeylindricus, dilute rufo-piceus, nitidus, crebre vageque sat fortiter punctatus, linea lata longitudinali media laevi. Scntellum laeve, nitidum, rufum. Elytra thorace paulo longiora, depressa, dense punctata, subtiliter cinereo-pubescentia, rufo-testacea, sub- 
nitida, fascia lata nigricante, seu nigricantia, basi piceo - rufa, apice testacea. Abdomen subtiliter punctulatnm, nitidum, rufo-piceum, ante apicem nigropiceum. Pedes testacei, coxis rufis, femoribus flavo-testaceis.

Abdominis segmentum inferius tertium maris apice processu longiore, segmentum quartum longe superante, elongato-triangulari, apice subrotundato, margine longe piloso instructum, reliqua integra.

8. C. albipes: Nigro-piceum, subnitidum, pedibus pallide teslaceis, capite coleopterorum latitudine, subquadrato, creberrime punctato, thorace utrinque crebre punclato. - Long. 3 lin.

Habitat in Puerto Rico, Dom. Moritz.

Nigro-piceum, subnitidum. Antennae capite thoraceque paulo breviores, tenuiores, articulo tertio secundo sesqui longiore, $4-8$ elongato-obconicis, aequalibus, ultimis sensim brèvioribus, ultimo subovato, apice abrupte acuminato, testaceae, articulis $3-8$ medio fuscis. Palpi testacei. Os rufopiceum. Caput thorace sesqui latius, coleopterorum latitudine, oblongosubquadratum, leviter convexum, tenuiter griseo-pubescens, crebre punctatum, fronte anterius infra oculos laevi, inter antennas utrinque distincte impressa. Oculi paulo infra medium capitis siti, modice prominuli. Thorax coleopteris dimidio angustior, latitudine sesqui longior, subcylindricus, fortius sat crebre punctatus, punctis versus medium subseriatis, linea longitudinali media laevi. Scutellum laeve, nitidum. Elytra thorace sesqui longiora, depressa, creberrime punctata, subtiliter cinereo-pubescentia, margine summo apicali ferrugineo. Abdomen densius sat distincte punctulatum, cinereopubescens, segmentis ultimis duobus margine pallidis. Pedes pallide testacei, coxis piceo-testaceis.

Abdominis segmentum inferius tertium apice processu lato subsemicirculari, segmentum quartum vix superante, margine filis longis nigris ciliato instructum, reliqua integra.

* 9. C. fulvipes: Brunneo-piceum, nilidum, pedilus lestaceis, capile coleopterorum latiludine, subquadrato, parcius profunde punclalo, thorare utrinque crebre punctato, elytris thorace paulo longioribus. - Long. 3 lin.

Habitat in ins. Puerto Rico, Dom. Moritz.

Statura omnino praecedentis. Castaneo-piceum, nitidum. Antennae capite thoraceque paulo breviores, articulo tertio secundo paulo longiore, sequentibus sensim paulo brevioribus, minus elongatis gracilibusque, ultimo truncato et apice abrupte subtiliter acuminato, rufo-piceae, apice testaceae. Palpi testacei. Mandibulae piceae. Labrum testaceum. Caput thorace sesqui latius, subquadratum, subdepressum, fortiter minus crebre punctatum, interstitiis parce sparsimque subtilius punctatis, fronte antice laeviore, inter antemnas utrinque obsolete impressa. Oculi ad capitis medium siti, minus prominuli. Thorax coleopteris vix dimidio angustior, latitudine sesqui longior, subcylindricus, crebrius profunde vage punctatus, plaga latiore media longitudinali laevi. Scutellum laeve. Elytra thorace paulo longiora, creberrime punctata, minus nitida, densius subtiliter griseo-pubescentia. Abdomen subtiliter obsoleteque punctulatum, longius pubescens, apice segmen- 
torumque singulorum marginibus piceo-testaceis. Pedes piceo-testacei, coxis concoloribus.

Abdominis segmentum inferius tertium maris apice processu lato, parallelo, apice truncato, ad segmenti quinti apicem prope elongato, distinctius punctato, longe nigro-piloso instructum, sextum apice acute emarginatum.

* 10. C. antiquum: Nigro-subaeneum, nifidum, pedibus piceis, femoribus supra testaceis, capite coleopterorum latitudine, depresso, subguadrato, parce obsolele punctato, opaco, thorace utrinque parce subseriatim punctalo. - Long. $4 \frac{1}{2}$ lin.

Habitat in Brasilia, Dom. Virmond et Westermann.

Statura fere Cr. melanocephali, nigro-subaeneum, nitidum. Antemnae capite sesqui longiores, tenues, articulo tertio secundo duplo prope longiore, 4 - 10 sensim brevioribus, ultimo apice abrupte acuminato, rufopiceae, articulo primo crassiore, apice rufescente. Palpi et labrum rufa. Mandibulae piceae. Caput thorace vix sesqui latius, oblongum, lateribus pone oculos tumidulım, subdepressum, nigro-aeneum, opacum, obsolete parce subtıliter punctatum, anterius sensim laeve, inter antennas leviter impressum. Oculi vix infra capitis dimidium siti. Thorax coleopteris paula angustior, latitudine sesqui longior, subcylindricus, dorso fortius biseriatim punctatus, lateribus punctis nonnullis subtilibus sparsus. Scutellum laeve. Elytra thoracis longitudine, depressa, fortius dense junctata, subtilissime griseo-pubescentia, subnitida. Abdomen parce subtiliterque punctulatum, suttiliter nigro-pubescens, apice nigro-pilosum, segmentis ultimis duobus nuargine apicali rufo-piceo. Pedes picei, femoribus superne piceo-testaceis.

Mas latet.

* 11. C. femorale: Nigro-piceum, nitidum, pedibus piceis, femoribus testaceis, capite coleopterorum latitudine, depresso, subquadrato, crebrius punctalo, thorace utringue crebre subserialim punclato. - Long. $4 \frac{1}{2}$ lin.

Habitat in Brasilia, Dom. Virmond.

Subdepressum, nigro-piceum, nitidum. Antennae capitis thoracisque prope longitudine, tennes, articulo tertio secundo duplo longiore, $4-8$ modice elongatis, aequalibus, sequentibus sensim brevioribus, ultimo apice abrupte acuminato, rufo-piceae. Os cum palpis rufo-piceum. Caput thorace duplo fere latius, oblongo-subquadratum, subdepressum, sat crebre profundius punctatum, anterius parce obsoleteque punctatum, inter antennas utrinque subimpressum. Oculi infra capitis medium siti. Thorax coleopteris plus dimidio angustior, latitudine sesqui longior, subcylindricus, dorso depressiusculus, utrinque fortius sat crebre punctatus, punctis partim sub-. seriatis, plaga media longitudinali laevi. Scutellum laeve, piceum. Elytra thorace paulo longiora, depressa, dense punctata, punctis maioribus nonnullis distantibús seriatis impressa. Abdomen parce obsoleteque subtilissime punctatum, margine laterali dilute, segmentorum marginibus apicalibus obscure rufo-piceis. Pectus piceum. Pedes rufo-picei, femoribus testaceis, coxis geniculisque piceis.

Abdominis segmentum superius sextum maris apice leviter emarginatum, inferius tertium apice processu magno, ad segmenti quinti apicem 
usque prope elongato, parallelo, apice rotundato, distinctius punctato, margine longe nigro-piloso instructum, reliqua integra.

* 12. C. dispar: Piceum, nitidum, pedibus rufis, capite thorace latiore, oblongo, parcius punctato, thorace dorso biseriatim, lateribus disperse punctato. - Long. 3 lin.

Habitat in Columbia, Dom. Moritz.

C. albipedi fere aequale, iam nigro-piceum, iam piceo-rufun, nitidum. Antennae capite thoraceque breviores, articulo secundo tertio vix breviore, sequentibus sensim paulo brevioribus, ultimo apice truncato et abrupte subacuminato, rufo-testaceae. Palpi rufo-testacei. Caput thorace paulo latius, oblongum, subdepressum, pone oculos minus crebre punctatum, ante oculos punctis parcis sparsum, inter antennas utrinque obsolete impressum. Oculi ad capitis medium siti. Thorax coleopteris dimidio angustior, latitudine sesqui longior, subcylındricus, dorso biseriatım, lateribus minus crebre disperse punctatus. Scutellum laeve. Elytra thorace tertia parte longiora, dense subtiliter punctata, subtiliter cinereo-pubescentia, minus nitida. Abdomen parcius subtiliter obsoleteque punctulatum, piceum, segmentis singulis margine apicali late rufo-piceis. Pedes iam rufo-picei, iam rufo-testacei, coxis omnibus concoloribus.

Abdominis segmentum inferius sextum maris apice profundius triangulariter incisum, quintum apice late leviter emarginatum, tertium apice processu triangulari, acuto, fere conico, ad segmenti quarti medium fere porrecto instructum.

*13. C. pallipes: Nigro-piceum, nitidum, pedibus favis, capile thorace latiore, oblongo, crebre punclato, thorace dorso utrinque crebre punclalo. - Long. $4 \frac{1}{2}$ lin.

Nordm. Symb. 149. 1.

Lathrobium pallipes Grav. Micr. 179. 2. Mon. 130. 4.

Lathrobium Gravenhorstii Kirby Faun. Boreali-Amer. 87. 3. t. 2. f. 2.

Habitat in Pensylvania, e mus. Knoch.

Statura $\mathrm{Cr}$. melanocephali, nigro-piceum, nitidulum. Antennae capite thoraceque paulo breviores, tenuiores, articulo tertio secundo paulo lon-giore, 4-7 modice elongatis, aequalibus, sequentibus sensim brevioribus, ultimo ovato, apice abrupte acuminato, rufo-testaceae. Palpi et labrum rufo-testacea. Caput thorace paulo latius, oblongum, crebre punctatum, anterius laeve, inter antennas utrinque impressum, tenniter subtiliterque griseo-pubescens. Oculi infra capitis medium siti. Thorax coleopteris paulo angustior, latitudine sesqui fere longior, subcylindricus, ntrinque sat crebre vage punctatus, spatio medio longitudinali laevissimo. Scutellnm punctis paucis obsoletis notatum. Elytra thorace paulo longiora, dense punctata, griseo-pubescentia. Abdomen crebrius subtiliter punctulatum, densius subtiliter griseo-pubescens, nigro-piceum, segmentis singulıs margine apicali rufo-piceo. Pedes coxis omnibus rufo-testaceis, femoribus flavis, tibiis tarsisque dilute rufo-testaceis. excisum.

Abdominis segmentum inferius sextum maris apice triangulariter 
* 14. C. latebricola: Nigrum, nitidum, pedibus testaceis, capile thoracis latitudine, oblongo, crebrius fortiusque punctato, thorace dorso biseriatim, utrinque crebrius punctalo. - Long. Iin.

Nordm. Symb. 150. 2.

Lathrob. cinct um Say Transact. Amer. Philoph. Soc. Philadelph. Nov. Ser. IV. 454. 3. (forte)

Habitat in America septentrionali.

Praecedenti affine, at duplo minus, nigro-piceum, nitidum. Antennae capire thoraceque paulo breviores, tenues, apice submcrassatae, articulo tertio secundo sesqui longiore, $\mathbf{4} \mathbf{- 7}$ modice elongatis, subaequalibus, sequentibus sensim paulo brevioribus et crassioribus, ultimo ovato, apice abrupte acuminato, rufo-testaceae. Palpi et labrum testacea. Mandibulae rufo-testaceae. Caput thoracis latitudine, oblongum, pone oculos crebre sat fortiter, ante oculos parce vageque punctatum, antice inter antennas utrinque sat distincte impressum, parce nigro-pubescens. Oculi paulo infra capitis medium siti. Thorax coleopteris paulo angustior, latitudine sesqui longior, subcylindricus, utrinque crebrius vage punctatus, spatio dorsali longitudinali laevissimo, utrinque punctorum numerosorum serie minus regulari terminato. Scutellum laeve. Elytra thorace paulo longiora, dense fortius punctata, subtilius cinereo-pubescentia. Abdomen crebre distinctius punctulatum, supra nigro-, subtus cinereo-pubescens, infra segmentis singulis apice tenuissime picen-marginatis. Pedes rufo-testacei; femoribus flavis. cisum.

Abdominis segmentum inferius sextum $m$ aris apice triangulariter in-

* 15. C. geniculatum: Nigrum, pedibus testaceis, coxis geniculisque piceis, capite thorace latiore, subquadrato, subtilius creberrime punctato, thorace utrinque creberrime punctato. - Long. 4 lin.

Habitat in Cayenna, Dom. Buquet.

Nigrum, parum nitidum, subtiliter griseo-pubescens. Antennae capite thoraceque prope longiores, tenues, articule tertio secundo sesqui longiore, $4-8$ modice elongatis, subaequalibus, sequentibus decrescentibus ultimo apice truncato et abrupte acuminato, rufo-piceae, articulis singulis apice fuscescentibus, ultımis immaculatis. Os cum palpis piceum, maxillaribus artıculo terminali dilute testaceo. Caput thorace sesqui latius, subquadratum, angulis posterioribus rotundatis, ante oculos angustatum, depressum, supra creberrime punctatum, subopacum, nigro-pubescens, parce nigro-pilosum, antice inter antennas parce punctatum, utrinque impressum. Oculi infra eapitis medium siti. Thorax coleopteris dimidio prope angustior, latitudine sesqui longior, parallelus, subdepressus, creberrime minus subtiliter subinaequaliter punctatus, linea longitudinali media latiore maculaque utrinque minuta basali laevissimis. Scutellum parce obsoleteque punctatum. Elytra thorace sesqui fere longiora, depressa, creberrime punctata, subtiliter cirrereo-pubescentia. Abdomen parcius subtilissime punctulatum, pube subtili densiore griseo-sericans, segmentis ultimis duobus margine apicali rufopiceo. Pedes obscure testacei, coxis nigro-piceis, femoribus flavis, geniculis fuscescentibus.

Mas latet. 
16. C. similipenne: Nigrum, nitidulum, pedibus teslaceis, coxis nigropiceis, capite thorace latiore, oblongo, dense punctato, elytris profunde punctatis, margine apicali piceo. - Jong. 4 lin.

Lathrob. similipenne Say Transact. Amer. Philoph. Soc. Philadelph. Nov. Ser. IV. 453. 1.

Habitat in Mexico, coll. Dom. Chevrolat.

Statura C. sulphuripedis, nigrum, nitidulum. Antennae capite sesqui longiores, tenues, articulo tertio secundo paulo longiore, $4-8$ eiongatoobconicis, subaequalibus, 9 et 10 sensim brevioribus, obconicis, ultimo ovato, apice abrupte obtuse acuminato, articulis duobus primis rufo-piceis, 3-7 nigro-piceis, reliquis \& rufo-testaceis. Palpi piceo-testacei. Mandibulae rufae. Labrum testaceum. Caput thorace sesqui prope latius, oblongo-ovatum, supra parum convexum, sat crebre profundius punctatum, antice laevius et parce punctatum, subtiliter nigro-pubescens, minus nitidum. Oculi ante capitis medium siti. Thorax coleopteris dimidio angustior, latitudine sesqui longior, parallelus, subdepressus, sat crebre profundeque punctatus, linea media latiore subelevata laevissima, parce nigro pubescens. Elytra thorace tertia parte longiora, subdepressa, dense fortius profunde punctata, nigro-pubescentia, nitidula, margine apicali tenui piceo-rufescente. Abdomen parcius subtiliusque punetatum, pube longiore depressa fusconigra vestitum, segmentis 4 primis apice anguste piceo-marginatis, quinto sextoque apice rufo-piceis. Pedes coxis piceis, femoribus pallide flavis, tibiis tarsisque rufo-piceis.

\section{M as latet.}

Obs. A C. sulphuripede sat distinctum antennis obscuris, capite maiore, dense punctato, thorace paulo longiore, subdepresso, lateribus nullo modo rotundato, elytris paulo longioribus, abdomine distinctius punctulato, coxis piceis, etc., a praecedente magis discedit capite oblongo-ovato, elytris fortius profundiusque minus confertim punctatis, abdomine minus subtiliter obsoleteque punctulato, antennis minus elongatis, etc.

17. C. assimile: Nigrum, subnitidum, pedibus piceis, femoribus flavis, clytris margine summo apicali testaceo, capite thorace paulo latiore, crebre punctato, opaco, thorace utrinque creberrime punctato. - Long. $3 \frac{1}{2}$ lin.

Habitat in Mexico, coll. Dom. Chevrolat.

Corpus gracilins, C. sulphuripedi aequale, nigrum; subnitidum. Antennae capite sesqui longiores, tenuiores, articulo tertio secundo vix sesqui longiore, $4-8$ elongato-obconicis, reliquis tribus brevioribus, ultimo subovato, apice abrupte acuminato, nigro-piceae, articulis ultimis tribus rufotestaceis. Mandibulae elongatae, piceae. Caput thorace paulo angustius oblongum, supra leviter convexum, opacum, dense punctatum, densius subtiliter griseo-pubescens, fronte anterius laevi, inter antennas impressa. Oculi ante capitis medium siti, sat prominuli, Thorax coleopteris paulo angustior, latitudine sesqui longior, subcylindricus, creberrime fortus profunde punctatus, margine posteriore lineaque media subelevata laevissimis, parce nigro-pubescens. Scutellum laeve. Elytra thorace tertia parte longiora, profunde hinc inde subseriatim creberrime punctata, subrugulosa, subtiliter dorso nigro-, lateribus griseo-pulfescentia, margine tenui apicali rufo-testa- 
ceo. Abdomen densius subtilinsque punctatum, longius griseo-pubescens, segmentis ultimis duobus margine apicali late rufo-testaceo, quatuor primis infra apice obscure piceo-marginatis. Pedes coxis piceis, trochanteribus rufo-testaceis, femoribus pallide flavis, tibiis nigro-piceis, apice cum tarsis saturate rufo-testaceis.

Mas latet.

* 18. C. ochropus: Nigro-piceum, nitidum, antennis pedibusque cum coxis anticis teslaceis, elylris margine apicali rufo-piceo, capile thorace latiore, parcius punctato, thorace utrinque crebre fortiter punctato. Long. 4 lin.

Habitat in Brasilia, Dom. Prof. Germar.

Statura et summa affinitas C. sulphuripedis, at panlo robustius, nigropiceum, nitidnm. Antennae breviusculae, capite paulo longiores, tenuiores, articulo tertio secundo sesqui longiore, 4-7 modice elongatis, aequalibus, sequentibus sensim brevioribus, ultimo cylindrico, apice truncato et abrupte acuminato, rufo-testaceae. Os testaceo-rufum, mandibulis apice piceis. Caput thorace sesqui latus, oblongum, supra subdepressum, pone oculos parcius subtiliusque punctatum, ante oculos laeve, inter antennas utrinque leviter impressum, tenuiter nigro-pnbescens, lateribus parce nigro-pilosum. Uculi versus capitis medium siti. Thorax coleopteris dimidio angustior, latitudine sesqui longior, lateribus ante medium levissime rotundatus, parum convexus, fortiter profunde sat crebre punctatus, linea media longitudinali j osterius subelevata laevi, parce nigro-pubescens. Scutellum laeve, opacum. Elytra thorace tertia fere parte longiora subdepressa, subtiliter nigroj ubescentia, confertissime profunde punctata, minus nitida, brunneo-picea, liumeris dilutioribus, margine apicali obscure rufescente. Abdomen parcius subtilusque punctatum, tenuiter nigro-pubescens, nigrum, nitidum, segmento quinto sextoque apice testaceo-marginatis. Pedes testacei, coxis anticis concoloribus, posterioribus piceis, femoribus dilutioribus, anticis apicem versus picescentibus.

Mas latet.

* 19. C. sulphuripes: Nigrum, nitidum, pedibus flavis, elytris piceis, margine apicali testaceo, capite thorace latiore, parcius punctato, thorace utrinque creberrime fortiler punclalo, - Long. 4 lin.

Habitat in Columbia, Dom. Moritz.

Praecedentibus paulo gracilius, supra nigrum, nitidum. Antennae capite thoraceque paulo breviores, tenuiores, articulo tertio secundo sesqui longiore, $4=8$ modice elongatis, subaequalibus, sensim brevioribus, ultimo apice truncato, obscure rufo-testaceae. Os piceum. Caput thorace sesqui prope latius, oblongum, supra leviter convexum, minus crebre punctatum, medio et antrorsum laeve, punctis paucis sparsum, inter antennas utrinque profundius impressum, antice saepe dilutius piceum, nigro-pubescens pilosumque. Oculi paulo infra capitis medium siti. Thorax coleopteris dimidio angustior, latitudine sesqui longior, subcylindricus, lateribus ante medium leviter rotundatis, creberrime sat fortiter punctatus, linea media longitudinali subelevata laevissima, parce nigro-pubescens. Scutellum laeve. Elytra 
thorace tertia parte longiora, subdepressa, dense sat fortiter punctata, subtiliter cinereo-pubescentia, nigro-picea, humeris dilutioribus, margine apicali testaceo. Abdomen crebrius subtiliusque punctulatum, nigrum, nitidum, segmentis ultimis duobus apice rufo-piceis, subtus interdum medio longitudidinaliter dilute rufo-piceum. Caput et thorax subtus cum pectore magis minusve dilute picea. Pedes pallide flavi, coxis rufo-testaceis.

M a s latet.

20. C. brevicorne: Subcylindricum, rufo-testaceum, nitidum, elytris pedibusque testaceis, capite thorace latiore, oblongo, crebre punctato, thorace crassiore, lateribus crebre punctato, elytris thorace paulo longioribus, subseriatim punctatis. - Long. 3 lin.

-. Habitat Novae Valenciae in Columbia, Dom. Moritz.

Statura fere praecedentis, nitidum, subtiliter nigro-pubescens, elytris pedibusque dilutioribus. Antennae capite parum longiores, apicem versus subincrassatae, articulo secundo tertioque aequalibus, elongato-obconicis, 4 - 10 crassitie haud longioribus, fere moniliformibus, ultimo breviter ovato, apice abrupte acuminato. Caput thorace paulo latius, oblongum, supra leviter convexum, crebre profundius punctatum, fronte antice laeviore, inter antennas utrinque fortius impressa. Oculi ad capitis mediuin siti, parum prominuli. Thorax coleopteris parum angustior, latitudine vix longior, basin versus subangustatus, modice convexus, lateribus crebre punctatus, punctis passim subseriatis, margine posteriore et plaga longitudinali media laevissimis. Scutellum laeve. Elytra thorace paulo longiora, sat crebre fortiterque subseriatim punctata. Abdomen parce subtilissine punctulatum. Pedes breviusculi, tarsis posteriorịbus brevibus, articulo primo sequentibus perparum longiore.

Mas latet.

$\mathrm{Obs}$. Specimen singulum, evidenter immaturum, capite thoraceque rufo-testaceis, nitidis, elytris abdomineque luteo-testaceis, pedibus flavis.

21. C. curticorne: Subcylindricum, nigrum, nilidum, antennis pedibusque rufo-testaceis, capite thorace latiore, oblongo, crebre punctato, thorace utringue dense punctato, elytris thoracis longitudine, subseriatim punctatis: - Long. $3 \frac{1}{3}$ lin.

Habitat in Brasilia, coll. Dom. Chevrolat.

Statura et summa affinitas praecedentis. Niger, nitidulus, densius nigro-pubescens. Antennae capite vix longiores, apicem versus sensim subincrassatae, articulo tertio secundo paulo longiore, $\mathbf{4}-10$ subcylindrieis, crassitie paulnlum longioribus, sensim paulo brevioribus, ultimo subovato, apice abrupte acuminato, totae rufo-testaceae. Palpi rufo-testacei. Mandibulae piceae. Caput maiusculum, thorace latius, snpra leviter convexum, sat crebre fortius profunde punctatum, antice laeviusculum, inter antennas utrinque impressum. Oculi paulo ante capitis medium siti, vix prominuli, Thorax coleopteris vix angustior, latitudine apicis paulo longior, basin versus subangustatus, modice convexus, sat crebre minus fortiter punctatus, linea media longitudinali laevi margineque basali laevissimis. Scutellum laeve. Elytra thoracis longitudine, creberrime hinc inde subseriatim pro- 
funde punctata, subrugulosa, basi picea. Abdomen crebrius subtiliter punctulatum, segmento quinto sextoque margine apicali rufo-testaceis. Caput et thorax subtus cum pectore rufescenti-picea. Pedes cum coxis saturate rufo-testacei, dense pubescentes, breviusculi, tarsis posterioribus brevibus, articulo primo sequentibus vix longiore.

\section{Mas latet.}

Obs. A praecedente distinctum videtur capite maiore, thorace longiore, cre. brius et minus fortiter punctato, elytris thorace haud longioribus.

* 22. C. curtum: Breve, subdepressum, piceum, subnitidum, pedibus testaceis, capite coleopterorum latiludine, subquadrato, dense punctato, thorace subquadralo, crebre punctalo. - Long. 3 lin.

Habitat in Brasilia, Dom. Virmond.

Praecedentibus parum angustius, at multo brevius, subdepressum, piceum, subnitidum. Antennae capite cum thorace paulo breviores, tenues, articulo tertio secundo paulo longiore; sequentibus sensim paulo brevioribus. ultimo ovato, apice abrupte acuminato, rufae. Labrum et palpi rufa. Mandibulae valde elongatae, rufo-piceae. Caput thorace plus dimidio latius, subquadratum, lateribus pone oculos rotundato-ampliatum, planum, punctis sat magnis at parum profundis, antrorsum evanescentibus, subrugulosum, antice subtilissime confertissimeque strigosum, tenuiter subtiliterque nigropubescens. Oculi versus capitis medium siti. Thorax coleopteris dimidio angustior, latitudine haud longior, lateribus subrotundatus, basin versus subangustatus, subdepressus, crebrius punctatus, linea longitudinali media laevi, basi subelevata, tenuiter subtiliterque nigro-pubescens. Srutellum punctulatum. Elytra thorace sesqui longiora, dense punctato-subrugosa, subtiliter cinereo pubescentia, margine laterali subcostato. Abdomen parcius punctulatum, nitidum, segmentis singulis margine apıcali rufo-piceo. Caput et thorax subtus cum pectore rufo-picea. Pedes cum coxis testaceo-rufi. Alae albo-hyalinae.

Abdominis segmentum inferius quintum maris apice medio subsinuatum, sextum acute emarginatum.

* 23. C. obscurum: Nigrum, nitidum, pedibus rufo-testaceis, capite thorace paulo latiore, oblongo, subliliter punctulato, opaco, thorace utrinque creberrime punctato. - Long. 4 lin.

Habitat m Cayenna, Dom. Buquet.

Nigrum. Antennae critis thoracisque fere longitudine, tenues, articulo primo longiore, apice leviter incrassato, tertio secundo sesqui longiore, 4-8 modice elongatis, subaequalibus, reliquis sensim brevioribus, ultimo breviter ovato, apice abrupte obtuse acuminato, rufae. Palpi et labrum rufa. Mandibulae piceae. Caput thorace paulo latius, oblongum, basi fortiter rotundatum, angulis posterioribus obtusis, prominentibus, lateribus pone oculos rectis, ante oculos leviter constrictum, antrorsum superne leviter angustatum, inferne leviter dilatatum, margine laterali inferiore inde prominente, supra subdepressum, subtiliter confertim punctatum, opacum, subtiliter griseo- fusco-pubescens, antice inter antennas utrinque foveola minuta impressum. Oculi ad capitis medium siti. Thorax coleopteris tertia parte angustior, 
latitudine sesqui longior, subcylindricus, modice nitidus, creberrime punctatus, linea angusta media longitudinali laevi subelevata. Scutellum opacum, laeve. Elytra thorace paulo longiora, dense punctata, densius subtiliter cinereo-pubescentia, opaca. Abdomen parum nitidum, subtiliter parcius punctulatum, griseo-pubescens, segmentis singulis margine tenui rufo-piceo terminatis. Pedes cum coxis testaceo-rufi.

Mas latet.

24. C. scitum: Nigrum, subnitidum, pedibus antennisque testaceis, his articulo primo apice piceo, capite thoracis latiludine, oblongo, creberrime punctato, thorace elongato, utrinque crebre fortilerque punctalo. - Long. 3 lin.

Habitat valle Araguensi Columbiae, Dom. Moritz.

Statura omnino praecedentis, nigrum, subnitidum. Antennae capite thoraceque paulo breviores, tenuiores, articulis $2-7$ modice elongatis, subaequalibus, sequentibus sensim paulo brevioribus, ultimo apice truncatulo, testaceae, articulo primo apice piceo, sequentibus nonnullis fuscescentibus. Palpi testacei. Os rufo-piceum. Caput thoracis latitudine, oblongum, creberrime punctatum, parum nitidum, subtilissime cinereo-pubescens. Oculi ad capitis medium siti, sat prominuli. Thorax coleopteris dimidio angustior, latitudine summa sesqui longior, lateribus ante medium cum angulis anterioribus rotundatus, basin versus subangustatus, modice convexus, lateribus crebre fortiterque punctatus, spatio medio longitudinalı laevissimo, subelevato, utrinque stria leviter impressa terminato. Scutellum punctatoinaequale. Elytra thorace paulo longiora, confertissime punctata, subrugulosa, parce griseo-pubescentia. Abdomen confertim subtiliter punctulatum, segmentıs singulis apice rufo-marginatis. Pedes flavi, coxis anterioribus rufo-testaceis.

Abdominis segmentum inferius maris sextum apice triangulariter excisum, quintum apice leviter emarginatum.

*25. C. pulchellum: Rufo-piceum, pedibus testaceis, capite oblongo, creberrime punctato thoraceque utrinque crebre punctato rufis, elytris nigro-piceis, margine apicali testaceo, abdomine supra nigro. - Long. $2 \frac{1}{2}$ lin.

Habitat in Columbia, Dom. Moritz.

Cr. fracticorni vix maius. Antennae capitis thoracisque fere longitudine, articulo secundo tertio aequali, sequentibus sensim brevioribus, ultimo apice truncato et apice abrupte subtiliter acuminato, testaceae, articulo primo apice fusco. Palpi testacei. Caput thorace vix latius, oblongum, leviter convexum, rufum, opacum, subtiliter griseo-pubescens, creberrime punctatum, inter antennas utrinque leviter impressum. Oculi versus capitis medium siti, modice prominuli. Thorax coleopteris dimidio angustior, latitudine sesqui fere longior, lateribus ante medium leviter rotundatus, modice convexus, rufo-piceus, mtidus, creberrime sat fortiter punctatus, linea lata lon. gitudinali media laevissima postice subelevata. Scutellum rufo-piceum, obsolete punctulatum. Elytra thorace paulo longiora, sat profunde confertissime punctata, subrugulosa, subtiliter cinereo-pubescentia, nigro-picea, margine 
apicali testaceo. Abdomen parcius subtilissime punitulatum, cinereo-pubescens, nigrum, segmentis singulis margine apicali obscure piceis, ultimis duobus margine apicali latiore rufo-testaceo, subtus disco anteriore pectoreque dilute rufo-piceis. Pedes pallide flavi, coxis rufo-testaceis.

\section{*26. C. agile: Nigrum, nilidum, pedilus rufo-testaceis, capite thorace la- tiore, oblongo, parcius punctato, thorace elongato, utrinque crebre pun- ctalo. - Long. 3 lin.}

Habitat in Brasilia, Dom. v. Olfers.

Cr. fracticorni sesqui maius, nigrum, nitidum. Antennae capite thoraceque longe breviores. Caput thorace panlo latius, oblongum, leviter convexum, parcius sat profunde punctatum, antice laevius, inter antennas utrinque leviter impressum, parce nigro-pubescens. Oculi versus capitis medium siti, sat prominuli. Thorax coleopteris dimidio angustior, latitudine duplo fere longior, subcylindricus, lateribus crebre punctatus, spatio dorsali longitudinali medio laevissimo, parce nigro-pubescens. Scutellum punctulatum. Elytra thorace paulo longiora, densius minus fortiter punctata, subtiliter cinereo-pubescentia. Abdomen confertim subtilissime punctulatum, densius griseo-pubescens, opacum. Pedes rufo-testacei.

Abdominis segmentum inferius sextum maris fissum, quintum apice profunde incisum.

Variat corpore rufo-piceo, pedibus pallide testaceis.

* 27. C. fracticorne: Nigrum, nilidum, pedibus testaceis, capite thorace angustiore, oblongo, parce punclato, thorace dorso biseriatim, utrinque crebrius punctalo. - Long. $2 \frac{1}{3}$ lin.

Mannerh. Bra.helytr. 38. 13. - Steph. Illustr. Britt. Ent. V. t. 27. f. 1. - Boisd. et Lacord. Faun. Ent. Paris. 1. 427. 1. - Nordm. Symb. 151. 3. - Rundo Brachelytr. Hal. 13. 1. - Er. Col. March, I. 500. 1.

Paederus fracticornis Payk. Faun. Suec. III. 430. 5.

Lathrobium fracticorne Grav. Micr. 54. 5. Mon. 130. 3. - Latr. Hist nat. Crust. et Ins. IX. 339. 5. - Gyll. Ins. Suec. II. 369. 5. - Sahlb. Ins. Fenn. I. 341. 7. - Germ. Faun. Ins. Europ. XII. 1.

Paederus glaberrimus Payk. Mon. Car. App. 136. 17- 18.

Habitat in Europa.

Nigrum, nitidum. Antennae capite thoraceque breviores, articulo secundo tertioque subaequalibus, sequentibus sensim paululum brevioribus et crassioribus, oblongo-subobconicis, ultimo apice truncatulo, piceo-testaceae, articulo primo apice fusco. Palpi maxillares testacei, articulo tertio fuscescente. Labrum piceum. Mandibulae testaceae. Caput thorace paulo angustius, oblongum, disperse punctatum, fronte media laeviore, parce nigropubescens. Oculi versus capitis medium siti, parum prominuli. Thorax coleopteris tertia parte angustior, latitudine sesqui longior, subcylindricus, lateribus crebrius punctatus, spatio longitudinali medio laevissimo, utrinque punctorum numerosorum serie sat regulari terminato, lateribus parce subtiliterque nigro-pubescens. Scutellum punctulatum. Elytra thorace panlulum longiora, densius punctata, fusco-pubescentia. Abdomen confertim sub- 
tilissime punctulatum, densius subtiliter fusco-pubescens. Pedes cum coxis anticis testacei, coxis posterioribus piceo-testaceis.

Abdominis segmentum sextum inferius $m$ aris apice profunde incisum, quintum leviter longitudinaliter impressum, apice medio subsinuatum.

\section{Dolicaon Laporte.}

Laporte Etud. Ent. I. p. 119.

Adelobium Nordm. Symb. p. 139.

Labrum brevissimum, bilobum.

Palpi maxillares articulo ultimo obluso.

Antennae rectae.

Tarsi articulo quarto simplice, posteriores arliculis 4 primis decrescentibus.

Corpus elongatum, lineare, aliis apterum, aliis alatum. Caput thoracis latitudine vel eodem parum angustius, subovatum, basi modice constrictum, collo quasi brevi crassiusculo thoraci immissum, exsertum, porrectum, oculis parvis rotundatis, leviter prominulis, ante capitis medium sitis. Labrum transversum, brevissimum, medio incisum. Mandibulae validae, falcatae, medio obtuse dentatae. Maxillae (t. IV. f. 27. b.) malis membranacess, interiore interne, exteriore subelongata apice barbatis. Palpi maxillares modice elongati, articulo primo brevi, minuto, secundo tertioque elongatis, hoc apicem versus sensim incrassato, ultimo minimo, globoso, obtuso. Labium (t. IV. f. 27. a.) mento transverso, apice truncato, ligula brevi, biloba, lobis rotundatis, membranea, paraglossis triangularibus, coriaceis, interne ciliatis, ligulam longe superantibus. Palpi labiales articulo primo obconico, secundo elongato, primo sesqui fere longiore, tertio minuto, tenui, subulato. Antennae filiformes, rectae, articulo primo reliquis paulo maiore, ultimo apice acuminato. Thorax oblongus, coleopterorum fere latitudine. Elytra nonnunquam brevia. Abdomen lineare, apice angustatum, stylis analibus exsertis. Pedes modice elongati, antici leviter incrassati, femoribus anticis subtus ante apicem obsolete dentatis, tarsis anticis articulis 4 primis leviter dilatatis, obcordatis, subtus spongioso-tomentosis, tarsis posterioribus longioribus, gracilibus, articulis 4 primis longitudine sensim decrescentibus.

$$
\text { o b s e r v a t i o n e s. }
$$

1. Habitus omnino Lathrobii, genus autem palporum maxillarium articulo nltimo obtuso, labro brevissimo et tarsorum posteriorum articulis primis elongatis evidenter distinctum. Quibus notis species Europaeae cum Capensi gigantea congruunt.

2. Mas abdominis segmento inferiore sexto profunde inciso, nonnunquam etiam quinto apicem versus leviter impresso distinctus.

3. Victus latet.

* 1. D. Lathrobioides: Niger, subnitidus, antennis pedibusque rufis, elytris thorace duplo brevioribus. - Long. 8 lin.

Laporte Etud. Ent. I. p. 120. t. 4. f. 1.

Adelobium brachypterum Nordm. Symb. 140. 1.

Habitat ad Promont. Bonae Spei, Dom. Prof. Lichtenstein.

Apterus, niger, subnitidus. Antennae capite paulo longiores, tenuiores, articulo tertio secundo duplo longiore, sequentibus decrescentibus, elongato 
subobconicis, ultimo fusiformi, praecedente paulo longiore, rubrae. Mandibulae piceae. Caput thoracis latitudine eodemque paulo brevius, minus depressum, crebre minus profunde punctatum, fronte anteriore et linea media longitudinali laevioribus. Thorax coleopteris prope latior, latitudine sesqui longior, basin versus vix angustatus, lateribus levissime rotundatus, basi apiceque truncatus, angulis anterioribus deflexis, subrectis, posteriorbus rotundatis, convexus, sat crebre minus profunde punctatus, linea media longitudinali laevi. scutellum piceum, laeve. Elytra thorace duplo breviora, subdepressa, crebre punctata, parce subtiliterque nigro-pubescentia, apice oblique truncata, angulo exteriore emarginato. Abdomen subtiliter minus confertim exasperato-punctatum, parce subtiliterque pubescens, subtus apice piceum. Pedes rufi, coxis piceis.

Abdominis segmentum inferius sextum maris profunde incisum, quintum integrum.

* 2. D. Illy ricus: Niger, nitidus, elytris thorace dimidio brevioribus, abdominis segmentis ultimis duobus, pectore antennisque rufis, pedibus testaceis. - Long. 3 lin.

Habitat in Illyria; Dom. Schüppel.

Habitu fere praecedentis, at longe minor, subcylindricus, apterus, niger, nitidus, capite thoraceque pernitidis. Antennae capite paulo longiores, apicem versus subincrassatae, articulo tertio secundo perparum longiore, sequentibus sensim panlo brevioribus et crassioribus, ultimo apice abrupte acuminato, rufae. Palpi maxillares articulo tertio fortiter incrassato. Mandibulae et labrum picea. Caput thorace paulo latius, minus depressum, parcius profundiusque punctatum, linea media longitudinali laevi, antice utrinque ad antennarum basin intra marginem incrassatum subimpressum. Thorax coleopteris paululum latior, latitudine sesqui longior, basin versus vix angustatus, lateribus subrectis, basi apiceque truncatus, angulis omnibus rotundatis, subcylindricus, crebrius profundiusque punctatus, linea latiore longitudinali laevi. Scutellum laeve. Elytra thorace dimidio breviora, dorso parce, lateribus crebrius punctata, tenuiter griseo-pubescentia, nitidissima, rufa. Abdomen parcius subtiliusque punctatum, tenuiter griseo-pubescens, segmento quinto sextoque rufis, illo summa basi nigro. Pectus rufum. Pedes testacei, coxis posticis rufis.

Abdominis segmentum inferius sextum maris profunde incisum, quintum integrum.

O bs. Sequentibus statura magis cylindrica et elytris brevioribus diffinis. Specimen Musei olim nom. Xantholini Illyrici a Com. Dejean Domino Schüppel communicatum est. Exinde monente Dom. Schüppel inter Lathrobia ill. Comes hanc speciem aptius enumeravit.

* 3. D. haemorrhous: Niger, nilidus, elytris thoracis longiludine anoque rufis, illis summa basi nigris, antennis pedibusque rufo-testaceis. Long. $2 \frac{1}{2}$ lin.

Habitat in Sardinia, Dom. Prof. Gené, in Sicilia, Dahl.

Linearis, subdepressus, alatus, niger, nitidus. Antennae capite sesqui longiores, apicem versus nullo modo incrassatae, articulo tertio secundo 
vix longiore, seanentibus sensim paulo brevioribus, ultimo aplce abrupte acuminato, rufo-testaceae. Palpi rufo-testacei, maxillares articulo tertio fortius incrassato. Os rufum. Caput thorace paulo angustius, subdepressum, crebrius princtatum, spatio lato medio, inter oculos interrupto, laeviore, apice utrinque foveola minuta notatum, parce nigro-pilosellum. Thorax coleopterorum latitudine, latitudine sesqui longior, lateribus subrectis, basi apiceque truncatus, angulis omnibus obtusis, subrotundatis, perparum con. vexus, crebrius subtiliusque punctatus, linea media longitudinali laevi, tenuiter griseo-pubescens. Scutellum laeve. Elytra thoracis longitudine, minus confertim subtilius punctata, tenuiter griseo-pubescentia, tota testaceo-rufa, nitida, basi summa magis minusve nigricante. Abdomen parcius subtiliter punctatum, minus subtiliter griseo-pubescens, segmentis quinto sextoque rufis, illo summa basi nigricante. Pedes toti cum coxis rufo-testacei.

Abdominis segmentum inferius maris profunde incisum, quintum apice obsolete impressum.

Obs. Proximus sequenti, at distinctus videtur, elytris nonnisi summa basi nigricantibus, abdominis segmentis quatuor anterioribus margine concoloribus, thorace paulo longiore, crebrius punctato.

* 4. D. gracilis: Niger, nitidus, elytris thorace longioribus, macula magna apicali anoque rufis, antennis pedibusque testaceis. - Long. 3 lin.

Lathrobium gracile Grav. Micr. 182. 5. - Latr. Hist, nat. Crust. et Ins. IX. 341. 11.

Habitat in Lusitania.

Statura ommmo praecedentis, niger, nitidus, capite thoraceque pernitidis. Antennae capite thoraceque breviores, tenues, apicem versus nullo modo incrassatae, articulo tertio secundo paulo longiore, sequentibus sensmı paulo brevioribus, ultimo oblongo-ovato, apice sensim acuminato, rufotestaceae. Os rufo-testaceum, palpis maxillaribus articulo tertio modice incrassato. Caput thorace paululum angustius, oblongum, parcius disperse punctatum. Thorax coleopterorum fere latitudine, latitudine tertia parte longior, lateribus subrectis, basi apiceque truncatus, angulis omnibus rotundatis, parum convexus, crebre subtilius punctatus, linea longitudinali media laevi, tenuiter subtiliterque griseo-pubescens. Scutellum laeve. Elytra thorace paululum longiora, sat crebre punctata, tenuiter griseo-pubescentia, nitida, nigra, macula permagna apicali rufa, elytri dımidiam partem occupante. Abdomen parcius punctulatum, griseo-pubescens, subnitidum, segmentis quatuor primis margine apicali tenui rufo, quinto rufo, basi dimidiatim nigro, sexto rufo. Pedes toti cum coxis testacei.

Abdominis segmentum inferius sextum maris profunde incisum, quintum apice obsolete longitudinaliter impressum.

* 5. D. biguttulus: Niger, nilidus, punctatus, elytris thorace paulo Tongioribus, macula apicali rufa, antennis pedibusque testaceis. - Long. $2 \frac{1}{3}-2 \frac{2}{3}$ lin.

Lathrobium biguttulum Boisd, et Lacord. Faun. Ent. Paris. I. 425. 7.

Habitat in Austria, Hungaria.

Statura praecedentis, at plerumque minor, niger, nitidus. Antemnae 
capite thoraceque breviores, tenues, articulo tertio secundo sesqui longiore, 4 - 10 sensim paulo brevioribus, ultimo ovato, apice abrupte obtuse acuminato; testaceae. Os rufo-testaceum, palpis maxillaribus articulo terío fortiter incrassato. Caput thorace paulo angustius, oblongum, subdepressum, parcius disperse punctatum, punctis in media fronte rarioribus, apice utrinque leviter foveolatum. Thorax coleopteris paulo angustior, latitudine tertia parte longior, lateribus rectis, parallelis, basi apiceque truncatus, angulis anterioribus rectis, posterioribus rotundatis, parum convexus, sat crebre punctatus, linea media longitudinali laevi parum distincta, tenuiter subtiliterque griseo-pubescens. Scutellum laeve. Elytra thorace paululum longiora, crebre subtilius punctata, tenuiter griseo-pubescentia, nigra, magna apicali laete rufa, elytri quartam fere vel tertiam partem occupante, in marginem lateraiem dilatata, sutura tamen nigra. Abdomen parcius punctulatum, griseo-pubescens, subtus apice piceum, segmentis intermediis tenuiter testaceo-marginatis. Pedes testacei, coxis omnibus picescentibus.

Abdominis segmentum inferius sextum $m$ aris profunde incisum, quintum apice obsolete impressum.

\section{Scimbalium $E r$.}

\section{Labrum breve, bilobum.}

Palpi maxillares articulo ultimo àcuto.

Anlennae rectae:

Tarsi articulo quarto simplice, posteriores articulis 4 primis sensim brevioribus.

Corpus elongatum, valde depressum, alatum. Caput porrectum, exsertum, collo quasi angustiore thoraci immissum, antrorsum angustatum, oculis parvis, haud prominulis, ante capitis medium sits. Labrum breve, bilobum, lobis rotundatis, basi corneum, apice memibranaceum. Mandibulae breviu sculae, validiusculae, basi interne fimbria angusta membranacea instructae, medio fortiter 3-dentatae, apice fortiter falcatae, acutae. Maxillae malis parvis, coriaceis, interiore interne, exteriore apice barbatis. Palpi maxillares breviores, articulo primo minimo secundo tertioque longitudine aequalibus, hoc apicem versus sensim leniter incrassato, quarto minuto, brevi, subulato. Labium mento brevi, transverso, ligula membranacea, profunde biloba, lobis rotundatis, paraglossis ligulam superantibus, linearibus, coriaceis, interne barbatis. Palpi labiales articulo primo minore, leviter obconico, secundo maiore, incrassato, tertio tenui, subuIato, secundo breviore. Antennae rectae, apicem versus subattenuatae, articulo primo crassiusculo, cylindrico, maiore, secundo duplo breviore, obconico, tertio secundo sesqui longiore, sequentibus sensim paulo brevioribus, elongato-subobconicis, ultimo elongato-fusiformi, apice sensim acuminato. Thorax coleopterorum fere latitudine, trapeziformis, basi apiceque truncatus, angulis anterioribus subrectis, posterioribus rotundatis. Scutellum apice rotundatum. Elytra apice introrsufm oblique truncata, angulo exteriore rotundato. Abdomen lineare, apice attenuatum, segmento sexto conico, stylis analibus exsertis. Pedes breviores, antici modice incrassati, femoribus tibiisque interne leviter sinuatis, tibiis posterioribus parce spinulosis, spinis apicalibus tenuibus, distinctis, tarsis anticis in utroque sexu in patel- 
lam ovalem, subtus tomentosam, dilatatis, posterioribus sat elongatis, tibiam longitudine aequantibus, articulis \& primis sensim breviorıbus, ultimo praecedentibus ambobus vix longiore.

O b s e r a t i n e s.

1. Genus sat distinctum, licet ab omnibus hucusque auctoribus cum Ache nio confusum, quocum corpore deplanato primo quidem intuitu congruit, oris autem, praecipue labii et tarsorum structura minime convenit.

2. Mas distinctus abdominis segmento inferiore sexto apice profunde triangulariter exciso, septimo inferiore conspicuo.

3. Victus latet.

* 1. Sc. anale: Piceum, nitidum, antennis, pedibus, ano elytrisque rufis, his thorace longioribus. - Long. $4 \frac{1}{2}$ lin.

Achenium an a le Nordm. Symb. 153. 2.

Habitat in Chersoneso Taurica et in Caucaso.

Achenio depresso paulo longius et minus depressum, nigro-piceum, nitidum. Antennae capite thoraceque longiores, rufae. Palpı rufi. Mandibulae rufo-piceae. Caput thorace angustius, antrorsum leviter angustatum, lateribus crebrius, medio parcius punctatum, parcius pube erecta nigra vestitum, lateribus pilosellum. Thorax coleopteris vix angustior, latitudine paululum longior, basin versus subangustatus, ląteribus subrectis, subdepressus, minus fortiter aequaliter crebre punctatus, linea media longitudinali laevi, pube subtili erecta nigra parcius vestitus. Scutellum subtiliter punctulatum. Elytra thorace paulo longiora, subtiliter dense punctata, tenuiter griseo-pubescentia, rufa, parum nitida. Abdomen densius subtiliusque punctatum, densius griseo-pubescens, piceum, segmentis 4 primis apice tenuiter rufomarginatis, quinto rufo, basi piceo, sexto toto rufo. Pedes testaceo-rufi, coxis concoloribus.

Obs. 1. A chenium Caucasicum Laporte Etud. Ent. I. p. 119 „fortiter punctatum, leviter pubescens, rufo-brunneum, antennis, oris partibus pedibusque dilute castaneis," a Dom. Godet in Caucaso lectum, forte idem, at descriptio nimis manca, ut equidem insectum illud pro alio quodam haberem, si ipse in Staphylinorum collectione sua, quam Dom. Godet examinandam mihi amice communicavit, aliud quoddam, cui magis conveniret, observassem.

2. Nomine Lathrobii phoenicuri hoc insectum Dom. Steven communicavit.

2. Sc. planicolle: Piceum, nitidum, antennis, pedibus, ano elytrisque rufis, his thoracis longitudine. - Long. $4 \frac{1}{2}$ lin.

Habitat in Italia, Dom. Schüppel, in Sicilia, Dom. Dr. Schultz.

Statura et summa affinitas praecedentis. Nigro-piceum, capite thoraceque saepius supra nigris, nitidis. Antennae capite thoraceque paulo longiores, rufae. Palpi rufo-testacei. Caput basi thorace parum àngustius, antrorsum modice angustatum, parcius profundiusque punctatum, fronte media late laeviore, pube brevi rara erecta nigra vestitum, lateribus nigro-pilosellum. Thorax coleopterorum latitudine, latitudine antica paulo longior, basin versus leviter angustatus, lateribus subrectis, supra subdepressus, crebrius minus subtiliter punctatus, linea media longitudinali laevi, parce subtilissime griseo-pubescens. Scutellum punctulatum, nigrum. Elytra thoracis longi- 
tudine, densius minus subtiliter punctata, rufa, nitida, subtiliter griseo-pubescentia. Abdomen minus subtiliter crebrius punctulatum, densius griseopubescens, segmentis 4 primis apice piceo-marginatis, quinto apice, sexto toto rufis. Pedes rufo-testacei, coxis nigro-piceis.

Obs. Praecedenti proximum, elytris autem brevioribus, capite thoraceque minus subtiliter minusque dense punctatis distinctum videtur.

\section{* 3. Sc. testaceum: Dilute testaceum, nitidum, capile thoraceque parce punctatis. - Long. $2 \frac{1}{2}$ lin.}

Habitat in Sicilia, Dom. Dr. Schultz.

Praecedentibus multo minus, fortiter depressum, testaceum, nitidulum. Antennae capite thoraceque paulo longiores. Caput thorace paulo latius, antrorsum leviter angustatum, parce punctatum, plaga angusta longitudinali media laevi, subtiliter griseo-pubescens, lateribus longe nigro-pilosellum. Thorax coleopteris paulo angustior, latitudine longior, hasin versus modice angustatus, utrinque parcius subtiliter punctatus, parcius subtiliter griseopubescens. Scutellum punctulatum. Elytra thoracis longitudine, dense subtiliter punctata, pube depressa grisea dense vestita. Abdomen dense subtıter punctulatum, pubescens, parce pilosellum, segmeutis 4 primis nonnunquam fuscescentibus.

Obs. Forte apterum.

\section{Acheninm Leach.}

Curt. Britt. Ent. III. t. 115. - Steph. Illustr. V. p. 265. - Boisd. et Lacord. Fuun. Ent. Paris. I. p. 420. - Er. Col. Narch. 1. p. 501.

Lathrobium Fam. II. Grav. Mon. p. 129.

Labrum bilobum, lobis divergentibus.

Palpi maxillares articulo ultimo aculo.

Antennae rectae.

Tarsi arliculo quarto simplice, posteriores arliculis 4 primis aequalibus, quinto his coniunclis aequali.

Corpus elongatum, valde depressum vel planum, alatum. Caput subcordatum, porrectum, exsertum, collo quasi angusto thoraci immissum, basi leviter emarginatum, angulis posterioribus rotundatis, antrorsum triangulariter angustatum, ante oculos subito angustius, oculis versus capitis medium sitis, parvis, rotundatis, haud prominulis. Labrum angustius, profunde bilobum, lohis elongatis, leviter divergentibus. Mandibulae breviusculae, validiusculae, basi interne dilatatae, medio fortiter unidentatae, apice fortiter falcatae, acutae. Maxillae mala interiore membranacea interne, exteriore cornea apice membranaceo barbatis. Palpi maxillares minus elongatae, articulo primo minuto, secundo tertioque aequalibus, hoc apicem versus sensim subincrassato, quarto minimo, conico-acuminato, seu obtuse subulato. Labium mento brevi, transverso, ligula brevi, membranea, biloba, lobis rotundatis, paraglossis coriaceis, ligulam haud superantibus. Palpi labiales articulis duobus primis subeylindricis, secundo paulo longiore et crassiore, tertio tenui, subulato, secundo breviore. Antennae rectae, apicem versus attenuatae, articulo primo crassiusculo, cylindrico, secundo hoc duplo breviore, obconico, tertio secundo sesqui longiore, sequentibus sensim minoribus, 
elongato-subobconicis, ultimo elongato-fusiforml, apice sensim acuminato. Thorax coleopteris paulo angustior, trapeziformis, apice truncatus, angulis anterioribus lateraliter leviter prominulis, posterioribus rotundatis. Scutellum triangulare. Elytra truncata. Abdomen lineare, apice angustatum, segmento septimo prominulo, inferiore bivalvi, valvulis apice acuminato, sursum uncinato terminatis. Pedes breviusculi, validiusculi, antici incrassati, femoribus tibiisque interne sinuatis et subdentatis, tibiis posterioribus setulosis, apicem versus leviter dilatatis, apice oblique truncatis, spinis apicalibus brevissimis, tarsis anticis in utroque sexu articulis 4 primis in patellam orbicularem subtus tomentosam dilatatis, posterioribus tenuibus, articulo primo brevissimo, secundo parum elongato, tertio huic subaequali, quarto iterum breviore, ultimo his coniunctis longitudine aequali.

\section{O b s e r v a t i n e s.}

1. Tarsis posterioribus brevibus Lathrobio affine, at tarsi tenuiores et articulus quintus longior, ceterum praecipue corpore deplanato, labro angusto, lobis magis elongatis, mandibulis brevioribus distinctum. Thorax saepius per plagas punctatus, plagis intermediis in medio dorso distinctioribus.

2. Mas abdominis segmento inferiore sexto apice inciso distinctus.

3. Victus palustris.

* 1. A. depressum: Nigrum, nitidum, pedibus, ano elytrisque rufis, his basi nigris, thorace paulo longioribus, capite parcius punctato, thorace per plagas punctato. - Long. 4 lin.

Nordm. Symb. 152. 1.

Lathrobium depressum Grav. Micr. 182. 6. Mon. 129. 2. - Latr. Hist. nat. C'rust. et Ins. 1X. 341. 12. Gen. Crust. et Ins. 1. 290. 2.

Achenium cordatum Boisd. et Lacord. Faun. Ent. Paris. I. 421. I.

Habitat in Lusitania, Italia.

Nigrum, nitidum. Antennae capite thoraceque paulo longiores, rufopiceae. Palpi rufo-testacei. Labrum rufo-piceum. Caput basi thoracis latitudine vel paulo latius, leviter emarginatum, antrorsum angustatum, triangulare, parcius punctatum, interstitiis disperse subtiliter punctulatis, fronte media sublaevi, parce subtiliterque nigro-pubescens. Thorax coleopteris paulo angustior, latitudine vix longior, basin versus leviter angustatus,! lateribus subrectis, basi cum angulis posterioribus rotundatus, angulis anterioribus subrectis, depressus, utrinque plagis tribus punctatus, plagis intermediis densius punctatis, distinctioribus, posterius subimpressis, interstitio laevissimo. Scutellum subtiliter parce punctatum. Elytra thorace paulo longiora, minus dense basi subseriatin, apice vage punctata, rufa, nitida, basi tertia fere parte nigra. Abdomen subtiliter densius punctatum, "subtiliter griseo-pubescens, nigrum, segmentis 4 primis apice tenuiter flavo-marginatis, quinto apice, sexto toto rufis. Pedes cum coxis anterioribus rufi, tibiis basi piceis. excisum.

Abdominis segmentum inferius sextum maris leviter triangulariter Variat femoribus posticis picescentibus. 
2. A. aеqualum: Nigrum, nilidum, pedibus, ano elytrisque rufis, his thorace sesqui longioribus, capile thoraceque sublilius crebre punctatis. Long. 4 lin.

Habitat in Aegypto, Dom. Prof. Ehrenberg.

Statura et summa affinitas praecedentis, at paulo latius, nigrum, nitidum. Antennae capite thoraceque vix longiores, rufo-piceae, densius pubescentes et pilosellae. Palpi rufo-testacei. Labrum rufo-piceum. Caput basi thoracis latitudine, leviter emarginatum, antrorsum angustatum, triangulare, supra subtilius licet profunde crebre fere aequaliter punctatum, fronte media vix laeviore, interstitiis parce subtilissime punctulatis, pube tenui subtilique erecta cinerea vestitum, lateribus parce pilosellum. Thorax coleopteris paulo angustior, latitudine antica vix longior, basin versus subangustatus, lateribus rectis, basi truncatus, angulis posterioribus late rotundatis, subtiliter sat crebre fere aequaliter punctatus, parce pube erecta subtili grisea vestitus, linea media longitudinali laevi, piceo-niger, angulis anterioribus dilutioribus. Scutellum parce punctatim, nigrum, opacum. Elytra thorace sesqui longiora, aequaiiter sat crebre subtiliter punctata, tota testaceo-rufa, pube erecta grisea densius vestita. Abdomen densius subtiliter punctatum, pube longiore depressa grisea densius vestitum, parce nigropilosellum, minus nitidum, nigrum; segmentis 4 primis apice tenuiter flavomarginatis, quinto margine apicali, sexto apice rufis, subtus magis piceum. Pedes cum coxis omnibus rufo - testacei, tibiis summa basi picescentibus.

Abdominis segmentum inferius quintum $m$ aris medio longitudinaliter impressum, sextum longitudinaliter impressum, apice triangulariter excisum.

Obs. A praecedente praecipue capitis, thoracis elytrorumque punctura crebriore, fere aequali, thorace basin versus vix angustato, elytris longioribus, totis rufis distinctum.

- 3. A. planum: Nigrum, nilidum, pedilus, ano ely/risque rufis, his lasi late nigris, thorace sesqui longioribus, capite thoraceque conferlim subtilius punclatis. - Long. 4 lin.

Habitat in Grusinia, Dom. Marschall v. Bieberstein. ‘

Statura et summa affinitas praecedentis, nigrum, nitidum. Antennae capitis thoracisque longitudine, rufo-piceae. Palpi rufi. Labrum rufo-piceum. Caput basi thoracis latitudine, leviter emarginatum, antrorsum angustatum, triangulare, crebre feré aequaliter punctatum, fronte media vix laeviore, interstitiis hinc inde puncto subtilissimo notatis, pube rara subtili erecta grisea vestitum, subtus longius pubescens. Thorax coleopteris paulo angustior, latitudine parum longior, basin versus subangustatus, lateribus rectis, basi subtruncatus, angulis posterioribus late rotundatis, anterioribus subrectis, depressus, crebruus subtiliter punctatus, linea longitudinali media laevi, punctorum crebrorum plaga utrinque terminata, nigerrimus, glaber. Scutellum nigrum, parce subtiliter punctatum. Elytra thorace sesqui longiora, densius aequaliter subtiliter punctata, testaceo-rufa, nitida, basi ultra tertiam partem nigra. Abdomen subtiliter confertim punctatum, nigrum, parum nitidum, segmentis quatuor anterioribus apice tenuissime flavo-marginatis, quinto margine apicali, sexto apice rufis. Pedes testaceorufi, coxis anterioribus concoloribus, posticis piceis, tibiis basi piceis. 
Abdominis segmentum inferius sextum maris apice leviter triangulariter excisum.

Obs. Differt a praecedente elytris basi nigris, thorace minus aequaliter punctato, glabro, capite minus crebre punctato; ab A. depresso et A. ephippio elytris longioribus, densius aequaliter punctatis, thorace basin versus vix angustato etc. magis distinctus.

* 4. A. ephippium: Nigrum, nitidum, elytris apice oblique rufis, thorace paulo longioribus, capite parcius punctato, thorace per plagas punctato. - Long. 4 lin.

\section{Habitat in Hungaria.}

A. depresso aequale et simillimum at paulo fortius depressum, nigrum, nitidum. Antennae capite thoraceque paulo longiores, rufo-piceae. Palpi et labrum rufa. Caput, thorax et elytra pube parca brevi subtili erecta grisea vestita. Caput basi thoracis latitudine, leviter emarginatum, antrorsum angustatum, triangulare, supra parcius fortius punctatum, interstitiis parce subtilissime punctatis, fronte media laeviore, lateribus pilosellum. Thorax coleopteris tertia parte angustior, basin versus angustatus, lateribus rectis, basi truncatus, angulis posterioribus late rotundatis, anterioribus rectis, modice prominulis, supra parcius inaequaliter punctatus, spatio medio longitudinali laevissimo, utrinque plaga punctorum crebrorum terminata. Scutellum laeve. Elytra thorace paulo longiora, minus dense inaequaliter hinc inde subseriatim punctata, rufo-testacea, basi late a humeris usque ad suturae apicem prope triangulariter descedente nıgra, seu nigra, angulo apicali exteriore late cum margine laterali et apicali rufo. Abdomen crebrius subtiliter punctatum, pube depressa grisea vestitum, segmentis 4 anterıribus apice tenuiter flavo-, quinto sextoque piceo-marginatis. Pedes cum coxis anterioribus iam rufi, iam rufo-, iam fusco-picei, tarsis testaceis.

Abdominis segmentum inferius se.tum maris apice leviter triangulariter excisum, quintum medio late leviter sinuatum.

Obs. Distinctum ab A.depresso praecipue corpore magis deplanato, elytrorum spatio nigro ultra medium descedente, sat determinato, ano concolore, etc.

* 5. A. basale: Nigrum, nitidum, elytris rufis, basi nigris, thorace paulo longioribus, capite parcius punctato, thorace per plagas punctato. Long. 4 lin.

Habitat in Sardinia, Dom. Frof. Gené.

Statura omnino A. depressi, et minoribus eius individuis aequale, nigerrimum, nitidum, capite thoraceque pube parciore erecta grisea nigraque vestitis. Antennae capite thoraceque paulo longiores, rufo-vel fusco-piceae, apice dilutiores. Palpi rufi. Labrum rufo-piceum. Caput basi thoracis latitudine, leviter emarginatum, antrorsum angustatum, triangulare, supra parcius, minus subtiliter punctatum, fronte media laeviore, interstitiis parce subtilissime punctatis, lateribus nigro-pilosellum. Thorax coleopteris paulo angustior, latitudine antica paulo longior, basin versus leviter angustatus, lateribus rectis, basi truncatus, angulis posterioribus late rotundatis, anterioribus acutiusculis, supra parcius punctatus, punctis utrinque in plagas tres longitudinales digestis, seriebus intermediis distinctioribus, crebrius pun- 
etatis, posterius leviter impressis, interstitio intermedio laevissimo, interstitiis lateralibus interioribus ante medium punctis numerosis repletis. Scutellum laeve. Elytra thorace paulo longiora, densius hinc inde subseriatim punctata, tenuiter subtiliterque griseo-pubescentia, saturate rufa, nitida, basi et humeris arcuatim quarta vel tertic parte nigra. Abdomen nigrum, subnitidum, dense subtilius punctatum, tenuiter grisen-pubescens, segmentis singulis apice tenuiter fusco-piceo-marginatis. Pedes nigro-picei, tarsis , testaceis. incisum.

Abdominis segmentum inferius sextum maris profundius triangulariter

Variat pedibus rufo piceis, coxis omnibus concoloribus.

Obs. Proximum A. depresso statura et elytrorum proportione, distinctum autem capite thoraceque minus subtiliter, elytris crebrius punctatis, ano concolore, pedibus obscurioribus, etc.

* 6. A. debile: Nigro-piceum, nilidum, pedibus testaceis, elytris thorace paulo longioribus, basi nigris anoque mifis, capite crebre punctato, thorace lateribus parce, medio biseriatim punctato. - Long. $3 \frac{3}{4}$ lin.

Habitat in Mesopotamia, Dom. Dr. Helfer, in Aegypto Dom. Prof. Ehrenberg.

Statura et summa affinitas A. depressi, at paululum minus et gracilius, nigro-piceum, nitidum. Antennae capite thoraceque paulo longiores, testaceae. Caput thorace paulo latius, antrorsum angustatum, basi leviter emarginatum, triangulare, nitidum, crebre fere aequaliter punctatum, interstitiis disperse subtilissime punctatis, fronte media parum laeviore, subtilissime griseo-pubescens. Thorax coleopteris paulo angustior, latitudine antica paulo longior, basin versus modice angustatus, lateribus rectis, basi truncatus, angulis posterioribus late rotundatis, anticis subrectis, nitidus, omnium subtilissime parce disperseque punctulatus, dorso biseriatim, lateribus parce vageque subtiliter punctatus. Scutelum obsolete punctulatum. Elytra thorace paulo lougiora, parcius, anterius subseriatim, posterius vage punctata, rufa-testacea, nitida, basi quarta fere parte nigricantia, parce subtilius griseo-pubescentia. Abdomen crebre subtiliterque punctatum, subtilius griseopubescens, nigrum, subritidum, segmentis 4 primis apice subtiliter piceomargilauis, quinto rufo, basi piceo, sexto toto rufo. Pectus piceum. Pedes cum coxis omnibus testacei, tibiis summa basi picescentıbus. excisum.

Abdominis segmentum inferius sextum maris apice triangulariter

Variat immaturus colore corporis estaceo elytris anoque dilutioribus, pedibus flavis.

Obs. Ab A. depresso elytris parcius, capite crebre punctatis, ab A. striato elytris longioribus latioribusque, ab omnibus thorace lateribus parce punctato distinctum.

* 7. A. striatum: Nigrum, nitidum, pedibus, abdominis segmentis ultimis duobus elylrisque rubris, his thorace parum longioribus, subseriatim punctatis, thorace per plagas punctato. - Long. $3 \frac{2}{3}$ lin.

Lathrobium striat um Latr. Hist, nat. Crust. et Ins. IX. 341. 13.

Habitat in Gallia, Italia. 
Statura omnino A. depressi, at paulo angustius, nigrum, nitidum, capite, thorace elytrisque pube rara erecta grisea vestitis. Antennae capite thoraceque paulo longiores, rufo-piceae. Os rufo-piceum. Caput basi thorace paulo latius, antrorsum fortiter angustatum, basi leviter emarginatum, subcordatum, crebre punctatum, interstitiis subtilissime disperse punctulatis, fronte media laeviore. Thorax coleopteris haud angustior, latitudine antica parum longior, basin versus modice angustatus, lateribus rectis, basi truncatus, - angulis posterioribus late rotundatis, anterioribus subrectis, subtilissime disperse punctulatus, utrinque triplagiatim subtilius parciusque punctatus, plagis angustis, intermediis distinctioribus, densius punctatis. Scutellum nigrum, parce subtiliterque punctatum. Elytra thorace parum longiora, parcius subseriatim punctata, tota rubra, nitida. Abdomen subtilius crebre punctatum, densius griseo-pubescens, nigro-piceum, subnitidum, segmentis 4 primis margine apicalı tenuissimo, testaceo, ultimis duobus totis rubris. Pedes cum coxis omnibus rufo-testacei, tibiis basi summa picescentibus.

Abdominis segmentum inferius sextum maris apice profundius triangulariter excisum.

Obs. Distinctum a praecedentibus coleopteris brevioribus, thorace haud latioribus, abdominis segmentis duobus ultimis totis rufis. Caput latiusculum, lateribus magis rotundatum, ideoque magis cordatum. Abdomen ante apicem sensim subdilatatum.

8. A. humile: Nigrum, capite thoraceque piceis, antennis, pedibus, ano elytrisque testaceis, his summa basi fuscescentibus, thorace parum lon. gioribus, vage punctatis. - Long. 3 lin.

Er. Col. March. I. 501. 1.

Lathrobium humile Nicolai Col. Halens. 38. 1.

Achen ium depressum Curt. Britt. Lint. III. $t$, 115. - Boisd, et Lacord. Faun. Ent. Paris. I. 421. 2.

Habitat in Germania.

Habitu omnino praecedentium, at duplo minus. Antennae capite thoraceque longiores, rufae. Palpi rufo-testacei. Caput basi thorace paulo latius, vix emarginatum, subcordatum, antrorsum angustatum, parcius subtiliusque punctatum, fronte media laeviore, parce griseo-pubescens, lateribus longius pilosellum, plerumque dilute rufo-, rarius fusco-vel nigro-piceum, nitidum. Thorax coleopterorum latituaine, latitudine antica parum longior, basin versus leviter angustatus, lateribus rectis, basi truncatus, angulis posterioribus rotundatis, anterioribus acutiusculis, parcius subtiliter punctatus, punctis utrinque in plagas tres longitudinales digestis, plagis intermediis angustioribus, magis regularibus, distinctioribus, medio nonnunquam leviter impressis, plerumque dilute rufo-, rarius fusco-vel nigro-piceus, nitidus, pube parca erecta grisea vestitus. Scutellum nigro-piceum, laeve. Elytra thorace perparum longiora, subtilius parciusque aequaliter punctata, pube tenui erecta grisea vestita, nitida, testacea, basi indeterminate nigricantia. Abdomen crebrius subtiliter punctatum, opacum, densius griseo-pubescens, segmentis 5 primis apice subtiliter flavescenti-marginatis, sexto piceo-testaceo. Pectus nigrum. Pedes testacei, coxis concoloribus, tibiis basi piceis.

Abdominis segmentum inferius sextum $\mathrm{maris}$ apice triangulariter excisum, quintum medio subsinuatum. 
9. A. ieiunum; Nigrum, capite, thorace elytrisque rufo-piceis, capite crebrius punctato, elytris thoracis longitudine, inaequaliter punclatis. - Long. $3 \frac{2}{3}$ lin.

Habitat in Sardinia, Mus. Reg. Taurin.

Statura et summa affinitas $A$. humilis, at paulo maius, A. striato aequale. Antennae capite thoraceque paulo longiores, rufae, apice dilutiores. Palpi rufo-testacei. Caput basi thorace paulo latius, cordatum, basi emarginatum, lateribus pone oculos rotundatum, antice fortiter angustatum, depressum, crebrius punctatum, interstitiis subtiliter punctulatis, fronte media laeviore, parce pubescens pilosumque, saturate rufo-piceum, nitidum, ore dilutiore. Thorax apice coleopterorum latitudine vel iis paululum latior, basin versus leviter angustatus, latitudine antica parum longior, basi cum angulis posterioribus fortiter rotundatus, apice utrinque oblique truncatus, angulis anterioribus prominulis, depressus, dorso biseriatim, versus latera parce disperse j unctatus, interstitiiz subtilissime parce punctulatis, lateribus parce pilosellus, saturate rufo-piceus, nitidus. Scutellum saturate rufo-piceum, laeve. Elytra thoracis longitudine, crebre inaequaliter minus subtiliter punctata, subrugosa, longius griseo-pilosa, rufo-picea, nitida. Abdomen apicem versus sensim leviter dilatatum, confertim minus subtiliter punctatum, griseo-pube. scens, minus nitidum, nigrum, segmentis 4 primis margine apicali tenui piceo-testaceo, quinto apice, sexto septimoque totis rufo-piceis. Pectus nigrum. Pedes dilute testacei, tibiis basi obscurioribus.

Obs. Ab A. striato differt colore, capite thoraceque minus crebre punctatis, ab A. humili statura maiore, capite basi profundius emarginato, abdomine minus subtiliter punctato, ab utroque elytris brevioribus, fortius et inaequaliter punctatis, subrugosis.

10. A. tenellum: Nigro-piceum, nitidum, ore, antennis, pedibus elytrisque testaceis, his thoracis longitudine, parce subtiliterque punclatis, capile parcius puncluto. - Long. 2 lin.

Habitat in Sardinia, Mus. Reg. Taurin.

Minutum, A. humili plus duplo minus, angustulum, valde depressum, piceo-nigrum, nitidum. Antennae capite thoraceque paulo longiores, testaceae. Caput basi thorace paululum latius, subcordatum, basi subemarginatum, lateribus pone oculos leviter rotundatum, apice sat fortiter angustatum, planum, sat fortiter profundeque disperse punctatum, fronte media laeviore, interstitiis laevissimis, tenuiter pubescens, lateribus longius pilosellum, ore testaceo. Thorax oblongus, apice coleopterorum basi latitudine aequalis, basin versus leviter angustatus, latitudine longior, basi apiceque truncatus, angulis posterioribus fortiter rotundatis, anterioribus obtusiusculis, modice prominulis, dorso biseriatim, utrinque parce subtiliusque disperse punctatus, tenuiter pilosellus. Elytra thoracis longitudine, apicen versus sensim paulo latiora, depressa, parce subtiliterque aequaliter punctata, tenuiter pilosella, nitida, luteo-testacea, basi prope scutellum picescentia. Abdomen apicem versus parum dilatatum, confertim subtiliter punctatum, densius griseo-pubescens, minus nitidum, nigrum, segmentis 5 primis margine apicali tenui testaceo, sexto apice septimoque toto piceis, subtus fere totum rufo-piceum. Pedes luteo - testacei. 


\section{Lathrobium Grav.}

Mannerh. Brachelytr. p. 37. - Curt. Britt. Ent. XIV. t. 650. - Steph. Illustr.

V. p. 265. - Boisd. et Lacord. Faun. Ent. Paris. I. p. 421.

Lathrobium Fam. IV. Grav. Mon. p. 130.

Labrum breve, bilobum.

Palpi maxillares articulo ultimo acuto.

Antennae reclae.

Tarsi articulo quarto simplice, posteriores articulis 4 primis aequalibus, ultimo his coniunctis breviore.

Corpus elongatum, lineare, plerumque alatum. Caput subquadratum, vel suborbiculatum, thoracis circiter latitudine, basi profunde constrictum, collo quasi brevi angusto thoraci immissum, exsertum, porrectum, oculis parvis rotnndatis, parum prominulis. Labrum transversum, bilobum, lobis divergentibus, totum corneum, apice setosum. Mandibulae falcatae, acutae, basi dilatatae, medio fortiter unidentatae. Maxillae (t. IV. f. 26. b.) malis coriaceis, interiore interne, exteriore apice dense barbatis. Palpi maxillares modice elongati, articulo primo minuto, secundo tertioque elongatis, hoc paulo longiore, apicem versus modice incrassato, quarto minuto, tenui, subulato. Labium (t. IV. f. 26. a.) mento brevi transverso, ligula membranea, biloba, lobis rotundatis, paraglossis acuminatis, membranaceis, ligulam paulum superantibus. Palpi labiales articulis duobus primis cylindricis, secundo paulo longiore, tertio secundo longitudine subaequali, at tenui, acuminato. Antennae filiformes, rectae, articulo primo reliquis paulo maiore, ultimo apice sensim acuminato. Thorax coleopterorum prope latitudine, saepius oblongus, basi apiceque truncatus, angulis omnibus rotundatis. Scutellum semicirculare. Elytra truncata, angulo exteriore rotundato. Abdomen lineare, apice angustatum, segmento septimo saepius conspicuo, stylis analibus valviformibus. Pedes breves, validi, antici incrassati, femoribus saepe subtus subdentatis, tibiis interne longitudinaliter excavatis, interne subdentatis, tibiis omnibus pubescentibus, posticis apice subcompressis, oblique truncatis, spinis apicalibus inaequalibus, altero sat distincto, altero minuto, tarsis anticis articulis 4 primis in patellam suborbicularem, subtus tomentosam dilatatis, posterioribus articulo primo secundo breviore, hoc subelongato, tertio quartoque brevibus, primo aequalibus, ultimo reliquis coniunctis breviore.

$$
\text { O b s e r va t i o n e s. }
$$

1. Corpus punctatum, punctis in capite et thorace saepius rarioribus, hoc nonnunquam dorso seriatis, pubescens, pube capitis thoracisque rariore, e punctis oriunda, erecta, brevissima, abdominis saepius densiore, depressa.

2. Mas abdominis segmento inferiore sexto inciso, praecedentibus saepius impressis, quinto nonnunquam apice sinuato, femina segmento inferiore sexto integro vel apice producto distinguuntur.

3. Victus sub musco, foliis deciduis et lapidibus in silvis paludosis.

* 1. L. brunnipes: Nigrum, nitidum, punctatum, thorace oblongo, elytris concoloribus, subtilius punctatis, antennis pedibusque mefis. - Long. 4 lin.

Grav. Micr. 56. 10. Mon. 131. 6. - Latr. Hist. nat. Crust. et Ins. IX. 340. 10. - Gyll. Ins. Suec. II. 366. 3. - Suhlb. Ins. Fenn. I. 338. 4. - Zetterst. Faun. Lappon. I. 83. 3. Ins. Lappon. 67. 3. - Mannerh. Brachelytr. 37. 6. - Boisd. 
et Lacord. Faun. Ent. Paris. 1. 422. 1. - Nordm. Symb. 141. 6. - Er. Col. March. I. 503. 1.

Paeder. brunnipes Fab. Ent. Syst. I. II. 537. 5. Syst. El. II. 609. 5. - Panz. Ent. Germ. 363. 6.

Paeder. elongatus var. c Payk. Faun. Suec. III. 429. 3.

Paeder. elongatus var. 1 Wallen. Faun. Paris. I. 275. 3.

Staph. dentatus Marsh. Ent. Britt. I. 515. 53.

Staph punctatus Fourcr. Ent. Par. I. 168. 14.

Le Staph. à pattes fuuves et à étuis pointillés Geoffr. Hist. Ins. I. 366. 14.

Habitat in Europa.

Statura et summa affinitas L. elongati, at plerumque paululum maius et robustius, nigrum, capite thoraceque pernitidis, pube parca brevi subtilique erecta grisea vestitis. Antennae capitss thoracisque longitudine, graciliores, articulo tertio secundo sesqui longiore, 4- 10 subaequalibus, elongato-obconicis, rufae. Palpi et labrum rufa. Mandibulae rufo-piceae. Caput thoracis prope latitudine, suborbiculatum, leviter convexum, crebre punctatum, punctis in media fronte paulo rarioribus. Thorax coleopteris vix angustior, latitudine tertia parte longior, lateribus rectis, parallelis, angulis ommibus subrotundatis, leviter convexus, crebre punctatus, linea media longitudinali laevi. Scutellum obsolete punctatum, tenuiter griseo-pubescens. Elytra thoracis longitudine, subtilius parciusque punctata, nitida, parcius subtiliter griseo-pubescentia. Abdomen omnium confertissime subtilissime punctatum, parum nitidum, pube subtili depressa densius vestitum, supra apice summo piceum, subtus apicem versus rufo-piceum. Pedes crassiusculı, rufo-testacei, coxis omnibus piceis.

Mas abdominis segmento inferiore quarto apicem versus obsolete impresso, quinto apice triangulariter impresso, sexto longitudinaliter impresso, apice utrinque sinuato, medio profunde inciso; femina eodem apice utrinque profundius sinuato, medio fortiter triangulariter producto.

* 2. L. elongatum: Nigrum, nitidum, punctatum, capite suborbiculato, thorace oblongo, elytris thorace longioribus, crebre punctatis, rufis, basi nigris, antennis pedibusque rufis. - Long. 4 lin.

Grav. Micr. 55. 8. Mon. 132. 2. - Latr. Hist. nat. Crust. et Ins. IX. 340. 8. Gen. Crust. et Ins. I. 289. 1. - Guér. lconogr. regn. an. Ins. t. 9. f. 4. Nordm. Symb. 141. 1. - Er. Col. March. I. 504. 2.

Staph. elongat us Linn. Syst. Nat. 1. II 685. 14. - Goeze Ent. Beitr. I. 719 14. - De Vill. Ent. I. 415. 14. - Schrank Enum. Ins. Austr. 232. 439. - Payk. Mon. Staph. 25. 17. - Marsh. Ent. Britt. 515. 52.

Paeder. elongatus Fab. Syst. Ent. 268. 2. Spec. Ins. I. 339. 3. Mant. Ins. I. 223. 3. Ent. Syst. I. II. 537. 3. Syst. El. II. 609. 3. - Walken. Faun. Paris. I. 275. 3. - Cederh. Faun. Ingr. 122. 374. - Payk. Faun. Suec, III. 428. 3. Panz. Faun. Germ. 9. 12. Ent. Germ. 362. 4. - Rossi Faun. Etr. Mant. I. 101. 224. Ed. Hellw. I. 446. 224. - Oliv. Encycl, meth. VIII. 628. 4.

St uph. variegatus Fourcr. Ent. Par. I. 172. 29.

Lathrob. elongatum Gyll. Ins. Suec. II. 363. 1. - Sahlb. Ins. Fenn. I. 337. 1. - Zetterst. Faun. Lappon. I. 81. I. Ins. Lappon. 67. 1. - Mannerh. Brachelytr. 37. 1. - Runde Brachelytr. Hal. 12. 1. (forte)

Habitat in Europa.

Corpus elongatum, lineare, nigrum, nitidum. Antennae capite thora- 
ceque breviores, crassiusculae, articulo secundo tertioque subaequalibns, 4-10 paulo minoribus, inter se iterum subaequalibus, obsconicis, rufae. Palpi et labrum rufa. Caput thoracis prope latitudine, suborbiculatum, supra leviter convexum, crebre punctatum, punctis in media fronte rarioriburs, parcius griseo-pubescens. Thorax coleopteris paulo angustior, latitudine tertia parte longior, lateribus rectis, parallelis, angulis omnibus rotundatis, supra leviter convexus, crebre punctatus, linea longitudinali laevi, parce subtiliterque griseo-pubescens. Scutellum obsoletius punctatum. Elytra thorace plerumque paulo longiora, dense punctata, tenuter griseo-pubescentia, vel rufa, basi nigra, vel nigra, apice rufa. Abdomen subtiliter confertissime punctatum, dense subtiliter griseo-pubescens, minus nitidum, apice piceum. Pedes testaceo - rufi, coxis piceis.

Mas abdominis segmento inferiore quinto leviter longitudinaliter impresso, sexto per totam longitudinem bicarinato, carinis parallelis, nigropubescentibus, interstitio anguste, impresso, apice triangulariter exciso; femin a eodem apice rotundato, medio leviter emarginato.

V ariat coleopteris thorace vel paulo longioribus, vel eidem longitudine aequalibus: specimina autem etiam coleopteris brevioribus alata occurrunt, in his autem, si mascula sunt, abdominis segmenti inferioris quinti structura minus quam in illis explicata, carinis et impressione longitudinali nec non sinubus apicalibus obsoletioribus, vel nonnunquam fere omnino obsoletis. Cave ne eiusmodi specimina pro specie peculiari habeas.

Obs. Abdominis segmentum sextum maris apud Gyllenh. 1. c. non bicarinatum sed "foveis duabus approximatis parallelis impressum" descriptum, nihilominus non ausim, insectum hocce pro alia quadam specie habere, cum fieri possit, errore quodam eius descriptionem turbatam esse, et iam minus quam olim (Col. March. 1. c.) hac de re dubito. Dom. Sahlberg et Zetterstedt forte bona fide diagnosi Gyllenhaliana usi sunt, et Dom. Runde eandem mutuavisse mihi persuasum, cum huncce auctorem maximam opusculi sui partem e Sahlbergio transscripsisse pateat.

* 3. L. fulvipenne: Nigrum, nitidum, punctalum, thorace oblongo, elytris thoracis longitudine, crebre punctatis, rufis, basi nigris, pedibus rufis. - Long. 4 lin.

Gyll. Ins. Suec. II. 365. 2. - Sahlb. Ins. Fenn. I. 338. 3.-Zetterst. Faun. Lapp. 1. 82. 2. Ins. Lappon. 67. 2. - Mannerh. Brachelytr. 37. 2. - Buisd. et Lacord. Faun. Ent. Paris. I. 424. 4. - Runde Brachelytr. Hal. 12. 3. - Nordm. Symb. 141. 2. - Er. Col. March. I. 505. 3.

Staph. fulvipennis Grav. Mon. 104. 106.

Lathrob. elongatum Boisd. et Lacord. Faun. Ent. Paris. I. 423.3.

Hahitat in Germania, Gallia.

L. elongato affine, angustius, nigrum, nitidum. Antennae vix capitis thoracisque longitudine, crassiusculae, articulo tertio secundo longıre, 4-10 sensim paulo brevioribus et paulo magis obconicis, rufae. Palpi et labrum rufo-picea. Mandibulae piceae. Caput thorace vix angustius, subovale, lateribus crebrius, fronte parcius punctatum. Thorax coleopteris parum angustior, latitudine sesqui longior, lateribus rectis, parallelis, angulis omnibus rotundatis, parcius griseo-pubescens, leviter convexus, sat fortiter crebre punctatus, linea media longitudinali laevi, subtiliter griseo-pubescens. Scutellum obsoletius punctatum. Elytra thoracis vix longitudine, sat crebre aequaliter punctata, rufa, summa basi nigra. Abdomen subtiliter confertim 
punctulatum, nitidulum, pube depressa grisea densius vestitum, summo apice piceo. Pedes crassi, rufo-testacei, coxis piceis.

Mas abdominis segmento inferiore sexto apice leviter triangulariter exciso, femin a eodem rotundato, integro.

Variat 1, Alatum, coleopteris thorace paululum longioribus, laete rubris.

2, Apterum, coleopteris thoracis longitudine vel eodem magis minusve brevioribus, rufo-piceis vel castaneis.

Obs. 1. Affine praecedenti, habitu graciliore, capite thoraceque magis oblongis saepius aegre distinguendum, constanter autem differt abdominis segmento inferiore in mare aequali, apice rotundato, medio profunde inciso, in femina apice rotundato, nullo modo emarginato. Utraque varietas abdominis structura convenit, neque praeter alarum defectum et elytrorum longitudinem, ab hoc dependentem, ullam differentiam video.

2. Nomen specificum fortuito idem huic speciei Gravenhorst et Gyllenhal imposuerunt. Paederum fulvipennem Fabr., a Gyllenhalio allatum, p. 295 descripsi.

4. L. rufipenne: Nigrum, nilidum, punclalum, capite thoraceque oblongis, elytris thorace longioribus, crebre punctatis, rufis, basi nigris, antennis pedibusque rufis. - Long. $3 \frac{1}{3}$ lin.

Gyll. Ins. Suec. III. 704. 1 - 2. - Sahlb. Ins. Fenn. I. 337. 2. - Mannerh. Brachelytr. 37. 3. - Nordm. Symb. 141. 3. - Er. Col. March. 1. 505. 4.

Habitat in Suecia et Germania septentrionali, Dom. Schüppel.

Praecedentibus affine, L. elongato habitu proximum, at dimidio minus, nigrum, nitidum. Antennae capite sesqui longiores, crassiusculae, articulo secundo tertioque subaequalibus, $4-10$ obconicis, inter se aequalibus, rufae. Palpi rufi. Mandibulae et labrum rufo-picea. Caput thoracis latitudine, leviter oblongum, supra leviter convexum, creberrime sat fortiter profundeque punctatum, fronte media vix laeviore, minus nitidum, tenuiter griseo-pubescens. Thorax coleopteris paulo angustior, latitudme sesqui longior, lateribus rectis, parallelis, angulis anterioribus minus, posterioribus fortius rotundatis, leviter convexus, creberrime fortius punctatus, linea media longitudinali laevissima, tenuiter griseo-pubescens. Scutellum obsolete parum-punctatum. Coleoptera thorace paulo longiora, minus dense subtilius punctata, griseo-pubescentia, nitida, rufa, basi tertia parte nigra. Abdomen confertissime subtiliter punctatum, pube breviuscula depressa grisea densius vestitum, apice summo piceo. Pedes ruf, coxis omnibus nigris.

Mas abdominis segmento quinto sextoque leviter longitudinaliter inpressis, hoc apice leviter triangulariter exciso, femina eodem acute rotundato.

Obs. L. punctulatum Mannerh. Brachelytr. 37. 4. Nordm. Symb. 141. 4. forte potius ad hane speciem pertinet: descriptio enim optime quadrat, si supponere licet, pro L. rufipenni enumeratam quandam L. fulvipennis varietatem esse.

* 5. L. multipunctum: Piceum, nitidum, capite thoraceque oblongo fortiter punctatis, elytris profunde seriatim punctalis, rufo-teslaceis, basi piceis, pedibus testaceis. - Long. $3-3 \frac{1}{2}$ lin.

Grav. Micr. 52. 2. Mon. 131. 11. - Latr. Hist. nat. Crust. et Ins. 1X. 338. 2. Gyll. Ins. Suec. III. 705. 3-4. - Mannerh. Brachelytr. 37. 5. - Boisd. ot 
Lacord. Faun. Ent. Paris. I. 423. 2. - Nordm. Symb. 141. 5. - Er. Col. March. I. 506. 5.

Lat hrob, line are Grav. Micr. 54. 6. Mon. 132. 13. - Latr. Hist. nat. Crust. et Ins. IX. 340. 7.

Var. Rufo-testaceum, abdomine piceo, elytris anogue testaceis.

Paederus testaceus Oliv. Ent. III. 44. 5. 3. t. 1. f. 6. Encycl. meth. VIII. 628.5.

Habitat in Europa.

Statura omnino praecedentium, at minus et gracilius, vel nigro-piceum, vel castaneum, vel rufo-testaceum, abdomine obscuriore. Antennae capite thoraceque longe breviores, minus graciles, articulo tertio secundo paulo longiore, 4- 10 sensim paulo brevioribus, rufae. Palpi rufi. Caput thorace paulo latius, subovatum, supra leviter convexum, crebre fortiter punctatum, punctis in fronte media parcioribus. Thorax coleopteris paulo angustior, latitudine plus sesqui longior, lateribus rectis, parallelis, angulis omnibus late rotundatis, leviter convexus, crebre profundeque punctatus, linea media longitudinali laevi, parce subtiliterque nigro-pubescens. Scutellum laeve. Elytra thorace vix longiora, anterius ultra medium confertim profunde seriatim, dein parcius et minus fortiter punctata, rufa- vel rufotestacea, basi saepe picea. Abdomen confertim subtilius punctatum, densius subtiliter griseo-pubescens, nigro-piceum, vel piceum, apice rufo-piceum, vel rufo-testaceum. Pedes testacei, coxis omnibus femoribusque anticis rufo-testaceis.

Mas abdominis segmento inferiore quinto fovea lata, antice tuberculis duobus rotundatis approximatis minutis at sat prominulis terminata impresso, sexto profunde inciso; femina eodem apice rotundato.

V a riat colore dilutiore capite, thoraceque rufo-castaneis, abdomine piceo, ano elytrisque testaceis, vel totus dilute testaceus, elytris anoque pallidioribus.

* 6. L. spadiceum: Rufo-piceum, subtilius punctatum, thorace oblongo, basin versus subangustato, abdominis segmentorum marginibus-ano pedibusque rufo-testaceis. - Long. 4 lin. Waltl.

Habitat in Austriae alpibus, Dom. Schïppel, in Bavaria meridionali, Dom.

L. elongato magnitudine aequale vel parum maius, paulo magis depressum, rufo-piceum, capite thoraceque nitidis. Antennae capitis thoracisque longitudine, minus tenues, articulo tertio secundo sesqui longiore, 4-10 sensim paulo brevioribus, elongato-obconicis, rufae. Palpi rufi. Caput thorace paulo latius, lateribus rotundatum, antice angustatum, parum convexum, subtilius crebre punctatum, magis fusco--piceum, subtiliter tenuiterque griseo-pubescens. Thorax coleopteris paulo angustior, latitudine sesqui longior, basin versus subangustatus, lateribus rectis, angulis anterioribus late, posterioribus leviter rotundatıs, subdepressus, crebre minus fortiter punctatus, linea longitudinali media laevi, parce subtiliterque pube breviore grisea obsitus. Scutellum parce obsoleteque punctatum. Elytra thorace vix longiora, subtilius aequaliter punctata, griseo-pubescentia, opaca. Abdomen dense subtilissime punctatum, pube brevi depressa grisea densiore obductum, opacum, rufo-piceum, segmentorum marginibus anoque rufotestaceis. Pedes graciliores cum coxis anterioribus rufo-testacei. 
Mas abdominis segmentis inferioribus $3-5$ leviter at sensim paulo magis impressis, sexto obsoletius canalieulato, apice fortius triangulariter exciso: femina eodem obsolete longitudinaliter bi-impresso, apice obtuse rotundato.

* 7. L. angusticolle: Subdepressum, nigrum, nitidum, sublilius punctatum, thorace obsolete bisulcato, elylris rufis, basi nigris. - Long. $3 \frac{1}{2}$ lin.

Boisd. et Lacord. Faun. Ent. Paris. I. 425. 6.

Habitat in Hungaria et Styriae alpibus, Dom. Schüppel, in Bavaria superiore, Dr. Waltl.

Habitu fere L. quadrati, at subdepressum, elongatum, gracile, nigrum, nitidum. Antennae capite thoraceque paulo longıres, graciles, articulo tertio secundo sesqui longiore, $4-10$ aequalibus, sat elongatis, teretibus, rufo-piceae, articulo orimo nigno-piceo. Palpi rufo-picei. Caput thorace paulo latius, suborbiculatum, subdepressum, creberrime subtilius punctatum, fronte media laeviore. Thorax coleopteris dimidio angustior, latitudine dimidio longior, basin versus subangustatus, lateribus subrectis, antice cum angulis anterioribus late rotundatis, angulis posterioribus leviter rotundatis, subdepresssus, crebre subtilius punctatus, postice obsolete late bisulcatus, sulcis densius punctatis, linea longitudinali media subelevata laevi. Scutellum laeve. Elytra thorace tertia parte longiora, depressa, subtilius dense, basi subseriatim, praeterea aequaliter punctata, rufa, basi parte tertia nigra, subtiliter tenuterque griseo-pubescentia. Abdomen dense subtiliter pnnctatum, pube subtili depressa grisea densius obductum. Pedes graciliores, nigri, tarsis rufo-piceis.

Mas abdominis segmento inferiore quinto apice late leviter sinuato, sexto bicarinato, apise inter carinas leviter triangulariter exciso; femina eodem apice rotundato.

* 8. L. bicolor: Elongalum, depressum, subtilius punctatum, teslaceum, nitidum, elytrorum basi abdomineque fuscescentibus, thorace angusto, obsolete bisulcalo. - Long. 3 lin.

Habitat in Carniolia (Dahl), Dom. Schïppel.

Habitu omnino praecedentis, at dimidio minus, gracile, depressum, rufotestaceum, capite, thorace elytrisque nitidis. Antennae capite thoraceque multo longiores, minus tenues, articulo tertio sectindo sesqui prope longiore, 4-10 sensim paulo brevioribus, elongato-subobconicis. Caput thorace sesqui prope latius, lateribus rotundatum, antrorsum angustatum, depressum, versus latera creberrime, disco inaequaliter parcius punctatum, subtiliter griseo-pubescens, lateribus parce nigro-pilosellum. Thorax coleopteris dimidio angustior, latitudine plus sesqui longior, basin versus subangustatus, lateribus subrectis, antice cum angulis anterioribus late rotundatis, angulis posterioribus leviter rotundatis, depressus, sat crebre subtiliter punctatus, linea media subelevata laevissima, sulco longitudinali obsoletissimo densius punctato utrinque terminata. Scutellum laeve. Elytra thorace vix longiora, depressa, dense subtilius, anterius subseriatim, praeterea aequaliter punctata, densius subtiliter griseo-pubescentia, basi fuscescentia. Abdomen confertissime subtiliter punctatum, vix nitıdum, pube brevi subtili de- 
pressa grisea densiore obductum, fusco-testacenm, apice testaceum. Pectus fusco-testaceum. Pedes graciliores, cum coxis rufo-testacei.

Mas abdominis segmento inferiore quinto medio obsolete impresso, apice late leviter emarginato, sexto longitudinaliter impresso, apice leviter triangulariter exciso; femin a eodem apice rotundato.

* 9. I. picipes: Depressum, piceum, parum nitidum, subtilius punctatum, thorace angusto, obsolete bisulcato. - Long. $2 \frac{1}{2}$ lin.

Habitat in Austria, Dom. Ultrich, in Bavaria superiore, Dom. Waltl, Tergesti ad littora maris (Dahl), Dom. Schïppel.

Statura omnino et summa affinitas praecedentis, at dimidio minus, depressum, nigro - vel brunneo-piceum, parnm nitidum, subtiliter griseo-pubescens. Antennae capite thoraceque longiores, minus tenues, articulo tertio secundo parum longiore, 4-10 subaequalibus, elongato-subobconicis, dilute rufo-piceae. Palpi et labrum rufa. Caput thorace plus sesqui latius, suborbiculatum, ore angustato, depressum, confertim subtilus punctatum. Thorax coleopteris duplo fere angustior, latitudine plus sesqui. longior, hasin versus vix angustatus, lateribus subrectis, antice cum angulis anterioribus late rotundatis, angulis posterioribus modice rotundatis, depressus, creberrime subtilius punctatus, medio obsolete bisulcatus, linea media longitudinali subelerata laevissimá. Scutellum parce punctulatum. Elytra thorace longiora, creberrime subtilius punctata, brunneo-picea, basi nigro-picea. Abdomen elytris angustius, subtiliter creberrime punctatum, nigrum, apice piceum. Pedes graciliores, picei, tarsis dilutioribus.

Mas abdominis segmento inferiore quarto leviter, quinto fortius longitudinaliter impressis, sexto bicarinato, inter carinas late canaliculato, et apice emarginato; femina eodem apice rotundato.

Variat elytris dilutius rufo-piceis, basi nigricantibus.

Obs. Praecedenti proximum, distinctum autem statura minore, colore, elytris paulo longioribus, capite crebrius punctato.

10. L. labile: Elongalum, subdepressum, nigrum, antennis, tibiis tarsisque rnfo-piceis, thorace oblongo, dorso biseriatim punctalo, elylris strialopunctatis, apice rufo-teslaceis. - Long. $1 \frac{2}{3}$ lin.

Habitat in Sardinia, Mus. Reg. Taurin.

Habitu omnino praecedentis, at multo minus, L. longulo aequale, elongatum, subdepressum, nigrum, nitidulum. Antennae capitis thoracisque prope longitudine, articulis $3 \mathbf{- 1 0}$ subobconicis, sensim paulo brevioribus, ultimo praecedente sesqui longiore, subcylindrico, apice abrupte acmminato, rufo-piceae. Caput thorace paulo latius, oblongum, latitudine plus sesqui longius, antrorsum subangustatum, supra perparum convexum, sat crebre profundeque punctatum, linea tenui longitudinali media laevi, pube brevi erecta grisea tenuiter vestitum, oris partibus piceis. Thorax coleopteris dimidio prope angustior, latitudine duplo fere longior, lateribus parallelis, angulis anteriorilus fortiter rotundatis, parum convexus, dorso biseriatim per totam longitıdinem punctatis, seriebus regularibus, crebre punctatis, basin versus sulculi instar leviter impressis, utrinque minus regulariter plagiatim punctatus, interstitio inter series dorsales laevissimo, pube brevi erecta nigra pare 
vestitus. Elytra thorace longiora, subdepressa, striis crebre fortiterqne punctatis, apice evanescentibus, confertis obsita, pube brevi erecta nigra tenuiter vestita, apice laete rufo-testacea. Abdomen minus confertim subtiliter punctatum, pube depressa grisea tenuiore vestitum, apice piceum. Pedes picei, tibiis tarsisque rufo-piceis, tarsis posticis articulo primo leviter elongato.

*11. L. quadratum: Nigrum, nitidum, punclatum, thorace subquadrato.

Gyll. Ins. Suec. II. 367. 4. - Sahlb. Ins. Fenn. 1. 339. 5. - Zetterst. Faun.

Lappon. I. 83. 4. Ins. Lappon. 67. 4. - Er. Col. March. J. 507. 6.

Staph. quadratus Payk. Mon. Staph. 29. 21. - Marsh. Ent. Britt. 517. 58.

Paed. filiformis Payk. Faun. Suec. III. 429. 4.

Var. a: Elytris immaculatis, antennis pedibusque piceis, his rarius testaceis. - Long. 3 - $3 \frac{1}{2}$ lin.

Lathrob. pilosum Grav. Micr. 56. 9. Mon. 131. 7. - Latr. Hist. nat. Crust. et Ins. IX. 340. 9. - Boisd. et Lacord. Faun. Ent. Paris. I. 426. 9.

Paed. filiformis Fab. Ent. Syst. 1. 1I. 538. 8. Syst. E1. II. 609. 8. - Panz. Ent. Germ. 363. 9.

Lathr. quadratum Mannerh. Brachelytr. 38. 9. - Runde Brachelytr. Ilal. 12. 5. - Nordm. Symb. 146. 16.

Var, b: Elytris macula apicali rufo-testacea, antennarum basi apiceque pedebusque testaceis. - Long. 3 lin.

Lathrob. terminatum Grav. Micr. 55. 7. Mon. 134. 17. - Latr. Hist. nat. Crust. et Ins. IX. 339. 6. - Mannerh. Brachelytr. 38. 10. - Curtis Britt. Ent. XIV t. 650. - Runde Brachelytr. Hal. 13. 6. - Nordm. Symb. 146. 17.

Habitat in Europa.

Corpus nigrum, nitidum, abdomine opaco. Antennae capitis thoracisque longitudine, articulo tertio secundo paulo longiore, 4-10 subaeyualibus, elongato-subobconicis, piceae aut testaceae, medio obscuriores. Palpi et os rufo-picea. Caput thorace angustums et multo minus, suborbiculatum, subdepressum, confertim subtiliter punctatum, fronte media parcius punctata, subtiliter griseo-pubescens, lateribus nigro-pilosellum. Thorax coleopteris patlo angustior, latitudine hand longior, quadratus, angulis omnibụs leviter rotundatis, parum convexus, confertim lateribus subtiliter, dorso fortius punctatıs, linea media longitudinali laevi parum distincta, subtiliter tenuiterque griseo-pubescens. Scutellum subtiliter punctulatum. Elytra thorace paulo longiora, subtilius dense punctata, tenuiter pubescentia, in varietate altera immaculata, in altera macula apicali exteriore rotundata rufo-testacea notata. Abdomen breviusculum, coleopteris paulo angustius, apice attenuatum, stylis analibus longius exsertis, omnium subtilissime confertissimeque punctulatum, pube tenussima grisea sericeum. Pedes crassiusculi, in varietate altera saepius piceo-testacei, in altera semper testacei, coxis in utraque piceis.

Mas abdominis segmento inferiore quarto quintoque obsolete canaliculatis, sexto profunde inciso; femina eodem apice fortuter triangulariter producto.

Obs. Paederum filiformem Fab. ad hanc speciem referendam esse, et ex citato Paykulo, et ex ipsa collectione auctoris patet, quamvis descriptio magis Cryptobio fracticorni congruere videtur, cui autem neque antennae neque pedes picei sunt. Nomen primum nihilominus praevaleat. 
* 12. L. scutellare: Nigrum, nitidum, punctatum, capite parcius punctato, thorace subquadrato, elyiris rufis, circa scutellum nigricantibus, pedibus testaceis. - Long. $2 \frac{2}{3}$ lin.

Nordm. Symb. 143. 10.

Habitat in Austria.

L. quadrato paulo minus et angustius, L. punctato aequale, nigrum, nitidum. Antennae capitis thoracisque fere longitudine, articulo tertio secundo sesqui prope longiore, $\mathbf{4} \mathbf{- 1 0}$ elongato-subobconicis, subaequalibus, rufo-piceae, medio obscuriores. Palpi rufo-testacei, maxillares articulo tertio piceo. Caput thorace angustius, suborbiculatum, parcius punctatum, media fronte sublaevi, subtiliter griseo-pubescens, parce nigro-pilosellum. Thorax coleopteris parum angustior, latitudine paululum longior, lateribus rectis, parallelis, angulis anterioribus leviter, posterioribus fortius rotundatis, leviter convexus, crebre punctatus, linea media longitudinali laevi, tenuiter subtiliterque griseo-pubescens. Scutellum sublaeve. Elytra thorace vix longiora, sat crebre punctata, laete rufa, circa scutellum nigricantia, subtiliter griseo-pubescentia. Abdomen subtilissime confertim punctatum, pube densiore subtili sericea grisea vestitum, opacum. Pedes testacei, coxıs omnibus nigris.

Mas abdominis segmento inferiore sexto leviter longitudinaliter im. presso, apice leviter emarginato; femina eodem apice acute rotundato.

13. L. angustatum: Nigrum, nitidum, punctalum, capite confertissime subtiliter punctato, thorace subquadrato, elytris rufis, basi nigris, pedibus testaceis. - Long. $2 \frac{2}{3}$ lin.

Boisd. et Lacord. Faun. Ent. Paris. I. 424. 5.

Habitat Lutetiae, Mus. Dom. Aubé.

Statura fere L. pilosi, at paululum angustius, et minoribus eius individuis aequale, nigrum, nitidum. Antennae capitis thoracisque longitudine, rufo-testaceae. Os rufo-testaceum. Caput thorace paululum angustius, subovatum, confertissime subtiliter punctatum, fronte media spatio angusto longitudinali laevi, tenuiter griseo-pubescens. Thorax coleopterorum prope latitudine, latıtudine paululum longior, leviter convexus, crebre• punctatus, linea media longitudinali laevi. Scutellum sublaeve. Elytra thorace paululum longiora, sat crebre profundeque punctata, tenuiter griseo-pubescentia, rufa, nitida, basi (parte elytrorum quarta) nigra. Abdomen confertim subtilissime punctatum, minus nitidum, densius griseo-pubescens. Pedes testacei, coxis anterioribus concoloribus, licet saturatioribus.

$\mathrm{Obs}$. L. scutellari adeo simile, ut praeter capitis puncturam vix distinguatur.

14. I. pectorale: Subdepressum, nigrum, ore, antennis, elytris, pectore anoque rufis, pedibus testaceis, capite parcius, thorace utrinque cre. brius punctato. - Long. 3 lin.

Ilabitat in Americae meridionalis ins. St. Thomae, Dom. Moritz.

Statura omnino L. filiformis, at paulo robustius et magis depressum. Antennae capite thoraceque paulo breviores, articulo tertio secundo paulo longiore, 4 - 10 sensim paulo brevioribus, leviter obconicis, rufo-testaceae. 
Palpi rufo-testacei. Os rufum. Caput thoracis latitudine, subquadratum, depressiusculum, nigro-piceum, nitidum, lateribus crebrius punctatum, densius pilosum, fronte laevi, punctis raris sparsis notata, subtus rufo-piceum. Thorax coleopteris parum angustior, latitudine paulo longior, basin versus subangustatus, lateribus rectis, angulis anterioribus obtusiusculis, posterioribus rotundatis, subdepressus, lateribus crebre punctatus, plaga media longitudinali laevi, supra nigro-piceus, nitidus, subtiliter nigro-puberulus, subtus piceo-rufus. Scutellum laeve, piceum. Elytra thorace paulo longiora, crebrius minus fortiter, anterius subseriatim punctata, rufa, subnitida, griseopubescentia. Abdomen subtilissime punctulatum, griseo-pubescens, nigropiceum, parum nitidum, segmento ultimo toto, reliquis margine rufis. Pectus rufum. Pedes breves, crassiusculi, testacei, coxis rufis.

$\mathrm{M}$ as abdominis segmento inferiore quinto apice late leviter emarginato, sexto profunde triangulariter exciso. F e min a latet.

* 15. L. Lu sitanicum: Subdepressum, nigrum, capite thoraceque oblongo, dorso biserialim punclato, parce punctatis, pernilidis, elytris subseriatim punclatis anogue rufis, pedibus testaceis. - Long. $3 \frac{1}{2}$ lin.

Lathrob. longiusculum Lusitanicum Grav. Micr. 181. 4.

Habitat in Lusitania.

L. quadrato aequale, at magis depressum, nigrum, opacum, capite thoraceque pernitidis. Antennae capite thoraceque paulo longiores, apice subattenuatae, graciliores, articulo tęrtio secundo paulo longiore, $4-10$ sensim paulo brevioribus, teretibus, penultimis leviter obconicis, rufo-testaceae. Palpi et labrum rufo-testacea. Caput thorace angustius et duplo fere minus, subovatum, depressiusculum, punctis raris sparsis impressum, lateribus longe nigro-pilosum. Thorax coleopteris paulo angustior, latitudine sesqui prope longior, basin versus vix angustatus, angulis anterioribus parum, posterioribus leviter rotundatis, subdepressus, dorso biseriatim, lateribus disperse parceque punctatus. Scutellum laeve. Elytra thorace paulo longiora, minus dense subtilius, dorso biseriatim, lateribus apiceque disperse punctata, rufa, nitida, parcius griseo-pubescentia. Abdomen minus elongatum, apice attenuatum, subtiliter confertissime punctatum, pube depressa grisea densius vestitum, opacum, segmentis quatuor primis margine summo, ultimis duobus totis rufis. Pedes cum coxis anterioribus rufo-testacei. latet.

Mas abdominis segmento inferiore sexto profunde inciso. Femina

Obs. A L. longiusculo Americano abunde distinctum.

* 16. L. longiusculum: Subdepressum, nigrum, nitidum, capite thoraceque oblongo, dorso biseriatim punclato, disperse punctatis, elytris seriatim punctatis pedibusque rufis, - Long. 5 lin.

Grav. Micr. 181. 4. Mon. 131. 9. - Nordm. Symb. 144. 14.

Var. Corpore toto rufo-testaceo.

L athr. politum Grav. Micr. 18̈0. 3. Mon. 131. 10.

Lathr. castane um Grav. Micr. 52. 1. Mon. 131. 10. - Latr. Hist. nat. Crust. et Ins. IX. 338. 1.

Habitat in America septentrionali. 
L. punctato aequale, at paulo magis depressum, nigro-piceum, nitidum, capite thoraceque nitidissimis. Antennae vix capitis thoracisque longitudine, articulo tertio secundo parum longiore, 4 - I0 sensim paulo brevioribus, rufo-testaceae. Palpi rufo-testacei. Os rufo-piceum. Caput thoracis prope latitudine, suborbiculatum, subdepressum, punctis raris sparsis impressum, lateribus parce pilosellum. Thorax coleopteris parum angustior, latitudine paulo longior, lateribus rectis, parallelis, angulis anterioribus leviter, posterioribus foriter rotundatis, subdepressus, dorso irregulariter biseriatim, lateribus disperse parcius punctarus, glaber. Scutellum piceum, laeve. Elytra thoracis longitudine, parcius leviterque dorso seriatim, lateribus et apice disperse punctata, parce griseo-pubescentia, nitida, rufa, basi picescentia Abdomen minus dense subtiliter punctulatum, parce subtiliterque griseopubescens, nitidum, segmentis omnibus margine apicali rufo-piceo. Pedes cum coxis rufo-testacei.

Mas abdominis segmento inferiore sexto apicem versus triangulariter impresso, apice intra impressionem triangulariter exciso; femin a eodem apice triangulariter producto.

Obs. L. politum Grav. nonnisi colore corporis rufo-testaceo differt, forte immaturum. - L. cast a n e um haud distinctum videtur, forte errore quodem inter Brunsvicensia cum L. ba dio allatum.

17. L. discolor: Supra nigro-piceum, nitidum, corpore subtus, antennis pedibusque rufis, capite thoraceque oblongo, dorso biseriatim punctato, disperse punclatis, elytris subseriatim punclatis. - Long. 3 lin.

Habitat in Americae meridionalis ins. St. Thomae, Dom. Moritz.

Statura onmino L. longiuscuii. Antennae capite thoraceque paulo breviores, crassiusculae, articulo tertio secundo paulo longiore, $4-10$ sensim paulo brevioribus, leviter obconicı, rufo-testaceae. Palpi rufo-testacei. Os rufo-piceum. Caput thoracis latitudine, subdepressum, disperse sat profunde punctatum, punctis lateribus et basi crebrioribus, in fronte raris, supra nigro--piceum, nitidum, parce nigro-pilosellum, subtus piceo-rufum. Thorax coleopteris paululum angustior, latitudine paulo longior, basin ver-. sus subangustatus, lateribus rectis, angulis anterioribus obtusis, posterioribus leviter rotundatis, parum convexus, crehrius punctatus, punctis lateribus vagis, dorso in series duas longitudiuales irregulares, saepius duplicatas digestis, spatio interiecto laevissimo, supra nigro-piceus, nitidus, glaber, subtus rufo-picens. Scutellum piceum, laeve. Elytra thorace vix longiora, minus dense, dorso subseriatim, lateribus et apice vage punctata, parce griseopubescentia, nigro-picea, nitida, margine apicali obsolete rufescente. Abdo- men subtiliter punctulatum, pube densiore depressa grisea vestitum, minus uitidum, supra piceum, apice segmentorumque singulorum marginibus, rufis, subtus cum pectore rufo-piccum. Y'edes rufo-testacei.

Mas abdominis segmento inferiore sexto profunde inciso, quinto foveola oblonga, ovata, narginibus carinatis inclusa, notato. Fe mina latet.

* 18. L. dimidiatum: Lineare, nigrum, nilidum, elylris apice thoraceque mufis, antennis pedibusque testaceis, capile subovalo, parce punctato, thorace oblongo, dorso biseriatim punctato. - Long. 2 lin.

Say Transact. Amer. Philusoph. Soc. Philudeljh. Nov. Ser. IV. 455. 5. 
Habitat in Carolina meridionali, Dom. Zimmrermann.

Statura et summa affinitas sequentis. Antennae capite thoraceque paulo breviores, articulo tertio secundo vix longiore, $4-10$ sensim paulo brevioribus, rufo-testaceae, medio picescentes. Os rufo-testaceum. Caput thoracis latitudine, subovatum, depressiusculum, parce punctatum, fronte media sublaevi, parce pilosum, nigrum, nitidum. Thorax còleopteris paulo angustior, latitudine paulo longior, basin versus vix angustatus, lateribus subrectis, angulis posterioribus rotundatis, anterioribus obtusiusculis, subdepressus, dorso punctorum seriebus duabus, e punctis 7 vel 8 compositis, posterjus subimpressis, lateribus punctis parcis minus subtilibus notatus, rufus, nitidus. Scutellum laeve, nigro-piceum. Elytra thorace paulo longiora, stria suturali impressa et dorso seriebus punctorum duabus sat regularibus, postice evanescentibus notata, lateribus parce subtiliter punctata, nitida, nigra, apice dimidiato rufa. Abdomen subtiliter punctulatum et subtiliter griseopubescens, nigrum, nitidum, segmentis 4 prinis apice tenuiter testaceo-marginatis, quinto apice, sexto toto testaceo. Pectus nigrum. Pedes pallide testacei.

Abdominis segmentum inferius sextum feminae apice rotundatum. Mas latet.

Obs. Differt a L nitido capitè minus quadrato, thoracis seriebus dorsalibus e punctis paucis compositis, punctis quoque lateralibus parcioribus.

* 19. L. nitidum: Lineare, nigrum, nitidum, thorace, elytris apice, antennis pedibusque rufo-testaceis, cupile subquadrato, parce punctalo, thorace oblongo, dorso biserialim punctalo. - Long.' $2 \frac{1}{3}$ lin.

Habitat in Columbia, Dom. Moritz.

Habitu fere Lithocharidis melanocephalae, at duplo maius et huius generis. Antennae capitis thoracisque prope longitudine, crassiusculae, articulo tertio secundo paulo longiore, $\mathbf{1}-\mathbf{1 0}$ sensim paulo brevioribus, leviter abconicis, rufo-testaceae. Os rufo-testaceum, mandibulis piceis. Caput thoracis latitudine, subquadratum, supra depressiusculum, subtilius parce punctatum, fronte sublaevi, lateribus subtiliter pubescens, nigrum, nitidum. Thorax coleopteris paulo angustior, latitudine paulo longior, basin versus subangustatus, lateribus rectis, angulis anterioribus leviter, posterioribus fortius rotnndatis, dorso punctorum seriebus duabus minus regularibus multipunctatis, utrinque punctorum plaga irregulari notatus, rufus, nitidus. Scutellum laeve. Elytra thorace paulo longiora, stria suturali impressa, seriebus nonnullis punctorum subtilium obsoletorumque, ultra medium evanescentibus notata, glabra, nitida, nigra, apice late laete rufo-testacea. Abdomen dense subtiliter punctatum, densius subtiliter cinereo-pubescens, nigrum, segmentorum marginibus apicalibus rufo-piceis. Pectus rufo-piceum. Pedes dilute testacei.

Mas abdominis segmento inferiore quinto apice leviter emarginato, sexto leviter triangulariter exciso; f emin a eodem apice rotundato.

Variat thorace piceo.

* 20. L. collare: Lineare, nigrum, nitidum, antennis, pedibus anoque rufotestaceis, thorace rufo, elytrisque subseriatim punclatis. - Long. $2_{3}^{2}$ lin.

Habitat in America septentrionali, Dom. Prof. Germar. 
Habitus et summa affinitas praecedentis, at sesqui maius. Antennae capitis thoracisque prope longitudine, minus tenues, articulo tertio secundo paulo longiore, sequentibus sensim paulo brevioribus, leviter obconicis, rufotestaceae. Os rufo-testaceum. Caput thorace paulo angustius, suborbiculatum, perparum convexum, parce sparsim punctatum, lateribus nigro-pilosellum, nigerrimum, pernitidum. Thorax coleopteris paulo angustior, latitudine paulo longior, lateribus rectis, angulis anterioribus leviter, posterioribus fortius rotundatis, leviter convexus, lateribus parcius disperse, dorso crebrius subseriatim punctatis, spatio medio longitudinali laevi, utrinque punctorum numerosorum serie sat regulari terminato, laete rufus, pernitidus, pilis parcis minutis erectis e punctis oriundis vestitus. Scutellum nigro-piceum, laeve. Elytra thorace tertia parte longiora, dorso sat regulariter seriatim punctata, seriebus 5, ante apicem evanescentibus, interstitiis laevissimis, lateribus et apice parce subtiliterque disperse punctata, nigra, nitida, callo humerali et margine apicali picescentibus. Abdomen subtilissime punctulatum, pube brevi depressa grisea densius vestitum, nigrum, segmentis 4 primis margine, quinto apice, sexto toto rufo-testaceis. Pectus nigrum. Pedes cum coxis testacei.

Mas latet. Femina abdominis segmento inferiore sexto apice leviter producto, acute rotundato.

Variat elytris rufo-piceis, disco picescentibus.

* 21. L. punctatum: Lineare, nigrum, nitidum, antennis pedibusque rufopiceis, capite parce punclato, thorace subquadrato elytrisque thoracis longitudine crebrius punctatis. - Long. 3 lin.

Zetlerst. Faun. Lappon. I. 81 5. Ins. Lappon. 68. 5. - Sahlb. Ins. Fenn. I. 340. 6. - Nordm. Symb. 141. 7. - Er. Col. March. I. 508. 7.

Lathrob. lineare Boisd. et Lacord. Faun. Ent. Paris. I. 426. 8.

Habitat in Germania.

L. filiformi affine, at robustius, nigrum, capite, thorace elytrisque nitidis. Antennae capitis thoracisque fere longitudine, articulo tertio secundo paulo longiore, 4-10 sensim paululum brevioribus et distinctius obconicis, rufo-testaceae. Palpi testacei. Os rufo-piceum. Caput thoracis prope latitudine, suborbiculatum, supra parum convexum, parce disperse punctatum, fronte media laeviore, parce griseo-puberulum, lateribus nigro-pilosellum. Thorax coleopterorum fere latitudine, latitudine parum (quadrante) longior, subquadratus, lateribus rectis, parallelis, angulis anterioribus leviter, posterioribus fortius rotundatis, parum convexus, crebrius punctatus, spatio angusto dorsali longitudinali laevi, tenuiter subtiliterque griseo-pubescens. Scutellum laeve. Elytra thoracis longitudine, crebrius punctata, tenuiter griseo-pubescentia. Abdomen subtiliter confertissime punctatum, densius griseo-pubescens, apice piceum, segmentis omnibus tenuiter piceo-margina tis. Pedes crassiusculi, rufo-picei.

Mas abdominis segmento inferiore sexto leviter canaliculato, apice leviter exciso; femina eodem apice producto, rotundato. 
* 22. I. filiforme: Lineare, nigrum, nitidum, antennis pedibusque piceis, capite, thorace oblongo elytrisque crebre punclatis, his thorace brevioribus. - Long. $2 \frac{2}{3}$ lin.

Grav. Mon. 134. - Nordm. Symb. 144. 13. - Er. Col. March. I. 508. 8.

Lathrob. lineare Gyll. Ins. Suec. II. 370. 6. - Sahlb. Ins. Fenn. I. 311. 8. Zetterst. Faun. Lappon. 1. 85. 6. Ins. Lappon. 68. 6. - Mannerh. Brachelytr. 37. 7. - Nordm. Symb. 142. 9.

Habitat in Europa.

Elongatum, lineare, tenue, nigrum, nitidum. Antennae capite thoraceque breviores, articulo secundo tertioque aequalibus, 4-10 sensim paulo brevioribus, subobconicis, piceo-testaceae. Palpi dilute piceo-testacei. Os piceum. Caput thoracis latitudine, subovatum, supra leviter convexum, sat crebre punctatum, fronte media laeviore, subtiliter pubescens. Thorax coleopteris vix angustior, latitudine plus sesqui fere longior, lateribus rectis, parallelis, angulis omnibus late rotundatis, sat fortiter crebre punctatus, linea media longitudinali laevi, subtiliter pubescens. Scutellum laeve. Elytra thorace paulo breviora, subtiliter crebre punctata, punctis passim subseriatis, tenuiter griseo-pubescentia. Abdomen subtiliter dense punctatum, pube subtiliore depressa grisea densius vestitum. Pedes picei vel nigri, tarsis ferrugineis.

$\mathrm{M}$ as abdominis segmento inferiore quinto obsolete longitudinaliter impresso, sexto apice anguste triangulariter impresso et exciso; femina eodem apice producto, rotundato.

* 23. L. pallidum: Lineare, testaceum, capile thoraceque oblongo parcius, elytris densius punctatis, nitidis, abdomine supra fuscescente. - Long. $2 \frac{1}{2}$ lin.

Nordm. Symb. 142. 8. - Er. Col. March. I. 509. 9.

Habitat in Germania, Berolini, ipse, in Austria et Illyria, Dom. Schïppel. Statura omnino L. filiformis, at minus elongatum, fulvo-testaceum, capite, thorace elytrisque nitidis. Antennae capite thoraceque paulo breviores, articulo tertio secundo parum breviore, 4 - 10 sensim minoribus, leviter obconicis. Caput thoracis latitudine, suborbiculatum, ore angustato, parce disperse punctatum, lateribus parce pilosellum. Thorax coleopterorum fere latitudine, latitudine tertia parte longior, parum convexus, crebrius punctatus, spatio medio longitudinali angusto laevi, glaber. Scutellum laeve. Elytra thorace paululum breviora, crebre minus profunde punctata, tenuiter pubescentia. Abdomen subtilissime confertissimeque pun ctatum, pube densa subtili grisea sericeum, vix nitidum, segmentis 5 anterioribus dorso nigricantibus. Pedes breves, validi, femoribus anticis fortius incrassatis.

Mas abdominis segmento inferiore quarto quintoque longitudinaliter leviter impressis, sexto profunde inciso; femina eodem apice producto, apice summo subtruncato.

* 24. L. dividuum: Lineare, depressum, piceum, capite thoraceque oblongis, dense punctatis, nitidis, elytris testaceis, basi piceis. - Long. 2 lin.

Habitat in Sardinia, Dom. Prof. Gené.

L. longulo paululum maius, at multo magis depressum. Antennae capite thoraceque vix breviores, crassiusculae, articulo tertio secundo paulo 
longiore, 4-10 sensim paulo brevioribus, rufo-testaceae, articulo ultimo apice pallidiore. Palpi testacei. Caput thoracis latitudine, oblongum, antrorsum leviter angustatum, depressum, profunde sat crebre punctatum, linea media longitudinali laevi, subtiliter griseo-pubescens, testaceo-piceum, subnitidum. Thorax coleopteris dimidio angustior, latitudine antica plus sesqui longior, basin versus leviter angustatus, lateribus rectıs, angulis anterioribus leviter, posterioribus fortius rotundatis, subdepressus, sat crebre punctatus, linea media longitudinali laevi, subtiliter tenuiterque griseo-pubéscens, testaceo-piceus, nitidus. Scutellum piceum, laeve. Elytra thorace panlo longiora, depressa, parce subtilissime obsoleteque punctata, parce pubescentia, dilute testacea, nitida, basi picea. Abdomen confertissime subtilissimeque punctatum, pube brevissima subtili grisea dense obductum, opacum, nigrum, segmentis 4 primis apice subtiliter piceo-marginatıs, quinto apice, sexto toto testaceo-piceis. Pectus piceum. Pedes breves, crassiusculi, picei, tarsis dilutioribus.

Mas abdominis segmento inferiore quinto longitudinaliter impresso, apicem versus bicarinato, interstitio apice carinula brevissima notato, carmulis omnibus apice prominulis, apice tridentato; sexto apice profunde triangulariter exciso; femina eodem apice rotundato.

*25. L. dilutum: Lineare, piceo-leslaceum, nitidum, capite thoraceque oblongo crebre punclatis, elylris thorace brevioribus, distincte punclatis. - Long. 2 lin.

Er. Col. March. I. 509. 10.

Habitat in Germania septentrionali.

L. longulo affine, at duplo maius, piceo-testaceum, nitidum. Antennae capite thoraceque paulo breviores, crassiusculae, articulo secundo tertioque subaequalibus, 4-10 sensim paulo brevioribus, subobconicis. Caput thoracis latitudine, suborbiculatum, ore angustato, producto, parum convexum, crebre punctatum, media fronte laeviore. Thorax coleopteris paulo angustior, latitudine sesqui longior, lateribus rectis, parallelis, angulis anterioribus late, posterioribus modice rotundatis, subdepressus, crebre punctatus, spatio angusto longitudinali medio laevi. Scutellum laeve. Elytra thorace paulo breviora, crebre fortius punctata. Abdomen subtiliter-confertissime punctatum, subtiliter densius griseo-pubescens. Pedes breves, crassiusculi, pallide testacei.

Mas latet. Femina abdominis segmento inferiore sexto apice producto, rotundato.

*26. L. longulum: Lineare, nigro-piceum, nitidum, capite thoraceque oblongo distincte, elytris obsolete punctatis, antennis pedibusque rufis. - Long. $1 \frac{2}{3}$ lin.

Grav. Micr. 53. 4, Mon. 134. 15. - Latr. Hist. nat. Crust. et Ins. IX. 339. 4. Gyll. Ins. Suec. II. 371. 7. IV. 483. 7. - Nordm. Symb. 143. 12. - Er. Col. Murch. I. 510. 11.

Lathrobium minutum Sahlb. Ins. Fenn. I. 341. 9. - Mannerh. Brachelytr. 38. 8.

- Runde Brachelytr. Ial. 12. 4. - Nordm. Symb. 143. 11.

Habitat in Europa. 
Minutum, lineare, tenue, apterum, nigrum, vel nigro-piceum, nitidum. Antemae crassiusculae, capitis thoracisque longitudine, articulo tertio secundo aequal, 4-10 sensim paulo brevioribus, rufae. Os rufum. Caput thorace paulo latius, subovatum, ore angustato, producto, subdepressum, parcius profundiusque punctatum, subtiliter griseo-pubescens. Thorax coleopteris parum angustior, latitudine plus sesqui longior, lateribus rectis, parallelis, angulis ommibus late rotundatis, crebre punctatus, spatio angusto longitudinali medio laevi, subtiliter griseo-pubescens. Scutellum laeve. Elytra thorace tertia parte breviora, minus dense obsoletius punctata, subtiliter griseo-pubescentia. Abdomen subtiliter dense punctatum, pube subtili depressa grisea densius vestitum. Pedes breviores, crassiusculi, cum coxis anterioribus rufo-testacei vel rufi.

Mas abdominis segmento inferiore sexto obsolete canaliculato, bisinuato; femin a eodem apice producto, rotundato.

Obs. Nomine L. minuti ill. Com. Dejean L. longulum Gyll. a Gravenhorstiano distinxit, equidem nequè e descriptione Gyllenhaliana, neque in specimine Suecico a Dom. Prof. Zetterstedt mihi communicato ullam differentiam video.

-27. L. scabricolle: Nigrum, antennis pedibusque rufis, capite orbiculato thoraceque suborbiculato conferlissime punctalo-subrugulosis. - Long. $3 \frac{1}{4}$ lin.

Habitat in Hercynia, Austria.

Corpus apterum, habitu Stilicum simulans, nigrum, opacum. Antennae capite thoraceque paulo breviores, articulo tertio secundo sesqui longiore, sequeritibus sensim paulo brevioribus, subobconicis, rufo-ferrugineae. Palpi rufi, maxillares articulo tertio fuscescente. Caput thorace paulo latius, orbiculatum, leviter convexum, confertissime punctato-subrugosum, subtiliter griseo-pubescens. Thorax coleopteris paulo latior, latitudine paulo longior, antice posticeque rotundatus, subovatus, leviter convexus, confertissime subtilius punctato-subrugulosus, subtiliter griseo-pubescens. Elytra thorace haud longiora, creberrime punctata, cinereo-pubescentia, obscure piceo-subaenea, nitidula. Abdomen subclavatum, confertim subtiliter punctulatum, cinereo-pubescens, subtus segmentis singulis piceo-marginatis. Pedes longiores, crassiusculi, rufi, coxis piceis.

Mas abdominis segmento inferiore quinto apice late subemarginato, sexto late obsolete canaliculato, apice leviter triangulariter exciso; femina eodem apice producto, acute rotundato.

Species mihi invisae, forte huius generis.

28. L. armatum: Nigrum, punctatum, thorace oblongo-quadrato, elylris antennisque piceis, pedibus rufis. - Long. $3 \frac{1}{2}$ lin.

Say Transact. Amer, Philoph. Soc. Philadelph. Nov. Ser. IV. 453. 1.

Habitat in Indiana Americae septentrionalis.

Corpus nigrum, punctatum. Antennae piceae, articulo primo obconico, secundo tertioque coniunctis haud longiore, his aequalibus, 4-10 moniliformibus, ultimo ovato, acuto. Palpi dilute picei. Thorax oblongo-quadratus, angulis rotundatis, absque linea media longitudinali laevi. Elytra nigro- 
picea, minus profunde punctata, stria suturali impressa. Pedes rufi, femoribus robustis, praecipue anticis, his infra prope apicem angulatis, tibiis leviter dilatatis compressisque, apice oblique truncatis, anticis intus obtuse sinuatis, tarsis articulo primo secundo haud longiore, quarto subtus sublobato.

Obs. L. brunnipedi affine videtur.

29. L. puncticolle: Nigrum, thorace fere toto punclato, elytris thorace longioribus, antennis (?) pedibusque castaneis. - Long. 5 lin.

Kirby Faun. Boreali - Amer. 86. 2.

Habitat in America boreali sub lat. $54^{\circ}$.

Corpus nigrum, subnitidum, thorace excepto pubescens. Caput obovatum, subtiliter dense punctatum, antennis mutilatis basi, mandibulis palpisque castaneis. Thorax oblongo - quadrangulus, angulis rotundatis, minus confertim punctatus, spatio ullo longitudinali laevi vix relicto. Elytra thorace longiora, dense punctata, obscure castanea. Pedes brumnei. - L. brunnipedi affine, at elytris longioribus, pedibus obscurioribus, femoribus anticis minus fortibus, muticis. (Kirby).

Obs. Tibiis anticis basi dentatis et tarsis anticis dilatatis indubie ad Lathrobia genuina referendum.

30. L. brevicorne: Depressum, caslaneum, capite, thorace elytrisque sultiliter confertissime punctatis, antennis brevibus, apicem versus incrassatis. - Long. 3 lin.

Latr. Hist. nat. Crust. et Ins. IX. 342. 11.

Habitat in Gallia.

Depressum, obscure castaneum, subopacum, exceptis thorace elytrisque. Antennae rufescentes, articulis brevibus, apicem versus sensim crassioribus. Palpi rufescentes. Caput elongatum, subtilissime punctatum, subrugulosum, linea media longitudinali (laevi?). Thorax elongatus, punctatissimus, aequalis. Elytra subtilissime punctata, leviter pubescentia. Pedes breves, rufopicei, femoribus obscurioribus. (Latr.)

O b s. De genere dubito, forte Lithocharidi adscribendum.

\section{Scopaeus $E r$.}

Labrum denticulatum.

Palpi maxillares articulo ultimo acuto, dislincto.

Ligula cornea, tricuspidata.

Antennae rectae.

Tarsi articulo quarto simplice.

Corpus parvulum, elongatum, alatum. Caput a thorace remotum, pedrinculo brevi tenui thoracis apici affixum, porrectum, thoracis latitudine, oculis parvis, rotundatis, modice prominulis. Labrum transversum, breve, apice denticulatum, denticulıs intermediis distinctioribus, interstitio profundius triangulariter inciso. Mandibulae leviter falcatae, acutae, medio fortiter acuteque tridentatae. Maxillae malis breviusculis, coriaceis, interiore interne, exteriore apice introrsum vergente barbatis. Palpi maxillares articulo primo brevi, secundo tertioq̣ue longitudine subaequalibus, illo leviter clavato, hoc 
fortiter incrassato, quarto minuto, tenui, subulato. Labium mento transverso, ligula cornea, apice tricuspidata, dentibus aequalibus, acutis, paraglossis linearibus, membranaceis, interne ciliatis. Palpi labiales articulo primo minuto, cylindrico, secundo maiusculo, crassiusculo, subovali, tertio minuto, tenui, acuminato. Antennae filiformes, rectae, articulo primo modice elongato, secundo tertioque obconicis, ultimo ovato, apice subacuminato. Thorax oblongus, apice magis minusve attenuatus. Scutellum subsemiorbiculare. Elytra apice truncata. Abdomen lineare, segmento septimo vix prominulo, stylis analibus haud distinctis. Pedes breviores, validiusculi, antici leviter incrassati, tibiis anticis interne subsinuatis et ante medium obtuse dentatis, posterioribus apice oblique truncatis, tarsis omnibus simplicibus, posterioribus articulis 4 primis sensim paulo brevioribus, primo subelongato, quinto his coniunctis multo breviore.

\section{O b s e r v a t i o n e s.}

1. Genus intermedium inter Lathrobium, Lithocharidem et Stilicum. corporis forma, imprimis capite remoto et thorace apice attenuato cum Stilico convenit, discedit autem praeter labrum minutum et palporum maxillarium articulum quartum distinctum corporis punctura subtilissima et pedibus breviusculis, minus gracilibus. A Lathrobio, quocum pedum structura omnino congruit, discedit tarsis anticis simplicibus et labro denticulato. Ad Lithocharidem proxime aggreditur, pedibus autem praecipue anticis validioribus, labro minore, lateribus haud membranaceo differt. Praeterea ab onnibus huius familiae generibus ligula cor. nea, tricuspidata distinctum.

2. Sexus differentia in abdominis segmentis inferioribus ultimis quaerenda.

3. Victus in locis humidis.

* 1. Sc. laevigatus: Subtilissime punctulatus, piceus, subnitidus, antennis pedibusque testaceis, capile orbiculato, thorace subovato, apice attenuato, basi foveola gemina impresso, elytris thorace longioribus. Long. $1 \frac{1}{2}$ lin.

Paederus laevigatus Gyll. Ins. Suec. IV. 483. 4-5.

Rugilus laevigatus Mannerh. Brachelytr. 40. 2.

Lathrobium laevigat um Er. Col. March. I. 510. 12.

Habitat in Europa.

Minutus, nigro-piceus, nitidulus, pube subtilissima brevissimaque cinerea sericans. Antenmae capite thoraceque longe breviores, crassiusculae, articulo tertio secundo paulo minore, $3-10$ sensim paulo brevioribus, penultimis crassitie vix longioribus, ultimo subovato, apice subito acuminato, rufo-testaceae. Palpi testacei, maxillares articulo tertio crasso, fusco. Os rufo-testaceum. Labrum apice $\mathbf{4}$-denticulatum, denticulis exterioribus obtusis, intermediis acutis, interstitio triangulariter exciso. Caput thorace paulo latius, suborbiculatum, modice convexum, confertissime subtilissimeque punctatum. Thorax coleopteris dimidio angustior, latitudine sesqui longior, subovatus, basi rotundatus, apice attenuatus, lateribus cum angulis anterioribus leviter rotundatus, basin versus subangustatus, modice convexus, confertissime subtilissimeque punctatus, basi foveolis duabus approximatis rotun.datis impressus. Elytra thorace tertia parte longiora, confertim subtilissime punctata, nigro-picea, margine apicali dilutiore. Abdomen subtilissime confertissimeque punctulatum, apice piceum, infra apice rufum, segmentis 4 an- 
terioribus apice testaceo-marginatis. Caput et thorax infra rufescunt. $\mathrm{Pe}$. des rufo-testacei.

Mas abdominis segmento inferiore sexto apice profunde exciso, excisura utrinque dente duplici, altero deorsum, altero longiore retrorsum spectante, terminata; femina eodem leviter triangulariter producto.

Variat immaturus colore testaceo.

2. Sc. didymus: Subtilissime punclulatus, niger, subnitidus, antennis pedibusque piceis, thorace oblongo, apice allenuato, basi foveola gemina impresso, elytris thorace longioribus. - Long. $1 \frac{1}{3}$ lin.

Habitat in Sardinia, Dom. Prof. Gené.

Praecedente magis, sequente minus gracilis, niger, subnitidus, pube brevissima subtilissimaque grisea sericans. Antennae capite sesqui longiores, articulo tertio secundo paulo minore, 3 - 10 sensim brevioribus, ultimo apice subito acuminato, ferrugineae, basi piceae. Palpi rufi, maxillares articulo tertio nigro. Os piceum. Caput thorace paulo latius, oblongtim, basi truncatum, angulis posterioribus rotundatis, antrorsum subangustatum, supra leviter convexum, omnium subtilissime confertissime punctatum. Thorax coleopteris dimidio prope angustior, latitudine tertia parte longior, basin versus subangustatus, apice attenuatus, angulis anterioribus obtusis, lateribus subrectis, angulis posterioribus rotundatis, minus convexus, confertissime subtilissimeque punctatus, basi foveolis duabus, carinula brevi distinctis, obsoletius impressus, apice linea subtilissima longitudinali medium versus evanescente exaratus. Elytra thorace paulo longiora, confertissime subtilissimeque punctata. Abdomen confertissime subtilissimeque punctatum, densius pubescens, infra segmentis 4 primis margine apicali tenui testaceo. Pedes picei.

Mas abdominis segmento inferiore quinto apice late levissime emarginato, sexto fortiter triangulariter exciso.

* 3. Sc. minutus: Elongalus, subdepressus, subtilissime punctatus, piceus, antennis pedibusque teslaceis, capite oblongo, thorace oblongo, apice attenuato, elytris thoracis longiludine. - Long. $1 \frac{1}{3}$ lin.

Habitat in Germania, Gallia.

L. minimo simillimus, at paululum maior, elongatus, linearis, subdepressus, nigro-piceus, subnitidıs, pube subtili brevissima grisea sericans. Antennae capite sesqui longiores, articulo tertio secundo subaequali, $3-10$ sensim brevioribus, ultimo ovato, apice acuminato, testaceae. Palpi testacei. Labrum apice sexdenticulatum, dentibus lateralibus obtusis, obsoletıs, intermediis acutissimis, interstitio leviter triangulariter exciso. Caput oblongum thorace latius, basi truncatum, angulis posterioribus leviter rotundatis, apicem versus sensim angustatum, parum convexum, omnium subtilissime punctulatum. Thorax coleopteris haud angustior, latitudine sesqui prope longior, basin versus leviter angustatus, apice attenuatus, lateribus subrectis, angulis anterioribus obtusis, posterioribus rotundatis, subdepressus, omnium subtilissime punctulatus, basi obsolete bifoveolatus, apice linea longitudinali abbreviata subtili exaratıs. Elyira thoracis longitudine, confertissime sub- 
tiliter punctata. Abdomen subtilissime punctulatum, densius pubescens, segmentis singulis apice subtilissime testaceo-marginatis. Pedes testace.

Mas abdominis segmento inferiore quinto apice obsoletissime bisinuato, sexto triangulariter exciso; femin a eodem leviter triangulariter producto.

Variat colore dilutiore piceo-testaceo.

Obs. L. minimo perquam affine, at paulo maior, antennis, palpis pedibusque testaceis, capite basi latiore, elytris distinctius punctatis etc. distinguendus.

4. Sc. minimus: Omnium subtilissime punctatus, niger, antennis pedibusque piceis, capile oblongo, thorace oblongo, apice altenuato, elytris thoracis longitudine. - Long. $1 \frac{1}{4}$ lin.

Luthrobium minimum Er. Col. March. I. 511. 13.

Habitat in Germania.

Praecedenti affinis, at dimidio minor, angustus, linearis, niger, pube suhtilissima cinerea obductus. Antennae capite plus sesqui longiores, articuln tertio secundo subaequali, $\mathbf{- 1 0}$ sensim vix brevioribus at paululum crassioribus, ultimo maiore, ovato, apice acuminato, rufo-piceae. Palpi rufopicei, maxillares articulo tertio crasso, fusco. Caput basi thorace paulo latius, oblongum, basi truncatum, angulis posterioribus rotundatis, antrorsum angustatum, parum convexum, omnium confertissime subtilissimeque punctatum. Thorax coleopteris paulo angustior, latitudine sesqui longior, basin versus subangustatus, apice attenuatus, lateribus rectis, angulis anterioribus obtusis, subrotundatis, posteriorbus rotundatis, subdepressus, subtrlissime confertissimeque punctatus, basi nonnunquam obsolete bifoveolatus, apice saepius lineola longitudinali brevi subtilissima impressus. Elytra thoracis longitudine, confertim subtilissime punctata, apice picescentia. Abdomen omnium subtilissime confertissimeque punctulatum, apice piceum, segmentis 4 primis subtiliter testaceo-marginatis. Pedes picei testaceive.

Mas abdominis segmento inferiore quinto apice late distinctius emarginato, sexto triangulariter exciso; femina eodem leviter triangulariter producto.

5. Sc. infirmus: Omnium subtilissime punctulatus, opacns, rufo-picens, abdomine nigricante, antennis pedibusque teslaceis, thorace oblongo, elytris thorace longioribus. - Long. $1 \frac{1}{3}$ lin.

Habitat in Aegypto, Dom. Prof. Ehrenberg.

Habitu fere Lithocharidis ochraceae, at huius generis, et duplo illa minor, subdepressus, dilute rufo-piceus, opacus, totus omnium subtilissime confertissimeque punctatus, pube subtilissima brevissimaque cinerea densius obductus, sericans. Antennae capite plus sesqui longiores, articulo secundo tertioque subaequalibus, $\mathbf{1}$ - $\mathbf{I 0}$ sensim paulo brevioribus, penultimis prope transversis, ultimo subgloboso, apice subito subacuminato, dilute testaceae (aput thoracis latitudne, oblongum, basi cum angulis posterioribus leviter rotundatum, antrorsum vix angustatım, depressiusculum. Thorax coleopteris dimidio prope angustior, latitudine paulo longior, basin versus subangustatus, lateribus rectis, apice utrinque oblique truncatus, angulis anterioribus obtusis, subrotundatis, posterioribus rotundatis, subdepressus, aequalis. 
Elytra thorace tertia parte longiora. Abdomen nigricans, segmentis 4 primis margine apicali, quinto apice, sexto toto dilute rufo-piceis. Pedes flavo - testacei.

Mas abdominis segmento inferiore sexto emarginato; femina eodem rotundato.

* 6. Sc. exiguus: Omnium subtilissime punctulatus, opacus, niger, antennis pedibusque testaceis, cupite, thorace elytrorumque apice rufo-piceis, elytris thorace oblongo parum longioribus. - Long. 1 lin.

Habitat in Pensylvania, Dom. Schiippel.

Habitu omnino praecedentis, at multo minor, linearis, subdepressus, omnium subtilissime confertissime punctatus, opacus, pube subtilissima brevissimaque cinerea densius obductùs, sericans. Antennae capite paulo longiores, articulo tertio secundo minore, 3-10'sensim paulo brevioribus, ultimo ovato, apice scuminato, laete testaceae. Palpi dilute luteo-testacei. Caput thorace paulo latius, oblongum, basi levissime, angulis posterioribus fortius 'rotundatis, antrorsum vix angustatum, supra parum convexum, rufopiceum, ore dilutiore. Thorax coleopteris paulo angustior, latitudine summa sesqui longior, basin versus leviter angustatus, lateribus rectis, apice utrinque oblique truncatus, angulis anterioribus obtusis, posterioribus rotundatis, parum convexus, basi linea longitudinali, mox evanescente, subtilissima obsolete carinatus, dilute rufo-piceus. Scutellum rufo-piceum. Elytra thorace paululum longiora, nigricantia, apice indeterminate rufo-picea. Abdomen nigrum, segmentis $\mathbf{5}$ anterioribus margine summo apıcali, sexto toto testaceis. Pectus piceum. Pedes laete flavo-testacei.

Mas abdominis segmento inferiore sexto apice triangulariter exciso. Femina latet.

\section{Sc.pygmaeus: Omnium subtilissime confertissimeque punctatus, opacus, niger, antennis pedibusque testaceis, capite thoraceque rufo-piceis, ely- tris thorace oblongo longioribus. - Long. $1 \frac{1}{4}$ lin.}

Habitat in ins. Puerto-Rico, Dom. Moritz.

Praecedenti proximus, at paulo maior et elytris longioribus distinctus, linearis, subdepressus, omnium subtilissime confertissimeque punctatus, opacus, pube subtilissima brevissimaque cinerea densius obductus, sericans. Antennae capite sesqui fere longiores, articulo secundo tertio paulo maiore, 4-10 sensim vix brevioribus at paulo crassioribus, ultimo apice acuminato, testaceae. Palpi dilute testacei. Caput thorace paulo latius, oblongum, basi truncatum, angulis posterioribus vix rotundatis, ante antennas subito angustatum, supra minus convexum, rufo-piceum. Thorax coleopteris dimidio prope angustior, latitudine plus sesqui longior, basin versus subangustatus, lateribus rectis, apice utrinque oblique truncatus, fere attenuatus, angulis anterioribus fortius rotundatis, posterioribus obtusis, subrotundatis, subdepressus, basi utrinque obsolete impressus, impressionibus carinula brevissirna obsoletiore distinctis, dilutius rufo-piceus. Scutellum rufo-piceum. Elytra thorace tertia fere parte longiora, nigricantia, humeris, sutura margineque apicali indeterminate anguste rufo-piceis. Abdomen nigrum, seg- 
mentis 4 primis margine summo apicali, quinto apice, sexto toto piceotestaceis. Pectus nigro-piceum. Pedes dilute flavo-testacei.

8. Sc. fasciatellus: Omnium subtilissime confertissimeque punctatus, opacus, niger, antennis, pedibus elytrisque testaceis, his fascia lata inaequali, capite piceo, subquadrato. - Long. $1 \frac{1}{6}$ lin.

Habitat in Puerto-Rico, Dom. Moritz.

Statura omnino praecedentium, omnium subtilissime confertissimeque punctatus, opacus, pube brevissima subtilissimaque cinerea densius obductus, sericans. Antennae capite paulo longiores, crassiusculae, articulo tertio secundo paulo minore, 3 - 10 sensim paulo brevioribus et crassioribus, penultimis fere transversis, ultimo apice subito acuminato, laete testaceae. Palpi dilute testacei. Caput thorace paulo latius, basi truncatum, angulis posterioribus leviter rotundatis, pone oculos haud, ante oculos subito angustatum, supra leviter convexum, rufo-piceum, ore dilutiore. Thorax coleopteris angustior, latitudine summa tertia parte longior, basin versus subangustatus, lateribus rectis, apice utrinque oblique truncatus, angulis omnibus obtusis, subrotundatis, anterioribus leviter prominentibus, subdepressus, aequalis, nigro-piceus. Elytra thorace paulo longiora, basi summa rufopicea, dein nigra, apice late inaequaliter cum lateribus inflexis testacea. Abdomen segmentis 4 anterióribus margine tenui apicali testaceo, infra quinto apice sextoque toto rufo-piceis. Pectus nigro-prceum. Pedes flavi, coxis anterioribus concoloribus, posticis testaceis.

Mas latet. Femina abdominis segmento inferiore sexto leviter triangulariter producto.

* 9. Sc. pulchellus: Laevissimus, nilidus, niger, antennis aldominisque basi testaceis, elytrorum puncto apicali pedibusque favis, capite orbiculato thoraceque oblongo-ovato, convexo rufis. - Long. $1 \frac{1}{3}$ lin.

Habitat in valle Araguensi Columbiae, Dom. Moritz.

Sc. laevigato paulo minor et gracilior, nitidus, capite, thorace elytrisque laevissimis. Antennae capite thoraceque paulo breviores, apicem versus leviter incrassatae, articulo secundo tertioque subaequalibus, $4-10$ sensim brevioribus et crassioribus, ultimo apice abrupte subacuminato, rufotestaceae. Palpi rufo-testacei. Caput thorace paulo latius, suborbiculatum, supra leviter convexum, piceo-rufum, parce nigro-pilosum. Thorax coleopteris angustior, latitudine summa sesqui longior, utrinque, licet antrorsum minus sensim quam basin versus angustatus, oblongo-ovatus, convexus, piceo-rufus, parce nigro-pilosus. Scutellum piceum. Elytra thorace paulo longiora, nigerrima, apice exterius puncto flavo notata. Abdomen omnium subtilissime punctulatum, nigrum, nitidum, segmentis anterioribus tribus totis, reliquis summo margine apicali testaceis, illis plerumque basi piceis. $\mathrm{Pe}$ ctus nigro-piceum. Pedes elongati, flavi.

Mas abdommis segmento inferiore sexto apice leviter triangulariter exciso. Femin a latet.

Variat capite thoraceque piceis. 


\section{Lithocharis $D e j$.}

Boisd et Lacord. Fuun. Ent. Paris. I. p. 431. - Er. Col. March. 1. p. 511. Medon Stsph. Illustr. V.p. 273. t. 127. f. 2. Sunius ibid p. 274.

Paederus Fam. I. Grav. Mon. p. 138.

Labrum apice bidenticulalum.

P'alpi maxillares arliculo quarto distinclo, aculo.

Ligula membranea, biloba.

Antennae rectae.

Tarsi arliculo quarto simplice.

Corpus minutum, elongatum, subdepressum, alatum. Caput plerumque thoracis latitudine, subquadratum, basi profunde constrictum, collo quasi tenui brevi thoraci immissum, exsertum, porrectum, oculis parvis rotundatis, parum prominulis. Labrum latum, transversum, lateribus explanatis rotundatisque membranaceis magis minusve dilatatis, apice medio plerumque bidenticulatum, inter dentes magis minusve emarginatum vel excisum. Mandibulae falcatae, acutae, medio fortiter acuteque 3 -vel 4-dentatae. Maxillae (t. IV. f. 29. b.) malis coriaceis, interiore interne, exteriore apice barbatis. Palpi maxillares leviter elongati, articulo primo, minuto, secundo tertioque elongatis, longitudine aequalibus, hoc incrassato, quärto mmimo, tenuissimo, acuto. Labium (t. IV. f. 29. a.) mento transverso, apice leviter late emarginato, ligula biloba, lobis angustioribus, apice subrotundatis, membraneis, valde distantibus, interstitio dense setoso, paraglossis membraneis, linearibus, ligulae lacinias vix superantibus. Palpi labiales articulo primo minuto, cylindrico, secundo subovato, maiusculo, tertio minuto, tenui, acuto. Antennae filiformes, rectae, articulo primo subelongato, ultimo apice acuminato. Thorax magis minusve distincte quadrangulus. Scutellum triangulare. Elytra truncata. Abdomen lineare, apice angustatum, segmento septimo parum conspicuo, stylis analibus haud distinctis. Pedes leviter elongati, antici nonnunquam subincrassati, tarsis anticis saepius leviter dilatatis, articulis primis feminae triangularibus, maris obcordatis, posterioribus simplicibus, magis minusve elongatis, articulis 4 primis longitudine sensim decrescentibus.

\section{o b s e r y a t i n e s.}

1. Oris fahrica ceterisque characteribas Stilico nimis forte affinis, a quo tamen habitu facillime distinguitur. Color plerisque testaceus vel ferrugineus, parum nitidus, punctura subtilis. Ceterum a Stilico praecipue antennis longioribus gracilioribusque, labro minus amplo, palporum maxillarium articulo quarto magis conspicuo, paraglossis ligulam haud superantibus, tarsorumque anticorum structura differt. Species nonnullae Lathrobiis similes, a qubus labro denticulato, tarsis anticis, paucis masculis exceptis, perparum vel haud dilatatis, posterioribus articulo primo magis minusve elongato discedunt.

2. Medon Steph. a reliquis huius generis speciebus (Sunius Steph.) labri bidentati causa distinctum, quod in his falso muticum exhibetur.

3. Mas abdominis segmento sexto inferiore exciso, quinto etiam nonnunquam emarginato, femina segmento inferiore sexto apice aut rotundato, aut triangulariter producto, Tarsi antici maris saepius leviter dilatati.

4. Victus sub lapidibus, sub foliis deciduis.

* 1. L. castanea: Rufo-picea, capite oblongo thoraceque creberrime punclatis, elylris thorace sesqui longioribus. - Long. 3 lin.

Er. Col. March. I. 512.1. 
Paederus castuneus Grav. Micr. 60. 3. - Latr. Hist. nat. Crust. et Ins IX. 348. 8. - Oliv. Eucycl. meth. VIII. 628. 6.

Rugilus castaneus Mannerh. Brachelytr. 40. 5.

Paederus quadratus Beck Beitr. 25. 39. t. 7. f. 39.

Medon Ruddii Steph. Mllustr, V. t. 127.f. 2.

Habitat in Germania, Gallia.

Sequentibus maior, rufo-picea, subnitida, capite abdomineque obscnrioribus. Antennae capite thoraceque paulo hreviores, tenuiusculae, articulo tertio secundo sesqui longiore, 4-10 sensim brevioribus et sensim magis obconicıs, ultimo fusiformi, apicem versus sensim acuminato. Labrum amplum, lateribus limbo membranaceo dilatatum, medio acute bidentatum. Caput thorace paulo latius, eodemque sesqui longius, oblongum, jarum convexum, creberrime punctatum, fronte anterius medio laeviore, subtiliter griseo-pubescens, lateribus parce nigro-pilosellum. Thorax coleopteris paulo angustior, latitudine antica vix brevior, basin versus angustatus, apice utrinque oblique truncatus, lateribus rectis, angulis omnibus subrotundatis, anterioribus lateraliter prominentibus, leviter convexus, subtiliter confertistime punctatus, subtiliter griseo-pubescens, lateribus parce nigro-pilosellus. Elytra thorace sesqui longiora, subtiliter confertissime punctata, densius subtiliter pubescentia, piceo-ferruginea. Abdomen subtilissime crebre punctulatum, pube depressa subtili fulvescente densius vestitum, piceum, apice et subtus ferrugineum. Pedes longiusculi, graciles, ferruginei.

Mas abdominis segmento inferiore quinto apice medio late emarginato, utrinque subsinnato, sexto acute triangulariter exciso; femin a eodem apice leviter triangulariter producto.

2. L. fuscula: Ferruginea, capile oblongo, subliliter punclato, subruguloso, fusco, thorace lateribus conferlissime subtilissimeque, dorso conferlim subtiliterque punctato, elytris thorace sesqui longioribus. Long. 2 lin.

Boisd. Lacord. Faun. Ent. Paris. I. 431. 1. - Er. Col. March. 1.,513 2. Rugilus fusculus Dannerh. Brachelytr. 40. 3.

Habitat in Germania, Gallia, Helvetia.

Praecedente plus duplo minor, ferrnginea, nitida, capite obscuriore. Antennae capite thoraceque breviores, crassiusculae, articulo tertio secundo parum longiore, 4-10 sensim brevioribus, ultimo apice subito acuminato, Labrum amplum, limbo laterali membranaceo auctum, medio bidenticulatum. Caput thorace vix latius, at paulo longius, oblongum, confertissime minus subtiliter punctato-subrugulosum, subopacum, subtiliter griseo-pubescens, lateribus pilosellum. Thorax coleopteris parun angustior, latitudine antica vix brevior, basin versus angustatus, lateribus rectis, apice utrinque oblique truncatus, angulis anterioribus obtusis, posterioribus rotundatıs, parum convexus, lateribus confertissime subtiliter punctatus, opacus, dorso confertim minus subtiliter punctatus, nitidnlus, linea media longitudinali laevi basi subelevata, antrorsum obsoleta, subtiliter griseo-pubescens, lateribus parce pilosellus. Elytra thorace sesqui longiora, subtilius conferim punctata, subtiliter griseo-pubescentia. Abdomen subtiliter confertim punctatum, fulvescenti-griseo- dense pubescens. Pedes graciliores, dilute testacei. 
Mas abdominis segmento quinto inferiore apice late et profunde sinuato, utrinque in dentem fortem producto, sexto acute emarginato; fe mina eodem apice leviter triangulariter producto.

* 3. L. brunnea: Dilute rufo-picea, capile oblongo, confertim punctato, thorace creberrime, lateribus subtilius punctato, elytris thorace parum longioribus. - Long. 2 lin.

Er. Col. March. I. 513. 3.

\section{Habitat in Germania.}

Statura et summa affinitas praecedentis, dilute rufo-picea, nitida, capite abdomineque obscurioribus. Antennae capite sesqui longiores, crassiusculae, articulo tertio secundo paulo longiore, 4 - 10 sensim paulo brevioribus, penultimis crassitie vix longioribus, ultimo apice subito acuminato. Labrum latiusculum, lateribus limbo membranaceo dilatatum, apice obsolete bidenticulatum. Caput thorace paulo latius, oblongo-subquadratum, confertissime minus subtiliter punctatum. Thorax coleopteris parum angustior, latitudine paulo brevior, basin versus subangustatus, lateribus rectis, apice utrinque oblique truncatus, angulis anterioribus obtusis, subrotundatis, posterioribus fortius rotundatis, parum convexus, creberrime dorso minus subtiliter, lateribus subtilius punctatus, linea longitudinali media laevi subelevata, antice obsoleta, subtilissime griseo-pubescens, lateribus parce nigropilosellus. Elytra thorace paulo longiora, minus confertim subtilius punctata, minus subtiliter griseo-pubescentia. Abdomen subtilissime punctulatum, densius griseo-pubescens, apice nigro-pilosellum. Pedes dilute rufo-testacei.

Mas abdominis segmento inferiore quinto apice levissime emarginato, sexto triangulariter exciso; femina eodem apice leviter triangulariter producto.

Obs. Praecedenti simillima, praecipue elytris brevioribus, minus confertim punctatis distinguenda.

* 4. L. diluta: Rufo-testacea, capile oblongo, antrorsum angustato thoraceque subtiliter punctalis, elytris thorace sesqui longioribus. Long. 2 lin.

Er Col. March. I. 514. 4.

Habitat in Germania.

Statura et summa affinitas praecedentium, rufo-testacea, nitida, abdomine piceo. Antemnae capite plus sesqui longiores, articulo tertio secundo paulo longiore, 4-8 sensim brevioribus, ultimis tribus sensim paulo maioribus, ultimo maiusculo, apice acuminato. Labrum latiusculum, lateribus limbo angustiore membranaceo auctum, apice obsoletius bidenticulatum. Caput thorace parum latius, at tertia parte longius, oblongum, antrorsum angustatum, subtiliter dense punctatum, antice linea tenui longitudinali media laevi subelevata, subtilissime griseo-pubescens, lateribus, nigro-pilosellum. Thorax coleopteris paulo angustior, latitudine paulo brevior, basin versus modice angustatus, lateribus rectis, apice utrinque oblique truncatus, anguliz anterioribus obtusis, posterioribus rotundatis, parum convexus, aequaliter confertissime subtiliter punctatus, subtilissime griseo-pubescens, lateribus parce nigro-pilosellus. Elytra thorace sesqui longiora, subtiliter confertis- 
sime punctata, subtiliterque griseo-pubescentia. Abdomen confertissime subtiliter punctulatum, densius griseo-pubescens, piceum, apicem versus rufotestaceum. Pedes dilute testacei.

Mas latet. Femin a abdominis segmento inferiore sexto apice leviter triangulariter producto.

* 5. L. rufiventris: Rufo-picea, capite thoraceque nigro-piceis, capile subquadrato, forlius punclato, medio laevi, thorace subtiliter punctalo, medio subliliter canaliculato, elytris thorace sesqui longioribus. Long. 2 lin.

Er. Col. March. 1. 514. 5.

Lathrobium rufiventre Nordm. Symb. 147. 19.

Habitat in Germania.

Statura et affinitas praecedentium, picea, nitida. Antennae capite sesqui longiores, apice leviter incrassatae, articulo tertio secundo paulo longiore, 4-10 sensim paulo brevioribus, penultimis crassitie vix longioribus, ultimo apice abrupte acuminato, rufae. Labrum apice obsoletius bidenticulatum. Os rufo-piceum. Caput basi thorace paululum latius, subquadratum, antrorsum subangustatum, punctatum, fronte media laeviore, subtiliter pubescens, lateribus pilosellum, nigrum, nitidum. Thorax coleopteris paulo angustior, longitudine antica paulo brevior, basin versus subangustatus, lateribus rectis, apice utrinque oblique truncatus, angulis anterioribus leviter, posterioribus fortius rotundatis, subtilius et minus confertim punctatus, linea longitudinali media laevi parum distincta, medio subtiliter canaliculata, subtiliter pubescens, nigro-pilosellus. Elytra thorace sesqui longiora, minus confertim subtilius punctata, griseo-pubescentia, lateribus parce nigro-pilosella. Abdomen subtiliter dense punctulatum subtiliterque griseo-pubescens, parce nigro-pilosellum, apice rufo-piceum. Pedes dilute rufo-picei.

F emina abdominis segmento inferiore sexto apice leviter triangulariter producto; mas eodem „paulo emarginato" sec. Nordm.

Variat corpore rufo, capite, thorace abdomineque supra praeter apicem piceis.

Obs. Capitis punctura minus conferta praecipue ab affinibus distincta.

* 6. L. ferruginea: Ferruginea, capite subquadrato, conferlissime fortiter punctalo, thorace crebrius profundiusque panctato, subliliter canaliculato, elylris thorace paulo longioribus. - Long. 2 lin.

Habitat in Austria, Dom. Schïppel.

Statura et affinitas praecedentium. Corpus ferrugineum, nitidum. Antennae capite plus sesqui longiores, apice subincrassatae, articula tertio secundo paulo longiore, $\mathbf{4}-\mathbf{I 0}$ sensim paulo brevioribus et crassioribus, ultimo apice subito acuminato. Labrum amplum, lateribus limbo membranaceo auctum, apice obsoletius bidentatum. Caput thorace vix latius, subquadratum, supra confertissime sat fortiter punctatum, fronte media vix laeviore, anterius subrugulosa, subtiliter pubescens, lateribus parce pilosellum. Thorax coleopteris paulo angustior, latitudine apicis vix brevior, basin versus modice angustatus, apice utrinque oblique truncatus, angulis anterioribus leviter, posterioribus fortius rotundatis, leviter convexus, minus 
confertim licet sat crebre fortius et sat profunde punctatus, linea media longitudinali laevi subtiliter canaliculata, subtiliter griseo-pubescens, lateribus parce nigro-pilosellıs. Elytra thorace paulo longiora, minus confertim aequaliter subtilius punctata, tenuiter pubescentia. Abdomen parcius subtiliusque punctatum, tenuiter pubescens, segmento quinto-basi piceo. Pedes dilute testacei.

Mas abdominis segmento inferiore quinto apice leviter bisinuato, sexto leviter triangulariter exciso. F e min a latet.

O bs. A praecedentibus praecipue capitis punctura forti confertissima distincta.

* 7. L. melanocephala: Nigro-picea, nitida, capite suborbiculato, parce punctalo, elytris piceo-testaceis, thorace paulo longioribus. - Long. $1 \frac{1}{2}-2$ lin.

Er. Col. March. I. 515. 6.

Paederus melanocephalus Fab. Ent. Syst. I. II. 538. 10. Syst. El. II. 610. 10.

- Panz. Ent. Germ. 363. 11. Faun. Germ. 36. 22.

Staph. tricolor Marsh. Ent. Britt. 516. 55.

Paederus bicolor Oliv. Ent. 111. 44. 7. 7. t. I. f. 4. - Grav. Micr. 59. 2. Mon.

138 3. - Latr. Hist. nat. Crust. et Ins. IX. 348. 7. - Oliv. Encycl. melh.VIII.

6.30. 12. - Panz. Faun. Germ. 104. 15.

Rugilus bicolor Mannerh. Brachelytr. 40. 4. - Runde Brachelytr. Hal. 14. 4.

Lithocharis bicolor Boisd. et Lacord. Fain. Ent. Paris. 1. 433. 3.

Lathrobium ruficorne Latr. Gen. Crust. et Ins. I. 290. 3.

Habitat in Europa temperata.

Antennae capite thoraceque breviores, apicem versus vix crassiores, articulo tertio secundo paulo longiore, 1- 10 sensim paulo brevioribus, ultimo acuminato, rufo-testaceae, medio nonnunquam fuscescentes. Os rufo-piceum. Labrum margine obsolete denticulatum. Caput thoracis latitudine, suborbiculatum, depressiusculum, parce subtulius punctulatum, fronte media laeve, lateribus parce nigro-pilosum, piceo-nigrum, nitidum. Thorax coleopteris parum angustior, laiitudine haud brevior, basin versus subangustatus, lateribus rectis, apice utrinque oblique truncatus, angulis anterioribus obtusis, posterioribus rotundatis, parum convexus, crebre punctatus, linea media Jongitudinali laevi, testaceo-rufus, nitidus. Scutellum rufum. Elytra thorace parum longiora, densius subtiliter punctata, tenuiter griseo-pubescentia, piceo-testacea, nitida. Abdomen confertim subtiliter punctulatum, pube subtili depressa grisea densius vestitum, parum nitidum, nigrum, segmentorum margine posteriore apiceque piceis. Pectus nigro-piceum. Pedes restacei, crassiusculi, tarsis posterioribus sat elongatis, anticis in utroque sexu simplicibus.

Mas abdominis segmento inferiore sexto longitudinaliter leviter im presso, apıce leviter triangulariter exciso; femin a eorlem apice leviter triangulariter producto.

* 8. L. angularis: Rufo-testacea, nitida, thorace rufo, capite, ano elytrisque nigris, his angulis exterioribus testaceis, capile thoraceque convexis elytrisque parce punclatis. - Long. $2 \frac{1}{2}$ lin.

Habitat Novae Valenciae in Columbia, Dom. Moritz, in Mexico, coll. Dom. Chevrolat. 
Primo intuitu Paederum simulat. Antenuae capite thoraceque paulo breviores, tenuiusculae, articulo tertio secundo sesqui longiore, quarto iterum dimidio breviore. 1- 11 sensim paulo longioribus, teretibus, ultimo apice acuminato, dilute testaceae. Palpi testacei. Labrum transversum, apice acute bidenticulatum, inter dentes proftundius sinuatum. Mandibulae valicliores, rufo-piceae. Caput thoracis latitudine, transversim subquadr:.tum, leviter convexum, ad latera et inter oculos parce vage punciatum it parce nigro-pilosum, nigrum, pernitidum. Thorax coleopteris parum angi.stior, latitudine tertia parte brevior, lateribus rectis, apice truncatus, angul s omnibus subrotundatis, supra convexus, punctis raris obsoletisque versus latera notatus, parce nigro-pilosus, ceterum laevissimus glaberrinusque, testaceo-rufus, pernitidus. Scutellum nigrum. Elytra thorace paulo longiora, leviter convexa, stria forti suturali puncisque subtilioribus parcis subseriatis impressa, parce griseo-pilosa, pernitida, nigerrima, angulo exteriore late ad suturam usque testaceo. Abdomen parce subtilissime punctulatum, tenuiter subtiliterque cinereo-pubescens, nitidum, segmentis \& anterioribus rufo-testaceis, apicalibus duobus nigris. Pectus rufum. Pedes graciliores, rufo-testacei, femoribus pallide flavescentibus, tarsis posterioriribus sat elongatis, antice simplicibus.

$\mathrm{M}$ as abdominis segmento inferiore quinto apice subsinuato, sexto leviter longitudinaliter impresso, apice emarginato. F e min a latet.

9. L. macularis: Rufa, nilida, elylrorum macula mogna iransversali anoque nigris, thorace fortiler convexo, elytris parce seriatim punclatis. - Long. 3 lin.

Habitat in Guyana Venezuelensi, Dom. Moritz.

Affinis praecedenti. Antennae capite thoraceque paulo breviores, te muiores, articulo tertio secundo vix breviore, $3-10$ sensin paulo brevioribus et crassioribus, levissime obconicis, ultimo oblongo, apice subito acuminato, testaceae. Palpi testacei. Labrum ay ice acute bidenticulatum, inter dentes profundius sinuatum. Mandibulae validiores. Ca ut thorace prope latius, basi truncatum, medio subsinuatum, antrorsum suhangustatum, supra leviter convexum, punctis raris sparsisque minus subtilibus impressum, parce nigro-pilosum, saturate rufum, pernitidum. Thorax coleopteris vix angustior, latitudine haud brevior, basin versus leviter angustatus, lateribus subrectis, apice truneatus, angulis anterioribus subrectis, posterioribus rotundatis, supra valde convexus, laevissimus, parce nigro-pilosus, saturate rufus, nitidus. Scutellum concolor. Elytra thorace parum longiora, stria lata suturali punctisque parcis seriatis minus subtilibus impressa, nitida, rufa, macula magna transversali a medio margine laterali ad suturae apicem deflexa summoque margine suturali nigris, apice testaceo. Abdomen subtilissime punctu latum, tenuiter subtiliterque cinereo-pubescens, rufum, segmentis apicalibus duobus nigris. Pectus rufum. Pedes longiores, graciliores, rufi, femoribus pallide flavis, tarsis posterioribus modice elongatis, anticis leviter dilatatis.

* 10. L. confluens: Subdepressa, nigra, ore thoracisque limbo rufo-piceis, elytris apice testaceis, capite thoraceque transversim subquadratis, creberrime punctalo-rugulosis. - Long. $1 \frac{3}{4}$ lin.

Lathrobium confluentum Say Transact. Amer. Philosoph. Soc. Philadelph. Nov. Ser. IV. 456. 8. (furte) 
Habitat in Carolina meridionali, Dom. Zimmermann.

Reliquis brevior, depressa. Antennae capite thoraceque breviores, crassiusculae, articulo secundo tertioque subaequalihus, 4-10 sensim paulo brevioribus et crassioribus, ultimo apice subito acuminato, medio fuscae, basi apiceque rufo-piceae. Os rufo-piceum, palpis testaceis. Caput thorace paulo latius, subquadratum, depressum, confertissime minus subtiliter punctato-rugosum, nigrum, opacum, subtilissime cinereo-pubescens. Thorax coleopteris paulo angustior, latitudine antica paulo longior, basin versus angustatus, lateribus rectis, apice utrinque oblique truncatus, angulis anterioribus prominulis posterioribusque subrotundatis, lateribus distinctius marginatus, subdepressus, confertissime minus subtiliter punctato-subrugosus, opacus, rufo-piceus, disco nigro, subtiliter cinereo-pubescens. Scutellum piceum. Elytra thorace sesqui longiora, crebre punctata, tenuiter pubescentia, nitida, nigro-picea, apice late testacea. Abdomen subtilius confertim punctatum, densius pubescens, subnitıdum, supra nigrum, apice summo rufopiceo, subtus medio rufo-piceum, apice testaceum. Pectus piceum. Pedes breviusculi, cum coxis rufo-testacei, tarsis posterioribus breviusculis, anticis in utroque sexu levissime dilatatis.

$\mathrm{Mas}$ abdominis segmento inferiore sexto apice leviter triangulariter inciso; femina eodem leviter triangulariter producto.

11. L. dorsalis: Subdepressa, confertissime subtililer punctata, opaca, piceo-rufa, antennis pedibusque rufo-testaceis, elytris dorso nigris, thorace subtilissime canaliculato. - Long. 2 lin.

Habitat in Puerto-Rico, Dom. Moritz.

Statura ommino praecedentis, subdepressa, ohscure rufo-ferruginea, vix nitida, tota confertissime subtiliter punctata, pube brevi subtili grisea densius vestita. Antennae capite paulo longıres, apicem versus sensim subincrassatae, articulo tertio secundo parum longiore, 4-10 sensim paulo brevioribus et crassioribus, penultimis vix transversis, ultimo ovato, apice leviter acuminato, saturate rufo-testaceae. Palpi rufo-testacei. Labrum apice medio bidenticulatum. Caput thorace latius, suborbiculatum, depressiusculum. Thorax coleopteris paulo angustior, laticudine antica paulo brevior, basin versus leviter angustatus, apice utrinque oblique truncatus, angulis anterioribus obtusis, modice prominulss, posterioribus rotundatis, pone medium lineola subtilissima vix perspicue canaliculatus. Elytra thorace sesqui longıora, subdepressa, dorso late nigra, margine tenui apicali et limbo lato laterali ferrugineis. Abdomen apice summo testaceo. Pedes rufo-testacei, crassiusculi, breviusculi, femoribus anterioribus infra subdentatis, tarsis posterioribus minus elongatis, anticis leviter dilatatis.

M as abdominis segmento inferiore sexto apice late triangulariter exciso, septimo conspicuo, Fe mina latet.

*12. L. depressa: Subdepressa, conferlim subtiliter punclata, parum nitida, rufo-ferruginea, capile transversim subquadralo, subruguloso, thorace basin versus obsolele subtilissime carinalo, elytris thorace paulo longioribus. - Long. $1 \frac{3}{4}$ lin.

Habitat in Columbia. 
Statura breviuscula depressa praecedentium, rufo-ferruginea, nitida, pube subtilissima grisea vestita, antennis pedibusque ferrugineo-testaceis. Antennae capite vix sesqui longiores, apicem versus leniter incrassatae, articulo tertio secundo haud longiore, $3-10$ sensim paulo brevioribus et crassioribus, ultimo apice abrupte acuminato, rufo testaceae. Palpi testacei. Labrum apice 4-denticulatum. Caput thorace paulo latius, basi truncatum, angulis posterioribus et lateribus leviter rotundatum, depressum, confertissime subtiliter punctatum, subrugulosum. Thorax coleopteris angustior, latitudine paulo brevior, basin versus modice angustatus, apice utrinque oblique truncatus, angulis anterioribus subrectis, modice prominentibus, posterioribus subrotundatis, supra depressus, confertim subtiliter punctatus, linea media longitudinali subelevata obsoleta, ante medium evanescente, nonnunquam subtilissime canaliculata, basi utrinque prope lineam elevatam obsolete longitudinaliter impressus, basi summa obsolete 4-punctatus. Elytra thorace paulo longiora, subtiliter dense punctata, stria suturali, pone medium abbreviata, punctata impressa. Abdomen subtilissime punctulatum, piceum, segmentorum marginibus apiceque summo dilutioribus, subtus cum reliquo corpore piceo-rufescens. Pedes rufo-testacei, breves, tarsis brevioribus, articulo quarto subcordato, quinto brevi, anticis in utroque sexu levissime dilatatis.

Mas abdominis segmento inferiore sexto apice triangulariter exciso; femin a eodem acute rotundato.

* 13. L. bis eriala: Depressa, confertissime subtiliter punclala, opaca, ferruginea, capite subquadrato, subruguloso, thorace basi 4-punctato, elytris thorace sesqui longioribus, dorso obsolete biseriatim punctatis. Long. $1 \frac{3}{4}$ lin.

Habitat in Columbia, Dom. Moritz.

Statura omnino et summa affinitas praecedentis, fusca ferrugineave, opaca, pube subtilissima grisea tenuiter vestita, omnium confertissime subtiliter punctata. Antennae capite paulo longiores, apice subincrassatae, arti culo tertio secundo paulo longiore, articulis 4-10 sensim paulo brevioribus et crassioribus, ultimo ovate, apice subito acuminato, testaceo-rufae. Palpi rufo-testacei. Labrum apice obsoletius bidenticulatum, inter denticulos sinuatum. Caput thorace paulo latius, transversim subquadratum, basi truncatum, angulis posterioribus leviter rotundatis, lateribus rectis, ante oculos subito angustatum, depressum, confertissime longitudinaliter subrugulosum. Thorax coleopteris paulo angustior, latitudine brevior, basin versus modice angustatus, lateribus rectis, apice utrinque oblique truncatus, angulis anterioribus subrectis, prominulis, posterioribus obtusis, depressus, linea media longitudinali elevata vix perspicua subtilissime carinatus, basi punctis 4 sat distinctis, transversim positis, intermediis subtiliaribus, notatus. Elytra thorace sesqui longiora, depressa, stria suturali duabusque dorsalibus paulo fortius punctats, apice obsolescentibus notata. Abdomen apice testaceum. Pedes testacei, breviusculi, tarsis brevioribus, depressiusculis, articulo quarto subcordato.

Mas abdominis segmento inferiore sexto apice emarginato; femina eodem rotundato. 
Obs. Proxima praecedenti, at elytris paulo longioribus, dorso bistriatis thorace basi evidenter 4 -punctato distinguenda.

* 14. L. oblitu: Subdepressa, picea, capite subquadrato, creberrime punclato, thorace creberrime subtiliter punctato, elytris thorace sesqui longioribus anoque rufo-piceis, pedibus rufo-testaceis. - Long. $1 \frac{2}{3}$ lin.

Habitat in Columbia, Dom: Moritz.

Statura brevis lataque praecedentis, nigro-picea, nitidula, ore elytris anoque rufo piceis. Antennae capite sesqui longiores, apice subincrassatae, articulo secundo tertioque subaequalibus, 4 - 10 sensim brevioribus et crassıoribus, ultimo apice subito acuminato, densius pilosellae, rufo-testaceae. Labrum apice obsolete bidentioulatum, interstitio inter dentes leviter triangulariter exciso. Caput thoracis latitudine, subquadratum, angulis posterioribus rotundatis, subdepressum, creberrime muns subtiliter punctatum, fronte media vix laeviore, subtiliter nigro-pubescens, lateribus nigro-pilosum. Thorax coleopteris parum angustior, latitudine paulo brevior, basin versus subangustatus, lateribus rectis, angulis anterioribus obtusis, modice prominulis, posterioribus rotundatis, subdepressus, creberrime subtilius punctatus, linea media longitudinali laevi, parum distincta, subtiliter nigro-pubescens, lateribus parce nigro pilosus. Elytra thorace sesqui longiora, subtulius dense punctata, griseo-pubescentia. Abdomen omnium subtilissime punctulatum, densius griseo-pubescens, segmentorum marginibus summis apiceque rufopicess. Corpus subtus rufo-piceum. Pedes breviusculi, rufo-testacei, tarsis posterioribus minus elongatis, anticis leviter dilatatis.

Mas abdominis segmento inferiore sexto apice triangulariter exciso; fe $\mathrm{m}$ in a eodem rotundato.

* 15. L. curtula: Subdepressa, nigro-picea, capile transversim subquadralo, parcius forliusque punctalo, medio laevi, thorace punctato, elylris thorace sesqui longioribus, apice anoque rufo-piceis, pedibus rufo-lestaceis. - Long. $1 \frac{1}{2}$ lin.

Habitat in Columbia, Dom. Moritz.

Statura omnino et summa similitudo praecedentis, nigro picea, nitida. Antennae capite sesqui longiores, apicem versus hand crassiores, articulo secundo tertioque aequalibus, $4-10$ sensim paulo brevioribus, penultimis crassitie vix longioribus, ultimo subito forticis acuminato, rufo-testaceae. Palpi rufo-testacei. Labrum apice obsolete bidentatum, inter dentes profundius incisum. Os rufo-piceum. Caput thorace vix latius, transversim subquadratum, angulis posterioribus subrectis, depressum, mmus dense fortius punctatum, fronte media laeviore, subtiliter nigro-pubescens, parce nigro-pilosellum, nigrum, nitidum. Thorax coleopteris angustior, latitudine tertia parte brevior, basin versus subangustatus, lateribus rectis, angulis anterioribus obtusis, Jeviter prominentibus, posterioribus subrotundatis, parum convexus, densius fortiusque punctatus, linea media longitudinali laevi, subtiliter tenuiterque nigro-pubescens, lateribus nigro-pilosellus, niger, nitidus. Elytra subtilius minus "dense punctata, parcius griseo-pubescèntia, fusco-picea, nitida, apice dilute rufo-picea. Abdomen breviusculım, obsolete punctulatum, longius et minus dense 'griseo-pubescens, nigro-piceum, 
ano rufo-piceo. Corpus subtus rufo-piceum. Pedes testacei, tarsis posterioribus leviter elongatis, anticis fortius dilatatis.

Mas abdominis segmento inferiore sexto apice leviter triangulariter exciso; fem in a codem rotundato.

16. L. posticata: Subdepressa, picca, nifidula, capite thoraceque parctus punctatis, elytris apice nigris, pedibus flavis. - Long. 1 lin.

Habitat in Puerto-Rico, Dom. Moritz.

Habitu omnino praecedentium, at duplo minor. Antennae capite sesqui longiores, articulo tertio secundo paulo minore, 3 - I0 sensim paulo bre vioribus et crassioribus, penultimis fere transversis, ultimo maiusculo, subovato, pilosellae, totae testaceae. Os testaceum. Labrum apice medio bidenticulatum, inter dentes leviter excisum. Caput thorace paulo latius, bası, lateribus et angulis posterioribus leviter rotundatis, antrorsum subangustatum, depressiusculum, crebrius punctatum, fronte media laeviore, subtiliter parceque puberulum, piceum, nitidum. Thorax coleopteris paulo angustior, latitudine antica prope brevior, basin versus modice angustatus, apice utrinque oblique truncatus, angulis anterioribus subrectis, leviter prominentıbus, posterioribus subrotundatis, leviter convexus, sat crebre minus subtiliter punctatus, linea media longitudinali laevi, pube erecta brevi subtilique parce vestitus, piceus, nitidus. Elytra thorace tertia parte longiora, densius subtiliusque punctata, subtiliter pubescentia, laete testacea, apice tertia parte nigerrima. Abdomen subtilissıme punctatum, longius tenuiter pubescens, supra piceum, apice testaceum, infra cum reliquo corpore rufo-testaceum. Pedes flavi, breviusculi, femoribus anticis posticisque leviter incrassatis, tarsis posterioribus minus elongatis, anticis leviter dilatatis.

Mas abdominis segmento inferiore sexto apice triangulariter exciso. F e mina latet.

* 17. L. corlicina: Brevis, subdepressa, sublilissime confertissimeque punctata, opaca, rufo-picea, cupite subquadrato, basi emarginato, thorace leniter carinato. - Long. 3 lin.

Paederus corticinus Grav. Micr. 184. 1. - Oliv. Encycl. meth. VIII. 629. 9.

Luthrob. rufescens Nordm. Symb. 148. 20.

Lathrob. millepunctat um Say Transact. Amer. Philosoph. Transact. Philadelph. Nov. Ser. IV. 456. 7.

Habitat in America septentrionali.

Corpus breviusculum, latum, subdepressum, rufo-piceum, opacum, pube subtilissima depressa grisea densius vestitum, capite abdomineque fuscis. Antennae capitis thoracisque prope longitudine, graciliores, apıcem versus haud crassiores, articulo tertio secundo sesyui longiore, $4-10$ sensim brevioribus, ultimo subovato, apice acuminato, rufo-testaceae. Labrum margine laterali dilatato, medio unidentatum. Caput maiusculum, thoracis latitudine, subquadratum, basi profundius emarginatum, depressiusculum, subtilissime confertissimeque punctatum, linea tenuissima longitudinali laevi. Thorax coleopteris paulo angustior, latitudine antica haud brevior, basin versus leviter angustatus, lateribus rectis, apice utrinque oblique truncatus, angulis anterioribus modice prominentibus, obtusis, posterioribus leviter ro- 
tundatis, parum convexus, subtilissime confertissimeque punctatus, linea media longitudinali tenui carinata laevi. Elytra thorace paulo longiora, subtilissime confertissimeque punctata, disco fuscescentia. Abdomen confertissime subtilissimeque punctatum, fuscum; segmentorum marginibus apiceque rufopiceis. Pedes testacei, tarsis posterioribus modice elongatis, anticis leviter dilatatis.

Mas abdominis segmento inferiore sexto apice late triangulariter emarginato; fe min a eodem leviter triangulariter producto.

V ariat dilutior corpore testaceo, elytris plaga dorsali determinata fusca.

* 18. I. hepatica: Subtilissime conferlissimeque punctata, opaca, fusca, antennis, abdominis segmentorum marginibus, elytrisque ferrugineis, his plaga fusca, pedibus testaceis, capile quadrato, thorace transversim subquadrato, leviter carinato. - Long. 3 lin.

Habitat in Columbia, Dom. Moritz.

L. corticinae aequalis, opaca, pube subtilissima grisea densius vestita. Antennae capite thoraceque vix breviores, apicem versus leviter attenuatae, articulo tertio secundo sesqui prope longiore, $\mathbf{4}-\mathbf{1 0}$ sensim paulo brevioribus et paulo magis transversis, ultimo apice fortiter acuminato, piceorufae. Labrum margine laterali membranaceo dilatato, apice medio denticulo prominulo instructum. Caput thorace paulo latius, subquadratum, lateribus rectis, basi late leviter emarginatum, angulis posterioribus subrectis, depressiusculum, subtilissime confertissime punctatum, linea tenuissima obsoleta longitudinali laevi, lateribus parce pilosum, fuscum. Thorax coleopteris paulo angustior, latitudine antica paulo brevior, basin versus leviter angustatus, apice utrinque oblique truncatus, angulis anterioribus subrectis, modice prominentibus, posterioribus rotundatis, subdepressus, subtilissime confertissimeque punctatus, linea angusta media longitudinali laevi, fortius elevata carinatus, lateribus parce pilosus, rufescenti-fuscus. Elytra thorace paulo longiora, subtilissime confertissineque punctata, ferruginea testaceave, plaga dorsali longitudinali indeterminata fusca. Abdomen omnium subtilissime punctulatum, fuscum, ano testaceo, segmentorum marginibus ferrugineis. Pedes longiusculı, dilute testacei, tarsis posterioribus minus elongatis, anticis in utroque sexu leviter dilatatis.

Mas abdominis segmento inferiore quinto apice trisinuato, sexto late triangulariter exciso, septimo conspicuo; femina segmento sexto apice rotundato, septimo occulto.

Obs. Differt ab L. corticina praecipue statura graciliore, capite basi minus profunde emarginato et elytris brevioribus.

* 19. L. cinnamomea: Subtilissime confertissimeque punctata, opaca, rufotestacea, capile, elylrorum plaga obsoleta abdomineque fuscis, pedibus testaceis, capite subyuadrato, thorace obsolete carinalo. - Long. $1 \frac{1}{2}$ lin.

Habitat in Columbia, Dom. Moritz.

Habitu omnino praecedentis, at dimidio minor, opaca, pube subtilissima depressa cinerascenti obducta. Antennae capitis thoracisque prope longitudine, apicem versus haud attenuatae, articulo tertio secundo sesqui longiore, 4 - 10 sensim brevioribus, cylindricis, ultimo subovato, apice acuminato, 
rufo-testaceae. Labrum transversum, limbo laterali membranaceo, fortiter dilatato, apice medio denticulo obsoleto armatum. Caput thorace vix latius, subquadratum, lateribus rectis, basi late leviter emarginatum, angulis posterioribus subrectis, supra leviter convexum, aequaliter confertissime subtilissime punctatum, lateribus pilosellum, rufo-piceum, ore dilutiore. Thorax coleopteris paulo angustior, latitudine antica vix brevior, basin versus modice angustatus, lateribus rectis, apice utrinque oblique truncatus, angulis anterioribus obtusiusculis, posterioribus subrotundatis, parum convexus, subtilissime confertissimeque punctatus, linea media longitudinali tenui subelevata laevi obsolete carinatus, lateribus parce pilosus, saturate rufo-testaceus vel rufus. Elytra thorace tertia fere parte longiora, subtilissime confertissimeque punctata, testacea, plaga indeterminata obsoletaque prope suturam fusca. Abdomen confertissime subtlissimeque punctatum, fuscum, segmento sexto toto, reliquis margine rufo-testaceis ferrugineisve. Pectus rufo-testaceum. Pedes dilutius testacei, longiusculi, tarsis posterioribus minus elongatis, anticis in utroque sexu leviter dilatatis.

Mas abdominis segmento inferiore sexto apice late triangulariter exciso; femina eodem apice leviter producto, acute rotundato.

Obs. Proxima praecedenti, at statura minore, graciliore, thorace obsolete carinato, elytris paulo longioribus, etc. distincta.

20. L. limbata: Sublilissime confertissimeque punctata, opaca, fusca, antennis testaceis, elylrorum limbo laterali et apicali pedibusque flavis, capile suborbiculato, thorace subquadrato, subtiliter carinato. - Long. 2 lin.

Habitat in Columbia, Dom. Moritz.

Habitus omnino L. ochraceae, at duplo fere maior, opaca, pube subtilissima cinerascenti densius vestita. Antennae capite thoraceque breviores, validiusculae, apicem versus neque attenuatae, neque incrassatae, articulo tertio secundo sesqui longiore, $4-10$ sensim paululum brevioribus, cylindricis, ultimo oblongo-subovato, apice fortius acuminato, rufo-testaceae, ante medium fuscescentes. Os testaceum. Labrum transversum, limbo laterali membranaceo fortiter dilatato, apice truncatulum et obsolete denticulatum. Caput thoracis prope latitudine, basi, lateribus et angulis posterioribus leviter rotundatis, supra leviter convexum, omnium, subtilissime confertissine punctatum, utrinque nigro-pilosellum, nigro-fuscum. Thorax coleopteris tertia parte angustior, latitudine haud brevior, basin versus haud angustatus, apice utrinque oblique truncatus, angulis anterioribus obtusis, posterioribus subrotundatis, parum convexus, omnium subtilissime confertissime punctatus, linea media longitudinali tenui, posterius fortius elevata, subtiliter carinatus, lateribus parce nigro-pilosus, fuscus. Elytra thorace paulo longiora, depressa, confertissime subtilissimeque, licet distinctins quam caput et thorax punctata, dorso fusca, limbo lato laterali apicalique determinate pallide flavotestaceis. Abdomen confertissime subtilissimeque punctatum, supra nigrofuscum, segmentis singulis testaceo-marginatis, infra rufo-testaceum, segmentis singulis basi lateraliter fuscis. Pectus fuscum. Pedes dilute testacei, femoribus flavis, tarsis posterioribus modice elongatis, anticis in utroque sexu simplicibus. 
Mas abdominis segmento inferiore sexto apice truncato, septimo exserto; femina sexto apice rotundato, septimo occulto.

* 21. L. fumata: Subtilissime conferlissimeque punctata, brunnea, pedibus testaceis, capite suborbiculato, nigro, thorace subquadrato, subtiliter carinato. - Long. $2 \frac{1}{4}$ lin.

Habitat in Brasilia, Dom. Melly.

Habitu omnino L. ochraceae, at plus sesqui maior. Antennae capite thoraceque paulo breviores, crassiusculae, apicem versus neque incrassatae, neque attenuatae, articulo tertin secundo paulo longiore, $4-10$ sensim paulo brevioribus, ultimo subovato, apice abrupte acuminato, piceae, apice rufo-ferrugineae. Labrưm transversum, limbo laterali membranaceo leviter dilatato, apice truncatum, obsolete denticulatum, rufum. Palpi rufo-picei. Caput thoracis latitudine, basi et lateribus leviter, angulis posterioribus fortiins rotundatum, ante oculos subito angustatum, supra parum convexum, anterius depressum, subtilissime confertissimeque punetatum, lateribus parce nigropilosum, nigrum, subnitidum. Thorax coleopteris paulo angustior, latitudine haud brevior, basin versus vix angustatus, lateribus rectis, apice utrinqte oblique truncatus, angulis anterioribus obtusis, posterioribus leviter rotundatis, subdepressus, omnium subtilissime confertissime punctatus, linea media longitudinali tenui leviter elevata, subtiliter at sat distincte carinatus, subtilissime griseo-pubescens, lateribus parce nigro-pilosus, brunneus, parum nitidus. Elytra thorace paulo longiora, confertim subtiliter pubescentia, rufescenti-brunnea, apicem versus sensim nigra, nitidula. Abdomen subtilissime punctulatum, subtiliter pubescens, supra obscure brunneum, subtus ferrugineum, segmentis basi obscurioribus. Pectus brumeum. Pedes testacei, tarsis posterioribus modice elongatis.

Mas latet. Femina abdominis segmento inferiore sexto apice leviter triangulariter producto, tarsis anticis simplicibus.

*22. L. infuscala: Sublilissime confertissimeque punctula, fusca, antennis pedibusgue teslaceis, elylris ferrugineis, disco fuscis, capile suborbiculato, nigro, thorace quadrato, obsolete carinalo. - Long. $1 \frac{1}{4}$ lin.

Habitat in Columbia, Dom. Moritz.

Habitus omnino et summa similitudo L. ochraceae, at dimidio minor, pube subtilissima grisea obducta, capite thoraceque lateribus parce nigrojilosis. Antennae capitis thoracisque prope longitudine, crassinsculae, apicem versus subincrassatae, articulo secundo tertioque subaequalibus, $4-10$ sensim paulo brevioribus et crassioribus, ultimo apice subito subacuminato, totae rufo-testaceae. Palpi rufo-testacei. Os rufo-piceum. Labrum apice subsinuatum, medio obsoletius bidenticulatum. Caput thoracis latitudine, basi, lateribus et angulis posteriorihus leviter rotundatis, ante oculos subito angustatum, supra posterius leviter convexum, anterius subdepressum, omnium subtilissime confertissimeque punctatum, nigrum, subnitidum. Thorax coleopteris panlo angustior, latıtudine hand brevior, lateribus rectis, parallelis, apice utrinque oblique truncatus, angulis anterioribus obtusis, posterioribus subrotundatis, parum convexus, omnium subtilissime confertissineque punctatus, linea media longitudinali tenui, subelevata, obso- 
lete carinatus, fusco-piceus, subnitidus. Elytra thorace teria parte longiora, subdepressa, confertissime subtilissimeque, licet distinctins quam caput et thorax, punctata, ferruginea vel fusco-testacea, plaga magna lata commnni fusca, seu fusca, limbo lato laterali apicalique fusco-testaceis. Abdomen confertissime subtilissimeque punctatum, longius pubescens, fuscum, segmentis 4 primis summo margine apicali, quinto apice lato, sexto toto testaceis. Pectus fuscum. Pedes fiavi, femoribus anticis posticisque leviter incrassatis, tarsis posterioribus minus elongatis, anticis in utroque sexu simplicibus.

Mas abdominis segmento inferiore sexto apice leviter emargmato; femin a eodem rotundato.

*23. L. ochracea: Sublilissime conferlissimeque punclata, opaca, ferruginea, capile subtriangulari nigro, thorace quadralo, obsolete carinalo. - Long. $1 \frac{2}{3}$ lin.

Boisd. et Lacord. Faun. Ent. Paris. I. 432. 1. - Er. Col. March, I. 516. 7. Paederus ochraceus Grav. Micr. 59. 1. Mon. 138. 1. - Latr. Hist. nat. Crust. et Ins. IX. 347. 6. - Panz. Faun. Germ 104. 14. - Oliv. Encycl. melh. IIII. 630. 14.

Paederus rubricollis Grav. Mon. 138 2. - Oliv. Encycl. meth. VIII. 630. 15. - Gyll. Ins. Suec. II. 376. 5. - Sahlb. Ins. Fenn. I. 314. 5.

Rugilus rubricollis Mannerh. Brathelylr. 40. 6. - Runde Brachelytr. Hal. 14. 3. Lit huch. te stacea Boisd. et Lacord. Faun. Ent. Paris. 1. 432. 2. (forte)

Habitat in Europa, in Americae ins. St. Johannis, Dom. Moritz, in Brasilia, Dom. Lhotzki.

Corpus ferrugineum vel rufo-testaceum, opacum, pube subtilissima griseo-sericea densius vestitum. Antennae capitis thoracisque fere longitudine, apicem versus neque attenuatae, neque incrassatae, articulo tertio secundo paulo longiore, 4 - 10 sensim hrevioribus, ultimo apice fortius acuminato. testaceae. Palpi et os testacea. Labrum apice medio obsoletius bidenticulatum, inter dentes leviter triangulariter excisum. Caput thoracis latitudine, basi truncatum, angulis posterioribus rotundatis, antrorsum angustatum, supra posterus leviter convexum, anterius 'depressiusculum, aequaliter" subtilissime confertiscimeque punctatum, lateribus parce pilosum, nigrum. Thorax coleopteris tertia parte angustior, latitudine haud brevior, basin versus hand angustatus, lateribus rectis, apice utrinque oblique truncatus, angulis anterioribus obtusis, posterioribus subrotundatis, subdepressus, subtilissime confertissimeque punctatus, linea tenui subelevata obsolete carinatus. Elytra thorace tertia parte longiora, confertissime subtilissimeque punctata. Abdo. men conferiissime subtilissimeque punctatum. Pedes dilute flavo-testacei, tarsis posterioribus modice elongatis, anticis in utroque sexu leviter dilatatis.

Mas abdominis segmento inferiore quinto apice late subsinuato, sexto foriter triangulariter exciso; femina eodem apice leviter producto rotundatoque.

* 24. I. obsoleta: Omnium subtilissime conferlissimeque punctala, opaca, nigro-picea, capite suborbiculato, thorace quadrato, aequali, pedibus anlennisque rufo piceis, his basi fuscis. - Long. $1 \frac{2}{3}$ lin.

Er. Col. March. I. 516. 8.

Lathrobium obsoletum Nordm. Symb. 146. 19. 


\section{Habitat in Germania.}

Statura et summa similitudo praecedentis, nigro-picea, opaca, pube subtili griseo-sericea densius vestita, capite thoraceque lateribus parce nigro-pilosellis. Antennae capitis thoracisque longitudine, apicem versus neque attenuatae, neque incrassatae, articulo tertio secundo paulo longiore, 4-10 sensim paulo brevioribus et paulo magis obconicis, ultimo ovato, apice acuminato, rufo-piceae, basi fuscae. Palpi rufo-picei, articulo tertio fusco. Labrum apice obsolete denticulatum. Caput thorace paulo angustius, basi, lateribus et angulis posterioribus leviter rotundatis, ante oculos subito angustatum, leviter convexum, subtilissime confertissimeque punctatum, ore rufo-piceo. Thorax coleopteris paulo angustior, latitudine haud longior, lateribus rectis, parallelis, basi apiceque truncatus, angulis anterioribus leviter, posterioribus fortius rotundatis, subdepressus, aequalis, confertissime subtilissimeque punctatus. Elytra thorace tertia parte longiora, subtilissime confertissimeque punctata. Abdomen omnium subtilissime punctulatum. Pedes rufo-picei vel rufo-testacei, tarsis posterioribus modice elongatis.

Mas abdominis segmento inferiore sexto apice leviter emarginato, tarsis anticis fortiter dilatatis; femina abdominis segmento inferiore sexto apice rotundato, tarsis anticis leviter dilatatis.

Varıat thorace, elytris anoque rufo-piceis, rarius antennis palpisque totis rufo-testaceis.

Obs. A praecedente, cui varietates dilutiores colore etiam similes sunt, differt thorace latiore, angulis anticis minus obtusis, supra ne obsolete quidem carinato, capiteque subtilius punctatis, antennarum basi, palporumque max. articulo tertio plerumque in dilutioribus etiam speciminibus piceis, tarsis anticis maris fortiter dilatatis, patellam ovalem formantibus.

25. L. obscurella: Omnium subtilissime confertissimeque punctata, opaca, fusco-picea, antennis pedibusque testaceis, capile subtriangulari, thorace oblongo - subquadrato, aequali. - Long. $1 \frac{1}{2}$ lin.

Habitat in Sardinia, Dom. Prof. Gené.

Praecedenti proxima, opaca, tota omnium subtilissime confertissimeque punctata, pube subtilissima fusco-grisea densiore sericans. Antennae capite thoraceque paulo breviores, validinsculae, apicem versus neque incrassatae, neque attenuatae, articulo tertio secundo paulo longiore, 4-10 sensim pauı brevioribus, ultimo subovato, apice subito acuminato, totae testaceae. Os testaceum. Labrum apice medio acute bidenticulatum. Caput basi thoracis latitudine, basi et angulis posterioribus leviter rotundatis, antrorsum sensim angustatum, supra parum convexum, nigrum. Thorax coleopteris paulo angustior, latitudine paulo longior, basin versus subangustatus, lateribus rectis, apice utrinque oblique truncatus, angulis anterioribus obtusis, posterioribus leviter rotundatis, parum convexus, aequalis, fusco-piceus. Elytra thorace paulo longiora, subdepressa, fusco-picea. Abdomen nigrum, segmentorum ventralium margine apicali rufo piceo. Pedes dilute testacei, tarsis posterioribus leviter elongatis, anticis leviter dilatatis.

Obs. Distinguitur a praecedente praecipue capite antrorsum magis angustato, thorace latitudine longiore, elytris contra paulo brevioribus. 
* 26. L. nigritula: Linearis, subtilius punctata, nigra, antennis pedibusque piceis, capile suborbiculato, thorace subquadrato. - Long. $1 \frac{1}{2}$ lin.

Habitat in Sicilia, Dom. Dr. Helfer.

Statura fere praecedentinm, at magis linearis, nigra, subnitida, subtiliter cinereo-pubescens. Antennae capite thoraceque paulo breviores, articulo tertio secundo paulo minore, $3-10$ sensim paulo brevioribus, ultimo apice subito acuminato, rufo-piceae. Os rufo-piceum. Labrum apice medio obsolete bidenticulatum. Caput thoracis latitudine, basi, lateribus et angulis posterioribus leviter rotundatis, parum convexum, confertim subtilius punctatum, linea media longitudinali laevi parum distinsta. Thorax coleopteris vix angustior, latitudine paululum longior, lateribus rectis, parallelis, apice ntrinque oblique truncatus, angulis anterioribus obtusis, posterioribus subrotundatis, parum convexus, subtilius confertim punctatus, linea media longitudinali laevi, posterius subelevata. Elytra thorace paulo longiora, subtilius confertim punctata, nigro-picea. Abdomen confertim subtiliter punctatum, segmentorum margine apicali anoque piceis. Pedes saturate rufotestacei vel rufo-picei, tarsis posterioribus minus elongatis, anticis in utroque sexu simplicibus.

Mas abdominis segmento inferiore sexto apice leviter emarginato; femin a eodem rotundato.

Obs. A praecedentibus praecipue punctura multo minus subtili distinguenda.

*27. L. debilis: Subdepressa, rufo-testacea, subtilissime conferlissimeque punctata, capile thoraceque subquadratis, elytris fuscis, apice pedibusque flavo-testaceis. - Long. $1 \frac{1}{2}$ lin.

Habitat in Columbia, Dom. Moritz.

Linearis, subdepressa, rufo-testacea, opaca, pube subtilissima cinerea obducta. Antennae capite sesqui longiores, apicem versus neque attenuatae, neque incrassatae, articulo tertio secundo paulo longiore, 4-10 sensim paulo brevioribus, ultimo oblongo, apice abrupte acuminato, flavo-testaceae. Palpi testacei. Labrum apice subsinuatum, medio obsoletius bidenticulatum. Caput thoracis latitudine, lateribus rectis, basi truncatum, angulis posterioribus subrectis, subquadratum, supra posterius leviter convexum, anterius subdepressum, omnium subtilissime confertissimeque punctatum, lateribus parce pilosellum. Thorax coleopterorum latitudine, latitudine haud brevior, lateribus rectis, parallelis, apice utrinque oblique truncatus, angulis aniterioribus obtusis, posterioribus rotundatis, subdepressus, subtilissime confertis simeque punctatus, linea media longitudinali, basin versus obsoletissima, vix observanda. 'Elytra thorace sesqui longiora, subtilissime confertissimeque punctata, nigro-fusca, apice determinate testacea. Abdomen coleopteris angustius, dense punctulatum, segmentis singulis nonnunquam basi fuscescentibus. Pedes flavi, breviusculi, femoribus posticis leviter incrassatis, tarsis posterioribus gracilioribus, leviter elongatis, antıcis in utroque sexu simplicibus.

Mas abdominis segmento inferiore quinto apice levissime, sexto leviter emarginato; femina eodem rotundato. 
* 28. K. humilis: Brevis, suldepressa, sublilissime conferlissimeque punctala, rufo-picea, capile Iransversim subquadrato, basi emarginato, thorace obsolete carinato, basi subtilissime canaliculalo, antennis tenuibus, arliculis duobus primus crassis. - Long. $1 \frac{3}{4}$ lin.

Habitat in Columbia, Dom. Moritz.

Statura brevis, latiuscula L. corticinae, at quadruplo minor, rufo-picea, pube subtilissima depressa grisea vestita, capite thoraceque nigricantibus, lateribus nigro-pilosellis. Antennae capite paulo longiores, apicem versus attenuatae, articulis duobus primis crassiusculis, sequentibus tenuibus, tertio secundo vix breviore, 4-10 sensin paulo brevioribus, ultimo oblongo, acuminato, pilosellae, rufo-testaceae. Labrum margine dilatatum, medio bidenticulatum. Caput thorace latius, transversim subquadratum, basi late emarginatum, angulis posterioribus vix rotundatis, depressiusculum, subtilissime aequaliter punctatum. Thorax coleopteris angustior, latitudine antica tertia parte brevior, basin versus modice angustatus, lateribus rectis, apice utrinque oblique truncatus, angulis anterioribus obtusis, modice prominentibus, posterioribus rotundatis, subdepressus, confertissime subtilissimeque punctatus, linea media longitudinali, subelevata, tenui, antrorsum subobsoleta, basi subtrliter canaliculata. Elytra thorace tertia parte longiora, subtiliter dense punctata. Abdomen confertissime subtilissimeque punctatum. Corpus subtus dilute rufo-piceum. Pedes breviusculi, testacei, tarsis posterioribus leviter elongatis, anticis parum dilatatis.

Mas latet. Femina abdominis segmento inferiore sexto apice leviter producto, emarginato.

$\mathrm{O} \mathrm{bs}$. Antennarum structura cum sequentibus duabus a praecedentibus facile distinguenda.

*29. L. sordida: Sublilissime confertissimeque punctata, rufo-testacea, subnitida, subdepressa, capite subquadralo, thorace subtilissime canaliculato, antennis tenuibus, articulis duobus primis crassis. - Long. $1 \frac{1}{4}$ lin.

Habitat in valle Araguensi Columbiae, Dom. Moritz.

L. ochracea minor, praecipue brevior, praecedente plus duplo minor, subdepressa, rufo-testacea, suhmtida, pube subtilissima grisea vestita, capite thoraceque lateribus parce nigro-pilosellıs. Antennae capite sesqui longiores, articulıs duobus primis crassis et sat magnis, sequentibus tenuibus, 3- 10 sensim paulo brevioribus, ultimo oblongo, apice acuminato, pilosellae, testaceae. Palpi testacei. Labrum apice medio obsolete bidenticulatum. Caput thorace prope latius, basi truncatum, angulis posterioribus et lateribus rectis, ante oculos subito angustatum, subdepressum, aequale. Thorax coleopteris paulo angustior, latitudine antica tertia parte brevior, basin versus angustatus, apice utrinque oblique truncatus, angulis anterioribus obtusis, leviter prominentibus, posterioribus rotundatis, parım convexus, linea media longitudinali exarata subtilissima, apice evanescente canaliculatus. Elytra thorace tertia parte longiora, angulo apicali exteriore dilutiore, dorso plaga obsoleta fuscescente. Abdomen densius pubescens. Pedes flavo-testacei, breviores, tarsis posterioribus hrevioribus, anticis in utrogue sexu simplicibus.

Mas abdominis segmento inferiore sexto apice profundius triangulariter exciso; femin a eodem roiundato. 
* 30. L. exilis: Omnium sublilissime conferlissimeque punclala, mufo-testacen, capite suborbiculato, nigro thoraceque subquadratis, pedibus flavis, antennis tenuibus, articulis duobus primis crassis. - Long. 1 lin.

Habitat in Columbia, Dom. Moritz.

L. ochraceae habitu similis at quadruplo fere minor, rufo-testacea, parum nitida, tota subtilissime confertissimeque punctulata, pube subtilissima cinerea vestita, capite solo nigro-piceo. Antennae capite thoraceque paulo breviores, articulis duobus primis crassis ac reliquis multo maioribus, his tenribus, 3 - 10 subaequalibus, ultimo oblongo, apice abrupte acuminato, piloselfae, flavo-testaceae. Palpi testacei. Os rufo-testaceum. Labrum apice leviter sinuatum, medio acute bidentatum. Caput thoracis latitudine, suborbiculatum. Thorax coleopteris paulo angustior, longitudine haud brevior, basin versus vix angustatus, lateribus rectis, angulis omnibus rotundatis, parum convexus, aequalis. Elytra thorace paulo longiora, dilutius testacea, plaga dorsali indeterminata obsoletiore fusca. Abdomen apice pilosellum. Pedes flavi, breviores, femoribus anticis posticisque leviter incrassatis, tarsis posterioribus tenuibus, minus elongatis, anticis in utroque sexu simplicibus.

Mas abdominis segmento inferiore sexto apice late triangulariter ex ciso, septimo exserto; femin a sexto apice rotundato, septimo occulto.

\section{Ophites $E r$.}

\section{Labrum breve, apice bidenticulatum.}

Palpi maxillares articulo quarto distincto, acuto. Antennae fractae.

\section{Tarsi articulo quarto simplice.}

Corpus elongatum, lineare, alatum. Caput oblongum, postice attenuatum, collo quasi longo tenui thoraci afñxum, exsertum, porrectum, oculis parvis, rotundatis, prominulis. Labrum transversum, breve, medio sinuatum et bidenticulatum. Mandibulae falcatae, acutae, medio fortiter acuteque dentatae. Maxillae (t. IV. f. 32. b.) malis corneis, interiore interne apiceque, exteriore subelongata apice dense barbatis. Palpi maxillares elongati, articulo primo brevi, secundo valde elongato, tenui, tertio huic aequali, apicem versus sensim subincrassato, quarto parvo, subulato, acuto. Labium (t. IV. f. 32. a.) mento transverso, ligula lata, biloha, lobis rotundatis, approximatis, membranacea, paraglossis angustis, acuminatis, coriaceis, pubescentibus, ligulam haud superantibus. Palpi labiales filiformes, articulo primo secundo paulo breviore, tertio huic aequali, acuminato. Antennae tenues, elongatae, fractae, articulo primo valde elongato, recto, secundo reliquis tenuiore et breviore, sequentibus sensim paulo brevioribus, ultimo apice truncatulo. Thorax angustus, fortiter elongatus, cylindricus, a medio apicem versus sensim attenuatus. Scutellum triangulare. Elytra truncata. Abdomen lineare, segmento superiore sexto apice trisinuato, septimo retractili, stylis analıbus distinctis, longioribus, acuminatis. Pedes elongati, graciles, coxis anticis elongatis, tarsis omnibus simplicibus, articulis 4 primis longitudine sensim decrescentibus.

\section{O b s e r vat i o n e s.}

1. Habitus in hac familia singularis, capitis thoracisque forma Casnoniam referens, neque etiam Raphidiae dissimilis, unde a Dejeanio nome. Rugili 
Raphidioidis speciei cuidam impositum est. Genus a' Stilico oris fabrica, qua cum $\mathrm{P}$ a e der o magis ronvenit, satis distinctum, a Paedero tarsorum articulo quarto simplice, ab omnibus huius familiae generibus, excepto Cryptobio, antennarum forma differt, ab hoc autem habitu, labri, palporum pedumque structura satis discedit.

2. Sexus differentia in abdominis segmento inferiore, in maribus inciso, in femina integro, rotundato, quaerenda.

* 1. O. versatilis: Nigro-piceus, nilidus, elytris thoracis nitidi longitudine, basi subseriatim punclatis, margine apicali pedibusgue albidis, his medio piceis. - Long. $4 \frac{1}{2}$ lin

T. 2. f. 1.

Habitat in Columbia, Dom. Moritz.

Niger, nitidus. Antennae nigro-piceae, articulo primo basi rufescente, ultimis ferrugineis. Palpi maxillares rufo-picei, articulo tertio medio nigricante. Os rufo-piceum. Caput nitidum, parcius subtiliter punctulatum, pube parciore minus depressa nigra tenuiter vestitum, posterius attenuatum, pedunculo piceo. Thorax coleopteris duplo angustior, elongatus, cylindricus, postice utrinque compressus, a medio inde antrorsum sensim attenuatus, utrinque parce subtiliterque subseriatim punctatus, nitidus, pube parea erecta instructus. Scutellum piceum, laeve. Elytra thoracis longitudine, basi interius fortiter densius seriatim, exterius apiceque parcius vage punctata, parce griseo-pubescentia et nigro-pilosa, nigro picea, nitida, margine apicali pallide flavo. Abdomen parcius subtilissime punctulatum, pube depressa cinerea tenuiter vestitum, apice piceo-testaceum, segmento superiore sexto apice acute bidentato. Pedes albidi, coxis nigro-piceis, antici femoribus subtus tibiisque totis piceis, posteriores femoribus apice late nigro-piceis, tibiis etian plerumque basi piceis.

Mas ahdominis segmento inferiore sexto profunde triangulariter exciso; fem in a eodem rotundato.

* 2. O. Raphidioides: Niger, nitidus, elytris thorace paulo longioribus, basi serialim punctatis, margine apicali pedibusque albidis, femoribus apice tibiisque anticis piceis. - Long. $4 \frac{1}{2}$ lin.

Habitat Carthagenae in Columbia, Dom. Gory.

Praecedenti proximus, at paulo robustior. Antennae ferrugineae, articulo primo apice piceo. Palpi maxillares rufo-testacei, articulo tertio medio piceo. Os nigro-piceum. Caput confertim subtilissime punctatum, pube subtili depressa cinerea dense obductum, posterius attenuatum, pedunculo piceo. Thorax coleopteris duplo angustior, elongatus, cylindricus, rostice subcompressus, medio leviter incrassatus, antrorsum sensim attenuatus, utrinque parcius subtiliter subseriatim punctatus, nitidus, pilis parcis erectis nigris instructus. Scutellum nigrum, laeve. Elytra thorace paulo longiora, basi densius seriatim punctata, seriebus interioribus longioribus, apice parce vage punctata, parce subtiliterque cinereo-pubescentia et nigropilosa, nigra, nitida, margine apicali pallide flavo. Abdomen confertissime subtilissimeque punctatum, pube subtilissima cinerea densius vestitum, apice piceo-testareum, segmento sexto dorsali apice acute bidentato. Pedes albi, coxis omnibus nigris, femoribus apice late nigricantibus, tibiis anticis nigro- 
piceis, posterioribus albis, apice subtestaceis, tarsis testaceis, posterioribus basi albis.

Mas abdominis segmento inferiore sexto apice emarginato; fe min a latet.

Obs. Distinguendus a praecedente antennis brevioribus, dilutiorious, capite latiore, pube densa cinerea vestito, thorace medio leviter incrassato, elytris longioribus, abdomine confertissime punctulato, densius pubescente, tibiis posterioribus basi haud nigricantibus.

3. O. velitaris: Niger, capite thoraceque opacis, elytris thorace longioribus, aequaliter punctatis, margine apicali pedibusque albidis, his medio piceis. - Long. $4 \frac{3}{4}$ lin.

Habitat in valle Araguensi Columbiae, Dom. Moritz.

Statura ommino et summa affinitas praecedentium, at vere distinctus. Corpus nigrum. Antennae rufo-piceae, articulo primo apice fusco. Palpi maxillares rufo-picei, articulo secundo tertioque medio fuscescentibus. Os piceum. Caput opacum, omnium confertissime subtilissimeque punctatoalutaceum, pube subtili depressa grisea ọbductum. Thorax coleopteris duplo angustior, elongatus, cylindricus, pone medium lateribus compressus, a medio inde apicem versus sensim leniter angustatus, glaber laevisque, opacus, linea media longitudinali, ante medium latıre, pone medium interrupta lateribusque pone medium nitidis. Scutellum laeve, opacum. Elytra thorace longiora, aequaliter densius, profundius et minus fortiter, basi etiam vix seriatim punctata, pube parca depressa grisea instructa, nigro-picea, nitida, margine apicali albido-testaceo. Abdomen confertim subtiliter punctatum, pube densiore subtili depressa grisea vestitum, "subnitidum, segmento quinto sextoque apice testaceis, sexto superiore apıce obtuse bidentato. Pedes coxis omnibus piceis, trochanteribus testaceis, femoribus albis, apice late nigro-piceis, posterioribus apice late testaceis, tarsis omnibus testaceis. tundato.

Mas latet. Femina abdominis segmento inferiore sexto apice ro-

\section{Stilieus Latr.}

Latr. Regn. Anim. IV.p. 436. - Encycl. meth. X.p. 494. - Er. Col. March. I.p. 519. Rugilus Curt. Britt. Ent. IV. t. 168. - Steph. Illustr. Britt, Ent. V. p. 277. Boisd. et Lacord. Faun. Ent. Paris. I. p. 433.

Labrum amplum, apice bispinosum.

Palpi maxillares articulo quarto vix distinclo.

Antennae rectae.

Tarsi articulo quarto simplice.

Corpus elongatum, alatum. Caput sat magnum, orbiculatum, pedunculo tenui brevi thoraci affixum, exsertum, porrectum, oculis parvis, rotundatis, prominulis. Labrum amplum, mandibulas obtegens, lateribus rotundatum, limbo laterali membranaceo, medio subsinuatum, acute bidenticulatum. Mandibulae falcatae, acutae, medio acute 3-vel 4-dentatae. Maxillae (t. IV. f. 31. b.) malis corneis, interiore interne, exteriore apice dense barbatis. Palpi maxillares modice elongati, articulo primo parvo, secundo tertioque elongatis, longitudine subaequalibus, hoc incrassato, quarto subulato, minimo, aegre conspicuo. Labrum (t. IV. f. 31. a.) mento transverso, ligula mem- 
branacea biloba, lobis rotundatis, brevissimis, distantibus, interstitio spisse setoso, paraglossis linearibus, membraneis, ligulam longe superantibus. Palpi labiales articulo primo cylindrico, secundo subovato, praecedente paulo longiore crassioreque, tertio minuto, tenui, acuto. Antennae filiformes, rectae, breviusculae crassiusculaeque, articulo primo maiusculo, longiore, secundo tertioque sequentibus paulo longioribus. Thorax subovatus, apice attenuatus. Scutellum parvum, triangulare. Elytra truncata. Abdomen lineare, segmento septimo retractili, stylis analibus haud distinctis. Pedes sat longi, graciles, coxis anticis elongatis, tarsis omnibus simplicibus, anticis articulis omnibus in utroque sexu linearibus.

\section{O b s e r vationes.}

1. Corpus obscurum, subtilissime pubescens, capite thoraceque confertissime punctatis, subrugulosis, hoc magis minusve distincte carinato. Capite lato, rotundato, a thorace remoto, hoc angustiore, apice attenuato, pedibus longioribus gracilioribusque habitum peculiarem prae se fert.

2. Nomen a Latreillio huic generi impositum, a Com. Dejean Cryptobiis Americanis tributum, restitui, qua de re conf. quod l. c. monui.

3. Sexus differentia abdominis segmentis inferioribus ultimis cognoscenda, segmento sexto in femina integro, rotundato, in mare apice exciso, nonnunquam etiam quinto fortiter impresso vel excavato.

4. Victus sub lapidibus et sub foliis deciduis.

* 1. St. fragilis: Niger, thorace oblongo, obsolete carinato, scutello pedibusque anticis sanguineis, elytris dense subtiliter punctatis, apice pallidis. - Long. 3 lin.

Enc. meth. X. p. 495. - Er. Col. March. I. 520. 1.

Paederus fragilis Grav. Non. 140. 7. - Latr Ifist. nat Crust. ef Ins. IX. 347.

4. Gen. Crust. et Ins. I. 292. 2. - Oliv. Encycl. meth. VIII. 629. 8.

Rugilus fragilis Curtis Britt. Ent. IV. t. 168. - Boist. et Lacord. Faun. Ent.

Paris. 1. 434. 2. - Germ. Faun. Ins. Europ. 18. 5. - Riunde Brachelytr. Mal. 14.2.

Staph. angustatus Fourcr. Ent. Par. I. 172. 28.

Habitat in Germania.

St. rufipede paululum maior et gracilior, niger, parum nitidus. Antennae capite thoraceque longe breviores, articulo tertio secundo sesqui longiore, sequentibus sensim paulo brevioribus et crassioribus, ultimo ovato, apice acuminato, basi nigro-piceae, extrorsum obscure testaceae. Palpi maxillares rufo-piceae, articulo tertio nigro, apice pallido. Labrum latum, amplum, nigrum, margine piceum, medio acute bidenticulatum. Caput coleopterorum latitudine, orbiculatum, confertissime subtiliter punctato-rugulosum, tenuiter subtilissime griseo-pubescens, opacum, nigrum. Thorax capitis prope longitudine, coleopteris duplo angustior, a medio antrorsum attenuatus, basin versus argustatus, convexus, rufo-sanguineus, opacus, subtilius crebre punctatus, tenuiter subtilissine griseo-pubescens, linea longitudinali media angusta laevi, haud elevata, subtiliter canaliculata. Scutellum punctulatum, rufum. Elytra thorace paulo Iongiora, subtiliter crebre punctata, densins subtiliter cinereo-pubescentia, subnitida, nigro-picea, extrorsum summo apice pallide testaceo. Abdomen subtilissime confertissimeque punctulatum, dense subtiliter cinereo pubescens. Pectus nigrum, mesosterno rufo. 
Pedes antici cum cosis ruf, intermedii coxis femoribusque rufis, tibiis piceis, tarsis testaceis, postici picei, tarsis testaceis.

Mas abdominis segmento inferiore quarto apice medio tuberculo minuto prominulo rufo, ciliarım longarum arcu cincto munito, quinto medio profunde excavato, fovea laevissma, marginibus eius lateralibus acutis, carnatis, nigro-ciliatis, apice proninulis, sexto inciso.

* 2. St. rufipes: Niger, thorace obsolete carinalo, antennis pedibusque rufo-piceis, elytris subtiliter punctatis, apice piceis. - Long. $2 \frac{2}{3}$ lin.

Er. Col. March. I. 521. 2.

Rugilus rufipes Germ. Faun. Ins. Europ. 18. 4.

Paed. orbiculatus Fab. Ent. Syst. I. II. 538. 9. Syst. E1. II. 603. 9.I .

St a ph. orbiculat us Marsh. Ent. Britt. 528. 85.

Rugilus orbiculat us Boisd. et Lacord. Faun. Ent. Paris. I. 434. 1.

Habitat in Germania, Gallia.

Niger, parum nitidus, capite thoraceque opacis, subtiliter breviterque pubescentibus. Antennae capite sesqui longiores, apicem versus haud incrassatae, articulo tertio secundo paulo longiore, $\mathbf{4}-\mathbf{1 0}$ sensim brevioribus, non autem crassioribus, rufae, apice magis testaceae. Palpi rufo-picei. Labrum rufescenti-piceum, apice medio acute bidenticulatum. Mandibulae piceae. Caput coleopterorum latitudine, orbiculatum, confertissime minus snbtiliter punctatum, longitudinaliter subrugulosum. Thorax coleopteris dimidio angustior, latitudine parum longior, basin versus leviter angustatus, modice convexus, confertıssime minus subtiliter punctatus, subrugosus, linea longitudinali medıa tenui laevi, subtiliter canaliculata, minus distincta, antrorsum obsoleta. Elytra thorace paulo longiora, subtiliter parcius punctata, tenuiter cinereo-pubescentia, fusco-picea, nitidula, apice sensim subdilutiora. Abdomen subtilissime dense punctatum, pube subtili cinerea subsericans, nigrum, subnitidum, apice piceum. Pedes piceo-rufo-testacei, coxis saturatius piceis.

M as abdominis segmento inferiore sexto apice inciso.

* 3. St. subtilis: Niger, thorace subcarinato, antennis pedibusque rufoteslaceis, femoribus posterioribus apice fuscescentibus, elylris apice concoloribus. - Long. $2 \frac{2}{3}$ lin.

Habitat in Austria, Dom. Schiippel, in Saxonia montana, Dom. Märkel.

Statura omnino praecedentis, niger, capite thoraceque opacis, subtiliter densius griseo-pubescens. Antennae capite paulo longiores, apicem versus sensim leviter incrassatae, articulo tertio secundo paulo longiore, 4-10 sensim paulo brevioribus et crassioribus, rufae. Mandibulae et palpi piceorufi. Labrum piceum, medio acute bidentatum. Caput coleopterorum latitudine, subovatum, omnium confertissime subtilius punctato-subrugosum. Thorax coleopteris dimidio angustior, latitudine longior, lateribus basin versus modice angustatus, leviter convexus, omnium confertissime subtilius punctato - rugulosus, linea media longitudmali laevi subelevata, subtilissime canaliculata, apicem versus evanescente. Elytra thorace paulo longiora, densius subtilusque punctata, piceo-nitidula, apice concolora. Abdomen confertim subtiliter punctatum, segmentis ultimis duobus apice piceis. P'edes 
rufo-testacei, coxis omnibus nigris, femoribus posterioribus apice fuscescentibus.

Mas abdominis segmento inferiore sexto apice triangulariter exciso.

Obs. 1. Differt a praecedente praecipue statura graciliore, capite thoraceque magis oblongis, multo subtilius punctato-rugulosis, thoracis linea laevi distinctiore, geniculis posterioribus infuscatis, a sequentibus thoracis linea media longitudinali minus elevata, elytris apice concoloribus.

2. Nomine Paederi subtilis a Dahlio Dom. Schüppel missus.

* St. similis: Niger, thorace carinato, antennis pedibusque rufo-testa-
ceis, elytris crebre punclatis, apice testaceis. - Long. $2 \frac{1}{2}$ lin.

Er. Col. March. I. 521.4.

Paederus orbiculatus Grav. Micr. 63. 6. Mon. 141. 8.

Rugilus orbiculatus Runde Brachelytr. Hal. 14. 1.

Habitat in Germania.

Praecedentibus paulo minor, niger, capite thoraceque opacis, subtiliter breviterque pubescentibus. Antennae capite parum longiores, articulo tertio secundo paulo longiore, 4 - 10 sensim paulo brevioribus et crassioribus, rufae. Palpi testacei. Labrum amplum, aoute bidenticulatum, piceum, margine rufescens. Mandibulae piceae. Caput coleopterorum latitudine, orbiculatum, confertissime punotatum, longitudmaliter subrugulosum. Thorax coleopteris dimidio fere angustior, latitudine vix longior, basin versus leviter angustatus, modice convexus, confertissime punctatus, subrugulosus, linea Jongitudinali media angusta subelevata laevi, per totam longitudinem canaliculata, Elytra thorace paulo longiora, profundius fortius orebre punctata, griseo -pubescentıa, nitidula, saturate nigro-picea, margine apicalı testaceo. Abdomen nigrum, subnitidum, confertim subtilissime punctatum, pube subtili depressa grisea subsericans. Pedes rufo-testacei, geniculis concoloribus, coxis omnibus nigro - piceis.

Mas abdominis segmento inferiore quinto semicirculariter impresso, impressione apice utrinque denticulo minuto prominulo terminata, sexto medio leviter impresso, apice acute emarginato.

Obs. Nomine Paederi an alis a Dahlio Dom. Schüppel communicatus.

* 5. St. geniculatus: Niger, thorace carinato, antennis pedibusque testaceis, femoribus posterioribus apice nigricantibus, elytris crebre punclatis, apice testaceis. - Long. $2 \frac{1}{3}$ lin.

Er. Col. March. I. 522. 4.

Habitat in Germania,

Statura et summa affinitas praecedentis, niger, capite thoraceque opacis, breviter subtiliterque pubescentibus. Antennae capite parum longiores, apicem versus leviter inorassatae, articulo tertio secundo paulo longiore, 4- 10 sensim brevioribus et crassioribus, ultimo breviusculo, apice acuminato, rufo-testaceae. Palpi rufo-testacei. Labrum amplum, apice acute bidenticulatum, piseum, margine rufescens. Mandibulae rufo-piceae. Caput coleopterorum latitudine, orbiculatum, confertissime punctatum, longitudinaJiter subrugulosum. Thorax coleopteris vix dimidio angustior, latitudine 
perparum longior, basin versus leviter angustatus, modice convexus, confertissime punctatus, subrugulosus, linea longitudinali media tenui laevi, subtiliter per totam fere longitudinem canáliculata. Elytra thorace paulo longiora, fortius crebre punctata, griseo-pubescentia, nigro-picea, nitidula, margine apicali piceo-testaceo. Abdomen confertim subtilissime punctatum, nigrum, nitidulum, pube subtili depressa grisea sericans. Pedes dilute testacei, coxis omnibus piceis, femoribus posterioribus apice fuscis.

Mas abdominis segmento inferiore quinto late profundeque impresso, impressione apice utrinque spina dentiformi, acuta, retrorsum prominula terminata, sexto leviter impresso, apice acute emarginato.

Obs. Proximus praecedenti et femina nisi elytris paulo longioribus et geniculis pedum posteriorum infuscatis vix distinguenda, mas praeterea abdominis segmento inferiore quinto apice spinis duabus longioribus armato diversus.

* 6. St. affinis: Niger, thorace carinato, pedibus testaceis, femoribus posterioribus apice tibiisque fuscis, elytris subtiliter punctutis, apice testaceis. - Long. $2 \frac{1}{4}$ lin.

Er. Col. March. I. 522. 5.

Habitat in Germania, Gallia.

Habitus et summa affinitas praecedentium, at paulo minor, niger, capite thoraceque opacis, breviter subtiliterque pubescentibus. Antennae capite paulo longiores, apicem versus subincrassatae, articulo tertio secundo sesqui prope longiore, $4-10$ sensim brevioribus et crassioribus, rufo-pireae. Palpi maxillares rufo-picei, articulo tertio fuscescente. Labrum amplum, apice acute bidenticulatum, piceum, margine rufescente. Caput vix coleopterorum latitudine, orbiculatum, confertissime fortius punctatum, longitudinaliter rugulosum. Thorax coleopteris duplo fere angustior, latitudine paulo longior, basin versus leviter angustatus, modice convexus, confertissime fortius punctatus, subrugulosus, linea longitudinali media latiore laevi, subelevata, subtiliter canaliculata, canalicula antrorsum evanescente. Elytra thorace paulo longiora, parcius subtiliter punctata, parce subtiliterque cinereo - pubescentia, piceo - subaenescentia, nitida, margine apicali testaceo. Abdomen confertim subtiliter punctulatum, densius subtiliter griseo-pubeseens, nigro-subaeneum, nitidulum. Pedes testacei, ooxis omnibus piceis, femoribus apice trbiisque magis minusve saturate fuscis.

Mas abdominis segmento inferiore sexto apice inciso.

Obs. Caput et thorax fortius, elytra parcius et subtilius quam in praecedenbus punctata.

7. St. fuscipes: Niger, thorace carinato, pedibus fusco-piceis, tarsis testaceis, elytris parce subtilissime punctatis, apice testaceis. - Long. $2 \frac{1}{4}$ lin.

Habitat in Sardinia, Dom. Prof. Gené.

Statura praecedentis, niger, parum nitidus, capite thoraceque opacis. Antennae capite sesqui longiores, apicem versus sensim subincrassatae, articulo tertio secundo paulo longiore, 4-10 sensim brevioribus et paulo crassioribus, rufo-piceae, articulo primo nigro. Palpi maxillares nigro-picei. Labrum nigro-piceum, apice subtiliter bidenticulatum. Caput coleopterorum 
latitudine, orbiculatum, confertissime fortius punctatum, fronte spatio minuto medio laeviore, tenuiter subtiliterque griseo-pubescens, parce nigro-pilosellum. Thorax coleopteris duplo angustior, latitudine longior, apicem versus magis quam in praecedentibus attenuatus, modice convexus, confertissime fortius punctatus, subtilissime tenuiter griseo-pubescens, lateribus parce nigro-pilosus, linea media longitudinali lata laevissima subelevata, summa basi obsolete canaliculata. Elytra thorace parum longiora, parce subtiliter obsolete punctata, tenuiter griseo-pubescentia, piceo-nigra, nitida, margine apicali testaceo. Abdomen nitidulum, subtiliter punctulatum, densius subtiliter griseo-pubescens. Pedes crassiusculi, fusco-picei, trochanteribus, summa tibiarum basi apiceque tarsisque rufescenti-testaceis.

Mas abdominis segmento inferiore sexto apice triangulariter exciso.

8. St. orbiculatus: Niger, thorace carinato, antennis pedibusque cum coxis rufo-testaceis, elytris subtiliter punctatis, apice piceis. - Long. 2 lin.

Encycl. meth. X. p. 495. - Er. Col. March. I. 523. 6.

Staph. orbiculatus Payk. Mon. Staph. 35. 26.

Paed. orbiculatus Payk. Faun. Suec. III. 431. 6. - Walken. Faun. Paris. 1. 275.

2. - Latr. Hist. nat Crust. et Ins. IX. 316. 3. Genera Crust. et Ins. I. 291. 1. - Oliv. Encycl. meth. VIII. 628. 9. - Gyll. Ins. Suer. II. 374. 3. - Zetterst. Faum. Lappon. I. 85. I. Ins. Lappon. 69. 3. - Sahlb. Ins. Fenn. I. 343. 3. Rugilus orbiculatus Mannerh. Brachelytr. 40. 1.

Habitat in Germania, Suecia.

Praecedentibus minor, niger, capite thoraceque opacis, subtiliter pubebescentibus. Antennae capite vix longiores, apicem versus sensim subincrassatae, articulo tertio secundo haud longiore et paulo tenuiore, 4-10 sensim brevioribus et crassioribus, rufae. Palpi rufo-testacei. Labrum acute bidentatum, fere bispinosum. Caput eoleopteris latius, suborbiculatum, basi truncatum, confertissime punctatum, vix rugulosum, linea media longitudinali laevi obsoleta. Thorax coleopteris dimidio angustior, latitudine paulo longior; basin versus leviter angustatus, modice convexus, confertissime punctatus, subrugulosus, linea longitudinali media latiore laevi, subelevata, per totam longitudinem subtiliter canaliculata. Elytra thorace paulo longiora, subtiliter parcius punctata, subtilius cinereo-pubescentia, obscure fusco-picea, margine apicali testaceo. Abdomen confertim subtiliter punctatum, subtiliter griseo-pubescens, subnitidum. Pedes toti rufo-testacei, coxis omnibus concoloribus.

Mas abdominis segmento inferiore sexto apice triangulariter exciso.

* 9. St. angularis: Piceus, capile thoraceque carinato rufescentibus, elytris angulis posterioribus pedibusque cum coxis teslaceis. - Long. 2 lin.

Habitat in Pensylvania et in Carolina, Dom. Zimmermann.

Statura fere St. affinis, at paulo minor. Antennae capite paulo longiores, articulo tertio secundo sesqui longiore, 4-10 sensim paulo brevioribus et crassioribus, piceo-rufae. Palpi rufo-testacei. Labrum piceum, apice medio subtiliter licet acute bidenticulatum. Caput coleopterorum latitudine, suborbiculatum, supra confertissime subtilius punctato-subrugulosum, densius subtiliter griseo-pubescens, opacum, piceo-subrufescens, subtus 
parce punctatum, nitidum, rufo-piceum. Thorax coleopteris plus dimidio angustior, latitudine longior, basin versus leviter angustatus, apicem versus fortius attenuatus, modice convex̃us, crebre subtilius punctatus, linea media longitudinali laevissima, rufo-piceus, subnitidus, tenuiter subtiliterque griseopubescens. Scutellum piceum. Elytra thorace raulo longiora, minus dense subtilius licet profunde punctata, tenuiter griseo-pubescentia, nitida, nigropicea, margine lato apicali humerisque testaceis. Abdomen confertim subtiliter punctatum, dense subtiliter griseo-pubescens, nitidulum, nigro-piceum, supra segmentis ultimis duobus, subtus omnibus margine apicali testaceo. Pectus nigro-piceum. Pedes toti cum coxis omnibus testacei.

Mas abdominis segmento inferiore quinto apice emarginato, sexto triangulariter exciso.

\section{St. iugalis: Niger, thorace fortius carinalo, antennis pedibusque cum} coxis testaceis, elytris fortiter punctatis, apice testaceis. - Long. $2 \frac{1}{2}$ lin.

Habitat prope Caracas Columbiae, Dom. Moritz.

Statura omnino praecedentium, niger, capite thoraceque opacis. Antennae capite paulo longiores, apice subincrassatae, articulo tertio secundo paulo longiore, 1 - 10 sensim brevioribus et crassioribus, testaceae. Palpi ıstacei, maxillares articulo ultimo apice fuscescente. Labrum amplum, apıce medio obsoletius bidenticulatum, nigro-piceum. Caput coleopterorum latitudine, orbiculatum, minns subtiliter confertisșime punctata-rugulosum, tenuiter subtiliterque griseo--pubescens, parce nigro-pilosellum. Thorax coleopteris duplo prope angustior, basin versus modice angustatus, apicem versus fortins attenuatus, convexus, confertissime minus subtiliter punctatus, subtilissime griseo-pubescens, parce nigro-pilosellus, linea media longitudinali modice elevata laevissima. Elytra thorace vix longiora, leviter inaequalia, forius profunde punctata, tenuiter nigro-pubescentia, nitidula, margine apicali dilute testaceo. Abdomen confertissime subtilissimeque punctulatum, subtiliter ${ }^{\prime n i g r o ~-~ p u b e s c e n s . ~ P e d e s ~ g r a c i l i o r e s, ~ t o t i ~ c u m ~ c o x i s ~ o m n i b u s ~ t e s t a c e i . ~}$

Mas abdominis segmento inferiore quinto apice trisinuato, sinu intermedio maiore, medio denticulo acuto rufescente instructo, sexto apice inciso.

* 11. St. carinatus: Niger, thorace fortius carinato, antennis testaceis, pedibus flavis, elytres' forliter profundeque punctatis. - Long. $2 \frac{1}{4}$ lin.

Habitat in Columbia, Dom. Moritz.

Statura omnino praecedentium, niger, capite thoraceque opacis. Antennae capite paulo longiores, apicem versus leniter incrassatae, articulo tertio secundo vix longiore, $\mathbf{4}-\mathbf{1 0}$ sensin brevioribus et crassioribus, testaceae. Palpi testacei. Labrum amplum, apice medio subtilissime bidenticulatum. Caput coleopterorum fere latitudine, suborbiculatum, confertissime fortius punctatum, subtilissime nigro-pubescens, parce nigro-pilosellum. Thorax coleopteris dimidio angustior, latitudiue longior, basin versus modice angustatus, apice fortius attenuatus, modice convexus, confertissime fortins punctatus, parce griseo-pubescens, linea longitudinali media laevi, elevata. Elytra thorace vix longiora, fortiter profundeque punctata, parce pubescentia, nigro-subaenea, ntida. Abdomen nigro-subaeneum, nitidulum, subtiliter griseo-pubescens. Pedes flavi, coxis concoloribus. 
Mas abdominis segmento inferiore quinto apice sinuato, sinu medio acute dentato, sexto profunde inciso.

\section{Species mihi invisa.}

12. St. dentatus: Niger, pedibus pallidis, elytris obscure rufis. - Long. ullira $1 \frac{1}{2}$ lin.

Rugilus dentatus Say Transact. Amer. Philosoph. Soc. Philudelph. Nov. Ser. IV. p. $45 \%$.

Habitat in America septentrionali.

Nigro-piceus. Caput longitudinaliter rugulosum. Antennae et palpi picei. Labrum amplum, medio bidentatum, piceum, lateribus rotundatum. Thorax capite minor, longitudinaliter rugulosus, convexus, linea longitudinali laevi. Elytra confertim subtiliter punctata, subtiliter pubescentia, stria suturali impressa, margine apicali obscure rufo testaceove. Pedes pallide flavescentes.

V a riat margine elytrorum apicali suturam versus nigro, thoracis linea laevi fere obsoleta. St. orbiculato minor, capite thoraceque fortius distinctiusque rugulosis, (\$ay,)

\section{Echiaster $E r$.}

Labrum apice 4-dentatum.

Palpi maxillares arliculo quarto vix distinclo.

Antennae reclae.

Tarsi articulo quarto simplice.

Corpus elongatum, subdepressum, alatum. Caput exsertum, pedunculo tenui brevissimo thoraci affixum, porrectum, suborbiculatum, oculis maiuscilis, lateribus modice prominulis, infra fortius convexis. Labrum (t. II. f. 2 . c.) transversum, mandibulas haud obtegens, apice fortiter acuteque 4-dentatum. Mandibulae longae, tenues, arcuatae, acutae, medio dente longo arcuato, interne subtilius dentato armatae. Maxillae (t. II. f. 2. b.) malis membranaceis, interiore interne, exteriore apice barbatis. Palpi maxillares articulo primo brevi, secundo modice elongato, tertio hoc paulo longiore, incrassato, ultimo subulato, acuto, minutissimo, vix conspicuo. Labium (t. II. f. 2. a.) mento transverso, apicc emarginato, angulis anterioribus in E. Iongicolli haud prominulis, in E. melanuro fortiter productis, ligula membranea, lobis brevissimis, leviter rotundatis, distantibus, interstitio setoso, paraglossis multo longioribus, linearibus, acuminatıs, interne ciliatis. Antennae breves, capite vix longiores, articulıs duobus primis crassiusculis, primo perparum elongato, secundo breviusculo, subgloboso, sequentibus sensim paulo brevioribus et crassioribus, ultimo subovato, apice subacuminato. Thorax elongatus, coleopteris angustior. Scutellum triangulare. Elytra depressa. Abdomen apicem versus sensim attenuatum, segmento quinto sextoque angustatis, elongatis, tubulıformibus, septimo retractili, stylis analibus haud exsertis. Pedes graciliores, breviusculi, tarsis articulis $\mathbf{4}$ primis longitudine decrescentibus, anticis simplicibus.

O b s e r va tiones.

1. Corpus punctura conferta scabriusculum, habitu fere $\mathrm{S}$ unii, at tarsi arti- 
culo quarto simplice, a Lith ocharide palporum maxillarium articulo quarto minimo, a Stili co labro breviore, 4-dentato, ab omnibus abdominis segmentis ultimis duobus elongatis et attenuatis discedens.

2. Sexus differentia latet.

* E. longicollis: Testaceus, opacus, punctato-scabriusculus, thorace elongato, apicem versus allenualo, abdomine segmentis ultimis duobus fuscis. - Long. $2 \frac{1}{4}$ lin.

T. II. f. 2 .

Habitat in valle Araguensi Columbiae, Dom. Moritz.

Testaceus, opacus, dense fortius punctatus, interstitiis scabriusculis, pilis brevissimis reclinatis rigidis vestitus. Antennae capite paululum longiores. Caput latitudine longius, pone oculos leviter angustatum et rotundatum, supra depressiusculum. Thorax coleopteris plus duplo angustior, elongatus, latitudine summa duplo longior, a medio basin versus subangustatus, apicem versus attenuatus, subdepressus. Elytra thoracis longitudine, depressa, posterius infuscata. Abdomen transversim subrugosum, segmentis ultimis duobus angustis, elongatis, fuscis, apice summo pilosum. Pedes dilute rufo - testacei.

* 2. E. melanurus: Testaceus, opacus, confertissime punclatus, thorace basin versus angustato, abdomine segmentis ultimis duobus nigris. Long. $1 \frac{1}{2}$ lin.

Habitat in valle Araguensi Columbiae, Dom. Moritz.

Praecedente dupln minor et minus elongatus, testaceus, opacus, confertissime subtilius punctatus, pube brevissima depressa grisea fulvo-micante tenuiter vestitus. Antennae capite haud longiores. Caput suborbiculatum, thorace duplo latius, depressiusculum, antice utrinque leviter longitudinaliter impressum. Thorax coleopteris duplo angustior, latitudine summa sesqui longior, ante medium leviter rotundatus, basin versus leviter angustatus, apicem versus attenuatus, depressiusculus, obsolete carinatus. Elytra thorace paulo longiora, depressa, fuscescentia. Abdomen segmentis ultimis duobus nigris. Pedes pallide testacei.

Obs. Oris partes huius speciei T. II. f. 2. a. b. c. dilineatae sunt.

\title{
Sunius Leach.
}

\author{
Er. Col. March. I. p. 523.
}

Astenus Dej. Boisd. et Lacord. Faun. Ent. Paris. I. p. 435. - Steph. Illustr. Britt. Ent. V. p. 275.

\section{Labrum medio bidenticulatum.}

Palpi maxillares articulo quarto vix distincto. Antennae rectae.

Tarsi articulo quarto lobo membraneo instructo.

Corpus elongatum, lineare, plerumque alatum. Caput magnum, basi fortiter constrictum, collo quasi angusto brevi thoraci affixum, exsertum, porrectum, oculis parvis, rotundatis, leviter prominulis. Labrum latum, transversum, medio bidenticulatum. Mandibulae longae, tenues, arcuatae, acutae, medio dente longo acuto et pone dentem denticulis 2 vel 3 armatae. Ma- 
xillae (t. IV. f. 33. b.) malis breviusculis, corneis, interiore interne, exteriore apice barbatis. Palpi maxillares leviter elongari, articulo primo minuto, brevi, secundo tertioque elongatis, longitudine subaequalibus, hoc incrassato, quarto subulato, subtilissimo, vix nisi oculo fortiter armato conspicuo. Labium (t. IV. f. 33. a.) mento brevi, transverso, ligula membranea, biloba, lobis rotundatis, sinu profundo distantibus, paraglossis angustis, acuminatis, membraneis interne ciliatis, ligulam parum superantibus. Palpi labiales articulo prumo breviore, cylindrico, secundo maiore ovato, tertio minuto, tenui, subulato. Antennae filiformes, rectae. Thorax subcordatus, licet antice haud emarginatus, sed subito angustatus. Scutellum parvum, triangulare. Elytra truncata. Abdomen lineare, apice obtusum, segmento septimo rectractili, stylis analibus haud distinctis. Pedes aliis breviusculi, aliis elongati, tarsis omnibus articulis tribus primis elongatis, longitudine decrescentibus, quarto brevissimo, subtus lobo membraneo aucto, quinto minuto, quartum parum excedente.

\section{O b s e r vationes.}

1. Corpus plerisque opacum, punctura densiore fere asperatum, pube brevissima parca inspersum, a reliquis huius tribus generibus imprimis tarsorum structura distinctum.

2. Abdominis segmentum inferius sextum in mare triangulariter incisum, in fernina integrum, rotundatum.

3. Victus sub lapidibus et foliis deciduis.

4. Sectiones in hoc genere praecipue secundum corporis habitum distinguendae videntur:

* (Genuini.) Corpore valde elongato, lineari, subdepresso, pedibus breviusculis, labro transverso, capite oblongo, apice leviter emarginato, thorace depressiusculo, plerumque oblongo, coleopteris latitudine subaequali, abdomine elongato, saepius basin versus leviter angustato.

* (Spurii.) Capite suborbiculato, apice truncato, labro plerumque medio leviter producto, thorace coleopteris angustiore, subgloboso, pedibus longioribus, habitu omnino Stilici, oris autem tarsorumque structura omnino cum genuinis congruentes.

\section{* (G e n u i n i).}

* 1. S. filiformis: Elongalus, linearis, niger, antennis pedibusque testaceis, capite thorace latiore, thorace basin versus angustato, elytris thorace paulo longioribus, apice latius tesiaceis. - Long. $2 \frac{1}{4}$ lin.

Er. Col. March. I. 525. 3.

Paederus filifurmis Latr. Gen. Crust. et Ins. I. 293. 4. - Oliv. Encycl, meth. VIII. 629. 10.

Paederus procerus Grav. Mon. p. 141.

Astenus procerus Boisd. et Lacord. Faun. Ent. Paris. I. 436. 1.

Paederus extensus Mannerh. Brachelytr. 39. 6.

Habitat in Europa.

S. angustato parum latior, at multo longior, niger, opacus, pube brevi depressa fulvo-grisea vestitus. Antennae capite sesqui longiores palpique testacei. Mandibulac rufo-testaceae. Caput thorace paulo latius, oblongosubquadratum, basi truncatum, lateribus pone oculos et angulis posteriori- 
bus rotundatis, supra et infra subtiliter confertissime punctato-rugosum. Thorax coleopteris angustior, latitudine summa paulo longior, apice cum angulis anterioribus rotundatus, basin versus angustatus, subdepressus, subtiliter confertissime punctato-rugulosus. Elytra thorace paulo longiora, dense minus fortiter at profunde punctăta, apice late subsinuatim testacea. Abdomen elongatum, paralleliın, crebrius punctulatum, subnitidum, subtus segmentis singulis margine apicali piceo. Pedes cum coxis anterioribus testacel.

Mas abdominis segmento inferiore sexto apice inciso.

*2. S. prolixus: Elongalus, linearis, niger, antennis pedibusque testactis, capile thorace lativre, thorace basin versus subangustato, elytris apice testaceis. - Long. $2 \frac{1}{3}$ lin.

Paederus cinctus Say Transact. Amer. Philosioph. Soc. Philadelph. Nov. Ser. IV 457. 2. (forte)

Habitat in America septentrionali, Dom. Zimmermann.

Statura et summa affinitas pracedentis, niger, opacus, subtiliter cinereopubescens. Antennae tenues, capite plus sesqui longiores palpique flavi. Mandibulae et labrum rufo-testacea. Caput thorace parum latius, oblongosubquadratum, basin versus ab oculis subangustatum, basi cum angulis posterioribus rotundatum, supra confertissime subtilius punctato-rugosum, opacum, subtus crebre fortiterque punctatum, nitidum. Thorax coleopteris vix angustior, latitudine paulo longior, lateribus ante medium subangulatus, basin versus leviter angustatus, subdepressus, confertissime rugoso-punctatus. Coleoptera thorace parum longiora, apicem versus leviter angustata, minus fortiter profunde dense punctata, interstitiis subrugulosis, apice testacea. Abdomen elongatun:, basin versus subangustatum, profundius punctatum, nitidulum, segmentis omnibus margine apicali rufo-piceo. Pedes cum coxis anterioribus flavo-testacei.

M as abdominis segmento inferiore sexto apice profunde inciso.

V a riat elytrorum margine apicali anguste lateve testaceo, nonnunquam etiam elytris rufo-piceis, macula magna discoidali nigra, apice late testaceis, vel thorace etiam et abdominis segmentis 4 anterioribus rufo-piceis.

$\mathrm{Obs}$. A praecedente differt praecipue pube longiore, antennis tenuioribus, thorace basin versus minus angustato, et capite subtus minus confertim fortiter punctato, coleopteris apicem, abdomine basin versus angustatis, etc.

* 3. S. linearis: Elongatus, niger, antennis pedibusque testaceis, capile thoracis latitudine, thorace basin versus subangusialo, elytris thorace paulo longioribus, apice late teslaceis. - Long. $1 \frac{3}{4}$ lin.

Habitat in America septentrionali, Dom. Zimmermann.

Statura elongata et summa affinitas praecedentium, at minor, S. angustato aequalis, niger, opacus, pube subtili depressa cmerea vestitus. Antennae tenuiores, capite plus sesqui longiores, ét palpi testacei. Mandibulae et labrum rufo-picea. Caput thoracis latitudine, oblongo-subquadratum, basi truncatum, angulis posterioribus fortiter rotundatis, supra confertissime subtiliter punctato-rugosum, opacum, subtus parcius profundiusque punctatum. Thorax coleopteris paulo angustior, latitudine paulo longior, lateribus 
ante medium subangulato-rotundatus, basin versus subangustatus, subdepressus, subtiliter confertissime punctato-rugulosus, margine basali apicalique piceo. Coleoptera apicem versus subangustata, thorace paulo longiora, crebrius fortiusque punctata, interstitiis subrugosis, subnitida, apice latius sinuation testacea. Abdomen elongatum, - basin versus sensim subangustatum, minus dense punctatum, nitidulum, segmentis singulis margine summo rufo-piceis. Pedes cum coxis anterioribus flavo-testacei.

Mas abdominis segmento inferiore sexto apice acute triangulariter exciso.

* 4. S. intermedius: Niger, antennis pedibusque testaceis, capite thorace latiore, thorace ovalo, elylris thorace paulo longioribus, fartiter punctatis, margine tenui apicali testaceo. - Long. '2 lin.

Er. Col. March. 1. 524. 2.

Habitat in Germaniae silvis.

Statura omnino S. angustati, at paululum maior et abunde distinctus, nitidulus, capite thoraceque opacis, subtiliter cinereo-puhescens. Antennae capite vix duplo longiores et palpi testacei. Mandibulae piceo-testaceae. Caput thorace latius, oblongo-subquadratum, basi truncatum, lateribus pone oculos cum angulis posterioribus rotundatum, supra leviter convexum, fortius confertim punctato-rugosum, subtus crebre fortiter profundeque punctatum. Thorax ante medium coleopteris paulo angustior, latitudine summa vix longior, lateribus ante medium subangulato-rotundatus, basin versus fortiter angustatus, leviter convexus, fortius confertim punctato-rugosus. Elytra thorace paulo longiora, crebre fortiter profunde punctata, nigra, margine summo apicali pallide testaceo. Abdomen basin versus subangustatum, crebrius fortiusque punctatum, segmentis singulis apice tenuiter testaceomarginatis. Pedes cum coxis anterioribus flavo-testacei.

Mas abdominis segmento inferiore quinto longitudinaliter obsolete impresso, sexto acute triangulariter exciso.

* 5. S. angustatus: Niger, antennis pedibusque testaceis, capite thorace latiore, thorace basin versus angustalo, elytris thorace sesqui longioribus, apice late testaceis. - I.ong. $1 \frac{2}{3}$ lin.

Er. Col. March. I. 524. I.

Staph. angustatus Payk. Mon. Staph. 36. 27. - Fab. Ent. Syst. 1. II. 528. 41. Syst. El. I1. 599. 50. - Panz. Ent. Germ. 356. 31. Paun. Germ. 11. 18. - Oliv. Ent. 11I. 42. 21. 24. t. 2. f. 81. - Marsh. Ent. Britt. 527. 83.

Paederus angustatus Payk. Faun. Suec. III. 431. 7.-Grav. Micr. 63. 7. Mon. 141. 9. - Latr. Hist. nat. Crust. et Ins. IX. 347. 5. Genera Crust. et Ins. I. 292. 3. - Oliv. Encycl. meth. VIII. 630. 13. - Gyll. Ins. Suec. II. 375. 4. - Sahlb. Ins. Fenn. I. 343. 4. - Mannerh. Brachelytr. 40. 7. - Runde Brachelytr. Hal. 13. 4. Astenus angustatus Boisd. et Lacord. Faun. Ent. Paris. I. 436. 2.

Staph. gracilis Payk. Mon. Staph. 38. 28. - Fab. Ent Syst. I. 1I. 528. 44. Syst. El. II. 599. 54. - Panz. Ent. Germ. 357. 34.

Habitat in Europa.

Niger, nitidus, capite thoraceque opacs, subtiliter cinereo-pubescens. Antennae capite vix duplo longiores, apice subincrassatae, testaceae. Palpi testacei. Mandibulae piceo-testaceae. Caput thorace paulo latius, oblongo- 
subquadratum, basi truncatum, lateribus pone oculos et angulis posterioribus rotundatis, supra depressiusculum, confertim punctato-subrugosum, infra sat crebre fortius profundiusque punctatum. Thorax coleopteris plus dimidio angustior, latitudine summa vix longior, lateribus ante medium fortiter rotundato-angulatis, basin versus valde angustatus, depressinsculus, confertim punctato-subrugosus. Elytra thorace sesqui prope longiora, crebre fortiter punctata, nigra, apice late sinuatim testacea. Abdomen basin versus subangustatum, parcius minns subtiliter punctulatum, longius pubescens, segmentis 4 primis margine tenui apicali testaceo. Fedes cum coxis anterioribus dilute flavo - testacei. exciso.

Mas abdominis, segmento inferiore sexto apice acute triangulariter

-6. S. bimaculatus: Niger, capite thorace latiore, thorace subovato, rufo-piceo, antennis, elytris pedibusque testaceis, his macula media nigra. - Long. $1 \frac{3}{4}$ lin.

Habitat in Sardinia, Dom. Prof. Gené.

Statura fere praecedentis, at paululum gracilior. Corpus totum pube minus brevi depressa cinerea parcius vestitum. Antennae capite duplo prope longiores, apice vix crassiores, flavo-testaceae. Palpi flavi. Os rufo-piceum. Caput thorace paululum latius, oblongum, basi et lateribus pone oculos leviter, angulis posterioribus fortius rotundatis, supra perparum convexum, confertissime punctato - rugolosum, opacum, nigro-piceum, subtus creberrime profundius punctatum, nigrum, subnitidum. Thorax coleopteris plus dimidio angustior, latitudine summa paulo longior, lateribus ante medium rotundatis, basin versus angustatus, subdepressus, confertim punctato-rugulosus, opacus, picescenti-rufus. Scutellum mgro-piceum. Elytra thorace panlo longiora, creberrime fortius profunde punctata, testacea, macula rotundata media, interdum sat minuta, nigra notata. Abdomen basin versus subangustatum, crebre fortius punctatum, nitidulum, nigrum, segmentis singulis piceo-testaceo-marginatis. Pectus nigro-piceum. Pedeg pallide flavo-testacei.

Mas abdominis segmento infertore sexto apice inciso.

V ariat aut thorace etiam nigro, abdominisque segmentis 4 primis supra concoloribus, aut dilutior, capite abdomineque rufis, illo fronte media nigricante, hoc segmento quinto solo praeter marginem apicalem nigro, nonnunquam etiam elytrorum macula evanescente.

* 7. S. limbatus: Niger, antennis pedibusque testaceis, capite thorace latiore, thorace basin versus angustato, elytris thoracis longitudine, sutura dimidia apiceque testaceis. - Long. $1 \frac{3}{4}$ lin.

Habitat in Columbia, Dom. Moritz.

S. angustato parum minor, niger, minus nitidus, pube depressa cinerea, in capite thoraceque subtiliore, in elytris abdomineque magis conspicua vestitus. Antennae capite thoraceque parum breviores, tenues, dilute testaceae. Palpi testacei. Mandibulae rufae. Caput thorace plus sesqui latins, coleopterorum prope latitudine, oblongum, pone oculos rotundatum, supra inter. oculos leviter convexum, ceterum depressum, subtilissime punctato-rugulo- 
sum. Thorax coleopteris duplo angustior, latitudine sesqui longior, lateribus ante medium leviter rotundatus, apice attenuatus, basin versus leviter angustatus, subdepressus, confertissime punctato-rugulosus. Elytra thoracis longitudine, dense profundeque punctata, limbo apicali cum sutura ad elytri medium fere adscendente testaceo. Abdomen basin versus sensim subangustatum, crebrius minus subtiliter punctatum, segmentis singulis margine tenui testaceo terminatis. Pedes cum coxis dilute testacei.

$\mathrm{Mas}$ abdominis segmento quinto longitudinaliter impresso, apice subsinuato, sexto apice inciso.

* 8. S. lateralis: Linearis, niger, antennis pedibusque flavis, capile thoraceque piceis, hoc basin versus angustato. elytris thorace paulo longioribus, tesiaceis, macula magna lalerali nigra. - Long. $1 \frac{3}{4}$ lin.

Habitat Novae Valenciae in Columbia, Dom. Moritz.

Habitu omnino S. filiformis, at paulo brevior. Antennae capite thoraceque paulo breviores, tenues, albido - flavae. Palpi pallide flavi. Caput thorace vix latius, oblongum, basi truncatum, angulis posterioribus subrotundatis, supra perparum convexum, subtiliter punctato-rugulosum, subtilissime parce griseo-pubescens, opacum, rufo-piceum. Thorax coleopteris parum angustior, latitudine summa perparum longior, lateribus ante medium cum angulis anterioribus fortius rotundatus, basin versus leviter angustatus, subdepressus, confertissıme punctato-rugulosus, densius subtilissime griseopubescens, lateribus parce nigro-pilosus, fusco-piceus, opacus. Scutellum nigro-piceum. Elytra thorace paululum longiora, confertim fortius punctata, subtiliter tenuiterque griseo-pubescentia, testacea, macula permagna laterali suturaque tenui nigris. Abdomen parallelum, minus dense subtiliterque punctatum, pube longiore depressa fusco-grisea densius vestitum, nigrum, nitidultum; segmentis singulis tenuiter testaceo-marginatis. Pectus nigrum. Pedes cum coxis pallide flavi.

Mas latet.

* 9. S. bisignatus: Elongatus, testaceus, elylris macula magna laterali, abdomine segmento quarlo quintoque nigris. - Long. $1 \frac{2}{3}$ lin.

Ilabitat prope Caracas Columbiae, Dom. Moritz.

Statura S. Iongiusculi, testaceus, vix nitidus, tenuiter subtiliterque griseopubescens, capite thoraceque lateribus parce nigro-pulosis. Antennae capite thoraceque paulo breviores, tenues, flavae. Palpi flavi. Caput thorace vix latius, basi truncatum, angulıs posterioribus rotundatis, latitudine paulo longius, subdepressum. subtiliter punctato-rugulosum. Thorax coleopterorum prope latitudine, latitudine paulo longior, lateribus ante medium subangulatis, depressus, subtilissime et vix perspicue punctato-rugulosus. Coleoptera apicem versus subangustata, thorace parum longiora, crebrius sat profunde punctata, interstitiis aequalibus, utroque macula magna rotundata laterali pone medium signato. Abdomen basin versus sensim leviter angustatum, anterius fortius, posterius subtiliter punctatum, segmento quarto piceo, quinto nigro. Pedes albido - testacei.

Mas abdominis segmento inferiore sexto apice profundius inciso. 
* 10. S. at le nualus: Elongatus, testaceus, elylris punclo posteriore, abdomine segmento quinlo nigris. - Long. 2 lin.

Habitat in valle Araguensi Columbiae, Dom. Moritz.

Praecedenti affinis, at magis elongatus, testaceus, capite thoraceque rufotestaceis, vix nitidus, pube subtili depressa cinerea tenuiter vestitus. Antennae capite paulo longiores, tenues, flavo-testaceae. Palpı testacei. Caput thoracis latitudine, oblongum, pone oculos cum basi rotundatum, subdepressum, subtiliter punctato-rugulosum. Thorax coleopteris vix angustior, latitudine longior, lateribus ante medium subangulatus, basin versus modice angustatus, subdepressus, sat evidenter punctato-rugulosus. Coleoptera apicem versus modice angustata, thorace tertia parte longiora, dense profundius punctata, interstitiis transversim subrugulosis, lateribus ante apicem macula minuta rotundata nigra notata. Abdomen elongatum, basin versus sensim angustatum, crebre minus subtiliter punctatum, segmento quinto nigro, margine apicali testaceo. Pedes dilute testacei.

Mas abdominis segmento inferiore quinto longitudinaliter impresso, sexto apice profundius inciso.

Obs. Differt a praecedente statura magis elongata, abdomina basin versus fortius angustato, elytris longioribus, capite basi haud truncato, thorace perspicue punctato - ruguloso, etc.

* 11. S. longiusculus: Elongatus, linearis, teslaceus, abdomine segmentis ultimis duobus nigris. - Long. $1 \frac{2}{3}$ lin.

Paederus longiusculu's Mannerh. Brachelytr 39. 5.

Paederus discopunctatus Suy Transact. Amer. Philosoph. Soc. Philadelph. Nov. Ser. IV. 457. 1.

Habitat in America septentrionali.

Siatura omnino praecedentium, rufo-testaceus, opacus, tenuiter subtiliterque griseo-pubescens, capitis thoracisque lateribus abdominisque apice nigro-pilosellis. Antennae capite thoraceque paulo breviores, tenues, flavae. Palpi flavi. Caput thorace vix latius, oblongum, basi cum angulis posterioribus rotundatum, supra confertissime subtiliter punctato-rugulosum, subtus crebre fortius punctatum. Thorax coleopteris angustior, latitudine longior, lateribus ante medium rotundatis, basin versus leviter angustatus, parum convexus, confertissime punctato-rugosus. Elytra thorace tertia parte longiora, crebre punctata. Abdomen elongatum, basin versus sensim subangustatum, crebrius minus subtiliter punctulatum, segmento quinto nigro, sexto nigro-piceo. Pedes flavi.

Mas abdominis segmento inferiore sexto profunde inciso.

* 12. S. testaceus: Elongatus, linearis, testaceus, immaculatus, antennis pedibusque pallidioribus. - Long. $2 \frac{1}{3}$ lin.

Habitat in Columbia, Dom. Moritz.

Habitu fere praecedentium, elongatus, linearis, subdepressus, totus testaceus, eapite thoraceque rufo-testaceis, vix nitidus, pube subtili depressa cinerea tenuiter vestitus, capitis thoracisque lateribus abdominisque apice parce nigro-pilosellis. Antennae capite thoraceque paulo breviores, tenues, pallide flavae. Palpi pallide testacei. Caput thorace haud latius, oblongum, 
basi truncatum, lateribus pone oculos et angulis posterioribus leviter rotundatis, supra anterius depressiusculum, subtiliter punctato-rugulosum, subtus crebre punctatum. Thorax coleopteris haud angustior, latitudine longior, lateribus ante medium rotundatis, basin versus leviter angustatus, subdepressus, subtiliter punctato-rugulosus, lateribus ante medium utrinque subimpressus. Elytra thorace paululum longiora, dense minus subtititer sat profunde punctata. Abdomen parallelum, subtilius punctulatum, segmento quinto basi fuscescente. Pedes pallide flavi.

Mas abdominis segmento inferiore quinto apice subsinuato, sexto profunde triangulariter exciso.

* 13. S. coarctatus: Elongalus, testaceus, capilè nigro thoraceque ovato rugulosis, elytris parce punctatis fascia media, abdomine fascia ante apicem nigris. - Long. 2 lin.

Habitat in valle Araguensi Columbiae, Dom. Moritz.

Reliquis fere gracilior, elongatus, subdepressus. Antennae capite thoraceque paulo breviores, tenues, articulo tertio secundo sesqui prope longiore, sequentibus sensim paulo brevioribus, ultimo elongato, acuminato, pallide testaceae, articulis $3-5$ medio fuscis. Palpi testacei. Caput thorace coleopterisve sesqui prope latius, basi cum angulis posterioribus rotundatum, supra posterius leviter convexum, subtiliter minus confertim longitudinaliter rugulosum, tenuiter griseo-pubescens, nigrum, minus nitidum, ore dilutiore, rufo-piceo. Thorax latitudine summa paulo longior, ante medium coleopteris prope latior, basin apicemque versus fortiter attenuatus, depressiusculus, longitudinaliter dense rugosus, parce pubescens, minus nitidus, rufus, medio piceus. Elytra thoracis longitudine, basi attenuata, parce profundius subseriatim punctata, parce pubescentia, nitida, fascia media nigra, ante fasciam rufo-, pone fasciam flavo-testacea. Abdomen apicem versus leviter incrassatum, parcius punctatum, tenuiter griseo-pubescens, subnitidum, testaceum, segmento quinto nigro-piceo. Pectus nigro-piceum. Pedes subelongati, pallide flavi, femoribus apice nigris, tibiis basi fuscis.

Mas abdominis segmento inferiore quinto medio leviter impresso, sexto apice utrinque leviter simuato, medio profunde inciso.

14. S. tristis: Niger, antennis pedibusque rufo-testaceis, capite thorace latiore, elytris thoracis longitudine, concoloribus. - Long. $1 \frac{2}{3}$ lin.

Habitat in Sardinia, Mus. Reg. Taurin.

S. filiformi latitudine aequalis, at brevior et minus gracilis, niger, opacus, pube depressa griseo-fusca densius vestitus. Antennae capite sesqui longiores, rufo-testaceae. Palpi testacei. Mandibulae et reliquae oris partes, labro nigro excepto, rufo-piceae. Caput basi thorace latius, latitudine baseos haud longius, basi emarginatum, angulis posterioribus retrorsum prouninentibus, rotundatis, lateribus pone oculos leviter rotundatis, ante oculos paulum angustatis, apice leviter emarginatum, supra postice leviter convexum, antrorsum planatum, confertissime punctato-rugulosum, subtus confertissime punctatum. Thorax basin versus angustatus, latitudine summa haud longior, basi apiceque utrinque oblique truncatus, depressus, confertissime punctatorugulosus, posterius linea longitudinali subtilissima impressa tenuissime ca- 
naliculatus. Coleoptera thorace haud longiora, neque eius basi latiora, subdepressa, apice oblique truncata, dense minus fortiter punctata, nigra, apice concolore. Abdomen minus confertim punctatum, punctis transversim rugulosıs, longius pubescens, segmentis singulis margine summo apicali piceotestaceis. Pedes cum coxis anterioribus rufo-testacei.

* 15. S. curtulus: Niger, opacus, antennis pedibusque rufo-testaceis, thorace transversim subquadrato, elytris thorace brevioribus. - Long. 2 lin.

Habitat in Sardinia, Dom. Prof. Gené.

Brevis, latiusculus, subdepressus, niger, opacus, pube depressa grisca densius vestitus. Antennae capite paulo longiores, tenuiores, rufo-testaceae. Palpi testacei. Caput thoracis latitudine, latitudine summa haud longior, basi leviter emarginatum, angulis posterioribus subrotundatis, lateribus ante oculos angustatum, supra parum convexum, subtilissime punctato-rugulosum, infra confertissime minus subtiliter punctatum, rufo-piceum. Thorax coleopterorum latitudine, latitudine paulo brevior, basi apiceque utrinque oblique truncatus, angulis omnibus obtusis, lateribus rectis, basin versus vix angnstatus, subdepressus, densius subtiliter punctatus. Elytra thorace paulo breviora, apice utrinque oblique truncata, dense minus subtiliter profunde punctata, margine summo apicali rufo-piceo. Abdomen coleopterorum latitudine, parallelum, minus subtiliter punctulatum, segmentis singulis margine apicali rufo-piceo. Pedes breviusculi, cum coxis testaceo-rufi. exciso.

Mas abdominis segmento inferiore sexto apioe acute triangulariter

\section{Species mihi invisa.}

16. S. binolatus: Tesiaceus, capite, elytrorum parte anoque nigris, pedibus pallidis. - Long. 2 lin.

Paederus binotatus Say Journ. Acad. Nat. Scienc, Philadelph. III. p. 151.

Habitat in America septentrionali.

Pallide testaceus, leviter pubescens, punctatus. Caput thorace maius, nigrum. Antennae et oris partes pallidae. Thorax longitudinaliter subovatus, dense punctatus. Elytra ante apicem macula magna laterali nigra. Abdomen segmento ultimo anoque nigris. Pedes albidi.

\section{* (S p u r i i).}

*17. S. bipunclat us: Elongatus, subdepressus, testaceus, pedibus pallidis, capite thoraceque confertim subtiliter punctato-subrugulosis, elytris puncto medio nigro notatis. - Long. $2 \frac{2}{3}$ lin.

Habitat in Columbia, Dom. Moritz.

Corpus elongatum, subdepressum, testaceum, parum nitidum, pube depressa grisea minus dense vestitum. Antennae capitis thoracisque prope longitudine, tenues, articulo primo sequentibus ambobus longitudine aequali, tertio secundo plus sesqui longiore, 4- 10 sensim paulo brevioribus, ultimo reliquis paululum crassiore, apice abrupte acuminato, flavae. Palpi flavi. Labrum transversum, medio leviter productum et acute bidentatum 
vel bispinosum. Caput thorace panlo latius, latitudine paulo longins, pone oculos sensim rotundato - angustatum, supra depressiusculum, subtiliter punctatum et concinne reticulato rugulosum, subtus parce obsoletius punctatum, lateribus prarce nigro-pilosellum. Thorax coleopteris dimidio angustior, latitudine simma vix longior, lateribus paulo ante medium subangulatis, apicem versus sensim angustatus, lateribus rectis, basin versus vix angustatus, angulis posterioribus rotundatis, depressiusculus, eodem modo ac caput subtiliter reticulato-rugulosus, versus latera utrinque obsolete impressus. Elytra thorace plus sesqui longiora, subdepressa, minns subtiliter sat profunde densius punctata, puncto medio nigro. Abdomen coleopteris angustius, apicem versus subangustatum, subtiliter punctulatum, apice densius pilosum. Pedes pallide flavi.

Mas abdominis segmento inferiore sexto apice profunde exciso.

* 18. S. hybridus: Niger, obscurus, ely/ris apice pedibusque flavis, capile thoraceque confertissime punctato - subrugulosis, hoc oblongo, lateribus obsolete impresso. - Long. $1 \frac{2}{3}$ lin.

Habitat in Columbia, Dom. Moritz.

Niger vel nigro-piceus, parum nitidus. Antennae capitis thoracisque longitudine, testaceae, articulo primo sequentibus ambobus paulo longiore. Palpi testacei. Labrum rufo-piceum, transversum, apice acute bidentatum. Caput thorace paulo latius, suborbiculatum, supra leviter convexum, subtillter confertissime punctato-subrugulosum, opacum, parce subtiliter griseopubescens, subtus parcius profundiusque punctatum, subnitidum. Thorax coleopteris duplo fere angustior, latitudine paulo longior, lateribus paulo ante medium rotundatis, basin versus angustatus, apicem versus subsinuatim attenuatus, modice convexus, subtiliter conferissime punctato-rugulosus, parce subtiliter cinereo-pubescens, utrinque lateribus obsolete impressus. Elytra thorace paulo longiora, fortius sat profunde crebreque punctata, subtiliter cinereo-puhescentia, apice late sinuatim flava, sutura nigra. Abdomen subtiliter punctulatum, densius cinereo-pubescens, segmentis singulis apice piceo-marginatis. Pedes pallide flavi.

Mas abdominis segmento inferiore sexto late profundeque sinuato.

*19. S. stigma: Rufo-piceus, opacus, capile thoraceque oblongo confertissime subliliter punctato-rugulosis, nigris, elytris thorace longioribus, testaceis, macula lalerali obliqua nigra. - Long. $1 \frac{1}{2}$ lin.

Habitat in Columbia, Dom. Moritz.

Statura omnino et summa affinitas praecedentis. Antennae capitis thoracisque prope longitudine, articulo primo sequentibus ambobus longiure, tertio secundo parum longiore, 4-10 sensim paululum brevioribus et crassioribus, ultimo ovato, apice subcompresso, testaceae. Palpi testacei. Os obscure rufo-testaceum. Labrum transversum, apice medio leviter productum et acute bidentatum. Caput thorace latius, suborbiculatum, basi truncatum, lateribus pone oculos cum angulis posterioribus rotundatis, supra levissime convexum, confertim subtiliter punctato-rugulosum, opacum, tenuiter griseo-pubescens, subtus crebre profundeque punctatum, nigrum vel nigro-piceum. Thorax coleopteris plus dimidio angustior, latitudine summa 
paulo longior, lateribus ante medium angulatis, dein subrotundatis, basin versus leviter angustatus, apicein versus smuato-attenuatus, supra leviter convexus, confertissime subtilius punctato-rugulosus, opacus, tenuiter griseo-pubescens, niger vel nigro-piceus. Scutellum rufo-piceum. Elytra thorace paulo longiora, dense profundius punctata, testacea, macula obliqua in medio latere, et sutura infra medium nigris. Abdomen dilute rufo-piceum, segmentorum marginibus apiceque testaceis, subnitidum, subtiliter pusctulatum, pube longiore depressa grisea densius vestitum. Pectus ruf piceum. Pedes pallide flavo-testacei.

Mas abdominis segmento inferiore sexto apice late profundeque sinuato.

* 20. S exiguus: Rufo-piceus, opacùs, capite nigricante thoraceque conferlissime punctaio-rugulosis, elytris thoracis longitudine antennisque testaceis, pedibus pallidis. - Long. I lin.

Habitat in Puerto-Rico, Dom. Moritz.

Statura fere praecedentium, at longe minor. Antennae capitis thoraci que prope longitudine, articulo primo sequentibus tribus coniunctis longitudine aequali, tertio secundo paulo longiore, $\mathbf{1}-\mathbf{1 0}$ sensim paululum brevioribus et crassioribus, ultimo maiusculo, ovato, apice acuminato, totae testaceae. Palpi flavi. Lal,rum transversum, apice medio leviter productum et acute dentatum. Caput horace paulo latius, suborbiculatum, supra leviter convexum, conferim punctato-rugulosum, opacum, tenuiter griseo-pubescens, nigro-piceum, os versus rufescens, subtus concolor, subnitidum, crebre frofundius punctatum. Thorax coleopteris paulo angustior, latitudine summa vix longior, lateribus ante medium angulatis, basin versus angustatus, supra modice convexus, dense minus subtiliter punctato-rugulosus, opacus, tenuiter griseo-pubescens, rufo-piceus. Elytra thoracis vix longitudine, basin versus sensim angustata, depressa, parce minus subtiliter punctata, parce cinereo-pubescentia. Abdomen subtiliter pinctulatum, longius cinereo-prbescens, piceo-testaceum, segmentorum margine apicali anoque dilutioribus. Pectus piceo-testaceum. Pedes albidi, femoribus anticis subtus leviter dilatatis.

* 21. S. naevius: Rufo-piceus, opacus, capite thoraceque transversim sub.quadrato subliliter puncloto-rugulosis, elytris thorace longioribus testaceis, macula laterali Irinsversa nigra. - Long. $1 \frac{1}{3}$ lin.

Habitat in Columbia, Dom. Moritz.

Praecedentibus affinis, at corpus breviusculum crassiusculumque, rufopiceum, opacum, pube depressa grisea densius vestitum. Antennae capitis thoracisque prope longitudine, articulo primo sequentibus ambobns paulo longiore, tertio secundo paulo longiore, $\$-10$ sensim paulo brevioribus at vix crassioribus, ultimo crassiore, ovato, apice acuminato, flavo-testaceae. Palpi testacei. Labrum breve, apice medio leviter productum et bidenticulatum. Caput thorace paulo latius, latitudine baseos prope brevius, basi leviter emarginatum, angulis posterioribus subrectis, ante oculos angustatum, supra parum convexum, subtiliter punctato-rugulosum, subtus parcius punctatum, nitidulım. Thorax coleopteris paulo angustior, latitudıne paulo brevior, basin versus leviter angustatus, apıce utrinque oblique truncatus, an- 
gulis anterioribus rectis, posterioribus obtusis, subrotundatis, supra parum convexus, confertissime subtiliter punctato-rugulosus. Elytra thorace tertia parte longiora, dense profundius punctata, testacea, lateribus paulo ante medium macula transversa nigra notata. Abdomen breviusculum, subtiliter punctulatum, apice testaceum. Pedes flavo - testacei.

Mas abdominis segmento inferiore sexto late profundeque sinuato.

\section{* 22. S. labeo: Teslaceus, thorace utrinque impresso, labro maximo, trilobo, femoribus anticis basi dilalatis. - Long. $1 \frac{1}{2}$ lin.}

Habitat in Americae ins. St. Johannis, Dom. Moritz.

Corpus totum dilute testaceum, nitidum, elytris abdomineque pallidioribus. Antemnae tenuiores, capite thoraceque longiores, articulis omnibus elongatis, primo sequentibus ambobus subaequali, tertio secundo sesqui longiore, sequentibus sensim paulo brevioribus at haud crassioribus, ultimo apice abrupte acuminato. Labrum maximum, bisinuatum, lobis lateralibus brevissimis, rotundatis, intermedio producto. Caput magnum, thorace paulo latius, postice rotundatum, antice elongatum, posterius leviter convexum, inter oculos utrinque profunde foveolatum, anterius utrinque leviter longitudinaliter impressum, margine laterali ab oculis inde elevato, parcius subtiliter punctulatum. Thorax coleopteris angustior, latitudine summa paulo longior, lateribus rotundato-ampliatus, basin versus angustatus, apicem versus attenuatus, ante apicem leviter constrictus, crebrius subtiliusque punctatus, dorsô obsolete carinatus, pone medium secundum marginem lateralem utrinque longitudinaliter impressus. Scutellum punctulatum. Elytra thorace vix longiora, densius punctata. Abdomen subtilissime punctulatum. Pedes pallide flavi, femoribus anticis fortiter compressis, basi dilatatis, subtus parce nigro-setulosis.

* 23. S. troglodytes: Rufo-castaneus, nilidus, subliliter punctatus, capite aequal, thorace subgloboso elytrisque nigro-piceis, his apice testaceis. - Long. 1 $\frac{1}{2}$ lin.

Habitat in Columbia, Dom. Moritz.

Habitus, statura et summa affinitas sequentis. Caput et thorax pube subtili erecta grisea, elytra et abdomen pube depressa cinerea vestita. Antennae capite thoraceque paulo breviores, crassiusculae, articulo prima sequentibus ambobus paulo breviore, his obconicis, subaequalibus, $4-10$ sensim paulo brevioribus et crassioribus, ultimo breviter ovato, pilosellae, nigro-fuscae, articulis tribus primis testaceis, ultimo ferrugineo. Palpi testacei, Labrum medio leviter sinuatum. Caput thoracis latitudine, orbiculatum, supra leviter convexum, subtilius sat crebre punctatum, nigro-piceum, nitidum. Thorax coleopteris paulo angustior, latitudine summa haud longior, basi, apice et lateribus, his praecipue ante medium, rotundatis, basin versus angustatus, convexus, subtiliter obsoleteque confertim punctatus, nigropiceus, vitidus. Elytra thorace sesqui longiora, leviter convexa, parcius subtiliten obsoleteque punctata, nigro-picea, nitida, apice tertia parte dilute testacea. Abdomen laevigatum, dilute rufo-castaneum, nitidum. Pectus piceum. Pedes pallide flavi. 
Mas abdominis segmento inferiore sexto late profundeque triangulariter exciso.

Variat capite, thorace elytrisque dilute rufo-castaneis, his apice testaceis.

Obs. A sequente praecipue distinctus thorace latiore, subgloboso, capite in utroque sexu aequali, fortius punctatis, antennis medio fusco-nigris, in individuis etiam iis, quae colore dilutiore cum illo congruunt.

*24. S. pusio: Rufo-castaneus, nilidus, subtilissime punclatus, capile foveolato, thorace subovato, elytris apice testaceis. - Long. $1 \frac{1}{2}$ lin.

Habitat in Columbia, Dom. Moritz.

Dilute rufo-castaneus, nitidus, capite thoraceque pube brevi subtili erecta fusca tenuiter vestitis. Antennae capite thoraceque breviores, crassiusculae, articulo primo sequentibus ambobus paulo breviore, tertio secundo paulo longiore, 4-10 sensim paulo brevioribus et crassioribus, ultimo apice abrupte obtuse acuminato, pilosellae, rufo-testaceae. Palpi testacei. Labrum transversum, apice rotundatum, medio sinuatum. Caput thorace paulo latius, suborbiculatum, convexum, subtilissime punctatum, fronte media in mare tri-impressa, foveis anterioribus duabus maioribus, laevigatis, interstitio elevato, compresso, piloso, feminae inter oculos utrinque late impressa. Thorax coleopteris duplo fere angustior, latitudine paulo longior, subovalis, fortiter convexus, subtiliter parcius punctatus. Elytra thorace paulo longiora, leviter convexa, parcius subtiliter punctata, apice testacea. Abdomen subtilissime parcius punctulatum. Pedes flavo-testacei.

Mas abdominis segmento inferiore sexto apice late profundeque triangulariter excisis.

Obs. Habitus omnino reliquorum, at corporis superficie laevi in hoc genere alienus videtur.

\section{Paederus Grav.}

Curt. Britt. Ent. III. t. 108. - Steph. Illustr. V. p. 297. - Boisd, et Lacord. Faun. Ent. Paris. I. p. 428. - Er. Col. March. I. p. 517.

Paederus Fa m. III. Grav. Mon. p. 142.

Labrum apice emarginatum.

Palpi maxillares articulo ultimo obtuso, distincto. .

Antennae rectae.

Tarsi articulo quarto bilobo.

Corpus elongatum, lineare, aliis alatum, aliis apterum. Caput thoracis plerumque latitudine, suborhiculatum, basi profunde constrictum, pedunculo brevissimo tenui thoraci immissum, exsertum, porrectum, oculis parvis, modice prominulis. Labrum transversum, medio anguste leviter emarginatum, Mandiculae falcatae, acutae, medio acute bidentatae. Maxillae (t. IV. f. 30. b.) malis membranaceis, interiore interne, exteriore apice barbatis. Palpi maxillares modice elongati, articulo primo brevi, secundo tertioque elongatis, subaequalibus, hoc apicem versus sensim incrassato, quarto minimo, obtuso. Labium (t. IV. f. 30. a.) mento transverso, ligula lata, biloba, lobis rotundatis, membranea, paraglossis subacuminatis, membranaceis, pu- 
bescentibus, interne ciliatis, ligulam paulo superantibus. Palpi labiales articulis duobus primis subaequalibus, cylindricis, tertio minimo, obtusiusculo. Antennae filiformes, rectae, articulo primo tertioque subelongatss, ultimo acuminato. Thorax ovatus, convexus, interdum globosus. Scutellum rotundato-triangulare. Elytra truncata. Abdomen lineare, apice conico-attenuatum, segmento septimo emınulo, stylis analibus distmctis. Pedes elongati, graciles, tarsis anticis in utroque sexu articulis 4 primis modice dilatatis, obcordatis, aequalibus, subtus dense tomentosis, posterioribus articulis 3 primis longitudine sensim decrescentibus, quarto profunde bilobo, subtus subtilius pubescentibus.

\section{O b s e r vation e s.}

1. Genus characteribus valde distinctum, corpore plerumque laetis coloribus insigni, nitido, capite thoraceque parce subtiliter punctatis, parce subtiliterque pilosellis.

2. Abdominis segmentum inferius sextum in mare per totam prope longitudinem incisum, feminae integrum.

3. Victus imprimis in ripis. Nonnullae species sociales occurrunt.

* 1. P. littoralis: Apterus, niger, elytris cyaneis, thorace, abdominis segmenlis 4 primis pedıbusque rufis, femoribus omnibus apice late nigris, antennis teslaceis, mediv fuscis. - Long. 4 lin.

Grav. Micr. 61. 4. - Mannerh. Brachely/r. 39. 2. - Sahlb. Ins. Fenn. I. 342. 1. - Buisd. et Lacord. Faun. Ent. Paris. 1. 429. 2. - Runde Brachelytr. Hal. 13. 1. - Er. Col. March. 1. 519. 3.

Paed. riparius var. Latr. Hist. nat. Crust. et Ins. I. 346. 2.

Paed. riparius Oliv. Ent. III. 41. 4. 2. t. 1. f. 2.

Staph. riparius Schrunk Enum. Ins. Austr. 233. 441.

Habitat in Germania, Gallia, Italia, Lusitania.

P. ripario paulo maior, praesertim robustior. Antennae capite thoraceque paulo breviores, articulo tertio secundo sesqui longiore, 4-10 sensim paulo brevioribus, testaceae, articulis 5-9 fuscis. Palpi maxillares testacei, articulo tertio apice fuscescente, labiales fusci. Mandibulae nigrae. Caput thoracis latitudine vel eodem paulo latius, orbiculatum, nigrum, nitidum, supra parum convexum, sparsim punctatum, utrinque nigro-pilosellum, ad antennarum basin utrinque leviter impressum. Thorax coleopterorum latitudine, vel iisdem paulo latior, globosus, convexus, rufus, nitidus, dorso biseriatim, lateribus sparsim parce subtiliterque punctatus, parce subtiliter que pilosus. Scutellum punctulatum, obscure rufum. Elytra thorace haud longiora, fortiter punctata, tenuiter cinereo-pubescentia, cyanea, nitida. Abdomen parce subtiliterque punctulatum, rufum, nitidum, segmentis ultimis duobus nigris. Pectus totum nigrum. Pedes cum coxis anterioribus rufo-testacei, femoribus onnibus apice laté nigris, tarsıs apice fuscescentilus.

Obs. Specimina ex Europa meridionali : Lusitania, Sicilia, Sardinia, Carinthia, paulo maiora, validiora, capite thoraceque maioribus, specie autem nullo modo a genuinis distincta. Individua Lusitanica in collectione Hoffmannseggiana nomine P. F in isterrae exstiterunt, Carinthiaca misit Dahl nom. P. speculatoris et diversicollis signata. 
* 2. P. brevipennis: Aplerus, niger, elylris coerulpis, thorace, abdominis segmentis 4 primis pedibusque rufis, femoribus posterioribus apice nigricantibus, antennis testaceis. - Long. 3 lin.

Boisd. et Lacord. Faun. Ent. Paris. I. 430. 3.

Habitat in Austria et Carinthia, Dahl, in Saxonia, Dom. Märkel, in Gallia, Dom. Anbé.

Siatura et summa affinitas P. littoralis, at duplo minor. Antennae capite thoraceque parum breviores, articulo tertio secundo sesqui longiore, 1-10 sensim paulo brevioribus, testaceae, articulis $5-9$ nonnunquam fuscescentibus. Palpi testacei, maxillares a:ticulo tertio apice summo subfuscescente. Mandibulae nigrae. Caput thoracis fere latitudine, orhiculatum, nigrum, nitidum, supra parum convexum, sparsim॰ punctatum, fronte media late laevi, inter oculos et inter antennarum basin utrinque leviter impressa, parce nigro-pilosum. Thorax coleoptera latitudine fere excedens, globosus, convexus, rufus, nitidus, dorso biseriatim, lateribus disperse parce punctatus, parce subtiliterque pilosus. Scutellım punctulatum, rufum. Elytra thorace paulo breviora, fortiter punctata, coerulea, nitida, nigro-pubescentia pilosellaque. Abdomen parce punctulatum; nigro-pilosellum, nitidum, rufum, segmentis ultimis duobus nigris. Pectus nigrum. Pedes toti rufotestacei, femoribus posterioribus apice summo perparum fuscescentibus, coxis ommibus testaceis, posticis basi nigricantibus.

Obs. P. brachypteri et tenuipennis nominibus a Dahlio missus.

* 3. P. Capensis: Apterus, niger, elytris coeruleis, thorare, abdominis segmentis 4 primis, mesosterno pedibusque rufis, femoribus apice libiisque basi fuscis, antennis teslaceis, medio fuscis. - Long. $3 \frac{2}{3}$ lin.

Hahitat in Africa australi, Dom. Drège.

P. littorali paulo minor et gracilior. Antennae capitis thoracisque longitudine articulo tertio secundo duplo longiore, $4-10$ sensim paulo brevioribus et apicem versus magis incrassatis, testaceae, articulis $\mathbf{4}-\mathbf{9}$ obscure fuscis. Palpi testacei. Mandibulae rufae. Caput thoracis fere latitudine, suborbiculatum, nigrum, nitidum, supra perparum convexum, utrinque crebrius subtiliusque punctatum, medio late longitudinaliter laeve, utrinque inter oculos obsolete, ad antennarum insertionem distinctius impressum. Tho rax coleopterorum latitudine, ovatus, lateribus ante medium rotundatis, basin versus modice angustatus, modice convexus, rufus, nitidus, dorso biseriatim, lateribus disperse parce obsoleteque punctatus. Scutellum piceum. Elytra thorace haud longiora, profunde fortiterque punctata, griseo-pubescentia, coerulea, nitida. Abdomen parce punctatum, nitidum, rufum, segmentis duobus ultimis nigris. Pectus nigrum, mesosterno rufo. Pedes coxis ommibus rufis, femoribus testaceis, apice late fuscis, tibiis fuscis, apice tarsisque obscure testaceis.

* 4. P. longipennis: Alalus, niger, elytris coeruleis, mandibulis, thorace oblongo, abdominis segmentis 4 primis pedibusque rufis, his geniculis nigris, antennis nigris, basi testaceis. - Long. 3 lin.

Er. Col. March. 1. 517. 1.

Paed. riparius Grav. Micr. 65. 5. Mon. 143. 11. - Zetterst. Ins. Lappon, 68. 1. 
Var. Tarsis tibiisque fuscis, his basi nigricanlibus. Paederus fuscipes Curtis Britt. Ent. 11I. t. 108.

Habitat in Europa.

Antennae capitis thoracisque longitudine, articulo tertio secundo duplo prope longiore, nigrae, articulis 3 vel 4 primis testaceis. Palpi maxillares testacei, articulo tertio apice nigro, labiales fusci. Mandibulae testaceae. Caput thoracis latitudine, suborbiculatum, nigrum, nitidum, supra parum convexum, utrinque parce punctatum, fronte media laevi, antice utrinque longitudinaliter impressum, parce pilosum. Thorax oblongus, coleopteris duplo fere angustior, latitudine sesqui longior, basin versus vix angustatus, lateribus ante medium subrotundatis, leviter convexus, dilute rufus, nitidus, dorso biseriatim, lateribus disperse parce punctatus, parce pilosellus. Scutellum sublaeve, nigrum. Elytra thorace sesqui longiora, dense punctata, tenuiter albido-pubescentia, parce nigro-pilosa, coerulea, nitida. Abdomen parce obsoleteque punctulatum, nitidum, rufum, segmentis ultimis duobus nigris. Pectus nigrum. Pedes cum coxis omnibus rufo-testacei, femoribus apice nigris, tibiis basi, tarsis apice nigricantibus.

Variat pedum geniculis minus magisve late nigrıs, vel interdum tibiis tarsisque fuscis, illis basi, his apice nigris, vel totis nigris.

* 5. P. Madagascariensis: Alatus, niger, elytris coeruleis, mandibulis, thorace oblongo, abdominisque segmentis 4 primis rufis, antennarum, palporum pedumque basi teslaceis. - Long. 3 lin.

Habitat in Madagascar, Dom. Goudot.

Statura et summa affinitas praecedentis. Antennae capitis thoracisque prope longitudine, articulo tertio secundo duplo prope longiore, 4-10 sensim paulo brevioribus et apicem versus paulo magis incrassatis, articulis 3 primis rufo-testaceis, secundo et tertio apice fuscescentibus, quarto basi rufo-testaceo. Palpi maxillares articulis duobus primis testaceis, tertio nigro, basi testaceo, labiales fusci. Mandibulae rufo-testaceae. Caput thorace paululum latius, orbiculatum, nigrum, nitidum, supra perparum convexum, utrinque crebrius punctatum, fronte media longitudinaliter laevi, utrinque inter oculos et ad antennarum insertionem subimpressum, parce pilosum. Thorax coleopteris dimidio angustior, latitudine tertia parte longior, lateribus anterius leviter rotundatus, basin versus leviter angustatus, modice convexus, rufus, nitidus, dorso biseriatim, lateribus disperse parce punctatus, parce subtiliterque pilosus. Scutellum sublaeve, nigrum. Elytra thorace sesqui longiora, dense fortiter profundeque punctata, tenuiter albido-pubescentia, coerulea vel virescenti-coerulea, nitida. Abdomen parce punctulatum, tenuiter pubescens, parce nigro-pilosellum, nitidum, segmentis 4 anterioribus rufis, posticis duobus nigris. Pectus nigrum. Pedes coxis troohanteribusque omnibus rufis, coxis posticis basi nigris, femoribus omnibus basi vix ultra medium testaceis, apice tibiis tarsisque totis nigris, tibiis nonnunquam apicem versus picescentibus.

* 6. P. caligatus: Alalus, niger, elytris coeruleis, mandibulis, thorace subovato abdominisque segmentis 4 primis rufis, palpis, antennarum pedumgue basi testaceis. - Long. 3 lin.

Habitat Lutetiae, Dom. Aubé, 
Statura P. longipenni aequalis, at angustior, habitu omnino P. riparii. Antennae capitis thoracisque prope longitudine, articulo tertio secundo sesqui prope longiore, $4-10$ sensim paulo brevioribus et crassioribus, ultimo breviter subovato, apice acuminato, nigrae, articulis tribus primis dilute testaceis. Palpi maxillares toti testacei. Mandibulae rufo-testaceae. Caput thoracis fere latitudine, orbiculatum, nigrum, nitidum, supra parum convexum, lateribus parce subtiliterque punctatum, utrinque inter oculos obsolete, ad antennarum basin distinctius impressum, parce nigro-pilosum. Thorax coleopteris paululum angustior, latitudine summa sesqui prope longior, ovatus, basin versus leviter angustatus, convexus, rufus, nitidus, punctis raris subtilissimis piligeris notatıs. Scutellum punctulatum, nigrum. Elytra thorace vix longiora, parcius sat fortiter punctata, coerulea, nitida, pube tenui depressa albida pilisque parcis erectis nigris vestita. Abdomen segmentis anterioribus 4 parce, ultimis duobus crebrius subtiliter punctulatis, illis rufis, his nigris. Pectus nigrum, mesosterno concolore. Pedes coxis omnibus trochanteribusque et femoribus ultra medium testaceis, dein nigri.

* 7. P. limnophilus: Alatus, niger, elytris coeruleis, thorace ovalo abdominisque segmentis 4 primis rufis, antennis pedibusque basi lestaceis, palpis testaceis, articulo tertio nigro. - Long. 3 lin.

Habitat in Saxonia, Dom. Märkel, in Gallia, Dom. Aubé.

Statura omnino praecedentis, at paululum minor. Antennae capitis thoracisque longitudine, articulo tertio secundo duplo prope longiore, 4 - 10 sensim paulo brevioribus at vix crassioribus, ultimo oblongo-ovato, acuminato, nigrae, articulis 4 primis testaceis, quarto apice piceo. Palpi maxillares testacei, articulo tertio toto nigro. Mandibulae nigrae, apice piceae. Caput thoracis latitudine, suborbiculatum, nigrum, nitidum, supra parum convexum, utrınque crebrius punctatum. frónte media longitudinaliter late laevi, anterius longitudinaliter utrinque leviter impressa, parce nigro-pilosum. Thorax coleopteris vix angustior, latitudine summa tertia parte longior, basin versus modice angustatus, ovatus, convexus, dilute rufus, nitidus, lateribus parce, dorso biseriatim subtiliter punctatus. Scutellum sublaeve, nigrum. Elytra thorace paululum longiora, crebre fortius punctata, coerulea, nitida, pube parca depressa albida pilisque raris erectis nigris vestita. Abdomen subtilius punctatum, tenuiter albido-pubescens, rufo-testaceum, nitidum, segmentis ultimis duobus nigris. Pectus nigrum, mesosterno concolore. Pedes coxis trochanteribusque et femoribus ad medium usque testaceis, dein nigri.

Variat tibiis apice tarsis basi fuscis.

Obs. Differt a praecedente praeter palporum mandibularumque colorem elytris paulo longioribus, crebrius minus profunde punctatis. A P. longipenni habitu, et palporum articulo tertio toto nigro facile distinguitur, a sequentibus mesosterno nigro discedit.

* 8. P. riparius: Alatus, niger, elytris coeruleis, thorace, abdominis segmenlis 4 primis, mesoslerno pedibusque rufis, femoribus omnibus apice nigris, antennis nigris, basi testaceis. - Long. $3 \frac{2}{3}$ lin.

Fab. Syst. Ent. 268. 1. Spec. Ins. I. 339. 1. Mant. Ins. I. 223. 1. Ent. Syst. 1. II. 536. 1. Syst. El. II. 608. 1. - Payk. Faun. Suec. III. 427 2. - Walken. Faun. Paris. I. 275. 1. - Cederh. Faun. Ingr. 121. 373. t. 3. f. d. - Panz. Faun. Germ. 9. 11. Ent. Germ. 362. 1.-Rossi Faun. Etr. 253. 626. (Ed, Hellw. 
I. 314. 626.) - Latr. Hist. nat. Crust. et Ins. IX. 345. 2. t. 79. f. 8. Gen. Crust. et Ins. I. 293. 5 - Gyll. Ins. Suer. II. 372. 1. - Mannerh. Brachely/r. 39. 3. - Sahlb. Ins. Fenn. 1. 343. 2. - Boisd. et Lacord. Faun. Ent. Paris. I. 428. 1. - Runde Brachelytr. Hal. 13. 1. - Er. Col. Murch. I. 518. 1.

Staph. riparius Linn. Faun. Suec. n. 846. Iter Gotl. p. 273. Syst. Nat. I. II. 684. 8. - Degeer Ins. IV. 28. 14. t. I. f. 18. - Müll. Prodr. 99. 1125. - Goeze Ent. Beitr. I. 217. 8. - De Vill. Ent. I. 4138 - Harr. Beschr. d. Ins. I. 253.417. - Fourrr. Ent. Par. I. 170. 21. - Payk. Mon. Staph. 27. 19. - Marsh. Ent. Britt. 503. 17.

Paederus oonfinis Zetterst. Ins. Lappon. 69. 2.

Staph. gregarius Scop. Ent. Carn. 102. 398.

Le Staph. à tête noire et à étuis bleus Geuffr. Ins. I. 369. 21.

Staph. septimus Schaeff. Icon. t. il. f. 3.

Habitat in Europa.

$P$. longipenni paulo maior, statura formaque intermedius inter humc et P. littoralem, ab utroque mesosterno rufo distinctus. Antennae capitis thoracisque longitudine, articulo tertio secundo plus sesqui longiore, $4-\mathbf{1 0}$ sensim paulo breviorihus et crassioribus, ultimo ovato, apice acuminato, nigrae, articulis 1 primis testaceis. Palpi maxillares testacei, articulo tertio apice nigro. Mandibulae rufo-testaceae. Caput thoracis latitudine, orbicu latum, nigrum, nitidum, supra perparum convexum, utrinque subtiliter parcius punctatum, fronte media late laevi, utrinque inter oculos et ad antennarum insertionem leviter impressa, parce nigro-pilosum. Thorax coleopteris angustior, basin versus sensim angustatus, convexus, rufus, nitidus, dorso biseriatim, lateribus parcissime subtilius punctatus. Scutellum punctulatum, rufo-piceum. Elytra thorace paululum longiora, fortiter punctata, tenuiter griseo-pubescentia, coerulea, nitida. Abdomen parcius punctılatum, tenuiter pubescens, nitidum, rufum, segmentis ultimis duobus nigris. Pectus nigrum, mesosterno rufo. Pedes cum coxis omnibus rufo-testacei, femoribus apice nigris, tarsis apice fuscescentibus.

Obs. Paed. riparius F. a Kirbio in opere splendido Fauna BorealiAmericana p. 86. $n$ I. inter insecta in America boreali (sub. Lat. 54 ${ }^{\circ}$ ) enumeratus, num huic nostro, an potius speciei cuidem confini subiungendus sit mihi haud perspectum.

9. P. Javanus: Alatus, niger, elytris cyaneis, thorace, abdominis segmentis 4 primis mesosternoque rufis, pedibus antennisque testaceis, his medio fuscis, femoribus posterioribus, tibiisque tarsisque omuibus nigris. - Long. 4 lin.

Habitat in Java, collect. Dom. Chevrolat.

Statura et summa affinitas P. riparii, at paululum maior. Antennae capitis thoracisque longitudine, articulo tertio secundo duplo longiore, 4 - 10 sensim paulo brevioribus, ultimo oblongo-ovato, apice fortiter acuminato, testaceae, articulis 5-9 fuscis. Palpi toti flavo-testacei. Mandibulae rufae. Caput thoracis latitudine, orbiculatum, nigrum, nitidum, supra perparum convexum, fronte utrinque parce inaequaliter punctata, inter oculos utrinque obsolete, ad antennarum insertionem leviter impressa, parce pilosellum. Thorax coleopteris paulo angustior, latitudine paulo longior, basin versus leviter angustatus, lateribus subrectis, convexus, utrinque parce subtiliter punctatus, rufus, nitirlus. Scutellum rufum. Elytra thorace paulo 
Iongiora, crebre sat profiunde punctata, cyanea, nitida, pilis depressis albidis aliisque erectis nigris tenuiter vestita. Ábdomen parce punctatum, nigropilosellum, rufum, segmentis ultimis duobus nigris. Pectus nigrum, mesosterno rufo. Pedes testacei, tibiis tarsisque omnibus, femorumque posticorum apice lato nigris.

Obs. A P. ripario differt praecipue pedum colore, a P. peregrino statura multo maiore, elytris fortius punctatis, Digro-pilosellis, palpis immaculatis.

* 10. P. aestuans: Alalus, niger, ely/ris coeruleis, thorace abdominis segmentis 4 primis, mesosterno pedibusque rufis, femoribus posticis apice nigris, antennis nigris, basi teslaceis. - Long. 3 lin.

Habitat in Senegalia, Dom. Buquet, in Aegypto, Dom. Prof. Ehrenberg.

Statura et summa affinitas $P$. longipennis. Antennae capitis thoracisque longitudine, articulo tertio secundo di1. lo longiore, 4 - 10 sensim paulo brevioribus et apicem versus magis incrassatıs, nigrae, articulis 4 primis flavo-testaceis. Palpi maxillares testacei, articulo tertio apice summo fuscescente. Mandibulae testaceae. Caput thoracis latitudine, suborbiculatum, nigrum, nitidum, parum convexum, utrinque crebrius subtiliusque punctulatum, fronte media late laevi, anterius utrinque leviter longitudinaliter im. fressa. Thorax oblongus, coleopteris duplo fere angustior, lateribus ante medium subrotundatis, basin versus vix angustatus, modice convexus, dilute tes aceo-rufus, nitidus, dorso biseriatim, lateribus disperse subtiliter punctatus. Scutellum rufum. Elytra thorace sesqui fere longiora, crebre punctata, coerulea, nitida, pube brevi depressa albida parcius vestita. Abdomen subtiliter punctulatum, tenuiter cinereo-pubescens, nitidum, testaceo-rufum, segmentis ultimis duobus nigris. Pectus nigrum, mesosterno rufo. Pedes cum coxis omnibus rufo-testacei, femoribus posticis apice nigris, tarsis articulis singulis apice summo nigricantibus.

* 11. P. Sabaeus: Alatus, niger, elytris coemuleis, thorace, abdominis segmentis 4 primis, mesosterno pedibusque anterioribus totis, posticis basi rufis, antennis totis testaceis. - Long. 3 lin.

Habitat in Abessynia et in Arabia felice, Dom. Prof. Ehrenberg, in Guinea, Mus. Dom. Westermann.

Statura et summa similitudo praecedentis. Antennae capite thoraceque paulo longiores, graciles, articulo tertio secundo duplo longiore, 4-10 sensim brevioribus et apicem versus paulo magis incrassatis, ultimo oblongo, apice fortiter acuminato, totae testaceae. Caput thorace paululum latius, orbiculalum, nigrum, nitidum, supra perparum convexum, utrinque subtilius crebriusque punctatum, fronte media late laevi, anterius utrinque leviter longitudinaliter impressa. Thorax oblongus, coleopteris dimidio angustior, lateribus anterius leviter rotundatis, basin versus angustatus, modice convexus, dilute rufus, nitidus, dorso biseriatim, lateribus disperse parce subtiliusque punctatus. Scutellum rufum. Elytra thorace plus sesqui longiora, crebre fortiterque punctata, tenuiter albido-pubescentia, cyanea, nitida. Ab. domen parcius minus subtiliter punctulatum, nitidum, testaceo-rufum, abdominis segmentis ultimis duobus nigris. Pectus nigrum, mesosterno rufo. 
Pedes anteriores toti rufo-testacei, posteriores coxis femoribusque testaceis, his apice, tibiis tarsisque nigris.

Obs. A praecedente praecipue pedum colore, a sequente antennis longioribus, tenuioribus, totis testaceis, thorace basin versus magis angustato, elytris longioribus et abdomine minus subtiliter punctato satis distinctus.

* 12. P. peregrinus: Alatus, niger, elytris coeruleis, thorace, abdominis segmenlis 4 primis, mesosterno pedumque basi rufis, antennis nigris, basi testaceis. - Long. 3 lin.

Habitat in Java, Dom. Com. Hoffnannsegg, in Bengala et in Ins. St. Mauritii, Mus. Dom. Westermann.

Statura et summa affinitas praecedentium. Antennae capitis thoracisque fere longitudine, articulo tertio secundo sesqui longiore, $4-10$ sensim paulo brevioribus at haud crassioribus, ultimo oblongo, apice acuminato, nigrae, articulis tribus primis testaceis, tertio apice nigro. Palpi maxillares testacei, articulo tertio apice summo fuscescente. Mandibulae testaceae. Caput thoracis latitudine, orbiculatum, nigrum, nitidum, supra perparum convexum, utrinque subtilius punctatum, fronte media late laevi, inter oculos et ad antennarum insertionem leviter impressa. Thorax coleopteris dimidio angustior, latitudine tertia parte longior, lateribus ante medium leviter rotundatis, basin versus subangustatus, modice convexus, testaceo-rufus, nitidus, dorso biseriatim, lateribus disperse subtiliter punctatus. Scutellum piceo-nigrum. Elytra thorace sesqui fere longiora, crebre profundeque punctata, tenuiter albido-pubescentia, cóerulea, nitida. Abdomen parce subtiliterque punctulatum, subtiliter tenuiterque griseo-pubescens, nitidum, testaceo-rufum, segmentis ultimis duobus nigris. Pectus nigrum, mesosterno rufo. Pedes antici toti rufo-testacei, posteriores coxis femoribusque testaceis, his apice late, tibiis tarsisque nigro-fuscis.

* 13. P. littorarius: Alatus, niger, elytris cyaneis, thorace, abdominis segmentis 4 primis, mesosterno pedibusque rufis, femoribus posticis apice fuscis, antennis testaceis, medio fuscis. - Long. $2 \frac{1}{3}$ lin.

Grav. Mon. 142. 10.

Paederus littoralis Oliv. Encycl, meth, VIII. 627. 2.

Habitat in America septentrionali.

Habitu P. riparii at triplo minor. Antennae capitis thoracisque longitudine, articulo tertio secundo sesqui longiore, $4-10$ sensim paulo brevioribus et crassioribus, ultimo oblongo, testaceae, articulis $5-9$ fuscis. Palpi testacei, Immaculati. Mandibulae piceae. Caput thoracis latitudine, orbiculatum, nigrum, nitidum, supra parum convexum, utrinque sparsim punctatum, medio late longitudinaliter laeve, fronte utrinque prope oculos leviter impressa. Thorax coleopteris parum angustior, latitudine tertia parte longior, lateribus ante medium leviter rotundatus, basin versus leviter angustatus, convexus, rufus, nitidus, dorso biseriatim, lateribus disperse parce punctatus. Scutellum rufo-piceum. Elytra thorace parum longiora, fortiter profundeque punctata, parce griseo-pubescentia et nigro-plosella, nigro-cyanea, nitida. Abdomen parce obsoleteque punctulatum, parce griseo-pubescens, nigro-pilosellum, nitilum, rufum, segmentis ultimis duobus nigris. Pectus nigrum, mesosterno rufo. Pedes cum coxis omnibus rufi, femoribus posticis apice saepius fuscescentibus. 
* 14. P. Mexicanus: Alatus, niger, elylris cyaneis, thorace, abdominis segmentis 4 primis, mesosterno pedibusque rufis, femoribus posterioribus apice nigris, antennis longioribus, testac:eis. - Long. $3 \frac{2}{3}$ lin.

Habitat in Mexico, Dom. Deppe.

Statura omnino P. aequinoctialis. Antennae capite thoraceque paulo longiores, articulo tertio secundo plus duplo longiore, $\mathbf{4}-\mathbf{1 0}$ sensim brevioribus at vix crassioribus, ultimo apice elongato, acuminato, totae testaceae. Palpi testacei, immaculati. Mandibulae nigro-piceae. Caput thorace panlo latius, orbiculatum, nigrum, nitidum, subdepressiusculum, crebrius ninus subtiliter punctatum, spatio minuto medio et antico laevibus, utrinque ad antennarum basin impressum. Thorax coleopteris duplo prope angustior, latitudine summa sesqui longior, lateribus anterius rotundatis, basin versus angustatus, ovatus, convexus, saturate rufus, nitidus, dorso utrinque sub seriatim, lateribus disperse parcius subtiliusque punctatus. Scutellım rufum. Elytra thorace sesqui longiora, crehre profundeque punctata, tenuiter cinereo-pubescentia, parce nigro-pilosella, cyanea, nitida. Abdomen coleopteris angustius, apicem versus sensim attenuatum, parce obsoletius punctatum, nigro-pilosellum, nitidum, saturate rufum, segmentis ultimis duobus nigris. Pectus nigrum, mesosterno rufo. Pedes cun coxis omnibus rufi, femoribus posterioribus apice fuscis, tarsis articulis singulis summa apice fuscescentibus.

* 15. P. aequinoctialis: Alalus, niger, elylris thorace paulo longioribus cyaneis, thorace, abdominis segmentis 4 primis mesosternoque rufis, pedum busi antennisque longioribus teslaceis, his medio nigris. Long. 4 lin.

Paed. columbinus Laporte Etud. Ent. I. 123. 3. (forte)

Habitat in Columbia, Cayenna.

P. ripario nonnunquam paulo maior. Antennae capite thoraceque longiores, articulo tertio secundo duplo longiore, 4-10 sensim paulo brevioribus at non crassioribus, ultimo apice abrupte acuminato, testaceae, articulis $4-8$ piceis, ultimis tribus ferrugineis. Palpi testacei, immaculati. Mandibulae piceae. Caput thoracis latitudine, orbiculatum, nigro-piceum, nitidum, supra depressiusculum, parce subtiliter punctatum, fronte media laevi, nigro-pilosellum. Thorax coleopteris dimidio angustior, latitudine sesqui longior, lateribus anterius leviter rotundatis, basin versus angustatus, subovatus, convexus, saturate rufus, nitidus, dorso biseriatim, utrinque disperse parcius subtilissime punctatus, subtiliter parceque nigro-pilosus. Scutellum rufum. Elytra thorace paulo longiora, crebre profundeque punctata, tenuiter cinereo-pubescentia, virescenti-cyanea. Abdomen coleopteris paulo angustius, parce punctulatum, omnium subtilissime alutaceum, subtiliter longius nigro-pilosum, subnitidum, saturate rufum, segmentis ultimis duobus nigris. Pectus nigrum, mesosterno rufo. Pedes coxis omnibus rufis, femoribus flavo-testaceis, posterioribus apice late nigris, tibiis tarsisque omnibus nigris.

Variat capite rufo-piceo. 
* 16. P. Brasiliensis: Alatus, niger, elytris thorace sesqui longioribus, cyaneis, thorace, abdominis segmentis 4 primis mesoslernoque rufis, pedibus basi flavo-testaceis, antennis lestaceis, medio fuscis. long. 4 lin.

Habitat in Brasilia.

Statura et magnitudo praecedentis. Antennae capite thoraceque paulo longiores, articulo tertio secundo duplo longiore, 4-10 sensim paulo brevioribus at vix crassioribus, ultimo apice abrupte acuminato, nigro-piceae, articulis tribus primis flavo-testaceis, ultimis tribus ferrugineis. Palpi maxillares testacei, articulo tertio apice nigricante. Mandibulae piceae. Caput thoracis latitudine, nigrum, nitidum, lateribus longe nigro-pilosum, supra depressiusculum, parce subtiliusque punctatun, fronte media late laevi, anterius utrinque longitudinaliter leviter impressa. Thorax coleopteris dimidio angustior, latitudine summa sesqui longior, lateribus anterius leviter rotundatis, basin versus angustatus, ovatus, convexus, rufus, nitidus, dorso biseriatim, lateribus disperse subtiliter punctatus, utrinque nigro-pilosellus. Scutellum rufum. Elytra thorace sesqui longiora, crebre profundeque fortiter punctata, parce cinereo-pubescentia et nigro-pilosella, cyanea, nitida. Abdomen parce subtilius punctulatum, tenuiter nigro-pilosellum, nitidum, rufum, segmentis ultimis dıobus nigris. Pectus nigrum, mesosterno rufo. Pedes omnes coxis femoribusque flavo-testaceis, his apice late nigris, tibiis tarsisque piceis, illis basi late nigris.

Obs. Differt a praecedente imprimis statura paulo robustiore, antennis minus elongatis, elytris paulo longioribus et fortius punctatis, tibiis apice et tarsis basi piceis.

* 17. P. tempestivus: Alalus, niger, elytris thoracis longitudine, cyaneis, thorace, abdominis segmentis 4 primis mesosternoque rufis, antennis testaceis, medio fuscis, pedibus anticis nigris, busi testaceis, posterioribus teslaceis, femoribus apice tibiis basi nigris. - Long. 4 lin.

Habitat in Columbia, Dom. Moritz, in Brasilia, Dom. Thorey.

Praecedentibus aequalis. Antennae capitis thoracisque longitudine, articulo tertio secundo plus duplo longiore, $4-10$ sensim paululum brevioribus at vix crassioribus, ultimo oblongo-fusiformi, nigro-fuscae, articulis 3 primis flavo-testaceis, ultimis 3 vel 4 ferrugineis. Palpi rufo-testacei, immaculati. Mandibulae validiores, piceae. Caput thoracis latitudine, orbiculatum, nigrum, nitidum, supra depressiusculum, vage subtilius punctatum, fronte ad antennarum insertionem utrinque obsoletius impressa. Thorax coleopterorum latitudine, latitudine sesqui fere longior, lateribus anterius modice rotundatus, basin versus angustatus, ovatus, sat convexus, saturate rufus, nitidus, vage subtiliter punctatus, linea media longitudinali laevissima. Scutellum obscure rufum. Elytra thoracis longitudine, crebre profundeque punctata, virescenti-cyanea, nitıda, parce cincreo-pubescentia et nigro-pilosa. Abrlomen coleopterorum latitudiue, parcius punctatum, cinereo- nigroque pilosum, saturate rufum, segmentis ultimis duobus nigris. Pectus nigrum, mesosterno rufo. Pedes posteriores dilute testacei, femoribus apice tibiis basi late nigris, antici nigri, coxis obscure rufo-testaceis, femoribus basi flavo-testaceis, tarsis nonnunquam piceis. 
Obs. 1. A praecedente praecipue elytris brevioribus et pedibus posterioribus apice dilute testaceis distinctus.

2. Specimen reliquis duplo maius, capite thoraceque grandioribus, ceterum autem haud distinctum, in Mexico in monte Orizaba lectum, nomine P. ruge-punctati Dom. Chevrolat examinandum communicavit.

* 18. P. mandibularis: Alatus, niger, elytris cyaneis, thorace, abdominis segmentis 4 primis mesosternoque rufis, pedibus antennisque testaceis, medio nigris. - Long. $4 \frac{1}{2}$ lin.

Habitat in Brasilia meridionali, Sellow.

Praecedentibus paulo maior, robustior. Antennae capitis thoracisque longitudine, articulo tertio secundo plus duplo longiore, 4 - 10 subaequalibus, ultimo oblongo-fusiformi, testaceae, articulis $4-8$ fuscis. Palpi maxillares testacei, immaculati. Mandibulae validiores, piceae, feminae utraque simplici, maris sinistra incrassata, valida, apice oblique truncata, ante apicem ohtuse dentata. Caput thoracis prope latitudine, orbiculato-subquadratum, nigrum, nitidum, supra depressiusculum, parce disperse punciatum, fronte inter oculos olsolete, inter antennas distiuctius impressa. Thorax coleopteris parum augustior, latitudine antica haud longior, basin versus modice angustatus, lateribus vix rotundatus, convexus, saturate rufus, dor: 0 biseriatim, lateribus disperse parceque subtiliter punctatus. Scutellum rufopiceum. Elytra thorace paulo longiora, fortiter profundeque punctata, parce cinereo-pubescentia, cyanea, nit:da. Abdomen parce punctulatum, omnium subtilissime alutaceum, parce nigro-pilosum, subnitidum, saturate rufum, segmentis ultimis duobus nigris. Pectus nigrum, mesosterno rufo. Pedes omnes coxis femoribrisque testaceis, nis apice late nigris, tibiis nigro-piceis, apice tarsisque obscure testaceis.

* 19. P. ferus: Alalus, niger, elytris cyaneis, thorace paulo longiorilus, thorace, abdominis segmentis 4 primis mesosternogue rufis, pedibus nigris, basi flavis, tursis anlennisque testaceis. - Long. 5 lin.

Habitat in Brasilia, Dom. Virmond.

Statura omnino P. conspicui, at paulo brevior. Antennae capitis thoracisque longitudine, articulo secundo tertio dimidio breviore, $1-10$ leviter decrescentibus, ultimo oblongo-fusiformi, testaceae, medio fuscescentes, basi flavescentes. Palpi testacei, immaculati. Mandibulae piceae, feminae simplices, maris sinistra incrassata, apice dilatata et oblique truncata. Caput thoracis latitudine, orbiculatum, nigrum, nitidum, supra depressiusculum, disperse punctatum, fronte utrinque unter oculos leviter, inter antennas distinctius impressa. Thorax antice coleopteris paulo latior, latitudine summa paulo longior, basin versus fortius angustatus, subovatus, lenter convexus, dorso biseriatim, lateribus disperse subtilius punctatus, rufus, nitidus, parce nigro-pilosellus. Scutellum piceo-rufum. Elytra thorace quadrante fere longiora, fortiter profundeque punctata, cyanea, nitida, parce cinereo-pilosella. Abdomen parce punctatum, nigro-jilosum, nitidum, segmentis 4 primis rufis, reliquis nigris. Pectus nigrum, mesosterno rufo. Pedes coxis testaceis, femoribus basi flavis, apice nigris, tibiis nigris, tarsis testaceis.

Obs. Proximus P. mandubilari, distinctus autem statura paulo maiore, capite haud quadrato, thorace anterius coleopteris latiore, posterius fortius angustato, tibiis 
totis nigris, a praecedentibus statura validiore, coleopteris thorace angustioribus et mandibula sinistra maris dilatata.

* 20. P. conspicuus: Alatus, niger, elylris cyaneis, capite, thorace, abdominis segmentis 4 anterioribus mesosternogue rufis, pedibus basi testaceis, antennis testaceis, medio nigris. - Long. $5 \frac{1}{2}$ lin.

Habitat in Columbia, Dom. Moritz.

Praecedentibus maior. Antennae capitis thoracisque longitudine, articulo tertio secundo plus duplo longrore, 4-10 sensim paulo brevioribus at hand crassioribus, testaceae, articulis $4-8$ nigris. Palpi testacei. Mandibulae rufae, feminae simplices, maris sinistra valida. Caput thoracis latitudine, orbiculatum, rufum, nitidum, versus os piceum, supra depressiusculum, subtiliter parceque punctatum, nigro-pilosellum, fronte media laevi, utrinque inter oculos obsolete, ad antennarum basin distinctius impressa. Thorax antice coleopterorum fere latitudine, latitudineque apicis vix longior, basin versus fortiter angustatus, lateribus subrotundatis, modice convexus, saturate rufus, nitidus, dorso biseriatim, lateribus disperse parceque subtiliter punctatus, nigro-pilosellus. Scutellum rufum. Elytra thorace paulo longiora, fortiter profundeque punctata, nigro-pilosa, cyanea, nitida. Äbdomen parce punctulatum, subnitidum, rufum, segmentis ultimis duobus nigris, subtilius nigro-pilosellum. Pectus nigrum, mesosterno rufo. Pedes coxis testaceis, femoribus flavis, apice late nigris, tibiis nigris, tarsis piceis, articulis ultimis duobus testaceis.

Variat fronte anterius nigra.

* 21. P. la etus: Apterus, niger, elytris coeruleis, thorace, abdomine toto, mesosterno pedibusque rufis, his geniculis posterioribus nigris, antennis longioribus, totis testaceis. - Long. $3 \frac{2}{3}$ lin.

Habitat in Mexico, Dom. Deppe.

Statura omnino P. littoralis, at elytris longioribus. Antennae capite thoraceque longiores, articulo tertio secundo duplo longiore, $4-10$ sensim paulo brevioribus at haud crassioribus, ultimo elongato, apice abrupte acuminato, totae testaceae. Palpi testacei, immaculati. Mandibulae rufopiceae. Caput thoracis latitudine, orbiculatum, nigrum, nitidum, supra depressiusculum, parce disperseque punctatum, utrinque inter oculos obsolete, ad antennarum basin distinctius impressum, nigro-pilosellum. Thorax coleopterorum latitudine, latitudine summa vix longior, basin versus leviter angustatus, lateribus rotundatus, subglobosus, convexus, testaceo-rufus, nitidus, dorso biseriatim, lateribus disperse parce subtilissime punctatus, parce subtiliterque nigro-pilosus. scutellum rufum. Elytra thorace paulo longiora, fortiter punctata, parce cineren-pubescentia, nigro-pilosella, coerulea, nitida. Abdomen parce obsoletiusque punctulatum, nigro-pilosellum, subnitidum, totum testaceo-rufum. Pectus nigrum, mesosterno rufo. Pedes cum coxis omnibus rufo-testacei, posteriores femoribus apice, tibiis basi nigricantibus.

22. P. melampus: Alalus, niger, elytris coeruleis, thorace abdominisque segmentis 4 primis rufis, palpis pedibusque nigris, basi mesosternoque piceis. - Long. 3 lin.

Habitat in India orientali, Mus. Dom. Hope. 
Statura P. ruficollis at dimidio minor. Antennae articulis duobus pri.. mis obscure testaceis (reliqui desunt). Palpi nigri, articulo primo piceo. Caput thoracis latitudine, orbiculatum, subcoerulescenti-nigrum, nitidum, supra parum convexum, vage subtiliter punctulatum, anterius utrinque late impressum. Thorax coleopteris paulo angustior, latitudine summa sesqui longior, lateribus ante medium leviter rotundatis, basin versus angustatus, ovatus, convexus, subtiliter punctatus, linea media longitudinali laevi, rufus, nitidus. Scutellum nigrum. Elytra thorace paulo longiora, dense minus fortiter punctata, tenuiter nigro-pubescentia. Abdomen segmentis anteriori. bus 4 rufo-testaceis, ultimis duobus nigris. Pectus nigrum, mesosterno piceo. Pedes nigri, coxis, trochanteribus femorumque summa basi piceis.

\section{P. extraneus: Niger, elytris cyaneis, thorace abdominisque segmentis} 4 primis rufis, antennis palpisque basi piceis. - Long. $3 \frac{2}{3}$ lin.

Wiedem. Zool. Mag. II. I. 133. 200.

Habitat in Bengala, Mus. Dom. Westermann.

Statura omnino P. riparii, at paululum maior. Antennae capitis thoraeisque prope longitudine; articnlo tertio secundo duplo prope longiore, 4 - 10 sensim brevioribus at vix crassioribus, ultimo elongato, nigrae, artienlis duobus primis obscure rufo-testaceis, superne picescentibus. Palpi piceo-testacei, articulo tertio nigro. Mandibulae nigrae. Caput thoracis latitudine, orbiculatum, supra perparum convexum, crebrius obsolete subtiliter punctulatum, nigrum, nitidum. Thorax breviter ovatus, coleopterorum prope latitudine, latitudine sumna parum longior, lateribus leviter rotundatus, basin versus angustatus, convexus, crebre obsoletius subtiliter punctatus, linea nedia longitudinali laevi, rufus, nitidus. Scutellum nigrum. Elytra thorace vix quarta parie longiora, crebre minus fortiter punctata, albo-pubescentia, cyanea, nitidula. Abdomen supra subtiliter punctatum, longius albido-pubescens, segmentis $\mathbf{4}$ prioribus rufis, reliquis nigris. Pectus nigrum. Pedes toti cum coxis nigri.

24. P. tamulus: Alatus, niger, capite elytrisque clialybeis, thorace abdominisque segmentis 4 primis rufis. - Long. 3 lin.

Habitat Leontopoli (Singhrapur) in India orientali, Mus. Dom. Hope.

Habitu P. riparii, at paululnm minor. Antennae capitis thoracisque longitudine, articulo tertio secundo duplo longiore, 4-10 sensim paulo brevioribus et paululum crassioribns, ultimo oblongo-fusiformi, nigrae, cinereo-pubescentes, articulis duobus primis subtus testaceis. Palpi nigri. Caput thoracis latitudine, orbiculatum, chalybeum, nitidum, supra depressiusculum, subtiliter crebre punctulatum, fronte media laeviore, parcius cinereo-pubescens parceque nigro-pilosum. Thorax coleopteris dimidio angustior, latitudine summa parum longior, lateribus rotındatus, basin versus angustatus, breviter ovatus, convexus; crebre subtiliter punctatus, linea longitudinali media laevi, rufus, nitidus, subtilissime albido-pubescens. Scutellum nigrum. Elytra thorace paulo longiora, dense subtilius punctata, nigro coerulea, nitida, densius albido-pubescentia. Abdomen tenuiter cinereo-pubescens, parce nigro-pilosellum, segmentis 4 primis rufis, reliquis 
nigris. Pectus nigrum, albido-pubescens. Pedes toti cum coxis omnibus nigri, albido - pubescentes.

Obs. Affinis praecedenti, at duplo fere minor, caput distinctius punctulatum, cyaneum, thorax magis oblongus, etc.

* 25. P. cyanocephalus: Alalus, niger, capite elytrisque cyaneis, thorace abdominisque segmentis 4 primis rufis, palpis pedibusque nigris, basi testaceis, mesosterno piceo. - Long. 3 lin.

Habitat in Siam, Dom. Kaden.

Statura omnino praecedentium. Antennae capite thoraceque longiores, graciles, articulo tertio secundo plus duplo longiore, 4-10 sensim paulo brevioribus at vix crassioribus, ultimo elongato, nigrae, articulis duobus primis rufo-piceis. Palpi piceo - testacei, articulo tertio nigro. Mandibulae rufo-piceae, apice rifescentes. Caput thorace paulo latius, orbiculatum, supra perparum convexum, disperse punctatum, punctis medio rarioribus, anterius utrinque leviter longitudinaliter impressum, parce albido-pilosum, cyaneum, nitidum. Thorax coleopteris duplo prope angustior, latitudine summa plus duplo longior, lateribus leviter rotundatus, basin versus angustatus, oblongo-ovatus, convexus, disperse subtiliter punctatus, rufus, nitidus. Scutellum piceum. Elytra thorace paulo longiora, parce obsoleteque punctata, sublaevigata, parcius albido - pubescentia, cyanea vel chalybea, nitida. Abdomen parce subtiliter obsoleteque punctulatum, longius albido-pubescens, segmentis 4 prioribus rufo-testaceis, reliquis nigris. Pectus nigrum, mesosterno rufo-piceo. Pedes densius albido-pubescentes, coxis, trochanteribus femoribusque rufo - testaceis, his apice, tibiis tarsisque nigris.

* 26. P. ruficollis: Alatus, nigro-cyaneis, elytris cyaneis, thorace rufo, antennis, palpis pedibusque nigris. - Long. $3 \frac{1}{3}-3 \frac{2}{3}$ lin.

Fab. Spec. Ins. I. 339. 2. Munt. Ins. 223. 2. Ent. Syst. I. II. 537.2. Syst. El. II. 608 2. - Payk. Faun. Suec. III. 427. 1. - Oliv. Ent. III. 44. 4. 1. t. 1. f. 1. Eincycl. meth. VIII. 627. 3. - Panz. Faun. Germ. 27. 22. Ent. Germ. 362. 2. Grav. Micr. 185. 2. Mon. 143. 13. - Latr. Hist. nat. Crust. et Ins. IX. 345. 1. - Gyll. Ins. Suec. II. 373. 2. - Mannerh. Brachelytr. 39. 4. - Boisd. et Lacord. Faun. Ent. Paris. I. 430. 4. - Guér. Iconogr. Regn. An. Ins. t. 9. f. 5. Runde Brachelytr Hal. 13. 3.

Staph. ruficollis Payk. Mon. Staph. 26. 18.

Staph. thoracicus Fourcr. Ent. Par. I. 170. 23.

Le Staph. noir à corcelet rouge Genffr. Ins. 1. 370. 23.

Habitat in Europa et in Asia occidentali (Persia).

P. ripario fere aequalis, nigro-cyaneus, nitidulus, pube subtilissima albida sericans, antennis, palpis pedibusque nigris, thorace solo rufo. Antennae capite thoraceque paulo longiores, articulo tertio secundo sesqui longiore, 4-10 sensim paulo brevioribus, ultimo elongato-fusiformi. Caput thoracis latitudine, orbiculatum, supra parum convexum, subtiliter punctatum, inter oculos et inter antennas utrinque leviter impressum, breviter nigro-pilosellum. Thorax coleopteris plus dimidio angustior, latitudine summa sesqui prope longior, lateribus ante medium rotundatis, basin versus angustatus, ovatus, convexus, subtiliter vage punctatus, linea media longitudinali laevi. Scutellum nigrum. Elytra thorace tertia parte longiora, crebrius subtiliusque punctata, cyanea. Abdomen subtiliter punctulatum. 
* 27. P. Iricolor: Alatus, niger, elylris cyaneis, thorace mesosternoque rufis, antenus pedibusque basi testaceis. - Long. $4 \frac{1}{2}$ lin.

Habitat in ins. St. Vincentii Americae, Dom. Hope.

P. ruficelli paulo maior et gracilior. Antennae capite thoraceque longiores, articulo tertio secundo duplo longiore, $4-10$ sensim paulo brevioribus, ultimo oblongo-fusiformi, nigrae, articulis tribus primis flavo-testaceis, ultimo ferrugineo. Palli maxillares rufi, articulo tertio apice late nigro. Mandibulae piceae. Caput thoracis latitudine, orbiculatum, nigrum, nitidum, supra depressiusculum, subtiliter parceque punctulatum, fronte anterius utrinque leviter longitudinaliter impressa, parce nigro-pilosellum. Thorax antice coleopteris vix angustior, latitudine antica vix longior, basin versus modice angustatus, lateribus leviter rotundatis, ovatus, convexus, testaceo-rufus, nitidus, utrinque parce subtilissime punctatus. Scutellum obscure rufum. Elytra thorace paulo longiora, crebre profundius punctata, subrugosa, cyanea, nitida, tenuissime griseo-pubescentia, parce nigro-pilosella. Abdomen nigrum, subnitidum, parce punctulatum, nigro-pilosellum. Pectus nigrum, mesosterno rufo. Pedes coxis femoribusque testaceis, his apice late nigris, tibiis tarsisque nigris.

28. P. erythroderus: Apterus, niger, elytris cyaneis, thorace mesosternoque rufis, pedibus antennisque leslactis, his medio, femoribus omnibus apice nigris. - Long. $4 \frac{1}{2}$ lin.

Habitat in monte Orizaba in Mexico, collect. Dom. Chevrolat.

Antennae cajitis thoracisque longitudine, articulo tertio secundo duplo prope longiore, 1 - 10 sensim paululum brevioribus, ultimo apice abrupte acuminato, articulis tribus primis flavo-testaceis, $4-9$ fuscis, ultimis duol,us rufo-testaceis. Palyi testacei, immaculati. Mandibulae piceae. Caput thoracis latitudine, orbiculatum, nigrum, nitidum, supra depressiusculum, vage obsolete punctatum, fronte media laevi, anterius utrinque leviter longitudinaliter impressa, parce nigro-pilosellum. Thorax coleopteris latior, latitudine antica vix longior, basin versus subangustatus, lateribus leviter rotundatus, valde convexus, dilute rufus, nitidus, lateribus parce vageque obsolete punctatus. Scutellum piceum. Coleoptera antrorsum leviter angustata, parce obsoletius exasperato-punctata, viridi-cyanea, nitida, nigropilosella. Abdomen parce punctatum, nigrum, subnitidum, nigro-pilosellum. Pectus nigrum, mesosterno rufo. Pedes antici rufo-testacei, coxis concoloribus, femoribus apice nigris, postici flavo-testacei, femoribus apice coxisque nigris.

* 29. P. thoracicus: Apterus, niger, elylris cyaneis, thorace rufo, antennis pedibusque testaceis. - Long. $4 \frac{1}{2}-5$ lin.

Hahitat in Mexico.

Habitu omnino P. littoralis at duplo fere maior. Antennae capitis thoracisque fere longitudine, articulo tertio secundo duplo longiore, $4-10$ sensim paulo brevioribus, ultimo oblongo-ovato, totae testaceae. Palpi rufotestacei. Mandibulae piceae. Caput thoracis latitudine, orbiculatum, supra leviter convexum, crebrıus punctatum, anterıus utrinque leviter longitudina. liter impressum, nigrum, nitidum, nigro-pilosellum. Thorax coleopteris 
paulo latior, latitudine antica haud longior, basin versus leviter angustatus, lateribus subrotundatus, valde convexus, subglososus, vage subtiliter punctatus, linea media longitudinali laevi, rufus, nitidus. Scutellum rufo-piceum. Coleoptera thorace fere breviora, basin versus sensim leviter angustata, apice coniunctim emarginata, crebrius fortiusque exasperato-punctata, cyanea vel viridi-cyanea, nitida, nigro - pilosella. Abdomen apicem versus modice incrassatum, sat crebre minus fortiter punctatum, nigrum, subnitidum, parcius nigro-pubescens. Pectus nigrum. Pedes nigri, coxis anticis rufis, tarsis omnibus piceo-testaceis, articulis ultimis duobus dilute testaceis.

* 30. P. chalybeus: Alatus, nigro-cyaneus, abdomine, pedibus antennisque nigris, his articulo secundo basi piceo. - Long. 4 lin.

Habitat in Madagascar, Dom. Goudot.

Statura omnino $\mathrm{P}$. ruficollis et maximis eius individuis parum maior, niger, capite, thorace elytrisque obscure cyaneis, subnitidulus. Antennae capitis thoracisque longitudine, articulo secundo subtus rufo-piceo, tertio secundo plus duplo longiore, $4-10$ sensim paulo brevioribus, ultimo elongato-fusiformi. Palpi nigri, articulo secundo basi piceo. Caput thoracis latitudine, orbiculatum, supra leviter convexum, crebrius subtiliusque vage punctatum, fronte media vix laeviore, anterius utrinque longitudinaliter leviter impressa, parce nigros pilosellum. Thorax coleopteris duplo fere angustior, latitudine summa sesqui longior, lateribus ante medium rotundatis, basin versus angustatus, ovatus, valde convexus, subtiliter vage punctatus, linea media longitudinali laevi, parce breviter subtiliterque nigro-pilosellus. Scutellum nigrum. Elytra thorace longiora, crebrius subtiliter punctata, tenuiter cinereo-pubescentia. Abdomen subtiliter punctulatum, subtiliter cinereo- nigroque pubescens.

* 31. P. coerulescens: Alalus, nigro-coeruleus, abdomine, pedibus antennisque nigris, his arliculis duobus primis subtus teslaceis. - Long. $2 \frac{1}{2}$ lin.

Habitat in Madagascar, Dom. Goudot.

Praecedente plus duplo minor, niger, capite, thorace elytrisque nigrocoeruleis, subnitidus, pube subtili brevique albida subsericans. Antennae capite thoraceque paulo longiores, articulo tertio secundo duplo prope longiore, 4-10 sensim brevioribus, ultimo oblongo, apice acuminato, nigrae, articulis duobus primis subtus testaceis. Palpi maxillares nigri, articulo secundo toto testaceo. Caput thoracis latitudine, orbiculatum, supra convexum, crebre subtilius punctatum, punctis in media fronte rarioribus, antice utrin que longitudinaliter impressum, parce nigro-pilosum. Thorax coleopteris plus dimidio angustior, latitudine summa tertia parte longior, lateribus ante medium rotundatis, basin versus angustatus, ovatus, convexus, aequaliter densius subtiliusque punctatus. Scutellum nigrum. Elytra thorace sesqui longiora, densius subtiliusque punctata', transversim subrugosa. Abdomen subtiliter punctulatum.

* 32. P. memnonius: Alatus, niger, albido-pubescens, elytris cyaneis, antennis, palpis pedibusque nigris, immaculatis. - Long. 3 lin.

Habitat in Aegypto, Dom. Prof. Ehrenberg. 
Statura P. ruficollis, et minimis eius individuis aequalis, niger, subnitidus, capite thoraceque nitidis, elytris cyaneis, nitidis, pube crassiore depressa albida nitidula densius vestıtus. Antemnae capitis thoracisque longitudine, articulo tertio secundo sesqui longiore, 4-10 sensim paulo brevioribus et magis obconicis, ultimo fusiformi, totae nigrae, albido-sericantes. Palpi nigri, immaculati, albido - sericantes. Caput thoracis latitudine, orbicalatum, supra leviter convexum, crebre punctatum, fronte media sublaevi, anterius utrinque leviter longitudinaliter impressa, parce nigro-pilosum. Thorax coleopteris duplo prope angustior, latitudine summa tertia parte longior, lateribus ante medium rotundatis, basin versus. modice angustatus, ovatus, convexus, crebrius subtiliusque punctatus, linea media longitudinali laevi parum distincta. Scutellum nigrum. Elytra thorace paulo longiora, crebre fortius punctata. Abdomen subtiliter punctulatum.

\section{* 33. P. fastuosus: Alatus, niger, elytris cyaneis, antennis palpisque testa- ceis. - Long. $3 \frac{3}{4}$ lin.}

Klug Col. Madag. 52. 45.

Habitat in Madagascar, Dom. Goudot.

Statura fere P. littoralis, at elytris longioribus, niger, nitidus, elytris vel virescenti - vel violaceo-cyaneis. Antennae capitis thoracisque longitudine, articulo tertio secundo duplo longiore, 4-10 sensim paulo brevioribus et crassioribus, ultimo fusiformi, totae testaceae, apice saepius obscuriores. Palpi testacei. Mandibulae rufae. Caput thoracis latitudine, orbiculatum, supra depressiusculum, utrinque crebrius punctatum, medio longitudinaliter laeve, anterius utrinque longitudinaliter impressum. Thorax coleopteris parum angustior, latitudine antica vix longior, basin versus leviter angustatus, lateribus vix rotundatus, modice convexus, utrinque crebrius disperse subtilius punctatus, linea media longitudinali laevi. Scutellum nigrum. Elytra thorace paulo longiora, fortiter profundeque crebre punctata, parce nigro-pilosella. Abdomen parcius subtiliusque punctulatum, nigropilosellum. Tarsi picei.

\section{* 34. P. fulvicornis: Apterus, niger, elytris brevibus, nigro-cyaneis, tibiis piceis apice, tarsis, antennis palpisque testaceis. - Long. 4 lin.}

Habitat in Java, Dom. Dr. De Haen.

Statura fere P. littoralis, at sesqui maior, niger, nitidus, elytris nigrocoeruleis. Antennae capite thoraceque paulo longiores, articulo tertio secundo duplo prope longiore, 4-10 sensim paulo brevioribus, ultimo elongato-fusiformi, fortiter acuminato, rufo-testaceae. Palpi rufo-testacei. Mandibulae piceae. Caput thorace paulo latius, orbiculatum, supra depressiusculum, parce subtiliterque punctatum, anterius utrinque fortius impressum. Thorax coleopterorum latitudine, latitudine summa paulo longior, lateribus anterins rotundatis, basin versus angustatus, fortiter convexus, subglobosus, utrinque parce disperseque subtilius punctatus, medio tenuissime obsolete canaliculatus. Scutellum nigrum. Coleoptera vix thoracis longitudine, basin versus angustata, parum exasperato-punctata, tenuiter griseo-pubescentia, parce nigro-pilosella. Abdomen apicem versus sensim leniter incrassatum, 
minus nitidum, parce obsoletius punctatum, fusco-pilosellum. Pedes nigri, tibiis piceis apice tarsisque fulvis.

* 35. P. rutilicornis: Aplerus, niger, elytris longioribus, nigro-subviolaceis, antennis palpisque testaceis: - Long. $5 \frac{1}{2}$ lin.

Habitat Bogotae in Columbia interiore, Dom. Buquet.

Habitu P. littoralis, at magnus, niger, nitidus, elytris nigro-subcyaneis, aut nigro-vılaceis, aut nigris, parce nigro-pilosus. Antennae capitis thoracisque longitudine, articulo tertio secundo duplo prope longiore, $4-10$ sensim brevioribus, ultimo fusiformi, apice acuminato, testaceae. Palpi maxillares testacei, labiales picei. Mandibulae nigro-piceae. Caput thoracis latitudine, subovatum, supra depressiusculum, parce subtiliterque punctatum, fronte media laeviore, antice utrinque leviter longitudinaliter impressa. Thorax coleopteris parum angustior, latitudine summa tertia parte longior, lateribus leviter rotundatus, basin versus angustatus, ovatus, convexus, utrinque disperse parceque subtiliter punctatus, plaga angusta longitudinali media laevi. Scutellum nigrum. Elytra thoracis longitudine, crebre fortiter profundeque punctata, subrugosa. Abdomen apicem versus sensim incrassatum, parcius subtiliusque punctatum, tenuiter nigro-pilosellum. Pedes nigri, tibiis tarsisque piceis, subtus fulvescenti-tomentosis.

- 36. P. coarctatus: Aplerus, niger, elytris brevibus, viridibus, abdomine apice obscure sanguineo, antennis palpisque testaceis. - Long. 5 lin.

Habitat in Brasilia, Dom. Prof. Germar.

Praecedente paulo minor. Antennae capite thoraceque longiores, articulo tertio secundo duplo longiore, sequentibus sensim paulo brevioribus, ultimo apice abrupte acummato, testaceae, medio obscuriores, nigro-pilosellae. Palpi testacei. Mandibulae piceae. Caput thoracis latitudine, orbiculatum, nigrum, nitidum, nigro-pilosellum, supra depressiusculum, parce subtiliterque punctatum, fronte media late laevi, antice utrinque leviter impressa. Thorax coleopteris multo latior, latitudine summa panlo longior, lateribus leviter rotundatus, basin versus angustatus, valde convexus, niger, nitidus, dorso biseriatim, lateribus disperse parceque subtiliter punctatus, nigro-pilosellus. Scutellum nigrum, laeve. Coleoptera angusta, thorace haud longiora, fortiter profundeque punctata, viridia, nitıda, nigro-pilosella. Abdomen apicem versus leniter incrassatum, parcius punctatum, nigro-pilosellum, nigrum, nitidum, segmentis duobus ultimis obscure sanguineis. Pectus nigrum. Pedes picei, femoribus apicem versus sensim nigris.

\section{Species mihi invisa e.}

37. P. australis: Rufus, capite abdominisque apice pedibusque nigris, elytris coeruleis.

Guér. Voyag. de la Coquille t. 1. f. 23. - Boisd. Faun. Ent. Ocean. p. 57.

Habitat ad Portum Jacksonii Novae Hollandiae.

P. ripario similis. 
38. P. morio: Ater, opacus, ely/ris brevissimis, coerulescentibus, thorace obovato, postice truncato, antennis ferrugineis.

Mannerh. Bruchelyir. 39. 1.

Habitat in ins. St. Dominici.

P. ripario duplo maior. Caput thorace multo latius, subdepressum, disperse punctatum, fronte obsoletius bi-impressa. Antennae tenues, capite cum thorace longiores. Thorax latitudine longior, ovatus, basi truncatus, convexus, disperse punctatus. Elytra thorace angustiora, latitudine breviora, apice introrsum oblique truncata, punctis leviter insculptis pilosis. Abdomen reliquo corpore fere longius, inflatum. Pedes praesertim postici, elongati. (Mannerh.) 


\section{Tribus quinta. \\ Pi n o p hi 1 i n i.}

Stigmata prothoracica occulta, spatio pone coxas anticas corneo.

Coxae posticae conicae.

Antennae sub frontis margine laterali insertae.

Labrum latum, transversum vel brevissimum, integrum Pinophilo, Taenodemati;

medio sinuatum, Palamino, Oedichiro, Procirro.

Mandibulae longae, tenues, falcatae, acutae, medio dentatae.

Maxillae malis brevioribus, interiore interne, exteriore apice barbatis.

Palpi maxillares articulo primo minuto, secundo elongato, tertio hoc plerumque breviore, quarto magno,

transverso, lineari Pinophilo;

transverso, securiformi Ta en odemati, Palamino, Oedichiro;

elongato - fusiformi, acuminato Procir ro.

Mentum corneum, transversum, breve.

Ligul a brevis, biloba, plerisque;

apice subsinuata Procirro.

Paraglossae distinctae,

ligulam superantes, lineares $\mathrm{Pinophilo,} \mathrm{Taenodemati,} \mathrm{Procirro;}$

ligulae aequales $\mathbf{O}$ edichiro;

ligula breviores $\mathrm{Pal}$ a min 0 .

Palpi labiales articulo tertio minuto, fere subulato.

Antennae rectae, filiformes, $\mathbf{1 1}$-articulatae, infra oculos sub capitis margine laterali insertae.

Caput exsertum, collo quasi tenui thoraci affixum, basi truncatum Pinophilo, Palamino;

basi rotundatum Oedichiro;

basi attenuatum Procirro.

Th o r a basi ab elytris remotus, subtus spatio pone coxas anticas corneo.

Elytra pectoris longitudine.

Abdomen elongatum, segmento septimo saepius occulto, 
marginatum Pinophilo, Taenodemati;

immarginatum Palamino, Oedichiro, Procirro.

$\mathrm{Pedes}$ graciliores, mutici, coxis anticis conicis, exsertis, intermediis approximatis, posticis conicis, tarsis 5-articulatis, posterioribus articulo primo leviter elongato, anticis dilatatis,

articulis 4 primis patellam formantibus, singulis transversis, subtus

membrana instructis Pinophilo, Palamino;

tomentoso-spongiosis Ta eno demati;

articulis 4 primis singulis dilatatis, subquadratis, fortiter convexis $\mathrm{O}$ e dichiro, Procirro.

\section{O b s e r v a t i o.}

Affinis tribui praecedenti et sequenti, cum utraque mandibulis longis, tenuibus, falciformibus et palpis maxillaribus elongatis, cum illa palporum maxillarium articulo primo brevi et coxis anticis oblongis, conicis, cum hac spatio pone coxas corneo convenit, ab utraque palporum maxillarium articulo ultimo magno, plerumque magis minusve securiformi, discedit.

\section{Pinophilus Grav.}

Grav. Micr. p. 201. - Laporte Etud. Ent. I. p. 121.

Pinophilus Nordm. Symb. p. 154. t. 2. $f$. 6. et Araeocerus Nordm. ibid. p. 157. Pityophilus Brullé Hist. nat. Ins. III. p. 75.

Lathrobium Fam. I. Grav. Mon. p. 129.

Palpi maxillares articulo quarlo transverso, lineari. Abdomen marginatum.

Tarsi antici articulis 4 primis dilatatis, coniunctis patellam formantibus.

Corpus mediae magnitudinis, elongatum, lineare, alatnm. Caput thoracis prope latitudine, subquadratum, basi profunde constrictum, collo quasi brevi thoraci immissum, exsertum, porrectum, subdepressum, oculis mediocribus, rotundatis, prominulis. Labrum latum, brevissimum, integrum. Mandibulae sat longae, falcatae, acutae, medio dente valido truncato armatae. Maxillae (t. IV. f. 34. b.) malis coriaceis, interiore interne, exteriore apice barbatis. Palpi maxillares elongati, articulo primo brevi, minuto, secundo tertioque subaequalibus, quarto his magnitudine aequali, at transverso, introrsum directo, facie palpitante per totam articuli latitudinem extensa. Labium (t. IV. f. 34. a.) mento transverso, ligula brevi, biloba, membranacea, paraglossis acuminatis, membranaceis, ligulam longe superantibus. Palpi labiales articulo primo maiore secundoque leviter elongatis, tertio parvo, subacuminato. Antennae filiformes, tenues, articulis singulis apice incrassatis, primo fortiore, secundo saepius sequentibus paulo crassiore, ultimo a medio inde abrupte acuminato. Thorax quadrangulus, plerumque basin versus angustatus, basi apiceque truncatus, angulis anterioribus subrectis, posterioribus obtusis vel rotundatis. Scutellum rotundatum. Elytra truncata. Abdomen lineare, coleopterorum latitudine, teretiusculum, marginatum, stylis analibus haud exsertis. Pedes breviores, antici incrassati, femoribus tibiisque interne sinuatis, his apice oblique truncatis, tarsis articulis quatuor primis fortiter dilatatis, subtus articulo singulo lobo transversali semicirculari membraneo, saepius ultra articulum ipsum dilatato, instructo, posteriores graciliores, tibiis apice oblique triuncatis, posticis apicem versus subdilatatis, 
compressis, tarsis articulo primo modice elongato, sequentibus duobus coniunctis aequali, quarto parvo, lobato.

\section{O b s e r vat i o n e s.}

1. Corpus punctulatum, plerumque tenuiter pubescens, capite thoraceque nonnunquam glabris, thorace dorso in nonnullis biseriatim punctato, fronte saepius posterius et ante oculos utrinque fortius punctata.

2. Genus Ara ecerus, corporis subdepressi, thoracis parum convexi, elytrorum planorum causa a Nordmanno distinctum, omnibus characteribus cum hoc genere congruit, neque habitu etiam satis dissimile videtur.

3. Dom. Brullé e latino vocabulo Pinus generis huius nomen a Gravenhörstio compositum esse opinatus, ut vocem hybridam e systemate elideret, Pinophilum in Pityophil um mutavit. Cum autem eruditum huius generis inventorem nomen illud e graeco rivos (squalor) composuisse patere videatur, non est quod istam a Dom. Brullé adhibitam emendationem recipiamus

4. Postea cel. Gravenhorst ipse hoc genus L a th r o bio subiunxit (Mon. p. 129.), quo forte evenit, quod exinde a plurimis auctoribus sit oblitum. Dom. Le a ch nomen novum, Lycidius, proposuit, a plurimis Entomologis receptum, in Catalogo collectionis Dejeanianae lapsu typographico Lyeidius dictum.

5. Mas pene prominulo, corneo, acuto, sursum curvato saepius cognoscendus, plerumque quoque abdominis segmenti inferioris sexti, interdum etian quinti structura distinctus.

6. De victu nihil constat. Genus Europae omnino alienum, in America, Africa et Asia obvium.

\section{P. tenebrosus: Niger, subopacus, antennis, palpis tarsisque fusco- testaceis, thorace oblongo-quadrato, dorso biseriatim punclato. - Long. 11 lin.}

Habitat in valle Araguensi Columbiae, Dom. Moritz.

Subcylindricus, niger, subopacus, densius griseo-pubescens, capite thoraceque glabris, parum nitidis. Antennae capite sesqui longiores, fuscotestaceae, articulo tertio nigricarite, secundo plus sesqui longiore, sequentibus sensim decrescentibus. Palpi fusco-testacei. Caput thorace paulo angustius, lateribus pone oculos crebre punctatum, fronte punctis paucis dispersis, secundum latera crebrioribus et confertioribus, impressa. Thorax coleopterorum latitudine, latitudine paulo longior, basin versus subangustatus, lateribus rectis, basi apiceque truncatus, angulis praecipue posterioribus rotundatis, leviter transversim convexus, punctis parcis, dorso subbiseriatis, ad latera dispersis, impressus, interstitiis omnium subtilissime punctulatis. Scutellum punctulatum. Elytra thorace longiora, dense minus fortiter punctata. Abdomen confertim subtilius punctatum, apice summo piceum. Pedes nigri, griseo-pubescentes, tarsis ferrugineis, anticis minoribus, tibia sesqui latioribus, orbiculatis.

Abdominis segmentum sextum inferius maris longitudinaliter impressum, apice profundius emarginatum, quintum apicem versus leviter longitudinaliter impressum.

* 2. P. torosus: Niger, nitidus, antennis tarsisque fusco-testaceis, thorace subquadrato, vage punctato. - Long. 10 lin.

Habitat in valle Araguensi Columbiae, Dom. Moritz.

Praecedenti aequalis, licet paulum minus elongatus, subcylindricus, ni- 
ger, subnitidus, capite thoraceque pernitidis, glabris. Antennae capite sesqui longiores, articulo tertio secundo paulo longiore, sequentibus sensim decrescentibus, fusco-testaceae, articulo primo nigro-piceo. Palpi fusco-picei. Caput thoracis prope latitudine, fronte disperse sat fortiter punctata. Thorax coleopterorum latitudine, latitudine hand longior, basin versus subangustatus, lateribus subrectis, basi apiceque, truncatus, angulis praecipue po. sterioribus rotundatis, leviter convexus, sparsim sat profunde punctatus, plagis tribus longitudinalibus laevioribus. Scutellum obsoletius parum-punctatum. Elytra thorace paulo longiora, crebre profunde punctata, parcius nigro-pubescentia. Abdomen densius nigro-pubescens, creberrime minus subtiliter punctatum, segmentis ultimis duobus punctato-rugosis, ultimo apice acute emarginato. Pedes nigri, tarsis piceis, anticis tibia parum latioribus, orbiculatis.

Abdominis segmentum sextum inferius $m$ aris leviter longitudinaliter impressum, apice profunde incisum, quintum apicem versus leviter canaliculatum, feminae integra, sextum crebre fortius punctatum, longitudinaliter subrugosum.

3. P. caliginosus: Niger, nilidus, antennis, palpis tarsisque fuscotestaceis, thorace oblongo, crebre punctalo, linea media longitudinali laevi. - Long. 7 lin.

Habitat in valle Araguensi Columbiae, Dom. Moritz.

Praecedentibus minor et angustior, subcylindricus, niger, subnitidus, griseo-pubescens, capite thoraceque glabris, pernitidis. Antennae capite thoraceque multo breviores, articulo tertio secundo parum longiore, 3-5 subaequalibus, sequentibus sensim decrescentibus, fusco-testaceae, articulis duobus primis piceis. Palpi fusco-testacei. Caput thorace paulo angustius, fronte disperse sat profunde punctata. Thorax coleopterorum latitudine, latitudine longior, basin versus subangustatus, lateribus rectis, basi apiceque truncatus, angulis praecipue posterioribus subrotundatis, leviter transversim convexus, crebre punctatus, punctis prope marginem lateralem et prope lineam mediam longitudinalem laevem magis confertis. Scutellum parce punctulatum. Elytra thoracis longitudine, sat dense punctata, griseo-pubescentia. Abdomen confertim punctatum, griseo-pubescens. Pedes nigri, tarsis fusco-testaceis, anticis tibia sesqui latioribus, orbiculatis.

Mas latet.

* 4. P. picipes: Niger, nitidus, pedibus rufo-piceis, thorace oblongo, dorso biseriatim punctalo. - Long. 7 lin.

Habitat Novı Aureliani in Georgia Americae, Dom. Philippi.

Subcylindricus, niger, subnitidus, capite thoraceque glaberrimis, perninitidis. Antennae articulis 2 primis rufis, secundo tertio paulo breviore, 3-4 aequalibus, quintoque iterum paulo breviore piceis (reliqui desunt). Palpi rufi. Caput thorace paulo angustius, vertice et oculorum margine interno crebrius punctatis, fronte punctis paucis dispersis impressa. Thorax coleopteris paululum latior, latitudine paulo longior, basin versus vix angustatus, lateribus rectis, basi apiceque truncatus, angulis omnibus leviter rotundatis, transversim convexus, omnium subtilissime punctulatus, dorso 
serie utrinque longitudinali sat regulari e punctis $6-\mathbf{7}$, lateribus punctis paucis dispersis impressus. Scutellum laeve. Elytra thoracis longitudine, fortiter profundeque punctata, parce pubescentia. Abdomen crebre subtilius punctatum, pube longiore depressa parce vestitum. Pedes crassiusculi, rufopicei, coxis nigris, femoribus posterioribus basi nigricantibus, tarsis anticis tibia sesqui latioribus, subovatis.

Abdominis segmentum inferius sextum maris longitudinaliter obsolete impressum, apice emarginatum, emarginatura bisinuata.

* 5. P. complanatus: Niger, pedibus piceis, thorace dense subtiliter purclato. - Long. 6 lin.

Habitat in Siam, Dom. Kaden.

Depressus, niger, ntidus, subtiliter pubescens. Antennae articulis duobus primis rufo-piceis (reliqui desunt). Mandibulae piceae. Caput thorace paulo angustius, supra parce disperseque minus fortiter punctatum, puncto quoque pilo brevi erecto instructo, interstitiis omnium subtilissime punctulatis. Thorax apice coleopterorum latitudine, basin versus angustatus, latitudine apicis haud brevior, lateribus leviter rotundatus, basi truncatus, apice utrinque subsinuatus, angulis anterioribus acutiusculis, posterioribus leviter rotundatis, subdepressus, dense subtiliter punctatus, subtiliter tenuiterque griseo-pubescens. Scutellum punctulatum. Elytra thorace paulo longiora, dense punctata, pube longiore grisea tenuiter vestita. Abdomen crebre punctatum, griseo-pubescens, apice summo picescente. Pedes picei, tarsis fulvis, anticis tibia sesqui latioribus, oblongis.

Mas latet.

* 6. P. niger: Niger, nitidus, tarsis rufo-piceis, thorace basin versus angustato, vage punctato, basi obsolete bi-impresso. - Long. $5 \frac{1}{2}$ lin.

Araeocerus niger Nordm. Symb. 157. 1.

Habitat in Brasiliae meridionalis prov. Montevideo, Sellow.

Subdepressus, niger, nitidus, capite thoraceque glabris. Antennae capite thoraceque paulo breviores, tenues, articulo tertio secundo paulo longiore, nigrae, apice piceae. Palpi nigri. Mandibulae piceae. Caput thoracis latitudine, latitudine brevius, subtilissime parce punctulatum, utrinque parce vageque fortiter punctatum. Thorax coleopteris paulo angustior, latitudine antica haud brevior, basin versus leviter angustatus, lateribus rectis, basi apiceque truncatus, angulis anterioribus subrectis, posterioribus rotundatis, leviter transversim convexus, basi obsolete longitudinaliter biimpressus, dorso biplagiatim crebre, lateribus parce sparsim punctatus, interstitiis subtilissime disperse punctatis. Scutellum subtiliter punctulatum. Elytra thorace paulo longiora, fortiter profunde punctata, parce subtiliterque nigro-pubescentia. Abdomen crebre punctatum, tenuiter nigro-pubescens. Pedes graciliores, nigri, tarsis dilute rufo-piceis, anticis membranis dilatatis tibia duplo prope latioribus.

* 7. P. Javanus: Niger, grisen-pubescens, pedibus rufo-testaceis, thorace subquadrato, aequaliter dense punctato. - Long. 6 lin.

Habitat in Java, Dom. Westermann. 
Statura omnino P. latipedis, niger, subopacus, griseo-pubescens. Antennae capite thoraceque paulo breviores, tenues, articulo tertio secundo sesqui longiore, sequentibus sensim decrescentibus, rufo-testaceae. Palpi testacei. Caput thoracis fere latitudine, postıce creberrime rugoso-punctatum, fronte anterius laevigata, nitida, parce subtiliter punctulata, ante oculos utrinque vage fortiter punctata. Thorax coleopteris paulo angustior, latitudine apicis paululum longior, basin versus subangustatus, lateribus rectis, basi apiceque truncatus, angulis anterioribus acutis, posterioribus obtusis, subrotundatis, leviter transversim convexus, aequaliter dense minus profunde punctatus, basi lineola tenuissima longitudinali laevi subelevata. Scutellum punctulatum. Elytra thorace paulo longiora, dense punctata, interstitiis transversim subrugosis. Abdomen crebre punctatum, metallico-versicolor, segmento quinto sextoque margine, sexto inferiore etiam summa basi rufopiceis. Pedes rufo-testacei, coxis piceis, tarsis anticis membranis valde dilatatis tibia plus duplo latioribus.

* 8. P. Aegyptius: Nigro-piceus, dense griseo-pubescens, ano pedibusque rufis, thorace basin versus angustato, aequaliter dense subtililiterque punclato. - Long. 6 lin.

Habitat in Aegypto, Dom. Dr. Waltl.

Statura et summa affinitas praecedentis, at paulo magis depressus, nigro-piceus, parum nitidus, pube depressa fusco-grisea densius vestitus. Antennae capite thoraceque breviores, tenues, articulo tertio secundo sesqui longiore, sequentibus sensim decrescentibus, testaceae. Palpi testacei. Caput subtriangulare, thorace paulo angustius, supra postice utrinque late creberrime punctatum, ceterum laevigatum, nitidum, omnium subtilissime parce punctulatum, fronte inter oculos utrinque vage fortius punctata. Thorax apice coleopteris paulo latior, latitudine apice vix longior, basin versus distincte angustatus, subdepressus, aequaliter dense subtiliter punctatus. Scutellum punctulatum. Elytra thorace paulo longiora, subtilius crebre punctata. Abdomen crebrius punctatum, supra segmento singulo medio puncto maiore utrinque unico notato, subtus pluribus sparso, segmento quinto margine apicali, sexto toto rufo-piceis. Pectus piceum. Pedes rufi, coxis omnibus nigris, tarsis anticis membranis fortiter dilatatis tibia plus duplo latioribus.

* 9. P. Capensis: Niger, nigro-pubescens, pedibus rufis, abdomine aeneonitidulo, thorace subquadralo, aequaliter dense punclato. - Long. 6 lin.

Habitat in Africa australi, Dom. Drège.

Statura et summa affinitas praecedentium, niger, opacus, nigro-pubescens, abdomine aenen-versicolore. Antennae capite thoraceque paulo breviores, tenues, articulo tertio secundo paulo breviore, sequentibus decrescentibus, rufo-testaceae. Palpi rufo-testacei. Caput thorace vix angustius, supra postice utrinque triangulariter creberrime fortiter intricato-punctatum, anterius laevigatum, nitidum, omnium subtilissime parce punctulatum, ante oculos utrinque vage fortiter punctatum. Thorax apice coleopterorum latitudine, latitudine haud longior, basin versus vix angustatus, lateribus rectis, basi apiceque truncatus, angulis anterioribus acutiusculis, posterioribus rotundatis, supra leviter transversim convexus, aequaliter confertissime punctatus, dense nigro-pubescens. Scutellum punctulatum. Elytra thorace 
tertia parte longiora, confertissime punctata, dense nigro-pubescentia. Abdomen crebre punctatum, tenuius pubescens, fortiter aeneo-relucens, subtus segmentis ultimis duobus punctis maioribus sparsis, apice piceis. Pedes rufi, coxis piceis, tarsis anticis membranis fortiter dilatatis tibia plus duplo latioribus.

10. P. latipes: Niger, griseo-pubescens, pedibus flavis, abdomine fortius punctato, thorace subquadrato, crebrius vage punctato. - Long. $6 \frac{1}{2}$ lin.

Grav. Micr. 202. 1. - Latr Hist. nat. Crust. et Ins. IX. p. 336. - Laporte Etud. Ent. I. 122. 1. - Nordm. Symb. 154. 1.

Lathrobium latipes Grav. Mon. 129. 1.

Habitat in America septentrionali.

Niger, parum nitidus, griseo-pubescens. Antennae capite thoraceque paulo breviores, tenues, articulo tertio secundo sesqui prope longiore, sequentibus decrescentibus, flavo-testaceae, articulis omnibus inde a tertio apice fuscescentibus. Os dilute rufo-piceum, palpis pallidis. Caput thoracıs fere latitudine, dense subtilissime punctulatum, vage subtiliter punctatum, postice et in media fronte grossius et parum profunde punctatum, ante oculos utrinque impressum. Thorax coleopteris paulo angustior, latitudine parum longior, basin versus leviter angustatus, lateribus subrectis, basi apiceque truncatus, angulis anterioribns subrectis, posterioribus obtusis, subrotundatis, leviter convexus, minus dense fortiter punctatus, linea tenui longitudinali media calloque utrinque antico laevioribus, undique omnium subtilissime punctulatus. Scutellum punctulatum. Elytra thorace tertia parte longiora, creberrime fortiter profundeque punctata. Abdomen crebrius fortiusque punctatum, segmentis omnibus margine rufo-piceo. Pedes flavi, coxis piceo testaceis, tarsis anticis membranis fortiter dilatatis tibia plus duplo latioribus, suborbiculatis.

Abrlominis segmentum inferıus quintum maris apice leviter emarginatum, sextum integrum, praeter basin laevissimum.

* 11. P. flavipes: Niger, griseo-pubescens, pedibus flavis, abdomine sub. tilius punctato, thorace basin versus anguslato, vage punctato. L.ong. $5 \frac{1}{2}$ lin.

Habitat in Puerto-Rico, Dom. Moritz.

Proximus praecedenti, at minor, praesertim angustior, niger, parum nitidus, griseo-pubescens. Antennae capite thoraceque paulo breviores, tenues, articulo tertio secundo paulo longiore, sequentibus decrescentibus, flavo-testaceae, articulis singulis a tertio inde apice fuscis. Os rufo-testaceum, palpis flavis. Caput thorace parum angustius, confertissime subtilissimeque punctulatum, postice utrinque crebrius fortiter punctatum, antice utrinque punctis nonnullis sparsis fortibus impressum, margine antico rufotestaceo. Thorax apice coleopteris vix angustior, latitudine antica paulo longior, basin versus modice angustatus, lateribus subrectis, basi apiceque truncatus, angulis omnibus leviter rotundatis, supra parum convexus, subtilissimeque punctulatus, minus fortiter vage punctatus, linea angusta longitudinali subelevata calloque utrinque antico laevibus. Scutellum parce punctulatum. Elytra thorace tertia parte longiora, crebre profunde punctata, opaca. Abdomen crebre subtilius punciatum, subtus, praecipue versus api- 
cem, punctis maioribus sparsum, apice summo et infra segmentorum omnium smargine summo apicali rufo-piceis. Pedes flavi, coxis nigro-piceis, tarsis anticis membranis fortiter dilatatis tibia plus duplo latioribus, suborbiculatis.

Abdominis segmentum inferius sextum maris integrum, praeter basin laevigatum.

\section{P. albipes: Niger, griseo-pubescens, pedibus flavis, abdomine subli- liter punctulato, thorace basin versus angustato, crebrius punctato. - Long. 5 $\frac{1}{2}$ lin.}

Habitat in Mexico, Mus. Dom. Chevrolat.

Statura et summa affinitas praecedentis Niger, opacus, griseo-pubescens. Antennae capite thoraceque paulo breviores, tenues, articulo tertio secundo sesqui longiore, sequentibus sensim decrescentibus, testaceae, articulis singnlis a quarto inde fuscescentibus. Palpi flavi. Mandibulae rufopiceae. Caput thorace vix angustins, supra densius subtiliter punctulatum, posterius utrinque obsolete punctatum, fronte anterius nitidiore, infra oculos utrinque punctis nonnullis maiusculis sparsa, ad antennarum basin utrinque leviter impressa, margine apicali angusto saturate rufo-testaceo. Thorax apice coleopterorum latitudine, latitudine antica paulo longior; basin versus leviter angustatus, lateribus subrectis, basi apiceque truncatus, angulis anterioribus et posterioribus subrotundatis, parum convexus, crebrius minus subtiliter punctatus, basi, linea angusta media longitudinali et callo utrinque pone apicem sublaevibus, ante basin et pone apicem obsolete bi-impressus. Elytra thorace paulo longiora, dense fortiter profundeque punctata, dorso nigro-, lateribus et margine apicali griseo-pubescentia. Abdomen densius subtiliter punctatum, densius griseo-pubescens, segmentis ultimis margine tenui apicali pallide testaceo. Pedes pallide flavi, coxis nigris, tarsis anticis membranis fortiter dilatatis tibia plus duplo latioribus, suborbiculatis.

Abdominis segmentum inferius sextum $\mathrm{m}$ a $\mathrm{r}$ is apice leviter emarginatum.

Obs. Differt a praecedente thorace paulo longiore, crebrius punctato, fronte distinctius punctulata, elytris fortius, abdomine subtilius punctatis, abdominis segmento inferiore sexto maris apice emarginato.

13. P. sulphuripes: Niger, griseo-pubescens, pedibus flavis, thorace basin versus subangustato, crebre punctato, bilineatim impresso. Long. $5 \frac{2}{3}$ lin.

Habitat in valle Araguensi Columbiae, Dom. Moritz.

Statura omnino et summa similitudo P. flavipedis. Niger, opacus, griseo-pubescens. Antennarum articuli 2 primi (reliqui desunt) palpique flavi. Mandibulae piceae. Caput thoracis prope latitudine, supra parcius sparsim subtiliter punctatum, fronte antice utrinque pnnctis nonnullis fortibus impressa, margine antico summo piceo. Thorax apice coleopteris latitudine aequalis, latitudine summa parum longior, basin versus leviter angustatus, lateribus subrectis, basi apiceque truncatus, angulis anterioribus subrectis, posterioribus obtusis, subrotundatis, parum convexus, sat crebre fortius punctatus, interstitiis, margine postico, callisque duobus minutis prope apicem laevibus; dorso per totam longitudinem lineis duabus parallelis leniter impressis, postice latioribus bi-canaliculatus. Scutellum punctulatum. Elytra thorace paulo 
longiora, dense profundeque punctata, apice pube densiore longioreque ciliata. Abdomen crebre minus fortiter punctatum, apice summo segmentorumque penultimorum margine apicali ferrugineo. Pedes pallide flavi, coxis nigris, tarsis anticis membranis dilatatis tibia plus duplo latioribus, suborbiculatis.

Abdominis segmentum inferius quintum maris apice subemarginatum, sextum longitudinaliter impressum, apice incisum.

O bs. Differt a praecedentibus duobus corpore paulo crassiore, thorace fortius punctato, distinctius longitudinaliter bi - impresso et abdominis segmento inferiore sexto maris impresso, apice profundius inciso.

* 14. P. fulvipes: Niger, griseo-pubescens, pedilus testaceis, thorace crebrius subliliter punctalo, basi obsolete bifoveolato. - Long. $4 \frac{1}{2}$ lin.

Habitat in Columbia, Dom. Moritz.

Praecedentibus simillimus, at paulo minor, praecipue brevior, niger, opacus, griseo-pubescens. Antennae capite thoraceque breviores, tenues, articulo tertıo sccundo parum longiore, $\mathbf{3}$ et $\mathbf{4}$ aequalibus, sequentibus derrescentibus, testaceae, articulis a tertio inde singulis apice fuscis. Palpi testacei. Mandibulae rufo-piceae. Caput thorace parum-ångustius, fronte laevı. pone oculos et ante oculos utrinque et apice punctis nonnullis maioribus sparsa, ad antennarum basin utrinque leviter impressa, margine apicali saturate rufo-testaceo, longius griseo-pilosum. Thorax coleopterorum prope latitudine, latitudine vix longior, basin versus subangustatus, lateribus subrectis, angulis anterioribus subrectis, posterioribus rotundatis, parum convexus, aequaliter minus dense subtiliter punctatus, basi foveolis duabus obsoletiusculis impressus. Scutellum crebre punctatum. Elytra thorace tertia parte longiora, creberrime profundius punctata, secundum suturam leviter impressa, longius pubescentia. Abdomen crebre minus fortiter punctatum, longius pubescens, segmentis ultimis duobus margine apicali piceotestaceo. Pedes testacei, coxis piceis, tarsis anticis membranis dilatatis tibia duplo latioribus, suborbiculatis.

Obs. P. Cayennensi Laport. Etud. Ent. I. 122. 1.: "Simillimus P. latipedi, statura autem multo minore, capite minore, thorace obsolete punctato, sublaevi, corpore minus pubescente, long. 4 lin, e Cayenna", forte a specie modo descripta haud distinctus, hac descriptione autem nequaquam cognoscendus. Lathrobium maius Brull. D' Orbign. It. Am. mer. Ins. t. 5. f. 9. ad hoc genus pertinere et huic speciei similis videtur, icon autem minus exacta, ut ad quamnam tot tantopere affinium specierum adhibenda sit discernatur.

15. P. suffusus: Niger, griseo-pubescens, palpis pedibusque fluvis, fronte elytrisque obscure castaneis, thorace crebre sublilius punctato. - Long. 5 lin.

Hábitat in Venezuela Guyanensi, Dom. Moritz.

Habitu omnino praecedentium, P. latipede paulo minor, niger, opacus, griseo-pubescens, capite thoraceque subnitidis, glabris. Antennae capitis thoracisque prope longitudine, tenues, articulo tertio secundo paulo longiore, sequentibus sensim decrescentibus, flavae, articulis singulis a quarto inde apice summo fuscis. Palpi flavi. Caput thorace parum latius, supra confertissime subtilissimeque punctulatum, posterins grossius parum profunde 
punctatum, fronte ante oculos utrinque punctis nonnullis sat fortibus impressa, castaneum, vertice nigricante, subtus nigrum, nitidum, ore testaceo. Thorax coleopterorum prope latitudine, latitudine haud longior, lateribus rectis, basin versus vix angustatus, basi apiceque truncatus, angulis anterioribus subrotundatis, posterioribus late rotundatis, leviter transversim convexus, confertissimé subtilissimeque alutacens, crebre minus profunde punctatus, margine postico, linea media longitudinali, callaque utrinque prope apicem parum distincto laevioribus, basi obsolete bifoveolatus. Scutellum sublaeve, opacum. Elytra thorace paulo longiora, confertissime profunde punctata, longius pubescentia, obscure castanea, opaca, basi nigricantia. Abdomen supra creberrime punctatum, subtus parcius profundiusque longius pubescens, segmentis singulis apice castaneo-marginatis.. Pedes flavi, coxis nigris.

Sexus differentia latet.

* 16. P. palmatus: Niger, nilidus, glaber, pedibus flavis, geniculis nigricantibus, abdomine obsolete punclato, thorace basin versus angusiato, crebre punctalo. - Long. $5 \frac{1}{2}$ lin.

Nordm. Symb. 155. 2.

Habitat in Parà interiore, Sieber.

Niger, nitidus, glaber. Antennae capite thoraceque paulo longiores, tenues, articulo tertio secundo sesqui longiore, sequentibus sensim decrescentibus, flavo-testaceae. Mandibulae piceae. Caput thoracis fere latitudine, supra postice et in media fronte transversim fortiter punctatum, apice punctorum serie transversali impressum, interstitiis laevissimis. Thorax coleopteris vix angustior, latitudine anteriore haud brevior, basin versus angustatus, lateribus anterius leviter, posterius fortius rotundatus, basi apıceque truncatus, angulis anterioribus subrectis, posterioribus obtusis, subdepressus, crebre fortiterque punctatus, linea media longitudinali parum distincta calloque utrinque anteriore laevihus. Scutellum laeve. Elytra thorace sesqui longiora, fortiter profundeque punctata. Abdomen coleopteris angustius, parcius obsolete punctatum. Pedes graciliores, flavi, coxis nigris, geniculis piceis, tarsis anticis membranis fortiter dilatatis tibia plus duplo latioribus, subovatis.

Mas latet.

* 17. P. terminatus: Rufo-caslaneus, nilidus, capile, thorace, elytrorum abdominisque apice pedibusque posterioribus nigris, his basi pallidis, thorace basin versus angustato, vage punctalo. - Long. $5 \frac{1}{2}$ lin.

Habitat in Columbia, Dom. Moritz.

Antennae capite thoraceque paulo breviores, tenues, articulo tertio secundo paulo longiore, sequentibus decrescentibus, rufo-testaceae, articulis singulis a secundo inde merlio fuscescentibus. Palpi rufo-testacei. Mandibulae rufo-castaneae. Caput thoracis prope latitudine, nigerrimum, glaberrimum, pernitidum, supra disperse subtiliter punctulatum, postice et ante oculos utrinque fortiter vage punctatum. Thorax coleopteris paulo angustior, latitudine haud brevior, basin versus angustatus, lateribus leviter rotumdatis, basi apiceque truncatus, angulis anterioribus subrectis, posterioribus 
late rotundatis, subdepressus, vage sat profunde punctatus, linea media longitudinali subelevata calloque utrinque antico laevibus, glaberrimis, niger, pernitidus. Scutellum basi punctatum, castaneum. Elytra thorace sesqui longıra, minus crebre sat profunde fortiterque punctata, rufo-castanea, apice sinuatim nigra, nitida, parce cinereo-pubescentia. Abdomen subtilius minus crebre punctatum, pube parca longiore depressa grisea vestitum, dilute rufo-castaneum, segmento quinto nigro, basi rufo-castaneo, sexto toto migro. Pectus castaneum. Pedes antici testacel, posteriores nigri, femoribus basi ultra medium pallide testaceis.

M a s latet.

18. P. brunneus: Niger, nitidus, pubescens, thorace, elylris pectoreque brunneo-rufis, antennis, palpis pedibusque flavis, thorace basin versus angustato, disperse punctato. - Long. $3 \frac{2}{3}$ lin.

Laporte Etud. Ent. I. 122. 2.

Habitat in valle Araguensi Columbiae, Dom. Moritz.

Praecedentibus minor. Antennae capitis thoracisque prope longitudine, tenues, articulo tertio secundo paulo longiore, sequentibus sensim decrescentibus, flavo-testaceae. Palpi flavo-testacei. Os rufo-testaceum. Caput thoracis latitudine, nigrum, nitidum, longius parce pılosum, supra leviter convexum, punctis parcis dispersis fortioribus posterius et inter oculos impressum, interstitiis laevissimis. Thorax vix coleopterorum latitudine, latitudine antica paulo longior, basin versus angustatus, lateribus leviter rotundatis, basi apiceque truncatus, angulis anterioribus subrectis, posterioribus late rotundatis, convexus, disperse fortius profundiusque punctatus, parce pilosus, brunneo-rufus, nitidus. Scutellum brunneo-rufum, laeve. Elytra thorace sesqui longiora, crebre fortiter profundeque punctata, parce pilosa, brunneo-rufa, nitidula. Abdomen parcius minus subtiliter punctatum, longius pubescens, nigrum, nitidım, segmentis singulis margine apicali tenui rufo-piceo. Peotus brunneo-rufum, coxis concoloribus, pedibus flavotestaceis, tarsis anticis membranis fortiter dilatatis tibia plus duplo longioribus, suborbiculatis.

Mas latet,

* 19. P. crassicollis: Niger, nitidus, antennis pedibusque favis, elytris rufo-castaneis, rude punctatis, thorace lato, biseriatim punctato. Long. 4 lin.

Habitat in valle Araguensi Columbiae, Dom. Moritz.

Habitu fere P. brevicollis at sesqui maior, niger, capite thoraceque pernitidis. Antennae capite sesqui Iongiores, tenues, articulo primo magis elongato, secundo sequentibus paulo longiore et crassiore, $3-5$ aequalibus, sequentibus decrescentibus, flavae. Palpi flavi. Mandibulae rufo-piceae. Caput thorace multo angustius, laevissimum, fronte punctis paucis sat magnis impressa. Thorax coleopterorum latitudine, latitudine paulo brevior, lateribus subrectis, basi apiceque truncatis, angulis anterioribus subrectis, posteriorıbus fortiter rotundatis, convexus, laevissimus, dorso utrinque serie minus regulari, circiter 6 -punctata, lateribus utrinque punctis tribus quatuorve singulıs sat profundis impressus. Seutellum parum-punctatum. Ely- 
tra thorace paulo longiora, dense punctis magnis profundis impressa, parce subtiliter pubescentia, castaneo - rufa, minus nitida. Abdomen crebrius punctatum, subtus parcius longiusque pubescens, supra pube densa depressa grisea micante vestitum, segmentis ultimis duobus margine apicali pallido. Pedes flavi, coxis piceis, tarsis anticis membranis sat dilatatis tibia duplo latioribus, suborbiculatis.

Sexus differentia latet.

*20. P. brevicollis: Nigro-piceus, griseo-pubescens, pedibus rufis, thorace lato, transverso, aequaliter crebre punctato. - Long. $3 \frac{1}{6}$ lin.

Habitat in Aegypto, Dom. Prof. Ehrenberg.

Reliquis plerisque minor et praecipue brevior, nigro-piceus, parum nitidus, griseo-pubescens. Antennae capite parum longiores, minus tenues, articulo secundo tertioque subaequalibus, sequentibus subobconicis, sensim brevioribus, ultimis leviter transversis, ultimo apice abrupte acuminato, rufo-testaceae. Palpi rufo-testacei. Caput thorace angustius, crebre fortius punctatum, fronte ante medium laeviore. Thorax coleoptera latitudine fere excedens, latitudine dimidio fere brevior, basin versus haud angustatus, lateribus subrectis, basi leviter rotundatus, apice truncatus, angulis omnibus rotundatis, leviter transversim convexus, aequaliter crebreque punctatus, basi medio obsolete bi-impressus. Scutellum subtiliter punctulatum. Elytra thorace sesqui longiora, crebre punctata, margine summo apicali rufo. Abdomen breviusculum, crebre punctatum, apice segmentorumque singulorum margine apicali rufo-piceis. Pedes rufi, coxis omnibus piceis, tarsis anticis tibia sesqui latioribus, suborbiculatis.

Sexus differentia latet.

\section{Taenodema Laporte.}

Lap. Etud. Ent. I. p. 120.

Gymnurus Nordm. Symb. p. 158. t. 2. $f .7$.

Palpi maxillares articulo quarto securiformi. Abdomen marginatum.

Tarsi anlici articulis 4 primis dilatatis coniunctis patellam formantibus.

Corpus mediae magnitudinis, elongatım, lineare, alatum. Caput thorace minus, subdepressum, subtriangulare, basi truncatum, collo quasi tenuiore brevi thoraci immissum, exsertum, porrectum, oculis ad angulos capitis posteriores sitis, mediocribus, rotundatis, prominulis. Labrum latum, brevissimum, integrum. Mandibulae falcatae, acutae, medio dente longiore bicuspi armatae. Maxillae (t. IV. f. 35. b.) malis coriaceis, interiore interne, exteriore apice barhatis. Palpi maxillares leviter elongati, articulo primo minimo, secundo elongato, subcylindrico, tertio hoc dimidio breviore, obconico, quarto triangulariter introrsum producto, securiformi. Labium (t. IV. f. 3j. a.) mento transverso, ligula brevi, membranacea, biloba, lobis rotundatis, apice pilorum fasciculo instructis, paraglossis acuminatis, membranaceis, ligulam longe superantibus. Palpi labiales articulo primo minuto, secundo leviter elongato, tertio parvo, subacuminato. Antennae filiformes, articulo ultimo ovato. Thorax coleopterorum prope latitudine, depressus, quadran- 
gulus, angulis anterioribus subrectis, posterioribus rotundatis. Scutellum triangulare. Elytra truncata. Abdomen lineare, coleopteris angustius, teretiusculum, marginatum, stylis analibus haud exsertis. Pedes breviores, antici incrassati, femoribus tibiisque intus sinuatis, tarsis articulis 4 primis fortiter dilatatis, transversis, subtus spongioso-tomentosis, posteriores graciliores, tibiis posticis compressis, apice oblique truncatis; tarsis articulo primo leviter elongato, sequentibus duobus coniunctis aequali, quarto parvo, lobato.

\section{O b s e r v a t i o n e s.}

1. Corpus punctulatum, pubescens, habitu generi praecedenti assimile, distinctum antennis pedibusque minus gracilibus, abdomine angustiore, tarsis anticis subtus tomentosis, palpis maxillaribus articulo securiformi terminatis.

2. Sexus differentia latet.

3. De victu nihil constat. Species nonnisi ex America aequinoctiali cognitae.

* 1. T. cyanescens: Nigra, nilida, capile thoraceque laevibus, cyaneis, nitidis, elylris punctatis, abdomine apice obscure rufo. - Long. 6 lin.

Gymnurus cyanescens Nordn. Symb. 159. 1. t. 2. f. 7.

Habitat in Parà Brasiliae, Sieber.

Nigra, subnitida, capite thoraceque supra cyaneis, nitidis, elytris nigrosubcyanescentibus. Antennae vix capitis thoracisque longitudine, articulo primo tertıo parum maiore, hoc secundo sesqui longiore, sequentibus sensim paulo brevioribus nec crassioribus, leviter obconicis, penultimo crassitie haud longiore, ultimo ovato. Caput et thorax. depressa, laevissima, glaberrima, polita, punctis raris hinc inde impressa. Caput thorace angustius, latitudine brevius. Thorax coleopterorum latitudine, latitudine paulo brevior, basin versus haud angustatus, basi leviter rotundatus, apice truncatus, angulis anterioribus levius, posterioribus fortius rotundatis. Scutellum obsolete subtilter punctatum. Elytra thorace paulo longiora, crebrius punctata, parce nigro-pubescentia. Abdomen coleopteris dimidio angustius, punctulatum, nigro-pubescens, segmento sexto apice rufo-castaneo. Pedes breviusculi, crassiusculi. Alae fuscae.

* 2. T. ve stita: Nigra, nitida, plagiatim cinereo-tomentosa, elytris cyaneis, pedibus piceis. - Long. 6 lin.

Gymnurusivestitus Nordm. Symb. 160. 2.

Habitat in Parà Brasiliae, Sieber.

T. cyanescente gracilior, nigra, nitida. Antennae nigro-piceae, articulo primo tertio haud longiore, licet paulo crassiore, subtus testaceo, secundo tertio plus duplo breviore, $3-6$ elongatis, teretibus sensim paululum brevioribus (reliqui desunt). Caput thoracis prope latitudine, latitudine postica haud brevior, fronte antice depressa et urrinque subimpressa, creberrime punctatum, cinereo-pubescens, macula frontali media subelevata laevissima, glabra. Thorax coleopteris parum angustior, latitudine tertia parte longior, basin versus leviter angustatus, depressus, basi truncatus, apice subbisinuatus, angulis anterioribus subrectis, posterioribus rotundatis, creberrime punctatus, postice carinatus, cinereo-tomentosus, margine basali, lateribus usque ad medium adscendente, parce subtiliterque punctato; calloque utrinque ad 
apicem sito laevissimo glabris, lateribus parce nigro-pilosellis. Scutellum cinereo - tomentosum. Elytra thoracis longitudine, crebre punctata, nigrocyanea, nitida, dense cinereo-tomentosa, margine basali angustiore apicalique latiore laevigatis, glaberrimis. Abdomen elongatum, coleopteris dimidio angustius, segmentis singulis basi punctulatis, cinereo-tomentosıs, apice laevigatis, glabris, lateribus nigro-pilosis, segmento septimo prominulo, bicuspi. Pedes cinereo-pubescentes, picei, posteriores elongati, femoribus dilutiorıbus.

\section{Species mihi invisa e.}

3. T. semicyanea: Ruguloso-punctala, nigra, capite, thorace elytrisque cyaneis. - Long. 6 lin.

Laporte Etud. Ent. I. 121.1.

Paederus semicyaneus Perty Delect. an. art. p. 33. t. 7. f. 8.

Habitat in Brasilia.

Caput, thorax et elytra ruguloso-punctata. Abdomen subcylindricum. Antennae capitis fere et thoracis longitudne. Pedes nigri, tarsorum articulo quarto bifido. (Perty).

O bs. Secundum iconem citatam caput thoracis longitudine, thorax latitudine multo longior, basin versus vix angustatus, elytra thoracis longitudine. Secundum Laporte abdominis segmenta apice testaceo-marginata.

4. T. a enea: Nigra, capite, thorace elytrisque aeneis, abdomine segmentis duobus margine ultimogue toto rubris.

Staph. a eneus Oliv. Ent. III. 42. 10. 6. t. 2. f. 11.

Habitat Surinami.

Antennae nigrae, longitudine thoracis. Caput, thorax elytraque aenea. Abdomen nigrum, segmento quarto quinto margine ultimoque toto rubris. Pedes nigri. (Oliv.)

Obs. Forte huius generis. Secundum iconem abdominis segmentum tertium et quartum apice rubra, quintum totum nigrum.

\section{Palaminus $E$ r.}

Palpi maxillares articulo quarto securiformi. Abdomen immarginatum.

Tarsi anlici articulis 4 primis coniunctis patellam formantibus.

Corpus minutum, elongatum, lineare, alatum. Caput thoracis fere latitudine, subtriangulare, basi truncatum, collo quasi angusto perbrevi thoraoi immissum, exsertum, porrectum, oculis sat magnis, rotundatis, prominulis. Labrum transversum, breve, medio sinuatum, sinu utrinque denticulo terminato. Mandibulae falcatae, acutae, medio dente valido simpline aonto armatae. Maxillae (t. IV. f. 36. b.) malis membranaceis, interiore intus, exteriore apice introrsum vergente barbatis. Palpi maxillares modice elongati, articulo primo brevi, minuto, secundo leviter elongato, tertio hoc paulo breviore, obconico, quarto triangulariter introrsum producto, securiformi. Labium (t. IV. f. 36. a.) mento transverso, apice profundius emarginato, ligula membranea, sinu lato biloba, lobis interne oiliatis, paraglossis ligula paulo brevioribus. Palpi labiales articulis duobus primis subaequalibus. 
tertio minuto acuminato. Antennae breviusculae, tenues, filiformes, articulis duobus primis reliquis paulo crassioribus, ultimo saepius praecedentibus maiore, obconico, truncato, apice abrupte acuminato. Thorax subcordatus, latitudine antica brevior, antice truncatus. Coleoptera apice coniunctim emarginata. Abdomen coleopteris angustius, elongatum, lineare, immarginatum, subdepressum, stylis analibus exsertis, acuminatis. Pedes parum elongati, antici subincrassati, tibiis apicem versus triangulariter sensim modice dilatatis, tarsis articulis 4 primis dilatatis, 3 primis triangularibus, transversis, subtus lobatis, quarto minuto, aegre distinguendo, quinto sat tenui, posteriores graciles, tibiis intermediis simplicibus, posticis ante apicem dilatatis, dein emarginatis, unde ante apicem externe dente triangulari arnıatae videntur, tarsis articulo primo modice elongato, quarto brevi, lobato.

\section{O b s e r a t i o n e s.}

1. Corpus punctatum, pilosellum, habitu omnino generum praecedentium, at minutum, et abdomine immarginato ab illis, depressiusculo a sequentibus distinctum. Capitis figura et oculorum situs ut in praecedentibus duobus generibus. Abdomen segmentorum 4 anteriorum sculptura e lineis impressis transversim reticulatis imbricatim texta insigne.

2. Sexus differentia abdominis segmenti inferioris sexti structura cognoscenda.

3. De victu nihil compertum. Species omnes ex America meridionali allatae.

* 1. P. pilosus: Niger, griseo-pilosus, antennis pedibusque albidis, thorace lateribus leviter rotundato, basin versus angustato, elytris thorace plus sesqui longioribus. - Long. 3 lin.

Habitat in Columbia, Dom. Moritz.

P. variabili duplo maior, niger, subnitidus, antennis, palpis pedibusque albido-flavescentibus. Antennae elongatae, capite thoraceque longiores, tenues, articulo ultimo reliquis aequali. Caput thoracis latitudine, latitudine baseos haud brevius, subtriangulare, fronte depressiuscula, parce obsoleteque inaequaliter punctatum, longius griseo-pilosum. Thorax coleopteris dimidio angustior, latitudine antica vix brevior, basin versus leviter angustatus, lateribus subrotundatis, basi apiceque truncatus. angulis anterioribus rectis, posterioribus rotundatis, leviter convexus, parcius inaequaliter et fere obsoletius punctatus, griseo-pilosus. Elytra thorace plus sesqui longiora, obsoletius punctata, pilis longis depressis griseis vestita. Abdomen segmentis 4 primis fortius dense imbricato-granulatis, quinto parce obsoletius granulato, sexto laevi, pilis parcis depressis griseis vestitum.

Abdominis segmentum inferius sextum maris apice emarginatum. Femin a latet.

- 2. P. piceus: Piceus, parcius albido-pubescens, antennis pedibusque albidis, thorace basin versus angustato, elytris thorace sesqui longioribus. - Long. 2 lin.

Habitat in Columbia, Dom. Moritz.

Piceus, nitidus, pube longiore minus depressa albida parcius vestitus, antennis, palpis pedibusque albidis. Antennae capitis thoracisque Jongitudine, tenues, articulo ultimo reliquis aequali. Caput thorace paulo latius, latitudine baseos paulo brevius, supra modice convexum, sat dense fortiter profundeque punctatum. Thorax coleopteris plus dimidio angustior, latitudine 
baseos parum brevior, basin versus fortius angustatus, lateribus rectis, basi apicèque truncatus, angulis anterioribus acutiusculis, posterioribus obtusis, parum convexus, crebrius sat fortiter profundeque punctatus, linea media longitudinali subelevata calloque utrinque pone basin subelevato laevibus. Elytra thorace sesqui longiora, crebre fortiter profundeque punctata, margine apicali laevi, dilutiore. Abdomen segmentis 4 primis dense fortiter imbricato-granulatis, quinto basi obsolete tuberculato, apice sextoque toto laevibus.

Obs. Specimen singulum, abdominis segmento inferiore sexto integro, subrotundato, sexu ambiguum. A praecedente statura multo minore, pilis brevioribus, punctis crebrioribus, profundis, a sequente colore et antennarum articulo ultimo haud crassiore, ab utroque thorace angustiore, lateribus haud rotundato et elytris brevioribus distinctus.

3. P. variabilis: Testaceus, parcius pubescens, thorace lateribus rotundato, basin versus angustalo, elytris thorace plus sesqui longioribus. Long. 2 lin.

T. 1. f. 8.

Habitat in Columbia et in Americae meridionalis ins. Puerto-Rico et St. Thomae, Dom. Moritz.

Testaceus, nitidus, albido-pubescens pilosusque, antennis pedibusque pallide flavis. Antennae capite thoraceque paulo breviores, tenues, articulo ultimo abrupte maiore. Caput thorace parum latius, transversum, antrorsum angustatum, basi truncatum, supra leviter convexum, grosse punctatum, parce breviterque pilosellum. Thorax coleopteris paulo angustior, latitudine antica paulo brevior, basin versus angustatus, lateribus rotundatus, basi truncatus, apice late leviter emarginatus, angulis anterioribus acutiusculis, posterioribus obtusis, parum convexus, parcius grosse punctatus, tenuiter pubescens, lateribus parce nigro-pilosellus. Scutellum laeve. Elytra thorace duplo prope longiora, minus dense fortiter punctata, pube depressa parcius vestita, apice summo pallidiore laevi. Abdomen coleopteris angustius, subcylindricum, segmentis quatuor anterioribus confertim grosse imbricato-granulatis, ultimis duobus laevibus.

Abdominis segmentum inferius sextum maris apice subemarginatum; feminae acuminatum, interstitio inter acumen et latera membranaceo.

Variat: 1, Coleopteris macula media communi fusca notatis.

2, Coleopteris plaga lata communi suturali apice abbreviata nigra.

3, Coleopteris plaga lata suturali aliaque laterali, ante apicem confluentibus, fuscis.

4, Coleopteris cruce dorsali vittaque laterali nigris, abdomine nigro.

5, Duplo vel triplo minor (long. $1 \frac{x}{2}$ lin.), pallide flavo-testaceus, immaculatus, antennis pedibusque albidis.

* P. testaceus: Testaceus, subtilius griseo-pubescens, thorace lateribus rotundato, elytris thorace duplo longioribus. - Long. $1 \frac{2}{3}$ lin.

Habitat in Pensylvania. Specimen a Dom. Zimmermann lectum dedit Dom. Schiippel. 
Rufescenti-testaceus, nitidus, parcius subtiliusque griseo-pubescens, abdomine saturatiore, longius pubescente, antennis pedibusque dilutioribus. Antennae capitis thoracisque prope longitudine, apicem versus sensim paululum crassiores, ultimo reliquis paulo maiore. Caput thoracis latitudine, basi truncatum, apice rotundatum, modice convexum, crebrius fortiusque punctatum. Thorax coleopteris paulo angustior, latitudine dimidio brevior, lateribus rotundatus, basin versus vix magis quam apicem versus angustatus, basi truncatus, apice leviter emarginatus, angulis anterioribus subrectis, posterioribus obtusis, convexus, disco crebrius profundiusque punctatus, limbo sublaevi. Elytra thorace duplo longiora, sat crebre profundeque punctata, margine apicali pallidiore laevi. Abdomen segmentis 4 primis dense grosseque imbricato-granulatis, quinto sextoque laevibus.

Abdominis segmentum inferius sextum maris apice profunde incisum. Femin a latet.

\section{Dedichirus $E r$.}

Palpi maxillares articulo quarto securiformi. Abdomen immarginatum.

Tarsi antici articulis 4 primis singulis dilatatis, incrassatis.

Corpus elongatum, teretiusculum, apterum. Caput thoracis fere latitudine, rotundatum, basi fortiter constrictum, collo quasi angustulo thoraci immissum, exsertum, porrectum, oculis mediocribus, rotundatis, leviter prominulis. Labrum brevissimum, medıo sinuatum, margine subtiliter denticulato. Mandibulae falcatae, acutae, medio dente simplice armatae. Maxillae (t. IV. f. 37. b.) malis tenuiter corneis, interiore minuta interne, exteriore latiore extus rotundata, apice introrsum verso barbatis. Palpi maxillares elongati, articulo primo minuto, secundo valde elongato, apicem versus parum incrassato, tertio hoc duplo prope breviore, obconico, quarto triangulariter introrsum producto, fortiter securiformi. Labium (t. IV. f. 37. a.) mento transverso, ligula biloba, lobis divaricatis, subrotundatis, membranea, paraglossis acuminatis, membraneis, pubescentibus, ligulam haud superantibus, una cum ligulae lobis palporum basi eorumque articulo primo occultis, difficulter observandis. Palpi labiales breviores, articulis duobus primis crassiusculis, primo breviore, tertio parvo, tenuiore. Antennae filiformes, tenuiores, articulo primo parum elongato, ultimo apice abrupte acuminato. Thorax oblongo-cordatus, apice truncatus, convexus. Scutellum elongatum, triangulare. Coleoptera thorace breviora, apice coniunctim emarginata. Abdomen elongatum, apicem versus sensim subincrassatum, immarginatum, subcylindricum, segmento septımo prominulo, bicorniculato, stylis analıbus nullis. Pedes leviter elongati, graciles, tibiis posticis apice compressis, subdilatatis, oblique emarginatis, tarsis anticis articulis quatuor primis in utroque sexu fortiter dilatatis, singulis subquadratis, tumidis, subtus membrana senicirculari lobatis, quinto minuto, posterioribus articulo primo elongato, quarto brevi, lobato.

\section{O b s e r vation e s,}

1. Genus insigne, habitu omnino Paederi, abdomine segmento septimo spinis duabus porrectis armato singulare, capitis orbiculati thoracisque figura, abdomine apicem versus incrassato, pedibus magis elongatis, tarsis anticis articulis quatuor primis singulis fortiter dilatatis et incrassatis a praecedentibus satis discedens. 
2. Mas abdominis segmento inferiore sexto apice emarginato, sinu membrana repleto distinctus.

3. De victu nihil constat.

-1. O. Paederinus: Rufo-teslaceus, nilidus, capile, elytris anoque nigris. - Long. 3 lin.

T. I. $f .9$.

Habitat in Sicilia, Dahl.

Paedero littorali duplo minor et gracilior, apterus, nitidus, rufus, capite, elytris abdominisque segmentis ultimis duobus nigris, undique parcius longiusque pilosus. Antennae capite duplo longiores, articulo tertio secundo paulo longiore, $3-10$ sensim paulo brevioribus, subobconicis, ultimo oblongo-ovato, apice abrupte acuminato, breviter pilosellae, testaceae. Palpi testacei. Os rufo-piceum. Caput thoracis latitudine, orbiculatum, vertice et inter oculos transversim fortiter parcius punctatum. Thorax apice coleopterorum fere latitudine, latitudine antica paulo longior, basin versus angustatus, basi apiceque truncatus, angulis anterioribus rotundatis, sat convexus, punctis magnis profundis, lateribus dispersis, dorso irregulariter biserıatis, impressus. 'Scutellum laeve, piceum. Elytra brevia, apice oblique truncata, fortiter profunideque punctata, parce nigro-pilosa. Abdomen cylindricum, segmento singulo punctorum profundorum seriebus tribus transversalibus cincto, griseo-pilosum, segmento septimo prominulo, corniculis duobus acuminatis, leviter divergentibus armato. Pedes testacei.

\section{Procirrus Lair.}

Latr. Regn. An. IV. p. 436. - Laporte Etud. Ent. I. p. 123.

Palpi maxillares articulo quarto elongato-fusiformi, acuminato. Abdomen immarginatum.

Tarsi antici articulis 4 primis singulis dilatatis, incrassatis.

Corpus minoris magnitudinis, valde elongatum, teres, alatum. Caput rotundatum, basi attenuatum, collo quasi tenui thoraci affixum, exsertum, porrectum, oculis mediocribus, rotundatis, leviter prominulis. Labrum transversum, breve, medio sinuatum. Mandibulae falcatae, acutae, medio dente magno bicuspi armatae. Maxillae (t. IV. f. 38. b.) malis membraneis, interiore interne, exteriore brevi apice barbatis. Palpi maxillares elongati, articulo primo minore obconico, reliquis tribus valde elongatis, longitudine aequalibus, ultimo fusiformi, apice acuminato. Labium (t. IV. f. 38. a.) mento transverso, ligula brevi, apice subsinuata, membranea, paraglossis acuminatis, membraneis, pubescentibus, ciliatis, ligulam longe superantibus. Palpi labiales breviores, articulis duobus primis cylindricis, secundo primo paulo longiore, tertio minuto, tenuiore. Antennae filiformes, tenues, articulis duobus primis reliquis paulo crassioribus, ultimo cylndrico, apice obtuse acuminato. Thorax elongatus, subcylindricus. Scutellum rotundatum. Elytra truncata. Abdomen elongatum, lineare, immarginatum, segmento sexto conico-acuminato, stylis analibus haud exsertis. Pedes elongati, antici leviter incrassati, tarsis articulis 4 primis in utroque sexu fortiter dilatatis, singulis subquadratis, tumidis, posteriores graciles, tibiis posticis apice com- 
pressis, oblique emarginatis, tarsis posterioribus articulo primo valde elongato, quarto minuto, lobato.

$$
\text { o b s e r a t ion e s. }
$$

1. Habitus fere Paederi, at multo gracilior, a reliquis huius tribus generibus palporum maxillarium articulo ultimo acuminato valde distinctus, capitis basin versus attenuati figura, oculis ante eius medium sitis, thorace valde elongato habitu ab illis divergens, tarsorum anticorum structura cum genere praecedente congruens.

2. Mas abdominis segmento inferiore sexto apice summo emarginato distinctus.

3. Victus latet.

* 1. P. Lefebvrei: Fusco-ferrugineus, opacus, confertim punctatus, subtiliter fulvo-pubescens. - Long. 4 lin.

Latr. Regn. An. IV. p. 436. not. - Guér. Iconogr. Ins. t. 9. f. 6. - Laporte Etud. Ent. I. p. 124.

Habitat in Sicilia.

Totus fusco-ferrugineus, abdominis apice, antennis, palpis pedibusque dilutioribus, ferrugineo-testaceis, confertim punctatus, opacus, subtiliter fulvo-pubescens. Antennae capite sesqui longiores, articulo primo modice elongato, cylindrico secundoque hoc dimidio breviore, elongato, obconico crassioribus, sequentibus tenuibus, tertio secundo paulo breviore, 3 et 4 aequalibus, 4-10 sensim paulo brevioribus, penultimis paulo crassioribus, leviter obconicis, ultimo praecedentibus ambobus paulo longiore, cylindrico, apice obtuse acuminato. Caput thoracis latitudine, supra modice convexum, basi subcarinatum. Thorax coleopteris angustior, latitudine duplo longır, basin versus sensim leviterque angustatus, basi apiceque truncatus, angulis anterioribus fortiter rotundatis, dorso depressiusculus. Coleoptera thoraci longitudine aequalia. 


\section{Tribus sexta. \\ s $\mathbf{e}$ n i n i.}

Stigmata prothoracica occulta, spatio pone coxas anticas corneo.

Coxae posticae conicae.

Antennae in fronte insertae

L abrum corneum, apice rotundatum, integerrimum Dianoo, Steno;

denticulatum Euaestheto.

Mandibulae longae, tenues, falcatae, acutae, ante apicem fortiter unidentatae.

Maxillae malis brevibus, interiore interne, exteriore apice membranaceis barbatisque.

Palpi maxillares elongati, graciles, articulo primo elongato, secundo tertioque singulis paulo longioribus, hoc apice magis minusve leviter incrassato, quarto minimo, vix nisi oculo fortissime armato conspiciendo.

Mentum corneum.

Ligul a membranea.

Paraglossae membraneae, ligulae connatae eamque paulo superantes

Dianoo, Euaetheto:

liberae, ovatae Steno.

Palpi labiales breves articulo secundo incrassato, tertio subulato.

Antennae breviores, tenues, 11-articulatae, articulis ultimis tribus magis minusve incrassatis clavatae subclavataeve, in fronte

inter oculos insertae Dianoo, Steno;

ad capitis marginem anteriorem insertae Euaesthe to.

C a put maiusculum, porrectum, collo quasi crasso thoraci immissum, oculis magnis, magis minusve prominentibus.

Thorax immarginatus, saepius cylindricus, basi apiceque truncatus, subtus integumento corneo integro.

Scutellum saepius vix distinctum.

Elytra pectore haud longiora.

Abdomen segmentis sex distinctis, septimo saepius prominulo. 
Pedes graciles, coxis anticis parvis, subconicis, leviter prominentibus, intermediis tenui spatio distantibus, posticis conicis, trochanteribus posticis fulcrantibus, tibiis inermibus, tarsis

5-articulatis Dianoo, Steno;

4-articulatis Euaestheto.

\section{O b s e r vat io.}

Sat distincta videtur haec tribus a praecedentibus duabus antennarum insertione et structura, palporum maxillarium articulo primo elongato, coxis anticis minutis. Ceterum palporum structura magis cum Paederinis convenit.

\section{Dianous Leach.}

Curt. Britt. Ent. III. t. 107. - Mannerh. Bruchelytr. p. 41. - Steph. Illustr. V. p. 304. - Boisd. et Lacord. Faun. Ent. Paris. I. p. 440. - Er. Col. March. I. $p .527$.

\section{Mentum transversum, quadratum.}

Tarsi 5-articulati.

Corpus elongatum, subcylindricum, alatum. Caput thorace latius, basii constrictum, collo quasi cylindrico thoraci immissum, exsertum, oculis mediocribus, rotundatis, leviter prominulis. Labrum latum, transversum, antice truncatum, margine integerrimo. Mandibulae falcatae, acutae, ante apicem unidentatae. Maxillae (t. V.f. 1. b.) malis corneis, interiore margine interno membranaceo, recto, barbato, exteriore apice introrsum verso membranaceo, barbato. Palpi maxillares elongati, articulis tribus primis elongatis, sensim paulo longioribus, teretibus, quarto subulato, subtilissimo, vix observando. Labium (t. V. f. I. a.) mento transversim quadrangulari, spatio membraneo inter mentum et palporum basin brevi, transverso, ligula biloba, lobis distantibus, oblongis, memhraneis, paraglossis membraneis, subtiliter ciliatis, ligulae lobis aequalibus iisque valde approximatis, fere connatis et aegre distinguendis. Palpi labiales breves, articulo primo tenui, leviter arcuato, secundo hoc paulo longiore, ovato, tertio minuto, subtili, subulato. Antennae in fronte anteriore inter oculos insertae, graciles, articulis duobus primis reliquis vix crassioribus, primo secundo breviore, tertio elongato, quarto duplo prope longiore, sequentibus $5(4-8)$ longitudine sensim decrescentibus, ultimis tribus paululum crassioribus, penultimis duobus obconicis, ultimo ovato, apice acuminato. Thorax coleopteris multo angustior, cylindricus. Scutellum minutum, triangulare. Elytra apice truncata. Abdomen marginatum, apice sensim angustatum, setis duabus exsertis terminatum. Pedes graciles, modice elongati, tarsis filiformibus, articulo primo leviter elongato.

$$
\text { o b s e r va tio n e s. }
$$

1. Corpus subtilissime pubescens, subtilius punctatum.

2. Habitus omni Steni, at oculi minus grandes prominentesque, antennae longiores, corpus subtiliter punctatum differentiam quandam habitualem praebent.

3. Mas abdominis segmento sexto ventrali apice emarginato, feminae eodem acute rotundato noscuntur.

4. Dom. Brullé hoc genus tarsorum articulo quarto bilobo distinxit a S te no (Hist. nat. Ins. VI. p. 85.), fugit autem huncce auctorem, permultas Stenorum species articulo tarsorum quarto fortiter biloio instructas esse, Dianoum autem a reliquis Stenis tarsorum structura nullo modo differre. .

5. Victus in rivorum ripis humidis. 
1. D. coerulescens: Nigro-coeruleus, nitidulus, subtiliter albido-pubescens, elytris macula rotundala rubra. - Long. $2 \frac{1}{2}$ lin.

Curt. Britt. Ent. III. t. 107. - Mannerh. Brachelylr. 41. 1. - Boisd. et Lacord. Faun. Ent. Paris. I. 440. - Er. Col. March. I. 528. 1.

Stenus coerulescens Gyll. Ins. Suec. II. 463. 1. - Sahlb. Ins. Fenn, I. 421. 1. Stenus biguttatus Ljungh Web. et Mohr Arch. I. 62. 5.

Habitat in Europa.

Corpus nigro-coeruleum, nitidulum, pube brevissima albida vestitum. Antennae capitis thoracisque prope longitudine, nigrae, apice obscure ferrugineae. Palpi nigri. Mandibulae rufae. Caput thorace sesqui latius, transversim suborbiculatum, basi profunde constrictum, dense subtilius punctatum, fronte subdepressa, leviter bisulcata, interstitio lato, leviter convexo, aeque ac frontis latera elevato. Thorax coleopteris dimidio angustior, lateribus ante medium modice rotundatus, posterius magis angustatus, basi coleopteris duplo angustior, latitudine summa longitudini aequali, subcylindricus, subtilius punctatus, punctis in medio dorso rarioribus. Elytra thorace sesqui fere longiora, sutura longitudinaliter depressa et basi impressa, dense subtilius punctata, pone medium macula rotunda rubra vel fulva, colore violaceo cincta, notata. Abdomen subtilissime punctulatum. Pedes tibiis tarsisque mgris, densius albido-pubescentibus.

\section{Stenus $L a t r$.}

Latr. Précis des caract. p. 77. Gen. Crust. et Ins. I. p. 294. - Fab. Syst. Et. II. p. 602. - Grav. Micr. p. 153. - Curt. Britt. Ent. IV. t. 164.

\section{Mentum triangulare.}

Tarsi 5-articulati.

Corpus elongatum, subcylindricum, aliis alatum, aliis apterum. Caput thorace paulo latius, basi leviter constrictum, collo quasi crasso thoraci immissum, oculis permagnis, rotundatis, prominulis. Labrum sat magnum, transversim semicirculare, margine integerrimo. Mandibulae falcatae, acutae, ante apicem fortiter acuteque unidentatae (seu apice acute bidentatae). Maxillae (t. V. f. 2. b.) malis corneis, interiore margine interno membranaceo, subrotundato, barbato, exteriore apice introrsum verso membranaceo: barbato. Palpi maxillares elongati, articulis primis elongatis, sensim longioribus, duobus primis teretibus, tertio apicem versus leviter incrassato, subcla. vato, quarto subulato, subtilissimo, oculo etiam fortiter armato aegre observando. Labium (t. V. f. 2. a.) mento triangulari, ligula biloba, lobis minimis, ovatis, approximatis, membraneis, paraglossis distantibus, basi coarctatis, apice rotundato-ampliatis, ligula multo maioribus, membraneis. Palpi labiales breves, articulo primo tenui, leviter arcuato, secundo hoc breviore, subovato, tertio minuto, subtili, subulato. Antennae in fronte anteriore insertae, te. nuiusculae, articulis duobus primis crassioribus, sequentibus magis minusie elongatis, dein sensim brevioribus, ultimis tribus reliquis distincte crassioribus, clavam oblongam formantibus. Thorax coleopteris angustior, magis minusve cylindricus. Scutellum vix conspicuum. Coleoptera coniuncta apice emarginata. Abdomen lineare, aliis marginatum, aliis immarginatum. Pedes magis minusve elongati gracilesque. 
O b s e r vation es.

1. Habitus huius generis peculiaris. Corpus omnibus magis minusve rude punctatum, colore nigro, rarius ad cupreum, saepius ad plumbeum vergente, pilis brevibus albidis, saepius subargenteis rarioribus densioribusve cinerascens, ore plerumque densius pubescente.

2. Mas plerumque abdominis segmento sexto inferiore apice emarginato, saepe etiam segmentis ventralibus pluribus emarginatis impressisve distinctus.

3. Singulariter in hoc genere ligula levissime mento affixa est, quo fit, ut agone mortis vi antiperistaltica oesophagus cum ligula, paraglossis palpisque labialibus prolabatur et promuscidis porrectae speciem prae se ferat. Hanc rem primus observasse videtur Olivier, bene eam recensuit Gyllenhal (Ins. Suec. II. p. 476). Dein Dom. Thion peculiarem de Stenorum instrumentis cibariis commentationem (Annal. Soc. Ent. Gall. IV. p. 153.) edidit, qua huius partis structuram exacte descripsit, quam partem antem pro vera promuscide habuit. Ipse specimibus recentibus dissectis non possum quin Gyllenhalianae opinioni accedam.

4. Victus palustris vel riparius. Species nonnullae gregariae in arena riparia humida agilissimi cursitant.

I. Tarsi articulo quarto simplice.

A. Abdomen marginatum.

* Elytra ma culata.

* 1. St. biguttatus: Nigro-subaeneus, dense profundeque punctatus, subiiliter albido-pubescens, palpis basi testaceis, elytris macula fulva.

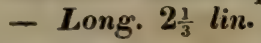

Fab. Syst. El. II. 602. 1. - Grav. Micr. 154. 2. Mon. 225. 2. - Latr. Hist. nat. Crusi. et Ins. IX. 352. 2. t. 80. f. 1. Gien. Crust. et Ins. 1. 294. 1. - Gyll. Ins. Suec. II. 464. 2. - Sahlb. Ins. Fenn. I. 421. 2. - Zetterst. Faun. Lappon. 1. 86. 1. Ins. Lappon. 69. 1. - Guér. Iconogr. Regn. An. Ins. t. 9. f. 8. Boisd. et Lacord. Faun. Ent. Paris. I. 443. 3. - Er. Col. March. I. 529.1.

Staph. biguttatus Linn. Faun. Suec. n. 851. Syst. Nat. I. II. 685. 15. - Fab. Gen. Ins. 241. 11 -12. Spec. Ins. 1. 336. 13. Mant. Ins. I. 221. 20. Ent. Syst. I. I1. 527. 36. - Miill. Prodr. 90. 1124. - Schrunk Enum. Ins. Aust. 235. 446. Fauna Buica I. 643. 871. - Goeze Ent. Beitr. I. 719. 15. - De Vill. Ent. I. 415. 15. - Panz. Faun. Germ. 11. 17. Ent. Germ. 355. 26. - Rossi Faun. Etr. ed. Hellw. 1. 312. 2. - Walk. Faun. Paris. I. 276. 2.

Paed. biguttatus Oliv. Ent. III. 44. 5. 4. t. 1. f. 3. a. b.

Sten. bipustulatus Ljungh Web. u. Mohr Archiv. I. 1. 63. 4. - Mannerh. Brachelytr. 41. 1. - Runde Brachelytr. Hal. 14: 1.

Staph. bipust ulatus Marsh. Ent. Britt. 527. 82.

Habitat in Europa.

Nigro-subaeneus, nitidulus, pube brevi depressiuscula albida cinerascens. Antemnae tenuiusculae, medio saepe piceae, articulo tertio quarto duplo longiore. Palpi nigri, articulo primo toto et secundo basi dilute testaceis. Mandibulae nigrae, apice piceae. Caput cum oculis thorace sesqui latius, crebre punctatum, fronte profunde excavata, carinula minuta autice ahbreviata longitudinali inter oculos leviter elevata. Thorax basi coleopteris duplo angustior, latitudine baseos duplo prope longior, subcylindricus, ante medium leviter rotundato-ampliatus, confertissime punctatus, pone medium canalicula dorsali utrinque abbreviata sat profunde impressus. Elytra thorace paulo longiora, ad medium baseos torulosa, confertissime rugoso-punctata, macula rotundata paululum infra medium fulva, annulo nionro cincta. Abdomen coleopteris paulo angustius, apicem versus sensim 
leviter attenuatum, subtiliter punctulatum, pilis brevibus depressis albidis argenteo-subsericans, praecipue versus latera. Pedes elongati, graciles, nigri, trochanteribus testaceis, tarsis elongatis, apice picescentibus.

Mas abdominis segmento inferiore sexto apice profunde emarginato, quinto apice medio leviter sinuato, intra sinum oblique retuso, excavatione laevi, margine utrinque prominulo obtuso terminata, quarto apice eodem modo at obsolete impresso; femina segmento sexto leviter triangulariter producto, apice subrotundato.

2. St. bipunctatus: Nigro-subaeneus, dense profundeque punclatus, densius albido-pubescens, palpis arliculo primo iestaceo, elytris macula fulva. - Long. $2 \frac{1}{2}$ lin.

Er. Col. March. 1. 530. 2.

Habitat in Europa, in Mesopotamia, Dr. Helfer.

Praecedenti proximus, at distinctus, minus gracilis, nigro-subaeneus, nitidulus, pube brevi depressiuscula albida cinerascens. Antennae nigrae, articulo tertio quarto duplo longiore. Palpi nigri, articulo primo solo obscure testaceo. Mandibulae rufo-piceae, basi nigrae. Caput thorace paulo latius, crebre punctatum, fronte modice excavata, excavatione medio longitudinaliter subelevata, carinula tenui longitudinal, antice sensim evanescente notata. Thorax basi coleopteris duplo angustior, latitudine baseos duplo prope longior, lateribus ante medium leviter rotundatus, subcylindricus, confertissime punctatus, interstitiis subrugosis, pone medium canalicula utrinque abbreviata profunde impressus. Elytra thorace paulo longiora, ad baseos medium torulosa, confertissime rugoso.-punctata, paulo infra medium macula rotundata fulva, annulo nigro cincta. Abdomen apicem versus sensim angustatum, crebre subtiliter punctatum, pilis brevibus depressis albidis, versus latera condensatis, argenteo-subsericans. Pedes nigri, trochanteribus nigro - piceis vel concoloribus, tarsis elongatis, apice picescentibus.

M as abdominis segmento inferiore sexto longitudinaliter impresso, apice profunde emarginato, quinto inde ab apice ad medium usque leviter late impresso, impressione laevi, lateribus margine utrinque leviter prominulo obtuso terminata, apice leviter sinuato, quarto integro; femina segmento sexto apice triangulariter producto.

Obs. I. Differt a praecedente statura paulo maiore, praecipue robustiore, antennis pedibusque minus elongatis, fronte minus profunde excavata, elytrorum macula paulo magis a sutura remota, aequali spatio a sutura et a margine exteriore distante, trochanteribus obscuris. Facilius distinguitur palporum articulo primo solo testaceo, secundo toto nigro.

2. Specimen in Lusitania a Com. Hoffmannsegg lectum, elytrorum macula dilatata insigne, in collectione Hoffmannseggiana nom. St. bimaculati distinctum fuit.

3. St. guttula: Niger, dense profundeque punctatus, densius albidopubescens, pedibus testaceis, femoribus apice late nigris, elylris macula fulva. - Long. 2 lin.

Müll. Germ. Mag. IV. 225. 23. - Er. Col. March. I. 531. 3.

Sten. Kirbyi Gyll. Ins. Suec. IV. 499. 2-3. - Curt. Britt. Ent. IV. t. 164.

Sten. biguttatus var. Grav. Mon. p. 226.

Sten. biguttatus var. 6 Gyl. Ins. Suec. II. 464. 2. 


\section{Habitat in Europa.}

Habitu ommino praecedentis, at duplo minor, niger, nitidulus, pube brevi depressiuscula albida obsitus. Antennae piceae, articulo primo nigro, tertio quarto sesqui longiore. Palpi pallide flavo-testacei, articulo tertio apice fuscescente. Mandibulae rufo-piceae, basi nigrae. Caput cum oculis thorace sesqui latius, creberrime sat fortiter punctatum, fronte profunde excavata, carinula minuta inter oculos parum elevata. Thorax basi coleopteris duplo angustior, latitudine baseos duplo longior, lateribus ante medium leviter rotundato-ampliatus, subcylindricus, creberrime sat fortiter punctatus, subinaequalis. Elytra thorace perparun longiora, dorso leviter convexa, confertissime sat fortiter profundeque punctata, macula paulo infra medium rotundata sat magna fulvo-rufa, annulo nigriore cincta. Abdomen coleopteris paulo angustius, apicem versus sensim leviterque attenuatum, sat crebre minus subtiliter punctulatum. Pedes testacei, coxis nigris, femoribus apice late nigricantibus, tarsis elongatis, picescentibus.

Mas abdominis segmentis inferioribus ultimis duobus apice medio subsinuatis, quinto medio utrinque longitudinaliter longius ciliato; fe min a segmento sexto apice modice producto, rotundato.

Variat palpis articulo secundo testaceo, apice nigricante, tertio nigricante, basi testaceo, tibiis nigro-piceis, medio dilutioribus.

* 4. St. bimaculatus: Niger, confertim profunde punctalus, parcius albido-pubescens, palpis pedibusque testaceis, illis apice fuscis, his geniculis nigris, elytris macula fulva. - Long. $2 \frac{2}{3}$ lin.

Gyll. Ins. Suec. II. 466. 3. - Sahlb. Ins. Fenn. 1. 422. 3. - Zetterst. Faun. Lappon. I. 87. 2. Ins. Lappon. 69. 2. - Runde Brachelytr. Hal. 14. 2. - Er. Col. March. I. 532. 4.

Sten. Juno Grav. Micr. 154. 1. Mon. 225. 1. - Latr. Hist, nat. Crust. et Ins. IX.

352. 1. - Boisd. et Lacord. Faun. Ent. Paris, I. 441. 1.

St aph. bigutt at us Marsh. Ent. Britt. 526. 81.

Habitat in Europa.

St. Junone sesqui maior, robustior, niger, opacus, pube brevissima depressiuscula albida subcinerascens. Antennae tenues, piceae, articulo primo nigro, tertio quarto sesqui longiore. Palpi dilute testacei, articulo tertio apice fusco. Maxillae rufo-testaceae, basi nigrae. Caput cum oculis thorace paulo latius, confertissime profunde punctatum, fronte haud excavata, at inter oculos utrinque longitudinaliter sulcato-impressa, interstitio medio sat elevato, antrorsum angustato. Thorax basi coleopteris dimidio angustior, lateribus praecipue ante medium rotundatus, latitudine summa vix longior, parum convexus, confertissime fortiter profundeque punctatus, subinaequalis, medio obsolete canaliculatus. Elytra thorace parum longiora, subdepressa, profunde fortiterque dense punctata, interstitiis subrugosis, macula minuta rotundata testacea paululum infra medium. Abdomen sat crebre at minus fortter profundeque punctatum, subnitidulnm, apicem versus levitor angustatum. Pedes testacei, coxis nigris, femoribus summo apice nigricantibus, tarsis elongatis, picescentibus.

$\mathrm{Ml}$ as abdominis segmento inferiore sexto apice profunde emarginato, modio laevigato, basi denticulo compresso prominulo armato, quinto medio 
leviter impresso, impressione laevigata, utrinque carinula compressa, sat rrominula, postice dentes instar producta terminata, apice inter carinas emarginato, medio denticulo prominulo minuto armato, quarto apice leviter impresso, impressione laevi, medio itidem denticulo minuto prominulo instructo; femin a segmento sexto modice producto, apice summo emarginato.

5. St. stigmula: Niger, opacus, confertim punctatus, densius albidopubescens, palpis pedibusque tesiaceis, his geniculis fuscescentibus, elytris macula fulva. - Long. 2 lin.

St enus Kirbyi Boisd. et Lacord. Faun. Ent. Paris. I. 442. 2.

Habitat in Austria, Dom. Ullrich, in Gallia, Dom. Aubé.

Habitu omnino St. speculatoris, at paulo minor, niger, opacus, pube brevissima depressa densiore albida cinereus. Antennae piceae, articulo primo nigro, tertio quarto sesqui longiore. Palpi pallide testacei, articulo tertio apice vix fuscescente. Mandibulac rufae, basi nigrae. Caput cum oculis thorace paulo latius, dense fortius punctatum, fionte modice impressa, inter oculos longitudinaliter bisulcata, interstitio leviter elevato, subcarinato. Thorax basi coleopteris duplo fere angustior, lateribus praecipue ante medium leviter rotundatus, latitudine summa paulo longior, subcylindricus, confertissime punctato-suhrugosus, medio obsolete canaliculatus. Elytra thorace vix longiora, subdepressa, confertissime fortius at minus profunde punctatosubrugosa, macula rotundata minuta rufo-testacea paulo infra medium. Abdomen apice attenuatum, confertim subtilius punctatum. Pedes rufo-testacei, coxis piceis, femoribus apice summo tibiisque basi fuscescentibus.

Mas abdominis segmente inferiore quarto quintoque late profundeque impressis, sexto apice profunde triangulariter exciso; femina sexto apice leviter productò, rotundata.

6. St. colan: Niger, opacus, confertim profunde punctolus, parce albidopubescens, anlennarum articulo primo, palpis pedibusque testaceis, elytris maeula minuta fulva. - Long. 2 lin.

Say Transact. Amer. Philoph. Soc. Philadelph. Nov. Ser. IV. 458. 2.

Habitat in Carolina meridionali, Dom. Prof. Germar.

Statura omnino praecedentis, niger, opacus, pube brevissima parca albida cinerascens. Antennae piceae, articulo primo testaceo, tertio quarto sesqui longiore. Palpi pallide flavo-testacei. Caput thorace sesqui latius, confertissime minus subtilter punctatum, fronte inter oculos late at parum profunde excavata, late leviter longitudinaliter bisuleata, iuterstitio parum elevato. Thorax basi coleopteris duplo angustior, latitudine baseos duplo prope longior, lateribus ante medium rotundato-ampliatus, subeylindricus, confertissime fortius punctatus, interstitiis subrugosis, pone medium canali. cula, dorsa utrinque abbreviata, profundiore impressus. Elytra thorace vix longiora, subdepressa, fortiter profundeque dense punctata, interstitiis subrugulosis, macula minuta rufo-testacea paula infra medium notata. $\Lambda$ bdomen apicem versus sensim subangustatum, sat crebre minus subtiliter punctatun, nitidulum, dorso segmentis singulis basi subtıliter longitudinaliter carinatis. Pedes testacei, coxis concoloribus, femoribus apicem versus obscurioribus, tarsis elongatis. 
Mas abdominis segmento inferiore quinto sextoque apice profundius emarginatis, hoc obsolete longitudinaliter impresso, illo apice intra sinum oblique retuso; fe min a segmento sexto apice leviter producto et rotundato.

Elytra immaculata. Pedes concolores.

* 7. St. Juno: Niger, parum nitidus, parcius albido-pubescens, palpis testaceis, apice fuscis, thorace obsoletius canaliculalo, abdomine dense forlius punctalo. - Long. $2 \frac{1}{2}$ lin.

Fab. Syst. El. II. 602. 2. - Ljungh Web. et Mohr Arch. 1. 1. 60. 1. - Gyll. Ins. Suec. 1I. 467. 4. - Sahlb. Ins. Fenn. I. 423. 4. - Zetterst. Faun. Lappon. I. 87. 3. Ins. Lappon. 69. 3. - Mannerh. Brachelytr. 41. 3. - Runde Brachel. Hal. 15. 3.

Staph. Juno Walken, Faun. Paris. I. 276. 1.

Stuph. clavicornis Fab. Gen. Ins. 242. 11-12. Spec. Ins. 1. 336. 14. Mant. Ins. I. 221. 21. Ent. Syst. 1. II. 527. 37. - Rossi Faun. Etr. Mant. 98. 220. Ed. Hellw. I. 443. 220.

St en. buphthalmus Latr. Hist. nat. Crust. et Ins. IX. 353. 6. t. 80. f. 2. Gen. Crust. et Ins. I. 295. t. 9. f. 2.

Sten. boops Grav. Mon. 226. 4. - Boisd. et Lacord. Fuun. Ent. Paris. I. 447. 10.

Habitat in Europa et in America septentrionali.

Niger, opacus, abdomine nitidulo, pube brevissima rariore albida parum cinerascens. Antennae .breviusculae, nigrae, articulo tertio quarto vix sesqui longiore. Palpi flavi, articulo secundo apice fusco, tertio fusco, hasi summa testaceo. Mandibulae nigrae, apice piceae. Caput cum oculis thorace paulo latius, sat fortiter dense punctatum, fronte modice impressa, inter oculos longitudinaliter profunde bisulcata, interstitio leviter elevato. Thorax basi coleopteris duplo fere angustior, lateribus ante medium modice rotundatus, latitudine summa paulo longior, subcylindricus, sat fortiter profundeque dense punctatus, dorso canalicula obsoleta, neque apicem, neque basin attigente, imipressus, basi depressiusculus. Elytra thorace paulo longiora, dorso a medio baseos longitudinaliter subtorosa, confertissime fortiter profundeque punctata, interstitiis praecipue medio intricato-rugosis. Abdomen coleopteris paulo angustius, dense minus subtiliter punctatum, dorso segmentis singulis summa basi longitudinaliter carinatis. Pedes nigri.

Mas pectore impresso, cinereo-villoso, abdominis segmento inferiore sexto inciso, quinto medio late profundeque excavato, excavatione laevi, utrinque margine acute carinato terminata, antice carinula abbreviata sat prominula armato, apice medio profunde emarginato, reliquis quatuor medio leviter impressis, subtiliter acute carinatis, femoribus posterioribus leviter incrassatis et mcurvis, tibiis posterioribus ante apicem subsinuatis, apice unco introrsum vergente terminatis; femina abdominis segmento inferiore sexto leviter triangulariter producto, apice summo subemarginato, pedibus simplicibus.

V ariat femoribus basi piceo-testaceis.

* 8. St. intricatus: Aler, parum nitidus, conferlim punctalus, palpis articulo primo flavo, thorace canaliculato elytrisque inaequalibus, his intricalo-rugosis, abdomine dense subtilius puncialo. - Long. $2 \frac{1}{3}$ lin. Giené.

Habitat in Hispania meridionali, Dom. Schïppel, in Sardinia, Dom. Prof. 
Habitu omnino praecedentis et minoribus eius individuis aequalis, ater, fere opacus, pube brevissima subtilissimaque albida vix cinereo-versicolor. Antennae graciliores, articulo tertio quarto sesqui longiore. Palpi nigri, articulo primo toto secundoque summa basi flavo-testaceis. Caput thorace paulo latius, creberrime profundius punctato-rugulosum, fronte modice excavata, bisulcata, sulcis latioribus minus profundlis, interstitio convexo, leviter elevato. Thorax basi coleopteris triplo prope angustior, lateribus ante medium leviter rotundatus, latitudine summa tertia parte longior, subcylindricus, inaequalis, dorso obsoletius canaliculato, basin versus depressiusculo, lateribus longitudinaliter subimpressis, creberrime fortiter profundeque punctatus, interstitiis inaequalibus et praecipue lateribus et pone medium intricatcrugulosis. Elytra thorace paulo longiora, medio longitudinaliter torosa, in medio disco et secundum suturam subimpressa, dense fortius profunde punctata, interstitiis inaequalibus et praecipue posterius fortiter intricato-rugosis. Abdomen coleopteris angustius, apicem versus sensim angustatum, crebre minus fortiter punctatum, segmentis dorsalibus singulis basi impressis et medio longitudinaliter carinulatis. Pedes nigri, tarsis elongatis.

Mas abdominis segmento inferiore sexto apice triangulariter exciso, basi bidenticulato, quinto longitudinaliter excavato, excavatione laevigata, utrinque carina acuta bidentata terminata, apice inter carinas emarginato, quarto longitudınaliter impresso, impressione angustiore, parum profunda, laevigata, carina acuta subtiliore simplice terminata; femin a segmento sexto leviter producto, apice subemarginato.

9. St. asphallinus: Niger, nilidus, dense fortiter punctatus, parce sultiliter albido-pubescens, palpis basi testaceis, thorace obsolete canaliculato, elytris intricato-rugosis, abdomine punctato. - Long. $2 \frac{1}{3}$ lin.

Habitat in Tyrol, Mus. Dr. Aubé.

Statura gracilior omnino St. atri, niger, nitidulus, pube minus brevi at rara vix cinereo-micans. Antennae mediocres, articulo tertio quarto paulo longiore. Palpi nigri, articulo primo toto et secundo basi ad medium usque dilute flavo-testaceis. Caput thorace sesqui latius, profunde fortiterque minus dense punctatum, fronte leviter impressa, late bisulcata, interstitio modice convexo elevatoque. Thorax basi coleopteris duplo angustior, lateribus ante medium fortiter rotundatus ibique coleopteris vix dimidio angustior, latitudine summa paulo longior, subcylindricus, medio canalicula brevi impressus, densius fortiter profundeque punctatus, interstitiis passim rugulosis. Elytra thorace parum longiora, subaequalia, crebre fortiter profundeque punctata, interstitiis intricato-rugosis. Abdomen basi coleopteris vix angustius, apicem versus sensim angustatum, parce minus subtiliter punctatum, nitidum. Pedes graciliores, nigri, tarsis modice elongatis.

Mas latet. Femina abdominis segmento inferiore sexto apice leviter producto, rotundato.

Obs. A praecedentibus elytris brevioribus, a St. atro praeterea punctura multo fortiore, abdominis parca, a sequentibus reliquis tarsis elongatis distinctus. 
* 10. St. at er: Niger, confertim profunde punctatus, densius albido-pubescens, palpis articulo primo flavo, thorace elongato, subliliter canalicalato, abdomine dense fortius punctalo. - Long. $2 \frac{1}{3}-2 \frac{1}{2}$ lin.

Mannerh. Brachelytr. 42. 4. - Boisd. et Lacord. Faun. Ent. Paris. 1. 447. 11. Er. Col.'March. I. 534. 6.

Sten. maurus Mannerh. Brachelytr. 41. 2. - Runde Brachelytr. Hal. 15. 4.

Habitat in Germania.

St. Junoni affinis, at saepe dimidio minor, gracilior, statura fere St. biguttati, ater, pube brevi depressiuscula densa alba cinereus. Antennae nigrae, articulo tertio quarto sesqui longiore. Palpi nigri, articulo primo toto et secundo summa basi pallide flavis. Mandibulae piceae, apice rufescentes. Caput cum oculis thorace vix sesqui latius, dense profundeque punctatum, fronte profundius excavata, inter oculos obsoletus bisulcata, interstitio parum elevato. Thorax basi coleopteris duplo angustior, lateribus ante medium leviter rotundatis, latitudine summa sesqui fere longior, subcylindricus, dense profundeque punctatus, interstitiis subrugulosis, dorso distinctius canaliculatus, canalicula neque basin neque apicem attingente. Elytra thorace paulo longiora, antice versus suturam leviter longitudinaliter torosa, confertim profunde fortiterque punctata, subrugulosa. Abdomen coJeopteris angustius, apicem versus sensim leviterque attenuatum, sat dense et minus subtiliter punctatum, dorso segmentis singulis summa basi carinatis. Pedes nigri, graciles, tarsis posticis elongatis.

Mas abdominis segmento inferiore sexto apice profunde et acute emarginato, longitudinaliter laevigato, bası subtiliter bidenticulato, quinto late longitudinaliter excavato, excavatione laevigata, utrinque carina elevata, postice denticuli instar prominula, apice inter carmas emarginato, quarto tertioque pariter longitudinaliter impressis, impressione antrorsum sensim laeviore, illo apice sinuato, impressione carina prominula, licet minus acuta terminata, carinis segmenti quarti quintique pilis introrsum vergentibus ciliatis, tibiis posticis ante apicem interne subdentatis; femina abdominis segmento inferiore sexto apice leviter producto, rotundato, tibiis posticis simplicibus,

* 11. St. carbonarius: Niger, opacus, confertim profunde punclatus, spissius albido-pubescens, palpis concoloribus, thorace obsolete canaliculato, elytris thoracis longitudine, abdomine parcius forliusque punclato. Long. 2 lin.

Gyll. Ins. Suec. IV. 505. 13 - 14. - Suhlb. Ins. Fenn. I. 432. 19. - Mannerh. Brachelytr. 44. 21. - Er. Col. March. I. 535. 7.

Habitat in Germania.

Praecedente minor, praesertim brevior, St. buphthalmo valde affinis, at robustior, niger, opacus, pube brevi depressa crassiuscula densiore albida argenteo-versicolor. Antennae breviusculae, articulo tertio quarto sesqui longiore. Palpi nigri, articulo etiam primo concolore. Caput thorace paulo latius, coleopteris dimidio fere angustius, fortiter profundeque dense punctatum, fronte subimpressa, late bisulcata, interstitio leniter convexo, parum elevato. Thorax basi coleopteris duplo angustior, anterius lateribus modice rotundatus, latitudine baseos duplo longior, suboylindricus, 
profunde creberrime punctatus, subrugosus, sıbinaequalis, medio obsolete canaliculatus, canalicula utrinque abbreviata. Elytra thoracis longitudine, dense profundeque punctata, subrugosa, anterius versus suturam longitudinaliter torulosa. Abdomen parcius minus subtiliter punctatum. Pedes nigri, tarsis posticis leviter elongatis.

$\mathrm{M}$ as abdominis segmento inferiore sexto quintoque longitudinaliter inpressis, apice emarginatis, quarto leviter longitudinaliter impresso, tertio apice obsolete impresso; femin a segmento sexto apice rotundato.

* 12. St. labilis: Plumbeo-niger, subnilidus, conferlim punctatus, densius albido-pubescens, palpis articulo primo piceo, fronte profunde bisulcata, thorace elongato, subtiliter obsolete canaliculato, abdomine densius minus subtiliter punctalo. - Long. 2 lin.

Sten. canaliculatus Suhlb. Ins. Fenn. 1. 428. 12.

Habitat in Fennia, Dom. Prof. Sahlberg.

Statura omnino St. buphthalmi, at gracilior, plumbeo-niger, nitidulus, pube densiore albida incanus. Antennae breviusculae, articulo tertio quarto parum longiore. Palpi nigri, articulo primo piceo. Caput thorace paulo latius, coleopteris plus dimidio angustius, dense profundeque punctatum, fronte haud excavata, late profundeque longitudinaliter bisulcata, interstitio convexo, aeque ac frontis latera elevato. Thorax elongatus, coleopteris duplo angustior, lateribus ante medium levissime rotundatus, cylindricus, dense profundeque punctatus, interstitiis passim subrugulosis, dorso subtiliter obsoletius per totam longitudinem canaliculatus. Elytra thorace parum longiora, aequalia, densius profunde punctata, interstitiis planis. Abdomen coleopteris paulo angustius, basin versus sensim angustatum, crebrius minus fortiter punctatum, nitidum. Pedes nigri, tarsis breviusculis.

Mas abdominis segmento inferiore sexto apice leviter emarginato, quinto quartoque medio longitudinaliter late depressis; fe mina latet.

Obs. Fronte haud impressa at fortiter bisulcata, thorace elongato, lateribus vix rotundato, canaliculato ab affinibus distinctus.

*13. St. ruralis: Niger, opacus, confertissime punetalus, subtilius densiusque albido-pubescens, palpis concoloribus, fronte late .leviter bisulcata, thorace oblongo, obsolete subtiliter canaliculato, elytris thorace longioribus, abdomine purcius subtiliusque punctato. - Long. $1 \frac{1}{2}-2$ lin.

Habitat in Austria, Dom. Ullrich.

Statura et summa affinitas St. buphthalmi. Niger, parum nitidus, pube brevi depressa albida cinerascens. Antennae breviusculae, artioulo tertio quarto paulo longiore, nigrae. Palpi nigri, articulo primo concolore. Caput thorace paulo latius, dense fortius profunde punctatum, fronte depressiuscula, late at parum profunde bisulcata, interstitio leviter convexo, parum elevato. Thorax basi coleopteris duplo angustior, lateribus ante medium leviter rotundatis, latitudine summa tertia parte longior, subcylindricus, dense profundeque punctatus, interstitiis leviter rugulosis, subinaequalis, obsolete canaliculatus, dorso pone medium depressiusculo. Elytra thorace paulo longiora, basin versus medio torulosa, dense profundeque punctata, 
interstitiis subrugosis. Abdomen apice angustatum, parcius subtiliusque punctatum. Pedes nigri, tarsis breviusculis.

Mas abdominis segmento inferiore sexto apice leviter emarginato; femin a eodem apice leviter producto, rotundato.

$\mathrm{Obs}$ Proximus et simillimus $\mathrm{St}$. buphthal mo, distinctus autem palpis basi concoloribus, elytris longioribus et abdomine parcius subtiliusque punctato. A praecedente thorace minus elongato et fronte minus profunde bisulcata, nec non abdominis in mare structura differt.

*14. St. stygicus: Plumbeo-niger, opacus, dense profundeque punctatus, densius albido-pubescens, palpis concoloribus, fronte profunde bisulcala, thorace elongato, utrinque subimpresso, abdomine densius forliusque punctato. - Long. $1 \frac{3}{6}$ lin.

Say Transact. Amer. Philosoph. Soc. Philadelph. Nov. Ser. IV. 458. 3.

Habitat in America septentrionali, Dom. Zimmermann.

Statura omnino St. buphthalmi at paulo gracilior, plumbeo-niger, pube breviore subdepressa albida densius aequaliter canus. Antennae breviusculae, nigrae, articulo tertio quarto paulo longiore. Palpi nigri, articulo primo apice piceo. Caput thorace panlo latius, coleopteris dimidio angustius, dense sat profunde punctatum, fronte leviter excavata, late profundius bisulcata, interstitio convexo et modice elevato. Thorax coleopteris duplo angustior, anterius lateribus parum rotundatus, latitudine summa sesqui fere longior, subcylindricus, dense sat fortiter punctatus, interstitiis subrugulosis, medio utrinque leviter impressus. Elytra thorace vix longiora, sat fortiter confertim punctata, anterius versus suturam leviter torulosa. Abdomen crebre minus subtiliter punctatum. Pedes nigri, tarsis breviusculıs. tundato.

Mas latet. Femina abdominis segmento inferiore sexto apice ro-

$\mathrm{Obs}$. Differt a St. buphthalmo fronte angustiore, profundius bisulcata, thorace elongato, lateribus parum rotundato, haud canaliculato, palpis basi concoloribus.

-15. St. e genus: Nigro-subaeneus, parum nilidus, subtilissime albido-pubescens, palpis concoloribus, thorace oblongo, dorso obsolete longitudinaliter bi-impresso, elytris thorace longioribus, abdomine dense fortius punctato. - Long. $1 \frac{1}{2}$ lin.

Habitat in Pensylvania, Dom. Zimmermann.

Habitu omnino St. huphthalmi at dimidio minor, nigro-subaeneus, obscure nitidulus, pube brevi subtilissima albida parce vestitus et vix cinerascenti-micans. Antennae breviusculae, articulo tertio quarto vix longiore, nigrae. Palpi nigri, basi concolores. Caput thorace vix latius, coleopteris duplo prope angustius, dense profundeque punctatum, fronte haud impressa, late obsoletius bisulcata, interstitio vix convexo, haud elevato. Thorax ante medium modice rotundatus et coleopteris dimidio, basi is duplo angustior, latitudine summa paulo longior, minus fortiter at profunde dense punctatus, interstitiis subrugulosis, subinaequalibus, dorso obsolete secundum totam longitudinem bi-impressus, impressionibus basi apiceque distinctioribus. Elytra thorace paulo longiora, dorso medio basin versus toruloso, confertim minus fortiter profunde punctata, interstitiis subtiliter rugulosis. Abdomen crebre minus subtiliter punctatum. Pedes nigri, tarsis breviusculis. 
Mas abdominis segmento inferiore sexto apice leviter triangulariter exciso, quinto quartoque leviter longitudinaliter impressis, impressione utrinque carma obsoleta terminata; femina segmento sexto apice leviter producto, rotundato.

*16. St. buphthaln:us: Niger, opacus, confertissime profunde punctatus, sublilins parciusque albido-pubescens, palpis articulo primo testaceo, thorace oblongo, obsolete canaliculato, elytris thoracis longitudine, abdomine densius fortiusque punctalo. - Long. $1 \frac{2}{3}-2$ lin.

Grav. Micr. 156. 6. Mon. 230. 9. - Gyll. Ins. Suec. II. 475. 10. - Sallb. Ins. Fenn. 1. 428. 11. - Mannerh. Brachelytr. 43. 11. - Kunde Brachelytr. Hal. 16. 9. - Er. Col. Murch. I. 536. 8.

Sten. buops Ljungh Web. Beitr. II. 158. 12.

Sten. clavicornis Panz. Faun. Germ. 27. 11. Ent. Germ. 356. 27.

Sten. canaliculatus Boisd. et Lacord. Faun. Ent. Paris. I. 449. 14.

St en. palposus Zetterst. Ins. Lappon. 70. 6. (forte)

Habitat in Europa.

Niger, pube brevi subtili subdepressa rariore albida subcinerascens. Antennae breviusculae, nigrae, articulo tertio quarto paulo longiore. Palpi nigri, articulo primo testaceo. Caput thorace paulo latius, coleopteris parum angustius, creberrime sat profunde punctatum, fronte vix impressa, late bisulcata, interstitio leviter convexo, subelevato. Thorax basi coleopteris duplo angustior, anterius lateribus leviter rotundatus, latitudine summa parum longior, subcylindricus, dense profunde punctatus, interstitiis subrugulosis, medio plerumque obsolete canaliculatus, dorso pone medium depressiusculus. Elytra thorace vix longiora, confertissime fortius sat profunde junctata, interstitiis subrugulosis, anterius versus basin longitudinaliter torulosa. Abdomen apicem versus sensim angustatum, densius minus subtiliter punctatum, parum nitidum. Pedes nigri, breviusculi, tarsis breviusculis.

Mas abdominis segmento inferiore sexto apice leviter triangulariter exciso; femina eodem apice rotundato.

Obs. St. palposus Zett. „palpis elongatis, articulo ultimo magno inflexo" forte specimen monstrosum vel fortuito deformatum.

* 17. St. colonus: Niger, nitidulus, confertissime profunde punctatus, subtiliter parcius albido-pubescens, palpis articulo primo testaceo, thorace oblongo, elytris thorace vix longioribus, abdomine parce subtiliterque punctato. - Long. $1 \frac{1}{2}$ lin.

Habitat in Pensylvania, Dom. Zimmermann.

Statura et summa affinitas praecedentis at minoribus eius individuis paululum minor, niger, pube brevi depressa subtili albida parca subcinerascens. Antennae breviores, articulo tertio quarto paulo longiore, nigropiceae. Palpi nigri, articulo primo testaceo. Caput thorace paulo latius, coleopteris vix dimidio angustius, sat fortiter profundeque dense punctatum, fronte haud impressa, late parum profunde bisulcata, interstitio aeque ac frontis latera elevato, subcarinato. Thorax basi coleopteris duplo prope angustior, ante medium lateribus parum rotundatus, latitudine summa paulo longior, subcylindricus, creberrime profunde punctatus, interstitiis subrugo- 
sis, dorso pone medium depressiusculus. Elytra thorace parum longiora, sat fortiter profunde punctata, interstitis transversim rugulosis, anterius longitudinaliter torulosa. Abdomen apicem versus sensim subangustatum, parce subtiliusque punctatum, nitidum. Pedes nigri, tarsis breviusculis.

Mas abdominis segmento inferiore quinto apice obsolete emarginato, sexto leviter triangulariter exciso; fem in a eodem rotundato.

Obs. A praecedente thorace haud canaliculato et imprimis abdomine parce punctato, a St. cinerascente colore magis nigro, punctura thoracis et elytrorum fortiore, interstitiis punctorum rugulosis distinctus.

* 18. St. morio: Plumbeo-niger, nitidulus, albido-pubescens, densius punctatus, capite coleopteris dimidio angustiore, fronte leviter excavata, obsolete bisulcata, thortce oblongo, aequali, elytris thorace longioribus, abdomine densius subtiliusque punctato. - Long. $1 \frac{1}{2}$ lin.

Grav. Mon. 230. 10. - Er. Col. March. I. 537. 9.

Sten. buphthalmus Zetterst. Faun. Lappon. 88. 5. Ins. Lappon. 70. 5.

Habitat in Germania.

Plumbeo-niger, nitidulus, pube densiore brevi depressa albida' cinerascens. Antennae mediocres, nigrae, articulo tertio quarto longiore. Palpi nigri, articulo primo testaceo. Caput thorace sesqui latius, coleopteris dimidio angustius, crebre profunde punctatum, fronte leviter excavata; excavatıone subaequali, sulcis longitudinalibus obsoletissimis, interstitio vix elevato. Thorax basi coleopterıs duplo angustior, anterius lateribus leviter rotundatus, latitudine summa haud longior, subcylindricus, aequalis, crebre profundeque punctatus, interstitiis planis. Elytra thorace sesqui fere longiora, leviter convexa, dense profundeque punctata, interstitiis aequalibus. Abdomen coleopteris paulo angustius, apicem versus sensim subangustatum, crebrius subtiliusque punctatum, nitidum. Pedes corpori concolores, tarsis breviusculis.

Mas abdominis segmento inferiore quinto apice leviter emarginato, sexto leviter triangulariter exciso; femina sexto apice leviter producto, rotundato.

* 19. St. incanus: Plumbeo-niger, nitidulus, densius albido-pubescens, subtilius punctatus, capite coleopteris dimidio angustiare, fronte profunde bisulcata, thorace oblongo, aequali, elylris thorace longioribus, abdomine parcius subtiliter punctalo. - Long. $1 \frac{1}{2}$ lin.

Er. Col. March. 1. 538. 10.

Habitat in Germania.

Statura omnino et summa affinitas praecedentis. Plumbeo-niger, nitidulus, pube densiore albida cinereus. Antennae breviusculae, articulo tertio quarto paulo longiore, nigrae. Palpi nigri, articulo primo piceo. Caput thorace sesqui prope latius, coleopteris dimidio angustius, minus dense punetatum, fronte haud impressa, late profundeque bisulcata, interstitio sulcorum convexo et aeque ac frontis latera elevato. Thorax angustior, lateribus ante medium leviter rotundatus, posterius angustatus, basi coleopteris plus duplo angustior, latitudine summa paulo longior, aequalis, densius subtiliusque punctatus, interstitiis planis. Elytra thorace paulo longiora, dorso lon- 
gitudinaliter torosa, fortius profundiusque minus dense punctata, interstitiis planis. Abdomen parcius subtiliter punctatum. Pedes nigri, tarsis breviusculis.

M a s abdominis segmento inferiore sexto apice leviter emarginato. Femin a latet.

Obs. A praecedente fronte haud impressa, abdomine parce subtiliterque punctato, a sequente punctura subtiliore, ab utroque fronte $\mathrm{p}$ rofunde bisulcata distinctus.

* 20. St. cinerascens: Plumbeo-niger, nilidulus, albido-pubescens, densius punclalus, capile coleopleris plus dimidio angustiore, fronte late leviter bisulcala, interstilio convexiusculo, thorace oblongo, postice depressiusculo, elylris thorace longioribus, abdomine parcius subliliter punctato. - Long. $1 \frac{1}{2}$ lin.

Er. Col. March. I. 539. 11.

Habitat in Germania.

Statura et summa affinitas St. morionis. Plumbeo-niger, nitidulus, pube densiore brevi depressa albida cinerascens. Antennae breviusculae, articulo tertio quarto vix longiore, nigrae. Palpi nigri, articulo primo piceo-testaceo. Caput thorace paulo latius, coleopteris dimidio prope angustius, dense fortius profundiusque punctatum, fronte haud excavata, leviter late bisulcata, interstitio latiusculo, leviter convexo, aeque ac frontis latera elevato. Thorax lateribus ante medium leviter rotundatus, posterius angustatus, basi coleopteris duplo angustior, latitudine summa paulo longior, dense profundeque punctatus, interstitiis angustis, planis, dorso pone medium depressiusculo vel late subimpresso. Elytra thorace paulo longiora, dorso antico medio levissime toroso, densius profunde punctata, interstitiis planis. Abdomen parce subtiliter punctatum. Pedes nigri, tarsis breviusculis.

Mas abdominis segmento inferiore sexto apice leviter emarginato; femina eodem apice rotundato.

Obs. Facillime cum St. morione confundendus, at distinctus videtur, capite paulo angustiore, fronte haud excavata, sulcis longitudinalibus distinctioribus, interstitio distincte elevato, abdomine parce subtiliterque punctato, antennarum articulo tertio quarto subaequali, tarsorum posticorum articulo secundo sequentibus haud longiore, nec non abdominis segmento inferiore quinto in mare apice haud emarginato.

* 21. St. atratulus: Plumbeo-niger, nitidulus, albido-pubescens, forliter profunde punclatus, capite coleopteris plus dimidio angustiore, fronte leviter bisulcuta, interstilio subcarinalo, thorace oblongo, aequali, elytris thorace longioribus, abdomine densius punclato. - Long. $1 \frac{1}{4}-1 \frac{1}{3}$ lin.

Er. Col. March. I. 540. 1\%.

Habitat in Germania.

Affinis praecedentibus, at saepius paulo minor, plumbeo-niger, puhe brevi depressa albida cinerascens. Antennae breves, articulo tertio quarto haud longiore, nigrae. Palpi nigri, articulo primo testaceo. Caput thorace paulo latius, coleopteris plus dimidio angustius, fortiter profundeque densius punctatum, interstitiis aequalibus, fronte haud exsavata, at distincte late bisulcata, interstitio sulcorum leviter elevato, convexo, subcarinato. Thorax lateribus ante medium modice rotundatus, posterins angustatus, basi coleo- 
pteris duplo prope angustior. latitudine summa haud longior, aequalis, fortiter profundeque densius punctatus, interstitiis planis, pone medium nonnunquam obsolete canaliculatus. Elytra thorace tertia parte longiora, dorso anterius medio toruloso, fortiter profundeque densius punctata, interstitiis planis. Abdomen coleopteris paulo angustius, apicem versus sensim angustatum, fortius crebriusque punctatum. Pedes nigri, tarsis breviusculis.

M as abdominis segmento inferiore quinto sextoque apice leviter emarginatis; femin a sexto apice leviter producto et rotundato.

Obs. A praecedentibus punctura fortiore, elytris paulo longioribus, antennis pedibusque brevioribus, a St. incrassato statura minore, fronte distinctius sulcata et abdomine parcius punctato distinctus. Corporis habitu et statura, punctura et frontis figura eximie cum $\mathrm{St}$. $\mathrm{n}$ igritulo congruit, at abdomen distincte marginatum.

*22. St. mendicus: Plumbeo-niger, nilidulus, griseo-pubescens, densius subtiliusque punctalus, capile coleopteris dimidio angustiore, parce punclato, fronte profunde bisulcala, elytris thorace paulo longioribus, abdomine parcius punctalo. - Long. $1 \frac{1}{2}$ lin

Habitat in Lusitania, Com. Hoffmannsegg.

Corpus breviusculum, crassiusculum, statura fere St. morionis, plumbeo-nigrum, nitidulum, pube subtili grisea tenuiter vestitum. Antennae breves, articulo tertio quarto paulo longiore, piceae, articulo primo nigro. Palpi nigro-picei, articulo primo testaceo. Caput thorace paulo latius, coleopteris dimidio angustius, parcius minus subtiliter punctatum, fronte depressa vel late subimpressa, sulcis minus latis at distinctioribus, profundis, interstitio haud convexo at aeque fere ac frontis latera elevato. Thorax lateribus ante medium modice rotundatus, coleopteris dimidio angustior, postice angustatus, basi coleopteris duplo angustior, latitudme summa haud longior, subcylindricus, densius subtiliusque licet sat profunde punctatus, interstitiis planis. Elytra thorace paulo longiora, dorso basin versus parum toroso, confertim minus fortiter profunde punctata, interstitiis aequalibus. Abdomen crassiusculum, minus confertim subtiliter punctatum. Pedes nigri, tarsis breviuscnlis. tundato.

Mas latet. Femina abdominis segmento inferiore sexto apice ro-

Obs. Capitis sculptura praecipue ab affinibus distinctus.

* 23. St. incrassatus: Plumbeo-niger, parcius albido-pubescens, confertissime profunde punctatus, capite coleopteris duplo angustiore, fronte obsolete bisulcata, thorace oblongo, aequali, elytris thorace longioribus, abdomine nilidulo, parce subtiliterque punctato. - Long. $1 \frac{2}{3}$ lin.

Er. Col. March. 1. 541. 13.

Habitat in Germania, Suecia.

St. cinerascenti affinis, plumbeo-niger, opacus, pube brevi depressa albida subcinerascens. Antennae breves, nigrae, articulo tertio quarto paulo longiore. Palpi nigri, articulo primo testaceo. Caput thorace parum latius, coleopteris duplo angustius, dense fortiter profundeque punctatum, fronte haud impressa, late obsoleteque bisulcata, interstitio parum convexo. Thorax basi coleopteris plus duplo angustior, anterius lateribus leviter rotun- 
datus, latitudine summa paulo longior, subeylindricus, fortiter profundeque confertissime punctatus, interstitiis subrugulosis, dorso ante basin late levissime subimpressus. Elytra lata, thorace paulo longiora, dense fortius sat profunde punctata, interstitiis praecipue posterius subrugulosis, anterius versus suturam leviter torosa. Abdomen maris apicem versus sensim leviterque angustatum, crassiusculım, feminae crassum, late marginatum, parce subtiliterque punctatum, nitidulum. Pedes corpori concolores, tarsis brevibus.

Mas abdominis segmento inferiore longitudinaliter subimpresso, apice leviter emarginato, sexto apice leviter triangulariter exciso; femina eodem apice leviter producto, rotundato.

Obs. Praecedentibus magnitudine et colore similis, differt autem capite minore, coleopteris abdomineque crasso latioribus, elytris rugulosis, etc. Feminas tres prope Berolinum legi, maris exemplum e Suecia nomine St buphthalmi mecum communicavit Dom. Prof. Zetterstedt.

*24. St. foraminosus: Plumbeo-niger, nitidulus, dense fortiter profundeque punctalus, subtiliter parceque albido-pubescens, capite coleopteris dimidio angustiore, fronte obsolele bisulcata, elytris thorace sesqui longioribus, abdomine fortius punctato. - Long. $1 \frac{1}{2}$ lin.

\section{Hahitat in Germania.}

Statura omnino praecedentium, plumbeo-niger, nitidulus, pube brevi depressiuscula albida parca vix cinerascens. Antennae breves, articulo tertio quarto paulo longiore, nigrae, pubescentes. Palpi toti nigri. Caput thorace paulo latius, coleopteris dimidio angustius, crebrus fortiter profundeque punctatum, fronte haud impressa, leviter bisulcata, interstitio lato, vix convexo. Thorax coleopteris paulo angustior, anterius lateribus sat fortiter rotundatus, postice angustatus, basi coleopteris duplo prope angustior, latitudine summa haud longior, leviter convexus, aequalis, fortiter profundeque crebre punctatus, interstitiis subrugulosis. Elytra thorace sesqui longiora, fortiter profunde dense punctata, interstitiis subrugulosis, anterius versus suturam leviter torulosa. Abdomen crebre fortius profunde punctatum. Pedes corpori concolores, tarsis mediocribus.

Mas latet. Femina abdominis segmento inferiore sexto apice leviter producto, rotundato.

$\mathrm{Obs}$. A praecedentibus thorace breviore, anterius fortius rotundato, praecipue autem punctura multo fortiore distinctus.

* 25. St. nitidus: Plumbeo-niger, nilidus, subtiliter albido-pubescens, parcius profunde punctatus, capite coleopleris plus dimidio angustiore, fronte profundius bisulcata, thorace pone medium canaliculato, elytris thorace paulo longioribus, abdomine parcius subtiliusque punctato. Long. $1 \frac{1}{2}$ lin.

Boisd. et Lacord. Faun. Ent. Paris. I. 450. 16.

Habitat in Sardinia, Dom. Prof. Gené, in Hispania meridionali, Dom. Schiippel, in Gallia, coll. Dom. Aubé.

Statura omnino St. cinerascentis, plumbeo-niger, nitidus, pube depressa albida parcius vestitus. Antennae breviusculae, articulo tertio quarto sesqui longiore, nigrae. Palpi nigri, articulo prımo testaceo. Caput thorace parum latius, crebrius minus fortiter profunde punctatum, fronte haud im- 
pressa, profunde bisulcata, sulcis convergentibus, interstitiis aeque ac frontis latera elevato, subcarinato. Thorax ante medium fortius rotundatus, coleopteris dimidio angustior, postice angustatus, basi coleopteris duplo angustior, latituline summa paululum longior, subcylindricus, minus confertim et minus fortiter profunde punctatus, interstitiis planis, posterius profundius canaliculatus. Elytra thorace paulo longiora, dorso longitudinaliter torulosa, parcius minus fortiter punctata, interstitiis planis. Abdomen parcius subtiliusque punctatum. Pedes nigri, tarsis breviusculis.

Mas abdominis segmento inferiore sexto apice leviter emarginato; femina eorlem rotundato. distinctus.

Obs. Punctura parciore et thorace posterius profunde canaliculato imprimis

* 26. St. a emulus: Plumbeo-niger, fortius profundeque punctatus, subtiliter albido-pubescens, fronte planiuscula, thorace elongato, subtiliter canaliculato, elytris thoracis longitudine, abdomine parcius subliliter punctato. - Jong. 2 lin.

Er. Col." March. I. 541 . 14.

Habitat in Germania et in Lapponia, Dom. Schïppel.

Plumbeo-niger, nitidulus, pube subtili albida tenuiter adspersus. Antennac: breviusculae, articulo tertio quarto sesqui longiore, nigrae. Palpi nigri, articulo primo toto et secundo summa basi dilute testaceis. Caput thorace sesqui latius, crebre fortiter profundeque punctatum, fronte planiuscula, utrinque obsolete sulcata, linea tenui longitudinali media subelevata laevi. Thorax elongatus, ante medium leviter rotundatus, posterius angustatus, basi coleopteris duplo angustior, latitudine summa sesqui longior, fortiter profundeque densius punctatus, interstitiis planis, dorso per totam longitudinem distincte tenuiter canaliculatus. Elytra thorace vix longiora, fortiter profundeque densius punctata, interstitiis planis. Abdomen subtiliter minus profunde parcius punctatum. Pedes nigri, tarsis breviusculis.

Mas latet. Femina abdominis segmento inferiore sexto apice leviter producto, rotundato.

Obs. Sequenti fronte planiuscula et thorace distincte subtiliter canaliculato affinis, corpore autem nitido, statura magis elongata, capite thorace elytrisque fortius et minus confertim, abdomine parcius subtiliusque punctatis distinctus.

* 27. St. canaliculatus: Plumbeo-niger, dense profundius punctatus, subtiliter albido-pubescens, fronte plana, thorace oblongo, subtiliter canaliculato, elytris thorace paulo longioribus, abdomine crebrius subtiliter punctato. - Long. $1 \frac{2}{3}$ lin.

Gyll. Ins. Suec. IV. 501. 10-11. - Mannerh. Brachelytr. 43. 12. - Er. Col. March. I. 542. 15.

Sten. buphthalmus var. (canaliculatus Kn.) Grav. Mon. p. 230.

St en. buphthalmus var. b Zetterst. Faun. Lappon. I. 88. 5. Ins. Lappon. 70. 5.

Habitat in Europa.

Statura omnino St. morionis, plumbeo-niger, parum nitidus, pube brevi, depressiuscula densiore cinerascens. Antennae perbreves, articulo tertio quarto subaequali, nigrae. Palpi nigri, articulo primo toto, secundo summa 
basi testaceo. Mandibulae rufae. Caput thorace paulo latius, coleopteris plus dimidio angustius, creberrime minus fortiter at profunde punctatum, fronte plana, aequali, sulcis frontalibus ommino fere obsoletis. Thorax anterius lateribus leviter rotundatus, posterius angustatus, basi coleopteris duplo angustior, latitudine summa paulo longior, subcylindricus, aequaliter dense minus fortiter profunde punctatus, interstitiis subrugulosis, per totan longitudinem linea tenuı at distinctiore canaliculatus. Elytra thorace paulo longiora, minus furtiter at sat profunde dense punctata, interstitiis planis. Abdomen nitidulum, minus subtiliter crebre punctatum. Pedes corpori concolores, tarsis brevibus, apice piceis.

Mas abdominis segmento inferiore sexto apice leviter emarginato; femina eodem leviter producto, rotundato.

* 28. St. орасиs: Subdepressus, niger, opacus, dense punctatus, subtilissime albido-pubescens, palpis fuscis, basi teslaceis, fronte lata, obsolete bisulcata, thorace subrotundato, ablomine densius punctato. - Long. $\mathbf{1} \frac{1}{2}$ lin.

Er. Col. March. I. 543. 16.

Habitat Berolini, Dom. Schïppel.

Habitı fere St. latifrontis, niger, opacus, pube albida subtilissima vix cinerascens. Antennae breves, articulo tertio quarto haud longiore, piceae, articulo primo nigro. Palpi fusci, articulo primo toto, secundo basi testaceo. Caput breviusculum, coleopteris latitudine subaequale, confertissime punctatum, fronte plana, late obsolete bisulcata, interstitio lato, levissime convexo. Thorax lateribus fortiter rotundatus, basin versus magis quam anterius angustatus, basi coleopteris duplo prope angustior, latitudine summa haud longior, parum convexus, aequalis, subtilius licet profunde confertim punctatus, interstitiis angustis, planis. Elytra thorace vix longiora, depressa, apice coniuncta late emarginata, minus fortiter sat profunde confertim punctata, interstitiis angustis, planiusculis. Abdomen subtiliter densius punctatum, subnitidum. Pedes nigri, tarsis brevibus.

tundato.

Mas latet. Femina abdominis segmento inferiore sexto apice ro-

*29. St.pusillus: Niger, dense punclatus, parce albido-pubescens, palpis articulo primo testaceo, fronte profunde bisulcala, thorace rotundato, elytris thorace sesqui longioribus, abdomine parcius punclato. Long. 1 - $1 \frac{1}{3}$ lin.

Er. Col. Murch. I. 544. 17.

Habitat in Germania, Anglia.

Statura omnino St. circularis, niger, pube brevi depressa albida parciore vix cinerascens. Antennae crassiusculae, articulo tertio quarto panlo longiore, nigrae. Palpi nigri, articulo primo testaceo. Caput thorace paulo latius, coleopteris dimidio fere angustius, confertissime punctatum, fronte sulcis duobus latis profundisque antice conniventibus impressa, interstitio aeque ac frontis latera elevato, subcarinato. Thorax lateribus fortiter rotundatus, coleopteris dimidio angustior, basin versus coarctatus, basi coleopte- 
ris plus duplo angustior, latitudine summa panlo brevior, dense punctatus, subinaequalis, dorso pone mediumí utrinque distinctius impressus. Elytra thorace sesqui fere longiora, sat fortiter profundeque dense punctata, interstitiis subrugulosis, subdepressa, prope suturam longitudinaliter subelevata. Abdomen breviuscnlum, apicem versus sensim angustatum, subtilius minus crebre punctatum. Pedes nigri, tar-is brevibus.

Mas aldominis segmento inferiore sexto apice leviter emarginato; femina eodem rotundato.

* 30. St. exiguus: Niger, dense punctalus, parce albido-pubescens, pal. pis arliculo primo testaceo, fronte profunde bisulcata, thorace rotundalo, elytris thoracis longiludine, abdomine parcius punclalo. - Long. $1-1 \frac{1}{4} \operatorname{lin}$.

Habitat in Anglia, Dom. Hope.

Statura et summa affinitas praecedentis, niger, nitidulus, pube brevi depressa albida parca vix cinerascens. Antennae breves, crassiusculae, articulo tertio quarto paulo longiore. Palpi nigri, articulo primo testaceo. Caput thorace sesqui latius, coleopteris paulo angustius, confertim fortius profunde punctatum, fronte haud impressa, at sulcis duobus fortibus profundisque antice conniventibus exarata, interstitio aeque ac frontis latera elevato, subcarinato. Thorax anterins modice rotundatus, coleopteris tertia parte angustior, postice coarctatus, basi coleopteris duplo angustior, latitndine summa vix brevior, minus confertim profunde punctatus, interstitiis vix rugosis, dorso pone medium utrinque oblique obsolete impressus, ceterum aequalis. Elytra thorace vix longiora, depressa, dorso anterius obsolete torulosa, dense profundeque punctata, interstitiis subrugulosis. Abdomen apicem versus sensim angustatum, minus confertim subtilius punctatum. Pedes nigri, tarsis breviusculis:

Mas abdominis segmento inferiore sexto apice leviter emarginato; fe min a eodem rotundato.

Obs. Differt a praecedente praeter elytra breviora punctura fortiore et thorace convexiore, minus inaequali.

* Elytra im maculata. Pedes testacei.

* 31. St. speculator: Niger, opacus, creberrime punclatus, antennis testaceis, fronte excavata, bisulcala, pedibus testaceis, genubus nigris, tarsis fuscis. - Long. $2 \frac{1}{2}$ lin..

Boisd. et Lacord. Faun. Ent. Paris. I. 445. 6. - Er. Col. March. I. 545. 18. Staph. clavicornis Scop. Ent. Carn. 100. 303. - Goetze Ent. Beitr. I. 725. 13. St aph. buphthalmus Schrank Beitr, zur Nuturgesch. 72. 21. Enum. Ins. Austr. 235. 445. Faun. Boica 1. 643. 870.

Sten. boоps Gyll. Ins. Suec. 11. 469. 5. - Sahlb. Ins. Fenn. I. 424 5. - Zetterst.

Faun. Lappon. I. 87. 4. Ins. Lappon. 70. 4. - Nunnerh. Brachelytr. 42. 5. Runde Brachelytr. Hal. 15. 5.

Sten.boops var. 1 Grav. Mon. p. 227.

St en. cicindeloides L.jungh Weber u. Mohr Archiv. 1. 1. 62. 1.

Habitat in Europa.

Statura omnino St. Junonis, niger, opacus, pube brevissima alba in 
thorace elytrisque parca, in abdomine pectoreque densiore, infra antennas densa. Antennae breviores, tenues, articulo tertio quarto paulo longiore, fusco-testaceae, clava fusca, articulis duobus primis nigris. Palpi dilute testacei, immaculati. Caput cum oculis thorace vix sesqui latius, creberrime sat fortiter profundeque punctatum, fronte leviter excavata, profundius bisulcata, interstitio leviter convexo, vix elevato. Thorax coleopteris vix dimidio angustior, lateribus modice rotundatus, basin versus paulo magis quam apicem versus angustatus, basi coleopteris duplo angustior, latitudine summa paulo longior, subinaequalis, creberrime sat fortiter profundeque punctatus, interstitiis subrugulosis, posteruus obsolete canaliculatus. Elytra thoracis longitudine, creberrime fortiter profundeque punctata, interstitiis rugulosis, humeris et anterius prope suturam torulosa. Abdomen fortius dense punctatum, niidlulum, distinctius cinereo-micans, dorso segmentis 4 anterioribus singulis summa basi carinatis. Pedes testacei, coxis geniculisque anguste nigris, tarsis elongatis, fuscescentibus.

Mas pectore impresso, longius densiusque griseo-pubescente, abdominis segmento inferiore quinto medio late longitudinaliter impresso, impressione lateribus posterius carina terminata, apice inter carinas utrinque denticuli instar prominulas leviter emarginato, sexto apice triangulariter exciso, femoribus posterioribus subincrassatis, interne densius pubescentibus. Femina abdominis segmento inferiore sexto apice summo emarginato.

*32. St. providus: Niger, creberrime punclatus, parce pubescens, palpis testaceis, apice piceis, fronte leniter excavata, bisulcala, thorace medio canaliculato, pedibus testaceis, genubus, tibiarum apice tarsisque fuscis. - Long. $2 \frac{1}{2}$ lin.

Er. Col. March. I. 546. 19.

\section{Habitat in Germania.}

Statura omnino et summa similitudo praecedentis. Niger, opacus, pube parca brevissima albida vix cinerascens. Antennae mediocres, articulo tertio quarto sesqui longiore, nigrae. Palpi testacei, articulo tertio apice piceo. Caput thorace paulo latius, creberrime fortiter profundeque punctatum, fronte leniter excavata, profundius bisulcata, interstitio leviter convexo, parum elevato. Thorax coleopteris vix dimidio angustior; lateribus ante medium rotundatis, posterius angustatus, basi coleopteris duplo angustior, latitudine summa paulo longior, leviter convexus, dense fortius profunde punctatus, interstitiis passim subrugulosis, medio canalicula brevi obsoletiore notatus. Elytra thoracis longitudine, subdepressa, dense fortiter profundeque punctata, interstitiis passun subrugulosis, dorso longitudinaliter, humeris leviter torosa. Abdomen minus fortiter crebre punctatum, nitidulum, distinctius cinereo-micans, dorso segmentis $\mathbf{4}$ anterioribus summa basi subtiliter carinatis. Pedes saturate testacei, coxis trochanteribusque nigris, femoribus apice, tibiis basi apiceque, tarsis totis fusco-piceis, his sat elongatis.

Mas pectore impresso, densius longiusque griseo-pubescente, abdomine infra segmentis 5 anterioribus longitudinaliter leviter impressis, impressione densius griseo-pubescente, lateribus a segmento secundo inde ciliis sensim longioribus, introrsum vergentibus, in segmento quinto carina, sensim magis prominente, apice in denticulum prorlucta terminata, hoc apice 
inter denticulos acutos late emarginato, segmento sexto profunde acuteque triangulariter exciso, femoribus posterioribus subincrassatis, posticis interne longius pubescentibus. Femina abdominis segmento inferiore sexto apice summo leviter emarginato.

Obs. Praecedenti simillimus, mas autem abdominis structura facile distinguendus, femina imprimis fronte paulo minus excavata, thorace dorso distinctius ranaliculato, antennis nigris, palpis apice fuscis et pedibus obscurioribus distincta.

* 33. St. scrutator: Niger, creberrime punctalus, parce pubescens, palpis basi pallide testaceis, fronte impressa, bisulcata, thorace obsolete canaliculato, pedibus piceis, femoribus basi testaceis. - Long. $2 \frac{1}{4}$ lin.

Sten. femoralis Er. Col. March. I. 547. 20.

Habitat in Germania.

Statura et summa affinitas praecedentium et parum minor, niger, opacus, pube brevissima depressa albida parciore vix cinerascens. Antennae tenues, articulo tertio quarto sesqui longiore, nigrae. Palpi picei, articulo primo toto, secundo basi, tertio summa basi testaceis. Caput thorace paulo latius, confertim fortius profunde punctatum, fronte medio excavata, profunde late bisulcata, interstitio convexo, modice elevato. Thorax antrorsum leviter rotundatus, coleopteris dimidio angustior, posterius angustatus, basi coleopteris plus duplo angustior, latitudine summa paulo longior, subcylindricus, creberrime fortius profunde punctatus, interstitiis subrugulosis, medio obsolete canaliculatus. Elytra thorace tertia parte longiora, parum convexa, fortiter profundeque dense punctata, interstitiis subrugulosis, anterius versus suturam longitudinaliter leviter torosa. Abdomen supra apicem versus sensim subtulius dense punctatum, segmentis singulis basi subtiliter carinatis, minus dense subtilius punctatum, nitidum. Pedes picei, coxis nigris, femoribus ultra medium piceo-testaceis, tarsis elongatis.

Mas pectore leviter impresso, haud villoso, abdominis segmento inferiore sexto apice inciso, quinto medio late impresso, impressione laevi, utrinque carina elevata, apice prominula terminata, apice late emarginata, quinto medio leviter impresso; femina segmento inferiore sexto apice summo subemarginato.

Obs. 1. A praecedentibus praeter palpos pedesque obscuriores et abdominis in maribus structuram praecipue elytris longioribus distinctus.

2. St. femorati (n. 43.) causa nomen mutavi.

* 34. St. sylve st er: Niger, creberrime punctalus, parce pubescens, palpis testaceis, articulo tertio fusco, fronte leviter excavata bisulcataque, thorace obsolete canaliculato, pedibus piceis, femoribus tesiaceis. - Long. 2 lin.

Er. Col. March. I. 547. 21.

Habitat in Germania.

Habitus et summa affinitas St. speculatoris, at duplo fere minor, niger, opacus, pube brevissima depressa albida parca vix cinerascens. Antennae mediocres, articulo tertio quarto sesqui longiore, nigro-piceae, articulis priunis duobus nigris. Palpi testacei, articulo ultimo fusco. Caput thorace paulo latius, confertissime fortus punctatum, punctis confluentibus subruguinsum. fronte leviter excavata, medio bisulcata, interstitio leviter convexo, 
parum elevato. Thorax coleopteris vix dimidio angustior, medio modice rotundatus, posterius fortius angustatus, basi coleopteris plus duplo angustior, latitudine summa paulo longior, subcylindricus, confertissime fortiter profundeque punctatus, interstitiis rugulosis, dorso medio obsolete canalıculatus. Elytra thorace parum longiora, dense fortiter profundeque punctata, interstitiis subrugulosis, anterius versus suturam longitudinaliter torulosa. Abdomen coleopteris paulo angustius, apicem versus sensim subtilius crebre punctatum; supra segmentis singulis basi subtiliter carinatis. Pedes piceotestacei, coxis nigris, femoribus apice tarsisque picescentibus.

Mas abdominis segmento inferiore sexto apice triangulariter exciso, quinto medio late impresso, impressione laevissima, utrinque carinula elevata, postice denticuli instar prominula terminata, apice late emarginata, quarto tertio secundoque apicem versus triangulariter impressis, impressionibus sensim obsoletioribus, laevibus; femina segmento sexto apice acute rotundato.

* 35. St. augur: Nigro-subaeneus, parum nitidus, creberrime fortiterque punctatus, palpis albidis, antennis pedibusque testaceis, femoribus apice picescentibus, fronte excavala, medio subcarinata, abdomine crebre subtilius punctato. - Long. $2 \frac{3}{4}$ lin.

Habitat in Columbia, Dom. Moritz.

St. speculatore paulo maior, nigro-subaeneus, nitidulus, pube brevi depressa albida passim densiore praecipue in abdomine variegatus. Antennae testaceae, clava angusta, fusca, articulo tertio quarto sesqui longiore. Palpi albidi. Caput thorace paulo latius, confertissime prófunde punctatorugulosum, fronte late excavata, in fundo obsolete bisulcata, interstitio angusto, parum elevato, subearinato. Thorax lateribus rotundatus, coleopteris paulo angustior, basin versus paulo magis quam apicem versus angustatus, basi coleopteris dimidio angustior, latitudine summa haud longior, convexus, crebre fortiter punctatus, transversim rugosus, medio obsolete canaliculatus. Elytra thorace paulo longiora, dense profunde fortiterque punctata, interstitiis subrugosis, prope suturam longitudinaliter torosa. Abdomen coleopteris angustius, apicem versus sensim angustatum, dense subtilius punctatum, dorso segmentis singulis basi carinatis. Pedes testacei, coxis nigris, femoribus apice late piceis, maris leviter incrassatis.

Mas abdomims segmento inferiore sexto per totam fere longitudiuem inciso; femin a eodem integro, apice rotundato.

* 36. St. metallicus: Niger, supra viridi-cupreus, profunde creberrime rugoso-punctatus, palpis albidis, antennis pedibusque teslaceis, thorace obsolete canaliculato. - Long. 2 lin.

Habitat in montibus prope Puerto Cabello Columbiae, Dom. Moritz.

Statura omnino St. speculatoris, at paulo minor, subtus niger, nitidus, supra obscure viridi-cupreus, nitidus, parce subtiliterque albido-pubescens. Antennae graciliores, articulo tertio quarto sesqui longiore, testaceae, articulo prumo flavo, clava fuscescente. Palpi albidi, articulo tertio pallide flavo. Caput thorace paulo latius, profunde rugaso-punctatum, fronte late leniter excavata, in medio profundius bisulcata, interstitio angusto, haud 
elevato, subcarinato, anterius leviter tricarinata. Thorax lateribus ante medium leviter rotundatis, coleopteris plus dimidio angustior, posterius angustatus, basi coleopteris plus duplo angustior, latitudine summa paulo longior, dorso subdepressus, creberrime profunde rugoso-punctatus, obsolete canaliculatus. Elytra thorace vix longiora, profunde creberrime punctata, interstitiis rugulosis, versus suturam longitudinaliter obsolete torosa. Abromen apicem versus sensim leviter angustatum, segmentis dorsalibus anterioribus crebre, posterioribus parce punctatis, inferioribus omnibus parce profundeque punctatis. Pedes testacei, coxis concoloribus, maris modice incrassati.

Mas ahdomine infra per totam longitudinem medio planato, segmento sexto profunde inciso; femina eodem apice acuminato.

* 37. St. croceipes: Niger, parum nilidus, subtiliter albido-pubescens, dense profundeque punctatus, palpis pallide lestaceis, antennis pedibusque testaceis, fronte leniler excavala, abdomine subtiliter punctato. Long. $1 \frac{2}{3}$ lin.

Habitat in montibus prope Puerto Cabello Columbiae, Dom. Moritz.

Niger, subnitidus, pube subtili densiore cinerascens. Antennae graciliores, articulo tertio quarto paulo longiore, testaceae, clava fuscescente. Palpi pallide testacei. Caput thorace sesqui latius, creberrime profundius punctatum, fronte late leniter excavata, medio leviter bisulcata, interstitio angusto, leviter elevato, subcarinato, antice leviter tricarinulata. Thorax lateribus ante medium leviter rotundatis, coleopteris duplo prope angustior, posterius angustatus, basi coleopteris triplo fere angustior, latitudine summa paulo longior, 'subcylindricus, profunde creberrime punctatus, interstitiis transversim subrugulosis, aequalis. Elytra thorace paulo longiora, densius profunde punotata, interstitiis vix rugulosis, dorso prope suturam longitudinaliter leviter torosa. Abdomen thorace paulo angustius, apicem versus sensim angustatum, confertim subtiliter punctatum, densius pubescens, segmentis dorsalibus anterioribus basi subtiliter carinatis. Pedes in utroque sexu graciles, testacei, coxis nigris.

Mas abdominis segmento inferiore tertio apice medio late leviter impresso, quinto apice triangulariter impresso, impressione utrinque carinula apice prominula terminata, sexto profunde inciso; femina segmento sexto apice testaceo, rotundato.

38. St. palpalis: Niger, fortiter punctatus, densius albido-pubescens, palpis albidis, antennis pedibusque testaceis, fronte excavala, abdomine subtiliter punctalo, - Long. $1 \frac{2}{3}$ lin.

Habitat in montibus prope Puerto Cabello Columbiae, Dom. Moritz.

Statura fere praecedentis, niger, nitidus, pube depressa cinerascens. Antennae elongatae, tenues, articulo quarto prope tertio aequali, testaceae, clava angusta, fuscescente. Palpi toti albidi. Caput thorace multo latius, oculis sat magnis, prominentibus, crebre minus fortiter punctatum, fronte profunde excavata, medio bisuleata, sulcis angustis, approximatis, interstitio angusto, vix elevato, subcarinato, laeviore, antice leviter tricarinata. Thorax medio rotundatus et coleopteris dimidio angustior, basi coleopteris duplo fere angustior, latitudine summa paulo longior, convexus, crebre sat fortiter 
profundeque punctatus, interstitiis transversim rugulosis. Elytra thorace parum longiora, subconvexa, crebre fortiter profundeque punctata, interstitiis vix rugosis, versus suturam longitudinaliter subelevata. Abdomen coleopteris angustius, apicem versus sensim attenuatum, confertim subtiliter punctatum, dense griseo-pubescens, segmentis dorsalibus anterioribus basi subtiliter carinatis. Pedes testacei, coxis omnibus nigra-picess, maris modice incrassati.

Mas abdomine infra secundum longitudinem ad segmentum quintum usque late impressum, seginento sexto apice profunde inciso. Femina latet.

39. St. agilis: Niger, nilidus, crebre profundeque punctatus, palpis albidis, antennis pedibusque testaceis. - Long. $1 \frac{1}{2}$ lin.

Habitat prope La Guayra Columbiae, Dom. Moritz.

Niger, nitidus, parce tenuissime pubescens. Antennae obscure testaceae, clava fuscescente. Palpi albidi, articulo tertio pallide flavescente. Caput thorace latius, crebre fortiter profundeque punctatum, fronte late impressa, fundo carina longitudinali laevi leviter elevata. Thorax basi coleopteris duplo fere angustior, lateribus ante medium rotundato-ampliatus, latitudine summa longior, subcylindricus, creberrime profunde fortiterque punctatus, aequalis. Elyrra thorace parum longiora, punctis magnis profundis dense impressa, medio longitudinaliter subelevata. Ahdomen coleopteris angustius, apicem versus sensim leviter angustatum, crebre minus subtiliter punctatum, tenuiter pubescens. Pedes flavo-testacei, coxis nigris.

Mas latet.

* 40. SI. fossulatus: Plumbe-niger, nitidulus, dense punclatus, densins albido-pubescens, palpis testaceis, pedibus testaceis, tibiis apice geniculisque fuscis, coleopteris pone' sculellum impressis. - Long. $2 \frac{1}{2}$ lin.

Habitat in Saxonia, Dom. Märkel.

Statura omnino St. lustratoris, plumbeo-niger, subnitıdus, pube minus brevi subtilique albida densiore einerascens. Antennae mediocres, articulo tertio quarto sesqui longiore, piceae, ariculis duobus primis nigerrimis. Palpi testacei, articulo tertio ante apicem picescente. Caput thorace paulo latius, dense profundius punctatum, fronte leniter exeavata, medio bisulcata, sulcorum interstitio convexo, leviter elevato, subtiliter curinato. Thorax coleopteris dimidio angustior, lateribus ante medum rotnindatis, posterius angustatus, basi coleopteris plus duplo angustior, latitudine summa paulo longior, confertim fortius profunde punctatus, subrugulosus, dorso nedio obsolete canaliculatus, lateribus medio utrinque leviter oblique impressus. Elytra thorace vix longiora, dense fortiter profundeque punctata, interstitiis subrugulosis, humeris et dorso ante medium longitudinaliter torosis, spatio communi infra scutellum orbiculari depressiore et leviter impresso. Abdomen coleopteris paulo angustius, apicem versus sensim angustatnm, dense minus subtiliter punctatum. Pedes testaces, coxis nigris, femoribus apice latiore, tibiis basi et apice, tarsorum elongatorum articulis singulis summo apice nigricantibus.

Mas abdominis segmento inferiore sexto apice triangulariter exciso, quinto medio late longitudinaliter impresso, impressione lateribus carina ob- 
tusa, pilis longioribus griseis ciliata terminata, apice inter carinas sinuato, quarto apice obsoletius longitudinaliter impresso, apice vix sinuato; f e mina segmento quinto apice late leviter emarginato, sexto apice rotundato.

* 41. St. lustrator: Plumbeo-niger, subnitidus, dense punctalus, subtiliter albido-pubescens, palpis basi albidis, pedibus testaceis, femoribus apice, tibiis tarsisque piceis. - Long. $2 \frac{1}{4}-2 \frac{1}{2}$ lin.

Er. Col. March. 1. 548. 22.

Habitat in Germania, in Gallia Mus. Dom. Aubé.

Plumbeo-niger, nitidulus, pube breviuscula depressa albida parciore subcinereis. Antennae longiores, tenues, articulo tertio quarto sesqui longiore, nigrae. Palpi nigri, articulo primo toto, secundo basi testaceo - albidis. Caput cum oculis thorace sesqui latius, dense fortius punctatum, fronte late leniter excavata, medio profundius bisulcata, interstitio leviter convexo, parum elevato. Oculi permagni. Thorax coleopteris vix dimidio angustior, lateribus paulo ante medium fortius rotundatis, posterius fortius angustatus, basi coleopteris plus duplo angustior, latitudine summa vix longior, convexus, aequalis, dense fortiter profundeque punctatus, interstitiis vix rugulosis, nonnunyuam obsolete canaliculatus. Elytra thorace paulo longiora, dense fortiter profundeque punctata, interstitiis subrugnlosis, leviter convexa, anterius versus suturam longitudinaliter torulosa. Abdomen minus subtiliter crebre punctatum, dorso convexum, segmentis singulis basi subtiliter carinatis. Pedes picei, coxis nigris, femoribus basi ultra medium testaceis, tarsis elongatis.

Mas abdominis segmento inferiore sexto apice triangulariter exciso, quinto utrinque carinato, carinis fortiter compressis, acutis, medio valde prominulis, spatio inter carinas vix impresso, polito, medio obsolete carinato, apice emarginato, segmentis antecedentibus tribus longitudinaliter late impressis, impressionis margine pilis longis flavescentibus dense ciliato; femina segmento sexto apice summo emarginato.

* 42. St. aterrimus: Subdepressus, aterrimus, crebre punclalus, antennis fusco-testaceis, basi nigris, palpis fuscis, basi testaceis, pedibus piceotestaceis. - Long. $2 \frac{1}{2}$ lin.

Er. Col. March. I. 549. 23.

Habitat in Germania, Gallia: Berolini, Dom. Schüppel, in Saxonia Dom. Märkel, Lutetiae, Dom. Aubé.

Habitus et statura St. tempestivi, aterrimus, vix nitidus, pube albida brevissima, subtilissima, parca, vix observanda. Antennae longiores, tenues, articulo tertio quarto paulo longiore, fusco-testaceae, articulis duobus primis nigris. Palpi picei, articulo primo toto, secundo basi testaceo. Caput transversum, thorace sesqui latius, nitidum, minus dense punctatum, fronte vix impressa, late obsoletius bisulcata, sulcorum interstitio parum convexo. Thorax lateribus ante medium modice rotundatis, statim pone medium angustatus, basi coleopteris plus duplo angustior, latitudine summa paulo longior, dense minus fortiter punctatus, punctorum interstitiis planis, dorso medio foveola minuta oblonga, pone medium utrinque obsolete oblique impressus. Coleoptera lata, thorace paulo longiora, parum convexa, minus profunde fortius densiusque punctata, interstitiis planis. Abdomen coleopte- 
ris angustius, apicem versus sensim angustatum, parcius subtiliusque punctatum, nitidum. Pedes picei vel rufo-picei, femoribus omnibus basi, anticis cum coxis trochanteribusque dilutioribus, tarsis valde elongatis.

M as abdominis segmento inferiore quinto apice late leviter emarginato, sexto triangulariter exciso; femin a eodem apice leviter producto, rotundato.

Obs. A D. Aubé et Märkel in Formica e rufae societatibus lectus.

* 43. St. femoratus: Niger, dense punctalus, parce pubescens, palpis articulo primo testaceo, fronte leviler bisulcala, thorace oblongo, medio obsolete canaliculato, elytris thorace longioribus, pedibus ferrugineis. Long. $1 \frac{1}{2}$ lin.

Say Transact. Amer. Philosoph. Soc. Philadelph. Nov. Ser. IV. 459. 4.

Hábitat in America septentrionali Knoch, e Pensylvania quoque frequens a Dom. Zimmermann missus.

Statura omnino sequentium, niger, parum nitidus, pube brevissima albida rariore vix cmerascens. Antennae mediocres, articulo tertio quarto paulo longiore, piceae, articulis duobus primis nigris. Palpi fusci, articulo primo toto, secundo basi pallide testaceo. Caput thorace sesqui prope latius, dense fortius profundiusque punctatum, fronte levissime excavata, late bisulcata, interstitio leviter convexo, parum elevato. Thorax coleopteris dimidio angustior, lateribus anterius rotundatus, posterius angustatus, basi coleopteris plus dimidio angustior, latitudine paulo longior, subcylindricus, fortius crebre punctatus, interstitiis subrugulosis, medio obsolete canaliculatus. Elytra thorace paulo longiora, subdepressa, fortiter profundeque dense punctata, interstitiis subrugulosis, anterius versus suturam longitudinaliter leviter torosa. Abdomen apicem versus sensim leviter angustatum, late emarginatum, confertim minus subtiliter punctatum. Pedes saturate rufo-testacei, coxis piceis, femoribus apice picescentibus, tarsis modice elongatis.

Mas abdominis segmento inferiore sexto apice leviter triangulariter exciso, quinto late emarginato; femina segmento sexto apice rotundato.

* 44. St. proditor: Niger, crebre punctatus, parce pubescens, palpis arliculis duobus primis teslaceis, fronte fortius bisulcata, thorace oblongo, obsolete canaliculato, elytris thoracis longitudine, femoribus basi rufopiceis. - Long. $1 \frac{2}{3}$ lin.

Er. Col. March. 1. 550. 24.

Habitat in Germania septentrionali.

Statura St. Argi. Niger, parum nitidus, pube brevi albida parca vix cinerascens. Antennae mediocres, articulo tertio quarto sesqui longiore, piceae, articulo primo nigro. Palpi testacei, articulo tertio fusco, secundo nonnunquam apice fuscescente. Caput thorace latius, crebre minus fortiter at profunde punctatum, fronte leviter excavata, fortius bisulcata, interstitio convexo, sat elevato, subcarinato. Thorax coleopteris vix dimidio angustior, ante medium rotundatus, posterius angustatus, basi coleopteris duplo angustior, latitudine summa vix longior, crebre fortius punctatus, interstitiis vix rugulosis, obsolete canaliculatus. Elytrá thoracis longitudine, dense profundeque sat fortiter punctata, interstitis vix rugulosis, anterius versus suturam longitudi- 
dinaliter leviter torosa. Abdomen minus confertim subtilius punctatum. Pedes nigro-picei, femoribus basi ultra medium rufo-piceis, tarsis modice elongatis.

$M$ as abdominis segmento inferiore sexto apice leviter triangulariter exciso, quinto longitudinaliter impresso, impressione apicem versus latiore, utrinque carina levi, antrorsum obsolescente terminata, apice inter carinas profundius sinuato; fe min a segmento sexto apice leviter producto, rotundato.

Variat pedibus totis nigro-piceis.

Obs. A St. Argo praeter abdominis in mare structuram differt colore magis nigro, elytris brevioribus, fronte profunde bisulcata, interstitio sat elevato. Forte ob frontis structuram merus St. Argus Grav. videatur, quem secundum specimina typica ad speciem mox describendam retuli.

*45. St. excubitor: Plumbeo-niger, nitidulus, albido-pubescens, crebre fortiterque punctatus, palpis articulo primo testaceo, fronte subimpressa, obsolete bisulcata, thorace oblongo, aequali, elytris thoracis longitudine, pedibus rufo-brunneis. - Long. $1 \frac{2}{3}$ lin.

Er. Col. March. I. 551. 25.

Habitat Berolini, Dom. Schiippel.

St. Argo proximus, plumbeo-niger, nitidulus, pube subtili albida densiore cinerascens. Antennae mediocres, articulo tertio quarto paulo longiore, obscure piceae, articulo primo nigro. Palpı nigro-picei, articulo primo pallide testaceo. Caput thorace sesqui latius, dense fortius profunde punctatum, fronte levissime excavata, medio late obsoletius bisulcata, interstitio latiore, perparum convexo, vix elevato. Thorax coleopteris paulo angustior, ante medium leviter rotundatus, posterius angustatus, basi coleopteris duplo prope angustior, latitudine summa vix longior, subcylindriens, aequalis, densius fortiter profundeque punctatus, interstitiis punctorum planis. Elytra thoracis longitudine, subdepressa, anterius versus suturam levissime torosa, densius fortiter profundeque punctata, interstitiis punctorum planis. Abdomen parcius subtiliter punctatum, late marginatum. Pedes rufo-brunnei, tarsis leviter elongatis.

Mas abdominis segmento inferiore sexto apice leviter triangulariter exciso, quinto late leviter emarginato; femina segmento sexto apice rotundato.

Obs. A praecedente differt colore et frontis structura, a sequente fronte leviter excavata, elytris brevioribus et abdomine minus anguste marginato distinguendus.

* 46. St. Argus: Plumbeo-niger, subnitidus, albido-pubescens, crebre profundeque punctalus, palpis articulo primo testacen, fronle obsoletius bisulcata, thorace oblongo, aequali, ely/ris thorace longioribus, femoribus basi rufo-piceis. - Long. $1 \frac{1}{2}-1 \frac{2}{3}$ lin.

Grav. Mon. 231. 12. - Er. Col. March. I. 352. 26.

Sten. opticus Gyll. Ins. Suec. IV. 504. 13-14. - Sahlb. Ins. Fenn. I. 431. 18.

- Mannerh. Brachelytr. 44. 20. - Runde Brachelytr. Ilal. 17. 14.

Habitat in Germania.

Plumbeo-niger, nitidulus, pube brevi depressa albida densiore cinera- 
scens. Antennae mediocres, articulo tertio quarto paulo longiore, nigropiceae, articulis duobus primis nigris. Palpi nigri, articulo primo testaceo. Caput thorace paulo latius, dense fortiter profundeque punciatum, fronte planiuscula, obsolete late bisulcata, interstitio perparum convexo. Thorax anterius leviter rotundatus, coleopteris dimidio angustior, posterius angustatus, basi coleopteris plus duplo angustior, latitudine summa vix longior, subcylindricus, aequalis, dense aequaliter fortiter profundeque punctatus, interstitiis planis. Elytra thorace paulo longiora, leviter convexa, dense aequaliter sat fortiter profundeque punctata, anterius versus basin obsolete torosa. Abdomen subcylindricum, minus late marginatum, subtilius minus dense punctatum. Pedes picei vel rufo-picei, femoribus basi ultra medium dilutioribus, tarsis leviter elongatis, articulo quarto subcordato.

$\mathrm{M}$ as abdominis segmento inferiore sexto apice leviter triangulariter exciso, quinto leviter emarginato; $\mathrm{fem}$ in a segmento sexto apice rotundato.

$\mathrm{Obs}$. A praecedentibus abdomine subcylindrico et tarsorum articulo quarto subcordato discedens, ceterum primo intuitu St. morioni et cinerascenti similis.

* 47. St. cautus: Plumbeo-niger, nilidulus, albido-pubescens, crebre profundeque punctatus, capile elytris dimidio angustiore, fronte forlius bisulcata, thorace oblongo, aequali, elytris thorace longioribus, pedibus palpis antennisque brunneis, his articulo primo nigro. - Long. $1 \frac{1}{3}$ lin.

Er. Col. March. I. 553. 27.

Habitat Berolini.

Praecedente paulo minor, statura omnino St. atratuli, plumbeo-niger, pube brevi subtili albida densiore cinerascens. Antennae mediocres, articulo tertio quarto paulo longiore, piceae, articulo primo nigro. Palpi picei, articulo primo testaceo. Caput thorace paulo latius, coleopteris plus dimidio angustius, densius fortiter profundeque punctatum, fronte haud excavata, late at parum profunde bisulcata, interstitio convexo, elevato. Thorax coleopteris plus dimidio angustior, lateribus ante medium modice rotundatus, posterius angustatus, basi coleopteris plus duplo angustior, aequalis, densius fortiter profundeque punctatus, interstitiis punctorum planis, vix rugulosis. Elytra thorace tertia parte longiora, subdepressa, densius fortiter profundeque punctata, interstitiis vix rugulosis. Abdomen coleopteris angustius, apicem versus sensim leviter angustatum, late marginatum, densius subtilius punctatum. Pedes rufo-brunnei, tarsis breviusculis.

Mas abdominis segmento inferiore sexto apice leviter emarginato; femina eodem rotundato.

$\mathrm{Obs}$. Statura intermedius inter St. Argum et fuscipedem, ab utroque fronte profundius bisulcata, elytris longioribus et abdomine late marginato distinctus.

* 48. St. vafellus: Niger, nitidulus, albido-pubescens, forliter punclatus, capite elytrorum latitudine, fronte fortius bisulcata, thorace oblongo, aequali, elytris thorace longioribus, palpis fuscis, articulo primo testaceo, pedibus rufo-brunneis. - Long. $1 \frac{1}{3}$ lin.

Er. Col. .March. I. 554. 28.

Hahitat Berolini.

Statura omnino St. fuscipedis, subplumbeo-niger, nitidulus, pube albida 
parca leviter cinerascens. Antennae mediocres, articulo tertio quarto paulo longiore, obscure piceae, articulo primo nigro. Palpi fusci, articulo primo testaceo. Caput thorace paulo latius, coleopteris latitudine aequale, densius fortiter profundeque punctatum, fronte haud excavata, late et parum pro. funde bisulcata, sulcorum interstitio sat convexo. Thorax coleopteris paulo angustior, lateribus anterius modice rotundatus, posterius angustatus, basi coleopteris duplo prope angustior, latitudine summa parum longior, subcylindricus, aequalis, densius fortiter profundeque punctatus, punctorum interstitiis planis. Elytra thorace paulo longiora, depressiuscula, aequalia, densius fortiter profundeque punctata, interstitiis planis. Abdomen coleopterorum latitudine, late marginatum, parce subtiliterque punctatum, pube densiore grisescente vestitum. Pedes rufo-brunnei, coxis nigris, tarsis breviusculis.

Mas latet. Femina abdominis segmento inferiore sexto apice subacuminato.

Obs. Affinis praecedenti, at minor, et coleopteris angustioribus distinctus. A St. fuscipede punctura subtiliore et abdomine late marginato, a St. Argo statura minore, frontis interstitio sulcorum magis elevato et coleopteris angustioribus depressis aequalibus differt.

* 49. St. fuscipes: Niger, subnilidus, griseo-pubescens, palpis fuscis, articulo primo flavo, pedibus ferrugineis, fronte planiuscula, obsolete bisulcata, thorace oblongo, aequali, elytris thoracis longiludine, abdomine tenuiler marginato. - Long. $1 \frac{1}{3}-1 \frac{1}{2}$ lin.

Grav. Micr. 157. 8. Mon. 232. 13. - Latr. Hist. nat. Crust. et Ins. IX. 354. 8. Gyll. Ins. Suec. II. 478. 13. - Sahlb. Ins. Fenn. I. 431. 17. - Zetterst. Fann. Lappon. I. 89. 8. Ins. Lappon. 70. 9. - Mannerh. Brachelytr. 44. 19. - Runde Brachelytr. Hal. 17. 13. - Er. Cal. March. I. 555. 30.

St en. fulvipes Boisd. et Lacord. Faun. Ent. Paris. I. 446. 9.

Habitat in Europa.

Niger, subnitidus, pube brevi crassiuscula albida minus conferta subcinerascens. Antennae breviusculae, piceae, articulis duobus primis nigris, tertio quarto sesqui longiore. Palpi nigro-picei, articulo primo testaceo. Caput thorace vix sesqui latius, dense sat fortiter profundeque punctatum, fronte planiuscula, late at parum profunde bisulcata, interstitio lato, perparum elevato, antice subcarinato. Thorax coleopteris parum latior, medio et anterius satis fortiter rotundatus, posterius angustatus, basi coleopteris dimidio angustior, latıtudine paulo longior, subcylindricus, aequalis, densius fortiter profundeque punctatus, interstitiis planis. Elytra thorace vix longiora, apice oblique truncata, aequaliter profunde fortiterque punctata, interstitiis planis, anterius versus suturam obsolete torulosa. Atae coleopteris vix duplo longiores. Abdomen subcylindricum, tenuius marginatum, parcius subtiliusque punctatum, nitidum. Pedes saturate rufo-testacei vel dilutius rufo-brunnei, coxis nigris, geniculis picescentibus, tarsis breviusculis.

Mas abdominis segmento inferiore sexto apice leviter emarginato; femin a eodem apice leviter producto, acute rotundato.

* 50. St. humilis: Apterus, niger, densius albido-pubescens, palpis testaceis, articulo lertio fusco, pedibus ferrugineis, fronte planiuscula, bisulcala, elytris depressis, thorace subbrevioribus. - Long. $1 \frac{1}{2}$ lin.

Er. Col. Mareh. 1. 55 1, 29. 
Sten.fuscipes Ljungh Web. Beitr. II. 159. 13.

Sten. Argus Gyll. Ins. Suer. IV. 503. I2-13. - Sahlb. Ins. Fenn. I. 430. 19. Mannerh. Brachelytr. 4318.

Sten. carbonarius Boisd. et Lacord. Faun. Ent. Paris. I. 450. 17.

Habitat in Germania.

St. fuscipede parmn maior, depressiusculus, apterus, niger, opacus, pube hrevissima albida parciore subcinerascens. Antennae breves, articulo tertio quarto paulo longiore, piceae, articulis duobus primis nigris. Palpi testacei, articulo tertio fusco. Caput thorace paulo latius, dense profundeque punctatum, fronte vix impressa, obsolete late bisulcata, interstitio lato vix convexo elevatoque. Thorax medio coleopteris dimidio prope angustior, lateribus rotundatus, basi coleopteris duplo angustior, latitudine haud longior, subdepressus, creberrime profunde punctatus, interstitiis rugulosis, dorso utrinque leviter oblique impressus. Elytra thoracis vix longitudine, apice oblique truncata, subdepressa, confertissime profunde punctata, interstitiis subrugulosis. Abdomen latius marginatum, dense profunde punctatum, subnitidum. Pedes rufescenti-testacei, coxis nigris, femoribus apice picescentibus, tarsis breviusculis.

Mas abdominis segmento inferiore sexto apice leviter triangulariter exciso, quinto late longitudmaliter subimpresso, apice emarginato; fe mina segmento sexto apice rotundato.

* 51. St. circularis: Niger, parum nitidus, thorace rotundato, palpis totis, antennis pedibusque teslaceis. - Long. $1-1 \frac{1}{4}$ lin.

Grav. Micr. 157. 8. - Latr. Hist. nat. Crust. et Ins. 1X. 354. 9. - Ir. Col. March. I. 556. 31.

Habitat in Europa.

Minutus, depressiusculus, niger, opacus, pube brevi subtilique albida parcius adspersus. Antennae breviores, articulo tertio quarto parum longiore, piceo-testaceae, articulis duobus primis dilntioribus, apice piceae. Palpi toti flavo-testacei. Caput thorace paulo latius, creberrime punctatum, fronte planiuscula, late et parum profunde bisulcata, interstitio lato, leviter convexo, parum elevato, antice subcarinato. Thorax coleopteris plus dimidio angustior, lateribus sat fortiter rotundatus, posterius fortius angustatus, basi coleopteris triplo angustior, latitudine brevior, parum convexus, confertissime profundius punctatus, interstitis rugulosis. Elytra thorace sesqui longiora, creberrime profunde punctata, interstitiis rugulosis, anterius versus suturam obsolete torosa. Abdomen breviusculum, apicem versus sensim attenuatum, late marginatum, dorso subdepressum, subtilius parciusque punctatum, nitidulum. Pedes saturate rufo-testacei, coxis piceis, geniculis vix fuscescentibus, tarsis breviusculis.

Mas abdominis segmento inferiore sexto apice leviter emarginato; femin a eodem rotundato.

* 52. St. declaratus: Niger, nilidulus, fronte plana, bisulcata, thorace rotundalo, palpis pedibusque piceo-teslaceis, illis articulo tertio, his geniculis fuscis. - Long. $1 \frac{1}{4}$ lin.

Er. Col. March. I. 557. 32.

Sten. circularis Grav. Mon. 233. 15. - Gyll. Ins, Suec. II. 479. 11. - Sahlb. 
Ins. Fenn. I. 432. 20. - Zetterst. Ins. Lappon. 71. 13. - Mannerh. Brachelytr. 44. 22. - Boisd. et Lacord. Fuun. Ent. Paris. I. 451. 18. - Runde Brachelytr. Hal. 17. 16.

\section{Habitat in Europa.}

Statura minuta et summa similitudo praecedentis. Niger, subnitidus, pube brevissima albida subcinerascens. Antennae breves, articulo tertio quarto panlo longiore, nigro-piceae, articulis duohus primis nigris. Palpi piceo - testacei, articulo tertio nigro-piceo. Caput thorace panlo latius, crehre punctatum, fronte vix impressa, profunde bisulcata, interstitio sat elevato, subcarinato. Thorax coleopteris plus dimidio angustior, lateribus fortuter rotundatus, posterius magis angustatıs, coleopteris triplo fere angustior, latitudine summa paulo brevior, convexiusculus, aequalis, creberrime fortius punctatus, interstitiis vix rugulosis. Elytra thorace sesqui longiora, confertim profunde punctata, interstitiis subrugulosis, anterius versus basin leviter torosa. Abdomen breviusculum, apicem versus sensim angustatum, late marginatum, subtilius parciusque punctatum, nitidulum. Pedes rufo-picei, geniculis obscurioribus, coxis nigris, tarsis breviusculis.

Mas abdominis segmento inferiore sexto apice leviter emarginato; femin a eodem apice rotundato.

Obs. Differt a praecedente corpore paulo magis depresso, magis cinerascente, fronte profundius bisulcata, interstitio sulcorum magis elevato, thorace elytrisque minus rugulosis, pedibus obscurioribus, palpis apice piceis, antennis piceis, basi nigris.

* 53. St. pumilio: Niger, parum nitidus, fronte impressa, thorace rotundato, palpis nigris, articulo primo testaceo, pedibus testaceo-piceis. - Long. $\frac{5}{6}$ lin.

Er. Col. March. I. 558. 33.

Habitat in Germania.

Proximus praecedentibus duobus, at dimidio prope minor, niger, vix nitidus, pube albida subtilissima parca haud cinerascens. Antennae breviusculae, articulo tertio quarto subaequali, nigro-piceae, articulis duobus primis nigris. Palpi nigro-picei, articulo primo testaceo. Caput thorace paulo latius, densius profunde fortiter punctatum, fronte levissime excavata, late bisulcata, interstitio angusto, leviter convexo, subcarinato. Thorax coleopteris plus duplo angustior, lateribus rotundatus, posterius vix magis quam anterius angustatus, basi coleopteris plus duplo angustior, latitudine summa prope brevior, leviter convexus, dense fortius profunde punctatus, interstitiis rugulosis. Elytra thorace sesqui longiora, leviter convexa, fortiter profundeque confertim punctata, interstitiis subrugulosis. Abdomen coleopteris angustius, apicem versus sensim angustatım, crebre profundeque punctatum, angustius marginatum. Pedes obscure testacei vel rufo-picei, geniculis vix obscurioribus, tarsis breviusculis, nigricantibus.

Mas abdominis segmento inferiore sexto apice triangulariter exciso, quinto late subemarginato; femin a segmento sexto apice rotundato.

Obs. Praecedentibus minor et minus depressus, a $\mathrm{St}$. circulari antennis palpisque nigricantibus et pedibus obscuriorious, a St. declarato colore haud cinerascente, frontis structura et palporum articulo secundo piceo distinctus. 


\section{B. A b.dom en: im marginat u m.}

* 54. St. nigritulus: Plumbeo-niger, densius profunde punclatus, albidopubescens, palpis arliculo primo testaceo, abdomine parcius subtiliter punctato. - Long. $1 \frac{1}{4}-1 \frac{2}{3}$ lin.

Gyll. Ins. Suec. IV. 502. 10 - 11. - Sahlb. Ins. Fenn. I. 429. 13. - Zetterst. Faun. Lapp. I. 91. 11. Ins. Lappon. 71. 14. - Mannerh. Bruchelyfr. 43. 14. Runde Brachelytr. Hal. 16. 11. - Er. Col. March. I. 559. 34.

Habitat in Europa.

Plumbeo-niger, nitidulus, pube breviuscula depressa albida cinerascens. Antennae breviusculac, articulo tertio quarto paulo longiore, nigrae. Palpi nigri, articulo primo piceo-testaceo. Caput thorace vix latius, dense fortiter profundeque punctatum, fronte planiuscula, obsoletius late bisulcata, interstitio leviter elevato, subcarinato. Thorax coleopteris dimidio angustior, lateribus anterius rotundatus, posterius angustius, basi coleopteris duplo angustior, latitudine summa paulo longior, subcylindricus, aequalis, densius aequaliterque fortiter profundeque punctatus, interstitiis planis. Elytra thorace paulo longiora, densius aequaliterque fortiter profundeque punctata, interstitiis planis, anterıus versus suturam longitudinaliter leviter torosa. Abdomen breviusculum, apicem versus sensim leviterque angustatum, parcius subtiliusque punctatum. Pedes nigri, tarsis breviusculis.

Mas abdominis segmento inferiore sexto apice levissime emarginato; femin a eodem rotundato.

V ariat pedibus piceis.

Obs. Magnitudo variat, maiores St buphthalmo, minores St. fuscipedi aequales, plerique statura St. morionis, ceterum mares plerumque minores, feminae maiores. In Lapponia se nonnisi specimina minimae staturae observasse Dom. Prof. Zetterstedt affert. - Habitu et colore similis $\mathrm{St}$. morioni; cinerascenti et imprimis atratulo, abdomine autem immarginato facile distinguendus.

* 55. St. campestris: Niger, conferlissime forliter punctalus, parcius albido-pubescens, palpis articulo primo testaceo, abdomine dense forlius punclalo. - Long. 2 lin.

Er. Col. March. I. 559. 35.

\section{Habitat in Germania.}

Affinis praecedenti, at paulo maior, niger, pube depressa albida subcinerascens. Antennae breves, articulo tertio quarto sesqui longiore, nigropiceae, articulo primo migro. Palpi nigro-picei, articulo primo pallide testaceo. Caput thorace paulo latius, dense fortiter profundeque punctatum, fronte haud impressa, late at parum profunde bisulcata, interstitio lato, levissime convexo, parum elevato. Thorax basi coleopteris dimidio angustior, lateribus anterius leviter rotundatus, posterius fortius angustatus, basi coleopteris duplo prope angustior, latitudine summa paulo longior, subcylindricus, aequalis, confertissime sat fortiter profundeque punctatus, interstitiis subrugulosis. Elytra thorace vix longiora, profunde fortiterque confertim punctata, interstitiis subrugulosis, anterius versus suturam obsolete torosa. Abdomen elongatum, cylindricum, segmentis quatuor primis basi leviter constrictis, dense sat fortiter profundeque punctatum. Pedes nigri, tarsis breviusculis, picescentibus. 
Mas abdominis segmento inferiore sexto apice leviter emarginato; femina eodem leviter producto, subacuminato.

Obs. A praecedente colore magis opáco, statura paulo maiore et magis elongata, abdomine cylindrico, fortius crebriusque punctato distinctus.

*56. SI. unicolor: Niger, dense fortiterque punctatus, albido-pubescens, palpis piceis, articulo primo testaceo, pedilus antennisque rufo-piceis, his basi nigris, abdomine crebre fortius punctalo. - Long. $1 \frac{2}{3}$ lin.

.Hâbitat in Anglia, Dom. Hope, in Lusitania, Com. Hoffmannsegg, in Hercynia, Dom. Saxesen, in Austria, Dom. Schüppel.

Statura omnino praecedentis, at paulo minor, niger, subnitidus, pube brevi depressa albida cinerascens. Antennae breves, articulo tertio quarto paulo longiore, piceae, articulis duobus primis nigris. Palpi nigro-picei, articulo primo toto, secundo basi pallide testaceo. Caput thorace paulo latius, fortiter profundeque crebre punctatum, fronte haud impressa, at late profundius bisulcata, interstitio convexo, aeque ac frontis latera elevato. Thorax coleopteris parum angustior, lateribus anterius rotundatus, posterius magis angustatus, basi coleopteris dimidio angustior, latitudine paulo longior, subcylindricus, dense sat fortiter profundeque punctatus, interstitiis subrugulosis. Elytra thoracis longitudine, apice oblique truncata, dense fortiter profundeque punctata, interstitiis planis, aequalia. Alae coleopteris vix duplo longiores. Abdomen cylindricuın, segmentis primis basi parum constrictis, crebrius fortiusque punctatum, subnitidum. Pedes rufo-brunnei, coxis geniculisque piceis.

Mas abdominis segmento inferiore sexto apice leviter emarginato; femin a eodem leviter producto, subacuminato.

Obs. 1. St. la tifronti similis, at tarsorum articulo quarto integro sat distinctus.

2. Specimina nom. St. nigri a Dahlio missa dedit Dom. Schüppel, at quem Com. Mannerheim sub nomine eodem (Brachelytr. 43. 13.) descripserit, mihi dubius est, cum abdomine marginato distinctus videatur. St. nigritulus Runde Brachelytr. Hal. 16. 11. forte magis ad hanc speciem vel ad St. latifrontem, quam ad Sten. nigritulum verum referenäus.

* 57. St. opticus: Niger, confertissime punctatus, parce albido-pubescens, palpis piceis, articulo primo testaceo, antennis pedibusque rufo-piceis, abdomine parcius subtiliter punctato. - Long. $1 \frac{1}{4}$ lin.

Grav. Mon. 231. 11. - Er. Col. March. I. 560. 36.

St en. femorellus Zetterst. Ins. Lappon. 71. 13.

Habitat in Europa.

Praecedentibus minor, St. circulari aequalis, niger, opacus, pube brevissima albida parca vix einerascens. Antennae breviusculae, articulo tertio quarto paulo longiore, piceae. Palpi picel, articulo primo testaceo. Caput thorace latius, creberrime punctatum, subrugulosum, fronte depressa, sulcis interstitioque elevato omnno fere obsoletis. Thorax coleopteris dimidio prope angustior, lateribus modice rotundatus, posterius magis angustatus, basi coleopteris duplo angustior, latitudine vix longior, subeylindricus, aequalis, confertissime minus fortiter at sat profunde punctatus, interstitiis subrugulosis. Elytra thorace paulo longiora, profunde fortius confertissime 
punctata, interstitiis subrugulosis, anterius versus suturam vix torosa. Abdomen coleopteris angustius, apicem versus sensim attenuatum, parcius subtiliter punctatum, nitidulum. Pedes rufo-picei, coxis nigris.

$M$ as abdominis segmento inferiore sexto apice leviter triangulariter exciso, quinto late leviter emarginato; femina segmento sexto apice acuminato.

58. St. chalcites: Nigro-subaeneus, nitidulus, fortiter punctatus, palpis pallidis, antennis pedibusque flavis, femoribus apice fuscis, abdomine subtiliter punctulato. - Long. $1 \frac{3}{4}$ lin.

Habitat in Columbia, Dom. Moritz.

Nigro-subaeneus, nititidus, lateribus parce albido-pnbescens. Antennae mediocres, articulo tertio quąrto paulo longiore, testaceae, apice obscuriores. Palpi pallide flavescentes. Caput thorace sesqui latius, crebre punctatum, fronte late excavata, obsolete bisulcata, interstitio vix elevato, angusto, evidenter carinato. Thorax coleopteris dimidio angustior, lateribus sat fortiter rotundatus, anterius et posterius aequaliter angustatus, basi coleopteris duplo angustior, latitudine haud longior, convexiusculus, crebre profundeque punctatus, transversim rugulosus. Elytra thorace paulo longiora, dense sat fortiter profundeque punctata, interstitiis subrugulosis, leviter convexa, anterius versus suturam leviter torosa. Abdomen coleopteris angustius, apicem versus sensim attenuatum, subtiliter punctulatum, supra segmentis singulis basi subtiliter carinatis, densius subtiliter dorso griseo-, lateribus albido-pubescens. Pedes flavo-testacei, coxis nigris, femoribus apice fuscescentibus, maris leviter incrassatis.

Mas abdominis segmento inferiore sexto profunde inciso; femina eodem apice acute rotundato.

\section{Tarsi articulo quàrto bilobo.}

A. Abdomen marginatum.

* 59. St. binotat us: Plumbeo-niger, confertim punctatus, densius albidopubescens, antennis palpisque piceis, his basi teslaceis, illis articulo primo nigro, - Long. $2 \frac{1}{2}$ lin.

Ljungh Weber u. Mohr Archiv. I. 1. 66. 6. - Grav. Mon. 229. 9. - Gyll. Ins. Suec. II. 474. 9. - Sahlb. Ins. Fenn. I. 427. 9. - Zetterst. Faun. Lappon. I. 89. 7. Ins. Lappon. 70. 8. - Mannerh. Brachelytr. 42. 9. - Buisd. et Lacord. Faun. Ent. Paris. I. 418. 12. - Runde Brachelytr, Hal. 16. 8. - Er. Col. March. I. 561. 37.

\section{Habitat in Europa.}

Elongatus, subdepressus, plumbeo-niger, parum nitidus, pube depressa albida aequaliter densius vestitus, incanus. Antennae breviusculae, articulo tertio quarto sesqui longiore, rufo-piceae, clava fuscá, articulo primo nigro. Palpi nigro-picei, articulo primo testaceo. Caput thorace paulo latius, crebrius minus fortiter punctatum, fronte planiuscula, inter oculos utrinque leviter impressa. Thorax coleopteris dimidio angustior, lateribus leviter rotundatus, latitudine summa paulo longior, depresso-cylindricus, crebre punctatus, interstitiis planis, dorso pone medium utrinque oblique impressus. Elytra thorace tertia parte longiora, dense minus fortiter profunde punctata, interstitiis pla- 
nis, aequalia. Abdomen crebre minus subtiliter punctatum. Pedes nigri, tarsis nigro-fuscis, brevibus, articulo tertio subcordato, quarto profunde bilobo.

M a s abdominis segmento inferiore sexto apice triangulariter exciso, quarto apice obsoletius impresso; femina segmento sexto apice triangulariter producto.

* 60. St. subimpressus: Plumbeo-niger, subtilius punctatus, densius albido-pubescens, antennis teslaceis, articulo primo nigro, tarsis palpisque piceis, his basi pallidis. - Long. $2 \frac{3}{4}$ lin.

Er. Col. March. I. 561, 3.

Habitat in Germania, Anglia.

St. binotato proximus, at duplo maior r, subdepressus, plumbeo-niger, subnitidus, pube depressa albida densiore incanus. Antennae breviores, articulo tertio quarto sesqui longiore, rufo-testaceae, apice vix obscuriores, articulo primo nigro. Palpi nigro-picei, articulo primo toto, secundo basi pallide testaceo. Caput thorace parum latius, crebre minus fortiter at pro. funde punctatum, fronte utrinque leviter impressa, interstitio leviter longitudinaliter convexo. Thorax coleopteris plus dimidio angustior, lateribus leviter rotundatus, latitudine summa parum longior, subdepressus, subtilius minus confertim punctatus, interstitiis planis, dorso pone medium utrinque oblique impressus. Elytra thorace sesqui prope longiora, crebrius subtilius at profunde punctata, interstitiis planis, anterius versus suturam obsolete torosa. Abdomen crebrius subtiliter punctatum. Pedes nigri, tarsis fuscescentibus, brevibus, articulo tertio cordato, quarto profunde bilobo.

Mas abdominis segmento inferiore sexto apice profunde semicirculariter exciso, quarto tertioque late semicirculariter impressis, impressione carinula leviter prominente utrinque terminata; femina segmento sexto apice medio triangulariter producto, acuminato.

* 61. St. plantaris: Plumbeo-niger, subtilius punclatus, densius albidopubescens, tarsis, palpis antennisque rufo-testaceis, his articulo primo nigro. - Long. $2 \frac{1}{2}$ lin.

Er. Col. March. I. 562. 39.

Sten. binotatus var. b Gyll. Ins. Suec. IV. 500, 9.

Habitat in Germania, Suecia.

Statura et summa affinitas St. binotati, at certe distinctus, elongatus, subdepressus, plumbeo-niger, subnitidus, pube depressa densiore incanus. Antennae breviores, articulo tertio quarto paulo longiore, testaceae, articulo primo nigro, clava ferruginea. Palpi toti testacei. Caput thorace paulo latius, subtilius punctatum, inter oculos utrinque leviter impressum, interstitio leviter convexo. Thorax coleopteris duplo prope angustior, lateribus leviter rotundatus, latitudine paulo longior, depresso-subcylindricus, subtilius at sat profunde crebrius punctatus, interstitiis planis, dorso pone medium utrinque oblique impressus. Elytra thorace sesqui fere longiora, densius minus fortiter profunde punctata, interstitiis planis, aequalia. Abdomen subtilius at sat profunde crebrius punctatum. Pedes nigri, tarsis testaceis, bre vibus, articulo tertio quartoque bilobis. 
Mas abdominis segmento inferiore sexto profunde inciso, quarto tertioque apice leviter impressis; femin a segmento sexto apice medio fortiter

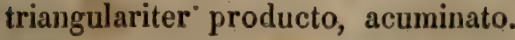

* 62. St. plancus: Niger, subtilius punctatus, parcius pubescens, antennis testaceis, articulo primo nigro, palpis testaceis, articulo terlio fusco, femoribus obscure piceis. - Long. 2 lin.

Habitat in Anglia, Dom. Hope, in Saxonia, Dom. Märkel.

Statura St. binotati, at minus elongatus depressusque, niger, nitidulus, parcius cinereo-pubescens. Antennae breviores, articulo tertio quarto paulo longiore, rufo-testaceae, clava fuscescente, articulo primo nigro. Palpi testacei, articulo tertio fusco. Caput thorace paulo latius, crebrius punctatum, fronte minus profunde late bisulcata, interstitio lato, leviter convexo elevatoque. Thorax coleopteris dimidio prope angustior, lateribus anterius rotundatus, posterius magis angustatus, basi coleopteris duplo prope angustior, latitudine summa vix longior, subcylindricus, minus dense subtilius at sat profunde punctatus, dorso pone medium utrinque obsolete oblique impressus. Elytra thorace paulo longiora, densius fortiusque profunde punctata, interstitiis planis, parum inaequalia, versus suturam longitudinaliter torulosa, anterius callosa. Abdomen subcylindricum, licet distincte margınatum, crebrius subtiliter punctatum. Pedes nigri, femoribus picescentibus, tarsis brevibus, dilatatis, articulo primo triangulari, secundo tertioque transversis, integris, quarto bilobo.

Mas abdominis segmento inferiore sexto apice triangulariter exciso, quinto quartoque longitudinaliter impressis, impressione utrinque carinula obtus a terminata, illo medio leviter excavato; femin a segmento sexto apice acute rotundato.

* 63. St. bifoveolatus: Niger, nitidulus, dense punctalus, parcius albidopubescens, palpis antennisque testaceis, his arliculo primo piceo, pedibus piceo-teslaceis, geniculis nigris, elylris thoracis longitudine. Long. $1 \frac{3}{4}$ lin.

Gyll. Ins. Suec. IV. 500. 9 - 10. - Sahlb. Ins. Fenn. I. 427 10. - Mannerh. Brachelytr. 43. 10.

Habitat in Suecia, Fennia, Dom. Schïppel.

Statura subcylindrica praecedentis, at paulo minor, niger, nitidulus, pube brevi depressa albida parcius aequaliter adspersus, subcinerascens. Antennae breviusculae, articulo tertio quarto paulo longiore, testaceae, articulo primo pireo, clava fuscescente. Palpi testacei. Caput thorace panlo latius, crebre profundius punctatum, fronte depressiuscula, obsolete late bisulcata, interstitio latiusculo, leviter ${ }_{\text {i }}$ convexo, panlulum magis quam frontis latera elevato. Thorax coleopteris dimidio angustior, lateribus anterius leviter rotundatus, posterius magis angustatus, basi coleopteris duplo angustior, subcylindricus, dense fortius profunde punctatus, interstitiis planis, utrinque obsolete oblique impressus, ceterum aequalis. Elytra thoracis longitudine, aequalia, densius fortiter profundeque punctata, punctorum interstitiis planis. Abdomen breviusculum, ambcylindricum, licet distincte marginatum, dense profundeque punctatum. des piceo-testacei, coxis nigris, femoribus apice 
nigricantibus, tarsis brevibus, articulis duobus prlmis elongato-triangularibus, tertio triangulari, quarto bilobo.

Mas abdominis segmerito inferiore sexto triangulariter exciso (Gyll); femina eodem apice triangulariter producto, leviter acuminato.

* 64. St. rusticus: Plumbeo-niger, subnitidus, dense punctatus, albidopubescens, palpis antennisque testaceis, his arliculo primo nigro, pedibus piceo-testaceis, geniculis nigris, elytris thorace longioribus, Long. 2 lin.

Habitat in Germania meridionali, Dom. Schïppel, Lutetiae, Dom. Aubé, in Anglia, Dom. Rudd.

Habitu fere St. tarsalis, et minoribus eius individuis aequalis, plumbeoniger, nitidulus, pube brevi depressa albida aequali minus densa cinerascens. Antennae mediocres, articulo tertio quarto paulo longiore, rufo-testaceae, articulo primo nigro, clava fuscescente. Palpi toti rufo-testacei. Caput thorace paulo latius, dense profundius punctatum, fronte depressiuscula, late bisulcata, interstitio sulcorum latiusculo, leviter convexo, aeque ac frontis latera elevato. Thorax coleopteris plus dimidio angustior, lateribus anterius leviter rotundatus, posterius magis angustatus, basi coleopteris plus duplo angustior, dense profundeque punctatus, punctorum interstitiis planis, pone medium utrinque obsolete oblique impressus, ceterum aequalis. Elytra thorace tertia parte longiora, dorso longitudinaliter leviter toroso, dense prefundeque punctata, interstitiis planis. Abdomen coleopteris paulo angustius, anicem versus leviter angustatum, subcylindricum, licet lateribus distincte marginatum, sat dense profundeque punctatum. Pedes piceo-testacei, coxis nigris, femoribus apice nigricantibus, tarsis brevibus, articulis duobus primis linearibus, parum elongatis, tertio subtriangulari, quarto bilobo.

Mas abdominis segmento inferiore sexto triangulariter exciso; femina eodem medio subacuminato.

* 65. St. tempestivus: Apterus, niger, nitidus, sublilius punctatus, parce pubescens, palpis antennisque testaceis, his articulo primo nigro, pedibus testaceis, geniculis nigris. - Long. $2 \frac{1}{3}$ lin.

Er. Col. March. I. 563. 40.

Habitat in Germania, Gallia, Anglia.

St. binotati speciminibus maioribus haud angustior, at brevior, apterus, subdepressus, niger, nitidus, pube brevissima parca albida haud cinerascens. Antennae mediocres, articulo tertio quarto paulo longiore, testaceae, articulo primo nigro, clava fuscescente. Palpi testacei. Caput thorace sesqui latius, crebrius minus fortiter punctatum, fronte late profundeque bisulcata, interstitio angustiore, aeque ac frontis latera elevato, subcarinato. Thorax coleopteris medio dimidio, basi duplo angustior, lateribus leviter rotundatus, latitudine summa vix longior, subdepresso-cylindricus, minus confertim subtilius punctatus, interstitiis planis, subinaequalis, dorso pone medium utrinque oblique impressus. Elytra thorace parum longiora, minus confertim subtilius functata, interstitiis punctorum planis inaequalia, apice oblique truncata. Abdomen f'arcius subtiliusque punctatum. Pedes testacei, cosis 
nigris, femoribus apice tibiisque basi piceis, tarsis breviusculis, articulo primo elongato - triangulari, secundo triangulari, tertio obcordato, quarto bilobo.

Mas abdominis segmento inferiore sexto apice triangulariter exciso; femin a eodem apice utrinque subsinuato, medio triangulariter producto, acuminato.

* 66. St. picipennis: Niger, nitiduhus, subtilius punctalus, parce pubescens, antennis palpisque testaceis, pedibus testaceis, medio fuscescentibus, elytris piceis, - Long. 2 lin.

Habitat in Saxonia, Dom. Märkel:

Praecedenti affinis, at brevior et minus depressus, niger, nitidulus, pube brevi depressa albida parce vestitus. Antennae breviusculae, articulo tertio quarto paulo longiore, dilute testaceae, articulo primo concolore, clava fuscescente. Palpi dilute testacei. Caput thorace latins, transversum, sat crebre profundeque minus fortiter punctatum, fronte late minus profunde bisulcata, interstitio convexo et paulo magis quam frontis latera elevato, subcarinato. Thorax coleopteris dimidio angustior, lateribus ante medium fortius rotundatus, pone medium fortius angustatus, basi coleopteris duplo angustior, latitudine summa haud longior, minus dense fortiterque licet profundius punctatus, interstitiis planis, dorsa medio utrinque oblique leviter impressus, ceterum aequalis. Elytra thorace paulo longiora, densius fortiusque profunde punctata, interstitiis planis, inaequalia, picea. Abdomen breviusculum, parcius subtiliter punctatum, segmentis dorsalibus 4 primis margine apicali subelevato, polito. Pedes testacei, coxis, femoribus apice, tibiis basi piceis, tarsis brevibus, articulis duobus primis subtriangularibus, tertio transversim obcordato, quarto profunde bilobo.

Mas latet. Femina abdominis segmento inferiare sexto apice testaceo-marginato, medio leviter triangulariter producto.

*67. St. languidus: Niger, nitidulus, subtilius punctatus, parcius pubescens, palpis antennisque obscure testaceis, his articulo primo nigro, pedibus piceis, basi apiceque obscure testaceis. - Long. $2 \frac{1}{2}$ lin.

Habitat in Sicilia, Dom. Dr. Schultz.

Habitu fere St. cordati, at duplo minor, niger, nitidulus, pube brevissima depressa albida minus dense vestitus, vix cinerascens. Antennae mediocres, articulo tertio quarto sesqui longiore, obscure rufo-testaceae, clava fuscescente, articulo primo nigro. Palpi testacei, articulo tertio picescente. Caput thorace paulo latius, crebrius subtiliusque punctatum, fronte late profundeque bisulcata, interstitio latiusculo, leviter convexo, aeque ac frontis latera elevato, laeviore. Thorax basi coleopteris duplo angustior, lateribus ante medium leviter rotundatis, latitudine summa haud longior, parum convexus, parcius subtiliter punctatus, dorsa pone medium utrinque oblique fortius impressus, ceterum aequalıs. Elytra thorace sesqui prope longiora, dense crebre subtilius punctata, inaequalia. Abdomen basi coleopteris paulo angustius, apicem versus sensim attenuatum, parcius subtiliter punctatum. Pedes picei, femoribus basi ultra medium, tibiis apice tarsisque obscure rufo - testaceis, his breviusculis, articulis duobus primis linearibus, tertio subtriangulari, integro, quarto profunde bilobo. 
Mas abdominis segmento inferiore sexto apice triangulariter emarginato; femina eodem apice utrinque subsinuato, medio triangulariter producto, acuminato.

* 68. St. cordatus: Niger, nitidus, fortius crebre punctalus, parce pubescens, palpis antennisque elongatis testaceis, his articulo primo piceo, pedibus testaceis, femoribus apice, tibiis basi nigris. - Long. 3 lin.

Grav. Mier. 198. 1. Mon. 226. 3.

Habitat in Lusitania, Com. Hoffmannsegg, in Sardinia, Prof. Gené.

Subdepressus, niger, nitidus, pube breviore depressa albida parcius vestitus. Antennae elongatae, capitis thoracisque fere longitudine, articulo tertio quarto paulo longiore, clava parum incrassata, rufo-piceae, articulo primo piceo. Palpi elongati, articulo tertio minus incrassato, testacei. Ca put thorace vix latius, fortiter crebrius punctatum, fronte late et parum profunde bisulcata, interstitio leviter convexo, aeque ac frontis latera elevato. Thorax coleopteris duplo prope angustior, lateribus ante medium fortiter rotundatus, posterius fortius angustatus, basi coleopteris triplo fere angustior, latitudine summa haud longior, parum convexus, crebre fortius punctatus, dorso medio late canaliculatus, pone medium utrinque leviter impres. sus. Elytra lata, thorace paulo longiora, fortius profunde dense punctata, inaequalia, anterius versus suturam distinctius callosa. Abdomen basi coleo. pterorum latitudine, apicem versus sensim fortius attenuatum, parce subtiliter punctatum, segmentis singulis basi e pube densiore cinereo-versicoloribus. Pedes testacei, femoribus apice late nigris, tibiis basi nigris, tarsis longioribus, articulo primo sat elongato, quarto angusto, bilobo.

$\mathrm{M}$ as abdominis segmento inferiore sexto apice emarginato; femina eodem apice medio leviter producto, rotundato.

* 69. St, hospes: Niger, subnilidus, dense forliter punclatus, parce allidopubescens, anlennis elongalis, piceis, palpis pedibusque testaceis, his geniculis nigris. - Long. $2 \frac{3}{4}$ lin.

Habitat in Corcyra, Dom. Schïppel.

Habitu fere praecedentis, at gracilior et duplo minor, niger, nitidus, pube longiore depressa albida parcius veśtitus. Antennae elongatae, graciles, articulo tertio quarto paulo longiore, testaceo-piceae, clava fuscescente. Palpi elongati, dilute testacei, articulo tertio obscuriore, minus incrassato. Caput thorace paulo latius, crebre fortiter profundeque punctatum, fronte utrinque fortius late longitudinaliter excavata, interstitio convexo, aeque fere ac frontis latera elevato, parcius punctato. Thorax coleopteris plus dimidio angustior, lateribus medio modice rotundatus, basin et apicem versus aequaliter angustatus et ibidem coleopteris duplo angustior, latitudine summa paulo longior, subcylindricus, dense fortiter profundeque punctatus, inter. stitiis subrugulosis, dorso leviter canaliculatus et utrinque obsolete bi-impressus. Elytra thorace tertia parte longiora, leviter inaequalia, dorso distinctius longitudinaliter toroso, dense fortiter profundeque punctata, interstitiis subaequalibus. Abdomen elongatum, basi coleopteris paulo angustius, basin versus sensim attenuatum, apicem versus sensim subtilius punctatum, nitidum. Pedes testacei, coxis nigris, femoribus apice late nigricantibus, 
tibjis basi piceis, tarsis longioribus, articulis tribus primis linearibus, primo sat elongato, quarto leviter bilobo.

Mas abdominis segmento inferiore sexto apice leviter emarginato. Femin a latet.

* 70. St. subaeneus: Nigro-subaeneus, nilidulus, dense fortius punctalus, densius albido-pubescens, antennis medio, palpis basi testaceis, pedibus testaceis, medio piceis. - Long. 2 lin.

St en. geniculatus Mannerh. Brachelytr. 43. 15.

Habitat Lutetiae, Dom. Aubé, in Gallia meridionali, Dom. Schïppel, in Sardinia, Dom. Prof. Gené, in Anglia, Dom. Rudd.

Statura St. impressi, nigro-subaeneus, nitidulus, pube depressa albida parciore subcinerascens. Antennae longiusculae, graciles, articulo tertio quarto paulo longiore, obscure testaceae, articulis duobus primis nigris, clava picea. Palpi articulo primo dilute, secundo obscure testaceo, tertio piceo. Caput thorace paulo latius, fortius dense profundeque punctatum, fronte utrinque leviter longiludinaliter excavata, interstitio leviter convexo, aeque fere ac frontis latera elevato, medio paulo laeviore. Thorax coleopteris plus dimidio angustior, lateribus medio modice rotundatus, posterius paulo magis angustatus, basi coleopteris duplo angustior, latitudine summa parum longior, subcylindricus, confertissime fortiter profundeque punctatus, interstitiis rugulosis, dorso leviter canaliculatus et utrinque obsoletius biimpressus. Elytra thorace tertia parte longiora, dense fortiter profundeque punctata, interstitiis vix rugulosis, dorso longitudinaliter leviter toruloso. Abdomen coleopteris paulo angustius, apicem versus sensim subangustatum, dense sat fortiter, licet apıcem versus sensim subtilius punctatum. Pedes saturate testacei, coxis nigris, femoribus apice, tibiis basi late piceis, tarsis longioribus, articulis tribus primis linearibus, primo sat elongato, quarto profunde bilobo.

Mas abdominis segmento inferiore sexto apice leviter emarginato; fem in a eodem rotundato.

Obs. Minus accurate a Mannerheimio descriptus. Specimen a Com. Dejean ipso sub eodem nomine communicatum dedit Dom. Schüppel.

* 71. St. aerosus: Nigro-aeneus, nitidus, dense punclatus, tenuiter albidnpubescens, antennis palpisque teslaceis, illis articulo primo nigro, his apice fuscescentibus, pedibus flavo-testaceis, geniculis nigricanlibus. Long. 2 lin.

Habitat in Sardinia, Dom. Prof. Gené.

Statura onnino praecedentis, laete nigro-aeneus, nitidus, pube subtili brevissima depressa albida parciore haud cinerascens. Antennae sat elongatae, tenues, articulo quarto tertio vix breviore, testaceae, articulo primo nigro, clava fuscescente. Palpi pallide testacei, articulo tertio apice fuscescente. Caput thorace sesqui fere latius, sat dense profunde punctatun, fronte late bisulcata, interstitio leviter convexo, aeque ac frontis latera elevato, medio longitudinaliter laeviore. Thorax coleopteris dimidio angustior, lateribus ante medium modice rotundatis, posterius magis angustatus, basi coleopteris duplo prope angustior, latitudine summa vix longior, dense for- 
tius profunde punctatus, interstitiis subrugulosis, leviter canaliculatus et dorso utrinque obsoletius bi-impressus. Elytra thorace tertia parte longiora, dense profundeque fortius punctata, interstitiis subaequalibus, leviter inaequalia, dorso longitudinaliter distinctius torosa. Abdomen apicem versus sensim subangustatum, crebre minus subtiliter punctatum. Pedes flavo-testacei, coxis, femoribus apice, tibiis basi piceis, tarsis longioribus, articulis tribus primis linearibus, primo sat elongato, quarto fortiter bilobo.

Mas abdominis segmento inferiore sexto apice leviter emarginato; femin a eodem rotundato.

$\mathrm{Obs}$. A praecedente colore, punctura minus forti et capite latiore, a St. im. presso punctura densiore, elytris longioribus, antennarum articulo primo nigro, palpis apice geniculisque piceis distinctus.

* 72. St. impressus: Nigro-subaeneus, nitidus, fortius punctatus, parce albido-pubescens, antennis palpisque testaceis, pedibus flavis. - Long. 2 lin.

Germ. Spec. Ins. 36. 59. - Er. Col. March. I. 564. 41.

Sten us proboscideus Germ. Faun. Ins. Europ. XV. 1.

Stenus Aceris Boisd. et Lacord. Faun. Ent. Paris. 1. 445. 7.

Stenus pallipes var. Grav. Mon. p. 233. (forte)

Habitat in Germania; Gallia, Anglia.

Subdepressus, nigro-subaeneus, nitidulus, pube brevissima albida parcius adspersus. Antennae mediocres, graciliores, articulo tertio quarto sesqui longiore, totae testaceae. Palpi testacei. Caput thorace sesqui latius, crebre punctatum, fronte haud excavata, at late profundeque bisulcata, interstitio convexo, aeque ac frontis latera elevato, linea media longitudinali laevi. Thorax coleopteris dimidio angustior, lateribus ante medium modice rotundatus, posterius magis angustatus, basi coleopteris duplo angustior, latitudine summa vix longior, parum convexus, densius punctatus, interstitiis subinaequalibus, dorso medio obsoletius canaliculatus, utrinque et ante et pone medium obsolete impressus. Elytra thorace vix longiora, densius fortiusque punctata, subinaequalia. Alae elytris duplo longiores. Abdomen apicem versus sensim angustatum, crebre minus subtiliter punctatum, nigrum, 'nitidum. Pedes flavo-testacei, coxis piceis, tarsis longiusculis, articulo primo sat elongato, quarto profunde bilobo.

Mas abdominis segmento inferiore sexto apice acute emarginato; femin a rotundato.

* 73. St. geniculatus: Niger, fortiter punctalus, leviler albido-pubescens, antennis palpisgue testaceis, apice fuscescentibus, pedibus testaceis, geniculis fuscis. - Long. 2 lin.

Grav. Mon. p. 228. - Er. Col. March. I. 564.042.

Habitat in Germania.

Elongatus, niger, minus nitidus, pube brevi depressa albida cinerascens. Antennae graciliores, articulo tertio quarto sesqui longiore, testaceae, clava fuscescente, articulo primo piceo. Palpi testacei, articulo tertio apice fuscescente. Caput thorace paulo latius, crebre sat profunde punctatum, fronte haud excavata, at late et parum profunde bisulcata, interstitio lato, 
parum elevato, linea tenui subelevata laevi subcarinato. Thorax coleopteris dimidio angustior, lateribus medio modice rotundatus, posterius paulo magis quam anterius angustatus, basi coleopteris duplo fere angustior, latitudine summa paulo longior, subcylindricus, creberrime sat fortiter punctatus, interstitiis subrugulosis, dorso obsoletissime canaliculatus. Elytra thorace vix longiora, creberrime fortiter punctata, interstitiis subrugulosis, anterius versus suturam longitudinaliter leviter torulosa. Alae integrae. Abdomen elongatum, fortius crebre punctatum. Pedes testacei, coxis piceis, geniculis fuscis, tarsis elongatis, gracilibus, articulis 1-3 linearibus, primo sat elongato, quarto angusto, bilobo.

$\mathrm{M}$ as abdominis segmento inferiore sexto apice leviter sinuato; femin a eodem rotundato.

* 74. St. flavipes: Niger, nilidulus, fortius punctalus, parcius albido-pubescens, antennis, palpis pedibusque flavis, immaculatis, thorace medio obsoletius canaliculato, abdomine late marginato. - Long. $1 \frac{2}{3}$ lin.

Er. Col. March. I. 566. 44.

Habitat in Germania.

Habitu omnino St. impressi, at paulo minor, subdepressus, niger, nitidus, pube parca subtili depressa albida adspersus. Antennae longiusculae, articulo tertio quarto parum longiore, flavo-testaceae, articulo primo concolore, clava fuscescente. Palpi flavo-testacei. Caput coleopterorum latitudine, densius fortiusque profunde punctatum, fronte late parum profunde bisulcata, interstitio leviter convexo, aeque ac frontis latera elevato, linea Jongitudinali laevi subcarinato. Thorax coleopteris paulo angustior, lateribus ante medium rotundatus, posterius fortius angustatus, basi coleopteris duplo angustior, latitudine summa vix brevior, parum convexus, densius fortiusque profunde punctatus, interstitiis subaequalibus, dorso leviter canaliculatus, canalicula basi apiceque obsolescente, medio utrinque obsolete oblique impressus. Elytra thorace paululum longiora, depressiuscula, vix inaequalia, densius fortiter profundeque punctata, interstitiis planis. Alarum rúdimenta elytris breviora. Abdomen apicem versus sensim attenuatum, Jate marginatum, minus dense et apicem versus sensim subtilius punctatum. Pedes flavo-testacei, coxis anticis rufo-testaceis, posterioribus rufo-piceis, tarsis longiusculis, articulis tribus primis linearibus, primo sat elongato, quarto bilobo.

Mas abdominis segmento inferiore sexto apice emarginato; femina eodem rotundato.

* 75. St palustris: Niger, nitidulus, fortius punctatus, parcius albidopubescens, antennis, palpis pedibusque flavis, antennis articulo primo, palpis articulo tertio, femoribus apice, tibiis basi late fuscis, thorace medio obsoletius canaliculato. - Long. $1 \frac{2}{3}$ lin.

Er. Col. March. 1. 565. 43.

Stenus proboscideus Gyll. Ins. Suec. II. 476. 11. - Sahlb. Ins. Fenn. 1. 429. 14. - Zetterst. Faun. Lappon. I. 88. 6. Ins. Lappon. 70. 7. - Mannerh. Brachelytr. 43. 16.

Habitat in Germania. 
Stalura et summa affinitas praecedentis. Niger, nitidulus, pube brevi depressa parciore albida parum cinerascens. Antennae longiusculae, articulo tertio quarto vix sesqui longiore, rufo-testaceae, extrorsum fuscae, articulo primo piceo. Palpi testacei, articulo tertio picescente. Caput thorace sesqui latius, crebre dense punctatum, fronte late parum profunde bisulcata, interstitio lato, leviter convexo, aeque ac frontis latera elevato, medio laeviore, subcarinato. Thorax coleopteris paulo angustior, lateribus ante me. dium lateribus sat fortiter rotundatus, posterins magis angustatus, basi coleopteris dimidio angustior, latitudine summa vix brevior, parum convexus, crebrius fortiusque punctatus, interstitiis subrugulosis, medio leviter canaliculatus, pone medium utrinque obsolete oblique impressus. Elytra thorace parum longiora, densius fortiusque profunde punctata, subinaequalia, anterius versus suturam subcallosa. Alarum rudimenta coleopteris breviora. Abdomen late marginatum, -dense anteriorius fortius, posterius subtilins punctatum. Pedes saturate testacei, coxis nigris, femoribus apice late et tibiis basi fusco-piceis, tarsis longiusculis, articulis tribus primis linearibus, primo sat elongato, quarto fortiter bilobo.

$\mathrm{M}$ as abdominis segmento inferiore sexto apice leviter triangulariter exciso; femin a eodem rotundato.

Obs. Distinctus a praecedente praeter antennarum, palporum pedumque constantem colorem thorace paulo longiore, posterius paulo minus angustato, tarsis minus elongatis, articulo quarto fortius bilobo, abdominis segmento inferiore sexto in mare fortius emarginato, etc.

* 76. St. fuscicornis: Niger, nilidulus, fortiter punctatus, antennis palpisque piceis, his basi testaceis, pedibus pice-testaceis, medio lale nigricantibus. - Long. $1 \frac{2}{3}$ lin.

Habitat Lutetiae, Dom. Aubé, in Helvetia, Dom. Godet.

Statura et summa affinitas praecedentis, niger, nitidulus, pube brevi depressa parca albida vix cinerascens. Antennae longiusculae, articulo ter tio quarto vix longiore, fusco-piceae, basi apiceque nigricantes. Palpi fusco-picei, articulo primo pallide testaceo. Caput thorace sesqui latius, fortius profundeque dense punctatum, fronte late bisulcata, interstitio convexo, aeque ac frontis latera elevato. Thorax coleopteris paulo angustior, lateribus medio modice rotundatus, basin apicemque versus fere aequaliter angustatus et ibidem coleopteris dimidio angustıor, latitudine summa haud longior, leviter convexus, dense sat fortiter profundeque punctatus, interstitiis praecipue latera versus subrugulosis, medio utrinque obsoletissime impressus. Elytra thorace paululum longiora, dense fortiter profundeque punctata, interstitiis subaequalibus, perparum convexa, sutura longitudinaliter depressiuscula. Abdomen apicem versus sensim subangustatum, late mar ginatum, dense, segmentis anterioribus 4 fortius, posterioribus 2 subtilius punctatum. Pedes rufo-picei, coxis nigris, femoribus apice, tibiis basi late nigricantibus, tarsis longioribus, articulis tribus primis linearibus, primo sat elongato, quarto fortiter bilobo.

$\mathrm{M}$ as latet. F emina abdominis segmento inferiore sexto apice acute rotundato.

Obs. Proximus praecedenti, distinctus autem antennis, palpis pedibusque obscurioribus, punctura crebriore et fortiore, thorace haud canaliculato, posterius paulo minus angustato. 
*77. St.pallip s: Niger, subnilidus, dense fortius punclatus, densius albido-pubescens, antennis, palpis pedibusque testaceis, abdomine subcylindrico, subtiliter marginalo. - Long. $1 \frac{2}{3}$ lin.

Grav. Micr. 157. 7. Mon. 233. 14. - Ljungh Web. ef Mohr Beitr. 11. 156. 10. Boisd. et Lacord. Faun. Ent. Paris. I. 416. 8. - Er. Col. March. I. 567. 45.

Habitat in Germania.

Statura et summa affinitas St. flavipedis, niger, subnitidus, pube brevissima depressa albida subcinerascens. Antennae longiusculae, tenues, articulo tertio quarto sesqui longiore, testaceae, articulo primo concoloze, clava fuscescente. Palpi flavo-testacei. Caput thorace paulo latius, crebre punctato-subrugulosum, fronte levissime excavata, late obsolete bisulcata, interstitio lato, perparum convexo elevatoque. Thorax coleopteris paulo angustior, lateribus sat fortiter rotundatus, posterius paulo magis quam anterius angustatus, basi coleopteris plus dimidio angustior, latitudine summa haud longior, parum convexus, dense fortius punctatus, interstitis subaequalibus, obsolete canaliculatus. Elytra thorace vix longiora, dense fortius sat profunde punctata, interstitiis snbinaequalibus, anterius versus suturam leviter torosa. Abdomen coleopteris paulo angustius, apicem versus sensim attenuatum, tenuiter marginatum, subcylindricum. dense anterius fortius, posterius subtilius punctatum. Pedes flavo-testacei, coxis posterioribus piceis, társis longiusculis, articulis tribus primis linearibus, primo sat elongato, quarto bilobo.

Mas abdominis segmento inferiore sexto apice leviter triangulariter exciso; femina eodem apice medio leviter triangulariter producto.

$\mathrm{Obs}$. A St. flavipede corpore angustiore, magis cinerascente, thorace medio ipso neque ante medium latiore, abdomine subtiliter marginato.

* 78. St. filum: Apterus, elongatus, subdepressus, niger, nitidulus, parce subliliter punclatus, parcius albido-pubescens, pedibus, palpis antennisque flavis, his articulo primo nigro. - Long. $1 \frac{2}{3}$ lin.

Er. Col. March. I. 568. 46.

Habitat in Germania, Gallia, Anglia.

St. flavipede haud brevior, at dimidio angustior et magis linearis, subdepressus, niger, nitidulus, pube brevi depressa parca albida subcinerascens. Antennae breves, articulo tertio quarto sesqui longiore, flavae, clava apice fuscescente, articulo primo nigro. Palpi flavi. Caput thorace sesqui latius, parce punctatum, fronte depressa, late minus profunde bisulcata, interstitio lato, perparum elevato, laeviore. Thorax coleopteris paulo angustior, medio leviter rotundatus, posterius paulo magis angustatus, basi coleopteris vix dimidio angustior, latitudine summa paulo longior, depresso-subcylindricus, parce subtilius punctatus, aequalis. Elytra thorace parum longiora, parcius subtiliusque punctata, aequalia. Alarum rudimenta coleopteris breviora. Abdomen elongatum, lineare, late marginatum, parcius subtiliusque punctatum. Pedes breviusculi, flavi, coxis nigris, tarsis brevibus, dilatatis, articulo tertio subcordato, quarto fortiter bilobo.

Mas abdominis segmento inferiore sexto apice triangulariter emarginato, quinto longitudinaliter subimpresso; femina segmento sexto apice triangulariter producto, subacuminato. 


\section{B. A b d o men i m m r in a t u m.}

- 79. St. tarsalis: Plumbeo-niger, densius albido-pubescens, crebre punctatus, tarsis, palpis antennisque rufo-lestaceis, his articulo primo nigro, abdomine crebrius punctalo. - Long. $2-2 \frac{1}{3}$ lin.

Ljungh Web. u. Mohr Beitr. II. 157. 11. - Gyll. Ins. Suec. II. 472. 8. - Suhlb. Ins. Fenn. I. 426. 8. - Zetterst. Faun. Lappon. I. 90. 10. Ins. Lappon. 71. 12.

- Mannerh. Brachelytr. 42. 8. - Er. Col. March. I. 569. 47.

Sten. buphthalmus Ljungh Web. et Mohr Archiv. 1. 1. 67. 7.

Sten. clavicornis Grav. Micr. 156. 5. Mon. 229. 7. - Boisd. et Lacord. Faun.

Ent. Paris. I. 448. 13.

Staph. clavicornis Rossi Faun. Etr. ed. Hellw. I. p. 312. not. n. 1.

Stenus ripurius Runde Brachelytr. Hal. 16. 10.

Habitat in Europa.

Plumbeo-niger, nitidulus, pube brevi depressa albida densiore cinerascens. Antennae mediocres, articulo tertio quartoque subaequalibus, rufotestaceae, clava fuscescente, articulo primo minuto, nigro. Palpi rufo-testacei. Caput thorace paulo latius, crebre subtilius punctatum, fronte depressiuscula utrinque leviter impressa. Thorax coleopteris dimidio angustior, lateribus medio leviter rotundatus, posterius paulo magis angustatus, basi coleopteris duplo angustior, latitudine summa haud longior, profunde crebrius punctatus, interstitiis planis, dorso utrinque pone medium oblique leviter impressus. Elytra thorace paulo longiora, densius fortiusque profunde punctata, anterius versus basin longitudinaliter leviter torosa. Abdomen apicem versus sensim attenuatum, minus subtiliter densius punctatum. Pedes corpori concolores, tarsis rufo-testaceis, breviusculis, dilatatis, articulo tertio obcordato, quarto bilobo.

Mas abdominis segmento inferiore sexto apice triangulariter emarginato; femina eodem apice leviter bisinuato, medio leviter triangulariter producto.

Obs. Steni riparii Rund. specimen inspiciendum benevole communicavit Dom. Prof. Germar.

* 80. St. vestigialis: Plumbeo-niger, albido-pubescens, crebre punclatus, tarsis, palpis antennisque testaceis, abdomine crebrius punctato. Long. $2 \frac{1}{3}$ lin.

Habitat in Mexico.

St. tarsali gracilior, plumbeo-niger, subnitidus, pube subtili depressa albida subcinerascens. Antennae mediocres, articulo tertio quarto paulo longiore, totae testaceae. Palpi testacei. Caput thorace sesqui latius, profunde crebre punctatum, fronte depressiuscula, utrinque leviter impressa. Thorax elongatus, cylindricus, basi coleopteris duplo angustior, medio perparum rotundato-incrassatus, latitudine summa plus sesqui longior, profunde confertissime punctatus, interstitiis subrugulosis, dorso pone medium oblique obsolete utrinque impressus. Elytra thoracis longitudine, dense profundeque punctata, basi medio leviter torulosa. Abdomen coleopteris paulo angustius, cylindricum, fortius profunde dense punctatum. Pedes corpori concolores, tarsis testaceis, longioribus, articulis duobus primis linearibus, primo elongato, tertio obcordato, quarto bilobo. 
Mas latet. Femina abdominis segmento inferiore sexto apice leviter triangulariter producto, subacuminato.

Obs. St. tarsali affinis, antennarum artículo primo testaceo thoraceque elongato, cylindrico facile distinguendus.

* 81. St. oculatus: Plumbeo-niger, crebre subtilius punctatus, albido-pubescens, palpis antennisque teslaceis, his articulo primo nigro, pedibus flavis, geniculis nigricantibus. - Long. $2 \frac{1}{2}$ lin.

Grav. Micr. 155. 3. Mon. 227. 5, - Gyll. Ins. Suec. II. 471 7. - Sahlb. Ins. Fenn. 1. 425. 7. - Zetterst. Faun. Lappon. I. 90. 9. Ins. Lappon. 71. 11. Mannerh. Brachelytr. 42. 7. - Boisd. et Lacord. Faun. Ent. Paris. I. 444. 5. Runde Brachelytr. Hal. 15. 7. - Er. Col. March. I. 569. 48.

Staph. similis Herbst Archiv. 151. 15.

Sten. similis Ljungh Web. u. Mohr Archiv. I. 1. 65. 5.

\section{Habitat in Europa.}

Plumbeo-niger, subnitidus, pube depressa albida 'densiore cinerascens. Antermae longiores, articulo tertio quarto sesqui longiore, testaceae, articulo primo nigro. Palpi testacei. Caput thorace paulo latius, crebre punctatum fronte utrinque late at parum profunde longitudinaliter impressa, interstitio lato, levissime convexo, vix elevato. Thorax coleopteris dimidio angustior, lateribus medio modice rotundatus, posterius vix magis quam anterius angustatus, basi coleopteris duplo prope angustior, latitudine summa haud longior, subcylindricus, dense punctatus, interstitiis subaequalibus, dorso pone medium utrinque oblique obsolete impressus. Elytra thorace paulo longiora, dense profundeque punctata, anterius versus suturam obsolete torosa. Abdomen crebre profundeque punctatum. Pedes flavi, coxis nigris, femoribus apice, tibiis basi nigris, tarsis longiusculis, articulis tribus primis linearibus, apice summo nigricantibus, primo elongato, quarto bilobo.

Mas abdominis segmento inferiore sexto profunde exciso, quarto apice medic sinnato et leviter impresso, sinu denticulo obtusiusculo utrinque terminato; femina segmento sexto apice rotundato, medio leviter acuminato.

* 82. St. flavicornis: Plumbeo-niger, crebre fortius punctalus, albidopubescens, antennis palpisque lestaceis, pedibus flavis, femoribus posticis apice fuscis, abdomine subtilissime punctato. - Long. $2 \frac{1}{2}$ lin.

Sten. geniculatus Say Transact. Amer. Philoph. Soc. Philadelph. Nov. Ser. IV. 458. 1 .

Habitat in Pensylvania, Dom. Zimmermann.

Statura et summa affinitas praecedentis. Plumbeo-niger, nitidulus, pube depressa albida cinerascens. Antennae longiores, articulo tertio quarto sesqui longiore, totae flavo-testaceae. Palpi flavo-testacei. Caput thorace sesqui latius, crebrius minus fortiter punctatum, fronte utrinque late leviter parum profunde longitudinaliter impressa, interstitio lato, perparum convexo, minus fere quam frontis latera elevato. Thorax basi coleopteris dimidio angustior, lateribus medio leviter rotundatus, latitudine summa vix longior, subcylindricus, dense fortius profunde punctatus, interstitiis vix rugulosis, pone mediun utrinque obsolete impressus. Elytra thorace paulo longiora, 
minus dense profunde fortiterque punctata, leviter convexa, anterius versus suturam leviter torosa. Abdomen crebre subtilissime punctatum, cylindricum, segmentis quatuor primis basi leviter constrictis, summa basi paulo fortius punctatis. Pedes flavi, coxis piceis, femoribus posticis solis apice fuscis, tarsis brevioribus, articulis duobus primis linearibus, primo leviter elongato, tertio triangulari, quarto fortius bilobo.

$\mathrm{Mas}$ abdominis segmento inferiore sexto apice profunde triangulariter exciso, quarto apice vix impresso; femina segmento sexto apice rotundato.

Obs. Nomine St. flavicornis Dej. signatam hanc speciem in collectione Dom. Chevrolat vidi.

- 83. St. solutus: Plumbeo-niger, dense subtilius punctatus, albido-pubescens, antennis, palpis pedibusque flavis, femoribus anticis ante apicem geniculisque poslerioribus nigris, abdomine sublilissime punctato. Long. $2 \frac{1}{2}$ lin.

Habitat Lutetiae, Dom. Dr. Aubé.

Statura et summa affinitas praecedentis. Plumbeo-niger, nitidulus, pube depressa albida cinerascens. Antennae longiusculae, articulo tertio quarto sesqui longiore, totae flavo-testaceae. Palpi flavo-testacei. Caput thorace sesqui prope latius, sat crebre minus fortiter punctatum, fronte depressiuscula, parum profunde bisulcata, interstitio lato, perparum convexo, medio laeviore. Thorax coleopteris paulo angustior, lateribus medio modice rotundatus, posterius paulo magis angustatus, basi coleopteris dimidio angustior, latitudine summa paulo longır, subcylindricus, sat dense subtilius profundıus punctatus, interstitiis planiusculis, utrinque pone medium leviter oblique impressus. Elytra thorace paulo longiora, crebre minus fortiter profundius punctata, interstitiis subaequalibus, dorso anterius longitndinaliter leviter toroso. Abdomen cylindricum, segmentis 4 anterioribus basi leviter constrictis, subtilissime crebre punctatum. Pedes flavo-testacei, coxis nigris, femoribus anticis ante apicem superne nigricantibus, posterioribus apice, tibits posterioribus basi late nigris, tarsis brevioribus, articulis duobus primis linearibus, primo leviter elongato, tertio triangulari, quarto fortiter bilobo.

Mas abdominis segmento inferiore sexto apice profunde triangulariter exciso, quarto apice medio leviter sinuato, et intra sinum leviter exciso; femina segmento sexto apice leviter producto, subacuminato.

Obs. A St. oculato facile distinctus antennarum articulo primo concolore et abdomine subtilissime punctato, a $\mathrm{St}$. flavicorni punctura thoracis elytrorumque subtiliore et densiore, tibiis posterioribus basi nigris etc.

* 84. St. cicindeloides: Niger, nitidus, grosse profunde aequaliter punctatus, parce pubescens, antennis palpisque testaceis, pedibus flavis, femoribus apice tibiisque basi late nigris, abdomine parcius punctato. - Long. $2 \frac{2}{3}$ lin.

Grav. Mier. 155. 4. Mon. 229. 6. - Gyll. Ins. Suec. MI 470. 6 - Sahlb. Ins. Fepn. I. 424. 6. - Mannerh. Brachelytr. 42. 6. - Boisd. et Lacord. Faun. Ent. Paris. I. 444. 4. - Kunde Brachelytr. Hal. 15. 6. - Er. Col. Narch. 1. 570. 49. Staph. buphthalmos Rossi Faun. Etr. 1. 252. 623. ed. Hellw. I. 311. 623 et not. p. 312. n. 3. 
St aph. clavicornis Rossi Faun. Etr. Mant. I. 98. 22. ed. Hellw. 1. 443. 220. Paed. bigutlatus var. Oliv. Ent. III. 44. t. 1. f. 3. d. Sten. similis var. $\beta$ Ljungh Web. u. Mohr Archiv. I. 1. p. 66.

\section{Habitat in' Europa.}

Niger, nitidulus, pube subtili depressiuscula albida rara vix cinerascens. Antennae mediocres, articulo tertio quarto paulo longiore, testaceae, clava fuscescente. Palpi flavo-testacei. Caput thorace parum latius, fortius crebriusque punctatum, fronte depressiuscula, late parum profunde bisulcata, interstitio leviter elevato. Thorax coleopteris dimidio angustior, lateribus medio leviter rotundatus, latitudine summa parum longior, subcylindricus, profunde fortiterque crebre punctatus, interstitiis subrugosis. Elytra thorace paulo longiora, grosse profundeque dense punctata, interstitiis rugulosis, leviter convexa, anterius versus suturam longitudinaliter vix torosa. Abdomen crassiusculum, segmentis singulis basi crebrius fortiusque, dein parce subtiliusque punctatis. Pedes coxis nigris, femoribus flavo-testaceis, basi summa apiceque lato nigro-piceis, tibiis piceis, apice tarsisque testaceis, his brevioribus, articulis tribus primis linearibus, primo leviter elongato, quarto bilobo.

Mas abdominis segmento sexto apice acute triangulariter exciso; $\mathrm{fe}$ min a eodem acute rotundato.

Obs.' Mas multo rarior obvius.

* 85. St. annularis: Niger, nilidus, grosse profundeque punctatus, parce pubescens, antennis palpis pedibusque piceis, femoribus basi annulo flavo, abdomine parce punclalo. - Long. $2 \frac{2}{3}$ lin.

Habitat in Pensylvania, Dom. Zimmermann.

Statura et summa affinitas praecedentis, niger, nitidulus, pube depressa albida parca vix cinerascens. Antennae mediocres, articulo tertio quarto sesqui longiore, nigro-piceae, medio rufo-piceae. Palpi rufo-picei, articulo tertio nigro-piceo. Caput thorace paulo latius, minus crebre fortius punctatum, fronte depressiuscula, late parum profunde bisulcata, interstitio lato, parum elevato, medio callo laevissimo instructo. Thorax coleopteris plus dimidio angustior, lateribus medio leviter rotundatus, posterius paulo magis angustatus, basi coleopteris duplo angustior, latitudine summa haud longior, subcylindricus, fortiter profundeque vage punctatus, interstitiis inaequalibus, dorso pone medium utrinque obsolete impressus, posterius rugis tribus longitudinalibus subelevatis laevissimis, callosis. Elytra thorace paulo longiora, grosse profundeque minus dense inaequaliter punctata, leviter convexa, versus suturam vix longitudinaliter torosa. Abdomen coleopteris paulo angustius, cylindricum, segmentis singulis parcius, basi fortius, apice subtilius punctatis. Pedes nigri, femoribus ante medium annulo lato flavo, tibiis apice tarsisque piceis, his brevioribus, articulis tribus primis linearibus, primo modice elongato, quarto fortiter bilobo.

Mas abdominis segmento sexio apice profunde exciso; femina eodem acute rotundato. 
* 86. St. operosus: Niger, nitidus, grosse profundeque incequaliter punctatus, glaber, antennis, palpis pedibusque testaceis, callis frontalibus carinulaque media thoracis laevissimis, abdomine crebrius punctato. Long. $2 \frac{1}{3}$ lin.

Habitat in Brasilia, Sellow.

Statura fere St. oculati, niger, nitidus, glaber. Antennae mediocres, articulo tertio quarto sesqui longiore, testaceae, clava fusca. Palpi flavotestacei. Caput thorace paulo latius, subtilius punctatum, fronte leviter late impressa, profundius bisulcata, interstitio lato, leviter elevato rugulisque duabus elevatis minoribus lateralibus prope oculos laevissimis, politis, facie unfra antennas dense albo-pubescente. Thorax coleopteris plus dimidio angustior, lateribus modice rotundatus, posterius aequaliter atque anterius angustatus, basi coleopteris duplo angustior, latitudine summa haud longior, subcylindricus, minus confertim inaequaliter fortiter profundeque punctatus, linea media longitudinali latiore, utrinque abbreviata, laevi, subelevata. Coleoptera thorace paulo longiora, fortiter profundeque minus dense inaequaliter punctata, modice convexa, anterius versus suturam torosa. Abdomen coleopteris angustius, apicem versus sensim leviter attenuatum, crebrius basi fortius, apice subtilius punctatum. Pedes rufo-testacei, coxis anterioribus concoloribus, posticis piceis, femoribus apice fuscescentibus, tarsis brevioribus, articulis duobus primis linearibus, primo leviter elongato, tertio triangulari, quarto fortiter bilobo.

Mas latet. Femina abdominis segmento inferiore sexto apice leviter triangulariter producto.

87. St. iugalis: Niger, nitidus, antennarum basi pedibusque flavis, his geniculis fuscis, capite, thorace elytrisque crebre profundeque punctatis, callis frontalibus laevissimis, abdomine parce subtiliter punctato. Long. 2 lin.

Habitat in Columbia, Dom. Moritz.

Statura fere praecedentis, antennis autem pedibusque magis elongatis. Corpus nigrum, nitidum, infra abdomine parce griseo-pubescente. Antennae elongatae, articulo tertio yuarto paululum longiore, fuscae, basi flavotestaceae. Palpi articulis dnobus primis flavis (tertius deest). Caput thorace paulo latius, profunde punctatum, fronte bisulcata, interstitio leviter elevato, antrorsum angustato, callo minuto rotundato prope oculum utrinque et carinulis duabus supra antennarum basin laevissimis, politis, infra antennas dense albido-pubescens. Thorax coleopteris dimidio angustior, medio leviter rotundatus, latitudine summa paulo longior, subcylindricus, crebre sat profunde punctatus, interstitiis leviter rugulosis, praecipue versus latera. Elytra thorace paulo longiora, leviter convexa, medio longitudinaliter late at parum distincte torosa, dense fortiter profundeque punctata, interstitiis subinaequalibus. Abdomen coleopteris paulo angustius, apicem versus sensim leviter angustatum, segmentis singulis basi leviter constrictis, anterioribus subtilius punctatis, ultimis duobus laevibus. Pedes flavi, coxıs anterioribus testaceis, femoribus apice, tibiis basi, tarsis medio fuscis, his longioribus, artıculis tribus primis linearibus, primo modice elongato, quarto fortiter bilobo.

Mas abdomims segmento inferiore sexto apice truncato. Femin a latet. 
* 88. St. callosus: Niger, nilidus, fortiter profundeque punctalus, parce pubescens, antennis, palpis pedibusque tesiceeis, femoribus apice nigris, fronte callis tribus laevissimis, abdomine parce punclato. - Long. $1 \frac{1}{2}$ lin.

Habitat in Pensylvania, Dom. Zimmermann.

Habitu omnino St. ricindeloidis, at quadruplo minor, niger, nitidus, pube brevi parca albida vix cinerascens. Antennae longiores, articulo tertio quarto sesqui longiore, testaceae, apice fuscescentes. Palpi testacei. Caput thorace paulo latius, subtilius confertim punctatum, densius albidopubescens, fronte depressa, obsolete bisulcata, interstitio latinsculo, leviter elevato, callo utrinque prope oculum minore carinulisque duabus minutis supra antennarum basin laevissimis, politis. Thorax coleopteris duplo fere angustior, lateribus leviter rotundatus, latitudine paulo longior, subcylindricus, fortius profunde crebreque inaequaliter punctatus, carinula media longitudinali subelevata, utrinque abbreviata, laevi. Elytra thorace paulo longiora, fortiter profundeque minus dense punctata, leviter convexa, anterius versus basin torosa. Abdomen coleopteris angustius, apicem versus sensim leviterque angustatum, parce subtiliter punctatum, segmentis quatuor primis basi modice constrictis. Pedes testacei, femoribus summa apice coxisque nigro-piceis, tarsis brevioribus, articulis duobus primis linearibus, primo leviter elongato, tertio triangulari, quarto fortiter bilobo.

Mas abdominis segmento inferiore sexto apice emarginato, quinto late subsinuato; femina segmento sexto apice rotundato.

89. St. frontalis: Niger, nitidus, forliter profundeque punctatus, antennis, palpis pedibusque testaceis, fronle callis tribus elevatis laevissimis, abdomine parcius punctato. - Long. $1 \frac{1}{3}$ lin.

Habitat in Columbia, Dom. Moritz.

Affinis praecedenti, niger, nitidus, parce subtiliterque albido-pubescens. Antennae breviores, articulo tertio quartoque subaequalibus, testaceae, clava fuscescente. Palpi testacei. Caput thorace parum latius, creberrime sat profunde punctatum, fronte depressa, leviter bisulcata, interstitio lato, subelevato, callo prope utrumque oculum minore carinulisque duabus supra antennarum basin laevissimis, politis. Thorax coleopteris duplo angustior, lateribus ante medium leviter rotundatis, latitudine summa paulo longior, cylindricus, lateribus crebre, dorso parcius fortiter profundeque punctatus, carinula media subelevata obsoleta laevi. Elytra thorace paulo longiora, leviter convexa, medio oblique leviter torosa, densius fortiter profundeque punctata, interstitiis subaequalibus. Abdomen coleopteris angustius, apicem versus sensim attenuatum, segmentis singulis medio leviter constrictis, parcius obsoletiusque punctatum. Pedes obscure testacei, coxis nigris, tarsis brevioribus, articulo primo leviter elongato, tertio triangulari, quarto bilobo.

Mas abdominis segmentis inferioribus longitudinaliter late impressis, impressione densius pubescente, quinto apice subsinuato, sexto profunde inciso. F e min a latet.

* 90. St. colubrinus: Elongatus, niger, nitidus, glaber, antennis, palpis pedibusque elongatis flavis, fronte excavata, laevissima, abdomine parce subtiliterque punctato. - Long. 3 lin.

Habitat in Madagascar, Dom. Goudot. 
Valde elongatus, tenuis, cylindricus, proxime sequentibus gracilior, niger, nitidus, glaber. Antennae elongatae, tennes, articulo tertio quarto paulo Jongiore, flavo-testaceae. Palpi elongati, flavo-testacei. Labrum margine testaceo. Caput thorace duplo latius, laevissimum, antice albido-pubescens, fronte inter oculos fortiter excavata. Oculi magni, valde prominuli. Thorax basi coleopteris vix duplo angustior, medio perparum incrassatus, latitudine plus sesqui longior, cylindricus, crebrius fortiusque subinaequaliter punctatus, linea media longitudinali abbreviata laevi. Elytra thoracis longitudine, parcius profunde punctata, humeris obtusis, vix prominulis. Abdomen elongatum, subtiliter parce punctatum, segmentis tribus primis basi modice constrictis. Pedes elongati, flavo-testacei, coxis rufo-testaceis.

Mas abdominis segmento inferiore sexto apice triangulariter emarginato, quinto, quarto tertioque late profundius canaliculatis, canalicula pubescente, utrinque ciliata. F e min a latet.

* 91. St. altenuatus: Elongatus, niger, nitidus, glaber, antennis, palpis pedibusque testaceis, fronte modice excavata, parce punctata, abdomine crebrius punctato. - Long. $2 \frac{1}{2}$ lin.

\section{Habitat in Madagascar, Dom. Goudot.}

Elongatus, gracilis, niger, nitidus, glaber. Antennae elongatae, tenues, articulo tertio quarto paulo longiore, testaceae. Palpi elongati, testacei. Labrum margine summo piceo. Caput thorace duplo latius, antice albidopubescens, fronte medio excavata, obsolete subtiliterque bisulcata, interstitio lato, nullo modo elevato, vage parceque punctata. Thorax coleopteris duplo angustior, medio levissime rotundato-incrassatus, latitudine duplo fere longior, cylindricus, dorso crebre, lateribus creberrime punctatus, interstitiis lateribus rugulosis, dorso linea media longitudinali, utrinque abbreviata, minus distincta, maculisque nonnullis minutis inaequalibus sparsis subelevatis laevibus. Elytra thorace paulo longiora, parcius profunde punctata, interstitiis aequalibus, leviter convexa, anterius versus suturam longitudinaliter leviter torosa, humeris fere rectangults, prominulis. Abdomen coleopteris dimidio angustius, elongatum, cylindricum, basi fortius, apice subtilius crebrius punctatum, segmentis quatuor primis basi leviter constrictis. Pedes elongati, tenues, rufescenti-testacei, coxis anticis concoloribus, tarsis longioribus, articulo primo elongato, tertio triangulari, apice emarginato, quarto fortiter bilobo.

Mas abdominis segmento inferiore sexto apice triangulariter exciso. F em in a latet.

* 82. St. prolixus: Elongatus, niger, nilidus, glaber, antennis, palpis pedibusque flavis, fronte modice excavata, utringue punctata, abdomine parce punctato. - Long. $2 \frac{3}{4}$ lin.

Habitat in Madagascar, Dom. Goudot.

Statura elongata gracili omnino praecedentis, at paulo maior, niger, nitidus, glaber. Antemnae elongatae, tenues, articulo tertio quarto sesqui longiore, flavae, clava testacea. Palpi flavi. Caput thorace plus dimidio latius, antice albido-pubescens, fronte leniter excavata, subtiliter bisulcata, interstitio lato, depresso, parcius subtilinsque punctata, linea media longitu- 
dinall laevi. Thorax coleopteris duplo prope angustior, medio haud incrassatus, latitudine plus sesqui longior, cylindricus, dorso parcius, lateribus crebre punctatus, interstitiis lateribus subrugulosis, dorso planis, linea media longitudinali laevi. Elytra thorace paululum longiora, minus dense sat fortiter profundeque punctata; leviter convexa, antice medio levissime torosa, humeris fere rectangulis. Abdomen coleopteris dımidio angustius, elongatum, cylindricum, segmentis 4 primis basi leviter constrictis, parce subtiliterque, segmentis 4 primis lateribus paulo fortius punctatum. Pedes graciles, pallide flavi, coxis dilute testaceis, tarsis longiusculis, articulo primo elongato, tertio triangulari, apice acute emarginato, quarto fortiter bilobo. tundato.

Mas latet. Femina abdominis segmento inferiore sexto apice ro-

Obs. Proximus praecedenti, at statura maiore, antennis, palpis pedibusque pallidioribus, capite angustiore, thorace medio haud crassiore, minus confertim punctatis, abdomine parcius punctato distinctus videtur.

* 93. St. gracilis: Elongatus, niger, nilidus, glaber, antennis, palpis pedibusque testaceis, fronte leviter excavala, uirinque punctala, abdomine laevissimo. - Long. $2 \frac{2}{3}$ lin.

Habitat in Madagascar, Dom. Goudot.

Elongatus, gracilis, cylindricus, niger, nitidus, glaber. Antennae modice elongatae, tenues, articulo tertio quarto paulo longiore, testaceae. Palpi elongati, flavi. Labrum margine tenui testaceo. Caput thorace sesqui latius, antice subtiliter albido-pubescens, fronte modice excavata, utrinque crebre subtilius punctata, linea media longitudináli laevi. Thorax coleopteris duplo fere angustior, medio vix incrassatus, latitudine duplo longior, cylindricus, lateribus longitudinaliter late subimpressus, dorso parcius, lateribus dense punctatus. Elytra thorace parum longiora, parcius minus profunde punctata, leviter convexa, antice versus basin obsolete torosa, humeris fere rectangulis, prominulis. Abdomen coleopteris angustius, elongatum, cylindricum, laevissimum, segmentis quatuor primis basi leviter constrictis. Pedes modice elongati, testacei, coxis anticis concoloribus, tarsis longioribus, articulo primo sat elongato, tertio triangulari, quarto fortiter bilobo.

Mas abdominis segmento inferiore quarto quintoque medio longitudinaliter breviter subtiliterque cinereo-pubescentibus, sexto apice leviter emarginato. $\mathrm{F}$ e $\mathrm{m}$ in a latet.

* 94. St. lubricus: Elongatus, niger, nitidus, glaber, antennis, palpis pedibusque flavo-testaceis, fronte leviter excavata, crebre punctata, elytris thorace paulo longioribus, inaequalibus, abdomine crebrius punclato. - Long. $2 \frac{1}{2}$ lin.

Habitat in Brasilia.

Proximus praecedentibus, at minus cylindricus, niger, nitidus, glaber. Antennae elongatae, tenues, articulo tertio quarto paulo longiore, flavae. Palpi elongati, pallide flavi. Caput thorace sesqui latius, antice densius albido-pubescens, fronte late levissime excavata, crebre fortius profunde punctata, breviter subtiliterque albido-pubescente. Thorax coleopteris plus dimidio angustior, medio haud incrassatus, latitudine duplo fere longior, 
cylindricus, dense fortiter profundeque aequaliter punctatus, interstitiis subrugulosis. Elytra thorace paulo longiora, minus confertim sat fortiter profundeque punctata, dorso prope suturam longitudinaliter anguste torosa, toro antice humeros versus vergente, extra torum late subimpressa, sutura depressiuscula, humeris fere rectangulis, leviter prominulis. Abdomen coleopteris dimidio angustius, cylindricum, segmentis anterioribus 4 crebre minus subtiliter punctatis, basi leviter constrictis, reliquis duobus parce subtiliterque punctatis, subtus segmentis intermediis longitudinaliter subtiliter cinereopubescentibus. Pedes flavo-testacei, coxis omnibus piceis, tarśis longioribus, articulo primo elongato, tertio triangulari, quarto fortiter bilobo. tundato.

Mas latet. Femina abdominis segmento inferiore sexto apice ro.

Obs. Distinctus a praecedente corpore minus gracili, elytris paulo latioribus et longioribus, inaequalibus.

* 95. St. anguinus: Elongatus, cylindricus, niger, nitidus, parce albidopubescens, antennis, palpis pedibusque flavis, fronte leviter excavala, parcius punctata, elytris thoracis longitudine, abdomine segmentis quatuor anterioribus profundius punctatis, basi dense pubescentibus. Long. 2 lin.

Habitat in Guyana Venezuelensi, Dom. Moritz.

Statura et summa affinitate St. elongati, at paulo minor, niger, nitidus, pube brevissima albida parca vestitus. Antennae elongatae, articulo tertio quarto paulo longiore, albido-flavae, apice fuscae. Palpi elongati, pallide flavi. Labrum margine testaceo. Caput thorace sesqui latius, fronte late levissime excavata, parcius et minus profunde punctata, parcius subtiliterque aibido-pubescente, infra antennas dense albido-villosum. Thorax coleopteris dimidio angustior, lateribus medio levissime rotundato-angustatus, latitudine duplo prope longior, cylindricus, aequaliter dense fortius profundeque punctatus, posterius linea media longitudinali tenui subelevata laevi. Elytra thoracis longitudine, leviter convexa, munus dense fortiter profundeque punctata, interstitiis aequalibus, humeris fere retangulis, prominulis. Abdomen coleopteris dimidio angustius, elongatum, segmentis quatuor primis crebre fortius profunde punctatis, basi constrictis et densius pubescentibus, ultimis parce subtiliterque punctatis. Pedes graciliores, pallide flavi, tarsis articulis 3 prims linearibus, primo elongato, quarto fortiter bilobo.

Mas abdominis segmento inferiore sexto profunde triangulariter exciso, quinto fortius longitudinaliter impresso, impressione lateribus ciliis densis longioribus introrsum vergentibus terminata, apice sinuato. F emin a latet.

$\mathrm{O}$ bs. A praecedentibus corporo pubescente, a sequentibus fronte leviter excavata et elytris brevioribus distinctus.

* 96. St. teres: Elongatus, cylindricus, niger, nilidus, glaber, antennis, palpis pedibusque flavis, fronte leviter excavala, crebrius punctata, abdominis segmentis quatuor anterioribus profundius parciusque punctatis, elytris thorace brevioribus. - Long. $2 \frac{1}{2}$ lin.

Habitat in Brasilia, Dom. Melly.

Statura elongata, gracilis, cylindrica praecedentium. Niger, nitidus, gla- 
ber. Antennae elongatae, tenues, articulo tertio quarto parum longiore, testaceae, basi flavae. Palpi elongati, pallide flavi. Labrum rufo-testaceum, basi nigrum. Caput thorace sesqui latius, antice albido-pubescens, fronte modice excavata, crebre fortius subinaequaliter punctata, posterius carinula media longiore, anterius carinulis duabus supra antennarum basin brevioribus, angustis, elevatis, laevibus. Thorax coleopteris paulo angustior, medio haud incrassatus, latitudine duplo fere longior, cylindricus, creberrime fortiter profundeque punctatus, interstitiis subrugulosis. Elytra thorace paulo breviora, fortiter profundeque densius punctata, interstitiis subinaequalibus, humeris obtusis, haud prominulis. Abdomen coleopteris parum angustius, elongatum, cylindricum, segmentis quatuor primis vage profundius punctatis, basi fortius constrictis, nltimis duobus parce subtilissime punctatis. Pedes modice elongati, flavi, coxis anticis testaceis, tarsis brevioribus, articulo primo leviter elongato, tertio obcordato, quarto fortiter bilobo.

Mas abdominis segmento inferiore sexto profunde triangulariter inciso, quinto longitudinaliter late impresso, apice sinuato, quarto tertioque longitudinaliter excavatis, excavatione margine ciliata. Femina latet. stinctus.

Obs. Coleopteris thorace brevioribus et perparum latioribus ab affinibus di-

* 97. St. elongatus: Elongatus, cylindricus, niger, nitidus, glaber, antennis, palpis pedibusque flavis, fronte leviter excavata, crebre punctata, abdomine segmentis quatuor anterioribus profundius punctatis, elytris thoracis longitudine. - Long. $2 \frac{1}{4}$ lin.

Habitat in Brasilia.

Statura praecedentium, niger, nitidus, glaber. Antennae elongatae, articulo tertio quartoque subaequalibus, pallide flavae. Palpi elongati, flavi. Labrum nigrum, margine exteriore flavescente. Caput thorace sesqui latius, antice albido-pubescens, fronte late levissime excavata, crebrius profunde punctata. Thorax coleopteris duplo prope angustior, medio vix incrassatus, latitudine duplo fere longior, cylindricus, fortiter profunde dense aequaliter punctatus, interstitiis subaequalibus. Elytra thoracis longitudine, fortiter profundeque minus dense punctata, leviter convexa, aequalia, humeris fere rectangulis, prominentibus. Abdomen coleopteris dimidio fere angustius, elongatum, cylindricum, segmentis quatuor primis profundius punctatis, basi leviter constrictis, ultimis duobus parce subtilissime punctatis, subtus medio longitudinaliter pubescens. Pedes modice elongati, flavi, coxis anticis testaceis, posterioribus piceis, tarsis longioribus, articulo primo elongato, tertio triangulari, quarto fortiter bilobo.

Mas abdominis segmento inferiore sexto profunde inciso, quinto apice late profundius sinuato; femina segmento sexta apice acute roturdato.

*98. St. iunceus: Elongalus, cylindricus, nigro-subvirescens, nitidulus, parce subtiliterque albido-pubescens, antennis, palpis pedibusque pallide flavis, fronte depressa, elytris thorace haud longioribus, abdomine crebre fortius punctato. - Long. $2 \frac{1}{2}$ lin.

Habitat in Columbia, Dom. Moritz.

Habitu fere praecedentium, St. oculato fere aequalis, at gracilior, plum- 
beo-niger, virescenti-nitidulus, pube brevi subtili albida aequali parcaque vix cinerascens. Antennae elongatae, tenues, articulo tertio quarto paulo breviore, pallide flavae, clava testacea. Palpi elongati, flavo-testacei. Labrum restaceum, summa basi nigricante. Caput thorace paulo latius, fronte depressa, minus dense sat profunde punctata, densius subtiliter albido-pu. hescente, infra antennas albo-villosum. Thorax coleopteris dimidio angustior, medio vix incrassatus, latitudıne duplo longior, cylindricus, aequaliter dense profundeque punctatus, interstitiis parum rugulosis. Elytra thorace haud longiora, leviter convexa, minus confertim fortiter profundeque punctata, interstitiis aequalibus. Abdomen coleopteris dimidio angustus, modico elongatum, segmentis 4 primis basi leviter constrictis, fortiter profundiusque crebre punctatum, segmento sexto parce subtiliterque punctato. Pedes grariliores, flavi, coxis testaceis, tarsis articulo primo elongato, secundo tertioque triangularibus, quarto fortiter bilobo.

Mas abdominis segmento inferiore sexto profunde longitudinaliter inciso, quinto longitudinaliter, quarto apice triangulariter impresso, impres: sionibus densius pubescentibus; femina segmento sexto apice rotundato.

* 99. St. ariolus: Plumbeo-niger, subnilidus, dense punctatus, densius albido-pubescens, antennis, palpis pedibusque flavis, fronte depressa, elytris thorace paulo longioribus, his et abdominis profundius punctulati segmentis singulis basi densius pubescentibus. - Long. $2 \frac{1}{2}$ lin.

Habitat in Columbia, Dom. Moritz.

Statura fere St. oculati, et parum gracilior, plumbeo - niger, subnitidus. Antennae elongatae, tenues, articulo tertio quartoque subaequalibus, flavae, clava fuscescente. Palpi elongati, flavi. Labrum testaceum, basi nigricans. Caput thorace sesqui prope latius, subtilius parciusque punctatum, fronte depressa, anterius obsolete bisulcata, densius subtiliter breviterque albidopubescens, infra antennas dense albido-villosum. Thorax coleopteris duplo angustior, medio leviter rotundato - incrassatus, latitudine sesqui fere longior, subcylindricus, creberrime minus fortiter punctatus, interstitiis subrugulosis, densius breviter subtiliterque albido-pubescens. Elytra thorace paululum longiora, fortiter profundeque dense punctata, leviter convexa, humeris obtusiusculis, prominentibus, basi dense, ceterum parce albido-pubescentia. Abdomen coleopteris dimidio angustius, modice elongatum, crebrius fortius profundiusque punctatum, segmentis quatuor primis basi fortins constrictis, parce albido-pubescens, segmentis 5 primis basi pube dense depressa albida obductis. Pedes graciliores, albido-flavi, tarsis articulo primo elongato, tertio triangulari, apice emarginato, quarto fortiter bilobo. tundato.

$\mathrm{Mas}$ latet. Femina abdominis segmento inferiore sexto apice ro-

Obs. Differt a praecedente praecipue statura minus gracili, thorace densius, elytris et abdominis segmentis basi dense sericeo-pubescentibus.

* 100. St. p'aganus: Plumbeo-niger, nilidulus, crebre profundeque punclatus, subtiliter albido-pubescens, antennis palpisque testaceis, his upice, illis basi apiceque fuscis, pedibus rufo-brunneis, tarsis testaceis. Long. $1 \frac{2}{3}$ lin.

Er. Col March. I. 571. 50.

Ilabitat in Germania, Anglia. 
Habitu et statura omnino St. unicoloris, plumbeo-niger, nitidulus, pube brevi depressa albida parciore cinerascens. Antennae breves, articulo tertio quarto paulo longiore, testaceae, articulis duobus primis piceis, clava fusca. Palpi testacei, articulo secundo apice fusco, tertio fusco, basi testaceo. Caput breviusculum, transversum, thorace paulo latius, dense fortius profunde punctatum, fronte depressa, late leviter bisulcata, interstitio lato, parum convexo, aeque ac frontis latera elevato. Thorax coleopteris dimidio angustior, lateribus leviter rotundatus, posterius magis angustatus, basi coleopteris duplo angustior, latitudine summa vix longior, subdepressus, dense profundeque aequaliter punctatus, interstitiis latera versus subrugulosis. Coleoptera thorace paululum longiora, fortius dense profundeque punctata, interstitiis subrugulosis. Abdomen coleopteris perparum angustius, apice leviter attenuatum, dense fortius profundeque punctatum. Pedes bre viusculi, rufo-brunnei, tarsis testaceis, brevibus, articulo primo vix elongato, secundo tertioque subtriangularibus, quarto fortiter bilobo.

Mas abdominis segmento inferiore sexto profunde inciso, quinto longitudinaliter late impresso, impressione carinula obtusiuscula terminata, apice trisinuato, quarto levius longitudinaliter impresso; femin a segmento sexto apice rotundato.

* 101. St. latifrons: Subdepressus, plumbeo-niger, subnitidus, crebre punctatus, subliliter albido-pubescens, antennis medio palpisque piceis, his basi testaceis, pedibus rufo-piceis, abdomine fortius crebre punctato. - Long. $1 \frac{2}{3}$ lins.

Er. Col. March. I. 572. Б1.

Sten. morio var. Grav. Mon, p. 231.

\section{Habitat in Europa.}

Praecedenti proximus, linearis, subdepressus, plumbeo-niger, subnitidus, pube brevi albida cinerascens. Antennae breviusculae, articulo tertio quarto paulo longiore, piceae, basi apiceque obscuriores. Palpi picei, articulo primo toto, secundo basi testaceo. Caput breve, thorace paulo latius, crebre profunde punctatum, fronte obsoletius late bisulcata, interstitio lato, parum convexo, aeque ac frontis latera elevato. Thorax coleopteris paulo angustior, lateribus leviter rotundatus, posterius paulo magis quam anterius angustatus, basi coleopteris dimidio angustior, latitudine summa vix longior, subdepressus, confertissime aequaliter profunde punctatus, interstitiis latera versus subrugulosis. Elytra thorace paulo longiora, dense profundeque punctata, interstitiis aequalibus, anterius versus suturam obsolete torosa. Abdomen elongatum, lineare, dense profundiusque punctatum. Pedes breviusculi, rufo-picei, coxis nigris, tarsis brevibus, articulo primo parum elongato, secundo tertioque triangularibus, quarto fortiter bilobo.

Mas abdominis segmento inferiore sexto profunde inciso, quinto longitudinaliter impresso, impressione apicem versus utrinque carinula obtusa terminato, apice sinuato, quarto apicem versus leviter impresso; femina segmento sexto apice acute rotundato.

O b s. Differt a praecedente corpore paululum magis depresso, punctura paulo minus forti, coleopteris thorace parum latioribus, palpis, antennis tarsisque dilutioribus. Simillimus quoque $\mathrm{St}$. unicolori, sulcis frontalibus antem minus profundis et tarsorum articulo quarto bilobo facile distinguendus. 
* 102. St. punctatus: Plumbeo-niger, subnitidus, crebre punctatus, albidopubescens, antennis palpisque testaceis, apice fuscis, pedibus obscure rufo-testaceis, abdomine fortius crebre punctalo. - Long. $1 \frac{1}{3}$ lin.

Habitat in Pensylvania, Dom. Zimmermann.

Habitu omnino St. cicindeloidis, at plus quadruplo minor, plumbeoniger, subnitidus, pube brevi albida cinerascens. Antennae breviores, articulo tertio quarto sesqui longiore, obscure testaceae, clava fuscescente. Palpi testacei, basi pallidi, apice fuscescentes. Caput thorace paulo latius, crebre fortiter profundeque punctatum, fronte depressa, obsolete bisulcata. Thorax coleopteris duplo angustior, lateribus medio parum rotundatis, latitudine vix longior, cylindricus, creberrime profunde punctatus, interstitiis rugulosis. Elytra thorace paulo longiora, fortiter profundeque dense punctata, interstitiis rugulosis, leviter convexa, anterius versus suturam longitudinaliter leviter torosa. Abdomen coleopteris angustius, apicem versus sensim leviter attenuatum, crebre profundeque punctatum, segmentis quatuor primis basi leviter constrictis. Pedes obsoure rufo-testacei, coxis posterioribus piceis, femoribus apice fuscescentibus, tarsis breviusculis, articulo primo leviter elongato, tertio triangulari, quarto fortiter bilobo.

Mas abdominis segmento inferiore sexto profunde triangulariter inciso; femina eodem apice rotundato.

O bs. In collectione Dom. Chevrolat hunc Stenum vidi nomine St. punctati Dej.

* 103. St. arculus: Plumbeo-niger, nitidulus, dense fortiter punctatus, parce albido-pubescens, anlennis, palpis pedibusque testaceis, pedibus rufo-piceis, tibiis basi testaceis. - Long. $1 \frac{1}{2}$ lin.

Habitat in Pensylvania, Dom. Zimmermann.

Habitu omnino St. callosi, at sesqui maior, plumbeo-niger, nitidulus, pube brevi depressa albida rariore vix cinerascens. Antennae articulis duobus primis testaceis (reliqui desunt). Palpi rufescenti-testacei, basi dilutiores. Caput thorace parum latius, crebre fortiter profundeque punctatum, fronte planiuscula, obsolete late bisulcala, interstitio parum convexo, vix magis quam capitis latera elevato, subcarinato. Thorax coleopteris duplo angustior, lateribus ante medium leviter rotundatus, latitudine summa vix longior, subcylindricus, dense fortiter profundeque punctatus, interstitiis leviter rugosis, dorso pone medium callo minuto ovali laevissimo. Elytra thorace paulo longiora, leviter convexa, dense fortiter profundeque punctata, interstitiis leviter rugosis. Abdomen coleopteris angustius, apicem versus sensim leviter attenuatum, segmentis 4 anterioribus basi constrictis, minus dense profundius punctatum. Pedes dilute rufo-picei, coxis, trochanteribus, femorum apice tibiisque obscurioribus, his basi determinate testaceis, tarsis breviusculis, articulo primo leviter elongato, tertio triangulari, quarto fortiter bilobo. tundato.

Mas latet. Femina abdominis segmento inferiore sexto apioe ro-

* 104. St. contractus: Niger, nitidus, fortiter punctatus, parce albidopubescens, palpis nigris, basi testaceis, tibiis basi albidis, coleopteris amplis, convexis. - Long. 1 lin.

Er. Col. March, I. 573. 52. 
Habitat in Germania, Gallia, Italia.

Magnitudine St. circulari aequalis, niger, nitidus, pube brevi albida parcius vestitus. Antennae breviusculae, articulo tertio quarto parum longiore, piceae, apice nigrae. Palpi nigro-picei, articulo primo pallicle testaceo. Caput parvulum, thorace parum latius, inaequaliter profundius punctatum, fronte obsolete bisulcata, interstitio parum convexo, non magis quam frontis latera elevato, laeviore. Thorax coleopteris plus duplo angustior, lateribus sat fortiter rotundatus, latitudine haud longior, convexiusculus, fortiter profundeque crebre punctatus, interstitiis rugulosis. Coleoptera ampla, capite plus duplo latiora, thorace sesqui longiora, convexiuscula, densius fortiter profundeque punctata, interstitiis subrugosis. Abdomen coleopteris multo angustius, apicem versus sensim attenuatum, breviusculum, parce profundius punctatum. Pedes nigri, tibiis basi albis, tarsis piceis, breviusculis, articulo primo leviter elongato, tertio triangulari, quarto fortiter bilobo.

Mas abdominis segmento inferiore sexto apice triangulariter inciso; femina eodem acute rotundato.

\section{Species mihi invisae.}

105. St. rotundatus: Nigro-aeneus, antennis longitudine capilis, elytris postice rotundatis, thorace globoso, abdomine subconico.

Ljungh Web. u. Mohr Archiv. I. 1. 67. 8.

Habitat in pratis Sjärsjöensibus (Sueciae).

Caput nigro-aeneum, breve, thorace latius, intra oculos porca tridente bis canaliculatum, punctatum. Oculi magni prominuli. Antennae nigrae, longitudine capitis, apice albo-pilosae, clavatae. Palpi nigri. Thorax aeneoniger, convexus, immarginatus, orbiculatus, temere punctatus, capite et elytris angustior, capiteque vix duplo longior. Scutellum nullum. Elytra aeneo-nigra, thorace dimidio latiora, pauloque longiora, postice rotundata, punctata. Alae - - - Abdomen apice attenuatum, vix marginatum, nigrum, nitidum, longitudine elytra vix superans. Subtus totus niger, tibiis tarsisque solis piceis. Statura Steni buphthalmi, sed vix magnitudine Staphylini pygmaei Payk. (Ljungh).

106. St. 4-punctatus: Niger, punctatus, thorace hexagonali, inaequali. - Long. ultra 1 lin.

Say Transact. Amer. Philosoph. Soc. Philadelph. Nov. Ser. IV. 459. 5.

Habitat in Missuria.

Corpus nigerrimum, immaculatum, profunde dense punctatum. Os testaceum. Palpi nigri. Thorax hexagonalis, margine laterali medio angulato, disco foveolis quatuor dilatatis, quincunce dispositis, linea media longitudi. nali leviter elevata distinctis, foveola vel foveolis duobus obsoletis ad marginem lateralem impressus. Abdomen et pectus impunctata, illo breviter piloso. Pedes picei. (Say).

$\mathrm{Obs}$. An rite huic generi adscriptus? 


\section{Euaesthetus Grav.}

Grav. Mon. p. 201.

Eri sthet us Mannerh. Brachelytr. p. 41. - Boisd. et Lacord. Faun. Ent. Paris. I. p. 438.

Mentum transversum, apice sinuato-emarginatum.

Tarsi 4-articulati.

Corpus minutum, oblongum, teretiusculum, alatum. Caput sat magnum, thoracis fere latitudine, basi leviter constrictum, thoraci immissum, exsertum, oculis parvis, modice prominulis. Labrum latum, transversum, apice dense acuteque denticulatum seu acute serratum. Mandibulae sat longae, falcatae, acutae, medio dente valido acuto armatae, pone dentem subtiliter denticulatae. Maxillae (t. V. f. 3. b.) malis corneis, interiore interne, exteriore apice membraneo barbatis. Palpi maxillares elongati, articulis tribus primis longitudine increscentibus, duobus primis teretibus, tertio incrassato, clavato, quarto minimo, subtilissimo, subulato, nonnisi oculo fortiter armato conspicuo. Labium (t. V. f. 3. a.) mento transverso, apice late emarginato, angulis anterioribus acute prominulis, spatio membranaceo inter mentum et ligulam brevi, transverso, ligula lata, medio leviter sinuata, membranacea, paraglossis ligulae connatis, eamque superantibus, acuminatis, membranaceis, subtiliter ciliatis. Palpi labiales breves, articulo primo minore, subovato, secundo crassiusculo, subovato, basi breviter pedunculato, tertio minuto, subtili, subulato. Antennae in frontis margine anteriore intra mandibularum basin insertae, basi distantes, breves, articulis duobus primis sequentibus paulo crassioribus maioribusque, articulis $\mathbf{3}-\mathbf{5}$ subaequalibus, $\mathbf{6}-\mathbf{8}$ sensim paulo brevioribus, ultimis tribus sensim maioribus, clavulam oblongam formantibus. Thorax lateribus anterius rotundatus, posterius angustatus, basi apiceque truncatus. Scutellum minimum, triangulare. Coleoptera apıce late coniunctim emarginata. Abdomen plerumque marginatum, apice obtusum. Pedes breviusculi, tarsis 4-articulatis, articulo primo ultimoque intermediis longioribus.

O b s e r vation e s.

1. Eua esthetus cum Steno summa affinitate coniunctus, licet aliquomodo Oxyteli habitum simulans, genus constituit tarsis 4-articulatis singulare et omnino optime distinctum, unde nomen ( $a b \varepsilon v$ et $\alpha \iota \sigma \vartheta \alpha \nu \nu_{0} \alpha_{\iota}$ ), quare emendatio Mannerheimii, qui illud errore quodam pro Eristheto exortum putat, mihi haud suscipienda videtur.

2. Mas abdominis segmento inferiore sexto apice inciso, praecedentibus impressis tuberculatisve distinguendus.

3. Victus in silvis sub foliis deciduis et in pratis.

* 1. E. scaber: Nigro-piceus, opacus, capile pedibusque rufis, capite, thorace elytrisque confertissime punctatis, thorace lineolis duabus rectis impresso. - Long. 1 lin.

Grav. Mon. 202. 1. - Gyll. Ins. Suec. II. 462. 1. - Germ. Faun. Ins. Europ. VII. 13. - Er. Col. March. I. 574. 1.

Erist het us s caber Mannerh. Brachelytr. 41. 1. - Salb. Ins. Fenn. I. 420. 1. Boisd. et Ladord. Faun. Ent. Paris. I. 439. 1.

Stenus bipunctatus Ljungh Web. et Mohr Arch. 1. 1. 68. 9.

Habitat in Germania, Suecia. 
Nigro-piceus, opacus, densius breviter subtilissime fusco-pubescens. Caput cum antennis palpisque saturate rufum, confertissime punctatum. Thorax coleopteris parum angustior, lateribus anterius rotundatus, posterius angustatus, basi coleopteris duplo angustior, perparum convexus, confertissime punctatus, dorso posterius lineolis duabus, ante medium abbreviatis, distantibus, parallelis, rectis inpressus. Elytra thorace paulo breviora, depressa, sat crebre punctata. Abdomen subtilissime punctulatum. Pedes rufi.

Mas abdominis segmento inferiore sexto apice profunde exciso, quinto aequali, quarto prope apicem tuberculis duobus minutis compressis approximatis instructo; femina segmento sexto apice rotundato.

* E. ruficapillus: Piceus, nilidulus, capite pedibusque rufis, capite thoraceque confertim punctatis, hoc lineolis duabus arcuatis impresso, elytris subtilissime punctulatis. - Long. $\frac{3}{4}$ lin.

Fr. Col. March. I. 575. 2.

Eristhetus ruficapillus Boisd. et Lacord. Faun. Ent. Paris. I. 439. 2.

Habitat in Germania, Gallia.

Habitu et summa similitudine praecedentis, at duplo fẹre minor, piceus, nitidulus, densius breviter subtilissime fusco-pubescens. Caput cum antennis palpisque rufum, confertim punctatum. Thorax coleopteris paulo angustior, lateribus anterius fortiter rotundatus, posterius angustatus, basi coleopteris duplo angustior, parum convexus, confertim punctatus, dorso posterius lineolis duabus leviter arcuatis, (introrsum convexis,) ante medium abbreviatis, modice distantibus, Impressus. Elytra thoracis longitudine, subdepressa, parcius subtilissime punctata, prope suturam subtilissime unistriata. Abdomen subtilissime punctulatum, segmentis singulis margine posteriore rufescente. Pedes rufi.

Mas abdominis segmento inferiore sexto apice exciso, quinto medio longitudinaliter canaliculato, quarto prope apicem tuberculis duobus minutis compressis, approximatis instructo; fem in a segmento sexto apice rotundato.

Obs. Differt a praecedente statura minore, colore dilutiore, minus opaco, elytris subtilissime punctatis, thoracis foveolis subarcuatis, minus distantibus. Primus hanc speciem nomine distinxit Dom. v. Winthem.

* 3. E. Americanus: Rufo-piceus, nitidulus, capite pedibusque rufis, capite thoraceque aequali confertim, elylris subtilissime punctatis. Long. $\frac{3}{4}$ lin.

Habitat in Pensylvania, Dom. Zimmermann.

Magnitudine praecedentis, at crassior, rufo-piceus, nitidulus, omnium subtilissime brevissimeque parcius fusco-pubescens. Caput confertim punctatum, rufum, antennis palpisque rufo-testaceis. Thorax coleopteris dimidio angustior, lateribus anterius modice rotundatus, posterius angustatus, basi coleopteris plus duplo angustior, convexus, confertim punctatus, aequalis. Elytra thoracis longitudine, convexiuscula, subtilissime punctulata, prope suturam distincte unistriata. Abdomen vix subtilissime punctulatum. Pectus piceum. Pedes rufo-testacei.

Mas abdominis segmento sexto profunde inciso, quinto apice late emarginato; femin a segmento sexto apice rotundato. 
4. E. immarginatus: Rufo-testaceus, conferlissime punctatus, abdomine immarginalo. - Long. 2 lin.

Habitat in valle Araguensi Columbiae, Dom. Moritz.

Rufo-testaceus, parum nitidus, subtilissime griseo-pubescens. Antennae tenues, elongatae, capite sesqui longiores, pallide flavae, clava parum incrassata, fuscescente. Palpi pallide flavi. Caput thorace paulo latius, confertim subtiliter punctatum. Thorax coleopteris dimidio angustior, elongatus, latitudine longior, ante medium leviter rotundatus, posterius leviter angustatus, basi coleopteris duplo prope angustior, subcylindricus, confertissime punctatus, aequalis. Elytra thorace paulo breviora, dense punctata. Abdomen immarginatum, dense subtiliter punctatum. Pedes flavo-testacei.

Mas latet. Femina abdominis segmento inferiore sexto acute ratundato. 


\section{Tribus septima.}

\section{(1) $\mathbf{x}$ y. $\mathbf{t} \mathbf{i}$ i.}

Stigmata prothoracica occulta.

Coxae posticae transversae, anticae conicae, prominentes.

Trochanteres postici simplices.

Labrum transversum, corneum, apice utrinque lacinia membranea auctum plerisque;

vel apice limbo membranaceo instructum Bledio, Syntomio;

bispinum Megalopi.

Mandibulae validiores, saepius prominentes, dentatae Genuinis;

muticae Megalopi, Osorinis, Coprophilinis.

Maxillae mala interiore interne, exteriore apice barbatis, hac haud dilatata,

corneis Megalopi, Osorinis;

membranaceis Genuinis, Coprophilinis.

Palpi maxillares filiformes Megal opi, Osorinis, Coprophilinis; articulo ultimo subulato Genuinis.

Mentum corneum,

oblongum Megal opi;

latitudine haud brevius Osorinis;

transversum Genuinis, Coprophilinis.

Ligula cornea Megalopi, Osorinis;

membranea Genuinis, Coprophilinis.

Paraglossae distinctae, membraneae, plerisque,

liberae Megalopi, Osorinis;

ligulae connatae Genuinis plerisque, Coprophilo;

nullae Bledio.

Palpi labiales breves, filiformes.

Antennae sub frontis margine laterali insertae,

11-articulatae plerisque;

magis munuse refractae Osorio, Genuinis, Acrognatho:

10-articulatae, clavatae Megal opi. 
Caput porrectum, thoraci immissum, basi parum constrictum plerisque; exsertum, thoraci pedunculo tenui affixum Ap ocello.

Thorax ab elytris magis minusve remotus, spatio pone coxas anticas absque integumento corneo.

Scutellum distinctum Megalopi, Osorinis, Coprophilinis et Trogophloeo*;

indistinctum $\mathrm{Ge}$ nuinis plerisque.

Elytra pectoris longitudine.

Abd ome n segmentis septem distinctis, septimo minuto at haud retractili, marginatum plerisque;

immarginatum Os orinis.

Pedes coxis anticis conicis, exsertis, posticis transversis, trochanteribus posticis simplicibus, tibiis

omnibus muticis Megalopi, Holotrocho, Trogophloeo, Apocello, Deleasteri, Micralymmati, Syntomio;

anticis vel anterioribus spinulosis Platystheto, Oxytelo, Phloeonaeo, Coprophilo;

anticis muricatis Osorio, Bledio, Acrognatho;

tarsis 5-articulatis Megalopi, Os orinis, Coprophilinis;

3-articulatis Genuinis.

$$
\text { O b s e r v a t i o. }
$$

Distinguitur haec tribus a Piestinis et Protein inis coxis anticis exsertis, conicis, spatio pone eas absque integumento corneo, a $\mathrm{Phl}$ oe och arinis et $\mathrm{Oma}$ linis trochanteribus posticis haud fulcrantibus. Praeterea abdominis segmento septimo distincto haud retractili insignis.

\section{Subtribus prima. \\ M e g a $\mathbf{l}$ o $\mathbf{i}$ n $\mathbf{i}$.}

Antennae 10-articulatae, clavatae.

Ligula cornea.

Tarsi 5-articulati.

Labrum bispinum.

Mandibula e breves, exsertae.

Maxillae malis angustis, leviter elongatis, corneis.

Palpi maxillares filiformes.

Mentum oblongum, corneum.

Ligula cornea.

Paraglossae membranaceae.

Palpi labiales articnlo ultimo subovato.

Antennae breves, 10-articulatae, rectae, apice distincte clavatae.

O culi magni, prominentes.

Thor ax subcylindricus, basi truncatus, ab elytris parum remotus.

Scutellum distinctum.

Abdomen marginatum.

Pedes coxis anticis minutis, intermediis approximatis, tibiis muticis, tarsis 5-articulatis. 


\section{Mregalops Dej.}

Corpus oblongum, crassiusculum, alatum. Caput sat magnum, thorace latius, porrectum, oculis lateralibus, permagnis, convexis. Labrum occultum, at nomnunquam labri loco spinae duae acutae corneae prominent. Mandibulae exsertae, falcatae, decussatae, medio denticulo minuto armatae. Maxillae (t. II. f. 3. b.) malis corneis, interiore breviore, interne membranea ciliataque, apice unco corneo armata, exteriore longiore, apice barbatula. Palpi maxillares mala exteriore paulo longiores, articulo primo parvo, tertio secundo paulo breviore, quarto hoc sesqui longiore, apice acuminato. Labium (t. II. f. 3. a.) mento latitudine prope longiore, apicem versus leviter angustato, apice truncato, ligula cornea, apice obtuse bidentata, paraglossis membranaceis, ligulam parum superantibus. Palpi labiales articulo primo leviter elongato, secundo hoc paulo breviore, tertio oblongo-ovato, apice subacuminato. Antennae breves, 10-articulatae, articulo primo crassiusculo, secundo elongato, ultimo maximo, cum praecedentibus duobus clavam sat distinctam, oblongo-ovalem, pubescentem formantibus. Thorax coleopteris angustior, subcylindricus. Scutellum sat magnum, semiorbiculare. Elytra pectus haud superantia, truncata, angulo exteriore rotundato. Abdomen parallelum, marginatum. Pedes graciliores, minus elongati, coxis intermediis levi spatio distantibus, tibiis omnibus simplicibus, tarsis articulis 4 primis sensim decrescentibus, quinto primo paulo longiore.

\section{O b s e r v tiones.}

1. Nescio qua similitudine deceptus cel. Gravenhorst speciem huius generis sibi cognitam inter $O x y$ por os collocaverit, quocum neque forma, neque insertione antennarum, neque palporum structura singulari convenit. Habitus potius quodammodo Sten o similis, praecipue oculis magnis, protuberantibus, antennis breviusculis, tenuibus, clavatis, et coxis anticis minutis: antennarum autem insertione et oris structura longe distat. Maxillarum et labri structura proxime ad Osorinos accedit.

2. Labri structura in hoc genere singularis videtur, mihi autem nondam satis perspecta. Labrum reliquorum plerorumque insectorum merum non vidi, loco eius spinam utrinque acutam prominere in nonnullis individuis observo.

3. Sexus differentia latet.

4. De victu nihil compertum. Species omnes hucusque cognitae Americanae.

* 1. M. caelatus: Niger, nilidus, cicatricosus, elytris pedibusque testaceis, nigro-variegatis. - Long. $2 \frac{1}{3}$ lin.

Oxy porus caelat us Grav. Micr. 197. 5. Mon. 235. 4. - Latr. Hist. nat. Crust. et Ins. IX. 359. 7. - Oliv. Encycl. VIII. 608. 8.

\section{Habitat in America septentrionali, Knoch.}

Niger, nitıdus. Antennae capite breviores, rufo-testaceae, articulo ul timo maximo, fusco-piceo. Mandibulae rufo-piceae. Caput inaequale, fortiter profundeque punctatum. Thorax coleopteris paulo angustior, latitudine paulo brevior, basin versus leviter angustatus, lateribus leviter rotundatus, margine laterali pluries denticulato, convexus, dense fortiter profundeque punctatus, callis irregularibus elevatis laevigatis inaequalis. Elytra inaequaliter fortiter profundeque punctata, callis elevatis laevigatis inaequalia, secundum suturam impressa, rufescenti-testacea, nitida, macula magna anguli 
apicis exterioris, maculisque nonnullis sparsis nigris. Abdomen laeve, segmentis singulis basi utrinque bifoveolatis, anterioribus quatuor singulis margine laterali macula testacea notatis. Corpus subtus capite thorace abdomineque punctatis, pectore laevissimo. Pedes testacei, femoribus ante apicem piceis.

* 2. M. punctatus: Niger, nitidus, capite thoraceque utrinque transversim plicato parcius punctatis, elytris disco punctis nonnullis approximatis impressis, maculis duabus magnis testaceis. - Long. $1 \frac{2}{3}$ lin.

Var. Elytris nigris, macula minima apicali interiore testacea.

Habitat in Columbia, Dom. Moritz.

Praecedente plus duplo minor, niger, nitidus. Antennae vix capitis longitudine, rufo-testaceae, clava magna, ovata, picea. Palpi flavi. Mandibulae rufo-piceae. Caput thorace sesqui fere latius, parcius grosse inaequaliter punctatum, fronte utrinque prope oculum longitudinaliter, antice transversim leviter impressa. Thorax coleopteris dimidio angustior, latitudine haud brevior, basin versus leviter angustatus, lateribus ante medium modice rotundatus, margine laterali integro, subcylindricus, plicis tribus transversalibus, fundo punctatis, medio late interruptis impressus, interstitiis laevissimis. Elytra in disco anteriore punctis nonnullis sat profundis fortibusque approximatis biseriatis notata, ceterum laevissima, secundum striam suturalem impressa, nigra, nitida, in altero specimine macula magna subquadrata infra humerum, aliaque ad angulum apicalem interiorem, in altero punctulo minuto ad suturae apicem testaceo signata. Abdomen laeve. Pedes testacei.

* 3. M. cephalotes: Niger, nitidus, pedibus testaceis, thorace utrinque transversim plicalo punctaloque, elytris disco anteriore striola impressa. - Long. $1 \frac{2}{3}$ lin.

\section{T. $2 . f .3$.}

Habitat in Columbia, Dom. Moritz.

Statura omnino praecetentis, niger, nitidus. Antennae capitis fere longitudine, rufo-piceae, basi testaceae, apice fuscae. Mandibulae rufo-piceae. Caput sat magnum, thorace plus sesqui latius, fronte punctis grossiusculis inaequaliter notata, prope oculum utrumque longitudinaliter, antice transversim leviter impressa. Thorax coleopteris paulo angustior, latitudine vix brevior, lateribus ante medium subangulato-rotundatis, basin versus non magis quam apicem versus angustatus, basi coleopteris dimidio angustior, transversim convexus, plicis 4 transversalibus fundo punctatis, medio interruptis impressus. Elytra stria suturali et in disco anteriore striola utrinque abbreviata longitudinali impressa, ceterum laevissima. Abdomen laeve. Pedes testacei. 


\section{Subtribus secunda.}

\section{(1) o $\mathbf{c} \mathbf{i}$ i.}

Antennae 11-articulatae.

Ligula cornea.

Tarsi 5-articulati.

L abr um transversum, apice utrinque lacinia parva membranea instructum.

Mandibulae validae.

Maxillae malis corneis, angustis, subelongatis.

Palpi maxillares filiformes, articulo primo minuto.

Mentum corneum,

apice emarginatum Osorio;

apice rotundatum $\mathrm{Hol}$ otrocho.

Ligula cornea.

Paraglossae membranaceae.

Palpi labiales breves, filiformes.

Antennae 11-articulatae, filiformes aut apicem versus sensim subincrassatae.

C a p u t magnum, crassum, basi haud constrictum.

Oculi parvi, hand prominentes.

Th or ax basi truncatus, ab elytris minus remotus.

Scutellum distinctum.

Abd omen immarginatum.

$\mathbf{P e d e s}$ coxis intermediis approximatis, tibiis

anticis spinuloso-muricatis Osorio;

omnibus muticis Holotrocho;

tarsis 5-articulatis.

\section{Osorius Leach.}

Latr. Regn. Anim. IV. p. 438. Nov. Annal. Mus. Hist. Nat. I. p. 83.

Molosoma Sáy Transact. Amer. Philosoph. Soc. Philadelph. Nov. Ser. IV. p. 462.

\section{Tibiae anteriores spinulosae.}

Corpus elongatum, cylindricum, alatum. Caput sat magnum, crassum, oculis parvis, rotundatis, haud prominulis. Labrum transversum, apice emarginatum, laciniis membraneis, elongato-triangularibus, interne fortiter ciliatis. Mandibulae validae, acutae, decussatae. Maxillae (t. V. f. 13. b.) malis leviter elongatis, corneis, interiore interne ciliata, exteriore apice barbata, utraque unco corneo introrsum verso armata. Palpi maxillares malam exteriorem parum excedentes, articulo primo minimo, secundo elongato, tertio hoc plus duplo breviore, quarto secundo subaequali, apice acuminato. Labium (t. V. f. 13. a.) mento latitudine sua haud breviore, apicem versus sensim angustato, apice emarginato, ligula cornea, integra, apice subacuminata, paraglossis linearibus, ligulam haud excedentibus, membranaceis, interne longe ciliatis. Palpi labiales articulo primo breviore crassioreque, reliquis duobus longitudine aequalibus, tertio apice subacuminato. Antennae brevio- 
res, apicem versus haud incrassatae, fractae, articulo primo elongato, sub capitis margine laterali recondito, tertio subobconico, parum elongato, ultimo ovato, subacuminato. Thorax basin versus sensim angustatus, basi coleopteris angustior, lateribus marginatus, basi truncatus, subtus antice tuberculo sat prominulo instructus. Scutellum apice rotundatum. Elytra ląteribus tenuiter marginata, apice truncata. Abdomen immarginatum, cylindricum, segmento sexto conico, apice truncato, segmento septimo parvo, conspicuo. Pedes breviusculi, intermedii basi approximati, tibiis margine exteriore angulato, supra angulum spinulis, infra angulum dentibus sat longis spiniformibus serrato, anterioribus facie posteriore muricatis, tarsis gracilibus, articulis 4 primis subaequalibus, quinto his coniunctis longitudine aequali.

\section{O b s e r v a t i o n e s.}

1. Corpus parce pubescens, capite thoraceque glabris.

2. Sexus differentia in plerisque latet.

3. Victus sub arborum putrescentium cortice, in cuniculis longitudinaliter erosis. Nympham quoque in simili cuniculo reperit Dom. Lacordaire (Nov. Annal. Mus. Hist. nat. II. p. 65.).

* 1. O. at er: Niger, nitidus, thorace parce subtilissime punctato, capile subtiliter punctulato, apice bispinoso. - Long. $5 \frac{1}{2}-6 \frac{1}{2}$ lin.

Perty Delect. An, Art. p. 30. t. 7. f. 1.

Habitat in Brasilia.

Corpus nigerrimum, nitidum. Antennae capite parum longiores, piceae. Palpi picei. Mandibulae muticae. Caput magnum, subtiliter punctulatum, lateribus supra oculos subtilissime longitudinaliter rugulosum, apice utrinque in spinam sat validam, licet parum elongatam, porrectam productum. Thorax latitudine antica brevior, basin versus sensim angustatus, basi coleopteris paulo angustior, lateribus anterius tenuiter, posterius fortius reflexo-mar ginatus, angulis posterioribus subprominulis, transversim convexus, parce omnium subtilissime punctulatus. Elytra thorace paulo longiora, subtilissime confertissime longitudinaliter ruguloso-strigosa, stria suturali impressa. Abdomen supra et lateribus laeve, subtus et segmento septimo parcius punctatum. Pedes picei.

* 2. O. intermedius: Niger, nilidus, thorace omnium subtilissime punctulato, capile subtiliter punctulato, apice emarginato. - Long. $6 \mathrm{lin}$.

Habitat in Columbia interiore, Dom. Buquet.

Statura et summa affinitas praecedentis. Niger, nitidus. Antennae cafite paulo longiores, nigro-piceae. Palpi rufo-picei. Mandibulae muticae. Caput sat magnum, thoracis latitudine, posterius laeve, anterius subtiiiter punctulatum, lateribus supra oculos nomnihil longitudinaliter rugulosum, apice late emarginatum, angulis anterioribus leviter prominulis.' Thorax latitudine antica paulo brevior, basin versus a medio inde sensim angustatus, basi coleopteris panlo angustior, apice iisdem paulo latior, lateribus anterius subtiliter, posterius fortius reflexo-marginatis, angulis posterioribus subrectis, haud proninulis, transversim convexus, laevis, vel omnium subtilissime obsoletissime punctatus. Elytra thorace paulo longiora, laevia, stria suturali 
impressa. Abdomen laeve, segmento sexto infero punctulato, septimo laevi. Pedes nigri, tarsis fulvo - piceis.

Obs. Praecedenti simillimus, differt autem capitis angulis anticis haud spinosis, thorace paulo longiore, angulis posterioribus haud prominulis, elytris laevibus.

3. O. Brasiliensis: Niger, nilidus, thorace capiteque sat crebre distinctius punclatis, hoc apice emarginato, - Long. 5 lin.

Guér. Iconogr. Ins. t. 9. f. 11. - Latr. Nov. Annal. Mus. Hist. nat. I. 86. 2.

Habitat Bahiae in Brasilia, Dom. Sellow.

Statura et summa affinitas praecedentium. Niger, nitidus. Antennae capite vix longiores, piceae. Palpi rufo-picei. Mandibulae muticae. Caput magnum, subtilius at sat distincte crebre punctatum, ante basin laevius, utrinque prope oculos longitudinaliter rugulosum, apice late emarginatum, angulis anterioribus prominentibus. Thorax latitudine antica tertia parte brevior, basin versus sensim angustatus, basi coleopteris paulo angustior, lateribus anterius subtiliter, posterius fortius reflexo-marginatis, angulis po sterioribus subrectis, haud prominulis, transversim convexus, crebre subtiliter, licet sat distincte punctatus. Elytra thorace paulo longiora, sparsim subtiliter punctata, subtiliter longitudinaliter rugulosa. Abromen laeve, lateribus subtilissime longitudinaliter rugulosa, segmento ultimo inferiore crebre fortiterque punctato-ruguloso, segmento septimo laevi. Pedes nigri, tarsis fulvis.

Oos. Praecedentibus simillimus, differt autem ab O. atro capite mutico, a praecedente thorace breviore, ab utroque eapite thoraceque distincte punctatis.

4. O. piceus: Niger, nilidus, antennis pedibusque rufis, thorace longiore capiteque parce subtilissime punctatis, hoc apice emarginato. - Long. $3 \frac{1}{2}$ lin.

\section{Habitat in Brasilia, Dom. Westermann.}

Habitu omnino praecedentium, at multo minor, nigro-piceus, nitidus. Antennae capite parum longiores, rufae. Palpi rufo-testacei. Mandibulae muticae. Caput thoracis apice paululum angustius, subtiliter obsoleteque parce punctatum, ante basin transversim laeve, circa oculos vix rugulosum, apice emarginatum, angulis anterioribus modice prominentibus. Thorax latitudine antica perparum brevior, basin versus sensim leviter angustatus, basi coleopteris paululum angustior, lateribus medio levissime rotundatis, anterius leviter, posterius fortius reflexo-marginatis, angulis posterioribus rectis, anterioribus acutis, leviter productis, modice transversim convexus, subtiliter obsoleteque parce punctatus, infra tuberculo iugulari rufo. Elytra thorace paulo longiora, laevia, stria suturali tenui impressa, brunneo-picea. Abdomen supra laeve glabrumque, infra parce punctatum et parce lutescenti-pilosum, supra nigro-piceum, apice et infra piceo-rufum. Pedes rufi.

* 5. O. incisicrurus: Niger, nilidus, thorace parce punctulato, longiludinaliter bi-impresso, capite maris apice tridentato, feminae fortiter emarginato, tibiis anterioribus profunde excisis. - Long. 6 lin.

Latr. Nov. Annal. Mus. Hist. nat. I. 85. 1. - Klug. Col. Madag. 51. 43. t. 1. f. 13. Habitat in Madagasear, Dom. Goudot. 
Statura omnino O. atri, nigerrimus, nitidus. Antennae capite paulo longiores, nigrae. Palpi picei. Mandibulae ante apicem dentatae. Labrum emarginatum. Caput thoracis latitudine, maris parce, feminae crebrius pùnctatum, postice laeve, lateribus prope oculos longitudinaliter rugulosum, fronte praecipue apicem versus depressiuscula, apice in mare tridentata, dente intermedio longiore, in femina medio triangulariter erosa. Thorax latıtudine antica brevior, basi coarctatus, lateribus subtiliter reflexo-marginatis, angulis posterioribus rectis, leviter prominulis, disperse subtilius punctatus, dorso sulculis duobus longitudinalibus, lateribus pone medium secundum marginem lateralem impressus. Elytra thorace paulo longiora, vage obsolete punctata, stria suturali impressa. Abdomen laeve, segmento sexto inferiore maris parce punctato. Pedes nigri, tarsis rufo-piceis, tibiis minus dilatatis, anterioribus extus prope apicem profunde excisis, postice haud muricatis.

* 6. O. rugifrons: Nigro-piceus, nitidus, punctalus, parce fulvo-pubescens, fronte dense longitudinaliter rugosa. - Long. $4 \frac{2}{3}$ lin.

Habitat in Java, Dom. Dr. De Haen.

Habitu praecedentium at minor, nigro-piceus, nitidus, capite thoraceque parcius, elytris abdomineque densius fulvo-pubescentibus. Antennae capite paulo longiores, piceae. Palpi rufo-picei. Caput thoracis latitudine, postice laeve, nitidum, spatio transversali inter oculos dense longitudinaliter strigoso, opaco, antice subtiliter longitudinaliter rugulosum, latera versus disperse exasperato-punctatum, apice emarginatum, angulis anterioribus haud prominentibus. Thorax latitudine antica brevior, basin versus sensim angustatus, basi coleopteris parum angustior, lateribus medio levissime rotundatis, posterius leviter reflexo-marginatis, angulis posterioribus obtusiusculis, transversim convexus, crebrius subtiliusque punctatus, linea media longitudinali laevi. Elytra thorace paulo longiora, sat crebre minus profunde punctata, stria suturali impressa. Abdomen apicem versus sensim modice incrassatum, crebre punctatum, segmentis singulis margine postico tenui rufo-piceo. Pedes rufo-picei.

* 7. O. cylindricus: Niger, nilidus, elytris, antennis pedibusque piceis, capile, thorace elylrisque parce, abdomine parcius punclato. - Long. $3 \frac{1}{3}$ lin.

Latr. Nov. Annal. Mus. Hist. nat. I. 86. 3.

Habitat in Mexico (Orizaba), Dom. Deppe.

Corpus elongatum, nigrum, nitidum. Antennae capite vix longiores, ab articulo septimo inde paulo crassiores, piceae, basi apiceque magis rufescentes. Palpi testacei. Labrum rufo-piceum. Caput thoracis latitudine, lateribus passim exasperato-punctatum, fronte inter oculos utrinque transversim longitudinaliter rugulosa, apice emarginata, angulis anterioribus acutıusculis, hand prominentibus. Thorax latitudine antica vix brevior, basin versus sensim angustatus, basi coleopteris paulo angustior, angulis posterioribus obtusis, sat convexus, punctis oblongis sat profundis at raris im-. pressus, dorso subseriatis. Elytra thorace parum longiora, punctis raris subseriatis impressa, picea. Abdomen subtilıssime alutaceum, parcius minus 
profunde punctatum, punctis in segmento quinto crebrioribus. Pedes dilute picei.

Variat minus maturus colore testaceo; tale specimen a Latreillio descriptum.

Obs. Affinis certe speciei sequenti, at magis elongatus, parcius punctatus.

* 8. O. latipes: Nigro-piceus, nitidus, elytris piceis, antennis pedibusque testaceis, capite, thorace elytrisque parce, abdomine crebre punctalis. - Long. $2 \frac{1}{3}$ lin.

Oxytelus latipes Grav. Mon. 198. 13. - Oliv. Encycl. meth. VIII. 616. 15.

Molosoma latipes Say Transuct. Amer. Philosoph. Soc. Philadelph. Nov. Ser. IV. p. 462.

Habitat in America septentrionali, e coll. Knochiana.

Nigro-piceus, nitidus, breviter subtiliter capite et thorace parce, elytris et abdomine densius fulvescenti-pubescens. Antennae testaceae, capite parum longiores, articulis ultimis $\mathbf{5}$ distincte crassioribus. Palpi rufo-testacei. Labrum et mandibulae rufo-picea. Caput thoracis latitudine, subtilissime alutaceum, fronte punctis grossiusculis parcius impressa, apice leviter emarginata, angulis anterioribus acutiusculis, haud prominentibus. Thorax latitudine vix brevior, basin versus ab apice ultra medium parum, dein fortius angustatus, angulis posterioribus obtusis, transversim convexus, parcius punctatus, punctis oblongis, in dorso biseriatis. Elytra thorace haud longiora, punctis mainsculis oblongis parcioribus vage impressa, brunnea-picea. Abdomen subtilissime alutaceum, sat crebre punctatum. Pedes rufo-testacei.

Obs. Specimen a Dom. Zimmermann e Carolina missum duplo maius, ceterum haud distinctum.

O b s e r v a t i o.

Speciem huius generis in resina Animae inclusam Dom. Hope Transact. Ent. Soc. Lond. II. p. 52. t. 7 . f. 1, hoc modo descripsit:

O. brunnicornis: Niger, nitidus, tibiis anterioribus dilatatis, antennis pedibusque brunneis. Corpus cylindricum, nitidum, nigrum, long. $4 \frac{3}{4}$ lin. Caput elongatum, mandibulis intus dentatis. Antennae brunneae, pubescentes, capite longiores, articulo primo basi contracto, apice dilatato, secundo minore, tertio praecedente longiore, sequentibus 7 aequalibus, extimo ovato, antice subconico. Thorax fere quadratus, capite brevior, laevis. Scutellum triangulare, magnum. Elytra thorace longiora, parum latiora, nigra, nitida, marginibus posticis brunneis. Pedes rufo-brunnei, tibiis anterioribus dilatatis, compressis, spinulosis.

\section{Holotrochus $E r$.}

\section{Tibiae muticae.}

Corpus elongatum, subcylindricum, alatum. Caput thorace minus et angustius, basi haud constrictum, oculis mediocribus, rotundatis, haud prominulis. Labrum transversum, apice subtruncatum. Mandibulae breves, validiusculae, muticae. Maxillae (t. V. f. 14. b.) malis corneis, exteriore apice barbata, interiare lineari, interne ciliata. Palpi maxillares erassiusculi, articulo primo minuto, secundo obconico, tertio hoc breviore, quarto iterum longiore, apice acuminato. Labium (t. V. f. 14. a.) mento latitudine sua haud breviore, lateribus et apice rotundato, ligula cornea, integra, paraglos- 
sis minutis, linearibus, membranaceis. Palpi labiales artículo primo crassiusculo: secundo hoc breviore, tertio elongato, apice acuminato. Antennae breviusculae, apicem versus sensim leviter incrassatae, articulo primo magis minusve elongato, sub capitis margine recondito, secundo crassiusculo, obconico, penultimis pluribus transversis, ultimo globoso. Thorax coleopterorum latitudine, iisque basi arcte applicatus. Scutellum rotundato-subtriangulare. Elytra truncata. Ahdomen elongatum, immarginatum cylindrieum, segmento sexto conico, apice truncato. Pedes breviusculi, tibiis simplicibus, margine exteriore spinulis brevissimis ciliato, tarsis 5-articulatis, articulis $\mathbf{4}$ primis minutis, inter se aequalibus, quinto his coniunctis longitudine aequali.

$$
\text { o b s e r v a tiones. }
$$

1. Corpus glabrum. Thorax basi utrinque obsolete impressus. Elytra stria suturali insculpta.

2. Genus ab Osorio tibiis muticis facile distinctum, habitu Lispino non nimis dissimile, a quo autem praeter coxas anticas exsertas abdominis segmento septimo conspicuo, statura magis cylindrica quam depressa et fronte immarginata discedit

3. Sexus differentia latet.

* 1. H. volvulus: Nigro-piceus, subnilidus, antennis pedibusque rufis, laevis, thorace basi ulrinque foveolulo. - Long. $2 \frac{1}{2}$ lin.

T. II. $f .4$.

Habitat in ins. Puerto - Rico, Dom. Moritz.

Corpus elongatum, subcylindricum, omnium subtilissime punctato-coriaceum, minus nitidum, piceum. Antennae capite paulo longiores, rufae. Palpi rufi. Caput thorace angustius, fronte antice emarginata. Thorax coleopterorum latitudine, transversim subquadratus, lateribus subrectis, parallelis, angulis omnibus rectis, anterioribus deflexis, modice transversim convexus, basi apud angulos posteriores utrinque foveola minuta impressus. Elytra thorace paulo longiora, stria suturali impressa. Abromen lateribus obsolete punctatum, segmento septimo profunde emarginato. Pedes rufi.

\section{H. cylindrus: Cylindricus, niger, nitidus, laevis, antennis pedibusque} rufis. - Long. 2 lin.

Habitat in ins. Puerto-Rico, Dom. Moritz.

Praecedente paulo minor et angustior, nitidus, niger. Antennae capite vix longiores, rufae. Os rufo-piceum. Caput thorace angustius, parce omnium subtilissime punctatum, fronte antice truncata. Thorax coleopterorum fere latitudine, latitudine vix brevior, lateribus rectis, parallelis, angulis omnibus rectis, anterioribus deflexis, transversim convexus, parce subtilissime punctatus. Elytra thorace parum longiora, omnimn subtilissime coriacea, stria suturali impressa. Abdomen parce obsoletius punctatum, segmento septimo apice* emarginato. Pedes rufi.

* 3. H. crassicollis: Brevis, cylindricus, niger, nitidus, antennis pedibusque piceis, capite, thorace elytrisque subtiliter punctatis. - Long. $1 \frac{3}{4}$ lin. Hahitat in Madagascar, Dom. Goudot.

Praecedentibus brevior, crassior, cylindricus, niger, nitidus. Antennae 
capitis longitudine, piceae. Caput thorace angustius, leviter convexum, parcius subtiliter punctatum, fronte antice leviter emarginata. Thorax coleopteris paulo latior, latitudine dimidio brevior, lateribus subrotundatis, basin versus subangustatus, fortiter transversim convexus, parcius subtiliusque licet sat distincte punctatus, postice utrinque obsolete impressus. Elytra thorace parum longiora, parce subtiliter obsoletius punctata, stria suturali sat profunda impressa. Abdomen omnium subtilissime confertissimeque punctato-coriaceum, punctis subtilibus obsoletisque sparsum, segmento septimo integro. Pedes picei.

\section{$S$ u b tribus tertia. (ct) n u i n i.}

\section{Antennae 11-articulatae.}

\section{Ligula membranea.}

Tarsi 3-articulati.

Labrum transversum, corneum, apice

limbo coriaceo instructum Bledio;

utrinque lacinia membranea auctum Platystheto, Oxytelo, Phloconaeo, Trogophloeo, A pocello.

Mandibulae falcatae, dentatae.

Maxillae malis membranaceis, interiore trapezoidea, interne ciliata, exteriore parallelopipeda, apice barbata.

Palpi maxillares articulo primo minuto, tertio leviter incrassato, quarto tenui, subulato.

Mentum transversum, corneum.

Ligula membranea.

Paraglossae ligulae connatae eamque haud superantes plerisque; nullae Bledio.

Palpi labiales hreves, articulo tertio subulato.

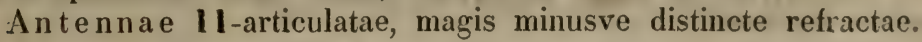

Oculi mediocres.

Thorax ab elytris remotus, basi plerumque rotundatus.

Scutellum plerumque obsoletum.

Abdomen marginatum.

Pedes coxis intermediis

distantibus Platys theto, Oxy telo;

approximatis Bledio, Phloeonaeo, Trogophloeo, Apocello;

tibiis anticis extus muricato-spinulosis Bledio;

exius seriatim spinulosis, Platystheto, Oxytelo, Phloe onaeo;

intermediis etiam spiuulosis Bledio, Platy stheto;

omnibus muticis Trogophloeo, A pocello;

tarsis 3 -articulatis, articulis 2 primis brevibus. 


\section{Bledius Leach.}

Mannerh. Brachelytr. p. 44.

Bledius Steph. Illustr. V.p. 307. - Hesperophilus ibid. p. 309.

Paraglossae nullae.

Pedes intermedii basi approximati.

Tibiae anteriores externe biseriatim spinulosae.

Corpus elongatum, lineare, subcylindricum, alatum. Caput thorace minus et angustius, porrectum, basi vix constrictum, oculis semiglobosis, modice prominulis. Labrum (t. V. f. 15. c.) transversum, medio subsinuatum, margine antico membrana prominula limbato, laciniis lateralibus parvis, angulatim prominulis, spatio intermedio setis crassiusculis dense ciliato. Mandibulae validiores, magis minusve prominentes, vel ante apicem vel medio dentatae. Maxillae (t. V. f. 15. b.) mala interiore margine exteriore coriaceo, interiore membraneo, apicem versus spinulis breviusculis ciliato, mala exteriore longiore, coriacea, apice dense barbata. Palpi maxillares mala exteriore parum longiores, articulo primo minuto, secundo elongato-obconico, tertio hoc paulo longi, re, leviter incrassato, quarto minuto, subulato. Labium (t. V. f. 15, a.) mento latitudine vix breviore, apice truncato, ligula membranea, biloba, lobis divergentibus, paraglossis nullis. Palpi labiales articulis duobus primis aequalibus, tertio his paulo longiore et tenuiore. Antennae fractae, breviusculae, articulo primo elongato, secundo tertioque obconicis, sequentibus longioribus, his sensim paululum maioribus, ultimis tribus nonnunquam distincte maioribus, ultimo ovato. Thorax coleopteris latitudıne subaequalis, lateribus pone medium ad angulos posteriores subito fortius convergentibus, convexus. Elytra truncata. Abdomen lineare, marginatum, infra convexum. Pedes breviusculi, coxis intermediis approximatis, tibiis anticis leviter incrassatis, externe biseriatim fortius spinulosis, inter spinulas dense setulosis, intermediis spinularum serie armatis, posticis muticis, ommibus seriatim pilosis, tarsis triarticulatis, articulo tertio primis duobus coniunctis multo longiore.

\section{O b s e r vatio nes.}

1. Genus a reliquis valde distinctum labri ligulaeque structura, et tibiis anticis incrassatis, fortius spinulosis. Corpus subtiliter tenuiterque pubescens.

2. Hesperophilus ab Anglis auctoribus nonnisi capite thoraceque in utroque sexu muticis distinctus.

3. Sexus differentia varia: in nonnullis caput et thorax masculorum cornuta, in aliis abdominis segmentum inferius sextum apice emarginatum, sinu autem membrana clauso, in aliis septimum in altero sexu aliter constructum, in aliis differentia quaevis me fugit.

4. Victus in riparum argilla arenave. Cuniculos fodiunt, quos per paria incolunt. Species nonnullae ripis littoribusve salsis propriae. Larvae eodem modo victitant. Species quaedam maris accolae alternatim undis submittuntur. Sectantur in quovis aetatis statu a D y schiri is eorumque larvis. (Conf. Rudd Ent. Mag. II. p. 160.). Vesperi copiosi volitant. Olent.

* 1. B. taurus: Fronte bicorni, niger, antennis pedibusque rufo-piceis, thorace subtiliter coriaceo, parcius punctalo, subtiliter canaliculata, maris spinoso. - Long. $3-3 \frac{1}{2}$ lin.

Mannerh. Brachelytr. 44. 2. - Runde Brachelytr. Hal. 18. 2.

Oxyt. taurus Germ. Faun. Ins. Europ. XII. 2. 
Oxyt. furcatus Oliv. Encycl. meth. VIII. 616. 12. (forte)

Var. Elytris testaceis, circa scutellum triangulariler fuscis.

Bledius Slerimshiri Curtis Britt. lint. III. $t$. I43.

Bledius Ruddii Steph. Illustr. Britt. Ent. V. t. 127. f. 3.

Habitat in Illyriae, in ins. Jonicarum, Sardiniae, Angliae littoribus marinis; haud infrequens etiam in ripis lacuum salsorum Germaniae interioris.

B. tricorni magnitudine aequalis, niger, parcius pubescens. Antennae capite sesqui longiores, apice leviter incrassatae, piceo-rufae. Os rufopiceum. Mandibulae ante apicem fortiter unidentatae. Caput maris laevigatum vel omnium subtilissime coriaceum, nitidum, vertice transversim leviter impresso, fronte planata, utrinque ad antennarum basin cornu valido compresso, erecto, subrecto, apice pubescente armata, feminae subtiliter coriaceo, opaco, vertice fronteque medio transversim leviter impressis, hac utrinque ad antennae basin cornu brevi, lato, compresso, truncato armata. Thorax coleopterorum prope latitudine, latitudine paulo brevior, lateribus anterius subrectis, infra medium subito fortiter conniventibus, angulis posterioribus obtusis, apice subbisinuatus, parum convexus, confertissime subtiliter coriaceus, minus fortiter parcius punctatus, subtiliter canaliculatus, maris ab apice ultra medium sensim angustatus, angulis anterioribus acutis, antrorsum prominentibus, apice medio in spinam longam porrectam, apice subcompressam, barbatam, producto, canalicula dorsali ante spinae basin evanescente, feminae muticus, lateribus ultra medium parallelis, angulis anterioribus subrectis, canalicula dorsali integra. Elytra thorace paulo longiora, crebrius minus fortiter punctata, iam tota nigra, iam testacea, spatio triangulari circa scutellum fusco. Abdomen subtilissime punctato-coriaceum, subtus crebrius punctatum, nitidum, ano piceo. Pedes piceo-rufi, coxis concoloribus.

Abdominis segmentum inferius septimum maris apice subtruncatum, feminae bisinuatum.

V a riat cornubus capitis thoracisque longioribus brevioribusve. Cornua capitis breviora nonnunquam posterius medio dilatata,

Obs. 1. Olivier thoracis spinam apice bifurcatam refert, forte pilis in spinae apice humore conglutinatis deceptus.

2. Bl. Ruddii Steph. statura minore et cornubus debilioribus a genuinis haud rite distinctus.

* 2. B. vitulus: Capite bicorni, nigro, testaceus, thorace subtiliter coriaceo, parcius punctato, canaliculato. - Long. $2 \frac{1}{2}-2 \frac{2}{3}$ lin.

Habitat in Arabia deserta, Dom. Prof. Ehrenberg.

Statura omnino B. bicornis, testaceus, subnitidus, parcius pubescens. Antennae capite sesqui longiores, articulo tertio secundo subaequali, apicem versus sensim leviter incrassatae, rufo-piceae, medio fuscae. Os rufopiceum. Mandibulae ante apicem fortiter unidentatae. Caput thorace paulo angustius, omnium subtilissime coriaceum, supra nigrum, subnitidum, fronte late leviter excavata, vertice transversim leviter impresso, margine laterali utrinque in cornu erectum breviusculum, latum, compressum, apice vel truncatum vel emarginatum elevata. Thorax coleopterorum latitudine, latitudine 
tertia parte brevior, lateribus anterius rectis, postice subito subsinuatoconiviventibus, angulis anterioribus acutiusculis, leviter prominulis, leviter convexus, confertissime subtiliter coriaceus, parce fortius punctatus, profundius canaliculatus. Elytra thorace paululum longiora, minus crebre sat profunde punctata. Ábdomen subtilissime punctato-coriaceum, subtus vage obsoleteque punctatum. "Alae albo-hyalinae.

Abrominis segmentum inferius septimum in utroque sexu apice leviter bisinuatum, lobo internedio maris trunctato, feminae acuminato.

Obs. Naribus maioribus capitis cornua máiora magis elevata et apice magis emarginata; feminae capitis structura omnino cum maribus minoribus congruunt.

* 3. B. bicornis: Fronte bicorni, niger, ore, antennis, pedibus elylrisque rufis, his sulura late nigris, thorace piceo, coriaceo, parcius punctato, canaliculalo: - Long. $2 \frac{1}{3}-2 \frac{2}{3}$ lin.

Oxyt. bicornis Ahrens Faun. Ins. Europ. VI. 15.

Bledius bicornis Runde Brachelytr. Hal. 18. 4.

Habitat in ripa lacus salsi Mannsfeldiensis, frequens; in Grusinia, Dom. Marschall v. Biberstein.

B. tricorni dimidıo minor, habitu potius B. tauri, niger, tenniter pubescens. Antennae capite sesqui longiores, articulo tertio secundo paulo breviore, apıcem versus leviter incrassatae, articulis ultimis tribus distincte paulo maioribus. Mandibulae modice prominentes, fortiter falcatae, ante apicem fortiter unidentatae. Os rufo-piceum. Caput thorace dimidio angustius, subtiliter confertissime eoriaceum, opacum, vertice fronteque transversim leviter impressis, hac utrinque ad antennarum basin cornu brevi, lato, compresso, maris subacuminato, feminae truncato, erecto armata. Thorax coleopteris vix angustior, latitudine paulo brevior, lateribus anterius ultra medium subrectis, parallelis, postice subito fortiter convergentibus, angulis posterioribus rotundatis, apice utrinque subsinuatus, parum convexus, confertissime subtilius coriaceus, minus confertion sat profunde punctatus, canaliculatus, iam niger, iam fusco-piceus, opacus. Elytra thorace paulo longiora, sat crebre profundeque punctata, vel nigro-picea, lateribus rufotestacea, vel rufo-testacea, sutura latius angustiusve picea. Abdomen subtiliter confertissime punctato-coriaceum, subtus crebrius, supra parce ob. soletius punctatum, parum nitidum, apice piceo-testaceum. Pedes rufotestacei.

Abdominis segmentum inferius septimum maris leviter emarginatum, femin a bisinuatum.

* 4. B. hinnulus: Fronte biluberculata, niger, antennis, pedibus, elytrisque testaceis, his macula communi picea, thorace rufo-piceo, subliliter coriaceo, parcius punctalo, canaliculato. - Long. $2 \frac{1}{3}$ lin.

Habitat in Russia meridionali, Dom. Godet, in Grusinia, Dom. Marschall v. Bieberstein.

Statura et summa affinitate B. bicornis, et minoribus eius speciminibus aequalis, at paulo gracilior, piceo-niger, tenuiter pubescens. Antemnae capite sesqui longiores, articulo tertio secundo breviore, ultimis tribus distincte paulo maioribus, rufo-testaceae. Os rufum. Mandibulae ante apicem 
sat fortiter unidentatae. Caput thorace angustius, nigro-piceum, opacum, subtilissime coriaceum, fronte utrinque longitudinaliter subimpressa, inter antennarum insertionem linea transversali profundiore exarata, medio puncto maiusculo impresso notata, maris postice late leviterque transversim impressa, margine laterali in utroque sexu supra antennarum basin morlice elevato, tuberculiformi, rufo-piseo. Thorax coleopteris parum angustior, latitudine parum brevior, lateribus anterius ultra medium subrectis, postice subito fortiter convergentibus, angulis posterioribus rotundatis, parum convexus, confertissime subtiliter coriaceus, minus crebre sat fortiter punctatus, canaliculatus, rufo-piceus, minus nitidus. Coleoptera thorace paulo longiora, minus confertim punctata, dilute testacea, macula oblonga communi in media sutura nigra piceave. Abrlomen subtilissime coriaceum, subtus obsolete punctatum, nigro-piceum, nitidulum, ano piceo-testaceo. Pedes testacei, coxis concoloribus.

Abdominis segmentum inferius septimum in utroque sexu apice bisinuatum, lobo intermedio $\mathrm{m}$ aris emarginate, femina e acuminato.

Obs. A praecedente praecipue statura graciliore, frontis margine laterali in utroque sexu haud in cornu formam elevato, elytris minus dense punctatis etc. distinctus.

* 5. B. iuvencus: Fronte subcornuta, niger, antennarum basi pedibusque rufis, thorace subtiliter coriaceo, parcius punclato, canaliculato. Jong. 2 lin.

Habitat in Rossia meridionali, Dom. Godet.

B. bicorni valde affinis, at paulo gracilior et dimidio minor, niger, longius pubescens. Antennae capite plus sesqui longiores, articulo tertio secundo paulo breviore, apicem versus leviter incrassatae, articulis ultimis tribus distincte paulo maioribus, fuscae, articulis duobus primis rufis. Mandibulae haud prominentes. Oris partes rufae. Caput thorace angustius, subtilissime confertissimeque punctato-coriaceum, opacum, vertice late pro. fundeque impresso, fronte late leviterque longitudinaliter excavata, inter antennarum basin linea tenui transversali exarata, margine laterali supra antennarum basin in cornu perbreve, latum, compressum, truncatum elevato. Thorax coleopterorum fere latitudine, latitudine vix brevior, lateribus anterius ultra medium rectis, 'parallelis, postice subito fortiterque convergentibus, basi truncatus, angulis posterioribus rotundatis, leviter convexus, subtiliter coriaceus, parum nitidus, minus crebre sat profunde punctatus, canaliculatus. Elytra thorace parum longiora, parcius et minus fortiter punctata, nigra, parum nitida, margine apicali piceo. Abdomen subtilissime punctato-coria ceum, subtus obsolete punctatum, nitidum, apice summo piceo-testaceo. Pedes testaceo-rufi, coxis anterioribus concoloribus.

Sexus differentia latet.

6. B. tricornis: Niger, antennis pedibusque piceis, elytris rufis, thorace subtiliter coriaceo, dense punctato, canaliculato, maris spinoso. Long. $2 \frac{2}{3}-2 \frac{1}{3}$ lin.

Mannerh. Brachelytr. 44. 1. - Boisd. et Lacord. Faun. Ent. Paris, I. 456. 1. Runde Brachelytr. Hal. 17. 1. - Er. Col. March, I. 578. 1. 
Staph. tricornis Herbst Archiv. 149. 9. t. 30. f. 8. - Payk. Mon. Staph. 51. 37. Faun. Suec. III. 396. 38. - Oliv. Ent. III. 42. 30. 41. t. 6. f. 56.

Oxyt. tricornis Grav. Micr. 109. 11. Mon. 196. 11. - Latr. Hist. nat. Crust. et Ins 1X. 365. 11. - Oliv. Encycl. meth. VIII. 616. 13. - Gyll. Ins. Suec. II. 444. 1. - Guér. Iconogr. Ins. t. 9. f. 10. a. b.

Staph. armatus Panz. Faun. Germ. 66. 17. (male)

Habitat in Europa.

Corpus nigrum, subnitidum, tenuiter griseo-pubescens. Antennae ca pite sesqui longiores, articulo secundo tertioque aequalibus, ab articulo septimo inde leviter incrassatae, iam nigro -, iam rufo-piceae. Mandibulae prominentes, ante apicem fortiter dentatae. Caput maris impunctatum, laevigatum vel omnium subtilıssime alutaceum, vertice impresso, fronte depressa, lateribus supra antennarum basin acute angulato-elevatis, feminae subtiliter confertissime alutaceum, fronte leviter convexa, sparsim punctata, lateribus supra antennarum basin obtuse angulato-elevatis, inter antennarum basin linea tenui transversali impressa. Thorax coleopteris parum angustior, latitudine apicis paululum brevior, basin versus sensim leviter angustatus, lateribus subrectis, paulọ pone medium subito fortius convergentibus, basi truncatus, angulis poterioribus obtusis, leviter convexus, subtiliter confertissime coriaceus, magis minusve crebre punctatus, canaliculatus, feminae muticus, maris apice medio in spinam longan, porrectam, canaliculatam productus, plerumque caput superantem, individuis maioribus longiorem, minoribus breviorem. Elytra thorace paulo longiora, dense profunde punctata, rufa, macula scutellari maiore minoreve nigricante. Abdomen supra utrinque parce obsoleteque, subtus crebre punctatum, ano piceo-rufo. Pedes rufo-, rarius nigro-picei.

7. B. unicornis: Niger, antennis pedibusque rufo-piceis, thorace subtiliter coriaceo, crebre punctato, canaliculalo, maris spinoso. - Long. 2 lin.

Mannerh. Brachelytr. 45. 3. - Runde Brachelytr. Hal. 18. 3.

Oxyt. unicornis Germ. Faun. Ins. Europ. XII. 3.

Habitat ad Germaniae interioris lacus salsos, et in Europae meridionalis littoribus.

Statura fere B. fracticornis, niger, subnitidus, tenuiter pubescens. An tennae capite paulo longiores, articulo tertio secundo subaequali, apicem versus sensim incrassatae, rufo-piceae, basi magis rufo-testaceae. Mandibulae leviter prominentes, arcuatae, ante apicem fortiter unidentatae, piceorufae. Oris partes omnes rufae. Caput maris laeve, nitidum, vertice excavato, fronte ante oculos linea obsoletiore transversali impressa, lateribus supra antennarum basin obtusius elevato-angulata, feminae subtilissime coriaceum, fronte media foveola minuta punctiformi notata, anterius utrinque ad antennarum basin leviter longitudinaliter impressa, margine laterali supra antennarum insertionem leviter elevato. Thorax coleopteris paula angustior, latitudine vix brevior, lateribus anterius ultra medium rectis, parallelis, po. stice subito fortiter convergentibus, basi truncatus, angulis posterioribus obtusis, leviter convexus, subtilissime coriaceus, crebrius profunde punctatus, subtiliter canalicılatus, feminae muticus, maris antice medio in spinan 
longam porrectam, haud canaliculatam, apice rufo-piceam productus. Elytra thorace paulo longiora, sat crebre profundeque punctata, callo humerali margineque apicali saepius picescentibus, nonnunquam tota obscure picea. Abdomen supra utrinque parce obsoleteque, subtus sat crebre minus profunde punctatum, ano piceo. Pedes rufi, coxis anterioribus concoloribus, femoribus posticis nigricantibus.

\section{B. mandibularis: Teslaceus, fronte nigricante, thorace obsolete pun- ctato, canaliculato, rufo-testaceo. - Long. $3 \frac{2}{3}$ lin.}

Habitat in America septentrionali (?), coll. Dom. Chevrolat.

Statura B. tricornis, testaceus, parum nitıdus, subtiliter griseo-pube scens. Antennae capite parum longiores, tenuiusculae, articulo tertio secundo paulo longiore, ultimis haud distincte crassioribus. Mandibulae elongatae, porrectae, parum incurvae, interne medio fortiter acuteque unidentatae, ante apicem leviter dilatatae, rufae, apice piceae. Palpi pallide testacei. Caput maiusculum, confertissime subtiliter alutaceum, parce obsoleteque punctatum, fronte inter oculos utrinque ohlique impressa, posterius canalicula brevi profundiore notata, rufo-testaceum, fronte verticeque nigricantibus. Thorax coleopterorum prope latitudine, latitudine paulo brevior, lateribus anterius ultra medium subrectis, parallelis, postice basin versus subito fortiterque convergentibus, basi truncatus, leviter convexus, subtilissime confertissimeque alutaceus, parce obsoleteque punctatus, canaliculatus, canalicula medio minus profunda, rufo-testaceus. Elytra thorace sesqui longiora, omnium subtilissime coriaceo-rugulosa, minus dense subtilius obsoletiusque punctata. Abdomen omnium subtilissime confertim alutaceostrigosum, infra parce obsoleteque punctatum.

Sexus differentia latet.

9. B. rubiginosus: Rufo-testaceus, fronte nigra, thorace crebrius fortiusque puncíalo, canaliculato, rufo, nitido. - Long. $2 \frac{1}{2}$ lin.

Habitat in Carolina meridionali, Dom. Zimmermann.

Habitu omnino B. fracticornis, at paulo maior, praecipue robustior, saturate rufo-testaceus, subnitidus, parce subtiliterque griseo-pubescens. Antennae capite sesqui longiores, articulo tertio secundo longitudine aequali, ab articulo septimo inde leviter incrassatae, testaceae, apice rufo-piceae. Mandibulae breviores, haud prominentes, leviter falcatae, ante apicem unidentatae, piceo-rufae. Palpi testacei. Caput thorace paulo angustius, omnium confertissime subtilissimeque punctato-alutaceum, parce obsoleteque punctatum, plica longitudinali prope oculum utrumque sat elevata, fronte utrinque leviter impressa, apice angulo utroque denticulo minuto obsoletoque terminato, minus nitidum, supra nigro-piceum, ore et infra rufum. Thorax coleopteris parum angustior, latitudine haud brevior, lateribus modice rotundatis, pone medium basin versus convergentibus, angulis posteriorihus rotundatis, convexus, canaliculatus, canalicula profundiore, crebrius fortiusque punctatus, interstitiis laevibus. Elytra thorace paulo longiora, dense profundeque punctata, dilutius testacea. Abdomen supra laeve, infra sparsim punctatum. Femora flavescenti-testacea.

Sexus differentia latet. 
10. B. lateralis: Rufus, nitidus, capile nigro, elylris sutura late nigricante, thorace profunde punctato canaliculatoque, disco piceo. - Long. 2 lin.

Habitat prope Puerto Cabello in Columbia, Dom. Moritz.

Statura omnino B. fracticornis, longius pubescens. Antennae capite sesqui longiores, articulo tertio secundo subaequali, apicem versus sensim incrassatae, rufae. Mandibulae falcatae, ante apicem fortius unidentatae, rufae. Palpi testacei. Caput thorace paulo angustius, nigrum, opacum, confertissime subtilissimeque coriaceum, fronte posterius foveola minuta punctiformi notata, antice utrinque obsolete longitudinaliter impressa, angulis anterioribus acutiusculis, prominulis. Thorax coleopteris paulo angustior, latitudine haud brevior, lateribus leviter rotundatis, a medio inde basin versus modice convergentibus, convexus, crebre fortiter profundeque punctatus, interstitiis laevibus, canalicula longitudinali, medio sat forti, basi apiceque subtilıre exaratus, rufo-piceus, nitidus, disco obscuriore. Elytra thorace paulo longiora, creberrime sat profunde punctata, rufa, subnitida, secundum suturam late picea. Abdomen supra omnium subtilissime confertissimeque, subtus crebrius fortiusque punctatum, rufum. Corpus subtus totum rufum. Pedes testacei.

* 11. B. politus: Nitidus, niger, antennis, pedibus elytrisque testaceis, his sutura nigra, thorace piceo-rufo, parce forlius punctato, canaliculato. - Long. $2 \frac{1}{3}$ lin.

Habitat in Carolına meridionali, Dom. Zimmermann.

Statura omnino B. fracticornis, at paululum maior. Corpus totum glabrum. Antennae capite sesqui longiores, articulo tertio secundo paulo breviore, ab articulo septimo inde leviter incrassatae, testaceae. Mandibulae breviores, parum curvatae, infra medium unidentatae, rufo-piceae. Palpi rufo-testacei. Caput thorace dimidio angustius, omnium subtilissime confertissimeque alutaceum, parce obsoleteque punctatum, plica longitudinali prope oculum utrumque sat elevata, fronte utrinque leviter impressa, lineaque transversali inter antennarum basin exarata, posterius inter oculos in toberculum latiusculum leviter elevata, apice utrinque denticulo subtili terminata, nigro-piceum, minus nitidum. Thorax coleopteris paulo angustior, latitudine haud brevior, lateribus levissime rotundatis, pone medium basin versus oblique convergentibus, angulis posterioribus obtusissimis, convexus, canaliculatus, parce disperse minus subtiliter punctatus, interstitiis politis, nitidus, piceo-rufus. Elytra thorace tertia parte Iongiora, parce fortius punctata, nitida, testacea, sutura apicem versus attenuata nigro-picea. Abdomen omnium confertissime subtilissimeque punctato-alutaceum, infra parce obsoletius punctatum, piceo-nigrum, nitidum, apice summo rufescente. Pectus nigrum, nitidum. Pedes cum coxis testacei.

Sexus differentia latet.

* 12. B. aquarius: Niger, antennis basi testaceis, elytris, tibiis tarsisque rufis, thorace sublilius alutaceo, opaco, crebre fortius punctato, poslice subtiliter canaliculato. - Long. $2 \frac{2}{3}$ lin.

Habitat Genevae, Dom. Chevrier. Dedit Dom. Prof. Germar. 
Habitu omnino B. tricornis et minoribus eius individuis aequalis, niger, parum nitidus, tenuiter griseo-pubescens. Antennae capite sesqui longiores, graciliores, articulo tertio secundo paulo breviore, apicem versus sensim leviter incrassatae, nigrae, basi testaceae. Mandibulae perparum prominentes, rufae. Palpi rufi. Caput thorace dimidio angustius, confertissime subtilissimeque punctato-alutaceum, fronte utrinque longitudinaliter leviter impressa et parcius obsoletiusque punctata, inter oculos posterius linea transversali leviter exarata, inter antennarum insertionem leviter transversim impressa. Thorax coleopterorum latitudine, latitudine summa vix brevior, lateribus rotundatus, postice sinuato-coarctatus, basi truncatus, angulis posterioribus acutiusculis, prommulis, sat convexus, confertissime subtiliter alıtaceus, crebre fortius punctatus, linea lata media longitudinali laevi (impunctata) posterius subtiliter canaliculata. Elytra thorace vix longıora, dense profundeque punctata, rufa, summa basi nigricantia. Abdomen confertissime subtilissimeque punctato-alutaceum, nitidulum, supra parce, infra crebrius punctatum. Pedes nigro - picei, tibiis tarsisque rufis.

Sexus differentia latet.

* 13. B. fracticornis: Niger, antennarum basi pedibusque rufis, coxis anterioribus piceis, thorace crebre fortiter punctato, canuliculalo. Long. 2 lin.

Mannerh. Brachelytr. 45. 5. - Runde Brachelytr. Hal. 18. 5. - Er. Col. March. I. 579. 2.

Staph. fracticornis Payk. Mon. Car. App. 135. 17-18. Fann. Suec. III.382. 19. Oxyt. fracticornis-Gyll. Ins. Suec. II. 446. 2. - Sahlb. Ins. Fenn. I. 408. 1

Oxyt. pallipes Gullicus Grav. Mon.p. 198.

Bledius pallipes Boisd. et Lacord. Funn. Ent. Paris. I. 458. 4.

Var. Elylris mufis.

Oxyt. tricornisvar. minor Grav. Mon. p. 196.

Habitat in Europa.

Niger, subnitidus, tenuiter subtiliterque fusco-pubescens. . Antemnae capite sesqui longiores, articulis ultimis distincte crassioribus, octavo sequentibus paulo minore, tertio secundo longitudine aequali, nigrae, basi rufae. Mandibulae breviusculae, fortiter falcatae, ante apicem dentatae, rufo-piceae, basi nigrae. Caput thorace paulo angustius, opacum, parce obsoleteque subtilius punctatum, utrinque ad antennarum basin leviter impressum. Thorax coleopteris paulo angustior, latitudine vix brevior, lateribus, angulis posterioribus et basi rotundatus, convexus, evidenter canaliculatus, dense fortiterque punctatus, interstitiis laevibus. Elytra thorace tertia parte longiora, dense profunde punctata, iam nigra, iam saturatius dilutiusve rufa, basi interiore suturaque magis minusve nigris. Abdomen omnium confertissime subtilissimeque punctatum, nitidum, ano rufo-piceo. Pedes rufo-testacei, coxis etiam anticis, nigro-piceis.

Abdominis segmentum inferius sextum maris apice sinuatum, sinu membrana repleto, feminae integrum. 
14. B. femoralis: Niger, subnilidus, ore pedibusque rufis, coxis piccis, femoribus picescentibus, thorace crebre profundeque punctato, canaliculato. - Long. $1 \frac{3}{4}$ lin.

Mannerh. Bruchelytr. 45. 9.

Oxytelus femoralis Gyll. Ins. Suec. IV. $497.3-4$.

Habitat in Suecia, Dom. Schïppel.

Habitus et summa affinitas praecedentis. Niger, subnitidus, subtiliter griseo-pubescens. Antennae capite sesqui longiores, articnlo tertio secundo dimidio breviore, apicem versus ab articulo septimo inde modice incrassatae, articulo octavo nono minore, totae nigro-piceae. Mandibulae falcatae, paulo ante apicem acute dentatae, rufae. Palpi rufo-testacei. Caput thorace paulo angustius, opacum, parce subtiliterque obsoletius punctatum, fronte utrinque leviter impressa. Thorax coleopteris paulo angustior, latitudine summa paulo brevior, lateribus parum rotundatis, basi subito oblique angustatus, angulis posterioribus subrotundatis, convexus, evidenter canaliculatus, crebre fortius punctatus, interstitiis subtiliter alutaceis. Elytra thorace tertia parte longiora, dense profunde punctata, piceo-nigra. Abdomen omnium subtilissime alutaceum, nitidulum, subtus parcius punctatum. Pedes rufi, coxis omnibus piceis, femoribus a basi inde magis minusve alutaceum.

Sexus differentia latet.

Obs. Differt a praecedente antennis nigro-piceis, thorace minus rotundato, evidenter alutaceo, minus dense punctato, etc.

* 15. B. longulus: Niger, nitidus, antennis elytris pedibusque rufis, thorace profunde punclalo, subliliter canaliculato. - Long. $1 \frac{2}{3}$ lin.

Er. Col. March, I. 579. 3.

Habitat in Germania.

B. fracticorni dimidio fere minor, praecipue brevior, niger, nitidus, tenuiter griseo-pubescens. Antennae capite sesqui fere longiores, articulo tertio secundo dimidio breviore, apicem versus ab articulo quarto inde leniter incrassatae, articulo octavo sequente vix minore, rufae, medio subfuscescentes. Os rufum. Mandibulae minus elongatae, leviter falcatae, medio bidenticulatae. Caput thorace angustius, subtiliter obsoleteque parce punctatum, fronte utrinque ad antennarum basin leviter impressa. Thorax coleopterorum fere latitudine, latitudine summa paulo brevior, lateribus fortiter rotundatus, basi truncatus, angulis posterioribus obtusissimis, convexus, distincte canaliculatıs, sat crebre profundeque punctatus, interstitiis laevibus vel oculo fortiter armato omnium subtilissime coriacea. Elytra thorace paululum longiora, densius profunde punctata, laete rufa. Abdomen omnium subtilissime confertissimeque punctatum, nitidum, ano concolore. Pedes rufi, coxis anterioribus concoloribus.

Sexus differentia latet. Abdominis segmentum septimum inferius in omnibus apice profunde bisinuatum.

* 16. B. procerulus: Nigro-piceus, antennis basi pedibusque testaceis, elylris caslaneis, thoracis longitudine, hoc dense fortiter punctato, canaliculato. - Long. $1 \frac{2}{3}$ lin.

Habitat in Austria, Dom. Schiippel. 
B. fracticorni dimidio minor et angustior, nigro-piceus, minus nitidus, parce griseo-pubescens. Antennae capite sesqui longiores, articulo tertio secundo paulo breviore, ab articulo septimo inde distinctins incrassatae, testaceae, apicem versus picescentes. Oris partes testaceae. Mandibulae haud prominentes, falcatae, ante apicem dentatae. Caput thorace parum angustius, omnium subtilissime alutaceum, sparsim subtilius obsoletiusque punctatum, fronte utrinque late leviter impressa. Thorax coleopteris parum angustior, latitudine haud brevior, lateribus subrectis, postice introrsum mo. dice rotundatis, angulis posterioribus obtusis, hasi truncatus, modice convexus, dense fortius profunde punctatus, interstitiis subtilissine alutaceis, medio profunde canaliculatus. Elytra thorace vix longiora, dense fortius profunde punctata, piceo-castanea, subnitida. Abdomen elongatum, omnium subtilissime alutaceum, nitidulum, apice rufo-piceum. Pedes testacei, coxis omnibus concoloribus.

\section{Sexus differentia latet.}

Obs. Hanc speciem, ab affinibus coleopteris thorace neque latioribus, neque longioribus distinctam, sub Oxyteli proceri nomine misit Dahl.

\section{* 17. B. nigricuns: Niger, subnitidus, ore, antennis, pedibus anoque rufo- testareis, elytris margine inflexo rufo, thorace crebre profundeque punclalo. - Long. $1 \frac{3}{4}$ lin.}

Habitat in Rossia meridionali, Dom. Godet.

Habitu omnino B. fracticornis, at paulo minor, niger, nitidulus, densius cinereo-pubescens. Antennae capite sesqui longiores, articulo tertio secundo longitudine subaequali, ab articulo septimo inde incrassatae, basi rufo-testaceae, apice rufae. Ores partes rufo-testaceae. Mandibulae haud prominentes. Caput thorace paululum angustius, omnium subtilissime alutaceum, opacum, subtiliter obsoleteque vage punctatum, fronte utrinque ad antennarum basin leviter longitudinaliter et inter antennas linea transversali impressa. Thorax coleopteris paulo angustior, latitudine vix brevior, lateribus anterius parum, posterius angulos posteriores versus fortius rotundatis, his obtusis, convexus, sat crebre fortiter profundeque punctatus, interstitiis laevibus, linea media longitudinali laevi, haud vero canaliculatus, supra niger, subtus rufo-piceus. Elytra thorace sesqui longiora, confertim sat profunde punctata, supra nigra, margine inflexo, interdum etiam callo humerali obscure rufis. Abdomen omnium confertissime subtiliter punctulatum, ano rufo-testaceo. Pedes rufo-testacei, coxis anterioribus concoloribus. Alae albae.

Abdominis segmentum sextum inferius maris apice emarginatum, sinu membrana clauso, fe min a integrum.

Obs. B. fracticorni dimidio fere minor, antennis totis coxisque anterioribus testaceis, thorace haud canaliculato etc. facile distinctus.

* 18. B. dissimilis: Niger, nitidus, antennis, pedibns anoque rufis, elytris thorace longioribus, rufo-castaneis, sutura late nigricante, thorace crebre profundeque punctato. - Long. $1 \frac{2}{3}$ lin.

Habitat in Germania, Austria, Hungaria, Istria et Gallia.

1 Statura omnino B. fracticornis, niger, "nitidus, tenuiter griseo-pubescens. Antennae capite sesqui fere longiores, articulo tertio secundo dimidio breviore, ab articulo septimo inde leviter incrassatae, rufo-testaceae. Oris partes rufo- 
testaceae. Mandibulae falcatae, ante apicem fortiter dentatae. Caput thorace paululum angustius, omaium subtilissime alutaceum, minus nitidum, fronte utrinque subtilissime obsolete punctata, ad antennarum insertionem leviter impressa. Thorax coleopteris paulo angustior, latitudine vix brevior, lateribus anterius parum, postice angnlos posteriores versus oblique subrotundatis, his obtusissimis, convexus, sat fortiter profundeque dense punctatıs, interstitiis laevibus, linea media longitudinali laevi subelevata. Elytra thorace tertia parte longiora, profundius dense punctata, saturate rufa, nitida, secundum suturam late nigricantia. Abdomen subtilissime confertiscimeque punctatum, nitidum, ano rufo. Pedes testacei, coxis anterioribus rufis.

Abdominis segmentum sextum inferius maris apice late emarginatum, sinu membrana clauso, lateribus utrinque spina longa, tenui, leviter sursum arcuata, acuta armatum, feminae integrum.

Obs. Proximus sequentibus, a B. rufipenni thorace multo crebrius punctato, elytris dorso nigricantibus, statura paulo minore etc., a B. crassicolli coleopteris thorace latioribus et longioribus distinctus. Mas praeterea abdomine infra apice spinis duabus longioribus, superne etiam conspicuis armato insignis.

* 19. B. rufipennis: Niger, nitidus, antennis, elytris pedibusque rufis, thorace parcius profunde punctato, elytris thorace longioribus.

Long. 2 lin.

Habitat in Austria.

Statura omnino B. fracticornis, niger, nitidus, parcius griseo-pubescens. Antennae capite sesqui longiores, tenuiores, articulo tertio longitudine secundo subaequali, ab articulo septimo inde leviter incrassatae, totae rufotestaceae. Mandibulae haud prominentes, falcatae, ante apicem dentatae. Caput thorace paulo angustius, omnium subtilissime alutaceum, minus nitidum, fronte utrinque leviter longitudinaliter impressa et parce subtiliterque pinctata, angulis apicalibus denticulo minutissimo terminata. Thorax coleopteris paulo angustior, latitudine haud brevior, lateribus ultra medium subrectis, postice oblique subrotundatis, basi truncatus, angulis posterioribus obtusissimis, convexus, parcius at sat fortiter profundeque punctatus, interstitiis laevigatis, linea lata media longitudinali laevi, haud canaliculatus. Elytra thorace paulo longiora, minus confertion profundius punctata, laete rufa, circa scutellum parvo spatio nigricantia. Abdomen ommium subtilissime alutaceum, parce obsoleteque punctatum, ano concolore. Pedes ruf, coxis concoloribus.

Abdominis segmentum inferius sextum maris late leviter sinuatum, sinu membrana repleto, utrinque denticulo seu spina breviore, subtili, acuta, leviter sursum curvata terminato, femina integrum.

$\mathrm{Obs}$. Olim pro sequentis varietate mili habitus, iam vero, speciminibus utriusque sexus pluribus examinatis, differentias constantes reperio. Distinctus videtur a sequente statura paulo maiore, thorace parce punctato, coleopteris thorace latioribus et evidenter longioribus, ano semper concolore etc. Abdominis structura mas medium tenet inter praecedentem et sequentem.

* 20. B. crassicollis: Niger, nilidus, antennis, elytris, ano pedibusque rufis, thorace crebre profundeque punctato, elylris thorace vix longioribus. - Long. $1 \frac{3}{4}$ lin.

Bledius crassicollis Boisd. et Lacord. Faun. Ent. Paris, I. 456. 2. - Er. Col. Mireh. I. 580. 4. 
Habitat in Germania.

Statura fere B. fracticornis, at paulo minor et gracilior, niger, nitidus, tenuiter griseo pubescens. Antennae capite dnj;o longiores, tenuiores, articulo tertio secundo paulo breviore, ab articulo septimo inde leviter incrassatae, rufae. Mandibulae haud prominentes, falcatae, ante apicem fortiter unidentatae, piceae. Oris partes inferiores rufae. Caput thorace parum angustius, opacum, fronte utrinque parce obsoleteque subtiliter punctata et ad antennarum insertionem fortius impressa, angulis apicalibus subdenticulatis. Thorax coleopteris haud angustior, latitudine summa parum brevior, lateribus anterius levissime, postice cum angulis posterioribus fortiter rotundatis, basi ipsa truncata, convexus, sat crebre fortiterque punctatus, interstitiis laevibus, haud canaliculatus, linea media longitudinali laevi. Elytra thorace perparum longiora, sat crebre profundeque punctata, saturate rufa, circa scutellum nigricantia. Abdomen omnium subtilissime confertissimeque punctatum, nitidum, ano rufo. Pedes rufi, coxis concoloribus.

Abdominis segmentum inferius sextum maris apice sinuatum, sinu membrana repleto, denticulo obtusiusculo utrinque terminato, feminae integrum.

Variat ano concolore.

*21. B. opacus: Niger, antennarum basi pedibusque teslaceis, elytris rufis, sutura nigvicanle, thorace subtiliter coriaceo, opaco, subtiliter canaliculato, parcius obsoletiusque punctato, angulis posterioribus sub. rotundatis. - Long. $1 \frac{3}{4}$ lin.

Er. Col. March. I. 581. 5.

Staph. opacus Block Ins. Vall. Plauens. 117. 7. t. 7. f. 7.

Bledius cast uneipen $n$ is Manierh. Brachelytr. 45. 6. - Boisd. et Lacord. Faun. Ent. Paris. I. 457. 3.

Habitat in Germania.

Niger, parce tenuiterque griseo-pubescens. Antennae capite sesqui fere longiores, articulo tertio secundo dimidio breviore, ab articulo septimo inde leviter incrassatae, nigrae, basi testaceae, vel testaceae, apice fuscescentes. Mandibulae parum prominentes, leviter falcatae, interne medio obsoletius bidenticulatae, rufo-piceae. Os inferius testaceum. Caput confertissime subtiliter coriaceum, subopacum, fronte utrinque longitudinaliter et inter antennarum insertionem transversim impressa, utrinque secundum oculi marginem interiorem longitudinaliter elevata, angulis apicalibus denticulo minuto terminatis. Thorax medio coleopteris parum angustior, latitudine tertia parte brevior, antrorsum subangustatus, lateribus praecipue ad angulos posteriores rotundatis, his obtusissimis, subrotundatis, modice convexus, confertissime subtiliter coriaceus, opacus, subtiliter canaliculatus, parcius parum profunde punctatus. Elytra thorace sesqui prope longiora, dense profunde punctata, testaceo-rufa, nitida, secundum suturam magis minusve late nigricantia. Abdomen omnium subtilissime confertissimeque punctatum, nitidum, ano piceo. Pedes rufo-testacei, coxis anterioribus concoloribus.

Sexus differentia latet. 
*22. B. erraticus: Niger, subnitidus, antennis, pedibus, elylris anoque rufis, thorace subtiliter coriaceo, parce obsoleteque punctato. - Long. $1 \frac{1}{2}$ lin.

Er. Col. March. I. 582. 6.

Habitat in Germania.

B. opaco proximus, at paulo minor, niger, subnitidus, tenuiter cinereopubescens. Antennae capite sesqui longiores, articulo tertio secundo dimidio breviore, ab articulo septimo inde modice incrassatae, rufae, articulis duobus primis testaceis. Oris partes rufo-testaceae. Caput thorace paulo angustius, omnium subtilissime confertissimeque coriaceum, subnitidum, fronte utrinque parce subtiliter obsoleteque punctata, et ad antennarum basin leviter impressa. Thorax coleopteris parum angustior, latitudine paulo brevior, lateribus subrotundatis, a medio versus basin subsinuato-angustatis, angulis posterioribus"obtusis, non vero obtusissimis, convexus, confertissime subtilissimeque coriaceus, opacus, parcius subtiliusque obsolete punctatus, linea media longitudinali laevi (inupunctata), haud canaliculatus, supra nigro - vel fusco-piceus, subtus rufus. Elytra thorace paulo longiora, minus confertim punctata, testaceo-rufa, nitida. Abdomen supra laeve, nitidum, nigro-piceum, ano rufo, subtus obsoletius punctatum, piceo-rufum, Pedes rufo-testacei.

Sexus differentia latet.

Variat elytris prope suturam nigricantibus vel totis nigro-piceis.

Obs. A B. opaco thorace haud canaliculato, fronte haud transversim impressa et elytris brevioribus distinctus.

* 23. B. pallipes: Niger, antennarum basi pedibusque testaceis, thorace subtiliter coriaceo, opaco, subtiliter canaliculato, parcius obsoletiusque punctato, angulis posterioribus obtusis. - Long. $1 \frac{3}{4}$ lin.

Mannerh. Brachelytr. 45. 8. - Runde Brachelytr. Mal. 19. 7.

Oxyt. pallipes Grav. Mon. 197. 12. - Oliv. Encycl. meth. VIII. 614. 14. - Gyll. Ins. Suec. II. 447. 3. IV. 497. 3. - Sahlb. Ins. Fenn. I. 408. 2.

Habitat in Austria, Dom. Ullrich, in Gallia, Dom. Aubé.

Statura et summa affinitas B. opaci. Niger, tenuiter griseo-puhescens. Antennae capite sesqui longiores, articulo tertio secundo duplo breviore, ab articulo septimo inde sensim leviter incrassatae, piceae, basi testaceae. Mandibulae parum prominentes, leviter falcatae, medio leviter bidentatae, rufo-testaceae. Palpi testacei, articulo tertio fuscescente. Os inferius testaceum. Caput thorace perparum angustius, subtilissime coriaceum, opacum, utrinque parce obsolete punctatum, fronte utrinque ad antennarum basin impressa. Thorax coleopteris paulo angustior, latitudine tertia parte brevior, lateribus modice rotundatus, basin versus a medio inde sensim angustatus, angulis posterioribus, licet obtusis, subprominulis, leviter convexus, confertissimeque coriaceus, opacus, subtiliter canaliculatus, parcius obsolete punctatus. Elytra thorace plus sesqui longiora, dense punctata, nigra, nitidula. Abdomen omnium subtilissime punctatum, nitidum, ano piceo. Pedes rufo-testacei, coxis anterioribus concoloribus.

Sexus differentia latet.

Obs. A B. opaco differt thoracis angulis posterioribus prominulis, elytris longioribus, densius punctatis, nigris, fronte haud transversim impressa.l 
* 24. B. atricapillus: Piceus, capile nigro, antennarum basi, elytris pedibusque pallide testaceis, thorace subtilissime alutaceo, parce obsoleteque punctalo, subtiliter canaliculato, - Long. $1 \frac{1}{2}$ lin.

Mannerh. Brachelytr. 45. 8. - Runde Brachelytr. Hal. 19. 6.

Oxyt. atricapillus Germ. Faun. Ins. Europ. XI. 4. - Nicolai Col. Halens. 40. 3.

Habitat in Germania.

Praecedente paulo minor et gracilior, piceus, parum nitidus, subtiliter griseo-pubescens. Antennae capite sesqui longiores, articulo tertio secundo multo breviore, ab articulo septimo inde modice incrassatae, testaceae, basi pallidiores, apice fuscescentes. Mandibulae leviter prominentes, minus falratae, acutae, medio fortiter unidentatae, rufo-testaceae. Oris partes testaceae. Caput thorace paulo angustius, omnium subtilissime alutaceum, fronte utrinque ad antennarum insertionem leviter impressa, nigrum, apacum. Thorax coleopteris paulo angustior, latitudine vix brevior, lateribus anterius subrectis, fere parallelis, pone medium subitu fortiter convergentibus, angulis posterioribus cum basi leviter rotundatis, convexus, confertissime subtilissimeque alutaceus, parce subtiliter obsoleteque punctatus, subtiliter canaliculatus, rufo-piceus, parum nitidus. Elytra thorace plus sesqui longiora, densius subtiliusque punctata, pallide testacea, prope suturam leviter infuscata. Abdomen parce subliterque punctatum, dorso plerumque nigrum, nitidum. Pedes cum coxis omnibus pallide testacei.

Sexus differentia latet.

* 25. B. паnus: Niger, nilidulus, antennarum basi, pedibus elytrisque testaceis, his sulura late nigra, thorace parce subtiliter obsoleteque punctalo, subliliter canaliculato. - Long. $1 \frac{1}{4}$ lin.

Habitat in Austria, Dom. Ullrich.

Habitu omnino B. fracticornis, at minutus, niger, nitidulus, tenuiter griseo-pubescens. Antennae capite sesqui longiores, articulo tertio secundo multo minore, ultimis tribus abrupte maioribus, nigrae, articulis dı obus pri . mis testaceis. Mandibulae parum prominentes, falcatae, inter medium et apicem unidentatae. Oris partes rufo-testaceae. Caput thorace parum angustius, omnium subtilissime coriaceum, fronte utrinque ad antennarum basin longitudinaliter impressa. Thorax apice coleopteris paulo angustior, basin versus angustatus, lateribus ante medium leviter, a media inde fortiter convergentibus, angulis posterioribus obtusis, convexus, omnium subtilissime coriaceus, parce subtiliter obsoleteque punctatus, subtiliter canaliculatus, subtus utrinque piceo-rufus. Elytra thorace paulo longiora, crebrius sat profunde punctata, testacea, secundum suturam late nigricantia.. Abdomen omnium subtilissime confertissimeque punctatum, nitidum. Pedes testacei, coxis anterioribus concoloribus.

Sexus differentia latet.

* 26. B. pusillus: Niger, antennarum basi, pedibus elytrisque rufis, thorace coriaceo, crebrius obsolete punctato, obsolete canaliculato. - Long. 1 lin.

Er. Col. Mareh. I. 583. 7.

Habitat in Germania, Gallia. 
Habitu prope B. crassicollis, at minutus, niger, tenuiter griseo-pubescens. Antennae capite sesqui longiores, articulo tertio secundo multo minore, ultimis tribus distincte licet minus abrupte maioribus, fusco-ferrugineae, articulis duobus primis testaceis. Mandibulae perparum prominentes, ante apicem obsolete unidentatae. Os rufum. Caput thorace parum angustius, omnium subtilissime alutaceum, nitidum, fronte utrinque obsolete punctata, inter antennarum insertionem sulco transversali, utrinque foveola minuta terminato, impressa. Thorax apice coleopteris parum angustior, latitudine paulo brevior, lateribus anterius subrectis, posterius a medio inde fortiter convergentibus, angulis posterioribus obtusis, leviter coriaceus, parum nitidus, crebrius minus subtiliter obsoletius canaliculatus, subtus rufus. Coleoptera thorace paulo longiora et latiora, minus confertim obsoletius punctata, rufa, nitida. Abdomen omnium subtilissime punctulatum, nigrum, nitidum, ano ventreque rufo-piceis. Pedes rufo-testacei, coxis anterioribus concoloribus.

Obs. B. nano paulo brevior, fronte linea transversali impressa, thorace mi nus subtiliter coriaceo punctatoque, obsolete canaliculato, elytris secundum suturam haud nigris etc. facile distinguendus.

\section{* 27. B. pygmaeus: Niger, antennarum basi, pedibus elytrisque testaceis,} thorace crebrius obsolete punctato. - Long. 1 lin.

Er. Col. March. I. 583. 8.

Habitat in Germania, Gallia.

Statura graciliore, minutus, B. pusillo longitudine aequalis, at angustior, niger, nitidus, tenuiter griseo - pubescens. Antennae capite sesqui longiores, articulo tertio secundo nulto minore, ultimis tribus distincte maioribus, fuscae, articulis duobus primis testaceis. Mandibulae perparum prominentes, ante apicem obsoletius unidentatae. Oris partes rufo-testaceae. Caput thorace paulo angustius, omnium subtilissime coriaceum, nitidum, fronte utrinque ad antennarum basin leviter impressa. Thorax coleopterorum latitudine, latitudine antica vix brevior, basin versus angustatus, lateribus anterius parum, a medio inde fortius conniventibus, angulis posterioribus obtusis, convexus, subtiliter coriaceus, crebrius obsolete punctatus, linea media longitudinali laevi (impunctata), haud canaliculatus, supra nigro-piceus, subtus lateribus piceo-rufus. Elytra thoracis longitudine, minus crebre obsoletius punctata, testaceo-rufa. Abdomen conferrim subtilissime punctatum, nigrum, nitidum, apice summo piceo-rufo, subtus ab apice inde rufescens. Pedes testacei, coxis concoloribus.

Obs. B. pusillo proximus, statura autem graciliore, coleopteris thorace neque longioribus, neque latioribus, thorace haud canaliculato etc. specie distinguendus.

* 28. B. troglodytes: Niger, antennis, elytris pedibusque pallide testaceis, thorace subtiliter canaliculato, parcius punctato, interstitiis laevigalis, fronte apice bituberculata. - Long. 1 lin.

Habitat in Carolina meridionali, Dom. Zimmermanin.

Praecedente paulo minor, niger, nitidus, parce subtiliterque cinereo-pubescens. Antennae capite sesqui longiores, tenuiores, articulo tertio secundo multo minore, apice sensim leviter incrassatae, pallide 
testaceae, apice nomnunquam picescentes. Maudibulae vix prominentes. Oris partes omnes testaceae. Ciaput thorace paulo angustius, laevigatum, fronte ad antennarum insertionem utrinque leviter impressa, apice utrinque tubereulo minuto terminata, inter tubercula emarginata. Thorax coleopteris paulo angustior, latitudine antica haud brevior, basin versus angustatus, lateribus leviter rotundatis, pone medium fortius conniventibus, angulis posterioribus obtusis, convexus, subtiliter canaliculatus, minus confertim subtilius punctatus, interatıtiis laevigatis, nigro-piceus, nitıdus. Elytra thorace sesqui longiora, dense subtiliter punctata, pallide rufo-testacea, secundum suturam obsolete infuscata. Abdomen supra laevigatum, infra parce subtiliterque punctatum, nigrum, nitidum. Pedes pallide flavo testacei.

Sexus differentia latet.

29. B. parvulus: Rufus, nitidus, capite nigro, thorace abdomineque supra piceis, elytris macula magna communi fusca, thorace canaliculato, parcius profunde punctato. - Long. $1 \frac{1}{s}$ lin.

Habitat Novae Valenciae in Columbia, Dom. Moritz.

Habitu fere B. nani. Antennae capite sesqui longiores, articulo tertio secundo dimidio breviore, apicem versus sensim subincrassatae, testaceae, apice nigricantes. Os rufo-testaceum. Mandibulae fortiter falcatae, acutae. Caput thoracis fere latitudine, omnium subtilissime coriaceum, fronte subconvexa, ad antennarum basin vix impressa, nigrum, parum nitidum. Thorax coleopteris paulo angustior, latitudine parum brevior, lateribus anterius subrectis, pone medium subito convergentibus, angulis posterioribus obtusis, convexus, subtilius canaliculatus, minus crebre fortius profunde punctatus, interstitiis laevibus, picens, nitidus. Coleoptera thorace paulo longiora et latıora, sat crebre profundeque punctata, pallide rufo-testacea, nitida, macula magna dorsali communi fusca. Abdomen laeve, nitidum, supra segmentis anterioribus margine postico, sexto toto piceo. Corpus subius totum rufum. Pedes testacei.

Sexus differentia latet.

30. B. pumilio: Testaceus, capite nigro, pedibus elytrisque pallidis, his macula ubsoleta fusca notalis, thorace parcius absolele punctato. Long. vix 1 lin.

Habitat in Columbia, Dom. Moritz.

Statura parva B. pygmaei, at hoc etiam paulo minor, ideoque minimus in hoc genere. Antennae capite paulo longiores, articulo tertio secundo multo minore, apicem versus sensim crassiores, testaceae. Os testaceum. Mandibulae leviter falcatae, acutae, ante apicem subtiliter unidentatae. Caput nigrum, subnitidum, fronte parce subtilissime punctulata, utrinque obsolete impressa. Thorax coleopteris paulo angustior, latitudine paulo brevior, lateribus anterius parum, postice cum angulis posterioribus fortiter rotundatis, convexus, parcius obsoletiusque punctatus, linea media longitudinali laevi, canalicula media utrinque abbreviata subtilissima exaratus, rufotestaceus, nitidus. Elytra thorace paulo longiora, crebre princtata, subtiliter pubescentia, pallide testacea, nitida, secundum suturam macula magna ob- 
longa fusca obsoletiore notata. Abdomen saturate testaceum, nitidum. Pectus et pedes pallide testacea,

Sexus differentia latet.

* 31. B. verres: Niger, parum nitidus, pedibus elytrisque pallide testaceis, his basi suturaque nigris, thorace sublilissime alutaceo, subtiliter punctato, canaliculato, fronte apice bidenticulata, antennarum basi maris elevata. - Long. 2 lin.

Habitat in Sardinia, Dom. Prof. Gené.

Niger, subtiliter griseo-pubescens. Antennae capite duplo prope longiores, articulo tertio secundo duplo breviore, ultimis 4 distincte crassioribus, densius pubescentes, nigrae, articulo primo piceo, secundo testaceo, articulis tribus primis maris elongatis. Mandibulae porrectae, minus falcatae, acutae, maris longiores, medio dente valido, acuto, fere erecto armatae, feminae muticae. Caput thorace angnstius, omnium subtilissime alutaceum. obsoletissime punctulatum, apice denticulis duobus approximatis, porrectis, maris longioribus, spinuliformibus armata, tuberculo ante oculos, cui antennae insertae sunt, in femina haud magis quam in reliquis prominulo, in mare magno, fere cylindrico et porrecto, antennarum insertione longe ultra frontem elevata. Thorax coleopteris paulo angustior, latitudine antica paulo brevior, lateribus anterius subrectis, parallelis, pone medium subito fortiter convergentibus, angulis posterioribus rotundatis, modice convexus, subtilissime alutaceus, subnitidus, orebrius subtiliter obsoleteque punctatus, canaliculatus. Elytra thorace sesqui longiora, densius subtiliusque punctata, pallide rufo-testacea, sutura late basique nigris. Abdomen parce punctatum, parcius griseo-pilosellum, nitidum. Pedes pallide testacei, coxis omnibus et femoribus anticis nigro-piceis, femoribus posterioribus albidis.

Abdominis segmentum inferius septimum $m$ aris apice leviter bisinuatum, feminae truncatum.

* 32. B. Niloticus: Nigricans, antennarum basi pedilusgue pallide flavis, thorace transverso, subtilissime coriaceo, crebrius punctato, subtiliter canaliculato, fronte apice bituberculata. - Long. $1 \frac{1}{2}$ lin.

Habitat in Aegypto, Dom. Prof. Ehrenberg.

Nigricans, parum nitidus, tenuiter griseo-pubescens. Antennae capite paulo longiores, articulo tertio secundo paulo breviore, apice sensim incrassatae, nigrae, articulis duobus primis testaceis. Os testaceum. Mandibulae elongatae, prominentes, leviter arcuatae, acutae, ante medium acute unidentatae. Caput thorace paulo angustius, subtilissime confertissimeque coriaceum, fronte utrinque super antennarum basin tuberculo rotundato, sat prominulo, testaceo munita, apice subretusa, bidenticulata. Thorax coleopteris parum angustior, Jatitudine paulo brevior, lateribus anterius rectis, pa. rallelis, pone medium subito fortiter convergentibus, basi angulisque foste. rioribus subrotundatis, leviter convexus, omnium subtilissime coriaceus, subnitidıs; subtiliter crebrius punctatus, subtiliter canaliculatus. Elytra thorace sesqui longiora, dense profundeque punctata. Abdomen supra laeve, subtus obsoletius punctatum. Pedes pallide testacei.

Mas mandibulis paulo longioribus, fronte subimpressa, tuberculis su- 
per antennarum basin denticulisque apicalibus magis prominulis, acutis a femina distinguendus.

Variat immaturus testaceus, capite nigricante.

*33. B. talpa: Niger, elylris nigro-cyaneis, nitidis, thorace opaco, subtiliter obsoleteque punclato, subliliter canaliculato. - Long. 2 lin.

Mannerh. Brachelytr. 45. 10. - Boisd. et Lacord. Faun. Ent. Paris. I. 458. 5.

Oxyt. talpa Gyll. Ins. Suec. II. 448. 4. - Sahlb. Ins. Fenn. I 409. 3. - Germ.

Faun. Ins. Europ. XI. 3. - Zetterst. Ins. Lappon. 73. 7.

Habitat in Suecia, Germania, Gallia.

Statura omnino B. fracticornis, niger, nitidus, longius griseo-pubescens. Antennae capite sesqui longiores, articulo tertio secundo multo minore, apicem versus leviter incrassatae, nigrae, articulo secundo piceo-testaceo. Mandibulae modice prominentes, leviter arcuatae, acutae, medio unidentatae, nigrae, apice piceo-rufae. Palpi nigri. Caput thorace angustius, omnium subtilissime coriaceunı, opacum, vage subtiliter obsoleteque punctatum, fronte utrinque leviter longitudinaliter impressa. Thorax coleopteris dimidio angustior, latitudine parum brevior, lateribus medio fortiter rotundatus, posterius fortiter sinuato-angustatus, angulis posterioribus subprominulis, convexus, omnium subtilissime coriaceus, opacus, minus confertim subtiliter obsoleteque punctatus, subtiliter canaliculatus. Elytra thorace sesqui longiora, sat crebre fortiterque punctata, obscure coerulea, nitida. Abdomen omnium subtilissime confertissimeque punctulatum, supra obsolete sparsim parceque, subtus crebrius fortiusque punctatum, nitidum. Pedes nigri, tarsis, trochanteribusque piceo-testaceis.

Sexus differentia latet.

* 34. B. subterraneus: Niger, pedibus piceo-testaceis, femoribus nigricantibus, thorace opaco, subtiliter canaliculato, subtiliter obsoleteque punctato. - Long. $1 \frac{3}{4}$ lin.

Er. Col. Murch. I. 584. 9.

Habitat in Germania.

Niger, tenuiter griseo-pubescens. Antennae capite paulo longiores, articulo tertio secundo dimidio breviore, apicem versus sensim leviterque incrassatae, nigrae, apice saepe fuscescentes, articulis duobus primis nonnunquam testaceis. Mandibulae prominulae, tenues, parum arcuatae, acutae, medio obsolete dentatae, rufae. Palpi piceo-testacei, articulo tertio nigropiceo. Caput thorace angustius, omnium subtilissime coriaceum, opacum, subtiliter obsoleteque vage punctatum, fronte utrinque ad antennarum basin longitudinaliter impressa. Thorax coleopteris dimidio fere angustior, latitudine parum brevior, lateribus ante medium rotundatus, pone medium sinuatoangustatus, angulis posterioribus obtusis, subprominulis, convexus, omnium subtilissime coriaceus, opacus, minus confertim subtiliter obsoleteque punctatus, subtiliter canaliculatus. Elytra thorace duplo prope longiora, subtilius creberrime punctata, subnitida, pube brevissima conspersa. Ahdomen omnium subtilissime confertissimeque punctatum, nitidum. Pedes coxis femoribusque nigro-piceis, trochanteribus, tibiis tarsisque piceo-testaceis.

Sexus differentia latet. 
* 35. B. arenarius: Niger, nilidus, anlennis apicem versus, tibiis tarsisque fusco-teslaceis, elylvis testaceis, basi suluraque nigris, thorace brevi, subtiliter canaliculato, parce subtiliterque punclato. - Long. $1 \frac{1}{2} \mathrm{lin.}$

Mannerh. Brachelytr. 46. 11. - Er. Col. March. I. 585. 10.

Staph. arenarius Payk. Faun. Suec. III. 382. 20.

Oxyt. arenarius Gyll. Ins. Suec. II. 448. 5. - Sahlb. Ins. Fenn. I. 409. 4.

Rudd Ent. Mag. II. p. 180.

Habitat in arena in lacumm ripis, in Suecia, Germania.

B. opaco duplo fere minor, niger, nitidus, tenuiter griseo-pubescens. Antennae capite paulo longiores, graciliores, articulo tertio secundo multo minore et duplo breviore, ultimis tribus abrupte distıncteque crassioribus, piceo-testaceae, articulis duobus primis nigris. Mandibulae modice prominentes, tenues, acutae, leviter arcuatae, medio obsolete bidentatae, rufae. Palpi nigri. Caput thorace dimidio angustius, omnium subtilissime coriaceum, parce obsoleteque punctulatum, subnitidum, fronte utrinque ad antennarum basin foveola minuta impressa, angulis apicalibus denticulo minimo prominulo acuto terminatis. Thorax coleopteris parum angustior, latitudine dimidio brevior, lateribus anterius subrectis, pone medium angulos posteriores versus subito sinuato-angustatis, his subprominulis, convexus, omnium subtilifsime coriaceus, nitidulus, subtiliter canaliculatus, nimus crebre subtiliter obsoleteque punctatus. Elytra thorace sesqui longiora, confertim subtiliter punctata, pallide rufo-testacea, hasi suturaque nigris, vel nigra, angulo apicali exteriore magis minusve late testaceo. Abdomen supra laeve, subtus crebre obsolete punctatum, nitidum. Pedes nigri, trochanteribus, tibiis tarsisque obscure testaceis.

Sexus differentia latet.

* 36. B. debilis: Niger, opacus, antennis, pedibus elylvisque pallide testaceis, his macula sculellari triangulari nigra, thorace sublilissime coriaceo, subtiliter punctato canaliculatoque. - Long. $1 \frac{3}{4}$ lin.

Habitat in Rossia meridionali, Dom. Godet.

B. arenario paulo longior, tenuiter pubescens, niger, capite thoraceque opacis, ahdomine subnitido. Antennae capite sesqui longiores, articulo tertio secundo paulo breviore, apicem versus sensim incrassatae, testaceae. Mandibulae porrectae, parum falcatae, tenues, edentatae, acutae, rufae. Oris partes reliquae testaceae. Caput omnium confertissime subtilissimeque coriaceum, nigrum, opacum, fronte utrinque ad antennarum insertionem vix impressa. Thorax coleopteris paulo angustior, latitudine parum longior, lateribus et basi leviter, angulis posteriorbus fortiter rotundatis, apice subemarginatus, leviter convexus, omnium confertissime subtilissimeque coriaceus, vage subtiliter obsoleteque punctatus, subtiliter canaliculatus, nigro-piceus, opacus. Elytra thorace paulo longiora, sat crebre subtilius punctata, pallide testacea, nitida, circa scutellum spatio parvo triangulari nigricante. Abdomen supra subtilissime confertissimeque punctatum, nigrum, nitidum, subtus crebrius punctatum. Corpus totum subtus rufo-piceum. Pedes cum coxis omnibus pallide testacei.

Sexus differentia latet. 
Species mihi invisae.

37. B. elongatus: Elongatus, niger, subnitidus, profunde punclatus, elytrorum macula oblonga rufa, pedibus pallidis, thorace orbiculalo, obsolete canaliculato.

Mannerh. Brachelytr. 45. 4.

Habitat Petropoli in terra argillacea.

Medius quasi inter B. tricornem et fracticornem, illo parum brevior, sed fere duplo angustior, thorace convexiore mutico et colore praeterea facile dignoscitur. (Mannerh.)

38. B. brunnipennis: Niger, obscurus, elytris pedibusque brunneis. Staph. brunnipennis Fab. Syst. El. II. 596. 31.

Habitat in India orientali.

Medius. Antennae nigrae, basi ferrugineae. Caput et thorax scabra, nigra, obscura. Elytra subpunctata, immaculata. Abdomen atrum, ano sive ultimo segmento brunneo. Pedes brunnei. (Fab.)

39. B. tuberculatus: Niger, elyiris teslaceis, ad suturam nigris, capite tuberculato.

Staph. tuberculatus Fabr. Ent. Syst. Suppl. 181. 49-50. Syst. El. 1I. 601. 62.

Habitat in India orientali.

Parvus. Caput magnum, nigrum, mandibulis exsertis, elongatis tuberculisque duobus elevatis, obtusis. Antennae testaceae. Thorax niger. Elytra testacea, ad suturam nigra. Abdomen nigrum, ano testaceo. Pedes testacei. (Fab.)

40. B. pallipennis: Testaceus, capite nigro, clypeo apice elevato, bidentato, thorace transverso, canaliculato. - Long. ultra $3 \frac{1}{2}$ lin.

Oxyt. pallipennis Say Act. Acad. Nat. Scienc, Philadelph. III. I. 15j. 1.

Habitat in Missuria.

Testaceus, punctatus, pubescens. Caput nigrum, antice sparsim punctatum, clypeo apice medio elevato, prominulo, bidentato. Antennae et carinae ad earum hasin pallide rufae. Mandibulae porrectae, piceae, medio bifidae, dente superiore breviore. Palpi pallidi. Thorax latitudine brevior, rufo-piceus, linea dorsali exaratus. Elytra apice et sutura fuscescentibus. Pedes albidi. (Say).

41. B. armatus: Dilute rufo-piceus, capite nigro, carina laterali apice

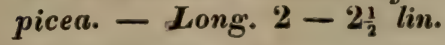

Oxyt. armatus Say Act. Acad. Nat. Scienc. Philadelph. III. I. 152. 2.

Habitat in America septentrionali.

Dilute rufo-piceus, punctatus, leviter pubescens. Caput nigrum, obsolete punctatum, carina verticali super anteriorem oculorum partem abbreviata, ad antennarum basin abrupte terminata, apice picea, clypei angulis anterioribus reflexis. Antennae et palpi pallide rufi. Mandibulae piceae. Thorax latitudine haud brevior, linea longitudinali exaratus, disperse punctatus, mar- 
gine nigricante. Elytra crebre distincte punctata, sutura nigricante. Femora testacea.

M a s dilutior, fronte inter oculos tuberculo munita, thorax linea longitudinali dorsali impunctata, abdomine dorso apice obscuriore. (Say).

42. B. cordatus: Niger, elytris albidis, maculà communi fusca. Long. $1 \frac{1}{2}$ lin.

Oxyt. cordatus Say Transact. Amer. Philoph. Soc. Philadelph. Nov. Ser. IV.461. 3.

Habitat in Virginia.

Niger, subtiliter punctatus. Mandibulae piceae. Antennae pallidae, apıce fuscescentes. Thorax angulis subrotundatis. Elytra flavescenti-alba, disco communi fuliginoso. Pedes flavescenti-albi, tibiis tarsisque obscurioribus.

Frequentissimus occurrit $\mathrm{m}$. Octobre in cuniculis sub arenae littoralis superficie, aestu alterno opertus. Variis pusillis Crustaceis, fluetu recedente sub arenam refugientibus pasci videtur. (Say).

43. B. fasciatus: Nigricans, elytris pallide flavis, abdomine testaceo, obsolete fusco-fascialo. - Long. $1 \frac{1}{2}$ lin.

Oxyt. fasciatus Say Act. Acad. Nat. Scienc. Philadelph. III. 1. 156. 4.

Habitat in Missuria.

Nigricans, punctatus, pubescens. Caput nigrum, impunctatum, subtilissime granulatum. Os et antennae testacea. Mandibulae piceae. Thorax nigro-piceus, grossius distincte punctatus, basi cum angulis posteriaribus rotundatus, ab elytris rematus. Elytra pallide flava, basi interne et sutura - fuscis, crebre grossius distincte punctata, apice obtuse rotundata. Pectus rufo-piceum. Pedes pallidiores. Abdomen supra rufescens, segmentis singulis linea transversali media obsoleta nigricante. (Say).

44. B. melanocephalus: Pallide testaceus, capite pectoreque nigris, sutura fusca. - Long. 1 lin.

Oxyt. melanocephalus Say Act. Acad. Nat. Scienc. Philadelph. III. 156. 3.

Habitat in Missuri fluminis ripis.

Pallide testaceus vel albidus. Caput nigerrimum, ore antennisque pallide testaceis. Mandibulae muticae. Elytra sutura nigricante. Pectus nigrum. Variat abdomine rufo-piceo. (Say).

45. B. emarginatus: Niger, elytris albidis, sutura fuliginosa. - Long. infra 1 lin.

Oxyt. emarginatus Say Transact. Amer. Philosoph. Soc. Philadelph. Nov. Ser. IV. 461.4.

Habitat in Indiana Americae septentrionalis.

Niger, punctatus. Caput crebre punctatum, at haud rugulosum, fronte inter antennas longitudinaliter bi-impressa. Antennae, mandibulae et palpi testacei. Thorax picescens, basi rotundatus, disperse distincte punctatus, linea dorsali evidenter canaliculatus. Elytra distincte punctata, vitta communi latiore fuliginosa, angulo apicali suturali obtuse rotundato. Pedes testacei, coxis femoribusque albidis.

Obs. Elytra apice ob angulum interiorem obtuse rotundatum profunde emarginata apparent. (Say). 


\title{
Platysthetus Mannerh.
}

\author{
Mannerh. Brachelytr. p. 46. \\ Oxytelus Fam. II. Grav. Mon. p. 194.
}

\section{Paraglossae apice liberae.}

Pedes intermedii basi distantes.

\section{Tibiae anteriores externe uni-seriatim spinulosae.}

Corpus oblongum, subdepressum, alatum. Caput sat magnum, porrectum, basi leviter constrictum, thoraci immissum, oculis rotundatis, modice prominulis. Labrum transversim subquadratum, laciniis membraneis triangnlaribus, acuminatis. Mandibulae modice prominentes, interne ante apicem bidentatae, basi membrana fimbriatae. Maxillae (t. V. f. 16. b.) malis membranaceis, interiore interne membranea, ciliata, exteriore longiore, apice dense barbata. Palpi maxillares mala exteriore paulo longiores, articulo primo minuto, secundo tertioque subaequalibus, apice leviter incrassatis, quarto minore, subulato. Labium (t. V. f. 16. a.) mento transverso, ligula membranea, lata, apice bisinuata, lobis lateralihus magis productis, acutis, paraglossis liberis, linearibus, falcatis, acutis, interne dense ciliatis. Palpi labiales articulo primo crassiusculo, cylindrico, secundo hoc paulo breviore, tertio secundo iterum longiore. Antennae fractae, apicem versus leniter incrassatae. Thorax transversus, caput excipiens, lateribus et basi rotundatus, ab elytris remotus. Elytra brevia, truncata, apice dehiscentia. Abdomen sursum reflectendum, supra planum, infra convexum. Pedes breviusculi, intermedii distantes, tibiis anterioribus externe uniseriatim spinulosis, anticis apice emarginatis, tarsis triarticulatis, articulo tertio reliquis duobus multo longiore.

\section{o b s e r v a t i o n es.}

1. Corpus glabrum. Thorax canaliculatus. Abdomen laevigatum.

2. Labri structura et pedibus intermediis basi distantibus cum Oxytelo convenit, differt autem habitu peculiari, ligula apice minus fortiter bisinuata, paraglossis basi ligulae connatis, palpis labialibus articulo ultimo haud subuliformi, pedibus intermediis fortius distantibus, tibiis intermediis externe spinulosis.

3. Mares capite maiore, plerique etiam fronte apice bispinosa, et abdominis segmentorum inferiorum structura distinguuntur.

4. Victus in fimo.

5. Metamorphosin Pl.morsitantis Dom. B ouché observavit et hoc modo descripsit: „Larva linearis depressa, antice angustata, parce setulosa, flava. Caput dilute piceum, lenticulare. Antennae 5-articulatae, articulis 3 primis cylindricis, tertio apice processu minuto elliptico aucto, reliquis ambobus mucronato-subulatis, penultimo apice setis duabus fortibus insiructo. Mandibulae lineares, arcuatae, apice obtusae, bidentatae, dentibus piceis, apice nigricantibus. Labrum quadratum. Maxillae oblongae, intus processu angusto, apice introrsum curvato, interne setis ciliato instructae. Palpi maxillares 5-articulatae, articulo secundo longiore, introrsum arcuato. Mentum rotundatum. Ligula oblongo-quadrangularis. Palpi labiales 2-articulati, ligulae medio insertae. Prothorax capitis latitudine, mesothorace angustior, posterius utrinque papilla prominula instructus. Meso - et metathorax abdominis latitudine. Abdomen segmentis singulis utrinque parce rugusis, ultimo fortiter attenuato, caudis duabus, setosis terminato. Long. 2 lin. Victitat hieme in stercore bovino. Nym pha oblongo-ovata, depressiuscula, parce setosa. Oculi nigri. Vertex setis duabus longis validis divergentibus. Mandibulae nigrae, apice tridentatae ut in imagine. Abdomen marginatum, segmento anali caudis duabus conicis terminato. Long. $1 \frac{\mathrm{T}}{2}$ lin. Hunc statum 14 diebus absolvit. (Hist. Ins. I. 182. 1. t. VIII. f. 14 - 21.) 
* 1. P. morsitans: Niger, nitidus, ore, libiis tarsisque testaceis, fronte depressa, canaliculata, thorace forlius canaliculato elytrisque crebre punctalis, longiludinaliter strigosis, his saepe testaceis. - Long. $1 \frac{1}{2}-2$ lin.

Mannerh. Brachelytr. 46. 2. - Runde Brachelytr. Hal. 19. 3. - Er. Col. March. I. 585. 1.

St aph. morsitäns Payk. Mon. Curc. App. 145. 23-24. Faun. Suec. III. 383. 21. - Marsh. Ent. Britt. 508. 28.

Oxyt. morsitans Gruv. Micr. 108. 9. Mon. 195. 9. - Gyll. Ins. Suec. II. 451. 7. - Sahlb. Ins. Fen!. 1 111. 6.

Staph. trilobus Oliv. Ent. III. 42. 20. 22. t. 5. f. 48. - Marsh.' Ent. Britt. 507. 26.

Oxyt. trilobus Latr. Hist nat. Crust, et Ins. IX. 364. 9. - Oliv. Encycl. meth. VIII. 615. 9.

Staph.pallidipennis Panz. Faun. Germ. 27. 16. Ent. Germ. 358. 46.

Staph. arenarius Fourcr. Ent. Paris. I. 172. 30.

Platyth. striolatus Boisd. et Lacord. Faun. Ent. Paris. I. 460. 2.

Oxyt. mordax Sahlb. Ins. Fenn. I. 411. 7.

Platysth. mordax Runde Brachelytr. Hal. 19. 2.

Habitat in Europa.

Niger, nitidus. Antennae capite sesqui longiores, articulo secundo longiore, 6- 10 transversis, sensim crassioribus, ultimo ovato, piceae. Palpi picei. Caput maris magnum, thorace latius, feminae thorace minus et angustius, subdepressum, fronte linea postica transversali impressa sulculoque medio longitudinali sat profundis, clypei spatio impresso, sparsim, pone oculos fortius crebriusque punctatum. Thorax coleopterorum latitudine, latitudine plus dimidio brevior, lateribus et basi rotundatus, angulis posterioribus obtuse rotundatis, apice bisinuatus, angulis anterioribus rotundatis, parum convexus, sat profunde canaliculatus, crebre punctatus, praecipue versus latera, longitudinaliter strigosus. Elyira thoracis fere longitudine, minus confertim punctata, subtiliter strigosa, picea vel piceo-testacea. Abdomen nigro-pilosellum. Pedes testacei, femoribus saepe piceis.

Abdominis -segmentum inferius septimum $\mathrm{m}$ aris profunde triangulariter excisum, medio spinulis duabus subtilibus acutis armatum, feminae apice medio leviter productum.

Obs. Oxyt. mordax Sahlb. a minoribus huius speciei individuis haud satis distinctus mihi videtur.

* 2. P. cornutus: Niger, nilidus, fronte crebre punctala, maris apice bispinosa, thorace fortius canaliculato elytrisque obsolete punctalis, his saepius testaceis. - Long. $1 \frac{1}{3}-1 \frac{2}{3}$ lin.

Mannerh. Brachelyır. 46. 1. - Boisd. et Lacord. Faun. Ent. Paris. I. 459. 1. Runde Brachelytr. Hal. 19. 1. - Er. Col. March. I. 586. 2.

Oxyt. cornutus Grav. Micr. 109. 10. Mon. 195. 10. - Latr. Hist. nat. Crust, et Ins. IX. 365. 10. - Oliv. Encycl. meth. VIII. 615. 10. - Gyll. Ins. Suec. II. 450. 6. - Zetterst. Faun. Lappon. I. 94. 5. Ins. Lappon. 73. 5. - Sahlb. Ins. Fenn. I. 410.5 .

Platysth. scybalarius Runde Brachelytr. Hal. 19. 4.

Habitat in Europa; in Syria Dom. Prof. Ehrenberg.

P. morsitanti magnitudine aequalis, at corpus paulo magis cylindricum, 
nigrum, subnitidum, omnium subtilissime alutaceum. Antennae capite plus sesqui longiores, articulo tertio secundo breviore, 6-10 sensim paulo crassioribus, non autem transversis, ultimo ovato, nigro-piceae. Caput maris thorace parum latius, feminae parum angustius, fronte subdepressa, sat crebre punctata, sulculo abbreviato medio sulcoque laterali longitudinalibus lineaque tenui transversali verticali impressa, margine antico in mare spinis duabus porrectis acutis validisque armato. Thorax apice coleopterorum latitudine, latitudine summa dimidio fere brevior, lateribus et basi eodem areu rotundatis, apice emarginatus, angulis anterioribus acutis, leviter convexus, subtiliter obsoleteque sparsim punctatus, evidenter canaliculatus. Elytra vix thoracis longitudine, subtiliter obsoleteque sparsım punctata, iam nigra, iam piceo-testacea, disco dilutiore. Pedes picei, tarsis, interdum etiam tibiis testaceis.

Abdominis segmentum inferius sextum maris apice leviter emarginatum, septimum medio late impressum, apice truncatum, feminae apice leviter triangulariter productum.

Obs. Individua Europae meridionalis et Asiae occidentalis saepius elytris concoloribus, Europae septentrionalis plerumque elytris disco luteis instructa sunt. PI. scybalarius a Dom. Prof. Germar benevole communicatus cum huius speciei exemplis minutis omnino convenit.

* 3. P. nodifrons: Niger, nitidus, libiis tarsisque teslaceis, cupile, thorace elylrisque sparsim punctatis, thorace profundius canalicula!o, latitudine duplo breviore. - Long. $1 \frac{1}{4}$ lin.

Mannerh. Brachelytr. 47. 3. - Er. Col March. I. 587. 3.

Oxyt. nodifrons Sahlb. Ins. Fenn. 1. 412.8.

Oxyt. nitens Sahlb. Ins. Fenn. I. 413.9.

Oxyt. morsitans var. c Gyll. Ins. Suec. H. 451. 7.

Habitat in Europa.

P. morsitante longe minor, niger, nitidus. Antennae capite duplo prope longiores, articulo tertio secundo breviore, $4-10$ sensim paulo crassioribus, penultimis leviter transversis, ultimo oblongo-ovato, nigrae. Os piceum. Mandibulae sat elongatae. Caput maris thorace paulo maius, feminae eodem vix minus, sparsim punctatum, super oculos sulculis nonnullis impressum, linea transversali verticali magis minusve obsoleta, margine laterali super antennarum basin fortius elevato, ceterum aequale. Thorax coleopterorum latitudine vel iisdem paulo latior, latitudine antica duplo brevior, lateribus et basi eodem arcu rotundatis, apice truncatus, angulis anterioribus subrotundatis, leviter convexus, sat profunde canaliculatus, sparsim subtilius fortiusve punctatus, interstitiis laevissimis. Elytra thorace vix longiora, prope suturam subtiliter unistriata, sparsim subtilius fortiusve punctata, interstitiis laevissimis. Abdomen subtiliter griseo-pilosellum. Pedes testacei, femoribus saepius piceis.

Abdominis segmentum inferius septimum maris longitudinaliter bica rinatum, apice truncatum, feminae apice leviter productum.

Obs. Haec species statura parum instabilis insigniter variat punctura, iam crebriore fortioreque $(O$. nodifrons Sahlb.), iam parciore et subtiliore $(O$. nitens Sahlb ): quae varietates speciminibus multis intermediis obviis haud rite specie distinguendae videntur. 
* 4. P. spinosus: Niger, nitidus, elytris pedibusque piceis, tarsis flavis, fronte maris apice bispinosa, capile, thorace elytrisque crebre punctalis, thorace profundius canaliculato, latiludine vix dimidio breviore. Long. $1 \frac{3}{4}$ lin.!

Habitat in Lusitania, Com. Hoffmannsegg, Lutetiae, Dom. Dr. Aubé.

Subdepressus, niger, nitidus. Antennae capite duplo prope longiores, articulo tertio secundo paulo longiore, $4-10$ sensim paulo crassioribus, penultimis haud transversis, ultimo oblongo-ovato, nigrae. Palpi nigropicei. Caput maris thoracis latitudine, feminae eodem paulo angustius, inter oculos crebre subtiliter punctatum, interstitiis laevissimis, fronte ad antennarum basin utrinque leviter impressa, vertice linea transversali tenui, super oculos sulculis duobus canaliculaque media brevissima obsoletaque longitudinalibus exarata, maris apice spinis duabus longis incumbentibus armata. Thorax apice coleopteris haud angustior, basin versus sensim modice angustatus, lateribus vix rotundatus, apice leviter bısinuatus, angulis anterioribus acutiusculis, posterioribus obtusis, basi leviter rotundatus, supra parum convexus, fortiter canaliculatus, crebrius subtiliter punctatus, interstitiis laevissimis. Elytra thorace haud longiora, parce subtiliter punctata, interstitiis laevissimis, nitida, nonnunquam fusco-picea. Abdomen subtiliter griseopilosellum. Pedes fusco-picei, tarsis flavis.

Abdominis segmentum inferius septimum maris apice truncatum, ad apicem denticulis duobus distantibus munitum, femina apice leviter triangulariter productum.

5. P. spiculus: Niger, nilidus, elytris fuscis, pedibus testaceis, capite, thorace elytrisque impunctatis, thorace subtiliter canaliculalo, fronte maris apice bispinosa. - Long. $\frac{4}{5}$ lin.

Habitat prope Caracas in Columbia, Dom. Moritz.

Minutus, subdepressus, niger, nitidus. Antennae capite paulo longiores, articulo tertio secundo paulo breviore et duplo tenuiore, $\mathbf{1}-\mathbf{1 0}$ sensim paulo crassioribus, ultimo ovato, nigrae. Palpi rufo-picei. Caput thorace paulo maius, impunctatum, fronte posterius linea transversali tenuissima et utrinque lineis tribus longitudinalibus sat profundis exarata, clypei spatio modice impresso, margine antico spinis duabus acutis incumbentibus armato. Thorax apice coleopteris latior, latitudine plus dimidio brevior, basin versus angustior, lateribus, basi angulisque posterioribus rotundatis, apice leviter bisinuatus, angulis anterioribus acutiusculis, parum convexus, subtiliter canaliculatus, ceterum laevissimus. Elytra thorace haud longiora, laevissima, dilute fusco-picea, nitida.'Pedes testacei.

Abdominis segmentum inferius septimum maris apice subbisinuatum. E emina latet.

* 6. P. Americanus: Niger, nilidus, elylris fusco-piceis, tibiis tarsisque testuceis, capite crebre punctato, fronte maris bispinosi, thorace obsolete canaliculato elytrisque omnium subtilissime punclulatis. - Long. $1 \frac{1}{2}$ lin.

Habitat in Pensylvania et Virginia, Dom. Zimmermann.

Niger, nitidus. Antennae capite plus sesqui longiores, articulo primo maris incrassato, tertio secundo paulo breviore, 6 - 10 sensim crassioribus, 
8- 10 transversis, ultimo subovato, nigrae. Mandibulae minus elongatae, palpique picei. Caput maris thoracis magnitudine, feminae eodem paulo minus, sat crebre punctatum, lateribus (in mare magis quam in femina) longitudinaliter strigosum, linea postica transversali subarcuata fortius impressa, clypei spatio utrinque foveolato, in mare depresso et apice spinulis duabus incumbentibus, haud ultra oris partes porrectis, minus conspicuis armato. Thorax coleopterorum prope latitudine, latitudine antica duplo brevior, lateribus, basi angulisque posterioribus eorem arcu rotundatis, leviter convexus, parce subtilissime punctulatus, canalicula media obsoletissima, vix observanda. Elytra thorace vix longiora, subtilissime punctulata, obscure fusco-picea, nitida. Pedes picei, tibiis tarsisque testaceis.

Abdominis segmentum inferius septimum maris apice truncatum, femina e leviter triangulariter productum.

\section{Oxytelus Grav.}

Mannerh. Brachelytr. p. 47.

\section{Paruglossae liberae.}

Pedes intermedii basi distantes.

\section{Tibiae anticae externe subtiliter uniseriatim spinulosae.}

Corpus elongatum, lineare, depressum, alatum. Caput porrectum, basi constrictum, collo quasi brevi crassiusculo thoraci immissum, oculis ovalibus, leviter prominulis. Labrum (t. V. f. 17. c.) parvum, transversum, apice leviter sinuatum, laciniis membraneis triangularibus, acuminatis. Mandibulae breviusculae, plerumque parum prominentes, apice obtuse bidentatae, interne membrana apice barbata fimbriatae. Maxillae (t. V. f. 17. b.) malis coriaceis, interiore interne membranea, apicem versus barbata, exteriore longiore, apice dense barbata. Palpi maxillares parum elongati, malam exterıorem vix superantes, articulo primo brevi, secundo tertio paulo longiore tertioque teretibus, quarto minuto, subulato. Labium (t. V. f. 17. a.) mento transverso, ligula membranea, lata, apice leviter bisinuata, paraglossis ligulam superantibus, liberis, acuminatis, introrsum falcatis, interne dense ciliatis. Palpi labiales articulo primo cylindrico, secundo hoc paulo longiore et tenuiore, tereti, tertio breviore, acuminato. Antennae subrefractae, apicem versus leniter incrassatae. Thorax transversus, basin versus leviter angustatus, basi subrotundatus, apice truncatus. Scutellum triangulare. Elytra brevia, truncata. Abdomen lineare, marginatum. Pedes breviusculi, coxis intermediis distantibus, tibiis externe spinulis uniseriatis ciliatae, anticis prope apicem excisis, tarsis triarticulatis, articulo primo leviter elongato, tertio reliquis duobus longitudine aequalibus.

$$
\text { o b s e r v a t i n e s. }
$$

1 Thorax in omnibus fere speciebus dorso longitudinaliter trisulcatus, sulco intermedio recto, lateralibus huic approximatis leviter arcuatis. Caput, thorax et elytra saepius longitudinaliter rugulosa, glabra. Abdomen parce subtiliter pubescens.

2. Sexus differentia in abdominis apice inferiore sita apud species singulas illustranda. Mares saepius capite maiore insignes; nonnunquam caput speciminibus masculis maioribus maius, minoribus minus et femineo subaequale.

3. Victus in stercore. 
* Thorax margine laterali crenula.

* 1. O. rugosus: Niger, parum nitidus, pedibus rufo-piceis, thorace trisulcato, margine crenalo, fronte punctato-rugosa, antice impressa laevique. - Long. $2 \frac{1}{4}$ lin.

Er. Col. March. I. 588. 1.

Staph. rugosus Fabr. Syst. Ent. 267. 19. Spec. Ins. I. 338. 24. Mant. Ins. I. 222. 34. Ent. Syst. I. 1I. 530. 54. Syst. E1. II. 601. 66. - Goeze Ent. Beitr. I. 724. 10. - Panz. Ent. Germ. 358. 43. - Marsh. Ent. Britt. 506. 24.

St aph. carin at us Pans. Faun. Germ. 57. 24.

oxyt. carinatus Grav. Micr. 106. 6. Mon. 187. 5. a. - Latr. Hist. nat. Crust. et Ins. IX. 363. 6. Gen. Crust. et Ins. I. 295. I. - Oliv. Encycl. meth. VIII. 613. 5. - Gyll. Ins. Suec. II. 452. 8. - Sahlb. Ins. Fenn. I. 413. 10. - Zetterst. Faun. Lappon. 1. 92. 1. Ins. Lappon. 72. 1. - Mannerh. Brachelytr. 47. 1. - Boisd. et Lacord. Faun. Ent. Paris. I. 463 3. - Runde Brachelytr. Hal. 20. 1.

Staph. piceus Oliv. Ent. III. 42. 20. 23. t. 3. f. 30.

St aph. piceus var. $\beta$ Payk. Mon. Staph. 20. 12. Fuun. Suec. III. 385. 22.

St aph. piceus var. 1 Walk. Faun. Paris. I. 270. 9.

St aph. striutus Ström Act. Nidros. IV. 35. - Müll. Prod. 99. 1122. - Goeze Ent. Beitr. 1. 728. 34.

Staph. sulcat us Fourcr. Ent. Par. 1. 168. 16.

Le Staph. noir à corcelet noir et silloné et bordé Geoffr. Ins. 1. 367. 16.

$\boldsymbol{V a r}$. Thorace piceo, antennis elytrisque rufis.

Oxyt. pulcher Grat. Micr. 107. 7. - Latr. Hist. nat. Crust. et Ins, 1X. 364. 7. Oxyt. terrestris Boisd. et Lacord. Faun. Ent. Paris. 1. 462. 2.

Staph. laqueatus Marsh. Ent. Britt. 513. 45.

Habitat in Europa.

Niger vel nigro - picens, nitidus. Antennae capite sesqui longiores, articulo tertio secundo subaequali, 5 - 10 sensim paulo crassioribus, nigrae. Palpi nigro-picei. Mandibulae piceae. Caput maris thoracis magnitudine, orbiculatum, feminae duplo fere minus, oblongum, creberrime punctatum, fronte subdepressa, posterius utrinque longitudinaliter obsolete impressa, utrinque dense strigosa, clypei spatio laevi, opaco. Thorax coleopteris paulo angustior, latitudine plus dimidio brevior, basin versus modice angustatus, lateribus, basi angulisque posterioribus rotundatis, subdepressus, dense sat profunde rugoso-punctatus, dorso trisulcatus, sulcis exterioribus antice, intermedio postice angustatis, lateribus depressus, margine laterali subtiliter crenato. Elytra thorace parum longiora, dense profundeque punctata, longitudinaliter rugulosa. Abdomen subtilissime punctulatum. Pedes rufo-picei.

Abdominis segmentum inferius quintum maris apice medio tuberculo minuto valde prominulo, acutiusculo armatum, sextum apice medio subtridenticulato, septimum profunde sinuatum, trilobum, lobo intermedio breviore; feminae seginentum septimum apice profunde sinuatum, lobo intermedio triangulari, lateralibus panlo longiore.

Variat minus maturus colore dilutiore, nonnunquam elytris rufopiceis, saepius totus magis minusve piceo-testaceus. - Varietatem punctis et rugis multo minus confertis, corpore nitido insignem communicavit Dom. Märkel. 
- 2. O. insectatus: Niger, nitidus, elylris pedibusque rufis, thorace trisulcato, fronte parcius, antice subtilissime punclata, thoracis margine crenato. - Long. 2 lin.

Grav. Mon. 189. 5. e. - Er. Col. March. I. 589. 2.

Oxyt. carinatus var. $b$ Gyll. Ins. Suec. II. 453. 8.

Habitat in Europa.

Praecedente minor, praesertim angustior, niger, nitidus. Antennae capite thoraceque breviores, articulo secundo tertioque subaequalibus, 4-10 sensim crassioribus, penultimis vix transversis, nigrae, articulo primo nigropiceo, 2-4 rufo-piceis. Os cum palpis piceo-rufum. Caput maris thorace maius, feminae dimidio minus, sparsim profundius punctatum, fronte utrinque inter oculos subtilissime strigosa, clypei spatio haud depresso, parce subtiliter punctato, nitido, utrinque impresso. Thorax coleopteris latitudine aequalis, latitudine dimidio brevior, lateribus leviter rotundatus, basin versus leviter angustatus, basi truncatus, angulis posterioribus obtusis, subdepressus, sat fortiter denseque punctatus, subrugulosus, dorso trisulcatus, sulco intermedio postice, exterioribus antice obsolescentibus, margine laterali dense crenulato. Elytra thorace haud longiora, sat crebre profundeque punctata, rufa, circa scutellum infuscata. Abdomen obsolete punctulatum, apice rufo-piceum. Pedes rufi.

Abdominis segmentum inferius sextum maris tuberculo oblongo minimo obsoletoque medio instructum, septimo apice profunde bisinuato, lobo intermedio lateralibus parum breviore, feminae apice medio leviter triangulariter producto.

3. O. fulvipes: Niger, nilidus, antennarum basi pedibusque testaceis, thorace trisulcato, fronte parce punctata, antice laevi, thorace brevi, margine obsolele crenato. - Long. 2 lin.

\section{Fr. Col. March. I. 590. 3.}

\section{Habitat in Germania.}

O. rugoso paulo minor, niger, nitidus. Antennae capite thoraceque paulo breviores, articulo tertio secundo paulo breviore, 4-II sensim paululum crassioribus, nigrae, articulis 4 primis rufis. Os rufum. Caput maris thoracis fere magnitudine, feminae paulo minus, fronte parcius sat profunde punctata, clypei spatio laevi, nitido, utrinque impresso. Thorax coleopteris paulo angustior, latitudine duplo brevior, basin versus angustatus, lateribus anterius fortiter rotundatus, basi truncatus, angulıs posticis obtusis, subdepressus, sat profunde parce punctatus, dorso trisulcatus, sulcis integris, exterioribus subarcuatis, utrinque late impressus, impressione crebre punctata, margine laterali obsolete crenulato. Elytra thorace paulo longiora, sat profunde minus dense punctata, hinc inde longitudinaliter rugulosa. Abdomen vix punctulatum, apice piceum. Pedes rufotestacei.

Abdominis segmentum inferius septimum maris apice bisinuatum, lobo intermedio longiore, apice emarginato, feminae apice rotundatum. 
* Thorax margine laterali integerrimo.

* 4. O. piceus: Niger, nilidus, antennarum basi, elytris pedibusque testaceis, thorace trisulcalo, fronte punctata, posterius cunaliculata, antice impressa laevique. - Long. $2 \frac{1}{4}$ lin.

Grav. Micr. 105. 5. Mon. 190. 6. - Latr. Hist. nat. Crust. et Ins. IX. 363. 5. t. 80. f. 4. - Oliv. Encycl. meth. VIII. 614. 6. - Gyll. Ins. Suec. II. 454. 9. - Sahlb. Ins. Fenn. I. 414. 11. - Zetterst. Faun. Lappon. I. 93. 2. Ins. Lapp. 73. 2. - Mannerh. Brachelytr. 47. 2. - Boisd. ef Lacord. Faun. Ent. Paris. I. 461. 1. - Runde Brachelytr. Hal. 20. 2. - Er. Col. March. I. 590. 4.

Staph. piceus Linn. Syst. Nat. I. II. 686. 25. - Fab. Syst. Ent. 267. 20. Spec. Ins. I. 338. 25. Mant. Ins. I. 222. 35. Ent. Syst. I. II. 530. 55. Syst. El. II. 60I. 67. - Goeze Ent. Beitr. I. 722. 25. - De Vill. Ent. I. 418. 25. - Payl. Mon. Staph. 20. 12. Faun. Suec. III. 384. 22. - Panz. Ent. Germ. 358. 44. Faun. Germ.

27. 14. - Marsh. Ent. Britt. 500. 23. - Walk. Fuun. Paris. 1. 270. 9.

Staph. sulcatus Miill. Prodr. 97. 1094.

Staph. rugosus Schrank Faun. Boic. I. 648. 886.

Habitat in Europa; in Syria, Dom. Prof. Ehrenberg.

Statura omnino $O$. rugosi, niger, nitidus. Antennae capite thoraceque breviores, articulo tertio secundo paulo breviore, ab articulo quinto inde abrupte incrassatae, articulis 6-10 fere transversis, 4 primis testaceis, reliquis fuscis, ultimo apice testaceo. Palpi testacei. Caput maris thorace sesqui maius, suborbiculatum, feminae dimidio minus, oblongum, crebrius subtiliusque punctatum, fronte inter oculos leviter carialiculata, clypei spatio subimpresso, laevi, nitido, margine exteriore elevato. Thorax coleopteris parum angustior, latitudine in mare duplo, in femina plus dimidio brevior, basin versus subangustatus, lateribus leviter rotundatus, angulis posterioribus obtusis, subdepressus, minus fortiter inaequaliter punctatus, dorso trisulcatus, sulcis exterioribus subarcuatis, antice obsolescentibus, intermedio integro, utrinque obsolete impressus, margine laterali integerrimo. Elytra thorace sesqui longiora, dense punctata, subtiliter longitudinaliter rugulosa, testacea. Abdomen laeve. Pedes flavi.

Abdominis segmentum inferius sextus $m$ aris apice bisinuatum, lobo intermedio longiore, apice truncato, septimo bis profunde inciso, lobis Tateralibus acuminatis, intermedio paulo breviore, apice tricuspi, femin a segmento septimo apice bisinuato, lobo intermedio lato, leviter triangulariter producto.

Variat minus maturus corpore magis minusve pallide testaceo, capite saepius obscuriore.

* 5. O. sculptus: Niger, nitidus, antennarum basi pedibusque testaceis, thoracis disro elylrisque piceis, thorace trisulcato, fronte crebre punctata, canaliculala, antice impressa laevique. - Long. 2 lin.

Grav. Mon. p. 191. - Say Transact. Amer. Philosoph. Soc. Philadelph. Nov. Ser. IV. 460. 1. - Er. Col. March. I. 591. 5.

Oxyt. longicornis Mannerh. Brachelytr. 48. 3. - Suhlb. Ins. Fenn. 1. 415. 12.

Hlabitat in Europa; in Aegypto Dom. Prof. Ehrenberg, in America septentrionali, Knoch.

Praecedente parum minor, niger, nitidus. Antennae capitis thoracisque fere longitudine, articulo tertio secundo paulo longiore, sequentibus sensim paulo crassioribus, haud transversis, nigrae, articulis tribus primis testaceis, 
ultimfo apice ferrugineo. Os testaceum. Caput in utroque sexu thorace minus et angustius, oblongum, fronte parcius subtiliusque punctata, medio canaliculata, clypei spatio depresso, laevi, opaco, margine laterali elevato, rufo-testaceo. Thorax coleopteris parum angustior, latitudine dimidio brevior, lateribus anterius fortius rotundatis, angulis posterioribus obtusis, subdepressus, minus fortiter punctatus, dorso trisulcatus, sulcis exterioribus subarcuatis, intermedio integro, lateribus impressus subtiliterque longitudinaliter rugulosus, disco plerumque rufo-piceo. Elytra thorace tertı parte longiora, sat crebre punctata, subtiliter confertim longitudinaliter rugulosa, fuscopicea. Abdomen supra laeve, subtus punctulatum, apice piceum. Pedes flavo - testacei.

Abdominis segmentum inferius septimum maris bis profunde incisum, lobo intermedio lateralibus aequali, apice emarginato, femina e apice leviter bisinuato.

Variat minus maturus corpore testaceo, capite obscuriore, antennis praeter basin nigris.

6. O. Bengalensis: Teslaceus, parum nitidus, fronte nigro-picea, leviter trisulcala, thorace rufo-testaceo, dorso trisulcato. - Long. $2 \frac{1}{4}$ lin.

Habitat in Bengala, Mus. Dom. Hope.

Praecedente paulo maior. Antennae capite thoraceque parum breviores, articulo tertio secundo sesqui longiore, 6-10 leviter transversis, fuscae, articulis 5 primis testaceis. Palpi testacei. Caput thoracis prope latitudine, fronte depressa, impunctata, postice sulco transverso profundiore distincta, inter oculos longitudinaliter obsolete trisulcata, clypei spatio leviter circulariter impresso, margine anteriore elevato, antice truncato, nigricans, margine anteriore testaceo. Thorax coleopteris vix angustior, latitudine plus dimidio brevior, lateribus rotundatus, basin versus angustatus, angulis po . sterioribus obtusis, planiusculus, obsoletius longitudinaliter strigosus, dorso trisulcatus, sulcis exterioribus leviter flexuosis, intermedio obsoletiore, rufotestaceus, opacus, margine summo laterali et basali nigricante. Elytra thorace parum longiora, plana, subtiliter longitudinaliter strigosa, subtiliter interpunctata, lateribus subtiliter marginata, sutura leviter elevata, testacea, opaca, circa suturam et prope angulum apicalem exteriorem leviter infuscata. Abdomen impunctatum, rufo-testaceum, opacum. Pectus rufo-testaceum. Pedes testacei.

* 7. O. collaris: Niger, pedibus testaceis, femoribus tibiisque medio piceis, thorace obsolete trisulcato, inaequali, rufo, fronte apice elongata emarginataque. - Long. $2 \frac{1}{3}$ lin.

Habitat in Terra Van-Diemenii, Dom. Schayer.

Corpus nigrum, nitidulum, thorace rufo. Autennae capite sesqui longiores, articulo tertio secunda paula longiore, ab articulo quinto inde incrassatae, articulis $6-10$ transversis, nigrae, articulis 3 primis basi rufis. Palpi nigri. Caput thoracis prope latitudine, suborbiculatum, fronte depressa, confertim punctata, intricato-rugulosa, inter oculos obsolete longitudinaliter bi-impressa, apice leviter producto, angustato, apice emarginato. Thorax coleopteris vix angustior, latitudine duplo brevior, lateribus rotundatus, ba- 
sin versus angustatus, angulis posterioribus obtusis, dense inaequaliter punctatus, dorso obsolete trisulcatus, utrinque fortius late impressus. Elytra thorace paulo longiora, fortius inaequaliter punctata, longitudinaliter subrugulosa, impressionibus nonnullis parum profundis leviter inaequalia. Abdomen sparsim subtilius punctatum. Pedes testacei, femoribus dilutioribus tibiisque medio fuscis.

Abdominis segmentum inferius septimum maris apice bisinuatum, lobo intermedio parvo, leviter prominulo, apice emarginato, testaceo. F e m in a latet.

* 8. O. Caffer: Niger, parum nitidus, tibiis tarsisque piceis, thorace bisulcalo, fronte strigosa, antice subimpressa laevique, apice bisinuala. Long. 2 lin.

Habitat ad Promont. Bonae Spei, Dom. Prof. Lichtenstein.

Statura omnino et summa affinitas $O$. sculpturati. Corpus nigrum, minus nitidum. Antennae capite vix longiores, articulo tertio secundo prope longiore, apicem versus sensim incrassatae, articulis 6-10 fortiter transversis, totae nigrae. Mandibulae et palpi picei. Caput thoracis latitudine, suborbiculatum, fronte posterius subtiliter strigosa, utrinque obsolete longitudinaliter impressa, medio posterius leviter canaliculata, clypei spatio subdepresso, laevi, lateribus subtiliter acute marginata, apice profundius bisinuata. Thorax coleopterorum latitudine, latitudine duplo brevior, lateribus leviter rotundatus, basin versus subangustatus, angulis posterioribus fere rectis, subdepressus, dense longitudinaliter rugulosus, dorso trisulcatus, interstitiis laevioribus, sulco intermedio posterius angustato, exterioribus subrectis, utrinque late profundius impressus. Elytra thorace paulo longiora, subtiliter punctata, dense strigosa, rugulosa. Abdomen parce subtiliterque punctatum. Pedes picei, coxis femoribusque nigricantibus.

Abdominis segmentum inferius septimum maris apice late parum profunde sinuatom. Fe min a latet.

Obs. Ab O. sculpturato imprimis fronte apice bisinuata, lateribus marginata et abdomine maris haud tuberculato distinctus.

* 9. O. sculpturatus: Niger, parum nitidus, pedibus testaceis, thorace trisulcato, fronte confertim strigosa, antice impressa laevioreque, apice rotundata. - Long. 2 lin.

Grav. Mon. 187. 5. b. - Gyll. Ins. Suec. II. 456. 10. - Sahlb. Ins. Fenn. I. 416. 13. - Mannerh. Brachelytr. 48. 4. - Runde Brachelytr. Hal. 20. 3. - Er. Col. March. I. 592. 6.

Oxyt. flavipes Boisd, et Lacord. Faun. Ent. Paris. I, 464. 4.

Habitat in Europa; ad Promont. Bonae Spei, Dom. Prof. Lichtenstein.

Statura fere $O$. picei, et parum mınor, niger, parum nitidus. Antennae capite paulo Inngiores, articulo tertio secundo longitudine subaequali, apicem versus fortius incrassatae, articulis 6-10 transversis, nigrae. Palpi picei. Caput maris iam thorace paulo maius, suborbiculatum, iam ut in femina paulo minus, punctulatum, confertissime subtiliter longitudinaliter strigosum, fronte medio foveolata, clypei spatio subdepresso, utrinyue sulcato, laeviore, maris nitidiore, feminae opaco, apice rotundato, subtiliter marginato. Thorax coleopteris parum angustior, latitudine plus dimidio brevior, lateribus 
leviter rotundatus, basin versus parum angustatus, angulis posterioribus subrectis, subdepressus, punctulatus, confertim subtiliter longitudinaliter rugulosus vel strigosus, dorso trisulcatus, sulcó intermedio apicem versus attenuato, exterioribus parum arcuatis, utrinque late leviter impressus. Elytra thorace paulo longiora, confertissime subtiliter strigosa, punctulata, nigropicea, opaca. Abdomen parce subtiliter punctulatum. Pedes testacei, coxis femoribusque saepe piceis.

Abdominis segmentum inferius sextum maris apice tuberculis duobus minutis testaceis munitum, septimum late profundeque sinuatum, feminae apice medio parum triangulariter producto, utrinque leviter sinuato.

* 10. O. inustus: Niger, nilidus, mandibulis rufis, pedibus testaceis, thorace obsolete trisulcalo, capite parce subtiliterque punclato. - Long. 2 lin.

Grav. Mon. 188. 5. c. - Er. Col. March. 1. 593. 7.

Habitat in Europa.

Habitu omnino O. picei, ad dimidio minor, niger, nitidus. Antennae capite sesqui longiores, articulo secundo tertio longitudine subaequali, ab articulo quinto inde modice incrassatae, articulis $6-10$ transversis, totae nigrae. Mandibulae rufae. Palpi picei. Caput maris thorace paulo maius, feminae paulo minus, paree subtiliter punctatum, clypei spatio laevi, aeque nitido, utrinque obsolete impressum, antice rotundatum. Thorax coleopteris parum angustior, latitudine plus dimidio brevior, bacin versus subangustatus, Jateribus anterius leviter rotundatus, angulis posterioribus obtusis, subdepressus, minus fortiter punctatus, lateribus parcius longitudinaliter subtiliter strigosus, dorso trisulcatus, sulco intermedio distinctiore, basin versus attenuato, exterioribus obsoletioribus, parum arcuatis, utrinque leviter longitudinaliter impressus, margine laterali quasi elevato-plicato. Elytra thorace vix longiora, crebre punctata, longitudinaliter rugulosa, picea. Abromen parce subtiliterque punctatum, subtiliter pubescens. Pedes testacei, femoribus plerumque medio piceis.

Abdominis segmentum inferius sextum maris apice tuberculis duobus minutis concoloribus munitum, septimum late profundeque sinuatum; femiı a apice medio parum triangulariter productum, utrinque leviter sinuatum.

* 11. O. incolumis: Niger, nilidus, elytris pedibusque luteis, thorace aequali. - long. 2 lin.

Habitat in Carolina meridionali, Dom. Zimmermann.

Niger, nitidus. Antennae capite paulo longiores, articulo tertio secundo vix longiore, ab articulo quinto inde incrassatac, articulis $6-10$ transversis, ultimo oblongo, piceae, basi rufae. "Palpi rufi. Os rufo-piceum. Caput maris iam thoracis latitudine, iam ut in femina codem dimidio angustius, fronte paroius subtiliter punctata, clypei spatio late excavato, apice obsolete bisinuato. Thorax coleopteris haud angustior, latitudine duplo brevior, lateribus parum rotundatus, basin versus vix angustatus, angulis posterioribus obtusis, leviter convexus, crebrius subtiliter punctatus, aequalis. Elytra thoracis longitudine, subtilius punctata, subtiliter longitudinaliter rugulosa, dilute lutea. Abdomen parce subtiliterque punctaium, parce pube- 
scens, segmentorum singulorum margine anoque piceo-testaceis. Pedes luteo - testacei.

Abdominis segmentum inferius sextum $m$ aris apice leviter bisinuatum, septimum profunde bisinuatum, lobo intermedio longiore, apice truncato; feminae medio leviter triangulariter productum.

* 12. O. luteipennis: Niger, nitidus, antennarum basi, elytris pedibusque testaceis, thorace trisulcato, fronte punctata, bisulcata, antice impressa laevique. - Long. 2 lin.

Er. Col. March I. 593. 8.

Habitat in Germania et in montibus Uralensibus.

Habitu omnino O. picei, at paulo minor, niger, nitidus. Antennae capite sesqui longiores, articulo secundo tertioque subaequalibus, ab articulo quinto inde crassiusculae, $6-10$ transversis, apicem versus fortius incrassatae, nigrae, articulis 5 primis testaceis. Mandibulae rufo-piceae. Palpi picei. Caput maris thoracis latitudine vel individuis minoribus eodem angustius, feminae thorace dimidio angustius, suborbiculatum, crebrius pun. ctatum, fronte inter oculos bisulcata, clypei spatio impresso, laevi, aeque nitido, margine exteriore elevato, antice utrinque denticulo terminato. Thorax coleopteris parum angustior, latitudine duplo fere brevior, lateribus modice rotundatus, basin versus leviter angustatus, angulis posterioribus obtusis, subdepressus, sat crebre punctatus, dorso trisulcatus, sulcis omnibus sat profundis, integris, exterioribus leviter flexuosis, utrinque longitudinaliter leviter impressus, margine laterali integerrimo. Elytra thorace paulo longiora, sat crebre punctata, subtiliter longitudinaliter rugulosa, luteo-testacea. Abdomen laeve. Pedes flavi,

Abdominis segmentum inferius sextum maris apice tuberculis duobus minutis rotundatis piceo-testaceis instructum, septimum profunde bisinuatum, lobo intermedio in mucronem sat elongatum, apice impressum elongato; feminae segmentum septimum apice bisinuatum, lobo intermedio rotundato, laterales vix superante.

Obs O. pice o simillimus, differt autem praecipue fronte parcius punctata, inter oculos bisulcata, clypei spatio fortius impresso, apice bidenticulato, et mas abdominis segmentis inferioribus ultimis aliter formatis.

* 13. O. Pensylvanicus: Piceus, antennarum basi, pedibus elytrisque testaceis, thorace trisulcato, fronte crebre subtilius punctata, antice impressa laevique. - Long. 2 lin.

Habitat in Pensylvania, Dom. Zimmermann.

Statura omnino praecedentis. Antennae capite sesqui longiores, articulo tertio secundo breviore, ab articulo quinto inde incrassatae, articulis $6-10$ transversis, ultimo oblongo, nigrae, articulis 4 primis testaceis. Os testaceum. Caput maris thoracis latitndine, orbiculatum, feminae thorace dimidio angustius, oblongum, fronte crebrius minus fortiter punctata, passim obsolete longitudinaliter rugulosa, clypei spatio impresso, laevi, nitido, margine exteriore elevato, antico maris leviter bisinuato, feminae rotundato, nigrum, nitidum. Thorax coleopterorum prope latitudine, latitudine plus dimidio brevior, basin versus parum angustatus, lateribus leviter rotundatus, angulis 
posterioribus obtusis, subdepressus, crebrius punctatus, dorso trisulcatus, sulco intermedio integro, exterioribus leviter arcuatis, obsoletioribus, utrinque evanescentibus, lateribus late impressus, piceus, nitidus. Elytra thorace paulo longiora, longitudinaliter rugulosa, parcius subtiliusque punctata, lutea. Abdomen laeve, supra nigro-piceum, infra testaceum, segmentis singulis basi piceis. Pectus nigro-piceum. Pedes flavi.

Abdominis segmentum inferius septimum mariș medio tuberculatum, apice profunde bisinuatum, lobo intermedio laterales vix superante, apice emarginato, feminae apice leviter triangulariter productum.

* 14. O. Madagascariensis: Testaceus, elytris pedibusque luteis, capite thoraceque supra nigro-piceis, hoc trisulcato, fronte subtiliter punclata, longitudinaliter strigosa, antice laevi, maris apice producta emarginataque. - Long. 2 lin.

Habitat in Madagascar, Dom. Goudot.

Statura omnino $O$. insigniti, at maximis eius induviduis paulo maior. Antennae capite sesqui longiores, articulo tertio secundo longitudine subaequali, ab articulo quinto inde incrassatae, articulis $\mathbf{0 - 1 0}$ transversis, totae testaceae. Os testaceum. Caput maris thoracis latitudine, suborbiculatum, feminae thorace dimidio angustius, fronte int $r$ oculos punctata, densius longitudinaliter rugulosa, clypei spatio depresso, laevi, minus nitido, margine laterali elevato, antico maris leviter producto, apice emarginato, feminae truncato, infra piceo-testaceum, supra piceo-nigricans, nitidulum. Thorax coleopteris parum angustior, latitudine plus dimidio brevior, basin versus modice angustatus, lateribus leviter rotundatis, angulis posterioribus obtusis, subdepressus, minus dense subtilius punctatus, lateribus late confertim fortius longitudinaliter ruguiosus, dorso trisulcatus, sulco intermedio integro, exterioribus subarcuatis, subintegris, lateribus late per totam fere longitudinem impressus, supra nigro-piceus, nitidulus, infra testaceus. Elytra thorace paulo longiora, densius punctata, dense longitudinaliter rugulosa, lutea. Abdomen laeve, testaceum. Pectus piceo-testaceum. Pedes lutei.

Abdominis segmentum inferius septimum $\mathrm{m}$ aris apice late emarginatum, feminae leviter productum.

* 15. O. insignitus: Niger, nitidus, pedibus flavis, ore, antennarum basi elytrisque testaceis, thorace piceo-rufo, trisulcalo, capite laevi, fronte posterius lateribus strigosa, antice utrinque foveolata, maris apice acuminata. - Long. $1 \frac{1}{3}-1 \frac{2}{3}$ lin.

Grav. Mon. 188. 5. $d$.

Oxyt. Americanus Mannerh. Brachelytr. 48. 5.

Habitat in America: in America septentrionali, Knoch, Com. Dejean, Dom. Zimmermann, in ins. St. Thomae, in Columbia, Dom. Moritz, in Brasilia, Dom. Thorey.

Praecedentibus minor. Antennae capite paulo longiores, articulo tertio secundo paulo longiore, ab articulo quinto inde incrassatae, articulis penultimis tribus fortius transversis, fuscae, articulo primo testaceo. Palpi testacei. Mandibulae rufo-piceae, maris elongatae, aculae, decussatae. Caput maris plerumque thoracis latitudine, feminae angustius, nigrum, nitidum, 
impunctatum, fronte utrinque leviter impressa, lateribus dense longitudinaliter strigosa, elypei spatio haud distincto, utrinque foveola profundiore impresso, margine antico in mare bisinuato, medio producto; acuminato, in femina truncato. Thorax coleopteris parum angustior, latitudine duplo fere brevior, basin versus in mare fortius quam in femina angustatus, lateribus, angulis posterioribus basique rotundatis, apice late leviter eniarginatus, subdepressus, rufo-piceus, subnitidus, crebre punctatus, dorso trisulcatus, sulcis sat profundis, integris, utrinque fortius longitudinaliter impressus. Scutellum piceum. Elytra thorace paulo longiora, crebre punctata, obsolete longitudinaliter rugulosa, dilute testacea, parum nitida. Abdomen laeve, nigrum, parum nitidum, ano piceo - testaceo. Pectus nigrum. Pedes flavi.

Abdominis segmentum inferius septimum maris apice late et parum profunde sinuatum, feminae rotundatum.

$\mathrm{Obs}$. Mas mandibulis elongatis capitisque margine antico medio acuminato prae reliquis huius generis speciebus insignis.

* 16. O. politus: Niger, nitidus, pedibus testaceis, elytris fuscis, thorace trisulcato, sulcis lateralibus obsoletis, capiteque parce subtilissime punctatis. - Long. $1 \frac{1}{4}$ lin.

Habitat in Austria,?Dom. Schüppel.

Statura omnino 0 . nitiduli, at paulo minus depressus, niger, pernitidus. Antennae articulis tribus nigro-piceis, tertio secundo longitudine subaequali (reliqui desunt). Palpi testacei. Caput thorace paulo angustius, parce subtilissime punctatum, interstitiis politis, anterius utrinque profundius longitudinaliter impressum, fronte antice et lateribus subtilissime marginata. Thorax coleopteris paulo angustior, latitudine plus sesqui brevior, basin versus leviter angustatus, lateribus modice, basi levissime rotundatis, angnlis posterioribus obtusis, apice utrinque subsinuatus, angulis anterioribus acutiusculis, subdepressus, parce subtiliterque punctatus, interstitiis medio laevissimis, versus latera subtilissime longitudinaliter strigosus, dorso trisulcatus, sulco intermedio profundiore, integro, exterioribus obsoletioribus, leviter arcuatis, utrinque profundius longitudinaliter impressus. Elytra thorace plus sesqui longiora, parcius subtiliter punctata, parce subtiliterque longitudinallter strigosa, fusco-picea, nitida. Abdomen laevissimum. Pedes testacei.

Abdominis segmentum inferius septimum feminae apice medio triangulariter productum. Mas latet.

* 17. O. intricat us: Niger, supra parum nilidus, elytrorum disco pedibusque piceo-testaceis, capite thoraceque confertissime punclato-rugosis, hoc trisulcato, fronte antice subdepressa laevioreque. - Long. $1 \frac{1}{3}$ lin.

Habitat in Austria, Dom. Schïppel, Smyrnae, Dr. Helfer.

Statura fere $\mathbf{O}$. nitiduli, niger, subtus nitidus, supra subopacus. Antennae capite paulo longiores, articulo secundo tertio tenuiore, at vix breviore, apicem versus sensim leviter incrassatae, articulis $7-\mathbf{1 0}$ transversis, nigrae. Mandibulae et palpi picei. Caput maris thoracis magnitudine, feminae paulo minus, confertissime rugoso-punctatım, fronte medio obsolete canaliculata, clypei spatio impresso, utrinque sulcato, laevi, subnitido. Thorax coleopterorum prope latitudine, latitudine duplo prope brevior, basin versus suban- 
gustatus, lateribus et basi leviter rotundatus, antice late leviter emarginatus, angulis anterioribus acutis, posterioribus obtusis, subrotundatis, subdepressus, confertim rugoso-punctatus, dorso trisulcatus, sulcis ommibus obsoletioribus, utrinque late leviter impressus. Elytra thorace paulo longiora, depressa, confertim punctata, dense longitudinaliter rugulosa, fusca, disco fusco-testacea. Abdomen supra densius subtiliter punctatum. Pedes piceo-testacei.

Abdominis segmentum inferius septimum maris late emarginatum, femin a e apice medio leviter productum.

Obs. O. nitidulo magnitudine aequalis, at paulo latior, punctura multo crebriore, thoracis sulcis ommbus obsoletis, corpore supra fere opaco distinctus.

* 18. O. nitidulus: Niger, nitidulus, elylris piceis, pedibus testaceis, capite thoraceque crebrius punctatis, subtiliter rugulosis, hoc trisulcato, fronte antice subimpressa, laevi. - Long. 1 - $1 \frac{1}{3}$ lin.

Grav. Micr. 107. 8. Mon. 186 4. - Latr. Hist. nat. Crust. et Ins. IX. 364. 8. Oliv. Encycl. meth. VIII. 613. 4. - Panz. Faun. Germ. 104. 13. - Gyll. Ins. Suec. II. 458. 12. - Sahlb. Ins. Fenn. 1. 416. 15. - Zetterst. Faun. Lappon. I. 93. 3. Ins. Lappon. 73. 3. - Mannerh. Brachelytr. 48. 7. - Boisd. et Lacord. Faun. Ent. Paris. I. 464. 5. - Runde Brachelytr. Hal. 20. 5. - Er. Col. March. 1. 594.9.

Staph. piceus Schrank Enum. Ins. Austr. 236. 449. Faún. Boic. I. 617. 885.

Staph. piceus, var. pygmaea Payk. Faun. Suec. III. p. 384.

Oxyt. rugulosus Say Transact. Amer. Philosoph. Soc. Philudelph. Nov. Ser. IV. 460. 2. - Harris Transact. Nat. Hist. Soc. Hartfort I. 69. 6.

Habitat in Europa frequens, in Aegypto, Dom. Prof. Ehrenberg, in America septentrionali, Dom. Zimmermann, in Mexico sec. Say.

Minutus, niger, nitidulus. Antennae capite sesqui longiores, articulo tertio secundo paulo minore, apicem versus sensim subincrassatae, articulis ultimis tribus maioribus, nigrae. Mandibulae et palpi picei. Caput maris thoracis magnitudine, feminae eodem paulo minus, minus confertim punctatum, longitudinaliter strigosum, fronte inter oculos transversim impressa, clypei spatio impresso, laevi, in utroque latere profundius longitudinaliter impresso vel late sulcato. Thorax coleopterorum prope latitudine, latitudine plus dimidio brevior, basin versus leviter angustatus, lateribus et basi leviter rotundatis, angulis posterioribus obtusis, subdepressus, sat crebre fortiterque punctatus, longitudinaliter subrugulosus, dorso trisulcatus, sulco intermedio sat profundo, integro, exterioribus obsoletioribus, subarcuatis, utrinque late impressus, margine laterali integerrimo. Elytra thorace sesqui longiora, creberrime punctata, longitudinaliter substrigosa, fusco-picea. Abdomen supra parce subtilissime punctatum. Pedes testacei.

Abdominis segmentum sextum inferius $\mathrm{m}$ ar is apice leviter emarginatum.

Obs. Oxyt. pedicellus Grav. Micr. 102. 2. Mon. 185. 2. - Latr. Hist. nat. Crust. et Ins. IX. 362. 2. - Oliv. Encycl. meth. VIII. 613. 2, mihi omnino dubius, forte ab hac specie haud distinctus, at typo perdito nunquam extricandus.

* 19. O. complanatus: Niger, opacus, pedibus testaceis, elytris fuscis, his, capite thoraceque subtilissime longiludinaliter strigosis, thorace trisulcato, angulis anterioribus acutiusculis. - Long. $1 \frac{2}{3}$ lin.

Ev. Col March. I. 595. 10. 
Oryt. depressus Gyll. Ins. Suec. HI. 457. 11. - Suhlb. Ins. Fenn. I. 416. 14. Mannerh. Brachelytr. 48. 5. - Runde Brachelytr. Hal. 20. 4.

\section{Habitat in Europa.}

O. piceo duplo fere minor, breviusculus, depressus, niger, subnitidus, capite, thorace elytrisque opacis. Antennae capite paulo longiores, articulo tertio secundo subaequali, apicem versus sensim leniter incrassatae, articulis 6 - 10 transversis, nigrae. Mandibulae rufo-piceae. Palpi picei. Caput maris thoracis magnitudine, feminae eodem paulo minus, totum subtilissime confertissimeque longitudinaliter strigosum, fronte lateribus subtiliter marginata, posterius subtiliter interpunctata, utrinque longitudinaliter obsolete impressa, clypei spatio parum impresso, margine anteriore rotundato, parum elevato. Thorax coleopteris parum angustior, latitudine duplo prope brevior, basin versus leviter angustatus, lateribus ante medium rotundatis, apice late leviter emarginatus, angulis anterioribus acutis, basi leviter rotundatus, angulis posterioribus obtusis, - subdepressus, subtilissime confertissime longitudinaliter strigosus, parce subtiliterque interpunctatus, dorso trisulcatus, sulco intermedio basin versus angustiore, exterioribus subarcuatis, obsoletioribus, utrinque leviter impressus. Elytra thorace paulo longiora, depressa, confertissime subtilissimeque longitudinaliter strigosa, obsoletius subtiliter interpunctata, nigra vel plerumque fusco-nigra, nonnunquam dilutius fusca. Abdomen supra sat dense subtiliter punctatum. Pedes testacei, femoribus interdum medio picescentibus.

Abdominis segmentum inferius sextum $m$ aris apice tuberculis duobus approximatis munitum, septimum late emarginatum, feminae apice medio triangulariter productum.

* 20. O. depressus: Niger, opacus, pedibus testaceis, capite, thorace elytrisque omnium subtilissime conferlissimeque longiludinaliter strigosis, thorace trisulcato, angulis anterioribus subrotundatis, abdomine confertim punclato. - Long. $\frac{3}{4}-1$ lin.

Grav. Micr. 103. 3. Mon. 185. 3. - Latr. Hist. nat. Crust. et Ins. IX. 362. 3. Oliv. Encycl. meth. VIII. 613. 3. - Panz. Faun. Germ. 104. 11. - Boisd. et Lacord. Faun. Ent. Paris. I. 465. 6. - Er. Col. March. I. 595. 11.

Oxyt. pusillus Mannerh. Brachelytr. 48. 8. - Sahlb. Ins. Fenn. I. 417. 16. Runde Brachelytr. Hal. 20. 6.

Staph. tetracarinatus Block Ins, vall. Plauens. 116. 5. $f$. 5 .

Var. Elytris fuscis.

Habitat in Europa.

Minutus, depressus, niger, subnitidus, capite, thorace elytrisque opacis. Antennae capite paulo longiores, articulo tertio secundo paulo tenuiore at vix breviore, apicem versus sensim crassiores, totae nigrae. Mandibulae et palpi picei. Caput maris thoracis magnitudine, feminae eodem paulo minus, confertissime subtilissime longitudinaliter strigosum, fronte utrinque longitudinaliter obsolete impressa, clypei spatio vix depresso, margine anteriore rotundato, leviter elevato. Thorax coleopteris paulo angustior, latitudine dımidio fere brevior, basin versus modice angustatus, lateribus parum rotundatus, apice truncatus, angulis anterioribus subrotundatis, basi leviter rotundatus, angulis posterioribus obtusis, subdepressus, confertissime subtilissimeque longitudinaliter strigosus, dorso trisulcatus, sulcis exterioribus 
obsoletioribus, utrinque leviter impressus. Elytra thorace paulo longiora, depressa, confertissime subtilissimeque longitudinaliter strigosa, parce subtiliter obsoleteque interpunctata, nigra, interdum fusca. Abdomen sat dense subtiliter punctatum. Pedes testacei.

Abdominis segmentum inferius septimum $\mathrm{m}$ aris apice late emarginatum, feminae medio leviter triangulariter productum.

* 21. O. pumilus: Niger, opacus, pedibus piceis, geniculis tarsisque testaceis, capite, thorace elytrisque subtilissime confertissimeque longiludi. naliter strigosis, thorace trisulcalo, angulis anlerioribus subrotundatis, abdomine crebrius subtiliter punclalo. - Long. 1 - $1 \frac{1}{3}$ lin.

Er. Col. March. I. 596. 12.

\section{Habitat Berolini, Dom. Schïppel.}

Statura et summa affinitate $\mathbf{O}$. depressi, at nonnunquam paulo maior, niger, nitidulus, capite, thorace elytrisque opacis. Antennae capite paulo longiores, articulo tertio secundo paululum minore, apicem versus leviter incrassatae, articulis $6-10$ transversis, ultimis tribus abrupte paulo maioribus. Os piceum. Caput in utroque sexu thorace paulo minus et angustius, subtilissime confertissime longitudinaliter strigosum, fronte depressiuscula, posterius medio foveola minuta oblonga impressa, clypei spatio subimpresso, antice rotundata et subtiliter marginata. Thorax coleopteris paulo angustior, latitudine plus dimidio brevior, lateribus modice, basi leviter rotundatus, basin versus vix angustatus, angulis posterioribus obtusis, apice truncatus, angulis anterioribus subrotundatis, subdepressus, subtilissime confertıssimeque longitudinaliter strigosus, dorso trisulcatus, sulco intermedio profundiore, exterioribus latis, obsolescentibus, subarcuatis, utrinque late leviterque impressus. Elytra thorace sesqui longiora, depressa, subtiliter confertissime longitudinaliter strigosa, subtiliter parce obsoletius interpun ctata. Abdomen crebrius punctulatum, nitidum. Pedes nigro-picei, geniculis tarsisque testaceis.

Abdominis segmentum inferius sextum $\mathrm{mar}$ is late emarginatum, medio spinulis tribus, oblique retrorsum vergentibus, distantibus, anteriore paulo minore, septimum apice medio spinis duabus approximatis, pariter retrorsum directis armatum; feminae segmentum septimum inferius apice medio triangulariter productum.

Obs. Mas abdomine apice infra 5 -spinoso sat insignis. Femina ab O. depress o praesertim pedibus obscurioribus, thorace paulo latiore, sulcis lateralibus obsoletioribus differt.

* 22. O. nanus: Niger, opacus, elytris fuscis, pedibus testaceis, femoribus picescentibus, capite thorace elytrisque omnium subtilissime confertissimeque longitudinaliter strigosis, thorace trisulcato, abdomine parce subtilissime punctato, nitido. - Long. $\frac{3}{4}$ lin.

Habitat in America septentrionali, Dom. Zimmermann.

Minutus, O. depresso aequalis et proximus, niger, nitidus, capite, thorace elytrisque opacis. Antennae capite paulo longiores, articulo tertio secundo multo minore, apicem versus incrassatae, articulis 6-10 transversis, ultimis tribus abrupte maioribus, nigrae. Os nıgro-piceum. Caput 
in utroque sexu thorace paulo angustius et minus, omnium confertissime subtilissimeque longitudinaliter strigosum, fronte utrinque leviter longitudinaliter impressa, posterius medio saepius obsolete sulcata, clypei spatio vix depresso, apice immarginata. Thorax coleopteris paulo angustior, latitudine dimidio brevior, lateribus et basi leviter rotundatus, basin versus vix angustatus, angulis posterioribus obtusis, apice truncatus, angulis anterioribus obtusiusculis, subdepressus, omnium subtilissime confertissimeque longitudinalıter strigosus, dorso distincte trisulcatus, sulcis integris, intermedio prafundiore, exterioribus leviter arcuatis, utrinque late levissime impressus. Elytra thorace paulo longiora, depressa, confertissime subtilissimeque longitudinaliter strigosa, parce subtiliter obsoleteque interpunctata. Abdomen parce subtilissime punctatum. Pedes testacei, coxis femoribusque saepius nigro - piceis.

Abdominis segmentnm inferius septimum maris apice late parum pro. funde sinuatum, feminae medio leviter triangulariter productum.

Obs. Ab O. depresso imprimis abdomine parce subtilissimeque punctato,-ab o. exiguo thorace fortius bisulcato, antennis totis nigris, mandibulis palpisque piceis distinctus.

*23. O. exiguus: Niger, opacus, ore, antennarum basi pedibusque testaceis, elytris fuscis, capite thoraceque subtilissime longitudinaliter strigosis, thorace dorso obsolete trisulcalo. - Long. $\frac{3}{4}$ lin.

Habitat in America septentrionali, Dom. Zimmermann.

O. depresso proximus et minimis eius individuis aeqralis, niger, nitidus, capite, thorace elytrisque opacis. Antennae capite paulo longiores, articulo tertio secundo minore, apicem versus sensim incrassatae, articulis 6 - 10 transversis, ultimis tribus multo maioribus, nigrae, basi testaceae. Os testaceum. Caput thorace paulo angustius, subtilissime confertissimeque longitudinaliter strigosum, fronte anterius utrinque longitudinaliter impressa et inter antennas obsolete transversim sulcata, margine anteriore rotundato, haud elevato. Thorax coleopteris parum angustior, latitudine dimidio brevior, basin versus modice angustatus, lateribus ante medium fortius, basi leviter rotundatus, angulis posterioribus obtusis, apice truncatus, angulis anterioribus subrotundatis, depressus, confertissime subtilissimeque longitudinaliter strigosus, dorso ohsolete trisulcatus, sulcis exterioribus subarcuatis, lateribus utrinque leviter impressus. Elytra thorace paulo longiora, depressa, confertissime subtilissimeque longitudinaliter strigosa; parce subtiliter obsoleteque interpunctata, fusca. Abdomen parce subtiliterque punctatum, subtilissime pubescens. Pedes flavo-testacei.

Abdominis segmentum inferius septimum maris apice bisinuatum, feminae late triangulariter productum.

*24. O. minimus: Niger, opacus, ore, antennarum basi pedibusque teslaceis, capite, thorace elytrisque confertissime sublilissimeque strigosis, thorace dorso fortius trisulcato. - Long. $\frac{3}{6}$ lin.

Habitat in Columbia, Dom. Moritz.

O. depresso simillimus et minimis eius individuis fere minor, depressus, niger, subnitidus, capite, thorace elytrisque opacis. Antennae capite 
sesqui longiores, articulo tertio secundo minore, apicem versus sensim incrassatae, nigrae, basi testaceae. Os testaceum. Caput maris thorace paulo maius, feminae eiusdem magnitudine, confertissime omniumque subtilissime longitudinaliter strigosum, utrinque longitudinaliter impressum, medio inter oculos canalicula hrevi impressum, margine anteriore rotundato, haud elevato. Thorax coleopteris paulo angustior, latitudine plus dimidio brevior, basin versus subangustatus, lateribus et basi leviter rotundatus, angulis posterioribus obtusis, apice truncatus, angulis anterioribus subrectis, subdepressus, confertissime omniumque subtilissime longitudinaliter strigosus, dorso profundius trisulcatus, sulcis exteriorihus arcuatis, utrinque sat profunde impressus. Elytra thorace paulo longiora, depressa, sparsim subtiliter punctata, confertissime subtilissimeque longitudinaliter strigosa. Abdomen supra parce subtiliter obsoleteque punctulatum. Pedes testacei.

Abdominis segmentum inferius septimum $m$ aris apice late emarginatum, femina medio leviter triangulariter productum.

\title{
Phloeonaeus $E$ r.
}

\author{
Er. Col. March. I. p. 597. \\ Aploderus Steph. Illustr. Ent. Britt. V. p. 321.
}

\section{Paraglossae ligulae connatae. \\ Pedes intermedii basi approximati. \\ Tibiae anticae externe subtiliter uniseriatim spinulosae.}

Corpus elongatum, lineare, depressum, alatum. Caput porrectum, basi modice constrictum, collo quasi brevi crasso thoraci immissum, oculis rotundatis, parum prominulis. Labrum minutum, transversum, apice truncatum, laciniis membranaceis triangularibus, acuminatis. Mandibulae leviter prominentes, falcatae, interne ante apicem subtiliter bidentatae, basi.membrana apice ciliata fimbriatae. Maxillae (t. V. f. 18. b.) malis membranaceis, interiore interne membranea, apice ciliata, exteriore paulo longiore, apice dense barbata. Palpi maxillares mala exteriore paulo longiores, articulo primo brevi, minuto, secundo apicem versus leviter incrassato, tertio huic longitudine subaequali, crassiusculo, quarto minuto, subulato. Labium (t. V. f. 18. a.) mento transverso, ligula membranea, lata, apice leviter bisinuata, lobis lateralibus productis, acutis, paraglossis linearibus, falcatis, acuminatis, liberis, ligulam superantibus, nfembranaceis, pubescentibus. Palpi labiales articulis tribus longitudine subaequalibus, tertio paululum tenuiore. Antennae subrefractae, longiores, apicem versus vix incrassatae. Thorax transversus, basin versus fortiter angustatus, basi apiceque truncatus. Scutellum breve, subrotundatum. Elytra truncata. Abdomen lineare, marginanatum. Pedes breviusculi, coxis intermediis approximatis, tibiis posterioribus externe ciliatis, anticis externe aut setulis ciliatis, ante apicem emarginatis ( $\mathrm{Ph}$. caelatus), aut pilis subtilibus ciliatis, apice subangustatis ( $\mathrm{Ph}$. caesus), tarsis brevibus, triarticulatis.

\section{O b s e r va tio n e s.}

1. Habitus omnino generis praecedentis, at thorax sulco medio nullo, ligula uni-sinuata, paraglossae ei connatae, antemnae magis elongatae, vix refractae, coxae intermediae haud distantes. 
2. Nomen a Dom. Stephensio propositum reieci, cum perperam compositum, et insuper ineptum sit: thorax nullo modo simplex.

3. Sexus differentia ut in genere praecedente.

4. Victus sub arborum cortice.

* 1. Ph. caelatus: Niger, pedibus teslaceis, elytris fuscis, thorace biimpresso, libiis anticis apice emarginatis. - Long. '2 lin.

Er. Col. March. 1. 597. 1.

Ox yt. caelatus Grav. Micr. 103. 4. Mon. 190. 7. - Latr. Hist, nat. Crust. et Ins. IX. 363. 4. - Oliv. Encycl. meth. VIII. 614. 7. - Panz. Faun. Germ. 104. 12. - Gyll. Ins. Suec. II. 459. 13. - Sahlb. Ins. Fenn. I. 417. 17. - Zetterst. Faun. Lappon. I. 93. 4. Ins. Lappon. 73. 4. - Mannerh. Brachelytr. 49. 9. - Boisd. et Lacord. Faun. Ent. Paris, I. 465. 7. - Runde Brachelytr. Hal. 21. 8.

Staph. brachypterus Marsh. Ent. Britt. 510. 35.

Staph. spinipes Block Ins, vall. Plauens. 116. 6. $f .6$.

Habitat in Europa.

Niger, subnitidus, pubescens. Antennae in utroque sexu vix capitis thoracisque longitudine, nigrae, basi piceae. Oris partes rufo-piceae. Caput maris thoracis magnitudine vel paulo maius, orbiculatum, feminae thorace paulo minus, oblongum, parcius obsolete punctatum, fronte posterius foveola minuta oblonga obsoletiore notata, anterius utrinque ad antennarum basin fortius longitudinaliter impressa. Thorax coleopteris angustior, latitudine plus dimidio brevior, antice emarginatus, angulis anterioribus acutis, lateribus rotundatus, basin versus angustatus, angulis posterioribus cum basi rotundatis, leviter convexus, parcius obsoletius punctatus, dorso foveolis duabus arcuatis impressus. Elytra thorace paulo longiora, dense fortius profunde punctata, fucca. Abdomen subtilissime coriaceum, parce subtiliterque punctulatum, apice piceum. Pedes testacei, tibiis anticis margine exteriore spinulis subtilibus ciliato, apice emarginato.

Abrominis segmentum sextum inferius maris apice leviter bisinuatum, septimum profunde emarginatum, feminae apice medio leviter triangulariter productum.

* 2. Ph. caesus: Niger, pedibus rufo-testaceis, elytris fuscis, thorace biimpresso, tibiis anticis integris. - Long. 2 lin.

Er. Col. March. I. 598. 2.

Habitat in Germania.

Statura et summa similitudo praecedentis. Niger, subnitidus, pubescens. Antennae feminae capitis thoracisque longitudine, maris paulo longiores, nigrae. Oris partes rufo-piceae. Caput maris thoracis latitudine, suborbiculatum, feminae paulo angustius, oblongum, crebre profundeque punctatum, fronte posterius profunde canaliculata, anterius utrinque ad antennarum basin impressa. Thorax coleopteris panlo angnstior, latitudine plus dimidio brevior, apice truncatus, lateribus basin versus angustatus, subrotundatus, basi subrotundatus, angulis anterioribus subrectis, posterioribus obtusis, leviter convexus, crebre profunde punctatus, dorso foveolis duabus arcuatis impressus, interstitio subelevato, laevi. Elytra thorace paulo longiora, dense fortiter profundeque punctata, fusca, nitidula. Abdomen subtilissime coria- 
ceum, parce obsnleteque punctatum, apice fusco-piceum. Pedes rufotestacei, tibiis anticis angustis, integris, spinulis subtilibus ciliatis.

Abdominis segmentum inferius sextum $m$ aris integrum, septimum leviter emarginatum, femin a apice medio leviter triangulariter productum.

\title{
Trogophloeus Mannerh.
}

\author{
Er. Col. March. 1. p. 599.
}

Trogophloeus Mannerh. Brachelytr. p. 49. Steph. Illustr. V. p. 322. - Taenosoma Mannerh. Brachelytr. p. 50. Steph. Illustr. V. p.323.-Carpa7imus Steph. ibid. p. 324 .

\section{Paraglossae ligulae connalae. \\ Pedes inlermedii basi approximali. \\ Tibiae omnes mulicae. \\ Tarsi breves.}

Corpus vel oblongum, vel plerumque elongatum, lineare, aliis subdepressum, aliis magis subcylindricum, alatum. Caput porrectum, basi plerumque leviter constrictum, oculis semiglobosis, modice prominulis. Labrum transversum, medio leviter sinuatum, laciniis membraneis parvis, triangularibus, spatio interiecto setulis rigidis dense ciliato. Mandibulae haud prominentes, apice bicuspes, interne medio bidentatae, basi membrana fimbriatae. Maxillae (t. V. f. 19. b.) mala interiore margine exteriore coriaceo, interiore membraneo, apicem versus barbato, mala exteriore paulo longiore, cortacea, apice membranea, dense barbata. Palpi maxillares parum elongati, articulo primo minuto, secundo subobconico, tertio hoc longiore crassioreque, ovato, quarto minuto, subulato. Labium (t. V. f. 19. a.) mento transverso, apice late emarginato, ligula membranea, lata, apice medio leviter sinuata, paraglossis ligulae omnino connatis eamque haud excedentibus, nomnisi spinularum serie suturae loco distingaendae. Palpi labiales ligula parum longiores, articulo primo secundo paulo breviore, tertio praecedentibus tenuiore et paulo breviore. Antennae articulo primo parum elongato, secundo tertioque plerumque reliquis paulo longioribus, ultimis tribus saepius paulo maioribus, quinto et septimo etiam nonnunquam contiguis paulo crassioribus, ultimo ovato. Thorax plerumque subcordatus. Elytra truncata. Abdomen plerumque lineare, marginatum. Pedes breviusculi, tenuiusculi, coxis intermediis approximatis, tibiis omnibus muticis, pubescentibus, tarsis brevibus, triarticulatis, articulis duobus primis brevissimis.

O b s e r v a $\mathrm{i}$ o n e s.

1. Corpus pube subtili sericea obductum. Punctura saepius subtilissima. Thorax saepius dorso longitudinaliter bi-impressus. Tarsis brevibus, tibia dimidia brevioribus hoc genus insigne videtur.

2. Tibiis inermibus optime Com. Mannerheim a praecedentibus hoc genus distinxit. Ta e nos oma (T. pusillus) ill. auctor inter $\mathrm{O}$ malides collocavit, tarsorum articulorum numero haud respecto, praeterea antennarum articulis tribus ultimis paulo maioribus distinctum. Temere a Dom. Stephens eiusdem insecti tarsi 5-articulati descripti sunt. Carpalimum (T. bilineatus - nomen a Leachio olim toto huic generi impositum) Dom. Stephens a Trogophloeo antennarum articulis ultimis 3 maioribus, a Taenosomate tarsis 3 -articulatis distinguit. Antennarum articuli 3 ultimi in aliis speciebus minus, in aliis magis a praecedentibus magnitudine discedunt, quod in Bledio etiam pari modo se habet.

3. Sexus differentia latet. ulignosis.

4. Victus aliis sub aroorum cortice, aliis in floribus, aliis in pratis et silvis 


\section{* Sc te t l l a ti.}

1. T. dilatatus: Niger, cinereo-pubescens, thorace subcordato, foveola arcuata impresso, coleopteris thorace duplo latioribus. - Long. $1 \frac{1}{2}$ lin.

Er. Col. March. I. 599. 1.

Habitat in Germania, Gallia; in Mesopotamia etiam a Dr. Helfer lectus.

Corpus latiusculum, subdepressum, nigrum, nitidulum, cinereo-pubescens. Antennae capitis thoracisque fere longitudine, graciles, apice sensim leniter incrassatae, nigro-piceae. Mandibulae rufae. Palpi nigri. Caput thorace paulo angustius, ad antennarum basin utrinque leviter impressum, subtiliter cinereo-pubescens. Thorax coleopteris duplo fere angustior, latitudine summa dimidio brevior, lateribus anterius valde rotundatis, postice coarctatus, basi coleopteris triplo angustior, basi apiceque truncatus, angulis anterioribus rotundatis, posterioribus obtusis, subdepressus, sulco arcuato, ferri equini figuram aequante, thoracis discum basi et lateribus ambiente, basi fortius impresso notatus, subtiliter cinereo-pubescens. Coleoptera apicem versus sensim leviter latiora, thorace plus sesqui longiora, subdepressa, confertim subtilissime punctata, densius cinereo-pubescentia. Abdomen sat latum, apice angustatum, confertim subtilissime punctulatum, cinereo-pubescens. Pedes nigri, tibiis fuscis, tarsis fusco-testaceis.

* 2. T. segnis: Niger, nitidulus, griseo-pubescens, pedibus mufo-piceis, thorace subcordato, postice foveola lunala impresso, coleopteris thorace plus sesqui latioribus. - Long. $1 \frac{1}{2}$ lin.

Habitat in Madagascar, Dom. Goudot.

Statura et summa afinitas praecedentis. Corpus nigrum, nitidulum, pube brevi subtili grisea densius vestitum. Antennae capitis thoracisque longitudine, tenuiores, apicem versus sensim levissime incrassatae, nigrae, articulo primo piceo. Palpi picei. Caput thorace angustius, dense subtilissime punctatum, fronte anterius utrinque longitudinaliter impressa. Thorax coleopteris plus dimidio angustior, latitudine brevior, lateribus anterius fortiter rotundatis, basin versus angustatus, basi coleopterornm basi duplo angustior, basi apiceque truncatus, angulis posterioribus obtusis, anterioribus rotundatis, parum convexus, dense subtiliter punctatus, basi impressione transversali lunata fortius notatus. Coleoptera thorace plus sesqui longiora, apicem versus sensim paululum Jatiora, confertissime subtiliter punctata. Abdomen crebre minus subtiliter punctatum, longius et minus subtiliter pubescens. Pedes rufo-picei.

Obs. Distinctus a praecedente punctura minus subtili, thorace latiore, postice minus constricto, sulco impresso lateribus haud adscendente etc.

* 3. T. Omalinus: Linearis, subdepressus, niger, pedibus testaceis, elytris fuscis, thorace plus duplo longioribus, thorace obsolete carinato, basi ulrinque oblique impresso. - Long. $1 \frac{1}{2}$ lin.

Habitat in Saxonia, Dom. Märkel, in Anglia, Dom. Rudd.

Habitu fere et statura Omalii deplanati, linearis, subdepressus, niger, nitidus, pube brevi depressa minus subtili grisea sericante densius vestitus. Antennae capitis thoracisque prope longitudine, apicem versus sensim leviter incrassatae, nigrae vel nigro-piceae, basi rufo-piceae. Mandibulae et palpi 
rufo-picei. Caput thorace parum angustius, supra utrinque parcius subtiliter punctatum, ad antennarum basin utrinque sulculo profundo impressum. Thorax coleopteris dimidio angustior, latitudine paulo brevior, lateribus leviter rotundatus, basin versus leviter angustatus, basi apiceque truncatus, angulis posterioribus obtusis, anterioribus rotundatis, parum convexus, parce subtilissime punctatus, dorso sulcis duobus longitudinalibus obsoletis appro. ximatis, interstitio subcarinato, postice utrinque oblique impressus. Elytra thorace triplo fere longiora, depressa, dense minus subtiliter punctata, fusca. Abdomen pectore vix longius, parce subtilissime punctulatum. Pedes testacei.

* 4. T. angustatus: Linearis, subdepressus, fuscus, antennis, pedibus elytrisque testaceis, his thorace plus sesqui longioribus, thorace longitudinaliler bi-impresso. - Long. $1 \frac{1}{2}$ lin.

Habitat in Bavaria superiore, Dom. Dr. Waltl.

Elongatus, linearis, subdepressus, pube brevi, minus subtili, flavescentigrisea vestitus. Antennae capite thoraceque paulo longiores, fortiusculae, apicem versus sensim paululum crassiores, testaceae. Os testacenm. Caput thoracis latitudine, utrinque parce subtilissime punctulatum, inter antennas ntrinque longitudinaliter impressum, nigrum, nitidulum. Thorax coleopteris dimidio angustior, latitudine haud brevior, basin versus sensim leviter angustatus, lateribus parum rotundatus, basi apiceque truncatus, angulis omnibus obtusiusculis, subrotundatis, parum convexus, subtilissime punctulatus, impressionibus duabus longitudinalibus, linea media longitudinali subcarinata disiunctis, parum profundis, subrectis notatus, fuscus, parum nitidus. Scutellum fuscum. Elytra thorace plus sesqui longiora, depressa, confertim subtiliter punctata, testacea. Abdomen parcius subtiliter punctatum, longius pubescens, nigrum, subnitidum, ano piceo-testaceo. Pectus nigrum. Pedes pallide testacei.

\section{* Exs c ut e 11 at $\mathrm{t}$.}

5. T. signatus: Elongatus, niger, subtiliter cinereo-pubescens, antennarum basi, thoracis angulis anterioribus, elytrorum macula pedibusque

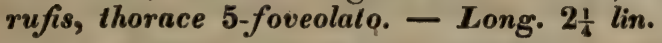

Erichs. Act. Acad. Caes. Leopold. Carol. Nat. Cur. Vol. XVI. Suppl. 229. 13. (Meyen 1t. III. 353. 13.).

Habitat in Chile, Dom. Prof. Meyen.

Elongatus, niger, nitidus, pube brevi cinerea vestitus. Antennae capite thorace paulo breviores, apicem versus leniter incrassatae, piceae, articulis duobus primis rufis. Os rufo-piceum. Caput thoracis latitudine, subtilissime punctatum, fronte ad antennarum basin utrinque longitudinaliter impressa, callo elevato supra antennas rufo, subtus totum obscure sanguinetm. Thorax coleopteris dimidio angustior, latitudine summa paulo brevior, lateribus antice rotundatis, basin versus sensim aequaliter angustatus, basi apiceque truncatus, angulis omnibus subrotundatis, parum convexus, crebre subtiliter punctatus, 5-foveolatus, foveolis duabus posterioribus approximatis, reliquis tribus in medio transversaliter dispositis, lateralibus rotundatis, intermedia lunata, supra nigro-piceus, angulis anterioribus obscure rufis. subtus saturate rufus. Coleoptera thoracis basi duplo latiora, eodemque sesqui 
longiora, confertim punctata, prope apicem versus suturam macula minuta rubra notata. Abdomen lineare, subtilissime punctulatum, segmento penultimo apice piceo. Pectus postice utrinque macula rubra signatum. Pedes omnes cum coxis rufo-testacei.

* 6. T. ferrugineus: Rubro-testaceus, subtiliter cinereo-pubescens, thorace trunsverso, dorso obsolete longitudinaliter bi-impresso. - Long. $1 \frac{1}{2}$ lin.

Habitat in Guyana Venezuelensi, Dom. Moritz.

Maioribus T. riparii individuis aequalis, rubro-testaceus vel dilute rufo-ferrugineus, parım nitidus, pube brevi subtili cinerea densius vestitus. Antennae capite thoraceque paulo longiores, fortiusculae, apicem versus sensim leniter incrassatae. Caput thorace angustius, fronte utrinque ad antennarum insertionem leviter impressa, fuscescente, ore testaceo. Thorax coleopteris paule angustior, latitudine dimidio brevior, lateribus leviter rotundatus, basin versus leviter angustatus, basi apiceque truncatus, angulis posterioribus obtusis, anterioribus subrotundatis, vix convexus, dorso foveolis duabus approximatis, longitudinalibus, obsoletioribus impressus. Elytra thorace sesqui longiora, confertim subtiliter punctata. Abdomen omnium confertissime subtilissimeque punctatum, longius pubescens. Pedes testacei.

* 7. T. angulatus: Elongatus, niger, subliliter cinereo-pubescens, elylris apice, anlennis basi pedibusque rufo-lestaceis, thorace basi bifoveolato, angulis anterioribus acutis, lateribus acute angulatis. - Long. $1 \frac{1}{2}$ lin. Habitat in Brasilia, Dom. Melly.

Linearis, niger, parum nitidus, pube subtili depressa griseo-sericea densius vestitus. Antennae capite thoraceque paulo breviores, apicem versus parum crassiores, nigrae, articulo primo testaceo, sequentibus 4 piceis. Palpi rufo-testacei, articulo tertio piceo. Caput thorace parum angustius, ad antennarum basin utrinque longitudinaliter impressum. Thorax latitudine summa paulo brevior, lateribus ante medium fortiter dilatatıs, angulatis, dein basin versus emarginato - angustatus, apice emarginatus, augulis anterioribus acuminatis, basi truncatus, angulis posterioribus obtusis, parum convexus, subtilissime confertissimeque alutaceus, foveolis approximatis binis prope basin, binis obsoletioribus in medio impressus. Coleoptera thoracis basi duplo fere latiora eodemque paulo longiora, confertim subtiliter punctata, secundum suturam longitudinaliter leviter impressa, fusco-picea, margine apicali testaceo. Abdomen confertissime subtilissimeque punctatum, longius pubescens, ano picescente. Pedes rufo-testacei.

* 8. T. fulvipes: Elongatus, niger, subtiliter cinereo-pubescens, antennarum basi pedibusque rufo-testaceis, thorace postice longitudinaliter bi-impresso, angulis anlerioribus acutis, lateribus obtuse angulatis. Long. 1 lin.

Habitat in ins. Puerto-Rico, Dom. Moritz.

Habitu omnino T. bilineati, linearis, niger, parum nitidus, pube subtili depressa densa cinereo-sericea obductus. Antennae capite thoraceque paululum breviores, apicem versus vix crassiores, fuscae, basi testaceae. Palpi testacei, articulo tertio fuscescente. Caput thorace parum angustius, ad an- 
tennarum basin utrinque impressum. Thorax coleopteris paulo angustior, latitudine summa paulo brevior, lateribus ante medium fortiter dilatatis, obtuse angulatis, basin versus angustatus, apice emarginatus, angnlis anterioribus acutıs, posterioribus obtusis, basi truncatus, parun convexus, subtilissime confertissimeque punctulatus, dorso impressionibus duabus longitudinalibus leviter arcuatis, antrorsum divergentibus notatus. Coleoptera thorace sesqui longiora eiusque basi duplo latiora, confertisaime subtiliter punctata, picea, margine apicali saepe dilutiore. Abdomen subtilissime punctulatum, apice piceum, subtus segmentorum marginibus rufo-piceis. Pedes rufotestacei, coxis omnibus concoloribus.

* 9. T. morio: Elongatus, niger, griseo-pubescens, tarsis testaceis, thorace posterius longiludinaliler bi-impresso, lateribus subangulato, elylris fortiler punctatis. - Long. $1 \frac{2}{3}$ lin.

Habitat in Pensylvania, Dom. Zimmermann.

Niger, subnitidus, cinereo-pubescens. Antennae capite thoraceque paulo breviores, graciles, apice levissime incrassatae, piceo-nigrae. Palpi nigropicei. Mandibulae rufo-piceae. Caput thorace angustius, ad antennarum basin utrinque impressum, subtilissime pubescens. Thorax ante medium coleopteris dimidio angustior, latitudine summa plus dimidio brevior, lateribus ante medium fortiter dilatatis, subangulatis, basin versus angustatus, basi apiceque truncatus, angulis anterioribus rotundatis, posterioribus obtusis, parum convexus, confertim subtiliter punctatus, subtiliter pubescens, dorso posterius impressionibus duabus longitudinalibus, medio subinterruptis notatus. Coleoptera thorace paulo longiora eiusque basi plus sesqui latiora, secundum suturam leviter impressa, creberrime sat fortiter punctata, longius pubescentia. Abdomen supra segmentis singulis basi subtilissime punctatis, parcius pubescens, subtus longius densiusque pubescens. Pedes nigri, geniculis tibiarumque apice rufo-piceis, tarsis rufo-testaceis.

* 10. T. scrobiculatus: Niger, nilidus, griseo-pubescens, anlennarum articulo primo pedibusque rufo-piceis, thorace cordalo, 7-foveolato, foveola posteriore lunata. - Long. $1 \frac{1}{2}$ lin.

Habitat in Saxonia montana, Dom. Märkel.

Statura fere et habitu T. dilatati, niger, nitidus, pube subtili fuscogrisea vestitus. Antennae capite thoraceque paulo breviores, temuiores, apice sensim leniter incrassatae, nigrae, articulo primo piceo-rufo. Palpi picei. Caput thorace paulo angustius, dense subtilissime punctatum, fronte anterius utrinque fortius longitudinaliter impressa. Thorax ante medium coleopteris dimidio angustior, latitudine summa dimidio brevior, lateribus ante medium fortiter rotundatis, basin versus fortius angustatus, basi coleopteris plus dupla angustior, basi apiceque truncatus, angulis posterioribus obtusis, anterioribus rotundatis, parum convexus, dense subtiliter punctatus, medio foveolis duabus rotundatis approximatis, versus angulos anteriores utrinque foveola pariter rotundata, at absaletiore, in ipsa apice foveolis duabus minoribus obsoletis, modice distantibus, inter medium et basin sulco transversali, utrinque abbreviato, arcuato vel lunato, profundiore impressus. Elytra thorace plus sesqui longiora, dense minus subtiliter punctata. Abdomen confertim subtilissime punctulatum, longius pubescens. Pedes rufo-picei 
* 11. T. bilineatus: Elongatus, niger, subtiliter cinereo-pubescens, antennarum arliculo primo pedibusque rufis, thorace transverso, subcordato, subdepresso, dorso 4-foveolato. - Long. 1 - $1 \frac{1}{4}$ lin.

Er. Col. March. I. 600. 3.

Carpalimus bilineatus Steph. Illustr. Britt. Ent. V. 467. 1.

Oxyt. corticinus Gyll. Ins. Suec. II. 645. 14. - Sahlb. Ins. Fenn. I. 418. 19.

Trogophl. corticinus Mannerh. Brachelytr. 49. 1.

Var. pedibus piceis.

Trogophl. inquilinus Er. Col. March. I. 603. 6.

Habitat in Europa.

Niger, subnitidus, subtiliter cinereo-pubescens. Antennae capitis thoracisque longitudine, apice perparum sensim incrassatae, piceo-nigrae, articulo primo rufo. Palpi rufi, articulo tertio nigro-piceo. Mandibulae basi nigrae. Caput thorace paulo angustius, inter oculos utrinque sat profunde impressum, omnium subtilissime confertissineque punctatum. Thorax coleopteris dimidio angustior, latitudine summa dimidio brevior, lateribus anterius fortiter rotundatus, basin versus angustatus, apice truncatus, basi levissime rotundatus, angulis posterioribus obtusis, anterioribus acutiusculis, leviter convexus, subtilissime confertissimeque punctatus, dorso foveolis duabus linearibus, longitudinalibus, basi apiceque profundioribus, medio subinterruptis, sat fortibus notatus. Coleoptera thorace sesqui longiora eiusque basi duplo prope latiora, antice secundum suturam impressa, minus subtiliter dense punctata. Abdomen subtilissime confertim punctatum. Pedes rufi, femoribus saepius medio piceis.

Variat pedibus et nonnunquam etiam antennarum articulo primo piceis.

* 12. T. memnonius: Elongatus, niger, cinereo-pubescens, antennarum basi pedibusque rufo-testuceis, thorace obsolete 4 -foveolato. - Long. $1 \frac{1}{4}$ lin.

Habitat in Aegypto, Dom. Prof. Ehrenberg.

Niger, nitidulus, subtiliter cinereo-pubescens. Antennae capite thoraceque paulo breviores, tenues, apice perparum incrassatae, nigro-piceae, articulo primo rufo, sequentibus duobus rufo-piceis. Mandibulae rufae. Palpi rufi, articulo tertio nigro. Caput thorace angustius, utrinque ad antennarum basin sat fortiter longitudinaliter impressum. Thorax coleopteris dimidio angustior, latitudine summa dimidio brevior, lateribus anterius fortiter rotundatus, basin versus angustatus, basi apiceque truncatus, angulis anterioribus posterioribusque obtusis, perparum convexus, confertissime subtilissimeque punctatus, dorso postice foveolis duabus arcuatis, obsoletis, subinterruptis impressus. Coleoptera thorace sesqui fere longiora eiusque basi duplo latiora, secundum suturam anterius leviter impressa, dense subtiliter punctata, pube brevissima minus subtili vestita. Abdomen supra omnium subtilissime punctulatum, infra densius pubescens, apice summo. piceo. Pedes rufo-testacei.

Obs. C. bilineato proximus, differt autem antennis brevioribus gracilioribusque, thorace latiore, anterius fortius dilatato, obsoletius foveolato. 
* 13. T. riparius: Elongatus, niger, sultiliter cinereo-pubescens, antennarum articulis duobus primis pedibusque rufis, thorace transverso, subdepresso, dorso longiludinaliler bi-impresso. - Long. $1 \frac{1}{2}$ lin.

Boisd. et Lacord. Faun. Ent. Paris. I. 467. 1. - Er. Col. March. I. 600. 2.

\section{Habitat in Europa.}

Niger, nitidulus, cinereo-pubescens. Antennae capitis thoracisque prope longitudine, crassiusculae, apicem versus sensim paulo crassiores, pubescentes, piceae, articulis duobus primis rufis. Os cum palpis rufum, his articulo tertio concolore. Caput thorace paulo angustius, utrinque ad antennarum basin sat profunde impressum, confertissime subtilissimeque punctatum, subtiliter pubescens. Thorax coleopteris paulo angustior, latitudine summa dimidio fere brevior, lateribus anterius fortiter rotundatus, basin versus angustatus, basi apiceque truncatus, angulis anterioribus acutiusculis, posterioribus nbtusis, parum convexus, subtilissime confertissimeque punctatus, subtiliter pubescen`, dorso posterius foveis duahus linearibus, longitudinalibus, leviter arcuatis, antice divergentibus impressus. Coleoptera thorace sesqui longiora eiusque basi sesqui latiora, secundum suturam antice leviter impressa, dense' fortius punctata, dense longius pubescentia. Abdomen supra omnium subtilissime alutaceum, subtilissime punctulatum, parcius pubescens, apice summo piceo, infra densius pubescens. Pedes rufi, coxis omnibus concoloribus.

Variat elytris piceis.

Obs. C. bilineato affinis, at statura paulo maiore, magis lineari, antennis crassioribus, articulis duobus primis rufis, coleopteris minus amplis, fortius punctatis, etc. distinctus.

* 14. T. elongatulus: Linearis, subdepressus, niger, densius cinereopubescens, antennarum basi pedibusque rufo-piceis, thorace subcordalo, dorso longiludinaliter bi-impresso. - Long. 1 lin.

Er. Col. March. 1. 601. 4.

\section{Habitat in Germania.}

Elongatus, linearis, niger, parum nitidus, subtiliter cinereo-pubescens. Antennae capite thoraceque paulo longiores crassiusculae, apicem versus sensim subincrassatae, nigrae vel fuscae, basi rufae. Os rufo-testaceum, palpis articulo tertio piceo. Caput thorace parum angustius, confertissime subtilissimeque punctatum, utrinque ad antennarum basin sat profunde impressum. Thorax coleopteris parum angustior, latitudine vix dimidio brevior, lateribus leviter rotundatus, basin versus angustatus, basi apiceque truncatus, angulis anterioribus obtusis, subrotundatis, posterioribus fortiter rotundatis, parum convexus, subtilissime confertissimeque punctatus, dorso posterius foveolis duabus linearibus longitudinalibus, subarcuatis, parum protundis impressus. Coleoptera thorace paulo longiora eiusque basi sesqui latiora, secundum suturam antice subimpressa, confertissime subtiliter punctata. Abdomen elongatum, lineare, subtilissime confertim punctulatum, minus subtiliter pubescens. Pedes rufi, femoribus saepe picescentibus.

$\mathrm{Obs}$. A praecedentibus statura minore, elongata et elytris subtilius punctatis distinctus. 
* 15. T. fuliginosus: Elongatus, niger, dense cinereo-pubescens, anlennarum basi pedibusque rufis, thorace transverso, lateribus rotundatoamplialo, leviler convexo, basi obsolete bifoveolato. - Long. $1-1 \frac{1}{4}$ lin.

Er. Col. March. 1. 602. 5.

Oxyt. fuliginosus Grav. Mier. 102. 1. Mon. 185. 1. - Latr. Hist. nat. Crust, et Ins. IX. 362. 1. - Oliv. Encycl. meth. VIII. 613. 1.

Habitat in Germania.

Niger, nitidus, pube subtili cinereo-sericea densius vestitus. Antennae capite thoraceque paulo breviores, apicem versus sensim subincrassatae, rufae, apice fuscescentes. Oris partes rufae. Caput thorace multo angustıus, omnium subtilissime confertissimeque punctatum, fronte utrinque ad antennarum basin profunde impressa. Thorax coleopteris parum angustior, latitudine summa dimidio fere brevior, lateribus ante medium dilatatis, rotundatis, basin versus angustatus, basi apiceque truncatus, angulis anterioribus subrectis, posterioribus obtusis, leviter convexus, medio per totam longitudinem subcarinatus, omnium subtilissime punctatus, basi obsolete bifoveolatus, impressionum dorsalium vix rudimento ullo. Coleoptera thorace paulo longiora eiusque basi sesqui latiora, secundum suturam per totam longitudinem Jeviter impressa, confertissime subtilissimeque punctata, nonnunquam picea. Abdomen confertissime subtilissimeque punctatum, apice summo piceo. Pedes rufi.

* 16. T. flavipes: Elongatus, niger, cinereo-pubescens, elytris apice, antennis basi pedibusque testaceis, thorace dorso longitudinaliter bi-impresso. - Long. $\frac{3}{4}-1$ lin.

Habitat in Americae meridionalis insulis St. Johannis et St. Thomae, Dom. Moritz.

Niger, nitidus, subtiliter cinereo-pubescens. Antennae capitis thoracisque longitudine, apicem versus leniter incrassatae, fuscae, articulis duobus primis testaceis. Oris partes testaceae. Caput thorace parum angustius, subtilissime obsolete punctulatum, fronte utrinque ad antennarum basin profunde foveolata. Thorax coleopteris paulo angustior, latitudine summa dimidio brevior, lateribus fortiter rotundatus, basin versus angustatus, apice truncatns, angulis anterioribus obtusis, basi cum angulis posterioribus rotundatus, leviter convexus, confertissime subtilissimeque punctatus, dorso foveolis duahus linearibus, longitudinalibus, subarcuatis, profundioribus impressus. Coleoptera thorace paulo longiora eiusque basi sesqui latiora, confertim subtiliter punctata, fusco-picea, margine apicali testaceo. Abdomen elongatum, subtilissime obsolete punctulatum. Pedes testacei.

*17. T. Niloticus: Elongatus, fuscus, cinereo-pubescens, capite abdomineque nigris, antennis pedibusque testaceis, thorace obsoletius 4-foveolalo. - Long. $\frac{2}{3}$ lin.

Habitat in Aegypto, a Dom. Prof. Ehrenberg copiose lectus.

Minutus, fuscus, capite abdomineque nigris, cinereo-pubescens. Antennae capitis thoracisque longitudine, apicem versus leviter incrassatae, articulis ultimis tribus abrupte paulo maioribus, testaceae, apice fuscescentes. Palpi flavi. Caput thorace parum angustius, omnium subtilissime punctula- 
tum, fronte utrinque impressa. Thorax coleopteris dimidio angustior, latitudine paulo brevior, basin versus angustatus, lateribus ante medium rotundatis, apice truncatus, angulis anterioribus obtusis, basi cum angulis posterioribus rotundatus, leviter convexus, omnium subtilissime punctulatus, dorso obsolete longitudinaliter bi-impressus, impressionibus medio subinterruptis. Coleoptera thorace sesqui longiora eiusque basi duplo latiora, confertim subtiliter punctata. Abdomen confertim subtilissime punctulatum, fortius pubescens. Pedes pallide flavi.

Variat minus maturus corpore testaceo, capite abdomineque fuscis.

* 18. T. corticinus: Elongatus, niger, subtilissime cinereo-pubescens, antennis concoloribus, pedum geniculis tarsisque piceis, thorace transverso, subcordalo, dorso fortius longitudinaliter bi-impresso. - Long. $\frac{3}{4}-1$ lin.

Er. Col. March. I. 603. 7.

Oxyt. corticinus Grav. Mon. 192, 8. - Oliv. Encycl. meth. VIII. $416 . \bullet 8$.

Oxyt. minimus Runde Brachelytr, Hal. 20. 7.

Habitat in Germania, frequens.

Niger, subnitidus, tenuiter subtiliterque cinereo-pubescens. Antennae capite thoraceque paulo breviores, minus tenues, apice leniter incrassatae, nigrae, articulis ultimis tribus distinctius abrupte paulo maioribus, articulo primo piceo-nigro. Palpi piceo-nigri. Caput thoracis prope magnitudine, confertim subtilissime punctatum, fronte ad antennarum basin utrinque foveolata. Thorax coleopteris paulo angustior, latitudine summa tertia parte brevior, lateribus rotundatus, bașin versus angustatus, apice truncatus, basi cum angulis posterioribus leviter rotundatus, angulis anterioribus acutiusculis, parum convexus, confertissime subtiliter punctatus, dorso foveis duabus linearibus longitudinalibus, leviter arcuatis impressus. Coleoptera thorace plus sesqui longiora eiusque basi sesqui latiora, antice secundum suturam Jongitudinaliter leviter impressa, confertim subtiliter punctata. Abdomen subtiliter obsoleteque punctulatum. Pedes nigri, trochanteribus, geniculis tibiarumque apice piceis, tarsis testaceis.

V ariat pedibus rufis, antennarum articulis tribus primis piceis.

* 19. T. exiguus: Subcylindricus, niger, subtilissime cinereo-pubescens, antennis palpisque concoloribus, pedum geniculis tarsisque piceis, thorace oblongo, basin versus anguslato, convexo, dorso obsolete foveolata. - Long. $\frac{2}{3}$ lin.

Er. Col. March. I. 604. 8.

Trogophl. impressus Boisd. ot Lacord. Faun. Ent. Paris. I. 467. 2. (forte)

Habitat in Germania, Gallia.

Statura subcylindrica fere Bledii cuiusdam, minutus, niger, parum nitidus, subtilissime cinereo-pubescens. Antennae capite thoraceque breviores, apicem versus leniter sensimque incrassatae, nigrae. Palpi nigri. Mandibulae rufae. Caput thoracis magnitudine, basi vix constrictum, fronte utrinque ad antennarum basin leviter impressa. Thorax coleopteris parum angustior, latitudine summa vix brevior, lateribus ante medium modice rotundatus, basin versus angustatus, basi subrotundatus, apice truncatus, angulis anterio- 
ribus obtusiusculis, posterioribus obtusis, subrotundatis, satis convexus, subtilissime confertim punctatus, impressionibus duabus oblongis dorsalibus obsoletissimis. Coleoptera thorace panlo longiora eiusque basi sesqui latiora, confertim subtilius punctata. Abdomen subtiliter punctulatum. Pedes picei, trochanteribus, geniculis, tibiarum apice tarsisque rufescentibus, interdum tibiis etiam totis rufis.

* 20. T. punctat ellus: Niger, nitidulus, parce cinereo-pubescens, pedibus piceis, capite thoraceque crebre, elylris dense fortilerque punclatis. Long. 1 $\frac{1}{2}$ lin.

Habitat in Carinthia, Dom. Schmidt.

Niger, nitidulus, pube subtili cinerea parcius vestitus, haud sericans. Antennae capite thoraceque paulo breviores, apicem versus leviter incrassatae, articulo secundo tertio multo maiore, crasso, quinto contiguis paulo crassiore, ultimis tribus paulo maioribus, nigrae, articulo primo rufo-piceo. Oris partes testaceae, palpis. nigro-piceis. Caput thoracis prope latitudine, crebre profundius et minus subtiliter punctatum, linea media longitudinali laevi, fronte ad antennarum basin utrinque foveolata. Thorax coleopteris paulo angustior, latitudine summa dimidio fere brevior, lateribus fortius rotundatus, basin versus angustatus, basi apiceque truncatus, angulis anterioribus subrotundatis, posterioribus obtusis, modice convexus, aequalis, crebre minus subtiliter profunde punctatus, linea media longitudinali laevi subcarinata. Coleoptera thorace paulo latiora et eiusdem basi sesqui latiora, dense fortiter profundeque punctata. Abdomen parce subtilissime punctulatum. Pedes picei, trochanteribus, geniculis tarsisque testaceis.

* 21. T. foveolatus: Niger, subtiliter cinereo-pubescens, pedibus piceis, thorace obsolete 4-foveolato, elytris dense fortius punctatis. - Long $\cdot \frac{2}{3}$ lin. Oxyt. foveolatus Salb. Ins. Fenn. I. 419. 20.

Habitat in Germania, Dom. Schüppel, in Sardinia, Dom. Prof. Gené.

T. corticino paulo minor, praecipue brevior, niger, minus nitidus, subtiliter cinereo-pubescens. Antennae capite thoraceque multo breviores, minus graciles, articulo secundo tertio multo maiore, crassiusculo, apice leniter incrassatae, nigrae, basi piceae. Palpi nigro-picei. Mandibulae testaceae. Caput thorace paulo angustius, opacum, fronte ad antennarum basin utrinque profunde impressa. Thorax coleopteris parum angustior, latitudine summa dimidio brevior, lateribus fortius rotundatus, basin versus angustatus, basi apiceque truncatus, angulis posterioribus rotundatis, anterioribus obtusis, supra leviter convexus, opacus, dorso foveolis 4 obliquis, binis prope basin, binis in medio sitis, omnibus obsoletioribus impressus. Coleoptera thorace sesqui longiora eiusque basi sesqui latiora, dense fortins profunde punctata. Abdomen subtilissime punctulatum. Pedes picei, geniculis tarsisque testaceis.

*22. T. troglodytes: Niger, subtilissime cinereo-pubescens, antennarum basi, pedibus elytrisque piceis, his apice testaceo-marginatis, thorace obsolete 4-foveolato. - Long: $\frac{2}{3}$ lin.

Habitat in Sardinia, Dom. Prof. Gené. 
Statura omnino praecedentis, niger, minus nitidus, capite thoraceque opacis. Antennae capitis thoracisque longitudine, minus graçiles, articulo secundo tertio crassiore, apicem versus sensim leviter incrassatae, nigricantes, basi piceae. Palpi picei. Caput thoracis fere latitudine, omnium subtilissime alutaceum, fronte depressiuscula, ad antennarum basin utrinque sulculo profundiore impressa. Thorax coleopteris paulo angustior, latitudine summa tertia parte brevior, lateribus, basi et angulis posterioribus rotundatis, basin versus angustatus, apice truncatus, angulis anterioribus rectis, supra parum convexus, omnium subtilissime alutaceus, subtilissime obsoletissimeque punctulatus, dorso foveolis quatuor obsoletioribus, binis prope basin; binis in medio sitis impressus. Coleoptera thorace paulo longiora eiusque basi sesqui latiora, minus dense subtiliter punctata, nitida, nigro-picea, margine apicali testaceo. Abdomen parcius subtilissime punctulatum. Pedes picei, trochanteribus, geniculis, tibiarum apice tarsisque testaceis.

Obs. Distinctus a praecedente thorace minus transverso, elytris paulo brevioribus, minus dense et minus fortiter punctatis, neque concoloribus.

* 23. T. pusillus: Elongalus, subdepressus, niger, subliliter cinereo-pubescens, antennarum basi pedibusque luteis, elytris fusco-testaceis, thorace transversim subcordato, dorso obsoletius 4 -foveolato. - Long. $\frac{3}{4}$ lin.

Er. Col. March. 1. 605. 9.

Aleoch ara pusilla Grav. Micr. 78. 17. Mon. 153. 16. - Latr. Hist. nat. Crust. et Ins. IX. 383. 17. - Gyll. Ins. Suec. II. 409. 31.

Taenodoma pusillum Mannerh. Brachelytr. 51. 2.

Oxyt. fuliginosus Gyll. Ins. Suec. II. 460. 14. - Sahlb. Ins. Fenn. I. 418. 18.

- Zetterst. Ins. Lappon. 73. 6.

Trogophl. corticinus Boisd. et Lacord. Faun. Ent. Paris. I, 468. 3.

Habitat in Europa.

Minutus, linearis, subdepressus, niger, parum nitidus, dense subtiliterque cinereo-pubescens. Antennae capite paulo longiores, fusco-testaceae, articulo primo testaceo, ultimis tribus distincte crassioribus, fuscis, tertio secundo multo minore, quinto contiguis paulo crassiore. Palpi testacei, articulo tertio fusco. Os testaceum. Caput thorace vix angustius, fronte inter oculos utrinque sulco sat profundo impressa. Thorax coleopteris paulo angustior, latitudine summa paulo brevior, lateribus leviter rotundatus, basin versus modice angustatus, basi subrotundatus, apice truncatus, angulis omnibus obtusis, subrotundatis, parum convexus, vix punctulatus, dorso foveis duabus oblongis, sublinearibus, medio interruptis, basi apiceque profundioribus, leviter impressus. Coleoptera thorace sesqui longiora eiusque basi sesqui latiora, confertissime subtilter punctata, basi secundum suturam leviter impressa, fusco - testacea. Abdomen confertissime subtilissimeque punctatum, apice piceum. Pedes flavo-testacei.

* 24. T. tenellus: Linearis, niger, subtilissime cinereo-pubescens, antennarum basi pedibusque testaceis, elytris fuscis, thorace subquadrato, dorso obsolete impresso. - Long. $\frac{3}{4}$ lin.

Er. Col. March. I. 605. 10.

Taenodoma gracile Mannerh. Brachelytr. 51. 1. (forte)

Habitat in Germania. 
Minutus, valde elongatus, linearis, subdepressus, niger, parum nitidus, subtilissime pubescens. Antennae capite sesqui longiores, crassae, apicem versus fortius incrassatae, articulo tertio secundo multo minore, quinto septimoque contiguis paulo crassioribus, ultimis tribus distincte maioribus, fuscae, articulo primo testaceo. Os testaceum. Caput thoracis magnitudine, omnium subtilissime confertissime punctatum, fronte inter antennas utrinque foveolata. Thorax coleopteris paulo angustior, latitudine vix brevior, lateribus parum rotundatis, basin versus subangustatus, basi cum angulıs posterioribus rotundatus, apice truncatus, angulis anterioribus subrectis, parum convexus, confertissime subtilissimeque punctatus, dorso obsolete bi-impressus, impressionibus basi profundioribus. Elytra thorace duplo prope longiora, confertissime subtiliter punctata, iam nigro-fusca, iam fusco-testacea. Abdomen confertim subtilissune punctatum, apice summo piceo. Pedes testacei.

V ariat thorace elytrisque piceis.

*25. T. subtilis: Linearis, niger, subtilissime cinereo-pubescens, antennis pedibusque testaceis, elytris fuscis, thorace oblongo, basin versus leviler angustato, dorso obsoletissime impresso. - Long. $\frac{3}{4}$ lin.

Fr. Col. March. I. 606. 11.

\section{Habitat Berolini.}

Statura minuta, tenui praecedentis, eique proximus, niger, parum nitidus, subtiliter cinereo-pubescens. Antennae capite sesqui longiores, crasslusculae, articulo tertio secundo multo minore, ultimis tribus distincte crassioribus, totae testaceae. Os testaceum. Caput thoracis latitudine vel eodem paulo latius, basi leviter constrictum, subtilissime confertissimeque punctulatum, inter antennas utrinque fortiter foveolatum. Thorax coleopteris paulo angustior, latitudine summa haud brevior, lateribus anterius rotundatus, basin versus angustatus, basi cum angulis posterioribus leviter rotundatus, angulis anterioribus obtusiusculis, parum convexus, omnium subtilissime confertissimeque punctatus, basi obsolete bi-impressus. Coleoptera tharace sesqui longiora eiusque basi plus sesqui latiora, secundum suturam longitu. dinaliter obsolete impressa, fusca. Abdomen confertissime subtilissimeque punctatum, apice piceum. Pedes breves, testacei.

$\mathrm{Obs}$. A praecedente praecipue thorace paulo longiore, basin versus distincte angustato, antennis totis testaceis distinguitur.

\section{Apocellus $E r$.}

Paraglossae ligulae connatae.

Pedes intermedii basi approximati.

Tibiae omnes muticae.

Tarsi modice elongati.

Corpus minutum, elongatum, lineare, apterum. Caput maiusculum, exsertum, porrectum, rotundatum, collo quasi tenui thoraci immissum, oculis mediocribus, leviter prominulis. Labrum latitudine paulo brevius, medio leviter sinuatum, laciniis membraneis linearibus. Mandibulae breves, haud exsertae, apice fortiter tridentatae, interne basi membrana margine barbata fimbriatae. Maxillae (t. V. f. 20. b.) malis membranaceis, apice barbatis, interiore interne ciliata, modice elongatis, exteriore longiore. Palpi maxil- 
lares mala exteriore vix longiores, articulo primo parvo, secundo apicem versus leviter incrassato, tertio hoc paulo longiore, crassiusculo, quarto parvo, subulato. Labium (t. V. f. 20. a.) mento transverso. ligula lata, membranea, apice leviter emarginata, paraglossis ligulae connatis eandemque haud superantibus. Palpi lahiales ligula paulo longiores, articulis longitudine crassitieque decrescentibus. Antennae refractae, modice elongatae, apicem versus sensim incrassatae. Thorax coleopteris angustior, subglobosus. Scutellum breviusculum, triangulare. Elytra breviuscula, truncata. Abdomen lineare, marginatum, supra planum, subtus convexum. Pedes elongati, graciles, coxis anticis conicis, liberis, intermediis subapproximatis, tibiis omnibus teretibus, pubescentibus, tarsis triarticulatis, articulis duobus primis brevibus, tertio elongato.

\section{O b s e r vat i o n e s.}

1. Habitu Stilici vel Falagriae reliquis Oxytelinis omnino alienus videtur. Corpus laevigatum, parce pilosellum.

2. Characteribus plerisque, oris imprimis structura, cum Trogophloeo convenit, distinctus autem habitu, corpore haud pubescente, pedibus magis elongatis, tarsis minus brevibus, tibia dimidia longioribus:

3. Sexus differentia in abdominis apice inferiore sita in speciebus describendis illustranda.

4. De victu nihil constat.

1. A. sphaericollis: Piceus, nitidus, abdomine nigro, antennarum basi pedibusque piceo-teslaceis. - Long. $1 \frac{1}{2}$ lin.

T. II. $f .5$.

Lathrobium sphaericolle Say. Transact. Amer. Philoph. Soc. Philadelph. Nov. Ser. $I V .455 .6$.

Habitat in Carolina, Dom. Zimmermann.

Antennae capitis thoracisque fere longitudine, apicem versus sensim incrassatae, fusco-piceae, basi piceo-testaceae. Os piceo-testaceum. Caput thoracis fere latitudine, suborbiculatum, piceum, laevissimum, fronte utrinque longitudinaliter impressa, impressione subtilissime strigosa, margine laterali super antennarum basin plicato-elevato. Thorax coleopteris paulo angustior, subglobosus, laevissimus, piceus, nitidus. Elytra thorace hand longiora, laevissima, basi summa subtilissime strigosa, picea, disco nigra, nitida. Abdomen laeve, nigrum. Pedes piceo-testacei. Corpus totum pilis raris erectis instructum.

Abdominis segmentum inferius sextum maris margine apicali medio dilatato, reflexo, leviter emarginato, subtiliter ciliato, flavido, septimum profunde excisum, lateribus lobatum, lobis conniventibus, feminae apice medio leviter triangulariter productum.

\section{* 2. A. ustulatus: Testaceus, elytris abdomineque apice nigris. - Long. $1 \frac{1}{3}$ lin.}

Habitat in Ins. St. Johannis Americae, Dom. Moritz.

Flavo-testaceus, nitidus, pilis parcis erectis vestitus. Antennae capitis thoracisque longitudine, apicem versus sensim incrassatae, testaceae, basi dilutiores. Caput thorace latius, suborbiculatum, laevissimum, fronte utrinque leviter longitudinaliter impressa, margine laterali super antennarum basin 
plicato-elevato. Thorax parvus, coleopteris duplo fere angustior, subquadratns, leviter convexus, laevissimus. Elytra thorace paulo longiora, laevissima, piceo-nigra, nitida, basi piceo - testacea. Abdomen laeve, segmentis 4 primis testaceis, reliquis picen-nigris. Pedes pallide testacei.

Abdominis segmentum inferius sextum maris apice medio leviter emarginatum, septimum profunde sinuatum, femin ae apice rotundatum.

3. A. albipes: Piceus, nitidus, antennis basi testaceis, abdominis segmento primo pedibusque albidis, femoribus apice fuscis. - Long. 1 lin.

Habitat in Columbia, Dom. Moritz.

Saturate fusco-piceus, nitidus, parce pilosus. Antennae capitis thoracisque longitudine, apicem versus sensim incrassatae, fuscae, basi testaceae, articulo ultimo ferrugineo. Palpi testacei. Caput thorace latius, suborbiculatum, laevissimum, rufo-piceum, fronte utrinque ad antennarum basin subimpressa, margine laterali super antennarum insertionem plicato-elevato. Thorax coleopteris multo angustior, latitudine haud brevior, lateribus anterius leviter rotundatus, basin versus subangustatus, convexus, laevissimus. Elytra thorace paulo longiora, laevissima. Abdomen segmento primo albido. Pedes albidi, femoribus apice ad medium usque fuscis.

Variat capite rufo-piceo.

\section{Subtribus quarta.

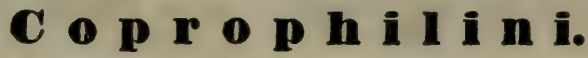

Antennae 11-articulatae. Ligula membranea.

Tarsi 5-articulati.

L abrum transversum, corneum,

apice utrinque lacinia membranea instructum Coprophilo, Acrognatho, Deleasteri;

apice toto membrana limbatum Syntomio.

Mandibulae muticae vel medio subdentatae,

haud prominentes Coprophilo, Deleasteri, Micralymmati, Synto mio;

prominentes, acutae Acrognatho.

Maxillae malis coriaceis membranaceisve, exteriore apice, interiore interne barbata.

Palpi maxillares filiformes, articulo primo brevi.

Ligula membranea, biloba.

Paraglossae ligulae aequales.

Palpi labiales breviusculi, filiformes.

Antennae 11-articulatae,

rectae Coprophilo, Deleasteri, Micralymmati, Syntomio;

subrefractae Acrognatho;

articulis ultimis distincte crassioribus subclavatae $A \mathrm{c}$ r o g n a th o, S y n t o mi o. 
Oculi mediocres.

Thor ax basi truncatus, ab elytris parum remotus.

Scutellum distinctum.

Abdomen marginatum.

$P$ edes coxis intermediis approximatis, tibiis

anterioribus spinulosis Coprophilo, A crognatho;

omnibus muticis Deleasteri, Micralymmati, Syntomio;

tarsis 5-articulatis.

O b s e r $\nabla$ a t i o.

Discedunt ab Oxytelinis genuinis praecipue palpis filiformibus et tarsis 5 -articulatis. DeleasterAnthophago, reliqua huius subtribus genera Omalio ab auctoribus adscripta sunt, a quibus, licet habitu is similes, praecipue ocellis nullis, elytris pectore haud longioribus, abdominis segmento septimo exserto distinguuntur.

\section{Coprophilus Latr.}

Latr. Regn. Animal. IV. p. 439. Nov. Annal. Mus. Hist. nat. I. p. 89.

\section{Paraglossae ligulae connatae.}

Anlennae reclae, apicem versus sensim subincrassatae.

Tibiae anteriores extus spinulosae.

Corpus elongatum, lineare, subdepressum, alatum. Caput porrectum, basi haud coarctatum, thoraci immissum eodemque angustius, oculis subovalibus, mediocribus, parum prominulis. Labrum (t. V. f. 21. c.) transversum, apice subsinuatum, laciniis membraneis minutis, triangularibus, interne ciliatis. Mandibulae haud prominentes, validae, medio subdentatae. Maxillae (t. V. f. 21. b.) mala interiore externe coriacea, interne membranea margine interiore ciliato, mala exteriore coriacea, apice dense barbata. Palpi maxillares articulo primo minuto, secundo elongato-obconico, tertio hoc paulo breviore, quarto secundo prope longiore, elongato-ovato, apice subacuminato. Labium (t. V. f. 21. a.) mento transverso, apicem versus leviter angustato, apice truncatum, ligula membranea, lata, apice late emarginata, paraglossis linearibus, ligulam haud excedentibus, membraneis, interne spinulis ciliatis. Palpi labiales articulis tribus longitudine aequalibus, ultimo ovato, subacuminato. Antennae rectae, apicem versus sensin subincrassatae, articulo primo crassiusculo, secundo tertio paulo breviore, 4-10 sensim paulo crassioribus et magis obconicis, ultimo ovato. Thorax coleopteris parum angustior, basin versus subangustatus. Scutellum triangulare, Elytra truncata, angulo exteriore obtuso. Abdomen lineare, late marginatum. Pe: des breviusculi, validiusculi, coxis intermediis carinula tenuissima disiunctis, tibiis integris, omnibus seriatim setulosis, anterioribus extus uni-seriatim spinulosis, tarsis $\mathbf{5}$-articulatis, articulis 4 primis brevibus, quinto his coniunctis subaequali.

\section{O b s e r vationes.}

1. Habitus aliquatenus Oxyteli. Corpus glabrum, capite thoraceque minus subtiliter punctatis, elytris seriatim punctatis, abdomine subtiliter pubescente.

2. Mas abdominis segmento ventrali septimo apice minus rotundato a femina distinguitur.

3. Victus sub lapidibus. 
* 1. C. striatulus: Niger, nitidus, ore pedibusque piceis, thorace bifoveolato, elytris fortiter punctato-striatis. - Long. 3 lin.

Er. Col. March. I. 609. 1.

Staph. striatulus Fab. Ent. Syst. I. II. 529. 27. Syst. El. II. 596. 35. - Panz. Ent. Germ. 354. 19.

Staph. rugosus Oliv. Ent. III. 42. 30. 42. t. 4. f. 43.

O malium rugosum Grav. Micr. 115. 7. Mon. 203. 11.-Latr. Hist. nat. Crust. et

Ins. IX. 372. 7. - Oliv. Encycl. meth. VIII. 476. 11. - Gyll. Ins. Suec. II. 233. 30. Anthobium rugosum Boisd. et Lacord. Faun. Ent. Paris. I. 469. 1.

Coprophilus rugosus Guér. Iconogr. Regn. An. Ins. t. 10. f. 2.

Oxyt. laesus Germ. Faun. Ins. Europ. XV. 2.

Habitat in Europa.

Corpus nigrum piceumve, nitidum. Antennae fere capitis thoracisque longitudine, apicem versus paululum incrassatae, nigro-piceae, apice rufescentes. Caput sat crebre inaequaliter punctatum, fronte super oculos striga transversali, utrinque ad antennarum insertionem fovea longitudinali impressa. Thorax coleopteris paulo angustior, latitudine parum brevior, basin versus leviter angustatus, lateribus antrorsum modice rotundatus, apice subemarginatus, angulis anterioribus leviter prominulis, suhdepressus, crebrius punctatus, basi foveolis duabus approximatis, medio fovea elongata, lineari, canaliculae instar impressus, lateribus late marginatus, margine obsolete crenulato. Scutellum punctis nonnullis impressum. Elytra thorace sesqui longiora, sulcata, sulcis fortiter pnnctatis, interstitiis laevibus, apice confertim ruguloso-punctata. Abdomen subtiliter punctulatum. Pedes rufo-picei.

\section{Acrognathus $E$.}

\section{Er. Col. March. I. p. 607.}

\section{Paraglossae apice liberae.}

Antennae subrefractae, articulis ullimis crassioribus. Tibiae anteriores spinulosae.

Corpus elongatum, lineare, alatum. Caput porrectum, basi leviter constrictum. Labrum (t. V. f. 22. c.) breve, medio sinuatum, utrinque lacinia sat elongata, acuminata, membranea, interne pilis longioribus ciliata auctum. Mandibulae elongatae, prominentes, falcatae, acutae. Maxillae (t. V. f. 22. b.) mala interiore membranea, margine exteriore corneo, interiore ciliato, apice barbatula; mala exteriore cornea, apice barbata. Palpi maxillares modice elongati, articulo primo minuto, secundo tertioque inter se longitudine subaequalibus, quarto his singulis sesqui fere longiore, apice acuminato. Labium (t. V. f. 22. a.) mento brevi, apice truncato, ligula membranea, sinu profundo biloba, lobis sublinearibus, divergentibus, paraglossis his connatis, eosque haud superantibus, apice summo liberis. Palpi labiales subelongati, articulo primo secundoque fere aequalıbus, tertio his tenuiore et parum longiore. Antennae subrefrcctae, articulo primo longiusculo crassiusculoque, secundo tertioque leviter elongatis, obconicis, hoc secundo paulo longiore, ultimis 3 vel 5 distincte crassioribus. Thorax coleopteris paulo angustior, basin versus subangustatus. Scutellum triangulare. Elytra truncata, angulo exteriore rotundato. Abdomen lineare, late marginatum. Pedes parim elongati, intermedii approximati, tibiis omnibus setulosis, posterioribus apice 
oblique truncatis, anterioribus a medio apicem versus sensim attenuatis, extus uniseriatim spinulosis, tarsis $\mathbf{5}$-articulatis, articulis 4 primis minutis, inter se aequalibus, quinto his coniunctis subaequali.

$$
\text { O b s e r v a t i o. }
$$

Habitus fere Trogophloei, at tibiae spinulosae, tarsi 5-articulati, et palporum articulus ultimus elongatus. Mandibulae prominentes affinitatem quandam cum Bledio probant. Antennae subrefractae, sub tuberculo frontis marginali insertae, articulis ultimis tribus saepe distinctius maioribus, ut in genere laudato utroque.

\section{* 1. A. mandibularis: Rubro-testaceus, capite piceo, elylris subliliter subserialim punctalis. - Long. 3 lin.}

Er. Col. March. I. 608. 1.

Omalium mandibulare Gyll. Ins. Suec. IV. 468. $29-30$.

Habitat in Germania, Gallia, Suecia, rarior.

Corpus rubro-testaceum, fere lateritium, opacum. Antennae capitis thoracisque fere longitudine, articulis ultimis tribus abrupte paulo maioribus, ultimo ovato, concolores. Caput fronte antice subretusa, parce punctata, nigricante, tuberculo utrinque marginali super antennarum insertionem elevato dilutiore. Oculi fortiter prommulı. Thorax coleopteris dimidio angustior, latitudine parum longior, basin versus leviter angustatus, lateribus et basi leviter rotundatus, apice truncatus, angulis anterioribus subrotundatis, posterioribus subrectis, leviter convexus, subtilissime alutaceus, parcius punctatus, linea media subelevata laevi, lateribus tenuiter marginatus, saturate rubro-testaceus, subtiliter pubescens. Elytra thorace sesqui longiora, subtilissime alutacea, subtiliter subseriatim punctata, lineis tribus subelevatis laevibus, dilutius rubro-testacea, subtiliter griseo-pubescentia. Abdomen subtilissime alutaceum, subtiliter pilosellum. Pedes testacei.

Abdominis segmentum inferius secundum maris tuberculo minuto apicali munitum, feminae muticum.

2. A. cephalotes: Piceus, capite maiusculo, oblongo, thorace elongato, dorso bisulcalo, rufo, elytris dense serialim punctatis, piceo-teslaceis. - Long. $3 \frac{1}{2}$ lin.

Habitat in Corcyra, Dom. Schïppel.

Latitudine praecedentis, at magis elongatus linearisque. Antennae capite thoraceque multo breviores, articulis $\mathbf{5}$ ultimis abrupte distincte maioribus, ultimo subovato, rufae. Os rufum, mandibulis piceis. Caput thorace paulo latius, oblongum, basi perparum constrictum, fronte lateribus crebre, medio biseriatim profundius punctata, nigro-piceum, basi rufescens. Oculi haud prominuli. Thorax coleopteris paulo angustior, latitudine paulo longior, basin versus leviter angustatus, lateribus subrectis, basi leviter rotundatus, apice late leviter emarginatus, angulis anterioribus acutiusculis, posterioribus obtusis, modice convexus, dorso longitudinaliter bisulcatus, sulcis et in utroque latere plaga longitudinali leviter flexuosa crebre punctatis, piceo-rufus, nitidus, uti caput pube erecta parca subtili vestitus. Elytra thorace sesqui prope longiora, dorso striatim, apice disperse crebreque fortius punctata, subtiliter griseo-pubescentia, piceo-testacea, dorso nigricantia. Abdomen crebre punctulatum, subtiliter griseo-pubescens, piceum, nitidum. Pectus nigro-piceum. Pedes breviusculi, testacei. 
* 3. A. palpalis: Testaceus, abdomine ante apicem, pectore fronteque piceis, elytris fortius seriatim punctatis. - Long. 1 lin.

Ev. Col March. I. 608. 2.

Habitat Berolini, Dom. Schüppel, in Saxonia, Dom. Märkel, in ins. Corcyra, Dom. Schïppel.

Minutus, subdepressus, testaceus, vix nitidus. Antennae capitis thoracisque longitudine, articulis septimo et octavo praecedentibus crassioribus, ultimis tribus his iterum maioribus et crassioribus, ultimo subovato, apice abrupte subacuminato, flavae, articulis ultimis 5 fuscis. Caput thoracis latitudine, basi minus distincte constrictum, fronte planiuscula, sabtilissime alutacea, parcius punctata, picescente, ore flavo. Palpi eiusdem structurae atque in praecedentibus, at paulo crassiores. Oculi leviter prominuli. Thorax coleopteris dimidio angustior, latitudine paulo longior, basin versus leviter angustatus, lateribus subrects, basi leviter rotundatus, apice leviter emarginatus, angulis anterioribus acutiusculis, posterioribus obtusis, leviter convexus, subtilissime alutaceus, vage punctatus, linea media sat lata subelevata laevi. Elytra thorace sesqui fere. longiora, subdepressa, dorso sat distincte regulariterque seriatim punctata, flavo - testacea, subnitida, subtilissime pubescentia. Abdomen ante apicem piceum. Pectus piceum. Pedes flavi.

Abdominis segmentum inferius septimum maris apice subrotundatum, femin a e acuminatum.

\section{Deleaster $\boldsymbol{E} r$.}

Er. Cul. March. I. p. 610.

Paraglossae liberae.

Palpi maxillares articulo ultimo penultimo sesqui longiore. Antennae rectae, filiformes.

Tibiae omnes muticae.

Corpus modice elongatum, subdepressum, alatum. Caput exsertum, porrectum, collo quasi cylindrico thoraci immissum, subovatum, oculis rotundatis, mediocribus, sat prominulis. Labrum (t. V. f. 24. c.) transversum, apice leviter sinuatum, laciniis membraneis triangularibus, interne ciliatis. Mandibulae parum prominentes, muticae. Maxillae (t. V. f. 24. b.) malis membranaceis, interiore interne, exteriore apice barbatis, Palpi maxillares parum elongati, articulo primo minimo, secundo elongato-obconico, tertio hoc breviore, quarto secundo paulo longiore, subacuminato. Labium (t. V. f. 21. a.) mento transverso, ligula membranea, lata, apice late profundeque sinuata, paraglossis liberis, linearibus, acutis, ligulam haud superantibus. Palpi labiales ligulam parum excedentes, articulis duobus primis cylindricis, secundo paulo breviore, tertio primo aequali, subovato. Antennae elongatae, validiusculae, rectae, articulo primo leviter elongato, secundo hoc triplo minore, subobconico, tertio iterum elongato, reliquis longitudine aequalibus, et sensim paululum crassioribus, ultimo ovato. Thorax coleopteris multo angustior, subcordatus. Scutellum apice rotundatum. Elytra sat ampla, singula apice leviter rotundata. Abdomen latum, late marginatum. Pedes elongati, graciles, coxis intermediis approximatis, tibiis omnibus subtiliter 
pubescentibus, tarsis 5-articulatis, articulis 4 primis obcordatis, subaequalibus, quinto his coniunctis paulo breviore.

O b s e r v a t i n e s.

1. Habitus omnino Anthophagi, at huius tribus, et accuratius inspectus sat distinctus.

2. Dom. Curtis hoc insectum pro generis Lesteuae typo proposuit, at oris partes Anthophagi exhibuit.

3. Mas differt a femina tarsis anterioribus articulis 4 primis leviter dilatatis, subtus subtiliter spongiosis, abdominis segmento inferiore septimo apice truncato neque rotundato.

4. Victus riparius.

* 1. D. dichrous: Teslaceus, eapite nigro, abdomine piceo. - Long. 3 lin.

Er. Col. March. I. 611. 1.

Anthophagus dichrous Grav. Micr. 188. 1. Mon. 221. 6.

Lesteua dichroa Latr. Hist. nat. Crust. et Ins. IX. 369. 7. - Guér. Iconogr. Regn. An. Ins. t. 10. f. 3. - Mannerh. Brachelytr. 55. 1. - Boisd. et Lacord. Fuun. Ent. Paris. I. 479. 1. - Runde Brachelytr. Hal. 23. 1.

Lesteua Leachii Curt. Britt. Ent. VII. t. 303.

St aph. Brassicae Schrank Faun. Boica. I. 644. 873. (forte)

Habitat in Germania, Gallia, Anglia.

Antennae capite thoraceque longiores, rufo-ferrugineae. Caput thorace sesqui latius, impunctatum, fronte medio convexa, lateribus super oculos et inter antennas longitudinaliter impressa, sub antennis linea sat profunda transversaliter divisa, nigrum, subnitidum, ore late rufo. Thorax coleopteris duplo fere angustior, latitudine summa paulo brevior, ante medium fortiter rotundatus, basin versus angustatus, basi apiceque truncatus, leviter convexus, parce punctatus, minus distincte canaliculatus, basi super scutellum et lateribus paulo infra medium foveola sat magna impressus, rufus, subnitidus. Scutellum parce subtilissime punctulatum. Elytra thorace duplo latiora et duplo longiora, subdepressa, dense subtiliter punctata, subtiliter flavescentipubescentia, rufo - testacea, subnitida. Abdomen dorso depressum, subtiliter punctulatum, subtilissime tenuiter flavescenti-pubescens, subnitidum, iam nigrum, iam piceum, iam piceo-testaceum, apicem versus magis nigricans. Pectus rufo-testaceum. Pedes testacei.

\section{Micralymma Westw.}

Westwood Magaz. of Zool, und Bot. II. p. 129. t. 4.

Palpi maxillares articuló ultimo penultimo triplo longiore.

Antennae rectae, filiformes.

Tibiae omnes muticae.

Corpus elongatum, sublineare, depressum, apterum. Caput oblongum, thorace paulo angustius, porrectum, basi vix constrictum, oculis mediocribus, rotundatis, parum prominulis. Labrum transversum, apice bisinuatum, margine ciliato (W.). Mandibulae haud prominentes, muticae. Maxillae mala interiore gracili, apice acuto intus setoso, exteriore maiore, sub apice articulata (Westw.). Palpi maxillares articulo primo minuto, secundo obco- 
nico, tertio hoc breviore, quarto iterum longiore, apice subacuminato. Mentum transversum. Ligula biloba. Palpi labiales breves, 3 -articulati, articulis sensim decrescentibus (Westw.). Antennae filiformes, apicem versus sensim paulo crassiores, articulo primo crassiusculo, secundo hoc paulo breviore tenuioreque, subobconico, tertio hoc longitudine aequali, at iterum paulo tenuiore, quarto sequentibusque subglobosis, sensim panlo latioribus, penultimis sensim transversis, ultimo breviter ovato, apice subacuminato. Thorax coleopteris paululum angustior, hasin versus leviter angustatus. Scutollum breve, apice leviter rotundatum. Elytra brevia, apice leviter rotundata. Abdomen elongatum, ab apice basin versus sensim subangustatum, late marginatum. Pedes breviusculi, intermedii basi approximati, tibiis omnibus muticis, tarsis 5 -articulatis, articulis 4 primis perbrevibus, inter se aequalibus, subtus pubescentibus, quinto his coniunetis paulo breviore.

\section{O b s e r vat i n e s.}

1. Corpus parcius subtiliter pubescens. Caput, thorax et elytra parce, abdomen paulo crebrius punctata.

2. Habitus obiter observatus, Aleocharam quandam, e. g. Homalotam simulat, Oxytelinis alienus, at characteres huius tribus et subtribus.

3. Sexus differentia latet.

4. Victus in littore maris, intra aestus surgentis et collabentis limites, quo fit, ut aestu alterno animalculum retegatur et altera vice per quatuor horas obtegatur.

5. Larra et nympha, a Dom. Johnston cum imagine lectae hoc modo a Dom. Westwood describuntur: "Larvae corpus elongatum, angustum. Caput oblongum, depressum. Mandibulae falcatae, intus medio fortiter dentatae. Maxillae stipite elongato, mala 2-articulata, articulis longitudine aequalibus, secundo tenuiore. Palpi maxillares 4. articulati, articulis 2 primis crassis, primo breviore, tertio quartoque tenuioribus, subaequalibus. Lábium quadrangulum, stipitibus palporum labialium cylindricis, liberis. Palpi labiales tenues, 2-articulati. Antennae 4-articulatae, articulo primo, secundo quartoque longitudine subaequalibus, tertio duplo longiore, processu laterali aucto. Prothorax segmentis sequentibus maior, his subaequalibus, excepto ultimo minore, ano tubuloso, utrinque cauda setosa 2 -articulata instructo. Pedes breves, praeter coxam 4-articulati, unguiculo singulo instructae. Nympha thoracis margine antico setis duabus perlongis et nonnullis brevioribus instructo, abdomine lateribus setoso, apice lobulis duabus angustis terminato.

1. M. brevipenne: Nigrum, subnilidum, parce subtiliter punctatum, antennis ante basin geniculisque piceis. - Long. $1 \frac{2}{3}$ lin.

O malium brevipenne Gyll. Ins. Suec. II. 234. 31. - Zetterst. Faun. Lappon. I. 56. 18. Ins. Lappon. 54. 26.

Micralymma Johnstonis Westw. Mag. of Zool. et Bot. II. p. 130. t. 4. f. 1 .

Habitat in littore maris Sueciae et Angliae. Specimen a Dom. Westwood missum e coll. Dom. Aubé descripsi.

Nigrum, subnitidum, parce subtiliter pubescens. Antennae capitis thoracisque prope longitudine, nigrae, articulo secundo tertioque piceis. Caput thorace paulo angustius, depressum, parce subtiliterque punctatum, fronte inter oculos et inter antennarum insertionem utrinque obsolete impressa. Tliorax latitudine anteriore paululum brevior, basin versus angustatus, lateribus ante medium fortıter rotundatis, pone medium subsinuatis, basi apiceque truncatus, angulis ommibus rotumdatis, parum convexus, parce subtiliterque punctatus, dorso longitudinaliter depressus, linea media longitudinali 
subelevata laevi. Elytra thorace haud longiora, apice singula leviter rotuindata, basin versus sensim leviter angustata. Abdomen crebrius subtiliusque punctulatum. Pedes nigri, geniculis piceis.

\section{Syntomium Curt.}

Curt. Britt. Ent. V. t. 228.

\section{Paraglossae ligulae connatae.}

Palpi muxillares articulo quarto tertio minore, acuminato. Antennae rectae, arliculis ultimis tribus abrupte crassioribus.

\section{Tibiae omnes mulicae.}

Corpus breviusculum, crassiusculum, alatum. Caput thorace paulo minus et angustius, porrectum, basi haud constrictum, oculis mediocribus, subglobosis, leviter prominulis. Labrum transversum, medio sinuatum, margine antico membrana prominula limbato, laciniis lateralibus parvis, angulatim prominentibus, sinu interiecto setis cråssiusculis dense ciliato. Mandibulae haud prominentes, breviusculae, crassiusculae, muticae, intus basi membrana ciliata fimbriatae. Maxillae (t. V. f. 23. b.) malis breviusculis, interiore membranacea, interne ciliata, exteriore coriacea, apice barbata. Palpi maxillares breviores, articulo primo minimo, secundo obconico, tertio paulo maiore, crassiusculo, quarto hoc minore, acuminato. Labium (t. V. f. 23. a.) mento transversim subquadrato, ligula lata, medio sinuata, membranea, apice medio spinulis duabus brevibus, acutis, corneis instructa, paraglossis ligulae aequalibus, eidemque connatis, sutura nonnisi setularum serie indicata. Palpi labiales ligulam vix superantes, articulis duobus primis aequalibus, tertio paulo minore. Antennae rectae, articulo primo secundoque crassiusculis, tertio sequentibus longiore, obconico, $4-8$ parvis, subglobosis, ultimis tribus distincte crassioribus, clavam oblongam formantibus. Thorax transversus, coleopteris angustior. Elytra apice singula rotundata, interne coniunctim sinuata. Abdomen coleopterorum latitudine, supra planum, laribus late marginatum, subtus convexum. Pedes breviusculi, coxis intermediis approximatis, tibiis omnibus simplicibus, tarsis $\mathbf{5}$-articulatis, articulis 4 primis brevibus, aequalibus, quinto his coniunctis aequali.

\section{O b s e r vation es.}

1. Corpus fortiter punctatum, tenuiter pubescens, colore metallico insigne.

2. Sexus differentia latet.

3. Victus in silvis umbrosis. Incessus lentus tardusque.

4. Larva glomeriformis, ovata, convexa, laevis, nigro-aenea, nitida, cum imagine occurrit. Specimina sicca e Carinthia a Dom. Schmidt cum imagine missa magis cum Silpharum, quam cum reliquorum Staphylinorum larvis congruere videntur, mihi haud-rite examinata.

* 1. S. a eneum: Viridi-aeneum, nitidum, antennis apice pedibusque rufopiceis, capite, thorace elytrisque profunde punctatis. - Long. paulum ultra 1 lin.

Omalium a eneum Mïller Germ. Mag. IV. 216. 17. - Gyll. Ins. Suec. IV. 466. $22-23$.

Syntomium nigro-aeneum Curlis Britt. Lint. V. t. 228. 
Habitat in Germania, Suecia, Anglia, locis umbrosis humidis lente tardeque per humum repens (Mïll.).

Corpus obesulum, virescenti-aeneum, nitidum, subtilissime pubescens. Antennae capitis thoracisque prope longitudine, crassiusculae, pilosellae, nigrae, apicem versus rufo-piceae. Caput thorace duplo minus, crebre fortiter punctatum, inter antennas bifoveolatum. Thorax coleopteris paulo angustior, latitudine duplo fere brevior, lateribus fortiter rotundatis, basin versus sinuato-angustatus, basi apiceque truncatus, angulis anterioribus rotundatis, posterioribus obtusiusculis, fortius convexus; creberrime fortite profundeque punctatus, linea media longitudinali laevi subcarinata, basi bifoveolatus, margine laterali subtiliter crenulato. Elytra thorace paulo longiora, leviter convexa, basi media subelevata, confertissime fortiter profundeque punctato-subrugosa. Abdomen laeve, lateribus rotundatum, margine laterali elevato. Corpus subtus nigrum, pectore punctato, abdomine laevi. Pedes rufo picei. 


\section{Tribus octava.}

\section{P i e s t i n i.}

Sligmata prothoracica occulta.

Coxae posticae transversae, anticae globosae, haud prominentes. Trochanteres postici simplices.

Labrum breve, transversum, apice medio sinuatum, corneum, utrinque lacinia interne ciliata auctum, lacinia

triangulari, membranea, labro contigua plerisque;

rhomboidea, membranea, labro continua L ep to chiro.

Mandibulae validae, dentatae, prominentes, saepius porrectae Le p to chiro, Piesto,

muticae, interne lacinia membranea ciliata fimbriatae, parum prominentes reliquis;

maris cornutae Prognathae.

Maxillae stipite extus sub palporum basi leviter dilatata, mala interiore angustiore, breviore, interne barbata, exteriore segmento inferiore minore corneo, apicali membraneo, dilatato, semicirculari plerisque;

parallelo Hypotelo.

Palpi maxillares filiformes, articulo primo minuto.

Mentum corneum, labii partes membraneas praeter ligulam abtegens.

Ligula membranea saepius biloba.

Paraglossae nullae plerisque;

ligulae connatae Hypotelo.

Palpi labiales breves, filiformes.

Antennae sub frontis margine laterali insertae, 11-articulatae, rectae, filiformes, nonnunquam corpore longiores.

C a p ut porrectum, thoraci immissum, basi leviter constrictum.

Thorax totus corneus, spatio etiam pone coxas anticas clauso, coleopterorum saepius latitudine,

basi ab elytris remotus Lep tochiro, Piesto, Is omalo;

elytrorum basi applicatus Lispino, Prognathae, Hypotelo. 
Scutellum distinctum.

Elytra pectoris longitudine.

Abdomen segmentis sex compositum, septimo haud exserendo, immarginatum, cylindricum L e p to chiro; immarginatum, subdepressum $\mathrm{L}$ is p in o; tenuissime marginatum Is o m al o; late marginatum Piesto, Prognathae, Hypotelo.

Pedes breviusculi, validiusculi, coxis anticis parvis, glohosis, ex acetabulis haud prominentibus, intermediis approximatis, trochanteribus posticis simplicibus, tibiis anticis,

margine exteriore crenato Leptochiro, Piesto;

integris, anterioribus spinulosis Prognathae, Hy potelo;

muticis Lispino, Is o malo;

spinis terminalibus altera validiore, tibiarum anticarum valida, tarsis $\mathbf{5}$-articulatis, simplicibus.

$$
\text { O b s e r.va } \mathbf{t} \text { i o n e s. }
$$

1. Proxima tribui praecedenti, quacum a Latreillio confusa est, at coxis anticis globosis haud exsertis, abdominis segmento septimo nullo modo conspicuo etc. satis distincta. Labri structura in utraque eadem.

2. Mas nonnunquam fronte cornuta spinosave, interdum etiam antennis elongatis insignis. Notae sexuales in abdominis apice haud observantur.

3. Victus sub arborum putrescentium cortice.

\section{Eeptochirus Germ.}

\section{Germ. Spec. Ins. nov. p. 35.}

Mandibulae exsertae, dentalae.

Tibiae anticae serratae.

Abdomen immarginatum.

Corpus mediocre, elongatum, depressum, abdomine angusto, cylindrico, alatum. Caput exsertum, porrectum, subquadratum, fronte interdum antrorsum prominente, oculis parvis, rotundatis, prominulis. Labrum (t. V. f. 7. c.) emarginatum, laciniis membraneis longioribus, parallelopipedis, intus ciliatis. Mandibulae validae, porrectae, fortiter dentatae. Maxillae (t. V. f. 7. b.) malis membraneis, interiore oblonga, intus barbata, exteriore suborbiculata, apice pubescente. Palpi maxillares articulo primo minuto, secundo elongato, subclavato, tertio hoc plus duplo breviore, obconico, quarto tertio paulo longiore, cylindrico, apice subacuminato. Labium (t. V. f. 7. a.) mento antrorsum angustato, lateribus sinuato, apice medio obsolete unidentato, ligula bifida, laciniis linearibus, divergentibus, membranaceis, intus ciliatis. Palpi labiales ligulae subaequales, articulis duobus primis cylindricis, tertio paulo minore, acuminato. Antennae capite thoraceque haud longiores, articulo primo magno, clavato, secundo minuto, globoso, reliquis moniliformibus. Thorax coleopterorum latitudine, quadratus, basi medio paulum productus, ab elytris remotus. Scutellum parvum triangulare. Coleoptera quaIrata, angulis posterioribus rotundatis. Abdomen coleopteris duplo angustius, subcylindricum, imınarginatum, segmento penultimo reliquis paulo longiore, ultimo conico. Pedes breves, femoribus incrassatis, tibiis angustis, anticis margine exteriore dense serrato, posterioribus muticis, tarsis brevissimis, debilibus, articulis quatuor primis minutis, aequalibus. 
O b s e r v a t i o n e s.

1. Corpus parce pilosellum, capite, thorace elytrisque supra glaberrimis. Thorax linea impressa canaliculatus. Elytra laevigata, stria suturali impressa.

2. A Latreillio aliisque nonnullis auctoribus cum Zirophoro commutatus, quocum fronte saepius cornuta, mandibulis exsertis dentatis et tibiis anticis serratis convenit, a quo autem praeter oris structuram abdomine immarginato cylindrico facile distinguitur.

3. Sexus differentia latet.

4. Victus gregarius sub arborum putrescentium cortice.

* 1. L. maxillosus: Niger, nitidus, fronte mutica, canaliculata, antice utrinque foveolata, apice producta, biloba. - Long. $4 \frac{1}{3}-6 \frac{1}{3}$ lin.

Var. a: Thorace pectore, elytrisque rufo-castaneis.

Jeptochirus brunneo-niger Perty Delect. An. Art. p. 32. t. 7.f. 7.

Leptochirus Cayennensis Laporte Etud. Ent. I. 125. 2. t. 4. f. 5.

Var. b: Thorace, pectore elytrisgue rufo-castaneis, his apice nigris.

Cucuius maxillosus Fab. Syst. El. II. 93. 8.

Habitat in America meridionali: Brasilia, Cayenna, Columbia, Mexico.

Niger, nitidus. Antennae capite thoraceque paulo breviores, pilosellae. Caput thorace paulo angustius, fronte plana, canaliculata, apice utrinque foveolata, medio producta, biloba. Thorax subquadratus vel latitudine parum brevior, lateribus rectis, apice late leviter emarginatus, planus, canaliculatus. Coleoptera thoracis longitudine latitudineque, plana, stria suturali impressa, margine inflexo punctulato. Abdomen parce pubescens, segmentis singulis basi utrinque parum-punctatis. Pedes' nigri, tarsis rufo-piceis, femoribus posticis fortius incrassatis.

Variat thorace, pectore elytrisque aut nigerrimis aut rufo-castaneis, his interdum apice nigris.

Frons nonnunquam, forte secundum sexum (an in femina?) ante apicem transversim subimpressa.

2. L. scoriaceus: Niger, nitidus, fronte mutica, canaliculata, apice bi-impressa, thorace transversim subquadrato. - Long. 9 lin.

Germ. Spec. Ins. nov. 35. 58. $t$. 1. $f$. 1 .

Zirophorus coriaceus Griff. Animal Kingd. XIV. p. 306. $t$, 32. $f .4$.

$V$ ar. Plus duplo minor, long. 5 lin.

Habitat in Brasilia; in Columbia interiore, Dom. Buquet; in Mexico, collect. Dom. Chevrolat.

Corpus totum nigerrimum, tarsis solis rufo-piceis. Antennae capiti thoracique longitudine subaequales, pilosellae. Caput thorace paulo angustius, fronte depressa, profunde canaliculata, antice haud protuberante, foveolis duabus transversis terminata. Thorax latitudine paulo brevior, lateribus rectis, parallelis, apice late leviter emarginatus, planus, canaliculatus, laevissimus. Elytra thorace paululum longiora, plana, laevissima, stria suturali impressa, lateribus inflexis obsolete parceque -punctatis. Abdomen utrinque parce punctatum. 
* 3. L. Mexicanus: Niger, nitidus, fronte mutica, canaliculala, apice bi-impressa, thorace quadrato. - Long. 7 lin.

Habitat in Mexico.

Corpus totum nigerrimum, nitidum, tarsis solis rufo-piceis. Antennae capitis thoracisque longitudine, pilosellae. Caput thorace paulo angustius, fronte profunde canaliculata, apice haud producta, foveolis duabus transver. sim terminata, punctis quatuor notata, binis ad apicem approximatis, binis in medio, magis distantibus. Thorax latitudine haud brevior, lateribus rectis, parallelis, apice truncatus, subdepressus, laevissimus, profunde canaliculatus. Elytra thorace paululum longiora, subdepressa, laevissima, stria suturali impressa, lateribus inflexis parce obsoleteque punctatis. Abdomen lateribus parce obsoleteque punctatum.

O bs. Differt a praecedente statura graciliore, minus plana, thorace latitudine haud breviore, fronte 4-punctata.

* 4. L. laticeps: Niger, nitidus, fronle mutica, plana, antice bifoveolala. - Long. $5 \frac{1}{2}-6$ lin.

Habitat in Java, Dom. De Haen.

Niger, nitidus, tarsis solis rufo-piceis. Antennae capite thoraceque breviores, pilosellae. Caput thoracis latitudine, fronte plana, laevissima, haud canaliculata, apice foveolis duabus minutis profundis distantibus impressa. Thorax latitudine brevior, lateribus rectis, basin versus subangustatus, apice late leviter emarginatus, planus, laevissimus, subtilius canaliculatus. Coleoptera thorace subangustiora et vix longiora, depressa, laevissima, stria suturali impressa, lateribus inflexis crebrius punctatis. Abdomen lateribus crebrius punctatum.

* 5. L. unicolor: Niger, nitidus, fronte postice canaliculata, anlice subimpressa, margine antico trideniato. - Long. 6 lin.

Laporte Etud. Ent. I. 125. 1.

Habitat in Java, Dom. De Haen.

Statura praecedentium, piceo-niger, nitidus. Antennae capite thoraceque paulo breviores, dense flavescenti-pilosae. Palpi rufo-picei. Caput thorace angustius, fronte profunde canaliculata, clypei spatio subdepresso, inea semicirculari sat profunde impressa circumdato, apice tridenticulato. Thorax latitudine brevior, lateribus levissime rotundatis, planus, laevissimus, profunde canaliculatus. Elytra thorace paulo longiora, plana, laevia, stria suturali impressa, lateribus inflexis parce punctatis. Abdomen lateribus parce punctulatum. Pedes dilute rufo-picei.

* 6. L. ebeninus: Niger, nitidus, fronte postice profunde canaliculata, antice subimpressa, margine antico bidenticulato. - Long. $3 \frac{1}{2}$ lin.

Habitat in Maragascar, Dom. Goudot.

Praecedente plus duplo minor, nigerrimus, nitidus. Antennae vix capitis thoracisque longitudine, crassiusculae, parce pilosellae. Palpi rufopicei. Caput thorace angustius, fronte profunde canaliculata, clypei spatio subimpresso, linea semicirculari impressa circumscripto, margine laterali el evato, apice denticulo prominulo terminato. Thorax latitudine brevior, la- 
teribus subrectis, antrorsum subangustatis, subdepressns, profunde canaliculatus, lateribus parce sat distincte punctatus. Elytra thorace longiora, depressa, laevia, stria suturali impressa, margine laterali punctorum serie notato. Abdomen parce obsolete punctulatum. Pedes picei, tarsis dilute rufo-piceis.

O os. Lep to chirus convexus Laporte (Etud Ent. I. p. 132.) absque dubio idem, at descriptio manca non satis quadrat, quam ob rem hoc insectum pro novo proponendum putavi.

7. L. brevicornis: Niger, nitidus, thorace piceo, fronte excavata, postice canaliculata, antice utrinque elevato producta. - Long. 5 lin.

-Habitat in Java, collect. Dom. Chevrolat.

Habitu omnino L. unicoloris, niger, nitidus, thorace piceo, nitido. An . tennae capite thoraceque paulo breviores, dense flavescenti-pilosae. Palpi rufo-picei. Caput thorace angustius, fronte tota excavata, lateribus elevatis, antice elevato-productis, postice canaliculata, clypei spatio linea impressa semicirculari terminato, margine antico mutico. Thorax coleopteris paulo latior, postice latitudine duplo fere brevior, antrorsum angustatus, leviter convexus, dorso canaliculatus, praeterea laevissimus, lateribus parce punctatis. Elytra thorace longiora, fere plana, laevissima, stria suturali impressa. Abdomen laeve, parce flavescenti-pilosellum, segmentis singulis margine postico piceo. Pedes flavescenti-piloselli, nigro-picei, tarsis rufescentibus.

\section{* 8. L. bispinus: Niger, nilidus, fronte bispinosa. - Long. $3 \frac{2}{3}$ lin.}

Habitat in Java, Dom. De Haen.

Corpus totum nigerrimum, nitidum. Antennae capitis thoracisque prope longitudine, pilosellae, piceae, articulo primo nigro. Mandibulae elongatae. Caput thorace paulo angustius, fronte plana, antice in spinas duas porrectas, sat validas, acutas producta, inter spinas profunde impressa. Thorax latitudine brevior, lateribus parallelis, vix rotundatis, apice leviter late emarginatus, planus, laevissimus, subtilius canaliculatus. Elytra thorace vix longiora, plana, laevia, stria suturali impressa, lateribus punctis paucis impressa. Abdomen laeve. Pedes trochanteribus tibiisque piceis, his apicem versus sensim dilutioribus, tarsis dilute rufo-piceis.

\section{* 9. L. Javanicus: Niger, nitidus, thorace sanguineo, fronte bispinosa. - Long. 7 lin.}

\section{Laporte Etud. Ent. I. 126. 3. t. 4. f. 6.}

Habitat in Java, Dom. De Haen.

Corpus nigerrimum, nitidum, thorace sanguineo. Antennae capite thoeeque paulo breviores, dense pilosellae, piceae, articulo ultimo ferrugineo. Mandibulae valde elongatae. Caput thorace angustius, fronte plana, antice in spinas duas sat validas longasque, acutas, porrectas producta, inter spinas excavata. Thorax latitudine brevior, lateribus perparum rotundatus, apicem versus subangustatus, planus, obsolete canaliculatus, lateribus punctis parcis impressus. Elytra thorace paulo longiora, plana, laevissima, stria suturali inpressa, margine laterali punctorum serie notato. Abdomen segmentis singulis basi utrinque punctorum piliferorum serie transversali impressis. Pedes nigri, tarsis dilute rufo piceis, femoribus anticis sanguineis. 


\section{Lispinus $E r$.}

Mandilulae mulicae, haud prominentes.

Tibiae anticae integerrimae.

Abdomen immargina/um.

Corpus lineare, subdepressum, alatum. Caput porrectum, tronte antice rotundata, subtiliter marginata, oculis rotundatis, leviter promintilis. Labrum minutum, utrinque lacinia triangulari membranea auctum. Mandibulae simplices, falcatae, porrectae, at minutae et haud prominentes. Maxillae (t. V. f. 8. b.) mala exteriore segmento prino sive basali corneo, secundo subsemicirculari, membraneo, costulis radialibus plicato, basi laevi, mala interiore extus cornea, apice denticulo introrsum curvato armata, margine interiore membraneo, apicem versus spinulis ciliato. Palpi maxillares breves, articulo primo minuto, secundo longiore, obconico, tertio brevi, crassiusculo, quarto iternm longiore, cylindrico. Labium (t. V. f. 8. a.) mento antrorsum angustato, utrinque bisinuato, apice rotundato, ligula sat ampla, triloba, lobis lateralibus latis, interne pubescentibus intermedio multo breviore, emarginato, Palpi ligula paulo longiores, articulis longitudine subaequalibus. Antennae capite thoraceque haud longiores, crassiusculae, articulo prinn tertioque reliquis transversis paulo longiores. Thorax quadrangulus, basi coleopteris applicatus. Scutellum minutum, triangulare. Elytra truncata. Abdomen lineare, subdepressum, immarginatum. Pedes breves, femoribus crassiusculis, compressis, tibiis tenuibus, omnibus muticis, tarsis minutis.

O b s e r v a t i o n e s.

1. Corpus glabrum, saepius punctatum, fronte semper mutica, elytris stria suturali impressa. A praecedente genere mandibulis tibiisque muticis, thorace basi truncato et minus ab elytris remoto, abdomine depressiusculo, a reliquis abdomine immarginato praeter oris structuram distinguitur.

2. Sexus differentia latet.

* 1. I. attenualus: Piceus, nitidus, pedibus rufis, crebre punctalus, fronte bifoveolata, thorace basi utrinque longitudinaliter impresso, apicem versus subangustato. - Long. $2 \frac{1}{3}$ lin.

Habitat in ins. Puerto-Rico, Dom. Moritz.

Corpus elongatum, sublineare, subdepressum, piceum, nitidum. Antennae capite thoraceque paulo breviores, crassiusculae, apicem versus leniter incrassatae, articulo tertio elongato, piceae. Os rufo-piceum. Caput thorace paulo angustius, crebrius subtiliter punctatum, fronte leviter convexa, inter oculos bi-impressa. Thorax basi coleopterorum latitudine, latitudine paulo brevior, apicem versus sensim leviter angustatus, lateribus subrectis, apice subemarginatus, parum convexus, creberrime punctatus, punctis oblongis, medio linea subtilissima utrinque abbreviata canaliculatus, basi utrinque longitudinaliter leviter impressus. Elytra thorace paulo longiora, sat crebre parum profunde punctata, stria suturali impressa. Abdomen obsoletissime punctulatum, apice rufo-piceum. Pedes rufi.

* 2. L. laticollis: Rufo-piceus, nitidus, parce subtilitergue punclatus, fronte aequali, thorace latiore, basi utrinque longitudinaliter impresso, apicem versus subangustalo. - Long. 2 lin.

Habitat in Cuba, Dom. Riehl.

Statura et summa affinitate praecedentis, rufo-piceus, nitidus. Anten- 
nae capite thoraceque vix breviores, apicem versus leniter incrassatae, articulo tertio elongato. Caput thorace angustius, parce subtilissime punctulatum, fronte leviter convexa, aequali. Thorax coleopteris paululum latior, latitudine dimidio brevior, apicem versus leviter angustatus, lateribus leviter rotundatis, apice late emarginatus, parum convexus, parce subtiliter punctatus, basi ad angulum utrumque posteriorem longitudinaliter impressus. Elytra thorace paululum longiora, parce subtiliter punctata, stria suturali impressa. Abdomen apicem versus leniter attenuatum, obsolete subtiliter punctatum, Pedes rufi, tarsis testaceis.

Obs. Distinctus a praecedente corpore minus cylindrico, punctura multo parciore subtilioreque et fronte haud foveolata.

* 3. L. striola: Piceus, nitidus, pedibus rufis, capite thoraceque crebre punctatis, hoc basi utrinque longitudinaliter impresso, lateribus parallelis, elytris parce subtiliter punctatis, disco striola longitudinali notatis. - Long. 2 lin.

Habitat in Columbia et in Americae meridionalis insulis.

Elongatus, linearis, subdepressus, piceus, nitidus. Antennae capite thoraceque breviores, apicem versus parum incrassatae, articulo secundo tertioque subaequalibus, piceae, articulo ultimo ferrugineo. Palpi rufo-picei. Caput thorace paulo angustius, crebre subtilius punctatum, fronte parum convexa. Thorax coleopterorum prope latitudine, latitudine parum brevior, lateribus subrectis, parallelis, apice leviter emarginatus, perparum convexus, crebre minus subtiliter punctatus, basi utrinque sulculo lato longitudinali impressus. Elytra thorace parum longiora, parce subtiliterque punctata, stria suturali striolaque basi apiceque abbreviata disci impressa. Abdomen parce subtiliter punctatum. Pedes rufi.

* 4. L. angustatus: Piceus, nilidus, pedibus rufis, capite thoraceque crebre, elytris abdomineque parcius punctatis, fronte bifoveolata, thorace postice utrinque impresso, basin versus angustato. - Long. 2 lin.

T. II. f. 6 .

Habitat in Madagascar, Dom. Goudot.

Elongatus, linearis, subdepressus, piceus, nitidus. Antennae capitis thoracisque prope longitudine, crassae, pone medium subincrassatae, piceae, articulo secundo tertioque aequalibus. Caput thorace paulo angustius, crebrius punctatum, fronte antice utrinque impressa. Thorax ante medium coleopterorum latitudine, latitudine paulo brevior, lateribus leviter rotundatis, pone medium angustatus, basi truncatus, angulis posterioribus rectis, apice sat profunde emarginatus; subdepressus, crebrius punctatus, medio linea subtilissima canaliculatus, basi ad angulum posteriorem utrinque foveola oblonga impressus. Elytra thorace longiora, parcius punctata, stria suturali impressa. Abdomen minus crebre punctatum, lateribus punctorum maiorum serie notatum. Pedes rufi.

5. L. linearis: Piceus, subnitidus, pedibus testaceis, parce punctatus, fronte aequali, thorace basi utrinque profunde longitudinaliter impressso, basin versus subangustato. - Long. $1 \frac{3}{4}$ lin.

Uabitat in montibus prope Puerto Cabello in Columbia, Dom. Moritz. 
Elongatus, linearis, subdepressus, piceus, minus nitidus. Antennae ca. pite paulo longiores, apicem versus subincrassatae, articulo secundo tertioque aequalibus, rufo-piceae. Caput thoracis fere latitudine, subtiliter parcius punctatum, fronte aequali hand impressa. Thorax coleopterorum prope latitudine, latitudine parum brevior, lateribus subrectis, basin versus sensim subangustatus, apice leviter emarginatus, subdepressus, sat crebre punctatus, basi ad angulum posteriorem utrinque sulco antrorsum sensim evanescente longitudinali impressus. Elytra thorace paulo longiora, crebrius punctata, stria profunda suturali impressa. Abdomen parcius obsoletiusque punctatum, apice rufo-piceum. Pedes rufo-testacei.

* 6. :L. tenellus: Piceus, nilidus, pedibus rufis, capite, thorace elytrisque parce punctatis, fronte bifoveolata, thorace basi utringue longitudinaliter impresso, leviter coarctalo. - Long. $1 \frac{1}{3}$ lin.

Habitat in Columbia et in Americae meridionalis ins. St. Johannis et Puerto - Rico, Dom. Moritz.

Habitu omnino praecedentium, at multo minor, elongatus, sublinearis, subdepressus, piceus, nitidus. Antennae capitis thoracisque prope longitudine, apicem versus leviter incrassatae, articulo secundo tertioque subaequalibus, dilute rufo-piceae. Caput parce subtilissime punctatum, fronte utrinque impressa. Thorax coleopterorum prope latitudine, latitudine paulo brevior, lateribus modice rotundatus, basin leviter angustatus, angulis posterioribus rectis, antice subemarginatus, subdepressus, subtiliter sparsim punctatus, basi ad angulum posteriorem utrinque sulco longitudinali impressus. Elytra thorace sesqui fere longiora, parce subtilissime punctata, stria suturali impressa. Abdomen subtilissime punctato-coriaceum, segmentorum marginibus apiceque dilutioribus. Pedes rufo-testacei.

7. L. exiguus: Rufo-testaceus, nitidus, laevis, thorace basi utrinque impresso, basin versus angustalo. - Long. 1 lin.

Habitat in ins. Puerto - Rico, Dom. Moritz.

Habitu omnino L. tenelli, at dimidio fere minor, rufo-testaceus, nitidus. Antennae capite paulo longiores, apice modice incrassatae, articulo secundo tertioque subaequalibus. Caput thorace parum angustius, laeve, fronte utrinque longitudinaliter impressa. Thorax antice coleopterorum prope latitudine, latitudine vix brevior, lateribus parum rotundatus, basin versus leviter angustatus, angulis posterioribus rectis, apice truncatus, subdepressus, laevis, basi ad angulum posteriorem utrinque foveola sat profunda impressus. Elytra thorace parum longiora, laevia, stria suturali obsoleta. Abdomen omnium subtilissime punctato-coriaceum. Pedes pallide testacei.

\section{Piestus Grav.}

Grav. Mon. p. 223. - Laporte Etud. Ent. I. p. 126.

Zirophorus Dalm Act. Holm. 1821. p. 371. Anal. Ent. p. 23.

Trichocoryne Gray Animal Kingd. XIV. p. 306.

Mandibulae dentatae.

Palpi maxillares articulo ultimo penultimo longiore.

Tibiae anticae externe crenalae.

Abilomen marginalum.

Corpus oblongum, depressum, alatum. Caput thorace minus et angu- 
stius, fronte inaequali, interdum cornubus duobus antrorsum directis horizontalibus munita, oculis parvis, parum prominulis. Labrum (t. V. f. 9. c.) transversum, apice truncatum, angulis anterioribus rotundatis, laciniis membraneis angustis, linearibus. Mandibulae validae, porrectae, dentatae. Maxillae (t. V. f. 9. b.) malis membranaceis, interiore intus, exteriore apice barbatis, hac externe rotundato-dilatata. Palpi maxillares articulo primo minuto, secundo elongato, subarcuato, tertio hoc duplo breviore, quarto secundo paulo longiore, cylindrico, apice obtuse acuminato. Labinm (t. V. f. 9. a.) mento antice rotundato, ligula membranacea, medio incisa, apice truncata, barbata. Palpi labiales breves, ligulam vix superantes, articulis longitudine subaequalibus. Antennae elongatae, interdum corpore longiores, articulo primo longiusculo, secundo parvo, obconico, tertio iterum elongato, clavato, apice saepe penicillato, sequentibus cylindricis, pubescentibus. Thorax coleopterorum latitudine, transversus, quadrangulus, basi medio productus, ab elytris remotus. Scutellum parvum, triangulare. Elytra truncata. Abdomen coleopteris vix angustius, minus elongatum, segmento penultimo reliquis paulo longiore, ultimo obtuso. Pedes breves, femoribus crassiusculis, tibiis angustis, anticis infra medium compressis; extus denticulatis, spina apicali validiore instructis, intermediis infra medium extus spinulis setiformibus ciliatis, posticis muticis, tarsis minutis, articulo ultimo reliquos, inter se aequales, coniunctos longitudine prope superans.

\section{o b s e r vation es.}

1. Corpus tenuiter pubescens, capite, thorace elytrisque glaberrimis. Thorax linea media longitudinali integra exaratus, ad angulos posteriores utrinque sulculo magis minusve abbreviato impressus. Elytra striis vel sulcis 5 vel 6 laevibus crenatisve exarata.

2. Huius generis speciem unam Fabricius inter Cucuios, alteram Olivie $\mathbf{r}$ inter Oxytelos proposuerunt; tertiam generis Piesti typum descripsit Gravenhorst. Postea Dalman genus Zirophorus condidit, quod cum Leptochiro Germ. confusum Latreille recepit (Regn. Anim. V. p. 438.). Nomen Gravenhorstianum, Leptochiro probe distincto, Dom. Laporte restituit, forte Lucii Buquetii collectione edoctus, cui notiones vel de genere, vel de specie Fabriciana communicavimus.

3. Mas in nonnullis speciebus antennis longioribus et articulo earum tertio fortius penicillato distinctus; in plerisque sexus differentia latet.

4. Victus sub arborum putrescentium corticibus. Hoc genus Americae calidiori proprium videtur.

5. Larvam forte speciei cuiusdam Cayennensis $\mathrm{Ziroph}$. longicornis sibi vocatam Dom. Lacordaire in silvis Conanensibus cum imagine observavit, long. 4 linearum, corpore curto, utrinque leviter attenuato, griseo, albido - venoso, capite nigro, mandibulis validis, crassis, bifidis, dente superiore elevato ut in imagine; reliquis oribus partibus vix oculo armato distinguendis, exceptis palpis duobus, articuio aciculari acutissimo terminatis; corporis segmentis singulis papillis binis transversim positis instructis; incessu admodum lento; odore foetido. Specimina nonnulla diebus 8 praeterlapsis in folliculum oblongum sese condiderunt, at imago non prodiit. (Nov. Annal. Mus. Hist. nat. II. p. 65.)

* 1. P. bicornis: Fronte bispinosa, niger, nitidus, abdomine apice rufo, thorace laevi, subtiliter canaliculato, elytris strialis. - Long. $4 \frac{1}{3}$ lin.

Laporte Etud. Ent. I. 128. 1.

Oxytelus bicornis Oliv. Encycl. meth. Ins. VIII. 615. 11.

Zirophorus fronticornis Dalm. Act. Holm. 1821.373. 1. Anal. Ent. 24.1.t.4.f. 1. 
Zirophorus striatus Guér. Iconogr. Ins. t. 9. $f .12$,

Var. Thorace, pectore, elytris pedibusque rufo-castaneis.

P. Oxyt elinus Laporte Etud. Ent. I. 128. 2.

Habitat in Columbia, Dom. Gory, Surinami, Dom. Schïppel.

Niger, nitidus. Antennae corporis dimidiam longitudinem superantes, nigrae, ab articulo quinto inde pube griseo-flavescente dense vestitae, interne longius dense pilosae, quasi barbatae. Mandibulae porrectae, apice acuto, leviter introrsum verso, extus ante apicem denticulo minuto munitae. Caput laeve, fronte aequali, antice fovea rhombea, parum profunda, fundo medio elevato impressa, apice spinis duabus porrectis, rectis, approximatis, acutis, sat longis validisque armata. Thorax latitudine dimidio brevior, lateribus rectis, ad angulos posteriores oblique emarginatis, angulis anterioribus rotundatis, planatus, leviter canaliculatus, basi angulo utroque posteriore leviter impresso. Elytra thorace parum longiora, striis $\mathbf{5}$ simplicibus exarata. Abdomen segmentis singulis basi subtiliter punctatis, penultimo apice ultimoque toto rufis, rufo-pilosis. Pedes nigri, tarsis piceis.

* 2. P. Lacordairei: Fronte bispinosa, niger, nitidus, ano pedibusque piceis, thorace laevi, subtiliter canaliculalo, elytris striatis. - Long. $3 \frac{1}{2}$ lin.

Laporte Etud. Ent. I. 129. 4.

Habitat in Cayenna, a Dom. Com. Dejean nomine Zirophori gregarii communicatus.

P. spinoso longitudine fere aequalis, at multo angustior et minus depressus, niger, nitidus. Antennae corpore tertia parte breviores, subtiliter griseo-pubescentes, parce pilosellae, articulis tribus primis glabris. Mandibulae capitis longitudine, porrectae, sat validae, rectae, ante apicem leviter introrsum arcuatum dentatae. Caput fronte excavata, apice spinis duabus validis, porrectis, parallelis, rectis, acutis, mandibulas longitudine aequantibus, distantibus armata. Thorax latitudine dimidio brevior, lateribus rectis, ad angulos posteriores oblique subemarginatis, angulis anterioribus subrotundatis, planatus, leviter canaliculatus. Elytra thorace paulo longiora, striis $\mathbf{5}$ subtiliter crenatis exarata, extus medio striola brevi subtili impressa. Abdomen minus subtiliter crebre punctulatum, segmentorum summis marginibus anoque piceis. Pedes rufo-picei.

* 3. P. spinosus: Fronte bispinosa, rufo-castaneus, nilidus, capite abdomineque nigris, thorace medio subtiliter punctulato canaliculatoque, elytris punctato-striatis. - Long. $3 \frac{1}{3}$ lin.

Laporte Etud. Ent. I. 128. 3. t. 4. $f .3$.

Cucuius spinosus Fab. Syst. El. 11. 93. 9. - Schönh. Syn. Ins. 111. 53. 8.

Zirophorus (?) spinosus Dalm. Anal. Ent, 25.3.

Piestus oxytelinus Perty Delect. An. art. p. 33. $t .9$. f. 9.

Habitat in Cayenna, Dom. Buquet.

Antennae corpore parum breviores, nigrae, subtiliter cinereo-pubescentes, parce pilosellae, articulis tribus primis castaneis, glabris. Mandibulae porrectae, capite paulo breviores, debiles, rectae, ante apicem dente inferiore. 
introrsum vergente armatae. Caput piceo-nigrum, nitidum, fronte subimpressa, canalicula media brevissima sulcoque arcuato inter antennas exarata, apice spinis duabus porrectis acutis valde distantibus armata. Thorax latitudine duplo fere brevior, lateribus rectis, ad angulos posteriores oblique emarginatis, angulis anterioribus subrotundatis, planus, medio subimpressus, leviter canaliculatus, basi foveola longitudinali impressus, medio foveolisque basalibus punctulatis, rufo-castaneus, nitidus. Elytra thorace paulo longiora, sulcis 5 sat profundis, fortiter punctatis exarata, externe striola abbreviata aliaque apicali impressa, rufo-castanea, nitida. Abdomen nigrum, nitidum, segurentis singulis basi crebre subtilius punctatis, penultimo apice ultimoque toto rufo-castaneis. Pectus rufo-c;astaneum. Pedes rufi.

$\mathrm{O}$ bs. Specimen a Fabricio descriptum in Museo regio Hafniensi asservatum, ipsum vidi, quare locum citatum ad hanc speciem spectare mihi compertum est, licet descriptio allata non omnino convenit.

4. P. capricornis: Fronte bidentala, rufo-piceus, nilidus, abdomine nigro-piceo, thorace subtiliter canaliculato, punctulato, elytris punctalo. striatis. - Long. $3 \frac{2}{3}$ lin.

Lapirte Etud. Ent. I. 129. 5. t. 4. f. 4 .

Habitat in ins. Guadeloupe, collect. Dom. Chevrolat.

Statura omnino praecedentis, at paululum maior. Antennae corpore paulo longiores, parce pilosellae, nigrae, articulis 3 primis rufo-piceis, glabris. Mandibulae hand porrectae, dextra extus cornu falcato, sinistra dente obtuso armata. Caput fronte inter oculos foveolis duabus maiusculis impressa, margine antico emarginato, utrinque dente prominente armato. Thorax latitudine diflo prope brevior, lateribus rectis, ad angulos posteriores oblique emaryinatis, angulis anterioribus subrotundatis, planus, disco sparsim punctatus, tenuiter canaliculatus. Elytra thorace longiora, striis 5 punctatis exarata, externe striola abhreviata media aliaque apicali impressa. Abdomen crebrius punctulatum, nigro-piceum. Tibiae anticae obsolete crenatae.

Obs. A Dom. Laporte Cayenna pro huius insecti loco natali indicata, an rite?

5. P. fulvipes: Fronte mutica, rufo.-picens, nilidus, pedibus fulvis, thorace subtilissime punclulato, canaliculato, elytris 5-sulcatis. - Long. $3 \frac{1}{2} \cdot \operatorname{lin}$.

Habitat in ins. Guadeloupe, Dom. Chevrolat.

P. penicillato maior, magis elongatus, rufo-piceus, nitidus. Antennae corpore paulo longiores, piceo-rufae, dense pubescentes, articulis tribus primis glabris, primo interne acute dentato, dente pilorum fasciculo penicillato. Caput fronte antice truncata, inter oculos utrinque profunde oblique impressa, spatio interiecto triangulari, leviter elevato, laterali incrassato, tumido. Thorax latitudine vix dimidio brevior, lateribus rectis, ad angulog posteriores oblique emarginatis, angulis anterioribus leviter rotundatis, minus depressus, subtilissime punctulatus, sat fortiter canaliculatus, basi utrinque ad angulos posteriores sulculo brevi prof:ndo impressus. Elytra thorace paulo longiora, striis 5 sat profundis, impunctatis exarata, interstitio primo medio bipunctato, extus ante medium lineola abbreviata tenui impressa. Abdomen crebre subtiliter punctulatum, ano segmentorumque singulorum margine postico dilutiore. Pedes testaceo-rufi. 
* 6. P. penicillatus: Fronte mutica, niger, nilidus, ano pedibusque piceis, thorace laevi, subliliter canaliculato, elylris 5-strialis. - Long. $2 \frac{1}{3}-3$ lin.

Zirophorus penicillatus Dalm. Act. Holm. 1821. 373. 2. Anal. ent, 24. 2. t. 4. $f .2$.

Hahitat in Americae meridionalis insulis: St. Barthelemy (Dalm.), PuertoRico. Dom. Moritz.

Niger, nitidus. Antennae corpori longitudine aequales vel eodem paulo longiores, articulo primo tuberculato, tuberculo pilorum fasciculo penicillato. Mandibulae mediocres, apice arcuatae bidentataeque. Caput fronte apice truncata, inter oculos utrinque sat profunde oblique impressa, spatio medio triangulari elevato. Thorax latitudine plus dimidio brevior, lateribus rectis, ad angulos posteriores oblique emarginatis, angulis anterioribus rotundatis, planatus, subtilius canaliculatus, basi utrinque ad angulum posteriorem sulculo brevi sat proftindo impressus. Elytra thorace paulo longiora, striis 5 sat profundis, in fundo obsoletius punctatis excarata, interstitiis subtilissime obsolete punctulatis, extus medio lineola brevi tenuique impressa. Abdomen segmentis singulis basi utrinque subtiliter punctatis, penultimo apice ultimoque piceis. Pedes picei.

* 7. P. erythropus: Fronte mutica, piceus, nitidus, pedibus rufis, thorace subtilissime punctulato, canaliculalo, elylris 5-striatis. - Long. $2 \frac{1}{3}$ lin. Trich ocoryne striata Gray An. Kingd. XIV, p. 306. t. 32. n. 5. (forte)

Habitat in Cuba, Dom. Riehl et collect. Dom. Chevrolat.

Habitu omnino P. minuti, at sesqui maior, saturate nigro-piceus, nitıdus. Antennae longitudine corporis, nigricantes, subtiliter pubescentes, articulis tribus primis rufo-piceis, glabris, primo pilorum fasciculo introrsum vergente penicillato. Caput fronte antice truncata, inter oculos utrinque oblique impressa, spatio interiecto triangulari subelevato, plica transversali suharcuata leviter elevata a vertice distincta. Thorax latitudine dimido brevior, lateribus subrectis, ad angulos posteriores oblique emarginatis, minus planus, parce subtilissime punctatus, sat fortiter canaliculatus, basi utrinque ad angulos posteriores sulculo brevi sat profunde impressus. Elytra thorace paulo longiora, striis $\mathbf{5}$ sat profundis, subtilius punctatis exarata, interstitiis subtiliter punctulatis, externe apice, nonnunquam etiam ante medium, striola tenui impressa. Abdomen sat crebre punctatum, segmentis 4 primis supra medio laevioribus. Pedes testaceo-rufi.

Obs. A P. minuto elytrorum striis punctatis facile distinguendus, a P: penicillato colore, corpore minus plano, elytrorum striis fortius punctulatis etc. distinctus.

* 8. P. minutus: Fronte mutica, castaneus, nitidus, thorace laevi, subtilius canaliculato, elytris 5-striatis. - Long. 2 lin.

Piestus sulcatus Laporte Etud. Ent. I. 129. 6. (forte)

Habitat in Columbia, Dom, Moritz.

Habitu omnino P. penicillati, at dimidio fere minor, castaneus, nitidus, capite thoraceque obscurioribus, piceis. Antennae maris corporis prope longitudine, articulo primo pilorum fasciculo penicillato, feminae corpore 
breviores, articulo primo simplice. Caput thorace angustius, fronte utrinque leviter impressa et profunde oblique arcuatim sulcata, vertice plicula subtili elevata transversa instructo. Thorax latitudine plus dimidio brevior, lateribus subrectis, ad angulos posteriores oblique emarginatis, fere planus, laevis, canalicula tenui exaratus, basi ad angulum posteriorem utrinque sulculo brevi sat profundo impressus. Elytra thorace parum longiora, striis $\mathbf{5}$ simplicibus sat profundis exarata, externe ad apicem striae sextae rudimento notata. Abdomen supra segmentis singulis utrinque subtiliter punctatis, subtus totum crebre distinctius punctatum. Pedes rufi.

* 9. P. pygmaeus: Fronte mutica, niger, nitidus, ore, antennis pedibus, elytrisque rufo-castaneis, thorace subtiliter punclalo, canaliculato, elytris 5-striatis. - Long. $1 \frac{3}{4}-2$ lin.

Laporte Etud. Ent. I. 130. 8.

Habitat in Brasilia; in Columbia Dom. Moritz.

Praecedenti affinis, at paulo minor, praecipue angustior. Antennae maris corpore longiores, feminae paulo breviores, fuscae, pubescentes, articulis tribus primis rufis, glabris, primo pilorum penicillo in mare crasso, in femina tenui instructo. Caput nigrum, ore castaneo, fronte utrinque subimpressa, inter antennas linea transversali, medio fortiter sursum arcuata, exarata. Thorax latitudine dimidio brevior, lateribus subrectis, postice ad angulos posteriores oblique emarginatis, angulis posterioribus ipsis prominulis, acutiusculis, anterioribus subrotundatis, planus, subtiliter punctulatus, canalicula media sat profunda et utrinque sulco profundo longiore longitudinali impressus, niger, nitidus, lateribus nonnunquam castaneis. Scutellum nigro-piceum, nitidum. Elytra thorace paulo longiora, striis $\mathbf{5}$ simplicibus sat profundis exarata, externe ad apicem striae sextae rudimento instructa, interstitiis subtilissime punctulatis, rufo-castanea, nitida. Abdomen supra subtiliter, subtus utrinque evidentius punctatum, nigro-piceum, nitidum, segmentorum marginibus anoque rufo-castaneis. Pectus piceum. Pedes rufi.

* 10. P. sulcatus: Fronte mutica, castaneus, nitidus, thorace subtilissime punctulato, canaliculato, elytris 6-sulcatis. - Long. $2 \frac{1}{3}$ lin.

Grav. Mon. 224. 1. - Lepell. et Serv. Encycl. meth. Ins. X. p. 123.

Habitat in Parà Brasiliae, Sieber.

Statura omnino P. minuti, castaneus, nitidus. Antennae maris corporis longitudine, feminae paulo breviores, articulo primo in mare pilorum fasciculo instructo, feminae nudo. Caput thorace angustius, subtiliter obsolete punctulatum, fronte inter antennas utrinque profunde arcuatim impressa. Thorax latitudine plus dinidio brevior, lateribus leviter rotundatis, ad angulos posteriores fortiter oblique emarginatis, angulis anterioribus subrotundatis, planatus, subtilissime punctulatus, linea longitudinali media sat profunda exaratus, basi utrinque sulco longiore sat forti Iongitudinali impressus. Elytra thorace paulo longiora, sulcis sex integris, sat profundis, subtiliter crenatis exarata, interstitio marginali subcarinato. Abdomen sat crebre, minus subtiliter punctatum, ano dilutiore. Pedes rufi. 
11. P. Mexicanus: Fronte mutica, niger, parum nitidus, pedibus mefopiceis, capite thoraceque punclatis, hoc canaliculato, utrinque sulcalo, elytris punctato - sulcatis. - Long. $2 \frac{1}{4}$ lin.

Laporte Etud. Ent. I. 130. 7.

Habitat in Mexico, collect. Dom. Chevrolat.

Subdepressus, niger, parum nitidus. Antennae corpore breviores, nigrae, subtiliter pubescentes, articulis 3 primis rufo-piceis, glabris. Palpi piceo-rufi. Caput crebre minus subtiliter punctatum, fronte inter oculos utrinque leviter oblique impressa, antice rotundata. Thorax latitudine plus dimidio brevior, antrorsum angustatus, lateribus rotundatis, pone medium profunde oblique emarginatis, sinu utrinque denticulo prominulo terminato, sat crebre subinaequaliter minus subtiliter punctatus, canalicula sat profunda media et utrinque sulco sat lato laterali, ultra medium adscendente impressus. Elytra thorace sesqui longiora, dorso sulcis 6 punctatis exarata, interstitiis angustis, elevatis, laevibus. Abdomen crebre punctatum, ano, segmentorumque singulorum margine postico rufo-piceo. Pedes rufo-picei.

o b s e r v a t i o.

Eleus is Laporte (Etud. Ent. I. p. 131.) Piesto affinis videtur, mihi omnino incognita et dubia, hoc loco forte inserenda. Genus intermedium descriptum est inter Leptochirum et Piestum, antennis brevioribus ut in illo, at apicem versus incrassatis, palpis articulo brevi, tenui acuminatoque terminatis, corpore depresso, capite maximo, quadrato, mandibulis porrectis, arcuatis, thorace brevissimo, capite minore, antice truncato, postice rotundato, coleopteris quadratis. Species singula, E. tibialis, nigra, capite fortiter punctato, thorace 4-foveolato, elytris abdomineque laevibus, tibiis et oris partibus rufescentibus, long. 3 lin. a Goudotio ex ins. Madagascar allata.

\section{Prognatha Latr.}

Latr. Regn. Animal. IV. p. 439. Nov. Annal. Mus. Ilist. nat. I. p. 89.

Siagonium Kirby et Spence Introd. 1. t. 1. f. 3. - Curt. Britt. Ent. 1. 1. 23. :

Mandibulae edentatae, maris cornutae.

Palpi maxillares articulo ultimo penultimo duplo longiore.

Tibiae anteriores spinulosae.

Abdomen marginatum.

Corpus elongatum, depressum, alatum. Caput, praesertim maris, sat magnum, fronte antice rotundata, medio immarginata, in mare prope oculum utrumque cornu horizontali, antrorsum porrecto, acuto armatum, oculis parvis, rotundatis, leviter prominulis. Labrum transversum, medio leviter sinuatum, laciniis membraneis parvis, angustis, linearibus. Mandibulae falcatae, acutae, parum prominentes, feminae simplices, maris extrorsum dilatatae, cornu magno, (mandibula ipsa maiore), horizontali, falcato, mandibulam simulante armatae. Maxillae (t. V. f. 10. b.) mala interiore angusta, exteriore semicirculari, utraque membranea, apice ciliata. Palpi maxillares articulo primo minuto, secundo modice elongato, tertio hoc multo breviore, quarto iterum elongato, secundo paulo longiore, apice subacummato. Labium (t. V. f. 10. a.) mento transverso, lateribus leviter angustato, apice truncato, ligula membranea, biloba. Palpi labiales breves, ligulam vix superantes, articulis tribus subaequalibus, ultimo subacuminato. Antennae maris fere corporis longitudine, feminae capite thoraceque paulo longiores, articulo primo reliquis 
crassiore, secundo tertioque elongato-obconicis, reliquis cyliudricis. Thorax quadrangulus, basi coleopteris arcte applicatus. Scutellum parvum, trian. gulare. Elytra truncata. Abdomen coleopterorum latitudine, lineare, marginatum. Pedes breviusculi, femoribus praecipue posticis leviter incrassatis, tibiis angustis, anticis margine exteriore subtiliter serratis, spina apicali maiore terminatis, tarsis minutis, articulis quatuor primis perbrevibus, subtus setulosis.

\section{O b s e r vatio nes.}

1. Corpus parce tenuiterque pubescens, capite thoraceque glabris, thorace aequali, haud canaliculato, elytris subseriatim punctatis.

2. Mas capite maiore, fronte excavata, utrinque cornuta, mandibulis pariter cornutis, antennis longioribus distinctus.

3. Victus sub arborum cortice.

* 1. P. quadricornis: Nigro-picea, nitida, elytris parce seriatim punctatis, castaneis. - Long. 2 lin.

Buisd. et Lacord. Faun. Ent. Paris. I. 454.

Siagonium 4-corne Kirby et Spence Introd. I. t. 1. f. 3. - Curt. Britt. Ent. I. $t .23$.

Prognatha rufipennis Blondel Annul. Scienc. Nat. X.p. 414. t. 18. f. 14- 15. - Guér. Iconogr. Regn. An. Ins. t. 10. f. 1.

Habitat in Anglia, Dom. Hope, Fontibus Bellaqueis Galliae, Dom. Aubé, Halae Saxonum, Dom. Alexander Klug.

Picea, nitida. Antennae maris corpore tertia parte breviores, feminae eodem dimidio vix longiores, pubescentes, rufae. Caput maris thoracis magnitudine, parce subtiliter punctatum, fionte late leviter excavata, antice laeviore, cornubus divergentibus, frontis apicem paulo superantibus, feminae thorace minus et angustius, crebrius minus subtiliter punctatum, fronte antice rotundata, lateribus marginata, inter antennas utrinque impressa. Thorax coleopteris paulo angustior, latitudine summa paulo brevior, lateribus leviter rotundatis, basin versus angustatus, basi coarctatus, apice leviter bisinuatus, basi truncatus, angulis posterioribus subrectis, subrlepressus, minus confertim subtilius licet profunde punctatus, aequalis. Elytra thorace sesqui longiora, subdepressa, praeter striam suturalem integram striis 4 obliquis postice abbreviatis, punctatis notata, lateribus et apice passim disperse punctata, rufo-castanea, nitıda. Abdomen crebrius punctatum, apice rufo. Pedes rufi.

2. P. humeralis: Nigro-picea, elytris crebre striatim punclatis, macula humerali rufa. - Long. 2 lin.

Siagonium humerale Germ. Faun. Ins. Europ. XVIII. 6.

Habitat in Hungaria montana, Dom. Dr. Frivaldsky.

Statura et summa similitudo praecedentis. Corpus nigrum, nitidum. Antennae maris corpore paulo longiores, feminae paulo breviores, obscure rufae. Caput magnum, in utroque sexu thorace paulo latius, subtiliter punctatum, fronte maris parcius subtiliusque punctata, anterius leviter declivi, sublaevi, postice transversim impressa, vertice fere plicato-elevato, cornubus parallelis, frontis apicem paulo superantibus, feminae crebrius punctata, anterius laeviore, utrinque fortius impressa, antice rotundata. Thorax coleo- 
pteris parum angustior, latitudine paulo brevior, lateribus rotundatus, basi truncatus, angulis posterioribus acutiusculis, depressns, parcius disperse minus fortiter at sat profunde punctatus, aequalis. Elytra thorace plus sesqui longiora, depressa, praeter striam suturalem integram striis senis, apice paululum abbreviatis, punctatis notata, lateribus crebrius subtiliter punctata, subtilissime longitudinaliter strigosa, nigro-picea, plaga magna humerali rufa. Abdomen laevigatum, ano piceo. Pedes rufo-picei.

$\mathrm{Obs}$. Antennis in utroque sexu longioribus, thorace basi fortius coarctato, elytris longioribus, crebrius punctato-striatis, abdomine laevigato, etc. a praecedente satis distincta.

\section{Isomalus $E r$.}

Mandibulae muticae.

Palpi maxillares articulo ultimo penultimo minore.

Tibiae muticae.

Abdomen subtiliter marginatum.

Corpus elongatum, lineare, valde depressum, planum, forte apterum. Caput porrectum, magnum, quadratum, in utroque sexu muticum, fronte antice rotundata, immarginata, oculis parvis, rotundatis, parum prominulis. Labrum minutum, transversum, angulo apicali utroque lacinia angusta membranea aucto. Mandibulae in utroque sexu minutae, muticae, vix prominentes, basi latiusculae, sensim acuminatae, introrsum falcatae. Maxillae (t. V. f. 11. b.) mala interiore angusta exterioreque semicirculari membraneis, hac basi cornea. Palpi maxillares breviusculi, articulo primo minimo, secundo tertio dimidio breviore, quarto secundo parum longiore, subacuminato. Labium (t. V. f. I1. a.) mento brevi, antrorsum angustato, utrinque bisinuato, apice rotundato, ligula lata membranea, apice trisinuata, ciliata, lobis lateralibus divergentibus, sinu intermedio setis duabus, lateralibus pilorum fasiciculo instructis. Palpi labiales ligula vix longiores, articulis decrescentibus, ultimo subacuminato. Antennae capite thoraceque haud longiores, filiformes, parce pilosellae, articulo primo paulo crassiore, secundo tertioque reliquis pauio tenuioribus, $4-10$ sensim paulo crassioribus, ultimo ovato. Thorax basin versus fortiter angustatus, lateribus subangulatus, ab elytris rernotus. Scutellum semicirculare. Elytra truncata. Abdomen coleopterorum latitudine, lineare, subtiliter marginatum. Pedes breves, femoribus subcompressis, tibiis angustis, omnibus simplicibus, extus versus apicem setulis dense ciliatis, tarsis minutis.

O b s e r v a t i o n e s.

1. Corpus glabrum. Caput posterius secundum marginem lateralem sulculo longitudinali exaratum. Thorax haud canaliculatus, lateribus saepius denticulatus. Elytra laevia, stria suturali nulla. A genere praecedente praeter oris structuram mandibulis fronteque in utroque sexu muticis, thorace ab elytris remoto, abdomine subtiliter marginato, tibiis muticis etc. discedit.

2. Genus Chasolium Laporte (Etud Ent. I. p. 132.) vix ab Isomalo distinctum, at tibiis anticis fortiter angulatis, externe subtilissime denticulatis, mandibulis prominentibus, thorace medio excavato, lateribus fortiter elevato descriptum, quam ob rem nomen illud recipere dubitavi. Species descripta Madagascarinensis, $\mathrm{Ch}$. Ernestini, cum Isomalo complanato convenire videtur. latent.

3. Mas capite paulo maiore a femina differe videtur. Reliquae differentiae 
* 1. I. complanalus: Niger, nitidus, capile thoraceque denliculato subtilissime canaliculatis, elytris testaceis, pedibus rufis. - Long. $1 \frac{3}{4}$ lin.

\section{T. II. f. 7.}

\section{Habitat in Madagascar, Dom. Goudot.}

Corpus nigrum, nitidum. Antennae piceae, apice nigricantes. Caput magnum, planum, subtilissime punctatum, medio subtiliter obsoleteque canaliculatum, utrinque stria profunda marginali exaratum. Thorax antice coleopterorum latitudine, apıce late subemarginatus, lateribus ante medium sub rectis, a medio inde fortiter angustatus, spatio aequali inter medium et basin dente prominulo angulatus, basi truncatus, planus, subtilissime obsoleteque punctulatus, subtiliter obsolete canaliculatus, angulo anteriore utroque striola brevi sat lata notato. Elytra thorace paulo longiora, parce obsoletissime punctata, plana, testacea, nitida, margine omni suturaque infuscatis. Abdomen planum, laeve, subnitidum, segmentis singulis tenuiter piceomarginatis. Pedes rufo-picei.

\section{* 2. 1. humilis: Niger, nitidus, antennis pedibusque piceis, elytris disco luteis, thorace obsoletius denticulato. - Long. $1 \frac{1}{2}$ lin.}

Habitat in Brasilia, Dom. Melly.

Corpus valde depressum, nigrum, nitidum. Antennae capite thoraceque paulo breviores, piceae. Os rufescens. Palpi testacei. Caput thorace paululum latius, laeve, pone oculos stria marginali longitudinali profunda impressum. Thorax antice coleopteris paulo angustior, basin versus angustatus, lateribus rotundatis, pone medium obsoletius denticulatis, làevis, dorso late subimpresso, medio obsolete subtiliter canaliculato, apice utrinque foveola minuta impressus. Elytra thorace paulo longiora, laevia, nitida, luteo-testacea, undique fusco-marginata. Abdomen laeve, segmentis singulis piceo-marginatis. Pedes picei, tibiis tarsisque testaceis.

\section{* 3. I. int erruptus: Supra niger, nifidus, subtus piceus, capile thorace-} que obsolete denticulato laevibus. - Long. $1 \frac{2}{3}$ lin.

Habitat Carthagenae in Columbia, Dom. Gory.

Corpus planum, supra nigrum, nitidulum, subtus rufo-piceum. Antennae capitis thoracisque prope longitudine, piceae, articulis primis rufis. Oris partes rufae. Caput thoracis latitudine, ad oculorum marginem interiorem sulculo brevi longitudinali utrinque exaratum, ceterum laevissimum. Thorax antice fere coleopterorum latitudine, latitudine summa haud brevior, lateribus rotundatus, basin versus fortiter angustatus, pone medium obsolete denticulatus, laevissimus, apice utrinque prope angulos anteriores leviter impressus. Elytra thorace sesqui longiora, laevia. Abdomen laeve, segmentis singulis piceo-marginatis. Pedes rufi.

4. I. bicolor: Nitidus, teslaceo-rufus, capite, thorace, elytris, ano femoribusque anterioribus nigris, thorace mutico. - Long. $2 \frac{1}{2}$ lin.

Habitat in Mexico, Mus. Dom. Chevrolat.

Reliquis maior. Antennae capite sesqui longiores, pilosellae, piceae. Os piceum. Caput thoracis latitudine, subquadratum, parce subtiliter pun- 
ctatum, punctis in media fronte crebrioribus et fortioribus, utrinque pone oculos sulco longitudinali marginali lato profundoque impressum, nigrum, nitidum. Thorax antice coleopterorum latitudine, lateribus ultra medium subrectis parallelisque, dein leviter rotundatis, basin versus fortiter angustatus, angulis posterioribus paululum prominulis, subrectis, planus, parce subtilissime punctatus, apice utrinque prope angulos anteriores foveola maiore, basi ad angulos posteriores foveola minore minus profunde impressus, niger, nitidus. Scutellum nigrum. Elytra thorace tertia parte longiora, laevia, nigra, nitida. Abdomen laeve, segmentis 4 primis testaceo-rufis, ultimis duobus nigris. Pectus cum pedibus posticis testaceo-rufum. Pedes antici rufo-picei, femoribus piceo-nigris.

\section{* 5. I. testaceus: Teslaceus, nilidus, elytris apice picescentibus, thorace mutico. - Long. $1 \frac{1}{3}$ lin.}

Habitat in Madagascar, Dom. Goudot.

I. complanato duplo minor. Antennae capite sesqui longiores, rufotestaceae. Caput thoracis latitudine, oblongum, planum, parce subtilissime punctatum, punctis in media fronte crebrioribus et distinctioribus, lateribus posterius sulculo longitudinali marginali longiore exaratum, rufo-testaceum, nitidum. Thorax antice coleopteris parum angustior, latitudine summa haud brevior, lateribus rotundatis, a medio inde hasin versus fortiter angustatus, parce omnium subtilissime punctulatus, disco late impresso, rufescentitestaceus, nitidus. Scutellum testaceum. Elytra thorace tertia parte longiora, parce subtilissime punctata, nitida, testacea, apice picescentia. Abdomen laeve, piceo-testaceum, nitidum, segmentis singulis pallido-marginatis. Pedes dilute testacei,

\section{Hypotelus $E$ r.}

Mandibulae muticae.

Palpi maxillares articulo ultimo penultimo duplo longiore.

Tibiae anteriores spinulosae.

Abdomen marginatum.

Corpus minutum, lineare, subdepressum. Capnt thorace paulo minus, porrectum, fronte antice rotundata, immarginata, oculis rotundatis, prominulis. Labrum breve, transversum, medio sinuatum ciliatumque setulis rigidis, laciniis membraneis parvis, subtiliter ciliatis. Mandibulae parvae, haud prominentes, muticae, interne ciliatae. Maxillae (t. V. f. 12. b.) malis oblongis, interiore membranea, apice ciliata, exteriore apice extrorsum oblique truncata spisseque barbata. Palpi maxillares articulo primo minuto, secundo maiusculo, obconico, tertio hoc paulo breviore, quarto his coniunctis aequali, cylindrico, apice obtuse acuminato. Labium (t. V. f. 12. a.) mento subsemicirculari, ligula lata, transversa, membranea, medio leviter incisa. Palpi labiales breves, crassiusculi, articulo primo maiore, secundo tertioque minutis. Antennae capitis thoracisque fere longitudine, crassiusculae, articulo primo fusiformi, medio introrsum subdentato, reliquis obconicis, 5-10 subaequalibus, ultimo ovato. Thorax yuadrangulus, basi coleopteris applicatus. Scutellum triangulare. Elytra truncata. Abdomen coleopterorum latitudine, lineare, marginatum. Pedes breviusculi, femoribus leviter incrassatis, tibiis 
anticis apicem versus sensim subdilatatis intermediisque angustis margine exteriore spinulis subtilibus ciliatis, posticis prope apicem nonnullis tantummodo spinulis munitis, tarsis minutis, articulo ultimo reliquis coniunctis vix aequali.

$$
\text { O b s e r v a t i o n e s: }
$$

1. Corpus parce pubescens, capite, thorace elytrisque glabris. Thorax haud canaliculatus. Elytra stria suturali impressa. Habitus fere Prognathae, a qua discedit palporum maxillarium articulo tertio brevi, maxillarum mala exteriore haud dilatata, mento apice rotundato, ligula minus fortiter biloba. Mandibularum mala exteriore parallela et paraglossis ciliarum serie distinctis ab omnibus reliquis huius tribus generibus discrepat et ad Oxytelinos accedit

2. Sexus differentia latet.

\section{* 1. I. pusillus: Niger, nitidus, elytris pedibusque testaceis. - Long. 1 lin.}

T. II. $f .8$.

\section{Habitat in Brasilia.}

Niger, nitidus. Antennae capitis thoracisque prope longitudine, fuscae, articulis tribus primis rufis. Os rufum. Caput thorace paulo angustius, basi leviter constrictum, subtiliter punctatum, fronte parum convexa, inter antennas utrinque obsolete impressa. Thorax medio coleopterorum fere latitudine, latitudine parum brevior, postice leviter angustatus, lateribus rotundatus, basi apiceque truncatus, angulis anterioribus subrotundatis, posterioribus obtusis, lateribus subtiliter marginatis, parum convexus, subtiliter licet sat distincte punctatus, lineola subtilissima canaliculatus. Elytra thorace parum longiora, sat distincte minus crebre punctata, stria suturali impressa, testacea, nitida, margine anteriore, exteriore suturaque tenui spatio infuscatis. Abdomen subtiliter obsoleteque parce punctatum, parce pilosellum, apice rufo-piceum. Pedes rufo-testacei.

\section{H. praecox: Testaceus, nitidus, capite nigro, thorace rufo. - Long. 1 lin.}

\section{Habitat in valle Araguensi Columbiae, Dom. Moritz.}

Praecedente haud longior at paulo latior. Antennae capite thoraceque paulo longiores, validiusculae, pilosellae, fuscae, articulis tribus primis testaceis. Palpi testacei. Caput thorace paulo angustius, fronte levissime convexa, parce subtiliter punctata, inter antennas utrinque leviter foveolata, nigrum, nitidum. Thorax coleopteris haud angustior, latitudine summa paulo brevior, lateribus fortiter rotundatis, a medio inde hasin versus fortiter angustatus, basi apiceque truncatus, angulis anterioribus obtusisusculis, posterioribus obtusis, subdepressus, parcius subtiliter punctatus, linea tenui longitudinali subtilissime canaliculatus, testaceo-rufus, nitidus. Elytra thorace sesqui longiora, parcius subtiliter punctulata, stria suturali impressa, nitida, testacea, apice picescentia. Abdomen parce omnium subtilissime punctatum, piceotestaceum, nitidum. Pectus nigro-piceum. Pedes rufo-testacei. 


\section{Tribus nona.}

\section{Ph 1 o e chari ni.}

Stigmata prothoracica occulta.

Coxae posticae transversae, anticae conicae, exsertae.

Trochanteres postici fulcrantes.

Ocelli nulli.

L abrum transversum, corneum, simplex vel apice limbo membraneo prominulo instructum.

Mandibula e breviusculae, falcatae, parum exsertae, intus lacinia membranea ciliata fimbriatae. barbata.

Maxillae mala interiore rhombea interne, exteriore oblonga apice

Palpi maxillares articulo primo parvo,

filiformes Olisthaero;

articulo tertio incrassato, quarto parvo, subulato Phlo e ocharidi.

Mentum corneum, perbreve, transversum, apice truncatum.

Ligula membranea, biloba.

Paraglossae ligulae aequales, connatae $\mathrm{Phl}$ oe ocharidi;

ligulae longe breviores Olis thaero.

Palpi labiales filiformes.

Antennae sub frontis margine laterali insertae, 11 -articulatae, rectae, filiformes.

Caput porrectum, thoraci immissum, basi haud aut vix constrictum.

Thorax coleopterorum latitudine iisque basi applicatus, subtus spatio pone coxas abque integmento corneo, membrana obducto, coxis obtecto.

Scutellum distinctum.

Elytra pectoris longitudine.

Abdomen elongatum, marginatum, segmentis sex distinctis, septimo retractili, rarius conspicuo.

P edes breviusculi, coxis anticis conicis, exsertis, intermediis approximatis, posticis transversis, tibiis spinulis terminalibus subtilioribus, tarsis 5-articulatis,

anticis dilatatis $\mathrm{Phl}$ oe och aridi;

simplicibus Olisthaero. 


\section{O b s e r a t i o n es.}

1. Duo tantummodo genera neque ultra tres species continens haec tribus ab omnibus satis distincta. Proxima videtur Omalinis, at ocelli nulli, maxillarum mala interior mutica, elytra pectore haud longiora et abdomen late marginatum. Affinis praecedentibus etiam duabus, at coxae posticae fulcrantes et labrum laciniis destitutum, ab Oxytelinis praeterea abdominis segmento septimo retractili, a Piestinis hoc segmento exserendo et coxis anticis conicis distincta. Quodammodo ad Tachyporinos etiam (imprimis Boletobium) se vergit, at stigmata antica occulta.

2. Sexus differentia vix observanda.

3. Victus sub arborum cortice.

\section{Olisthaerus Dej.}

\section{Palpi maxillares filiformes.}

Corpus elongatum, lineare, depressum, alatum. Caput exsertum, basi constrictum, ore attenuato, oculis parvis, rotundatis, vix prominulis. Labrum transversum, apice truncatum, simplex. Mandibulae leviter prominentes, muticae, apice falcatae. Maxillae (t. V. f. 4. b.) stipite modice elongato, mala exteriore cornea, apice membranacea barbataque, interiore membranacea, interne barbata. Palpi maxillares articulo primo minuto, secundo modice elongato, subarcuato, apicem versus sensim incrassato, tertio hoc parum breviore, leviter obconico, quarto hoc paulo minore, acuminato. Labium (t. V. f. 4. a.) mento brevi, transverso, partes labii membraneas parum obtegens, ligula rotundata, apice bifida, paraglossis ligula multo brevioribus, apice liberis. Palpi labiales articulis duobus primis cylindricis, inter se aequalibus, tertio oblongo-ovato, illis singulis minore. Antennae apicem versus sensim leviter incrassatae, articulis tribus primis obconicis, longitudine subaequalibus, primo paulo crassiore, quarto quintoque subglobosis, sequentibus sensim paulo magis transversis, ultimo breviter ovato. Thorax coleopterorum latitudine, basin versus subangustatus, basi apiceque truncatus. Scutellum sat magnum, triangulare. Elytra apice interne recte, externe oblique truncata. Abdomen elongatum, lineare, lateribus marginatum. Pedes breviusculi, intermedii basi approximati, tibiis parcius spinulosis, tarsis parum elongatis, articulis 4 primis sensim leviter aequaliterque decrescentibus, quinto his coniunctis paulo breviore.

O b s e r va t i o n e s.

1. Caput et thorax laevissima. Elytra substriata, stria suturali profundiore impressa. Abdomen pubescens parceque pilosellum.

2. Victus sub Pinuum putrescentium cortice.

* 1. O. megacephalus: Rufo-castaneus, nilidus, capite thoracis latitudine, piceo. - Long. prope 3 lin.

Omalium megacephalum Zetterst. Faun. Lappon. I. 56. 17. Ins. Lappon. 54. 25.

Habitat in Lapponia, Dalecarlia.

Corpus laete castaneum, glabrum, pernitidum, abdomine obscuriore, pubescente. Antennae capite thoraceque parum breviores, rufo-ferrugineae. Caput thoraci latitudine vix inferius, inter antennas linea levi arcuata impressum, ceterum laevissimum, fronte picea. Thorax coleopterorum latitudine, latitudine dimidio brevior, lateribus leviter rotundatis, pone medium leviter subsinuato - angustatus, apice late subemarginatus, basi truncatus, an- 
gulis posterioribus rectis, subdepressus, laevissimus. Scutellnm laevissimum. Elytra thorace tertia parte longiora, crebrius longitudinaliter substriata. Abdomen supra parcius et obsoletius, subtus crebrius sat distincte punctatum, parcius lutescenti-pubescens, segmentis superioribus 5 primis basi nigris. Pedes magis rufi.

Obs. Utrumque sexum novi, at differentiae sexuales me fugiunt.

\title{
* 2. O. substriatus: Rufus, nitidus, capile thorace angusliore elytrisque piceis. - Long. $2 \frac{2}{3}$ lin.
}

Omalium substriatum Gyll. Ins. Suec. II. 232. 29. - Sahlb. Ins. Fenu I. 288. 27. - Zetterst. Faun. Lappon. I. 55. 16. Ins. Lappon. 53. 24.

Habitat in Lapponia, Dalecarlia.

Antennae capitis thoracisque prope longitudine, rufae. Caput thorace dimidio angustius, depressum, laevissimum, inter antemnas transversim impressum, nigro-piceum, pernitidum, ore rufo. Thorax coleopterorum latitudine, latitudine dimidio brevior, lateribus leviter rotundatis, ad summam basin subsinuatis, basi apiceque truncatus, angulis posterioribus rectis, subdepressus, laevissimus, basi prope angulum posteriorem utrinque obsolete foveolatus, rufus, pernitidus. Scutellum rufum. Elytra thorace sesqui longiora, substriata, nigro - picea, pernitida, margine summo apicali rufescente. Abdomen supra infraque sat crebre punctatum, parcius pubescens, rufum, nitidum. Pectus rufum. Pedes rufi.

Mas abdominis segmento anali minore et magis acuminato, septimo prominulo distinguendus.

Obs A praecedente statura paulo minore, capite minus grandi, elytris longioribus, abdomine dorso evidentius crebriusque punctato, colore corporis magis rufo, elytrorum nigro-piceo, constanter differre videtur.

\section{Phloeocharis Mannerh.}

\author{
Mannerh. Brachelytr. p. 50.
}

\section{Palpi maxillares subulati.}

Corpus pusillum, elongatum, subdepressum, alatum. Caput thorace minus et angustius, basi leviter constrictum, porrectum, oculis semiglobosis, prominulis. Labrum transversum, medio leviter emarginatum, apice membraneo-limbatum. Mandibulae haud porrectae, ante medium unidentatae, margine interiore ad dentem usque limbo membraneo ciliato fimbriato. Maxillae (t. V. f. 5. b.) malis coriaceis, interiore apice introrsum oblique truncato barbata, exteriore hanc paululum superante apice barbata. Palpi maxillares breviusculi, articulo primo minuto, secundo leviter elongato, tertio incrassato, quarto tenui, subulato. Labium (t. V. f. 5. a.) mento brevi, transverso, antrorsum angustato, apice truncato, ligula membranea, brevi, biloba, paraglossis liberis, ligulam vix superantibus, membraneis, interne ciliatis. Palpi labiales articulo primo eylindrico, secundo hoc multo breviore, tertio primo longitudine aequali, at tenuiore, apice subacuminato. Antennae capite thoraceque breviores, articulo primo cylindrico secundoque ovato crassiusculis, tertio tenuiore, obconico, 4-10 subglobosis, sensim paulo maioribus et crassioribus, ultimo ovato. Thorax sat am- 
plus, transversus. Scutellum triangulare. Elytra apice truncata, ad angulum exteriorem emarginata. Abdomen marginatum, apice leviter angustatum. Pedes breviusculi, intermedii basi approximati, tibiis pubescentibus, tarsis breviusculis, articulis 4 primis brevibus, quinto his coniunctis longitudine aequali, anticis leviter dilatatis.

\section{O b s e r va tion e s.}

1. Corpus totum punctulatum, minus subtiliter pubescens.

2. Sexus differentia latet.

3. Victus sub truncorum cortice sicco.

* 1.Ph. subtilissima: Griseo-pubescens, fusco-nigra, elytris abdominisque segmientorum marginibus rufo-brunneis, ore, anlennis pedibusque testaceis. - Long. $\frac{3}{3}$ lin.

Mannerh. Brachelytr. 50. 1. - Er. Col. March. 1. 612. 1.

Habitat in Europa sub cortice Pirus.

- Fusco-nigra, parum nitida, pube minus subtili depressa fulvescentigrisea vestita. Antennae testaceae. Caput minutum, subtilissime punctulatum, ore testaceo. Thorax coleopterorum latitudine, latitudine plus dimidio brevior, lateribus leviter rotundatis, antrorsum subangustatus, basi apiceque truncatus, angulis anterioribus rotundatis, posterioribus subrectis, levissime convexus, subtilissime punctulatus, dorso obsolete longitudinaliter bi-impressus. Elytra thorace sesqui longiora, densius punctata, rufo-brunnea. Abdonen subtiliter punctulatum, segmentorum singulorum margine rufo-piceo. Pedes rufo-testacei. 


\section{T r i b u s d e c i ma. \\ (1) m a i n i.}

Sligmala prothoracica occulta. Coxae posticae transversae, anticae conicae, exsertae. Trochanteres postici fulcrantes: Ocelli duo.

Labrum transversum, corneum,

apice membrana medio sinuata vel biloba anctum Lesteuae, Olophro, Deliphro, Omalio;

utrinque lacinia parva acuminata membranea ciliata instructum Lathrimaeo.

Mandibulae breves, falcatae, dentatae Anthophago, Lesteuae; muticae reliquis.

Maxillae malis membraneis, interiore breviore, apice unco corneo armata, exteriore apice barbata,

lineari Anthophago, Acidotae, Omalio, Anthobio;

externe rotundato-dilatata Arpedio, Lathrimaeo, Deliphro;

utraque lineari, elongata, cornea Lesteuae, Olophro.

Palpi maxillares filiformes, articulo primo minuto.

Mentum corneum, transversum, antrorsum angustatum, apice truncatum.

Ligula membranea, lata, biloba, paraglossis nullis.

Palpi labial es breviores, filiformes.

Antennae sub frontis margine laterali insertae, 11-articulatae, rectae, filiformes.

C aput porrectum, thoraci immissum, fronte ocellis duobus instructa.

Thorax lateribus marginatus, basi coleopterorum basi approximatus.

Scutellum distinctum.

Elytra pectore magis minusve longiora, nonnunquam abdominis maximam partem obtegentia, lateribus immarginata, angulo apicali exteriore fortiter rotundato.

Abd omen depressum, subtiliter marginatum, apice rotundatum, segmentis 6 distinctis. 
Pedes coxis anticis conicis, exsertis, intermediis approximatis vel nonnunquam tenui spatio distantibus, posticis transversis, trochanteribus posticis fulcrantibus, tibiis aut inermibus aut spinulosis, spinis terminalibus subtilibus, tarsis 5-articulatis, posterioribus

articulis 4 primis sensim decrescentibus, primo magis minusve elongato Anthophago, Lesteuae, Arpedio, A cid otae;

articulis $\mathbf{2}$ primis aequalibus, sequentibus duobus paulo longioribus $\mathrm{Olo-}$ phro, Lathrimaeo, Deliphro;

articulis 4 primis aequalibus, brevibus, coniunctis articulo ultimo longitudine aequalibus Omalio, Anthobio;

unguiculis simplicibus plerisque;

lacinia membranea instructis Anthophago*:

$$
\text { o b s e r v a t ion e s. }
$$

1. Tribus valde distincta, ocellis duobus frontalibus, maxillarum mala interiore apice unco corneo terminata, elytris pectore longioribus, apice exteriore rotundatis insignis, e generibus Anthophago et Omalio Grav. composita, exclusis speciebus nonnullis, quae aut inter Oxytelinos Coprophilinos aut inter Proteinin os genera peculiaria constituunt.

2. Abdominis segmentum sextum in mare truncatum, vel inferne emarginatum, septimum prominulum; femina stylo bifido ex ano saepius prominulo instructa.

\section{Anthophagus Grav.}

Grav. Micr. p. 120. - Er. Col. March. I. p. 614.

Mandibulae ante apicem bidentatae.

Maxillae malis membranaceis.

Palpi maxillares articulo ultimo penultimo aequali.

Tibiae muticae.

Tarsi postici arliculo primo elongato.

Corpus oblongum, subdepressum, alatum. Caput exsertum, thoracis latitudine vel eodem latius, rhombeum, basi constrictum, collo quasi cylindrico thoraci immissum, oculis mediocribus, rotundatis, prominulis. Ocelli pone oculorum marginem superiorem siti. Labium transversum, apice subsinuatum, Mandibulae apice acuto introrsum falcato, ante apicem acute bidentatae. Maxillae (t. V. f. 25. b.) malis membranaceis, exteriore apice, interiore intus barbatis, hac unco corneo terminata. Palpi maxillares modice elongati, articulo primo minuto, reliquis tribus inter se longitudine aequalibus, tertio leviter obconico, quarto apice subacuminato. Labium (t. V. f. 25. a.) mento brevi, transverso, apice vix sinuato, ligula membranea, biloba, lobis interne sinuatis. Palpi labrales articulo primo breviusculo, secundo longiore, crassiusculo, tertio iterum minore subacuminato. Antennae filiformes, satis elongatae gracilesque. Thorax coleopteris multo angustior, subcordatas seu basin versus angustatus. Scutellum triangulare. Elvtra pectus perparum excedentia. Abdomen late marginatum. Pedes elongati, graciles, tarsis articulo primo leviter elongato, quarto subtus pilorum fasciculo instructo, quinto plerumque laciniis duabus membraneis, unguiculo ipso longitudine aequali bus instructo.

$$
\text { O b s e r v a t i o n ê. s. }
$$

1. Corpus iam glabrum iam subtilissime subtiliterve pubescens. Caput, thorax et elytra punctulata. Frons ante ocellos lineolis duabus obliquis insculpta. 
2. Habitu, thorace subcordato pedibusque elongatis, gracilibus ad Caraborum nonnullorum genera v. c. ad Dromium accedunt Anthophagus et Lesteua.

3. Mas differt abdominis segmento septimo infra conspicuo. Specierum nonnullarum (A. armiger, alpinus) mares capite dilatato, antice bispinoso mandibulisque elongatis crassatisque excellunt.

4. Victus in herbis, fruticibus et floribus.

* Unguiculi basi membrana lineari, libera, unguiculo ipso fere aequali, instructi.

* 1. A. armiger: Rufo-teslaceus, pectore abdomineque nigro-piceis, elytris testaceis, thorace transversim quadrato, crebrius punctato, basi foveolalo, fronte maris apice bispinosa. - Long. $2 \frac{1}{2}-3$ lin.

Gruv. Micr. 122. 3. Mon. 221. 5.

Staph. bicornis Block Ins. vall. Plauens. 118. 10, $f .10$.

Habitat in Germaniae montanis. Suecicum etiam specimen dedit Dom. Schiippel.

A. testaceo paulo maior et latior. Antennae capite thoraceque multo longiores, testaceae. Caput parce subtiliterque punctulatum, inter oculos striolis duabus obliquis impressum, rufo-testaceum, basi nonnunquam piceum, feminae vix thoracis latitudine, maris thorace latius, medio late at parum profunde impressum, apice ad antennarum insertionem spina valida porrecta utrinque armatum, mandibulis prominentibus, incrassatis, incurvis, decussatis. Thorax coleopteris duplo fere angustior, latitudine dimidio brevior, lateribus anterius leviter rotundatis, basin versus parum angristatus, angulis posterioribus rectis, parum convexus, margines versus distinctius crebriusque, medio parcius obsoletiusque punctatus, basi supra scutellum foveola transversa impressus, rufo-testaceus, nitidus, medio interdum picescens. Scutellum laeve, rufo-testaceum, rarius piceum. Elytra thorace plus duplo longiora, sat crebre punctata, parce subtiliter pubescentia, luteotestacea, nitida. Abdomen parce subtiliter punctulatum, tenuissime griseopubescens, nigrum, nitidum, margine saepius irregulariter obscure testaceo. Pectus nigro-piceum. Pedes rufo-testacei.

Variat elytris brevioribus, thorace vix duplo longioribus.

* 2. A. alpinus: Nigro-piceus, antennarum basi, elytris pedibusque teslaceis, thorace subquadrato, vage punctato. - Long. $1 \frac{1}{2}-2$ lin.

Mas capile magno, apice bispinoso, mandibulis magnis, incurvis.

Anthophag. mandibularis Gyll. Ins. Suec. IV. 460, 2-3. - Sahlb. Ins. Fenn. I. 275. 4 .

Anthophag. maxillosus Zetterst. Faun. Lappon. 1. 45. 3. Ins. Lappon. 48.4.

Fem. capile thorace angustione, mutico.

Staph. alpinus Fab. Ent. Syst. I. II. 526. 33. Syst. El. II. 598. 43. - Payk. Faun. Suec. III. 387. 27. - Oliv. Ent. III. 42. 32. 45. t. 6. f. 55.

Les teua alpina Latr. Hist. nat. Crust. et Ins. IX. 368. 1. Gen. Crust. et Ins. I. 297. 2. - Lepell. et Serv. Encycl. meth. Ins. X. 216. 1. - Runde Brachelytr, Hal. 24. 5.

Anthophag. alpinus Grav. Micr. 188. 2. Mon. 220. 1. - Zetterst. Faun. Lapp. I. 46. 4. Ins. Luppon. 4S. 5.

Anthophag. alpinus var. a Gyll. Ins. Suec. II. 194. 2. 
Anthophag. Lapponicus Sahlb. Ins. Fenn. I. 275. 3. - Zetterst. Ins. Lappon, 47. 2. Lesteua Lapponica Mannerh. Brachelytr. 56. 5.

Lesteua fluvipennis Boisd. et Lacord. Faun. Ent. Paris. I. 480. 2.

Habitat in Suecia boreali; in Alpibus Tyrolensibus, Dom. Prof. Ahrens, Helveticis Dom. Heer, in montıbus Silesiae, Dom. Märkel.

A. Caraboide dimidio minor. Antennae capite thoraceque longiores, nigrae, articulis 2, 3 vel 4 primis testaceis. Caput parce subtiliter obsoleteque punctatum, inter oculos lineolis duabus obliquis impressum, nigropiceum, subnitidum, ore testaceo, feminae thoracis latitudine, maris thorace multo latius, inaequale, apice ante antennarum insertionem spina porrecta utrinque armatum, mandibulis valde prominentibus, incrassatis, incurvis. Tho$\operatorname{rax}$ coleopteris dimidio angustior, latitudine vix brevior, lateribus anterius modice rotundatis, basin versus leviter angustatus, angulis posterioribus rectis, leviter convexus, vage sat distincte punctatus, dorso longitudinaliter obsolete bi-impresso, spatio interiecto subelevato, laevi, nigro- vel fusco-piceus, subnitidus, margines versus rufescens. Scutellum laeve, piceum. Elytra thorace duplo longiora crebre fortiterque punctata, pallide testacea. Pectus et abdomen nigra, nitida. Pedes rufo-testacei.

Obs. Femina mare multo frequentior: Dom. Märkel singuỉum inter quadragenas vel quinquagenas feminas marem observavit.

* 3. A. Omalinus: Nigro-piceus, nitidus, capite thoraceque rufo-piceis, antennis, pedibus elytrisque testaceis, thorace transversim subquadrato, parce obsoleteque punctalo. - Long. $1 \frac{1}{2}$ lin.

Zetterst. Faun. Lappon. I. 46. 5. Ins. Lappon. 48. 6.

Anthophag. alpinus var. b Gyll. Ins. Suec. IV. 194. 2.

Anthophag. alpinus Sahlb. Ins. Fenn. I. 274. 2.

Lesteua alpina Mannerh. Brachelytr. 56. 6.

Habitat in Lapponia, Dom. Zetterstedt, in Dalecarlia, Dom. Schönherr, — „in Pini sylvestris frondibus" Gyll. ,in foliis Betulae albae” Zetterst.

A. alpino paulo minor et paulo magis dilatatus. Antennae capite thoraceque paulo longiores crassiusculae, totae laete testaceae. Caput in utroque sexu thorace angustius, vix punctatum, striolis duabus obliquis inter oculos sat profundis impressum, piceo- vel rufo-testaceum, subnitidum. Thorax coleopterorum basi dimidio angustior, latitudine paulo brevior, lateribus ante medium leviter rotundatis, basin versus vix angustatus, angulis posterioribus rectis, leviter convexus, aequalis, punctis obsoletis, raris, ad marginem basalem crebrioribus impressus, rufo-testaceus, subnitidus. Scutellum laeve, piceo-testaceum. Elytra thorace plus duplo longiora, apicem versus sensim dilatata, crebrius punctata, dilute testacea. Pectus et abdomen nigra, nitida. Pedes testacei.

Mas nonnisi antennis longioribus abdominisque segmento sexto infero emarginato distinguitur.

* 4. A. Austriacus: Niger, ore, antennis, pedibus elytrisque testaceis, thorace transversim quadrato, subtiliter vage punctalo. - Long. $2 \frac{1}{2}$ lin.

Habitat in Austria, Dom. Schiippel, in Carinthia, Dom. Schmidt.

Statura fere A. testacei, niger, capite thoraceque parum nitidis, sub- 
aeneis. Antennae capite thoraceque longiores, crassiusculae, obscure testaceae, articulis 4-6 vel $4-8$ fuscescentibus. Os testaceum. Caput in utroque sexu thorace angustius, vage punctatum, inter ocnlos striolis duabus obliquis impressum, antice ad antennarum basin utrinque foveolatum. Thorax coleopteris paulo angustior, latitudine tertia parte brevior, lateribus ante medium leviter rotundatis, basin versus parum angustatus, angulis posterioribus obtusiusculis, parum convexus, vage subtiliter punctatus, dorso longitudinaliter obsolete bi-impressus, spatio interiecto impunctato, marginibus obscure testaceis. Scutellum laeve, nigro piceum. Elytra thorace duplo longiora, sat crebre fortiterque punctata, testacea. Abdomen confertim subtiliter subrugoso-punctatum, subtiliter griseo-pubescens, nigrum, nitidum. Pectus nigrum. Pedes testacei, femoribus onınibus maris incrassatis.

* 5. A. Caraboides: Rufo-teslaceus, abdomine ante apicem capileque piceis, thorace subcordalo, subliliter punctato. - Long. '2 lin.

Grav. Micr. 120. 1. Mon. 221. 2. - Zetterst. Faun. Lappon. I. 45. 2. Ins. Lappon. 47. 3. - Er. Col. March. 1. 614. 1.

Staph. Caraboides Linn. Faun. Suec n. 854 Syst. Nat. I. II. 685. 20. - Fabr. Syst. Ent. 267. 18. Spec. Ins. 1. 337. 23. Mant. Ins. I. 222. 33. Ent. Syst. I. 1 I. 530. 53. Syst. El. II. 601. 65. - Schrank Enum. Ins. Austr. 234. 443. - Goeze Ent. Beitr I. 720. 20. - De Vill. Ent. I. 417. 20. - Cederh. Faun. Ingr. 119. 366. - Walk. Faun. Paris. I. 271. 10. - Payk. Mon. Staph. 19. 11. Fa"n. Suec. III. 386. 25. - Oliv. Ent. HI. 42. 22. 26. t. 2. f. 17. - Panz. Ent. Germ. 358. 42. - Marsh. Ent. Britt. 521. 67.

Lesteua Caraboides Mannerh. Brachelytr. 55. 3. - Runde Brachelytr. Hal. 23. 3. Anthophag. Caraboides var. a. b Gyll. Ins. Suec. II. 192. 1. - Sahlb. Ins. Fenn. 1. 274. 1.

Staph. fulvus Degeer Ins. IV. 25. 12.

Lesteua test acea Boisd. et Lacord. Faun. Ent. Paris. I. 482. 5.

Habitat in Europa.

Antennae capite thoraceque multo longiores, testaceae. Cajut in utro. que sexu thoracis latitudine, parcius punctulatum, inter oculos striolis duabus obliquis sat profundis impressum, rufo-testaceum, plerumque magis minusve picescens, ore semper rufo-testaceo. Thorax coleopteris duplo angustior, latitudine haud brevior, lateribus anterius rotundatus, basin versus angustatus, angulis posterioribus subrectis, parum convexus, parcius subtililiter punctatus, dorso nonnunquam obsolete longitudinaliter bi-impressus, rufo-testaceus, parum nitidus. Scutellum laeve, rufo-testaceum, nitidum. Elytra thorace duplo longiora, sat crebre fortiterque punctata, dilutius testacea. Abdomen rufo-testaceum, postice macula magna picea, apice summo iterum testaceo. Pectus testaceum. Pedes flavi.

* 6. A. abbreviatus: Testaceus, abdomine apice, capite pectoregue nigropiceis, elytris fascia fuscesente, thorace subcordato. - Long. $1 \frac{2}{3}-2$ lin.

Carabus abbreviatus Fab. It. Norvag. p. 263. Spec. Ins. 313. 85. Mant. Ins. I. 205. 120. Ent. Syst. I. 1. 167. 188. Syst. El. I. 209. 215. - Panz. Ent. Germ. 367. 114 - 115. Faun. Germ. 36. 2. - Illig. Käf. Pr. 205. 90.

Lesteua angusticollis Mannerh. Brachelytr. 56. 4.

Habitat in Europa.

Praecedente paulo gracilior. Antennae capite thoraceque multo lon- 
giores, testaceae. Palpi pallidi. Caput in utroque sexu thoracis latitudine, parcius punctatum, inter oculos striolis duabus obliquis sat profundis impressum, nigro-piceum, nitidum, ore testaceo. Thorax coleopteris duplo angustior, latitudine summa haud brevior, lateribus anterius rotundatus, basin versus angustatus, angulis posterioribus subrectiș, paruan convexus, parcius subtiliter punctatus, nonnunquam longitudinaliter obsolete bi-impressus, rufotestacens, subnitidus, disco nonnunquam fuscescente. Scutellum lrevissimum, piceo-testaceum, nitidum. Elytra thorace plus duplo longiora, crebre profundius punctata, parce subtilissime griseo-pubescentia, nitida, lutea, fascia media sinuata dilute fusca, nonnunquam magis minusve obsolescente, sutura nonnunquam infuscata. Abdomen parcius subtiliter punctatum, nitidum, iam nigrum basi testaceum, iam testaceum apice late nigro-picenm. Pectus nigro - piceum. Pedes pallide flavi.

$\mathrm{O}$ bs. Proximus praecedenti et forte mera eius varietas, statura autem graciliore, thorace basin versus paulo magis angustato, elytris fascia fuscescente, pectore piceo etc. distinguendus videtur.

* 7. A. scutellaris: Testaceus, nilidus, abdomine ante apicem, fronte, scutello pectoreque nigro-piceis, thorace crebre punclato, elytris luteis, circa scutellum infuscatis. - Long. $2 \frac{1}{4}$ lin.

Habitat Genevae. Specimen a Dom. Chevrier sibi communicatum dedit Dom. Prof. Germar.

Praecedentibus paulo mainr. Antennae capite thoraceque longiores, validiores, testaceae. Palpi dilute testacei. Caput thoracis latitudine, fronte posterius crebre fortius punctata, striolis duabus obliquis impressa, anterius parce punctata, leviter impressa et utrinque foveolata, nitidum, rufo-testaceum, supra posterius nigro piceum. Thorax coleopteris dimidio angustior, latitudine vix brevior, lateribus ante medium rotundatus, basin versus angu- status, angulis posterioribus rectis, parum convexus, sat crebre profundius punctatus, linea media longitudinali laevi, rufescenti-testaceus, nitidus, parce subtiliter griseo - pubescens. S'cutellum laevissimum, nigro - piceum, nitidum. Elytra thorace duplo longiora, densius profunde punctata, subtiliter griseopubescentia, macula communi triangulari circa scutellum nigricante. Abdo. men parcius subtilissime punctulatum, subtiliter pubescens, testaceum, nitidum, macula maiore rotundata ante apicem nigro-picea. Pectus nigro-piceum. Pedes flavi.

Obs. A praecedentibus duobus thorace pubescente, a sequente colore, elytris brevioribus, thorace lateribus minus rotundato distinctus.

* 8. A. testaceus: Rufo-testaceus, nitidus, capile thoracegue rufis, hoc subquadrato, crebre punctato. - Long. $2 \frac{1}{4}$ lin.

Grav. Micr. 121. 2. Mon. 221. 3. - Er. Col. March. I. 615. 2.

Lesteua te stacea Mannerh. Brachelytr. 55. 2. - Runde Brachelytr. Hal. 23. 2. Lesteu a Caraboides Boisd. et Lacord. Faun. Ent. Paris. 1. 480. 3.

Anthophag. Caraboides var, c Gyll. Ins. Suec. I. 192. 1. - Sahlb. Ins. Fenn. I. 274. 1 .

Habitat in Europa, in fruticibus.

A. Caraboide sesqui fere maior, rufo-testaceus, nitidus, capite thoraceque saturatioribus, testaceo-rufis. Antennae capite thoraceque multo lon- 
giores. Caput in utroque sexu thorace paulo angustius, crebrius sat distincte punctatum, antice laevius, fronte planiuscula, inter oculos striolis duabus, vix obliquis, profundis impressum. Thorax coleopteris plus dimidio angustior, latitudine haud brevior, lateribus anterius fortius rotundatus, basin versus leviter angustatus, angulis posterioribus rectis, leviter convexus, sat crebre fortius punctatus, postice linea media longitudinali abbreviata laevi, subelevata, subtiliter griseo-pubescens. Scutellum laeve. Elytra plus duplo longiora, crebre fortiterque punctata, tenuiter griseo-pubescentia. Abdomen parcius subtiliter punctulatum, subtiliter griseo-pubescens, ante apicem saepe fuscescens. Pedes dilutius testacei.

V ariat interdum capite thoraceque fuscescentibus: forte A. Caraboidis var. d et e Gyll. Sahlb. (l. supra c.) huc referendae.

* 9. A. praeustus: Rufo-testaceus, nitidus, abdomine ante apicem elytrorumque macula magna apicali nigris, thorace transversim subquadrato, crebre punctato. - Long. $2 \frac{1}{4}$ lin.

Müller Germ. Mag. IV. 22S. 25.

L esteua praeusta Runde Brachelytr. Hal. 23. 2.

Lesteua bimaculata Boisd. et Lacord. Faun. Ent. Paris. I. 481. 4.

Habitat in Germania, Gallia, Hungaria.

Statura et summa affinitas A. testacei, rufo-testaceus, nitidus. Antennae capite thoraceque multo longiores, crassiusculae. Caput in utroque sexu thorace angustius, fronte depressa, crebrius fortiusque punctata, striolis duabus obliquis profundis impressa, antice laeviore. Thorax coleopteris dimidio angustior, latitudine paulo brevior, lateribus anterius fortius rotundatus, basin versus leviter angustatus, angulis posterioribus rectis, parum convexus, crebre fortius punctatus, linea media longitudinali subelevata, an-. tice abbreviata, laevi, subtiliter griseo-pubescens. Scutellum laeve. Elytra thorace plus duplo longiora, sat crebre fortiter punctata, longius griseopubescentia, macula magna rotundata apicali nigra, marginem haud attingente. Abdomen parce subtilissime punctulatum, parce pubescens, nitidum, supra infraque macula magna nigra ante apicem.

\section{* Unguiculi simplices.}

* 10. A. plagiatus: Niger, pubescens, crebre punctatus, fronte impressa, thorace cordato. basi foveolato, antennis pedibusque fusco-testaceis. Long. $2-2 \frac{1}{2}$ lin.

Var. a: Elytris thorace plus duplo longioribus, plaga discoidali rufescente.

Grav. Micr. 123. 5. 189. 3. Mon. 222. 8. - Gyll. Ins. Suec. II. 195. 3. - Zetterst. Faun. Lappon. I. 44. 1. Ins. Lappon. 47. 1, - Sahlb. Ins. Fenn. 1. 276. 5. - Germ. Faun. Ins. Europ. XIII. 5.

Staph. plagiatus Fab. Ent. Syst. Suppl. 180. 32. Syst. El. 11. 597. 42. - Payk. Faun. Suec. 11I. 387. 26.

Lesteua plagiata Mannerh. Brachelylr. 56. 7. - Boisd. et Lacord. Faun. Ent. Paris. I. 482. 6. - Runde Brachelytr. Hal. 24. 6.

Var. b: Elytris thorace plus duplo longioribus, sulura sanguinea.

Lesteua suturalis Boisd. et Lacord. Faun. Ent. Paris. I. 283. 7. 
Var. c: Elylris thorace plus duplo longioribus, concoloribus.

Staph. plagiatus var. Payk. Faun. Suec. III. 387. 26.

Anthophag. plagiatus var. b Gyll. Ins. Suec. II. 195. 3. - Sahlb. Ins. Fenn. I. 276. 5 .

Anthophag. nigrita Mïll. Germ. Mag, IV. 226. 24.

$V$ ar. d: Elytris thorace vix duplo longioribus, fusco-piceis, long. 2 lin. L esteua longipes Mannerh. Brachelytr. 56. 9. (forte)

Var. e: Thorace canaliculalo, elytris thorace vix duplo longioribus, nigris, concoloribus.

L esteua globulicollis Mannerh. Brachelytr. 56. 8.

Anthophag. globulicollis Zetterst. Ins. Lappon. 49. 8.

Var. $f$ : Thorace canaliculato, elytris thorace sesqui longioribus, disco rufescentibus.

\section{Habitat in Europa.}

A. testaceo plerumque maior et latior, niger, subnitidus, tenuiter griseopubescens. Antemnae capite thoraceque multo longiores, picea-rufae, basi interdum nigricantes, articulo ultimo elongato. Os piceo-rufum. Caput in utroque sexu thorace angustius, crebrius punctatum, inaequale, fronte inter oculos impressa, striolisque duabus obliquis sulcata, medio obsoletius distinctiusve canaliculata. Thorax coleopteris dimidio angustior, latitudine paulo brevior, lateribus fortiter rotundatus, basi coarctatus, angulis posterioribus rectis, subprominulis, leviter convexus, crebre fartius punctatus, basi supra scutellum impressione transversa, et utrinque in ipso angulo baseos foveola minuta rotundata notatus, dorso interdum medio longitudinaliter obsolete impressus, in aliis distinctius obsoletiusve canaliculatus, in aliis linea media longitudinali laeviore, posterius subelevata. Scutellum laeve. Elytra sat crebre fortiterque punctata, nigra, iam plaga media longitudinali, iam sutura sanguineis, iam immaculata. Abdomen subtiliter subtus densius punctulatum. Pedes piceo-rufi.

Obs. 1. Maiore individuorum copia examinata varietates citatae specie mihi non satis distinctae videntur. Varietates a et c elytris thorace plus duplo longioribus inter se conveniunt et praeter elytrorum colorem vix differunt. Antennarum basis, palpi et pedes in utraque iam nigro-, iam rufo-picei, iam rufi. V a r. b, genuinis iam paulo maior, iam dimidio minor, elytrorum longitudine cum is congruens, at thorace lateribus paulo minus rotundato, forte specie distineta, at characteres haud sufficere videntur. Hanc ex Austria misit Dahl nom. Anthophagi variegati et variantis. - Var. d, nom. Anthophagi Kunzei a Dom. Heer ex Helvetiae montibus missa, elytris brevioribus, genuinis paulo minor, thorace parum convexo, aequali a var. e distincta, quae colore et statura cum var. c congruit, et thorace paululum convexiore, distinctius canaliculato et elytris paulo brevioribus discedit. Specimina eius e Dalecarlia a Dom. Schönherr sibi communicata dedit Dom. Schüppel. - Var. f tandem, cuius specimen Tyrolense dedit Dom. Waltl, colore cum var a, thoracis structura cum var. e convenit, ab omnibus autem coleopteris multo brevioribus et thorace vix latioribus longius discedit.

2. Staph. nigrophthalmus Block Ins. Vall. Plauens. 117. 9. f. 9. huius speciei specimen immaturum colore testaceo exhibere videtur.

* 11. A. caesus: Testaceus, fronte, thorace elytrisque brunneis, abdomin „e apicem brunneo, thorace oblongo, profunde canaliculalo. - Lon $3 \frac{1}{2}$ lin.

Habitat in America septentrionali, Knoch. 
Antennae elongatae, dimidio corpore longiores, articulo ultimo paululum incrassato, testaceae. Caput thorace plus dimidio angustius, vage punctatum, inaequale, inter oculos impressum, saturate rufo-testaceum, supra posterius nigro-brunneum. Thorax coleopteris paulo angustior, latitudine paulo longior, lateribus fortiter rotundatus, basin apicemque versus aequaliter angustatus, angulis posterioribus minutis, acntiusculis, prominulis, convexus, canalicula profunda, basi foveola terminata, exaratus, sat crebre fortiterque punctatus, tenuiter griseo-pubescens, subtus saturate testaceus, supra nigrobrunneus, nitidus, margine antico posticoque rufescente. Scutellum piceum, impressum. Elytra thorace paulo longiora, crebre sat fortiter punctata, brumnea, apicem versus sensim nigro-picea. Abdomen testaceum, ante apicem nigricans. Pectas testaceum. Pedes elongati, testacei.

Species mihi invisae.

12. A. brunneus: Rufo-brunneus, pedibus abdomineque pallidioribus, thorace linea foveolaque dorsali impresso. - Long. infra $2 \frac{1}{2}$ lin.

Say Act. Acad. Nat. Scienc. Philadelph. III. p. 158.

Habitat in fluminis Missouri ripis.

Rufo-brunneus, punctatus, breviter pubescens. Caput inaequale, inter oculos et inter antennas impressum. Antennae, palpi et pedes testacei. Mandibulae apice piceae. Thorax dense punctatus, subrotundatus, angulis posterioribus rectis, linea dorsali basi foveola terminata canaliculatus. Elytra dense punctata, angulo posteriore laterali rotundato, suturali acuto. Abdomen pallide rufo-brunneum, dorso macula fusca ante apicem, segmentis singulis undique fusco-marginatis. (Say.)

13. A. verticalis: Rufo-brunneus, elytris segmentorumque abdominis marginibus testaceis. - Long. infra 2 lin.

Say Transact. Amer. Philosoph. Soc. Philadelph. Nov. Ser. IV. p. 463.

Habitat in Pensylvania.

Castaneus, punctatus, leviter pubescens. Caput thorace obscurins, sparsim punctatum, verticis disco impresso, inter antennas inaequale, antennis et ore pallidioribus. Thorax convexus, utrinque rotundatus, basi contractus, linea impressa basi puncto dilatato terminata evidenter canaliculatus. Elytra rufo-testacea, punctata, apice obscura. Abdomen linea dorsali impressa, segmentis singulis in utroque latere macula apicali triangulari. Pedes femoribus testaçeis, tibiis tarsisque dilutioribus.

Obs. Affinis A. brunneo, at abdominis segmenta haud fusco-marginata, sin. gula autem macula triangulari, ad marginem posteriorem fortius dilatata et marginem lateralem prope attingente signata. (Say.) 


\section{Lestena Lat $r$.}

Latr. Précis d. caract. d. gen. d. Ins. p. 75. - Er. Cul. March. I. p. 616.

Mandibulae medio unidentatae,

Maxillae malis elongatis, corneis.

Palpi maxillares articulo ultimo penultimo triplo longiore.

Tibiae muticae.

Tarsi postici articulo primo elongato.

Corpus oblongum, subdepressum, alatum apterumve. Caput exsertum, thorace vix angustius, rhombeum, basi constrictum, oculis mediocribus, rotundatis, sat prominulis. Ocelli super oculorum marginem superiorem siti. Labrum (t. V. f. 26. c.) breve, apice leviter sinuatum, membrana medio sábsinuata auctum. Mandibulae leviter falcatae, acutae, medio denticulo armatae. Maxillae (t. V. f. 26. b.) malis corneis, elongatis, linearibus, exteriore barbatula, interiore unco terminata, interne barbata. Palpi maxillares articulo primo tertioque brevi, secundo quartoque elongatis, quarto terio triplo longiore. Labium (t. V. f.^26. a.) mento transverso, apicem versus angustato, apice truncato, ligula membranea, biloba, lobis rotundatis. Palpi labiales articulo primo tertioque elongatis, secundo brevi. Antennae filiformes, graciles; ariiculo primo cylindrico, sequentibus subobconicis, ultimo ovato, apice acuminato. Thorax coleopteris angustior, lateribus rotundatus, basin versus angustatus. Scutellum triangulare. 'Elytra pectus parum superantia, angulo apicali exteriore rotundato. Abdomen late marginatum, apice subacuminatum. Pedes elongati, graciles, tibiis pubescentibus, posticis articulo primo elongato.

O b s e r a tiones.

1. Corpus subtiliter pubescens. Caput, thorax et elytra dense punctata. Frons utrinque longitudinaliter leviter impressa, impressione inter oculos foveolata, antice clypei spatio impressione semicirculari distincto.

2. Mas abdominis segmento sexto subtus truncato, segmento igitur septimo conspicuo a femina distinguitur.

3. Habitus omnino generis praecedentis, quocum confunditur. Oris structura omnino distinctiva. Palporum maxillarium differentia facillime diagnosi potest. Praeterea frons in Lesteua utrinque longitudinaliter impressa, in Anthophago medio lineolis duabus obliquis insculpta differentiam quandam habitualem suppeditat.

4. Species nonnisi Europaeae cognitae. Victus ad rivulos in herbis: indigeuas. praecipue in muscis rivulorum affluvie humidis observavi.

5. Latreillianum servavi nomen huic generi, quod speciei eius vulgari conditum fuit. Nomen Gravenhorstianum praecedenti generi proprium maneat.

* 1. L. bicolor: Alata, nigra, pubescens, crebre punctata, antennis pedibusque fusco-testaceis, thoracis angulis posterioribus rectis, elytris thorace plus duplo longioribus, fuscis. - Long. 2 lin.

Fr. Col. March. I. 616. I.

Staph. bicolor Fab. Ent. Syst. I. II. 529. 47. Fab. Syst. El. II. 600. 60. -Walk. Faun. Paris. 1. 270.8.

Lesteua punctulat a Latr. Hist. nat. Crust. et Ins. IX. 369. 2. Gen. Crust. et Ins. IX. 297. 1. t. 9. f. 1.

Staph. оbscurus Payk. Faun. Suec. HII. 388. 28.

Anthophag. obscurus Grav. Micr. 122. 4. Mon, 221. 7. - Gyll. Ins. Suec. II. 195. 4. - Zetterst. Faun. Lappon. I. 47. 6. Ins. Lappon, 49. 7. - Sulib. Ins. Fenn. I. 176. 6. 
L esteu a obs cura Mannerh. Brachelytr. 57. 10. - Boisd. et Lacord. Faun. Ent. Paris. I. 483. 8. - Runde Brachelytr. Hal. 24. 7. Anthophag. intermedius Grav. Mon. 221. 4.

Carabus dimidiatus Panz. Faun. Germ. 36. 3. Ent. Germ. 367. $114-115$.

Carabus Staphylinoides Marsh. Ent. Britt. 464. 87.

Staph. multipunctatus Block Ins. vall. Plauens. 117. 8. f. 8. (forte)

Staph. macroelytron Fourcr. Ent. Par. I. 164. 4.

Le Staph. noir à long étuis Geoffr. Hist. d. Ins. I. 362. 4.

Habitat in Europa.

Nigra, nitida, tenuiter griseo-pubescens. Antennae capite thoraceque paululum longiores, piceo-testaceae, articulis duobus primis saepe fuscescentibus. Palpi testacei. Caput thorace paulo angustius, sat crebre punctatum, fronte utrinque leviter longitudinaliter impressa, impressione utra. que inter oculos foveolata. Thorax coleopteris dimidio angustior, latitudine summa paulo brevior, lateribus anterius fortiter rotundatus, postice coarctatus, angulis posterioribus rectis, leviter convexus, confertim minus subtiliter punctatus, basi supra scutellum foveola transversa impressus, interdum etiam versus apicem medio longitudinaliter obsolete impressus. Scutellum laeve. Elytra thorace plus duplo longiora, dense fortius punctata, fusca, iam nigrofusca, interdum subaenea, iam fusco-testacea. Abdomen confertim subtiliter punctatum. Pedes piceo-testacei.

2. L. pubescens: Alata, nigra, densius pubescens, subtiliter punctata, ore, antennis pedibusque rufis, thoracis angulis posterioribus acutiusculis, elytris thorace duplo longioribus, fuscis. - Long. 2 lin.

Mannerh. Brachelytr. 57. 12. - Er. Col. March, I. 617. 2.

Habitat in Germania.

Statura omnino et summa similitudo L. bicoloris. Nigra vel fusco-nigra, nitidula, pube tenui cinerea densius vestita. Antennae capite thoraceque multo longiores, graciles, rufae, basi dilutiores. Palpi rufi. Caput thorace angustius, sat crebre subtilius punctatum, fronte utrinque profundius longitudinaliter impressa, ore piceo-rufo. Thorax coleopteris dimidio angustior, latitudine vix brevior, lateribus ante medium fortiter rotundatus, basin versus angustatus, angulis posterioribus acutiusculis, leviter prominulis, parum convexus, sat crebre subtiliter punctatus, basi supra scutellum obsoletius impressus. Scutellum obsolete punctulatum. Elytra thorace duplo longiora, sat crebre subtilius punctulata, fusca vel fusco-nigra. Abdomen confertim subtilissime punctulatum. Pedes rufo-testacei.

Obs. 1. Thorax nonnunquam medio dorso utrinque foveolatus: specimen tale descripsit Com. Mannerheim.

2. Differt a L. bicolore pubescentia densiore, punctura subtiliore, antennis longis, gracilibus, fronte utrinque profundius longitudinaliter impressa, thoracis angulis posterioribus acutiusculis etc.

* 3. L. maura: Alata, nigra, 'pubescens, antennis pedibusque piceis, thoracis angulis posterioribus oblusis, elytris thorace plus duplo longioribus.

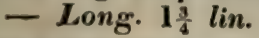

Habitat in Sardinia, Dom. Prof. Gené.

L. bicolore paulo minor, nigra, nitidula, densius griseo-pubescens. 
Antennae capite thoraceque vix longiores, piceae, articulis duobus primis nigricantibus. Palpi picei. Caput thorace paulo angustius, fronte utrinque longitudinaliter, antice transversim impressa. Thorax coleopteris dimidio angustior, latitudine summa haud brevior, lateribus anterius fortiter rotundatus, basin versus angustatus, angulis posterioribus obtusis, leviter convexus, confertim subtilius punctatus, dorso medio nonnunquam obsoletc bifoveolatus. Scutellum laeve. Elytra thorace plus duplo longiora, nigro-fusca. Abdomen crebrius subtilissime punctulatum. Pedes iam nigro-, iam rufo-picei.

Obs. Proxima L. bicolori, at statura paululum minore, antennis paulo brevioribus, frontis impressionibus longitudinalibus profundioribus, inter oculos haud foveolatis et thoracis angulis posterioribus obtusioribus distineta.

4. L. Sicula: Picea, subnitida, tenuiter griseo-pubescens, thorace breviore, lateribus foveolato, dorso obsolete bi-impresso, elytris thorace plus duplo longioribus. - Long. 2 lin.

Habitat in Sicilia, Dom. Grohmann.

L. bicolore paulo brevior et latior, saturate rufo-picea, nitidula, tenuiter griseo-pubescens, ore, antennis pedibusque rufis. Caput thorace dimidio angustius, dense profunde punctatum, fronte planiuscula, inter oculos utrinque obsolete impressa. Thorax coleopteris dimidio angustior, latitudine summa tertia parte brevior, lateribus anterius fortiter rotundatus, basi angustatus, angulis posterioribus obtusis, perparum convexus, crebre profunde punctatus, dorso obsolete longitudinaliter bi-impressus, lateribus utrinque medio foveola minuta rotundata notatus. Scutellum parce punctatum. Elytra thorace plus duplo longiora, subdepressa, fortius profunde dense punctata. Abdomen crebrius subtiliter punctulatum, dorso nigricans.

* 5. . punctata: Aptera, picea, pubescens, crebre forlius punctata, antennis pedibusque rufis, elytris thorace vix longioribus, fortiter punctatis. - Long. vix 2 lin.

Er. Col. March. I. 618. 3.

Habitat in Germania.

L. bicolore paulo minor, nigro-, rarius brunneo- vel rufo-picea, subnitida, tenuiter pubescens. Antennae capite thoraceque longiores, crassiusculae, rufae. Caput thorace paulo angustius, apicem versus attenuatum, sat crebre profunde punctatum, fronte inter oculos utrinque oblique impressa, antice inter antennas utrinque foveolata, ore rufo. Thorax coleopteris angustior, latitudine summa vix brevior, lateribus ante medium fortiter rotundatis, angulis posterioribus subrectis, postice fortiter angustatus, leviter convexus, sat crebre fortius punctatus, lateribus medio foveolatus. Scutellum punctulatum. Elytra thorace vix duplo longiora, sat crebre fortiter punctata. Abdomen subtilissime punctulatum. Pedes rufi.

Species mihi invisa, forte huius generis.

6. L. longula: Nigro-fusca, densius pubescens, subtilius creberrime punctulala, antennis, elytris pedibusque testaceis, thorace latiore, cordato, elytris longioribus, fronte bifoveolata.

Mannerh. Brachelytr. 57. 11. 
Habitat in Fennia meridionali.

L. bicolori similis, subtilius et crebrius punctulata, thorace latiore, elytrisque thorace triplo longioribus, dum in $L$. bicolori elytra thorace vix duplo longiora (?), quare ut species diversa consideranda. (Mannerh.)

\section{Arpedium $\boldsymbol{E} \boldsymbol{r}$ : \\ Er. Col. March. F. p. 618.}

Mandibulae muticae.

Maxillae malis membranaceis.

Palpi maxillares articulo ultimo penultimo longitudine aequali. Tibiae muticae.

Tarsi postici articulo primo elongato.

Corpus oblongum, subdepressum, iam alatum, iain apterum. Caput exsertum, thorace angustins, subtriangulare, basi colli ad instar sat distincte coarctatum, fronte immarginata, oculis parvis, rotundatıs, haud prominulis. Ocelli super oculorum marginem superiorem siti. Labrum transversum, medio subsinuatum. Mandibulae breviusculae, validiusculae, acutae, muticae. Maxillae (t. V. f. 27. b.) mala interiore membranea, extus cornea, oblique truncata, margine ciliato, mala exteriore membranacea, apice subsemicirculariter dilatata,-margine barbato. Palpi maxillares articulo primo minuto, secundo, tertio quartoque inter se longitudine subaequalibus, hoc subacumiato. Labium (t. V. f. 27. a.) mento apicem versus sensim angustato, apice truncato, ligula membranea, subsiluata, lobis exterioribus paulo magis prominulis, ciliatis. Palpi labiales articulis tribus longitudine subaequalibus. Antennae filiformes, graciles, articulis 2-10 elongato-subobconicis, ultimo ovato, subacuminato. Thorax coleopteris paulo angustior, transversim subquadratus. Scutellum triangulare. Elytra pectus paulo superantia, angulo exteriore fortiter rotundato. Abdomen depressum, tenuiter marginatum. Pedes modice elongati, tibiis pubescentibus, tarsis anticis leviter dilatatis, subtus villosis, articulis 4 primis transversis, cordatis, quinto his coniunctis longitudine aequali, posterioribus tenuibus, articulis 4 primis simplicibus, subtus longius pubescentibus, articulo quinto his coniunctis breviore, postici articulo primo elongato.

O b s e r a t i o n e s.

1. Caput et thorax parcius, elytra densius punctata. Frons ante ocellos lineola brevi longitudinali, ad antennarum insertionem foveola insculpta. Thorax margine laterali medio foveola notatus.

2. Habitus fere Omalii floralis, at thoracis forma magis Acidotam refert. Maxillarum mala exteriore dilatata $\mathrm{L}$ a th $\mathrm{rim}$ a $\mathrm{e}$ propinquum, tarsorum autem structura et palporum maxillarium articulis ultimis duobus longitudine aequalibus distinctum.

3. Mas abdominis segmento sexto superiore et inferiore truncato, septimo prominulo distinctus.

4. Victus sub lapidibus et sub truncorum cortice.

* 1. A. quadrum: Oblongum, subdepressum, nigrum, antennis pedibusque teslaceis, thorace subquadrato parce, elytrisque crebre forliter punclalis piceis, limbo testaceo. - Long. 2 lin.

Er. Col. March. I. 619. 1.

Omalium quadrum Grac. Mon. 215. 18. - Oliv. Encycl, meth. VIII. 478. 18. - 
Gyll. Ins. Suec. IV. 461. 3-4. - Suhlb. Ins. Fenn. I. 278. 3. - Zetterst. Ins. Lappon. 50. 4. - Mannerh. Brachelytr, 52. 9. - Boisd. et Lacord. Faun. Ent. Paris. 1. 487. 4 ,

Anthobium castaneum Runde Brachelytr. Hal. 23. 3.

\section{Habitat in Germania, Suecia.}

Corpus oblongum, subdepressum, nigrum, nitidum, glabrum. Antennae capite thoraceque paulo longiores, apicem versus haud incrassatae, rufae, articulo primo testaceo. Palpi testacei. Caput thorace plus duplo minus, parce punctatum, fronte inter oculos et inter antennas foveolis binis sat profundis impressa. Thorax coleopteris vix angustior, latitudine parum brevior, subquadratus, lateribus parum rotundatus, basi apiceque truncatus, angulis omnibus rotundatis, subdepressus, parcius inaequaliter sat fortiter punctatus, ad marginis lateralis medium utrinque foveolatus, margine omni rufotestaceo. Scutellum parce punctatum. Elytra thorace duplo prope longiora, nonnisi abdominis segmentum primum tegentia, subdepressa, crebre sat fortiter profundeque interius subseriatim punctata, fusco-picea, nitida, limbo exteriore et apicali fusco-testaceo. Abdomen parce subtilissime obsoletis. simeque punctulatum, parce subtiliter pubescens, minus nitidum. Pedes rufo-testacei.

Mas tibiis anticis medio dentatis distinctus.

* 2. A. brachypterum: Piceum, parum nitidum, parce pubescens, capite thoraceque subquadrato parce subtiliterque punclatis, hoc utrinque profunde foveolato, elytris crebre fortius punctatis. - Long. $1 \frac{2}{3}$ lin.

Omalium brachypterum Grav. Micr. 114. 5. Mon. 208. 9. - Latr. Hist. nat. Crust. et Ins. IX. 372. 5. - Oliv Encycl. meth. VIII. 476. 9.

Omalium impressum Zetterst. Faun. Lappon. I. 52. 9. Ins. Lappon. 51. 14.

Omalium Gyllenhalii Sahlb. Ins. Fenn. I. 286. 23. - Zetterst. Ins. Lupp. 52. 16. Anthobium Gyllenhalii Mannerh. Brachelytr. 54. 10.

Habitat in Germania, Lapponia, Fennia.

Corpus oblongum, subdepressum, piceum, parum nitidum, minus subtiliter at parce pubescens. Antennae rufo-testaceae, pilosellae. Caput thorace duplo minus, parce subtiliter obsoleteque punctatum, fronte inter oculos striolis duabus minutis, profundis, apice inter antennas foveolis duabus minutis impressa, margine apicali tumidulo, saturatius piceum. Thorax coleopteris vix latior, latitudine paulo brevior, lateribus leviter rotundatus, basi apiceque truncatus, angulis omnibus rotundatis, supra parum convexus, parce subtilissime punctulatus, ad marginem lateralem utrinque paulo ante medium foveola minuta rotundata sat profunda impressus. Scutellum parce subtiliter obsoleteque punctatum. Elytra thorace sesqui longiora, depressa, creberrime minus subtiliter punctata. Abdomen crebrius subtiliter punctulatum. Pedes testacei.

Variat 1, Colore iam magis nigro-, ian magis rufo-piceo, elytris in illis saepius dilutioribus;

2, Elytris thorace iam vix iam plus sesqui longioribus. Specimina illa aptera, haec alata esse videntur.

Obs. Dom. Prof. Zetterstedt Om. Gyllenhalii ab O. pubescente statura paulo maiore, pubescentia tenuiore, pedibus paulo dilutioribus differe observat, quae 
autem differentiae forte non satis constantes me fugiunt; specimina nostra Lapponica Fennicaque tam inter se quam cum typo Gravenhorstiano conveniunt, quare nomini Gravenhorstiano illa subiunxi.

* 3. A. humile: Lineare, depressum, pubescens, nigrum, capile, thorace elytrisque piceo-testaceis, dense aequaliter punctatis. - Long. vix ultra 1. lin.

Habitat in montibus Uralensibus, Prof. Eversmann.

Habitu omnino Omalii plani, et ninoribus eius individuis aequale, lineare, depressum, pube subtili brevi depressa fulvescenti-grisea densius vestitum. Antennae capitis thoracisque prope longitudine, apicem versus sensim leviterque incrassatae, articulis 4 primis laete testaceis, reliquis fuscescentibus. Caput thoracis prope latitudine, breve, planum, aequale, subtilius at sat profunde dense punctatum, piceo-testaceum, nitidum. Thorax coleopterorum prope latitudine, latitudine dimidio brevior, lateribus leviter rotundatus, basi apiceque truncatus, angulis posterioribus obtusis, subrotundatis, depressus, dense minus subbtiliter profunde punctatus, aequalis, piceotestaceus, nitidus. Elytra thorace duplo longiora, subdepressa, dense fortius profunde punctata, piceo-testacea, nitida. Abdomen parce subtilissime punctatum, nigrum, nitidum. Pectus nigrum, nitidum. Pedes flavo-testacei. videtur.

$\mathrm{Obs}$. Exemplum singulum palporum tarsorumque structura huius generis esse

Species mihi invisa, forte huins generis:

4. A. Sibiricum: Oblongum, glabrum, nigrum, antennis, thoracis limbo, elytris pedibusque testaceis.

O malium Sibiricum Mannerh. Brachelytr. 52. 8.

Habitat prope Barnaul Sibiriae.

A. quadro simillimum, parcius punctatum, capite thoraceque respecta magnitudine multo minoribus et abdomine longiore fere unice diversum. (Mannerh.)

\section{Acidota Leach.}

Mannerh. Brachelytr. p. 55. - Steph. Illustr. V. p. 358. - Boisd. et Lacord. Faun. Ent. Paris. I. p. 476. - Er. Col. Murch. I. p. 620.

Mandibulae muticae.

Maxillae malis membranaceis.

Palpi maxillares articulo ultimo penultimo vix longiore.

Tibiae spinulosae.

Tarsi postici articulo primo elongato.

Corpus elongatum, subdepressum, alatum. Caput exsertum, thorace angustius et multo minus, oblongum, basi vix constrictum, fronte apice marginata, oculis parvis, prominulis. Ocelli super oculorum marginem superiorem positi. Labrum breve, transversum, integrum. Mandibulae validiısculae, at breves, muticae. Maxillae (t. V. f. 28. b.) malis membranaceis, exteriore interiorem paulo superante, hac interne ciliata, illa apice barbatula. Palpi maxillares modice elongati, articulo primo minuto, secundo longiore tertioque hoc paulo breviore leviter obconicis, quarto secundo longitudine 
aequali, tertio paululum longiore, oblongo-ovato, subacuminato. Labium (t. V. f. 28. a.) mento transverso, apice truncato, ligula membranea, profunde biloba, lobis interne sinuatis. Palpi labiales articulo primo longiore, secundo hoc duplo breviore, tertio primo aequali, subacuminato. Antennae filiformes, articulo primo tumidulo, ovato, secundo tertio paululum breviore tertioque subobconicis, sequentibus longitudine sensim licet levissime decrescentibus, penultimis crassitie vix longioribus, ultimo oblongo-ovato, acuminato. Thorax sat amplus, apicem versus subangustatus, lateribus late marginato. Scutellum triangulare. Elytra abdominis primum segmentum obtegentia, angulo exteriore rotundato. Abdomen late marginatum, parallelum, apice rotundato-acuminatum. Pedes breviores, tibiis subtiliter spinulosis, tarsis omnibus simplicibus: antici articulis 4 primis inter se aequalibus, brevibus, quinto his coniunctis longitudine aequali, intermedii articulo primo elongato, sequentibus tribus inter se aequalibus, brevibus, quinto reliquis quatuor coniunctis paulo breviore, postici articulo primo elongato, secundo subelongato, tertio quartoque inter se aequalibus, brevibus, quinto reliquis coniunctis dimidio breviore.

\section{O b s e r vationes.}

1. Corpus glabrum. Caput et thorax fortius, abdomen subtilius, elytra subseriatim punctata. Frons antice ad antennarum insertionem utrinque foveolata impressave.

2. A Deliphro tarsorum posticorum articulo primo magis quam secindo elongato, ligula profunde biloba etc., a reliquis Omalinis pedibus validiusculis, tibiis distincte spinulosis differt. Ligulae structura cum Anthophago et Anthobio congruit.

3. Mas segmento utroque sexto truncato, septimo conspicuo distinctus.

4. Victus in sylvis sub muscis.

1. A. crenata: Picea, antennis pedibusque rufis, thorace leviter convexo, aequali, elytris fortiter striato-punctatis. - Long. 3 lin.

Mannerh. Brachelytr. 55. 3. - Steph. Illustr. V. t. 127. f. 6. - Boisd. et Lacord. Faun. Ent. Paris. I 476. 1. - Er. Col. March. I. 620. 1.

Staph. erenat u Fab. Ent. Syst. I. II. 525. 26. Syst. El. II. 596. 34. - Payk. Mon. Curc. App. 146. 45. Fuun. Suec. III. 403. 47. - Panz. Ent. Germ. 354. 18. - Walk. Faun, Paris. I. 272. 15.

Omal. crenatum Oliv. Encycl. meth. VIII. 476. 6. - Gyll. Ins. Suec. II. 230. 27. - Sahlb. Ins. Fenn. I. 288. 26. - Zetterst. Faun. Lappon. I. 55. 15. Ins. Lappon. 53. 23.

Omal. castuneum Grav. Mon. 207. 8. - Oliv. Encycl. meth. VIII. 476. 8.

Var. Rufo-testacea.

Omal. rufum Grav. Micr. 115. 6. Mon 207. 7. - Latr. Hist. nat. Crust, et Ins. IX. 372. 6. - Oliv. Encycl. meth. VIII. 476. 7.

A cid ot a rufa Mannerh. Brachelytr. 55. 1. (forte)

\section{Habitat in Europa.}

Corpus elongatum, lineare, glabrum, iam obscure castaneo-piceum, abdominis segmentorum marginibus rufis, iam totum rufum vel rufo-testaceum. Antennae capite thoraceque paulo longiores, apice vix crassiores, rufo-ferrugineae. Palpi testacei. Caput parvum, thorace quadruplo minus, crebre profundeque punctatum, fronte plana, antice inter antennas bifoveolata, margine antico elevato, Thorax basi coleopterorum prope latitudine, 
latitudine haud brevior, lateribus leviter rotundatus, antrorsum leviter angustatus, basi apiceque truncatus, angulis anterioribus rotundatis, posterioribus obtusis, supra leviter convexus, crebre profundeque punctatus, linea media utrinque abbreviata laevi, margine laterali explanato, relevato, medio subfoveolato. Scutellum parum-punctatum. Elytra thorace plus sesqui longiora, fortiter profundeque interne sat regulariter striato-punctata. Abdomen minus fortiter crebre punctatum. Pedes rufi.

* 2. A. cruentata: Rufo-testacea, thorace subdepresso, longitudinaliter bi-ampresso, elytris thorace duplo longioribus, interne serialim punctatis. - Long. $2 \frac{1}{3}$ lin.

Mannerh. Brachelytr. 55. 2. - Er. Col. March. 1. 621. 2.

Omal. rufum Gyll. Ins. Suec. II. 228. 26. - Sahlb. Ins. Fenn. I. 288. 25.

Habitat in Germania, Suecia.

Praecedente minor, brevior et magis depressa, rufo-testacea, nitida, glabra. Antennae capite thoraceque longiores, crassiusculae, apicem versus haud incrassatae, articulis 4-10 cylindricis, sensim paulo brevioribus; prioribus eorum crassitie longioribus, longius puhescentes. Caput thorace triplo fere minus, crebre fortiter punctatum, fronte inter oculos bifoveolata, anterius longitudinaliter utrinque impressa, margine antico elevato. Thorax coleopteris parum angustior, latitudine dimidio fere brevior, lateribus leviter rotundatus, antrorsum subangustatus, basi apiceque truncatus, angulis anterioribus rotundatis, posterioribus subrectis, parum convexus, crebre sat profunde punctatus, dorso depressiusculus, obsolete longitudinaliter bi-impressus, ad marginis lateralis medium utrinque foveola rotundata sat profunda notatus. Scutellum basi punctatum. Elytra thorace duplo fere longiora, profunde punctata, punctis ad suturam in series sat regulares dispositis. Abdomen minus fortiter crebrius punctatum, dorso rufo-piceum, segmentorum marginibus rufo-testaceis. Pectus piceum. Pedes rufo-testacei.

* A. A. ferruginea: Rufo-testacea, nilida, thorace depresso, obsolete longitudinaliter bi-impresso, elylris thorace paulo longioribus, inlerne subseriatim punctatis. - Long. 2 lin.

Boisd. et Lacord. Faun. Ent. Paris. I. 477, 2. (forte)

Omalium guadrum Zetterst. Faun. Lappon. I. 54. 14.

Omalium quadraṫum Zetterst. Ins. Lappon. 53. 22.

Habitat in Suecia. Exemplum a Gyllenhal nomine Omal. rufi nissum dedit Dom. Schïppel.

Praecedente plus dimidio minor, rufo-testacea, nitida, glabra. Antennae capitis thớacisque longitudine, crassiusculae, apicem versus haud incrassatae, articulis 4-10 cylindricis, primis eorum crassitie vix longioribus, ultimis subbrevioribus, pilosellae. Caput thorace triplo fere minus, crebrius profundiusque punctatum, punctis in media fronte rarioribus, hac inter oculos impressionibus duabus obliquis, postice conniventibus, antice foveola profunctiore terminatis, inter antennas foveolis duabus latioribus notata, margine anteriore praecipue ad latera elevato. Thorax coleopterorum latitudine, latitudine dimidio brevior, antrorsum vix angustatus, lateribus perparum rotundatus, basi apiceque truncatus, angulis posterioribus subrectis, anteriu- 
ribus rotundatis, parum convexus, crebre fortius profunde punctatus, dorso depressus, obsolete longitudinaliter bi-impressus, utrinque prope marginis lateralis medium foveola rotundata profunde impressus. Scutellum basi punctatum. Elytra thorace tertia parte longiora, subdepressa, crebre profundeque punctata, punctis interne in series nonnullas minus regulares, geminatas digestis. Abdomen crebre fortius punctatum. Pedes dilutius testacei.

Obs. Distincta videtur a praecedente statura minore, antennis elytrisque brevioribus, his minus regulariter striato-punctatis, abdomine minus subtiliter punctato, etc.

* 4. A. subcarinata: Pubescens, rufo-picea, capite, thoracis abdominisque dorso nigricantibus, thorace subcarinato, elyiris crebre profunde punctatis. - Long. $2 \frac{1}{4}$ lin.

Habitat Bostoniae in America septentrionali, Dom. Zimmermann.

Statura omnino praecedentium, subdepressa, pube minus subtili fulvescenti vestita. Antennae capite thoraceque vix longiores, articulis 4-10 subcylindricis, sensim paulo crassioribus at vix brevioribus, rufae. Palpi rufi. Caput thorace quadruplo prope minus, crebrius minus fortiter at profunde punctatum, fronte subaequali, inter oculos et inter antennas foveolis bınis minutis levius impressa, margine antico leviter elevato, nitidum, nigrum, antice rufescens. Thorax coleopteris parum angustior, latitudine paululum brevior, antrorsum subangustatus, lateribus modice rotundatus, basi apiceque truncatus, angulis anterioribus rotundatis, posterioribus obtusis, leviter convexus, crebrius fortiusque profunde punctatus, dorso depressiusculus, longitudinaliter late obsolete bi-impressus, interstitio subcarinato, laevi, utrinque prope marginis lateralis medium foveola rotunda impressus, margine laterali explanato, relevato, obsolete crenulato, piceus, nitidus, limbo omni rufescente. Scutellum basi punctatum. Elytra thorace plus sesqui longiora, margine laterali planato, apicali depresso, tota aequaliter crebre fortiter profundeque punctata, rufo-picea, nitida. Abdomen crebre minus subtiliter punctulatum, subtus piceo-rufum, supra nigro-piceum, limbo laterali rufescente, nitidum. Pectus piceo-rufum. Pedes rufi.

Obs. Nomine O malii subcarinati S ay i. litt. communicata.

\section{Olophrum $\boldsymbol{E}$.}

Er. Col. March. I. p. 622.

Mandibulae muticae.

Maxillae malis elongatis, corneis.

Palpi maxillares articulo penultimo ultimo duplo breviore.

Tibiae muticae.

Tarsi postici articulis duobus primis subelongatis, inter se aequalibus.

Corpus crassiusculum, convexiusculum, ovatum vel oblongum, iam alatum, iam apterum. Caput thorace multo minus et angustius, subdeflexum, basi haud constrictum, fronte immarginata, oculis parvis, subprominulis. Ocelli super oculorum marginem superiorem siti. Labrum (t. V. f. 29. c.) transversum, integrum, apice membrana prominula biloba auctum. Mandibulae validiusculae, subrectae, muticae, apice acuto introrsum curvato. Mla- 
xillae (t. V. f. 29. b.) malis elongatis, corneis, interiore interne tenuiter ciliata, exteriore apice barbatula. Palpi maxillares articulo primo minuto, secundo sat elongato, tertio breviore, subobconico, quarto iterum longiore, praecedente duplo fere longiore, subacuminato. Labium (t. V. f. 29. a) mento latitudine baseos breviore, antrorsum valde angustato, apice subemarginato, ligula membranea, apice truncata vel subsinuata. Palpi labiales articulo primo elongato, secundo tertioque minutis, illo paulo breviore. Antennae filiformes, articulo primo parum crassiore, secundo tertio vix breviore, sequentibus subcylindricis, longitudine sensim levissime decrescentibus, penultimo crassitie sua vix longiore, ultimn ovato, acuminato. Thorax sat amplus, coleopterorum fere longitudine. Elytra sat ampla, abdominis maiorem minoremve partem obtegentia. Abdomen tenuiter marginatum, apice subacuminatum. Pedes minus elongati, tibiis inermibus, pubescentibus, tarsis anticis articulis 4 primis subdilatatis, transversim cordatis, quinto his coniunctis paulo breviore, intermediis articulo primo subelongato, sequentibus tribus brevibus, inter se aequalibus, quinto his coniunctis (primo excepto) longitudine aequali, posticis articulis primis duobus subelongatis, tertio quartoque brevioribus, quinto praecedentibus tribus coniunctis longitudine fere aequali. Tarsorum omnium articuli 4 primi subtus longius densiusque pubescentes.

\section{O bservationes.}

1. Corpus glabrum. Caput, thorax et elytra punctata. Abdomen glabrum. Frons inter oculos lineolis foveolisve nullis insculpta.

2. Maxillarum structura Lesteuae proximum.

3. Mas abdominis segmento sexto truncatulo, septimo prominulo distinctus.

4. Victus in sylvis sub musco, foliis deciduis, lapidibus.

* 1. O. piceum: Convexum, piceum, nitidum, antennis pedibusque rufis, elytris fortiler vage punclatis. - Long. $2 \frac{1}{4}$ lin.

Er. Col. March. I. 623. 1.

Omalium piceum Gyll. Ins. Suec. II. 200. 3. - Zetterst. Faun. Lappon. I. 49. 3. Ins. Lappon. 50. 5. - Mannerh. Brachelytr. 51. 4-Boisd. et Lacord. Faun. Ent. Paris. I. 485. 1. - Runde Brachelytr. Hal. 21. 1.

Silpha Blattoides Ahrens Act. nov. Halens. II. I1. 20. 12. t. 2. f. 3.

Habitat in Germania, Hungaria, Anglia, Suecia.

Corpus breve, convexum, brunneo-piceum, saepe etiam rufo-piceum vel testaceum. Antennae capitis thoracisque fere longitudine, rufae vel rufo-testaceae. Caput maiusculum, crebrius fortiusque punctatum, inter antennas foveolis duabus minutis impressum, ore testaceo. Thorax coleopterorum latitudine, latitudine duplo fere brevior, basi levissime rotundatus, apice leviter emarginatus, lateribus rotundatus, angulis anterioribns posterioribusque aequaliter rotundatis, apice basi latitudine aequali, margine laterali late explanato, disco convexo, sat crebre profunde fortiterque punctatus. Scutellum laeve. Elytra thorace duplo longiora, basi thoracis medio angustiora, apicem versus sensim leviter dilatata, convexa, fortiter profundeque sat crebre aequaliter punctata. Abdomen laeve, apice piceo-testaceum. Pedes rufi vel testacei. 
* 2. O. obt e ctum: Nigro-piceum, antennis pedibusque rufis, elytris dense vage punctatis. - Long. 2 lin.

Habitat in America septentrionali, Dom. Zimmermann.

Statura omnino et summa affinitas praecedentis. Nigro-piceum, minus nitidum Antennae capitis thoracisque longitudine, rufo-testaceae. Caput crebrius punctatum, inter oculos et inter antennas'obsolete bifoveolatum, ore testaceo. Thorax coleopteris paulo angustior, latitudine duplo brevior, basi levissime rotundatus, apice leviter emarginatus, lateribus rotundatus, angulis anterioribus rotundatis, posterioribus obtusis, subrotundatis, leviter transversim convexus, lateribus marginatus, margine autem haud explanato, dense punctatus, marginibus rufo-piceis. Scutellum parce punctatum. Elytra thorace plus duplo longiora, apicem versus sensim leniter dilatata, dense sat profunde punctata, margine apicali rufo-piceo. Abdomen laeve, apice testaceum. Pedes rufi, femoribus nonnunquam picescentibus.

Obs. Differt ab O. pic eo corpore minus convexo, punctura subtiliore, capite minore, thorace angustiore, elytris longioribus.

* 3. O. fuscum: Leviler convexum, piceum, antennarum basi pedibusque rufis, elytris forliter punctatis, punctis interne subserialis. - Long. 2 lin.

Er. Col. March. 1. 623. 2.

Omalium fuscum Grav. Mon. 211. 16. - Oliv. Encycl. meth. VIII. 478. 17.

Habitat in Germania.

Habitu et summa affinitate $O$. picei, at dimidio minus, angustius, minus convexum, brunne-piceum, nitidulum. Antennae capite thoraceque paulo longiores, piceae, apice rufescentes, articulo primo rufo, interdum totae rufae. Caput crassiusculum, vage crebrius sat fortiter punctatum, fronte inter oculos foveolis duabus obsoletis, inter antennas duabus profundioribus impressa, palpis mandibulisque rufo-piceis. Thorax coleopterorum basi latitudine aequalis, latitudine dimidio brevior, lateribus leviter rotundatus, apice basi angustior, angulis anterioribus rotundatis, posterioribus obtusis, subro. tundatis, nargine laterali late explanato, disco modice convexo, crebrius vage fortius punctatus, versus margines rufescens. Scutellum punctis pallcis profundis impressum. Elytra thorace duplo prope longiora, apicem versus sensim leniter dilatata, parum convexa, crebre sat fortiter punctata. punctis anterius versus suturam subseriatis. Abdomen laeve. Pedes rufi.

Obs. Variat minus maturum corpore rufo-testaceo: tale specimen O. ass imili simile, distinctum autem statura paulo maiore, elytris longiorious, densius punctatis, frontis foveolis anticis maioribus.

4. O. assimile: Testaceum, abdomine piceo, elylris fortiler punctatis, Long. $1 \frac{2}{3}$ lin.

Er. Col. March. I. 624. 3.

Staph. as similis Payk. Faun. Suec. 111. 409. 53.

Omalium as simile Gyll. Ins. Suec. 1I. 202. 4. - Sahlb. Ins. Fenn. I. 278. 4. Mannerh. Brachelytr. 51. 5.

Habitat in Germania, Suecia, in silvis, sub foliis deciduis putrescentibus.

Habitu omnino O. picei, at plus duplo minus. Antennae capite thoraceque paulo longiores, apicem versus paulo crassiores, pilosellae, testaceae. 
Caput crassiusculum, crebre profunde punctatum, apice inter antennas foveolis duabus minutis notatum, rufo-testaceum, nitidum, - Thorax coleopteris paulo angustior, latitudine dmidio brevior, lateribus leviter rotundatus, angulis anterioribus rotundatis, posterioribus obtusiusculis, basi apiceque latitudine aequalibus, margine laterali explanato, disco convexus, fortius profunde sat crebre punctatus, ad medium marginis lateralis utrinque foveolatus, rufotestaceus, nitidus. Scutellum parce punctatum, rufo-testaceum. Elytra thorace sesqui longiora, parum convexa, crebrius fortiter profundeque punctata, testacea. Abdomen testaceo-piceum. Pectus testaceum. Pedes flavo-testacei.

* 5. O. boreale: O'longum, nigro-piceum, nilidum, antennarum basi, thoracis elytrorumque limbo pedibusque teslaceis, thorace parcius profunde punclato, lateribus postice subsinuato. - Long. 2 lin.

Omalium boreale Gyll. Ins. Suec. I1. 198. 1. - Sahlb. Ins. Fenn. I. 277. 1. Zetterst. Faun. Lappon. I. 48. I. Ins. Lappon. 49. 1. - Mannerh. Brachelytr. 51. 1. Staph. borealis Payk. Mon. Curc. App. 146. 47 - 48. - Faun. Suec. III. 411. 57. (mas)

Habitat in Lapponia, Dalecarlia, Dom. Schïppel.

Corpus oblongun, subdepressum, nigro-piceum, nitidum, glabrum. Antennae capite thoraceque paulo longiores, tenuiores, apicem versus vix incrassatae, articulo ultimo oblongo, apice abrupte subacuminato, piceae, basi dilutiores, rufae. Palpi picei. Caput crebre fortius punctatum, inter antennas obsoletius bifoveolatum, apice laevigatum. Thorax coleopieris paulo angustior, latitudine plus dimidio brevior, lateribus fortiter rotundatis, basin versus leviter angustatis, postice subsinuatis, basi levissime rotundatus, apice truncatus, angulis posterioribus obtusis, at nullo modo rotundatis, anterioribus rotundatis, leviter convexus, parcius profunde punctatus, dorso ante basin et margine laterali leviter explanato ante medium foveolatis, limbo omni dilutiore, rufo-piceo. Scutellum laeve. Elytra thorace plus duplo longiora, crebre, fortiter profundeque punctata, punctis suturam versus subsinuatis, margine apicali testaceo. Pectus minus fortiter punctatum. Abdomen supra laevigatum, subtus parcius punctulatum, apice piceo-testaceum. Pedes dilute rufo-picei.

Obs. O. fusco affine, distinctnm autem statura angustiore, thorace lateribus postice subsinuato, angulis posterioribus nullo modo rotundatis.

* 6. O. rotundicolle: Oblongum, convexum, piceum, thorace dense profundius punctalo, angulis posterioribus fortiter rolundatis. - Long. $2 \frac{2}{3}$ lin.

Omal. rotundicolle Sahlb. Ins. Fenn. I. 281. 11. - Zetterst. Ins. Lappon. 49. 3. - Mannerh. Bruchelytr. 51. 3.

Habitat in Fennia, sec. Sahlberg, in Dalecarlia, Dom. Schïppel.

Habitu ommino $\mathrm{O}$. consimilis, at paulo maius, piceum, nitidum, glabrum. Antennae capitis thoracisque prope longitudine, tenuiores, apicem versus haud incrassatae. Palpi testacei. Caput dense fortius profunde punctatum, inter antennas leviter bifoveolatum, fronte planiuscula, basi incrassatum. Thorax coleopteris vix angustior, latitudine parum brevior, apicem versus subangustatus, lateribus rectis, basi leviter rotundatus, apice leviter bisinua- 
tus, angulis anterioribus obtusis, posterioribus late fortiterque rotundatis, fortiter convexus, dense fortius profunde punctatus, punctis in medio dorso fortioribus et minus confertis, anterius medio longitudinaliter impressus. Scutellum profunde punctatum. Elytra thorace duplo prope longiora, modice convexa, dense fortiter profundeque punctata, punctis vix seriatis, nonnisi abdominis segmentum primum obtegentia. Abdomen supra laeve, subtus parce obsoletius punctatum, parum nitidum. Pectus profunde punctatum. Pedes piceo-rufi.

* 7. O. alp estre: Oblongum, convexum, piceum, elytris limbo apicali tesla. ceo, thorace dense profundeque punctato, lateribus postice subsinuato. - Long. $2 \frac{1}{2}$ lin.

Habitat in Helvetiae alpibus, Dom. Prof. Heer.

O. fusco vix latius, at sesqui fere longius, convexum, piceum, nitidnm, glabrum. Antennae capitis thoracisque fere longitudine, apicem versus vix incrassatae, rufo-piceae, basi dilutiores. Caput fortius profunde punctatum, fronte antice inter antennas transversim impressa utrinque subfoveolata, margine antico incrassato, laevigato, ore piceo-rufo. Thorax coleopteris parum angustior, latitudine dimidio fere brevior, basi apiceque truncatus, laterihus rotundatis, postice subsinuatis, basin versus subangustatus, angulis anterioribus rotundatis, posterioribus obtusiusculis, leviter prominulis, valde convexus, dense profunde punctatus, ante basin nonnunquam obsolete impressus, limbo omni rufo-piceo. Scutellum crebre profundeque punctatum. Elytra thorace duplo longiora, abdomins partem minorem tegentia, convexa, fortiter profundeque crebre punctata, punctis suturam versus subseriatis, rufo. picea, limbo apicali testaceo. Abdomen laeve, apice summo piceo-testàceo. Pedes rüi vel picei.

* 8. O. consimile: Oblongum, nigrum, subnitidum, antennis, pedibus elytrisque piceis, his margine apicali teslaceo, thorace convexo, confertim subtilius punclato, lateribus postice subsinuato. - Long. $2 \frac{1}{3}$ lin.

Omal. consimile Gyll. Ins. Suec. II. 199. 2. - Sahlb. Ins. Fenn. I. 277. 2. -

Zetterst, Faun. Lappon. I. 48. 2. Ins. Lappon. 49. 2. - Mannerh. Brachely/r. 51. 2. Staph. borealis fem. Payk. Faun. Suec. 111. 411.57.

Habitat in Lapponia, Dalecarlia, Dom. Schïppel, in Rossia, Redowsky.

O. boreali paulo magis oblongum, nigrum; subnitidum, glabrum. An tennae capitis thoracisque prope longitudine. tenuiores, apicem versus haud incrassatae, piceae. Palpi picei. Caput minus fortiter densius punctatum, fronte inter antennas bifoveolata. Thorax coleopteris paulo angustior, lateribus rotundatis, postice subsinuatis, basi leviter rotundatus, apice subsinuatus, angulis anterioribus rotundatis, posterioribus obtusis, leviter prominulis, minus fortiter licet profunde confertim punctatus, ante basin medio impressús, limbo laterali anguste explanato, parcius profundiusque punctato. Scutellum parce profundeque punctatum. Elytra thorace plıs duplo longiora, aequaliter densius fortiter profundeque punctata, picea, limbo apicali testaceo, abdominis tertiam fere partem obtegentia. Abdomen supra laeve, subtus parcius obsoletiusque punctatum. Pectus fortiter punctatum. Pedes picei. 
9. O. emarginatum: Nigro-piceum, thorace postice rotundalo, antice emarginalo. - Long. infra 2 lin.

Omalium rotundicolle Suy Transact. Amer. Philoph. Soc. Philadelph. Nov. Ser. IV. 462.2.

Habitat in Pensylvania.

Grosse profundeque crebre punctatum. Antennae fusco-piceae, articulis tribus primis testaceis. Thorax transversim ovalis, antice profunde emarginatus, aequaliter punctatus, angulis posterioribus rotundatis, marginibus piceis. Elytra aequaliter punctata, longa, margine apicali piceo. Abdomen supra piceum, segmentorum marginibus apicalibus dilutioribus, infra picescens. Pedes saturate testacei. (Say.)

\section{Lathrimaeum $E r$.}

\section{Er. Col. March. I. p. 624.}

Mandibulae muticae.

Maxillae malis membranaceis, exteriore dilatala.

Palpi maxillares articulo ultimo penullimo longiore.

Tibiae mulicae.

Tarsi postici articulis duobus primis subelongatis, inter se aequalibus.

Corpus latum, subdepressum, alatum apterumve. Caput thorace multo minus et angustius, basi sat distincte constrictum, fronte marginata, oculis mediocribus, rotundatis, prominulis. Ocelli super oculorum marginem superiorem siti. Labrum (t. V. f. 30. r.) transversum, truncatum, apice utrinque lacinia lineari membranea auctum. Mandibulae sat breves, muticae. Maxillae (t. V. f. 30. b.) mala interiore membranacea, extus cornea, denticulo cornen terminata, apice oblique truncata, ciliata, exteriore membranea, apice subsemicirculariter dilatata, barbata. Palpi maxillares articulo primo ninuto, secundo sat elongato, tertio breviore, quarto hoc plerumque duplo longiore, apice subacuminato. Labium (t.V. f. 31). a.) mento brevi, antrorsum angustato, apice truncato, ligula membranea, transversa, apice truncata, medio leviter incisa. Palpi labiales breviusculi, articulo primo tertioque subaequalibus, secundo his breviore. Antennae filiformes, articulo secundo tertio paululum breviore, sequentibus longitudine sensim levissime decrescentibus, penultimo crassitıe sua haud breviore, ultimo ovato. Thorax am. plus, coleopteris latitudine subaequalis, lateribus late marginatus, Scutellum triangulare. Elytra sat ampla, abdominis maximam partem tegentia, angulo apicis exteriore rotundato. Abdomen brevuusculum, apice subacuminatum. Pedes minus elongati, tibiis simplicibus, pubescentibus, tarsis anticis simplicibus, articulis $\mathbf{4}$ primis brevibus, inter se aequalibus, articulo quinto his coniunctis longitudine aequali, intermediis articulis $\$$ primis longitudine decrescentibus, primo subelongato, quinto his coniunctis breviore, posticis articulis duobus primis subelongatis, inter se aequalibus, tertio breviore, quarto brevi, quinto his coniunctis breviore.

$$
\text { O b s e r va tio n e s. }
$$

1. Caput, thorax et elytra punctata, plerumque glabra; caput distincte foveolatum; thorax magis minusve distincte canaliculatus, dorso postico saepius foreis duabus obliquis postice comiventibus obsolete impressus; elytra ampla. 
2. Habitus fere generis praecedentis, at maxillarum malae neque elongatae, - neque corneae, exterior externe rotundato - ampliata, ut in Arpedio; ab Olophro palporum maxillarium articulo ultimo minus elongato et fronte profundius foveolata distinguendum.

3. Sexus differentia ut in praecedentibus.

4. Victus in silvis sub musco et foliis putrescentibus.

* 1. L. melanocephalum: Testaceum, capile nigro thoraceque Iransverso, conaliculato, lale marginalo, apice profunde emarginalo profunde punclatis, elytris amplis, creberrime forliler subseriatim punclatis. - Long. 2 lin.

Silpha melanocephala Illig. Schneid. Mag. V. 596. 4. Kaef. Preuss. 350. 2. Panz. Ent. Germ. I. 122. 19. Fuun. Germ. 255.

Habitat in Germania.

Corpus ablongo-subquadratum, parum convexum, testaceum, nitidum, glabrum. Antemae capitis thoracisque fere longitudine, articulis $4-10$ sensim paulo brevioribus et crassioribus, ultimo subovato, apice acuminato, nigrae, articulis 4 primis testaceis. Palpi testacei. Caput thorace triplo fere minus, creberrime punctatum, apice laeve, supra utrinque longitudinaliter impressum, inter antennas utrinque foveolatum, margine anteriore utrinque elevato, nigro-subaeneum vel piceum, nitidum. Thorax coleopteris parum angustior, latitudine media duplo fere brevior, lateribus rotundatis, basi truncatus, apice profunde emarginatus, angulis anterioribus acutiusculis, prominentibus, posterioribus subrectis, leviter prominulis, parum convexus, distinctius canaliculatus, basi supra scutellum leviter impressus, lateribus late explanatis, medio impressis. Scutellum parce punctatum. Elytra thorace plus duplo longiora, abdomen fere totum tegentia, apice coniunctim rotundata, parum convexa, creberrime sat fortiter punctata, punctis plerisque in series sat regulares dispositis. Abdomen laeve. Pectus profunde punctatum, interdum piceo-testaceum, Pédes testacei.

* 2. L. luteum: Testaceum, pectore nigro, thorace transverso, apice profundius emarginalo, dorso utrinque obsolete oblique impresso, profunde punctato, elylris amplis, fortiter creberrime subsexiatim punctatis. Long. $1 \frac{2}{3}$ lin.

Habitat in Lusitania.

L. melanocephalo affine, testaceum, subnitidum, glabrum. Antennae capitis thoracisque longitudine, apicem versus sensim leniterque incrassatae, articulo ultimo ovato, apice fuscescentes. Caput thorace duplo minus, posterius fortius sat crebre, anterius subtiliter parce punctatum, fronte inter oculos et inter antennas utrinque impressa, margine laterali supra antennarum insertionem elevato. 'Thorax coleopteris parum angustior, latitudine plus dimidio brevior, lateribus rotundatus, basi truncatus, apice emarginatus, angulis anterioribus rotundatis, posterioribus abtusiusculis, subdentatis, leviter convexus, crebre sat fortiter punctatus, dorso pone medium fovealis duabus oblongis, obliquis, pastice conniventibus, obsolete impressus, margine laterali minus late explanato, medio foveolato. Seutellum parce punctatum. Elytra ampla, abdomen fere totum tegentia, thorace plus duplo longiora, modice convexa, sat crebre fortiterque subseriatim punctata. Abdomen supra 
laeve, subtus lateribus obsoletius punctulatum. Pectus fortiter punctatum, nigrum. Pedes testacei.

Obs. Intermedium quasi inter L. melanocephalum et atrocephalum, ab utroque autem thorace haud canaliculato distinctum.

* 3. L. atrocephalum: Testaceum, capile'nigro-piceo thoraceque transverso, obsolete canaliculato, apice leviter emarginato profunde punctatis, elytris crebre forlitergue subseriatim punclatis. - Long. $1 \frac{1}{2}$ lin.

Er. Col. March. I. 625. 1.

Omal. atrocephalum Gyll. Ins. Suec. IV. 463. 4-5. - Boisd, et Lacord. Faun. Ent. Paris. I. 486. 3.

Omal. melunocephalum Runde Brachelytr. Hal. 22. 3.

Silpha melanocephala Marsh. Ent. Britt. 127. 39.

Habitat in Germania, Suecia.

Snbovatum, leviter convexum, testaceum, nitidum, glabrum. Antennae capitis thoracisque longitudine, apice sensim leviterque incrassatae, testaceae, apice fuscae. Caput thorace duplo fere minus, posterius sat crebre fortiterque, anterius parce subtiliterque punctatum, fronte inter oculos oblique, inter antennas profundius utrinque impressa, margine laterali supra antennarum basin leviter elevato, piceum, nitidum. Thorax coleopteris paulo angustior, latitudine duplo fere brevior, lateribus rotundatus, basi truncatus, apice leviter late emarginatus, angulis anterioribus rotundatis, posterioribus obtusiusculis, subdentatis, modice convexus, sat fortiter profundeque dense punctatus, obsoletius canaliculatus, basi supra scutellum obsolete impressum, margine laterali minus late explanato, modice foveolato. Scutellum parce punctatum. Elytra ampla, abdomen fere totum tegentia, thorace plus duplo longiora, leviter convexa, sat fortiter crebreque subseriatim punctata. Abdomen laeve. Pectus dense profundeque punctatum.

V a riat rarissime corpore nigro, antennis concoloribus, pedibus solis piceis. Specimen singulum Dom. Schïppel Berolini legit.

* 4. L. fusculum: Fuscum, nitidum, capite nigro, thorace elytrisque confertissime punctatis, thorace transverso, obsolete canaliculato, dorso utrinque oblique impresso, apice leviter emarginalo. - Long. $1 \frac{1}{4}$ lin.

Er. Col. March I. 626. 2.

\section{Habitat in Germania.}

L. atrocephalo ninus, praesertim angustius et magis depressum; obscure fuscum, subnitidum, glabrum. Antennae capitis thoracisque longitutudine, apice sensim leviter incrassatae, fusco-testaceae, apice nigrae. Caput thorace duplo fere minus, creberrime punctatum, apice laevi, fronte inter oculos utrinque impressa, inter antennas utrinque profunde foveolata, margine laterali supra antennarum basin elevato, nigrum, ore rufo-piceo. Thorax coleopterorum hasi parum angustior, latitudine díplo fere brevior, lateribus rotundatus, basi truncatus, apice leviter emarginatus, angulis anterioribus subrotundatis, posterioribus obtusis, parum convexus, dense punctatus, obsolete canaliculatus, postice foveis duabus oblongis, obliquis postice conniventibus impressus, margine laterali minus late explanato, medio foveolato, nigro-fuscus, marginibus dilutioribus. Scutellum parce punctatum. Elytra thorace duplo longiora, abdomen dimidium tegentia, apicem versus 
sensim leviter dilatata, subdepressa, confertissime punctata, fusca vel fuscotestacea. Abdomen subtilissime punctulatum, nigro-piceum.- Pectus fortiter punctatum. Pedes fusco-testacei.

* 5. L. sordidum: Dilute testaceum, nilidum, peclore abdomineque nigro-piceis, capite. Thorace elylrisque fortiter profundeque punclatis, thorace transverso, apice truncato. - Long. $1 \frac{1}{2}$ lin.

Habitat in America septentrionali, e collectione Knochiana.

L. atrocephalo angustius, magis depressum, flavo-testaceum, nitirlun, pectore abdomineque piceis. Antenuae capitis thoracisque longitudine, apicem versus sensim leviterque incrassatae. Caput thorace duplo fere minus, parcius punctatum, fronte inter oculos et inter antennas foveolis binis obJongis minutis impressa. Thorax coleopterorum basi parum angustior, latitudine dimidio brevior, lateribus rotundatus, basi apiceque truncatus, angulis anterioribus rotundatis, posterioribus obtusis, parum convexus, sat fortiter profundeque vage punctatus, dorso foveola media duabusque obliquis, omnibus valde obsoletis, lateribus utrinque foveola profundiore impressus. Scutellum laeve. Elytra thorace duplo longiora, abdominis tertiam fere partem obtegentia, apicem versus sensim leviterque dilatata, subdepressa, secumdum suturam impressa, crebre fortiter profundeque punctata. Abdomen parce. obsoletissime punctulatum. Pedes pallide testacei.

* 6. L. canaliculat um: Nigrum, pubescens, ore, antennarum basi, thorace subquadralo pedibusque tesiaceis, elytris forliter punclatis, flavis. - Long. 2-2 $2 \frac{1}{3}$ lin.

Habitat in Germaniae, Austriae, Hungariae, Syrmiae montibus.

Antemnac capite thoraceque paulo longiores, apicem versus sensim subincrassatae, fuscae, articulis 4 primis testaceis. Caput thorace dimidio fere angustius, oblongum, parcius obsoletiusque punctatum, fronte depressa, inter oculos utrinque sulco minus profundo impressa, nigrum, ore late testaceo. Thorax coleopterorum basi parum angustior, maris latitudine perparum, feminae dimidio brevior, lateribus leviter rotundatis, basi truncatus, apice subemarginatus, angulis anterioribus rotundatis, posterioribus obtusiusculis, leviter convexus, minus confertim punctatus, sribtiliter canaliculatus, margine laterali posterius depresso, testaceum, subnitidum. Scutellum iam testaceum, iam nigrum. Elytra thorace duplo prope longiora, apicem versus sensim paulo latiora, subdepressa, densius sat fortiter punctata, flavo-testacea, abdominis nonnisi basin tegentia. Abdomen parce obsoleteque punctulatum, maris nigrum, nitidum, apice piceum, ano acuminato, feminae rufo-testaceum. Pectus parce punctatum, nigrum. Pedes testacei.

Mas femoribus anterioribus leviter inerassatis, anticis medio subus denticulo armatis, tibiis intermediis incurvis, medio interne emarginatis, sinu superius denticulo terminato, femina pedibus omnibus simplicibus. Praeterea femina thorace breviore et abdomine testaceo distincta.

$\mathrm{Obs}$. Spurium in hoc genere videtur, a reliquis speciebus capite elongato, inter antennarum basin haud foveolato, thorace convexo, margine laterali haud dilatato, tarsis elongatis, corpore pubescente et differentia sexuali discedens, oris autem structura partiumque proportione non tam mihi differre videtur, ut generi peculiari constituendo characteres satis sint. 


\title{
Deliphrum $\boldsymbol{E}$.
}

\author{
Er. Col. March. I. p. 627.
}

Mandibulae muticae.

Maxillae malis membranaceis, exteriore dilatata.

Palpi maxillares articulo ultimo penultimo longiore.

Tibiae spinuloste.

Tarsi postici arliculis duobus primis subelongatis, inter se aequalibus.

Corpus latum, subdepressum, alatum. Caput thorace minus et angustius, obtusiusculum,. basi modice constrictum, fronte immarginata, nculis mediocribus, rotundatis, modice prominulis. Ocelli super oculorum marginem superiorem siti. Labrum breve, truncatum, apice membrana brevi biloba auctum. Mandibulae breves, validiusculae, acutae, simplices. Maxillae mala interiore membranacea, extus cornea, denticulo corneo terminata, apice oblique truncata, ciliata, exteriore membranea, apice dilatata, rotundata, barbata. Palpi maxillares articulo primo minuto, secundo sat elongato, tertio breviore, quarto tertio multo longiore. Labium mento transverso, antrorsum angustato, apice truncato, ligula membranea, transversa, medio subemarginata. Palpi labiales breviusculi, articulo primo tertioque longioribus, secundo breviore. Antennae filiformes, articulo tertio secundo parum longiore, sequentibus longitudine sensim levissime decrescentibus, penvltimo crassitie hand breviore, ultimo ovato. Thorax subquadrangulus, angulis rotundatis. Scutellum triangulare. Elytra longiora, angulo exteriore rotundato. Abdomen marginatum, antice parallelum, postice rotundatum, apice subacuminatum. Pedes minus elongati, tibiis subtiliter at distincte spinulosis, tarsis anticis articulis 4 primis brevibus, subcordatis, haud dilatatis, inter se aequalibus, quinto his coniunctis breviore, intermediis articulis duobus primis subelongatis, tertio quartoque brevibus, utrisque inter se aequaJibus, quinto his coniunctis breviore, posticis articulis duobus primis leviter elongatis, inter se aequalibus, tertio paulo breviore, quarto brevi, quinto reliquis coniunctis multo breviore.

$$
\text { O b s e r v a t i o n e s. }
$$

1. Affine generi praecedenti, imprimis oris etiam structura, distinctum praecipue tibiis spinulosis. Habitus quoque corpore laeviore, capite thoraceque fere laevibus, statura etiam saepius magis elongata divergens. Habitus propius ad $\mathrm{Oma-}$ liu $\mathrm{m}$ accedit, distinguitur autem tarsorum articulis primis leviter elongatis, antennis gracilioribus et maxillarum mala exteriore haud dilatata.

2. Sexus differentia ut in praecedentibus.

* 1. D. te ct um: Nigrum, nitidum, subtiliter punctulatum, antennarum basi, thoracis trunsversi, obsolete cunaliculati margine, elytris pedibusque testaceis. - Long. $1 \frac{1}{2}$ lin.

Er. Col. March. 1. 627. 1.

Staph. tectus Payk. Mon. Staph. 68. 48, Faun. Suec. III. 411. 56. - Oliv. Ent. III. 42. 36. 52. $t$. 3. $f .21$.

Omal. tert u m Grav. Mon. 213. 19. - Oliv. Encycl. meth. VIII. 478. 19. - Gyll. Ins. Suec. II. 202. 5. - Sahlb. Ins. Fenn I. 278. 5. - Zetterst. Faun. Lappon. I. 49. 4. Ins. Lappon. 50. 6. - Mannerh. Brachelytr. 52. 11. - Boisd. et Lacord. Faun. Eut. Paris. I. 487. 5.

Omal. La eve Gruv. MLon, 211. 15. - Oliv, Enrycl. melh, Ins. VIII. 177. 15. 
Habitat in Germania, Suecia.

Breviusculum, latum, parum convexum, nigrum, nitidum, capite thoraceque subaeneis. Antennae capite thoraceque longiores, apicem versus sensim leviter incrassatae, nigrae, articulis 3 primis testaceis. Palpi picei. Caput breviusculum, obsolete subtilissime punctulatım, fronte ad oculos utrinque oblique sulcata. Thorax coleopterorum basi paulo angustior, latitudine duplo prope brevior, lateribus rotundatus, antrorsum subangustatus, basi apiceqne truncatus, angulis omnibus obtusis, subrotundatis, leviter convexus, crebre subtiliter punctatus, subtiliter obsoleteque canaliculatus, margine laterali et basali testaceo. Elytra thorace plus duplo longiora, ampla, abdominis dimidiam partem tegentia, apicem versus sensim paulo latiora, creberrime minus fortiter punctata, lutea. Abdomen omnium subtilissime punctulatum, segmento ultimo testaceo. Pedes testacei, coxis omnibus concoloribus.

2. D. crenat um: Brunneum, nitidum, antennarum basi pedibnsque testaceis, capite thoraceque subtilius punctalis, hoc dorso medio bipunctalo, elytris punclato-striatis. - Long. $2 \frac{1}{4}$ lin.

Omal. crenut um Grav. Micr. 114. 4. Mon. 207. 6.

Habitat in Germania.

Habitu omnino Omalii brunnei, at sesqui maius, praecipue latius, subdepressum, rufo-brunneum, nitidum, glabrum. Antennae capitis thoracisque fere longitudine, apicem versus vix incrassatae, articulo quarto reliquis duplo minore, 5 - 10 subobconicis, ultimo ovato, fusco-nigrae, articulis 4 primis testaceis. Caput subtiliter vage punctatum, fronte inter oculos striolis duabus obliquis ohsoletioribus, et ad antennarum insertionem utrinque foveola minus profunda impressa. Thorax coleopteris parum angustior, latitudine dimidio hrevior, lateribus leviter rotundatis, angulis posterioribus subrectis, depressis, leviter convexus, crebrius subtiliter punctatus, dorso medio punctis duobus maioribus impressus. Scutellum parce subtiliter punctatum. Elytra thorace vix duplo longiora, crebre punctato-striata. Abdomen parce subtilissime punctulatum. Pedes testacei.

* 3. D. arcticum: Piceo-testaceum, nilidum, thorace transverso, aequali elytrisque crebrius vage punclatis. - Long. $1 \frac{1}{2}$ lin.

Habitat in Lapponia, Dom. Schiippel.

Habitu omnino praecedentis, at plus duplo minus, subdepressum, piceotestaceum, nitidum, glabrum. Antennae capite thoraceque paulo longiores, apicem versus sensim leniter incrassatae, pilosellae, testaceae. Caput parce subtiliter punctatum, antice laevigatum, inter oculos foveolis binis obsoletioribus, inter antemnas binis distinctioribus impressum. Thorax coleopterorum prope latitudine, latitudine duplo prope brevior, lateribus leviter rotundatus, apice leviter emarginatus, basi truncatus, angulis posterioribus subrectis, anterioribus obtusiusculis, leviter convexus, angulis posterioribus depressis, ad marginem lateralem utrinque pone medium leviter impressus, ceterum aequalis, aequaliter crebrius subtiliusque punctatus. Scutellum laeve. Elytra thorace duplo prope longiora, parcius minus subtiliter profunde punctata, punctis nullo modo seriatis, abdominis vix quartam partem obtegentia. Abdomen dilatatum, laeve. Pectus punctatum. Pedes testacei. 
* 4. D. algidum: Oblongum, nigrum, nilidum, antennarum arliculo primo pedibusque rufis, thorace transverso, confertim subtiliter punctalo, elytris conferlissime punclatis. - Long. $2-2 \frac{1}{3}$ lin.

Habitat in montibus Hercyniae, tempore vernali in nive lectum a Don. Saxesen.

Statura oblonga, subdepressa Arpedii quadri, nigrum, nitidulum, glabrum. Antennae capite thoraceque paulo longiores, apicem versus haud incrassatae, nigrae, articulo primo obscure rufo. Os inferne piceo-rufum, palpis maxillaribus nigro-piceis. Caput thorace parce subtiliterque punctatum, fronte utrinque prope oculos oblique impressa, antice inter antennas utrinque leviter bifoveolata, margine apicali tumidulo. Thorax coleopteris parum angustior, latitudine dimidio brevior, antrorsum subangustatus, lateribus leviter rotundatis, basi apiceque truncatus, angulis omnibus subrotundatis, subdepressus, confertim subtiliter punctatus, margine laterali ante medium foveolato. Scutellum parce punctulatum. Elytra thorace triplo prope longiora, apicem versus sensim subdilatata, subdepressa, confertissime punctata, punctorum paulo maiorum sat distantium seriebus tribus notata, maris apice recte truncata, abdominis basin vix superantia, feminae apice oblique truncata, paulo longiora, abdominis dimidiam partem tegentia. Abdomen laeve. Pedes rufi.

* 5. D. angustatum: Oblongum, nigrum, nitidum, antennarum basi pedibusque testaceis, capite thoraceque angustiore quadrato laevibus, elytris confertim subseriatim punclatis, fuscis, limbo apicali testaceo. Long. $1 \frac{3}{4}$ lin.

Habitat in Thuringia; Austria.

Corpus oblongum, snbdepressum, nigrum, nitidum. Antennae capite thoraceque paulo longiores, apicem versus sensim subincrassatae, nigrae, basi testaceae. Palpi nigri, basi testacei. Caput oblongum, parcius subtilissime punctatum, fronte inter oculos foveolis duabus minutis profundis notata, inter antennas transversim impressa. Thorax coleopteris plus dimidio angugustior, latitudine parum brevior, lateribus vix rotundatis, basin versus subangustatus, hasi apiceque truncatus, angulis omnibus obtusis, subrotundatis, leviter convexus, parce omnium subtilissime punctulatus, margine sumıno laterali piceo. Scutellum impressum. Elytra thorace plus duplo longiora, subdepressa, confertim punctata, punctis hinc inde in series dispositis, fusca, nitida, limbo apicali testaceo. Abdomen laeve, ano acuminato. 'Pedes testacei, coxis anterioribus concoloribus.

\section{Omalium Grav. \\ Er. Col. March. I. p. 628. \\ Anthobium Mannerh. Brachelytr. p. 53.}

Mandibulae muticae.

Maxillae malis membranaceis.

Palpi maxillares articulo ultimo penultimo longiore.

Tibiae subtilissime spinulosae.

Tarsi arliculis 4 primis brevissimis, aequalibus.

Corpus oblongum vel clongatum, subdepressum, alatum. Caput thorace 
minus et angustius, basi sat profunde distincteque constrictum, fronte lateribus marginata, oculis mediocribus, rotundatis, prominulis. Ocelli super oculorum marginem superiorem siti. Labrum transversum, apice sinnatum, membrana brevissima ciliata prominula anctum. Mandibulae breves, muticae. Maxillae (t. V.f. 31.b.) malis membranaceis, exteriore oblonga, apice barbatula, interiore - extus cornea, apice denticulo terminata, oblique truncata ciliataque. Palpi maxillares articulo primo minuto, secundo modice elongato, tertio brevi, quarto iterum longiore, apice subacuminato. Labium (t. V. f. 31 . a.) mento transverso, apicem versus angustato, apice truncato, ligula membranea, biloba, lobis rotundatis. Palpi labiales breviusculi, articulo primo tertioque longioribus, secundo breviore. Antennae apicem versus leviter incrassatae, articulo primo maiore, crassiusculo, secundo tertioque subaequalibus, penultimis transversis, ultimo subovato. Thorax coleopteris saepe paulo angustior, lateribus marginatus. Scutellum triangulare. Elytra abdominis basin obtegentia, angulo apicis exteriore rotundato. Abdomen magis minusve elongatum, lateribus marginatum, apice rotundatum. Pedes breviusculi, tibiis subtilissine et vix perspicue spinulosis, tarsis brevibus, articulis 4 primis brevissimis, inter se aequalibus, haud dilatatis, quinto his coniunctis aequali vel longiore.

\section{O b s e r va tio nes.}

1. Corpus aliis glaberrimum, aliis subtilissime pubescens, plerisque oblongum, nonnunquam lineare, subdepressum. Antennarum articuli penultimi plerisque transversi. Ceterum a praecedentibus hoc genus tarsorum structura sat distinctum.

2. Sexus differentia ut in praecedentibus.

3. Victus aliis in herbis, fruticibus, aliis sub arborum cortice.

4. Nomen Leachianam, quod Com. Mannerheim huic tribuit, sequenti generi restitui.

* 1. O. rivulare: Nigrum, nitidulum, antennarum basi pedibusque testaceis, elytris fusco-testaceis, capite thoraceque crebre punctatis, hoc foveolis duabus oblongis, subarcualis, profundis. - Long. 2 lin.

Grav. Micr. 116. 8. Mon. 209. 12. - Latr. Hist. nat. Crust. et Ins. IX. 373. 8. t. 80. f. 6. Gen. Crust. et Ins. I. 298. 1. - Oliv. Encycl. meth. VIII. 477. 12. - Gylt. Ins. Suec. II. 214. 14. - Sahlb. Ins. Fenn. I. 282. 13. - Zetterst. Faun. Lappon. 1. 51. 7. Ins. Lappon. 51. 12. - Er. Col. March. 1. 629. 1.

Staph. rivularis Payk. Mon. Stuph. 65. 46. Faun. Suec. 111. 407. 50. - Oliv. Ent. III. 42. 35. 49. t. 3. f. 27. - Panz. Faun. Germ. 27. 15. Ent. Germ. 357. 37. - Marsh. Ent. Britt. 513. 13.

Anthobium rivulare Mannerh. Brachelytr. 53. 1. - Boisd. et Lacord. Faun. Ent.

Paris. I. 470. 2. - Runde Brachelytr. Hal. 22. 1.

Omal. incisum Grav. Mon. 209. 12. b.

Staph. cursor Müll. Prodr. 97. 1095. - Goeze Ent. Beitr. I. 727. 22.

Var. Elytris fuscis.

Omal. Oxyacanthae Boisd, et Lacord. I. 471. 4.

Habitat in Europa.

Nigrum, nitidulum. Antennae capite thoraceque paruh breviores, apicem versus sensim modice incrassatae, articulis $7-10$ transversis, nigrae, basi rufae. Caput sat crebre punctatum, apice laevissimum, fronte postice foveolis duabus minoribus, rotundatis, profundis, antice utrinque foveola oblonga, latiore, minus profunda impressa, oris partibus testaceis. Thorax 
coleopteris angustior, latitudine plus dimidio brevior, lateribus anterius rotundatus, basin versus leviter angustatus, angulis posterioribus rectis, anterioribus rotundatis, parum convexus, sat crebre profundeque punctatus, dorso foveolis duabus oblongis, subarcuatis, basi latioribus profundioribusque, et ad apicem plerumque foveola tertia intermedia minuta obsoletiore impressus, limbo basali et laterali saepe testaceo. Scutellum laeve, piceum, vel piceotestaceum. Elytra thorace duplo longiora, dense sat fortiter profundeque punctata, secundum suturam subimpressa, fusco-testacea, vel fusco-picea, nitıdula. Abdomen subtilissıme punctulatum, nigrum, margine piceo, apice summo testaceo. Pedes testacei.

* 2. O. monilicorne: Nigrum, nilidulum, anlennarum basi pedibusque rufis, capite thoraceque parce subliliter punclatis, hoc foveolis duabus oblongis obsoletioribus impresso. - Long. $1 \frac{1}{2}$ lin.

Gyll. Ins. Suec. II. 219. 18. - Sahlb. Ins. Fenn. I. 283. 5.

Habitat in Suecia, Dom. Schïppel, in montibus Hercyniae, Dom. Saxesen.

O. rivulari paulo minus, magis elongatum, nigrum, nitidum. Antennae capite thoraceque paulo breviores, ab articulo sexto inde abrupte crassiores, articulis $7-10$ transversis, nigrae, articulis 5 primis rufis. Caput parvum, punctis raris subtilibus sparsum, fronte postice foveolis duabus minutis, rotundatis, profundis, antice inter antennas utrinque foveola maiore, profun. diore impressa, oris partibus rufis. Thorax coleopteris angustior, latitudine dimidio brevior, lateribus antice cum angulis anterioribus rotundatis, basin versus leviter angustatus, angulis posterioribus subrectis, parmm convexus, margine laterali posterius depresso, dorso foveolis duabus oblongis parum profundis impressus, sparsin subtiliter punctatus. Scutellum laeve. Elytra thorace duplo longiora, subtilius licet sat profunde confertim punctata, nigropicea, nitida. Abdomen omnium subtilissime parce punctulatum, apice summo rufo-piceo. Pedes rufo-testacei.

* 3. O. exiguum: Nigrum, nilidulum, pedibus testaceis, elytris fusco-piceis, capite thoracegue dense punctatis, hoc foveolis duabus oblongo-ovalis, profundis impresso. - Long. 1 lin.

Gyll. Ins. Suec. II. 218. 17. - Zetterst. Faun. Lappon. I. 51. 7. Ins. Lapp. 51. 13. Anthobium exiguum Mannerh. Brachelytr. 53. 3.

Habitat in Germania.

Habitu fere $\mathrm{O}$. rivularis, at quadruplo ninus, nigrum, subnitidum. Antennae capitis thoracisque prope longitudine, crassiusculae, ab articulo septimo inde apicem versus sensim leniter incrassatae, articulis penultimis duobus leviter transversis, fusco-mgrae. Caput confertim punctatum, antice laevigatum, fronte utrinque longitudinaliter impressa, impressione utraque postice foveola minuta rotundata sat profunda, antice foveola oblonga profundiore notata, medio longitudinaliter leviter convexa, ore piceo. Thorax coleopteris angustior, latitudine dimidio brevior, lateribus anterius cum angulis anterioribus rotundatis, basin versus leviter angustatus, angulis pasterioribus subrectis, parum convexus, margine laterali posterius depressn, dorso pone medium foveolis duabus oblongo-ovatis profundis impressus, confertim sat profunde subtilius punctatus. Scutellum laeve. Elytra thorace duplo 
Iongiora, fortius profunde denseque punctata, subrugulosa, secundum suturam ultra medium leviter impressa, nigro-fusca, subnitida. Abdomen omnium subtilissime punctulatum. Pedes testacei.

* 4. O. Oxyacanthae: Nigrum, nilidulum, pedibus testaceis, elylris fuscopiceis, capite thoraceque crebre punclatis, hoc sulcis duobus subarcuatis impresso. - Long. parum ultra 1 lin.

Gruv. Mon. 210. 12. e.

Anthob. caesum Boisd. et Lacord. Faun. Ent. Paris. 1. 470. 3.

Habitat in Germania, Gallia.

Habitu fere $\mathbf{O}$. rivularis at plus triplo minus, $O$. exiguo prope aequale, nigrum, nitidulum. Antennae capitis thoracisque fere longitudine, ab articulo septimo inde apicem versus sensim leniterque incrassatae, nigro-fuscae. Caput crebre punctatum, apice laevigatum, fronte posterius inter oculos et antice inter antennas foveolis binis oblongis profundioribus impressa, ore rufo. Thorax coleopteris paulo angustior, latitudine duplo fere brevior, basin versus parum magis quam apicem versus angustatus, angulis anterioribus obtusis, posterioribus subrectis, parum convexus, margine laterali posterius et angulis posterioribus depressis, dorso impressionibus duabus sublinearibus, extrorsum leviter arcuatis, et antice foveola tertia minore oblonga intermedia notatus, sat crebre subtilius at sat profunde punctatus. Elytra thorace plus duplo longiora, subdepressa, sat fortiter profundeque dense punctata, secundum suturam ultra medium subimpressa, fusca. Abdomen omnium subtilissime punctulatum. Pedes testacei.

* 5. O fossulatum: Nigrum, subnitidum, pedibus testaceis, elytris fuscis, capite thoraceque crebre subliliter punclatis, hoc dorso foveis duabus ovatis profundis impresso, apicem versus angustato. - Long. $1 \frac{2}{3}$ lin.

Er. Col. March. I. 630. 2,

O mal. caesum Gyll. Ins. Suec. 11. 215. 15. - Sahlb. Ins. Fenn. I. 283. II.

Anthob. caesum Mannerh. Brachelytr. 53. 2.

Habitat in Germania.

O. rivulari paulo minus, praecipue brevius, nigrum. Antennae capitis thoracisque longitudine, apicem versus ab articulo septimo inde sensim leviterque incrassatae, fusco-testaceae, basi nigricantes. Caput subtilius confertissime punctatum, vix nitidum, fronte posterius sulculis longitudinalibus anticeque foveolis oblongis binis profundis impressa. Thorax roleopteris dimidio angustior, latitudine dimidio brevior, lateribus leviter rotundatus, antrorsum, non vero basin versus, angustatus, angulis anterioribus subrotundatis, posterioribus acutiusculis, parum convextis, margine laterali late explanato, pone medium impresso, dorso pone medium foveolis duabus ovatis, antrorsum attenuatis, profundis, approximatis et plerumque ante apicem impressione oblonga obsolete notatus, subtiliter crebre punctatus, subnitidus, marginibus saepe piceis. Scutellum laeve. Elytra thorace duplo longiora, subdepressa, lateribus latius marginata, secundum suturam et infra basin subimpressa, confertim fortius punctata, nigro-picea vel fusco-testacea. Abdomen laeve, nitidum. Pedes testacei. 
* 6. O. cаев и m: Nigrum, opacum, pedibus testaceis, elytris fuscis, capile thoraceque confertissime punctalis, hoc dorso foveolis duabus oblongis profundis impresso, basin versus angustato. - Long. $1 \frac{1}{2}$ lin.

Grav. Mon. 209. 12. a. - Er. Col. March. I. 630. 3.

Omal. Oxyacanthae Gyll. Jns. Suec. II, 217.16.

Anthob. Oxyacanthae Mannerh. Brachelytr. 53. 3. - Runde Brachel. Hal. 23. 2.

Habitat in Germania.

Statura et summa affinitas praecedentis. Nigrum. Antennae capitis thoracisque longitudine, apice leviter incrassatae, nigrae, apicem versus fuscotestaceae. Ciaput confertissime punctatum, subrugulosum, opacum, fronte planiuscula, posterius lineolis duabus longitudinalibus profundis, antice utrinque foveola obsoletiore impressa. Thorax coleopteris paulo angustior, latitudine dimidio brevior, lateribus cum angulis anterioribus rotundatus, basin versus leviter angustatus, angulis posterioribus subrectis, parum convexus, margine laterali explanato, pone medium fortius impresso, dorso foveolis duabus oblongis, sat profundis, tertiaque ante apicem minore, obsoletiore, oblonga, intermedia impressus, dense punctatus, nigro-piceus, parum nitidus, marginibus omnibus piceis vel fusco-testaceis. Scutellum laeve. Elytra thorace duplo longiora, subdepressa, lateribus angustius marginata, secundum suturam et pone basin subimpressa, dense fortius profunde punctata, fusca, parum nitida. Abdomen subtilissime punctulatum, parum nitidum. Pedes testacei.

* 7. O. repandum: Nigrum, opacum, antennis pedibusque rufis, thorace elytrisque rufo-piceis, disco nigricantibus, capile thoraceque creberrime punctatis, hoc dorso foveolis duabus oblongis impresso. - Long. $1 \frac{1}{2}$ lin.

Habitat in America septentrionali, Dom. Zummermann.

Statura et summa affinitas praecedentium. Antennae capitis thoracisque fere longitudine, apice sensim leviter incrassatae, rufae. Caput subtiliter confertissime punctatum, fronte plana, posterius sulculis duobus longitudinalibus profundis, antice inter antennas utrinque foveola rotundata, minus profunda impressa, supra nigrum, parum nitidum, subtus cum ore rufopiceum. Thorax coleopteris angustior, latitudine dimidio fere brevior, lateribus leviter rotundatus, margine explanato, pone medium impresso, repando, angulis posterioribus subrectis, apice leviter emarginatus, angulis posterioribus acutiusculis, dorso parum convexus, foveolis duabus minus amplis profundisque, oblongis, antice sulculo obsoleto desinentibus impressus, confertim subtiliter punctatus, parum nitidus, piceo-rufus, disco fuscescente. Scutellum laeve, nigrum. Elytra thorace plus sesqui longiora, subdepressa, laterihus angustius marginata, secundum suturam leviter impressa, confertissime fortius sat profunde punctata, parum nitida, piceo-rufa, dorso nigricantia. Abdomen subtilissime punctulatum, nigrum, vix nitidum, ano rufo-piceo. Pectus nigrum. Pedes rufi.

* 8. O. minimum: Depressum, nigrum, opacum, ore pedibusque teslaceis, elytris fuscis, punctatis, thorace 4-foveolato, laleribus angulato. Long. $\frac{2}{3}$ lin.

Er. Col. March. 1. 631. 5. 
Habitat Berolini, Dom. Schiippel.

O. pusillo affine, at paulo minus, lineare, subdepressum, nigrum, opacum. Antennae capite thoraceque multo breviores, articulis duobus primis crassiusculis, secundo subgloboso, dein ab articulo sexto inde iterum crassiores, piceae. Os testaceum. Caput triangulare, şupra impunctatum, utrinque longitudinaliter impressum, fronte lateribus et apice subtiliter marginata. Thorax coleopteris paulo angustior, latitudine plus dimidio brevior, lateribus rotundatis, medio angulatis, basi apiceque truncatus, angulis anterioribus rotundatis, posterioribus obrusis, foveis quatuor oblongis magnis profundisque, exterioribus ad marginem lateralem sitis, omnibus a basi ultra medium adscendentibus, impressus. Elytra thorace duplo prope longiora, depressa, confertim distmcte punctata, fusca. Abdomen subtilissime punctulatum. Pedes testecei.

9. O. pusillum: Depressum nigrum, opacum, laeve, ore, antennis pedibusque testaceis, thorace dorso bifovevlato. - Long. 1 lin.

Grav. Mon. 205. 5. - Oliv. Encycl. meth. VIII. 475. 3. - Gyll Ins. Suec. 11. 220. 19. - Sahlb. Ins. Fenn. I. 284. 16. - Er. Cul. March. I. 631. 4.

Anthob. pusillum Mannerh. Brachelytr. 53. 5.

Habitat in Europa sub cortice Pinus.

Lineare, depressum, impunctatum, opacum, subsericeo-micans, nigrum, thorace elytrisque saepe piceis vel piceo-testaceis. Antennae capite thoraceque paulo breviores, apice incrassatae, articulis 6-10 transversis, rufotestaceae, articulis penultimis 4 fuscis. Os rufo-testaceum. Caput fronte planiuscula, postice utrinque ante ocellum puncto minuto, apice foveis duabus maioribus impressa. Thorax coleopteris angustior, latitudine duplo fere brevior, lateribus anterius modice rotundatus, basin versus leviter angustatus, basi apiceque truncatus, angulis anterioribus rotundatis, posterioribus rectis, subdepressus, dorso pone medium foveis duabus oblongis sat profundis, in medio marginis lateralis foveola rotundata impressus. Elytra depressa, thorace duplo fere longiora. Abdomen elongatum, lineare, segmentis margine postico testaceo. Pedes testacei.

* 10. O. florale: Nigrum, nilidum, pedibus rufis, thorace obsolele bifoveolato, elytris subseriatim punctatis. - Long. 2 lin.

Fr. Col. March. I. 633. 7.

Staph. floralis Payk. Mon. Staph. 67. 47. Faun. Suec. IH. 406. 49. - Fab. Ënt.

Syst. I. II. 530. 52. - Walk. Faun. Paris. I. 272. 16.

Stenus floralis Fub. Syst. El. H. 604. 6.

Omal. Viburni Grav. Micr. 117. 9. Mon. 210. 13. - Latr. Hist. nat. Crust. et

Ins. IX. 373. 9. - Oliv. Encycl. meth. VIII. 477. 13. - Gyll. Ins. Suec. II. 224.

23. - Sahlb. Ins. Fenn. 1. 285.21.

Anthob. Viburni Mannerh. Brachelytr. 54. 7. - Boisd, et Lacord. Faun, Ent.

Paris. I. 472. 5. - Runde Brachelyir. Hal. 23. 4.

St aph. rufipes Fourcr. Ent. Paris. I. 168. 15.

Le Staph. no ir à corcelet lisse et bordé Geoffr. Hist. Ins. 1. 367. 15.

Habitat in Europa.

Statura et magnitudo omnino 0 . rivularis, nigrum, nitidum, subtilissime 
pubescens. Antennae capite thoraceque breviores, crassiusculae, apicem versus ab articulo quinto inde incrassatae, nigrae, apice magis minusve ferrugineo-testaceae. Palpi picei. Caput posterius parcius punctatum, anterius laevigatum, fronte posterius lineolis duabus minutis, antice utrinque foveola rotundata impressa. - Thorax coleopteris paulo angustior, latitudine dimidio brevior, lateribus modice rotundatus, temuiter marginatus, basin apicemque versus aequaliter angustatus, basi apiceque truncatus, angulis anterioribus rotundatis, posterioribus subrectis, leviter convexus, crebre punctatus, dorso foveolis duabus oblongis, valde obsoletis impressus. Scutellum laeve. Elytra thorace vix duplo longiora, subdepressa, confertim subruguloso-punctata, punctis praecipue versus suturam subseriatis. Abdomen subtilissime punctulatum. Pedes rufi, femoribus interdum picescentibus.

Variat thoracis margine elytrisque piceis, antennisque totis rufis.

* 11. O. nigrum: Nigrum, nilidum, anlennarum basi pedibusque rufis, thorace margine piceo, dorso obsoletius bifoveolato, elytris subseriatim punclatis. - Long. $1 \frac{1}{2}$ lin.

Grav. Mon. 212. 17. - Oliv. Encycl. meth. VIII. 478. 17.

Omalium Salicinum Gyll. Ins. Suec. IV. 467. 24-25.

Anthob. Salicinum Mannerh. Brachelytr. 54. 12.

Habitat in Suecia, Dom. Schüppel, in Bavaria, Dom. Dr. Waltl.

Praecedenti affine, at paulo minus, nigrum, nitidum, subtilissime pubescens. Antennae capitis thoracisque fere longitudine, ab articulo quinto inde leniter incrassatae, nigrae, articulis 5 primis rufis. Palpi rufi. Caput parcius punctatum, fronte inter oculos striolis duabus minutis, distantibus, inter antennas utrinque foveola maiore, sat profunda, rotundata impressa. Thorax coleopteris paulo angustior, latitudine plus dimidio brevior, lateribus modice rotundatis, latius marginatis, apicem versus paulo magis quam basin versus angustatus, basi apiceque truncatus, angulis anterioribus rotundatis, posterioribus subrectis, dorso modice convexus, sat crebre punctatus, foveolis duabus oblongis obsoletioribus impressus, margine praecipue laterali piceo-rufo. Scutellum parce subtiliter punctatum. Elytra thorace duplo longiora, subdepressa, confertim subruguloso-punctata, punctis passim subseriatıs, nigro-picea. Abdomen subtiliter punctulatum. Pedes rufo-testacei.

* 12. O. Salicis: Nigrum, nilidum, anlennis pedibusque rufis, thorace fortius punclalo, dorso bifoveolato, elytris fortius subserialo-punclatis. - Long. 2 lin.

Gyll. Ins. Suec. II. 226. 24. - Sahlb. Ins. Fenn. I. 286.22.

Anthob. Salicis Mannerh. Brachelytr. 54. 11.

Habitat in Suecia, Dom. Schiippel.

Statura omnino O. brunnei, lineare, subdepressum, nigrum, nitidum, glabrum. Antemne capite thoraceque paulo breviores, ab articulo septimo inde leviter incrassatae, rufae. Palpi rufi. Caput parce punctatum, apice laevigatum, fronte inter oculos foveolis duabus aninutis, punctiformibus, inter antennas foveis duabus maioribus rotundatis impressa, ore rufo-piceo. Thorax coleopteris paulo angustior, latiturline dimidio brevior, lateribus leviter rotundatus, basin apicemque versus aequaliter angustatus, basi apiceque trun- 
catus, angulis anterioribus obtusis, posterioribus subrectis, leviter convexus, crebre fortius profundiusque punctatus, dorso foveis duabus oblongis approximatis leviter impressis, margine laterali praecipue posterius explanato, rufo-piceo. Scutellum parce subtiliter punctatum. Elytra thorace duplo prope longiora, subdepressa, fortius profundiusque dense punctata, punctis versus suturam confertioribus subseriatis, saepe confluentibus. Abdomen parcius subtiliter punctatum. Pedes rufo-testacei.

* 13. O. brunneum: Rufo-testaceum, nilidum, capite, ano elytromumque macula apicali nigris, capite thoraceque crebre punctatis, elytris crebre punctato-striatis. - Long. 2 lin.

Oliv. Encycl. meth. VIII. 475. 5. - Gyll. Ins. Suec. II. 227. 25. - Sahlb. Ins. Fenn. I. 287. 24. - Er. Col. March. 1. 633. 8.

Staph. brunneus Payk. Mon. Staph. 63. 45. Faun. Suec. 1II. 404. 47.

Omal. brunneum var. 2 Grav. Micr. 114. 2.

Anthob. brun n eum Mannerh. Brachelytr. 54. 13. - Boisd. et Lacord. Faun. Ent. Paris. I. 475. 7.

Staph. mela nocephalus Fab. Mant. Ins. I. 222. 32. Ent. Syst. I. I. 529. 29.

Syst. El. II. 601. 63. - Panz. Ent. Germ. 357. 38.

Staph. melanocephalus Cederh. Faun. Ingr. 119. 365. (forte)

Habitat in' Europa, sub arborum cortice.

Rufo-testaceum, nitidum, glabrum. Antennae capitis thoracisque longitudine, apicem versus leniter incrassatae, artieulis ultimis 5 crassioribus, ultimo ovato, rufo-ferrugineae. Caput crebrius vage punctatum, fronte posterius ante ocellos punctis duobus profundis, minutis, antice inter antennas utrinque fovea latiore impressa, nigro-piceum, ore rufo. Thorax coleopteris paulo angustior, latitudine dimidio brevior, lateribus rotundatus, basi apiceque truncatus, angulis anterioribus rotundatis, posterioribus subrectis, modice convexus, crebre sat profunde punctatus, dorso obsolete bi-impressus, margine laterali depresso, angusto, posterius latiore. Scutellum parce punctatum. Elytra thorace vix duplo longiora, crebre striato-punctata, macula apicali rotundata nigra. Abdomen supra parcius subtiliter punctulatum, infra dense fortius punctatum, segmentis ultimis duobus nigro-piceis. Pedes rufo - testacei.

*14. O. lucidum: Rufum, nitidum, capite, pectore, elytrorum sutura apiceque abdominisque apice nigris, capile thoraceque crebre punctatis, elytris punclato-strialis. - Long. $1 \frac{1}{4}$ lin.

Er. Col. March. I. 634.9.

Staph. brunneus var. $\beta$ Payk. Mon. Staph. 64. 45. Faun. Suec. III. 405.47.

Omal. brunneum var. b Gyll. Ins. Suec. II. 227. 25. - Sahlb. Ins. Fenn. 1. 287. 24.

Omal. brunneum var. 1 Grav. Mon. 206. 5. - Latr. Hist. nat. Crust. et Ins. IX. 3713.

Habitat in Germania, Gallia, Suecia, sub cortice Pinus.

Habitu O. brunnei, at plus triplo minus, subtilissime pubescens. Antennae capite thoraceque paulo breviores, apice crassiores, articulis 6-10 transversis, ultimo globoso, rufo-ferrugineae. Caput creberrime fortiter punctatum, fronte convexiuscula, antice bifoveolata, nigro-piceum, nitidum, ore rufo. Thorax coleopteris paulo angustior, latitudine dimidio fere bre- 
vior, lateribus modice rotundatus, basi apiceque truncatus, angulis anterioribus obtusis, subdeflexis, posterioribus obtusiusculis, subdepressis, modice convexus, sat fortiter creberrime punctatus, dorso pone medium obsolete bifoveolatus, rufus, nitidus. Scutellum parce punctatum, piceum, nitidum. Elytra thorace vix duplo longiora, sat fortiter crebreque punctato-striata, rufo-testacea, sutura apiceque late nigris. Abdomen crebre subtilius punctulatum, rufo-testaceum, dorso fere toto ab apice inde nigro-piceo. $\mathrm{Pe}$ ctus nigro-piceum. Pedes testacei.

* 15. O. vile: Elongalum, nigricans, sublililer pubescens, antennarum basi pedibusque teslaceis, thorace leviler bifoveolato, elytris crebre profundius punctatis. - Long. vix ultra 1 lin.

Habitat in Saxonia montana, Dom. Märkel.

Statura praecedentis, at paululum minus, elongatum, subdepressum, piceo-nigrum, nitidum, pube brevissima subtili aequaliter adspersum. Antennae capite thoraceque breviores, articulis duobus primis crassiusculis, ab articulo sexto iterum incrassatae, articulis $6-10$ fortiter transversis, nigricantes, articulis 6 primis rufo-testaceis. Caput crebrius punctatum, anterius laevius, fronte antice utrinque impressa. Thorax coleopteris paulo angustior. latitudine parum brevior, lateribus leviter rotundatus, basin versus paulo magis quam anterius angustatus, basi apiceque truncatus, angulis posterioribus subrectis, parum convexus, dense punctatus, dorso obsoletius longitudinaliter bi-impressus. Elytra thorace duplo prope longiora, subdepressa, dense minus subtiliter punctata, punctis nonnunquam seriatis. Abdomen parce omnium subtilissime obsolete punctulatum. Pedes testacei.

$\mathrm{Obs}$. Thoracis impressiones nonnunquam obsoletae.

* 16. O. striat um: Nigrum, pedibus teslaceis, thorace obsolete canaliculato bifoveulatoque, elytris punctalo - striatis. - Long. I lin.

Grav. Micr. 119. 12. Mon. 216. 23. - Latr. Hist: nat. Crust et Ins. IX. 374. 12. - Oliv. Encycl. meth. VIII. 479. 23. - Gyll. Ins. Suec. II. 231. 28. - Er. Col. March. 1. 632.6.

Anthob. st riatum Mannerh. Brachelytr. 55. 15. - Boisd. et Lacord. Faun. Ent. Paris. I. 475. 11.

Staph. minutus Oliv. Ent. III. 42. 38. 56. t. 6. f. 53.

Habitat in Europa.

Minutum, nigrum, subnitidum. Antennae capitis thoracisque fere longitudine, ab articulo septimo inde leniter incrassatae, nigrae, articulo primo plerumque testaceo, sequentibus saepe piceis. Caput parcius subtiliter punctatum, fronte convexiuscula, posterius utrinque obsolete impressa, antice profundius bifoveolata. Thorax coleopteris angustior, latitudine duplo fere brevior, antrorsum subangustatus, lateribus parum rotmndatus, apice leviter emarginatus, basi truncatus, angulis posterioribus subrectis, parum convexus, utrinque ad antennarum marginem lateralem obsolete impressus, dorso longitudinaliter obsolete bi-impressus, obsolete canaliculatus, crebre punctatus. Scutellum laeve. Elytra ampla, thorace plus duplo longiora, apicem versus sensim dilatata, confertim subtilius punctato-striata, 1am nigra, iam picea. Abdomen laeve, apice piceum, segmento apicali nonnunquam testaceo. Pedes testacei. 
* 17. O. pygmaeum: Oblongo-ovatum, levitèr convexum, rufo-testaceum, pubescens, capite, thorace elytrisque crebre subtiliter punclatis. Long. $1 \frac{1}{4}$ lin.

Gyll. Ins. Suec. II. 223. 22. - Mannerh. Bruchelytr. 52. 7. - Boisd. et Lacord. Faun. Ent. Paris. I. 488. 6.

Staph. pygmaeus Payk. Faun. Suec. III. 410. 55.

Habitat in Germania, Knoch, in Suecia, Dom. Schïppel.

Oblongo-ovatum, leviter convexum, rufo-testaceum, nitidum, minus subtiliter griseo-pubescens. Antennae capitis thoracisque fere longitudine, pilosellae, articulis ultimıs 5 sensim crassioribus, $7-10$ transversis, ultimo subovato. Caput sat crebre punctatum, fronte antice inter antennas utrinque longitudinaliter impressa, margine laterali leviter elevato. Thorax coleopteris paulo angustior, latitudine duplo fere brevior, lateribus leviter rotundatis, medio subangulatis, apicem versus paulo magis quam basin versus angustatus, basi apiceque truncatus, angulis anterioribus obtusis, deflexis, posterioribus obtusis, modice convexus, dense punctatus, aequalis, angulis posterioribus late depressis. Elytra thorace duplo fere longiora, leviter convexa, dense punctata. Abdomen omnium subtilissime parce punctulatum.

Mas trochanteribus posticis dilatatis, securiformibus et abdominis segmento quinto inferiore apice medio reflexo, acute bidentato insignis.

* 18. O. inflatum: Ovalum, convexum, piceo-rufum, nilidum, subglabrum, capile, thorace elytrisque crebre profundeque punctatis. - Long. $1-1 \frac{1}{4}$ lin.

Gyll. Ins. Suec. III. 700. 22-23. - Sahlb. Ins. Fenn. I. 285. 20. - Zetterst. Faun. Lappon. I. 53. 12. Ins, Lappon. 52. 19. - Mannerh. Brachelytr. 51. 6.

Habitat in Sriecia, Dom. Schïppel, in Fennia, Dom. Sahlberg, in Germania Dom. Ratzeburg.

O. pygmaeo fere aequale, at brevius et magis convexum, piceo-testaceum, nitidum, vix pubescens. Antennae capitis thoracisque longitudine, longius pilosellae, articulis $\mathbf{7}-\mathbf{1 0}$ abrupte maioribus, subperfoliatis, ultimo ovato. Caput sat crebre punctatum, apice laeve, fronte antice inter antennas obsolete bifoveolata. Thorax coleopteris paulo angustior, latitudine vix duplo brevior, lateribus leviter rotundatus, margine reflexo, obsolete crenulato, basi truncatus, angulis posterioribus rectıs, antrorsum subangustatus, apice leviter emarginatus, angulis anterioribus acutiusculis, convexus, creberrime sat profunde punctatus. Scutellum laeve. Elytra thorace duplo longiora, lateribus leviter rotundata, convexa, sat fortiter profundeque punctata. Abdomen omnium subtilissime parce punctulatum, apice testaceum. Pedes testacei.

* 19. O. rufulum: Oblongum, rufo-testaceum, parce pubescens, elytris fortiter subserialim, capite thoraceque subliliter punctatis, hoc basin versus anguslato. - Long. $1 \frac{1}{4}$ lin.

Habitat in Austria, Dom. Ullrich.

o. pygmaeo fere aequale, at minus ovatum, subdepressum, rufo-testaceum, nitidum, minus subtiliter parce pubescens. Antennae capite thoraceque paulo longiores, crassae, articulo tertio quartoque tenuioribus, apicem ver- 
sus sensim leviterque subincrassatae, pilosellae. Caput parce subtilissime punctulatum, fronte antice obsolete bifoveolata. Thorax coleopteris dimidio angustior, latitudine dimidio brevior, lateribus anterius modice rotundatus, basin versus leviter angustatus, basi apiceque truncatus, angulis anterioribus rotundatis, posterioribus rectis, leviter convexus, aequalis, crebrius subtiliter punctatus, angulis posterioribus depressis. Scutellum laeve. Elytra thorace vix duplo longiora, minus confertim at sat profunde subseriato-punctata. Abdomen laeve, apicem versus piceum, ano testaceo. Pedes testacei.

20. O. brevicorne: Elongatum, subdepressum, subliliter pubescens, nigrum, nitidulum, antennarum basi pedibusque rufo-testaceis, thorace leviter bi-impresso, elytris thorace duplo longioribus, conferlim punctatis, subrugulosis. - Long. 1 lin.

Habitat in Sardinia, Mus. Reg. Taurin.

Habitu omnino O. monilicornis, at plus duplo minus, nigrum, nitidulum, pube brevissima subtilissimaque grisea tenuiter vestitum. Antennae capite paulo longiores, dense pubescentes, articulis $\mathbf{5}$ primis rufis, sequentibus crassioribus, 6-10 transversis, ultimo subgloboso, apice obtuse acuminato, nigris. Palpi rufo-testacei. Caput thorace paulo angustius, subtiliter punctulatum, fronte inter oculos utrinque obsolete sulcata, antice inter antennas distinctius bi-impressa. Thorax coleopteris paulo angustior, latitudine paulo brevior, lateribus aute medium modice rotundatus, basin versus paulo ma. gis quam antrorsum angustatus, basi apiceque truncatus, angulis anterioribus obtusis, posterioribus subrectis, leviter convexus, dense minus subtiliter profunde punctatus, dorso pone medium foveolis duabus oblongis longitudinalibus approximatis leviter impressus, angulis posterioribus depressis, subtus piceus. Elytra thorace duplo longiora, apice truncata, minus subtiliter confertim punctata, longitudinaliter obsolete strignsa. Abdomen segmento primo solo obtecto, lineare, parce subtilissime punctatum, glabrum. Pedes rufotestacei.

* 21. O. lineare: Elongalum, subdepressum, glabrum, nilidum, rufum, capite thoraceque crebre punctatis, hoc dorso foveolis duabus oblongis impresso, elylris crebre subseriatim punctatis. - Long. $1 \frac{1}{2} \mathrm{lin}$.

Zetterst. Faun. Lappon. I. 53. 13. Ins. Lapp. 53. 21. - Er. Col. March. I. 636. 13. Habitat in Lapponia (Zetterst.), in Germania, Dom. Schïppel.

Statura fere $O$. deplanati, at angustius et magis depressum, lineare, glabrum, nitidum, rufum. Antennae capite thoraceque multo breviores, crassiusculae, apicem versus incrassatae, articulis $6-10$ fortiter transversis, perfoliatis, pilosellae. Caput subtilius sat profunde creberrime punctatum, fronte antice inter antennas foveolis duabus rotundatis profundius impressa. Thorax coleopteris parum angustior, latitudine dimidio brevior, lateribus rotundatus, basin versus leviter angustatus, basi apiceque truncatus, angulis anterioribus rotundatis, posticis subrectis, dorso subdepressus, leviter longitudinaliter bi-impressus, creberrime punctatus. Scutellum punctis nonnullis subtilibus impressum. Elytra thorace duplo fere longiora, subdepressa, sat profunde crebreque punctata, punctis subseriatis, praecipue suturam versus. Abdomen subtiliter puncfatum, apicem versus rufo-piceum. Pedes testacei. 
* 22. O. te staceum: Elongatum, subdepressum, subtililer pubescens, rufotestaceum, nilidum, capile, thorace elytrisque crebre punctatis, thorace aeguali. - Long. $1 \frac{1}{2}$ lin.

O mal. pygmaeum Grav. Mon. 206. 4.

Omal. brunneum var. 3 Grav. Micr. 114. 3.

O.mal. deplanat um var. b Er. Col. Murch. I. 635. 10.

Habitat in Germania.

Elongatum, subdepressum, rufo-testaceum, nitidum, parcius subtiliter pubescens. Antennae capitis thoracisque prope longitudine, apicem versus leviter incrassatae, ab articulo sexto inde distincte paula crassiores, articulis penultimis autem vix transversis. Caput thorace angustius, subtriangulare, confertim minus subtiliter punctatum, antice bifoveolatum. Thorax coleopteris parum angustior, latitudine plus dimidio brevior, lateribus rotundatus. basin versus leviter angustatus, basi apiceque truncatus, angulis anterioribus rotundatis, posterioribus subrectis, leviter convexus, aequalis, dense minus subtiliter punctatus. Scutellum punctatum. Elytra tharace plus sesqui longiora, dense minus subtiliter punctata. Abdomen parce omnium subtilissime punctulatum, apicem versus subdilatatum. Pedes dilutius testacei.

Obs. O. deplanato proximum, at parcius pubescens, fortius punctatum, antennis longioribus, abdomine sublaevi etc. satis distinctum. Ab O. pygmaeo corpore lineari, subdepresso, thorace basin versus angustato etc. differt.

* 23. O. deplanalum: Elongalum, subdepressum, subtililer pubescens, piceo-nigrum, nitidum, antennis, pedibus elytrisque rufis, capite, thorace elytrisque confertissime subtiliter punctatis. - Long. $1 \frac{1}{2}$ lin.

Gyll. Ins. Suec. II. 222. 21. - Sahlb. Ins. Fenn. I. 284. 18. - Er. Col. March. I. 635.10.

Anthob. deplanatum Mannerh. Brachelytr. 54. 14.

O mal. depressum Grav. Micr. 113. 2. Mon. 205. 2. - Latr. Hist. nat. Crust. et

Ins. IX. 371. 2. - Oliv. Encycl. meth. VIII. 475. 2.

Anthob. depressum Boisd. et Laeord. Faun. Ent. Paris. I. 474. 9.

Var. Thorace dorso obsolete bifoveolato.

Anthob. ablongum Boisd. ot Lacord. Faun. Ent. Paris. I. 473. 8.

Habitat in Europa.

Corpus lineare, subdepressum, densius subtiliter pubescens, nigro-piceum, subnitidum. Antennae capite thoraceque breviores, crassiusculae, apicem versus vix incrassatae, articulis $6-10$ transversis, fere perfoliatis, totae rufae, vel rufo-testaceae. Caput thorace angustius, depressum, creberrime punctatum, fronte antice inter antennas foveolis duabus minutis impressa, ore rufo-testaceo. Thorax coleopteris parum angustior, latitudine dimidio brevior, lateribus anterius rotundatus, basin versus modice angustatus, basi apiceque truncatus, angulis anterioribus rotundatis, posterioribus subrectis, leviter convexus, confertim subtiliter punctatus, dorso foveolis duabus oblongis valde obsoletis impresso, picea-niger, margine laterali basalique rufo-testaceo. Scutellum subtiliter punctulatum, nigro-piceum. Elytra thorace plus- sesqui longiora, subdepressa, confertim subtiliter punctata, rufotestacea. Abdomen subtilissime punctulatum, piceum, nonnunquam rufopiceum vel rufum, segmento quinto nigro. Pedes rufi. 
* 21. O. concinnum: Elongatum, subdepressum, parce omnlum subtilissime pubescens, nigrum, nilidum, antenuis pedibusque rufis, capile thoraceque sublilius crebre punctatis, elytris punctato-subrugulosis, rufis piceisve. - Long. $1 \frac{1}{2}$ lin.

Var. thorace dorso obsolete bifoveolato.

Staph. concinnus Marsh. Ent. Britt. 510. 34.

Habitat in Germania.

Statura et summa affinitas praecedentis. Lineare, subdepressum, nigrum, nitidum, capite, thorace elytrisque parce omnium subtilissime pubescentibus vel subglabris, abdomine pube subtili depressa distinctiore vestito. Antennae capite paulo longiores, crassiusculae, apicem versus haud incrassatae, articulis $4-10$ transversis, piceo-rufae. Os piceum. Caput thoracis prope latitudıne, suborbiculatum, depressiusculum, crebre subtilius punctatum, antice obsolete bifoveolatum. Thorax coleopteris parum angustior, latitudine dimidio brevior, lateribus leviter rotundatus, basin versus snbangustatus, basi apiceque truncatus, angulis anterioribus rotundatis, posterioribus subrectis, parum convexus, crebre subtilius punctatus, dorso iam omnino aequali, iam foveis duabus oblongis magis minusve obsoletis impresso, limbo laterali plerumque rufo-piceo. Elytra thorace duplo prope longiora, crebre punctata, longitudinaliter substrigosa, iam nigro- iam rufo-picea. Ábdomen subtiliter punctatum. Pedes rufo-testacei.

Obs. Praecedenti proximum et simillimum, punctura autem capitis thoracisque minus subtili et minus densa, elytris longitudinaliter substrigosis, nec non capite, thorace elytrisque subglabris distinctum videtur.

* 25. O. planum: Elongatum, subdepressum, nigrum, nitidum, antennarum basi pedibusque testaceis, elytris fusco-tesiaceis, thorace obsolete canbliculato. - Long. 1 - $1 \frac{1}{3}$ lin.

Grav. Micr. 112. 1. Mon. 204. 1. - Latr. Hist. nat. Crust. et Ins. IX. 370. 1. Oliv. Encycl. meth. VIII. 475. 1. - Gyll. Ins. Suec. II. 221. 20. - Sahlb. Ins. Fenn. I. 284. 17. - Zetterst. Faun. Lappon. I. 53. 11. Ins. Lappon. 52. 18. Er. Col. March. I. 636. 12.

St aph. planus Payk. Mon. Curc. App. 145. 11-12. Faun. Suec. III. 405. 48.

Anthol. planum Mannerh. Brachelytr. 54. 6. - Boisd. et Lacord. Faun. Ent. Paris. I. 475 . 10.

Staph. flavipes Fab. Ent. Syst. I. II. 527. 39. Fab. Syst. El. II. 599. 48. Panz. Ent. Germ. 356. 29.

St aph. fla vipes Linn. Faun. Suec, n. 856. Syst. Nat. I. II. 685. 22. - Miill. Fuun. Frid. 23. 226. Prodr. 97. 1099. - Goeze Ent. Beitr. I. 721. 22. - De Vill. Ent. 418. 22. (forte)

Habitat in Europa.

Elongatum, lineare, subdepressum, nigrum, nitidum, glabrum. Antennae capite thoraceque paulo breviores, rufo-testaceae, articulis $6-11$ abrupte crassioribus, fuscis. Os rufo-testaceum. Caput thorace paulo angustius, parce subtiliterque punctatum, fronte planą, posterius inter oculos et antice inter antemnas foveolis binis impressa, oculis sat prominulis. Thorax coleopteris vix angustior, latitudine plus dimidio brevior, lateribus sat fortiter rotmindatus, basin versus coarctatus, basi apiceque truncatus, angulis anteriorilius subrotundatis, posterioribus acutiusculis, prominulis, subdepressus, sat 
crebre subtiliter punctatus, obsolete canaliculatus, dorso nommunquam utrinque obsolete impressus, apice utrinque foveola rotundata, in margine ipso sita notatus. Scutellum laeve. Elytra thorace duplo longiora, depressa, sat crebre subtiliter punctata, piceo-testacea vel fusco-picea. Abdomen subtilissime punctulatum. Pedes rufo-testacei.

*26. O. philanthus: Subdepressum, nigrum, ore, antennis pedibusque testuceis, ely/ris flavis, limbo apicali nigro. - Long. $1 \frac{1}{2}$ lin.

St uph. philantlu s Fab. Nint. Syst. Suppl. 181. 46. Syst. El. II. 600. 58.

Habitat ad promont. Bonae Spei, Dom. Bergins.

Oblongum, depressum, nigrum, nitidum. Antennae capite thoraceque breviores, articulís ultimis 6 abrupte crassioribus, $6-10$ transversis, ultimo subovato, laete testaceae. Os testaceum. Caput subtilissime parcius punctatum, fronte utrinque sulco longitudinali flexuoso, parum profundo impressa. Thorax coleopteris parum angustior, latitudine dimidio brevior, lateribus leviter rotundatis, basi apiceque truncatus, angulis anterioribus rotundatis, posterioribus obtusiusculis, subdepressus, sat crebre subtiliter punctatus, medio obsoletissime canaliculatus. Scutellum laeve. Elytra thorace plus sesqui longiora, apice coniunctim leviter rotundata, depressa, confertissime subtiliter punctata, flava, margine laterali fuscescente, limbo apicali lato nigro. Abdomen subtiliter punctulatum. Pedes testacei.

* 27. O. pedicularium: Ollongum, subdepressum, teslaceum, pectore, scutello, elytris apice, abdomine ante apicem picescentibus, thorace foveolis duabus oblongis obsoletis impresso. - Long. 1 lin.

Habitat in ins. Puerto-Rico, Dom. Moritz.

O. pusillo haud longius, at sesqui latius, depressum, testaceum, subnitidum. Antennae capite thoraceque paulo breviores, apice fortius incrassatae, articulis 7-10 transversis, ultimo subgloboso, testaceae, apicem versus fuscescentes. Caput subtilissime punctulatum, fronte posterius foveolis mi nutis, rotundatis sat profundis, antice inter antennas maioribus binis impres, rufo-testaceum. Thorax coleopteris parum angustior, latitudine duplo brevior, lateribus leviter rotundatus, basi apiceque truncatus, angulis anterioribus rotundatis, posterioribus obtusiusculis, subdepressus, subtilissime punctulatus, dorso foveolis duabus oblongis, distantibus, obsoletioribus impressus, testaceus. Scutellum piceum. Elytra thorace duplo longiora, subtiliter minus confertim punctata, flavo-testacea, apice subpicescentia. Abdomen parce subtilissime punctulatum, testaceum, ante apicem subpicescens. Pectus piceum. Pedes flavo - testacei.

Species mihi invisae, forte huius generis.

28. O. la eviusculum: Depressum, nigrum, nitidum, antennarum basi, thoracis marginibus pedibusque testaceis, thorace transverso, foveolalo, vix punctulato, elytris longioribus fuscis, subtiliter punclulatis.

Gyll. Ins. Suec. IV. 464. 13-14. - Sahlb. Ins. Fenn. 1. 282. 12. - Zetterst. Ins. Lappon, 51. 11.

Var. b, thorace tolo rufescente, corpore subtus rufo-piceo.

$V$ ar. $c$, ut var. b, sed abdomen eliam supra rufo-testaceum. 
Habitat in Suecia.

O. rivulari simile et affine, sed paulo maius, latius, thorax vix et elytra subtilius punctulata etc. Caput maiusculum, porrectum, subtriangulare, depressum, nigrum, nitidum, obsolete punctulatum, foveis duabus verticis profundis, brevibus, aliisque duabus anterioribus oblongis impressum; os testaceum, palpis apice fuscis; oculi magni, laterales, globosi, nigri. Antennae capite cum thorace longiores, pubescentes et pilosae, articulo primo magno, clavato, testaceo, secundo breviore obconico, eiusdem coloris, tertio aeque longo, obconico, apice fusco, 4, 5 brevioribus, nodosis, 6- 10 sensim multo maioribus, cyathiformibus, nigris, ultimo adhuc maiore, ovato, acuminato, concolore. Thorax transversus, basi apiceque truncatus, lateribus ante medium parum ampliatus, posterius nonnihil angustior, angulis rectis, supra parum convexus, inaequalis, foveis nempe duabus mediis oblongis, at obsolete impressus et intra margines, posterius latius, depressus, obsoletissime punctulatus, aut niger, nitidus, lateribus posterius testaeeis, ut in a, aut totus rufo-testaceus, ut in b et c. Scutellum breve, triangulare piceum, subtilissime punctulatum. Elytra antice thoracis basi latiora, humeris rotundatis, thorace duplo longiora, apice truncata, angulo exteriore rotundato, supra depressa, confertim subtiliter vage punctulata, aut saturatius picea, aut dilutius fusco-testacea, basi apiceque semper dilutiora. Abdomen pone elytra vix illorum longitudine, subdepressum, laeve, nitidum, marginibus elevatis, apice rotundatum, in a, b nigrum, in var. c rufo-testaceum. Corpus subtus in a et b nigrum, nitidum, laeve, in var. c rufo-piceum. Pedes mediocres, toti rufo-testacei. (Gyll.)

29. O. Fahraei: Depressum, glabriusculum, nitidum, nigrum, elytris piceis, pedibus teslaceis, thorace subquadrato, lateribus subrolundato, posterius paulo angustalo elytrisque elongatis, crebre punctatis, - Long. 1-1 $\frac{1}{4}$ lin.

Zetterst. Ins. Lappon. 52. 17.

Habitat in Lapponia, Norvagia.

Affine 0 . pubescenti, sed glabritie corporis, antennarum forma etc. distinctum. Ab Arped. brachyptero (O. Gyllenhali), cui etiam subsimile videtur, antennarum colore etc. mox differt. Antennae fere thorace breviores, extrorsum distincte crassiores, totae nigricantes. Os et palpi nigra. Thorax subconvexus, punctulatus, sed vix foveolis impressus, structura ut in diagnosi. Elytra thorace duplo longiora, picea, crebre et certo situ subseriatim punctulăta. Pedes flavo-testacei. (Zett.)

30. O. fenestrale: Elongatum, subtiliter crebre punctatum, pubescens, piceo-nigrum, antennis elongatis, fuscis, pedibus fusco-lestaceis, thorace rotundato, obsolete canaliculato. - Long. $1 \frac{1}{4}$ lin.

Zetterst. Faun. Lappon. I. 50. 6. Ins. Lappon. 50. 10.

\section{Habitat in Lapponia Tornensi.}

Magnitudo O. rivularis. Caput triangulare, subtiliter parce punctulatum, fronte inter antennas bifoveolata, nitidum, nigrum, ore piceo. Antennae thorace longiores, filiformes, pubescentes, nigro-fuscae. Thorax subtransversus, rotundatus, undique marginatus, supra subconvexus, in medio longitudinaliter leviter canaliculatus, totus pubescens, nitidus, niger. Scutellum 
magnum, triangulare, punctatum. Elytra thorace plus quam duplo longiora, creberrime et subtliter, attamen profundius, quam ille, punctata, pubescentia, nigro-picea. Alae amplae, albo-hyalinae. Corpus nitidum, nigrum, ano piceo. Pedes obscure testacei. (Zetterst.)

31. O. pubescens: Brevius, subtiliter crebre punctatum, pubescens, piceonigrum, antennis mediocribus fuscis, thorace rotundalo, non canaliculato. - Long. circiter 1 lin.

Zetterst. Faun. Lappon. I. 52. 10. Ins. Lappon. 52. 15.

Habitat in Lapponia.

O. fenestrali valde affine et simile, sed paulo minus, antennis elytrisque, ut videtur, brevioribus, thorace non canaliculato, et pube paulo longiore supra vestitum, distinctum. Antennae capite thoraceque parum longiores, filiformes. Thorax subtiliter punctatus, non canaliculatus, niger. Elytra thorace duplo longiora, crebre subrugoso-punctata, pubescentia, fere pilosa, picea. Pedes fusco-lutei.

32. O. alpinum: Ovatum, convexum, tenuissime pubescens, profunde punotatum, totum testaceum, pedibus pallidioribus, antennis exirorsum subfuscescentibus. - Long. $\frac{3}{4}$ lin.

Zetterst. Ins. Lappon. 52. 20.

Habitat in Lapponia meridionali.

O. pygmaeo affine et sat simile, sed paulo brevius, et latius, elytris paulo longioribus profundiusque punctatis, corpore pallidiore etc. abunde distinctum. Totum nitidum, omnium subtilissime rigide pubescens, flavescentitestaceum, oculis nigris, et vertice macula fusca. Antennae thorace vix longiores, pubescentes, testaceae, extrorsum crassiores, fuscescentes. Thorax convexus, transversus, lateribus subrotundatus, totus punctatus, sed foveolis nullis impressus. Elytra thorace fere dimidio longiora, distincte punctata, punctis certo situ seriatim dispositis. Abdomen pone elytra eorum longitudine, laeve, Pedes flavescentes. (Zett.)

33. O. luridum: Oblongo-ovatum, rufo-piceum, antennis extrorsum gradatim crassioribus pedibusque testaceis, thorace postice angustiore, elytris confertissime punctatis.

Gyll. Ins. Suec. III. 701. 22-23. - Sahlb. Ins. Fenn. I. 285, 19.

Habitat in Smolandia, Fennia.

Magnitudo et fere statura O. pygmaei, sed distinctum, thorace postice angustiore, etc.; ab $O$. inflato differt: corpore longiore, minus convexo, antennarum structura etc. Caput subtriangulare, brunneum, punctatum, inter antennas vix impressum, ore testaceo; oculi laterales, subglobosi, nigri. Antennae capite thoraceque longiores, pallide testaceae, tenue pubescentes, articulo primo valde elongato, apice incrassato, obconico, secundo etiam crasso, sed brevi; tertio tenui, longiusculo, obconico; quarto parvo, globoso, 5-10 gradatim crassioribus, truncatis, ultimo adhuc crassiore, ovato. Thorax longitudine latior, basi apiceque truncatus, lateribus tenue marginatus, ante medium rotundato-dilatatus, posterius angustior, angulis subrectis, supra 
modice convexus, aequalis, rufo-piceus, parum nitidus, crebre punctatus. Scutellum parvum, triangulare, piceum, laeve. Elytra thorace duplo lon. giora, antice thoracis basi latiora, posterius nonnihil dilatata, apice truncata, angulo exteriore rotundato, supra in dorso subdepressa, saturatius picea, confertissime et sat profunde punctata, pilis minutissimis griseis parce adspersa. Abdomen pone elytra illorum fere longitudine, latum, marginatum, piceum, laeve, ano subacuminato, testaceo. Corpus subtus pallidius rufotestaceum, nitidum, laeve. Pedes tenues, pallide testacei. (Gyll.)

\section{O. marginatum: Piceum, punctatum, antennis pedibusque obscure} rufis. - Long. 1 lin.

Say Transact. Amer. Philosoph. Soc. Philadelph. Nov. Ser. IV. 463. 1.

Habitat in Missuria superiore.

Corpus oblongo-ovale, piceum, punctatum. Caput disperse, apice ob solete punctatum, inter antennas utrinque foveola, et basi- utrinque sulculo impressum. Antennae cinereo-pilosellae, obscure rufo-piceae, basi rufae. Palpi rufi. Thorax transversim subquadratus, aequaliter punctatus, margine posteriore obscure piceo. Elytra oblongo-quadrata, ultra abdominis medium elongata, apice angulis exterioribus rotundatis, interioribus acuminatis, substriata, margine exteriore humerum versus piceo. Abdomen supra margine laterali et segmentorum singulorum margine posteriore obscure rufo. Pedes picei, apice dilutiores. (Say.)

\section{O. cursor: Nilidulum, nigrum, elytris pedibusque picescentibus. - Long. 1 $\frac{1}{3}$ lin.}

Grav. Mon. 208. 10.

Habitat in Borussia.

Caput orbiculatum, thorace panlo minus, laeve, nitidum, nigrum, antennis, capite thoraceque paulo longioribus, fuscis. Thorax convexiusculus, suborbiculatus, coleopteris paulo minor, nitidus, laevis, niger. Coleoptera subtransversa, laevia, fusco-picea. Pedes ochracei. (Grav.)

$\mathrm{Obs}$. Species dubia, typo in collectione Hellwigana perdito aegre unquam recognoscenda.

\section{Anthobium Leach.}

Steph. Illustr. V p. 335. - Er, Col. March. 1. p. 637.

Mandibulae muticae.

Maxillae malis membraneis.

Palpi maxillares articulo ultimo penultimo longiore.

Tibiae muticae.

Tarsi articulis 4 primis aequalibus, brevibus, dilalatis.

Corpus latiusculum, breviusculum, subdepressum, alatum. Caput thorace multo minus et angustius, breviusculum, basi distincte constrictum, fronte plana, immarginata, oculis sat magnis, rotundatis, prominulis. Ocelli inter oculos siti. Labrum transversum, apice subsinuatum. Mandibulae breves, muticae. Maxillae (t. V. f. 32. b.) malis membranaceis, exteriore oblonga, apice barbatula, interiore extus cornea, apice denticulo terminata, 
oblique subemarginata ciliataque. Palpi maxillares articulo primo minuto, secundo modice elongato, tertio breviore, quarto hoc sesqui longiore, apice subacuminato. Labium (t. V. f. 32. a.) mento antrorsum angustato, apice truncato, ligula biloba, lobis coniunctis profunde emarginatis. Palpi labiales breviusculi, articulo primo tertioque longioribus', secundo duplo breviore. Antennae filiformes vel apicem versus perparum incrassatae, articulo tertio secundo paulo longiore. Thorax coleopteris parum angustior, lateribus tenuiter marginatus. Scutellum triangulare. Elytra sat ampla, plerumque abdominis maximam partem obtegentia, angulo apicali exteriore rotundato. Abdomen lateribus rotundatum, late marginatum, apice subacuminatum. Pedes breves, femoribus sat validis, tibiis subcurvatis, pubescentibus, tarsis brevibus, articulis 4 primis brevibus, inter se longitudine aequalibus, magis minusve dilatatis, subtus dense pubescentibus, quarto cordato, quinto illis coniunctis longitudine aequali.

\section{o b s e r v a tio ne s."}

1. Corpus plerisque latiusculum, breviusculum, elytris maximam abdominis partem obtegentibus, aut glabrum aut subtiliter pubescens.

2. Tarsorum structura generi praecedenti proximum, at articuli primi magis dilatati, ceterum antennis gracilioribus, oculis maioribus et magis prominentibus, ocellis non super sed inter oculorum marginem superiorem sitis discedens. Ligula eadem forma ac in Anthophago et Acidota.

3. Mas abdominis segmento inferiore sexto profundius sinuato quam in reliquis Omalinis distinctus. Nonnullarum specierum feminae elytris angulo apicali interiore producto, acuminato insignes.

4. Victus in floribus.

1. A. florale: Nigrum, nitidulum, antennis, ore pedibusque testaceis, elytris thorace plus duplo longioribus, upice inleriore in utroque sexu truncatis. - Long. $1 \frac{1}{2}$ lin.

Mannerh. Brachelytr. 54. 8.

Omal. florale Grav. Micr. 118. 10. Mon. 210. 14. - Latr. Hist. nat. Crust. et Ins. IX. 375. 10. - Oliv. Encycl. meth. VIII. 477. 14.

Staph. floralis Panz. Faun. Germ. 11. 12. Ent. Germ. 358. 41.

Habitat in Germania, Gallia.

A. minuto duplo maius, praecipue latius, nigrum, nitidulum, capite thoraceque glabris, elytris abdomineque parce omnium subtilissime pubescentibus. Antennae maris capitis thoracisque longitudine, feminae capite thoraceque paulo breviores, apicem versus leviter incrassatae, laete testaceae. Os testaceum. Caput parce subtiliter obsoleteque punctatum, fronte inter oculos et inter antennas foveolis binis impressa, utrinque ad oculum subtiliter longitudinaliter strigosa. Thorax coleopteris angustior, latitudine duplo fere brevior, lateribus leviter rotundatus, basi apiceque truncatus, angulis anterioribus rotundatis, posterioribus obtusiusculis, leviter transversim convexus, parcius subtiliter punctatus, ad marginem lateralem pone medium utrinque impressus. Scutellum laeve. Elytra lata, thorace plus duplo longiora, apice interiore truncata, angulo suturali acutiusculo, confertissime punctata, iam nigro-picea, iam testaceo-fusca, nitida. Abdomen nigrum, apice summo testaceo. Pedes testacei. 
2. A. triviale: Nigrum, ore, antennis pedibusque testaceis, thorace piceo, elytris fusco-testaceis, thorace duplo longioribus, apice interiore in uiroque sexu truncalo. - Long. $1 \frac{1}{2}$ lin.

Er. Col. March. I. 639. 2.

Anthob. florale Boisd. et Lacord. Faun. Ent. Paris. I. 472. 6. (forte)

Habitat in Germania, Gallia, Anglia.

Praecedenti affine, at angustius et magis elongatum, nigrum, subnitidum, glabrum, abdomine subtilissime pubescente. Antennae capite thoraceque longiores, graciliores, apicem versus leniter incrassatae, testaceae. Os testaceum. Caput fronte inter oculos et inter antennas foveolis binis impressa, ad oculum utrinque subtiliter longitudinaliter strigosa. Thorax coleopteris paulo angustior, latitudine dimidio brevior, lateribus leviter rotundatus, basin versus subangustatus, basi apiceque truncatus, angulis anterioribus rotundatis, posterioribus obtusiusculis, parum convexus, sparsim minus subtiliter punctatus, nigro-piceus, marginibus rufescentibus. Scutellum laeve. Elytra thorace plus duplo longiora, dense sat fortiter punctata, fusco-testacea, limbo apicali dilutiore, apice interiore truncato. Abdomen nigrum vel piceum, apice summo testaceo. Pedes testacei.

3. A. nigrum: Nigrum, nitidum, antennarum basi pedibusque testaceis, elytris thorace plus duplo longioribus, profunde punclatis, fuscis, apice inleriore truncato. - Long. $1 \frac{1}{3}$ lin.

Habitat in Helvetia.

Statura fere et summa affinitate A. floralis, nigrum, nitidum, parce subtiliter pubescens. Antennae maris capitis thoracisque fere longitudine, feminae iisdem paulo breviores, apicem versus sensim leviter incrassatae, nigrofuscae, articulis 5 primis testaceis. Os testaceum. Thorax coleopteris paulo angustior, latitudine dimidio brevior, lateribus leviter rotundatus, basi apiceque truncatus, angulis anterioribus rotundatis, posterioribus obtusis, leviter convexus, lateribus pone medium depressis, aequaliter sat crebre minus subtiliter profunde punctatus, linea media longitudinali laeviore. Scutellum laeve. Elytra ampla, thorace plus duplo longiora, angrilo apicali interiore in utroque sexu truncato, dense fortiter profundeque punctata, nigro-fusca, nitida. Abdomen parce subtilissime punctatum. Pedes testacei.

Obs. Antennis bicoloribus et punctura fortiore facile ab A. florali distinctum.

* 4. A. obsoletum: Nigrum, parum nitidum, ore, antennarum basi pedibusque testaceis, elytris thorace duplo longioribus, fuscis, apice interiore truncato. - Long. $1 \frac{1}{2}$ lin.

Habitat in Lusitania.

Statura fere praecedentium at paulo minus, subdepressum, nigrum, parum nitidum, capite thoraceque glabris, elytris abdomineque pube subtilissima brevissimaque adspersis. Antennae capite thoraceque paulo breviores, apicem versus leniter incrassatae, testaceae, articulis ultimis $\mathbf{5}$ fuscis. Caput vage subtiliter punctatum, inter oculos obsolete bifoveolatum, inter antenuas utrinque obsolete impressum, ad oculum utrinque subtilissime strigosum, ore testaceo. Thorax coleopteris angustior, latitudine dimidio brevior, late- 
ribus modice rotundatus, basi apiceque truncatus, angulis anterioribus rotundatis, posterioribus subrectis, depressus, vage subtiliter punctatus. Scutellum laeve. Elytra thorace duplo longiora, dense subtilius punctata, fusca, apice interiore truncato. Abdomen subtilissime punctulatum, apice summo testaceo. Pedes testacei.

M a s latet.

* 5. A. excavatum: Elongalum, nigrum, nitidum, antennarum basi, tibiis tarsisque teslaceis, fronte lale excavata, antice utrinque carinulata, thorace longiludinaliter impresso, dorso utrinque tuberculato, elytris crebre punclatis, apice coniunction rotundatis. - Long. $1 \frac{1}{2}$ lin.

Habitat in Helvetia, Dom. Schüppel.

Elongatum, lineare, subdepressum, nigrum, glabrum. Antennae capite thoraceque parum breviores, apicem versus sensim incrassatae, nigrae, articulis 5 primis testaceis. Palpi testacei. Os piceum. Caput thorace paulo angustius, impunctatum, fronte late at minus profunde excavata, antice in utroque latere carinula elevata sat prominula acutaque longitudinali instructa, minus nitidum. Thorax coleopteris paulo angustior, latitudine duplo prope brevior, lateribus rotundatus, basi apiceque truncatus, angulis anterioribus rotundatis, posterioribus obtusis, supra parum convexus, angulis posterioribus depressis, dorso late longitudinaliter impressus, impressionis margine utrinque ante medium leviter elevato et tuberculo minuto prominulo instructo, basi et lateribus crebrius subtiliter punctulatus, minus nitidus. Scutellum laevissinum. Elytra thorace triplo prope longiora, apice coniunctim rotundata, dense minus subtiliter profundius punctata, fusco-picea, nitida. Abdomen laeve, nigrum, nitidum, apice testaceum. Pedes nigro-picei, geniculis, tibiis tarsisque testaceis.

F e min a latet.

* 6. A. abdominale: Rufo-testaceum, elytris lestaceis, thorace plus duplo longioribus, apice interiore in utroque sexu truncalo, thorace angulis poslerioribus ollusis, dorso foveolis duabus longitudinalibus magis minusve obsoletis impresso, abdomine maris nigro. - Long. $1 \frac{1}{2}-1 \frac{3}{4}$ lin.

Er. Col. March I. 639. 8.

Omalium abdominale Grav. Mon. 219. 27. - Oliv. Encycl. meth. VIII. 480. 27.

- Runde Brachelytr. Hal. 22.7.

Dermestes semicoleoptratus Panz. Fan. Germ. 24. 6.

Habitat in Germania.

Corpus oblongum, subdepressum, glabrum, abdomine subtilissime parce puhescente. Antennae capite thoraceque paulo longiores, apicem versus leviter incrassatae, testaceae. Caput vage punctatum, fronte inter oculos lineolis duabus longitudinalibus, inter antennas foveolis duabus obsoletis impressa, rufo-testaceum, subnitidum, basi nigricante. Thorax coleopteris paulo angustior, latitudine dimidio brevior, Jateribus rotundatus, basi apiceque truncatus, angulis ommibus obtusis, anterioribus subrotundatis, subdepressus, minus confertim subtiliter punctatus, linea leviter impressa, medio obsoleta canaliculatus, dorso foveolis duabus longitudinalibus, approximatis, interdum sat distinctis, saepius obsoletis impressus, rufo-testaceus, parum nitidus, 
medio in mare saepe longitudinaliter nigricans. Scutellum laeve, iam nigrum, iam piceo-testaceum. Elytra thorace plus duplo longiora, dense fortius punctata, testacea, circa scutellum nonnunquam fuscescentia. Abdomen maris nigrum, feminae testaceum, iam immaculatum. Pectus maris iam nigrum, iam testaceum, feminae testaceum. Pedes testacei.

* 7. A. limbatum: Rufo-testaceum, elytris testaceis, apice interiore in utroque sexu truncalo, thorace angulis posterioribus rectis, obsolete canaliculato. - Long. $1 \frac{1}{2}$ lin. Ullrich.

Habitat in Hercyniae floribus Salicis, Dom. Saxesen, in Austria, Dom.

A. abdominali- affine, at duplo fere minus, angustius, glabrum, abdomine apice subtiliter pilosello. Antennae apicem versus leniter incrassatae, capite thoraceque paulo longiores, testaceae, articulis ultimis 5 nigro-fuscis. Caput parce punctatum, fronte inter oculos lineolis duabus abbreviatis longitudinalibus, inter antennas foveolis duabus minutis impressa, rufo-testaceum, nitidulum, basi nigricans. Thorax coleopteris paulo angustior, latitudine dimidio brevior, lateribus rotundatus, basi apiceque truncatus, angulis anterioribus rotundatis, posterioribus subrectis, parum convexus, parce subtiliter punctatus, dorso obsolete canaliculatus, rufo-testaceus, subnitidus, longitudinaliter infuscatus. Scutellum laeve, iam nigrum, iam piceo-testaceum. Elytra thorace duplo longiora, sat dense fortius punctata, apice in utroque sexu truncata, luteo-testacea, circa scutellum nonnunquam infuscata. Abdomen laeve, nigrum. Pectus nigrum. Pedes testacei.

Variat elytris fuscis.

Obs. Differt ab A. abdominali praecipue statura angustiore et thoracis angulis posterioribus subrectis, femina mari haud dissimili.

* 8. A. ophthalmicum: Rufo-testaceum, conferlissime subtiliter punctatum, elytris flavo-testaceis, thorace duplo longioribus, apice interiore in utroque sexu truncalo. - Long. 1 lin.

Staph. ophthalmicus Payk. Faun. Suec. III. 419. 54.

Omal. ophthal micum Gylt. Ins. Suec. 11. 215. 7. - Germ. Faun. Ins. Europ. XIII.

6. - Mannerh. Brachelytr. 53. 14. - Boisd. et Lacord. Faun. Ent. Paris. 1. 490.

9. - Runde Brachelytr. Hal. 22. 5.

Omal. pallidum Grav. Mon. 217. 25. - Oliv. Encycl. meth. Ins. VIII. 480. 25.

Habitat in Suecia, Germania.

A. minuto paulo latius, rufo-testaceum, parum nitidum, glabrum, abdomine parcius subtilissime pubescente. Antennae capitis thoracisque longitudine, apicem versus leviter incrassatae, testaceae, apice fuscescentes. Caput confertim subtiliter punctatum, fronte planiuscula, inter antennas foveolis duabus minutis impressa. Thorax coleopteris paulo angustior, latitudine plus dimidio latior, lateribus leviter rotundatus, basi apiceque truncatus, angulis anterioribus rotundatis, posterioribus subrectis, subdepressus, confertissime subtiliter punctatus, obsolete canaliculatus. Scutellum laeve. Elytra thorace duplo longiora, subdepressa, confertim fortius profundeque punctata, dilutius testacea. Abdomen subtilissime punctulatum. Pedes testacei. 
* 9. A. Sorbi: Testaceum, parce subtiliterque punctatum, elytris flavotestaceis, thorace duplo longioribus. - Long. $\frac{3}{4}$ lin.

Er. Col. March. 1. 640. 5.

Omal. Sorbi Gyll. Ins. Suec. II. 206. 8. - Mannerh. Brachelytr. 53. 15. - Runde Brachelytr. Hal. 22.6.

Omal. ophthalmicum Grav. Mon. 216. 24. - Oliv. Encycl. meth. VIII. 479. 24.

- Boisd. et Lacord. Faun. Ent. Paris, I. 490. 9.

Silpha lutea Marsh. Ent. Britt. 128. 41.

Var. a: Abdomine nigro.

Omal. testaceum Grav. Mon. 218. 26. - Oliv. Encycl. meth. VIII. 480. 26.

Var. b: Pectore abdominisque apice nigris.

Var. c: Pectore abdomineque nigris.

Silpha torquata Marsh. Ent. Britt. 127. 40.

Habitat in Europa.

A. minuto duplo minus, luteo-testaceum, subnitidum, elytris pedibusque dilutioribus. Antennae capitis thoracisque fere longitudine, apicem versus sensim incrassatae, pilosellae, pallide testaceae, apicem versus fuscescentes. Caput parce obsoleteque punctulatum, fronte inter oculos et inter antennas foveolis binis minutis impressa. Thorax coleopteris angustior, maris latitudine dimidio brevior, feminae duplo fere brevior, lateribus leviter rotundatis, basi apiceque truncatus, angulis anterioribus rotundatis, posterioribus subrectis, depressis, parum convexus, vage subtiliter punctulatus. Elytra thorace duplo vel plus duplo longiora, apice coniuncta subrotundata, dense fortius punctata. Abdomen iam testaceum, versus apicem saepe infuscatum, iam nigrum. Pectus iam testaceum, ian nigrum. Pedes pallide testacei.

* 10. A. tempestivum: Nigrum, antennarum basi thoraceque rufo-testaceis, ore, pedibus elytrisque luteis, his circa sculellum.infuscatis. Long. 1 lin.

Habitat in Sardinia, Dom. Prof. Gené.

Statura omnino A. minuti, glabrum, abdomine parce subtiliterque pubescentibus. Antennae capitis thoracisque fere longitudine, apicem versus leniter incrassatae, testaceae, articulis ultimis 5 nigricantibus. Caput thorace vix angustius, fronte depressa vel subimpressa, crebre punctata, inter antennas utrinque leviter impressa, nigrum, nitidum, ore testaceo, fronte media macula piceo-testacea. Thorax coleopteris dimidio prope angustior, latitudine dimidio brevior, lateribus leviter rotundatus, basi apiceque truncatus, angulis anterioribus rotundatis, posterioribus obtusis, leviter convexus, crebre subtilius punctatus, obsolete canalıculatus, rufo-testaceus, nitidus. Scutellum laevissimum, nigrum. Elytra thorace plus duplo longiora, crebre fortius profundeque punctata, apice coniunctim leviter rotundata, lutea, nitida, circa scutellum nigricantia. Pectus et abdomen nigra, nitidula. Pedes testacei.

F emin a latet.

* 11. A. scut ellare: Rufo-teslaceum, scutello, pectore abdomineque nigris, elytris teslaceis, thorace duplo longioribus, apice interiore maris truncalo, feminae acuminato. - Long. vix 1 lin.

Omal. testaceum Boisd. et Lacord. Faun. Ent. Paris. I. 489. 8. 
Habitat in Austria, Gallia.

Statura omnino A. minuti, rufo-testaceum, parum nitidum, totum subtiliter tenuiterque pubescens. Antennae capitis thoracisque longitudine, apicem versus leniter incrassatae, testaceae, apicem versus fuscescentes. Caput subtilissime punctulatum, fronte inter oculos punctis duobus profundis, inter antennas foveolis duabus minutis obsoletis impressa, basi summa nigricans. Thorax coleopteris paulo angustior, latitudine dimidio brevior, lateribus rotundatus, basi apiceque truncatus, angulis anterioribus rotundatis, posterioribus subrectis, leviter convexus, subtiliter punctulatus. Scutellum laeve, nigro-piceum. Elytra thorace plus duplo longiora, subdepressa, confertim fortius punctata, testacea, apice interiore in mare truncato, in femina producto, acuminato. Abdomen et pectus nigra. Pedes testacei.

Obs. Omal. testaceum Grav., secundum exemplum typicum ab auctore benevole communicatum, ad A. S or bi retuli.

* 12. A. minutum: Nigrum, antennarum basi pedilusque testaceis, elytris fuscis, maris apice interiore truncalo, feminae acuminato. - Long. I lin.

Er. Col. March. I. 638. 1.

Silpha minut a Fab. Ent. Syst. 1. I. 254. 26. Syst. El. I. 342. 25. - Panz. Ent. Germ. 122. 18. - Herbst. Col. V. 207. 32. - Schönh. Syn. II. 132. 27.

Omal. Ranunculi Grav. Micr. 110. 11. Mon. 215. 20. - Latr. Hist. nat. Crust. et Ins. IX. 374. 11. - Oliv. Encycl. meth. VIII. 478. 20. - Gyll. Ins. Suec. II. 204. 6. - Sahlb. Ins. Fenn. I. 279. 6. - Zetterst. Faun. Lappon. I. 50. 5. Ins. Lappon. 50. 7. - Mannerh. Brachelytr. 52. 12. - Boisd. et Lacord. Faun. Ent. Paris. I. 489. 7. - Runde Brachelytr. Hal. 22. 4.

Habitat in Europa, in floribus pratensibus.

Parvum, depressiusculum, nigrum, subnitidum, glabrum, abdomine parce subtilissime pubescente. Antennae capite thoraceque vix breviores, crassinsculae, testaceae, apice fuscae. Caput parce subtiliter punctulatum, fronte longitudinaliter bi-impressa, ore testaceo. Thorax coleopteris angustior, latitudine dimidio prope brevior, transversim quadratus, lateribus leviter rotundatis, basi apiceque truncatus, angulis anterioribus rotundatis, posterioribus rectis, parum convexus, margine laterali depresso, parcins subtiliter punctulatıs, utrinque ad marginis lateralis medium obsolete foveolatus. Scutellum laeve. Elytra abdominis maximam partem obtegentia, subdepressa, dense fortius punctata, punctis hinc inde subseriatis, fusca vel testaceofusca, subnitida, apice interiore in mare truncato, in femina producto, acilminato, dehiscente. Abdomen laeve, apıce summo piceo. Pedes validiusculi, testacei.

* 13. A. flavipenne: Nigrum, parum nilidum, antennarum basi, pedibusque tesiaceis, thorace brevi, canaliculato, elytris thorace plus duplo longioribus, pallide testaceis. - Long. I lin.

Habitat in Lapponia, a Dom. Prof. Zetterstedt pro Om. Ranunculi Gyll. communicatum.

Statura et summa affinitate A. minuti, nigrum, parum nitidum, glabrum, abdomine subtilissime pubescente. Antennae capite thoraceque paulo breviores, apicem versus haud incrassatae, testaceae, articulis ultimis 5 nigris. Palpi testacei. Mandibulae rufae. Caput subtilissime parce punctulatum, 
fronte antice ntrinque leviter oblique impressa, inter antennas profundius foveolata. Thorax coleopteris paulo angustior, latitudine duplo brevior, lateribus leviter rotundatus, basi apiceque truncatus, angulis anterioribus rotundatis, posterioribus obtusis, parum convexus, margine laterali posterius subdepresso, medio foveolato, parce subtiliter punctulatus, medio leviter canaliculatus. Scutellum laeve. Elytra thorace plus duplo longiora, subdepressa, sat dense fortius punctata, flavo-testacea, angulo interiore maris truncato. Abdomen suhtilissime punctulatum, nitidulum. Pedes testacei.

F e min a latet.

Obs. Ab A. minuto praeter colorem antennis brevioribus, apicem versus haud incrassatis, thorace latiore, breviore, canaliculato, elytris brevioribus sat distinctum.

*14. A. montanum: Subdepressum, nigrum, parum nilidum, pedilus antennisque lestaceis, his apice nigris, elytris thorace plus triplo longioribus, fuscis, maris apice coniunctim rolundatis, feminae acuminatis. Long. vix 1 lin.

Habitat in Austriae Helvetiaeque alpibus.

A. minuto paulo minus, subdepressum, nigrum, minus nitidum, glabrum. Antennae capite thoraceque paulo longiores, testaceae, articulis ultimis tribus paulo maioribus, nigricantibus. Os piceum. Caput thorace paulo angustius, vix punctulatum, fronte postice utrinque ohsolete oblique bisulcata, antice leviter bifoveolata. Thorax coleopteris paulo angustior, latitudine dimidio brevior, lateribus leviter rotundatus, basi apiceque truncatus, angulis anterioribus rotundatis, posterioribus rectis, subdepressus, parce subtiliter obsoleteque punctatus, subtilissime canaliculatus. Scutellum laeve. Elytra thorace plus triplo longiora, in utroque sexu abdomen fere totum tegentia, maris apice coniunctum fortiter rotundata, feminae angulo apicali interiore acuminato, subdepressa, crebre punctata, fusca, basi nigricantia, apice indeterminate testacea. Pedes testacei.

Obs. Ab A. minuto statura minore, magis depressa, colore capitis thoraeisque opaco, hoc parce obsolete punctato, elytris multo longioribus, maris apice haud truncatis, antennis longioribus, articulis ultimis tribus solis maioribus distinctum.

* 15. A. luteicorne: Subdepressum, nigrum, parum nitidum, ore, antennis pedibusque luteis, elytris fuscis, thorace plus duplo longioribus, feminae apice acuminalis. - Long. vix 1 lin.

Habitat in Sicilia, Dom. Grohmann.

Statura et summa affinitas praecedentis. Nigrum, parum nitidum, glabrum. Antennae luteo-testaceae (articuli ultimi tres desunt). Os testaceum. Caput thorace paulo angustius, vix punctulatum, fronte inter oculos bifoveolata, inter antennas transversim impressa. Thorax coleopteris paulo angustior, latitudine vix dimidio brevior, lateribus leviter rotundatus, basi apiceque truncatus, angulis anterioribus rotundatis, posterioribus subrectis, subdepressus, parce subtiliter obsoleteque punctatus, obsolete subtiliter canaliculatus. Scutellum laeve. Elytra thorace plus duplo longiora, subdepressa, dense hinc inde subseriatim punctata, fusca, apice testaceo-marginata, angulo apicali interiore acuminato. Pedes testacei. 
Mas latet.

Obs. Praecedenti proximum, et imprimis elytris multo brevioribus, vix ultra abdominis dimidiam partem tegentibus distinctum.

* 16. A. anale: Nigrum, nitidum, ano, pedibus antennisque testaceis, his apice fuscis, elylvis fuscis, forlius punctatis, maris thorace duplo longioribus, apice roiundatis, feminae thorace plus triplo longioribus, acuminatis. - Long. $\frac{2}{3}-1$ lin.

Habitat in montibus Saxoniae, Austriae, Croatiae.

Statura omnino A. minuti, nigrum, nitidum, glabrum. Antennae vix capitis thoracisque longitudine, apice sensim leniterque incrassatae, testaceae, plerumque apicem versus fuscescentes. Os piceum. Caput thorace angustius, fronte inter oculos lineola obliqua, inter antennas foveola minuta levique utrinque impressa, ceterum laeve. Thorax coleopteris paulo angustior, latitudine paulo brevior, lateribus fortius rotundatus, basi apiceque truncatus, angulis ommibus obtusis, modice convexus, parce obsoleteque punctatus. Scutellum laeve. Elytra maris thorace duplo longiora, apice coniuncta rotundata, feminae thorace plus triplo longiora, angulo apicali interiore acuminato, dense fortius profundiusque punctata, fusca, apice saepius testaceo-limbata. Abdomen ano maris laete rufo-testaceo, feminae piceo. Pedes testacei.

Obs. Elytris fortius punctatis imprimis ab affinibus distinctum.

* 17. A. luteipenne: Nigrum, ore, antennis, pedibus coleopterisque luteis, his thorace triplo longioribus, maris apice rotundatis, feminae acuminatis. - Long. 1 lin.

Habitat in Saxonia montana, Dom. Märkel.

Statura omnino A. longipennis, subdepressum, nigrum, opacum, glabrum. Antennae capitis thoracisque longitudine, apicem versus vix incrassatae, testaceae. Os testaceum. Caput thorace angustius, impunctatum, fronte utrinque leviter longitudinaliter impressa. Thorax coleopteris paulo angustior, latitudine plus dimidio latior, lateribus fortius rotundatus, basi apiceque truncatus, angulis anterioribus rotundatis, posterioribus obtusis, parum convexus, parce obsoleteque punctatus, subtiliter obsoleteque canaliculatus. Scutellum laeve, testaceum. Elytra thorace triplo longiora, maris apice coniuncta rotundata, feminae angulo interiore acuminato, crebre minus fortiter punctata, interstitiis subtilissime rugulosis, luteo-testacea,- vix nitida. Abdomen ano maris testaceo, feminae piceo. Pedes testacei.

* 18. A. longipenne: Testaceum, coleopleris thorace plus triplo longioribus, maris apice truncalis, feminae coniunctim rotundatis, - Long. 1 lin.

Er. Col. March. I. 640. 4.

Habitat in Germania, Suecia.

Statura A. minuti, licet colore corporis testaceo et elytris multo longioribus valde distinctum. Corpus glabrum. Antennae capitis thoracisque prope longitudine, apicem versus leniter incrassatae. Caput subtilissime parce punctulatum, foveolis duabus minutis inter oculos, duabusque inter antennas impressum, rufo-testaceum, subnitidum, summa basi nigricante. Thorax 
coleopteris paulo angustior, latitudine plus dimidio latior, lateribus leviter rotundatus, basi apiceque truncatus, angulis anterioribus rotundatis, posterioribus obtusiusculis, margine laterali antice anguste, postice latius depresso, disco leviter convexus, parce obsoleteque punctulatus, utrinque ad marginis lateralis medium subfoveolatus, rufo-testaceus, parum nitidus. Scutellum rufo-testaceum, laeve. Elytra thorace plus triplo longiora, abdomen fere totum tegentia, praesertim in femina, dense fortius punctata, testacea, subnitida, apice interno in mare truncato, in femina magis producto, angulo suturali acutiusculo, cum elytro altero coniunctim rotundato. Abdomen maris nigrum, apice testaceum, feminae totum testaceum. Pectus et pedes testacea.

Obs. Specimina duo feminea elytris apice interiore longius producto acuminatis, cum maribus et feminis genuinis e Croatia a Dom. Parreyss communicata, specie haud differre videntur.

Species mihi invisae, forte huius generis.

19. A. fimetarium: Rufo-piceum, nitidum, crebre punctatum, antennarum basi, thoracis elytrorumque limbo pedibusque pallidioribus, thorace transverso, canaliculato, elytris substriatis, abdomen fere tolum oblegentibus, maris truncutis, feminae apice interiore sinuato-acuminatis.

Omal. fimetarium Mannerh. Brachelytr. 52. 10.

Habitat in stercore in ins. Sitcha Americae borealis.

Deliphro tecto maius, fortius punctatum, thorace breviore, canaliculato, elytrisque longioribus, substriatis, in femina sinuatis diversum. (Mannerh.)

20. A. Lapponicum: Nigrum, obscurum, subtilissime punctatum, antennarum basi, thoracis laleribus, elytris pedibusque pallidis, thorace convexo,

Omal. Lapponicum Mannerh. Brachelytr. 52. 13. - Zetterst. Ins. Lappon. 50. 9.

Habitat in Lapponia.

A. minuto (Om. Ranunculi) duplo minus, subtilius punctulatım, tho race convexo, posterius minus angustato et elytris brevioribus facile distin guendum. (Mannerh.)

O b s e r vationes.

1. Huic tribui forte adscribendum est genus mihi invisum:

\section{Boreaphilus Sahlberg.}

Palpi anteriores 4-articulati, articulo tertio clavato, ultimo parvo, sulbulato, posteriores minuti, filiformes. Mandibula elongata, tenuis, falcata, integra. Antennae subfiliformes, extrorsum paulo crassiores. Corpus postice dilatatum. Caput orbiculatum, subexsertum. Thorax oblongus.

1. B. Henningianus: Piceus, punctulatus, parce pubescens, ore, antennis pedibusque testaceis, segmentorum ventralium marginibus abdomineque supra piceo-nigris, abdomine ovato, lateribus elevato-marginatis. - Long. $1 \frac{1}{4}$ lin.

Habitat in Lapponia boreali rarissime. In littore lacus Mandujarvi sub quisquiliis tria specimina die 9. Augusti 1830 legit F. Sahlberg. 
Statura corporis Anthophagiv quodammodo similis. Capnt thorace latins, piceum, subnitidum, crebre punctatum, inaequale, fronte late et sat profunde excavata, versus thoracem parum impresso-emarginatum. Os et palpi piceo. testacea. Antennae longe ante oculos in angulo frontis insertae, longitudine thoracis, extrorsum paulo crassiores, testaceae, articulo primo elongato, incrassato, secundo et tertio paulo brevioribus et angustioribus, tribus insequentibus brevibus, $7-10$ parum incrassatis, ultimo longiore, ovato, acuto. Oculi nigri, prominuli. Thorax latitudine longior, antice paulo angustior, pro emarginatura capitis parum rotundato-productus, lateribus anguste marginatus, paulo ante medium angulato-dilatatus, postice truncatus, parce pubescens, fusco-piceus, foveis tribus, una ntrinque laterali et tertia profundiore paulo ante basin impressis. Scutellum minutum, subtriangulare, fuscopiceum. Elytra thorace paulo latiora, eodemque et latitudine sua fere dimidio longiora, posterius parum dilatata, apice subtruncata, angulis exterioribus rotundatis, supra ferrugineo-picea, crebre punctata, parce pubescentia. Abdomen ovatum, depressum, lateribus late elevato-marginatis, nigro-piceum, vix punctulatum, subpubescens, marginibus segmentorum piceo-nigris. Pedes elongati, rufo - testacei.

\section{Sahlb. Ins. Fenn. I. 433. 1. - Zetterst, Ins. Lappon. 72. 1.}

2. Alterum genus, quod huius tribus esse videtur, est Coryphium Kirby, a Stephensio Ent. Britt V. p. 344. descriptum, mihi invisum et incognitum. Corpus ei depressum, subpubescens. Caput triangulare, inaequale, oculis prominulis. Antennae filiformes, apicem versus sensim incrassatae, articulo basali valido, basi angustato, sequentibus duobus clavatis, reliquis turbinatis, ultimo ovato, acuminato. Palpi breves, maxillares articulo penultimo rotundato, ultimo fortius incrassato, truncato. Thorax capite angustior, lateribus subtiliter marginatus., Elytra oblonga, dimidio abdomine longiora. Abdomen dilatatum, marginatum, apice acuminato. Pedes graciles, simplices, tarsis 5-articulatis, articulo ultimo praecedentibus duobus coniunctis longiore.

A Boreaphilo hand distinctum esse hoc genus supponerem, nisi palporum descriptiones impedirent, quo minus alterum alteri subjungam. Non autem omnine deest quod dubitem, B or e a phili palpos maxillares rite observatos esse. Ceterum. capite latiore et thorace angustiore utrumque genus inter Omalinos sat insigne. 


\section{Tribus undecima.}

\section{P r t e i n i n i.}

Stigmato prothoracica occulta.

Coxae posticae transversae, anticae cylindricae, haud prominentes.

Trochanleres postici fulcrantes.

La b.rum transversum, corneum, apice membrana biloba auctum $\mathrm{Pr}$ oteino.

Mandibula e breves, haud prominentes, muticae.

Maxilla mala exteriore coriacea, apice barbata, interiore cornea, apice unco duplice terminata Proteino, unco simplice terminata Megarthro, Phloe obio.

Palpi maxillares articulo primo minuto, brevi, secundo incrassato, tertio hoc minore, quarto augustiore, subacuminato.

Mentum corneum.

Ligula membranea, biloba Proteino, Megarthro, Phloeobio; integra Micropeplo.

Paraglossae distinctae Proteino, Megarthro, Phloeobio; ligulae aequales Proteino, Phloeobio;

ligulam longe superantes $\mathrm{Meg}$ arthro.

Palpi labiales perbreves.

Antennae sub clypei margine laterali insertae, 11-articulatae, saepius clavatae vel apice leviter incrassatae, liberae plerisque; 9-articulatae, capitulatae, receptae Micropeplo.

C a put thoraei immissum, porrectum, ocellis nullis plerisque; ocello singulo Phloe obio.

Thorax marginatus, infra spatio pone coxas anteriores corneo.

Scutellum distinctum.

Elytra pectere longiora, abdomen fere totum tegentia Proteino;

abdominis summan basin tegentia Megarthro, Phloeobio, Glyptomati, Micropeplo. 
Abdomen segmentis 6 distinctis, septimo nonnunquam eminulo, marginatum Proteino, Megarthro, Phloeobio, Micropeplo; immarginatum Glyptomati.

Pedles breves, coxis anticis cylindricis, oblique positis, haud exsertis, intermediis

approximatis Proteino, Phloeobio;

tenui spatio distantibus Megarthro, Glyptomati;

late distantibus Micropeplo;

posticis transversis, trochanteribus posticis fulcrantibus, tibiis inermibus, tarsis

5-articulatis Proteino, Megarthro, Phloeobio;

3 -articulatis Glyptomati, Micropeplo.

O b.s e r a t i o.

Proxima haec tribus praecedenti, at coxis anticis haud exsertis et paraglossis plerumque distinctis discedit. Coxarum anticarum forma cum Nitidulis convenit.

\section{Proteinns $L$ atr.}

Latr. Précis d. caract. gén. des Ins. p. 9.

Antennae 11-articulatae, liberae, articulis ultimis tribus maioribus.

Tarsi 5-articulati.

Corpus parvum, ovatum, leviter convexum. Caput thorace multo minus, subtriangulare, clypeo rotundato, oculis sat magnis, prominulis, ocellis oninino nullis. Labrum transversum, medio subsinuatum, apice membrana brevi biloba auctum. Mandibulae minutae, muticae. Maxillae (t. V. f. 33. b.) 'mala interiore cornea, apice acute bidentata, interne membrana tenui aucta, exteriore coriacea, apice barbata. Palpi maxillares brevinsculi, articilo primo brevi, tenui, secundo magno, incrassato, obconico, tertio brevi, transverso, quarto tenuiore, longiore, tereti. Labium (t. V. f. 33. a.) mento transverso, antrorsum angustato, apice truncato, ligula membranea, biloba, lobis truncatis, paraglossis ligulae connatis eamque haud excedentibus. Palpi labiales breves, ligulam haud superantes, articulo primo longiore, secundo brevissimo, tertio minuto, secundo autem longiore. Antennae articulis duobus primis maioribus crassioribusque, ultimis tribus sensim maioribus, ultimo subgloboso. Thorax transversus. Scutellum triangulare. Elytra sat ampla, abdominis segmenta duo anteriora obtegentia, apice truncata, angulo exteriore rotundata. Abdomen latiusculum, lateribus marginatum, apice acuminatum. Pedes breviuseuli, coxis intermediis mesosterni carina tenui longitudinali discretis, tibiis omnibus simplicibus, tarsis 5 -articulatis, articulis 4 primis subaequalibus, quinto his coniunctis multo breviore.

$$
\text { O b s e r vationes. }
$$

1. Corpus subtiliter pubescens, punctulatum.

2. Habitus fere Nitidularum quarundam, imprimis Cercorum, quibus etiam ab auctoribus multis associatur.

3. Mas abdominis segmento inferiore sexto emarginato cognoscitur.

4. Victus in floribus et in fungis. 
* I. P. Irachyplerus: Niger, nitidulas, anlennarum arliculo primo pedibusque testaceis, elylris crebre punclulatis. - Long. $\frac{3}{4}$ lin.

Latr. Hist. nat. Crust. et Ins. X. 46. 1. Gen. Crust. et Ins. I. 298. 1. - Lepell. Enc. meth. X. 215. 1. - Mannerh. Brachelytr. 57. 1. - Buisd. et Lacord. Faun. Ent. Paris. I. 491. 1. - Runde Brachelytr. Hal. 24. 1. - Fr. Col. March. I. 642. 1 .

Dermestes braclypterus Fub. Ent. Syst. I. I. 235. 46. Syst. El. I. 320. 4j. Payk. Faun. Suec. I. 288. 14

Cateretes brachypterus Herbst Col. V. 13. 2. t. 45. f. 2. - Gyll. Ins. Suec. I. 251. 6. - Sahlb. Ins. Fenn. I. 84. 5. - Schönh. Syn. II. 150. 6.

Omal. brachypterum Gyll. Ins. Suec. J. 207. 9. - Sahlb. Ins. Fenn. 1. 279. 7. Omal. ovat um Grav. Hon. 215. 22. - Oliv. Encycl. meth. Ins. VIII. 479. 22.

Habitat in Europa, in floribus et in fungis.

Breviter ovatus, leviter convexus, niger, nitidus, subtiliter griseo-pubescens. Antennae capitis thoracisque longitudine, nigrae, articulo primo testaceo. Oris partes testaceae, labro palpisque maxillaribus piceis. Caput laeve, fronte ad oculos utrinque oblique obsolete impressa. Thorax coleopteris angustior, latitudine duplo brevior, lateribus leviter rotundatus, a medio inde antrorsum angustatus, apire leviter emarginatus, basi subsintatus, angulis anterioribus obtusis, posterioribus subrectis, leviter transversim convexus, laevis, margine basali et apicali nonnunquam rufo-piceo. Scutellum laeve. Elytra thorace plus duplo longiora, ampla, lateribus leviter rotundata, leviter convexa, snbtilius crebre punctata. Abdomen subtilissime punctulatum. Pedes rufo-testacei, coxis anterioribus concoloribus.

* 2. P. brevicollis: Niger, subnitidus, antennis piceis, pedibus testaceis, elytris creberrime punctatis, fusco-piceis. - Long. 1 lin.

Habitat in Italia, Dom. Schiippel, Lutetiae. Dom. Aubé.

Ovatus, subdepressus, parce minus subtiliter griseo-pubescens, niger, nitidus, capite thoraceque minus nitidis. Antennae capitis thoracisque longitudine, piceae, clava nigra, articulo primo rarius rufescente, maris fortins clavatae, feminae graciliores, apice lenius incrassatae. Palpi picei. Caput laeve, fronte utrinque ad oculi marginem interiorem oblique impressa. Thorax coleopterorum basi parum angustior, latitudine plus duplo brevior, lateribus rotundatus, a medio inde apicem versus leviter angustatus, apice levissime emarginatus, basi subhisinuatus, angulis posterioribns acutiusculis, anterioribus rotundatis, parum convexus, laevis, angulis posterioribus depressis. Scutellum laevissimum. Elytra thorace plus duplo longiora, creberrime minus subtiliter punctata, obscure fusco-picea, nitida, humeris dilutioribus. Abdomen subtilissime punctulatum, pube brevissima subtilissime adspersum. Pedes testacei, coxis anticis concoloribus.

Obs. Differt a praecedente statura paulo maiore, subdepressa, antennarum basi haud testacea, elytris distinctius punctatis, etc.

* 3. P. macropterus: Niger, nilidulus, antennarum arliculis duobus primis pedibusque testaceis, elytris piceis, crebre punctalis. - Long. $\frac{2}{3}$ lin.

Er. Col. March. 1. 643. 2.

O mal. macropterum Gyll. Ins. Suec. I. 209. 10. - Sahlb. Ins. Fenn. I. 280. 8. Habitat in Germania. 
P. brachyptero paulo minor, breviter ovalis, convexus, niger, nitidulus, parce subtiliterque griseo-pubescens. Antennae capite thoraceque paulo hreviores, piceae, articulis duobus primis late rufo-testaceis. Caput laeve, fronte inter oculos utrinque oblique impressa, apice leviter bifoveolata. Thorax coleopterorum basi parum angustior, latitudine duplo prope brevior, lateribus leviter rotundatus, a basi apicem versus aequaliter subangustatus, hasi subsinuatus, apice late emarginatus, angulis anterioribus rotundatis, posterioribus acutiusculis, leviter convexus, laevis. Scutellum laevissimum. Elytra thorace plus duplo longiora, lateribus leviter rotundata, leviter convexa, crebre subtiliter punctata. Abdomen subtilissime punctulatum. Pedes testacei, coxis anticis concoloribus.

Obs. Differt a P. brachyptero antennarum articulis duobus primis testaceis, thorace non a medio sed a basi inde antrorsum angustato, lateribus minus, angulis anterioribus magis rotundatis, posterioribus magis acutis. - Gyllenhal hane speciem thorace punctulato a P. brach y ptero distinguit, thorax autem revera laevis est, et puncturae speciem nonnisi pilis subtilissimis offert.

* 4. P. atomarius: Fusco-piceus, antennis pedibusque pallidis, elytris crebre punctulalis. - Long. $\frac{2}{5}$ lin.

Habitat in Germania.

Habitu omnino P. brachypteri, at triplo vel quadruplo minor, breviter subovalis, parum convexus, fusco-piceus, nitidulus, subtiliter pubescens. Antennae capitis thoracisque longitudine, pallide flavescentes, apice fuscescentes. Oris partes testaceae. Caput laeve, inter oculos utrinque foveola rotundata obsoletiore impressum, apice obsolete bifoveolatum. Thorax basi colenpteris panlo angustior, latitudine duplo brevior, lateribus leviter rotundatus, a basi inde antrorsum subangustatus, apice leviter emarginatus, basi subbisinuatus, angulis anterioribus rotundatis, posterioribus acutiusculis, leviter convexus, laevis. Elytra thorace triplo longiora, ampla, lateribus leviter rotundata, leviter convexa, crebre subtiliter punctata. Abdomen apice dilutius. Pedes pallide testacei.

O bs. Proximus praecedenti, at statura duplo minore et thorace paulo breviore distinctus videtur.

\section{Megarthrus Kirby.}

Steph. Illustr. Britt. Ent. V. p. 330.

Megarthrus * Er. Col. March. I. p. 644.

Antennae 11-articulatae, articulo ultimo maiore.

Frons ocello nullo.

Tarsi 5-articulati.

Corpus parvum, latiusculum, subdepressum, alatum. Caput thorace multo minus et angustius, subtriangulare, basi constrictum, collo quasi crassiusculo thoraci immissum, porrectum, fronte marginata, oculis subglobosis, sat prominulis, ocellis nullis. Labrum frontis margine reconditum, transversum, breve, apice membrana integra prominula fimbriata. Mandibulae minutae, muticae. Maxillae (t. V. f. 34 . b.) mala interiore cornea, elongata, apice acuminata, interne setulis pancis ciliata, exteriore coriacea, apice membranea barbataque, interiorem parum superante. Palpi maxillares breviu- 
sculi, articulo primo minimo, secundo sat magno, obconico, tertio brevi, quarto secundo paulo breviore, tenuiusculo, acuminato. Labium (t. V. f. 31. a.) mento latitudine parum breviore, antrorsum sensim angustato, apice truncato, ligula membranea, brevi, medio subsinuata, paraglossis ligulam longe superantibus, liberis, acuminatis. Palpi labiales breviusculi, articulis duobus primis subaequalibus, tertio panlo minore. Antennae breviusculae, apicem versus sensim subincrassatae, articulo ultimo crassiusculo, subgloboso, basalibus duobus reliquis multo maioribus crassioribusque. Thorax transversus, coleopterorum prope latitudine, lateribus late marginatus. Elytra abdominis nonnisi summam basin tegentia, apice truncata, angulo exteriore obtuso. Abdomen breviusculum, apicem versus angustatum, late marginatum. Pedes breviusculi, coxis intermediis subapproximatis, mesosterni carinula discretis, tibiis omnibus muticis, tarsis 5 -articulatis, articulis 4 primis brevibus, aequalibus, quinto his coniunctis breviore.

$$
\text { O b s e.rva tion e s. }
$$

1. Corpus punctatum, pube brevi adspersum, thorace profunde canaliculato, angulis posterioribus excisis insigne.

2. Mas abdominis segmento inferiore sexto apice emarginato, nec non pedum posteriorum structura distinctus.

3. Victus sub arborum cortice.

* 1. M. depressus: Niger, opacus, pedibus ferrugineis, thorace lateribus rolundalo. - Long. 1 lin.

Er. Col. March. I. 644. I.

Staph. depressus Payk. Mon. Staph. 70. 49. Faun. Suec. 111. 412. 58. - Oliv. Ent III. 42. 36. 51. $t .3 . f .26$.

Omal. depressum Gyll. Ins. Suec. II. 210. 11. - Sahlb. Ins. Fenn. I. 280. 9. Zetterst. Ins. Lappon. 50. 8. - Mannerh. Brachelytr. 53. 16.

Phloe obium depressum Boisd, et Lacord. Faun. Ent. Paris, I. 494. 4.

Omal. macropterum Gruv. Mon. 215. 21. - Oliv. Encycl. meth. VIII. 479. 21.

Habitat in Europa.

Corpus parvum, latinsculum, subdepressum, nigrum, opacum, omnium subtilissime pubescens. Antennae piceae, articulis duobus primis crassioribus nigris. Palpi nigro-picei. Caput omnium subtilissime rugulosum, fronte utrinque late impressa, antice rotundata, margine subincrassato. Thorax coleopteris parum angustior, latitudine duplo brevior, basi apiceque truncatus, lateribus rotundatis, antrorsum modice angustatus, angnlis anterioribus obtusis, posterioribus emarginatis, denticulis duobus obtusiusculis, leviter convexus, confertim subruguloso-punctatus, tenuiter at profunde canaliculatus, margine laterali parum depresso. Scutellum punctulatum, obsoletius canaliculatum. Elytra thorace duplo longiora, dense punctata, nigro-picea. Abdomen subtiliter punctulatum, ano piceo. Pedes rufo-ferruginei, femoribus saepe nigro - piceis.

Pedes posteriores maris femoribus subincrassatis, tibiis leviter incurvis.

* 2. M. sinuatocollis: Niger, opacus, pedibus rufis, thorace canaliculato, lateribus angulato. - Long. 1 lin.

Phloeobium sinuato colle Boisd. et Lacord. Faun. Ent. Paris. I. 493. 3.

Habitat in Helvetia, Gallia. 
Statura omnino praecedentis, nigrum, opacum, subtiliter pubescens. Antemnae fusco-nigrae. Palpi picei. Caput subtiliter rugulosum, utrinque late longitudinaliter impressum, margine anteriore lateribus parum elevato. Thorax coleopteris vix angustior, latitudine duplo brevior, antrorsum subangustatus, basi leviter trisinuatus, apice emarginatus, lateribus subrotundatus, medio angulatus, angulis anterioribus obtusis, posterioribus emarginatis, denticulis obtusiusculis, disco leviter convexus, creberrime rugoso-punctatus, tenuiter at sat profunde canaliculatus, lateribus explanatus. Scutellum confertim punctatum. Elytra thorace vix duplo longiora, confertissime sat fortiter punctata, nigro-picea. Abdomen obsolete punctulatum, subtilissime rugulosum, ano piceo-testaceo. Pedes rufi.

* 3. M. denticollis: Nigro-piceus, opacus, antennarum articulo primo pedibusque rufis, thoracis margine rufo. - Long. 1 lin.

Omalium denticolle Beck Beitr. 26. 40. t. 7. f. 40.

Megarthrus marginicollis Er. Col. March. 1. 644. 2.

Phloeobium marginicolle Boisd: et Lacord. Faun. Ent. Paris. 1. 492. 1.

Silpha hemiptera var. a Illig. Käf. Pr. 355. 1.

Habitat in Europa.

Statura praecedentium, niger, opacus. Antennae piceae, articulo primo rufo. Caput ruguloso-punctatum, utrinque late longitudinaliter impressum, - interstitio subcarinato, margine anteriore acute elevato. Thorax basi coleopteris haud angustior, latitudine vix duplo brevior, apice truncatus, basi subtrisinuatus, lateribus parum rotundatis, angulis anterioribus rotundatis, posterioribus acute emarginatis, bidenticulatis, disco leviter convexus, rugosopunctatus, tenuiter at profunde canaliculatus, lateribus explanatis rufis. Scutellum crebre punctatum, canaliculatum. Elytra subdepressa, sat forticer creberrime punctata, margine apicali rufo-piceo. Abdomen punctulatum, nigrum, apice rufo-ferrugineum. Pedes rufi.

Pedes maris intermedii femoribus incrassatis, tibiis leviter incurvis, postici femoribus incrassatis, trochanteribus fortiter dilatatis, tibiis ante apicem emarginatis, apice uncinatis.

* 4. M. hemipterus: Ferrugineus, opacus, capile nigro. - Long. 1 lin. Er. Col. March. 1. 645. 3.

Silpha hemiptera Illig. Schneid. Mag. V. 597. 5. - Panz. Faun. Germ. 25. 6. Silpha hemiptera var. $\beta$ Illig. Käf. Pr. 355. 1.

Omal. depressum var. c Gyll. Ins. Suec. Il. 69911.

Staph. melanocephalus Oliv. Ent. HII. 42. 38. 55. t. 4. f. 52.

Phloeobium nitiduloides Boisd. et Lacord. Faun. Ent. Paris. I. 493. 2.

Megarthrus rufescens Steph. Illustr. V. t. 127. fo. 5. (mas)

Habitat in Europa.

Praecedentibus paululum maior, ferrugineus, opacus, subtiliter griseo-pubescens. Antemue testaceae, apice fuscescentes. Caput parvum, ruguloso-punctatum, utrinque late impressum, margine anteriore acute elevato, nigrum, ore ferrugineo. Thorax basi coleopterorum latitudine, latitudine plus duplo brevior, antrorsum angustatus, basi subtrisinuatus, apice 
leviter emarginatus, lateribus subrotundatis, angulis anterioribus obtusis, subrotundatis, posterioribus leviter emarginatis, denticulo anteriore obtuso, posteriore minimo, acutiusculo, disco leviter convexus, subtilius punctatus, sat profunde canaliculatus, margine laterali, late explanato, medio late impresso. Scutellum crebre punctatum. Elytra thorace duplo fere longiora, sat fortiter dense rugoso-punctata, secundum marginem lateralem impressa. Abdomen punctulatum.

Pedes $m$ aris femoribus posterioribus leviter incrassatis, tibiis intermediis leviter incurvis, simplicibus, posticis interne sinuatis, medio dentatis.

\title{
Phloeobium Dej.
}

\author{
Megarthrus ${ }^{* *}$ Er. Col. March. I. p. 646.
}

\section{Antennae 11-arliculatae, articulo ultimo maiore.}

Frons ocello singulo.

Tarsi 5-articulati.

Corpus parvum, latiusculum, subdepressum, alatnm. Caput thorace parum angustius, margine laterali et antico dilatato, hoc truncato, oculis globosis, prominulis, ocello singulo in media fronte. Labrum deflexum. Mandibulae minutae, muticae. Maxillae mala interiore cornea, apice acuminata, exteriore coriacea, apice membranea barbataque, interiorem haud superante. Palpi maxillares articulo primo minimo, secundo sat magno, incrassato, tertio hoc paulo breviore et tenuiore, quarto iterum tenuiore, at secundo longitudine aequali, acuminato. Labium mento latitudine paulo breviore, antrorsum sensim angustato, apice subtruncato, ligula membranea, biloba, paraglossis latis, ligulam haud superantibus. Palpi labiales breviusculi, articulo primo brevi, secundo oblongo, cylindrico, tertio hoc paulo breviore, tenui, acuminato. Antennae sub frontis margine dilatato insertae, tenues, articulo primo clavato secundoque oblongo - obconico paulo crassioribus, penultimis tribus leviter incrassatis, ultimo oblongo-ovato, crassiusculo. Thorax transversus, coleopterorum latitudine, lateribus late marginatıs. Elytra abdominis nonnisi summam basin obtegentia, apice truncata, angulo exteriore subrotundato. Abdomen breviusculum, latiusculum, apice rotundato-attenuatum, late marginatum. Pedes breviusculi, coxis mtermediis approximatis, tibiis muticis, tarsis 5 -articulatis, articulis 4 primis brevibus, aequalibus, quinto his coniunctis longitudine subaequali.

O b s e r v a t i o e s.

1. Genus in hac familia ocello unico singulare, praecedenti generi propinquum, at corpore minus depresso capitis structura, thorace minus distincte canaliculato et angulis posterioribus minus evidenter excisis, antennis longioribus, ligula minus brevi distinctum. Nomen huic Dejeanianum servavi.

2. Sexus differentia ut in praecedente.

3. Victus sub arborum cortice.

* 1. Ph. clypeatum: Teslaceum, opacum, capitis margine anleriore dilatato, angulato, thorace basi utrinque denticulato. - Long. 1 lin.

Silpha clypeata Müll. Germ. Mag. IV. 204. 12. - Germ. Fuun. Ins. Europ. V. 5. Megarthrus clypeatus Er. Col. March. I. 646. 4.

Phloeobium corticale Boisd. et Lacord. Faun. Ent. Paris. 1. 494. 5. 
Habitat in Germania, Gallia.

Megarthro hemiptero paulo minor, praesertim angustior, totus testaceus, opacus, subtiliter pubescens. Antenmae nigrae. articulo ultimo testaceo. Caput sat magnum, profunde punctatum, fronte leviter convexa, antice leviter excavata, margine dilatato, antice truncato, lateribus bis inciso. Thorax coleopteris haud angustior, basi utrinque subsinuatus, medio magis prominente, ante angulum exteriorem denticulo minuto instructus, apice subsinuatus, lateribus parum rotundatis, angulis omnibus subrecris, parcius punctatus, miuus profunde canaliculatus, medio convexus, lateribus late explanatis, pone medium impressis, margine obsolete crenulato. Scutellum parce punctatum. Elytra thorace plus sesqui longiora, leviter convexa, sat profunde minus crebre punctata, secundum marginem lateralena subtilissime crenulatum medio impressa. Abdomen obsolete punctulatum.

Pedes $\mathrm{mar}$ is femoribus posterioribus vix incrassatis, tibiis intermediis incurvis.

\section{Glyptoma.}

Tharaxophorus Motschoulsky Bull. d. l. Soc. Imp. de Moscou. 1837. V. 98.

Antennae 11-articulalae, liberae.

Tarsi 3-arliculati.

Abdomen immarginatum.

Corpus minutum, oblongum, lineare, alatum. Caput porrectum, thoracis latitudine, suborbiculatum, basi modice constrictum, oculis parvis, subrotundatis, haud prominulis. Mandibulae haud prominentes. Palpi filiformes. Mentum trapezoideum, antrorsum angustatum. Antemae 11-articulatae, aut totae aut apice incrassatae. Thorax coleopterormm latitudine, marginatus, basi coarctatus. Scutellum triangulare. Elytra truncata. Abdomen immarginatum. Pedes breves, intermedii basi tenui spatio distantes, tibiis omnibus simplicibus, tarsis triarticulatis, articulis duobus primis brevissimis.

O b s e r v a $\mathrm{t}$ o $\mathrm{n}$ e $\mathrm{s}$.

1. Corpus opacum, plerumque glabrum. Thorax impressionibus et elevationinibus inaequalis: elevationes longitudinales costas saepe referunt. Elytra costis longitudinalibus sculpta. Abdomen depresso-cylindricum, aequale.

2. Tarsis triarticulatis et corporis sculptura Micropeplo affinis, a quo autem corpore lineari, elytris metathoracem vix excedentibus, abdomine immarginato, antennis distincte 11-articulatis, liberis, etc. satis discrepat. Ab Oxytelinis coxis anticis haud exsertis et a Piestinis, quibus in multis propinquum videtur, tarsis triarticulatis differt. Habitus Coly diorum genera quaedam in animum revocat, at aldominis structura prohibet, quo minus pro Colydio quodam, Bitomae affini, elytris abbreviatis, habeatur.

3. Nomen generis, a Dom. Motschoulsky propositum mutandum putavi, minus ob cacophoniam - Thoracophorus enim vocandum esset - quam quia Thorax terminus est partis, qua Insecta omnia instructa sunt. Cf. Linn. Phil. Bot. §. 250. Fabr. Phil. Ent. §. 33.

4. Sexus differentia latet.

5. Victus sub arborum cortice.

* 1. G. crassicorne: Caslaneum, rude punctatum, elytris unicostatis, antennis crassis, cylindricis, - Long. $1 \frac{1}{2}$ lin.

T. II. f. 9.

Habitat Novae Valenciae in Columbia, Dom. Moritz. 
Corpus elongatum, castaneum, opacum, tenuiter pubescens. Antennae capitis thoracisque longitudine, crassae, articulis $2-10$ aequalibus, ultimo apice obtuse acuminato, praecedentibus haud crassiore. Caput thoracis-latitudine, suborbiculatum, fronte convexa, immarginata, crebre sat fortiter punctata. Thorax subcordatus, lateribus anterius rotundatis, postice coarctatus, leviter convexus, punctis creberrimis grossiusculis cicatricosus, postice utrinque foveolatus. Scutellum minutum, triangulare. Elytra thorace sesqui longiora, confertim punctata, punctis grossis exterius profundis, interius obsoletioribus, costa singula longitudinali media elevata integra, Abdomen dense, grosse, minus profunde punctatum. Pedes rufi.

Obs. Antennarum structura a reliquis speciebus satis differt, at reliquae notae omnino conveniunt, quare rite sub eodem genere militare videtur.

\section{G. corticinum: Castaneum, thorace lateribus crenulalo elytrisque costatis, antennis articulis ultimis 5 crassioribus. - Long. parum ultra 1 lin.}

Thorax ophorus corticinus Motschoulsky Bull. d. l. Soc. Imp. des Nat. de Moskou. 1837. V. p. 98. $t .7 . f . A$.

Habitat in Italia, Dom. Schiippel, Lotetiae collect. Dom. Aubé, qui specimen unicum in trunco fagi inter pusillas Formicas legit. Varsoviae etian ad radices arborum sub cortice a D. D. Waga et Motschoulsky lectum.

Saturate rufo-ferruginenm. Antennae capite thoraceque paululum bre. viores, crassiusculae, articulis ultumis 5 crassioribus, $7-10$ transversis, apicali apice obtuse acuminato. Caput thorace paulo angustius, fronte lateribus acute marginata, inter oculos longitudinaliter $\mathbf{f}$-carinata, carinnlis interioribus postice duplicatis. Thorax coleopteris paulo angustior, latitudine paulo brevior, marginatus, postice subito angustatus, angulis anterioribus dentiformibus, prominulis, subdepressus, supra sexcostatus, costis externis submarginalibus, interstitiis vage rugulosis, margine laterali subtiliter crenulato. Scutellum maiusculum, medio impressum. Elytra thorace paulo longiora, 5-costata, costis alternis elevatioribus, extima marginali, interstitiis vage elevato-rugulosis. Abdomen subtiliter rugulosum, segmento sexto laevi, testaceo. Pedes rufi

3. G. costale: Castaneum, thorace lateribus integro elytrisque coslatis, antennis brevibus, apice subclavalis. - Long. vix ultra I lin.

Habitat in America septentrionali.

Statura praecedentis, at paulo minus. Castaneum, opacum. Antennae capite paulo longiores, articulis tribus ultimis modice incrassatis, clavam oblongam minus distinctam formantibus. Caput thoracis prope latitudine, marginatum, lineis pluribus elevatis longitudinalibus sculptum, clypei spatio laevi. Thorax coleopterorum fere latitudine, subquadratum, angulis anterioribus acutiusculis, prominulis, posterioribus oblique truncatis vel subemarginatis, truncaturae angulo posteriore denticuli instar prominulo, subdepressus, costis longitudinalibus 6 sat elevatis sculptus, costis externis submarginalibus, reliquis 4 discoidalibus, interstitiis singulis linea singula longitudinali elevata subtili notatis. Elytra costata, costis alternis obsoletio- 
ribus, alternis (3 dorsalibus 1-que laterali) elevatioribus, interstitiis punctulatis. Abdomen segmentis 5 prioribus apice granulosis, sexto laevi.

4. G. denticolle: Castaneum, thorace inaequali, lateribus quadridentato, elytris costatis, antennis minutis, clavatis. - Long. parum ultra 1 iin.

Habitat in ins. Puerto - Rico, Dom. Moritz.

Corpus testaceo-ferrugineum, capite, thorace abdomineque supra nigricantibus. Antennae capite perparum longiores, articulo primo longiore cylindrico secundoque crassioribus, $3-8$ tenuibus, arcte contiguis, inter se subaequalibus, ultimis tribus incrassatis, clavam oblongam formantibus. Caput thoracis longitudine, fronte lateribus et antice marginata, medio bituberculata, clypei spatio linea arcuata impressa terminato. Thorax coleopteris paululum angustior, latitudine brevior, subdepressus, costis, tuberculis foveolisque inaequalis, margine laterali dilatato, 4-dentato, postice subito angustato. Elytra regulariter costata, costis tribus dorsalibus, quarta infra marginem lateralem, interstitiis subtiliter punctulatis. Abdomen subtilissime punctato-rugulosum.

\section{G. exile: Rufo-ferrugineum, thorace inaeguali, lateribus inlegro, elytris tricostalis, antennis brevibus, clavatis. - Long. $\frac{3}{4}$ lin.}

Habitat in Americae merid. ins. St. Thomae, Dom. Moritz.

Praecedentibus plus duplo minus, testaceo-ferrugineum, opacum. Antennae capite sesqui longiores, articulis ultimis tribus distincte maioribus, clavam oblongam formantibus. Caput thoracis fere latitudine, lateribus acute marginatum, fronte plagis duabus longitudinalibus elevatis. Thorax coleopterorum prope latitudine, angulis anterioribus rectis, haud prominulis, lateribus anterius rectis, dein pone medium subito sinuato-angustatis, subdepressus, modice inaequalis, lineis 5 sat subtilibus elevatis longitudinalibus sculptus, externis submarginalibus. Elytra thorace sesqui longiora, costata, costis tribus dorsalibus, quarta laterali, interstitiis laevibus. Abdomen laeve.

6. G. sculptile: Fuscum, capite nigro, thorace rufo, quadrisulcalo, laleribus integro, elytris multicostatis, anlennis subclavalis. - Long. $\frac{3}{4}$ lin.

Habitat in valle Araguensi Columbiae, Dom. Moritz.

Minutum, praecedenti aequale, at paulo gracilius. Antennae capite sesqui longiores, tenuiusculae, articulis ultimis tribus distincte maioribus, testaceae. Caput thoracis latitudine, subtiliter marginatum, fronte subdepressa, lineis duabus elevatis obsoletioribus longitudinalibus notata, nigrum, opacum. Thorax antice coleopteris parum angustior, angulis anterioribus rectis, hand prominulis, lateribus anterius leviter rotundatis, pone medium constrictis, depressus, sulcis quatuor longitudinalibus sat latis, interioribus rectis, antice abbreviatis, exterioribus profundioribus, integris, repandis inaequalis, fuscorufus, opacus. Elytra thorace sesqui longiora, striata, interstitiis elevatis, alteruis elevatioribus, fusca, opaca. Abdomen laeviusculum, fuscum, opacum, segmentis singulis margine apicali testaceo. Pedes rufo-testacei. 
Latr. Gen. Crust. et Ins, IV. p. 377.

Anlennae receptae, 9-arliculatae, capilulatae.

Tarsi 3-articulali.

Corpus minutum, subovatum, crassiusculum, alatum. Caput a thorace receptum eodemque minus et angustius, subtriangulare, oculis mediocribus, semiglobosis, morlice prominulis. Labrum transversum, integrum, corneum. Mandibulae parvae, muticae, haud prominentes. Maxillae (t. V. f. 35. h.) mala interiore angusta, cornea, exteriore trapezoidea, apice dilatata, rotundata, barbata. Palpi maxillares articulo primo tenui, minuto, secundo sat magno, fortiter incrassato, tertio brevi transverso, quario conico. Labium (t. V. f. 35. a.) mento sat magno, ante apicem constricto, ligula brevi, angustiore, rotundata, membrålea, palpis brevissimis, articulis decrescentibus, ultimo fere obsoleto. Antennae 9 articulatae, articulis duobus primis crassiusculis, primo maiusculo, ovato, secundo hoc minore, apice attenuato, sequentibus tribus tenuibus, elongatis, penultimis tribus haud crassioribus at brevibus, ultimo maximo, globoso, capitulum antennae globosum formante. Thorax transversus, basi coleopterorum latitudine, iisque arcte applicatus, antrorsum angustatus, lateribus late explanato-marginatis, subtus excipiendis antennis secundum marginem lateralem profunde scrobiculatis. Scutellum sat magnum, triangulare. Elytra ampla, at nonnisi abdominis summam basin obtegentia. Abdomen acuminatum. Pedes breves, tenues, simplices, intermedii basi distantes, tarsis brevibus, triarticulatis.

O b s e r va t i o n e s.

1. Corporis habitus singular is sculptura singulari, praeterea antennis capitulatis, receptis et pedibus intermediis late distantibus insigne hoc genus, a multis auctoribus perperam $\mathrm{N}$ itidulis adscriptum.

2. Antennarum capitulum non solidissimum sed articulis tribus connatum videtur, unde forte antennae revera 11-articulati haberi possint.

3. Tarsi a Dom. Curtis loco apud M. tesserulam citato 4-articulati descripti, mhi autem non ultra tres articuli observati sunt.

4. Mas abdominis segmento inferiore sexto apice emarginato distinctus.

5. Victus in quisquiliis.

* 1. M. porcatus: Viger, antennarum basi pedibusque rufis, elytris basi leviter convexis, 4-costatis, interstitiis crebre punclatis. - Long. 1 lin.

Charp. Hor. Ent. p. 202. t. 8. f. 9. - Er. Col. Murch. I. 646. 1.

Stuph. porcatus lint. Syst. I. II. 530. 56. Syst. El. II. 602. 68. - Payk. Mon. Staph. 71. 50. Faun. Suec. III. 413. 59. - Oliv. Ent. III. 42. 35. 50. t. 4. f. 33. - Punz. Ent. Germ. 368. 45.

Nitidula porcat a Marsh. Ent. Britt. 137. 26.

Omalium porcat um Gyll Ins. Suec. II. 211.12.

Nitidula sulcata Herbst Col. V. 247. 22. t. 54. f. 6. - Panz. Ent. Germ. I. 129. 31. - Schönh. Syn. II. 148. 64.

Habitat in Europa.

Niger, opacus. Antennae rufae, capitulo piceo. Caput confertim subtiliter rugulosum, fronte depressa, antice posticeque linea transversa, medio linea longitudinali impressa, margine tenuiter elevato,-prope oculos angulato. Thorax basi coleopterorum fere latitudine, longitudine duplo fere latior, an- 
trorsum valde angustatus, lateribus medio obtuse angulafis, angulis posteribus acntiusculis, disco modice convexo, lineis elevatis impresso-areolato, areolis subtilissime confertissimeque rugulosis, lateribus late explanatis, medio puncto diapliano piceo, margine elevato. Scutellum laeve. Elytra thorace sesqui longiora, leviter convexa, apice depressa, sutura costisque quatuor elevatis, costis exterioribus duabus apice paulum abbreviatis, interstitiis lateribusque crebre profunde punctatis, his costis duabus elevatis, inferiore marginali, arcuata. Abdomen supra segmentis $2-54$-foveatis, foveis magnis, profundis, carinis valde elevatis angustis divisis, sexto confertim subtiliter punctulato. Pedes rufi.

* 2. M. caelalus: Niger, antennarum basi pedibusque rufis, elytris basi convexis, 4-costatis, interstitiis crebre punclatis, - Long. $\frac{4}{5}$ lin.

Er. Col. March I. 617, 2.

Habitat in Germania.

M. porcato minor, praecipue brevior, niger, opacus. Antennae rufae, capitulo piceo. Caput omnium confertissime subtiliter punctato-rugulosum, fronte haud depressa, linea longitudinali levi tenuique transversa antica impressum. Thorax basi coleopterorum latitudine, longitudine plus duplo latior, antrorsum valde angustatus, lateribus medio subangulatis, disco convexo, confertissime subtiliter punctato-rugoso, rugis elevatis parum distinctis areolato, lateribus late explanatis, margine elevato. Scutellum laeve. Elytra thorace sesqui latiora, elevato-convexa, apice depressa, dorso costis $\mathbf{4}$, lateribus 2, suturaque elevatis, interstitiis crebre fortiterque punctatis, ut in M. porcato. Abdomen segmentis 2-4 4-foveatis, foveis magnis, profundis, carinis angustis divisis, quinto sextoque confertissime rugoso-punctatis, illo basi 4-foveolato. Pedes rufi.

O bs. M. porcato valde affinis, differt autem statura breviore, elytris magis elevatis, abdominis segmento quinto basi tantum foveolato, thorace obsolete call. cellato etc.

\section{M. fulvus: Testaceus, elytris subelevalis, tricostalis, interstitiis puncta-} tis. - Long. 1 lin.

Habitat Lutetiae, Mus. Dom. Chevrolat.

Testaceus, immaculatus. Caput inter antennarum basin transversim impressum, fronte posterius lineis nonnullis elevatis subtilibus longitudinalibus sculpta, apice in altero sexu acuminata, in altero obtusa. Thorax latitudine coleoptera parum excedens, latitudine summa duplo fere brevior, antrorsum angustatus, angulis posterioribus rectis, disco leviter convexo, lineis elevatis cancellato-areolato, lateribus late explanatis, mar-gine elevato. Elytra subelevata, apice depressa, sutura costisque tribus dorsalibus, extima marginali, elevatis, interstitiis crebre sat profunde punctatis, lateribus sat crebre profundeque punctatis, costis duabus elevatis, superiore recta, costae marginali aequali, inferiore arcuata, marginali, itidem sat fortiter elevata. Abdomen segmentis $2-4$ basi 4 -foveolatis, foveolis transversis, sat profundis, interstitiis angustissimis discretis, quinto basi 4-foveolato, interstitio medio elevato, tuberculiformi.

Obs. M. Staphilinoidi perquam affinis, at differt thorace minus dilatato, abdominis segmenti quinti tuberculo longe minus prominulo, elytris minus depressis, margine laterali bicarinato, carina laterali superiore haud, ut in illo, obsoleta. 
* 4. M. Staphylinoides: Piceus, thoracis lateribus, anlennis pedibusque rufis, elytris 3-costalis, interstitiis punctatis. - Long. 1 lin.

Nitidula Staphylinoides Marsh. Ent. Britt. 137. 25.

Micropepl. Maillei Guér. Iconogr. Ins. t. 10. f. 4. Schïppel.

Habitat in Anglia, Dom. Spence, in Gallia Dom. Auhé, in Italia, Dom.

M. porcato panlo minor et angustior, piceus, nitidus. Antennae rufae. Caput posterius subtiliter rugulosum, antice laeve, fronte depressa, linea longitudinali anticaque transversali impressa, margine elevato, apice in aliis individuis acuminato, in aliis obtuso. Thorax coleopteris fere latior, latitudine plus duplo la:vior, antrorsum valde angustatus, lateribus medio subangulatis, angulis posterioribus acutis, disco leviter convexo, lineis elevatis cancellato-areolato, piceo, lateribus late explanatis, rufis, margine leviter elevato. Scutellum obsolete impressum. Elytra thorace paulo longiora, subdepressa, costis tribus dorsalibus suturaque elevatis, interstitiis crebre sat profunde punctatis, lateribus sat crebre profunde punctatis, costis duabus elevatis, superiore recta, subtili, obsoleta, inferiore arcuata, marginali, sat fortiter elevata. Abdomen segmentis 2-4 4 -foveatis, foveis magnis, profundis, carinis tribus divisis, carina intermedia magis elevata, quinto sextoque laevibus, illo basi 4 -foveolato, carina valde elongata a basi ad medium percurrente, apice acuminata cristato. Pedes rufi.

* 5. M. tesserula: Viger, antennarum basi pedibusque rufis, elytris 3-costatis, interstiliis laevibus. - Long. $\frac{2}{3}$ lin.

Curtis Ent. Britt. $\boldsymbol{V}, \boldsymbol{t}, 204$.

Omal. Staphylinoides Gyll. Ins. Suec. II. 213. 13. - Sahlb. Ins. Fenn. I. 280. 10.

Habitat in Suecia; in Carinthia, Dom. Schmidt.

M. porcato duplo minor, niger, nitidulus. Antennae nigrae, basi rufae. Caput fronte depressa, longitudinaliter trisulcata, sulco intermedio profundiore, antice linea transversali impressa, margine laterali tenniter elevato. Thorax coleopterorum latitudine, latitudine duplo brevior, antrorsum valde angustatus, angulis posterioribus subrectis, disco parum convexo, lineis elevatis cancellato-areolato, lateribus late explanatis, piceis, puncto medio pellucido, margine subelevato. Scutellum laeve. Elytra thorace paulo longiora, leviter convexa, apice depressa, costis tribus dorsalibus suturaque elevatis, interstitiis lateribusque laevibus, his unicostatis, costa arcuata, marginali, sat elevata. Abdomen segmentis 2-4 minus fortiter 4-foveatis, ultimis duobus laevibus. Pedes rufi.

S $p$ ecies $m$ ihi invis a.

6. M. obtusus: Testaceus, capile antice rolundato.

Newman Ent. Magaz. II. 201.

Habitat prope Halifax.

Totus pallide brunneus. M. Staphylinoide minus elongatus, at paulo latior, elytrorum costis magis elevatis et capite antice non acuminato sed rotundato distinctus.

Obs. M. fulvo affinis, at distinctus videtur. 
O b s e r v a t i o.

Huic forte tribui inseratur genus, ab auctore hoc modo descriptum:

\section{Pseudopsis Newman.}

\section{Newman Ent. Mag. II. p. 313.}

Caput elongatum, angustum, antice rotundatum, epicranio valde depresso, partibus lateralibus supra oculos iterumque parte media longitudinali elevatis, clypeo prono, rotundato; antennae filiformes, 11-articulatae, extus incrassatae, articulo apicali conico; palpi maxillares articulo apicali elongato, acuto, tenuissimo, proximo quadruplo maiore; alia instrumenta cibaria haud examinata. Prothorax depressus, fere circularis, sed antice et postice paulo truncatus, lateribus lineisque $\mathbf{4}$ disci longitudinalibus perspicue olevatis. Elytra valde depressa, marginibus, sutura lineisque 2 singuli disci longitudinalibus perspicue elevatis. Abdominis segmenta 7 nuda, haud elytris tecta, media depressa, lateribus elevata, apicem versus magnitudine pedetentim decrescentia, apice elongato, angusto.

\section{Ps. sulcatus: Niger, ore, antennis pedibusque fuscis.}

Caput nigrum, ore fusco, fronte depressa, linea utrinque laterali supra oculos tertiaque inter oculos longitudinalibus elevatis, hac obsoletiore et minus regulari. Antennae fuscae, moniliformes, 11-articulatae, articulo apicali subconico, penultimis transversis, basin versus sensim minoribus. Palpi maxillares articulo apicali longo, tenui, acuminato, praecedente incrassato, apicali quadruplo longiore. Thorax capite latior, depressus, margine laterali lineisque quatuor longitudinalibus omnino rectis disci evidenter elevatis, interie ctis sulcis 5. Coleoptera thorace latiora, depressa, margine, sutura lineis-: que duabus evidenter elevatis, lineis non omnino rectis, sed apicem versus sensim suturae magis approximatis. Abdomen segmentis septem omnino liberis, medio depressis, lateribus elevatis, sensim decrescentibus, ultimo elongato, angusto. Thorax, elytra et abdomen obscure nigra. Pedes fusci. - Long. 1 $\frac{x}{2}$ lin. - Captus in insula Vectis a Dom. Walker. 


\section{ADDENDA ET EMENDANA.}

\section{Myrmedonia.}

\section{p. 41.}

\section{M. obscura:}

Secundum specimen a Dom. Westermann amice communicatum accuratius describenda:

Rufo-testacea. crebrius punclata, capite abdomineque nigris, hoc seg. meuto superiore primo apice trispinoso. - Long. 3 lin.

Antennae capite vix duplo longiores, crassae, articulo secundo tertio duplo breviore, 4 - 11) transversis, ultimo conico, ferrugineae, articulis 3 primis rufo-testaceis. Caput thoracis latitudine, fronte planiuscula, alutacea, obsoletius punctata, nigrum, minus nitidum, ore testaceo. Thorax coleopteris paulo angustior, latitudine vix brevior, basin versus subangustatus, lateribus leviter rotundatus, subdepressus, sat crebre fortius punctatus, subtiliter fulvo-pubescens, rufo-testaceus, nitidus. Elytra thoracis longitudine, crebre fortius punctata, subtiliter fulvo-pubescentia, rufo-testacea, nitida. Abdomen supra parce, infra crebre punctatum, supra segmento primo apice producto, spinis tribus sat elongatis, acutis, lateralibus paulo longioribus, terminato, quinto medio obsolete tuberculato, sexto apice obsolete tridentato, nigrum, nitidum, segmentis singulis inferioribus piceo-marginatis, ano rufo-piceo. Pectus rufo-testaceum. Pedes testacei.

Obs. Proxima certe M. spinigerae, sed distincta pnnctura fortiore, thorace longiore et abdominis structura, neque sexu solo differens. Femina utriusqus speciei latet.

\section{Falagria.}

p. 52.

10. F. thoracica: adde

Aleoch, ruficollis Waltl 1sis. 1838. IV. 268. 4. 


\section{Tachyusa.}

p. 73 adde

* 7-8. T. uvida: Nigra, subnitida, antennis pedibusque teslaceis, ely/ris fuscis, abdomine lineari, thorace subquadrato fronleque lale canaliculatis. - long. $1 \frac{1}{2}$ lin.

Habitat in insula Vectis frequens ad littora maris sub fucis putrescentibus, Dom. Rudd.

Statura omnino et summa affinitate Tachyusae laesae, nigra, subnitida, densius subtiliusque griseo-pubescens. Antennae capite thoraceque longiores, apicem versus perparum incrassatae, totae testaceae. Caput thoracis latitudine, suborbiculatum, dense evidenter licet subtiliter punctatum, deyressiusculım, fronte late, feminae leviter, maris profunde canaliculata. Thorax coleopteris dimidio angustior, latitudine haud brevior, basin versus leviter angustatus, lateribus rectis, basi leviter rotundatus, apice utrinque oblique truncatus, angulis anterioribus fortiter rotundatis, subdepressus, dense subtiliter punctatus, secundum totam longitudinem in mare late profundeque in femina levius canaliculatus. Elytra thoracis longitudme, subdepressa, confertissime subtilius punctata. Abdomen lineare, nitidum, minus subtiliter punctatum, parcius pubescens, apice summo fulvo-tomentoso, segmentis aequalibus. Pedes testacei.

Obs. Distincta a T. laesa punctura et pube minus subtilibus, fronte in utroque sexu canaliculata, thorace magis canaliculato quam excavato, antennis totis testaceis etc.

p. 74 adde

* 9-10. T. chalybea: Nigro-cyanea, nitidula, subtilissime griseo-pubescens, thorace subquadralo, leviter canaliculato, tarsis tesíaceis. Long. $1 \frac{3}{4}$ lin.

Habitat in ins. Vectis. Nomine Ischnopodae chalybeae a Dom. Rudd communicata.

Habitu fere T. umbraticae, at paulo maior, corpore cyanescenti-nigro, capite, thorace elytrisque cyaneis, nitidula, omnium subtilissime punctulata, pube subtilissima fusco-sericea obducta. Antennae capite thoraceque paulo longiores, tenues, apicem versus leviter incrassatae, articulo tertio secundo paulo longiore, nigrae. Caput thoracis prope latitudine, suborbiculatum, basi fortiter constrictum, fronte media leviter impressa, ore nigro. Thorax coleopteris dimidio angustior, latitudine hand brevior, neque basin neque apicem versus angustatus, lateribus anterius leviter, angulis anterioribus fortiter rotundatis, apice truncatus, basi leviter rotundatus, subdepressus, canalicula parum profunda, anterius obsolescente impressus. Coleoptera thorace paulo longiora. Abdomen coleopteris paulo angustius, parallelum, segmentis subaequalibus, anterioribus basi profundius transversim impressis. Pedes nigri, tarsis testaceis.

Obs. Forte a T. coerulea (p. 76. n. 14.) haud distincta, at huic frons impressa, et thorax canaliculatus.

* 10 - 11. T. immunita: Nigra, subtilissime griseo-pubescens, elytris fuscis, pedibus lestuceis, thorace subquadrato, maris late leviter impresso, feminue basi obsolete foveolato, abdomine parallelo. - Long. $1 \frac{1}{2} \mathrm{lin}$.

Habitat in Anglia, Dom. Rudd. 
Statura et summa sinilitudine Homalotae elongałae, subdepressa, minus gracilis, nigra, minus nitiduda, dense subtilissime griseo-pubescens. Antennae capıtis thoracisque longitudine, minus tenues, apicem versus sensim subincrassatae, articulo secundo tertioque subaequalibus, fuscae, artirulis basalibus nigricantibus. Palpi fusci. Caput thoracis latitudine, orbicnlatum, fronte leviter convexa, omnium subtilissime punctulatum. Thorax coleopteris paulo angiustior, latitudine haud brevior, neque basin neque apicem versus angustatus, lateribus angulos anteriores versus parum rotundatis, subdepressus, subtilissime dense punctatus, iam dorso late leviter, iam basi obsolete impressus. Elytra thorace paulo longiora, dense subtilissime punctata. Abdomen parallelum segmentis subaequalibus, superioribus 4 anterioribus subtilissime punctulatis, 2 posterioribus sublaevibus. Pedes testacei.

$\mathrm{Obs}$. Anceps in hoc genere, Homalotam elongatulam statura, colore et punctura simulat, at tarsorum posticorum articulo primo satis elongato instructa. Thorace vel late impresso vel subaequali forte sexu variat.

\section{IIomalota.}

p. 93.

23. H. plana: Eandem ex America septentrionali misit Dom. Zimmermann.

p. 130. adde

* 108 - 109. H. paedida: Nigra, opaca, dense subtiliter punclala, fuscopubescens, antennis longis, crassis, nigris, pedibus elytrisque luteis, his circa scutellum et laleribus infuscat is. - Long. $1 \frac{1}{4}$ lin.

Habitat in Madagascsar, Dom. Goudot.

Statura et summa affinitate H. lividipennis, at plus duplo minor et magis depressa, nigra, dense subtiliter punctata, pube subtili depressa fusca obducta. Antennae capite thoraceque paulo longiores, validae, articulo secundo tertioque subaequalibus, obconicis, $\mathbf{4}-\mathbf{1 0}$ cylindricis, crassitie haud brevioribus, ultimo praecedentibus ambobus aequali, subacuminato, nigrae. Caput thorace angustius, fronte leviter convexa. Thorax basi coleopterorum latitudine, antrorsum leviter angustatus, latitudine dimidio brevior, lateribus modice rotundatus, apice leviter emarginatus, angulis posterioribus obtusis, anterioribus rotundatis, deflexis, subdepressus, aequalis. Coleoptera thorace pauluim longiora, depressa, sordide lutea, circa scutellum et lateribus fuliginosa. Abdomen apicem versus angustatum, apice pilosellum, infra segmentis singulis apice late testaceo-marginatis. Pedes flavi.

\section{Oxyporla.}

p. 151. adde

* 21 - 22. O. contractula: Brevis, nigra, subnitida, subtiliter pubescens, dense punctata, antennis pedibusque ferrugineis, thorace transverso, basi bisinuato, apice rotundato. - Long. 1 lin.

Habitat in Madagascar, Dom. Goudot.

O. curtulae affinis et eadem hạud longior, at duplo prope latior, Aleochara morione latior et convexior, habitu fere Tachypori, nigra, nitidula, densius pube subtili fusca sericante vestita, dense minus subtiliter punctata. 
Antennae capite thoraceque paulo longiores, articulo secundo tertio maiore, praecipue crassiore, apicem versus vix incrassatae, articulo ultimo maiusculo, ovato, rufo-ferrugmeae, articulo ultimo piceo. Caput inflexum, ore leviter producto, testaceo. Thorax coleopteris latitudine aequalis, latitudine baseos plus dimidio brevior, basi profundius bisinuatus, angulis posterioribus acutis, lateribus et apice eodem arcu rotundatus, convexus, obsolete piceo-marginatus. Coleoptera thorace vix longiora, apice late emarginata, dorso depressiuscula, minus subtiliter punctata. Abdomen breviusculum, apicem versus fortius angustatum, acuminatum, segmentis piceo-marginatis, lateribus nigro-setulosum. Pedes rufo-ferruginei.

$\mathrm{Obs}$. Ore producto in hor genere aliena, et Gymnusae vel Myllaenae propior videtur, at palpi labiales distincte articulatae. Habitum etiam potius Aleocharae quam Oxypodae prae se fert, at palpis labialibus triarticulatis, articulo tertio penultimo duplo longiore ab illo genere distat. Thorace basi sinuato, punctura et imprimis antennarum structura $\mathrm{O}$. curtula e proxima.

\section{Meochara.}

p. 160. adde

* 3-4. A. loricata: Rufa, nilida, abdomine nigro, ano pedibusque teslaceis, capile, thorace elyirisque parce profundeque, abdomine crebrius punctatis. - Long. 2 lin.

Habitat in Guinea; specimen singulum in Formicae cuiusdam nido repertum amicissime dedit Dom. Westermann.

Antennae breves, capite sesqui longiores, articulo tertio secundo sesqui prope longiore, apicem versus leniter incrassatae, subcompressae, articulis 6- 10 transversis, ultimo breviter ovato, apice acuminato, totae testaceae. Caput thorace plus duplo angustius, fronte punctis paucis maioribus setuliferis notata, ceterum laevissimum, rufo-piceum, ore testaceo. Thorax amplus, coleopteris paulo latior, latitudine duplo prope brevior, antrorsum leviter angustatus, laterihus et angulis omnibus rotundatis, apice emarginatus, basi subbisinuatus, fortius transversim convexus, punctis maiusculis setuliferis sparsis, latera versus crebrioribus, interstitiis laevissimis, rufus, nitidus. Sculllum piceum. Coleoptera thoracis longitudine, apice late emarginata, angulo apicali exteriore rotundato, punctis raris grossiusculis setuliferis sparsis notata, interstitiis laevissimis, rufo-testacea, limbo laterali et apicali picescente. Abdomen crassiusculum, apicem versus subangustatum, segmentis quatuor anterioribus crebrius punctatis, setulis depressis nigris vestitis, nigris, nitidis, ultimıs duobus laevibus, testaceis. Pectus rufum. Pedes testacei.

\section{Placusa.}

p. 196.

4. P. infima: Forte huc referatur:

Aleoch. tachyporoides Walt Isis 1838. IV. 268. 5.

\section{Dinarda.}

p. 201.

1. D. dentata: Sperimina maiora minoraque commixta in Formicae $r$ ufae nidis lecta $\mathrm{D}$ om.

Märkel benevole communicavil. 
p. 210.

\section{Myllaena.}

2. M. int ermedia: adde

Centroglossa att enuata Matthews Ent. Mag. V. 196. 2.

\section{p. 211.}

3. M. minuta: adde

Centroglossa minut a Matth. Ent. Mag. V. 196. 3.

Obs. Species reliquae tres a Dom. Matthews huic generi adscriptae thorace coleopteris latitudine aequali a praecedentibus distinctae, mihi haud extricatae, forte Oxypodae adscribendae.

\section{Gymnusa.}

p. 212.

* 2. G. laticollis: adde

Deinopsis fuscatus Matthews Ent. Mag. V. p. 193.

Dom. Matthews labium palpis et ligulae laciniis perditis mutilatum delineavit et palpos maxillares tarsosque perperam 3-articulatos 1. c. exhibuit. Genus Deinopsis igitur delendum, nomen autem specificum in G. fuscatam mutandum.

\section{Iypocyptus.}

\section{p. 216.}

2. H. discoideus: adde

Cypha biguttata Malthews Ent. Mag. V. p. 198. (forte)

\section{Conurus.}

p. 222.

5. C. crassus: adde

Tachyp. moestus Say Transact. Am. Philoph. Soc. Philad. Nov. Ser, IV. 466. 2.

p. 226.

11. C. cinctulus: adde

Tachypor. opicus Say Transact. Am. Philosoph. Soc. Philad. Nov. Ser. IV. 467. 5. Nomen in C. opicum mutandum.

\section{Tachyporus.}

p.' 233.

3. T. rufus: adde

Tachyp. formosus Matthews Ent. Mag. V.p. 197.

Nomen in T. formosum mutandum.

p. 237.

11. T. arduus: adde

Tachyp. iocosus Say Transuct. Am. Philosoph. Soc. Philad. Nov. Ser. IV. 466. 3,

Nomen in T. i ocosum mutandum. 
p. 211.

18. T. brunneus: adde

Tachyp. faber Suy Transact. Amer. Philosoph. Soc. Philad. Nov. Ser. IV. 468. 7.

p. 242. adde

22. T. acaudus: Abbreviatus, testaceus, thorace lalevibus pallidiore. Long. infra 1 lin.

Suy Transact. Amer, Philosoph. Soc. Philadelph. Nov. Ser. IV. 467. 6.

Habitat in Indiana Americae septentrionalis.

Testaceus, politus. Caput nigro-piceum. Antennae fuscae, articulis 4 primis obscure flavescentibus. Palpi flavescentes, articulo ultimo aciculari. Thorax testaceus, disco et basi fuscescentibus, lateribus pallidioribus et fere pellucentihus. Elytra rufo-testacea, leviter pubescentia, regione scutellari fuscescente, angulo apicali suturali rotundato, unde coniuncta acute emarginata apparent. Abdomen elytris duplo brevius, nigro-aenenm, pubescens. Pedes pallide flavi. Tibiae spinulosae. - Similis T. iocoso, at latior, licet abdomine fortiter contracto. (Say.)

23. T. acuductus: Nigro-piceus, thoracis angulis posterioribus, antennis pedibusque testaceis, elytris minutissime acuductis. - Long. 1 lin.

Kirby Faun. Boreali-Amer. 90. 1.

Habitat in America boreali, prope Aedes Cumberlandianas, sub lat. 54.

Obscure piceus, glaber, laevis, nitidus. Antennae et os testacea. Thorax laevissimus, coleopteris latior, angulis posterioribus testaceis. Elytra capite thoraceque coniunctis longiora, picea, angulo apicali exteriore testaceo, oculo probe armato inspecta subtilissime aciculata, praecipue prope suturam, immixtis punctis minutissimis. Abdomen perbreve, conicum, vix marginatum, piceum, segmentis apice dılutioribus. (Kirby.)

24. T. affinis: Nigro-piceus, nitidus, anlennis pedibusque testaceis, elytris caslaneis, punctulalissimis. - Long. 1 lin.

Kirby Faun. Boreali-Amer. 91. 2.

Habitat in America boreali. Lectus cum praecedente.

T. acuducto simillimus: thoracis angulis posterioribus haud testaceis, elytris pallide castaneis, dense subtiliter punctatis, nullo modo aciculatis distinctus. (Kirby.)

p. 252.

17. T. gibbulus: Nomen in T. ventriculum mutandum et addendum:

Tachyp. ventriculus Say Transact. Amer. Philosoph. Soc. Philadelph. Nov. Ser. IV. 466.3.

p. 256. adde

*20-21. T. Iuridus: Nigro-piceus, nitidus, thoracis limbo laterali et abdominis segmentorum marginibus rufo-testaceis, elylris luteo-testaceis. Long. $2 \frac{1}{2}$ lin.

Habitat in Americae septentrionalis montibus Catskill, Dom. Zimmermann. 
Statura T. flavipedis, nigro-piceus, nitidus. Antennae capitis thoracisque longitudine, articulo tertio secundo paulo longiore, 5-10 crassioribus, aequalibus, subobconicis, ultimo ovato, nigrae, articulis 4 primis piceis. Palpi picei. Caput subtilissime punctulatum. Thorax coleopterorum latitudine, latitudine baseos dimidio brevior, antrorsum leviter angustatus, apice levissime emarginatus, angulis anterioribus perparum prominentibus posterioribusque obtusis, subrotundatis, leviter convexus, dense subtilissime alutaceostrigosus, parce subtilissime interpunctatus, margine apicali basalique tenui et laterali latiore rufescenti-testaceo. Elytra thorace sesqui longiora, parcius subtiliter punctata, luteo-testacea, nitida, postice leviter infuscata. Abdomen distinctius punctatum, pube brevi adspersum, segmentis 5 anterioribus margine apicali, sexto toto rufescenti-testaceis. Pedes piceo-testacei.

Mas latet.

Femin a abdominis segmento superiore sexto trifido, laciniis lateralibus convergentibus, intermedia longiore, acuminata; inferiore integro, apice triangulariter producto.

p. 258. adde

23-24. T. fulvipes: Niger, nilidulus, antennarum basi apiceque pedibusque testaceis, elytris thorace paulo longioribus, hoc angulis posterioribus acuminatis. - Long. $2 \frac{2}{3}$ lin.

Habitat in Java, Mus. Dom. Westermann.

T. rufipede paulo brevior et latior, depressiusculus, niger, nitidulus, capite, thorace elytrisque omnium subtilissime punctulatis. Antennae capite thoraceque breviores, articulo tertio secundo paulo breviore, articulis 5-10 crassioribus, sensim paulo brevioribus, piceis, ultimo ovato, luteo, 4 primis rufo-testaceis. Caput fronte leviter convexa, ore concolore, palpis testaceis. Thorax basi coleopterorum latitudine, latitudine baseos duplo prope brevior, angustatus, lateribus rotundatus, basi late emarginatus, angulis posterioribus retrorsum spectantibus, acutis. Elytra thorace paulo longiora, obscure brunnea, basi et sutura late nigricantibus, limbo laterali nigerrimo. Abdomen crebre minus subtiliter punctatum. Pedes rufo-testacei.

M a s latet.

Femin a abdominis segmento superiore sexto quadrifido, laciniis subaequalibus, acntis.

p. 261.

29. T. axillaris: adde

Tachyp. fumipennis Say Transact. Amer. Philosoph. Soc. Philadelph, Nov. Ser. IV. 464. 3.

Nomen in T. fumipennem mutandum.

\section{Trichophyus.}

p. 268.

* 1. Tr. pilic ornis: Specimen huius insecti rarissimi integrum Dom. Mïrkel benevole dedil, ex quo antennarum descriptio hoc modo emendetur: Antennae capite thoraceque paulo longiores, articulo primo secundo- 
que crassitie solita, primo subcylindrico, secundo obconico, reliquis omnibus aequaliter tenuibus, longitudine subaequalibus, ultimo reliquis paululum longiore, undique pilosis.

\section{Boletobius.}

p. 280.

21.

B. pygmaeus: adde

Megacronus elegans Matthews Ent. Mag. V.p. 197. (forte)

Ta chin. trimuculatus Suy Transact. Amer. Philosoph. Soc. Philadelph. Nov. Ser. IV. 464. 3.

Specimen ex America septentrionali, ab hac specie nullo modo distinctum Dom. Ziinmermann nisit.

p. 2S1. adde

23. B. obsoletus: Niger, thorace, elytrorum arcu, abdominis segmento. rum marginibus pedibusque flavescentibus. - Long. ultra $2 \frac{1}{2}$ lin.

Tachin. obsoletus Say Transact. Amer. Philosoph. Soc. Philadelph. Nov. Ser. IV. 464. 2.

Habitat in Virginia, mense Octobre.

Niger. Antennae fuscae, articulis 4 primis flavescentibus, ultimo apice fulvo. Os testaceum. Thorax testaceus. Elytra certo situ obsolete striata, stria suturali impressa, basi, sutura et margine apicali testaceis. Abdomen segmentis singulis apice piceis. Pedes pallide flavescentes. (Say.)

24. B. cincticollis: Niger, thoracis margine posteriore, elytrorum stria pedibusque flavescentibus. - Long. infra 2 lin.

Tachin. cincticollis Say Transact. Amer. Philosoph. Soc. Philadelph. Nov. Ser. IV. 465.4.

Habitat in Indiana Americae septentrionalis:

Niger. Os flavescens, palpis pallide flavis. Antennae fuscae, articulis 3 primis flavescentibus, quarto piceo. Thorax margine basali et margine laterali basin versus dilatato testaceis. Scutellum piceum. Elytra apice substriata, stria suturali impressa et punctorum remotorum seriehus tribus, prima prope suturam, secunda in medio dorsi, tertia in margine laterali, pallide flavescentia, macula ovali, dilatata, ab apice ultra medium extensa, coerulescenti-nigra, suturam haud attingente, cum linea marginali nigricante, ante humerum abbreviata confluente. Abdomen supra segmentis singulis apice piceis. Pedes pallide flavi. - A reliquis thoracis margine posteriore discolore distinctus. (Say.)

\section{Mycetoporus.}

p. 284.

4. M. lepidus: Hanc quoque speciem Dom. Zimmermann ex America septentrionali misit, cui forle subiungatur:

Tachinus humidus Suy Transurt. Amer. Philosoph. Soc. Philadelph. Nov. Ser. JV. $46 \tilde{5} .5$. 
p. 285.

6. M. pronus: Forle huc allegatur:

Mycetop. brevicornis .Matthews Ent. Mag. V. p. 197.

\section{Platyprosopus.}

p. 294. adde

3. P. tamulus: Niger, griseo-pubescens, elytris, ano, antennis pedibusque rufis. - Long. $6 \frac{1}{2}$ lin.

Habitat in Bengala, Mus. Dom. Westermann.

P. elongato haud longior, at crassior, niger, subnitidus, totus griseopubescens, pube capitis densiore, thoracis parciore. Antennae capite sesqui longiores, articulo tertio secundo sesqui longiore, et palpi dilute rufi. Labrum castaneum. Caput thoracis prope latitudine, oblongum, lateribus rectis, totum dense subtilius punctatum. Thorax coleopteris vix angustior, latitudine paulo longior, basin versus subangustatus, apice truncatus, basi leviter rotundatus, dense subtilius punctatus, linea media longitudinali laevi. Elytra thorace tertia parte longiora, dense subtiliter punctata, rubra. Abdomen dense subtiliter punctatum, apice attenuatum, segmentis ultimis duobus rufis. Pedes cum coxis anticis rufi.

\section{P. fuliginosus: Niger, fusco-pubescens, elytris fuscis, pedibus rufis.} - Long. 6 lin.

Habitat in Bengala, Mus. Dom. Westermann.

P. elongato crassior, niger, opracus, pube brevi depressa fusca densius aequaliter vestitus. Antennae capite thoraceque paulo breviores, articulo tertio secundo duplo prope longiore, rufae. Palpi rufo-testaceae. Caput thoracis prope latitudine, oblongo-ovatum, creberrime subtiliter punctatum. Thorax coleopterorum latitudine, latitudine paulo longior, basin versus subangustatus, apice truncatus, basi leviter rotundatus, confertissime subtiliter punctatus, obsolete subtiliter carinatus. Elytra thorace paulo longiora, dense subtiliter punctata, fusca, opaca. Abdomen apicem versus angustatum. dense subtiliter punctatum, supra nigrum, segmentis singulis apice castaneo-marginatis, penultimo apice, ultimo toto rufis, infra rufo-piceum, segmento penultimo apice, ultimo toto rufo. Pedes dilute rufi.

Obs. Proximus praecedenti, at paulo robustior, opacus, pube fusca, punctura capitis thoracisque subtiliore et conferta, elytris brevioribus et colore distinctus.

\section{Xantholinus.}

p. 313. adde

* 14-15. X. aulicus: Laete cyaneus, nitidus, antemis pedibusque nigris, elytris rufis, capile subtriangulari, laevi. - Long. $5 \frac{1}{2}$ lin.

Habitat in Brasilia, Dom. Westermann.

Corpus laete cyaneum, splendidum. Antennae capite paulo longiores, articulo tertio secundo paulo longiore, nigrae, articulo secundo piceo, ultimo apice fulvo. Caput thorace paulo latius, antrorsum angustatum, basi emarginatum, angulis posterioribus rotundatis, laeve vel parce omnium subtilissime punctatum, sulcis intermediis frontis anticae conniventibus, punctis 
prope oculos utrinque tribus, et serie punctorum in capitis basi transversali impressum. Thorax latitudine paulo longior, hasin versus vix angustatus, lateribus subrectis, apice truncatus, angulis anterioribus subrectis, transversim convexus, laevissimus, intra angulum utrumque anteriorem puncto singulo maiusculo notatus. Scutellum obsolete punctatum. Elytra thorace paulo longiora, dorso parcius obsoletiusque subtiliter, lateribus crebrius distinctiusque punctata, rufa, purpureo-nitentia. Abdomen punctatum, parce minus subtiliter griseo-pubescens. Pedes nigri, tarsis testaceis.

p. 319.

29. X. glabratus: adde

Xanth. occidentalis Walt It. Andalus. 11. p. 58.

Staph. ferrugineus Rossi Faun. Etr. I. 218. 610. Ed. Hellw. 307. 610.

p. 326.

42. X. consentaneus: adde

Xanth. cephalus Say Transact. Am. Philosoph. Soc. Philad. Nov. Ser, IV. 452. 2. Gyrohypn. assimilis Kirby Faun. Boreali-Amer. 88. 1.

Nomen in $\mathbf{X}$. ce phalum mutandum.

p. 329.

47. X. Hesperius: adde

Xanth. limbatus Walth It. Andalus. II. p. 5i.

p. 330.

48. X. obscurus: Forte huic adscribalur:

Xanth. hamatus Say Transact. Am. Philosoph. Soc. Philad. Nov. Ser. IV. 453. 3.

\section{Leptacinus.}

\section{p. 335.}

4. L. batychrus: adde

Xanth. tener Waltl It. Andalus. II. p. 59.

\section{Palaestrinus.}

\section{p. 344.}

1-2. P. mutillarius: Niger, thoracis apice, abdomine infra et fasciis duabus dorsalibus cinereo-villosis, elytris rufis, fulvo-pubescentibus. Long. 5 lin.

Habitat in Bengala, Mus. Dom. Westermann.

Niger. Antennae capite paulo longiores, articulo tertio secundo sesqui longiore, articulis $4-10$ sensim paulo brevioribus, ultimo apice truncato et inferne subtiliter acuminato. Palpi rufo-picei, filiformes, apice truncati. Caput thorace paulo latius, orbiculatum, fortiter convexum, sat fortiter dense punctatum, punctis confluentibus longitudinaliter rugulosum, pube longiore cinerea parcius vestitum. Thorax coleopteris duplo angustior, basin versus angustatus, latitudine antica haud longior, basi cum angulis posterioribus rotundatus, apice truncatus, angulis anterioribus subrotundatis, fortiter con- 
vexus vel elevatus, dense fortiter punctatus, disco subtiliter nigro-pubescente, limbo cinereo-villoso. Scutellum nigrum, fulvo-pubescens. Elvtra thorace longiora, depressa, rufa, villis depressis fulvis vestita. Abdomen coleopteris angustius, supra nigro-pubescens, fasciis duabus cinereo-villosis, posteriore segmentum quartum occupante, anteriore basali, lateribus descendente et maculam permagnam triangularem includente; infra segmentis 4 anterioribus aequaliter cinereo-villosis, quinto nigro-, sexto cinereo-pubescente. Pectus cinereo-pubescens. Pedes picei, cinereo-pubescentes, coxis anticis castaneis, tibiis anticis incrassatis, externe laevigatis glabratisque.

p. 315. Inter Palaestrinum et Staphylinum novum genus inducendum est:

Caranistes Er.

\section{Antennae rectae.}

Palpi articulo ullimo apice truncato.

Pedes intermedii basi leviter distantes.

\section{Tarsi posteriores deplanati.}

Corpus elongatum, alatum. Caput thorace maius, grossum, basi fortiter constrictum, oculis parvis, vix prominulis, intra marginem lateralem in capitis facie anteriore sitis, ovalibus, obliquis. Labrum transversum, bilobum, corneum, fortiter setosum, limbo laterali angusto, bilobo. Mandibulae validae. Maxillae mala exteriore breviore, apice barbata. Palpi maxillares articulo primo minuto, secundo tertioque leviter obconicis, subaequalibus, quarto paulo longiore, cylindrico, apice subcompresso, truncato. Palpi labiales articulo primo minuto, secundo obconico, tertio paulo longiore, cylindrico, apice compresso truncatoque. Antennae filiformes, apice compressae. Thorax coleopteris angustior. Scutellum triangulare. Elytra apice rotundata. Abdomen apicem versus subangustatum, marginatum. Pedes coxis intermediis parum distantibus, tibiis omnibus spinulosis, tarsis anticis dilatatis, tibia paulo latioribus, posterioribus, depressis, articulis 4 primis sensim decrescentibus.

\section{o b s e r vatio.}

Tarsis posterioribus depressis cum Haematode, Cordylaspide et Scariphaeo conveniens, at maxillarum mala exterior haud elongata et tarsi posteriores ipsi angusti. A S taphylino praeter tarsorum structuram palpis maxillaribus apice truncatis discedit. Habitu proximus videtur $\mathrm{Pal}$ aestrino, at pedes intermedii parum distantes, tibiae anticae haud incrassatae, tarsi antici tibir latiores, et tarsi posteriores depressi.

1. C. Westermanni: Niger, capite, thorace elytrisque obscure coeruleis, abdomine macula magna dorsali atro-tomentosa, apice ferrugineo, pedibus castaneis. - Long. $7 \frac{1}{2}$ lin.

Habitat in Bengala, Mus. Dom. Westermann.

Antennae capite paulo longiores, filiformes, apice compressae, articulo tertio secundo duplo longiore, $\mathbf{4}-\mathbf{1 0}$ sensim paululum brevioribus crassioribusque, penultimis latitudine paulo brevioribus, ultimo truncatulo, medio abrupte subacuminato, fuscae, subtiliter densius pubescentes, articulo primo castaneo. Palpi rufo-picei. Caput thorace multo maius, coleopterorum latitudine, crassum, lateribus subrectis, basi emarginatum, angulis posterioribus rotundatis, infra nigrum, supra convexum, dense punctato-rugosum, 
nigro - coeruleum, opacum, subtiliter cinereo-puhescens. Thorax coleopteris angustior, basin versus angustatus, latitudine antica vix longior, basi cum angulis posterioribus rotundatus, apice utrinque oblique truncatus, angulis anterioribus acutiusculis, prominulis, convexus, confertim punctato-rugulosus, subtiliter cinereo-pubescens, lateribus nigro-pilosus. Scutellum atro-tomentosum. Elytra thorace paulo longiora, apice rotundata, subtiliter punctatorugulosa, nigro-coerulea, opaca, subtiliter cinereo-pubescentia, apice flavescenti-ciliata, ad suturam densius nigro-pubescentia. Abdomen nigrum, segmento penultimo apice, ultimo toto ferrugineo, tenuiter griseo-pubescens, parcius nigro-pilosum, segmentis secundo tertioque dorsalibus macula magna e tomento aterrimo. Pedes rufo-castanei, coxis nigricantibus.

\section{Staphylinns.}

\section{p. 349.}

4. St. villosus: adde

Creophilus villosus Kirby Faun. Boreali-Amer. 95. 1.

p. 360.

21. St. cingulatus:

St. chrysurus Kirby Faun. Boreali-Amer. 94. 1,

e Nova Scotia, licet minor, long. $5 \frac{\pi}{2}$ lin., nullo modo distinctus videtur.

p. 361. adde

22-23. St. marmoratus: Niger, tomento fusco-nebuloso vestitus, antennarum basi, palpis pedibusque testaceis, femoribus medio nigris, Long. 5 lin.

Habitat in Java, Mus. Dom. Westermann.

Statura omnino St. murini, niger, vix nitidus. Antennae articulo tertio secundo sesqui longiore, quarto crassitie longiore, sequentibus transversis, nigrae, articulis 4 primis testaceis. Palpi testacei. Labrum testaceum. Caput, thorax et elytra tomento denso depresso fulvo-fuscoque variegato obducta. Caput thorace paulo latius, subdepressum. Thorax coleopteris angustior, basin versus subangustatus, latitudine paulo longior, lateribus rectis, basi cum angulis posterioribus rotundatis, angulis anterioribus acutiusculis, subdepressus. Scutellum macula magna nigro-tomentosa. Elytra thorace vix longiora. Abdomen segmentis duobus anterioribus dorsalibus fulvo-tomentosis, nigro-variegatis, reliquis subtiliter nigro-tomentosis, basi e pube cinerea maculatim variegatis, infra omnibus basi cinereo-pubescentibus. Pectus cinereo-pubescens. Pedes testacei, femoribus supra et annulo medio nigris.

p. 376. adde

*50-51. S1. mysticus: Niger, fusco-pubescens elytris brunneis abdomineque nigro-maculosis, tibiis tarsisque rufo-piceis. - Long. 7 lin.

Habitat in America septentrionali, Dom. Riehl.

St. maculoso affinis, at minor et magis depressus, St. fusco-maculato aequalis, niger, opacus. Antennae capite paulo longiores, articulo tertio secundo sesqui longiore, sequentibus crassitie haud brevioribus, ultimo annee 
abrupte subacuminato, piceae, articulo primo infra testaceo. Palpi rufi. Caput thorace paulo minus et angustius, antrorsum leviter angustatum, subdepressum, supra dense punctatum, fusco-pubescens. Thorax coleopteris vix angustior, latitudme sublongior, lateribus subrectis, parallelis, basi cum angulis posterioribus rotundatus, apice truncatus, angulis anterioribus rectis, leviter convexus, dense subtiliter punctatus, subtilissime carinatus, subtiliter fusco-pubescens. Scutellum macula magna rotundata atro-holasericea. Elytra thorace vix longiora, dense subtiliter punctata, brunnea, nigro-maculosa, e pube fuscescente nigricanteque subtili obsolete variegata. Abdomen dense subtiliter punctulatum, subtiliter fulvescenti-pubescens, supra segmentis singulis lituris duabus nigro-tomentosis signatis, ultimo rufo-piceo. Pedes tibiis tarsisque rufo-piceis.

Obs. A St. maculoso distinctus colore obscuriore, statura minore et magis depressa, thorace subtiliter punctato.

p. 389.

75. St. fuscicornis: adde

Ocypus scabrosus Curtis Linn. Transact. XVIII. 196. 28.

\section{Deypus.}

p. 409.

8. O. masculus: adde

Staph aethiops Waltl It. Andal. II. p. 66.

Nomen in St. a ethiofem mutandum. - Specimina illaesa densius nigro-tomentosa, abdominis segmentis dorsalibus basi macula minuta media e pube lutea signatis.

\section{Belonuchus.}

p. 426. adde

Species mihi invisae, forte huius generis:

14. B. ephippiatus: Niger, elytris rufis. - Long. ullra 6 lin.

Staph. ephippiatus Say Transact. Amer. Philosoph. Soc. Philadelph. Nov. Ser. IV. 448. 1 .

Habitat in Mexico.

Niger, politus. Caput linea longitudinali inter oculos, orbitis superioribus punctis 3 vel 4, super hos serie e punctis 4 vel 5 et singulis 2 vel 3 , basi utrinque serie e punctis 4 impressum. Palpi picei. Antennae articulo ultimo oblique truncato. Thorax semiovalis, punctis utrinque paucis dispersis impressus, seriebus dorsalibus punctis 4 vel 5 compositis. Scutellum dense punctatum, nigrum. Elytra cinnamomeo rufa, subtiliter pubescentia punctataque. Abdomen supra tenuiter pubescens, nigro-coerulescens, versicolor. (Say.)

15. B. connexus: Niger, elytris pedibusque rufis. - Long. ultra 3 lin. Staph. connexus Say Transact. Am. Philosoph. Soc. Philad. Nor. Ser. IV. 448. 2. Habitat in Mexico. 
Niger, politus. Caput orbitis punctatis et utrinque disperse punctatum, fronte inter antennas fortiter impressa, et supra hanc impressionem utrinque puncto singulo notata. Palpi nigro-picei. Thorax seriebus dorsalibus punctis ultra $\overline{5}$ fortibus compositis, lateribus utrinque punctis parcis dispersis impressus. Elytra cinnamomeo-rufa, brevissime pubescentia, subtiliter punctata. Pedes elytris concolores. - Similis praecedenti, at pedibus rufis, abdomine supra nigerrimo, haud versicolore, clypeo medio leviter producto. (Say.)

\section{Philonthus.}

p. 437.

16. Ph. a ene us: Locis cilatis adde

Phil. politus Kirby Faun. Boreali-Amer, p. 91. 1.

Phil. mandibularis Kirby Faun. Boreali-Amer. p. 92. 2.

$\mathrm{Obs}$. Ph. politum Kirby ad marem, $\mathrm{Ph}$. mandibularem ad feminam referas.

p. 457. adde

* 47-48. Ph. inquietus: Niger, nitidus, antennarum basi, elytronum limbo pedibusque testaceis, elytris dense profundeque punclatis, capile ovato. - Long. $2 \frac{1}{2}$ lin.

Habitat in America septentrionali, Dom. Zimmermann.

Statura omnino $\mathrm{Ph}$. sordidi et minoribus eius individuis aequalis, niger, nitidus, capite thoraceque nigro -. subaeneis, politis. Antennae capite thoraceque paulo breviores, articulo tertio secundo paulo longiore, 4-10 subcylindricis, longitudine et crassitie subaequalibus, ultimo ovato, apice truncato et inferne subacuminato, nigrae, articulo primo infra, secundo toto testaceis. Palpi piceo-testacei. Caput thoracis prope latitudine, ovatum, leviter con-vexum, fronte supra punctis paucis sparsis, inter oculos utrinque punctis duobus oblique positis impressus. Thorax coleopteris dimidio angustior, latitudine paulo longior, lateribus subrectis, antrorsum vix angustatus, basi rotundatus, apice truncatus, angulis anterioribus ottusiusculis, deftexis, posterioribus obtusis, leviter convexus, seriebus dorsalibus punctis 4 sat remotis, postico paulo remotiore, compositis, lateribus punctis praeter marginalia utrinque 5 impressus, punctis omnibus minus subtilibus. Scutellum crebre punctatum, tenuiter griseo-pubescens. Elytra thorace paulo longiora, densius fortiusque punctata, parce griseo-pubescentia, limbo laterali, apicali suturalique tenui testaceo. Abdomen crebre punctulatum, griseo-pubescens, segmentis omnibus apice late testaceo-limbatis. Pedes testacei, coxis anterioribus concoloribus, coxis anticis femoribusque dilutioribus, tarsis anticis in utroque sexu simplicibus.

p. 461. adde

54-55. Ph. iopterus: Niger, nitidus, elytris crebre punctatis, violaceis, splendidis. - Long. 4 lin.

Habitat Bogotae in Columbia interiore, Dom. De Haen.

$\mathrm{Ph}$. candenti proximus, nigerrimus, nitidus, capite thoraceque nitidissimis, elytris splendide violaceis. Antennae capite paulo longioses, articulo tertio secundo paulo longiore, $4-10$ brevibus, leviter transversis, ultimo 
subgloboso, apice leviter emarginato et inferne acuminato. Mandibulae longiores, falcatae, acutae. Caput thorace latius, breviter obovatum, fronte subdepressa, supra punctis sparsis, inter oculos utrinque duobus transversim positis, fortioribus notata, antice medio foveolata. Thorax coleopteris duplo angustior, latitudine longior, basin versus vix angustatus, lateribus subrectis, basi leviter rotundatus, angulis anterioribus deflexis, fortiter rotundatis, posterioribus obtusis, transversim convexus, seriebus dorsalibus punctis 5, aequaliter distantibus compositis, lateribus utrinque punctis 6 impressis, punctis omnibus minus subtilibus. Scutellum subtilius crebre punctatum. Elytra thorace paulo longiora, crebre minus fortiter punctata, pube subtili depressa nigra tenuiter vestita. Abdomen apicem versus leviter angustatum, subtiliter parcius punctulatım, parcius nigro-pubescens. Pedes elongati, graciles, coxis intermediis distantibus, tibiis omnibus subtiliter spinulosis, tarsis anticis simplicibus. (Mas.)

$\mathrm{Obs}$. Praeter elytrorum colorem a Ph. candente imprimis antennis multo brevioribus, thorace longiore, angulis anterioribus fortius rotundatis distinctus.

56. Ph. ebeninus: Huic adscribendus videtur:

Staph. quisquiliarius var. longicornis Walt. It. Andalus. II. p. 57.

p. 470. adde

69-70. Ph. promtus: Niger, nilidus, coxis anticis testaceis, elytris brevioribus, forlius punclatis, capite ovato. - Long. $3 \frac{1}{2}$ lin.

Habitat in Pensylvania, Dom. Zimmermann.

Statura Ph. bipustulati, niger, nitidus, capite thoraceque pernitidis. Antemnae capitis thoracisque prope longitudine, articulo tertio secundo paulo longiore, $\mathbf{1}-10$ subaequalibus, crassitie paulo longioribus, ultimo ovato, apice truncato et inferne acuminato, totae nigrae. Palpi concolores. Caput thorace plus dimidio angustius, ovatum, punctis parcis utrinque super ocılos, et utrinque duobus transversim positis inter oculos impressum. Thorax coleopter's paulo angustior, latitudine baseos vix longior, antrorsum leviter angustatus, lateribus subrectis, basi cum angulis posterioribus rotundatus, apice truncatus, angulis anterioribus deflexis, subrotundatis, convexus, seriebus dorsalibus punctis $\mathbf{5}$, aequaliter distantibus, compositis, lateribus punctis praeter marginalia utrinque 5 impressus, punctis minus subtilibus. Scutellum subtiliter punctulatum. Elytra thoracis longitudine, sat crebre minus subtiliter punctata, glabra. Abdomen dense subtiliter punctatum, subtiliter cinereo-pubescens, segmentis ventralibus margine apicali rufo-piceo. Pedes picei, coxis anticis totis laete testaceis, intermediis approximatis, tibiis omnibus spinulosis.

Tarsi antici feminae leviter dilatati. Mas latet.

$\mathrm{Obs}$. Elytris brevioribus, fortius punctatis ab affinibus distinctus.

71. Ph. flavolimbalus: Eundem Dom. Zimmermann e Carolina meridionali misit, nonnisi elytrorum limbo laterali obsoleto dislinctum.

p. 473.

74. Ph. ventralis: Forte huc pertinet:

Staph. dimidiatus Say Transact. Amer. Philosoph. Soc. Philadelph. Nov. Ser. IV. 450. 6. 
p. 476.

80. Ph. rufimanus:

Habitat etiam in Helvetia, Sardinia.

Varietatem pèdibus anterioribus nigris, coxis solis laete rufo-testaceis, cum genuino in Sardinia lectam nuperrime Prof. Gené misit.

p. 481. adde

88-89. Ph. tachiniformis: Niger, thorace sanguineo, pedibus piceis. - Long. $2 \frac{1}{2}$ lin.

Staph. tachin iformis Say Transact. Amer. Philosoph. Soc. Nov. Ser. IV. 450. 7.

Habitat in Mexico.

Niger. Caput parvum, ovale, politum, punctis utrinque duobus inter oculos, $\mathbf{8}$ vel 10 supra oculos impressum. Antennae fuscae, basi obscure piceac. Os piceum. Thorax sanguineus, seriebus dorsalibus punctis 5, a basi et ab apice remotis, compositis, lateribus punctis utrinque duobus, margine tribus, triangulariter positis inpressus. Elytra subaenea, crebre subtiliter punctata, pube depressa vestita. Pedes testacei, posticis, tibiis et tarsis obscurioribus. (Say.)

p. 485.

96. Ph. fulvipes: Locis citatis adde

Phil. fulvipes Kirby Faun. Boreali-Amer. 93. 4.

p. 486.

97. Ph. brunneus: Forte huc referatur:

Phil. picatus Kirby Faun. Boreali-Amer. 93. 3.

p. 493.

111. Ph. (?) stenoides: adde

Staph. stenoides Grav. Mon. 90. 86.

p. 494. adde

*112-113. Ph. pretiosus: Viridi-aeneus, capile thoraceque cupreoauratis, fulgidis. - Long. 8 lin.

Habitat Bogotae in Columbia interiore, Dr. De Haen.

Insectum splendidissimum, corpore laete viridi-aureo, nitidn, capite thoraceque supra purpurascenti-aureis, splendidis. Antennae capite thoraceque paulo breviores, apicem versus haud incrassatae, articulo tertio secundo sesqui longiore, $\mathbf{4}-\mathbf{1 0}$ sensim paulo brevioribus, ultimn ovato, apice oblique subemarginato, inferne acuminato, nigrae, articulis tribus primis viridibus. Caput thorace paulo latius suborbiculatum, sparsim punctatum, fronte media laevi. Thorax coleopteris plus dimidio angustior, latitudine longior, hasin versus leviter angustatus, lateribus anterius rotundatis, posterius subsinuatis, basi rotundatus, apice truncatus, angulis anterioribus deflexis, subrectis, posterioribus obtusis, convexus, seriebus dorsalibus irregularibus, 7-9-punctatis, lateribus punctis parcis impressus. Scntellum parce punctatum. Elytra thorace paulo longiora, parcius et minus fortiter punctata, parcius nigro-pubescentia. Abdomen sensim angustatum, parce sub- 
tiliterque punctatum, tenuiter nigro-pubescens. Pedes virides, coxis intermediis approximatis, tibiis posterioribus spinulosis, tarsis nigris.

Tarsi antici maris modice dilatati. Femin a latet.

p. 499.

117. Ph. orphanulus pro Ph. orphano substiluendus.

p. 501.

124-125. Ph. ferrugat us: Elongatus, depressus, ferrugineus, fronte nigra, abdomine piceo, capite subquadralo. - Long. $4 \frac{1}{2}$ lin.

Hahitat in Java, Mus. Dom. Westermann.

Statura elongata, depressa omnino Belonuchi haemorrhoidalis. Antennae capite sesqui longiores, articulo primo leviter elongato, tertio secundo paulo longiore, sequentibus sensim paulo brevioribus et crassioribus, $5-10$ transversis, ultimo ovato, apice oblique subemarginato et inferne acuminato, ferrugineae, medio fuscescentes, summo apice flavescente. Mandibulae longiores, falcatae, acntae. Caput thorace latius, subquadratum, fronte depressa, fortius parce punctata, punctis medio subseriatis, nitidum, supra nigro- infia rufo-piceum. Thorax coleopteris angustior, basin versus angustatus, latitudine antica vix longior, lateribus subrectis, basi rotundatus, apice utringue oblique truncatus, angulis anterioribus acutiusculis, prominulis, posterioribus obtusis, depressus, seriebus dorsalibus 8-10-punctatis, lateribus parce punctatus, saturate ferrugineus, nitidus, oblique inspectus subsericans. Scutellum rufo-piceum, crebre punciatum. Elytra thorace paulo longiora, depressa, densius punctata, punctorum maiorum distantium seriebus duabus notata. saturate ferruginea, nitida, griseu-pubescentia. Abdomen apicem versus sensim attenuatum, minus dense punctatum, griseo-pubescens pilosumque, piceum, segmentis 4 promis apice obscure ferrugineo marginatis, ultimis duobus apice testaceis. Pectus piceum. Pedes ferruginei, coxis intermediis modice distantibus, tibiis omnibus spinulosis.

Tarsi antici feminae leviter dilatati. Mas latet.

\section{p. 501.}

\section{Ph. haematurus: adde}

Staph. apicalis Say Transact. Am. Philesoph. Soc. Philad. Nov. Ser. IV. 451. 8.

Nomen in $\mathbf{P h}$, apicalem mutandum.

p. 515. adde speciem mihi invisam, forte huius generis:

151. Ph. apicicornis: Nigro-coeruleus, capite transverso, laevigalo, punctato, ore, mandibulis basi ferrugineis, antennis basi rufis, medio nigris, apice flavis, thorace oblongo, postice rotundato, angulis anticis acuminatis, supra latvigalo, vage punctato, elytris brunneo-aemeis, micantibus, subrugosis, villosis, abdomine marginato, subrugoso, villoso, pedilus ferrugineis. - Long. 5-6 lin.

St aph. apicicornis Guér. Voyag. d. l. Coquille, Zool. II. II. p. 62. Ins. t. 1. f. 21.

Habitat in Nova Guinea.

Antennae coloribus insignes: articulis $\mathbf{3}$ primis rufis, sequentibus $\mathbf{5}$ nigris, ultimis 3 ochraceis. Corpus totum nigro-coerulescens, oris partibus, mandibularum basi pedibusque rufo-ferrugineis, elytris rubro-cupreis, violaceo - micantibus. : (Guér.) 
p. 603. adde

\section{Lathrobium.}

* 26 - 27. I. Stilicinum: Elongatum, nigrum, elytris piceis, antennis pedibusque ferrugineis, capile suborbiculato thorrceque subovato conferlissime punctalis, subrugulosis. - Long. $2 \frac{2}{3}$ lin.

Habitat in Sardinia, Dom. Prof. Gené.

Corpus elongatun, subdepressum, nigrum, minus nitidum, totum subtiJissime griseo-pubescens. Antennae capite thoraceque paulo breviores, articulo secundo tertioque subaequalibus, sequentibus sensim paulo brevioribus, rufo-ferrugineae. Mandibulae rufo-piceae. Palpi rufo-testacei. Caput thorace paulo latius, suborbiculatum, supra leviter convexum, confertissime punctatum, subrugulosum. Thorax coleopteris paulo angustior, latitudine paulo longior, basin versus subangustatus, angulis posterioribus rotundatis, antice apicem versus rotundato-attenuatus, subdepressus, confertissime punctatus, subrugulosus. Elytra thorace paulo longiora, crebre fortius punctata, picea, nitidula. Abdomen dense subtiliter punctatum. Pedes ferruginei.

Mas abdominis segmento inferiore quinto obsolete longitudinaliter inpresso, apice leviter emarginato, sexto basi bicarinato, apice triangulariter exciso, femin a eodem rotundato-producto.

Variat elytris piceo-testaceis.

Obs. Capitis thoracisque forma et punctura non minus ac L. scabricolle Stilici habitum prae se ferens, at huius generis, L. scabricolli affine, at alatum, corpore minore, subdepresso, thorace magis elongato, elytris longioribus etc. perquam distinctum.

p. 638.

\section{Snnius.}

\section{S. filiformis: adde}

Paederus filum Waltl. Isis. 1838. IV. 267. 1.

p. 650.

\section{Paederus.}

1. P. littoralis:

P. confinis Zetterst. Ins. Lappon. 69. 2,

ab auctore benevole communicatus $P$. littorali genuino paulo minor et alatus, ceterum autem nullo modo distinctus, ut non possim quin huius varietatem eum habeam. Deleatur igitur apud P. riparium. (p. 654.)

p. 660. adde

* 20 - 21. P. melanurus: Alatus, testaceus, abdomine apice nigro. Long. 3 lin.

Habitat Ticini, inundante Ticino fluvio a Dom. Gené olim lectus, nuperrime benevole communicatus.

Statura omnino P. riparii, colore corporis cum capite, pectore elytrisque laete testaceo, abdominis ultimis duobus segmentis solis nigerrimis eximius. Antennae capitis thoracisque longitudine, articulo tertio secundo duplo longiore, $4-10$ sensim paulo brevioribus et crassioribus, ultimo oblongo-ovato, apice oblique acuminato, flavescenti-testaceae, apicem versus fuscescentes. Palpi immaculati. Caput thoracis latitudine, orbiculatum, supra leviter convexum, parce subtiliterque puuctulatum, utrinque ad antel- 
narum basin subimpressum, parce nigro-pilosellum. Thorax coleopterorum latitudine, latitudine paulo longior, basin versus leviter angustatus, lateribus anterius rotundatis, subovatus, leviter convexus, parce obsoletissime junctatus, parce pilosus. Elytra thorace paulo longiora, crebre profundeque punctata, parce nigro-pilosella. Abdomen parcius punctulatum, nigro-pilosellum. Pedes dilute testacei, geniculis subfuscescentibus.

Obs. Descriptus a Dom. Prof. Gené in opusculo mihi inviso: De quibusdam Coleopteris Italiae novis aut rarioribus. Tentam. inaug., Ticin. Reg. 1830.

p. 666.

37. P. australis: adde

uér. Voyag. d. l. Coquille, Zool. II. II. p. 63.

P. ripario statura et coloribus proximus, at pedibus totus nigris. (Guér.)

Obs. Quo differat a P. melampode non patet.

p. 667. addè

39. P. cyanipennis: Ater, nitidus, elytris rugosis, elongatis, cyaneis, antennis brunneis, basi ferrugineis, pedibus alris. - Long. 3 lin.

Guér. Voyag. d. l. Coquille, Zool. II. II. p. 62. Ins. t. I.f. 22.

Habitat Limae.

Niger, nitidus. Caput orbiculatum, punctatum, pilosellum. Antennae brumneae, pubescentes, articulis tribus primis rufescentibus. Thorax globosus, nitidus, parce disperse punctatus, pilosellus. Elytra oblonga, rugosa, laete violacea, splendida. Abdomen nigrum, rugosum, pilosellum, marginatum. Pedes graciles, nigri. (Guér.)

\section{p. 760.}

\section{Bledius.}

1. B. $\operatorname{taurus:}$ adde

Bled. Stephensii Westwood Zool. Journ. HII. p. 61, 301, 509. t. 11. f. 4.

\section{Platystethus.}

Obs. Falso plerisque locis Platysthetus scripsi.

p. 783.

3. Pl. nodifrons: adde

Oxyt. asphaltinus Waltl Isis. 1838. IV. 267. 2.

p. 800.

\section{Phloeonaeus.}

1. Ph. caelatus: adde

Oxyt. biarcuatus Matthews Ent. Mag. V. p. 198.

p. 837.

\section{Prognatha.}

1. P. quadricornis: adde

Siagon. 4-corne Westw. Zool. Journ. III. p. 61.

p. 857.

Lesteua.

5. L. punctata: Var. pallida, immatura huius speciei esse videtur: Anthophag. villosus Waltl. Isis. 1838. IV. 268. 3. 


\section{EXPLICATIO TABULARUM.}

Fig. 1. Peliusa labiata.

\section{Tab. I.}

"2. Euryusa sinuata.

3. Pronomaea rostrata.

4. Tanygnathus terminalis.

5. Holisus analis.

6. Diochus nanus.

7. Scytalinus serpentinus.

8. Palaminus variabilis.

"9. Oedichirus Paederinus.

Fig. 1. Ophites versatilis.

\section{Tab. II.}

"2. Echiaster longicollis; a labium, b maxilla, c labrum E. melanuri.

"3. Megalops cephalotes; a labium, b maxilla.

4. Holotrochus volvulus.

,5. Apocellus sphaericollis.

"6. Lispinus angustatus.

"7. Isomalus complanatus.

"8. Hypotelus pusillus.

"9. Glyptoma crassicorne.

\section{Tab. III.}

Fig. 1. Myrmedoniae (humeralis) labium.

"2. Autaliae (impressae), labium.

"3. Falagriae (sulcatae) labium.

"4. Bolitocharae (lunulatae) labium.

" 5. Ocalea e (castaneae) labium.

"6. Caloderae (nigritae) labium.

"7. Tachyusae (coarctatae) labium.

"8. Homalotae (elongatulae) labium.

9. A leocharae (fuscipedis) labium.

, 10. Oligotae (pusillimae) labium.

"11. Gyrophaenae (nanae) labinu.

, 12. Peliusae (labiatae) labium.

"13. Placusae (infimae) labium.

"14. Euryusae (sinuatae) labium.

"15. Dinardae (dentatae) labium.

"16. Lomech us a (emarginatae) tabium.

"17. Silusae (rubiginosae) labium.

"18. Pronomaeae (rostratae) labium.

"19. Gymnusae (brevicollis) labium. 
Fig. 20. M yllaenae (dubiae) labium.

"21. Myrmedoniae (humeralis) maxilla.

"22. Homalot ae (elongatulae) maxilla.

"23. Euryusae (sinuatae) maxilla.

"24. Dinard a e (rubiginosae) maxilla.

"25. Lomechusae (emarginatae) maxilla.

"26. Silusa e (rubiginosae) maxilla.

"27. Pronomaeae (rostratae) maxilla.

"28. Gymnusae (brevicollis) maxilla.

"29. Myllaenae (dubiae) maxilla.

\section{Trab. I V.}

Fig. 1. Hy p ocypti (granuli): a labium, b maxilla.

"

99

9

9

99

2. Conuri (pubescentis): labium.

3. Tachypori (obtusi): a labium, b maxilla.

4. Habroceri (capillaricornis): a labiam, b maxilla, c antenna.

5. T a chini (rufipedis): a labium, b maxilla.

6. Boletobii (atricapilli): a labium, b maxilla.

7. Mycetop ori (lepidi): a labium, b maxilla.

9. A cylophori (glabricollis): a labium, b muxilla.

10. Eurypori (pieipedis): ar labium, b maxilla.

11. Astrapaei (Ulmi): a labium, b maxilla.

12. Philonthi (splendendis): a labium, b maxilla.

13. Heterothopis (dissimilis): a labium, b maxilla.

14. St aphylini (maxillosi) labium.

15. Ocypodis (morionis) labium.

16. Haematod is (bicoloris): a labium, b maxilla.

17. Cordylaspid is (pilosi): a labium, b maxilla.

18. Scariphaei (luridipennis): a labium, b maxilla, c tarsus posticus, superne et a latere inspeclus.

19. Sterculiae (formicariae): a labium, b maxilla.

20. Scytalini (serpentini): a labium, b maxilla.

21. Xantholini (glabrati): a labium, b maxilla.

22. Leptacini (batychroi): a labium, b maxilla.

23. Holisi (humilis): a labium, b maxilla.

24. Othii (fulvipennis): a labiem, b maxilla.

25. Platyprosopi (Beduini): a labium, b maxilla, c labrum.

26. Lathrobii (brunnipedis): a labium, b maxilla.

27. Dolica on is (lathrobioidis): a labium, b maxilla.

28. Cryptobii (fracticornis): a labium, b maxilla.

29. Lithocharidis (ochraceae): a labium, b maxilla.

30. Paederi (riparii): a labium, b maxilla.

31. Stilici (rufipedis): a labium, b maxilla.

32. Ophit is (versatilis): a labium, b maxilla.

33. Sunii (angustati): a labium, b maxilla.

34. Pinophili (latipedis): a labium, b maxilla. 
Fig. 35. Taen odemat is (cyanescentis): a labium, b maxilla.

, 36. Pal amin i (variabilis): a labium, b maxilla.

"37. Oedichiri (Paederini): a labium, b maxilla.

"38. Proeirri (Lefebvrei): a labium, b maxilla.

\section{Tab. W.}

Fig. 1. Dianoi (coerulescentis): a labium, b maxilla.

$"$ 2. Steni (speculatoris): a labium, b maxilla.

"3. Euaestheti (scabri): a labium, b maxilla.

", Olisthaeri (megacephali): a labium, b maxilla.

5. Phloeocharid is (subtilissimae): a labium, b maxilla.

6. Oxypori (rufi): a labium, b maxilla.

7. Leptoch iri (scoriacei): a labium, b maxilla, c labrum.

8. Lispini (angustati): a labium, b maxilla.

9. Piesti (penicillati): a labium, b maxilla, c labrum.

10. Prognathae (humeralis): a labium, b maxilla.

11. Is omali (complanati): a labium, b maxilla.

12. Hypoteli (pusilli): a labium, b maxilla.

13. Os orii (atri): a labium, b maxilla.

"14. Holotroch i (volvuli): a labium, b maxilla.

"15. Bledii (tricornis): a labium, b maxilla, c labrum.

"16. Platystethi (morsitantis): a labium, b maxilla.

"17. Oxyteli (picei): a labium, b maxilla, c labrum.

"18. Phloe onaei (caelati): a labium, b maxilla.

"19. Trogophloei (elongatuli): a labium, b maxilla.

"20. Apocelli (sphaericollis): a labium, b maxilla.

"21. Coprophili (striatuli): a labium, b maxilla, c labrum.

"22. A crognathi (mandibularis): a labium, b maxilla, c labrum.

23. Syntomii (aenei): a labium, b maxilla.

24. Deleasteris (dichroi): a labium, b maxilla, c labrum.

25. Anthophagi (alpini): a labium, b maxilla.

26. Lesteuae (punctatae): a labium, b maxilla, c labrum.

27. Arpedii (quadri): a labium, b maxilla.

28. Acidotae (crenatae): a labium, b maxilla.

29. Olophri (picei): a labium, b maxilla, c labrum.

30. Lathrimaei (atrocephali): a labium, b maxilla, c labrum.

31. Omalii (rivularis): a labium, b maxilla.

32. Anthobii (floralis): a labium, b maxilla.

33. Prote in i (brachypteri): a labium, b maxilla.

34. Megarthri (hemipteri): a labium, b maxilla.

35. Micropepli (porcati): a labium, b maxilla.

Obs. Labia omnia absque palpo labialí sinistro delineavi, ut ligulae paraglossarumque figura distinctius conspiciatur. 


\title{
INDEX NOMINUM.
}

\author{
Synonyma litteris obliquis distincta sunt.
}

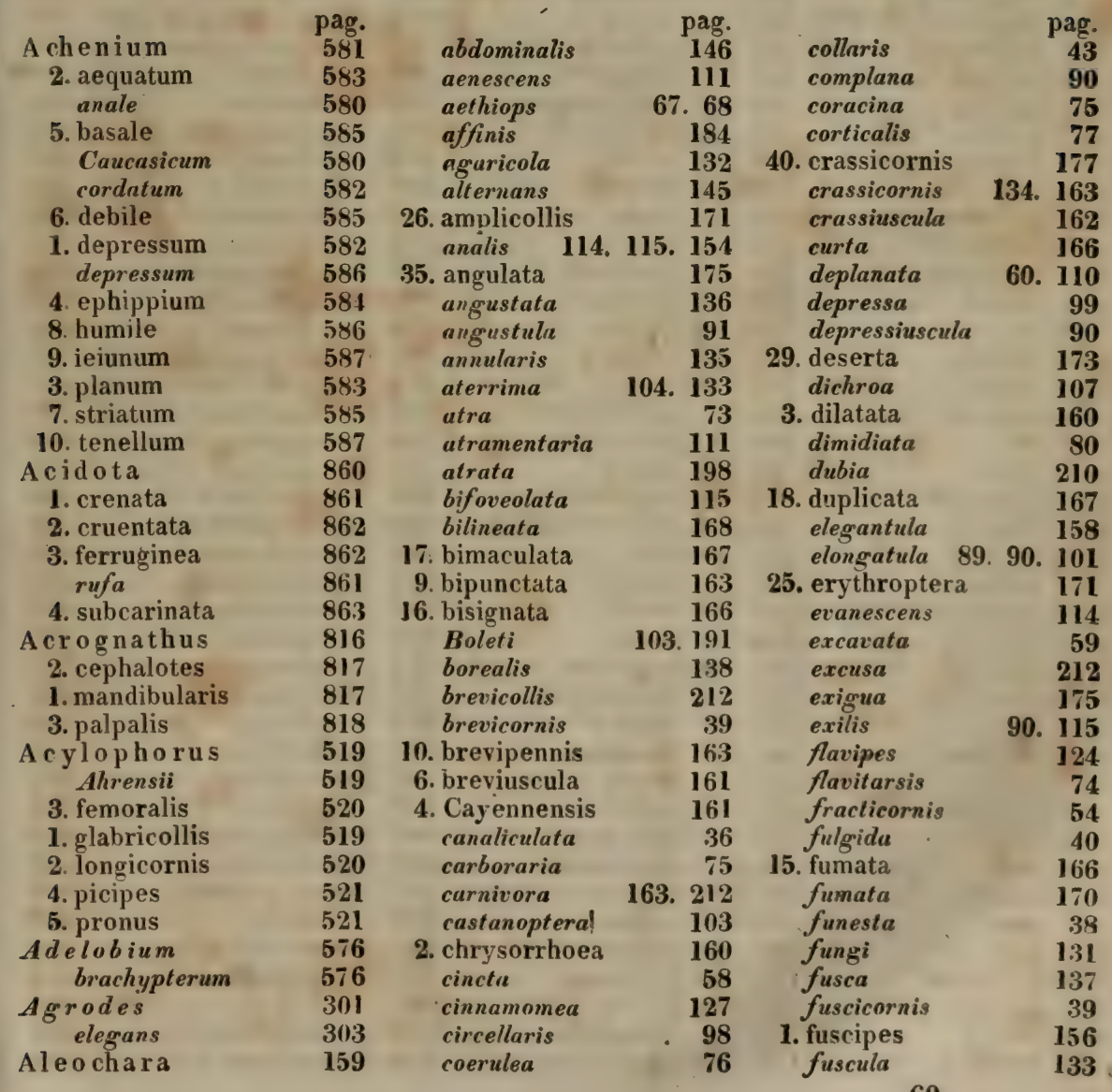


Index nominum.

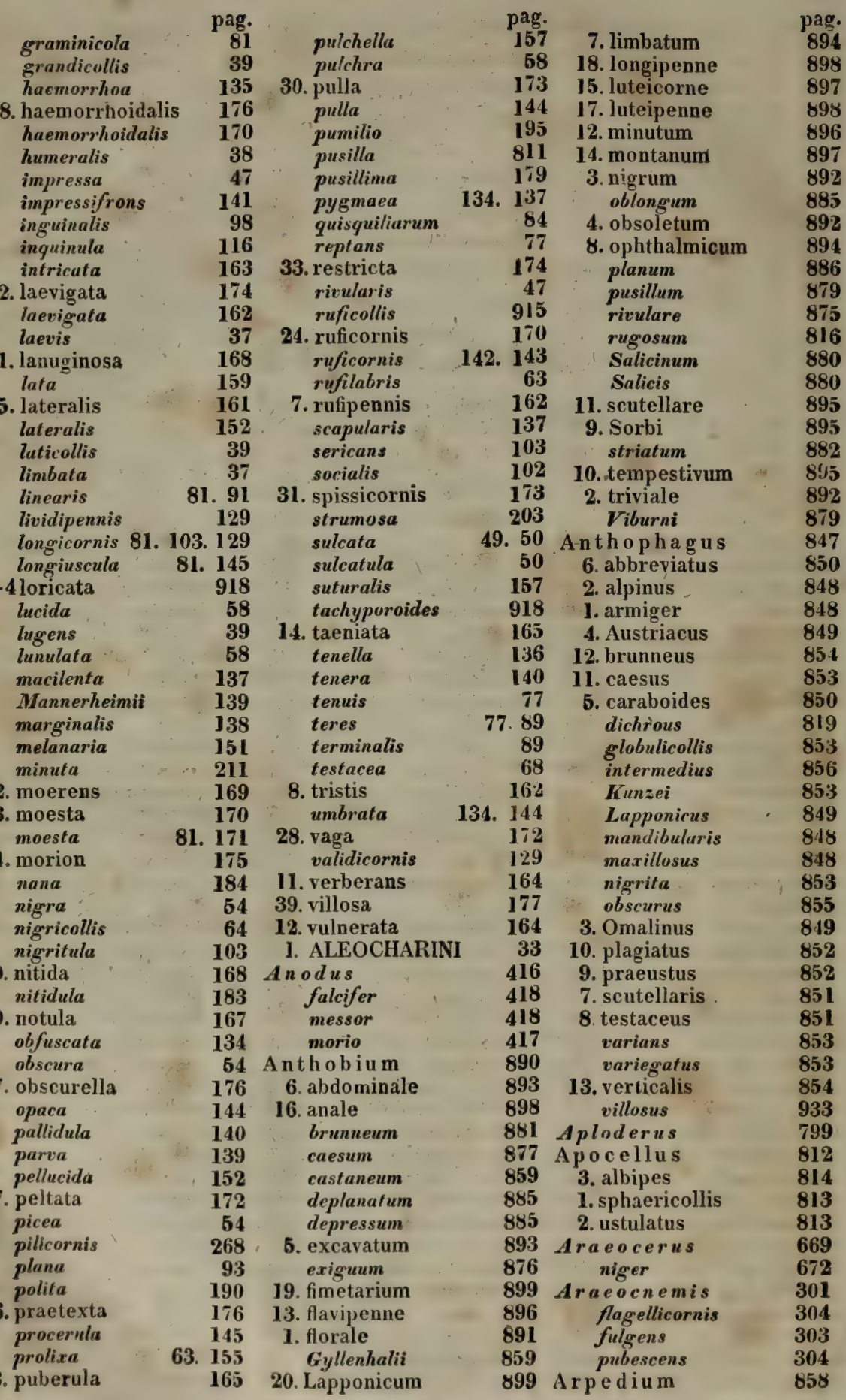




\begin{tabular}{|c|c|c|c|c|c|}
\hline 2. brachypterum & ${ }_{859}^{\text {pag. }}$ & 2f. opacus & $\begin{array}{c}\text { pag. } \\
771\end{array}$ & carbonaria & pag. \\
\hline 3. humile & 860 & 40. pallipennis & 779 & castanoptera & 103 \\
\hline 1. quadrum & 858 & 23. pallipes & 772 & cincta & 59 \\
\hline 4. Sibiricum & 860 & pallipes & 767 & cinnamomea & 127 \\
\hline Astenus & 637 & 29. parvulus & 775 & circellaris & 98 \\
\hline angustatus & 640 & 11. politus & 766 & collaris & 43 \\
\hline procerus & 638 & 16. procerulus & 768 & complana & 90 \\
\hline Astilbus & 36 & 30. pumilio & 775 & compressa & 136 \\
\hline Astrapaeus & 552 & 26. pusillus & 773 & crassicornis & 135 \\
\hline rufipes & 415 & 27. pygmaeus & 774 & depressa & 99 \\
\hline 1. Ulini & 553 & 9. rubiginosus & 765 & depressiuscula & 90 \\
\hline Clmineus & 5.53 & Rudddii & 761 & evanescens & 114 \\
\hline Atemeles & 202 & 19. rufipennis & 770 & excavata & 110 \\
\hline Autalia & 46 & Skrimshiri & 761 & exilis & 90 \\
\hline 1.impressa & 47 & 35. subterraneus & 777 & flavipes & 124 \\
\hline 2. rivularis & 47 & 33. talpa & 777 & forticornis & 65 \\
\hline Belonuchus & 419 & 1. taurus & 760 & fracticornis & 81 \\
\hline 8. agilis & 423 & 6. tricornis & 763 & funesta & 38 \\
\hline 9. avidus & 423 & 28. troglodytes & 774 & fungi & 131. 132 \\
\hline 15. connexus & 927 & 39. tuberculatus & 779 & fuscula & 133 \\
\hline 2. dichrous & 420 & 7. unicornis & 764 & haemorrhoa & $1: 1$ \\
\hline 14. ephippiatus & 927 & 31. verres & 776 & humeralis & 36 \\
\hline 13. formosus & 426 & 2. vitulus & 761 & impressifrons & 141 \\
\hline 9. gagates & 424 & Boletobius & 268 & inguinalis & 98 \\
\hline 1. haemorrhoidalis & 420 & 1. analis & 269 & limbata & 37 \\
\hline 6. latro & 422 & 14. atricapillus & 276 & linearis & 81 \\
\hline 10. $\operatorname{minax}$ & 424 & 10. axillaris & 274 & longiuscula & 81. 91 \\
\hline 5. mordens & 422 & 9. bicolor & 274 & 1. lucida & 58 \\
\hline 12. mundus & 425 & 7. cernuus & 272 & 2. lunulata & 58 \\
\hline 13. planiceps & 425 & 24. cincticollis & $9: 2$ & luridipennis & 136 \\
\hline 3. Satyrus & 421 & 17. cinctus & 278 & minutissima & 134 \\
\hline 4. Xanthopterus & 121 & 2. cingulatus & 270 & nigriceps & 100 \\
\hline Bisnius & 427 & 13. dimidiatus & 276 & nigricollis & 64 \\
\hline Bledius. & 760 & 20. exoletus & 280 & nigritula & 103 \\
\hline 12. aquarius & 766 & 4. formosus & 271 & 3. obliqua & 59 \\
\hline 35. arenarius & 778 & 3. inclinans & 271 & oblonga & 90 \\
\hline 41. armatus & 779 & 16. lunulatus & 278 & pallıdula & 140 \\
\hline 24. atricapillus & 773 & merdarius & 272. 281 & parvula & 13.9 \\
\hline 3. bicornis & 762 & 11. niger & 275 & patruelis & 132 \\
\hline 38. brunnipennis & 779 & 5. obscurus & 272 & planiuscula & 90 \\
\hline castaneipennis & 771 & 23. obsoletus & 922 & prolixa & 63 \\
\hline 42. cordatus & 780 & 22. pulchellus & 281 & pulchra & 58 \\
\hline 20.crassicollis & 770 & 21. pygmaeus & 280 & pumilio & 195 \\
\hline 36. debilis & 778 & 8. rufus & 273 & quisquiliarum & 84 \\
\hline 18. dissimilis & 769 & atus & 272 & reptans & 77 \\
\hline 37. elongatus & 779 & 15. speciosus & 277 & sericans & 103 \\
\hline 45. emarginatus & 780 & 12. striatus & 275 & socialis & 102 \\
\hline 22. erraticus & 772 & 18. trimaculatus & 279 & tenella & 136 \\
\hline 43. fasciatus & 780 & 19. trinotatus & 279 & teres & 89. 114 \\
\hline 14. femoralis & 268 & Bolitochara & 57 & terminalis & 89 \\
\hline 13. fracticornis & 767 & agaricola & 132 & validicornis & 129 \\
\hline 4. hinnulus & 762 & analis & 114 & 4. varia & 59 \\
\hline 5. iuv & 763 & angustula & 91 & Boreaphilus & 899 \\
\hline 10. lateralis & 766 & annularis & 135 & 1. Henningianus & 899 \\
\hline 11. longulus & 768 & atra & 73 & Brachydirus & 353 \\
\hline 8. mandibularis & 765 & atramentaria & 111 & xunthocerus & 353 \\
\hline 44. melanocephalus & 780 & atrata & 198 & Bryochuris & 268 \\
\hline 25. nanus & 773 & at errima & 104 & analis & 270 \\
\hline 17. nigricans & 769 & bifoveolata & 115 & Cafius & 294. 427 \\
\hline 32. Niloticus & 776 & Boleti & 103. 109 & apicalis & 426 \\
\hline
\end{tabular}


Index nominum.

\begin{tabular}{|c|c|c|c|c|c|}
\hline aterrimus & $\begin{array}{l}\text { pag. } \\
492\end{array}$ & 4. pubescens & $\begin{array}{l}\text { pag. } \\
221\end{array}$ & Deliphrum & $\begin{array}{l}\text { pag. } \\
872\end{array}$ \\
\hline fucicola & 454 & 6. tumidus & 223 & 4. algidum & 874 \\
\hline fulminans & 295 & 12. varians & 227 & 5. angustatum & 874 \\
\hline nunus & 479 & 13. venustulus & 227 & 3. areticum & 873 \\
\hline nigritulus & 492 & COPROPHILINI & 814 & 2. crenatum & 873 \\
\hline pumilus & 492 & Coprophilus & 815 & 1. tectum & 873 \\
\hline splendidulus & 478 & rugosus & 816 & Dermestes & \\
\hline xantholoma & 452 & 1. striatulus & 816 & brachypterus & 903 \\
\hline Callicerus & 85 & Cordylaspis & 311 & semicoleoptratus & 893 \\
\hline hybridus & 85 & 1. pilosus & 312 & Dianous & 688 \\
\hline obscurus & 84 & tuberculatus & 342 & 1. coerulescens & 689 \\
\hline Spencei & 84 & Coryphium & 900 & Diglossa & 208 \\
\hline Calodera & 61 & Creophilus & 347 & 1. mersa & 209 \\
\hline 10. aethiops & 68 & badiipennis & 400 & Dinarda & 200 \\
\hline 2. forticornis & 65 & chloris & 401 & 1. dentata & 201 \\
\hline 4. humilis & 65 & ciliaris & 351 & Diochus & 300 \\
\hline 5. longitarsis & 66 & Erithacus & 401 & 1. nanus & 301 \\
\hline 1. nigricollis & 64 & erythrocephalus & 351 & Dolicaon & 576 \\
\hline 3. nigrita & 65 & fasciatus & 349 & 5. biguttulus & 578 \\
\hline 12. protensa & 69 & maxillosus & 348 & 4. gracilis & 578 \\
\hline 9. riparia & 68 & oculatus & 352 & 3. haemorrhous & 577 \\
\hline 7. rubens & 67 & variegatus & 351 & 2. Illyricus & 577 \\
\hline 6. rubicunda & 66 & villosus & 349 & 1. Lathrobioides & 576 \\
\hline testacea & 68 & Cryptobium & 561 & Drusillu & 35 \\
\hline 8. uliginosa & 66 & 26. agile & 575 & canaliculata & 36 \\
\hline 11. umbrosa & 69 & 8. albipes & 566 & exarata & 72 \\
\hline Carabus & & 10. antiquum & 567 & Echiaster & 636 \\
\hline abbreviatus & 850 & 17. assimile & 570 & 1. longicollis & 637 \\
\hline dimidiatus & 856 & 1. badium & 562 & 2. melanurus & 637 \\
\hline Staphylinoides & 856 & 3. bicolor & 563 & Eleusis & 836 \\
\hline Caranistes & 925 & 20. brevicorne & 572 & tibialis & 836 \\
\hline 1. Westermanni & 925 & 2. Carolinum & 563 & Emus & 346 \\
\hline Carpalimus & 801 & 21. curticorne & 572 & aeneicollis & 413 \\
\hline bilineatus & 806 & 22. curtum & 572 & aeneocephulus & 412 \\
\hline Cateretes & & 12. dispar & 568 & angustatus & 417 \\
\hline brachypterus & 903 & 7. fasciatum & 563 & attenuatus & 543 \\
\hline Centroglossa & 209 & 11. femorale & 567 & boops & 548 \\
\hline sttenuata & 919 & 27. fracticorne & 575 & brunnipes & 410 \\
\hline conurvides & 210 & 9. fulvipes & 566 & Carinthiacus & 381 \\
\hline minuta & 919 & 15. geniculatum & 569 & chalcocephalus & 412 \\
\hline Chasolium & 838 & 14. latebricola & 569 & chloropterus & 373 \\
\hline Ernestini & 838 & 6. longipenne & 565 & chrysocephalus & 371 \\
\hline Cillaeus & 7 & 4. melanocephalum & 564 & cyaneus & 405 \\
\hline Conurus & 218 & 23. obscurum & 573 & erythropterus & 378 \\
\hline 3. australis & 221 & 18. ochropus & 571 & floralis & 526 \\
\hline 9. basalis & 225 & 13. pallipes & 578 & fossor & 377 \\
\hline 8. binotatus & 224 & 5. prolixum & 564 & fuscatus & 417 \\
\hline 19. bipunctatus & 230 & 25. pulchellum & 574 & fuscomaculatus & 376 \\
\hline 7. bipustulatus & 223 & 24. scitum & 574 & hirtus & 346 \\
\hline (11) cinctulus & 226 & 16. similipenne & 570 & impressus & 530 \\
\hline 5. crassus & 222 & 19. sulphuripes & 571 & inauratus & 363 \\
\hline 15. fumatus & 228 & Cuсиius. & & laevigutus & 529 \\
\hline 16. fusculus & 229 & maxillosus & 825 & lateralis. & 525 \\
\hline 2. grossus & 220 & spinosus & 832 & marginalis & 361 \\
\hline 10. interruptus & 225 & Сурһа & 214 & maxillosus & 348 \\
\hline 1. littoreus & 219 & biguttata & 919 & molochinus & 535 \\
\hline 17. lividus & 229 & Deinopsis & 919 & morio & 417 \\
\hline 14. obsoletus & 228 & fuscatus & 919 & murinus & 362 \\
\hline 11.' opicus & 919 & Deleaster & 818 & nebulosus & 373 \\
\hline 18. pedicularius & $2: 30$ & 1. dichrous & 819 & nigripes & 416 \\
\hline
\end{tabular}




\begin{tabular}{|c|c|c|c|c|c|}
\hline & pag. & & pag. & & pag. \\
\hline $\begin{array}{l}\text { nitidus } \\
\text { occultus }\end{array}$ & $\begin{array}{l}526 \\
526\end{array}$ & $\begin{array}{l}\text { 10. thoracica } \\
20 \text {. venustula }\end{array}$ & $\begin{array}{l}52 \\
55\end{array}$ & $\begin{array}{l}\text { 8. dispar } \\
\text { 7. dissimilis }\end{array}$ & \\
\hline $\begin{array}{l}\text { occultus } \\
\text { olens }\end{array}$ & $\begin{array}{l}526 \\
405\end{array}$ & $\begin{array}{l}\text { 20. venustula } \\
\text { Gabrius }\end{array}$ & $\begin{array}{r}55 \\
427\end{array}$ & $\begin{array}{l}\text { 7. dissimilis } \\
\text { 11. flaveola }\end{array}$ & $\begin{array}{l}186 \\
188\end{array}$ \\
\hline $\begin{array}{l}\text { olens } \\
\text { picipennis }\end{array}$ & $\begin{array}{l}405 \\
413\end{array}$ & $\begin{array}{l}\text { Gabrius } \\
\text { Glyptoma }\end{array}$ & 908 & $\begin{array}{l}\text { 11. flaveola } \\
\text { 5. gentilis }\end{array}$ & $\begin{array}{l}188 \\
185\end{array}$ \\
\hline $\begin{array}{l}\text { picipennis } \\
\text { praecox }\end{array}$ & 542 & 2. corticinum & 909 & 10. lucidula & 187 \\
\hline pubescens & 372 & 3. costale & 909 & 15. manca & 190 \\
\hline rufipalpis & 418 & 1. crassicorne & 908 & 19. minima & 192 \\
\hline rufipes & 415 & 4. denticolle & 910 & 3. nana & 184 \\
\hline scintillans & 546 & 5. exile & 910 & nana & 185 \\
\hline similis & 409 & 6. sculptile & 911 & 2. nitidula & 183 \\
\hline speciosus & 360 & Goerius & 404 & nitidula & 184 \\
\hline stercorarius & 380 & Goniodes & 202 & 16. polita & 190 \\
\hline subuliformis & 516 & Gymnurus & 679 & 14. socia & 189 \\
\hline tristis & 537 & cyanescens & 680 & 12. splendidula & 188 \\
\hline vicinus & 552 & vestitus & 680 & 17. strictula & 191 \\
\hline Encephalus & 183 & Gymnusa & 211 & 6. vinula & 186 \\
\hline complicans & 183 & 1. brevicollis & 212 & Habrocerus & 242 \\
\hline Eristethus. & 746 & dubia & 210 & 1. capillaricornis & 243 \\
\hline ruficapillus & 747 & 2. fuscata & 919 & Haematodes & 340 \\
\hline scaber & 746 & (2.) laticollis & 212 & 1. bicolor & 340 \\
\hline Euaesthetus & 746 & Gyrohypnus & 306 & Hesperophilus & 760 \\
\hline 3. Americanus & 746 & alternans & 297 & Heterothops & 515 \\
\hline 4. immarginatus & 748 & analis & 314 & 2. binotatus = & 516 \\
\hline 2. ruficapillus & 747 & assimilis & 924 & 3. dissimilis & 517 \\
\hline 1. scaber & 746 & aterrimus & 492 & 5. exilis & 518 \\
\hline Eulissus & 306 & batychrus & 335 & 6. nitens & 518 \\
\hline ater & 318 & consentaneus & 326 & 1. praevius & 516 \\
\hline chalybaeus & 309 & flavipennis & 326 & 4. 4-punctulus & 517 \\
\hline Mannerheimii & 310 & fulminans & 295 & Holisus & 298 \\
\hline Eury porus & 553 & glaber & 325 & 2. analis & $29 !$ \\
\hline 1. picipes & 554 & glabratus & 319 & 3. debilis & $29 !$ \\
\hline 2. puncticollis & 554 & lentus & 326 & 4. Guildingii & 300 \\
\hline Euryusa & 199 & linearis & 335 & 1. humilis & 299 \\
\hline 1. sinuata & 199 & longiceps & 332 & Holotrochus & 757 \\
\hline Falagria & 48 & macrocephalus & 297 & 3. crassicollis & 758 \\
\hline 21. albicincta & 56 & melanocephalus & 296 & 2. cylindrus & 758 \\
\hline 23. albofasciata & 56 & merdarius & 319 & 1. volvulus & 758 \\
\hline caesa & 49 & meridionalis & 323 & Homalota & \\
\hline 7. concinna & 51 & nanus & 479 & 42. aemula & 10 \\
\hline 22. deliciata & 56 & nigriceps & 297 & 20. aequata & 9 \\
\hline 4. discisa & 50 & nigritulus & 492 & 84. alternata & 119 \\
\hline 11. discreta & 53 & ochraceus & 328 & 118. ambigua & 1: \\
\hline 2. dissecta & 49 & ochropterus & 320 & 70. analis & 11 \\
\hline 6. divisa & 51 & parumpunctatus & 335 & 99. anceps & 12 \\
\hline 12. fissula & 53 & pilicornis & 296 & 122. angustata & $1: 36$ \\
\hline 17. gratilla & 54 & procerulus & 511 & 19. angustula & \\
\hline lineolata & 52 & punctulutus & 328 & 120. annularis & 13 \\
\hline 19. munda & 55 & pyropterus & 319 & 22. arcana & \\
\hline 18. naevula & 55 & relucens & 319 & 117. aterrima & 13: \\
\hline 16. nigra & 54 & splendidulus & 479 & 62. atramentaria & 11 \\
\hline 15. obscura & 54 & tenuicurnis & 338 & 89. atratula & 12 \\
\hline 9. percisa & 52 & tricolor & 332 & 117. atricilla & 10 \\
\hline picea & 54 & xantholomu & 452 & 66. autummalis & 1 \\
\hline polita & 50 & Gyrophaena & 182 & 76. bisulcata & 11 \\
\hline 5. scissa & 50 & 4. affinis & 184 & 128, borealis & 13 \\
\hline 14. soluta & 53 & amabilis & 185 & 27. brevicornis & \\
\hline 8. stricta & 51 & 18. Boleti & 191 & 36. brunnea & 9 \\
\hline 1. sulcata & 49 & 1. complicans & 183 & 33. caesula & g \\
\hline sulcata & 50 & 9. congrua & 187 & 7. callicera & 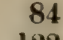 \\
\hline 3. sulcatula & 50 & I3. corruscula & 189 & 91. cauta & 1 \\
\hline
\end{tabular}


Index nominum.

\begin{tabular}{|c|c|c|c|c|c|}
\hline 92. celata & pag. & 50. marcida & pag. & 2. discoideus & $\begin{array}{l}\text { pag. } \\
216\end{array}$ \\
\hline 88. cinctella & 121 & 129. marginalis & 138 & favicornis & 181 \\
\hline 104. cinnamomea & 127 & 78. melanura & 117 & globulus & 215 \\
\hline 34. circellaris & 98 & 21 nigella & 92 & granulum & 215 \\
\hline 68. clancula & 114 & 38. nigrifrons & 100 & 3. laeviusculus & 216 \\
\hline 115. clientula & 133 & 83. nigripennis & 119 & 1. longicornis & 215 \\
\hline 100 concolor & 126 & 101. notha & 126 & 5. pulicarius & 217 \\
\hline 54. conformis & 108 & 67. oblita & 113 & 4. seminulum & 217 \\
\hline 119. crassicornis. & 134 & 40. oblonga & 101 & Hypotelus & 840 \\
\hline 81. curticollis & 118 & 80. obsoleta & 118 & 2. praecox & 341 \\
\hline 30. cuspidata & 96 & 4. occulta & 83 & 1. pusillus & 841 \\
\hline 11. debilicornis & 87 & 45. ochracea & 104 & Ino & 8 \\
\hline 24. debilis & 94 & 114. orbata & $1: 32$ & Ischnopoda & it \\
\hline 82. decipula & 119 & 116. orphana & 133 & Ischnosoma & 281 \\
\hline 60. deplanata & 110 & 108-9. paedida & 917 & Isomalus & $8: 38$ \\
\hline 37. depressa & 99 & 5. pagana & 83 & 4. bicolor & 839 \\
\hline 52. dichroa & 107 & 72. palleola & 115 & 1. complanatus & 839 \\
\hline 75. didyma & 116 & 132. pallidula & 140 & 2. humilis & 839 \\
\hline dimidiata & 80 & 131. parva & 139 & 3. interruptus & 839 \\
\hline 106. discors & 128 & 8. pavens & 85 & 5. testaceus & 840 \\
\hline 17, elongatula & 89 & 49. picta & 106 & Lathrimaeum & 869 \\
\hline 59. excavata & 110 & 23. plana & 93 & 3. atrocephalum & 870 \\
\hline 71. exilis & 115 & plana & 96 & 6. canaliculatum & 871 \\
\hline 90. fervidula & 121 & 35. procidua & 98 & 4. fusculum & 870 \\
\hline 63. festinans & 112 & 53. propinqua & 108 & 2. luteum & 869 \\
\hline 79. flavipennis & 118 & pulicaria & 122 & 1. melanocephalum & 869 \\
\hline 97. flavipes & 124 & quisquiliarum & 85 & 5. sordidum & 871 \\
\hline 112. fungi & 131 & 13. ravilla & 88 & Lathrobium & 588 \\
\hline 126. fusca & 137 & 93. recondita & 123 & 13. angustatum & 596 \\
\hline 65. gemina & 112 & 3. rigidicornis & 82 & 7. angusticolle & 593 \\
\hline 25. gracilenta & 94 & 110. rubicula & 130 & 28. armatum & 603 \\
\hline 10. gracilicornis & 86 & 127. scapularis & 137 & badium & 562 \\
\hline 1. graminicola & 81 & 56. semilutea & 109 & 8. bicolor & 593 \\
\hline 12. gregaria & 87 & 85. seminigra & 120 & bicolor & 563 \\
\hline 121. haemorrhoa & 135 & 105. semirufa & 128 & biguttulum & 578 \\
\hline 41. hepatica & 102 & sericans & 103 & 30. brevicorne & 604 \\
\hline 102. hirta & 126 & 87. silacea & 120 & 1. brunnipes & 588 \\
\hline 28. illota & 95 & 43. socialis & 102 & castaneum & 596 \\
\hline 31. immersa & 96 & 44. sodalis & 104 & cinctum & 569 \\
\hline 103. importuna & $127^{\prime}$ & 95. sordidula & 123 & 20. collare & 599 \\
\hline 134. impressifrons & 141 & 51. spelaea & 107 & confluentum & 615 \\
\hline 58. incana & 109 & 86. stigma & 120 & depressum & 582 \\
\hline 73. inconspicua & 116 & 94. subida & 123 & 25. dilutum & 602 \\
\hline 74. inquinula & 116 & 98. subsinuata & 125 & 18. dimidiatum & 598 \\
\hline 29. intrusa & 96 & 123. tenella & 136 & 17. discolor & 598 \\
\hline 14. labilis & 88 & 140. tenera & 140 & 24. dividuum & 601 \\
\hline 57. laesicollis & 109 & 109. terminata & 130 & 2. elongatum & 589 \\
\hline 9. languida & 86 & 111. testudinea & 131 & elongafum & 590 \\
\hline 18. linearis & 91 & 46. trimaculata & 105 & 22. filiforme & 601 \\
\hline livida & 129 & 2. umbonata & 82 & fracticorne & 575 \\
\hline 108. lividipennis & 129 & 77. ustulata & 117 & 3. fulvipenne & 590 \\
\hline 107. longicornis & 129 & 48. varia & 106 & gracile & 578 \\
\hline 47. lunata & 105 & 15. velata & 88 & Gravenhorstii & 568 \\
\hline 55. lurida & 108 & 113. vernacula & 131 & humile & 586 \\
\hline 124. luridipennis & 136 & 64. vestigialis & 112 & 10. labile & 594 \\
\hline 96. luteicornis & 124 & 6. vestita & 84 & laevigatum & 605 \\
\hline 16. luteipes & 89 & 61. viduata & 111 & latipes & 674 \\
\hline 69. luteola & 114 & 32. vilis & 97 & lineare 592.601$)$. & 601 \\
\hline 26. macella & 93 & Hygronoma & 79 & 16. longiusculum & 5.97 \\
\hline 125. macilenta & 137 & 1. dimidiata & 80 & 26. longulum & 602 \\
\hline 130. Mannerheimii & 139 & Hyросурtus & 214 & 15. Lusitanicum & 597 \\
\hline
\end{tabular}




millepunctatum
minimum
minutum

5. multipunctum

19. nitidum obsoletum

23. pallidum pallipes

I4. pectorale phoenicurum

9. picipes pilosum politum

21. punctatum

29. puncticolle punctulatum

11. quadratum rufescens ruficorne

4. rufipenne rufiventre

27. scabricolle

12. scutellare similipenne

6. spadiceum sphaericolle

26-27. stilicinum striatum terminatum

Leistotrophus Gravenhorstii

Leptacinus

4. batychrus

1. brevicornis

8. clavicornis

6. debilis

2. filarius

9. nothus

3. parumpunctatus

7. subtilis

5. tenellus

10. tenuicornis

Leptoch irus

8. bispinus

7. brevicornis brunneo-niger Cayennensis convexus

6. ebeninus

9. Javanicus

4. laticeps

1. maxillosus

3. Mexicanus

2. scoriaceus

5. unicolor

Lesteua

$$
\text { alpina }
$$

1. bicolor bimaculata pag.

$61 !$

607

602

591

599

623

601

568

596

580

594

595

596

600

604

591

595

619

614

591

613

603

596

570

592

813

932

585

595

358

359

333

335

334

337

336

334

338

335

337

336

338

825

827

827

825

825

827

826

829

826

825

826

825

826

855

848. 849

850

855

852 pag.

caraboides $\quad 850.851$ dichroa Aavipennis globulicollis

Lapponica

Leachii

longipes

6 . longula

3. maura

obscura

plagiata praeusta

2. pubescens

5. punctata punctulata

4. Sicula . suturalis testacea

Lispinus

4. angustatus

1. attenuatus

7. exiguus

2. laticollis

5. linearis

3. striola

6. tenellus

Lithocharis

8. angularis bicolor

13. biseriata

3. brunnea

1. castanea

19. cinnamomea

10. confluens

17. corticina

15. curtula

27. debilis

12. depressa

4. diluta

11. dorsalis

30. exilis

6. ferruginea

21. fumata

2. fuscula

18. hepatica

22. infuscata

20. limbata

9. macularis

7. melanocephala

26. nigritula

14. oblita

25. obscurella

24. obsoleta

23. ochracea

16. posticata

5. rufiventris

29. sordida

testacea

Lom echus a

dentata
819
849

853

849

819

853

857

856

856

852

852

856

857. 933

855

8.7

852

850. 851

828

829

828

830

828

829

829

830

610

614

614

617

612

610

620

615

619

618

625

616

612

616

627

613

622

611

620

622

621

615

614

625

618

624

623

623

619

613

626

623

202

201

3. emarginata

4. inflata

2. paradoxa

1. strumosa

Medon

Ruddii

Megacronus

elegans

formosus

MEGALOPINI

egalops

1. caelatus

3. cephalotes

2. punctatus

Megarthrus clypeatus

3. denticollis

1. depressus

4. hemipterus

marginicollis rufescens

2. sinuatocollis

Micraly m ma

1. brevipenne

Johnstonis

pag.

204

205

202

208

610

611

268

922

271

750

751

751

752

752

904

907

906

905

906

906

906

905

819 


\begin{tabular}{|c|c|c|c|c|c|c|}
\hline 17. collaris & $\begin{array}{r}\text { pag. } \\
43\end{array}$ & 1. Paederinus & $\begin{array}{l}\text { pag. } \\
685\end{array}$ & 21. lineare & & pag. \\
\hline 19. coriacea & 43 & Oligota & 179 & 14. lucidum & & 881 \\
\hline 15. frontalis & 42 & 6. apicata & 182 & 33. luridum & & 889 \\
\hline 8. fulgida & 40 & 2. atomaria & 180 & macropterum & 903. & 905 \\
\hline 5. funesta & 38 & 5. flavicornis & 181 & mandibulare & & 117 \\
\hline 4. humeralis & 38 & 4. granaria & 181 & 34. marginatum & & 90 \\
\hline 23. inscita & 45 & 1. pusillima & 179 & megacephalum & & 344 \\
\hline 21. labida & 14 & 3. subtilis & 180 & melanocephalum & & 70 \\
\hline 3. limbata & 37 & Olisthaerus & 843 & 8. minimum & & 78 \\
\hline 7. lugens & 39 & 1. megacephalus & 843 & 2. monilicorne & & 376 \\
\hline 9. marginicollis & 40 & 2. substriatus & 844 & 11. nigrum & & 880 \\
\hline 22. munda & 44 & Olophrum & 863 & ophthalmicum & 894. & 895 \\
\hline 10. obscura & 41.915 & 7. alpestre & 867 & ovatum & & 903 \\
\hline 18. ochracea & 43 & 4. assimile & 865 & 4. Oxyacanthae & & 377 \\
\hline 25. parilis & 45 & 5. boreale & 866 & Oxyacanthae & & 875 \\
\hline 2. plicata & 36 & 8. consimile & 867 & pallidum & & 894 \\
\hline 6. rigida & 39 & 9. emarginatum & 868 & 27. pedicularium & & 887 \\
\hline 13. speciosa & 42 & 3. fuscum & 865 & 26. philanthus & & 887 \\
\hline 11. spinigera & 41 & 2. obtectum & 865 & piceum & & 864 \\
\hline 26. tumidula & 46 & 1. piceum & 864 & 25. planum & & 886 \\
\hline 24. turbida & 45 & 6. rotundicolle & 866 & porcatum & & 911 \\
\hline Nitidula & & X. OMALINI & 846 & 31. pubescens & & 889 \\
\hline porcata & 911 & Omalium & 874 & 9. pusillum & & 879 \\
\hline Staphylinoides & 913 & abdominale & 893 & 17. pygmaeum & & 883 \\
\hline sulcata & 911 & aeneum & 821 & pygmaeum & & 885 \\
\hline Ocalea & 60 & 32. alpinum & 889 & quadratum & & 862 \\
\hline 2. badia & 61 & assimile & 865 & quadrum & 858. & 862 \\
\hline 1. castanea & 60 & atrocephalum & 870 & Ranunculi & & 896 \\
\hline 6. decumana & 62 & boreale & 866 & 7. repandum & & 878 \\
\hline 5. murina & 62 & brachypterum & 859. 903 & 1. rivulare & & 875 \\
\hline 4. procera & 61 & 20. brevicorne & 884 & rotundicolle & 866. & 868 \\
\hline 7. prolixa & 13 & brevipenne & 820 & 19. rufulum & & 883 \\
\hline 8. rufilabris & 63 & 13. brunneum & 881 & rufum & 861. & 862 \\
\hline 3. spadicea & 61 & brunneum & 881.885 & rugosum & & 816 \\
\hline Ocypus. & 403 & 6. caesum & 878 & Salicinum & & 880 \\
\hline 8. Aethiops & $9 \cdot 27$ & caesum & 877 & 12. Salicis & & 880 \\
\hline 6. alpestris & 408 & castaneum & 861 & Sibiricum & & 860 \\
\hline 11. alpicola & 411 & 24. concinnum & $8 \$ 6$ & Sorbi & & 895 \\
\hline 18. ater & 416 & consimile & 867 & Staphylinoides & & 913 \\
\hline 10:brunnipes & 410 & crenatum & 861.873 & 16. striatum & & 882 \\
\hline 20. cerdo & 417 & 35. cursor & 890 & substriatum & & 844 \\
\hline pressus & 418 & denticolle & 907 & tectum & & 872 \\
\hline 14. cupreus & 412 & 23. deplanatum & 885 & 22. testaceum & & 885 \\
\hline 2. $c$ & 405 & deplanatum & 885 & testaceum & & 895 \\
\hline 22.falcifer & 418 & depressum 885. & .905 .907 & Viburni & & 879 \\
\hline 15. fulvipennis & 413 & 3. exiguum & 876 & 15. vile & & 882 \\
\hline 12. fus & 411 & 29. Fahraei & 888 & Ophites & & 627 \\
\hline 3. Italicus & 406 & 30. fenestrale & 888 & 2. Raphidioides & & 628 \\
\hline 4. macrocephalus & 407 & fimetarium & 899 & 3 velitaris & & 629 \\
\hline (8) masculus & 409 & 10. florale & 879 & 1. versatilis & & $6 \cdot 28$ \\
\hline ephalus & 407 & flo & 891 & OSOR & & 753 \\
\hline 19. morio & 417 & 5. fossulatum & 877 & Osorius & & 753 \\
\hline 1. olens & 405 & fuscum & 865 & 1. ater & & 754 \\
\hline 17. pedator & 415 & Gyllenhalii & 859 & 3. Brasiliensis & & 753 \\
\hline 13. pir & 412 & impressum & 859 & nicornis & & 757 \\
\hline 9. picipes & 409 & incisum & 875 & 7. cylindricus & & 756 \\
\hline scabrosus & 927 & 18. inflatum & 883 & 5. incisicrurus & & 755 \\
\hline 7. similis & 408 & laeve & 872 & 2. intermedius & & 754 \\
\hline 16. $\mathrm{T}$ & 414 & 28. lae & 887 & 8. la & & 757 \\
\hline Oedichirus & 684 & 20. Lapponicum & 899 & 4. piceus & & 755 \\
\hline
\end{tabular}




\begin{tabular}{|c|c|c|c|c|c|c|c|c|}
\hline 6. rugifrons & & $\begin{array}{l}\text { pag. } \\
756\end{array}$ & brunneus & & pag. & furcatus & & 761 \\
\hline Othius & & 294 & caelatus & & 751 & 11. incolumis & & 791 \\
\hline 1. fulvipennis & & 295 & cellaris & & 219 & 2. insectatus & & \\
\hline 5. macrocephalu & & 297 & chrysomelinus & & $2 ? 6$ & 15. insignitus & & \\
\hline 2. melanocephal & & 295 & cinctus & & 558 & 17. intricatus & & \\
\hline 4. pilicornis & & 296 & erythropterus & & 234 & 10. inustus & & \\
\hline 3. punctipennis & & 296 & 5. iemoralis & & 558 & laesus & & 81 \\
\hline Oxypoda & & 141 & flavipes & & 255 & latipes & & \\
\hline 10. abdominalis & & 146 & hypnorum & & 234 & longicornis & & \\
\hline 7 alternans & & 145 & 7. lateralis & & 559 & 12. luteipennis & & \\
\hline 28. amicta & & 154 & lunulatus & & 278 & 14. Madagascarien & nsis & \\
\hline 29. analis & & 154 & 4. maior & & 557 & melanocephalus & & \\
\hline 26 cingulata & & 153 & 3. Mannerheimii & & 557 & 24. minimus & & \\
\hline $21-22$ cortractul & & 917 & marginatus & 235. & 259 & minimus & & \\
\hline 27. corticina & & 153 & marginellus & & 263 & $\operatorname{mordax}$ & & \\
\hline 19 cunetans & & 150 & 2. maxillosus & & 556 & morsitan & & \\
\hline [7. cuniculina & & 149 & melanocephalus & & 236 & 22. nanus & & \\
\hline 21. $\mathrm{ct}$ & & 151 & merdarius & 236. & 284 & nit & & \\
\hline ntula & & 158 & $\min$ & & 235 & 18. nit & & \\
\hline 18. $\mathrm{e}$ & & 150 & picipes & & 554 & nodifrons & & \\
\hline 16. exoleta & & 149 & naeus & & 281 & pallipennis & & \\
\hline 13. ferr & & 147 & ruf & & 254 & pallipes & 767. & 77 \\
\hline $33 \mathrm{ft}$ & & 156 & 1. ruf & & 556 & pedicellus & & \\
\hline 30. & & 154 & Schönherri & & 556 & 13. Pensylvanicus & & \\
\hline 12 helv & & 147 & 8. stygicus & & 558 & 4. pic & & \\
\hline 24. 1 & & 152 & aneus & & 259 & 16. $\mathrm{pc}$ & & 7 \\
\hline 20.1 & & 150 & sut & & 245 & & & \\
\hline i & & 129 & tes & & 221 & 21. pur & & 79 \\
\hline 6. lon & & 144 & tho & & 281 & pus & & 9 \\
\hline 2. lut & & 143 & $3-i$ & & 279 & 1. ru & & 8 \\
\hline lute & & 142 & 6. vitt & & 558 & us. & & 79 \\
\hline 34. ma & & 156 & VII. OX & & 749 & uratus & & -10 \\
\hline 22. $\mathrm{m}$ & & 151 & O. GEI & & 759 & 5. sculptus & & 78 \\
\hline obfu & 132. & 134 & Oxyt & & 785 & talpa & & 77 \\
\hline 4. орая & & 144 & anus & & 793 & tat & & $-\infty$ \\
\hline 23. $\mathrm{p}$ & & 152 & are & & 778 & stris & & 78 \\
\hline 15. & & 148 & & & 779 & tri & & 76 \\
\hline & & 145 & nus & & 933 & uni & & \\
\hline 31. $\mathrm{p}$ & & 155 & & & 773 & V. PAEDERINI & & \\
\hline 15. 1 & & 8 & 6. $B$ & & 789 & Paede & & 64 \\
\hline & & 13 & bis & & 933 & octialis & & 6.5 \\
\hline 36. ] & & 57 & bic & & 831 & 10. ae & & 65 \\
\hline 32.1 & & 155 & & & 800 & fatus & & 6 \\
\hline 1. 1 & & 142 & 8. $\mathrm{C}$ & & 790 & 37. au & 666. & $9:$ \\
\hline 9. & & 1 & & 786. & 787 & bic & & 61 \\
\hline 25. & & 153 & 7. $\mathrm{co}$ & & 789 & bigultatus & 690. & 73 \\
\hline & & 176 & anatus & & 795 & bin & & 61 \\
\hline 35. & & & & & & 16. $\mathrm{Br}$ & & \\
\hline & & 145 & $c$ & & 782 & 2. $\mathrm{br}$ & & \\
\hline & & 144 & & 806. & 809 & brunnipès & & $F$ \\
\hline OXYH & & 522 & 20. dep & & 796 & 6. cali & & \\
\hline $0 x y$ & & 555 & & & 796 & 3. $\mathrm{Ca}$ & & 0. \\
\hline $\mathrm{Ay}$ & & 233 & natus & & 780 & & & 61 \\
\hline 1000 & & 232 & 23. exiguus & & 798 & 30. chalybeus & & 66 \\
\hline & & 556 & & & 78 & & & \\
\hline & & 276 & & & 768 & $36 . \mathrm{c}$ & & 66 \\
\hline & & 270 & flavipes & & 790 & 31. coerulescens & & 66 \\
\hline 2-maculate & & 219 & fracticornis & & 767 & columbinus & & \\
\hline & & 260 & & 000. & 811 & confinis & 634. & 93 \\
\hline Blun & & 559 & 3. fulvipes & & 787 & 20. conspicuus & & 66 \\
\hline
\end{tabular}




\begin{tabular}{|c|c|c|c|c|c|c|c|}
\hline corticinus & & $\begin{array}{l}\text { pag. } \\
619\end{array}$ & vestitus & & pag. & 20. coelites & $\begin{array}{l}\text { pag. } \\
\mathbf{4 4 0}\end{array}$ \\
\hline cyanipennis & & $9: 33$ & Palaestrinus & & 343 & coeruleipennis & 433 \\
\hline cyanocephalus & & 662 & 2. aureus & & 344 & 139. compressicollis & 508 \\
\hline dimidiatus & & 488 & 1-2. mutillarius & & 924 & 62. corruscus & 465 \\
\hline discopunctatus & & 643 & 1. Sykesii & & 344 & 57. corvinus & 462 \\
\hline diversicollis & & 650 & Palaminus & & 681 & 4. cribratus & 431 \\
\hline elongatus & & 589 & 2. piceus & & 681 & 99. cribricollis & 487 \\
\hline 3. erythroderus & & 663 & 1. pilosus & & 682 & 9. cyanipennis & 433 \\
\hline extensus & & 638 & 4. testaceus & & 683 & 73. debilis & 472 \\
\hline extraneus & & 661 & 5 variabilis & & 683 & 24. decorus & 442 \\
\hline fastuosus & & 665 & Pelecyphorus & & 553 & denigrator & 450 \\
\hline ferus & & 659 & picipes & & 554 & 124. dimidiatipennis & 500 \\
\hline filiformis & 595. & 638 & Peliusa & & 192 & 86. dimidiatus & 480 \\
\hline filum & & $9: 32$ & 1. labiata & & 193 & dimidiatus & 475 \\
\hline Finisterrae & & 650 & Pella & & 36 & 75. discoideus & 474 \\
\hline ornis & & 575 & Philonthus & & 426 & 56 ebe & 929 \\
\hline frae & & $6: 30$ & 16. aeneus & 437. & 928 & 132. egr & 505 \\
\hline fulg & & 319 & 68. aeruginosus & & 469 & 138. ela & 508 \\
\hline 4. fulvicornis & & 665 & agilis & & 470 & 145. elc & 511 \\
\hline fulvi & & 295 & 148. ag & & 513 & 136. ep & 507 \\
\hline fuse & & 652 & 44. albilabris & & 455 & 107, cxiguus & 491 \\
\hline imus & & 575 & 34. albipes & & 449 & fasciatus & 397 \\
\hline 9. Javanus & & 654 & 79. a & & 476 & 69. fer & 469 \\
\hline$i m p$ & & 36 & 105. al & & 490 & $124-5$. ferrugatus & 931 \\
\hline 1. lae & & 660 & 22. a & & 441 & 133. fer & 505 \\
\hline lae & & 605 & 111. an & & 495 & 2i3. fib & 442 \\
\hline 7: lir & & 653 & 82. a & & 477 & 60.1 & 464 \\
\hline 1. lit & & 650 & 100. ans & & 487 & iolatus & 486 \\
\hline & & 656 & & & 473 & 46. $f$ & 456 \\
\hline 13. lit & & 656 & 130. api & & 931 & 21. fl & 441 \\
\hline 4.10 & & 651 & J51. a & & 931 & 53. fla & 460 \\
\hline & & 643 & 14. as & & 436 & 71 flavolimbatus & 929 \\
\hline arien & asis & 652 & & & $5 \cdot 26$ & flavopterus & 450 \\
\hline aris & & 659 & 108. as & & 492 & 126. fo & 501 \\
\hline 22. me & & 660 & 109. a & & 492 & $f r$ & 536 \\
\hline mel & & 614 & 19. a & & 410 & 42. $\mathrm{fi}$ & 451 \\
\hline $20-1.1$ & & 932 & 18. a & & 439 & 96. $\mathrm{fo}$ & 930 \\
\hline 2. $n$ & & 664 & at & & 546 & 91. & 482 \\
\hline $14 N$ & & 657 & 129. B & & 503 & 58. f & 463 \\
\hline 38. $\mathrm{n}$ & & 667 & 114. b & & 495 & 10. f & 434 \\
\hline o & & 623 & $128 . \mathrm{b}$ & & 503 & ornis & 470 \\
\hline us 6 & & 634 & 33. b & & 448 & 48. $\mathrm{ft}$ & 457 \\
\hline 12. peregrinus & & 656 & 135. b & & 506 & 32. $\mathrm{g}$ & 448 \\
\hline & & 638 & $67 . \mathrm{b}$ & & 468 & 55. $\mathrm{g}$ & 461 \\
\hline & & 611 & 127. b & & 502 & naturus & 504 \\
\hline 8. $\mathrm{ri}$ & & 653 & 50. blat & & 458 & 112. he & 494 \\
\hline & 650. & 651 & boo & & 548 & 37. he & 451 \\
\hline & & & & & 461 & 118,1 & 497 \\
\hline 26. ru & & 662 & 97. br & 486. & 930 & 147. & 512 \\
\hline atus & & 659 & 54. ca & & 460 & 6. h & 432 \\
\hline nis & & & & & 531 & ndus & 479 \\
\hline 1. $\mathrm{s}$ & & & 15. $\mathrm{c}$ & & 437 & & 530 \\
\hline & & & $63 \mathrm{C}$ & & 466 & 72. $j$ & 472 \\
\hline$s p$ & & & 30. $c$ & & 446 & uietus & 928 \\
\hline ta & & & 87. $\mathrm{c}$ & & 480 & edius & 429 \\
\hline.$t$ & & & 45. $c$ & & 455 & terus & 928 \\
\hline & & & & & 367 & 00. & 481 \\
\hline 29. th & & & 43. ci & & 454 & 124. lat & 500 \\
\hline 27. tri & & & & & 432 & 81. 1: & 477 \\
\hline lor & & 331 & 140. cinerascens & & 509 & 8. laevicollis & 433 \\
\hline
\end{tabular}


Index nominum.

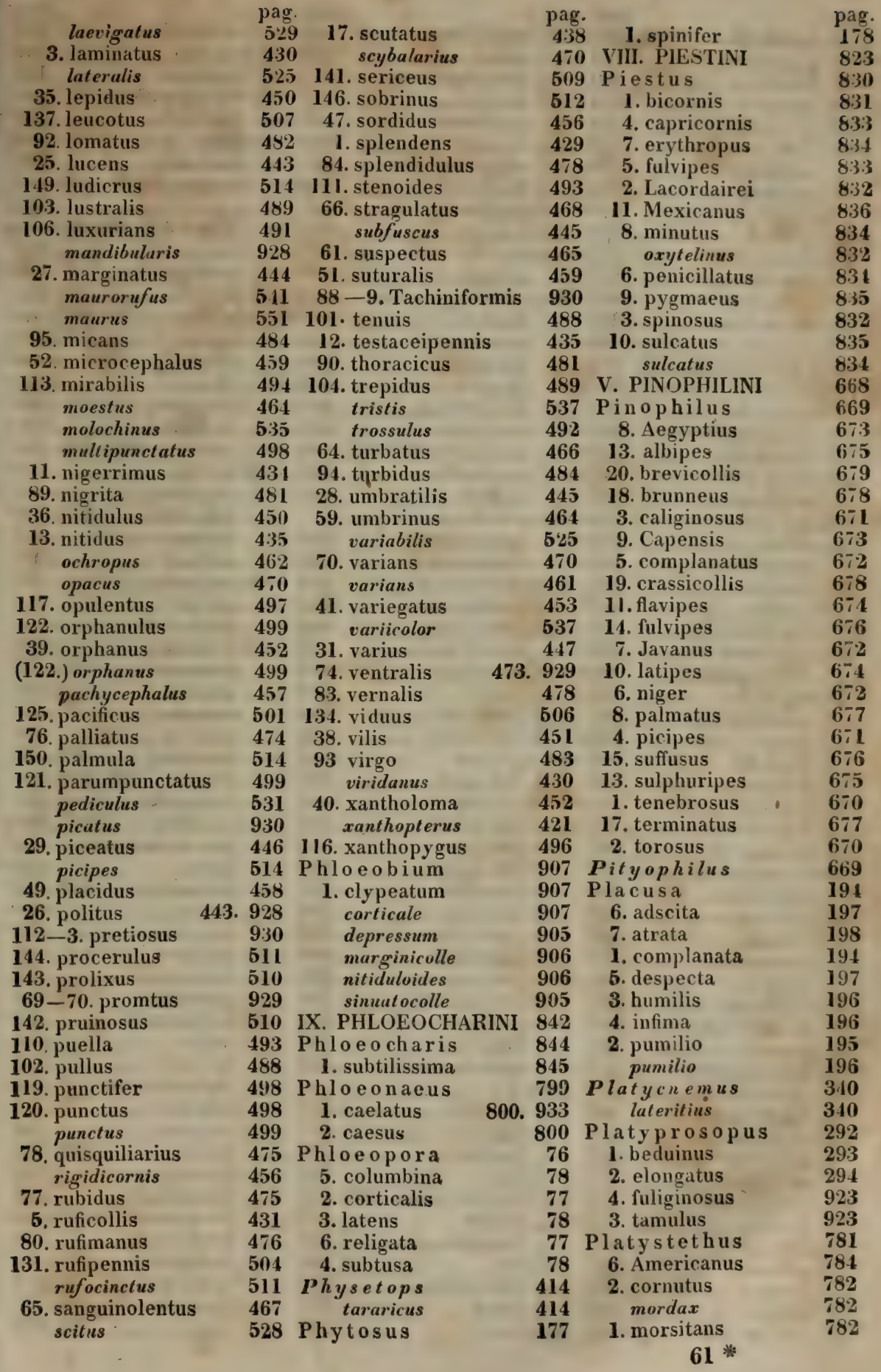




\begin{tabular}{|c|c|c|c|c|c|}
\hline 3. nodifrons & 783. 933 & 39. scintillans & 549 & Americanus & 312 \\
\hline scybalarius & 782 & 6. scitus & 528 & Sphenoma & 142 \\
\hline striolatus & 782 & 32. semiobscurus & 544 & abdominalis & 146 \\
\hline 5. spiculus & 784 & 42. tenellus & 542 & III. STAPHILININI & 290 \\
\hline 4. spinosus & 784 & 27. umbrinus & 541 & ST. GENUINI & 3339 \\
\hline orus & 36 & 45. vicinus & 552 & Staphylinus & 345 \\
\hline ochraceus & 43 & 36. virgulatus & 547 & & 413 \\
\hline rocirrus & 685 & 12. viridulus & 532 & aeneocephalus 379. & $3 \gamma 1$ \\
\hline 1. Le & $6 \triangleleft 6$ & 5. xanthopus & 527 & & 412 \\
\hline rognatha & 836 & Raphirus & 523 & aene & 7.444 \\
\hline 2. humeralis & 837 & Remus & 427 & & 681 \\
\hline 1. quadricornis & 837 & sericeus & 509 & aethiops & 927 \\
\hline rufil & 837 & Rugilus & 629 & 77. Afer & 389 \\
\hline rono & 207 & bicolor & 614 & affinis & 332 \\
\hline 1. ro & 208 & castuneus & 611 & agilis & 472 \\
\hline EININI & 901 & dentatus & 636 & albipes & 449 \\
\hline rot & 02 & & 630 & alp & 848 \\
\hline 4. a & 04 & & 611 & allernans & 297 \\
\hline terus & 3 & atus & 605 & amoenus & $43: 3$ \\
\hline 2.1 & & orbiculatus 631.632. & 634 & 269. 275 . & .528 \\
\hline 3.1 & 93 & ollis & 623 & 92. anceps & 396 \\
\hline Pset & 14 & $r u / i$ & 631 & angularis & 275 \\
\hline 1. sl & 14 & Scaphidium & & angustatus. & 640 \\
\hline ue & 523 & atum & 215 & mus & 318 \\
\hline us & 46 & rne & 215 & & 473 \\
\hline 37. & 48 & Scari & 342 & 46. anti & 373 \\
\hline 17.1 & 35 & nnis- & 343 & $a p$ & 9331 \\
\hline Imus & 534 & Schi & 358 & ornis & 931 \\
\hline 保 & 31 & ensis & 359 & 3. arc & 348 \\
\hline anus & 532 & Scim & 579 & 778. & 782 \\
\hline 33. & & & 580 & & 761 \\
\hline 4. & & 2. $]$ & 580 & assimi & 865 \\
\hline 16. & 34 & eum & 581 & afer & 416 \\
\hline 1. & 24 & Sco & 604 & aterrimus & 492 \\
\hline 24.1 & & & 606 & 439. & 463 \\
\hline 14.1 & & & 608 & pillus & 276 \\
\hline & 5 & ellus & 9 & $a t r$ & 528 \\
\hline 20. & 37 & 5. & 608 & coerulescens & 406 \\
\hline 35.1 & & $\mathbf{1}, 1$ & 605 & atr & 383 \\
\hline & & & 607 & attenuatus & 546 \\
\hline 2 & & & 6 & & 344 \\
\hline & & 9. & 609 & & 369 \\
\hline & & 7. 1 & 608 & 71. au & 387 \\
\hline 2.1 & & Sey & 305 & cens & 405 \\
\hline 40. 1 & & nus & 305 & & 383 \\
\hline 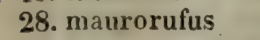 & 12 & Siag & 836 & 99 . badiipennis & 400 \\
\hline & & o & 837 & & 390 \\
\hline 18 & & quad & 837 & balt & 348 \\
\hline 31 & 14 & Silpha & & rensis & 503 \\
\hline 3 & & blatt & 864 & batychrus & 335 \\
\hline 23. & & & 90 & bicinctus & 381 \\
\hline & & ra & & 95. & 855 \\
\hline 25. & & & 895 & bicornis & 848 \\
\hline inus & & melanocephala 869. & 870 & bigutlatus & 691 \\
\hline & & & 896 & bimaculatus 2 & .470 \\
\hline & & & 895 & & 506 \\
\hline & & Silu & 205 & 40. bip & 370 \\
\hline & & & 206 & 163. & 168 \\
\hline & & & 20 & 168. & 468 \\
\hline ctus & 551 & Smilax & 341 & 470.6 & 690 \\
\hline
\end{tabular}


pag.

blandus :... 458

Bluttinus, 235

Boleti 191

Bombylius $\quad 316$

boops 458

burealis $\quad 866.867$

brachypterus 163. 800

Brassicas. $\quad 819$

brevicollis $\quad 212$

brevicoruis 461

brunneus 98. 486. 881

brunnipennis 779

brunnipes $\quad 410$

buphihalmus - 706

63. Buquetii 383

54. caesareus $\quad 378$

29. calidus … 364

73. caliginosus $\quad 388$

103. canaliculatus $\quad 40.3$

canaliculatus $\quad 36$

capucinus $\quad \mathbf{5 3 1}$

Carabuides $\quad \mathbf{8 5 0}$

carbonarius 437. 447

carinatus $\quad 786$

56. castaneus $\quad 379$

casianopterus $\quad 377$

celer 480

cellaris 219. 221

60. chalcocephalus $\quad 381$

chalcocephalus 412. 413

100 chloris 401

44. chloropterus $\quad \ldots \quad \mathbf{3 7 2}$

chloroventris $\quad 537$

81. chrysaster $\quad 393$

38. Chrysis $\quad 369$

42. chrysocephalus $\quad 371$

86. chrysocomus $\quad 394$

chrysomelinus 242, 235

236. 239

chrysopterus 384,391

34. chrysopygus $\quad 366$

36. chrysurus $\quad 367$

$\begin{array}{lr}\text { chrysurus } & 926 \\ \text { cinctulus } & 432\end{array}$

cinctus 257. 514. 530

cinerascens $\quad 509$

5. cinerarius $\quad \mathbf{3 5 0}$

21. cingulatus $\quad 360$

78. cinnamopterus $\quad 390$

clavicornis $694,706.732$

734

coenosus $\quad 436$

coeruleipennis $\quad 433$

coerulescens 405.439

collaris $\quad 43$

97. columbinus _.. 400

compressicollis $\quad \mathbf{5 0 9}$

compressus _.... 418

15. comptus

concinnus 461. 886 pag.

concolor fixmon $\mathbf{5 2 4}$

conformis

conicus inus ititum $\mathbf{2 3 5}$

connexus $\quad 927$

contaminatus 467

corruscus $\quad 465$

crassicollis 411

crenatus . 861

cruentaíus 861

cruentus andint 527

cupreus 413

80. cupricollis 391

cursor is if 875

3:3. cyanelytrius $\quad 366$

cyaneus 405

41. cyanicollis $\quad 370$

cyanipennis $\quad 433$

82 cyanomelas $\quad 392$

69. Daaricus $\quad 386$

debilis is 472

decorus $\mathbf{4 4 2}$

denigrator

dentatus

depressus

diaphanus

dilatatus

68. dimidiatus

dimidiatus $\quad 480.929$

discoideus 470.474

dispar 232. 235. 236

241. 245

distinctus $\quad 526$

divisus $\quad \mathbf{3 7}$

dubius 448

ebeninus $\quad 461$

edentulus

elegans

elongatus

323. 332

328. 589

emarginatus 203. 204

emmesus

ephippiatus

101. Erithacus

8. erythrocephalus 351

67. erythrocnemus $385^{\circ}$ erythropennis 372

3. erythropterus $\quad 377$

erythropterus 377.378

erythropus 383

14. facialis $\quad \mathbf{3 5 4}$

94. fasciatus 397

fasciatus 184. 348

\begin{tabular}{l} 
37. faustus $\quad 368$ \\
\hline
\end{tabular}

Fellmanni $\quad 547$

85 femoratus $\quad 393$

64. ferox $\quad \mathbf{3 8 4}$

ferrugineus $\quad 924$

17. fetialis

fimetarius

flavescens

flavipes
456. 472

350

886 pag.

favopterus 450. 485. 529

favopunctatus $\quad 3 \times 1$

flaralis $\quad 879.891$

fodiens $\quad 377$

formosus $\quad 426$

70. fossator 386

52. fossor 377

fracticornis 328. 767

fragilis $\$ 57$

frontalis. $\quad 536$

fulgens 30:3

fulgidus 295.319. 526

527

fuliginosus $\quad \mathbf{5} 37$

fulmikans 29.3

fulvipennis $\quad \mathbf{5 9 0}$

62. fulvipes $\quad 381$

fulvipes $\quad 450.485$

65. fulvomaculatus $\quad 384$ fulvopterus 295

fulvus $\quad \mathbf{8 5 0}$

fumarius $\quad 482$

fuscatus 411. 416

75. fuscicornis $\quad 389$

fuscipennis 444. 526

fuscipes 163. 264. 410

51. fuscomaculatus $\quad 376$ fuscus $\quad$ 137. 457

72. gentilis $\quad 387$

geometricus $\quad 162$

glaber 325. 326. 529

glabratus $\quad 319$

glabricollis $\quad \mathbf{5 1 9}$

globulifer 409

90. Goryi 39 .

gracilis $\quad 610$

gregarins $\quad 654$

Groenlandicus $\quad \mathbf{5 2 6}$

89. haemorrhoidalis $\quad 394$

haemorrhoidalis 367.420

Havaniensis 490

87. Herculeanus $\quad 394$

30. hilaris 365

1. hirtus $\quad 3.16$

79. Hottentottus $\quad 390$

hybridus $\quad 361$

hypnorum 2:35

immaculatus $\quad 379$

immundus 473.479

impressus 47.530

27. inauratus $\quad 363$

6. incanus $\quad 350$

infuscatus $\quad \mathbf{3 5 9}$

intermedius $\quad 4 \% 9$

interruptus $\quad 370$

inversus $\quad 531$

32. iopterus $\quad 366$

iracundus $\quad \mathbf{5 2 6}$

irregularis 481

Juno 694 


\begin{tabular}{|c|c|c|c|c|c|c|c|}
\hline laevicollis & 433. & 536 & morio & 411. & 417 & 81. praelongus & 391 \\
\hline laevigatus & 263. & 529 & morsitans & 419. & 782 & procerulus & 511 \\
\hline laminatus & 429. & 430 & multipunctatus & 498. & 856 & puberulus & 413 \\
\hline 9. lanio & & 352 & 24. murinus & & 361 & 43. pubescens & 371 \\
\hline Lapponicus & & 536 & murinus & & 361 & pubescens 219. 221. & .371 \\
\hline laqueatus & & 786 & 50-1.mysticus & & 926 & pullus & 484 \\
\hline - latebricola & & 382 & 98. myrtillinus & & 400 & punclatostriatus & 284 \\
\hline lateralis & & 525 & nanus & 184. & 479 & punctatus & 589 \\
\hline laticeps & & 437 & 22. nebulosus & & 360 & punctipennis & 296 \\
\hline laticollis & & 536 & nebulosus & & 348 & punctulatus 328.332. & $2.4 \mathrm{il}$ \\
\hline 17. latro & & 374 & niger & 409. & 429 & punctus & 499 \\
\hline latus & & 259 & nigriceps & & 99 & 102. purpurascens & 462 \\
\hline lentus & - & 326 & nigricollis & & 64 & pusillus & 485 \\
\hline lepi & & 450 & nigrita & & 481 & pygnaeus & 883 \\
\hline 25. leucomus & & 362 & nigritulus & & 492 & 35. py & 367 \\
\hline hthalmus & & 412 & nigritus & & 437 & ferus & 319 \\
\hline leuc & & 73 & nigrof fulvus & & 556 & tus & 593 \\
\hline $\lim t$ & 37. & 310 & nigrophthalmus & & 853 & 4-punctatus & 546 \\
\hline line & 332. & 335 & nitens & 409. & 448 & quisquiliurius & 475 \\
\hline litto & 219. & 279 & nitidicollis & & 448 & 39. regalis & 369 \\
\hline lon & & 332 & nitidulus 235. & 211. & 450 & rel & 320 \\
\hline ornis & & 929 & nitidus 319. & 435. & 465 & icornis & 456 \\
\hline lucens & & 443 & 525. & 530. & 551 & riparius & 654 \\
\hline lucidus & 448. & 472 & 66. nobilis & & 384 & rivularis & 875 \\
\hline lug & & 409 & obscurtus & 416. & 417 & licollis & 439 \\
\hline 8. hug & & 394 & & & 855 & ruficollis & 662 \\
\hline lug & & 389 & obtusus & & 232 & ruficornis & 543 \\
\hline lun & 58. & 278 & ochro & 328. & 332 & rufilabris & 519 \\
\hline $1 . \ln$ & & 395 & terus & & 381 & rufipennis & 504 \\
\hline luv & & 484 & $o c h$ & & 462 & 254.255 & 263 \\
\hline 9. lut: & & 381 & 45. oc & & 373 & 543. & 879 \\
\hline ephalus & & 401 & 10. oculatus & & 352 & rufi & 526 \\
\hline tron & & 855 & olens & & 405 & rufocis & 551 \\
\hline is & & 219 & & 470. & 771 & rufus & 535 \\
\hline sus & & 375 & Lalmicus & 405. & 894 & rugifrons & 406 \\
\hline & & 405 & atus & 631. & 634 & rugosus 786.788. & 816 \\
\hline alis & & 361 & 16. orr & & 356 & rutilus & 318 \\
\hline tus & 263. & 444 & atus & & 474 & sanguinolentus & 467 \\
\hline lus & 263. & 530 & lipennis & & 782 & saphyrınus & 309 \\
\hline rmoratı & & 926 & us & & 281 & 28. sa & 364 \\
\hline ma & & 23 & $p a$ & & 514 & 18. sc & 357 \\
\hline es & & 409 & apunctatus & & 335 & scintillans & 549 \\
\hline fus & 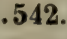 & 546 & ornis & & 470 & scit & 528 \\
\hline n & & 55 & $u s$ & & 479 & 49. sc & 375 \\
\hline losus & & 348 & tor & & 415 & nentarius & 397 \\
\hline sus & & 405 & rans & & 412 & curus & 544 \\
\hline$h$ & & 407 & & & 550 & 74. se & 388 \\
\hline & 28 & 295 & us & & 887 & & 486 \\
\hline & 881. & 906 & nicurus & & 380 & sericeicollis & 413 \\
\hline & & 235 & 786. & 788. & 795 & sericeus & 412 \\
\hline & & 485 & ennis 412. & 413. & 536 & cornis & 524 \\
\hline$s 236$ & 272 & 284 & es & 409. & 537 & 26. Sibiricus & 363 \\
\hline melinus & & 526 & pilicornis & & 296 & silphoides & 245 \\
\hline icus & 438. & 43 & pilosus & & 342 & 408. 417. & 438 \\
\hline & & 48 & iatus & & 852 & & 733 \\
\hline crocephalus & & 459 & tus & & 511 & olex & 470 \\
\hline & & 882 & planus & 465. & 886 & socialis & 102 \\
\hline & & 46 & politus & 444. & 498 & sordidus & 456 \\
\hline lochinus & & 53 & & & 911 & & 800 \\
\hline ordax & & 406 & praecux & 540. & 542 & splendens & 429 \\
\hline
\end{tabular}




\begin{tabular}{|c|c|c|c|c|c|c|}
\hline splendidulus & & $\begin{array}{l}\text { pag. } \\
478\end{array}$ & violaceus & $\begin{array}{l}\text { pag. } \\
392\end{array}$ & 15. egenus & $\begin{array}{c}\text { pag } \\
698\end{array}$ \\
\hline 58. stercorarius & & 380 & violuceus. & 406 & 97. elongatus & $\begin{array}{l}698 \\
741\end{array}$ \\
\hline striatulus & & 816 & 55. vulpinus & 379 & 45. excubitor & 714 \\
\hline striatus & 275. & 786 & 11. xanthocerus & 353 & 30. exiguus & 706 \\
\hline strigatus & & 413 & xantholoma & 452 & femoralis & 708 \\
\hline strumosus & 201. & 203 & xanthopygus & 496 & 43. femoratus & 713 \\
\hline subcyaneus & & 406 & zonatus & 390 & femorellus & 720 \\
\hline subfuscus & & 455 & VI. STENINI & 657 & 78. filum & 731 \\
\hline subpunctatus & & 411 & Stenus & 689 & 82. flavicornis & 733 \\
\hline subterraneus & & 259 & Aceris & 728 & 74. flavipes & 729 \\
\hline subuliformis & 457. & 517 & 26. aemulus & 704 & floralis & 879 \\
\hline sulcatus & 50. & 786 & 71. aerosus & 727 & inosus & 703 \\
\hline & & 788 & 39. agilis & 711 & 40. fos & 711 \\
\hline 96. superbus & & 398 & 95. anguinus & 740 & 89. fro & 737 \\
\hline tachiniformis & & 930 & 8j. an & 735 & fulv & 716 \\
\hline Tataricus & & 414 & 103. arculus & 744 & 76. $\mathrm{fu}$ & 730 \\
\hline tectus & & 872 & 46. Argus & 714 & 49. fus & 716 \\
\hline tenellus & & 5.31 & Argus & 717 & fus & 17 \\
\hline tenuipennis & & 408 & 99. ariolus & 742 & 73. ge & 728 \\
\hline tenuis & & 488 & 9. asphaltinus & 695 & latus & 27. 733 \\
\hline 31. tepi & & 365 & 10. ater & 696 & 93. $\mathrm{gr}$ & 739 \\
\hline 93. terminalis & & 396 & 42. aterrimus & 712 & 3. gu & 691 \\
\hline ter & & 457 & 21. atratulus & 701 & 69. & 726 \\
\hline tus & & 361 & 91. at & 738 & 50. & 716 \\
\hline 13. tes & & 354 & 35. a & 709 & 72. & 728 \\
\hline test & & 457 & eolatus & 723 & 19. in & 700 \\
\hline telrucarinatus & & 796 & tatus & 690 & atus & 702 \\
\hline thor & 481. & 662 & biguttatus 68 & 692 & 8. $\mathrm{i}$ & 694 \\
\hline 76. tom & & 389 & 4. bimaculatus & 692 & 87. it & 736 \\
\hline tomentosus & 219. & 221 & 59. binotatus & 721 & 98. & 741 \\
\hline tricolor 326. & 331. & 383 & atus & 722 & 7. Ju & 694 \\
\hline & & 614 & netatus & 691 & $\boldsymbol{J}_{u}$ & 692 \\
\hline tricornis & 764. & 767 & bipunctatus & 746 & byi & 691. 693 \\
\hline trilobus & & 782 & bipustulatus & 690 & 12. la & 697 \\
\hline trimaculatus & 279. & 281 & boops $\quad 694.699$. & 706 & 67. 1a & 725 \\
\hline tristis & 412. & 537 & 16. buphthalmus & 699 & 101. la & 743 \\
\hline tuberculatus & & 779 & buphthalmus & 700 & 94. lt & 739 \\
\hline Ulimi & & 553 & 704. 732. & 734 & 41. & 712 \\
\hline Ulmineus & & 553 & 88. $\mathrm{ca}$ & 737 & 100. & 42 \\
\hline$u m$ & & 445 & estris & 719 & 77. ps & 731 \\
\hline$u m b$ & & 464 & liculatus & 704 & & 728 \\
\hline uni & & 405 & liculatus & 699 & 38. $p$ & $71+3$ \\
\hline asis & & 416 & 11. carbonarius & 696 & & 69 \\
\hline etus & & 295 & onarius & 699 & 75. $p$ & 72 \\
\hline enctatus & & 318 & 47. ca & 715 & 66. $p$ & 72 \\
\hline variabilis & 525. & 527 & 58. $\mathrm{c}$ & 721 & 62 & -0 \\
\hline 147.4 & & 480 & eloides & 731 & 61.pla & 72 \\
\hline 7. vari & & 351 & leloides & 796 & proboscideus & 728. 72 \\
\hline variegutus & & 589 & ascens & 701 & 44. proditor & 71 \\
\hline & & 447 & 51. ci & 717 & 92. $\mathrm{p}$ & 73 \\
\hline 12. ve & & 354 & cin & 717 & 32. & 70 \\
\hline vel & & 485 & clavicornis & 732 & 53. $\mathrm{pu}$ & 71 \\
\hline velutinus & & 385 & coerulescens & 689 & 102. pu & -8 \\
\hline vent & & 473 & 6. $\mathrm{co}$ & 693 & 29. & 70 \\
\hline 19. ve & & 357 & 17. ce & 699 & 106.4- & 74 \\
\hline ver & 232. & 478 & ubrinus & 737 & & 73 \\
\hline 20. versicolor & & 359 & 104. contractus & $\mathbf{7 4 4}$ & 105. rc & 74 \\
\hline & & 375 & latus & 726 & 13. $\mathrm{r}$ & 69 \\
\hline 4. vil & & 349 & eipes & 710 & 14.1 & 72 \\
\hline villosus & 361. & 362 & 52. declaratus & 717 & 33. scrutator & \\
\hline
\end{tabular}


Index nominum.

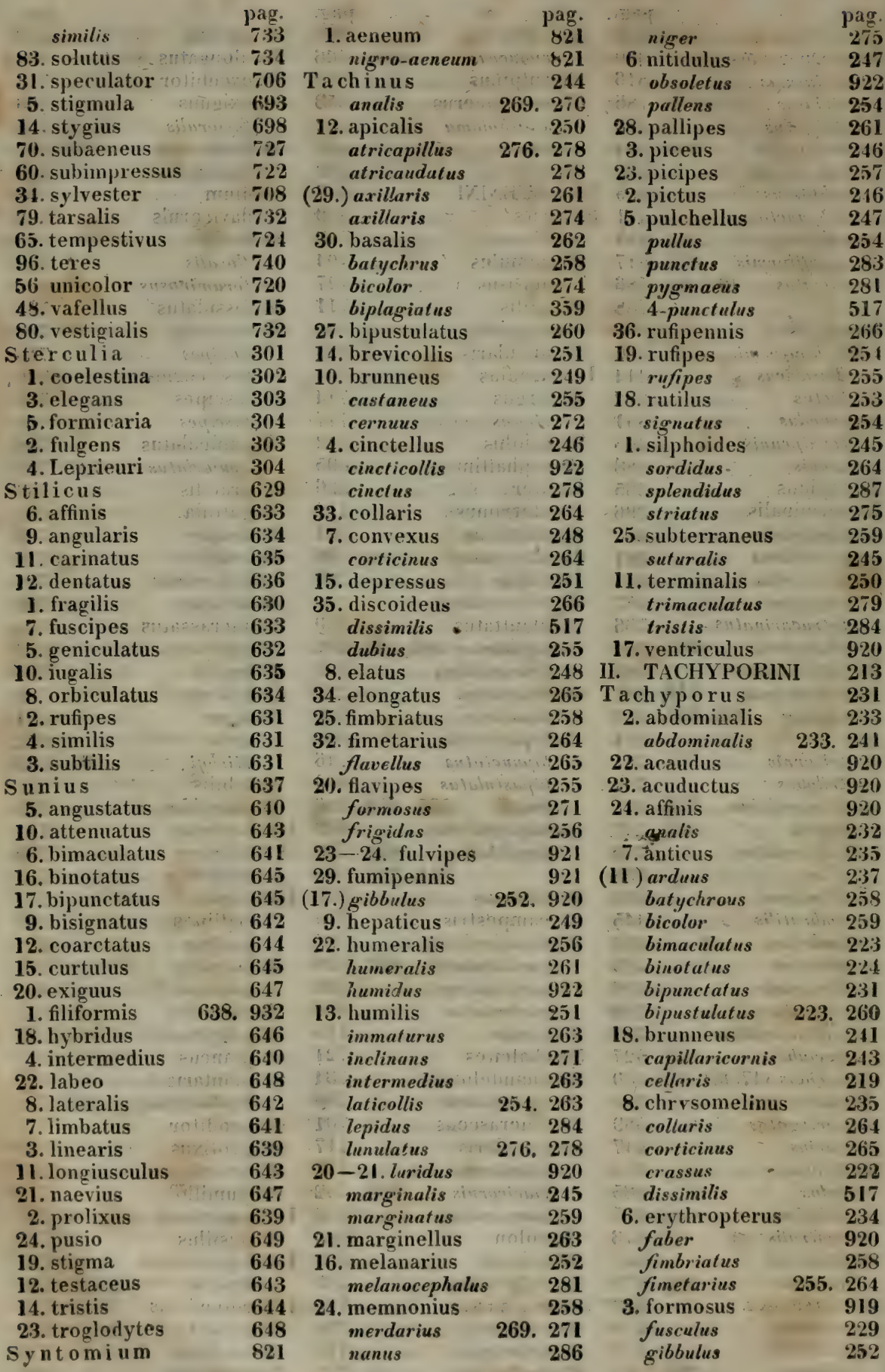




\begin{tabular}{|c|c|c|c|c|c|c|c|}
\hline granulum & & $\begin{array}{l}\text { pag. } \\
215\end{array}$ & 6. exarata & & $\begin{array}{r}\text { pag. } \\
72\end{array}$ & 9. morio & pagi \\
\hline humeralis & & 257 & 4. ferialis & & 71 & 17. Niloticus & (1) 808 \\
\hline 12. humerosus & & 238 & 11. flavitarsis & & 74 & 3. Omalinus & 803 \\
\hline 6. hypnorum & & 234 & 10. fugax & & 74 & 20. punctatellus & 810 \\
\hline immaturus & & 263 & 10-11. immunita & & 916 & 23. pusillus & 811 \\
\hline interruptus & & 224 & 7. laesa & & 73 & 13. riparius & 807 \\
\hline 11. locosus & & 919 & rubicunda & & 66 & 10. scrobiculatus & 805 \\
\hline lateralis & & 238 & 5. scitula & & 72 & 2. segnis & 802 \\
\hline laticollis & & 263 & 9. umbratica & & 73 & 5. signatus & 803 \\
\hline lepidus & & 284 & $7-8$. uvida & & 916 & 25. subtilis & 812 \\
\hline limbatus & & 245 & Taenodema & & 679 & 24. tenellus & 811 \\
\hline littoreus & & 219 & 4. aenea & & 681 & 22 troglodytes & 810 \\
\hline marginalis & & 245 & 1. cyanescens & & 680 & Tympanophorus & 402 \\
\hline marginatus & & 235 & 3. semicyanea & & 681 & canaliculatus & 403 \\
\hline marginellus & & 263 & 2. vestita & & 680 & Velleius & 523 \\
\hline memnonius & & 258 & Taenosoma & & 801 & dilatatus & 524 \\
\hline moestus & & 919 & gracile & & 811 & lirridipennis & 313 \\
\hline 16. nanus & - & 240 & pusillum & & 811 & XANTHOLININI & 291 \\
\hline 21. nigriceps & & 242 & Tanygnathus & & 288 & $\mathrm{X}$ antholinus & 306 \\
\hline 19. nigricornis & & 242 & 2. collaris & & 289 & horeta & 316 \\
\hline nitid & & 241 & 3. laticollis & & 289 & 17. analis & 314 \\
\hline 20. obscurellus & & 242 & 1. terminalis & & 288 & 26. ater & 318 \\
\hline 1. obtusus & & 232 & Tasgius & & 415 & 49. attenuatus & 330 \\
\hline opicus & & 919 & confinis & & 416 & $14-15$ & 923 \\
\hline pallipes & & 261 & rufipes & & 415 & 43. brunneipennis & 327 \\
\hline pedicularius & 229. & 230 & Thoraxophorus & & 908 & cadaverinus & 320 \\
\hline pubescens & & 221 & corticinus & & 909 & 32. cali & $32 t$ \\
\hline pullus & & 254 & Triacrus & & 398 & liculatus & 307 \\
\hline punctus & & 283 & dilatus & & 393 & terus & 321 \\
\hline 14. pusillus & & 239 & Trichocoryne & & 830 & 16. $\mathrm{ca}$ & 315 \\
\hline pusill & & 240 & striata & & 834 & 42. $c e$ & 924 \\
\hline 13. ruficollis & & $2: 99$ & Trich oderma & & 410 & 11. $\mathrm{ch}$ & 312 \\
\hline ruficollis & 238. & 241 & Trichophya & & 267 & 6. cha & 309 \\
\hline rufipes & & 255 & pilicornis & 268. & 921 & pterus & 311 \\
\hline (3.) rufus & & $23: 3$ & Trichophyus & & 267 & 37. $\mathrm{cc}$ & 324 \\
\hline 4. saginatus & & 234 & 1. pilicornis & & 268 & (42.) $c$ & 326 \\
\hline sagi & & 236 & Trichopygus & & 515 & pterus & 311 \\
\hline 15. scitulus & & 240 & dissimilis & & 516 & 38. de & 324 \\
\hline scutellaris & & 241 & nite & & 518 & 23. di & 317 \\
\hline sericeus & & 221 & pumilio & & 517 & 3. div & 308 \\
\hline signatus & & 254 & Trigonophorus & & 399 & 36. ele & 323 \\
\hline 9. solutus & & 236 & myrtillinus & & 400 & 39 , en & 324 \\
\hline splendidus & & 287 & hloeus & & 801 & $e p$ & 335 \\
\hline subterraneus & & 259 & 7. angulatus & & 804 & Irocephalus & 320 \\
\hline suturalis & & 245 & ustatus & & 803 & 14. $\mathrm{fe}$ & 315 \\
\hline 10. tersus & & 237 & 11. bi & & 806 & 2. $\mathrm{fl}$ & 307 \\
\hline 17. tran & & 240 & 18. corticinus & & 809 & 28. fulgidus & 319 \\
\hline trinotatus & & 220 & corticinus & 806. & 811 & fulgidus & 319 \\
\hline truncatellus & & 230 & 1. dilatatus & & 802 & 21. ga & 316 \\
\hline vent & & 920 & 14. el & & 807 & 40. $\mathrm{g}$ & 325 \\
\hline T achyusa & & 69 & 19. ex & & 809 & 29. gla & 319 \\
\hline 8. atra & & 73 & ugineus & & 804 & ha & 924 \\
\hline 3. balte & & 71 & 16. fla & & 808 & 47. $\mathrm{He}$ & 329 \\
\hline 13. carb & & 75 & 21. f & & 810 & 44. $\mathrm{h}$ & 327 \\
\hline $9-10$. chalybea & & 916 & 15. fuliginosus & & 808 & 18.illucens & 315 \\
\hline 2. coarctata & & 71 & 8. fulvipes & & 804 & 13. insignis & 312 \\
\hline 14. coerulea & & 72 & impressus & & 809 & 4. laticeps & 308 \\
\hline 1. $\mathrm{c}$ & & 70 & & & 806 & 41. 1e & 325 \\
\hline 12. coracina & & 75 & 12. memnonius & & 806 & 8. limbatus & 310 \\
\hline
\end{tabular}




\begin{tabular}{|c|c|c|c|c|c|}
\hline - imbatus & $\begin{array}{l}\text { pag. } \\
924\end{array}$ & parumpunctatus & $\begin{array}{l}\text { pag. } \\
\mathbf{3 3 5}\end{array}$ & 51. tricolor & $\begin{array}{c}\text { pag. } \\
\mathbf{3 3 1}\end{array}$ \\
\hline sinearis & 332 & 34. pectoralis & 322 & 27. vagepunctatus & 318 \\
\hline longiceps. & 332 & 16. phoenicopterus & 314 & 20. vagus & 315 \\
\hline lubricus & 321 & pilicornis & 296 & 14. volvulus & 317 \\
\hline lucidus & 313 & 50. procerus & 331 & Zirophorus & 830 \\
\hline lynceus & 309 & 46. punctulatus & 328 & coriaceus & 825 \\
\hline Mannerheimii & 310 & pyropterus & 319 & fronticornis & 831 \\
\hline meridionalis & 323 & 45. rufescens & 328 & penicillatus & 834 \\
\hline minutus & 335 & 35. rufipennis & 322 & spinosus & 832 \\
\hline ohscurus & 330 & 25. rutilus & 318 & striatus & 832 \\
\hline cidentalis & 924 & 12. speciosus & 312 & Zyras & 36 \\
\hline ochraceus & 329. 332 & tener & 924 & Haworthi & 40 \\
\hline
\end{tabular}




\section{LIBR I CITATI.}

Act. Aead. Caes. Leop. Carol. Nat. Cur.: Nova Acta Physico-Medica Academiae Caesareae Leopoldino-Carolinae Naturae Curiosorum.

Act. Arad. nat. Scienc. Philadelph.: Journal of the Academy of natural Sciences of Philalephia.

Act. Holm: Kongl. Svenska Vetenskaps Academiens Handlingar.

Act. nov. Halens.: Neue Schriften der naturforschenden Gesellschaft zu Halle.

Act. Nidr.: Det Trondhjemske og Norske Videnskabers Selskabs Skrivter. Kiöbenh.

Att. Reg. Scienc. Acad. Taurin.: Memoralia Regiae Scienciarum Academiae Taurinensis.

Ahrens. Faun. Ins. Europ.: A. Ahrensii Fauna Insectorum Europae. Hal. 1812. etc. (Cont. Germar.)

Annal. Scienc. nat.: Annales des Sciences naturelles. Paris.

Beck Beitr.: Beck, Beiträge zur bairischen Insectenfaune, oder Beschreibung und Abbildung neuentdeckter Käfer, etc. Augsburg 1817.

Block Ins. vall. Plauens. cont. in: Becker, der Plauensche Grund bei Dresden. Nürnb. 1799.

Boisd. Faun. Ent. Ocean.: Boisduval, Faune Entomologique de l'Oceanie. Par. 1835.

Boisd. et Lacord. Faun. Ent. Paris.: Boisduval et Lacordaire, Faune Entomologique des environs de Paris. Par. 1835.

Bouché Hist. nat. Ins.: Bouché, Naturgeschichte der Insecten, besonders in Hinsicht ihrer ersten Zustände als Larven und Puppen. Berl. 1834.

Brullé Hist. nat. Ins.: Audouin et Brullé, Histoire naturelle des Insectes. Paris 1834. etc.

Bull. d. I. Soc. Imp. d. Moskou: Bulletin de la Société Imperiale des Naturalistes de Moskou.

Cederh. Faun. Ingr.: Cederhjelm, Faunae Ingriae Prodromus, exhibens methodicam descriptionem Insectorum Agri Petropolensis. Lips. 1798.

Charp. Har. Ent.: Charpentier, Horae Entomologicae. Wratislav. 1825.

Creutz. Ent. Vers.: Creutzer Entomologische Versuche. Wien 1799.

Curtis Britt. Ent.: Curtis, Brittish Entomology, being illustrations and descriptions of the genera of Insects found in Great Britain and Ireland. Lond, 1824. etc.

Dalm. Anal. Ent.: Dalman, Analecta Entomologica. Holm. 1823.

Degeer Ins.: Degeer, Memaires pour servir a l'histoire des insectes. Stockholm 1752. etc.

Dej. Cat.: Catalogue des Coléoptères de la collection de M. le Comte Dejean. Paris 1837.

Don. Britt. Ins.: Donovan, the Natural History of Brittish Insects. Lond. 1792-1816.

Encycl. Meth.: Encyclopedie Methodique, Histoire naturelle des Insectes. Paris $1782-1824$. 
Libri citati.

Ent. Nag.: The Entomological Magazine. Lond. 1833-38.

Er. Col March.: Erichson, die Käfer der Mark Brandenburg. Berl. 1837 - 39.

Fab. Syst. Ent.: Fabricii Systema Entomologiae. Flensb. et Lips. 1775.

Fab. Gen. Ins. : Fabricii Genera Insectorum. Chilon. 1776.

Fab. It. Norvag : Fabricius, Reise nach Norwegen. Hamb. 1779.

Fab. Spec. Ins. : Fabricii Species Insectorum. Hamb. et Kilon. 1781.

Fab. Mant. Ins. : Fabricii Mantissa Insectorum. Hafn. 1787.

Fab. Ent. Syst.: Fabricii Entomologia Systematica emendata et aucta. Hafn. $1792-98$.

Fab. Syst. El.: Fabricii Systema Eleutheratorum. Kil. 1801.

Fourcr. Ent. Par.: Fourcroy, Entomologia Parisiensis s. Catalogus Ins., quae in agro Parisiensi reperiuntur, secundum methodum Geoffroyanam etc. Par. 1785.

Frisch Ins. Germ.: Frisch, Beschreibung von allerlei Insecten in Deutschland. Berlin 1766.

Fuessl. Verz. Schueiz. Ins.: Fuessly, Verzeichniss der ihm bekannten Schweizerischen Insecten. Zürich u. Winterth 1775.

Geoffr. Hist. Ins.: Geoffroy, Histoire abbrégée des Insectes. Paris 1764.

Germ. Faun. Ins. Europ. : v. Ahrens.

Germ. Mag.: Germar, Magaxin der Entomologie. Halle 1813-21.

Germ. Spec. Ins.: Germar, Insectorum Species novae aut minus cognitae. Hal. 1824.

Goeze Ent. Beitr.: Goeze, Entomologische Beiträge zu des Ritters Linné zwölften Ausgabe des Natursystems Leipz. 1777.

Grav. Micr.: Gravenhorst, Micreptera Brunsvicensia etc. Brunsv. 1802.

Grav. Mon.: Gravenhorst, Monographia Micropterorum. Gotting. 1806.

Gray An. Kingd.: The Animal Kingdom, arrang. by Cuvier, with supplementary additions to each order, by Griffith, Vol. XIV., The Insecta, by Gray. London 1832.

Guér. Icon. Regn. an.: Guérin, Iconographie du Règne Animal de Mr. le B. Cuvier. Paris.

Guér. Mag. Zool.: Guér. Magasin de Zoologie.

Guér. Voy. d. l. Coquille: Voyage autur du monde, excuté p. o. d. r. sur la Corvette d. s. M. la Coquille p. l. a. 1822-25. par Duperrey. Zoologie Atl. 1826, Texte: Crust. Arachn. et Ins. par. Guérin Meneville. 1838.

Gyll. Ins. Suec.: Gyllenhal, Insecta Suecica. Scar. 1808- 28.

Harrer Beschr. d. Ins : Harrer, Beschreibung derjenigen Insecten, welche Herr D. J. Schäffer in 280 ausgemalten Kupfertafeln herausgegeben hat. Regenb. 1784.

Heer Obs, Ent.: Heer Observationes Entomologicae. Turic. 1836.

Herbst Arch.: Archiv der Insectengeschichte, herausgegeben von J. C. Fuessly. Zürich u. Winterth. 1781.

Herbst Col.: Natursystem aller bekannten in - und ausländischen Insecten von C. G. Jablonsky, fortgesetzt von J. F. W. Herbst. Berl, 1789-1801.

Illig. Käf. Pr. : llliger, Verzeichniss der Käfer Preussens. Halle 1798.

Illig. Mag.: Illiger, Magazin für Insectenkunde. Braunschw. 1801 -7.

Isis: Isis, Encyclopädische Zeitschrift, vorzüglich für Naturgesch., vergl. Anatomie und Physiologie, von Oken. Leipz.

Kirby Faun. Boreali-Amer.: Richarson Fauna Boreali-Americana, or the Zoology of the Northern parts of America, etc. - Part IV. The Insects, by W. Kirby. Norwich 1837.

Kirby et Spence Introd.: Kirby and Spence, Introduction to Entomology. London $1818-1827$.

Klug Col. Madag.: Klug Bericht über eine auf Madagascar veranstaltete Sammlung von Insecten aus der Ordnung Coleoptera. Berl. 1834. (Physicalische AbhandI. der Königl. Acad, der Wissensch. zu Berlin, aus d. J. 1832.)

Klug Juhrb: Klug Jahrbiicher der Insectenkunde. Berl. 1834.

Laporte Etud. Ent.: Laporte Etudes Entomologiques. Paris 1835. Latreille Préris $d$. caract.: Latreille Précis des caractères génériques des Insectes.
Briv, 1796.

Latreille Uist. nat. Crust. ef Ins.: Latreille Histoire naturelle générale et particulière des Crustacés et des Insectes. Paris $1802-5$.

Latreille Gen. Crust. et Ins.: Latreille Genera Crustaceorum et Insectorum. Paris et Argentorat. $1806-7$. 
Latreille Regn. An.: Cuvier Regne Animal, distribué d'après son organisation. Nouv. Ed.: Crustac. Arachn. et Ins. par Latreille. Paris 1829.

Ledebour It.: Ledebour Reise durch das Altai-Gebirge und die Songarische Kirgisensteppe; Berl. 1829.

Linn. Faun. Suec: : Linné Fauna Suecica, Editio altera, auctior. Stockbolmiae 1761.

Linn. Iter Gotl.: Linné Oeländska och Gothländska Resa förättad ar 1741. Stockh. och UpsaI. 1745.

Linn. Syst. Nat.: Linné Systema Naturae perRegna tria naturae, Ed. 12. Họlm 1767.

Linn. Transact.: Transactions of the Linnean Society of London.

Mag. Zool. and Bot.: Magazine of Zoology and Botany, cond. by Jardine, Selby and Jolunston: Lond. Edinb. and Dublin 1836 etc.

Mannerh. Brachelytr.: Mannerh. Précis d'un nouvel arrangement de la famille des Brachélytres. St. Pétersb. 1830. (Mém. présentés à l’Acad. Imp. des sciens. de St. Pétersbourg par divers savans, T. I.)

Marsh. Ent. Britt. Marsham Entomologia Brittanica. London 1802.

Mart. Engl, Ent.: Martyn, the English Entomologist, exhibiting all the Coleopterous Insects found in England. London 1792.

Ménétr. Calal.: Ménétries, Catalogue raissonée des Objects de Zoọlogie recueillis dans un voyage au Caucase etc. St. Pétersbourg 1832.

Meyen It. : Meyen, Reise um die Erde. Dritter Theil. Zoologischer Bericht. Breslau u. Bonn 1834.

Müll. Faun. Frid.: Müller, Fauna Insectorum Fridrichsdalina. Hafn. et Lips. 1764.

Mlüll. Prodr.: Müller, Zoologiae Danicae Prodromus. Hafn. 1776.

Nicol. Col. Hal.: Nicolai, Dissertatio sistens Coleopterorum species agri Halensis. Hal. 1822.

Nordm. Symb.: Nordmann, Symbolae ad Monographiam Staphylinorum. Petrop. 1837. (Mém. présentés à l'Acad, Imp. des sciences de St. Pétersbourg. T. IV.)

Nov. Ann. Mus. Hist. nat.: Nouvelles Annales du Muséum d'histoire naturelle, Par. 1832 etc.

Nouv. Mém. d. l. Sac. Imp. des nat. de Mosk. Nouveaux mémoires de la Société Imperiale des Naturalistes de Moskou.

Oliv. Ent.: Olivier, Entomologie ou Histoire naturelle des Insectes. Par, 1789-1808.

D’Orbign. It.: D'Orbigny Voyage dans l'Amerique méridionale (le Brésil, la républ. orient. de l'Uruguay, la Patagonie, la républ. Argentine, du Chili, du Pérou, de Bolivia) excuté dans le cours des années $1826-33$. Par.

Pall. It.: Pallas, Reise durch verschiedene Provinzen des Russischen Reichs. \$t. Petersburg $1772-76$.

Panz. Ent. Germ. : Panzer, Entomologia Germanica, exhibens Insecta per Germaniam Indigena. Norimb 1795 ,

Panz. Faun. Germ. : Panzer, Faunae Insectorum German. Initia. Norimb. 1789-1810.

Payk. Faun. Suec.: Paykull, Fauna Suecica. Upsal. 1800.

Payk. Mon. Staph. : Paykull, Monographia Staphylinorum Sueciae Upsal. 1789.

Payk. Mon. Car.: Paykull, Monographia Caraborum Sueciae. Upsal. 1790.

Payk. Mon. Curc.: Paykull, Monographia Curculionum Sueciae, Upsal. 1792.

Payk. Mon. Hist.: Paykull Monographia Histeroidum. Upsal. 1811.

Percheron Gén. Ins. : Guérin et Percheron Genera des Insectes. 1835.

Perty Delect. An, art.: Delectus Animalium articulatorum quae in itinere per Brasiliam annis $1817-20$ collegerunt Spix et Martius, dig. descr. ping. cur. Perty, ed. Martius. Monach. 1830.

Potiver Op. : Petiveri Opera, historiam naturalem spectantia. Lond. 1767.

Preyssl. Böhm. Ins.: PreyssIer, Verzeichniss Böhmischer Insecten. Prag 1790.

Rutzelurg Forstins.: Ratzeburg, die Forstinsecten, oder Abbildung und Beschreibung der in den Wäldern Preussens und der Nachbarstaaten als schädlich oder nützlich bekannt gewordenen Insecten. Berlin 1837.

Rossi Faun. Etr.: Fauna Etrusca, sistens Insecta, quae in Provinciis Florentina et Pisana praesertim collegit P. Rossius. Liburn. 1790. Eiusd. Mantissa Insect., exhibens species nuper in Eturia collectas. Pis. $1792-94$.

Ed. Hellw.: Rossii Fauna Etrusca, iterum edita et annotationibus perpetuis aucta a Hellwig. Helmst. 1795.

Royle Himalaja: Forbes Royle, Illustrations of the Botany and other Branches of the natural history of the Himalajan Mountains and of the Flora of Cashmere. Lond. 1835. 
Runde Brachelyfr. Hal.: Runde Brachelytrorum species agri Halensis, Hal. 1835.

Suhlb. Ins. Fenn.: Sahtberg, Insecta Fennica, dissertationibus academicis ed. Helsingf. 1817 ete.

Schäff. Abhandl : Schäffers Abhandlungen von Insecten. Regenb. $1764-79$.

Schäff. Elem. Ent.: Schäfferi Elementa Entomologica. Ratisbon. 1766.

Schäff. Icon.: Schäfferi Icones Insectorum circa Ratisbonam indigenorum. Regensb. 1769.

Schneid. Mag.: Schneider, Neuestes Magazin ftir Liebhaber der Entomologie. Stralsund 1791-94.

Schrank Beilr. z Naturgesch.: Schrank Beiträge zur Naturgeschichte. Leipz. 1776.

Schrunk Enum. Ins. Austr.: Schrank Enumeratio Insectorum Austriae. Aug. Vindel. 1781.

Schrank Faun. Boic.: Schrank Fauna Boica, durchgedachte Geschichte der in Bajern einheimischen und zahmen Thiere. N Nürnb. 1798.

Scop. Ent. Carn.: Scopoli Entomologia Carniolica. Vindabon, 1763.

Scop. Ann. hist. nat.: Scopoli Annus historico-naturalis I-V. Lips. 1769-72.

Shaw Gener. Zool. : Shaw General Zoology or Systematic Natural History. Lond. 1806.

Steph. Illustr.: Stephens Illustrations of Brittish Entomology, Mandibulata. Lond. 1827 etc.

Sturn Catal. : Sturm, Catalog meiner Insectensammlung. 1. Theil. Käfer. Nürnb. 1826.

Sulz. Kennz: Sulzer, die Kennzeichen der Insecten. Zürich 1761.

Sulz. Hist. Ins.: Sulzer, abgekürzte Geschichte der Insecten. Winterth. 1776.

Transact. Amer. Philosoph. Soc.: Transactions of the American Philosophical Society, held at Philadelphia.

Transact. Ent. Soc.: The Transactions of the Entomological Society of London. Lond. 1834 etc.

Transact. Hist. Nat. Soc. Hartf.: Transactions of the Natural History Society of Hartfort. Hartf. 1836.

De Vill. Ent.: C. Linnaei Entomologia, cur. et aug. De Villers. Lugd. 1789.

Walk. Faun. Paris.: Walkenaer Faune Parisienne, Insectes, ou Histoire abbrégée des Insects des environs de Paris. Par. 1802.

Waltl It. Andal.: Waltl, Reise durch Tyrol, Oberitalien und Piemont nach dem südlichen Spanien. Passau 1835.

Weber et Mohr Archiv.: Weber und Mohr, Archiv fuir systematische Naturgeschichte. Leipzig 1804.

Weber Beitr.: Weber, Beiträge zur Naturkunde. Kiel 1805 - 10.

Wiedem. Zool. Mag.: Wiedemann, zoologisches Magazin. Kiel u. Altona 1817-23.

Zetterst. Faun. Lappon.: Zetterstedt Fauna Insectorum Lapponiae. Hamm 1828.

Zetterst. Ins. Lappon.: Zetterstedt Insecta Lapponica. Lips. 1838.

Zool. Journ.: The Zoological Journal. Edited by Vigors, Lond. 1825 ete. 

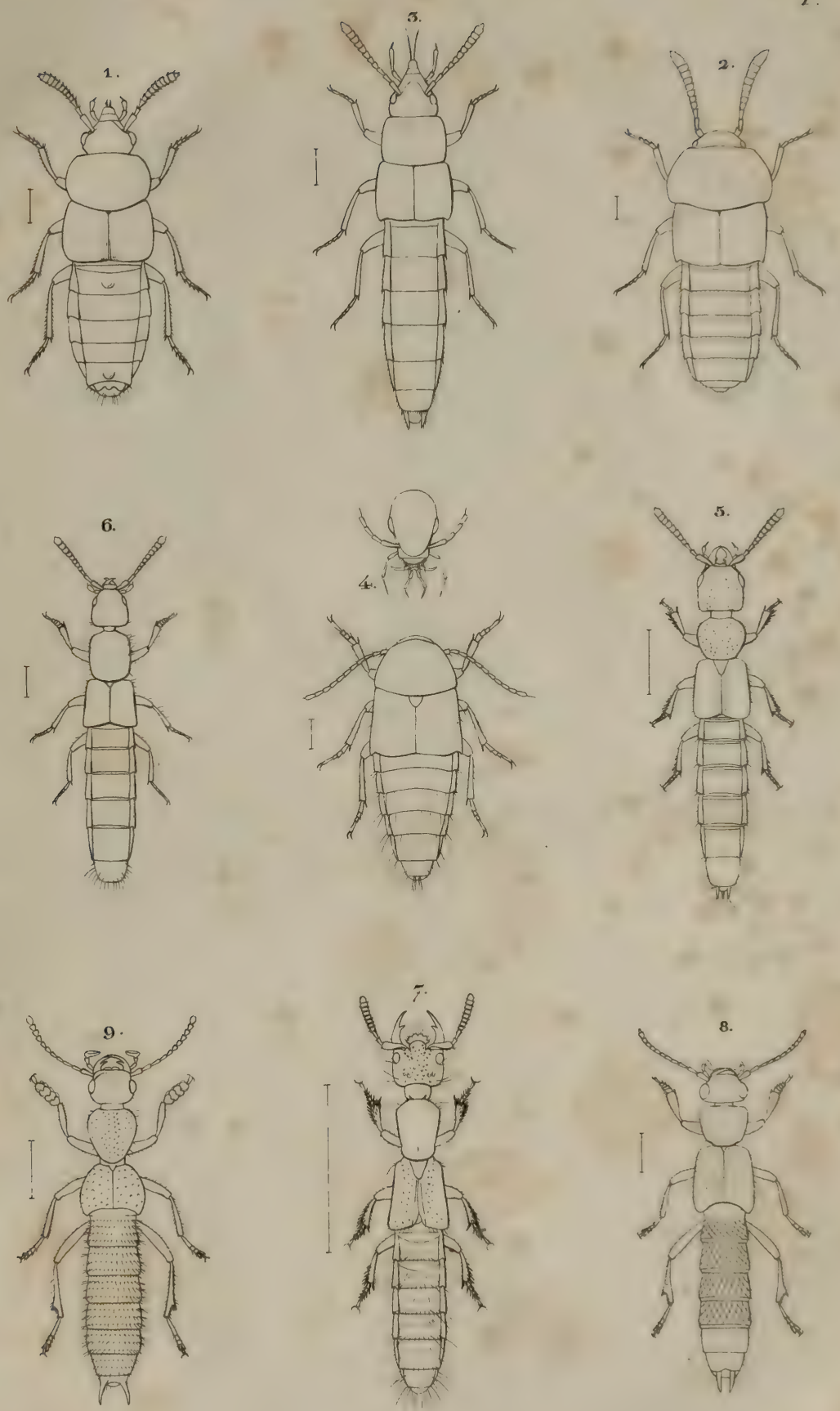


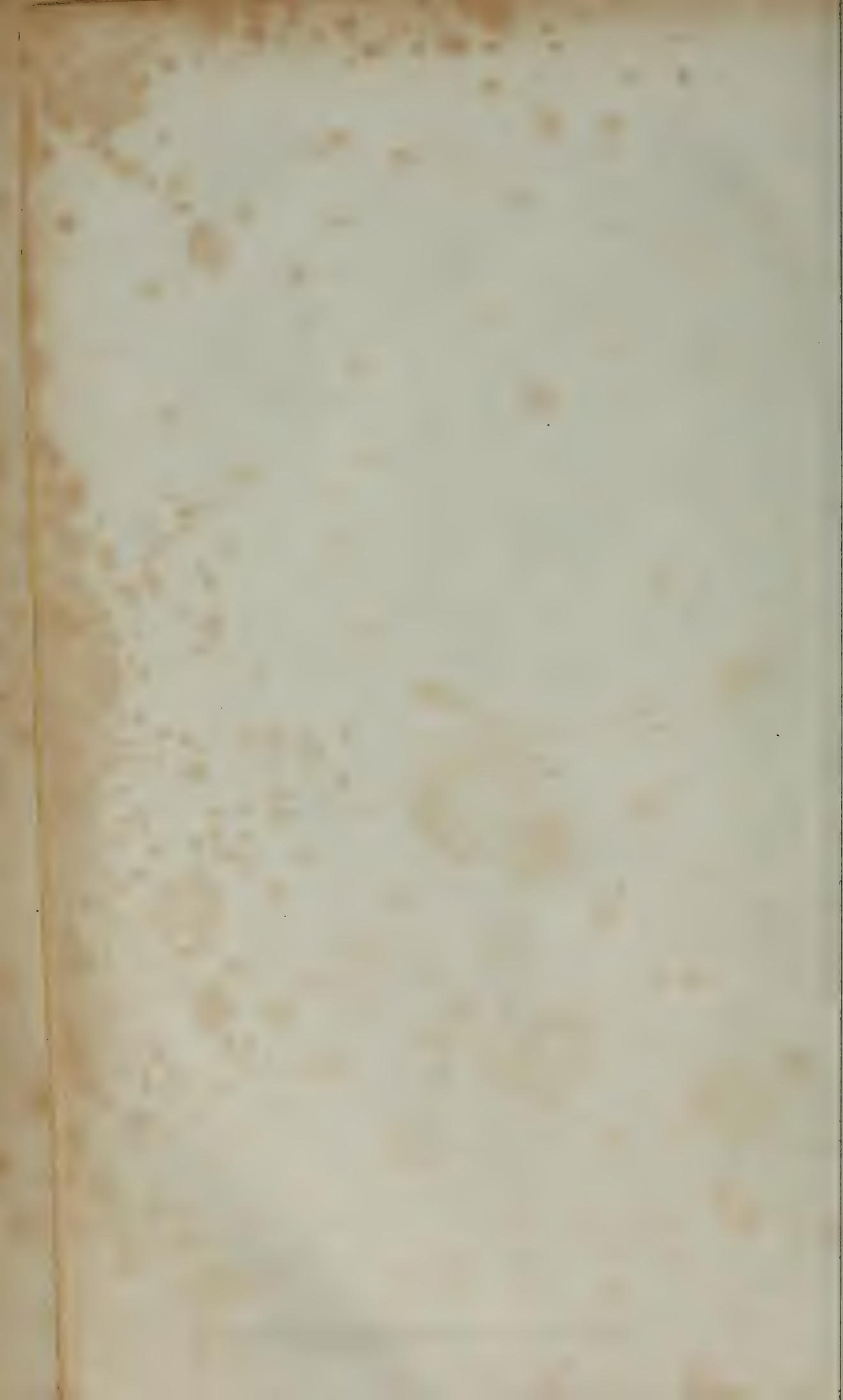



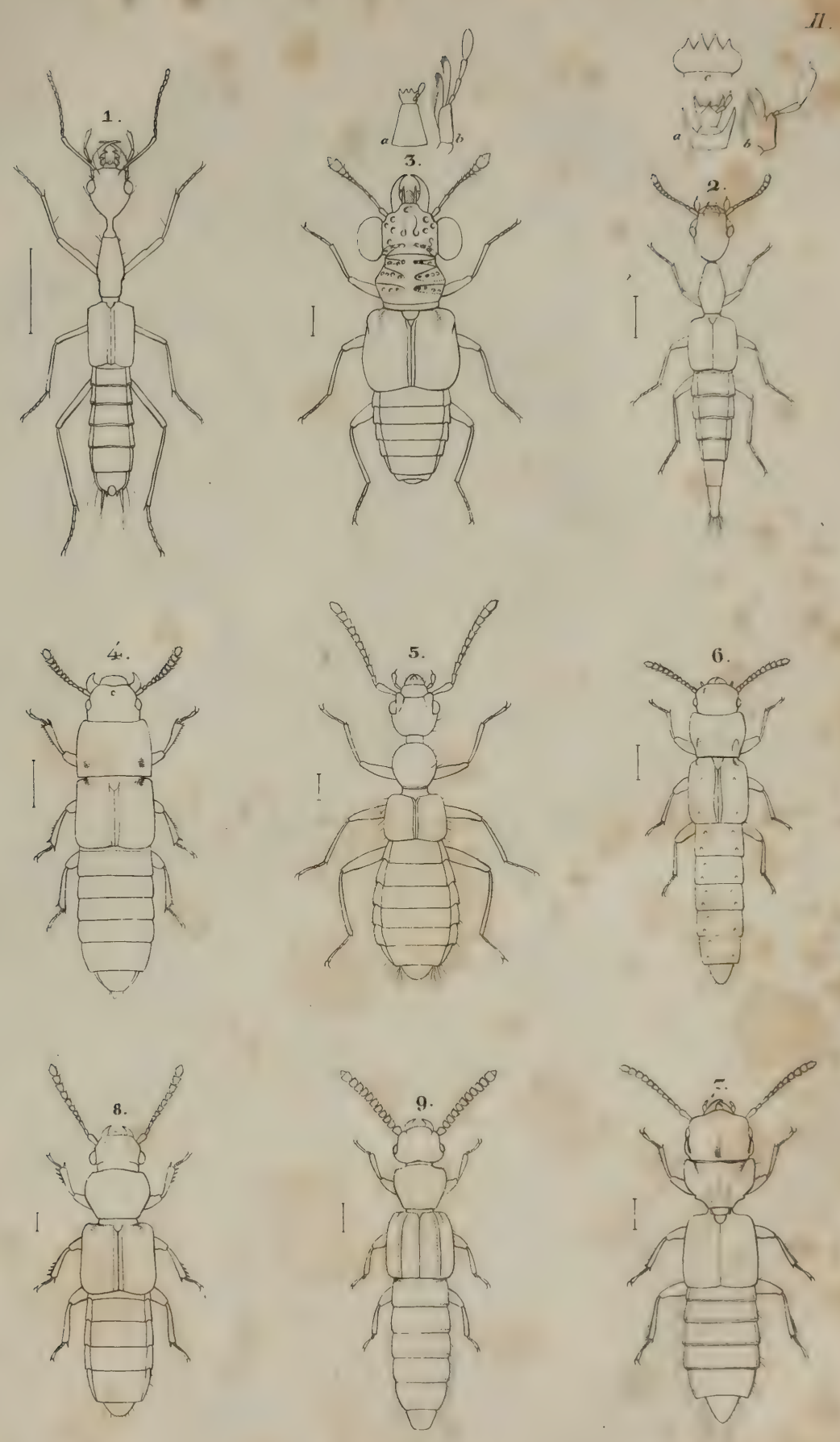


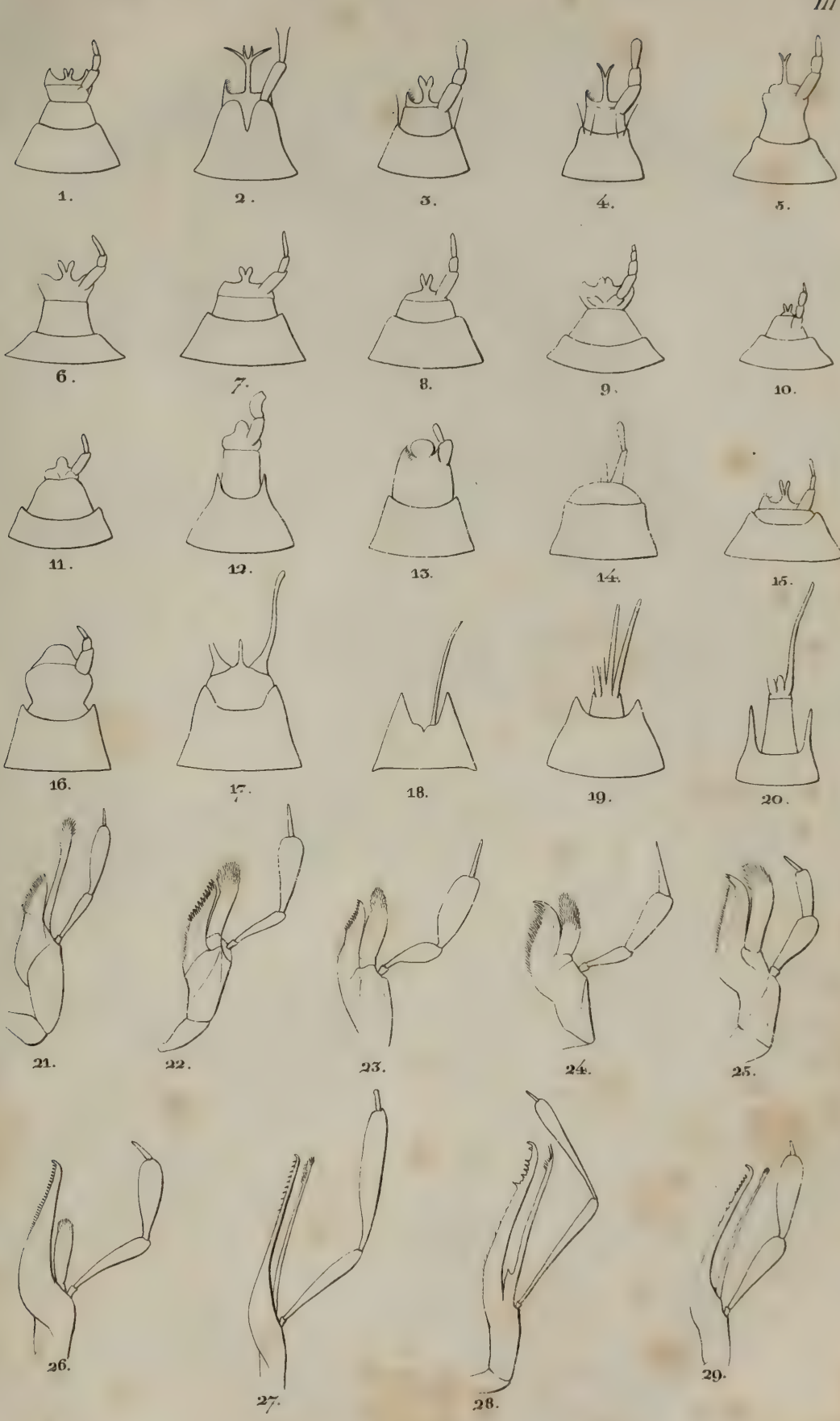



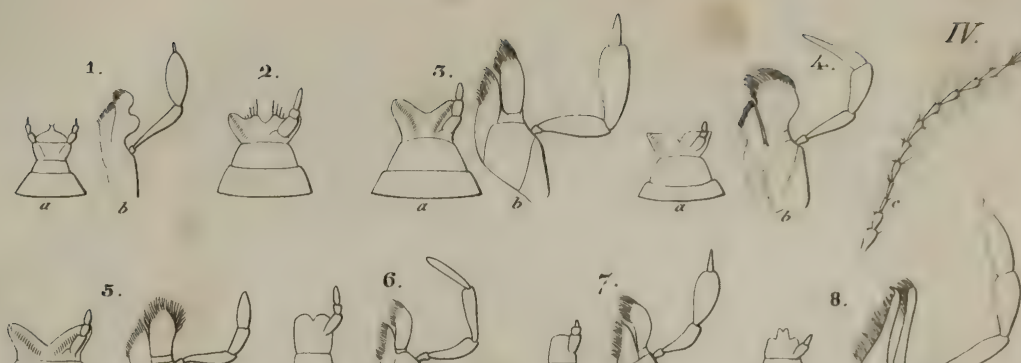
Sa

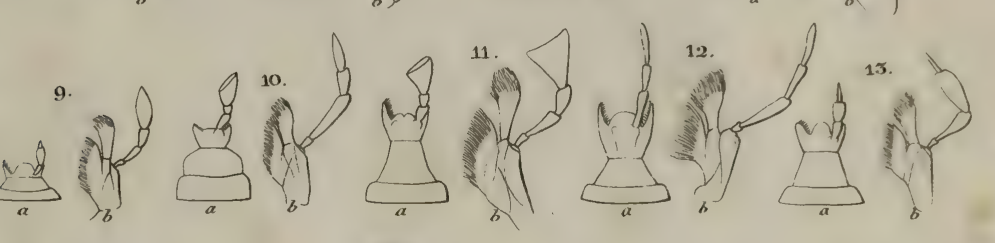

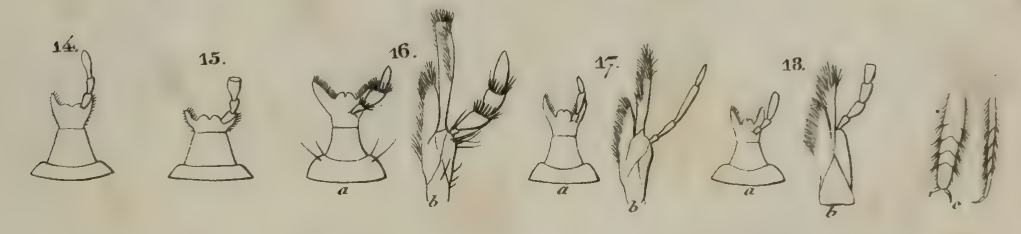
An

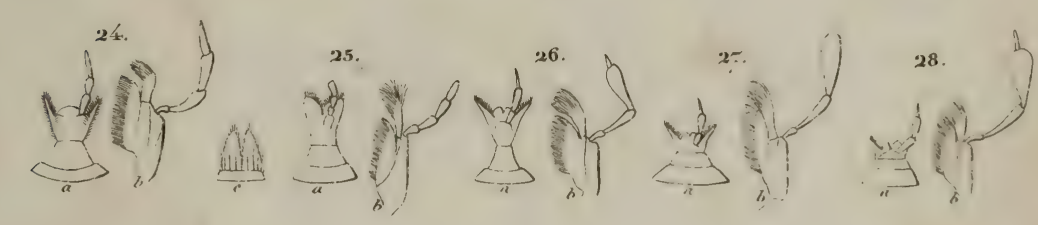

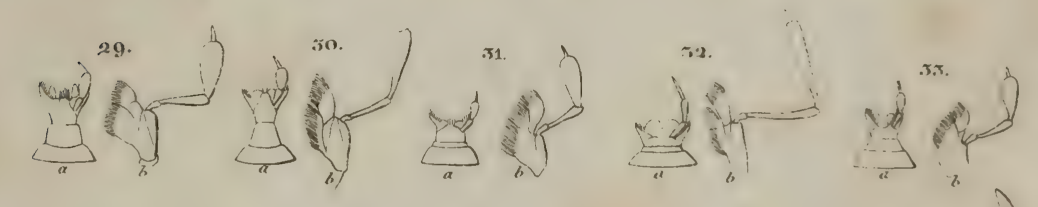

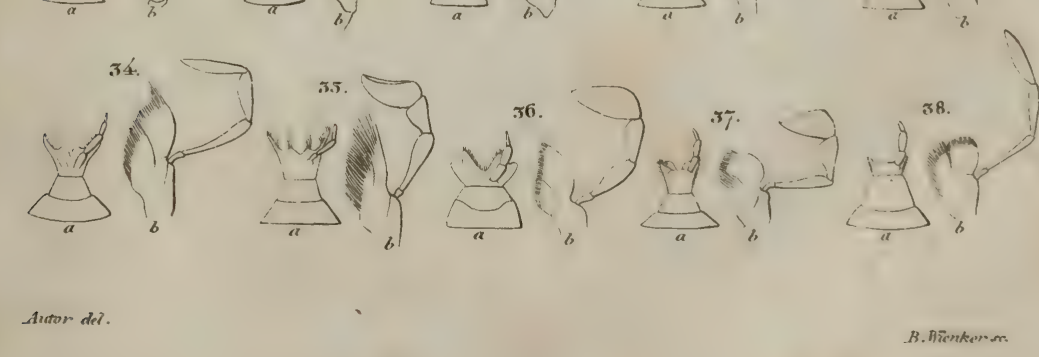





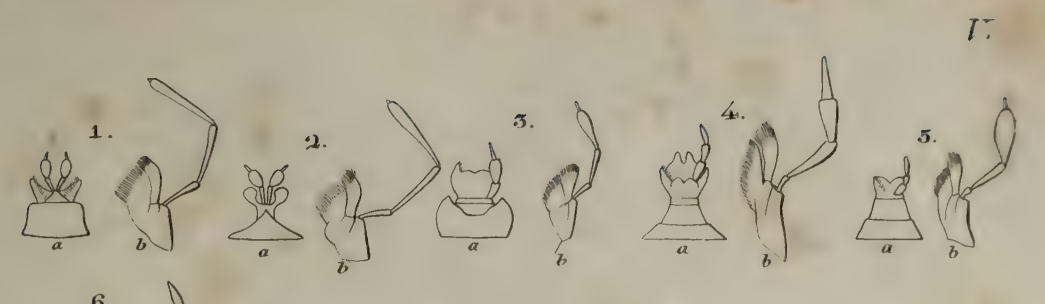

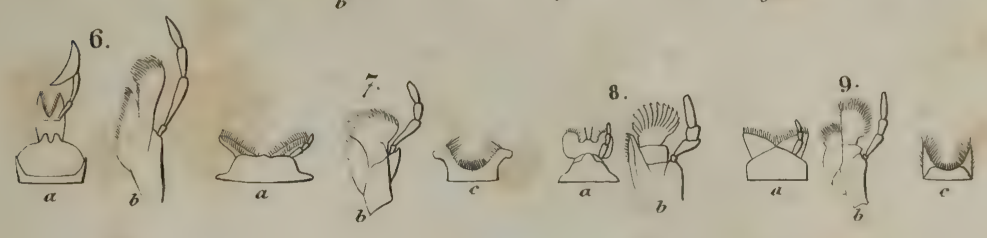

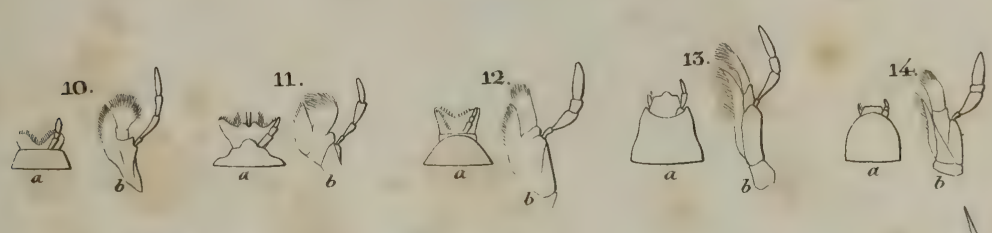

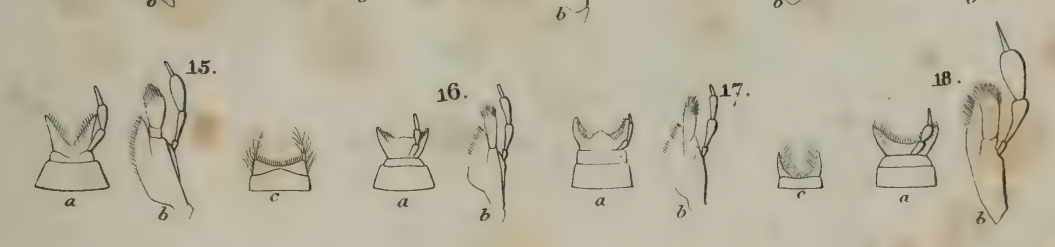

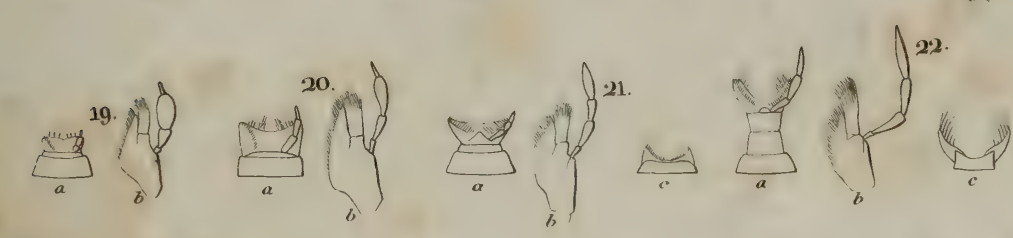

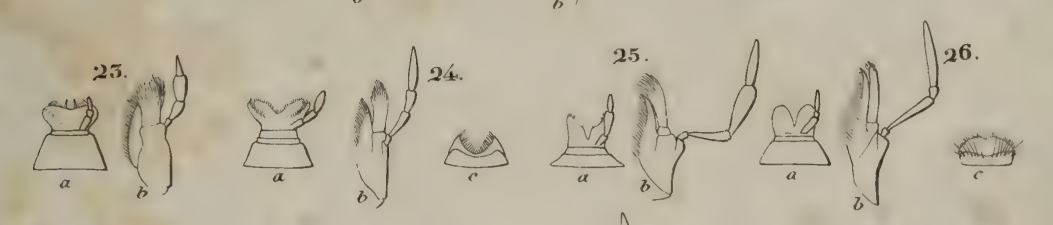

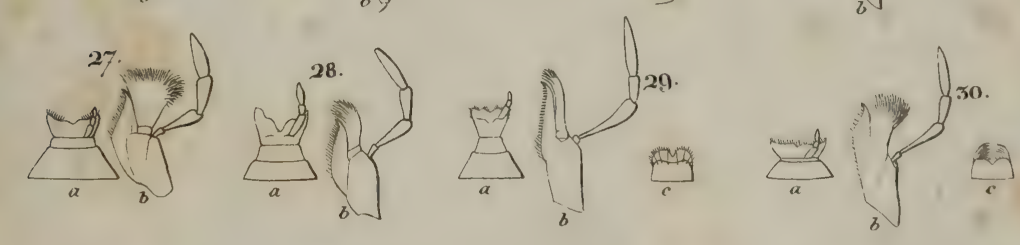

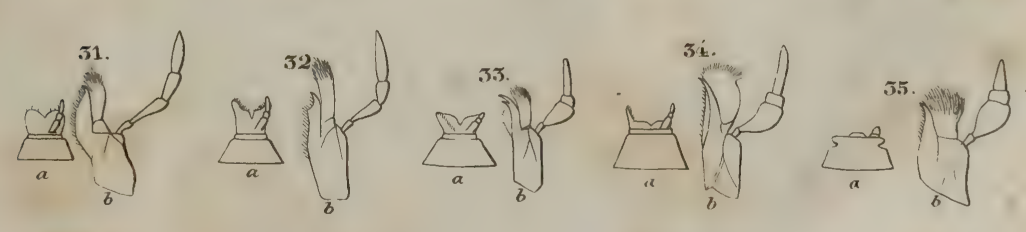








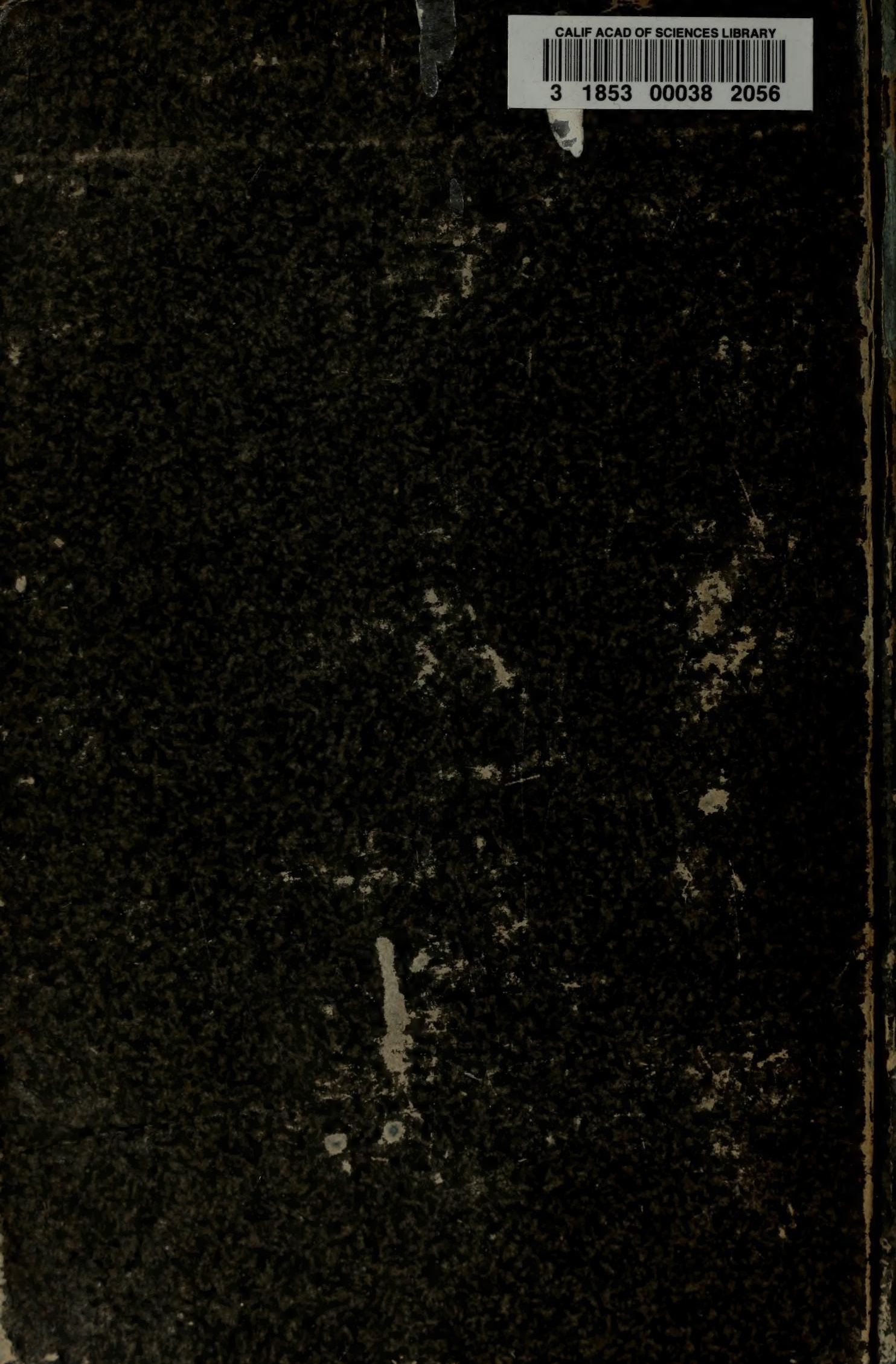

